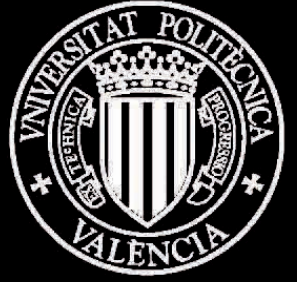

UNIVERSITAT
POLITÉCNICA
DE VALĖNCIA

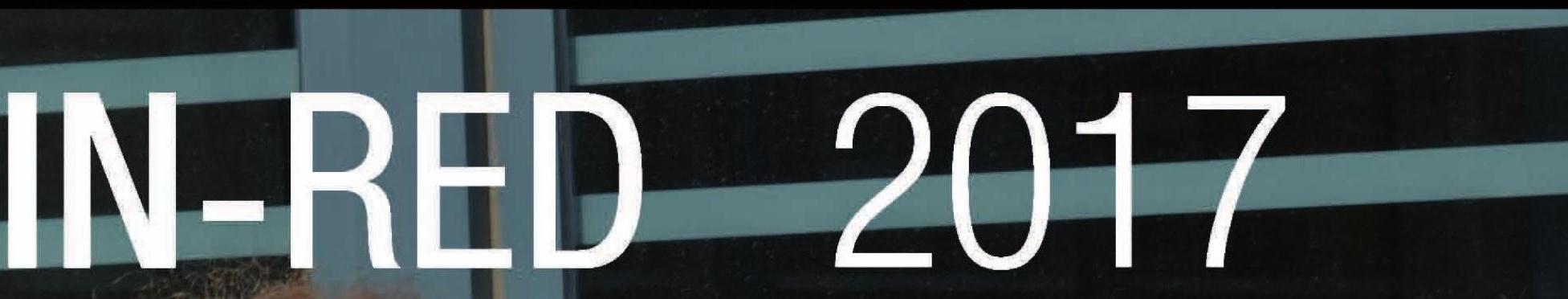

Congreso Nacional de Innovación

Educativa y de Docencia en Red

13 y 14 de jullio de 2017

Vicerrectorado de las Tecnologias de la Información y de las Comunicaciones

Vicerrectorado de.Estudios, Calidad y Acreditación

inred-blogs.upv.es

MoOGTec

Docencia 


\section{Colección Congresos UPV}

Los contenidos de esta publicación han sido evaluados por el Comité Científico que en ella se relaciona y según el procedimiento que se recoge en http://ocs.editorial.upv.es/index.php/INRED/

\section{Editores}

Vicente Botti Navarro

Miguel Ángel Fernández Prada

\section{Editado por}

Editorial Universitat Politècnica de València, 2017

www.lalibreria.upv.es / Ref.: 6363_01_01_01

ISBN: 978-84-9048-568-2 (versión cd)

DOI: http://dx.doi.org/10.4995/INRED2017.2017.6901

\section{(c) $(1) \Theta$}

In-Red 2017 - III Congreso Nacional de Innovación Educativa y Docencia en Red de la Universitat Politècnica de València se distribuye bajo una licencia de Creative Commons Reconocimiento-NoComercial-SinObraDerivada 4.0 Internacional. Basada en una obra en http://ocs.editorial.upv.es/index.php/INRED/INRED2017 


\section{Prólogo}

Innovar, aprender y enseñar con las TIC, motivar, activar... son palabras que suenan constantemente en las tendencias actuales de la educación, en los docentes que cada día intentan mejorar y responder a unas necesidades de cambio.

INRED 2017 pretende hacerse eco de estas inquietudes y tendencias, siendo una invitación abierta a todos aquellos docentes creativos, innovadores, emprendedores... que quieran inspirar, y ser inspirados, con su trabajo, experiencia e investigación en la educación superior.

En su tercera edición, INRED tratará el aprendizaje en movimiento, tecnologías móviles, aulas abiertas, competencias, recursos tecnológicos, proyectos colaborativos en red... todo ello con la finalidad de mejorar el proceso de enseñanza-aprendizaje en los centros universitarios. Se proponen pues distintas áreas temáticas a las que esperamos se unan muchos miembros de la comunidad docente en la educación superior. 


\section{Objetivos}

- Compartir experiencias de producción de recursos tecnológicos en el aula, con el fin de servir de modelo y ayuda para la comunidad docente.

- Animar al profesorado a experimentar estrategias innovadoras que reviertan en la mejora del proceso de enseñanza-aprendizaje en la formación universitaria.

- Debatir sobre los retos actuales planteados a la universidad como institución directamente implicada en la mejora de los procesos de formación.

- Favorecer la creación de redes de trabajo e investigación conjunta de procesos innovadores en la docencia universitaria. 


\section{Editores}

Prof. Dr. Vicente Botti Navarro

Vicerrector de las Tecnologías de la Información y las Comunicaciones de la UPV

Prof. Dr. Miguel Ángel Fernández Prada

Vicerrector de Estudios, Calidad y Acreditación de la UPV

\section{Comité Ejecutivo}

Presidente: Prof. Dr. Francisco Mora Más

Rector Magnífico de la Universitat Politècnica de València

Prof. Dr. Vicente Botti Navarro

Vicerrector de las Tecnologías de la Información y las Comunicaciones de la UPV

Prof. Dr. Miguel Ángel Fernández Prada

Vicerrector de Estudios, Calidad y Acreditación de la UPV

\section{Comité Científico}

CoPresidente: José Enrique Simó Ten (Universitat Politècnica de València)

CoPresidente: Francisco Javier Oliver Villarroya (Universitat Politècnica de València)

$\mathrm{D}^{\mathrm{a}}$. Ana Rosa Abadía Valle (Universidad de Zaragoza)

D. Jesús Alba Fernández (Universitat Politècnica de València)

D. José Álvarez Teruel (Universitat d'Alacant)

$D^{a}$. Eva Antonino Daviu (Universitat Politècnica de València)

D. Rafael Balart Gimeno (Universitat Politècnica de València)

D. Pablo Beneit Mayordomo (Universitat Politècnica de València)

$D^{a}$. Ma Pilar Bonet Espinosa (Universitat Politècnica de València)

D. Ignacio Bosch Roig (Universitat Politècnica de València)

D. Juan Luis Bravo Ramos (Universidad Politécnica de Madrid)

$D^{a}$. Concepción Bueno García (Universidad de Zaragoza)

$D^{a}$. Pilar Aurora Cáceres González (Universitat Politècnica de València)

$\mathrm{D}^{\mathrm{a}}$. Ángeles Calduch Losa (Universitat Politècnica de València)

D. Andrés Camacho García (Universidad Politécnica de Madrid)

D. Francisco Javier Camacho Torregrosa (Universitat Politècnica de València)

D. David Carabantes Alarcón (Universidad Complutense de Madrid)

D. Juan Carlos Casamayor Rodenas (Universitat Politècnica de València)

D. Enrique Castaño Perea (Universidad de Alcalá de Henares)

Da. Susana Collado Vázquez (Universidad Rey Juan Carlos)

$\mathrm{D}^{\mathrm{a}}$. Alicia Cordero Barbero (Universitat Politècnica de València)

D. Antonio Cucala Felix (Universitat Politècnica de València)

D. David de Andrés Martínez (Universitat Politècnica de València)

D. Carlos Delgado Kloss (Universidad Carlos III de Madrid)

D. Josep Doménech i de Soria (Universitat Politècnica de València) 
D. Joan Domingo Peña (Universitat Politècnica de Catalunya)

$\mathrm{D}^{\mathrm{a}}$. Eva Emmanuel Martínez (Universidad del País Vasco)

D. Jaume Fabregat Fillet (Universitat Politècnica de Catalunya)

$\mathrm{D}^{\mathrm{a}}$. Ana Fernández Laviada (Universidad de Cantabria)

D. Miguel Ferrando Bataller (Universitat Politècnica de València)

D. Miguel Ángel Fortea Bagán (Universitat Jaume I)

Da. Vanessa González Fernández (Universidad de Sevilla)

$\mathrm{D}^{\mathrm{a}}$. Amparo Graciani García (Universidad de Sevilla)

$D^{a}$. Fuensanta Hernández Pina (Universidad de Murcia)

D. Adolfo Hilario Caballero (Universitat Politècnica de València)

$\mathrm{D}^{\mathrm{a}}$. Sara Ibáñez Asensio (Universitat Politècnica de València)

$D^{a}$. Noelia Ibarra Rius (Universitat de València)

D. Miguel Leiva Brondo (Universitat Politècnica de València)

$D^{a}$. Victoria Lizama Abad (Universitat Politècnica de València)

D. Martín Llamas Nistal (Universidad de Vigo)

D. Salvador Llinares Ciscar (Universitat d'Alacant)

D. Carmen Llinares Millán (Universitat Politècnica de València)

D. Faraón Llorens Largo (Universitat d'Alacant)

$\mathrm{D}^{\mathrm{a}}$. $\mathrm{M}^{\mathrm{a}}$ Gracia López Patiño (Universitat Politècnica de València)

$D^{a}$. Mercedes López Santiago (Universitat Politècnica de València)

D. Juan Antonio Marín García (Universitat Politècnica de València)

D. José Luís Martínez de Juan (Universitat Politècnica de València)

D. Víctor Martínez Gómez (Universitat Politècnica de València)

$D^{a}$. $M^{a}$ Asunción Martínez Mayoral (Universidad Miguel Hernández)

$\mathrm{D}^{\mathrm{a}}$. Susana Martínez Naharro (Universitat Politècnica de València)

$\mathrm{D}^{\mathrm{a}}$. M Jesús Martínez Usurralde (Universitat de València)

D. Germán Moltó Martínez (Universitat Politècnica de València)

$D^{a}$. Llucia Monreal Mengual (Universitat Politècnica de València)

D. Juan Antonio Monsoriu Serra (Universitat Politècnica de València)

D. Juan Carlos Morales Sánchez (Universitat Politècnica de València)

$D^{a}$. Josefa Mula Bru (Universitat Politècnica de València)

$\mathrm{D}^{\mathrm{a}}$. Teresa Pardo Vicente (Universitat Politècnica de València)

$\mathrm{D}^{\mathrm{a}}$. Esther Pérez Martell (Universidad de Las Palmas de Gran Canaria)

$\mathrm{D}^{\mathrm{a}}$. $\mathrm{M}^{\mathrm{a}}$ Asunción Pérez Pascual (Universitat Politècnica de València)

$\mathrm{D}^{\mathrm{a}}$. $\mathrm{M}^{\mathrm{a}}$ José Pérez Peñalver (Universitat Politècnica de València)

D. José Manuel Prats Montalbán (Universitat Politècnica de València)

$\mathrm{D}^{\mathrm{a}}$ Mari Paz Prendes Espinosa (Universidad de Murcia)

D. Israel Quintanilla García (Universitat Politècnica de València)

D. Miguel Rebollo Pedruelo (Universitat Politècnica de València)

$\mathrm{D}^{\mathrm{a}}$. Amparo Ribes Greus (Universitat Politècnica de València)

D. Luis José Rodríguez Muñiz (Universidad de Oviedo)

$\mathrm{D}^{\mathrm{a}}$. Francesca Romero Forteza (Universitat Politècnica de València)

D. Sixto Romero Sánchez (Universidad de Huelva)

D. José Vicente Salcedo Romero de Ávila (Universitat Politècnica de València)

$\mathrm{D}^{\mathrm{a}}$. Carla Sentieri Omarrementeria (Universitat Politècnica de València)

D. Eduardo Vendrell Vidal (Universitat Politècnica de València)

D. Jordi Vidal Perona (Universitat de València)

D. Emilio Vivancos Rubio (Universitat Politècnica de València)

D. Víctor Yepes Piqueras (Universitat Politècnica de València) 


\section{Comité Organizador}

$D^{a} . M^{a}$ Nieves Alfonso García

$\mathrm{D}^{\mathrm{a}}$. $\mathrm{M}^{\mathrm{a}}$ Pilar Bonet Espinosa

Da. Pilar Aurora Cáceres González

$D^{a}$. Susana Martínez Naharro

D. Juan Carlos Morales Sánchez 


\section{1}

Producción de recursos tecnológicos para facilitar el proceso de enseñanza-aprendizaje apps, software, espacios virtuales... 


\title{
Diseño de un video tutorial para la mejora del aprendizaje de conceptos y procedimientos difíciles en el Área de Química Analítica
}

\section{P. Parrilla Vázquez ${ }^{*}$, M.D. Gil García, M. Martínez Galera y M.J. Martínez Bueno}

Departamento de Química y Física, Área de Química Analítica, Facultad de Ciencias Experimentales, La Cañada 04120, Universidad de Almería, e-mail: parrilla@ual.es

\begin{abstract}
The study presented here examines the incorporation of a video tutorial as a supplement to learning in an advanced Instrumental Analytical Chemistry course. The video tutorial was based on "matrix effect" problem and it was designed by the instructor using audio narration from Powerpoint in the "screencast" mode. It was uploaded to the courses Web site portal (Blackboard Learn) at the University of Almeria. The video has been shown to serve as a suitable learning that prepares students for laboratory more effectively, with an average of $70 \%$ more students answering questions correctly after watching the video than after receiving only teaching assistant instruction.
\end{abstract}

Keywords: Analytical Chemistry, Matrix Effect, Screencast video

\begin{abstract}
Resumen
El estudio que se presenta examina la incorporación de un video tutorial como un suplemento para el aprendizaje en un curso avanzado de Química Analítica Instrumental. El video tutorial se basó en el problema del "efecto matriz" y fue diseñado por el profesor utilizando narración de audio a partir de Powerpoint en la modalidad de "screencast". También fue incorporado en la página Web de las asignaturas (Blackboard Learn) en la Universidad de Almería. El video demostró ser adecuado para preparar a los estudiantes de laboratorio más efectivamente, con un $70 \%$ más de estudiantes que respondieron correctamente las cuestiones después de la visualización del video, en comparación a cuando solamente recibieron la explicación del profesor en clase.
\end{abstract}

Palabras clave: Química Analítica, Efecto Matriz, video Screencast 


\section{Introducción}

En los últimos años, con las prestaciones ofrecidas por las nuevas tecnologías, están apareciendo los videos tutoriales, que son sistemas instructivos de autoaprendizaje que muestran al alumno el desarrollo de algún procedimiento o los pasos para realizar una determinada actividad (He, 2012 y Jordan, 2016). Un video tutorial se caracteriza por su facilidad a la hora de explicar conceptos o procesos complejos de manera visual y clara (Arasasingham, 2011 y Bloom, 1984).

Nuestra experiencia docente nos permite afirmar que los estudiantes, en numerosas ocasiones, presentan dificultades para comprender y relacionar determinados conceptos de Química Analítica que les permitan adquirir las competencias necesarias en las diferentes materias. Este hecho se hace más patente en la actual situación en la que, debido al diseño de los planes de estudio de Grado, las asignaturas de prácticas de Análisis Instrumental se imparten después que las teóricas, en el curso siguiente, existiendo un único instrumento por técnica, lo que impide que todos los alumnos puedan manejarlo durante las prácticas de laboratorio o, simplemente, situarse lo suficientemente cerca de él.

Actualmente, los estudiantes consiguen información a través de dispositivos electrónicos tales como ordenadores, smartphones y tabletas. Sin embargo, los mejores video tutoriales que suplementen la información recibida en las clases presenciales no siempre están disponibles para todos los usuarios, no se adaptan a la programación o competencias asignadas, o no están diseñados por profesionales con suficiente experiencia docente para facilitar el aprendizaje del estudiante.

En este trabajo se propone el diseño de un video tutorial útil para algunas materias que se imparten en el área de Química Analítica, independientemente de la asignatura y titulación. No se pretende la 
sustitución de estos contenidos por los incluidos en las clases presenciales, sino que el objetivo es que sea un modo de usar la tecnología para suplementar aquellos conceptos, técnicas y procedimientos difíciles de entender y que se describen en las clases presenciales. Por ello, el tema seleccionado se ha diseñado con este único objetivo específico y no para presentar a los estudiantes una ampliación a la programación de las asignaturas.

El material docente elaborado se ha incorporado en la plataforma Blackboard Learn de la Universidad de Almería (UAL) y se han establecido los procesos de evaluación para comparar los rendimientos y el grado de adquisición de competencias con aquellos adquiridos con la explicación tradicional en clase presencial y la lectura de libros de texto habituales.

\section{Objetivos}

El objetivo del presente trabajo consiste en la elaboración de un video tutorial sobre el problema analítico del "efecto matriz", exponiendo los aspectos relacionados con este problema, así como las distintas alternativas y procedimientos para solucionarlo. El aprendizaje de este problema analítico está incluido en diferentes asignaturas del Grado de Químicas, Ciencias Ambientales e Ingeniería Quimica. Este estudio se ha aplicado a las asignaturas "Experimentación en Química Analítica" ( $4^{\circ}$ curso del Grado en Ciencias Ambientales) y "Laboratorio de Análisis Aplicado" (4 curso del Grado de Químicas), quedando posteriormente el material elaborado a disposición de poder ser aplicado en otras asignaturas.

\section{Desarrollo de la innovación}


En el procedimiento de trabajo se incluyen las siguientes etapas: a) Selección de los conceptos, procedimientos y técnicas difíciles de asimilar, b) Preparación del video tutorial, c) Desarrollo de instrumentos de evaluación que permitan evaluar la adquisición de competencias específicas y transversales de la materia tratada, los cuales serán utilizados antes y después de la aplicación del material elaborado, d) Aplicación del video tutorial elaborado, e) Evaluación de los resultados obtenidos y f) Validación del material elaborado.

El estilo del video tutorial se ha basado en la voz, texto escrito, gráficos e imágenes que se han organizado convenientemente para favorecer el aprendizaje de los alumnos.

Desde el punto de vista técnico, el video elaborado se ha grabado en la modalidad de "Screencast" conteniendo narración de audio a partir de Powerpoint.

El video tutorial se encuentra a disposición de todos los estudiantes, quienes podrán decidir su necesidad de utilizarlo o no, así como cuando y donde, según sus propias necesidades.

\section{Resultados}

Los conceptos tratados en el presente video han sido objeto de cuestiones que fueron completadas por los alumnos tras recibir las correspondientes explicaciones en clases presenciales siguiendo el método tradicional y después de visualizar el video. De esta forma, se valoraron las dificultades encontradas por los alumnos en la comprensión de estos conceptos antes y después de utilizar el material elaborado.

\subsection{Asignatura "Laboratorio de Análisis Aplicado"}


Los conocimientos de los alumnos sobre el efecto matriz se han evaluado a través de un cuestionario con 15 preguntas tipo test. El video se aplicó a un grupo de practicas de laboratorio de 10 alumnos. Previamente a la visualización del video los alumnos realizaron el cuestionario en clase y solamente 2 de los 10 alumnos superaron el examen con calificaciones de 6.0 y 5.3 sobre 10 . Posteriormente, se incluyó el video y el cuestionario nuevamente en la página web de la asignatura a través de la plataforma Blackboard Learn y, tras su visualización, todos los alumnos participantes superaron el examen, mejorando en todos los casos su calificación con la excepción de uno, que repitió la calificación de 3.3. Las calificaciones fueron las siguientes: 3 alumnos con una calificación de Aprobado (5.3, 5.3 y 6.7), 3 alumnos con calificación de Notable $(8.0,8.0$ y 8.7) y 3 alumnos con una calificación de sobresaliente (9.3 en todos los casos). En la Figura 1 se muestran de forma comparativa las calificaciones obtenidas por los alumnos antes y después de la visualización del video.

\section{CALIFICACIONES}

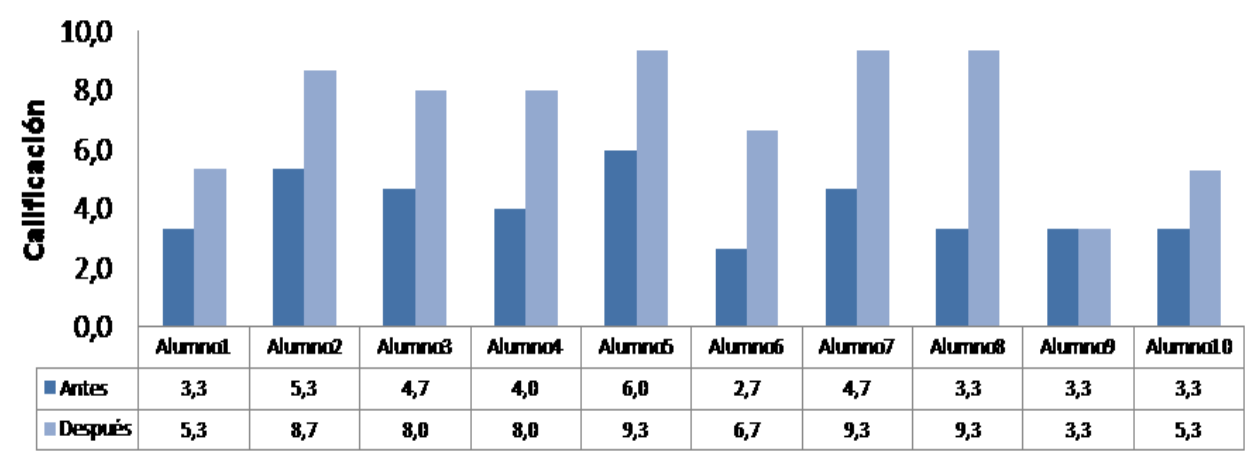

Figura 1. Calificaciones obtenidas por los alumnos antes y después de la visualización del video 


\section{En relación al examen, constaba de 15 cuestiones sobre el efecto matriz,} que se muestran a continuación:

1. ¿Cuál de las siguientes definiciones del Efecto Matriz es la correcta?

a) Señal analítica debida a un compuesto o varios compuestos que contiene la muestra problema.

b) Variación de la concentración del analito en la muestra debido a la presencia de otros compuestos.

c) Variación significativa de la señal del analito en una muestra con respecto a la señal del analito en disolvente.

d) Presencia de una señal en la muestra diferente a la del analito que origina un incremento en su señal.

2. ¿Cómo se determina cuantitativamente el efecto matriz (ME)?

a) Comparando las señales que se obtienen en un blanco de muestra con las señales que se obtienen en un blanco de disolvente.

b) Comparando las pendientes de las rectas de calibrado preparadas con patrones en disolvente y en extracto blanco de matriz

c) Comparando tanto las pendientes como las ordenas en el origen de las rectas de calibrado preparadas con patrones en disolvente y en matriz.

d) Comparando la señal de un patrón del analito en disolvente y en la muestra real.

3. ¿Cuándo se considera que no existe ME?

a) Cuando la señal medida de una concentración de analito en la muestra es significativamente mayor que su señal en disolvente.

b) Cuando se produce un incremento en la señal del analito en la muestra con respecto a la señal que se obtiene en disolvente.

c) Cuando existe tanto un incremento como una disminución de la señal del analito en disolvente con respecto a la señal que se obtiene en una muestra.

d) Cuando las señales del analito en disolvente y en extracto blanco de muestra no son significativamente diferentes.

4. ¿Cuándo existe un fuerte efecto de la matriz sobre la señal del analito?

a) $\mathrm{ME}(\%)<50 \%$

b) $\mathrm{ME}(\%)>\mid \pm 50 \%$

c) $10 \%<\operatorname{ME}(\%)<50 \%$

d) $\mathrm{ME}(\%)< \pm 50 \%$

5. ¿Cómo se define interferencia en Química Analítica?

a) Componente de la muestra que presenta una señal que interfiere en la señal del analito y que origina tanto errores aleatorios como si stemáticos.

b) Componente de la muestra que presenta una señal que interfiere en la señal del analito y que afecta solo su identificación.

c) Componente de la muestra que no se puede detectar pero que interfiere solo en la identificación del analito.

d) Componente de la muestra que presenta una señal que interfiere en la señal del analito y que afecta solo a la cuantificación del analito.

6. ¿Cuál de las siguientes afirmaciones en espectrometría de masas en tándem (MS/MS) acerca del efecto que tiene la presencia de interferencias en la medida de un analito no es correcta?

a) La presencia de interferencias en la muestra puede originar un falso positivo.

b) La presencia de interferencias en la muestra puede originar un falso negativo.

c) La presencia de interferencias en la muestra causas problemas en la identificación y/o cuantificación del analito.

d) La presencia de interferencias origina errores proporcionales a la concentración de analito.

7. ¿Cuándo se dice que el resultado de un análisis es un falso negativo en MS/MS?

a) El analito está presente en la muestra pero a una concentración por debajo del límite de detección.

b) El analito no está presente en la muestra pero se observa una de las dos transiciones al mismo tiempo de retención.

c) El analito está presente en la muestra pero debido a la presencia de interferencias no se cumplen los criterios de identificación.

d) El analito y la interferencia eluyen al mismo tiempo de retención aunque no tienen transiciones en común. 
8. ¿Cuáles son los principales factores que causan efecto matriz en la detección mediante MS?

a) La fuente de ionización.

b) El tipo de espectrómetro de masas.

c) Las condiciones del espectrómetro de masas.

d) Todas las respuestas son correctas.

9. Indica cuál de las siguientes afirmaciones es correcta.

a) En GC-MS la señal del analito en la muestra se incrementa debido a la interacción de los componentes de la matriz con los sitios activos del inyector.

b) En LC-MS se origina principalmente el incremento de la señal del analito en la muestra

c) El fenómeno de supresión de la señal se origina principalmente en GC-MS.

d) La supresión de la señal depende de la naturaleza del analito y no de la técnica de análisis.

10. ¿Cuáles son las zonas del cromatograma donde se observa generalmente un mayor efecto matriz?

a) La primera parte del cromatograma es la única en la que aparecen los componentes de la matriz.

b) La parte central del cromatograma debido a que eluyen la mayor parte de componentes de la matriz.

c) La parte final del cromatograma es la que presenta un mayor efecto matriz debido a los componentes menos retenidos.

d) Ninguna de las respuestas es correcta.

11. Indica cuál de las siguientes estrategias puede reducir el efecto matriz

a) Cuantificar los analitos en las muestras usando curvas de calibrado preparadas con extracto blanco de matriz.

b) Modificar las condiciones del sistema de LC o GC hasta conseguir la separación de los analitos del resto de componentes de la matriz.

c) Añadir un estándar interno que eluya al tiempo de retención del analito.

d) Cuantificar los analitos con el método de adición de estándar.

12. Indica cuál de las siguientes afirmaciones en el análisis mediante LC-MS es correcta

a) El ME depende del analito y se origina principalmente en el sistema de inyección.

b) El ME depende del analito y se origina en las primeras etapas del proceso de ionización.

c) El ME no depende del analito sino que su efecto produce una disminución constante de la señal del analito.

d) El ME depende del analito siendo el incremento de la señal el efecto más común.

13. Una de las estrategias para reducir las interferencias de matriz es incluir etapas de limpieza más efectivas. Indica cuales son los principales inconvenientes que conlleva la inclusión de esta etapa

a) Se incrementa el tiempo pero se reduce el coste del análisis.

b) Se incrementa el tiempo pero mejoran las recuperaciones.

c) Se incrementa el tiempo y el coste del análisis pero se pueden producir pérdidas de los

d) Siempre se produce pérdida de los analitos.

14. ¿Cuál es el método más eficaz y que presenta menos inconvenientes para compensar el $\mathrm{ME}$ en el análisis de residuos de pesticidas en aguas de diferente naturaleza?

a) Curva analítica.

b) Curva de calibrado en matriz.

c) Adición de estándar.

d) Adición de estándar interno.

15. Una de las técnicas utilizadas para reducir el efecto matriz en GC consiste en la adición de protectores del analito. Indique la opción correcta

a) Los agentes protectores solo se añaden a las muestras y no a los patrones de calibrado.

b) El agente protector debe interaccionar con el analito y no con el resto de componentes de la matriz.

c) Los agentes enmascarantes interaccionan con los sitios activos del sistema de GC.

d) Todas las respuestas son correctas. 
En la Figura 2 se muestra de forma comparativa el porcentaje de aciertos antes y después de la visualización del video para cada una de las cuestiones.

\section{PORCENTAJE DE ACIERTOS}

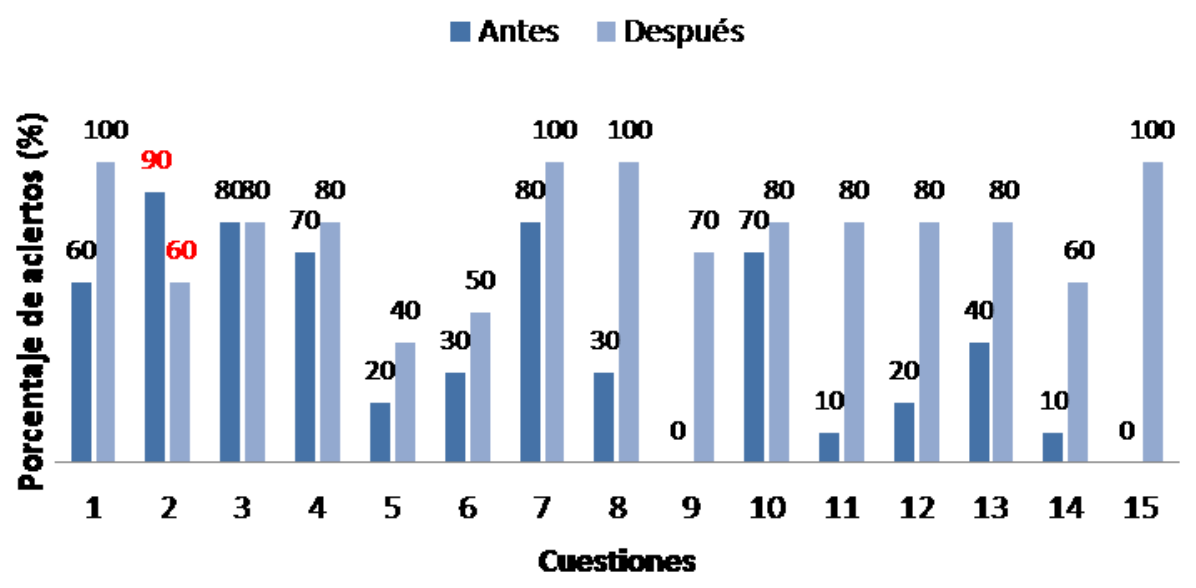

Figura 2. Porcentaje de aciertos antes y después de la visualización del video

Antes de la visualización del video ningún alumno contestó correctamente dos de las cuestiones del test (Cuestiones 9 y 15), teniendo el mayor número de aciertos las Cuestiones 2, 3, 4 y 7 con un 90\% la Cuestión 2, 80\% las Cuestiones 3 y 7, y $70 \%$ la Cuestión 4. Sin embargo, como se ha mencionado anteriormente, tras la visualización del video el porcentaje de aciertos se incrementó en todos los casos, con la excepción de uno de los alumnos que obtuvo el mismo número de aciertos antes y después de la visualización.

En relación a las cuestiones planteadas, todos los alumnos después de visualizar el video contestaron correctamente 4 de las cuestiones del test (Cuestiones 1, 7, 8 y 15), 6 de las cuestiones (Cuestiones 3, 4, 10, 11, 12 y 13) fueron contestadas correctamente por el $80 \%$ de los alumnos, 2 de 
las cuestiones (Cuestiones 9 y 14) las contestaron correctamente el 70 y $60 \%$ de los alumnos, respectivamente y solo 2 de las Cuestiones (Cuestiones 5 y 6) las contestaron correctamente el 40 y $50 \%$ de los alumnos, respectivamente.

En la Figura 2, puede observarse que el uso del video mejoró en la mayoría de los casos el número de aciertos, principalmente en el caso de la Cuestión 15 que antes de la visualización del video fue contestada incorrectamente por todos los alumnos y tras la visualización el número de aciertos fue del $100 \%$. Otro ejemplo que es posible destacar son las Cuestiones 9, 12, 14 y 15, en las que más del $50 \%$ de los alumnos mejoraron. En cuanto a la Cuestión 3, puede observarse que fue la única cuestión que obtuvo el mismo porcentaje de aciertos (80\%) antes y después de la visualización, pudiendo deducirse que en ningún caso el video consiguió la asimilación correcta del contenido al que se refiere la Cuestión 3.

Por último, hay que hacer notar los resultados obtenidos en la Cuestión 2, la cual fue respondida correctamente antes de la visualización del video por el $90 \%$ de los alumnos y tras ver el video el número de aciertos descendió y tan solo el $60 \%$ de los alumnos la contesto correctamente.

Estudiando con más detalle la Cuestión 2 que se muestra a continuación:

2. ¿Cómo se determina cuantitativamente el efecto matriz (ME)?

a) Comparando las señales que se obtienen en un blanco de muestra con las señales que se obtienen en un blanco de disolvente.

b) Comparando las pendientes de las rectas de calibrado preparadas con patrones en disolvente y en extracto blanco de matriz

c) Comparando tanto las pendientes como las ordenas en el origen de las rectas de calibrado preparadas con patrones en disolvente y en matriz.

d) Comparando la señal de un patrón del analito en disolvente y en la muestra real.

La respuesta correcta es la opción b), sin embargo todos los alumnos que respondieron incorrectamente dicha cuestión marcaron como respuesta correcta la opción c). La determinación cuantitativa del efecto matriz se aborda en el video, diferenciando entre el concepto de interferencia de 
matriz que causa normalmente un incremento constante de la señal del analito y que es independiente de la concentración y por tanto solo afecta a la ordenada en el origen de la recta de calibrado y el concepto de efecto matriz que afecta a la señal del analito en la muestra y que varía con la concentración, afectando a la pendiente de la recta de calibrado. La justificación de este resultado puede ser debida a que en la respuesta c) se comparan dos parámetros, ordenada en el origen y pendiente, frente a la respuesta $b$ ) donde solo se compara un parámetro, la pendiente. Si no se tiene claro qué opción elegir, el alumno optará por la respuesta c) por ser más global. Posiblemente, sea necesario clarificar un poco más en el video el concepto tratado en esta cuestión.

\subsection{Asignatura "Experimentación en Química Analítica"}

Se trata de una asignatura de carácter práctico impartida en $4^{\circ}$ curso del Grado en CCAA. En esta asignatura se aborda el problema del efecto matriz utilizando el método de la adición de patrón en la determinación de hierro en vinos mediante espectrofotometría UV-Vis. Aunque en el programa de la asignatura teórica "Análisis Instrumental” se explica la calibración mediante la adición de patrón o adición de estándar para corregir problemas relacionados con el efecto de la matriz de la muestra sobre la señal del analito, en un seminario previo a dicha práctica se les explica a los alumnos el problema del "efecto matriz", considerándolo con un enfoque más amplio.

En este sentido, es importante señalar que el video elaborado sobre el "efecto matriz", aborda esta problemática en profundidad cubriendo así los objetivos de un curso avanzado de Análisis Instrumental, incluyendo las técnicas cromatográficas acopladas a la Espectrometría de Masas. Sin embargo, esta técnica no se incluye en la única asignatura de Análisis Instrumental cursada por los alumnos de Ciencias Ambientales, 
por lo que los conocimientos de estos alumnos sobre el efecto matriz se evaluaron a través de un cuestionario con 5 preguntas tipo test, excluyendo las preguntas que requieran el conocimiento de la técnica de Espectrometría de Masas.

Previamente a la visualización del video el único alumno matriculado en la asignatura realizó el cuestionario en clase superando el examen con una calificación de 6.0 sobre 10. Posteriormente, se incluyó el video y el cuestionario nuevamente en la página web de la asignatura a través de la plataforma Blackboard Learn y, tras la visualización del video, la calificación obtenida mejoró considerablemente hasta un sobresaliente (10.0).

El examen constaba de 5 cuestiones sobre el efecto matriz, que se muestran a continuación:

1. En el caso de que exista efecto matriz sobre la señal del analito, ¿a qué sería debido?

a) A los compuestos de la matriz

b) A interferencias en el disolvente

c) A interferencias de la matriz y el disolvente

d) Todas las respuestas son incorrectas

2. ¿Qué efectos produce el efecto matriz en la señal de los analitos?

a) Siempre se produce una disminución de la señal

b) Siempre se produce un aumento de la señal

c) Variación de la respuesta del analito en presencia de matriz con respecto a la respuesta en disolvente

d) El efecto matriz no produce variación de la señal

3. ¿Cómo se puede reducir el efecto matriz?

a) El efecto matriz es imposibe de reducir

b) Una posible solución sería mejorar el paso de limpieza y diluir el extracto de la muestra

c) Una solución sería preconcentrar la muestra

d) La única solución sería diluir el extracto de la muestra

4. ¿Cuándo se debe usar el método de la adición de patrón para el análisis de una muestra real?

a) Cuando exista efecto matriz y sea difícil conseguir una matriz que esté libre de los analitos de interés

b) Cuando no exista efecto matriz

c) Cuando exista efecto matriz y se tengan muchas muestras que analizar

d) Cuando exista efecto matriz y tengamos poca cantidad de muestra real

5. ¿Cuándo se considera un efecto matriz suave?

a) $\mathrm{ME}(\%)<-20 \%$

b) $-20 \%<\mathrm{ME}(\%)<+20 \%$

c) $\mathrm{ME}(\%)<50 \%$

d) $-30 \%<\mathrm{ME}(\%)<30 \%$ 
Antes de la visualización del video el alumno contestó correctamente tres de las cuestiones del test (Cuestiones 1, 2 y 4). Sin embargo, tras la visualización de video el alumno contestó correctamente las 5 cuestiones del test. En el caso de la Cuestión 3 (¿Cómo se puede reducir el efecto matriz?), el video muestra los diferentes métodos para reducir o compensar el efecto matriz del forma gráfica y clara, lo que ha permitido la asimilación de estos procedimientos y, por tanto, la contestación correcta de esta pregunta. En relación a la Cuestión 5 (¿Cuándo se considera un efecto de la matriz suave?), se trata de un aspecto memorístico que igualmente, con la visualización del video quedó completamente aprendido.

\section{Conclusiones}

Se ha elaborado un video tutorial sobre el "efecto matriz" donde se exponen los conceptos relacionados con este problema, así como las hipótesis que lo justifican y los distintos procedimientos para reducirlo o compensarlo. El video se ha aplicado en las asignaturas "Laboratorio de Análisis Aplicado" (4 $4^{\mathrm{o}}$ curso del Grado de Químicas) y "Experimentación en Química Analítica" (4 ${ }^{\circ}$ curso del Grado en Ciencias Ambientales), comprobándose que mejora efectivamente el aprendizaje del citado concepto, introduciendo a los estudiantes en un curso avanzado de Análisis Instrumental moderno.

\section{Referencias}

Arasasingham, R.D., Martorell, I. y McIntire, T. (2011). En J. College Sci. Teach., vol. 40, p. 70-79.

Bloom, B.S. (1984). En Educ. Res., vol. 13, p. 4-16. 
He, Y., Swenson, S. y Lents N. (2012). “On line video tutorials increase learning of difficult concepts in an undergraduate Analytical Chemistry course" en J. Chem. Educ., vol. 89, p. 1128-1132.

Jordan, J.T., Box, M.C., Eguren, K.E., Parker, Th.A., Saraldi-Gallardo, V.M., Wolfe, M.I. y Gallardo-Williams, M.T. (2016). "Effectiveness of student-generated video as a teaching tool for an instrumental technique in the Organic Chemistry laboratory" en J. Chem. Educ., vol. 93, p. 141145. 


\title{
Un simulador para asistir en la enseñanza del teorema de Bayes*
}

\author{
María Jesús Bárcena ${ }^{1}$, María Araceli Garín ${ }^{1}$, Ana Martín ${ }^{1}$, Fernando \\ Tusell $^{1,3}$ y Aitziber Unzueta ${ }^{2}$ \\ ${ }^{1}$ Dpto. Economía Aplicada 3 (Econometría y Estadística), UPV-EHU \\ ${ }^{2}$ Dpto. Matemática Aplicada, Estadística y Computación, UPV-EHU \\ ${ }^{3}$ Autor al que dirigir correspondencia
}

\begin{abstract}
Teaching some basic concepts in Statistics greatly benefits from individual practice with immediate feedback. In order to provide such practice to a large number of students we have writen a simulator described below, first of a planned series of teaching aids. It is designed to assist in the teaching of Bayesian concepts and, in particular, to instill in students the idea that probabilities can change as evidence accumulates.
\end{abstract}

Keywords: Bayesian statistics, Statistics, simulator.

\begin{abstract}
Resumen
La enseñanza de algunos conceptos básicos de Estadística se beneficia de prácticas individuales con realimentación inmediata. Para poder llevarlas a cabo con un gran número de alumnos hemos escrito un simulador que se describe a continuación, primero de una serie que planeamos. Su propósito es incrementar la familiaridad de los estudiantes con conceptos básicos de la estadística bayesiana; en particular, familiarizarles con la idea de que las probabilidades cambian a medida que la información aumenta.
\end{abstract}

Keywords: estadística bayesiana, Estadística, simulador.

\footnotetext{
*Este proyecto ha contado con una subvención del SAE de la Universidad del País Vasco (UPVEHU), en la convocatoria 2015-2017 de Programas de Innovación Educativa.
} 


\section{Introducción}

El teorema de Bayes, expresable en su forma más simple mediante la igualdad

$$
P(A \mid B)=\frac{P(B \mid A) P(A)}{P(B)}
$$

permite "invertir" probabilidades: de la probabilidad condicional de $B$ dado $A$ y las respectivas marginales permite pasar a la probabilidad condicional de $A$ dado $B$.

Muchos ejemplos pueden ser utilizados para imbuir en los estudiantes la importancia práctica de (1). El de la diagnosis médica es uno: la probabilidad $P(A \mid B)$ de padecer la enfermedad $A$ dada la presencia del síntoma $B$ puede obtenerse en términos de la probabilidad del síntoma dada la enfermedad, $P(B \mid A)$, y de las respectivas probabilidades marginales de enfermedad y síntoma, $P(A)$ y $P(B)$.

Adquirir familiaridad con los conceptos involucrados - en particular, asimilar que en el enfoque bayesiano la probabilidad es un grado subjetivo de creencia, que cambia a la luz de la evidencia disponible - requiere interacción repetida con (1), más allá de la que un ejemplo en clase permite adquirir. El asignar ejercicios en clase para ser realizados por los alumnos y luego corregidos es una posibilidad, pero muy costosa en tiempo para el profesorado y sólo proporciona realimentación diferida a los alumnos.

El simulador que se describe a continuación proporciona una alternativa. Construido sobre una historia real que admite un tratamiento simple, obliga al estudiante a familiarizarse con la actualización de distribuciones a priori a medida que nueva información se hace disponible, le proporciona realimentación inmediata cuando lo hace mal, y ello sin una carga agobiante sobre el profesorado.

La Sección 2 describe la historia que hemos utilizado, en una recreación simplificada, como motivación de un juego en que los estudiantes deben encontrar un submarino perdido. La Sección 3 describe la implementación, incluyendo cuestiones como coste, escalabilidad y seguridad. La Sección 5 incluye algunos comentarios sobre el papel que atribuimos a este tipo de simuladores en nuestra enseñanza.

\section{La pérdida del USS Scorpion}

\subsection{La historia}

El USS SCORPION fue un submarino nuclear de ataque en la Armada de los Estados Unidos. Desapareció el 22 de mayo de 1968, en las proximidades del archipiélago de las Azores, cuando retornaba a su base en Norfolk tras una misión. Las causas son todavía inciertas: se especuló con una explosión, la accidental activación de un torpedo, un encuentro con buques soviéticos y diversos fallos mecánicos.

Cuando transcurrieron varios días sin contacto y se hizo evidente que algo había acontecido, se inició la búsqueda del submarino. La zona contigua a la última posición conocida se dividió en 400 sectores, a cada uno de los cuales se asignó una probabilidad a priori de albergar el buque, basada en la opinión de expertos acerca de las posibles causas, reacciones probables del capitán ante cada una, régimen de corrientes, etc. 
La búsqueda se realizó utilizando métodos bayesianos, con asesoramiento de estadísticos. Tales métodos habían sido ya puestos en práctica con éxito en la búsqueda de una bomba nuclear accidentalmente caída cerca de Palomares, en España, en 1966.

Tras varios meses de búsqueda, el USS SCORPION fue localizado en octubre de 1968, a más de 3000m de profundidad y a unas 400 millas náuticas de las Azores.

(Cressie y Wikle 2011) y (McGrayne 2012) ofrecen descripciones de la búsqueda del USS SCORPION con atención a los aspectos estadísticos. La Wikipedia también ofrece una historia detallada y enlaces a otras fuentes de información. Una referencia interesante, más técnica, es (Davey y col. 2016), mostrando las técnicas de búsqueda bayesianas empleadas en el caso de vuelo Malaysian Air Lines MH370, desaparecido en 2014. Nuestra presentación de la teoría relevante sigue estrechamente la primera referencia.

\subsection{Aproximación bayesiana a la búsqueda}

Sea $Y_{i}$ una variable aleatoria con dos estados: $Y_{i}=0$ significa "El submarino está presente en el sector $i . "$ mientras $Y_{i}=1$ significa lo contrario.

Análogamente, sea $X_{i}$ una variable aleatoria codificando el resultado de rastrear el sector $i$ : $X_{i}=0$ si el submarino no se localiza en dicho sector y $X_{i}=1$ cuando sí se localiza.

Claramente $X_{i}$ depende de $Y_{i}$ :

- Si el submarino no está presente en el sector $i$-ésimo, no lo podemos localizar allí:

$$
P\left(X_{i}=1 \mid Y_{i}=0\right)=0 .
$$

- Si, por el contrario, sí que está en el sector $i$-ésimo, la probabilidad de localizarlo allí es $p$ :

$$
P\left(X_{i}=1 \mid Y_{i}=1\right)=p .
$$

Un rastreo del sector correcto no está garantizado que tenga éxito: $p<1$ : podemos no localizar el submarino en un rastreo del sector $i$-ésimo aunque realmente esté allí.

Supongamos que la probabilidad a priori de encontrar el submarino en el sector $i$ ésimo es $\pi_{i}$; si rastreamos dicho sector sin éxito, la probabilidad a posteriori de que el submarino esté allí es, utilizando (1):

$$
\begin{aligned}
P\left(Y_{i}=1 \mid X_{i}=0\right) & =\frac{P\left(X_{i}=0 \mid Y_{i}=1\right) P\left(Y_{i}=1\right)}{P\left(X_{i}=0\right)} \\
& =\frac{P\left(X_{i}=0 \mid Y_{i}=1\right) P\left(Y_{i}=1\right)}{P\left(X_{i}=0 \mid Y_{i}=0\right) P\left(Y_{i}=0\right)+P\left(X_{i}=0 \mid Y_{i}=1\right) P\left(Y_{i}=1\right)} \\
& =\frac{(1-p) \pi_{i}}{\left(1-\pi_{i}\right)+(1-p) \pi_{i}} \\
& =\pi_{i} \frac{(1-p)}{1-p \pi_{i}}
\end{aligned}
$$


Llamamos la atención de los estudiantes sobre el hecho de que una búsqueda infructuosa del sector $i$-ésimo no excluye la posibilidad de que realmente esté allí, pero hace la probabilidad a posteriori más pequeña que la probabilidad a priori: el ratio

$$
\frac{(1-p)}{1-p \pi_{i}}
$$

que multiplica a $\pi_{i}$ en (2) es menor que 1 , y tanto menor cuanto mayor sea $p$. Como consecuencia de un rastreo infructuoso del sector $i$ las probabilidades de los demás también se modifican. Para $j \neq i$ tenemos:

$$
\begin{aligned}
P\left(Y_{j}=1 \mid X_{i}=0\right) & =\frac{P\left(X_{i}=0 \mid Y_{j}=1\right) P\left(Y_{j}=1\right)}{P\left(X_{i}=0\right)} \\
& =\frac{1 \times \pi_{j}}{1-p \pi_{i}} \\
& =\pi_{j} \frac{1}{1-p \pi_{i}}
\end{aligned}
$$

De nuevo como la intuición sugiere, el hecho de que el submarino no ha sido encontrado en un rastreo del sector $i$ incrementa nuestra creencia de que puede encontrarse en algún otro sector $j, j \neq i$, pues el factor que multiplica la probabilidad a priori $\pi_{j}$ en (3) es mayor que 1.

\section{El simulador: uso e implementación}

\subsection{Objetivos condicionando el diseño}

El objetivo no es construir una herramienta para enseñar, sino para adquirir familiaridad con algo ya aprendido, aunque quizá no completamente asimilado e internalizado. En consecuencia, la escasa teoría relevante (básicamente el contenido de la Sección precedente) se presenta en clase y previamente al uso del simulador se entrega a los estudiantes un guión describiendo su funcionamiento.

Un requerimiento era que el simulador había de construirse con los recursos disponibles, sin necesitar mano de obra especializada o hardware adicional. En la práctica, ello supone que había de ser programado por nosotros y debía funcionar sobre alguno de los servidores del Departamento, sin cargar en exceso los mismos ni perturbar sus otras funciones. Fue preciso algún aprendizaje de JAVASCRIPT por nuestra parte, al concluirse tempranamente que ésta era la herramienta adecuada.

Finalmente, otro de los requerimientos condicionando el diseño es que había de servir a un número elevado de estudiantes, geográficamente dispersos. Esto reduce las opciones a un simulador basado en una página web, que no requiera instalación de ningún software en la máquina cliente y pueda correr en cualquier navegador con JAVASCRIPT activado. 


\subsection{Implementación}

Se ha programado un simulador que enfrenta al estudiante a las mismas decisiones que hubo de tomar el equipo de búsqueda del USS SCORPION, pero en una situación simplificada: en lugar de los 400 sectores en que se dividió la zona de búsqueda, sólo nueve se presentan por el simulador sobre un mapa (ver Figura 1).

\section{Fig. 1: Pantalla inicial del simulador}

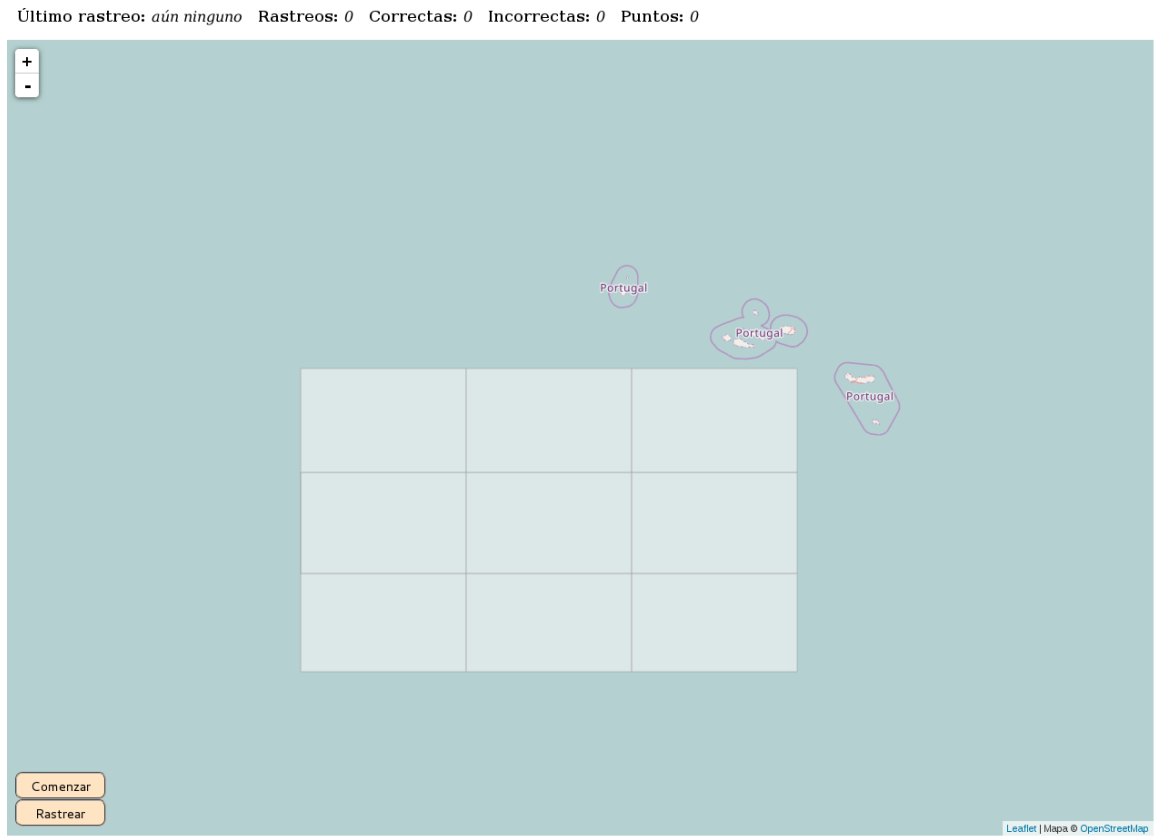

Para arrancar el simulador, el estudiante debe pinchar el botón COMENZAR en el margen inferior izquierdo del mapa. El simulador entonces genera una nueva instancia del juego asignando probabilidades a priori a los nueve sectores rastreables, los representa en un mapa y coloca la silueta de un buque de búsqueda junto a la esquina sudeste del área rastreable (Figura 2).

Un click en cualquiera de los sectores proporciona información sobre su probabilidad $a$ priori en cualquier momento. Esta probabilidad se codifica también como saturación de color en una paleta de verdes ${ }^{1}$.

La primera búsqueda es trivial: simplemente basta seleccionar el sector con la mayor probabilidad a priori. Para ello, el estudiante sólo debe arrastrar el buque de búsqueda al sector correspondiente y hacer click sobre él, o sobre el botón RASTREAR en la esquina inferior izquierda: esta última alternativa se ha mostrado necesaria en algunas tabletas con pantallas pequeñas.

Después de cada elección del estudiante, el simulador actualiza las cabeceras con el último sector rastreado, número de rastreos "correctos" e "incorrectos" y puntos

${ }^{1}$ Una diferente paleta apta para daltónicos está también disponible, si la necesidad surge. 
obtenidos. Un rastreo es "correcto" si se realiza sobre el sector que más probablemente puede contener el submarino.

El simulador informa al estudiante cuándo el submarino es encontrado, lo que da fin al juego, o actualiza las probabilidades de cada sector y permite al estudiante seguir la búsqueda. Estas probabilidades actualizadas, sin embargo, no se muestran ni se modifica la coloración de cada sector en la pantalla de inmediato. La pantalla siempre muestra las probabilidades a priori ANTES de realizado el último rastreo. Es misión del estudiante el actualizarlas mediante las fórmulas (2)-(3).

Puede indicarse a los estudiantes, o dejar que lo descubran por si mismos, que en cada etapa tienen sólo dos posibilidades potencialmente correctas: el último sector rastreado - que incluso después de una búsqueda infructuosa podría seguir siendo el más prometedor - o aquél de los no rastreados que previamente al último rastreo tenía máxima probabilidad a priori — pues la actualización bayesiana opera multiplicando todas las probabilidades a priori de los sectores no rastreados por el mismo factor, y por tanto preserva su orden; véase (3)-.

El juego finaliza con el hallazgo del submarino y la oferta al estudiante de guardar la puntuación obtenida (cociente de rastreos correctos entre rastreos efectuados en una escala de 10, o como se determine). La puntuación no depende de lo larga que sea la búsqueda, sino de la corrección de las decisiones tomadas. Es opción del profesor dar a los estudiantes un sólo acceso al juego o (como nosotros preferimos) darles opción de jugar repetidamente, conservando sólo su última nota.

Fig. 2: Pantalla del simulador, iniciado el juego y antes de la primera búsqueda. El barco de búsqueda puede verse en la esquina sudeste. El usuario ha hecho click sobre uno de los sectores, lo que abre una lengüeta mostrando su probabilidad a priori. Tonalidades de verde más oscuro codifican mayores probabilidades a priori.

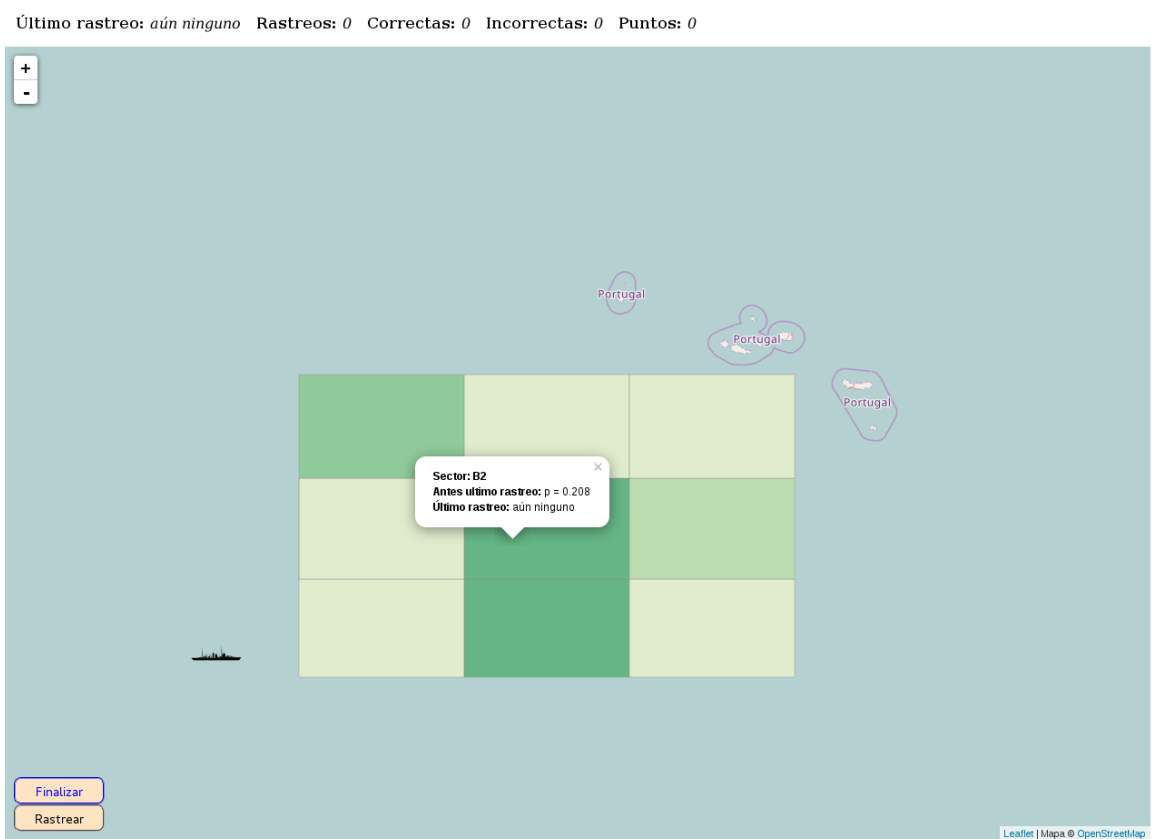




\subsection{Aspectos de la implementación}

Cuando por primera vez pensamos en este proyecto, concebimos una página web en $\mathrm{PHP}^{2}$, principalmente porque esta era la técnica empleada en otros proyectos previos. En nuestros intentos de representar un mapa y situar objetos en él, pronto reparamos en la simplicidad y elegancia del la librería LEAFLET ${ }^{3}$, escrita en JAVASCRIPT. El uso de LEAFLET libera de las complejidades asociadas a la representación espacial, proyecciones, zoom, etc. y permite descargar teselas de lugares públicos sin coste. Esto nos permite concentrarnos en los aspectos puramente estadísticos de la simulación. Adicionalmente, JAVASCRIPT es un lenguaje maduro, expresivo y desarrollado, que proporciona todas las facilidades requeridas para un proyecto de esta naturaleza (generador de números aleatorios, coma flotante, etc.).

Hay una ventaja adicional en el uso de JAvascript. A diferencia de PHP, que se ejecuta íntegramente en el servidor, JAVASCRIPT es interpretado y ejecutado en las máquinas clientes, sin requerir más que un navegador razonablemente actual y con JAVASCRIPT activado. Esto hace que nuestra aplicación sea escalable prácticamente sin límites. Podemos servir a números muy grandes de estudiantes, incluso con recursos de servidor y caudal de red moderados. La única carga significativa sobre el servidor se produce al inicio, con la descarga de la página web y librerías de soporte (que pueden descargarse también de lugares alternativos y en todo caso permanecen en cache para sucesivas ejecuciones). Al final del juego, las puntuaciones de los estudiantes deben ser guardadas, pero esto es una demanda infrecuente (e insignificante) sobre el servidor.

Hay un posible inconveniente en el uso de JAVASCRIPT. El hecho de que es un lenguaje interpretado que se ejecuta en la máquina cliente significa que el programa puede ser inspeccionado por el usuario. Esto puede dificultarse ofuscando la fuente o cargándola en forma pre-procesada (en un fichero $\cdot j \mathrm{j}$ ); pero es cierto que un usuario técnicamente competente y con la suficiente determinación y tenacidad puede acceder a la fuente si se lo propone.

Esto probablemente no representa un problema en una aplicación como la nuestra. Las vulnerabilidades de seguridad sólo son de temer cuando los incentivos exceden el coste de del ataque preciso. Dado el muy modesto esfuerzo que requiere la actividad que este simulador propone al alumnado, no es verosímil que nadie intente invertir mucho tiempo y energía en vulnerar el código, máxime en presencia de una política como la nuestra de "juega cuanto quieras hasta que tu nota sea óptima". No obstante, la posibilidad existe.

En algunos detalles de la implementación se ha hecho "trampa". El submarino no está desde el principio en ningún sitio. Lo que aleatorizamos es el número de rastreos que el estudiante deberá efectuar: esto es para evitar la posibilidad de un hallazgo al primer intento, que privaría al estudiante de la oportunidad de practicar lo que queremos que practique - y a nosotros de la oportunidad de comprobar que lo ha hecho con corrección-. En todo evento, el estudiante deberá al menos realizar seis rastreos. Esto es fácil de cambiar.

\footnotetext{
${ }^{2}$ Véase por ejemplo https:/secure.php.net. Visitada el 8 de marzo de 2017.

${ }^{3}$ Ver http://leafletjs.com. Visitada el 8 de marzo de 2017.
} 
Otro aspecto que el profesor puede desear ajustar es el valor del parámetro $p$-la probabilidad de éxito al rastrear el sector correcto. Se sigue del párrafo precedente que no tiene ninguna influencia sobre la duración del juego; pero si la tiene - y muy grande - sobre la actualización del las probabilidades a priori. Si $p$ se fija muy grande, un rastreo infructuoso reduce drásticamente la probabilidad a posteriori de que el sector rastreado albergue el submarino. La elección subsiguiente por tanto será casi invariablemente el sector con mayor probabilidad a priori antes del último rastreo. Los estudiantes no tardarán en detectar la pauta, que permite jugar sin hacer recurso a las fórmulas (2)-(3) - lo que desvirtúa la finalidad didáctica del simulador- Es por ello aconsejable fijar $p$ no muy alto. Un valor en torno a 0,4 es adecuado.

El simulador es accesible en http://www.et.bs.ehu.es/bayes y la fuente está disponible en https://github.com/FernandoTusell/BayesSim.git, para su utilización o modificación por terceros sin mas limitaciones que las contenidas en la licencia GPL. Agradecemos correcciones y modificaciones, particularmente en forma de pull requests.

\section{Recursos similares}

Previamente a iniciar nuestro proyecto rastreamos Internet en búsqueda de trabajo similar al realizado. Aunque no encontramos nada cubriendo el tema preciso que buscábamos, hay abundantes recursos que utilizan juegos o simulaciones de alguna especie con finalidad didáctica. La mayoría de ejemplos que hemos encontrado están relacionados con diseño experimental y tienen una historia que en ocasiones se remonta a los trabajos pioneros (Mead y Stern 1973) y (Pike 1974); véase (Stern, Latham y Stern 2009), por ejemplo.

Más cercano a nuestros objetivos de introducir a los estudiantes a los rudimentos del planteamiento bayesiano es (Erickson 2017), que propone dos ejemplos de actividades, con énfasis en gráficos de mosaico como ayuda a la intuición.

Aunque no directamente relevantes a nuestro propósito, es de interés una espléndida colección de juegos interactivos disponibles en la página web de Statistics New Zealand $^{4}$; la utilización de Flash Player ${ }^{\mathrm{TM}}$ unida a un contenido bien concebido proporciona un resultado muy atractivo. La orientación es diferente de la nuestra, en cuanto son juegos más dirigidos a enseñar que a practicar lo aprendido.

\section{Discusión}

La enseñanza en Estadística, como en otras especialidades, requiere diferentes estrategias para diferentes temas y audiencias en diferentes momentos. Pensamos que no hay reemplazo para la interacción directa entre un profesor motivador e involucrado y sus estudiantes de cara a la adquisición de ideas de relativa complejidad o profundidad.

Hay sin embargo nociones no particularmente difíciles, pero que requieren tiempo y práctica para permear las mentes de los estudiantes. Este es el ámbito en el que

\footnotetext{
${ }^{4}$ At http://www.stats.govt.nz/tools_and_services/schools_corner/Activities/ Interactive-Games.aspx, visitada el 10-marzo-2017.
} 
situamos ayudas a la enseñanza como la presentada, que permiten hacer trabajar a un grupo numeroso de estudiantes sobre instancias únicas de un mismo problema y obteniendo realimentación inmediata a sus aciertos y errores.

Planeamos extender nuestro trabajo a la construcción de simuladores orientados a este tipo de temas, que requieren para su asimilación práctica sobre ejemplos. No deja de ser interesante que algunos de los que más naturalmente se prestan a implementación en un formato similar al empleado en el trabajo aquí presentado ya aparecen anticipados en (Mead y Stern 1973) y (Pike 1974). Es una muestra del gigantesco avance en la disponibilidad de recursos educativos basados en ordenador que lo que era en aquel momento casi visionario pueda hoy ser implementado en tiempo razonable, por no especialistas y con esfuerzo y recursos muy modestos.

\section{Referencias}

Cressie, Noel y Christopher K. Wikle (2011). Statistics for Spatio-Temporal Data. Wiley.

Davey, Samuel y col. (2016). Bayesian Methods in the Search for MH370. SpringerVerlag.

Erickson, Tim (2017). "Beginning Bayes". En: Teaching Statistics 39.1, págs. 30-35.

McGrayne, S.B. (2012). The Theory That Would Not Die: How Bayes' Rule Cracked the Enigma Code, Hunted Down Russian Submarines, and Emerged Triumphant from Two Centuries of Controversy. Yale Univ. Press.

Mead, R. y R.D. Stern (1973). "The use of the computer in the teaching of statistics (with discussion)". En: Journal of the Royal Statistical Society, Ser. A A136, págs. 191-225.

Pike, D.J. (1974). "Statistical games as teaching aids". En: Journal of the Royal Statistical Society, Ser. D (The Statistician) D25, págs. 109-115.

Stern, David, Sonya Latham y Roger Stern (2009). "Statistical games to support problem-based learning". IBS SUSAN Conference Proceedings. Retrieved from http : / / www . reading . ac . uk/ssc/resources / Docs / SUSAN / Statistical_ Games_to_supportproblem-based_learning.pdf. 


\title{
Apps para la innovación docente en Criminología
}

\section{Lorea Arenas García ${ }^{\mathrm{a}}$, Ana Isabel Cerezo Domínguez}

${ }^{a}$ Docente investigadora en formación de la Universidad de Málaga (lorea@uma.es), ${ }^{b}$ Profesora Titular de Derecho penal y Criminología de la Universidad de Málaga (aicerezo@uma.es).

\begin{abstract}
:
The appearance of mobile internet devices or smartphones has revolutionized the way we interact with our environment. Thanks to the new abilities of these software applications or Apps, it is now possible to perform multiple tasks simultaneously under a limited budget without geographical barriers. This study aims to identify their advantages and applications in the studies of Criminology, in order to reinvent the qualitative research in educational activities. The expected results allow to anticipate a development of the students skills related to ICT management, in their academic training, the design of research projects and the improvement of scientific reports.
\end{abstract}

Keywords: ICT, Apps, educational innovation, methodology, qualitative techniques, digital skills.

\begin{abstract}
Resumen:
La aparición de dispositivos móviles con internet o smartphones han revolucionado el modo de interactuar con nuestro entorno. Gracias a las prestaciones de las aplicaciones de software o Apps es posible llevar a cabo múltiples tareas de forma simultánea sin barreras geográficas y escaso presupuesto. El presente estudio tiene como objeto identificar sus ventajas y aplicaciones en los estudios de Criminología de cara a reinventar la investigación cualitativa en la acción docente. Los resultados esperados permiten anticipar un desarrollo de las competencias de los alumnos con relación al manejo de las TIC en su formación académica, en el planteamiento de proyectos de investigación y en la elaboración de informes cientificos.
\end{abstract}

Palabras clave: TIC, Apps, innovación docente, metodología, técnicas cualitativas, competencias digitales. 


\section{Introducción}

En la última década la aparición de dispositivos móviles con internet o smartphones han revolucionado la forma de interactuar con la realidad que nos rodea. El envío y recepción de información a tiempo real desde cualquier ubicación transforma el significado de las relaciones y reporta funcionalidad a los procesos de comunicación tradicionales. De esta forma, es posible utilizar el móvil o la tablet para recibir noticias, conversar, participar en redes sociales, comprar y vender, buscar empleo, aprender, etc. En definitiva, llevar a cabo múltiples tareas y gestiones con la ayuda de un dispositivo y la instalación de aplicaciones de software o Apps tan variadas y versátiles como las necesidades a las que responden. A lo anterior, se suma la presencia de un mercado centralizado en el que cualquier usuario puede crear y ofertar su App potenciando su expansión, sobre todo en el sector del ocio y entretenimieto.

No obstante, otros muchos ámbitos, tales como la docencia y la investigación, no son ajenos a las prestaciones que las apps brindan para transmitir conocimientos ${ }^{1}$, organizar las clases y tareas de los profesores ${ }^{2}$, así como ejecutar una investigación empírica con los estudiantes. En este último aspecto se centra el presente trabajo, en las prestaciones que ofrecen las apps para reinventar la investigación cualitativa en el marco de la acción docente. Se trata de un tema muy novedoso escasamente abordado en nuestro país ${ }^{3}$ en las ciencias sociales y del que no se encuentran precedentes en el campo de la educación en criminología ${ }^{4}$.

\subsection{Tipos de Apps}

Todas las aplicaciones de software permiten al sujeto -ya sea profesor o alumnorecopilar información sobre sus propias percepciones o las de otros individuos en relación a un tema en particular, si bien pueden disntinguirse entre aquellas aplicaciones genéricas, utilizadas por diversas disciplinas científicas que hacen uso de técnicas cualitativas, sobre todo de métodos etnográficos (Álvarez, 2008), de las que son especializadas o creadas ad hoc para recabar información de temas concretos de investigación, tales como el miedo al delito y la criminalidad presente en ciertos barrios o zonas.

\footnotetext{
${ }^{1}$ Los apps sirven para aprender, entrenar la memoria, mantener activo nuestro cerebro, organizar nuestro tiempo de estudio, etc. Prueba de ello son la creación de apps como: Luminosity, Goconqr, Selfcontrol, Studious, Babylon, iRae, Khan Academy, Mindomo, etc.

${ }^{2}$ Entre ellas destacan: Remind101, Teacher Aide, TED, Educreations, Nearpod, Viper, Attendance, Box, Trello, etc.

3 En el ámbito comparado cada vez es más frecuente la utilización de las apps en la docencia e investigación. Véanse: García y otros (2015) y Sugie (2016).

4 En España las apps educacionales en criminología se identifican con la descarga de material didáctico y glosarios. Véase: http://noticias.universia.es/educacion/noticia/2016/01/05/1135147/5-aplicaciones-imprescindibles-estudiantes-criminologia.htm
}

(cc) EY-NC-ND 2017, Universitat Politècnica de València

Congreso IN-RED (2017) 
En el primer grupo destacan, entre otras, Quicktapsurvey y SurveyMonkey. Se trata de dos aplicaciones que permiten diseñar, administrar y gestionar una encuesta, tanto en modo online como offline. En el gráfico inferior se observa un ejemplo de una interfaz de este tipo de apps. Con carácter general, el usuario puede crear, elegiendo diversos modelos y contenidos, cada pantalla del cuestionario. De igual forma, como se aprecia en la parte derecha de la imagen, la app permite analizar los resultados obtenidos de 300 encuestados sobre un ítem en particular de forma automática.

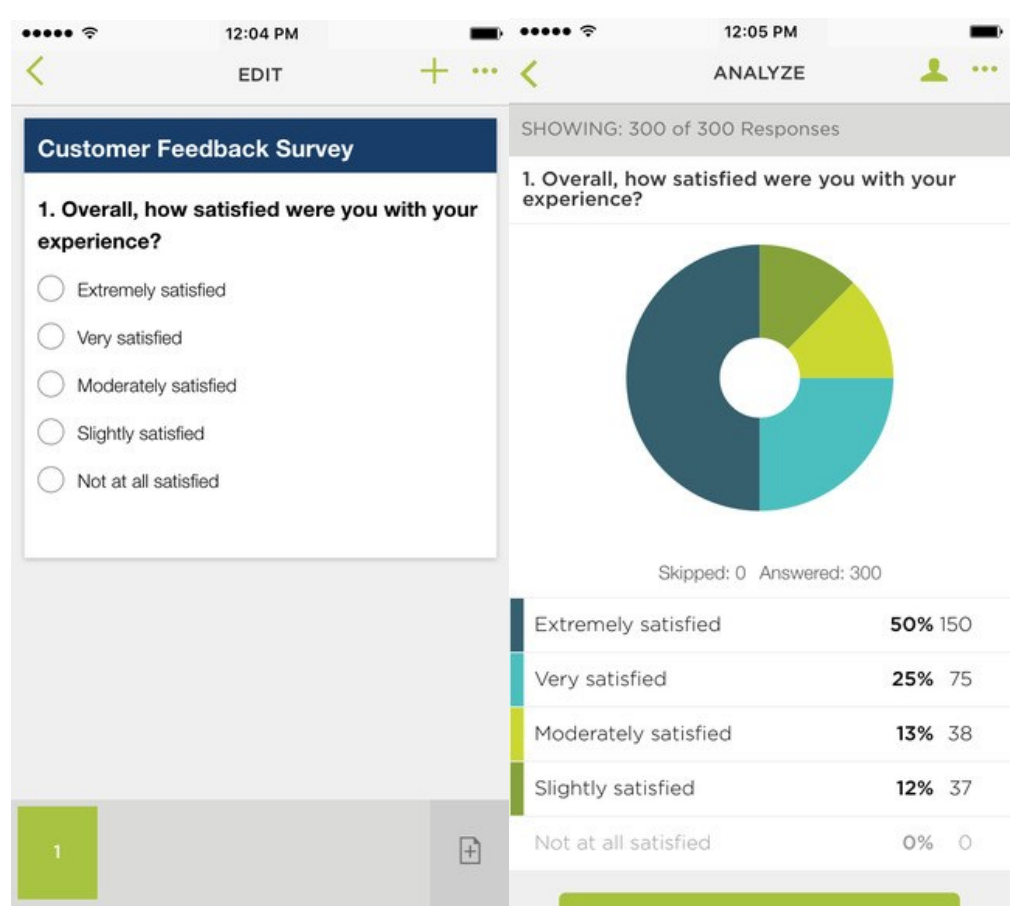

Fig. 1 Apps genéricas para el diseño de encuestas.

En esta línea, aunque ciñéndose únicamente a las propias percepciones de un sujeto que observa la realidad -y que suele dirigir la investigación- encontramos la aplicación Observe ${ }^{5}$. Es especialmente útil para que el alumno analice mediante la observación directa o participante los fenómenos que acontecen a nuestro alrededor. Observe no solo registra a tiempo real todos los datos, sino que permite su volcado y posible comparación con la de otros alumnos que hayan realizados observaciones conjuntas.

\footnotetext{
5 En el ámbito criminológico español son inexisentes las plantillas estandarizadas que permitan sistematizar información etnográfica. A fecha de hoy se viene todavía utilizando el tradicional cuarderno de campo para realizar anotaciones. Itunes PREVIEW. STUART M.SEPP. https://itunes.apple.com/us/app/observe/id439532109? mt=8 [Consulta: 31 de mayo de 2017].
}

(c) EY-NC-ND 2017, Universitat Politècnica de València 


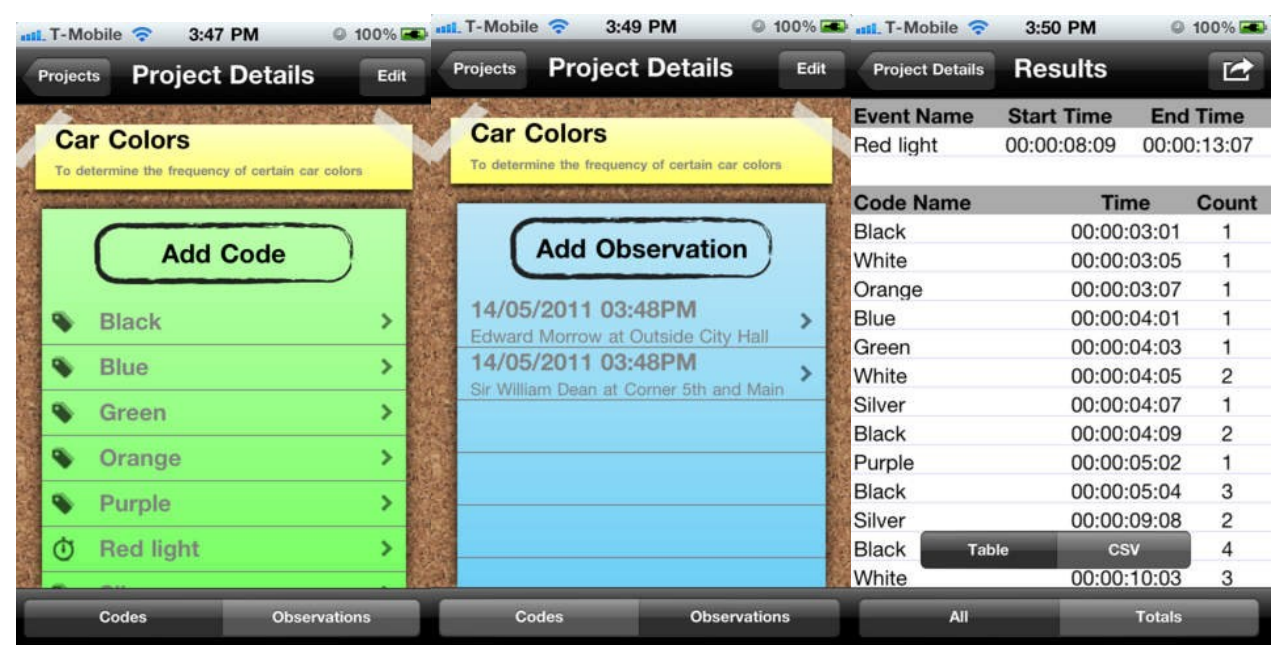

Fig. 2 Apps para la observación directa y participante.

Del segundo grupo destacan aquellas aplicaciones que hacen uso del sistema de geolocalización o GPS del dispositivo móvil con el fin de cruzar los datos provenientes de las percepciones con coordenadas temporales (horas y segundos) y espaciales (posición X e Y). Con carácter general, se emplean desde postulados teóricos situacionales que analizan y explican el fenómeno delictivo otorgando relevancia al factor ambiental, como serían los estudios con mapas del delito (Vozmediano y San Juan, 2010). o mapping crime. En este sentido, destaca la aplicación FOCA ${ }^{6}$ desarrollada por la University College de Londres. La herramienta permite recopilar datos que "proporcionan una idea de cuándo y dónde se experimenta miedo a la delincuencia, y por quién".

\footnotetext{
${ }^{6}$ FOCA es una app gratuita y disponible en Google Play. Para más información veáse: Mapping fear of crime dynamically on everyday transport.
}

(c)) BY-NC-ND 2017, Universitat Politècnica de València 


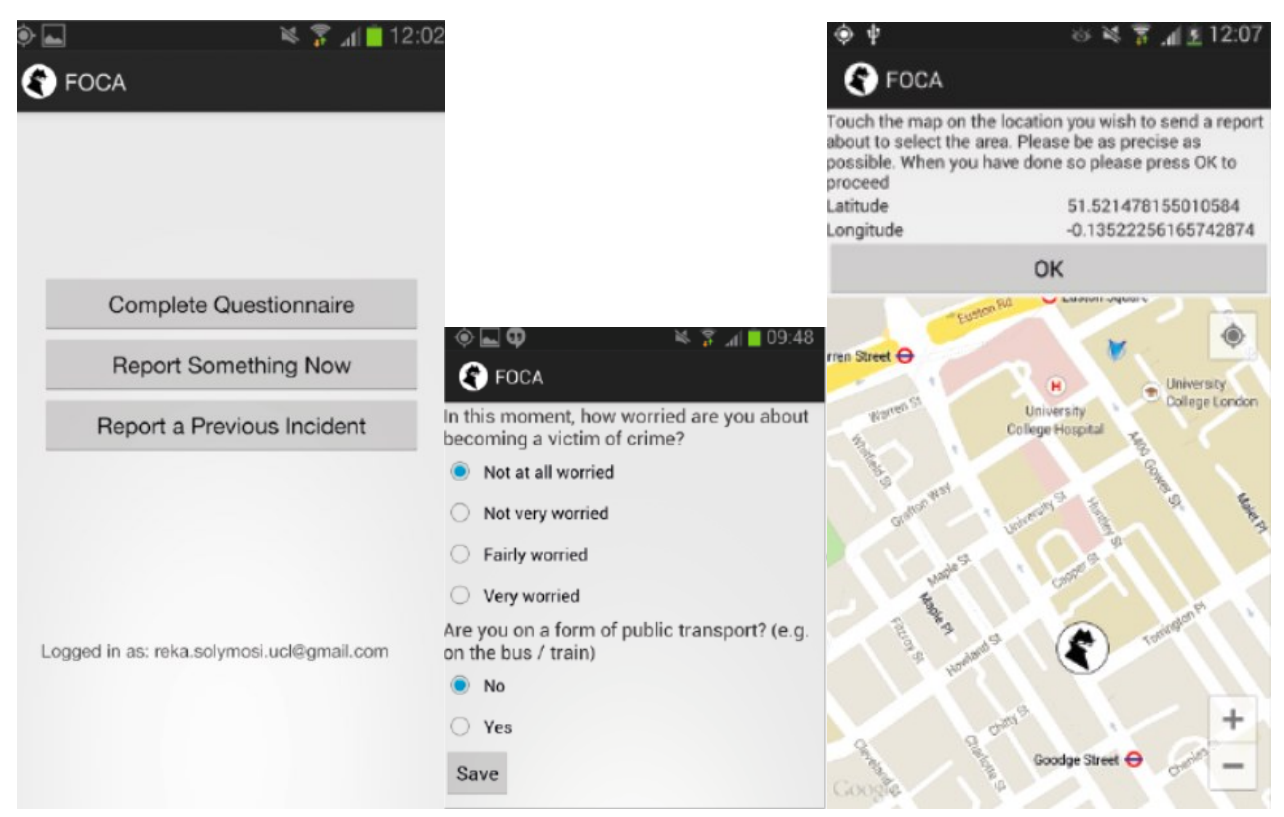

Fig. 3 Apps especializadas en medir el miedo al delito.

En la imagen superior se observan tres de las principales pantallas de la app. El sujeto puede completar un cuestionario en diversos momentos del día (mañana y noche) o bien informar sobre un suceso repentino del que ha sido víctima o testigo. En la segunda pantalla (imagen central), se estima el nivel del miedo y otras variables, como sería si se encuentra en un medio de transporte público, así como otra información adicional a determinar (sexo, edad, lugar de residencia, etc). En la tercera y última imagen (parte derecha), se muestra el mapa donde ha tenido lugar el evento que se informa.

\subsection{Ventajas y desventajas de su aplicación}

En términos generales, ambos tipos de apps -genéricas y especializadas- son muy versátiles y sirven de complemento ideal para mejorar el aprendizaje y la investigación en comparación a las herramientas tradicionales.

Principales ventajas de las apps:

- Ya están integradas en las rutinas de vida de los sujetos, especialmente de los jóvenes.

- Al tratarse de una herramienta para la investigación puede ser empleada por profesores del grado de Criminología de materias muy diversas.

- Se requiere de una escasa o nula inversión económica (el precio de la app, en su caso). 
- Su inmediatez. En cuestión de pocos días se puede finalizar un trabajo de campo que hubiese llevado meses con un cuestionario tradicional.

- La magnitud de la muestra. Las apps permiten abarcar muestras muy grandes de sujetos de diferentes cursos y clases.

- El carácter anónimo de la interacción que se produce entre el sujeto y su dispositivo móvil facilita recabar información íntima o comprometida (acoso entre iguales, agresiones sexuales sufridas, etc.).

- La recolección automática de respuestas a tiempo real. A cada momento se puede constatar los resultados de la investigación, lo que resulta de vital importancia a la hora de subsanar errores o tomar nuevas decisiones.

En cuanto a las desventajas:

- Los estudiantes o profesores que no contaran con acceso a internet en el móvil quedarían fuera de la acción.

- La ausencia de un entrevistador o figura de autoridad durante la encuesta puede provocar que se reste importancia al procedimiento o no se proporcione toda la información.

\section{Objetivos}

Con la utilización de las apps de recolección de datos se podrían alcanzar los siguientes propósitos:

2.1. Crear y administrar cuestionarios 2.0, así como tratar los datos recabados y su posterior presentación en clase. Por ejemplo, los alumnos podrían desarrollar proyectos para estimar la victimización sufrida (en delitos sexuales, violencia de género, robos, etc) y medir el miedo al delito en función del lugar de residencia y rutinas de vida, entre otros.

2.2. Sistematizar los datos de la observación directa o participante.

2.3. Diseñar nuevas apps especializadas o proyectos de investigación cuya metodología se fundamente en la recolección de datos cualitativos provenientes de percepciones de sujetos.

\section{Desarrollo de la innovación}

El empleo de la app se llevaría a cabo con estudiantes del grado de Criminología cuya edad media es inferior a 21 años de edad, por lo que estos nativos digitales ${ }^{7}$ poseerían

\footnotetext{
${ }^{7}$ Los jóvenes menores de veinte años son sus mayores representantes. Estos han crecido inmersos en un continuo bombardeo digital y han integrado la tecnología en su aprendizaje más temprano (Small y Vorgan, 2009). La mente joven en desarrollo codifica la información de forma diferente a como lo haría un adulto al tiempo que su atención está más limitada y focalizada en
} 
un smartphone y estarían muy familiarizados con las TICs. Así mismo, no tendrían necesidad de desplazarse para realizar el trabajo de campo siendo suficiente la mera instalación de la app en el móvil. Dependiendo de la asigntaura y del curso, cada profesor podría optar por desarrollar los objetivos que pretende alcanzar aplicando una de las apps anteriormente mencionadas. De igual forma, cabría su administración de forma simultánea en diversos grupos y cursos académicos.

\subsection{Planteamiento de la actividad}

Los dos primeros objetivos de la acción docente se desarollarían a modo de tarea teórico-práctica requiriendo del compromiso y participación del alumno tanto en clase como en el trabajo de campo. Si se trata de la creación y administración de un cuestionario relativo a la propia victimización sufrida, se debe incentivar su participación haciendo especial hincapié en la relevancia de la investigación al tiempo que se recalca su carácter anónimo y confidencial. En el caso de ejecutar una observación directa o participante, se debe plantear la actividad en diferentes contextos sociales para que el alumno sea más versátil a la hora de discriminar qué aspectos de la realidad ha de registrar.

\subsection{Formación}

El primer paso para desarrollar la innovación es la formación del alumno en aplicaciones de software y nuevas tecnologías. A pesar de que se presupone que los estudiantes mantienen una relación natural con las mismas, es necesario explicar el funcionamiento y potencialidades de las apps de recolección de datos, la elección de la más adecuada dentro de las ofertadas y el tratamiento de los datos. Así mismo, y dependiendo de la formación metodológica del grupo en concreto, sería necesario administrar conocimientos sobre diseño de cuestionarios y selección de contactos clave ${ }^{8}$. De igual forma, si está desempeñando una observación directa o participante, se le ha de instruir para que identifique y registre en el dispositivo todas aquellas situaciones de la vida cotidiana. Por último y, con referencia al objetivo 2.3, se deben reforzar las habilidades del alumno en la gestión y búsqueda de recursos bibliográficos relacionados con las nuevas tecnologías, y en su capacidad para proyectar soluciones digitales a necesidades reales.

\footnotetext{
varios estímulos a la vez. Por ello, la televisión es percibida como "lenta y aburrida" o un libro "una cadena de palabras, sosa e inmutable". Por el contrario, el ciberespacio contenido en el smartphone que guardan en el bolsillo les conecta con el mundo exterior, con sus amigos y, en definitiva, con todas aquellas formas de ocio que brinda internet. Así, lo habitual es que el joven vea la televisión mientras recibe wasaps, consulta el correo electrónico, juega on-line o lee un libro. Los adultos, sobre todo aquellos que rondan los 40 años de edad, también están inmersos en la era digital, sin embargo se consideran inmigrantes digitales (Small y Vorgan, 2009) al pasar menos tiempo expuestos a las tecnologías.

8 En la observación participante, como en cualquier otra metodología que requiera del acceso y contacto a un grupo determinado, es esencial que el alumno esté formado en competencias que posibiliten recabar información sobre los sujetos, sus costumbres, lugares de reunion, disposición a ser contactados, etc. (Álvarez, 2008).
}

(c) $)$ EY-NC-ND 2017, Universitat Politècnica de València 


\subsection{Puesta en marcha de la actividad}

Una vez impartida la formación comienza la tarea práctica. Si la app es genérica, los alumnos deberán emplear varias sesiones en diseñar el cuestionario, por el contrario, si se opta por una app especializada, tan solo será necesario su mera descarga. En cuanto a las tareas vinculadas al objetivo tercero (2.3), la parte práctica daría comienzo con exposiciones individuales o grupales sustentadas en dinámicas que generen debates sobre las ideas innovadoras.

\subsection{Seguimiento de la actividad}

Al igual que cualquier otra tarea, se debe temporalizar su ejecución fijando una fecha de inicio y final. En el caso de que sea el alumno quien haya creado y gestionado su propio cuestionario, se debe contar con el control y apoyo externo del profesor, sobre todo si surgen problemas que puedan comprometer la recogida de datos o la ejecución del trabajo de campo. En este sentido, se debe apostar por un sistema de evaluación continua que comprenda la evaluación periódica da datos. Si la tarea consiste en el diseño de nuevas apps especializadas o proyectos de investigación, el seguimiento debería enfatizar la planificación de un calendario prolongado de exposiciones.

\subsection{Análisis y tratamiento de la información}

Una de las principales ventajas de las apps es la recolección rápida de grandes cantidades de información. En este sentido, es esencial que el alumno sepa determinar la calidad de la misma y si ha sido correctamente grabada. Un vez tratada la información, la misma puede utilizarse para aprender a redactar un informe con datos empíricos y preparar una exposición de resultados, competencias vinculadas a la elaboración final del trabajo fin de grado.

\section{Resultados}

Los impactos de la innovación docente se traducen en la adquisición de nuevas competencias por parte del alumnado y el profesorado.

\subsection{En el alumnado:}

1. Desarrollar nuevas habilidades en el campo de las TICs más allá del manejo de las herramientas 2.0 habituales (campus virtual y correo electrónico).

2. Aprender a plantear, diseñar y ejecutar una investigación empírica empleando herramientas metodológicas 2.0 .

(cc) EY-NC-ND 2017, Universitat Politècnica de València 
3. Mejorar sus competencias relacionales con contactos clave de los contextos a investigar, esto es, pautas de presentación, argumentación y persuasión.

4. Analizar y tratar grandes cantidades de datos estadísticos provenientes de apps.

5. Redactar informes y mejorar esta competencia de cara al trabajo fin de grado.

6. Mejorar la expresión oral y las dotes comunicativas para transmitir ideas innovadoras.

7. Recibir formación en competencias específicas (geolocalización o mapping, victimología, etc.).

8. Diseñar intervenciones eficaces y eficientes para prevenir el delito una vez analizados los datos. Por ejemplo: elaboración de diagnósticos medioambiantales en determinadas calles, barrios o zonas con el fin de elaborar propuestas de prevención situacional, implementar estrategias que reduzca determinados tipos de delincuencia no denunciada y la percepción de seguridad, etc.

\subsection{En el profesorado:}

1. Desarrollar nuevas habilidades en el campo de las TICs más allá del manejo de las herramientas 2.0 habituales (campus virtual y correo electrónico).

2. Utilizar para la acción formativa el diseño y ejecución de investigaciones empíricas empleando herramientas metodológicas 2.0.

3. Mejorar la acción formativa práctica al elaborar estudios empíricos y reales con carácter previo o en el trabajo fin de grado.

4. Conseguir un mayor grado implicación y atención del alumno en comparación a las tareas tradicionales.

\section{Conclusiones}

Las aplicaciones de software en dispositivos móviles con acceso a internet ofrecen grandes ventajas y oportunidades para desarrollar acciones de innovación docente. El hecho de que se trate de una herramienta ampliamente utilizada por los jóvenes propicia su fácil integración en las tareas al tiempo que resulta llamativa y original. En este nuevo marco 2.0 es necesario una implicación activa del profesorado en nuevas tecnologías capaces de revolucionar el mundo de la docencia. Dicha implicación debe ser constante y adaptada a los continuos avances científicos que modifican la vida cotidiana. En este orden de ideas, no parece posible desvincular la acción formativa de la utilización de las TIC, ni tampoco preparar profesionalmente a los estudiantes si no obtienen de estas una utilidad alternativa al propio ocio y entretenimiento. En definitiva, se hace imprescindible elaborar y ejecutar propuestas docentes adaptadas a los nuevos tiempos. 


\section{Referencias}

Álvarez Álvarez, C. (2008). "La etnografía como modelo de investigación en educación", en Gaceta de Antropología, vol. 24 (1), 10, p. 1-15.

García, B., Welford, J. y SMith, B. (2015). "Using a Smartphone app in qualitative research: the good, the bad and the ugly", en Qualitative Research, 3, p. 508-525.

SMALl, G. Y Vorgan, G. (2009). El cerebro digital: cómo las nuevas tecnologías están cambiando nuestra mente. Barcelona: Editorial Urano.

Solymosi, R. (2014). Mapping fear of crime dynamically on everyday transport. London: UCL Jill Dando Institute of Security and Crime Science.

SugIE, N. (2016). "Utilizing Smartphones to study disadvantaged and hard-to-reach groups", en Sociological Methods Reseach, 18, p. 2-34.

VozMEdiAnO SANZ, L. Y SAN JuÁN GUILLÉn, C. (2010). Criminología ambiental: Ecología del delito y de la seguridad. Barcelona: Editorial UOC.

\section{Páginas webs:}

ANÁLISIS DE LAS MEJORES APPS IOS Y ANDROID PARA LA EDUCACIÓN. EDUCA APPS. http://www.educapps.es. [Consulta: 31 de mayo de 2017].

ITUNES PREVIEW. STUART M.SEPP. https://itunes.apple.com/us/app/observe/id439532109?mt=8 [Consulta: 31 de mayo de 2017].

FOCA. REKA SOLYMOSI UCL.

https://play.google.com/store/apps/details?id=uk.ac.ucl.uctzrso.foca\&hl=es. [Consulta: 31 de mayo de 2017].

QUICKTAPSURVEY. http://www.quicktapsurvey.com/lg/es/ [Consulta: 31 de mayo de 2017].

SURVEYMONKEY. https://es.surveymonkey.com/mp/iphone-survey-app/ [Consulta: 31 de mayo de 2017].

UNIVERSIA ESPAÑA. http://noticias.universia.es/educacion/noticia/2016/01/05/1135147/5aplicaciones-imprescindibles-estudiantes-criminologia.html. [Consulta: 31 de mayo de 2017].

(cc) EY-NC-ND 2017, Universitat Politècnica de València

Congreso IN-RED (2017) 


\title{
Elaboración de material multimedia y uso de un entorno virtual en el proceso de enseñanza-aprendizaje de las prácticas de laboratorio en Química Física
}

\section{Isabel López Tocón}

Departamento de Química Física, Facultad de Ciencias, Universidad de Málaga. Campus de Excelencia Internacional Andalucía Tech. E-29071 Málaga. E-mail: tocon@uma.es

\begin{abstract}
Using new technologies, such as the Moodle e-learning platform, a new and more active didactic strategy has been developed in the training of lab practices in subjects assigned to the Department of Physical Chemistry, specifically in the subject Basic Operations of Laboratory, which is taught in the first year of the Degree in Chemistry. A new multimedia and audiovisual teaching material has been designed and elaborated on the most basic procedures that are carried out in a chemical lab. This educational material serves as a support for the teacher in the lab classes, besides supposing a complement to the practices' script for the students. In this way, we try to facilitate the autonomous learning of the student, to optimize the working time in the lab and to increase the availability of the teacher. A question bank has also been developed for each lab practices in order to carry out on-line tests of knowledge once the practice is finished.
\end{abstract}

Keywords: b-learning methodology, educational multimedia pills, on-line training, Moodle platform.

\begin{abstract}
Resumen
Haciendo uso de las nuevas tecnologías, como es la plataforma educativa Moodle, se ha desarrollado una nueva estrategia didáctica más activa y dinámica en la impartición de las prácticas de laboratorio en asignaturas adscritas al Departamento de Química Física, y en concreto en la asignatura de Operaciones Básicas de Laboratorio, que se imparte en el primer curso del Grado en Química. Se ha diseñado y elaborado un nuevo material didáctico multimedia y audiovisual, sobre los procedimientos más básicos que se realizan en un laboratorio químico, y que sirve como apoyo para el docente en las clases presenciales de laboratorio, y como complemento al guión de prácticas que recibe el alumno. De esta forma se intenta facilitar el aprendizaje autónomo del estudiante, optimizar el tiempo de trabajo en el laboratorio y aumentar la disponibilidad del profesor. También se ha elaborado un banco de preguntas para cada una de las prácticas con objeto de realizar pruebas de conocimiento on-line, una vez finalizada la práctica en el laboratorio.
\end{abstract}

Palabras clave: Metodología b-learning, píldoras multimedia, Formación virtual, Plataforma Moodle. 


\section{Introducción}

Conforme al actual modelo de sociedad digital, la aplicación de las nuevas TICs en el ámbito educativo (Cabrero, 2007) está suponiendo un gran cambio en el proceso de enseñanza-aprendizaje de cualquier materia de conocimiento, ya que nos permite modernizar la metodología docente (Salinas, 2004). De esta forma, se está pasando de un modelo didáctico-pedagógico tradicional, basado en impartición de clases magistrales, donde la relación profesor-estudiante era la de transmisor-receptor de conocimiento, a un modelo de aprendizaje virtual y electrónico (e-learning) donde el alumno es más autónomo y toma un papel más relevante en su propia formación educativa (Rice, 2010). No obstante, entre estos dos modelos educativos extremos, se viene imponiendo en la mayoría de las asignaturas regladas de cualquier Grado, un modelo intermedio donde se combinan las clases presenciales con actividades formativas on-line a través de una plataforma educativa, lo que conlleva a un aprendizaje semipresencial conocido como blended-learning (blearning) (Bartolomé, 2004). Este modelo pedagógico es más efectivo y práctico que el estrictamente presencial o el puramente on-line, ya que se beneficia de la presencia del profesor como docente y orientador de las actividades formativas, y de la tecnología de comunicación asincrónica que facilita un aprendizaje independiente y colaborativo (Alemany, 2007).

La plataforma Moodle implementada en los Campus Virtuales de la mayoría de Universidades favorece la creación de un entorno virtual para cualquier asignatura de una forma sencilla y de fácil manejo, donde se pueden implementar diferentes recursos docentes entre ellos, documentos escritos en formato pdf, glosario de términos científicos, tareas o problemas a resolver, pruebas de conocimiento o cuestionarios, etc. Se trata de una nueva herramienta docente que permite modernizar las técnicas pedagógicas de aprendizaje e introducir nuevos métodos de evaluación continua. De esta forma se consigue también, adaptar cualquier asignatura de Grado a los nuevos criterios de evaluación continua establecidos en el Espacio Europeo de Enseñanza Superior, EEES (López, 2016).

Por tanto, haciendo uso de las nuevas TICs se pretende desarrollar, bajo un entorno virtual y haciendo uso de la plataforma Moodle, una nueva estrategia didáctica más activa y dinámica, basada en el método b-learning, en la impartición de las prácticas de laboratorio de asignaturas adscritas al Departamento de Química Física, y en concreto en la asignatura de Operaciones Básicas de Laboratorio que se imparte en el primer curso del Grado en Química. Para ello se va a diseñar y elaborar un nuevo material didáctico multimedia y audiovisual de los procedimientos más básicos que se realizan en el laboratorio en un formato de píldoras educativas e-learning, además de crear un banco de preguntas virtuales sobre las prácticas de laboratorio, que sirva de autoevaluación para el alumno.

\subsection{Contexto}

La asignatura de Química Física General forma parte del Módulo Básico en el Grado en Química y se imparte en el primer curso durante el primer semestre a un grupo numeroso de alumnos entre 85-100 alumnos. Esta asignatura, de 6 créditos presenciales, es

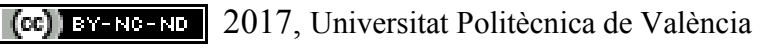

Congreso IN-RED (2017) 
completamente teórica y sus correspondientes prácticas de laboratorio se integran en la asignatura de Operaciones Básicas de Laboratorio, también de 6 créditos presenciales y que se imparte durante el segundo semestre a cuatro grupos reducidos con casi 24 alumnos por grupo.

Generalmente, las prácticas de laboratorio que se realizan en este primer curso corresponden a tratamientos y procedimientos básicos dentro del entorno de un laboratorio químico, cuyo conocimiento exhaustivo y preciso resulta fundamental y esencial para desarrollar las destrezas y las competencias necesarias a la hora de trabajar en el laboratorio de forma autónoma. Al tener un carácter general estas prácticas de laboratorio, algunas de ellas forman parte también del programa práctico de otras asignaturas de primer curso que imparte el Departamento de Química Física en otras titulaciones como por ejemplo, las asignaturas de Química Física General y Química en los Grados en Ingeniero Químico y Medio Ambiente, respectivamente. Por tanto, se puede extender y extrapolar este proyecto de innovación docente a otras asignaturas de primer curso, sobretodo, en aquellos Grados que forman parte de las Ciencias Experimentales y que cuentan también con un grupo numeroso de alumnos.

\subsection{Antecedentes}

La docencia durante las prácticas de laboratorio, en cualquier asignatura de carácter experimental, supone un reto para el profesor porque se tienen que ajustar en el reducido tiempo disponible en el laboratorio, tanto la explicación de los aspectos teóricos de la práctica, por parte del docente, como la propia ejecución del experimento, por parte del alumno.

La introducción teórica que realiza el profesor antes de iniciar la práctica en el laboratorio conlleva una dinámica expositiva diferente a la que se puede realizar en una clase magistral ya que intervienen distintas pautas didácticas a seguir como son, la exposición del fundamento teórico de la práctica, la explicación del funcionamiento del material de laboratorio, el tratamiento matemático de los datos experimentales hasta obtener el resultado que se va buscando y sin olvidar además, la indicación de las normas de seguridad a tener en cuenta en cada práctica de laboratorio. Con este procedimiento se pretende alcanzar un doble objetivo, en primer lugar, conseguir que el alumno asimile y comprenda la experimentación y en segundo lugar, facilitar el trabajo autónomo del alumno en el laboratorio.

Todo este desarrollo teórico resulta imprescindible para los estudiantes de primer curso en el Grado en Química, por varios motivos: se trata de un alumnado novel siendo, para algunos de ellos, la primera vez que se encuentran en el entorno de un laboratorio químico, y también se solventa de esta forma, el desfase temporal entre las clases teóricas y las prácticas de laboratorio, ya que en esta asignatura se da el caso de realizar alguna práctica de laboratorio cuyo fundamento teórico no se ha tratado previamente en las clases expositivas de teoría, lo que conlleva un mayor grado de dificultad para la comprensión y asimilación de la experiencia de laboratorio que se va a realizar. Todo este procedimiento 
teórico, previo a la realización de la práctica, presenta como principal inconveniente el tiempo excesivamente largo que se emplea en dicha exposición, realizada principalmente en pizarra, en detrimento del tiempo para ejecutar la propia práctica en el laboratorio.

\section{Objetivos}

Se pretende desarrollar una nueva estrategia didáctica más activa y dinámica en la impartición de las prácticas de laboratorio haciendo uso de las nuevas tecnologías. Se va a diseñar y elaborar un nuevo material educativo multimedia y audiovisual que sirva como apoyo para el docente en las clases presenciales de prácticas de laboratorio en Química Física, además de suponer un complemento al guión de prácticas. De esta forma se intenta facilitar el aprendizaje autónomo del estudiante, optimizar el tiempo de trabajo en el laboratorio y aumentar la disponibilidad del profesor en el laboratorio.

Por tanto, los objetivos que se pretenden alcanzar son:

1.- Elaborar un material didáctico multimedia y audiovisual que sirva como apoyo a las clases presenciales de las prácticas de laboratorio en Química Física.

2.- Mejorar la calidad en la exposición teórica de las prácticas de laboratorio sustituyendo los medios tradicionales como es la pizarra por presentaciones multimedia.

3.- Reducir el tiempo de la introducción teórica de la práctica con objeto de no restar tiempo a la ejecución de la propia práctica en el laboratorio, lo cual conlleva una mayor disponibilidad del profesor durante la estancia en el laboratorio.

4.- Facilitar el aprendizaje autónomo del alumno y favorecer una rápida asimilación del trabajo de campo en un laboratorio químico

5.- Optimizar la eficacia del alumno a la hora de realizar las prácticas lo que se traduce en un mejor aprovechamiento de la estancia y del tiempo de trabajo en el laboratorio, y redunda en una mejora de las habilidades y destrezas adquiridas por el alumno.

6.- Crear un banco de preguntas en el Campus Virtual de la asignatura correspondientes a las prácticas de laboratorio con el fin de elaborar, posteriormente, varias pruebas de conocimiento que sirvan como autoevaluación para el alumno.

\section{Desarrollo de la innovación}

En primer lugar, se ha procedido a la actualización de los guiones de prácticas de laboratorio correspondientes a la asignatura de Operaciones Básicas de Laboratorio. Se han insertado figuras explicativas del procedimiento de la práctica y tablas que deben ser completadas con los resultados obtenidos, de forma que la experiencia de laboratorio quede totalmente finalizada con los cálculos teóricos correspondientes y dando el valor de la magnitud a determinar, evitando de esta forma el tomar solo los datos experimentales sin llegar a realizar el tratamiento matemático que lleva implícito una práctica. Estos guiones

(c) EY-NC-ND 2017, Universitat Politècnica de València 
se encuentran en el Campus Virtual en formato pdf y disponible para los alumnos antes de realizar las prácticas de laboratorio.

El siguiente paso, ha sido el más laborioso, ya que se pretende crear de un modo básico píldoras formativas e-learning con una duración no superior a 10 minutos, es decir, unidades educativas multimedia, independientes y modulables, de los procedimientos más básicos que se desarrollan en un laboratorio químico. De esta forma se pretende ir extendiendo el número de unidades en un futuro, que puedan ser consumidas por parte del alumno de forma autónoma y que sirvan como complemento a la asignatura con formación educativa blended. Se ha comenzado por los temas más sencillos, pero no menos importante para un alumnado novel, como es la presentación y descripción del entorno de un laboratorio químico, las nociones básicas de seguridad en el laboratorio, el manejo del material de laboratorio, las operaciones de pesada de un cuerpo y pipeteo de un líquido y la preparación de disoluciones a partir de un líquido más concentrado y de un sólido.

Se trata de presentaciones multimedia utilizando el programa PowerPoint donde se expone el fundamento teórico de la práctica, su desarrollo en el laboratorio mediante la incorporación de fotografías realizadas en el propio laboratorio y el tratamiento matemático de la misma, y van acompañadas de una grabación de audio que narra la propia presentación de forma automática. La grabación del audio se puede hacer directamente en el documento de PowerPoint, o bien, utilizando el programa de libre acceso ScreenCast-OMatic. En este último caso, la voz del docente no se graba de forma nítida y clara y se ha optado por utilizar otro programa de libre acceso, disponible en la web, en la cual convierte un texto escrito en un fichero MP3 de audio. Esto ha supuesto un trabajo adicional con el que no se contaba, porque se ha tenido que redactar un documento de cada una de las presentaciones, tal y como se quiere grabar en la presentación.

También, con el material fotográfico de laboratorio que se ha conseguido, se ha elaborado un banco de preguntas en la plataforma Moodle sobre nociones generales, relacionado con el nombre y uso del material de laboratorio y con las normas de seguridad, y otro más específico sobre los conceptos químicos que se recogen en las prácticas realizadas, con el fin de crear varias pruebas de conocimiento o cuestionarios virtuales, que contribuyan a la evaluación continua de la asignatura al igual que se ha realizado en otras materias (López, 2016). Estos cuestionarios constan de 20 a 30 preguntas, muy variadas en cuanto formato, verdadero/falso, multi-respuesta, emparejamiento y numérica, tienen como límite de tiempo una hora y se realizarán una vez que se hayan concluido las experiencias realizadas en el laboratorio químico.

La línea de trabajo en el laboratorio consiste en: visualizar la correspondiente presentación multimedia, ya que no todos los alumnos siguen la metodología b-learning y llegan al laboratorio sin las nociones previas de la práctica que hay que realizar, aclarar las dudas sobre el procedimiento de la práctica utilizando los guiones, y a continuación se pasará a ejecutar la práctica en el laboratorio. Una vez terminado el periodo de prácticas se abrirán los cuestionarios virtuales. 


\section{Resultados}

La incorporación de las TICs y de la metodología didáctica b-learning en la asignatura de Operaciones Básicas de Laboratorio se esta efectuando durante el presente curso académico 2016-2017. Todavía no se tienen resultados concluyentes porque se está ejecutando la docencia en este segundo cuatrimestre. No obstante se ha realizado un sondeo inicial mediante una breve encuesta de satisfacción a los estudiantes a través de la plataforma virtual y se han analizado de forma numérica, algunos parámetros significativos para los primeros cuestionarios que ya han realizado los alumnos (Tabla 1), como son el porcentaje de participación, el porcentaje de aciertos en las preguntas propuestas y la calificación media obtenida.

En general, hay que destacar un elevado porcentaje de participación en los dos primeros cuestionarios, entre un 86.1 y un $83.3 \%$. El rango de aciertos en las preguntas realizadas en estos cuestionarios oscila entre un valor máximo del $100 \%$ a $99.5 \%$ y un valor mínimo del $44 \%$ a $33 \%$, resultando una muy buena calificación media de 8.8 y 8.1 para estos dos primeros cuestionarios.

Tabla 1. Porcentajes de participación, rango de aciertos en las preguntas y calificación media obtenida en cada uno de los cuestionarios.

\begin{tabular}{|c|l|l|l|l|}
\hline & & \multicolumn{3}{|c|}{ CURSO 2016-2017 } \\
\hline Tema & Cuestionario & $\begin{array}{l}\text { Porcentaje de } \\
\text { Participación }\end{array}$ & $\begin{array}{l}\text { Porcentaje } \\
\text { de Aciertos }\end{array}$ & $\begin{array}{l}\text { Calificación } \\
\text { media }\end{array}$ \\
\hline $\mathbf{1}$ & $\begin{array}{l}\text { Normas de Seguridad en el } \\
\text { Laboratorio }\end{array}$ & 86.1 & $99.5-44.4$ & 8.8 \\
\hline $\mathbf{2}$ & $\begin{array}{l}\text { Uso del material de } \\
\text { Laboratorio }\end{array}$ & 83.3 & $100.0-33.3$ & 8.1 \\
\hline $\mathbf{3}$ & Prácticas Química Física & 77.7 & $75.3-43.5$ & 6.2 \\
\hline
\end{tabular}

No obstante, era de esperar unos resultados de este tipo ya que se trata de nociones básicas del laboratorio químico, como son las normas de seguridad y el conocer el nombre y el uso del material de vidrio/porcelana del laboratorio. Sin embargo, los datos obtenidos en el tercer cuestionario, específico de las prácticas de Química Física, son mucho más significativos. En este caso, la participación descciende a un $77.7 \%$, el porcentaje de aciertos también desciende ligeramente entre un $75 \%$ a $43 \%$, lo que lleva a una menor calificación media de un 6.2. Aunque esta calificación es más baja que en los cuestionarios anteriores todavía está en el rango de aprobado. Era de esperar un resultado de este tipo ya que se trata de un cuestionario más elaborado sobre conceptos químicos y problemas numéricos puestos en práctica en el laboratorio, además de tratarse de un cuestionario prácticamente individualizado para el alumno, al confeccionarse las 10 preguntas de la prueba de conocimiento de forma aleatoria dentro de un banco de preguntas con más de 50

(cc) EY-NC-ND 2017, Universitat Politècnica de València 
items. La ligera disminución en la participación de este último cuestionario se debe, probablemente, a que algunos alumnos deciden abandonar los estudios de química.

En cuanto a la opinión del alumnado sobre el entorno virtual de la asignatura, se ha realizado una encuesta de satisfacción que ha sido respondida por el $80 \%$ de los estudiantes (Tabla 2). En esta encuesta también se incluyeron algunas preguntas referentes a la clase y sus antecedentes académicos, resultando que un $46 \%$ son mujeres frente a un $51 \%$ de hombres, el $86.5 \%$ tienen menos de 20 años mientras que un $10.8 \%$ tienen más de 21 años. Prácticamente toda la clase, el $86.5 \%$, ha estudiado la asignatura de Física y Química durante el Bachillerato y para el $70.3 \%$ es su vocación y fue su primera opción en la preinscripción universitaria frente a un $27.1 \%$ en la que reconoce que no es su vocación y no fue su primera opción en la preinscripción. Hay que resaltar, además, que un $10 \%$ de la clase no ha cursado ninguna asignatura de Química en una titulación oficial previa a la Universidad.

Tabla 2. Encuesta de satisfacción relativa al entorno virtual de las prácticas de laboratorio.

\begin{tabular}{|l|l|l|}
\hline PREGUNTA & RESPUESTAS & CURSO \\
& & $\mathbf{2 0 1 6 - 2 0 1 7}$ \\
\hline $\begin{array}{l}\text { ¿Cuántas veces ha } \\
\text { consultado la página } \\
\text { web de la asignatura? }\end{array}$ & $\begin{array}{l}\text { Algunas veces } \\
\text { Poco }\end{array}$ & $51.4 \%$ \\
& Ninguna & $40.5 \%$ \\
\hline $\begin{array}{l}\text { Valora el contenido de } \\
\text { la página web de la } \\
\text { asignatura en el Campus } \\
\text { Virtual según las }\end{array}$ & Bien & $5.41 \%$ \\
siguientes propuestas: & Regular & $0 \%$ \\
\hline $\begin{array}{l}\text { Las actividades } \\
\text { formativas propuestas } \\
\text { en la página web: }\end{array}$ & Aun no la he utilizado & $13.5 \%$ \\
\hline ¿Qué actividad docente & Son suficientes para cada tema. & $43.2 \%$ \\
formativa te gusta más? & Son pocas. & $32.4 \%$ \\
& Cuestionarios virtuales. & $8.1 \%$ \\
& Otras actividades de la web. & $0 \%$ \\
\hline En general, las pruebas & Son útiles porque ayudan a estudiar. & $13.5 \%$ \\
de nivel o cuestionarios & Son útiles porque ayudan a aprobar. & $64.8 \%$ \\
virtuales: & Son útiles porque ayudan a estudiar y aprobar. & $18.9 \%$ \\
\hline & No les veo utilidad alguna. & $27.1 \%$ \\
\hline
\end{tabular}

De forma breve, casi un $90 \%$ de los encuestados ha visitado frecuentemente la página web de la asignatura en el Campus Virtual y el $66 \%$ considera que está bien en cuanto a contenidos. En cuanto a las actividades virtuales que se proponen en la web, el $64.8 \%$ considera que son suficientes, siendo los cuestionarios virtuales y las exposiciones 
presenciales en el laboratorio las actividades formativas que más gusta a un $40.5 \%$ y $27.1 \%$ de los encuestados, respectivamente, y un $75 \%$ considera que los cuestionarios virtuales son muy útiles porque le ayudan a estudiar. No obstante, hay que destacar que a un $22 \%$ no le gusta ninguna actividad formativa. Al final del curso se volverá a realizar esta encuesta y posiblemente se obtengan otros resultados más acordes a la visión general del curso y se podrá establecer además, una comparación entre las calificaciones finales obtenidas en esta asignatura durante el curso anterior donde no existía esta metodología docente, con la del presente curso.

\section{Conclusiones}

En este trabajo se ha creado un entorno virtual dentro de la plataforma Moodle de la asignatura Operaciones Básicas de Laboratorio que se imparte en el primer curso del Grado en Química de la UMA. Se ha informatizado y actualizado todo el material didáctico que se utiliza en clase, en concreto, los guiones de prácticas de laboratorio, se ha elaborado un material multimedia sobre las operaciones más básicas de laboratorio en formato de píldoras formativas e-learning y se han creado varias pruebas de conocimientos o cuestionarios on-line específicos de las prácticas y otros con carácter más general sobre el material de laboratorio, su utilización, normas de seguridad y dispositivos presentes en el laboratorio. De esta forma se ha establecido una nueva metodología pedagógica más participativa donde se combinan el material expositivo multimedia con breves explicaciones o indicaciones, antes de iniciar las prácticas, y actividades on-line que contribuyen a un estudio continuado de la asignatura de forma no presencial.

En general, se puede decir que esta nueva metodología docente ha tenido muy buena acogida, al igual que las actividades virtuales formativas con una elevada participación entre $70-80 \%$. Según la encuesta de satisfacción realizada entre los estudiantes, estos consideran que la web de la asignatura está bien en contenidos y que las actividades formativas que se proponen, entre ellas, los cuestionarios virtuales son útiles para estudiar la asignatura además de ser suficientes, posiblemente no quieren aumentar el número de actividades debido a la sobrecarga global de trabajo durante el curso por parte de otras materias de estudio. Todavía no se puede realizar una comparación entre las calificaciones obtenidas en convocatorias de cursos anteriores y la actual, donde se ha puesto en marcha esta metodología, ya que aún se están impartiendo las clases.

Agradecimiento. Este trabajo se enmarca dentro del Proyecto Docente PIE15-027, correspondiente a la Convocatoria de Proyectos de Innovación Educativa 2015-2017 de la Universidad de Málaga.

\section{Referencias}

1. CABRERO, J. (2007). Nuevas tecnologías aplicadas a la educación. Madrid: McGraw Hill.

2. SALINAS, J. (2004). "Innovación docente y uso de las TIC en la enseñanza universitaria" en Revista de Universidad y Sociedad del Conocimiento (RUSC), Vol. 1, $n^{\circ} 1$.

(cc) EY-NC-ND 2017, Universitat Politècnica de València

Congreso IN-RED (2017) 
3. RICE W. (2010). Moodle desarrollo de cursos E-learning. Madrid: Anaya Multimedia.

4. BARTOLOMÉ, A.R. (2004). "Blended Learning. Conceptos básicos" en Pixel-Bit. Revista de Medios y Educación, 23, pp. 7-20.

5. ALEMANY D. (2007). "Blended learning: modelo virtual-presencial de aprendizaje y su aplicación en entornos educativos” en TIC@ aula 2007, Vol. 39.

6. LÓPEZ TOCÓN, I. (2016). "Las TIC como elemento innovador en el proceso de enseñanzaaprendizaje en la asignatura de Química Física General" en $V$ Congreso Internacional Multidisciplinar de Investigación Educativa (CIMIE16). Disponible en: http://amieedu.org/actascimie16/wp-content/uploads/2016/06/232_A3.pdf

7. LÓPEZ TOCÓN, I. y otros (2015). "Elaboración de pruebas de conocimiento en un entorno virtual como método de evaluación continua" en XII Jornadas Internacionales de Innovación Universitaria. Educar para Transformar: Aprendizaje Experiencial. Madrid: 365-372. Disponible en: http://abacus.universidadeuropea.es/bitstream/handle/11268/4351/jiiu_2015_43.pdf?sequence=2 


\title{
UEVALUA: El uso de las nuevas tecnologías para la evaluación y seguimiento de los estudiantes de Grado en Fisioterapia
}

\author{
Martínez-Pascual, Beatriz ${ }^{1}$, De la Cueva-Reguera , Mónica ${ }^{2}$, García-Mateos, Mónica ${ }^{3}$, \\ Fernández- Martínez, Silvia ${ }^{4}$, González- de-Ramos, Cristina ${ }^{5}$, Blanco- Morales, María ${ }^{6}$. \\ 1,2,3,4,5,6 Facultad de Ciencias Biomédicas y de la Salud, Universidad Europea de Madrid. \\ 1beatriz.martinez@universidadeuropea.es, ${ }^{2}$ monicadelacueva@universidadeuropea.es, \\ ${ }^{3}$ monica.garcia@universidadeuropea.es, ${ }^{4}$ silvia.fernandez@universidadeuropea.es, \\ 다istina.gonzalez@universidadeuropea.es, ${ }^{6}$ maria.blanco@universidadeuropea.es.
}

\begin{abstract}
Universidad Europea de Madrid has implemented in September 2016 a digital platform to facilitate the management, monitoring and assessment of the clinical education taking place in Hospitals and other clinical sites:UEVALUA.

The aim of this qualitative phenomenological study was to describe the experience with this new digital platform among physical therapy students, academic tutors and clinical supervisors making use of the platform in the first quarter of 2016/2017 academic course.

Through a theoretical sampling 13 participants were included. Data were collected using focus groups. A qualitative analysis was conducted using Atlas -Ti v6.0. The identified themes included: a) Difficulties in using the platform; b) The early training; c) Advantages of the platform; d) The impact of the platform on the students'performance and assessment; and d) Improvement proposals.

Keywords: Physical therapy, clinical education, digital learning, assessment, qualitative research, Phenomenology.
\end{abstract}

\section{Resumen}

En el curso 2016/2017 el Grado de Fisioterapia de la Universidad Europea de Madrid ha puesto en marcha una plataforma digital para facilitar la gestión, el seguimiento y la evaluación de las asignaturas de prácticas clínicas que se realizan en hospitales o clínicas: UEVALUA.

El objetivo de este estudio es conocer la experiencia vivida respecto a esta nueva plataforma por parte de los estudiantes y tutores académicos y clínicos del Grado en Fisioterapia, que han utilizado la nueva plataforma en el primer trimestre del curso 2016/2017.

Se ha planteado un diseño cualitativo de tipo fenomenológico descriptivo. Se ha utilizado un muestreo teórico con un tamaño final de la muestra de 13 individuos. La herramienta de recogida de datos utilizada ha sido el Grupo de Discusión. Los datos se han analizado con software Atlas-Ti v6.0. Los temas identificados incluyen : a) Complicaciones con el manejo de la plataforma; b) La formación inicial; c) Ventajas de la plataforma; d) El 
impacto del uso de una herramienta digital sobre el rendimiento y evaluación de los estudiantes, y d) Propuestas de mejora.

Palabras clave: Fisioterapia, formación clínica, aprendizaje digital, evaluación, investigación cualitativa, fenomenología.

\section{Introducción}

La formación de Grado en Fisioterapia está regulada por la ORDEN CIN/2135/2008, de 3 de julio, donde se establecen los objetivos y competencias que todo estudiante debe adquirir para el desarrollo de la profesión.

Las prácticas académicas externas constituyen una actividad de naturaleza formativa realizada por los estudiantes universitarios y supervisada por la Universidad. Su objetivo es permitir a los mismos aplicar y complementar los conocimientos adquiridos en su formación académica, favoreciendo la adquisición de competencias que les preparen para el ejercicio de actividades profesionales, faciliten su empleabilidad y fomenten su capacidad de emprendimiento según el Real Decreto 592/2014, de 11 de julio por el que se regulan las prácticas académicas externas de los estudiantes universitarios.

El modelo académico de la Universidad Europea apuesta por una enseñanza basada en competencias que desarrolla gracias a la realización de las diferentes asignaturas de prácticas externas (Estancias clínicas I y II, Practicum) que se imparten en el Grado en Fisioterapia, formación que da acceso a una profesión regulada por la Ley 44/2003, de 21 de noviembre, de Ordenación de las Profesiones Sanitarias.

El objetivo fundamental de la Plataforma Digital de Prácticas Clínicas (UEVALUA) es facilitar la gestión de estas actividades formativas, así como el seguimiento y la evaluación de los objetivos de aprendizaje asociados con cada una de las asignaturas, resolviendo de esta forma las dificultades del anterior sistema.

Esta plataforma facilita el nexo entre el tutor clínico, el tutor académico de la Universidad, el Coordinador Académico de Prácticas y el estudiante. Es además un soporte informático donde quedan registradas todas las actividades formativas del estudiante, desde los documentos propios, a las calificaciones, evitando así la disparidad de documentos y lo inadecuado de los mismos (Martinez y Estrany et al., 2014).

Cabe destacar que las plataformas e-learning nos permiten crear nuevos espacios de aprendizaje en internet, con una amplia gama de funcionalidades, que sin duda puede resultar difícil de entender, usar y mantener, por el personal docente no informático, por

(c)) BY-NC-ND 2017, Universitat Politècnica de València 
ello, sólo es posible utilizar las e-learning si se dispone de campus virtuales, y dicho uso mejora el trabajo académico, la calidad de la enseñanza aprendida y la optimización de recursos (Fernández-Pampillon, 2009).

No hay que olvidar que contribuye a un Campus más Ecológico, puesto que el uso del papel se ve disminuido considerablemente ayudando al cuidado del medioambiente. La implementación de esta nueva ayuda tecnológica es sin duda un avance en la gestión y sobretodo en el seguimiento de la formación de los estudiantes de grado.

\section{Objetivos}

\subsection{Objetivo general}

1. Conocer la experiencia que aporta la plataforma a los estudiantes.

2. Conocer la experiencia que aporta la plataforma al tutor clínico y al tutor académico de prácticas de la universidad.

\subsection{Objetivos específicos}

1. Observar el impacto de la herramienta en la comunicación entre estudiantes y tutores.

2. Analizar el impacto de la herramienta en el proceso de evaluación de las prácticas clínicas en los estudiantes.

3. Aportar propuestas de mejora para su desarrollo en el próximo curso académico.

\section{Desarrollo de la innovación}

Para dar respuesta a nuestros objetivos de investigación es necesario el estudio de las experiencias y la construcción de significados lo que nos dirige a una metodología cualitativa (Starks y Trinidad, 2007). Klopper (2008) señala que la investigación cualitativa aporta datos y participa en la generación de hipótesis para posteriores trabajos en diferentes contextos como la clínica, la gestión, la docencia y la investigación.

En la presente investigación se analiza el impacto de la plataforma UEVALUA vista desde diferentes enfoques y por tanto aporta una visión más real del impacto de la nueva plataforma en los participantes.

La importancia de la metodología cualitativa radica en que aporta datos para ayudar a comprender el qué, el cómo y por qué (Sheldon, 2005). Esto comprende describir los mecanismos detrás de los procesos y acciones de los profesionales, comprender resultados heterogéneos, identificar factores que pueden influir en la implementación de una intervención, describir las experiencias de las personas que reciben esa intervención, y describir los resultados desde el punto de vista de los participantes (Centre for Reviews and Dissemination, 2008). 
Dentro de la metodología cualitativa, este estudio se enmarca dentro de un diseño de tipo fenomenológico descriptivo por grupos de discusión (Giorgi 2012; 2005). En él se describirá la experiencia vivida durante la evaluación y seguimiento de las prácticas clínicas de estudiantes y tutores del grado en fisioterapia a través de la plataforma UEVALUA.

\subsection{Población a estudio}

Para la participación en este estudio se realizó una muestra de conveniencia pues en este proyecto no se pretendía generalizar sino profundizar de manera concreta en los individuos y su situación (Pérez-Serrano, 1994). El muestreo intencional de tipo teórico no obedece a unas reglas fijas, ni especifica de antemano el número de unidades a seleccionar. Se orienta a la selección de aquellas unidades y dimensiones que le garanticen mejor la cantidad (saturación) y la calidad y riqueza de la información.

\subsection{Criterios de inclusión}

- Mayores de 18 años.

- Firma del consentimiento informado.

Tabla 1. Selección de participantes.

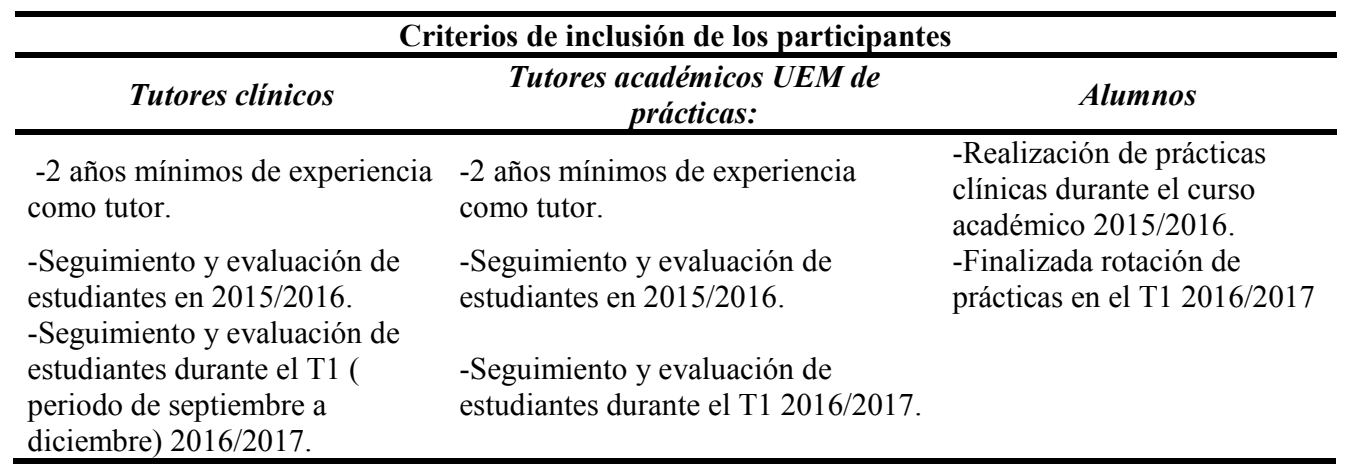

\subsection{Criterios de exclusión}

- Sujetos que no firmen el consentimiento informado.

- Aquellas personas que no consientan realizar grabación de audio.

\subsection{Muestreo por conveniencia}

- Centros u hospitales que cumplan los criterios para los tutores clínicos.

- Profesores del departamento de fisioterapia que habían tutorizado alumnos en prácticas y que cumplían los criterios de inclusión y exclusión.

- Alumnos que habían finalizado la rotación en T1, comprobando aquellos que cumplían los criterios de inclusión. 
Los datos obtenidos permitieron realizar una primera toma de contacto vía correo electrónico, informando de manera individual a los sujetos identificados del proyecto que íbamos a llevar a cabo y preguntando por su disponibilidad para realizar un grupo de discusión.

\subsection{Técnicas de recogida de la información}

Con las respuestas obtenidas se realizan 3 grupos de discusión; uno de alumnos, otro de tutores académicos y por último, uno de tutores clínicos.

\section{Grupos de discusión}

El moderador del grupo de discusión trata de permitir una discusión libre y al mismo tiempo moderar hacia una particular dirección de acuerdo con los temas que conviene tratar.

Para ello el moderador tiene un guion (Blández, 2000). Se inicia el grupo de discusión con una presentación en la que se informa de las normas del grupo de discusión y a continuación se plantean unas preguntas clave.

\section{Recogida de datos}

Los grupos de discusión fueron grabados en audio, durante las sesiones programadas.

Pérez Serrano (1994) los encuadra en los llamados elementos de registro mecánico. La grabación en audio permite registrar con exactitud una conversación o debate oral.

Las grabaciones en audio permiten volver a escuchar lo que se ha dicho, tanto en los escenarios de la acción, como en los grupos de discusión. Para ello se utilizó una grabadora Olympus modelo VN-731PC. Se informaba al participante de la grabación, tanto de manera escrita a través del consentimiento informado como de manera oral previa al comienzo de cada entrevista.

\subsection{Procedimiento de procesamiento, tratamiento y análisis de datos}

El análisis de los resultados se realizó mediante el programa informático de análisis cualitativo Atlas-Ti v6.0. Este es un programa de análisis cualitativo de carácter inductivo. El objetivo de este programa es facilitar el análisis cualitativo de grandes volúmenes textuales, archivos de sonido, imagen o vídeo. Es de gran ayuda a la hora de agilizar el análisis cualitativo y su interpretación como, por ejemplo, la segmentación de textos en pasajes o citas, la codificación o la escritura de comentarios y anotaciones (Muñoz, 2008). Para asegurar los criterios de credibilidad y rigor (Lincoln y Guba, 1985) se realiza una triangulación de los participantes ya que se recoge información de tres colectivos diferentes, los alumnos, los tutores clínicos y los tutores académicos, hecho que asegura la validez interna del estudio. La validez externa se asegurar con la descripción exhaustiva que se realiza en el apartado de introducción sobre la asignatura de estancias clínicas II y el 
sistema educativo universitario Español, contexto donde se desarrolla la presente investigación.

\section{Resultados}

Este epígrafe se compone de 5 apartados en relación a cada una de las redes obtenidas tras el análisis de los datos recogidos a través de las grabaciones en audio de los grupos de discusión: Complicaciones del uso de la nueva plataforma respecto al manejo, Formación inicial sobre el manejo de la plataforma, Impacto de la plataforma en el rendimiento del alumno, Ventajas del uso de la plataforma y Propuestas de mejora.

Las citas se nombran según el instrumento de recogida de la información (GD para grupos de discusión), la persona que emitió dicha información (A para alumnos, TC para los tutores clínicos y TA para el tutor académico) y el minuto del audio donde se recoge la información.

\subsection{Complicaciones del uso de la nueva plataforma respecto al manejo}

Esta familia está compuesta por un total de 30 códigos. Se divide en tres subcategorías o subfamilias: Aplicación móvil de la plataforma, Falta de claridad en el User Experience de la plataforma y los Problemas de accesibilidad. La figura que se muestra a continuación representa el árbol-estructura sobre las dificultades encontradas por los participantes durante la utilización de la plataforma UEVALUA (Fig1).

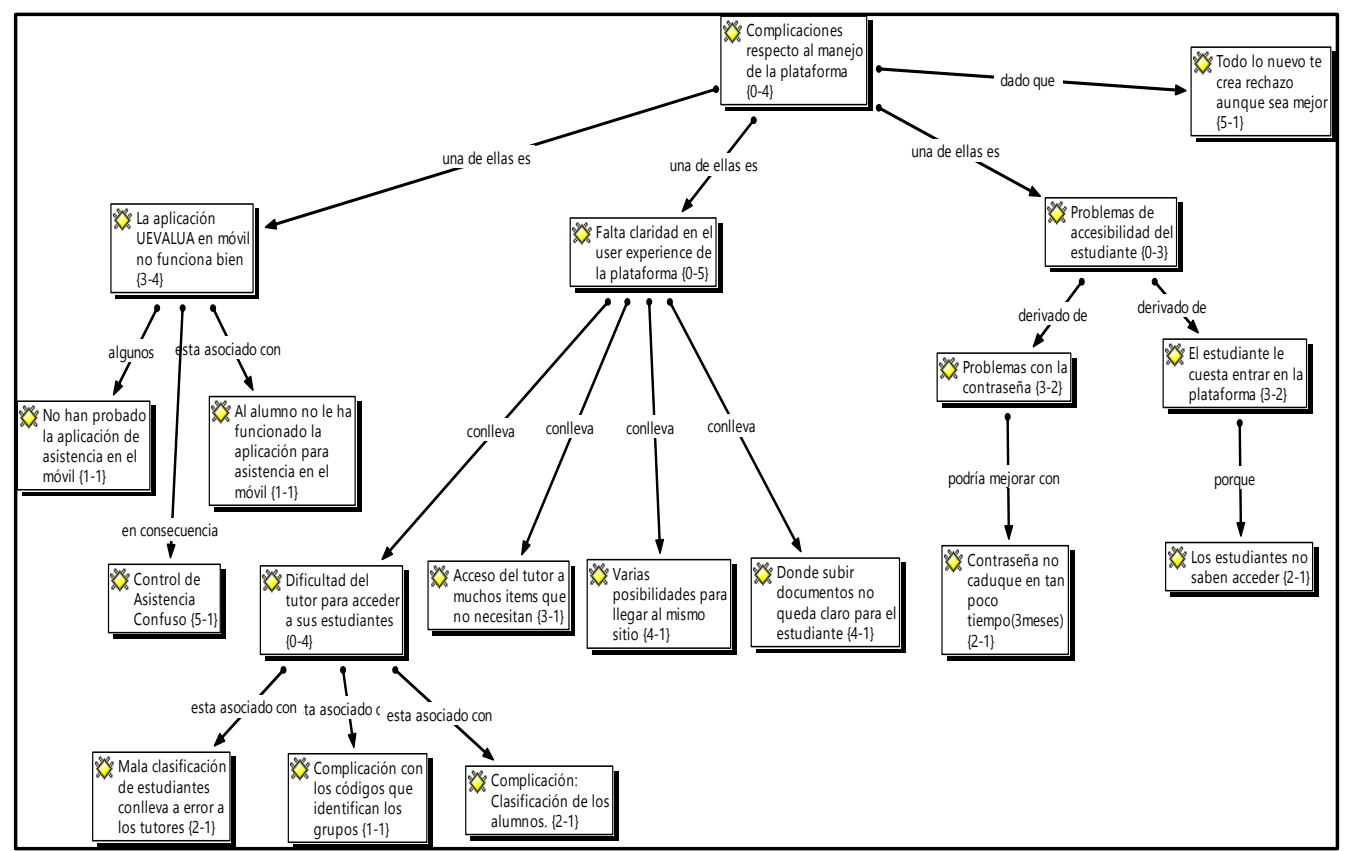

Fig 1. Árbol-estructura sobre las dificultades encontrados por los participantes durante la utilización de la nueva plataforma (Elaboración propia).

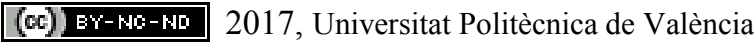
Congreso IN-RED (2017) 
UEVALUA: El uso de las nuevas tecnologías para la evaluación y seguimiento de los estudiantes de Grado en Fisioterapia

En la subcategoría Aplicación móvil de la plataforma se destaca la dificultad que tienen algunos participantes para utilizar la aplicación móvil:

"Por ejemplo, cuando me pusieron la nota de las prácticas en el ordenador me salía y sin embargo, en el móvil no. Además con datos móviles no me funciona y con datos wifi si" (GD, A1, 26.52).

"Yo me la bajé pero la dejé de usar porque no funcionaba bien. Primero, que no me dejaba acceder y luego me dejó acceder pero no me aparecía nada de la información"(GD, A2, 27.13).

Otro motivo recogido por los participantes es que el control de asistencia es confuso. La aplicación móvil se pensaba que facilitaba el registro de asistencia del estudiante, sin embargo, las citas cuestionan la utilidad de la aplicación para la asistencia:

"La asistencia los tutores no la están haciendo por la plataforma, no conozco a ningún alumno que lo haga, lo hacen en papel, lo escanean y lo suben a la plataforma" (GD, TA1, 14.49).

"Como va con el pin, es un pin que tiene el tutor, tienes que estar detrás de ellos, yo hice el control de asistencia firmando, como se hacía antes" (GD, A3, 14.49).

"La idea era que vinieran y nosotros tikamos que han venido, pero no ha funcionado, no hemos podido hacerlo" (GD, TC3, 29.37).

Respecto a la Falta de claridad en el user experience de la plataforma los tutores académicos encontraron complicado el acceso a los estudiantes que estaban en prácticas en ese momento. Además recogieron que la plataforma permite llegar al mismo sitio mediante diferentes vías:

"El tutor en las rotaciones generales tiene acceso, puede puntuar y calificar el tutor clínico también a la rotación de neurología...Igual otra opción es que solo pueda acceder el tutor práctico de neurología a las calificaciones de neurología" (GD, A3, 15.25).

"Yo creo que el problema es localizar donde están las cosas, donde las ha subido el alumno, eso lleva mucho tiempo, te puedes tirar una hora intentando buscar el documento y tienes que escribir al alumno, no lo encuentro aqui donde lo has subido" (GD, TA2, 5.16).

"Puedes llegar al mismo sitio por muchas zonas, te pierdes" (GD, TC4, 02:00). Otro aspecto destacado dentro de la subcategoría Falta de claridad en el user experience de la plataforma es que los estudiantes tuvieron mucha dificultad para saber dónde subir los documentos de evaluación:

(c)) BY-NC-ND 2017, Universitat Politècnica de València Congreso IN-RED (2017) 
"A lo mejor te metes en la tarea de Anexo y no tiene un acceso directo a la tarea donde se sube el anexo...No sabes muy bien si lo estás subiendo bien o no" (GD, A1, 1.53).

“La plataforma en sí podía ser más intuitiva, podía ser más clara, porque te hace dudar donde subir las cosas y de donde sacar la información”" (GD, A3, 5.39).

En cuanto a la subcategoría Problemas de accesibilidad los participantes destacan la poca practicidad que tiene el hecho de que la contraseña se deba solicitar en persona en el campus. Además recogen que la contraseña caduca en 3 meses y deban volver al campus:

“El tema de la contraseña...me había caducado. Entonces he intentado volver a restaurarla y me dice que tengo que volver a la universidad. Entonces no puedo subir los documentos y la tutora está esperando"(GD, A4, 00.24).

Los tutores clínicos exponen que el estudiante no sabe acceder a la plataforma o tiene dificultad para hacerlo:

“ El chico que tenemos ahora es estupendo pero no ha sido capaz de subir nada a la plataforma... les cuesta mucho entrar en la plataforma” ( GD, TC4, 21.24).

Por último, todos los participantes recogieron el hecho de que todo lo nuevo crea rechazo aunque sea mejor.Sin embargo, también señalaban que la plataforma aporta ventajas respecto al anterior sistema de evaluación, punto que se expone en el Epígrafe "Ventajas del uso de la nueva plataforma". Esta reflexión fue realizada por todos los colectivos, los cuales reconocen el hecho de que cualquier sistema nuevo crea cierto grado de rechazo inicial puesto que les requiere mayor dedicación y tiempo:

"El tema de los tutores al fin y al cabo algo nuevo siempre da algo de miedo, es el tema de cómo funciona ...es costoso...pero creo que en un par de meses cuando ya se hayan familiarizado es algo fácil, sencillo, entre comillas solo cambiando algunas cosillas y rápido” (GD, $A 4,1.22)$.

"Ellos también ver una carga de trabajo añadida y no quieren hacer cambios, en los cambios siempre hay resistencia” (GD, TA3, 15.34).

"Lo que he vivido con mis compañeros al inicio es que esto es un lío. Pero es normal, a todos nos cuestan los cambios hasta que nos acostumbremos" (GD, TC4. 1:04).

\subsection{Formación inicial sobre el manejo de la plataforma}

Esta familia está compuesta por un total de 13 códigos. Se divide en dos subcategorías o subfamilias que muestran opiniones opuestas; mientras que para algunos la formación inicial ha sido clara y concisa, para otros ha sido insuficiente y no ha resuelto las dudas sobre el manejo de la plataforma y los documentos de evaluación. La figura que se muestra a continuación representa el árbol-estructura que muestra la relación entre los diferentes códigos sobre el manejo de la plataforma UEVALUA (Figura 2). 


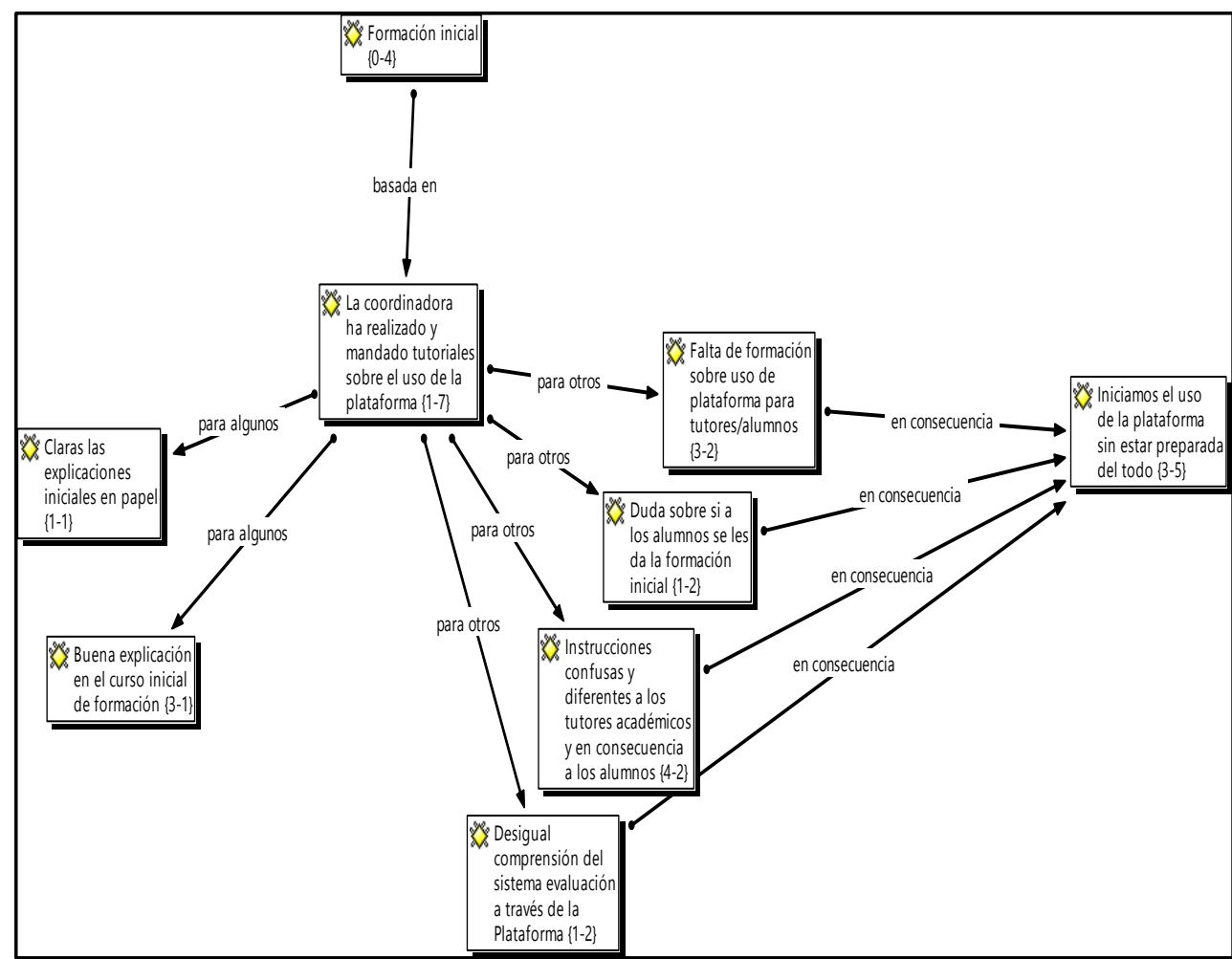

Fig 2. Árbol-estructura sobre la Formación inicial sobre el manejo de la plataforma UEVALUA (Elaboración propia).

Como aspecto más positivo de la formación se destaca que las explicaciones dadas han sido claras y por tanto, han tenido gran utilidad y han facilitado el manejo de la plataforma. Sin embargo, parte de los participantes enuncian la falta de formación sobre el uso de la plataforma:

“A mí como coordinadora, nadie me dio formación” ( GD, TC1, 27.18).

"Las explicaciones que nos mandaron en papel, me parecieron bastante claras" ( GD, TC4,02.04).

Los tutores académicos destacan la falta de unanimidad en las instrucciones dadas. Para ellos el principal motivo de esto es que se ha iniciado la plataforma sin estar preparados:

“Este año hemos vuelto a empezar a “matacaballo” por detrás del alumno” (GD, TA4, 30.40).

“Las instrucciones no son dadas iguales a todos los profesores” (GD, TA5, 2.35).

"El trimestre uno ha sido un poco locura porque no podían subir nada, no tenían el acceso, no han quitado la subida de diario reflexivo en la plataforma, sigue ahí, ha sido un poco complicado" (GD, TA3, 4.24).

(cc) EY-NC-ND 2017, Universitat Politècnica de València 


\subsection{Impacto en el rendimiento del estudiante}

Esta familia está compuesta por 30 códigos y se divide en 3 subcategorías o subfamilias: Formato papel vs Formato digital, la Actitud del estudiante actual y Feedback al estudiante. Esta familia emerge solamente de la experiencia de los tutores clínicos.

La figura que se muestra a continuación representa el árbol-estructura para ilustrar la relación entre los códigos de la familia de Impacto sobre el rendimiento del estudiante ( Figura 3).

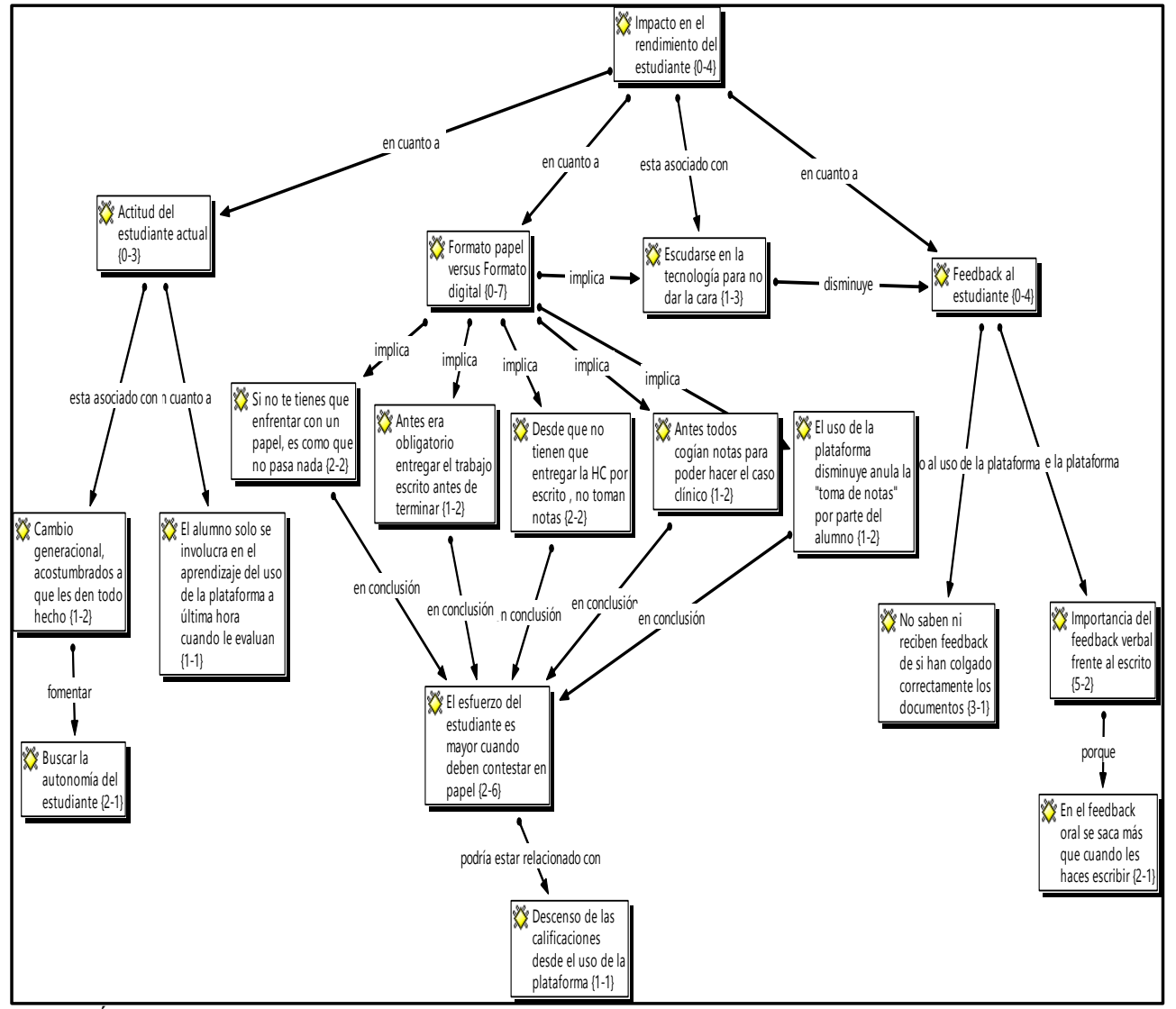

Fig 3. Árbol -estructura sobre el Impacto del uso de la plataforma UEVALUA en el rendimiento de los estudiantes.

En la subcategoría Formato papel vs Formato digital se destaca el hecho de la no obligatoriedad de entregar el trabajo por escrito al tutor clínico desde el uso de la plataforma. Este cambio parece haber tenido un impacto en la conducta de los estudiantes a la hora de tomar notas en el día a día de la práctica clínica:

"Antes, cuando se trabajaba en papel, era obligatorio entregar el trabajo en papel antes de que se finalizaran las prácticas" (GD, TC2, 34.39).

"He visto que desde que no tiene que traer la historia clínica en papel, no toman notas" ( GD, TC3, 41.54).

(c)) EY-NC-ND 2017, Universitat Politècnica de València 
UEVALUA: El uso de las nuevas tecnologías para la evaluación y seguimiento de los estudiantes de Grado en Fisioterapia

El hecho de no tener que entregar nada por escrito al tutor evita al alumno la situación de tenerse que enfrentar cara a cara con la situación:

"Si no te enfrentas a alguien con un papel en ese mismo momento, es como si no pasa nada" ( GD, TC3, 33.27).

"El papel es una manera de enfrentarse cara a cara. Con el ordenador está la pantalla delante, pero no la persona que te lo va a corregir" (GD, TC1, 34.21).

$\mathrm{Y}$ esta distancia parece tener un impacto en el esfuerzo del estudiante y en las calificaciones obtenidas en la práctica clínica:

"A mí me parece que se esforzaban más cuando tenían que entregarlo por escrito, contestar a ese escrito" ( GD, TC3, 18.08).

"Las notas eran antes mucho más altas que ahora" (GD, TC2, 11.03).

En la subcategoría Feedback al estudiante vuelve a emerger el tema del papel, pues cuando el alumno debía entregarlo en papel, el tutor se sentaba con él para darle un feedback oral:

"Parece que se saca más de ellos cuando les haces escribir" (GD, TC2, 0.23).

"Tengo una conversación con el alumno, que es mucho mejor que dejarlo por escrito, le aporta mucho más" (GD, TC1, 0.17).

Por otro lado, se percibe una falta de feedback respecto a la confirmación de si han subido a la plataforma los documentos correctamente:

"No sé si hice bien todo, si todos pueden ver lo que yo he colgado" (GD, A5, 3.07).

"Hice la clínica al principio del trimestre pasado y no tengo manera de saber si lo hecho bien, si lo hecho mal..."(GD, A3, 3.50).

Para los participantes el uso de la plataforma digital disminuye las opciones de dar un feedback verbal al estudiante. Esta situación permite al estudiante protegerse tras la pantalla de su ordenador, "Escudarse en la tecnología para no dar la cara":

"La gente se escuda mucho en la tecnología para no dar la cara. Tú lo puedes leer en el ordenador, sin que nadie vea lo que estás leyendo, Aunque la coordinadora de la universidad esté viendo su trabajo, tú no te enfrentas ni a esa persona ni a ese momento" ( GD, TC3, 32.34).

En la subcategoría Actitud del estudiante actual se destaca la percepción de los participantes respecto al cambio generacional que observan en los estudiantes:

"Han cambiado mucho las generaciones...Yo tampoco soy muy vieja pero ha habido un cambio brutal, están acostumbrados a que todo se lo dan hecho, y si de les exige, encima la culpa es tuya" ( GD, TC1, 43.07).

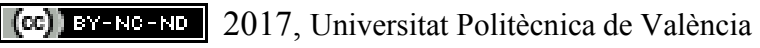
Congreso IN-RED (2017) 
“Es una pena porque para nosotros las prácticas era lo mejor de la carrera” ( $G D, T C 3,43.28)$.

Otro aspecto destacado por los participantes en esta subcategoría de Actitud del estudiante actual es la necesidad de buscar la Autonomía del estudiante en su trabajo diario en las prácticas clínicas:

"Yo les hecho una mano pero intento que sean ellos los que saquen el contenido de ese paciente" GD; TC4; 36.54).

"Yo les hago que ellos trabajen en casa, sin tenerles que obligar ni perseguirles. Si les digo lo que tienen que hacer les estoy cerrando la cabeza” ( GD, TC1, 39.54).

\subsection{Ventajas del uso de la plataforma}

Esta familia está compuesta por 15 códigos y se divide en 3 subcategorías o subfamilias: Sencilla porque no necesita conocimientos de informática para usarla, La plataforma es útil y La plataforma mejora la comunicación estudiante vs Cínica vs tutor académico. La figura representa el árbol-estructura que ilustrar los códigos de esta familia ( Figura 4).

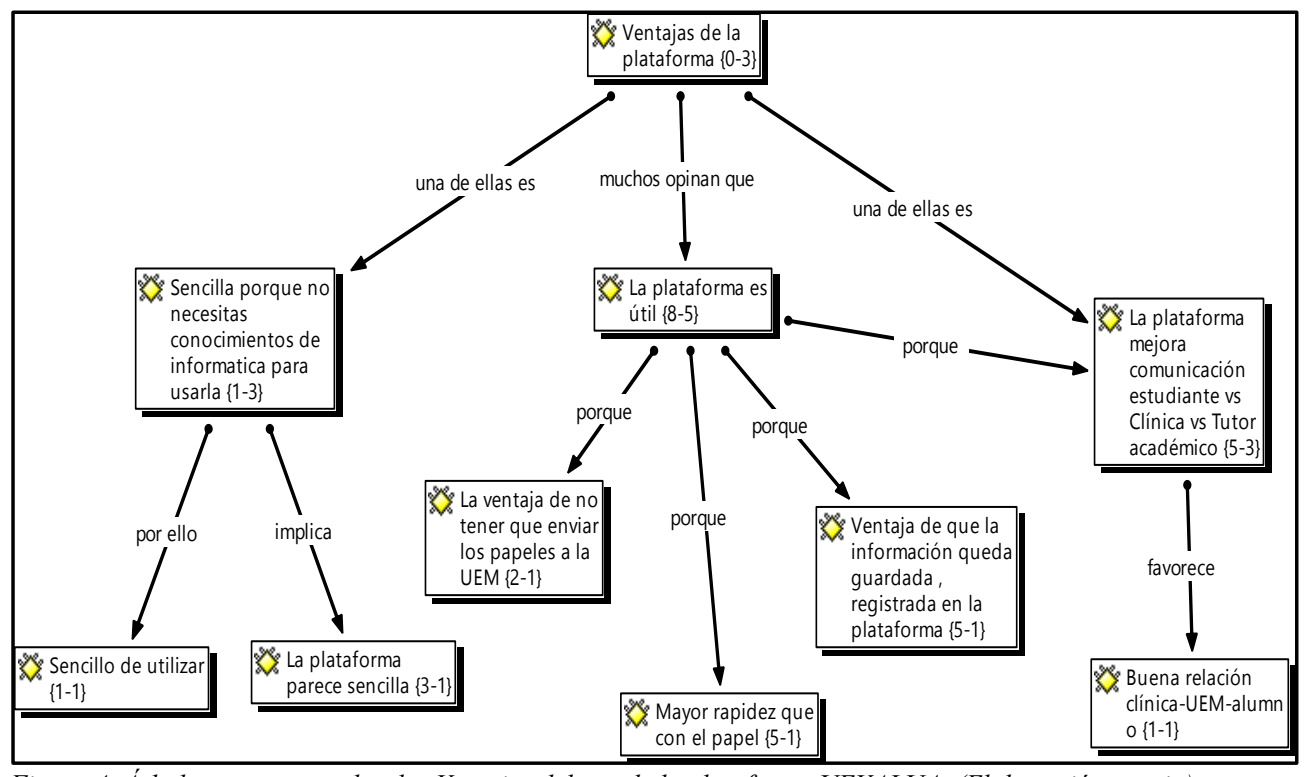

Figura 4. Árbol-estructura sobre las Ventajas del uso de la plataforma UEVALUA. (Elaboración propia).

En la subcategoría Sencilla porque no necesita conocimientos de informática para usarla se destaca la ventaja de la sencillez del uso de la plataforma:

"Es muy intuitiva, no necesitas conocimientos informáticos ni nada” (GD, TC2, 26.39).

“La plataforma es muy sencilla a priori, es muy visual” ( GD, TC3, 25.49).

"Yo creo que en un par de meses cuando ya se haya familiarizado, es algo fácil, sencillo y rápido" (GD, A4, 1.30).

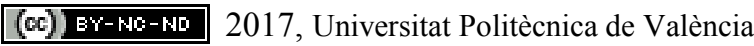
Congreso IN-RED (2017) 11 
UEVALUA: El uso de las nuevas tecnologías para la evaluación y seguimiento de los estudiantes de Grado en Fisioterapia

En la subfamilia de la Plataforma es útil se destaca la mayor rapidez en el trámite de los documentos con la universidad. Al mismo tiempo, el hecho de que los documentos queden registrados en la plataforma es una ventaja compartida por todos los participantes:

"Es una herramienta que me resulta útil y cómoda y evita tener papeles para arriba y para abajo" ( GD, TC2, 49.48).

"Todo está ahí cargado. Si una compañera se da la baja, yo puedo entrar con su perfil. No tienes que mandar nada por correo" ( GD, TC4, 44.59)

La última subcategoría de esta familia es La plataforma mejora la comunicación estudiante vs Cínica vs tutor académico:

"Reune tanto a la universidad, como a nosotros como a las prácticas, entonces es un elemento bastante útil” (GD, A3, 9.34)

"La mejora importante de esa plataforma es que los dos tutores, clínico y académico estan juntos, entonces el alumno recibe un feedback en la misma plataforma de los dos "(GD, TA2, 14.09)

\subsection{Propuestas de mejora}

Esta familia está compuesta por 24 códigos y se divide en 3 subcategorías o subfamilias, cada una perteneciente a uno de los tres colectivos que han formado parte del estudio: Propuestas de los tutores clínicos, Propuestas de los estudiantes y Propuestas de los tutores académicos. La figura representa el árbol-estructura para ilustrar la relación entre los diferentes códigos que componen esta familia ( Figura 5).

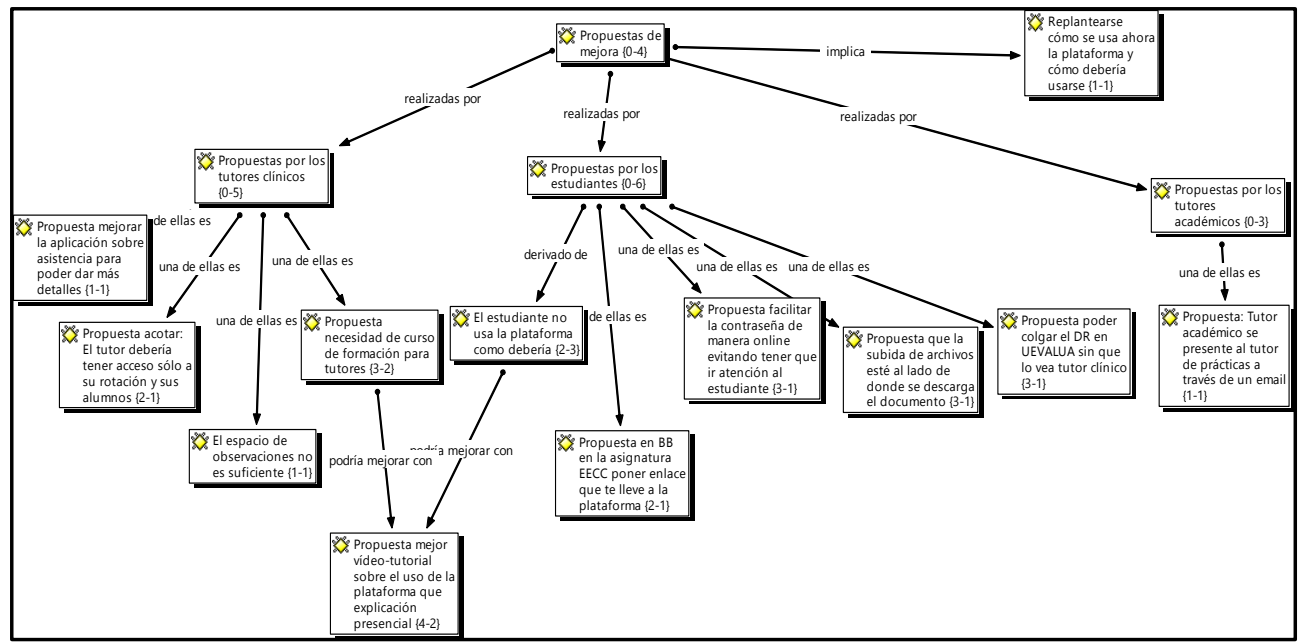

Fig 5. Árbol-estructura sobre las Propuestas de mejora de la plataforma UEVALUA.

La subcategoría Propuestas de los tutores clínicos se centra en mejorar la aplicación del control de asistencia para poder dar más detalles sobre el desempeño del alumno y en limitar el acceso de cada tutor al grupo de alumnos que está tutorizando:

“Hay que acotarlo. Que te salgan sólo tus alumnos” ( GD, TC4,27.52)

(c)) BY-NC-ND 2017, Universitat Politècnica de València Congreso IN-RED (2017) 
"Echo de menos, poder poner "Fulanito" ha venido hoy pero ha llegado tarde y debe recuperar 2 horas. En observaciones no es suficiente." (GD, TC3, 30.01).

La subcategoría de Propuestas de los estudiantes recoge sus sugerencias para facilitar el uso de la plataforma. Los estudiantes opinan que se debería simplificar el proceso para la obtención de la contraseña:

"Podrían facilitar la contraseña a través de la página web y evitar la espera en atención al estudiante" (GD, A2, 5.23)

Otra propuesta de mejora es que el enlace a la nueva plataforma se vinculase al espacio del Blackboard que tienen las materias de Estancias Clínicas y Practicum, pudiendo acceder directamente desde allí a UEVALUA:

"Otra cosa que estaria bien sería en la asignatura del campus virtual poner un enlace que te llevara a la plataforma" (GD, A2, 19.51)

Las propuestas de mejora de los tutores académicos se recogen en la subcategoría Propuestas del tutor académico. Como acciones de mejora proponen que el tutor académico y el tutor clínico se pongan en contacto a través de la plataforma antes de la rotación del estudiante:

"Estaría bien mandar un mensaje a los tutores "yo soy tutora académica de este alumno, ante cualquier cosa póngase en contacto conmigo"'”(GD, TA1, 20.17)

En relación con esta familia de Propuestas de mejora, una acción a tener en cuenta sería la de elaborar un vídeo- tutorial para explicar el uso de la plataforma. Los participantes se plantean que cómo usan la plataforma en la actualidad no tiene porqué ser la mejor forma de hacerlo:

"Hay que plantearse, cómo estamos usando hoy la plataforma, y cómo la podríamos utilizar" ( GD, TC2, 46.47)

"Un vídeo explicativo de 1 minuto..Un tutorial que sea corto, conciso, (GD, A3, 16.42)

\section{CONCLUSIONES}

La experiencia de los participantes respecto al uso de la plataforma refleja el concepto de que todo lo nuevo crea un rechazo inicial. En su vivencia, los participantes han encontrado complicaciones en cuanto al manejo de la plataforma y ventajas en el uso de la misma. Todos los participantes destacan como principal complicación una deficiente User Experience, que implica una falta de claridad en la navegación por la plataforma, que, a priori, describen como fácil de utilizar.

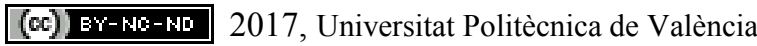
Congreso IN-RED (2017) 
Respecto al impacto de la herramienta en la comunicación entre estudiantes y tutores, los resultados recogen un impacto negativo en el feedback estudiante-tutor clínico al afirmar, el tutor, que el estudiante se escuda en la tecnología para no dar la cara, lo que disminuye la comunicación oral entre ellos.

En cuanto al impacto de la herramienta en el proceso de evaluación, han sido los tutores clínicos, los que han destacado que el uso de la plataforma ha repercutido negativamente en el rendimiento del estudiante, al considerar que el nivel de responsabilidad de este último se ve afectado al no tener que entregar ningún documento en papel.

Respecto a las ventajas destacadas por todos grupos, se destaca el hecho de que el uso de la plataforma supone un espacio de registro para todos los documentos de evaluación y seguimiento, lo que agiliza además los trámites de calificación entre la Universidad y el centro de prácticas externo. El hecho de que exista un espacio común de comunicación entre estudiante-tutor clínico-tutor académico, es también considerado una ventaja por todos ellos.

Las propuestas de mejora son un elemento común en todos los grupos de discusión y apuestan por simplificar la navegación del usuario en la plataforma, reforzar la formación inicial a todos los grupos buscando la homogeneidad en la misma y mejorar el funcionamiento de la aplicación móvil.

Podemos concluir que la novedad de esta plataforma, implementada hace sólo 3 meses, podría conllevar el hecho de que sean las complicaciones el tema más destacado del estudio. Consideramos que la continuidad en el uso de la plataforma por parte de todos los actores participantes, disminuirá parte de las mismas ya que el nivel de manejo será mayor y los usuarios se podrán beneficiar de todo el potencial de la misma. Las acciones de mejora propuestas podrán ayudarnos a optimizar el uso de esta nueva plataforma de evaluación de prácticas clínicas externas.

\section{Referencias}

Blández, J. (2000). La investigación-acción, un reto para el profesorado. Barcelona: Inde Publicaciones.

Centre for Reviews and Dissemination. Incorporating Qualitative Evidence in or alongside effectivenesss reviews. In Centre for Reviews and Dissemination (eds). Systematic Reviews: CDR's guidance for undertaking reviewa in health care. USA: Centre for Reviews and Dissemination. University of York; 2008.

Fernández-Pampillón Cesteros, A. (2009). Las plataformas e-learning para la enseñanza y el aprendizaje universitario en Internet.

(c)) EY-NC-ND 2017, Universitat Politècnica de València Congreso IN-RED (2017) 
Giorgi, A. (2005). The phenomenological movement and research in the human sciences. Nursing science quarterly, 18(1), 75-82.

Giorgi, A. (2012). The descriptive phenomenological psychological method. Journal of Phenomenological psychology, 43(1), 3-12.

Gutiérrez Cárdenas, L., \& Leco Berrocal, M. I. (2015). Del "Cuaderno de Prácticas" a la "Plataforma de Evaluación de Prácticas Clínicas "en odontología.

Klopper, H. (2008). The qualitative research proposal. Curationis, 31(4), 62-72.

Ley 44/2003 de 21 de noviembre para la ordenación de profesionales sanitarios, num. 280 de 22 de noviembre de 2003.

Lincoln, Y. S., y Guba, E. G. (1985). Naturalist inquiry. California: Sage.

Muñoz, J. (2008). Análisis cualitativo de datos textuales con ATLAS. ti 5. Barcelona: Universitat Autónoma de Barcelona, 2005.

Orden CIN 2135/2008 de 3 de julio, por la que se establecen los requisitos para la verificación de los títulos universitarios oficiales que habiliten para el ejercicio de la profesión de Fisioterapeuta, num 1743 de julio de 2008.

Pérez Serrano, G. (1994). Investigación cualitativa. Retos e interrogantes. Madrid: La Muralla.

Real Decreto 592/2014 de 11 de julio por el que se regulan las prácticas académicas externas de los estudiantes universitarios, num. 184, de 30 de julio de 2014.

Reynés, M. R. M., Bertos, J. E., Vila, M. C., \& Ramón, M. I. (2014). Seguimiento, tutorización y evaluación de prácticas externas mediante plataforma virtual de trabajo colaborativo: la experiencia en el Grado de Geografía. Revista de investigación en educación, 2(12), 254-267.

Sheldon, T. A. (2005). Making evidence synthesis more useful for management and policymaking.

Starks, H., \& Trinidad, S. B. (2007). Choose your method: A comparison of phenomenology, discourse analysis, and grounded theory. Qualitative health research, 17(10), 1372-1380.

Vélez Vélez, E., González Hernández, A., Hernández Salinero, F., Rodríguez, P., \& Santiago, M. (2012). Seguimiento y evaluación de las prácticas clínicas tuteladas con ayuda de la plataforma Moodle: Experiencia piloto y propuesta de mejora. Enfermería Global, 11(26), 86-101.

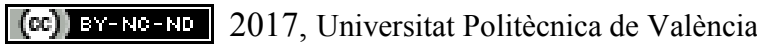
Congreso IN-RED (2017) 


\title{
Aprendizaje autónomo del estudiante apoyado en recursos audiovisuales en el contexto de un Grado de Ingeniería Informática: experiencias con metodologías de enseñanza activas ${ }^{*}$
}

\author{
Enrique Vallejo ${ }^{1}$, Pablo Fuentes ${ }^{1}$ y Mariano Benito M $^{2,1}$ \\ ${ }^{1}$ Universidad de Cantabria, Santander, España \\ ${ }^{2}$ Recore Systems, Eindhoven, Holanda
}

\begin{abstract}
The course Introduction to Computer Networks from the University of Cantabria has a low success, with complaints about the lack of sufficient practical classes that reinforce the theoretical contents. An innovation project has been developed to develop a set of multimedia materials that replace some master classes and increase the amount of practical sessions, following a flipped classroom model. Specifically, six videos have been developed, each of them accompanied by a self-learning activity, and an associated practical session. Such sessions followed approximately a Problem-Based Learning approach.

The impact of the project has been evaluated, on the motivation, withdrawal and academic results. The response of the students is positive, with a slightly increase in the classroom attendance. Students indicate that they prefer this type of learning. However, monitoring tools show that activity attendance is significantly lower than expected. Academic results show a rate of student withdrawal similar to previous years, but a slightly higher rate of students passing the course. Overall, the results of the project is very positive, given the increased student motivation, and a similar approach will be considered in forthcoming courses.
\end{abstract}

Keywords: Multimedia learning resources, flipped classroom, self-learning.

\section{Resumen}

\footnotetext{
*Este proyecto está apoyado por la III Convocatoria de Proyectos de Innovación Docente del Vicerrectorado de Profesorado de la Universidad de Cantabria y por el Ministerio de Economía, Industria y Competitividad bajo el contrato TIN2016-76635-C2-2-R (AEI/FEDER, UE). Pablo Fuentes está financiado por el Ministerio de Educación, Cultura y Deporte, beca FPU13/00337. Trabajo realizado mientras Mariano Benito pertenecía a la Universidad de Cantabria.
} 
Aprendizaje autónomo del estudiante apoyado en recursos audiovisuales en el contexto de un Grado de Ingeniería Informática: experiencias con metodologías de enseñanza activas

\begin{abstract}
La asignatura Introducción a las Redes de Computadores de la Universidad de Cantabria presenta un rendimiento bajo, con queja de la falta de clases prácticas que refuercen los contenidos teóricos. Para atacar el problema, se ha desarrollado un conjunto de materiales audiovisuales que reemplacen algunas de las clases teóricas y aumenten la cantidad de sesiones prácticas en el aula siguiendo un modelo de flipped classroom. En concreto, se han desarrollado seis vídeos para el auto-aprendizaje por parte del alumno, acompañados de tests de autoevaluación y de seis sesiones prácticas en el aula. En dichas sesiones, se ha seguido aproximadamente una metodología de aprendizaje basado en problemas.

Se ha evaluado el impacto del proyecto sobre la motivación, seguimiento y resultados del alumnado. La respuesta del alumnado al cambio metodológico es positivo, aumentándose ligeramente la asistencia a clase y seguimiento de la asignatura. Sin embargo, el seguimiento de los recursos es mucho más bajo de lo esperado. Los resultados académicos muestran una tasa de alumnos presentados similar a la de cursos previos, pero una tasa de aprobados ligeramente superior. Globalmente, el resultado del proyecto es muy positivo, y plantea seguirse un esquema similar en cursos posteriores.
\end{abstract}

Keywords: Recursos docentes audiovisuales, clase invertida, autoaprendizaje.

\title{
1 Introducción
}

El exceso de clases magistrales está identificado como uno de los problemas más claros de cara a la motivación y seguimiento de los alumnos. El abuso de clases magistrales se justifica desde el profesorado con la necesidad de cubrir un cierto temario en un tiempo limitado, pero incide negativamente en la motivación del alumnado, el seguimiento de la asignatura y la adquisición de competencias, lo que finalmente afecta a los resultados académicos. En concreto, esto viene ocurriendo en la asignatura "G661 Introducción a las Redes de Computadores" del Grado en Ingeniería Informática de la Universidad de Cantabria. La asignatura presenta una tasa de aprobados baja, típicamente ligeramente inferior al $50 \%$. Una de las quejas recurrentes de los alumnos es la falta de suficientes clases de problemas en el aula que refuercen los contenidos teóricos estudiados en la asignatura.

Esta falta de más clases prácticas se asocia a la imposibilidad de cubrir el temario propuesto de la asignatura con más clases prácticas siguiendo la organización que se ha empleado en cursos anteriores. Diferentes metodologías propuestas para atacar este conjunto de problemas incluyen entre otras las clases invertidas (Lage y Treglia 2000; Santiago y Díez 2016), cambios de metodología como el uso de materiales audiovisuales (Ronchetti 2010), o estrategias de Aprendizaje Basado en Problemas (ABP) (Wood 2003). Estas propuestas han tenido mucho auge recientemente, motivadas por las plataformas de autoaprendizaje online como cursos MOOC basados en diferentes plataformas (Sparks 2011).

Para solventar la situación de la asignatura, en el curso académico 2016-17 se ha planteado un Proyecto de Innovación Docente. El objetivo de este proyecto es modificar la metodología docente de la asignatura, desarrollando para ello un conjunto de 
materiales audiovisuales que reemplacen algunas de las clases teóricas y que permitan aumentar la cantidad de clases de problemas en el aula. Los contenidos adquiridos en dichos materiales audiovisuales se refuerzan mediante pruebas de autoevaluación a través de la plataforma online de la asignatura, y se comentarán en la siguiente clase presencial.

Este cambio busca de forma directa un aumento del número de sesiones de prácticas en el aula. De forma indirecta, también se busca una mejora en los resultados de la asignatura por diferentes motivos: se obliga a los alumnos a llevar al día los contenidos y realizar una serie de actividades de autoevaluación; se espera mejorar la motivación del alumnado, gracias al trabajo continuo en la asignatura; y finalmente, se espera que esto se traduzca en un aprendizaje más profundo y una mejora en los resultados de la asignatura.

De esta forma, las contribuciones principales de este artículo son las siguientes:

- Se presenta un caso de aplicación de modificación de metodologías docentes en una asignatura de Ingeniería Informática, empleando materiales audiovisuales, clases invertidas y aprendizaje basado en problemas.

- Se presentan detalles técnicos del desarrollo de los contenidos, así como algunos problemas encontrados, principalmente problemas técnicos y aspectos que no resultan agradables para los alumnos como la duración de los vídeos.

- Se analizan los resultados del cambio metodológico aplicado, teniendo en cuenta la impresión informal de los alumnos, herramientas de monitorización de las actividades, encuestas de satisfacción y resultados académicos. La impresión global de los alumnos es muy positiva, si bien el seguimiento de las actividades es moderado. El seguimiento de la asignatura aumenta levemente, y con él la tasa de aprobados en la única convocatoria hasta la fecha.

\section{Realización del proyecto}

En esta sección se presentan la planificación docente de la asignatura, los problemas encontrados y las perspectivas futuras.

\subsection{Planificación de la propuesta docente}

La asignatura "G661 - Introducción a las Redes de Computadores" tiene 62 alumnos matriculados, descontando Erasmus. De acuerdo a los criterios establecidos, las sesiones de problemas en el aula asociadas a cada una de las sesiones de auto-aprendizaje se dividen en dos grupos diferentes. El horario de la titulación asigna estos dos grupos en martes y jueves respectivamente, lo que ha limitado en algún caso las semanas en las que era posible realizar el desdoble, al ser alguno de los dos días festivos.

Se han seleccionado seis sesiones para el aprendizaje autónomo del alumno. De estas seis sesiones, una no emplea vídeos (únicamente un texto escrito), pero otra emplea dos vídeos diferentes, por lo que se han desarrollado un total de seis vídeos para seis sesiones. Estas sesiones se han realizado durante Octubre (2 sesiones), Noviembre (2 sesiones), Diciembre (1 sesión) y Enero (1 sesión). Cada uno de los seis vídeos tiene asociado un test de autoevaluación asociado en el curso de Moodle de la asignatura. 
Aprendizaje autónomo del estudiante apoyado en recursos audiovisuales en el contexto de un Grado de Ingeniería Informática: experiencias con metodologías de enseñanza activas

Como métricas de seguimiento del proyecto, se han identificado los siguientes aspectos:

- Seguimiento de los recursos: proporción de alumnos que realizan las actividades de auto-aprendizaje, de acuerdo a las páginas de monitorización de los vídeos y los tests de autoevaluación.

- Encuesta de seguimiento para cuantificar la satisfacción del alumno.

- Resultados académicos de la asignatura: tasas de aprobado y porcentaje de alumnos presentados.

El único presupuesto disponible para la realización del proyecto está asignado a la difusión de resultados. Por este motivo, toda la realización de materiales audiovisuales se ha realizado por el equipo de trabajo, y las herramientas empleadas han sido libres y/o gratuitas.

No se contempla dentro del proyecto la modificación de los mecanismos de evaluación empleados en la asignatura. Indirectamente, esto permite la comparación de los resultados académicos del curso en que se ha desarrollado el proyecto frente a cursos anteriores.

\subsection{Herramientas de edición de vídeo y audio seleccionadas}

En primer lugar, se seleccionaron las herramientas técnicas apropiadas. Para el proceso de grabación y edición de vídeo y audio es necesario contar con unos conocimientos mínimos, si bien existen manuales paso por paso disponibles en la web.

Tras probar diferentes herramientas, el conjunto de herramientas empleado finalmente ha sido el siguiente:

- Captura de pantalla: OBS Studio 0.16.2. (Open Broadcaster Software 2017).

- Edición de vídeo: Avidemux 2.6.14 (Avidemux 2017) para el recortado y concatenado sin recodificación de pistas de vídeo o audio; ShotCut (Meltytech 2017) para la edición no lineal y recodificación de vídeo.

- Edición de audio: Audacity 2.1.2 (Audacity 2017) para desarrollar efectos de audio en cortinillas de cierre y reducción de ruido.

La sección 2.4 detalla algunos problemas sufridos en el proceso de elección de herramientas.

\subsection{Materiales desarrollados}

Se han desarrollado seis vídeos, seis tests de autoevaluación y seis sesiones de problemas en el aula.

Los vídeos desarrollados se han capturado a partir de la pantalla del ordenador personal, en múltiples cortes. Para ello, se ha empleado la herramienta OBS Studio seleccionando el codec H.264 con una resolución de 1366x768 (suficiente para una visualización clara por parte del alumno). El audio del profesor se ha capturado a partir de un micrófono integrado en el monitor. Las diferentes pistas capturadas se 


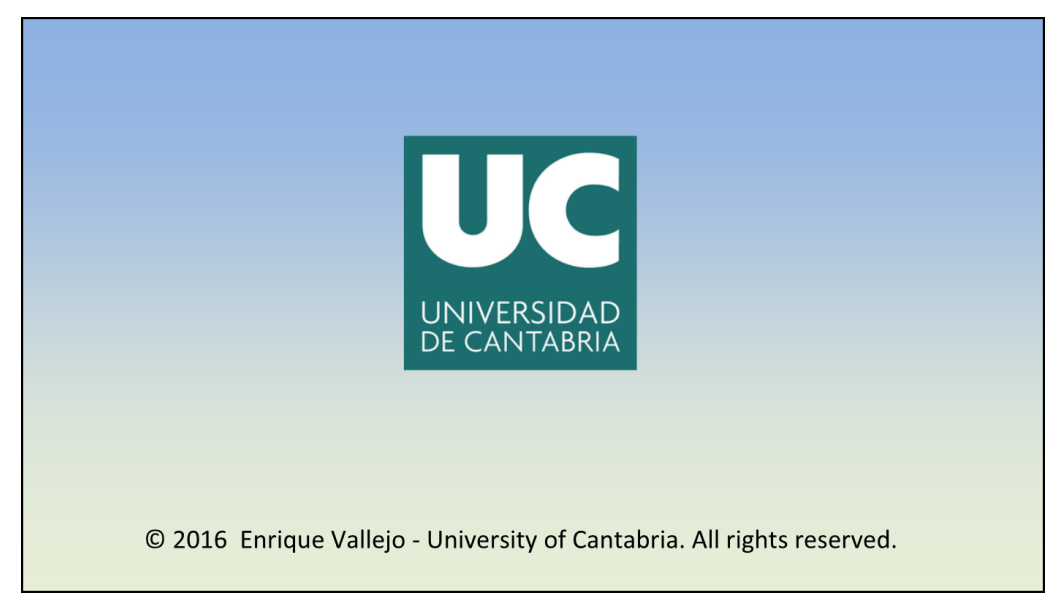

Fig. 1: Sencilla cortinilla empleada para remarcar el final de los vídeos.

han recortado (al comienzo y final de la misma) ajustando a un keyframe para evitar la recodificación de toda la secuencia empleando Avidemux, y también se han concatenado con esta herramienta. La pista de audio se ha editado con Audacity para reducir el ruido de fondo. Por otra parte, se ha desarrollado una cortinilla que indica el final del vídeo basado en una imagen estática con un fundido realizado con ShotCut, combinado con unos todos desarrollados con Audacity. La imagen empleada en la cortinilla final se muestra en la figura 1. Por desgracia, por una incompatibilidad entre la codificación de las secuencias, el concatenado de esta cortinilla ha requerido la recodificación de la secuencia completa, lo que podía implicar un proceso de unos 45 minutos por vídeo; este tiempo, en cualquier caso, depende de las prestaciones del equipo en que se realiza la recodificación.

Debido a su tamaño, los vídeos no pueden hospedarse en el servidor de Moodle de la Universidad. Consultados los técnicos del Centro de Formación en Nuevas Tecnologías de la Universidad de Cantabria (CeFoNT), estos vídeos se alojaron en YouTube, y se enlazaron en el curso de Moodle de la asignatura, incrustados en un elemento del tipo "Página" que permite presentar un código HTML.

La Figura 2 muestra la página de gestión de YouTube con los 6 vídeos publicados. Esta página incluye también una estadística básica del número de visionados de cada uno de los vídeos, que no implica la visualización del vídeo completo.

Los materiales desarrollados se han basado en los contenidos tradicionalmente empleados en la asignatura, si bien se ha intentado que el vídeo sea lo más demostrativo posible, y no una simple (y desmotivadora) sucesión de transparencias. En este sentido, se han grabado varias demos (por ejemplo, para temas de codificación de audio y vídeo para su transmisión por la red) y se han añadido múltiples animaciones en las transparencias empleadas. La duración de cada vídeo se comprende entre 25 y 32 minutos, significativamente inferior a una clase teórica.

Asociado a cada uno de los vídeos, se ha desarrollado un test de autoevaluación en Moodle. Aunque los alumnos reciben una nota tras finalizarlo, este test no tiene peso en la calificación de la asignatura, y está destinado únicamente al auto-aprendizaje 


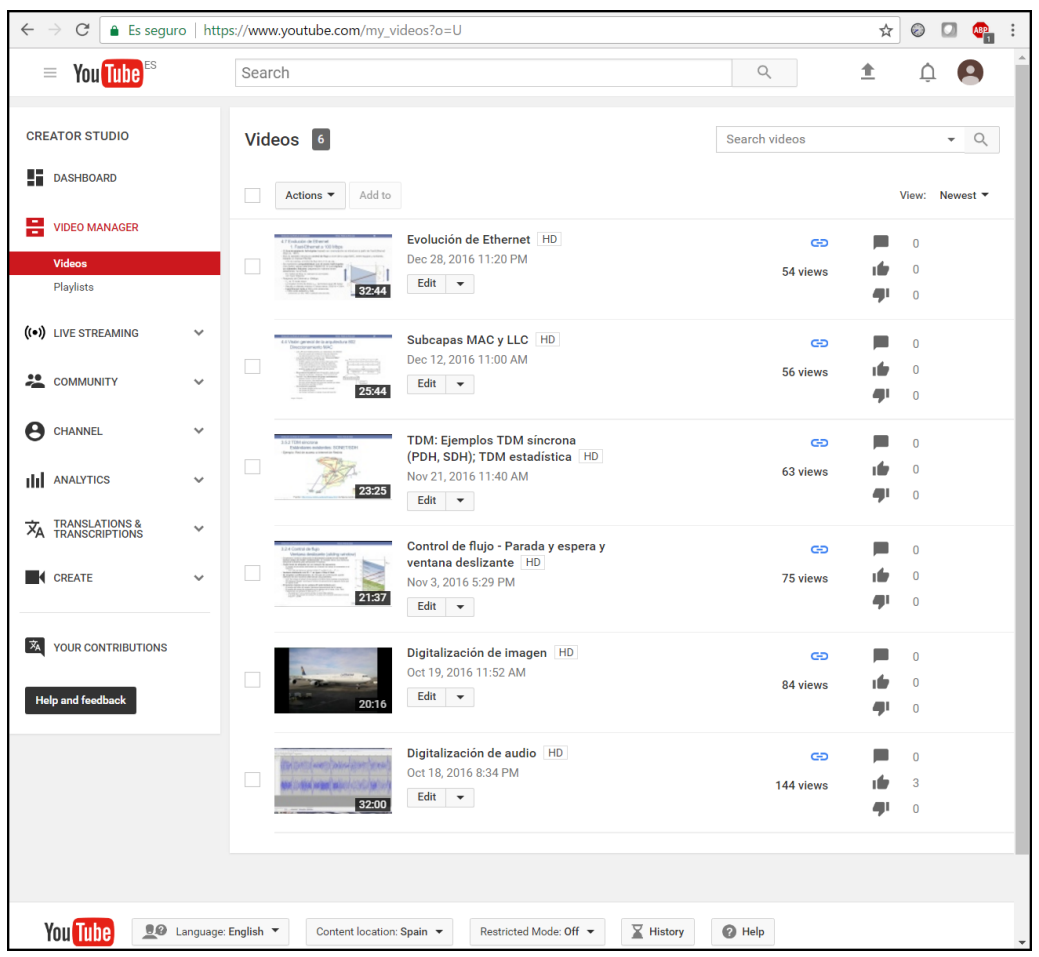

Fig. 2: Captura de la interfaz de gestión de los vídeos subidos en YouTube.

por parte del alumno. Se han desarrollado por tanto seis tests diferentes, con entre 3 y 6 preguntas por test. Las preguntas comprenden preguntas de diferentes tipos, incluyendo respuesta múltiple con una o varias respuestas posibles, respuesta corta, relacional y preguntas calculadas. La Figura 4 muestra una captura de uno de los tests de autoevaluación desarrollados.

Para las sesiones presenciales en el aula, se ha asignado una temática diferente a cada uno de los dos grupos de alumnos. En un grupo, se ha planteado un estudio de la tecnología HFC (Hybrid Fiber-Coaxial), la tecnología empleada para prestar servicios de acceso a Internet por operadores de cable. En el otro grupo, se ha centrado el estudio en la tecnología de acceso a Internet por fibra óptica, basada en el estándar más extendido en España GPON, G.984. En ambos casos, las actividades realizadas comprenden los diferentes aspectos que se estudian en la asignatura, como puede ser la codificación de señales digitales, multiplexación, cálculo de la velocidad de transmisión, cálculo de overheads, mecanismos de control de flujo, etc.

Aprovechando el proceso, se han desarrollado también tests de autoevaluación para el resto de contenidos de la asignatura, pensados como apoyo al repaso de los contenidos impartidos en las sesiones presenciales. La Figura 3 muestra el total de tests de autoevaluación disponibles en Moodle para los alumnos, junto con el número de intentos realizados en cada uno de ellos una vez finalizado el periodo docente. La figura 4 muestra los contenidos de parte de uno de los tests. 


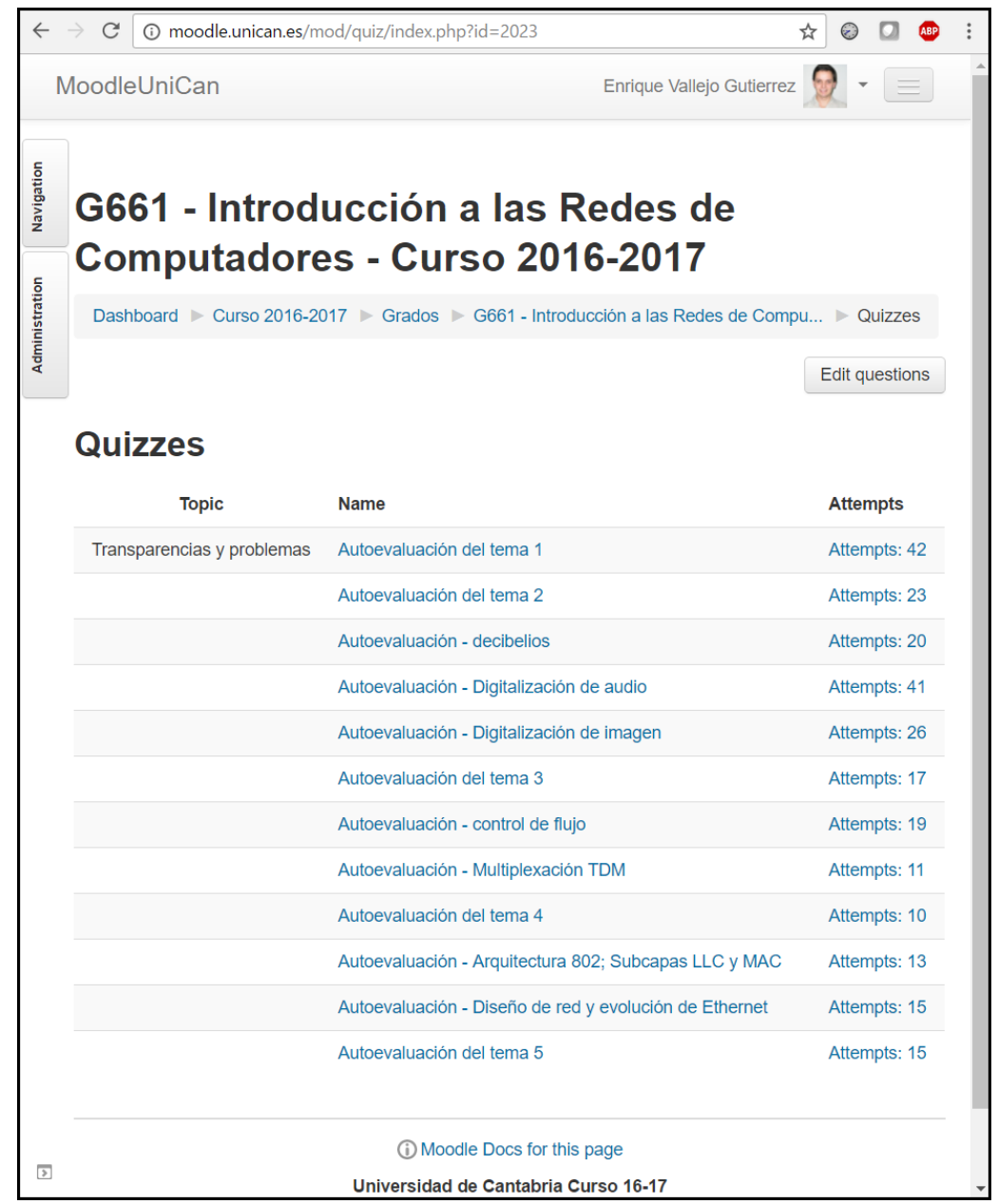

Fig. 3: Captura de pantalla de los tests desarrollados en Moodle.

Las sesiones de prácticas en el aula desarrolladas en el contexto de este proyecto han seguido un estudio de un caso de una tecnología concreta. A un grupo se le han desarrollado una serie de problemas sobre los accesos a Internet por fibra óptica mediante tecnología GPON, y al otro grupo un conjunto similar de problemas sobre el acceso mediante redes híbridas de fibra-coaxial (DOCSIS). El motivo para elegir estas temáticas (además de la resolución de problemas más específicos de la asignatura) es doble: Por una parte, estas dos son las tecnologías de acceso a Internet de alta velocidad más extendidas, y se han desarrollado los problemas para que resulten llamativos al alumno. Por otra parte, al presentar un sistema completo se le presenta al alumno un sistema muy complejo en el que se estudian los diferentes elementos (aspectos de transmisión de la señal, codificación y modulación, multiplexación, control de acceso al medio, etcétera), lo que hace que afronte un problema complejo con múltiples variables, similar al considerado en los exámenes de la asignatura. 


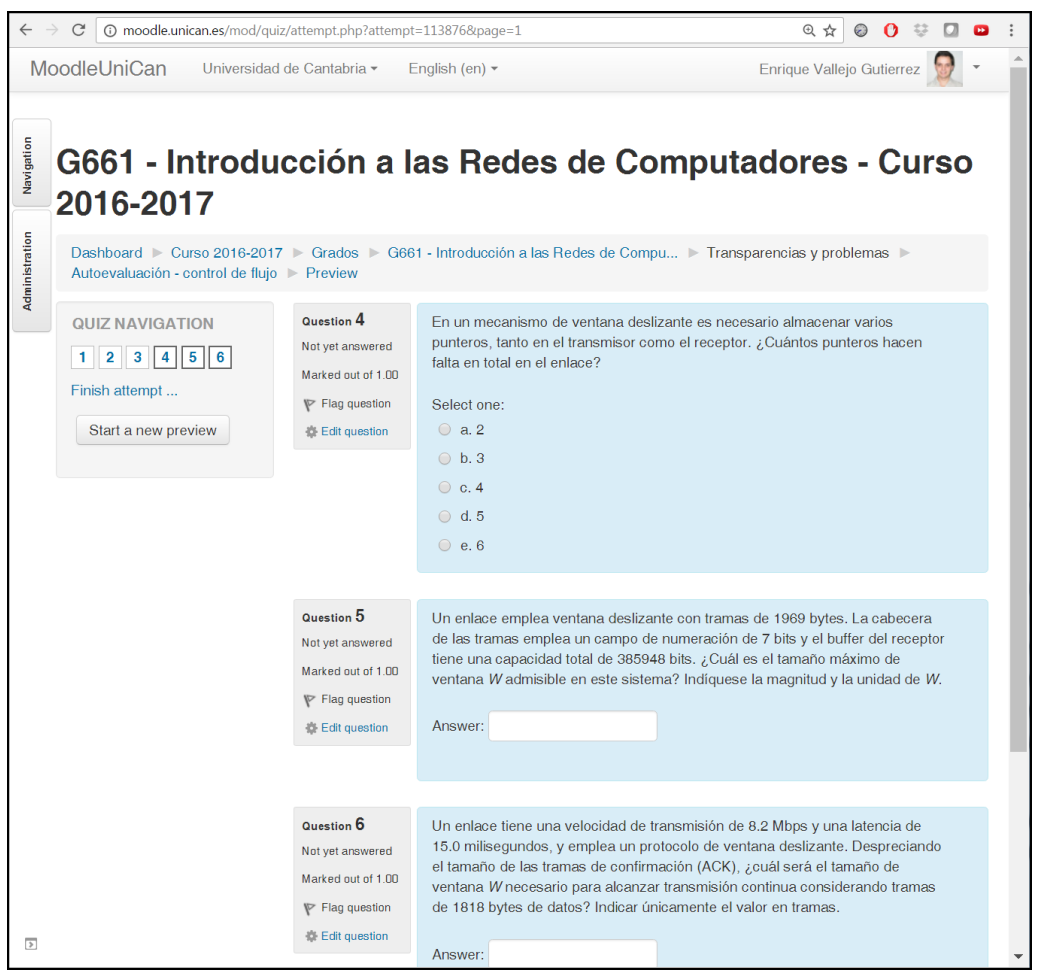

Fig. 4: Captura de uno de los tests de Moodle empleados como apoyo de la sesión de auto-aprendizaje.

\subsection{Dificultades y problemas técnicos encontrados}

En esta sesión se comentan algunas dificultades encontradas durante las primeras fases del desarrollo del contenidos para el proyecto.

Por una parte, la selección de las herramientas de captura y edición de vídeo apropiadas ha sido más complejo de lo pensado inicialmente. La solicitud inicial del proyecto contemplaba una partida económica destinada a la compra de un software comercial apropiado y suficientemente potente y estable, pero al no asignarse, se han analizado diferentes herramientas gratuitas. Varias herramientas probadas durante la fase inicial resultaron inapropiadas. En algún caso, esto se debió a estar limitadas en sus capacidades; por ejemplo, Microsoft Expression Encoder 4 (que es la herramienta empleada en alguno de los cursos de formación de la Universidad de Cantabria) en su versión gratuita no permite la codificación en H.264 (códec apropiado para la distribución de vídeo en alta definición). En algún otro caso, se probaron aplicaciones que sí disponían de suficientes prestaciones técnicas, pero que no eran lo suficientemente estables y fallaban durante la ejecución; por ejemplo, el editor no lineal OpenShot servía para el propósito buscado, pero fallaba (perdiendo todo el trabajo realizado) en ciertas operaciones, como la previsualización de un vídeo cargado. En concreto, con esta herramienta se probaron diferentes versiones, tanto estables como versiones de desarrollo, sin encontrar ninguna lo suficientemente estable, lo que resultó en una pérdida de tiempo considerable. 
Por otra parte, también se consideró en el presupuesto inicial la compra de un monitor, si bien este tipo de gastos no se consideraba dentro del proyecto. El uso de un único monitor ha resultado problemático en varios casos. En concreto, en varias ocasiones el programa de captura ha fallado mientras se ejecutaba, pero al disponer a pantalla completa de los materiales de la asignatura (que se pretendían capturar) no se ha apreciado el fallo. Este tipo de problemas se han resuelto al encontrar un monitor viejo que no tenía uso, y emplearlo de apoyo durante la captura.

Finalmente, se ha encontrado que es necesario un esfuerzo muy significativo en la preparación de los materiales. Aunque ya se disponía de transparencias de la asignatura del curso previo, éstas estaban orientadas a apoyar una clase presencial muy basada en las explicaciones en la pizarra. Al no disponer de la misma, ha sido necesario adaptar significativamente algunos aspectos, aumentando la cantidad de animaciones empleadas y el uso de contenidos adicionales (capturas de "demos"). De forma similar, también ha sido necesario preparar de forma muy clara un guion muy claro para cada uno de los elementos a grabar, ya que la improvisación que puede emplearse en una clase presencial interactiva no resulta viable en una grabación, y una pequeña duda o vuelta atrás resulta mucho más indeseable.

\section{Respuesta del alumnado e impacto del programa}

En esta sección se comenta la realimentación obtenida de los alumnos sobre el programa realizado. Para ello, se comentan primero las impresiones proporcionadas por los alumnos en conversaciones informales. Después, se analizan las métricas de seguimiento proporcionadas por las herramientas informáticas. Finalmente, se analizan los resultados académicos obtenidos en la única convocatoria de la asignatura hasta la fecha.

\subsection{Impresiones informales de los alumnos}

En conversaciones informales, los alumnos indican que les parecen muy interesantes los vídeos empleados, tanto en los contenidos como el formato, y que prefieren este tipo de enfoque docente frente a las clases magistrales tradicionales. Algún alumno sugería partirlos en trozos más pequeños (de los 20-30 minutos actuales a dos vídeos de 10-15 minutos); aunque esto no parece algo viable a priori (ya que no parece suficiente para cubrir un concepto relativamente complejo) se puede analizar para cursos posteriores.

\subsection{Seguimiento de los vídeos y tests}

Sin embargo, las herramientas de monitorización indican que el seguimiento es inferior a lo deseado, y decreciente según avanza el tiempo. En la plataforma de YouTube se proporcionan estadísticas sobre el visionado de los vídeos. En dichas estadísticas se observa que la cantidad de visionados por vídeo es inferior al número de alumnos, y que desciende según avanza la asignatura (de casi un $90 \%$ en los primeros vídeos a menos de un $50 \%$ en los últimos). Aunque estas estadísticas son coherentes con la asistencia a clase habitual en el plan de estudios (y con su evolución decreciente según avanza el cuatrimestre), sería deseable obtener valores más elevados. La figura 5 muestra estadísticas del primero de los vídeos durante las primeras dos semanas y media desde su publicación. En concreto, se observa cómo el vídeo se ha visto varias veces, si bien 
Aprendizaje autónomo del estudiante apoyado en recursos audiovisuales en el contexto de un Grado de Ingeniería Informática: experiencias con metodologías de enseñanza activas

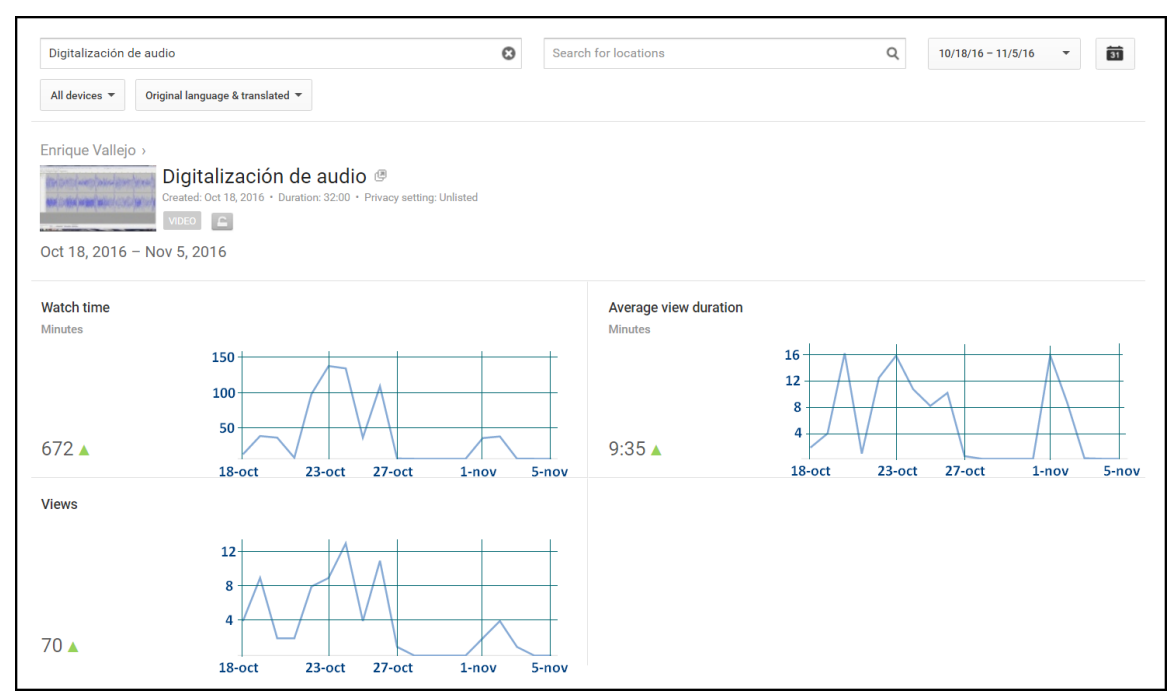

Fig. 5: Captura de estadísticas de visionado del vídeo relativo a codificación de audio, proporcionadas por la herramienta de análisis de YouTube. Imagen editada para incluir los ejes de referencias para facilitar su análisis.

la duración promedio de cada visionado no alcanza la tercera parte de la duración del vídeo. En general, el tiempo de visionado promedio de cada vídeo ha cubierto únicamente entre un $29 \%$ y un $42 \%$ de la duración del mismo. Aun descontando una estimación de los visionados de prueba realizados durante la preparación del vídeo, esto se traduce en una penetración baja en el público objetivo.

Este análisis lo corroboran los tests de autoevaluación de Moodle. La Figura 3 contiene el número de intentos realizados en cada uno de los tests. Considerando que el número de alumnos es de 62, en solo dos casos se ha llegado a un $50 \%$ de intentos del test de autoaprendizaje respecto al total de alumnos en la asignatura. En el peor caso, llega a haber únicamente 13 intentos $^{1}$, en torno al $10 \%$. Preguntados al efecto, algunos alumnos sugieren la aplicación de bonus en la calificación por el hecho de realizar estos tests como herramienta de motivación; es decir, entienden los tests como una carga y no como una ayuda a su proceso de aprendizaje.

\footnotetext{
${ }^{1}$ En algún caso hay valores inferiores, pero no se corresponden a la autoevaluación asociada a un vídeo, sino a un tema completo.
} 


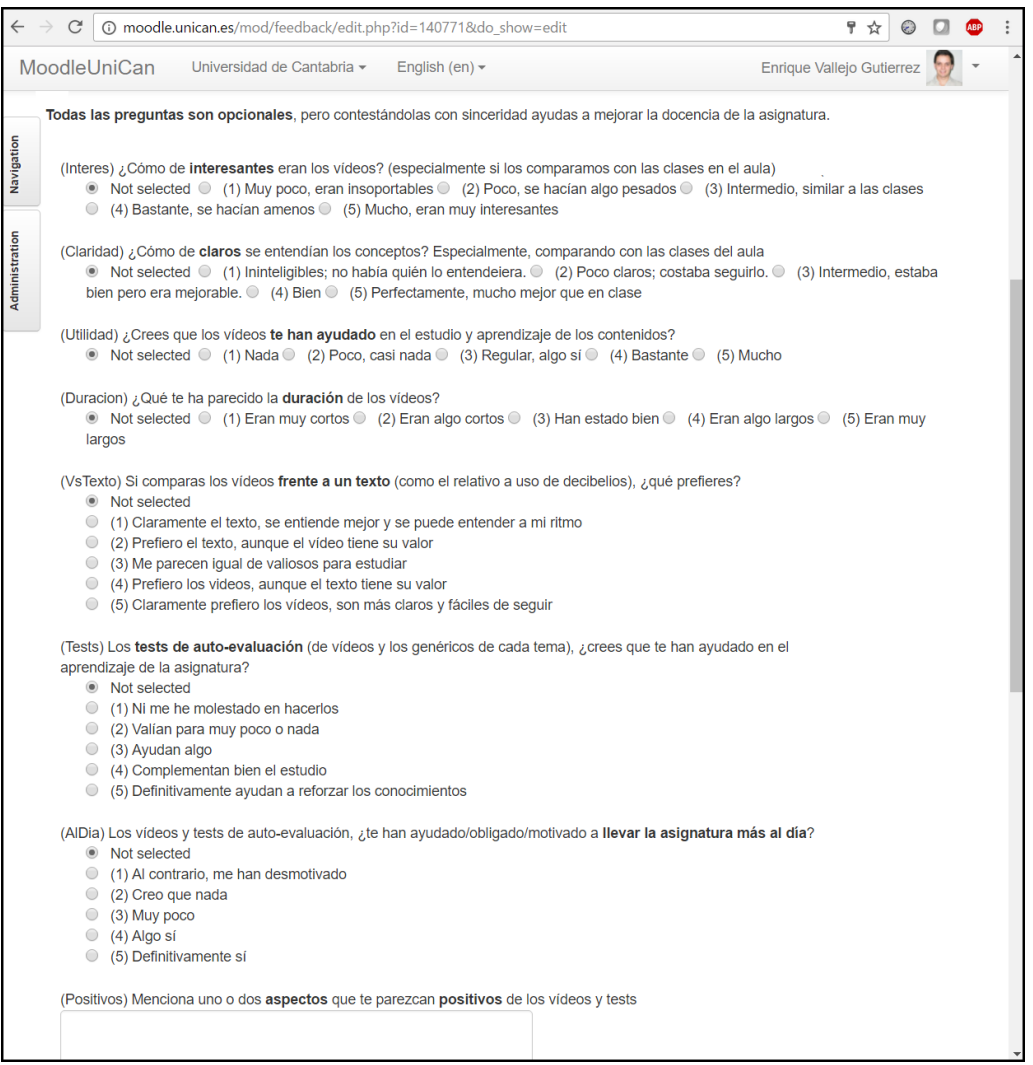

Fig. 6: Captura de las primeras 8 preguntas de la encuesta de satisfacción al alumnado.

\subsection{Encuesta de satisfacción}

Se ha realizado a los alumnos una encuesta de satisfacción sobre el programa piloto. La encuesta se realizaba a través de la página de Moodle de la asignatura, y contenía un total de 9 preguntas de selección más tres preguntas abiertas: aspectos positivos, aspectos negativos y sugerencias. La figura 6 muestra las primeras preguntas de la encuesta; las preguntas de selección restantes preguntan por el número de sesiones y la satisfacción general.

La encuesta se puso a disposición de los alumnos en la última quincena de curso y se dejó abierta, sin fecha límite de finalización. Se animó insistentemente a los alumnos a participar, pero no se les incentivó de ninguna manera. En total, se recogieron 24 respuestas de los alumnos. El significado de cada una de las puntuaciones puede encontrarse en la figura 6 para las primeras 8 preguntas, y se indica para las siguientes. La calificación media de las preguntas de selección se muestra a continuación:

- ¿Cómo de interesantes eran los vídeos? Calificación promedio: 3.83

- ¿Cómo de claros se entendían los conceptos? Calificación promedio: 4.00 


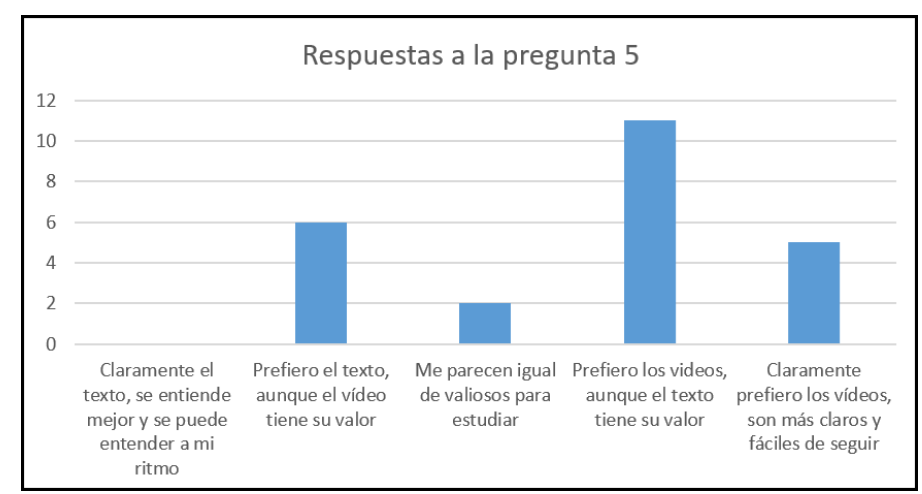

Fig. 7: Respuestas a la pregunta 5: Si comparas los vídeos frente a un texto (como el relativo a uso de decibelios), ¿qué prefieres?

- ¿Crees que los vídeos te han ayudado en el estudio y aprendizaje de los contenidos? Calificación promedio: 3.92

- ¿Qué te ha parecido la duración de los vídeos? Calificación promedio: 3.75

- Si comparas los vídeos frente a un texto (como el relativo a uso de decibelios), ¿qué prefieres? Calificación promedio: 3.63

- Los tests de auto-evaluación (de vídeos y los genéricos de cada tema), żcrees que te han ayudado en el aprendizaje de la asignatura? Calificación promedio: 3.04

- Los vídeos y tests de auto-evaluación, ¿te han ayudado/obligado/motivado a llevar la asignatura más al día? Calificación promedio: 3.25

- Respecto al número de sesiones con vídeos de auto-aprendizaje, ¿cuántas harías? (1 - Muchas menos o ninguna; 5 - Casi todas las clases basadas en vídeos) Calificación promedio: 3.79

- ¿Cuál es tu satisfacción general con este programa piloto? (1 - No me ha gustado nada; decepcionante; 5 - Me ha gustado mucho) Calificación promedio: 3.96.

En todas las preguntas, las respuestas han seguido una distribución unimodal, excepto en las relativas a la preferencia por un texto o un vídeo (marcada como VsTexto en la figura 6), y en los tests de autoevaluación. En el segundo caso, había un pequeño pico de tres alumnos que indicaban que no se habían molestado en responder a los tests. En el primer caso, la figura 7 muestra la distribución de respuestas, en donde valores a la izquierda indican la preferencia por un texto y valores a la derecha por un vídeo.

En cuanto a los comentarios recibidos, los principales aspectos valorados positivamente han sido la posibilidad de repetir el vídeo si algo no se entiende, la claridad en la explicación (enlazado con el hecho de que sea audiovisual) y la flexibilidad horaria. Los principales aspectos negativos se han centrado en la duración excesiva de los vídeos, la dificultad de los tests y el tipo de pregunta que difiere del examen final, y la cantidad 
de contenidos que perciben los alumnos. En cuanto a sugerencias, las respuestas fueron bastante variadas, desde insistir en acortar la duración, solicitar calificación extra por completar los tests de auto-evaluación y realizar la mayor cantidad de problemas en el aula posibles. En general, muchos comentarios recibidos siguen la misma línea que los observados en trabajos previos (Ronchetti 2010).

\subsection{Resultados académicos}

En el momento de escribir este documento solo se ha realizado una de las dos convocatorias anuales de la asignatura. El número de alumnos presentados fue de 43 , un $69,4 \%$ de los alumnos matriculados. Comparativamente, este porcentaje en una única convocatoria en los tres cursos anteriores había variado en el rango $65 \%-82 \%$, por lo que no puede determinarse que el cambio metodológico haya influido en el porcentaje de alumnos presentado.

Respecto al número de alumnos que aprueban la asignatura, la tasa de aprobados frente a matriculados en una convocatoria ha sido de un $41,9 \%$. En los tres cursos anteriores, en la convocatoria de Febrero esta tasa se ha movido en el rango 23,4\%-38,9\%, por lo que el resultado académico sí que puede considerarse claramente superior al de cursos previos.

\subsection{Análisis subjetivo}

En esta sección se presenta una valoración de la experiencia observada por el profesor de la asignatura. Esta valoración es subjetiva, y se basa únicamente en una impresión personal y un análisis propio de los resultados.

En primer lugar, se ha recibido una respuesta muy positiva de la gran mayoría de los alumnos, tanto en comentarios individuales como en la encuesta de valoración del proyecto o de la asignatura; algunos alumnos han aprovechado las mismas para mostrar su aprecio, agradeciendo el trabajo y animando a seguir por el mismo camino.

Sorprendentemente, los tests de autoevaluación no han sido muy seguidos por los alumnos. Estos tests se han desarrollado como una ayuda al estudio, pero los alumnos lo han percibido como una tarea (carga) adicional, y no la han realizado ya que no tenía impacto directo en la nota final. Aparentemente, no aprecian el valor de los mismos como herramienta de aprendizaje. La dificultad de los tests era deliberadamente elevada, para exigir bastante a los alumnos tras cada visualización de un contenido, pero en algunos casos esto les echaba para atrás.

Resulta muy llamativa la respuesta ante la preferencia por medios escritos o audiovisuales. En opinión del profesorado, siempre resulta más claro y práctico un buen libro o texto escrito que un vídeo, tanto por la facilidad para hojearlo o leerlo en diagonal, como por la facilidad de seguirlo con el detenimiento necesario. En este sentido, la respuesta de los alumnos mostrada en la figura 7 es variada, existiendo dos tendencias pero una mayoría que se decanta por preferir el uso de materiales audiovisuales. Probablemente esto no es más que una muestra de la evolución de la sociedad, a la que debe adaptarse el proceso de enseñanza y aprendizaje.

El esfuerzo destinado a la preparación de contenidos ha sido muy significativo. Por cada vídeo de unos 20-30 minutos ha resultado necesario invertir varias horas de trabajo, 
si se tiene en cuenta la preparación de software, desarrollo de contenidos, múltiples pruebas, grabación, edición, subida a Internet, etc. El esfuerzo es muy elevado y no resulta fácilmente visible para los alumnos. Por otra parte, las clases prácticas en el aula no han seguido una metodología pura de aprendizaje basado en problemas, dada la poca proactividad de los alumnos a colaborar en grupos siguiendo diferentes roles. Este aspecto se debe trabajar más en ocasiones posteriores.

Resulta ligeramente decepcionante que la tasa de alumnos presentados se haya mantenido en el mismo rango que en años anteriores, si bien esto se compensa con la mayor tasa de aprobados dentro de los alumnos que sí se han presentado. En este sentido, el proyecto puede considerarse generalmente positivo.

\section{Conclusiones y perspectivas de futuro}

De acuerdo al análisis presentado en las secciones previas, puede considerarse que el proyecto se ha desarrollado con relativo éxito.

Se ha evaluado el impacto del proyecto sobre la motivación, seguimiento y resultados del alumnado mediante varias actuaciones: una encuesta informal en el aula, la monitorización del seguimiento de las herramientas informáticas, el uso de una herramienta de encuesta formal online, y el análisis de resultados académicos frente a los obtenidos en años previos. Las respuestas informales recibidas en el aula sugieren que los alumnos prefieren este tipo de docencia frente a las clases seminales tradicionales. Sin embargo, las herramientas de monitorización de los vídeos y tests de autoevaluación sugieren que el seguimiento es bajo, mucho más de lo esperado.

Los resultados académicos son positivos, con una tasa de aprobados más elevada que en convocatorias equivalentes de cursos previos, pero con una tasa de alumnos presentados más baja. En este sentido, resulta llamativo que los alumnos han valorado positivamente el programa pero no está claro si ha influido positivamente en su motivación a no abandonar la asignatura. Eso sí, el hecho de que la tasa de alumnos aprobados frente a presentados sea significativamente más elevada es una muestra clara del resultado positivo.

Para cursos posteriores se planteará mantener el programa seguido, y si es posible aumentarlo. Sin embargo, el esfuerzo requerido por parte del profesor es significativo y no se ve recompensando claramente. Sería interesante estudiar la posibilidad de una valoración expresa de este tipo de actividades por parte de los organismos académicos.

\section{Referencias bibliográficas}

Audacity (2017). Audacity website. URL: http://www . audacityteam.org/ (visitado 05-10-2016).

Avidemux (2017). Avidemux website. URL: http://fixounet.free.fr/avidemux/ (visitado 05-10-2016).

Lage Maureen J., Glenn J. Platt y Michael Treglia (2000). "Inverting the Classroom: A Gateway to Creating an Inclusive Learning Environment". En: The Journal of Economic Education 31.1, págs. 30-43. DOI: 10.2307/1183338. 
Meltytech, LLC (2017). ShotCut website. URL: https: //www. shotcut.org/ (visitado 05-10-2016).

Open Broadcaster Software (2017). OBS Studio. URL: https :// obsproject.com/ (visitado 05-10-2016).

Ronchetti, Marco (2010). "Using video lectures to make teaching more interactive". En: International Journal of Emerging Technologies in Learning (iJET) 5.2, págs. 45-48. ISSN: 1863-0383.

Santiago, Raúl y Alicia Díez (2016). The Flipped Classroom. URL: http: / / www . theflippedclassroom.es/ (visitado 10-09-2016).

Sparks, Sarah D. (2011). Lectures Are Homework in Schools Following Khan Academy Lead. URL: http://www . edweek. org/ew/articles/2011/09/28/05khan_ep. h31.html (visitado 15-03-2017).

Wood, Diana F (2003). "Problem based learning". En: BMJ 326.7384, págs. 328-330. ISSN: 0959-8138. DOI: 10 .1136/bmj . 326.7384 .328. eprint: http://www . bmj . com/content/326/7384/328.full.pdf. 


\title{
Puesta en marcha de un catálogo de demostraciones experimentales en asignaturas básicas.
}

\author{
Rosario Isabel Vilaplana Cerdáa, Romina Del Rey Tormos ${ }^{a}$, Oscar Gomis Hilario ${ }^{a}$ Jesús \\ Alba Fernández ${ }^{b}$, Francisco Javier Manjón Herrera ${ }^{c}$, Vanessa Paula Cuenca Gotor ${ }^{\mathfrak{c}}$ y \\ Juan Antonio Monsoriu Serrac
}

${ }^{a}$ Universitat Politècnica de Valéncia, Escuela Politécnica Superior de Alcoy, Departamento de Física Aplicada, Pz. Ferràndiz i Carbonell s/n - 03801 Alcoy (Alicante).rovilap@fis.upv.es, osgohi@fis.upv.es, roderey@,fis.upv.es

bUniversitat Politècnica de Valéncia, Escuela Politécnica Superior de Gandia, Departamento de Física Aplicada, C/Paraninfo n ${ }^{\circ} 1$ - 46715 Grao de Gandia. jesalba@fis.upv.es

${ }^{c}$ Universitat Politècnica de Valéncia, Escuela Técnica Superior de Ingeniería del Diseño, Departamento de Física Aplicada, Camino de Vera s/n - 46022 Valencia. fjmanjon@fis.upv.es, vacuego@fis.upv.es, imonsori@fis.upv.es,

\section{Resumen}

En este trabajo se muestran los primeros pasos que se han llevado a cabo dentro de un proyecto PIME de la convocatoria 2016-2017 del Vicerrectorado de Estudios, Calidad y Acreditación de la Universidad Politécnica de Valencia titulado "Metodologías activas en asignaturas básicas. Creación de un catálogo de demostraciones experimentales o proyectos como recursos didácticos para la motivación de título". Este proyecto persigue como objetivo la creación de un catálogo de demostraciones experimentales sencillas, realizadas con materiales fácilmente disponibles y de bajo coste. Se pretende utilizar este recurso en las clases de teoría o problemas para poner de manifiesto fenómenos físicos y su relación con los modelos teóricos que los explican, favoreciendo su comprensión, así como involucrar a los estudiantes en alguna de estas demostraciones experimentales a través de pequeños proyectos. Aqui se presentan los primeros diseños de estas demostraciones experimentales que serán implantadas de forma más generalizada a partir de los siguientes cursos.

Palabras claves: Metodologías Activas, Motivación, Asignaturas Básicas, Competencias, Demostraciones Experimentales, Aprendizaje Basado en Proyectos.

\section{Summary}

We present in this work the first steps carried out within a 2016-2017 PIME of the Vice Chancery for Studies, Quality and Accreditation the Polytechnic University of Valencia entitled "Active methodologies in basic subjects. A 
catalogue of experimental Physics demonstrations designed as teaching resources for the degree motivation". This project aims the design of a catalogue of simple experimental Physics demonstrations made with readily available low cost materials. It is intended to use this resource during lessons of theory and problems to demonstrate physical phenomena and their relationship to the theoretical models, favouring their understanding as well as to involve the students in the design of some of these experimental demonstrations through the implementation of small projects. The first designs of these experimental Physics demonstrations that will be implemented in a more general way the following courses are here presented.

Key words: Active Methodologies, Motivation, Basic Subjects, Competences, Experimental Demonstrations, Project-Based Learning.

\section{Introducción}

En este trabajo se pretende exponer la puesta en marcha del Proyecto de Innovación y Mejora Educativa (PIME) titulado: "Metodologías activas en asignaturas básicas. Creación de un catálogo de demostraciones experimentales o proyectos como recursos didácticos para la motivación de título", que está enfocado a la creación e implementación de un catálogo de demostraciones experimentales de Física.

Las demostraciones experimentales de Física están asociadas al desarrollo de la ciencia moderna y fueron utilizadas desde el siglo XVII en sociedades científicas, academias, salones y conferencias para todo tipo de público. También han sido empleadas de forma generalizada como herramientas docentes en instituciones educativas y universidades constituyéndose como prácticas docentes habituales en diferentes países. A pesar de que su uso está recogido explícitamente en el proyecto europeo "Tuning" (González, Wagenaar, 2003) de Física para la armonización de titulaciones universitarias, en nuestro país no forma parte de las prácticas docentes generalizadas. A este respecto, nos consta que en la Facultad de Ciencias Físicas de la Universitat de València existe un proyecto docente que ha incorporado el uso de las demostraciones experimentales como herramienta habitual en sus clases, y que dicho proyecto ha obtenido resultados altamente satisfactorios (Ferrer 2012). En concreto, a fecha de hoy, ya disponen de una colección que contiene más de 100 demostraciones experimentales de diferentes temas de Física utilizada por más de 30 profesores con docencia en 20 asignaturas de Física de 17 grados diferentes de ciencias, ciencias de la salud e ingeniería, y algunos estudios de máster llegando a involucrar a más de 2000 estudiantes.

Algunos de los estudiantes que llegan a la universidad no han cursado Física durante la enseñanza secundaria y la mayoría de quienes sí lo han hecho no han realizado prácticas de laboratorio o visto demostraciones experimentales, por lo que en general desconocen los fenómenos físicos más básicos. Las demostraciones experimentales o prácticas caseras (Díaz, 2007) se caracterizarán por el uso de materiales fácilmente asequibles y de bajo coste, que los propios alumnos pueden llegar a diseñar. Las demostraciones experimentales pueden ser una herramienta muy útil para transmitir al alumno que detrás de los fenómenos cotidianos

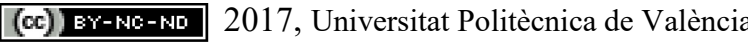


que acontecen se encuentran las leyes físicas y que con el diseño de experimentos sencillos podemos llegar a demostrarlos, entenderlos y estudiarlos con los modelos teóricos que los explican. En otras palabras, con el uso de las demostraciones experimentales se pretende fomentar la capacidad de sorpresa del alumnado ante los fenómenos naturales y mostrarle que detrás de la mayoría de los dispositivos que usamos casi siempre hay una o varias leyes físicas involucradas, llegando a constituir la base de su funcionamiento. De un modo más general, el uso de demostraciones experimentales permite articular un proceso de observación racional en el que se emitan conclusiones en términos de los modelos físicos estudiados en el ámbito teórico, algo esencial en la comprensión del método científico; además de ofrecer la posibilidad de involucrar de forma activa a los alumnos en su propio proceso de aprendizaje.

Es conocido que la calidad de la docencia universitaria en enseñanzas técnicas, así como la mejora del aprendizaje se puede conseguir, entre otros muchos recursos, con metodologías activas (Aparicio, González, Sobrevila, 2005) (Calvo, Lopez-Guede, Zulueta, 2010) (Alba, Torregrosa, del Rey, 2015). Como hemos descrito previamente, la propia naturaleza intrínseca de las demostraciones experimentales hace que sea posible involucrar a los alumnos de forma activa y en primera persona en el proceso de aprendizaje. En este sentido, consideramos que se puede involucrar a los alumnos en el desarrollo de alguna de las demostraciones experimentales con los recursos que se generarán en este PIME haciendo uso de este modo de metodologías activas en el aula. Esto permite pasar de un planteamiento centrado en el profesor a uno más orientado al estudiante. Dicho de otro modo, el propio estudiante, al explicar qué ha diseñado y cómo ha diseñado su experimento, puede pasar a hacer la función del profesor lo que permite desarrollar la empatía de los alumnos hacia el profesorado y tener la oportunidad de trabajar algunas competencias transversales asignadas a las asignaturas de Física.

En este trabajo se muestran los primeros recursos generados en este proyecto, como resultado de la puesta en marcha de la creación del catálogo de demostraciones experimentales. Estos recursos, a fecha de la redacción de este trabajo, todavía no han podido ser aplicados de modo generalizado en el aula, a excepción de algunas demostraciones experimentales y un pequeño proyecto desarrollados en clase (el mostrado en este trabajo a modo de ejemplo). En cualquier caso, estos pocos recursos nos han servido como experiencias piloto y nos han permitido comprobar que los alumnos responden con alto grado de motivación. A partir del siguiente curso, podremos aplicar el catálogo de demostraciones experimentales en el aula de una manera más global y no solamente los recursos presentados en este trabajo. Será entonces cuando verdaderamente podremos evaluar el objetivo perseguido y la metodología aplicada. Así mismo, es de destacar que este método facilitará el desarrollo y la evaluación de algunas de las competencias que la titulación tiene asignadas como punto de control a las asignaturas de Física, que pueden variar dependiendo de la titulación.

\section{Objetivos}

El objetivo de este trabajo es presentar los primeros recursos generados en el proyecto PIME titulado: "Metodologías activas en asignaturas básicas. Creación de un catálogo de 
demostraciones experimentales o proyectos como recursos didácticos para la motivación de título", así como poner de manifiesto el carácter multidisciplinar que puede presentar este tipo de recursos.

El desarrollo de estas demostraciones experimentales, conlleva la generación de nuevos recursos tales como fichas descriptivas, vídeos y cuestionarios que permiten a profesores y estudiantes ver y pensar los fenómenos físicos de forma permanente, más allá del uso instantáneo del material en el aula. Esta colección (o banco) se está desarrollando de forma colaborativa por los profesores que participan en el proyecto PIME. Es conocido que, con las metodologías activas basadas en el PBL (aprendizaje basado en proyectos) la carga del profesor se multiplica (Alba, Torregrosa, del Rey, 2015). Con la creación del catálogo o banco de experimentos, distribuyendo muy bien los esfuerzos, será posible multiplicar los recursos didácticos sin que aumente significativamente la carga del profesor.

El carácter multidisciplinar de este trabajo presenta la ventaja de estar formado por un número importante de profesores de una asignatura básica (Física), de gran importancia en todas las enseñanzas técnicas, que se imparte en distintos grados (Grado en Ingeniería en Diseño Industrial y Diseño del Producto, Grado en Ingeniería Mecánica, Doble Grado en Ingeniería Informática y Administración y Dirección de Empresas y Grado en Ingeniería de Sistemas de Telecomunicación, Sonido e Imagen) de distintas escuelas (Escola Politécnica Superior de Alcoi, Escola Politécnica Superior de Gandia y Escola Técnica Superior d'Enginyeria del Diseny) de los tres campus universitarios de la Universitat Politècnica de València (Campus de Alcoi, Campus de Gandia y Campus de Vera).

Otro objetivo que se pretende más a largo plazo consiste en conseguir involucrar a más profesores en las próximas convocatorias y consolidar un grupo de trabajo de innovación docente con aquellos participantes que demuestren un interés para participar activamente en la consecución de este proyecto inicial.

\subsection{Objetivos específicos}

En este apartado de "objetivos específicos" creemos interesante numerar los objetivos específicos del Proyecto de Innovación y Mejora Educativa al que este trabajo hace referencia:

a) Crear una colección de demostraciones experimentales disponible para el profesorado que imparte docencia en asignaturas de Física para su uso en directo en las clases de teoría y problemas. En el siguiente apartado se muestran imágenes de algunos de los primeros experimentos diseñados para alcanzar el objetivo del proyecto.

b) Desarrollar recursos asociados a las demostraciones como fichas descriptivas, vídeos y cuestionarios disponibles para profesores y estudiantes con el fin de ver y pensar los fenómenos físicos, más allá de los instantes de uso en el aula. En el siguiente apartado, se muestra alguna de las primeras fichas descriptivas a modo de ejemplo.

c) Usar metodologías activas: involucrar a los alumnos en el desarrollo de alguna de estas demostraciones experimentales de modo que ellos tomen más iniciativa y

(cc) EY-NG-ND 2017, Universitat Politècnica de València

Congreso IN-RED (2017) 
protagonismo, desarrollando por grupos, sus propias demostraciones experimentales tutorizadas por el profesor.

d) Crear rúbricas o describir formas de evaluación adecuadas para evaluar actividades desarrolladas usando demostraciones experimentales o las actividades grupales, de modo que se pueda añadir algún apartado que ayude al profesor en la evaluación de las competencias transversales asignadas como punto de control a las asignaturas de Física en los Grados y/o en los Másteres dentro del Proyecto Institucional de la Comisión de Título de la UPV.

\section{Desarrollo de la innovación}

Dado que la puesta en marcha de la creación del catálogo de demostraciones experimentales y la innovación en sí dentro del aula, todavía no han podido ser aplicadas totalmente, en este apartado mostramos como estamos desarrollando, o creando, los recursos para poder disponer del catálogo de experimentos más adecuado, y optimizando siempre que sea posible, con el esfuerzo del profesorado implicado.

Como somos profesores de tres campus diferentes, estamos usando la herramienta Google Drive como almacén compartido del material ofimático para poder llevar a cabo el desarrollo de este proyecto innovador. En la captura de pantalla (ver figura 1) mostramos la estructura de directorios creada con el fin de que cada profesor pueda ir subiendo las fichas y el material correspondiente a las prácticas demostrativas o actividades grupales que desarrolle y a su vez pueda modificar o corregir ficheros del resto de los profesores sin necesidad de reunirse físicamente.

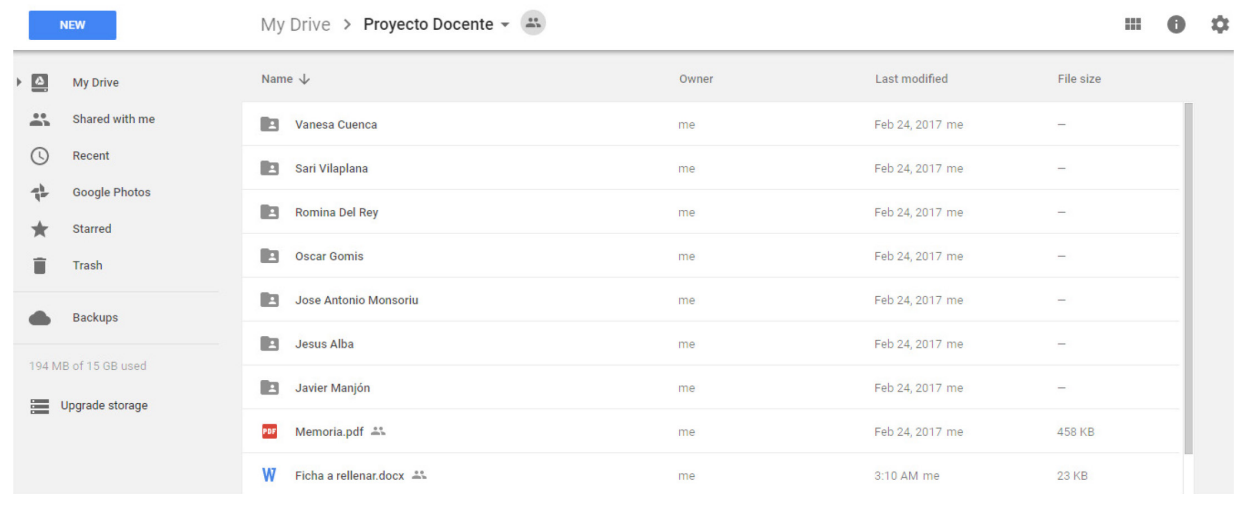

Fig. 1 Captura de pantalla de la carpeta proyecto docente en el Google Drive

Uno de los ficheros clave que se ha definido para que todos sigamos un modelo estándar es el que mostramos en la figura 1 con la imagen de un documento Word de título "Ficha a rellenar". El contenido de este fichero se muestra en la figura 2. 


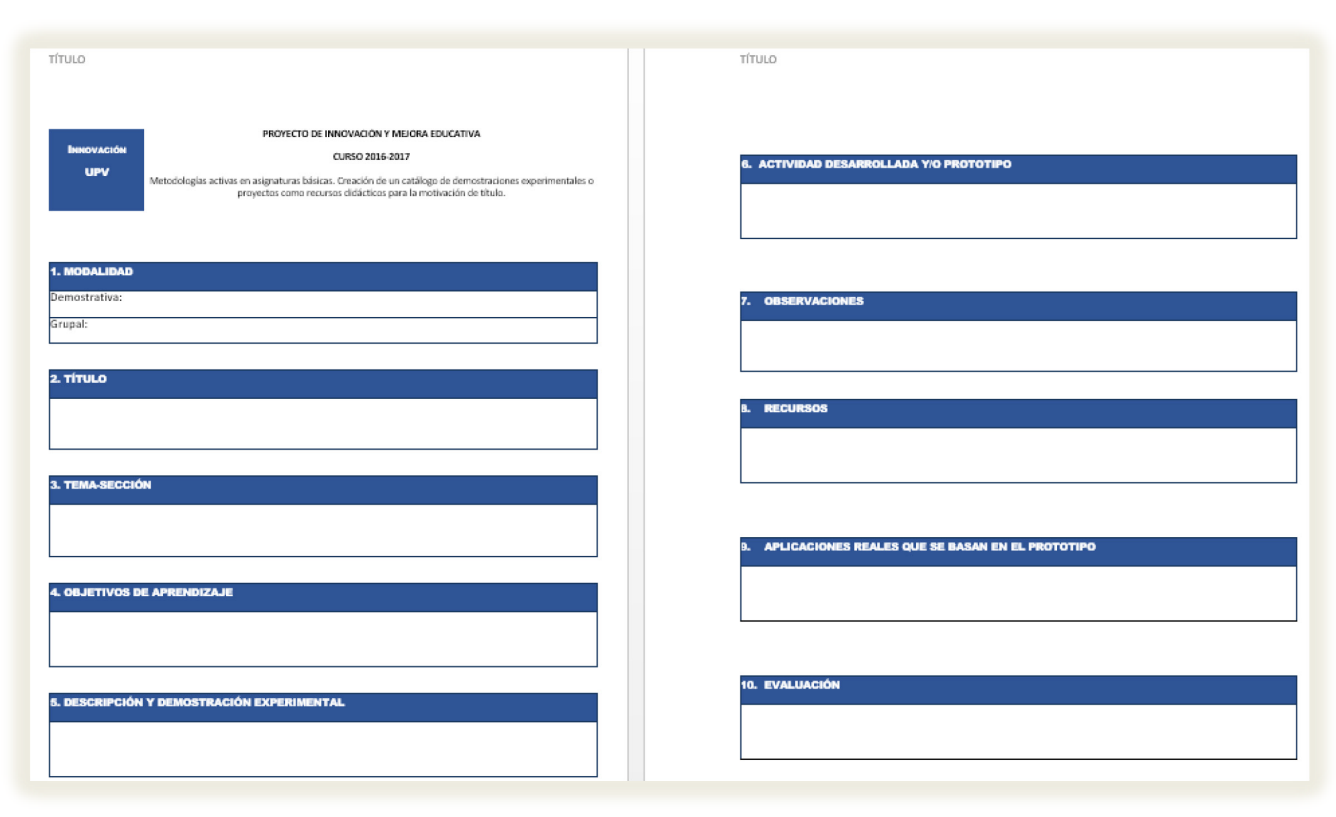

Fig. 2 Ficha a rellenar y sus apartados

El contenido de este fichero se distribuye en 10 apartados:

Apartado 1 "Modalidad"; Cabe destacar que el profesor podrá desarrollar dos tipos de actividades: una práctica demostrativa o una actividad grupal o pequeño proyecto en clase. Esto vendrá indicado en el apartado 1.

Apartado 2 "Título"

Apartado 3 "Tema-Selección”

Apartado 4 "Objetivo de aprendizaje"

Apartado 5 "Descripción y demostración experimental"

Apartado 6 "Actividad desarrollada y/o prototipo"

Apartado 7 "Observaciones"

Apartado 8 "Recursos"; material generado, en el caso de tratarse de una práctica demostrativa, cada profesor deberá crear el material por triplicado. De este modo, en cada campus se dispondrá de un prototipo para poder llevarlo a clase.

Apartado 9 "Aplicaciones reales que se basan en el prototipo"

Apartado 10 "Evaluación”; el profesor planteará un posible modo de evaluación, y en el caso de escoger rúbricas se puede incluir alguna pregunta para que el profesor pueda evaluar alguna de las competencias transversales asignadas como punto de control en sus asignaturas. En el siguiente apartado de "Resultados" se presenta un ejemplo completo de una de estas

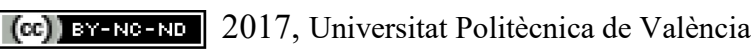

Congreso IN-RED (2017) 
fichas que es uno de los pequeños proyectos prototipos usados en clase y desarrollado por los alumnos.

\section{Resultados}

A modo de resultados presentamos algunos ejemplos de los prototipos ya diseñados, así como un ejemplo de una de las fichas asociada a un pequeño proyecto.

\subsection{Prototipos diseñados}

Como hemos mencionado previamente, uno de los objetivos del proyecto es generar un catálogo de demostraciones experimentales y sus correspondientes materiales asociados (prototipo, vídeos y cuestionarios o rúbricas) que permitan a profesores y estudiantes ver y pensar los fenómenos físicos de forma permanente y usarlos para impartir docencia en las asignaturas de Física tanto en clase de teoría como en problemas. Las imágenes de la Tabla 1 muestran algunos de los prototipos ya diseñados.

\section{Tabla 1: Ejemplos de prototipos}

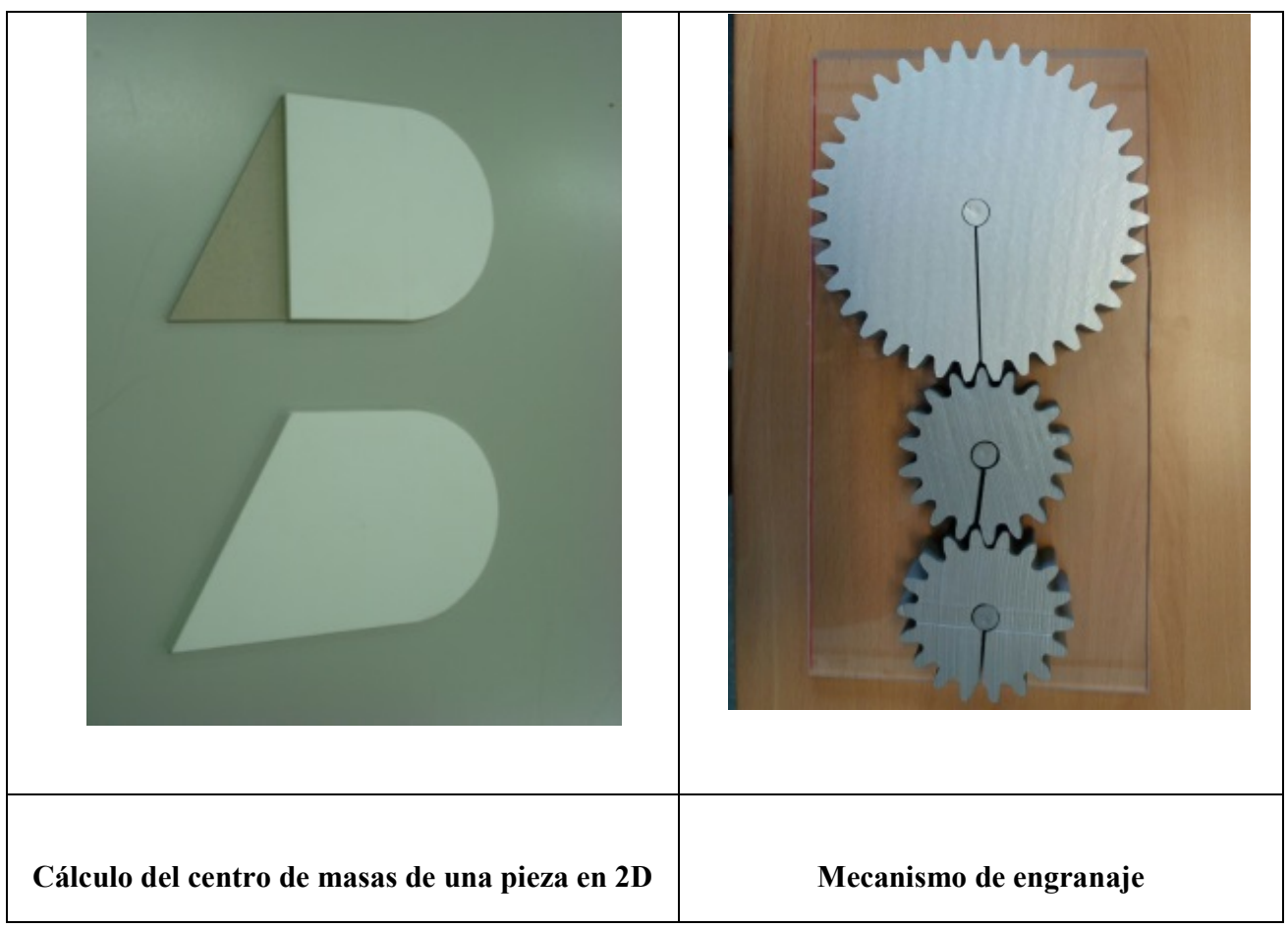




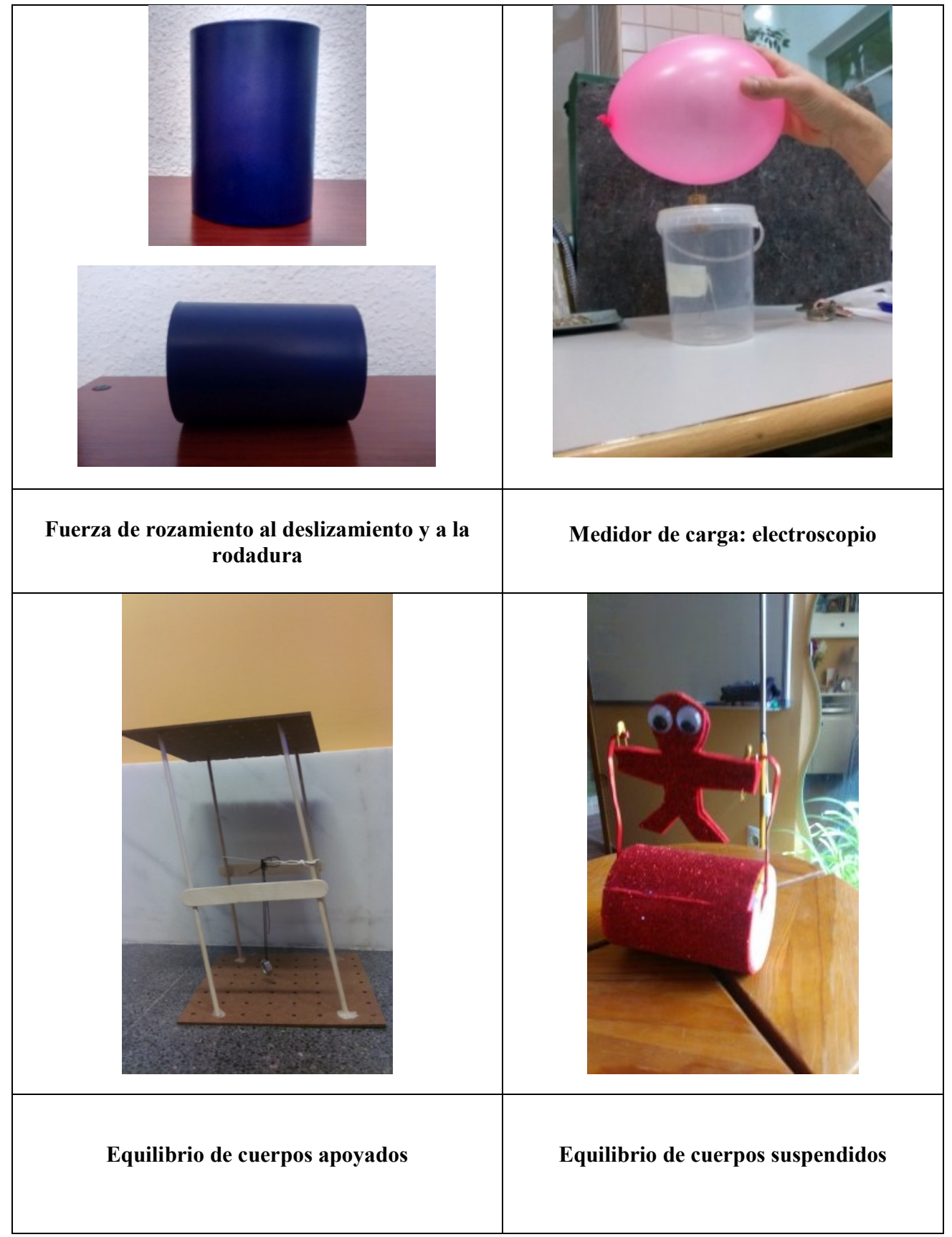

A continuación mostramos un ejemplo de una de las fichas subida al Google Drive. Se trata de una actividad grupal en la que los alumnos crean sus propios prototipos. Esta actividad ha servido como experiencia piloto y nos han permitido comprobar que los alumnos responden con alta motivación y grado de implicación a estas actividades.

(cc) EY-NG-ND 2017, Universitat Politècnica de València

Congreso IN-RED (2017) 


PROYECTO DE INNOVACIÓN Y MEJORA EDUCATIVA
CURSO 2016-2017
INNOVACIÓN
UPV \begin{tabular}{c}
$\begin{array}{c}\text { Metodologías activas en asignaturas básicas. Creación de un catálogo de } \\
\text { demostraciones experimentales o proyectos como recursos didácticos } \\
\text { para la motivación de título. }\end{array}$ \\
\hline 1. MODALIDAD \\
\hline Demostrativa: \\
\hline Grupal: $\quad \mathrm{X}$ \\
\hline
\end{tabular}

\section{TÍTULO}

Centro de masas de una pieza en 2D

\section{TEMA-SECCIÓN}

Estática. Centro de gravedad, centro de masas y centroide. Teoremas de Pappus-Guldin.

\section{OBJETIVOS DE APRENDIZAJE}

El alumnado será capaz de:

1. Diferenciar los conceptos de centro de gravedad, centro de masas y centroide.

2. Calcular numéricamente y experimentalmente (método de la plomada) el centro de masas de una pieza en $2 \mathrm{D}$.

3. Aplicar los teoremas de Pappus-Guldin.

4. Ver la relación que hay entre el equilibrio de una pieza y su centro de masas. 


\section{DESCRIPCIÓN Y/O DEMOSTRACIÓN EXPERIMENTAL}

Algunos sistemas continuos en 2D se pueden descomponer en piezas más simples (ver Figura 1) de modo que podemos reducir un sistema continuo a un sistema discreto:

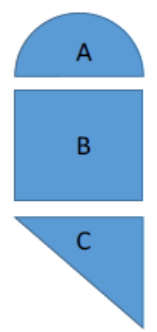

Figura 1: Pieza continua descompuesta en tres subpiezas A, B y C.

El cálculo del Centro de Gravedad (CG) /Centro de Masas ( CM)/Centroide (C) se obtiene a partir de una media ponderada según la gravedad ( CG) , la masa ( CM) o el área (C) de las coordenadas geométricas de las subpiezas:

\begin{tabular}{|c|c|c|}
\hline Centro de gravedad & Centro de masas & Centroide \\
\hline $\begin{array}{c}\text { Punto donde situamos el peso } \\
\text { de la pieza }\end{array}$ & $\begin{array}{l}\text { Punto donde situamos la masa de la } \\
\text { pieza }\end{array}$ & Centro geométrico \\
\hline$\vec{r}_{C G}=\left(x_{C G}, y_{C G}\right)=\left(\frac{\sum_{i=1}^{N} p_{i} x_{i}}{\sum_{i=1}^{N} p_{i}}, \frac{\sum_{i=1}^{N} p_{i} y_{i}}{\sum_{i=1}^{N} p_{i}}\right.$ & $\vec{r}_{C M}=\left(x_{C M}, y_{C M}\right)=\left(\frac{\sum_{i=1}^{N} m_{i} x_{i}}{\sum_{i=1}^{N} m_{i}}, \frac{\sum_{i=1}^{N} m_{i} y_{i}}{\sum_{i=1}^{N} m_{i}}\right)$ & $\vec{r}_{C}=\left(x_{C}, y_{C}\right)=\left(\frac{\sum_{i=1}^{N} A_{i} x_{i}}{\sum_{i=1}^{N} A_{i}}, \frac{\sum_{i=1}^{N} A_{i} y_{i}}{\sum_{i=1}^{N} A_{i}}\right)$ \\
\hline$\vec{r}_{C G}=\frac{\sum_{i=1}^{N} m_{i} g_{i} \vec{r}_{i}}{\sum_{i=1}^{N} m_{i} g_{i}}=\frac{\sum_{i=1}^{N} n}{\sum_{i=1}^{N} n}$ & cuando $\mathrm{g}_{\mathrm{i}}=\mathrm{g} \forall \mathrm{m}_{\mathrm{i}}$ & \\
\hline
\end{tabular}

Para encontrar las coordenadas geométricas $(x, y)$ de alguna de las subpiezas puede ser útil usar los teoremas de Papuss-Guldin los cuales están enunciados para el centroide:

\section{$1^{\mathrm{er}}$ TEOREMA DE PAPPUS-GULDIN}

“El área lateral A que engendra una línea de longitud $\mathrm{L}$, al girar alrededor de un eje $\mathrm{X}$ contenido en su plano y que no la corte es igual al producto de la longitud de la línea por la longitud de la circunferencia que describe su centroide en su giro alrededor del eje $\mathrm{X}^{\prime \prime}$

$$
\mathrm{A}=2 \pi \mathrm{y}_{\mathrm{C}} \mathrm{L}
$$

\section{$2^{\text {do }}$ TEOREMA DE PAPPUS-GULDIN}

"El volumen $V$ que engendra una superficie plana de área $A$, al girar alrededor de un eje $X$ contenido en su plano y que no la corte es igual al producto de la superficie que gira por la longitud de la circunferencia que describe su centroide en su giro alrededor del eje $\mathrm{X}^{\prime \prime}$

$$
\mathrm{V}=2 \pi \mathrm{y}_{\mathrm{C}} \mathrm{A}
$$




\section{ACTIVIDAD DESARROLLADA}

\section{Material}

1. Distintos materiales: cartulinas, madera, plásticos, etc...

2. Tijeras

3. Pagamento

4. Hilo

5. Regla, escuadradas

\section{Descripción}

1. Pedir a los alumnos que se distribuyan en grupos de 3 o 4 personas.

2. Diseñar una pieza $2 \mathrm{D}$ (formada por cuadrados, rectángulos, círculos, semicírculos, triángulos,...) que pueda reducirse a un sistema discreto y construirla por duplicado con materiales iguales y distintos (ver Figura 2).

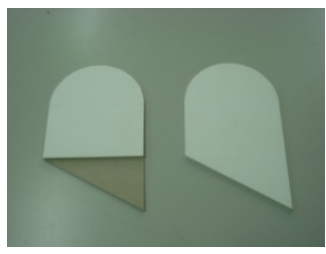

Figura 2 : Pieza formada por un semicirculo, un rectángulo y un triángulo.

3. Calcular numéricamente el centro de masas de la pieza homogénea, indicando claramente la posición del sistema de referencia utilizado: orientación de ejes OX y OY y origen del sistema de referencia.

4. Calcular el centro de masas experimentalmente usando el método de la plomada para la figura homogénea y la heterogénea (ver Figura 3). Obtener las coordenadas de los puntos de intersección de las rectas trazadas a partir de la plomada.
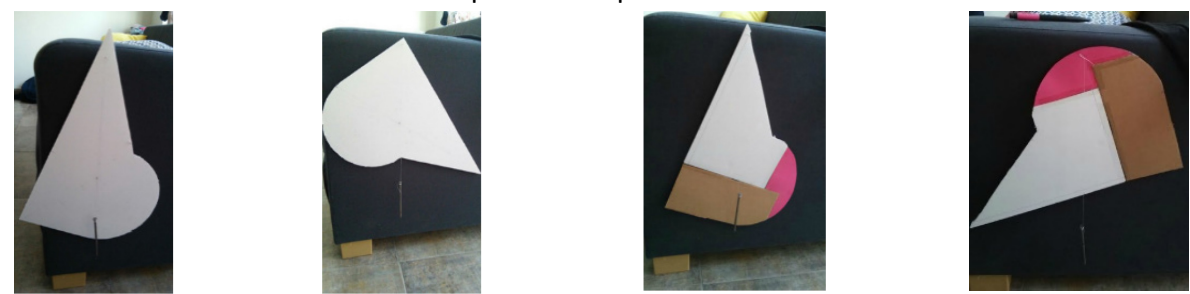

Figura 3: Pieza homogénea y heterogénea colgada de dos puntos diferentes y sus plomadas.

5. Rellenar la Tabla 1:

\begin{tabular}{|c|c|c|}
\hline Centroide calculado & $\begin{array}{c}\text { Centro de gravedad experimental } \\
\text { de la pieza homogénea }\end{array}$ & $\begin{array}{c}\text { Centro de gravedad experimental } \\
\text { de la pieza heterogénea }\end{array}$ \\
\hline & & \\
\hline
\end{tabular}

Tabla 1: Valores de $C$ teórico y del CM experimental de la pieza homogénea y heterogénea.

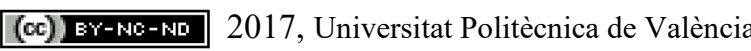

Congreso In-Red (2017) 
6. Comprobar el equilibrio haciendo girar las piezas homogénea y heterogénea apoyando su CM sobre un dedo (ver Figura 4).

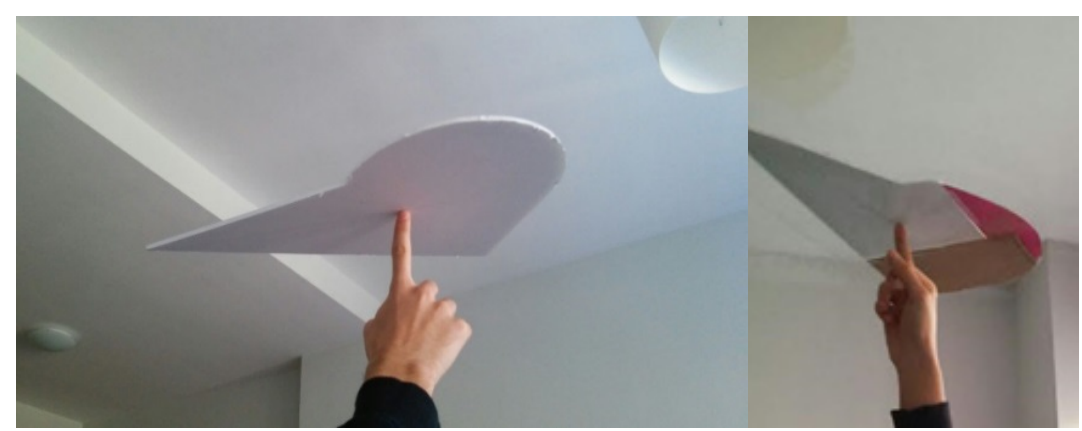

Figura 4: Piezas homogénea y heterogénea con $\mathrm{CM}$ indicado por el dedo.

7. Los alumnos entregan el cálculo realizado y algunos de ellos lo realizan en la pizarra (se pueden escanear todos los ejercicios y subirlos a una plataforma digital para que vean más ejemplos).

8. Se exponen todas las piezas colocándolas juntas (ver Figura 5) en algún lugar de la clase al terminar la sesión:

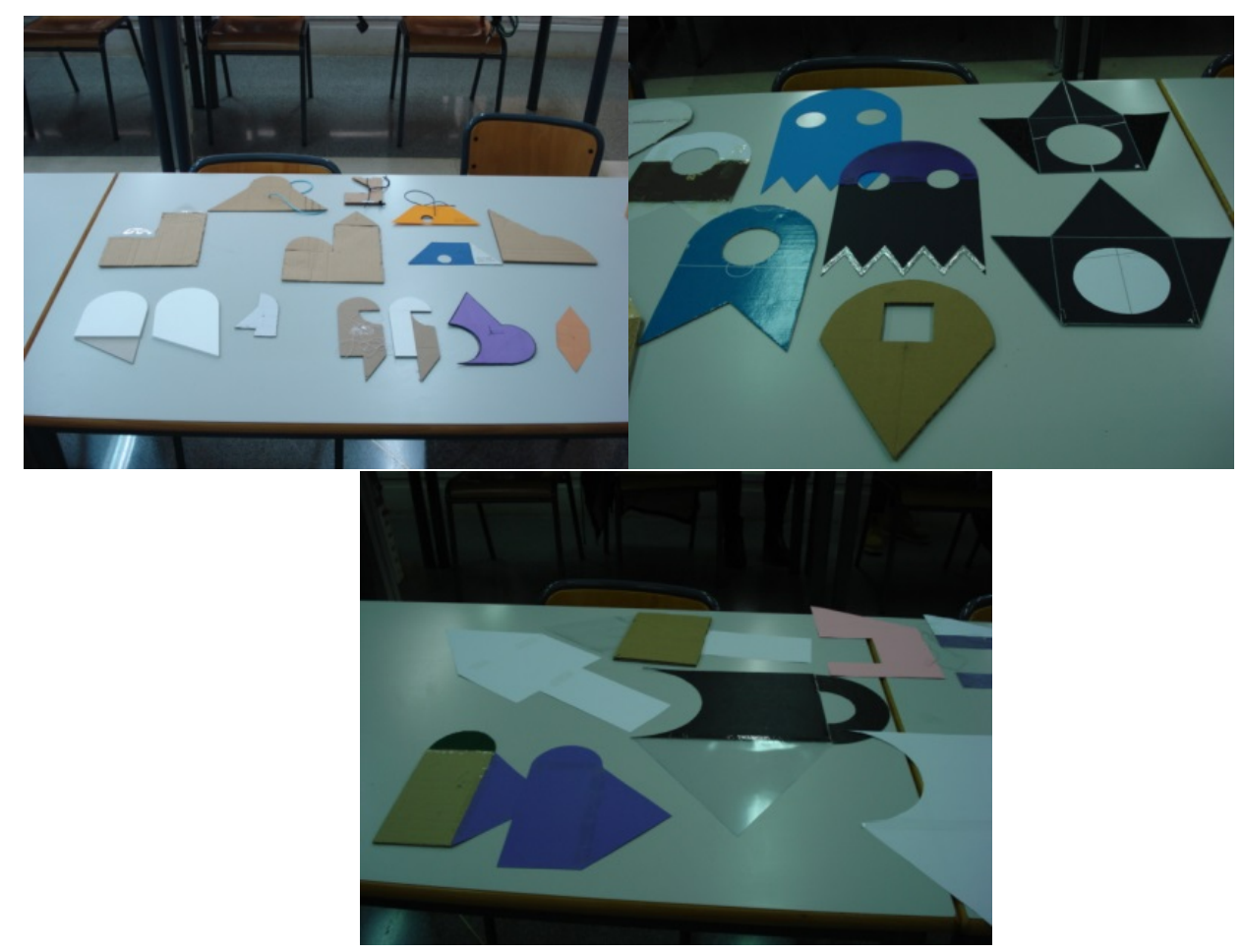

Figura 5: Muestrario de piezas diseñadas por los alumnos. 


\section{OBSERVACIONES}

1. Si no se usan materiales con densidades de masa muy distintas en el diseño de la pieza no homogénea, el cambio en la posición del CM es muy pequeño y difícil de apreciar usando el método de la plomada.

2. La actividad funciona mejor si se les pide a los alumnos que vengan a clase con las piezas ya diseñadas y con el cálculo del centroide realizado teóricamente.

\section{RECURSOS}

Se generan muchas figuras distintas una por grupo. Y se les puede pedir que cedan alguna.

\section{APLICACIONES REALES QUE SE BASAN EN EL PROTOTIPO}

Ejemplo del centro de gravedad:

El péndulo físico.

Ejemplo del centro de masa:

El estudio de la traslación y la rotación de un sólido rígido homogéneo o heterogéneo respecto a su centro de masas y al eje de rotación que pasa por él.

\section{EVALUACIÓN}

a) Entregar los cálculos del centroide de la pieza diseñada por cada grupo.

b) Entregar la tabla 1 cumplimentada y una valoración de los resultados obtenidos.

c) Entregar por escrito la explicación de la diferencia entre centro de gravedad, centro de masas y centroide.

Fig. 3 Ejemplo de ficha ya completada

\section{Conclusiones}

En este trabajo hemos mostrado cómo desarrollar metodologías activas en asignaturas básicas basadas en la creación de un catálogo de demostraciones experimentales o proyectos como recursos didácticos cuyo objetivo es motivar, por un lado, a los alumnos mejorando el aprendizaje y la comprensión de los modelos teóricos y, por otro lado, a los profesores para mejorar los resultados docentes. La metodología todavía no ha podido ser implementada totalmente en el aula, ya que el proyecto de innovación docente al que este trabajo hace referencia ha sido concedido ya comenzado el curso 2016-2017. Hasta la fecha hemos podido organizar recursos, distribuir carga de profesorado y empezar a disponer de los primeros elementos del catálogo de experimentos y realizar alguna experiencia piloto en el aula.

Lo que esperamos tras la puesta en práctica del proyecto es que tanto en el caso de las actividades grupales o pequeños proyectos, como en el caso de llevar a clase un prototipo, 
los alumnos estén más activos y puedan pasar de "simplemente" ver y escuchar a "realmente" experimentar con el prototipo y hasta crear los suyos propios. En algunos casos ya hemos comprobado que este cambio de enfoque hace que el clima de la clase sea muy dinámico y que los alumnos estén realmente más activos e involucrados con la actividad. Esperamos que se consoliden más los conceptos y no sólo se memoricen. Dicho de otro modo, al cumplir el objetivo del proyecto esperamos que se incremente la capacidad del alumno de resolver problemas en los que se les exige que tengan que pensar y comprender y no sólo recordar para poder resolverlos.

Es de destacar que a nosotros, como profesores, también nos motiva este proyecto ya que se nos dota de más herramientas para trabajar con los alumnos en clase. Y lo más importante, esta metodología de trabajo permite que la clase magistral se enriquezca convirtiéndose en una clase magistral dialogada y preguntada en la que los alumnos ganan protagonismo y están más activos (Cury 2007).

Otra conclusión importante que queremos resaltar es el hecho de que organizarnos como proyecto educativo en el que participamos varios profesores de Física que impartimos diferentes asignaturas en distintos campus universitarios y en el que todos participamos de forma activa permite generar un buen número de recursos educativos con un esfuerzo que no es excesivo. En nuestro caso, nos hemos propuesto generar al menos dos prototipos y una actividad grupal por cada profesor este primer año, y como ya hemos mencionado previamente, crear por triplicado los prototipos. Con ello conseguimos que en cada campus podamos disponer de todos los prototipos. También hemos tomado consciencia de cómo el esfuerzo colaborativo entre profesores - hoy en día facilitado por los recursos tecnológicos de que se disponen - es una herramienta que se puede explotar, de modo que se consiga mejorar los resultados docentes con un esfuerzo razonable. Finalmente resaltar que la situación que a nivel más profundo se pretende corregir es la de fomentar la capacidad de sorpresa ante los fenómenos naturales y articular el proceso de observación racional de modo que el alumno sea capaz de emitir conclusiones en términos de los modelos físicos que se estudian en el ámbito teórico. Dicho de otro modo, entrenarles en el uso y comprensión del método científico.

\section{Referencias}

ALBA J., TORREGROSA C., DEL REY R. (2015) Aprendizaje basado en proyectos: Primera experiencia en la asignatura de Física del Grado en Ingeniería de Telecomunicación, Sonido e Imagen. Universitat Politècnica de València Congreso IN-RED (2015)

APARICIO, F., GONZALEZ, R. M. Y SOBREVILA, M. A. (2005). Formación de Ingenieros. Objetivos, métodos y estrategias. Instituto de Ciencias de la Educación, UPM.

CALVO, I., LOPEZ-GUEDE, J.M. Y ZULUETA, E. (2010). Aplicando la metodología Project Based Learning en la docencia de Ingeniería Técnica en Informática de Gestión, Revista de Formación e Innovación Educativa Universitaria. Vol. 3, No 4, 166-181

CURY, A. (2007). Padres Brillantes, Maestros Fascinantes. Brasil, Planeta. ISBN: 9788408063605

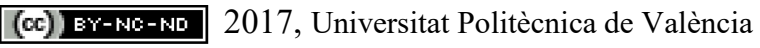

Congreso IN-RED (2017) 
DIAZ M. (2007) fq-experimentos. Experimentos caseros de Física y Química.

$<$ http://fq.experimentos.blogspot .com.es/> [Consulta: 29 de mayo de 2017]

FERRER C. (2012) Demostraciones experimentales de Física para el aula. $<$ http://fisicademos.blogs.uv.es/?page_id=29> [Consulta: 29 de mayo de 2017]

GONZÁLEZ, J. y WAGENAAR, R. (2003): Tuning Educational Structures in Europe. Informe Final - Proyecto Piloto, Fase 1, Bilbao, Universidad de Deusto.

VILAPLANA, R. GOMIS O. AND HYDER A. (2011) "Working in terms of competences: activities designed using active methodologies". Safeeullah Soomro New Achievements in Technology, Education and Development. Croatia: In-Tech. Cap. 22, Pags: 352-372. 


\title{
Las Wikis como Recurso Didáctico para la Enseñanza en Asignaturas del Área de Ciencias Experimentales
}

Ana M. Díez-Pascual ${ }^{\mathrm{a}}$, Pilar García Díaz ${ }^{\mathrm{b}}$, Rafael Cambralla Diana ${ }^{\mathrm{b}}$ y Miguel Ángel Ortega Núñez ${ }^{c}$

a Departamento de Química Analítica, Química Física e Ingeniería Química, am.diez@uah.es. bepartamento de Teoría de la Señal y Comunicaciones, pilar.garcia@uah.es; rafael.cambralla@uah.es; ${ }^{c}$ Departamento de Medicina y Especialidades Médicas. Universidad de Alcalá

\begin{abstract}
A wiki is a collaborative website that provides development and modification of its content and structure to every member in an interactive, easy and fast way. It is a simple and valuable tool for the teaching-learning process that allows both teachers and students to collaborate in the generation of knowledge. This paper describes the teaching experience in the implementation of a wiki as a voluntary activity in a practical subject of the first course of the degree in Chemistry. This methodology has been used for the elaboration of a bilingual glossary with the conceptual terms learned during the classes. The didactic strategy has been positive, although the percentage of participation in the wiki has been scarce. Only the students most committed with the subject were involved in the construction of the wiki. Therefore, it is necessary to introduce modifications in the approach of the activity in order to obtain more satisfactory results.
\end{abstract}

Keywords: Wiki, competences, methodology, collaborative work, teachinglearning, glossary of terms, feedback

\section{Resumen}

Una wiki es un sitio web colaborativo donde sus miembros pueden crear y modificar los contenidos y su estructura de forma interactiva, fácil y rápida. Es una herramienta sencilla y valiosa para el proceso de enseñanzaaprendizaje que permite tanto a los docentes como a los alumnos colaborar en la generación de conocimiento. Este trabajo recoge la experiencia docente en la implementación de una wiki como actividad voluntaria en una asignatura práctica del primer curso del Grado en Química. Esta metodología se ha utilizado para la elaboración de un glosario bilingüe con los términos conceptuales aprendidos durante las clases presenciales. La estrategia didáctica ha resultado positiva, si bien el porcentaje de participación en la misma ha sido escaso. Solo los alumnos más comprometidos con la asignatura se involucraron en la construcción de la wiki. Por tanto, se requiere introducir modificaciones en el planteamiento de la actividad para conseguir resultados más satisfactorios.
} 
Las Wikis como Recurso Didáctico para la Enseñanza en Asignaturas del Área de Ciencias Experimentales

Palabras clave: wiki, competencias, metodología, trabajo colaborativo, enseñanza-aprendizaje, glosario de términos, feedback

\section{Introducción}

Una wiki es un sitio web cuyas páginas pueden ser editadas por múltiples usuarios a través del navegador, entendiéndose por navegador un programa que permite visualizar la información que contiene una página web (ya esté alojada en un servidor dentro de la world wide web o en uno local). En la wiki los usuarios pueden crear y modificar los contenidos, el formato y su estructura de forma interactiva, fácil y rápida (Cabero y Llorente, 2007); dichas facilidades la convierten en una herramienta eficaz para la escritura colaborativa, donde los miembros cooperan en el desarrollo de contenidos sobre una temática concreta. Las wikis pertenecen al mismo grupo de herramientas para uso compartido de contenidos web que los blogs o los foros (López Sastre y Pérez Köhler, 2007), si bien hay importantes diferencias entre estos tres sitios web. Un blog suele tener un único autor o editor, el cual incluye a modo de diario personal contenidos de su interés, que son comentados por los lectores. El autor administra su espacio blog y tiene la capacidad de hacer visible o no los comentarios referentes a sus contenidos. Como diferencia fundamental, en una wiki cualquier usuario puede acceder a la edición de los bloques de contenidos y participar en la discusión comentando dichos bloques. Por otro lado, un foro es un sitio de discusión online asincrónico donde los usuarios publican mensajes relacionados con un tema, fomentando así el debate espontáneo. Se parece a la parte de discusión del blog o de la wiki, pero estos últimos tienen la función adicional de recopilación de contenidos.

Las wikis aplicadas en docencia permiten que los estudiantes muestren los hitos alcanzados a lo largo de su proceso de aprendizaje (García Díaz, 2016). Además contribuyen positivamente al proceso de enseñanza-aprendizaje desempeñando una serie de funciones de gran importancia como son: la motivación y persuasión del estudiante para realizar actividades de la asignatura, el apoyo al aprendizaje autónomo, el establecimiento de una vía de comunicación directa entre el profesor y los alumnos fuera del entorno del aula y la evaluación formativa de carácter continuo (Ortega Núñez, 2016).

Los sitios de alojamiento web más utilizados en el área de la educación para la creación de wikis son: PBworks, Wetpaint, Wikia, Google Sites y Wikispaces. Todos ellos utilizan servicios web gratuitos y un servidor remoto transparente al usuario. En la experiencia que se describe a continuación se ha empleado Wikispaces, un servicio lanzado por Tangient LLC en 2005, que fue comprado por Wikispaces TSL Educación en 2014 (ver Figura 1).

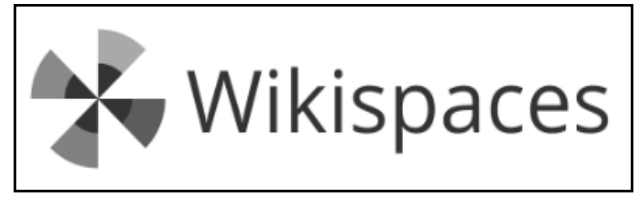

Fig. 1 Logo del servicio gratuito de Wikispaces (tomado de la página web www.wikispaces.com)

(cc) EY-NC-ND 2017, UniversitatPolitècnica de València

Congreso IN-RED (2017) 
Las actividades que se mencionan posteriormente están referidas a Wikispaces, si bien es posible llevar a cabo las mismas acciones con cualquier otro servicio wiki disponible actualmente. El profesor presentó a los alumnos la actividad a realizar con la wiki, con el fin de que comprendieran el uso de la aplicación, el objetivo de la actividad y su dinámica (López Sastre, 2007). La actividad se planteó dentro de la asignatura "Operaciones Básicas de Laboratorio", del primer curso del Grado en Química. Debido al carácter experimental de la asignatura, la actividad se consideró totalmente voluntaria, con un posible efecto positivo sobre la calificación final en la asignatura. La experiencia descrita en este documento es un comienzo de la reflexión en la metodología antes de incluirlo como actividad obligatoria en la asignatura.

\section{Objetivos}

- Analizar el potencial de las wikis en el contexto de la educación superior universitaria.

- Valorar una experiencia del uso educativo de wikis en el área de ciencias experimentales.

- Favorecer el trabajo tanto autónomo como colaborativo entre los alumnos. Ser capaz de coordinarse, organizar su tiempo y dividir las tareas.

- Iniciar a los estudiantes en la búsqueda bibliográfica de información, aprender y actualizar conocimientos.

- Promover el uso adecuado de las nuevas tecnologías.

- Fomentar su capacidad de discusión y sentido crítico, de toma de decisiones, capacidad de selección, síntesis y sistematización de conocimientos.

\section{Desarrollo de la innovación}

La asignatura de Operaciones Básicas de Laboratorio, materia obligatoria anual de 9 créditos ECTS del primer curso del Grado en Química de la Universidad de Alcalá (curso académico 2016-2017), incluye un laboratorio específico de "Introducción a la Experimentación en Química Analítica”. Dicho laboratorio consiste en clases prácticas impartidas en grupos pequeños donde el alumno desarrolla experimentos para aprender a aplicar e interpretar los principios básicos estudiados en las clases teóricas.

Esta parte de la asignatura tiene como objetivo iniciar a los estudiantes en la sistemática del proceso analítico y capacitarlos para desarrollar criterios científicos en la evaluación de resultados analíticos. Entre sus competencias específicas se encuentran fomentar el trabajo en equipo así como conocer y saber usar el instrumental y el aparataje que se utiliza habitualmente en este tipo de laboratorios. Para alcanzar estas competencias resulta fundamental la familiarización con la terminología específica del área, por lo que es muy importante realizar actividades donde se maneje dicha terminología. Un entorno adecuado para su desarrollo es una wiki donde los alumnos pueden ir revisando y editando el trabajo en grupo, lo que fomenta tanto su aprendizaje autónomo como el trabajo colaborativo. Este tipo de actividades permiten realizar tareas que no podían llevarse a cabo en clase por el límite de tiempo y carácter de la misma.

La Figura 2 muestra la página de inicio que se encuentra cualquier miembro al acceder a la wiki mediante su cuenta de Wikispaces. La wiki que aquí presentamos consta de dos secciones: 
Las Wikis como Recurso Didáctico para la Enseñanza en Asignaturas del Área de Ciencias

zona de contenidos y área de discusión o comentarios. En la primera el profesor plantea la actividad a realizar. En el área de discusión los miembros pueden insertar comentarios relacionados con la actividad. Es una zona de debate colectivo, tanto entre alumnos como entre alumnos y profesor. Es en este contexto donde el docente puede aportar ideas y comentarios que reconduzcan la elaboración de la actividad propuesta.

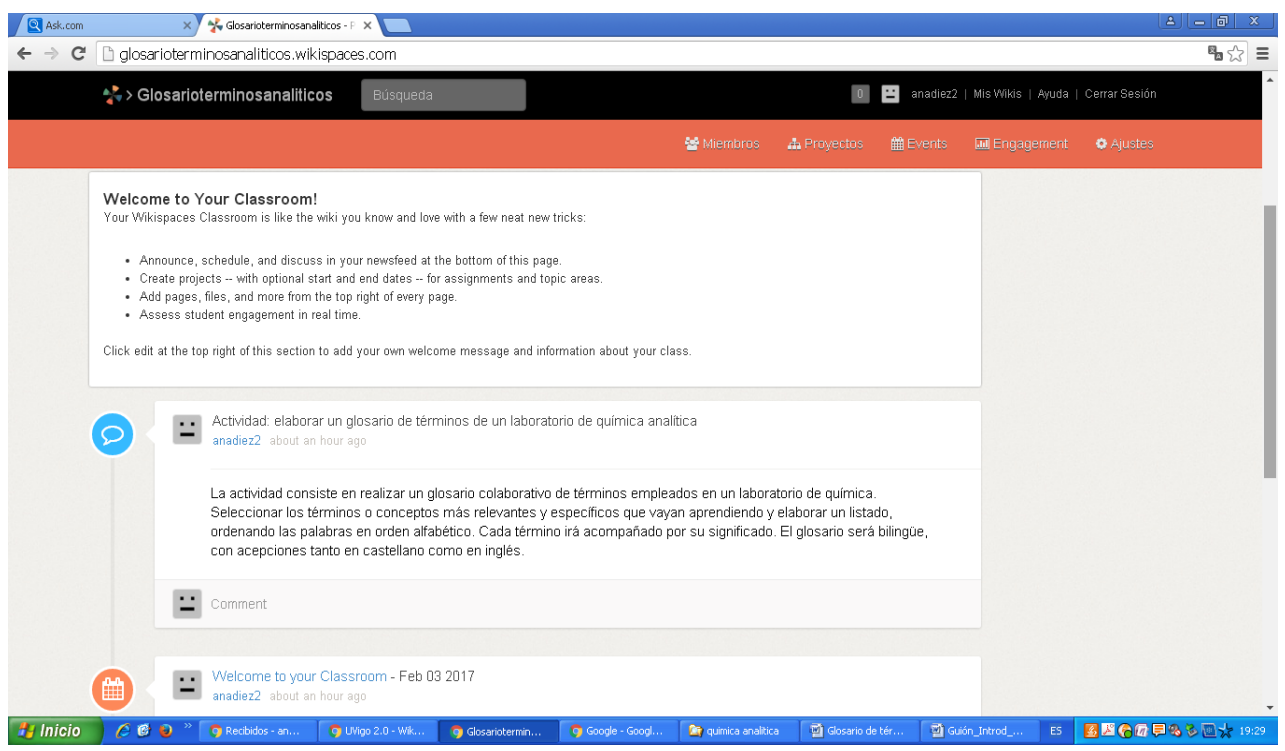

Fig. 2 Página de inicio de la wiki de la asignatura Operaciones Básicas de Laboratorio del primer curso del Grado en Química (curso académico 2016-2017).

La wiki se presentó en un seminario durante el cual se explicó su forma de utilización desde el registro en Wikispaces. La actividad consistió en realizar un glosario colaborativo entre todos los alumnos. Tenían que seleccionar los términos o conceptos más relevantes y específicos que hubiesen aprendido durante las prácticas y elaborar un listado ordenado alfabéticamente. Cada término debía ir acompañado por su significado (o significados) en el contexto de la materia estudiada, de modo similar a como se realiza en la Wikipedia. El glosario sería bilingüe, con acepciones tanto en castellano como en inglés. Para elaborar la actividad, es conveniente consultar bibliografía específica (Cuadros Rodríguez, 2013). El profesor proporciona "feedback" a través de la wiki, de manera que los alumnos puedan ir mejorando los contenidos a medida que el curso avanza.

La primera tarea consistió en realizar el listado de términos o conceptos que constituyen el glosario. Para ello, algunos alumnos presentaron una primera propuesta, y el resto del grupo añadió, modificó o suprimió los diferentes términos hasta lograr el consenso o acuerdo de todo el grupo. Se sugirió nombrar un coordinador del grupo para gestionar la dinámica grupal. La segunda tarea consistió en distribuir la redacción de los distintos conceptos en la wiki. Todos los alumnos leyeron lo redactado y aportaron, si lo consideraron oportuno, modificaciones en las definiciones de cada concepto. $\mathrm{Y}$ así sucesivamente hasta finalizar el glosario. Lo último a realizar fue dar el formato apropiado al glosario, unificar la tipografía empleada, asociarle un

(c)) BY-NC-ND 2017, UniversitatPolitècnica de València

Congreso IN-RED (2017) 
background común, incorporar imágenes y otros recursos gráficos. También se incorporó al final del glosario la bibliografía empleada (textos impresos y referencias en formato electrónico).

\section{Resultados}

Una vez creada la wiki "glosarioterminosanaliticos", los dos primeros alumnos que ingresaron no interpretaron bien la actividad a realizar e introdujeron solo los términos sin indicar su significado. Posteriormente otros dos miembros acometieron la elaboración del glosario de términos, indicando su acepción en los dos idiomas requeridos. Otra estudiante introdujo nuevos términos y ordenó todo el conjunto por orden alfabético. La figura 3 muestra fragmentos del glosario realizado por los estudiantes. Periódicamente, el profesor realizó algunas correciones al glosario, publicando los comentarios correspondientes.

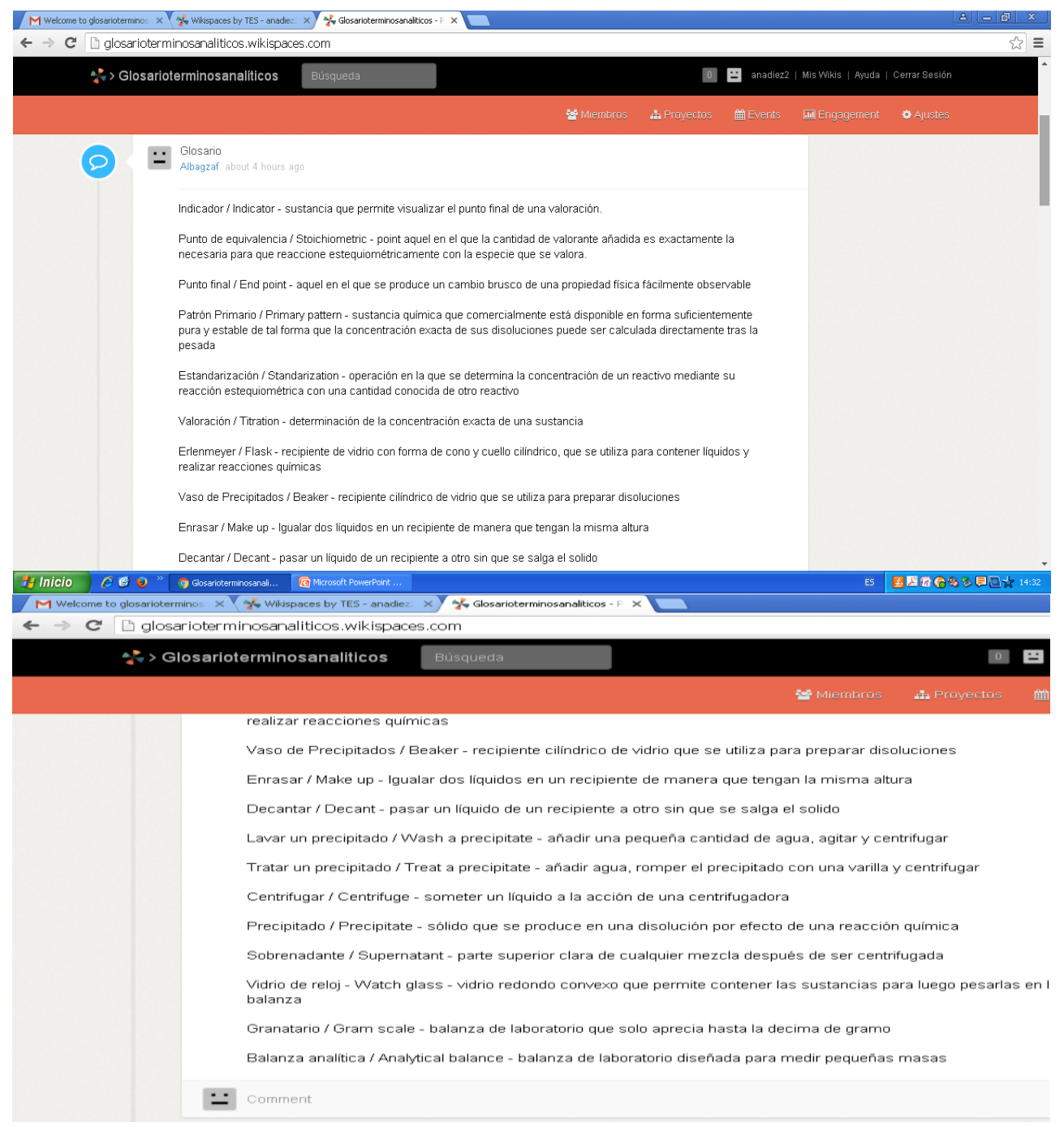

Fig. 3 Fragmentos del glosario creado por los estudiantes en la wiki

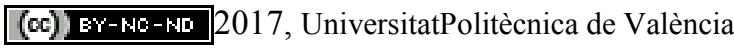

Congreso In-Red (2017) 
Las Wikis como Recurso Didáctico para la Enseñanza en Asignaturas del Área de Ciencias

La figura 4 muestra los miembros que participaron en la wiki. De los 96 estudiantes de primer curso de Grado en Química, solo 5 participaron en la actividad voluntaria.

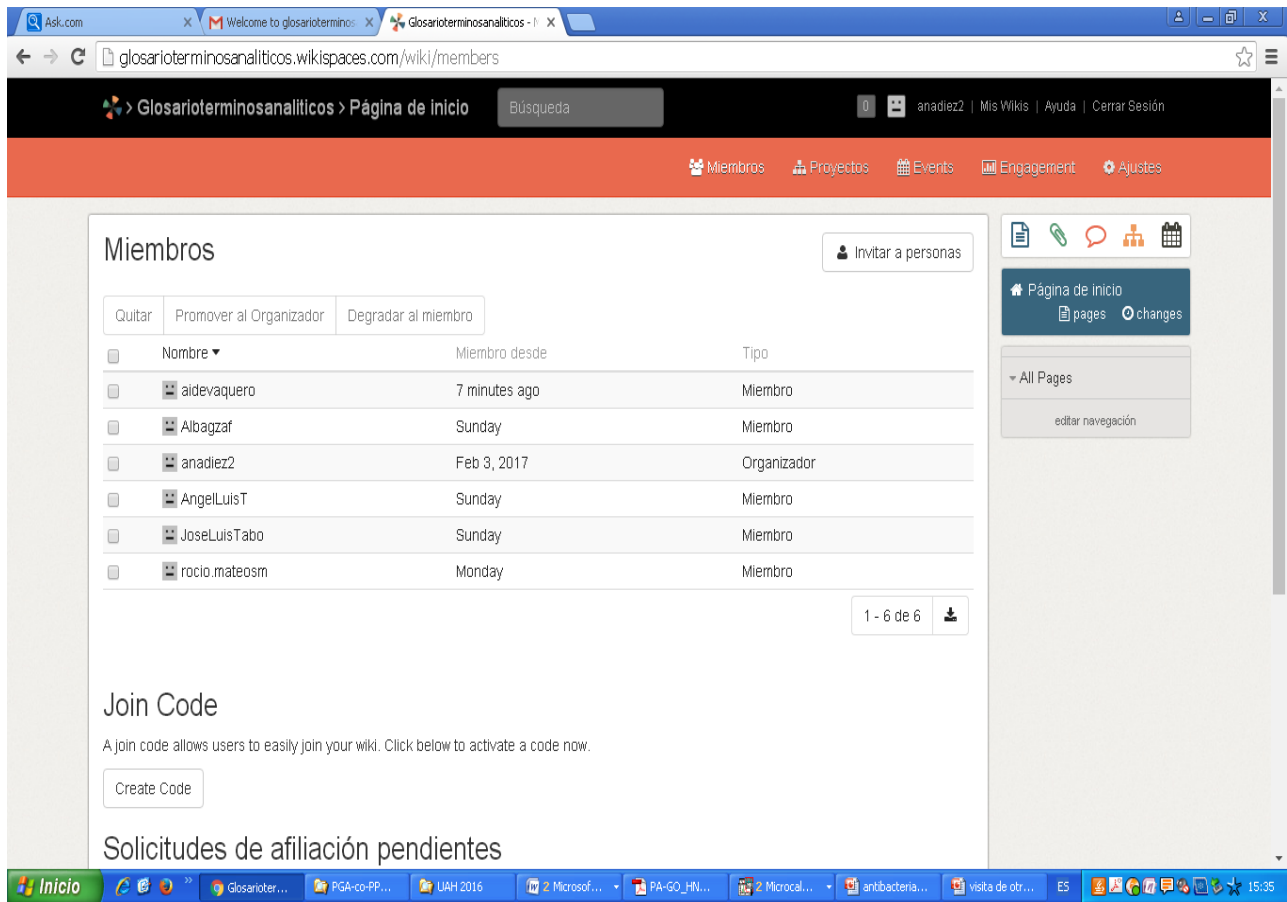

Fig. 4 Miembros que participaron en la wiki "glosarioterminosanaliticos"

La Tabla 1 recoge la estadística de participación en la wiki. En la asignatura de Operaciones Básicas de Laboratorio hay una tasa de aprobados muy baja, del 33\%. Como puede deducirse de la ¡Error! No se encuentra el origen de la referencia., la participación en la wiki fue muy escasa, solo el 5,2\% de los estudiantes contribuyeron a la actividad. Todos los miembros de la wiki aprobaron la asignatura en la convocatoria ordinaria. De hecho, tres de ellos sacaron la máxima calificación. De los alumnos aprobados, el 15,6\% corresponde a miembros de la wiki. Se analizó también el tiempo que los estudiantes dedicaron a realizar la actividad, encontrándose un rango bastante amplio, entre 1 y 6 horas dependiendo de su grado de involucración.

Tabla 1. Estadística de participación de los alumnos en la wiki y su relación con la calificación en la asignatura de Operaciones Básicas de Laboratorio.

\begin{tabular}{cc}
\hline Estadística & Alumnos (\%) \\
\hline Participación en la wiki sobre alumnos matriculados & 5,2 \\
Participación en la wiki sobre presentados a examen & 5,9 \\
Participación en la wiki sobre alumnos aprobados & 15,6 \\
Aprobados en asignatura sobre participación en la wiki & 100 \\
\hline
\end{tabular}

(cc) EY-NC-ND 2017, UniversitatPolitècnica de València 


\section{Conclusiones y perspectivas futuras}

Una conclusión inmediata del análisis de resultados es que todos los alumnos que emplearon la herramienta wiki aprobaron la asignatura. Teniendo en cuenta que se presentó como una actividad de carácter voluntario, se puede deducir que los alumnos más comprometidos con la asignatura se involucraron también en la construcción de la wiki. La no obligatoriedad de la actividad fomenta una mejor gestión del aprendizaje por parte de los alumnos, centrando su esfuerzo en el contenido de lo que escriben y no en la calificación de la actividad.

La baja participación del alumnado podría estar relacionada con el escaso tiempo del que disponen y la poca flexibilidad. La evaluación continua frecuentemente provoca solapamiento de las actividades propuestas en diferentes asignaturas, causando coincidencia prácticamente simultánea en los periodos de actividad más intensa. Con el fin de evitar esta situación se sugiere establecer criterios flexibles y consensuados con los estudiantes para los plazos y tiempos de trabajo con la wiki.

Se plantea también la posibilidad de diseñar otras actividades, de manera que los alumnos tengan la opción de elegir aquella(s) que les parezcan más interesantes para potenciar su aprendizaje. Entre ellas se encontrarían: (1) Realizar una evaluación crítica de un documento científico del área de la química analítica relacionado con los temas estudiados, el cual se colocaría en la wiki. Los alumnos deberían leer el artículo con atención y escribir una breve evaluación crítica de los objetivos del trabajo, métodos, resultados y conclusiones. Se les entregaría una lista de ayuda con preguntas relacionadas con los conceptos estudiados que aparecen en la publicación. Así, los alumnos deberán identificar los términos específicos relacionados con la materia. (2) Redacción sobre un tema de actualidad relacionado con la química analítica donde se apliquen los conocimientos y la terminología específica aprendida. Se trataría de una redacción colaborativa donde los estudiantes tendrían que coordinarse en la escritura, corrigiendo y adaptando lo que escriban los otros compañeros. Serían ellos mismos los que seleccionasen el tema a desarrollar, lo que les llevaría a explorar en la bibliografía de la materia. (3) Respuesta a preguntas concretas relacionadas con la temática de la asignatura. Esta actividad requeriría el uso del vocabulario específico y una mayor capacidad de síntesis para responder a cuestiones concretas. Serviría para afianzar los conocimientos adquiridos durante las clases, repasar los conceptos y prepararse para las diferentes pruebas de la asignatura. Algunas de las cuestiones serían en forma de ejercicios numéricos. Los alumnos responderían de forma colaborativa, y el profesor no corregiría explícitamente las respuestas, sino que las comentaría en el área de discusión.

\section{Referencias}

CABERO, J ., LLORENTE, M. (2007). "La interacción en el aprendizaje en red: uso de herramientas, elementos de análisis y posibilidades educativas" en Revista Iberoamericana de Educación a Distancia, $10,2,98-123$

CUADROS RODRÍGUEZ, L., GÁMIZ GRACIA, L., CARRASCO PANCORBO, A., RUIZ SAMBLÁS, C. (2013). "Glosario de términos analíticos". Grupo Regional Andaluz de la Real Sociedad Española de Química Analítica, 1 edición. ISBN 978-84-616-4720-0. URL: http://www.revistaquimica.cl/wp-content/uploads/2016/02/Glosario-Terminos-Analiticos.pdf 
Las Wikis como Recurso Didáctico para la Enseñanza en Asignaturas del Área de Ciencias Experimentales

GARCÍA DÍAZ, P., ORTEGA NÚÑEZ, M.A., CAMBRALLA DIANA, R., DÍEZ-PASCUAL, A. M. (2016) "Experiencia de implementación de una wiki como apoyo a la docencia presencial en enseñanzas universitarias". VIII Encuentro de Innovación en Docencia Universitaria: "Nuevas apuestas educativas : Entre la docenciapresencial y la innovación tecnológica" (25 y 26 de abril de 2016. Facultadde Biología, Ciencias Ambientales y Química. Universidad de Alcalá). Alcalá de Henares, Madrid.

LÓPEZ SASTRE, R.J. (2007). “Aprendizaje y software social: comunidades de práctica y Wikis en el EEES”. Alcalá de Henares: Servicio de Publicaciones de UAH.

LÓPEZ SASTRE, R.J., PERÉZ KÖHLER, A. (2007). "Innovación Docente y Software Libre”. II Encuentro sobre Innovación en Docencia Universitaria. Universidad de Alcalá.

ORTEGA NÚÑEZ, M.A., GARCÍA DÍAZ, P., DÍEZ-PASCUAL, A.M. (2016) El proceso de la innovación en el contexto de la educación superior universitaria. Madrid, LDL. ISBN : 978-84944970-5-6.

(cc) EY-NC-ND 2017, UniversitatPolitècnica de València 


\title{
'Labyrinth', una aplicación móvil para el aprendizaje basado en problemas: evaluación de los usuarios sobre su eficacia como herramienta de aprendizaje.
}

\author{
Rocío Fortún Rabadán ${ }^{\text {a,b }}$, Lindsey Bruton ${ }^{\mathrm{c}, \mathrm{d}}$, Carolina Jiménez Sánchez ${ }^{\mathrm{a}, \mathrm{b}}$, María \\ Ortiz Lucas, ${ }^{\mathrm{a}, \mathrm{b}}$, Miriam Clavel Rodríguez .
}

aDepartamento de Fisioterapia. Universidad San Jorge. Zaragoza (rfortun@usj.es; cjimenez@usj.es; mortiz@usj.es; alu.23159@usj.es) brupo de Investigación iPhysio. Universidad San Jorge. Zaragoza. 'Instituto de Lenguas Modernas. Universidad San Jorge. Zaragoza (labruton@usj.es). dMITLHE, Multidisciplinary Innovation in Teaching and Learning. Universidad San Jorge. Zaragoza.

\begin{abstract}
Current learning theories promote the employment of active methodologies, placing the learner at the centre of the learning process as protagonist. Both problem and case-based learning, methodologies embracing this perspective, have been widely used in health sciences.

Other intrinsic factors key to learning such as self perception, motivation and confidence also play an important role in the learning process and outcomes.

This paper focuses on student perceptions of 'Labyrinth', a web-based application which permitted learners to solve cases requiring electrotherapy treatment. An anonymous online questionnaire was developed to evaluate students' perceptions of how 'Labyrinth' contributes to and supports learning. The contents of the questionnaire aimed to raise awareness in the learner of the importance of personal effort and self-motivation in achieving learning goals.

Direct and relevant correlations were found between students perceptions about the global utility of 'Labyrinth', and their self-perceived levels of confidence, motivation, effort and cognitive development during the use of the application.

These findings highlight the need for reflection on these intrinsic learning factors in order that awareness and consequent development of key learning habits are encouraged.
\end{abstract}

Keywords: Case-based learning; web-based application; intrinsic learning factors; self-awareness; self-motivation; physiotherapy; electrotherapy. 


\section{Resumen}

Las teorias actuales del aprendizaje proponen la aplicación de metodologías activas, situándose el alumno en el centro del proceso de aprendizaje. Dentro de estas metodologías encontramos el aprendizaje basado en problemas o en casos, ampliamente utilizado en Ciencias de la Salud.

Otros factores intrínsecos claves para el aprendizaje como la auto-percepción, la motivación y la confianza, juegan un papel importante en el proceso y los resultados del aprendizaje.

Este articulo se centra en las percepciones de los estudiantes sobre 'Labyrinth', una aplicación web que permite resolver casos que requieren tratamiento electroterápico.

Se desarrolló un cuestionario anónimo online para evaluar las percepciones de estudiantes de Fisioterapia respecto a cómo 'Labyrinth' contribuye y apoya el aprendizaje. El contenido del cuestionario tenía como objetivo sensibilizar sobre la importancia del esfuerzo personal y la auto-motivación para alcanzar los objetivos de aprendizaje.

Se encontraron correlaciones directas y relevantes entre las percepciones de los estudiantes acerca de la utilidad global de 'Labyrinth' y sus niveles de confianza, motivación, esfuerzo y desarrollo cognitivo autopercibidos durante su uso.

Estos hallazgos evidencian la necesidad de reflexión sobre estos factores intrinsecos de aprendizaje a fin de fomentar la concienciación y el consiguiente desarrollo de los hábitos de aprendizaje fundamentales.

Palabras clave: Aprendizaje basado en casos; aplicación online; factores intrínsecos del aprendizaje; auto-percepción; fisioterapia; electroterapia.

(cc) EY-NC-ND 2017, Universitat Politècnica de València 


\section{INTRODUCCIÓN}

Este estudio se centra en valorar la utilidad de 'Labyrinth' para asistir y contribuir al aprendizaje en base a la percepción de los usuarios. 'Labyrinth' consiste en una aplicación online basada en la resolución de casos clínicos, diseñada para facilitar a los estudiantes de fisioterapia la consecución de los objetivos de aprendizaje, así como fomentar su reflexión sobre sus propios recursos. Con estos fines, en el desarrollo de esta herramienta innovadora y de los métodos para su evaluación se tuvieron en cuenta muchos factores que han evidenciado beneficios en el área de la pedagogía, y que se exponen a continuación.

\subsection{Factores intrínsecos y Aprendizaje basado en problemas.}

El trabajo de la psicóloga Carol S. Dweck (Dweck, 2007) sobre motivación y teorías implícitas de la inteligencia, identificó en la población de estudio dos modalidades de creencias sobre la inteligencia, a las que denominó respectivamente "inteligencia fija" presunción de que la inteligencia es una cualidad estática que se posee o no se posee-, e "inteligencia en desarrollo" -convicción de que esta cualidad es plástica y por tanto puede aumentarse-. Varias investigaciones mostraron que el tipo de creencia que los estudiantes tienen sobre la inteligencia repercute directamente en sus resultados académicos, y que educarles en la creencia de la inteligencia en desarrollo aumenta su seguridad en sus posibilidades y por tanto mejora dichos resultados de manera significativa (Blackwell, 2007; Good, 2003).

La auto-percepción de los estudiantes respecto a otros aspectos también ha mostrado influir en el rendimiento académico (Pajares,1996). La auto-percepción de la capacidad de esfuerzo se relaciona directamente con la creencia de una capacidad de aprendizaje creciente, dado que la inteligencia y el desarrollo de competencias deben acompañarse necesariamente de esfuerzo (Dweck, 2007). En base a ello, el esfuerzo garantiza la posibilidad de obtener buenas calificaciones, colocando los resultados directamente en manos del estudiante.

El proceso de aprendizaje es enormemente dependiente del factor motivación, definiéndose ésta como el interés que tiene el estudiante por su propio aprendizaje o por las actividades que le conducen a él, y en la que podemos diferenciar entre motivación extrínseca y motivación intrínseca (Ryan, 2000). Hablamos de motivación extrínseca cuando una persona realiza una tarea para lograr un resultado (por ejemplo, un estudiante que estudia para un examen con el fin de obtener una buena calificación). Por el contrario, una persona que realiza una tarea por placer o interés está intrínsecamente motivado. La motivación intrínseca ha mostrado mejorar tanto el proceso como los resultados de aprendizaje. Por tanto, si el estudiante percibe una actividad como motivante, interesante y divertida, sus posibilidades de aprendizaje aumentan (Shute, 2013), siendo éste calificado como aprendizaje activo (Dias, 2017).

Respecto a los aspectos cognitivos implicados en el proceso y los resultados del aprendizaje, la neurociencia nos indica cuán numerosos factores influyen en ellos, comenzando por la percepción, la atención y la memoria, en base a las cuales puede alcanzarse la comprensión de conceptos, nociones e inferencias, siendo el fin último su integración aplicada en la resolución de problemas (Vermunt, 1996). Las actividades pedagógicas en las que los conceptos adquiridos deben aplicarse metacognitivamente, 
llevan implícita la auto-evaluación del nivel de comprensión de los contenidos y de la capacidad para relacionar conceptos (Schmitz, 2004). Consecuentemente, facilitan al estudiante la toma de conciencia y decisiones sobre sus capacidades, necesidades, y hábitos de estudio. Estos aspectos cognitivos son también recogidos por las teorías constructivistas (Vygotsky, 1980), basadas en que el conocimiento se construye a partir de nueva información que se asienta sobre los conceptos previamente existentes (Glaserfield, 1989). Por ello, si la actividad facilita la relación de conceptos nuevos con otros adquiridos previamente, será en teoría más eficaz como herramienta de aprendizaje.

Los diversos aspectos expuestos, auto-percibidos por los estudiantes respecto a sus recursos -seguridad en sus posibilidades, esfuerzo, motivación, comprensión y relación de conceptos-, se contemplan en las teorías del aprendizaje actuales, que proponen situar al estudiante en el centro del proceso de aprendizaje, como protagonista tanto del proceso como de los resultados alcanzados (Vermunt, 1996). En esta línea, se ha evidenciado cómo las metodologías de enseñanza basadas en la resolución de problemas (Problem Based Learning, denominado en adelante PBL por sus siglas en inglés) fomentan dichos factores intrínsecos del aprendizaje respecto a los formatos tradicionales basados en la clase magistral (Wood, 2003; Schmidt, 2011).

En ciencias de la salud, el trabajo consistente en la resolución de casos clínicos resulta una herramienta útil dentro de las metodologías PBL, requiriendo al estudiante una transferencia de los conocimientos teóricos adquiridos a los contextos prácticos donde tendrán que ser aplicados (Kolodner, 2003). A pesar de que estas prácticas de enseñanza llevan tiempo aplicándose en Fisioterapia, se encuentra poca evidencia sobre su efectividad en la formación en esta rama de la salud que nos ocupa. No obstante, la existente parece indicar estos mismos resultados positivos a los investigados en otras ciencias como Medicina y Enfermería, fomentando que los estudiantes apliquen conceptos importantes de su formación académica a situaciones aproximadas a los contextos clínicos reales (Solomon, 2005; Dyer, 2015), promoviendo la integración y relación conceptual, el proceso metacognitivo necesario para el razonamiento clínico, y la motivación intrínseca del alumno.

\subsection{Integración de las TIC y la lengua inglesa}

Por otra parte, el uso de las Tecnologías de la Información y Comunicación en docencia ha supuesto un gran avance, promoviendo el desarrollo de las competencias digitales en los estudiantes acorde a las necesidades tecnológicas y de autonomía que el mundo actual depara a los futuros profesionales (Greenhalgh, 2001; Nicklen 2016), y permitiendo también un mejor aprovechamiento del tiempo fuera del aula (Crawford, 2011).

Paralelamente, el uso del inglés como lengua franca se hace necesario en el contexto actual de globalización. La utilización de este idioma para la transmisión de contenidos y para la realización de actividades basadas en PBL como son los casos clínicos, requiere de un trabajo previo de los docentes en el diseño de la actividad, sirviéndose de metodologías como el Aprendizaje Integrado de Contenido y Lenguaje (Content and Language Integrated Learning, CLIL en adelante por sus siglas en inglés) (Coyle, 2010). El enfoque CLIL se integra dentro del caso clínico para mejorar la comprensión y accesibilidad de los contenidos presentados en inglés, a estudiantes cuya lengua materna no es ésta.

(cc)) BY-NC-ND 2017, Universitat Politècnica de València 
En el presente estudio, el equipo multidisciplinar encargado de diseñar la App y llevar a cabo la investigación, analiza las respuestas de los estudiantes frente a cuestiones sobre la utilidad global de la aplicación como herramienta de estudio, y sobre el papel de 'Labyrinth' en la facilitación de los factores intrínsecos del aprendizaje expuestos, considerando que ambos serán elementos clave en su proceso y resultados de aprendizaje.

En las siguientes secciones del artículo se describen los objetivos de la investigación, así como el diseño y características de la herramienta 'Labyrinth', del cuestionario de evaluación utilizado y del estudio piloto. Posteriormente se exponen y analizan los Resultados, que serán discutidos en el apartado final de Conclusiones, incluyendo posibles limitaciones y planteando nuevas líneas de investigación.

\section{OBJETIVOS}

La presente investigación se centró en explorar la percepción de los estudiantes respecto a la utilización de 'Labyrinth'como herramienta de aprendizaje para la resolución de casos clínicos. Específicamente se plantearon los siguientes objetivos:

- Evaluar la percepción de los estudiantes respecto a la utilidad global de 'Labyrinth' y de sus características específicas para alcanzar los objetivos de aprendizaje de la actividad.

- Cuantificar el grado en que los estudiantes vieron fomentados los factores intrínsecos del aprendizaje durante el uso de 'Labyrinth'.

- Observar si el grado de facilitación de dichos factores percibido por los estudiantes se relaciona con su valoración global de utilidad de 'Labyrinth' como herramienta de aprendizaje.

\section{DESARROLLO DE LA INNOVACIÓN}

\subsection{App 'Labyrinth'}

'Labyrinth', una aplicación basada en PBL (problem-based learning; Wood, 2003) accesible desde móviles, tablets y PCs, fue concebida para presentar casos clínicos sobre técnicas de electroterapia a los estudiantes de la asignatura "Procedimientos Generales de Fisioterapia I" (figura 1). La aplicación, íntegramente en inglés, sigue la metodología CLIL (Coyle 2011) para facilitar la comprensión de las instrucciones y los contenidos en dicha lengua.

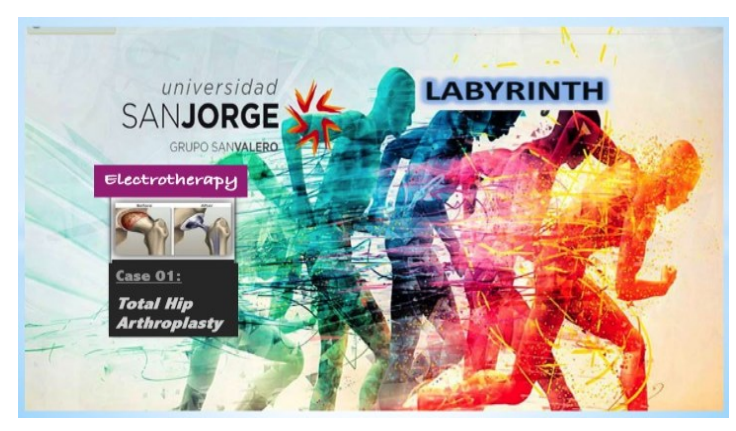

Figura 1. Pantalla inicial de Labyrinth'.

(cc)) EY-NC-ND 2017, Universitat Politècnica de València Congreso In-Red (2017) 
'Labyrinth' consiste en 6 niveles principales divididos a su vez en sub-niveles (figura 2).

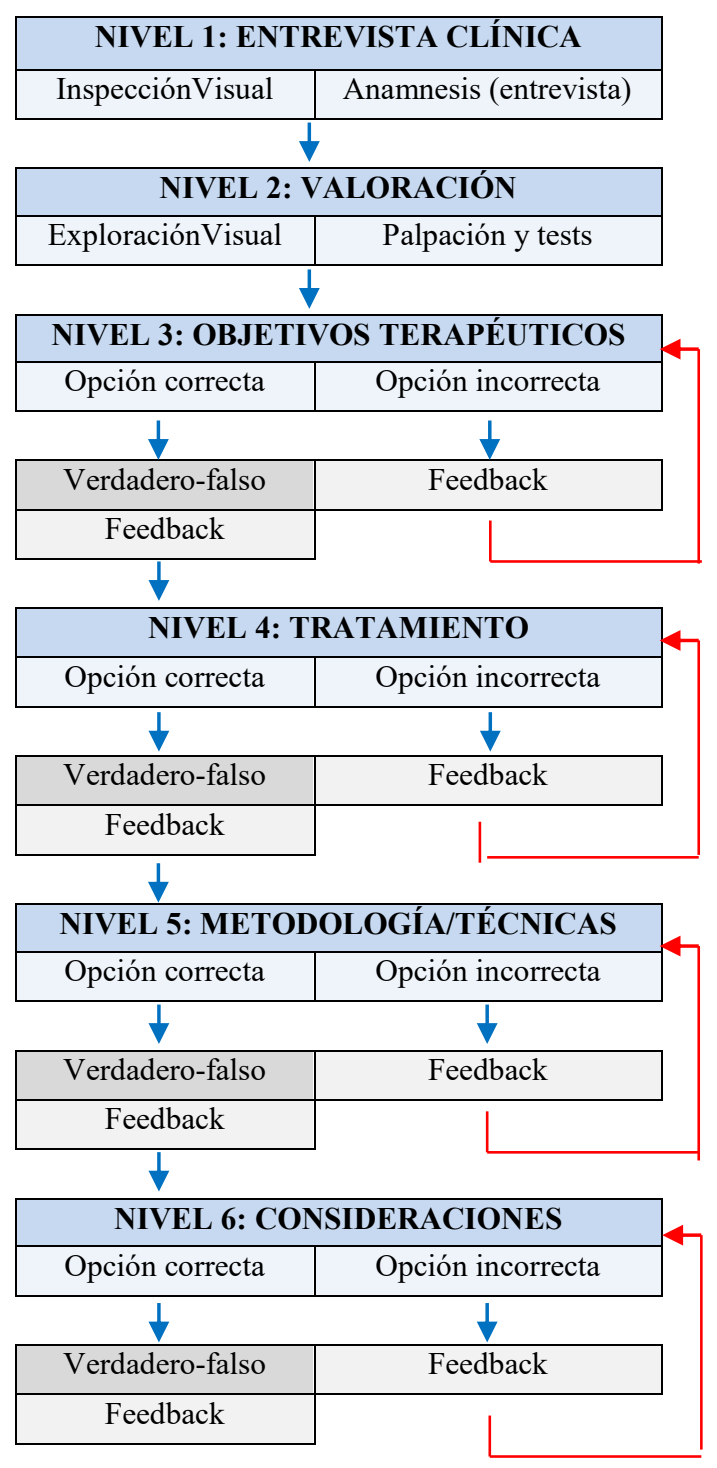

Figura 2. Niveles de la Aplicación 'Labyrinth'

La presentación del caso clínico comienza con la descripción y contextualización de un paciente. A continuación, a través de su uso en la interfaz para estudiantes, se requiere a los alumnos resolver el caso clínico presentado, debiendo para ello testar y relacionar sus conocimientos sobre la materia de electroterapia, tomando decisiones nivel tras nivel dentro del múltiple abanico de respuestas válidas que ofrece, y que dirigen hacia diferentes estrategias terapéuticas. 
En los niveles 1 y 2, los estudiantes deben tomar decisiones respecto a los factores más relevantes y específicos que deben conocer de la evaluación del paciente, en base a los cuales establecererán los objetivos de tratamiento.

En los niveles 3 a 6, utilizan la información conseguida anteriormente para proponer el abordaje terapéutico del problema clínico, identificando los objetivos de tratamiento y seleccionando las técnicas de electroterapia a aplicar, así como las precauciones y consideraciones a tener en cuenta en su patología.

En estos niveles, si el estudiante selecciona una opción incorrecta, recibe un feedback que le ayuda a comprender su equivocación y le redirige de nuevo a la selección de opciones. Por el contrario, si elige una opción correcta, debe completar un cuestionario "verdaderofalso" para confirmar el adecuado razonamiento clínico y descartar el azar en su acierto. Una vez este paso es completado con éxito, el estudiante puede acceder al siguiente nivel, y así consecutivamente hasta alcanzar la resolución del caso clínico.

El hecho de que existan varias opciones correctas en cada nivel, permite a los estudiantes avanzar en varias vías, de modo que el desconocimiento de una parte de la materia no impida la resolución del caso, sino fomente su búsqueda de alternativas en base a una nueva relación de conceptos.

La aplicación, a través de la interfaz para profesores, permite a los docentes facilitar información complementaria en cada nivel, en forma de documentos, links y material audiovisual, para apoyar el contraste de hipótesis en el razonamiento clínico del estudiante. Además permite acceder a los resultados de trabajo de los alumnos, así como a un foro en línea con los estudiantes.

\subsection{Encuestas de evaluación}

Se diseñó un cuestionario online anónimo con el objetivo de evaluar la percepción de los estudiantes respecto a la actividad, inmediatamente tras el uso de 'Labyrinth'.

En primer lugar los estudiantes registraron variables académicas (nota media del expediente académico, alumnos de primera o posteriores convocatorias y regularidad en su asistencia a las clases), así como datos demográficos (edad, género y nacionalidad), si bien en ningun momento revelaron su identidad.

El resto del cuestionario desarrollado consistió en escalas tipo Likert de 0 a 10 , exponiéndose afirmaciones en las que los estudiantes debían seleccionar un número conforme a su percepción respecto al enunciado, siendo 0 "estoy totalmente en desacuerdo/nunca" y 10 "estoy completamente de acuerdo/siempre". Dicho cuestionario se dividió en dos secciones que se exponen a continuación:

En la primera sección los estudiantes evaluaron el grado en el que la aplicación fomentó sus propios factores intrínsecos del aprendizaje, específicamente los siguientes:

1. Sentimiento de seguridad para poder superar la asignatura;

2. Motivación e interés por estudiar la asignatura;

3. Esfuerzo personal empleado en la actividad;

(cc)) EY-NC-ND 2017, Universitat Politècnica de València

Congreso In-Red (2017) 
4. Comprensión de la materia;

5. Facilidad para relacionar los diferentes conceptos de la asignatura.

Así mismo se les solicitó asignar una puntuación a la valoración global de Labyrinth como herramienta de estudio y aplicación de conocimientos.

En la segunda sección los alumnos evaluaron de 0 a 10 el grado de utilidad de la App 'Labyrinth' y algunas de sus características, valorando específicamente:

1. Utilidad para resolver casos clínicos;

2. Utilidad para aplicar los conocimientos de la asignatura;

3. Utilidad para comprobar la integración de los contenidos de la asignatura;

4. Utilidad del foro en la resolución de dudas;

5. Dificultades debidas al idioma inglés;

6. Utilidad para preparar el examen;

7. Utilidad de la accesibilidad desde PC, tablet y móvil.

Se reservó un espacio al final del cuestionario donde se permitió a los estudiantes expresar cualquier tipo de observación o comentario.

\subsection{Estudio Piloto}

La intervención del presente estudio piloto tuvo lugar durante una clase habitual programada de 100 minutos de la asignatura "Procedimientos Generales de Fisioterapia I", que fue divididida en tres partes. Inicialmente el docente presentó el funcionamiento de Labyrinth. A continuación, durante 45 minutos y en grupos de 3-4 personas, los estudiantes trabajaron con Labyrinth en la resolución del caso clínico, siendo animados a utilizar un foro online habilitado para debatir y consultar entre ellos y con otros grupos. Los docentes también estuvieron disponibles para apoyar a los alumnos en caso de ser requerido.

Tras la finalización del tiempo de trabajo con Labyrinth, completaron el cuestionario online anónimo durante 20 minutos.

\section{RESULTADOS}

\subsection{Análisis Estadístico}

Para categorizar las características basales de la muestra, las variables se describen como número (porcentaje) y media (desviación estándar). Las variables cuantitativas se sometieron al test Kolmogorov-Smirnov para determinar su distribución y utilizar las pruebas estadísticas correctas acorde con los resultados. La correlación entre las variables se determinó mediante el cálculo del coeficiente de correlación de Pearson o de Spearman según la normalidad o no de dichas variables.

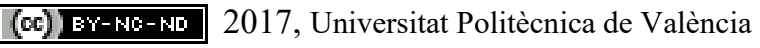

Congreso IN-RED (2017) 


\subsection{Resultados de correlaciones}

La correlación entre la valoración global de la aplicación y cada uno de los ítems que evaluaban el nivel de satisfacción de los estudiantes con sus factores intrínsecos del aprendizaje, fue elevada: $\mathrm{r}>0.83$ y $\mathrm{p}<0.001$ en todos los casos (figuras 1 a 5).

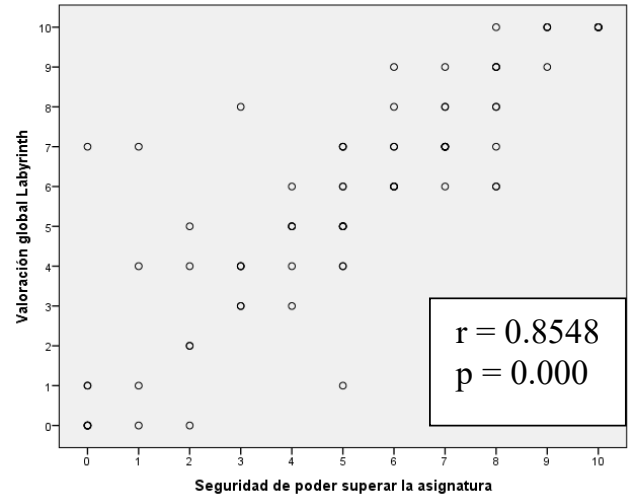

Figura 1. Gráfico de dispersión entre la valoración global de 'Labyrinth' y la seguridad de poder superar la asignatura. $p$ : valor-p; $r$ : coeficiente de correlación de Pearson.

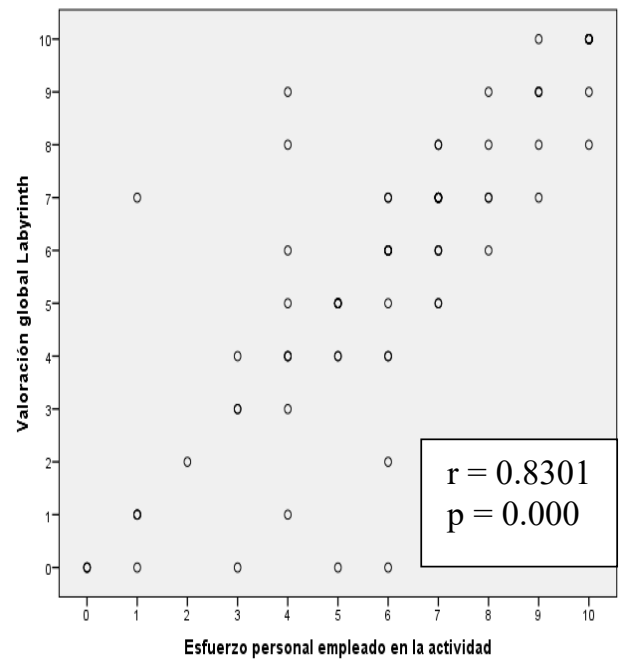

Figura 3. Gráfico de dispersión entre la valoración global de 'Labyrinth' y la percepción de esfuerzo personal empleado. $p$ : valor-p; $r$ : coeficiente de correlación de Pearson.

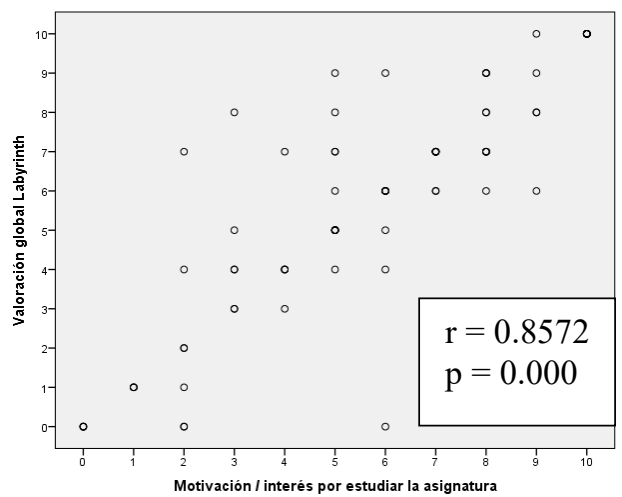

Figura 2. Gráfico de dispersión entre la valoración global de 'Labyrinth' y la motivación-interés por estudiar la asignatura. $p$ : valor-p; $r$ : coeficiente de correlación de Pearson.

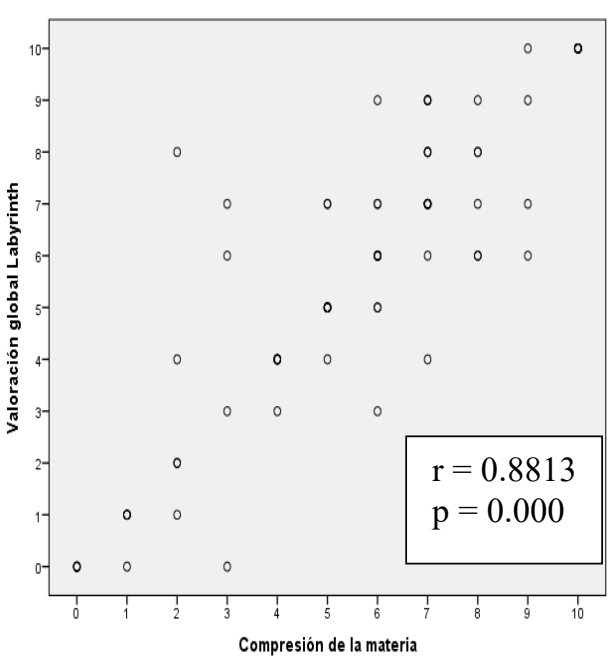

Figura 4. Gráfico de dispersión entre la valoración global de 'Labyrinth' y la ayuda que supone para comprender la materia. $p$ : valor-p; $r$ : coeficiente de correlación de Pearson. 


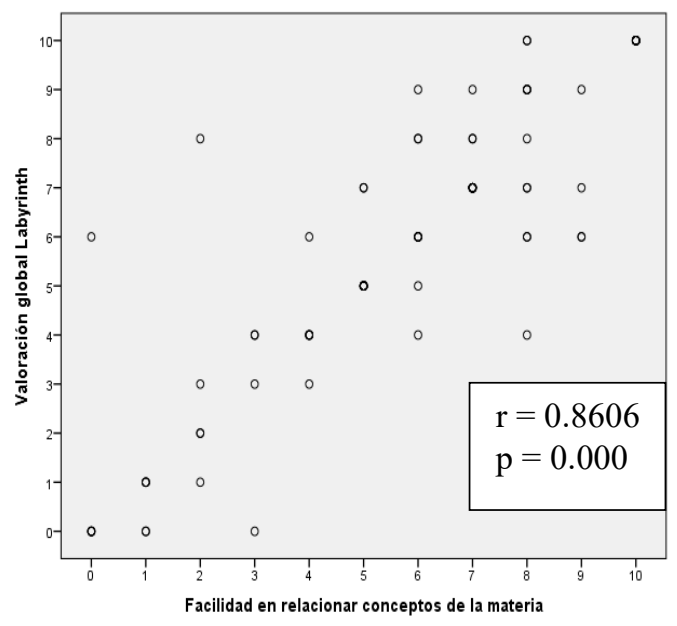

Figura 5. Gráfico de dispersión entre la valoración global de 'Labyrinth' y la facilidad en relacionar conceptos de la materia. p: valor-p; r: coeficiente de correlación de Pearson.

La relación entre la percepción de los usuarios sobre el grado en que 'Labyrinth'fomentaba estos factores intrínsecos claves para el aprendizaje y otras variables analizadas -donde se valoraba la aplicación como herramienta de ayuda para el aprendizaje (resolución de casos clínicos, aplicación de los conocimientos de la asignatura, comprobar el aprendizaje de los conceptos de la asignatura), así como la utilidad de las características de la aplicación (resolución de dudas a través de un foro, uso del inglés como lenguaje vehicular, poder trabajar con la aplicación fuera de clase, acceso a través de PC, Tablet y móvil), también tuvieron valores de correlación aceptables y significativos, aunque menores que los comentados previamente: $\mathrm{r}>0.64$ y $\mathrm{p}<0.001$; con la excepción del inglés como lenguaje vehicular de la aplicación, donde no se encontró ningún tipo de correlación.

Las Tablas 2 y 3 muestran los resultados expuestos de correlaciones entre cada uno de los factores intrínsecos del aprendizaje percibidos por los estudiantes, y su valoración de la utilidad de Labyrinth, global y específica.

Tabla 2. Resultados de correlaciones respecto a la valoración global de utilidad de 'Labyrinth'.

\begin{tabular}{|l|c|c|c|c|c|}
\hline \multicolumn{1}{|c|}{$n=79$} & \multicolumn{5}{|c|}{ FACTORES INTRÍNSECOS DEL APRENDIZAJE } \\
\hline $\begin{array}{l}\text { UTILIDAD DE } \\
\text { 'LABYRINTH': }\end{array}$ & $\begin{array}{c}\text { Seguridad } \\
\text { de poder } \\
\text { superar la } \\
\text { asignatura }\end{array}$ & $\begin{array}{c}\text { Motiva- } \\
\text { ción por } \\
\text { estudiar la } \\
\text { asignatura }\end{array}$ & $\begin{array}{c}\text { Esfuerzo } \\
\text { personal } \\
\text { empleado }\end{array}$ & $\begin{array}{c}\text { Compren- } \\
\text { sión de la } \\
\text { materia }\end{array}$ & $\begin{array}{c}\text { Facilidad } \\
\text { para } \\
\text { relacionar } \\
\text { conceptos }\end{array}$ \\
\hline Valoración global & $r=0.8548^{*}$ & $r=0.857^{*}$ & $r=0.8813^{*}$ & $r=0.8301^{*}$ & $r=0.8606^{*}$ \\
& $p=0,0000$ & $p=0,0000$ & $p=0,0000$ & $p=0,0000$ & $p=0,0000$ \\
\hline
\end{tabular}


Tabla 3. Resultados de correlaciones respecto a la valoración de la utilidad específica de 'Labyrinth'.

\begin{tabular}{|c|c|c|c|c|c|}
\hline$n=79$ & \multicolumn{5}{|c|}{ FACTORES INTRÍNSECOS DEL APRENDIZAJE } \\
\hline $\begin{array}{l}\text { UTILIDAD DE } \\
\text { 'LABYRINTH': }\end{array}$ & $\begin{array}{l}\text { Seguridad } \\
\text { de poder } \\
\text { superar la } \\
\text { asignatura }\end{array}$ & $\begin{array}{l}\text { Motiva- } \\
\text { ción por } \\
\text { estudiar la } \\
\text { asignatura }\end{array}$ & $\begin{array}{r}\text { Esfuerzo } \\
\text { personal } \\
\text { empleado }\end{array}$ & $\begin{array}{c}\text { Compren- } \\
\text { sión de la } \\
\text { materia }\end{array}$ & $\begin{array}{l}\text { Facilidad } \\
\text { para } \\
\text { relacionar } \\
\text { conceptos }\end{array}$ \\
\hline $\begin{array}{l}\text { Herramienta útil para } \\
\text { resolver casos clínicos }\end{array}$ & $\begin{array}{l}r=0.7076 \\
p=0,0000\end{array}$ & $\begin{array}{l}r=0.7179 \\
p=0,0000\end{array}$ & $\begin{array}{l}r=0.7413 \\
p=0,0000\end{array}$ & $\begin{array}{l}r=0.7707 \\
p=0,0000\end{array}$ & $\begin{array}{l}r=0.6776 \\
p=0,0000\end{array}$ \\
\hline $\begin{array}{l}\text { Herramienta útil para } \\
\text { aplicar conocimientos }\end{array}$ & $\begin{array}{l}r=0.7043 \\
p=0,0000\end{array}$ & $\begin{array}{l}r=0.7169 \\
p=0,0000\end{array}$ & $\begin{array}{l}r=0.6929 \\
p=0,0000\end{array}$ & $\begin{array}{l}r=0.7640 \\
p=0,0000\end{array}$ & $\begin{array}{l}r=0.6915 \\
p=0,0000\end{array}$ \\
\hline $\begin{array}{l}\text { Me permite compro- } \\
\text { bar si he aprendido } \\
\text { los conceptos }\end{array}$ & $\begin{array}{l}r=0.6627 \\
p=0,0000\end{array}$ & $\begin{array}{l}r=0.6976 \\
p=0,0000\end{array}$ & $\begin{array}{l}r=0.6960 \\
p=0,0000\end{array}$ & $\begin{array}{l}r=0.7302 \\
p=0,0000\end{array}$ & $\begin{array}{l}r=0.6791 \\
p=0,0000\end{array}$ \\
\hline $\begin{array}{l}\text { La resolución de } \\
\text { dudas a través del } \\
\text { foro ha sido útil }\end{array}$ & $\begin{array}{l}r=0.6726 \\
p=0,0000\end{array}$ & $\begin{array}{l}r=0.7035 \\
p=0,0000\end{array}$ & $\begin{array}{l}r=0.5947 \\
p=0,0000\end{array}$ & $\begin{array}{l}r=0.7473 \\
p=0,0000\end{array}$ & $\begin{array}{l}r=0.6506 \\
p=0,0000\end{array}$ \\
\hline $\begin{array}{l}\text { El hecho de que esté } \\
\text { en inglés me supone } \\
\text { un impedimento }\end{array}$ & $\begin{array}{l}r=0.1386 \\
p=0,0000\end{array}$ & $\begin{array}{l}r=0.1723 \\
p=0,0000\end{array}$ & $\begin{array}{l}r=0.1676 \\
p=0,0000\end{array}$ & $\begin{array}{l}r=0.2111 \\
p=0,0000\end{array}$ & $\begin{array}{l}r=0.1692 \\
p=0,0000\end{array}$ \\
\hline $\begin{array}{l}\text { Me gustaría trabajar } \\
\text { con la App para } \\
\text { preparar examen }\end{array}$ & $\begin{array}{l}r=0.6855 \\
p=0,0000\end{array}$ & $\begin{array}{l}r=0.7416 \\
p=0,0000\end{array}$ & $\begin{array}{l}r=0.7000 \\
p=0,0000\end{array}$ & $\begin{array}{l}r=0.6840 \\
p=0,0000\end{array}$ & $\begin{array}{l}r=0.6419 \\
p=0,0000\end{array}$ \\
\hline $\begin{array}{l}\text { Es útil que esté } \\
\text { disponible en móvil, } \\
\text { tablet y PC }\end{array}$ & $\begin{array}{l}r=0.7273 \\
p=0,0000\end{array}$ & $\begin{array}{l}r=0.7225 \\
p=0,0000\end{array}$ & $\begin{array}{l}r=0.6300 \\
p=0,0000\end{array}$ & $\begin{array}{l}r=0.7430 \\
p=0,0000\end{array}$ & $\begin{array}{l}r=0.6833 \\
p=0,0000\end{array}$ \\
\hline
\end{tabular}

\section{CONCLUSIONES}

Los resultados de la encuesta muestran que la valoración de la utilidad de la aplicación tiene una relación directamente proporcional con los factores intrinsecos que su uso fomenta (seguridad, motivación, esfuerzo, comprensión y capacidad de relación de conceptos), y que se consideran clave para el aprendizaje.

Por tanto se cumplen nuestros objetivos tenidos en cuenta en el diseño de Labyrinth, pudiendo concluir que sus características -posibilidad de diferentes respuestas válidas, permitiendo diferentes procesos de razonamiento potencialmente correctos y por tanto más adaptados a la realidad de la práctica clínica; fomento de la auto-reflexión tras cada respuesta testando su veracidad mediante preguntas específicas sobre su selección, y accediendo a un feedback posterior; acceso a un foro en línea y a material específico de 
consulta y profundización de conocimientos a través de la propia aplicación; posibilidad de varios intentos, disminuyendo la frustración en el proceso de llegar a una solución final; así como su accesibilidad desde el teléfono móvil adaptadándose a la ubicuidad del actual mundo-, se relacionan con mayor satisfacción percibida por los usuarios respecto a sus propios recursos atitudinales y cognitivos.

Así mismo, el diseño del cuestionario de evaluación de Labyrinth persiguió el objetivo de aumentar la conciencia de los estudiantes sobre cómo sus propias percepciones de seguridad, motivación, esfuerzo y capacidades cognitivas, influyen en su consecución de los objetivos de aprendizaje. Con este fin, la elaboración de la encuesta se basó en el cuestionario SALG (student assessment of learning gains; Seymour, 2000), cuyos enunciados están destinados a fomentar la reflexión de los estudiantes sobre qué, cómo y cuánto han aprendido a través de diferentes actividades y enfoques pedagógicos. El citado cuestionario se fundamenta en la asunción de que los estudiantes, aunque quizá no capacitados para evaluar el desempeño del profesor, son capaces de estimar de manera realista el grado en que ciertos aspectos metodológicos empleados durante diferentes actividades pedagógicas fomenta su aprendizaje. Los resultados obtenidos mediante el uso de esta herramienta de evaluación adaptada del cuestionario SALG, en base a la percepción de los estudiantes, nos han permitido identificar los elementos que contribuyen y asisten el aprendizaje, y aquellos otros que podrían ser mejorados en aspectos concretos.

En este sentido, el hecho de que los contenidos de la aplicación estén desarrollados íntegramente en inglés podría suponer un impedimento para fomentar los factores intrínsecos del aprendizaje, motivo por el cual se invirtió trabajo en su facilitación mediante la metodología CLIL. Finalmente podemos concluir que los estudiantes no perciben dificultades añadidas por esta causa, ya que el uso de inglés como lenguaje vehicular fue el único ítem que no se correlacionó positiva ni negativamente con dichos factores.

El diseño observacional de este estudio piloto nos ha permitido detectar y determinar la relación positiva existente entre la percepción de los usuarios sobre cómo Labyritnh promueve estos factores intrinsecos del aprendizaje, y la valoración global que otorgan a la aplicación y a sus características. Estos hallazgos abren nuevas líneas de investigación sobre la importancia de estos factores en el proceso de enseñanza-aprendizaje, no habiendo sido explorados en profundidad en el campo de la formación de profesionales de la salud, y pocas veces tenidos en cuenta por la evidencia científica.

La reflexión y toma de conciencia sobre estos factores es imprescindible para la optimización de las estrategias docentes y de los hábitos de estudio.

\section{REFERENCIAS BIBLIOGRÁFICAS}

BLACKWELL, L., TRZESNIEWSKI, K., y DWECK, C.S. (2007). "Implicit theories of intelligence predict achievement across an adolescent transition: A longitudinal study and intervention". Child Development, 78: 246-263.

COYLE, D., HOOD, P., MARSH, D. (2010). CLIL: Content and Language Integrated Learning: Cambridge University Press.

(c)) EY-NC-ND 2017, Universitat Politècnica de València

Congreso IN-RED (2017) 
CRAWFORD, T.R. (2011). "Using problem-based learning in web-based components of nurse education”. Nurse Educ Pract, 11 (2): 124-130.

DIAS, J. (2017). "Teaching operations research to undergraduate management students: The role of gamification”. The International Journal of Management Education, 15: 98-111.

DWECK, C.S. (2007). Mindset: The new psychology of success. New York: Ballantine Books.

DYER, J.O., HUDON, A., MONTPETIT-TOURANGEAU, K., CHARLIN, B., et al. (2015). "Example-based learning: comparing the effects of additionally providing three different integrative learning activities on physiotherapy intervention knowledge". BMC Med Educ, 15: 37-49.

GLASERSFELD, E. (1989). Cognition, construction of knowledge, and teaching. Synthese, 80 (1): $121-140$

GOOD, C., ARONSON, J., e INZLICHT, M. (2003). "Improving adolescents' standardized test performance: An intervention to reduce the effects of stereotype threat". Applied Developmental Psychology, 24: 645-662.

GREENHALGH, T. (2001). "Computer assisted learning in undergraduate medical education". British Medical Journal, 322 (7277), 40-44.

KOLODNER, J.L., CAMP, P.J., CRISMOND, D., FASSE, B, et al (2003). "Problem-Based Learning Meets Case-Based Reasoning in the Middle-School Science Classroom: Putting Learning by Design(tm) Into Practice". Journal of the Learning Sciences, 12 (4): 495-547.

NICKLEN, P., KEATING, J.L., MALONEY, S. (2016). "Exploring Student Preconceptions of Readiness for Remote-Online Case-Based Learning: A Case Study", JMIR Medical Education, 2 (1): 1-9.

PAJARES, F. (1996b) "Assessing self-efficacy beliefs and mathematical problem solving of gifted students". Contemporary Educational Psychology, 21: 325-344.

RYAN, R.M. y DECI, E.L. (2000). "Intrinsic and Extrinsic Motivations: Classic Definitions and New Directions”. Contemporary Educational Psychology, 25: 54-67.

SCHMIDT, H.G., ROTGANS, J.I., YEW, E.H. (2011). "The process of problem-based learning: what works and why". Med Educ, 45 (8): 792-806.

SCHMITZ, T.W., KAWAHARA-BACCUS, T.N. y JOHNSON, S.C. (2004). "Metacognitive evaluation, self-relevance, and the right prefrontal cortex". NeuroImage, 22: 941-947

SEYMOUR, E., WIESE, D., HUNTER, A., DAFFINRUD, S.M. (2000). Creating a better mousetrap: on-line student assessment of their learning gains; National Meeting of the American Chemical Society; San Francisco, CA.

SHUTE, V.J. Y VENTURA, M. (2013). Stealth assessment: Measuring and supporting learning in games. Cambridge, MA: Massachusetts Institute of Technology Press Books.

SOLOMON, P. (2005), "Problem-based Learning: A review of current issues relevant to physiotherapy education". Physiotherapy Theory and Practice, 21 (1): 37-49.

VERMUNT, J.D. (1996). "Metacognitive, cognitive and affective aspects of learning styles and strategies: A phenomenographic analysis". Higher Education, 31: 25-50.

VYGOTSKY, L.S. (1980). Mind in society: The development of higher psychological processes. Harvard university press.

WOOD, D.F. (2003). "Problem based learning". BMJ, 326 (7384): 328-330.

(cc)) EY-NC-ND 2017, Universitat Politècnica de València 


\title{
Utilización de técnicas Kanban para la gestión de tesis doctorales
}

\section{T. Boronat, N. Montanes, D. Garcia-Sanoguera, O. Fenollar, V. Fombuena}

Grupo de Innovación de Prácticas Académicas (GIPA), Universitat Politècnica de València, Plaza Ferrándiz y Carbonell s/n, Alcoy, Alicante (ESPAÑA).

\begin{abstract}
The development of a doctoral thesis is a team work to be done by the doctorate and his supervisors. A huge list of jobs have to be faced by both. So, communication and coordination between them is mandatory in order an adequate support and track of the doctorate work is provided.

This job presents how Kanban technique is applied in the development of a doctoral thesis. The Kanban techniques allow to organize tasks through boards, in a very visual and simple way which facilitates the communication between doctorate and the directors. Recently web and mobile applications that implement Kanban techniques have appeared. These applications allow a dalily collaboration in the thesis, they allow to assign tasks, to know the state of its progress, to hold conversations, to provide constant feedback and finally to see which tasks have already been completed. In a short time, a large part of emails, telephone conversations and chats to notify the status of a task have been eliminated. In a short time, a large part of emails, phone conversations and chats to notify the status of a task have been eliminated.
\end{abstract}

Keywords: Teamwork, Trello, multiplatform tool, Learning monitoring

\section{Resumen}

A pesar de lo que pueda parecer, el desarrollo de una tesis doctoral no es un trabajo individual que debe realizar el doctorando, es un trabajo en equipo con los supervisores. Obliga al estudiante de doctorado y a los directores a hacer frente a una enorme lista de tareas para completar y recordar. Es necesario una coordinación y comunicación entre ellos para que los directores proporcionen un apoyo adecuado y rastreen el progreso del trabajo del estudiante.

Este trabajo propone la utilización de las técnicas Kanban para la gestión de una tesis doctoral. Las técnicas Kanban permiten organizar tareas a través de tableros, de una manera muy visual y simple lo que facilita la comunicación entre doctorando y directores. Últimamente han aparecido aplicaciones web y móvil que implementan las técnicas Kanban y por lo tanto permiten colaborar diariamente de manera virtual en la tesis, permiten asignar tareas, conocer el estado de su progreso, mantener conversaciones, proporcionar retroalimentación constante y finalmente ver aquellas tareas que ya se han completado. En poco tiempo se puede prescindir de una gran parte de correos electrónicos, conversaciones telefónicas y chats para notificar el estado de una tarea. 
Palabras clave: Kanban, tesis doctoral, trabajo en equipo, monitoreo del aprendizaje

\section{Introducción}

El desarrollo de una tesis doctoral es una experiencia para lograr la más alta calificación que la educación superior puede aportar. Una tesis es también una oportunidad para aplicar los conocimientos y habilidades adquiridos durante años en los estudios de grado y máster. El desarrollo de una tesis no es una cuestión banal, puede ser frustrante ya que se requiere para hacer una cantidad considerable de trabajo y el estudiante tiene que asumir su propia responsabilidad para la gestión de su aprendizaje. El trabajo a realizar durante el doctorado no está establecido por otros. Se espera que el doctorando inicie discusiones, pida ayuda cuando sea necesario, discuta acerca de lo que debería estar aprendiendo y así sucesivamente. El doctorando debe autogestionarse y debe decidir que debe ser capaz de planificare su trabajo, esto se debe identificar como una oportunidad no como una deficiencia.

Una tesis de doctoral es un proyecto de investigación individual, pero no debe ser completado completamente solo por el doctorado, el estudiante tiene la orientación de al menos un supervisor académico. El director de tesis debe tomar la iniciativa para obtener los recursos físicos para el correcto desarrollo del trabajo, el tema de investigación debe estar claramente definido para encajar en el impulso innovador del programa de investigación del supervisor que establecerá los límites al nivel de creatividad de investigación. Los desarrollos obtenidos son una copropiedad del supervisor y del estudiante de doctorado. Existe un gran interés tanto por el estudiante como por el supervisor de que el trabajo siga adelante para publicar trabajos conjuntos. A pesar de que la propiedad de los resultados es conjunta debe haber suficiente autonomía para que el estudiante pueda hacer una contribución original que justifique la concesión del doctorado.

Últimamente la supervisión de un estudiante no depende de un único supervisor. Las tesis doctorales son de tal envergadura que suelen afectar a más de un área de conocimiento por lo que es necesario disponer de un especialista de los diferentes temas afectados en el estudio. Los equipos de supervisores se establecen con un supervisor principal y uno o dos supervisores asociados.

Para gestionar el trabajo colaborativo entre el doctorado y los supervisores es necesario utilizar alguna herramienta o protocolo que facilite la interacción entre los miembros. En este trabajo se propone utilizar una herramienta de gestión de proyectos basada las técnicas Kanban. La herramienta permite colaborar diariamente de manera virtual en la tesis, permite asignar tareas, conocer el estado de su progreso, mantener conversaciones, proporcionar retroalimentación constante y finalmente ver aquellas que ya se han completado.

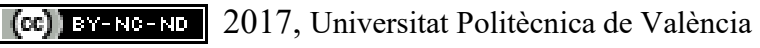




\section{Objetivos}

El objetivo del presente estudio es presentar la metodología Kanban para la gestión de una tesis doctoral. Las técnicas Kanban se basa en un sistema de tarjetas desarrollado por Toyota con el objetivo de mejorar la eficiencia del proceso de fabricación de vehículos. Jim benson y Tonianne DeMaria Barry lo adecuaron para ser utilizado por equipos de trabajo e individuos. La adaptación la denominaron "Kanban personal".

Por otro lado, la herramienta presentada también fomenta el trabajo en equipo entre los miembros de una tesis doctoral (directores y doctorando) de forma que se favorezca la cooperación y un ambiente de confianza mutua entre los componentes.

\section{Desarrollo}

En los últimos tiempos, el uso de dispositivos tecnológicos ha invadido todas las facetas de la vida, incluida la educación y la gestión de proyectos. Existe un gran mercado de aplicaciones para cualquier propósito. Existen varias aplicaciones que permiten la aplicación de las técnicas Kanban de gestión de proyectos entre las que destacan: Kanbachi, Kanbanflow, Archmule, Boards, Asana y Trello. El presente trabajo muestra la utilización de Trello como herramienta que aplica las técnicas Kanban personales y su aplicación a la gestión de un proyecto singular como es una tesis doctoral.

Trello se basa en el paradigma de administración de proyectos Kanban. Kanban (kan japonés, que significa visual y prohibición, que significa tarjeta o tablero) es un sistema de información que controla armónicamente un proceso de producción, como la producción de un producto o la realización de una tesis doctoral. En este sistema visual, las tarjetas, que contienen información sobre cada uno de los procesos necesarios para alcanzar el objetivo, actúan como testigos del flujo de trabajo. Trello ofrece funcionalidades para la comunicación entre todos los componentes de un equipo, la definición de tareas y su asignación a los miembros. Además, permite compartir la información necesaria para llevar a cabo la tarea asignada y los resultados obtenidos asociados con la tarea ejecutada.

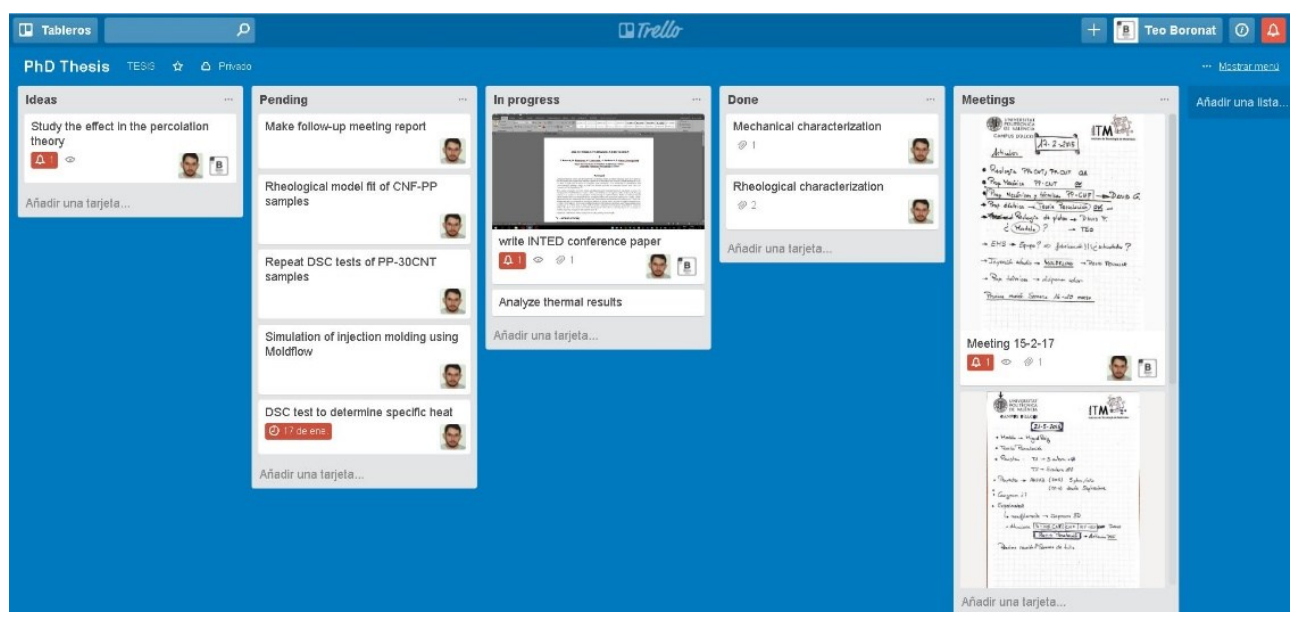

Fig. 1 Escritorio de Trello 
En Trello los proyectos están representados por paneles, que contienen listas de tareas. Una tesis doctoral será un proyecto. Estas listas contienen tarjetas (correspondientes a tareas en las que se puede subdividir una tesis). La figura 1 muestra el panel para una tesis con varias listas de tareas. Las tarjetas se pueden mover de una lista a otra, reflejando, por ejemplo, el flujo de una tarea desde la concepción hasta la planificación hasta que se ha ejecutado. Cada tarjeta (ver Figura 2) permite asignar diferentes atributos de una tarea, tales como:

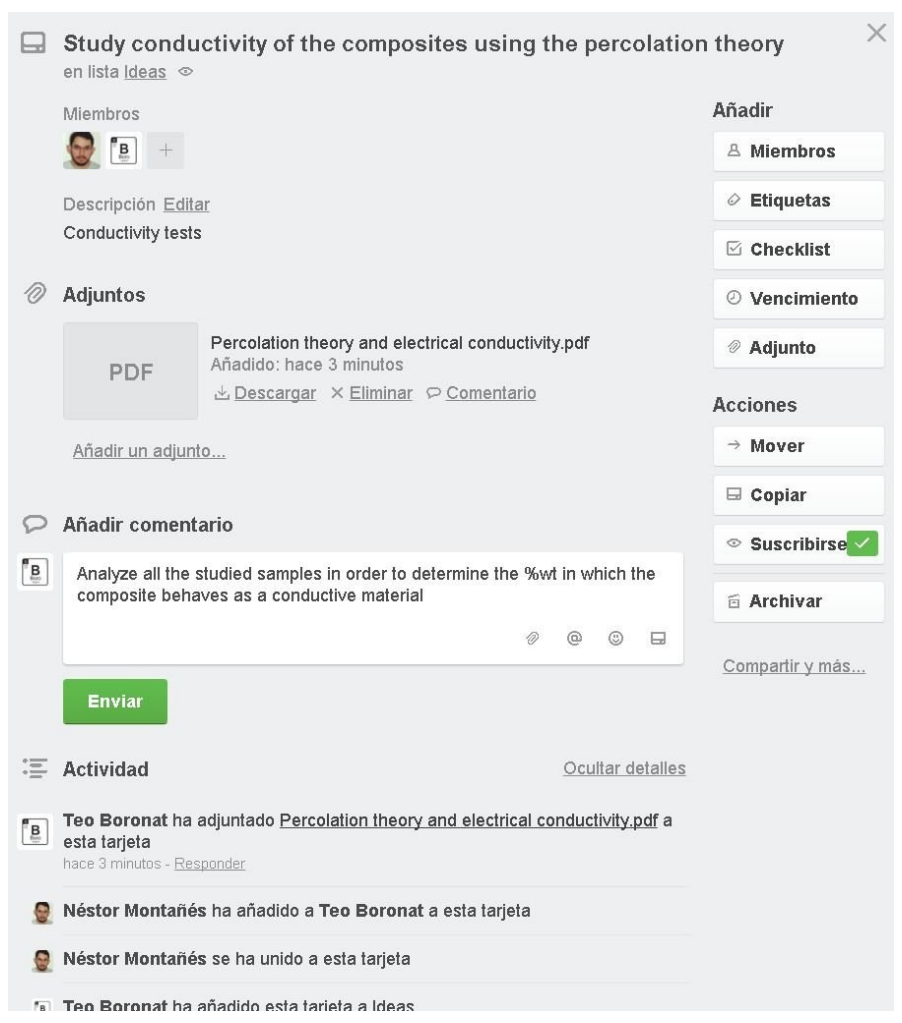

Fig. 2 Tarjeta de una tarea de Trello

La herramienta Trello se ha utilizado como plataforma colaborativa para la gestión de una tesis doctoral en de la Escuela de Doctorado de la Universitat Politècnica de València. El desarrollo de una tesis doctoral en el campo de la ingeniería es eminentemente práctico. Al inicio de la tesis doctoral se le mostró al alumno la herramienta Trello y se explican las principales funcionalidades a utilizar en el trabajo diario.

La gestión de la tesis se divide en varias etapas como "estado del arte", "experimental", "redacción". La etapa experimental, que es la principal, se divide en varias etapas más pequeñas ya que es muy extensa. Para cada etapa, los supervisores definen las actividades a realizar, los resultados o entregables a obtener y una estimación de la dedicación que debe realizar el doctorando.

Desde la primera etapa el doctorado configura su panel de trabajo como mejor le convenga. Como Trello es una herramienta altamente configurable, el doctorado puede tomar el manejo de diferentes maneras. A partir de la experiencia se ha podido comprobar que los

(cc) EY-NC-ND 2017, Universitat Politècnica de València 
estudiantes de doctorado generalmente organizan sus "Tarjetas" (las tareas a realizar) siguiendo dos estrategias principales:

- Crear una lista de tareas para cada etapa. Los estudiantes que siguen esta estrategia crean una lista con todas las tareas que deben realizarse para cada una de las etapas. El estado de cada tarea (creada, asignada, en proceso, en espera de aprobación, en revisión o finalizada) se indica mediante el uso de las "Etiquetas" proporcionadas por la herramienta. Al final de la tesis, todas las tareas se etiquetan como completadas.

- Distribuya el panel a un número fijo de listas de tareas. Los estudiantes que siguen esta estrategia usualmente crean al menos tres listas, llamadas pendientes, en progreso, y hechas. Sin embargo, algunos estudiantes crean otras listas, como revisar o aprobar por el supervisor. En esta estrategia, las tareas se trasladan de una lista a otra, siguiendo una ruta que comienza en la lista de tareas de la izquierda y termina en la lista a la derecha del panel. Las etiquetas se utilizan para clasificar las tareas en grupos: editar, repetir, memoria, presentación final, etc. Al final del curso, los alumnos han podido mover todas las tareas a la lista de tareas realizadas.

Independientemente de la estrategia elegida, durante el desarrollo de la tesis, los supervisores pueden ver cómo está progresando el trabajo. Usando la función "Adjuntar un archivo", el doctorando puede vincular a una tarjeta los resultados parciales de la tarea o la entrega final de una etapa. Trello ofrece la posibilidad de vincular un archivo desde una carpeta que todos los miembros del equipo pueden compartir en servicios externos como Google Drive o Dropbox.

La suscripción del supervisor a los paneles de trabajo del doctorado hace posible detectar la necesidad de algún tipo de apoyo o guía para seguir avanzando. El procedimiento que se define al principio de la tesis para que los alumnos puedan indicar la necesidad de ayuda es el siguiente:

- Los estudiantes asignan al supervisor a la tarjeta de la tarea sobre la cual tienen el problema. La herramienta envía un mensaje automatizado al profesor, informándole que el doctorando tiene una pregunta que hacer acerca de una tarea específica.

- El supervisor recibe el mensaje y accede a la tarjeta de tareas. Una vez que se ha consultado la descripción del problema y en caso de que sea necesario adjuntar con la resolución de la tarea, el supervisor realiza sus contribuciones mediante la función "Escribir un comentario" en la tarjeta de tareas. El doctorado recibe un mensaje automatizado indicando que el miembro supervisor ha hecho un comentario sobre la tarea.

- Por último, el alumno accede a la tarjeta, modifica su estado (cambiando su etiqueta) y elimina la asignación al supervisor de la tarea en caso de que no sea necesaria otra intervención por su parte.

(cc)) EY-NC-ND 2017, Universitat Politècnica de València 


\section{Resultados}

La experiencia de utilizar las técnicas Kanban y su aplicación con la herramienta Trello en el campo de la enseñanza ha sido muy satisfactoria tanto por el supervisor como por el doctorado participante.

A continuación, se presentan algunas de las reflexiones ofrecidas por los participantes en esta iniciativa.

\subsection{Supervisor}

El principal beneficio observado por los autores de este artículo es que el supervisor puede tener un contacto directo y continuo con el doctorado incluso cuando está en una estancia en el extranjero. Este contacto permite:

- Conocer en cualquier momento el progreso de la obra encomendada. El profesor puede acceder a los paneles de trabajo del estudiante para saber si la dedicación planeada para realizar las tareas asignadas es suficiente. También permite saber qué tareas duran más y aquellas que requieren menos esfuerzo.

- Asegurar que la tesis esté al día. El supervisor puede corroborar que el estudiante no está perdido o está divagando sobre algún aspecto trivial.

- Trello le permite resolver un problema específico. El supervisor puede establecer directrices para los estudiantes de doctorado puede avanzar su trabajo.

\subsection{Doctorando}

A partir de la retroalimentación de los estudiantes que han utilizado la herramienta Trello se puede afirmar que están satisfechos con su uso como una plataforma de apoyo para el trabajo en equipo. Estas son algunas de las razones:

- Permite tener una visión clara y estructurada de todo el trabajo relacionado con la tesis. No sólo el trabajo ya realizado, también el trabajo pendiente.

- Permite centralizar todos los resultados parciales obtenidos en una sola plataforma.

- Evita el mal uso o la pérdida de documentos.

\section{Conclusiones}

Trello es una herramienta bien pensada, diseñada y probada que cubre los requisitos que una plataforma integrada para la coordinación y comunicación de los equipos de trabajo debe cumplir.

En este proyecto piloto no se pretendía solamente, pero no lo suficiente, proporcionar a los estudiantes una herramienta útil para llevar a cabo su trabajo de manera eficiente. También se buscó una forma de racionalizar el proceso de seguimiento de la investigación estudiantil, mecanizando algunas tareas básicas de validación de entrega de resultados parciales.

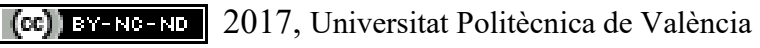


La simplificación del proceso de seguimiento de los estudiantes da como resultado un ahorro de tiempo que puede ser utilizado para proporcionar una retroalimentación específica y adaptada a las necesidades específicas del doctorado.

Uno de los problemas planteados por los autores fue si la herramienta sería aceptada por los estudiantes. En ningún caso se pretendía que el aprendizaje de Trello supusiera un gran esfuerzo, ya que ese no es el objetivo principal de la tesis. Debe tenerse en cuenta que no ha sido detectadoningún problema derivado del uso de la herramienta, en gran parte, por su interfaz simple, clara e intuitiva

\section{Referencias}

BENSON, J y DEMARIA BARRY, T. (2011) Personal Kanban. LondresCreatespace

DELGADO, A.,LLUIS-MESQUIDA, A. Y MAS, A. (2014) "Utilización de Trello para realizar el seguimiento del aprendizaje de equipos de trabajo". López, D. (coord.) En: Actas del Simposio/Taller XX JENUI. Oviedo: JENUI. 769-822

JAPAN MANAGEMENT ASSOCIATION (1998) Kanban y Just In Time en Toyota.la direccion empieza en las estaciones. Prod. Press

TRAVER, V.J., TRAVER, J.A. (2004) “iPor qué no enseñamos a aprender cooperativamente?”. ”. López, D. (coord.) En: X Jornadas de Enseñanza Universitaria de la Informática (X JENUI). Alicante: JENUI. 297-304

Página web de Trello. $<$ https://trello.com/> [Consulta: 2 de abril de 2017] 


\title{
Hacia la traducción integral de vídeo charlas educativas
}

\author{
Santiago Piqueras ${ }^{1}$, Alejandro Pérez ${ }^{1}$, Carlos Turró ${ }^{2}$, Manuel Jiménez ${ }^{2}$, \\ Albert Sanchis $^{1}$, Jorge Civera ${ }^{1}$ y Alfons Juan ${ }^{1}$ \\ ${ }^{1}$ Dep. de Sistemas Informáticos y Computación, Universitat Politècnica de València \\ ${ }^{2}$ Área de Sistemas de la Información y las Comunicaciones, UPV
}

\begin{abstract}
More and more universities and educational institutions are banking on production of technological resources for different uses in higher education. The MLLP research group has been working closely with the ASIC at $U P V$ in order to enrich educational multimedia resources through the use of machine learning technologies, such as automatic speech recognition, machine translation or text-to-speech synthesis. In this work, developed under the Plan de Docencia en Red 2016-17's framework, we present the application of innovative technologies in order to achive the integral translation of educational videos.
\end{abstract}

Keywords: multilingual, translation, MOOCs

\section{Resumen}

Cada vez son más las universidades e instituciones educativas que apuestan por la producción de recursos tecnológicos para diversos usos en enseñanza superior. El grupo de investigación MLLP lleva años colaborando con el ASIC de la UPV con el fin de enriquecer estos materiales haciendo uso de tecnologías de machine learning, como son el reconocimiento automático del habla, la traducción automática o la síntesis de voz. En este trabajo, bajo el marco del Plan de Docencia en Red 2016-17, abordaremos la traducción integral de vídeos docentes mediante el uso de estas tecnologías.

Keywords: multilingüe, traducción, MOOCs 


\section{Introducción}

En los últimos años, se ha producido un rápido crecimiento en la producción de recursos tecnológicos en la enseñanza superior y, especialmente, de material multimedia. Hoy en día son muchas las universidades e instituciones educativas que, al igual que la Universitat Politècnica de València (UPV), apuestan por la generación de vídeos docentes para su uso en MOOCs o, en general, como OER (Open Educational Resources) para diversos usos en enseñanza superior (p.e. en flip teaching).

Desde 2011, el grupo de investigación MLLP (Machine Learning and Language Processing, www.mllp.upv.es) y el ASIC (Área de Sistemas de la Información y las Comunicaciones) de la UPV trabajan juntos en el desarrollo de tecnologías innovadoras para la producción de vídeos docentes. Este trabajo conjunto se ha enmarcado, principalmente, de 2011 a 2014 en el proyecto europeo transLectures (Silvestre-Cerdà y col. 2012; Valor-Miró y col. 2017; transLectures 2012), de 2014 a 2016 en el proyecto europeo EMMA (Valor-Miró y col. 2017; EMMA 2017) y, desde 2016, también en el proyecto nacional MORE.

En transLectures se abordó la generación de subtítulos multilingües para repositorios de vídeos educativos mediante el uso de tecnologías de transcripción y traducción automáticas. En el marco del proyecto se generaron transcripciones y traducciones automáticas en castellano, catalán e inglés para todos los vídeos del repositorio poliMedia. Además, a través de la convocatoria 2013-14 del Plan Docencia en Red de la UPV ( $D e R$ 2013-14), se solicitó la colaboración de algunos profesores para la evaluación y refinamiento de las herramientas desarrolladas. Los resultados mostraron que el uso de estas tecnologías suponía una reducción sustancial en la dedicación temporal a la hora de generar subtítulos (Valor Miró y col. 2015).

Los desarrollos tecnológicos de transLectures tuvieron su continuidad en EMMA, donde se realizaron importantes avances en los sistemas de Automatic Speech Recognition (ASR) y Machine Translation (MT). Este proyecto daba especial importancia a la producción de MOOCs por lo que, aparte de la subtitulación multilingüe de vídeos educativos, se consideró también la traducción automática de documentos de texto. Además, en EMMA se añadieron nuevas lenguas de trabajo, concretamente: italiano, francés, portugués, holandés y estonio. De nuevo, los sistemas y herramientas fueron positivamente evaluados en colaboración con el profesorado de la UPV en el marco del programa Docencia en Red 2014-15 (DeR 2014-15; Valor Miró y col. 2016).

Partiendo de la experiencia adquirida en transLectures y EMMA, en MORE se persigue un objetivo algo más ambicioso: incluir la Sintesis de Voz (TTS, del inglés Text-To-Speech) para abordar la traducción integral automática de OER. Esto sería, concretamente, producir una versión alternativa de un material educativo concreto (un MOOC, una vídeo-charla) como si hubiese sido creada originariamente en el idioma destino. Con el fin de atacar la traducción integral, en Docencia en Red 2016-17 ( $D e R$ 2016-17) se ha incorporado el registro de voz, donde el profesorado ha sido invitado a registrar grabaciones de voz en castellano, catalán e inglés.

En este documento se describe, de forma resumida, el desarrollo de sistemas de síntesis de voz adaptada en el marco de Docencia en Red 2016-17 y MORE. En la sección 2 se presentarán cuáles son los objetivos de este trabajo. En la sección 3 se detallan los tres pasos principales identificados: obtención del registro de voz del profesorado, desarrollo de herramientas de síntesis de voz e integración de las herramientas en el 
flujo de procesamiento de vídeo charlas para su traducción integral. En la sección 4 se muestran los resultados obtenidos y, por último, en la sección 5 se dan algunas conclusiones y líneas de trabajo futuro relacionadas con la traducción integral de vídeo charlas docentes.

\section{Objetivos}

Nuestro objetivo primordial es el desarrollo de sistemas automáticos que permitan la traducción integral de vídeo charlas de UPV media. Definimos traducción integral de una vídeo charla como la traducción conjunta del audio e imagen (diapositivas) de la charla. El resultado de este proceso es un archivo multimedia que pueda ser visionado por el alumnado en su lengua de preferencia de manera íntegra. Es evidente que la traducción integral manual, es decir, la regrabación y retraducción de los vídeos de un repositorio como UPV media, ya sea a dos o más idiomas, es inviable. Es por ello que se propone el uso de sistemas automáticos que ayuden a reducir considerablemente el coste de este proceso.

Este trabajo está centrado en la generación de pistas de voz adaptadas al locutor que puedan ser integradas en la vídeo charla traducida. A este fin, hemos identificado tres pasos necesarios:

1. Obtención de un registro de voz multilingüe de los profesores de UPV en las tres lenguas mayoritarias en UPV media: catalán, español, inglés (Sección 3.1).

2. Desarrollo de sistemas tecnológicos innovadores que permitan la generación de voz adaptada al locutor, así como la generación de voz adaptada en lenguas que el locutor original no habla (adaptación interlingüe) (Sección 3.2).

3. Integración de las herramientas de síntesis en el procesado de los vídeos (Sección 3.3).

\section{Desarrollo de la innovación}

\subsection{Registro de voz en Docencia en Red 2016/17}

Uno de los principales objetivos del programa Docencia en Red 2016/17 es el de crear una base de datos, que denominaremos DeR-TTS, con registros de profesores que permita realizar traducción integral de los vídeos educativos de UPV media ( DeR 2016-17). Este programa piloto contempla el registro de frases en catalán, español e inglés, las tres principales lenguas que ofrece UPV media. Como paso inicial, se desarrolló una interfaz web que permitiera la creación de esta base de datos (Figura 1).

Como podemos ver, esta interfaz nos muestra el usuario, idioma, frase actual y número de frases ya registradas. Mediante los controles, podemos registrar (leer) la frase actual, escuchar nuestra grabación y volverla a registrar si fuera necesario. Una vez estemos contentos con nuestro registro, apretamos el botón de aceptar, momento en el cual se almacena en la base de datos y se muestra la siguiente frase. Asimismo, se ofrece la opción de saltar frases si no se está seguro de la pronunciación y de volver a frases ya registradas si fueron aceptadas por error. Estos controles pueden ser activados mediante clicks del ratón o atajos de teclado. 


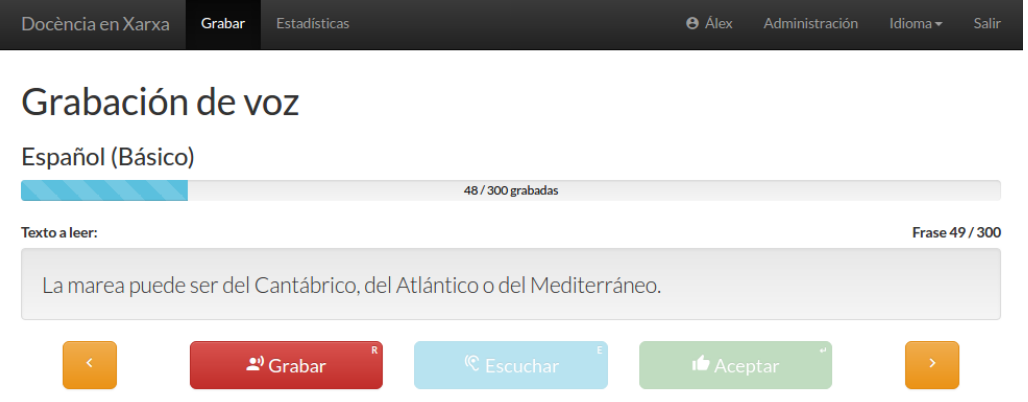

Fig. 1: Interfaz de registro de voz para Docencia en Red

A cada profesor participante se le solicita que registre frases sólo en los idiomas que se considere capaz, con un mínimo de 300 frases en total, a fin de garantizar un cierto grado de calidad, y un máximo de 300 por idioma. Las frases fueron extraídas de forma semi-supervisada de distintas fuentes, tales como diarios, MOOCs o Wikipedia; y editadas si fuera necesario para facilitar su lectura.

\subsection{Síntesis de voz adaptada al locutor}

Los sistemas de síntesis de voz han mejorado de forma considerable en los años recientes gracias a la aplicación de técnicas avanzadas de machine learning y, en concreto, a las redes neuronales y al deep learning. Esta tecnología puntera, que ya ha dado frutos en otras áreas del procesamiento del lenguaje como ASR y MT, permite abordar problemas que quedaban fuera del alcance de las técnicas tradicionales.

En este sentido, la aproximación tradicional a la síntesis de voz requiere disponer de una base de datos de alta calidad (eso es, registrada en condiciones de estudio) y tamaño considerable para cada locutor y lengua de las cuales se quiera obtener voz sintética. Estas restricciones limitan la aplicabilidad de la síntesis de voz adaptada a repositorios educativos; dado su elevado coste y la imposibilidad de sintetizar voz adaptada a lenguas que el profesor no habla.

Para dar respuesta a esta problemática, en los últimos dos años se han desarrollado sistemas multilingües y multi-locutor, que permiten la adaptación de la voz sintética con menos datos e incluso sin disponer de registros del profesor en la lengua destino (adaptación interlíngüe). Estos sistemas, basados en la tecnología de redes neuronales, son capaces de combinar información procedente de registros de voz de distintos locutores y lenguas en un mismo modelo; resultando en una mejora de la naturalidad e inteligibilidad de la voz sintética. Los requisitos para una síntesis de calidad son menos estrictos que en la aproximación tradicional, dado que la red es capaz de utilizar todos los audios registrados de manera eficiente. 


\subsection{Traducción integral}

En la Figura 2 se muestra un esquema del proceso de traducción integral que seguiría un vídeo docente, que está formado habitualmente por un vídeo grabado por el profesor, y las diapositivas sobre las que se desarrolla la charla (Figura 3). El objetivo es, por un lado, traducir el audio de la charla y, por otro, traducir los textos de la imagen (las diapositivas), todo ello de forma automática.

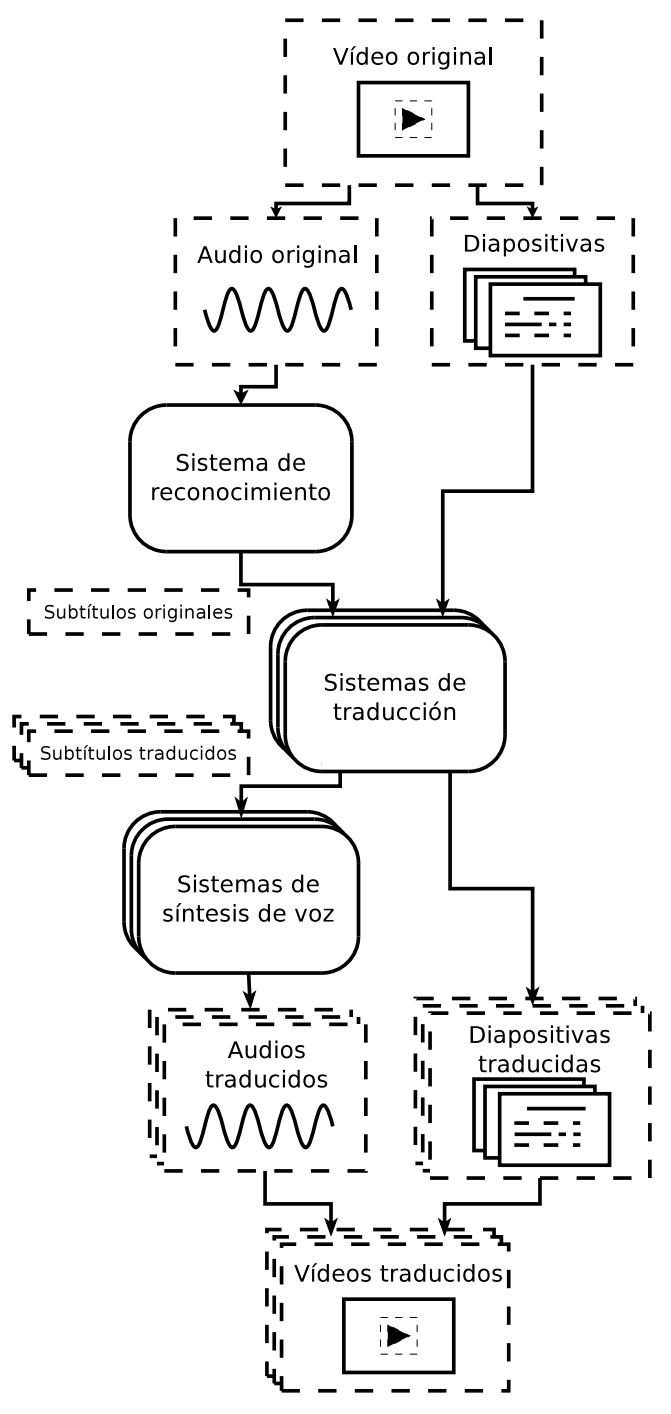

Fig. 2: Traducción integral

Para generar una pista de voz sintetizada en otro idioma, el primer paso es obtener una transcripción del audio original. Esto se consigue mediante el uso de sistemas de ASR. Una vez generada la transcripción, ésta es traducida a los idiomas destino a través de sistemas de MT. Por último, una vez tenemos subtítulos en distintas lenguas, usaremos sistemas TTS para sintetizar la voz del locutor en cada una de ellas. De forma paralela a este proceso, el texto de las diapositivas es extraído y posteriormente 
traducido por los sistemas de MT. Las diapositivas traducidas, junto con las pistas de audio sintetizado, se integran para formar versiones en distintas lenguas del objeto de aprendizaje original.

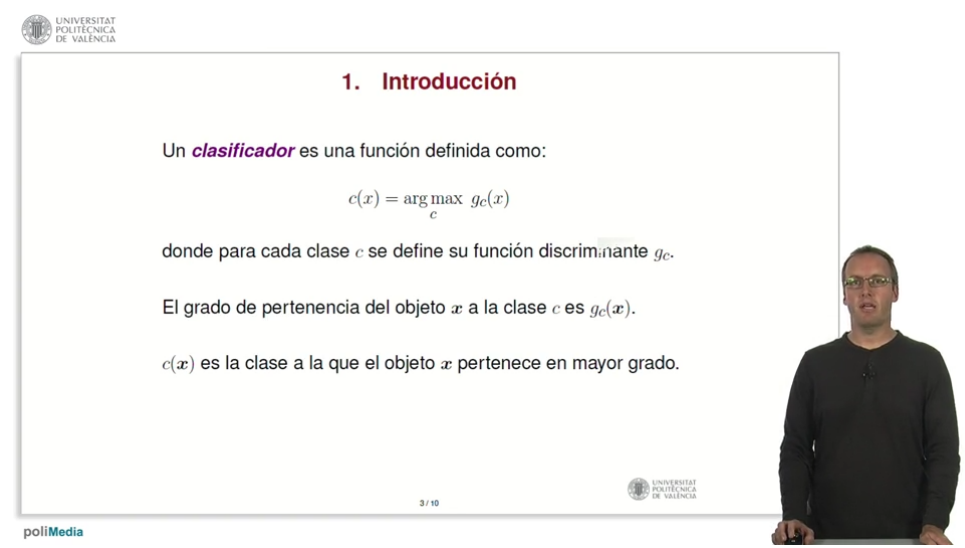

Fig. 3: Ejemplo de vídeo charla en UPV media

\section{Resultados}

A fecha de marzo de 2017, la base de datos DeR-TTS contiene voz de 41 locutores distintos. De estos 41, 16 han registrado su voz sólo en un idioma (14 en español), 15 han registrado su voz en dos idiomas, y 10 han registrado su voz en los tres idiomas. La Tabla 1 presenta un resumen de las estadísticas de DeR-TTS; mostrando número de locutores, número de horas y número de frases registradas por idioma.

Tabla 1: Estadísticas de la base de datos DeR-TTS. Se muestra el número de locutores número de horas y número de frases para cada uno de los tres idiomas registrados: catalán (ca), español (es) e inglés (en).

\begin{tabular}{|c|c|c|c|}
\hline \multicolumn{2}{|c|}{ idiomas $\mathrm{n}^{\circ}$ loc. } & duración (h) & frases (miles) \\
\hline ca & 19 & 6,3 & 4,5 \\
\hline en & 19 & 9,7 & 6,5 \\
\hline es & 38 & 13,9 & 3,8 \\
\hline Total & 41 & 29,9 horas & 20,4 frases \\
\hline
\end{tabular}

La acogida entre el profesorado del registro de voz como parte de Docencia en Red ha sido buena. La mayoría de participantes han registrado más de las 300 frases exigidas, y se ha dado más de un caso de participantes que han registrado todas las frases disponibles. En futuras convocatorias, queda abierta la puerta a incrementar el número de frases por idioma para dar la opción de seguir registrando voz a aquellos que así lo deseen.

Por otra parte, el desarrollo de sistemas adaptados de TTS con redes neuronales está avanzando satisfactoriamente; y ya se han obtenido primeros resultados sobre la base de datos DeR-TTS. Estos resultados confirman que los sistemas multilingües y multi-locutor logran un resultado superior a los sistemas tradicionales, validando así nuestra hipótesis de poder alcanzar síntesis de calidad con pocos datos por locutor. 
Un análisis de corte más técnico de estos resultados se podrá encontrar en (Piqueras y col. 2017).

Por último, se han llevado a cabo tareas de integración de los sistemas de TTS dentro de la plataforma del MLLP para acercarnos más la traducción integral. A modo de demostración, en la siguiente URL se pueden encontrar algunos vídeos que han sido procesados automáticamente por los sistemas de transcripción y traducción, luego sintetizados por sistemas de voz adaptados, y finalmente alineados con las diapositivas para obtener su traducción integral:

http://mllp.upv.es/inred-17-demo/

\section{Conclusiones y trabajo futuro}

La traducción integral de vídeo charlas en educación superior mediante tecnologías innovadoras permitirá superar las barreras lingüísticas existentes en la generación de contenido multimedia. En este trabajo, hemos presentado los pasos que el MLLP y el ASIC están llevando a cabo para implementar la traducción integral en las vídeo charlas de UPV media. Se ha descrito el proceso de obtención de una base de datos de registros de voz, el desarrollo tecnológico de sistemas de voz adaptados al locutor y el esquema de traducción integral implementado. Los resultados resultan prometedores, y nos animan a seguir trabajando en esta línea.

El siguiente paso es estudiar la integración las herramientas de adaptación y generación de voz en la plataforma UPV media, tal y como ya se hizo con los sistemas de ASR y MT. Esta integración es esencial para medir el impacto de la traducción integral en un repositorio educativo grande como UPV media. De manera paralela, se sigue trabajando en la mejora de todos los sistemas automáticos involucrados en la traducción integral, tanto en calidad como en tiempo de procesamiento.

\section{Acknowledgements}

El trabajo de investigación aquí presentado ha recibido fondos del programa europeo FP7/2007-2013 en virtud del acuerdo de subvención $\mathrm{n}^{\circ} 287755$ (transLectures) y del ICT PSP/2007-2013 como parte del Competitiveness and Innovation Framework Programme (CIP) en virtud del acuerdo de subvención $\mathrm{n}^{\circ} 621030$ (EMMA); así como del proyecto de investigación nacional TIN2015-68326-R (MINECO/FEDER) (MORE) y de la beca VALi+d de la Generalitat Valenciana ACIF/2015/082. 


\section{Referencias bibliográficas}

Docencia en Red. DeR 2013-14. URL: http://www. upv.es/entidades/VTIC/info/ Docencia_en_Red_2013_2014.pdf.

- DeR 2014-15. URL: http://www.upv.es/entidades/VTIC/info/Docencia_en_ Red_2013_2014.pdf.

- DeR 2016-17. URL: http://www.upv.es/entidades/VTIC/info/Docencia_en_ Red_2016-2017.pdf.

EMMA. Página web. URL: https://platform.europeanmoocs.eu/.

MLLP. www.mllp.upv.es. URL: https://www.mllp.upv.es/.

Piqueras, Santiago y col. (2017). "Evaluation of Multi-speaker and Multilingual Long Short-Term Memory Recurrent Neural Networks for Acoustic Modeling in Speech Synthesis". En: Proceedings of InterSpeech (sent).

Silvestre-Cerdà, Joan Albert y col. (2012). "transLectures". En: Proceedings of IberSPEECH 2012. Madrid (Spain), págs. 345-351.

transLectures. Página web. URL: https://www.translectures.eu.

Valor Miró, Juan Daniel y col. (2015). "Evaluación de la revisión de transcripciones y traducciones automáticas de vídeos poliMedia". En: I Congreso Nacional de Innovación Educativa y Docencia en Red (INRED-2015). Universitat Politècnica de València, págs. 463-467.

- (2016). "Generación eficiente de transcripciones y traducciones automáticas en poliMedia". En: II Congreso Nacional de Innovación Educativa y Docencia en Red (INRED-2016). Universitat Politècnica de València.

Valor-Miró, Juan Daniel y col. (2017). "Multilingual videos for MOOCs and OER". En: Journal of Educational Technology $\&$ Society (in press). 


\title{
Experiencia en la elaboración de vídeos didácticos por alumnos de Fisiología como parte de su proceso de aprendizaje.
}

\author{
Isabel Sánchez-Vera ${ }^{\mathrm{a}}$, Esther Escudero ${ }^{\mathrm{b}}$, Úrsula Muñoz $^{\mathrm{c}}, \mathbf{M}^{\mathrm{a}}$ José Borrego $^{\mathrm{d}}$ y Rima \\ Barhoum $^{\mathrm{e}}$
}

aisanver@ceu.es, $\quad{ }^{b}$ estheresc@ceu.es, $\quad{ }^{c}$ ursula.muñozmoron@ceu.es, $\quad$ dmajoborrego@ceu.es, erbarho@ceu.es. Todos los autores tienen la misma procedencia: Sección de Fisiología. Dpto. Ciencias Médicas Básicas. Facultad de Medicina. Universidad San Pablo CEU, Madrid.

\begin{abstract}
The discipline of physiology is challenging to teach. For this reason Physiology I teachers' of Medicine degree are actively involved in updating the teaching methodology used. For this aim, in the last years we have tried to promote the acquisition of different competencies by students such as: increasing their autonomy to monitor their own progress in the subject, searching for knowledge in multiple sources, managing several communication styles and collaborative work to deepen the knowledge and promote its divulgation in the academic environment. For these purposes we have been designer different proposals to the students as the management of engines of computer searches and bibliographic repositories, the creation of didactic videos and the sharing of information and knowledge acquired by students through a computer forum. In this report we have done an analysis and reflection on the acceptance of this methodology among all students of the four groups that taken this academic year 2016-2017.
\end{abstract}

Keywords: didactic vídeos, computer forum, creativity

\section{Resumen}

En la asignatura de Fisiología I del Grado de Medicina los profesores participantes en su impartición están comprometidos de forma activa en actualizar la metodología docente a utilizar. Para ello en los últimos años hemos pretendido fomentar la adquisición de distintas competencias por parte del alumnado como son: el aumento de su autonomía para gestionar su progreso en la asignatura, la búsqueda de conocimientos en fuentes diversas, el manejo de distintas modalidades de comunicación de conocimiento y el trabajo colaborativo para profundizar en la el conocimiento y fomentar su divulgación en el entorno académico. Con esta intención se han ido planteando distintas propuestas a los alumnos como el manejo de motores de búsquedas informáticos y repositorios bibliográficos, realización de vídeos didácticos y puesta en común de la información y conocimientos adquiridos por los alumnos a través de un foro informático. En la presente memoria hemos hecho un análisis y reflexión sobre la aceptación de esta metodología entre todos los alumnos de los cuatro grupos que compone este curso académico 2016-2017. 
Experiencia en la elaboración de vídeos didácticos por alumnos de Fisiología como parte de su proceso de aprendizaje.

Palabras clave: vídeo, foro, creatividad.

\section{Introducción}

En los últimos años los métodos de enseñanza están sufriendo un cambio paulatino con el objetivo de buscar nuevas herramientas con las que los alumnos puedan aprender de una forma más eficiente a la vez que divertida (Arceo et al., 2002; Álvarez et al., 2008). Esta nueva tendencia se está empezando a aplicar también en la enseñanza universitaria de modo que muchos profesores buscan alternativas a las clases tradicionales (Barr at el., 1995). En este contexto también se pretende que los alumnos se sitúen en el centro de las actividades docentes, ya que ellos son los verdaderos protagonistas de su aprendizaje. Además, no hay que olvidar que aunque se utilicen nuevas herramientas didácticas los alumnos deben adquirir las competencias necesarias y que los resultados del aprendizaje deben ser evaluados por el profesor (Molero et al., 2005; Monereo et al., 2003).

En el ámbito de las Ciencias de la Salud el aprendizaje basado en nuevas metodologías no está demasiado desarrollado (Ferro et al., 2009; García, 1993). La mayor parte de las veces a los estudiantes de estas Titulaciones se les enseña a pensar acorde al método científico, pero no se desarrollan suficientemente habilidades como la creatividad o la innovación (Gargallo et al., 2015). En los últimos años los profesores del Área de Fisiología hemos propuesto diferentes metodologías didácticas complementarias a las clases magistrales teóricas y las clases prácticas (Castaño et al., 2007). En nuestra experiencia con los alumnos del Grado en Medicina, tradicionalmente les hacíamos prepararse por su cuenta una parte del temario de nuestra asignatura y exponerlo en clase por grupos mediante presentaciones orales. Aunque se les daban ciertas directrices para llevar a cabo las exposiciones, el resultado eran presentaciones muy largas, pocas veces ajustadas al tiempo disponible y con un contenido excesivo y a veces innecesario. Por ello, las exposiciones resultaban difíciles de seguir por sus compañeros y nuestra impresión es que los alumnos perdían la atención y la motivación, por lo que el aprendizaje no era el adecuado (Machemer et al., 2007). Por otro lado, una de las dificultades con la que nos encontrábamos era poder evaluar de forma objetiva el esfuerzo realizado por los alumnos, ya que se sabe que no todos los alumnos se implicaban por igual, de modo que la carga de trabajo no estaba distribuida de forma equitativa entre todos los miembros del equipo.

En nuestra sociedad, el acceso continuo a la información, completamente digitalizada y audiovisual, permite el uso de los vídeos para reforzar el conocimiento de los alumnos de una forma entretenida a la vez que eficaz (Roman et al., 2007). Mediante la visualización de imágenes se pueden aclarar conceptos de forma más clara y el uso de vídeos en el aula se ha extendido como herramienta didáctica de apoyo para el docente. La elaboración de un vídeo conlleva varias etapas, entre las que destacamos: selección de los contenidos y de los objetivos que se pretenden alcanzar, recoger la documentación para la elaboración del guion, esto es, investigar, buscar bibliografía de fuentes fiables, documentarse, y por último, editarlo con los recursos tecnológicos disponibles (Ferrés et al., 1991). Es decir, la elaboración de un vídeo es un trabajo que hay que planificar y desarrollar y que requiere

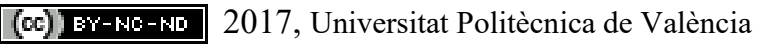

Congreso IN-RED (2017) 
tiempo y esfuerzo. Es por ello que pensamos que si los alumnos elaboraban ellos mismos sus propios vídeos, estarían aprendiendo la materia a lo largo de este proceso sin apenas darse cuenta (Ruth at el., 2016).

Por este motivo, con el desarrollo de esta experiencia buscamos por un lado fomentar la creatividad y motivación de los alumnos, haciéndoles partícipes de su propio aprendizaje y por otro lado, valorar de forma real y lo más objetiva posible el grado de implicación de cada alumno en el trabajo realizado fuera del aula.

\section{Objetivos}

El objetivo principal que se plantea es la elaboración por parte de los alumnos de vídeos explicativos de una parte del temario de la asignatura de Fisiología. De este modo se pretende que el diseño y la edición del vídeo les sirva como proceso de aprendizaje, además de poder utilizarse como material didáctico para el resto de sus compañeros.

El objetivo secundario es que el profesor sea capaz de evaluar de forma lo más objetiva posible el trabajo que han realizado fuera del aula.

\section{Desarrollo de la innovación}

La experiencia docente se ha llevado a cabo en la asignatura Fisiología I, que se imparte en el primer semestre del $2^{\circ}$ curso del Grado en Medicina (www.uspceu.com). Dicha asignatura es de carácter obligatorio y consta de 7,5 créditos ECTS. La experiencia docente se ha llevado a cabo de forma simultánea en los cuatro grupos lo que supone un total de 148 alumnos matriculados.

\section{Técnicas, instrumentos y recursos utilizados}

Para llevar a cabo esta experiencia docente se ha empleado la plataforma BlackBoard (vía intranet), que permite el desarrollo de forma integral de la enseñanza y aprendizaje en línea (on-line). Esta plataforma frece una gran variedad de recursos que permiten impartir y distribuir contenidos en distintos formatos (texto, audio, vídeo y animación), realizar evaluaciones en línea, llevar a cabo el seguimiento académico de los alumnos participantes, originar tareas y desarrollar actividades en ambientes colaborativos.

\section{Metodología de trabajo}

Organización de los grupos de clase para la elaboración del vídeo

$\mathrm{Al}$ inicio del curso cada grupo de $2^{\circ}$ de Medicina se dividió en tres equipos. Cada equipo se encargó de estudiar y desarrollar un tema de los tres que fueron propuestos por el profesorado y que forman parte del programa de la asignatura. Los temas a elegir fueron: "Adaptaciones cardiorrespiratorias a las altas presiones", "Adaptaciones 
Experiencia en la elaboración de vídeos didácticos por alumnos de Fisiología como parte de su proceso de aprendizaje.

cardiorrespiratorias a las bajas presiones" y "Adaptaciones cardiorrespiratorias al ejercicio". Los alumnos podían elegir de forma voluntaria en qué equipo querían participar. Los tres grupos en los que se dividió la clase tuvieron aproximadamente el mismo número de alumnos. Por tanto, dado que había cuatro grupos y cada grupo estaba dividido en tres equipos, hubo un total de 12 equipos compuestos cada uno de 12 ó 13 alumnos. De este modo, cada equipo debía preparar fuera del aula una presentación en formato vídeo con los contenidos del tema que tenía asignado.

Creación de un foro como herramienta de comunicación para la elaboración del vídeo. A cada equipo se le creó en el campus virtual de la plataforma Blackboard un foro en el que sólo estaban incluidos los alumnos pertenecientes a ese equipo y los profesores de la asignatura. Dicho foro se creó como canal de comunicación entre los propios alumnos y entre los alumnos y el profesor, para preparar de forma eficaz y autónoma parte del temario de la asignatura, que luego debería ser presentado al resto de la clase en formato vídeo (Figura 1).

En la Figura 1 se pueden ver los foros creados en el campus virtual.

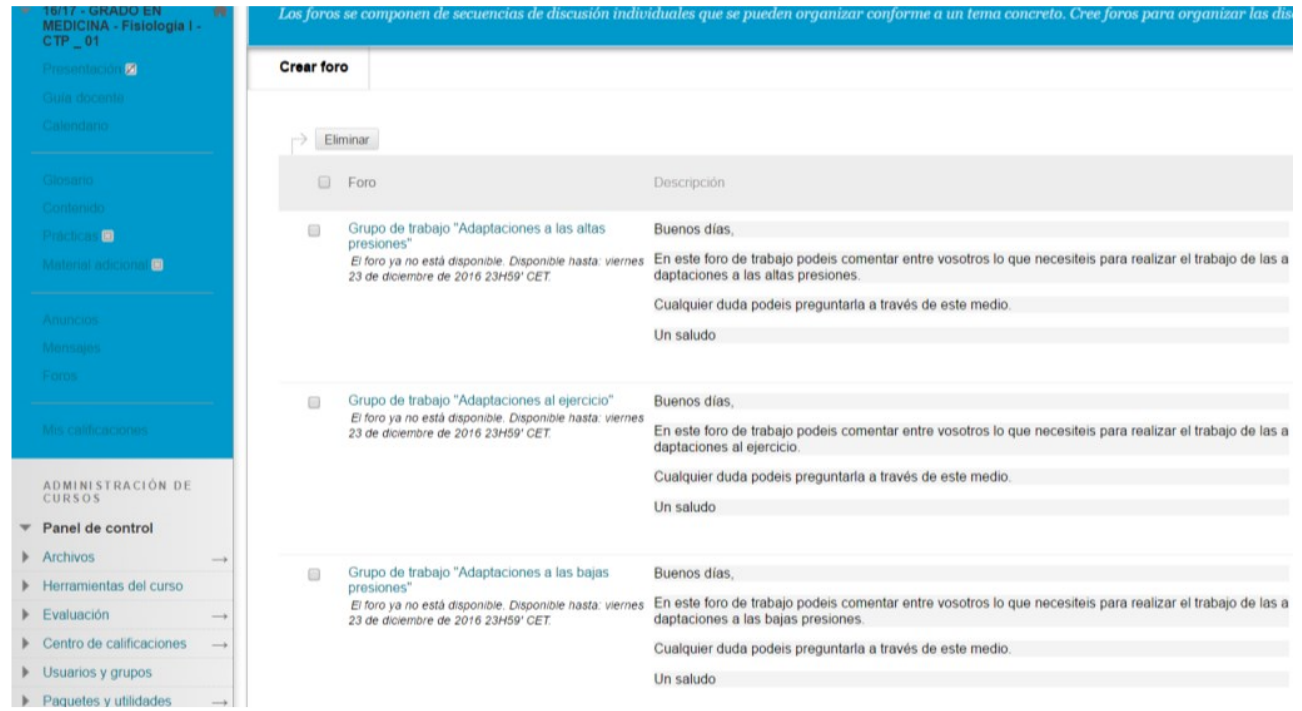

Figura 1. Creación del foro en el Campus Virtual.

\section{Indicaciones para la realización del vídeo.}

Cada equipo podía elegir qué contenidos querían incluir en el vídeo, es decir, tenían total libertad para desarrollarlo como quisieran y hablar de los aspectos que ellos consideraran oportunos. Solo se le dieron dos indicaciones:

- El vídeo debía tener una duración máxima de 10 minutos. Si se excedían en dicho tiempo no se admitirían para su evaluación.

- Todo lo relativo a la preparación del vídeo, dudas que iban surgiendo así como discusiones relativas al contenido debían ser expuestas en el foro.

(cc) EY-NC-ND 2017, Universitat Politècnica de València 


\section{Tutorización del trabajo}

A mitad del semestre se hizo una tutoría académica en la que los alumnos tenían que enseñar a los profesores el desarrollo de su trabajo, con el fin de orientarles y comprobar cómo lo estaban llevando a cabo. De forma continuada los profesores tutelaron el foro, de modo que el contenido que los alumnos iban subiendo era supervisado y se les iban haciendo las sugerencias oportunas, con el fin de optimizar su trabajo y que no incluyeran aspectos poco relevantes o erróneos.

Visualización de los vídeos.

Al final del semestre se dedicaron tres días a la proyección de los vídeos. Cada día se vieron los 4 vídeos del mismo tema elegido (uno por cada grupo del curso). Al finalizar la clase se hizo una votación y se les pidió a todos los alumnos que escribieran en una hoja el título del vídeo de cada tema que más les había gustado. Por otra parte, los profesores de la asignatura se reunieron para volver a visualizar los vídeos y evaluar fundamentalmente el contenido, pero también la edición del vídeo, originalidad, creatividad, participación e implicación de cada alumno.

Aunque en un principio no estaba previsto y la experiencia se desarrolló como una actividad obligatoria dentro de la asignatura, dada la buena acogida que hubo por parte de los alumnos se decidió organizarlo a modo de concurso, de manera que según la votación de los alumnos y de los profesores se otorgaron unos diplomas a los tres vídeos más votados de entre los doce.

\section{Análisis de la experiencia}

Una vez terminada la experiencia docente se elaboró una encuesta en la que los alumnos valoraron el desarrollo de la misma. Las preguntas que se les formularon fueron las siguientes:

1. Valore del 1 al 10 el esfuerzo que le ha supuesto la realización del vídeo para el trabajo de las adaptaciones (1 nada esfuerzo; 10 muchísimo esfuerzo)

2. Marque con una $X$ lo que ha supuesto para usted la realización del vídeo:

- Me ha supuesto mucho esfuerzo y no me ha servido absolutamente para nada.

- Me ha supuesto mucho esfuerzo pero me han servido para aprender.

- Me ha supuesto el mismo esfuerzo que cualquier otra actividad pero no he aprendido.

- Me ha supuesto el mismo esfuerzo que cualquier otra actividad y me ha servido para aprender de forma divertida.

- Me ha supuesto el mismo esfuerzo que cualquier otra actividad y me ha servido para aprender de forma aburrida.

- $\quad$ No me ha supuesto esfuerzo pero tampoco he aprendido.

- $\quad$ No me ha supuesto esfuerzo y he aprendido.

3. ¿Cree que es bueno que se siga haciendo esta actividad para futuros alumnos? Marque $\mathrm{Si} / \mathrm{No}$ 
Experiencia en la elaboración de vídeos didácticos por alumnos de Fisiología como parte de su proceso de aprendizaje.

4. Escriba a continuación si tiene alguna sugerencia/recomendación acerca de la realización del vídeo.

\section{Resultados}

\section{Valoración por parte de los profesores respecto a la elaboración de los vídeos.}

En la elaboración del vídeo los profesores valoramos dos aspectos:

En primer lugar el contenido académico de los mismos. En este sentido todos los vídeos mostrados tuvieron una elevada calidad en cuanto a su contenido. El abordaje del tema fue muy adecuado y los contenidos que se mostraron fueron precisos y de calidad científica. No hay que olvidar que los alumnos tenían plena libertad para incluir en él lo que consideraran más oportuno ya que solamente se les había dado el título del tema a desarrollar. Este hecho hizo que los distintos vídeos elaborados fueran muy diferentes, aún entre los que trataban del mismo tema, lo que hace más enriquecedora la experiencia ya que con la visualización de todos los vídeos se abordan más aspectos dentro de un mismo tema. De hecho, nos sorprendieron muy gratamente algunas ideas que se incluyeron en los vídeos, lo que pone de manifiesto que con el desarrollo de esta experiencia se potencian otras habilidades de los alumnos, como la creatividad, la originalidad y la innovación, además potenciar un espíritu crítico y riguroso.

En segundo lugar también quisimos valorar la edición de los vídeos. Tratándose de alumnos que estudian Medicina y, por tanto, no tendrían porqué estar familiarizados con estas herramientas, queremos resaltar que de los doce vídeos que se presentaron nueve de ellos tuvieron un formato excelente. Este hecho pone de manifiesto que la mayor parte de los alumnos están acostumbrados a utilizar esta herramienta de forma cotidiana por lo que no les resulta complicado utilizarlas como recurso para su aprendizaje. En el caso de los alumnos que tuvieron más dificultades tecnológicas éstos fueron capaces de resolver los problemas que les fueron surgiendo y así adquirieron una nueva habilidad para el aprendizaje.

\section{Valoración por parte de los alumnos respecto a la elaboración de los vídeos.}

Los resultados de las encuestas se muestran a continuación. En la Figura 2 se muestra el esfuerzo percibido por los alumnos respecto al desarrollo de esta actividad. Como se puede ver en una escala del 1 al 10, la mayor parte de los alumnos consideraron que la elaboración de los vídeos les ha supuesto un esfuerzo medio alto (puntuación 7-8) y sólo una pequeña parte de los alumnos consideraron que les ha supuesto mucho o poco esfuerzo. 


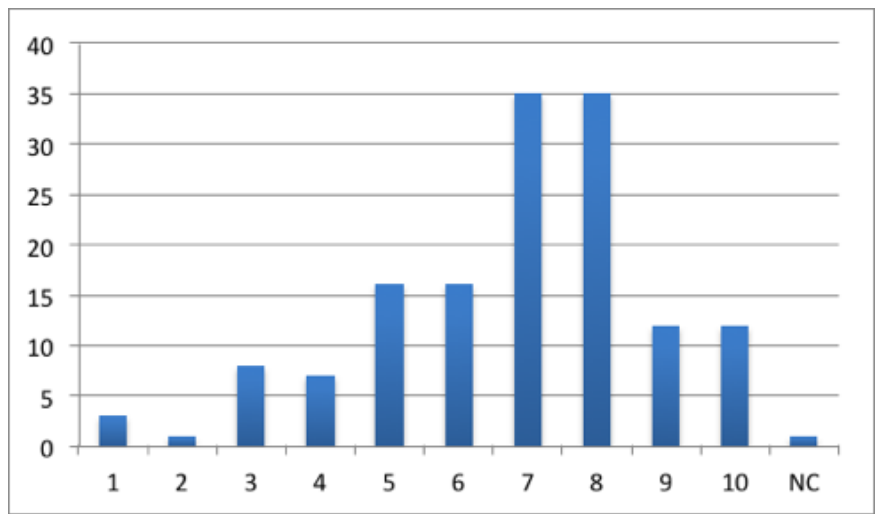

Figura 2. Esfuerzo percibido por los alumnos al realizar esta actividad

Respecto a la pregunta en la que se les consulta si creen que se debe seguir haciendo esta actividad para futuros alumnos, la respuesta ha sido mayoritariamente afirmativa (Figura 3).

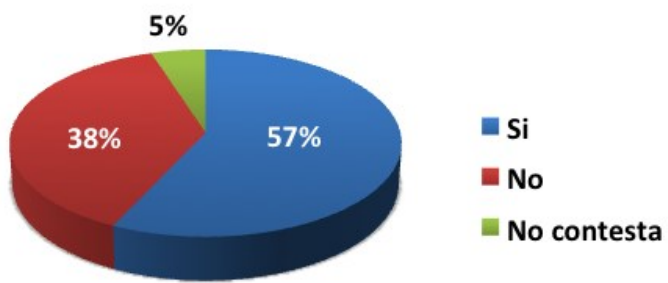

Figura 3. Resultados de la encuesta acerca de si se debe seguir realizando esta actividad.

Por último, quisimos saber si los alumnos consideraban positiva esta actividad en cuanto a su aprendizaje. Como se puede ver en la Figura 4, un $61 \%$ de todos los alumnos consideran que sí han aprendido al realizar el vídeo.

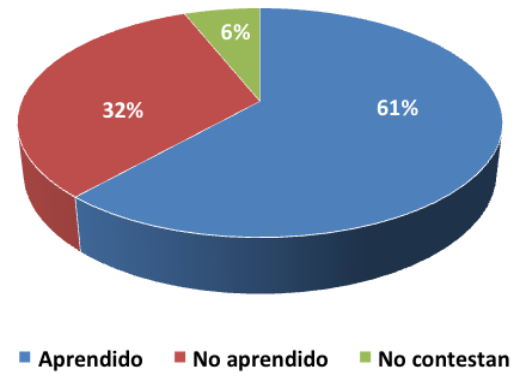

Figura 4. Percepción de los alumnos sobre su aprendizaje. 
Experiencia en la elaboración de vídeos didácticos por alumnos de Fisiología como parte de su proceso de aprendizaje.

Para finalizar, entre las sugerencias de los alumnos para mejorar esta actividad citaremos a continuación las más relevantes. Entre los comentarios de los alumnos queremos destacar la opinión de que es un buen método para aprender y que fomenta el trabajo en grupo. Como sugerencia de mejora una gran mayoría de los alumnos propuso que los grupos fueran más pequeños, es decir, con un número más reducido de alumnos.

\section{Resultados respecto al uso del foro}

Con el foro se pone a disposición del alumno una herramienta on-line que les permite "estar conectados" entre ellos y con el profesor de modo que tienen un "canal oficial" de comunicación y no tienen que buscar otras alternativas que suelen usar más a menudo como Google, Ask o WhatsApp. El foro se encuentra disponible en la plataforma del estudiante teniendo un acceso fácil y ágil al mismo. Por otro lado el profesor puede ver el trabajo que realizan sus alumnos, por lo que es capaz de discernir entre aquellos alumnos que participan en el foro y los que no, pudiendo incentivar la participación en el mismo. Además, a través de la participación del profesor se pueden resolver dudas, se les puede guiar, orientar y tutelar el trabajo.

Tras analizar el número de participaciones de los alumnos en el mismo y realizando el análisis sobre el conjunto de la totalidad de los alumnos que están matriculados en la asignatura, hemos encontrado los datos que mostramos a continuación.

La participación de los alumnos ha sido del $11 \%$ respecto al número de alumnos en total que han participado en el foro: alumnos totales de los cuatro grupos (Figura 5).

\section{\% participación}

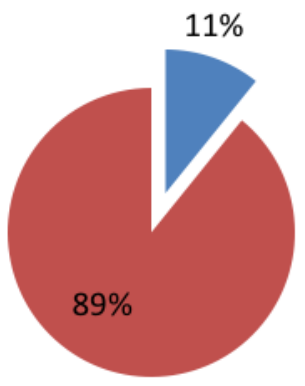

Figura 5. Porcentaje de participación en el foro de los 148 alumnos matriculados

Analizando los resultados observamos un porcentaje de participación en los foros bajo. Debemos tener en cuenta que no se han contabilizado a la hora de valorar a los participantes ni las entradas de los profesores ni las de los alumnos que han utilizado el foro repetidamente. 
Consideramos que la baja participación en el foro durante este curso se ha podido deber a varios motivos:

- Los alumnos no están familiarizados aún con el foro al ser la primera asignatura de su carrera que les ofrece esta posibilidad.

- Los alumnos, a pesar de que se les explicó, no han utilizado el foro para dialogar entre ellos (excepto en un grupo que si lo ha hecho), si no para preguntar dudas al profesor y colgar información.

- La interferencia de otras vías de comunicación con la que los alumnos están más familiarizados (WhatsApp) puede estar dificultando la participación en el foro.

Analizando los datos por sexos (Figura 6) observamos que el porcentaje de mujeres que han participado en la experiencia docente respecto al total de alumnos es de un $46 \%$ versus un $54 \%$ de hombres, no existiendo diferencias estadísticamente significativas en este aspecto. Sin embargo, hay que aclarar que del total de 148 alumnnos, un $71 \%$ se corresponde con mujeres y un $29 \%$ son hombres, por lo que si tenemos en cuenta estos datos cabría decir que los hombres han tenido una mayor participación en el uso del foro.

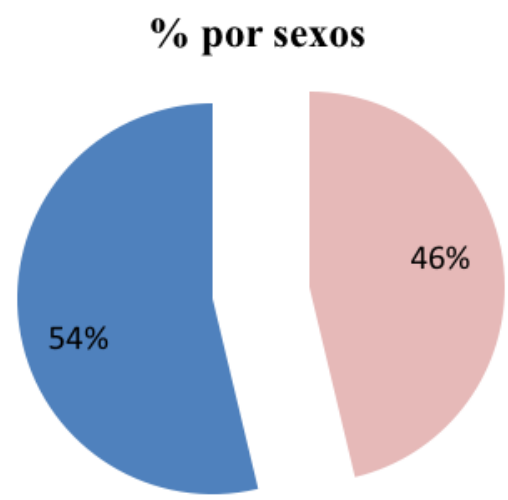

Figura 6. Participación por sexos en el foro teniendo en cuenta la totalidad de alumnos de segundo curso de Medicina

A pesar de que los porcentajes de participación no hayan sido elevados los profesores lo valoramos de manera positiva. Como se ha referido previamente, un grupo si lo utilizó como chat de la asignatura y fue muy enriquecedor, lo que nos anima a mantener el foro en los próximos cursos.

Se adjunta a continuación un ejemplo del uso de la plataforma como foro (Figura 7). 
Experiencia en la elaboración de vídeos didácticos por alumnos de Fisiología como parte de su proceso de aprendizaje.

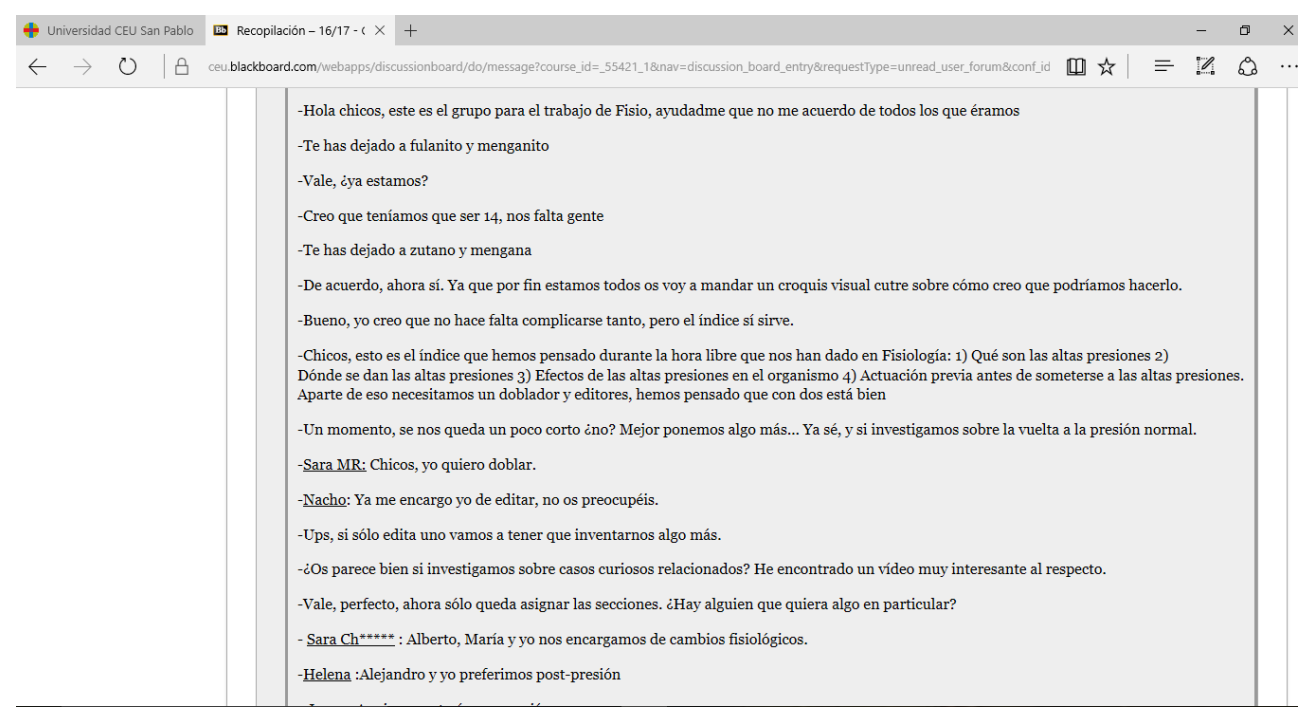

Figura 7. Ejemplo del uso del foro.

\section{Conclusiones}

Consideramos que la elaboración de un vídeo didáctico por los alumnos es una herramienta válida para favorecer un sistema de aprendizaje más activo y participativo por su parte. No sólo les permiten alcanzar los conocimientos de Fisiología, sino que también les ayuda a formarse en el uso de nuevas tecnologías como instrumento laboral, les ayuda a comprender la racionalización de los tiempos y a relacionarse entre ellos en un ambiente colaborativo, competencias todas ellas que les serán demandadas cuando se sumerjan en la vida profesional.

A pesar de la escasa participación de los alumnos en el uso del foro creemos que es una herramienta eficaz para tutelar el trabajo autónomo del alumno y para incrementar la comunicación entre profesores y alumnos y la de los alumnos entre ellos. Atribuimos su escasa participación al hecho de que es la primera vez que se les ofrece esta herramienta. Nos planteamos de cara al futuro nombrar un alumno voluntario que funcione como líder y se encargue de moderar el foro para mantenerlo en actividad sin depender tanto de la participación del profesor. Pensamos que así los alumnos lo puedan entender más como una sala propia de discusión en la que aportar ideas, dudas y conocimiento y en la que ellos sean los principales protagonistas.

En definitiva, como conclusiones finales podemos decir que el uso de herramientas docentes basadas en las nuevas tecnologías tiene una buena aceptación por parte de los alumnos, les motiva y les hace más participativos. Con la elaboración de vídeos didácticos los alumnos aprenden nuevos contenidos a la vez que se potencia su creatividad y se divierten. El proceso de diseño y desarrollo de un vídeo les estimula para

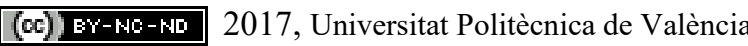

Congreso IN-RED (2017) 
aprender de forma autónoma, saber discernir entre los conceptos que son más importantes, buscar información contrastada, colaborar entre ellos y trabajar en equipo.

\section{Referencias}

ARCEO FDB, ROJAS GH, GONZÁLEZ ELG (2002). Estrategias docentes para un aprendizaje significativo: una interpretación constructivista. Libro electrónico: mapas.eafit.edu.co.

ÁLVAREZ B, GONZÁLEZ MIERES C, GARCÍA RODRÍGUEZ N (2008). La motivación y los métodos de evaluación como variables fundamentales para estimular el aprendizaje autónomo. Revista de Educación Universitaria 1.

BARR, R.B Y TAGG, J. (1995). "From teaching to learning. A new paradigm for undergraduate education", en Change, 27 (6), pp. 13-25. Revista electrónica de Tecnología Educativa, $\mathrm{n}^{\circ} 29$

CASTAÑO, C. Y ROMERO, R. (2007): Las TIC en los procesos de formación. Nuevos medios, nuevos escenarios para la formación. En Cabero, J. y Romero, R. (coordinadores): Diseño y Producción de TIC para la formación. Barcelona: UOC.

FERRÉS, J. Y BARTOLOMÉ, A. (1991). EL VÍDEO, enseñar vídeo, enseñar con el vídeo. Barcelona: Gustavo Gili, S.A.

FERRO SOTO C, MARTÍNEZ SENRA AI, OTERO NEIRA MC (2009). Ventajas del uso de las TICs en el proceso enseñanza-aprendizaje desde la óptica de los docentes universitarios españoles.

GARCÍA VALCÁRCEL, A. (1993). "Análisis de los modelos de enseñanza empleados en el ámbito universitario", en Revista Española de Pedagogía, 194, 27-53.

GARGALLO, B, GARCÍA- FÉLIX, I, MORERA, C. Y BENAVENT, A. (2015). Métodos innovadores y enfoques de aprendizaje en estudiantes universitarios.

Doi:http://dx.doi.org/10.4995/INRED2015.2015.1576

MACHEMER, P. L. . Y CRAWFORD, P. (2007). "Student perceptions of active learning in a large crossdisciplinary classroom", en Active Learning in Higher Education, 8 (1), 930 .

MOLERO LÓPEZ-BARJAS D., RUIZ CARRASCOSA J (2005). La evaluación de la docencia universitaria. Dimensiones y variables más relevantes. Revista de Investigación Educativa 23 (1). 
Experiencia en la elaboración de vídeos didácticos por alumnos de Fisiología como parte de su proceso de aprendizaje.

MONEREO C. Y POZO J. I. (2003). La universidad ante la nueva cultura educativa, Enseñar y aprender para la autonomía. Madrid: Síntesis.

ROMÁN, P. Y LLORENTE, M (2007). El diseño de vídeos educativos: el vídeo digital. En Cabero, J. y Romero, R. (coordinadores): Diseño y Producción de TIC para la formación. Barcelona: UOC.

RUTH S. CONTRERAS ESPINOSA Y JOSE LUIS EGUIA (2016): Gamificación en aulas universitarias. Bellaterra : Institut de la Comunicació, Universitat Autònoma de Barcelona. ISBN 978-84-944171-6-0.

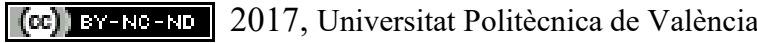




\title{
Diseño y evaluación de un laboratorio virtual de vectores en 3D
}

Vanessa P. Cuenca-Gotor ${ }^{\mathrm{a}, \mathrm{b}}$, Marcos H. Giménez ${ }^{\mathrm{a}, \mathrm{c}}$, José A. Gómez-Tejedor ${ }^{\mathrm{a}, \mathrm{d}}$, Rosa Martínez-Sala $^{\mathrm{a}, \mathrm{e}}$, Juan A. Monsoriu, ${ }^{\mathrm{a}, \mathrm{f}}$, Isabel Salinas ${ }^{\mathrm{a}, \mathrm{g}}$ y Juan A. Sans ${ }^{\mathrm{a}, \mathrm{h}}$

${ }^{a}$ Departamento de Física Aplicada, Universitat Politècnica de València, Camino de Vera s/n, 46022 Valencia, Spain, ${ }^{\mathrm{b}}$ vacuego@ fis.upv.es, ${ }^{\mathrm{c}} \mathrm{m}$ mgimene@ fis.upv.es, ${ }^{\mathrm{d}}$ jogomez@ fis.upv.es,

ermsala@fis.upv.es, ${ }^{\mathrm{f}}$ jmonsori@ $@$ fis.upv.es, ${ }^{\mathrm{g}}$ isalinas@ fis.upv.es y ${ }^{\mathrm{h}}$ juasant2@ upvnet.upv.es

\begin{abstract}
In Physics, many quantities are vectors, and their use requires typical operations such as: addition, substraction, scalar multiplication, scalar product (dot product), vector product (cross product) and scalar triple product. This is a very basic topic in all General Physics courses for Engineering degrees. However, we have detected that some students lack of a deep understanding of vector operations and their properties.

In this work, we present a virtual laboratory (developed using the tool "Easy Java Simulations") for the study and understanding of these topics. The user can introduce the components of the input vectors and gets a $3 D$ representation, which can be scaled and rotated for a better visualization. Any of the aforementioned operations can be selected, and the result is shown both numerically and graphically. The user can also modify any represented vector. In this way, the virtual lab provides a real time visualization of how the change affects the result. The possibility of limiting the changes to either magnitude or direction is also included.

The efficiency of the virtual laboratory has been tested analyzing the results obtained in two groups of students (virtual laboratory vs. traditional resources). A satisfaction survey has been also carried out.
\end{abstract}

Keywords: virtual laboratory, Physics, Easy Java, vector analysis.

\section{Resumen}

En Física, un gran número de magnitudes son vectores, y su uso requiere operaciones típicas tales como: suma, resta, multiplicación por un escalar, producto escalar, producto vectorial y producto mixto. Se trata de conceptos básicos en todos los cursos de Física General para grados en Ingeniería. Sin embargo, algunos estudiantes carecen de una comprensión profunda de las operaciones vectoriales y sus propiedades.

En este trabajo presentamos un laboratorio virtual (desarrollado utilizando la herramienta "Easy Java Simulations") para el estudio y comprensión de estos conceptos. El usuario puede introducir las componentes de los vectores de entrada y obtiene una representación $3 D$, que puede escalar y girar para una mejor visualización. Se puede seleccionar cualquiera de las operaciones 
antes mencionadas, y se muestra el resultado tanto numérica como gráficamente. El usuario puede también modificar cualquiera de los vectores representados. De esta forma, el laboratorio virtual proporciona una visualización en tiempo real de cómo el cambio afecta al resultado. También se incluye la posibilidad de modificar únicamente el módulo o la orientación.

Para comprobar la eficiencia del laboratorio virtual, se han analizado los resultados obtenidos por dos grupos de estudiantes (laboratorio virtual vs. recursos tradicionales). También se ha realizado una encuesta de opinión.

Palabras clave: laboratorio virtual, Física, Easy Java, análisis vectorial.

\section{Introducción}

En los temas de Mecánica que se imparten en las asignaturas de Física de primer curso, los estudiantes han de adquirir conceptos básicos que pueden resultar de difícil comprensión, o complicados de dominar. Los laboratorios virtuales son una de las herramientas más versátiles de que pueden disponer los estudiantes para facilitar este aprendizaje (Vidaurre, 2002). En primer lugar, ponen el foco en el aprendizaje activo, utilizando unas herramientas con las que los alumnos de hoy día están ampliamente familiarizados, y con significativas ventajas en la educación, como la interactividad y la respuesta dinámica (Jimoyiannis, 2001).

En segundo lugar, los laboratorios virtuales no tienen por qué limitarse a realizar más rápido un ejercicio tipo, sino que pueden permitir el control de las variables de un proceso, y por tanto analizar su influencia, mostrando además las representaciones necesarias (imágenes, gráficas, animaciones) para asimilar los conceptos y relaciones subyacentes. De esta forma, constituyen una herramienta de apoyo para el desarrollo de competencias transversales como la comprensión e integración de conceptos, análisis y resolución de problemas y pensamiento crítico, principalmente. En este contexto, los procesos de aprendizaje basados en laboratorios virtuales han demostrado proporcionar varias ventajas (Esquembre, 2002), aunque su eficacia pedagógica está condicionada a una integración completa en el proyecto docente global (Steinberg, 2000).

En este trabajo presentamos tanto el diseño como la evaluación de un nuevo laboratorio virtual (http://personales.upv.es/mhgimene/lab/vectores.html) para el estudio y comprensión de las operaciones vectoriales y sus propiedades tales como: suma, resta, multiplicación por un escalar, producto escalar, producto vectorial y producto mixto. El laboratorio virtual desarrollado proporciona una visualización en tiempo real de dichas operaciones y muestra cómo el cambio de los parámetros implicados afecta al resultado.

El presente laboratorio virtual se ha desarrollado utilizando la herramienta "Easy Java Simulations" (EJS) (Esquembre, 2004; http://www.um.es/fem/Ejs), basada en Open Source

(cc) EY-NC-ND 2017, Universitat Politècnica de València

Congreso IN-RED (2017) 
Physics (Christian, 2001). EJS es una herramienta de gratuita que permite crear applets interactivos en Java o JavaScript (HTML5), principalmente para fines de enseñanza o aprendizaje. El laboratorio virtual desarrollado es independiente de la plataforma, por lo que puede visualizarse utilizando cualquier navegador web.

Para la evaluación del laboratorio desarrollado se han realizado encuestas a los estudiantes a través de la plataforma PoliformaT (https://poliformat.upv.es), con el objetivo de conocer su opinión, la valoración de la utilidad y claridad del laboratorio virtual, el grado de desarrollo de las competencias transversales, y dar lugar así a un proceso de retroalimentación. También se han comparado los resultados de aprendizaje en dos grupos piloto, uno en el que se ha implementado el presente laboratorio virtual y otro en el que ha utilizado una metodología tradicional.

Con el objetivo de valorar la influencia del uso del laboratorio virtual de Vectores sobre el aprendizaje de los alumnos, durante el presente curso académico (16/17) se han seleccionado dos grupos de control, pertenecientes al primer curso de dos títulos de grado de la Escuela Técnica Superior de Ingeniería del Diseño de la Universitat Politècnica de València, y a dos asignaturas cuyos programas incluyen el tema de Vectores. En el grupo de la asignatura "Complementos de Física" del grado en Ingeniería Mecánica se impartió esta tema de forma clásica, y en el grupo de la asignatura "Física Básica" del grado en Ingeniería Eléctrica se utilizó el laboratorio virtual.

\section{Objetivos}

Los principales objetivos del laboratorio virtual son:

- Visualizar un vector, comprender qué son sus componentes en un sistema ortonormal de referencia, y comprobar que esas componentes determinan el vector.

- Asimilar las operaciones básicas entre vectores, y entre vector y escalar, tanto analítica como gráficamente, y comprender sus propiedades.

- Que el estudiante compruebe que sabe realizar estas operaciones.

- Visualizar cómo la modificación de un operando afecta al resultado de las diferentes operaciones.

- Comprender las relaciones entre diversas propiedades geométricas y las operaciones entre vectores.

\section{Desarrollo de la innovación}

El laboratorio virtual de vectores (con opción de elegir el idioma entre español, valenciano e inglés) permite que el estudiante introduzca las componentes de tres vectores y un escalar, y que seleccione una de las seis operaciones disponibles (suma, resta, producto escalar, producto vectorial y producto mixto de vectores, además de multiplicación de escalar y vector). Los vectores y el resultado de la operación (cuando éste sea un vector) se muestran 
en una representación 3D en la que el usuario puede modificar de forma interactiva tanto el punto de vista como la escala.

Como alternativa a la introducción manual de componentes de un vector, el usuario puede modificarlas arrastrando su extremo en el visor. De este modo, puede observar de forma interactiva cómo afectan las modificaciones al resultado de la operación seleccionada. Se puede elegir que el arrastre del extremo del vector sea libre, que afecte únicamente a su módulo, o que cambie solamente su orientación. Además, se dispone de botones de copiar y pegar para, por ejemplo, utilizar el resultado de una operación como operando de otra.

El laboratorio incluye botones para visualizar diversas propiedades geométricas de interés: el ángulo que forman dos vectores, la proyección de uno sobre otro, el paralelogramo que definen, o el paralelepípedo constituido por tres vectores.

La Figura 1 muestra una captura del laboratorio virtual. El visor presenta una representación 3D de un sistema ortonormal de referencia, junto con los vectores y elementos adicionales. La representación es totalmente interactiva, pudiendo arrastrar con el ratón el extremo de un vector para modificarlo, o cualquier otro punto para cambiar el punto de vista de la perspectiva. La escala se controla con la deslizadera "Zoom" ubicada en el panel "Visualización".

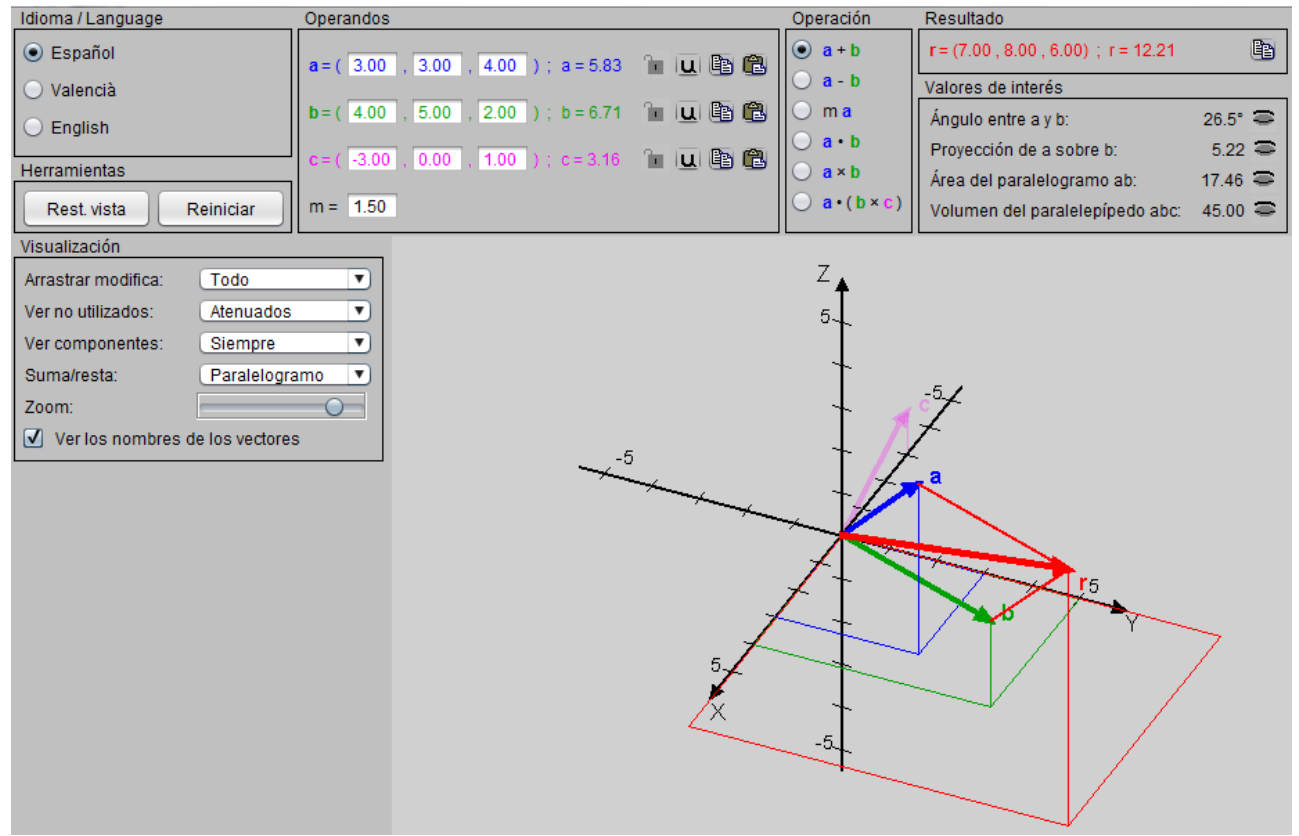

Fig. 1. Pantalla inicial de la aplicación.

Dado que el puntero del ratón se desplaza en dos dimensiones, no es posible modificar por arrastre las tres componentes de un vector de forma simultánea. Por esta razón, sólo varían dos de ellas (cuáles en concreto depende del punto de vista de la perspectiva). Sin embargo, es posible controlar una única componente cualquiera pulsando la correspondiente tecla. Por ejemplo, si se arrastra el extremo de un vector mientras se mantiene pulsada la tecla X, sólo varía esta componente.

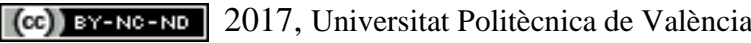


El panel "Operandos" (Figura 2) permite al estudiante introducir valores numéricos concretos para las tres componentes de cualquier vector, y muestra automáticamente el correspondiente módulo a la derecha. Al escribir en un campo numérico, su color de fondo es amarillo. La tecla INTRO permite validar la entrada, pasando el fondo a ser blanco. Si en lugar de eso pasa a ser rojo, significa que la entrada no es un número válido. También se puede introducir el valor de un escalar para utilizarlo en la operación de multiplicación por un vector. Cabe destacar además que cada vector tiene asociado un color (azul, verde, violeta) que permite identificarlo rápidamente, tanto en el visor como en los diferentes paneles.

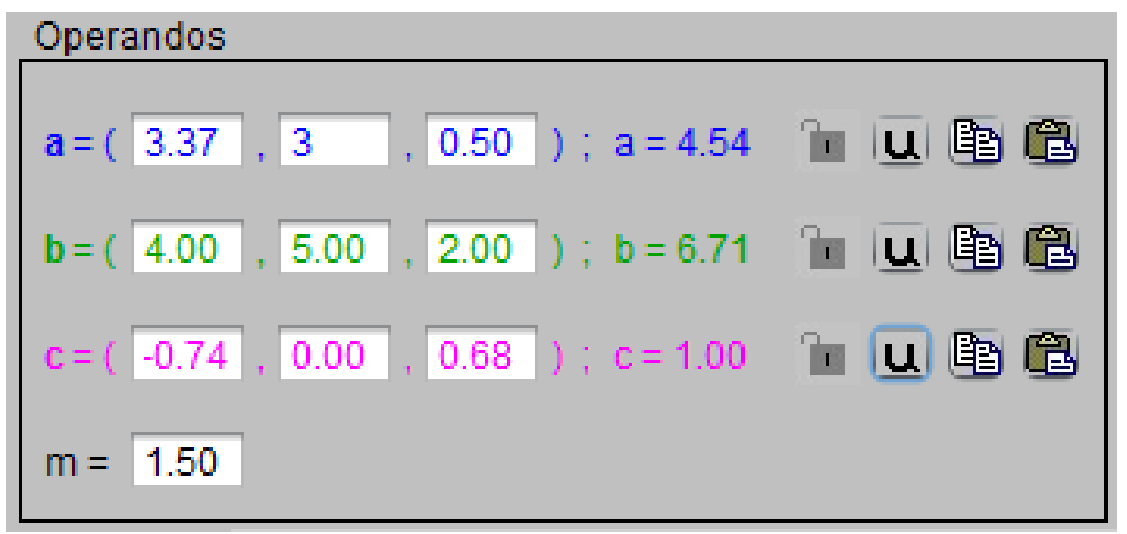

Fig. 2. Detalle del panel "Operandos".

El laboratorio virtual proporciona diferentes botones de control. Además de los de copiar y pegar ya mencionados, están los de bloquear (no se puede modificar las componentes, ni en el visor ni el panel) y los de transformar en vector unitario.

El panel "Operación" (Figura 3) permite elegir una de las seis disponibles. Cuando el resultado es un escalar, su valor se muestra en el panel "Resultado". En caso de que el resultado sea un vector, el panel muestra sus componentes y módulo, y también aparece representado en rojo en el visor. Como ejemplo, la Figura 4 muestra el resultado del producto vectorial de dos vectores.

\begin{tabular}{|c|c|c|}
\hline Operación & \multicolumn{2}{|l|}{ Resultado } \\
\hline \multirow{6}{*}{$\begin{array}{l}\text { a+b } \\
a-b \\
m a \\
a \cdot b \\
a \times b \\
a \cdot(b \times c)\end{array}$} & Valor $=29.48$ & 鴊 \\
\hline & Valores de interés & \\
\hline & Ángulo entre $\mathrm{a} y \mathrm{~b}$ : & $14.5^{\circ} \boldsymbol{\sigma}$ \\
\hline & Proyección de a sobre b: & $4.40 \overline{\boldsymbol{\sigma}}$ \\
\hline & Área del paralelogramo ab: & $7.64 \equiv$ \\
\hline & Volumen del paralelepípedo abc: & $0.69 \equiv$ \\
\hline
\end{tabular}

Fig. 3. Detalle de los paneles "Operación", "Resultado" y "Valores de interés". 


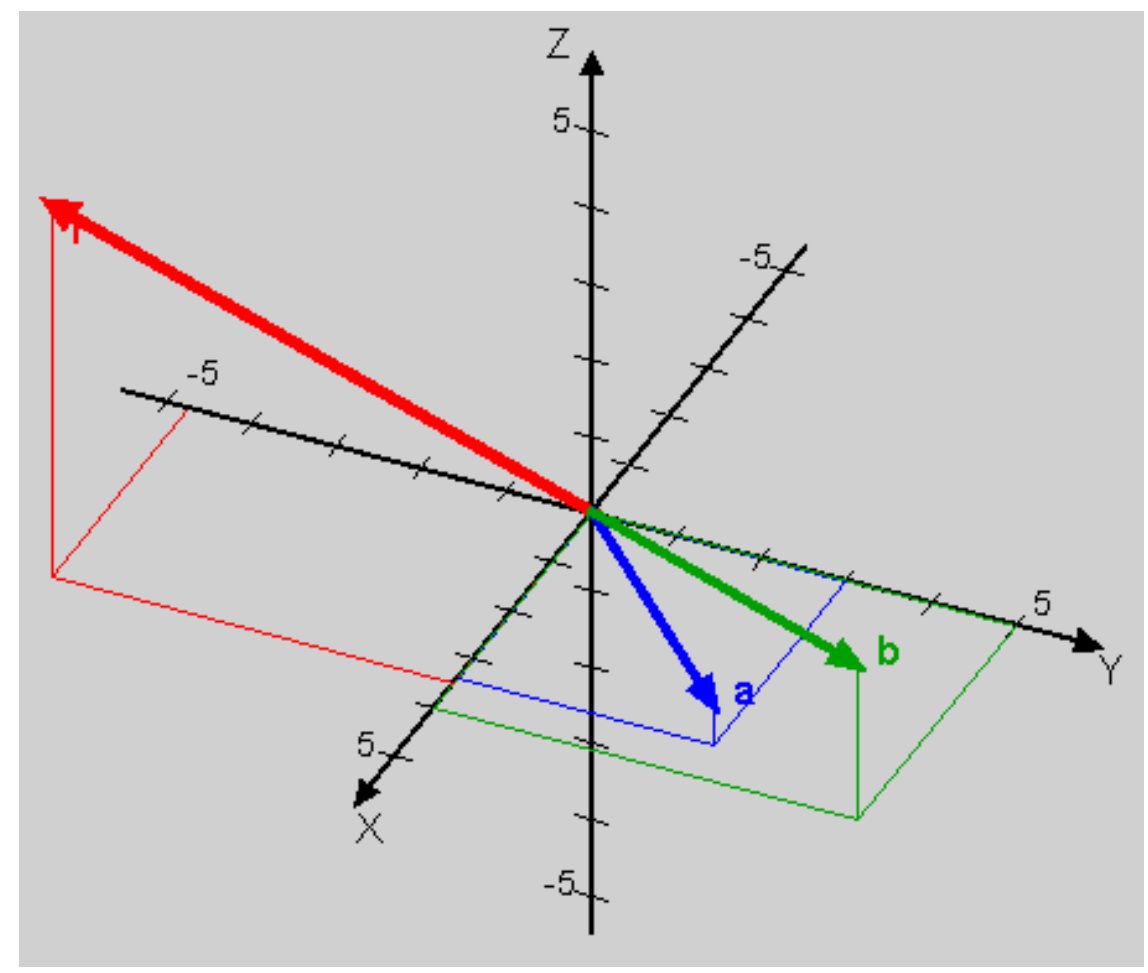

Fig. 4. Visualización del producto vectorial $\mathbf{a} \times \boldsymbol{b}$

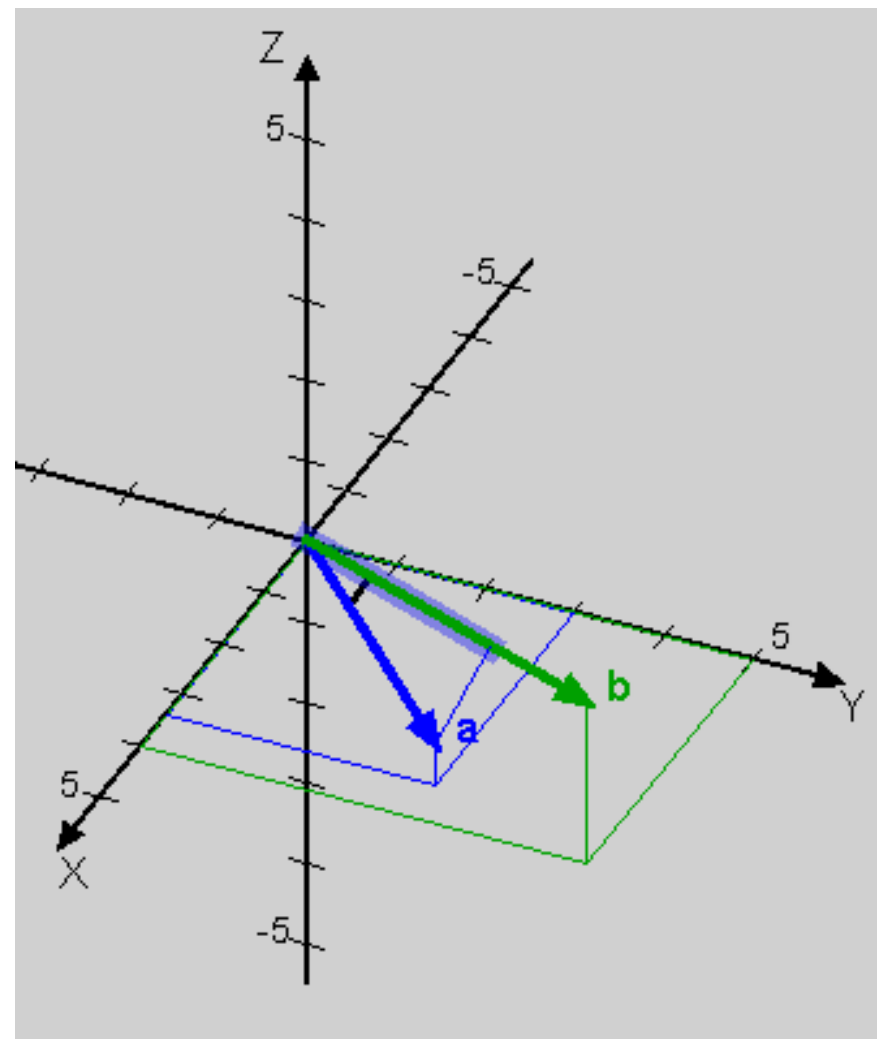

Fig. 5. Visualización de la proyección de $\boldsymbol{a}$ sobre $\boldsymbol{b}$ y del ángulo entre los vectores.

(cc)) EY-NC-ND 2017, Universitat Politècnica de València 
El panel "Valores de interés" (Figura 3) muestra los valores de cuatro propiedades geométricas relevantes: el ángulo entre dos vectores, la proyección de uno sobre otro, el área del paralelogramo que definen, y el volumen del paralelepípedo constituido por tres vectores. Utilizando los correspondientes botones de ojo abierto/cerrado, puede activarse o desactivarse la representación gráfica correspondiente. Como ejemplo, la Figura 5 muestra el ángulo entre vectores, y la proyección de uno sobre otro, mientras que en la Figura 6 se representa el paralelogramo definido por dos vectores y el paralelepípedo constituido por tres de ellos.
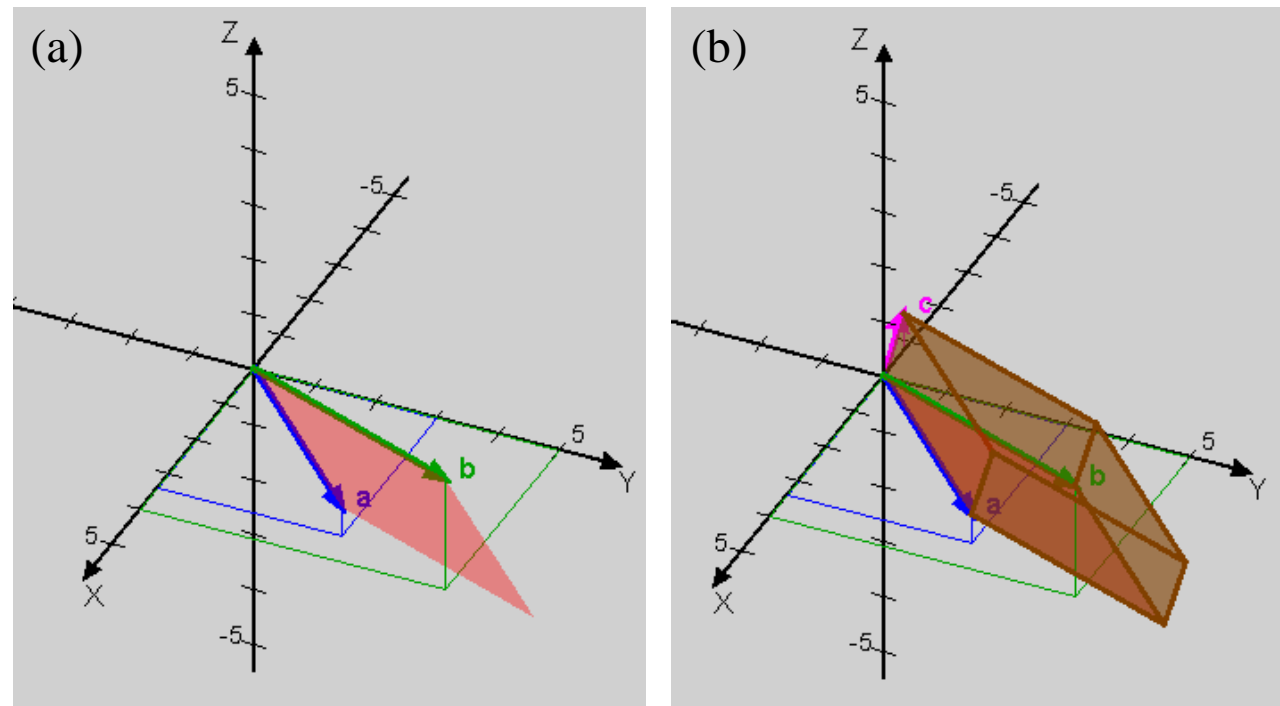

Fig. 6. (a) Paralelogramo definido por dos vectores; (b) paralelepípedo definido por tres vectores.

El panel "Visualización" permite al estudiante controlar diversas opciones de representación. Por ejemplo, la lista desplegable "Suma/resta" establece la forma de representar gráficamente la correspondiente operación (Figura 7), bien mediante la regla del paralelogramo, bien como aplicación sucesiva de los operandos.
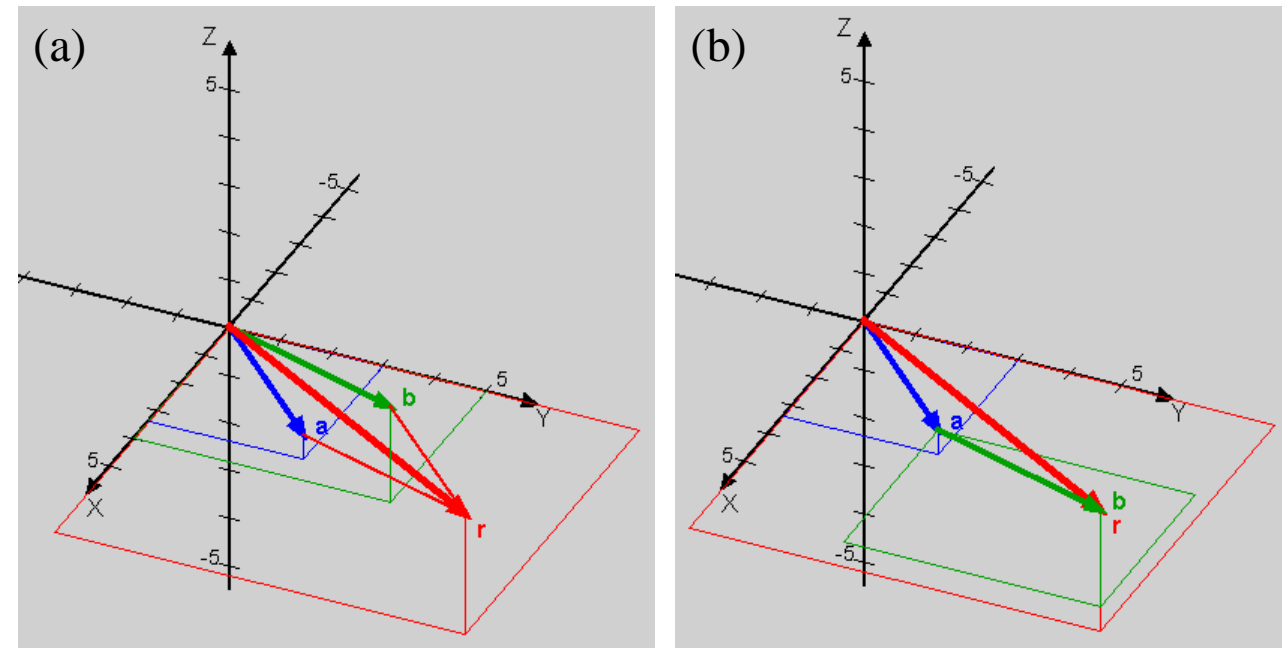

Fig. 7. Suma de vectores: (a) regla del paralelogramo; (b) secuencia de vectores. 


\section{Resultados}

\subsection{Método de evaluación}

Con el objetivo de valorar la influencia del uso del laboratorio virtual de Vectores sobre el aprendizaje de los alumnos, durante el presente curso académico (16/17) se han elegido dos grupos de control. Los dos grupos pertenecen al primer curso de dos títulos de grado de la Escuela Técnica Superior de Ingeniería del Diseño de la Universitat Politècnica de València y a dos asignaturas en las que figura en sus programas el tema de Vectores. En el grupo de la asignatura "Complementos de Física" del grado en Ingeniería Mecánica se impartió el tema de Vectores de forma clásica, y en el grupo de la asignatura "Física Básica" del grado en Ingeniería Eléctrica se utilizó el laboratorio virtual.

Para poder analizar el efecto del uso del laboratorio virtual sobre el rendimiento académico de los estudiantes se realizaron unas pruebas, de respuesta numérica abierta, mediante la utilización de la herramienta de examen de PoliformaT. Con este fin se realizó un primer examen para establecer el nivel de conocimiento de los estudiantes, sobre el tema de vectores, en el punto de partida. Posteriormente, una vez que el tema se había impartido con cada uno de los procedimientos, se volvió a realizar otro examen utilizando la misma plataforma. Asimismo, para conocer cuál era el grado de satisfacción del alumno respecto de la utilización del laboratorio virtual se realizó una encuesta anónima. La encuesta planteaba siete cuestiones y las respuestas fueron valoradas con cinco niveles (TDA: totalmente en desacuerdo, DA: en desacuerdo, IND: indiferente, A: de acuerdo y TA: totalmente de acuerdo).

\subsection{Test de rendimiento académico}

En primer lugar, al comparar los resultados obtenidos en las pruebas realizadas antes de impartir el tema encontramos que el valor medio de las puntuaciones era muy similar en los dos grupos: en "Física Básica" con una media de 5,4 y una desviación estándar de 2,5 y en "Complementos de Física" con una media de 5,2 y una desviación estándar de 2,9. Tal y como era de esperar, después de impartir el tema las puntuaciones medias de los exámenes mejoraron de forma ostensible en los dos grupos. En "Física Básica" la nueva media fue 9,1 con una desviación estándar de 1,5; en "Complementos de Física" la nueva media fue 8,3 y la desviación estándar 1,9. En las gráficas mostradas en la Figura 8, se aprecia cómo las puntuaciones de los exámenes fueron en ambos casos claramente superiores después de impartir el tema, y también menos dispersas. Sin embargo, se observa que en el grupo que utilizó el laboratorio virtual, un porcentaje mayor de alumnos obtuvo la puntuación más alta. De hecho, la puntuación media de los alumnos del grupo que utilizó el laboratorio virtual mejoró un $68 \%$ frente al $60 \%$ del grupo que empleó el método clásico.

No obstante, dado que el desarrollo normal del curso no permitió que las circunstancias en las que se realizaron los exámenes fueran exactamente las mismas para los dos grupos, no podemos afirmar que la mejoría de los resultados observada en el grupo que utilizó el laboratorio virtual sea atribuible completamente a este último. Por esta razón, se realizó una encuesta de opinión, cuyos resultados se analizan en el apartado siguiente.

(c)) BY-NC-ND 2017, Universitat Politècnica de València

Congreso IN-RED (2017) 


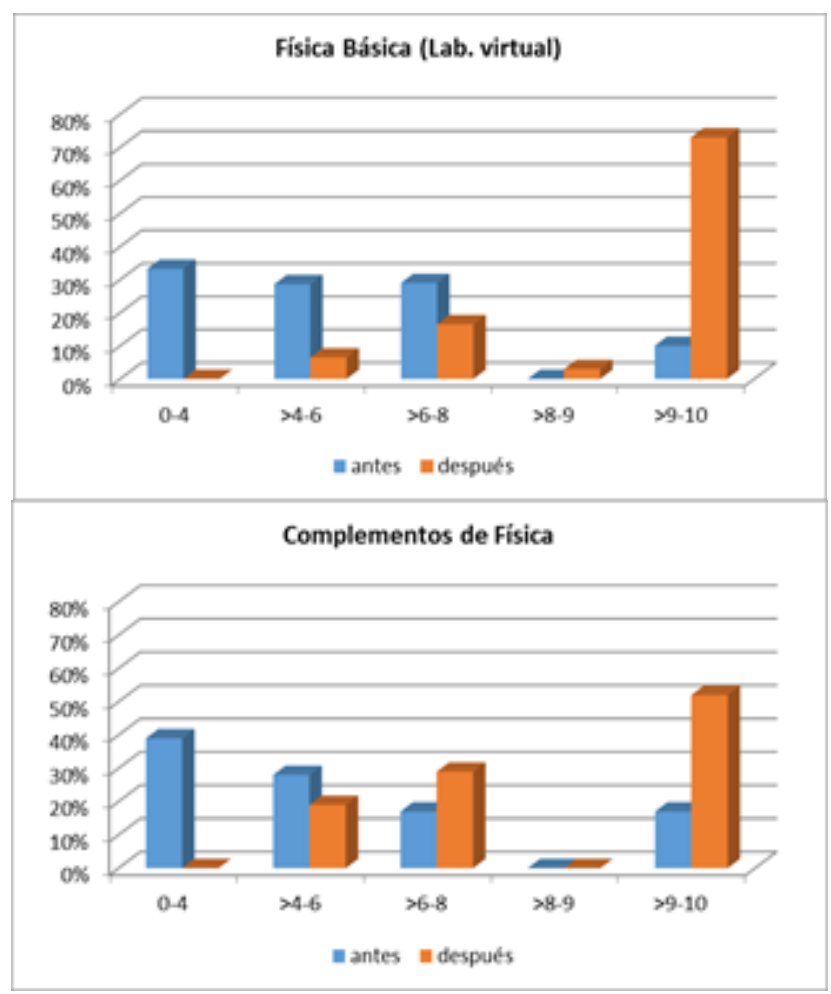

Fig. 8. Representaciones gráficas del porcentaje de alumnos que han obtenido una determinada calificación en los exámenes de cada uno de los grupos, antes y después de impartir el tema.

\subsection{Encuesta de opinión}

La encuesta se realizó, obviamente, en el grupo de estudiantes que había utilizado el laboratorio virtual. En la Tabla 1 se muestran las preguntas y las respuestas obtenidas sobre una muestra de 30 alumnos.

Las respuestas de las cuestiones que están relacionadas con la manejabilidad del laboratorio virtual nos dicen que más del $75 \%$ de los estudiantes exploró las opciones que esta herramienta ofrece (Q6), y el $90 \%$ encontró que el manejo del laboratorio virtual era intuitivo y sencillo (Q2).

La percepción del estudiante sobre la mejoría experimentada en la comprensión del tema de vectores, después de haber utilizado el laboratorio virtual, es también muy positiva ya que el $83 \%$ manifiesta haber mejorado (Q4) y que le ha sido útil (Q1).

Dada la importancia de la motivación en el proceso de aprendizaje se analiza la pregunta Q5, que está vinculada con este factor. Esta cuestión trata de indagar sobre el efecto motivador del laboratorio virtual comparado con el material aportado por el profesor de una forma más tradicional, como apuntes, notas, diapositivas, etc. En la Figura 9 se muestra mediante un gráfico qué porcentaje de los estudiantes respondió en cada uno de los cinco niveles utilizados para valorar la pregunta. Observamos que un porcentaje muy elevado, el 
$83 \%$, encontró más motivadora la utilización del laboratorio frente a un $17 \%$ que o bien no lo consideró así en absoluto, 7\%, o no apreció diferencia, 10\%.

Tabla 1. Preguntas y resultados de la encuesta de opinión.

\begin{tabular}{|l|l|c|c|c|c|c|}
\hline Pregunta & TDA & DA & IND & A & TA \\
\hline Q1 & $\begin{array}{l}\text { Me ha resultado útil el laboratorio virtual de } \\
\text { "Vectores". }\end{array}$ & 2 & 3 & 10 & 15 \\
\hline Q2 & $\begin{array}{l}\text { Me ha resultado fácil e intuitivo el manejo del } \\
\text { laboratorio virtual de "Vectores". }\end{array}$ & 0 & 3 & 7 & 20 \\
\hline Q3 & $\begin{array}{l}\text { En general, mi nivel de compresión de los conceptos } \\
\text { antes de utilizar el laboratorio virtual de "Vectores" era } \\
\text { bueno. }\end{array}$ & 0 & 5 & 4 & 14 & 7 \\
\hline Q4 & $\begin{array}{l}\text { Mi nivel de compresión de los conceptos después de } \\
\text { utilizar el laboratorio virtual de "Vectores" ha mejorado } \\
\text { respecto a mi nivel previo. }\end{array}$ & 0 & 3 & 2 & 21 & 4 \\
\hline Q5 & $\begin{array}{l}\text { Me resulta más motivador repasar el tema "Vectores" } \\
\text { utilizando el laboratorio virtual de "Vectores", que } \\
\text { revisar el material proporcionado por el profesor } \\
\text { (apuntes, notas, diapositivas...) }\end{array}$ & 2 & 0 & 3 & 11 & 14 \\
\hline Q6 & $\begin{array}{l}\text { Cuando he utilizado el laboratorio virtual de "Vectores" } \\
\text { he explorado muchas de las opciones que ofrece. }\end{array}$ & 0 & 0 & 7 & 10 & 13 \\
\hline Q7 & $\begin{array}{l}\text { Mi valoración general del laboratorio virtual de } \\
\text { "Vectores" es buena. }\end{array}$ & 0 & 0 & 3 & 10 & 17 \\
\hline
\end{tabular}

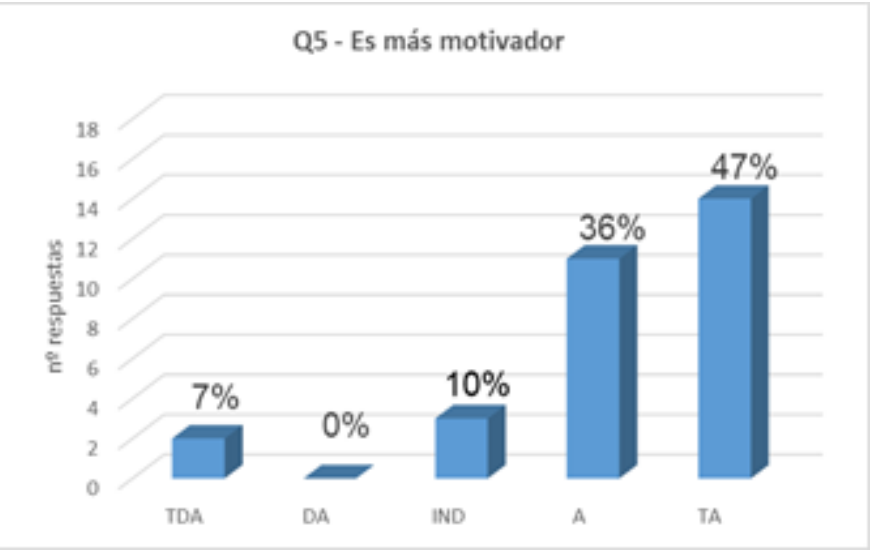

Fig. 9. Representación gráfica del porcentaje de estudiantes que respondió en cada uno de los cinco niveles de la pregunta Q5.

La pregunta Q7 da respuesta a la valoración general del laboratorio. Como se puede observar en el gráfico de la Figura 10, la valoración de los estudiantes es muy positiva ya que el $90 \%$ estuvo de acuerdo o totalmente de acuerdo con la afirmación de que es bueno. 


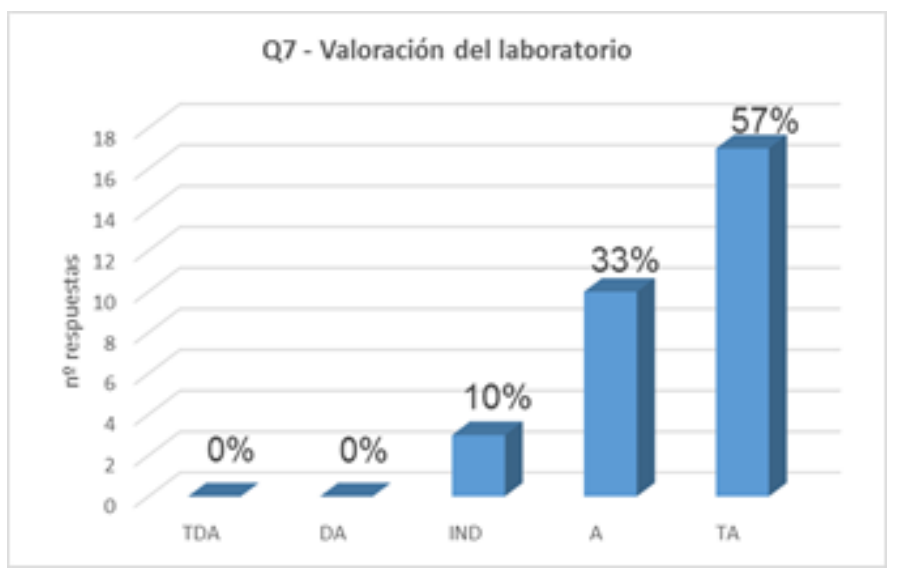

Fig. 10. Representación gráfica del porcentaje de estudiantes que respondió en cada uno de los cinco niveles de la pregunta $Q 7$.

\subsection{Competencias transversales}

Este laboratorio proporciona a los estudiantes los medios para desarrollar su propia comprensión sobre los vectores y sus operaciones. El profesor actúa como guía, dando a los estudiantes las herramientas y mostrándoles las diferentes formas en que pueden aplicarse al proceso de aprendizaje. De este modo, el laboratorio virtual que presentamos sirve de herramienta para la obtención de varias competencias clave transversales (http://www.upv.es/contenidos/COMPTRAN/index-en.html), que ayudarán al alumno a tener una formación más completa para su futuro profesional. El estudiante debe:

- Demostrar la comprensión e integración de los conocimientos, tanto en la propia especialización como en otros contextos más amplios (CT1 - comprensión e integración).

- Aplicar los conocimientos a la práctica, atendiendo a la información disponible y estableciendo el proceso a seguir para alcanzar los objetivos con eficacia y eficiencia (CT2 - aplicación y pensamiento práctico).

- Realizar tareas que requieren procesos de razonamiento más o menos complejos y, en muchos casos, no simplemente una acción asociativa y de rutina. También debe identificar y definir los elementos significativos de un problema para su análisis y resolución efectivos (CT3 - análisis y resolución de problemas).

- Desarrollar un pensamiento crítico, interesado en las bases sobre las que se basan las ideas, acciones y juicios, tanto propios como ajenos. Esto implica cuestionar las suposiciones que subyacen a nuestras formas habituales de pensar y actuar (CT9 - pensamiento crítico).

- Utilizar el aprendizaje de manera estratégica, autónoma y flexible, para manipular el conocimiento, actualizarlo y seleccionar lo que es apropiado para un contexto específico en función del objetivo perseguido (CT11 - aprendizaje permanente). 
El estudiante debe prepararse para enfrentar situaciones complejas acomodando los recursos disponibles. El uso de estas herramientas (laboratorios virtuales) promueve la autonomía y la iniciativa. El estudiante aprende y aplica conocimientos y habilidades de manera autónoma.

\section{Conclusiones}

Este trabajo presenta un laboratorio virtual diseñado para ayudar a los estudiantes a profundizar en las operaciones con vectores y sus propiedades. El uso de esta herramienta, que permite introducir diferentes vectores, visualizar su representación 3D y operar con ellos, ofrece una aproximación sencilla y completa al cálculo vectorial. La encuesta de satisfacción mostró un alto grado de motivación en los alumnos que usaron esta herramienta, que se vio reflejado en un aumento significativo del porcentaje de alumnos con nota más alta.

Las competencias transversales vinculadas al uso de este laboratorio virtual han sido enumeradas destacando los aspectos docentes más relevantes de este recurso.

\section{Agradecimientos}

Los autores desean agradecer al Instituto de Ciencias de la Educación de la Universitat Politècnica de València (UPV) su apoyo en los grupos de innovación docente MoMA y e-MACAFI, y por subvencionar el proyecto PIME B24. J.A. Sans agradece el apoyo financiero del programa de becas "Ramón y Cajal", y al Instituto de Diseño para la Fabricación y Producción Automatizada de la UPV por permitirle conseguir una venia docendi en el Departamento de Física Aplicada de la UPV.

\section{Referencias}

CHRISTIAN, W. y BELLENI, M. (2001). Physlets: Teaching physics with interactive curricular material. Upper Saddle River, NJ, USA: Prentice Hall.

ESQUEMBRE, F. (2002). "Computers in physics education" en Computer Physics Communications, vol. 147 , p. 13-18.

ESQUEMBRE, F. (2004). "Easy Java Simulations : a software tood to create scientific simulations in Java" en Computer Physics Communications, vol. 156, p. 199-204.

JIMOYIANNIS, A. y KOMIS, V. (2001). "Computer simulations in physics teaching and learning" en Computer \& Education, vol. 36, p. 183-204.

STEINBERG, R.N. (2000). "Computers in teaching science: To simulate or not to simulate" en American Journal of Physics, vol. 68, p. S37-S41.

VIDAURRE, A., RIERA, J., GIMÉNEZ, M.H. y MONSORIU, J.A. (2002). "Contribution of digital simulation in visualizing physics processes" en Computer Applications in Engineering Education, vol. 10, p. 45-49.

(c)) EY-NC-ND 2017, Universitat Politècnica de València

Congreso IN-RED (2017) 


\title{
Una propuesta de mejora para el auto aprendizaje de la Competencia Comunicativa Oral en español: R/ele/CCO
}

\section{$M^{a}$ del Mar Sáinz González ${ }^{a}$, Francesca Romero Forteza ${ }^{b}$}

a'Universitat Politècnica de València (Spain, masaigon@upv.es), bUniversitat Politècnica de València (Spain, fromero@upv.es)

\begin{abstract}
This investigation focuses on the lack of web resources for Autonomous learning of oral communicative competence in Spanish, which we think can applied to other languages. The oral communicative competence is, according to the MCERL, the aim in and of itself when we learn a language. The Web resources are centered in the learning of languages based on exercises of trial and error and repetition, leaving aside the communicative level of the language. Therefore, we propose a web resource for an autonomous learning of Spanish as a foreign language which is focused on the learning of conversational characteristics in Spanish.
\end{abstract}

Keywords: Oral communicative competence, Autonomous learning of languages, ELE, Design Web based resources

\section{Resumen}

Este trabajo se centra en la falta de recursos web centrados en el auto aprendizaje de la competencia comunicativa oral en español, que pensamos, podemos hacer extensible a otras lenguas. La competencia comunicativa oral es, según el MCERL, el fin en si mismo cuando aprendemos una lengua. Los recursos web están centrados en el aprendizaje de lenguas basados en ejercicios de prueba y error y repetición, dejando de lado el plano comunicativo de la lengua. Por ende, proponemos un recurso web para el auto aprendizaje de español como lengua extranjera centrado en el aprendizaje de rasgos conversacionales en español.

Palabras clave: competencia comunicativa oral, auto aprendizaje de lenguas, ELE, diseño de recursos web.

\section{Introducción}

No hace demasiados años afirmábamos que las tecnologías de la información y la comunicación -TIC a partir de ahora- estaban invadiendo todas y cada una de las parcelas de nuestra vida. Pasado un tiempo constatamos que las TIC se han incorporado a nuestras vidas 
y han modificado nuestra cotidianidad. Estas herramientas han penetrado en todos los ámbitos sociales desde el profesional al personal. Cada vez realizamos más actividades a través de las TIC desde el desarrollo de Internet y, posteriormente, desde la creación de la World Wide Web. Numerosas tareas profesionales y personales se ven simplificadas y agilizadas gracias a su uso. Y el ámbito de la enseñanza es un claro ejemplo de este hecho.

En particular, la enseñanza de lenguas siempre se ha caracterizado por la utilización de cualquier tecnología que mejorara, en el sentido de que fuera, el proceso de adquisición de una lengua. Así hemos utilizado libros, diccionarios, periódicos, pizarras, casetes, proyectores, televisión, vídeo... y al poco tiempo de aparecer los ordenadores se incorporaron en las clases de lengua.

\section{El aprendizaje de lenguas asistido por ordenador (ALAO)}

La disciplina que se ocupa de este campo de investigación es conocida por la sigla CALL, Computer Assisted Language Learning o el equivalente en nuestro contexto ALAO, Aprendizaje de lenguas asistido por ordenador. Estas siglas conviven con otras que señalan alguna vertiente de las múltiples que tiene este ámbito científico. Así encontramos NBLT, Network-Based Language Teaching o Enseñanza de lenguas basada en la web, WELL, WebEnhanced Language Learning o Aprendizaje de idiomas mejorado en la web , ICALL, Intelligent Computer Assisted Language Learning o Aprendizaje de lenguas asistido por computadora inteligente, MALL, Mobile Assisted Language Learning o Aprendizaje de lenguas asisitido por dispositivos móviles, etc.

En esta investigación utilizamos la sigla ALAO por considerarla la más genérica y porque da cabida a todas y cada una de las múltiples modalidades que se basan o usan la informática para el aprendizaje de lenguas.

El ALAO se inició durante los años 60 del siglo pasado, con los primeros ordenadores, pero no fue hasta los años 80 cuando se extendió. Aunque en la década siguiente, en los 90 , con la aparición del CD-ROM fue cuando se produjo una verdadera expansión. Posteriormente, el surgimiento de Internet, la web y los avances tecnológicos constantes han superado muchas de las barreras y propulsado el aprendizaje lingüístico como no había sido imaginado antes. Por su parte, el estudio ALAO alcanza tanto los aspectos de análisis previos para el desarrollo de materiales, como la creación, la implementación y la evaluación de los resultados obtenidos. Es decir, aglutina todos los aspectos susceptibles de estudio del aprendizaje de lenguas asistido por ordenador.

Más recientemente, con los recursos de la web 2.0, junto a los dispositivos móviles, se están ampliando las posibilidades del aprendizaje lingüístico a través de la red. La mayoría de los recursos de ALAO se desarrollan a través de las aplicaciones de la web 2.0 y para utilizarse en plataformas diversas, en contraste con las etapas anteriores en que predominaba el uso del ordenador local. Si uno de los mayores déficits de los materiales para la adquisición de lenguas a través de la tecnología era la imposibilidad de interactuar de forma significativa

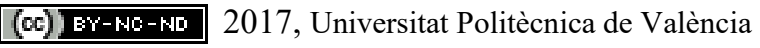

Congreso IN-RED (2017) 
con otro hablante, ahora ha desaparecido. Contamos con numerosas y variadas herramientas de comunicación, de expresión y de colaboración. Se ha flexibilizado la modalidad de acceso y se han diversificado los formatos. Lo cual ha provocado la proliferación de materiales y cursos para el aprendizaje de lenguas.

\section{El aprendizaje de español como lengua extranjera a través de la web}

Actualmente existen numerosísimos recursos informáticos para el auto aprendizaje de español como lengua extranjera (ELE) puesto que la demanda social es cada vez mayor, tanto para recursos web como para dispositivos móviles, que dotan al usuario de libertad y comodidad. Sin embargo, esta oferta no es tan completa como cabría esperar, como veremos, la mayor parte de los recursos web que existen actualmente no tratan la complejidad que requiere la adquisición de la competencia comunicativa en su totalidad (Cruz, 2002, 2014).

Hemos analizado los 50 portales web para el aprendizaje del ELE mejor posicionados en Google para comprobar qué tipo de aprendizaje proporcionan. Así, hemos podido constatar que los recursos pertenecientes a instituciones públicas conforman solo tres del total analizado, estos son: AVE, Radio Fle y Aprender ELE-UPV. En su totalidad son recursos que denotan un trabajo muy cuidado de la enseñanza de español, aunque no llegan a trabajar la competencia comunicativa oral, que es la que nos ocupa en esta investigación. El aprendiz puede escuchar ejemplos de uso de la lengua, como por ejemplo en Radio FLE, pero no puede llegar a interaccionar con otros usuarios.

En segundo lugar, de los recursos analizados, el 19\% son gestionados por docentes de ELE. En este grupo sobresalen algunos como Blog para aprender español, A vueltas con E/LE o Charla en español, entre otros. Se observa que se centran en los problemas que suelen tener los aprendices de español focalizándose en temas gramaticales como la formación verbal.

En tercer lugar, los sitios web analizados pertenecen mayoritariamente a empresas privadas, en este grupo encontramos dos subtipos, por un lado, pequeñas empresas o academias de idiomas que formalizan una web que complementa la enseñanza en el aula como Lingolia. Y por otro, grandes empresas privadas que crean recursos web y para dispositivos móviles para el auto aprendizaje de idiomas y no solo español, este es el caso de Duolingo, Rosetta Stone o Fluencia. Estos recursos comienzan a trabajar la competencia comunicativa oral mediante la repetición de frases o palabras, no obstante, no podemos entender que este trabajo sea completo, puesto que el estudiante aprende a pronunciar palabras y tonos. No debemos olvidar que la lengua es un instrumento de comunicación (Albelda \& Fernández, 2006) y el fin del aprendizaje de una lengua es adquirir la capacidad de comunicarse usándola.

En conjunto, los recursos analizados trabajan la competencia comunicativa escrita pero limitan la práctica de la lengua oral a la repetición y la pronunciación de frases. 


\section{Desarrollo de la innovación}

Como hemos podido comprobar en los apartados anteriores, los recursos web de auto aprendizaje en la web están centrados en aspectos gramaticales y estructuralistas, en el aprendizaje por repetición de estructuras sintácticas en el plano comunicativo de la lengua. De esta manera, y en base a este análisis, hemos decicido crear un recurso de auto aprendizaje de español como lengua extranjera con las aportaciones tecnológicas del procesamiento del habla (PLN) y aspectos concretos tecnológicos que se necesitan para un recurso de estas características.

$\mathrm{R} / \mathrm{ele} / \mathrm{CCO}$ es un recurso de auto aprendizaje de español como lengua extranjera que tiene como fundamento el educativo los aspectos clave de una conversación en español, y los rasgos que la caracterizan culturalmente y que hacen que su aprendizaje sea complicado. Este es un recurso innovador ya que fomenta el aprendizaje de español con los aspectos más modernos de la ciencias del habla en este idioma mejorando la competencia comunicativa a estudiantes que no tienen a su alcence personas con quien mejorar la competencia comunicativa. Debemos entender que la competencia conversacional es un aspecto fundamental en el aprendizaje de cualquier idioma, no solo en español, por lo que es necesario cada vez con más frecuencia crear herramientas que mejoren estos aspectos. Existen herramientas como Duolingo o Rosetta Stone (entre otras) que comienzan a utilizar las ciencias del habla para el aprendizaje de idiomas mediante ejercicios con base estructuralista. La repetición de frases o sintagmas no es un varemo de mejora de la competencia comunicativa oral ni de la competencia conversacional. Por este motivo, R/ele/CCO es una herramienta de innovación, parte de conversaciones cortas que se van complicando a medida que el alumno completa una unidad didáctica. Y así, partimos del planteamiento de que el estudiante es capaz de mejorar los aspectos intrínsecos de la competencia conversacional mejorando tanto en aspectos de oralidad como gramaticales o de vocabulario. Es decir, el plantemiento que subyace de R/ele/CCO es que mediante la conversación en ese idioma el alumno mejora otros aspectos de la lengua que están plenamente relacionados con la comunicación.

Nuestro recurso actualmente cuenta con los niveles A1 y A2 del Marco Común Europeo de Referencias para las Lenguas, cada nivel está dividido en diferentes unidades didácticas en la que el alumno a parte de conversar con el programa, aprende vocabulario y estructuras sintácticas y gramaticales, todo ello, sin olvidar el plano comunicativo, ya que lo hace directamente, conversando.

La pregunta que surge es, si es posible realizar este tipo de recurso por qué no existen en el plano actual. Para ello debemos de entender que, el PLN es un ciencia tecnológica en constante evolución, hay aspectos que aún están en desarrollo, sobre todo, en relación con el español, lengua menos desarrollada que otras como el inglés. En un primer momento, creamos R/ele/CCO siguiendo las directrices de Sphinx ${ }^{1}$ mediante el lenguaje informático

${ }^{1}$ Tutorial creado por los expertos de la Universidad de Carnegie Mellon (Pensilvania)

(cc) BY-NC-ND 2017, Universitat Politècnica de València

Congreso IN-RED (2017) 
Java. Entorno a esto, nos encontramos con problemas, el principal, que el ordenador no era capaz de entender los sonidos de personas no experimentadas con el idioma, es decir, nuestro futuros estudiantes. El programa acudia al corpus intrínseco en él y limitado, y no encontraba las coincidencias necesarias. Llisterri (2003: 6) evalúa los problemas en las pruebas de sistemas de conversión de texto en habla y viceversa en tres parámetros como la inteligibilidad, la comprensión y la calidad global que se ve mermada por los dos anteriores. Los dos primeros aspectos se veían marcados en nuestras primeras pruebas con el recurso.

Por ello, comenzamos a navegar en la red y encontramos un procesador de habla a texto con mayor corpus y menos tiempo de respuesta, dicho procesador es IBMWatson ${ }^{2}$. Watson supone una mejora para nuestro recurso, porque no cuenta con un corpus, es decir, es un software inteligente, que aprende con cada pregunta y respuesta, por esto, es más comodo trabajar con Watson que con el medio anterior. Watson nos permite trabajar el procesamiento del lenguaje natural y el procesamiento de habla a texto desde una perspectiva más inteligente, aprendiendo cada día más.

Pues bien, ahora connocemos todo lo que puede hacer la informática por el aprendizaje de segundas lenguas, hemos de atender a aspectos pedagógicos necesarios para la creación de un recurso web de auto aprendizaje de segundas lenguas. Para la comodidad de estudiante, necesitamos las siguientes características:

1. La creación de una vía de comunicación bidireccional entre la web y el usuario, es decir, un apartado centrado para que el aprendiz pueda consultar dudas de cualquier tipo con el recurso con la mayor facilidad.

2. El registro del trabajo del alumno en el recurso es fundamental, mediante un registro inicial el estudiante podrá acceder a su trabajo en el mismo punto en el que se quedó en la ocasión anterior.

3. En cuanto a los contenido, pensamos que nuestro recurso debe fundamentalmente, presentar una estructuración, secuenciación, flexibilidad y presentación de los contenidos a trabajar. Es primordial, dotar al alumno de las pautas necesarias para elegir, en la medida de lo posible, los puntos que quiere estudiar.

4. R/ele/CCO está pensado para responder al alumno con una retroalimentación formativa, intentando dar al aprendiz la solución a su error, haciendo del error algo en lo que aprender.

5. Otro de los aspectos fundamentales de $\mathrm{R} / \mathrm{ele} / \mathrm{CCO}$ es, la base de las conversaciones auténticas y naturales. Los ejercicios de nuestro recurso son las conversaciones del estudiante con el ordenador, estas conversaciones son lo más real posible, desde presentaciones hasta conversaciones que van complicándose en base a la dificultad adquirida en torno a los niveles del MCERL. Con este aspecto, ligamos el aspecto de conciencia lingüística, necesario para un correcto auto aprendizaje de la lengua.

$\mathrm{R} / \mathrm{ele} / \mathrm{CCO}$ tiene una estrucutra joven que intenta transmitir un ambiente de confianza en el proceso de auto aprendizaje de español. Para ello, hemos utilizado imágenes libres de

${ }^{2}$ http://www-03.ibm.com/marketing/mx/watson/watson-for-a-smarter-planet/index.html 
derechos de autor que focalizan desde el primer momento el proceso de auto aprendizaje de la conversación en el recurso.

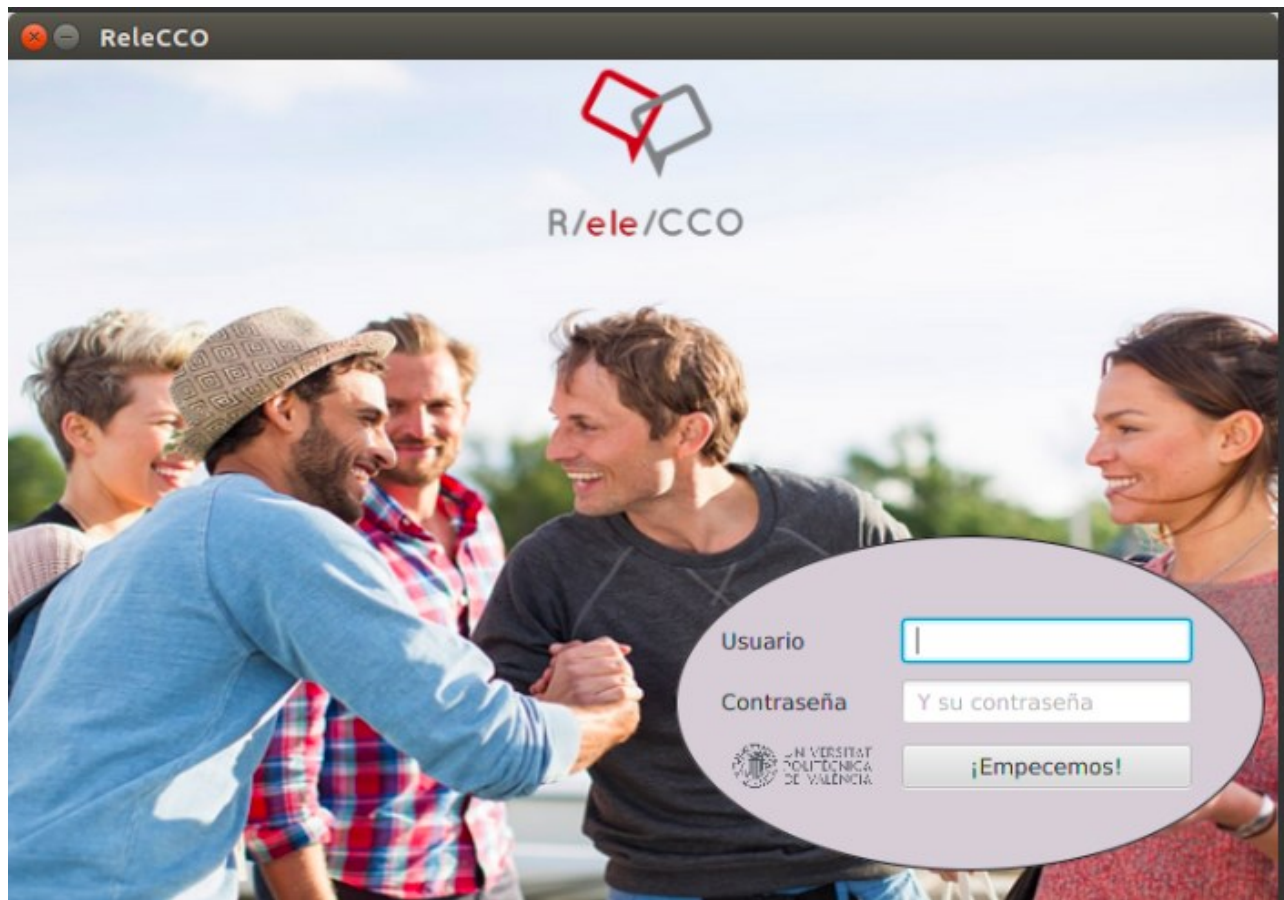

Imagen 1: R/ele/CCO

En pantallas posteriores el alumno tiene en su alcence diferentes aspectos del programa por los que navegar como: características, contacto y niveles de aprendizaje con los temas a tratar en cada unidad, dando la libertad al estudiante de elegir el tema que quiera trabajar. Pensamos que es necesario dotar al estudiante de libertad de elección sin crear una ruta prediseñada de aprendizaje.

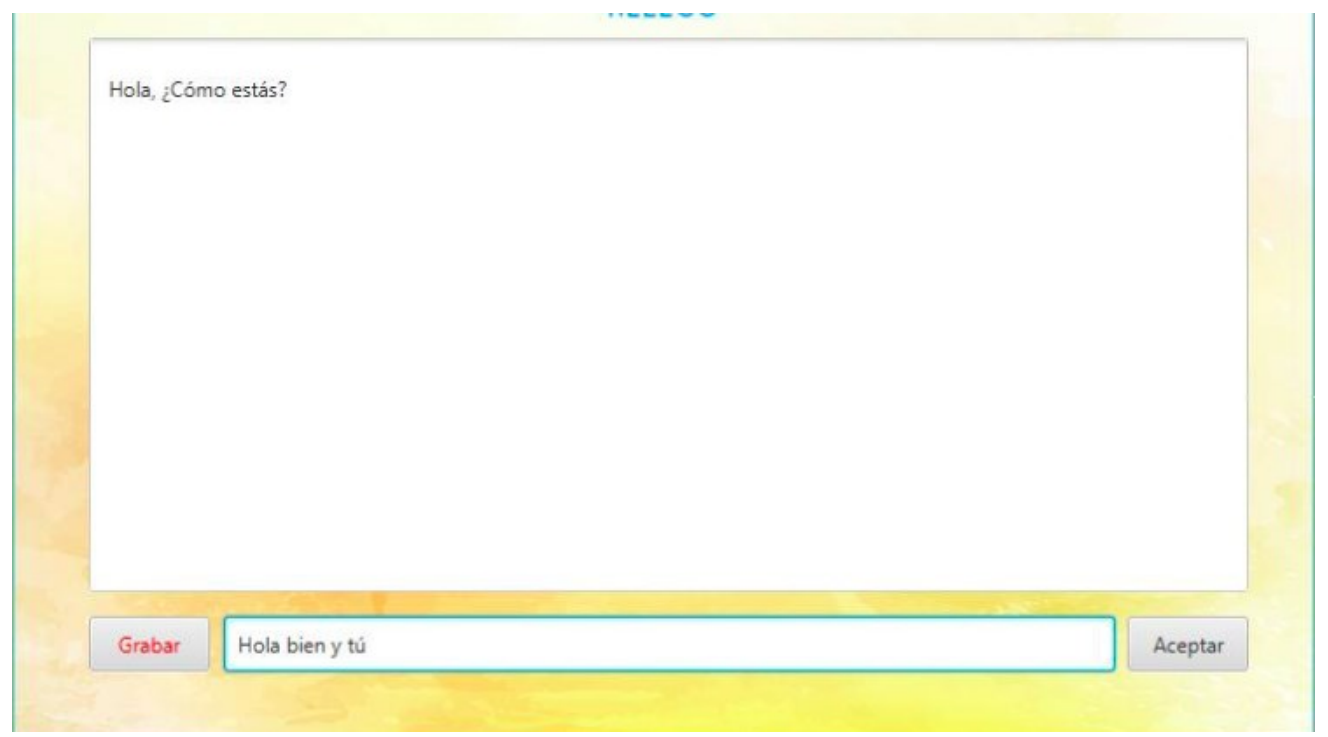

(cc) EY-NC-ND 2017, Universitat Politècnica de València

Congreso IN-RED (2017) 
Imagen 2: R/ele/CCO

Como podemos observar en esta pantalla, la conversación entre ordenador y estudiante funciona de la siguiente manera: el ordenador es el primero en comenzar con el turno de habla y el estudiante (con un micrófono) efecturá el segundo turno de habla y cuando esté conforme con lo que ha dicho enviará el mensaje, creando así una conversación en tiempo real con la que mejorar rasgos comunicativos en español.

No obstante, no podemos ofrecer resultados sobre la efectividad y la opinión de los usuarios porque estamos a la espera de sacar el recurso tanto en versión web como móvil.

Para concluir, pensamos que esta web es capaz de cubrir las necesidades de los estudiantes de español como lengua extranjera para con la competencia comunicativa oral en dicha lengua, utilizando las innovaciones tecnológicas necesarias para llevar a cabo el proceso de auto aprendizaje del español como segunda lengua.

\section{Conclusiones}

A lo largo de este artículo, hemos visto que tanto las tecnología del habla como las tecnologías de la comunicación han fundamentado los cambios necesarios para el auto aprendizaje de lenguas asisitido por ordenador y actualmente, también por dispositivos móviles. Asimismo, hemos visto que los recursos de auto aprendizaje de español carecen de las herramientas necesarias para el trabajo de la competencia comunicativa oral, fundamentando la enseñanza en otros aspectos y vinculando esta competencia a la repetición de estructuras sintácticas.

Por eso, $\mathrm{R} /$ ele/CCO supone un cambio en el concepto de auto aprendizaje de la competencia comunicativa oral en contrapunto a los recursos de auto aprendizaje de español como lengua extranjera. Atendiendo al panorama actual, comprobamos que es necesario que un recurso web se fundamente en torno a las novedades y ventajas que la tecnología nos brinda para poder hacer realidad las necesidades de aprendizaje del estudiante de español como lengua extranjera.

\section{Referencias}

ALBELDA, M., \& FERNÁNDEZ, M.J. (2006). La enseñanza de los registros lingüísticos en E/LE. Una aplicación a la conversación coloquial. Revista de didáctica: MarcoELE, 3, 1-31

CRUZ, M. (2002). Enseñar español en la era de Internet. Las www y la enseñanza del español como lengua extranjera. Barcelona, España: Editorial Octaédro.

CRUZ, M. (2014). Veinte años de tecnologías y ELE. Reflexiones en torno a la enseñanza de español como lengua extranjera en la era de Internet. Revista de didáctica: Marco ELE, 19, 1-18.

IBMWATSON. Watson para un mundo más inteligente. <http://www03.ibm.com/marketing/mx/watson/watson-for-a-smarter-planet/index.html> [Consulta $: 2$ de abril de 2016] 
Llisterri, J. (2003). "Las tecnología del habla : entre la ingeniería y la lingüística" En Actas del I Congreso Internacional La ciencia ante el públio. Cultura humanística y desarrollo tecnológico. Salamanca : Instituto Universitario de Estudios de la Ciencia y la Tecnología.

MCERL (2002). Marco Común Europeo de Referencia de Lenguas. Madrid, España: Instituto Cervantes.

(cc) EY-NC-ND 2017, Universitat Politècnica de València 


\title{
Óptimo aprovechamiento de las sesiones de laboratorio
}

\author{
Jennifer Gonzalez Ausejo ${ }^{a}$, Raquel Oliver Valls ${ }^{a}$, José Gámez Pérez ${ }^{a}$ y Luís Cabedo \\ Mas $^{a}$
} a Departamento de Sistemas Industriales y Diseño, Universitat Jaume I, ausejo@uji.es, roliver@uji.es,
gamez@uji.es y lcabedo@uji.es.

\begin{abstract}
This paper shows the teaching experience applied to the laboratory sessions of the subject of Science and Technology of Materials that is taught in the second year of the degrees of Electrical Engineering, Mechanical Engineering and Industrial Technologies Engineering in the Universitat Jaume I. The purpose of this experience is to facilitate the learning of the basic theoretical knowledge related to laboratory practice to develop and to make the students aware of the importance of preparing the practice prior to its development. This has been done by developing and using means or transmission formats of the contents to know before the practice which are more attractive and visual than the existing practice script.
\end{abstract}

Keywords: previous knowledge, visual, evaluation, methodology

\begin{abstract}
Resumen
En este trabajo se muestra la experiencia docente aplicada a las sesiones de laboratorio de la asignatura de Ciencia y Tecnología de Materiales que se imparte en segundo curso de los grados de Ingeniería Eléctrica, Mecánica y en Tecnologías Industriales en la Universitat Jaume I. El propósito de esta experiencia es facilitar el aprendizaje de los conocimientos teóricos básicos relacionados con la práctica de laboratorio a desarrollar y sensibilizar a los alumnos sobre la importancia de preparar la práctica previamente a su desarrollo. Esto se ha realizado mediante el desarrollo y uso de medios o formatos de trasmisión de los contenidos a conocer previamente a la práctica que sean más atractivos y visuales que el guion de prácticas existente actualmente.
\end{abstract}

Palabras clave: conocimientos previos, visual, evaluación, metodología

\section{Introducción}

El planteamiento de clases prácticas y de laboratorio en cualquier asignatura permite reforzar los conocimientos expuestos en las clases teóricas relacionando los conceptos teóricos con la experiencia. Por lo que si las sesiones de laboratorio o prácticas se aprovechan adecuadamente son una forma rápida y eficiente de aprender. Sin embargo, el aprovechamiento de las practicas se puede ver limitado por el desconocimiento de los fundamentos teóricos implicados en la misma. 
La gran evolución e implementación de las tecnologías informáticas de la comunicación (TIC) en los últimos años ha permitido avanzar y modificar las metodologías docentes, adaptándolas a la evolución de los sistemas de comunicación actuales más llamativos y atractivos para las nuevas generaciones (Salinas, 2004). Esta nueva generación de alumnos utiliza con total soltura las nuevas tecnologías como herramienta útil y eficiente de estudio.

Debido a este contexto, las metodologías docentes deben ser adaptadas a estos nuevos escenarios de aprendizaje utilizando las TIC como herramienta docente para la trasmisión de los conocimientos, a la vez que se capta su atención en mayor medida que lo que lo hace un simple texto.

\section{Objetivos}

El objetivo principal de este trabajo es facilitar a los alumnos el aprendizaje de los conceptos teóricos que se van a aplicar durante el desarrollo de las prácticas de laboratorio de la asignatura de Ciencia y Tecnología de Materiales por medio de la modificación de la metodología docente utilizada, para el óptimo aprovechamiento de la práctica.

Concretamente los objetivos planteados con esta metodología son:

- Facilitar el aprendizaje de los conocimientos teóricos básicos relacionados con la práctica de laboratorio a desarrollar.

- Evaluar los conocimientos previos de los alumnos antes de la manipulación de los equipos en el laboratorio.

- Concienciar a los alumnos de la importancia de los contenidos teóricos previos con anterioridad al desarrollo de la práctica.

\section{Desarrollo de la innovación}

La asignatura de Ciencia y Tecnología de Materiales, que se imparte en segundo curso de los grados de Ingeniería Eléctrica, Mecánica y en Tecnologías Industriales en la Universitat Jaume I, es una asignatura troncal que consta 4 créditos de enseñanza teórica y 1 crédito de enseñanza práctica.

Las enseñanzas prácticas consisten en clases de laboratorio donde los alumnos utilizan los equipos y técnicas de evaluación de las propiedades de los materiales para reforzar y/o complementar los contenidos expuestos en las clases teóricas.

Para el óptimo aprovechamiento de las sesiones prácticas se requiere del conocimiento de los fundamentos teóricos concretos implicados en la práctica, el funcionamiento y el fundamento de los equipos e instrumentos de medida, etc. a utilizar durante ésta. Estos contenidos mínimos han sido redactados en un guion de prácticas.

Sin embargo, actualmente el alumnado no prepara este material con anterioridad a la asistencia al aula. Ello ha conducido a que el profesor/a realice una introducción teórica como una clase magistral en el laboratorio con el fin que el alumnado conozca los

(c)) BY-NC-ND 2017, Universitat Politècnica de València

Congreso IN-RED (2017) 
fundamentos teóricos mínimos necesarios para el aprovechamiento de la práctica (resumen de la metodología actual mostrada en la Tabla 1). Los resultados de la aplicación de esta metodología durante diversos cursos muestran que no hay un óptimo aprovechamiento de las sesiones de prácticas.

Tabla. 1: Comparativa de la metodología docente aplicada en cursos anteriores y la metodología propuesta

\begin{tabular}{|c|c|c|c|}
\hline & \multicolumn{2}{|c|}{ Actualmente } & \multirow{2}{*}{ Propuesta } \\
\hline & Ideal & Realidad & \\
\hline $\begin{array}{l}\text { Material: conceptos } \\
\text { teóricos que se van a } \\
\text { aplicar durante el } \\
\text { desarrollo de las } \\
\text { prácticas }\end{array}$ & \multicolumn{2}{|c|}{ Guion de prácticas: texto } & $\begin{array}{c}\text { Video/audio/ } \\
\text { presentación power } \\
\text { point }\end{array}$ \\
\hline $\begin{array}{c}\text { En casa: previamente } \\
\text { a la práctica }\end{array}$ & $\begin{array}{l}\text { Estudio del guion } \\
\text { de prácticas }\end{array}$ & - & $\begin{array}{c}\text { Estudio del nuevo } \\
\text { material } \\
\text { desarrollado }\end{array}$ \\
\hline \multirow{2}{*}{$\begin{array}{l}\text { En el aula/ } \\
\text { laboratorio }\end{array}$} & Puesta en común & Clase magistral & $\begin{array}{c}\text { Tests de } \\
\text { autoevaluación }\end{array}$ \\
\hline & \multicolumn{3}{|c|}{ Desarrollo práctica } \\
\hline $\begin{array}{c}\text { En casa: } \\
\text { posteriormente a la } \\
\text { práctica }\end{array}$ & \multicolumn{3}{|c|}{ Redacción memoria de práctica } \\
\hline
\end{tabular}

Tabla. 2: Propuesta de actuación y objetivos de la metodología planteada.

\section{\begin{tabular}{l|l} 
Propuesta de actuación & Objetivo
\end{tabular}}

Preparación del material nuevo $\quad$ Facilitar el aprendizaje de los conocimientos teóricos desarrollado: video/audio/ presentación power point. básicos relacionados con la práctica de laboratorio a desarrollar.

Evaluar los conocimientos previos de los alumnos antes de la manipulación de los equipos en el laboratorio.

Tests de autoevaluación Concienciar a los alumnos de la importancia de los contenidos teóricos previos con anterioridad al desarrollo de la práctica.

Por ello, en este trabajo se plantea la modificación de la metodología docente utilizada para un óptimo aprovechamiento de la práctica.

Para lograr los objetivos previamente expuestos, en este proyecto se han realizado distintos cambios en la metodología (ver Tabla 1 y 2):

- Por un lado, se han desarrollado materiales docentes utilizando distintos formatos o medios de difusión para su estudios previamente a la práctica en sustitución del guion de prácticas y la explicación magistral al inicio de la sesión de prácticas.

- Además se han realizado tests de autoevaluación en el aula para garantizar que se lleva a cabo la preparación previa de la práctica y evaluar el grado de 
conocimiento de los contenidos mínimos para la manipulación de los equipos de laboratorio.

Concretamente los contenidos teóricos, procedimientos a desarrollar durante la práctica, normas de laboratorio, etc., han sido expuestos por medio de audios, presentaciones de power point y vídeos.

Para cada práctica se ha desarrollado el material con un formato distinto, adaptándose a éste en función del contenido concreto de la práctica a desarrollar. El fin último es determinar si los tres formatos propuestos son útiles y qué ventajas e inconvenientes plantean para que los alumnos, con estos materiales, puedan revisar y conocer de manera más sencilla y atractiva los contenidos de la sesión de prácticas.

Los materiales desarrollados están disponibles de manera permanente en la plataforma Moodle (Aula Virtual), de modo que los alumnos pueden consultarlos tantas veces como lo crean conveniente para afianzar los conocimientos y elaborar la memoria de prácticas con mayor grado de aprendizaje real o efectivo.

Los resultados de los tests son tenidos en cuenta en la nota final del laboratorio.

\section{Resultados}

Para evaluar el impacto de la propuesta impulsada en este proyecto sobre el aprovechamiento de las sesiones de prácticas por parte de los alumnos, se ha realizado una amplia encuesta al finalizar la asignatura.

Se ha tenido en cuenta la visión crítica de los alumnos a través de sus opiniones para analizar la propuesta y así poder mejorar la efectividad de la práctica de laboratorio mediante este tipo de material en cursos sucesivos.

Adicionalmente, se ha realizado un breve estudio estadístico de las calificaciones de los alumnos en cursos pasados y en el presente curso, habiendo sido aplicada la metodología expuesta en este proyecto.

\subsection{Implicación de los alumnos}

Los alumnos desde el primer momento han mostrado interés por la metodología desarrollada, no han puesto objeción en la realización de los test de evaluación de los conocimientos previos a la realización de la práctica.

Los resultados de los test muestran que los alumnos han preparado concienzudamente la práctica ya que el $89 \%$ de los alumnos ha realizado al menos el $75 \%$ del cuestionario bien. Además, la nota media de las memorias de prácticas se ha incrementado, con respecto a otros grupos de años anteriores, realizando las mismas prácticas.

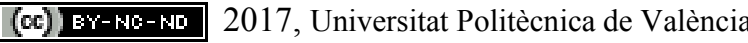

Congreso IN-RED (2017) 


\subsection{Valoración de las encuestas}

La Tabla 3 muestra la encuesta de satisfacción del estudiantado sobre la metodología aplicada. Todas las cuestiones se han valorado en una escala Likert 5, donde 1 es "no adecuado o totalmente en desacuerdo" y 5 "adecuado o totalmente de acuerdo". Además, se han realizado cuestiones de respuesta si/no para evaluar el cambio en la concepción de la importancia de la preparación de la práctica previamente a su desarrollo. También se ha preguntado a los alumnos sobre si esta metodología debería implementarse en otras asignaturas y/o cursos sucesivos. Con el fin de conocer más información se han realizado preguntas abiertas en el cuestionario. Los resultados de las encuestas (valoración media/ contestación si/no) se muestran junto a las cuestiones en la Tabla 3.

El orden de las cuestiones ha sido definido meticulosamente para favorecer la reflexión del alumno durante el desarrollo del mismo.

Todas las cuestiones obtuvieron puntuaciones superiores al 4 como puede ser observado en la Tabla 3.

Tabla. 3: Cuestionario de valoración de la metodología aplicada

\begin{tabular}{|c|c|}
\hline Cuestión & $\begin{array}{l}\text { Valoración media } \\
\quad(\text { de } 1 \text { a } 5) \\
\end{array}$ \\
\hline $\begin{array}{l}\text { 1. Valora si los materiales utilizados para exponer el contenido } \\
\text { teórico de la práctica } X \text { te han parecido adecuados. }\end{array}$ & $\begin{array}{c}\text { P1: 4,44 (audio) } \\
\text { P2: 4,31(video) } \\
\text { P3: 4,06 (power } \\
\text { point) } \\
\text { P4: 4,19 (vídeo) }\end{array}$ \\
\hline $\begin{array}{l}\text { 2. Los materiales utilizados para la exposición del contenido teórico } \\
\text { de la práctica tienen una duración adecuada }\end{array}$ & 4,06 \\
\hline $\begin{array}{l}\text { 3. El formato de los materiales proporcionados han hecho más } \\
\text { ameno el estudio de la práctica con respecto a una guía escrita de } \\
\text { la memoria }\end{array}$ & 4,44 \\
\hline $\begin{array}{l}\text { 4. Conocer los contenidos teóricos básicos, objetivos, procedimiento } \\
\text { a desarrollar en las prácticas, etc., previamente al desarrollo de la } \\
\text { práctica favorece el entendimiento de las prácticas }\end{array}$ & 4,81 \\
\hline $\begin{array}{l}\text { 5. La realización del test previamente al desarrollo de la práctica } \\
\text { permite hacer una autoevaluación de los conocimientos } \\
\text { adquiridos. }\end{array}$ & 4,31 \\
\hline $\begin{array}{l}\text { 6. La realización del test y su resolución al inicio de la sesión de } \\
\text { prácticas me ha permitido completar el conocimiento necesario } \\
\text { para la correcta comprensión de la práctica. }\end{array}$ & 4,38 \\
\hline $\begin{array}{l}\text { 7. Conocer y evaluar los conceptos tratados en la práctica } \\
\text { previamente al desarrollo de la memoria ha favorecido unos } \\
\text { mejores resultados finales en la memoria de prácticas (nota de la } \\
\text { memoria). }\end{array}$ & 4,50 \\
\hline $\begin{array}{l}\text { 8. Disponer del material explicativo de la práctica ha facilitado la } \\
\text { redacción de la memoria de prácticas. }\end{array}$ & 4,75 \\
\hline $\begin{array}{l}\text { 9. Antes de realizar esta asignatura, ¿creías necesario conocer el } \\
\text { contenido teórico básico, objetivos, procedimiento a desarrollar } \\
\text { en las prácticas, etc., antes de iniciar la práctica? }\end{array}$ & $\begin{array}{l}\text { Si: } 50 \% \\
\text { No: } 50 \%\end{array}$ \\
\hline
\end{tabular}




\begin{tabular}{|c|c|}
\hline Cuestión & $\begin{array}{l}\text { Valoración media } \\
\text { (de } 1 \text { a } 5 \text { ) }\end{array}$ \\
\hline $\begin{array}{l}\text { 10. Contestación No en la cuestión anterior: } \\
\text { ¿Tras realizar las prácticas aplicando esta metodología, has } \\
\text { cambiado de opinión? }\end{array}$ & $\begin{array}{c}\text { Si: } 87,5 \% \\
\text { No: } 12,5 \%\end{array}$ \\
\hline $\begin{array}{l}\text { 11. Contestación Si en la cuestión anterior: } \\
\text { ¿Ha servido la metodología utilizada en clase para que creas } \\
\text { aún más necesario conocer el contenido teórico básico, } \\
\text { objetivos procedimiento a desarrollar en las prácticas, etc., antes } \\
\text { de iniciar la práctica? }\end{array}$ & $\begin{array}{l}\text { Si: } 87,5 \% \\
\text { No: } 12,5 \%\end{array}$ \\
\hline $\begin{array}{l}\text { 12. Valora el esfuerzo extra que te ha supuesto preparar la práctica } \\
\text { antes de la sesión. }\end{array}$ & 3,13 \\
\hline $\begin{array}{l}\text { 13. En general, valora el grado de satisfacción con la metodología } \\
\text { aplicada. }\end{array}$ & 4,56 \\
\hline $\begin{array}{l}\text { 14. ¿Te gustaría que se aplicase esta metodología en las prácticas de } \\
\text { otras asignaturas? }\end{array}$ & $\begin{array}{l}\text { Si: } 87,5 \% \\
\text { No: } 12,5 \%\end{array}$ \\
\hline \multicolumn{2}{|l|}{ Preguntas abiertas } \\
\hline \multicolumn{2}{|c|}{$\begin{array}{l}\text { En caso que los materiales no te pareciesen adecuados o no te ayudasen al estudio puedes } \\
\text { dar las razones o exponer alternativas que te parezcan más idóneas. }\end{array}$} \\
\hline \multicolumn{2}{|c|}{$\begin{array}{c}\text { Finalmente, ¿qué ventajas consideras que ha supuesto esta metodología en tu proceso de } \\
\text { aprendizaje? }\end{array}$} \\
\hline \multicolumn{2}{|c|}{ Señala aspectos qué cambiarías de la metodología aplicada. } \\
\hline
\end{tabular}

De acuerdo con las valoraciones de los alumnos todos los formatos utilizados para la trasmisión de los contenidos de la práctica son adecuados y han sido valorados positivamente (cuestión 1). A partir de los comentarios de los alumnos (preguntas abiertas) se extrae que los vídeos son los medios de exposición de los contenidos teóricos más adecuados para el contenido específico de esta asignatura: "los materiales que incluían vídeo los recordaba más fácilmente, además de ser más ameno de estudiar”. Sin embargo, los audios son valorados por los alumnos como un material de estudio que requiere de una mayor concentración para la comprensión de los contenidos expuestos, además que supone una mayor dificultad el hecho de mantener la concentración durante toda la duración del audio en ausencia de imagen.

En cuanto a la duración de los audios/ vídeos (cuestión 2), la utilización de entre 10 y 13 min se ha valorado positivamente.

Otras conclusiones extraídas de la encuesta son que el formato de los materiales desarrollados (cuestión 3), audios, videos y presentaciones power point, captan mayor atención que un simple texto (guion de prácticas convencional) lo que hace más ameno el estudio de la práctica.

Los alumnos han tomado consciencia de la necesidad y utilidad de conocer los contenidos teóricos básicos, objetivos, procedimiento a desarrollar en las prácticas, etc., con anterioridad al desarrollo de la práctica, como se deriva de la alta puntuación de la cuestión 4 y de las preguntas directas 9 y 10 o 11 . De estas contestaciones se deduce que, antes de la experiencia desarrollada, el $50 \%$ de los alumnos no creían necesario conocer el contenido teórico básico, objetivos, procedimiento a desarrollar en las prácticas, etc., con antelación a

(c)) BY-NC-ND 2017, Universitat Politècnica de València 
la práctica. Sin embargo, el $87.5 \%$ de estos alumnos han cambiado su opinión tras la experiencia docente realizada. Además, aquellos alumnos que antes de la experiencia creían necesaria la preparación previa de la práctica, tras ésta el $87.5 \%$ ha reforzado su posición. De los comentarios de los alumnos, se extrae que el desarrollo de la asignatura, trabajando los contenidos teóricos previos al desarrollo de la práctica, favorece el entendimiento de las mismas.

En cuanto a la evaluación por medio de un test de los conocimientos adquiridos previamente al desarrollo de la práctica mediante los materiales desarrollados (cuestiones 5 a 8), los alumnos han valorado positivamente esta estrategia como método de autoevaluación. Ya que mediante el test han podido comprobar qué conocimientos de los expuestos en el material de estudio han sido adquiridos y cuáles requerían de un mayor refuerzo. Esto les ha permitido la correcta comprensión de la práctica. Asimismo, la realización de la evaluación previa al desarrollo de la práctica ha favorecido unos mejores resultados finales en la memoria final, ya que los errores conceptuales evidenciados en cursos anteriores no han sido observados en este caso.

Los alumnos también han expuesto que el hecho de disponer de los materiales explicativos de la práctica para la redacción de la memoria ha facilitado la tarea de redacción, análisis y discusión de los resultados experimentales.

Para finalizar la encuesta, se han realizado unas preguntas de valoración global de la metodología aplicada (cuestiones 12 a 14), obteniéndose que el grado de satisfacción global es del 4.56 (cuestión 13).

Se les ha instado a que aportasen puntos de mejora y ventajas que supone esta metodología. Estos son algunos de los comentarios sobre las ventajas / valoraciones de la experiencia que aporta la metodología utilizada frente a la metodología anterior:

- Iba muy preparado a las prácticas, sabiendo lo que iba a hacer y qué iba a pasar. Ayudaba mucho a realizar la memoria. En lo que más lo he notado es en saber qué estaba haciendo y no estar paseándome por el laboratorio sin más.

- Llevar los conceptos claros al laboratorio y aclarar detalles solamente durante la sesión.

- Me ha permitido obtener más conocimientos durante el laboratorio, mejorando así mi comprensión global de la asignatura.

- La facilidad de entender los procesos que se van a llevar a cabo y comprender mejor la práctica en general.

- Considero que he aprendido mucho más con esta metodología que con lo que normalmente hacemos en cualquier otra clase de laboratorio (guion de la práctica y breve explicación del profesor). De esta manera sabemos ya antes de empezar la sesión el procedimiento general que vamos a seguir, así como lo que se pretende con ello, de forma que el tiempo de laboratorio se optimiza y el/la profesor/a puede remarcar aquello que es de más importancia en lugar de tener que explicar todo de forma general.

- Óptimo aprovechamiento de las sesiones de laboratorio.

2017, Universitat Politècnica de València Congreso In-Red (2017) 
En cuanto a las sugerencias planteadas por los alumnos para la mejora de la experiencia en cursos sucesivos, los estudiantes han comentado:

- Intentaría hacer más simplificados los PowerPoints, no mucho más porque sino no quedarían claros los conceptos. Pero en ocasiones se hacía muy pesado, sobretodo el escuchar el audio.

- No cambiaría nada (repetida varias veces).

Por último, se ha preguntado si les gustaría que se aplicase esta metodología en las prácticas de otras asignaturas (cuestión 14), obteniéndose que el 87.5\% de los alumnos apoyan esta iniciativa, aún suponiéndoles un esfuerzo extra la preparación de la práctica, valorado con un 3,13 sobre 5 (cuestión 12).

\subsection{Estudio estadístico de las calificaciones de los alumnos}

Con el fin de aportar datos cuantitativos que respalden la idoneidad de la metodología de trabajo expuesta en las sesiones prácticas de laboratorio, se ha desarrollado un breve estudio estadístico de las calificaciones de los alumnos en los últimos cuatro cursos escolares. Los datos estadísticos se muestran en la Tabla 4.
Tabla. 4: Comparativa de los valores de media, mediana y desviación estándar de las calificaciones de los últimos 4 cursos escolares de los alumnos de asignatura de Ciencia y Tecnología de Materiales de los grados de Ingeniería Eléctrica, Mecánica y en Tecnologías Industriales en la Universitat Jaume I.

\begin{tabular}{|c|c|c|c|c|}
\hline $\begin{array}{c}\text { Curso } \\
\text { académico }\end{array}$ & $2013 / 2014$ & $2014 / 2015$ & $2015 / 2016$ & $2016 / 2017$ \\
\hline Media & 7,7 & 8,3 & 7,3 & 8,7 \\
\hline Mediana & 8,1 & 8,1 & 8,1 & 8,5 \\
\hline $\begin{array}{c}\text { Desviación } \\
\text { estandar }\end{array}$ & 1,4 & 0,3 & 0,6 & 0,7 \\
\hline
\end{tabular}

Los resultados estadísticos mostrados en la Tabla 4 muestran una clara mejora de las calificaciones de los alumnos al ser aplicada la metodología propuesta para las sesiones prácticas de laboratorio con respecto a los cursos anteriores. Los valores más elevados de media y mediana de las calificaciones del curso 2016/2017 con respecto a los obtenidos para los tres cursos anteriores, en los que se aplicaba la metodología expuesta en la Tabla 1 (Realidad) demuestran la mejora del proceso de aprendizaje y rendimiento de los alumnos con respecto a la metodología de trabajo aplicada en cursos anteriores.

\section{Conclusiones}

Del presente trabajo se puede concluir que el aprendizaje de los conocimientos previos de una práctica de laboratorio mediante materiales docentes basados en audios, vídeos y presentaciones interactivas, y su evaluación con anterioridad al desarrollo de la práctica de laboratorio, favorece el aprendizaje de los conocimientos teóricos básicos relacionados con la práctica de laboratorio.

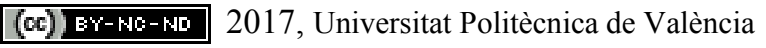


Adicionalmente esta metodología ha resultado en la concienciación de los estudiantes en la importancia de la preparación de la práctica previamente al desarrollo de la misma.

Se ha constatado que la metodología aplicada supone el aprovechamiento óptimo de las sesiones de laboratorio, dando lugar a la mayor comprensión global de la asignatura de materiales, como puede ser observado por el incremento de las calificaciones medias y la mediana tras ser aplicada la metodología expuesta.

\section{Referencias}

SALINAS, J. (2004). Innovación docente y uso de las TIC en la enseñanza universitaria. Revista de Universidad y Sociedad del Conocimiento (RUSC). [artículo en línea]. UOC. Vol. 1, n ${ }^{\mathrm{o}}$ 1. [Fecha de consulta: 31/03/17]. <http://www.uoc.edu/rusc/dt/esp/ salinas1104.pdf> 


\title{
Elementos motivadores incorporados en los Polimedias plus, vídeos didácticos y screencast para aumentar y mejorar el aprendizaje del estudiante
}

\author{
José Gabriel Ríos Lizanaa, Javier Oliver Villarroya ${ }^{\mathrm{b}}$ y Pilar Aurora Cáceres \\ González ${ }^{\mathrm{c}}$
}

${ }^{\mathrm{a}}$ Técnico de audiovisuales del ICE. jorioli@ice.upv.es, ${ }^{\mathrm{b}}$ Grupo MIST-DSIC. ICE-UPV. fjoliver@dsic.upv.es y ${ }^{\mathrm{C} A s e s o r}$ pedagógico. ICE-UPV.pcaceres@ice.upv.es.

\begin{abstract}
In order to attract students' attention and increase their motivation and participation when they are learning through an audiovisual resource (Polimedia plus, screencast, didactic videos), a system of processing and visualization of generated resources has been implanted that allows the teacher to include a greater amount of material within these resources (reinforcement questions, links to web pages, ...). In this way, it is also achieved that the student is not a mere spectator of the content, he interacts with it to improve his learning.
\end{abstract}

Keywords:Interaction, attention, motivation, Polimedia plus, didactic videos, screencast, training, online, web.

\footnotetext{
Resumen

Con el fin de captar la atención del estudiante e incrementar su motivación y participación cuando aprende a través de un recurso audiovisual (polimedia plus, screencast, vídeos didácticos), se ha implantado un sistema de procesamiento y visionado de los recursos generados que permite al profesor incluir una mayor cantidad de material (preguntas de refuerzo, "links" a páginas web...) dentro de estos recursos. De esta manera, además se consigue que el estudiante, no sea un mero espectador del contenido que está visualizando sino que interactúe con él para que consiga un mayor aprendizaje.
}

Palabras clave: interacción, atención, motivación, Polimedia plus, videos didácticos, screencast, formación, online, web. 


\section{Introducción}

En los últimos años ha habido una proliferación en la elaboración de materiales multimedia de apoyo a la docencia. El mayor hándicap con el que nos encontramos es la escasa interacción de estos materiales, convirtiéndolos únicamente en un medio más de transmisión de contenidos, sin posibilidad de "participación" por parte de los estudiantes, con lo que, en muchos casos, el alumno no ve la totalidad del recurso puesto que no conseguimos mantener su atención hasta el final.

Para intentar paliar estas deficiencias, en el Gabinete de Recursos Educativos y Multimedia (GREM), del Instituto de Ciencias de la Educación (ICE) de la Universitat Politècnica de València (UPV), se está implantando un sistema de software desarrollado íntegramente por José Gabriel Ríos Lizana (técnico de audiovisuales del ICE), que controla todo el proceso de producción de materiales, desde las solicitudes de servicios de los usuarios, pasando por la conversión e incorporación automática de los archivos generados, hasta la publicación en un repositorio web de dichos materiales con la novedad de poder añadir a los mismos, unas capas de superposiciones textuales o gráficas (SDK) en el tiempo y otra de control de la reproducción (EDL), que permite la interactividad con menús y botones que ayudan al profesor a planificar cómo tiene que seguir el estudiante la explicación que se reproduce en estos.

Existen otras aplicaciones web, como EDpuzzle, que también permiten de manera similar generar preguntas en un determinado punto del vídeo. EDpuzzle es una herramienta pensada para que el profesor pueda realizar un mejor seguimiento y evaluación del contenido, más que para el estudiante, ya que le obliga a registrarse e identificarse en la aplicación y acceder con un código que tiene que suministrarle el profesor, no existiendo feedback de las respuestas contestadas. A diferencia de EDpuzzle, esta herramienta que aquí presentamos no obliga al estudiante a identificarse, ni a que el vídeo esté en un repositorio externo (Youtube, khanacademy, learnzillion...) y no controlado por la entidad (el GREM del ICE en este caso). Permite añadir superposiciones textuales o gráficas en el tiempo superpuestas al vídeo, con enlaces a páginas web para que el estudiante tenga más información sobre los temas tratados en el vídeo y permite al profesor una mayor amortización o reutilización de los materiales. Además, mediante la capa de control de la reproducción, permite incluir menús y botones que llevan al vídeo a los puntos correspondientes para que el profesor pueda ofrecer un feedback al alumno sobre la respuesta correcta o errónea de forma inmediata y desde el mismo vídeo que se está reproduciendo, puesto que "salta" a las partes del video donde se encuentra la explicación correspondiente a cada respuesta.

\section{Objetivos}

- Posibilitar la interactuación del estudiante con el recurso educativo durante la explicación del contenido por parte del profesor. 
- Retomar la explicación de forma fácil al poder saltar directamente a los bloques o temas del vídeo definidos por el profesor.

- Posibilitar una mayor cantidad de información al poder añadir enlaces a páginas web y a otros vídeos a un solo click de ratón.

- Conseguir una mayor motivación y atención del alumno al solicitar de manera expresa su interactuación con el vídeo.

- Rentabilizar al máximo una grabación de vídeo al aumentar la reutilización del mismo mediante la inserción de material sensible a cambios en la capa de superposición que puede ser modificada por parte del profesor.

- Potenciar el sistema técnico de producción del GREM para la generación de vídeos.

\section{Desarrollo de la innovación}

Los cambios acontecidos en la Universidad durante los últimos años: integración al Espacio Europeo de Educación Superior, la implantación del Plan Docencia en Red, el desarrollo de la metodología "Clase Inversa", entre otras muchas acciones, han llevado al profesorado a la necesidad de generar y producir un sinfín de materiales didácticos adaptados a las nuevas características del alumnado (generación Z) para conseguir una mayor implicación en su aprendizaje.

En estos cambios, el Gabinete de Recursos Educativos y Multimedia (GREM) de la UPV ha tenido un papel relevante, no sólo en su responsabilidad para facilitar ayuda técnica a los profesores y el apoyo pedagógico ofrecido correspondiente, al formar parte del Instituto de Ciencias de la Educación (ICE) de nuestra universidad, sino también a la hora de plantear innovaciones para mejorar la calidad de los materiales producidos.

En esta línea de innovación, en el GREM se han ido produciendo avances en los últimos años: publicación de los materiales en alta definición y calidad; mejora del plató y de la cabina de edición..., siendo el último de dichos avances el que se presenta en esta comunicación. La idea principal que se propone es no cambiar el sistema técnico de producción de los vídeos, sean estos del tipo que sean, sino que en una revisión posterior se seleccionen los bloques de la explicación y se decida dónde estarán los saltos, las pausas para las preguntas y las diferentes opciones o respuestas, todo ello configurado en una capa de datos de control y asociada al vídeo a la hora de reproducir el mismo.

De esta forma el estudiante ya no visualiza los vídeos de una forma pasiva, sino de una forma activa (como se puede apreciar en la imagen de la Figura 1). 


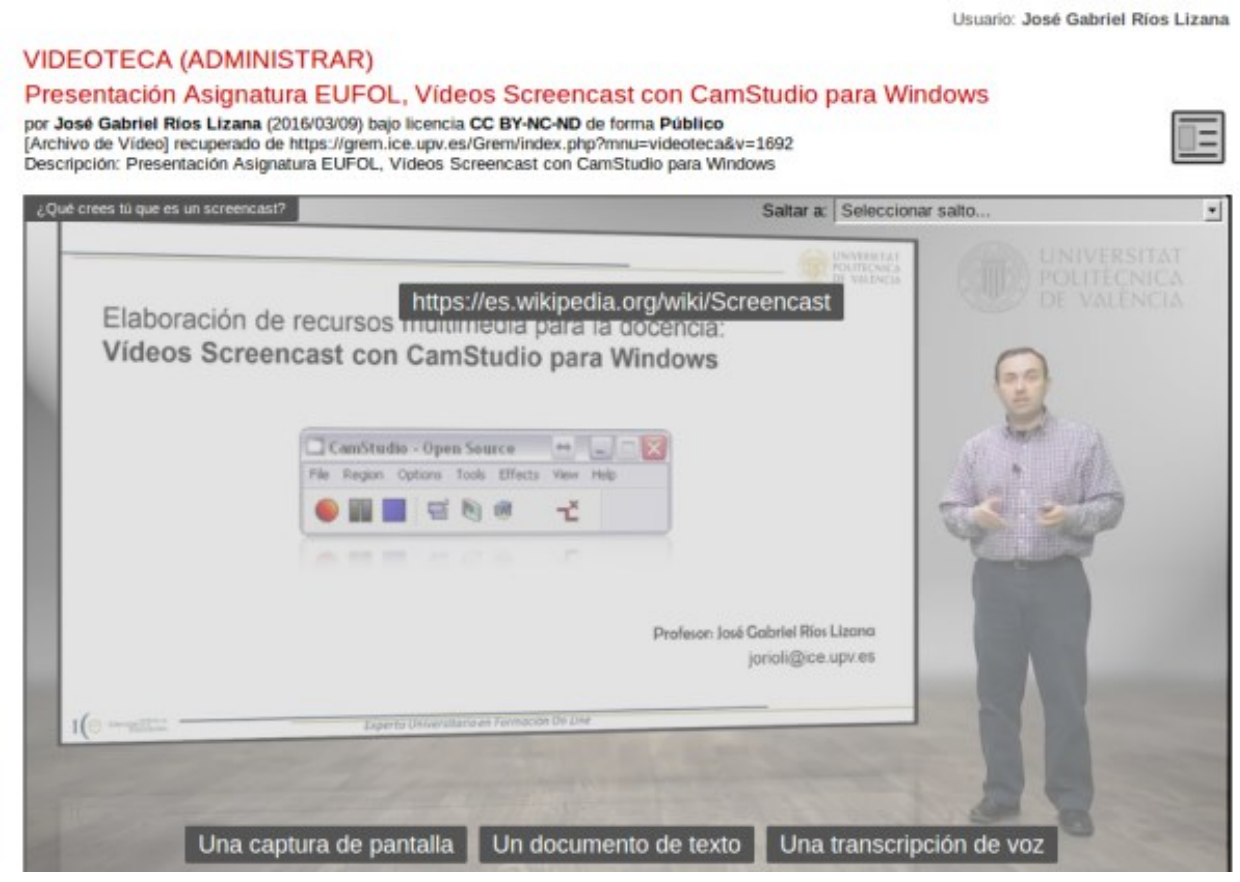

Fig. 1 Imagen del resultado visual de una pregunta con tres opciones posibles y el apoyo de un enlace a una página web de consulta.

La aplicación, como vemos en la imagen de la Figura 2, permite asignar varias opciones, donde el profesor, por ejemplo, tras formular una pregunta al estudiante, lo puede dirigir, en caso de que no sepa contestar dicha pregunta, al tema donde este concepto se explica, bien en un documento almacenado en el repositorio de Poliformat o a una página web, mediante su enlace URL correspondiente; también puede volver al punto del vídeo donde se explica el contenido (es decir, el estudiante puede volver a ver la explicación si no sabe contestar una pregunta determinada).

Por otro lado, incorpora un editor de subtítulos para diferentes idiomas, que pueden seleccionarse, indistintamente, para mostrarse durante la visualización del vídeo.

También permite cinco capas de superposiciones textuales y gráficas que pueden coincidir en el tiempo para el material más sensible a cambios (URL a páginas web, citas de leyes, cursos, fechas...), con funciones de enlaces web a otras páginas o vídeos que permiten aumentar la cantidad de información suministrada al estudiante, así como reutilizar al máximo un vídeo a lo largo del tiempo, ya que esta información se puede cambiar sin necesidad de volver a grabar el vídeo de nuevo. 


\section{VIDEOTECA (ADMINISTRAR)}

Presentación Asignatura EUFOL, Videos Screencast con CamStudio para Windows por Jose Gabriel Rios Lizana (2016/03/09) bajo licencia CC BY-NC-NO de forma Püblico

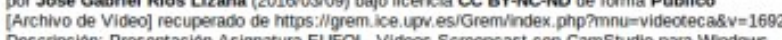
Descripcion: Presentacion Asignatura EUFOL. Videos Screencast con CamStudio para Windows

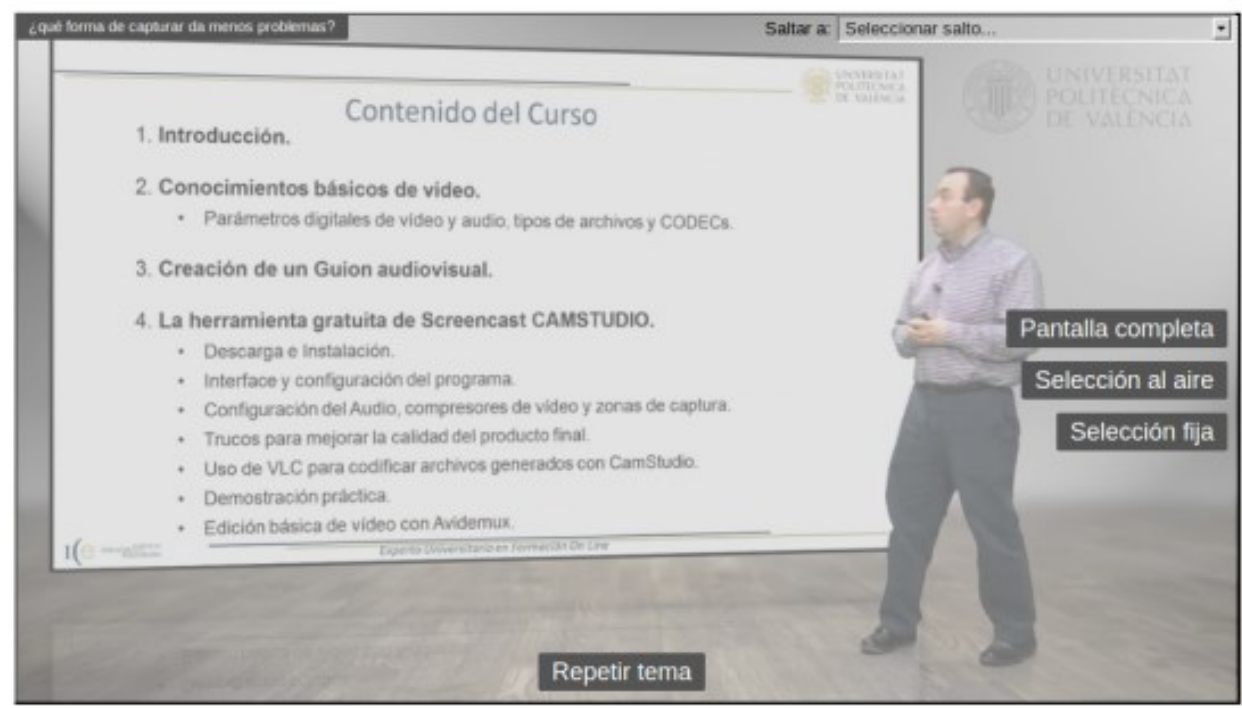

Fig. 2 Imagen del resultado visual de una pregunta con cuatro opciones, siendo una de ellas el volver a visualizar el contenido si el estudiante no sabe la respuesta.

Con la incorporación de todos estos elementos a los videos producidos, estamos seguros que se da un paso muy importante para contribuir a la mejora del aprendizaje de los alumnos.

\subsection{Procesos para la elaboración}

\subsubsection{Producción del vídeo}

La grabación del vídeo se realiza mediante el sistema normal habitual de producción de un Polimedia Plus, vídeo didáctico o screencast, es decir, de forma lineal y en un único archivo de vídeo.

Sin embargo, ahora es necesario que el profesor planifique la explicación de forma que, a la hora de grabar el vídeo:

a) Formule preguntas concretas que tendrán que responder sus estudiantes.

b) Realice pausas, para dar tiempo al estudiante a reflexionar sobre una explicación puntual, buscar una información adicional...

c) Plantee opciones de respuesta para que el estudiante seleccione la que considere correcta.

d) Felicite al estudiante cuando la respuesta ofrecida sea la correcta.

e) Ofrezca feedback al estudiante cuando la respuesta seleccionada sea incorrecta, explicándole, por ejemplo, mediante un contraejemplo por qué es errónea antes de redirigir el vídeo de nuevo a la posición de la pregunta o a otra parte. 


\subsubsection{Publicación del vídeo}

Una vez que el vídeo está grabado, el sistema realiza la conversión y subida del mismo a la plataforma haciendo las correspondientes copias de seguridad y, una vez disponible, se publica automáticamente en el repositorio web, donde se le asigna una dirección URL y queda a disposición del profesor y del resto de la comunidad universitaria para su visualización y posible incrustación en Poliformat u otra plataforma.

Presentación Asignatura EUFOL, Vídeos Screencast con CamStudio para Windows por José Gabriel Ríos Lizana (2016/03/09) bajo licencia CC BY-NC-ND de forma Público [Archivo de Video] recuperado de https://grem.ice.upv.es/Grem/index.php?mnu=videoteca\&v=1692 Descripción: Presentación Asignatura EUFOL, Videos Screencast con CamStudio para Windows

Fig. 3 Imagen de la cita que aparece en la parte superior del vídeo.

Como se ve en la Figura 3, el vídeo siempre lleva asociados los metadatos que hacen referencia al mismo: datos de título, autores, fecha de creación, licencia de uso, tipo de archivo y dirección URL, agradecimientos y descripción. Estos datos son visibles siempre incluso cuando se incrusta en otra web, lo que facilita su búsqueda e identificación.

\subsubsection{Generación de clips o partes del vídeo}

\begin{tabular}{|c|c|c|c|c|c|c|}
\hline Saltos $y$ bloques $\vee$ & Edición & 0 (b) & 00:00:00.000 & 00:00:04.126 & $\therefore-\cdots-\cdots$ & $\checkmark \mathbf{A} \bullet$ \\
\hline - $700 \%$ & Guardar & A & b) & $-\cdots$ & C 1 & \\
\hline
\end{tabular}

Fig. 4 Sección del interface de la herramienta de edición, que permite la selección de los tipos de bloques en la pista EDL de la linea de tiempos en un archivo de vídeo grabado de forma lineal.

Una vez se tiene el vídeo publicado, la herramienta ofrece la opción de crear los saltos y bloques (como se puede ver en la Figura 4) que permiten convertir nuestro vídeo en un vídeo interactivo. Esto se realiza de forma gráfica mediante la utilidad de edición proporcionada por la herramienta web, donde de una forma sencilla se pueden marcar y configurar los siguientes tipos de fragmentos o bloques en la pista EDL (Edition Decision List):

- Saltos o bloques: se configura el tiempo de inicio de un tema o el bloque de la explicación y permite asignarle un nombre. Este nombre de bloque se mostrará en la parte superior izquierda mientras se reproduce el video y en la utilidad de "saltar a:". Dicha utilidad aparece en la parte superior derecha de la ventana de vídeo, tanto cuando se pulsa sobre el nombre del tema o bloque actual o cuando el sistema pausa el vídeo para requerir la intervención del estudiante. 


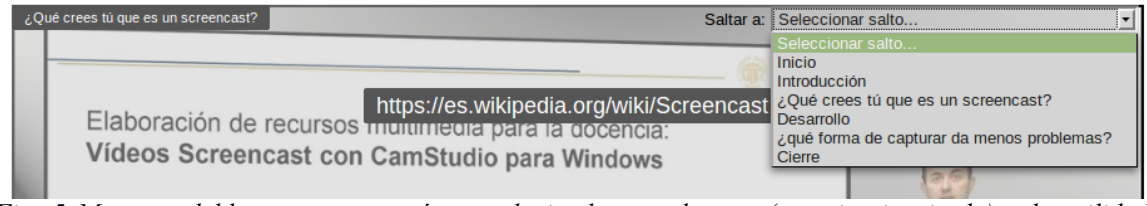

Fig. 5 Muestra el bloque que se está reproduciendo actualmente (superior izquierda) y la utilidad "saltar a" (superior derecha) donde mediante un desplegable se puede seleccionar el punto del temario deseado.

- Saltos o bloques vistos. Permite saltar a determinados puntos del vídeo, pero sólo aparecerán en la utilidad de "Saltar a" cuando el estudiante ya los haya visto, para que pueda repasar, no permitiendo así el avance o salto de temas no visualizados del vídeo.

- Saltos o bloques ocultos. La funcionalidad de este tipo de bloque es permitir saltar a determinados puntos del vídeo, o reproducir determinados bloques del mismo, pero sin que aparezcan reflejados ni en la ventana de vídeo ni en la utilidad de "Saltar a". De esta manera, el estudiante no los ve y se pueden esconder partes del vídeo que el profesor no quiere que visualicen los estudiantes.

- Preguntas. Es un punto, o bloque, donde al final del mismo se pausa el vídeo y se requiere que el estudiante realice alguna acción. Como veremos más adelante, existen distintas tipologías docentes para mantener la atención del estudiante. La pregunta en sí puede ser sobreimpresa mediante texto, pero es mejor que también sea formulada por el profesor en el propio vídeo, y se mostrará en la utilidad "Saltar a". El sistema no tiene límite de cantidad de preguntas a incorporar.

- Preguntas vistas. Al igual que los bloques vistos, las preguntas vistas sólo se mostrarán y se podrán acceder a ellas una vez hayan sido vistas por el estudiante, para que pueda repasar.

- Respuestas. Son bloques del vídeo marcados y asignados a un botón de una pregunta; también pueden contener un enlace a una página web y, por lo tanto, a otros vídeos disponibles online. El sistema permite tener en pantalla hasta 25 botones de respuesta por pregunta, que pueden ser posicionados de forma gráfica, como puede verse en la Figura 6. La ubicación de estos botones en el video es una decisión del profesor en función de lo que más le interese en cada momento. 


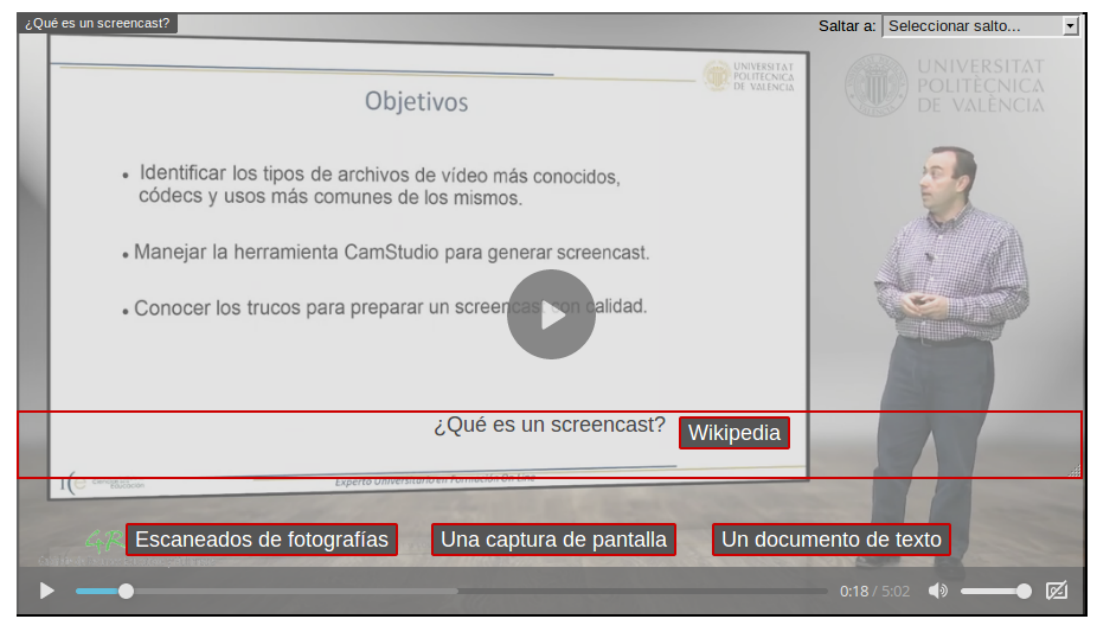

Fig.6. Resalte de los botones y texto de la pregunta para modificar su disposición en la ventana de vídeo mediante la herramienta gráfica moviéndolos con el ratón.

\subsubsection{Generación de contenido superpuesto al vídeo y subtitulos}

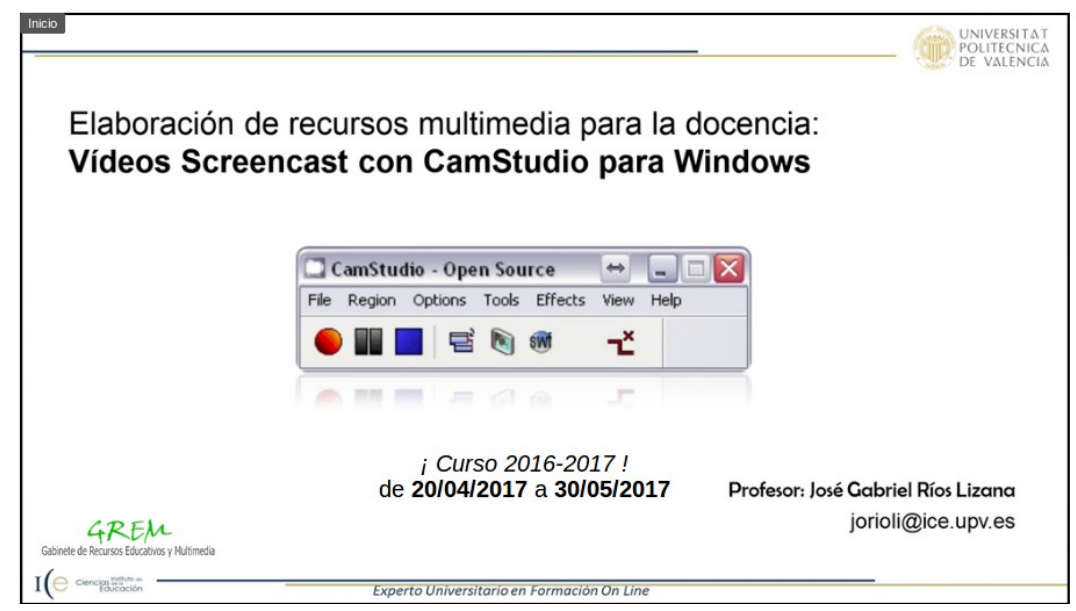

Fig. 7 Visualización de contenido superpuesto al vídeo, como el logotipo del GREM, con un hipervínculo a la página del GREM, y la convocatoria del curso y fechas de inicio y final del mismo.

La herramienta permite la superposición de cinco capas textuales y gráficas simultáneamente en el tiempo que posibilitan tener enlaces a URL, y que se visualizan sobre el vídeo, como se puede ver en la Figura 7, facilitando así personalizar el mismo, añadir información adicional, o amortizar al máximo la utilización del vídeo poniendo en estas capas la información más sensible a cambios en el tiempo, como fechas, páginas web, artículos de leyes, etc. 
También tiene integrado un editor de subtítulos para varios idiomas. Este editor, de forma gráfica y mediante una línea de tiempos permite ir generando los textos y los puntos de entrada y salida para su visualización, un idioma por pista, como se puede ver en la Figura 8 .

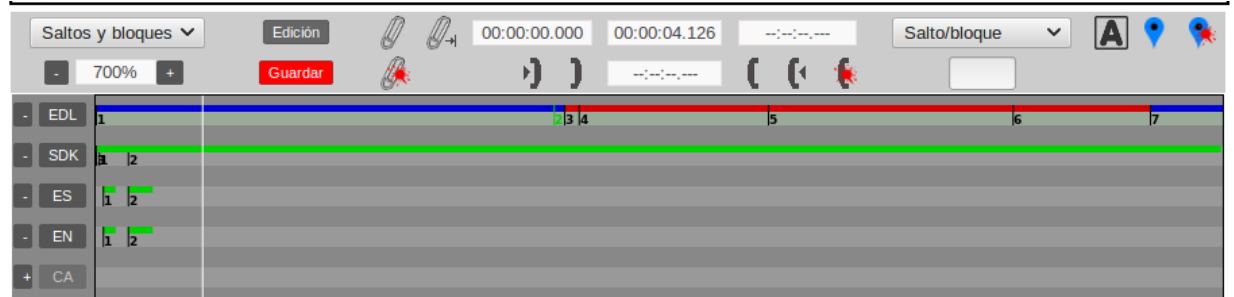

Fig. 8 Visualización de la interface de edición mediante línea de tiempos para las pistas de subtitulos (ES, EN $C A)$, superposiciones (SDK) y bloques para saltos, preguntas y respuestas (EDL).

\subsection{Tipologías básicas de la utilización de preguntas en docencia}

Una de las técnicas habituales en la docencia para captar la atención del estudiante y mantener su interés durante la explicación es la formulación de preguntas por parte del profesor. Por lo tanto, creemos que la introducción de distintos tipos de preguntas en los videos educativos es un avance muy importante.

Así, a lo largo del mismo vídeo, se pueden utilizar varias tipologías para conseguir que el estudiante no pierda la atención y aprenda mejor los contenidos. A modo de ejemplo, se ha hecho una selección de las tipologías básicas que se podrían aplicar, pero el sistema puede configurar muchas más, con la combinación de más de una tipología, como veremos más adelante.

\subsubsection{Pausa y revisión}

Es la tipología más sencilla. Permite parar el vídeo en un punto en concreto y preguntar al estudiante si quiere continuar o prefiere volver a reproducir el vídeo desde un punto que ya ha marcado el profesor para ver de nuevo la explicación.

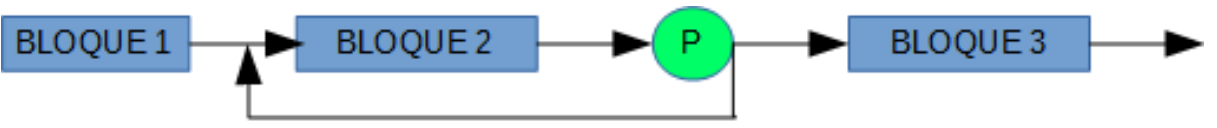

Fig. 9 Tipología 1. Pausa y revisión.

\subsubsection{Pausa para ver contenidos previos}

Se pausa el vídeo para que el estudiante pueda alcanzar los conocimientos básicos mediante un enlace a una página web u otro vídeo online, que se abrirá en una pestaña aparte del navegador, antes de continuar con el siguiente contenido.

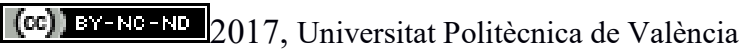




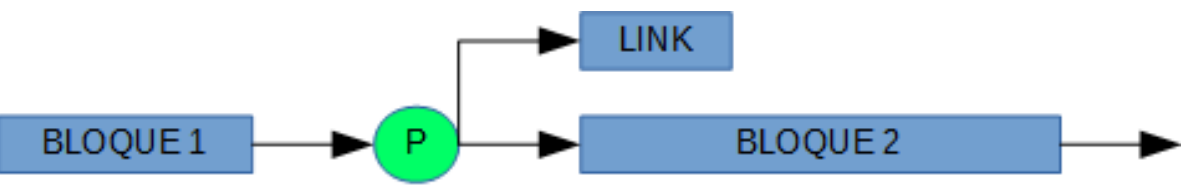

Fig. 10 Tipología 2. Pausa para ver contenidos previos.

\subsubsection{Pausa para ver contenidos extra}

Se pausa el vídeo para dar opción al estudiante a ver un contenido extra. Por ejemplo, el profesor le da la opción al estudiante de ver la demostración de una fórmula, antes de continuar con la resolución del problema donde se aplica dicha fórmula. El estudiante decide si quiere ver la demostración o seguir con la resolución del problema.

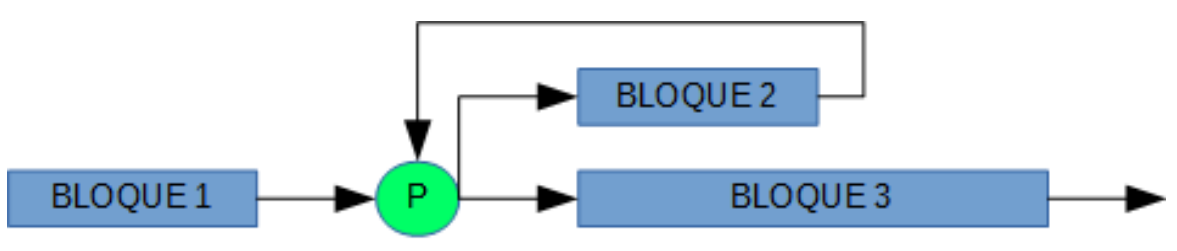

Fig. 11 Tipología 3. Pausa para ver contenidos extra.

\subsubsection{Pregunta con varias respuestas}

Se pausa el vídeo y se propone una pregunta o ejercicio con diferentes respuestas posibles, donde sólo una es correcta. El estudiante escogerá una respuesta y, si es errónea, el vídeo salta al punto de la explicación donde el profesor comenta que es errónea y por qué, volviendo de nuevo a la pregunta inicial.

También puede simplificarse visualizando siempre el mismo vídeo para todas las respuestas erróneas antes de volver a la pregunta.

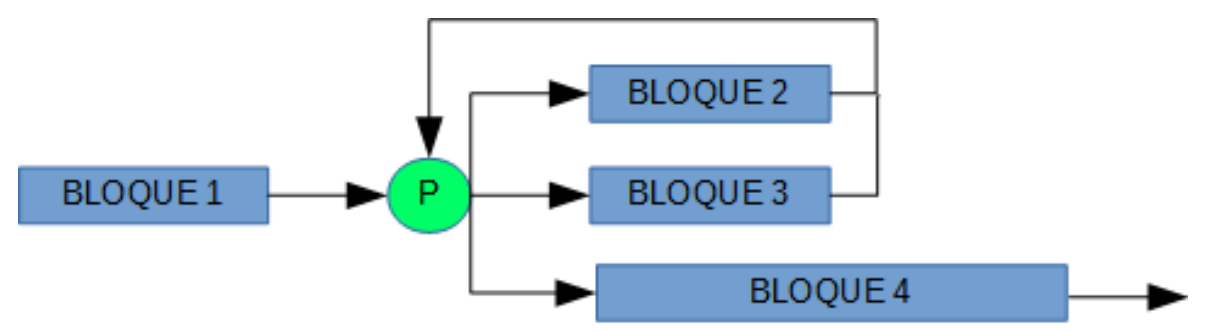

Fig. 12 Tipología 4. Pregunta con varias respuestas.

\subsubsection{Proceso en paralelo}

En un determinado punto del video, se permite al estudiante seleccionar qué camino quiere seguir para la resolución de un problema, por ejemplo, el camino largo o el corto, de forma

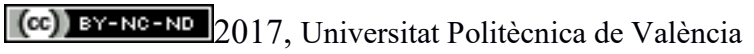

Congreso IN-RED (2017) 
gráfica o analítica, etc. De esta manera, se adapta mejor al ritmo y estilo de aprendizaje de cada uno.

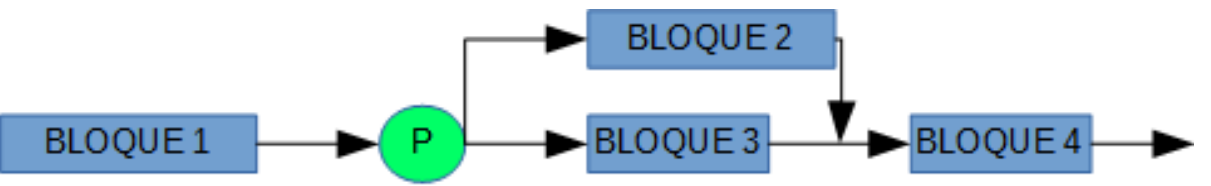

Fig. 13 Tipología 5. Proceso en paralelo.

\subsubsection{Ejemplo de implementación con varias tipologías}

Además de los casos anteriores, hay que destacar que también se puede hacer una mezcla de todas las opciones que hemos presentado en un punto como, por ejemplo, que para que el estudiante conteste a una pregunta propuesta por el profesor se le proporcione un enlace a una página web con más información u otro vídeo para la visualización, a la vez que tiene la opción de revisar el último concepto explicado si no le quedó claro.

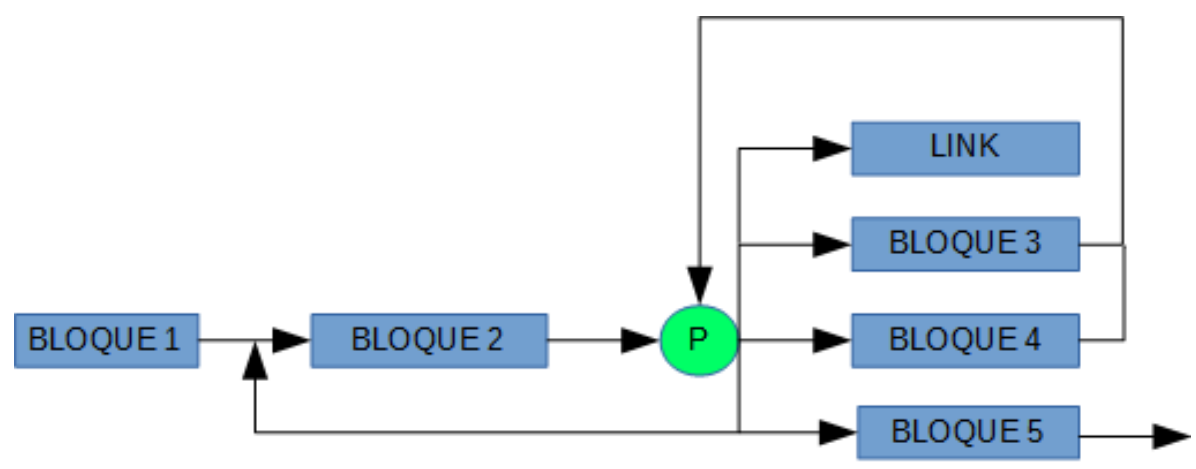

Fig. 14 Utilización de varias tipologías en una misma pregunta.

\section{Resultados}

La incorporación de todos estos elementos en los vídeos generados como materiales de apoyo a la docencia, creemos que conseguirán una mayor implicación de los estudiantes, con lo que su motivación aumentará y, con ella, y en mayor medida, su aprendizaje.

Además, se conseguirá que cada estudiante visualice el material audiovisual adaptándolo a su propio ritmo y estilo de aprendizaje, puesto que los diferentes bloques programados por el profesor así lo permitirán.

\section{Conclusiones}

La tecnología ha permitido revolucionar nuestras vidas y también nuestra forma de enseñar y aprender. En este trabajo, hemos presentado una nueva aportación del GREM de la UPV que va a facilitar a nuestro profesorado la producción de material audiovisual docente de 
mayor calidad al introducir de forma explícita interactividad con menús y botones que van a ayudar al profesor a planificar cómo tiene que seguir el estudiante la explicación correspondiente. Esperamos que, siguiendo en esta línea, el GREM de la UPV pueda, poco a poco, incorporar todos estos avances en los materiales producidos por nuestros profesores, facilitando la tarea en el menor tiempo posible.

\section{Referencias}

AMAYA, V.: La pregunta como procedimiento didáctico en el aula de ELE. Revista electrónia de didáctica, $\mathrm{n}^{\mathrm{o}}$ 5. Disponible en http://www.mecd.gob.es/dctm/redele/MaterialRedEle/Revista/2005 05/2005 redELE_5 02Anaya.pdf?documentId=0901e72b80dfa2ce

OLMEDO JARA, R. (2014). Selección, elaboración, adaptación y utilización de materiales, medios y recursos didácticos en Formación Profesional para el Empleo. SSCE0110. IC Editorial.

SALINA, J. (2002). Medios didácticos para una nueva Universidad. Jornada sobre Innovación: El aprendizaje en entornos virtuales. Universidad Pública de navarra, Pamplona 18 abril.

SOTOS SERRANO, M. Las preguntas en el aula. Análisis de la interacción educativa. Disponible en https://previa.uclm.es/ab/educacion/ensayos/pdf/revista16/16 16.pdf

UNIVERSIDAD POLITÉCNICA DE VALENCIA. Los objetos de aprendizaje como recurso para la docencia universitaria: criterios para su elaboración. http://www.upv.es/contenidos/DOCENRED/infoweb/docenred/info/U0687016.pdf [Consulta: 29 de marzo 2017] 


\title{
Material multimedia para aumentar el rendimiento académico de los trabajos en grupo.
}

\author{
María Dolores Mauricio ${ }^{a}$, Soraya L. Vallés ${ }^{\mathrm{a}}$, José M. Vila ${ }^{\mathrm{a}}$, Martín Aldasoro ${ }^{\mathrm{a}}$ y Eva \\ Sernab.
}

åDepartamento de Fisiología, Universitat de Valencia. M.dolores.mauricio@uv.es, ${ }^{b}$ Departamento de Patología, Universitat de Valencia. Eva.serna@uv.es

\begin{abstract}
Multimedia can be considered a useful tool for improving the learning. In this study we analyze the marks that students get in a group activity with and without the use of a multimedia material made by teachers. The scores are obtained using a rubric previously tested for this activity and the results show an increase in the final qualification for student groups who used the multimedia material. We also analyze the scores by units following the rubric and we note that scores increase 4.0 points for a maximum of 10 in the methodology unit. Moreover, we collect the opinion of our students about the multimedia material and how it helped them to better understand the work they had to do in the activity group. Teachers give their opinion too. In conclusion, this multimedia material is a good tool to guide group activity and get higher marks.
\end{abstract}

Keywords: multimedia material, evaluation, group activity, university education.

\section{Resumen}

El uso de materiales multimedia puede favorecer el proceso de aprendizaje. En este estudio se analizan las calificaciones obtenidas en una actividad grupal con y sin ayuda de un material multimedia elaborado por los profesores de la asignatura. Las calificaciones se obtienen con una rúbrica adecuada para evaluar la actividad de grupo y muestran un incremento de la nota final para los equipos de estudiantes que tuvieron a su disposición el material multimedia. Se realiza un análisis de las calificaciones desglosando los distintos apartados de la rúbrica y se aprecia que el apartado de metodología es el más sensible al material multimedia, incrementando la calificación en 4.0 puntos sobre 10. Se recoge la opinión de los alumnos y del equipo docente en la dinámica de la actividad grupal con y sin el material multimedia y se concluye que dicho material supone una buena guía para orientar a los alumnos en la actividad por equipos.

Palabras clave: material multimedia, evaluación, trabajo en grupo, enseñanza universitaria. 


\section{Introducción}

La enseñanza universitaria debe buscar estrategias didácticas que resulten atractivas para los estudiantes mediante la mejora de los recursos ya existentes o la creación de nuevos materiales de apoyo. En este sentido, el uso de materiales multimedia puede favorecer el proceso de aprendizaje tanto individual como en grupo (Marquès, 2000).

Las características educativas que presentan los sistemas multimedia dependerán de la calidad de los mismos, aunque hay cierto consenso en considerar entre sus ventajas la adecuación al ritmo de aprendizaje, la secuenciación de la información, la flexibilidad de utilización o la atracción que supone la imágen animada. Suele ser habitual aceptar que la materia a estudiar se asimila mejor fijándonos en un gráfico o esquema u oyendo un sonido (Salinas, 1996).

Además de proporcionar información, el material multimedia puede orientar al estudiante, remarcando los conceptos más importantes, reforzando los puntos más conflictivos o aumentando la motivación, uno de los principales motores del aprendizaje (Polanco, 2005).

Existen dos modelos de material multimedia: presentacion multimedia y multimedia interactivo. En la primera opción el control de la comunicación está en manos del profesor mientras que en la segunda, se requiere de la participación del usuario, al cual se le ofrecen trayectorias alternativas en función de su respuesta. Ambos sistemas presentan aplicabilidad en la enseñanza (Salinas, 1996).

A la hora de incorporar estos recursos a la educación superior, es necesario o bien formar a los docentes para que sepan crear su propio material multimedia o bien ofrecer un servicio de calidad que se encargue de la parte técnica y oriente al profesor en la elaboración del mismo. En la Universitat de València existen convocatorias anuales de proyectos de innovación educativa, que en una de sus modalidades ofrecen la ayuda técnica para elaborar un material multimedia. Nuestro equipo docente desarrolló un proyecto a cargo de la mencionada convocatoria durante el curso académico 2015-2016 (Projectes innovació educativa 2015-2016. Código proyecto: UV-SFPIE_RMD15-313422).

En nuestro caso el material elaborado entraría dentro de la definición de presentación multimedia y se dividía en tres partes. La primera consistía en una introducción en la que se exponían brevemente los antecedentes del tema, se planteaba la hipótesis de trabajo y se proponía un protocolo experimental para su resolución. En la segunda parte, se explicaba el procedimiento técnico y la obtención de los registros experimentales. Por último, se mostraba cómo se debían interpretar los resultados y el razonamiento para llegar a la conclusión. El material elaborado se puede consultar en los

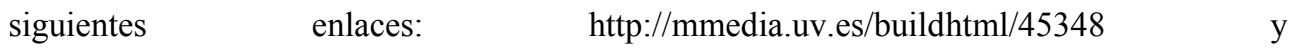
http://mmedia.uv.es/buildhtml/45327.

El material multimedia fue diseñado especialmente para ayudar a los alumnos en una actividad grupal concreta que forma parte del programa de la asignatura. Con la experiencia previa del equipo docente en esta actividad grupal, habíamos detectado que la comprensión de la metodología resultaba complicada para los estudiantes. Por ello, el desarrollo de un material multimedia nos parecía una buena opción para reforzar la actividad y obtener mejores resultados de aprendizaje y académicos.

(c)) EY-NC-ND 2017, Universitat Politècnica de València 


\section{Objetivos}

El objetivo general es la valoración del impacto sobre el aprendizaje del uso de un material multimedia de elaboración propia.

Objetivos específicos:

1. Comparar las calificaciones obtenidas por los equipos del curso 20152016 que realizaron la actividad sin la ayuda del material multimedia, con las obtenidas por los equipos del curso 2016-2017 que han tenido a su disposición el material multimedia.

2. Analizar las calificaciones, desglosándolas por apartados según la rúbrica de evaluación, de los trabajos en equipo sin y con ayuda del material multimedia, con la finalidad de saber que apartados han sido más sensibles.

3. Recavar la opinión tanto de los alumnos, como de los profesores del impacto del material multimedia sobre la dinámica de los trabajos grupales.

\section{Desarrollo de la innovación}

Durante el curso académico 2015-2016, 59 alumnos de la asignatura de Fisiología impartida durante el primer cuatrimestre del primer curso del Grado de Podología de la Universitat de València, realizaron la actividad grupal propuesta sin ayuda de ningún material multimedia. Estos alumnos componen la población que denominaremos "sin MM". Durante el curso 2016-2017, 57 alumnos de la misma asignatura y grado, realizaron el mismo trabajo pero con la ayuda del material multimedia. Estos estudiantes pertenecen a la población que denominaremos "con MM". La tabla 1 recoge la composición de las dos poblaciones de estudio.

Tabla 1. Composición de las poblaciones de estudio.

\begin{tabular}{lllll}
\hline Población & $\begin{array}{l}\text { Número de } \\
\text { alumnos } \\
\text { participantes }\end{array}$ & $\begin{array}{l}\text { Equipos de } \\
\text { trabajo }\end{array}$ & $\begin{array}{l}\text { Equipos de } \\
\text { cuatro } \\
\text { miembros }\end{array}$ & $\begin{array}{l}\text { Equipos de } \\
\text { cinco } \\
\text { miembros }\end{array}$ \\
\hline Sin MM & 59 & 14 & 11 & 3 \\
Con MM & 57 & 13 & 8 & 5 \\
\hline
\end{tabular}

Sin MM: estudiantes que realizaron la actividad sin la ayuda del material multimedia.

Con MM: estudiantes que realizaron la actividad con el material multimedia.

Los alumnos de ambas poblaciones, distribuidos por equipos debían elaborar un manuscrito y exponer sus conclusiones al resto de la clase. El proceso sería evaluado según los criterios contenidos en una rúbrica, que previamente ya había demostrado ser discriminativa y adecuada para evaluar trabajos en grupo. (Mauricio, 2016)

En líneas generales la rúbrica confeccionada contenía 4 bloques.

1. Manuscrito, $60 \%$ de la nota

2. Exposición oral, $20 \%$ de la nota 
3. Participación en el equipo, $10 \%$ de la nota

4. Actitud, $10 \%$ de la nota

El primer bloque, "Manuscrito", analizaba el trabajo escrito presentado por el grupo y valoraba tanto la estructura ( 1 punto) como el contenido ( 5 puntos). Éste se dividía a su vez en cuatro partes:

1. Introducción, donde se describían los antecedentes del tema, la hipótesis y los objetivos del trabajo.

2. Metodología, donde se describía la técnica utilizada.

3. Resultados y discusión donde se interpretaban las gráficas y se obtenía la conclusión del trabajo.

4. Bibliografía

Para conseguir el primer objetivo se compararon las calificaciones globales obtenidas en cada una de las poblaciones usando la misma rúbrica de evaluación. Con la finalidad de conocer los aspectos sobre los que más había incidido el material multimedia (segundo objetivo), se desglosaron estas calificaciones según los apartados del contenido del manuscrito detallados en la rúbrica.

Para alcanzar el tercer objetivo, impacto del material multimedia sobre la dinámica de los trabajos grupales según alumnos y profesores, se pasó una encuesta a los alumnos y se registró el número de tutorías que cada profesor había recibido con motivo de la elaboración del manuscrito.

De los 57 alumnos de la población MM, 41 respondieron a la encuesta en la que se pedía una valoración en una escala del 1 al 10 de dicho material, en respuesta a las siguientes preguntas:

¿Cómo valorarías en términos generales la utilidad del material multimedia?

¿El material multimedia te ha ayudado a aclarar dudas?

También se preguntaba el número de veces que individualmente habían necesitado consultar el material. Tenían que marcar una de las cuatro opciones:

He necesitado consultar el material:

a) Menos de 5 veces

b) Entre 5-10 veces

c) Entre 10-20 veces

d) Más de 20 veces

\section{Resultados}

Utilizando la rúbrica se evaluaron los 14 equipos de la población sin MM obteniéndose una nota media de 6,8 y los 13 equipos de la población con $\mathrm{MM}$ obteniéndose una calificación media de 7.9. Todos los equipos superaron la nota mínima para aprobar. El número de sobresalientes (calificaciones desde 9 hasta 10 puntos), notables (desde 7 hasta 8.9) y aprobados (desde 5 hasta 6.9) se detalla en la tabla 2.

(cc)) EY-NC-ND 2017, Universitat Politècnica de València 
Tabla 2. Nota media y número de sobresalientes, notables y aprobados de las dos poblaciones de estudio.

\begin{tabular}{lllll}
\hline Población & $\begin{array}{l}\text { Nota media de los } \\
\text { equipos }\end{array}$ & $\begin{array}{l}\text { Número de } \\
\text { sobresalientes }\end{array}$ & $\begin{array}{l}\text { Número de } \\
\text { notables }\end{array}$ & $\begin{array}{l}\text { Número de } \\
\text { aprobados }\end{array}$ \\
\hline Sin MM & 6.8 & 4 & 6 & 4 \\
Con MM & 7.9 & 5 & 5 & 3 \\
\hline
\end{tabular}

Sin MM: estudiantes que realizaron la actividad sin la ayuda del material multimedia.

Con MM: estudiantes que realizaron la actividad con el material multimedia.

Los contenidos que potenció el trabajo multimedia fueron aquellos relacionados con la metodología, pues se observó un aumento de 4 puntos en la calificación media de la población con MM (5.6 versus 9.6 para la población sin MM y con MM respectivamente) (Tabla 3). El apartado de introducción no mejoró y el de resultados lo hizo ligeramente. Las notas medias obtenidas por las dos poblaciones se muestran en la tabla 3. El apartado de bibliografía no se modificó por lo que no se muestran las calificaciones.

Tabla 3. Calificaciones medias desglosadas por apartados en las dos poblaciones de estudio.

\begin{tabular}{llll}
\hline Población & Introducción & Metodología & Resultados \\
\hline Sin MM & 8.3 & 5.6 & 5.5 \\
Con MM & 7.2 & 9.6 & 6.2 \\
\hline
\end{tabular}

Sin MM: estudiantes que realizaron la actividad sin la ayuda del material multimedia.

Con MM: estudiantes que realizaron la actividad con el material multimedia.

Los alumnos valoraron la utilidad del material multimedia con una nota media de 9.5 y la capacidad para aclarar las dudas con un 8.8. Afirmaron haber consultado el material entre 5 y 10 veces de media como muestra la figura 1.

Por último, los profesores detectaron una disminución en el número de tutorías relacionadas con la actividad grupal. La población de estudio que no dispuso del material multimedia solicitó entre 3 y 4 tutorías de media por grupo, mientras que los equipos con el material multimedia a su disposición realizaron entre 0 y 1 tutorías. 


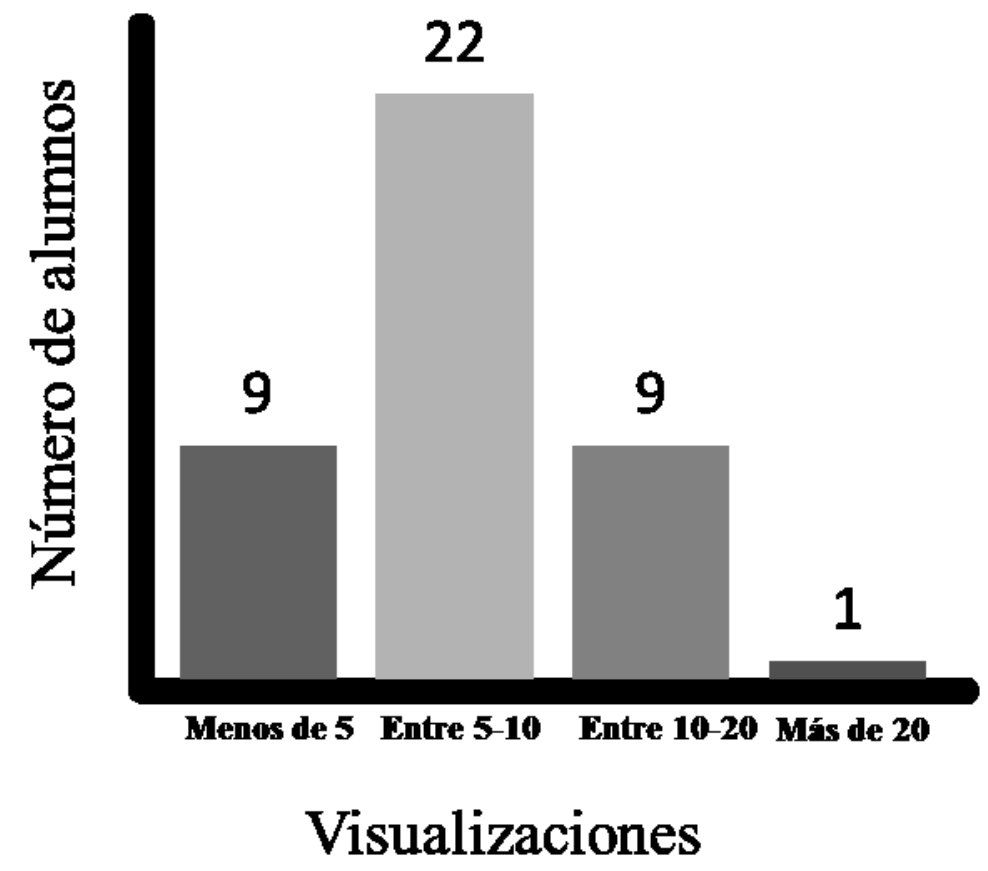

Fig. 1. Número de veces consultado el material multimedia por alumno.

\section{Conclusiones}

La finalidad de nuestro estudio era valorar mediante las calificaciones obtenidas en el trabajo grupal si el material multimedia había resultado útil y había mejorado la nota final del equipo. En vista de los resultados se puede decir que sí ha sido efectivo, ya que la nota final de la actividad se ve incrementada en 1.1 puntos de media cuando se usa dicho material, pasando de un 6.8 a un 7.9.

Especialmente se reforzó la comprensión de la parte metodológica, que solía ser la más complicada para los estudiantes. En este apartado la nota media subió cuatro puntos con la ayuda del material. Cabe resaltar que el material multimedia fue elaborado por los profesores de la asignatura con experiencia previa en esta actividad grupal y por tanto, conocedores de los puntos del trabajo con resultados más flojos. Por eso, el material fue elaborado centrándose en gran medida en la parte metodológica, de hecho el material se divide en tres partes y una de ellas está dedicada íntegramente a la técnica.

Cuando se les pide a los estudiantes que valoren el material multimedia con una nota del 1 al 10, el resultado es muy satisfactorio. Los alumnos valoran la utilidad del material para realizar el trabajo con una nota muy alta, 9.5 y la capacidad del mismo para aclarar dudas con un 8.8. Estos resultados sugieren que el material multimedia sirve para dirigir al grupo de estudiantes en la realización de su trabajo, resolviendo gran parte de las dudas que van surgiendo a lo largo del proceso. Este último dato está en concordancia con la disminución del número de tutorías solicitadas a los profesores. El curso que no disponía

(cc) EY-NC-ND 2017, Universitat Politècnica de València

Congreso IN-RED (2017) 
del material multimedia consultó al docente más veces, lo que refuerza nuestra conclusión de que el material es una excelente guía para realizar la actividad grupal.

Por otra parte, los resultados del presente estudio detectan un descenso en la calificación media del apartado de introducción. Este hecho podría estar relacionado con lo que se acaba de comentar, es decir, disponer del material multimedia hace que los alumnos se sientan guiados y soliciten menos tutorías, por tanto la relación con el profesor disminuye que es quien detecta las debilidades del grupo y las corrige. En otras palabras, durante las tutorías el docente ofrece una ayuda más personalizada y orienta al equipo en la búsqueda bibliográfica que es la base para escribir una buena introducción.

Sin embargo, es complicado que en estas tutorías (normalmente de despacho o de aula), los docentes podamos explicar bien la técnica, ubicada en laboratorios de investigación (no docentes) y con disponibilidad limitada para los estudiantes. De ahí, nuestra insistencia en que el apartado de metodología quedase bien claro en el material multimedia elaborado. A la vista de las calificaciones desglosadas por apartados, este objetivo se ha cumplido, no obtante se ha detectado una debilidad en el apartado de introducción que habrá que mejorar en los próximos cursos.

Como conclusión final podemos afirmar que el material multimedia es una manera asíncrona de impartir la materia, los estudiantes pueden consultarlo cuándo, dónde y tantas veces como quieran, lo que ofrece flexibilidad al proceso de aprendizaje. El material ha tenido una buena aceptación por parte de los alumnos como guía para la confección del trabajo y las calificaciones finales se han visto incrementadas.

\section{Referencias}

MARQUES, P. (2000). Ventajas e inconvenientes del material multimedia educativo. Departamento de Pedagogía Aplicada, Facultad de Educación, UAB $<$ http://peremarques.net/ventajas.htm> [Consulta: 20 de febrero de 2017].

MAURICIO, M.D. (2016) "Diseño de una rúbrica para evaluar trabajos en grupo: revisión y reflexión" en Congreso de Innovación Educativa y Docencia en Red. Universitat Politècnica de València. Disponible en $<$ http://ocs.editorial.upv.es/index.php/INRED $>$

POLANCO, A. (2005). "La motivación en los estudiantes universitarios". Revista Electrónica "Actualidades Investigativas en Educación. Vol. 5, núm. 2, pp. 1-13 $<$ http://www.redalyc.org/articulo.oa?id=44750219 $>$ [Consulta: 10 de marzo de 2017]

SALINAS, J. (1.996): "Multimedia en los procesos de enseñanza - aprendizaje: Elementos de discusión". Ponencia en el Encuentro de Computación Educativa. Santiago de Chile, 2-4 mayo. 


\title{
Evaluación de la mejora del proceso de enseñanza-aprendizaje mediante la integración de objetos de aprendizaje reutilizables en un curso abierto $\mathrm{OCW}$
}

\author{
Ignacio Zabalza a , Begoña Peña, Eva María Llera, Sergio Usón, Amaya Martínez, Luis \\ Miguel Romeo \\ Universidad de Zaragoza - Departamento de Ingeniería Mecánica, 50018 Zaragoza, España. ae-mail: \\ izabal@unizar.es
}

\begin{abstract}
En un contexto de Recursos Educativos Abiertos (REA), el concepto de Objetos de Aprendizaje Reutilizables (OAR), en formato digital y de carácter independiente y autónomo, resulta de gran interés para su uso en contextos educativos múltiples como los cursos abiertos (OCW, por sus siglas en inglés).

El objetivo de este trabajo es presentar los principales resultados obtenidos hasta la fecha en un proyecto de innovación docente financiado por la Universidad de Zaragoza durante los cursos académicos 2015-16 y 2016-17 (Ref. PIIDUZ_15_079, $16 \_165$ y 16_032). En este proyecto, se han creado 25 OARs en forma de videos docentes bajo licencias Creative Commons para mejorar los resultados de aprendizaje de cinco asignaturas en el campo de la Termodinámica y la Ingeniería Térmica, que actualmente se imparten en tres titulaciones distintas. Para evaluar la mejora del proceso de enseñanzaaprendizaje obtenida mediante los vídeos, se han preparado y lanzado diferentes cuestionarios para los estudiantes.

Hasta el momento, los resultados muestran que la mayoría de los estudiantes están satisfechos con esta experiencia de innovación. En este sentido, consideran que el uso de videos docentes ha mejorado su proceso de aprendizaje, aumentando su motivación para estudiar y ayudándoles a entender los conceptos más complejos.
\end{abstract}

Keywords: $O A R, O C W, R E A$, vídeos docentes, innovación docente.

\section{Introducción}

Un buen número de Universidades englobadas dentro del Consorcio de Educación Abierta (Open Education Consortium), entre las que se incluye la Universidad de Zaragoza (España), están promoviendo el acceso abierto al conocimiento a través de portales de acceso público que incorporan un conjunto de cursos abiertos OpenCourseWare (OCW), poniéndolos así a disposición de toda la comunidad de profesores, estudiantes o cualquier persona que desee aprender sobre una determinada materia. 
Uno de los principales desafíos a la hora de diseñar un OCW es cómo producir, gestionar y publicar contenidos de calidad, que puedan ser revisados y actualizados de un modo eficiente. Con este fin, surge el concepto de los Objetos de Aprendizaje Reutilizables (OAR) que constituyen elementos de aprendizaje autónomos con posibilidad de ser reutilizados en distintos contextos educativos. Por lo general, los OAR utilizan elementos multimedia accesibles por los estudiantes en cualquier momento y en cualquier lugar. De este modo, se proporciona al alumnado una experiencia de aprendizaje visual e interactiva, que puede incluir diversos elementos de autoevaluación, facilitando así el aprendizaje autónomo (Rehak y Mason, 2003).

Diversos estudios sugieren que los OAR constituyen un buen complemento a la enseñanza tradicional, contribuyendo a mejorar los resultados de la evaluación, aumentando la eficacia del aprendizaje (Windle et al., 2011; Zabalza et al., 2017), pudiendo utilizarse también en el modelo de clase invertida (Peña et al., 2017).

Los OAR se plantean generalmente como una respuesta a una necesidad de aprendizaje, por lo que después de su implementación es importante analizar el grado en el que se ha satisfecho dicha necesidad (Kay y Knaack, 2007). Sin embargo, los criterios de calidad comúnmente evaluados actualmente siguen siendo bastantes diferentes (Leacock y Nesbit, 2007; Singh y Bernard, 2016), por lo que se hace necesaria una sistematización de conceptos y criterios para la evaluación de los OAR (Pinto, Gómez-Camarero y FernándezRamos, 2012).

En este trabajo se presenta la metodología seguida y los principales resultados obtenidos hasta la fecha en un proyecto de innovación docente en que se ha hecho una evaluación de la mejora del proceso de enseñanza-aprendizaje mediante el uso vídeos docentes como objetos de aprendizaje reutilizables integrables dentro de un curso OCW. Este proyecto ha sido financiado por la Universidad de Zaragoza durante los cursos académicos 2015-16 y 2016-17. En concreto, los objetivos específicos del proyecto de innovación son:

- Aprovechar las oportunidades que ofrecen las nuevas tecnologías del aprendizaje y del conocimiento para mejorar la calidad docente y el proceso de enseñanzaaprendizaje en asignaturas del ámbito de la termodinámica y la ingeniería térmica, que actualmente se imparten en la Escuela de Ingeniería y Arquitectura de la Universidad de Zaragoza.

- Actualizar y mejorar los videos didácticos producidos en el curso académico anterior, a partir de la retroalimentación proporcionada por los alumnos.

- Publicar todo el conjunto de videos docentes desarrollados en un curso abierto dentro de la plataforma OCW de la Universidad de Zaragoza, como apoyo el estudio de los fundamentos básicos de la termodinámica y la ingeniería térmica.

- Consolidar y ampliar un grupo de profesores especializados en la elaboración y utilización de vídeos docentes como objetos de aprendizaje conceptuales, procedimentales y actitudinales en el ámbito de la termodinámica y la ingeniería térmica.

(cc) EY-NC-ND 2017, Universitat Politècnica de València 


\section{Objetivos}

El objetivo general de este trabajo es presentar las actividades realizadas en un proyecto de innovación orientado a la elaboración de un conjunto de 25 nuevos objetos de aprendizaje modulares en forma de vídeos docentes con licencias Creative Commons que faciliten el aprendizaje autónomo del alumnado en el campo de la termodinámica y la ingeniería térmica.

Se persigue divulgar una metodología, aplicable a cualquier área de conocimiento, que permita la definición y desarrollo de vídeos docentes, así como la evaluación de las mejoras obtenidas en el aprendizaje mediante su uso en asignaturas de grados universitarios. Asimismo, a través del análisis de los resultados obtenidos, se pretende demostrar que el uso de vídeos docentes permite mejorar la eficiencia en el proceso de consecución por parte del alumnado de los resultados y las competencias específicas de las asignaturas dentro de este campo, mejorando así los resultados de la evaluación y el grado de motivación y satisfacción de estudiantes y profesores.

\section{Desarrollo de la innovación}

La Tabla 1 resume las principales actividades que forman parte de la metodología seguida en este proyecto de innovación docente durante el año académico 2016-17 para el desarrollo de videos docentes y su integración en un OCW. En cuanto al calendario de dichas actividades, las tres primeras tuvieron lugar al inicio del curso académico, las actividades 4 y 5 se están desarrollando durante el curso y, finalmente, la actividad 6 se realizará al final del curso académico, tras la correspondiente validación y autorización por parte de la Universidad de Zaragoza.

Tabla 1. Metodología seguida en el proyecto de innovación docente durante el curso 2016-17

\begin{tabular}{ll}
\hline $\mathbf{N}^{\mathbf{o}}$ & \multicolumn{1}{c}{ Actividad } \\
\hline 1 & Actualización y mejora de los vídeos docentes del curso anterior \\
\hline 2 & Planificación de los nuevos vídeos docentes a realizar \\
\hline 3 & Preparación de cuestionarios para la evaluación de la mejora del proceso de enseñanza-aprendizaje \\
\hline 4 & Creación y uso de los vídeos docentes y lanzamiento de los cuestionarios \\
\hline 5 & Recopilación y análisis de datos. Planteamiento de acciones de mejora \\
\hline 6 & Publicación de la colección completa de vídeos docentes en una plataforma OCW \\
\hline
\end{tabular}

A partir del análisis de los vídeos docentes elaborados en el curso anterior, realizado a partir del feedback proporcionado por los estudiantes, se plantea en primer lugar, la reedición parcial de los vídeos elaborados con objeto de corregir algunas deficiencias detectadas e incorporar diversas mejoras. De este modo, se consigue la mejora continua del trabajo realizado.

El siguiente paso consiste en la planificación de los vídeos/objetos de aprendizaje a realizar, su temática y duración, la definición de las asignaturas en las que se van a utilizar, el 
profesor responsable de su elaboración, así como la fecha prevista de realización. En este punto se incluye también la definición de una plantilla común para todos los videos y la selección de las licencias Creative Commons (CC) para los vídeos elaborados. En la Tabla 2 se muestra la temática del conjunto completo de los 25 videos docentes -nuevos o existentes- que se integrarán en el curso $\mathrm{OCW}$, indicándose entre paréntesis el número total de vídeos por cada tema.

Tabla 2. Temática (y número) de vídeos docentes utilizados en las asignaturas

\begin{tabular}{ll}
\hline \multicolumn{2}{c}{ Temas } \\
\hline Tutorial del programa “Engineering Equation Solver”-EES (3) & Ciclos de refrigeración (2) \\
\hline Propiedades de las sustancias puras (4) & Psicrometría (2) \\
\hline Modelo de gas ideal (2) & Método de diferencias finitas-MDF (2) \\
\hline Balance de energía en sistemas cerrados (1) & Intercambiadores de calor (2) \\
\hline Balance de masa y energía en volúmenes de control (2) & Convección forzada exterior (1) \\
\hline Ciclos de potencia con turbina de gas-Brayton (1) & Motores Térmicos (1) \\
\hline Ciclos de potencia con turbina de gas-Rankine (2) & \\
\hline
\end{tabular}

Tal como se puede observar en la Tabla 3, las cinco asignaturas seleccionadas para el uso de los vídeos docentes se imparten en tres titulaciones distintas de la Universidad de Zaragoza

Tabla 3. Asignaturas seleccionadas para el uso de vídeos docentes

\begin{tabular}{llcccc}
\hline \multicolumn{1}{c}{ Asignatura } & \multicolumn{1}{c}{ Titulación } & Curso & $\begin{array}{c}\text { Créditos } \\
\text { ECTS }\end{array}$ & $\begin{array}{c}\mathbf{N}^{\mathbf{0}} \mathbf{d e} \\
\text { vídeos } \\
\text { usados }\end{array}$ & $\begin{array}{c}\mathbf{N}^{\mathbf{0}} \text { de } \\
\text { estudiantes }\end{array}$ \\
\hline $\begin{array}{l}\text { Termodinámica Técnica y } \\
\text { Fundamentos de Transmisión } \\
\text { de Calor }\end{array}$ & $\begin{array}{l}\text { Grado en Ingeniería } \\
\text { de Tecnologías } \\
\text { Industriales }\end{array}$ & $2^{\text {o }}$ & 6 & 19 & 70 \\
\hline $\begin{array}{l}\text { Termodinámica Técnica y } \\
\text { Fundamentos de Transmisión } \\
\text { de Calor }\end{array}$ & $\begin{array}{l}\text { Grado en Ingeniería } \\
\text { Mecánica }\end{array}$ & $2^{\text {o }}$ & 6 & 19 & 64 \\
\hline $\begin{array}{l}\text { Termodinámica Técnica y } \\
\text { Fundamentos de Transmisión } \\
\text { de Calor }\end{array}$ & $\begin{array}{l}\text { Grado en Ingeniería } \\
\text { Electrónica y } \\
\text { Automática }\end{array}$ & $2^{\text {o }}$ & 6 & 10 & 85 \\
\hline Ingeniería Térmica & $\begin{array}{l}\text { Grado en Ingeniería } \\
\text { de Tecnologías } \\
\text { Industriales }\end{array}$ & $2^{\text {o }}$ & 6 & 2 & 50 \\
\hline Máquinas y Motores Térmicos & $\begin{array}{l}\text { Grado en Ingeniería } \\
\text { Mecánica }\end{array}$ & $3^{\circ}$ & 6 & 2 & 70 \\
\hline
\end{tabular}


La siguiente actividad es la preparación de cuestionarios para evaluar cuantitativamente el grado de satisfacción y la mejora del proceso de enseñanza-aprendizaje obtenida a través de los vídeos docentes. Se plantean tres cuestionarios anónimos a realizar en distintos momentos del curso: un cuestionario inicial, donde se pregunta al alumnado sobre sus expectativas en cuanto a su participación en el proyecto de innovación docente; un cuestionario intermedio, donde el alumnado hace una valoración de cada video docente visionado en el contexto de la asignatura en la que se utiliza; y un cuestionario final, donde el alumnado hace una valoración final del proyecto de innovación docente. Tanto el cuestionario intermedio como el cuestionario final están realizados en base a una escala de tipo Likert de 5 puntos ( 1 a 5 ).

Tras el lanzamiento de los cuestionarios y videos docentes en la plataforma Moodle de la Universidad de Zaragoza, se recopilan y analizan todas las respuestas a los cuestionarios con objeto de poder implementar acciones de mejora en los videos, corregir posibles deficiencias detectadas y definir nuevas necesidades docentes para próximos cursos.

El conjunto completo de 25 vídeos realizados serán publicados al final del curso académico dentro de la plataforma OCW de la Universidad de Zaragoza (http://ocw.unizar.es/ocw). Para ello se creará un curso OCW denominado "Material audiovisual de apoyo al estudio de la termodinámica y la ingeniería térmica" en el que se integrarán de un modo coherente todos los vídeos realizados. Esta plataforma OCW de carácter abierto será la utilizada para la visualización de los vídeos docentes en próximos cursos académicos en sustitución de la plataforma interna Moodle. De este modo, cualquier estudiante o persona interesada en esta materia podrá acceder libremente a todos los objetos de aprendizaje creados.

\section{Resultados}

Puesto que los resultados de la aplicación de los vídeos docentes en las cinco asignaturas mostradas en la Tabla 3 han sido similares, seguidamente, a modo de ejemplo, se presentan los principales resultados obtenidos en una asignatura. En concreto, se ha seleccionado la asignatura "Termodinámica Técnica y Fundamentos de Transmisión de Calor", ya que cuenta con un mayor número de estudiantes participantes (70), además de ser la asignatura en la que se ha utilizado un mayor número de vídeos (19). Esta asignatura se imparte en el segundo año del Grado en Ingeniería de Tecnologías Industriales. La asignatura consta de 6 créditos ECTS, equivalentes a 150 horas de trabajo, que incluyen 60 horas presenciales repartidas entre clases magistrales, resolución de problemas y prácticas de laboratorio/simulación, y 90 horas no presenciales dedicadas al estudio personal, la resolución de trabajos tutorados y la evaluación.

La participación de los estudiantes en los distintos cuestionarios planteados ha disminuido a lo largo del curso, manteniéndose no obstante elevada en aquellas encuestas marcadas como obligatorias. Teniendo en cuenta lo anterior, la participación alcanzó el 97\% en el cuestionario inicial, el $52 \%$ en el cuestionario intermedio, descendiendo hasta el $15 \%$ en el cuestionario final, debido a que éste fue realizado en fechas próximas al periodo de exámenes. 


\subsection{Cuestionario inicial}

Casi el $20 \%$ de los estudiantes encuestados manifiesta que ha visualizado previamente distintos tipos de videos docentes actualmente proporcionados en un total de diez asignaturas pertenecientes al Grado en Ingeniería de Tecnologías Industriales. Sin embargo, la mayoría de los estudiantes (78\%) consideran insuficiente el uso actual de estos elementos de aprendizaje, afirmando que suelen buscar y visualizar por su cuenta vídeos docentes disponibles en la red relacionados con las temáticas de las asignaturas de su titulación. Por tanto, se aprecia un destacado interés hacia el uso de videos docentes para la mejora de los resultados de aprendizaje.

Por otra parte, entre los diferentes tipos de videos docentes que se pueden plantear, la mayoría de los estudiantes afirman que están interesados en visualizar videos de aplicaciones prácticas relacionadas con la asignatura $(29 \%)$ y en vídeos específicamente realizados por el profesor para explicar los contenidos de la asignatura (25\%). El resto de estudiantes, muestra su preferencia por visualizar vídeos ya existentes recomendados por el profesor, relativos a salidas profesionales $(16 \%)$, noticias $(15 \%)$ y conferencias $(15 \%)$ relacionadas con la temática de la asignatura.

\subsection{Cuestionario intermedio}

Para cada video docente elaborado se planteó un cuestionario según una escala de tipo Likert de 5 puntos ( 1 a 5). En la Fig. 1 se presentan los valores estadísticos promedio de los distintos aspectos evaluados en los videos docentes usados. Se trata, por tanto, de los valores promedio obtenidos para el conjunto de 19 vídeos utilizados en la asignatura seleccionada, no habiéndose detectado variaciones significativas en la valoración individual de cada vídeo docente utilizado. Debe destacarse que la mayoría de los estudiantes (más del $40 \%$ ) otorga una puntuación de 4 puntos en los aspectos de amenidad, duración, utilidad para la resolución de dudas y calidad técnica de los videos docentes. Asimismo el 50\% de los estudiantes asigna una puntuación de 4 puntos como calificación global de los videos. Por tanto, se concluye que la mayoría de los estudiantes han quedado muy satisfechos con los videos visualizados. 


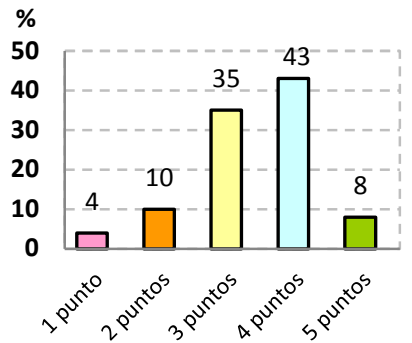

Amenidad y capacidad de motivación
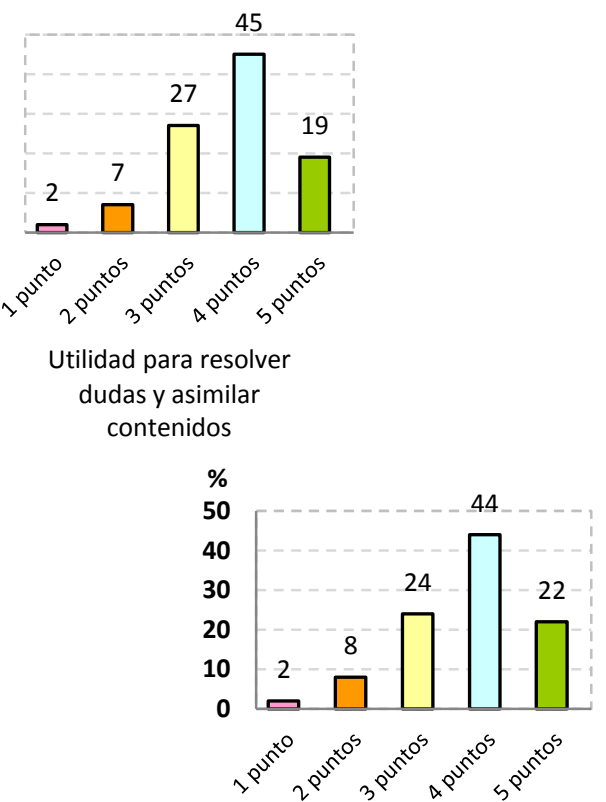

Calidad técnica del vídeo

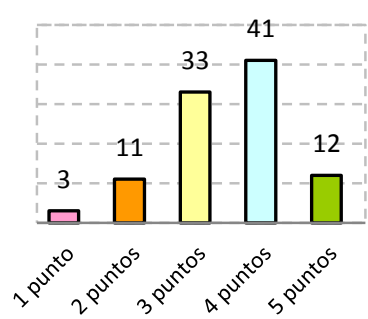

Adecuación de la duración del vídeo

Fig. 1 Valores estadísticos promedio de la evaluación de los vídeos docentes en la asignatura objeto de análisis

\subsection{Cuestionario final}

De cara a la valoración final se planteó igualmente un cuestionario con una escala de tipo Likert de 5 puntos ( $1=$ nada de acuerdo, $2=$ poco de acuerdo, $3=$ algo de acuerdo, 4=bastante de acuerdo, $5=$ totalmente de acuerdo), cuyos resultados se muestran en la Fig. 2.

Alrededor del $50 \%$ de los estudiantes están en desacuerdo o muy en desacuerdo con el hecho de que visualizar videos les haya restado tiempo de estudio. Por otra parte, aunque la mitad de los estudiantes piensa que ha mejorado su proceso de aprendizaje, el mismo porcentaje considera que no hay una relación clara entre la visualización de videos y el aumento de su motivación para el estudio. Esto podría explicarse por la complejidad y variedad de factores que influyen en la motivación de los estudiantes. Por otro lado, el $60 \%$ de los estudiantes considera deseable o altamente deseable extender el uso de videos docentes a otras asignaturas de su titulación. Su interés en disponer de más videos docentes 
para la asignatura analizada no es tan claro, tal vez debido al alto número de videos utilizados a lo largo del curso. Por último, cabe destacar que todos los estudiantes dan una calificación global al proyecto de innovación docente superior a 3 puntos, y el $60 \%$ otorga una puntuación entre 4 y 5 puntos.

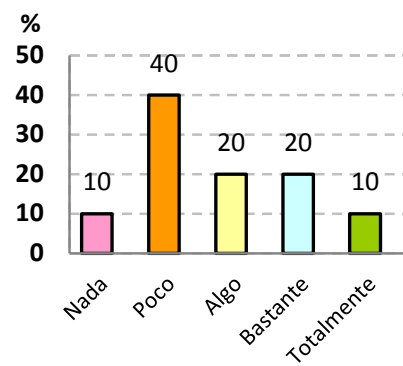

Visionar vídeos me ha quitado tiempo de estudio

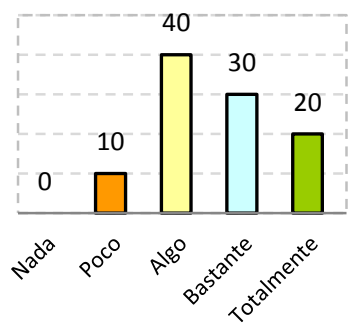

Visionar videos ha mejorado mi aprendizaje

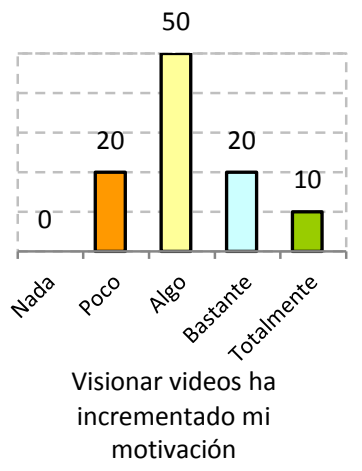

motivación 


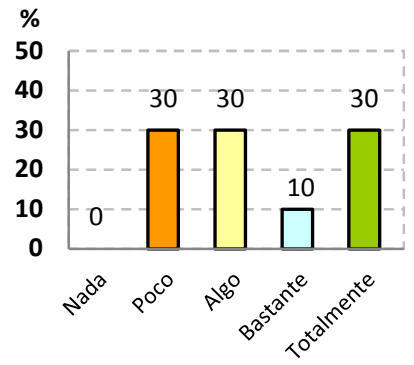

Conveniencia de disponer de más vídeos docentes

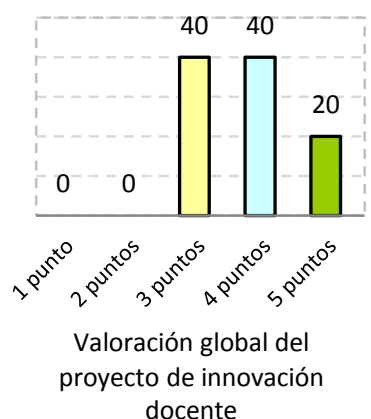

Fig. 2 Valores obtenidos del cuestionario final en la asignatura objeto de análisis

\footnotetext{
Valoración global del

royecto de innovación
}

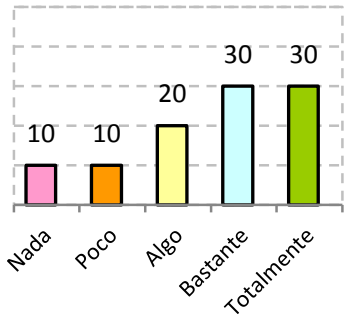

Conveniencia de usar vídeos docentes en otras asignaturas 


\section{Conclusiones}

Aunque el proyecto de innovación docente presentado en este trabajo está siendo aplicado en el ámbito de la termodinámica y la ingeniería térmica, la metodología seguida para el desarrollo de videos docentes y la evaluación cuantitativa de su impacto en el proceso de enseñanza-aprendizaje es completamente replicable en cualquier disciplina y área de conocimiento. Además, la metodología es relativamente fácil de implementar y no requiere de grandes esfuerzos adicionales por parte de los profesores, siendo especialmente adecuada para redes colaborativas de profesores interesados en la innovación y la mejora de la actividad docente. Los resultados presentados en esta comunicación demuestran que la visualización de videos docentes en un contexto universitario permite mejorar el proceso de aprendizaje, aprovechando mejor el tiempo dedicado a las clases magistrales y las sesiones prácticas.

\section{Referencias}

REHAK, D. y MASON, R. (2003). "Engaging with the Learning Object Economy", en Reusing Online Resources: A Sustainable Approach to E-Learning (A. Littlejohn, ed.), pp. 22-30, London: Kogan Page.

WINDLE, R.J. et al. (2011). "The characteristics of reusable learning objects that enhance learning" en British Journal of Educational Technology, vol. 42, no.5, pp. 811-823.

ZABALZA, I., PEÑA, B., LLERA, E.M., MARTíNEZ, A. y ROMEO, L.M. (2017). "Development of educational videos as reusable learning objects for their integration into an Open Courseware on fundamentals of thermodynamics and thermal engineering" en Proceedings of the 11th annual International Technology, Education and Development Conference (INTED 17). Valencia.

PEÑA, B., ZABALZA, I., USÓN, S., LLERA, E.M., MARTÍNEZ, A. y ROMEO, L.M. (2017). "Pilot experience for the application of the flipped classroom in subjects of the field of thermal engineering" en Proceedings of the 11th annual International Technology, Education and Development Conference (INTED 17). Valencia.

KAY, R.H. y KNAACK, L. (2007). "Evaluating the learning in learning objects" en Open Learning, vol. 22, no.1, pp. 5-28.

LEACOCK, T.L. y NESBIT, J.C. (2007). "A Framework for Evaluating the Quality of Multimedia Learning Resources" en Educational Technology \& Society, vol. 10, no. 2, pp. 44-59.

SINGH, R:G. y BERNARD, M.A. (2016). "Quality assurance for reusable learning objects on a peerto-peer network" en International Journal of Emerging Technologies in Learning, vol. 11, no. 10, pp. $4-10$.

PINTO, M., GOMEZ-CAMARERO, C. y FERNÁNDEZ-RAMOS, A. (2012). "Los recursos educativos electrónicos: perspectivas y herramientas de evaluación" en Perspect. em Ciência da Informação, vol. 17, no.3, pp. 82-99.

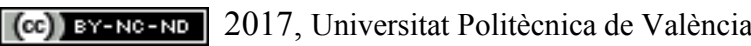




\title{
ExamRandomizeR: Una aplicación web para la generación de exámenes aleatorizados que faciliten situar el Examen como herramienta de aprendizaje y no solo de evaluación en el aula de matemáticas ${ }^{*}$
}

\author{
Elvira Ferre Jaén ${ }^{1}$, Laura del Río Alonso ${ }^{1}$ y Antonio Maurandi López ${ }^{1}$
}

${ }^{1}$ Universidad de Murcia

\begin{abstract}
In this paper we present the development and usage of an interactive application for teaching mathematics, which facilitates the improvements of teaching and learning processes and it promotes the participation of students in the development of a dinamic class. The application has been programmed with $R$ and the package Shiny.

The application is able to generate, from a set of previously introduced questions, different randomized versions of the original exam, with their corresponding answers, thereby facilitating and automating the exam creation work.
\end{abstract}

Keywords: Evaluation, Didactics, Mathematics, R-project, Programming, Shiny, $R$

\section{Resumen}

En este trabajo se presenta el desarrollo y uso de una aplicación web interactiva como herramienta docente para la docencia de las matemáticas, que permite mejorar el proceso de enseñanza-aprendizaje del alumnado y desarrollar en el aula estilos educativos interactivos para fomentar la participación de los y las estudiantes. La aplicación ha sido programada con $R$ y la librería Shiny.

Esta aplicación es capaz de generar de forma aleatoria, a partir de una serie de preguntas introducidas previamente, exámenes aleatorizados, diferentes, junto con sus correspondientes soluciones, pudiendo asi facilitar y automatizar estas tareas.

Keywords: Evaluación, Didáctica, Matemáticas, R-project, Programación, Shiny, $R$

\footnotetext{
*Proyecto desarrollado con colaboración del Servicio de Apoyo a la Investigación (SAI) de la Universidad de Murcia
} 
ExamRandomizeR: Una aplicación web para la generación de exámenes aleatorizados que faciliten situar el Examen como herramienta de aprendizaje y no solo de evaluación en el aula de matemáticas

\section{Introducción}

A pesar de que la relevancia de la Didáctica de las Matemáticas en los estudios de Ciencias Sociales es incuestionable, es un hecho conocido que el aprendizaje de las matemáticas entraña una gran dificultad para estudiantes de titulaciones no técnicas. Esta dificultad, además, se constata en la enseñanza de las matemáticas en todos los niveles educativos.

En el ejercicio de la docencia, el examen se entiende y se utiliza como una herramienta cuyo único objetivo es el de evaluar el proceso de enseñanza aprendizaje y cuantificar el conocimiento adquirido por el alumnado al final del mismo.

Desde este punto de vista, el examen suele generar rechazo entre el alumnado y cierto grado de ansiedad (Lyons y Beilock 2012), perdiéndose de esta manera gran parte del potencial didáctico que esta herramienta puede ofrecer, aunque para ello sea necesario emplearlo con otros fines y otras metodologías, tal como propone el profesor Mazur (Mazur 2009).

Con esta premisa en mente, y con el objetivo último de crear en el aula un ambiente de aprendizaje dinámico e interactivo, donde el estudiantado pueda evaluar tanto como el equipo docente la adquisición de los contenidos que se trabajan en cada momento, hemos desarrollado con el lenguaje de programación R (R Core Team 2017) y la librería Shiny (Chang y col. 2016), una aplicación web interactiva de sencillo manejo, que puede ser utilizada tanto por docentes como por discentes.

La aplicación permite, a partir de un examen base que contendrá un listado de preguntas de tipo uniforme, como puede ser, el de respuesta múltiple, generar diversos exámenes o modelos de examen en los que se reordenan de forma aleatoria tanto las preguntas como las respuestas, utilizando semillas de aleatorización, lo que permite volver a generar los mismos exámenes si fuera preciso.

La herramienta se presenta como una aplicación de acceso web que devuelve los resultados aleatorizados tanto en ficheros tex de IATEX (Project 2017), Markdown (Gruber 2017), formato txt de texto plano (ASCII) o directamente en pdf.

Existen, aparte de esta aplicación, otras herramientas interesantes y bastante completas de creación de exámenes como son: el paquete exams de R (Grün y Zeileis 2009), esta herramienta, aunque es muy completa, no se centra en los mismos objetivos que la nuestra y adolece de una interface web de fácil uso para usarla sin conocimientos de $\mathrm{R}$, no obstante se trata de una potente herramienta para generar exámenes dinámicos que pueden ser diferentes para cada persona y dispone de una licencia GNU General Public Licence. Otra opción es "Schoolhouse Test 4" (School Housetest Tecnologies 2017) diseñado expresamente para docentes. Schoolhouse Test 4 te permite crear exámenes con muchas opciones, incluyendo aleatorización de preguntas y dispone de un modulo para matemáticas. No obstante se trata de software privativo, hay que adquirir una licencia y solo está disponible para el sistema operativo Windows.

Se pueden encontrar otras herramientas web para crear formularios para ser contestados on-line, algunas de estas te permiten aleatorizar ítems como es "Qualtrics 360 plataform" (Qualtrics 360 platform 2017), aunque esta no tiene una licencia que permita su uso sin un contrato de servicios. Otro buen ejemplo de cuestionarios on-line lo constituye la aplicación Encuestas de la Universidad de Murcia (Web de ENCUES- 
TAS Version 2.5). Ninguna de estas últimas te permite generar exámenes para ser distribuidos en papel, circunscribiéndose a cuestionarios on-line si prestar atención a la presentación de formulas matemáticas. De esta forma pensamos que nuestro desarrollo es pertinente y pone a disposición de docentes y discentes una interesante opción para crear modelos de exámenes con las particularidades que pasamos a especificar.

\section{Objetivos}

Los objetivos de este trabajo son los siguientes:

1. Crear una aplicación que sea capaz de generar exámenes partiendo de un examen inicial, por medio de permutaciones aleatorizadas de las preguntas y de las respuestas de cada pregunta.

2. Que la aplicación permita la introducción de formulas matemáticas complejas en los exámenes sin que ello genere errores en el formato final.

3. Que la aplicación permita crear claves/plantillas de corrección para cada uno de los exámenes generados.

4. Que los formatos de salida sean variados y permitan la interacción de docentes y discentes: $\mathrm{LT}_{\mathrm{E}} \mathrm{X}$, Markdown, txt, pdf.

5. Que la aplicación tenga un diseño cómodo para su uso de forma intuitiva y con acceso vía web.

\section{Desarrollo de la innovación}

Se plantearon cuatro fases en el desarrollo de la aplicación:

1. Una primera fase donde nos centramos en el desarrollo del algoritmo de randomización. Este no es complejo y no ocupa más de 150 lineas de código, pero ha de ser robusto y de fácil mantenimiento.

2. Una segunda fase de diseño de la aplicación web con un o dos formatos de salida a fin de poder ponerla en semiproducción.

3. Una tercera etapa de prueba en la que diferentes docentes del área de Didáctica de las Ciencias Matemáticas la probaron en el desarrollo de su clases y en los exámenes de las diferentes asignaturas del área. Muchas de las sugerencias de estos docentes fueros incluidas como mejoras a la aplicación y otras aún están pendientes de ser implementadas.

4. Una cuarta etapa de mejora de los formatos de salida para adaptarla a las diversas necesidades y formas de aplicación.

5. Una quinta etapa de mejora de los formatos de carga de datos para por ejemplo poder leer directamente de una plantilla escrita en Markdown

6. Una última etapa de adaptación de los css de la aplicación a los colores institucionales. 
ExamRandomizeR: Una aplicación web para la generación de exámenes aleatorizados que faciliten situar el Examen como herramienta de aprendizaje y no solo de evaluación en el aula de matemáticas

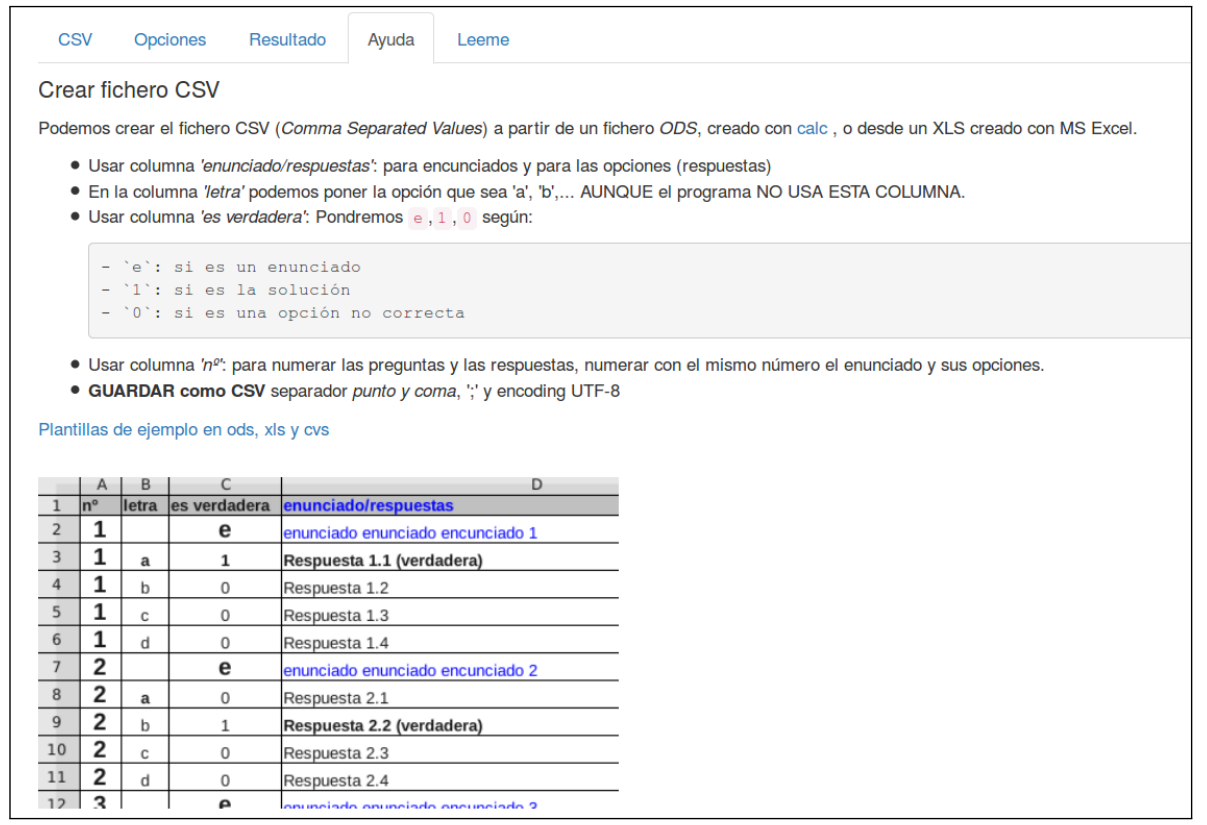

Fig. 1: Aspecto de la hoja de cálculo modelo para la creación de exámenes.

Actualmente nos encontramos en la última fase del proyecto.

\section{Resultados}

La aplicación en su actual versión 3.1.4 puede ser accedida y utilizada desde la url: http://gauss.inf.um.es:8080/examrandomizer/. Hasta la fecha ha sido empleada con asiduidad durante los cursos de 2015/2016 y 2016/2017 con gran aceptación por parte del profesorado de las asignaturas de Matemáticas y su Didáctica I y II , del segundo y tercer curso del Grado en Educación Primaria de la Universidad de Murcia.

El empleo de la aplicación requiere de cuatro fases:

1. Carga de datos

2. Especificación de opciones para la creación de los exámenes

3. Selección del formato de salida y creación de exámenes

4. Descarga y edición de los modelos de examen

En la fase de "carga de datos", hay que subir el modelo de examen base en un formato csv que se explica con detalle en el apartado ayuda, ver Figuras 1 y 2. El examen base debe contener los enunciados de las preguntas y las posibles respuestas, indicando con un código cual de las preguntas es la correcta. Se facilita una hoja de cálculo como ejemplo que sirve de base para crear un examen y adquirir la rutina de carga de datos.

En la fase de "especificación de opciones para la creación de los exámenes", debemos ser consistentes en la forma de las preguntas, estas deben de ser, para estas primeras versiones de la aplicación, todas del mismo tipo, es decir, si optamos por cuatro 


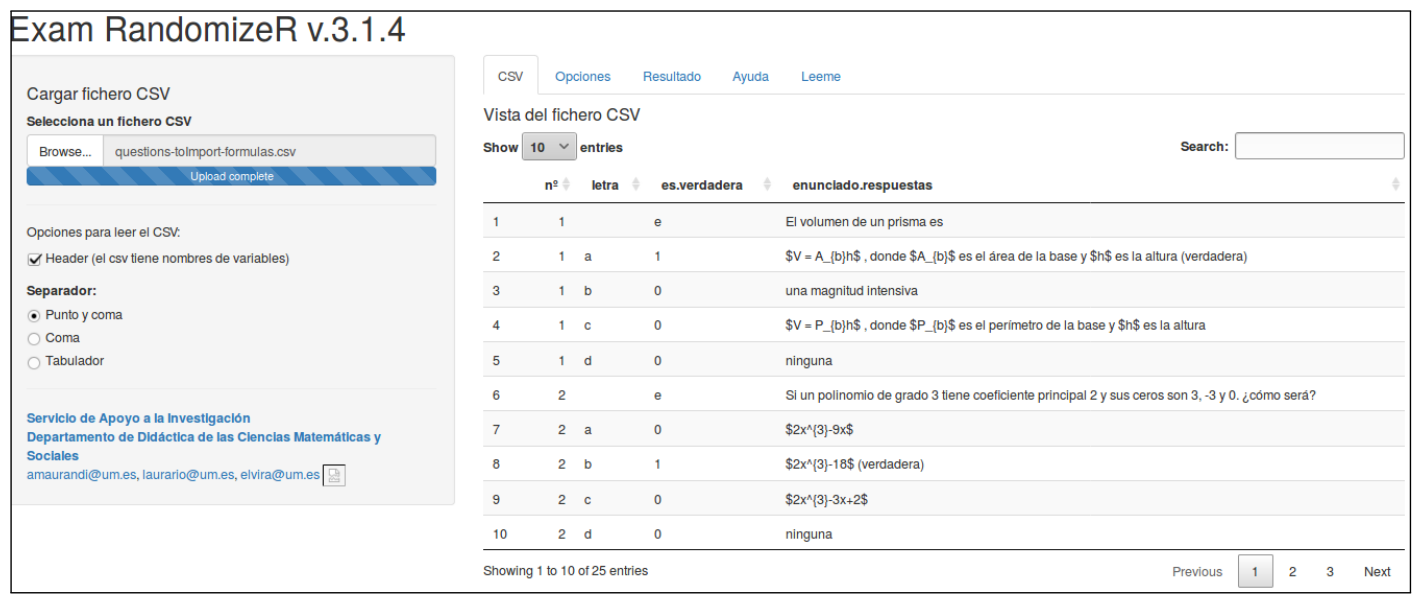

Fig. 2: Carga de datos en formato csv.

respuestas posibles con una sola respuesta válida, todas las preguntas deberán de ser de ese formato. También deberemos especificar el número de exámenes o modelos que deseamos generar, y si queremos aleatorizar el orden de las preguntas, las respuestas de cada pregunta o ambas cosas, ver Figura 3 y 4.

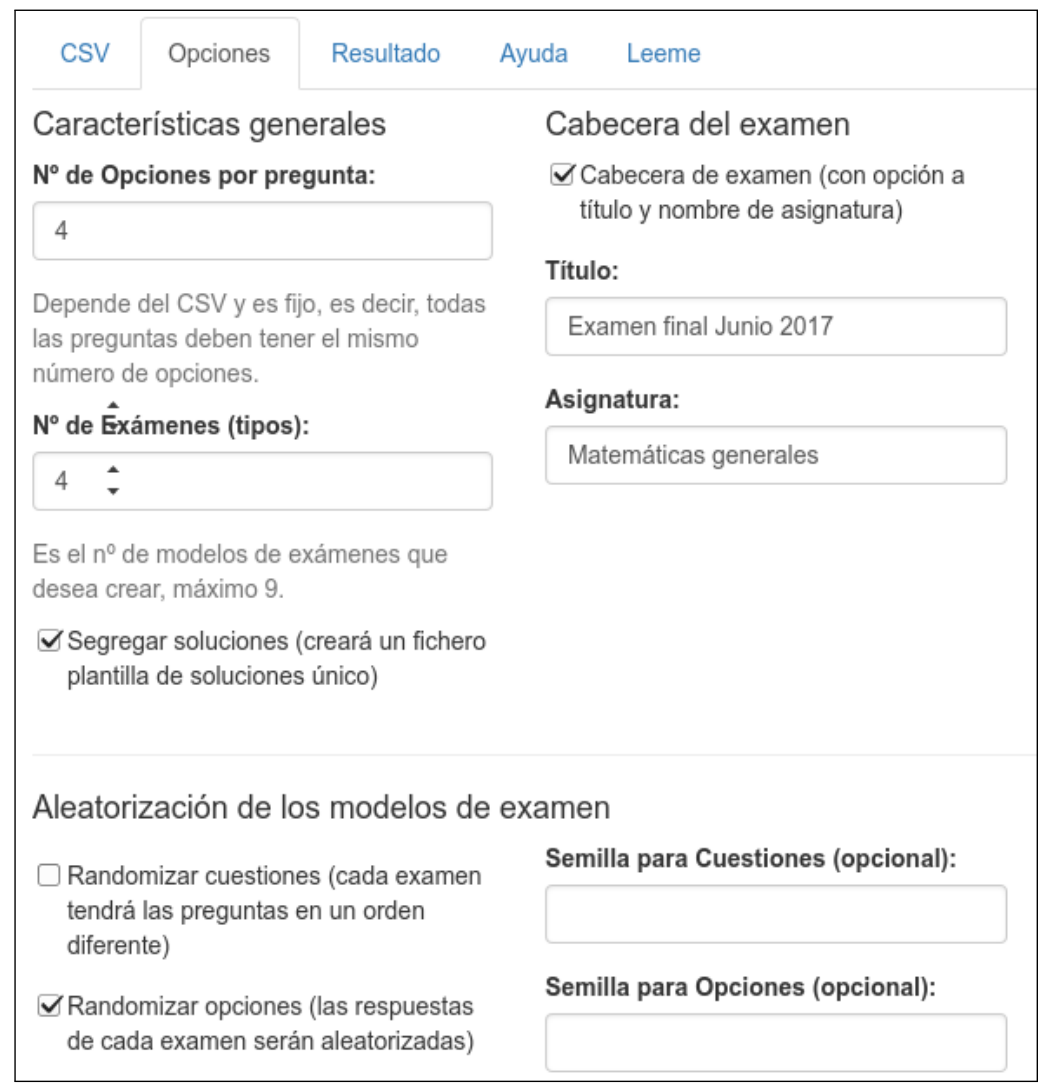

Fig. 3: Opciones de creación de exámenes. 
ExamRandomizeR: Una aplicación web para la generación de exámenes aleatorizados que faciliten situar el Examen como herramienta de aprendizaje y no solo de evaluación en el aula de matemáticas

"Aleatorización de modelos de examen". La posibilidad de desvincular la aleatorización de las preguntas y las respuestas permite presentar varios modelos del mismo examen donde el orden de las preguntas es el mismo, pero el orden de las respuestas es diferente. Todas estas herramientas permiten crear múltiples "exámenes", y fomentar que, aunque alguna pregunta haya aparecido en otras ocasiones, contestar el examen requiera volver a razonar y pensar la respuesta que se da. Una utilidad que surge de esta posibilidad es que, el hecho de disponer de numerosos modelos para exámenes, desanima al alumnado a intentar copiar de los compañeros, pues se incrementa la dificultad de comunicación y se estimula que se centren en la resolución del propio examen.

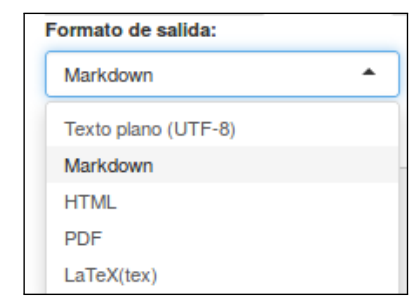

Fig. 4: Opciones: Formatos de salida.

La etapa, "descarga y edición", actualmente está implementada para obtener los exámenes en html. Markdown, txt, tex y pdf, de forma que es sencillo incluir las preguntas tipo test en un examen más general o generar exámenes solo de preguntas tipo test. Otros formatos de salida, como por ejemplo docx están siendo desarrollados en estos momentos.

La última etapa, "descarga y edición", actualmente está implementada para obtener los exámenes en Markdown y txt, de forma que es sencillo incluir las preguntas tipo test en un documento de examen más general o generar exámenes solo de preguntas tipo test, el resto de formatos mencionados están siendo desarrollados en estos momentos.

\section{Conclusiones}

Nuestro objetivo final es implementar en el aula un proyecto basado en lo que se conoce como Interactive teaching, cuya premisa es que la aplicación práctica capacita a los y las estudiantes a comprender la profundidad de los materiales de estudio (Yakovleva y Yakovlev 2014).

Estos estilos de aprendizaje interactivo proporcionan cuatro formas básicas de retroalimentación:

- Los logros de los y las estudiantes son medibles, el profesorado que hace uso de estilos de enseñanza interactivos está mejor preparado para conocer cómo dominan sus estudiantes un material determinado.

- Flexibilidad en la enseñanza, este tipo de metodología involucra comunicaciones bidireccionales permiten al docente hacer ajustes rápidos en los procesos y enfoques de enseñanza.

- La práctica hace la perfección. La instrucción interactiva mejora el proceso de aprendizaje. 
- La motivación del estudiante. La enseñanza de dos vías disipa la pasividad del estudiante

En este sentido, la aplicación "ExamRandomizeR", aunque se encuentra en un estado avanzado de desarrollo, todavía estamos progresando en otros aspectos fundamentales como los formatos de salida, especialmente en el empleo de plantillas avanzadas de IATEX. La ventaja de generar salidas directamente a Markdown nos permitirá aprovechar el potencial de este lenguaje para crear formato html fácilmente y por lo tanto nos permite crear herramientas de evaluación en web. Este hito es importante, pues las herramientas on-line son esenciales si queremos aplicar la estrategia de aprendizaje interactivo sugerida por el profesor Mazur.

Pretendemos, por otro lado, aparcar el modelo clásico de profesor o profesora que resuelve problemas en clase, y plantear en su lugar sesiones interactivas en las que los y las estudiantes aprendan preguntando y resolviendo aquellas cuestiones generadas por el grupo, razonando y generando debate en clase, relegando el estilo clásico de aprendizaje "memorizando recetas".

Para resolver durante las sesiones prácticas las cuestiones que le surgen al alumnado tras el uso de ExamRandomizeR, pretendemos seguir el siguiente esquema (Mazur 2009):

1. Planteamiento de las preguntas

2. Tiempo para pensar en la respuesta (2 minutos)

3. Respuesta individual de cada alumno o alumna (levantar manos y recuento de respuestas)

4. Planteamos un debate y dejamos tiempo para que comuniquen su razonamiento a los compañeros

5. Responden otra vez

6. Explicación de la respuesta correcta por parte del docente

Mediante este proceso, al hacer que el alumnado discuta, el foco de la información se desplaza del o la docente, y se centra sobre el alumnado, permitiéndoles razonar sobre los conceptos planteados y ver dónde se encuentran con respecto al resto de la clase, sin que eso afecte a su nota final, por lo que este sistema se convierte en un tipo de evaluación informativa que se lleva a cabo de manera continua.

Nos basamos en el hecho de que si los y las estudiantes comprenden los conceptos básicos, si son capaces de contestar correctamente los cuestionarios generados aleatoriamente con ExamRandomizeR podrán resolver correctamente los problemas convencionales.

En resumen, planteamos que el alumnado necesita adquirir una comprensión razonada de la información que reciben, siendo de limitada utilidad la mera memorización de ecuaciones o teorías matemáticas, si no va acompañado de la comprensión y razonamiento de esas teorías mediante su uso. En definitiva, en la enseñanza de las matemáticas es necesario trabajar en la construcción de modelos mentales para que se asimile la información presentada en clase. 
ExamRandomizeR: Una aplicación web para la generación de exámenes aleatorizados que faciliten situar el Examen como herramienta de aprendizaje y no solo de evaluación en el aula de matemáticas

\section{Ejemplo completo de utilización}

Comenzamos creando una serie de preguntas de múltiple respuesta donde solo una es correcta, lo hacemos con la aplicación Calc de la suite ofimática LibreOffice.

\begin{tabular}{|c|c|}
\hline $\mathrm{n}^{\circ}$ letra & es verdadera enunciado/respuestas \\
\hline 1 & El volumen de un prisma es \\
\hline $1 \mathrm{a}$ & $\left.1 \$ \mathrm{~V}=\mathrm{A} \_\mathrm{b}\right\} \mathrm{h} \$$, donde $\left.\$ \mathrm{~A} \_\mathrm{b}\right\} \mathrm{b}$ es el área de la base y $\$ \mathrm{~h} \$$ es la altura (verdadera) \\
\hline $1 \mathrm{~b}$ & 0 una magnitud intensiva \\
\hline $1 \mathrm{c}$ & $0 \$ \mathrm{~V}=\mathrm{P}\{\mathrm{b}\} \mathrm{h} \$$, donde $\$ \mathrm{P}\{\mathrm{b}\} \$$ es el perimetro de la base y $\$ \mathrm{~h} \$$ es la altura \\
\hline $1 \mathrm{~d}$ & 0 ninguna \\
\hline 2 & Si un polinomio de grado 3 tiene coeficiente principal 2 y sus ceros son $3,-3$ y 0 . ¿cómo será? \\
\hline $2 \mathrm{a}$ & $0 \$ 2 x^{\wedge}\{3\}-9 x \$$ \\
\hline $2 \mathrm{~b}$ & $1 \$ 2 x^{\wedge}\{3\}-18 \$$ (verdadera) \\
\hline $2 \mathrm{c}$ & $0 \$ 2 x \wedge\{3\}-3 x+2 \$$ \\
\hline $2 \mathrm{~d}$ & O ninguna \\
\hline 3 & ¿Qué nombre recibe la diferencia entre los valores extremos de una variable estadística? \\
\hline 3a & OMediana \\
\hline $3 \mathrm{~b}$ & OModa \\
\hline $3 \mathrm{c}$ & 1 Recorrido (verdadera) \\
\hline $3 \hat{d}$ & 0 ninguna \\
\hline
\end{tabular}

Fig. 5: Creación de examen con Calc de LibreOffice.

Nuestro propósito en este ejemplo es crear varios modelos de examen, ya que tenemos un grupo muy numeroso, vamos a crear 4 grupos, y podemos seleccionar si aleatorizar el orden de las preguntas y el orden de las respuestas, solo el orden de las preguntas o solo el de las respuestas, está ultima opción produce exámenes que se parecen, pues las preguntas son las mismas pero presentan las respuestas en diferente orden. Gracias a la plantilla de soluciones podremos corregir los exámenes sin confundirnos a pesar de ser muy parecidos.

Como se puede ver en la figura 3, seleccionamos las opciones sobre el formato: $\mathrm{N}^{\circ}$ de Opciones por pregunta igual a $4, \mathrm{~N}^{\circ}$ de exámenes (tipos) a crear, también igual a 4. Verificamos que está seleccionado Segregar soluciones para crear un fichero independiente con las respuestas. Seleccionamos Cabecera de Examen para editar el Titulo y la Asignatura. En Aleatorización de los modelos de examen seleccionamos Randomizar opciones.

Un resumen del proceso de creación de exámenes se puede ver en la pestaña resultados" de la aplicación, ver figura 6 , junto con el aspecto de los ficheros después de la descarga. El examen creado contendrá el Titulo y Asignatura que consignáramos en Opciones, un ejemplo se puede ver en la figura 7. 


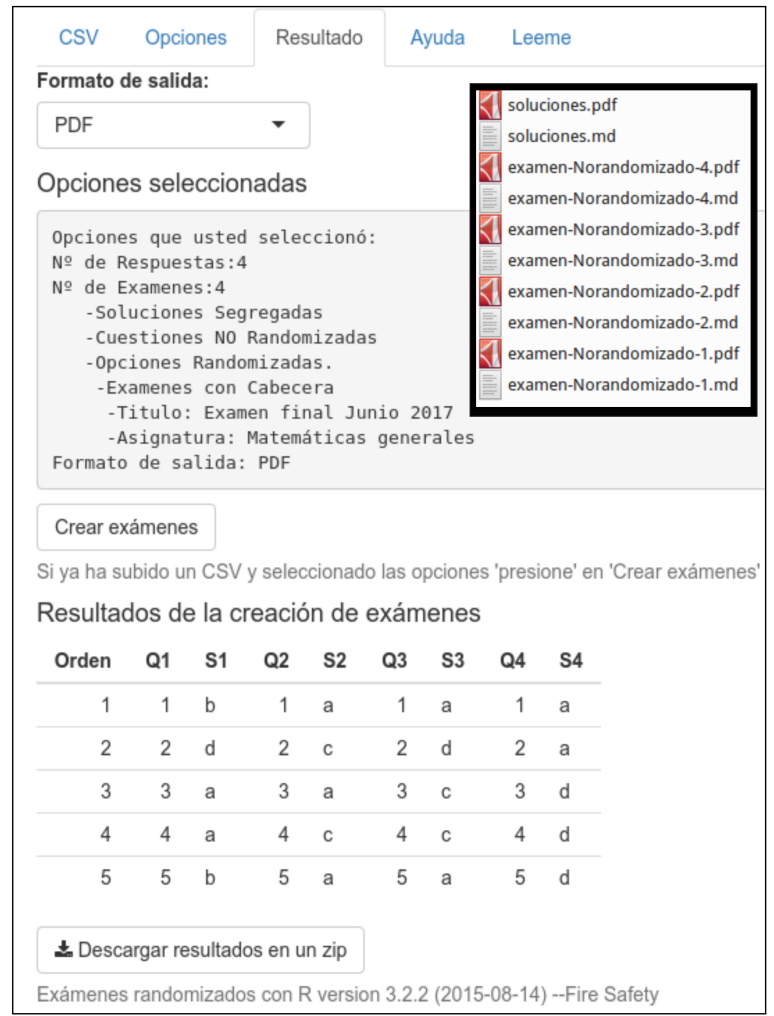

Fig. 6: Resultado de la creación de exámenes en formato pdf.

\section{Examen final Junio 2017}

Matemáticas generales

Modelo de Examen $n^{\circ}: 3$

- Estudiante(nombre completo):

- DNI:

- Curso y grupo:

- Fecha:

1. El volumen de un prisma es

a. $V=A_{b} h$, donde $A_{b}$ es el área de la base y $h$ es la altura (verdadera)

b. ninguna

c. $V=P_{b} h$, donde $P_{b}$ es el perímetro de la base y $h$ es la altura

d. una magnitud intensiva

2. Si un polinomio de grado 3 tiene coeficiente principal 2 y sus ceros son $3,-3$ y 0 . ¿cómo será?
a. ninguna
b. $2 x^{3}-3 x+2$
c. $2 x^{3}-9 x$
d. $2 x^{3}-18$ (verdadera)

Fig. 7: Vista de uno de los modelos de examen creados en formato pdf. 
ExamRandomizeR: Una aplicación web para la generación de exámenes aleatorizados que faciliten situar el Examen como herramienta de aprendizaje y no solo de evaluación en el aula de matemáticas

\section{Referencias bibliográficas}

ATICA, Universidad de Murcia. Web de ENCUESTAS Version 2.5. https: //encuestas . um.es.

Chang, Winston y col. (2016). shiny: Web Application Framework for R. R package version 0.14.2.

Gruber, John (2017). Daring Fireball. [Web; accedido el 31-03-2017].

Grün, Bettina y Achim Zeileis (2009). "Automatic Generation of Exams in R". En: Journal of Statistical Software 29.10, págs. 1-14. DOI: 10.18637/jss.v029.i10.

Lyons, Ian M y Sian L Beilock (2012). "When math hurts: math anxiety predicts pain network activation in anticipation of doing math". En: PloS one 7.10, e48076.

Mazur, Eric (2009). Confessions of a converted lecturer. Youtube. URL: https : // youtu. be/WwslBPj8GgI.

Project, LaTeX (2017). The LaTeX Project. [Web; accedido el 31-03-2017].

Qualtrics 360 platform (2017). Question Randomization. https://www . qualtrics . com/support / employee-insights / onboarding / 360-onboarding/gettingstarted/. [Accedido 27-May-2017].

R Core Team (2017). R: A Language and Environment for Statistical Computing. R Foundation for Statistical Computing. Vienna, Austria.

School Housetest Tecnologies (2017). Schoolhouse Test 4. http://help. schoolhousetech. com/category/6-schoolhouse-test. [Accedido 27-May-2017].

Yakovleva, Nadezhda O y Evgeny V Yakovlev (2014). "Interactive teaching methods in contemporary higher education". En: Pacific Science Review 16.2, págs. 75-80. 


\title{
POESÍA A DOS BANDAS: Innovación Docente a Través de la Literatura y la Traducción
}

Bruno Echauri Galván

Universidad de Alcalá (bruno.echauri@uah.es)

\section{Silvia García Hernández}

Universidad de Alcalá (silvia.garciah@uah.es)

\begin{abstract}
This paper shows the development of a Teaching Innovation Project carried out with some students of two different degrees: Hispanic Studies and Modern Languages and Translation, at the University of Alcalá. Our main objective here is to show how the project was conducted and the results obtained. The idea for the project emerged from a key aspect: the literary vocation of some students in both degrees. With this in mind, the creation of a bilingual collection of poems was proposed. Firstly, students in Hispanic Studies would create some poems that could be translated, or rather "recreated", by the Translation students. The main objectives of this interdisciplinary project are to promote creativity and increase students' motivation, as well as to reinforce both the use of English as a foreign language and the practice of literary translation by using original texts created by other classmates. By doing this, group work was also encouraged. Connected to collaborative work, another innovative element included in this project is the use of ICT, since students have worked together not only in face-to-face meetings, but also by means of new technologies such as Blackboard Collaborate, among others, which have enabled them to keep contact, and share documents and opinions in real time.
\end{abstract}

Keywords: poetry, literary translation, innovation, new technologies, creativity, motivation, group work.

\footnotetext{
Resumen

El presente trabajo muestra el desarrollo de un proyecto de innovación docente llevado a cabo con alumnos de dos grados, Estudios Hispánicos y Lenguas Modernas y Traducción, en la Universidad de Alcalá. El objetivo de estas páginas es exponer el desarrollo y resultados de este proyecto que surge de la visión de un aspecto fundamental: la vocación literaria de algunos alumnos de ambos grados. Partiendo de esta base, se propuso la realización de un poemario bilingüe en el que los alumnos del grado en Estudios Hispánicos crearan poemas que pudieran ser traducidos o, más bien, "re-creados", por parte de los alumnos traductores. Los objetivos principales de este proyecto interdisciplinar son los de fomentar la creatividad y aumentar la motivación de los alumnos de ambos grados, así
} 
como reforzar el uso de la lengua extranjera y la práctica de la traducción literaria con textos originales creados por otros compañeros, fomentando asi el trabajo colaborativo. Además, otro de los puntos innovadores de este proyecto es que los alumnos pudieran trabajar juntos a través de las nuevas tecnologías, utilizando, entre otras, la herramienta Blackboard Collaborate, que les permitiera estar en contacto, compartir documentos y opiniones en tiempo real.

Palabras clave: poesía, traducción literaria, innovación, nuevas tecnologías, creatividad, motivación, trabajo en grupo.

\section{Introducción}

El texto que ocupa las siguientes páginas presenta un proyecto de innovación docente realizado en la Universidad de Alcalá durante el curso 2016/2017 por cuatro profesores (el doctor Bruno Echauri Galván, la doctora Silvia García Hernández, la doctora Maya García de Vinuesa y el doctor Jonathan Sell) y veinte alumnos de dos grados diferentes: el segundo curso de Estudios Hispánicos (EEHH en adelante) y el tercer y cuarto curso de Lenguas Modernas y Traducción (LLMMyT en adelante).

La idea para la realización de este proyecto de innovación docente surge de dos pilares fundamentales: el talento y vocación literaria de algunos alumnos del grado en Estudios Hispánicos y la posibilidad de que la calidad de sus escritos redundara en su beneficio y en el de otros ámbitos de la universidad. En este sentido, la asignatura Traducción Literaria, Edición y Corrección de Textos, impartida por la profesora García de Vinuesa, ofrece la plataforma perfecta para una actividad transversal con estos alumnos.

Una vez escogidos los dos grupos con los que se pretende trabajar, el proyecto se organiza alrededor de un propósito tangible e ilusionante para todos los participantes: la creación de un poemario bilingüe en el par de lenguas inglés-español. Pero detrás de este fin hay también otros objetivos que pasan a detallarse a continuación.

\section{Objetivos y bases teóricas}

Al margen del poemario bilingüe mencionado en el apartado anterior, el proyecto de innovación que se está describiendo busca conseguir otra serie de objetivos. El siguiente listado los presenta en detalle, añadiendo justificaciones teóricas cuando se estima necesario:

\subsection{Objetivo 1}

Potenciar la creatividad de los alumnos: Subrayar la creatividad como factor a potenciar en el proceso de aprendizaje (también de una segunda lengua), como mecanismo de renovación y actualización de la enseñanza en todos los niveles y como motor de nuevas ideas e iniciativas es una reivindicación de muchos autores (De la Torre, 2009 o Gervilla

(c)) BY-NC-ND 2017, Universitat Politècnica de València 
Castillo, 2003 entre otros). En esta línea, se busca canalizar el talento (literario en este caso) del alumnado de modo que no sea únicamente una actividad periférica de tiempo libre y pueda repercutir en su carrera universitaria.

En línea con lo anterior, uno de los principales objetivos que ayudaron a cohesionar al grupo de profesores participantes es el intento de que la creatividad vaya ganando espacio dentro del currículo de los grados de letras. Y no se trata únicamente de amenizar el proceso de aprendizaje: también se busca explotar algunas capacidades del alumno que no se ven potenciadas tradicionalmente, que los alumnos desarrollen una mente y una capacidad creativa determinada y que aquellos que ya las tienen, las perfeccionen al mismo tiempo que esto tiene una recompensa en sus calificaciones finales. Por ello, el trabajo de los traductores en este proyecto fue tomado en consideración en su nota final ${ }^{1}$.

\subsection{Objetivo 2}

Estimular la motivación del alumnado a través de la innovación: Autores como ChaínNavarro, Martínez-Solís y Sánchez-Baena (2008) constatan que la desmotivación es uno de los males de la educación superior en nuestro país, y es necesario hacerle frente. En este sentido, los mismos autores señalan que la innovación docente puede ser uno de los mecanismos para paliar el desencanto que en ocasiones invade a parte de los alumnos e incluso a los propios docentes. Nuestro proyecto apuesta por crear una actividad diferente con aspectos novedosos e innovadores como los siguientes:

- La naturaleza puramente creativa de la tarea.

- El trabajo de traducción con textos puramente originales.

- La colaboración entre alumnos de distintos cursos y grados, potenciando así el trabajo en grupo interdisciplinar.

- El uso de una herramienta virtual (Blackboard Collaborate) no utilizada con anterioridad y que permite compatibilizar el trabajo telemático con la interacción directa por videoconferencia.

- La publicación en papel de los poemas y traducciones de los alumnos.

\subsection{Objetivo 3}

Refuerzo de la segunda lengua: Este objetivo se divide a su vez en dos vertientes dependiendo del grupo meta. En el caso de EEHH, se busca dar continuidad al contacto con el inglés y aumentar el interés de los alumnos por esta lengua. Hay que tener en cuenta que en el caso de EEHH, su contacto en la universidad con una L2 termina tras el primer curso. En nuestra opinión, este tipo de actividades puede ayudar a mantener o incluso incrementar

\footnotetext{
1 Esto no se pudo hacer con los alumnos de EEHH por no cursar ninguna de las asignaturas impartidas por los profesores involucrados. Por ello, queremos destacar especialmente su entrega completamente altruista en la elaboración de este proyecto.
} 
su deseo de no abandonar el estudio de un segundo idioma al trabajar en un ámbito que les motiva como es el literario.

En el caso de LLMMyT, el proyecto se orienta al perfeccionamiento del idioma y a un mejor manejo de la lengua inglesa $\mathrm{y}$, especialmente, del lenguaje literario. Este refuerzo de la segunda lengua es lo que explica el uso de la traducción inversa en el proyecto. Bien aplicada, la traducción inversa puede reportar numerosos beneficios. Entre ellos, se cuenta un incremento de la competencia cultural del traductor, una menor posibilidad de malinterpretar el texto original y un mayor cuidado en el empleo de la lengua meta (Posey, 2009). En esta misma línea, traducir a una segunda lengua implica normalmente una mayor afinidad con el autor original del texto, algo que muchos traductores consideran fundamental, especialmente en el ámbito de la poesía (Posey, 2009).

Por otro lado, pese a que muchas veces la traducción inversa ha sido denostada, etiquetando sus resultados (generalmente a priori) de falta de naturalidad, autores como McAlister (citado en Posey, 2009), defienden que es posible traducir un texto hacia una segunda lengua y hacerlo de forma clara y correcta. En este caso, consideramos que el resultado encaja perfectamente con las palabras de McAlister, ya que creemos que la calidad de las traducciones es realmente alta, más si tenemos en cuenta que los traductores se enfrentaban a su primer desafío de este tipo. Pero, en este sentido, preferimos dejar que cada uno extraiga sus propias conclusiones tras leer atentamente los ejemplos que se presentan unas páginas más adelante.

\subsection{Objetivo 4}

Mejora de la enseñanza de la traducción poética: Otro de los propósitos de este proyecto es mejorar la docencia en el ámbito de la traducción poética, en especial en lo que respecta a alumnos que se adentran por primera vez en este ámbito. En este sentido, se solicita a los traductores que elaboren un comentario en el que expliquen los principales rasgos del poema original y meta, así como los desafíos fundamentales a los que se han enfrentado durante el proceso traductológico. Un análisis de dichos comentarios y la recopilación de las dudas planteadas en los distintos talleres permiten establecer las dificultades más comunes entre los estudiantes. Dichos problemas abren un amplio campo de investigación y pueden servir como base para determinar pautas y prácticas docentes más adecuadas a las necesidades de aquellos alumnos que contactan por primera vez con la traducción literaria. Las pautas que se establezcan podrán utilizarse en cursos posteriores para mejorar el proceso de enseñanza y de aprendizaje en la sección de traducción poética de la asignatura de Traducción Literaria.

\subsection{Objetivo 5}

Fomentar el trabajo en grupo: En este sentido, se busca romper el círculo de confort del alumnado mezclando estudiantes de grados distintos sin experiencia previa en trabajos en común. Esto implica, por un lado, una importante labor de control por parte del profesorado

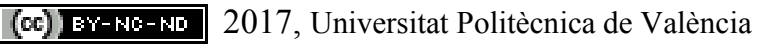

Congreso IN-RED (2017) 
y una disponibilidad adicional para resolver las dudas logísticas y de contenido que puedan ir surgiendo, así como para organizar los talleres a los que acudirán ambos grupos de manera conjunta. Pero por otro, genera grandes beneficios, ya que fomenta el intercambio de ideas entre alumnos con intereses e inquietudes distintos, pero también coincidentes en algunos casos. Al mismo tiempo, esta mezcla consigue que los estudiantes se acerquen a ámbitos del mundo de las letras que no les son del todo conocidos, entrando en contacto directo con las ideas de un escritor en el caso de los traductores, o acercándose al mundo de la traducción y sus complejidades en el de los autores.

\section{Desarrollo de la innovación}

\subsection{Requisitos previos y necesidades}

Antes de comenzar con el grueso del proyecto, fue necesario dar varios pasos. En primer lugar, establecer los recursos humanos y materiales a utilizar en el desarrollo de esta actividad. Entre los primeros, basta contar con los cuatro docentes implicados y un número de alumnos mínimo que haga viable el proyecto. Entre los segundos, las necesidades son escasas: las copias necesarias de poemas y traducciones, un aula con ordenador donde celebrar los encuentros entre escritores y traductores y alguna herramienta telemática que facilite la comunicación entre los participantes. En este caso, se emplea la plataforma virtual Blackboard de la que dispone la Universidad de Alcalá.

Este espacio virtual optimiza el trabajo en varios sentidos. En primer lugar, permite subir materiales como los poemas originales, las distintas versiones de las traducciones o los materiales empleados en los talleres para que los alumnos los consulten en cualquier momento. Asimismo, facilita la comunicación telemática entre las partes, ya que permite asegurar que las convocatorias para los talleres y otras actividades relacionadas son recibidas por el total de los participantes. Asimismo, crea una red cerrada de mensajes en la que cualquier miembro del proyecto puede contactar con otro vía correo electrónico cuando lo desee.

Sin embargo, dentro del amplio abanico de recursos que ofrece Blackboard, la herramienta cuya utilización conviene destacar especialmente es Blackboard Collaborate, un entorno virtual que permite dividir a los participantes en distintos grupos y en el que los alumnos pueden trabajar de forma telemática en tiempo real. Con este recurso, poetas y traductores pueden intercambiar archivos a la vez que interactúan con sus compañeros, bien a través de video conferencia, bien de forma escrita en el chat habilitado a tal efecto. Por otro lado, Blackboard Collaborate permite a los profesores monitorizar el trabajo de los estudiantes cuando este se está llevando a cabo, así como realizar presentaciones de contenido en tiempo real que luego pueden guardarse para el acceso a posteriori de los participantes no conectados en ese momento. En definitiva, este recurso simplifica significativamente las labores de coordinación de alumnos y profesorado, ya que los estudiantes siempre disponen de un entorno propio al que conectarse sin necesidad de reunirse físicamente, algo que resulta especialmente importante cuando el grupo lo componen alumnos procedentes de distintas partes de la Comunidad de Madrid. Y lo hace 
además a través de una interfaz sencilla e intuitiva que los alumnos de ambos grados rápidamente comprendieron tras unas breves explicaciones en el segundo taller presencial.

Otro aspecto a preparar de antemano fue el reparto de tareas entre los docentes participantes. En este sentido, se determinó que el profesor Bruno Echauri asumiese las labores de organización y coordinación del proyecto, la profesora Maya García la de proporcionar las explicaciones teóricas necesarias sobre el proceso de traducción llevado a cabo por los alumnos y el comentario que debían desarrollar al respecto, y la profesora Silvia García la de preparar y analizar los cuestionarios finales completados por los alumnos. Estos tres profesores se encargaron también de seleccionar los poemas y conducir los distintos talleres. Por su parte, el profesor Jonathan Sell asumió las labores de revisión y edición de los poemas dado el valor añadido y la perspectiva que aporta al proyecto que un profesor nativo se encargue de esta fase del trabajo. De este modo, se consigue una mayor naturalidad en el texto meta y se pueden identificar e incluir u omitir matices que a profesores de nacionalidad española se les escapen.

En cuanto a los plazos de trabajo y las fechas límite, ambos vinieron condicionados fundamentalmente por el calendario académico. Puesto que la asignatura de Traducción Literaria, Edición y Corrección de Textos se imparte a lo largo del primer cuatrimestre, este periodo generaba automáticamente la ventana de tiempo en la que trabajar con los alumnos. Por ello, el proyecto se puso en marcha al poco de comenzar el curso, con sesiones iniciales para determinar el número de participantes o dar las primeras instrucciones, entre otros. A continuación, se planificaron tres talleres presenciales comunes para los alumnos de EEHH como de LLMMyT a completar poco después de las vacaciones navideñas puesto que se necesitaba tiempo para evaluar los resultados finales e incluirlos en la calificación de los alumnos de traducción. Terminado el cuatrimestre, comenzó un proceso final de revisión y edición por parte del profesor Jonathan Sell para preparar los poemas para su publicación. Todos y cada uno de estos pasos se detallan en el siguiente apartado.

\subsection{Fases}

El primer encuentro con los alumnos afectó únicamente al grupo de EEHH. En este taller, se aportaron más detalles sobre los poemas: se fijó una fecha de presentación y se acordó que cada autor debía hacer entrega 3 o 4 poemas de estilo libre centrados en el siguiente tema: (in)experiencias. Este tópico da gran libertad al alumno y le invita transmitir sus vivencias y lo que le queda por vivir, abriéndose al lector e interiorizando que este es en gran medida su trabajo, por y para ellos.

Recopilados los poemas, se seleccionaron los que formarían parte de la antología, para lo cual se tuvieron en cuenta distintos criterios. Por un lado, la calidad literaria. Por otro, la dificultad de los textos, sobre todo en base a las capacidades del grupo de traductores. En este sentido, hemos tenido la fortuna de contar con un grupo de LLMMyT que posee un alto nivel de capacidades y conocimientos, por lo que el margen en lo que a complejidad de los textos se refiere fue bastante amplio. Otras variables a tener en cuenta

(c)) BY-NC-ND 2017, Universitat Politècnica de València

Congreso IN-RED (2017) 
fueron la cantidad y longitud de los poemas. Ambas tienen como misión cumplir dos objetivos. Por un lado, no sobrecargar a los alumnos con una carga de trabajo excesiva. Por otro, reunir una cantidad de poemas suficiente para crear una antología bilingüe adecuada para una publicación. En base a todos estos criterios, los poemas escogidos finalmente fueron 23 sobre un total de 34 .

Hecho esto, se establecieron los emparejamientos, para lo cual se recuperan tres de los parámetros anteriores: capacidad del traductor, longitud y cantidad de poemas. Siguiendo estos criterios se buscaba encontrar un equilibrio entre dificultad y volumen de los textos a traducir. Finalmente, surgieron 8 grupos: 4 parejas, dos tríos de dos traductores y un escritor, otro trío a la inversa y un cuarteto formado por dos escritores y dos traductores. A continuación, tuvo lugar el primer taller conjunto.

En este encuentro, autores y traductores se conocieron por primera vez personalmente. Posteriormente, se organizaron los grupos de trabajo y se entregaron los poemas correspondientes. Durante este taller, se dio tiempo a los traductores para realizar una primera lectura y plantear sus dudas, tanto a "sus" autores en particular como al resto de compañeros. A esta ronda de preguntas siguió un debate en el que se intentaron aportar distintas soluciones (véase apartado 4). Como trabajo para la siguiente sesión, se pidió que preparasen un primer borrador y corrigiesen los posibles errores del original.

Finalmente, se presentaron las utilidades de la plataforma virtual y de la herramienta Blackboard Collaborate. A pesar de que muchos alumnos la desconocían, el manejo fácil e intuitivo de esta aplicación hace que sea relativamente sencillo familiarizarse con ella. Como se mencionaba anteriormente, Blackboard Collaborate permite dividir a los alumnos en distintos grupos para que puedan trabajar de manera independiente (con o sin la supervisión del profesor). Asimismo, ofrece la posibilidad de mantener videoconferencias, chatear o intercambiar archivos y mantener tutorías en línea en cualquier momento. Herramientas como esta facilitan sobremanera la consecución de proyectos de este tipo en el que se involucran personas de distintos grados, con distintos horarios y responsabilidades que resulta complicado conjugar. Dado que Blackboard también ofrece la posibilidad de colgar archivos para su posterior descarga, el profesorado sube a esta plataforma todos los poemas originales al concluir el taller; de este modo, todos los estudiantes del grupo pueden, en cualquier momento, leerlos si así lo desean.

El tercer encuentro con los alumnos se centró en las principales dificultades encontradas al elaborar el primer borrador, dudas a las que sus compañeros, y el profesorado en última instancia, sugirieron posibles soluciones. También se procedió a la lectura en voz alta de algunos de los poemas, un paso que en ocasiones puede pasarse por alto pero que permite medir la idoneidad del texto meta en distintos aspectos: ritmo, efectos sonoros, puntuación, etcétera. Tener al lado al escritor original supone una enorme ventaja, ya que se trata de la persona que más interiorizada tiene la sonoridad del poema y, por consiguiente, es la más indicada para orientar al traductor en la difícil tarea de encontrar una armonía sonora relativamente similar. 
Posteriormente, se mostró al grupo un esquema con los puntos a tratar en el comentario sobre la traducción que están realizando: estilo del autor, elementos de variación y registro, prosodia, rima u ortotipografía con función dramática, entre otros. Esta parte se orienta fundamentalmente a los traductores, aunque los escritores deben también realizar una labor de apoyo a los primeros en caso de que necesiten resolver alguna duda. Este esquema cumple además otra función en el taller: mostrar a los alumnos puntos de la traducción en los que podían no haber reparado hasta entonces y, de este modo, 1) abrir un debate en torno a ellos y 2) repasar y perfeccionar las traducciones teniendo estos puntos en cuenta. A destacar, elementos como la ortotipografía o el tono según la intención dramática, factores que en ocasiones son relegados a un segundo plano pero cuya adecuada traducción no se puede obviar si queremos lograr un texto meta de alto valor literario. Finalmente, se anunció que para el siguiente encuentro, los alumnos deberán haber concluido la traducción de los poemas y el comentario.

El último taller comenzó con una nueva lectura en voz alta de textos originales y meta. Posteriormente, con la perspectiva que otorga haber terminado ya el trabajo, se comentaron las principales dificultades encontradas a la hora de realizar las traducciones y elaborar el comentario al respecto.

También se buscó conocer de viva voz la experiencia por parte de los alumnos a lo largo del proyecto, a fin de identificar los puntos fuertes y débiles del proyecto y preparar posibles mejoras para darle continuidad de distintas formas en el futuro. Asimismo, se busca su parecer con respecto a la posibilidad de realizar esta actividad en cursos venideros, incidiendo en temas como la utilidad de la tarea, el grado de aprendizaje alcanzado con ella o el interés que les ha despertado, todos ellos con respuestas muy positivas. A la conclusión del taller, se entrega a todos los participantes un cuestionario a este respecto que deberán rellenar por escrito.

Finalizado el trabajo con los alumnos, comienza el proceso de edición por parte del profesorado, a cargo del profesor Jonathan Sell. En este sentido, se buscó la colaboración de un profesor nativo para dotar al texto meta de la mayor naturalidad posible y descubrir, si los hubiera, errores que a los que tienen el inglés como segunda lengua puede costar más identificar. Conviene recalcar a este respecto que no hubo cambios significativos en ningún poema, lo que también prueba la calidad de las traducciones realizadas. Revisados y editados, los poemas se subieron a la plataforma para que los alumnos los consultasen y se abrió un periodo de resolución de dudas en el que pudieron contactar con el profesor Jonathan Sell para preguntar cualquier cosa relacionada con este último proceso de revisión y edición.

Al margen de las fases anteriores, también resulta fundamental el trabajo fuera del aula, tanto por parte del profesorado como, lógicamente, por parte de los alumnos. Entre los cometidos de los primeros se cuentan labores de coordinación, supervisión y orientación como la preparación de todo el material necesario para los talleres, monitorización del aula virtual y del trabajo en línea de los alumnos, asistencia a desdobles cuando alguno de los grupos de trabajo no puede asistir a alguno de los talleres o tutorías para resolver las dudas de los alumnos. Cabe destacar que pasadas las primeras semanas, en las que los alumnos de

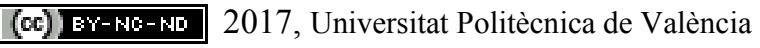

Congreso IN-RED (2017) 
EEHH plantearon alguna duda sobre la elaboración de los poemas, este recurso fue aprovechado principalmente por los alumnos de LLMMyT con el objetivo de pulir sus traducciones o responder a ciertas preguntas relacionadas con la elaboración del comentario que debían preparar al final.

Los alumnos, por su parte, deben completar varias horas de trabajo autónomo en las que no participa el profesorado. Para ello, cada grupo ha utilizado los recursos a su disposición en la medida en que ha creído más oportuno. Al margen de las herramientas propuestas por la universidad, los alumnos emplearon también otros mecanismos para comunicarse entre ellos: grupos de Whatsapp, herramientas como Google Drive, videoconferencias o, por supuesto, el correo electrónico. El contacto directo varió en función de las posibilidades de cada grupo, pero conviene subrayar el consenso en torno a su utilidad y valor. La posibilidad de este contacto directo entre autores y traductores es una de las grandes ventajas de este proyecto y un motivo más de satisfacción para todos los participantes.

\section{Resultados}

Para evaluar los resultados obtenidos, remitimos al lector al apartado 2, puesto que intentaremos medir el éxito del proyecto en base a la consecución de los objetivos establecidos anteriormente. En primer lugar, el resultado más tangible de todo el proyecto ha sido un poemario bilingüe pendiente de publicación del que se adjuntan dos ejemplos:

ARDIENDO.

Tu sonrisa egocéntrica se ha tornado de colores ceniza.

Has quemado todos los botones de tu camisa $\mathrm{y}$ ahora me pides que te arrope con mi cuerpo.

Las sílabas se han calcinado en tu lengua, pero tus te quiero aún arden debajo del paladar.

Tu pecho sube y baja al compás de las llamaradas.

Arden tus ojos.

Los mismos ojos que un día fueron agua.
BURNING.

\section{Your egocentric smile}

is now coloured ash.

you have burnt all the buttons of your shirt and now you are asking me to wrap you up with my body.

The syllables have charred in your tongue but your I love you's are still burning under the palate.

Your chest goes up and down to the beat of the flashes.

Your eyes are burning.

The same eyes that once were water. 
Tú también eres humano

No mires a tus infiernos,

has salido de ellos

dejando la puerta abierta,

pero eres afortunado en la huida

el fuego ha dejado huella en tu gesto,

derretido la plata para sueños,

evaporado las ansias del amor.

Has sufrido la pérdida,

descubierto la soledad,

saboreado la impotencia.

Hoy Orfeo estás de enhorabuena;

eres humano y perderás la cabeza por ello.
You're human too

Don't look at your circles of hell, you made it out alive leaving an open gate,

But you are fortunate in your escape: hellfire left a mark on your face, melt the daydreams' dough, and burnt off the thirst for love. You suffered from loss, discovered solitude and savoured helplessness.

Orpheus, you're in luck today; you're human and it will cost your head.

Para medir aspectos como la motivación, el desarrollo del trabajo en grupo, el manejo de la segunda lengua y otros factores incluidos en el proyecto, los alumnos participantes completaron un cuestionario en función del grado al que pertenecían, con los siguientes resultados:

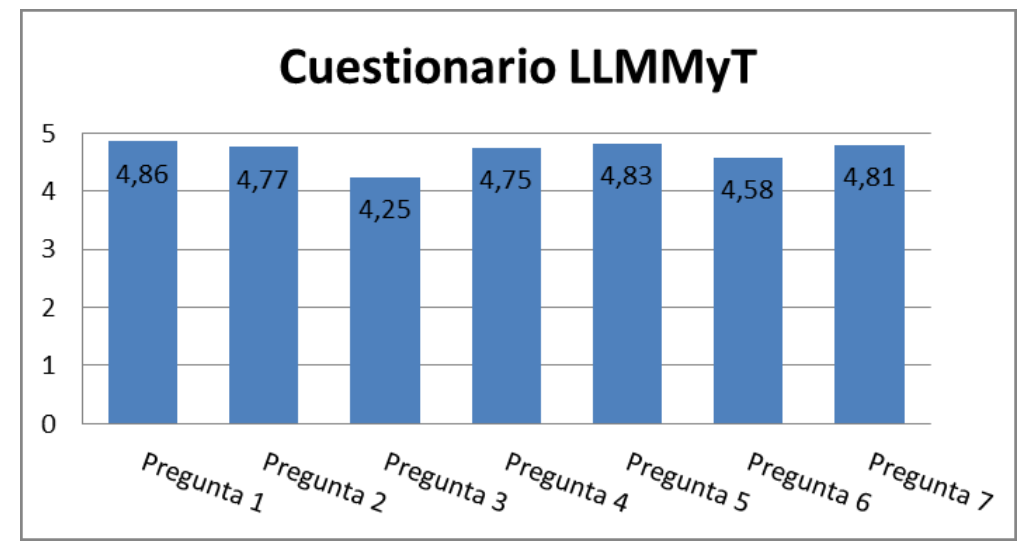

Pregunta 1: Fomento del interés por la traducción literaria y motivación por seguir en contacto con esta disciplina.

Pregunta 2: Utilidad de la iniciativa para identificar y resolver problemas relacionados con la traducción poética

Pregunta 3: Manejo y utilidad de herramientas informáticas Aula Virtual y Blackboard Collaborate

Pregunta 4: Grado de satisfacción con el trabajo con personas de una disciplina distinta a la tuya

Pregunta 5: Grado de ayuda al trabajar con el autor del poema que has traducido

Pregunta 6: Grado de satisfacción con los talleres presenciales

Pregunta 7: Utilidad de la iniciativa para la motivación y la mejora de la visión de la experiencia universitaria

(cc) EY-NC-ND 2017, Universitat Politècnica de València

Congreso IN-RED (2017) 


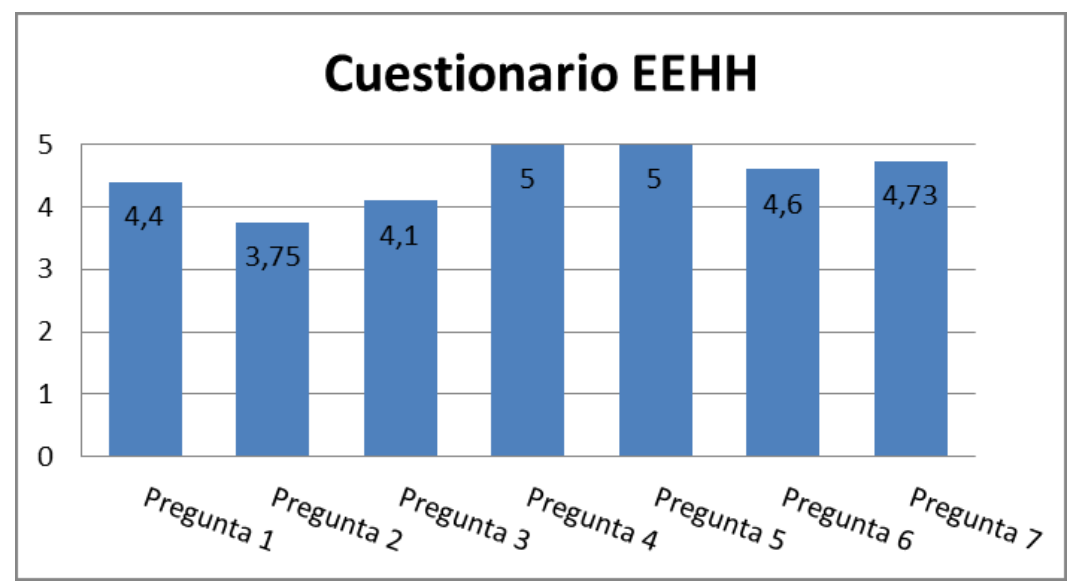

Pregunta 1: Fomento del interés por la el inglés como L2 y motivación por seguir en contacto con esta lengua. Pregunta 2: Utilidad de la iniciativa como un estímulo a tu creatividad.

Pregunta 3: Manejo y utilidad de herramientas de herramientas informáticas Aula Virtual y Blackboard Collaborate Pregunta 4: Grado de satisfacción con el trabajo con personas de una disciplina distinta a la tuya

Pregunta 5: Grado de satisfacción al trabajar con el traductor de tu obra.

Pregunta 6: Grado de satisfacción con los talleres presenciales.

Pregunta 7: Utilidad de la iniciativa para la motivación y la mejora de la visión de la experiencia universitaria

El análisis de los resultados cualitativos de los comentarios de los alumnos de LLMMyT mostró una satisfacción mayoritaria con la experiencia y coinciden en que ha fomentado su interés por la traducción literaria, su motivación para seguir en contacto con esta disciplina y su capacidad para resolver problemas relacionados con la traducción poética.

El trabajo transversal con alumnos de otro grado les ha resultado muy positivo y enriquecedor. A este respecto, muchos destacan la posibilidad de colaborar con el autor original y cómo esto les ha permitido resolver dudas, trasladar connotaciones adecuadamente y ganar confianza a la hora de traducir sus poemas. También resaltan la buena relación con los alumnos de EEHH y las nuevas ideas y perspectivas que estos les han aportado. Aunque en menor medida, también valoran positivamente su experiencia con la herramienta Blackboard Collaborate, destacando las posibilidades que les ha ofrecido la hora de compartir material y poder comunicarse en tiempo real de manera virtual. Sin embargo, también señalan fallos puntuales en el sistema que han obstaculizado su trabajo en contadas ocasiones.

Por último, en lo que respecta a su nivel de satisfacción con este tipo de iniciativas, existe unanimidad en las respuestas de todos los estudiantes, que han valorado la pregunta 
con la máxima puntuación. Todos los traductores consideran que su experiencia en la participación a lo largo de este proyecto ha sido muy motivadora y que ha mejorado su visión de la experiencia universitaria. De la misma manera, comentan que este proyecto ha sido una práctica muy positiva para su formación como futuros traductores e incluso algunos han manifestado su interés en seguir formándose en el campo de la traducción literaria. Por último, en sus comentarios agradecen haber tenido la oportunidad de participar en una actividad que fomenta la creatividad de los alumnos.

Los resultados de los cuestionarios de EEHH muestran que la participación de estos alumnos en el proyecto ha aumentado su interés por la lengua inglesa. Asimismo, muchos consideran que su motivación por seguir en contacto con el inglés se ha incrementado, y apuntan también que actividades de este tipo suponen un estímulo para su creatividad y les animan a seguir trabajando es sus creaciones propias.

El grado de satisfacción referente al trabajo con compañeros de otro grado es también muy elevado. Los escritores definen la experiencia, al igual que sus compañeros de LLMMyT, como muy enriquecedora y subrayan que este proyecto les ha permitido acercarse a sus poemas desde una perspectiva distinta: la de los traductores. Asimismo, coinciden en destacar este tipo de actividades como un modo de mejorar la experiencia universitaria, puesto que se trata de una forma diferente y emocionante de acercarse a la enseñanza en la que sus propias creaciones y opiniones juegan un papel fundamental.

Por último, en lo referente al manejo de herramientas informáticas como Blackboard y sus distintas utilidades, los alumnos de EEHH coinciden con los traductores en que, a pesar de problemas esporádicos, su capacidad para utilizar estos recursos ha mejorado.

En cuanto a las pautas orientadas a mejorar la enseñanza de la traducción poética, se ha trabajado con los comentarios de los alumnos de LLMMyT así como con las preguntas que han ido surgiendo en los distintos encuentros. A continuación, se presentan algunos de los puntos conflictivos a los que se dio solución ${ }^{2}$ y que serán tenidos en cuenta a la hora de mejorar la docencia en próximos cursos:

I) Priorizar forma o contenido, respetar la métrica, pérdida de significado: Estas tres son dudas recurrentes de los alumnos participantes en el proyecto. La respuesta puede basarse en contrastar dos posibilidades. La primera sería seguir un enfoque tradicional, basado en una reproducción fiel del poema original en la que se sigue un modelo traductológico palabra por palabra que elimina la creatividad del traductor del proceso. Esta línea es fácilmente descartable si se muestran traducciones literales de varios poemas que se hayan trasladado a la lengua española en comparación con otras alternativas.

Por otro lado, existe otra aproximación a este tipo de traducción, basada en la ya clásica premisa de Benjamin (1994) de mantener el sentido a través de la libertad en la traducción. A este punto de partida creemos conveniente añadir las palabras de Eco (2004),

\footnotetext{
${ }^{2}$ Los puntos conflictivos y pautas para abordarlos son más, pero por motivos de espacio se han incluido únicamente algunos ejemplos representativos.
}

(c)) BY-NC-ND 2017, Universitat Politècnica de València 
quien defiende alejarse del sentido literal para trascender el texto de partida y tratar de recrearlo en otra lengua a través de un equilibrio entre fidelidad al poema y reinvención del mismo, lo cual requiere un rol más activo por parte del traductor.

Como describe el párrafo anterior, esta última corriente no debe interpretarse como el contrario a la primera. En nuestra opinión, el objetivo de la traducción poética debe ser tratar de crear un efecto similar al del original, lo que no implica un nivel de fidelidad preestablecido, sino una búsqueda de la similitud a través de la reproducción y no del calco. Para conseguirlo, debe enseñarse al traductor que fidelidad y creatividad no son excluyentes en una misma tarea, sino que puede moverse entre ambos polos. En este sentido, es importante sistematizar el proceso. Grosso modo, lo que deberá hacer en primer lugar será identificar la acústica, la métrica, la rima, el empleo de lenguaje y la retórica que contiene el original. Una vez identificadas y analizadas y a fin de alcanzar ese efecto cercano al del escritor, el traductor deberá escoger qué aspectos mimetizar, cuáles pasar a segundo plano y cuáles modificar. Para esto, el traductor no puede verse encorsetado por normas rígidas, sino que es necesaria cierta dosis de creatividad y un margen de maniobra que los enfoques en los que equivalencia significa máxima fidelidad al original no permiten.

II) Traducción de expresiones idiomáticas y registros coloquiales: Estas dudas pueden ligarse con otros aspectos léxicos y semánticos relevantes a la hora de afrontar la traducción de un poema: neologismos, falsos amigos o dialectos, entre otros. En este sentido, una buena práctica a enfatizar para guiarnos en la traducción es la de estudiar la obra del autor para descubrir el uso que este suele hacer del lenguaje, tratar de comprender lo que se esconde detrás y, eventualmente, trazar paralelismos entre otros poemas del mismo escritor y aquel a cuya traducción nos enfrentamos (Gómez-Pato, 2012). En este caso, la presencia del autor original evita esta tarea de investigación, pero conviene subrayar esta directriz como algo necesario en la mayor parte de los casos.

En lo que atañe a expresiones idiomáticas, refranes y casos similares conviene señalar al traductor novel que lo habitual será tratar de encontrar equivalentes en la lengua meta al tiempo que se comprueba si el autor ha respetado o alterado estas estructuras; a continuación, el traductor deberá imitar esta práctica con su equivalente en español para conservar el efecto del original (Gómez-Pato, 2012). Una vez más, conocer las tendencias del autor en este sentido y si hace un uso convencional o rupturista del lenguaje puede resultar extremadamente útil.

\section{Conclusiones}

A través de este proyecto de innovación docente se pretendía encontrar una manera innovadora de hacer partícipes a los alumnos de su propio proceso de aprendizaje, en el que pudieran ser protagonistas y no meros receptores de información, a través de una metodología novedosa y colaborativa.

Como se deriva de los resultados del proyecto y del grado de satisfacción de los alumnos (y profesores) participantes, los objetivos planteados en un principio se han cumplido satisfactoriamente. Con el desarrollo del proyecto, hemos conseguido estimular 
la creatividad de los alumnos, tanto de los creadores de los poemas originales como de los traductores como re-creadores de los poemas en lengua inglesa. Asimismo, como los propios alumnos han indicado, la motivación para continuar en contacto con la lengua inglesa en el caso de los alumnos de EEHH y de la traducción literaria en el caso de los de LLMMyT ha mejorado, así como su visión general de la experiencia universitaria.

Sin embargo, no sólo se ha conseguido motivar y promover la creatividad de los alumnos, sino que también, a través de este proyecto diferente y novedoso, se ha fomentado el trabajo en grupo entre alumnos de grados distintos con excelentes resultados, introduciendo las nuevas herramientas tecnológicas como Blackboard Collaborate para facilitar el contacto entre ellos y el intercambio de ideas y documentos, dándoles la posibilidad de trabajar en cualquier momento y lugar desde cualquier dispositivo conectado a internet.

Por último, conviene recalcar el alto grado de transferibilidad de este proyecto, si no en su totalidad, al menos parcialmente. Los pocos recursos materiales necesarios, la flexibilidad de grados con los que se puede trabajar (al menos en el lado de los escritores) y el balance coste-beneficios que generan, hacen que experiencias como la descrita en las páginas anteriores supongan una mejora en el proceso de enseñanza y de aprendizaje para todas las partes implicadas.

\section{Referencias}

- BENJAMIN, W. (1994). La tarea del traductor. En M.A. Vega, Textos clásicos de teoría de la traducción, 285-296. Madrid: Cátedra.

- CHAÍN-NAVARRO, C., MARTÍNEZ-SOLÍS, L. y SÁNCHEZ-BAENA, J.J. (2008). "Motivar desde la innovación en la enseñanza universitaria: El blog Qalidad". RED: Revista de Educación a Distancia, 21.

- DE LA TORRE, S. (2009). "La universidad que queremos: estrategias creativas en el aula universitaria". Revista Digital Universitaria, 10(12). Disponible en http://www.revista.unam.mx/vol.10/num12/art89/art89.pdf

- ECO, U. (2004). Experiences in translation. Toronto: University of Toronto Press.

- GERVILla CASTILlO, A. (2003). Creatividad aplicada. Una apuesta de futuro. Madrid: Dykinson.

- GÓMEZ-PATO, R.M. (2012). Apuntes para una didáctica de la traducción de poesía / notes on poetry translation and teaching. Teoría De La Educación: Educación y Cultura En La Sociedad De La Información, 13(1), 236-265.

- POSEY, M. (2009). The advantages of L2 translation in The Cat in the Hat: A closer look at translation directionality. Letras, 46, 87-100.

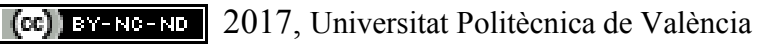




\title{
Utilización de wikis como recurso docente en estudios universitarios de Ingeniería en Telecomunicación
}

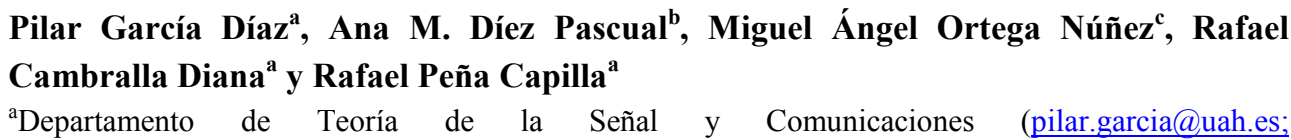
${ }^{2}$ Departamento de Teoría de la Señal y Comunicaciones (pilar.garcia@uah.es;
rafael.cambralla@uah.es; rafael.pena@uah.es); ${ }^{b}$ Departamento de Química Analítica, Química Física

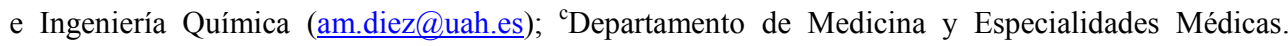
Universidad de Alcalá, Madrid.

\begin{abstract}
A wiki is an easy-to-use on-line tool for teachers and students. This free software allows users to edit its pages in asynchronous way, with no need for users to work as the same place nor time. The main goal of using wikis at the University is to achieve collaboration among students for generating material of a subject. This methodology turns the students into exclusive publishers and takes them responsibility for the end product, which encourages the self-control and the self-management of the learning process. The contents in a wiki cover a wide spectrum: notes of the subject, tests, audio-visual material or exercises proposed to solve in a collaborative way. The teacher has to provide feedback to the students in order to guide them and make sure the knowledge in the wiki is not mistaken.
\end{abstract}

Keywords: wiki, collaborative learning, virtual space, formative evaluation.

\footnotetext{
Resumen

Una wiki es una herramienta on-line de uso sencillo para profesores y alumnos. Este software gratuito permite la edición de páginas web a todos los usuarios, no requiriendo coincidencia ni espacial ni temporal. El objetivo principal para su empleo en docencia universitaria es lograr la colaboración entre estudiantes en la generación de contenidos. Con esta metodología los estudiantes se convierten en los editores exclusivos y responsables directos del producto final, fomentando asi el autocontrol y la autogestión sobre su propio aprendizaje. Los contenidos a desarrollar en una wiki cubren un amplio espectro: apuntes de la asignatura, ensayos, material audiovisual o ejercicios propuestos para resolver de forma colaborativa. El profesorado que asiste la wiki proporciona feedback a sus alumnos, los tutoriza y guía velando por la veracidad del material.
}

Palabras clave: Wiki, aprendizaje colaborativo, espacio virtual, evaluación formativa. 


\section{Introducción}

El origen de las wikis data en el año 1995, cuando Ward Cunningham creó el primer WikiWikiWeb. Este era un sistema de creación, intercambio y revisión de información en la Web de forma fácil, automática y sobre todo, rápida. Cunningham seleccionó el término "wiki" ya que significa "rápido" en hawaino. En un principio, la finalidad de las wikis era crear una base de datos en línea de forma simple y funcional. Hoy día, son numerosos sus usos y aplicaciones: comunicación en grupos de trabajo, creación de enciclopedias o escritura colectiva de novelas, entre otros.

Una wiki es una aplicación informática colaborativa ubicada en un servidor y que permite que los documentos allí alojados puedan ser modificados por los usuarios (pudiendo crear, editar, borrar o corregir el contenido de la página de manera sencilla, interactiva y rápida). El vocablo "colaborativo" hace referencia a que la wiki es un espacio creado, y en proceso de transformación, por el conjunto de los usuarios. El término interactivo describe la relación que las personas establecemos con los materiales (Cabero y Llorente, 2007), en este caso, con las herramientas tecnológicas e Internet.

La mayor ventaja de las wikis consiste en que éstas permiten crear y desarrollar páginas de manera instantánea a través de una interfaz muy simple. Hoy día se trata de una herramienta popular, dado que tanto la interfaz como el código que se utilizan son sencillos. Además, su uso está generalizado por ser gratuitos tanto el software de la aplicación, como el acceso a los diversos sitios web donde ésta se aloja.

Otra de sus ventajas es el ahorro de tiempo y el aumento de la eficiencia en los grupos de trabajo al reducir el tráfico de correos electrónicos entre las personas que integran el equipo. Todas las aportaciones se introducen directamente en la wiki, quedando registrados tanto los cambios como el usuario que los realizó. También hay cabida para las diversas discusiones, opiniones o reflexiones que generan esas modificaciones. La wiki proporciona un espacio común donde todo queda registrado. Hay que resaltar que la autoría de los artículos no es obra de una única persona u organización, sino de un conjunto de individuos con intereses y gustos afines, diluyéndose de esta manera el concepto de autoría.

A partir del 2004, los servicios Web 2.0 introdujeron las comunidades basadas en la Web. Las wikis funcionaban entonces como herramientas que facilitaban la creatividad, la colaboración y ofrecían a los usuarios la posibilidad de compartir contenidos y otros recursos, sin importar su diversidad o ubicación geográfica. Las wikis fueron uno de los servicios más exitosos de la Web 2.0. Resulta inevitable nombrar a Wikipedia, la enciclopedia libre y de construcción colectiva, como el ícono de lo que representa las posibilidades de esta tecnología informática en Internet. Wikipedia es actualmente el sexto sitio Web más visitado en todo el ciberespacio, por encima de sitios tan reconocidos como Blogger, MSN, Twitter, Myspace, Microsoft, Amazon, ebay y Apple, entre otros.

Existe otro concepto de $\mathrm{Web}$ basado en el término hipertexto. Julio Cabero (Cabero, 2002) define los hipertextos como "una organización no lineal y secuencial de la información, donde es el usuario el que decide el camino a seguir, y las relaciones a establecer entre los

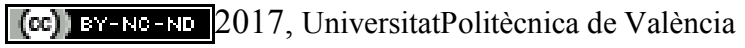

Congreso IN-RED (2017) 
diferentes bloques informativos que se le ofrecen, pudiendo en algunos de ellos incluso comprobar nuevas relaciones no previstas por el diseñador del programa". Con el desarrollo de las herramientas colaborativas, el lector deja de ser sólo lector (pasivo) para convertirse en un lector-autor (activo). Aparece de esta manera la colaboración o altruismo on-line que "constituye un fenómeno social y económico surgido en los últimos tiempos en el ámbito de Internet, que estudiado desde un punto de vista económico es inaudito" (Sarasa, 2006). Una persona deposita su conocimiento de manera altruista y gratuita para que otras puedan utilizar este contenido, sin la obligación de entregar nada a cambio. Con el conocimiento de unos y otros se va construyendo la red.

En un wiki tradicional existen tres presentaciones por cada página:

- Un código fuente que los usuarios pueden editar. Normalmente es un texto plano y sólo es visible para el usuario cuando la operación "edición" se encuentra activa.

- Una plantilla -generalmente creada por el administrador del wiki y no modificable por los usuarios- que define la disposición y los elementos comunes de todas las páginas que la componen.

- El código HTML compilado en tiempo real por el servidor a partir del código fuente cada vez que la página ejecuta la operación de compilación.

La estructura de las wikis suelen presentar un menú vertical a la izquierda que incluye los elementos o herramientas orientados a facilitar la navegación (como son los enlaces de la propia wiki, cambios recientes, herramientas de apoyo para subir archivos, entre otros). A estos elementos hay que añadir los recursos propios para editar y añadir comentarios por parte de los usuarios en la sección de discusión.

Además de las tareas de mantenimiento propias del software, la wiki precisa que se realicen una serie de labores de mantenimiento como: correcciones de estilo, ortografía, gramática, correcciones de enlaces, imágenes, etc. Son los propios usuarios quienes se encargan del mantenimiento de los contenidos. Desde el registro de cambios suele haber otras funciones, como el "Historial de revisión" donde se muestran versiones antiguas de la página. El usuario editor puede desde esta página ver y restaurar una versión anterior del contenido. El método y filosofía utilizados tanto para la creación como para la corrección es la revisión por iguales, definida como "Método usado para mejorar la calidad de los trabajos escritos, deja abierto el trabajo al escrutinio y, frecuentemente, la anotación o edición por un número de autores iguales en rango al autor. El principio empleado es que distintas personas verán diferentes errores, incrementando de esta forma la probabilidad de su hallazgo y posibilidad de enmendarlos. Esta tradición es conocida desde hace tiempo, en la comunidad académica, y permite incrementar la calidad del trabajo" (Molist, 2002).

Desde su inicio, el estándar que se utilizó fue la sintaxis del WikiWikiWeb. Actualmente, los formatos son diferentes dependiendo del motor de la wiki. En general, las wikis simples permiten sólo tratamiento de texto básico, mientras que otras más complejas disponen de soporte para tablas, imágenes, fórmulas e incluso elementos interactivos como encuestas y juegos. Ante tanta variedad de lenguajes de programación y viendo la dificultad que supone 
para los usuarios, se está volviendo a utilizar un lenguaje normalizado y estándar que facilite su uso y popularización.

\subsection{Funciones de las wikis en el proceso de enseñanza y aprendizaje}

Las wikis constituyen una excelente forma de permitir que los estudiantes reflejen los hitos alcanzados a lo largo de su proceso de aprendizaje (Díez Pascual, 2016; García Díaz y otros, 2016). Además contribuyen positivamente al proceso de enseñanza-aprendizaje cumpliendo una serie de funciones de notoria importancia como son: la motivación y persuasión del estudiante para realizar actividades de la asignatura, el apoyo a la indagación que contribuye al aprendizaje autónomo, el establecimiento de una línea de comunicación directa entre profesor y estudiante, retirando los límites del aula física, la evaluación formativa de carácter continuo (Ortega Núñez y otros, 2016). A continuación desarrollamos brevemente las características enumeradas:

- Motivación del estudiante: Nadie pone en duda que el estudiante universitario medio se encuentra plenamente integrado en el uso de las nuevas tecnologías. Las aplicaciones de Internet tienen un elevado grado de penetración entre los jóvenes. Aproximando los objetivos docentes a las aplicaciones por las que los alumnos sienten afinidad, se ejerce cierto grado de persuasión de éstos para potenciar su interés por actividades que les ayudarán indudablemente a mejorar su aprendizaje. Las actividades docentes tradicionales, aun siendo válidas para la comprensión de contenidos, tienen menores posibilidades de resultar atractivas entre el estudiantado. Podemos afirmar que en general, el empleo de herramientas innovadoras incrementa las probabilidades de éxito en el proceso aprendizaje por el simple hecho de la curiosidad que siente el aprendiz por la metodología.

- Apoyo al estudiante en la indagación para el aprendizaje: Está demostrada la correlación entre el interés y necesidad que siente el estudiante y los logros conseguidos tras cursar cierta asignatura. Cuando el docente presenta u tema de forma que capta el interés de los alumnos, consiguiendo que hagan suya la necesidad de saber, el éxito docente está garantizado (Finkel, 2000). El propio estudiante decidirá satisfacer su necesidad a partir del material facilitado por el docente y quizás también nuevo material recopilado por el primero. Las wikis ponen al servicio de los protagonistas del aula un espacio de recogida de los saberes aprendidos, permitiendo la difusión inmediata entre docentes y estudiantes. Con el trabajo generado colaborativamente se refuerza así el proceso de aprendizaje.

- Comunicación directa estudiante-docente: La aplicación wiki ofrece la posibilidad de comunicación directa con el profesor o profesores de la asignatura. Es una prolongación de la experiencia en el aula, prolongando la comunicación tanto individual como colectiva entre estudiantes y docente. El estudiante tiene a su disposición una vía por la cual recibe feedback, permitiendo la evaluación formativa y autoevaluación. Aunque el profesor no escriba directamente los

(cc) EY-NC-ND 2017, UniversitatPolitècnica de València

Congreso IN-RED (2017) 
contenidos, se encuentra presente en todo momento al igual que los alumnos. La wiki ofrece la posibilidad de que todos los participantes puedan interactuar sin necesidad de coincidir en tiempo y lugar, facilitando el trabajo en colaboración y en consecuencia el desarrollo de contenidos de calidad.

- Herramienta de evaluación: Como ya se ha mencionado, el profesor puede, a partir de la actividad en las wikis, realizar la evaluación del proceso de aprendizaje así como analizar la evolución y el progreso del conjunto de alumnos durante el trascurso de la asignatura. Nos estamos refiriendo al término de "evaluación continua". Desde la zona de discusión en la aplicación wiki, el docente asume la labor de corregir, orientar, proponer nuevas líneas de trabajo y recomendar lecturas o referencias bibliográficas específicas para determinados contenidos. El objetivo de estas actividades de revisión es prevenir a los estudiantes de cometer errores que pudieran desalentarles en su progreso y elaboración de conocimiento, a la vez que permitirles la exploración e indagación de forma autónoma. Queremos hacer notar que las misiones anteriores son compartidas con los estudiantes, a los que se les cede cierto control en la gestión y rumbo de la asignatura.

- Autorregulación y autocontrol del aprendizaje por parte del estudiante: Esta función se encuentra conectada con el anterior referente a la cesión de poder al estudiante. Resulta muy significativo para el estudiante sentirse responsable de su propio aprendizaje, y esto le lleve a adquirir las competencias establecidas en la guía docente. La persona aprende a gestionarse a sí misma en un determinado contexto precisamente con el uso de la práctica. $\mathrm{Al}$ estudiante se le hará difícil al comienzo, pero poco a poco aprenderá a dirigirse cada vez mejor. La autorregulación y autocontrol constituyen una potente herramienta para el desarrollo académico, personal y profesional del individuo.

\section{Desarrollo}

Durante el primer cuatrimestre del curso académico 2015-2016 se ha implementado la metodología wiki en la asignatura de Comunicaciones Digitales de las titulaciones Grado de Ingeniería en Sistemas de Telecomunicación, de carácter obligatorio en el curso tercero de 1 titulación; y Máster Universitario de Ingeniería en Telecomunicación de la Universidad de Alcalá, en Madrid. La asignatura en el Grado se convierte en materia de complementos de formación para el Máster, de modo que ambas son semejantes en algunos aspectos. Sin embargo se aprecian algunas diferencias. Las más destacadas son el número de estudiantes que cursan simultáneamente la asignatura (50 alumnos matriculados en el Grado frente a 11 alumnos en la asignatura del Máster Universitario), y el tiempo promedio de estudio fuera del aula por parte de los alumnos.

La idea de llevar a cabo esta experiencia surge durante a partir del conocimiento del uso de aplicaciones wiki en otras asignaturas (López Sastre, 2008; López Sastre, 2007). Desde el punto de vista docente, el objetivo principal es promover un mayor interés en los 
Utilización de wikis como recurso docente en estudios universitarios de Ingeniería en Telecomunicación

estudiantes por la asignatura, lo cual redunda en un mejor conocimiento de la misma y una mejora de rendimiento académico.

Durante la presentación de la wiki en el aula se detalló su dinámica de utilización desde la plataforma Aula Virtual (Blackboard) de la Universidad de Alcalá: los mecanismos de edición y discusión y las normas básicas de colaboración en un trabajo colaborativo. La Figura 1 muestra la página de inicio de la wiki desde dicha plataforma.

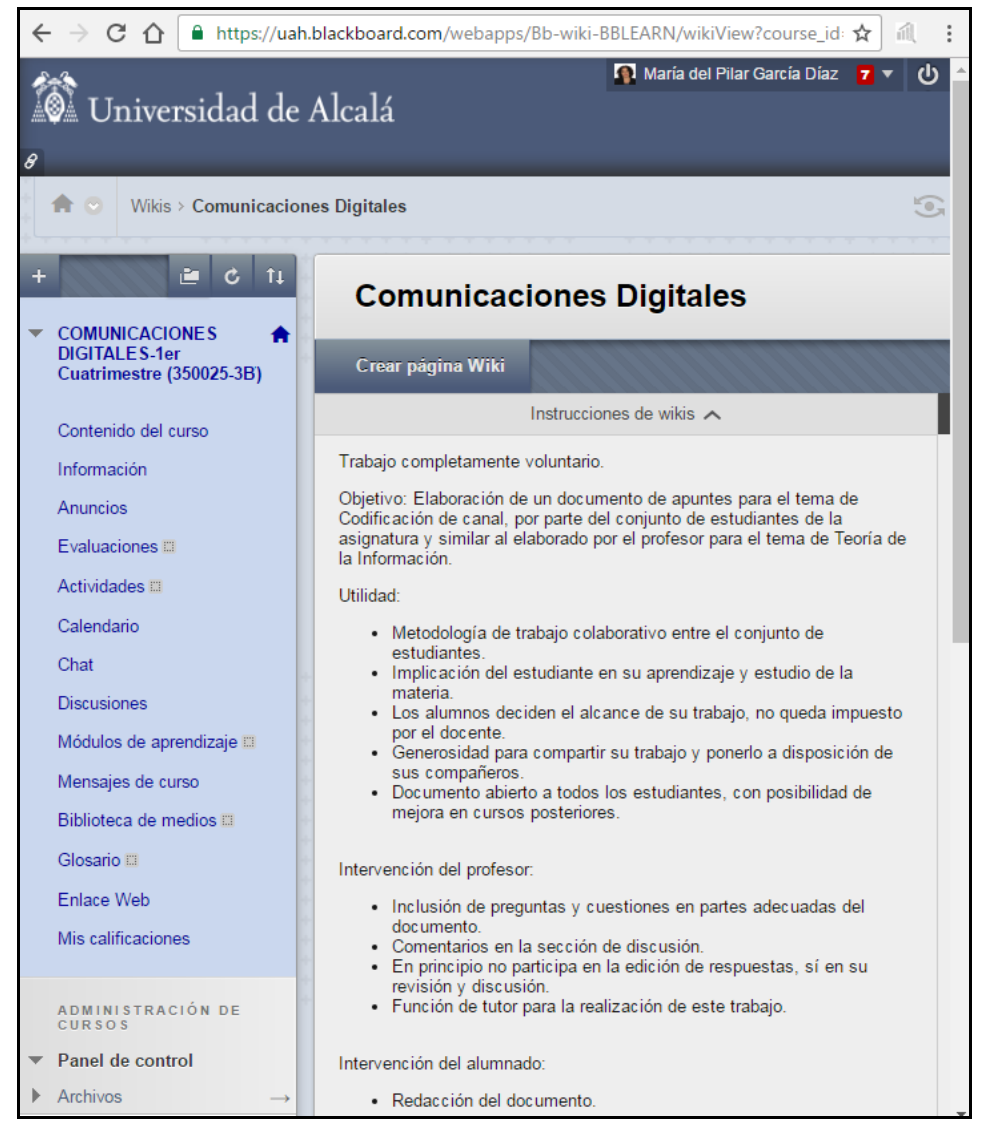

Figura 1 Página de inicio de la wiki de la asignatura Comunicaciones Digitales para los estudios de Grado en Ingenieria en Sistemas de Telecomunicación.

El desarrollo que recoje el presente documento consiste en una wiki para la creación de apuntes de la asignatura, redactados de forma colaborativa y exclusiva por los estudiantes con carácter voluntario sin consecuencia directa en la calificación final de la asignatura. En futuras implementaciones podremos ampliar el conjunto de actividades y trabajos como resolución de ejercicios, problemas y cuestiones tipo test, generación de glosario de términos, inserción de videos, evaluación de alumnos, evaluación del profesorado y/o autoevaluación. La Figura 2 presenta un extracto del índice de contenidos facilitado por el docente como guía de redacción de apuntes de la asignatura de Comunicaciones Digitales.

(cc) EY-NC-ND 2017, UniversitatPolitècnica de València

Congreso IN-RED (2017) 


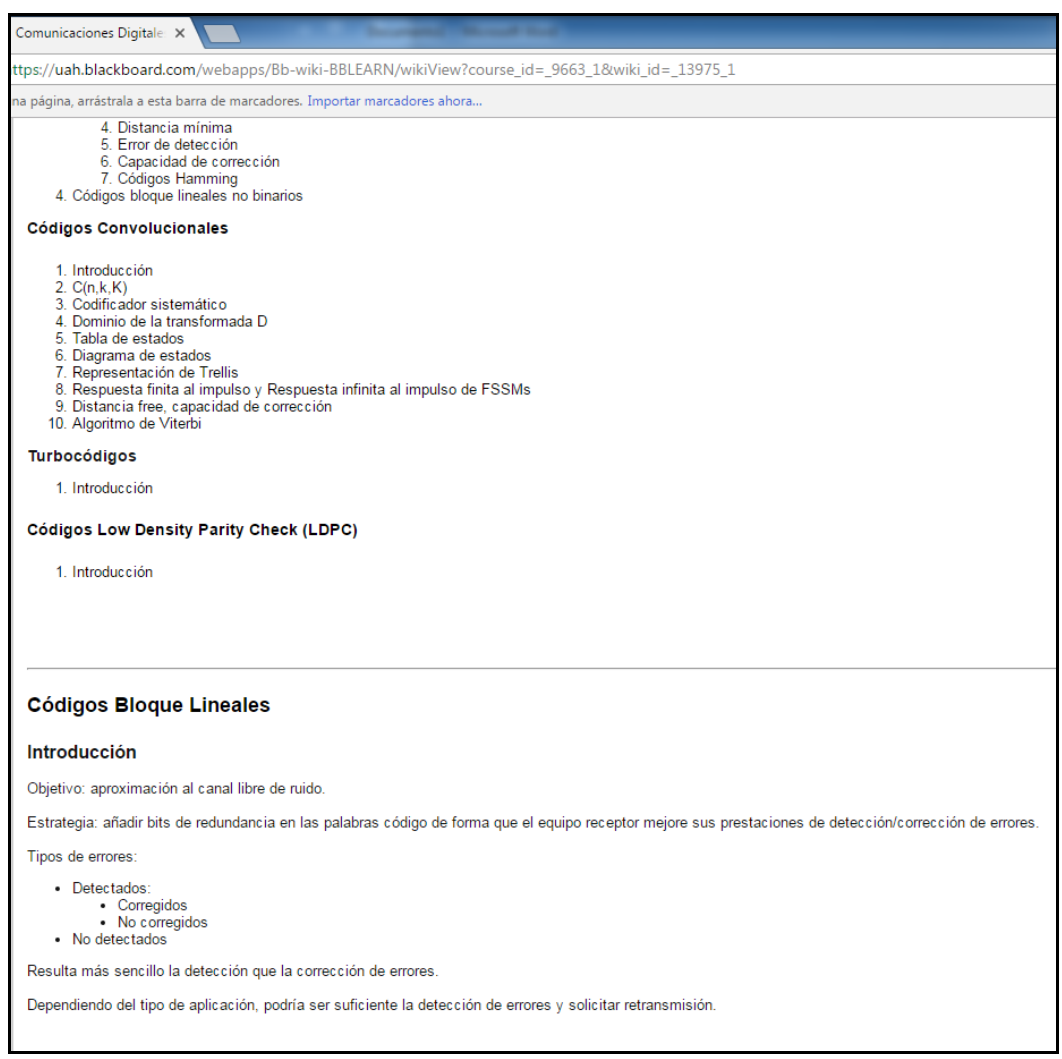

Figura 2 Ejemplo de extracto de página de apuntes de la asignatura a tratar en la wiki.

\section{Resultados}

En esta sección presentamos los resultados académicos medios alcanzados por los alumnos que participaron en la actividad de la wiki habilitada para la asignatura de Comunicaciones Digitales en el Grado en Ingeniería en Sistemas de Telecomunicación y en el Máster Universitario de Ingeniería en Telecomunicación. La finalidad es obtener conclusiones sobre el beneficio del uso de esta metodología en el proceso de enseñanza y aprendizaje de los estudiantes.

La Tabla 1 y la Figura 3 recogen las estadísticas de participación en la wiki para los estudiantes que cursaron la asignatura en el Máster, mientras que la Tabla 2 y la Figura 4 hacen lo propio para la misma asignatura en el Grado. Esta asignatura tiene un número de alumnos bastante reducido en el Máster respecto al Grado. Esta característica aporta mayor interacción alumno-docente en los grupos menos numerosos, lo cual contribuye a mejores resultados académicos medios. Sin embargo, con una muestra escasa de estudiantes en la asignatura del Máster, somos cautelosos con nuestras conclusiones.

(cc) EY-NC-ND 2017, UniversitatPolitècnica de València 
Utilización de wikis como recurso docente en estudios universitarios de Ingeniería en

Tabla 1. Estadísticas de participación en la wiki y de resultados académicos en la asignatura de Comunicaciones Digitales en el Máster Universitario de Ingeniería en Telecomunicación.

\begin{tabular}{cc}
\hline Estadística & $\begin{array}{c}\text { Alumnos } \\
(\mathbf{\%})\end{array}$ \\
\hline Participación en la wiki sobre alumnos matriculados & 72,7 \\
Participación en la wiki sobre presentados a examen & 77,8 \\
Participación en la wiki sobre alumnos aprobados & 77,8 \\
Aprobados en la asignatura sobre participación en la wiki & 87,5 \\
\hline
\end{tabular}

Esta asignatura mantiene una elevada tasa de aprobados en el Máster, muy próxima al $100 \%$. Como puede deducirse en la Tabla 1 y Figura 3, la gran mayoría de los alumnos aceptaron de buen grado la herramienta wiki para trabajar la asignatura: más de un $70 \%$. El $87,5 \%$ de los miembros de la wiki aprobaron la asignatura en la convocatoria ordinaria. Visto de otro modo el $77,8 \%$ de los estudiantes que aprobaron la asignatura, corresponden a usuarios de la wiki. Esto indica que la mayoría de los aprobados provienen de los usuarios en la wiki, aunque hubo alumnos que superaron la asignatura sin mostrar evidencias de uso de esta herramienta.

Por otra parte, un análisis pormenorizado de las calificaciones numéricas asociadas a los alumnos en la convocatoria, indica que el total de las participaciones en la wiki corresponden al $80 \%$ de los alumnos con mejores calificaciones, todos ellos aprobaron la asignatura. El 50\% de las participaciones en la wiki corresponden al $40 \%$ de los alumnos con mejores calificaciones.

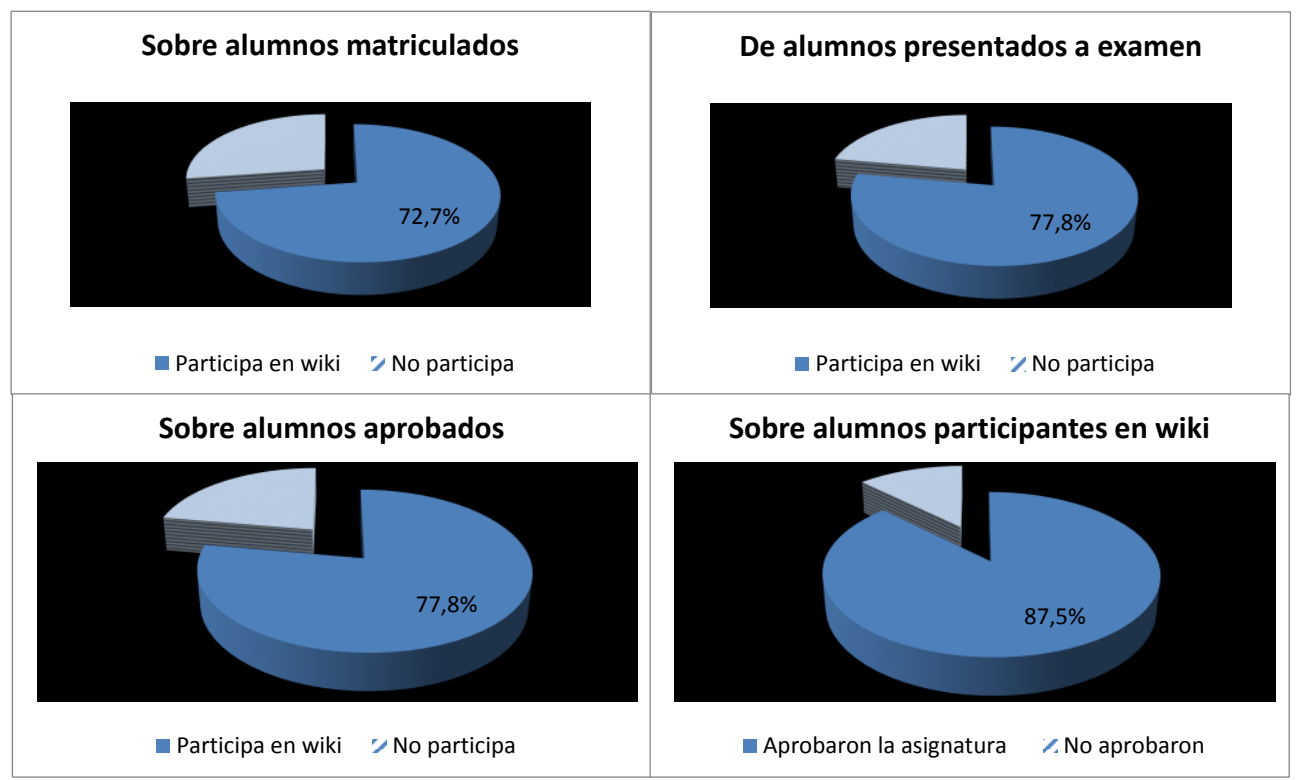

Fig. 3 Resumen de la Tabla 1, estadísticas de participación en la wiki y resultados académicos en la asignatura de Comunicaciones Digitales en el Máster Univerisitario de Ingeniería en Telecomunicación.

(c)) EY-NC-ND 2017, UniversitatPolitècnica de València 
En lo que respecta a la asignatura en el Grado en Ingeniería en Sistemas de Telecomunicación, el total de matriculados durante el pasado curso académico fue de 50 alumnos, lo cual significa una muestra válida para las medidas que presentamos en estas páginas. En la Tabla 2 y Figura 4 puede observarse que la participación en la wiki fue escasa, solo el $13,2 \%$ de los estudiantes que realizaron las pruebas de evaluación. Este porcentaje se duplica cuando consideramos los alumnos aprobados, de los cuales el 28,6\% corresponde a usuarios wiki en la asignatura.

Tabla 2. Estadísticas de participación en la wiki y de resultados académicos en la asignatura de Comunicaciones Digitales en el Grado en Ingeniería en Sistemas en Telecomunicación.

\begin{tabular}{cc}
\hline Estadística & $\begin{array}{c}\text { Alumnos } \\
(\mathbf{\%})\end{array}$ \\
\hline Participación en la wiki sobre alumnos matriculados & 12,0 \\
Participación en la wiki sobre presentados a examen & 13,2 \\
Participación en la wiki sobre alumnos aprobados & 28,6 \\
Aprobados en la asignatura sobre participación en la wiki & 66,7 \\
\hline
\end{tabular}

Es destacable que la mayoría de los participantes en la wiki aprobaron la asignatura en la convocatoria ordinaria $(66,7 \%)$. Éstos alumnos se sitúan precisamente entre el $53 \%$ de las mejores calificaciones en el acta final.

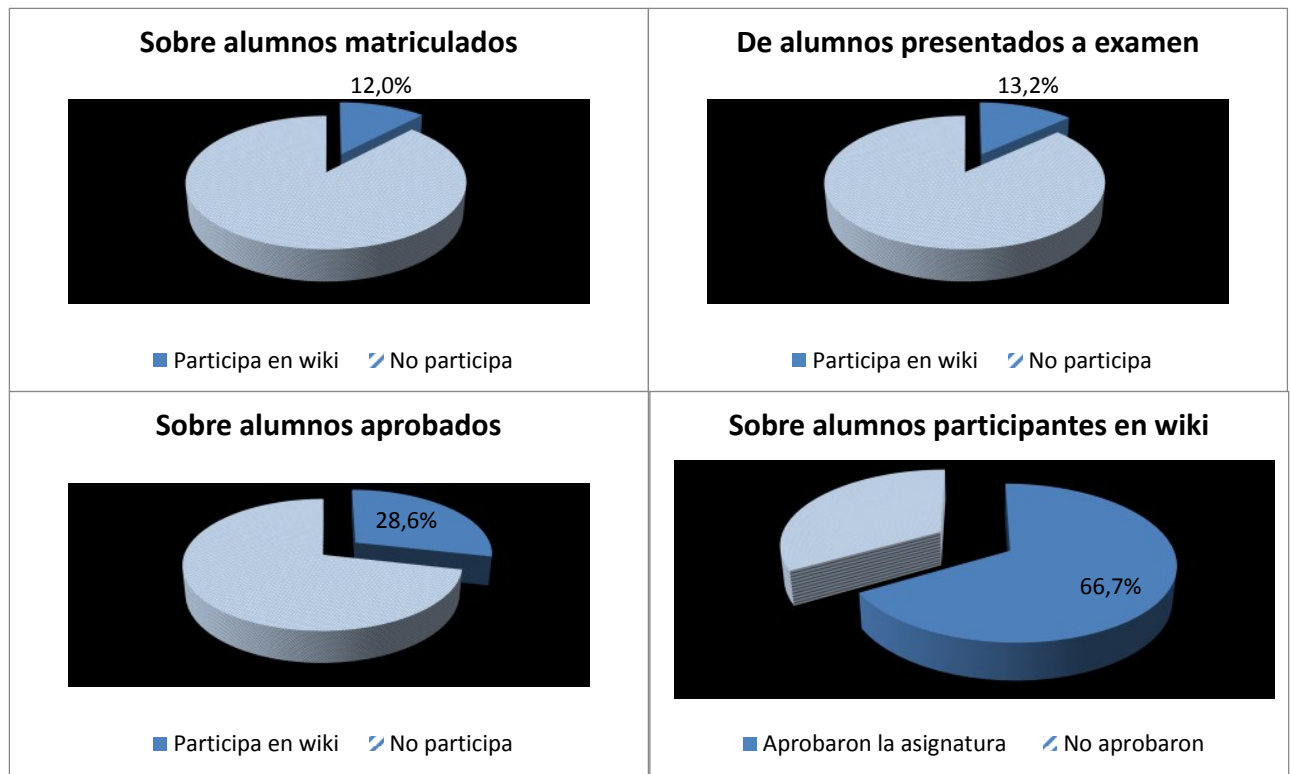

Fig. 4 Estadísticas y resultados académicos de los estudiantes de la asignatura en el Grado en Ingeniería con respecto al uso de la wiki. 


\section{Conclusiones y propuestas a partir de la experiencia con Wikis}

La conclusión directa a partir del análisis de los resultados anteriores es que la mayoría de alumnos que emplearon la herramienta wiki aprobaron la asignatura. Recordando que se presentó como una actividad de carácter voluntario, se puede deducir que en general, los estudiantes que se involucraron en la actividad de la wiki corresponden a alumnos implicados en la asignatura.

Los autores no creemos adecuada la aplicación de un sistema de calificación sobre la actividad en la wiki, al menos no para la totalidad de los alumnos. Aunque la interfaz de la aplicación ofrece un histórico de ediciones realizadas, identificado nombres de usuario, fecha y hora para cada una de las páginas de forma independiente, ésta carece de un histórico similar para los accesos de lectura por parte de sus miembros. Recordando la naturaleza colaborativa de la wiki como software social, existe la posibilidad de que algunos estudiantes trabajen en grupo en la actividad fuera del aula, accediendo a la edición de contenidos desde un único usuario wiki pero con la participación de todo el grupo. Esta situación concreta no quedaría registrada en la aplicación.

Por esta razón nuestra opinión se aproxima más a ofrecer al estudiante mayor autocontrol de su trabajo y aprendizaje, renunciando el docente a parte del control sobre sus alumnos. Permitiendo el carácter voluntario en la participación de los estudiantes en la wiki, éstos no sienten la obligatoriedad en realizar una, pocas o muchas modificaciones en las páginas de la aplicación, centrando el esfuerzo en su aprendizaje, en el contenido de lo que escribe (calidad) y no en el número de entradas que realice (cantidad).

\subsection{Propuestas para futuras implementaciones de la metodología wiki}

A partir de la experiencia de implementación de wikis en la asignatura de las titulaciones mencionadas, enumeramos sugerencias que aplicaremos nosotros mismos en futuras actividades. Consideramos que la integración de una nueva herramienta debiera realizarse de forma gradual, adaptando la metodología en todo momento a la situación y contexto del estudiantado.

- Presentación detallada la herramienta wiki en el aula aclarando las particularidades de la interfaz, el modo previsto de uso, los plazos planificados para la generación de contenidos y el método de evaluación. Se pretende con ello el completo entendimiento de la finalidad y objetivos docentes.

- Entendemos por evaluación de la actividad de la wiki, el acompañamiento del estudiantado durante la creación y existencia de la wiki y realizado por el profesor o profesores. Dado que la finalidad de la evaluación es ayudar al estudiante en su proceso de aprendizaje, se trata de inducir al alumno cierto grado de autonomía para su aprendizaje, facilitándole pautas para que él mismo pueda corregir los errores cometidos en el proceso.

(cc) EY-NC-ND 2017, UniversitatPolitècnica de València

Congreso IN-RED (2017) 
- Establecimiento de criterios flexibles para los plazos y tiempos de actividad con la wiki. En general muchos alumnos no dedican el tiempo indicado en las guías docentes de las asignaturas que cursan. Ello conlleva, lamentablemente, a que los tiempos de trabajo sobre una asignatura particular se distribuyen en ráfagas, en vez de forma continuada (como dictan las técnicas de estudio más eficaces). Además se produce coincidencia temporal en los periodos de actividad más intensa por la mayoría de alumnos. La wiki seguirá un proceso de crecimiento proporcional a este hecho: inicialmente evolucionará rápidamente durante un intervalo de tiempo breve para luego alcanzar un largo periodo indefinido de letargo. Para conseguir un crecimiento más duradero proponemos una planificación flexible y consensuada con los estudiantes. Ellos mismos pueden establecer las medidas a tomar que eviten extensos periodos de inactividad en la aplicación.

- Debido a la colaboración simultánea de numerosos editores, el formato de los contenidos puede llegar a ser variado o incoherente. Se aconseja transferir la función de maquetador de páginas a una o varias personas para prevenir un formato cambiante o lo que es peor, inexistencia del mismo. No obstante recomendamos el acuerdo inicial de los autores en el establecimiento de un formato básico para los contenidos de la wiki. Se puede definir con antelación el tipo y tamaño de fuente, el formato para la inserción de figuras y archivos adjuntos, referencias bibliográficas, etc.

- Planteamiento inicial de un formato de modo que la función de imprimir las páginas que proporcina la aplicación plasme la totalidad de contenidos de las páginas de la wiki al archivo a imprimir. La wiki no es un mero contenedor de información, debiera tener un aspecto y formato adecuados para el uso futuro más allá de la duración del curso académico. La función de impresión en documento con formato $p d f$ debiera contener toda la información, incluidos los archivos adjuntos en formato legible.

- También podrían establecerse, prevaleciendo la flexibilidad, otros roles o funciones especializadas entre los estudiantes. Ejemplos de éstas pueden ser la búsqueda de bibliografía, creación de etiquetas indexadas, corrector de ortografía u organización de la estructura general.

- Resulta habitual la aparición de comentarios en la zona de discusión del tipo: "Si no os parece bien lo que he añadido podéis cambiarlo", o bien "Sentiros libres para cambiar lo que queráis". La aparición de estos mensajes constatan que los participantes no sienten pleno permiso para editar, sino que expresan cierta inhibición por la posible no aprobación de sus compañeros. Si se permite el diálogo entre ellos sobre este asunto puede tranquilizar a los miembros más tímidos y potenciar su participación en la wiki.

- Por último sugerimos explorar la función de notificación a todos los usuarios de cambios en la wiki. El conocimiento de actividad de unos usuarios en la wiki puede potenciar la actividad del resto de miembros. Este hecho se pone de manifiesto en las redes sociales, donde a veces un comentario va seguido de una avalancha de intervenciones. 


\section{Referencias}

CABERO, J. (2002). Navegando, construyendo: la utilización de los hipertextos en la enseñanza. Medios de comunicación, recursos y materiales para la mejora educativa II, Cabero, J. et al. (coords.). Sevilla, CMIDE del Excmo. Ayuntamiento de Sevilla y SAV de la Universidad de Sevilla, pp. 227243.

CABERO, J. y LLORENTE, M. (2007). La interacción en el aprendizaje en red: uso de herramientas, elementos de análisis y posibilidades educativas. Revista Iberoamericana de Educación a Distancia, 10 (2), pp. 98-123.

DÍEZ PASCUAL, ANA M. (2016). "Propuesta de utilización de las wikis en asignaturas del grado en Farmacia". Trabajo Final de Máster. Universidad de Alcalá, < http://biblioteca.uah.es/ > [Consulta: 15 de marzo 2017]

FINKEL, D. (2000). Dar clase con la boca cerrada. Publicaciones de la Universidad de Valencia. ISBN 978-84-370-7268-5.

GARCÍA DÍAZ, M. PILAR; ORTEGA NÚÑEZ, MIGUEL ÁNGEL; CAMBRALLA DIANA, RAFAEL y DÍEZ PASCUAL, ANA M. (2016) "Experiencia de implementación de una wiki como apoyo a la docencia presencial en enseñanzas universitarias". Vicerrectorado de Docencia y Estudiantes de la Universidad de Alcalá. En: VIII Encuentro de Innovación en Docencia Universitaria: "Nuevas apuestas educativas: Entre la docencia presencial y la innovación tecnológica" (25 y 26 de abril de 2016. Facultad de Biología, Ciencias Ambientales y Química. Universidad de Alcalá). Alcalá de Henares, Madrid.

LÓPEZ SASTRE, R. J., MANCHO, G., PORTO REQUEJO, M. D., PENA DÍAZ, C., VALERO, C., VITALARAU, B. (2008). FILWIT: Innovando con Wikis en el aula. En: III Encuentro sobre Innovación en Docencia Universitaria. (16 de octubre de 2008. Universidad de Alcalá). Alcalá de Henares, Madrid.

LÓPEZ SASTRE, R.J. (2007). “Aprendizaje y software social: comunidades de práctica y Wikis en el EEES”. Alcalá de Henares: Servicio de Publicaciones de UAH.

MOLIST, M. (2002). Wiki: la web más participativa. <http://ww2.grn.es/merce/2002/wiki.html> [Consulta: mayo 2016]

ORTEGA NÚÑEZ, M. A.; GARCÍA DÍAZ, M. P. y DÍEZ PASCUAL, A. M. (2016) El proceso de la innovación en el contexto de la educación superior universitaria. Madrid, LDL. ISBN : 978-84944970-5-6.

SARASA, A. (2006). Usando la Wikipedia como motivación en el proceso de aprendizaje. Revista Latinoamericana de Tecnología Educativa, 5 (2), pp. 433.442.

(cc) EY-NC-ND 2017, UniversitatPolitècnica de València 


\title{
Microvideos como herramienta docente en Química General
}

\author{
Sergio Armenta, Francesc Albert Esteve-Turrillas
}

Departamento de Química Analítica, Universitat de València, Edificio Jeroni Muñoz, c/ Dr. Moliner 50,46100 Burjassot, España (sergio.armenta@uv.es, francesc.a.esteve@uv.es)

\begin{abstract}
The objective of the present communication is the preparation of short duration videos, less than 2 minutes (microvideos) where the main ideas of the different topics of the subject General Chemistry would be summarized in a fashion way, enhancing the teaching/learningn process. The development of the videos must be done by the students to fix the main concepts of the lectures and to acquire transversal key competences such as collaborative learning, problem solving skills, self-directed learning and organizative and technologic skills.The obtained results can be considered as preliminar reults, because of effectivity has been evaluated qualitatively. To obtain more realistic conclusions, the activity should be performed next years and use control groups to quantitatively evaluate the impact of this activity on the teaching/learning process.
\end{abstract}

Keywords: microvideos, digital tools, colaborative learning, problema solving, self-directed learning.

\begin{abstract}
Resumen
El objetivo del presente trabajo es la elaboración de videos de corta duración, inferior a 2 minutos (microvideos) en los que se resuma, de una forma atractiva, las principales ideas de diferentes temas de la asignatura Química General II, facilitando el proceso de enseñanza/aprendizaje. La creación de los videos de aprendizaje corre a cargo de los estudiantes para profundizar no solamente en los conceptos teóricos de la asignatura sino también para la adquisición de competencias transversales como serían el trabajo colaborativo, resolución de problemas, aprendizaje autónomo así como competencias tecnológicas y organizativas. Los resultados obtenidos son preliminares, por lo que se han obtenido datos de efectividad meramente cualitativos. Para extraer conclusiones mas realistas, se desarrollará esta actividad en cursos futuros así como se usarán grupos control en los que no se aplique esta herramienta. De esta forma se podrá evaluar cuantitativamente su impacto a largo plazo en el proceso de enseñanza/aprendizaje.
\end{abstract}

Palabras clave: microvideos, herramientas digitales, trabajo colaborativo, resolución de problemas, trabajo autónomo. 


\section{Introducción}

La teoría de Howard Gardner, llamada teoría de las Múltiples Inteligencias (MI), (Gardner, 1983), define inteligencia como una mezcolanza de diferentes habilidades o aptitudes que incluyen musical, lingüística, lógica-matemática, espacial, interpersonal, intrapersonal, natural, kinestésica y existencial. Gardner ubica el término inteligencia dentro de un contexto social "la habilidad para resolver problemas, o para crear productos, que tengan un valor o utilidad en un determinado escenario".

En este sentido, está claro que los avances tecnológicos han cambiado la forma de actuarpensar-vivir de la sociedad actual. El modo de vida actual esta basado en las premisas más rápido, más cerca, más accesible,... A medida que la tecnología avanza, lo hace también la demanda de un nivel de accesibilidad instantánea de los usuarios. El mundo se ha convertido en un mundo digital y las aulas están siguiendo el mismo camino. La forma de enseñar y aprender no son ajenas a dicho cambio. El profesor continua siendo el punto de atención, pero ahora se disponen de nuevos y numerosos recursos.

El viejo cliché "una imagen vale más que mil palabras" se hace cada vez más una realidad. Las imágenes, y en mayor grado los videos, añaden autenticidad y realidad al contexto pedagógico. Las imágenes y los videos han sido una herramienta pedagógica desde hace mucho tiempo, como Anuli Akanegbu describe en EDTECH MAGAZINE desde el empleo de la "linterna mágica" hasta las recientes tecnologías basadas en visualizaciones en streaming.

Por tanto, el motivo principal de esta propuesta es destacar la importancia del video con motivos educativos y adaptar las características de dichos videos a las exigencias de la sociedad/estudiante actual.

En este proyecto, nos centraremos en la realización de videos como material suplementario a las clases magistrales. Este tipo de videos se usan generalmente al principio de un tema para proporcionar al estudiante el contexto o background del conocimiento, o al final del tema como material suplementario para reforzar los conocimientos adquiridos.

Desde hace tiempo se ha hecho hincapié y discutido ampliamente en el empleo y la preparación por parte de los profesores del video como herramienta pedagógica. Sin embargo, tal y como describe Allam (2006), parece evidente que el desafio pedagógico para los alumnos de crear imágenes y videos para ser usados en términos pedagógicos además de resultar atractivo y útil, permite que los estudiantes adquieran competencias transversales, entre las que cabría destacar habilidades de búsqueda científica, trabajo colaborativo, resolución de problemas, así como competencias tecnológicas y organizativas. Desde el punto de vista pedagógico, el foco está en el estudiante que se convierte en creador de conocimiento. En este sentido, se debe considerar igual de importante el proceso de creación como el objeto creado.

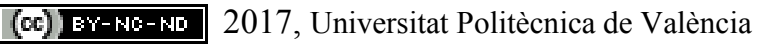


Las principales características que debe tener el video creado se enumeran a continuación:

- La duración del video debe ser corta (inferior a 2 minutos) debido a que la atención de los estudiantes es limitada cuando se observan contenidos visuales. Es preferible dividir los videos en dos con actividades focalizadas.

- Los videos deben estar disponibles para ser visualizados fuera de clase, por tanto, se debe proporcionar una página web o link para que los estudiantes puedan ver el video cuando quieran y tantas veces como consideren oportuno.

En cuanto a la asignatura de Química General II decir que se imparte en el segundo cuatrimestre del primer curso del grado en Química. El número de estudiantes matriculados es de 220-240 divididos en cuatro grupos de 60 estudiantes aproximadamente. Respecto a los resultados académicos cabe destacar que el porcentaje de estudiantes aprobados respecto a matriculados es de 54\% en el periodo comprendido entre 2010-11 y 2015-2016, siendo el 57.9\% el correspondiente al año 2015-2016.

\section{Objetivos}

El principal objetivo del presente trabajo es la elaboración de videos de corta duración, inferior a 2 minutos (microvideos) en los que se resuma, de una forma atractiva, las principales ideas de diferentes temas de la asignatura Química General II, facilitando el proceso de enseñanza/aprendizaje. La creación de los videos de aprendizaje corre a cargo de los estudiantes para profundizar no solamente en los conceptos teóricos de la asignatura sino también para la adquisición de competencias transversales como serían el trabajo colaborativo, resolución de problemas, aprendizaje autónomo así como competencias tecnológicas y organizativas.

\section{Desarrollo de la innovación}

Esta tarea se ha realizado siguiendo el esquema propuesto:

- Clases magistrales participativas (dependiendo del tema seleccionado el número de sesiones puede variar entre 3-6).

- Seminario, donde el docente ha comunicado a los estudiantes en que consiste el trabajo, se definen claramente los objetivos, se realiza un reparto del tiempo y los papeles de cada miembro del grupo (selección de conceptos teóricos que deben aparecer en el video, escritura del guión, grabación y edición del video y dirección) y definición clara de los resultados esperados y la evaluación.

- Tutorías grupales (mínimo 2/3 sesiones), seguimiento del proceso de realización del video.

- Seminario, visionado y evaluación de la actividad realizada.

En cada una de las sesiones de trabajo, tanto las que se han realizado en presencia del profesor como las que no, se han redactado actas de reunión, para facilitar el seguimiento y 
la evaluación del proceso. Dicha acta incluye fecha, asistentes, acuerdos y actividades futuras.

La evaluación es un aspecto particularmente relevante para asegurar el cumplimiento de la actividad propuesta. Dicha evaluación se realizará mediante el uso de rúbricas analíticas, un instrumento cuya principal finalidad es compartir los criterios de realización de las tareas de aprendizaje y de evaluación con los estudiantes y entre el profesorado. De esta forma se pretende que los alumnos sean conocedores de los diferentes niveles de cumplimiento de la actividad o de parte de ella, desde el menos aceptable hasta la resolución ejemplar, desde lo considerado como insuficiente hasta lo excelente.

Se pretende que los estudiantes puedan autoevaluarse y que el feedback sea casi inmediato, permitiendo a los estudiantes conocer el resultado de su trabajo en base a estándares conocidos previamente al desarrollo de la tarea.

Adicionalmente, se han realizado encuestas tanto a los estudiantes como a los docentes para establecer el grado de satisfacción correspondiente al desarrollo de la actividad y de los materiales elaborados.

\section{Resultados}

A continuación se muestran parte de los resultados obtenidos durante la preparación del material definitivo en el grupo D de la asignatura de Química General II del Grado en Química el año 2016-17. El número de alumnos implicados en la actividad fue de 40, distribuidos en grupos (8) de 4-5 miembros.

En la actividad desarrollada, cada grupo preparó un microvideo de 2 minutos de duración en el que se resumen los aspectos más importantes de cada uno de los temas implicados en la asignatura. En el caso de Química General II los temas son los siguientes:

Tema 1. Energía de las reacciones químicas

Tema 2. La dirección del cambio químico

Tema 3. El equilibrio en las reacciones químicas

Tema 4. Cambios de estado de sustancias puras

Tema 5. Disoluciones

Tema 6. Equilibrio ácido-base

Tema 7. Equilibrios de formación de complejos

Tema 8. Equilibrios de solubilidad

Tema 9. Equilibrios de oxidación-reducción

Tema 10. La velocidad del cambio químico

(c)) EY-NC-ND 2017, Universitat Politècnica de València

Congreso IN-RED (2017) 
Para la elaboración de los videos por parte de los estudiantes se utilizaron programas para la edición y creación de presentaciones como el VIDEOSCRIBE, TRUSCRIBE, POWTOON, GOANIMATE, y VIDEOMARKERFX entre otros.

En la Figura 1 se adjuntan diferentes capturas de pantalla obtenidas de los videos creados por los estudiantes de Química General II, grupo D, año 2016-2017.
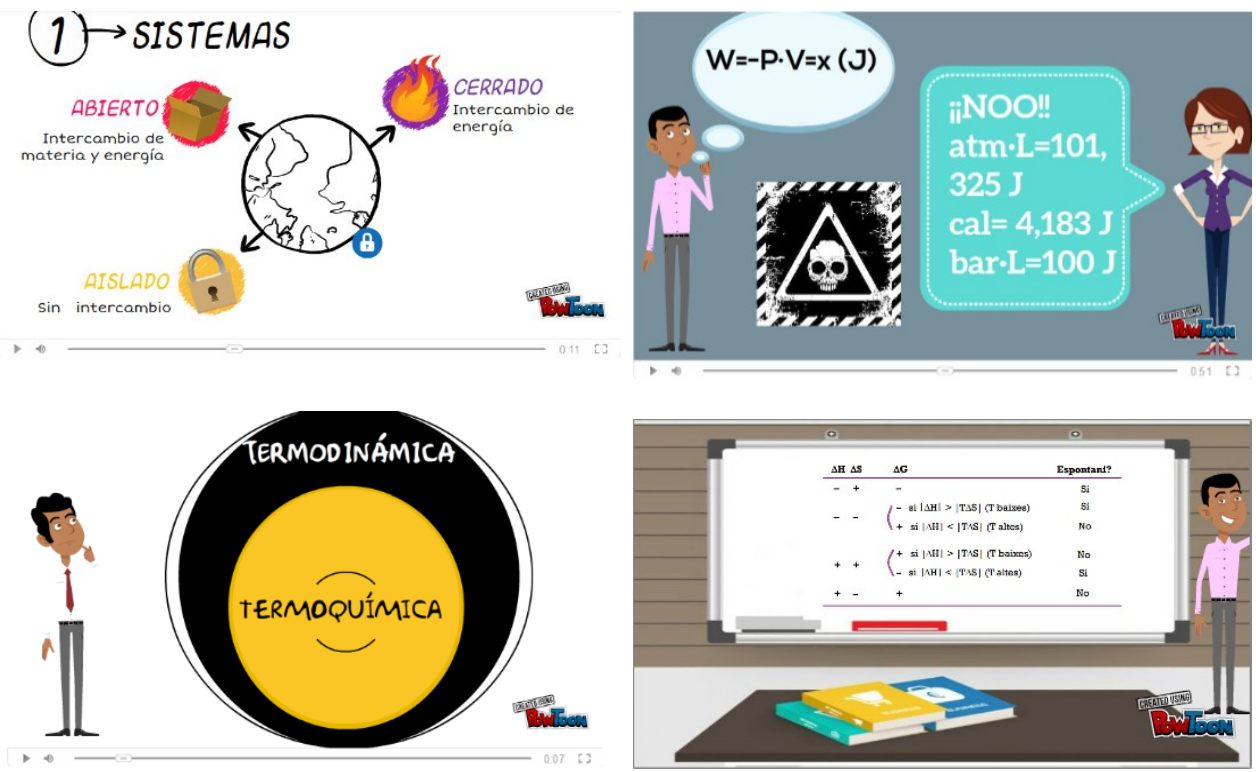

Fig. 1 Capturas de pantalla de los videos realizados por los estudiantes de Química General II, grupo D, 20162017.

Los resultados de aprendizaje que aparecen en la guía docente y que se pretenden desarrollar y evaluar con la actividad propuesta son:

1. Realizar una distribución de tareas que permita el correcto desarrollo del trabajo en equipo.

2. Realizar una correcta planificación de las tareas que permita realizarlas puntualmente.

3. Saber gestionar los conflictos que puedan surgir con aportación de ideas al colectivo y con responsabilidad compartida.

4. Justificar y debatir con argumentos racionales hechos científicos de manera adecuada y rigurosa.

La evaluación de dicha actividad forma parte de la evaluación de las sesiones de tutorías grupales, seminarios, elaboración de trabajos y/o exposiciones orales y se ha realizado mediante el empleo de rúbricas diseñadas para ello (ver Figura 2). El porcentaje en el que la

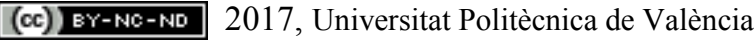


actividad expuesta contribuye a la nota final es un $25 \%$, que se obtendrá de la siguiente forma:

Evaluación del proceso (50 \%). Esta nota se obtiene como media de la evaluación del profesor y la autoevaluación del propio grupo.

Evaluación del resultado (50\%). Esta nota se obtiene como media de la evaluación del profesor y la evaluación del resto de grupos (compañeros de clase).

Rúbrica objeto para aprendizaje cooperativo- video Química General II

Prof. Sergio Armenta

Grupo

\begin{tabular}{|l|l|l|l|l|l|}
\hline \multicolumn{1}{|c|}{ CATEGORIA } & $\mathbf{4}$ & $\mathbf{3}$ & $\mathbf{1}$ & NOTA \\
\hline $\begin{array}{l}\text { CONCEPTOS } \\
\text { TEÓRICOS }\end{array}$ & $\begin{array}{l}\text { Todos los conceptos teóricos } \\
\text { importantes han sido } \\
\text { plasmados. }\end{array}$ & $\begin{array}{l}\text { La mayor parte de los } \\
\text { conceptos teóricos } \\
\text { importantes han sido } \\
\text { plasmados. }\end{array}$ & $\begin{array}{l}\text { Alguno de los conceptos } \\
\text { teóricos importantes ha } \\
\text { sido plasmado. }\end{array}$ & $\begin{array}{l}\text { No se han plasmado los } \\
\text { conceptos teóricos } \\
\text { importantes }\end{array}$ & \\
\hline EDICIÓN DEL VIDEO & $\begin{array}{l}\text { El vídeo ha sido editado de } \\
\text { forma sobresaliente. }\end{array}$ & El vídeo ha sido editado & $\begin{array}{l}\text { La edición del vídeo es } \\
\text { deficiente }\end{array}$ & El vídeo no ha sido editado & \\
\hline GUIÓN & $\begin{array}{l}\text { El guión del video es } \\
\text { sobresaliente. }\end{array}$ & $\begin{array}{l}\text { El guión del vídeo es } \\
\text { aceptable. }\end{array}$ & $\begin{array}{l}\text { El guión del vídeo es } \\
\text { mejorable. }\end{array}$ & No hay guión. & \\
\hline DIRECCIÓN & $\begin{array}{l}\text { La dirección del proyecto se } \\
\text { ha realizado de forma } \\
\text { brillante. }\end{array}$ & $\begin{array}{l}\text { La dirección del proyecto } \\
\text { ha sido aceptable. }\end{array}$ & $\begin{array}{l}\text { La dirección del proyecto es } \\
\text { mejorable. }\end{array}$ & $\begin{array}{l}\text { La dirección del proyecto no } \\
\text { ha existido. }\end{array}$ & \\
\hline $\begin{array}{l}\text { DURACIÓN DEL } \\
\text { VIDEO }\end{array}$ & $\begin{array}{l}\text { La duración del vídeo se } \\
\text { ajusta a los límites } \\
\text { establecidos. }\end{array}$ & $\begin{array}{l}\text { La duración del vídeo } \\
\text { supera los límites } \\
\text { establecidos en un 25\%. }\end{array}$ & $\begin{array}{l}\text { La duración del vídeo supera } \\
\text { los límites establecidos en } \\
\text { un } 50 \% .\end{array}$ & $\begin{array}{l}\text { La duración del vídeo supera } \\
\text { los límites establecidos en un } \\
75 \% \text { o no llega a los mínimos } \\
\text { establecidos. }\end{array}$ & \\
\hline
\end{tabular}

Rúbrica para proceso aprendizaje cooperativo- video Química General II Prof. Sergio Armenta

Grupo

\begin{tabular}{|c|c|c|c|c|c|}
\hline CATEGORIA & 4 & 3 & 2 & 1 & NOTA \\
\hline $\begin{array}{l}\text { PARTICIPACIÓN } \\
\text { GRUPAL }\end{array}$ & $\begin{array}{l}\text { Todos los estudiantes } \\
\text { cooperan con entusiasmo }\end{array}$ & $\begin{array}{l}\text { Al menos } 3 / 4 \text { de los } \\
\text { estudiantes cooperan }\end{array}$ & \begin{tabular}{|l|} 
Al menos la mitad de los \\
estudiantes presentan ideas \\
propias
\end{tabular} & $\begin{array}{l}\text { Sólo una participa } \\
\text { activamente }\end{array}$ & \\
\hline $\begin{array}{l}\text { RESPONSABILIDAD } \\
\text { COMPARTIDA }\end{array}$ & $\begin{array}{l}\text { Todos comparten por igual la } \\
\text { responsabilidad sobre la } \\
\text { tarea }\end{array}$ & $\begin{array}{l}\text { La mayor parte de los } \\
\text { miembros del grupo } \\
\text { comparten la } \\
\text { responsabilidad en la tarea }\end{array}$ & $\begin{array}{l}\text { La responsabilidad es } \\
\text { compartida por } 1 \frac{1}{2} \text { de los } \\
\text { integrantes del grupo }\end{array}$ & $\begin{array}{l}\text { La responsabilidad recae en } \\
\text { una sola persona }\end{array}$ & \\
\hline $\begin{array}{l}\text { GESTIÓN DE LOS } \\
\text { CONFLICTOS }\end{array}$ & $\begin{array}{l}\text { Los conflictos surgidos } \\
\text { durante el proyecto se han } \\
\text { resuelto correctamente con } \\
\text { la participación de todos los } \\
\text { miembros. }\end{array}$ & $\begin{array}{l}\text { Algunos conflictos surgidos } \\
\text { durante el proyecto se han } \\
\text { resuelto correctamente } \\
\text { con la participación de } \\
\text { todos los miembros. }\end{array}$ & $\begin{array}{l}\text { Algunos conflictos surgidos } \\
\text { durante el proyecto se han } \\
\text { resuelto correctamente } \\
\text { pero sólo por la implicación } \\
\text { de algún individuo. }\end{array}$ & $\begin{array}{l}\text { No se han resuelto los } \\
\text { conflictos. }\end{array}$ & \\
\hline $\begin{array}{l}\text { DISTRIBUCIÓN DE } \\
\text { LAS TAREAS }\end{array}$ & $\begin{array}{l}\text { Cada estudiante tiene una } \\
\text { tarea definida y la } \\
\text { desempeña correctamente. }\end{array}$ & $\begin{array}{l}\text { Cada estudiante tiene una } \\
\text { tarea asignada, pero no } \\
\text { está claramente definida o } \\
\text { no es consistente. }\end{array}$ & \begin{tabular}{|l|} 
Hay tareas asignadas a los \\
estudiantes, pero los \\
estudiantes no las realizan.
\end{tabular} & No se asignan tareas. & \\
\hline $\begin{array}{l}\text { PLANIFICACIÓN DE } \\
\text { LAS TAREAS }\end{array}$ & $\begin{array}{l}\text { Las tareas se planifican } \\
\text { adecuadamente y se } \\
\text { realizan de acuerdo con el } \\
\text { cronograma. }\end{array}$ & $\begin{array}{l}\text { Las tareas se planifican } \\
\text { adecuadamente pero no } \\
\text { se realizan de acuerdo con } \\
\text { el cronograma. }\end{array}$ & $\begin{array}{l}\text { Las tareas no se planifican } \\
\text { adecuadamente. }\end{array}$ & $\begin{array}{l}\text { No hay cronograma ni } \\
\text { planificación }\end{array}$ & \\
\hline
\end{tabular}

Fig. 2 Rúbricas utilizadas durante la evaluación del proceso y del producto en la elaboración de microvideos en la asignatura Química General II, siendo el 4 una calificación excelente y el 1 insuficiente.

Finalmente, los alumnos han realizado un total de 8 microvideos; 2 del tema 1 (Energía de las reacciones químicas), 1 del tema 2 (La dirección del cambio químico), 1 del tema 3 (El equilibrio en las reacciones químicas), 1 del tema 4 (Cambios de estado de sustancias

2017, Universitat Politècnica de València

Congreso IN-RED (2017) 
puras), 1 del tema 5 (Disoluciones), 1 del tema 6 (Equilibrio ácido-base) y otro del tema 7 (Equilibrios de formación de complejos).

A modo de ejemplo, en la Tabla 1 se muestra el resumen de las puntuaciones obtenidas por los diferentes grupos en las rúbricas de objeto (microvideos). Las notas de los alumnos corresponden a la media de las valoraciones del resto de grupos obtenida por cada grupo en cada categoría.

Tabla 1. Resumen de las puntuaciones obtenidas en las rúbricas-objeto por los diferentes grupos de alumnos.

\begin{tabular}{|c|c|c|c|c|c|c|c|c|c|}
\hline Alumnos & Gr.1 & Gr.2 & Gr.3 & Gr.4 & Gr.5 & Gr.6 & Gr.7 & Gr.8 & \\
\hline Categoría & $\begin{array}{c}\text { Nota } \\
\text { media }\end{array}$ & $\begin{array}{l}\text { Nota } \\
\text { media }\end{array}$ & $\begin{array}{c}\text { Nota } \\
\text { media }\end{array}$ & $\begin{array}{c}\text { Nota } \\
\text { media }\end{array}$ & $\begin{array}{l}\text { Nota } \\
\text { media }\end{array}$ & $\begin{array}{c}\text { Nota } \\
\text { media }\end{array}$ & $\begin{array}{c}\text { Nota } \\
\text { media }\end{array}$ & $\begin{array}{c}\text { Nota } \\
\text { media }\end{array}$ & Media \\
\hline $\begin{array}{l}\text { Conceptos } \\
\text { teóricos }\end{array}$ & 3,7 & 2,9 & 3,7 & 4,0 & 4,0 & 3,3 & 3,4 & 3,7 & 3,6 \\
\hline $\begin{array}{l}\text { Edición del } \\
\text { video }\end{array}$ & 3,3 & 2,7 & 3,3 & 3,9 & 3,3 & 2,7 & 3,3 & 3,5 & 3,2 \\
\hline Guión & 3,0 & 2,9 & 3,0 & 3,6 & 3,7 & 2,7 & 3,1 & 3,7 & 3,2 \\
\hline Dirección & 3,4 & 3,1 & 3,4 & 3,7 & 3,6 & 2,7 & 3,3 & 3,8 & 3,4 \\
\hline $\begin{array}{l}\text { Duración del } \\
\text { video }\end{array}$ & 3,0 & 4,0 & 3,9 & 3,9 & 2,7 & 3,7 & 3,6 & 4,0 & 3,6 \\
\hline \multicolumn{10}{|l|}{ Profesor } \\
\hline Categoría & Nota & Nota & Nota & Nota & Nota & Nota & Nota & Nota & Media \\
\hline $\begin{array}{l}\text { Conceptos } \\
\text { teóricos }\end{array}$ & 3 & 3 & 4 & 4 & 4 & 4 & 3 & 4 & 3,6 \\
\hline $\begin{array}{l}\text { Edición del } \\
\text { video }\end{array}$ & 4 & 2 & 3 & 4 & 3 & 2 & 3 & 3 & 3,0 \\
\hline Guión & 4 & 3 & 3 & 3 & 4 & 2 & 2 & 3 & 3,0 \\
\hline Dirección & 4 & 3 & 4 & 4 & 3 & 3 & 3 & 4 & 3,5 \\
\hline $\begin{array}{l}\text { Duración del } \\
\text { video }\end{array}$ & 2 & 4 & 3 & 3 & 1 & 3 & 2 & 4 & 2,8 \\
\hline
\end{tabular}

Como puede observarse en la Tabla 1, la evaluación por parte de los alumnos ha sido bastante similar a la proporcionada por el profesor, lo que indica cierto grado de validez en la forma de evaluar y al mismo tiempo se les hace participes de esta etapa del proceso enseñanza/aprendizaje.

Indicar que la nota media obtenida por los alumnos para la rúbrica-objeto fue de 3.3 (8.2), mientras que para la rúbrica-proceso fue de 3.5 (8.8), siendo el valor global de 3.4 (8.5).

De forma adicional, se les pasó una encuesta a los estudiantes para evaluar el grado de satisfacción con la actividad realizada. Las preguntas de la encuesta junto con los porcentajes de respuestas se puede observar en la Tabla 2. 
Tabla 2. Porcentaje de respuestas obtenidas en la encuesta realizada sobre la actidad (número de encuestas 33).

\begin{tabular}{|c|c|c|c|c|}
\hline & Nunca & $1 \mathrm{vez}$ & $1-10$ veces & mas de 10 \\
\hline $\begin{array}{c}\text { ¿Has realizado algún tipo de } \\
\text { trabajo audiovisual } \\
\text { previamente? }\end{array}$ & 42 & 15 & 42 & 0 \\
\hline & $<2 \mathrm{~h}$ & $2-5 h$ & $5-10 h$ & $>10 \mathrm{~h}$ \\
\hline $\begin{array}{l}\text { ¿Cuánto tiempo has dedicado } \\
\text { a la realización de vídeo? }\end{array}$ & 3 & 42 & 33 & 21 \\
\hline & $\mathbf{S i}$ & No & NS/NC & \\
\hline $\begin{array}{l}\text { ¿Has participado en todas las } \\
\text { tareas necesarias para realizar } \\
\text { el vídeo? }\end{array}$ & 67 & 24 & 9 & \\
\hline & Casa & Aula & Biblioteca & Otros \\
\hline $\begin{array}{c}\text { ¿Dónde se han realizado } \\
\text { mayoritariamente las sesiones } \\
\text { de preparación de los } \\
\text { microvídeos? }\end{array}$ & 56 & 0 & 44 & 0 \\
\hline & Libro & Internet & $\begin{array}{c}\text { Apuntes de } \\
\text { clase }\end{array}$ & Otros \\
\hline $\begin{array}{l}\text { ¿Qué tipo de material } \\
\text { bibliográfico se ha empleado } \\
\text { en la preparación del } \\
\text { contenido del vídeo? }\end{array}$ & 8 & 34 & 58 & 0 \\
\hline & Telefono movil & Tableta/iPad & Ordenador & Otros \\
\hline $\begin{array}{c}\text { ¿Desde qué dispositivo se ha } \\
\text { editado el vídeo? }\end{array}$ & 14 & 9 & 77 & 0 \\
\hline & $\begin{array}{c}\text { Totalmente de } \\
\text { acuerdo }\end{array}$ & De acuerdo & $\begin{array}{c}\text { En } \\
\text { desacuerdo }\end{array}$ & $\begin{array}{c}\text { Muy en } \\
\text { desacuerdo }\end{array}$ \\
\hline $\begin{array}{l}\text { ¿Crees que el microvídeo te } \\
\text { ha ayudado a comprender } \\
\text { mejor está tema de la } \\
\text { asignatura? }\end{array}$ & 36 & 55 & 9 & 0 \\
\hline $\begin{array}{l}\text { ¿Crees que el microvídeo ha } \\
\text { ayudado a comprender mejor } \\
\text { o recordar este tema de la } \\
\text { asignatura a tus compañeros? }\end{array}$ & 21 & 70 & 9 & 0 \\
\hline $\begin{array}{l}\text { ¿Crees que el microvídeo de } \\
\text { otros compañeros te ha } \\
\text { ayudado a comprender el resto } \\
\text { de Temas de la asignatura? }\end{array}$ & 27 & 61 & 12 & 0 \\
\hline $\begin{array}{c}\text { ¿Crees que la visualización de } \\
\text { los vídeos realizados te ha } \\
\text { ayudado a mejorar los } \\
\text { conocimientos de la } \\
\text { asignatura? }\end{array}$ & 6 & 82 & 12 & 0 \\
\hline $\begin{array}{l}\text { ¿Cuál ha sido tu grado de } \\
\text { satisfacción con las actividades } \\
\text { de microvídeos propuesta? }\end{array}$ & 15 & 55 & 30 & 0 \\
\hline
\end{tabular}

Como puede observarse en los resultados de la encuesta realizada, la mayoría de los estudiantes, entre el 88 y el $91 \%$ (totalmente de acuerdo y de acuerdo), considera que la actividad les ha sido útil a ellos mismos y al resto de sus compañeros para comprender 
mejor los conocimientos de la asignatura. Sin embargo, este porcentaje disminuye al $70 \%$ cuando se les pregunta por el grado de satisfacción con la actividad propuesta, probablemente debido al tiempo que implica el desarrollo de la actividad.

\section{Conclusiones}

Como conclusión, la experiencia ha resultado muy positiva, tanto para los alumnos como para el profesorado.

Al haber una participación íntegra de todos los representates del grupo (el $67 \%$ de los estudiantes afirman que han participado en todas las actividades), se fomenta el trabajo en equipo y el interés por la experiencia de todos los miembros del grupo. Con la actividad propuesta, se fomenta el interés por la asignatura, se repasan los apuntes, y se refuerzan de un forma simple los conceptos mas relevantes del tema.

Los resultados obtenidos son preliminares, por lo que se han obtenido datos de efectividad meramente cualitativos. Para extraer conclusiones mas realistas, se desarrollará esta actividad en cursos futuros así como se usarán grupos control en los que no se aplique esta herramienta. De esta forma se podrá evaluar cuantitativamente su impacto a largo plazo en el proceso de enseñanza/aprendizaje de los alumnos.

\section{Referencias}

Allam, C., (2006) "Using filmmaking to teach students about Shakespeare, urban regeneration and other stuff”, DIVERSE Conference, Glasgow.

EDTECH MAGAZINE, Akanegbu, A. Vision of Learning: A History of Classroom Projectors, $<$ http://www.edtechmagazine.com/k12/article/2013/02/vision-learning-history-classroom-projectors $>$ [Consulta: 28 de marzo de 2017]

GARDNER, H. (1983) Frames of mind: the Idea of multiple intelligence, New York, Basic Books. 


\title{
Las nuevas narrativas en el proceso de enseñanza- aprendizaje en las facultades públicas de Periodismo
}

\section{Berta García Orosa ${ }^{a}$ y Lara Lozano Aguiar ${ }^{b}$}

aProfesora Titular en la Facultad de Ciencias de la Comunicación y miembro del grupo de investigación Novos Medios de la USC (berta.garcia@usc.es), bDoctoranda y colaboradora del grupo de investigación Novos Medios de la USC (laralozanoaguiar@gmail.com).

\begin{abstract}
The emergence of new social media platforms has produced a significant change, not only in academic content in university course of studies, but also in the presentation of these to students. The teaching-learning processes are currently marked by the demands of the new narratives. But... What extent have the contents of the curriculum of the degrees in Journalism taught in the public universities in Spain? In order to answer this question, we have analyzed the way in which the Spanish public schools present the offers of Degree in Journalism through the websides. Furthermore, we have deepened in the characteristics of the curriculum of those subjects whose content be about the demands of digital narratives such as multimedia, transmedia and hypertext.
\end{abstract}

Keywords: new narratives, transmedia, management communication, journalism and university teaching processes

\begin{abstract}
Resumen
La irrupción de las nuevas plataformas de social media han producido un cambio significativo, no solo en los contenidos académicos en los planes de estudios universitarios, sino también a la hora de presentar éstos a los alumnos. Los procesos de enseñanza-aprendizaje se ven marcados actualmente por las exigencias de las nuevas narrativas, pero ihasta que punto se han actualizado y adecuado a la era 2.0 los contenidos de los planes de estudios de los grados en Periodismo impartidos en las universidades públicas en España?

Con el fin de dar respuesta a esta cuestión, hemos analizado la forma en la que las facultades públicas españolas presentan las ofertas de Grado en Periodismo a través de los portales web y hemos profundizado en las caracteristicas de los planes de estudios de aquellas materias cuyo contenido responde a las exigencias de narrativas digitales como multimedia, transmedia e hipertexto.
\end{abstract}

Palabras clave: nuevas narrativas, transmedia, gestión de comunicación, periodismo y procesos de enseñanza universitaria 


\section{Introducción y marco teórico}

Una de las principales innovaciones en el periodismo digital en los últimos años son las nuevas narrativas, la búsqueda de nuevas formas de aproximación al lector especialmente la transmedia (Irala, 2014; Alzamora, Tárcia, 2012; Larrondo, 2016). Al mismo tiempo, estas denominadas nuevas narrativas se fueron haciendo un hueco también como estrategia para la enseñanza y el aprendizaje (McEwan; Egan, 1998). Es precisamente en este doble sentido en el que se realiza el análisis propuesto por esta comunicación: por una parte, como elemento a tener en cuenta dentro de la evolución del Periodismo y, por tanto, importante en los estudios sobre el mismo, y, en otro sentido, como herramienta de enseñanza-aprendizaje. Antes de la metodología y el análisis de los resultados se ofrece una aproximación a las nuevas narrativas en periodismo.

Los Laboratorios de Innovación constituyen el elemento visible de una apuesta importante por la experimentación en los medios de comunicación digitales (Salaverría, 2015; Peñafiel, 2016; Bender, 2004; Serrano-Cobos, 2016) fundamentalmente en la búsqueda de nuevas formas de contar historias basadas en hechos reales que atrapen al lector. Los documentos textuales eran inicialmente volcados en la red y en esa búsqueda de nuevas narrativas fueron creados los hipertextos, los documentos multimedia e interactivos adaptándose paulatinamente a las características de la red (Bolter, 1991; Díaz-Noci, 2001).

Siguiendo a Gifreu (2013) y sus estudios sobre el documental, como forma de la no ficción interactiva, podemos definir cuatro grandes fases en la evolución de las narrativas multimedia e interactivas y su convergencia con el periodismo:

1. Aparición (1980-1990). Se corresponde con la emergencia del medio interactivo y los primeros desarrollos experimentales sobre soportes físicos de memoria óptica. Si bien, las narrativas no lineales y transmedia fueron puestas en práctica con anterioridad en los medios analógicos.

2. Experimentación (1990-2000). La popularización del ordenador personal impulsa los productos culturales en soporte CD-ROM y DVD-ROM, mientras que se inicia la presencia de los medios en Internet.

3. Consolidación (2000-2010). La evolución de la red y su expansión permite un desarrollo progresivo de las producciones en línea, sustituyendo los soportes físicos y confluyendo con los medios sociales y los dispositivos móviles.

4. Diversificación (2010-actualidad). El crecimiento de la producción del documental interactivo y el reportaje multimedia definen el escenario actual, donde los medios apuestan por la innovación narrativa e implementan nuevas propuestas, como la realidad virtual, el periodismo de datos y las estrategias transmedia.

El concepto de narrativa carece por el momento de una definición unívoca en las Ciencias Sociales. Desde que Todorov en 1969 acuñó el término narratología para designar la nueva teoría de la narración literaria, la definición de narración evolucionó a través de las que enfocan el concepto en la configuración del mensaje (Smith, 1981), con definiciones que incluyen las nociones de tiempo y propósito (Phela 2005) o las que incluyen al receptor y el consumo de mensajes como parte de la narrativa (Ochs and Capps, 2001; Seale, 2000). A partir de los diferentes modelos de análisis de narrativas de diferentes ámbitos (también el periodístico) se elaboraron modelos de estudio (destacamos los de Propp, 1968; Labov,Waletsky, 1977, Genette, 1972, Ricoeur, 1984) hasta hoy en los que la narrativa se concibe a través de un status que supera al texto para comprenderlo como un fenómeno desarrollado en un determinado contexto comunicativo que en relación directa con él establece un nuevo significado y campo de análisis (Hyvärinen, 2007). En esta comunicación asumimos este enfoque que entiende la narración como una representación

(cc) EY-NC-ND 2017, Universitat Politècnica de València

Congreso IN-RED (2017) 
de la experiencia construida a través del discurso en el que se otorga sentido, se posibilita su comunicación y se orienta la acción.

Pese a las diferentes conceptualizaciones de estas nuevas fórmulas (crossmedia, multiplataforma, multimodalidad, hiperserialidad, hiperdiégesis, media híbridos, transficción, narrativas transmediales, plataformas múltiples y mercancía intertextual, inmersivo), los estudios recientes sobre narrativas se han fijado sobre todo en la dimensión transmedia.

El término transmedia nace específicamente en un texto titulado Transmedia Storytelling de Jenkins (2003) si bien se indica en varias ocasiones raíces anteriores (Freeman, 2014 o Montoya; Vásquez; Salinas, 2013) e incluso algunos autores observan el uso de diferentes canales para comunicar desde el inicio de los tiempos (Moloney, 2011). Las dificultades conceptuales de la narrativa transmedia en la actualidad (Mora, 2014; Rodríguez Ferrándiz, Peñamarín, 2014) constituyen un verdadero desafío para la narratología y la semiótica textual narrativa ya que como apunta Scolari se trata de:

Campos de estudio fuertemente monomedia - existe una semiótica del teatro, de la radio, del cine, etcétera, pero todavía no tenemos una semiótica del transmedia - y poco acostumbrados al análisis de narrativas multimodales de alta complejidad, caracterizadas por textualidades hiperfragmentadas, y decenas de personajes y programas narrativos (Guerrero, Scolari, 2016).

En este trabajo asumiremos la definición de una estructura narrativa diferenciada que se expande a través de varios medios que cuentan algo diferente, con la participación del usuario y la capacidad del mundo narrativo de ser abordado a través de cualquiera de las unidades textuales que la componen (Jenkins, 2003, 2006; Scolari, 2009). Frente a los conceptos multiplataforma y crossmedia, basados en los soportes y la combinación entre ellos y los usuarios, no son una adaptación de un lenguaje o un mensaje a diferentes soportes (Rodríguez-Ferrándiz; Ortiz; Sáez, 2014) sino creaciones concebidas inicialmente como transmediáticas.

\section{Objetivos y metodología}

Con este estudio queremos mostrar como las universidades públicas españolas presentan la información sobre los grados en periodismo ofertados a través de sus páginas webs y determinar si aprovechan las nuevas narrativas para hacerlo - estudiaremos la estructura y acceso al contenido - . Por otro lado, atendemos a las características de los grados y a las particularidades de su contenido. La recopilación de datos se realizó entre los días 2 y 10 de marzo de 2017 en las páginas web oficiales y en los planes de estudio (atendiendo tanto a la parte teórica como a seminarios y prácticas) correspondientes al curso académico $2016 / 2017$.

El estudio de las web de las facultades parte de la estructura de la página, la distribución del contenido en la misma así como sus características. Para ello determinamos una batería de categorías de análisis distribuidas en de tres partes: contenido multimedia e hipertexto, contenido específico e interactividad y participación.

El primer apartado atiende al uso de imágenes, contenido audiovisual o enlaces que ofrece la página web en su portada. Por otro lado, en el contenido específico detallaremos si el portal incluye información como el plan de estudios, profesorado, salidas profesionales, apartado de noticias (de la propia facultad en la que se imparte el Grado en Periodismo), servicios tales como agenda, contacto...

En el tercer epígrafe estudiamos la posibilidad que tienen los estudiantes interesados para ponerse en contacto con el centro universitario e interactuar; bien en la propia web, a través de un formulario o a través de redes sociales referenciadas en el portal. 
A continuación completamos el estudio de los portales web con un análisis más específico del grado en Periodismo. Partimos de la distribución de créditos en cuanto a cinco ejes básicos: materias de formación básica, materias obligatorias, asignaturas optativas, prácticas externas en empresas y Trabajo Final de Grado. A esto sumamos una categorización de asignatura segundo el medio de comunicación o área base (prensa, radio, televisión, medios digitales, comunicación corporativa...), sobre conocimientos básicos de diferentes ámbitos con influencia en el periodismo (derecho, política, historia, economía) y sobre conocimientos específicos (redacción, locución, géneros, técnicas narrativas...).

A partir de esta categorización, hacemos una selección de aquellas materias relacionadas con el ámbito digital y con las nuevas narrativas emergidas tras la evolución del periodismo hacia el 2.0. Así, a través de los programas docentes — correspondientes a esta última selección- queremos conocer los contenidos y técnicas que ofrecen a quienes cursan dicha materia. Nos centraremos en la especialización que ofrecen así como las características de sus prácticas y seminarios: si atiende al uso de nuevas técnicas de narración como el transmedia, si echa mano de nuevas plataformas social media u otros canales, si su bibliografía va acorde con la rápida evolución de la materia en el ámbito, si se apoya en trabajos dinámicos y de creación o si los trabajos académicos simplemente son teóricos.

Observamos pues interesante abordar esta dimensión que atiende al contenido tanto de páginas web de facultades como de materias e incluirla como una nueva idea, no solo de base para el cambio sino también de innovación, en los procesos de enseñanza-aprendizaje de estudios universitarios.

\section{Presentación de resultados}

\section{1. ¿Cómo presentan la información los portales web de los grados en Periodismo? Información de servicio, sin llamar la atención del público}

La primera toma de contacto de un alumno con un grado universitario probablemente sea a través de la página web oficial de la institución que la oferta. Es necesario por tanto que este portal sea un reflejo de lo que realmente significa el plan de estudios. La primera impresión de la web es esencial así como su funcionalidad. Por este motivo hemos analizado como se presentan los grados de Periodismo en las universidades públicas en España. En una primera aproximación se ha analizado la estructura de éstas y se observó que la mayoría no cuenta con una URL única, por lo que son extensiones de la página oficial de la universidad que alberga el grado. De las analizadas, solo la facultad de Periodismo de la Universidad Miguel Hernández ofrece una web propia con contenidos creados por alumnos entre los que destaca la revista 'Reporteros'. Las demás no hacen referencia a contenidos propios en portada, excepto en contadas ocasiones a través de vídeos que funcionan a modo de incentivo y captación de alumnos como es el caso de la oferta de grado de la Universidad de Navarra. En este sentido, se observa como no hacen uso de las nuevas narrativas y potencialidades de lo digital para 'vender' sus contenidos. Tampoco aprovechan el producto generado por el alumnado como muestra de los resultados en seminarios, por poner un ejemplo.

Si nos paramos en la estructura propiamente dicha, el $60 \%$ de las webs analizadas presenta una distribución a tres columnas. Con respecto al número de 'apartados' en el menú, dos ofrecen una amplia selección con más de 30 'sub-menús', ocho de los portales presentan más de 20, nueve registran más de 10 y solo dos de las web tienen menos de 10 opciones.

Por otro lado se ha observado si la página ofrece la opción de login a la intranet o a la aula virtual desde la portada. Tras el estudio se constata que ocho de las 21 webs objeto de estudio no presentan esta opción desde la pantalla de inicio por lo que dificulta el acceso 'directo' a la plataforma virtual. Sí viene referenciado, sin embargo, la opción de 'Ayuda o contacto' con el centro en caso de solicitar información o solucionar dudas. 
Atendiendo a las características del contenido que ofrece la página observamos que el número de gráficos y audio es nulo, el vídeo solo aparece en cuatro portales web y las imágenes - aunque se usan hasta en 13 ocasiones - solo apoyan el diseño de la web y no buscan llamar al estudiante. Con todo, el uso de enlaces - y por extensión del hipertextoes generalizado, especialmente si atendemos a contenido específico del grado: horarios del curso, tutorías, planes de estudio, docencia...

Otro de los apartados de la ficha de análisis de las portadas de los portales hace hincapié en el contenido específico sobre cursos y profesorado. Constatamos que todas las webs analizadas ofrecen información de las materias. No ocurre lo mismo con la información relativa a los horarios; esta no aparece como apartado único en un $25 \%$ de los casos. La misma tendencia se da en cuanto a la información del profesorado al no aparecer en seis de los portales analizados. Así pues, también se observa que el $40 \%$ de las páginas web no informan sobre las salidas profesionales del grado, pero además, las que si lo hacen no incorporan en sus discursos los nuevos perfiles para los que los periodistas deben estar capacitados en la era 2.0 .

A lo anterior hay que añadir la carencia de actualización e información del día a día que denotan los portales. Solo tres presentan apartado específico de 'Agenda' y la web de la Complutense es la única que añade una sección específica de 'Noticias' relativas a la universidad y al grado en Periodismo en concreto.

En este primer apartado de análisis hay una referencia especial a la participación e interactividad que presentan las portadas de las webs. En un primer lugar se observa que el acceso directo, además de gestión, en redes sociales es del $60 \%$, pero hay que apuntar que solo 4 de estas son específicas para el grado en Periodismo, o para la facultad de Comunicación; el resto responden a la institución universitaria. No sacan partido a los contenidos creados en la propia carrera universitaria y tampoco aprovechan la difusión que las plataformas digitales ofrecen como canales de distribución de contenidos. Dentro de las que si gestionan este recurso/herramienta para llegar a sus estudiantes y a sus potenciales alumnos hacen un uso mayor de Facebook y Youtube, seguido de la red de microblogging Twitter.

En cuanto a la posibilidad de interactuar dentro del propio portal, esta conexión únicamente se materializa a través de formularios. Así, casi el 50\% de las webs analizadas hacen uso de él. Sin embargo, la posibilidad de comentar no es posible, excepto en aquellas webs — seis en total- que disponen de un 'Buzón de sugerencias o quejas', eso sí, no es público y funciona como el formulario. Cabe destacar el servicio ‘¿Te llamamos?', ofertado por la Universidad de Salamanca en el apartado dedicado al grado en Periodismo.

\subsection{Comparativa de los planes de estudios: estructura y distribución de materias}

Con la implementación del grado en lugar de la licenciatura en Periodismo, los planes de estudio responden a períodos formativos compuestos por un total de 240 créditos denominados ETC en cuatro cursos. La categorización de estos responde a tres parámetros básicos: materias obligatorias, de formación básica y optativas. A continuación presentamos esta distribución en los grados analizados así como los itinerarios/especialización que ofertan $-\mathrm{y}$ que aparecen referenciados de forma explícita en los planes de estudio en versión digital-: 
Tabla 1. Distribución de créditos e itinerarios ofertados en grado

\begin{tabular}{|c|c|c|c|c|}
\hline UNIVERSIDAD & $\begin{array}{c}\text { ETC } \\
\text { Obligatoria } \\
\end{array}$ & $\begin{array}{c}\text { ETC } \\
\text { Optativa } \\
\end{array}$ & $\begin{array}{c}\text { ETC } \\
\text { Básica }\end{array}$ & ITINERARIOS \\
\hline $\begin{array}{l}\text { UPF Pompeu } \\
\text { Fabra }\end{array}$ & 104 & 52 & 62 & $\begin{array}{c}4 \text { (Economía, Humanidades, Política, } \\
\text { Derecho) }\end{array}$ \\
\hline UV Valencia & 139,5 & 22,5 & 60 & NO \\
\hline $\begin{array}{l}\text { UNIZAR } \\
\text { Zaragoza }\end{array}$ & 150 & 24 & 60 & NO \\
\hline Carlos III Madrid & 120 & 144 & 60 & $\mathrm{NO}$ \\
\hline $\begin{array}{l}\text { USC Santiago de } \\
\text { Compostela }\end{array}$ & 132 & 60 & 66 & NO \\
\hline $\begin{array}{c}\text { ULL La Laguna } \\
\text { Tenerife }\end{array}$ & 126 & 24 & 60 & NO \\
\hline $\begin{array}{l}\text { UAB Autónoma } \\
\text { de Barcelona }\end{array}$ & 102 & 60 & 60 & $\begin{array}{c}4 \text { (Ciberperiodismo, Análisis/Planificación, } \\
\text { Política/econ, Cultura/sociedad) }\end{array}$ \\
\hline Jaume I Castellón & 138 & 45 & 66 & NO \\
\hline UM Murcia & 144 & 18 & 60 & $\mathrm{NO}$ \\
\hline $\begin{array}{l}\text { Rey Juan Carlos } \\
\text { Madrid }\end{array}$ & 144 & 18 & 60 & NO \\
\hline UMA Málaga & 120 & 54 & 60 & NO \\
\hline US Sevilla & 120 & 54 & 60 & $\mathrm{NO}$ \\
\hline $\begin{array}{l}\text { UMH Miguel } \\
\text { Hernández Elche }\end{array}$ & 150 & 24 & 60 & NO \\
\hline $\begin{array}{c}\text { UCM } \\
\text { Complutense } \\
\text { Madrid }\end{array}$ & 108 & 66 & 60 & NO \\
\hline EHU País Vasco & 120 & 48 & 60 & $\begin{array}{c}1 \text { (Mención en Dirección de } \\
\text { Comunicación) }\end{array}$ \\
\hline $\begin{array}{l}\text { UCLM Castilla } \\
\text { La Mancha }\end{array}$ & 120 & 54 & 60 & $\begin{array}{c}2 \text { (Periodismo Digital y Periodismo } \\
\text { Especializado) }\end{array}$ \\
\hline UVA Valladolid & 126 & 30 & 60 & NO \\
\hline UNAV Navarra & 141 & 30 & 60 & $\begin{array}{l}2 \text { (Comunicación Institucional y } \\
\text { Comunicación en Moda) }\end{array}$ \\
\hline UPSA Salamanca & 168 & 6 & 60 & NO \\
\hline $\begin{array}{l}\text { URV Rovira i } \\
\text { Virgili }\end{array}$ & 120 & 36 & 60 & NO \\
\hline Illas Baleares & 126 & 24 & 60 & NO \\
\hline
\end{tabular}

Con respecto a los ETC de TFG y Prácticas Externas, el número varía y se encuentra en el primer caso entre los 6 y los 12 créditos y en el trabajo final entre los 6, 12, 18 o incluso 24 en el grado en la Rey Juan Carlos.

Profundizando en las características de las materias ofertadas, se procede a una clasificación en cuanto a especialidad por canal: radio, televisión (audiovisual), prensa y ciberperiodismo o periodismo digital. A estas tres, se ha añadido la comunicación corporativa por ser ésta y los gabinetes, en general, una área importante de la comunicación y especialmente un campo que recibe un gran número de titulados en Periodismo especialmente en la era 2.0 con la necesidad de gestionar cuentas oficiales en plataformas digitales como las redes sociales, por ejemplo-. 
Tabla 2. Distribución de asignaturas por especialidad en cuanto a canal y formación

\begin{tabular}{|c|c|c|c|c|c|c|c|}
\hline UNIVERSIDAD & DIG. & RADIO & TV & PR. & $\begin{array}{l}\text { COM. } \\
\text { CORPOR. }\end{array}$ & $\begin{array}{c}\text { ESP. } \\
\text { DESTREZA }\end{array}$ & F. CONOC. \\
\hline UPF Pompeu Fabra & 1 & $\mathrm{X}$ & 1 & $\mathrm{X}$ & $\mathrm{X}$ & 29 & 84 \\
\hline UV Valencia & 1 & 1 & 1 & $\mathrm{X}$ & 1 & 17 & 20 \\
\hline UNIZAR Zaragoza & 3 & 4 & 6 & 1 & 2 & 26 & 15 \\
\hline Carlos III Madrid & 3 & 1 & 3 & $\mathrm{X}$ & 1 & 25 & 20 \\
\hline $\begin{array}{l}\text { USC Santiago de } \\
\text { Compostela }\end{array}$ & 4 & 1 & 4 & 2 & 2 & 14 & 16 \\
\hline $\begin{array}{l}\text { ULL La Laguna } \\
\text { Tenerife }\end{array}$ & 1 & 1 & 4 & 1 & 1 & 11 & 21 \\
\hline $\begin{array}{l}\text { UAB Autónoma de } \\
\text { Barcelona }\end{array}$ & 4 & 1 & 4 & 2 & 2 & 28 & 23 \\
\hline Jaume I Castellón & 1 & 3 & 5 & $\mathrm{X}$ & $\mathrm{X}$ & 20 & 16 \\
\hline UM Murcia & 1 & 1 & 1 & $\mathrm{X}$ & $\mathrm{X}$ & 19 & 16 \\
\hline $\begin{array}{l}\text { Rey Juan Carlos } \\
\text { Madrid }\end{array}$ & 2 & 2 & 4 & 1 & $X$ & 11 & 15 \\
\hline UMA Málaga & 2 & 2 & 5 & 2 & 1 & 19 & 21 \\
\hline US Sevilla & $\mathrm{X}$ & $\mathrm{X}$ & 4 & 1 & 1 & 26 & 37 \\
\hline $\begin{array}{c}\text { UMH Miguel } \\
\text { Hernández Elche }\end{array}$ & 1 & 1 & 4 & $\mathrm{X}$ & 1 & 19 & 16 \\
\hline $\begin{array}{c}\text { UCM Complutense } \\
\text { Madrid }\end{array}$ & 1 & 1 & 2 & 2 & 1 & 15 & 37 \\
\hline EHU País Vasco & 2 & 1 & $\mathrm{X}$ & 1 & 3 & 11 & 8 \\
\hline $\begin{array}{c}\text { UCLM Castilla La } \\
\text { Mancha }\end{array}$ & 4 & 2 & 2 & $X$ & 1 & 20 & 13 \\
\hline UVA Valladolid & 2 & 1 & 3 & $\mathrm{X}$ & 1 & 18 & 16 \\
\hline UNAV Navarra & 2 & 3 & 3 & 1 & $\mathrm{X}$ & 9 & 26 \\
\hline UPSA Salamanca & 1 & 2 & 3 & 1 & 1 & 12 & 27 \\
\hline $\begin{array}{l}\text { URV Rovira i } \\
\text { Virgili }\end{array}$ & 2 & $X$ & 1 & $X$ & 1 & 6 & 16 \\
\hline Illas Baleares & 2 & 2 & 3 & 1 & 2 & 7 & 11 \\
\hline
\end{tabular}

Con el estudio, en el que se han tenido en cuenta tanto las asignaturas optativas como las que conforman bloques concretos de especialización, se ha detectado un mayor número de materias centradas en lo audiovisual. En segundo lugar están las relativas al mundo digital pero con un carácter práctico de edición como veremos más adelante al hablar del contenido y del tratamiento de nuevas narrativas. En cuanto a la radio y prensa, éstas se sitúan en tercer y cuarto lugar. Incluso las materias relacionadas con la comunicación en gabinetes/organizacional acumulan un mayor número de horas - aunque hablemos en este caso de materias optativas, por lo general - que las que atienden a contenidos para medios impresos. 
Además de esta clasificación, el estudio incorpora otra diferenciación para materias cuya base es la formación de capacidades para el desarrollo del rol de periodista - especializadas en destrezas propias de la profesión-y por otro lado para aquellas que, aunque forman al periodista en temas que lo involucran y de los que debe estar al tanto, son más de formación básica: economía, historia (del periodismo, de España, de los cibermedios...).

Atendiendo por tanto a esta clasificación se ha detectado un gran número de materias sobre otros campos del conocimiento que aportan el bagaje necesario del periodista. Esta tendencia se da incluso en las materias optativas. De las universidades analizadas, la Pompeu Fabra es la que se posiciona en primer lugar con un total de 84 materias, seguida de los grados en la Complutense y en la Universidad de Sevilla con 37 asignaturas cada una. Con todo, la media está en 23 materias con este carácter.

\subsection{El tratamiento y estudio de nuevas narrativas en las materias especializadas en el ámbito digital}

La base de esta investigación es el análisis de los planes de estudio de las materias enmarcadas en el ámbito digital. Así pues, se han seleccionado aquellas que, de alguna forma, versan sobre el tratamiento informativo o forman al alumnado en destrezas para el ciberperiodismo. Con el fin de determinar las características de los contenidos que presentan, se elabora una ficha basada en un método cualitativo y que atiende a dos vertientes: por un lado la teórica y por otro la práctica (seminarios y clases interactivas de laboratorio). Dentro de estos dos ejes, se han estudiado diferentes categorías que se presentan a continuación con los resultados obtenidos.

\subsubsection{De la especialización en soportes a las exigencias de los nuevos lenguajes narrativos}

Lo de hacer periodismo online requiere el conocimiento previo de las exigencias del canal y por tanto también de la forma en la que vamos a expresar la idea que se quiere transmitir. Es por ello que la irrupción del mundo digital obliga a establecer cambios que derivan en nuevas narrativas, que deben ser una base fundamental en los procesos enseñanzaaprendizaje.

En los 21 grados analizados, seleccionamos 44 materias como aquellas que versan sobre aspectos del periodismo digital. Es decir, hablamos de dos materias aproximadamente por grado - entre las que la mayoría son de carácter optativo-, un número muy bajo teniendo en cuenta las exigencias de la actualidad.

En este estudio se ha observado que 38 de las 44 materias analizadas enfocan sus contenidos a la creación, edición y producción de noticias para portales web. De éstas, un $45 \%$ también dedica algún tema a la gestión de redes sociales así como a su presentación como nuevos canales en los que distribuir contenido. Cabe señalar que además de estos contenidos, el funcionamiento de las bases de datos y su utilidad forman parte de los temas del plan de estudios de tres asignaturas analizadas: 'Nuevos Soportes y Arquitectura de la Información' (USC), 'Construcción de Servicios de Información Digital' (UM) y 'Ciberperiodismo' (UNAV).

Además de lo anterior, hay que destacar la forma en que tratan la información para los canales señalados. Emergen aquí los conceptos hipertexto, hipermedia, multimedia o interactivo para referirse a las narrativas que acaparan las materias más recientes en los estudios universitarios de Periodismo. Pero, ¿abarcan estos términos las múltiples posibilidades narrativas que han surgido y que propician las plataformas 2.0 en el discurso periodístico? Tras el estudio podemos afirmar que los programas de las materias distan mucho de lo que se está haciendo en realidad. De hecho, la investigación reserva un apartado especial al estudio de las narrativas transmedia, y solo se detectó su presencia en 12 de las 38 materias seleccionadas. Es más, esta presencia se reduce a una referencia

(cc) EY-NC-ND 2017, Universitat Politècnica de València

Congreso IN-RED (2017) 
bibliográfica en 5 materias siendo el resto parte del temario y, en el mejor de los casos, entendido como estrategia editorial ('Nuevos Formatos y Productos para la Red', USC) o como fenómeno fan, especialmente en contenidos de ficción ('Comunicación y Participación Ciudadana en la Red', Carlos III Madrid).

Tabla 3. Distribución de materias según narrativas e información sobre bibliografía

\begin{tabular}{|c|c|c|c|c|}
\hline UNIVERSIDAD & ASIGNATURA & $\begin{array}{c}\text { TIPO DE } \\
\text { NARRATIVA }\end{array}$ & $\begin{array}{c}\text { ESP. } \\
\text { TRANSMEDIA }\end{array}$ & BIBLIOGRAFÍA \\
\hline $\begin{array}{l}\text { UPF Pompeu } \\
\text { Fabra }\end{array}$ & $\begin{array}{c}\text { Análisis del Periodismo } \\
\text { Digital }\end{array}$ & NO & NO & $2009 \_2014$ \\
\hline UV Valencia & Periodismo Digital & $\mathrm{NO}$ & NO & $2001 \_2016$ \\
\hline \multirow[t]{3}{*}{$\begin{array}{l}\text { UNIZAR } \\
\text { Zaragoza }\end{array}$} & $\begin{array}{c}\text { Comunicación e } \\
\text { Información Digital }\end{array}$ & $\begin{array}{l}\text { Hipertexto, } \\
\text { multimedia }\end{array}$ & $\mathrm{NO}$ & 2004_2012 \\
\hline & $\begin{array}{c}\text { Proyecto de } \\
\text { Comunicación Digital }\end{array}$ & $\begin{array}{l}\text { Hipertexto, } \\
\text { multimedia }\end{array}$ & NO & $2005 \_2012$ \\
\hline & $\begin{array}{c}\text { Narrativa Audiovisual: } \\
\text { Reportaje y } \\
\text { Documental }\end{array}$ & NO & NO & 1999_2011 \\
\hline \multirow[t]{4}{*}{ Carlos III Madrid } & Periodismo en Red & $\begin{array}{l}\text { Hipertexto, } \\
\text { multimedia }\end{array}$ & NO & 1995_2014 \\
\hline & $\begin{array}{l}\text { Comunicación y } \\
\text { Participación } \\
\text { Ciudadana en Red }\end{array}$ & No especifica & $\begin{array}{l}\text { Transmedia } \\
\text { como fenómeno } \\
\text { fan }\end{array}$ & 1997_2014 \\
\hline & $\begin{array}{c}\text { Comunicación } \\
\text { Multimedia: el relato } \\
\text { periodístico }\end{array}$ & $\begin{array}{l}\text { Hipertexto, } \\
\text { multimedia } \\
\text { (Apartado } \\
\text { específico narr. } \\
\text { interactivas) }\end{array}$ & NO & 2012 \\
\hline & $\begin{array}{l}\text { Recursos Narrativos } \\
\text { para el Relato } \\
\text { Periodístico }\end{array}$ & $\begin{array}{l}\text { La micronoticia. } \\
\text { Twitter }\end{array}$ & NO & No especifica \\
\hline \multirow[t]{4}{*}{$\begin{array}{l}\text { USC Santiago de } \\
\text { Compostela }\end{array}$} & Multimedia & $\begin{array}{l}\text { Hipertexto, } \\
\text { multimedia }\end{array}$ & $\begin{array}{c}\text { Solo en } \\
\text { bibliografía }\end{array}$ & 2001_2015 \\
\hline & $\begin{array}{l}\text { Teoría y Análisis de } \\
\text { Cibermedios }\end{array}$ & Hipert, multime & NO & 2001_2016 \\
\hline & $\begin{array}{l}\text { Nuevos Soportes y } \\
\text { Arquitectura de la } \\
\text { Información }\end{array}$ & Varias & $\begin{array}{c}\text { Tema } \\
\text { específico }\end{array}$ & $1999 \_2016$ \\
\hline & $\begin{array}{l}\text { Nuevos Formatos y } \\
\text { Productos para la Red }\end{array}$ & $\begin{array}{l}\text { Hipertexto, } \\
\text { multimedia }\end{array}$ & $\begin{array}{l}\text { Transmedia } \\
\text { como estrategia } \\
\text { editorial }\end{array}$ & $2000 \_2010$ \\
\hline $\begin{array}{l}\text { ULL La Laguna } \\
\text { Tenerife }\end{array}$ & Ciberperiodismo & $\begin{array}{l}\text { Hipertexto, } \\
\text { multimedia }\end{array}$ & NO & 2001_2016 \\
\hline \multirow[t]{2}{*}{$\begin{array}{l}\text { UAB Autónoma } \\
\text { de Barcelona }\end{array}$} & $\begin{array}{l}\text { Escritura Periodística } \\
\text { en Multimedia e } \\
\text { Interactivos }\end{array}$ & $\begin{array}{l}\text { Hipertexto, } \\
\text { multimedia }\end{array}$ & $\begin{array}{c}\text { Solo en } \\
\text { bibliografia }\end{array}$ & 1995_2015 \\
\hline & Géneros y Formatos & Hipertexto, & Tema & $2003 \_2015$ \\
\hline
\end{tabular}




\begin{tabular}{|c|c|c|c|c|}
\hline & $\begin{array}{l}\text { Audiovisuales } \\
\text { Multimedia }\end{array}$ & $\begin{array}{l}\text { multimedia, } \\
\text { transmedia }\end{array}$ & específico & \\
\hline & $\begin{array}{c}\text { Producción Periodística } \\
\text { Multiplataforma }\end{array}$ & $\begin{array}{l}\text { Hipertexto, } \\
\text { multimedia }\end{array}$ & $\begin{array}{c}\text { Solo en } \\
\text { bibliografía }\end{array}$ & 2000_2012 \\
\hline & $\begin{array}{c}\text { Tendencias de } \\
\text { Desarrollo de Internet }\end{array}$ & NO & NO & 1990_2016 \\
\hline & $\begin{array}{c}\text { Gestión de Contenidos } \\
\text { Digitales }\end{array}$ & No especifica & NO & 1999_2011 \\
\hline \multirow[t]{2}{*}{$\begin{array}{l}\text { Jaume I } \\
\text { Castellón }\end{array}$} & Ciberperiodismo & No especifica & $\begin{array}{c}\text { Solo en } \\
\text { bibliografía }\end{array}$ & 2000_2015 \\
\hline & Narración audiovisual & Audiovisuales & NO & 1991_2011 \\
\hline UM Murcia & $\begin{array}{l}\text { Construcción de } \\
\text { Servicios de } \\
\text { Información Digital }\end{array}$ & No especifica & NO & 1998_2012 \\
\hline \multirow[t]{2}{*}{$\begin{array}{l}\text { Rey Juan Carlos } \\
\text { Madrid }\end{array}$} & $\begin{array}{c}\text { Planificación y } \\
\text { desarrollo de proyectos } \\
\text { en la red }\end{array}$ & $\begin{array}{l}\text { Hipertexto, } \\
\text { multimedia }\end{array}$ & $\begin{array}{c}\text { Análisis } \\
\text { desarrollo de } \\
\text { narr. transmedia } \\
\text { globales }\end{array}$ & 2001_2016 \\
\hline & Periodismo multimedia & $\begin{array}{l}\text { Hipertexto, } \\
\text { multimedia }\end{array}$ & NO & 1998_2015 \\
\hline \multirow[t]{2}{*}{ UMA Málaga } & Información en Internet & $\begin{array}{l}\text { Hipertexto, } \\
\text { multimedia }\end{array}$ & NO & 2002_2013 \\
\hline & $\begin{array}{l}\text { Periodismo Ciudadano } \\
\text { y Redes Sociales }\end{array}$ & $\begin{array}{l}\text { Hipertexto, } \\
\text { multimedia e } \\
\text { interactivas }\end{array}$ & NO & 2003_2012 \\
\hline US Sevilla & No hay materias & - & - & - \\
\hline $\begin{array}{l}\text { UMH Miguel } \\
\text { Hernández Elche }\end{array}$ & $\begin{array}{c}\text { Comunicación Digital e } \\
\text { Internet }\end{array}$ & No especifica & NO & 1994_2010 \\
\hline $\begin{array}{c}\text { UCM } \\
\text { Complutense } \\
\text { Madrid }\end{array}$ & Multimedia & $\begin{array}{l}\text { Hipermedia, } \\
\text { multimedia e } \\
\text { interactivas }\end{array}$ & $\begin{array}{c}\text { Tema } \\
\text { específico }\end{array}$ & 2002_2010 \\
\hline \multirow[t]{2}{*}{ EHU País Vasco } & $\begin{array}{l}\text { Edición y Produción } \\
\text { Multimedia }\end{array}$ & $\begin{array}{l}\text { Hipertexto, } \\
\text { multimedia }\end{array}$ & $\begin{array}{c}\text { Solo en } \\
\text { bibliografía }\end{array}$ & 2000_2015 \\
\hline & $\begin{array}{l}\text { Periodismo Social en } \\
\text { Internet }\end{array}$ & $\begin{array}{l}\text { Narrativas en } \\
\text { storify }\end{array}$ & NO & 2002_2011 \\
\hline \multirow[t]{4}{*}{$\begin{array}{l}\text { UCLM Castilla } \\
\text { La Mancha }\end{array}$} & $\begin{array}{l}\text { Técnicas del Mensaje } \\
\text { en Prensa e Internet }\end{array}$ & No especifica & NO & 1999_2009 \\
\hline & Ciberperiodismo & No especifica & NO & 2011_2015 \\
\hline & $\begin{array}{l}\text { Taller de Periodismo } \\
\text { Multimedia I }\end{array}$ & No especifica & NO & 2000_2013 \\
\hline & $\begin{array}{l}\text { Taller de Periodismo } \\
\text { Multimedia II }\end{array}$ & No especifica & NO & 2000_2013 \\
\hline UVA Valladolid & Ciberperiodismo & No especifica & $\begin{array}{c}\text { Solo en } \\
\text { bibliografía }\end{array}$ & 2001_2016 \\
\hline
\end{tabular}

(c)) BY-NC-ND 2017, Universitat Politècnica de València 


\begin{tabular}{|c|c|c|c|c|}
\hline & $\begin{array}{c}\text { Periodismo } \\
\text { Participativo en la Red }\end{array}$ & En red & NO & 2000_2012 \\
\hline \multirow[t]{2}{*}{ UNAV Navarra } & $\begin{array}{l}\text { Comunicación } \\
\text { Multimedia }\end{array}$ & $\begin{array}{l}\text { Hipertexto, } \\
\text { multimedia e } \\
\text { interactivas }\end{array}$ & NO & 2008_2015 \\
\hline & Ciberperiodismo & $\begin{array}{l}\text { Hipermedia, } \\
\text { multimedia e } \\
\text { interactivas }\end{array}$ & $\begin{array}{l}\text { NO (Aunque } \\
\text { habla de } \\
\text { formatos } \\
\text { integrados) }\end{array}$ & 2003_2017 \\
\hline $\begin{array}{c}\text { UPSA } \\
\text { Salamanca }\end{array}$ & Periodismo Digital & NO & NO & 2003_2015 \\
\hline \multirow[t]{2}{*}{$\begin{array}{l}\text { URV Rovira i } \\
\text { Virgili }\end{array}$} & $\begin{array}{l}\text { Diseño Gráfico y } \\
\text { Multimedia }\end{array}$ & $\begin{array}{l}\text { Hipertexto, } \\
\text { multimedia }\end{array}$ & NO & 2002_2014 \\
\hline & Periodismo en Internet & $\begin{array}{l}\text { Hipertexto, } \\
\text { multimedia }\end{array}$ & NO & 2005_2014 \\
\hline Illas Baleares & Periodismo Digital & $\begin{array}{l}\text { Hipertexto, } \\
\text { multimedia }\end{array}$ & NO & 2004_2010 \\
\hline
\end{tabular}

\subsubsection{Los seminarios: actualizados en herramientas pero con base narrativa tradicional}

Los planes de estudio de las asignaturas analizadas presentan, por lo general, pocos detalles de la planificación de la materia. No especifican más allá de los índices de los temas si observamos las referencias relativas a la parte teórica de la asignatura. Con todo, los seminarios, aportan mayor información pero esta sigue siendo escueta y no se puede descubrir si realmente llevan un discurso actualizado, si se valen de nuevas herramientas o si sacan partido a las nuevas narrativas no solo como contenido, sino como forma de enseñanza.

La idea de transmedialidad que podría desarrollarse en los procesos de aprendizaje no aparece referenciada en ninguno de los planes estudiados. Incluso la parte teórica de los mismos está 'desconectada' de los seminarios y en muy pocos casos la teoría es llevada a la práctica de forma creativa. Aunque en todos los programas se combinan las clases teóricas con seminarios y prácticas de laboratorio, estas últimas no van más allá de la producción de contenidos lineales que no trascienden del ámbito universitario. El sistema parece que sigue dando prioridad a la parte teórica, dejando para las prácticas externas en empresas el conocimiento real de la evolución del sector periodístico.

En la mayoría de las materias analizadas, el trabajo práctico de seminario consiste en crear un proyecto de carácter multimedia, trabajar en su constante actualización y gestionar redes sociales que aporten valor añadido al mismo. Este se complementa en ciertos casos con herramientas actuales e innovadoras que favorecen la irrupción de nuevos géneros como el multimedia o la webzine que propone la materia 'Información para Internet' en la universidad de Málaga o el Storify en 'Periodismo Ciudadano y Redes Sociales' del mismo programa de grado. Otras como 'Comunicación Digital e Internet' en la Jaume I orientan su discurso hacia el marketing y enfocan su programa hacia la comunicación corporativa, valiéndose además de recursos para desarrollo de contenido en plataformas de social media.

Durante los seminarios son muchos los programas utilizados según muestra el análisis de los planes de estudio. Entre ellos los de edición son los más usados, pero los programas incorporan nuevas herramientas por lo que en este aspecto si que proporcionan a los alumnos recursos actuales. Destacan por tanto programas de análisis en redes sociales como 
Gephy del que hace referencia la materia 'Nuevos Formatos y Productos para la Red' (USC). Sin embargo, detectamos la carencia de seminarios dedicados en exclusiva a técnicas para la aplicación de nuevas narrativas, narrativas que aparecen referenciadas en la bibliografía básica en pocas ocasiones — referencias que están desactualizadas, en los programas aparecen muy pocas de los últimos dos años 2015-2016) -

Una de las dimensiones donde mayor uso tienen las herramientas antes señaladas es en los análisis de caso propuestos en los seminarios. Con todo, observamos que la formación en investigación se reduce a pequeños estudios.

\subsection{Contenidos para la participación. La interacción como finalidad en los procesos digitales}

Una de las características que marcan las asignaturas seleccionadas es la importancia que dan a la gestión de la interacción entre periodista y usuario. En este aspecto se observa una evolución en los planes de estudio ya que en materias donde la radio, la televisión o la prensa son los principales canales, no se atiende a esta nueva dimensión que emerge en la era 2.0. Es tanta la importancia que recibe que incluso hay asignaturas específicas del tema con títulos como 'Comunicación y participación ciudadana en red' en el grado de la Carlos III o 'Periodismo Participativo en la Red' impartida en la Universidad de Valladolid. También se han detectado seminarios y partes teóricas enfocadas a la formación del periodista como community manager. A pesar de que el número de materias para el ámbito digital es muy bajo, si que hay constancia del cambio de los discursos a juzgar por la incorporación de materias como 'Técnicas del Mensaje en Prensa e Internet' que combinan estrategias para ambos canales y ofrecen comparativas.

\section{Conclusiones}

El número de usuarios que cada día accede a webs o tiene aplicaciones móviles con el fin de informarse aumenta día tras día, por ello los contenidos deben ir adaptándose a la forma de consumo de los lectores.

Los planes de estudio de los grados en Periodismo ofertan un número reducido de asignaturas de especialización en estrategias digitales. A esto hay que añadir el carácter optativo de las mismas, cuando las plataformas digitales son los canales actuales de distribución de contenidos. Los planes de estudio deben actualizar sus contenidos y determinar nuevas estrategias, incluyendo materias sobre nuevas narrativas y lenguajes para dar respuesta a las exigencias de los nuevos soportes. Además, los programas deben tener en cuenta la constante evolución de lo digital, por ello la parte teórica debe incorporar resultados de investigaciones recientes que consten como parte de la bibliografía —en esta investigación hay programas donde la referencia más actual data de 2010 -

A lo anterior hay que sumar la necesidad de formación para gestionar la interacción con el lector. Los ciudadanos hoy en día son parte activa de la información gracias a la variedad de herramientas que están a su disposición y en las que dejan constancia de sus opiniones. Por ello, es necesario formar gestores de comunicación, que sepan empatizar con el lector - entendido ahora como participativo e incluso prosumidor- para que el discurso informativo refleje mejor que nunca las ideas latentes en la sociedad. Al fin y al cabo, el periodismo sigue siendo el motor que da visibilidad a la opinión pública por lo que debemos aprovechar el mejor acceso al pensamiento ciudadano.

(cc) EY-NC-ND 2017, Universitat Politècnica de València

Congreso IN-RED (2017) 


\section{Referencias bibliográficas y recursos electrónicos}

ALZAMORA, G. y TÁRCIA, L. (2012). "Convergence and transmedia: semantic galaxies and emergent narratives in journalism" en Brazilian journalism research, vol. 8, 1, p. 22-34. $<$ http://bjr.sbpjor.org.br/bjr/article/view/407/0> [Consulta: 15 de enero de 2017]

BENDER, W. (2004). "The seven secrets of the media lab" en BT technology journal, vol. 22, 4, p. 56.

BOLTER, J. D. (1991). Writing Space. The Computer, Hypertext, and the History of Writing. Nueva Jersey: Lawrence Erlbaum Associates. $<$ https://case.edu/affil/sce/authorship/bolter.pdf $>$ [Consulta: 15 de enero de 2017]

DÍAZ-NOCI, J. (2001). La escritura digital: hipertexto y construcción del discurso informativo en el periodismo electrónico. Bilbao: Universidad del País Vasco. ISBN: 84-8373-378-1 DOI: 10.7764/cdi.38.760

FREEMAN, M. (2014). “Advertising the Yellow Brick Road: Historicizing the Industrial Emergence of Transmedia Storytelling” en International Journal of Communication, 8, p. 2362-2381.

GENETTE, G. (1972). Figures III. Paris: Éditions du Seuil. ISNB: ISBN 978202002039.

GIFREU, A. (2013). El documental interactivo. Evolución, caracterización y perspectivas de desarrollo. Barcelona: Editorial UOC.

GUERRERO-PICO, M. Y SCOLARI, C. (2016). "Narrativas transmedia y contenidos generados por los usuarios: el caso de los crossovers" en Cuadernos.info, 8, 183-200.

HYVÄRINEN, M. (2008). "Analyzing narratives and story-telling” en ALASUUTARI, P.; BICKMAN, L. y BRANNEN, J. The SAGE handbook of social research methods. Sage, p. 447-460.

IRALA HORTAL, P. (2014): "Nuevas narrativas en el periodismo actual. El periodismo transmediático" en Estudios sobre el Mensaje Periodístico. vol. 20, 1, p. 147-158. Madrid, Servicio de Publicaciones de la Universidad Complutense. $<$ http://search.proquest.com/openview/5bf8c2fd2810f17ca1b98f958cfce5b8/1?pqorigsite $=$ gscholar\&cbl=237533 $>$ [Consulta: 19 de febrero de 2017]

JENKINS, H. (2003). "Transmedia storytelling. Moving characters from books to films to video games can make them stronger and more compelling” en Technology Review, 10.

JENKINS, H. (2006). Convergence Culture: Where Old and New Collide. New York: University Press. ISBN: 9780814742952

LABOV, W. y WALETSKY, J. (1967). "Narrative analysis: oral versions of personal experience" en Journal of Narrative and Life History, vol. 7, 1-4, p. 3-38.

LARRONDO URETA, A. (2016). "El relato transmedia y su significación en el periodismo. Una aproximación conceptual y práctica" en Trípodos, 38, 31-47.

MCEWAN, H. Y EGAN, K. (comp) (1998). La narrativa en la enseñanza, el aprendizaje y la investigación. Buenos Aires: Amorrortu

MOLONEY, K. (2011). Porting Transmedia Storytelling To Journalism. Denver. $<$ http://www.colorado.edu/journalism/photojournalism/Transmedia_Journalism.pdf $>$ [Consulta: 15 de enero de 2017] 
MONTOYA, D. F.; VÁSQUEZ, M. Y SALINAS, H. (2013). "Sistemas intertextuales transmedia: exploraciones conceptuales y aproximaciones investigativas" en Revista Coherencia, vol. 10, 18, $\mathrm{p}$ 137-159. <http://publicaciones.eafit.edu.co/index.php/co-herencia/article/view/2136/2093> [Consulta: 19 de marzo de 2017]

MORA, V. L. (2014). “Acercamiento al problema terminológico de la narratividad transmedia" en Caracteres. Estudios culturales y críticos de la esfera digital, vol. 3, 1. $<$ http://revistacaracteres.net/revista/vol3n1mayo2014/problema-terminologico-transmedia/> [Consulta: 19 de marzo de 2017]

OCHS, E. Y CAPPS, L. (2001). Living Narrative. Creating Lives in Everyday Storytelling. Cambridge, MA: Harvard University Press. ISBN: 978-0674010109

PEÑAFIEL, C. (2016). "Reinvención del periodismo en el ecosistema digital y narrativas transmedia" en AdComunica, Revista Científica de Estrategias, Tendencias e Innovación en Comunicación, 12, p. 163-183.

PHELAN, J. (2005). Living to Tell about It. A Rhetoric and Ethics of Character Narration. Ithaca: Cornell University Press. ISBN: 978-0801442971

PROPP, V. (1958). Morphology of the Folktale. Indiana Univ. Research Center in Anthropology. Folklore and Linguistics, 10

RICEUR, P. (1983). Temps et récit I. Paris: Éditions du Seuil. ISBN: 978-2020134521.

RODRÍGUEZ FERRÁNDIZ, R. Y PEÑAMARÍN, C. (2014). "Narraciones transmedia y construcción de los asuntos públicos" en CIC Cuadernos de Información y Comunicación, vol. 19, p. $9-16$

SALAVERRÍA, R. (2015). "Los labs como fórmula de innovación en los medios" en El profesional de la información, vol. 24, 4, p. 397-404. <http://dx.doi.org/10.3145/epi.2015.jul.06> [Consulta: 25 de marzo de 2017]

SCOLARI, C. (2009). "Transmedia Storytelling: Implicit Consumers, Narrative Worlds, and Branding in Contemporary Media Production" en International Journal of Communication, v. 3, p. 586-606.

SEALE, C. (2000). "Resurrective practice and narrative" en ANDREWS, M.; SCLATER, S. D.; SQUIRE, C. y TREACHER, A. Lines of Narrative. Psychosocial Perspectives. London and New York: Routledge. ISBN: 978-0415242332.

SERRANO-COBOS, J. (2016). "Tendencias tecnológicas en internet: hacia un cambio de paradigma" en El profesional de la información, vol. 25, 6, p. 843-850. <https://doi.org/10.3145/epi.2016.nov.01> [Consulta: 2 de enero de 2017]

SMITH, B. H. (1981). "Narrative version, and narrative theories" en MITCHELL, W. J. On Narrative. Chicago: University of Chicago Press. ISBN: 0226532178.

El texto de esta comunicación está elaborado en el marco del proyecto "Usos y preferencias informativas en el nuevo mapa de medios en España: modelos de periodismo para dispositivos móviles" (Referencia: CSO2015-64662-C4-4-R), del Ministerio de Economía y Competitividad. Este proyecto está cofinanciado por el fondo estructural FEDER. 


\title{
Recursos audiovisuales en la enseñanza universitaria de la Electrónica: una experiencia aplicada al ámbito de las Ingenierías
}

\author{
Raúl Rengel $^{\mathrm{a}^{*}}$, María J. Martín ${ }^{\mathrm{a}}$, Elena Pascual ${ }^{\mathrm{a}}$, Ignacio Íñiguez-de-la-Torre ${ }^{\mathrm{a}}$ y \\ Beatriz G. Vasallo ${ }^{a}$
}

${ }^{a}$ Universidad de Salamanca, Departamento de Física Aplicada, Salamanca, España. *raulr@usal.es

\begin{abstract}
The present paper details an experience in the innovative use of different audiovisual resources in the classroom and in virtual campuses concerning the teaching of Electronics in Engineering degrees. Among these techniques, we propose the use of real-time screen capture, the technical analysis of science fiction films as a basis to tackle group activities and the accomplishment by students of video lab reports. In particular, among the methodologies addressed, video reports with smartphones have revealed to be the easiest to implement. It is also the methodology with more direct and positive advantages, both for teachers and students, in terms of evaluation of competences, performance and time devoted to the task. Videotutorials have allowed to mitigate some limitations of the lab work, and the technical analysis of fiction films may serve an an additional motivation issue for the students. As a general conclusion, the results obtained allow affirming that these audiovisual resources are a very adequate complement in the teaching of Electronics.
\end{abstract}

Keywords: Electronics, audiovisual resources, videotutorial, laboratory practices, evaluation of competencies, motivation, collaborative work, cinema and teaching

\section{Resumen}

En este trabajo se detalla la experiencia en la utilización innovadora de diferentes recursos audiovisuales en el aula y en los campus virtuales en la enseñanza de la Electrónica en titulaciones de Ingeniería. Entre estas técnicas, proponemos la realización de videotutoriales mediante captura de pantalla a tiempo real, el análisis técnico de filmes de ciencia ficción como base para abordar trabajos grupales y la realización, por parte del alumnado, de informes de prácticas de laboratorio en formato de vídeo. En particular, de entre las metodologías abordadas la realización de videoinformes grabados con el teléfono móvil ha demostrado ser la más sencilla de implementar y la que más ventajas directas y constatables ofrece tanto a los docentes como a los alumnos, en términos de evaluación de competencias, rendimiento y tiempo dedicados la tarea. Los videotutoriales han permitido paliar algunas de las limitaciones propias del trabajo en el 
Recursos audiovisuales en la enseñanza universitaria de la Electrónica: una experiencia aplicada al ámbito de las Ingenierías

\begin{abstract}
laboratorio, y el análisis técnico de películas de ficción puede servir como un elemento más de motivación de los alumnos. Como conclusión general, los resultados obtenidos permiten afirmar que estos recursos audiovisuales son un complemento muy adecuado en la enseñanza de la Electrónica.
\end{abstract}

Palabras clave: Electrónica, medios audiovisuales, videotutorial, prácticas de laboratorio, evaluación de competencias, motivación, trabajo colaborativo, cine y enseñanza

\title{
Introducción
}

Como consecuencia de la evolución, principalmente en las últimas dos décadas, de las nuevas tecnologías de la información e internet y su difusión en todos los niveles de la sociedad, los estudiantes universitarios de hoy pertenecen de pleno derecho a la denominada generación de "nativos digitales" que ha crecido rodeada de ordenadores, videojuegos, videocámaras, teléfonos móviles, etc. Para ellos, los medios audiovisuales y las tecnologías de la información y la comunicación (TIC) resultan una forma natural de interactuar y adquirir conocimientos que suelen priorizar frente a formas tradicionales de transmisión de información, provocando que sea imprescindible un cambio de paradigma en la forma de enseñar y de aprender (Prensky, 2001), o al menos, tener en cuenta este fenómeno a la hora de plantear las tareas relacionadas con estos procesos.

En este contexto, surge la posibilidad de emplear de manera innovadora recursos audiovisuales en el aula (y en los campus virtuales) que vayan más allá de la mera utilización tradicional de documentales técnicos. Se plantean por tanto varias posibilidades:

- La captura en vídeo a tiempo real de una lección, con el fin de que pueda ser revisada posteriormente por los alumnos, hace que sea más sencillo entender ciertos conceptos y reforzar su adquisición (Smith, 2009). En este contexto las tecnologías audiovisuales pueden resultar un apoyo determinante como refuerzo a la docencia. Disponer de una amplia variedad de materiales permite un aprendizaje más eficiente y efectivo, ya que alumnos con diferentes ritmos de aprendizaje pueden trabajar con el material que mejor se adapte a su propia forma de aprehender la información (Carver, 1999). En particular, la tecnología de captura de pantalla permite grabar imágenes de un monitor, movimientos del ratón, pulsaciones de teclas, selección de menús, etc., así como el audio de la persona que maneja el ordenador (Wells, 2012). La grabación puede ser almacenada en diferentes formatos y reproducida vía web o ser descargada, permitiendo al alumno reproducirla, pararla, rebobinarla o verla tantas veces como sea necesario. Se trata por tanto de una tecnología innovadora y efectiva, que permite crear vídeos de apoyo que refuercen los contenidos del curso: las presentaciones en vídeo no son un medio universal para mejorar el aprendizaje de todos los estudiantes, pero sí son un componente de un diseño educativo que permite dirigirse a estudiantes con capacidades y estilos de aprendizaje distintos (Fernandez, 2015).

(c) EY-NC-ND 2017, Universitat Politècnica de València 
- Tanto el cine como la televisión son medios de comunicación de masas sin los cuales sería absolutamente imposible entender la sociedad actual, y como tales han demostrado un gran potencial para la divulgación de información y la formación de las personas. En particular, para las generaciones actuales de jóvenes el medio audiovisual es no solamente una forma natural de procesar la información, sino el entorno preferente en muchos casos para acceder a la misma y comprender numerosos conceptos. Por otra parte, algunos autores han apuntado a la relación entre la utilización de medios audiovisuales y las conexiones emocionales que afectan al modo de aprendizaje (Chen, 2012). El uso de documentales didácticos está consolidado en el entorno educativo a lo largo de las últimas décadas, pero la utilización de obras de ficción en el ámbito docente es mucho más reciente y ha estado en general adscrita a disciplinas como la medicina (García Sánchez, 2012) o el derecho (School, 2007), dada la amplitud de obras cinematográficas de ficción relacionadas con estas materias. Si bien la utilización de materiales audiovisuales como refuerzo al aprendizaje no es novedoso en el ámbito de la Electrónica (Olmo, 2012; Drofenik, 2002: Stumpf 2010), hasta la fecha no tenemos constancia del uso de películas de ficción con este fin. En el presente texto mostramos los resultados de una experiencia de innovación docente basada en la utilización de filmes del ámbito de la denominada ciencia ficción para abordar la realización de trabajos grupales relacionados con diversas tecnologías electrónicas.

- Por último, en el ámbito de las prácticas de laboratorio es posible plantear también alternativas a la forma tradicional de elaborar informes, introduciendo la realización, por parte de los alumnos, de informes en formato de vídeo que resuman el trabajo realizado y los resultados obtenidos. La proliferación y acceso universal entre nuestros alumnos a teléfonos móviles que incorporan cámaras de gran resolución, en combinación con el reciente pero hoy día prácticamente universal uso de los campus virtuales en nuestras universidades permite abordar esta tarea de manera sencilla y efectiva. El formato propuesto permite también reforzar una serie de competencias transversales de gran utilidad en el contexto de las ingenierías.

En esta comunicación mostraremos una serie de experiencias llevadas a cabo en los últimos años en diferentes titulaciones del ámbito de las ingenierías, como son la Ingeniería Informática, la Ingeniería Mecánica o la Ingeniería de Materiales, en la Facultad de Ciencias y en la Escuela Politécnica Superior de Zamora, pertenecientes a la Universidad de Salamanca, y relacionadas con los ámbitos anteriormente mencionados. Las experiencias realizadas abarcan diferentes cursos universitarios y condiciones (desde grupos con un elevado número de alumnos a grupos muy reducidos).

\section{Objetivos}

Los objetivos a desarrollar tienen su origen en las observaciones constatadas a lo largo de años de experiencia en la docencia en asignaturas de electrónica en diferentes ingenierías. En primer lugar, la tendencia natural de los estudiantes a prestar especial atención a todo tipo de información proporcionada a través de las TIC, y en particular, los medios audiovisuales. En segundo lugar, si bien el problema de la confiabilidad de los contenidos disponibles en internet es generalizado, en nuestro caso observamos una gran escasez de 
materiales audiovisuales fiables y en castellano relacionados con nuestro ámbito de enseñanza (la Electrónica, en diferentes asignaturas y niveles). Esto limita considerablemente la posibilidad de utilizar materiales ya existentes, más teniendo en cuenta la dificultad para que se adapten específicamente a los contenidos exactos de las asignaturas y los circuitos electrónicos específicos tratados en ellas. Por ello, nos planteamos una serie de objetivos de carácter general:

- Nuestra experiencia en el desarrollo de las prácticas de laboratorio aconseja disponer de material de apoyo para reforzar los conocimientos que se adquieren durante su realización, puesto que las prácticas forman parte de los contenidos evaluables de la asignatura. En su desarrollo, por tanto, los alumnos deben atender tanto a la parte de aprendizaje como a la evaluación de la práctica. Ello redunda en que hay menos tiempo para la reflexión y la ponderación de lo observado, siendo necesario reforzar las explicaciones que se dan in situ de modo que los alumnos puedan volver sobre ellas con más calma tras el trabajo en el laboratorio.

- Plantear nuevas forma de mejorar la motivación de los alumnos hacia las asignaturas de Electrónica, explorando nuevas posibilidades más allá de métodos ya probados como son los trabajos tutorizados o el aprendizaje basado en proyectos (Rengel, 2012).

- Buscar modos más dinámicos de abordar la realización de informes de laboratorio, que redunden también en una mayor motivación hacia el trabajo de prácticas y la comprensión in situ de diferentes conceptos y ejercicios.

A partir de estos objetivos generales, y teniendo como objetivo también aumentar el grado de motivación de los alumnos, fomentar su análisis crítico y para asentar los conocimientos prácticos de los alumnos sobre circuitos electrónicos, nos planteamos como objetivos particulares las siguientes actuaciones:

\subsection{Realizacion de tutoriales en vídeo}

Uno de nuestros objetivos principales ha sido el desarrollo de nuevos materiales docentes consistentes en tutoriales en vídeo, de duración breve, centrados en (pero no limitados a) las prácticas de laboratorio de las diferentes asignaturas, y realizados mediante la tecnología de captura de pantalla. El contenido de estos videotutoriales consiste fundamentalmente en explicaciones y descripciones de circuitos y análisis de los mismos llevados a cabo en el laboratorio. Para ello se han empleado programas de simulación (como por ejemplo PSPICE o QUCS) y software gratuito de captura de vídeo como es CamStudio.

\subsection{Análisis de escenas cinematográficas como base para realizar trabajos en grupo}

La utilización, con fines docentes, de fragmentos de películas de ciencia ficción, haciendo que los estudiantes sean capaces de discernir entre los elementos tecnológicos con base realista y los puramente fantasiosos que aparecen en las obras de ciencia ficción, y aplicando este análisis a la realización de un trabajo grupal sobre diferentes tecnologías electrónicas a partir de las conclusiones obtenidas.

\subsection{Evaluación de las actividades de laboratorio mediante vídeos}

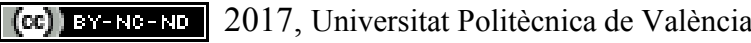


En las prácticas de electrónica digital, en lugar del tradicional informe de prácticas escrito, se utilizan diferentes metodologías. En una de ellas se ha implementado la evaluación a partir de vídeos explicativos realizados por los propios estudiantes en el laboratorio al finalizar cada una de las prácticas obligatorias. Los vídeos han de cumplir una serie de requisitos para garantizar que se trabajan las diversas competencias de manera adecuada.

\section{Desarrollo de la innovación}

\subsection{Tutoriales en vídeo}

El trabajo se ha realizado en dos partes. En primer lugar se han realizado los vídeos que han servido como banco de pruebas para determinar tanto la duración más adecuada como el estilo de la narración, contenidos, etc. En concreto se ha trabajado en esta primera etapa en seis tutoriales de una asignatura que de primer cuatrimestre del primer curso (Fundamentos Físicos, del Grado en Ingeniería Informática de la Facultad de Ciencias). Se realizaron los guiones de los tutoriales, incluyendo las pautas básicas de los contenidos que se quieren transmitir de circuitos en simuladores como el PSPICE y QUCS sobre los que trabajar en las explicaciones y en concreto sobre las siguientes prácticas y temas:

- Introducción a la simulación con PSPICE

- Rectificación y diodos

- Polarización del transistor MOSFET

- Funcionamiento de un optoacoplador

- MOSFET en conmutación

- Familias lógicas

Los vídeos se realizaron mediante el software gratuito de captura de pantalla CamStudio, subiéndose posteriormente de forma privada a Youtube mediante una cuenta específica de la asignatura en Gmail. Los enlaces se publicaron en Studium (campus virtual de la Universidad de Salamanca) y estaban a disposición de los alumnos matriculados de modo que pudieran hacer un doble uso de los mismos. En primer lugar, se les indicó que debían ver de forma obligatoria los tutoriales antes de acudir al laboratorio, de modo que pudieran tener una idea más clara de cuáles eran los aspectos fundamentales teóricos y técnicos de la práctica. En segundo lugar, podían revisar lo aprendido en el laboratorio una vez terminada la práctica, sin necesidad de acudir a una tutoría presencial o volver a tener que realizar el montaje de la práctica en el banco de trabajo. Mediante los datos de registro del campus virtual se llevó el control de qué alumnos habían accedido a los vídeos y cuándo lo habían hecho.

En una segunda etapa el equipo docente analizó los resultados, la incidencia en el trabajo de laboratorio y el uso que habían hecho los alumnos de estos nuevos materiales.

\subsection{Análisis de una película de ciencia ficción}

(cc)) EY-NC-ND 2017, Universitat Politècnica de València 
La experiencia se llevó a cabo en la Escuela Politécnica Superior de Zamora, en dos asignaturas con perfiles bien diferenciados desde el punto de vista del número de alumnos. En primer lugar, en la asignatura "Fundamentos de Electrónica", del segundo curso del Grado en Ingeniería Mecánica, con cerca de 50 alumnos matriculados, donde la asistencia y la participación en la mayor parte de actividades es muy elevada. La segunda fue la asignatura "Física", del primer curso del Grado en Ingeniería Informática en Sistemas de Información, con menos de 10 alumnos matriculados, y donde por ser un grupo de tamaño reducido la interacción profesor-alumno es mucho más cercana, resultando también más sencillo establecer pautas de trabajo que involucren una participación activa de los estudiantes y conocer de primera mano su reacción ante las diferentes tareas propuestas.

Para llevar a cabo la experiencia docente tomamos como base la película Minority report, dirigida por Steven Spielberg en el año 2002 y que refleja de manera muy verosímil la posible evolución de numerosas tecnologías actuales en el ámbito de la electrónica, la robótica, la informática, etc. En su producción se contó con el asesoramiento de expertos reconocidos internacionalmente en disciplinas científicas y tecnológicas. El punto de partida no es una valoración de la calidad cinematográfica de la película o el visionado completo de la misma, sino que el aspecto relevante es que resulta perfectamente adecuada para introducir una serie de temas sobre los que los alumnos tenían que realizar un trabajo grupal. El procedimiento para llevar a cabo este experimento docente fue el siguiente. Antes de comenzar el cuatrimestre realizamos un análisis completo de la película, elaborando una completa ficha didáctica sobre la misma que incorporase toda la información relevante para la actividad posterior incluyendo:

- Un apartado técnico (en el que se da la información sobre fecha de producción, director, actores y sinopsis).

- Un apartado didáctico orientado al docente (donde se indican los objetivos educativos, el contexto referencial, el formato de presentación de la actividad a los alumnos, el método para la visualización de los cortes seleccionados, los contenidos didácticos, el desglose secuencial y la valoración del tema y la película). Es particularmente importante el desglose secuencial, realizado mediante un visionado detallado de los aspectos puramente técnicos de la película, empleando para ello el programa de código abierto VirtualDub (Fig. 1). El número de cortes obtenido (en torno a 22) fue combinado posteriormente mediante Windows Movie Maker, obteniendo un total de cuatro vídeos de entre 2 minutos y medio y 5 minutos de duración. Los vídeos se pusieron a disposición de los alumnos en Studium, el campus vitual de la Universidad de Salamanca.

- Un último apartado didáctico orientado al estudiante con expresión de objetivos de la actividad, orientaciones para la reflexión crítica y/o debate de carácter ético en relación con la evolución de la electrónica (¿cuáles son los límites de la tecnología y hasta dónde llegará la invasión de nuestra privacidad en el futuro?), los recursos a utilizar y descripción del trabajo a realizar.

(c) EY-NC-ND 2017, Universitat Politècnica de València 


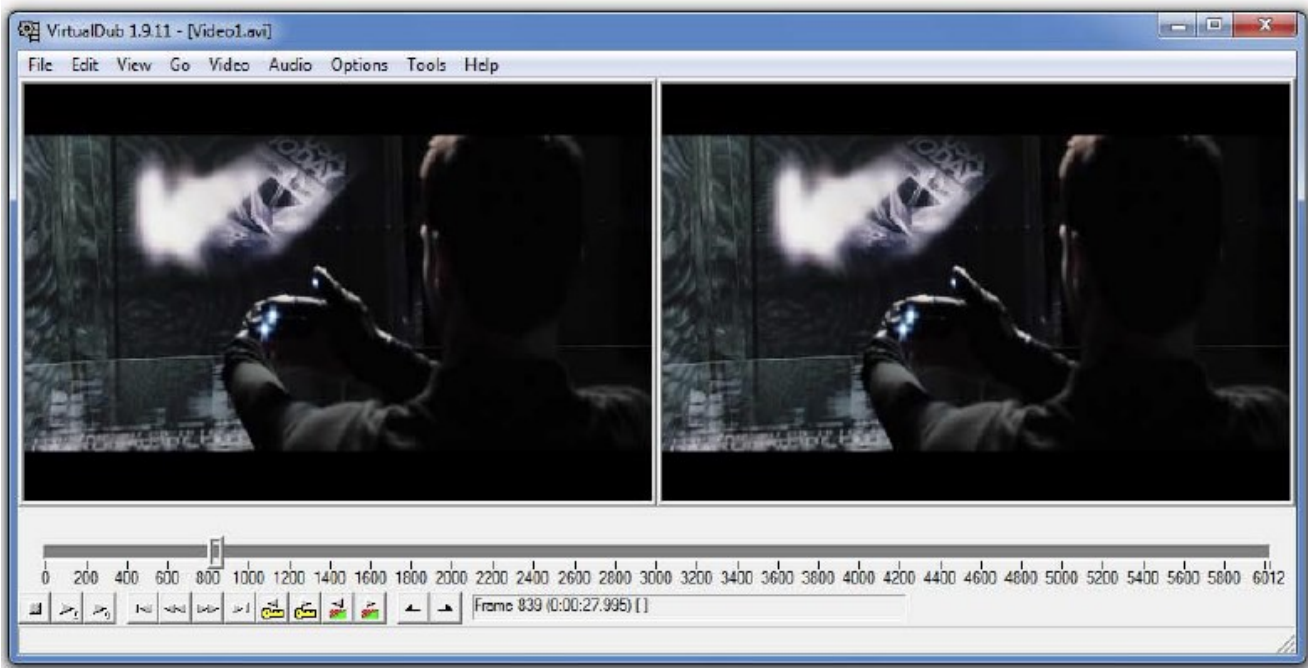

Fig. 1 Realización de los cortes de fragmentos de película con Virtual Dub.

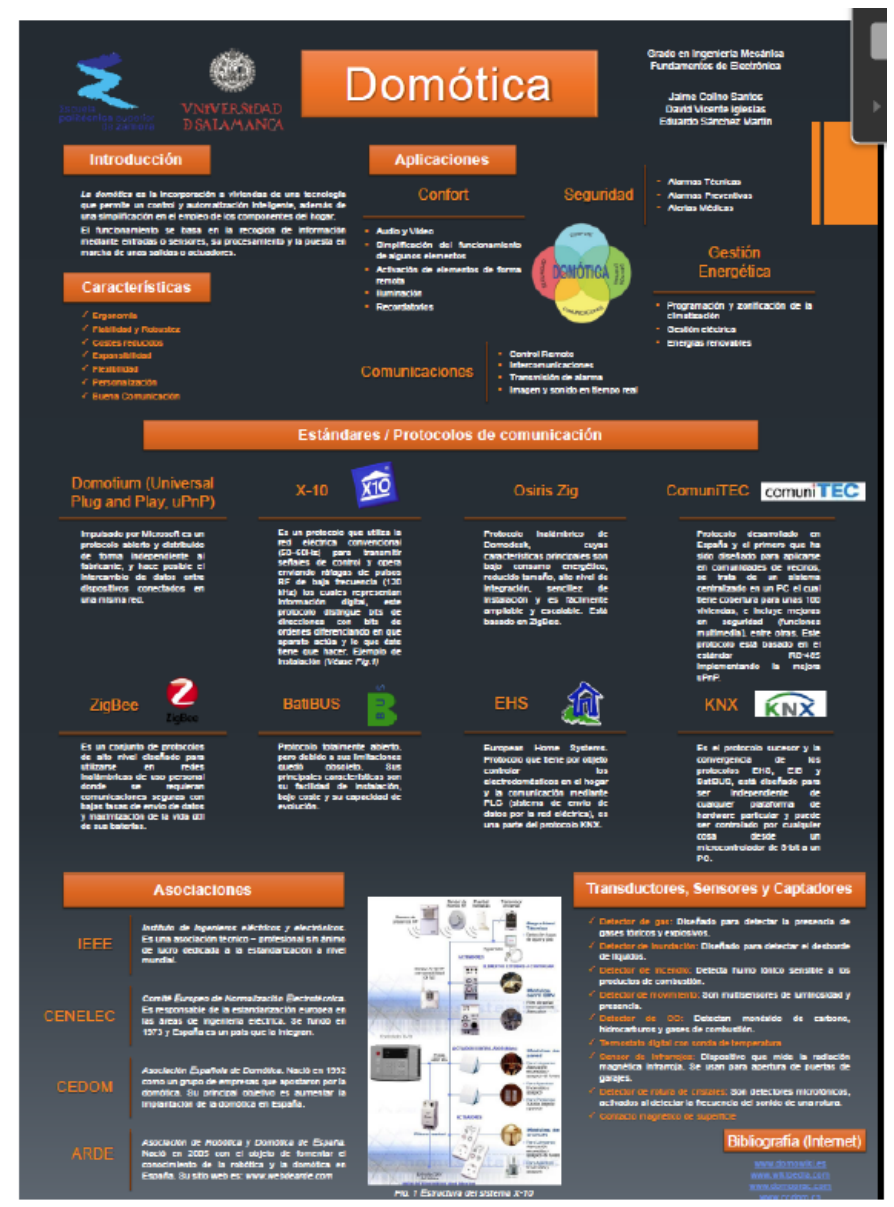

Fig. 2 Ejemplo de póster realizado por los alumnos

(c)) EY-NC-ND 2017, Universitat Politècnica de València

Congreso In-Red (2017) 
La actividad con los alumnos consistía en (tras haber visionado los cortes seleccionados) realizar inicialmente un debate con el fin de determinar una serie de temas relacionados con la Electrónica sobre los que llevar a cabo un trabajo monográfico (póster resumen que debería ser expuesto en una sesión de grupo completo), así como evaluar la credibilidad y viabilidad de los avances tecnológicos mostrados en la película. Al tratar con dos grupos con perfil muy diferenciado seguimos dos estrategias diferentes: en el grupo más numeroso, abrimos un foro en Studium con los cortes de la película y algunos fotogramas adicionales seleccionados con el fin de tener un debate más organizado. Preferimos optar por un debate on-line que permitiese a los alumnos de forma voluntaria realizar una reflexión más detenida desde su domicilio. Como aliciente para la participación se estableció que quien lo hiciera tendría preferencia a la hora de escoger el tema para la realización del trabajo de entre los finalmente seleccionados. El debate on-line fue en todo momento supervisado y guiado por los profesores.

En el grupo más pequeño, tras el visionado y el debate preliminar se establecieron los temas para la realización del trabajo, proporcionando a los alumnos la matriz de rúbricas para guiar la elaboración del póster y su presentación. Finalmente se realizó la exposición de los trabajos en una sesión de grupo completo, en la que cada grupo disponía de un máximo de 6 minutos para explicar de manera resumida el tema tratado. Se complementó esta exposición con una exposición virtual de los pósters en la página web de la asignatura (Fig 2).

\subsection{Videoinformes de laboratorio}

Esta experiencia se ha venido realizando en los últimos 6 cursos académicos en diferentes titulaciones, en concreto en las asignaturas "Arquitectura de Computadores I", del Grado en Ingeniería Informática en Sistemas de Información, y "Fundamentos de Electrónica", de Grado en Ingeniería Mecánica (ambas en la Escuela Politécnica Superior de Zamora), así como en "Fundamentos Físicos" y "Periféricos", del Grado en Ingeniería Informática de la Facultad de Ciencias de la Universidad de Salamanca. Se ha aplicado principalmente a la elaboración de informes relacionados con la implementación de circuitos digitales, realizados en subgrupos pequeños de 2 o 3 alumnos. Antes de acudir al laboratorio, se informa a los alumnos de las pautas de realización del vídeo, contenidos y formatos. Por ejemplo, se indicó que los vídeos deberían tener una duración total aproximada de 3 o 4 minutos para cada práctica, y no ocupar más de $256 \mathrm{MB}$ de tamaño. Al haber una duración estipulada, es importante que los alumnos piensen antes de realizar el vídeo en quién de los componentes del grupo se va a ocupar de realizar la locución, qué se quiere contar, etc. El vídeo se realiza al terminar cada uno de los circuitos que se implementan en el laboratorio, y entre las pautas de realización deben incluir:

- Mostrar un esquema del circuito implementado, indicando su funcionalidad.

- Indicar y mostrar los elementos que se han empleado en el circuito, señalando además de manera clara cuáles son las entradas y salidas del mismo.

- Mostrar el funcionamiento completo del circuito (normalmente comprobando de manera completa la tabla de verdad).

(c) EY-NC-ND 2017, Universitat Politècnica de València 
- Mostrar la simulación por ordenador que acompaña a la realización física del circuito (en el laboratorio se trabaja en paralelo con simuladores (PSPICE por ejemplo) a la vez que se realiza el montaje de los circuitos en el entrenador.

Una vez realizado el vídeo y tras haber comprobado en el propio laboratorio que no existen problemas de imagen o sonido, los alumnos disponen de un plazo de 24-48 horas para subirlo al campus virtual, donde será posteriormente revisado por el equipo docente. Para la evaluación disponemos de una matriz de rúbricas que facilita la tarea. Únicamente se sube un informe por cada grupo de trabajo (típicamente de 2 o 3 personas).

\section{Resultados}

\subsection{Tutoriales en vídeo}

Las explicaciones que están incluidas en los videotutoriales han servido como un complemento muy adecuado a lo explicado de manera oral en el laboratorio y en las clases magistrales. La propia naturaleza del trabajo en el laboratorio (limitación horaria, ambiente relativamente ruidoso, número elevado de grupos) en ocasiones puede no resultar una forma efectiva de transmitir conocimientos. Por tanto estos tutoriales no pretendían ser una herramienta exclusiva que reemplazase al trabajo de laboratorio, sino un refuerzo que ayudase a los alumnos a afianzar conocimientos y a comprender de manera más clara las funcionalidades de ciertos elementos con los que se trabaja en el laboratorio.

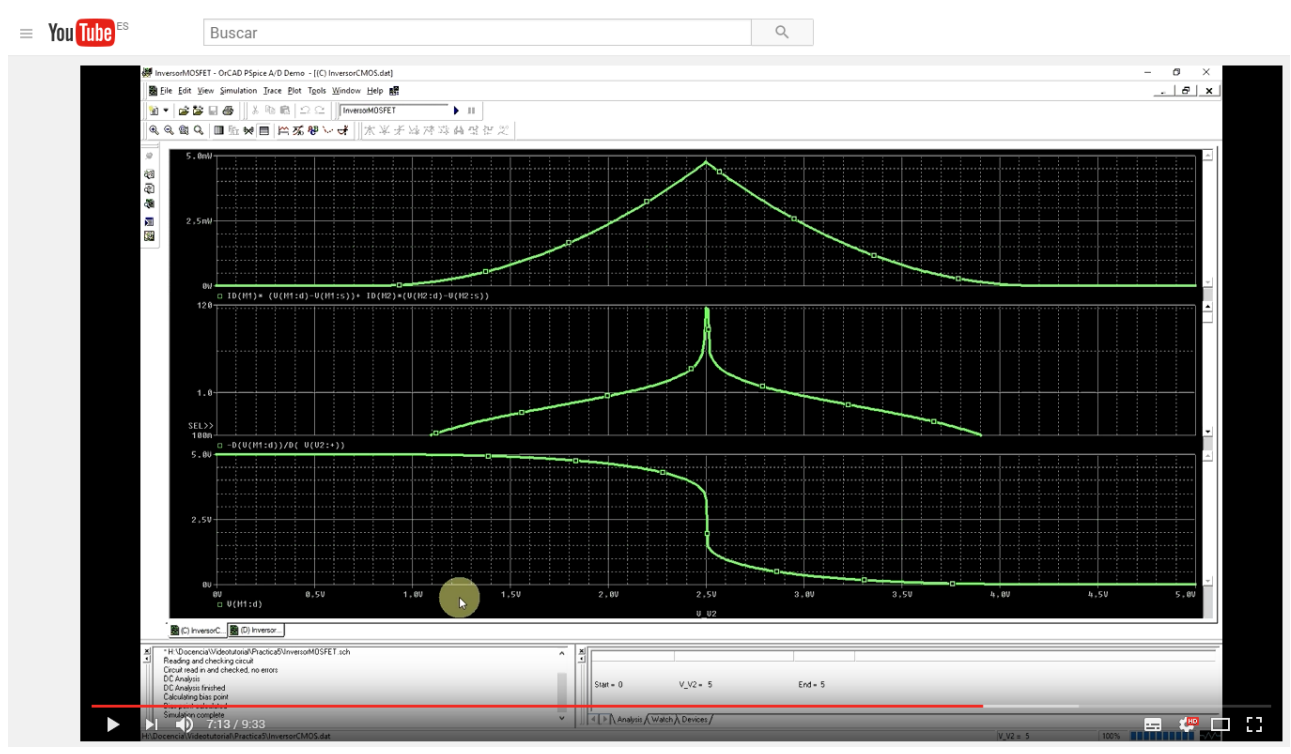

Fig 3. Fotograma de un tutorial en video realizado mediante captura de pantalla

La experiencia nos ha demostrado que la gran mayoría de alumnos han seguido las indicaciones y acudieron al laboratorio habiendo visionado previamente los tutoriales. Durante las prácticas en sí, sin embargo, debemos señalar que la influencia de los tutoriales en el desempeño de los estudiantes ha sido un tanto desigual. En algunos grupos los tutoriales servían de manera muy clara para ayudar a los alumnos a desarrollar y entender la práctica (especialmente para la realización de las simulaciones PSPICE), mientras que en 
otros grupos no se observaba una correlación directa entre haber visionado el tutorial y la obtención de un rendimiento efectivo. En este caso quedó clara la importancia de la implicación personal de cada alumno y el grado de dedicación a la tarea. Entre quienes hicieron un aprovechamiento efectivo de los tutoriales se apreció una tendencia clara a obtener buenos resultados tanto en el desarrollo como en la evaluación de las prácticas.

En general, los tutoriales en vídeo han permitido ampliar la base de alumnos que adquieren una visión final global más clara del propósito de varios circuitos electrónicos, y han supuesto una herramienta más para que los estudiantes puedan organizar de mejor forma la adquisición de conocimientos, siendo también un contenido que puede ser empleado en cursos sucesivos sin necesidad de esfuerzo adicional por parte de los profesores. Los vídeos realizados por el equipo docente, incluyendo el uso de simuladores, ayudan a los estudiantes a profundizar en el comportamiento no sólo de circuitos analógicos, sino también de circuitos digitales de carácter básico. Además, creemos que este trabajo redunda favorablemente en asentar en los alumnos los aspectos más relevantes y aplicados de los principales circuitos con los que trabajamos en las diferentes asignaturas, disponiendo por tanto de nuevos contenidos audiovisuales preparados para uso tanto en la docencia presencial como en la docencia online.

La valoración que han realizado los alumnos sobre los tutoriales en vídeo ha sido en general muy positiva. En una encuesta realizada en el campus virtual, el $77 \%$ ha considerado que es una iniciativa interesante, mientras que el $23 \%$ se ha mostrado indiferente a la misma, siendo nulo el porcentaje de valoraciones negativas. En una escala de Likert la valoración de los tutoriales ante la pregunta "Los contenidos de los tutoriales en vídeo sobre las prácticas me han parecido adecuados" ha recibido una valoración de 3.9, siendo 5 el grado máximo de acuerdo con la afirmación.

En la literatura existe una gran cantidad de experiencias que emplean diferentes tipos de recursos multimedia como soporte para las clases presenciales. Por citar algunos ejemplos, en (Escobar, 2010) se emplean videos educativos en la enseñanza de medicina ocupacional obteniendo resultados muy extremadamente positivos; en (Sancho, 2006) se presenta también una interesante metodología combinada mediante prácticas tradicionales y elearning en el campo de la microbiología, o en (Zapata-Revilla, 2010), donde se muestran los satisfactorios resultados obtenidos de la aplicación de diferentes técnicas TIC (entre ellas material de video sobre procedimientos experimentales de laboratorio) para apoyar el estudio de alimentos en nutrición y dietética humana en la rama de ciencias de la salud. En nuestro caso, el resultado de la experiencia no ha mostrado mejoras significativas desde el punto de vista académico. La diferencia de la calificación media que encontramos entre el grupo de control y el grupo en el que se ha realizado la experiencia no es estadísticamente significativa. Sin embargo, sí podemos afirmar que el principal beneficio es el relacionado con el logro de una mayor autonomía de los alumnos en el laboratorio y un mayor interés por las prácticas, además de cómo es lógico la disponibilidad de nuevo material docente online para la enseñanza de la Electrónica. Sería por tanto necesario diseñar una metodología específica adicional que nos permitiera ahondar en la mejora y ampliación de estos videotutoriales para lograr un mayor rendimiento académico efectivo.

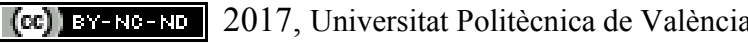




\subsection{Análisis de una película de ciencia ficción}

En cuanto a los resultados que podemos extraer de la actividad relacionada con el análisis técnico de las tecnologías que aparecen en una obra de ficción cinematográfica, tanto en el grupo grande como en el pequeño, la participación en el foro de debate de Studium sobre los cortes de la película fue relativamente escasa. En el grupo grande, el tratarse de una actividad voluntaria (se buscaba que quien participase lo hiciese de forma reflexiva y razonada, dado que la tarea a realizar requiere un cierto grado de madurez y predisposición) hizo por otra parte que la calidad de las participaciones fuese bastante elevada, apareciendo incluso nuevos temas que inicialmente no habían sido previstos por el equipo docente. En ese sentido supuso un resultado muy satisfactorio, puesto que algunos alumnos buscaron información en internet y ampliaron claramente sus conocimientos previos. Sin embargo, a modo de autocrítica podemos señalar que quizá la explicación de los objetivos de la actividad fue insuficiente, puesto que para algunos alumnos pudo ser complicado establecer la relación entre lo visto en la ficción y la tecnología del mundo real. Estos aspectos fueron fácilmente corregibles en el debate y presentación de la actividad de carácter presencial, como comprobamos con el grupo pequeño.

En cuanto a la opinión de los alumnos al respecto, al concluir la docencia de la asignatura realizamos una encuesta anónima general a los estudiantes en las que varios ítems estaban relacionados con esta actividad. En dicha encuesta, los items relacionados con la innovación y originalidad de la actividad y su utilidad para comprender las tecnologías actuales fueron bien valorados (media 3.6 sobre 5), aunque el grado de motivación adicional tuvo paradójicamente un valor inferior (media 3.2). En el grupo pequeño la actividad fue mejor valorada. Podemos afirmar que este tipo de actividad probablemente tenga más alcance y relevancia con alumnos de últimos cursos, que dispongan de la base de conocimientos y madurez necesarias para explotar al máximo las posibilidades que ofrece.

Como se ha comentado en la introducción, este tipo de experiencias didácticas está más consolidado en disciplinas como la medicina (García Sánchez, 2012) o el derecho (School, 2007), en las que los resultados publicados y sus autores muestran un alto grado de satisfacción con las mismas. En nuestro caso, para poder evaluar el alcance cuantitativo de la experiencia mostramos en la Figura 4 la calificación media de los trabajos en grupo obtenida por los alumnos en dos cursos académicos, el 2012-13 (en el que se realizó la actividad) y el curso inmediatamente anterior (2011-2012) en el cual no se realizó. Existe una ligera mejoría en la calificación de los trabajos (de 6 a 6.7) si bien no es posible atribuirla en exclusiva a la experiencia realizada, ya que en general en el curso 2012-2013 el grupo tuvo un rendimiento ligeramente mejor. 


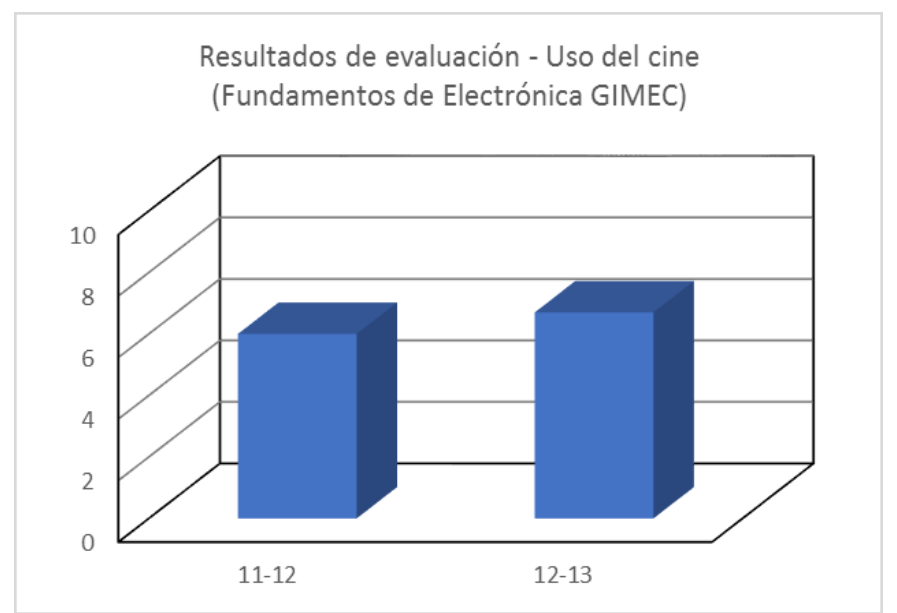

Fig 4. Nota media obtenida por los alumnos en la evaluación del trabajo en grupo en los cursos 2011-2012 y 2012-2013 (en este último se desarrolló la actividad "Análisis de una película de ciencia ficción")

\subsection{Evaluación mediante informes de prácticas en vídeo}

En general los resultados de esta actividad han sido muy satisfactorios, ya que por una parte los vídeos sirven como evaluación directa de las competencias adquiridas por los alumnos, y por otra parte para los alumnos es una forma más natural y sencilla de realizar los informes. En líneas generales, la calidad de las explicación y detalles ofrecidos por parte de los estudiantes en los videoinformes ha sido bastante alta, dado que habitualmente muestran mayor interés en completar este tipo de tareas que un informe tradicional. Ello redunda en mejores calificaciones en las prácticas evaluadas mediante videoinformes que en aquellas evaluadas mediante informes tradicionales en papel. Por otra parte, la preferencia de los alumnos fue clara por el método del videoinforme, posiblemente por tratarse de un formato al que se encuentran muy acostumbrados por el uso prácticamente universal de teléfonos inteligentes, videocámaras, etc. En una encuesta realizada a los alumnos, la afirmación "Prefiero la cumplimentación de un informe por escrito a la realización de un vídeo como informe de prácticas" obtuvo una valoración de 1.9, siendo el 1 el máximo desacuerdo en la escala de Likert: por tanto, hay una preferencia clara hacia este nuevo tipo de formato, que ahorra tiempo en su realización y valoración y permite afianzar mejor las competencias.

En la Figura 5 mostramos los resultados comparativos de utilizar la evaluación de las prácticas de laboratorio mediante videoinformes y mediante sistemas de evaluación tradicionales, para dos asignaturas diferentes (Fundamentos de Electrónica, del Grado en Ingeniería Mecánica, GIM y Fundamentos Físicos, del Grado en Ingeniería Informática, GII). En la primera los resultados se muestran desde el curso 2011-12 puesto que esta iniciativa se comenzó a desarrollar con bastante antelación comparado con la titulación de Ingeniería Informática (2014-15). La experiencia en el Grado en Ingeniería Mecánica es por tanto de mayor alcance en el tiempo, y además se desarrolla en la mitad de las prácticas de la asignatura (las que corresponden a la parte de Electrónica Digital de la asignatura de Fundamentos de Electrónica). En ambas titulaciones se muestra una mejora importante en

(cc) EY-NC-ND 2017, Universitat Politècnica de València

Congreso IN-RED (2017) 
la evaluación de los alumnos mediante este sistema (aunque debemos destacar que es menos significativa en la Ingeniería Informática puesto que únicamente se emplea esta técnica en una de las seis prácticas de laboratorio).
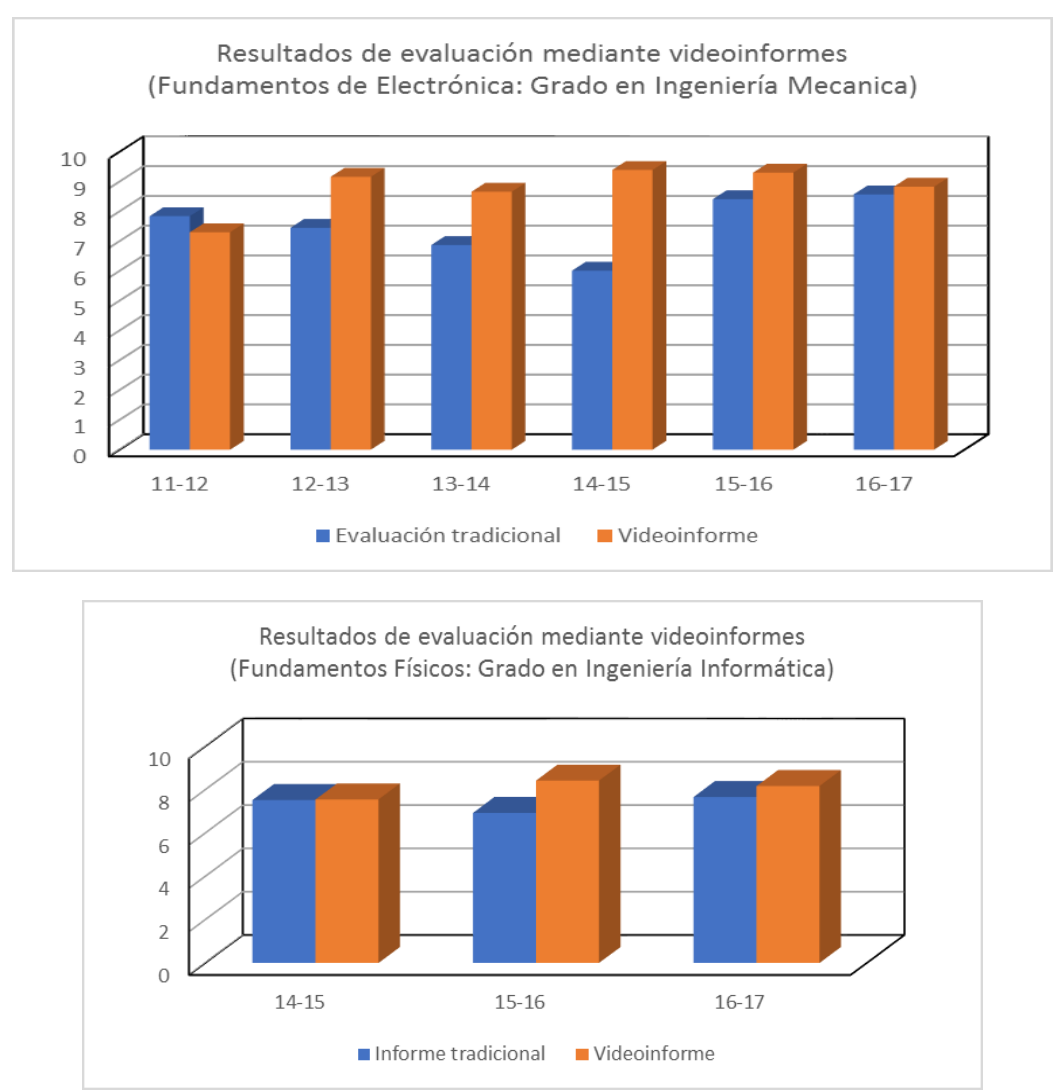

Fig 5. Comparativa de los resultados obtenidos por los alumnos en las prácticas mediante el informe tradicional o mediante la realización del videoinforme (gráfica superior GIM, y gráfica inferior GII).

\section{Conclusiones}

En los últimos años hemos realizado una serie de experiencias de innovación educativa encaminadas a introducir, de manera parcial y paulatina, nuevas técnicas y metodologías didácticas en la enseñanza de la Electrónica en asignaturas de Ingeniería y Ciencias en la Universidad de Salamanca. Para ello hemos optado por la utilización de recursos audiovisuales, tanto tutoriales en vídeo creados por los docentes, como videoinformes elaborados por los alumnos, e incluso empleando cortes seleccionados de obras de ficción cinematográficas. Los resultados en general han sido muy satisfactorios, permitiéndonos dotarnos de nuevos recursos docentes que acompañan a los medios tradicionales utilizados en el aula.

Partiendo de la base de que los resultados obtenidos no permiten afirmar que de manera general estos nuevos medios y métodos deban en absoluto reemplazar a los tradicionales, sí hemos encontrado que son un complemento muy adecuado que redunda en una mayor 
Recursos audiovisuales en la enseñanza universitaria de la Electrónica: una experiencia aplicada al ámbito de las Ingenierías

motivación de los estudiantes y una implicación más intensa en las asignaturas. En particular, de las propuestas llevadas a cabo, probablemente la realización de videoinformes grabados con el teléfono móvil sea la más sencilla de implementar y la que más ventajas directas y constatables ofrece tanto a los docentes como a los alumnos, en términos de rendimiento y tiempo dedicado a esta tarea.

Por otra parte, los videotutoriales pueden ser una herramienta muy valiosa para la docencia, al ser recursos diseñados específicamente para los contenidos propios de las asignaturas impartidas, teniendo además la ventaja adicional de ser un material elaborado en el idioma nativo de los estudiantes.

Por último, emplear cortes de películas de ciencia ficción como base para el debate y la realización de trabajos en grupo es también una experiencia positiva, pero que a la vista de los resultados obtenidos probablemente sea más adecuada para alumnos de últimos cursos de grado en el marco de asignaturas optativas, en las que se pueda realizar con el tiempo y el detalle requeridos para constituir una profundización efectiva en cuanto a la adquisición de conocimientos en un tema concreto.

\section{Referencias}

CARVER, C. A., HOWARD, R. A. Y LANE, W. D. (1999). "Enhancing student learning through hypermedia courseware and incorporations of student learning styles," IEEE Trans. Educ., (1999, vol. 42, no. 1, pp. 33-38)

CHEN, C.-M. Y COL. (2012). "Identifying the Correlations of Different Multimedia Materials on Learning Emotion and Performance", en Proceedings of the 2nd International Conference on Consumer Electronics, Communications and Networks, Yichang, China. Disponible

en:

$<$ http://ieeexplore.ieee.org/xpl/articleDetails.jsp?arnumber=6202281. $>$ [Consulta: 31 de Marzo 2017]

GARCÍA SÁNCHEZ, J. E. Y GARCÍA SÁNCHEZ, E. (2012), "La revista de medicina y cine y la formación médica", Revista de Medicina y Cine, vol. 8, issue 2, pp. 51-52

DROFENIK, U. Y KOLAR, J. W. (2002). "Survey of Modern Approaches of Education in Power Electronics", en Proceedings of the $17^{\text {th }}$ Applied Power Electronics Conference and Exposition Annual IEEE Conference, Dallas, EE.UU. Disponible en:

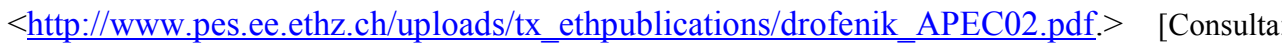
31 de Marzo 2017]

ESCOBAR-PINZON, L.C., ROSSBACH, B., CLAUS, M., Y Letzel, S. (2010). "Die Praxis - Experiences with Educational Videos in Teaching Occupational Medicine", en 3rd International Conference of Education, Research and Innovation (ICERI 2010). Madrid. SPAIN. Disponible en: https://library.iated.org/view/ESCOBARPINZON2010DI [Consulta: 18 de Mayo de 2017]

FERNANDEZ, G., SHOWDHURY, B. Y BEVINAKOPPA G, (2015). "Using screen capture for teaching and learning", en Recent advances in computer supported education, Proceedings of the 2nd International Conference on Engineering and Technology Education (ETE'15)

(cc) EY-NC-ND 2017, Universitat Politècnica de València 
OLMO, A. GONZÁLEZ, I. MOLINA, A. Y RIVERA, O. (2012). "Integration of multimedia contents in the teaching of electronics". En: Proceedings of Technologies Applied to Electronics Teaching (TAEE 2012), Vigo. Disponible en: $<$ http://ieeexplore.ieee.org/xpls/abs_all.jsp?arnumber=6235406 $>$. [Consulta: 31 de Marzo 2017]

PRENSKY, M. (2001). "Digital natives, digital immigrants part 1," On Horizon (2001, vol. 9, no. 5, pp. 1-6)

SANCHO, P., CORRAL, R., RIVAS, T., GONZALEZ, M.J., CHORDI, A. Y and TEJEDOR, C. (2006). A Blended Learning Experience for Teaching Microbiology. American Journal of Pharmaceutical Education 70 (5) pp. 1-9. Disponible en : https://www.ncbi.nlm.nih.gov/pmc/articles/PMC1637024/ [Consulta: 18 de Mayo de 2017]

SCHOOL OF LAWS, UNIVERSITY OF WASHINGTON. "Law on TV, Video, and Film".

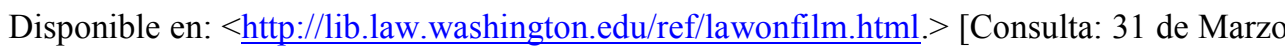
2017]

SMITH, L. E. R. (2009). Does digitally enhanced instruction benefit student learning, Master's of Science in Information Science thesis, North Carolina : University of North Carolina, $\quad<$ https://cdr.lib.unc.edu/indexablecontent/uuid:7aea2686-c3e1-4610-bfbab0d6a317d505> [Consulta: 31 de Marzo 2017]

STUMPF, P. (2010). "Multimedia Material for Teaching and e-Learning in Nonlinear Dynamics and Power Electronics", en Proceedings del IEEE International Symposium on Industrial Electronics (ISIE 2010), Bari, Italia. Disponible en: $<$ http://ieeexplore.ieee.org/xpls/abs_all.jsp?arnumber=5637638.. . [Consulta: 31 de Marzo 2017]

RENGEL, R., MARTIN, M. J., VASALLO, B. G. (2012). "Supervised Coursework as a Way of Improving Motivation in the Learning of Digital Electronics". IEEE Transactions on Education, vol. 55, issue: 4, pp. 525-528.

WELLS, J. BARRY, R. M. Y SPENCE, A. (2012). "Using video tutorials as a carrot-andstick approach to learning," IEEE Transactions on Education, vol. 55, pp. 453-458.

ZAPATA-REVILLA, M.A., DIEZ-MARQUES, C., GARCIA-MATA, M., PEREZRODRIGUEZ, M.L., REDONDO-CUENCA, A., TENORIO-SANZ, D., Y VILLANUEVA-SUAREZ, M.J. (2010). "Developing Audiovisual Learning Materials in Food Analysis". 3rd International Conference of Education, Research and Innovation (ICERI 2010), Madrid (Spain). Disponible https://library.iated.org/view/ZAPATAREVILLA2010DEV [Consulta: 18 de Mayo de 2017] 


\title{
¿Qué recursos didácticos conocen y usan nuestros alumnos?
}

\section{D. de Andrés Martínez ${ }^{\mathrm{a}}$, E. Antonino Daviu ${ }^{\mathrm{b}}$, C. Gisbert Doménech ${ }^{\mathrm{c}}$ J.C. Ruiz García ${ }^{\mathrm{d}}$, A. Palomares Chust ${ }^{\mathrm{e}}$, A. Peña Cerdán ${ }^{\mathrm{f}}$}

${ }^{a}$ Universitat Politècnica de València, Dpto. de Informática de Sistemas y Computadores, ddandres@disca.upv.es, ${ }^{b}$ Universitat Politècnica de València, Dpto .de Comunicaciones, evanda@upvnet.upv.es, ' Universitat Politècnica de València, Dpto. de Biotecnología, cgisbert@btc.upv.es, ${ }^{d}$ Universitat Politècnica de València, Dpto. de Informática de Sistemas y Computadores, jcruizg@disca.upv.es, ${ }^{e}$ Universitat Politècnica de València, Dpto. de Sistemas Informáticos y Computación, apalomares@dsic.upv.es, ${ }^{f}$ Universitat Politècnica de València, Dpto. de Proyectos Arquitectónicos, anpecer2@pra.upv.es

\begin{abstract}
The Universitat Politècnica de València (UPV) is promoting for some years now, the design, elaboration and use of different multimedia learning materials, such as videos, screencasst and slide-based presentations. The goal is to support and encourage the out-of-class work of students. Although a lot of effort has been placed so far in improving the content of such materials, few research has been carried out on the use of such materials and its actual impact on the students' learning process and academic performance. This research wants to determine the degree of awareness and relevance that students provide to the existence and use of this type of multimedia materials. The study will be focused on three different areas of expertise, such as those defined by the engineering, architecture and tourism domains. It will compare the importance for students of the different available materials at UPV with respect to other multimedia resources available on Internet.
\end{abstract}

Keywords: Multimedia resources, learning, out-of-class work, Riunet

\begin{abstract}
Resumen
La Universitat Politècnica de València (UPV) lleva ya unos años promoviendo e incentivando el diseño, elaboración y uso de distintos tipos de materiales multimedia, como videos explicativos, screencasts $y$ presentaciones, con el objetivo de dinamizar el trabajo del alumno fuera del aula. Aunque muchos trabajos se han centrado en los últimos años en desarrollar mejores contenidos multimedia, poca investigación se ha llevado a cabo hasta la fecha en el estudio del uso que los alumnos hacen de dicho material y en el impacto que el mismo tiene, en un primer momento, en su proceso de aprendizaje, y finalmente, en sus resultados académicos. El objetivo de esta comunicación es determinar el grado de conocimiento y uso que dan los alumnos al material multimedia del que disponen. Este estudio se efectuará en distintas áreas de conocimiento en el ámbito de la ingeniería, la arquitectura y el turismo. Se pretenden identificar el grado de conocimiento que tienen los alumnos de los recursos multimedia de la UPV y el grado de
\end{abstract}


uso que hacen de este material y de otros materiales multimedia disponibles en Internet.

Palabras clave: Recursos multimedia, aprendizaje, trabajo no-presencial, Riunet

\section{Introducción}

La introducción de recursos multimedia en la educación permite a los profesores mejorar sus métodos de enseñanza y evaluación a través de una serie de herramientas que combinan texto, gráficos, audio y vídeo (Barra, 2014), transformando las clases del presente en entornos de aprendizaje ricos, interactivos y centrados en el estudiante (Mahajan, 2012). En el año 2007 se inició en la Universitat Politècnica de València (UPV) el programa "Docencia en Red", con el fin de incentivar al profesorado en la elaboración de materiales multimedia educativos con el fin de incluirlos en Riunet, el repositorio institucional de la UPV (Universitat Politècnica de València, 2013). Entre los materiales que se elaboran en el marco de este programa se incluyen los objetos de aprendizaje mostrados en la Fig. 1. Todos los recursos elaborados se depositan en RiuNet donde se publican en abierto. El programa sin duda ha resultado exitoso puesto que el número de materiales se incrementa anualmente a muy buen ritmo (actualmente, a 29 de marzo de 2017, el repositorio cuenta con un total de 6425 objetos de aprendizaje) y contribuye también a la difusión de la UPV al resto del mundo. Como ejemplo, en el curso 2014-15 se elaboraron en la UPV dentro de este programa 665 materiales educativos realizados por un total de 140 participantes.

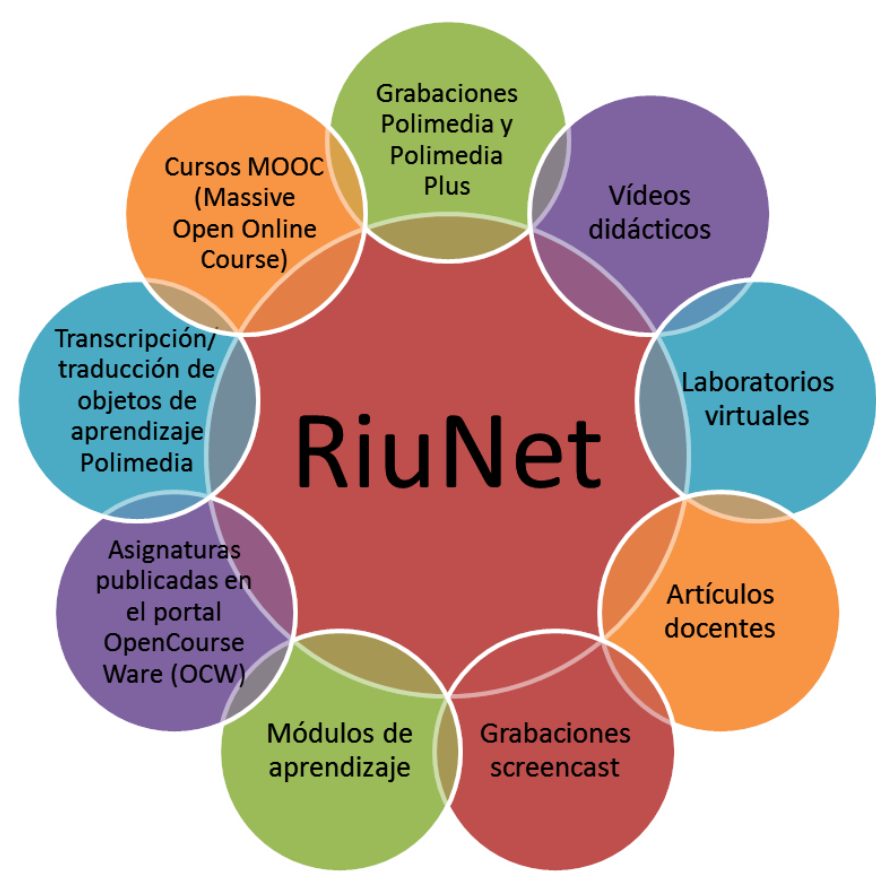

Fig. 1 Objetos de aprendizaje recogidos en el repositorio institucional de la UPV (RiuNet).

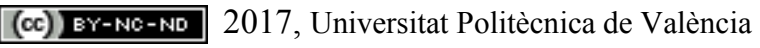

Congreso IN-RED (2017) 
Sin embargo, la utilización de objetos de aprendizaje como recurso didáctico requiere de nuevos enfoques en su diseño, en la metodología docente y en las estrategias de aprendizaje del alumno (Instituto de Ciencias de la Educacion - Área de Sistemas de Información y Comunicaciones, 2008). Como indica Androulla Vassiliou, Comisaria de Educación, Cultura, Multilingüismo y Juventud, "las tecnologías de la información y la comunicación están evolucionando muy rápidamente y las cuestiones relacionadas con su uso en el ámbito educativo resultan cada vez más complejas. Si las herramientas TIC han de convertirse en instrumentos efectivos e integrales en la educación, el seguimiento y la evaluación de este proceso son indispensables" (Agencia Ejecutiva en el Ámbito Educativo, Audiovisual y Cultural, 2011).

En la mayor parte de trabajos relacionados con recursos didácticos, hasta la fecha, dicha evaluación se ha centrado en la satisfacción del alumnado con los objetos de aprendizaje generados para una asignatura concreta (Moltó, 2012), o con la nueva metodología docente soportada por estos recursos didácticos (Jordán, 2014). Sin embargo, no se disponen de datos relativos a las estrategias de aprendizaje desplegadas por el estudiante, que le deben llevar a desarrollar diversas competencias de gestión de la información, organización y planificación, entre otras. Como ejemplo de los aspectos que deberían evaluarse, más allá del impacto particular de la utilización de objetos de aprendizaje en una asignatura determinada, cabría preguntarse cuál es el grado de conocimiento que tienen nuestros alumnos acerca de los recursos multimedia disponibles en el repositorio institucional, si los utilizan para su aprendizaje de forma autónoma o lo hacen únicamente bajo indicación el profesor, si conocen los diferentes tipos de materiales que pueden encontrar en este repositorio y cómo localizarlos, si los valoran adecuadamente, o si les resultan realmente útiles.

Las respuestas a estas cuestiones y la comparación de resultados entre distintas áreas de conocimiento nos van a permitir, además, conocer la conveniencia de elaborar o no otros materiales complementarios, de realizar una mayor difusión entre los alumnos de los recursos disponibles, de aumentar la concienciación del interés que representan estos objetos de aprendizaje para su formación autónoma, determinar aquellos que han resultado más exitosos en cada área de conocimiento y qué aspectos clave han contribuido a su éxito.

Conocedores y participantes de este programa de la UPV "Docencia en Red", en el Equipo de Innovación y Calidad Educativa TASCA (Tools And Strategies for Competences Assessment) nos planteamos una serie de preguntas a las que se pretende dar respuesta en este trabajo, que se enmarca dentro del Proyecto de Innovación y Mejora Educativa PIME/2016/A/029 titulado "Uso e impacto en la docencia universitaria del material didáctico multimedia-UPV". En la Fig. 2 se muestran las preguntas a las que se pretende dar respuesta en este trabajo, en relación al uso e impacto del material didáctico multimedia de la UPV en la docencia universitaria. 
¿Conocen nuestros alumnos los recursos multimedia del repositorio?

¿Utilizan nuestros alumnos dicho recursos?

¿Lo hacen únicamente en el caso de indicarlo el profesor?

¿Conocen realmente todo lo que pueden encontrar en este repositorio?

¿Saben valorarlo?

¿En el caso de utilizar estos materiales, les resultan útiles?

Fig. 2 Preguntas plateadas en el trabajo sobre el uso e impacto del material didáctico multimedia de la UPV en la docencia universitaria.

Las respuestas a estas cuestiones y la comparación de resultados entre áreas de conocimiento nos van a permitir, además, conocer la conveniencia de elaborar o no otros materiales complementarios, de dar más difusión entre los alumnos a los recursos de que disponen, de aumentar la concienciación del interés que representan estos objetos docentes para su formación autónoma, determinar aquellos que han resultado más exitosos en cada área de conocimiento, etc.

En estos momentos nos encontramos en una situación en la que los alumnos que llegan a la Universidad han crecido rodeados de información y tecnología, están acostumbradas a la velocidad y les gusta la innovación (Prensky, 2010). Por otra parte, y en nuestra opinión, están demasiado acostumbrados a que les den todo hecho, por lo que buscan la respuesta fácil sin contrastar, sin buscar información, porque todo tiene que estar en las presentaciones que los profesores depositan en las plataformas docentes (PoliformaT, instancia de SAKAI, en el caso de la UPV). Esto conlleva también a que su atención y concentración en clase sea bastante reducida.

Con esta situación pensamos que es interesante analizar si la inversión que se realiza en la elaboración de todos estos materiales multimedia y que supone un esfuerzo por parte del profesorado se utiliza correctamente. Para que el proceso de enseñanza-aprendizaje sea satisfactorio, los alumnos deben conocer lo que tienen a su disposición, saber valorarlo y darle uso. Los materiales didácticos son herramientas de gran interés para el fomento del aprendizaje autónomo, y los estudios que queremos realizar nos indicarán si están o no infrautilizados. Ayudará también a que el alumno valore la importancia de aprender a aprender para que su proceso de aprendizaje sea lo más eficaz posible, ofreciendo los mejores resultados posibles en base a las tareas encomendadas y al tiempo disponible para hacerles frente. El Espacio Europeo de Educación Superior reconoce este hecho y valora el trabajo del alumno a través de créditos de tipo ECTS, que cuantifican tanto el trabajo presencial del alumno, como el trabajo no presencial que éste debe realizar de forma autónoma. Típicamente la relación entre trabajo presencial y no presencial es de 1:1,5, lo que significa que el trabajo fuera de clase supera al realizado en clase, por lo que conseguir que ese tiempo sea provechoso para el alumno resulta de la máxima importancia. La

(cc) EY-NC-ND 2017, Universitat Politècnica de València

Congreso IN-RED (2017) 
utilización de todos los materiales elaborados en nuestra Universidad y otros que puedan consultar son de gran importancia para conseguir un buen aprendizaje fuera del aula.

Para facilitar el análisis de la situación actual, el resto del artículo se articula de acuerdo a la siguiente estructura. La Sección 2 presenta los diferentes hitos planteados en el proyecto. La Sección 3 detalla el contexto y los aspectos técnicos de la innovación realizada. La Sección 4 analiza los resultados obtenidos y la Sección 5 resume las contribuciones realizadas y el trabajo futuro a abordar.

\section{Objetivos}

El objetivo principal del trabajo es contestar a las preguntas planteadas en la Fig.2, para así conocer el uso que se le está dando por parte del alumnado de los recursos multimedia que se elaboran en la UPV y su opinión al respecto. Estos recursos, depositados en el repositorio Riunet de la UPV, son sin duda herramientas de gran valor para el aprendizaje de los alumnos. Los profesores están contribuyendo a que cada curso el número de recursos aumente y evaluar su utilización por parte del alumnado pensamos que es de gran interés.

Los hitos que se han planteado son:

- Medir el grado de conocimiento que los alumnos tienen de los recursos multimedia UPV.

- Evaluar la utilización de los recursos en el contexto de las asignaturas que imparten los profesores del grupo TASCA por parte de nuestro alumnado.

- Evaluar la utilización de recursos multimedia de los alumnos en otras asignaturas.

- Conocer el grado de satisfacción de los alumnos con los recursos utilizados y sus propuestas de mejora.

- Comparar resultados y definir el planteamiento de nuevas actuaciones relacionadas: difusión, preparación de nuevos materiales, etc.

En esta comunicación se muestran los primeros datos recopilados en diferentes asignaturas y titulaciones de la Universitat Politècnica de València, durante el perimer semestre del curso 2016/2017. Los datos has sido recogidos a través de un cuestionario web realizado a los alumnos y se han extraído las primeras conclusiones.

\section{Desarrollo de la innovación}

Con el fin de conseguir los objetivos planteados, se ha elaborado un cuestionario a través de Google Forms para obtener información de los materiales didácticos multimedia conocidos y utilizados por alumnos en 6 asignaturas (Arquitecturas Telemáticas, Informática de Gestión, Arquitectura e ingeniería de computadores, Cultivo in vitro y transformación genética de plantas, Mejora Genética para la producción vegetal, Sistemas Informáticos en Red Seguros y Confiables) de 6 titulaciones diferentes (Grado en Ingeniería de Tecnologías y Servicios de Telecomunicación, Grado en Turismo, Grado en Ingeniería Informática, Grado en Biotecnología, Grado en Ingeniería Agroalimentaria y del Medio Rural, y Máster Universitario en Ingeniería de Computadores y Redes, respectivamente).

El cuestionario básico elaborado se muestra en la Fig. 3.

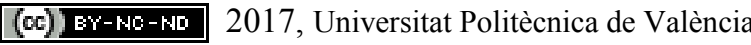




\section{Materiales didácticos multimedia}

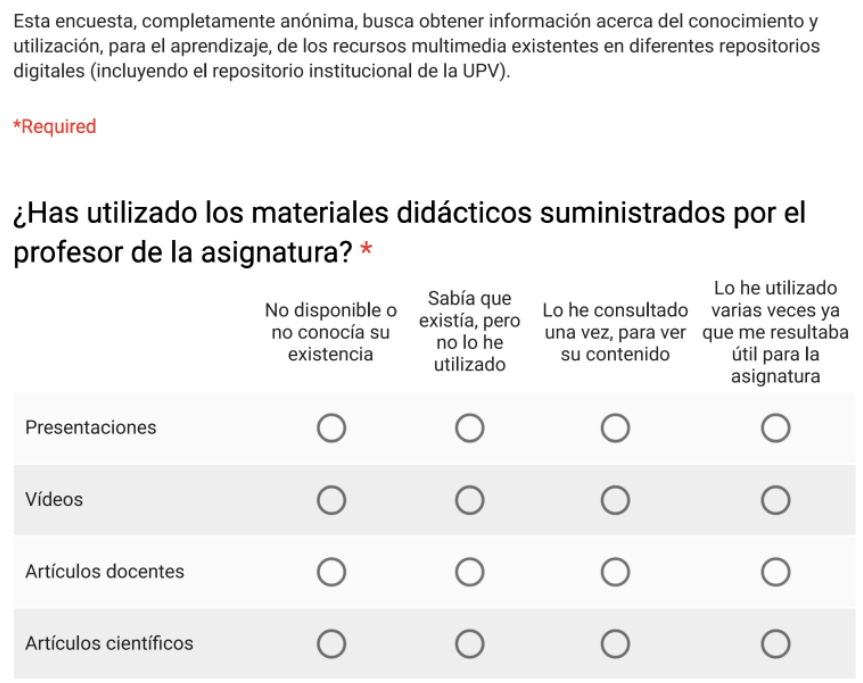

¿Conoces y/o utilizas para el aprendizaje los siguientes repositorios de recusos didácticos multimedia? *

\begin{tabular}{|c|c|c|c|c|}
\hline & $\begin{array}{c}\text { Es la } \\
\text { primera } \\
\text { vez que lo } \\
\text { oigo }\end{array}$ & $\begin{array}{c}\text { Lo } \\
\text { conozco, } \\
\text { pero no lo } \\
\text { he } \\
\text { utilizado } \\
\text { nunca }\end{array}$ & $\begin{array}{l}\text { Lo he } \\
\text { utilizado } \\
\text { alguna vez, } \\
\text { de forma } \\
\text { esporádica }\end{array}$ & $\begin{array}{l}\text { Lo he } \\
\text { utilizado en } \\
\text { diversas } \\
\text { ocasiones y } \\
\text { asignaturas }\end{array}$ \\
\hline \multicolumn{5}{|l|}{ RiuNet (https://riunet.upv.es/) } \\
\hline \multicolumn{5}{|l|}{ mediaUPV (https://media.upv.es/) } \\
\hline \multicolumn{5}{|l|}{ PoliBuscador (http://polibuscador.upv.es) } \\
\hline \multicolumn{5}{|l|}{$\begin{array}{l}\text { poli[OCW] } \\
\text { (http://www.upv.es/contenidos/OCW/) }\end{array}$} \\
\hline \multicolumn{5}{|l|}{ UPV[X] (http://edx.upv.es/) } \\
\hline \multicolumn{5}{|l|}{ Coursera (https://www.coursera.org/) } \\
\hline \multicolumn{5}{|l|}{ edX (https://www.edx.org/) } \\
\hline \multicolumn{5}{|l|}{$\begin{array}{l}\text { Open Education Consortium } \\
\text { (http://www.oeconsortium.org/) }\end{array}$} \\
\hline YouTube (https://www.youtube.com/) & & & & \\
\hline
\end{tabular}

Indica otros repositorios de recursos didácticos multimedia que conozcas

Your answer

Fig. 3 Cuestionario sobre el conocimiento y uso, por parte de los alumnos, del material didáctico multimedia.

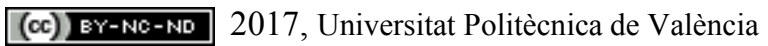


Para aprovechar toda la potencia de Google Forms, y reducir la complejidad del cuestionario, se ha creado una plantilla básica que se ha replicado para cada asignatura. Las respuestas proporcionadas por los alumnos se recogen en una hoja de cálculo diferente para cada cuestionario (asignatura), por lo que es muy cómodo para realizar un análisis de estos datos en base a las asignaturas particulares, los cursos en los que se imparten, o en conjunto.

\section{Resultados}

Hay que destacar que, por el momento, únicamente disponemos de los datos recogidos en asignaturas impartidas durante el primer cuatrimestre del curso 2016-2017, por lo que deberemos esperar al final del presente curso para poder obtener datos del segundo cuatrimestre $\mathrm{y}$, por tanto, más representativos del conjunto de alumnos de la UPV. Sin embargo, el análisis de los datos datos recogidos permite obtener una primera idea acerca del conocimiento y uso de los repositorios de material multimedia existentes.

En primer lugar, cabe indicar que un total de 101 alumnos respondió a la encuesta en las 6 asignaturas consideradas, siendo la asignatura de máster la que menor participación registró (únicamente 3 alumnos) y la del Grado en Turismo la que mayor número de alumnos participó (42). La distribución de alumnos por asignatura se muestra en la Fig. 4.

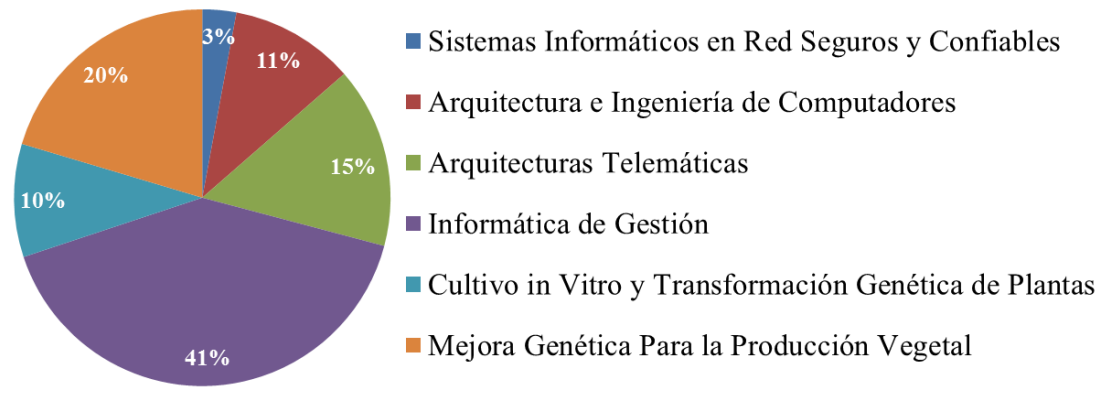

Fig. 4 Distribución en asignaturas de los alumnos que participaron en el cuestionario.

En cuanto a la distribución de alumnos por curso (ver Fig. 5), cabe destacar que para cada curso disponemos de información relativa a una única asignatura (dos en el caso de cuarto curso), debido a la distribución de la carga docente del conjunto de profesores participante en este estudio. Asimismo, la participación de los alumnos de máster ha sido testimonial (un 3\% del total, correspondiente únicamente a 3 alumnos), por lo que los datos obtenidos en este nivel no pueden considerarse representativos del conjunto de estudiantes de máster, aunque se tendrán en cuenta para el análisis global de los datos. 


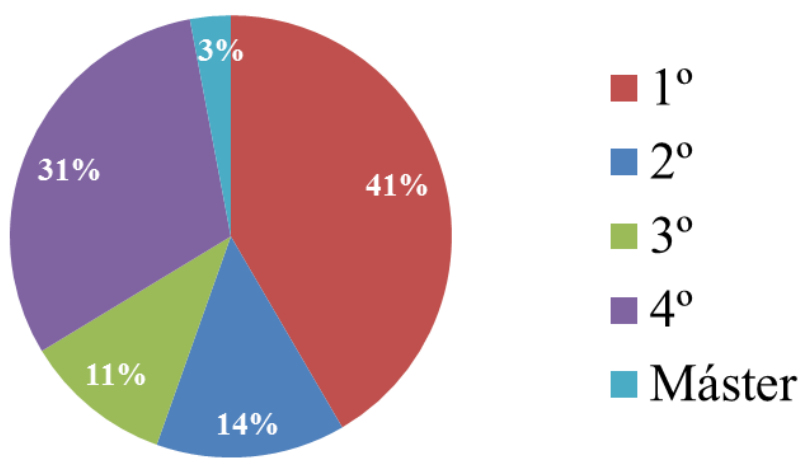

Fig. 5 Distribución en cursos de los alumnos que participaron en el cuestionario.

A continuación se analizarán los datos obtenidos en las dos cuestiones planteadas desde la perspectiva del curso del alumnado participante y en su conjunto.

\subsection{Utilización de los materiales didácticos suministrados por el profesor}

Esta sección analiza el uso que los alumnos declaran haber hecho de los materiales proporcionados por el profesor, principalmente a través del LMS de la UPV (PoliformaT). La distribución del uso que hacen los alumnos de este material, agrupados por cursos, se muestra en la Fig. 6.

En primer lugar, cabe destacar el uso masivo que se hace de las presentaciones (transparencias, diapositivas) que suele utilizar el profesor durante sus clases y que deja disponibles para el alumnado. Cerca del $90 \%$ de los alumnos hacen uso prácticamente exclusivo de este material, un $50 \%$ hace uso de los vídeos indicados, y prácticamente ningún alumno, salvo honrosas excepciones, consulta otros materiales suministrado. Es especialmente preocupante que alrededor del $30 \%$ de los alumnos declare ni siquiera conocer la existencia de este material.

Esta dependencia de las presentaciones del profesor se relaja algo en cursos superiores (alrededor de un $70 \%$ de los alumnos la siguen consultando de manera asidua), ya que los alumnos alcanzan mayor independencia (aprenden a aprender) y buscan consultar nuevos materiales para entender y dominar las materias cursadas. Al menos la mitad del alumnado en estos cursos declara consultar, aunque no demanera asidua, el material complementario en forma de artículos docentes o de investigación. Es significativo el gran uso que se hace de los vídeos, particularmente en cuatro curso, posiblemente debido al carácter práctico de las asignaturas ofertadas como optativas en estos cursos y que suelen proporcionar material audiovisual para reforzar el dominio de las herramientas utilizadas a nivel profesional.

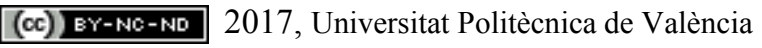




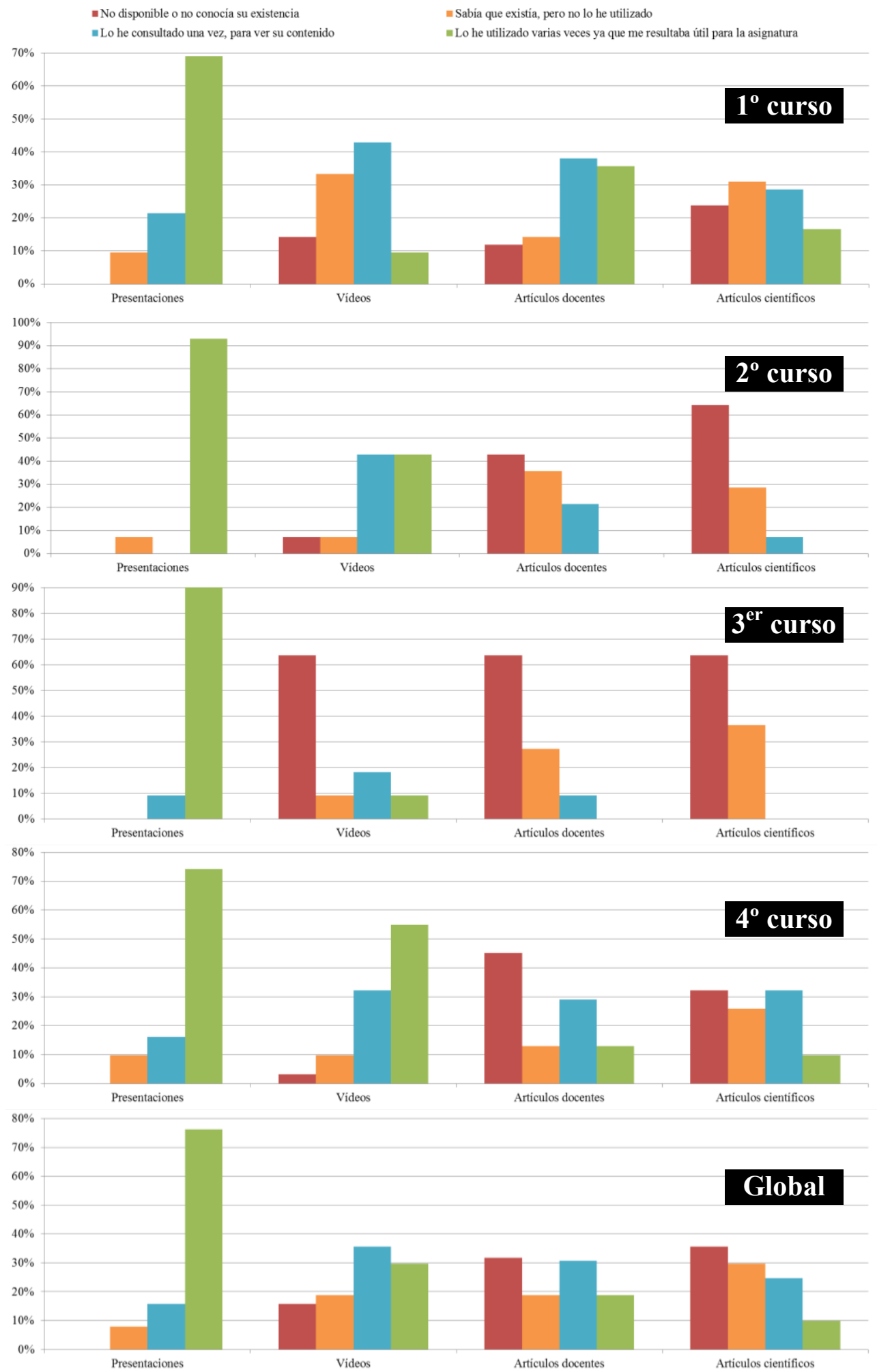

Fig. 6 Conocimiento y utilización por parte del alumno, agrupado por cursos, del material proporcionado por el profesor (presentaciones, vídeos, artículos docentes y artículos científicos). 


\subsection{Conocimiento y utilización de repositorios de materiales didácticos}

En esta sección se analiza el conocimiento y utilización que declaran hacer o haber hecho los alumnos de los diversos repositorios de materiales didácticos existentes, tanto los institucionales de la UPV (Riunet, por ejemplo) como otros de carácter abierto. La distribución del conocimiento y uso declarado, agrupado por cursos, se muestra en la Fig. 7.

En primer lugar, cabe destacar el éxito abrumador de YouTube como canal de distribución de vídeos, donde los alumnos buscan información relativa a las asignaturas que están cursando. En cursos superiores, aunque el porcentaje de alumnos que lo utilizan como vehículo principal para la búqueda de material complementario se reduce ligeramente, continúa situándose por encima del $70 \%$.

En general, los diversos repositorios y buscadores de materiales didácticos son unos grandes desconocidos para los alumnos de la UPV. A nivel institucional, al menos el 50\% de los alumnos ha utilizado alguna vez PoliBuscador, para la localización de todo tipo de recursos didácticos, y mediaUPV, para la localización y visualización de recusos didácticos en formato vídeo. Curiosamente el repositorio institucional de recursos, Riunet, está completamente infrautilizado hasta que los alumnos alcanzan cursos superiores y tratan de localizar recursos adicionales a los proporcionados directamente por el profesorado.

Las grandes plataformas que ofrecen MOOC (Massive Open Online Courses) tampoco tienen gran aceptación entre nuestro alumnado. Únicamente UPV[X], la plataforma MOOC institucional, presenta cierto reconocimiento por parte del alumnado (alrededor del $30 \%$ lo ha utilizado alguna vez).

Hay que remarcar que los resultados obtenidos en segundo curso, que indican un mayor conocimiento de los repositorios existentes que en niveles superiores, se corresponden con una única asignatura. Será preciso analizar los datos recogidos al finalizar el segundo cuatrimestre del curso para poder hacer determinar si estos mejores resultados se deben (muy posiblemente) a la labor realizada por el profesorado en dicha asignatura (o asignatura previas), o a una evolución de la tipología y método de estudio del alumnado.

(cc) EY-NC-ND 2017, Universitat Politècnica de València 


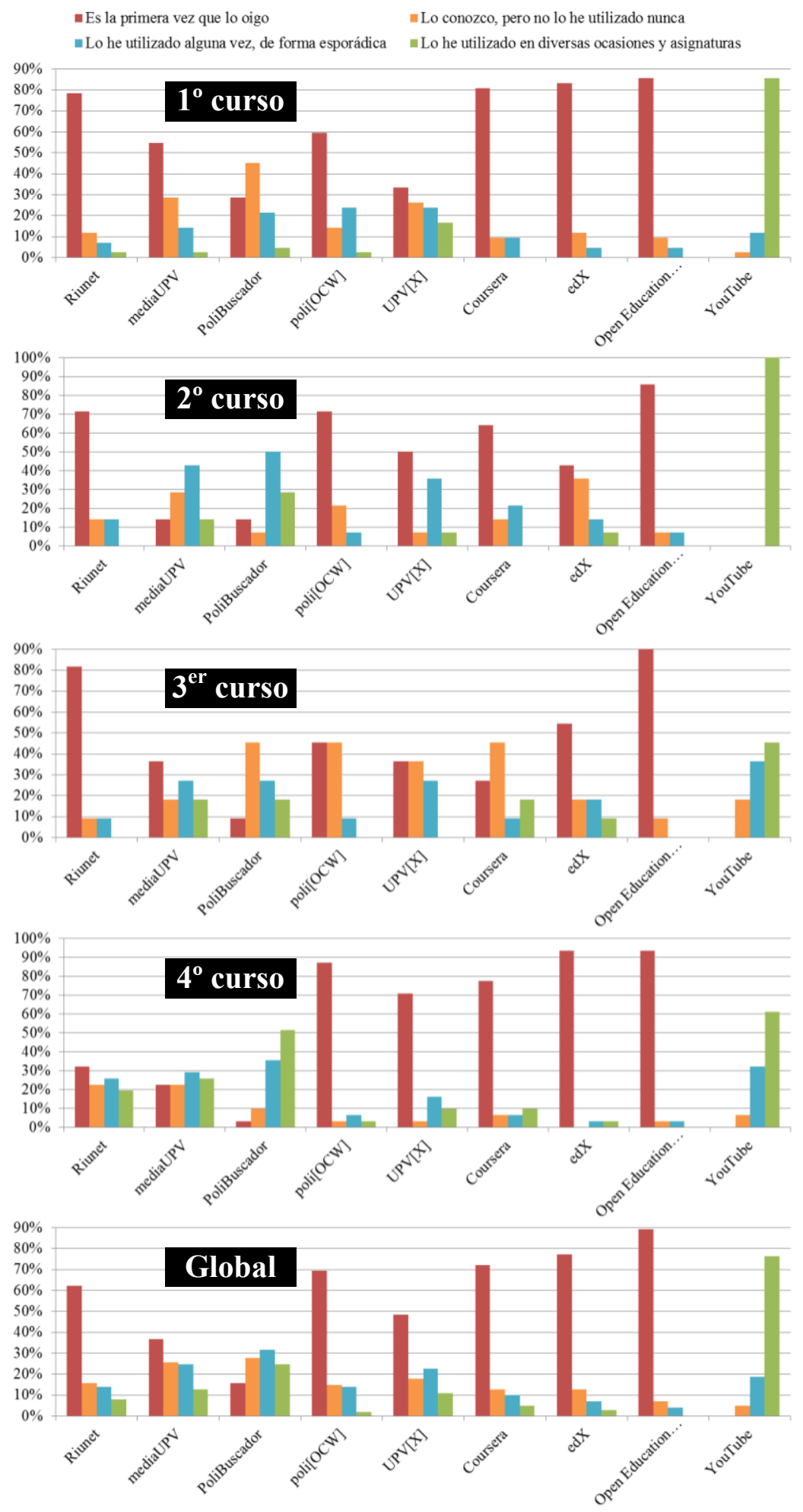

Fig. 7 Conocimiento y utilización por parte del alumno, agrupado por cursos, de repositorios de materiales didácticos.

(cc)) BY-NC-ND 2017, Universitat Politècnica de València Congreso In-Red (2017) 


\section{Conclusiones}

A pesar de encontrarnos en la fases iniciales del proyecto y, por tanto, disponer únicamente de resultados parciales correspondientes a un único cuatrimestre del curso académico, el análisis de los datos recogidos muestra ciertas tendencias generales y, en general, preocupantes.

Las universidades en general, y la UPV en particular, están realizando un esfuerzo enorme para poner a disposición del alumnado multitud de recursos didácticos a través de diferentes repositorios y de herramientas para localizar los recursos deseados en los mismos. Sin embargo, esta iniciativa puede no estar dando los frutos deseados, ya que el conocimiento que tienen los alumnos de estos recursos es mínimo, y únicamente en últimos cursos hacen cierto uso de los materiales disponibles.

Es por tanto, labor de los profesores involucrados en las diferentes asignaturas, promover la utilización de los buscadores y repositorios entre los alumnos para que desarrollen su autonomía y las competencias de búsqueda y gestión de la información y de aprender a aprender. De hecho, la mayor parte de los alumnos únicamente busca información en las presentaciones que el profesor deja disponibles en el LMS o, para información de tipo práctico, a través de YouTube. Sería necesario realizar actividades en las que los alumnos tuvieran que localizar la información complementaria necesaria a través de estos repositorios, para favorecer su conocimiento y uso, y el desarrollo de las habilidades correspondientes por parte del alumnado.

El trabajo futuro a desplegar durante la duración de este proyecto consta de las siguientes fases:

- Recogida y análisis de los datos de las asignaturas impartidas durante el segundo cuatrimestre del curso actual.

- Verificación de los datos recogidos en las encuestas a través de la comprobación de las estadísticas de uso, suministradas por el LMS de la UPV, de los diferentes recursos proporcionados en cada asignatura.

- Comprobación de las estadísticas de uso, proporcionadas por Riunet, acerca de los diferentes recursos disponibles en el repositorio institucional de la UPV. Así, podremos determinar el uso que se hace de estos recursos, distinguiendo aquellos accesos que se realizan localmente (Valencia, España) de los que se realizan a nivel internacional (otros países). Por ejemplo, muchos accesos al material multimedia en español se realiza desde países latinoamericanos, mientras que el alumnado propio de la UPV tiende a ignorar este material. Si esta hipótesis se corrobora, deberán definirse políticas para fomentar el uso interno de estos materiales.

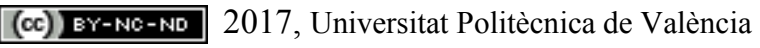




\section{Referencias}

AGENCIA EJECUTIVA EN EL ÁMBITO EDUCATIVO, AUDIOVISUAL Y CULTURAL (EACEA P9 EURYDICE). (2011). Cifras clave sobre el uso de las TIC para el aprendizaje y la innovación en los centros escolares de Europa 2011. Comisión Europea.

BARRA, E. (2014). Nuevos métodos y herramientas para la creación y utilización de recursos multimedia en la educación. Tesis Doctoral. Valencia: Universidad Politécnica de Madrid.

INSTITUTO DE CIENCIAS DE LA EDUCACION - ÁREA DE SISTEMAS DE INFORMACIÓN Y COMUNICACIONES. (2008). Los objetos de aprendizaje como recurso para la docencia universitaria: criterios para su elaboración. Valencia: Universitat Politècnica de València.

JORDAN, C., PEREZ, M. J., SANABRIA, E. (2014). Investigación del impacto en un aula de matemáticas al utilizar flip education en Pensamiento Matemático, vol. 4, no. 2, p. 9-22.

MAHAJAN G. (2012). "Multimedia in Teacher Education: Perceptions \& Uses" en Journal of Education and Practice, vol. 3, issue 1, p. 5-13.

MOLTÓ, G. (2012) "Producción y Uso de Vídeo-Ejercicios Didácticos en Asignaturas de Programación". En: XVIII Jornadas de Enseñanza Universitaria de la Informática. 255-262.

PRENSKY, M. (2010). Nativos e Inmigrantes Digitales. Cuadernos SEK 2.0.

THE COUNCIL OF EUROPE INTERNET PORTAL, (2013). Bologna for Pedestrians. < http://www.coe.int/t/dg4/highereducation/EHEA2010/BolognaPedestrians_en.asp\#P132_13851> [Consulta: 29 de marzo de 2017]

UNIVERSITAT POLITÈCNICA DE VALÈNCIA (2013). RiuNet, Repositorio Institucional UPV. < https://riunet.upv.es> [Consulta: 29 de marzo de 2017] 


\title{
Desarrollo de una actividad experiencial para la enseñanza de estadística.
}

\section{Ángel Peiró-Signes ${ }^{\mathrm{a}}$, Oscar Trull-Domínguez ${ }^{\mathrm{b}}$ y Marival Segarra-Oña ${ }^{\mathrm{c}}$}

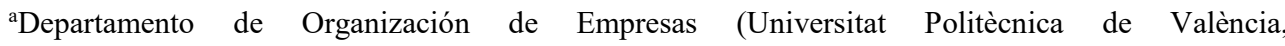
anpeisig@omp.upv.es), bDepartamento de Estadística e Investigación Operativa Aplicada y Calidad (Universitat Politècnica de València, otrull@eio.upv.es) y ${ }^{\mathrm{c} D e p a r t a m e n t o ~ d e ~ O r g a n i z a c i o ́ n ~ d e ~ E m p r e s a s ~}$ (Universitat Politècnica de València, maseo@omp.upv.es).

\begin{abstract}
This paper describes how to apply an experiential learning activity to show the basis of statistical concepts applied in the industry. The activity simulates a real application of a packaging line in an randomly selected production period. The activity allows the students to share an experience to build on top further superior leanings. This paper develops the experience with the instructions to garatee its application and efficacy in the class session. Preliminary results on the preceptions of the students about the contents treated on the session are encouraging.
\end{abstract}

Keywords: experiential learning, critical thinking, simulation, statistics

\begin{abstract}
Resumen
Este artículo describe como aplicar una actividad de aprendizaje experiencial para ilustrar las bases de los conceptos estadísticos aplicados en la industria. La actividad simula una aplicación real de una linea productiva de empaquetado en un periodo de tiempo aleatorio de producción. La actividad permite a los alumnos compartir una experiencia que sobre los que se puede construir aprendizajes de nivel superior. Este artículo desarrolla la experiencia con instrucciones para garantizar la correcta aplicación y eficacia en la sesión de aula. Los resultados preliminares de la percepción de los estudiantes sobre los contenidos son esperanzadores.
\end{abstract}

Palabras clave: Aprendizaje experiencial, pensamiento crítico, simulación, estadística.

\section{Introducción}

A la hora de planificar los profesores tienen en mente varios aspectos. Por una parte, están los aspectos determinados por los condicionantes de los planes de estudios, es decir, contenidos y competencias que deben trabajarse. Por otro lado, encontramos otros aspectos relacionados con el desarrollo del curso como la participación, la motivación del alumnado o la capacidad de las actividades propuestas para conseguir los objetivos planteados. 
Este artículo presenta una actividad de aprendizaje experiencial para ilustrar algunos de los conceptos fundamentales de la estadística. El objetivo central de esta experiencia es exponer a los alumnos a una serie de aspectos de estadística de gran aplicación para la gestión de los procesos en la industria. De forma más concreta, los conceptos de media, desviación típica, variabilidad, número de defectos y capacidad de los procesos. La experiencia nos servirá de iniciador para explorar conceptos más complejos de tipo estadístico que pueden aplicarse en el ámbito industrial.

\section{Objetivos}

Según LaForge y Busing (1998), toda actividad de aprendizaje experiencial sigue una serie de pasos que van desde la fase de planificación, pasando por las fases de introducción y ejecución de la actividad, para finalizar en la fase de retroalimentación.

Este artículo tiene como objetivo desarrollar y testar una actividad de aprendizaje experiencial perfilando todas las fases de la experiencia. La fase de planificación es crucial para el éxito de la actividad. Comprende el establecimiento de objetivos y la determinación de las bases, normas y recursos necesarios para desarrollar la actividad, se determina la forma de gestionar el desarrollo de la actividad y la fase final de discusión y retroalimentación.

La dificultad a la que se enfrenta el profesor a la hora de diseñar tiene que ver con la capacidad de crear una actividad, que sin llegar a la complejidad de la realidad productiva, refleje de forma relevante los aspectos importantes que se quieren desarrollar en el curso (Halpern y Hakel, 2003). Asimismo, la actividad debe permitir a los estudiantes enfrentarse a situaciones que requieran tomar decisiones durante el proceso. Buscamos también al final de la experiencia un proceso de reflexión sobre aquellos aspectos que han emergido durante la actividad. De esta forma, mediante la reflexión crítica se consigue una mayor significancia del aprendizaje (Kolb, 1984; Wheeler y McLeod, 2002).

En definitiva, esta actividad pretende ir más allá del mero conocimiento de algunos conceptos básicos de estadística y del análisis de datos. Enlaza la estadística con situaciones del mundo productivo industrial.

Por otro lado, uno de los aspectos más complicados de la tarea docente tiene que ver con la motivación del alumno o, al menos, la no desmotivación del mismo. Para mantener el interés del alumno, los profesores utilizan distintas estrategias que normalmente involucran de forma más activa al alumno en las sesiones. Las actividades de aprendizaje experiencial han demostrado su capacidad y eficacia a la hora de dinamizar el trabajo del aula (Peiro-Signes and Segarra-Oña, 2015), incluso en distintos niveles educativos (Peiro-Signes, 2015). La actividad de aprendizaje experiencial presentada en este artículo pretende también mantener interés y participación del alumno en la sesión de aula y, simultáneamente, trabajar algunas capacidades de tipo transversal que son de gran importancia para el desarrollo de los futuros graduados.

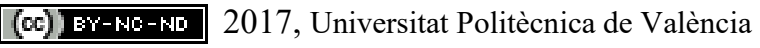




\section{Desarrollo de la innovación.}

La primera fase del desarrollo es la planificación. Para poder planificar debemos establecer claramente cuales van a ser los objetivos de aprendizaje. En un temario típico de estadística podemos encontrar objetivos como: identificar, conocer, representar y describir distribuciones de variables aleatorias - tanto discretas como continuas - determinando sus parámetros de posición, dispersión y forma; realizar inferencias sobre la población de distribuciones y aplicarlos al control de calidad; etc.

Un aspecto clave a la hora de planificar es establecer la conexión entre los objetivos de aprendizaje del asignatura y la actividad. Esta conexión es lo que va a permitir la percepción por parte del alumno de la actividad como útil en lugar de una pérdida de tiempo.

Esta actividad está ligada con los objetivos antes comentados de: conocer conceptos básicos de estadística, reconocer su aplicación a situaciones reales, comprender la importancia del concepto de variabilidad y sus consecuencias, y analizar la capacidad de los procesos industriales. Consiste en la simulación de un proceso industrial de envasado en bolsas. Los alumnos son divididos en grupos que simularán este proceso industrial. Después de una breve introducción donde se dan las instrucciones, cada grupo, con los materiales y recursos establecidos, deberá llenar bolsas de plástico. Tras unos minutos de producción, la producción para y se inicia la fase de reflexión y discusión. Para ello, se plantean una serie de preguntas a los grupos para estimular la discusión acerca de los aspectos que han ocurrido durante la experiencia. Finalmente, el facilitador de la actividad realiza una recapitulación de lo ocurrido para ayudar a los estudiantes a entender los conceptos de estadística involucrados en una actividad típica industrial, el uso que se puede dar a los datos y análisis realizados y las posibles formas de mejorar los resultados a partir de dicho análisis. Esta actividad está planteada para una duración de entre 40 y 50 minutos, dependiendo en el nivel del curso.

\section{a. Introducción}

Para preparar la actividad es importante crear cierta curiosidad en el alumnado. Para ello, con anterioridad a la entrada de los alumnos, el facilitador debería de tener preparada el aula con grupos de mesas y todos los materiales que cada grupo va a utilizar. A la entrada de los alumnos en el aula, atendiendo al tamaño de la clase, el instructor formará grupos de tres a cinco alumnos. Los grupos deben formarse rápidamente para centrar la atención en la actividad. Una vez los alumnos están divididos en grupos y situados en sus mesas el instructor debe de establecer las reglas del ejercicio.

\section{b. Desarrollo}

Cada grupo dispondrá de una caja con alubias blancas donde selectivamente se han puesto algunas alubias pintas, un vaso donde se ha realizado una marca a lo largo de todo su perímetro para marcar hasta donde hay que llenar cada bolsa, bolsitas transparentes de plástico, una báscula electrónica, una hoja de toma de datos y un bolígrafo.

El proceso de producción comienza una vez el instructor ha distribuido a los equipos en las mesas y ha dado las instrucciones. Cada equipo tiene entre 5 y 10 minutos para formar paquetes de alubias blancas mediante un medidor volumétrico (un vaso). El tiempo exacto se 
ajusta para conseguir que todos los grupos dispongan de, al menos, 50 datos. Cada grupo debe de llenar el vaso hasta la marca indicada para conseguir la cantidad de alubias que debe ir en cada bolsa. Cada bolsa medida será pesada en una báscula y se anotará su peso exacto con dos decimales en la hoja de recogida de datos. Para poner un poco de presión, similar al que puede haber en el mundo industrial, mediremos también la productividad de los equipos. Cada minuto que pase durante la actividad será marcado por el instructor y los responsables de cada equipo deberán anotar en la hoja de datos el número de bolsas elaboradas hasta el momento. Este apartado nos permitirá posteriormente enriquecer el debate generado confrontando los conceptos de productividad y calidad. Asimismo, dos de los equipos recibirán respectivamente y sin saberlo un vaso con la marca de volumen un poco por debajo del resto y otro con la línea un poco por encima. De esta manera, las medias de datos de estos equipos serán respectivamente inferiores y superiores a la del resto.

\section{c. Discusión y debate}

Al finalizar el periodo marcado, se informa a los alumnos de que el tiempo se ha acabado y se les pedirá que paren inmediatamente de producir más bolsas. En este momento empieza la fase de análisis de los datos y retroalimentación de la experiencia. En esta fase, se recomienda a los alumnos utilizar el ordenador o algún tipo de hoja de cálculo. La primera tarea será calcular los parámetros de centrado y dispersión: media, mediana, rango y desviación típica sobre el peso de las bolsas fabricadas. Los alumnos a partir de los datos deberán también realizar un histograma que les permita ver la distribución de datos. El instructor recoge los datos globales de todos los equipos e incita a comparar los resultados de cada uno de los grupos.

Preguntas como ¿Por qué los datos que obtenemos no son iguales? ¿Qué elementos determinan la distribución de datos en el proceso? ¿Qué equipo produce mejor?¿Qué parámetro tenemos que ver para evaluar la calidad de un proceso productivo?¿Cómo puedo variar la media en el proceso? ¿Cómo puedo disminuir la variabilidad del proceso?, son preguntas que pueden dirigir el debate hacia algunos de los aspectos clave que se quieren trabajar en la experiencia: ¿Qué causa la variabilidad? ¿Cómo mejorar la variabilidad de los procesos? ¿Cómo mejorar los resultados de un proceso sin mejorar la variabilidad? ¿Qué relación tiene la variabilidad con el consumo de materiales, las pérdidas o los beneficios en un proceso?

Posteriormente se introduce un límite de peso inferior para las bolsas. Las bolsas deben de pesar, al menos, $\mathrm{x}$ gramos para ser aceptables por nuestro cliente. De forma que los alumnos tienen que calcular que porcentaje de bolsas se encontrarían fuera del peso establecido y proponer medidas para su reducción y/o eliminación. A partir de unos datos sobre el coste de mano de obra, la productividad obtenida, el coste de la bolsa, horas de trabajo,... los alumnos deberán calcular el coste anual de las bolsas que no llegan al peso establecido. De forma similar, a partir de los costes de producción (materia prima, bolsa y mano de obra), tendrán que determinar a partir de qué sobrepeso convendría romper la bolsa para realizar una bolsa nueva.

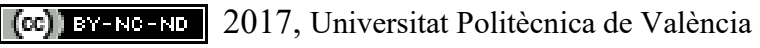


Esta fase del análisis permite a los alumnos aplicar las herramientas estadísticas para tomar decisiones en entornos industriales muy cercanos a la realidad. Para estimular la discusión el instructor puede plantear preguntas como: ¿por qué debe haber un límite de peso inferior? ¿si no existiera ese límite que problemas y podríamos tener con nuestros clientes? ¿qué repercusión tiene la variabilidad en la calidad del producto? ¿y en el coste?.

Finalmente, en la tercera parte del análisis, los alumnos tienen que buscar en las bolsas cuantas judías pintas tienen. Las judías pintas representan defectos. Si en una bolsa hay más de 3 defectos se considera que la bolsa es defectuosa. Este apartado del ejercicio nos permite diferenciar el concepto de defecto y pieza defectuosa, valorar el porcentaje aproximado de defectos en el producto y la probabilidad de bolsas defectuosas que fabricaremos. Preguntas como ¿qué diferencia hay entre defecto y bolsa defectuosa? ¿Qué implicación tiene cada uno de ellos desde el punto de vista del cliente? ¿cómo se puede reducir el número de defectos? ¿Cómo se puede reducir el número de piezas defectuosas?, pueden estimular el debate y la discusión acerca de estos aspectos.

Después de la experiencia los estudiantes deberían de reconocer cómo los conceptos y herramientas estadísticas facilitan la toma de decisiones en la industria, evaluar el impacto cuantitativo y económico de la variabilidad de un proceso o analizar críticamente cuáles pueden ser sus causas y posibles soluciones.

Al final del periodo de retroalimentación y debate, el instructor puede empezar una pequeña lección magistral de los conceptos experimentados de forma más estructurada, que permita a los estudiantes pensar de una forma más profunda sobre lo vivido en la experiencia y llegar a niveles superiores de aprendizaje (Meyers, 1986; Smith, 2003).

\section{Resultados}

Este artículo plantea la utilización de una actividad de aprendizaje experiencial en el aula. El éxito o fracaso de la actividad deberá evaluarse en forma de resultados. Para ello se debe realizar una evaluación de los resultados al final del curso y después de varias aplicaciones. El análisis de los resultados debe ser complementado al final del curso con una evaluación del alcance de los objetivos propuestos tras introducir actividades experienciales adicionales. Para una evaluación preliminar, planteamos una pequeña encuesta mediante una escala a Likert 1 a 5 donde 1 corresponde a totalmente en desacuerdo y 5 a totalmente de acuerdo. Las preguntas de la Figura 1 se plantean en los términos "Si el examen se realizara hoy ¿crees que recibirías la máxima nota en las preguntas siguientes?". Este test permite al instructor evaluar de manera sencilla el impacto del ejercicio y determinar si son necesarios ajustes para conseguir los objetivos propuestos. Los resultados preliminares sobre la primera experiencia (ver figura 1) en un grupo de 25 alumnos son esperanzadores. Los alumnos perciben que su conocimiento sobre los conceptos trabajados en la experiencia son lo bastante buenos como para responder correctamente a las preguntas planteadas en un hipotético examen. Estos resultados, aun conociendo de sus limitaciones, parecen indicar que la experiencia tiene un gran potencial para producir aprendizajes significativos en los estudiantes.

(c)) EY-NC-ND 2017, Universitat Politècnica de València 
Explica la diferencia entre defecto y pieza defectuosa

Explica cuando un proceso es capaz y sobre qué elementos deberíamos de trabajar para conseguir que fuera capaz.

Explica cómo puede afectar la variabilidad a la calidad de un producto.

Explica por qué existe variabilidad en los procesos. ¿Qué concepto estadístico está relacionado con la variabilidad?

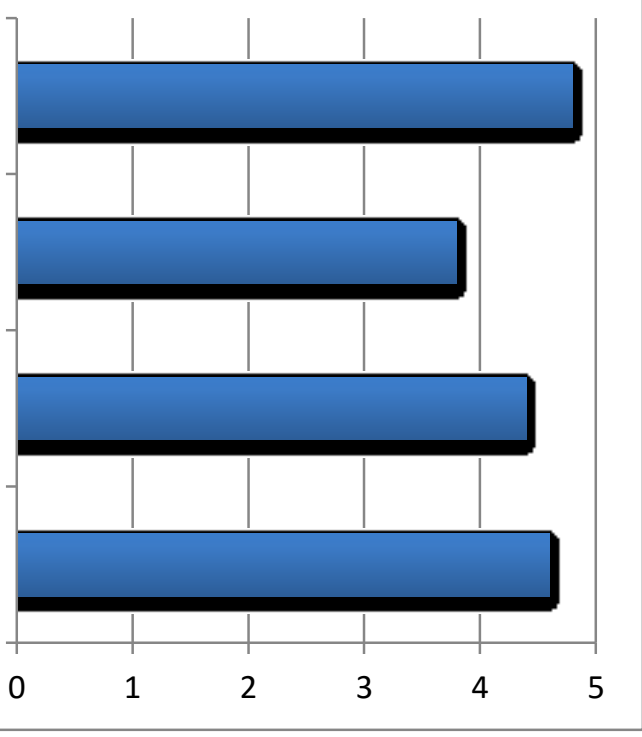

Fig. 1 Resultados medios sobre el cuestionario de evaluación de la actividad.

\section{Conclusiones}

Este artículo presenta una actividad de aprendizaje experiencial diseñada para la enseñanza de conceptos estadísticos. La actividad pretende ayudar a conseguir un aprendizaje más significativo y relacionado con las actividades futuras de los egresados de asignaturas de grado en el área industrial y de ingeniería. Esta experiencia cubre aspectos fundamentales de la recogida, cálculo y presentación de datos estadísticos así como, del análisis y evaluación para la mejora en la toma de decisiones. En este artículo se muestran las numerosas posibilidades que tiene la experiencia para relacionar conceptos y visualizar aspectos complejos de los entornos productivos que sería difícil cubrir mediante metodologías docentes tradicionales. Adicionalmente, la percepción de los alumnos sobre la retención de los conceptos tratado es elevada tras la experiencia lo que anima a utilizar esta metodología frente a otras tradicionales que aparentemente parecen menos eficaces.

\section{Agradecimientos}

Este trabajo forma parte del estudio desarrollado por el Grupo de Aprendizaje Experiencial (GAE) creado como EICE en la Universidad Politécnica de Valencia (UPV). Los autores desean agradecer a la UPV por el apoyo a través del PIME 2017 " Adaptación y desarrollo de aprendizajes experienciales al contexto de las asignaturas ".

\section{Referencias}

HALPERN, D. y HAKEL, M. (2003). "Applying the science of learning”. Change, vol. 35, issue 4, p. 36-41. 
KOLB, D. (1984). Experiential learning: Experience as the source of learning and development.

Englewood Cliffs, NJ: Prentice Hall.

LAFORGE, R. y BUSING, M. (1998). "The use of industrial software to create experiential learning activities in operations management courses". Production and Operations Management, vol. 7, issue 3, p. 325-334.

MEYERS, C. (1986). Teaching students to think critically. San Francisco, CA: Jossey-Bass.

PEIRO-SIGNES, A., SEGARRA-OÑA, M., DE MIGUEL-MOLINA, M., J. ALBORS-GARRIGÓS, J. y DE-MIGUEL-MOLINA B. (2015). "The experiential learning activity: benefits and difficulties in real learning environments". Proceedings of ICERI2015 Conference, p. 7231-7237.

PEIRO-SIGNES, A. y SEGARRA-OÑA, M.; (2015). "Experiential learning as a dynamizer of class activity”. Proceedings of ICERI2015 Conference, p. 1010-1013.

SMITH, G. (2003). "Beyond critical thinking and decision making: Teaching business students how to think". Journal of Management Education, vol. 27, issue 1, p. 24-51.

WHEELER, J., y MCLEOD, P. (2002). "Expanding our teaching effectiveness: Understanding our responses to in-the-moment classroom events". Journal of Management Education, vol. 26, issue 6, p. 693-716. 
Revolución en las aulas universitarias con la ayuda de las metodologías gamificación, clase inversa... 


\title{
Diseño, Desarrollo y Evaluación del MOOC "Introducción a la Gestión de Proyectos"
}

\author{
Alberto Palomares Chust ${ }^{a}$, Ignacio Despujol Zabala ${ }^{b}$ \\ ${ }^{a}$ Departamento de Sistemas Informático y Computación (DSIC), UPV, apalomares@dsic.upv.es \\ ${ }^{\mathrm{b}}$ Área de Sistemas de Información y Comunicaciones (ASIC), UPV, ndespujol@asic.upv.es
}

\section{Resumen}

En este artículo se analizan los aspectos más significativos del curso MOOC "Introducción a la Gestión de Proyectos" que la UPV imparte en EDX. La formación en Gestión de Proyectos es actualmente muy importante para todo tipo de empresas y organizaciones, y las perspectivas laborales para los profesionales formados en esta disciplina son muy buenas. Normalmente estos cursos suelen ser bastante caros e inaccesibles para muchos estudiantes, y por lo tanto es necesario desarrollarlos desde las Universidades Públicas (Servicio Público). Por otra parte, desde EDX tenían un interés estratégico preferente por el desarrollo de cursos en español en este tipo de disciplinas, para su expansión en toda el área de Sudamérica. Uno de los aspectos más innovadores de este curso MOOC es que se ha aplicado una metodología de mejora continua, es decir, se ha utilizado la información recogida en cada una de las ediciones para intentar mejorar la siguiente edición (corrección de errores, nuevos contenidos, etc.). Hasta el momento se han desarrollado 3 ediciones y la $4^{a}$ está prevista para empezar en Junio del 2017. Los resultados del curso son bastante buenos y además han ido mejorando en cada edición ( $n^{\circ}$ alumnos, certificados emitidos, ingresos, opiniones, etc.).

Palabras clave: MOOC, UPVX, EDX, Gestión de Proyectos, Project Management Institute (PMI) 


\section{Introducción}

Los MOOC (Massive Open Online Course) son cursos que se realizan en línea, dirigidos a un amplio número de participantes, en principio ilimitado, además abiertos a todo el mundo, y en muchos casos gratuitos. Los MOOC pueden ser clasificados en tres grupos principales: basados en la red de aprendizaje, basados en las tareas a desarrollar y basados en el contenido (Lane, 2012). Los MOOC basados en el contenido, conocidos como xMOOC, son los que más éxito han tenido (Daniel, 2012).

Los primeros cursos que pueden considerarse MOOC's propiamente dichos datan del año 2008. Desde entonces están suponiendo una verdadera revolución en la educación superior, y de manera complementaria, tambien en los planes de formación para empresas y organizaciones de todo tipo. Se estima que a finales del año 2016 unas 700 universidades de todo el mundo habían producido unos 7000 MOOC's en los que se habían matriculado unos 60 millones de estudiantes (Shah, 2016). El año 2012 fue denominado "año del MOOC" por diferentes medios de comunicación como el New York Times (Pappano, 2012).

La Universidad Politécnica de Valencia (UPV) estableció en el año 2007 un Plan de actuación llamado Plan de Docencia en Red $^{1}$, que pretendía favorecer el uso de las TIC en la práctica docente, apoyando al profesor en todo los procesos relacionados con acciones innovadoras y proporcionando tanto recursos como servicios de apoyo que facilitaran el uso de estas tecnologías en la práctica docente.

En este contexto se ha desarrollado el sistema Polimedia, que permite grabar vídeos docentes de alta definición de forma rápida y sencilla, usando unos estudios audiovisuales de bajo coste (Turró, Cañero \& Busquets, 2010). Estos proyectos han permitido ir consolidando a la UPV como una institución de referencia en la elaboración de materiales docentes on-line ${ }^{2}$, y toda esta experiencia acumulada ha sido fundamental para participar activamente en el desarrollo de MOOC's (Despujol, 2014).

Los cursos MOOC requieren de Plataformas Tecnológicas desarrolladas específicamente para poder satisfacer las necesidades de este tipo de cursos: proporcionar a los alumnos los materiales necesarios para el curso (documentos, exámenes, videos, etc.), foros que les permiten interaccionar entre sí y con el profesorado que los imparte, etc. Algunas de las plataformas más conocidas de MOOC's son EDX, Udacity, Open2study, Coursera, etc.

La plataforma EDX $^{3}$, desarrollada por la Universidad de Harvard y el Instituto Tecnológico de Massachusetts (MIT), se ha consolidado, desde su aparición el año 2012, como uno de los principales proveedores de cursos MOOC de alta calidad en el mundo.

\footnotetext{
1 https://www.upv.es/contenidos/DOCENRED/indexc.html

2 DATOS GENERALES (Marzo 2017): unos 16.875 objetos de aprendizaje grabados, más de 1.000 profesores involucrados y un canal educativo en Youtube (6.380 vídeos, 87.000 suscriptores y 22,8 millones de visualizaciones)

3 https://www.edx.org/
} 
Algunas de las principales instituciones universitarias del mundo están adheridas e imparten sus cursos MOOC en esta plataforma: Harvard, MIT, Berkeley, Sorbonne, Imperial College London, ETH Zurich, Technische Universitat Munich, Universiyty Chicago, University of Edinburgh, etc. EDX ha superado los 10 millones de usuarios únicos (datos de febrero $2017)^{4}$.

Una característica de los cursos que se ofertan en EDX es que los alumnos de todo el mundo pueden acceder libre y gratuitamente a todos los contenidos, y por lo tanto también permiten a empresas y organizaciones diseñar programas de formación para sus empleados. Los alumnos que realizan un curso completo, realizan los exámenes y obtienen la calificación mínima exigida para aprobar el curso, pueden optar a obtener un certificado que expide EDX, que tiene un determinado coste (por ejemplo para el MOOC que se describe en este artículo es de 50 \$). Es decir, la formación propiamente dicha es gratuita y solamente la certificación tiene un pequeño coste para los alumnos. Las denominadas Inscripciones Verificadas son las que optan por un certificado verificado y pagan por su expedición.

La UPV está adherida a EDX desde Noviembre del 2014, siendo una de las primeras universidades españolas en impartir sus cursos MOOC en esta prestigiosa plataforma. La UPV dispone de una versión local de plataforma denominada UPVX (http://upvx.es/). Uno de los objetivos de UPVX es poder lanzar las primeras versiones de los cursos MOOC para poder testearlos, ver el grado de aceptación, corregir errores, etc. Es decir, UPVX permite hacer un control de calidad de estos cursos, ya que la Plataforma EDX es muy exigente en cuanto a los requisitos de calidad que deben cumplir los cursos para ofertarlos. Durante el año 2015 ya se impartieron más de 30 cursos MOOC de la UPV en EDX, siendo la institución con mayor crecimiento en cursos MOOC en la plataforma. Además es una de las exitosas por lo que se refiere a la tasa de finalización de los mismos, un 9,6\%, muy por encima del aproximadamente 5\% de la media de los cursos en EDX.

Entre los MOOC que la UPV imparte en EDX está el curso "Introducción a la Gestión de Proyectos", que ha sido desarrollado por Alberto Palomares Chust, Profesor del Departamento de Sistemas Informáticos y Computación (DSIC) de la UPV, adscrito a la Escuela Politécnica Superior de Gandía (EPSG), y además es miembro del Project Management Institute (PMI) ${ }^{6}$, socio del Capítulo de Valencia del $\mathrm{PMI}^{7}$ y con la certificación Project Management Professional (PMP) ${ }^{8}$.

\footnotetext{
4 http://blog.edx.org/celebrating-10-million-edx-learners-worldwide

5 https://courses.edx.org/courses/course-v1:UPValenciax+IGP101.x+2T2016/info

${ }^{6}$ El PMI es una Organización sin ánimo de lucro que promueve la profesión de la Dirección de Proyectos mediante la definición y publicación de estándares, la promoción de certificaciones profesionales mundialmente reconocidas, la dinamización de comunidades colaborativas, la financiación de programas de investigación y la potenciación de oportunidades de desarrollo profesional. Actualmente es la principal organización a nivel internacional en el campo de la Gestión de Proyectos, y tiene unos 500.000 socios de prácticamente todos los países del mundo http://www.pmi.org/.

7 El PMI está presente en casi todo el mundo a través de sus Capítulos nacionales o regionales http://www.pmi-valencia.org/

${ }^{8}$ La certificación PMP es la más reconocida a nivel internacional en el campo de la Gestión de Proyectos.
} 
El motivo principal para empezar a desarrollar este MOOC fue el hecho de que la formación en Gestión de Proyectos es actualmente de una gran importancia para todo tipo de empresas y organizaciones, de muchos sectores, y a nivel internacional. Las perspectivas para los profesionales formados en Gestión de Proyectos son muy buenas, tanto por las mejores posibilidades para encontrar empleos como por la calidad/salarios de dichos empleos.

Según el informe que elabora anualmente el PMI "PMI's Pulse of the Profession" 9, "la gestión de proyectos es esencial para el éxito de las organizaciones. Está demostrado que aquellas organizaciones que invierten en Gestión de Proyectos obtienen unos resultados mejores que aquellas que no lo hacen, ya que consiguen finalizar más proyectos cumpliendo plazos, costes, criterios de calidad, etc". Empresas y organizaciones de casi cualquier sector y prácticamente en todos los países del mundo requieren profesionales formados en Gestión de Proyectos.

Es importante poner de manifiesto que en general es difícil encontrar cursos en el campo de la Gestión de Proyectos asequibles para una parte significativa de la población, ya que los cursos suelen ser bastante caros. Esta es una razón fundamental para desarrollar este tipo de formación desde una Universidad Pública como la UPV.

\section{Objetivos}

El objetivo de este curso (tal y como aparece textualmente en la descripción en EDX) es el siguiente: "Introducir algunos conceptos básicos de la Gestión de Proyectos / Project Management (PM), según las metodologías del Project Management Institute (PMI). El PMI es la Principal Organización Mundial en el campo de la Dirección de Proyectos (www.pmi.org). Sus guias están basadas en las "Buenas Prácticas" de profesionales de todo el mundo, y sus certificaciones, por ejemplo el Project Manager Professional (PMP) son muy demandadas por empresas de todos los sectores".

Este MOOC es un curso muy básico de Gestión de Proyectos (GP) y no se requieren conocimientos específicos previos para poder realizarlo. Consta de 4 Unidades.

1. Introducción a la Gestión de Proyectos

2. Gestión del Tiempo de un Proyecto

3. Gestión de Riesgos de un Proyecto

4. $\quad$ Final (exámenes)

\footnotetext{
${ }^{9}$ http://www.pmi.org///media/pmi/documents/public/pdf/learning/thought-leadership/pulse/pulse-of-the-profession-2017.pdf
} 


\section{Desarrollo de la innovación}

La preparación de este curso estaba todavía en una fase intermedia cuando los responsables de EDX comunicaron a la UPV su interés preferente por el desarrollo de cursos en español relacionados con ciertos campos en particular, por ejemplo Emprendimiento, Negocios, Gestión de Proyectos, etc. El motivo concreto era su importancia estratégica para la expansión de EDX en toda el área de Sudamérica.

Esta es una de las razones que impulsaron y aceleraron el desarrollo de este curso, adelantando los plazos previstos inicialmente para su producción y publicación. Hasta el momento se han desarrollado las siguientes ediciones:

- La primera edición del MOOC se desarrolló en la plataforma UPVX. Periodo programado: Junio-Julio 2015.

- La segunda edición del MOOC se desarrolló en la plataforma EDX. Periodo programado: Noviembre-Diciembre 2015.

- La tercera edición del MOOC se desarrolló en la plataforma EDX. Periodo Programado: Junio-Julio 2016.

- Tercera edición (Self Paced) ${ }^{10}$ la tercera edición ha seguido estando disponible en EDX hasta su cierre definitivo en Junió de 2017.

- La cuarta edición está programada para empezar en Junio del 2017.

Uno de los aspectos más innovadores en el desarrollo de este curso MOOC es que se ha aplicado una metodología de mejora continua, es decir, se ha recogido y analizado la información generada por los alumnos en los foros de la plataforma en cada una de las ediciones (opiniones, preguntas, dudas, problemas, etc) y esta información se ha utilizado para corregir algunos errores, incorporar algunos contenidos adicionales, crear debates específicos en los foros sobre algunos temas en los que los alumnos suelen tener más problemas, etc. Por lo tanto el curso MOOC ha ido mejorando sus contenidos en cada una de las ediciones.

\footnotetext{
${ }^{10}$ Es lo que se denomina en modo "Self Paced" que se puede traducir como "a su ritmo", para que los alumnos puedan realizarlo por su cuenta, pero sin el soporte contínuo de los profesores en los foros que se realiza en los periodos programados.
} 


\section{Resultados}

En el próximo apartado se presentan diferentes datos para mostrar el grado de difusión y aceptación del MOOC, en sus diferentes ediciones, especialmente de la tercera que es la más reciente en el momento de escribir este artículo.

\section{$3^{a}$ Edición (Junio-Julio 2016). EDX. Resultados Cuantitativos.}

Inscripciones / Inscripciones Verificadas

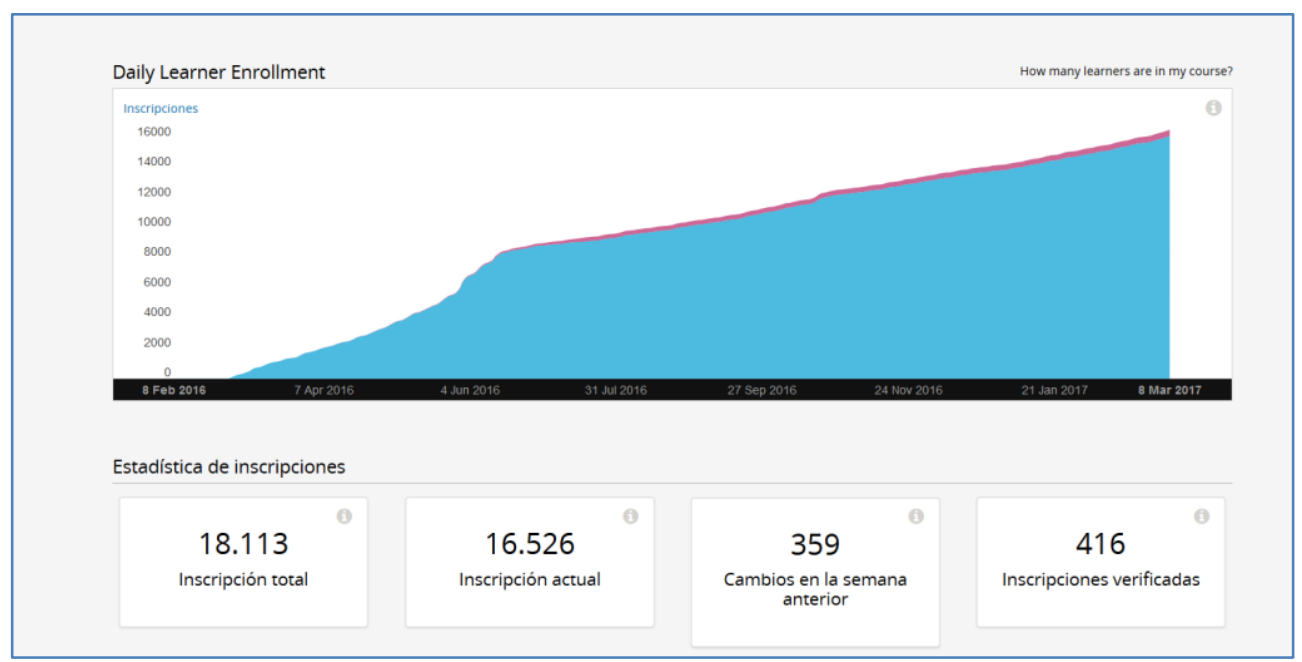

Figura 1: inscripciones/inscripciones verificadas de los alumnos

Edad de los alumnos

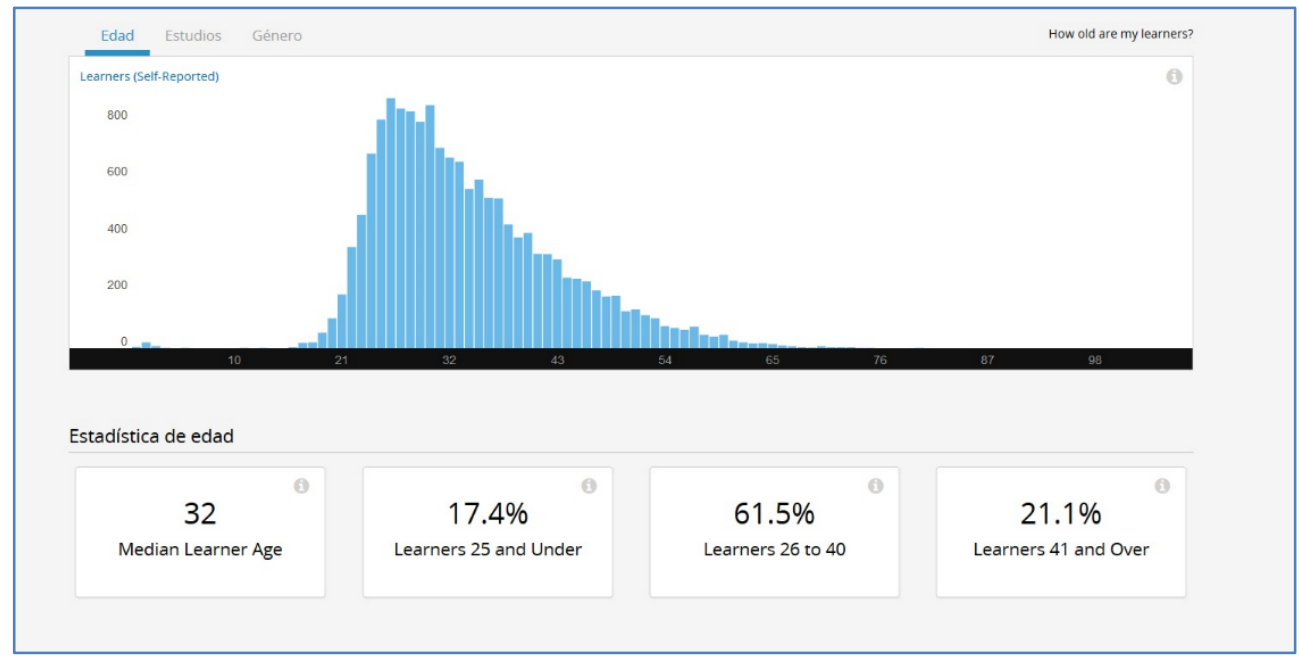

Figura 2: edad de los alumnos 


\section{Nivel de Estudios}

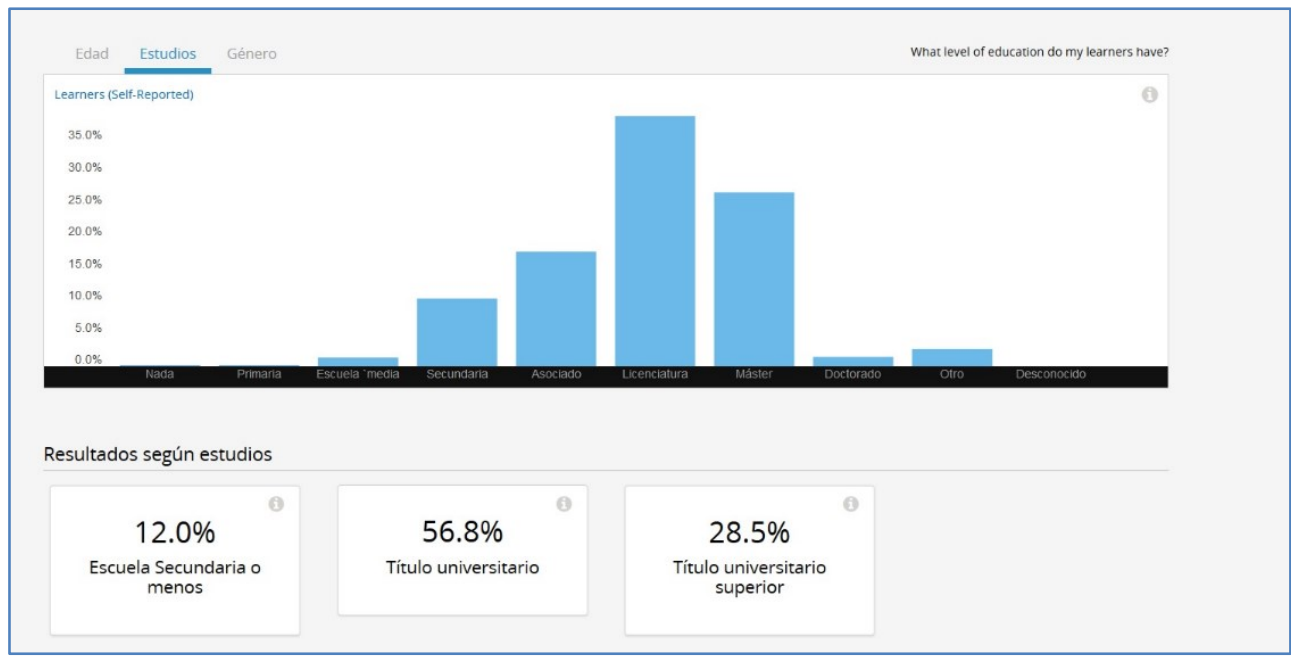

Figura 3: nivel de estudios de los alumnos

Distribución Geográfica de los Alumnos

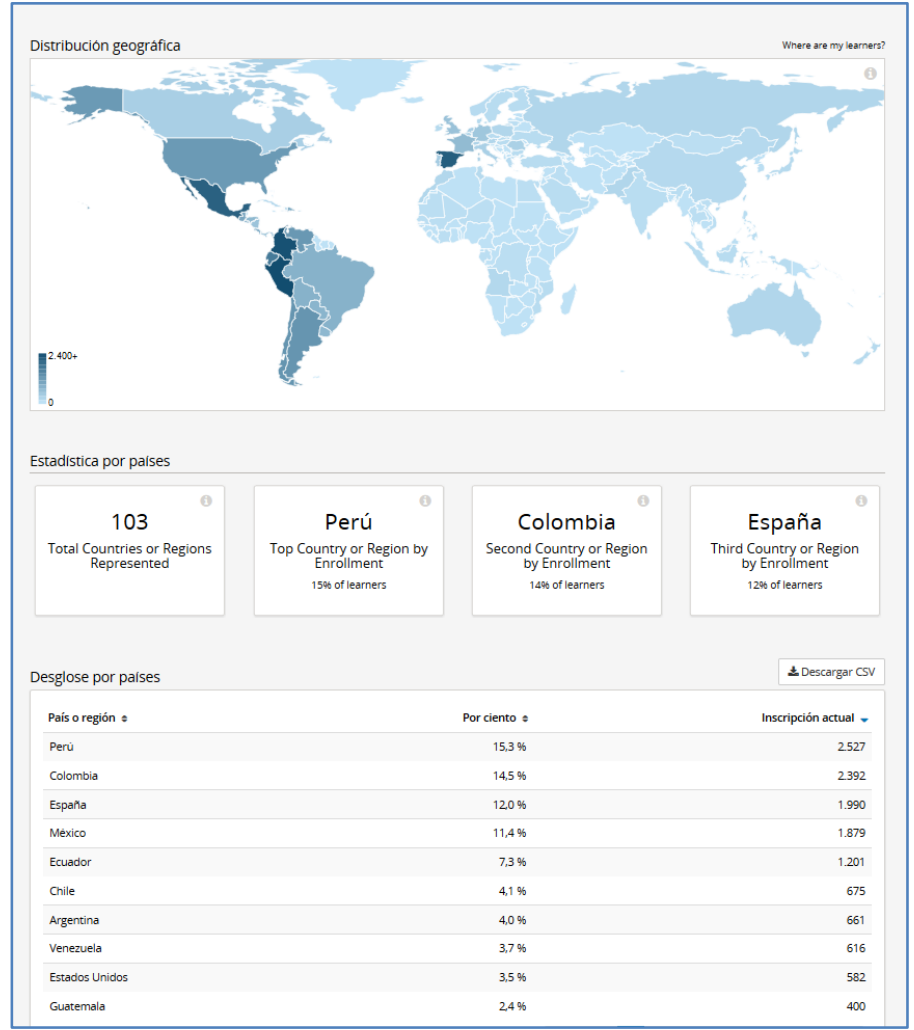

Figura 4: distribución geográfica de los alumnos

(c)) EY-NC-ND 2017, UPV

Congreso In-Red (2017) 


\section{$3^{a}$ Edición (Junio-Julio 2016). EDX. Resultados Encuestas ${ }^{11}$}

Sugerencias de los Alumnos (texto libre)

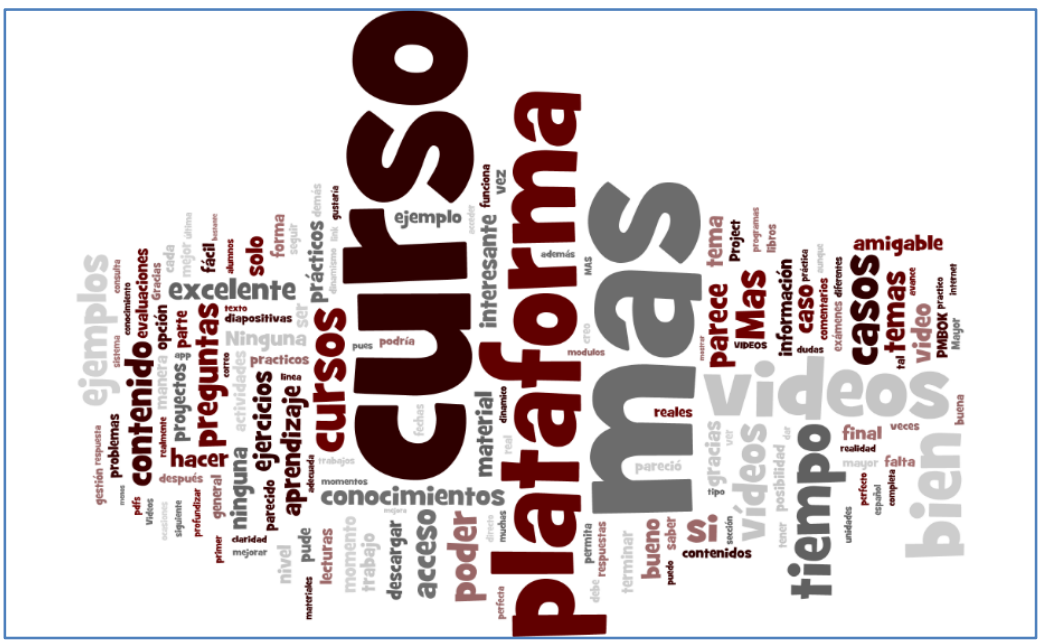

Figura 5: Sugerencias de los alumnos (nube de palabras realizada a partir de 470 respuestas)

Opinión sobre la Frecuencia de Publicación y Ritmo de Aprendizaje del Curso

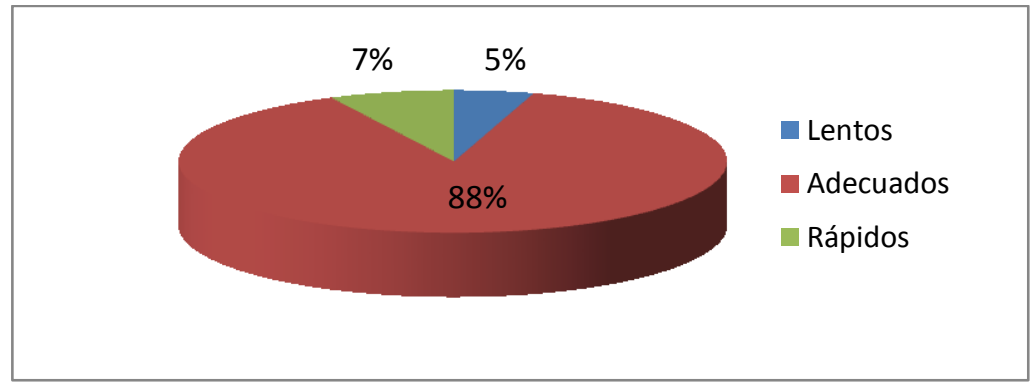

Figura 6: Frecuencia de Publicación y Ritmo de Aprendizaje (calculada a partir de 1091 respuestas)

Opinión sobre la Duración de los Vídeos

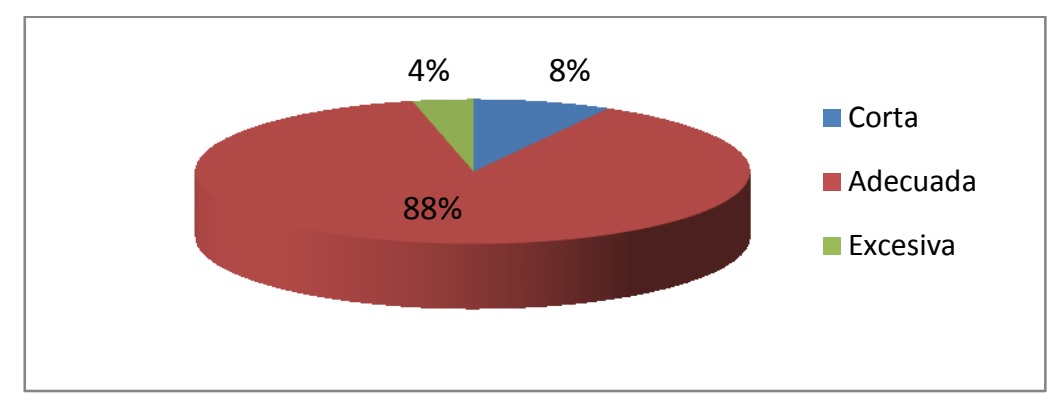

Figura 7: Duración de los Videos (calculada a partir de 1080 respuestas)

\footnotetext{
${ }^{11}$ Respuestas proporcionadas por los alumnos en las encuestas realizadas al finalizar el curso
} 
Opinión sobre el Contenido de los Videos

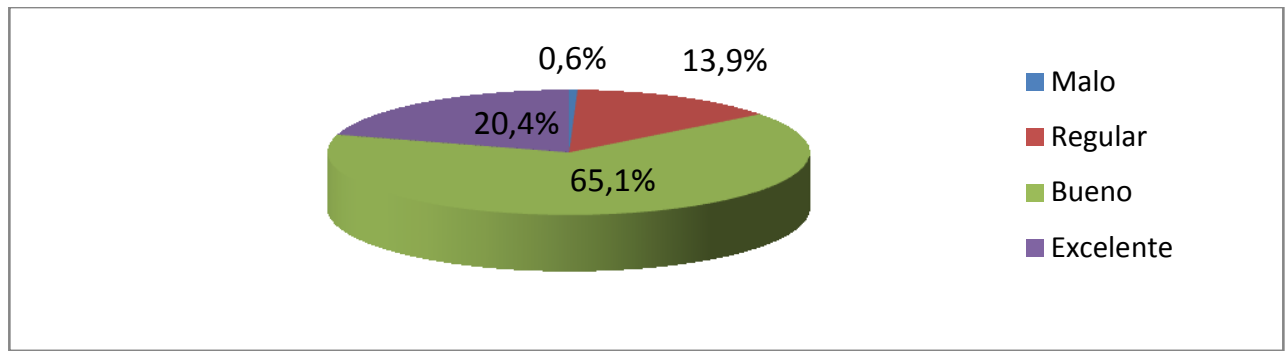

Figura 8: Contenido de los Videos (calculada a partir de 1069 respuestas)

Opinión sobre Exámenes y Actividades

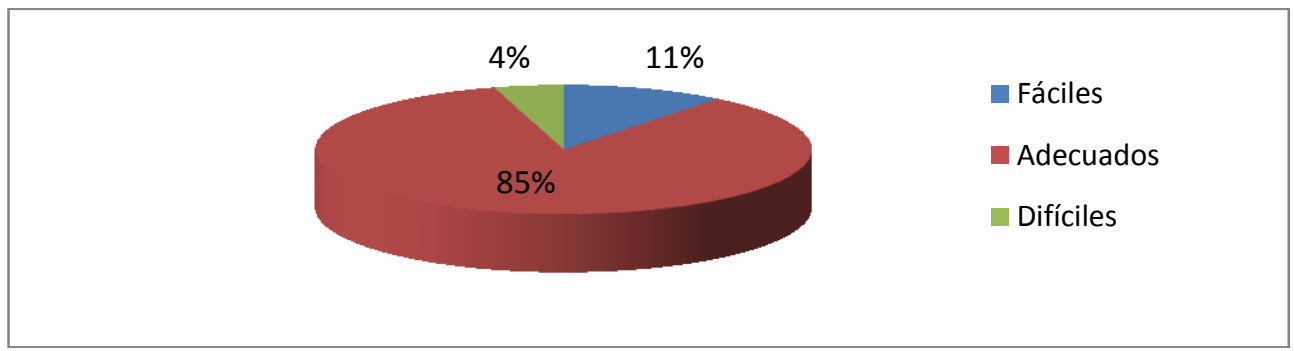

Figura 9: Exámenes y Actividades (1065 respuestas)

Opinión sobre el Nivel del Curso

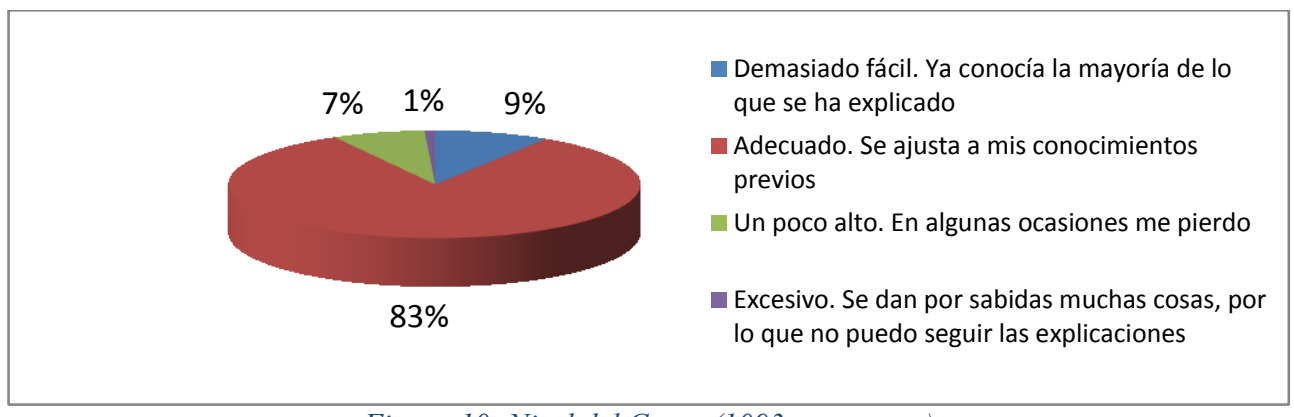

Figura 10: Nivel del Curso (1093 respuestas)

Opinión sobre la Tutorización (Resolución de Dudas)

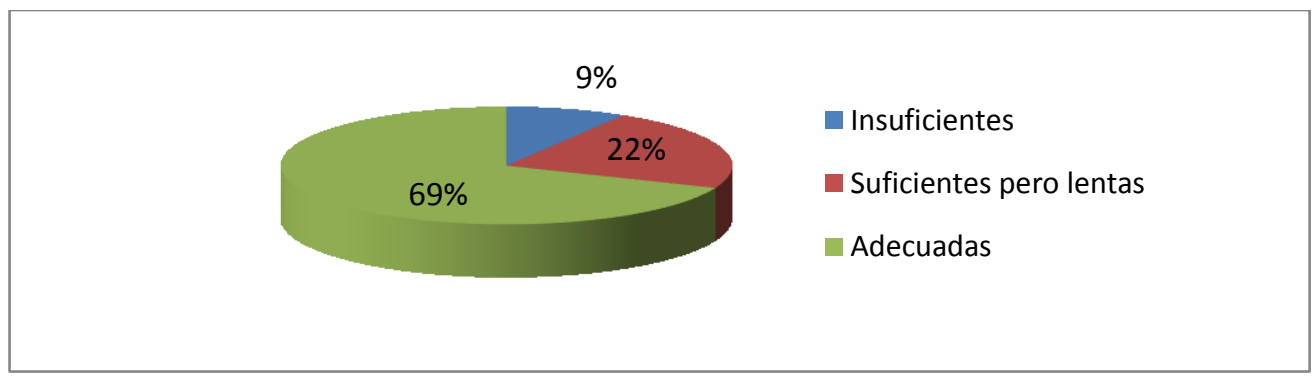

Figura 11: Tutorización (1054 respuestas) 
Opinión sobre el Aprendizaje

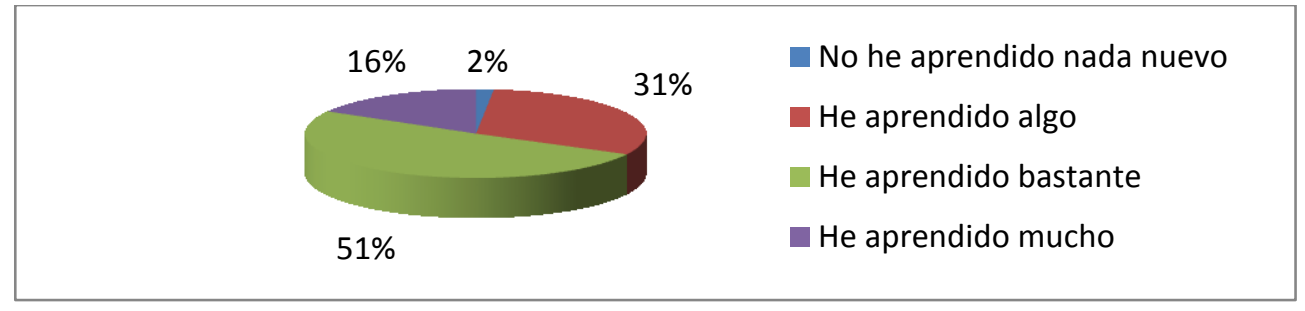

Figura 12: Aprendizaje (1076 respuestas)

Opinión sobre el Sistema de Aprendizaje

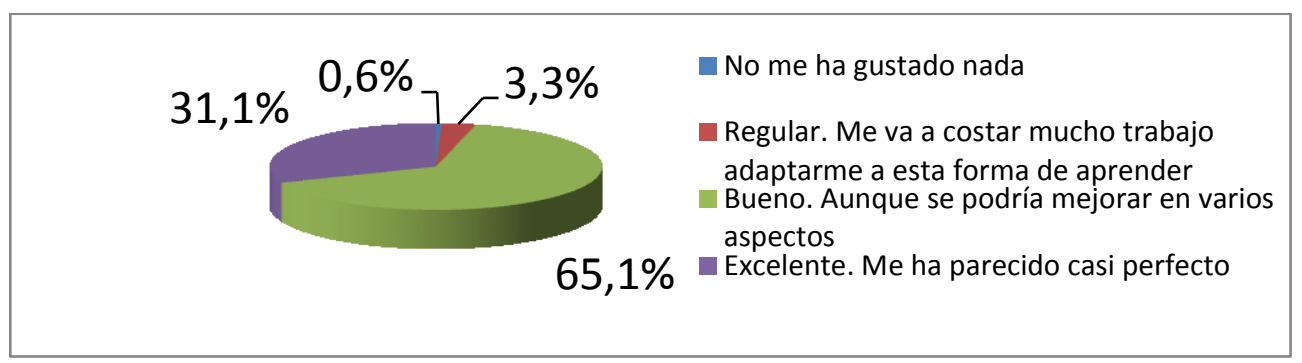

Figura 13: Sistema de Aprendizaje (1088 respuestas)

Opinión sobre Expectativas del Curso (valoración del 1 al 5)

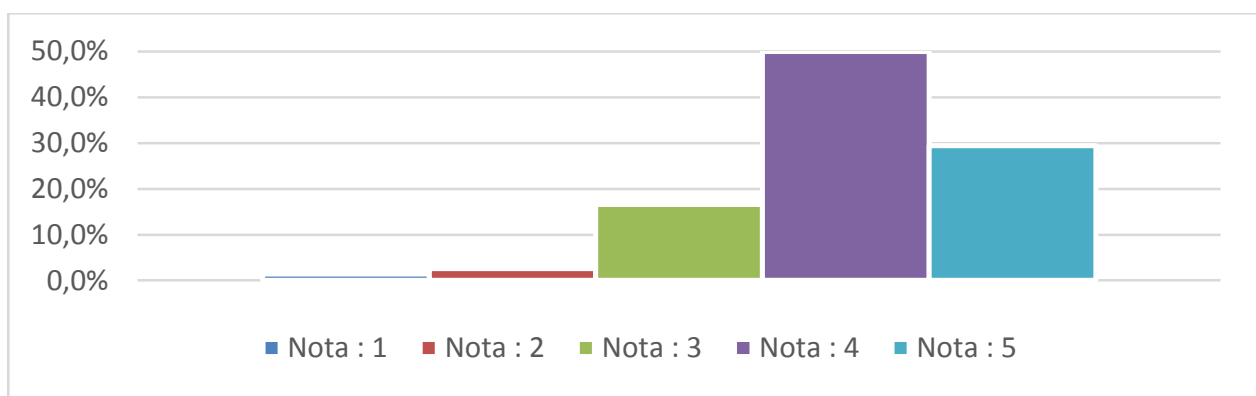

Figura 14: Expectativas (1035 respuestas)

Opinión sobre Dedicación (¿Cuántas horas le han dedicdo al curso?)

Este punto es muy importante ya que los alumnos quieren saber "a priori" el tiempo que le tienen que dedicar al curso. Los resultados son los siguientes (1027 respuestas):

- $\quad$ Entre 1 y 3 horas: $49,03 \%$

- $\quad$ Entre 3 y 5 horas: $22,86 \%$

- $\quad$ Entre 5 y 7 horas: $9,68 \%$

Estos datos nos indican que una recomendación bastante adecuada, para la mayoría de los alumnos que realizan el curso, es que con una dedicación de unas 4-5 horas semanales durante las 5-6 semanas planificadas para realizar el curso es suficiente para poder aprobarlo. Esta información se utiliza en las recomendaciones que se hacen a los nuevos 
alumnos sobreel tiempo que tienen que dedicar para realizar el curso (información basada en los datos).

\section{$2^{a}$ Edición (Noviembre-Diciembre 2015). EDX}

Inscripciones / Inscripciones Verificadas

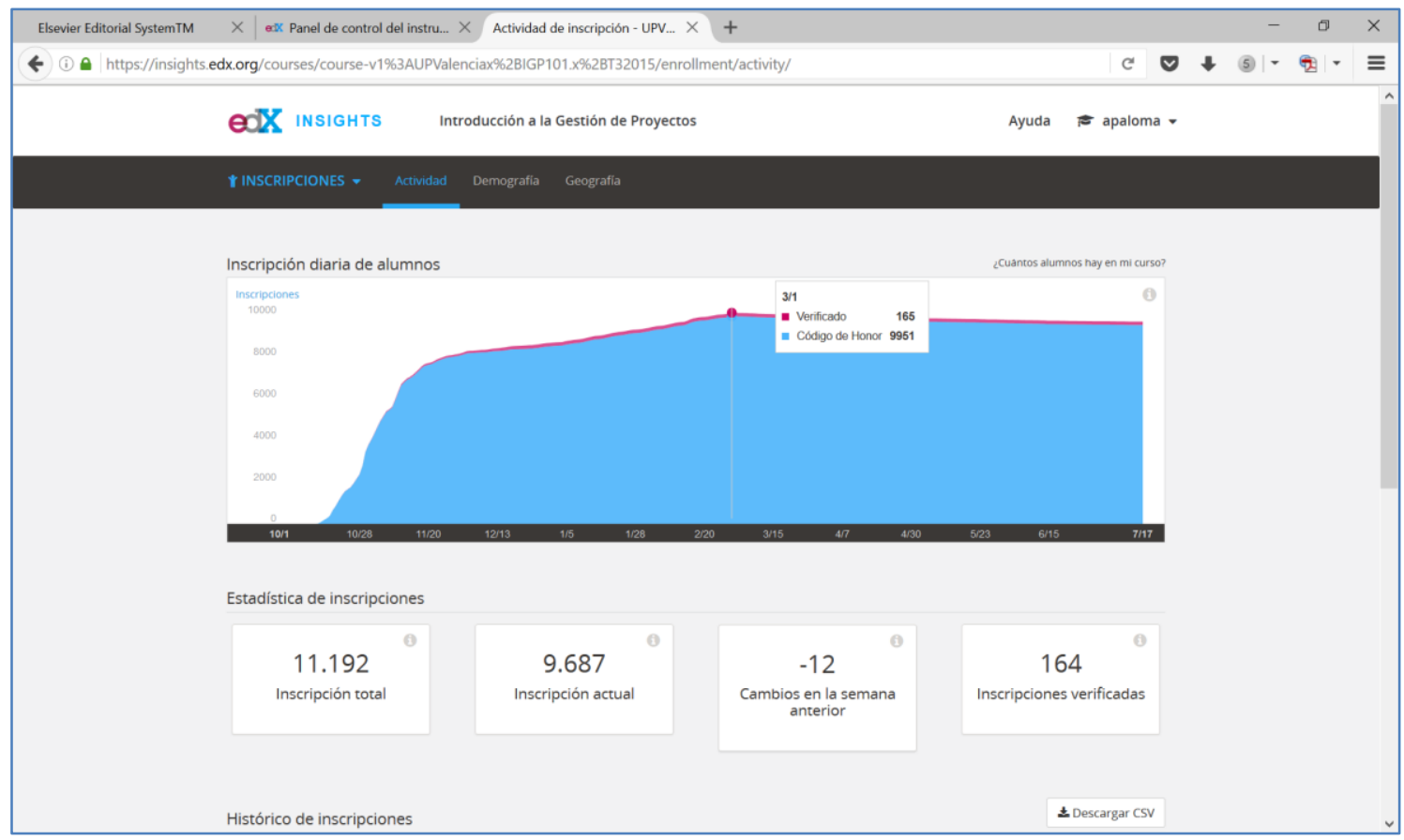

Figura 15: inscripciones/inscripciones verificadas de los alumnos

\section{Distribución Geográfica / Edad / Nivel de Estudios de los Alumnos}

Los datos correspondientes a la $2^{\mathrm{a}}$ edición son muy similares a los de la tercera edición, que se describen en el apartado anterior, y por esta razón no se representan.

\section{$1^{a}$ Edición (Junio-Julio 2015). UPVX}

Esta edición se relizo en UPVX y sólo se muestran algunos datos básicos del curso:

- $\quad \mathrm{N}^{\mathrm{o}}$ de Alumnos Matriculados: 3193

- $\quad \mathrm{N}^{0}$ de Alumnos que han Interactuado con el Curso: 992

- $\quad \mathrm{N}^{0}$ de Alumnos Aprobado el Curso: 542 (Certificado UPV Gratuito). 


\section{Conclusiones}

La conclusión principal es que este curso, en general, está teniendo unos resultados bastante buenos (con respecto a otros cursos MOOC) y además, y quizás lo que es más importante, es que estos resultados han ido mejorando en cada una de las ediciones del curso. Consideramos que la mejora de los resultados se debe principalmente a que se ha aplicado un proceso de mejora continua. A continuación se describen brevemente algunos de los principales resultados del curso:

El número de alumnos inscritos en el curso (en las 3 ediciones) está por encima de los 30.000 , de los cuales aproximadamente unos 600 han realizado la inscripción verificada en EDX, es decir, han pagado los $50 \$$ requeridos para obtener el certificado del curso. Por lo tanto, los ingresos totales del curso en la plataforma están actualmente por encima de los $30.000 \$$.

El perfil de un alumno del curso es hispanoamericano ${ }^{12}$, titulado superior, con una edad por encima de los 25 años. Es decir, básicamente es un alumno posgraduado, probablemente trabajando o quizás buscando su primer empleo, pero que necesita formación adicional en el campo de la Gestión de Proyectos para mejorar su empleo actual o para encontrarlo.

Este perfil de los estudiantes del curso, coincide, en líneas generales, con el que la literatura describe para otros cursos MOOC. Así, por ejemplo, un estudio sobre los estudiantes inscritos en los cursos que la Universidad de Pennsylvania desarrolla en la plataforma Coursera confirma el predominio de alumnos con estudios superiores Emanuel (2013). Es decir, los MOOCs no están llegando a estudiantes muy desfavorecidos económicamente y con muy pocas oportunidades educativas como quizás se podría suponer a priori. Para realizar estos cursos los alumnos tienen que tener un nivel digital aceptable Yuan\&Powell (2013).

Tal y como se puede comprobar en los propios foros que la plataforma EDX proporciona, los alumnos consideran, de manera bastante generalizada, que este MOOC un buen curso, y los comentarios mayoritariamente son favorables. Ha habido alumnos que explícitamente han comentado que el curso les ha permitido mejorar profesionalmente, por ejemplo

http://blog.edx.org/quieres-mejorar-en-tu-carrera-profesional-y-no-sabes-como-2?track=blog

Desde EDX han informado a la UPV que este curso ( $3^{\text {a }}$ edición) es uno de los 10 que más éxito está teniendo a nivel mundial en el modo de funcionamiento "self-paced". En este sentido se debe destacar la participación del personal de apoyo de la UPV, los denominados "Servipolis", que permiten dinamizar los foros de la plataforma, facilitando el trabajo de los profesores, especialmente en la resolución de dudas genéricas (relacionadas con diferentes aspectos del uso de la plataforma EDX), pero también de dudas de contenido, ya que con el desarrollo de diferentes ediciones y su presencia en los foros, también están dominando la materia del curso.

${ }^{12}$ Los alumnos de Perú, Colombia, España, Mexico y Ecuador representan aproximadamente el $70 \%$ de los inscritos en el MOOC. 


\section{Referencias}

DANIEL, J. (2012). Making sense of MOOCs: Musings in a maze of myth, paradox and possibility. Journal of Interactive Media in Education. < $\underline{\text { http://www- }}$ jime.open.ac.uk/jime/article/view/2012-18>. [Consulta: 22 abril 2015].

DESPUJOL, I. (2014). Servicios TIC de apoyo a la docencia. Universitat Politècnica de València. < http://es.slideshare.net/ndespujol/presentacin-global-serviciosmmedia-asic-2014>. [Consulta: 21 julio 2015].

EMANUEL, E.J. (2013). Online education: MOOCs taken by educated few. Nature, 503(342). < http://dx.doi.org/10.1038/503342a >. [Consulta: 22 abril 2015].

LANE, L. (2012). Three kinds of MOOC. < http://lisahistory.net/wordpress/2012/08/threekinds-of-moocs/>. [Consulta: 22 abril 2015].

PAPPANO, L.. The Year of the MOOC. The New York Times. http://www.nytimes.com/2012/11/04/education/edlife/massive-open-onlinecourses-are-multiplying-at-a-rapid-pace.html? r=0. [Consulta: 2012, November].

SHAH, D. Monetization over Massiveness: A Review of MOOC Stats and Trends in 2016. Class Central. <https://www.class-central.com/report/moocs-stats-and-trends2016/>. [Consulta: 2016, December].

TURRO, C. CAÑERO A., \& BUSQUETS, J. (2010). Video learning objects creation with Polimedia. Proceedings of the 2010 IEEE International Symposium on Multimedia. isbn=978-0-7695-4217-1.

YUAN, L. \& POWEL, S. (2013). MOOCs and open education: Implications for higher education (JISC CETIS white paper). <http://publications.cetis.ac.uk/2013/667>. [Consulta: 22 abril 2015]. 


\title{
"Protégete del sol, protégete del Lupus". Integración curricular en el grado de Farmacia a través de la Metodología aprendizaje Servicio.
}

\author{
Uriel Gallego, $M^{\mathrm{a}}$; Abarca Lachén, $E^{\mathrm{b}}$; Berenguer Torrijo, $\mathrm{N}^{\mathrm{c}}$; Sáez-Benito Suescun, \\ L d Sáez-Benito Suescun, A ${ }^{\mathrm{e}}$; Gómez Rincón, Cf.
}

aUniversidad San Jorge, muriel@usj.es ${ }^{\mathrm{b}}$ Universidad San Jorge, eabarca@usj.es ${ }^{\mathrm{c}}$ Universidad San Jorge, nberenguer@usj.es, ${ }^{\mathrm{d}}$ Universidad San Jorge, 1saezbenito@usj.es ${ }^{\mathrm{e}}$ Universidad San Jorge, amsaezbenito@usj.es $f$ Universidad San Jorge, cgomez@usj.es .

\begin{abstract}
Resumen
El proyecto "Protégete del sol, protégete del Lupus", emplea la estrategia metodológica de Aprendizaje Servicio como herramienta de integración curricular en la formación del futuro farmacéutico. El objetivo que se pretende alcanzar es aplicar, en un paciente crónico, un caso de intervención dermofarmacéutica, concretamente, se va a tratar la fotosensibilidad en el paciente de Lupus.

En esta iniciativa, van a participar alumnos de $3^{\circ}$ y $5^{\circ}$ curso del grado de Farmacia de la Universidad San Jorge. Las asignaturas implicadas en el aprendizaje planteado son: Fisiología III (3⿻), Inmunología $\left(3^{\circ}\right)$, Dermofarmacia $\left(5^{\circ}\right)$, Medicamento Individualizado $\left(5^{\circ}\right)$ y Estancias Clínicas $\left(5^{\circ}\right)$. El objetivo de aprendizaje es la integración horizontal y vertical de asignaturas del grado de farmacia con un enfoque común, que es la salud del paciente crónico, concretamente, el paciente de Lupus; al cual se le ofrece un servicio: la información, prevención, análisis y dermoconsejo farmacéutico.

Se va a trabajar con la Asociación de Pacientes ALADA (Asociación de Enfermos de Lupus y Antifosfolípido de Aragón. El proyecto conlleva una serie de actividades que tratan de compaginar el aprendizaje activo de los alumnos, mediante metodologías novedosas, con un servicio sanitario a la sociedad, representada, en este caso, por esta asociación de pacientes.
\end{abstract}

Palabras clave: aprendizaje servicio, lupus, metodologías educativas innovadoras, educación en farmacia, asociaciones de pacientes, TICs. 


\section{Introducción}

Cambio del rol farmacéutico: En los últimos años, desde los ámbitos profesional y académico, se ha impulsado un cambio en la práctica profesional del farmacéutico hacia una orientación marcadamente asistencial. Así, se ha definido que, en el ámbito de la farmacia comunitaria y/o hospitalaria, el farmacéutico deberá estar capacitado para ejercer su responsabilidad como especialista del medicamento, dentro de un equipo multidisciplinar de salud (van Mil et al., 2004). Este nuevo enfoque se ha denominado Atención Farmacéutica (Wiedenmayer et al., 2006). Desde diversas materias, los estudiantes deberán adquirir las habilidades clínicas, metodológicas y de comunicación necesarias, para la prestación de servicios profesionales farmacéuticos y para la Práctica Basada en la Evidencia. En este nuevo contexto, resulta fundamental el diseño de actividades de aprendizaje que contribuyan a la integración de contenidos entre materias básicas y específicas y favorezcan, de este modo, la capacitación profesional del estudiante. El diseño de actividades de enseñanza-aprendizaje en colaboración con asociaciones de pacientes proporciona un marco teórico-práctico de gran valor pedagógico para el futuro profesional sanitario.

El lupus eritematoso sistémico (LES) es una enfermedad reumática que afecta a 40.000 personas en España. Es una enfermedad autoinmune de curso crónico para la cual no existe un tratamiento definitivo. Como enfermos crónicos, los pacientes de LES deben recibir un seguimiento farmacoterapéutico adecuado. Tal es la importancia de dicho seguimiento que la Sociedad Española de Farmacia Hospitalaria ha propuesto recientemente un Modelo de Selección y Atención Farmacéutica de Pacientes Crónicos entre ellos con LES (SEFH, 2013.) Así, el estudiante de farmacia, deberá familiarizarse con la sintomatología clínica de esta enfermedad, los posibles tratamientos existentes, así como sus causas y consecuencias. Evidentemente, el abordaje del paciente no puede realizarse a través de una única disciplina, por ello, el uso de metodologías docentes, que favorezcan la integración curricular, resulta imprescindible para formar profesionales capaces de adaptarse al modelo de Aprendizaje a lo Largo de la Vida ("Life-Long Learning"). Por ello, la búsqueda de metodologías que permitan un aprendizaje efectivo, resulta fundamental en la actual práctica docente (Abadía et al, 2011). El uso de metodologías participativas desarrolladas en grupos, potencia la integración de los conocimientos adquiridos (Walters, 1999; Waters, $\mathrm{J}$ et al., 2005). Por otro lado, las actividades incluidas en las denominadas pedagogías de la experiencia, buscan favorecer el contacto directo del estudiante con la realidad que debe conocer, desencadenando procesos de aprendizaje significativo (Puig, et al., 2006). Entre las diversas metodologías utilizadas en este ámbito, destaca el Aprendizaje-Servicio (ApS), que combina el servicio a la comunidad con la instrucción académica. El ApS tiene como pilares fundamentales la experiencia, la reflexión y la reciprocidad para favorecer, además de la adquisición de conocimientos y competencias profesionales, la responsabilidad social y cívica en el estudiante (Eyler y Giles, 1999). El servicio, planteado como una respuesta a necesidades reales de la sociedad y combinado con el aprendizaje, añade valor y transforma a ambos (Honnet y Poulsen, 1989; Puig et al., 2006). Por otro lado, cualificación y responsabilidad social deben formar un binomio inseparable (Mangas y Martínez, 2012), por ello con este proyecto pretendemos contribuir a la formación de farmacéuticos

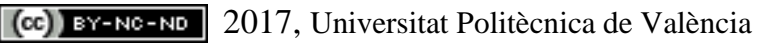

Congreso IN-RED (2017) 
altamente capacitados y, a la vez, dotados de principios éticos que guíen su futura práctica profesional. Los afectados por lupus tienen un alto grado de fotosensibilidad de la que derivan reacciones fotosensibles como erupciones cutáneas, fiebre, fatiga o dolor articular; incluso pueden desencadenar brotes. Por lo tanto, los pacientes deben minimizar la exposición solar. Tras mantener varias reuniones con la asociación, desde esta se puso de manifiesto la necesidad de realizar iniciativas y disponer de información que permita concienciar a los pacientes de la importancia de la fotoprotección como estrategia preventiva básica. El futuro farmacéutico, en el contexto de la farmacia clínica como profesional sanitario cercano y fácilmente accesible para el paciente, podrá contribuir de forma significativa a este cometido. Para ello, deberá integrar los aprendizajes realizados en diversas materias:

-Inmunología: Se abordan las bases fisiológicas del Lupus como enfermedad autoinmunitaria.

- Fisiología III: Se proporcionan los conocimentos necesarios para comprender la importancia de la piel como barrera y su relación con la respuesta inmunitaria.

- Dermofarmacia: Se llevará a cabo el aprendizaje teórico/ práctico de los conceptos relacionados con: la radiación solar, los daños que esta genera en la piel y las estrategias de protección solar y el cuidado dermatológico.

- Medicamento Individualizado: Capacita al alumno para la elaboración de fórmulas magistrales, medicamentos adaptados a las necesidades específicas de un paciente.

- Estancias Clínicas: Puesta en práctica en un escenario real, como es la farmacia comunitaria u hospitalaria, de lo aprendido y generalización de la estrategia de intervención dermofarmacéutica y farmacoterapéutica al Lupus y otras enfermedades crónicas.

La integración de dichas asignaturas y los cursos a los que pertenecen en el grado de Farmacia de la Universidad San Jorge, se plasma en la Figura 1. 


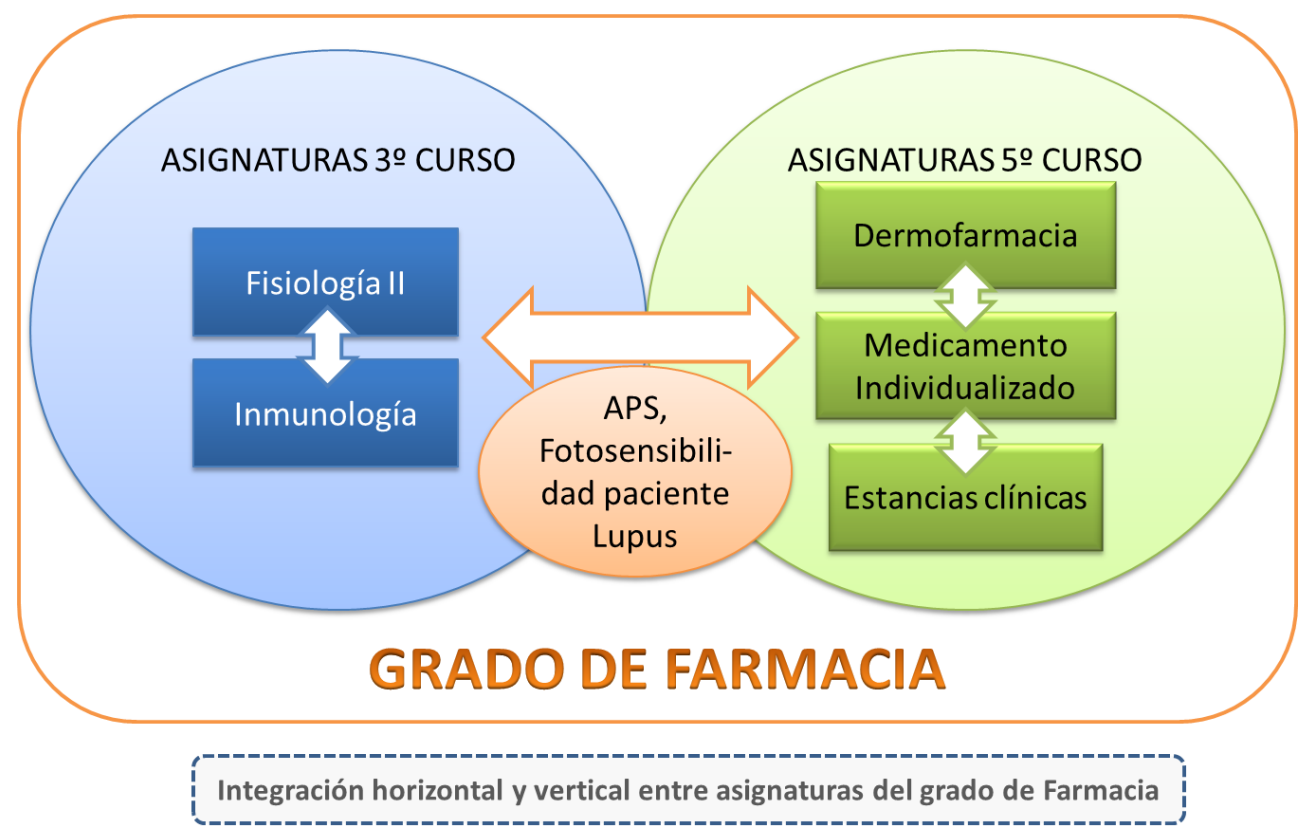

Fig. 1 Cursos y materias implicadas en el proyecto.

La puesta en marcha de este proyecto trata de dar respuesta a las necesidades formativas del alumno de farmacia como profesional del equipo de salud a través del Aprendizaje Servicio; a la vez que se cubren necesidades específicas de los pacientes que forman parte de ALADA. Así, una vez identificadas y definidas las necesidades de aprendizaje de los estudiantes y de servicio a los pacientes de la Asociación, se diseñan un conjunto de actividades que permitan alcanzar los objetivos del proyecto.

\section{Objetivos}

Objetivo general:

Capacitar al futuro farmacéutico para realizar consejo dermofarmacéutico y análisis de la piel en pacientes con lupus y contribuir a concienciar a los pacientes sobre la importancia de la fotoprotección.

Objetivos específicos:

En el siguiente apartado, en el que se describen las diferentes actividades realizadas en el proyecto, se enumerarán también los objetivos específicos de cada actividad.

\section{Desarrollo de la innovación}

La Figura 2 describe de forma esquemática el conjunto de actividades de enseñanzaaprendizaje previstas en el proyecto (Figura 2) así como su temporalización (Tabla 1.-)

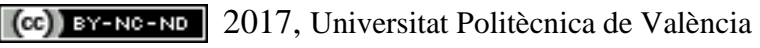

Congreso IN-RED (2017) 


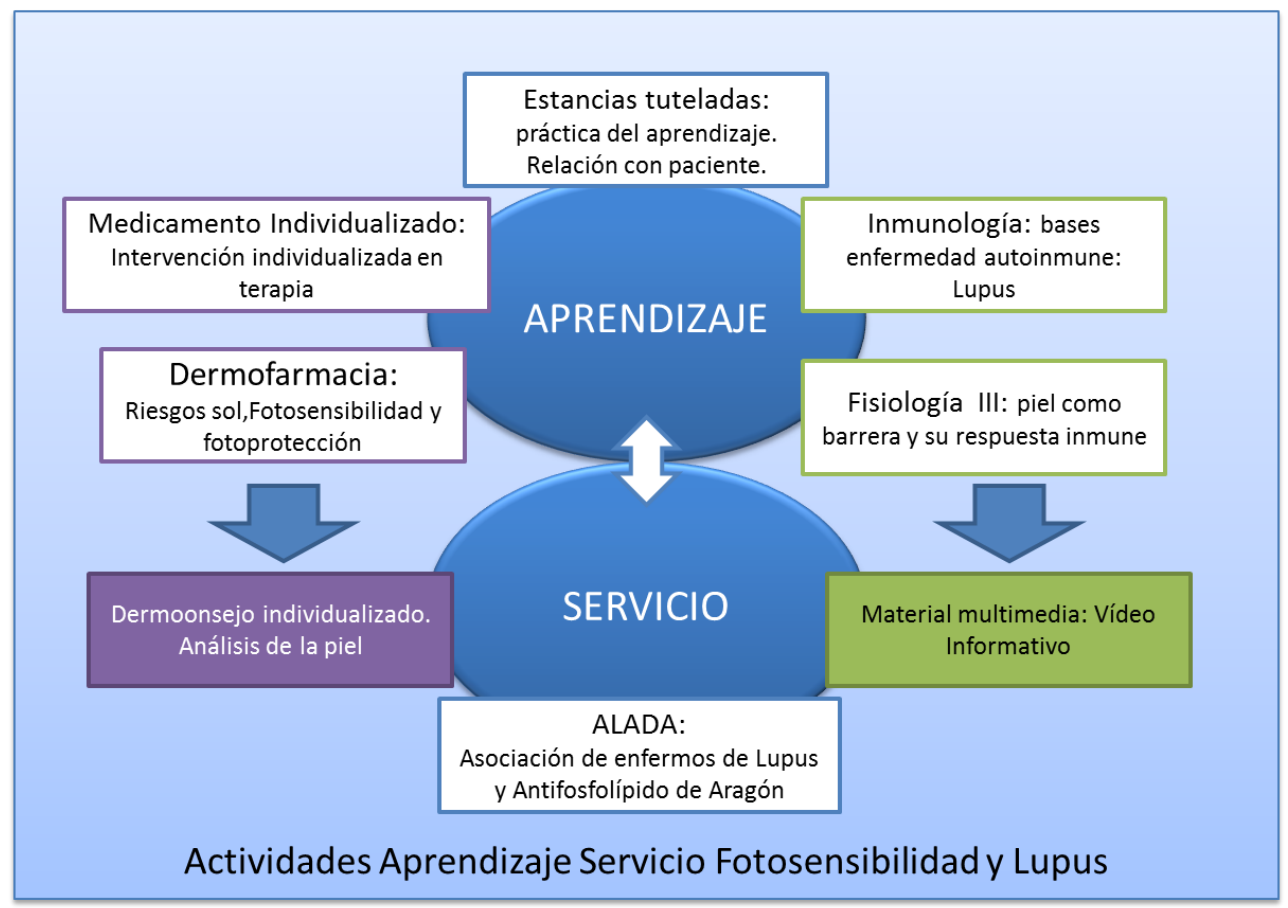

Fig. 2 Actividades de enseñanza-aprendizaje previstas en el proyecto

Tabla 1.- Cronograma de las actividades del proyecto

\begin{tabular}{|c|c|c|c|c|c|c|c|c|c|}
\hline & $\begin{array}{l}\text { Nov } \\
16\end{array}$ & $\begin{array}{l}\text { Dic } \\
16\end{array}$ & $\begin{array}{l}\text { Ene } \\
17\end{array}$ & $\begin{array}{l}\text { Feb } \\
17\end{array}$ & $\begin{array}{c}\text { Mar } \\
17\end{array}$ & $\begin{array}{l}\text { Abr } \\
17\end{array}$ & $\begin{array}{l}\text { May } \\
17\end{array}$ & $\begin{array}{l}\text { Jun } \\
17\end{array}$ & $\begin{array}{l}\text { Poste- } \\
\text { rior }\end{array}$ \\
\hline $\begin{array}{l}\text { Actividad 1: Seminario } \\
\text { teórico práctico sobre } \\
\text { protección solar }\end{array}$ & $\mathrm{X}$ & & & & & & & & \\
\hline $\begin{array}{l}\text { Actividad 2: Aprender } \\
\text { enseñando a otros }\end{array}$ & $X$ & $X$ & & & & & & & \\
\hline $\begin{array}{l}\text { Actividad 3: Diseño de } \\
\text { vídeos divulgativos para } \\
\text { ALADA }\end{array}$ & $\mathrm{X}$ & $X$ & & & & & & & \\
\hline $\begin{array}{l}\text { Actividad 4: Workshop } \\
\text { "Protégete del sol, } \\
\text { protégete del Lupus" }\end{array}$ & & $X$ & & & & & & & \\
\hline $\begin{array}{l}\text { Actividad 5: Puesta en } \\
\text { práctica de lo aprendido }\end{array}$ & & & & $\mathrm{X}$ & $\mathrm{X}$ & $\mathrm{X}$ & $\mathrm{X}$ & & \\
\hline
\end{tabular}




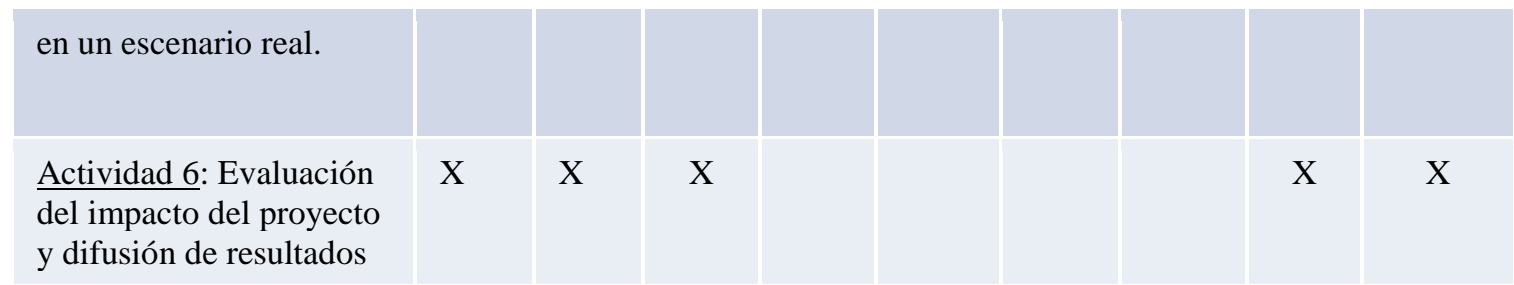

\section{Actividad 1: Seminario teórico práctico sobre protección solar}

Participantes: Alumnos de $5^{\circ}$ de Farmacia en el contexto de las asignaturas Dermofarmacia y Medicamento individualizado.

\section{Objetivos:}

1) Presentación del proyecto a los estudiantes, concienciación de la utilidad real que tiene su participación.

2) Recuerdo de conceptos adquiridos sobre la patología del Lupus, sus causas y tratamientos así como la importancia de la protección solar en estos pacientes.

3) Abordaje de conceptos nuevos y específicos: Radiación solar, impacto que el sol genera en la piel, protectores solares y productos para el sol.

Descripción: Se utilizará el Aprendizaje basado en problemas a través de la resolución de casos prácticos sobre protección solar, consejo y composición de preparados dermocosméticos para el cuidado y la protección de la piel ante el sol. Para ello, se proporcionará a los estudiantes toda la documentación necesaria, así como blibliografía específica para su documentación. Por otro lado, se llevará a cabo una demostración práctica para que los estudiantes aprendan el manejo del equipo: "analizador de piel". Este equipo permite, para que posteriormente puedan utilizarlo con pacientes reales, determinar el grado de pigmentación de la piel, la identificación de daños tisulares y, en definitiva, constituye una herramienta de gran utilidad para la identificación del factor de protección solar más adecuado para el paciente.

\section{Actividad 2: Aprender enseñando a otros}

Participantes: Alumnos de $5^{\circ}$ de Farmacia en el contexto de las asignaturas Dermofarmacia y Medicamento individualizado.

\section{Objetivos:}

1) Afianzar los conocimientos adquiridos en el seminario mediante la elaboración de materiales didácticos para los estudiantes de $3^{\circ}$.

2) Contribuir a la integración curricular vertical de contenidos en el grado de Farmacia.

3) Incrementar la calidad del servicio que se prestará a los pacientes de ALADA

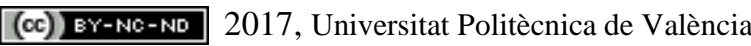


Descripción: Con la información adquirida en el seminario /taller, los alumnos deben realizar una wiki (herramienta colaborativa). Con ella crearán una herramienta virtual, para transmitir de forma clara los conceptos fundamentales aprendidos a sus compañeros de $3^{\circ}$ curso:

-Qué es la radiación solar, y concretamente la UV

-Qué daños provoca la radiación en la piel

-Qué son los fotoprotectores y qué tipos de fotoprotectores podemos tener.

\section{Actividad 3: Diseño de vídeos divulgativos para ALADA}

Participantes: Alumnos de $3^{\circ}$ de farmacia de las asignaturas Fisiología III e Inmunología.

Objetivo: Favorecer procesos de aprendizaje significativo de los conceptos abordados en materias básica mediante su "profesionalización" a través del diseño de vídeos divulgativos para pacientes con lupus.

Descripción: Los estudiantes de $3^{\circ}$ curso deberán elaborar en grupos de 4-5 alumnos un vídeo en el que, de forma sencilla y amena, expliquen a los pacientes por qué la radiación solar es negativa para su salud y como deben protegerse de ella. Para ello contarán, además de con los contenidos teóricos de las propias materias, con la herramienta elaborada por los estudiantes de $5^{\circ}$ curso. Los trabajos serán evaluados por los docentes y por un comité de expertos formado por profesionales y pacientes. Los estudiantes de $5^{\circ}$ curso también contribuirán a la evaluación de sus compañeros favoreciendo de este modo la reflexión sobre su propio proceso de aprendizaje, ya que podrán valorar la calidad de su propio trabajo a través de la influencia en el trabajo de otros. Finalmente, los vídeos que la asociación considere de utilidad, serán puestos a su disposición para su libre difusión a nivel nacional.

\section{Actividad 4: Workshop "Protégete del sol, protégete del Lupus"}

Participantes: Alumnos de $3^{\circ}$ y $5^{\circ}$ del grado en Farmacia de la Universidad San Jorge, docentes, 10 pacientes de la asociación ALADA, profesionales farmacéuticos y representantes del Colegio de Farmacéuticos de Zaragoza.

Objetivo: A través de la intervención dirigida por docentes y farmacéuticos comunitarios, los estudiantes realizarán el diagnóstico de la piel y emitirán consejo dermofarmacéutico a pacientes con Lupus.

Descripción: La actividad se llevará a cabo en las instalaciones de la Universidad San Jorge. En ella, equipos formados por estudiantes de distintos cursos, realizarán distintas intervenciones con los pacientes bajo la supervisión de los docentes y de farmacéuticos comunitarios tutores de estancias clínicas. 
En este taller, se trabajarán los conceptos adquiridos por los alumnos, realizando una intervención individualizada a los pacientes en los que, además, se llevará a cabo una determinación de su piel.

Se dividirá la actividad en "estaciones" por las que irán rotando los equipos, de forma que sea algo dinámico. Cada equipo; formado por pacientes, alumnos y supervisores (docentes y tutores), pasará por:

-Proyección del vídeo creado por los alumnos.

-Determinaciones e informes con el equipo "Analizador de piel”: Los alumnos realizarán a los pacientes, mediante el uso del equipo "analizador de piel", una determinación del grado de pigmentación de su piel y del factor de protección solar más adecuado.

-Consejos dermofarmacéuticos individualizados sobre protección solar, diferentes de antisolares, diferencias entre filtros químicos y físicos, diferencias en tipos de formas cosméticas y texturas, consejos de aplicación y protección.

El servicio realizado a cada paciente, durante esta sesión, constará de una intervención individualizada, además de una exposición informativa útil y práctica para la mejora en la calidad de vida y manejo de su enfermedad.

Para el alumno, será la oportunidad de demostrar lo aprendido y ponerlo al servicio de un paciente.

\section{Actividad 5: "Puesta en práctica de lo aprendido en un escenario real."}

Participantes: alumnos de $5^{\circ}$ curso, tutores de prácticas tuteladas, docentes y Colegio de Farmacéuticos.

Objetivo: Dentro de las estancias clínicas, los alumnos, van a extrapolar lo aprendido en este proyecto; podrán repetir la experiencia del workshop, con pacientes reales.

Descripción: Los alumnos pueden encontrarse pacientes con Lupus, tanto en farmacia comunitaria, como en hospital (área de pacientes externos). Además, algunas de las farmacias en las que van a realizar sus estancias, están dentro de un proyecto en que se trata el mismo problema: "Frena el sol, frena el lupus". Los alumnos, documentarán dichas experiencia, sumándolas a la memoria de sus estancias (cuentan en dicha memoria con un apartado para ello).

\section{Actividad 6: Evaluación del impacto del proyecto y difusión de resultados}

Participantes: Docentes, Estudiantes y pacientes

Objetivo: Establecer el impacto real del proyecto en todos los agentes implicados.

Descripción: A lo largo del proyecto, se llevarán a cabo diversas actividades de evaluación, con el objetivo de valorar la evolución del proceso de aprendizaje; para

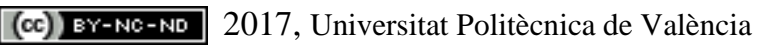

Congreso IN-RED (2017) 
identificar y corregir posibles problemas o desviaciones de los objetivos planteados. Así mismo, se diseñarán herramientas específicas de evaluación para determinar el impacto en el alumno, en el docente y en el paciente. Para ello, se elaborarán rúbricas de evaluación (autoevaluación, heteroevaluación, coevaluación) y encuestas y se realizará un grupo focal con algunos de los participantes. De este modo se podrá evaluar el impacto del proyecto en los participantes desde una perspectiva cuantitativa y cualitativa. Los resultados obtenidos serán elaborados para su difusión a través de diversos canales, tanto divulgativos como específicos.

La evaluación que el rofesorado realiza sobre la actividad de los alumnos, se realiza analizando la adquisición de competencias, así como la valoración del trabajo realizado en grupo y el nivel de las actividades llevadas a cabo.

En el workshop final se evaluarán, mediante una rúbrica, la actividad y grado de satisfacción de los alumnos con el trabajo realizado. Los pacientes evaluarán, también mediante una rúbrica, dos secciones diferentes:

-La actividad que los alumnos han realizado en dicha actividad, la información que les han proporcionado y la creación de los vídeos.

-Su grado de conformidad y satisfacción con lo que el proyecto les ha aportado.

\section{Resultados}

Se ha generado material didáctico sobre daños y protección solar, que ha sido enviado a la asociación ALADA en dos formatos: el formato web y, a petición de su presidente, un formato de presentación (power point) para poder ser empleado en sus acciones formativas

Se han creado vídeos divulgativos sobre riesgos del sol en pacientes con Lupus.

Toda la información generada en las actividades fue plasmada en un formato web, que permitió incorporar además las TICs en este proyecto. El acceso a la página web es el siguiente:

https://sites.google.com/view/solylupus

Se realiza una evaluación multifactorial del proyecto, obteníendose resultados de valoración del mismo por parte de los alumnos y por parte de los pacientes.

El 100\% de los participantes contestaron a la evaluación.

Los resultados de ambas evaluaciones fueron muy positivos. Ambos resultados han sido recogidos en la Tabla 2.- y Tabla 3.-

Table 2. Resultados de evaluación de estudiantes. 
"Protégete del sol, protégete del Lupus". Integración curricular en el grado de Farmacia a través de la Metodología aprendizaje Servicio.

\begin{tabular}{|c|c|}
\hline $\begin{array}{l}\text { Las actividades realizadas me han permitido desarrollar competencias } \\
\text { profesionales de importancia en mi formación. Valora del } 1 \text { al } 10 .\end{array}$ & $8.95(\mathrm{DS}=1.16)$ \\
\hline $\begin{array}{l}\text { ¿Consideras que las actividades realizadas mejorarán tu práctica profesional } \\
\text { como farmacéutico?Valora de } 1 \text { a } 10 .\end{array}$ & $8.91(\mathrm{DS}=1.41)$ \\
\hline $\begin{array}{l}\text { Valora del } 1 \text { a } 10 \text { el grado de dificultad de las actividades realizadas siendo } \\
1 \text { el mínimo y } 10 \text { el máximo. }\end{array}$ & $4,41(\mathrm{DS}=2.22)$ \\
\hline $\begin{array}{l}\text { Valora del } 1 \text { al } 10 \text { la utilidad de la interacción con estudiantes de otros } \\
\text { cursos de tu mismo grado para tu proceso de formación }\end{array}$ & $8.84(\mathrm{DS}=1.50)$ \\
\hline $\begin{array}{l}\text { ¿Consideras que los docentes deben repetir esta actividad en próximos } \\
\text { años?Respuesta: Sí/No }\end{array}$ & $95.45 \%$ contestaron Sí. \\
\hline Recomendarías esta actividad a otros estudiantes. Respuesta: Sí/No & 95.45\% contestaron Sí. \\
\hline
\end{tabular}

Table 3. Resultados de evaluación de los pacientes.

\begin{tabular}{lc}
\hline \multicolumn{1}{c}{ PREGUNTA } & RESULTADO \\
\hline $\begin{array}{l}\text { Puntúa del } 1 \text { al } 10 \text { la utilidad para personas con lupus de los vídeos } \\
\text { realizados por los estudiantes }\end{array}$ & 9.6 (DS=0.55) \\
$\begin{array}{l}\text { Puntúa del } 1 \text { al } 10 \text { el grado de utilidad como paciente de la información } \\
\text { recibida sobre protección solar }\end{array}$ & 9.8 (DS=0.45) \\
$\begin{array}{l}\text { Puntúa del } 1 \text { al } 10 \text { el grado de utilidad como paciente de la información } \\
\text { recibida sobre los efectos negativos del sol en el desarrollo del lupus }\end{array}$ & 9.8 (DS=0.45) \\
$\begin{array}{l}\text { Puntúa del } 1 \text { al } 10 \text { el grado de utilidad como paciente de la información } \\
\text { personalizada sobre el análisis de la piel. }\end{array}$ & 10 (DS=0) \\
$\begin{array}{l}\text { Valora tu satisfacción, del } 1 \text { al 10, con las explicaciones e intervenciones de } \\
\text { los estudiantes durante el workshop. }\end{array}$ & $100 \%$ contestaron Sí. \\
\hline Recomendarías esta actividad a otras personas con lupus & $100 \%$ contestaron Sí. \\
\hline
\end{tabular}

\section{Conclusiones}

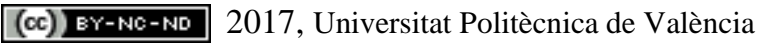

Congreso IN-RED (2017) 
Como conclusión, este proyecto ha utilizado como eje vertebrador para la integración curricular el paciente con Lupus y como estrategia didáctica el Aprendizaje Servicio en colaboración con la asociación ALADA (Asociación de enfermos de Lupus y Antifosfolípido de Aragón); esto ha dado como resultado el favorecer la adquisición de competencias en los estudiantes del grado de farmacia para la intervención clínica en pacientes polimedicados crónicos. La asociación ha recibido información útil para su función informativa y divulgativa entre los pacientes. Los pacientes han tenido la oportunidad de conocer más en profundidad su piel, los peligros del sol para su enfermedad y la forma de prevenirlos. Además, el contacto paciente-futuro farmacéutico, genera un nexo de contacto fundamental, que permite a los alumnos saber qué su aprendizaje tiene una repercusión directa sobre los pacientes crónicos y a los pacientes que pueden contar con los farmacéuticos para el cuidado y prevención de sus salud. De este modo, gracias a la metodología del ApS se ha conseguido ir más allá de la capacitación profesional y enfatizar en la dimensión social de la formación universitaria.

\section{Referencias}

ABADÍA-VALLE, AR; MUÑOZ GONZALVO, MJ; SOTERAS, F. (2011). “¿Existen alternativas a las clases magistrales? Una experiencia en Fisiología Ocular del grado de Óptica y Optometría". Arbor 187(3): 189-194.

EYLER, J., \& D. E. GILES, J. (1999). Where's the Learning in Service-Learning? San Francisco: Jossey-Bass.

HONNET, E.P; POULSEN, S. (1989). "Principles of good practice in combining service and learning". Wingspread Special Report. Racine WI: The Johnson Foundation.

MANGAS, S. L., \& MARTÍNEZ-ODRÍA, A. (2012). "La implantación y difusión del Aprendizaje-Servicio en el contexto educativo español. Retos de futuro de una metodología de enseñanza-aprendizaje para promover la innovación en la Educación Superior". Revista del Congrés Internacional de Docència Universitària i Innovació (CIDUI).

PUIG, JM; BATLLE, R; BOSCH, C; PALOS, J. (2006). Aprendizaje servicio. Educar para la ciudadanía. 238pp. Editorial Octaedro. ISBN: 9788480639019

SEFH, 2013: Modelo de selección y atención farmacéutica de pacientes crónicos de la sociedad española de farmacia hospitalaria. Editor y Director Responsable: Sociedad Española de Farmacia Hospitalaria (SEFH). ISBN: 978-84-695-8597-9.

VAN MIL JW, SCHULZ M, TROMP TF (2004). "Pharmaceutical care, European developments in concepts, implementation, teaching, and research: a review". Pharm World Sci. 2004 Dec; 26(6): 303-11.

WALTERS M. R. (1999). "Case-stimulated learning within endocrine physiology lectures: an approach applicable to other disciplines". Advance Physiology Education 276, 74-78.

WATERS, J.R; VAN METER, P; PERROTI, W; DROGO, S; CYR, R,J. (2005). "Cat dissection vs. sculpting human structures in clay: an analysis of two approaches to 
"Protégete del sol, protégete del Lupus". Integración curricular en el grado de Farmacia a través de la Metodología aprendizaje Servicio.

undergraduate human anatomy laboratory education". Advance Physiology Education 29(1):27-34.

WIEDENMAYER K, SUMMERS R, MACKIE C. (2006) Organización Mundial de la Salud. Desarrollo de la Práctica de Farmacia Centrada en la Atención del Paciente. Manual<www.fip.org/files/fip/publications/DevelopingPharmacyPractice/DevelopingPhar macyPracticeES.pdf> [Consulta : 01/04/2017]

(c) EY-NC-ND 2017, Universitat Politècnica de València 


\title{
Notas móviles y resolución de problemas en equipo: del texto al dibujo
}

\author{
María de Miguel Molina ${ }^{a}$, Virginia Santamarina Campos ${ }^{b}$, Blanca de Miguel Molina ${ }^{a}$ \\ y $\mathbf{M}^{\mathbf{a}}$ Ángeles Carabal Montagud ${ }^{\mathrm{b}}$ \\ ${ }^{a}$ Departamento de Organización de Empresas, Universitat Politècnica de València, \\ mademi@omp.upv.es, 'bepartamento de Conservación y Restauración de Bienes Culturales, \\ Universitat Politècnica de València.
}

\begin{abstract}
Mobile notes can synthesize different points of view, merging mental models, and therefore helping to understand and solve complex problems in a cooperative way. The sequences of the process can be changed and students are able to add ideas in a more creative way, not only using keywords but also drawings. This tool has been used in different subjects from Graduate and Undergraduate levels, and from two different Faculties (Business Administration \& Management and Fine Arts), which has allowed us to compare the results in the learning process. Moreover, we can evaluate some transversal competences of the students such as teamwork and leadership or planning and managing of time.
\end{abstract}

Keywords: cooperative learning, teamwork, conceptual maps, mobile notes, problem-analysis, problem-solving.

\begin{abstract}
Resumen
Las notas móviles pueden sintetizar distintos puntos de vista, uniendo modelos mentales, ayudando a entender y resolver problemas de una modo cooperativo. Las secuencias del proceso pueden cambiarse y los estudiantes pueden ir añadiendo ideas de una manera más creativa, sea utilizando palabras clave como dibujos. Esta herramienta la hemos utilizado en distintas asignaturas de Grado y de Master, en dos Facultades diferentes (Administración y Dirección de Empresas, y Bellas Artes), lo que nos permite comparar los resultados en el proceso de aprendizaje. Asimismo, nos puede servir para evaluar ciertas competencias transversales de los estudiantes, como el trabajo en equipo y liderazgo o la gestión del tiempo.
\end{abstract}

Palabras clave: aprendizaje cooperativo, trabajo en equipo, mapas conceptuales, análisis de problemas, resolución de problemas. 


\section{Introducción}

El uso de notas móviles (entendidas como piezas de papel con pegamento en un extremo que permite pegarlas y despegarlas según interesa) nos permite obtener modelos más eficientes y ricos para resolver problemas, ya que proporcionan una herramienta flexible para su análisis. Además, el diseño de mapas conceptuales móviles aporta claridad mostrando las ideas de una manera visual. Las secuencias del proceso pueden variarse, añadiendo ideas de una manera creativa, utilizando palabras clave o dibujos. Los objetivos y retos de cada sesión necesitan ser diseñados por anticipado para guiar a los alumnos durante el proceso de aprendizaje, independientemente de a qué área pertenezca la asignatura.

Por otro lado, se trabajan dos competencias transversales (UPV, 2007):

Trabajo en equipo y liderazgo: "implica crear y desarrollar un clima de confianza mutua entre los componentes que permita trabajar de forma responsable y cooperativa...compartir conocimientos, compromiso y responsabilidad. Supone el reparto de tareas y roles y el respeto a las normas y reglas de juego establecidas por y para el grupo".

Planificación y gestión del tiempo: "implica ser capaz de organizar y distribuir correctamente el tiempo del que disponemos y distribuirlo en función de las actividades necesarias para alcanzar nuestros objetivos a corto, medio y largo plazo".

El uso de mapas conceptuales, teniendo claros los objetivos y la manera de evaluarse, son una herramienta muy potente para afianzar los conceptos clave y conseguir un alineamiento constructivo, de manera que se estimule la participación de los estudiantes (Biggs, 2004).

Además, el trabajo colaborativo es fundamental a la hora de resolver problemas (Arquilla y Motta, 2011), ya que distintos actores pueden estar involucrados y las relaciones interpersonales son fundamentales (Muñoz González, 2014). Y estas son competencias transversales o "soft" que demandan los empleadores (Wu-Pong et al., 2013), más allá de conocimientos específicos.

\section{Objetivos}

El objetivo de la dinámica es analizar un problema complejo y buscar soluciones utilizando los mapas conceptuales móviles, de manera que a través de preguntas de enfoque el alumno vaya de lo general a lo específico, para buscar una solución en equipo.

De acuerdo con el "Modelo para la enseñanza del diseño creativo" de Glen et al. (2015: 190), podemos desarrollar distintas actividades:

1. Identificar problemas: a los equipos se les plantea un reto (o pregunta de enfoque) y deben identificar problemas y oportunidades.

2. Observación: pensando de la misma manera que el usuario.

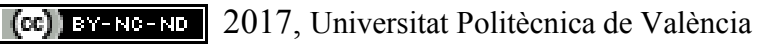


3. Visualización y reflexión: mostrando los resultados de la observación a toda la clase de manera visual para compartir, hacer preguntas y explicar.

4. Brainstorming de ideas, votando las mejores para reducir las soluciones.

5. Usar y probar prototipos, observando a los usuarios para captar nuevas ideas.

6. Test de viabilidad, explorando las opciones de modelos de negocio y las distintas posibilidades de generar valor.

En este caso, se han desarrollado actividades de los tipos 1, 3 y 4 . De todos modos, dependiendo de la asignatura o session se podrían añadir otras actividades. Por ejemplo, se podría hacer un juego de rol (role-playing) para aplicar las actividades $2 \mathrm{y} / \mathrm{o} 5$. O hacer un estudio de caso utilizando la actividad 6.

\section{Desarrollo de la innovación}

Antes de comenzar la dinámica, son importantes dos tareas por parte del profesor:

- Redactar unas instrucciones previas para los estudiantes.

- Comprar el material necesario. Nosotros compramos tarjetas de la marca post-it que nos permiten manejar distintos tamaños, colores y formas.

Los grupos se forman con 3-5 alumnos. Se les plantea un reto y ellos deben identificar los distintos problemas, expresándolos con palabras clave o dibujos en notas móviles de un color determinado.

De acuerdo con el proceso de resolución de problemas, los grupos buscarán soluciones para cada problema por medio de la tormenta de ideas (brainstorming), de forma que al final se seleccionará una solución consensuada para cada problema. Dicha solución se expresará también con palabras clave o dibujos en una nota móvil de otro color, y que se conectará con el problema a resolver. Es decir, de cada problema una nota y de cada solución otra nota. En este momento, el professor revisará los modelos de cada grupo para detector información que falte por completer.

Al mostrar este modelo con las notas móviles pegadas en la pared, tendremos dos filas de ideas, problemas y soluciones. Entonces se plantea un nuevo reto, que es proponer medidas para prevenir que esos problemas aparezcan. Estas medidas, se escribirán o dibujarán en una nota móvil mayor y con un tercer color (Figura 1).

Asimismo, se podría plantear un tercer reto que sería establecer otras conexiones entre problemas y soluciones. Es decir, conectar soluciones que pueden ser communes para solucionar varios problemas.

Con el modelo final, el resto de grupos se desplazan por el aula para observar los modelos del resto de equipos y así pueden comparar dichos modelos con el suyo propio. Pero la mitad del grupo se queda en su modelo para explicar dudas a los "visitantes" o recoger las "recomendaciones" de sus compañeros. Acabada la ronda, cada grupo vuelve a reunirse para enriquecer su modelo con todas las ideas aportadas.

(c) $)$ EY-NC-ND 2017, Universitat Politècnica de València 


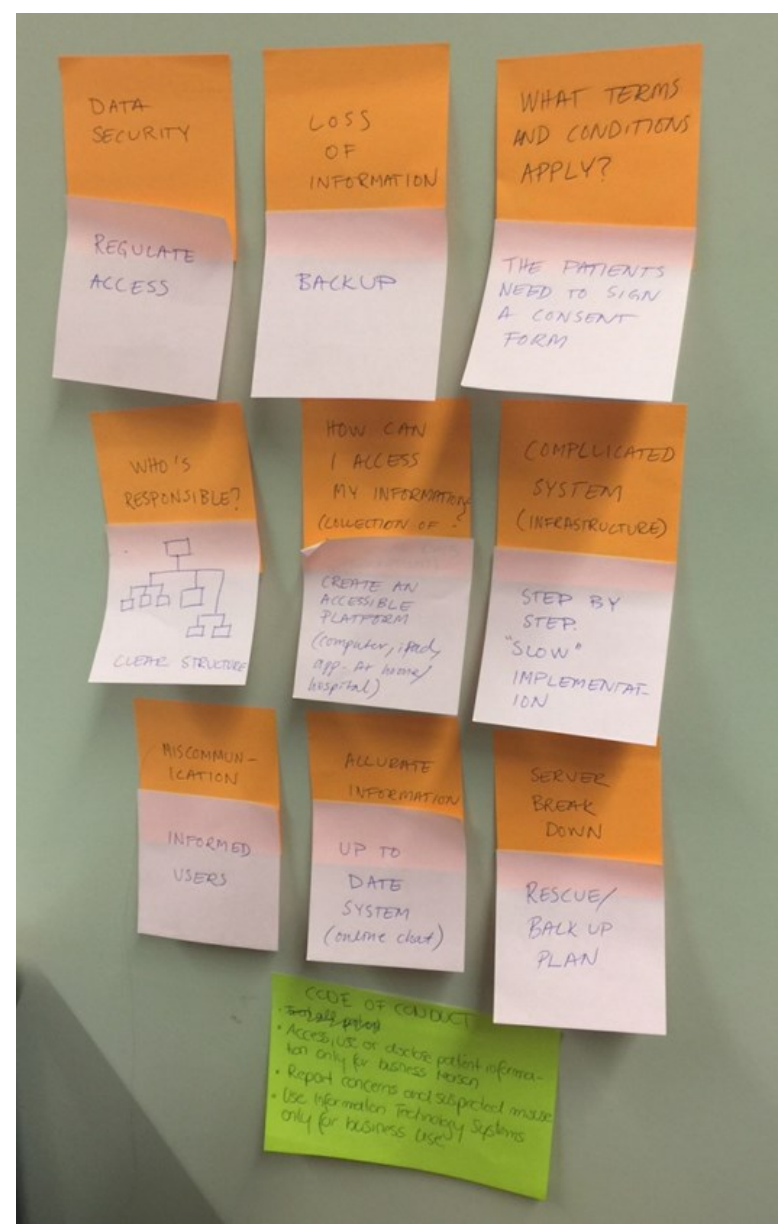

Fig. 1. Mapa del ejercicio desarrollado por los estudiantes de Máster.

Fuente: fotografia propia, curso 2016-2017.

\section{Resultados}

Aplicamos este esquema a una sesión de la asignatura 'Senior Management and Information \& Communication Technologies’ del Máster Universitario en Gestión de Empresas, Productos y Servicios de la Facultad de Administración y Dirección de Empresas. La sesión se dedicó al concepto general de "Protección de Datos" (Laudon \& Laudon, 2016) y se les propuso a los estudiantes un ejercicio de dicho manual (p. 191), en el que el reto es regular una base de datos informática sobre pacientes de un hospital y su uso para comunicarse entre médicos y pacientes.

El primer paso, es que los grupos identifiquen qué problemas sobre la protección de datos pueden surgir. Seguidamente, deben proponer una solución para cada problema. A los alumnos se les proporciona como apoyo un documento que contiene la regulación principal sobre Protección de Datos de la Unión Europea.

(c) EY-NC-ND 2017, Universitat Politècnica de València 
El Segundo reto es proponer un breve "código de conducta" que sirva para prevenir dichos problemas.

Tras estos pasos, se da el trabajo colaborativo para enriquecer el modelo que vuelve a revisarse por el equipo (Figura 2).

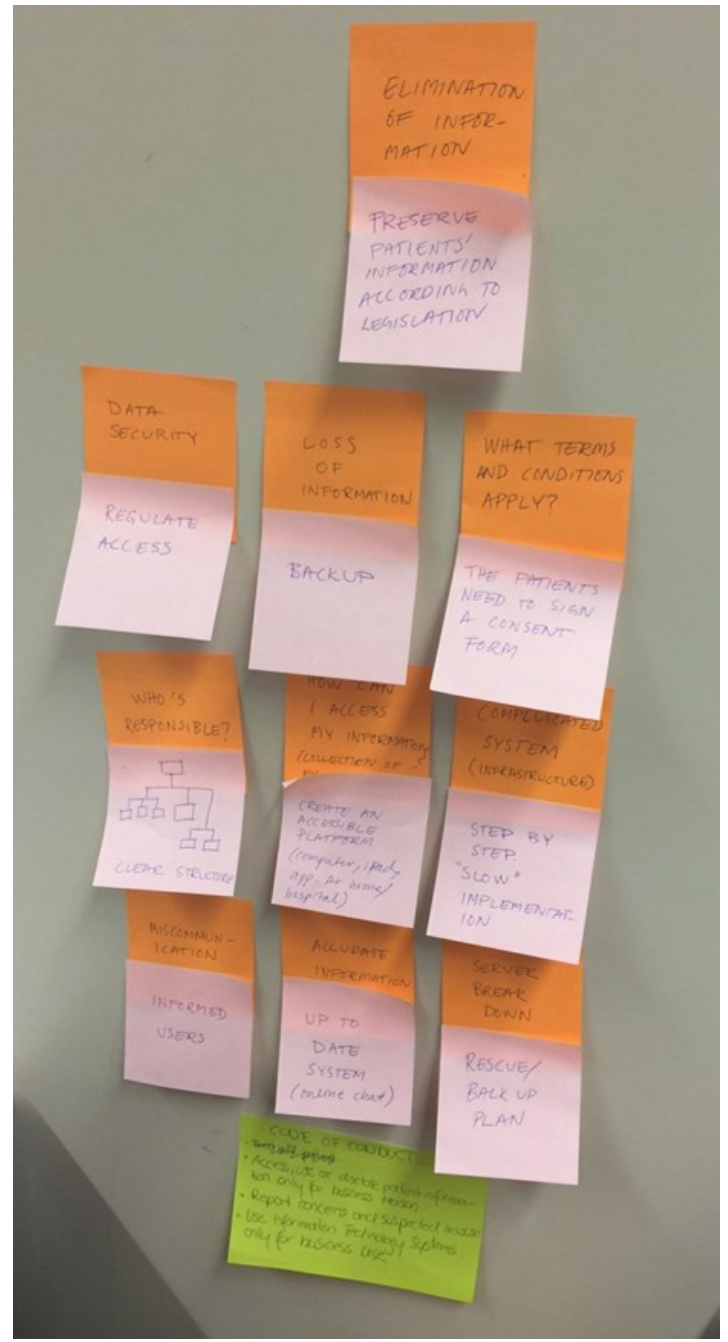

Fig. 2. Modelo revisado por los estudiantes.

Fuente: fotografía propia, curso 2016-2017.

Además, comparamos los resultados con los del Máster en Conservación y Restauración del Patrimonio, de la Facultad de Bellas Artes (Santamarina et al., 2016). En ambos casos, podemos comprobar que las ideas pueden representarse por texto (palabras clave) o con dibujos, dependiendo del reto propuesto y los objetivos (Figura 3).

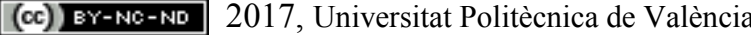




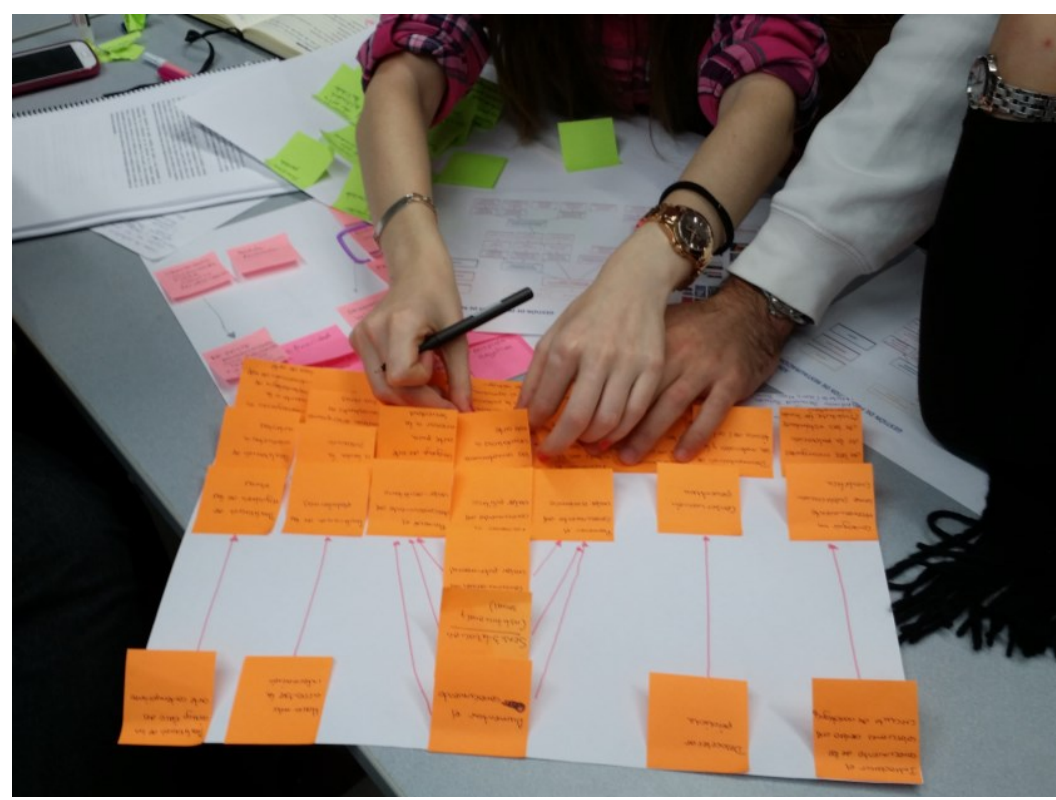

Fig. 3. Estudiantes del Máster de Restauración realizando mapas conceptuales.

Fuente: fotografia propia, curso 2016-2017.

Este tipo de ejercicios visuales, les ayuda a organizar ideas y a entender las relaciones o "conectores" entre los problemas y las soluciones. Además, las notas móviles permiten hacer cambios y resolver errores de una manera más sencilla, a la vez que los colores ayudan a diferenciar los conceptos.

La integración de distintos puntos de vista de modo colaborativo es muy importante en la resolución de problemas, por lo que el resultado final es más rico, pero, al mismo tiempo, es sencillo de comprender. Además, les ayuda a reflexionar sobre la necesidad de tener en cuenta el punto de vista de distintos actores.

\section{Conclusiones}

Esta experiencia nos ha mostrado que el uso de notas móviles ayuda a impulsar el trabajo colaborativo en distintas asignaturas, se usen palabras clave o dibujos. El intercambio de ideas enriquece la visión de los problemas y la generación de posibles soluciones.

Es cierto que los cursos de postgrado suelen tener grupos pequeños, por lo que estas dinámicas son más sencillas de aplicar y además ayudan a impulsar el trabajo colaborativo en equipo, a la vez que ayudan a gestionar el tiempo puesto que cada fase tiene un tiempo máximo para que la dinámica pueda completarse en la sesión. Incluso si los estudiantes no son expertos en la materia, y vienen de titulaciones distintas, este trabajo colaborativo les ayuda a trabajar en equipos interdisciplinares. 
Se abren distintas preguntas a la hora de evaluar este trabajo, puesto que es difícil marcar elementos objetivos que ayuden al profesor, siendo más una evaluación por observación en el aula, combinada con el resultado final. Algunas sugerencias podrían ser: valorar la integración del equipo, valorar la cantidad y calidad de ideas expuestas (problemas detectados y/o soluciones propuestas), valorar el número de conexiones entre los problems y soluciones, valorar la capacidad de síntesis (a través de palabras clave o dibujos), valorar la creatividad a la hora de exponer el mapa, valorar el ajuste al tiempo dado, etc.

\section{Referencias}

ARQUILLA, V. y MOTTA, R. (2011). "Student brain: tools and methods to support the students' creativity and to improve the learning and co-learning processes. The Polibrain case" En: INTED2011: 5th International Technology, Education and Development Conference, pp. 46514661.

BIGGS, J. (2004). Calidad del aprendizaje universitario. Madrid: Narcea.

GLEN, R.; SUCIU, CH.; BAUGHN, C.CH. y ANSON, R. (2015). "Teaching design thinking in business schools" en The International Journal of Management Education, vol. 13, no. 2, pp. 182-192. <http://dx.doi.org/10.1016/j.ijme.2015.05.001> [consulta: 25 marzo de 2017].

LAUDON, K.C. y LAUDON, J.P. (2016). Management information systems: managing the digital firm. Boston: Pearson.

MUÑOZ GONZÁLEZ, J.M.; SERRANO RODRÍGUEZ, R. y MARÍN DÍAZ, V. (2014). "El aprendizaje colaborativo y su desarrollo a través de mapas mentales. Una innovación educativa en la formación inicial docente" en Educatio Siglo XXI, Vol. 32.

SANTAMARINA CAMPOS, V.; CARABAL-MONTAGUD, M.A.; DE-MIGUEL-MOLINA, M. y DE MIGUEL MOLINA, B. (2016). "La resoluciones de problemas a través de mapas conceptuales móviles cooperativos". En: Congreso Nacional de Innovación Educativa y Docencia en Red IN-RED 2016. Valencia: Editorial UPV, <doi: http://dx.doi.org/10.4995/INRED2016.2016>.

UNIVERSITAT POLITĖCNICA DE VALÈNCIA (2007). Competencias Transversales. $<$ http://www.upv.es/contenidos/COMPTRAN/indexc.html> [Consulta: 23 de marzo de 2017]

WU-PONG, S. et al. (2013). "The Future of the Pharmaceutical Sciences and Graduate Education: Recommendations from the AACP Graduate Education Special Interest Group" en American Journal of Pharmaceutical Education, vol. 77, no. 4. 


\title{
Valoración de las herramientas y metodologías activas en el Grado en Ingeniería de Obras Públicas
}

Tatiana García-Segura ${ }^{a}$, José V. Martít y Víctor Yepes ${ }^{\mathrm{c}}$

aICITECH. Universitat Politècnica de València, tagarse@cam.upv.es, ' Innovación y Calidad Educativa EXCELCON. Departamento de Ingeniería de la Construcción y Proyectos de Ingeniería Civil. Universitat Politècnica de València, jvmartia@cst.upv.es, y 'ICITECH. Equipo de Innovación y Calidad Educativa EXCELCON. Departamento de Ingeniería de la Construcción y Proyectos de Ingeniería Civil. Universitat Politècnica de València, vyepesp@cst.upv.es.

\begin{abstract}
The change in the orientation of the higher education system has given rise to a teaching model focuses on student learning and skills acquisition. The communication presents the tools used for the "inverse class" teaching. A questionnaire has been designed to evaluate the active methodology and tools used in the class. Results indicate that the most valued tool is Lessons, followed by PoliformaT resources and pdf slides. Polimedia videos and videos of constructive methods present little deviation, indicating that all students agree with the usefulness of such technologies. It is also important to note that there is no disagreement with the active methodology. In particular, the correction of questions is the most valued activity in the learning process.
\end{abstract}

Keywords: technological resources, tools, active methodology, inverse class, questionnaire

\footnotetext{
Resumen

El cambio en la orientación del sistema de educación superior ha dado lugar a un modelo de enseñanza centrada en el aprendizaje del estudiante y la adquisición de habilidades. La comunicación presenta la valoración por parte de los alumnos de los recursos utilizados en la docencia de la "clase inversa". Se ha diseñado un cuestionario para evaluar la metodología activa y herramientas utilizadas. De los resultados se destaca que la herramienta mejor valorada es Lessons, seguida de Recursos de Poliformat y diapositivas en pdf. Los vídeos de polimedia y los vídeos de procedimientos constructivos presentan poca desviación, indicando que todos los alumnos están de acuerdo con la utilidad de dichas tecnologías. También es importante destacar que no hay ningún alumno en desacuerdo con la metodología activa. En concreto, la corrección de entregables es la actividad más valorada en el proceso del aprendizaje.
}

Palabras clave: recursos tecnológicos, herramientas, metodología activa, clase inversa, cuestionario 


\section{Introducción}

En los últimos años, ha habido un giro significativo en la orientación del sistema de educación superior como consecuencia de la Declaración de Bolonia (1999). El Espacio Europeo de Educación Superior (EEES) pretende construir un área de acuerdos y procesos comunes. Las universidades han adaptado sus estudios para cumplir con el compromiso. En primer lugar, se ha modificado la estructura de la enseñanza universitaria en España, dando lugar a los estudios de Grado, Máster y Doctorado, basados en los sistemas de transferencia de créditos europeos (ECTS). En segundo lugar, se ha revisado el modelo de enseñanza para adecuarlo a una formación centrada en el aprendizaje del estudiante y la adquisición de habilidades. En este sentido, la propuesta curricular debe seguir la nueva filosofía pedagógica, es decir, se centra en la adquisición de competencias en lugar de en la adquisición de conocimientos. Además, se promueve la competitividad, empleabilidad y movilidad.

Se distinguen dos categorías principales de concepción pedagógica (Kember et al. 2001): la enseñanza como transmisión del conocimiento y la enseñanza como ayuda al aprendizaje. La primera considera a los estudiantes como receptores pasivos de información. Sin embargo, la segunda concepción pedagógica se centra en fomentar el aprendizaje de los estudiantes. En este último caso, se busca que los estudiantes asuman un papel activo y participativo en el proceso educativo (Kane 2004). A pesar de que la profesión de ingeniero está ligada al análisis y resolución de problemas, en los estudios de ingeniería se ha tendido hacia la enseñanza deductiva. Para acabar con esta tendencia, la Universitat Politècnica de València (UPV), y en particular la Escuela Técnica Superior de Ingenieros de Caminos, Canales y Puertos, está impulsando el aprendizaje por competencias para conseguir un perfil académico-profesional más enfocado a las demandas actuales y futuras. En este contexto se encuentra el fomento de metodologías como la "clase inversa", en la que el profesor planifica actividades de aprendizaje para que el alumno sea el protagonista de su aprendizaje, participe en la formación de su propio conocimiento y se les permita la autoevaluación.

El Equipo de Innovación y Calidad Educativa EXCELCON, centrado en la gestión de proyectos y construcción (Pellicer et al. 2014; Pellicer et al. 2017), destaca la importancia de habilidades como liderazgo, gestión, comunicación, trabajo en equipo y pensamiento crítico, para puestos de gestión en la industria de la construcción (Yepes at al. 2012). En este sentido, se ha propuesto una serie de requerimientos que deben cubrir los estudios de posgrado en el ámbito de la gestión de la construcción (Yepes at al. 2016), así como una metodología innovadora para planificar los estudios de máster (Pellicer et al. 2013), en consonancia con un modelo que evalúa la desviación de cada programa a las necesidades de mercado (Yepes at al. 2012). Las competencias transversales, como es el caso del pensamiento crítico, pueden desarrollarse en las aulas a la vez que se trabajan otras competencias técnicas (García-Segura et al. 2016; Yepes et al. 2016). Asimismo, se pueden utilizar metodologías activas como herramientas para concienciar a los alumnos de los nuevos retos que presenta la sostenibilidad (Pellicer et al. 2016; Penadés-Plà et al. 2016; García-Segura et al. 2015). Este estudio analiza las herramientas y la metodología activa en

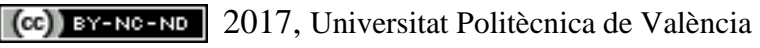

Congreso IN-RED (2017) 
estudios de ingeniería, particularmente en la asignatura Tipologías y Procedimientos de las Construcciones de la Ingeniería Civil (I).

\section{Objetivos}

Esta comunicación tiene como objetivos los que se relacionan a continuación:

1. Mostrar los recursos tecnológicos y herramientas utilizados en la asignatura Tipologías y Procedimientos de las Construcciones de la Ingeniería Civil (I).

2. Valorar la importancia de las herramientas y metodologías activas en el proceso de aprendizaje.

\section{Desarrollo de la innovación}

La innovación planteada consiste en la utilización de herramientas, así como metodologías activas para facilitar el proceso de enseñanza-aprendizaje. Este estudio analiza las respuestas de los estudiantes a un cuestionario diseñado para evaluar la utilización de herramientas y metodología de "clase inversa" en la asignatura Tipologías y Procedimientos de las Construcciones de la Ingeniería Civil (I) durante el curso académico 2016-2017. Esta asignatura pertenece al segundo año del Grado en Ingeniería de Obras Públicas.

Las variables estudiadas se encuentran relacionadas con las características del alumno, las notas de los exámenes y su actitud frente a las tecnologías educativas y metodologías activas de aprendizaje. Se utiliza un cuestionario de preguntas de respuesta múltiple para conocer las características del estudiante y las notas, mientras su actitud frente a la innovación planteada se evalúa mediante la escala de Likert (1-5), siendo su valoración creciente desde 1 hasta 5. El valor "1" significa para el alumno, que se podría prescindir de la herramienta, mientras que el "5" equivale a considerar dicha herramienta como imprescindible. A continuación se muestra las variables y las opciones planteadas en el cuestionario:

- $\quad$ Sexo: 1(Hombre), 2(Mujer)

- Edad: 1(18-19), 2(20-21), 3(más de 21 años),

- Horas de estudio semanales: 1(< $1 \mathrm{~h} /$ semana), 2(1-3h/semana), 3(>3 h/semana)

- Notas del primer parcial: 1(no presentado), 2(suspenso), 3(aprobado), 4(notable), 5(sobresaliente)

- Notas segundo parcial: 1(no presentado), 2(suspenso), 3(aprobado), 4(notable), 5(sobresaliente)

- Actitud frente a la utilidad de la herramienta recursos de PoliformaT: 1,2,3,4,5

- Actitud frente a la utilidad de las diapositivas en pdf : 1,2,3,4,5

- Actitud frente a la utilidad de las diapositivas en Power Point: 1,2,3,4,5

- Actitud frente a la utilidad de los vídeos Polimedia: 1,2,3,4,5

- $\quad$ Actitud frente a la utilidad del libro de apuntes: $1,2,3,4,5$

(c) ) EY-NC-ND 2017, Universitat Politècnica de València 
- Actitud frente a la utilidad de los vídeos de procedimientos constructivos: $1,2,3,4,5$

- Actitud frente a la utilidad de la herramienta Lessons de PoliformaT: 1,2,3,4,5

- Actitud frente a la utilidad del Portafolio en espacio compartido del PoliformaT: $1,2,3,4,5$

- Actitud frente a la utilidad de la metodología de la clase inversa: $1,2,3,4,5$

- Actitud frente a la utilidad de la corrección de entregables: $1,2,3,4,5$

\section{Herramienta "Recursos" de PoliformaT}

La carpeta "Recursos" contiene documentos útiles para el desarrollo de la asignatura y el aprendizaje del alumno. No sólo se proporcionan los temas que se ven en clase, también se facilita bibliografía para que los alumnos puedan ampliar sus conocimientos.

\section{Diapositivas en pdf y Power Point}

Las diapositivas facilitadas a los alumnos muestran los contenidos de la asignatura distribuidos por temas. Éstas aportan imágenes y ejemplos que no se recogen en el libro de la asignatura. Las diapositivas se facilitan en pfd y Power Point. Las diapositivas en Power Point disponen de enlaces a vídeos. Se analiza si los alumnos prefieren las diapositivas en Power Point o si se puede prescindir de éstas.

\section{$\underline{\text { Vídeos Polimedia }}$}

Es una tecnología educativa basada en vídeos para presentar un tema. El profesor explica los contenidos con la ayuda de diapositivas. Además, el profesor aparece en el vídeo para mejorar la comunicación no verbal. Esta tecnología educativa permite que el alumno pare la explicación del profesor cuando necesite más tiempo para tomar nota o consultar algo.

\section{Libro de apuntes}

El libro de la asignatura contiene los contenidos explicados en detalle. Los alumnos pueden recurrir al libro para entender mejor el tema. Además, éste contiene bibliografía de consulta.

\section{Vídeos de procedimientos constructivos}

El objetivo de la asignatura Tipologías y Procedimientos de las Construcciones de la Ingeniería Civil (I) es que los alumnos aprendan diferentes procedimientos constructivos. Es por ello que se consideró importante aportar videos de procedimientos constructivos correspondientes a la ingeniería civil.

\section{Lessons}

Esta herramienta permite conocer la planificación completa de las clases. El profesor crea itinerarios formativos para que los alumnos dispongan de todos los elementos necesarios para el desarrollo de las clases. Los alumnos conocen de antemano los temas que se verán en cada clase, los documentos que necesitarán, así como las actividades previas y de aula que deberán realizar. Se crean condiciones de acceso a los distintos elementos publicados. Esta herramienta es propia de las metodologías activas como puede ser la metodología de clase inversa. 


\section{Portafolio}

El portafolio es un conjunto documental que recoge las tareas realizadas por el alumno durante el curso. Los estudiantes comparten con el profesor un espacio virtual donde se incluyen los documentos que evidencian las habilidades desarrolladas y los conocimientos adquiridos. Esta herramienta permite a su vez realizar el proceso de evaluación, ya que muestra las habilidades, esfuerzo, progreso y logros de los estudiantes.

\section{Clase inversa}

Este tipo de clase se sale del modelo de enseñanza tradicional, pues la clase magistral se sustituye por "deberes" en el aula, mientras los contenidos son aprendidos online fuera del aula. En esta asignatura, se ha decidido seguir el modelo de clase inversa incluyendo la lección magistral participativa. Los contenidos son presentados mediante distintas herramientas (diapositivas, vídeos, libros, otros documentos de PoliformaT...). Durante las clases, se diseñan distintas actividades de aprendizaje para profundizar en los contenidos y ofrecerles feedback. Asimismo, se utilizarán estas actividades para que el alumno adquiera competencias transversales. Como proceso de evaluación del aprendizaje, se recomienda la evaluación formativa. Esta metodología es consistente con la taxonomía Bloom, ya que deja los niveles inferiores (recordar, entender) para el desarrollo en casa, y los superiores (aplicar, analizar, evaluar y crear) para desarrollarlos en el aula. Asimismo, se sigue la estrategia del EEES, ya que el alumno será un "ser activo", mientras el profesor hará de "guía" en el proceso de aprendizaje.

\section{Corrección de entregables}

Para llevar a cabo un aprendizaje activo, los alumnos realizan entregables previos al desarrollo de cada clase. Asimismo, en clase también se realizan entregables con la supervisión de los profesores. Las respuestas se pueden resolver con una lectura atenta del libro correspondiente y demás recursos de PoliformaT. Además, los alumnos pueden consultar distintas fuentes como la bibliografía de la asignatura, internet, etc. Durante el desarrollo de las clases, se corrigen los entregables mediante una evaluación formativa. El profesor aprovecha para matizar, ampliar y exponer la materia.

\section{Resultados}

A continuación se analizan los resultados obtenidos del cuestionario. El tamaño de la muestra ha sido $N=22$. De acuerdo con la Figura 1, el $73 \%$ de los estudiantes es hombre, mientras el $27 \%$ es mujer. El $73 \%$ de los estudiantes tiene más de 21 años, el $41 \%$ tiene entre 20 y 21 años y el 5\% tiene menos de 20 años. Las horas dedicadas al estudio semanal fueron menos de 1 hora (18\%), entre 1 y 3 horas (64\%) y más de 3 horas (18\%). Las notas del primer parcial fluctúan entre no presentado y sobresaliente. El mayor porcentaje corresponde notable (32\%), seguido de aprobado (23\%), sobresaliente (23\%), suspenso (18\%) y no presentado (5\%). Sin embargo, todos los encuestados se presentaron al segundo parcial y ninguno obtuvo la nota de sobresaliente. El 27\% de los estudiantes suspendió el examen, mientras el $50 \%$ obtuvo aprobado y el $23 \%$ notable.

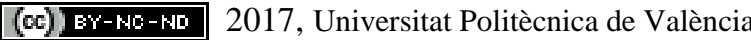




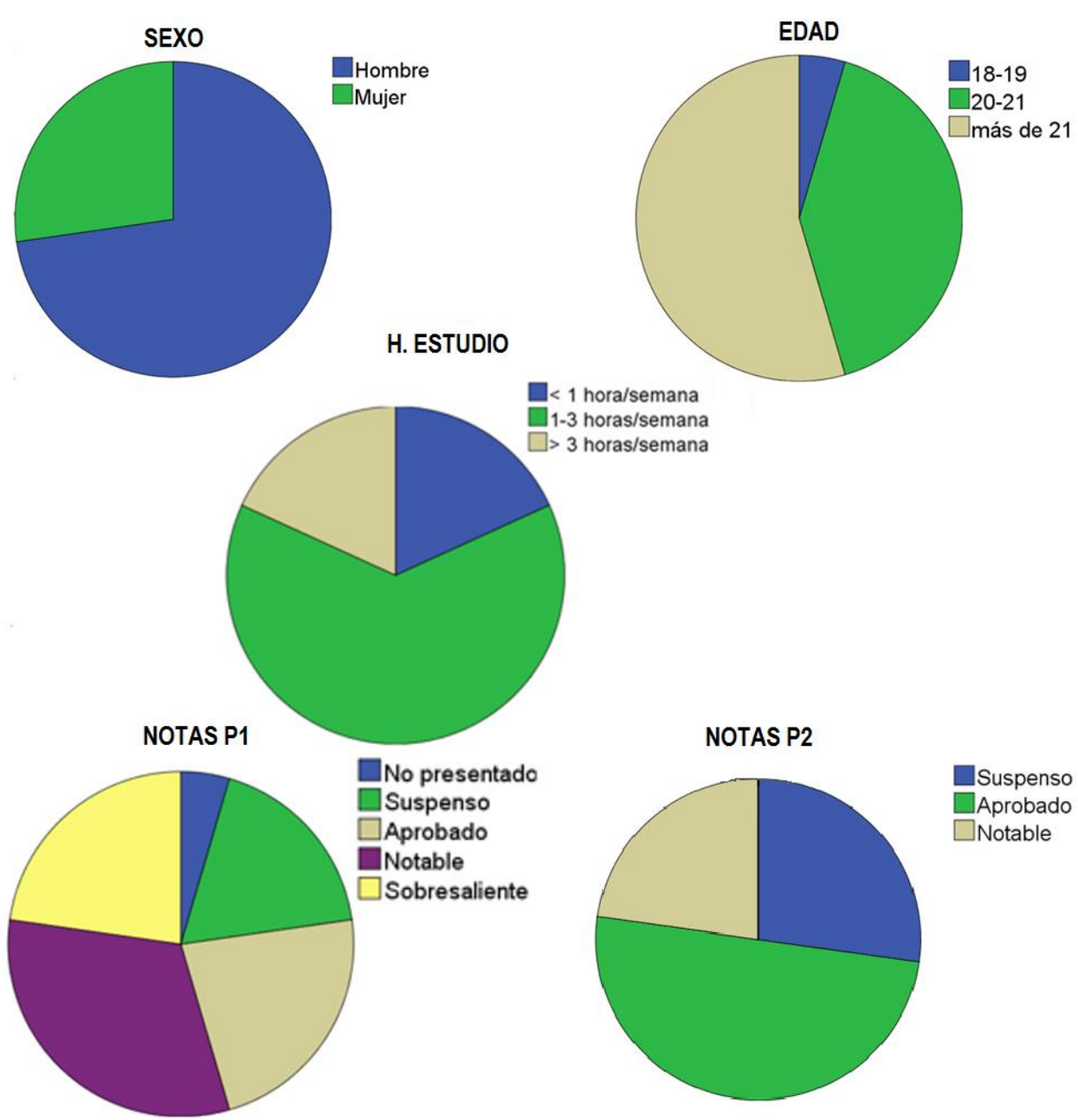

Fig. 1 Caracterización de la muestra analizada

La Tabla 1 resume los resultados estadísticos de las variables. Se agrupan las respuestas en calificaciones negativas (1,2), neutras (3) y positivas (4,5). La Tabla 2 muestra los porcentajes de cada grupo de respuestas. Respecto a las tecnologías educativas, los estudiantes están generalmente de acuerdo con la utilización de la herramienta recursos de PoliformaT. Ningún estudiante está en desacuerdo con esta herramienta. Las diapositivas las prefieren generalmente en pdf $(86 \%)$. Por tanto, los resultados indican que se podría prescindir de las diapositivas en Power Point. Hay dos alumnos muy en desacuerdo con las diapositivas en Power Point y cuatro en desacuerdo. Esto representa el 27\% de la muestra. Respecto a las diapositivas en pdf, no hay ningún estudiante muy en desacuerdo, y sólo dos en desacuerdo. La distribución de opiniones referentes a las diapositivas en pdf queda del modo siguiente: negativas $(9 \%)$, neutras $(5 \%)$ y positivas $(86 \%)$.

Los videos de polimedia están muy bien valorados por los estudiantes, pues ninguno está en desacuerdo con esta tecnología y el 55\% muestra una actitud positiva. El libro de apuntes

2017, Universitat Politècnica de València

Congreso IN-RED (2017) 
tiene peor puntación, el 50\% de las calificaciones han sido negativas. Esto indica que los estudiantes prefieren que el profesor les explique el tema, a tener que leerlo ellos en un libro. Por tanto, la tecnología educativa de los videos de Polimedia funciona adecuadamente. El $45 \%$ de los estudiantes muestra una actitud neutra, mientras el $55 \%$ de los estudiantes muestra una actitud positiva. Los vídeos de procedimientos constructivos también son muy bien valorados. Ningún estudiante está en desacuerdo, mientras el $73 \%$ de los estudiantes está de acuerdo con esta tecnología.

La herramienta Lessons es la mejor valorada de todas, y la que menos desviación presenta. El 59\% de los estudiantes están de acuerdo, y el $41 \%$ está muy de acuerdo con esta herramienta. La opinión respecto al Portafolio presenta mucha divergencia. Mientras hay 2 estudiantes muy en desacuerdo con esta herramienta, 7 estudiantes están muy de acuerdo.

En relación a las metodologías activas, no hay ningún alumno en desacuerdo. El 14\% tiene una actitud neutra y el $86 \%$ tiene una actitud positiva hacia la metodología de la clase inversa. Asimismo, la corrección de entregables, también está muy bien valorada. Ésta presenta mejor media y menor desviación típica que la metodología de clase inversa en general. El 5\% de las calificaciones han sido neutras y el $95 \%$ han sido positivas. Por tanto, hay alumnos que prefieren la corrección de entregables a otras actividades de la metodología activa.

Tabla 1. Descripción estadística de las variables

\begin{tabular}{ccccc}
\hline & Media & Desviación típica & Mínimo & Máximo \\
\hline Recursos PoliformaT & 4,32 & 0,72 & 3 & 5 \\
Diapositivas en pdf & 4,14 & 0,89 & 2 & 5 \\
Diapositivas en Power Point & 3,32 & 1,25 & 1 & 5 \\
Vídeos Polimedia & 3,82 & 0,85 & 3 & 5 \\
Libro de apuntes & 2,95 & 1,21 & 1 & 5 \\
Vídeos procedimientos constructivos & 3,95 & 0,72 & 3 & 5 \\
Lessons & 4,41 & 0,50 & 4 & 5 \\
Portafolio & 3,64 & 1,33 & 1 & 5 \\
Metodología de la clase inversa & 4,23 & 0,69 & 3 & 5 \\
Corrección entregables & 4,68 & 0,57 & 3 & 5
\end{tabular}


Tabla 2. Porcentajes de calificaciones

\begin{tabular}{cccc}
\hline & $\begin{array}{c}\text { Porcentaje de } \\
\text { calificaciones } \\
\text { negativas (1,2) }\end{array}$ & $\begin{array}{c}\text { Porcentaje de } \\
\text { calificaciones } \\
\text { neutras (3) }\end{array}$ & $\begin{array}{c}\text { Porcentaje de } \\
\text { calificaciones } \\
\text { positivas (4,5) }\end{array}$ \\
\hline Recursos PoliformaT & $0 \%$ & $14 \%$ & $86 \%$ \\
Diapositivas en pdf & $9 \%$ & $5 \%$ & $86 \%$ \\
Diapositivas en Power Point & $27 \%$ & $23 \%$ & $50 \%$ \\
Vídeos Polimedia & $0 \%$ & $45 \%$ & $55 \%$ \\
Libro de apuntes & $50 \%$ & $14 \%$ & $36 \%$ \\
Vídeos procedimientos constructivos & $0 \%$ & $27 \%$ & $73 \%$ \\
Lessons & $0 \%$ & $0 \%$ & $100 \%$ \\
Portafolio & $23 \%$ & $14 \%$ & $64 \%$ \\
Metodología de la clase inversa & $0 \%$ & $14 \%$ & $86 \%$ \\
Corrección entregables & $0 \%$ & $5 \%$ & $95 \%$ \\
\hline
\end{tabular}

\section{Conclusiones}

La presente comunicación presenta la metodología utilizada para llevar a cabo el proceso de enseñanza-aprendizaje en la asignatura Tipologías y Procedimientos de las Construcciones de la Ingeniería Civil (I). Se muestran tanto las estrategias de aprendizaje activo como las herramientas y tecnologías educativas utilizadas. Se analizan las respuestas de los estudiantes a un cuestionario. Las variables estudiadas están relacionadas con el perfil de los estudiantes y su actitud frente a la utilidad de la herramienta recursos de PoliformaT, diapositivas en pdf, diapositivas en Power Point, vídeos Polimedia, libro de apuntes, vídeos de procedimientos constructivos, herramienta Lessons de PoliformaT, metodología de la clase inversa y corrección de entregables.

Los estudiantes están generalmente de acuerdo con la utilización de la herramienta recursos de PoliformaT. Prefieren las diapositivas en pdf que en Power Point. Los videos de polimedia y los vídeos de procedimientos constructivos están muy bien valorados por los estudiantes. Ningún estudiante está en desacuerdo con esta tecnología. Les resulta más útil la explicación on-line de los contenidos, que el libro de apuntes. La herramienta Lessons es la mejor valorada de todas, y la que menos desviación presenta. Respecto a la metodología activa, no hay ningún estudiante en desacuerdo. La corrección de entregables, en particular, es la más "imprescindible". De los resultados se deduce que hay alumnos que prefieren la corrección de entregables a otras actividades de la metodología activa.

\section{Agradecimientos}

Los autores agradecen el apoyo recibido por la Universitat Politècnica de València (Equipo de Innovación y Calidad Educativa EXCELCON).

(cc) EY-NC-ND 2017, Universitat Politècnica de València

Congreso IN-RED (2017) 


\section{Referencias}

BOLOGNA DECLARATION (1999). "Towards the European Higher European Area". En: Conference of Ministers responsible for Higher Education in 29 European countries. June, Bologna, Italy.

GARCÍA-SEGURA, T. et al. (2015). "Hybrid harmony search for sustainable design of posttensioned concrete box-girder pedestrian bridges", en Engineering Structures, vol 92, p.112-122.

GARCÍA-SEGURA, T. et al. (2016). "Assessment of transverse and specific competences in civil engineering studies: 'critical thinking"'. En: 11th International Technology, Education and Development Conference (INTED 2017). 6-8 de marzo, Valencia, pp. 3683-3692.

KANE, L. (2004). "Educators, learners and active learning methodologies", en International Journal of Lifelong Education, vol. 23, issue 3, p. 275-286.

KEMBER, D., KWAN, K.P. y LEDESMA, J. (2001). "Conceptions of good teaching and how they influence the way adults and school leavers are taught", en International Journal of Lifelong Education, vol. 20, issue 5, p. 393-404.

PELLICER, E., SIERRA, L.A. y YEPES, V. (2016). "Appraisal of infrastructure sustainability by graduate students using an active-learning method“, en Journal of Cleaner Production, vol. 113, p. 884-896.

PELLICER, E., YEPES, V. y ORTEGA, A.J. (2013). "Method for planning a graduate program in construction management", en Journal of Professional Issues in Engineering Education and Practice $A S C E$, vol 139, issue 1,p. 33-41.

PELLICER, E., et al. (2017). "Market demands on construction management: A view from graduate students", en Journal of Professional Issues in Engineering Education and Practice ASCE, (accepted, in press).

PELLICER, E. et al. (2014). Construction Management. New York: Wiley Blackwell.

PENADÉS-PLÀ, V. et al. (2016). "A review of multi-criteria decision making methods applied to the sustainable bridge design”, en Sustainability, vol. 8, issue 12, p. 1295.

YEPES, V., PELLICER, E. y ORTEGA, J.A. (2012). "Designing a benchmark indicator for managerial competences in construction at the graduate level", en Journal of Professional Issues in Engineering Education and Practice ASCE, vol. 138, issue 1, p. 48-54

YEPES, V. et al. (2016). "Acquisition of competences in a Master Degree in Construction Management". En: 10th International Technology, Education and Development Conference (INTED 2016). 7-9 de marzo, Valencia, pp. 718-727.

YEPES, V., MARTI, J.V. y GARCÍA-SEGURA, T. (2016). "Desarrollo y evaluación de la competencia transversal "pensamiento crítico" en el grado de ingeniería civil". En: Jornadas de Innovación Educativa y Docencia en Red IN-RED 2016. 7-8 de julio, Valencia, pp. 1-14. 


\title{
Uso del WhatsApp en Comunidades Interactivas de Aprendizaje: Perspectiva Estudiantil sobre Ejercicios de Pronunciación en la Clase de Inglés para Propósitos Específicos
}

Karol Cubero y Lucia Villanueva

Universidad Nacional de Costa Rica

\begin{abstract}
The Internet, the multiplicity of tools and applications on a mobile device have transformed different areas of life today and education is no exception. Mobile learning is acquiring a growing relevance in academic and educational spaces. This article describes a learning session by implementing WhatsApp to facilitate activities to practice English pronunciation. With a sample of 30 students, mostly between the age of 20 to 25 years, they were the participants of a class session facilitated by the use of WhatsApp, based on pronunciation exercises with specific tourism content, addressed to these students who belong to the Sustainable Tourism Business Management major.
\end{abstract}

Keywords: WhatsApp, pronunciation, learning communities, mobile learning, formative evaluation.

\section{Resumen}

Internet y la multiplicidad de herramientas y aplicaciones accesibles en un dispositivo móvil se han convertido en multifacéticas herramientas en todos los ámbitos de la vida actual y el ambiente educativo no es la excepción. El aprendizaje móvil esta adquiriendo cada vez mayor relevancia en espacios académicos y formativos. El presente trabajo describe una sesión de aprendizaje haciendo uso de la aplicación WhatsApp para mediar actividades en el idioma Inglés. Se trabajó con una muestra de 30 estudiantes con edades, en su mayoría, entre 20 y 25 años, a quienes se les facilitó, mediante la aplicación del WhatsApp, actividades enfatizadas en ejercicios de pronunciación con contenido turístico específico, dirigidos a estudiantes pertenecientes a la carrera de Gestión Empresarial del Turismo Sostenible.

Palabras clave: WhatsApp, pronunciación, comunidades de aprendizaje, aprendizaje móvil, evaluación formativa.

\section{Introducción}

En los días que vivimos, es inminente el uso de los teléfonos celulares y sus aplicaciones tecnológicas incorporadas. Cada vez más dependemos de este aparato por las facilidades que nos presenta en múltiples tareas desde las más cotidianas hasta las más complejas, con fines 
Uso del WhatsApp en Comunidades Interactivas de Aprendizaje: Perspectiva Estudiantil sobre Ejercicios de Pronunciación en la Clase de Inglés para Propósitos Específicos

académicos de aprendizaje o no. Entonces, su incorporación al campo educativo es un hecho ineludible que los docentes debemos aplicar y al que nos obliga a estar informados e investigar al respecto para sacarles el mejor provecho con propósitos de aprendizaje. Si para nuestros estudiantes e incluso para los docentes mismos es difícil apartarse de este aparato inteligente, ¿porqué no hacer de él una herramienta útil y un compañero más en los propósitos educativos? Las tecnologías cambian vertiginosamente y de igual manera sus posibles beneficios o limitaciones. Es por ello que los docentes debemos estar actualizados y en constante investigación de las mismas para ser aplicadas como herramienta educativa. Esta es una invitación constante. En este sentido, es que la presente investigación busca como docentes de inglés como lengua extranjera, analizar el aprovechamiento de la aplicación de WhatsApp, basándose en la motivación e interés demostrada por los estudiantes hacia sus teléfonos celulares y en este caso, estudiando uno de las habilidades de la lengua como lo es la pronunciación. Precisamente, la pronunciación del inglés es una dificultad presente en muchos de los estudiantes y no es, muchas veces, abordada de la mejor manera en el aula. Las bondades que presenta esta aplicación permite su práctica con materiales auténticos y en tiempo real, lo que favorece la interacción y la cooperación entre pares con una evaluación cualitativa.

\section{Objetivos de la Propuesta}

\section{Objetivo General:}

Identificar perspectivas estudiantiles sobre el uso del WhatsApp en el aprendizaje del Idioma Inglés para propósitos específicos mediante actividades y ejercicios de pronunciación aplicada a estudiantes de la carrera de gestión empresarial del Turismo Sostenible de la UNA, Sede Regional Chorotega, Guanacaste

\subsection{Sustentos Teóricos}

\subsubsection{Aprendizaje móvil}

Según Brazuelo F. y Gallego D. (2011), el aprendizaje móvil se describe como la modalidad educativa que facilita la construcción del conocimiento, la resolución de problemas de aprendizaje y el desarrollo de destrezas o habilidades diversas de forma autónoma y ubicua gracias a la mediación de dispositivos móviles portables. Al respecto, Hockly y Dudeney (2014) proponen una serie de actividades basadas en el uso del teléfono celular entre las cuales se encuentran actividades básicas basadas en simples mensajes de texto a otras ya más complejas. Ellos establecen que los teléfonos celulares son excelentes herramientas para ayudar a los estudiantes a producir el idioma meta, pero advierten que los profesores deben siempre de preguntarse porque se esta implementando el aprendizaje móvil y asi tener claridad en lo que se desea alcanzar. Otras opiniones también positivas respecto a esta metodología como herramienta de soporte en las clases de inglés nos la ofrecen Thornton, y Houser (2005) al destacar que gracias a la innovación tecnológica, el aprendizaje móvil se convertirá en el centro de atención en educación en un futuro próximo ya que las

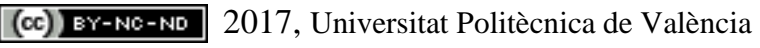

Congreso IN-RED (2017) 
posibilidades y facilidades de usar una herramienta como el teléfono móvil amplia las oportunidades de que los alumnos aprendan de forma significativa (p. 49)

\subsubsection{La aplicación de WhatsApp en la mediación de aprendizajes}

La aplicación de WhatsApp es una multiplataforma de mensajería que permite enviar y recibir mensajes sin pagar por SMS ya que utiliza los datos móviles ya obtenidos. Esta aplicación resulta muy atractiva por sus diversas características, primeramente porque es gratuita y luego porque se pueden crear grupos, resulta fácil de usar y desde esta se pueden enviar un número ilimitado de imágenes, vídeos y mensajes de audio promoviendo asi una interacción en tiempo real. Esta aplicación ha sido sumamente exitosa durante los últimos años pues ha captado la atención de millones de usuarios entre estos académicos, docentes e investigadores. Hidalgo (2013) sostiene que los alumnos ya lo usan en entornos educativos sin que ningún profesor les haya propuesto hacerlo. Los usos académicos que los estudiantes le dan es principalmente la creación de grupos para ponerse de acuerdo en trabajos en equipo que mandan en clase y consultar dudas a los compañeros.

Ademas, este permite activar y promover redes de aprendizaje los que se conocen como entornos de aprendizaje en línea que ayudan a los participantes a desarrollar sus competencias colaborando y compartiendo información. En ese sentido, Koper, 2009 define que las redes de aprendizaje están diseñadas para tratar de enriquecer la experiencia de aprendizaje en los contextos de educación desde las cuales se intercambian experiencias y conocimiento con otros, se brinda y recibe apoyo de otros participantes, se promueve diferentes tipos de evaluación.

1.1.3 Ventajas en el uso del WhatsApp en la mediación del aprendizaje del Inglés

Muchos investigadores concuerdan a nivel general que el uso del WhatsApp en la educación puede ser positivo si existe un claro planteamiento de objetivos académicos y se destaca las siguientes ventajas:

- Promueve un un entorno motivador y lúdico, ofrece la posibilidad de trabajar en tiempo y contexto real, las respuestas son espontáneas, permite la exposición inmediata al idioma meta mediante la interacción y la cohesión grupal.

- Potencia la construcción activa y colectiva del aprendizaje, la herramienta, se puede integrar como banco de material educativo alternativo y complementario. También facilita la adquisición de la competencia en la búsqueda y selección de la información en la que los educandos pueden indagar e investigar en la web materiales educativos significativos sobre los contenidos que se ven en clase.

- Facilita el pensamiento crítico ente el alumnado mediante la propuesta de preguntas que generen debate y diálogo acerca de los contenidos de clase.

- Realizar diagnósticos sobre los conocimientos previos de los estudiantes acerca de contenidos.

- Realizar evaluaciones de seguimiento sobre la adquisición del conocimiento entre el alumnado fomentando la re-elaboración de su propio conocimiento para comunicarlo. 
Uso del WhatsApp en Comunidades Interactivas de Aprendizaje: Perspectiva Estudiantil sobre Ejercicios de Pronunciación en la Clase de Inglés para Propósitos Específicos

- De igual forma Barhoumi Chokri (2015) destaca que el WhatsApp facilita la socialización de productos de aprendizaje en la que los estudiantes cooperan, colaboran y participan en las actividades propuestas.

- En relación al aprendizaje del Inglés, Colon et al. (2012) manifiestan las posibilidades del aprendizaje mediante el uso de WhatsApp en el desarrollo de habilidades de lectura mediante el envío de breves mensajes, plantean que los estudiantes se sintieron motivados hacia la lectura en Inglès.

- Se brinda la posibilidad al alumnado de interactuar a diario en la lengua meta lo que ha supuesto un estímulo a los educandos para ganar agilidad en la lengua inglesa así como perder el miedo al usar el idioma

\subsubsection{Desventajas en el uso de WhatsApp en la mediación de aprendizajes}

Autores e investigadores que han llevado a cabo estudios e investigaciones sobre la temática, han encontrado dificultades durante la realización de sus proyectos. A continuación, se puntualizan algunas de las principales dificultades encontradas.

Gutiérrez-Colon et al. (2012) mencionan en su proyecto que a los participantes inicialmente no les agradaría recibir mensajes académicos una vez terminado su horario de la facultad. En cambio, una vez finalizada la investigación se concluyó que los alumnos no percibieron esta metodología como intrusiva.

Otra desventaja a la que apuntan varios autores por ejemplo Kennedy et al. (2008) y Thornton et al. (2005), es el hecho que las pantallas de los teléfonos móviles son muy pequeñas. Por lo tanto, hay que crear ejercicios adecuados a la medida de las pantallas para que las actividades estén especialmente diseñadas para el aprendizaje móvil y no se hagan tediosas o pesadas de leer.

\subsection{5 ¿Porqué enseñar pronunciación?}

Al estudiar cualquier lengua extranjera se hace fundamental estudiar su pronunciación. La pronunciación es un elemento esencial dentro de los componentes de la habilidad de la conversación y que aunado al manejo idóneo de las otras habilidades como la comprensión auditiva, la escritura y la lectura, demuestran cuan proficiente un individuo es en la lengua extranjera en cuestión. Es así como la práctica de la pronunciación se vuelve muy importante para poder comunicarse efectivamente e interactuar utilizando la lengua meta, convirtiéndose, indiscutiblemente, en la delimitación de la competencia comunicativa del hablante.

De acuerdo a nuestra experiencia como profesoras de lengua extranjera, en este caso de inglés, hemos podido observar las dificultades que tienen los estudiantes al momento de pronunciar este idioma extranjero y esto, principalmente, porque el idioma inglés difiere del español en muchos aspectos pero en especial, porque la mayoría de las palabras en inglés no se pronuncian como se escriben y también porque hay sonidos de ese idioma que no existen en español. Esto representa una mayor dificultad para los hispano hablantes que desean hablar inglés y por ello es causa de frustración en el proceso de aprendizaje de muchos estudiantes.

(cc) EY-NC-ND 2017, Universitat Politècnica de València

Congreso IN-RED (2017) 
El estudio de la pronunciación en el aula, entonces, es un gran reto, no solo para el estudiante sino también para el profesor quien tiene que aplicar las estrategias más convenientes para ayudar a sus aprehendientes a adquirir la pronunciación correcta del idioma. La realidad, en muchas ocasiones, es que no se le da el tiempo suficiente para enseñar en el aula aspectos referentes a la pronunciación y en muchos casos, ni siquiera se contempla la pronunciación como un contenido específico de estudio dentro del programa académico. En otros casos, la pronunciación se enseña de manera aislada, sin darle oportunidad al estudiante de percibir esta competencia de la lengua de manera integrada, con todos sus componentes. Este panorama complica el manejo eficiente del idioma por cuanto , si no se tiene la pronunciación correcta, el hablante no podrá darse a entender en su sentido correcto y completo, lo que se prestaría a verdaderos mal entendidos. Si existe una carencia en este sentido, no solo afecta la comunicación oral, sino que perjudica también las otras habilidades de la lengua ya mencionadas como la lectura, la comprensión auditiva y hasta la escritura.

\subsubsection{Elementos de la pronunciación}

La Real Academia de la Lengua Española define el término pronunciar como la acción de emitir y articular sonidos. Iruela (2003) explica la importancia de la pronunciación en la función comunicativa de la lengua cuando hace referencia a la composición de la competencia comunicativa de acuerdo al Marco Común Europeo de Referencia para las Lenguas (MCER). En este sentido, la competencia comunicativa según MCER se compone de competencias lingüísticas, pragmáticas y socioculturales. Dentro de las competencias lingüísticas se encuentran, a su vez, otras categorías o grupos como los son las competencias referentes a la léxica, a la gramática, a la semántica, a la fónica, ortográfica y la ortoépica. Cada una de estas competencias se vinculan entre sí pero en especial la competencia fónica que está unida, por ejemplo, con la léxica al considerar que un individuo ha adquirido una palabra cuando la puede pronunciar con claridad y la reconoce de manera auditiva. O bien, en el caso de la ortoépica que es la competencia referida a leer en voz alta y de forma correcta un texto o verso con solo conocer las reglas de pronunciación. Todo lo anterior, ilustra las interrelaciones entre los diferentes componentes de la competencia comunicativa, su complejidad y dinamismo y en el que la pronunciación juega un papel relevante. Iruela (2003).

\subsubsection{Enseñanza de la Pronunciación}

En lo referente a los componentes de la pronunciación, Wei (2006) destaca la necesidad de dejar de lado viejas prácticas en cuanto a la enseñanza de la pronunciación de una lengua extranjera e ir más allá de la enseñanza basada en la discriminación de sonidos, contrastes de sonidos en palabras, vocales y consonantes. El estudio de la pronunciación en el aula comprende un conjunto de componentes. Para Scarcella y Oxford (1994) citado por Wei (2006), esos componentes son los siguientes:

Entonación: Se refiere al tono en la que un sonido de voz es pronunciado. Una buena entonación nunca sonara monótono o aburrido.

Acento y ritmo: Muy relacionados ya que el acento contribuye al ritmo. El acento o énfasis en una sílaba, en una oración o conexiones, produce el ritmo o música de la lengua. En inglés el ritmo, por lo general, ocurre en intervalos regulares. 
Uso del WhatsApp en Comunidades Interactivas de Aprendizaje: Perspectiva Estudiantil sobre Ejercicios de Pronunciación en la Clase de Inglés para Propósitos Específicos

Consonantes: Se refiere a los sonidos producidos o pronunciados con un bloqueo del paso del aire. Lo que se estudia en este aspecto es la sustitución, omisión, articulación, conexiones o links y clusters.

Vocales: Al contrario de las consonantes, las vocales se pronuncian con el paso libre del aire. Se estudia de las vocales aspectos como sustitución, articulación, duración, reducción y enlaces o links.

En cuanto a los enfoques de enseñanza de la pronunciación, los mismo han ido evolucionando en los últimos 35 años y hoy se pueden encontrar diferencias en los enfoques tradicionales y en los que están en tendencia.

Scarcella y Oxford (1994) citado por Wei (2006) realizan una comparación entre un enfoque de enseñanza tradicional de la pronunciación y un enfoque basado en la investigación o "Research Based Approach" y en la que se destacan diferencias importantes como que en el enfoque basado en la investigación, prive la necesidad de aprender pronunciación para darse a entender en el idioma extranjero. No se busca entonces, la imitación de acentos nativos sino que se respetan los acentos propios del aprehendiente y los mismos son valorados como carácter e identidad cultural. Esto se une a una enseñanza integral en donde se estudia el ritmo y la entonación a la vez que se motiva al estudiante, quien es el centro de su propio aprendizaje.

Tabla 1. Comparación de enfoques en la enseñanza de la pronunciación

\begin{tabular}{|l|l|}
\hline Enfoque Basado en investigación & Enfoque tradicional \\
\hline $\begin{array}{l}\text { El objetivo es ganar suficientes habilidades en la } \\
\text { pronunciación para que la calidad de la } \\
\text { pronunciación no inhiba la comunicación }\end{array}$ & $\begin{array}{l}\text { El objetivo de la instrucción es adquirir una } \\
\text { pronunciación nativa. }\end{array}$ \\
\hline $\begin{array}{l}\text { En vez de enfatizar en los sonidos, los profesores } \\
\text { se concentran en el stress y la entonación. }\end{array}$ & El énfasis primario es enseñar sonidos. \\
\hline $\begin{array}{l}\text { El énfasis de la instrucción es enseñar la } \\
\text { pronunciación con un enfoque comunicativo }\end{array}$ & $\begin{array}{l}\text { Los sonidos se enseñan no con el enfoque } \\
\text { comunicativo mediante ejercicios o "drills" } \\
\text { aislados. }\end{array}$ \\
\hline $\begin{array}{l}\text { El profesor provee a los estudiantes de } \\
\text { transcripciones fonéticas solo cuando ellas son } \\
\text { útiles para los estudiantes en tutorías. }\end{array}$ & $\begin{array}{l}\text { Transcripciones fonéticas son componentes } \\
\text { básicos de las clases tradicionales de } \\
\text { pronunciación. }\end{array}$ \\
\hline $\begin{array}{l}\text { La motivación de los estudiantes es básica para } \\
\text { aprender exitosamente el idioma. El estudiante } \\
\text { juega un papel primordial para el mejoramiento } \\
\text { de su propia pronunciación. Se enseñan } \\
\text { estrategias de auto monitoreo y de auto atención. }\end{array}$ & $\begin{array}{l}\text { Estudiantes no toman responsabilidad por } \\
\text { el mejomiento de su } \\
\text { pronunciación. }\end{array}$ \\
\hline $\begin{array}{l}\text { La estima o afecto es crucial en la enseñanza de } \\
\text { la pronunciación. Estudiantes aprenden técnicas } \\
\text { de relajación para bajar los niveles de ansiedad y } \\
\text { resistencia a mejorar la pronunciación. }\end{array}$ & $\begin{array}{l}\text { La estima o afecto no se considera como } \\
\text { una importante actividad instructiva }\end{array}$ \\
\hline
\end{tabular}

\section{Fuente: Wei (2006)}

Igualmente, para Scarcella y Oxford (1994) citado por Wei (2006) establecen técnicas de enseñanza de la pronunciación bajo el enfoque no tradicional de investigación en las cuales destacan las que refuerzan el auto monitoreo, el estudio por cuenta propia, corrección individual y uso de la tecnología, entre otros aspectos.

(c)) BY-NC-ND 2017, Universitat Politècnica de València

Congreso IN-RED (2017) 
Tabla 2. Técnicas de enseñanza de la pronunciación bajo el enfoque investigativo

\begin{tabular}{|c|c|}
\hline Técnicas & Contenidos \\
\hline Auto monitoreo & Aprenden a auto monitorearse para mejorar su inteligibilidad \\
\hline $\begin{array}{l}\text { Sesiones tutoriales de } \\
\text { estudio individual }\end{array}$ & $\begin{array}{l}\text { Empieza con un diagnóstico de cada estudiante y se le diseña al } \\
\text { estudiante un programa personalizado }\end{array}$ \\
\hline Corrección Individual & $\begin{array}{l}\text { Reporte de los resultados de cada producción del estudiante de manera } \\
\text { individual. }\end{array}$ \\
\hline $\begin{array}{l}\text { Actividades } \\
\text { Comunicativas }\end{array}$ & Diseñadas para que los estudiantes practiquen sonidos específicos. \\
\hline $\begin{array}{l}\text { Versiones escritas de } \\
\text { presentaciones orales }\end{array}$ & $\begin{array}{l}\text { En niveles más avanzados, se les puede entregar a los estudiantes las } \\
\text { estrategias para el análisis de la versión escrita de su propia producción } \\
\text { oral. }\end{array}$ \\
\hline $\begin{array}{ll}\text { Asistencia en } \\
\text { computadora de } \\
\text { aprendizaje del idioma }\end{array}$ & $\begin{array}{l}\text { Profesor utiliza apoyos visuales de patrones de discurso para enseñar } \\
\text { entonación, stress, y sonidos de manera grupal o individual. }\end{array}$ \\
\hline Explicaciones & $\begin{array}{l}\text { Explicaciones de cómo se producen los sonidos deben mantenerse al } \\
\text { mínimo, aunque las instrucciones sobre qué hacer con los órganos } \\
\text { vocales sí puede ayudar bajo ciertas circunstancias. }\end{array}$ \\
\hline $\begin{array}{l}\text { Utilización de sonidos } \\
\text { conocidos }\end{array}$ & $\begin{array}{l}\text { Comparación con la primera lengua del estudiante puede ayudarlo a } \\
\text { producir la lengua meta. }\end{array}$ \\
\hline $\begin{array}{l}\text { Incorporación de nuevos } \\
\text { elementos }\end{array}$ & Con dirección o ayuda del profesor \\
\hline $\begin{array}{l}\text { Estrategias } \\
\text { comunicativas }\end{array}$ & $\begin{array}{l}\text { Los estudiantes pueden aprender algunas estrategias comunicativas para } \\
\text { darles la impresión de que su pronunciación es mejor de lo que realmente } \\
\text { pueda estar como metodología de recuperación, práctica para la } \\
\text { comunicación. }\end{array}$ \\
\hline Estrategias afectivas & Para disminuir la ansiedad y ganar confianza. \\
\hline
\end{tabular}

Fuente: Wei (2006)

Cheng (1998) citado por Wei (2006) recomienda, diversas estrategias para enseñar pronunciación. Algunas de ellas son proveer material significativo como artículos y lecturas para practicar ritmo, acento o stress, entonación, "linkings" o enlaces. A su vez, el uso de canciones, juegos y trabalenguas, incrementa la motivación y es divertido para los estudiantes. Muy importante también es el evaluar el progreso de los estudiantes para mantener una buena motivación en ellos. En este último aspecto, pesa mucho la manera en que se evalúa. La evaluación cualitativa es una muy recomendable opción para mantener a los estudiantes motivados e interesados y más aún cuando la evaluación se realiza entre pares. Por ello, a continuación, se explica aspectos relevantes relacionados con la evaluación cualitativa.

\subsubsection{La evaluación cualitativa de los aprendizaje}

La evaluación cualitativa ha generado cierto agrado y resonancia en los últimos años, al proponer un proceso de enseñanza-aprendizaje desde niveles más integrales y holístico. Se dice holístico porque toma en cuenta varios elementos que intervienen en ella: los objetivos, procesos, métodos, recursos, contexto e instrumentos. Al respecto Alfaro (1996) expresa que la evaluación cualitativa se percibe como un proceso de investigación integral, la cual aporta 
Uso del WhatsApp en Comunidades Interactivas de Aprendizaje: Perspectiva Estudiantil sobre Ejercicios de Pronunciación en la Clase de Inglés para Propósitos Específicos

evidencias diarias de la participación del estudiante en la práctica académica. Esta evaluación acentúa la importancia de observar e interpretar situaciones y experiencias, más que en resultados numéricos y situaciones controladas como lo hace la evaluación cuantitativa. La evaluación cualitativa invita a la evaluación permanente, con el objetivo de retroalimentar y reorientar a lo largo del proceso educativo. Para lograr mediar estas prácticas, es necesario plantearse estrategias e instrumentos que respondan a cómo evaluar.

\subsubsection{Estrategias e Instrumentos de Evaluación Cualitativa}

Bordas y Cabrera (2001) afirman que las estrategias de evaluación planeadas con el fin de recopilar información para reforzar el aprendizaje son determinantes en el proceso de enseñanza-aprendizaje, por tanto, generan un aprendizaje profundo, desarrollador de habilidades de autoconocimiento y autorregulación en un contexto participativo. Las estrategias de evaluación pueden ser muy variadas, entre estas: los diarios reflexivos, portafolios, la entrevista, el estudio de caso, panel, exposiciones, entre otras. Estas estrategias se refuerzan utilizando instrumentos como las rúbricas, que favorecen una evaluación centrada en el proceso. Estas son herramientas que se utilizan para emitir criterios sobre el desempeño del estudiante en áreas específicas. Dichos criterios son los parámetros a utilizar para ayudar al estudiante a mejorar. De hecho, los criterios para calificar un área en específico se dan a conocer previamente a los estudiantes y contribuir así para su mejor preparación. Las rúbricas se aplican tanto para el alumno como para el profesor y se dan de manera auto evaluativa, de pares o grupal.

\subsection{9 ¿Por qué aplicar la evaluación cualitativa?}

La enseñanza aprendizaje desde el enfoque humanista, pretende revalorizar a las personas como actores activos, al considerar todas sus particularidades e individualidades y promover un profundo autoconocimiento, un reencuentro con su integridad. Al hablar de proceso formativo consideramos también el proceso evaluativo. El valor humanístico que se pueda agregar a la evaluación reside en respetar y potencializar esa integridad, atendiendo diferencias, sean estas culturales, étnicas, religiosas o personales. Los educadores deben de hacer de la evaluación cualitativa una práctica continua, bajo procedimientos sistematizados que consideren no solo los aspectos cognitivos, sino también los socio-afectivos, las habilidades, ritmo de aprendizaje y el contexto de los estudiantes. Durante el planeamiento de una evaluación integral, las actividades de aprendizaje son insumos importantes en la valoración del proceso de aprendizaje, en donde se reconocen las fortalezas y las debilidades por medio de la retroalimentación. Esta dinámica permite abrir espacios de intercambio que reorienten, ajusten y mejoren el proceso, según el logro de los objetivos planteados a nivel individual y colectivo. La práctica continua hace que los estudiantes vayan perdiendo el temor a verse y sentirse evaluados, pues experimentan seguridad, creatividad y respeto. Igualmente, a nivel colectivo, la evaluación cualitativa fomenta valores como la solidaridad, cooperación y comunicación.

(c)) EY-NC-ND 2017, Universitat Politècnica de València

Congreso IN-RED (2017) 
En nuestra experiencia como profesoras de un idioma extranjero, hemos verificado los beneficios de la evaluación cualitativa al evaluar estudiantes en el desempeño específico de un idioma, esto no solo en el aspecto cognitivo, sino afectivo. Esta concepción es un elemento motivador para el estudiante, pues fomenta el aprender a aprender, lo cual contribuye a formar la autonomía y autoestima del estudiante en un ambiente lleno de experiencias agradables y amigables.

\subsection{Propuesta: Mediación de aprendizaje basada en ejercicios de pronunciación en una clase de Inglés para Propósitos Específicos}

A continuación se detalla la propuesta utilizada en la mediación de los aprendizajes en dos cursos de Inglés con propósitos específicos. Se exponen los objetivos y la descripción de las actividades realizadas con la finalidad de determinar el grado de efectividad de implementar el aprendizaje móvil mediante la aplicación del WhatsApp para realizar prácticas de pronunciación del idioma Inglés.

- Identificar la efectividad de la aplicación del WhatsApp en la mediación de actividades relacionadas con la pronunciación del idioma Inglés.

- Mediar, a través de comunidades de aprendizaje en línea desde la aplicación WhatsApp, actividades de pronunciación y de contenido especifico con instrucciones claras para guiar a los educandos en la práctica del acento, entonación, ritmo y sonidos del idioma Inglés.

- Promover en las sesiones, el aprendizaje colaborativo mediante WhatsApp y una transparente realimentación facilitada por los mismos participantes de la comunidad (grupo de WhatsApp) mediante una rúbrica de evaluación facilitada por las mediadoras.

Temas: Acento, entonación, ritmo y sonidos finales de verbos pasados regulares

Materiales: Teléfono inteligente, Acceso a Internet, lectura y dialogo en audio formato mp3 pregrabado, aplicación de WhatsApp, audífonos, rúbrica de evaluación pronunciación.

\section{Procedimientos:}

1. Informar a los estudiantes los objetivos de la implementación del aprendizaje móvil en algunas sesiones de clases.

2. Realizar comunidades de aprendizaje( grupos de WhatsApp),organizando el grupo de educandos en pequeños grupos de comunidades de aprendizaje de máximo 10 estudiantes.

3. Se solicita a los estudiantes agruparse en grupos según la comunidad de aprendizaje que integra. Una vez listos se remiten las instrucciones vía WhatsApp de la actividad 1.

Actividad 1:Enviar mediante la aplicación de WhatsApp, las instrucciones y la actividad a realizar tendientes a practicar algunos aspectos de pronunciación. Instrucción enviada al WhatsApp: Escuchen el audio grabado por la profesora, este contiene un extracto de un 
Uso del WhatsApp en Comunidades Interactivas de Aprendizaje: Perspectiva Estudiantil sobre Ejercicios de Pronunciación en la Clase de Inglés para Propósitos Específicos

articulo sobre trabajos turísticos, verifiquen comprensión y dirijan su atención a patrones de pronunciación, entonación, acento, ritmo y sonidos finales del idioma Inglés.

- Se adjunta el audio con la lectura que deben escuchar y de la cual se realizarán las actividades requeridas.

- Se solicita a los estudiantes que reproduzcan la lectura y que tomen unos minutos para su comprensión.

- Una vez que clarifican compresión, se les solicita que se graben, imitando y procurando similitud en los aspectos de pronunciación destacados, entonación, acento, ritmo y sonidos lo mas similares a la pronunciación del audio clip.

- El docente guía a los estudiantes en la realización de sus productos, monitoreando sus practicas de repetición y apoyándoles en algunas dificultades emergentes.

- Al terminar su grabaciones, los estudiantes se evalúan formativamente entre si mediante una rubrica de evaluación que se reparte al terminar sus productos. Luego envían su realimentación al WhatsApp, donde en sus comunidades de aprendizaje se extiende la oportunidad de mejorar y valorar sus fortalezas y debilidades en la pronunciación del inglés.

Actividad 2: Enviar mediante la aplicación de WhatsApp, las instrucciones y la actividad realizar tendiente a practicar algunos aspectos de pronunciación. Instrucción enviada al WhatsApp: Escuchen el audio, este contiene un dialogo describiendo una visita a un lugar turístico. Verifiquen comprensión y dirijan su atención a patrones de pronunciación, entonación, acento, ritmo y sonidos finales del idioma Inglés

- Se adjunta el audio con el dialogo que deben escuchar y del cual se realizará la actividad requerida.

- Se solicita a los estudiantes, formar parejas desde su comunidad de aprendizaje en linea, que reproduzcan el dialogo las veces que requieran para su comprensión.

- Una vez que clarifican compresión, se les solicita que se graben realizando el dialogo, imitando y procurando similitud en los aspectos de pronunciación destacados, entonación, acento, ritmo y sonidos lo mas similares a la pronunciación del audio clip.

- Durante las grabaciones de ambas actividades, el docente monitorea el desempeño de los estudiantes, observando su actitud hacia la mediación de las actividades desde el WhatsApp.

- Asi mismo se guía a los estudiantes en la realización de sus productos, mediante practicas de repetición constantes.

- Al terminar su grabaciones, los estudiantes se evalúan formativamente entre si mediante una rubrica de evaluación que se reparte al terminar sus productos. Al evaluarse formativamente, guiados con la rubrica de evaluación formativa, se comparten los comentarios motivando la realimentación de pares que consideren pertinente destacar tanto a nivel de debilidades como fortalezas.

(cc) EY-NC-ND 2017, Universitat Politècnica de València

Congreso IN-RED (2017) 
Estas actividades fueron aplicadas a dos grupos de estudiantes de la Carrera de gestión empresarial del turismo, luego de realizar las actividades mediadas desde el WhatsApp se solicito a los estudiantes contestar un cuestionario con el fin de conocer sus perspectivas sobre la implementación del WhatsApp en la clase para practicar pronunciación del Idioma Inglés.
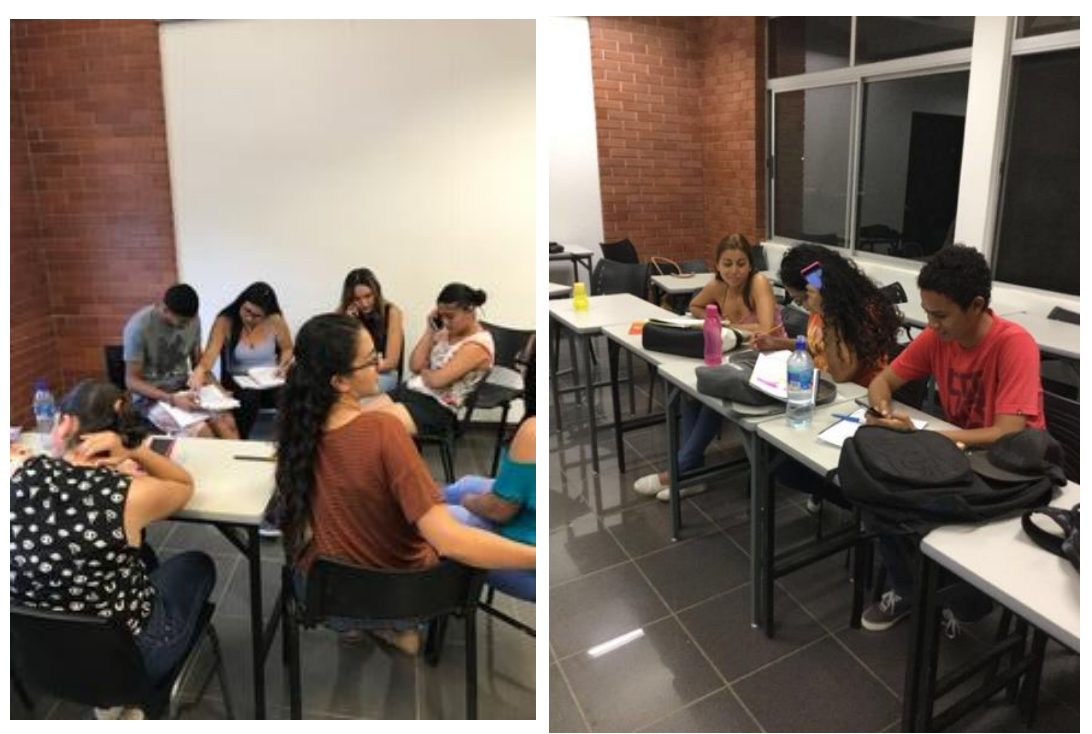

Fig. 1. Fotografías de los estudiantes

\subsubsection{Percepción de los estudiantes sobre el uso del WhatsApp}

Con el objetivo general de identificar las perspectivas de los estudiantes sobre el uso del WhatsApp en el aprendizaje del idioma inglés para propósitos específicos, se realizó una encuesta sobre este aspecto y a continuación se analizan los resultados.

\subsubsection{Objetivos específicos}

- Analizar la frecuencia y posibilidad de uso del WhatsApp.

- Analizar y descubrir la aceptabilidad del whatsApp en la esnseñanza de la pronunciación del inglés.

- Conocer las preferencias y familiaridad de los estudiantes con respecto a la tecnología, redes sociales o aplicaciones electrónicas.

- Motivar al estudiante al aprendizaje, aprovechando las herramientas tecnológicas.

Dentro de la metodología se seleccionaron 30 estudiantes de la carrera de la Gestión Empresarial del Turismo Sostenible de la Universidad Nacional, Sede regional Chorotega, Campus Liberia, 15 de ellos mujeres y 15 hombres con edades que oscilan entre los 20 a 25 años en su gran mayoría.

\subsubsection{Percepción de los estudiantes sobre el uso del whatsApp}

Con el objetivo general de identificar las perspectivas de los estudiantes sobre el uso del WhatsApp en el aprendizaje del idioma inglés para propósitos específicos, se realizó una encuesta sobre este aspecto y a continuación se analizan los resultados.

(cc) EY-NC-ND 2017, Universitat Politècnica de València 
Uso del WhatsApp en Comunidades Interactivas de Aprendizaje: Perspectiva Estudiantil sobre Ejercicios de Pronunciación en la Clase de Inglés para Propósitos Específicos

\section{Objetivos específicos}

- Analizar la frecuencia y posibilidad de uso del WhatsApp.

- Analizar y descubrir la aceptabilidad del whatsApp en la esnseñanza de la pronunciación del inglés.

- Conocer las preferencias y familiaridad de los estudiantes con respecto a la tecnología, redes sociales o aplicaciones electrónicas.

- Motivar al estudiante al aprendizaje, aprovechando las herramientas tecnológicas.

Dentro de la metodología se seleccionaron 30 estudiantes de la carrera de la Gestión Empresarial del Turismo Sostenible de la Universidad Nacional, Sede regional Chorotega, Campus Liberia, 15 de ellos mujeres y 15 hombres con edades que oscilan entre los 20 a 25 años en su gran mayoría. ( $80 \%$ de los estudiantes). De estos estudiantes, todos dijeron contar con teléfono celular inteligente siendo el hogar y la universidad los sitios donde suelen conectarse con mayor frecuencia.

Gráfico 1: Tipo de Aparato utilizado para conectarse a internet

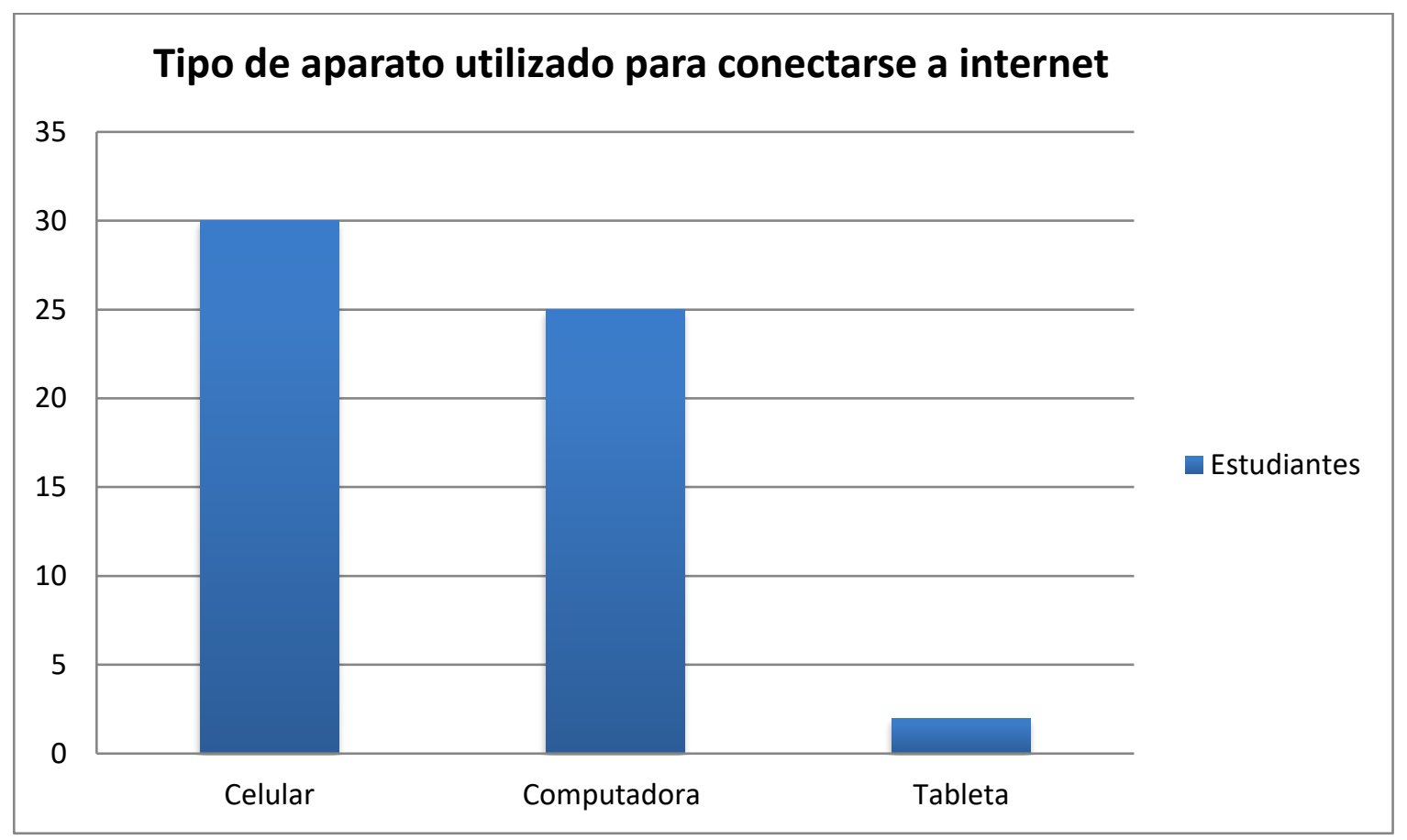

Un $85 \%$ de los estudiantes dijeron utilizar el Internet siempre y casi igual número de estudiantes dijeron contar con algún perfil o cuenta en redes sociales, siendo Facebook el más utilizado seguido por el whatsApp. 
Gráfico 2. Uso de Redes Sociales - perfiles y cuentas

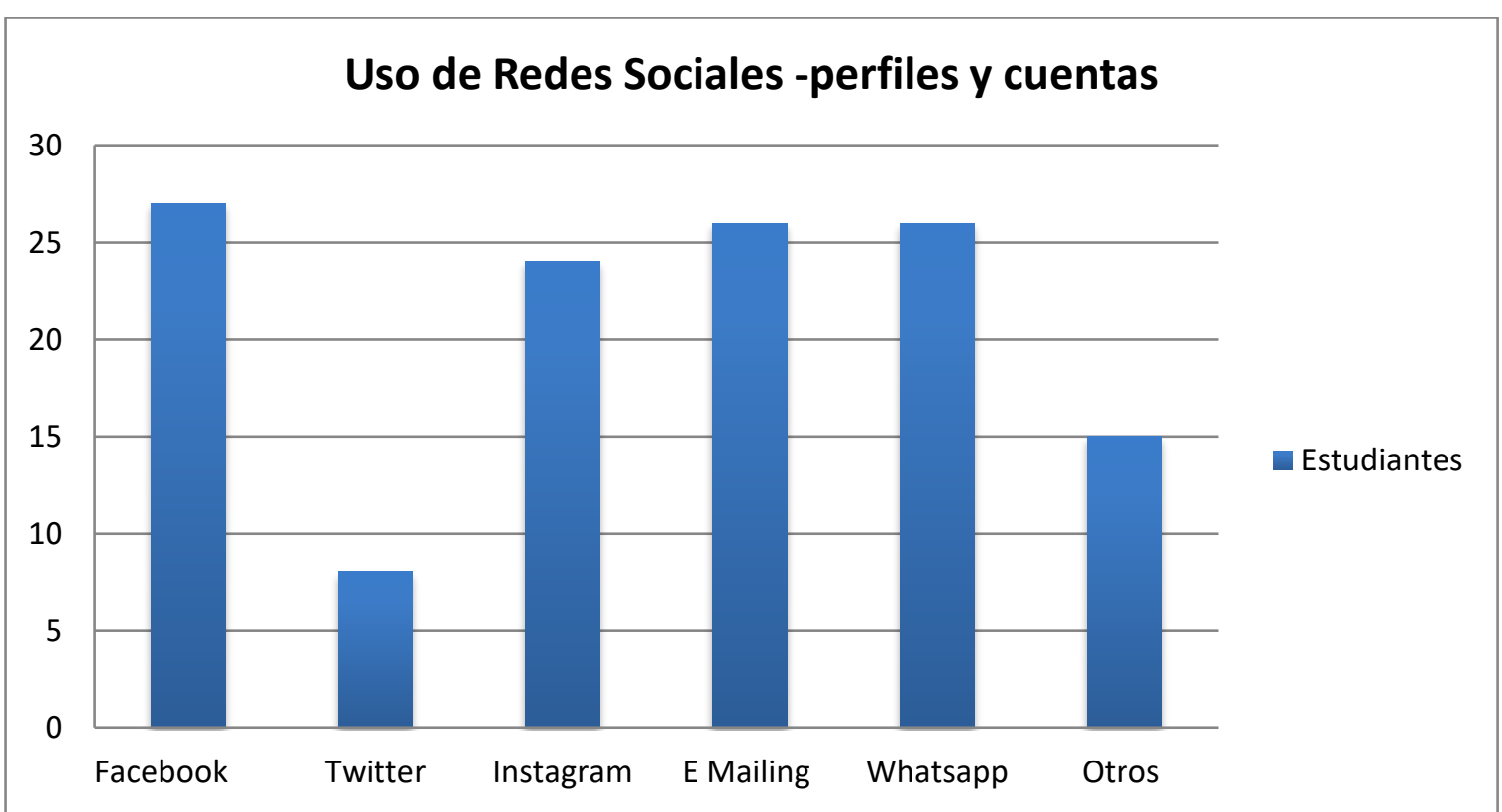

Ante la pregunta de qué forma utiliza usted aplicaciones tecnológicas, una mayoría indicó que utiliza videos o audios para aprender inglés mientras que una pequeña parte del grupo dijo casi no utilizarlo para compartir ideas o foros de discusión en línea. Lo anterior demuestra que para los estudiantes les es muy atractivo las herramientas audiovisuales para aprender. El gráfico 1 presenta esta información con más detalle. 
Uso del WhatsApp en Comunidades Interactivas de Aprendizaje: Perspectiva Estudiantil sobre Ejercicios de Pronunciación en la Clase de Inglés para Propósitos Específicos

Gráfico 3. Uso de aplicaciones tecnológicas

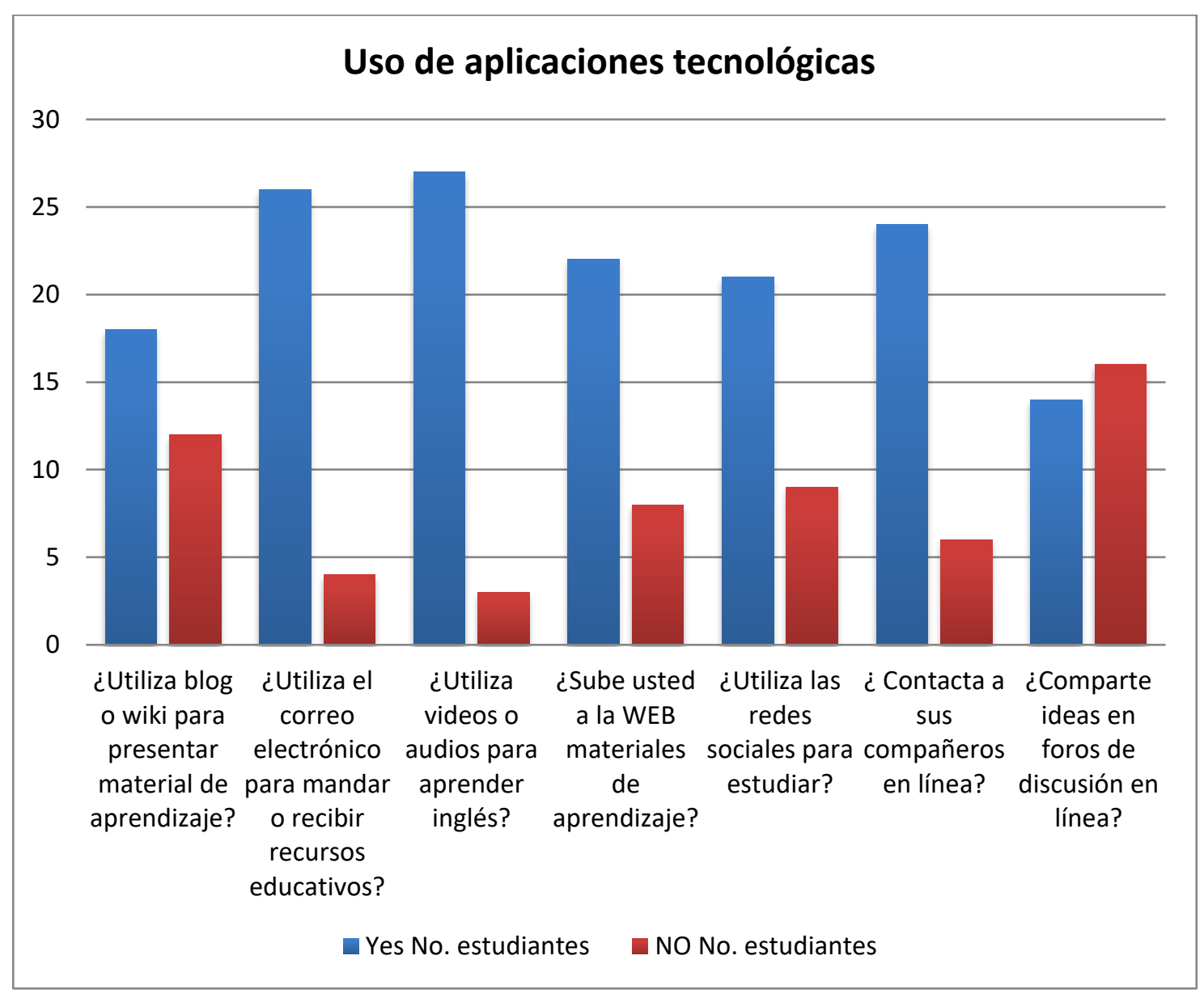

Una mayoría de los estudiantes manifestaron, en igual medida, ser más competentes al utilizar el whatsApp y navegar por Internet, lo que significa que los alumnos se sienten muy familiarizados con éstos y no tienen problema de echar mano de ellos para aprender. 
Gráfico 4: Qué tan competente es utilizando las aplicaciones para propósitos de Aprendizaje

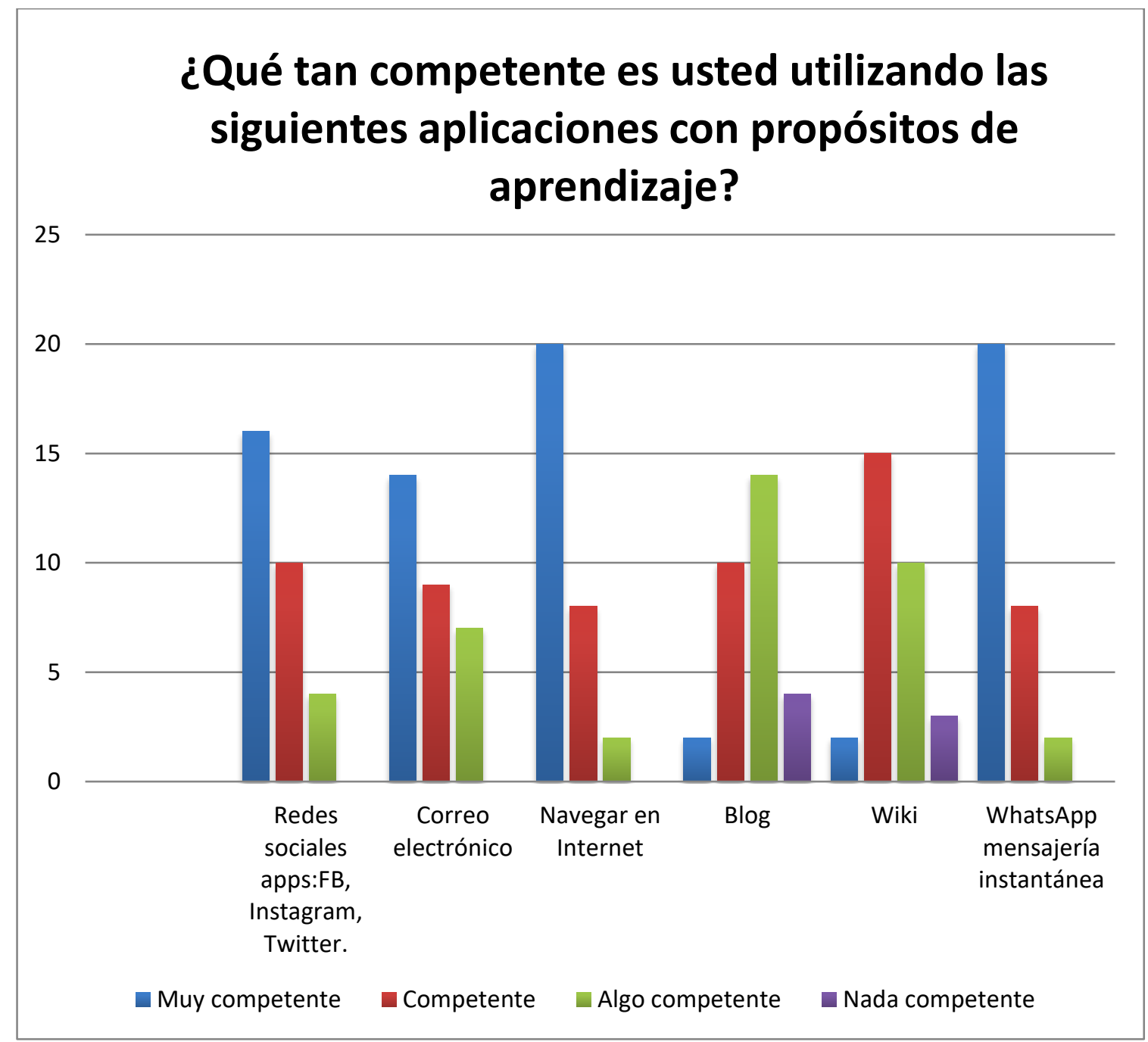

Al preguntarles la frecuencia en el uso de las diferentes aplicaciones para aprender, los estudiantes respondieron que utilizan más el navegar por Internet. Le sigue WhatsApp y muy cerca las redes sociales. Con esta información vemos que persiste la incidencia del uso del WhatsApp.Por otra parte, al preguntar sobre el uso del whatsApp en diferentes tareas académicas, las respuestas en general muestran una mayor tendencia a estar de acuerdo en que ésta aplicación es una ayuda para su proceso de aprendizaje. Llama la atención, por ejemplo, las respuestas a como el WhatsApp incrementa relaciones con amigos , o bien, como juega un papel preponderante como medio informativo del quehacer universitario. 
Uso del WhatsApp en Comunidades Interactivas de Aprendizaje: Perspectiva Estudiantil sobre Ejercicios de Pronunciación en la Clase de Inglés para Propósitos Específicos

En la tabla de abajo se muestran los aspectos cuestionados a los estudiantes, seguidos del gráfico que ilustra las respuestas a los mismos.

Tabla 3: El uso WhatsApp como herramienta de aprendizaje

\begin{tabular}{|c|c|c|c|c|c|c|}
\hline & Pregunta & $\begin{array}{l}\text { Totalmente } \\
\text { de acuerdo }\end{array}$ & $\begin{array}{c}\text { De } \\
\text { acuerdo }\end{array}$ & Indecisa & $\begin{array}{c}\text { En } \\
\text { desacuerdo }\end{array}$ & $\begin{array}{l}\text { Totalmente } \\
\text { en } \\
\text { desacuerdo }\end{array}$ \\
\hline $\begin{array}{l}\text { Creo que el WhatsApp es importante como medio } \\
\text { de aprendizaje, especialmente para compartir } \\
\text { información relacionada con Turismo. }\end{array}$ & 1 & 14 & 13 & 1 & 2 & \\
\hline $\begin{array}{l}\text { Con los chats del WhatsApp en la Universidad me } \\
\text { mantengo informada de las obligaciones en los } \\
\text { diferentes cursos. }\end{array}$ & 2 & 20 & 9 & 1 & & \\
\hline $\begin{array}{l}\text { Teniendo clases en WhatsApp me ayuda a } \\
\text { desarrollar las habilidades de trabajo en equipo, }\end{array}$ & 3 & 8 & 12 & 6 & 3 & \\
\hline $\begin{array}{l}\text { WhatsApp me habilita a copmpartir información y } \\
\text { conectar ideas con compañeros. }\end{array}$ & 4 & 17 & 12 & 1 & & \\
\hline $\begin{array}{l}\text { WhatsApp aumenta mi interés y motivación en } \\
\text { clase }\end{array}$ & 5 & 11 & 12 & 4 & 3 & \\
\hline $\begin{array}{l}\text { Etiqutando a mis compañeros en posts útiles me } \\
\text { ayuda a aprender mejor. }\end{array}$ & 6 & 8 & 13 & 8 & 1 & \\
\hline $\begin{array}{l}\text { WhatsApp incrementa mi particiación en el } \\
\text { aprendizaje. }\end{array}$ & 7 & 8 & 13 & 7 & 2 & \\
\hline $\begin{array}{l}\text { Siento que WhatsApp learning es una pérdida de } \\
\text { tiempo. }\end{array}$ & 8 & 6 & 8 & 5 & 11 & \\
\hline $\begin{array}{l}\text { Conversando en el WhatsApp me ayuda a } \\
\text { mantener las relaciones sociales. }\end{array}$ & 9 & 11 & 13 & 5 & 1 & \\
\hline $\begin{array}{l}\text { WhatsApp no incrementa mi autoestima porque } \\
\text { no puedo expresar mis pensamientos } \\
\text { abiertamente. }\end{array}$ & 10 & 5 & 4 & 8 & 9 & 4 \\
\hline $\begin{array}{l}\text { WhatsApp incrementa la comunicación con mis } \\
\text { amigos de manera más eficiente. }\end{array}$ & 11 & 17 & 12 & 1 & & \\
\hline $\begin{array}{l}\text { WhatsApp es nuevo para mí y no me siento } \\
\text { cómodo usándolo }\end{array}$ & 12 & & 3 & & 19 & 8 \\
\hline Me estresa el WhatsApp stresses & 13 & & 4 & 9 & 14 & 3 \\
\hline $\begin{array}{l}\text { Mis notas serían mejores si pudiera contactar a } \\
\text { mis profesores a través del WhatsApp fuera del } \\
\text { horario de clase. }\end{array}$ & 14 & 6 & 9 & 9 & 6 & \\
\hline $\begin{array}{l}\text { Me doy cuenta que el WhatsApp ha cambiado la } \\
\text { manera en que aprendo. }\end{array}$ & 15 & 1 & 9 & 13 & 6 & 1 \\
\hline $\begin{array}{l}\text { WhatsApp no me ayuda a mi aprendizaje porque } \\
\text { no es fácil de usar. }\end{array}$ & 16 & 1 & 4 & & 14 & 11 \\
\hline $\begin{array}{l}\text { WhatsApp me ayuda a comprender conceptos de } \\
\text { manera más eficiente. }\end{array}$ & 17 & 4 & 12 & 5 & 7 & 2 \\
\hline $\begin{array}{l}\text { WhatsApp no es efectivo para obtener un buen } \\
\text { aprendizaje porque crea problemas técnicos. }\end{array}$ & 18 & & 1 & 9 & 13 & 7 \\
\hline
\end{tabular}


Gráfico 5: El uso del WhatsApp como herramienta de Aprendizaje

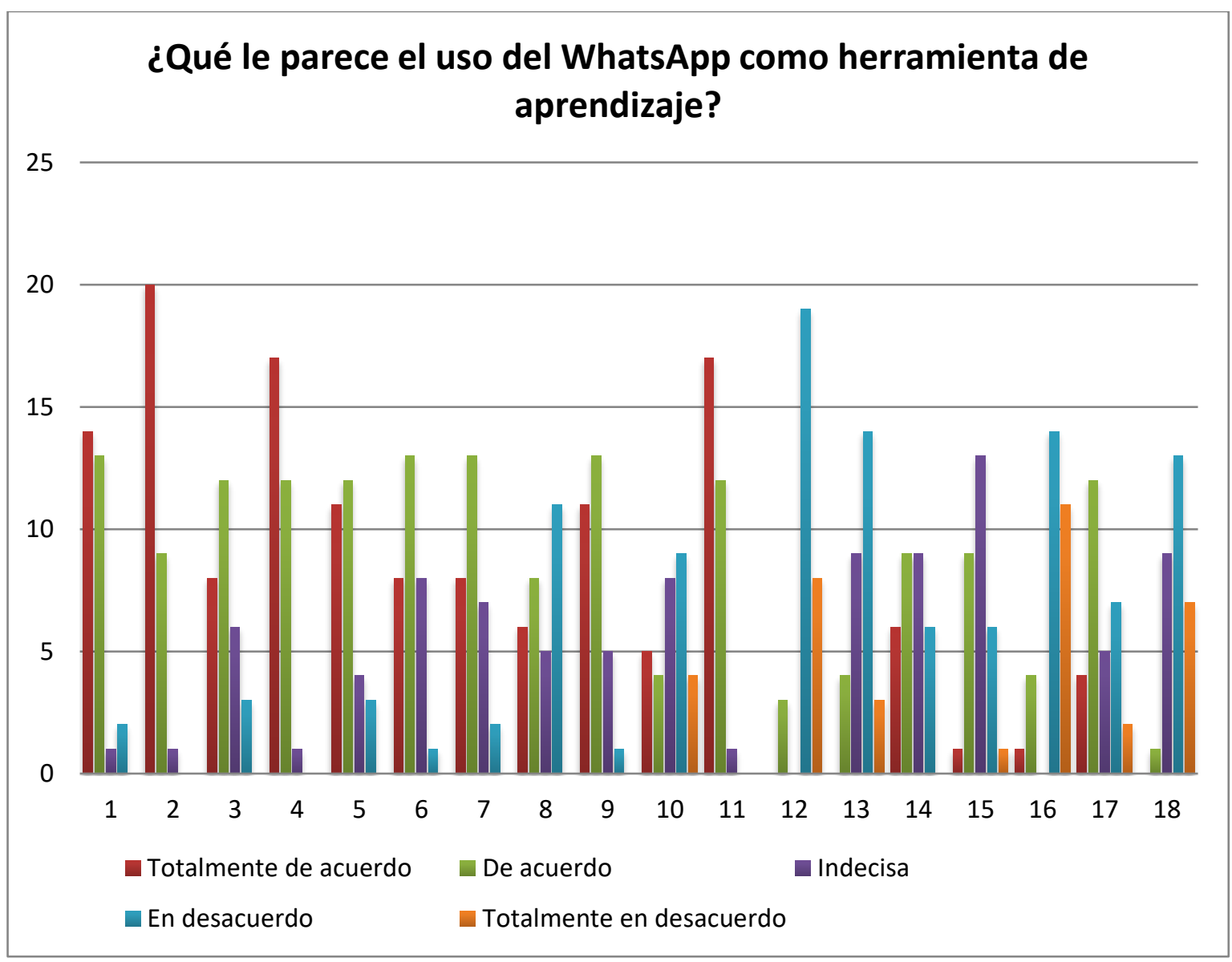

Las respuestas de opinión demuestran también mucha apertura sobre el uso del whatsApp para fines académicos, haciendo la aclaración que su buen uso y aceptación dependerá de la responsabilidad de cada quien al momento de utilizarlo o bien que puede ser un distractor al recibir otros chats o informaciones al momento de estar trabajando o estudiando.

\subsection{Resultados y Conclusiones}

En nuestro contexto educativo costarricense el uso de dispositivos móviles con propósitos académicos y como parte de la mediación del aprendizaje del idioma Inglés es aún limitado. En muchos países Europeos y especialmente en España, ha habido un gran interés en la incorporación de dispositivos móviles y ya son muchos los docentes de diferentes áreas del saber que día a día ven en los teléfonos inteligentes una oportunidad, un instrumento para 
Uso del WhatsApp en Comunidades Interactivas de Aprendizaje: Perspectiva Estudiantil sobre Ejercicios de Pronunciación en la Clase de Inglés para Propósitos Específicos

mediar los aprendizajes. Aunque en Costa Rica ha habido un incremento en la implementación de las TICS en la mediación de los aprendizajes, el uso y la implementación de dispositivos móviles en la mediación de los aprendizajes es aún muy limitado. Todos concordamos en el hecho de que los teléfonos celulares inteligentes han cambiado radicalmente nuestras sociedades, quien hubiese atinado hace décadas atrás que un dispositivo móvil serviría para realizar innumerables actividades influyendo y transformado radicalmente nuestra cotidianidad en tan importantes maneras. Estos dispositivos han sido ampliamente aceptados en otros países por ser herramientas con un gran atractivo, sus características inteligentes acceso a internet, cámara, grabación de audio e imagen y las variadas aplicaciones a las que se puede acceder los hace aún más atractivos. Por lo que ya son muchos los investigadores, académicos y docentes que los incorporan en la mediación académica y estos son generalmente bien aceptados en los procesos de aprendizaje.

En nuestro caso especifico nuestros estudiantes se mostraron positivos y abiertos ante la oportunidad de implementar el WhatsApp como herramienta para mediar practicas de pronunciación. Ellos en su mayoría enfatizaron que es una buena idea para facilitar el aprendizaje ya que se pueden beneficiar de diferentes maneras y ante esto puntualizaron que esta aplicación en el aprendizaje es popular, es gratis, casi todos los estudiantes la tienen, es una buena idea para compartir información y llevar a cabo discusiones académicas. Además, se fortalecen relaciones sociales en el curso pues se comparte en tiempo real con una herramienta que es de fácil manejo y que representa mayor atractivo interactivo a la hora de interactuar entre pares. Esta interacción entre compañeros y profesor mediante el grupo WhatsApp resulta divertida, y entretenida bajando los niveles de ansiedad que se genera al aprender y producir un idioma extranjero. interactuar con compañeros y profesor.

Algunas de las preocupaciones expuestas por los estudiantes ante la implementación de esta aplicación en el aula es el hecho de no contar con acceso a internet y que este se sobre use en clases, saturándolos con actividades y tareas académicas. Entre las sugerencias a resaltar, los estudiantes mencionaron incluir en los chats de WhatsApp links de otras aplicaciones como "You Tube", juegos interactivos, canciones, fotos, videos, presentaciones y ejercicios interactivos con nota. Igualmente, sugieren realizar los chats con comunidades pequeñas y no saturarlo con muchos mensajes para no sentirse "invadidos" con mucha información. Insisten en un uso responsable y que se tome con seriedad y no para enviar información que no se relacione con objetivos de aprendizaje.

\section{Bibliografia}

ALFARO, G. (1996). Evaluación cualitativa: técnicas y estrategias. San José, Costa Rica: EUNA.

BARHOUMI, CH, (2015) 'The effectiveness of whatsapp mobile learning activities guided by activity theory on students' knowledge management:. Contemporary educational technology, Vol.6 2015 (3), pp.221-238 https://eric.ed.gov/?id=EJ1105764

(Consulta : 22 Marzo de 2017)

BORDAS, M. Y CABRERA F. (2001). "Estrategias de evaluación de los aprendizajes centrados en el proceso". Revista Española de Pedagogía. Año LIX, enero abril , pp.25 - 48.

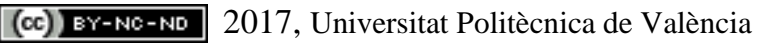

Congreso IN-RED (2017) 
( Consulta : 25 Marzo de 2017)

BRAZUELO, F., GALLEGO, D. (2011). Mobile Learning. Los dispositivos móviles como recurso educativo. Sevilla: Editorial MAD, S.L

CALDERÓ, R. (2014). El uso del teléfono móvil y de la aplicación WhatsApp para el aprendizaje de verbos frasales ingleses en alumnos de nivel intermedio. Trabajo Final de Master. La Rioja: Universidad Internacional de La Rioja http://reunir.unir.net/bitstream/handle/123456789/2639/caldero\%20gene.pdf?sequence=1\& isAllowed=y (Consulta : 20 Marzo de 2017)

DALE, P., Y POMS, L., (2005). English Pronunciation Made Simple. New York : Longman

GUTIÉRREZ, M., GIBERT, M.I., TRIANA, I., GIMENO, A., APPEL, C. \& HOPKINS, J. (2013). “Improving learners' reading skills through instant short messages: A sample study using WhatsApp." University of Ulster. En: worldcall: sustainability and computer-assisted language learning Conference.Glasgow pp.80-84. Disponible en https://www.researchgate.net/publication/255718202_Improving_learners\%27_reading_ski 1ls_through_instant_short_messages_a_sample_study_using_WhatsApp

HIDALGO, G. (2013). “Uso del teléfono móvil: posibilidades didácticas y riesgos en los jóvenes" Trabajo Final de Master. Almeria: Universidad Almeria.

http://repositorio.ual.es/bitstream/handle/10835/2353/Trabajo.pdf?sequence=1\&isAllowed

( Consulta : 20 Marzo de 2017)

HOCKLY, N., DUDENEY, G. (2014). Going mobile: Teaching with hand-held devices. Estados Unidos:Delta Publishing.

IRUELA, G. (2007). “¿Qué es la pronunciación ?’” RedEle Revista Electrónica Didáctica. Número 9.

( Consulta : 25 Marzo de 2017)

KOPER, R. (2009). Learning Network Services for Professional Development. Berlin: Heidelberg: Springer.

THORNTON, P., HOUSER, C. (2005). "Using mobile phones in English education in Japan. en Journal of Computer Assisted Learning, 21,217-228. http://dx.doi.org/10.1111/j.1365-2729.2005.00129.x

( Consulta : 20 Marzo de 2017)

WEI , M. (2006). “A Literature Review on Strategies for Teaching Pronunciation". Maryland : University of Maryland at College Park.

http://files.eric.ed.gov/fulltext/ED491566.pdf

( Consulta : 25 Marzo de 2017)

(c)) EY-NC-ND 2017, Universitat Politècnica de València

Congreso In-Red (2017) 


\title{
Luces y sombras del Flipped Teaching con estudiantes de primero de turismo
}

\author{
Francisco J. Boigues ${ }^{\mathrm{a}}$, Vicente Estruch ${ }^{\mathrm{b}}$ y Anna Vidal ${ }^{\mathrm{c}}$ \\ Departamento de Matemática Aplicada de la UPV-Campus Gandia. \\ Grup d'Innovació Educativa i Reserca en Màteries Cientifiques \\ afraboipl@mat.upv.es, ${ }^{b}$ vdestruc@mat.upv.es, ${ }^{c}$ avidal@mat.upv.es,
}

\begin{abstract}
The Inverted Classroom, or Flip Classroom is a pedagogical method that modifies the traditional order of teaching. In this paper, we describe a Flip experience developed with students of the first course, of the Tourism Grade and analyze the impact of the new methodology, both on performance and on attitude towards mathematical tasks performed with the help of the program Microsoft Excel ${ }^{\odot}$. The results do not indicate an improvement in performance. However, they do indicate an improvement in the attitude towards mathematical activities.
\end{abstract}

Keywords: Flip, performance, attitude, mathematics, Microsoft Excel $^{\odot}$.

\begin{abstract}
Resumen
El Aula Invertida o Clase Flip es un método pedagógico que modifica el orden tradicional de la enseñanza. En este artículo se describe una experiencia Flip desarrollada con estudiantes del primer curso del Grado de Turismo, y se analiza el impacto de la nueva metodología, tanto en el rendimiento como en la actitud hacia las tareas matemáticas realizadas con la ayuda del programa Microsoft Excel ${ }^{\odot}$. Los resultados no indican una mejora en el rendimiento. Sin embargo, sí indican una mejora en la actitud hacia las actividades matemáticas.
\end{abstract}

Palabras clave: flip, rendimiento, actitud, matemáticas, Microsoft Excel ${ }^{\odot}$.

\section{Introducción}

El término Aula Invertida, o Inverted Classroom, fue acuñado por un grupo de profesores de economía en la Universidad de Miami (Ohio). Hay que buscar sus raíces en el método del caso utilizado en las escuelas de negocios, derecho y humanidades, donde se desarrollaba una discusión en clase acerca de una lectura que el alumnado debía haber preparado previamente en casa (Lage, Platt y Treglia, 2000). Posteriormente, en 2007, Jonathan Bergmann y Aaron Sams, dos profesores de química de la Woodland Park High School, Colorado, grabaron y subieron a la red videos con los contenidos de sus asignaturas (Bergamnn y Sams, 2105), para ayudar a los estudiantes ausentes, siendo de los primeros en defender esta herramienta como instrumento de enseñanza. Posteriormente, al comprobar el 
uso extensivo de los vídeos por todo el alumnado, variaron el orden, exigiendo al alumnado visualizar en casa y tomar notas de un vídeo, como tarea previa a la clase presencial. De esta manera el alumnado disponía de más tiempo en clase para poner en práctica los conocimientos adquiridos, resolver dudas y realizar proyectos o experimentos. Este cambio metodológico supuso un aumento de la interacción profesor-alumno, una educación más personalizada en la que disminuye el protagonismo del docente para convertir al alumno en el protagonista del proceso de aprendizaje. De esta forma Bergamnn y Sams invirtieron las actividades con respecto al modelo tradicional, siendo este el germen de su Inverted Classroom.

Además de Aula Invertida o Clase al Revés, es habitual la utilización de términos en inglés como Flip Teaching, Flipped Classrom o Flipped Learning. Quizás la expresión Flipped Teaching (FT) es, seguramente, la más extendida.

El FT supone cambiar la estructura tradicional del aprendizaje en la que el docente suele dedicar mucho tiempo, inicialmente, a la explicación de los temas en el aula. En el caso del FT los contenidos de la parte teórica, que tradiciaonalmente exponía el profesor en el aula (clase magistral) la preparan los alumnos en casa. De esta forma, se hace un uso más efectivo del tiempo en el aula, dedicándolo a actividades de aprendizaje centradas en los estudiantes. En realidad, los estudiantes no necesitan tanto al profesor en el aula, durante la exposición teórica, sino más bien en la resolución de problemas. Sin embargo, tradicionalmente, la resolución de problemas es realizada, por lo general, fuera de la clase y sin la ayuda directa del profesor. Por lo tanto, parece razonable una inversión de la clase tradicional, de manera que el alumnado adquiera la información básica a través de vídeos, lecturas, y otras fuentes, en su casa, reservando la clase presencial para trabajos más activos dinámicos y participativos, como la resolución de problemas, la realización de prácticas o el trabajando en equipo. Esta metodología implica al alumno en su propio aprendizaje, y en las actividades presenciales se puede ofrecer una retroalimentación inmediata, incrementándose la interacción alumno/profesor además de propiciar la colaboración entre los propios estudiantes (Pearson, 2013).

Lo que marca la diferencia entre la clase tradicional y el FT no es tanto el uso de vídeos en el aprendizaje, sino cómo se integran todos los recurso en el desarrollo del aprendizaje general (Tucker, 2012). No basta con invertir el orden de presentación de los recursos e introducir los vídeos en el material formativo. El elemento fundamental del cambio es resolver cómo utilizar mejor el tiempo en la clase con el alumnado. La clase debe convertirse en el lugar de trabajo mediante el estudio de problemas, avanzando conceptos, y participando en el aprendizaje colaborativo. En Hughes (2012) se detalla cómo diseñar diferentes estrategias para "dar la vuelta" al aula universitaria y en Touron, Santiago y Díez (2014), se muestran algunas experiencias didácticas. Entre las páginas web españolas que tratan esta metodología destaca la de Javier Touron (Talento-Educación-Tecnología Touron).

Algunas investigaciones demuestran con evidencias empíricas la potencia del FT para mejorar tanto la motivación, como el rendimiento de los estudiantes, en educación secundaria y en educación superior, (Walsh, 2013b; Szoka, 2013). Bergmann y Sams

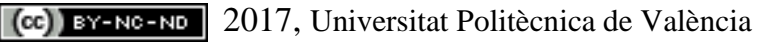

Congreso IN-RED (2017) 
(2015) también comprobaron que sus estudiantes aprendían más y mejoraban sus calificaciones con el FT. En el ámbito universitario y en diversas asignaturas como Biología (Moravec, Williams, Aguilar-Roca y O’Dowd, 2010), Diseño de Software (Gannod, Burge y Helmick, 2008), Álgebra Lineal (Talbert, 2014) e Introducción a la informática Científica (Talbert, 2012), se demuestra la eficacia del FT, tanto a nivel de resultados, con un mayor número de aprobados, como en la adquisición de competencias transversales como son la capacidad de adquirir conocimientos técnicos por cuenta propia, capacidad de autocorrección, alto nivel de trabajo a pesar de tener falta de base inicial, etc.

Otras ventajas, consensuadas por profesores universitarios que han adoptado e investigado sobre la metodología FT, son la mayor implicación y compromiso por parte del alumnado, el aprendizaje más profundo y el que permite una mayor adaptación al ritmo de cada estudiante (Walsh, 2013a). Goodwin y Miller (2014) indican que el problema de las clases magistrales es a menudo una cuestión de ritmo, puesto que se pretende que todos los alumnos tengan que aprender los conceptos explicados prácticamente al mismo ritmo. Si embargo es normal que algunos estudiantes tengan problemas para asimilar los conceptos explicados en una clase magistral o que carezcan de los conocimientos previos que se necesitan para entender los conceptos presentados, y no puedan seguir el ritmo establecido. La utilización de vídeos didácticos permite al alumnado establecer el propio ritmo e incluso poder repasar, en cualquier momento, los conceptos teóricos.

Varios autores remarcan la importancia de medir la utilidad del FT en cuanto al aprendizaje. Goodwin y Miller (2014) señalan que no se tienen evidencias científicas directas que establezcan que el FT mejora el aprendizaje de los estudiantes. Touron y Santiago (2015) ofrecen varias evidencias acerca de la eficacia de esta metodología en cuanto a su utilización y en cuanto a la mejora del rendimiento y la disminución del fracaso escolar. Sin embargo señalan la necesidad de investigar mas sobre la influencia del FT en una mejora directa del aprendizaje del estudiante. O'Flaherty y Phillips (2015) realizan una revisión de 28 artículos, correpondientes a cinco países, donde se analizan los tipos de recursos docentes utilizados, las actividades realizadas durante las clases, el apoyo para desarrollar recursos, la aceptación pedagógica del FT por el personal académico y estudiantes, y la evaluación de resultados. Los resultados indican claras evidencias indirectas acerca de la mejora del rendimiento académico y la satisfacción de los estudiantes y el profesorado. Pero escasean pruebas concluyentes acerca de la contribución del FT al aprendizaje a lo largo de la vida y otras habilidades del siglo XXI, tanto en la educación de grado como en la de posgrado. Por otra parte, Yoshida (2016) indica que, aunque la gran mayoría de investigaciones que miden la percepción que tienen estudiantes y profesores en cuanto a la utilidad de la metodología FT se centran más en la utilidad relacionada con la tecnología, también es importante la utilidad en el proceso de aprendizaje. Por tanto también es interesante centrarse en todo el proceso de aprendizaje para aseguran la calidad del "aprendizaje invertido".

Recientemente, Fidalgo (2016) propone estudiar el impacto de lo que denomina Micro Flip Teaching (MFT) sobre los resultados del aprendizaje del alumnado. Fidalgo (2016) define el MFT como el Flipped Teaching aplicado sólo en determinadas partes de un tema y no 
necesariamente en toda una asignatura. Una de las características del MFT es que se puede aplicar sólo a parte de un curso. De estas investigaciones se concluye que el MFT repercute en la mejora tanto del aprendizaje como en la consolidación de conocimientos.

\section{Objetivos}

En este artículo pretendemos analizar si la aplicación de la metodología FT puede mejorar tanto el rendimiento como la actitud del alumnado. En concreto, nos planteamos las siguientes preguntas.

a. ¿Se constata algun tipo de modificación en las actitudes de los estudiantes al introducir el FT?

b. ¿Influye la metodología FT empleada en el redimiento?

c. ¿El factor actitud influye en el rendimiento, independientemente de la metodología docente seguida?

\section{Desarrollo de la experiencia}

\subsection{Participantes y contexto}

El experimento se ha realizado sobre 497 alumnos del Grado en Turismo de la Universitat Politècnica de València-Campus de Gandia que cursaban la asignatura Matemáticas del primer cuatrimestre, de primer curso, a lo largo de 6 cursos consecutivos: desde 2011-2012 hasta 2015-2016 (Tabla 1)

Tabla 1. Procedencia de los participantes en la experiencia

\begin{tabular}{|ccccccc|}
\hline Curso & $2011 / 12$ & $2012 / 13$ & $2013 / 14$ & $2014 / 15$ & $2015 / 16$ & $2016 / 17$ \\
\hline No de participantes & 91 & 89 & 80 & 74 & 87 & 76 \\
\hline
\end{tabular}

La asignatura Matemáticas del Grado en Turismo es una asignatura obligatoria que se imparte en el primer cuatrimestre del primer curso, y tiene un peso de 4'5 créditos, repartidos en 3'5 créditos para teoría/problemas de aula y 1 crédito para prácticas en laboratorio de informática.

La parte de prácticas en aula informática consta de cinco sesiones presenciales de 2 horas de duración cada una. En las cuatro primeras sesiones se trabajan, utilizando una hoja de cálculo, en concreto Microsoft $\operatorname{Excel}^{\odot}$, algunos contenidos vistos en la clase de teoría/problemas de aula (Tabla 2). En la última sesión, se hacía un control para evaluar lo aprendido durante las 4 sesiones anteriores.

En el curso 2016/2017 se siguió, en la parte de prácticas en aula informática, una metodología Flipped Teaching (que en adelante denominaremos Flip), y en los anteriores cursos se siguió una metodología, que denominaremos Tradicional, consistente en sesiones de prácticas guiadas, con ejercicios propuestos a resolver, y entregar al final de cada práctica. 
Tabla 2. Contenidos de las prácticas

\begin{tabular}{|cl|}
\hline Sesión & \multicolumn{1}{c|}{ Contenidos } \\
\hline $\mathbf{1}$ & Tablas, gráficos y parámetros de variables unidimensionales \\
\hline $\mathbf{2}$ & Variables bidimensionales. Regresión y correlación \\
\hline $\mathbf{3}$ & Matrices y sistemas de ecuaciones lineales \\
\hline $\mathbf{4}$ & Funciones, imágenes, anti imágenes y gráficas. Matemáticas financieras. \\
\hline $\mathbf{5}$ & Control global de las prácticas \\
\hline
\end{tabular}

\subsection{Metodología Tradicional versus metodología Flip}

\subsubsection{Metodologia Tradicional}

A continuación, describimos con más detalle la metodología que hemos denominado Tradicional. A todos los estudiantes se les proporcionaba, al principio de cada sesión de prácticas, una guía detallada según la cual había que estudiar una serie de ejercicios, cuya resolución aparecía en la guía. Los ejercicios se trabajaban utilizando como apoyo la hoja de cálculo Excel. El profesor explicaba, en la primera parte de la sesión, el contenido de la guía y, posteriormente, resolvía las dudas que surgiesen a los alumnos mientras estos reproducían la resolución de los ejercicios descrita en la guía. Esta primera parte ocupaba entre 85 y 90 minutos, aproximadamente. En la segunda parte de la práctica se proponía a los alumnos otros ejercicios, parecidos a los trabajados en la primera parte de la sesión, cuyos enunciados aparecían al final de la guía. Los alumnos debían resolver los ejercicios propuestos, para lo cual disponían de 30 minutos, aproximadamente. Los ejercicios presentados eran evaluados por el profesor, que valoraba el trabajo realizado con una nota entre 0 y 10. En este caso de metodología Tradicional, el profesor disponía de un solo archivo de respuestas por estudiante para evaluar la práctica.

\subsubsection{Metodologia Flip}

En el caso de la metodología Flip, también se trabajaba sobre una guía, la cual se proporcionaba a los alumnos con suficiente antelación a la sesión presencial de la práctica. Se establecía una fecha límite concreta, también previa a la sesión presencial, antes de la cual los alumnos debían entregar al profesor los ejercicios (propuestos en la guía) resueltos, utilizando como soporte un archivo Excel. El profesor, antes de la sesión presencial, corregía las entregas recibidas. Posteriormente, ya en la sesión presencial, en la primera parte de ésta, el profesor comentaba los errores más comunes en las respuestas de los alumnos. Esta parte ocupaba entre 45 y 50 minutos, aproximadamente. El resto del tiempo, entre 65 y 70 minutos aproximadamente, se dedicaba a que los estudiantes resolviesen una serie de ejercicios propuestos. Al final de la sesión presencial, los estudiantes enviaban al profesor un archivo Excel con la resolución de los problemas propuestos. En cada una de las cuatro primeras prácticas en las que se siguió la metodología Flip, los alumnos 
presentaron dos archivos Excel con ejercicios resueltos, que fueron calificados de 0 a 10 cada uno. La media aritmética de estas dos notas constituía la nota final de la práctica.

\subsubsection{Instrumentos de recogida de datos y método de análisis}

Por lo tanto, para cada estudiante, y para las dos metodologías, se disponía finalmente de 4 notas de 0 a 10 (correspondientes a 4 prácticas), o lo que es lo mismo, una suma acumulada máxima de 40 puntos. El valor de dicha suma va asociado a un porcentaje de aciertos en las respuestas a los problemas propuestos. Además, disponíamos de información sobre las veces que los estudiantes habían accedido a los guiones de las prácticas de los cursos 2015/2016 y 2016/2017, y por tanto del número medio de accesos a los guiones de las prácticas.

En el contexto de una u otra metodología (Tradicional o Flip), los trabajos presentados por cada alumno sirvieron como elemento para valorar la actitud del mismo frente a la asignatura y por ende frente a las matemáticas. El nivel global de aciertos en las soluciones aportadas puede considerarse, en su conjunto, como una medida indirecta de la actitud frente al quehacer matemático dado que, por ejemplo, un número bajo de aciertos, en general, se comprobó que va asociado al hecho de que, a pesar de las facilidades, no se ha tenido interés en obtener las soluciones correctas o, en muchos otros casos, no se han realizado algunas sesiones de prácticas. También, en general, el nivel de aciertos está directamente relacionado con la forma de presentar el trabajo (formato cuidado, claridad de la respuesta, etc.).

Para aquellos alumnos con un $80 \%$ aciertos o más, se interpretó que tenían interés en hacer las cosas bien en sentido amplio, y fueron calificados como "actitud positiva" hacia las matemáticas, lo cual fue codificado con la letra A. Para los alumnos que tenían entre un $60 \%$ y un $80 \%$ de aciertos, se considera que tienen un "interés medio" en hacer las cosas bien en sentido amplio, y se les clasificó como "actitud mejorable", lo cual fue codificado con la letra B. Finalmente, a los restantes estudiantes, se les asignó "actitud negativa", lo cual fue codificado con la letra $\mathbf{C}$ (tabla 3 ).

Tabla 3. Valoración de la actitud matemáticas

\begin{tabular}{|lccc|}
\hline Actitud hacia las matemáticas & Positiva (A) & Mejorable (B) & Negativa(C) \\
\hline Porcentaje de acierto & $80 \%-100 \%$ & $60 \%-80 \%$ & $0 \%-60 \%$ \\
\hline Valoración sobre $\mathbf{4 0}$ & $32-40$ & $24-32$ & $0-24$ \\
\hline
\end{tabular}

En la quinta sesión de prácticas, todos los estudiantes, independientemente de la metodología seguida en las sesiones de prácticas, tuvieron que realizar una prueba de evaluación final, que constaba de 8 preguntas, el objetivo de las cuales era medir el rendimiento final en la adquisición de la competencia "Utilizar Excel para resolver problemas de matemáticas". El resultado de esta prueba se valoró entre 0 y 10 puntos. De esta forma, para cada alumno se dispone de una valoración de la actitud (A, B o $\mathbf{C})$ de un descriptor del método seguido en las clases (Tradicional o Flip) y de una valoración numérica del rendimiento final (valor entre 0 y 10).

(cc) EY-NC-ND 2017, Universitat Politècnica de València

Congreso IN-RED (2017) 
En primer lugar, se calcularon los porcentajes para cada actitud, dependiendo de la metodología utilizada, con el objetivo de determinar si la metodología utilizada influye en la actitud del alumno. Por otra parte, se recurrió al ANOVA multifactorial, con Suma de Cuadrados tipo III, para establecer la influencia en el rendimiento de los factores: actitud del alumno, metodología utilizada y la interacción de los dos factores anteriores.

\section{RESULTADOS}

\subsection{Analisis sobre las actitudes}

El análisis de las actitudes frente a las matemáticas según se haya seguido una metodología u otra indica que la metodología utilizada influye claramente (fig. 1)

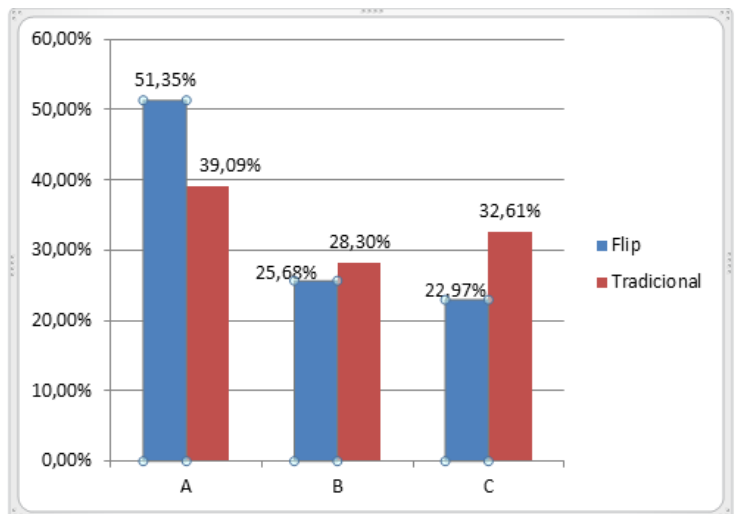

Fig. 1 Porcentaje de alumnos para cada actitud dependiendo de la metodología seguida

Se observa que el porcentaje de alumnos con actitud positiva (A) es claramente superior en el caso de aplicación de la metodología Flip, $(p$-valor $<0.05)$ de donde se infiere que dicha metodología puede ser un elemento motivador añadido para los alumnos que ya de por sí tendrían una actitud positiva hacia las matemáticas con el método Tradicional. No pueden establecerse diferencias estadísticamente significativas entre el porcentaje de alumnos con actitud $\mathbf{B}$ que han seguido la metodología Tradicional en comparación con los que siguieron la metodología Flip. Asimismo, el porcentaje de alumnos con "actitud negativa" (C) es significativamente inferior (aproximadamente 10 puntos porcentuales, $p$-valor $<0.05$ ) en el grupo que ha seguido la metodología Flip (23\% aprox.) en comparación con los alumnos que no han seguido dicha metodología (32.6\%).

Además, al considerar los cursos 2015-16 y 2016-17, se observa claramente, sobre todo al principio de la asignatura, un mayor acceso a los guiones de las prácticas en el curso 201617 , en el que se siguió la metodología Flip (ver figura 2) 


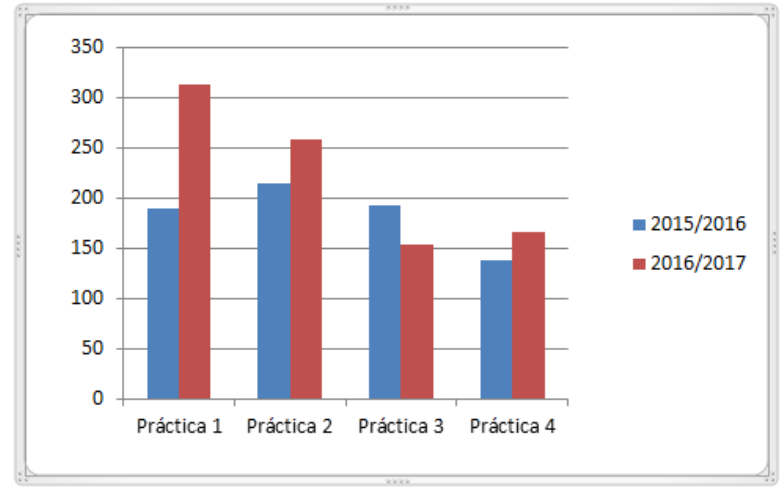

Fig. 2 Número de accesos a los guiones e las prácticas (cursos 20115-16 y 2016-17)

\subsection{Analisis sobre Rendimiento}

Los resultados del ANOVA multifactorial se resumen en la tabla 4

Tabla 4. ANOVA multifactorial para el rendimiento final, con suma de cuadrados Tipo III. Las razones-F se basan en el cuadrado medio del error residual.

\begin{tabular}{lccccc}
\hline Fuente & $\begin{array}{c}\text { Suma de } \\
\text { Cuadrados }\end{array}$ & Gl & $\begin{array}{c}\text { Cuadrado } \\
\text { Medio }\end{array}$ & Razón- $F$ Valor- $P$ \\
\hline FACTORES & & & & & \\
Act: Actitud & 246,697 & 2 & 123,349 & 21,65 & 0,0000 \\
Met: Métodología & 0,040202 & 1 & 0,040202 & 0,01 & 0,9331 \\
INTERACCIONES & & & & & \\
Act-Met & 72,8463 & 2 & 36,4231 & 6,39 & 0,0018 \\
RESIDUOS & 2763,06 & 485 & 5,69704 & & \\
TOTAL (CORREGIDO) & 3816,83 & 490 & & & \\
\hline
\end{tabular}

Para elaborar la tabla ANOVA se descompone la variabilidad de la variable Rendimiento en contribuciones debidas a dos factores: Actitud y Metodología. Al escoger la opción de la suma de cuadrados Tipo III, la contribución de cada factor se mide eliminando el efecto del otro factor. Los valores- $P$ son indicadores de la significación estadística de cada uno de los factores. Hay dos valores- $P$ mucho menores que 0,05: El correspondiente al factor Actitud y el correspondiente a la interacción entre Actitud y Metodología, lo cual indica que el factor Actitud y la interacción Actitud-Metodología tienen un efecto estadísticamente significativo sobre el rendimiento, con más del 95,0\% de nivel de confianza (incluso a un $99 \%)$.

En la figura 3 se representan los valores medios de rendimiento para cada actitud (A, B y C) considerando las dos metodologías. Para cada valor medio se ha representado también el intervalo de confianza. La figura 3, a), b) y c) es útil para visualizar los efectos de los factores considerados, Actitud, Metodología y la interacción de ambos factores, respectivamente. La superposición de intervalos de confianza significa que no existen

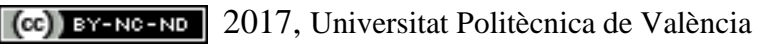

Congreso IN-RED (2017) 
diferencias significativas entre las medias al considerar diversas cualidades de los factores. Para interpretar la interacción entre Actitud y Metodología (figura 2 c). Las 2 líneas trazadas en la figura 3 c) representan cada uno de los niveles de Metodología (azul para Flip y rojo para Tradicional). Dichas líneas conectan las medias para los 3 niveles de Actitud. Si no existiese ninguna interacción, las dos líneas serían aproximadamente paralelas. Cuanto más fuerte sea la interacción entre Actitud y Metodología, más diferente es la forma de las líneas. En nuestro caso queda claro que las diferencias significativas en el rendimiento debido a la interacción entre actitud y metodología se observan fundamentalmente en la actitud $\mathrm{C}$.

(a)

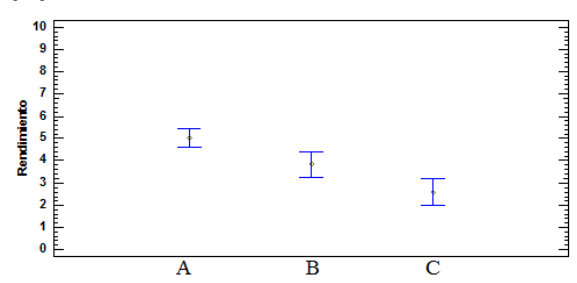

(b)

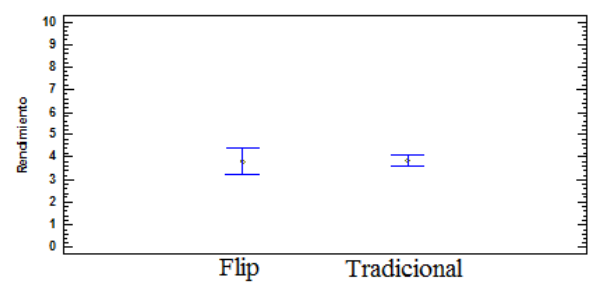

(c)

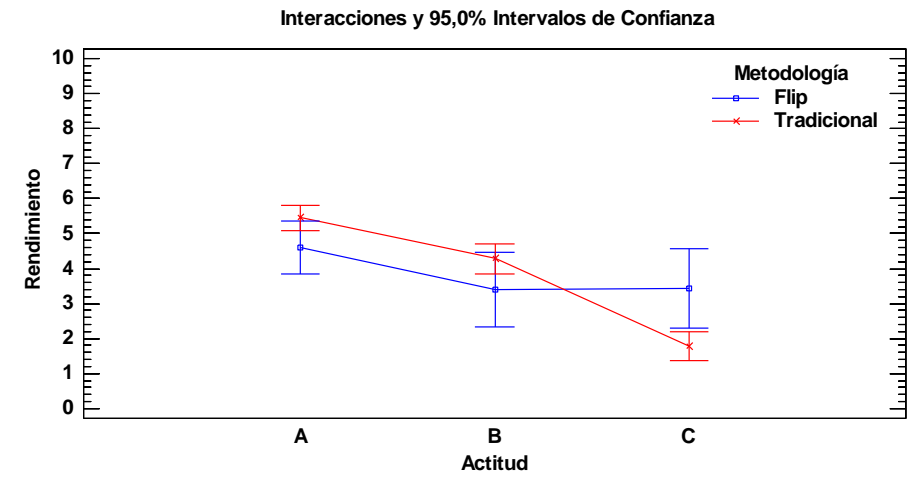

Figura 3. Representaciones de la media del Rendimiento al tener en cuenta los factores: Actitud (a), Metodología (b) e Interacciones entre los factores (c). Para cada rendimiento medio se ha representado también el intervalo de confianza a un nivel del $95 \%$.

Asimismo, se observa que para las actitudes A y B no pueden establecerse diferencias estadísticamente significativas en el rendimiento final dependiendo de la Metodología. Por su parte, para la actitud $\mathbf{C}$ y metodología Flip se obtiene un rendimiento significativamente mayor (valor- $P=0,0018$ ) que para la misma actitud y la metodología Tradicional.

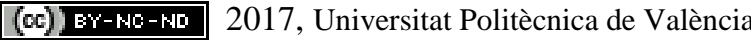




\section{Discusión y Conclusiones}

En general, no podemos afirmar que haya mejorado el rendimiento final con el cambio de metodología. Aun siendo cierto que los alumnos con peor actitud (C) experimentan una mejora en su rendimiento con el FT, éstos siguen teniendo un rendimiento muy por debajo de lo que se espera de un universitario comprometido con sus estudios.

En cambio, sí se observa una mejora en la actitud frente a las matemáticas con el FT al aumentar el porcentaje de estudiantes que se implican más con las tareas a realizar. Además, se observa claramente un aumento significativo (lógico) enlos accesos a los recursos que se ponen a disposición de los alumnos para estudiar la asignatura de matemáticas.

Es obvio también que la metodología FT implica mucho más trabajo y mayor dedicación para el profesor. Por una parte hay que preparar más materiales de aprendizaje. Por otra parte es necesario realizar un seguimiento más intenso de los estudiantes en la realización de sus tareas. La herramienta estadísticas de la plataforma docente PoliformaT de la Universitat Politècnica de València refleja que los profesores de la asignatura accedieron a la plataforma en el curso 2015-16 2808 veces frente a los 6174 accesos del curso 2016-17 (casi un 120\% más).

A la luz de los resultados obtenidos, quedan cuestiones interesantes por analizar como por ejemplo ¿Hasta qué punto debe utilizarse la metodología FT en estudiantes de primer curso de Grado para que el alumnado adquiera un conocimiento matemático más comprensivo? Nos atrevemos a conjeturar que quizás, en el caso concreto de alumnos de primer curso de Grado, sin experiencia previa en trabajo bajo metodología FT, se obtendrían mejores resultados recurrirendo a una metodología Micro Flip Teaching bien estructurada.

\section{Agradecimientos}

Este trabajo se ha realizado gracias al apoyo del Vicerrectorado de Estudios, Calidad y Acreditación de la UPV al Proyecto PIME 2016-2017 "Puesta en marcha de diversas experiencias con el enfoque Flipped Teaching en asignaturas de Matemáticas y Física".

\section{Referencias}

BERGMANN, J., SAMS A. (2015). Dale la vuelta a tu clase: Lleva tu clase a cada estudiante, en cualquier momento y cualquier lugar. Biblioteca Innovación educativa. Editorial SM.

FIDALGO-BLANCO, A., MARTINEZ-NUÑEZ, M., BORRAS-GENE, C., SANCHEZ-MEDINA, J.J. (2016)."Micro flip teaching-An innovative model to promote the active involvement of students" en Computers in Human Behavior, Volume 72, p.713-723.

http://dx.doi.org/10.1016/j.chb.2016.07.060.

GANNOD, G., BURGE, J., HELMICK, M. (2008). "Using the inverted classroom to teachsoftware engineering" en Proceedings of the International Conference on Software Engineering (ICSE). Leipzig, Germany. p. 10-18.

GOODWIN, B. Y MILLER, K. (2013). "Evidence on Flipped Classrooms is Still Coming" en. Educational Leadership. 70(6), 78-80.

(cc) EY-NC-ND 2017, Universitat Politècnica de València

Congreso IN-RED (2017) 
HUGHES, H. (2012). "Introduction to Flipping the College Classroom". Amiel, T. y Wilson, B. (Eds.). Proceedings of EdMedia: World Conference on Educational Media and Technology 2012. Association for the Advancement of Computing in Education (AACE), p. 2434-2438.

LAGE, M.J., PLATT, G.J. y TREGLIA, M. (2000). "Inverting the classroom: A gateway to creating an inclusive learning environment" en The Journal of Economic Education, vol. 31, issue 1, p. 30-43

MORAVEC, M., WILLIAMS, A., AGUILAR-ROCA, N., O'DOWD, D.K. (2010). "Learn before lecture: a strategy that improves learning outcomes in a large introductory biology clas" en CBE Life Sci Educ, vol. 9, p. 473-481.

O'FLAHERTY, J., PHILLIPS, C. (2015). "The use of flipped classrooms in higher education: A scoping review" en Internet and Higher Education 25 85-95

PEARSON PARTNERS ON FLIPPED LEARNING. (2013). Electronic Education Report. 7/8/2013, Vol. 20 Issue 14, p5-5. 1/2p. Biblioteca digital ITESM:EBSCO Business Source Premier.

SZOKA, J. (2013). Measured Results Demonstrate Enhanced Learning Outcomes in the Flipped Classroom [mensaje en un blog]. EmergingEdTech. Recuperado de http:// www.emergingedtech.com/2013/05/measured-results-demonstrate-enhanced-learning-outcomes-inthe-flipped-classroom/.

TALBERT, R. (2012). "Inverted Classroom” en Colleagues, vol. 9, issue 1, article 7. Disponible en: http://scholarworks.gvsu.edu/colleagues/vol9/iss1/7

TALBERT R. (2014). "Inverting the Linear Algebra Classroom" en Primus (Problems, Resources, and Issues. Mathematics Undergraduate Studies), vol. 24, issue 5, p. 361-374.

TOURÓN, J., SANTIAGO, R., DÍEZ, A. (2014). The Flipped Classroom: Cómo convertir la escuela en un espacio de aprendizaje. (Innovación Educativa) Madrid: Digital-Text. Grupo Océano.

TOURÓN, J., SANTIAGO, R. (2015). "El modelo Flipped Learning y el desarrollo del talento en la escuela" en Revista de educación n 368, p. 196-231.

TOURÓN, J. Javier Touron. Talento-Educación-Tecnología. http://www.javiertouron.es/> [Consulta: 8 de marzo de 2017].

TUCKER, B. (2012). “The flipped classroom” en . Education Next, 12 (1), p. 82-83.

WALSH, K. (2013a). Flipped Classroom Panel Discussion Provides Rich Insights into a Powerful Teaching Technique. [mensaje en un blog]. EmergingEdTech. Recuperado de http://www.emergingedtech.com/2013/06/flipped-classroom-panel-discussion-provides-rich-insightsinto-a-powerful-teaching-techniquel.

WALSH, K. (2013b). Gathering Evidence that Flipping the Classroom can Enhance Learning Outcomes. [mensaje en un blog]. EmergingEdTech. Recuperado de http://www.emergingedtech.com/2013/03/gathering-evidence-that-flipping-the-classroom-canenhance-learning-outcomes/.

YOSHIDA, H. (2016). "Perceived Usefulness of Flipped Learning on instructional design for elementary and secondary education: with focus on pre-service teacher education" en International Journal of Information and Education Technology, 6(6), 430-434. 


\title{
Un modelo para representar el estado anímico de los estudiantes en el aula*
}

\author{
Elena del $\mathrm{Val}^{1,2}$, Juan M. Alberola ${ }^{1,2}$ y Bexy Alfonso ${ }^{2}$ \\ ${ }^{1}$ Universitat Politècnica de València \\ ${ }^{2}$ Florida Universitària
}

\begin{abstract}
Students' affective state has influence in their learning process. Specifically, a positive state has positive consequences in aspects such as motivation and achievements. Even though the affective state is represented in the long-term, this can be modified through the emotions that emerge during the classes. In this paper, we present a model to represent the students' affective state in order to identify those factors that are related to positive affective states. Considering this model, we collected students' emotions during different lessons in different subjects. The results show that lessons that are more related to positive affective states are those oriented to working on projects and those that revise the previous content.
\end{abstract}

Keywords: affective state, students, emotions.

\section{Resumen}

El estado anímico de los estudiantes tiene una influencia directa en el proceso de enseñanza-aprendizaje. En concreto, un estado positivo permite mejorar aspectos como la motivación y los logros conseguidos. A pesar de que el estado anímico representa un estado a largo plazo, éste puede ser modificado a través de las emociones que tienen los estudiantes en función de las clases. En este artículo, presentamos un modelo para representar el estado anímico de los estudiantes con la finalidad de identificar qué factores influyen para conseguir estados positivos que faciliten su aprendizaje. Considerando este modelo, hemos recogido resultados midiendo las emociones que tienen los alumnos durante las distintas sesiones de varias asignaturas. Los resultados demuestran que las clases que generan más emociones positivas son aquellas en donde se trabaja por proyectos y en las que se repasan conceptos anteriores.

Keywords: estado anímico, estudiantes, emociones.

\footnotetext{
*Proyecto financiado por la Universitat Politècnica de València
} 


\section{Introducción}

El estado anímico de los estudiantes representa un rol muy importante en la educación debido a su influencia en los procesos cognitivos y comportamientos que tienen sobre las personas (Mehrabian 1996, Ryckman 2007, Chalfoun et al. 2006). En un entorno educativo, esto significa que un estado anímico positivo tiene consecuencias positivas sobre el proceso de enseñanza-aprendizaje (mayor motivación, mejores logros, mejor bienestar general, etc.). Por tanto, si podemos orientar nuestras estrategias educativas para conseguir unos estados anímicos más positivos en los estudiantes, mejorarán las posibilidades de mejorar aspectos como la satisfacción, el porcentaje de comprensión, la rapidez de adquisición de conocimiento o la motivación.

Modificar el estado anímico implica actuar sobre un conjunto de características que representan un estado a largo plazo. Sin embargo, las emociones son estudiadas como respuestas a estímulos (Ortony et al. 1988, Lazarus 1994, Scherer 2001). Por tanto, si podemos adaptar las estrategias educativas para conseguir producir emociones positivas, el estado anímico a largo plazo de los estudiantes tendería a mejorar, con el correspondiente resultado positivo sobre el proceso de enseñanza-aprendizaje.

Las emociones deben ser analizadas desde una perspectiva multidimensional, en la cuál se mida cómo varían las emociones entre los estudiantes, dependiendo de distintos factores. Por ejemplo, deberemos de analizar si la variación de las emociones puede explicarse por variables como las diferencias académicas entre las actividades, por las metodologías, por los tipos de clase, por los tipos de asignaturas, etc. Estos aspectos son fundamentales para diseñar correctamente intervenciones educativas (Pekrun et al. 2007).

En este artículo proponemos un modelo para representar el estado anímico de los estudiantes con la finalidad de observar el impacto que tienen diferentes estrategias educativas en el mismo. Las consideraciones prácticas sobre cómo podemos conseguir emociones positivas en los estudiantes podemos extraerlas a través del análisis de las observaciones de clases. En nuestro enfoque, presentamos un proceso que nos permite capturar las emociones que producen en los estudiantes los distintos eventos que ocurren en las clases. Para validar este modelo, presentamos datos sobre su aplicación práctica en varias asignaturas durante un curso académico.

El artículo se organiza de la siguiente manera. En la Sección 2 describimos el modelo propuesto para representar el estado anímico de los estudiantes. En la Sección 3 definimos el proceso para obtener información relativa a los estados de los estudiantes en las distintas clases. En la Sección 4 presentamos algunos datos sobre la evaluación del modelo en un entorno real. Finalmente, en la Sección 5 remarcamos las conclusiones principales del trabajo y orientaciones futuras. 


\section{Modelo del estado anímico de los estudiantes}

El modelo propio que proponemos para representar el estado anímico de los estudiantes (Figura 1) tiene en consideración un conjunto de circunstancias que influyen en el mismo y por tanto, en los factores de aprendizaje que queremos evaluar. Este conjunto de circunstancias se compone de tres dimensiones: individual, entorno, y social. Para cada dimensión, consideramos dos tipos de características: las que son estáticas y mantienen un valor fijo durante un período largo de tiempo y no suelen cambiar (un curso, un año académico, un semestre, etc.) y las que son dinámicas, que suelen cambiar cona frecuencia más alta (p.e. cada clase). En este sentido, aspectos como el horario de una asignatura se definirían como características estáticas puesto que suelen ser los mismos a lo largo del curso, mientras que aspectos como el tipo de clase se definirían como características dinámicas, puesto que puede haber una clase que utilice una metodología de lección magistral y otra puede trabajarse por equipos.

La dimensión individual representa el conjunto de características que tienen que ver con un estudiante individual y está compuesta de dos características estáticas: intereses y personalidad. Los intereses representan los objetivos personales del estudiante a largo plazo (p.e. aprender lo máximo posible, satisfacción personal, realizar el mínimo esfuerzo para aprobar, hacerlo bien en los exámenes para tener una buena nota, etc.). La relación entre personalidad y aprendizaje está ampliamente documentada en la literatura (Ibrahimoglu et al. 2013). En nuestro caso, consideramos los rasgos de personalidad definidos por el modelo Big Five para caracterizar la personalidad de los estudiantes (Costa y McCrae 1992). La dimensión individual también tiene una única característica dinámica, que la definimos como expectativas. Estas expectativas representan una esperanza con respecto a alguna cosa (p.e. aprobar un examen de cálculo porque se me da muy bien). La gente tiende a comportarse de una manera que su comportamiento encaje con sus expectativas, y por tanto, el conocimiento de las expectativas de un estudiante también es útil para adaptar el diseño de los programas de aprendizaje o de las metodologías (Sander et al. 2000). Por ejemplo, si los profesores conocen lo que esperan sus estudiantes, podrán ser capaces de adaptar su comportamiento a las expectativas de ellos, lo cuál debería tener un impacto positivo en los niveles de satisfacción de los mismos (Voss et al. 2007).

La dimensión del entorno define el conjunto de características que envuelven al contexto de aprendizaje, incluyendo una serie de características estáticas como la duración de la clase o los descansos entre asignaturas. Además, también establecemos un conjunto de características dinámicas que cambian más frecuentemente como la metodología que usa el profesor, el período lectivo en que se encuentra, los eventos planificados (exámenes, vacaciones, entregas, etc.), o las tareas que se realizan durante la clase (si son tareas realistas, estimulantes, adecuadas, etc.).

La dimensión social se caracteriza por un conjunto de características dinámicas que tienen que ver con la relación entre los individuos. El clima de la clase es uno de los factores que consideramos en el contexto social y se clasifican en: (a) consistentemente positivos y de apoyo, (b) consistentemente negativos y no apoyo, y (c) ambiguos. La relación entre alumno y profesor tiene un impacto en las emociones del alumno. Por ejemplo, los estudiantes y los profesores pueden crear un clima positivo que permita alinear sus objetivos (Schunk et al. 2002). La relación entre estudiante y grupo de compañeros es también importante e influye en los sentimientos de los estudiantes $\mathrm{y}$ en las emociones que emergen, tales como aquellas relacionadas con los logros y 


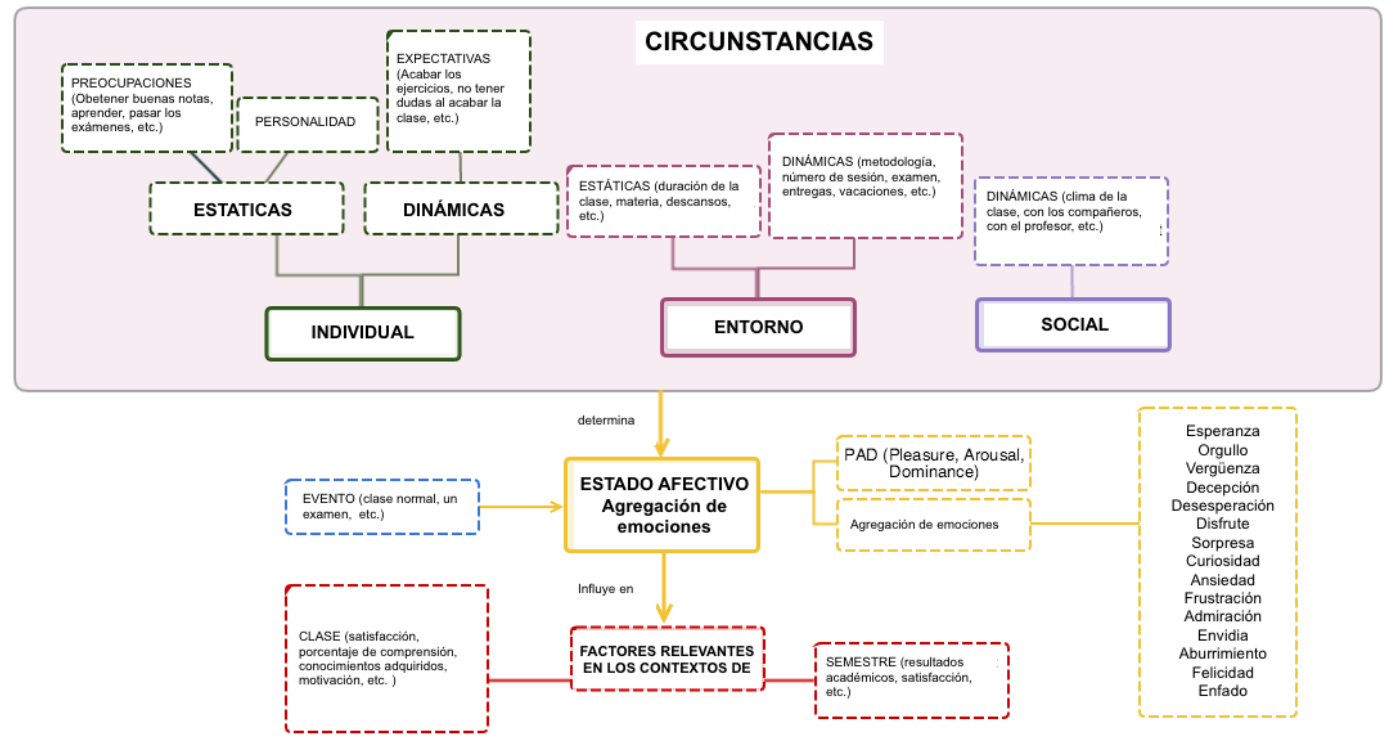

Fig. 1: Modelo que representa el estado anímico del estudiante.

fracasos, así como la aceptación y rechazo de otros (Graham 1991), o el aliniamiento con las aspiraciones académicas de los compañeros (Wang et al. 1997).

Estas tres dimensiones componen las distintas circunstancias que tienen un efecto directo con el estado anímico de un estudiante. La parte emocional de un estudiante tendrá un efecto directo en este estado anímico. Según (Meyer y Turner 2006), el estado anímico parece ser el mejor término para describir las emociones con el paso del tiempo. Nuestro modelo incluye dos maneras de establecer las emociones de los estudiantes: a través del modelo PAD (Placer, Excitación y Dominio), y como una agregación de emociones que relacionan estudiantes y entornos de aprendizaje. El estado anímico de un estudiante influye en los factores del contexto de aprendizaje. Estos factores se clasifican en el modelo como factores a corto plazo (satisfacción, porcentaje de comprensión, rapidez de adquisición de conocimientos y motivación) y factores a largo plazo (resultados académicos y satisfacción).

\section{Proceso}

A continuación describimos las partes del proceso que nos permite representar los distintos modelos que representan los estados anímicos de los estudiantes (Figura 2). Este proceso nos permite capturar los cambios de estados a través del tiempo y en función de las emociones que se provocan en las clases.

En la imagen podemos ver una serie de pasos requeridos para obtener información sobre los estudiantes. Esta información la recogemos en tiempo real durante las distintas clases. En un primer momento (identificado como Paso 1), los estudiantes rellenan una encuesta sobre las características estáticas que definen su dimensión individual (es decir, sobre sus intereses y su personalidad) y el profesor rellena la información 


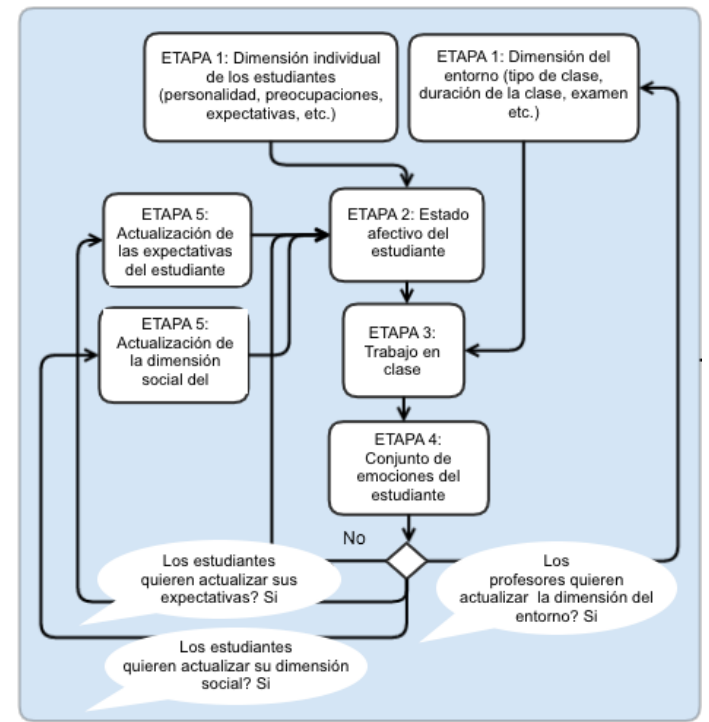

Fig. 2: Proceso para representar el estado anímico.

correspondiente a las características estáticas de la dimensión del entorno (es decir, la asignatura, duración de la clase, etc.). Como hemos comentado anteriormente, esta información permanece constante durante un período largo de tiempo y por tanto, se realiza una única vez al principio del proceso. Con respecto a las características dinámicas, bien al inicio de cada clase o bien al final de la misma, el profesor rellena (Paso 2) la información referente a las características dinámicas de la dimensión del entorno (metodología usada, fecha del calendario, proximidad a exámenes o períodos de vacaciones, etc.). Por su parte, los estudiantes rellenan al principio de cada clase (Paso 3) una encuesta respecto a las características dinámicas que definen su dimensión individual, es decir, sus expectativas para esa propia clase (terminar las tareas, no aburrirse, etc.) así como su estado afectivo mediante el modelo PAD. El Paso 3 está asociado al tiempo en el cuál se desarrolla la clase. Una vez la clase termina, en el Paso 4 los estudiantes rellenan otra encuesta con la información referente a su estado afectivo mediante un conjunto de emociones que sienten en ese momento. Después, antes de que tenga lugar la siguiente clase, los estudiantes pueden modificar la información que define su dimensión social (Paso 5). Finalmente, el profesor también puede modificar aspectos de la dimensión del entorno para observar cómo afectan los cambios del entorno en el estado afectivo de los estudiantes. La información recogida durante un período de tiempo, puede usarse para realizar simulaciones. 


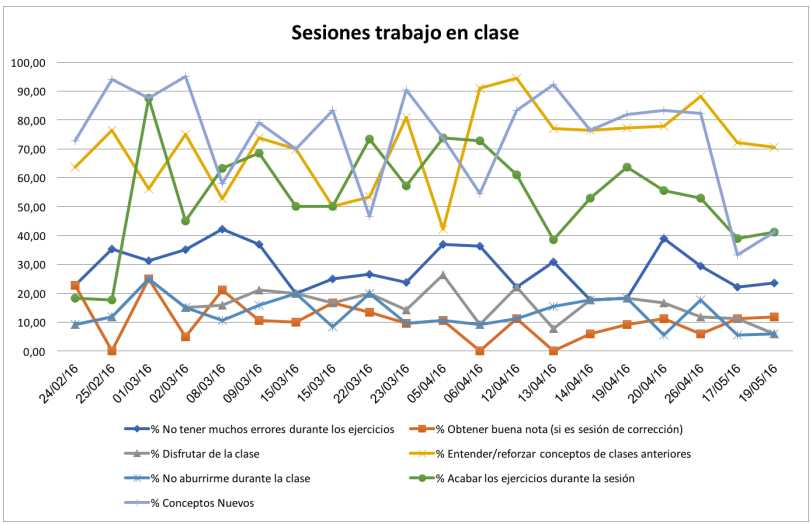

Fig. 3: Análisis temporal sobre las preocupaciones de los alumnos antes de empezar una clase de sesión de trabajo.

\section{Evaluación}

En esta sección presentamos la validación del modelo aplicado a tres asignaturas durante el curso 2015-2016. Los alumnos (20 alumnos de media en cada clase), durante un periodo aproximado de dos meses (65 clases) realizaron un test al inicio y al final de cada sesión. El test del inicio recogía información sobre sus expectativas y sobre sus preocupaciones antes de comenzar la clase. Hay que remarcar que las preocupaciones dependerán del estado en que esté el alumno en ese momento (p.e., si un alumno va mal en una asignatura, puede estar preocupado por reforzar los conceptos anteriores, mientras que si un alumno va bien, puede estar preocupado por disfrutar de la clase). El test del final recogía información sobre las emociones que tenían al acabar la clase.

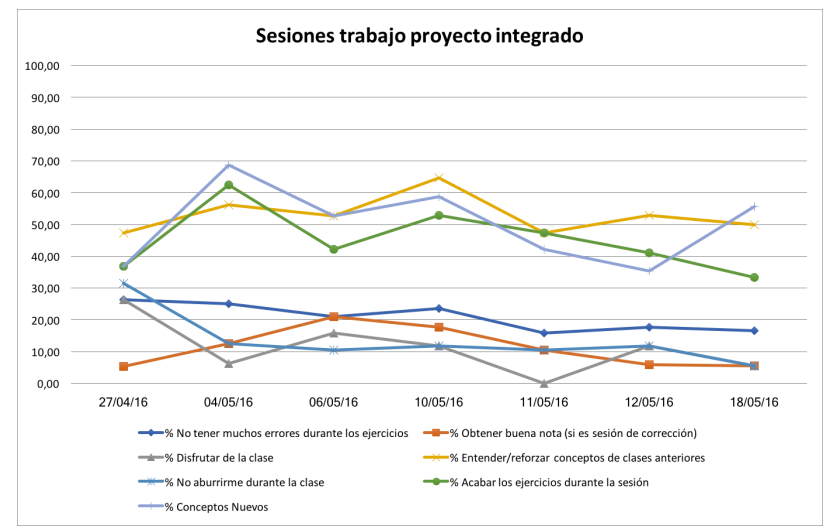

Fig. 4: Análisis temporal sobre las preocupaciones de los alumnos antes de empezar una clase de proyecto.

A partir de esta información, hemos analizado la evolución de las preocupaciones de los alumnos en distintos tipos de clase (e.g., trabajo en clase, trabajo por proyectos, repaso, y exámenes). También hemos analizado qué es lo que más les preocupaba a los alumnos a lo largo de los dos meses. Por otro lado, hemos analizado cómo han 


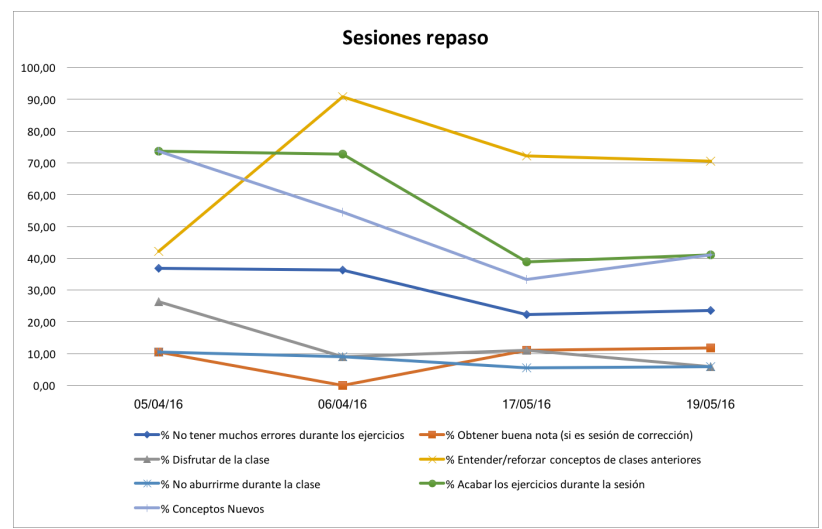

Fig. 5: Análisis temporal sobre las preocupaciones de los alumnos antes de empezar una clase de repaso.

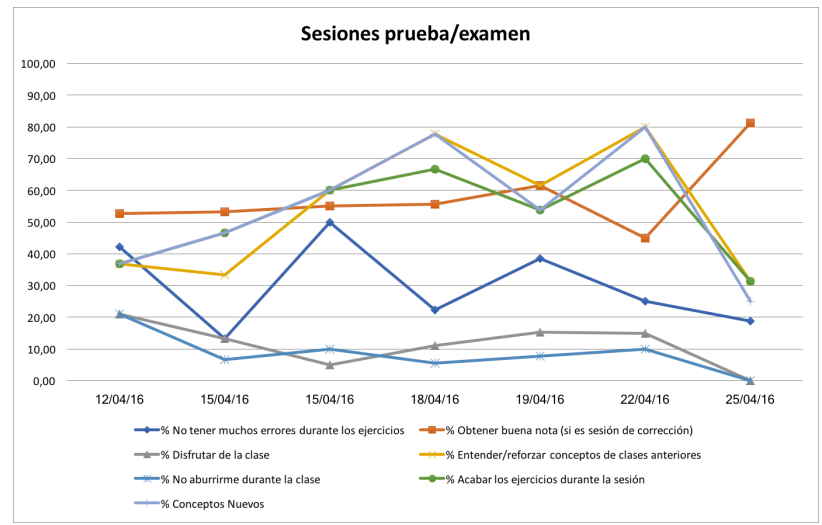

Fig. 6: Análisis temporal sobre las preocupaciones de los alumnos antes de empezar una clase de prueba/examen.

evolucionado las emociones positivas y negativas en los tipos de clase mencionados anteriormente y qué emociones, en promedio, han tenido los alumnos.

Las Figuras 3, 4, 5 y 6 muestran la evolución de las preocupaciones de los alumnos antes de empezar las clases. En las gráficas se puede observar que lo que más preocupaba a los alumnos en las sesiones de trabajo en clase de forma conjunta era entender y reforzar conceptos de clases anteriores, no aburrirse durante la clase y acabar los ejercicios. En sesiones de trabajo por proyectos las preocupaciones son similares a las clases donde se trabajaba de forma conjunta con el profesor pero el grado de preocupación es mucho menor. En el caso de sesiones de repaso se ve un claro cambio en las preocupaciones de los alumnos. En estas clases lo que más les preocupó a los alumnos era entender/reforzar los conceptos de las clases anteriores. Por último, en las clases donde hubo algún tipo de prueba o examen obtener buena nota era su principal preocupación junto con acabar los ejercicios. 


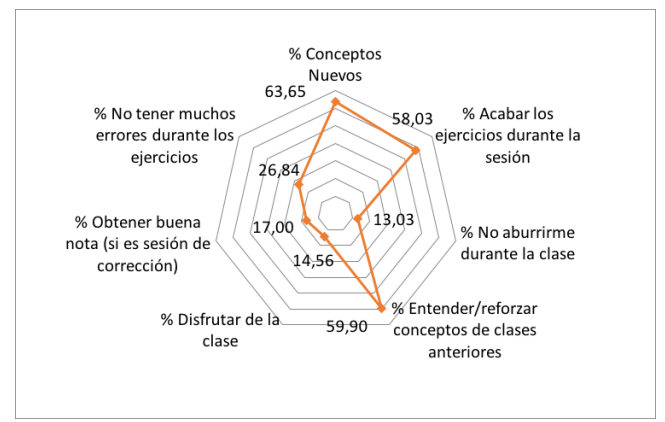

Fig. 7: Preocupación media de los alumnos antes de empezar la clase.

En general, las principales preocupaciones de los alumnos son aprender conceptos nuevos, entender y/o reforzar conceptos de clases anteriores, y acabar los ejercicios durante la sesión (ver Figura 7).

En las Figuras 8, 9, 10 y 11 se muestra la evolución de las emociones positivas y negativas en los distintos tipos de clase. En las clases de trabajo en grupo con el profesor se observa que en general las emociones son positivas, superiores al $50 \%$. Algo similar sucede en las sesiones de trabajo por proyectos donde las emociones positivas están alrededor del $70 \%$. En las sesiones donde hubo un examen o una prueba las emociones son en general positivas excepto en la última clase. Las clases de repaso son las que mejores emociones positivas generan estando muy cerca del $90 \%$.

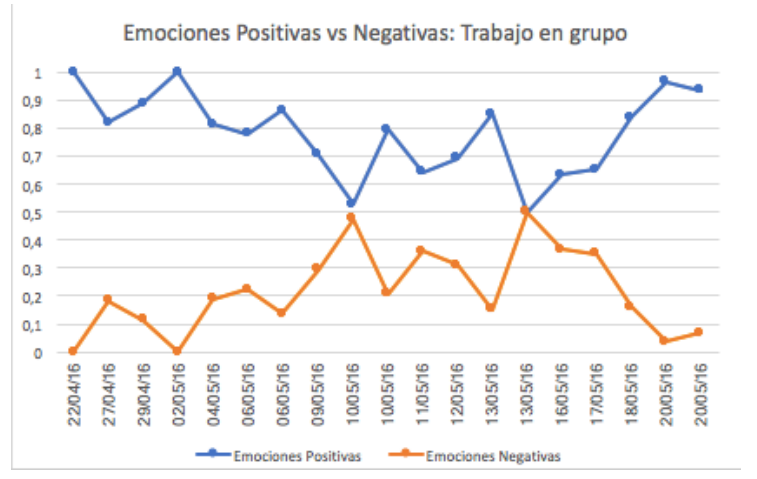

Fig. 8: Análisis temporal sobre las preocupaciones de los alumnos al acabar clases de trabajo.

Dentro de las emociones positivas y negativas, la Figura 12 muestra cómo se distribuyen en promedio en las emociones consideradas. En el caso de las emociones positivas, la emociones más predominantes son la esperanza (24\%) y la curiosidad $(26 \%)$. En el caso de las emociones negativas, la más predominante es la frustración (33\%). El aburrimiento es la siguiente emoción negativa más presente $(16 \%)$. 


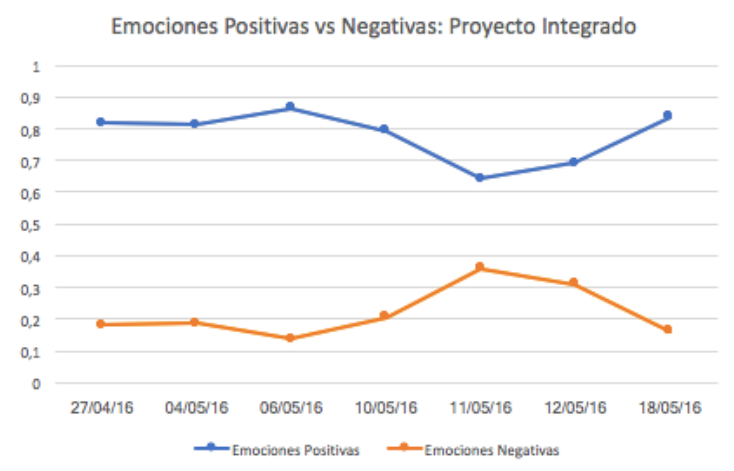

Fig. 9: Análisis temporal sobre las preocupaciones de los alumnos al acabar clases de proyectos.

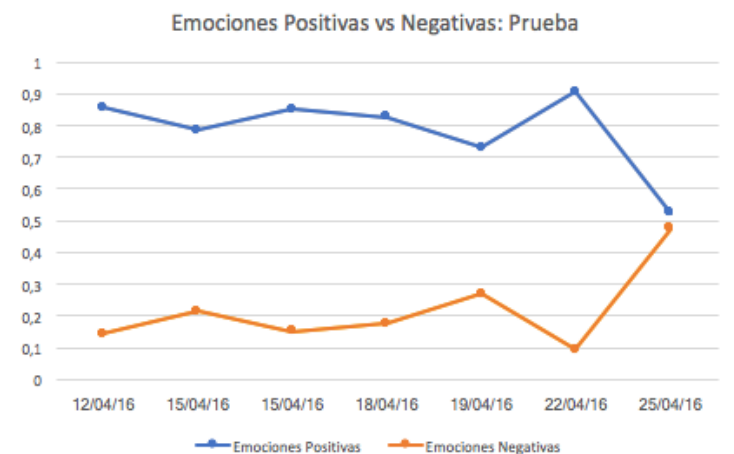

Fig. 10: Análisis temporal sobre las preocupaciones de los alumnos al acabar clases de prueba/examen.

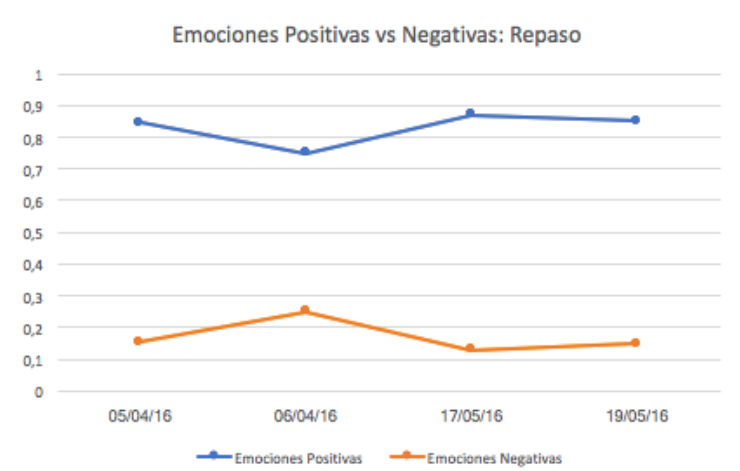

Fig. 11: Análisis temporal sobre las preocupaciones de los alumnos al acabar clases de repaso. 


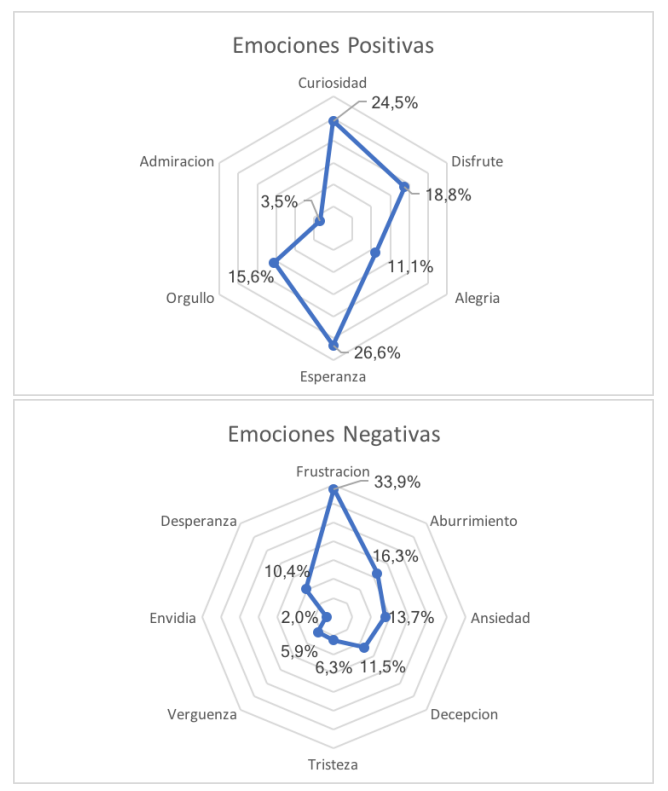

Fig. 12: Preocupación media de los alumnos al acabar la clase.

\section{Conclusiones}

Las emociones desempeñan un papel importante en los entornos de aprendizaje. En este artículo proponemos un modelo que considera un conjunto de factores y eventos desde una perspectiva temporal multi-nivel para anlizar su influencia en las emociones del estudiante. Esta perspectiva multi-nivel temporal considera tres dimensiones que incluyen características estáticas y dinámicas: individuales (preocupaciones, personalidad y expectativas), ambiental o del entorno (características relacionadas con la planificación y organización de la clase) y sociales (el clima de clase, la relación alumnos-compañeros, y la relación profesor-alumno). Este conjunto de características y los acontecimientos que pueden ocurrir durante una clase, influyen en las emociones del estudiante, y por lo tanto, en los factores de aprendizaje esperados tales como satisfacción, adquisición del conocimiento, motivación o comprensión. Basándonos en este modelo, hemos realizado un conjunto de encuestas para analizar la influencia de algunos de los aspectos considerados en el modelo. Los resultados nos muestran que la preocupación principal, independientemente del tipo de clase, es entender los conceptos explicados en clases anteriores y los nuevos y acabar los ejercicios.

La experiencia podría ser replicable a otros escenarios distintos (titulaciones, asignaturas, etc.) puesto que el proceso utilizado es independiente y el modelo permite capturar esta información específica. Por otro lado, el trabajo por proyecto y las clases de repaso son las clases que generan emociones más positivas. Como trabajo futuro, nos planteamos incluir más información del modelo para poder completar el análisis y en base a éste poder realizar simulaciones que nos ayuden a la toma de decisiones en el diseño de las clases. 


\section{Referencias bibliográficas}

P. Chalfoun, S. Chaffar, and C. Frasson, Predicting the emotional reaction of the learner with a machine learning technique,in ITS06, 2006.

P. T. Costa and R. R. McCrae, Four ways five factors are basic, Personality and individual differences, vol. 13, no. 6, pp. 653-665, 1992.

S. Graham, A review of attribution theory in achievement contexts, Educational Psychology Review, vol. 3, no. 1, pp. 5-39, 1991.

N. Ibrahimoglu, I. Unaldi, M. Samancioglu, and M. Baglibel, The relationship between personality traits and learning styles: A cluster analysis, Asian Journal of Management Sciences and Education, vol. 2, no. 3, 2013.

R. Lazarus, Emotion and Adaptation. Oxford University Press, 1994.

A. Mehrabian, Pleasure-arousal-dominance: A general framework for describ- ing and measuring individual differences in Temperament, Current Psychology, vol. 14, no. 4, pp. 261-292, 1996.

D. K. Meyer and J. C. Turner, Re-conceptualizing emotion and motivation to learn in classroom contexts, Educational Psychology Review, vol. 18, no. 4, pp. 377-390, 2006.

A. Ortony, G. L. Clore, and A. Collins, The Cognitive Structure of Emotions. Cambridge University Press, July 1988.

R. Pekrun, A. C. Frenzel, T. Gotz, and R. P. Perry, The Control-Value Theory of Achievement Emotions: an Integrative Approach to Emotions in Education, in Emotion in education, pp. 13-36, Academic Press, 2007.

R. M. Ryckman, Theories of Personality. PSY 235 Theories of Personality Series, Thomson/Wadsworth, 2007.

P. Sander, K. Stevenson, M. King, and D. Coates, University students expectations of teaching, Studies in Higher education, vol. 25, no. 3, pp. 309-323, 2000.

K.R.Scherer, Appraisal considered as aprocess of multilevel sequential checking, Appraisal processes in emotion: Theory, methods, research, vol. 92, p. 120, 2001.

D. Schunk, P. Pintrich, and J. Meece, Motivation in Education: Theory, Research, and Applications. Pearson/Merrill Prentice Hall, 2008.

R. Voss, T. Gruber, and I. Szmigin, Service quality in higher education: The role of student expectations, Journal of Business Research, vol. 60, no. 9, pp. 949-959, 2007.

M. C. Wang, G. D. Haertel, and H. J. Walberg, What Helps Students Learn? Spotlight on Student Success., 1997. 


\title{
Evaluación de Diferentes Metodologías de Aprendizaje Activo desde el Punto de Vista del Estudiante en la Asignatura Genómica del Grado de Biotecnología
}

\section{Santiago Vilanova y José Gadea}

Departamento de Biotecnología, Universitat Politècnica de Valéncia, Camino de Vera s/n 46022, Valéncia. igadeav@,ibmcp.upv.es sanvina@upvnet.upv.es

\begin{abstract}
Biotechnology is a discipline where autonomous learning can be easily implemented. The speed at which strategies and technologies are developed makes mandatory a learning method more focused in "how to learn" than in "what to learn". The objective of this study is to evaluate the student's level of satisfaction regarding the learning strategies applied in the subject "Genomics" of the UPV Biotechnology Degree. Among these methodologies, we have used project-based learning, case studies and flip-teaching. Results seem to indicate a high percentaje of satisfaction when these methodologies are applied.
\end{abstract}

Keywords: autonomous learning, flip-teaching, active learning, project, biotechnology

\footnotetext{
Resumen

La Biotecnología es una disciplina donde puede implementarse el aprendizaje autónomo. La velocidad a la que las tecnologías y estrategias están cambiando hace necesario un aprendizaje más enfocado a "cómo aprender", más a "qué aprender”. El objetivo de esta comunicación es evaluar el grado de satisfacción de los estudiantes en referencia a los métodos docentes aplicados en la asignatura Genómica del Grado de Biotecnología de la UPV. Entre estas metodologías, hemos aplicado aprendizaje basado en proyectos, estudio de casos y clase inversa. Los resultados parecen indicar que un alto porcentaje de alumnos está satisfecho con un aprendizaje basado en estas metodologías.
}

Palabras clave: aprendizaje autónomo, clase inversa, aprendizaje activo, proyectos, biotecnología 


\section{Introducción}

El aprendizaje autónomo implica la intervención del estudiante en el establecimiento de sus objetivos, procedimientos, recursos, evaluación y momentos de aprendizaje (Crispin et al, 2011). Estas estrategias confían en un aprendizaje activo, eliminando el sistema pasivo basado en clases magistrales, pone énfasis en un aprendizaje más profundo y un mejor entendimiento del tema tratado, aumenta la responsabilidad por parte del estudiante e incrementa su sentido de autonomía, y al mismo tiempo, proporciona un ambiente donde la relación profesor-alumno puede ser replanteada.

Entre las estrategias que se plantean para ejercitar el aprendizaje autónomo, el diseño de proyectos en equipos de estudiantes es la que hemos seleccionado para esta experiencia docente. El aprendizaje basado en proyectos es una metodología que permite a los alumnos adquirir los conocimientos y competencias clave en el siglo XXI mediante la elaboración de proyectos que dan respuesta a problemas de la vida real. El trabajo en equipos, por otra parte, refuerza otras competencias transversales, ya que actualmente las organizaciones requieren de personas que sepan administrarse dentro de los equipos de trabajo (Northwest Regional Educational Laboratory, 2006).

La Biotecnología es una disciplina donde puede y debe implementarse el aprendizaje autónomo. La inmensidad de avances que se están produciendo en esta ciencia, y en concreto en Genómica, la asignatura donde hemos implementado esta iniciativa, hace imposible cubrir todos los conocimientos que un estudiante podría requerir para la práctica profesional. Por otra parte, la velocidad a la que las tecnologías y estrategias están cambiando, quedándose obsoletas en varios años, hace necesario un aprendizaje más enfocado a "cómo aprender", más a "qué aprender". Este aprendizaje debe incluir la búsqueda de todas las posibilidades existentes para solucionar un determinado problema y la toma de decisiones para seleccionar una determinada estrategia de trabajo, sin tener la certeza de que sea la única manera de abordar dicho problema. También implica enfrentarse a situaciones en las que "no se sabe todo" y "no se controla todo", un escenario al que los estudiantes no están acostumbrados. Finalmente, un proyecto biotecnológico real será multidisciplinar, por lo que un aprendizaje cooperativo donde se elimine la excesiva competitividad existente entre los alumnos de Biotecnología podría ser beneficioso para ellos a largo plazo.

\section{Objetivos}

Desde el curso académico 2012-2013, llevamos proponiendo diseños de proyectos en Genómica como ejercicio de aprendizaje autónomo a los estudiantes de Biotecnología de tercer curso de la Universidad Politécnica de Valencia. Los proyectos consisten en emular los diferentes pasos que un profesional en biotecnología deberá realizar al enfrentarse a un proyecto de estas características, búsqueda bibliográfica, selección de tecnologías, toma de decisiones, diseño experimental, localización de reactivos y equipamiento, presupuesto económico y cronograma de realización, basándose en cada punto en estudios similares que ya estén publicados en contextos diferentes. Con esto, los alumnos se enfrentan a la realidad de un proyecto de investigación (o un proyecto empresarial), que requiere no sólo 
un conocimiento teórico de un ámbito concreto de la Biotecnología, sino tener en cuenta muchos otros factores que condicionan el éxito real del proyecto.

Por otra parte, este curso 2016-2017 hemos iniciado una estrategia docente de clase inversa, con tareas planteadas a los estudiantes, cuyo objetivo es intentar que se consolide y/o se sepa aplicar la información teórica que los estudiantes reciben con clases magistrales distribuidas selectivamente a lo largo de la asignatura. Ésta consta de 5 bloques temáticos, cada uno de las cuáles introduce, desarrolla y ejemplifica la aplicación de un subcampo de la Genómica. Para ello los estudiantes realizan tareas en Google Drive, que alternan entre lectura de artículos científicos seleccionados, visionado de videos o búsqueda de información en la web.

La presente comunicación pretende resumir esta experiencia docente, detallando las conclusiones a las que tanto profesores como estudiantes hemos llegado.

\section{Desarrollo de la innovación}

\subsection{Encuestas de evaluación}

Mediante el uso de encuestas enfocadas a evaluar la experiencia de los estudiantes en esta iniciativa, se contactará a los estudiantes de Biotecnología del curso 2016-2017, y se elaborarán resultados que permitan la interpretación detallada. Las encuestas pretenden desvelar su grado de satisfacción con este tipo de docencia, la repercusión de este tipo de aprendizaje en el conocimiento de la asignatura, la originalidad y valor añadido de los mismos, relación profesor-alumno, etc. Las encuestas Se realizaron online utilizando la herramienta de formularios de Goole Drive (https://www.google.com/intl/es_ALL/drive/).

La encuesta consta de 21 ítems con la siguiente escala de evaluación de Likert (Briones, 1995) : Muy en desacuerdo(1), En desacuerdo(2), Indiferente(3), De acuerdo(4) o Muy de acuerdo(5). Los ítems se subdividen en cuatro secciones: a) estructura general de la asignatura, b) la experiencia en la realización de casos prácticos, c) la experiencia en la realización de tarea de clase inversa, y d) la experiencia en la realización de trabajos/proyectos de investigación

El cuestionario fue el siguiente:

\section{(EA) Estructura general de la asignatura}

EA1. Me ha resultado más EFECTIVA que la clase tradicional (profesor explicando y alumnos atendiendo) para entender los contenidos y su aplicación.

EA2. Me ha resultado más ENTRETENIDA que la clase tradicional (profesor explicando y alumnos atendiendo) para entender los contenidos y su aplicación.

EA3. Me ha ayudado a COMPRENDER contenidos en lugar de MEMORIZARLOS

EA4. Me ha ayudado a SABER APLICAR contenidos en lugar de MEMORIZARLOS

EA5. Hace que el profesor esté más implicado en la docencia, y por tanto interacciono más con él.

EA6. En un plan de estudios ideal sin tanta sobrecarga, recomendaría este tipo de docencia a otras asignaturas. 
EA7. Respecto a las otras asignaturas con las que se ha compartido en el año ¿Has dedicado más o menos tiempo de estudio a GENOMICA?

\section{(CP) Casos Prácticos}

CP1. Me han ayudado a CONSOLIDAR los contenidos teóricos

CP2. Me han ayudado a ver cómo se APLICA la teoría en la realidad

CP3. Me han quitado el miedo a enfrentarme a artículos científicos

CP4. Me han confundido más que ayudado

\section{(T) Tareas}

T1. Me han servido de BASE para la materia que se iba a explicar en clase, si son anteriores, o de CONSOLIDACIÓN, si son posteriores

T2. Me han quitado mucho tiempo de estudio

T3. Siendo sincero/a...¿Qué porcentaje de las tareas has contestado como si fuera a ser puntuada como una pregunta de examen?

\section{(P) Proyectos}

P1. Me han ayudado de discriminar entre información más relevante y menos relevante para mis objetivos

P2. Me han ayudado a darme cuenta de que puedo seguir adelante sin entender todos los detalles de un proyecto

P3. Me han ayudado a unir información proveniente de diferentes fuentes para resolver problemas específicos

P4. Me han ayudado a mejorar mis habilidades en estructurar la información escrita y oral

P5. Me han ayudado a mejorar mis habilidades en trabajar con otros en grupo

P6. Me han ayudado a mejorar mis habilidades en organizar y planificar mi tiempo

P7. Me ha motivado especialmente ver que soy capaz de crear un proyecto que nadie ha planteado hasta entonces.

\subsection{Análisis de datos}

Los datos obtenidos a partir de las encuestas se analizaron mediante la aplicación hojas de calculo de Google Drive.

Por otra parte, el análisis Heatmap se realizó mediante el programa online Clusvis (Metsalu et al. 2015; http://biit.cs.ut.ee/clustvis/). Los clusters dentro filas y columnas se calcularon usando las distancias euclideas y el método de ligamiento completo respectivamente.

\section{Resultados}

Disponemos actualmente de más de 70 encuestas realizadas con el objetivo de evaluar si la experiencia había sido positiva, y con objeto de mejorarla, donde las sugerencias de los estudiantes sean tenidas en cuenta. Esto representa el $70 \%$ de los estudiantes matriculados este año, por lo que consideramos la encuesta significativa. Un $24 \%$ de los encuestados 
están matriculados en el grupo de Alto Rendimiento Académico del Grado en Biotecnología, y un $76 \%$ en el grupo que se imparte en castellano.

A continuación pasamos a detallar los resultados más relevantes obtenidos en este proyecto:

\subsection{Estructura de la asignatura.}

Los estudiantes fueron preguntados si la estructura de la asignatura, de modo general (incluyendo tareas de clase inversa, clases magistrales alternas, y realización de trabajos de investigación, así como su división temática en casos, les ayudaba a comprender y/o a saber aplicar los contenidos en lugar de a memorizarlos, así como si este tipo de docencia les parecía más efectiva respecto a la docencia clásica de clase magistral, y si les parecía más entretenida. Finalmente, se les preguntaron aspectos generales como si recomendarían este tipo de docencia en un plan de estudios ideal sin tanta carga académica, y si habían dedicado más o menos tiempo de estudio a esta asignatura como consecuencia del tipo de docencia.

A rasgos generales, un $35 \%$ de los estudiantes consideró esta estructura más efectiva que la clase tradicional (EA1 Fig 1.), y hasta un 68 \% la consideró más entretenida (EA2 Fig 1.), lo que indica que la tendencia general es positiva. No obstante, llama la atención el porcentaje de estudiantes que aún se decantan por un aprendizaje más clásico, ya que el 20 $\%$ consideran esta estructura más inefectiva, y un $40 \%$ no ven ninguna ventaja respecto al aprendizaje tradicional (EA1 Fig 1.). En un futuro, pretendemos estudiar en detalle este grupo de alumnos, para intentar evaluar cuántos de ellos son indiferentes ante todo en cualquier caso, y cuántos de ellos prefieren el sistema clásico. Ante esto, hay que recalcar que muchos de ellos pueden preferir un sistema de memorización pasiva, al que ya están habituados desde pequeños, y que les genera unos mejores rendimientos en cuanto a notas, frente a un nuevo sistema que les obliga a implicarse activamente en el aprendizaje. Pensamos que estos últimos necesitan que les expliquemos las ventajas del aprendizaje autónomo para conseguir su implicación.

Por otra parte, la tendencia también es muy positiva en cuanto a si el método docente les ha ayudado a comprender y saber aplicar mejor los conceptos de la asignatura (EA3 Fig 1. y EA4 Fig 1.). Un $52 \%$ considera positiva la experiencia, frente a un $30 \%$ que no ve diferencia entre este método y el aprendizaje clásico. Sólo un $13 \%$ considera la experiencia negativa. Igual que antes, es el grupo intermedio el que conviene estudiar con más detalles para saber cuántos de estos estudiantes prefieren de base un sistema clásico por lo habituados que están a ese tipo de aprendizaje. Igualmente, el hecho de que el sistema de clase inversa haya sido implantado en esta asignatura recientemente puede hacer que los resultados en este grupo intermedio sean mejorables. 


\section{Estructura de la asignatura}

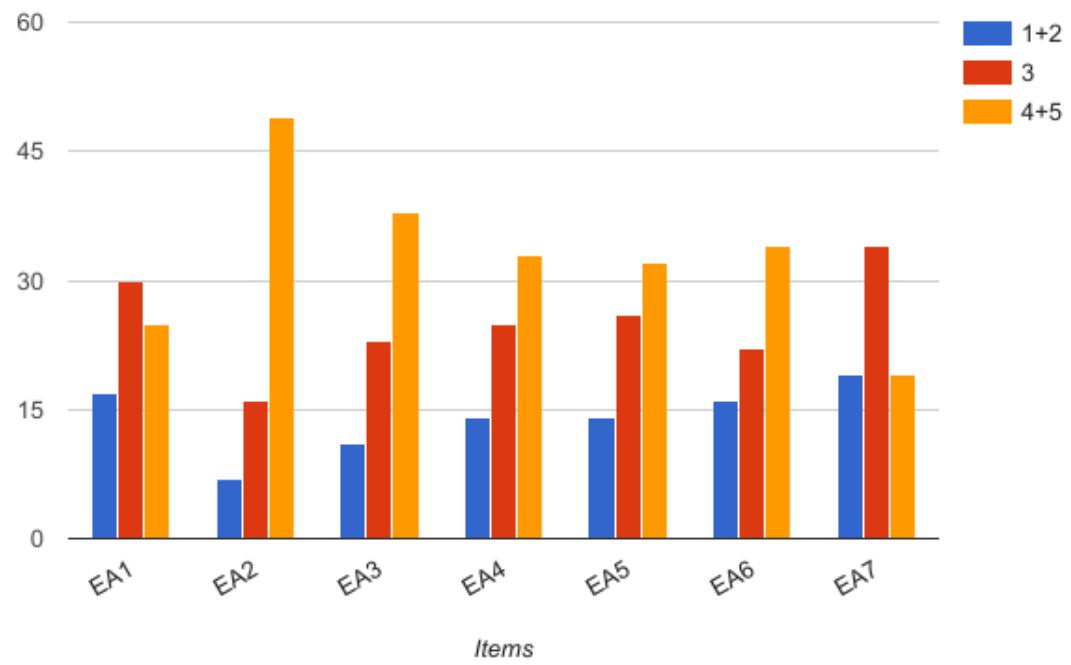

Fig. 1. Diagrama de barras que indica las puntuaciones de los items para la sección Estructura general de la asignatura. Se han sumado las puntuaciones 1 y 2 que muestran disconformidad (Muy en desacuerdo y En desacuerdo) así como las puntuaciones 4 y 5 que muestran conformidad (De acuerdo y Muy de acuerdo). Los items EA1 a EA7 están detallados en el apartado 3.1. En el eje de ordenadas se representa el número de alumnos que han respondido.

Finalmente, es de destacar que un $46 \%$ de los encuestados recomendaría este tipo de docencia frente a un $21 \%$ que no lo haría (EA6 Fig 1.). Igualmente, es interesante resaltar positivamente que nuestro sistema $\mathrm{NO}$ ha requerido más tiempo de dedicación a esta asignatura respecto a otras que comparte en el año docente (EA7 Fig 1.), indicando que este tipo de sistema es perfectamente integrable y realizable sin desequilibrar la carga docente y sin "monopolizar" a los alumnos para nuestra asignatura. Según nuestra encuesta, la relación profesor-alumno, curiosamente, no parece verse favorecida con este sistema (EA5 Fig 1.).

\subsection{La estructura en casos prácticos}

Los estudiantes fueron preguntados, de nuevo, si una estructura en casos prácticos ayuda a comprender y saber aplicar los contenidos, y los resultados son similares a los obtenido para las preguntas similares en el apartado anterior: como dato muy positivo, un $77 \%$ de los estudiantes piensa que este división las ayuda mucho a saber aplicar los contenidos (CP2 Fig. 2), ya que así pueden individualizar los conceptos y aplicarlos en casos tipo. Preguntados si con la lectura de artículos científicos (muchos casos plantean este tipo de ejercicios) habían conseguido perderle el miedo a lecturas de artículos, conseguimos nuestro objetivo con creces en un $40 \%$, mientras que un $36 \%$ todavía no han sido capaces de alcanzar este objetivo (CP3 Fig 2.). La lectura en un idioma extranjero (el $100 \%$ de los artículos propuestos están en inglés) puede ser una causa de este último porcentaje, lo que queda fuera de nuestros objetivos. 


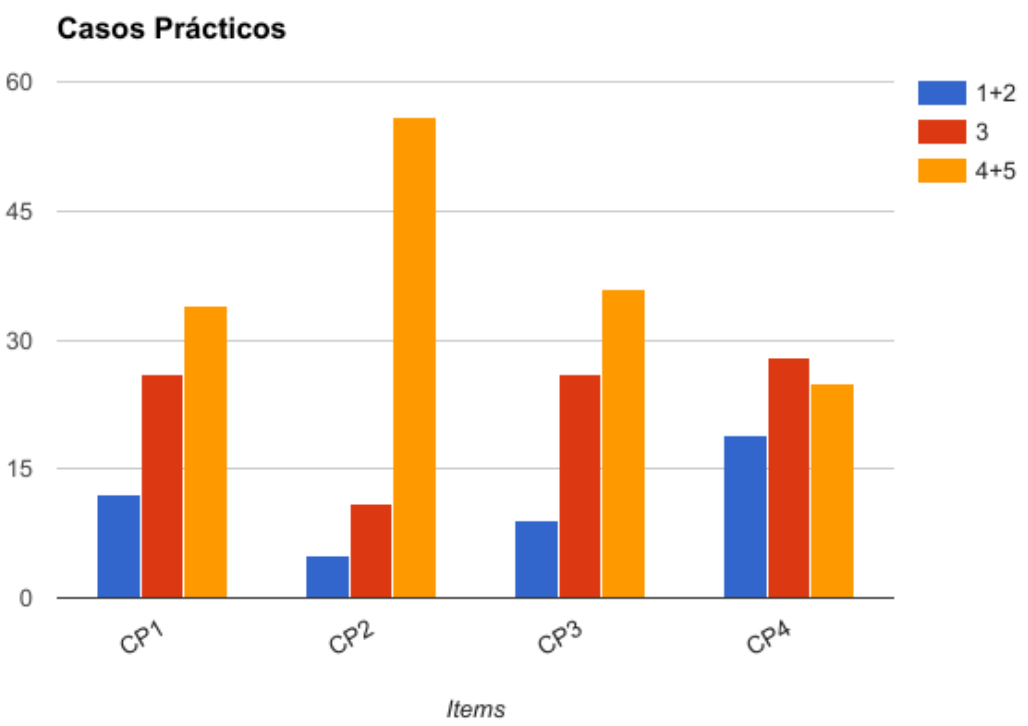

Fig. 2. Diagrama de barras que indica las puntuaciones de los items para la sección estructura general de la asignatura. Se han sumado las puntuaciones 1 y 2 que muestran disconformidad (Muy en desacuerdo y En desacuerdo) asi como las puntuaciones 4 y 5 que \%muestran conformidad (De acuerdo y Muy de acuerdo). Los items CP1 a CP4 están detallados en el apartado 3.1.En el eje de ordenadas se representa el número de alumnos que han respondido.

\subsection{Las tareas en casa (La clase inversa).}

El punto más conflictivo de la encuesta lo encontramos en la implantación del sistema de clase inversa. Preguntados si este tipo de clases con tareas en casa, anteriores o posteriores a los conceptos temáticos, que sirvan de base, o ayuden a consolidar los contenidos, había sido útil, las respuestas siguen una distribución normal centrada en el punto central (ni sí ni no), con un $30 \%$, un $27 \%$ en contra y el resto más indiferentes (T1 Fig 3.). Este es el primer año de la implantación en nuestra asignatura de la clase inversa, y quizá este resultado refleja las enormes posibilidades de mejora que tenemos todavía. Sin embargo, no perderemos de vista la posibilidad de que la clase inversa no sea considerada por los estudiantes como una mejor opción en lo que respecta a la realización de tareas en casa. $\mathrm{Al}$ mismo tiempo, un $48 \%$ de los estudiantes indican que la realización de estas tareas le ha quitado mucho tiempo de estudio (T2 Fig 3.), lo que quizá se refleja en la calidad de las respuestas, ya que hasta un $35 \%$ confiesa que no han respondido a las tareas como si fueran preguntas de examen, probablemente por la falta de tiempo en su realización (T3 Fig 3.). En años posteriores, consideramos que las tareas deberían ajustarse en tiempo y cantidad para evitar la saturación y conseguir una mayor implicación del alumno en las mismas. 


\section{Tareas}

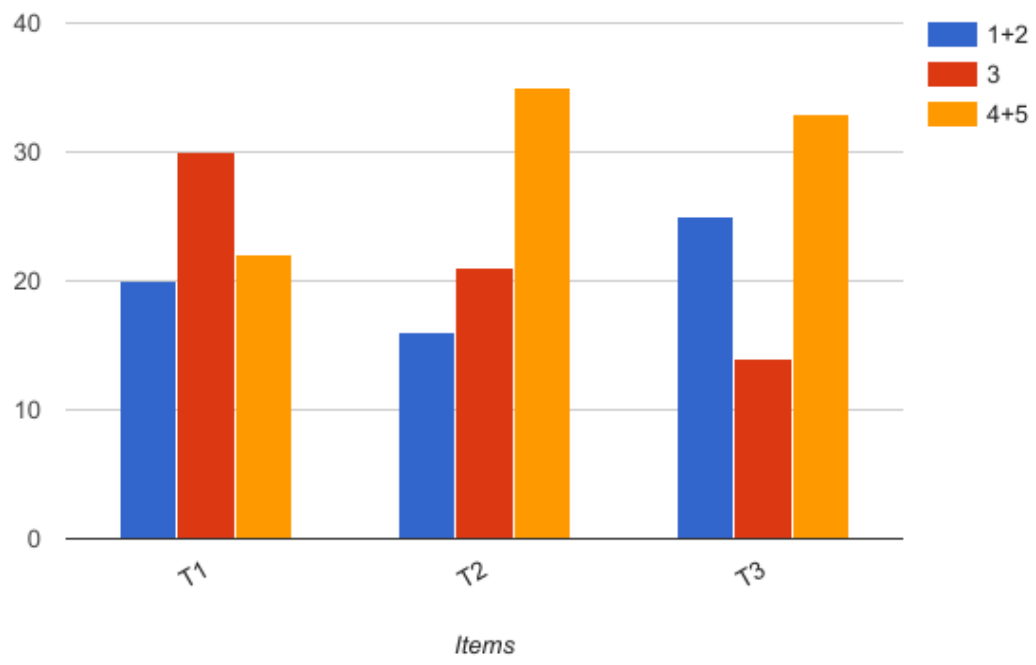

Fig. 3. Diagrama de barras que indica las puntuaciones de los items para la sección Tareas en casa. Se han sumado las puntuaciones 1 y 2 que muestran disconformidad (Muy en desacuerdo y En desacuerdo) así como las puntuaciones 4 y 5 que muestran conformidad (De acuerdo y Muy de acuerdo). Los items T1 a T3 están detallados en el apartado 3.1. En el eje de ordenadas se representa el número de alumnos que han respondido.

\subsection{Los trabajos/proyectos de investigación}

Este punto es con diferencia el aspecto más positivo de la asignatura. Implantados desde el año 2012-2013, estos trabajos han supuesto desde hace años un modo de involucrar a los estudiantes en proyectos casi reales, y el feedback recibido durante estos años ha sido muy positivo. Desgraciadamente, no tenemos encuestas de años anteriores, pero pretendemos enviar esta parte de la encuesta a los estudiantes de años anteriores para conocer la posible repercusión de haber realizado estos trabajos cuando los egresados ya están integrados en el mundo laboral.

Este tipo de trabajos serviría para evaluar la Competencia Transversal "Diseño de Proyectos". Los estudiantes fueron preguntados por aspectos como los siguientes: si les ha ayudado a discriminar información relevante e irrelevante para un determinado objetivo (P1 Fig 4.), si les ha ayudado a entender que pueden seguir adelante sin entender todo un proceso (P2 Fig 4.), si les ha ayudado a buscar e integrar diferentes fuentes para crear algo nuevo (P3 Fig 4.), si les ha ayudado a trabajar en grupo y a planificar su tiempo (P4,P5 y P6 Fig 4.), y si les ha motivado crear algo nuevo desde cero (P7 Fig 4.). Aunque los porcentajes individuales de cada pregunta pueden ser analizados con detalle, la tendencia general es muy positiva y nos ayuda a seguir con esta iniciativa original que, que sepamos, no realiza ninguna otra asignatura del actual plan de estudios. Un $60 \%$ reconoce que la realización de estos trabajos le ha motivado, frente a sólo un $16 \%$ que lo ve negativamente, y un $20 \%$ que está en un punto medio (P7 Fig 4.). Algunos porcentajes particularmente 
interesantes: más de un $60 \%$ considera que les ha ayudado a trabajar en grupo (P5 Fig 4.), un $72 \%$ indica que le ha ayudado a encontrar fuentes diversas y crear algo nuevo (P3 Fig 4.), o un $67 \%$ ha aprendido que no es necesario entenderlo todo al detalle para poder construir y entender un proyecto (P2 Fig 4.), importante para iniciales en la multidisciplinaridad de proyectos como los que se manejan en esta asignatura.

Finalmente, preguntados qué sentían mientras realizaban este proyecto, más de un $50 \%$ contestó esta opción: "Nunca he olvidado que era una obligación, pero encantado/a de que me obliguen a cosas asi!".

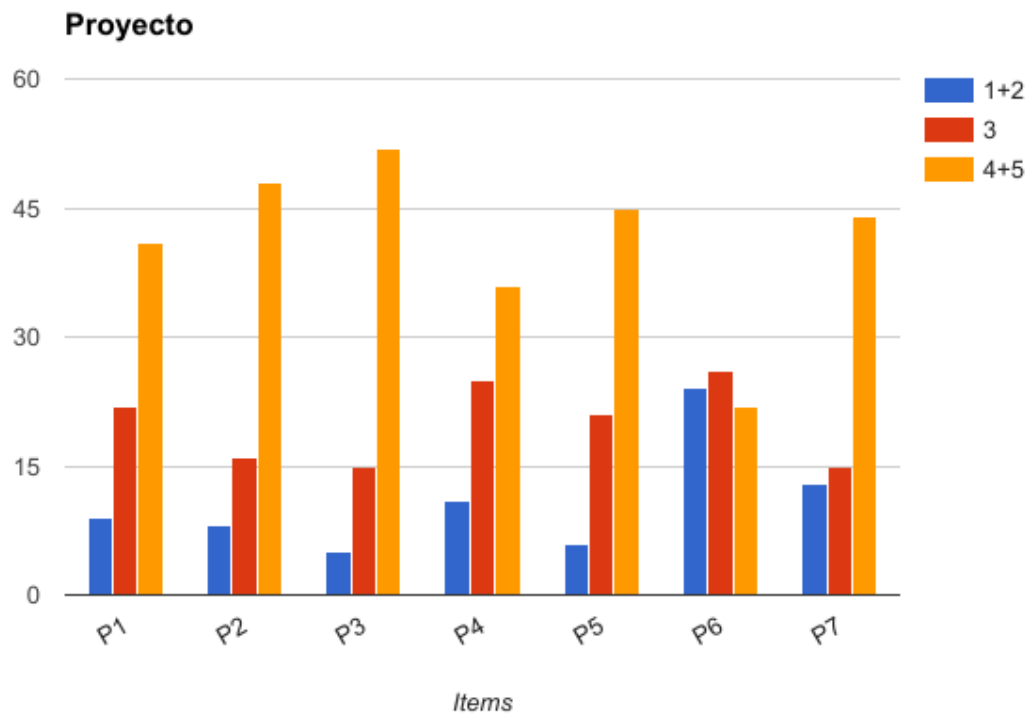

Fig. 4. Diagrama de barras que indica las puntuaciones de los items para la sección Proyecto de investigación. Se han sumado las puntuaciones 1 y 2 que muestran disconformidad (Muy en desacuerdo y En desacuerdo) así como las puntuaciones 4 y 5 que muestran conformidad (De acuerdo y Muy de acuerdo). Los items P1 a P7 están detallados en el apartado 3.1.En el eje de ordenadas se representa el número de alumnos que han respondido.

\subsection{Preferencias generales de los alumnos}

Analizando mediante un Heatmap los resultados en global se puede establecer que los alumnos caen en 3 categorías. Un pequeño grupo formado por 5 alumnos $(6,8 \%)$ que contestan Muy en desacuerdo y En desacuerdo a casi la totalidad de las preguntas (Cluster A Fig 5.). Un segundo grupo formado por 24 alumnos (32.9\%) cuyas respuestas en general fueron indiferentes (Cluster B Fig 5.). Por último, un grupo de 44 alumnos (60.3\%) cuyas respuestas en general apoyaron la metodología aplicada en clase (Cluster C Fig 5.). Esto indica que la mayoría de los alumnos ve aspectos positivos en esta manera de impartir las clases. 


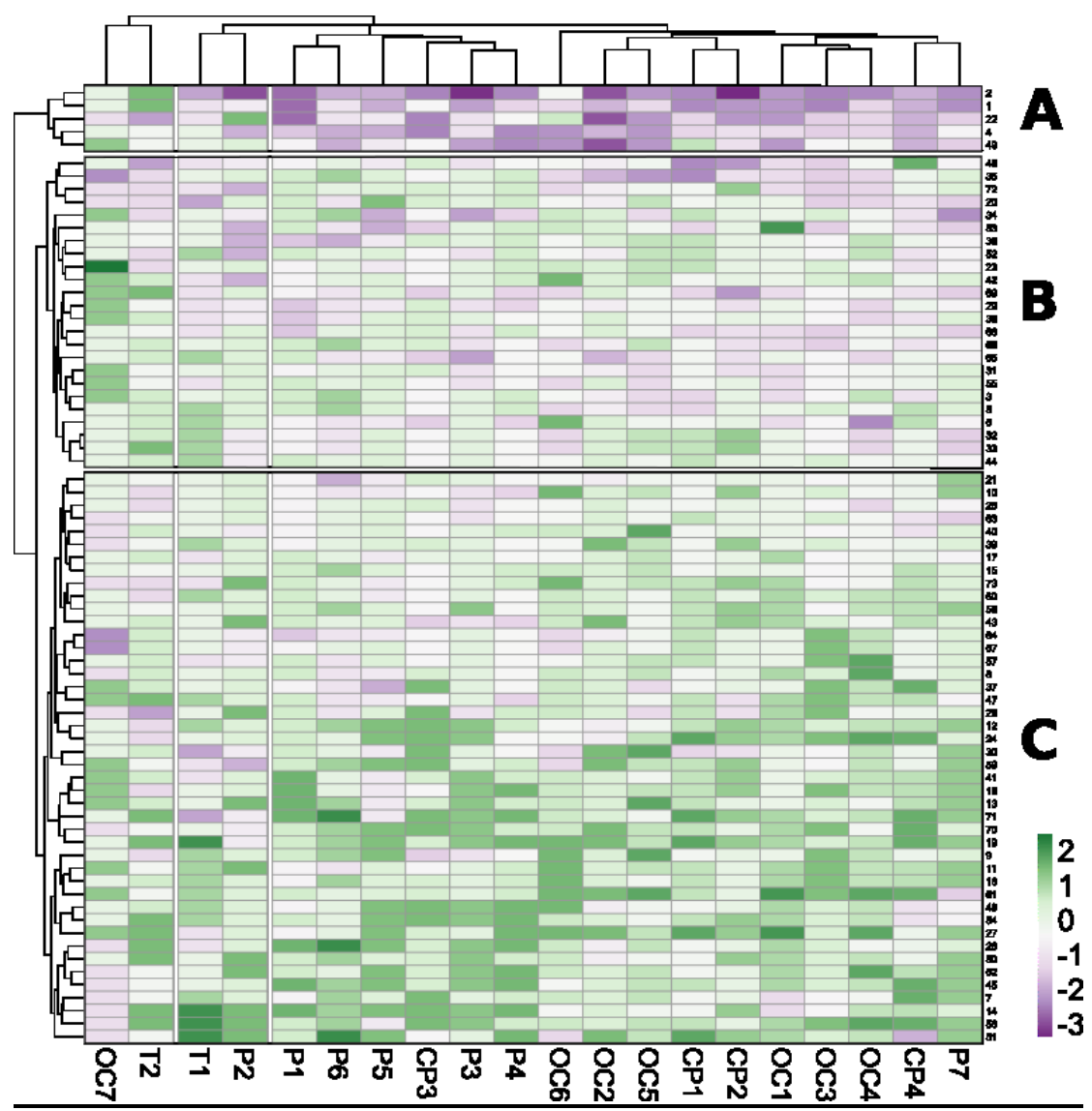

Fig. 5. Heatmap para los items evaluados (columnas) y todos los alumnos (filas). El programa indica la existencia de tres clusters de alumnos $(A, B y C)$.

\section{Conclusiones}

De modo general, estos resultados nos animan a continuar con el sistema docente que hemos implantado en esta asignatura del grado de Biotecnología, y que alterna clases magistrales, trabajos de investigación y clase inversa. Con seguridad, muchos aspectos de la misma, a raíz de los resultados obtenidos, son susceptibles de mejora. Los más mejorables apuntan sin duda a la implantación y ejecución de la clase inversa, un proyecto piloto que hemos iniciado este año y que lógicamente requiere un período de puesta a punto para que encaje con nuestros objetivos y con el tipo de asignatura, y que al mismo tiempo sea atractivo para el alumno. Los aspectos que ya parecen más enraizados y que según la encuesta parece ser una excelente iniciativa son los proyectos de investigación aplicada, implantados ya desde hace unos años pero sólo éste hemos elaborado encuestas que evalúen de modo estadístico la opinión de los alumnos.

En resumen, la implantación de estrategias de aprendizaje autónomo que ponga énfasis en un aprendizaje más aplicado, que aumente la responsabilidad por parte del estudiante e incremente su sentido de autonomía, es visto con buenos ojos por una alta proporción del 
alumnado y podría ser implantado de un modo organizado en los planes docentes, sustituyendo o alternando con estrategias docentes más tradicionales.

\section{Referencias}

BRIONES, G. (1995). Métodos y Técnicas de Investigación para las Ciencias Sociales,2a . reimp., Ed. Trillas, México.

CRISPIN BERNARDO, MARÍA LUISA, AND MA. DEL CARMEN DORIA SERRANO (2011). Aprendizaje autónomo orientaciones para la docencia. México: Universidad Iberoamericana. http://www.uia.mx/web/files/publicaciones/aprendizaje-autonomo.pdf.

METSALU, T., VILO, J. (2015). ClustVis: a web tool for visualizing clustering of multivariate data using Principal Component Analysis and heatmap. Nucleic Acids Research, 43, W566-W570. http://doi.org/10.1093/nar/gkv468

NORTHWEST REGIONAL EDUCATIONAL LABORATORY (2006). Aprendizaje por proyectos. http://www.eduteka.org/AprendizajePorProyectos.php; ABP en Eduteka. [Consultado el 25 de Marzo de 2017]. 


\title{
Los debates políticos como herramienta docente en otros contextos
}

\section{María de Miguel Molina ${ }^{\mathrm{a}}$, Daniel Catalá Pérez ${ }^{\mathrm{b}}$ y Ana Albalat-Mascarell ${ }^{\mathfrak{c}}$}

${ }^{a}$ Departamento de Organización de Empresas, Universitat Politècnica de València, mademi@omp.upv.es, ${ }^{b}$ Departamento de Organización de Empresas, Universitat Politècnica de València, dacapre@ade.upv.es, y ${ }^{\mathrm{c}}$ Departamento de Lingüística Aplicada, Universitat Politècnica de València, analmas@idm.upv.es

\begin{abstract}
At polytechnical universities where our different subjects are offered, analysis of documents related to political discourse is far from frequent. However, this kind of documents may provide valuable information that can be used in Social Science subjects as well as in the teaching of foreign languages at a technical university. In recent years, we have used different political programmes and transcripted debates in order to apply content analysis like an objective tool to search and gather information. Also, we have used content analysis to explore the deployment of linguistic and rhetorical patterns that allow language learners to deal with some key pragmatic skills within a foreign language teaching environment. In this case, we analyse the debates of the last Presidential Elections in the United States of America and their use in the subject Research Methodologies and we compare it with other activities of the subject English for Specific Purposes. With a proper design of the session, we can work on the specific competence of each subject to guide students to apply content analysis to meet their objectives around a hot topic of discussion today.
\end{abstract}

Keywords: political debates, content analysis, discourse analysis, foreign language teaching, instrumental competence, research methodologies.

\footnotetext{
Resumen

En una universidad politécnica como en la que se encuadran nuestras asignaturas, no es habitual el análisis de documentos relacionados con el discurso político. Sin embargo, estos nos proporcionan una información muy valiosa para poder desarrollarse tanto en asignaturas de las Ciencias Sociales como en las ofertadas para conseguir la acreditación del conocimiento de una lengua extranjera en los planes de estudio de titulaciones técnicas. Los programas de los partidos políticos o aquellos debates que han sido transcritos pueden servirnos para utilizar el análisis de contenido bien como una herramienta objetiva de búsqueda de información, bien para identificar y clasificar los recursos lingüisticos y retóricos empleados en dichos contextos y ligados a las competencias pragmáticas cuya adquisición se trabaja en los laboratorios de idiomas. En este caso,
} 
analizamos el uso de los debates de las últimas elecciones a Presidente de los Estados Unidos de América en el ámbito académico de las metodologías de investigación cualitativas y lo comparamos con otras actividades en el ámbito del inglés para fines especificos. Con una planificación adecuada, se puede trabajar la competencia especifica requerida en cada asignatura para que los alumnos conozcan y manejen esta herramienta en torno a un tema de actualidad.

Palabras clave: debates politicos, análisis de contenido, análisis del discurso, competencia instrumental, metodologías de investigación.

\section{Introducción.}

De acuerdo con el proyecto Tuning (European Union, 2007), las "competencias representan una combinación dinámica de conocimiento, comprensión, habilidades y aptitudes". Además, las competencias pueden ser específicas de una asignatura o genéricas (transversales).

Asimismo, dentro de las transversales, encontramos la competencia "instrumental específica" que está íntimamente relacionada con la asignatura que se desarrolla. De acuerdo con la Universitat Politècnica de València (UPV, 2012), "esta competencia hace referencia al uso de las herramientas y tecnologías necesarias para el ejercicio profesional asociado a cada titulación. El estudiante será capaz de identificar las herramientas más adecuadas en cada caso, conociendo sus utilidades y siendo capaz de integrarlas y combinarlas para poder resolver un problema, realizar un proyecto o un experimento".

En los casos que presentamos, se ha trabajado esta competencia para que los alumnos sean capaces de conocer la utilidad del método de "análisis de contenido" y cuándo y cómo aplicarlo.

De acuerdo con Berg y Lune (2014), el análisis de contenido en Ciencias Sociales puede utilizarse tanto en análisis cualitativos como cuantitativos, inductivos (Grounded Theory) o deductivos (comprobar teorías). Va más allá de contar palabras, examinando significados o temas que pueden ser manifiestos o latentes en un texto particular. De este modo, ayuda a los estudiantes a entender la realidad social de una manera científica, así como también a potenciar sus habilidades lingüísticas y pragmáticas en el marco de un tema o contexto discursivo en particular.

Concretamente, en el caso de la enseñanza de idiomas para fines específicos dentro del ámbito universitario, el análisis de contenido puede resultar un instrumento útil para analizar detalladamente transcripciones de discursos auténticos y poner de relieve ciertos características del lenguaje oral que, de otro modo, pasarían inadvertidos para los estudiantes, repercutiendo positivamente en su proceso de aprendizaje. De acuerdo con Chan (2017), el aprendiz de un idioma extranjero, sobre todo aplicado a contextos específicos, agradece el uso de transcripciones de situaciones reales en áreas concretas de trabajo. Además, el análisis de contenido mediante transcripciones puede equipararse a

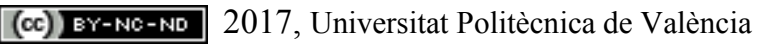


otras herramientas como las WebQuest (Gural y Shulgina, 2015) para fomentar el aprendizaje autónomo y permanente del alumno.

En la actualidad, se dispone en el mercado de algunos software que ayuda a todos estos tipos de análisis como son: VOSviewer, ATLASti, Vantage, etc. En los casos que presentamos, al tratarse de primeras sesiones para los alumnos, no se utilizaron pues se dejaron para sesiones posteriores.

En definitiva, el análisis de contenido se configura, por tanto, como una valiosa herramienta, rigurosa y sencilla, que contribuye a dar respuesta a muchas de las necesidades y los objetivos definidos en un contexto de investigación docente (Ruiz Silva 2004, p. 45). Por ejemplo, Cabrera Ruiz (2009) plantea el análisis de contenido como un método recurrente para la interpretación y evaluación de cualquier tipo de información obtenida en un proceso de investigación educativa; Certad (2015) aplica el análisis de contenido como estrategia evaluativa para un entorno de aprendizaje colaborativo; y Boronat Mundina (2005) lo emplea como metodología para iniciar a los alumnos de postgrado en tareas de investigación. Además, desde un enfoque tal vez más cercano al del presente trabajo, Messinger (2012) introduce a los alumnos de Grado en la utilización de la herramienta a través del análisis de las bandas sonoras de las películas de Harry Potter.

Tanto Messinger (2012) como Boronat Mundina (2005), coinciden en la importancia de escoger un objeto de análisis que resulte atractivo para los alumnos a la hora de iniciarlos en el uso de esta herramienta. En este sentido, se ha considerado que el análisis de un debate político de plena actualidad podría cumplir con este objetivo.

\section{Objetivos.}

Se siguió un método deductivo, pues nuestro primer objetivo era que, basándose en una investigación publicada, se comprobase si esos resultados previos se cumplían o no en un ámbito distinto y en un periodo de tiempo diferente.

Este tipo de estudios comparativos también les ayuda a no perder la mirada crítica ante un documento, sea del tipo que sea, para ir más allá y sacar sus propias conclusiones. De hecho, el análisis de contenido permite construir un nuevo documento distinto al anterior, pero basado en él, más completo, sintético y estructurado, gracias al vínculo que el uso de la herramienta establece entre tres diferentes niveles de lenguaje (Ruiz Silva 2004, p. 46):

- El nivel superficial, formado por el conjunto de información presente en el documento objeto de análisis.

- El nivel analítico, que consiste en la clasificación, ordenamiento de la información y construcción de categorías.

- El nivel interpretativo, en el que los alumnos tratan de comprender el sentido de la información analizada (nivel de superficie), una vez organizada (nivel analítico) y dotándola de un sentido nuevo. 
Asimismo, una vez comprobados dichos resultados, el segundo objetivo era comparar con otras experiencias cómo los patrones lingüístico-discursivos sirven como ejemplo a los alumnos de cómo persuadir y potenciar una imagen de credibilidad y profesionalidad empleando estas estrategias retóricas en el idioma a aprender (en este caso, el inglés).

\section{Desarrollo de la innovación.}

Nuestro punto de partida era el trabajo de Lee y Lim (2016), que se basa en mensajes de redes sociales de Hillary Clinton y Donald Trump publicados durante 2015, para establecer cualidades (traits) y temas (issues) masculinos y femeninos.

Para nuestra práctica en la asignatura de metodologías de investigación cualitativas se eligió el Primer Debate Presidencial Clinton vs. Trump de 2016, emitido en la NBC y transcrito por la revista TIME.

Seguimos los pasos del análisis de contenido descritos por Berg y Lune (2014):

1. Preparación de los datos en texto escrito. No era necesario pues la transcripción ya estaba hecha.

2. Definición de la unidad de análisis (palabra, tema, frase, párrafo). En este caso, primero había que identificar en el trabajo de Lee y Lim (2016) la información.

3. Categorías y esquema de codificación. La información recopilada tenían que clasificarla en: cualidades masculinas, cualidades femeninas, temas masculinos y temas femeninos.

4. Discusión de la codificación por grupos, para dar consistencia al diseño. En esta fase, deben acordarse las categorías y su codificación, para que todo el equipo investigador siga el mismo esquema (Tabla 1).

Tabla 1. Códigos acordados por los equipos

\begin{tabular}{|c|c|}
\hline feminine traits & masculine traits \\
\hline TF1 warm & TM1 strong \\
TF2 caring & TM2 tough \\
TF3 understanding & TM3 assertive \\
TF4 compassionate & TM4 competent \\
TF5 expressive & TM5 instrumental \\
TF6 family-oriented & TM6 achievement-oriented \\
\hline feminine issues & masculine issues \\
\hline IF1 education & IM1 economy \\
IF2 health & IM2 military \\
IF3 human right & IM3 foreign affairs \\
IF4 women's rights & IM4 technology \\
\hline
\end{tabular}

(cc) EY-NC-ND 2017, Universitat Politècnica de València 


\begin{tabular}{|c|c|}
\hline IF5 animal right & IM5 science, crime \\
IF6 child care & IM6 terrorism \\
IF7 poverty & IM7 gun problems \\
IF8 arts & \\
IF9 environment & \\
IF10 social welfare & \\
\hline
\end{tabular}

5. Con esta clasificación ya se puede codificar todo el texto. Conforme se va leyendo, se apuntan los códigos. Si fuesen muchos textos, podríamos utilizar un software que nos facilitase este trabajo.

6. Se re-comprueba la consistencia, por ejemplo comparando entre dos compañeros si se ha codificado la misma información.

\section{Resultados.}

El siguiente paso es escribir los resultados del proceso de codificación, interpretando y justificando el porqué de dichos resultados. Al tratarse de un estudio cualitativo, interpretación y teoría deben ir de la mano para dar consistencia científica a los resultados.

Por ejemplo, determinados resultados pueden ir acompañados de extractos del texto entrecomillados que justifiquen esa interpretación.

Se les pidió a los estudiantes que los resultados se mostrasen comparando a ambos candidatos, y posteriormente cada grupo expuso sus conclusiones al resto de la clase.

Los resultados obtenidos mostraron que, en este debate, Clinton expresaba cualidades y temas femeninos en su mayoría, aunque en ocasiones también citaba temas masculinos. Por otro lado, Trump solo mostraba cualidades masculinas y todos sus temas también eran masculinos.

Los resultados no solo ayudaron a entender y practicar el análisis de contenido, sino también a debatir sobre su utilidad. En este caso, los dos candidatos podrían derivar sus próximos discursos o debates en cualidades o temas que no han mencionado, para llegar a un mayor número de electores. Asimismo, los debates muestran a los candidatos de una manera más clara que las redes sociales, que era la base del trabajo de Lee y Lim (2016), que pueden ser manejadas por otras personas contratadas para ello (community managers).

Al comparar esta práctica de la asignatura de Metodologías de investigación, con otras actividades realizadas en Inglés para fines específicos, vemos que el análisis de discursos políticos también puede servir para detectar estrategias lingüísticas y retóricas utilizadas en cada unidad de análisis codificada de acuerdo a las dicotomías descritas. En el caso que se compara, por ejemplo, serían cualidades masculinas y cualidades femeninas, temas masculinos y temas femeninos. 
Así, al utilizar recursos retóricos, los candidatos pueden emplear matizadores, realzadores y marcadores de actitud muy diferentes (Hyland, 2015) en función de las cualidades y temas tratados. De este modo se pueden observar diferencias significativas en cuanto a las estrategias metadiscursivas preferidas por los candidatos.

Sin embargo, si no se observan grandes diferencias en lo que respecta al número de elementos retóricos empleados según el tema y la cualidad tratada, los estudiantes solo tienen en cuenta las variables cualitativas a la hora de tomar ejemplo de las transcripciones para trabajar los recursos pragmáticos y discursivos del idioma.

\section{Conclusiones.}

El análisis de contenido de temas de actualidad nos ayuda no solo a trabajar la competencia instrumental específica (uso de metodologías de investigación o estrategias pragmáticas orales en una lengua extranjera) sino otras como el trabajo en equipo o el pensamiento crítico. Es decir, más allá de la indudable aplicabilidad de la técnica en el campo de la investigación social (cuantitativa y/o cualitativa), el análisis de contenido ayuda al alumno a organizar su pensamiento, configurándose, por tanto, como una herramienta que promueve y facilita el proceso de aprendizaje.

Se ha combinado el uso de un trabajo científico junto a un texto divulgativo, de manera que en este caso también se perciba la utilización del método científico en diferentes profesiones y no meramente en el ámbito académico. Se amplia, así, el horizonte de los alumnos al descubrir los diferentes contenidos que pueden ser objeto de análisis y se verifica y enfatiza la proyección práctica que puede tener, en concreto, esta herramienta.

\section{Referencias}

BERG, B.L. y LUNE, H. (2014). Qualitative research methods for the social sciences. Harlow: Pearson Education.

BORONAT MUNDINA, J. (2005). "Análisis de contenido. Posibilidades de aplicación en la investigación educativa" en Revista Interuniversitaria de Formación del Profesorado, Volume 19, Issue 2, pp. 157-174. < http://www.redalyc.org/articulo.oa?id=27419209> [Consulta: $29 \mathrm{de}$ marzo de 2017]

CABRERA RUIZ, I. (2009). "El análisis de contenido en la investigación educativa: propuesta de fases y procedimientos para la etapa de evaluación de la información" en Pedagogía Universitaria, Volume 14, Issue 3, pp. 71-93. ISSN 1609-4808. $<$ http://cvi.mes.edu.cu/peduniv/index.php/peduniv/article/view/501> [Consulta: 29 de marzo de 2017]

CERTAD, P.A. (2015). "Diseño de un instrumento para la evaluación de entornos de aprendizaje colaborativo" en Tendencias emergentes en evaluación formativa y compartida en docencia: El papel de las nuevas tecnologias, Santander: Ed. Universidad de Cantabria, pp. 325-354.

CHAN, C. (2017). "Investigating a research-informed teaching idea: The use of transcripts of authentic workplace talk in the teaching of spoken business English" en English for Specific

(c)) BY-NC-ND 2017, Universitat Politècnica de València

Congreso IN-RED (2017) 
Purposes, Volume 47, pp. 72-89. <http://dx.doi.org/10.1016/j.esp.2016.12.002> [Consulta: 29 de marzo de 2017]

EUROPEAN UNION (2007). Tuning Educational Structures in Europe (competences). $<$ http://www.unideusto.org/tuningeu/competences.html> [Consulta: 23 de marzo de 2017]

GURAL, S. y SHULGINA, E. (2015) "Socio-Cognitive Aspects in Teaching Foreign Language Discourse to University Students" en Procedia - Social and Behavioral Sciences, Volume 200, pp. 3-10. <https://doi.org/10.1016/j.sbspro.2015.08.002> [Consulta: 29 de marzo de 2017]

HYLAND, K. (2015). "Metadiscourse" en The International Encyclopedia of Language and Social Interaction, Volume 1, pp. 1-11. <http://dx.doi.org/10.1002/9781118611463.wbielsi003> [Consulta: 29 de marzo de 2017]

LEE, J. y LIM, Y. (2016). "Gendered campaign tweets: The cases of Hillary Clinton and Donald Trump" en Public Relations Review, Volume 42, Issue 5, pp. 849-855. $<$ http://dx.doi.org/10.1016/j.pubrev.2016.07.004> [Consulta: 23 de marzo de 2017]

MESSINGER, A.M. (2012). "Teaching Content Analysis through Harry Potter" en Teaching Sociology, Volume 40, Issue 4, pp. 360-367 < http://journals.sagepub.com/doi/abs/10.1177/0092055X12445461> [Consulta: 29 de marzo de 2017]

RUIZ SILVA, A. (2004). "Texto, testimonio y metatexto : el análisis de contenido en la investigación en educación” en La práctica investigativa en ciencias sociales, Bogotá: Universidad Pedagógica Nacional UPN, pp. 44-59.

UNIVERSITAT POLITĖCNICA DE VALÈNCIA, UPV (2012). Competencias Transversales, competencia instrumental especifica. $<$ http://www.upv.es/contenidos/COMPTRAN/info/955170normalc.html> [Consulta: 23 de marzo de 2017] 


\title{
Preferencias en el aprendizaje de Investigación Operativa: Docencia inversa y presencial
}

\author{
María del Carmen Basa ${ }^{a}$ Marina Seguraa ${ }^{\text {, Concepción Ginestara }}{ }^{\text {, Concepción Maroto }}{ }^{a}$ \\ aDepartamento de Estadística e Investigación Operativa Aplicadas y Calidad, UPV
}

\begin{abstract}
The use of online resources for learning is increasing in business higher education, not only in the flipped classroom approach but also in order to supplement face-to-face lectures. The objectives of this paper are eliciting students' preferences and assessing the learning resources (books, slides and videos) in teaching the Operations Research in Business Administration and Management degree.

The students' preferences have been obtained using Analytic Hierarchy Process, a quantitative method, appropriate for eliciting and aggregating individual preferences to provide information from a group of people. In addition, the use and assessment of the teaching resources have been analysed using the Likert scale, a qualitative method frequently used in higher education studies.

The students who prefer videos the most are those from flipped classroom, although the videos have also affected students from traditional face-to-face teaching. In general, the slides, which synthesize and outline the concepts being studied, represent the resources more used by students of face-to-face groups. Nevertheless, there are significant differences amongst the students' preferences by group.

Finally, the videos also contribute to students skills, mainly in autonomous learning. The results and the students' suggestions encourage the teachers to continue developing additional videos with case studies and real applications.
\end{abstract}

Keywords: Student preferences, teaching resources, flipped classroom, blended learning, active learning, cooperative learning

\section{Resumen}

La creciente utilización de los recursos en línea en la formación de administración y dirección de empresas aparece tanto en el modelo de docencia inversa como complemento a la docencia presencial. Los objetivos del trabajo son obtener las preferencias de los alumnos y valorar los recursos docentes (libros, diapositivas y videos) en el aprendizaje de Investigación Operativa del Grado de Administración y Administración de Empresas. 
Las preferencias se han obtenido mediante AHP, método cuantitativo apropiado para obtener y agregar preferencias individuales, generando preferencias agregadas de grupo. Además, hemos analizado los recursos docentes mediante la escala de Likert, método cualitativo muy utilizado en los estudios de educación superior.

Los alumnos que prefieren más los videos son los de docencia inversa, aunque los videos también han influido en los estudiantes de docencia presencial. En general, las diapositivas, que sintetizan los conceptos, representan el recurso más utilizado en la docencia presencial. Sin embargo, existen diferencias significativas entre las preferencias de los alumnos por grupo.

Por último, los videos también contribuyen a la adquisición de competencias, principalmente al aprendizaje autónomo de los alumnos. Los resultados y las sugerencias recibidas nos animan a seguir desarrollando videos con casos prácticos y aplicaciones reales.

Palabras clave: Preferencias, materiales docentes, docencia inversa, aprendizaje activo, aprendizaje colaborativo

\section{Introducción}

En los últimos años, las instituciones de educación superior han experimentado diversos cambios condicionados por las exigencias de la sociedad actual. La adaptación de los títulos de grado al Espacio Europeo de Educación Superior (EEES) y el uso generalizado de las nuevas Tecnologías de la Información y Comunicación (TIC) en el ámbito de la educación superior son algunos de los factores ineludibles que han provocado un cambio en la aplicación de las metodologías docentes y una necesidad de adaptar y flexibilizar la oferta formativa a la realidad actual.

Estos nuevos cambios exigen al profesorado una renovación organizativa de las materias y una reflexión sobre cómo introducir las nuevas tecnologías, tan apreciadas por los estudiantes universitarios actuales, en sus asignaturas con el objetivo de mejorar el aprendizaje de los alumnos. Una de las tareas principales del profesorado es conseguir que los alumnos adquieran la habilidad y capacidad de seguir aprendiendo a razonar, a pensar, a deducir y a inferir conocimientos adaptándose a las nuevas metodologías de enseñanza-aprendizaje de la nueva era digital (García-Barrera, 2013).

Arbaugh et al. (2009) destacan el creciente uso de la formación online y semipresencial en los estudios de gestión y administración de empresas y defienden el interés de los métodos de investigación cuantitativos junto con los cualitativos en los estudios sobre educación. La mayoría de los trabajos publicados se han centrado más en disciplinas, tales como gestión, marketing, finanzas o contabilidad que en la formación global. En el ámbito de la Investigación Operativa, entre los trabajos recientes que analizan el impacto de los videos como material complementario a las clases presenciales podemos citar a Winch y Cahn (2015) y Sharkey y Nurre (2016).

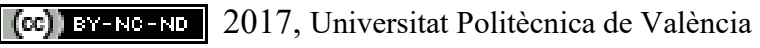


La Universitat Politècnica de València (UPV) ha desarrollado una experiencia piloto durante los cursos 2015-16 y 2016-17, basada en el modelo de clase inversa en las asignaturas de segundo y tercer curso del Grado en Administración y Dirección de Empresas (ADE). La docencia inversa (flipped classroom) consiste en invertir el modelo tradicional de docencia, sustituyendo la lección magistral por un conjunto de materiales en línea (vídeos, lecturas, artículos, etc.), gracias al apoyo de las TIC, que el alumno debe consultar de forma previa a la asistencia a las sesiones de aula. De esta forma, las sesiones de aula se convierten en clases prácticas en las que el alumno debe trabajar activamente, de forma individual o grupal, y el docente actúa como apoyo o guía (Bergmann y Sams, 2012; Zhang et al., 2012).

Entre las ventajas que ofrece el modelo de docencia inversa con respecto a la docencia presencial tradicional, podríamos destacar una mayor implicación del estudiante, un aprendizaje más significativo y colaborativo, una mayor adaptación al ritmo de cada estudiante, un mayor aprovechamiento de las horas de clase presencial y un aprendizaje más flexible y con nuevos enfoques gracias al apoyo de la tecnología (Fulton, 2012; Roehl, 2013).

Hay que destacar que los materiales empleados en este modelo son una de las claves principales para que funcione y se obtengan buenos resultados. Es por eso que se le debe dar mucha importancia a los materiales en línea de los que dispone el alumno para trabajar de forma autónoma y se deben estudiar evidencias que muestren la calidad de dichos materiales empleados para la mejora continua de la aplicación de la docencia inversa.

\section{Objetivos}

El objetivo general del presente trabajo es analizar la utilidad de los materiales elaborados para la docencia de Investigación Operativa en el aprendizaje de los alumnos de Grado en Administración y Dirección de Empresas y su contribución a la adquisición de competencias específicas y transversales.

En particular, los objetivos específicos son los siguientes:

1. Cuantificar y analizar las preferencias de los alumnos por los distintos materiales docentes desarrollados por los profesores para el aprendizaje de Investigación Operativa, que incluyen libros, transparencias y vídeos.

2. Conocer la percepción de los alumnos sobre los vídeos elaborados y su contribución al desarrollo de las competencias.

En los siguientes apartados describimos las características principales de la asignatura Investigación Operativa, la metodología docente y el sistema de evaluación que aplicamos, así como los materiales docentes desarrollados expresamente para el Grado en ADE. A continuación se detalla la metodología del trabajo, que incluye la técnica multicriterio Analytic Hierarchy Process (AHP) para elicitar las preferencias de los alumnos y la escala de Likert que habitualmente se aplica en este tipo de estudios. Por último, se presentan los resultados, las conclusiones y las propuestas de mejora. 


\section{Desarrollo de la innovación}

\subsection{Descripción de la asignatura, metodología docente y sistema de evaluación}

La Investigación Operativa forma parte de la materia básica y obligatoria "Métodos cuantitativos para la empresa" y se imparte en el primer cuatrimestre del tercer curso del Grado en ADE (Facultad de Administración y Dirección de Empresas, UPV). Su objetivo es que los alumnos aprendan a formular modelos de optimización para resolver problemas reales de toma de decisiones, así como los conceptos y las técnicas necesarias para resolver modelos de programación lineal, entera, no lineal, multiobjetivo y multicriterio mediante software profesional e interpretar los resultados con la finalidad de mejorar las decisiones empresariales.

Esta asignatura tiene 6 créditos ECTS, 3 créditos de teoría y 3 créditos de prácticas, 1 de prácticas de aula y 2 de prácticas informáticas. En el aula se combina la presentación de modelos, métodos y aplicaciones por parte del profesor con la realización de ejercicios por parte de los alumnos, generalmente en grupos, aplicando el aprendizaje colaborativo. También, en las diez sesiones de dos horas en el aula informática los alumnos trabajan en grupos formulando modelos, que después resuelven e interpretan las soluciones, con la ayuda del profesor. La implantación de esta metodología, enfocada hacia el aprendizaje de los alumnos, tiene ya una larga trayectoria y su origen en varios Planes de Innovación Educativa desarrollados en la UPV (Maroto et al., 1997; Alcaraz et al., 2003; Alcaraz et al., 2004).

La Investigación Operativa se organiza en tres grupos: mañanas, tardes y grupo ARA (Alto Rendimiento Académico). En este último grupo la asignatura se imparte en inglés. Además, durante los cursos 2015-16 y 2016-17 se ha implantado un cuarto grupo de docencia inversa en el marco de una experiencia piloto. El grupo de docencia inversa tiene las mismas clases de laboratorio informático que los demás, pero menos horas de aula, ya que en este modelo el trabajo previo de los alumnos sustituye la presentación del profesor, enfocándose las clases de aula como clases prácticas.

El sistema de evaluación es el mismo para todos los grupos, basado en la evaluación continua del trabajo realizado en grupos de 2-3 alumnos en diez sesiones de prácticas informáticas. En estas clases se plantean y resuelven modelos de toma de decisiones y se interpretan los resultados. Al finalizar cada clase práctica los alumnos deben subir el modelo y el informe realizado a poliformaT. Estos informes representan el 20\% de la calificación final. Asimismo se realizan 2 exámenes, uno sobre la primera mitad del temario y el otro sobre la segunda mitad, cada uno de los cuales vale el $40 \%$ de la calificación final. Por tanto, los alumnos tienen a mitad de semestre una calificación parcial (P1) correspondiente al 50\% de la nota global y otra P2 de la segunda parte de la materia. Los alumnos que no superan la asignatura pueden realizar un examen de recuperación de todo el temario ( $80 \%$ de la calificación), manteniéndose la nota de las prácticas informáticas que se haya obtenido en el curso.

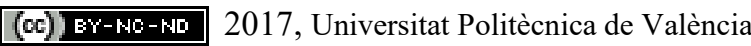

Congreso IN-RED (2017) 


\subsection{Diseño del material docente}

Antes de la implantación del grupo de docencia inversa el material docente básico de la asignatura estaba formado por un libro de texto expresamente diseñado para impartir la asignatura en el grado en ADE y transparencias de apoyo a las presentaciones del profesor. El libro incluye tanto el material para las explicaciones teóricas como los casos prácticos a desarrollar y resolver en el aula y en el laboratorio informático. Este libro está publicado en castellano y en inglés para el grupo ARA y ambos disponibles en papel y como libros electrónicos (Maroto et al., 2012, Maroto et al., 2014).

Las transparencias en Powerpoint de los 8 temas de la asignatura, basadas en los libros citados, están disponibles en poliformaT para los alumnos, también en castellano e inglés. Durante el curso 2015-16 se grabaron vídeos con la explicación de las transparencias de toda la asignatura como apoyo adicional para los alumnos del grupo de docencia inversa. Estos vídeos se grabaron mediante la herramienta Powerpoint y están disponibles en PoliformaT con enlaces al repositorio UPV \{Media\} (https://media.upv.es). Los alumnos tienen disponible un total de 17 vídeos de toda la asignatura con una duración entre 8 min y 55 min, dependiendo de la complejidad de los temas y del número de ejemplos.

Aunque se prepararon para el grupo de docencia inversa, los vídeos están disponibles para los alumnos de todos los grupos. Conscientes de la importante contribución que puede suponer la disponibilidad de vídeos como material complementario a las clases presenciales, durante el curso 2016-17 se han preparado tres vídeos en inglés para el grupo ARA en los que se explican conocimientos difíciles para algunos alumnos, pero básicos y muy importantes para el aprendizaje de la materia.

\subsection{Metodología}

Para alcanzar los objetivos planteados en este estudio se ha diseñado una encuesta con el fin conocer las preferencias y la percepción de los alumnos sobre el material docente. La encuesta se ha dirigido a todos los grupos de la asignatura Investigación Operativa del grado en ADE durante el curso académico 2016-2017.

El cuestionario se entregó en papel a los alumnos en clase en la última semana del curso (diciembre 2016) y también se envió a través de un formulario on-line, elaborado con la herramienta Google Docs, a todos los alumnos para que pudieran responder aquellos que no hubieran estado presentes en el aula el día que se realizó la encuesta. La encuesta es anónima en ambos casos.

El cuestionario se ha dividido en cuatro partes:

Parte I. Características del alumno (grupo, asistencia habitual a las clases, calificación obtenida en la primera parte de la asignatura que representa el 50\% de la evaluación total, Parcial 1). 
Parte II. Preferencias y valoración de los materiales docentes de la asignatura

II.a) Preferencias por los materiales docentes para el aprendizaje de Investigación Operativa mediante el método AHP.

II.b) Grado de utilización del material docente (libro, transparencia y vídeos). Se ha empleado una escala de Likert de 5 puntos ( $1=$ Nada, $5=$ Mucho).

II.c) Valoración de los vídeos como material de apoyo. Se ha empleado una escala de Likert de 5 puntos (1=Nada, $5=$ Mucho).

Parte III. Contribución de los vídeos al desarrollo de las competencias específicas (CE) y transversales $(\mathrm{CT})$ trabajadas en la asignatura. Se ha empleado una escala de Likert de 5 puntos ( $1=$ Ninguna, $5=$ Muy Alta $)$.

Parte IV. Sugerencias de mejora para la elaboración de materiales docentes.

Para obtener las preferencias de los alumnos por los materiales para el aprendizaje de la Investigación Operativa se ha diseñado una pregunta basada en el método AHP que nos permite determinar el peso de cada tipo de material, tanto para los alumnos individualmente como a nivel de grupo.

La figura 1 ilustra la jerarquía del método AHP, ampliamente implantado para elicitar las preferencias de los stakeholders en numerosos ámbitos de investigación (Saaty y Peniwati, 2008). En la asignatura se había explicado previamente este método como técnica de toma de decisiones colaborativa. En síntesis, teniendo en cuenta que el objetivo global es el aprendizaje de Investigación Operativa los alumnos comparan dos a dos los distintos tipos de materiales: libro, transparencias y vídeos, asignando su importancia relativa mediante la escala cuantitativa de Saaty en una matriz de comparaciones (Saaty y Vargas, 2001).

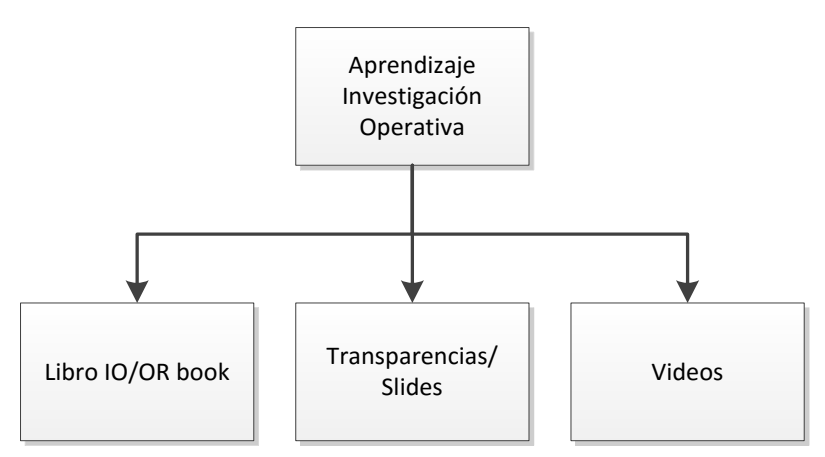

Fig. 1 Jerarquía de los materiales docentes en la asignatura Investigación Operativa

(cc) EY-NC-ND 2017, Universitat Politècnica de València

Congreso IN-RED (2017) 


\section{Resultados}

\subsection{Porcentaje de respuestas y representatividad}

La tabla 1 recoge el número de alumnos matriculados en cada grupo y la respuestas obtenidas. Se ha obtenido una tasa de respuesta del $58,8 \%$ del total, si bien este porcentaje es menor en el grupo de docencia inversa, que presenta un número muy reducido de alumnos matriculados, similar al de otras asignaturas del proyecto piloto. Además dos de los ocho alumnos tenían exención de asistencia y no realizaron ninguna actividad a lo largo del curso ni se presentaron a los exámenes. Teniendo en cuenta lo anterior, la tasa de respuesta real sería similar a la del grupo más numeroso de mañanas.

Tabla 1. Número de alumnos matriculados y porcentaje de respuesta por grupos

\begin{tabular}{|c|c|c|c|}
\hline Grupo & Matriculados & Respuesta & \% Respuesta \\
\hline Mañanas & 64 & 32 & $50 \%$ \\
\hline Tardes & 31 & 23 & $74,19 \%$ \\
\hline ARA & 33 & 22 & $66,6 \%$ \\
\hline D. Inversa & 8 & 3 & $37,5 \%$ \\
\hline TOTAL & 136 & 80 & $58,8 \%$ \\
\hline
\end{tabular}

De los 80 alumnos que responden, 74 cumplimentaron la encuesta presencialmente en clase y 6 la remitieron online, 3 de los cuales no asisten a clase y los otros 3 sí. Casi la totalidad de alumnos que responden la encuesta asisten habitualmente a las clases de teoría y prácticas de aula $(92,50 \%)$. Hay que destacar que asistir a clase de forma habitual para el grupo de docencia inversa se refiere a asistir a las clases presenciales, que representan menos horas en este caso que en los restantes grupos. Este nivel de representatividad se tendrá en cuenta a la hora de interpretar los resultados.

Como se puede observar en la figura 2 los alumnos que responden la encuesta, que asisten mayoritariamente a clase, presentan mejores calificaciones con mayor porcentaje de buenas notas, en especial sobresalientes, y con menor tasa de suspensos en comparación con el total de alumnos. Se utiliza la nota Parcial 1 debido a que es la única disponible en el momento de cumplimentar el cuestionario y con la finalidad de comparar la tasa de rendimiento y las calificaciones de los alumnos que responden frente al total. 


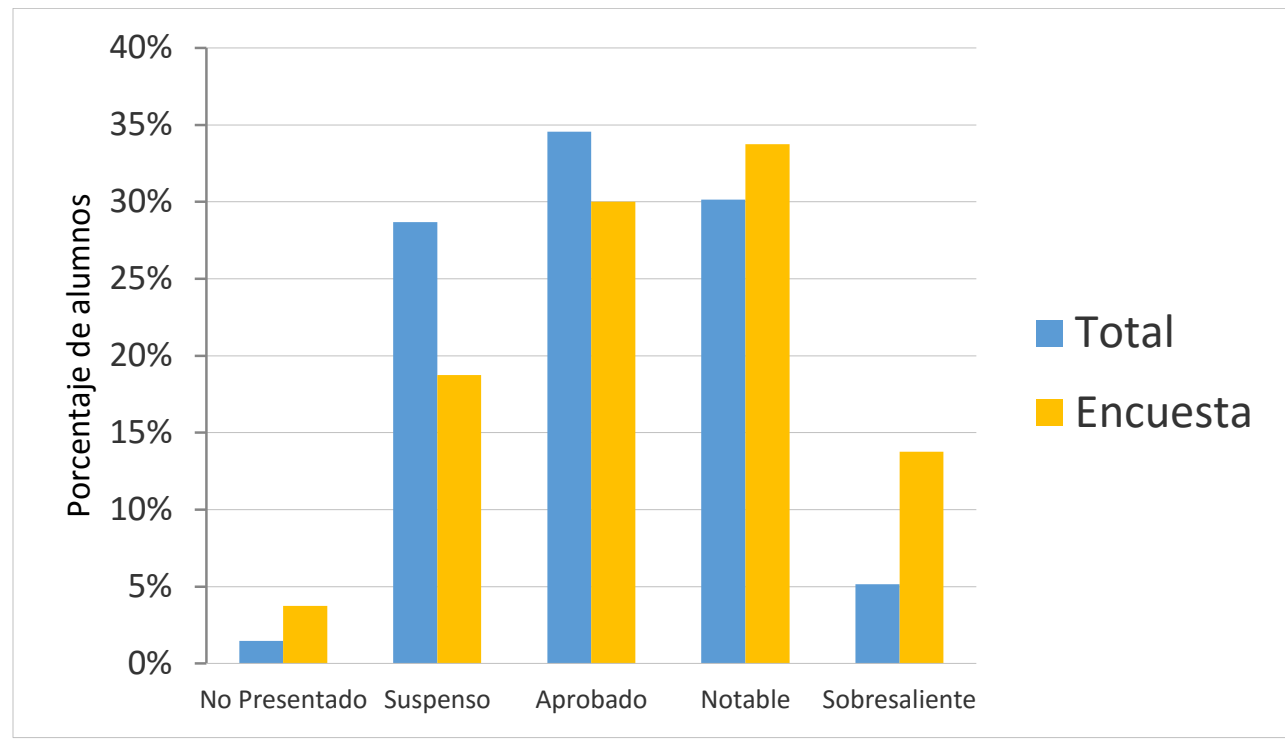

Fig. 2 Porcentaje de alumnos del curso y de los que responden la encuesta según Nota Parcial 1

\subsection{Preferencias de los alumnos por los diferentes tipos de materiales docentes}

Previo al cálculo de las preferencias mediante AHP hay que determinar el índice de inconsistencia de la matriz de comparación por pares de cada alumno. El 32,5\% del total presenta una inconsistencia elevada (superior a 0,12 ) y por tanto estas respuestas se eliminan del análisis. Este porcentaje varía entre el $27,3 \%$ en el grupo de tardes y el $36,4 \%$ en el grupo ARA. Aunque sólo 6 de los 80 alumnos que han respondido la encuesta no asisten habitualmente a clase, el $66 \%$ de sus respuestas son inconsistentes, duplicando el porcentaje de inconsistencia de los estudiantes que sí asisten a las clases, siendo éste un indicador de un mayor grado de aprendizaje de los alumnos que asisten a clase, ya que todos habían realizado un caso práctico en el laboratorio basado en esta técnica. Hay que resaltar que el nivel de asistencia a las prácticas de laboratorio informático, base de la evaluación continua, está cercano al $100 \%$.

El conocimiento de la técnica AHP de los alumnos que asisten a clase y su repercusión en la capacidad de responder a las comparaciones por pares de forma más consistente también se confirma al comparar el porcentaje de alumnos cuyas matrices han presentado una consistencia aceptable con otra investigación en la que participaron alumnos de ADE sin estudio previo de la técnica. En este caso el porcentaje de matrices inconsistentes fue del 57,5 (Segura, 2011).

La figura 3 representa las preferencias de los alumnos por el libro, las transparencias y los vídeos en el aprendizaje de Investigación Operativa. Los pesos a nivel de grupo y total se han obtenido aplicando la media geométrica a las respuestas de los alumnos consistentes para obtener una matriz agregada, que es consistente y a partir de la cual se calculan los pesos de los materiales para cada grupo, tal y como se procede en toma de decisiones colaborativa

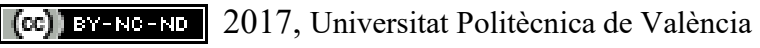

Congreso IN-RED (2017) 
para construir la preferencia de un grupo de personas a partir de las preferencias individuales (Saaty y Peniwati, 2008).

Aunque a nivel global las transparencias son el recurso más utilizado por la mayoría, la figura 3 muestra diferencias importantes por grupos. El grupo de mañanas es el que más peso da a las transparencias, mientras que los vídeos son mucho más importantes en docencia inversa. Por otra parte, el grupo con docencia en inglés es el que más peso da al libro, con un peso similar a las transparencias y el grupo de tardes destaca por ser el grupo presencial que más peso da a los vídeos. Estas diferencias entre grupos (sin considerar la docencia inversa por el reducido número de alumnos, por lo que $\mathrm{N}=77$ ) son significativas estadísticamente al $95 \%$ aplicando el test de Kruskal-Wallis en todos los casos, excepto la comparación entre videos y libro cuya diferencia es significativa al $90 \%$.

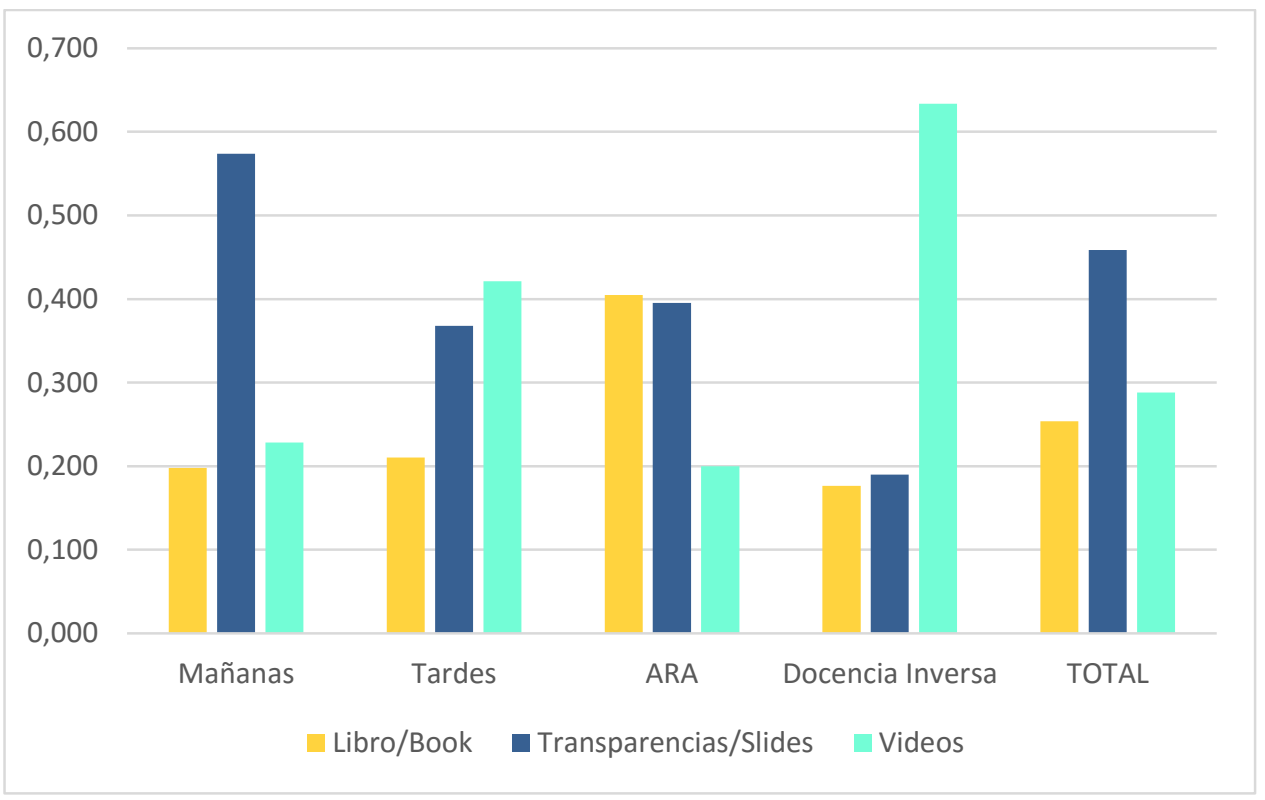

Fig. 3 Preferencias de los alumnos por los materiales docentes. Peso obtenido mediante AHP.

\subsection{Grado de utilización del material docente de la asignatura}

La figura 4 muestra el grado de utilización del material docente, que corresponde al libro diseñado expresamente para la asignatura, las transparencias y los vídeos grabados. El grado de utilización del material se ha analizado según la asistencia o no a clase con el fin de identificar las posibles diferencias entre los dos grupos, aunque hay que tener en cuenta que la escasa representatividad de los que no asisten a clase, ya que sólo hay 6 respuestas frente a 74 que sí asisten habitualmente.

Los resultados muestran que los vídeos son el material docente más utilizado por los alumnos que no asisten $(4,83)$, seguido de las transparencias (3) y el libro $(2,83)$. Por el contrario, los 
alumnos que asisten habitualmente a clase valoran con un grado de utilización medio las transparencias $(3,84)$, seguidas del libro $(2,8)$ y finalmente los vídeos $(2,61)$, aunque hay que destacar que no hay mucha diferencia entre la puntuación media entre libro y vídeos para los alumnos que asisten a clase.

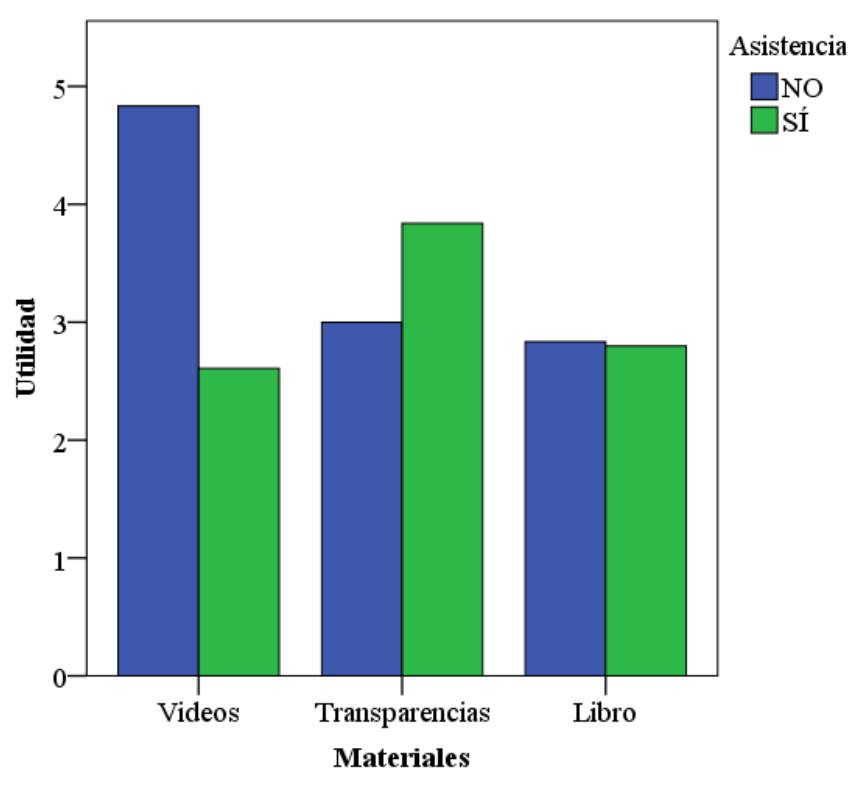

Fig. 4 Utilización material docente según asistencia a clase basado en escala de Likert

La figura 5 representa el grado utilización material docente según la calificación obtenida. Se observa que en promedio las transparencias son el material de aprendizaje más utilizado por los alumnos, independiente del mayor o menor aprovechamiento reflejado en la calificación obtenida a mitad de curso. Lo mismo se puede decir del grado de utilización del libro de texto. Sin embargo, la utilización de los vídeos es mayor en aquellos alumnos que tienen calificaciones más bajas (suspenso y aprobado). El número de alumnos no presentados es muy reducido, tanto a nivel global de la asignatura $(4,3 \%)$ como en los que responden la encuesta $(3,8 \%)$. Esta mayor proporción de alumnos suspendidos entre los que más ven los videos, unida a que son también los que no asisten a las clases presenciales teóricas y prácticas en aula, consideramos que es debida a que estos alumnos no trabajan ni resuelven los casos prácticos, muy relevantes para asimilar los conceptos en asignaturas cuantitativas como Investigación Operativa. 


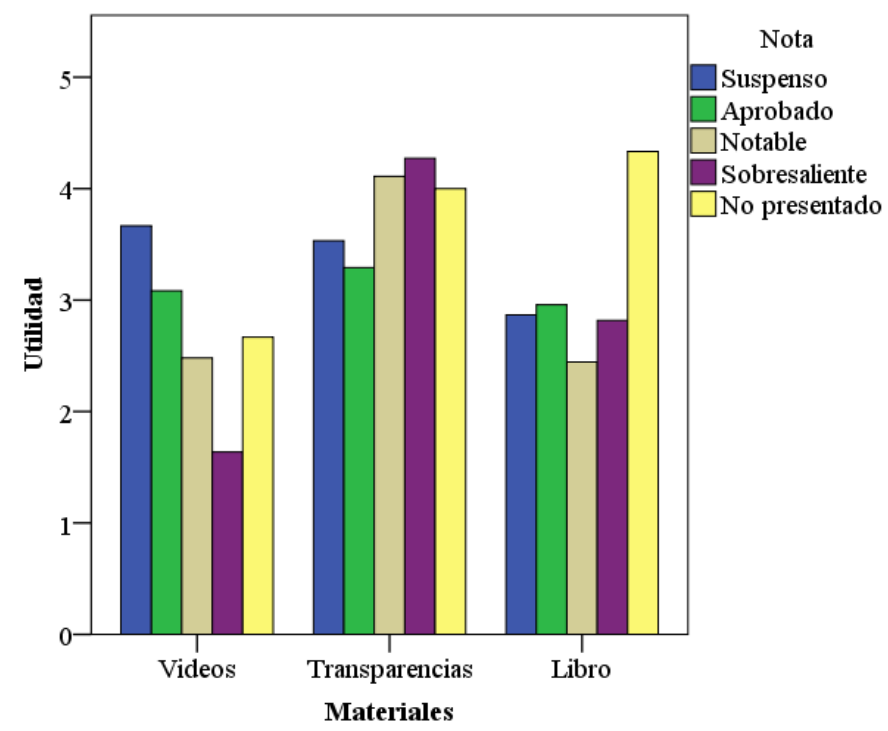

Fig. 5 Grado utilización material docente según la calificación de los alumnos

En la figura 6 podemos observar la distribución del grado utilización del material docente por grupos basado en la escala de Likert. Al comparar estos resultados con los obtenidos mediante AHP (figura 3) vemos cómo la escala de Likert discrimina entre grupos mucho menos que la técnica AHP, basada en una escala cuantitativa ( Cochran, 2012).

Las diferencias más importantes se observan en los resultados de ambas metodologías, como la mayor utilización de las transparencias por el grupo de mañanas y de vídeos por el grupo de docencia inversa. Si bien a partir de AHP, las diferencias entre grupos son todas significativas, no ocurre lo mismo al aplicar el test no paramétrico de Kruskal-Wallis con una corrección de Bonferroni para comparaciones múltiples a los datos de la encuesta procedentes de la escala de Likert. En este análisis no se ha considerado el grupo de docencia inversa por el pequeño número de alumnos de esta modalidad.

Los resultados obtenidos muestran que no existen diferencias significativas entre los grupos de mañana, tarde, y ARA para el grado de utilización de los vídeos. Por el contrario, sí que existen diferencias significativas al 95\% de confianza entre los grupos para el grado de utilidad de las transparencias. Estas diferencias se observan entre el grupo de la mañana y el grupo de la tarde, siendo el grupo de la mañana el que más emplea las transparencias como material docente. Finalmente, el grado de utilidad del libro también es estadísticamente significativo al $95 \%$ para los distintos grupos, encontrándose dichas diferencias entre el grupo ARA y el de la mañana, siendo el grupo ARA el que emplea más el libro como material docente de la asignatura. 


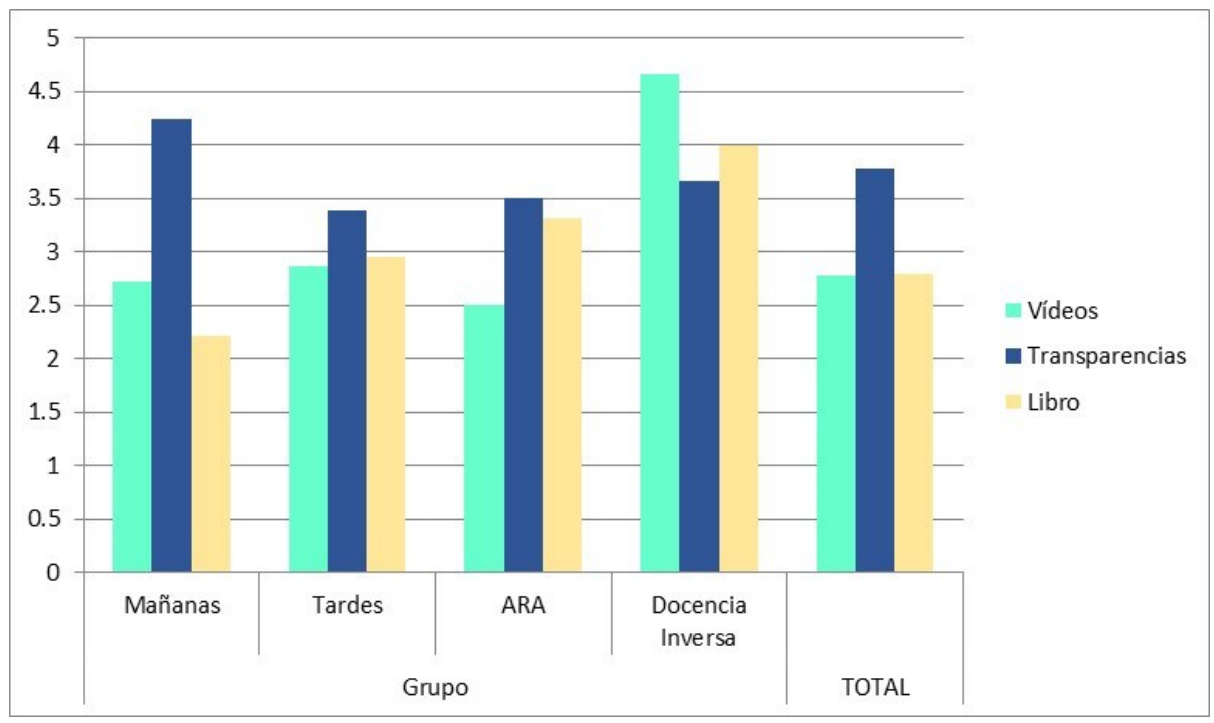

Fig. 6 Grado utilización material docente por grupos según la escala de Likert

\subsection{Valoración de los vídeos como material de apoyo}

A continuación se presentan los resultados sobre la utilidad, calidad y cantidad de los vídeos como material de apoyo de la asignatura (tabla 2) usando la escala de Likert. Los alumnos han asignado una puntación de 3,90 a la calidad de los vídeos, un 3,53 a la utilidad que les dan y una puntuación menor $(3,35)$ a la cantidad de estos. Se puede interpretar que los alumnos desearían un mayor número de vídeos. La tabla 2 pone de manifiesto que los alumnos del grupo de docencia inversa son los que mejor evalúan los vídeos tanto en utilidad, cantidad y calidad.

Tabla 2. Valoración de las características de los vídeos

\begin{tabular}{|c|c|c|c|c|}
\hline \multicolumn{1}{|c|}{} & Utilidad & Cantidad & Calidad \\
\hline \multirow{4}{*}{ Grupo } & Mañanas & 3,74 & 3,96 & 4,30 \\
\cline { 2 - 5 } & Tardes & 3,15 & 2,85 & 3,35 \\
\cline { 2 - 5 } & ARA & 3,50 & 2,79 & 3,86 \\
\cline { 2 - 5 } & Docencia Inversa & 4,67 & 4,67 & 4,67 \\
\hline \multicolumn{2}{|c|}{ TOTAL } & 3,53 & 3,35 & 3,90 \\
\hline
\end{tabular}

\subsection{Contribución de los vídeos al desarrollo de competencias}

Según el estudio de competencias, los alumnos opinan que los vídeos tienen una mayor contribución a la competencia específica "Aprender autónomamente", que es uno de los objetivos de los vídeos, el trabajo autónomo por parte de los alumnos. A esta competencia,

(cc) EY-NC-ND 2017, Universitat Politècnica de València

Congreso IN-RED (2017) 
le siguen en puntuación las competencias transversales "Aplicación y pensamiento práctico" y "Análisis y resolución de problemas".

Por el contrario, la competencia menos valorada es el "Trabajo en equipo y liderazgo", ya que en este caso, los vídeos son una herramienta muy útil para el trabajo autónomo, pero, según los alumnos no fomenta el trabajo en equipo. Este resultado contrasta con los mencionados en otros trabajos publicados (Arbaugh et al., 2009). Hay que tener en cuenta que esta competencia se trabaja en las clases prácticas de laboratorio informático y en las clases prácticas de aula donde los alumnos trabajan en grupos y aprenden de forma colaborativa.

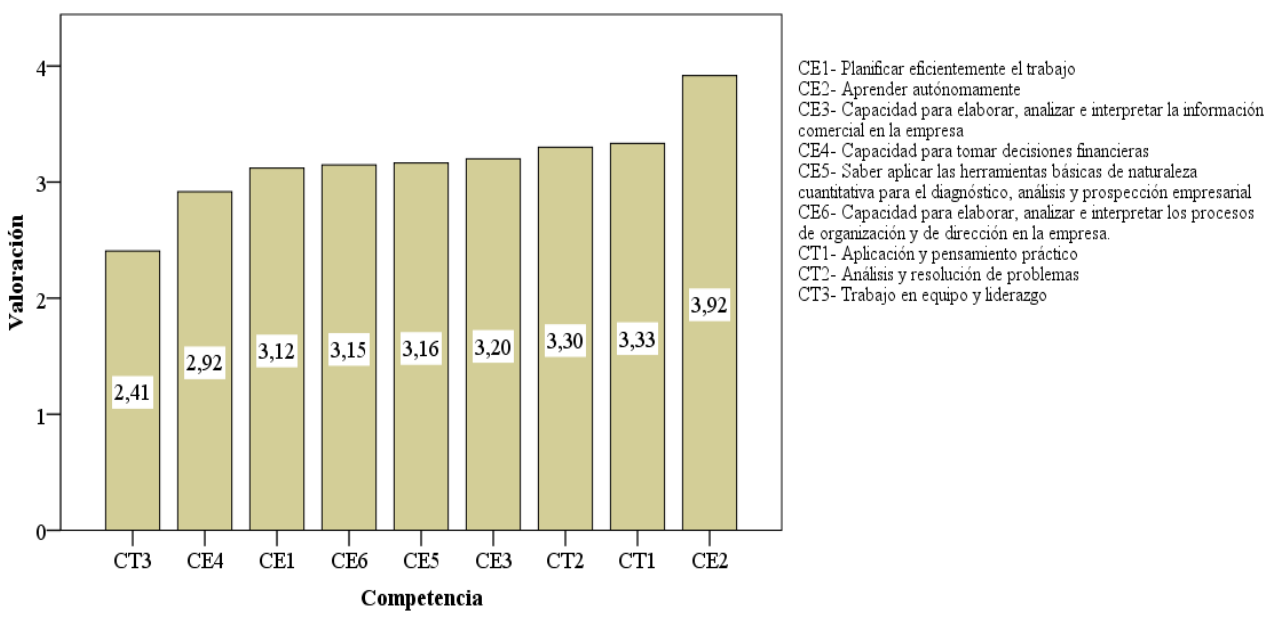

Fig. 7 Contribución de los vídeos al desarrollo de competencias

\subsection{Sugerencias de los alumnos para la mejora del material docente}

El cuestionario incluye una pregunta abierta para recoger las sugerencias de mejora y observaciones que han realizado los alumnos sobre el material docente de la asignatura.

En primer lugar, un número muy importante de alumnos destaca los exámenes resueltos, disponibles en PoliformaT, como un material importante para preparar la asignatura. Grabar videos con los ejercicios que se hacen en las clases presenciales y la solución de los exámenes es otra de las sugerencias. Asimismo, sugieren reducir la duración de los videos, incluir más ejemplos de aplicaciones reales y más explicaciones escritas de los gráficos y esquemas en las transparencias. Algunos alumnos de los grupos presenciales indican que no conocían la existencia de vídeos destinados a la docencia inversa. 


\section{Conclusiones}

La principal contribución de este trabajo es la aplicación de un método cuantitativo muy utilizado en toma de decisiones colaborativa (AHP), poniendo de manifiesto su mayor poder discriminante frente a otros métodos basados en escalas cualitativas, de uso más frecuente en estudios sobre educación. Autores como Arbaugh et al. (2009) y Cochran (2012) defienden el interés y complementariedad de ambos tipos de metodologías.

Si bien los alumnos del grupo de docencia inversa son los que más prefieren, utilizan y valoran los vídeos como material de aprendizaje, éstos también han tenido una influencia importante en los alumnos de docencia presencial.

Globalmente las transparencias, que recogen de forma sintética y esquemática los conceptos de la asignatura, son el recurso de aprendizaje más utilizado por los alumnos de docencia presencial, independientemente de su calificación. El libro de texto se utiliza más en el grupo ARA y el grupo de tardes recoge los alumnos presenciales que más utilizan los vídeos.

Los vídeos, grabados expresamente para la docencia inversa, amplían y flexibilizan las oportunidades de aprendizaje y permiten mayor adaptación al ritmo de estudio de cada alumno que la clase presencial. Por tanto, no sólo ayudan a aquellos que no han asistido a alguna clase, sino también a aquellos que tienen mayor dificultad con la materia, que pueden pararlos, tomar notas sobre las transparencias o verlos varias veces, si es necesario tal y como se ha puesto de manifiesto también en otros trabajos (Sharkey y Nurre, 2016).

La relación positiva que hemos encontrado entre la visualización de vídeos y los alumnos que no han aprobado el primer parcial se puede atribuir a que en los vídeos no se han incluido casos prácticos adicionales resueltos, que sí se trabajan en el aula y que los alumnos que no asisten a clase y la sustituyen por la visualización de vídeos únicamente, no los resuelven de forma autónoma. El trabajo de estos casos prácticos es esencial para la comprensión de los conceptos en materias de naturaleza cuantitativa como es el caso de Investigación Operativa.

En cuanto a la percepción de los alumnos sobre los vídeos y su contribución al desarrollo de las competencias de la asignatura se confirma la importante contribución de los vídeos en la competencia de aprender autónomamente, que es la que recibe la mayor valoración. Por el contrario, el uso de vídeos no contribuye en gran medida al desarrollo de la capacidad 'trabajo en equipo', competencia que se trabaja en las clases prácticas de aula y laboratorio.

El hecho de que los alumnos tengan los exámenes resueltos con explicaciones detalladas, por una parte mejora el aprendizaje de los alumnos y por otra, reduce su necesidad de tutorías. También se ha observado que la disponibilidad de vídeos para la docencia inversa, con la presentación de los contenidos de las clases presenciales, ha reducido la asistencia a clase de los alumnos, en particular en el grupo más numeroso.

Los resultados del trabajo, unido a las sugerencias de los alumnos, nos indican que el aprendizaje se podría mejorar completando el material con vídeos sobre una amplia variedad de casos prácticos y aplicaciones reales. En esta línea continuaremos intentado mejorar y facilitar el aprendizaje de Investigación Operativa.

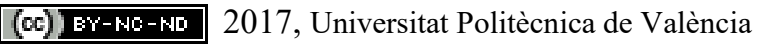




\section{Referencias}

ALCARAZ, J. et al. (2003). "Autonomous web-based learning of Operations Research" en International Conference on Engineering Education ICEE2003. Abstracts. Valencia.

ALCARAZ, J. et al. (2004). "Teaching Innovation of Operations Research Through a Web-Based System" en 7th Internacional Workshop on Higher Education and its Perspectives. Actas. Havana (Cuba).

ARBAUGH, J.B. et al. (2009). "Research in online and blended learning in the business disciplines: Key findings and possible future directions" en Internet and Higher Education 12, 71-87.

BERGMANN, J. y SAMS, A. (2012). Flip YOUR Classroom. Reach Every Student in Every Class Every Day. International Society for Technology in Education.

COCHRAN, J.J. (2012). "You want them to remember? Then make it memorable! Means for enhancing operations research education" en European Journal of Operational Research 219, 659-670.

GARCÍA-BARRERA, A. (2013). "El aula inversa: cambiando la respuesta a las necesidades de los estudiantes” en Avances en Supervisión Educativa, 19.

FULTON, K. (2012). "Upside down and inside out: Flip your classroom to improve student learning" en Learning \& Leading with Technology, 39, p. 12-17.

MAROTO, C. et al. (2012). Investigación Operativa en Administración y Dirección de Empresas. Valencia: Editorial UPV. Disponible en papel y libro electrónico.

MAROTO, C. et al. (2014). Operations Research in Business Administration and Management. Valencia: Editorial UPV. Disponible en papel y libro electrónico.

MAROTO, C. et al. (1997). "Operational Research Teaching in Computer Science through Six Years of Innovative Education Experience" en XV EURO and XXXIV INFORMS Joint International Meeting: OR/MS for the New Millennium. Abstracts.

ROEHL, A. (2013). "Bridging the field trip gap: Integrating webbased video as teaching and learning partner in interior design education" en Journal of Family \& Consumer Sciences, 105, p. 42-46.

SAATY, T.L. y PENIWATI, K. (2008). Group decision making: drawing out and reconciling differences. RWS Publications.

SAATY, T.L. y VARGAS, L.G. (2001). Models, methods, concepts \& applications of the analytic hierarchy process. Kluwer Academic Publishers.

SEGURA, M. (2011). Gestión forestal sostenible y participativa del monte mediterraneo: agregación de preferencias mediante AHP y programación por metas. Trabajo Fin de Master. Master Universitario de Ingenieria de Análisis de Datos, Mejora de Procesos y Toma de Decisiones. Universitat Politecnica de Valencia.

SHARKEY, T.C. y NURRE, S.G. (2016). "Video Tutorials Within an Undergraduate Operations Research Course: Student Perception on Their Integration and Creating A Blended Learning Environment" en INFORMS Transactions on Education 17(1):1-12.

WINCH, J.K y CAHN, E.S. (2015). "Improving Student Performance in a Management Science Course With Supplemental Tutorial Videos" en Journal of Education for Business, 90:7, 402-409.

ZHANG, J., WANG, Y. y ZHANG, B. (2012). "Introducing a New Teaching Model: Flipped Classroom" en Journal of Distance Education, vol 4, p. 46-51. 


\title{
De las aulas universitarias a la red. Un proyecto innovador aplicado al aprendizaje y difusión de la literatura catalana barroca
}

Eulàlia Miralles $^{\mathrm{a}}$, Verònica Zaragoza ${ }^{\mathrm{b}}$

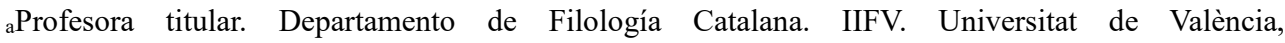
eulalia.miralles@uv.es. b Profesora colaboradora. Universitat Oberta de Catalunya, vzaragozago@uoc.edu.

\begin{abstract}
This paper focuses on the description and analysis of an innovative educational experience in the field of the Baroque Catalan Literature. This experience, which has recently been implemented as a pilot test in universities thanks to the a project of innovative teaching, concentrates on the use of tecnological resources and the development of an initial project of Transmedia Storytelling to foster the motivation of students and generate a more meaningful learning. This case study is grounded in the implementation of the resources and active methodologies of the course on Early Modern Catalan Literature, traditionally based on conventional educational strategies and despised by the historiography. With this goal in mind, we address the theoretical aspects and preliminary goals and explain its developments, to try to reveal the pedagogical benefits that an experience like that one we present here can imply for teaching old literature at the universitarian level.
\end{abstract}

Keywords: Transmedia Storytelling; use of TICs in the educational process; active learning; cooperative learning; project of innovative teaching; higher education; Baroque Catalan Literature.

\footnotetext{
Resumen

Esta comunicación se centrará en la descripción y el análisis de una experiencia docente innovadora en el ámbito de la enseñanza de la literatura catalana barroca. La experiencia, implementada recientemente como actividad piloto en aulas de nivel de enseñanza superior gracias a la concesión de un proyecto de innovación docente, se centra en el uso de los recursos tecnológicos y en el establecimiento de un proyecto de narrativa transmedia inicial, con el fin de favorecer una mayor motivación en los alumnos y revertir en un aprendizaje activo más significativo. Este estudio
} 
De las aulas universitarias a la red. Un proyecto innovador aplicado al aprendizaje y difusión de la literatura catalana barroca

de caso se cimienta en la implementación de los recursos y metodologías activas en la asignatura de Literatura Catalana Moderna, tradicionalmente denostada por la historiografía y basada en entornos educativos convencionales. Para ello, planteamos los aspectos teóricos y objetivos previos a la puesta en marcha del proyecto y explicamos el desarrollo del mismo, para tratar de deslindar los beneficios pedagógicos que una experiencia como la que aqui planteamos puede implicar en la enseñanza de literatura antigua en niveles universitarios.

Palabras clave: narrativa transmedia; uso de las TICs en el proceso de educativo; aprendizaje activo; aprendizaje cooperativo; proyecto de innovación docente; educación superior; literatura catalana barroca.

\section{Introducción: algunas precisiones y delimitación teórica}

El presente trabajo pretende explicar y poner en valor los beneficios pedagógicos de una experiencia de innovación docente aplicada como actividad piloto a la enseñanza universitaria de literatura catalana barroca, la cual se había venido sustentando en metodologías tradicionales de enseñanza-aprendizaje: la lección magistral y el comentario de texto del profesorado en el aula, y el método de evaluación clásico (realización de ejercicios periódicos y examen final), sin atender al gran abanico de posibilidades que las nuevas tecnologías pueden ofrecer al docente.

Como veremos, esta experiencia pretende superar dichos entornos convencionales, centrándose precisamente en la aplicación de las tecnologías de la información y la comunicación (TICs) y, más específicamente, en una propuesta de adaptación de un proyecto colectivo de narrativa transmedia, como elementos que pueden contribuir firmemente al aprendizaje autónomo y a una mayor participación e implicación de las y los estudiantes en la mejora de los procesos de enseñanza-aprendizaje.

En particular, en este estudio planteamos y analizamos los primeros resultados del proyecto de innovación educativa y mejora de la calidad docente concedido por la Universitat de València a la propuesta «De l'aula a la xarxa: literatura catalana del barroc» (UVSFPIE_RMD16-418839), coordinado por Eulàlia Miralles (con formación y experiencia específica en entornos de enseñanza virtual) y adscrito al 'Programa B: Renovación de metodologías docentes', que según convocatoria «persigue experimentar escenarios de ensayo de nuevos instrumentos metodológicos y renovadas técnicas de mejora de los procesos de enseñanza-aprendizaje». En definitiva, con este estudio de caso que aportamos, adaptado a un nivel superior de la enseñanza de la literatura catalana antigua, pretendemos proporcionar nuevos datos al debate sobre los beneficios pedagógicos de la aplicación de recursos tecnológicos de apoyo al aprendizaje (Canós \& Ramón 2005). Más concretamente, queremos mostrar la idoneidad de plantear un proyecto de práctica colectiva de transmedia, explorada con fines pedagógicos con el objetivo de ayudar a los alumnos en la profundización del conocimiento de ciertos autores del período estudiado, desde planteamientos nunca abordados en el campo de la enseñanza de la literatura catalana. En 
ese sentido, no hace falta justificar que la planificación de dicho proyecto y su aplicación a la disciplina de la enseñanza de la literatura venía motivada por la necesidad de flexibilizar los procedimientos educativos para adaptarse a las necesidades que plantea una sociedad como la nuestra, la llamada Sociedad de la Información y el Conocimiento, que debería fundamentarse en sistemas de enseñanzas caracterizados por la «modularidad y la interconexión» (Salinas, 2004).

Por otra parte, en cuanto a la utilidad de la narrativa transmedia planteada en el campo de la innovación educacional (también conceptualizada como transmedia storytelling, crossmedia o narrativas multimedia), más allá de su presencia en los ámbitos del entretenimiento, de la información y de la amplia cultura, ${ }^{1}$ en la última década han sido ampliamente avalados sus usos pedagógicos en contextos de educación secundaria y superior (Ossorio 2014) debido, entre otras cuestiones, a la mayor implicación emocional de los alumnos y al papel claramente autónomo que estos asumen en este tipo de experiencias pilotadas por los mismos, frente al papel orientador y mediador ejercido por el/la docente, alejado del de los entornos educativos tradicionales.

Antes de empezar, debemos precisar que por narrativa transmedia se entiende «Aquella forma de producir contenidos que construye un relato global a través de relatos independientes en diferentes formatos, y cuya convergencia aporta una historia única que se complementa con las historias y características de cada una de las partes que forman el todo. En ella, el público deja de ser un ente pasivo y pasa a interactuar combinando los distintos medios que tiene a su alcance para crear a su manera el discurso y obtener la información que reclama, así como para intercambiar con otros usuarios o consumidores datos, consejos y experiencias basadas en la historia central y en las historias parciales» (Ossorio 2013: 489).

Pese a que ha sido poco explotada como recurso docente en la enseñanza de las literaturas, ${ }^{2}$ no hay duda de que la narrativa transmedia puede abrir la puerta a nuevas posibilidades de aprendizaje en un ámbito tradicionalmente árido y poco atractivo para las y los estudiantes como había sido el de la literatura catalana moderna. Por esta razón, a través de un proyecto de estas características, se conminó al alumnado a explorar y a explotar nuevas plataformas narrativas y medios digitales que les permitiesen crear un contenido unitario relacionado con la asignatura ('la historia global') y a difundirlo a través de los variados canales digitales de los que son usuarios, con resultados positivos tanto a nivel cognitivo como socio-afectivo, como veremos.

1 Aunque no se base en proyectos puramente de aplicación docente, es interesante revisar el espacio 'Narrativa Interactiva' del Grado de Multimedia de la Universitat Oberta de Catalunya $<\underline{\text { http://multimedia.uoc.edu/blogs/narrativa/es/> }}$, con útiles recursos y los trabajos realizados por los estudiantes y profesores [Consulta: 12/01/2017].

2 En este sentido, resulta una experiencia significativa en la difusión de contenidos el proyecto transmedia inspirador Las Sinsombrero: «...un proyecto crossmedia, que utiliza diferentes formatos y plataformas (televisión, internet y publicación), con el objetivo de recuperar, divulgar y perpetuar el legado de las mujeres olvidadas de la primera mitad del siglo XX en España. Desde las figuras femeninas de la Generación del 27 hasta todas aquellas mujeres que con su obra, sus acciones y su valentía fueron y son fundamentales para entender la cultura y la

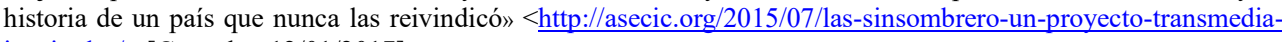
inspirador/> [Consulta: 12/01/2017].

Congreso In-Red (2017) 


\section{Objetivos}

El principal objetivo planteado a las y los estudiantes a través de la experiencia docente que aquí se analiza fue específicamente el diseño y la pretensión de implementación de un proyecto de narrativa transmedia, a través de un uso optimizado de las TICs y los medios combinados (creación de perfiles y cuentas en las redes sociales más influyentes como Facebook, Twitter, representación de obras de teatro, composición de canciones y vídeos grabados para ser reproducidos en medios digitales, hasta la creación de un wikiproyecto, etc.): con ello se les invitaba a confeccionar, a través de múltiples plataformas de expresión y perspectivas, una propuesta de discurso unitario dedicado a dar a conocer a algunos de los principales autores de la literatura catalana moderna, de manera parcelada, pero necesariamente con contenidos interconectados entre sí. Por lo tanto, el objetivo principal del proyecto era que entre todas y todos los alumnos, supervisados por el profesor-guía, se pudiese construir un relato combinado y colectivo sobre el barroco literario, basado en sus principales protagonistas o temas, y que los relatos, creados de manera independiente, convergiesen en la misma historia global.

\subsection{Justificación múltiple del proyecto: profundización y creación de contenidos, mayor índice de participación en las aulas y difusión del período en la red}

Por motivos históricos suficientemente conocidos y explorados, la literatura catalana de la edad moderna ha ocupado un lugar secundario en los planes de estudio de literatura catalana (Rossich 2011). Aunque de unos años a esta parte, la academia ha superado la antinomia Decadència/Renaixença, los estudiantes llegan a la universidad con el prejuicio de la Decadència interiorizado, porque la literatura catalana que estudian en Secundaria y en Bachillerato prolonga, mayoritariamente, la visión de esta etapa como un período literariamente oscuro, decadente y sin excesivo interés; en algunos casos concretos el panorama es incluso peor, puesto que el alumnado ni tan solo es capaz de enumerar algún autor u obra de dicha época. Teniendo en cuenta esta situación, se consideró conveniente y útil explorar en un nivel universitario nuevos procesos experimentales y aplicar ciertos cambios metodológicos que permitiesen a los alumnos adentrarse en un conocimiento más profundo de este período. Se pretendía con ello la creación de un proyecto narrativo innovador, a través de una iniciativa que, de hecho, contribuiría también a la creación de contenidos multimedia contrastados que pudiesen ser relanzados con las nuevas tecnologías, dirigidos no solo al público del ámbito universitario, sino a un público consumidor de contenidos más amplio (que pudiese responder, con una actitud claramente activa). Con ello, el proyecto adquiría un gran interés por partida doble.

Dicho esto, otros de los objetivos concretos que perseguía dicha experiencia docente estaban encaminados a una mayor profundización del aprendizaje y a la dinamización del entorno docente, y se pueden resumir en:

1. Motivar una mayor atención e implicación de los alumnos.

2. Estimular su capacidad de reflexión sobre el período literario. 
3. Generar nuevos roles en el entorno docente y nuevos procesos reflexión que parten del alumno y que se expanden más allá de las clases presenciales, en base al aprendizaje cooperativo y al trabajo colaborativo.

Efectivamente, la experiencia estaba orientada a mejorar la adquisición de habilidades y competencias establecidas en el Documento-Marco sobre la Integración del Sistema Universitario Español en el Espacio Europeo de Educación Superior (EEES), en torno a metodologías docentes dinámicas (rol activo y autónomo en el aprendizaje y en la generación de nuevos conocimientos, desarrollo de la capacidad de reflexión y síntesis...) y colaborativas, pero partía de un modo especial de la voluntad de acercar emocionalmente a los estudiantes del Grado en Filología Catalana a uno de los períodos más desconocidos de la literatura catalana, el de la edad moderna, y, más concretamente, el barroco, con la finalidad de hacerles comprender la vigencia del discurso de los autores barrocos en nuestros días y su utilidad. Por ello, la propuesta pretendía enfatizar el rol activo del estudiante, implicado desde un primer momento, ya fuere identificando los posibles canales de creación y de difusión del discurso (según su capacidad de retroalimentación con el público consumidor de los contenidos, los propios estudiantes u otros usuarios), así como los puntos cardinales de la historia unitaria que debían narrar cada uno de ellos. Sin embargo, el trabajo previo a la planificación fue diseñado y supervisado por los profesores participantes en el proyecto, que aportaron la edición de los textos y las fuentes e información contrastada que permitiese a los estudiantes empezar a crear contenidos, así como las líneas fundamentales que debía seguir el proyecto, según los principios básicos de la transmedia tales como el Worldbuilding o construcción de un mundo unitario (un tema, obra o autor determinado); la serialidad; la multiplicidad; la expansión; la subjetividad...

\section{Desarrollo de la innovación}

\subsection{Diseño previo del proyecto}

Dicho esto, la experiencia docente que aquí se analiza se ha aplicado para el curso 20162017 (1er semestre, septiembre-enero), en los aularios de la Facultat de Filologia, Traducció i Comunicació de la Universitat de València; concretamente con los alumnos de $4^{\circ}$ del Grado de Filología Catalana, en la asignatura de carácter obligatorio "Literatura catalana de l'edat moderna", impartida por dos profesores, que contaba con una matrícula considerable, de 48 estudiantes (para los cuales se presuponía una buena alfabetización en el mundo digital). Antes de abordar las líneas de trabajo, cabría explicar que el grado de Filología Catalana de la Universitat de València cuenta con dos asignaturas que abordan este período en su plan de estudios: en $1^{\circ}$, "Literatura catalana medieval i moderna" y, en $4^{\circ}$, "Literatura catalana de l'edat moderna". Aunque en la asignatura de $1^{\circ}$ se asignan tan solo 3 créditos para el desarrollo de los contenidos sobre los siglos XVI-XVIII, los estudiantes pueden entrar en contacto con la producción literaria del período y se les dota de los instrumentos necesarios básicos (periodización, contexto histórico-cultural, etc.) para que puedan afrontar con garantías de éxito la asignatura de $4^{\circ}$, más monográfica. Ésta, "Literatura catalana de l'edat moderna", de 6 créditos $(3+3)$, combina clases teóricas

2017, Universitat Politècnica de València 5 
expositivas sobre los elementos de construcción del discurso en el renacimiento, barroco e ilustración, y clases prácticas de comentario de textos, desdobladas con la mitad del alumnado, que se busca que sean esencialmente participativas. En definitiva, la metodología propia del aprendizaje convencional, basado en parte en la lección magistral, permite al alumnado acceder a los textos y entenderlos, pero la experiencia docente hasta la fecha venía corroborando que éstos no superaban la distancia existente con la literatura del período: son capaces de diseccionarla pero incapaces de sentirla emocionalmente puesto que la perciben lejana, distante.

\subsection{Implementación del proyecto}

En lo que respecta a la implementación del proyecto, puesto que la asignatura de $4^{\circ}$ es de carácter más monográfico y se basa en una selección forzosa de algunos textos o autores representativos, y asumiendo, además, que el grupo de estudiantes que lo suelen cursar es más reducido, decidimos experimentar una primera fase del proyecto con este grupo, menos masificado, puesto que los niveles educativos superiores apuntan hacia un feedback individual útil menor cuando las dimensiones del grupo es mayor. La duración de dicha asignatura es de un semestre (unas 16 semanas) con cuatro horas de clase presencial a la semana, lo que consideramos que nos debiera permitir alcanzar nuestros objetivos en un plazo de tiempo más prolongado. Por otro lado, por razones prácticas, se optó por acotar cronológicamente el contexto al siglo XVII, concerniente al barroco, el más desarrollado en las clases presenciales.

Así pues, establecido el grupo de trabajo y diseñada la propuesta sobre el siglo XVII, en la primera sesión del curso, se planteó al alumnado la posibilidad de participar de forma voluntaria en una experiencia docente de narrativa transmedia utilizando el instrumento que usan habitualmente para comunicarse y aprender: la red. Para ello, se establecieron adecuadamente los objetivos y premisas de la actividad, planteada solo como complemento de las clases presenciales basadas en las metodologías tradicionales ya comentadas. Se propuso a los alumnos interesados la posibilidad de trabajar voluntariamente en este proyecto novedoso, planteado sin repercusiones en la evaluación de la asignatura. Posteriormente, en las sesiones iniciales, desde posicionamientos del aprendizaje cooperativo, se pidió a los alumnos que reflexionaran sobre los problemas derivados de la enseñanza de un período tradicionalmente minusvalorado y maltratado, con obras prácticamente desconocidas para ellos, como lo es la época moderna. Puesto que el proyecto requería una planificación previa, al delimitar el mensaje global que luego difundirían las y los alumnos, se estableció ésta sobre la base de la necesidad de difundir los autores modernos y sus obras, desde diferentes prismas, pero de manera unitaria.

En segundo lugar, para reparar este desconocimiento, se les pidió que 'inventaran' nuevas formas de transmisión y difusión de la literatura de esta época de forma lúdica, introduciendo en este aspecto la gamificación como herramienta docente para incentivar un aprendizaje activo y entretenido. De hecho, a pesar de que la participación en este proyecto no era una actividad evaluable, se decidió invertir la dotación económica del proyecto en la 
compra de materiales educativos para los alumnos participantes, como premio que les fue comunicado cuando hubo finalizado dicha experiencia docente.

Además, con la voluntad de que se sintieran artífices del proyecto que iban a desarrollar, las instrucciones y directrices que los profesores dieron al alumnado fueron mínimas. En este sentido, consideramos que uno de los aspectos más interesantes de esta iniciativa y que confiere valor al proyecto, de acuerdo con las nuevas líneas de innovación docente, es que convierte al profesor en guía, sin abandonar a los alumnos en este camino de aprendizaje autónomo (Solá, 2004).

Los puntos establecidos previamente con las y los alumnos para el diseño de esta práctica de transmedia fueron:

1. Se establecieron 7 grupos de trabajo conformados por 3-6 estudiantes, que trabajaron de manera coordinada, con un portavoz encargado de coordinar al equipo y de dialogar con el profesor para hacerle llegar las cuestiones y problemas metodológicos o de contenido a los que se enfrentaba el grupo. El profesor tan sólo supervisaba los trabajos de cada grupo y asegura la calidad del contenido de cada proyecto concreto, caso que fuera necesario.

2. Se precisaron las parcelas y temas de trabajo, centrados siempre en un texto barroco en catalán. Para ello, se incentivaron las actividades llevadas a cabo concretamente sobre autores y obras específicamente valencianas aunque podían desarrollar cualquier iniciativa que se ocupara del área lingüística catalana (aparte de Valencia, también de Cataluña, las Islas Baleares, el Rosellón o el Alguer).

3. Para el diseño previo de las diferentes plataformas de la acción transmedia, se invitó a las y los alumnos a imaginar y proponer narrativas para difundir esta literatura en la red, estableciendo previamente la disponibilidad y accesibilidad de varios recursos. Se les concedió libertad en la decisión de los canales y formato de difusión del contenido, de cada parcela o microproyecto, que debían combinarse equilibradamente con una propuesta de contenido acorde a los objetivos establecidos. Y es que cabe tener presente que la narrativa transmedia «disecciona el mensaje en pequeños mensajes independientes, cada uno de los cuales será distribuido después con un formato concreto y en una serie de plataformas concretas con la intención de que sea el receptor quien establezca qué mensajes consumirá para comprender la idea transmitida» (Ossorio 2014: 26-27). Como ejemplo que les pudiese motivar, se les ilustró y motivó con el vídeoclip satírico La vida es sueño de Aldo Narejos (como Calderón de la Barca), Berto Romero (como Miguel Cervantes) y Ana Morgade (como sor Juana Inés de la Cruz), tres personajes mediáticos que reivindican la vigencia, la utilidad y la modernidad del discurso barroco a través de autores paradigmáticos de la literatura española de la época. Lo hacen al son del ritmo musical pegadizo del reggaetón, que busca conectar con los jóvenes a través de una vía que les resulte conocida pero precisamente para denunciar la pérdida de referentes culturales y literarios clásicos

2017, Universitat Politècnica de València 
De las aulas universitarias a la red. Un proyecto innovador aplicado al aprendizaje y difusión de la literatura catalana barroca

y el empobrecimiento musical, léxico y cultural derivados de ciertos productos musicales comerciales de moda.

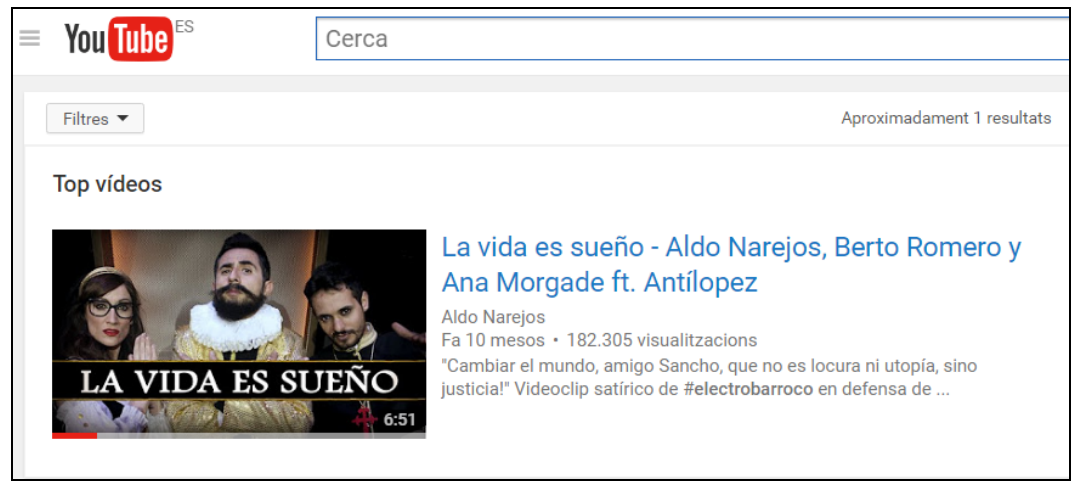

Fig. 1 Video “La Vida es sueño”. Fuente: Youtube

4. Se fijaron como lenguas de difusión de la actividad el catalán, el español y el inglés, de acuerdo con uno de los objetivos complementarios de la experiencia innovadora: la máxima difusión de los contenidos creados por los alumnos y alumnas y la transferencia de conocimientos a la sociedad y visibilidad en entornos más amplios que el universitario.

Establecidas las líneas esenciales del proyecto, y después de dos sesiones presenciales en el aula, se identificaron las limitaciones del alumnado, y el profesorado les dispuso algunas habilidades y herramientas que permitieran superarlas. Se optó, pues, por el coaching educativo, sugiriéndoles a continuación varias propuestas de desarrollo del proyecto, que fuesen complementarias para los diferentes proyectos planteados por ellos. Aunque en su momento no se estableció la actividad explícitamente como un proyecto transmedia, en la etapa de configuración de las propuestas de los canales y contenidos de difusión, se orientó de manera unitaria el trabajo colectivo, estableciendo puntos de contacto entre los diferentes sectores y temas de trabajo para crear una narrativa interactiva unitaria.

\section{Primeros resultados}

La implementación del proyecto transmedia planteado, en un nivel inicial, como complemento de la asignatura "Literatura catalana de l'edat moderna" se ha concretado en varias iniciativas, interactivas entre ellas, que reflejan la participación activa de las y los alumnos y la dinamización de un entorno docente, que va más allá de las aulas, a través de:

1. Creación y actualización de páginas o perfiles en redes sociales como Facebook, centradas en el período en general, como Barroc a la carta (con una descripción que 
explicita los propósitos de la iniciativa: «El Barroc no només té espai als manuals de literatura, i aquesta pàgina vol ser un espai per compartir-lo») $<$ https://www.facebook.com/Barroc-a-la-carta-362885270729896/>, o creadas sobre autores específicos, como el clérigo dietarista valenciano Joaquim Aierdi $<$ https://www.facebook.com/joaquimaierdi/> o el clérigo Franscesc Mulet, al que se ha dedicado una página con teñido carácter escatológico y satírico propio de la época, como sugiere su título Miss Barrocful <https://www.facebook.com/missbarrocful/> -con la descripción significativa: «Miss Barrocful és una iniciativa per fer-vos conéixer un autor del Barroc valencià: el Pare Mulet. Les creadores d'aquesta pàgina formen part de l'estudiantat de Filologia Catalana a la UV i, en concret, de l'assignatura Literatura catalana de l'edat moderna; és per això que s'ha decidit crear aquest compte. Francesc Mulet (16241675), o més conegut com al Pare Mulet, va ser un frare dominic i predicador que va conrear poesia satírica de temàtica escatològica, com és l'obra en què nosaltres ens centrarem: El tractat del pet.»)- y el correspondiente perfil en otra red social de numerosos usuarios: Instagram https://www.instagram.com/missbarrocful/ (imitando el estilo de la más famosa entre los jóvenes marca de artículos de regalo y de frases motivadoras 'Mr. Wonderful'):
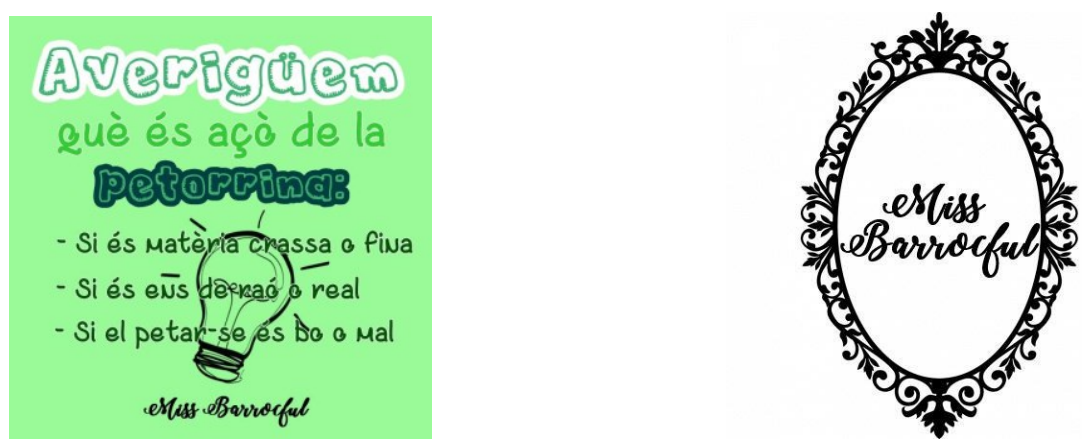

Fig. 2 i 3 Fotografias de la página de facebook "Miss Barrocful" creada por los alumnos en el marco del proyecto transmedia

Como se infiere de estas fotografías, sobre el contenido de las páginas, las y los alumnos mostraron un gran interés en el mantenimiento y actualización de los espacios interactivos, con recreaciones fotográficas acompañadas de transcripciones de fragmentos de obras barrocas, con gran inmersión e implicación de los mismos.

2. Creación y mantenimiento de un blog dedicado a Bernat Català de Valeriola, con entradas con la trascripción de su obra acompañadas de fotografías documentadas $<\underline{\text { http://bernardocataladevaleriola.blogspot.es }}>$ 
De las aulas universitarias a la red. Un proyecto innovador aplicado al aprendizaje y difusión de la literatura catalana barroca

3. Grabación y elaboración de vídeos didácticos, con la participación e implicación de los propios estudiantes en la recopilación, lectura, declamación, representación y canto de los versos de los poetas y dramaturgos del período:

3.1. Vídeo 1: «Romanç que escrigué Fontano embarcat, caminant per lo riu Mossa (Francesc Fontanella)» $<$ https://www.youtube.com/watch?v=yayM4ULeIM\&feature=youtu.be $>$

3.2. Vídeo 2: «Teatre de l'edat moderna: Entremés de la sogra i la nora» $<$ https://www.facebook.com/lia.gutie/videos/10211546699847860/>

3.2. Vídeo 3: «Del Barroc al Present» (sobre uno de los poemas del libro Poesia Festiva, del autor Carles Gasulla d'Ursino) $<$ https://www.youtube.com/watch?v=BbjBzm lpdI\&feature=youtu.be $>$

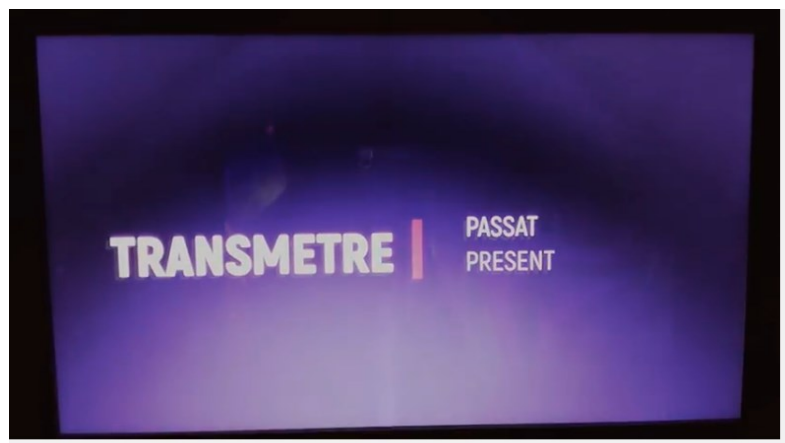

Fig. 4 Vídeo "Del Barroc al Present", elaborado por estudiantes. Fuente: Youtube

\section{Conclusiones}

En este artículo hemos explicado con qué motivación se trató de experimentar con recursos de innovación docente en una asignatura de enseñanza de literatura catalana moderna, tradicionalmente mal conocida por los estudiantes: estos recursos se basan fundamentalmente en el uso de las TICs como apoyo y profundización de los contenidos, y concretamente en el diseño de un proyecto transmedia que permita la difusión de contenidos relacionados con la literatura catalana barroca. Por ello, hemos señalado aspectos teóricos con los que conceptuar la Narrativa Transmedia, para poder aplicarla como recurso de innovación en la enseñanza universitaria. Después de haber delimitado los objetivos y aspectos relacionados con el diseño e implementación del proyecto, hemos explicado los resultados concretos de estas experiencias.

Algunas de las iniciativas llevadas a cabo por los grupos de trabajo en esta prueba piloto de de la Universitat de València aplicada a la asignatura obligatoria "Literatura catalana de l'edat moderna", nos han permitido apuntar algunos de los resultados más destacados 
observados hasta el momento, que muestran los beneficios de la implementación de propuestas de innovación docente como estas en el ámbito de la enseñanza de la literatura, en la línea de lo que han apuntado otros trabajos ${ }^{3}$ :

- la dinamización de la aula y participación voluntaria de la mayoría de las y los estudiantes de la asignatura (32 sobre 48), que han demostrado una mayor implicación, atención y asimilación de los contenidos de la asignatura, a través de la apropiación y recreación de los textos para crear nuevos materiales;

- el avance en el aprendizaje autónomo pero fundamentalmente cooperativo, partiendo del trabajo en grupos, y la estimulación de la cohesión del grupo, mediante actividades externas al entorno docente (elaboración de fotografías en lugares emblemáticos de la ciudad, grabación de vídeos y vídeoclips...);

- el desarrollo complementario del trabajo de las competencias (habilidades comunicativas y de síntesis, selección y citación de la información...) a partir de actividades interactivas entre ellas y totalmente voluntarias;

- la dinamización y la gamificación del entorno educativo, que facilitó además la asunción de roles activos y autónomos de las y los alumnos con el apoyo del profesorado...

En cuanto a las mejoras concretas obtenidas tras la realización de esta actividad docente, los excelentes resultados generales de una prueba de síntesis final sobre la literatura del período nos permitió inferir una mejor comprensión de los contenidos de la asignatura, y una mejor valoración de la importancia de estas interacciones (mayor visibilidad del período, problemas historiográficos en los que siempre se había visto envuelto...), lo cual nos permitió valorar como positiva la implementación de la actividad. Además, efectivamente, uno de los beneficios advertidos en esta experiencia que hemos explicado es que la excelencia educativa, la calidad y las buenas prácticas docentes quedan garantizadas en la medida de que se trata de un proyecto que requiere un diálogo entre profesorado y alumnado que puede contribuir, sin duda, a aumentar el feedback que favorece el aprendizaje.

Por dicho beneficio y otros aspectos apuntados más arriba, consideramos que es interesante seguir las líneas estratégicas implementadas con la concesión de este proyecto de innovación docente, pero ampliando las plataformas de difusión de la literatura catalana barroca, a través de la consolidación de los canales ya creados para ello, pero también con la creación de nuevos medios que permitan consolidar el proceso de innovación docente en

\footnotetext{
${ }^{3}$ Así lo concluyen otros estudios centrados en la aplicación de la narrativa trasnmedia a las aulas universitarias: «La narrativa transmedia es una estrategia de comunicación aplicable al mundo educativo universitario. El hecho de que la narrativa transmedia sea, en resumen, una forma de contar historias o emitir mensajes, permite que sea aplicable al mundo educativo, por cuanto éste supone la transmisión de mensajes cuyo contenido son conocimientos de las distintas áreas del saber. Por ello, las estrategias transmedia aportarían, al igual que lo hacen en los entornos de ficción, información o publicidad, posibilidades de enriquecimiento de los mensajes originales, a la vez que potenciaría la participación de los alumnos y fomentaría la necesidad de reforzar su autosuficiencia y su capacidad crítica, al exigirles seleccionar y elegir el camino a seguir, discriminar información, ampliar lo ofrecido y, en definitiva, convertirse en protagonistas de su propio proceso de aprendizaje.» (Ossorio 2014: 36).
} 
De las aulas universitarias a la red. Un proyecto innovador aplicado al aprendizaje y difusión de la literatura catalana barroca

los aularios de literatura catalana, muy anclados aun en la metodologías y los entornos tradicionales.

Entre los nuevos proyectos que podrían pender de esta experiencia de narrativa transmedia cabría, por ejemplo, la implementación de una página web interactiva, gestionada por el alumnado, que recogiese todo este tipo de iniciativas en la red. Para ello, con el fin de mejorar la experiencia docente, una de las propuestas que consideramos que podrían enriquecer el proyecto, con una mayor participación de las y los estudiantes sería el establecimiento de un nuevo criterio significativo: proponiendo este proyecto como trabajo evaluable de la asignatura, el nombre de estudiantes aumentaría y, por lo tanto, también las iniciativas presentadas.

Vistos los resultados positivos de la experiencia de innovación docente, esta iniciativa deberá ser planteada en un futuro proyecto coordinado entre diferentes universidades que imparten la asignatura, reparando algunas mejoras a introducir, lo que contribuiría a incrementar la implicación activa del alumno en los procesos de aprendizaje, un mayor número de canales de difusión en los que visibilizar nuestras letras barrocas y la creación de una red de estudiantes implicados en una geografía amplia.

\section{Referencias}

CANÓS L. \& RAMÓN F. (2005): “Aplicación de las nuevas tecnologías para el trabajo autónomo del alumno" en Actas del XX Simposium Nacional de la Unión Científica Internacional de Radio. URSI. Gandía: Universitat Politècnica de València, p. 1-4.

Ossorio, M.A. (2013): "Posibilidades de la Narrativa Transmedia aplicada al Periodismo" en F. Ortega, L. Cardeñosa (ed.), Las media enterprises y las industrias culturales. Investigar la comunicación y los nuevos medios, Salamanca: Universidad de $\quad$ Salamanca, pp. $\quad$ 488-497 $<\underline{\text { http://comunicacion3punto0.files.wordpress.com/2013/06/comunicacion3punto0libroactas2012.pdf }>}$ [consulta: 25/03/2017].

OSSORIO, M.A. (2014): “Aplicación de la narrativa transmedia en la enseñanza universitaria en España: Aprendizaje colaborativo, multiplataforma y multiformato". Revista Internacional de Tecnología, Ciencia y Sociedad. vol. 3, núm. 2, < http://tecnociencia-sociedad.com $>$ [republicado de Revista Internacional de Tecnología, Conocimiento y Sociedad 3(2), 2014 (pp. 25-38)] [consulta: 25/03/2017].

Rossich, A. (2011). "La literatura catalana de l'edat moderna: historiografia i crítica" en Panorama crític de la literatura catalana. Edat moderna. Barcelona: Vicens Vives, 17-42.

SALINAS, J. (2004). "Innovación docente y uso de las TIC en la enseñanza universitaria”. Revista de Universidad y Sociedad del Conocimiento (RUSC), vol. 1, n $\mathrm{n}^{\mathrm{o}}$ 1. UOC. <http://www.uoc.edu/rusc/dt/esp/salinas1104.pdf $>$ [Consulta: 10/01/2017].

SolÀ, M. (2004). "La formación del profesorado en el contexto del Espacio Europeo de Educación Superior Avances alternativos". Revista Interuniversitaria de Formación del Profesorado, vol. 18, núm. 3, p. 91-105. 


\title{
La metodología de clase inversa en la UPV: Una experiencia en el laboratorio de matemáticas
}

\author{
Carmen Coll, Damián Ginestar, Esther Sanabria y Elena Sánchez \\ Departamento de Matemática Aplicada, Universitat Politècnica de València \\ (ㅆcoll@mat.upv.es,dginesta@mat.upv.es, esanabri@mat.upv.es y esanchezj@mat.upv.es)
}

\begin{abstract}
In this paper, we analyze the experience of introducing the flip teaching methodology in the laboratory practices of Mathematics II. In this subject our students learn differential equations, Laplace transform and their applications, concepts that a priori are not too attractive to students of engineering degrees, but are very useful in the development of different subjects that are part of their training. In order to make the students more motivated, we have redesigned the activities carried out in Mathematics II practices, preparing several materials and strategies that activate the interest of the students. Some of these materials are available before practice sessions and others, such as problem-solving, discussion or debates, are used in the classroom itself at the time of practice. The main novelty is the screencast videos we have recorded, where we explain how to approach the different types of exercises that we solve using the program Mathematica. This increases student opportunities for active learning in class, where the teacher can offer a more personalized guidance and interact better with the students. The interaction with the teacher and the other classmates generates an environment that facilitates learning, as we have seen through specific evaluation tests.
\end{abstract}

Keywords: Flip teaching (or flipped classroom), methodology, evaluation, active participation.

\footnotetext{
Resumen

En este trabajo analizamos la experiencia de introducir la metodología denominada clase inversa (o 'flip education') en las prácticas de laboratorio de Matemáticas II. En esta asignatura trabajamos ecuaciones diferenciales, transformada de Laplace y sus aplicaciones, conceptos que a priori no resultan demasiado atractivos para los alumnos de los grados de ingeniería, pero resultan de gran utilidad en el desarrollo de las distintas materias que forman parte de su titulación. Con el fin de conseguir una mayor motivación entre nuestro alumnado, hemos utilizando la metodología de clase inversa en las prácticas de Matemáticas II, rediseñado las actividades realizadas en dicha asignatura y preparado materiales que activen el interés de los alumnos.
} 
La principal novedad son los vídeos 'screencast' que hemos grabado, donde explicamos cómo abordar los distintos tipos de ejercicios que trabajamos utilizando el programa Mathematica, de manera que el tiempo que los alumnos pasen en el laboratorio con el profesor lo aprovechen para resolver las dudas que les hayan surgido y aclarar los conceptos principales de cada sesión. Esta interacción con el profesor y el resto de compañeros genera en el aula un ambiente que facilita el aprendizaje, como hemos comprobado mediante pruebas de evaluación especificas.

Palabras clave: clase inversa, metodología, evaluación, participación activa.

\section{Introducción}

Las ecuaciones diferenciales siempre han formado parte de los contenidos de las asignaturas de matemáticas de todas las ingenierías, en particular, de las impartidas en las titulaciones de la Escuela Técnica Superior de Ingeniería del Diseño (ETSID) de la Universitat Politècnica de València (UPV). Actualmente, estos contenidos se imparten en Matemáticas II, que es una asignatura troncal del segundo curso de las titulaciones: Grado en Ingeniería Eléctrica, Grado en Ingeniería Electrónica Industrial y Automática y Grado en Ingeniería Mecánica. Tanto los contenidos como la metodología de esta asignatura han experimentado cambios importantes: los contenidos han pasado de tener un carácter más teórico a combinarse con las prácticas de laboratorio, en las que trabajamos con el apoyo del programa Mathematica de Wolfram (Wolfram Research, 2017).

Puesto que en la actualidad nuestros alumnos son nativos tecnológicos resulta natural plantearse de qué manera podemos introducir las nuevas tecnologías en las aulas para que éstas contribuyan a mejorar su motivación y consoliden su formación. En nuestra asignatura las prácticas se realizan en un laboratorio informático, entorno que consideramos óptimo para dedicar parte del tiempo a actividades que involucren más activamente al alumnado.

Estas reflexiones nos han llevado a participar en el Proyecto clase inversa de la UPV (PCI, 2017) y, por tanto, a diseñar nuevas actividades y estrategias para las clases de prácticas, de manera que los alumnos trabajen algunos contenidos de cada sesión (suficientemente accesibles a su nivel) fuera del aula y de manera autónoma. En nuestro caso, los alumnos aprenden de forma no presencial a través de la visualización de vídeos 'screencast' complementados con apuntes, mientras que otras actividades, como resolución de problemas, discusiones y debates, se realizan en el aula.

Nos resulta interesante aplicar la metodología de clase inversa en las prácticas de la asignatura, ya que los alumnos pueden utilizar fuera del aula el programa informático con el que vamos a trabajar, puesto que la UPV dispone de licencias docentes del programa Mathematica para la comunidad universitaria. El alumno cuenta con todo el material, tanto en formato de apuntes como en forma de vídeos, lo que le permite realizar una puesta a punto previa a cada sesión de prácticas. Esto conduce a que el profesor interactúe de forma más activa con los alumnos, pudiendo destinar parte del tiempo en el aula para aclarar las dudas que 
les hayan podido surgir en la previsualización del material, o bien profundizar en las distintas estrategias utilizadas en cada sesión. De esta forma, los roles de alumno y profesor cambian y, por tanto, estamos utilizando la metodología conocida como clase inversa (Lage et. al. 2000).

Esta metodología, también conocida en la literatura como 'flip education' o 'flipped classroom', permite convertir el aula en un lugar para resolver problemas, avanzar conceptos de forma colaborativa (Bergmann et. al. 2012), dándole así un valor añadido a la actividad del profesor. Por otro lado, sabemos que, en otras universidades, han sido desarrolladas experiencias en esta misma línea con buenos resultados dentro de nuestra materia (Yong et. al. 2015, Kinney 2016).

En nuestro caso, con esta metodología los estudiantes están más motivados para ir a clase y participan de forma activa en todas las actividades que se les propone. Por otra parte, sus opiniones sobre esta metodología son bastante positivas, aunque siempre existen alumnos reticentes al cambio.

\section{Objetivos}

Los objetivos generales que pretendemos alcanzar realizando esta experiencia son:

- Consolidar los resultados de aprendizaje de los alumnos de Matemáticas II adoptando la clase inversa como metodología en las prácticas de la asignatura.

- Conseguir que los alumnos alcancen las competencias trabajadas tras las acciones realizadas en cada práctica y, así, conseguir el aprendizaje del programa Mathematica en la materia que nos ocupa.

Para ello, los objetivos específicos que nos proponemos al iniciar esta nueva metodología son los siguientes:

- Crear una unidad de aprendizaje en la plataforma PoliformaT de la UPV donde estén diseñadas las prácticas que vamos a realizar a lo largo del curso.

- Elaborar material didáctico en forma de apuntes.

- Diseñar y grabar vídeos 'screencast' para que sean visualizados por el alumno con anterioridad a la clase presencial.

- Preparar tareas cortas que los alumnos deben realizar posteriormente a la visualización de los vídeos.

- Escoger una lista de ejercicios o cuestiones para trabajar en grupo en el aula de forma presencial.

- Dinamizar la sesión presencial para que los alumnos interactúen en el aula aportando diferentes opciones y alternativas a la resolución de los ejercicios propuestos en la puesta en común final.

- Preparar exámenes de respuesta múltiple para la evaluación individual de los alumnos.

2017, Universitat Politècnica de València

Congreso In-Red (2017) 


\section{Desarrollo de la innovación}

El programa de la asignatura Matemáticas II corresponde a la materia: ecuaciones diferenciales, transformada de Laplace y sus aplicaciones. Esta asignatura consta de 6 créditos: 3 créditos teóricos, 1 crédito de prácticas de aula y 2 créditos de prácticas informáticas. Respecto a asignaturas similares de planes de estudio anteriores correspondientes a la formación de los Ingenieros Técnicos Industriales, se ha optado por dar un enfoque más práctico de estos contenidos al adaptarlos a las titulaciones de grado. Ahora priorizamos las técnicas que favorecen la utilización de los conceptos estudiados en diferentes campos, así como el uso de herramientas y paquetes matemáticos más afables y eficientes a la hora de realizar los problemas. El modelo adoptado para impartir la asignatura consiste en combinar la teoría con prácticas de aula y prácticas de laboratorio, en las que trabajamos con el apoyo del programa Mathematica.

Con la implantación de la clase inversa en las prácticas no sólo pretendemos que el alumno aprenda a manejar el programa Mathematica para resolver ecuaciones diferenciales, mediante comandos que encuentren las soluciones tanto analítica como numérica de este tipo de ecuaciones, sino que además confiamos en que desarrolle las competencias transversales: "Análisis y resolución de problemas" y "Pensamiento crítico" que le permitan discernir no sólo si el proceso aplicado para resolver un problema es el correcto, sino que también sea capaz de valorar si existen aspectos que se puedan mejorar en dicho proceso. Por otro lado, esperamos que esta metodología refuerce el uso del programa en la resolución de ejercicios aplicados a la ingeniería, trabajando de esta forma otras competencias muy importantes para estos graduados como: "Comprensión e integración" y "Aplicación y pensamiento práctico". Todas estas competencias transversales forman parte del catálogo que la UPV ha considerado que todos sus egresados deben tener al finalizar sus titulaciones tanto de grado, como de máster (UPV, 2017).

El introducir en nuestras prácticas metodologías más activas como la clase inversa, nos ha llevado a rediseñar contenidos específicos para cada una de las sesiones de prácticas. La elaboración de estos contenidos se ha realizado en dos etapas: en la primera se elaboró el material didáctico en forma de apuntes y guías de trabajo para facilitar que el alumno realizase correctamente los ejercicios planteados con la ayuda del software informático. En la segunda etapa, hemos grabado presentaciones en forma de vídeos, denominados "screencast", con ejemplos concretos que ayudarán al alumno a abordar los problemas que se plantearán en las siguientes sesiones de prácticas. Y, por último, hemos elaborado tareas participativas en el aula, que se utilizan para evaluar el trabajo realizado por los alumnos fuera y durante la clase.

El programa de prácticas de ordenador de la asignatura Matemáticas II se muestra a continuación:

- Práctica 1: Introducción al programa Matemática

- Práctica 2: Ecuaciones diferenciales de primer orden

- Práctica 3: Ecuaciones diferenciales de orden superior

- Práctica 4: Sistemas de ecuaciones diferenciales 
- Práctica 5: Métodos numéricos para ecuaciones diferenciales

- Práctica 6: Transformada de Laplace

Para desarrollar esta nueva metodología hemos elaborado un plan de trabajo que involucra tanto las actividades que se deben realizar antes y durante la sesión en el laboratorio, como una coordinación exhaustiva entre las clases teóricas y las clases prácticas de la asignatura.

La organización de los materiales disponibles en cada práctica, así como las actividades que deben realizar, se muestra a los alumnos a través de la plataforma educativa de la UPV, denominada PoliformaT, donde hemos vertebrado, a través de la herramienta Lessons disponible en ella, los pasos que los alumnos deben seguir para finalizar con éxito cada práctica. Por ejemplo, en el caso de la práctica 2: Ecuaciones diferenciales de primer orden, hemos preparado tres vídeos titulados:

- Ecuaciones diferenciales Exactas. Factor integrante

- $\quad$ Solución general de la ecuación diferencial de orden 1

- $\quad$ Problema de valor inicial. Solución particular

que los alumnos deben visualizar antes de entrar en el laboratorio. Los objetivos que los alumnos deberían alcanzar tras visualizar estos vídeos vienen indicados en forma de conclusiones en la última diapositiva de cada uno de ellos, como se muestra en la Fig. 1.

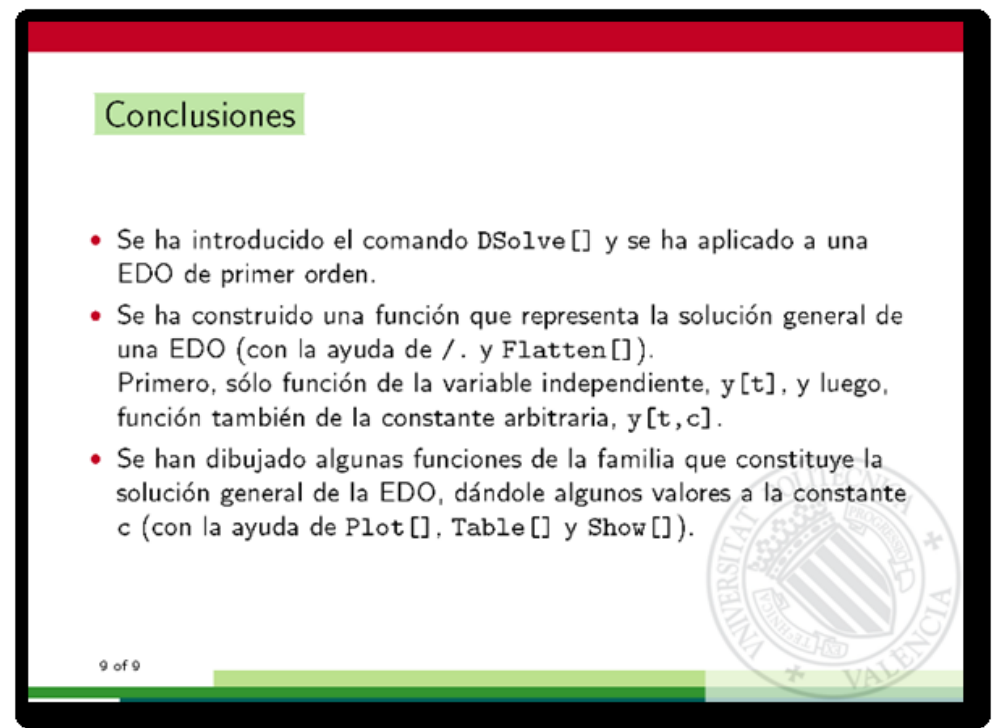

Fig. 1: Objetivos desarrollados en la práctica "Solución general de la ecuación diferencial de orden 1"

Para comprobar que efectivamente se han alcanzado dichos objetivos, las actividades en el laboratorio comienzan revisando los contenidos teóricos que se van a trabajar y planteando ejercicios relacionados con ellos. Los alumnos deben resolver los problemas en el aula, dejando el tiempo necesario para resolver todas las posibles dudas y preguntas que planteen al respecto, de manera que aprovechen este tiempo presencial para profundizar en los conceptos introducidos en los vídeos. En esta línea pretendemos que los "screencasts" ayuden al alumno a trabajar fuera del aula, a su propio ritmo y de forma más dinámica, los concep-

2017, Universitat Politècnica de València

Congreso In-Red (2017) 
tos que posteriormente se aplicarán en los problemas de las sesiones de prácticas de la asignatura.

Cada práctica se ha diseñado para ser realizada en dos sesiones consecutivas. En la primera sesión intentamos que el alumno tome conciencia de lo que ha aprendido y de las capacidades que ha alcanzado antes de enfrentarse a la evaluación definitiva de la práctica en la segunda sesión.

Para ello, al comenzar la clase hacemos al alumno unas preguntas relacionadas con los contenidos que se han introducido en los vídeos "screencast", sobre la práctica que vamos a realizar, a través de un test en PoliformaT. Con esto pretendemos confirmar que el alumno ha visualizado los vídeos $\mathrm{y}$, por tanto, está preparado para trabajar los conceptos necesarios en la sesión.

Posteriormente se le plantean una serie de ejercicios, con dificultad creciente, para que compruebe por sí mismo si realmente ha entendido lo explicado y es capaz de aplicarlo a la resolución de estos problemas. Esta prueba puede realizarse individualmente o por grupos dependiendo de lo que el profesor considere más oportuno en cada sesión. En esta etapa el alumno puede preguntar todas las dudas que le vayan surgiendo a la hora de plantear o resolver los ejercicios, tanto al profesor que se encuentra dentro del aula, como a sus compañeros de grupo. Una vez finalizada la resolución de los ejercicios propuestos y antes de dar la solución correcta de los mismos se abre un debate donde cada grupo propone diferentes alternativas, aportando ideas para la resolución de los problemas, lo que a menudo genera interesantes debates sobre cuál sería la mejor solución. Finalmente, el trabajo realizado por cada alumno quedará registrado en un archivo, que se adjuntará a través de una tarea de PoliformaT, para que el profesor pueda supervisar en todo momento la labor realizada en cada sesión. Con estas actividades pretendemos que el alumno desarrolle la capacidad de análisis e integración de ideas y conceptos, así como la adaptación y aplicación de los mismos a la resolución de problemas relacionados con su especialidad.

En la segunda sesión de cada práctica evaluamos los conocimientos que han adquirido los alumnos. Para ello, realizamos en el aula una prueba individual donde tienen que resolver una serie de ejercicios relacionados con la materia que se ha trabajado en la sesión anterior. La calificación de estos ejercicios formará parte de la nota final de prácticas de la asignatura.

La evaluación de las prácticas se ha diseñado como una mezcla de pruebas objetivas, de elección múltiple, y problemas de desarrollo. Todas ellas están planteadas de forma que exigen a los alumnos la aplicación de principios, temas relacionados entre sí, interpretación de datos y resultados e incluso, en algunos casos concretos, emisión de juicios.

Finalmente, con el objetivo de evaluar la efectividad de esta metodología, hemos analizado los resultados de la encuesta que la UPV ha pasado de forma anónima a los alumnos al final del curso. En esta encuesta, totalmente independiente de la de evaluación del profesorado, se les pregunta sobre su opinión sobre la metodología de clase inversa, si ésta les parece adecuada para la asignatura Matemáticas II, así como si ha mejorado su percepción respecto a la adquisición de contenidos, la aplicabilidad de éstos en otras materias de su especialidad, etc. 
Las conclusiones de los resultados obtenidos se utilizarán para mejorar los planteamientos docentes en nuestra asignatura en cursos sucesivos.

\section{Resultados}

En la encuesta hemos constatado que con la aplicación de la metodología de clase inversa los estudiantes están más motivados para ir a clase y, participan de forma más activa en las actividades planteadas en el aula, con la que en su gran mayoría están de acuerdo. Por otra parte, sus opiniones sobre qué les ha parecido y cómo les ha afectado esta nueva metodología son bastante positivas, como vemos a continuación en los resultados de la encuesta que la UPV les ha pasado a los alumnos. En ella se les ha pedido que puntúen con una escala Likert, según el baremo de 1=Total desacuerdo hasta 5=Total acuerdo, las siguientes cuestiones:

- Con la aplicación de la metodología de clase inversa realizada en esta asignatura, muestra tu grado de acuerdo con las siguientes afirmaciones:

- He ido a clase con el trabajo previo realizado

- Ha contribuido a aumentar mi implicación en la asignatura

- Me ha resultado gratificante

- Ha requerido mucho tiempo por mi parte

- Ha permitido que el profesor dispusiera de más tiempo en clase para aclarar dudas

- Ha fomentado el trabajo en grupo

- Me ha ayudado a llegar mejor preparado a los exámenes

- Lo que más te ha gustado de la aplicación de la metodología de clase inversa realizada en esta asignatura ha sido:

- Los materiales facilitados por el profesor (vídeos y documentos utilizados)

- El trabajo realizado en clase (actividades de aula)

- El trabajo realizado en casa necesario para seguir las clases

- La relación con el profesor, más cercana y de trabajo conjunto

- La relación con mis compañeros

- El sistema de evaluación empleado

- La preparación de la asignatura por parte del profesor: todo organizado y planificado

- Valoración General

- Estoy muy satisfecho con esta experiencia/metodología

- Recomendaría esta experiencia/metodología a mis compañeros

- Me gustaría que esta metodología se aplicara al resto de asignaturas 
Comentamos a continuación los resultados más significativos sobre las opiniones de los alumnos de cada uno de los tres grados de la ETSID donde se ha aplicado la metodología de clase inversa.

\section{Grado en Ingeniería Eléctrica}

Los alumnos del Grado en Ingeniería Eléctrica han sido los más participativos a la hora de contestar la encuesta, ya que aproximadamente un $66 \%$ de los alumnos que la han utilizado en sus prácticas han opinado sobre ella. También han sido a los que más les ha gustado la experiencia, ya que han otorgado puntuaciones positivas de 3, 4 o 5 en un $95,5 \%$ a estar muy satisfecho con ella y en un $91 \%$ a recomendarla a sus compañeros. Además, en un significativo porcentaje del 86,2\% les gustaría aplicarla al resto de asignaturas (Fig. 2).

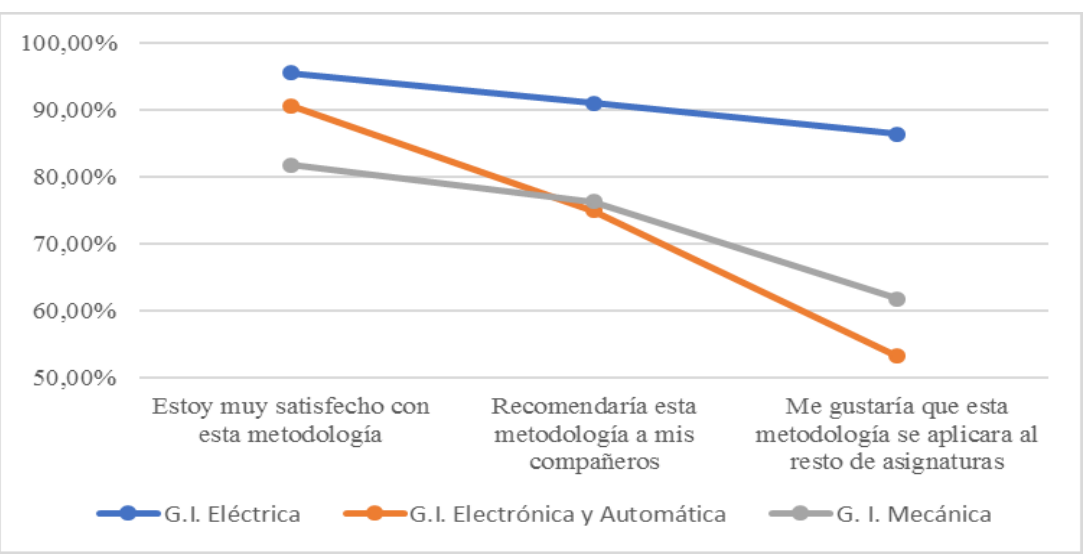

Fig. 2: Valoración general de la metodología clase inversa por parte de los alumnos de los distintos Grados

Algunos de los apartados de la encuesta más relacionados con la motivación y el aprendizaje han obtenido resultados muy favorables entre los alumnos de este grado. Por ejemplo, en el ítem "Ha contribuido a aumentar mi implicación en la asignatura" las respuestas positivas (puntuaciones de 3 a 5) alcanzan el 90,5\%, así como en el apartado "Ha permitido que el profesor dispusiera de más tiempo en clase para aclarar dudas" que llegan al 95,5\% y la afirmación "Me ha ayudado a llegar mejor preparado a los exámenes" que obtiene un $95,4 \%$ de respuestas positivas o muy positivas (Fig. 3). 


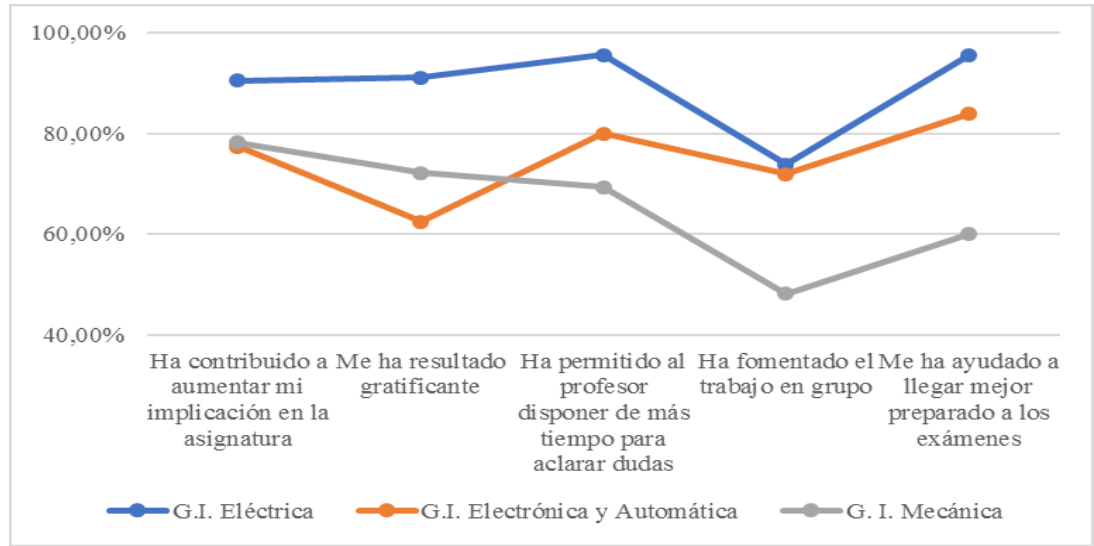

Fig. 3: Satisfacción de los alumnos de los distintos Grados con las afirmaciones relativas a la clase inversa

Los apartados relacionados con la interacción con el profesor y el resto de compañeros también salen muy bien parados, ya que el ítem "La relación con el profesor, más cercana $y$ de trabajo conjunto" obtiene un $99,9 \%$ de respuestas positivas o muy positivas y al $100 \%$ de los alumnos les ha gustado "La relación con mis compañeros", "El trabajo realizado en clase (actividades de aula)" y "El sistema de evaluación empleado". Por otro lado, estos alumnos valoran también muy positivamente la organización y planificación de la asignatura por parte del profesor (Fig. 4).

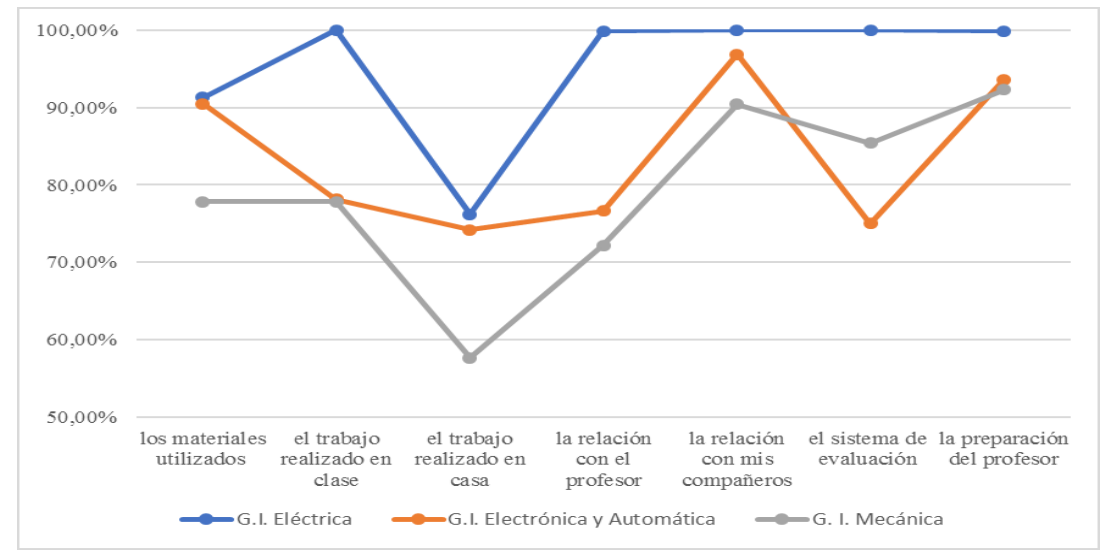

Fig. 4: Aspectos más favorables de la experiencia de clase inversa para los alumnos de los distintos Grados

Además, esta nueva metodología no les supone una carga de trabajo extra, ya que sólo un $18 \%$ de los alumnos opinan, con puntuaciones altas de 4 a 5 , que "Ha requerido mucho tiempo por mi parte", aunque sólo un 50\% reconoce haber ido a clase con el trabajo previo realizado (Fig 5). 


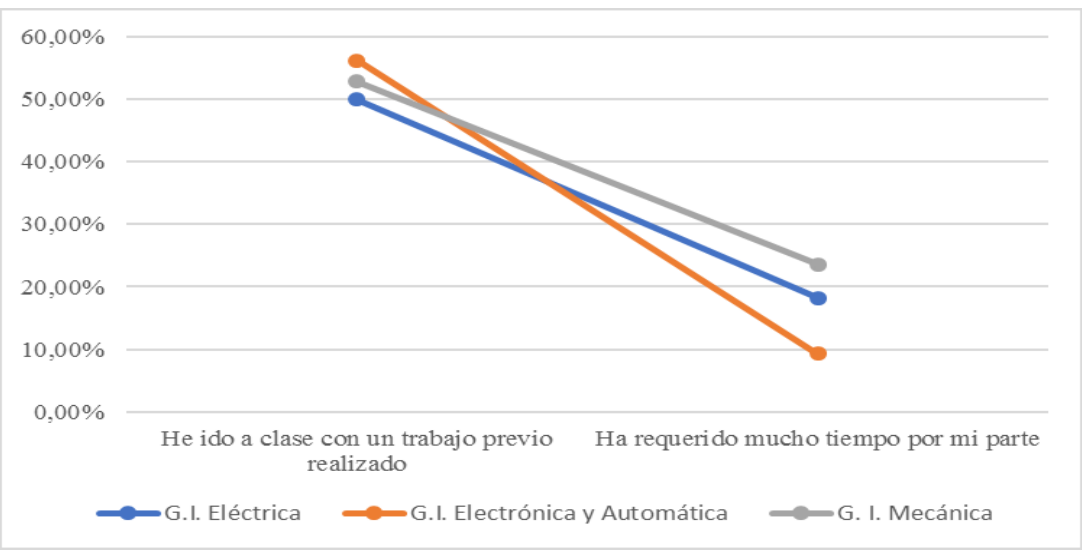

Fig. 5: Opiniones sobre el tiempo invertido en la nueva metodología por los alumnos de los diferentes grados

\section{Grado en Ingeniería Electrónica Industrial y Automática}

Aunque los alumnos del Grado en Ingeniería Industrial y Automática han sido los menos participativos a la hora de contestar la encuesta, sólo un $20 \%$ ha respondido las cuestiones planteadas, han sido, sin embargo, los que más comentarios libres nos han aportado al respecto. Las puntuaciones positivas ( 3 a 5 ) en el ítem "Estoy muy satisfecho con esta metodología" alcanzan un porcentaje del $90,5 \%$ en este caso y casi un $75 \%$ de los alumnos están de acuerdo en recomendarla a otros compañeros, aunque el porcentaje de aplicarla al resto de asignaturas baja a un 53,2\% en este grado (Fig. 2).

En el apartado de la encuesta relacionado con la mayor implicación en la asignatura los porcentajes positivos (puntuaciones de 3 a 5) rozan el 77,4\% y en el ítem sobre llegar mejor preparado a los exámenes alcanzan el 83,9\% (Fig. 3).

En este caso "Los materiales facilitados por el profesor (vídeos y documentos utilizados)" también han gustado al 90,5\% de los alumnos y en los ítems sobre la interacción destaca la relación con el resto de compañeros que alcanza un 96,9\%, con puntuaciones de 3 a 5, así como "La preparación de la asignatura por parte del profesor: todo organizado y planificado" que obtiene un 93,6\% de alta satisfacción entre los alumnos (Fig. 4).

En los alumnos de este grado, la percepción de sobrecarga ha sido menor ya que sólo un 9,3\% de los alumnos, opinan con puntuaciones altas de 4 a 5, que esta metodología ha requerido mucho tiempo por su parte, además de que un mayor porcentaje de alumnos, que ronde el 56\%, reconoce haber ido a clase con el trabajo previo realizado (Fig. 5).

Los comentarios libres que realizan estos alumnos se refieren principalmente al hecho de que la extensión de esta metodología al resto de asignaturas no les parece buena idea, como podemos ver en sus afirmaciones: "No en todas las asignaturas sería factible esta metodología", "Para esta asignatura este método es muy correcto, pero no estoy segura de si este método sería muy buena idea para otras asignaturas". Aunque también nos hacen sugerencias a la hora de plantear las actividades: "Sería ideal hacer un proyecto conjunto donde se puedan practicar los conocimientos adquiridos en las prácticas y combinarlos en las diferentes disciplinas de la ingeniería", así como de evaluar las tareas propuestas: "No me 
gusta que haya un examen final. Creo que haber realizado todas las prácticas y su trabajo previo, aparte de asistir a las clases, debería ser suficiente".

\section{Grado en Ingeniería Mecánica.}

En el Grado en Ingeniería Mecánica han respondido las preguntas de la encuesta aproximadamente un $40 \%$ de los alumnos. En este caso, las puntuaciones de 3 a 5 en el ítem "Estoy muy satisfecho con esta metodología" alcanza un porcentaje del $81 \%$ y un $76 \%$ el apartado sobre recomendar esta metodología a sus compañeros, aunque el porcentaje de aplicarla al resto de asignaturas, al igual que en los grados anteriores, baja a un 61,8\% (Fig. 2).

En este caso, en los apartados relacionados con la motivación sigue destacando el ítem sobre la mejora en la implicación de la asignatura, donde las puntuaciones de 3 a 5 alcanzan un porcentaje del $78,2 \%$, aunque aquí también desataca el ítem "Me ha resultado gratificante" que alcanza un $72,2 \%$ (Fig. 3 ).

En los apartados relacionados con la interacción destaca, como en los otros grados, la relación con el resto de compañeros, así como la preparación de la asignatura por parte del profesor, que alcanzan un $92,3 \%$ y un $90 \%$ de puntuaciones de 3 a 5 entre los alumnos, respectivamente (Fig. 4).

La percepción de sobrecarga aquí ha sido mayor que en el resto de grados, un 23,6\% de los alumnos opinan, con puntuaciones de 4 a 5 , que es esta metodología ha requerido mucho tiempo por su parte, aunque en el porcentaje de alumnos que reconoce haber ido a clase con el trabajo previo realizado, que en este caso es del $52,8 \%$, no hay mucha diferencia con el resto de grados (Fig. 5).

\section{Conclusiones}

Del análisis de las respuestas obtenidas en la encuesta, podemos concluir que aplicando la metodología de la clase inversa hemos mejorado en los dos principales objetivos que nos habíamos propuesto: aumentar la motivación de los alumnos y mejorar su aprendizaje significativo. Por otro lado, hemos conseguido aumentar y mejorar la relación con el profesor y el resto de compañeros que, desde nuestro punto de vista, también es muy importante para generar un buen ambiente en el aula.

Por tanto, consideramos la experiencia muy satisfactoria y estamos motivados para mejorar las carencias detectadas, trabajando en cursos sucesivos para mejorar las tareas planteadas, priorizando la modelización de problemas multidisciplinares e intentando que serán lo más realistas e integrados en el área profesional de los futuros graduados que nos sea posible. Aunque es importante darse cuenta que nuestra asignatura se encuentra en segundo curso y la formación de los alumnos todavía no es suficiente para abordar problemas muy específicos de la titulación que están cursando. 


\section{Referencias}

BERGMANN, J. and SAMS, A. (2012). Flip Your Classroom: Talk to Every Student in Every Class Every Day. International Society for Technology in Education. ISBN 9781564843159.

KINNEY, M. W. (2016). "Teaching an Online Sophomore-Level Differential Equations Course with Mathematica Supplements". CODEE Journal, Vol. 11, Article 1.

LAGE, M. J., PLATTl, G. J. and TREGLIA, M. (2000). "Inverting the classroom: A gateway to creating an inclusive learning environment". The Journal of Economic Education, 31 (1), p. 30-43.

PROYECTO CLASE INVERSA (2017) Universitat Politécnica de Valencia.

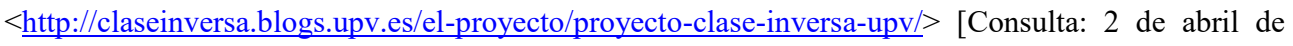
2017]

UNIVERSITAT POLITÈCNICA DE VALÈNCIA (2017). Proyecto institucional Incorporación de las competencias transversales en el currículo de los egresados de la UPV.

$<$ http://www.upv.es/entidades/ICE/info/U0724624.pdf $>$ [Consulta: 2 de abril de 2017]

WOLFRAM RESEARCH (2017). Mathematica de Wolfram.

$<$ http://www.wolfram.com/mathematica/?source=nav $>$ [Consulta: 2 de abril de 2017]

YONG, D., LEVY, R. and LAPE, N. (2015). "Why No Difference? A Controlled Flipped Classroom Study for an Introductory Differential Equations Course”, PRIMUS, 25 (9-10), p. 907-92. 


\title{
Implementación de la plataforma GOOGLE CLASROOM en la asignatura "Tratamiento de Residuos" para la realización de experiencia de clase inversa.
}

\section{Samper ${ }^{a}$, D. Garcia-Garcia ${ }^{a}$, JM Ferri ${ }^{a}$, A. Carbonell-Verdu ${ }^{a}$ y J. Lopez-Martinez ${ }^{a}$}

${ }^{a}$ UniversitatPolitècnica de València. Departamento de Ingeniería Mecánica y de Materiales. PlazaFerrándiz y Carbonell, 03801 Alcoy (Alicante) España. e-mail: masammad@epsa.upv.es

\begin{abstract}
During the academic year 2016-17 the flipped classroom methodology was implemented using the GOOGLE CLASS platform in the "waste treatment" subject. This methodology has allowed students to have more time in the classroom to solve doubts and practical problems, increasing collaborative work. Using this methodology, the self-assessment test score increased compared to other years and students prefer this methodology to the traditional master class as indicated in an anonymous survey.
\end{abstract}

Keywords: methodology, flipped classroom, self-assessment.

\begin{abstract}
Resumen
Durante el curso académico 2016-17 se ha implantado la metodología de clase inversa utilizando la plataforma GOOGLE CLASSROOM en la asignatura "Tratamiento de Residuos". Esta metodología ha permitido que los alumnos dispongan de más tiempo en el aula para resolver dudas y realizar prácticas, aumentando el trabajo colaborativo. Mediante esta metodología la nota media del test de autoevaluación subió respecto a otros años y los alumnos prefieren está metodología a la tradicional clase magistral según indicaron en una encuesta anónima.
\end{abstract}

Palabras clave: metodología, clase invertida, autoevaluación. 


\section{Introducción}

Todas las personas son conscientes del cambio exponencial que representa el uso de la tecnología en la vida cotidiana. Especialmente, los jóvenes de hoy pasan la mayoría de las horas del día en contacto con diferentes aparatos electrónicos, desde móviles de última generación (smartphones), pasando por dispositivos tipo tablets hasta los más convencionales, pero no menos importantes, ordenadores. Esto se debe principalmente al modo de obtener la información, que ha ido evolucionando, pasando de la obtención de la información a través de libros y por medio de las clases magistrales que impartían los docentes a la obtención de información instantánea que nos ofrece internet.

Si bien es verdad que esto es un indicador del desarrollo de la población en diferentes ámbitos (tecnológico, bienestar, etc), no deja de ser un problema en otros ámbitos como la enseñanza. El modelo estandarizado de la enseñanza universitaria se basa en una gran carga lectiva donde más de un $60 \%$ de las horas que se imparten en una asignatura son de clases donde se explican conceptos teóricos y el resto se reparte entre prácticas de laboratorio (para el caso de grados en ingeniería o grados de ciencias) y trabajos a realizar en casa. Por tanto, el alumnado de hoy, presenta niveles de concentración muy bajos, en asignaturas cuyo contenido teórico es elevado, ya que se están acostumbrando a aprender mediante el uso de esta tecnología. Es por ello que la investigación sobre la metodología de impartición docente debe crear nuevos modelos de enseñanza donde se priorice el uso de este tipo de tecnologías, sabiendo que este es el medio por el que el alumnado presta mayor atención.

Desde hace muy pocos años autores como Jonathan Bergmann y Aaron Sams (Bergmann,2012) basaron sus clases haciendo que el alumnado cooperara más durante el tiempo de clase y dejaban ciertos aprendizajes de tipo conceptual, como tareas para realizar en casa. Concretamente, el docente realizaba en el horario lectivo tareas de tipo práctico a sabiendas que los alumnos ya habían realizado las tareas de casa (tipo conceptual) y se aprovechaba para reforzar dichos conceptos de una forma aplicada. A esta metodología innovadora le llamaron "clase inversa" (Barrera, 2013) (Jordan-Lluch, 2014). El material teórico-conceptual era subido a una plataforma virtual por el docente en formato digital, donde se podía encontrar material tipo videos explicativos, chats interactivos, documentos, etc.

En el presente trabajo, se ha aplicado la metodología "clase inversa" a la asignatura "Tratamiento de Residuos" impartida en el Grado de Ingeniería Química y se ha usado "GOOGLE CLASSROOM" como plataforma virtual donde poder subir material teórico-conceptual en formato video (Gálvez, 2015) (López Rodríguez,2016), mensajería para poder resolver dudas particulares con el alumno, exámenes para realizar autoevaluaciones incluso para realizar el examen final de la asignatura (Tourón, 2014). El propósito final de este estudio fue el de valorar las posibles mejoras de la metodología aplicada y el grado de atención del alumnado como clave para mejorar los resultados académicos, evaluar de forma continua la implicación. Finalmente se hizo una encuesta al alumnado para evaluar el índice de aceptación del método con respecto a los métodos tradicionales a los que estaban habituados.

\section{Objetivos}

El principal objetivo del presente trabajo es el empleo y evaluación de la plataforma GOOGLE CLASSROOM para la interacción alumno-profesor en las clases de "Tratamiento de Residuos" de cuarto curso del Grado de Ingeniería Química. Se ha decidido la implementación de dicha plataforma con el fin de agilizar y mejorar dicha interacción entre los integrantes de la clase facilitando de esta forma el desarrollo y la aplicación de la metodología de clase inversa para el desarrollo de las mismas. Ya que mediante dicha metodología es el alumno el que debe adquirir los conocimientos de forma autónoma con ayuda del material aportado por el profesor previamente a las clases presenciales dejando las sesiones lectivas para fomentar el aprendizaje práctico y la cooperación entre los alumnos, es por ello que la 
plataforma GOOGLE CLASSROOM es una buena alternativa para dotar a los alumnos del material necesario para su autoaprendizaje.

\section{Desarrollo}

A continuación se desarrollará la experiencia con el empleo de GOOGLE CLASSROOM en el desarrollo de la asignatura de "Tratamiento de Residuos" impartida mediante metodología inversa. Para la implantación de dicha metodología es necesario un trabajo previo por parte del profesor así como la colaboración activa por parte del alumnado, ya que dicha aplicación permite una continua comunicación entre alumno-profesor, y alumno-alumno, permitiendo la generación de debates sobre la asignatura siendo el profesor el moderador del debate y el encargado de resolver cuestiones incorrectas.

\subsection{Preparación de la clase mediante GOOGLE CLASSROOM}

En primer lugar el profesor realizó una guía didáctica con los temas a desarrollar en cada una de las diferentes sesiones de la asignatura. En este caso se optó por la realización de videos explicativos de cada uno de los tema a impartir, se optó por este sistema ya que se pensó que es la forma más amena de interacción con el alumnado, además de uno de los mejores complementos para la clase invertida (Gálvez, 2015). En los videos grabados por el profesor de la asignatura se tratan aspectos fundamentales que se pondrán en práctica en las sesiones presenciales. Cada vídeo grabado tiene una duración inferior a los 12 minutos.

Una vez realizada la guía didáctica y grabados los vídeos de cada una de las sesiones programadas se optó por utilizar la plataforma GOOGLE CLASSROOM como sistema de interacción entre alumno y profesor. Para ello en primer lugar el profesor debe registrarse en la plataforma de GOOGLE CLASSROOM, figura 1 .

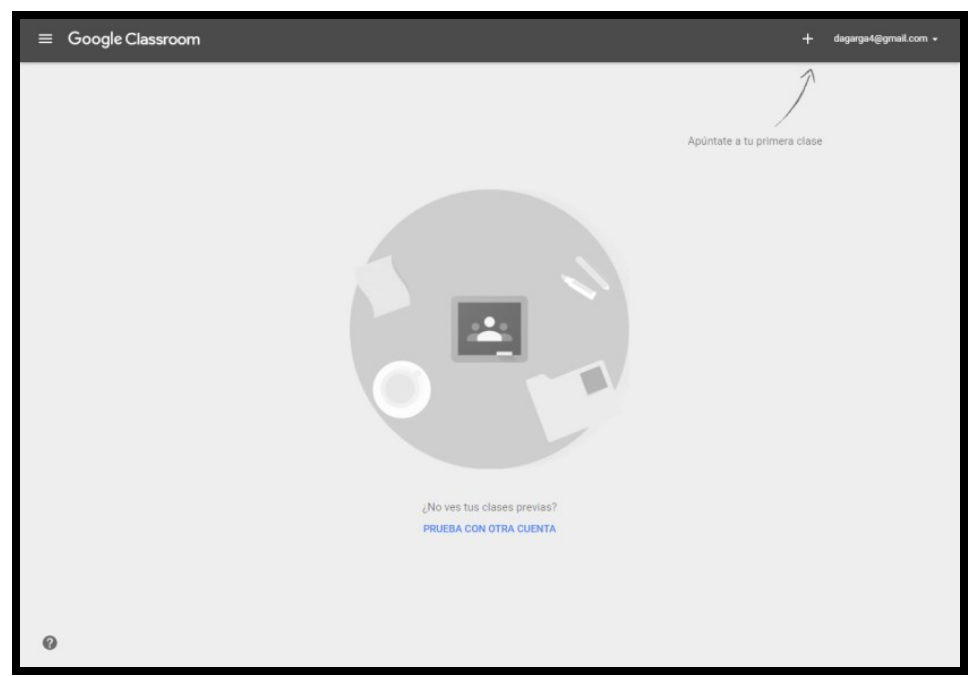

Fig. 1 Registro en la plataforma GOOGLE CLASSROOM

Una vez registrado en la plataforma se creó la clase, en este caso "Tratamiento de Residuos" una vez creada la primera clase se puede modificar el aspecto estético de la plataforma (imagen de la plataforma y colores). Una vez creada la clase, el profesor proporcionó el código de la clase (el cual es suministrado por la plataforma) a los alumnos de la asignatura. Estos desde cualquier ordenador pueden entrar a la clase creada introduciendo el código proporcionado, figura 2, permitiendo acceder a todo el material docente disponible.

(cc)) BY-NG-ND 2017, Universitat Politècnica de València 


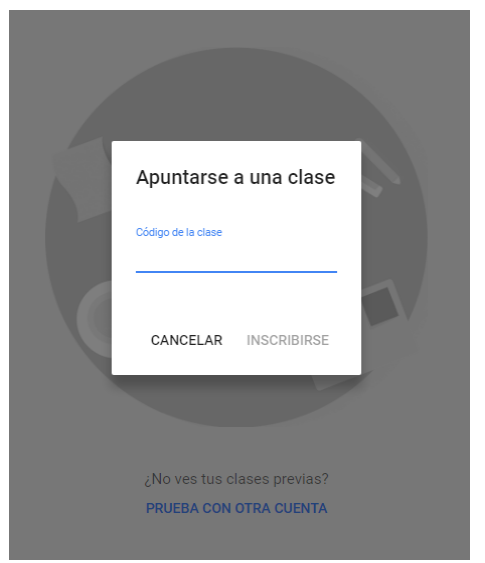

Fig. 2 Acceso a la plataforma GOOGLE CLASSROOM mediante código de acceso

Tras crear la clase el profesor subió los diferentes video de cada una de las lecciones a la plataforma, siendo notificados todos los participantes de la clase. Los videos de todos los temas fueron colgados en la plataforma una semana antes del inicio del curso académico.

Además, los videos pueden consultarse en los siguientes enlaces:

https://www.youtube.com/watch?v=MBJ7ExmVJvo\&t=84s

https://www.youtube.com/watch?v=J3qN6hRObaQ

https://www.youtube.com/watch?v=MRO9-shc3ks\&t=88s

https://www.youtube.com/watch?v=Ji9J6TQUfng\&t=350s

https://www.youtube.com/watch?v= Jxwhn6hOis

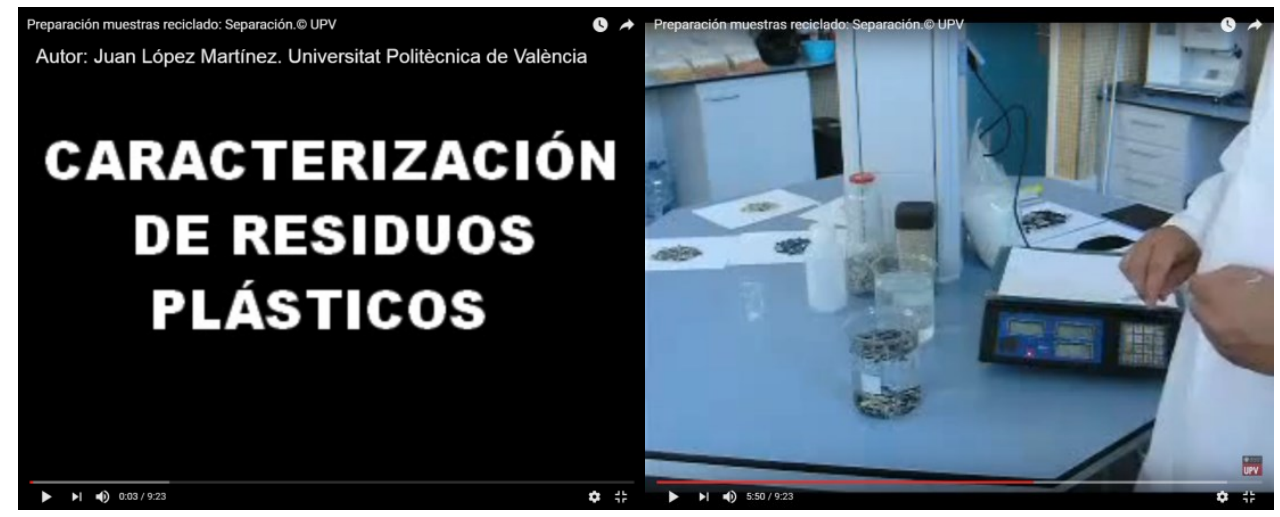

Fig. 3 Ejemplo de video realizado por el profesor y accesible desde la plataforma GOOGLE CLASSROOM

\subsection{Aplicación de la metodología de clase inversa}

La experiencia de clase inversa se realizó a lo largo del curso 2016/2017 a los 17 alumnos de la asignatura de "Tratamiento de Residuos" de cuarto curso del Grado de Ingeniería Química para el desarrollo de las prácticas de laboratorio. Inicialmente los alumnos se dividieron en grupos de 3-4 personas, en cada sesión de prácticas los grupos tenían asignados videos diferentes, un total de 5 vídeos para las 5 sesiones prácticas. Los alumnos tras la visualización de los vídeos pondrían en práctica los conocimientos adquiridos en el laboratorio que estaba organizado en tareas multipuesto. Tras la experiencia adquirida en otros años, se optó por el desarrollo de clase invertida unida a las prácticas organizadas en multipuesto para evitar que el profesor sea quien explica y realiza la práctica siendo el alumno un mero espectador que solamente anota resultados sin intervenir en el desarrollo de la práctica y manejo de los equipos.

(c) EY-NC-ND 2017, UniversitatPolitècnica de València 
Para aplicar este tipo de metodología los alumnos debían visualizar el vídeo correspondiente a cada tema disponible en la plataforma GOOGLE CLASSROOM antes de asistir a las sesiones prácticas de la asignatura, cada grupo tenía asignado un vídeo diferente antes de cada sesión práctica para el correcto desarrollo de las tareas multipuesto. Además, los alumnos una vez finalizado la visualización del vídeo debían de realizar un test de autoevaluación, el cual fue preparado a través de la plataforma de GOOGLE, y que será muy similar al examen de evaluación final planteado para la asignatura. Este examen de autoevaluación no tiene valor en la nota final, únicamente sirve al alumno para saber qué aspectos necesitan reforzar antes de asistir a clase o poder plantear en clase todas las dudas relacionadas con el tema.

La primera parte de las sesiones presenciales estuvieron dedicadas a la resolución y aclaración de posibles dudas en el proceso de autoaprendizaje de los alumnos. El resto de la clase fue principalmente prácticas en laboratorio multipuesto donde se ponía en práctica todo lo aprendido con el trabajo previo en casa de forma colaborativa, convirtiéndose el profesor en un guía de prácticas sin intervenir si no es necesario, solo para dudas puntuales o por el mal uso de equipos. Las prácticas se desarrollaron en grupos de 3-4 personas que trabajaron autonomamente pasando secuencialmente por las cinco prácticas programas durante las diferentes sesiones de prácticas.

\subsection{Evaluación de la asignatura}

Una vez finalizadas todas las clases presenciales el proceso de evaluación consistió en dos partes. Una de ellas fue un test de evaluación acerca de los conceptos fundamentales visto a lo largo de la asignatura. Dicha evaluación consistió en 40 preguntas tipo test de verdadero o falso. Dicho test se realizó a través de la plataforma GOOGLE CLASSROOM y el resultado aparecía directamente una vez finalizado el test. El $60 \%$ de la nota de la asignatura se obtuvo a partir de informes en los que se le pedía al alumno que describieran las tareas realizadas en las sesiones prácticas.

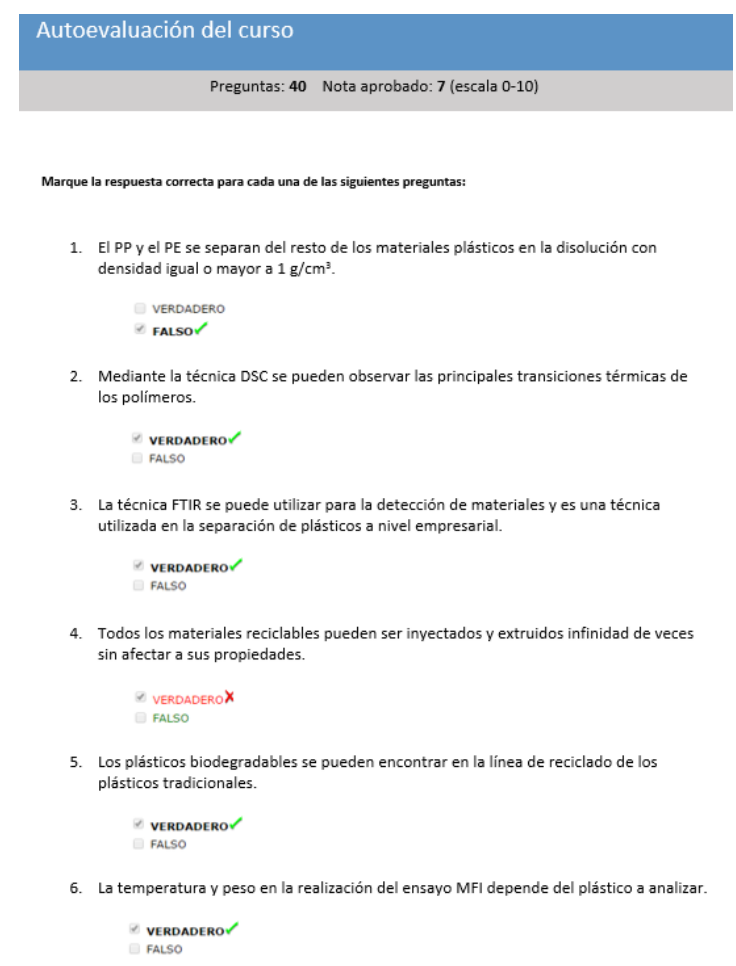

Fig. 4 Ejemplo de autoevaluación de la asignatura "Tratamiento de Residuos" 


\section{Resultados}

En la asignatura "Tratamiento de Residuos" impartida mediante la metodología de clase inversa participaron 16 de los 17 alumnos matriculados. De media, 14 alumnos habían visualizado previamente los videos sugeridos por el profesor antes de las clases prácticas, tal y como se había pedido para poder realizar correctamente la actividad, lo que supone la participación activa del 87,5 \% de los alumnos. Así mismo, se planteó a los alumnos realizar de forma anónima una evaluación de la metodología empleada en la asignatura, como es la aplicación de la clase invertida apoyada con vídeos docentes a través de la plataforma GOOGLE CLASSROOM, para ello se utilizó un cuestionario realizado por el profesor y disponible en la plataforma al finalizar el test de evaluación de la asignatura.

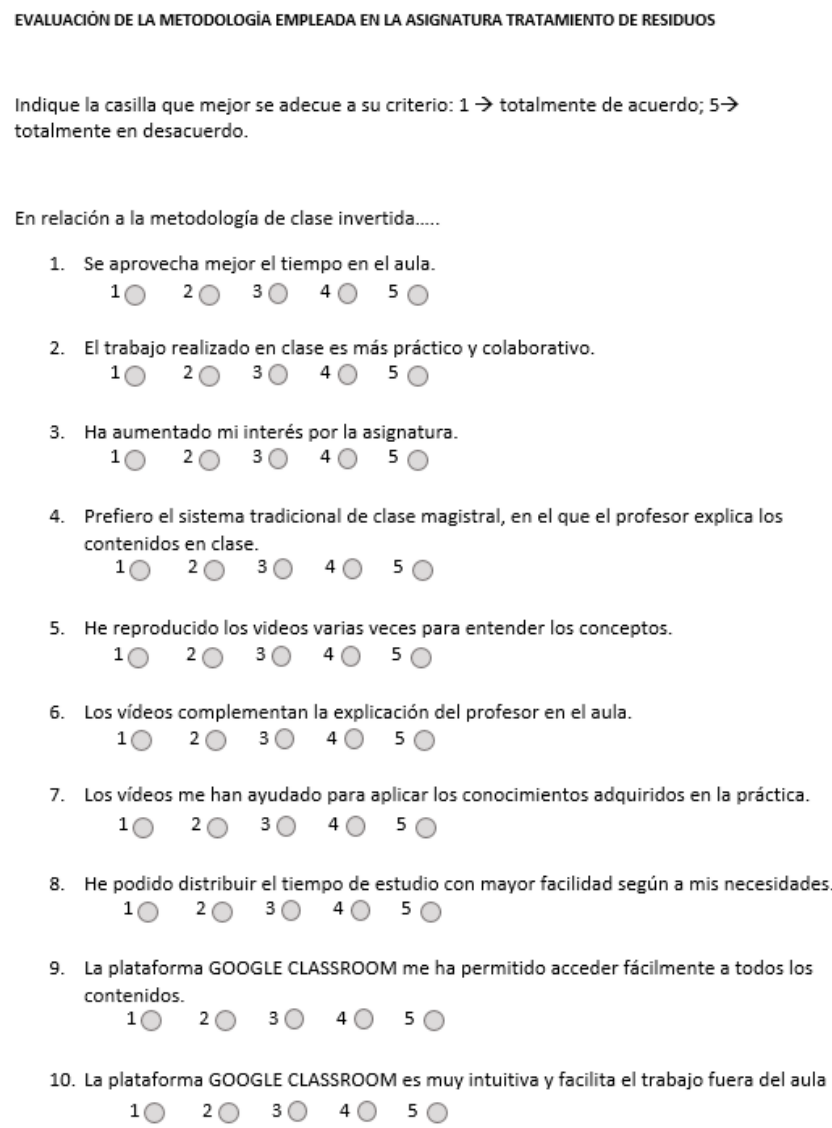

Fig. 5 Plantilla utilizada para la evaluación de la metodología clase inversa utilizando GOOGLE CLASSROOM

La calificación media obtenida por los alumnos en el cuestionario final de autoevaluación de la asignatura y que corresponde con el $40 \%$ del total de la nota de la asignatura fue de $8,4 \pm 1,6$ puntos sobre un máximo de 10 puntos. La calificación media del examen escrito tipo test de la asignatura en el curso 2015-2016

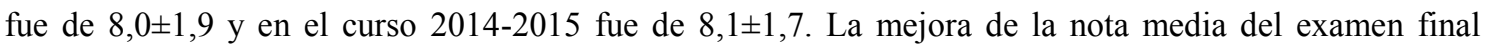
puede ser debida a que a lo largo del curso los alumnos han tenido la posibilidad de realizar diferentes test propuestos después de la visualización de los diferentes videos y plantear en clase las dudas surgidas durante el visionado del video y/o la realización del test. 


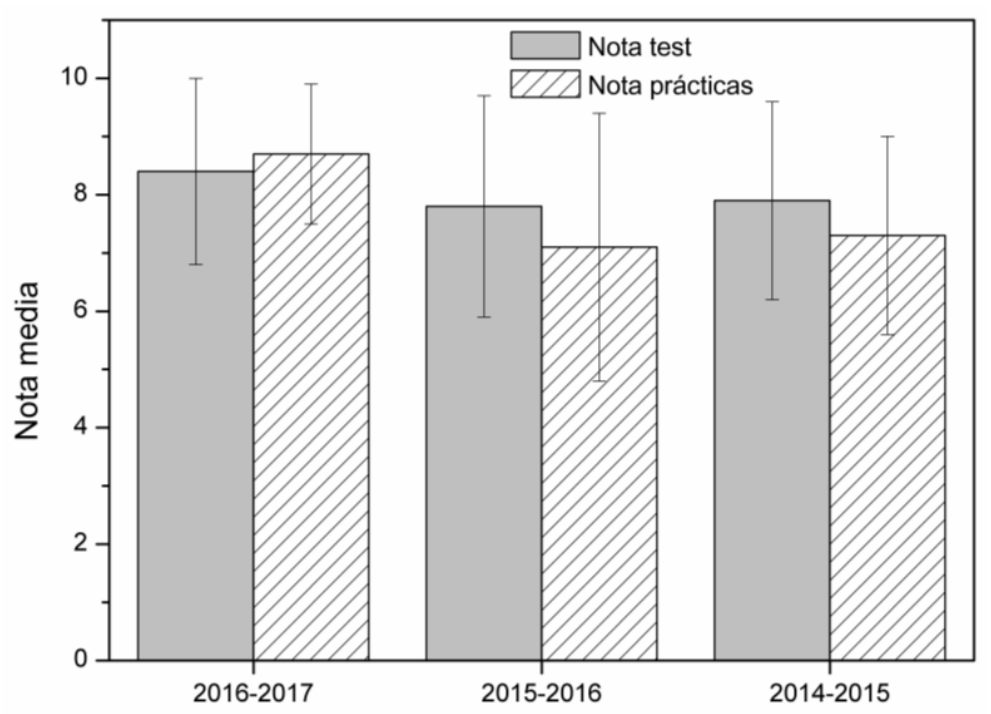

Fig. 6. Nota media de la asignatura "Tratamiento de residuos" en diferentes cursos académicos.

Por otra parte, el trabajo desarrollado durante las prácticas por los alumnos se ha visto influenciada positivamente por la metodología empleada durante la asignatura, clase inversa más tarea multipuesto, ya que los alumnos han podido trabajar en pequeños grupos de forma autónoma y manejando ellos los equipos, generando una mayor predisposición y motivación del alumnado que se ha reflejado en la mejora de los informes de prácticas y de la nota final. La nota media de prácticas obtenida en el curso 2016-2017 ha sido de 8,7 $\pm 1,2$ puntos sobre 10 , que comparado con otros años supone un importante incremento, tal y como se puede observar en la figura 6, ya que en el curso 2015-2016 la nota media fue de 7,1 $\pm 2,3$ y en el curso 2014-2015 la nota media fue de 7,3 $\pm 1,7$. El incremento en la nota de prácticas puede ser debido a que los alumnos han participado activamente en el desarrollo de estas, consolidando los conceptos adquiridos en las sesiones teóricas y en los videos visualizados.

En cuanto a la evaluación por parte de los alumnos sobre la metodología seguida en el desarrollo de la asignatura, la cual se realizó mediante encuesta anónima y que realizaron 15 de los 17 alumnos matriculados, los resultados obtenidos se pueden apreciar en la tabla 1. El 73,3\% de los encuestados (11 alumnos) estaban completamente de acuerdo con la afirmación: se aprovecha mejor el tiempo en el aula. El 60\% de los alumnos ( 9 alumnos) estaban completamente de acuerdo con la afirmación: el trabajo realizado en clase es más práctico y colaborativo. El 26,7\% de los encuestados (4 alumnos) estaban completamente de acuerdo con la afirmación: ha aumentado mi interés por la asignatura; y el 40\% (6 alumnos) estaban bastante de acuerdo. El 66,7\% de los encuestados (10 alumnos) no estaban nada de acuerdo con la afirmación: prefiero el sistema tradicional de clase magistral, en el que el profesor explica los contenidos de la clase. El 66,7 \% de los encuestados (10 alumnos) están completamente de acuerdo con la afirmación: los vídeos complementan la explicación del profesor en el aula. El 60\% de los alumnos (9 alumnos) están completamente de acuerdo con la afirmación: los videos me han ayudado para aplicar los conocimientos adquiridos en la práctica. El 80\% de los alumnos (12 alumnos) están completamente de acuerdo con la afirmación: la plataforma GOOGLE CLASSROOM me ha permitido acceder fácilmente a todos los contenidos. El 73,3\% de los encuestados están de acuerdo con la afirmación: la plataforma GOOGLE CLASSROOM es muy intuitiva y facilita el trabajo fuera del aula. 
Tabla 1. Resultados de evaluación de la metodología

\begin{tabular}{|c|c|c|c|c|c|}
\hline \multirow[b]{2}{*}{ Según la afirmación: } & \multicolumn{5}{|c|}{$\mathrm{N}^{0}$ de alumnos que han contestado } \\
\hline & 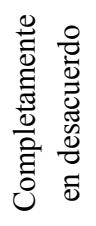 & 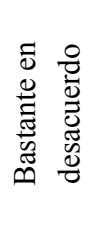 & 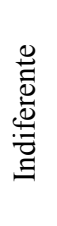 & 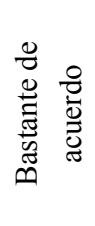 & 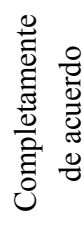 \\
\hline Se aprovecha mejor el tiempo en el aula & 0 & 0 & 1 & 3 & 11 \\
\hline El trabajo realizado en clase es más práctico y colaborativo & 0 & 0 & 2 & 4 & 9 \\
\hline Ha aumentado mi interés por la asignatura & 0 & 1 & 3 & 6 & 4 \\
\hline $\begin{array}{l}\text { Prefiero el sistema tradicional de clase magistral, en el que } \\
\text { el profesor explica los contenidos en clase }\end{array}$ & 10 & 5 & 0 & 0 & 0 \\
\hline $\begin{array}{l}\text { He reproducidos los videos varias veces para entender los } \\
\text { conceptos }\end{array}$ & 3 & 1 & 5 & 3 & 3 \\
\hline $\begin{array}{l}\text { Los vídeos complementan la explicación del profesor en el } \\
\text { aula }\end{array}$ & 0 & 0 & 1 & 4 & 10 \\
\hline $\begin{array}{l}\text { Los vídeos me han ayudado para aplicar los conocimientos } \\
\text { adquiridos en la práctica }\end{array}$ & 0 & 0 & 1 & 5 & 9 \\
\hline $\begin{array}{l}\text { He podido distrubuir el tiempo de estudio con mayor } \\
\text { facilidad según mis necesidades }\end{array}$ & 1 & 1 & 3 & 5 & 5 \\
\hline $\begin{array}{l}\text { La plataforma GOOGLE CLASSROOM me ha permitido } \\
\text { acceder fácilmente a todos los contenidos }\end{array}$ & 0 & 0 & 0 & 3 & 12 \\
\hline $\begin{array}{l}\text { La plataforma GOOGLE CLASSROOM es muy intuitiva y } \\
\text { facilita el trabajo fuera del aula }\end{array}$ & 0 & 0 & 0 & 4 & 11 \\
\hline
\end{tabular}

\section{Conclusiones}

La aplicación de la metodología de aula invertida en la asignatura "Tratamiento de Residuos" ha sido beneficiosa para los alumnos, ya que ha aumentado la nota media del test de evaluación y de los informes de prácticas de la asignatura, respecto a las notas obtenidas en otros cursos académicos. Además, hay que destacar la gran aceptación por parte de los alumnos, según la encuesta anónima realizada sobre la metodología aplicada en la asignatura, ya que destacan como puntos fuertes: el mejor aprovechamiento del tiempo en el aula, los videos complementan la explicación del profesor en el aula, la plataforma utilizada permite acceder fácilmente a todos los contenidos y la plataforma utilizada es intuitiva y facilita el trabajo fuera del aula.

Por tanto, destacamos que los videos docentes son un buen complemento para la aplicación del aula invertida, ya que las horas presenciales se aprovechan para resolver dudas y tener más tiempo para realizar trabajo práctico. Por otro lado hay que destacar el uso de la plataforma GOOGLE CLASSROOM, ya que es una herramienta práctica e intuitiva que permite el trabajo desde cualquier dispositivo.

Dada la buena experiencia obtenida con la implementación de esta metodología, no solo por la mejora en la nota obtenida por los alumnos sino también por la motivación extra que han presentado, se pretende seguir con esta metodología en años sucesivos e incluso aplicarla a otras asignaturas. 


\section{Referencias}

BARRERA, A.G. (2013). El aula inversa: cambiando la respuesta a las necesidades de los estudiantes. Avances en Supervisión Educativa.

BERGMANN, J and SAMS, A. (2012). Flip your classroom: Reach every student in every class every day. International Society for Technology in Education.

GALVEZ, A. and GARCIA A. (2015). Uso del vídeo docente para la clase invertida: evaluación, ventajas e inconvenientes. Obtido em.

JORDAN-LLUCH, C., PEÑALVER, M.J.P., and SANABRIA-CODESAL, E (2014)., Flipped Classroom: Reflexiones y opiniones de los implicados. Jornadas de Innovación Educativa y docencia en Red de la Universitat Politècnica de València.

LÓPEZ RODRÍGUEZ, D., et al. (2016). Elaboración de material para la realización de experiencias de clase inversa (flipped classroom).

TOURÓN, J., SANTIAGO, R., and DIEZ, A. (2014). The Flipped Classroom: Cómo convertir la escuela en un espacio de aprendizaje. Grupo Océano. 


\title{
Buenos días: la clase de hoy es un juego ¿y porqué no?
}

\section{N. Montanes ${ }^{\text {a }}$, R. Balart ${ }^{\mathrm{a}}$, L. Sánchez-Nacher ${ }^{\mathrm{a}}$, L. Quiles-Carrillo ${ }^{\mathrm{a}}$ y V. Fombuena ${ }^{\mathrm{a}}$}

${ }^{a}$ Grupo de Innovación de Prácticas Académicas (GIPA), Universitat Politècnica de València, Plaza Ferrándiz y Carbonell s/n, Alcoy, Alicante (ESPAÑA).

\begin{abstract}
The authors have developed a game based on traditional question-andanswer challenge as an alternative method to master classes. An important part of the contents and topics of the subjects taught by the authors are developed using this new methodology. It is based on gamification, teamwork and collaborative learning combined with an adaptation of the Aronson puzzle technique. This game can be done in any type of environment or classroom, during the class time assigned to the subject and hardly requires additional material. On the other hand, with the development of the game, the Transversal Competences of the Universitat Politècnica de València "Comprehension and Integration", "Teamwork and Leadership", "Effective Communication" and "Planning and Time Management" are worked. Student satisfaction has been evaluated using this alternative teaching method presentin very positive results. Although the implementation of the method is recent, no barely records are available, it appears that the academic performance is increasing.
\end{abstract}

Keywords: master classes, gamification, collaborative learning, transversal competences.

\footnotetext{
Resumen

Los autores han desarrollado un juego basado en los tradicionales juegos de preguntas y respuestas como método alternativo a las clases magistrales. Una parte importante de los contenidos y temarios de las asignaturas impartidas por los autores son desarrollados mediante esta nueva metodología, que se basa en la gamificicación, en el trabajo en equipo y en el aprendizaje colaborativo combinado con una adapctación de la técnica puzzle de Aronson. Dicho juego se puede realizar en cualquier tipo de entorno o aula, en el tiempo de clase asiganado a la asignatura y apenas requiere de material adicional. Además con su aplicación se trabajan en clase al mismo tiempo las Competencias Tranversales de la Universitat Politècnica de València de "Comprensión e Integración", "Trabajo en Equipo y Liderazgo", "Comunicación Efectiva" y "Planificación y Gestión del Tiempo". Se ha evaluado la satisfacción del alumnado con respecto a este método alternativo de docencia con resultados muy positivos. Del mismo modo, aunque la implantación del método es reciente, no disponiendose de apenas registros, parece que se está logrando incrementar el rendimiento académico.
} 
Palabras clave: clase magistral, gamificación, aprendizaje colaborativo, competencias transversales.

\section{Introducción}

Durante la realización de diversos cursos formativos, varios compañeros de departamento entramos en contacto con nuevas e innovadoras prácticas pedagógicas. Consideramos oportuno intentar emplear estas nuevas prácticas pedagógicas en nuestras actividades docentes, pues mediante la aplicación de las mismas se ha comprobado que mejoran los resultados tanto académicos, como de aprendizaje de los alumnos. Diversos estudios demuestran que a las 24 horas de una sesión con experiencias prácticas, los alumnos retienen el $75 \%$ de los conocimientos adquiridos, mientras que este porcentaje va disminuyendo hasta un 50\% cuando se han adquirido mediante la discusión en grupo y hasta un 5\% si se trata de una lección magistral (SALINAS).

Tras un proceso de revisión de diversos documentos, publicaciones, etc. y de la captación de información, de un modo más exhaustivo, de las ventajas de implantar una docencia alejada de las clases magistrales en nuestras aulas, decidimos centrarnos en la gamificación, en el trabajo en equipo y el aprendizaje colaborativo, combinándolo con la técnica puzle de Aronson, para desarrollar una metodología docente propia. Además pretendíamos que, más allá del temario exacto con el que se aplicara, fuese algo semejante a los llamados "materiales a prueba de profesores" (BONAFE), de tal modo que pueda perdurar en el tiempo y de la que otros docentes puedan hacer uso.

Debemos puntualizar que la gamificación la entendemos como "el término utilizado para referirnos a la aplicación de mecánicas de juego en ámbitos que normalmente no son lúdicos" (DETERDING y col.) (LLAGOSTERA), pues existen otros autores que circunscriben su significado a la "aplicación de elementos conceptuales propios del diseño de videojuegos a entornos distintos del juego" (PRIETO MARTIN y col. 2014).

Por otro lado, al hablar del aprendizaje colaborativo, hacemos referencia al término acuñado por Vygotsky ya en 1978 (VIGOTSKY): "el aprendizaje colaborativo consiste en aprender de otros y con otros". Esto significa que, ante un proyecto común, cada individuo aporta su perspectiva individual, construyéndose un nuevo proyecto, lo que supone la necesidad de que se deba cooperar y colaborar en grupo.

En cuanto a la técnica puzle, es una técnica de aprendizaje cooperativo que permite que los alumnos compartan en grupo una gran cantidad de información (MARTINEZ y col.). Por ello es la utilizada para el desarrollo de una de las partes de la metodología docente que presentamos.

Consideramos que se hace imprescindible la sustitución de los sistemas clásicos de docencia, por nuevas prácticas educativas en las que el alumnado no sea un mero receptor de las informaciones y datos expuestos por el profesorado, sino un agente activo que intervenga en su propio proceso de enseñanza-aprendizaje. Hay que tratar de lograr que los conocimientos adquiridos a lo largo de la carrera perduren de tal forma que los alumnos no solo se conviertan, tras acabar sus estudios, en profesionales capaces, sino en sujetos

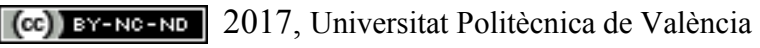

Congreso IN-RED (2017) 
capaces de desarrollar e innovar. Lo que exponemos a continuación supone el intento de crear una metodología que resulte más eficaz y motivadora para los alumnos.

\section{Objetivos}

El objetivo principal es el desarrollo de un juego basado en los tradicionales juegos de preguntas y respuestas como método alternativo a las clases magistrales. Esta nueva metodología está basada en la gamificación, en el trabajo en equipo y en el aprendizaje colaborativo combinado con una adaptación de la técnica puzle de Aronson. Con todo ello lo que se pretende lograr es un incremento en el interés y motivación del alumnado, con el fin de maximizar los contenidos y/o conocimientos adquiridos por parte del mismo sobre los temas y materias tratadas en las aulas.

Por otro lado, la Universitat Politècnica de València (UPV) ha creado un proyecto con el objetivo de orientar sus prácticas docentes hacia el nuevo paradigma educativo que ve la educación superior como una formación basada en competencias. La UPV ha estipulado trece competencias transversales en su proyecto. El objetivo secundario de esta nueva metodología presentada es trabajar en las aulas cuatro de las trece competencias transversales de la UPV. Estas cuatro competencias tranversales de la UPV desarrolladas a través de esta nueva metodología son (UPV 2017):

- Comprensión e Integración: comprender quiere decir "percibir y tener una idea clara de lo que se dice, se hace o sucede o descubrir el sentido profundo de algo". Para demostrar que algo se ha comprendido, la persona identifica y recupera la información y la explica con sus propias palabras, interpretando e integrando las ideas desde su propia perspectiva.

- Trabajo en Equipo y Liderazgo: el trabajo en equipo implica crear y desarrollar un clima de confianza mutua entre los componentes que permita trabajar de forma responsable y cooperativa. El término más apropiado para describir esta situación es COMPARTIR: compartir conocimientos, compromiso y responsabilidad. Supone el reparto de tareas y roles y el respeto a las normas y reglas de juego establecidas por y para el grupo.

- Comunicación Efectiva: comunicarse efectivamente significa tener desarrollada la capacidad de transmitir conocimientos y expresar ideas y argumentos de manera clara, rigurosa y convincente, tanto de forma oral como escrita, utilizando los recursos apropiados adecuadamente y adaptándose a las circunstancias y al tipo de público.

- Planificación y Gestión del Tiempo: esta competencia implica ser capaz de organizar y distribuir correctamente el tiempo del que disponemos y distribuirlo en función de las actividades necesarias para alcanzar nuestros objetivos a corto, medio y largo plazo. 


\section{Desarrollo de la innovación}

Esta nueva metodología es aplicable en casi cualquier tipo de asignatura con mucha carga teórica, como alternativa a la clásica clase magistral. Además, se puede realizar en cualquier tipo de entorno o aula, en el tiempo de clase asignado a la asignatura y apenas requiere de material adicional.

Nuestra primera experiencia de aplicación fue en la asignatura de "Envase y Embalaje", con una asignación de 4.5 créditos en el tercer curso, segundo cuatrimestre, del Grado en Ingeniería en Diseño Industrial y Desarrollo de Productos. La media de alumnos por curso en esta asignatura se sitúa en 68. El tiempo de clase para el desarrollo de la parte teórica de la asignatura es de 2 horas semanales ( 15 semanas).

Las aulas en las que se imparte dicha asignatura de "Envase y Embalaje" presentan una distribución típica, con la zona del profesor en alto, con la la mesa, la pizarra y la pantalla del cañon-proyector y la zona de los alumnos más baja que la del profesor, con mesas y sillas formando filas. Esto no es un impedimento para la realización del juego, ya que tanto en la fase preparatoria del juego, como durante la fase de juego, las cuales se describen seguidamente, los alumnos se agrupan en distintas zonas del aula y si es necesario se le da la vuelta a determinadas mesas. El único material que deben traer los alumnos es lápiz y papel, y el tema impreso (en caso de no disponer de ordenadores o tablets en el aula; nuestro caso) para trabajarlo en clase. Los alumnos no han de preparar nada previamente a la sesión. Una vez terminada la sesión de juego, los alumnos habrán adquirido los concimientos trabajados, pero de una manera más agradable que la tradicional clase magistral.

En el presente curso académico estamos implantando esta metodología en otras varias asginaturas del área de Ciencia de los Materiales, esperando obtener resultados plenamente satisfactorios para todas las partes implicadas en la docencia.

A continuación, se detalla y describe esta nueva metodología.

\subsection{Reglas del Juego}

\subsubsection{Componentes del Juego}

Podemos diferenciar:

- Temario: tema a trabajar de una longitud media de 30 folios.

- Batería de preguntas: 30 o 35 preguntas tipo test por grupo, con 4 respuestas posibles, relacionadas al temario.

- Grupos: al menos dos grupos de un mínimo de 4 y un máximo de 6 alumnos por grupo.

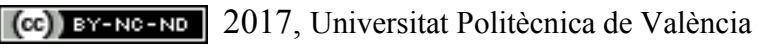

Congreso IN-RED (2017) 
- Dado: sirve cualquier dado convencional que posea como mínimo el mismo número de caras que grupos van a jugar. No obstante, es conveniente que sea de proporciones especiales, es decir, lo suficientemente grande como para que todos los grupos lo puedan ver al mismo tiempo (por ejemplo, un cubo de $\pm 20 \mathrm{~cm}$ de lado).

\subsubsection{Bases del Juego}

El objetivo del juego radica en obtener el mayor número de puntos posibles a fin de ganar el juego, para lo cual habrá que responder correctamente, de forma conjunta, el mayor número de preguntas posibles de aquellas que realicen el resto de grupos.

No obstante, dado que no se trata de un mero juego de entretenimiento, sino que se persigue un objetivo pedagógico, se hace necesario un aliciente motivacional que impulse el deseo de ganar el juego, más allá de la mera satisfacción. Por ello, el ganar el juego supone la consecución de 0,4 puntos otorgados por el profesor a todos los miembros del grupo ganador, puntos que se sumaran a la nota obtenida en un próximo examen.

\subsection{Desarrollo del Juego}

En el desarrollo del juego podemos diferenciar dos fases: la fase preparatoria y la fase de juego.

\subsubsection{Fase Preparatoria}

Consiste en la preparación de los elementos necesarios para la realización del juego.

En esta fase:

- Los alumnos se dividen en grupos de 4 a 6 miembros cada uno, entre los que se nombrará un portavoz, un tira-dado y un cronometrador.

- Los grupos se numeran (grupo 1, grupo 2, etc.).

- El profesor proporciona al alumnado el tema a trabajar de una longitud media de 30 folios y los componentes del grupo se lo dividen, a fin de trabajar las partes de modo individual.

- Durante los siguientes 15 a 20 minutos, los alumnos deben trabajar de modo individual aquella parte del temario que les ha sido asignada, intentando comprender y asimilar los contenidos fundamentales.

- Una vez transcurrido el primer tiempo, los componentes del grupo deberán poner en común, uno a uno, los conocimientos comprendidos en su parte del temario, intentando que el resto de componentes del grupo tome conciencia de la materia, lo 
que no debería ocuparles más de unos 20-25 minutos (tiempo que de creerlo necesario se puede ampliar). De esta forma cada integrante del grupo asume el rol de profesor, tratando de transmitir los conocimientos que adquirido al trabajar, asimilar y comprender su parte del temario. Transcurrido este segundo tiempo cada integrante del grupo será conocedor del $100 \%$ del tema proporcionado por el profesor.

- Finalmente, los componentes de cada grupo, preferentemente de modo individual $\mathrm{y}$, de ser posible y quedarles tiempo, poniéndolo posteriormente en común, realizaran una batería 5-6 preguntas cada uno, en base a la parte del tema que han trabajado. Esta última etapa de la fase preparatoria no deberá durar más de 20 minutos.

Durante todas estas etapas el profesor debe estar para resolver aquellas dudas o problemas que puedan surgirles a los alumnos, así como para ayudarles a gestionar los tiempos. En base a la dificultad del temario y del alumnado con el que se trabaje, esta fase no debería superar la mitad del tiempo total de clase, en nuestro caso 1 hora.

\subsubsection{Fase de Juego}

La fase de juego comienza con la elección del grupo que iniciará el juego. Todos los grupos tiraran una vez el dado y el que saque un cinco será el que comience el juego. En caso de que más de un grupo saque dicho número, repetirían la tirada con el fin de desempatar.

Se inicia el juego y el tira-dado del grupo que lo hace tira el dado. El número que sale corresponderá al grupo que deberá realizarles la pregunta, el cual escogerá de su batería de preguntas aquella que considere conveniente y su portavoz se la leerá. El grupo que es preguntado dispondrá de 15 segundos para que su portavoz dé la respuesta, tiempo que controlará el cronometrador del equipo que les pregunta.

En caso de que acierten la pregunta que se les ha realizado, el grupo ganará un punto y volverá a tirar repitiéndose el proceso. En caso de que fallen la pregunta, el turno pasará al grupo colocado a su derecha, el cual realizará el mismo proceso.

\section{Resultados}

De la discusión y debate con otros docentes, así como con parte de nuestros alumnos en referencia a los cambios introducidos, se extrae la conclusión de una mejora en el interés y en los resultados académicos obtenidos, así como una mayor motivación por parte del alumnado.

Las clases son de asistencia obligatoria, por lo que el faltar a las mismas no es una posibilidad. Pero mediante la observación hemos comprobado que hay un mayor interés del alumnado por la concurrencia al aula desde la aplicación de esta nueva metodología, dado que llegan con más antelación a la necesaria y no manifiestan un denotado afán por irse cuando finaliza la clase.

(c)) BY-NC-ND 2017, Universitat Politècnica de València 
No obstante, a fin de testear esta nueva metodología de un modo algo más empírico y menos subjetivo que la mera observación, realizamos un pase de encuestas en la asignatura anteriormente mencionada (Envase y Embalaje), mediante las cuales intentamos confirmar nuestras consideraciones.

Efectuamos una encuesta de cinco preguntas a los alumnos, solicitándoles que contestaran en base a tres parámetros: SI, NO y TAL VEZ.

La primera pregunta iba encaminada a averiguar sus preferencias en cuanto al tipo de clase, la segunda hacía referencia a la facilidad en la adquisición de los conocimientos, la tercera a los niveles motivacionales, la cuarta la conformamos como pregunta de control volviendo a referirnos al tipo de docencia y, por último, la quinta se refería al trabajo grupal. Estas eran las preguntas:

- Pregunta 1: ¿Preferirías que la asignatura se diera mediante una clase magistral?

- Pregunta 2: En cuanto a la adquisición de los conocimientos ¿Se facilita mediante el sistema de juego?

- Pregunta 3: ¿Te es fácil mantener el interés en el juego?

- Pregunta 4: ¿Te es más interesante la asistencia a una clase magistral?

- Pregunta 5: Si pudieras elegir ¿desearías trabajar de modo individual?

Finalizado el proceso de pase de encuestas y recopilación de respuestas, obtuvimos los resultados que se exponen en la Tabla 1:

Tabla 1. Resultados encuesta

\begin{tabular}{|l|c|c|c|}
\hline & SI & NO & TAL VEZ \\
\hline Pregunta 1 & $5 \%$ & $90 \%$ & $5 \%$ \\
\hline Pregunta 2 & $93 \%$ & $3.6 \%$ & $3.4 \%$ \\
\hline Pregunta 3 & $95 \%$ & $2 \%$ & $3 \%$ \\
\hline Pregunta 4 & $5 \%$ & $92.5 \%$ & $2.5 \%$ \\
\hline Pregunta 5 & $22 \%$ & $75 \%$ & $3 \%$ \\
\hline
\end{tabular}

Estos resultados nos llevan a unas conclusiones semejantes a las que llegamos mediante la mera observación de los comportamientos sociales del alumnado. Así pues, resulta evidente que la experiencia es positiva y comporta los esperados beneficios. Además, para el caso de la asignatura citada, Envase y Embalaje, pasamos de un $11.11 \%$ de alumnos suspendidos al final de la evaluación continua, a un $4.69 \%$ al siguiente año de aplicación de la nueva metodología descrita, lo que significa una mejora de más del doble del rendimiento académico. 


\section{Conclusiones}

Si bien ya lo hemos dicho en el apartado anterior, querríamos recalcar que la conclusión que se desprende tanto de la práctica docente realizada, como de los resultados obtenidos de la misma, supone afirmar que resulta altamente interesante el uso de este tipo de técnicas y metodologías, pues se incrementan los niveles de atención e interés del alumnado, lo que, a su vez reporta una mejora tanto en los resultados académicos, como en los propios del proceso de enseñanza-aprendizaje.

Así pues, consideramos que la modificación y sustitución de las clásicas clases de carácter magistral y sus consecuentes pruebas evaluativas, en las que la totalidad de la puntuación a obtener depende exclusivamente de la capacidad de memorización y repetición de conceptos y datos por parte del alumnado, por una docencia basada en un proceso enseñanza-aprendizaje en el que se integre e involucre a los alumnos, resulta en todo caso un gran acierto.

\section{Referencias}

BONAFE, J. M. (1993). Proyectos curriculares y práctica docente.

DETERDING, S., D. DIXON, R. KHALED and L. NACKE (2011). "From game design elements to gamefulness: defining "gamification"". Proceedings of the 15th International Academic MindTrek Conference: Envisioning Future Media Environments, Tampere, Finland, ACM.

LlAGOSTERA, E. (2012). "On gamification and persuasion." Proceedings of the SBGames, Rio de Janeiro, Brazil: 2-4.

MARTINEZ, J. and F. GOMEZ (2010). "La técnica puzzle de Aronson: descripción y desarrollo." Arnaiz, P.; Hurtado, Ma. D. y Soto, FJ (Coords.) 25.

PRIETO MARTIN, A., D. DIAZ MARTIN, J. MONSERRAT SANZ and E. REYES MARTIN (2014). "Experiencias de aplicación de estrategias de gamificación a entornos de aprendizaje universitario." ReVision 7(2).

SALINAS, J. (1995). Organización escolar y redes: Los nuevos escenarios del aprendizaje. "Cabero, J.; Martínez, F. (Coord.): Los nuevos canales en la enseñanza.", Centro de Estudios Ramón Areces S.A.: -.

UPV, U. P. d. V. (2017). "Competencias Transversales UPV." from http://www.upv.es/contenidos/COMPTRAN/, [Consulta: Marzo 2017].

VIGOTSKY, L. (2001). "Psicología pedagógica. Un curso breve." Argentina. Editorial Aique.: 67-468.

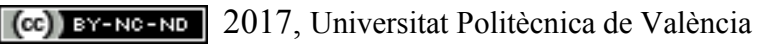

Congreso IN-RED (2017) 


\title{
Google Street View como herramienta docente: Una actividad formativa desde el Research Based Learning
}

\author{
Miriam Marcoa, Viviana Vargas ${ }^{b}$, Manuel Martín-Fernández ${ }^{c}$, Faraj A. Santirsod, \\ Enrique Gracia ${ }^{\mathrm{e}}$ y Marisol Lila \\ aDepartamento de Psicología Social. Universitat de València. E-mail: Miriam.Marco- \\ Francisco@uv.es, ${ }^{b}$ Departamento de Psicología Social. Universitat de València. E-mail: \\ vivianav@gmail.com, ${ }^{c}$ Departamento de Psicología Social. Universitat de València. E-mail: \\ Manuel.Martin@uv.es, ${ }^{\mathrm{d}}$ Departamento de Psicología Social. Universitat de València. E-mail: \\ Faraj.Santirso@uv.es, e Departamento de Psicología Social. Universitat de València. E-mail:

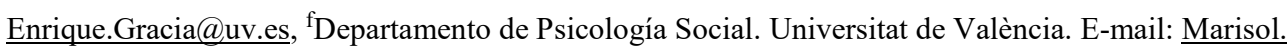 \\ $\underline{\text { Lila@,uv.es }}$
}

\begin{abstract}
From the Research Based Learning approach, it has been highlighted the importance of introducing new teaching tools in order to let students to acquire practical knowledge about a subject from a scientific perspective. This paper presents a structure practice developed and applied in the subject of Psychology of Social and Community Intervention of the Degree of Psychology (University of Valencia). "Learning by doing. Using Google Street View as a research tool" is a practice where students use the tool Google Street View to assess the neighborhood disorder after which they get feedback of the result of their work. This activity promotes the debate, and then a work by projects is presented, where students have to design a community intervention based on the concepts learned in the practice. The proposed activity had a very positive response from the students due to the novelty of the concept, the introduction of new technological tools such as Google Street View, and the autonomous work by students. Future research would benefit from assessing the effectiveness of this practice.
\end{abstract}

Keywords: Research Based Learning, Learning by doing, Google Street View, new teaching tools

\section{Resumen}

Desde la perspectiva del Research Based Learning se ha destacado la importancia de introducir nuevas herramientas docentes que permitan a los estudiantes adquirir conocimientos prácticos sobre una materia desde un punto de vista científico, conectando con la investigación. En este trabajo se presenta una práctica estructurada desarrollada y aplicada en la asignatura de Psicología de la Intervención Social y Comunitaria del Grado de Psicología de la Universidad de Valencia. "Aprender haciendo. La utilización de Google Street View como herramienta de investigación" es una práctica que consiste en que los alumnos utilicen la herramienta Google Street View para evaluar el desorden del vecindario y posteriormente obtengan retroalimentación del resultado de su trabajo. Con esta actividad 
se fomenta el debate, y posteriormente se presenta un trabajo por proyectos donde los estudiantes deben diseñar una intervención comunitaria basada en los conceptos vistos en la práctica. La actividad propuesta tuvo una respuesta muy positiva por parte de los alumnos por lo novedoso del concepto, la introducción de nuevas herramientas tecnológicas como Google Street View, y la capacidad de trabajo autónomo por parte de los alumnos. Futuros estudios son necesarios para evaluar la efectividad de dicha práctica.

Palabras clave: Research Based Learning, Aprender Haciendo, Google Street View, nuevas herramientas docentes 


\section{Introducción}

Tradicionalmente la investigación y la docencia se han tratado como dos funciones independientes y diferenciadas en el ámbito universitario. Sin embargo, tanto para docentes como para los y las estudiantes, es importante integrar estos dos aspectos y considerarlos como parte de un todo: la teoría no avanza ni evoluciona si no se basa en la investigación científica, mientras que la investigación no es válida si no se basa en el conocimiento teórico. Es por ello por lo que en las últimas décadas el trabajo académico universitario consiste en combinar ambos perfiles, dando lugar a una práctica integradora que se traduce en el papel del docente-investigador.

Desde este punto de vista, los alumnos, que están inmersos en el sistema universitario, deben ser capaces de comprender la importancia que la investigación tiene para el avance del conocimiento científico. Así como también, deben conocer las oportunidades que tienen de ser parte de este avance a través de la generación de su propio conocimiento científico (Lee, 2004). Por ello, es necesario que desde la docencia universitaria se fomente el interés de los alumnos en la investigación y en todo lo que ésta supone (Badley, 2002; Elton, 2001).

Desde la perspectiva del Research Based Learning, se propone la importancia de introducir nuevas herramientas docentes que permitan a los estudiantes adquirir conocimientos prácticos sobre una materia concreta desde un punto de vista científico, vinculándolo con la investigación y el avance del conocimiento (Griffits, 2004; Hutchings, 2007; Jenkins, 2004). Técnicas como los estudios de caso, el trabajo de campo, o los trabajos por proyectos formarían parte de esta nueva perspectiva (Healey y Jenkins, 2009).

\begin{tabular}{|c|c|c|c|}
\hline \multirow{6}{*}{$\begin{array}{l}\text { ÉNFASIS EN EL } \\
\text { CONTENIDO DE } \\
\text { INVESTIGACIÓN }\end{array}$} & \multicolumn{2}{|c|}{ LOS ESTUDIANTES PARTICIPAN } & \multirow{5}{*}{$\begin{array}{l}\text { ÉNFASIS EN LOS } \\
\text { PROCESOS Y } \\
\text { PROBLEMAS DE } \\
\text { INVESTIGACIÓN }\end{array}$} \\
\hline & Research-tutored & Research-based & \\
\hline & $\begin{array}{c}\text { Participar en } \\
\text { discusiones sobre } \\
\text { investigación }\end{array}$ & $\begin{array}{l}\text { Llevar a cabo } \\
\text { investigaciones }\end{array}$ & \\
\hline & Research-led & Research-oriented & \\
\hline & $\begin{array}{c}\text { Aprender sobre la } \\
\text { investigación } \\
\text { actual en la } \\
\text { materia }\end{array}$ & $\begin{array}{l}\text { Desarrollar } \\
\text { habilidades y } \\
\text { técnicas de } \\
\text { investigación }\end{array}$ & \\
\hline & LOS ESTUDIAN & SON OYENTES & \\
\hline
\end{tabular}

Fig. 1 La naturaleza del aprendizaje basado en la investigación (fuente: Healey y Jenkins, 2009) 
Partiendo de esta base, se ha diseñado un proyecto docente con el objetivo de acercar la investigación a las aulas universitarias. Para ello, se ha establecido un plan formativo estructurado en el que se han desarrollado diferentes actividades o prácticas donde se introduce la investigación en este contexto. En este trabajo nos vamos a centrar en una de esas actividades en concreto, exponiendo las bases de esta práctica, y la forma en que se ha preparado e impartido.

\section{Objetivos}

\subsection{Objetivo general}

En este trabajo se presenta una actividad docente que se ha desarrollado y se ha aplicado en la asignatura de Psicología de la Intervención Social y Comunitaria del Grado de Psicología de la Universidad de Valencia. El objetivo general de la actividad es fomentar la curiosidad científica de los alumnos, desde una perspectiva basada en el Research Based Learning.

\subsection{Objetivos específicos}

- Introducir herramientas de Aprender Haciendo como alternativa a la enseñanza tradicional.

- Presentar a las y los alumnos la importancia del contexto social y estructural del vecindario a la hora de estudiar distintos problemas sociales.

- Presentar a las y los alumnos el concepto de desorden del vecindario y enseñar un instrumento de observación válido y preciso del mismo.

- Fomentar el aprendizaje acerca de los procesos sociales y la intervención en la comunidad mediante trabajo de campo.

- Favorecer el trabajo en equipo y la discusión sobre los resultados científicos.

\section{Desarrollo de la innovación}

La práctica que se expone en este trabajo tiene por nombre "Aprender haciendo. La utilización de Google Street View como herramienta de investigación”. Como se ha comentado anteriormente, esta actividad docente se diseñó para llevarse a cabo dentro de la asignatura de Psicología de la Intervención Social y Comunitaria, dentro del Grado de Psicología. Esta actividad docente de innovación educativa consiste en presentar a los alumnos un instrumento para medir el desorden del vecindario (una variable especialmene relevante en el estudio de diferentes problemas sociales) mediante la aplicación tecnológica Google Street View. En la actualidad, esta herramienta es cada vez más utilizada para evaluar características del vecindario por las grandes ventajas que presenta (Odgers, Caspi, Bates, Sampson, y Moffit, 2012). A continuación, se describe la actividad principal de la práctica propuesta, consistente en que las y los alumnos utilicen dicha herramienta para la

(cc) EY-NC-ND 2017, Universitat Politècnica de València

Congreso IN-RED (2017) 
evaluación del desorden social en los vecindarios. Posteriormente, son presentados en conjunto los resultados obtenidos por los/as alumnos/as, y se muestran mapas de desorden del vecindario obtenidos a partir del trabajo de cada uno de ellos/as.

\subsection{Prueba piloto}

Se llevó a cabo un estudio piloto en el que se realizó esta práctica en el curso académico 2015-2016 en varios grupos de la asignatura de Psicología de la Intervención Social y Comunitaria como una actividad incluida en el plan docente de la asignatura. El estudio piloto fue desarrollado en dos sesiones presenciales realizadas en el aula y una sesión no presencial en la que los alumnos debían realizar una tarea en casa. En la primera sesión presencial se les explicó a los/as alumnos/as el contenido de la práctica, así como la importancia del contexto y de las variables contextuales en el estudio de diferentes problemas sociales. Además se presentó el concepto teórico de desorden del vecindario. A continuación, se presentaron algunos instrumentos de observación realizados anteriormente por investigadores para la valoración del desorden social (Marco, Gracia, Tomás y LópezQuílez, 2015). Sin embargo, debido a los inconvenientes de estos instrumentos observacionales, los investigadores han comenzado a utilizar en mayor medida herramientas tecnológicas, entre estas la aplicación Google Street View. Asimismo, se les explicó en qué consistía esta herramienta, y se realizó una práctica en la que los/as alumnos/as debían evaluar entre todos los diferentes ítems de desorden del vecindario contenidos en una escala de observación. Los/as alumnos/as ante cada ítem debían llegar a un acuerdo con respecto a la puntuación. Una vez alcanzado un alto grado de consenso, se repartieron entre los/as alumnos/as diferentes áreas de Valencia, las cuales debían evaluar en parejas utilizando el Google Street View.

Una vez concluída la sesión presencial, los y las estudiantes debían realizar por parejas la evaluación del área asignada durante una sesión no presencial. Para ello se les pidió que seleccionaran aquellas fotos virtuales que creyeran más representativas del desorden del vecindario de las áreas que tenían asignadas. Asimismo, se les pidió que llegasen a un acuerdo y evaluaran el desorden general del vecindario sobre la base de sus observaciones. Una vez hubieran terminado con la evaluación, debían enviar el resultado a los docentes a través del aula virtual de la asignatura.

Por último, en la segunda sesión presencial la docente mostró a toda la clase los resultados de los trabajos realizados por los/as alumnos/as. Entre los resultados se presentaron algunas características psicométricas de la escala, así como mapas de desorden del vecindario según la valoración de los propios alumnos/as. Estos resultados fueron comparados con los obtenidos anteriormente mediante una escala observacional física donde se visitó de forma directa las áreas y se evaluaron mediante observaciones in situ (Marco et al., 2015). 


\subsection{Desarrollo de la práctica}

Una vez realizado el estudio piloto, se procedió a diseñar la práctica de forma sistematizada y crear fichas de contenido estructuradas para cada una de las sesiones de la práctica. Se planificó 3 sesiones para abarcar todo el contenido necesario. A continuación, se describe el desarrollo de la práctica en las 3 sesiones tal y como se muestra en las fichas de contenido.

\subsubsection{Sesión 1}

Objetivos:

- Presentar a los alumnos la importancia del contexto y el vecindario a la hora de estudiar distintos problemas sociales

- Presentar a los alumnos el concepto de desorden del vecindario

- Enseñar un instrumento de observación de desorden del vecindario

- Realizar una práctica guiada sobre cómo evaluar el desorden del vecindario mediante Google Street View utilizando la escala observacional presentada

- Llegar a un alto nivel de acuerdo entre los alumnos en cuanto a la evaluación de desorden del vecindario

Duración: 120 minutos

Material del docente: Diapositivas power point, instrumento de desorden del vecindario.

Dinámica de trabajo: Exposición teórica y trabajo en gran grupo

Procedimiento:

- El docente explica mediante power point la importancia del contexto y el vecindario a la hora de estudiar distintos problemas sociales poniendo ejemplos específicos: delitos, violencia de género, maltrato infantil, etc. (15 min.).

- Seguidamente, el docente explica las diferentes características contextuales que se han estudiado, y presenta el concepto de desorden del vecindario y las teorías que lo explican (15 min).

- El docente explica las diferentes formas que se han utilizado para evaluar el desorden del vecindario, y se explica qué son los instrumentos observacionales y su utilidad (15 min).

- El docente presenta un instrumento de observación validado realizado por el grupo docente que evalúa desorden del vecindario (Marco et al., 2015). El instrumento contiene 6 ítems de desorden físico (colillas y basura en la calle, botellas o latas vacías, graffitis, coches abandonados, y pintadas de carácter político o reivindicativo) y 5 ítems de deterioro físico (casas vacías, comercios o locales abandonados, viviendas abandonadas, zonas residenciales muy deterioradas, y zonas recreativas muy deterioradas). (15 min.).

- A continuación, se les explica a los alumnos la herramienta de Google Street View, su modo de funcionamiento, sus ventajas respecto a las observaciones directas y se presentan algunos estudios que lo han utilizado (15 min.).

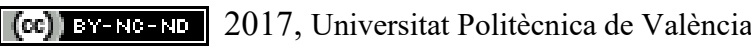

Congreso IN-RED (2017) 
- Se realiza una práctica guiada sobre cómo evaluar el desorden del vecindario mediante Google Street View utilizando la escala observacional presentada anteriormente Cada uno de los alumnos sale al ordenador de clase a realizar la práctica, el docente le pide que recorra un área concreta y que comente a los compañeros lo que va encontrando, y finalmente proponga una puntuación a los diferentes ítems de la escala. Entre todos los alumnos han de llegar a un acuerdo sobre la puntuación para cada ítem. Si existen discrepancias entre los alumnos, llegar a un punto en común y asumir normas que se van a seguir siempre que se dé la misma situación.El docente anticipa los posibles problemas que puedan surgir en la visualización, y cómo solventarlos. Se practica en conjunto hasta que todos los ítems han quedado claros y los alumnos llegan a un alto grado de acuerdo (45 min.).

- Antes de la finalización de la sesión, se recuerda a los alumnos que la semana siguiente deben volver a traer el ordenador.

\subsubsection{Sesión 2}

Objetivos:

- Que los alumnos, en parejas, realicen la evaluación de una zona concreta (diferentes sectores censales de la ciudad) y rellenan los diferentes ítems del cuestionario de evaluación de desorden

- Que los alumnos lleguen a un alto nivel de acuerdo sobre las puntuaciones. Además, deben hacer capturas de pantalla sobre los elementos más relevantes del área correspondiente, y escribir las observaciones que crean oportunas

Duración: 120 horas

Material de los alumnos: Web de Google, instrumento de desorden del vecindario y mapa de la ciudad de Valencia.

Materiales del docente: Web de Google.

Dinámica de trabajo: Trabajo en parejas.

Procedimiento:

- El docente explica que hoy se va a realizar la práctica de Google Street View. Los alumnos se ponen por parejas, y el docente les reparte un mapa de la ciudad de Valencia (ver Figura 1). Cada pareja de la clase tendrá un mapa diferente, dividido en sectores censales. Se explica que deben completar el instrumento de desorden del vecindario para cada uno de los sectores censales que contenga su mapa, y deben realizar una pequeña ficha sobre cada uno de ellos, las observaciones que quieran poner, y fotos virtuales sobre las zonas más características del sector censal en concreto (15 min.).

- Los alumnos trabajan en parejas durante la clase. Si tienen dudas, el docente les ayuda a la consecución del trabajo de manera correcta (1 h. y 45 min.).

(c) ) EY-NC-ND 2017, Universitat Politècnica de València 
- En caso de que no les dé tiempo a acabar, podrán continuar el trabajo fuera del aula durante la semana, y deberán entregar la actividad mediante el aula virtual de la asignatura en los dos días siguientes.

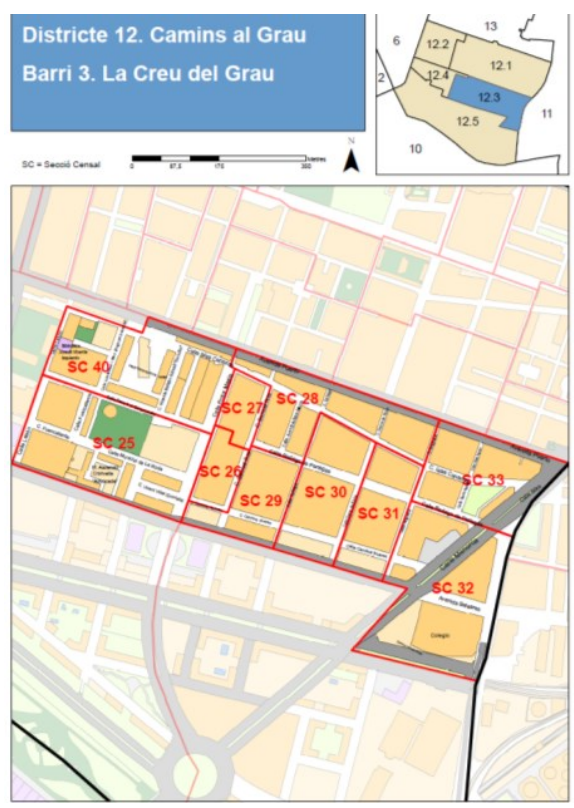

Fig. 2 Ejemplo de mapa de trabajo

\subsubsection{Sesión 3}

Objetivos:

- Presentar a los alumnos los resultados de sus análisis para que vean el producto de su trabajo

- Analizar con ellos las características psicométricas del instrumento de desorden del vecindario mediante el uso de Google Street View

Duración: 120 horas

Materiales del docente: Diapositivas power point.

Dinámica de trabajo: Exposición del docente.

Procedimiento:

- El docente comienza la clase recapitulando lo que se ha hecho hasta ahora y agradeciendo a los alumnos por su trabajo en las sesiones anteriores (10 min.).

- A continuación, el docente muestra a los alumnos los resultados de sus análisis: enseñará la fiabilidad del instrumento (si se han obtenido resultados similares a los obtenidos con observaciones in situ), el grado de acuerdo entre los alumnos, y mostrará los mapas de desorden que se han podido crear gracias al trabajo de los alumnos (30 min.).

(c)) EY-NC-ND 2017, Universitat Politècnica de València

Congreso IN-RED (2017) 
- El docente presenta algunas de las fotos virtuales realizadas por los alumnos más significativas, y las compara con fotografias hechas in situ para mostrar la similitud entre ambas (15 min.)

- Por último, el docente abre un debate entre los alumnos donde se comente por qué el desorden del vecindario puede ser tan importante para este tipo de problemas sociales, y planteen de qué forma podrían intervenir para disminuir el desorden del vecindario en las áreas donde más desorden se ha encontrado. Para ello, se realiza una actividad grupal donde los alumnos ideen una intervención comunitaria en un barrio con altos niveles de desorden físico y otras características negativas del vecindario, y presenten su proyecto de forma oral llevando a cabo estrategias de márketing social (50 min.).

\section{Resultados}

La primera puesta en práctica sistematizada de la práctica "Aprender haciendo. La utilización de Google Street View como herramienta de investigación" se llevó a cabo durante el primer cuatrimestre del curso 2016-2017 en un total de 3 grupos de la asignatura de Psicología de la Intervención Social y Comunitaria. En este apartado se muestran algunos de los resultados obtenidos por los alumnos, que fueron compartidos y discutidos en la última sesión.

En la Figura 2, se muestran ejemplos de las fotografías realizadas por los alumnos que fueron presentadas en la sesión.
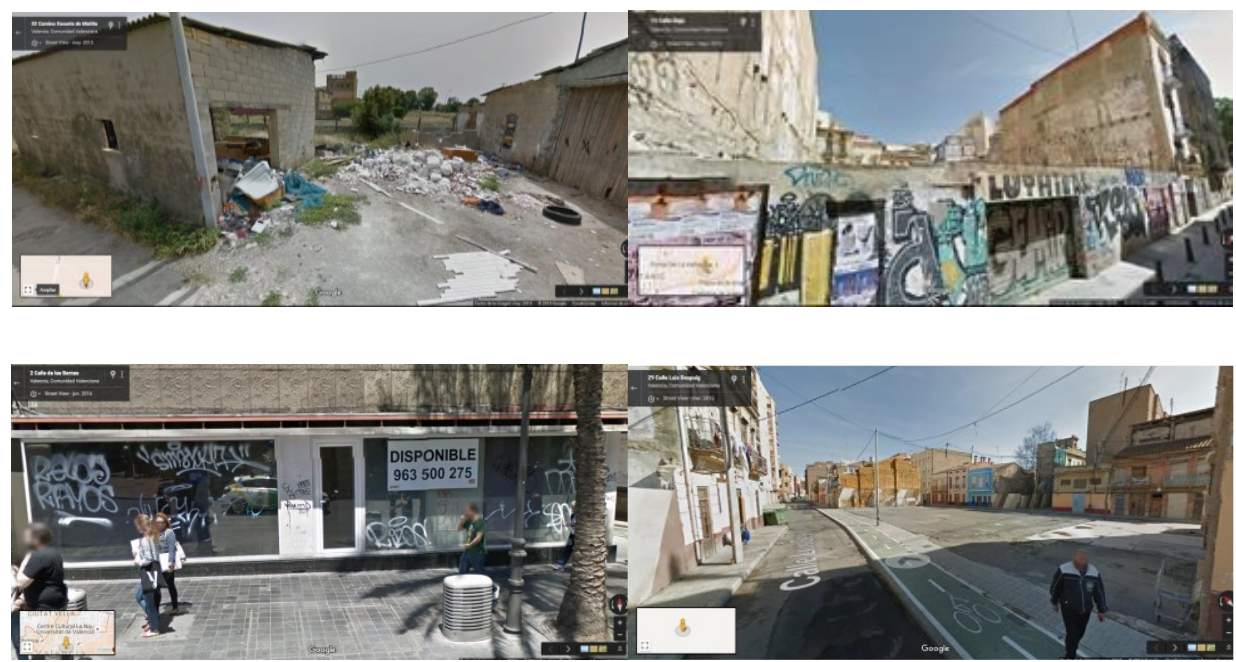

Fig. 3 Ejemplos de los alumnos sobre los items Basura en la calle, Grafitis, Locales Abandonados y Zonas residenciales muy deterioradas respectivamente, recogido con Google Street View 
Además, se les presentó una comparativa entre las fotografías tomadas por ellos mediante Google Street View, y fotografías in situ de las mismas áreas (Figura 3).

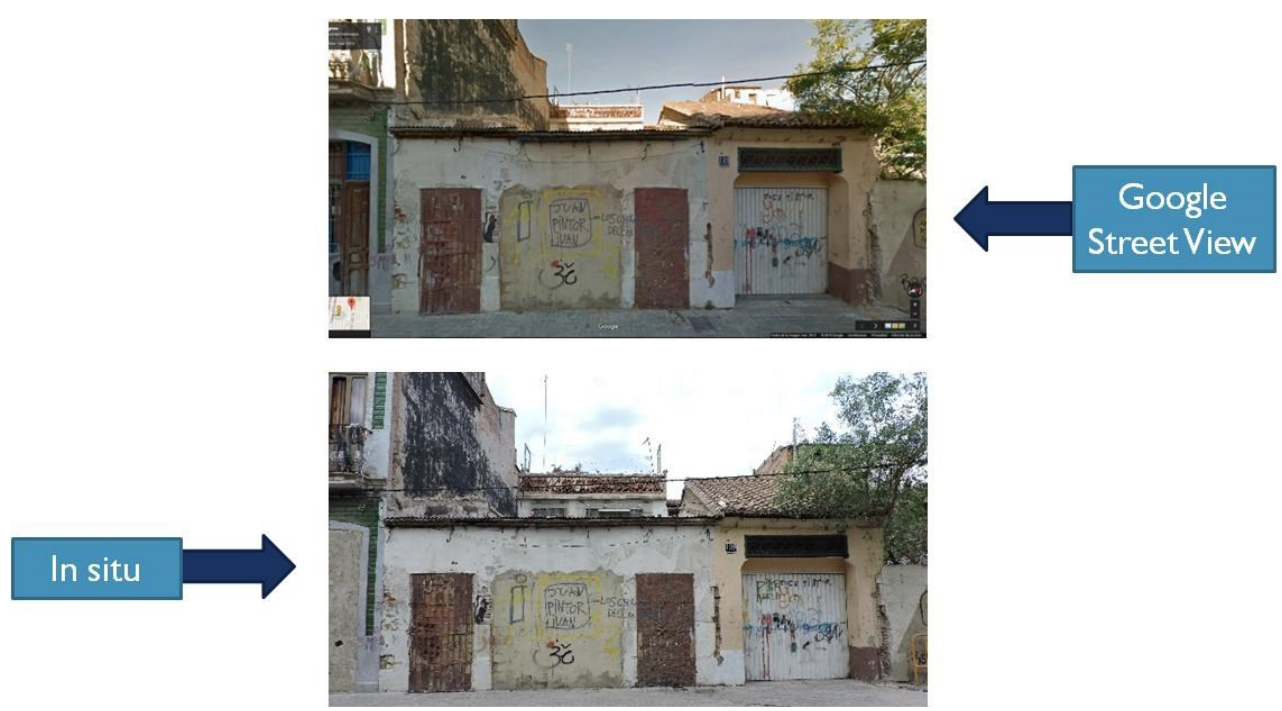

Fig. 4 Comparativa entre una fotografia tomada mediante Google Street View por los alumnos y una fotografia in situ

A continuación, se presentaron los diferentes análisis y mapas que mostraban visualmente la similitud entre las puntuaciones totales de deterioro físico y desorden físico obtenidas por los alumnos y alumnas, y las puntuaciones obtenidas en una evaluación in situ en la misma área (Marco et al., 2015) (Figura 4).
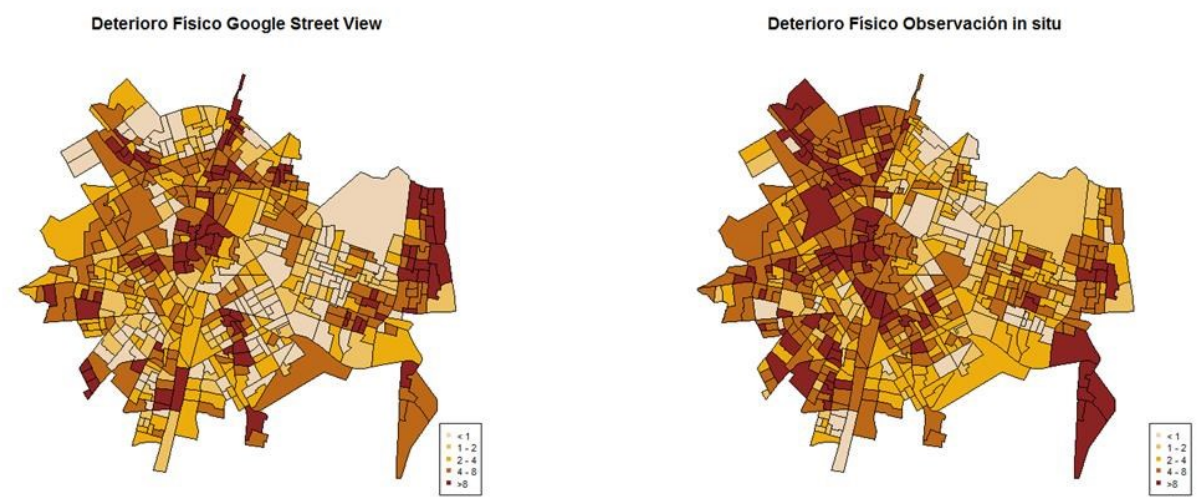

Fig. 5 Ejemplo de mapa presentado a los alumnos comparando las puntuaciones de desorden obtenidas mediante Google Street View y las obtenidas en observación in situ.

(cc) EY-NC-ND 2017, Universitat Politècnica de València

Congreso IN-RED (2017) 
Después, se discutió en grupos acerca de los resultados obtenidos, analizando las áreas que, según sus observaciones, presentaban mayores niveles de desorden, y las dificultades que habían tenido a la hora de realizar la observación virtual.

A continuación, se generó un debate entre los alumnos sobre la importancia de este tipo de variables para los problemas sociales. Por último, se realizó una actividad grupal donde los alumnos crearon una intervención comunitaria en un barrio con altos niveles de desorden físico y otras características negativas del vecindario, y posteriormente presentaron su proyecto de forma oral llevando a cabo estrategias de márketing social. Los alumnos mostraron un gran interés en la creación de sus propios proyectos, y las presentaciones grupales de los proyectos fueron de una alta calidad.

\section{Conclusiones}

En este trabajo se ha presentado una práctica docente basada en el paradigma. Research Based Learning, la cual propone el aprendizaje a través de la curiosidad científica. Esta práctica docente va más allá de la enseñanza tradicional y presenta el Aprender haciendo como una alternativa que implica al alumnado en su propio aprendizaje, acercándole a la investigación científica en el marco de su propia disciplina académica.

La valoración que el equipo docente ha llevado a cabo respecto a la actividad ha sido muy positiva. Esta actividad no sólo ha tenido muy buena acogida por parte de los y las estudiantes, sino que les ha resultado una oportunidad para aprender a utilizar nuevas herramientas tecnológicas y potenciar sus capacidades de aprendizaje autónomo. Asimismo, los y las estudiantes valoraron muy positivamente la retroalimentación propuesta por el equipo docente y la posibilidad de discutir y compartir los resultados que habían obtenido en su investigación tanto con sus compañeros como con los propios docentes.

Este ha sido el primer año en el que se ha aplicado esta práctica en la asignatura de Psicología de la Intervención Social y Comunitaria de forma sistemática, y nuestro objetivo es continuar realizándola durante los próximos años con el fin de evaluar científicamente la satisfacción de los alumnos/as, la percepción de los profesores, así como el cambio de actitudes hacia la investigación una vez acabada la asignatura. En futuros estudios se prevé proporcionar resultados basados en el rigor científico sobre la efectividad de la aplicación de esta práctica en la asignatura de referencia.

\section{Agradecimientos}

Este proyecto ha sido realizado en el marco de la convocatoria de innovación del Vicerectorat de Polítiques de Formació i Qualitat Educativa de la Universitat de València (UV-SFPIE_RMD16-417684). 


\section{Referencias}

BADLEY, G. (2002). "A really useful link between teaching and research" en Teaching in Higher Education, vol. 7, issue 4, p. 443-455.

ELTON, L. (2001). "Research and teaching: what are the real relationships?" en Teaching in Higher Education, vol. 6, issue 1, p. 43-56.

GRIFFITS, R. (2004). "Knowledge production and the research-teaching nexus: the case of the built environments disciplines" en Studies in Higher Education, vol. 29, issue 6, p. 709-726.

HEALEY, M., y JENKINS, A. (2009). Developing Undergraduate Research and Inquiry. York: HE Academy.

HUTCHINGS, W. (2007). Enquiry-Based Learning: Definitions and Rational. Manchester: University of Manchester.

JENKINS, A. (2004). A guide to the research evidence on teaching-research relationships. York: Higher Education Academy.

LEE, R. (2004). "Research and teaching: making - or breaking - the links" en Planet, vol. 12 , p. 9-10.

MARCO, M., GRACIA, E., TOMÁS, J.M., y LÓPEZ-QUíLEZ, A. (2015). “Assessing neighborhood disorder: Validation of a three-factor observational scale" en The European Journal of Psychology Applied to Legal Context, vol. 7, issue 2, p. 81-89.

ODGERS, C.L., CASPI, A., BATES, C.J., SAMPSON, R.J. y MOFFIT, T.E. (2012). "Systematic social observation of children's neighborhoods using Google Street View: a reliable and cost-effective method" en Journal of Child Psychology and Psychiatry, vol. 53 , issue 10 , p. 1009-1017. 


\title{
Evolución de la docencia en Teoría de Grafos en las últimas décadas
}

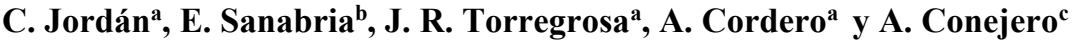

Instituto Universitario de Matemática Multidisciplinar, Universitat Politècnica de València, ${ }^{b}$ Departamento de Matemática Aplicada, Universitat Politècnica de València y

${ }^{c}$ Instituto Universitario de Matemática Pura y Aplicada, Universitat Politècnica de València, (cjordan@mat.upv.es, esanabri@mat.upv.es, jrtorre@mat.upv.es, acordero@mat.upv.es, aconejero@mat.upv.es)

\begin{abstract}
In this work we present the innovation carry on the subject "Grafos modelos $y$ aplicaciones" of the Bachelor's Degree in Informatics Engineering of the Escuela Técnica Superior de Ingeniería Informática (ETSINF) of the Universitat Politècnica de València (UPV). We comment the implementation of the methodologie and used teaching materials in the process that have lead us to it.
\end{abstract}

Keywords: competences, methodologie, evaluation, flip teaching, $O C W$, MOOC, Graph Theory.

\begin{abstract}
Resumen
En este trabajo presentamos la innovación realizada en la asignatura Grafos modelos y aplicaciones del plan de estudios del Grado en Ingeniería Informática impartida en la Escuela Técnica Superior de Ingeniería Informática (ETSINF) de la Universitat Politècnica de València (UPV). Comentamos los materiales docentes generados y utilizados, la implementación de la metodología y el proceso que nos ha llevado a ello.
\end{abstract}

Palabras clave: competencias, metodología, evaluación, flip teaching, $\mathrm{OCW}$, $M O O C$, educación inversa, teoría de grafos.

\section{Introducción}

Es un hecho irrefutable que la enseñanza universitaria ha experimentado un cambio considerable en las últimas décadas. Las causas de este cambio son múltiples, por un lado, la estabilidad y democratización de la sociedad y el desarrollo de nuevas líneas pedagógicas $y$, por otro, el crecimiento exponencial que ha experimentado la tecnología, que se ha adueñado de nuestros hogares, lugares de trabajo, etc., cambiando sustancialmente la sociedad en la que vivimos. En particular, podemos destacar las conocidas como TIC, relacionadas con internet, los medios de comunicación, generación de vídeos, etc., cuyo desarrollo ha ido acompañado de un claro abaratamiento de costes y facilidad de manejo de los diferentes dispositivos que permiten crear y editar vídeos de calidad, así como de la posibilidad de difundirlos posteriormente en la red de forma casi automática. 
Desde la experiencia que nos avala con una OCW y un MOOC premiados, presentamos en la primersa sección de este trabajo la evolución de la enseñanza de la Teoría de grafos en la Escuela de Informática (ETSINF) de la Universitat Politècnica de València (UPV), empezando en los años 90 y llegando hasta la actualidad, en la que hemos incorporado a nuestra docencia la metodología "flip teaching". Observamos que la materia mencionada ha recibido diferentes nombres y ubicaciones en los distintos cursos a lo largo de distintos planes de estudio que se han ido implantando durante este periodo.

En la segunda sección, comentamos como llevamos a cabo la metodología de la clase inversa a partir del material creado, tanto audiovisual como impreso.

\section{Evolución de la Teoría de Grafos en la ETSINF}

La Teoría de grafos empezó a impartirse en el año 1985 dentro de las materias que conformaban el plan de estudios de Ingeniero en Informática. La materia era totalmente teórica y la metodología utilizada la clase magistral, habitual en aquellos años en prácticamente todas las aulas. La participación de los alumnos en las clases era escasa. En cuanto a material docente, se disponía de los apuntes del profesor, que los alumnos compraban en repografía, los apuntes tomados en clase y las hojas de problemas. En el año 1996 publicamos un libro en la editorial Reverté (Jordán, 1996), ad hoc para la asignatura impartida en aquellos momentos, pero que si no es complementado con otros materiales, resulta muy teórico para la asignatura tal y como está concebida hoy en día. Con la aparición de los laboratorios informáticos, en los años 90 se incorporaron a la asignatura prácticas con el programa de cálculo simbólico Mathematica ${ }^{\circledR}$, al que se accedía por una red bastante inestable y deficitaria para el número de usuarios.

La asignatura cambió de nombre, y, dada la reducción de créditos que le correspondieron, se redujo su contenido, oportunidad que aprovechamos para darle un carácter mucho más aplicado.

Los autores, ante el cambio observado en la idiosincrasia de nuestros alumnos y las corrientes pedagógicas que empezaron a surgir, propugnando centrar el aprendizaje en el alumno, se plantearon modificar las metodologías docentes adecuándolas al perfil de los nuevos estudiantes. Así, aunque la principal metodología utilizada era la clase magistral, esta se tornó más y más participativa, incorporando actividades donde se pedía a los alumnos que plantearan y resolvieran semanalmente cuestiones teóricas nuevas sobre la materia que habían estudiado o propusieran problemas que se pudieran resolver previa modelización a partir de la teoría de grafos.

En 2003, la UPV decidió desarrollar Polimedia, un sistema de grabación HD de objetos de aprendizaje en vídeos de forma simple y rápida, en estudios audiovisuales que se crearon en el campus de la universidad (Turró, 2010). De esta forma, el profesorado fue animado a realizar contenidos digitales de aprendizaje de calidad, al tiempo que asesorado en cuestiones técnicas, por el programa Docencia en red que continúa actualmente en vigor en

(c)) BY-NC-ND 2017, Universitat Politècnica de València

Congreso IN-RED (2017) 
la UPV. Dentro de las actividades impulsadas por este programa se encuentran las Open Course Ware (OCW), iniciativa llevada a cabo inicialmente por el Instituto Tecnológico de Massachusetts en 2001 (MIT, 2017). Estas asignaturas construidas a partir sólo de texto o incluyendo vídeos, enlaces, applets, etc. constituyen el primer paso al acceso libre al conocimiento a todo aquel que disponga de internet.

Como consecuencia de estos movimientos educativos y tecnológicos, los autores crearon vídeos relativos a la teoría de grafos y empezaron a experimentar con distintas metodologías, como se refleja en los diferentes artículos publicados y ponencias presentadas al respecto (Jordán, 2008(1), 2008(2), 2009, 2010(2)).

A raíz del curso del profesor Miguel Valero (Valero 2010), impartido dentro del programa de formación del profesorado del Instituto de Ciencias de la Educación (ICE) de la UPV, la metodología de esta asignatura terminó por dar un gran salto en el curso 2010-2011. Empezamos a combinar la lección magistral con la participación de los alumnos en clase y la entrega semanal, por grupos e individualmente, de problemas que eran corregidos y devueltos la semana siguiente; acercándonos a la metodología que poco después se instauró de forma normativa, y que todos conocemos como "Bolonia".

Como consecuencia de esta nueva línea de actuación creamos una OCW para nuestra asignatura, Estructuras matemáticas para la informática 2 (Jordán, 2010(1)), que fue premiada por el OpenCourseWare Consortium en Boston, 2010. La asignatura fue y sigue siendo utilizada como material docente a la hora de impartir teoría de grafos.

Como consecuencia de la evolución de la tecnología surgieron los Massive On-line Open Courses (MOOC) (Pernías, 2012), como continuación natural de las asignaturas OCW. En principio un mismo objetivo, extender el conocimiento a todos aquellos lugares a los que llegue internet, pero en esta ocasión utilizando como base los vídeos, programando el estudio de la asignatura y evaluando el aprendizaje de los alumnos que la cursan.

Complementando la mencionada asignatura $\mathrm{OCW}$, que trata la teoría de grafos de un modo más teórico, creamos un MOOC centrado en las aplicaciones de dicha teoría: Aplicaciones de la teoría de grafos a la vida real (UPVX, (2013); EDX, (2014)(1), (2014)(2)), que recibió una mención especial en los premios MECD de la primera edición de Miriadax.

Es obligado señalar que la UPV instaló dentro de la plataforma educativa de Sakai (Sakai Project) el servicio PoliformaT que, entre otra funcionalidades, permite el intercambio de ficheros entre profesores y alumnos, correos, exámenes, etc.

En relación a las herramientas de aprendizaje, al mismo tiempo que han avanzado las tecnologías de comunicación, ha cogido impulso la metodología conocida como "flip teaching” (Bergmann, (2012), University of Washington) o clase inversa. Nuestra trayectoria nos ha llevado a implementarla en nuestras aulas a partir del material docente del que disponemos, tanto impreso como digital, y que seguimos incrementando actualmente (Jordán 2010 (3), 2011 (1), 2011 (2), 2011 (3); Cordero 2015 (1)).

En relación a este tipo de metodología, es preciso comentar que no es realmente nueva. Profesores preocupados por la docencia, que habitualmente utilizan la evaluación continua, 
la están empleando, sin necesidad de ponerle nombre. Desde nuestro punto de vista, la diferencia más importante se establece cuando se realiza a través de material audiovisual, debido al sesgo tecnológico que presentan la mayoría de nuestros alumnos.

En ocasiones nos hemos preguntado, ¿es mejor el material audiovisual que el escrito? Pensamos que no tiene porqué ser así. Pero debemos tener en cuenta que para los jóvenes de hoy el cambio tecnológico no ha existido. Cuando nacieron la tecnología estaba ya al alcance de su mano y no conciben un mundo en el que para comunicarse haya que acudir a un dispositivo fijado a una mesa o para buscar referencias sea necesario visitar una biblioteca. Asimismo, están acostumbrados a disponer de mucha información de forma rápida $\mathrm{y}$ en formatos de calidad, que a menudo simplifican las ideas que se quieren transmitir. Desde nuestro punto de vista, el utilizar únicamente este tipo de materiales conduce a que se pierde capacidad de concentración y de profundizar en los temas, dando la impresión de que se conoce una materia cuando lo único que se hace es una lectura transversal pero no un análisis en profundidad de los contenidos. Por ello, creemos que debemos proponer alguna actividad en que esta lectura rápida no sea suficiente (Cordero, $2015(2))$.

Teniendo todo esto en cuenta, impartimos la asignatura Grafos, modelos y aplicaciones utilizando educación inversa, dentro del Proyecto clase inversa de la UPV (PCI, 2016).

Además, las últimas corrientes pedagógicas hacen hincapié en que es necesario centrar la atención no sólo en los contenidos que el alumno debe adquirir sino en las competencias y habilidades que debería obtener.

En este sentido, incorporamos en la evaluación de la asignatura la creación y presentación de un póster sobre un artículo científico de actualidad en el que la teoría de grafos juegue un papel importante. Desarrollamos así las competencias transversales: Aplicación y pensamiento práctico, Conocimiento de problemas contemporáneos y Comunicación efectiva, además de aquellas naturalmente más ligadas al contenido de la asignatura como son Análisis y resolución de problemas y Comprensión e integración. Además, dado que también forma parte de la evaluación la resolución, por grupos de dos o tres alumnos, de ejercicios más complejos planteados con un mínimo de diez días de antelación, contribuimos a desarrollar la competencia Trabajo en grupo y liderazgo.

Finalmente, nos gustaría señalar que interaccionamos con otra asignatura de cuarto curso llamada Concurso de Programación, facilitando que los alumnos vean un mismo problema desde dos perspectivas distintas, ayudando por tanto a que desarrollen además la competencia transversal Pensamiento crítico.

\section{La metodología de la asignatura Grafos, modelos y aplicaciones}

La asignatura Grafos, modelos y aplicaciones (GMA) es una asignatura optativa de 4,5 créditos de cuarto, situada en el semestre B del plan de estudios del Grado en Informática impartida en la ETSINF de la UPV.

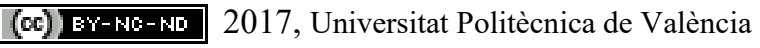

Congreso IN-RED (2017) 
Comentamos a continuación, con más detalle, los elementos claves en la implementación de la metodología de la clase inversa en esta asignatura.

\subsection{Guía didáctica}

Como ya hemos dicho, la metodología básica utilizada es la clase inversa a partir de materiales audiovisuales. Este tipo de metodología exige, en primer lugar, una buena programación, no solo del curso, sino semana a semana. Por ello, desde el primer día de curso, en realidad una semana antes de empezar este, los alumnos van a disponer, semanalmente, de lo que llamamos guía didáctica. En ella explicitamos:

$>$ Enlaces web a la asignatura OCW y el MOOC

$>$ Vídeos a revisar antes de las clases de la semana con los enlaces respectivos

$>$ Problemas a resolver antes de la sesión de aula, donde se les preguntará sobre la solución desarrollada

$>$ Problemas a entregar, realizados por parejas, que serán debidamente corregidos y devueltos como máximo en el término de una semana

> Controles tipo test a resolver mediante la plataforma educativa PoliformaT de la UPV

$>$ Indicación aproximada de lo que se espera trabajar en cada una de las sesiones de la clase presencial

$>$ Notas, observaciones o aclaraciones sobre cualquier tema que surja en ese momento

\subsection{Preguntas flip}

Denominamos así al listado de preguntas relativas a los vídeos que los alumnos han visionado y a partir de la cual desarrollaremos una parte de la clase.

Estas preguntas, realizadas a los estudiantes por turnos, tienen un objetivo múltiple:

$>$ Permiten profundizar en la materia y favorecer el aprendizaje. Las preguntas son de dos tipos, unas en las que se revisa la materia y otras relativas a relaciones entre conceptos, cuestiones teóricas, etc. En muchas ocasiones, recogen los "puntos negros" en los que, sabemos por experiencia, los alumnos tienen tendencia a caer. Se establece un pequeño debate con "feedback" inmediato, ya sea por parte del profesor o por parte de un compañero, al respecto de si una respuesta es o no correcta, original, si hay algo que no se ha tenido en cuenta en su razonamiento, o un paso que no ha sido justificado, si hay alguna otra respuesta válida, etc.

$>$ Mejoran la expresión oral. Saber expresarse en lenguaje científico, tanto oralmente como por escrito, es necesario para un graduado en ingeniería. Por ello, verbalizar 
definiciones o razonamientos y ser corregidos al momento es de gran utilidad, ya que, además, se les da pautas para empezar la frase, formas de construir oraciones para que el contenido sea preciso y no tenga problemas de dobles interpretaciones, etc.

$>$ Fomentan la participación. Cuando un alumno no sabe la respuesta o ésta es incompleta, la pregunta rebota a otro alumno, pudiéndose establecer un pequeño debate.

$>$ La clase es más amena que si el profesor diera la misma información en una clase magistral. Al tratarse de una serie continuada de preguntas-respuestas, los alumnos están más atentos pensando en la posible respuesta, razonando si el compañero ha dado la opción correcta, etc.

$>$ Permiten conocer a los alumnos. Tras las primeras sesiones el profesor conoce los nombres de sus estudiantes, utilizándolo a la hora de dirigirse a ellos, por ejemplo en la preguntas. Todo ello genera un ambiente más cordial y en general muy agradable, que favorece el aprendizaje y además facilita la evaluación.

\subsection{Problemas puntuables}

En grupos de dos, los alumnos tienen que resolver, aproximadamente cada diez días, un boletín de problemas. Se les indica que o bien los resuelvan de forma conjunta o bien lo hagan por separado, reuniéndose después para discutir las soluciones aportadas, eligiendo por consenso la que consideren más adecuada. Es conocido que, tanto la discusión sobre un tema como la explicación de una determinada materia es una de las mejores formas de aprendizaje que existen. Además, de esta forma fomentamos el trabajo en grupo, otra de las competencias transversales que los graduados de la UPV deben obtener al finalizar sus estudios.

\subsection{Colecciones de problemas para resolver en clase.}

Una hoja de problemas por tema en los que se incluyen tanto preguntas teóricas como de aplicación a resolución de problemas reales previa modelización en teoría de grafos. Son más fáciles que los del apartado anterior; forman parte del trabajo individual, permiten conocer y asimilar la materia y sirven de preparación, junto a su posterior presentación y discusión en clase, para poder abordar los problemas puntuables comentados en el anterior apartado.

\subsection{Póster y presentación}

Al principio de curso se proporciona a los alumnos una lista de artículos científicos entre los que cada grupo, el mismo formado para la entrega de los ejercicios puntuables, debe elegir uno para su análisis, sintetización en un póster de tamaño A1 y posterior presentación ante sus compañeros y profesores. Al final de curso celebramos una mini jornada que

(c)) BY-NC-ND 2017, Universitat Politècnica de València 
consiste en la exposición de los pósteres en el hall de la ETSINF. Tras permanecer expuestos durante una semana, los alumnos proceden a la presentación de su trabajo en un aula ante compañeros y profesores. Estos rellenarán rúbricas tanto para la presentación global como para la individual de cada ponente. Dichas rúbricas están colgadas en PoliformaT desde principio de curso, sirviendo de guía de las partes que el alumno debe trabajar cara a la realización y presentación del póster.

\subsection{Evaluación}

Creemos que la evaluación forma parte del proceso de aprendizaje, por ello consideramos los siguientes apartados:

$>$ El 20\% de la evaluación se lleva a cabo a partir de entregas de problemas. Los dos alumnos de cada grupo trabajan en equipo resolviéndolos y generando una solución conjunta

D El $20 \%$ corresponde a los controles tipo test. Se trata de exámenes tipo test en los que las preguntas se extraen aleatoriamente en cada ocasión de una batería de cuestiones. Estas cuestiones son en general de tipo teórico, relacionando conceptos. Como creemos que el objetivo de la evaluación es mejorar el aprendizaje, cada test es enviado dos veces, la de prueba, que no genera puntuación alguna y la definitiva, puntuable. De esta manera, el alumno puede darse cuenta de si conoce o no la materia antes del test que proporcionará la nota. En muchas ocasiones, al resolver el de prueba, descubre relaciones en las que no había pensado o que tenía equivocados algunos conceptos. En cualquier caso, el haber hecho la prueba no puntuable le permite profundizar en la materia, mejorar la puntuación y desde luego que su aprendizaje sea significativo

> El 25\% corresponde a la evaluación del póster y su presentación por parte del profesor mientras que el $10 \%$ es la parte de la evaluación por pares

> Finalmente, el $25 \%$ corresponde a la observación del profesor

\subsection{Relación con la asignatura Competición de programación}

La última innovación relativa a la asignatura GMA es la colaboración con la asignatura Competición de Programación (CP), que en la ETSINF responde a la necesidad que tienen los egresados de dominar la programación para superar los procesos de selección de personal en empresas de software. Detrás de las principales competiciones internacionales de programación están empresas como Google, Apple, Yahoo, Microsoft o Facebook. Y son muchas las empresas de ámbito internacional, además de las citadas, que seleccionan a sus ingenieros de software de entre los que participan en las competiciones de programación. El temario de esta asignatura cubre los aspectos más relevantes de la 
Algorítmica, donde se incluyen temas de la Teoría de grafos, aspectos que el alumno deberá utilizar y combinar adecuadamente para resolver los problemas planteados.

La asignatura GMA se plantea como uno de sus objetivos la resolución algorítmica de problemas relativos a la vida real, tipificados previa transformación en problemas teóricos en el ámbito de la teoría de grafos. Esta transformación del problema es lo que se conoce como modelización matemática. Por todo ello, aunque las asignaturas GMA y CP tengan perfiles muy diferentes, el enfoque dado a GMA resulta muy útil como apoyo a la resolución de problemas de $\mathrm{CP}$.

En este sentido, cabe recordar que uno de los objetivos principales de cualquier grado universitario es formar a los futuros egresados para que puedan seguir aprendiendo por ellos mismos a lo largo de la vida y, en buena medida, esta capacidad es la buscada por las compañías cuando valoran los resultados en competiciones de programación. Entendemos que esta experiencia es un buen ejemplo de cómo la colaboración entre profesores de distintos departamentos puede enriquecer notablemente la calidad de la enseñanza de las asignaturas implicadas al mismo tiempo que se mejora la formación de los alumnos y disminuye la dispersión de contenidos (Calvo 2016).

\subsection{Competencias transversales}

La asignatura GMA solo es punto de control, es decir, nuestra evaluación en dichas competencias aparece en el expediente de los alumnos, de las competencias transversales CT10: Conocimiento de problemas contemporáneos y CT3: Análisis y resolución de problemas. Sin embargo, como hemos comentado anteriormente, también se trabajan otras como: CT1: Comprensión e integración, CT2: Aplicación y pensamiento, CT6: Trabajo en grupo y liderazgo, CT8: Comunicación efectiva, CT9: Pensamiento crítico y CT11: Aprendizaje permanente (Alcover 2015; Jordán 2015 (1); Conejero 2015).

Todas estas competencias transversales forman parte del catálogo que la UPV ha considerado que todos sus egresados deben tener al finalizar sus titulaciones tanto de grado, como de máster.

\subsection{Valoración de la educación inversa a través de las encuestas}

A lo largo de los años hemos realizado diferentes encuestas a los alumnos.

Las primeras encuestas on-line fueron realizadas a la asignatura ya extinta, EMI2, durante el curso 2010-2011. Fue el primer año en que utilizamos la metodología de docencia inversa a partir de la OCW combinada con una evaluación continua muy controlada y el resultado fue muy bueno (Jordán 2010 (1), 2010 (2), 2011 (1), 2011 (2)). Podemos destacar los siguientes aspectos: aumentó el porcentaje de aprobados en primera convocatoria (89\%), aumentó el número de notables y sobresalientes, los alumnos opinaron que apenas habían tenido que estudiar antes del examen, pero el porcentaje de abandonos fue similar al de otro años. Sin embargo, al año siguiente repetimos la experiencia y los resultados fueron muy distintos.

La metodología inversa en la asignatura de cuarto curso GMA ha dado buenos resultados dede el primer año, 2013, en que empezó a impartirse, como consecuencia quizás del mayor

(cc) BY-NC-ND 2017, Universitat Politècnica de València

Congreso IN-RED (2017) 
grado de madurez de los alumnos. Estos están en general muy contentos con la metodología, piensan que el aprendizaje es muy bueno, pero al igual que todos los estudiantes, de cualquier curso y/o asignatura a los que hemos pasado una encuesta opinan que conlleva mucho más tiempo de dedicación que la tradicional (Jordán 2014 (1), 2015 (1)).

Sin embargo, la educación inversa en primer curso no aporta grandes diferencias en cuanto a resultados a los obtenidos con la metodología clásica, quizás por la mayor dificultad de que los estudiantes se involucren realmente en el proyecto. Aproximadamente el $50 \%$ de los alumnos se decantaría por esta opción (Jordán 2014 (2), 2015 (2)). Los resultados de las encuestas parecen indicar una cierta resistencia a la innovación por parte de los estudiantes. Los alumnos de la franja baja de notas prefieren una metodología tradicional, lo que en nuestra opinión se debe a que se le hace más duro tener que trabajar la materia a diario. Por su parte, el que los alumnos de la franja más alta se decanten por enseñanza tradicional puede deberse a que en esta se encuentran más cómodos y son más independientes a la hora de organizarse. Observamos que esta tendencia cambia en el cuarto curso.

\section{Conclusiones}

La metodología seguida en la asignatura GMA aúna la metodología de la clase inversa con la evaluación continua haciendo uso de la nuevas tecnologías, en lo que incluimos la asignatura OCW y MOOC, al tiempo que trabajamos diversas competencias transversales. Todo ello contribuye a mejorar el aprendizaje significativo de los contenidos trabajados en ella, pero no queremos terminar este trabajo sin dejar constancia de algunas reflexiones al respecto.

En primer lugar, como ya comentamos en la introducción, un graduado en ingeniería debe saber utilizar adecuadamente el lenguaje científico tanto oral como escrito. Los vídeos contribuyen a ello menos que los documentos escritos. Por eso, creemos conveniente reforzar este apartado recomendando estudiar parte de la materia o repasarla a partir de la parte de texto de la OCW o libros de los que recomendamos a principio de curso en la bibliografía, además de la práctica que obtenemos con el trabajo continuado en clase.

En segundo lugar, el éxito de esta metodología, y en realidad de cualquier otra, depende de la actitud de profesor y alumno. Pero la "flip teaching" exige al estudiante que se involucre más, que mantenga una actitud más activa en clase. Las técnicas que utilizamos fomentan, en general, la motivación, pero requieren la responsabilidad, por parte del alumno, de un trabajo continuado al que, aunque a medio-largo plazo da mejores resultados, en muchas ocasiones no está acostumbrado y no siempre está dispuesto a realizar. Por todo ello, el éxito de nuestra metodología depende mucho más de esta actitud que otras metodologías más tradicionales a las que el alumno está habituado, como la lección magistral. 


\section{Referencias}

ALCOVER et al., (2015) "Influencia de la educación inversa en el aprendizaje y adquisición de competencias transversales" En: Congreso Nacional de Innovación Educativa y Docencia en Red = Congrés Nacional d'Innovació Educativa i Docència en Xarxa (IN-RED 2015)

BERGMANN, J. AND SAMS, A., (2012) "Flip Your Classroom: Talk to Every Student in Every Class Every Day". En: International Society for Technology in Education

CALVO et al. (2016) "Modelos de la teoría de grafos aplicados a problemas de competiciones de programación" En: Congreso Nacional de Innovación Educativa y Docencia en Red (IN-RED 2016)

CONEJERO, J.A. y JORDÁN, C., (2015) "El póster científico como medio para desarrollar la competencia de comunicación." En: XIII Jornadas de Redes de Investigación en Docencia Universitaria. Nuevas estrategias organizativas y metodológicas en la formación universitaria para responder a la necesidad de adaptación y cambio

CORDERO, A., JORDÁN, C., TORREGROSA, J. R., (2015) "How do current students face math problems solving?" En: Proceedings of 9th International Technology, Education and development Conference, INTED, pp. 4716-4721, Madrid, 2015.

CORDERO, A., JORDÁN, C., TORREGROSA, J. R., SANABRIA-CODESAL, E., (2015), "Towards a better learning model through OCWs and MOOCs". International Journal of artificial intelligence and interactive multimedia, vol 3, No. 4, pp. 26-30, 2015.

EDX: APLICACIONES DE LA TEORÍA DE GRAFOS A LA VIDA REAL (I) .

https://www.edx.org/course/aplicaciones-de-la-teoria-de-grafos-la-upvalenciax-tgv201x-1>[Consulta: 2 de abril de 2017][ Cristina Jordán y Alberto Conejero]

EDX: APLICACIONES DE LA TEORÍA DE GRAFOS A LA VIDA REAL (II) en edX. https://www.edx.org/course/aplicaciones-de-la-teoria-de-grafos-la-upvalenciax-tgv201x-2$0>$ [Consulta: 2 de abril de 2017][ Cristina Jordán y Alberto Conejero]

JORDÁN LLUCH, C. (2015) "Desarrollo de competencias transversales en el aula y Experiencias Flipped Classroom", En: Congreso Nacional de Innovación Educativa y Docencia en Red = Congrés Nacional d'Innovació Educativa i Docència en Xarxa (IN-RED 2015)

JORDÁN LLUCH, C. y TORREGROSA SÁNCHEZ, J.R., (1996). Introducción a la teoría de grafos y sus algoritmos. Valencia: Editorial Reverté. [dos/tres autores: todos]

JORDÁN LLUCH, C. y TORREGROSA SÁNCHEZ, J.R., (2008) "Docencia en red: un paso adelante en el uso de nuevas tecnologías", En: Proc. de las VI Jornadas de redes de investigación en docencia universitaria, (2008. Alicante) p.726.

JORDÁN LLUCH, C. y TORREGROSA SÁNCHEZ, J.R., (2008), "Los objetos de aprendizaje y el nuevo contexto educativo". En: Actas del V Congreso Iberoamericano de Docencia Universitaria, (2008, Valencia).

JORDÁN LLUCH, C. (2009), "Utilización correcta e incorrecta de los ficheros Polimedia" En: Actas de la JIDINF'09 (2009, Valencia).

JORDÁN, C., "Estructuras Matemáticas para la Informática II "[On line]. Available: http://www.upv.es/ocwasi/2010/6024, [Cristina Jordán, 2010].

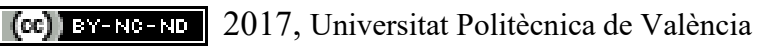


JORDÁN LLUCH, C. y TORREGROSA SÁNCHEZ, J.R., (2010). "Las OCW en el nuevo contexto educativo", En: Actas de las VIII Jornadas de Redes de Investigación en Docencia Universitaria, (2010, Alicante)

JORDÁN, C., (2010), “Adaptación de la asignatura EMI2 al nuevo contexto educativo", En: Actas de la JIDINF'10, 2010, Valencia.

JORDÁN, C., SANABRIA-CODESAL, E., (2011), "La asignatura OCW Estructuras matemáticas para la informática II y los créditos ECTS”, En: XIX CUIEET, Barcelona. 2011.

JORDÁN, C., (2011), "Evaluación continua en la asignatura Estructuras matemáticas para la informática II", En: IX Jornadas de Redes de investigación en docencia Universitaria, pp. 26-36, 2011, Alicante.

JORDÁN, C., (2011),’Una experiencia de evaluación continua”, En: Actas de la JIDINF'11, 2011, Valencia.

JORDÁN, C., PÉREZ, M.J., SANABRIA-CODESAL, E., (2014), “"Flipped clasroom”: Reflexiones y opiniones de los implicados”, En: Congreso Nacional de Innovación Educativa y Docencia en Red, INRED, 2014.

JORDÁN, C., PÉREZ, M.J., SANABRIA-CODESAL, E., (2014), "Investigación del impacto en un aula de matemáticas al utilizar "flip education"”, En: Pensamiento Matemático, Vol. 4. No. 2, pp.922,2014

JORDÁN, C., PÉREZ, M.J., SANABRIA-CODESAL, E., (2015), "Educación inversa, una metodología innovadora ¿Coincide la percepción que tienen los alumnos de ella con la nuestra?" En: XIII Jornadas de Redes de Investigación en Docencia Universitaria. Nuevas estrategias organizativas y metodológicas en la formación universitaria para responder a la necesidad de adaptación y cambio, Alicante, 2015

JORDÁN, C., SANABRIA-CODESAL, E., (2015), ¿Qué opinan de la metodología "flip teaching" loa alumnos de nuevo ingreso?" XXIII Congreso universitario de innovación educativa, 2015.

MIT OPENCURSEWARW/FREE ONLINE COURSE MATERIALS-MASSACHUSSETTS (2017)

$<$ https: \locw.mit.edu>

OPEN EDUCATION CONSORTIUM < http://www.oeconsortium.org>

PerníAS, P. y LuJÁn-MorA, S., (2012), "MOOC. Los MOOC: Orígenes, historia y tipos" En : Comunicación y Pedagogía 269-270. <http://www.centrocp.com/los-mooc-origeneshistoria-y-tipos>

PROYECTO CLASE INVERSA (PCI), (2017), Universitat Politécnica de Valencia. $<$ http://claseinversa.blogs.upv.es/el-proyecto/proyecto-clase-inversa-upv/> [Consulta: 2 de abril de 2017]

Turro, C., CAÑERo, A., Busquets, J., (2010). "Video Learning Objects Creation with Polimedia”. En: IEEE International Symposium on Multimedia, pp. 371-376.

\section{SAKAI PROJECT https://sakaiproject.org/}

UNIVERSITAT POLITĖCNICA DE VALÈNCIA, (2017). Proyecto institucional Incorporación de las competencias transversales en el currículo de los egresados de la UPV.

$<$ http://www.upv.es/entidades/ICE/info/U0724624.pdf> [Consulta: 31 de marzo de 2017] 
UNIVERSITY OF WASHINGTON. FLIPPING THE CLASSROOM

$<$ http://www.washington.edu/teaching/teaching-resources/engaging-students-in-

learning/flipping-the-classroom/>[Consulta: 29 de abril de 2015]

UPVX. Aplicaciones de la Teoría de Grafos a la vida real

$<$ http://cursografos.upvx.es/ficha $>$ [Consulta: 2 de abril de 2017][ Cristina Jordán y Alberto Conejero]

VALERO-GARCÍA, M. ESPONA, M., (2010), "Adaptación de asignaturas al EEES".

Curso de formación permanente del ICE de la UPV, Valencia, 2010. 


\title{
Diversificación metodológica y microproyectos para la formación integral del alumnado universitario
}

\author{
Marta Abanades a, Verónica Baena ${ }^{b}$, Miriam Jiménez ${ }^{c}$ y Elisabet Marina ${ }^{d}$ \\ a Profesora Adjunta en la Universidad Europea de Madrid. Departamento de Educación, \\ Comportamiento y Procesos Sociales. E-mail: marta.abanades@universidadeuropea.es \\ ${ }^{\mathrm{b}}$ Catedrática de Marketing en la Universidad Europea de Madrid, Departamento de Empresa. E-mail: \\ veronica.baena@universidadeuropea.es, \\ ${ }^{c}$ Directora del Máster Universitario en Educación Bilingüe en la Universidad Europea de Madrid. \\ Departamento de Educación, Comportamiento y Procesos Sociales. E-mail: \\ miriam.jimenez@universidadeuropea.es, \\ ${ }^{\mathrm{d}}$ Asesora especialista Unidad de Atención a la Diversidad en la Universidad Europea de Madrid. \\ Departamento de Educación, Comportamiento y Procesos Sociales. E-mail: \\ elisabet.marina@universidadeuropea.es
}

\begin{abstract}
The educational field is considered as a space for training not only future professionals, but also citizens, so that skills such as critical thinking and the transmission of values have to be present in the curriculum design of any university program syllabus. The main aim of this paper is to describe the design of a course and the implementation of different methodologies, specially Experiential Learning, as a means to achieve the integral training of students in the Degree in Primary Education. Diversification of methodologies in the class was carried out on the basis of the results of teachers' observations and meetings, and it was planned bearing in mind the development of the required competences and values.

The main results obtained show a deeper understanding of the concept of equality, both in terms of gender and ethnicity. Likewise, the activity described in this study encouraged creativity among students, as was verified by the external collaborator. In both cases, the feedback received was positive. As recommendations, future studies require the participation of students of different grades and postgraduates to identify new collaborative activities for students.
\end{abstract}

Keywords: Experiential learning, Integral Training, Values, Skills Development 
Diversificación metodológica y microproyectos para la formación integral del alumnado universitario

\section{Resumen}

El ámbito educativo se considera un lugar de formación no solo de futuros profesionales, sino también de ciudadanos, de manera que la transmisión de valores y destrezas como el pensamiento crítico deben estar presentes en el diseño curricular de cualquier plan de estudios universitario. El objetivo de esta comunicación es la descripción del diseño de una asignatura y la implementación de diversas metodologías, especialmente el Aprendizaje Experiencial, como instrumento para conseguir la formación integral de los estudiantes del Grado en Educación Primaria. La diversificación metodológica en el aula se llevó a cabo sobre la base de la observación e intercambios de impresiones del profesorado y se planificó teniendo en cuenta los valores y el desarrollo competencial requerido.

Los principales resultados obtenidos muestran una comprensión más profunda del concepto de igualdad, tanto en lo que concierne al género como a la etnia. Asimismo, la actividad descrita en este trabajo fomentó la creatividad entre el alumnado, tal y como fue constatado por el colaborador externo. En ambos casos, el feedback recibido fue positivo. Como recomendaciones, en futuros estudios se hace necesario la participación de alumnos de diferentes grados y postgrados para identificar nuevas actividades de colaboración para los estudiantes.

Palabras clave: Aprendizaje Experiencial, Formación Integral, Valores, Desarrollo de Competencias

(cc) EY-NC-ND 2017, Universitat Politècnica de València 


\section{Introducción}

La adaptación al Espacio Europeo de Educación Superior (EEES) supone la transición desde un modelo educativo centrado en la enseñanza hacia un modelo centrado en el aprendizaje, suponiendo un gran "cambio cultural" para la universidad como institución educativa (Fernández March, 2006).

Por otro lado, otros aspectos como la emergente sociedad del conocimiento (Castells, 2002) donde el procesamiento de información ha sido sustancialmente alterado por una revolución tecnológica, tiene reflejo directo y significativo en todos los niveles de la sociedad, y por tanto, no puede ser ajeno el ámbito educativo. Además, la preocupación de las universidades por ofrecer una formación integral del alumno en conocimientos, competencias y valores, hacen que el papel del docente universitario esté experimentando grandes cambios. En este sentido, el cambio de paradigma del EEES ha revolucionado de forma significativa los principios y valores que sostienen la función docente en Educación Superior (De Miguel Díaz, 2006), constatando la necesidad de promover aspectos tan esenciales como el desarrollo personal y una ciudadanía democrática (Huber, 2008).

La globalización, las crisis, las Tecnologías de la Información y la Comunicación, los conflictos, los medios de comunicación...todos ellos afectan a nuestra percepción del mundo y moldean nuestros modos de pensar de diversas formas. Así las universidades no deben perder su relevancia como espacios para el desarrollo del pensamiento crítico y la transmisión de valores, como cualquier otra institución social. Numerosos investigadores están comenzando a centrarse en estos acontecimientos con el objeto de introducir e implementar diferentes metodologías en la Educación Superior, de manera que los estudiantes puedan adquirir contenidos, desarrollar competencias y destrezas y, al tiempo, interiorizar y transmitir valores, lo que permitiría a los estudiantes convertirse en los profesionales y ciudadanos que nuestras sociedades necesitan.

Este nuevo escenario educativo conlleva un cambio significativo en cuanto a los métodos de enseñanza-aprendizaje utilizados (Grimaldo-Moreno y Arevalillo-Herráez, 2011) así como una necesidad imperiosa de cambio metodológico (De Miguel Díaz, 2006), exigiendo supuestos que tengan significatividad en la realidad, así como prácticas que reflejen el futuro desempeño profesional. Es necesario, por tanto, el diseño de métodos que incluyan pasar de una pedagogía de la selección a una pedagogía de la inclusión, pasar de una pedagogía monocultural a una pedagogía intercultural y esforzarse por construir una ciudadanía activa (Martín y Puig, 2008). Dentro de este marco de acción, que prioriza la formación integral de las personas sobre la adquisición de conocimientos, se integran educación en valores y el desarrollo de competencias.

En otras palabras, la implantación del nuevo sistema universitario exige cambiar la actual dinámica de enseñanza y aprendizaje por otra donde los estudiantes sean una parte activa, asuman responsabilidades y pasen de sujetos pasivos a ser protagonistas de su propio aprendizaje (Whitehead, 2008). Solo así, los alumnos estarán realmente preparados para los cambios que se producen en el entorno social y profesional (De Juan et al., 2008).

(c) $)$ EY-NC-ND 2017, Universitat Politècnica de València 
Para lograrlo, el EEES fomenta el aprendizaje autónomo por parte del estudiante y la implantación de metodologías activas de aprendizaje en el aula. En línea con lo anteriormente expuesto, es preciso señalar que la Comisión para la renovación de las Metodologías Educativas en la universidad constata que la reforma de las metodologías educativas debe resultar un proceso imprescindible a abordar, reflexionando sobre métodos capaces de transferir los conocimientos teóricos en supuestos prácticos, así como en la búsqueda de metodologías que propicien un acercamiento a la realidad profesional (CRUE, 2006). Es en esta "renovación metodológica" (Fernández March, 2006) donde metodologías activas como el aprendizaje experiencial cobran especial relevancia, al facilitar el desarrollo de competencias personales y sociales conectando la realidad educativa con la social.

Esta metodología, activa e innovadora, así como la referida a Aprendizaje y Servicio y Aprendizaje Dialógico, promueven el espacio necesario para que el estudiante sirva a la comunidad como ciudadano responsable. Asímismo, con la implantación de estas metodologías activas, la universidad resulta no sólo un espacio educativo sino además, un espacio de integración e inclusión en la Sociedad y por tanto, agente activo en la formación de una ciudadanía crítica (Francisco Andrea y Moliner, Lidón, 2010); facilitando dichas metodologías el desarrollo de competencias socio-emocionales en el alumno, así como la adquisición de valores y la responsabilidad personal cívica. Autores como Folgueira y Martínez (2009) evidencian la eficacia de dicha metodología en lo que respecta al desarrollo de competencias generales como la responsabilidad social y el compromiso ciudadano, la capacidad de aplicar conocimientos a la práctica, el trabajo en equipo, la valoración y respeto por la diversidad cultural o la capacidad de identificar y resolver un problema.

En este sentido, es preciso destacar que la universidad a la que pertenecen los autores, ha estado trabajando de manera continua, no solo para incorporar el EEES en la aulas, sino también, para enriquecer a los profesores y estos a sus alumnos en metodologías activas para el éxito en el proceso de enseñanza-aprendizaje (Benito y Cruz, 2005). Esta comunicación pretende constatar cómo se fomenta la formación en valores y competencias, mediante las diferentes metodologías (flipped classroom, aprendizaje colaborativo, aprendizaje servicio, aprendizaje experiencial y aprendizaje dialogico), en la una de las materias Didáctica de la Lengua, dentro del grado en Primaria. Además todas las actividades se desarrollaron en diferentes entornos fuera del campus con la colaboración de multiples agentes sociales para un mayor aprendizaje vivencial y experiencial.

\section{Objetivos}

El objetivo de la Educación en la actualidad es el de formar profesionales competentes y ciudadanos capaces de tomar las decisiones adecuadas para llevar nuestras sociedades hacia la igualdad y la sostenibilidad, tanto en lo económico como en lo social y medioambiental. En ese sentido, la finalidad de la experiencia que se describe es la de implementar actividades asociadas con las metodologías activas (en especial con el Aprendizaje Experiencial) para fomentar la Educación en Valores y el desarrollo de competencias junto a la adquisición de contenidos, tal como el EEES exige actualmente.

(c)) BY-NC-ND 2017, Universitat Politècnica de València 
Si bien el desarrollo competencial se estableció como prioritario desde la implantación del EEES, es cierto que la evaluación del mismo ha sido, hasta ahora, una cuestión que quedaba relegada a un segundo plano, priorizándose los contenidos frente a las competencias y valores a la hora de ofrecer feedback y calificaciones. La intención de los investigadores de este equipo es analizar el desarrollo de competencias, entre otras cuestiones, a través de distintas experiencias de aprendizaje con el objetivo de mejorarla y optimizar al máximo el tiempo de dedicación a las asignaturas por parte de los estudiantes dentro y fuera del aula.

Nuestra hipótesis, en este caso, es que los estudiantes, al experimentar en primera persona diferentes metodologías y reflexionar sobre ellas, gracias en parte al uso de las rúbricas, harán uso de destrezas tales como las comunicativas o de comprensión de la realidad del contexto para la aplicación de los conocimientos teóricos a la práctica. En esta comunicación se detallarán las metodologías incluidas en la asignatura de Didáctica de la Lengua II a través de diversas actividades, así como los resultados obtenidos por los estudiantes, cuantitativa y cualitativamente, y comprobaremos también si estos resultados han mejorado o no con respecto a cursos anteriores.

\section{Desarrollo de la innovación}

En el momento de planificar la asignatura de Didáctica de la Lengua II, perteneciente al Grado en Educación Primaria, se observó la necesidad de que los estudiantes experimentasen las metodologías que después tendrán que aplicar en su labor docente, además de la relevancia del trabajo sobre valores y el desarrollo de competencias. Así, se contemplaron en las actividades las metodologías siguientes: Flipped Classroom, Aprendizaje Experiencial, Aprendizaje y Servicio, Aprendizaje Cooperativo y Aprendizaje Dialógico.

Es importante señalar que durante los dos últimos cursos se han venido implantando de forma paulatina metodologías como el Aprendizaje y Servicio, lo que permitió la introducción de rúbricas en que las competencias estaban muy presentes a través de distintos ítems, o la flipped classroom, con el consiguiente fomento de la competencia de autonomía y de uso de las TIC. No obstante, en el presente curso, 2016/17, se decidió diseñar la asignatura de modo que todas las metodologías activas tuviesen cabida, del modo que se describe en los siguientes epígrafes.

Con el objeto de que los estudiantes asimilasen las diferencias entre unas metodologías y otras de manera deductiva, estas se fueron trabajando en diferentes semanas. Asimismo, se fueron relacionando con diferentes valores y competencias, lo que se reflejó en los contenidos y en la evaluación, en este caso gracias a las rúbricas. A continuación se describen las actividades y su relación con metodologías, valores y competencias. 


\subsection{Descripción de actividades}

La distribución de las actividades fue semanal o quincenal, en función de la dificultad de las mismas. La asignatura se desarrolló a lo largo de los meses de enero, febrero y marzo del presente curso académico y comenzó con sesiones virtuales en las que se reforzaban los contenidos teóricos que los estudiantes debían trabajar de manera autónoma y que tendrían su reflejo en las primeras actividades que se llevaron a cabo en las primeras sesiones presenciales.

\subsubsection{Aprendizaje Experiencial}

El Aprendizaje Experiencial se puso en marcha de dos maneras: la primera, a través de un enfoque por el cual los estudiantes experimentaban las diferentes posibilidades en cuanto a metodologías y técnicas de forma vivencial; la segunda, gracias a un microproyecto específico para el área de Lengua y Literatura.

En cuanto a lo primero, uno de los ejemplos sería el del fomento de la escritura creativa. Para mostrarles a los estudiantes de qué modo podrían favorecerla en el alumnado de Primaria, se realizaron en clase varios experimentos que consistieron en la escritura a partir de sonidos, de imágenes, de fragmentos de obras literarias y de frases introductorias. Así, los estudiantes lograron despertar su creatividad y escribieron tanto narrativa como lírica, dependiendo de sus preferencias. La calidad de sus escritos fue en aumento desde la primera experiencia y, para demostrar la importancia de sus recién escritos textos, se les solicitó que incluyesen en la carpeta de aprendizaje los dos de los que se sintiesen más orgullosos, lo que desencadenó la escritura de nuevos textos fuera del aula para asegurarse de que su satisfacción con las obras presentadas era lo más alta posible.

En lo que respecta a la segunda cuestión, el microproyecto consistió en la creación de un texto sobre Madrid adaptado al nivel que requirió el colaborador externo. En este caso, el colaborador externo fue una exestudiante procedente de Alemania y que actualmente trabaja como profesora de Español como Lengua Extranjera en dicho país. Sus estudiantes están cursando el nivel A1 y ella precisaba de textos apropiados para sus conocimientos para una sesión sobre Madrid. La colaboración permitió que los textos fuesen valorados no solo por el profesorado sino también por el partner, que proporcionó retroalimentación acerca de cuáles habían resultado más útiles y por qué motivo. Como puede apreciarse, en todos los casos la calificación fue de aprobado.

(c)) BY-NC-ND 2017, Universitat Politècnica de València

Congreso IN-RED (2017) 
Figura 1. Calificaciones obtenidas en la actividad (evaluación del colaborador externo y de la profesora de la asignatura)

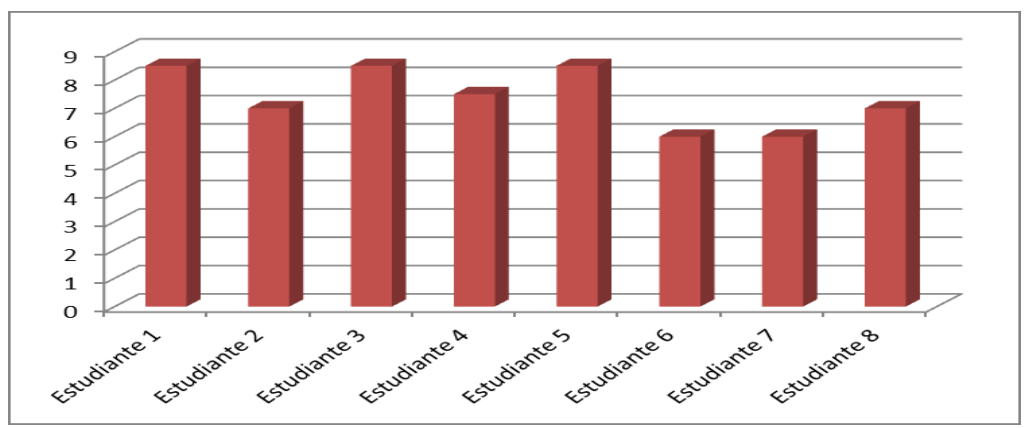

Tabla 1. Rúbrica de la actividad

\begin{tabular}{|c|c|c|c|}
\hline Participación & $\begin{array}{l}0(0 \%) \text { El estudiante } \\
\text { no ha participado en } \\
\text { ninguna fase de la } \\
\text { actividad. }\end{array}$ & $\begin{array}{l}1(10 \%) \text { El estudiante } \\
\text { ha participado en la } \\
\text { fase oral o en la fase } \\
\text { escrita de la actividad, } \\
\text { pero no en ambas. }\end{array}$ & $\begin{array}{l}2(20 \%) \text { El estudiante } \\
\text { ha participado en } \\
\text { ambas fases de la } \\
\text { actividad (oral y } \\
\text { escrita). }\end{array}$ \\
\hline Adecuación & $\begin{array}{l}0(0 \%) \text { El estudiante } \\
\text { no ha comprendido las } \\
\text { necesidades del } \\
\text { colaborador y su texto } \\
\text { no proporciona la } \\
\text { solución necesaria. }\end{array}$ & $\begin{array}{l}1,5(15 \%) \text { El estudiante } \\
\text { ha comprendido las } \\
\text { necesidades del } \\
\text { colaborador, pero el } \\
\text { texto no se ajusta } \\
\text { completamente a las } \\
\text { mismas. }\end{array}$ & $\begin{array}{l}3(30 \%) \text { El estudiante } \\
\text { ha comprendido las } \\
\text { necesidades del } \\
\text { colaborador y su texto } \\
\text { proporciona una } \\
\text { solución adecuada. }\end{array}$ \\
\hline $\begin{array}{l}\text { Gramática y } \\
\text { vocabulario }\end{array}$ & $\begin{array}{l}0(0 \%) \text { El estudiante } \\
\text { no ha empleado de } \\
\text { forma adecuada la } \\
\text { gramática y el } \\
\text { vocabulario no se } \\
\text { ajusta a las } \\
\text { necesidades del } \\
\text { colaborador. }\end{array}$ & $\begin{array}{l}1(10 \%) \text { El estudiante } \\
\text { ha empleado } \\
\text { adecuadamente la } \\
\text { gramática y el } \\
\text { vocabulario, aunque } \\
\text { hay algunos errores en } \\
\text { el texto. }\end{array}$ & $\begin{array}{l}2(20 \%) \text { El estudiante } \\
\text { ha empleado de } \\
\text { manera adecuada tanto } \\
\text { la gramática como el } \\
\text { vocabulario en todo } \\
\text { momento. }\end{array}$ \\
\hline $\begin{array}{l}\text { Ortografía y } \\
\text { puntuación }\end{array}$ & $\begin{array}{l}0(0 \%) \text { El estudiante } \\
\text { ha cometido } \\
\text { numerosos errores de } \\
\text { ortografía y } \\
\text { puntuación (más de } 5) \text {. }\end{array}$ & $\begin{array}{l}1,5(15 \%) \text { El estudiante } \\
\text { ha cometido algunos } \\
\text { errores de ortografía y } \\
\text { puntuación (entre } 2 \mathrm{y} \\
5) .\end{array}$ & $\begin{array}{l}3(30 \%) \text { El estudiante } \\
\text { no ha cometido errores } \\
\text { de ortografía y } \\
\text { puntuación (máximo } \\
1 \text {, que podría ser una } \\
\text { errata). }\end{array}$ \\
\hline
\end{tabular}

\subsubsection{Flipped classroom}

El Aula Invertida o flipped classroom es una metodología que suele trabajarse en las asignaturas híbridas o semipresenciales, pero que resulta también de gran utilidad en los casos en que los contenidos que hay que asimilar son numerosos y el periodo lectivo breve, ya que permite a los estudiantes acceder a la teoría antes de asistir al aula y, así, aprovechar el tiempo en la misma con actividades prácticas. Para esta metodología, la actividad seleccionada fue el estudio de los arquetipos tradicionales, y su discusión, en la película Shrek, de manera que no solo se analizaron los personajes principales de los cuentos (contenido de Primaria), sino que también se compararon con sus posibles contestaciones 
desde el arte actual y, por tanto, la reflexión sobre los valores que transmitían y transmiten (valentía, pasividad, etcétera).

\subsubsection{Aprendizaje y Servicio}

La actividad de Aprendizaje y Servicio incluyó a la organización Serve the City y la Asociación Valdeperales, una asociación de un barrio madrileño que trabaja con niños y niñas de familias procedentes de múltiples países, con el fin de darles soporte y contribuir a su participación en la comunidad. Así, los estudiantes diseñaron dos actividades, una de escritura creativa y otra de teatro interactivo, para poder ponerlas en práctica en la asociación mencionada.

La acción se desarrolló bajo la supervisión del profesorado y de los responsables de la asociación, además de contar con la colaboración de los voluntarios de Serve the City, después de lo cual se solicitó tanto a los niños y niñas que participaron como a los supervisores una evaluación de ítems como la creatividad, el cumplimiento de objetivos y la adaptación y flexibilidad de los estudiantes respecto al diseño inicial y su posterior aplicación, con sus condiciones particulares.

Gracias a esta metodología se trabajaron competencias, entonces, como la capacidad de adaptación, la aplicación de los conocimientos teóricos a la práctica y la organización y gestión del tiempo, así como destrezas propias de los docentes, como la adecuación de la tarea a la edad de los participantes o su habilidad para gestionar el aula. La calificación fue, en todos los casos, superior al 7,6 (lo que se correspondería con un Notable).

Figura 2. Calificaciones obtenidas en esta actividad (evaluación del colaborador externo y de la profesora de la asignatura)

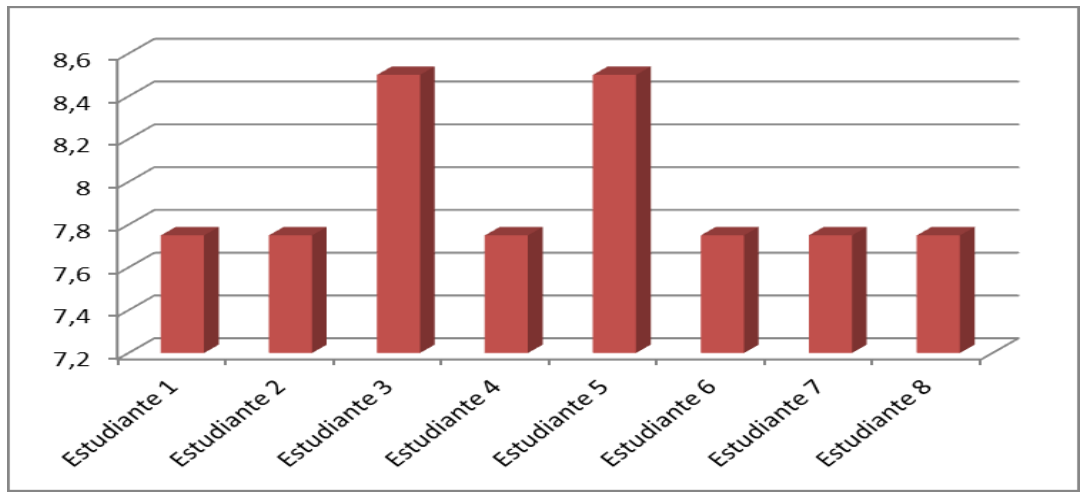

(cc) EY-NC-ND 2017, Universitat Politècnica de València 
Tabla 2. Rúbrica básica de la actividad

\begin{tabular}{|l|l|l|l|}
\hline Adecuación al público & $\begin{array}{l}0(0 \%) \text { La actividad no } \\
\text { es nada adecuada }\end{array}$ & $\begin{array}{l}1,5(15 \%) \text { La actividad } \\
\text { es adecuada }\end{array}$ & $\begin{array}{l}3(30 \%) \text { La actividad } \\
\text { es muy adecuada }\end{array}$ \\
\hline Uso de recursos & $\begin{array}{l}0(0 \%) \text { El uso de } \\
\text { recursos es } \\
\text { insuficiente }\end{array}$ & $\begin{array}{l}1,5(15 \%) \text { El uso de } \\
\text { recursos es suficiente }\end{array}$ & $\begin{array}{l}3(30 \%) \text { El uso de } \\
\text { recursos es incluye } \\
\text { posibilidades para la } \\
\text { adaptación de las } \\
\text { actividades }\end{array}$ \\
\hline $\begin{array}{l}\text { Relación con el área de } \\
\text { Lengua y Literatura }\end{array}$ & $\begin{array}{l}0(0 \%) \text { La actividad } \\
\text { no está nada } \\
\text { relacionada con el área }\end{array}$ & $\begin{array}{l}0,5(5 \%) \text { La actividad } \\
\text { está relacionada con el } \\
\text { área }\end{array}$ & $\begin{array}{l}1(10 \%) \text { La actividad } \\
\text { está estrechamente } \\
\text { relacionada con el área }\end{array}$ \\
\hline Participación & $\begin{array}{l}0(0 \%) \text { El estudiante } \\
\text { no participa }\end{array}$ & $\begin{array}{l}0,75(7,5 \%) \text { El } \\
\text { estudiante participa en } \\
\text { el diseño de la } \\
\text { actividad }\end{array}$ & $\begin{array}{l}1,5(15 \%) \text { El estudiante } \\
\text { participa en el diseño y } \\
\text { en el desarrollo de la } \\
\text { actividad }\end{array}$ \\
\hline Creatividad & $\begin{array}{l}0,75(7,5 \%) \text { La } \\
\text { actividad es creativa }\end{array}$ & $\begin{array}{l}1,5(15 \%) \text { La actividad } \\
\text { es muy creativa }\end{array}$ \\
\hline
\end{tabular}

\subsubsection{Aprendizaje Cooperativo}

La principal actividad de Aprendizaje Cooperativo se realizó mediante la técnica de los expertos. Se dividió la clase en dos grupos, debido al reducido número de estudiantes, y se les asignó una corriente literaria a cada uno. La finalidad de la actividad era analizar la evolución a lo largo de las distintas épocas de la importancia del ser humano y de la espiritualidad, no solo desde un punto de vista teórico, sino también a través de los textos y autores.

Los estudiantes colaboraron primero en parejas según la corriente trabajada y después acudieron a sus grupos de referencia, exponiendo la información encontrada para, después, compararla con el resto de épocas y tendencias. De este modo, el documento que resultó como producto final incluía un detallado análisis de la evolución de la cuestión ejemplificada a través de los distintos autores, y los estudiantes lograron (re)aprender las características de las distintas corrientes sin apenas dificultad.

\subsubsection{Aprendizaje Dialógico}

Esta metodología, que en realidad hunde sus raíces en la Mayéutica griega, implica un diálogo con el estudiante y el fomento de los métodos inductivo y deductivo. Los debates acerca de la cuestión de la igualdad han ocupado un lugar de relevancia a la hora de implementar esta metodología, si bien se ha llevado a cabo también en el análisis e interpretación de textos literarios, tales como canciones y cuentos, que han servido como base para la observación de cualquier progreso en la comprensión de contenidos y valores de la asignatura.

\section{Resultados}

Si bien a nivel cuantitativo las calificaciones finales no parecen haber evolucionado favorablemente y aunque la diferencia no es significativa, no podemos extraer conclusiones al respecto sin cotejarlas con los resultados a nivel cualitativo, puesto que la evaluación es ahora mucho más completa y la satisfacción del alumnado, de acuerdo con las opiniones 
vertidas en las entrevistas informales, es mayor. Asimismo, hemos tenido únicamente en cuenta la modalidad presencial de la asignatura, puesto que la modalidad semipresencial ya partía del uso de metodologías como la flipped classroom.

Figura 3. Evolución de las calificaciones entre 2012 y 2016

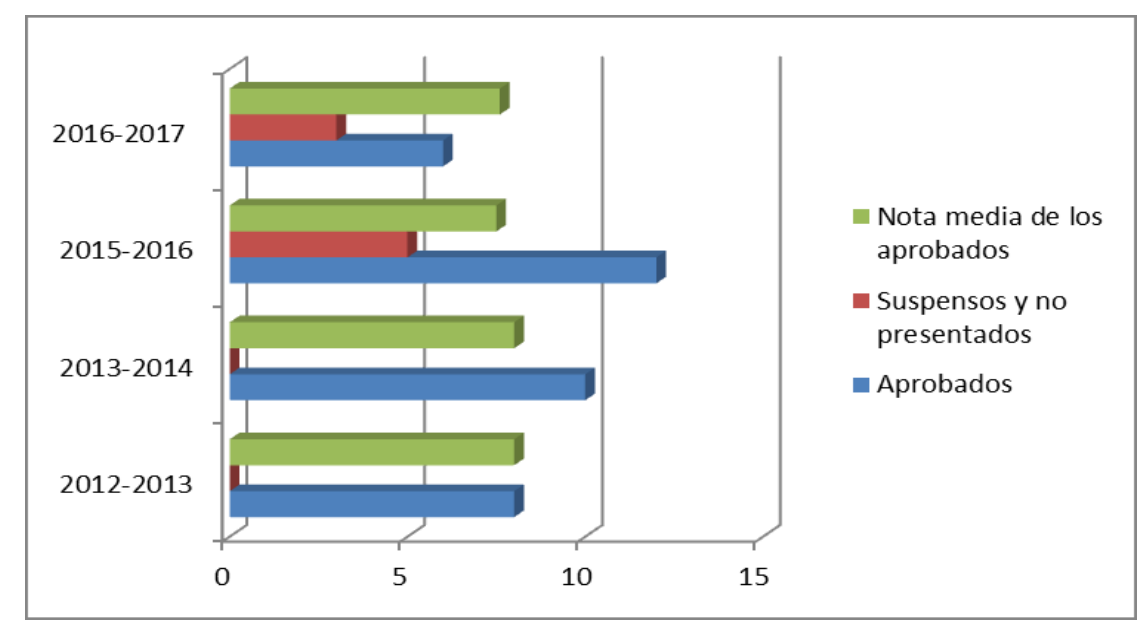

En lo que respecta a la Educación en Valores, se ha apreciado una comprensión más profunda del concepto de igualdad, tanto en lo que concierne al género como a la etnia. Esta observación se sustenta en las participaciones de los estudiantes en diversos debates, así como en la aplicación de dichos conceptos de forma correcta a las actividades desarrolladas, no solo en Didáctica de la Lengua II -con especial hincapié en los microproyectos y una actividad específica sobre la relevancia, vida y obra de varias escritoras desconocidas para ellos a priori-, sino también en Didáctica de las Ciencias Sociales II, en la cual colaboraron con Save the Children en la elaboración de unidades didácticas.

Por lo que se refiere a competencias, las competencias transversales más relevantes (planificación y gestión del tiempo, trabajo en equipo, habilidades comunicativas e interpersonales, iniciativa y autonomía, flexibilidad y adaptación, responsabilidad social) se han sido evaluadas a través de rúbricas gracias a la diversidad de metodologías empleadas y actividades realizadas, las cuales han permitido que se produzca no solo una evaluación tradicional -esto es, por parte del profesorado-, sino también autoevaluación, coevaluación y evaluación por parte de los colaboradores externos, en el caso del Aprendizaje Experiencial y el Aprendizaje y Servicio. En concreto, la evaluación de los textos sobre Madrid proporcionó información sobre las habilidades comunicativas escritas (la redacción, adecuación a las normas gramaticales y de ortografía y puntuación) y sobre la aplicación de conocimientos teóricos a la práctica (la habilidad para reconocer las características del nivel lingüístico de los receptores de los textos y la adaptación de los mismos a dicho nivel).

Asimismo, la evaluación del microproyecto de Aprendizaje y Servicio ofreció información acerca de las habilidades comunicativas orales y escritas de los estudiantes, su capacidad de aplicación de conocimientos teóricos a la práctica, la flexibilidad y adaptación (ya que las condiciones iniciales descritas en el diseño de la actividad variaron y tanto la 
temporalización como las propias tareas tuvieron que sufrir modificaciones), la planificación y gestión del tiempo (por ejemplo, a través de la previsión de tiempos y recursos que se iban a necesitar) y la iniciativa y autonomía, dado que las decisiones debían tomarlas y proponerlas los propios estudiantes. Su capacidad para fomentar la creatividad pudo ser valorada también por el colaborador externo, que estuvo presente en todo momento y pudo observar el desarrollo de las acciones y la gestión del aula por parte de las estudiantes implicadas.

En ambos casos, el feedback recibido fue positivo. La Asociación Valdeperales indicó que los recursos habían sido suficientes, que las estudiantes se habían desempeñado correctamente en el desarrollo de la misma y en el trato con los niños y niñas, y que la actividad era apropiada para el público al que iba dirigido. Los niños y niñas, por su parte, se mostraron satisfechos y contentos y Serve the City ha expresado su intención de seguir colaborando con los estudiantes del Grado en Educación Primaria y otros en el diseño e implementación de actividades.

\section{Conclusiones}

No son muchos los trabajos realizados sobre innovación en los procesos de aprendizaje encaminados a la formación integral del estudiante universitario. Los pocos que han abordado este tema no pueden generalizarse a todo el sistema educativo, ya que en la mayoría de los casos, fueron llevados a cabo con estudiantes de universidades norteamericanas y británicas pertenecientes a titulaciones técnicas o de ciencias de la salud (Hunt, Eagle y Tchen, 2004; Meterissian, Liberman y McLeod, 2007, entre otros). Este artículo pretende contribuir a la literatura y subsanar esta limitación, centrándose en el aspecto metodológico y en la inclusión de actividades que permitan a los estudiantes desarrollar sus competencias como futuros docentes, trabajadores y ciudadanos y ser evaluados sobre su progreso en ese aspecto.

En este sentido, los resultados obtenidos en este trabajo señalan que aún obteniendo buenos resultados en las diferentes actividades realizadas mediante las metodologías explicadas, es posible plantearse acciones futuras. Concretamente, vivir experiencias fuera del campus con agentes colaborades externos siempre brinda una oportunidad de experimentar una completa formación en valores y competencias. En futuras actividades, proponemos realizar diferentes actividades en varias realidades sociales, teniendo en cuenta alumnos de diferentes cursos y materias. De esta manera, los alumnos también podrán formar y aprender entre sus compañeros, acercándose cada vez más a la realidad de su profesión.

Consideramos que la actividad descrita en este trabajo proporciona, además, diferentes implicaciones prácticas para las personas involucradas en el diseño de los planes de estudio de los Grados universitarios. Concretamente, los resultados obtenidos pueden resultar de utilidad tanto a los profesores como coordinadores/directores de titulación para determinar futuras acciones y el desarrollo de planes estratégicos que faciliten una visión integradora de las competencias adquiridas y desarrolladas por parte los alumnos a lo largo de la 
Diversificación metodológica y microproyectos para la formación integral del alumnado universitario

carrera. Por otro lado, los cambios a los que nos enfrentamos en EEES hacen necesario que las universidades profundicen en la necesidad de conocer a su alumnado y adaptar tanto sus programas formativos como las metodologías docentes empleadas. Por ejemplo, en la universidad, los docentes también deberían tener la función de ser mentores, acompañando al alumno y orientándole en competencias para acercarle a su profesión. Este artículo refuerza dicha idea y muestra cómo el profesorado, mediante tutorías, es capaz de favorecer la transmisión y desarrollo de competencias y valores en sus alumnos.

Por todo lo anteriormente expuesto, esperamos que futuros estudios aplicados a diferentes cursos y titulaciones de grado y postgrado (i.e., Grado en Educación, Máster Universitario en Educación Bilingüe, Máster Universitario en Formación de Profesorado, etc.) puedan utilizar los resultados obtenidos en este trabajo como punto de partida para identificar nuevas actividades que puedan ayudar a los estudiantes, a la vez que estimularles en la adquisición y desarrollo de las competencias necesarias para su formación integral.

(c) EY-NC-ND 2017, Universitat Politècnica de València

Congreso IN-RED (2017) 


\section{Referencias Bibliográficas}

-. Benito, Á. y Cruz, A. (2005). Nuevas claves para la docencia universitaria en el Espacio Europeo de Educación Superior: en el espacio europeo de educación superior (Vol. 10). Narcea Ediciones.

- Castells, M. (2002). La dimensión cultural de Internet. Institut de Cultura: Debates Culturales.

Recuperado de http://www.uoc.edu/culturaxxi/esp/articles/castells0502/castells0502.html.

- Consejo de Coordinación Universitaria (2006): Propuestas metodológicas para la renovación de las metodologías educativas. Madrid:MEC.

-. De Juan, M. D., González, E., Parra, J. F., Kanther, A. y Sarabia, F. J. (2008) Antecedentes del aprendizaje autorregulado del estudiantes universitario de marketing Actas del XX Encuentro de Profesores Universitario de Marketing, 17-19 de septiembre de 2008, Gran Canarias (España).

- De Miguel Díaz, M. (Dir); Alfaro Rocher, I.J.; Apodaca Urquijo, P.; Arias Blanco, J.M.; García Jiménez, E.; Lobato.; Fraile, C. y Pérez Boullosa, A. (2006). Modalidades de enseñanza centradas en el desarrollo de competencias orientaciones para promover el cambio metodológico en el Espacio Europeo de Educación Superior (pp. 159-172). Ediciones Universidad de Oviedo. Consultado en http://www.academia.edu/5817175/Modalidades_de_Ense\%C3\%B1anza_Centradas_en_el _Desarrollo_de_Competencias_Orientaciones_para_Promover_el_Cambio_Metodol\%C3\% B3gico_en_el_Espacio_Europeo_de_Educaci\%C3\%B3n_Superior.

- Fernández March, A. (2006). Metodologías activas para la formación de competencias. Educación S.XXI. Núm. 24 (pp.35-56). Consultado en http://revistas.um.es/educatio/article/view/152/135.

- Folgueiras Bertomeu, P. y Martínez Vivot, M. (2009). El desarrollo de competencias en la universidad a través del aprendizaje y servicio solidario. Revista Interamericana de Educación para la Democracia (RIED), 2(1), 55-76.

- Francisco, Andrea y Moliner, Lidón (2010). El Aprendizaje Servicio en la Universidad: una estrategia en la formación de ciudadanía crítica. REIFOP, 13 (4). Recuperado de www.aufop.com. Consultado en 7 Mayo 2016.

- Grimaldo-Moreno, F. y Arevalillo-Herráez, M. (2011). Metodología docente orientada a la mejora de la motivación y rendimiento académico basada en el desarrollo de competencias transversales. IEEE-RITA Vol. 6, Núm. 2, May.

- Huber, G.L. (2008). Aprendizaje activo y metodologías activas. Revista de Educación (número extraordinario, pp.59-81). Consultado en www.revista educación.mec.es/re2008/re2008_04.ppdf 
Diversificación metodológica y microproyectos para la formación integral del alumnado universitario

-. Hunt, L., Eagle, L., y Tchen, P. (2004). Balancing marketing education y information technology: matching needs or needing a better match? Journal of Marketing Education, 26, 75-88.

-. Meterissian, S., Liberman, M. y Mcleod, P. (2007). Games as teaching tools in a surgical residency, Medical Teacher, 29(9/10), 258-270.

- Romero Ariza, M. (2010). El aprendizaje experiencial y las nuevas demandas formativas. Revista de Antropología Experimental no 10. Especial Educación 8: (pp. 89-102).

Whitehead, A. N. (1919). The Concept of Nature. Gutenberg Ebook. 


\title{
Gamificación en la universidad II: aprendemos a divertirnos enseñando. Se divierten aprendiendo
}

\section{Teresa San-Miguel, Javier Megías y Eva Serna}

Departament de Patologia, Facultat de Medicina i Odontologia, Universitat de València. Teresa SanMiguel (teresa.miguel@uv.es), Javier Megías (javier.megías@uv.es), Eva Serna (eva.serna@uv.es)

\begin{abstract}
After the success last year using gamification as a motivating method in the degree of Biomedical Engineering (UV-UPV), we introduce it this year in degree in Podiatry $(U V)$. On the basis of the results of our first study, we focus on the use of Kahoot application in order to improve our students' motivation and subsequently, their califications. Despite the short timeexperience, the improvement in academic results has been evident. Although it could be due to many causes, it has been influenciated by this action. In addition, during the development of this type of activity the involvement and fun of our students does not cease to amaze us. They enjoy their successes and also their failures. We enjoyed with an spectacular feedback, which was almost non-existent during the classic class format.
\end{abstract}

Keywords:gaming, KAHOOT, motivation, TIC, m-learning

\section{Resumen}

Tras el éxito el curso pasado de la gamificación como método motivador en el grado de Ingeniería Biomédica (UV-UPV), utilizamos el método este año en el grado en Podología (UV). A la luz de los resultados del primer estudio nos centramos en el uso de la aplicación Kahoot, para tratar de mejorar la motivación de los estudiantes hacia nuestra asignatura, y en consecuencia, sus calificaciones. A pesar de lo corta que es la experiencia, hemos obtenido una importante mejora en el rendimiento, que si bien puede atribuirse a diveresas causas, en parte ha sido influenciada por esta iniciativa .Durante el desarrollo de este tipo de actividad no deja de sorprendernos la implicación y diversión de nuestros estudiantes. Ellos disfrutan de sus aciertos y también de sus fallos. Nosotros disfrutamos de un feedback espectacular, que era casi inexistente con el formato clásico de clase.

Palabras clave: ludificación, gamificación, KAHOOT, motivación, TIC, mlearning 


\section{Introducción}

La lección magistral resulta increíblemente útil cuando se cumplen dos premisas: la primera es que el orador domina a la perfección, no sólo la materia a transmitir sino también los puntos fuertes de la misma. La segunda, el tema ha de ser interesante para el receptor. Cuando enseñamos en los primeros cursos de un grado universitario, nos enfrentamos entre otros problemas, a que la materia, bien por su generalidad o bien por su concreción, puede quedar lejos del campo de proyección profesional que ha gestado el estudiante en su mente. Para paliar este problema, los profesores no podemos ser meros transmisores de conocimiento; en la medida de lo posible debemos investigar y trasladar al alumno la utilidad futura que tendrá interiorizar los conocimientos que queremos hacerle llegar. El Espacio Europeo de Educación Superior (EEES) insta al docente a mejorar sus técnicas pedagógicas, y a implementar las nuevas tecnologías en su día a día (Tejedor 2007).

Si bien ya es cotidiano el apoyo visual mediante presentaciones informatizadas, cada vez más, recurrimos a otros recursos multimedia, como vídeos, archivos de tipo .gif y otras animaciones, que incorporan audio además de imagen, para captar la atención y el interés de nuestra audiencia. Aún así, en una sociedad altamente hiperestimulada, la lucha contra las distracciones en el aula, está en el día a día. El estudio NMC Horizon Report 2016 Higher Education Edition, propone las estrategias basadas en el Bring Your Own Device (BYOD) para atajar este problema. Con ella, se pretende que ese ordenador portátil que cada vez más alumnos llevan, o ese teléfono móvil con el que se distraen, se introduzca en las vías de enseñanza-aprendizaje. La clave: mientras utilizan el teléfono con una aplicación para aprender o para aprender jugando, no pueden estar utilizándolo para otros fines. De hecho, la importancia de este diseño pedagógico en la educación actual, ha derivado en el desarrollo de toda una rama del conocimiento, englobada en el llamado m-learning o mobile-learning, fundamentado básicamente en el uso de dispositvos móviles (teléfonos, tabletas u ordenadores portátiles) en la docencia. De esta manera, KAHOOT entra en escena (https://kahoot.it/).

El programa KAHOOT permite, como ya describimos en nuestro anterior trabajo (SanMiguel 2016), elaborar concursos en línea, de una manera rápida y sencilla. Ludifica el aprendizaje pues la resolución del test se hace de manera interactiva: aparecen en pantalla las respuestas de los estudiantes representadas en gráficos de barras (figura 1) y ese feedback inmediato, indique acierto o error, incentiva al estudiante a seguir mejorando durante las posteriores preguntas del concurso (Pintor 2014). Tras cada pregunta, ordena a los participantes por la rapidez en acertar la pregunta y son varios los trabajos que describen la influencia sobre la motivación que tiene introducir puntuaciones en los juegos de aula de manera análoga a como lo hacen los videojuegos (Cortizo 2011, Mauricio 2015).

La motivación del estudiante es un elemento esencial para el aprendizaje, por ello pretendemos utilizar la tecnología KAHOOT con nuestros alumnos de Biología Celular y Tisular de primer curso del grado de Podología (UV). Se trata de un grado con estudiantes de muy diversas procedencias (PAU desde Bachiller, desde Ciclos Formativos de Grado Superior, para mayores de 25, para mayores de 50, numerosos segundos titulados etc). La asignatura Biología Celular y Tisular constituye una herramienta sobre la que construir el

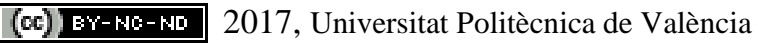

Congreso IN-RED (2017) 
aprendizaje de las siguientes materias que encontraran durante la carrera, pero sus contenidos quedan aparentemente muy distantes de la práctica profesional que desempeñará el podólogo, por lo que mejorar su motivación es un aspecto que necesitamos trabajar para que los alumnos integren los contenidos académicos, cognitivos y procedimentales que deseamos en ellos y puedan sacar provecho de ellos en los siguientes cursos del grado.

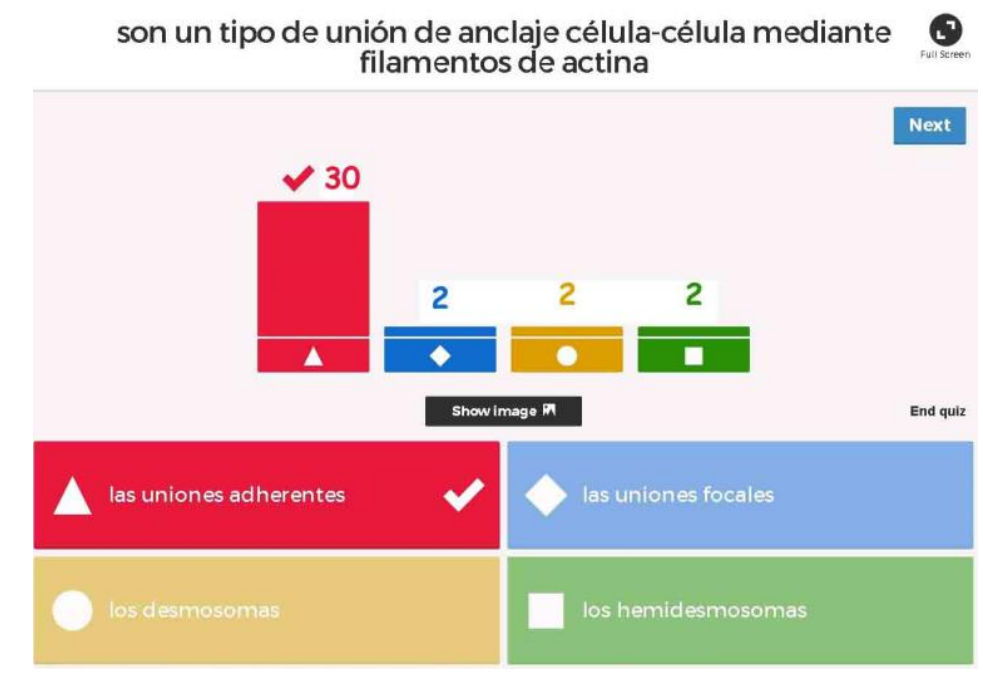

Fig. 1. Representación del resumen de resultados en gráficos de barras que muestra KAHOOT tras cada pregunta del concurso. Permite detectar respuestas erróneas que los alumnos escogen y explicarlas antes de proseguir con el concurso.

\section{Objetivos}

El objetivo principal de nuestra experiencia es mejorar el rendimiento de la sesión de repaso de la asignatura Biología Celular y Tisular, de 2 horas de duración. Con ello, pretendemos mejorar el rendimiento global en la asignatura. Esta sesión, tradicionalmente destinaba:

- Una hora a remarcar los aspectos que por nuestra experiencia entrañan mayores dificultades

- Una hora a resolver dudas concretas de los estudiantes. Esta hora no se usaba completa, ya que sólo los alumnos más precavidos llevaban dudas preparadas y el resto manifestaba escasa motivación e interés.

Para lograr nuestro objetivo, nos marcamos 5 subobjetivos:

1. Programar 2 mini-test con el programa KAHOOT

2. Romper con la ausencia de participación en la sesión de repaso de la asignatura

3. Ilustrar planteamientos diferentes sobre los contenidos teóricos de una forma práctica y visual

4. Cambiar el uso distractivo de teléfonos móviles y ordenadores portátiles a un uso aplicado al aprendizaje

5. Valorar el rendimiento académico frente al curso anterior.

(c)) EY-NC-ND 2017, Universitat Politècnica de València

Congreso In-Red (2017) 


\section{Desarrollo de la innovación}

La experiencia se llevó a cabo en la sesión de repaso de la asignatura, a la que asistieron 36 alumnos (el 50\% de los matriculados). Con 7 días de antelación, se les informó de que parte de dicha sesión se destinaría a una actividad dinámica. Se prepararon 2 cuestionarios KAHOOT, uno de nivel básico y uno de nivel medio.

Atendiendo a descripciones de problemas de conectividad a la red cuando es elevado el número de estudiantes que entran en una sala de KAHOOT, se organizó a la clase en 10 grupos de 3-4 personas, según la afinidad personal de los integrantes.

El primer concurso, que constaba de 10 preguntas de contenidos básicos, sirve para:

- comprobar los problemas de conectividad en caso de que los hubiera

- familiarizarse con el entorno de software

- $\quad$ aumentar el nivel de confianza a la hora de contestar

El segundo concurso constaba de 15 preguntas de nivel medio. En él se introducen imágenes y diagramas que obligan al estudiante a aplicar sus conocimientos para resolver las cuestiones. Además se remarcan aspectos que la experiencia nos indica que suelen tener confusos (figura 2).

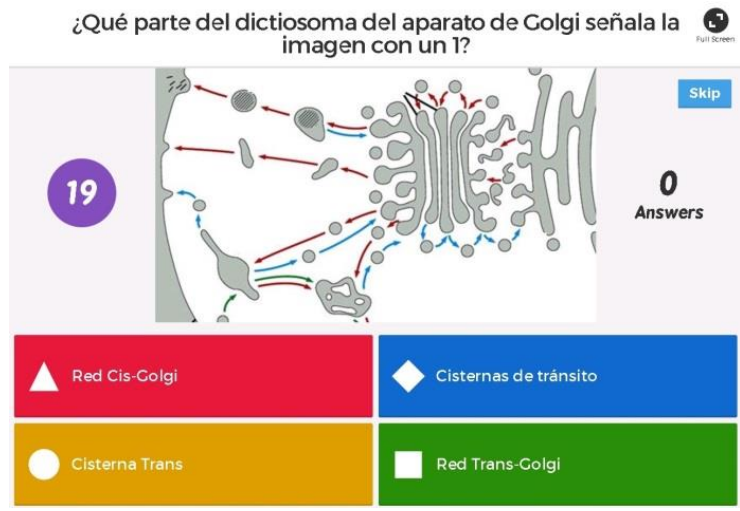

Fig. 2. Pregunta de un concurso con imagen. Permite utilizar imágenes similares a las empleadas en clase o invertidas, forzando al estudiante a replantearse su forma de aprendizaje.

Para conocer la valoración de los alumnos sobre la actividad realizada, más allá de nuestras propias impresiones, al finalizar la sesión se les proporcionó un breve cuestionario voluntario y anónimo. Las preguntas incluidas fueron:

- ¿Cuál es tu nivel de satisfacción con la experiencia de la práctica? Muy satisfecho-Satisfecho-Neutral-Insatisfecho-muy insatisfecho

- ¿Cómo consideras este tipo de actividades innovadoras como método para afianzar conceptos? excelente-bueno-indiferente-regular-malo

- ¿Encuentras práctico comenzar con una prueba de nivel básico? Muy útilbastante útil-indiferente-poco útil-nada útil

(c)) EY-NC-ND 2017, Universitat Politècnica de València

Congreso IN-RED (2017) 
- ¿Consideras que te ha resultado útil para conocer cómo se plantean cuestiones de la asignatura? Muy útil-bastante útil-indiferente-poco útil-nada útil

- ¿Prefieres realizar estas actividades de manera individual o grupal?

Por otra parte, aunque sea una corta experiencia y puedan ser diferentes los factores que influyen en los resultados académicos, comparamos las calificaciones del examen teórico en primera convocatoria del curso 2015-2016 con las obtenidas en la primera convocatoria tras nuestra experiencia KAHOOT en el presente curso 2016-2017.

\section{Resultados}

\subsection{Evolución de la web}

El primer resultado destacable es la evolución de la web KAHOOT desde febrero que la utilizamos en Ingeniería Biomédica (UPV-UV) a Diciembre que la hemos utilizado en Podología (UV): nuestra intuición nos llevó en la primera ocasión a formar grupos. La aplicación KAHOOT en estos meses, ha desarrollado ese modo de juego (figura 3); los usuarios ya pueden elegir si el tipo de concurso será individual o colectivo.

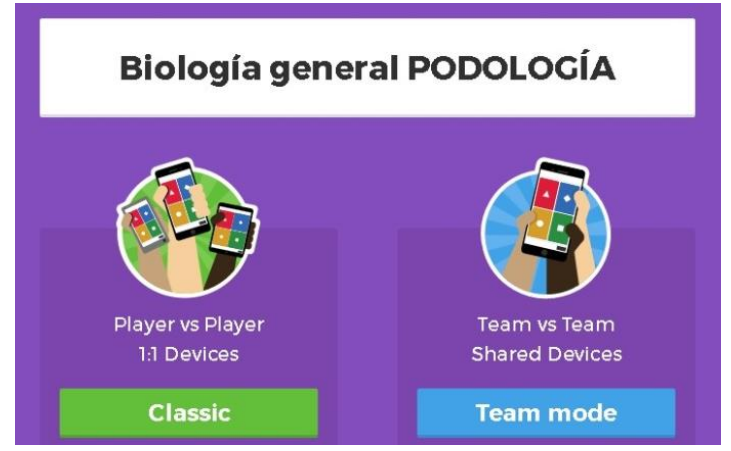

Fig. 3. Modos de juego ofrecidos por la aplicación. El Team mode es una reciente incorporación

\subsection{Valoración de los estudiantes}

El 100\% de los asistentes a la sesión participó de forma voluntaria en la actividad. Más allá de los resultados cuantificables, el entusiasmo de los participantes fue excepcional. Literalmente, querían hacer otro concurso más cuando acabamos con el segundo.

El nivel de satisfacción con la actividad fue muy elevado. Únicamente uno de los participantes que se encontraba satisfecho por el aspecto lúdico, no encontraba esencialmente útil el sistema para afianzar conceptos (figura 4). 


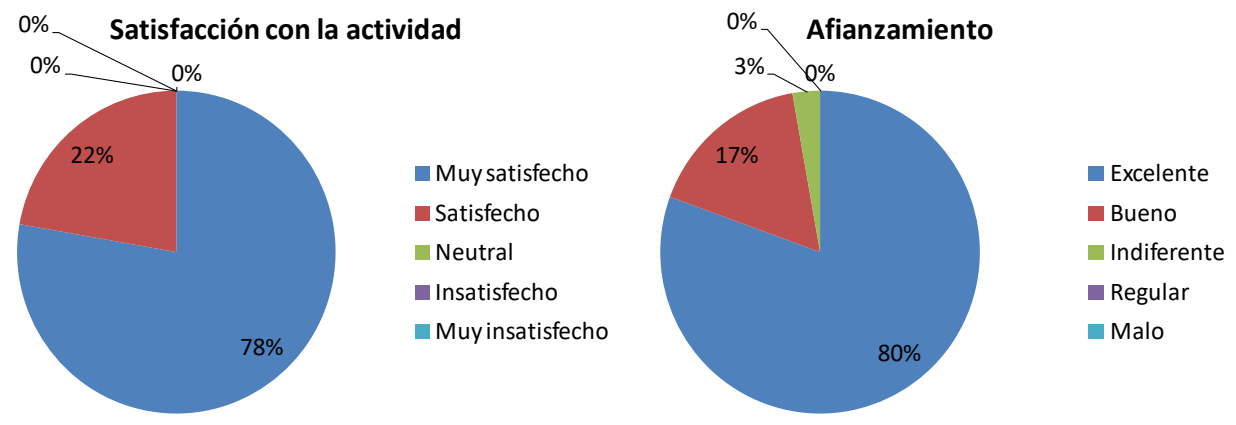

Fig. 4. Satisfacción de los estudiantes con la actividad y utilidad como método de refuerzo

Para valorar nuestra estrategia docente al planificar la actividad, los alumnos agradecen comenzar con una prueba de nivel básico, que les permite conocer la interfaz y hacerse con la dinámica del juego. Además, consideran muy útil conocer diferentes formas de preguntar conceptos que pueden resultar muy abstractos a nivel teórico

De cara a mejorar nuestra forma de plantear las actividades, preguntamos sobre realizar la actividad de manera grupal o individual y los alumnos insisten en que aprenden más trabajando en parejas o tríos que de manera aislada (figura 5).

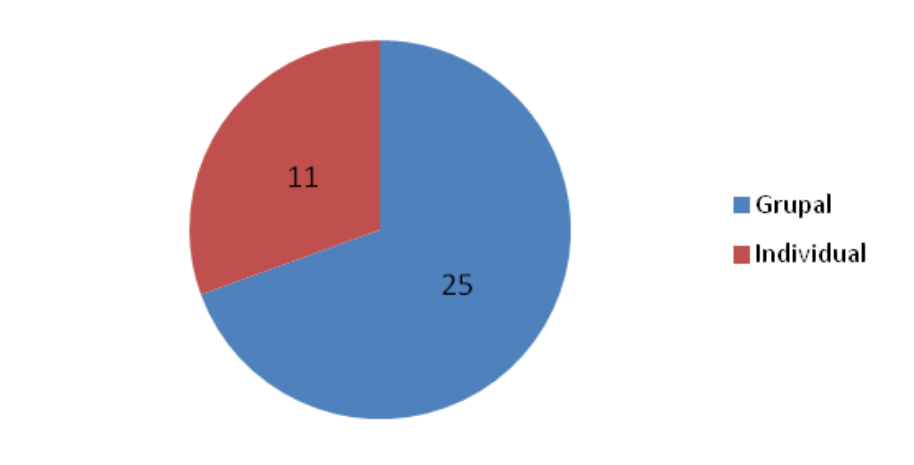

Fig. 5. Preferencia de los estudiantes por hacer la actividad de manera individual o grupal

\subsection{Mejora en las calificaciones}

Por último, comparamos los resultados académicos entre dos cursos consecutivos. La mejora ha sido evidente (figura 6). La proporción de aprobados ha subido desde el 32,5\% al $47,2 \%$ de aprobados en primera convocatoria.

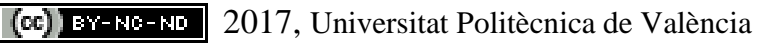

Congreso IN-RED (2017) 


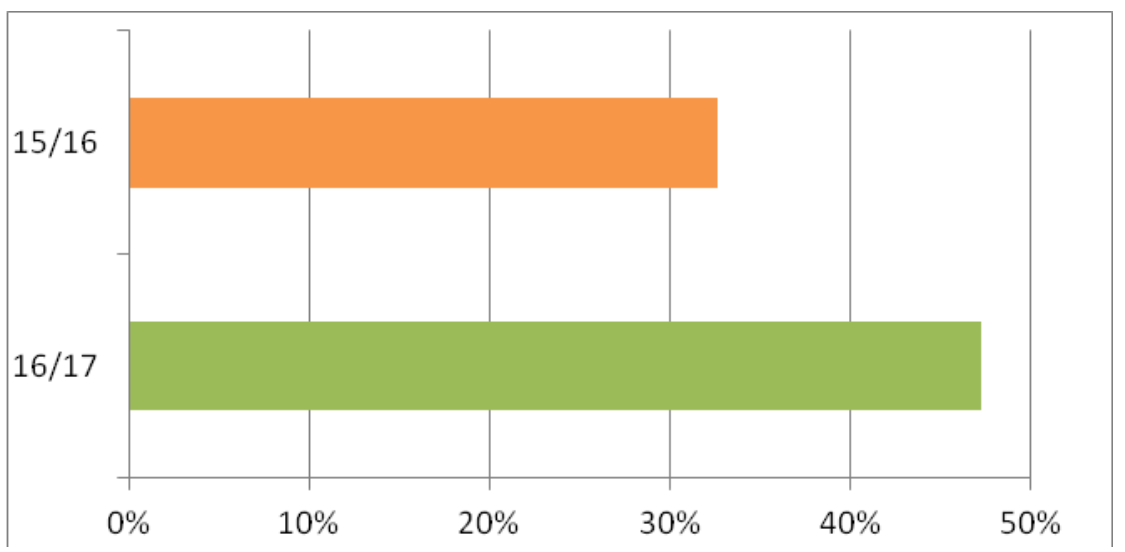

Fig. 6. Proporción de alumnos que alcanzan el aprobado en el examen teórico de Biología Celular en primera convocatoria en el curso 2015-2016 y 2016-2017

\section{Conclusiones}

La ludificación del aula universitaria es una alternativa novedosa en nuestra universidad y sobre todo, en la Facultad de Medicina y Odontología. Aunque parte del profesorado se muestra escéptico a este tipo de métodos en la formación universitaria, nuestros resultados en el grado de Podología concuerdan con trabajos previos en Odontología (Pintor Holguín 2014 y Serna 2015) e Ingeniería Biomédica (San-Miguel 2016) entre otros, mostrando que para los alumnos, jugar constituye una vía válida de adquirir conocimiento.

Uno de los aspectos más destacable fue la sorpresa que supuso el hecho de que fuera un juego, con su música, imágenes y puntuaciones. Los estudiantes se mostraban encantados. No obstante, esto incide en una de sus limitaciones, que sería el abuso. Mientras KAHOOT resulta francamente útil usado de manera esporádica, su uso continuado podría hacerle perder parte del efecto estimulante; este hecho a su vez, enfatiza el papel del docente en la elección y planificación de la iniciativa de manera minuciosa para optimizar los beneficios de su utilización, como ya han descrito otros autores (Kapp 2012, Zichermann 2011).

De las encuestas recopiladas, extraemos que todos los alumnos que participaron,se mostraron satisfechos o muy satisfechos con la actividad y únicamente un alumno se manifestó indiferente ante la utilidad de este tipo de dinámicas. Los resultados en la primera convocatoria de esta asignatura, son tradicionalmente malos, con tasas de aprobado que rondan el $30 \%$. Es evidente que son numerosos los factores que influyen en el rendimiento académico, y que no puede atribuirse a un cambio en una actividad, pero es muy destacable que este año en primera convocatoria, hemos alcanzado el aprobado en casi el 50\% de los matriculados. Este resultado es espectacular y estamos convencidos del efecto beneficioso que ha tenido la ludificación del aula en ello, y la remodelación de la sesión de repaso, logrando una atención y participación muy superior a la obtenida en cursos previos. Habría resultado ideal poder comparar los resultados entre los alumnos que participaron en la sesión de repaso frente a los que no asistieron, pero resultó imposible pues para incentivar su participación, se garantizó el anonimato de los participantes y la asistencia a la sesión era 
además, voluntaria. Por otra parte, el hecho de tener la opción de asistir a la sesión ya muestra una voluntad aumentada por parte de los estudiantes implicados, lo que constituiría también un sesgo; probablemente, las calificaciones de los asistentes sea intrínsecamente superior a la de los no asistentes, cada año, con independencia de la planificación que se le de a la sesión. No obstante, nos planteamos definir mejor todos estos parámetros para mejorar la valoración de estas actividades en cursos futuros.

Nuestra solución en ediciones anteriores a otra de las limitaciones de KAHOOT, que era la conectividad, había sido formar grupos. Ahora la propia plataforma propone la formación de grupos como método de juego. Podemos concluir que los estudiantes, al igual que nosotros, prefieren realizar estas actividades de forma grupal.

Queremos remarcar que uno de los elementos más didácticos que incluye este juego, es su pausa tras cada pregunta. El juego queda detenido sobre el gráfico de barras que muestra el número de participantes que han elegido cada una de las opciones. En ese momento, el docente puede aprovechar para explicar por qué la respuesta correcta es la que es, y sobre todo, incidir en el por qué de la incorrección de otras. Esto permite sobre una sóla pregunta, poder repasar diversos contenidos, de manera intercalada y con la atención de los estudiantes y así poder incidir positivamente sobre la asimilación y entendimiento de los conceptos.

Además de la increíble mejora en los resultados obtenidos en el examen, el desarrollo de la actividad fue muy estimulante. Comprobamos como la utilización de esta herramienta interactiva aumenta la participación de los estudiantes en la clase de repaso, aumenta la atención y favorece su implicación en el proceso de aprendizaje afectando positivamente en las calificaciones. Los alumnos querían más preguntas, más concurso, estaban francamente ilusionados respondiendo. Esta retroalimentación a su vez, nos motiva a nosotros como docentes a planificar de nuevo la actividad y a disponer de recursos que nos permitan adaptarnos a las demandas de nuestros estudiantes en función de cómo respondan ante nuestras intervenciones. Así, podemos aprovechar que los estudiantes se divierten aprendiendo, y nosotros podemos divertirnos con ellos, enseñando.

Podemos concluir que la gamificación con KAHOOT en el aula representa una herramienta potencial para impulsar cambios de actitud en los estudiantes y que en último término, esto repercute positivamente sobre el aprendizaje de los alumnos.

\section{Bibliografía}

CORTIZO PÉREZ, J.C.; CARRERO GARCÍA, F.; MONSALVE PIQUERAS, B.; VELASCO COLLADO, A.; DÍAZ DEL DEDO, L.I. y PÉREZ MARTÍN, J. (2011). “Gamificación y Docencia: Lo que la Universidad tiene que aprender de los Videojuegos". En: Retos y oportunidades del desarrollo de los nuevos títulos en educación superior. VIII Jornadas Internacionales de Innovación Universitaria. Universidad Europea de Madrid (2011 Madrid). Disponible en <http://hdl.handle.net/11268/1750> 
KAHOOT. Wang, A.I.; Brand, J. ; Brooker, J. y Versvik, M. (2013). Norwegian University of Science and Technology (NTNU). Trondheim, Noruega (Høgskoleringen 1, 7491 Trondheim, Noruega)

KAPP, K.M. (2012). The Gamification of Learning and Instruction: Game-Based Methods and Strategies for Training and Education. San Francisco, CA: John Wiley

MAURICIO, M.D.; SERNA, E. y VALLES, S.L. (2015). "Experiencias en la aplicación de la gamificación en $1^{\circ}$ Curso de Grado de Ciencias de la Salud”. En: Congreso de Innovación Educativa $y$ Docencia en Red. Universitat Politècnica de València (2015 Valencia). Disponible en <http://ocs.editorial.upv.es/index.php/INRED/>

NMC and the EDUCAUSE Learning Initiative (ELI). NMC Horizon Report - 2016 Higher Education Edition <http://www.nmc.org/publication/nmc-horizon-report-2016-higher-education-edition> [Consulta: 1 de abril de 2016]

PINTOR HOLGUÍN, E.; GARGANTILLA MADERA, P.; HERREROS RUIZ VALDEPEÑAS, B. y LÓPEZ DEL HIERRO, M. (2014). "Kahoot en docencia: una alternativa práctica a los clickers". En: XI Jornadas Internacionales de Innovación Universitaria. Educar para transformar. Universidad Europea de Madrid (2014 Madrid). Disponible en 〈http://hdl.handle.net/11268/3603>

SOCRATIVE. MasteryConnect. Salt Lake City, UT (222 South Main, Suite 200. Salt Lake City, UT 84101, USA)

SERNA, E.; MAURICIO, M.D.; SAN-MIGUEL, T. y MEGÍAS, J. (2016). "Experiencia de gamificación en Docencia Universitaria: aprendizaje activo y entretenido". En: Congreso de Innovación Educativa y Docencia en Red. Universitat Politècnica de València (2016 Valencia). Disponible en <http://ocs.editorial.upv.es/index.php/INRED/INRED2016/paper/view/4292>

SAN-MIGUEL, T.; MEGÍAS, J. y SERNA, E. (2016). "Gamificación en la universidad: una experiencia basada en el "bring your own device" en educación superior". En: Congreso de Innovación Educativa y Docencia en Red. Universitat Politècnica de València (2016 Valencia). Disponible en <http://ocs.editorial.upv.es/index.php/INRED/INRED2016/paper/view/4397>

TEJEDOR, F.J. Y GARCÍA-VALCÁRCEL, A. (2007). "Causas del bajo rendimiento del estudiante universitario (en opinión de los profesores y alumnos). Propuestas de mejora en el marco del EEES". Revista de Educación, vol. 342, p. 443-473

ZICHERMANN, G. Y CUNNINGHAM, C. (2011). Gamification by Design: Implementing Game Mechanics in Web and Mobile Apps. Cambridge, MA: O'Reilly Media 


\title{
Uso de un blog docente para el desarrollo del pensamiento crítico y la capacidad de expresión oral y escrita en ciencias del deporte
}

Vicente J. Beltrán-Carrilloa, Javier Valenciano-Valcárcel ${ }^{\mathrm{b}}$ y Joan Pere MolinaAlventosa $^{\mathbf{c}}$

${ }^{a}$ Centro de Investigación del Deporte. Universidad Miguel Hernández de Elche. vbeltran@umh.es, bFacultad de Educación de Toledo. Universidad de Castillla-La Mancha. Javier.Valenciano@uclm.es

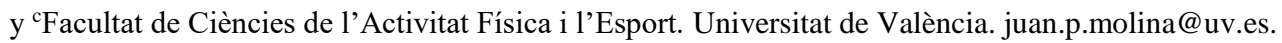

\begin{abstract}
The innovative teaching project described in this document was carried out in the subject Theory of Physical Education and Sport, belonging to the Physical Activity and Sport Sciences Degree (Miguel Hernández University of Elche). The project consisted in the use of a teaching blog to foster critical thinking and the ability of oral and written expression. The participation in the blog was related to a voluntary task which let the students increase their final mark in the subject. The students made oral comments (YouTube videos) or written comments to the entrances proposed by the lecturer. These entrances were about current topics related to physical activity and sport. At the end of the subject, the lecturer sent a Google form to the students to know their opinion about this innovative teaching project. The students' opinion regarding the utility of the blog as a teaching resource was positive.
\end{abstract}

Keywords: Blog, entrance, comment, video, reviewer, award.

\begin{abstract}
Resumen
El proyecto de innovación docente que se describe en este documento se desarrolló en la asignatura de Teoría de la Educación Física y el Deporte, perteneciente al Grado en Ciencias de la Actividad Física y el Deporte de la Universidad Miguel Hernández de Elche. El proyecto consistió en el uso de un blog docente para el desarrollo del pensamiento crítico y la capacidad de expresión oral y escrita. La participación en el blog estaba vinculada a un trabajo opcional con el que los estudiantes podían incrementar la nota final de la asignatura. Los alumnos realizaron comentarios orales (vídeos de YouTube) o escritos a las entradas propuestas por el profesor, sobre temas de actualidad relacionados con la actividad física y el deporte. Al finalizar la asignatura, el profesor envío un formulario de Google a los alumnos para conocer su opinión sobre este proyecto de innovación. La opinión de los alumnos sobre la utilidad del blog como recurso docente fue positiva.
\end{abstract}

Palabras clave: Blog, entrada, comentario, vídeo, evaluador, premio. 
Uso de un blog docente para el desarrollo del pensamiento crítico y la capacidad de expresión oral y escrita en ciencias del deporte.

\section{Introducción}

El proyecto de innovación docente que se describe en este documento se desarrolló en la asignatura de Teoría de la Educación Física y el Deporte, perteneciente al Grado en Ciencias de la Actividad Física y el Deporte de la Universidad Miguel Hernández de Elche. En esta asignatura es de 6 créditos ECTS, pertenece al primer curso de grado y se imparte durante el primer semestre. En el curso 2016-2017 se matricularon en esta asignatura 149 estudiantes.

Este proyecto docente se llevó a cabo para fomentar el pensamiento crítico entre el alumnado. El pensamiento crítico se relaciona con conocimientos y competencias que deberían potenciarse en todos los niveles educativos (Boisvert, 2004; Guzman Silva y Sánchez Escobedo, 2006; Rojas Viteri, Pérez Narváez y Álvarez Zurita, 2016). Sin embargo, muchos profesores pensamos que el pensamiento crítico no se incentiva suficientemente en las aulas universitarias, mientras que el conocimiento técnico recibe mucha más atención y se aborda en profundidad.

Junto al pensamiento crítico, la capacidad de expresión oral y escrita representa otra competencia de especial relevancia para la vida personal y profesional de los estudiantes universitarios (Peña González, 2011; Ruiz Muñoz, 2012). De manera preocupante, observamos que muchos alumnos no poseen una adecuada capacidad de expresión oral y escrita, con la que debería contar todo titulado universitario.

Por último, sabemos que, en la actualidad, los estudiantes universitarios se sienten especialmente atraídos por las nuevas tecnologías de la información y la comunicación y por las posibilidades que ofrece internet para comunicar y recibir opiniones e ideas. Concretamente, el uso de blogs docentes ha resultado ser una estrategia interesante para la innovación y la mejora de los procesos de enseñanza-aprendizaje en educación superior (Molina Alventosa, Valenciano Valcárcel y Valencia Peris, 2015; Molina Alventosa, Valencia Peris y Suárez Guerrero, 2016).

Con la intención de paliar las debilidades y aprovechar las oportunidades identificadas anteriormente, se planteó un proyecto docente cuyos objetivos se concretan en el siguiente apartado.

\section{Objetivos}

Los objetivos de este proyecto de innovación docente fueron fomentar entre el alumnado el pensamiento crítico y favorecer su capacidad de expresión oral y escrita. Estos objetivos, que están totalmente relacionados con los propósitos fundamentales de la asignatura, se abordaron mediante el uso de un blog docente al que se puede acceder en el siguiente enlace: http://teoriaefd.blogspot.com.es/

Al tratarse de un blog vivo, a comienzo del curso 2017-2018, las entradas a las que se hace alusión en este documento se eliminarán para ir introduciendo las entradas correspondientes al próximo curso.

(cc) EY-NC-ND 2017, Universitat Politècnica de València

Congreso IN-RED (2017) 


\section{Desarrollo de la innovación}

\subsection{El blog dentro del sistema de evaluación de la asignatura}

La participación en el blog docente estaba vinculada a un trabajo opcional con el que los estudiantes podían incrementar la nota final de la asignatura hasta 0,5 puntos, siempre y cuando aprobasen el examen de la asignatura con una nota igual o superior a 5 puntos.

La participación en el blog consistió en la realización de comentarios a las entradas que fue publicando el profesor. El texto de los comentarios escritos se publicaba en el blog, mientras que los comentarios orales se hacían llegar grabándolos en vídeo, subiéndolo a YouTube, e indicando en el comentario a la entrada del blog el enlace para acceder al vídeo. El profesor publicó cinco entradas a lo largo de la asignatura. Tres de ellas requirieron un comentario por escrito y las otras dos un comentario oral. Los alumnos tuvieron siempre una semana de plazo para realizar sus comentarios a las distintas entradas. Cada estudiante podía realizar un solo comentario en cada entrada.

Los comentarios que cumplieron los criterios de calidad establecidos por el profesor (ver apartado 3.2) fueron premiados con 0,1 puntos, que se añadían a la nota final de la asignatura. En caso de que los alumnos suspendieran el examen, la nota obtenida con la participación en el blog se guardaba para las convocatorias de septiembre y diciembre.

Al explicar el sistema de evaluación, se advirtió a los estudiantes que los comentarios irrespetuosos o de muy baja calidad podían no solo no ser premiados, sino bajar 0,1 en la nota final de la asignatura.

\subsection{Los criterios de evaluación de los comentarios}

Los criterios de evaluación de los comentarios a las entradas del blog fueron definidos por el profesor y comunicados al alumnado el día de la presentación de la asignatura y su guía docente. Estos criterios fueron los siguientes:

\subsubsection{Criterios de evaluación para comentarios expresados por escrito}

- Calidad de las ideas (buenas ideas por ser útiles e invitar a los lectores a comportarse de un modo más inteligente y adecuado en la sociedad, por ser originales y ofrecer nuevas perspectivas del tema que se está discutiendo, por estar bien justificadas y por ser éticamente adecuadas).

- Orden de las ideas (existe un hilo conductor, el orden de las ideas es adecuado, no se repite la misma idea al principio y al final del texto, se nota que las ideas se han pensado y ordenado antes de redactar).

- Calidad de la expresión escrita (bien escrito, fácil de leer y entender, sin faltas de ortografía ni abreviaturas como "xq", impropias del lenguaje académico).

- Cantidad de información (que se aproxime a las 400 palabras de límite, sin pasarse).

3.2.2. Criterios de evaluación para comentarios orales grabados en vídeo

(c)) EY-NC-ND 2017, Universitat Politècnica de València

Congreso In-Red (2017) 
Uso de un blog docente para el desarrollo del pensamiento crítico y la capacidad de expresión oral y escrita en ciencias del deporte.

- Calidad de las ideas (buenas ideas por ser útiles e invitar a los espectadores a comportarse de un modo más inteligente y adecuado en la sociedad, por ser originales y ofrecer nuevas perspectivas del tema que se está discutiendo, por estar bien justificadas y por ser éticamente adecuadas).

- Orden de las ideas (existe un hilo conductor, el orden de las ideas es adecuado, no se repite la misma idea al principio y al final del vídeo, se nota que las ideas se han pensado y ordenado antes de la exposición oral).

- Calidad de la expresión oral (uso adecuado del lenguaje oral y corporal, discurso fácil de seguir y que se entienda bien, evitar vocabulario que pueda resultar irrespetuoso, no leer ningún papel).

- El vídeo debe ser de una duración superior a 1 minuto e inferior a 2 minutos.

\subsection{Procedimiento de evaluación}

Para evaluar los comentarios se utilizó un sistema de coevaluación, en el que los evaluadores de los comentarios eran alumnos que se prestaban voluntariamente a realizar esta labor. Los alumnos interesados en ser evaluadores debían escribir un e-mail al profesor y los cinco primeros que lo hicieron fueron elegidos como evaluadores. Cada uno de los cinco evaluadores debía encargarse de realizar su función en una de las cinco entradas del blog.

Estos evaluadores eran anónimos para el resto de compañeros, con el objetivo de que pudieran sentirse libres para ejercer su función, sin temor a problemas de relación con los compañeros por no premiar algún comentario.

Cuando se publicaba la entrada que debían evaluar, el evaluador recibía un e-mail por parte del profesor, que contenía las siguientes indicaciones respecto al procedimiento de evaluación:

- Leer los comentarios de los compañeros. En un archivo Word, redactar un informe con los apartados que se indican a continuación:

1) Premiados (indicar los apellidos y el nombre de todos los premiados, primero los apellidos, y ordenados alfabéticamente. Indicar también cuál es el mejor comentario a juicio del evaluador).

2) No premiados (indicar apellidos y nombre de los no premiados, ordenados alfabéticamente, y las razones para no premiar cada uno de los comentarios).

3) Resumen de las ideas de los compañeros (anotar y ordenar las ideas principales que van apareciendo, en unos 4-5 párrafos de 2-3 líneas aproximadamente). Una vez terminado este proceso, el evaluador enviará por e-mail el informe al profesor. El plazo para la entrega de este documento es de una semana a partir de la fecha en la que acaba el plazo para realizar comentarios. El profesor asignará 0,1 al evaluador y 0,1 a cada alumno cuyo comentario haya sido premiado. El profesor también presentará en clase el resumen de las ideas elaborado por el evaluador del blog.

(c) EY-NG-ND 2017, Universitat Politècnica de València

Congreso IN-RED (2017) 
- El evaluador debe tratar de premiar bastantes comentarios para que los alumnos se animen a participar en futuras entradas. No hay ningún problema si se premian todos los comentarios. Eso sí, se debe evitar que un comentario que sea claramente de baja calidad según los criterios de evaluación resulte premiado. Es importante que el alumno perciba que no vale cualquier cosa.

\subsection{Las entradas publicadas}

La entradas publicadas fueron las siguientes:

\subsubsection{Entrada 1: Carreras de larga duración ... ¿Vida o muerte? (Comentario escrito).}

Una vez leído el artículo cuyo enlace se muestra a continuación, ¿qué contestaríais al autor? http://www.elmundo.es/blogs/elmundo/guantanamo/2012/10/01/desperdiciar-la-vida.html

Este enlace vinculaba a un artículo de Salvador Sostres publicado en el diario El Mundo, en el que el autor realiza una dura crítica a los participantes y organizadores de carreras de larga duración.

\subsubsection{Entrada 2: Éxito profesional (Comentario oral).}

En un futuro cercano acabaréis vuestro grado y buscaréis trabajo. Por eso me gustaría preguntaros lo siguiente: ¿Qué significa para vosotros el éxito profesional? ¿En qué circunstancias os consideraríais con éxito profesional?

\subsubsection{Entrada 3: La gestión de la fama (Comentario escrito).}

Una vez visto el vídeo de Valentino Rossi, cuyo enlace se muestra a continuación, ¿qué opinión queréis manifestar?

https://www.youtube.com/watch?v=w5YkwaJFlvw

Este enlace vinculaba a un vídeo de YouTube en el que Valentino Rossi parece dar una patada a una aficionada cuando trata de avanzar en moto entre la multitud.

3.4.4. Deporte y medio ambiente (Comentario escrito).

¿Qué puedes hacer en un futuro, como profesional de las ciencias del deporte, para promocionar el respeto al medio ambiente?

\subsubsection{Fútbol y evasión fiscal (Comentario oral).}

¿Crees que verdaderamente existe evasión fiscal por parte de futbolistas famosos? ¿Qué opinas de esta situación? Presenta tu comentario oral sin mencionar a ningún futbolista famoso en concreto.

\subsection{Presentación del resumen y concesión del premio simbólico al mejor comentario}

Una ver recibido el informe del evaluador, el profesor presentaba el resumen de las ideas procedentes de los comentarios de los alumnos. Posteriormente, el profesor aportaba alguna reflexión u opinión personal sobre el tema de la entrada. Finalmente, daba de nuevo la voz a los estudiantes para establecer una breve discusión y llegar a conclusiones finales.

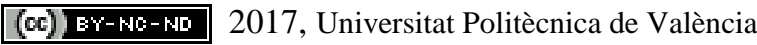


Uso de un blog docente para el desarrollo del pensamiento crítico y la capacidad de expresión oral y escrita en ciencias del deporte.

Tras finalizar este proceso, el profesor nombraba al estudiante que, a juicio del evaluador, había realizado el mejor comentario para que se acercara y entregarle un regalo de "valor simbólico y no material", como muestra de su agradecimiento y reconocimiento ante el buen trabajo realizado. Esto regalos fueron pequeños obsequios que había recibido el profesor por su asistencia a congresos científicos. Por ejemplo, un llavero, una bolsa de congreso, una libreta, etc.

En el momento de conceder el regalo, el profesor pensaba unas palabras para darle mayor solemnidad a la entrega, con ciertas dosis de humor. Por ejemplo, "te entrego este llavero, para que lleves siempre contigo la llave del conocimiento, que tantas puertas te abrirá en la vida". Tras la entrega, toda la clase aplaudía al alumno premiado.

\section{Resultados}

La primera entrada recibió el comentario por escrito de 33 estudiantes, la segunda entrada recibió el comentario oral de 12 estudiantes, la tercera entrada recibió el comentario escrito de 35 estudiantes, la cuarta entrada recibió el comentario escrito de 29 estudiantes, la quinta entrada recibió el comentario oral de 8 estudiantes.

Todos los evaluadores cumplieron a la perfección con su función. Además, la inmensa mayoría de los comentarios fueron premiados por cumplir con los criterios de evaluación establecidos.

Una vez finalizada la asignatura, el profesor envío al alumnado un formulario de Google para conocer sus opiniones sobre el blog. Este formulario fue contestado por 24 estudiantes. De ellos, 16 estudiantes habían realizado algún comentario en el blog, mientras que 8 no habían realizado ningún comentario.

Los alumnos que habían participado en el blog manifestaron, en sus respuestas a una pregunta abierta, haberlo hecho por los siguientes motivos:

- Los temas de las entradas les parecían interesantes.

- Podían subir nota.

- La participación en el blog les servía para mejorar su capacidad de expresión oral y escrita y la capacidad de pensamiento crítico, habilidades necesarias en cualquier ámbito profesional.

- La participación en el blog les servía para hacerles pensar y reflexionar sobre temas de actualidad.

- Les parecía una actividad entretenida.

- Se discutían y ofrecían posibles soluciones a los problemas relacionados con los temas de la entrada.

Los alumnos que no participaron en la entrada manifestaron, en sus respuestas a una pregunta abierta, no haberlo hecho por los siguientes motivos:

- Falta de tiempo, especialmente en el caso de alumnos que compaginaban trabajo y estudios. Este fue el motivo expresado con mayor frecuencia.

- Por pensar que no podría hacer un comentario de suficiente calidad que pudiera llegar incluyo a restarles nota. Este motivo fue expresado por dos estudiantes.

(c) EY-NG-ND 2017, Universitat Politècnica de València

Congreso IN-RED (2017) 
- Por problemas técnicos relacionados con la publicación de la entrada. Un alumno comentó que intentó publicar su comentario en un par de ocasiones y no quedó registrado. Esto le desanimó para participar en futuras entradas.

Posteriormente, en el cuestionario se planteaba una pregunta de respuestas cerradas, expresada en los siguientes términos:

Creo que el blog de la asignatura, como recurso docente, puede ser útil para...

En la Tabla 1 se concreta la frecuencia (n) y el porcentaje (\%) de alumnos que señalaron cada respuesta.

Tabla 1. Utilidades del blog como recurso docente según los alumos. Frecuencia y porcentaje de alumnos que señaló cada una de las posibles respuestas

\begin{tabular}{lcc}
\hline Posibles respuestas & n & $\%$ \\
\hline Favorecer la capacidad de expresión oral y escrita & 22 & 91,6 \\
Favorecer el pensamiento crítico & 21 & 87,5 \\
Mejorar la capacidad de exponer, defender y debatir ideas & 18 & 75 \\
Fomentar el interés por estar informado y adquirir nuevos conocimientos & 15 & 62,5 \\
Incrementar el interés por la asignatura & 13 & 54,1 \\
Fomentar la ética profesional & 12 & 50 \\
Favorecer nuestra conciencia social/medioambiental y nuestro compromiso & 12 & 50 \\
con una sociedad más justa & & 0 \\
Creo que no vale para nada & 0 & 0 \\
\hline
\end{tabular}

Nota: El cuestionario fue cumplimentado por 24 estudiantes.

Finalmente, el cuestionario acababa con la siguiente pregunta de respuesta abierta:

¿Crees que la participación en el blog puede ser útil para algo más? Indica para qué.

Los estudiantes comentaron que el blog también podía ser de utilidad para comprender mejor algunas partes de la asignatura, para romper con la rutina, captar su atención y hacer más entretenida la asignatura. Asimismo, destacaron que el blog generaba cierta competitividad por hacer los mejores comentarios que les resultaba atractiva.

\section{Conclusiones}

El nivel de participación en el blog fue aceptable, si tenemos en cuenta que se trató de un trabajo voluntario. Probablemente, los alumnos percibieron el blog como un recurso 
Uso de un blog docente para el desarrollo del pensamiento crítico y la capacidad de expresión oral y escrita en ciencias del deporte.

docente útil y formativo porque el trabajo era voluntario y sólo aquellos con verdadero interés participaron. Además, esta experiencia docente fue muy satisfactoria para el profesor de la asignatura. No se pone en duda que la exigencia, por parte del profesorado, de trabajos obligatorios puede ser interesante para el aprendizaje del alumno. Sin embargo, en este tipo de trabajos existe el riesgo de que muchos estudiantes no muestren el nivel de implicación y rigor esperado por el profesor. Esto puede acabar desencadenando experiencias docentes poco motivantes, que a la larga pueden acabar mermando la vocación e implicación del profesor en tareas docentes.

La participación en comentarios orales fue claramente más baja que la participación por medio de comentarios escritos. La razón de esta diferencia no quedó clara con los motivos expresados por los estudiantes para no realizar comentarios en el blog. Quizá se realizaron menos comentarios orales porque el proceso de elaboración podría ser más costoso, o porque les diera vergüenza que su vídeo pudiera ser visto por otros compañeros de clase. No obstante, en futuras experiencias se debería preguntar directamente acerca de esta cuestión.

La percepción del profesor de esta asignatura fue que, tanto los estudiantes que realizaron comentarios como los evaluadores, participaron en el blog con rigor y responsabilidad. El profesor también percibió que el uso del blog sirvió para conseguir los objetivos educativos propuestos. Las respuestas de los estudiantes al formulario de Google refuerzan igualmente la idea de que el blog fue un recurso educativo útil para el desarrollo del pensamiento crítico y la capacidad de expresión oral y escrita. En este sentido, otras experiencias con edublogs han sugerido que los blogs son recursos educativos interesantes para la formación de los estudiantes (Molina Alventosa, Valenciano Valcárcel y Valencia Peris, 2015; Molina Alventosa, Valencia Peris y Suárez Guerrero, 2016).

Por último, la concesión de un premio simbólico por parte del profesor al mejor comentario según el evaluador, pareció fomentar cierta competitividad que motivaba a los alumnos a demostrar al profesor y al resto de compañeros que ellos también eran capaces de realizar comentarios acertados e inteligentes. Esta situación, bien canalizada, podría tener cierto valor educativo, si la competitividad nos lleva a tratar de sorprender con comentarios inteligentes a unos compañeros y a un profesor por los que sentimos respeto intelectual. Sin embargo, una competitividad irrespetuosa, que inhibiera la participación de los alumnos que se perciben menos competentes, o generadora de envidias y recelos, acabaría siendo negativa para el proceso de enseñanza-aprendizaje.

\section{Referencias}

BOISVERT, J. (2004). La formación del pensamiento crítico. Teoría y práctica. México. Fondo de cultura económica.

GUZMAN SILVA, S. y Sánchez Escobedo, P, (2006). "Efectos de un programa de capacitación de profesores en el desarrollo de habilidades de pensamiento crítico en estudiantes universitarios en el Sureste de México" en Revista Electrónica de Investigación Educativa (REDIE), vol. 2, no 2, [http://redie.uabc.mx/vol8no2/contenido-guzman.html]

(c) EY-NC-ND 2017, Universitat Politècnica de València

Congreso IN-RED (2017) 
MOLINA ALVENTOSA, J. P., VALENCIANO VALCÁRCEL, J. y VALENCIA PERIS, A. (2015). "Los blogs como entornos virtuales de enseñanza aprendizaje en Educación Superior" en Revista Complutense de Educación, vol. 26 (especial TIC en Educación), pp. 15-31.

MOLINA ALVENTOSA, J. P., VALENCIA PERIS, A. y SUÁREZ, C. (2016). "Percepción de los estudiantes de una experiencia de uso didáctico de blog docente en Educación Superior" en Educación XX1, vol. 19, n 1, pp. 91-113.

PEÑA GONZÁLEZ, F. J. (2011). "Leer y escribir. Prácticas necesarias en la universidad" en Educere, vol. 15, nº 52, pp. 711-719.

ROJAS VITERI, J.C., PÉREZ NARVÁEZ, H.O. y ÁLVAREZ ZURITA, A.M. (2016). “El pensamiento crítico en la educación” en Revista Publicando, vol. 3, n 9, pp. 110-118.

RUIZ MUÑOZ, M. J. (2012). "El desarrollo de competencias orales y escritas en el marco del Espacio Europeo de Educación Superior (EEES). Reflexiones, propuestas y experiencias en el Grado en Publicidad y Relaciones Públicas" en Revista de Comunicación Vivat Academia, año XIV, $\mathrm{n}^{\circ}$ Especial, pp. 133-144. 


\title{
Prácticas de Matemáticas 2: de la clase tradicional a la clase inversa
}

Anna Vidal Melóa, Francisco J. Boigues Planes ${ }^{b}$ y Vicente D. Estruch ${ }^{c}$

Grup d'Innovació Educativa i recerca en Matèries Científiques. Universitat Politècnica de ValènciaCampus de Gandia. Departament de Matemàtica Aplicada. aavidal@mat.upv.es, bfraboipl@mat.upv.es y ${ }^{\mathrm{c}}$ vdestruc@mat.upv.es.

\begin{abstract}
In honour of Confucius when he said "I hear and I forget. I see and I remember. I do and I understand" and through Universitat Politècnica de València efforts to promote active methodologies as a starting point in the construction of learning processes, the so-called Flipped Teaching technique or reversed class has gained a significant importance in our subjects. The improvement lies in several aspects. The work commonly done at home, such as problem solving, has shifted from home to the classrooms. Moreover, the teacher acts as a mentor rather than a purveyor of knowledge. Through this methodology, the relevance of the lecturer decreases placing emphasis on the student and the learning process. Thus, students can prepare the theoretical part in advance and take the opportunity to conduct practical activities and teamwork as well as to clarify doubts during on-site classes in real time. Collaboration between students and professors guidance play a decisive role in the teaching and learning process. In this paper, we will outline the carried out experience to reverse the lessons involved in the subject "Mathematics 2" belonging to the first year of the Degree in Telecommunication, Sound and Image Systems Engineering as a result of two projects specialized in educational innovation.
\end{abstract}

Keywords: Flipped Teaching, active methodologies, team work, Mathematics.

\section{Resumen}

Haciendo honor a Confucio cuando dijo "Me lo contaron y lo olvidé, lo vi y lo entendí, lo hice y lo aprendi', y gracias a los esfuerzos de la Universitat Politècnica de València por potenciar las metodologías activas como punto de partida en la construcción de los aprendizajes, el Flipped Teaching o clase inversa está tomando una especial relevancia en nuestras asignaturas, dado que da gran importancia al trabajo que comúnmente se hacía en casa, como era la resolución de problemas, y que ahora se aborda en el aula, donde el papel del profesor es el de orientador más que de transmisor de conocimientos. En esta metodología se rebaja el protagonismo del docente para hacer más énfasis en el del alumno y su aprendizaje. Los estudiantes pueden preparar la teoría en casa con anterioridad, aprovechando la clase 
presencial para realizar actividades más prácticas, trabajos en grupo y aclarar las dudas que les vayan surgiendo en la resolución de problemas en tiempo real, a través de la colaboración con sus compañeros de equipo junto con las orientaciones del profesor, constituyendo todo este proceso una parte muy significativa en su aprendizaje. En este trabajo, describiremos la experiencia llevada a cabo para invertir la clase en la asignatura Matemáticas 2 del primer año del Grado en Ingeniería de Sistemas de Telecomunicación, Sonido e Imagen, resultado de dos proyectos de innovación educativa.

Palabras clave: Flipped Teaching, metodologías activas, trabajo en grupo, Matemáticas.

\section{Introducción}

La Universitat Politècnica de València (UPV) impulsa la aplicación de metodologías docentes activas que potencien el trabajo en equipo, la resolución de problemas, la realización de prácticas, etc. Es el punto de partida en la construcción y puesta en prática de nuevas formas de aprender, como es el caso del Flipped Teaching (FT) o clase inversa. Este nuevo enfoque del aprendizaje supone que el estudiante trabaje en casa la parte teórica, de manera autónoma, mediante materiales seleccionados o creados por el profesor (vídeos, apuntes, etc), dedicando la clase presencial a realizar prácticas, actividades grupales y a aclarar las dudas que vayan surgiendo en la resolución de problemas. En el FT, resulta fundamental interacción colaborativa entre compañeros y, cómo no, el trabajo del profesor, cuyo papel será principalmente el de orientar o guíar en el proceso de aprendizaje. Desde hace varios años el FT está tomando una especial relevancia en la UPV, aumentando año tras año el número de profesores y de asignaturas que adoptan esta metodología.

Gracias al apoyo del Vicerrectorado de Estudios, Calidad y Acreditación de la UPV, dos Proyectos de Innovación Docente han facilitado a los miembros del "Grup d'Innovació Educativa i Recerca en Matèries Científiques" (GIERMAC) abordar y hacer realidad el enfoque FT en el aula. El primer paso fué analizar la posible introducción de esta nueva metodología en nuestras asignaturas, con el PIME "Estudio sobre la aplicación del Flip Teaching en asignaturas de Matemáticas y Física" (convocatoria 2015-2016). En segundo lugar se han estudiado los resultados de aplicar la metodología FT, con el PIME "Puesta en marcha de diversas experiencias con el enfoque FT en asignaturas de Matemáticas y Física" (convocatoria 2016-2017). En ambos proyectos se ha contado con un equipo interdisciplinar de profesores (Departamento de Matemática Aplicada y Departamento de Física Aplicada), desarrollándose en asignaturas de diversos Grados (Vidal et al, 2016).

Matemáticas 2, asignatura de primer curso del Grado en Ingeniería de Sistemas de Telecomunicación, Sonido e Imagen (Campus de Gandia-UPV) es una de las asignaturas

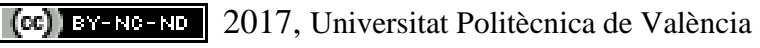

Congreso IN-RED (2017) 
involucradas en estos proyectos. En este trabajo se presenta la experiencia y la labor docente realizada desde el curso 2015-2016 en dicha asignatura.

En el FT son importantes, además de la creación y el uso de vídeos, las actividades que los alumnos desarrollan en el aula. A la hora de diseñar actividades, en conveniente tener presente la denominada pirámide del aprendizaje de Blair que mostramos en la Figura 1. Esta pirámide plasma la conocida idea de Confucio: "Me lo contaron y lo olvidé, lo ví y lo entendí, lo hice y lo aprendí", y resume cómo aprenden los estudiantes de forma más efectiva, así como el impacto que tienen las diversas actividades en dicho aprendizaje. En la parte izquierda de la Fig. 1, aparece la influencia de tres canales perceptivos (auditivo, visual y cenestésico o kinestésico) relacionándolos con la actividad del estudiante, activa o pasiva. En parte de la derecha de la figura, se muestran las actividades que pueden desarrollarse junto con el porcentaje de retención, después de 24 horas, en función de la actividad o tarea.

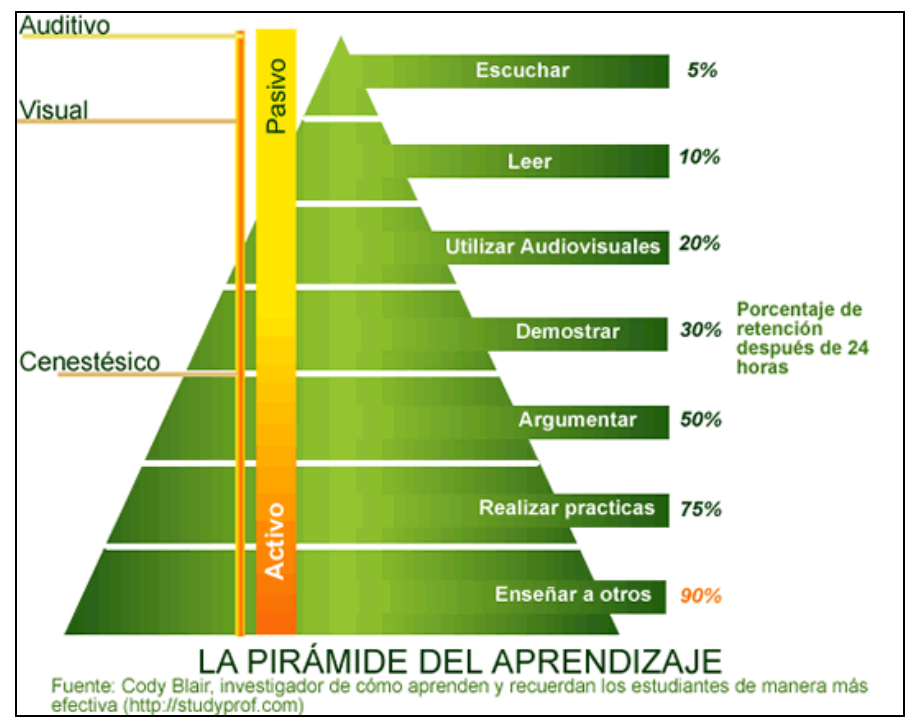

Fig. 1 Pirámide del aprendizaje de Blair

Como puede apreciarse, el porcentaje de retención en aquellas actividades que solo suponen escuchar al profesor es de un 5\%. Siendo estas actividades sumamente pasivas, son necesarias en muchos casos. Para hacerlas más efectivas, es recomendable combinarlas con preguntas, para que el alumno recapacite y exponga, por sí mismo, aquello que ha entendido. Para ello puede elaborar, por ejemplo, esquemas o mapas conceptuales.

La lectura también constituye una actividad pasiva y supone una retención del 10\%. No obstante constituye una actividad imprescindible dado que la comprensión lectora es fundamental para analizar guías, manuales, protocolos, o simplemente por el placer que puede aportar leer un texto. La lectura puede complementarse con actividades más dinámicas, como subrayar, hacer un resumen o contestar a una batería de preguntas que reflejen lo aprendido. 
La utilización de medios audiovisuales permite retener un 20\%. Dichos medios son muy valorados por el alumnado puesto que los estudiantes son muy receptivos a las tecnologías interactivas. Téngase en cuenta que el uso de vídeos tutoriales de internet está bastante generalizado, sea para preparar exámenes, para repasar lo aprendido o para abordar nuevos contenidos en el caso de no poder asistir a clase. Por otra parte no todos los estudiantes tienen el mismo ritmo de aprendizaje, y la posibilidad de pausar y rebobinar, que ofrecen los vídeos, es de gran ayuda (Bergamnn y Sams, 2015). Los medios audiovisuales son una buena herramienta para captar la atención del estudiante, pero es necesario realizar posteriormente actividades para ampliar y profundizar sobre el tema en cuestión.

La demostración (simulaciones y experimentos) supone una retención del 30\%, y puede complementarse, por ejemplo, con actividades colaborativas. Se puede aprovechar la metodología del puzle de Aronson (Aronson et al., 1978,1997) para alguna de estas actividades.

Argumentar supone una tarea compleja que implica que el estudiante practique diversas competencias, como comprender el tema, elegir entre diversas alternativas, posicionarse y saber defender determinada postura ante sus compañeros. En este caso el porcentaje de retención aumenta hasta el 50\%. Este aspecto puede ser utilizado en clase por el profesor, antes de introducir un tema, pidiendo la opinión o una argumentación a sus estudiantes o creando de grupos de discusión.

Parece claro que se aprende más cuando se hace activamente más, es decir, cuando se realiza una práctica, alcanzándose el $75 \%$ de retención en este caso. Se trata de que planteemos a nuestros estudiantes actividades prácticas y ejercicios en clase (resolución de problemas, proyectos, experimentos, análisis de casos, etc.). Estas actividades pueden realizarse en grupos pequeños.

Finalmente, la actividad que facilita más retención, el 90\%, es la de enseñar a otros, puesto que esto supone, primero, tener cierto dominio del tema a explicar y después pensar la mejor forma de expresarlo para lograr la comprensión de los receptores. Para esto pueden plantearse exposiciones en grupo. También en este caso la utilización del puzle de Aronson aporta beneficios en el sentido de que, repartiendo la materia a exponer, finalmente todo el equipo acaba aprendiendo dicha materia

Con el segundo PIME, "Puesta en marcha de diversas experiencias con el enfoque Flipped Teaching en asignaturas de Matemáticas y Física" (convocatoria 2016-2017) se ha aplicado esta metodología en algunas de las asignaturas involucradas en ambos proyectos. En este trabajo se presenta la labor docente realizada desde el curso 2015-2016 en una de ellas, Matemáticas 2.

Matemáticas 2 es una asignatura anual que se imparte en el primer curso del Grado en Ingeniería de Sistemas de Telecomunicación, Sonido e Imagen (GISTSI) del Campus de Gandia de la UPV. Tiene un total de 9 créditos ECTS repartidos en 4.6 ECTS de clases de teoría y práctica de aula, 3 ECTS de clases de seminario de problemas y 1.4 ECTS de prácticas de laboratorio informático, distribuidos en 7 prácticas de dos horas de duración. Las prácticas se realizan con la ayuda del paquete de cálculo $\mathrm{Matlab}^{\oplus}$, y son las siguientes:

(c)) BY-NC-ND 2017, Universitat Politècnica de València

Congreso IN-RED (2017) 
1. Iniciación al Matlab ${ }^{\oplus}$ y sus aplicaciones matemáticas

2. Ecuaciones paramétricas y polares (de los corazones, flores, mariposas...)

3. Ajuste e interpolación

4. Integración aproximada

5. Examen de las prácticas del primer semestre

6. Representación de superficies: forma cartesiana y paramétrica

7. Representación de superficies en forma discreta

Las cinco primeras prácticas se realizan durante el primer semestre. En la nota de la asignatura, un $20 \%$ corresponde a la nota de prácticas, un $70 \%$ a diversas pruebas parciales de teoría y problemas y un $10 \%$ al portafolio. A pesar de no ser muy alto el porcentaje de la nota asignado a prácticas (20\%), los resultados de cursos anteriores indican que una cuarta parte del alumnado aprueba la asignatura gracias a las prácticas.

Según un informe del Vicerrectorado para el Desarrollo de las Tecnologías de la Información y de las Comunicaciones realizado durante el curso 2015-16, los estudiantes creen que es más conveniente aplicar el FT en asignaturas prácticas. Este hecho se ha tenido en cuenta en nuestra asignatura a la hora aplicar esta metodología. En este trabajo nos centramos en el proceso llevado a cabo para pasar de las prácticas tradicionales a las invertidas. Cabe mencionar que, de forma puntual, se ha aplicado el FT en clases de teoría de aula, recurriendo al llamado Micro Flip Teaching (MFT). El MFT es una variante del FT, pero aplicado en este caso sólo en partes de algún que otro tema y no necesariamente en todo un tema o una asignatura. Existen estudios que avalan la repercusión del MFT en la mejora del aprendizaje y en la consolidación de conocimientos (Fidalgo, 2017).

Existen muchas herramientas que facilitan poder implementar la metodología FT. En nuestro caso la herramienta Lessons de la plataforma de la UPV, PoliformaT, ha sido muy util para crear recursos de forma sencilla y atractiva permitiendo integrar otras utilidades de PoliformaT. Además, gracias a que los Lessons permiten la interacción con los usuarios, hemos podido ir perfeccionando las unidades creadas a partir de la opinión de los estudiantes.

\section{Objetivos}

Uno de los objetivos docentes que llevó a incorporar el FT en las prácticas de laboratorio fue aprovechar las clases presenciales para la realización de un trabajo en grupo. Aunque, anteriormente, al alumnado también se le exigía la realización de un trabajo similar, este se hacía posteriormente a la sesión de prácticas, en horas no lectivas. Con frecuencia aparecían problemas en los grupos, como incompatibilidad de horarios, falta de compromiso por parte de algún miembro, etc. Al invertir las clases prácticas, las horas presenciales se dedican a la realización del trabajo en grupo, evitándose así muchos problemas, a la vez que se facilita que el profesor pueda estar más pendiente del aprendizaje efectivo. 


\section{Desarrollo de la innovación}

La idea central de la metodología FT es la de dar la vuelta al método de enseñanza común o modelo tradicional. Y eso es lo que se ha hecho con las prácticas informáticas de la asignatura. Durante muchos años hemos ido innovando en la realización de las prácticas informáticas, haciendo uso de diversas metodologías, (Vidal et al, 2012, 2013, 2014). Hasta el curso 2014-2015 el alumno tenía a su disposición un guion en formato pdf para cada una de las prácticas. En la sesión presencial el profesor explicaba el guion y era quien dirigía la práctica. Dichos guiones tenían unas secciones más teóricas y otras, denominadas en su día "Manos a la obra", en la que se ponía en práctica la teoría para resolver determinado problema con la ayuda de Matlab $^{\odot}$. En estas secciones, más prácticas, se trabajaban los comandos necesarios para la resolución del problema en cuestión, y se exigía al alumnado que trabajara sobre los comandos indicados. Por lo tanto, durante las dos horas de cada una de las prácticas, el estudiante se limitaba a escuchar al profesor y a repetir aquello que se indicaba en el guion. En los últimos minutos de la sesión presencial, el profesor explicaba el trabajo en grupo, que los estudiantes debían realizar y entregar en un plazo de diez días. La nota de prácticas se obtenía de la valoración del trabajo, sin examen alguno.

Sin embargo, como se ha indicado anteriormente, surgían problemas entre miembros de los grupos de trabajo. Además, en ocasiones, no existía una clara correlación entre la nota obtenida en las pruebas parciales de determinado estudiante con las de sus prácticas. De hecho, algunos estudiantes sugerían la realización de un examen de prácticas. Para evitar este tipo de situaciones, con la incorporación del FT en las prácticas, se han aprovechado las horas presenciales para la ejecución del trabajo en grupo. De esta manera, el profesor ha podido observar la colaboración real de los miembros del grupo y, además, comprobar la adquisición de ciertas competencias transversales. También se ha añadido una evaluación individual de las prácticas al final de las mismas.

La puesta en práctica de los proyectos de innovación señalados anteriormente, ha supuesto la inversión de las prácticas de la asignatura desde el curso 2015-2016. A continuación explicamos los pasos y la metodología seguidos en el proceso de inversión.

\subsection{Generación y elaboración de material}

En el material Sesión de Clase Inversa realizado por Pilar Aurora Cáceres y Susana Martínez acerca del Proyecto Flip en la UPV, que puede encontrarse en la site Proyecto clase inversa de PoliformaT, se indica la importancia de la selección o elaboración de buenos materiales, con la ayuda de las tecnologías adecuadas, así como también del diseño de actividades de aprendizaje significativas tanto para la sesión no presencial como para el aula. Todo esto lleva implícitas varias fases: la primera es la selección de los contenidos de la materia que realmente son importantes para el aprendizaje del alumnado; la segunda elaborar o seleccionar los materiales que recojan dichos contenidos; finalmente determinar qué contenidos pueden trabajar los alumnos, de forma autónoma, en su casa, con los materiales elaborados/seleccionados, y qué contenidos trabajar presencialmente en el aula.

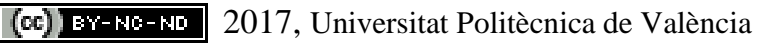

Congreso IN-RED (2017) 
Una de las páginas web españolas en las que se pueden encontrar experiencias y recursos para invertir la clase es "The flipped classroom". En el enlace

http://www.theflippedclassroom.es/un-ejemplo-de-ficha-para-planificar-nuestra-clase-inversa/

se puede encontrar un ejemplo de ficha para planificar una clase inversa, que mostramos en la Figura 2.

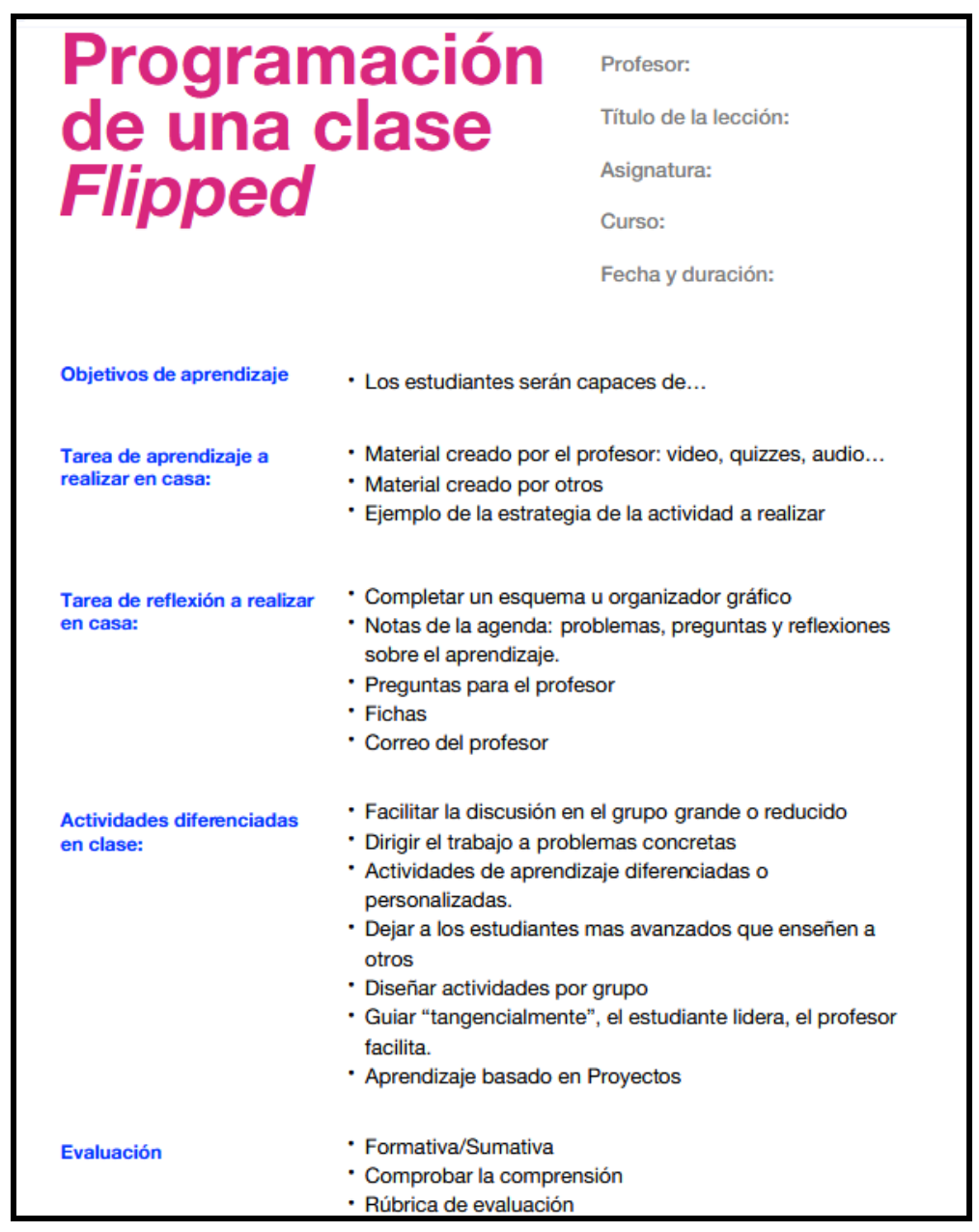

Fig. 2 Ficha de programación de una clase Flip

Lo novedoso de la clase invertida es, sin duda, la parte en la que el estudiante realiza un trabajo autónomo previo a la clase presencial. Esto exige por parte del alumnado dedicación y compromiso, por parte del profesor un cuidadoso trabajo de selección de los materiales de aprendizaje y una distribución adecuada de los tiempos. Sin embargo no es menos importante el trabajo presencial en el aula. Para ello es fundamental que el docente planifique y estructure de forma adecuada el aprendizaje del estudiante (Tourón, Santiago y Díez, 2014). 
Teniendo en cuenta todo lo precedente, en el proyecto "Estudio sobre la aplicación del Flip Teaching en asignaturas de Matemáticas y Física" nos planteamos en su día como objetivo principal, elaborar una amplia colección de fichas de planificación o programación. Se trataba de fichas Flip, similares a la de la Figura 2, que permitieran englobar los objetivos, las actividades y los recursos necesarios para poder realizar cada una de las actividades Flip programadas. En la Figura 3 mostramos una de las fichas elaboradas, la de integración aproximada, correspondiente a la asignatura Matemáticas 2. Pueden obtenerse el resto de fichas de esta asignatura y de otras asignaturas, participantes en los mencionados proyectos de innovación, en

\section{http://flipeandoencampusgandia.simplesite.com}

Las fichas Flip, correspondientes a cada una de las prácticas, facilitaron la estructuración de los recursos necesarios y de las actividades a realizar en cada una de las prácticas.
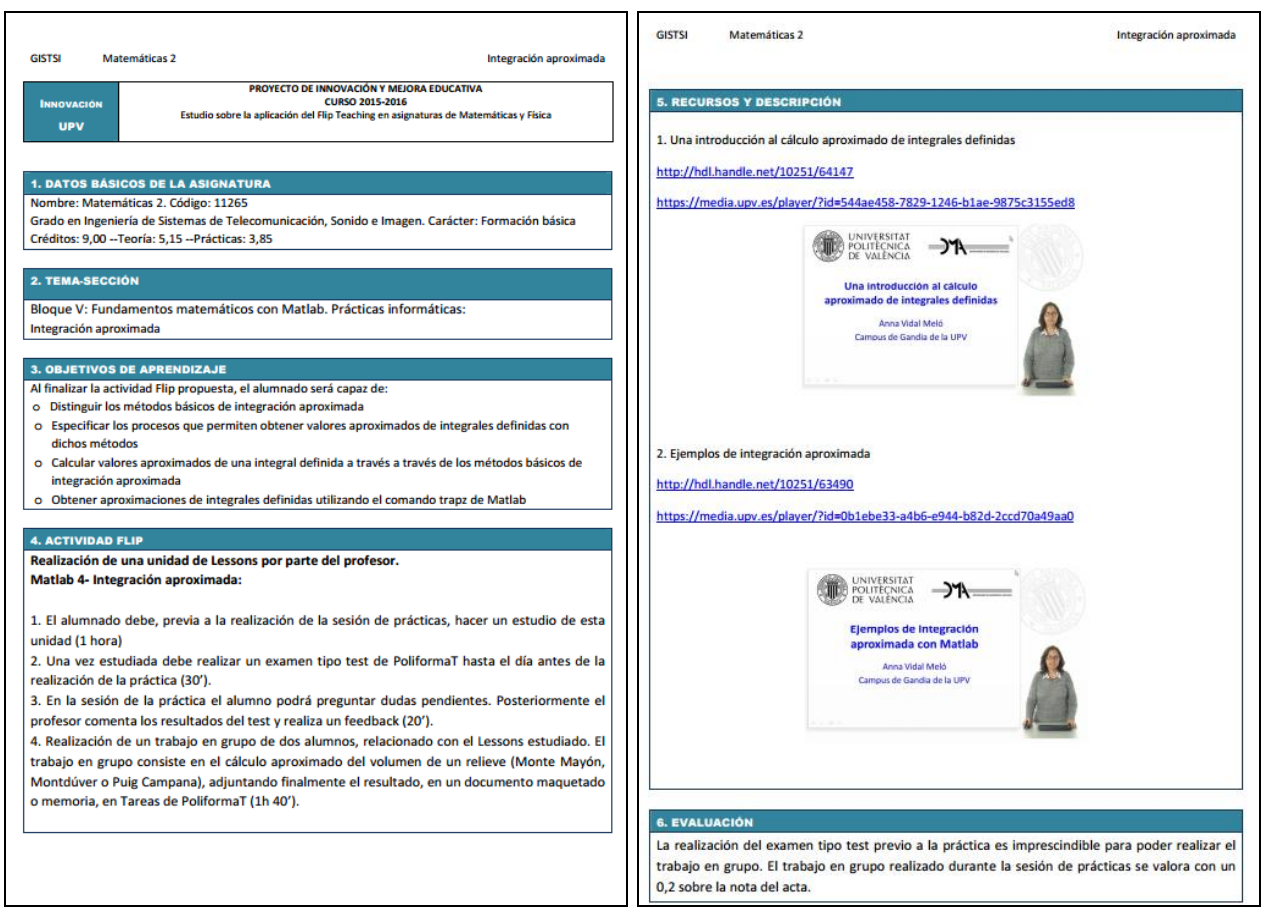

Fig. 3 Ficha Flip correspondiente a la práctica sobre integración aproximada

En cuanto a los recursos necesarios, se inició una búsqueda de recursos multimedia, en particular vídeos, tanto dentro del repositorio institucional de la UPV, Riunet, como en distintas plataformas de la red. Finalmente, aunque algunos vídeos han sido obtenidos de la plataforma YouTube, otros han sido creados exprofeso. En concreto, varios Polimedia y screencast que han pasado a formar parte del repositorio de Objetos de Aprendizaje de la UPV, tras ser aprobados en el Plan de Docencia en Red 2015-2016: Una introducción al ajuste polinómico de datos por mínimos cuadrados, utilizando Matlab; una introducción a la interpolación polinómica con Matlab; una introducción a la interpolación segmentaria con

(c)) EY-NC-ND 2017, Universitat Politècnica de València

Congreso IN-RED (2017) 
Matlab: comando spline; una introducción al cálculo aproximado de integrales definidas; y, finalmente, ejemplos de integración aproximada.

Una vez elaborada la ficha Flip, pasamos a la creación de las unidades didácticas correspondientes a cada una de las prácticas, salvo de la primera (más adelante indicaremos la razón de ello). Para la creación de unidades didácticas se utiliza la herramienta Lessons de PoliformaT. Los guiones de prácticas son sustituidos por Lessons, lo cual facilita poder enlazar distintos elementos de PoliformaT. Por ejemplo, al final de cada Lesson insertamos un enlace a un examen PoliformaT, con dos finalidades. La primera es que el estudiante compruebe si ha adquirido los conocimientos necesarios para poder llevar a cabo con éxito el trabajo que se le exigirá en la sesión presencial. La segunda es que esto permite controlar qué estudiante ha estudiado el material correspondiente y el nivel de comprensión alcanzado. La fecha de cierre del examen es el día anterior a la sesión presencial de la práctica, lo cual permite hacer un análisis de la situación antes de la sesión presencial. Se aprovecha la posibilidad que tiene la herramienta Lessons para elaborar cuestionarios y poder preguntar a los estudiantes su opinión sobre el contenido generado, como se muestra en la Figura 4.

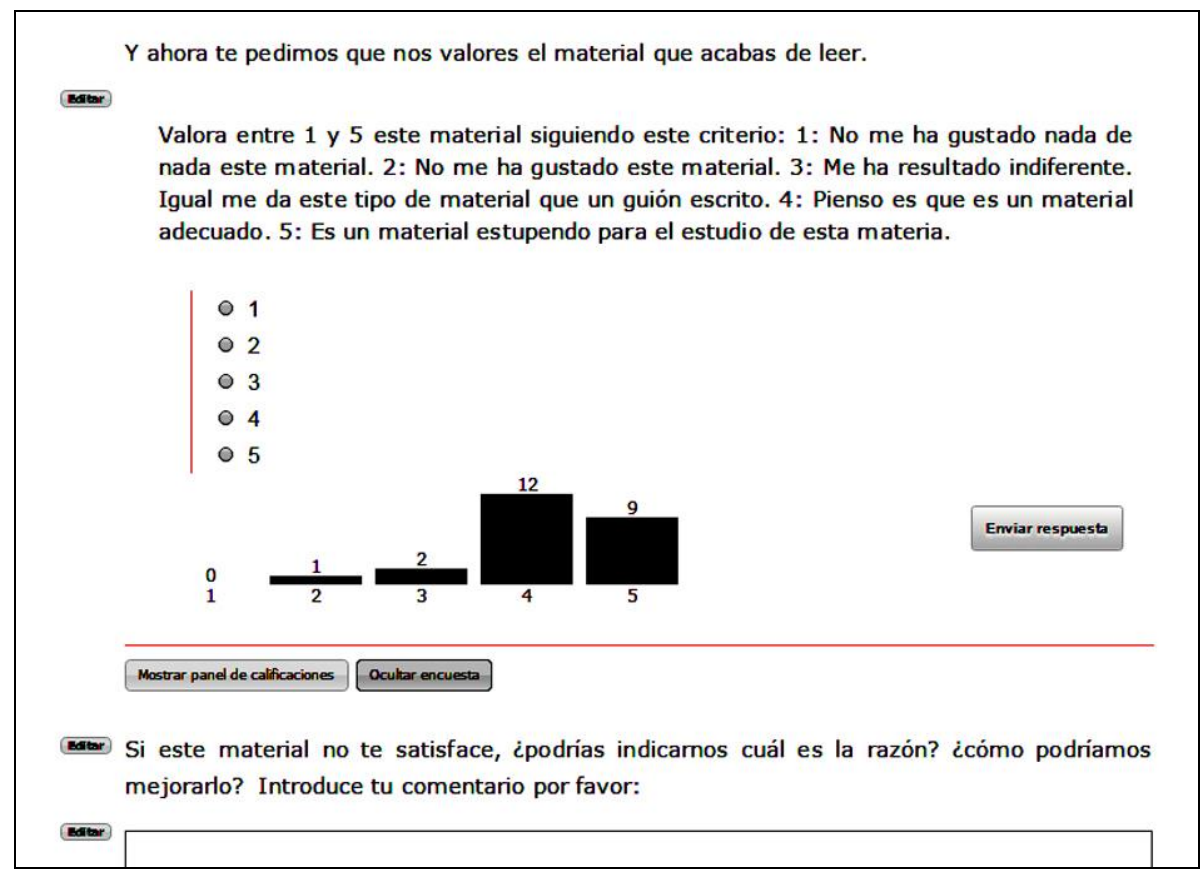

Fig. 4 Cuestionario sobre el contenido del Lessons

En uno de los Lessons, en el que se insertaron varios Polimedia, un par de estudiantes indicaron la necesidad de poder tener acceso a las diapositivas de los vídeos para poder leer los contenidos tranquilamente y poder consultarlos más tarde en caso de necesidad. Según indicaban, sin disponer de las diapositivas resultaba pesado estudiar los contenidos y tenían que pausar el vídeo continuamente. A partir de esas observaciones, en los siguientes Lessons, antes del Polimedia correspondiente, había un hipervínculo que permitía imprimir 
las transparencias, y por lo tanto seguir mejor la explicación del vídeo. Últimamente, y de nuevo al considerar las observaciones de los estudiantes en los Lessons, también se ha insertado un enlace al Foro de PoliformaT, para que puedan resolver aquellas dudas que puedan surgir a medida que avanzan en el estudio.

Por último, cabe señalar que antes de la sesión presencial se elabora, utilizando la aplicación Tareas de PoliformaT, la actividad del trabajo en grupo que deben realizar durante dicha sesión. La Tarea lleva adjunto un fichero con información y, en su caso, otros posibles ficheros que pueden servir de plantilla para la memoria del trabajo (Figuras 5 y 6 ). La fecha de apertura de la Tarea es la de inicio de la sesión presencial.

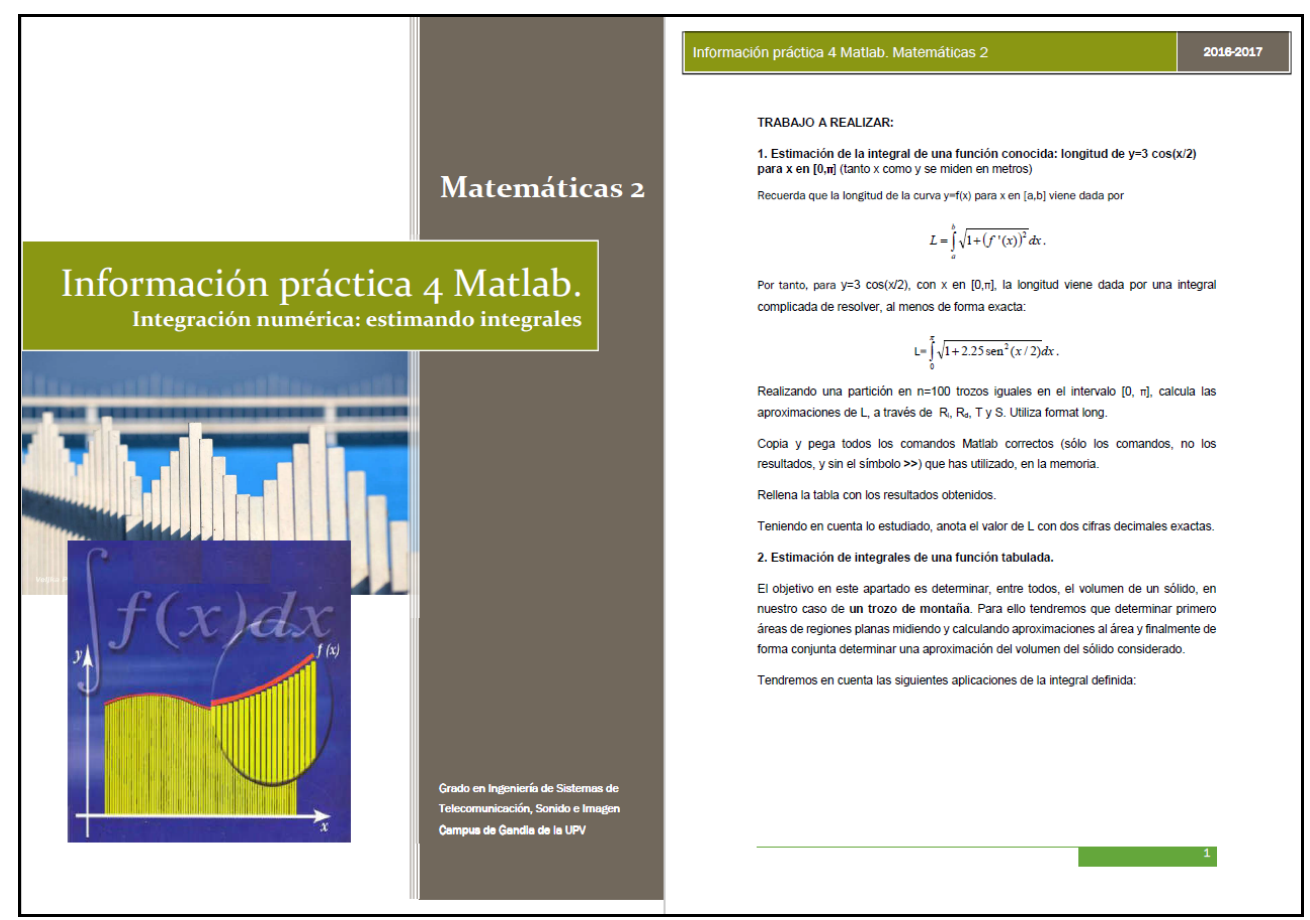

Fig. 5 Primeras hojas del documento informativo correspondiente al trabajo en grupo a realizar

\subsection{Desarrollo de la sesión práctica}

Al inicio de la sesión práctica se resuelven, en su caso, las posibles dudas que plantean los estudiantes para, posteriormente, pasar a comentar los resultados del examen PoliformaT del final del Lesson. Para esto, es muy útil la herramienta Estadísticas del menú Exámenes ya que los propios estudiantes pueden apreciar en qué preguntas han tenido más dificultad. Aquellas preguntas con peores resultados se explican de forma detallada para proporcionar el feedback correspondiente.

En algunos Lessons se aconseja al estudiante la realización de un resumen, necesario para la realización posterior del trabajo. Durante la sesión presencial de prácticas se comprueba qué estudiantes han realizado dicha labor. 


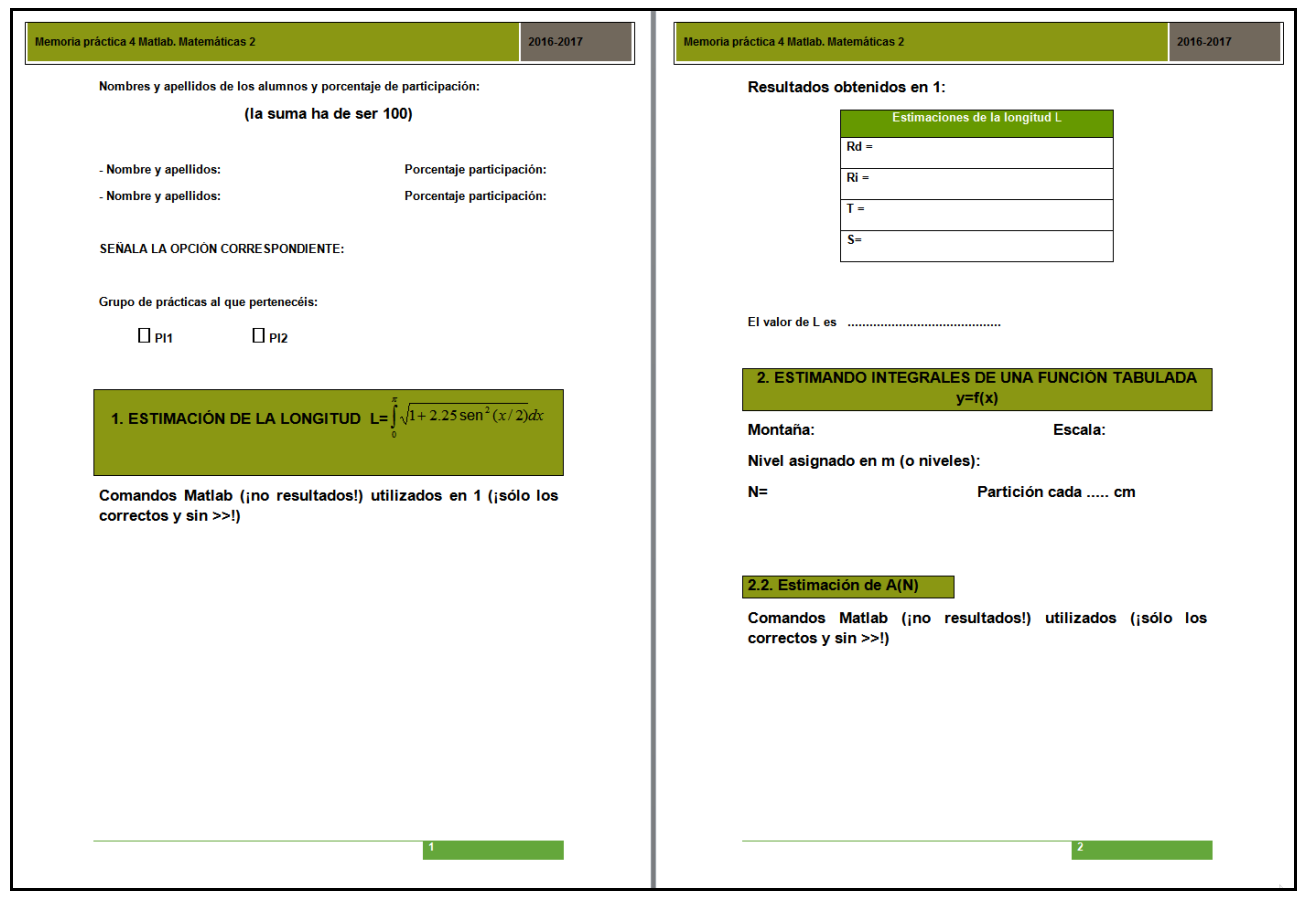

Fig. 6 Primeras hojas la plantilla de una de las memorias a entregar

A continuación se forman los grupos de trabajo, de dos o tres alumnos. Posteriormente se procede a explicar el trabajo o proyecto a realizar, utilizando como apoyo el documento informativo disponible en Tareas de PoliformaT. Son variados los proyectos que se realizan en dichas prácticas (Vidal et al., 2012, 2013, 2014). Durante el resto de la sesión, los estudiantes trabajan en el proyecto planteado, que en ocasiones es un trabajo colaborativo entre grupos. En estos casos se ha utilizado el programa iTALC (Enseñanza inteligente y aprendizaje con computadoras) en el aula. Se trata de un software libre que permite, entre otras cosas, ver lo que sucede en cada uno de los equipos del aula y proyectar alguno de ellos, favoreciendo el trabajo colaborativo. Finalmente, los estudiantes deben adjuntar, en la Tarea creada al efecto, el archivo o archivos correspondientes al trabajo realizado.

Llegados a este punto, cabe plantearse cómo afrontar un problema importante: ¿Qué hacer con los estudiantes que no completan la fase inicial (no presencial) de estudiar el Lessons y realizar el examen tipo test?. En el blog Profesor 3.0 (Prieto, 2016) se dan soluciones para este punto débil del Flip, aconsejándose la realización de tareas con una metodología que permita comprobar el estudio previo y que motive a los estudiantes a estudiar los materiales. Las herramientas Exámenes y Estadísticas de PoliformaT permiten controlar el seguimiento de los contenidos en la fase no presencial. Los estudiantes que incumplen son ubicados en la última fila del aula, separados del resto de estudiantes. Su trabajo durante la sesión de prácticas consiste en realizar la tarea que deberían haber realizado en casa (preparación del Lessons) y la realización del examen previo, debiendo obtener, en este caso, al menos un 6 para poder realizar el trabajo en grupo y así obtar a la puntuación de la práctica. A estos alumnos se les daba un día de plazo para la realización del trabajo. En 
general, ninguno de estos alumnos entregó el trabajo en tiempo y forma en la primera práctica FT. Pero la experiencia sirvió de motivación para que en las siguientes prácticas estos alumnos se adaptaran a la nueva metodología.

\section{Resultados}

Durante el curso 2015-2016 (metodología FT) se ha notado una mejora en las notas de prácticas respecto a las del curso anterior (metodología tradicional):

- Durante el curso 2014-2015, el porcentaje de alumnos con nota superior o igual a 5 fue del 64.3\%, mientras que en el curso 2015-2016 aumentó hasta el 76.8\%.

- La nota media de los alumnos con nota igual o superior a 5 durante el curso 20142015 fue de 7.8, valor que se incrementó hasta el 8.6 en el siguiente curso.

Otro de los resultados positivos está relacionado con la calidad del material creado con Lessons. En cada uno los Lessons les pedimos a nuestros estudiantes que hicieran una valoración, obteniéndose muy buenos resultados, como se refleja en la Figura 7. La escala utilizada fue: 1: No me ha gustado nada de nada este material; 2: No me ha gustado este material. 3: Me ha resultado indiferente. Igual me da este tipo de material que un guion escrito; 4: Pienso que es un material adecuado; 5: Es un material estupendo para el estudio de esta materia.
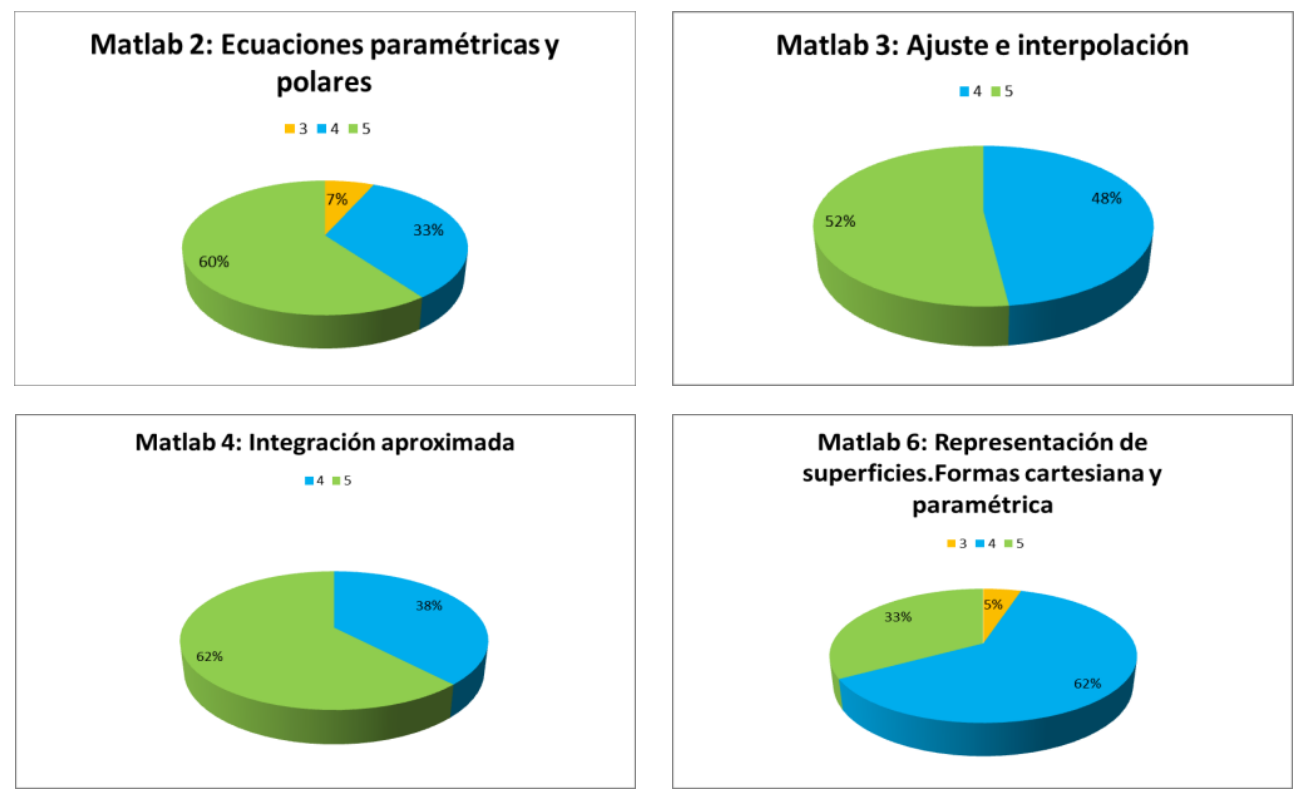

Fig. 7 Opinión del alumnando acerca de los Lessons

La primera práctica de la asignatura sigue la metodología tradicional, detallada en el apartado 2 sobre el desarrollo de la innovación, como una continuación del sistema de aprendizaje que traen los estudiantes como bagaje. Son estudiantes de primer curso que acaban de entrar en la universidad, no adaptados todavía al funcionamiento de las clases, a

(c)) BY-NC-ND 2017, Universitat Politècnica de València

Congreso IN-RED (2017) 
asignaturas con distintos métodos de evaluación, etc. Una vez realizada esta primera práctica se les habla de lo que es el Flipped Teaching y cómo van a desarrollarse las prácticas posteriores. Al final del primer semestre del curso 2016-2017, aprovechando que el estudiante ya puede comparar entre la metodología tradicional, utilizada en la primera práctica, y la metodología FT utilizada en el resto de prácticas, pasamos a los estudiantes una encuesta, similar a la que durante dos años ha sido utilizada por la UPV, para conocer la valoración de los alumnos en lo que respecta a la metodología empleada. Hemos comparado estos resultados con los que aparecen en el informe del Vicerrectorado de Estudios, Calidad y Acreditación de la Universitat Politècnica de València sobre la evaluación del Flip Teaching durante el curso 2015-2016. Este estudio fue realizado para 201 asignaturas y 233 profesores de 13 centros distintos de la UPV. En las Figuras 8, 9 y 10 se comparan los resultados obtenidos con nuestros estudiantes con los que aparecen en el citado informe, apreciándose en nuestro caso unas valoraciones similares o superiores.

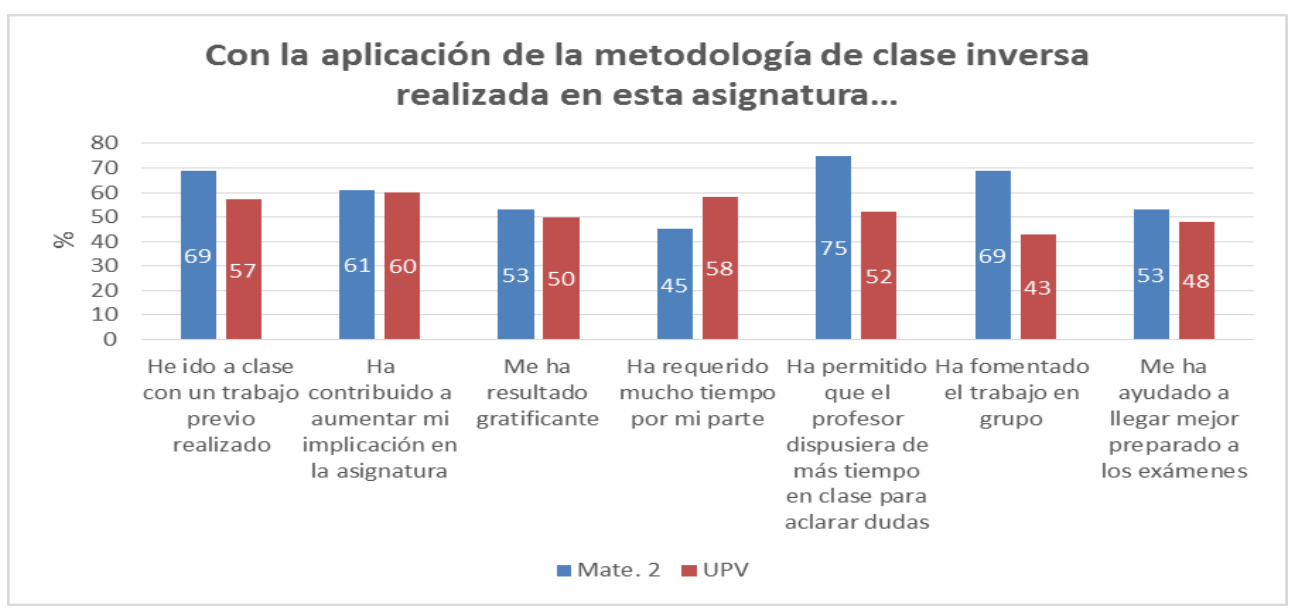

Fig. 8 Opinión sobre la aplicación de la clase inversa

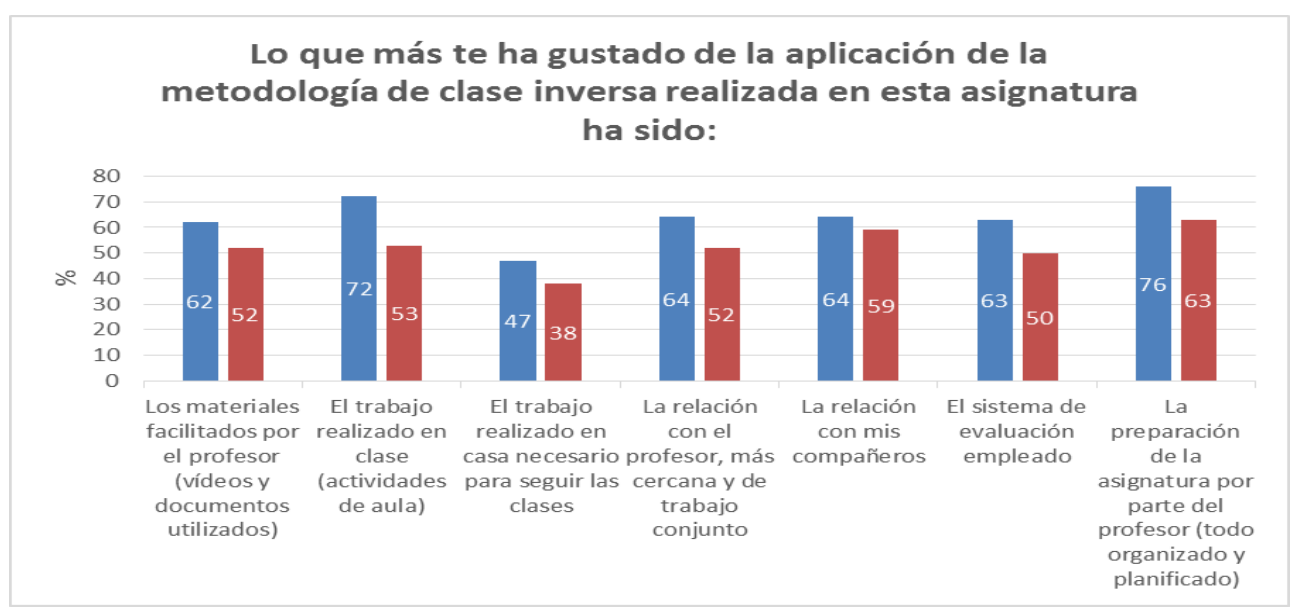

Fig. 9 Lo que más les ha gustado de esta metodología 


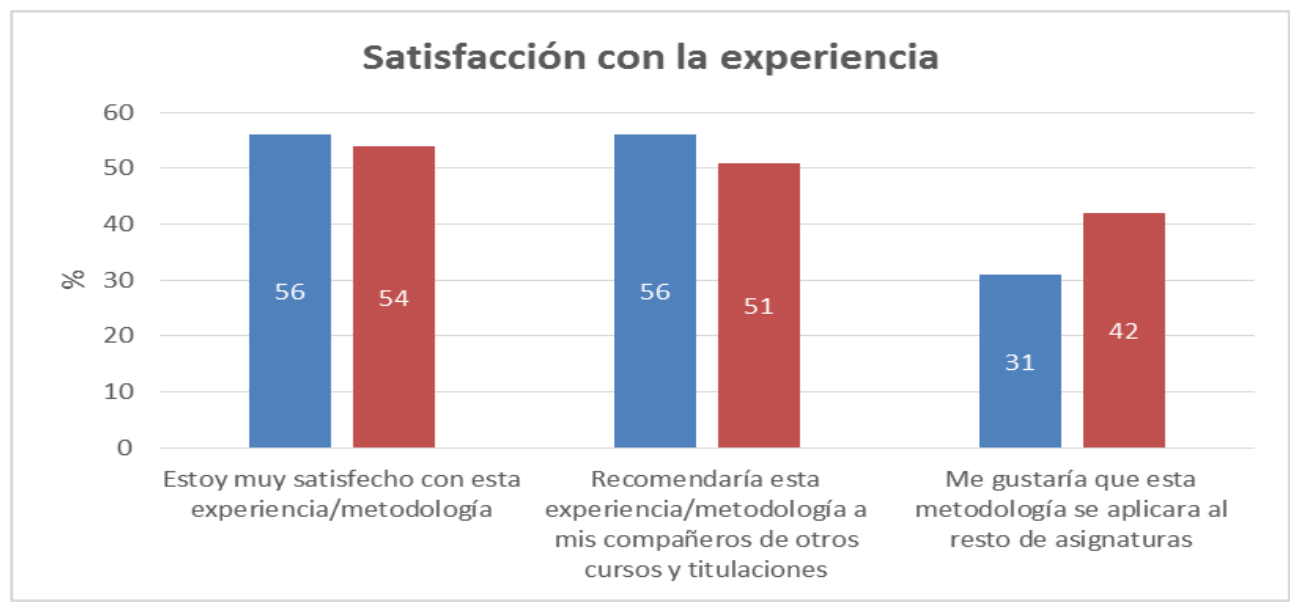

Fig. 10 Satisfacción con la experiencia

En la encuesta, pedimos además a nuestros estudiantes que indicasen al menos dos aspectos positivos y dos negativos a destacar de la metodología FT. Entre los aspectos positivos destaca el que esta metodología les ayuda a llevar la asignatura al día, que aprenden más y mejor, la accesibilidad al material y el trabajo en grupo. Entre los aspectos negativos destaca el que la metodología FT les supone más trabajo, seguido de que se echa en falta la explicación "en directo" del profesor y que seguir el ritmo les crea cierta sensación de ansiedad.

\section{Conclusiones}

El FT no es un método para que el estudiante estudie a su antojo o trabaje sólo. Requiere que el docente planifique y estructure de forma adecuada el aprendizaje del estudiante, y que se controlen al máximo todas y cada una de las fases de esta metodología, destacando en particular la fase no presencial. El FT requiere programación previa, y la elaboración y/o búsqueda de recursos que implica un gran esfuerzo para el docente. En la encuesta, los estudiantes han valorado bien la preparación de la asignatura por parte del profesor $(76 \%)$ así como el trabajo realizado en clase (72\%), al que también señalan como uno de los ítems positivos. El poder terminar y entregar el trabajo en la misma sesión de prácticas puede que hay influido también en esta valoración. Respecto a los aspectos negativos, fundamentalmente la ansiedad y el aumento de la carga de trabajo, cabe señalar que se trata de estudiantes de primer curso, acostumbrados a estudiar un tiempo relativamente corto antes de cada examen. A muchos estudiantes no les gusta que se les planifique el estudio y prefieren ir a su ritmo. El FT requiere un cambio en la mentalidad y en la rutina de los estudiantes. A pesar de todo, reconocen que el FT les ayuda a preparar mejor las asignaturas y a ir más al día.

Haber adoptado el FT en nuestras prácticas ha supuesto una mejora en las notas de prácticas respecto a las del curso anterior y los estudiantes han valorado bien el material proporcionado. Teniendo en cuenta los resultados aportados, pensamos que la elección e implementación de la metodología FT ha sido adecuada.

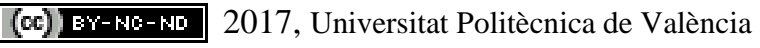

Congreso IN-RED (2017) 


\section{Agradecimientos}

Este trabajo se ha realizado gracias al apoyo del Vicerrectorado de Estudios, Calidad y Acreditación de la UPV al Proyecto PIME 2016-2017 "Puesta en marcha de diversas experiencias con el enfoque Flipped Teaching en asignaturas de Matemáticas y Física".

\section{Referencias}

ARONSON,E., BLANEY, N., STEPHIN, C., SIKES, J. \& SNAPP, M. (1978). The Jigsaw Classroom. Beverly Hills, California. Sage Publications.

ARONSON, E., PATNOE, S. (1997). The Jigsaw Classroom, Building Cooperation in the Classroom. United States. Longman (second edition).

BERGMANN, J.SAMS, A. (2015). Dale la vuelta a tu clase: Lleva tu clase a cada estudiante, en cualquier momento y cualquier lugar. SM.

CACERES GONZALEZ., P.A., MARTINEZ NAHARRO, S. " Proyecto flip teaching en la UPV: cómo invertir nuestras clases a través de las herramientas tecnológicas”. ICE-ASIC.

FIDALGO-BLANCO, A., MARTINEZ-NUÑEZ, M., BORRAS-GENE, O., \& SANCHEZ-MEDINA, J. J. (2017). "Micro flip teaching-An innovative model to promote the active involvement of students" en Computers in Human Behavior, 72, 713-723.

SANTIAGO, R. Y DIEZ, A. (2015) The flipped classroom. <http://www.theflippedclassroom.es/> [Consulta: 15 de marzo 2017]

PRIETO MARTÍN, A. (2016) “¿Funciona el modelo flipped con alumnos españoles? Aspectos críticos para lograr el éxito de los métodos de fomento del estudio previo y flipped classroom y flipped learning)“ en Profesor 3.0, 1 de agosto 2016. <http://profesor3punto0.blogspot.com.es/2015/04/claves-para-el-exito-de-los-metodos-de.html> [Consulta: 15 de marzo 2017]

TOURÓN, J., SANTIAGO, R. y DIEZ, A. (2014). The Flipped Classroom: Cómo convertir la escuela en un espacio de aprendizaje. Grupo Océano. Digital-Text.

VIDAL MELÓ, A., ROIG SALA, B., ESTRUCH FUSTER, V.D., BOIGUES PLANES, F.J., DEL REY, R., Y ALBA, J. (2012). "Rompiendo con la rutina: dos experiencias matemáticas con el puzle de Aronson" en XX CUIEET. Las Palmas de Gran Canaria. 12 páginas.

VIDAL MELÓ, A., ROIG SALA, B., ESTRUCH FUSTER, V.D., Y BOIGUES PLANES, F. J. (2013). "Una yincana para descubrir y generar curvas en un trabajo cooperativo", en Actas del XXI CUIEET. Valencia. 950-961.

VIDAL MELÓ, A., ROIG SALA, B., ESTRUCH FUSTER, V.D., BOIGUES PLANES, F. J., DEL REY, R., ALBA, J. y SAPENA PIERA, A. (2014). "El poder de la colaboración”, en Actas de las Jornadas de Innovación Educativa y Docencia en Red. 689-703.

VIDAL MELÓ, A., ESTRUCH FUSTER, V.D., BOIGUES PLANES, F. J., DEL REY, R., ALBA, J., ROIG, B. Y TORREGROSA CABANILLES, C. (2016). "Flipped Teaching: una metodología en construcción”, en Actas de las Jornadas de Innovación Educativa y Docencia en Red. 375 - 389.

VIDAL, A. (2017) Proyecto de Innovación educativa: Flipped Teaching. $<$ http://flipeandoencampusgandia.simplesite.com> [Consulta: 15 de marzo 2017]. 


\title{
Aplicación de la Clase Inversa en la Enseñanza de la Electrónica Analógica en un Grupo de Alto Rendimiento Académico
}

\author{
Beatriz Trenor ${ }^{\mathrm{a}}$, Gema Prats-Boluda ${ }^{\mathrm{a}}$ Y Yiyao Ye Lin ${ }^{\mathrm{a}}$
}

${ }^{a}$ Universitat Politècnica de València. Departamento de Ingeniería Electrónica (btrenor@eln.upv.es; geprabo@eln.upv.es; yiye@eln.upv.es).

\begin{abstract}
The need of increasing the participation of the student in the teaching and learning process at University has led to the concept of flip teaching. This methodology is characterized by the fact that the student works on the theoretical concepts independently and using mainly audiovisual materials. Later, the student works on applied activities in the teaching room under the teacher supervision, in order to reinforce his learning. The objective of the present study is to evaluate the impact of flip teaching in analog electronics in the Degree of Engineering in Electronics and Automatics. This methodology has been applied during the academic years 2014-2015, 20152016, and 2016-2017 in the group of high academic performance (ARA group), in which English is the medium of instruction. 95\% of our students considered that flip teaching was a very adecuate methodology for the teaching and learning process of this course. Furthermore, the evaluation methods based on the tool SOCRATIVE have been positevely accepted. Finally, the academic performance was higher in the ARA group with respect to the rest of the groups, which did not happen in previous years when no flip teaching was applied at all.
\end{abstract}

Keywords: Flip teaching, high academic performance group, Polimedia, SOCRATIVE.

\footnotetext{
Resumen

De la necesidad de una mayor participación del alumnado universitario en el proceso de enseñanza-aprendizaje ha surgido el concepto de la docencia inversa. Mediante el uso de esta metodología, el alumno trabaja, de manera independiente, los conceptos más teóricos, con la ayuda de material audiovisual principalmente. Posteriormente, en clase, el alumno realiza actividades más prácticas dirigidas por el profesor y así afianza los conceptos aprendidos. El objetivo del presente trabajo es evaluar el impacto de dicha metodología en la enseñanza de la electrónica analógica en la titulación de Grado en Ingeniería Electrónica y Automática. Se ha aplicado la docencia inversa en los cursos 2014-2015, 2015-2016 y 2016-2017 en el grupo de alto rendimiento académico, que cursa la asignatura en inglés. La valoración del alumnado ha sido muy positiva: un $95 \%$ del alumnado considera muy adecuada la metodología. Además, los métodos de evaluación mediante el uso de la herramienta SOCRATIVE se han valorado positivamente y el rendimiento académico del grupo ARA ha mejorado con
} 
respecto a los demás grupos, lo cual no sucedió en años anteriores cuando no se aplicaba la docencia inversa.

Palabras clave: Clase Inversa, Grupo de alto rendimiento académico, Polimedia, SOCRATIVE.

\section{Introducción}

La docencia tradicional se basa en las lecciones magistrales donde la pasividad del alumno ralentiza su proceso de aprendizaje. La adaptación al espacio europeo de educación superior (EEES) de la educación universitaria en España ha permitido la introducción y fomento de metodologías más activas en el proceso de enseñanza-aprendizaje en las aulas. Especialmente, para las asignaturas más prácticas, es necesario que el alumno se involucre y asuma su responsabilidad en el proceso de aprendizaje. Debido a estas necesidades y al auge de las nuevas tecnologías audiovisuales se va instaurando en docencia la clase inversa o flipped classroom. Esta metodología ha sido fuertemente influenciada por la estrategia educativa de Peer Instruction y la enseñanza just-in-time (Mazur 1996; Santiago y Díez). Mediante este tipo de docencia, el alumno, de manera individual y responsable, adquiere los conceptos más teóricos con el material (principalmente audiovisual) proporcionado por el profesor. Posteriormente, en las sesiones presenciales con el profesor, en el aula, los alumnos pueden plantear sus dudas y centrarse en las tareas de aplicación más prácticas de la asignatura. Desde el punto de vista de la pirámide de aprendizaje de Bloom definida en 1956 y revisada en 2000 (Bloom 1956; Eduteka), la clase inversa fomenta que el alumno realice las tareas de la base (comprender y recordar) de manera independiente y en el aula se centre en las tareas más altas de la pirámide (crear, evaluar, analizar, aplicar).

El concepto de flipped teaching fue introducido en 2007 por los profesores Sams y Bergmann del Instituto Woodland Park en Colorado, al proponer un sistema de recuperación de clases mediante grabaciones de vídeo. Los resultados de esta experiencia fueron muy positivos (Sams y Bergmann, 2013) y esta metodología se está extendiendo a nivel mundial.

El impulso de esta iniciativa en la Universitat Politècnica de València desde el Vicerrectorado de las Tecnologías de la Información y de las Comunicaciones y el Instituto de Ciencias de la Educación en los últimos años, nos llevó a los profesores de la asignatura de Electrónica Analógica (titulación de Grado en Ingeniería Electrónica Industrial y Automática en la Escuela Técnica Superior de Ingeniería del Diseño) a aplicarla en clase.

Para aplicar la metodología de la clase inversa, quisimos hacerlo en uno de los 3 grupos de la asignatura, en el grupo menos numeroso, para poder llevar un seguimiento más apropiado. El grupo menos numeroso es el grupo de alto rendimiento académico (grupo ARA) en el cual la docencia se imparte en inglés. Por este motivo, las grabaciones de los elementos Polimedia se realizaron en inglés.

Una de las mayores dificultades que encontramos los profesores de la aplicación de esta metodología estaba relacionado con la evaluación. Por ello, decidimos emplear diversos métodos de evaluación capaces de motivar al alumnado. En concreto empleamos una

(c)) EY-NC-ND 2017, Universitat Politècnica de València

Congreso IN-RED (2017) 
herramienta para realizar tests en línea desde los teléfonos móviles, llamada SOCRATIVE (SOCRATIVE), ya que el empleo de las nuevas tecnologías para la evaluación parece motivar más al alumno.

\section{Objetivos}

El objetivo principal del presente trabajo es la aplicación de la docencia inversa para el proceso de enseñanza-aprendizaje de la asignatura de electrónica analógica en un grupo de alto rendimiento académico. Para ello, se han empleado grabaciones polimedia, realización de cuestiones y tests en línea mediante la herramienta SOCRATIVE. Otro objetivo del presente trabajo era valorar el grado de aceptación de esta metodología por parte del alumnado y si la perciben como una carga adicional excesiva o no, así como la mejora en su rendimiento académico.

\section{Desarrollo de la Innovación}

La experiencia de docencia inversa descrita en el presente trabajo se desarrolla en el contexto de la asignatura de Electrónica Analógica, asignatura troncal de segundo curso (cuatrimestre B) de la titulación Grado en Ingeniería Electrónica Industrial y Automática, en la Escuela Técnica Superior de Ingeniería del Diseño. Se trata de una asignatura con un gran número de alumnos (entre 150 y 175) divididos en tres grupos. El grupo en el cual se ha realizado la clase inversa es el grupo ARA, cuya docencia se desarrolla en inglés. Dicho grupo cuenta con un número de alumnos de 34 en el presente curso (2016-2017), 24 en el curso anterior (2015-2016) y 23 alumnos en el curso 2014-2015. Además hay dos grupos más, un grupo de mañana y un grupo de tarde, que cursan la asignatura en castellano y son grupos más numerosos (entre 65 y 75 alumnos). El temario de la asignatura es amplio y complejo y requiere la realización de muchos ejercicios prácticos para una comprensión profunda de la asignatura. Por ello, con el objetivo de dejar más tiempo en clase a la realización de ejercicios que afianzan los conocimiento adquiridos en teoría, los profesores de la asignatura planteamos la posibilidad de emplear la metodología de la docencia inversa. Para comenzar con esta experiencia, nos centramos en el grupo más reducido (grupo ARA) y así realizar un mejor seguimiento. A continuación se describe la metodología empleada en el curso 2014-2015 y mejorada en los cursos 2015-2016 y 20162017.

La metodología docente empleada en la asignatura, aunque tradicional, se ha adaptado progresivamente al espacio europeo de educación superior (EEES) e incluye diversas actividades y sistemas de evaluación. Los alumnos disponen de las diapositivas empleadas en las clases de teoría, de diversas colecciones de problemas para resolver en casa y en clase, así como de exámenes resueltos de años anteriores. Además, los alumnos disponen de documentos para la preparación y realización de las prácticas de laboratorio. La evaluación consta de dos pruebas parciales y una final en la que se evalúan los conocimientos adquiridos en las prácticas de laboratorio (preguntas tipo test que 
constituyen un $25 \%$ de la nota final), los conceptos teóricos y resolución de problemas (cuestiones de respuesta abierta que constituyen un $60 \%$ de la nota final). Finalmente, los alumnos realizan en grupos de tres un proyecto de diseño y simulación que exponen oralmente en clase para mejorar sus habilidades de documentación y presentación oral (15\% de la nota final).

Las técnicas de docencia inversa se han introducido en el grupo ARA, mediante el uso de 11 elementos polimedia, vídeos grabados en inglés con el contenido de 2 de los 8 temas de la asignatura. La teoría del tema 3 y el tema 7,2 temas cruciales en la asignatura, está explicada en los 11 vídeos. En la programación diaria de la asignatura, a la cual los alumnos tienen acceso y se muestra una parte en el anexo 1, se indica los vídeos que tienen que ver los alumnos antes de asistir a clase. Además, los alumnos deben resolver en casa unas cuestiones sencillas acerca de los vídeos visualizados para afianzar su comprensión. En clase, los propios alumnos y/o el profesor corrigen en la pizarra dichas cuestiones. Durante la corrección los alumnos plantean sus dudas y el profesor las resuelve. A continuación, los alumnos realizan en línea unas preguntas tipo test, mediante el uso de la aplicación SOCRATIVE desde sus teléfonos móviles. Las notas obtenidas en dichos tests (registradas mediante el software SOCRATIVE en una hoja excel) podrán suponer hasta un punto adicional en la nota final de la asignatura. Cabe destacar que la resolución de las cuestiones y las preguntas del test las realiza el alumno con una mejor comprensión de los conceptos teóricos puesto que ha visualizado previamente los vídeos en una ambiente más distendido que en clase, pudiendo retroceder si algo no le ha quedado claro. Otra ventaja clara es un aumento del tiempo dedicado en clase a la resolución posterior de ejercicios y problemas más prácticos. Durante las clases presenciales de los temas 3 y 7, la mayor parte del tiempo los alumnos han trabajado en la resolución de ejercicios activamente con el apoyo del profesor.

En el curso 2014-2015, los alumnos disponían de los vídeos correspondientes al tema 3 únicamente. Al finalizar el curso, se les pasó la encuesta del anexo 2, y dado que la aceptación fue muy positiva (ver sección de resultados) se decidió ampliar el material de polimedia grabando vídeos del tema 7 para los cursos 2015-2016 y 2016-2017. La introducción de la herramienta SOCRATIVE ha tenido lugar durante el presente curso 2016-2017 y los alumnos han realizado asimismo una encuesta de 4 preguntas en línea acerca de esta herramienta, vía PoliformaT (ver sección de resultados).

\section{Resultados}

En esta sección se describen los resultados de la aplicación de la metodología de docencia inversa en los cursos 2014-2015, 2015-2016 y 2016-2017.

En los 3 cursos, durante la primera clase del tema 3, en la que los alumnos debían traer las cuestiones resueltas y haber visualizado 2 de los vídeos, el profesor observó que prácticamente todos los alumnos habían visto los vídeos y traían las cuestiones resueltas. Algún alumno admitió honestamente que no había visto el vídeo por despiste o por falta de tiempo. Por tanto, un primer e importante resultado positivo fue conseguir que

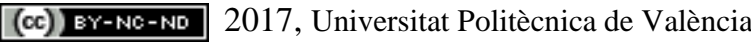

Congreso IN-RED (2017) 
prácticamente la totalidad del alumnado asistiera a clase con buenos conocimientos del tema a trabajar durante la sesión presencial. El profesor hace un breve sondeo oral acerca de los vídeos y los alumnos muestran una aceptación inicial, comentando que han podido ver los vídeos con tranquilidad y retrocediendo en algunos casos. En los vídeos, el profesor utiliza las diapositivas del tema (accesibles en poliformaT) y además realiza cálculos sencillos en una Tablet que se pueden seguir con claridad en el vídeo, como si fuera la pizarra de un aula.

Durante la corrección de las cuestiones, los alumnos plantean numerosas dudas o dificultades que han tenido para resolverlas, afianzando así los conceptos trabajados. Posteriormente, durante la resolución de ejercicios prácticos por parte de los alumnos en clase, el profesor se pasea por las mesas resolviendo dudas a medida que van surgiendo. La implicación del alumnado es muy significativa. Puesto que el grupo no es muy numeroso, el profesor puede dedicar el tiempo necesario para atender correctamente a los alumnos durante estas sesiones.

Al finalizar los cursos 2014-2015 y 2015-2016, un total de 17 y 20 alumnos, respectivamente, respondieron a la encuesta mostrada en el anexo 2 , y cuyas respuestas se describen en la Figura 1.

Como muestra la Figura 1, los alumnos han asumido la responsabilidad de visualizar los vídeos y en general opinan que les ha supuesto un ahorro de tiempo puesto que afianzan los conceptos de manera más efectiva. Los vídeos les han parecido fáciles de seguir, excepto a un alumno en el curso 2015-2016. En cuanto al ritmo, parece que en el curso 2015-2016 $45 \%$ de los alumnos piensan que es demasiado lento. Quizás el ritmo de los vídeos del tema 7 que no visualizaron los alumnos del curso anterior era demasiado lento. Esta observación será de ayuda para intentar grabar vídeos de los capítulos restantes a un ritmo más rápido. Las explicaciones realizadas en la Tablet durante los vídeos, similares a las que hace el profesor en la pizarra, también han tenido una gran aceptación. En el curso 2015-2016 un $45 \%$ de los alumnos han visualizado los vídeos sin detenerse, posiblemente porque el ritmo fuera lento para ellos. En cuanto a las cuestiones resueltas en casa y corregidas en clase acerca de los vídeos han resultado ser difíciles para un $12 \%$ y $40 \%$ en los cursos 2014 2015 y 2016-2016, respectivamente. Finalmente, un 95\% de los alumnos en los 2 cursos están de acuerdo con el uso de esta metodología y un $60 \%$ de los alumnos desearía tener vídeos para todos los temas de la asignatura. Por este motivo, los profesores de la asignatura vamos a ampliar el número de grabaciones para futuros cursos.

En esta encuesta los alumnos añadieron opiniones y sugerencias personales entre las cuales nos gustaría destacar las siguientes: i) los vídeos iniciales eran demasiados largos. En efecto la duración aproximada de los vídeos del tema 3 son de 20 minutos, y posteriormente se siguienron las indicaciones de la UPV para grabar vídeos Polimedia de 10 minutos en el tema 7. ii) Los alumnos preferirían resolver en clase más ejercicios, para lo cual se debería incrementar la práctica de la clase inversa mediante grabación de más vídeos.

En el presente curso 2016-2017, los alumnos realizan las preguntas tipo test mediante la aplicación SOCRATIVE en línea en sus teléfonos móviles o en los ordenadores de clase. Las notas obtenidas son muy altas, obteniendo unas medias de $87 \%$ y $85.6 \%$ en los 2 tests 
Aplicación de la Clase Inversa en la Enseñanza de la Electrónica Analógica en un Grupo de Alto Rendimiento Académico

correspondientes a los vídeos del tema 3 , y unas medias de $80 \%, 80.6 \%$ y $93.1 \%$ en los 3 tests correspondientes a los vídeos del tema 7. Las notas elevadas muestran que los alumnos han adquirido correctamente los conceptos teóricos básicos y han visualizado los vídeos con atención. En la tabla 1 se resume la opinión de los alumnos acerca del uso de la herramienta SOCRATIVE para la evaluación de los conocimientos adquiridos a través de los vídeos.

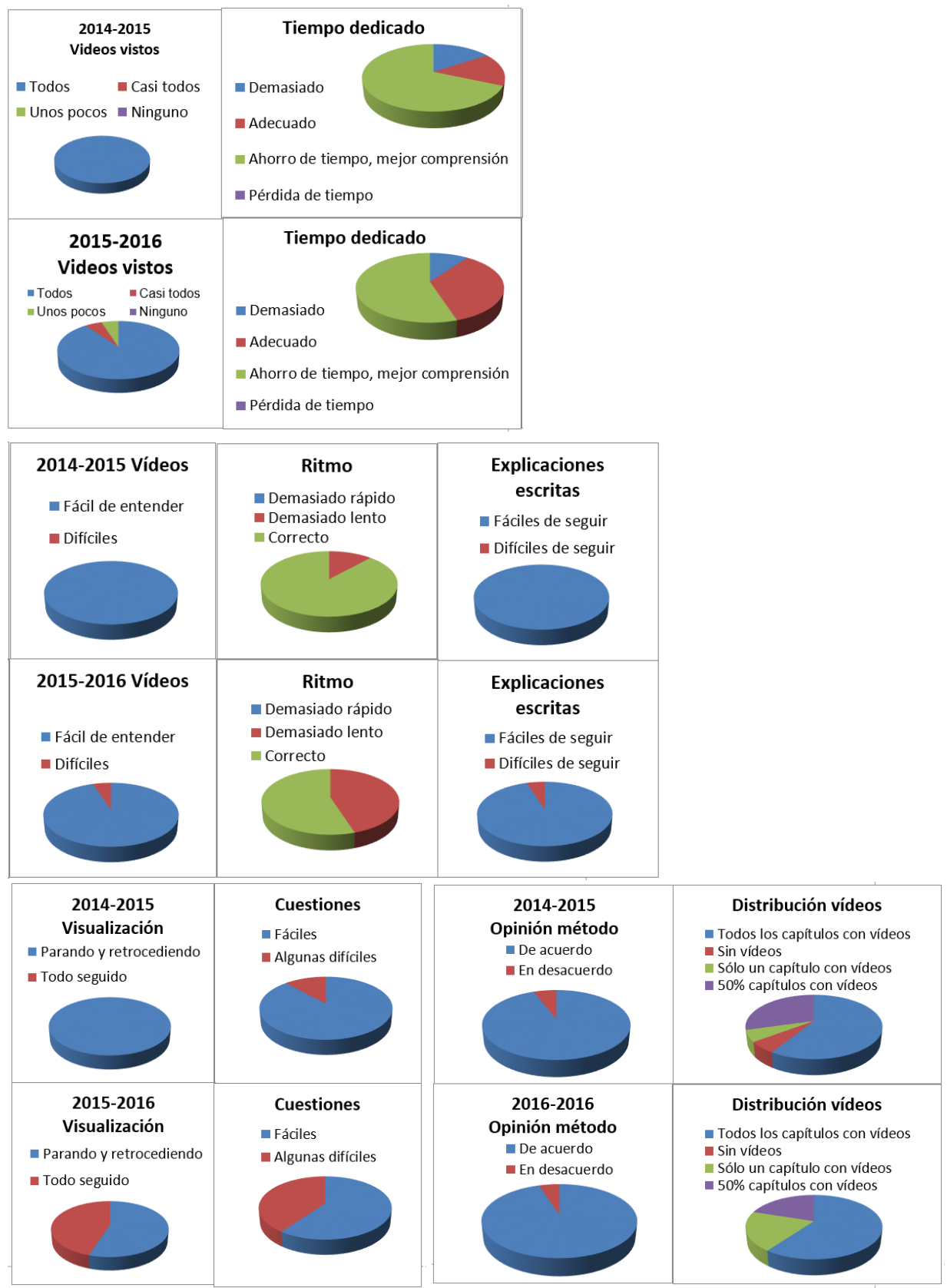

Fig. 1 Resultado de la encuesta (ver anexo 2) realizada por el alumnado en los curso 2014-2015 y 2015-2016.

(cc) EY-NC-ND 2017, Universitat Politècnica de València

Congreso IN-RED (2017) 
Tabla 1. Resultados de la encuesta acerca de SOCRATIVE

1. Los cuestionarios realizados en clase con la aplicación SOCRATIVE me han parecido adecuados para evaluar su comprensión de los vídeos

\begin{tabular}{|c|c|c|c|c|}
\hline $\begin{array}{c}\text { Totalmente en } \\
\text { desacuerdo }\end{array}$ & En desacuerdo & NS/NC & De acuerdo & Totalmente de acuerdo \\
\hline 0 & 1 & 1 & 10 & 7 \\
\hline $\mathbf{2 .}$ Las preguntas de la herramienta SOCRATIVE me han servido de motivación para ver los vídeos \\
\hline $\begin{array}{c}\text { Totalmente en } \\
\text { desacuerdo }\end{array}$ & En desacuerdo & NS/NC & De acuerdo & Totalmente de acuerdo \\
\hline 0 & 5 & 3 & 10 & 1 \\
\hline
\end{tabular}

3. La herramienta Socrative me parece una herramienta adecuada para la evaluación

\begin{tabular}{|c|c|c|c|c|}
\hline $\begin{array}{c}\text { Totalmente en } \\
\text { desacuerdo }\end{array}$ & En desacuerdo & NS/NC & De acuerdo & Totalmente de acuerdo \\
\hline 0 & 1 & 0 & 15 & 3 \\
\hline
\end{tabular}

4. Las preguntas de la herramienta SOCRATIVE se adecuan al contenido de los vídeos

\begin{tabular}{|c|c|c|c|c|}
\hline $\begin{array}{c}\text { Totalmente en } \\
\text { desacuerdo }\end{array}$ & En desacuerdo & NS/NC & De acuerdo & Totalmente de acuerdo \\
\hline 0 & 0 & 1 & 9 & 9 \\
\hline
\end{tabular}

De los resultados de la encuesta se deduce que el hecho de tener un cuestionario no sea suficiente motivación para ver los vídeos. En nuestra opinión, la propia responsabilidad que se deposita en los alumnos les motiva para ver los vídeos. Además pueden comprobar que si no lo ven no podrán seguir las clases. En general los alumnos están de acuerdo con este método para evaluar la comprensión de los vídeos. Debe destacarse que sólo 19 alumnos han rellenado la encuesta y por tanto las conclusiones extraídas podrían ser más sólidas si hubieran contestado los 34 alumnos. Esta encuesta se hizo a través de PoliformaT y quizás los alumnos no eran conscientes de la fecha límite para rellenarla.

Finalmente, considerando los resultados académicos obtenidos en el curso 2015-2016 se puede realizar una comparación entre el grupo con docencia inversa y el resto de grupos. Cabe destacar que la comparación realizada tiene ciertas limitaciones que comentaremos a continuación, pero puede servir como un indicio de que la metodología aplicada es beneficiosa.

En la tabla 2 se muestran las medias y desviaciones típicas de las notas del grupo ARA y del resto de grupos en los cursos 2013-2014, 2014-2015 y 2015-2016. Además, puesto que las notas no siguen una distribución normal, se muestran también las medianas y los diagramas de caja (Box plot) en la Figura 2.

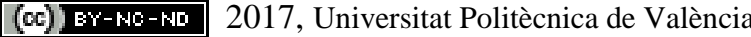


Tabla 2. Resultados Académicos de los distintos cursos y grupos.

\begin{tabular}{|c|c|c|c|c|}
\hline $\begin{array}{c}\text { Curso } \\
\text { Académico }\end{array}$ & Grupo & Media & $\begin{array}{c}\text { Desviación } \\
\text { típica }\end{array}$ & Mediana \\
\hline \multirow{2}{*}{$2013-2014$} & ARA & 6.46 & 1.51 & 6.1 \\
\cline { 2 - 5 } & Resto de grupos & 6.86 & 1.78 & 7 \\
\hline \multirow{2}{*}{$2014-2015$} & ARA & 5.78 & 2.06 & 5.81 \\
\cline { 2 - 5 } & Resto de grupos & 5.38 & 2.19 & 5.69 \\
\hline \multirow{2}{*}{$\mathbf{2 0 1 5 - 2 0 1 6}$} & ARA & $\mathbf{6 . 3 6}$ & $\mathbf{1 . 3 7}$ & $\mathbf{5 . 9 5}$ \\
\cline { 2 - 5 } & Resto de grupos & $\mathbf{5 . 2 9}$ & $\mathbf{1 . 7 5}$ & $\mathbf{5 . 4}$ \\
\hline
\end{tabular}

Si realizamos una comparación estadística de las medias de los distintos grupos, siguiendo el test t-student, la diferencia de medias entre el grupo ARA y el resto de grupos es significativa $(\mathrm{p}<0.05)$ únicamente en el curso 2015-2016.

Puesto que la distribución de notas no sigue una variable normal y el tamaño de muestra no es grande, se ha realizado también el test Wilcoxon. El resultado obtenido ha sido que las medianas del grupo ARA y el resto de grupos pueden considerarse iguales con una probabilidad de 0.2593 , 0.4558 y 0.0137 en los cursos 2013-2014, 2014-2015 y 2015-2016, respectivamente. Por tanto, puede considerarse que las medianas son significativamente distintas ( $p<0.05)$ únicamente en el curso 2015-2016. 

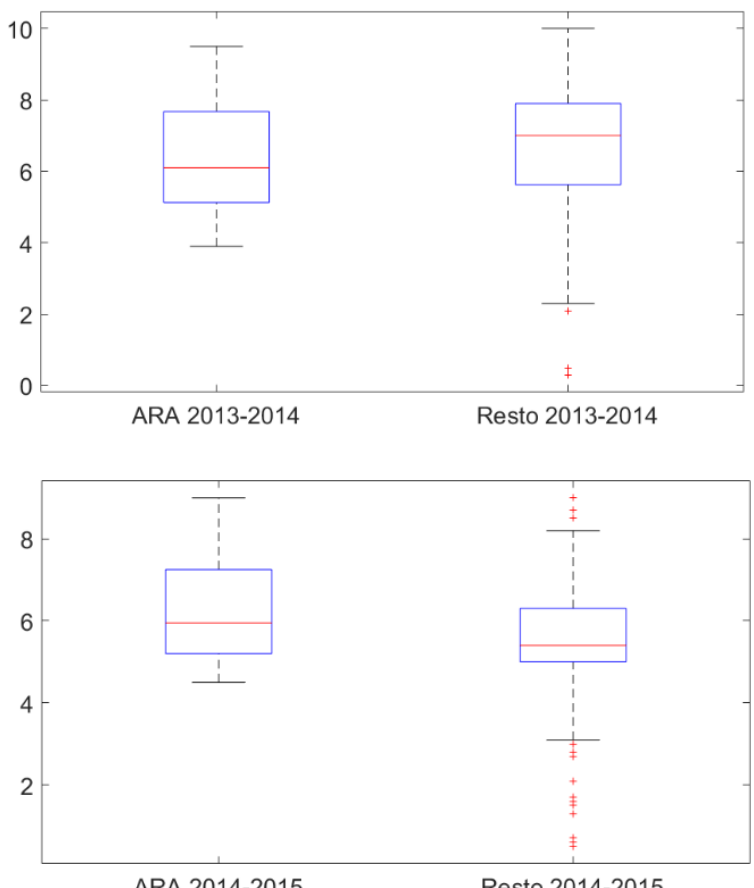

ARA 2014-2015

Resto 2014-2015

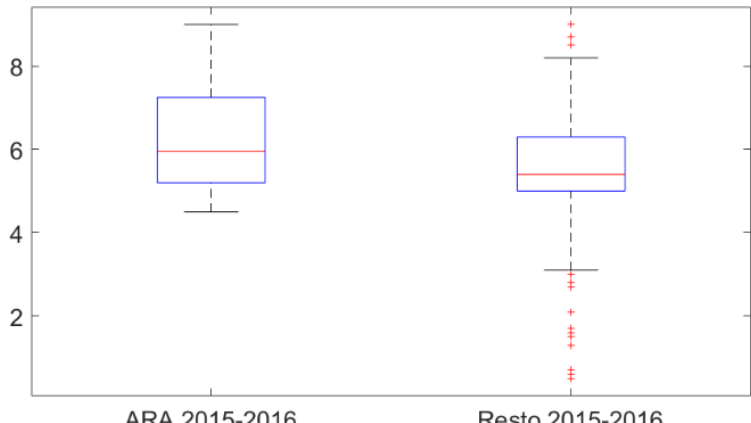

Fig. 2 Resultados académicos de los distintos grupos y cursos académicos representados en diagramas de caja (Box plot).

Como limitaciones de esta comparación debe considerarse que la docencia inversa se ha empleado en 2014-2015 en un solo tema (tema 3) de 8 temas que tiene la asignatura y en 2015-2016 en dos temas (tema 3 y tema 7). Sin embargo, el tema 3 y el tema 7 son 2 de los temas más importantes de la asignatura en los que se introducen conceptos que aparecen en todos los ejercicios de la asignatura. Son concepto difíciles de afianzar.

Por otra parte, los alumnos del grupo ARA, en general, tienen una motivación especial. Son alumnos que están dispuestos a cursar la asignatura en inglés a pesar de su dificultad y que en general pueden tener resultados académicos mejores. Sin embargo, en el curso 20132014, cuando no se aplicaba la metodología de clase inversa, la nota media no era superior en el grupo ARA, por tanto no siempre son alumnos con mejores resultados académicos.

(c) ) EY-NC-ND 2017, Universitat Politècnica de València 
Por supuesto, hay muchos otros factores que influyen en los resultados, como por ejemplo el hecho de que el profesorado en los distintos grupos no es el mismo.

\section{Conclusiones}

Los alumnos y el profesorado valoran positivamente la aplicación de la docencia inversa en el proceso de enseñanza-aprendizaje de la electrónica analógica. El 95\% de los alumnos están de acuerdo con el uso de esta metodología y un $60 \%$ de los alumnos desearía tener vídeos para todos los temas de la asignatura. Las cuestiones resueltas en casa y corregidas en clase así como el uso de la herramienta SOCRATIVE (test en línea) son herramientas válidas para la evaluación de la clase inversa. Esta metodología de trabajo permite mejorar el rendimiento académico y la satisfacción de los alumnos en su proceso de aprendizaje.

\section{Referencias}

BLOOM, B. S. and KRATHWOHL, D. R. (1956). Taxonomy of Educational Objectives: The Classification of Educational Goals. Handbook I: Cognitive Domain. New York: Longmans Green

EDUTEKA. Taxonomía de Bloom para la era digital. <http://eduteka.icesi.edu.co/articulos/TaxonomiaBloomDigital $>$ [Consulta: 28 Marzo 2017]

MAZUR, E. (1996) Peer Instruction: A User's Manual, New York: Prentice Hall.

SAMS, A. y BERGMANN, J. (2013). "Flip Your Students' Learning”. Educational Leadership, 70(6), 16-20.

SOCRATIVE, by Master Connect <https://www.socrative.com/> [Consulta : 28 Marzo 2017].

SANTIAGO, R. Y DIEZ, A. The flipped classroom. <http://www.theflippedclassroom.es/metodologia-teaching-methods/> [Consulta: $21 \mathrm{de}$ marzo de 2016]

(c) EY-NG-ND 2017, Universitat Politècnica de València

Congreso IN-RED (2017) 
ANEXO 1.

PROGRAMACIÓN DIARIA DE LA ASIGNATURA PARA LOS ALUMNOS. MES

\begin{tabular}{|c|c|c|}
\hline & Monday (8:30-10:30) & Tuesday (11:30-14:30) \\
\hline & - LECTURE - & - LECTURE / LABORATORY - \\
\hline 30 & $\begin{array}{l}\text { Presentation + Projects } \\
\text { CHAPTER 1. INTRODUCTION } \\
\text { (total 1h) } \\
\text { EXERCISES }\end{array}$ & $\begin{array}{l}31 \text { CHAPTER 2. ANALOG SIGNALS } \\
\text { (total 3h) }\end{array}$ \\
\hline 6 & NO CLASS & $\begin{array}{l}7 \\
\text { LABORATORY EXP. 1: Instruments and } \\
\text { diode circuits } \\
\text { Previous calculations }\end{array}$ \\
\hline 13 & $\begin{array}{l}\text { CHAPTER 3. ANALOG } \\
\text { SYSTEMS (total 9h) } \\
\text { Watch videos } 1 \text { and } 2 \\
\text { Questions videos } 1 \text { and } 2\end{array}$ & $\begin{array}{ll}14 & \\
\text { CHAPTER 3. ANALOG SYSTEMS } \\
\text { Watch videos } 3 \text { and } 4 \\
\text { Questions videos } 3 \text { and } 4\end{array}$ \\
\hline 20 & $\begin{array}{l}\text { CHAPTER } \\
\text { SYSTEMS }\end{array}$ & $\begin{array}{l}\text { CHAPTER 3. ANALOG SYSTEMS } \\
\text { Watch video } 5 \\
\text { Questions video } 5 \\
\text { EXERCISES } 1 \text { (Chapter } \mathbf{1 , 2}, \mathbf{3} \text { ) }\end{array}$ \\
\hline 27 & $\begin{array}{l}\text { EXERCISES } 1 \text { (Chapter 1,2,3) } \\
\text { 1h CHAPTER 4. FUNCTIONAL } \\
\text { BLOCKS (total 3h) }\end{array}$ & \begin{tabular}{|l}
28 \\
CHAPTER 4. FUNCTIONAL BLOCKS \\
CHAPTER 5. AMPLIFIERS WITH \\
TRANSISTORS (total $\mathbf{6 h}$ )
\end{tabular} \\
\hline
\end{tabular}

(c) EY-NC-ND 2017, Universitat Politècnica de València Congreso In-Red (2017) 
ANEXO 2

\section{ANALOG ELECTRONICS. ANONYMOUS SURVEY.}

1. Did you watch the videos posted in PoliformaT?
a. Yes, all of them.
b. Most of them (3 or more).
c. A few of them (1 or 2$)$.
d. None of them.

2. What do you think about the time you spent watching the videos?

a. It took me too much time.

b. The investment of time was worth it.

c. I think I saved time because I understood the aspects in the videos and reinforced them in class.

d. It was a waist of time.

3. How did you find the videos?

a. Easy to understand.

b. Difficult to follow.

4. How was the rhythm of the videos?
c. The rhythm was too fast.
d. The rhythm was too slow.
e. The rhtyhm was all right.

5. How did you find the written explanations in the videos?
f. Easy to understand

g. Difficult to follow.

6. How did you watch the videos?

a. I stopped and/or went backwards sometimes.

b. Without any stop.

7. How did you find the questions about the videos?

a. They were easy to solve.

b. I had some trouble solving the questions.

8. How did you like the method of watching videos in chapter 3 ?

a. I liked the method used in chapter 3, I think the videos helped to understand the theoretical aspects and we had more time to work in class on the practical aspects.

b. I don't think the videos are a good system to assimilate the theoretical aspects and prefer the explanations made in class, as in the rest of the chapters.

9. The methodological distribution of analog electronics should be:

a. All chapters should have videos. Although this would require investment of time at home, the student can take more profit of the class sessions based on exercises and discussions based on the video contents.

b. I prefer the traditional teaching, with no videos at all.

c. Only one chapter with videos is OK.

d. $50 \%$ of the chapters should use the videos methodology.

10. Free suggestions to improve the teaching methods based on videos:

11. Other suggestions to improve teaching methods in analog electronics classes:

(c) EY-NC-ND 2017, Universitat Politècnica de València

Congreso IN-RED (2017) 


\title{
La clase inversa y el aprendizaje servicio: fusión de dos metodologías convergentes para el aprendizaje de lengua extranjera
}

\section{Daniela Gil-Salom ${ }^{a}$ Ángeles Lence ${ }^{b}$}

Departamento de Lingüística Aplicada, Universitat Politècnica de València, ${ }^{a}$ dagil@idm.upv.es, b $\underline{\text { malence@,idm.upv.es. }}$

\begin{abstract}
This work presents the result of fusing two pedagogical active methodologies,: flipped classroom and service learning, in the teaching of two transversal subjects of foreign languages: German and French. Therefore, the implementation of the flipped classroom by carrying out a service-learning project is shown and the way they complement each other is highlighted with practical examples of two different levels of the ERFL, German A1 and French B1. With the results, it can be seen, that the two methodologies not only match perfectly, but the flipped classroom is being implemented by developing a service-learning project. With the aim of designing a good articulated project with social commitment, students learn the content in a gratifying way, reflect on their direct or indirect implication in the community and develop skills for their future profession.
\end{abstract}

Keywords: flipped classroom, service learning, transversal skills, German as a foreign language, French as a foreign language.

\begin{abstract}
Resumen
Este trabajo presenta el resultado de fusionar dos metodologías pedagógicas activas, como son la clase inversa (CI) y el aprendizaje-servicio (ApS), en la docencia de dos asignaturas transversales de lengua extranjera: alemán y francés. Para ello, mostraremos la implementación de la clase inversa llevando a cabo un proyecto ApS y destacaremos cómo se complementan, con ejemplos prácticos en dos niveles distintos del MCREL, Alemán A1 y Francés B1. Con el resultado, veremos que se trata de dos metodologías que no solo casan perfectamente, sino que la CI se implementa al llevar a cabo un proyecto ApS: con el objetivo de diseñar un proyecto bien articulado con compromiso social, el alumnado aprende la materia de forma gratificante, reflexiona sobre su implicación directa o indirecta en la comunidad y desarrolla competencias para su futura profesión.
\end{abstract}

Palabras clave: clase inversa, aprendizaje-servicio, competencias transversales, alemán como lengua extranjera, francés como lengua extranjera. 


\section{Introducción}

En los últimos cursos, la UPV ha apostado por dos metodologías innovadoras para la práctica docente en contexto politécnico: la clase inversa (CI) y el aprendizaje-servicio (ApS). La primera arrancó con la experiencia piloto en el curso 2014/15 y la segunda en el curso 2016/17, aunque ambas estaban ya presentes sin el reconocimiento académico.

La CI es un modelo pedagógico centrado en el alumno que se fundamenta en la utilización de tecnologías digitales al servicio de la enseñanza-aprendizaje (Barreras, MA, 2016: 176). Al mismo tiempo, posibilita que el aula se convierta en un espacio de aprendizaje creativo y reflexivo. De este modo, el docente tiene una visión global del aprendizaje ya que diseña técnicas o actividades didácticas que le permiten desarrollar diferentes enfoques metodológicos.

El ApS es también un modelo pedagógico centrado en el alumno, especialmente en su compromiso social, que combina el aprendizaje a través de la experiencia y la acción al servicio de la comunidad: el alumnado aprende dando un servicio a la sociedad. Este aprendizaje se desarrolla en el aula que se convierte, al igual que en la CI, en un espacio participativo, creativo y reflexivo, donde el docente incentiva la autonomía del alumno (García, 2016:215) y el trabajo en equipo con el objetivo de realizar un proyecto bien articulado.

En este trabajo pretendemos exponer cómo ambas metodologías son perfectamente aplicables puesto que se complementan y se apoyan la una en la otra con idénticos objetivos en una asignatura.

\section{Objetivos}

Los objetivos de este trabajo son, por un lado, ejemplificar la implementación de la metodología de la clase inversa llevando a cabo un proyecto ApS, y por otro, destacar cómo se complementan ambos enfoques metodológicos

Para ello, vamos a desarrollar dos ejemplos prácticos en dos asignaturas de lengua extranjera: alemán y francés en dos niveles distintos del Marco Común de Referencia Europeo de las Lenguas (MCREL) ${ }^{1}$, A1 y B1 respectivamente.

\section{Desarrollo de la innovación}

A continuación se presentan las dos experiencias que se han llevado a cabo durante el pasado curso 2016/17 en Alemán A1 y Francés B1.

\subsection{La asignatura Alemán 1}

3.1.1. Contexto académico: se trata de una asignatura optativa transversal de la UPV, formada por siete grupos de estudiantes pertenecientes a diez titulaciones de ocho ERT distintas, con una matrícula de 170 personas y una carga docente de 4,5 / 6 créditos según titulación. El proyecto ApS se llevó a cabo en un grupo ubicado en la ETSINF y

\footnotetext{
${ }^{1}$ MCERL http://cvc.cervantes.es/ensenanza/biblioteca ele/marco/default.htm
} 
constaba de 20 estudiantes de las titulaciones Grado en Ingeniería Informática y Grado en Ingeniería de Organización Industrial.

3.1.2. Proyecto ApS: el proyecto diseñado para esta experiencia se titula "PROYECTO graTICs": aprendizaje del alemán apoyado en herramientas TIC gratuitas. La idea en la que se sustenta este proyecto es fomentar el aprendizaje de la lengua alemana en la enseñanza pública no universitaria, dada su importancia en el terreno académico y profesional contemporáneo. Al mismo tiempo, la puesta en práctica de la experiencia desarrolla las competencias transversales y específicas de la asignatura.

3.1.3. Objetivos del proyecto ApS: con este proyecto se pretende llamar la atención sobre la falta de oferta de lengua alemana en los centros públicos. Es una carencia formativa que sufre la mayoría del alumnado de la enseñanza pública, tanto de secundaria y bachiller, como de módulos formativos.

3.1.4. Objetivos académicos: reforzar y asentar conocimientos como la pronunciación, el vocabulario, la morfología y la sintaxis de la lengua alemana, así como desarrollar todas las competencias transversales, especialmente: Comprensión e integración (CT01), Aplicación y pensamiento práctico (CT02), Diseño y proyecto (CT05), Trabajo en equipo y liderazgo (CT06), Comunicación efectiva (CT08), Conocimiento de problemas contemporáneos (CT10) o Aprendizaje permanente (CT11). Pero sobre todo, es importante crear una oportunidad para iniciar proyectos interdisciplinares, al trabajar de forma creativa estudiantes de distintas titulaciones en objetivos comunes.

3.1.5. Metodología: el trabajo dedicado a este proyecto se desarrolla tanto en sesiones presenciales como no presenciales y es de carácter individual o grupal, según la actividad programada.

Las fases que componen este proyecto ApS son las siguientes:

1. Lectura previa de documentos sobre el nuevo enfoque metodológico y ejemplos de proyectos similares, así como de contenidos teóricos de la materia de la asignatura, todo ello ubicado en Recursos de PoliformaT. Esta preparación previa a las clases presenciales responde a los fundamentos de la metodología propia de la CI.

2. Formación de grupos de trabajo: el alumnado se distribuye en grupos de tres/cuatro personas para definir el pre-diseño de los distintos sub-proyectos de forma presencial. El trabajo colaborativo es propio de la metodología ApS y es igualmente protagonista en las actividades presenciales asociadas a la clase inversa.

3. Búsqueda de fuentes y material. Trabajo presencial y no presencial. En esta fase se combina la investigación individual del alumnado fuera del aula (proceso que comparten ambas metodologías) con la puesta en común (fase de comunicación entre pares para la toma de decisiones) con el resto del grupo, para decidir aquellas fuentes y herramientas a utilizar. Aquí confluyen CI y ApS de una manera significativa para desarrollar estas competencias transversales. 
4. Diseño final de los sub-proyectos en sesiones no presenciales. Dos grupos se dedican a la aplicación de diseño propio y cuatro grupos a las aplicaciones y herramientas gratuitas en línea.

5. Desarrollo de la acción durante dos sesiones presenciales. Desplazamiento a tres aulas de Ciclos Formativos de Informática del IES Serpis de Valencia. Puesta en práctica de los conocimientos adquiridos en sesiones de trabajo presenciales y sesiones no presenciales en un contexto real.

6. Resultados del proyecto: según la reflexión de los estudiantes, en general el proyecto favorece el aprendizaje y refuerzo de los contenidos de la asignatura. De forma voluntaria, cuatro grupos realizaron un vídeo para darle visibilidad al proyecto mediante su difusión en páginas web de instituciones educativas, tales como el mismo IES Serpis y la UPV.

7. Evaluación del proyecto: por un lado, los destinatarios del proyecto evalúan a sus "formadores" mediante un cuestionario y, por otro, los estudiantes que realizan el servicio evalúan todo el proceso a través de un texto reflexionando sobre el proyecto global, el del grupo y sobre la propia actuación a nivel individual.

3.1.6. Evaluación: para la evaluación académica se diferencian igualmente dos niveles: valoración individual, basada en un texto de reflexión y valoración del trabajo en grupo según el grado de implicación en el proyecto, cada uno con un peso de 0,5 puntos de la nota final.

3.1.7. Resultados: en lo relativo a la competencia lingüística, se observa un mejor aprendizaje de la lengua alemana según la percepción de los estudiantes, tal como se observa en los vídeos presentados como trabajo final del proyecto; un ejemplo de ello se muestra en la página web del Centro de Cooperación al Desarrollo (CCD) de la UPV: https://youtu.be/HgJOOwW4yng. El diseño de materiales llevado a cabo por los propios estudiantes desarrolla así el proceso metacognitivo descrito por Flavell (1985). Del mismo modo, el propio diseño se ve enriquecido por la interdisciplinariedad del perfil académico del alumnado. En cuanto a la competencia cívica, supone una oportunidad para concienciar al alumnado de su responsabilidad individual ante la sociedad.

\subsection{La asignatura Francés B1}

3.2.1. Contexto académico: se trata de una asignatura optativa transversal de la UPV, que consta de dos grupos de estudiantes pertenecientes a veinte titulaciones de diez ERT distintas, con una matrícula de 106 personas y una carga docente de 4,5 / 6 créditos según titulación. El proyecto ApS se llevó a cabo en el grupo ubicado en la ETSIE y constaba de 10 estudiantes de distintos Grados (Grado en Ingeniería Industrial, Grado en Biotecnología y Grado en Administración y Dirección de Empresas).

3.2.2. Proyecto ApS: "Posters para el ApS: difusión bilingüe (castellano/francés) de proyectos de Origines". El proyecto se basa en la difusión de los proyectos de educación e inserción laboral que la asociación Origines lleva a cabo en dos islas senegalesas, Fadiouth y Ehidj. Simultáneamente, la puesta en práctica de la experiencia desarrolla las competencias transversales y específicas de la asignatura (Lence, 2014).

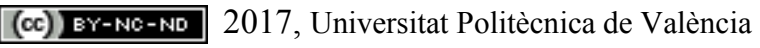


3.2.3. Objetivos académicos: adquirir mejor competencia lingüística poniendo en práctica la comunicación efectiva (CT-8), comprender los objetivos de la tarea e integrarlos sin esfuerzo en su formación (CT-01); aprender a desarrollar un pensamiento crítico (CT2); aprender a ser creativo en una actividad innovadora en la UPV (CT-04) al seleccionar y manipular imágenes, buscar la originalidad en la presentación; aprender a diseñar y presentar un proyecto (CT-05), fundamental para su PFG; aprender a trabajar en equipo y liderar (CT.06), pues hay que distribuir el trabajo, negociar, decidir y coordinar; aprender a ser responsable, a tener un comportamiento ético y de respeto hacia los demás (CT-07); aprender a reconocer los problemas contemporáneos importantes (CT-9) como la brecha educativa; experimentar una inmersión intercultural, un aprendizaje permanente (CT-10) que le motive a saber más sobre otros contextos; aprender a gestionar y planificar el tiempo (CT-11) para que los resultados sean acordes al tiempo establecido sin someterse a estrés alguno; por último, aprender a ser consciente de lo importantes que son sus estudios específicos para transformar la sociedad (Lence, 2016:457).

3.2.4. Objetivos del proyecto ApS: para la difusión de los proyectos de Origines, se trata de involucrar al alumnado en la producción de material que dé visibilidad a los mismos para su presentación en contextos académicos como es el caso del congreso ApSU17 que se celebrará en octubre próximo. A tal fin y con la participación activa del alumnado en jornadas o congresos de cooperación al desarrollo o de aprendizaje de lenguas, se pretende igualmente producir conocimiento a través del debate entre ponentes y de las intervenciones del público en general.

Al mismo tiempo, buscamos promover la concienciación en la sociedad dando a conocer la realidad de otro país y las líneas de acción que lleva a cabo una ONG como Origines para mejorar la situación de niños, niñas y jóvenes en riesgo de abandono escolar o de exclusión social.

3.2.5. Metodología: partiendo del enfoque de las metodologías activas, la puesta en marcha del proyecto se estructura del siguiente modo: de los 6 créditos de los que consta la asignatura, hemos dedicado a ApS 0,5 créditos TA/PA, que corresponden a dos sesiones presenciales y 2 créditos PL, correspondientes a seis sesiones de prácticas.

Las fases que componen este proyecto ApS son las siguientes:

1. Presentación del profesor de documentos sobre el nuevo enfoque metodológico y ejemplos: definición, descripción y aplicación del ApS, con el material alojado en Recursos de PoliformaT. (TA/PA1)

2. Presentación de Moussa Sarr, coordinador de Origines, sobre Senegal y los entornos en los que se llevan a cabo los proyectos de educación y de inserción laboral (islas Fadiouth, Ehidj ...). (TA/PA2)

3. Formación del grupo de trabajo y distribución por binomios: pre-diseño de los distintos apartados. (PL1)

4. Búsqueda de fuentes y material para elaborar el póster. (PL2)

5. Puesta en común y diseño del póster. (PL3)

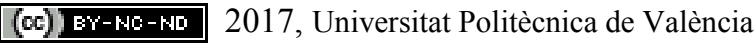

Congreso In-Red (2017) 
6. Desarrollo de la acción: presentación del póster en contexto francófono. (PL4)

7. Resultados del proyecto. (PL5)

8. Evaluación del proyecto que incluye reflexión. (PL6)

La presentación real del póster en castellano tendrá lugar en el VIII Congreso Nacional e Internacional ApSU en Sevilla, del 13 al 14 de octubre de 2017. Se trata además de un proyecto financiado por GLOCAL2017.

3.2.6. Evaluación: para la evaluación académica se establecen dos niveles: una valoración individual, a partir de un texto de reflexión y una valoración del trabajo en equipo que valora la participación en el proyecto, con un peso de 1 punto de la nota final.

\subsubsection{Resultados}

Los resultados generales del proyecto reflejan la adquisición de la lengua francesa desarrollando a la vez las competencias transversales. Gracias al proyecto, se materializa un servicio a la sociedad como es la difusión de los proyectos de una ONG. Con ello, se contribuye a la mayor visibilidad de actividades relacionadas con el ApS en la UPV. Además, vemos aumentada la motivación del alumnado por la tarea gratificante de procurar un mundo más justo (Lence, 2015:61).

\section{Resultados conjuntos}

Desde el punto vista del alumnado, la aplicación de la CI y del ApS supone una vía innovadora de aprendizaje e investigación a la vez que permite despertar o reforzar los valores cívicos y de concienciación sobre la realidad más allá de las aulas. La práctica significativa del saber facilita el acercamiento a problemas contemporáneos y a la reflexión, no solo sobre el aprendizaje, sino también sobre uno mismo y sobre los demás, desarrollando el espíritu crítico como nos apunta Deeley (2016:164) dándole así un sentido más amplio a ese aprendizaje.

Desde la perspectiva del docente, la aplicación de técnicas y enfoques nuevos, aunque al principio suponga un esfuerzo añadido (Gil-Salom, 2015), proporciona una gran satisfacción profesional, difícil de medir cuantitativamente, ya que depende, como en el caso del alumnado, del grado de implicación.

Desde la propia experiencia, sentimos el impulso de querer saber más sobre ambos enfoques, haciendo hincapié en el ApS puesto que se trata de una metodología en la que aún existen lagunas, especialmente en lo relativo a la evaluación y que, por otro lado, es un enfoque que aún no siendo nuevo, sí lo es en la UPV (Macías-Mendoza, MartínezUsarralde \& Gil-Salom, 2016; Macías-Mendoza \& Gil-Salom, 2017).

\section{Conclusiones}

Todos estamos de acuerdo en la importancia del aprendizaje activo, reflexivo, autónomo y responsable. Hemos visto que la CI y el ApS son dos metodologías que pueden perfectamente fusionarse para el aprendizaje de lengua extranjera, tanto si se trata de un

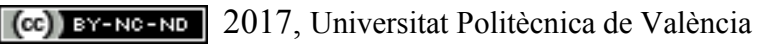


nivel de iniciación (A1) como de uno intermedio (B1), pues ambas implementan el aprendizaje de las competencias lingüísticas y transversales.

En el caso de la lengua alemana, la asignatura de Alemán A1 ya contaba con la experiencia de cursos anteriores en CI al formar parte del proyecto del mismo nombre iniciado por la UPV en el curso 2014/15, pero ha sido con esta experiencia con la que se inicia en la metodología ApS.

En el caso de la lengua francesa, la asignatura de Francés B1, reconocida institucionalmente como asignatura asociada al ApS, la CI se ha aplicado hasta ahora solo de forma intuitiva, al no haberse solicitado en tiempo y forma su inclusión como CI. Sin embargo, al comprobar que ambas metodologías se fusionan perfectamente, hemos solicitado su reconocimiento para el próximo curso en la asignatura de Francés 2 (B2) habiendo sido aceptada.

Tal como hemos indicado en los resultados conjuntos, a partir de estas experiencias, uno de nuestros objetivos es profundizar, tanto en el enfoque metodológico de la CI, como en la metodología ApS para optimizar la programación docente en asignaturas de lengua extranjera.

Por último, confiamos en que este trabajo pueda contribuir a la consolidación de las competencias transversales definidas por la UPV, especialmente de la que se refiere a la "Responsabilidad ética, medioambiental y profesional" para que esta universidad, referente en desarrollo tecnológico, destaque igualmente "por sus compromisos en materia de responsabilidad social” respondiendo a su Plan Estratégico 2020.

\section{Referencias}

BARRERAS GÓMEZ, M.A. (2016) Experiencia de la clase inversa en didáctica de las lenguas extranjeras, Educatio Siglo XXI, vol. 34, issue 1, p. 173-196, http://dx.doi.org/10.6018/j/253281

DEELEY, S.J. (2016) El aprendizaje-servicio en educación superior. Teoría, práctica y perspectiva crítica. Madrid: Narcea.

Flavell, J.H. 1985. Cognitive development. Englewood Cliffs. NJ: Prentice Hall.

GARCÍA GómEZ, A. (2016) Aprendizaje inverso y motivación en el aula universitaria, Pulso. Revista de Educación, 39, 199-218.

GIL-SALOM, D. (2015) “Alemán para Grado en Ingeniería Informática aplicando flipped teaching”, en Skorczynska Sznajder, H., Carrió Pastor, M. L., Saz Rubio, M. M., Tamarit Vallés, I. T. Estudios de lingüística aplicada I Valencia: Universitat Politècnica de València. http://hdl.handle.net/10251/53329.

LENCE GUILABERT, A. (2016) “Aprendizaje y servicio en asignaturas de francés: difusión del alumnado del proyecto educativo de Origines en Senegal", Actas VII Congreso Nacional y II Internacional de Aprendizaje-Servicio Universitario (APS U7), p 451-459, Universidade de Santiago de Compostela. http: //dx.doi.org/10.15304/978841653397. 
LENCE GUILABERT, A. (2015) Formation et évaluation en compétences interculturelles pour ingénieurs, Cuadernos de Filología Francesa, $\mathrm{n}^{\circ}$ 26, Universidad de Extremadura, p 45-63. http://hdl.handle.net/10251/78992

LenCE Guilabert, A. (2014) “Cooperación para el desarrollo en educación: Origines en Francés II y competencias transversales" Actas II Jornadas de Innovación Docente en la ETSIT (JIDTEL'2014). En homenaje a Elvira Bonet, Editorial Universitat Politècnica de València.

MacíAs-MendozA, D., MARTíneZ-Usarralde, M.J. y GIL-SAlOM, D. (2016) "La formación en competencias transversales y el Aprendizaje Servicio (ApS): feliz maridaje en la Universitat Politècnica de València" en Fernández Prada, MÁ.; Botti Navarro, VJ. (2016). In-Red 2016. II Congreso nacional de innovación educativa y docencia en red. Editorial Universitat Politècnica de València. http://hdl.handle.net/10251/70954.

MACÍAS-MENDOZA, D. Y GIL-SALOM, D. (2017). Aprender y enseñar lenguas. (en prensa)

MCERL http://cvc.cervantes.es/ensenanza/biblioteca_ele/marco/default.htm

Plan Estratégico de la Universitat Politècnica de València 2020 https://www.upv.es/organizacion/la-institucion/documentos/Plan_Estrategico_UPV_20152020 Resumen_ejecutivo.pdf 


\title{
Room Escape: Propuesta de Gamificación en el Grado de Fisioterapia
}

\author{
Carolina Jiménez Sánchez ${ }^{a, b}$, Raquel Lafuente Ureta ${ }^{a}$, María Ortiz Lucas ${ }^{a, b}$, Lindsey \\ Bruton $^{\text {c,d }}$, Verónica Millán Luna ${ }^{a}$ \\ aDepartamento de Fisioterapia. Universidad San Jorge. Zaragoza (cjimenez@usj.es; rlafuente@usj.es; \\ mortiz@usj.es; emillan@usj.es). ${ }^{b}$ Grupo de Investigación iPhysio. Universidad San Jorge. Zaragoza. \\ 'Instituto de Lenguas Modernas. Universidad San Jorge. Zaragoza (labruton@usj.es). ${ }^{d}$ MITLHE, \\ Multidisciplinary Innovation in Teaching and Learning. Universidad San Jorge. Zaragoza.
}

\begin{abstract}
In line with current learning theories, teaching in Higher Education increasingly employs approaches and activities that place the learner at the centre of the learning-teaching process. One such approach is gamification: the use of principles normally encountered in games in a non-game context for educational purposes.

This paper considers the use of a gamification activity, Room Escape. The activity is used in the context of the subject General Procedures in Physiotherapy in the Physiotherapy degree programme at Universidad San Jorge. A Case-based Learning approach was adopted and the habitual characteristics of Escape Room activities were adapted to facilitate the desired learning outcomes.

An anonymous, online questionnaire measuring the students perceptions of their learning gains and the efficacy of the activity as a learning tool, was completed by students after the activity.

Results show a positive assessment, particularly in terms of the degree of motivation and effort made by students to complete the task, aspects key to successful learning. Learners recognized that they could have been better prepared for the activity but that it was indeed an activity that facilitated learning with its case-study approach and allowed them to consolidate their understanding of concepts related to the subject.
\end{abstract}

Keywords: gamification; room escape; case-based learning; electrotherapy; physiotherapy 


\begin{abstract}
Resumen
En línea con las teorías de aprendizaje actuales, la enseñanza en la Educación Superior emplea cada vez más enfoques y actividades que sitúan al alumno en el centro del proceso de aprendizaje-enseñanza. Uno de estos enfoques es la gamificación: el uso de principios normalmente encontrados en juegos en un contexto ajeno al juego con fines educativos.

Este trabajo considera el uso de una actividad de gamificación, Room Escape. La actividad se utiliza dentro de la asignatura Procedimientos Generales en Fisioterapia en el Grado de Fisioterapia de la Universidad San Jorge. Se adoptó un enfoque de Aprendizaje Basado en Casos y las características habituales del Room Escape fueron adaptadas para facilitar los resultados de aprendizaje deseados.

Se realizó un cuestionario anónimo online para evaluar las percepciones de los estudiantes sobre sus ganancias de aprendizaje y la eficacia de la actividad como herramienta de aprendizaje.

Los resultados muestran una evaluación positiva, particularmente en términos del grado de motivación y esfuerzo, aspectos clave para el éxito del aprendizaje. Los estudiantes reconocieron que podrían haberse preparado mejor pero que la actividad facilitó el aprendizaje con su enfoque de estudio de casos permitiéndoles consolidar su comprensión de conceptos relacionados con el tema.
\end{abstract}

Palabras clave: gamificación; room escape; aprendizaje basado en casos; electroterapia; fisioterapia

(cc)) EY-NG-ND 2017, Universitat Politècnica de València 


\section{Introducción}

La metodología Room Escape es una forma de gamificación que permite a los participantes involucrarse directamente entre ellos y con los objetivos de aprendizaje de una manera que promueve la comunicación, la delegación, el pensamiento crítico, la atención al detalle y el pensamiento lateral apelando directamente a la motivación intrínseca más que a la motivación extrínseca de los alumnos.

\subsection{Gamificación}

Kapp (Kapp, 2012) define un juego como "un sistema en el que los jugadores se involucran en un desafío abstracto, definido por las reglas, la interactividad y la retroalimentación, que da lugar a un resultado cuantificable que provoca a menudo una reacción emocional".

La gamificación es definida por muchos como una forma de usar los principios del juego (es decir, desafíos, retroalimentación, interactividad) en contextos no comunes (Attali, 2015). Aunque el juego y la diversión a menudo no están asociados con el aprendizaje, muchos aspectos del juego y los propios juegos son muy propicios para el aprendizaje. Por ello, los educadores han visto un aumento en el compromiso y la retención de conocimientos cuando se utilizan juegos (Bruder, 2015).

Para entender mejor la gamificación y sobre todo su uso en el ámbito de la educación es necesario conocer una serie de elementos que suelen estar presentes en la gamificación (Kapp, 2012; Zichermann, 2011) (Fig.1).

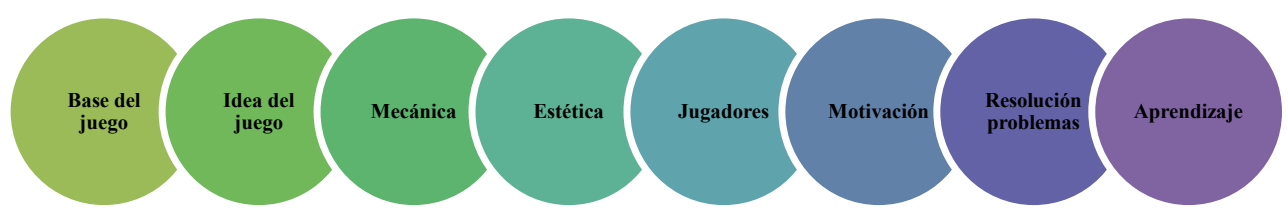

Figura 1. Elementos de la Gamificación

Algunos expertos en juegos utilizan la teoría de la autodeterminación (Ryan, 2000), una teoría de la motivación relacionada con el apoyo a nuestras tendencias naturales o intrínsecas a comportarnos de manera efectiva y saludable, explicándose así cuál es la razón por la cual la gamificación funciona en la educación.

Cuando hablamos de la motivación podemos diferenciar entre la motivación extrínseca y la motivación intrínseca. Hablamos de motivación extrínseca cuando una persona realiza una tarea para lograr un resultado (por ejemplo, un estudiante que estudia para un examen con el fin de obtener una buena calificación). Por el contrario, una persona que realiza una tarea por placer o interés está intrínsecamente motivada. La gamificación se concentra más en satisfacer las necesidades intrínsecas de los estudiantes, proporcionando un feedback inmediato, el control sobre el material y una curiosidad inspiradora (Kapp, 2012). De esta forma, debido a que los estudiantes quieren participar, el conocimiento mejora, al igual que el aprendizaje y el desarrollo. Además, la gamificación ayuda a las personas a aprender haciendo, lo que en última instancia mejora tanto los procesos como los resultados (Shute, 2013) pudiéndose hablar por tanto de un aprendizaje activo (Días, 2017) (Tabla 1).

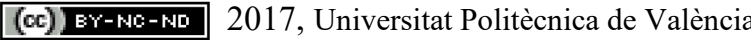


Tabla 1. Principios del Proceso de Gamificación

\begin{tabular}{|c|c|c|c|}
\hline Principio & Descripción & Bases teóricas & Beneficios esperados \\
\hline Orientación & $\begin{array}{c}\text { Participante en el centro } \\
\text { de la experiencia }\end{array}$ & $\begin{array}{l}\text { Autoeficacia, foco de } \\
\text { control }\end{array}$ & $\begin{array}{l}\text { Mayor compromiso, } \\
\text { sentido de control y } \\
\text { autoeficacia }\end{array}$ \\
\hline $\begin{array}{l}\text { Elementos } \\
\text { persuasivos }\end{array}$ & $\begin{array}{l}\text { Basado en teorias } \\
\text { psicológicas y del } \\
\text { comportamiento }\end{array}$ & $\begin{array}{c}\text { Etapas de la teoria del } \\
\text { cambio }\end{array}$ & $\begin{array}{c}\text { Adopción de nuevas } \\
\text { iniciativas e incremento } \\
\text { de satisfacción }\end{array}$ \\
\hline $\begin{array}{l}\text { Orientación en } \\
\text { el aprendizaje }\end{array}$ & $\begin{array}{c}\text { Enfocado en la } \\
\text { adquisición del } \\
\text { conocimiento, desarrollo } \\
\text { de habilidades, } \\
\text { motivación y } \\
\text { comportamiento }\end{array}$ & $\begin{array}{c}\text { Teoría del } \\
\text { comportamiento, } \\
\text { autoeficacia y } \\
\text { aprendizaje } \\
\text { experiencial }\end{array}$ & $\begin{array}{c}\text { Desarrollo de } \\
\text { capacidades y recursos } \\
\text { personales y } \\
\text { organizativos }\end{array}$ \\
\hline $\begin{array}{l}\text { Recompensa } \\
\text { por logros }\end{array}$ & $\begin{array}{c}\text { Enfoque en el retorno de } \\
\text { la inversión justificable y } \\
\text { previsible }\end{array}$ & $\begin{array}{c}\text { Teoría del } \\
\text { comportamiento y } \\
\text { aprendizaje } \\
\text { experiencial }\end{array}$ & $\begin{array}{c}\text { Aumento de la } \\
\text { satisfacción personal }\end{array}$ \\
\hline $\begin{array}{l}\text { Experiencia de } \\
\text { trabajo }\end{array}$ & $\begin{array}{c}\text { Experiencias de apoyo, } \\
\text { divertidas y atractivas }\end{array}$ & $\begin{array}{l}\text { Jerarquia de } \\
\text { necesidades }\end{array}$ & Adquisición y retención \\
\hline $\begin{array}{l}\text { Factores de } \\
\text { diversion }\end{array}$ & $\begin{array}{l}\text { Inclusión de elementos de } \\
\text { humor, juego y diversión }\end{array}$ & $\begin{array}{c}\text { Teoría del aprendizaje } \\
\text { social }\end{array}$ & $\begin{array}{c}\text { Aumento de la } \\
\text { satisfacción personal y } \\
\text { el bienestar }\end{array}$ \\
\hline Transformación & $\begin{array}{l}\text { Combinación de } \\
\text { colaboración y } \\
\text { competición }\end{array}$ & $\begin{array}{c}\text { Teoria del liderazgo y } \\
\text { del equipo }\end{array}$ & $\begin{array}{l}\text { Estimulo de la } \\
\text { productividad }\end{array}$ \\
\hline Orientación & $\begin{array}{c}\text { Bienestar social y } \\
\text { organizativo }\end{array}$ & $\begin{array}{l}\text { Autocompetencia y } \\
\text { comportamiento } \\
\text { organizativo }\end{array}$ & $\begin{array}{l}\text { Aumento del bienestar } \\
\text { personal y organizativo }\end{array}$ \\
\hline Investigación & $\begin{array}{l}\text { Investigación } \\
\text { colaborativa }\end{array}$ & $\begin{array}{l}\text { Evaluación } \\
\text { necesidades } \\
\text { organizativas }\end{array}$ & $\begin{array}{c}\text { Supervisión y toma de } \\
\text { decisiones }\end{array}$ \\
\hline Conocimiento & $\begin{array}{l}\text { Basado en el } \\
\text { conocimiento ya sea } \\
\text { como resultado o como } \\
\text { retroalimentación }\end{array}$ & $\begin{array}{c}\text { Entrenamiento } \\
\text { organizativo, } \\
\text { aprendizaje adulto }\end{array}$ & $\begin{array}{c}\text { Desarrollo personal, } \\
\text { capacidades } \\
\text { organizativas y } \\
\text { recursos }\end{array}$ \\
\hline
\end{tabular}

\subsection{Room Escape}

Las salas de escape (Room Escape) son una forma relativamente reciente de gamificación que posiblemente tienen sus raíces en juegos tales como dragones y mazmorras o la caza del tesoro. Según Nicholson (Nicholson, 2015), las salas de escape son juegos de acción en 
vivo donde los jugadores descubren pistas, resuelven rompecabezas y realizan tareas en una o más habitaciones con el fin de alcanzar una meta específica (por lo general escapando de la habitación) en una cantidad limitada de tiempo.

La experiencia del Room Escape comienza cuando los jugadores conocen a su Game Master (conductor del juego) que les resume al inicio lo que va a suceder durante la siguiente hora dándoles las reglas para el juego. Si hay una historia de fondo, los jugadores pueden ver previamente un video o recibir un fragmento de texto para leer.

Una vez que comienza el juego la puerta se cierra y permanece bloqueada a la vez que comienza un reloj de cuenta regresiva. Es entonces cuando los jugadores exploran la sala en busca de pistas ocultas de tal forma que en algún momento se descubre un rompecabezas o un enigma debiendo averiguar cómo se puede resolver. La solución a este enigma conducirá a algo más, tal vez un código para un candado, por ejemplo. El equipo sigue trabajando en los distintos retos compartiendo información sobre lo que se encuentra. El rompecabezas final proporciona la llave para abrir la puerta y "escapar" de la habitación.

\subsection{Aprendizaje Basado en Casos}

El Aprendizaje Basado en Casos (Case-based Learning; CBL) es un enfoque educativo donde los estudiantes trabajan en pequeños grupos colaborativos para resolver problemas que se presentan en contextos similares a aquellos en los que es probable que se encuentren en la práctica profesional (Crawford, 2011). En este tipo de metodología el alumno es el responsable de identificar las necesidades relacionadas con el caso y a partir de ello, proponer posibles soluciones mediante exploración, colaboración, análisis y discusión (Hmelo-Silver, 2004).

\section{Objetivos}

\subsection{Objetivo principal}

El objetivo principal del presente estudio fue determinar los efectos de la actividad Room Escape, fundamentada en la metodología Aprendizaje Basado en Casos, en el aprendizaje de los estudiantes universitarios de la asignatura Procedimientos Generales de Fisioterapia 1 mediante sus propias percepciones expresadas en los resultados de un cuestionario.

\subsection{Objetivos específicos}

Los objetivos específicos tratan de conocer la percepción de los usuarios del impacto de la actividad en las siguientes áreas:

- Destrezas de aprendizaje (aplicación de conocimientos, adquisición e integración de conceptos, etc.).

- Factores intrínsecos al aprendizaje (seguridad, motivación, esfuerzo, etc.).

\subsection{Objetivos de aprendizaje de la actividad}

A través de la actividad se pretende fomentar las siguientes competencias:

- Aplicar conocimientos específicos del contenido desarrollado en la asignatura Procedimientos Generales de Fisioterapia 1.

- Analizar casos clínicos con la intención de comprender y plantear un tratamiento fisioterapéutico de forma práctica desde el punto de vista de la fisioterapia. 
- Adquirir y desarrollar competencias profesionales a través de la recreación de un contexto clínico real.

- Trabajar dentro de un equipo participando de forma colaborativa aportando conocimientos e ideas para la resolución de la actividad propuesta.

- Tomar conciencia del nivel de asimilación de conceptos y potenciar el espíritu de superación.

\section{Metodología/Desarrollo de la innovación}

\subsection{Participantes}

La experiencia tuvo lugar en el primer semestre del curso académico 2016-2017 con los alumnos matriculados en la asignatura Procedimientos Generales de Fisioterapia 1 del $2^{\circ}$ curso del Grado de Fisioterapia de la Universidad San Jorge.

\subsection{Descripción de la preparación de la actividad Room Escape PGF-1}

Para la realización de la actividad Room Escape se procedió a realizar una adaptación de este tipo de actividad para que se pudiera aplicar a la asignatura PGF-1 siguiendo los principios de la gamificación en el aula anteriormente descritos.

A continuación se muestran las diferencias y similitudes fundamentales entre el Room Escape "clásico" y el Room Escape "adaptado" (Tabla 2).

Tabla 2. Comparativa Room Escape "clásico" y Room Escape "adaptado"

\begin{tabular}{ccc}
\hline & Room Escape Clásico & Room Escape Adaptado \\
\hline Temático & No temático & Temático \\
Número de participantes & Limitado; Pequeño & Limitado; Grupo de prácticas \\
Espacio & No compartido & Compartido \\
Duración & Entre 60 y 90 minutos & Máximo 60 minutos \\
Game Master & $\mathrm{Si}$ & $\mathrm{Si}$ \\
Fundamento & Actividad de entretenimiento & Actividad de gamificación \\
Conocimiento previos & No necesarios & Necesarios \\
\hline
\end{tabular}

Una de las diferencias más importantes entre ambas actividades es que en el Room Escape "adaptado" la clave para conseguir escapar del aula está directamente relacionada con la preparación previa de la materia del área temática de la asignatura, además de la capacidad de lógica, observación y deducción de los alumnos.

Siguiendo la propuesta planteada para la realización del Room Escape para la asignatura Procedimientos Generales de Fisioterapia I (PGF-1), las docentes prepararon un vídeo (material digital) introductorio para describir el objetivo y la normativa de la actividad a la vez que se buscaba motivar a los alumnos (Fig. 2). 


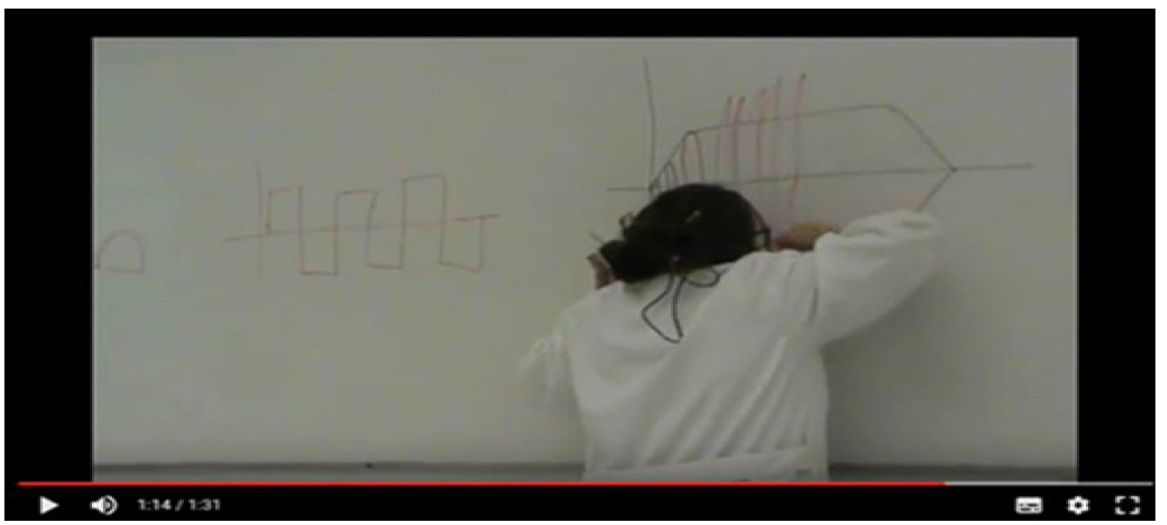

Figura 2. Video-Presentación del Room Escape PGF-1

Para la resolución de los casos clínicos se desarrollaron pruebas relacionadas entre sí que incluían puzles, rompecabezas, acertijos y diferentes cuestiones empleando materiales como cajas, candados, cinchas, ordenadores y aparatos de electroterapia entre otros (Fig. 3).

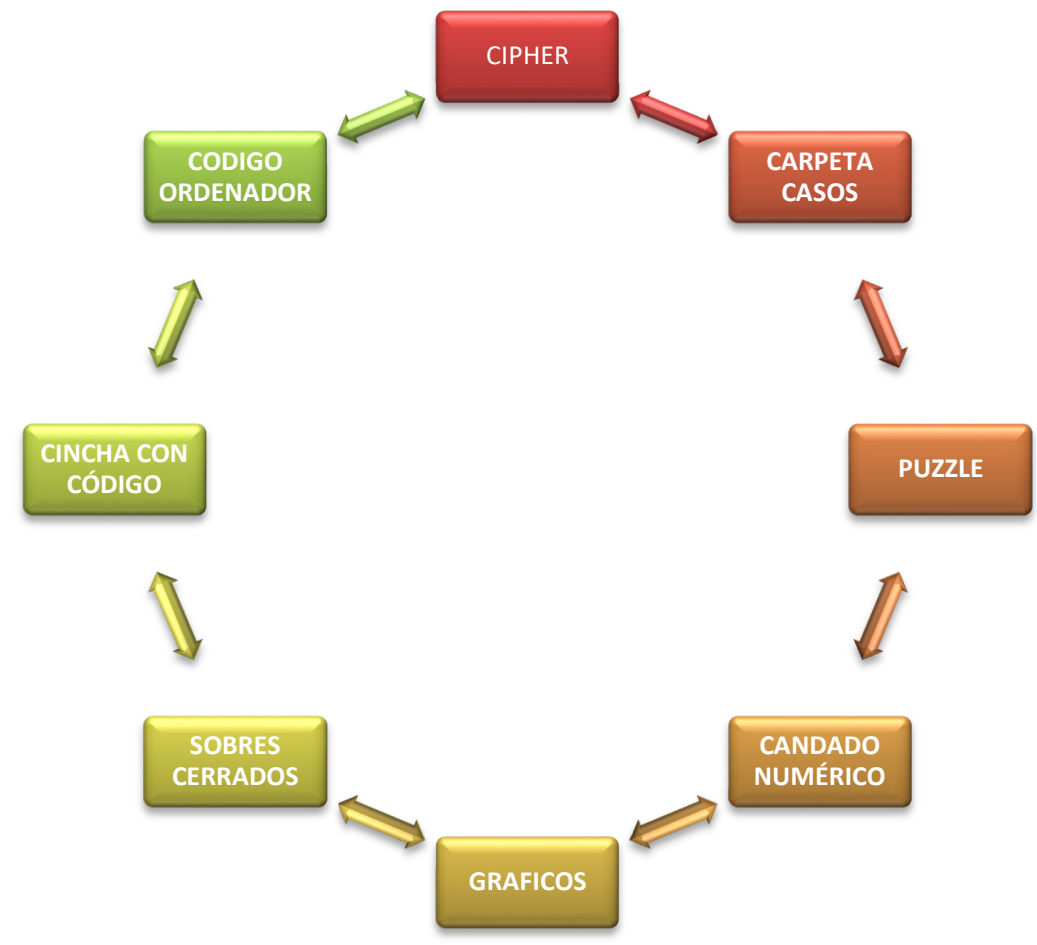

Figura 3. Pruebas del Room Escape PGF-1

Como material de trabajo se elaboraron siete casos clínicos directamente relacionados con el tratamiento mediante electroterapia, área de conocimiento propio de la asignatura PGF-1 (Fig. 4). 


\section{Caso 1}

Juan se dio un golpetazo en el hombro derecho hace 2 días. ¡Que torpe! Va al arreglahuesos que le dice que lleva algo inflamado en el tendón ese que siempre se lesiona tanto... ¿Cómo se llamaba? Me suena algo de supra y espinoso...

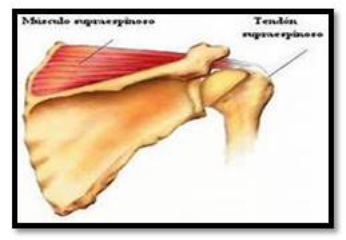

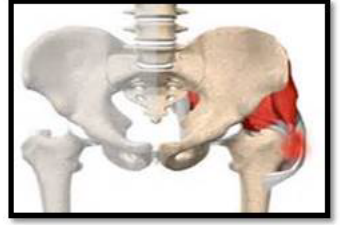

Caso 2

Lucia viene a mi centro porque tiene inflamada la parte externa de la cadera izquierda desde hace una semana (que me lo he apuntado muy bien esta vez en su ficha). ¡Creo que lo que tiene es eso que se llama bursitis trocantérea!

Caso 3

Viene un chico de mi pueblo que tiene en la mano derecha una contusión sobre una cicatriz. ¡Ah! ¡A ver que se os ocurre hacer con esta tan zona superficial y pequeña!

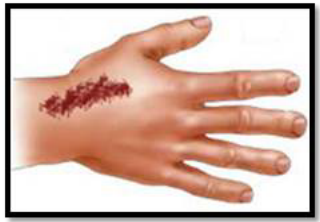

\section{Caso 4}

Un chaval del equipo de futbol del barrio ha venido con un super esguince en el tobillo izquierdo. ¡Y lleva un mes así! Dice que le duele y lo lleva muy hinchado. Buff, ¿qué le pondríais a este chico? A lo mejor tenéis unas gráficas de formas de onda que os ayudan...

\section{Caso 5}

Lola es una paciente que viene a darme guerra de vez en cuando porque le duele la espalda baja desde hace muuchooooo tiempo. ¿Cómo ayudo yo a esta mujer para quitarle ese dolor?

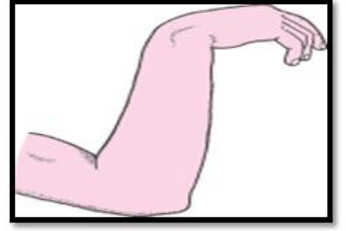

Caso 6

Mi vecino Luis sufrió una fractura de húmero con la mala suerte que se lesionó también un nervio del brazo. ¡Ese que sube la mano y los dedos para arriba! Ahora parece que tiene la mano derecha caída. ¿Cómo le ayudo yo? Había unas curvas para diagnosticar y tratar...

\section{Caso 7}

Pablo es un policía que viene a la consulta tres días a la semana desde hace tres semanas. Presenta atrofia en el vasto interno tras una cirugía meniscal. Comenta que nota fatiga muy rápidamente al hacer cualquier actividad que implique resistencia de las extremidades inferiores. ¿Cómo puedo ayudarle? Código: 4narAnl2try4PgfÑL84yd65e0MyNDd3

Laura es una señora que ha estado en la Unidad de Cuidados Intensivos (UCI) durante muchos meses porque tuvo un accidente de tráfico. Tiene importante debilidad en las extremidades inferiores y aún no es capaz de mantenerse sentada ni ponerse en pie. Llevo dos días trabajando con ella. ¡Espero poder ayudarla! Código: 784nafNAOen4932arIR5Nfd5138kair

Julio es un deportista que practica halterofilia y que quiere aumentar el tamaño de las fibras musculares rápidas explosivas. ¿Puedo ayudarle a conseguirlo? Código: XPt4gjorq934oiaFALKrRRkiM89nws 


\subsection{Procedimiento/Implementación Room Escape PGF-1}

Dentro de la organización general de la asignatura PGF-1, los alumnos estaban divididos en grupos de trabajo reducidos para la ejecución de las clases prácticas, con un máximo de 14 alumnos por grupo. Cada grupo tenía un horario y un día de la semana definido para estas clases prácticas con un docente responsable. Fue en la última clase práctica donde se realizó la actividad Room Escape PGF-1 para la cual se procedió a dividir cada uno de estos grupos de prácticas en dos equipos equitativos que iban a competir entre ellos para ser el primer equipo en "salir de la habitación" (Fig. 5).

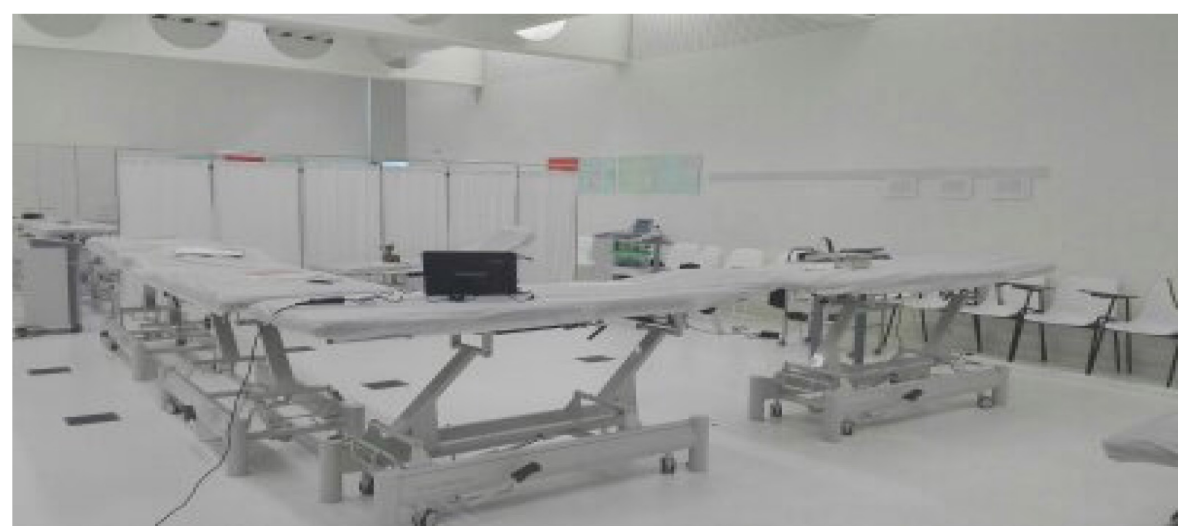

Figura 5. Sala Room Escape PGF-1

En los días previos a su realización, se instó a los alumnos a revisar la documentación sobre el bloque de electroterapia, pudiendo dividirse la preparación de la materia entre los componentes de cada equipo.

La actividad se llevó a cabo en el aula habilitada para la realización de clases prácticas donde el espacio se separó en dos áreas mediante el empleo de biombos y camillas. En cada uno de los espacios se "encerraba" a los alumnos de cada equipo sin que pudieran tener contacto con el otro equipo teniendo todo el material necesario para realizar la actividad.

Antes de comenzar la actividad, se puso el video explicativo para contextualizar la situación creando el ambiente adecuado. En él, la vieja y alocada profesora de electroterapia que interviene en la última práctica, les explica que están encerrados en el aula porque disfruta haciendo pensar a los alumnos obligándoles así a integrar y aplicar los conceptos aprendidos en la asignatura PGF-1 a través de enigmas...

Posteriormente comenzó a "correr" el tiempo en el que cada equipo, de forma cooperativa, debía resolver los siete casos clínicos anteriormente descritos a través de la resolución de las distintas pruebas. El Room Master (docente) les animó en todo momento a trabajar siempre en equipo, explorando el espacio y los materiales existentes a su alrededor y aprovechando el tiempo al máximo entre todos los integrantes. De esta forma, sería más fácil relacionar las distintas pistas encontradas con los casos clínicos para poder resolverlos en el menor tiempo posible y así obtener la llave del aula para "escapar" (Fig. 6). 


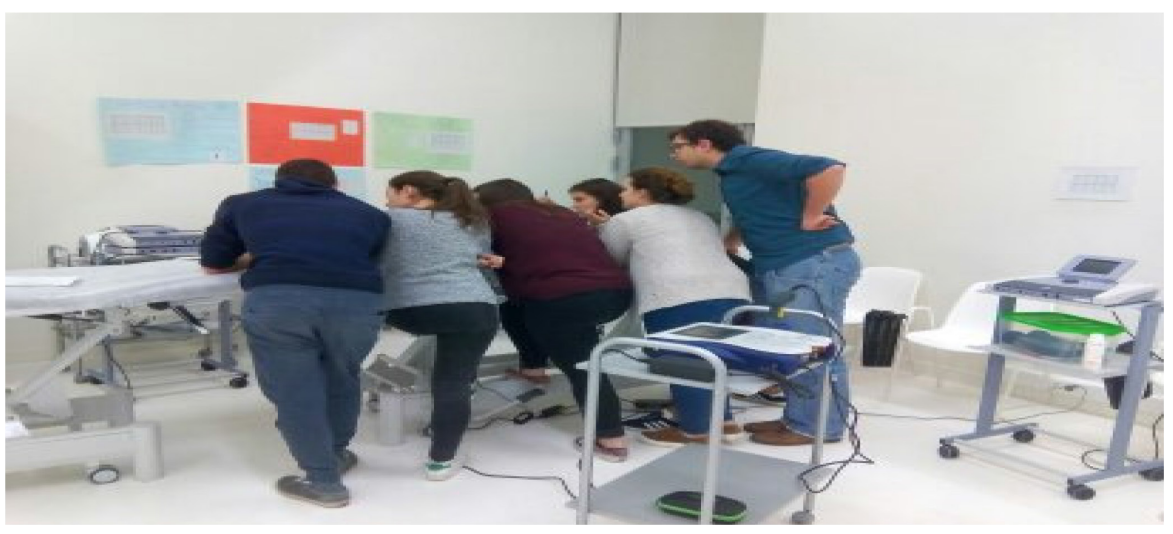

Figura 6. Desarrollo Room Escape PGF-1

Una opción disponible en caso de necesidad era la consulta de la documentación del bloque de electroterapia. El equipo que solicitase dicha información tenía 1 minuto de consulta teniendo el hándicap de reducir 5 minutos su tiempo restante. Asimismo, en caso de error en algunas pruebas, también se les descontaba esa cantidad de tiempo.

La duración máxima de la actividad era de 60 minutos siendo el equipo ganador aquel que logrará "escapar" antes del aula consiguiendo un premio simbólico ambos equipos.

\subsection{Instrumento de evaluación}

Se diseñó un cuestionario anónimo en línea con el objetivo de solicitar a los estudiantes que reflexionaran sobre sus propios hábitos de estudio, grado de motivación e interés con el propósito de sensibilizar a los estudiantes sobre su papel en el proceso de aprendizaje. Dentro del cuestionario había secciones que consideraban las diversas actividades y metodologías utilizadas en la asignatura pidiendo a los estudiantes que estimaran el impacto de cada una sobre su aprendizaje. La evaluación de cada ítem se realizó mediante una escala de Likert de 0 a 10, siendo 0 "estoy totalmente en desacuerdo/nunca" y 10 "estoy completamente de acuerdo/siempre.

Para los fines de este estudio, solo se tuvieron en cuenta las respuestas a las preguntas relativas a la actividad Room Escape. En ellas se solicitaba información sobre la utilidad de la actividad para resolver casos clínicos, aplicar los conocimientos de la asignatura y comprobar la comprensión de los conceptos de la asignatura. También se les preguntó sobre el impacto de dicha actividad sobre su confianza, motivación, esfuerzo realizado en la actividad, ayuda en la comprensión de la materia y ayuda en la relación de conceptos de la asignatura. Finalmente se les preguntó sobre la preparación previa de la actividad, si la habían preparado o no y si consideraban que era necesario habérsela preparado previamente y se pidió una valoración global de la actividad.

\section{Resultados}

79 estudiantes contestaron a la encuesta, 39 varones $(49.4 \%)$ de edad media 21.00 (SD 4.35).

La figura 7 muestra el impacto que consideraron los estudiantes que tuvo la actividad en adquirir destrezas de aprendizaje en relación a la resolución de casos clínicos, aplicar los 
conocimientos de la asignatura y comprobar la compresión de los conceptos de la asignatura. Si bien los tres aspectos fueron positivamente valorados por los estudiantes (el $75 \%$ de los estudiantes asignaron una puntuación igual o superior a 5 en los tres ítems), el $50 \%$ de los estudiantes puntuó con una superior a 8 el ítem "aplicar los conocimientos de la asignatura". Los valores de la puntuación del ítem "comprobar la compresión de los conceptos de la asignatura" fueron superiores a los de los otros dos ítems.

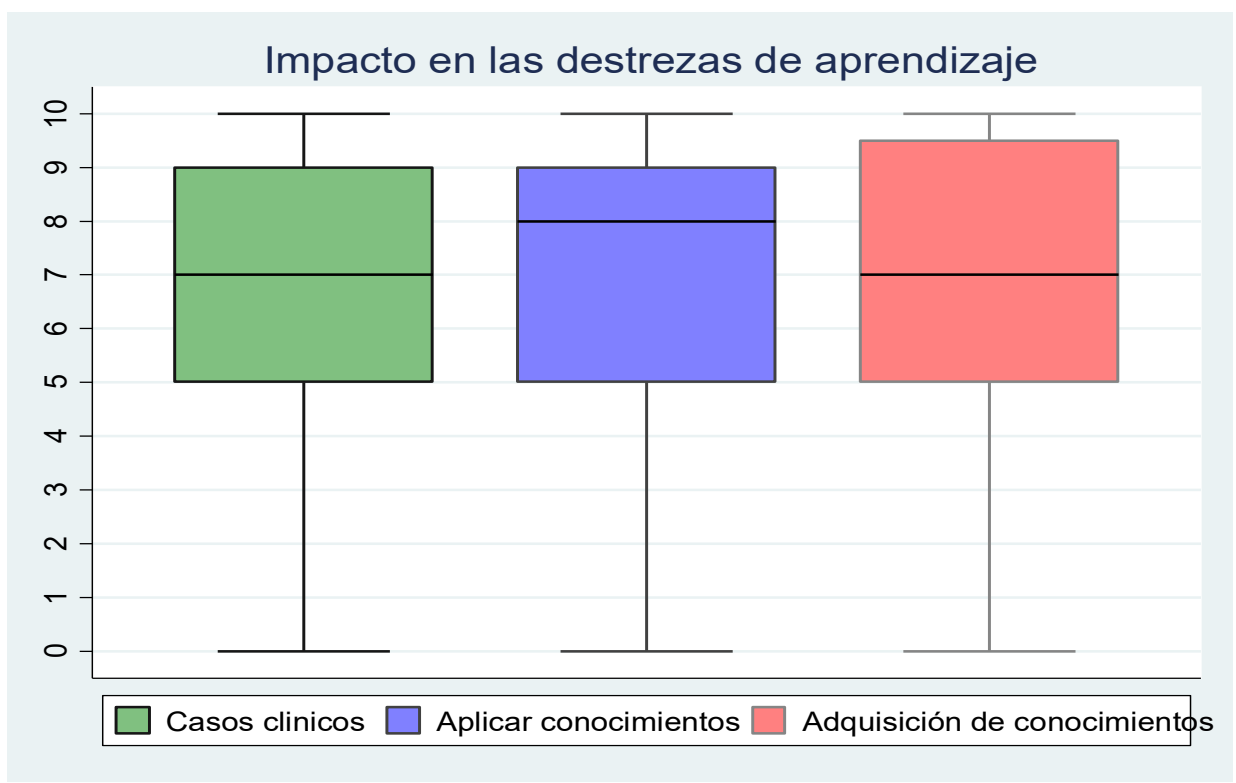

Figura 7. Diagrama de caja de la percepción de la actividad "Room Escape” sobre las destrezas de aprendizaje

La percepción sobre el impacto sobre los factores intrínsecos del aprendizaje se describe en la figura 8 . Si bien todos los factores fueron valorados positivamente por los estudiantes, la actividad no supuso un aumento considerable en la confianza del estudiante en poder superar la asignatura. El resto de factores fue igualmente valorado por los estudiantes (el $75 \%$ de los estudiantes asignaron una puntuación igual o superior a 5 en los tres ítems), si bien se valoraron la motivación/interés por estudiar la asignatura y el esfuerzo personal empleado en la actividad con una puntuación ligeramente superior a la ayuda en la comprensión de la materia y la ayuda en la relación de conceptos de la asignatura.

$\mathrm{Al}$ comparar entre el trabajo previo realizado por los estudiantes para realizar la actividad y la percepción de la necesidad de preparar previamente la asignatura (figura 9), los alumnos mostraron una baja preparación de la actividad (el 50\% puntuó la pregunta igual o inferior a un 5 y el $75 \%$ igual o inferior a un 6) y por el contrario percibieron que era necesario hacer un trabajo previo para participar en la actividad (el 75\% puntuó la pregunta igual o superior a un 5 y el $50 \%$ igual o superior a un 8 ). 


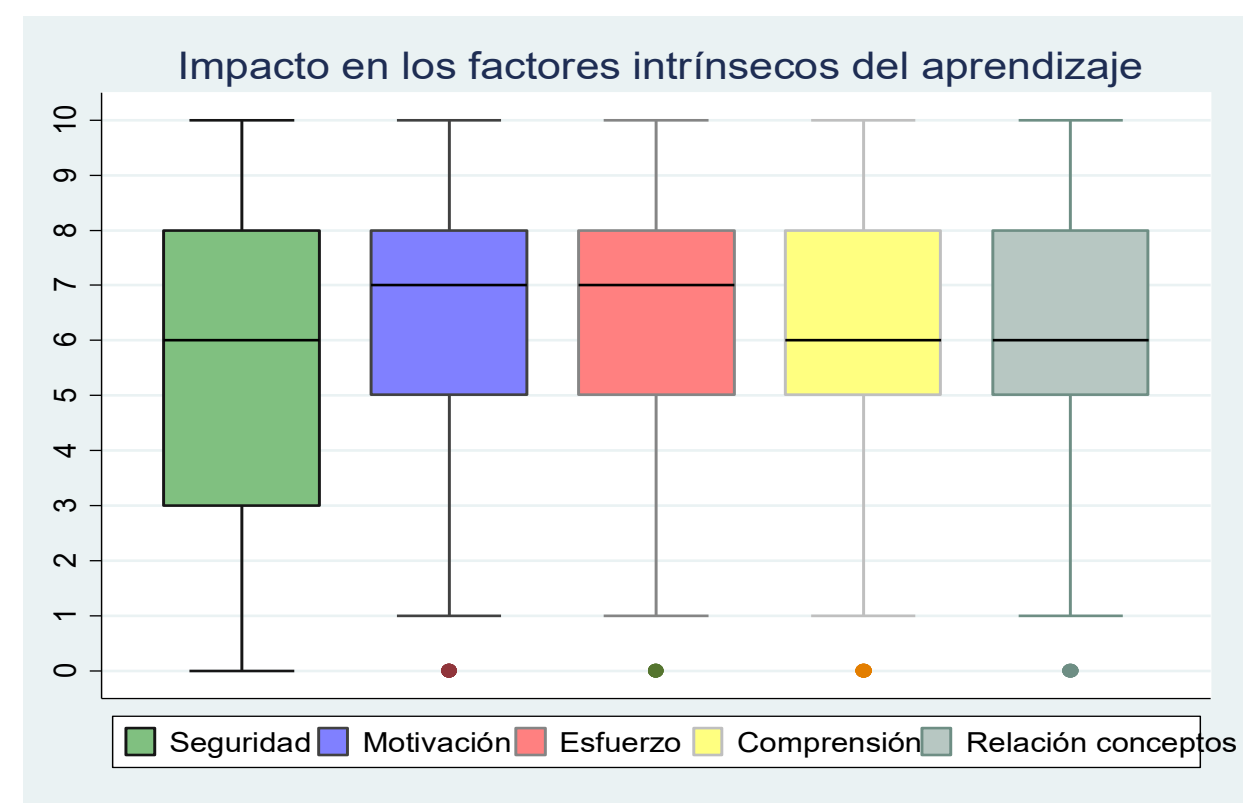

Figura 8. Diagrama de caja de la percepción de la actividad "Room Escape" sobre los factores intrínsecos del aprendizaje

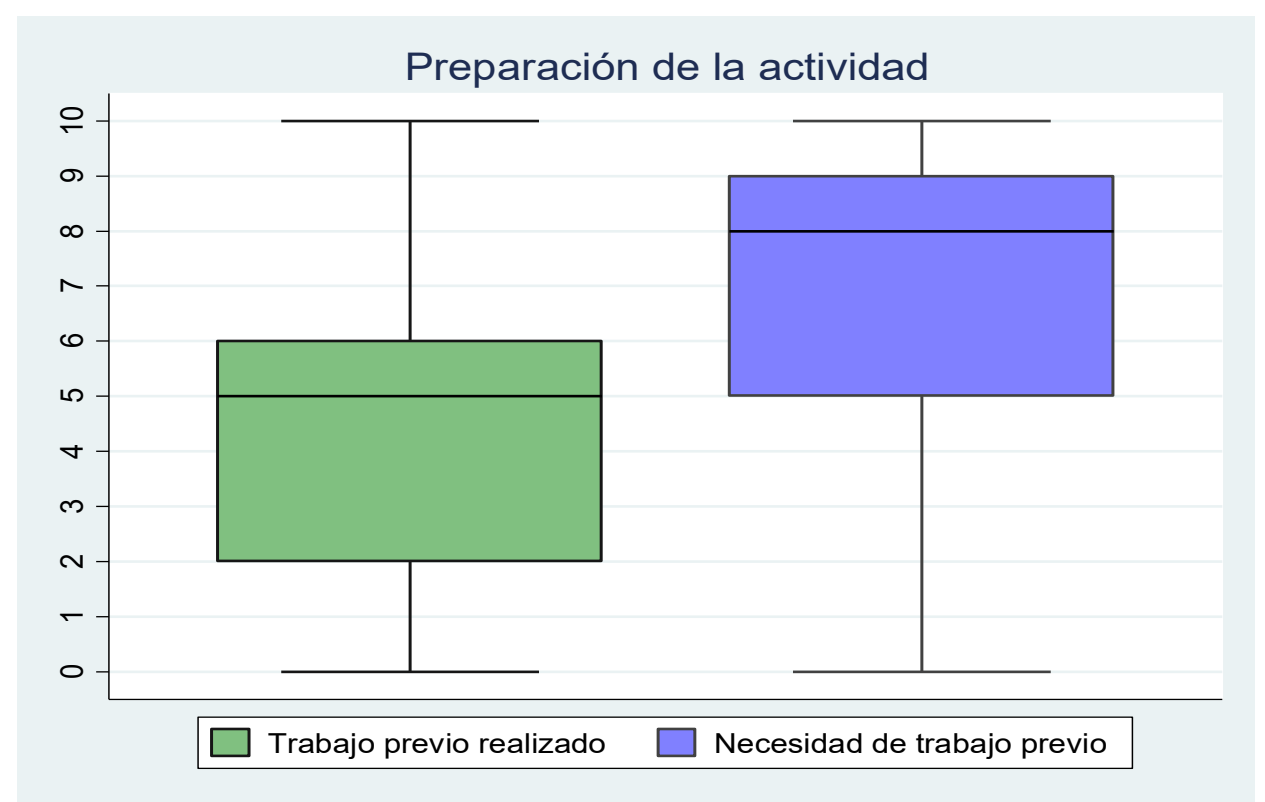

Figura 9. Diagrama de caja donde se describe la preparación previa de la actividad realizada por los estudiantes y la percepción de la necesidad de realizar un trabajo previo para realizar la actividad

Al hacer la valoración global de la actividad, el 75\% de los alumnos asignó una puntuación mayor o igual a 4 , el $50 \%$ de los alumnos asignó una puntuación mayor o igual a 6 y el 25\% de los alumnos asignó una puntuación mayor o igual a 8. 


\section{Conclusiones}

Si se analizan los datos obtenidos sobre el impacto de las destrezas del aprendizaje evaluadas (resolución de casos clínicos y aplicación y adquisición de conocimientos), encontramos una alta valoración percibida por parte de los alumnos con respecto a dicha actividad, destacando ligeramente los dos últimos. Habría que valorar por qué la resolución de casos clínicos fue ligeramente menos valorada ya que la actividad estaba planteada con los casos clínicos como hilo conductor, debiendo dar una solución de tratamiento en cada caso clínico y además programar los parámetros de tratamiento en los aparatos de electroterapia.

A la vista de los resultados, cabe destacar el impacto positivo en los factores motivación y esfuerzo respecto a los factores intrínsecos del aprendizaje evaluados. Esto puede estar directamente relacionado con que la actividad Room Escape es un juego de acción en vivo que tiene lugar en el mundo físico, creando oportunidades para que los jugadores se involucren directamente entre sí en búsqueda de forma colaborativa de una solución a las cuestiones planteadas. La repercusión sobre la percepción como ayuda en la comprensión de la materia y ayuda en la relación de conceptos de la asignatura fue similar a los dos ítems previos lo que puede deberse a que la actividad planteada abarcaba e intentaba relacionar todo el temario de la materia. Faltaría dilucidar por qué algunos alumnos mostraron puntuaciones menores en la seguridad para poder sacar la asignatura.

Los alumnos percibieron claramente la necesidad de realizar un trabajo previo para poder realizar la actividad y admitieron en general no haber hecho un trabajo previo adecuado. Esto nos conduce a dos conclusiones. Por un lado, la necesidad de establecer acciones de motivación previas a las actividades adicionales. A los estudiantes se les indicó que era necesario un trabajo previo para realizar la actividad y se les indicó que no tenían que estudiarse todo el temario sino repartirse los temas entre ellos, pero no percibieron esa realidad previamente a la realización de la actividad. Consideramos que con un trabajo previo mayor los alumnos podrían valorar de forma aún más positiva la actividad sobre los ítems previamente comentados (destrezas y factores intrínsecos del aprendizaje) y sobre la valoración global de la actividad.

Por otro lado, para futuras ocasiones, sería conveniente realizar una evaluación más completa de las competencias desarrolladas durante la actividad que incluyera no sólo la autoevaluación sino la coevaluación y la heteroevaluación. De esta forma se obtendrían datos más objetivos, fiables y completos de la efectividad del Room Escape como actividad pedagógica.

La resolución de casos dentro de la actividad Room Escape requiere un estudio y análisis de la materia además del desarrollo de pensamiento crítico y lateral y atención al detalle, todo ello clave para el desarrollo de las competencias de la vida académica y profesional. 
Todos estos resultados nos permiten concluir que la actividad de gamificación Room Escape dentro de la asignatura Procedimientos Generales de Fisioterapia 1 puede ayudar a los estudiantes a:

- Estimular la motivación y el entusiasmo para aprender.

- Identificar sus propias fortalezas y debilidades.

- Proporcionar resultados y retroalimentación que mejoren el conocimiento de sí mismos.

- Facilitar el desarrollo de competencias profesionales que les preparen para la vida laboral.

\section{Referencias}

ATTALI, Y. y ARIELI-ATTALI, M. (2015). "Gamification in assessment: Do points affect test performance?" Computers \& Education, vol. 83, p. 57-63.

BOGOST, I. (2008). "The rhetoric of video games". In K. Salen (Ed.), The ecology of games: Connecting youth, games, and learning. Cambridge, MA: The MIT Press: p. 117- 140.

BRUDER, P. (2015). "Game on: Gamification in the classroom". The Education Digest, vol. 3, p.5660.

BRULL,S. y FINLAYSON, S. (2016). "The Importance of Gamification in increasing Learning". Journal of Continuous Education in Nursing, vol. 47, issue 8, p. 372-375.

COOK, W. (2013). "Five reasons you can't ignore gamification". Chief Learning Officer Magazine, vol.5, issue 8. Retrieved from http://www. clomedia.com/2013/05/08/five-reasons-you-cant-ignoregamifica $\neg$ tion/ [20/03/2017].

CRAWFORD, TR. (2011). "Using problem-based learning in web-based components of nurse education". Nurse Educ Pract, vol.11, issue 2, p. 124-130.

DIAS, J. (2017). "Teaching operations research to undergraduate management students: The role of gamification". The International Journal of Management Education, vol. 15, p. 98-111.

HMELO-SILVER, CE. (2004). "Problem-Based Learning: What and How Do Students Learn?" Educational Psychology Review, vol. 16, issue 3, p. 235-266.

KAPP, K. (2012). "The gamification of learning and instruction: game-based methods and strategies for training and education". San Francisco, CA: Pfeifler.

NICHOLSON, S. (2015). "Peeking behind the locked door. A survey of escape room facilities". White paper retrieved from: http://scottnicholson.com/pubs/erfacwhite.pdf [20/03/2017].

OPRESCU, F., JONES, C., KATSIKITIS, M. (2014). "I play at work- ten principles for transforming work processes through gamification”. Frontiers in Psychology, vol. 5, p. 1-5.

RANDEL, J.M., MORRIS, B.A., WETZEL, C.D., WHITEHILL, B.V. (1992). "The effectiveness of games for educational purposes: A review of recent research". Simulation and Gaming, vol. 23, p. 261-276. 
RYAN, RM., y DECI, EL. (2000). "Intrinsic and extrinsic motivations: Classic definitions and new directions". Contemporary Educational Psychology, vol. 25, p. 54-67.

SHUTE, VJ., y VENTURA, M. (2013). "Stealth assessment: Measuring and supporting learning in games”. Cambridge, MA: Massachusetts Institute of Technology Press Books.

ZICHERMANN, G. y CUNNINGHAM, C. (2011). "Gamification by Design: Implementing Game Mechanics in Web and Mobile Apps”. Cambridge, MA: O’Reilly Media.

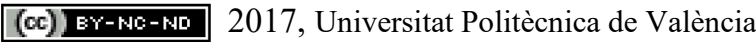




\title{
Comparativa de Dos Técnicas Basadas en Roles para el Desarrollo de Software desde una Perspectiva Industrial
}

\author{
Silvia Rueda Pascual ${ }^{1}$, Juan Cabotá i Soro ${ }^{1}$, Jose Ignacio Panach Navarrete ${ }^{1}$, Javier \\ Martínez Plume $^{2}$, Mariano Pérez Martínez ${ }^{1}$, Sergio Casas Yrurzum ${ }^{2}$ \\ ${ }^{1}$ Departament d'Informàtica, Escola Tècnica Superior D'Enginyeria, Universitat de València, 46100, \\ Burjassot, Valencia. \\ ${ }^{2}$ Instituto de Robótica y de las TICs. Parque Científico, Universitat de València, C/ Catedrático José \\ Beltrán 2, 46980, Paterna, Valencia. \\ \{silvia.rueda,juan.cabota,j.ignacio.panach,javier.martinez-plume, mariano.perez,sergio.casas\}@uv.es
}

\begin{abstract}
Both the degree in Telematic Engineering and the degree in Multimedia Engineering have a subject of Software Engineering. One competence of this subject is to train students as professionals for the real world. For this aim, we have applied two versions of a role-playing game where there are both clients, who ask for a system development project, and developers. In the degree in Telematic Ingineering, the teacher plays the role of client, while students play the role of developers. Regarding the degree of Multimedia Engineering, students play both the role of client and developer at the same time (for different projects). In this paper, we tackle both experiences and we show a comparative of results. For Telematic Engineering, we ensure that the workload is the same for all the students. Moreover, the teacher can control directly the work of the students since he/she knows perfectly the project that needs to be developed. Regarding Multimedia Engineering, we try to enhance the students' creativity since they must devise themselves a project to develop. Moreover, the students learn how to develop both roles, which can be useful for the real world.
\end{abstract}

Keywords: role-playing, software engineering, software projects

\section{Resumen}

Dentro de los grados de Ingeniería Telemática e Ingeniería Multimedia se imparte la asignatura de Ingeniería del Software. Una de las competencias de esta asignatura es formar a los alumnos como profesionales para el mundo real. Para ello, hemos aplicado dos variantes de un juego de rol donde hay clientes, que solicitan un proyecto informático, y desarrolladores. En el Grado de Ingeniería Telemática (GIT), el rol de usuario final lo tomaba un único profesor, mientras que los usuarios jugaban el rol de desarrolladores. En el Grado de Ingeniería Multimedia (GIM), los estudiantes jugaban a la vez el rol de cliente y de desarrolladores (para proyectos distintos). En este artículo se abordan ambas experiencias y se presenta una comparativa de los resultados obtenidos con ellas. En el caso de GIT se garantiza que la carga de trabajo es para todos los estudiantes la misma. Además, el profesor puede llevar un seguimiento más directo al 
conocer de primera mano el caso a desarrollar. En el caso de GIM se potencia la creatividad de los alumnos, ya que deben inventarse el proyecto a desarrollar. Además, los alumnos aprenden a desempeñar dos roles que les pueden ser útiles en el mundo real.

Palabras clave: juego de roles, ingeniería del software, proyectos software

\section{Introducción}

Una de las competencias del Grado de Ingeniería Telemática (GIT) y del Grado de Ingeniería Multimedia (GIM) de la Universidad de Valencia es la de formar a profesionales que se incorporen al mundo profesional como analistas de sistemas para el desarrollo software. En la asignatura de Ingeniería del Software, presente en ambas titulaciones, se imparten conocimientos sobre el desarrollo software. Normalmente, se suele partir de problemas que se presentan a los alumnos por escrito, donde vienen todos los requisitos especificados de forma inequívoca y detallada. Esta forma de proceder es cómoda tanto para los alumnos como para el profesorado porque se sabe a qué atenerse a la hora de desarrollar un sistema. Sin embargo, es muy poco realista. En el mundo real, los analistas se basan en entrevistas con los clientes a través de las cuales extraen los requisitos de forma oral. Las especificaciones de requisitos escritas son desarrolladas por los propios analistas tras varias entrevistas con el cliente.

Existen trabajos previos que han abordado estudios sobre qué técnicas son mejores para impartir la asignatura de Ingeniería del Software. Uno de estos trabajos es el desarrollado por Beecham et al. [4]. Según este trabajo, la preparación, la docencia y la evaluación del trabajo del alumno en entornos educativos de ingeniería del software requiere mucho esfuerzo y estrategia por parte del docente si los comparamos con otras asignaturas. Según Beecham et al., simulaciones del mundo real que estén bien diseñadas pueden servir para mostrar a los alumnos cómo funcionan los proyectos de desarrollo reales.

Siguiendo esta filosofía, durante el curso 2015-2016 pusimos en práctica un juego de rol en la asignatura de Ingeniería del Software en la titulación GIT. En [5] se publicaron los resultados iniciales obtenidos durante esa primera experiencia. De forma resumida, las conclusiones fueron que el juego de roles hacía que los estudiantes obtuvieran menos requisitos de los que realmente existían, pero la calidad respecto a la corrección de la especificación era mejor con el juego de roles.

Para contrastar estas ideas, durante el curso 2016-2017 hemos puesto en marcha una replicación de esta idea en GIT y GIM. Según los trabajos de Basili [3], son necesarias varias replicaciones de la misma experiencia para obtener resultados significativos. La replicación en GIT ha sido exactamente igual que la utilizada en el curso 2015-2016, mientras que en la titulación GIM se ha modificado. En ambas titulaciones la propuesta está basada en la existencia de dos roles: (1) cliente, que es la persona que solicita el desarrollo de un proyecto informático; (2) desarrollador, que es la persona que extrae los requisitos del cliente y lleva a cabo el desarrollo. Las diferencias a la hora de aplicar el juego de roles en cada una de las titulaciones es la siguiente:

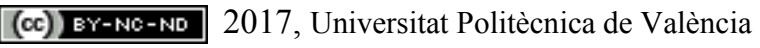

Congreso IN-RED (2017) 
- GIT: en esta titulación el rol de cliente lo ha jugado un único profesor, de forma que todos los estudiantes han desarrollado el mismo proyecto.

- GIM: en esta titulación el rol de cliente lo jugaban los mismos estudiantes, junto con el rol de desarrollador. Cada equipo de estudiantes se inventaba un proyecto informático que debían explicar a otro equipo. A su vez, esos mismos alumnos jugaban el rol de desarrollador para otro cliente que les explicaba a ellos el proyecto que debían desarrollar. De esta forma, ponían en práctica ambos roles.

En ambos casos, los estudiantes debían concertar entrevistas con el cliente y extraer los requisitos que debía tener el sistema. El trabajo de los desarrolladores consistía en extraer los requisitos del cliente y reportarlos en diagramas de Casos de Uso y en un documento de especificación de requisitos. En este artículo vamos a analizar la comparativa de ambas técnicas para aplicar el juego de roles, destacando las ventajas e inconvenientes de cada una de ellas.

Analizando los datos extraídos, podemos afirmar de forma resumida que la ventaja de la técnica usada en GIT es que los requisitos están cerrados y es sencillo hacer un seguimiento. Por el contrario, la dedicación del profesor es elevada, ya que debe concertar entrevistas con todos los alumnos. La ventaja de la técnica usada en GIM es que los alumnos viven dos experiencias distintas que les pueden ser útiles en el mundo real. Como contrapartida, el profesor tiene menos control sobre los proyectos desarrollados y tiene que evaluar varios proyectos distintos.

El artículo se compone de las siguientes secciones. En la Sección 2 se describen los objetivos que hay detrás de la propuesta del juego de roles. En la Sección 3 se explican los detalles de las dos técnicas aplicadas en GIT y GIM. En la sección 4 se hace una comparativa de resultados de ambas técnicas. Por último, en la Sección 5 se abordan las conclusiones.

\section{Objetivos}

El principal objetivo de la incorporación de un juego de rol en la asignatura de Ingeniería del Software es enseñar a los alumnos cómo extraer los requisitos software de los clientes a través de entrevistas reales, cómo especificarlos en un documento y cómo defender estos resultados aprendiendo a gestionar los tiempos de manera adecuada. Esta forma de trabajar es la que se encontrarán en el mercado laboral una vez finalicen los estudios. Este objetivo se enmarca dentro de las siguientes líneas de actuación estratégicas de la Universidad de Valencia:

- (L1): Fomento de la participación de los estudiantes en la mejora de los procesos de aprendizaje.

- (L2): Realización de actividades que faciliten la conexión de los egresados con el mercado de trabajo.

- (L3): Mejora de los planes de estudio con la vista puesta en la acreditación y obtención del sello de calidad. 
Este objetivo se ha aplicado en la titulación GIT y GIM de la Universidad de Valencia en grupos de 43 y 40 alumnos respectivamente dentro de la asignatura de Ingeniería del Software.

\section{Desarrollo de la Innovación}

El juego de roles en la docencia de la Ingeniería del Software y más concretamente en la captura de requisitos, es una técnica que se ha aplicado anteriormente en otros trabajos, como el de Al-Ani y Yusop [2]. La aproximación seguida es que uno de los profesores juega el rol de cliente, mientras que los alumnos juegan el rol de analistas desarrolladores. El cliente no es informático y por tanto desconoce el lenguaje UML, por lo que los analistas no pueden basar sus preguntas o correcciones en estos diagramas. Toda la entrevista se debe hacer de forma verbal, aunque se acepta la validación de prototipos.

La innovación educativa consiste en sustituir los enunciados de un proyecto software por entrevistas reales con un profesor o con un grupo de compañeros, de forma que los requisitos del proyecto se deben extraer a partir de estas entrevistas entre clientes y analistas. A continuación, detallamos el proceso seguido en las titulaciones GIT y GIM.

\subsection{GIT: Proceso usando un único profesor con el rol de cliente}

En esta titulación se ha aplicado la misma técnica que se aplicó en el curso anterior (20152016). En este caso, el rol de cliente lo juega un único profesor y los alumnos juegan todos el rol de desarrolladores. A continuación se describen los pasos, resumidos de forma gráfica en la Fig. 1:

1. Los alumnos se agrupan en grupos de 5 a 6 personas. Estos grupos serán fijos para el desarrollo de todo el proyecto.

2. Cada uno de los grupos concierta una entrevista inicial con el profesor que juega el rol de cliente. Los estudiantes deben acudir a la entrevista teniendo preparadas una serie de preguntas para guiar la reunión. Durante la entrevista, el cliente explica las necesidades que tiene respecto al nuevo sistema software a desarrollar. Los analistas pueden preguntar en cualquier momento cualquier duda que les surja.

3. Después de esta entrevista inicial, los analistas empiezan a elaborar un diagrama de Casos de Uso de UML [1] junto con un Documento de Especificación de Requisitos para registrar los requisitos capturados.

4. Bajo demanda de los desarrolladores, el cliente se puede reunir más veces con los desarrolladores, con un máximo de 3 reuniones totales por grupo. Durante las sucesivas reuniones, el cliente puede resolver cualquier duda planteada por los desarrolladores, pero no puede corregir o completar información expresada mediante los Casos de Uso o el Documento de Especificación de Requisitos. Sí se acepta la corrección de prototipos en caso de que alguno de los grupos los desarrolle (en ningún caso se les obliga a hacer uso de prototipos).

5. Al finalizar las entrevistas, los alumnos deben entregar la siguiente información:

a. Diagrama de Casos de Uso, con las plantillas en formato de Alto Nivel.

b. Documento de Especificación de Requisitos.

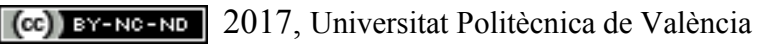

Congreso IN-RED (2017) 
c. Plantilla en Excel con información referente al esfuerzo que les ha supuesto capturar los requisitos y elaborar la documentación.

6. Finalmente los alumnos hacen una presentación de resultados en público.

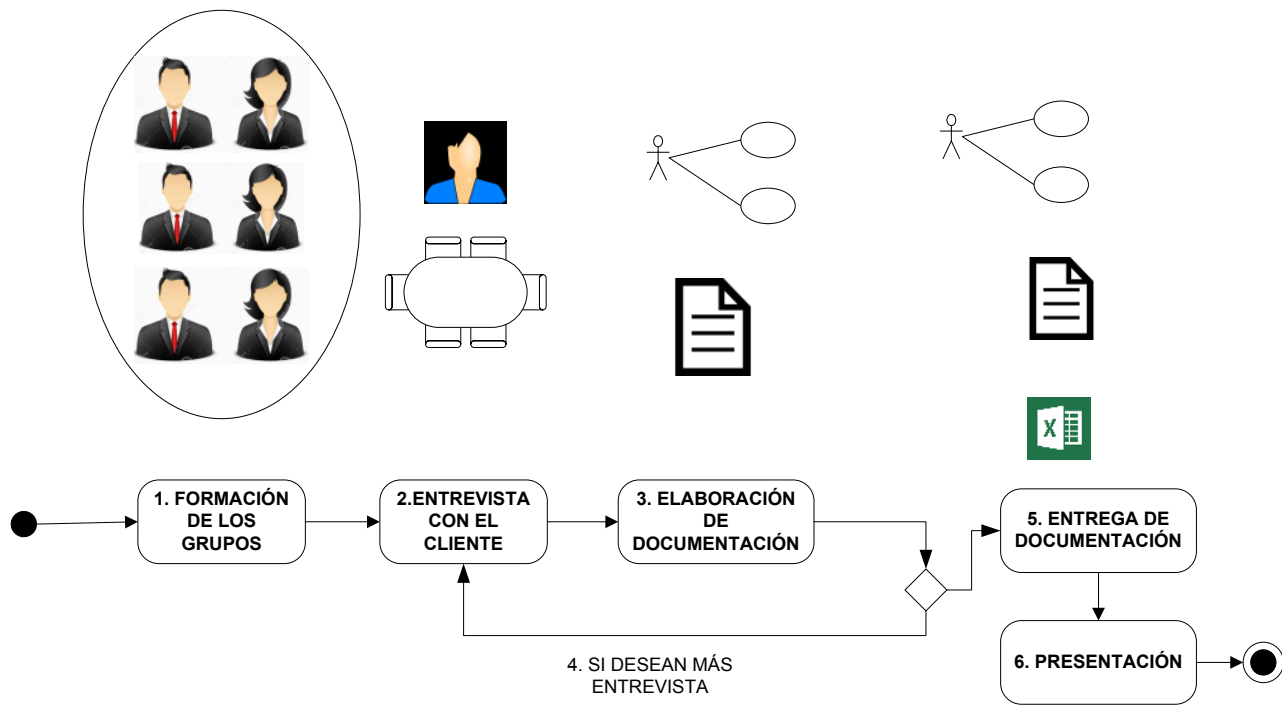

Fig. 1. Diagrama de Actividad con las actividades del juego de roles

Para llevar a cabo el juego de roles utilizamos una serie de instrumentos:

- Hoja Excel donde capturar datos sobre el avance del trabajo de los estudiantes: Esta hoja tenía celdas que los propios estudiantes debían rellenar sobre cómo habían hecho la captura de requisitos. En concreto se preguntaban los siguientes elementos:

Tabla 1. Hoja Excel

\begin{tabular}{|l|l|}
\hline Cantidad & $\mathrm{N}^{\circ}$ requisitos funcionales \\
\cline { 2 - 2 } & $\mathrm{N}^{\mathrm{o}}$ requisitos no-funcionales \\
\cline { 2 - 2 } & $\mathrm{N}^{\mathrm{o}}$ total requisitos \\
\cline { 2 - 2 } & $\mathrm{N}^{\mathrm{o}}$ páginas \\
\hline Completitud & $\mathrm{N}^{\mathrm{o}}$ requisitos que coinciden profesor \\
\hline Rendimiento & $\mathrm{N}^{\mathrm{o}}$ preguntas \\
\cline { 2 - 2 } & $\mathrm{N}^{\mathrm{o}}$ preguntas relevantes \\
\hline Diversidad & $\mathrm{N}^{\mathrm{o}}$ requisitos solapados \\
\hline Calidad & $\mathrm{N}^{\mathrm{o}}$ requisitos nuevos \\
\cline { 2 - 2 } & $\mathrm{N}^{\mathrm{o}}$ requisitos mal especificados \\
\hline
\end{tabular}

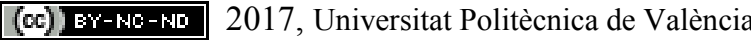


Todos estos datos persiguen determinar de manera independiente al criterio subjetivo del profesor, en qué medida los alumnos han elaborado unos DERS adecuados, si han perdido mucho tiempo, si han dedicado un esfuerzo suficiente, etc. Además, a partir de estos datos se pretende definir una medida de la calidad de la solución obtenida, independiente de criterios subjetivos de los profesores. Esta medida de calidad $Q$, se obtiene comparando los datos de los estudiantes con los datos de los documentos obtenidos por los profesores. Para ellos se tuvieron en cuenta sólo los valores de completitud y calidad de los datos recogidos de los alumnos, tal y como puede verse en la ecuación (1), pues son los que más se ajustan al objetivo perseguido.
COMP $=$ № requisitos que coinciden profesor/ № total requisitos profesor $N E W=$ № requisitos nuevos/ № total requisitos profesor $B A D=\mathrm{N}$ o requisitos mal especificados/ № total requisitos profesor

$$
Q=C O M P+N E W-B A D
$$

- Proyecto a desarrollar: el proyecto a desarrollar era un sistema de gestión de vuelos. Los usuarios deben poder comprar billetes, crear vuelos, modificar vuelos, gestionar trayectos, etc.

- Herramienta para modelar: se ha utilizado Visual Paradigm como herramienta de modelado UML para construir los diagramas de Casos de Uso.

- Repositorio SVN: para que todos los miembros del equipo pudieran trabajar de forma simultánea y colaborativamente, hemos utilizado un repositorio SVN con el que compartir los modelos UML desde la propia herramienta Visual Paradigm.

\subsection{GIM: Proceso en el que los estudiantes juegan ambos roles, el de cliente y el de desarrollador.}

Los alumnos de esta titulación desempeñan tanto el rol de cliente, como el de desarrolladores. A continuación, se describe el procedimiento seguido, representado gráficamente en la Fig. 2:

Sesiones de teoría:

1. Se forman grupos de trabajo de 4 a 6 estudiantes, que serán fijos para el desarrollo de todo el proyecto. Los miembros de cada grupo de trabajo deben asistir al mismo grupo de laboratorio, de manera que puedan trabajar conjuntamente durante las horas de prácticas.

2. En las primeras sesiones de teoría de la asignatura, cada grupo desempeña el rol de cliente. Los miembros de cada grupo se reúnen y definen una aplicación software que encargarán a otro grupo de trabajo. Se describen en un documento cuáles deben ser las funcionalidades que quieren que tenga dicha aplicación desde el punto de vista del cliente.

3. El profesor de la asignatura recoge los documentos de todos los grupos, los revisa para determinar que el alcance del proyecto sea adecuado, ni demasiado extenso ni demasiado simple.

(c)) BY-NC-ND 2017, Universitat Politècnica de València 
4. El profesor asigna el trabajo definido por un grupo que actúa como cliente a otro grupo del mismo laboratorio que actuará como desarrollador.

5. A continuación, los estudiantes pasan a desempeñar también el papel de analistas/desarrolladores. El profesor les encarga realizar el Documento de Especificación de Requisitos (DERS) del proyecto que se les ha asignado. La especificación del proyecto se realiza a partir del documento con la descripción funcional, y mediante entrevistas con el grupo que hace el papel de cliente.

Sesiones de laboratorio:

6. Para el desarrollo de las prácticas, se forman parejas de estudiantes que deben pertenecer al mismo grupo de trabajo.

7. Durante las sesiones de laboratorio, las parejas formadas ponen en práctica los conocimientos de Ingeniería del Software adquiridos en las clases de teoría, mediante diferentes ejercicios. Posteriormente, aplican las destrezas adquiridas al proyecto que se les ha asignado.

8. En la última sesión de laboratorio, cada uno de los grupos realiza una exposición en público, de 15 a 20 minutos de duración, en la que defiende ante el profesor de prácticas y ante el resto de compañeros, entre los que se encuentran el grupo que actuó como cliente, la solución propuesta, incluyendo todas las fases de análisis y diseño de software.

Cabe destacar que, para cada proyecto, tanto el grupo que ha desempeñado el rol de cliente, como el grupo que desempeña el rol de desarrollador, estarán en el mismo laboratorio. De esta manera se facilita que los desarrolladores puedan resolver dudas que puedan surgir durante las sesiones de prácticas.

De la misma manera, las diferentes parejas que forman parte de un grupo de trabajo, asisten al mismo laboratorio. Esto fomenta la cooperación y colaboración entre las diferentes parejas.

El hecho de que haya diferentes parejas en un mismo grupo de trabajo, implica que se desarrollarán diferentes soluciones para un mismo proyecto. En la exposición final se presentan las diferentes soluciones adoptadas para un mismo trabajo, el profesor las valora en público y se invita al resto de alumnos a comentarlas.

Para llevar a cabo el juego de roles utilizamos una serie de instrumentos:

- Proyecto a desarrollar: el proyecto a desarrollar dependía de cada equipo quejugaba el rol de cliente, por lo que había tanto proyectos como equipos.

- Herramienta para modelar: se ha utilizado Visual Paradigm como herramienta de modelado UML para construir los Casos de Uso, al igual que en GIT. 


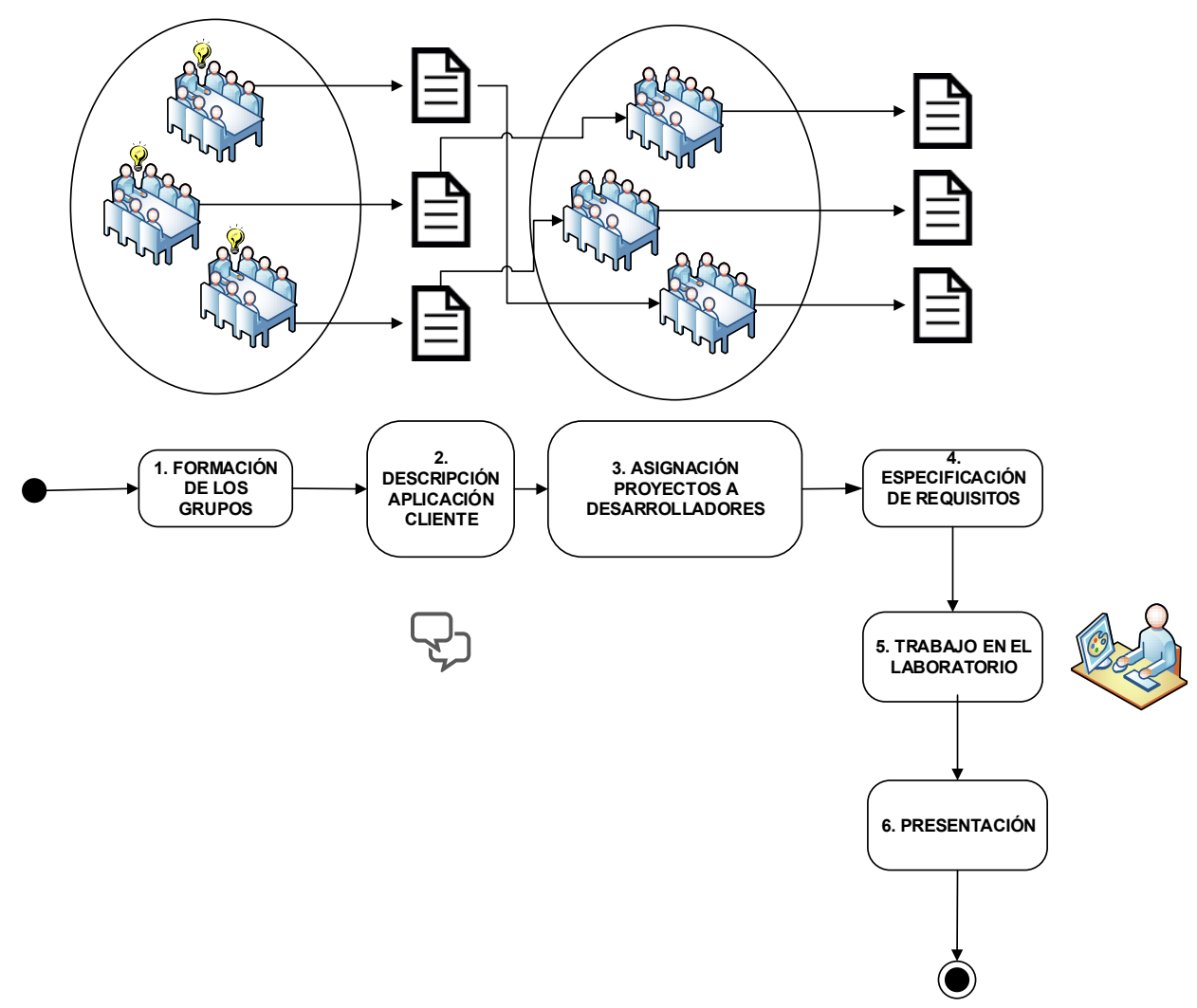

Fig. 2 Diagrama de Actividad con las actividades del juego de roles

\section{Resultados}

En ambas titulaciones se dispone de una nota asignada por los profesores de la asignatura tanto para el documento DERS realizado por los alumnos como para la presentación pública del trabajo que los alumnos realizaron en grupo. La medida de resultados final se calcula en base a la media de cada una de estas partes, asignando a cada una de ellas el mismo peso.

Dado que en el caso de la titulación de GIT se disponen además de los datos analizados por los alumnos que incluyen parámetros para medir la calidad (Tabla 1), hemos podido utilizar la métrica calidad $(\mathrm{Q})$. La idea de introducir este parámetro es utilizar un método menos subjetivo de evaluación, ya que los profesores que evalúan no tienen siempre los mismos criterios, por mucho que se intente realizar una evaluación lo más imparcial posible y por mucho que se marquen unos criterios comunes de evaluación.

En la titulación de GIM los alumnos no realizan estos cuestionarios, pues sería impracticable que los profesores elaborasen DERS para todos los grupos de alumnos, ya que a diferencia de GIT, el proyecto sobre el que se analizan los requisitos es distinto para cada grupo. Por tanto, en el caso de GIM no disponemos de la métrica de calidad (Q).

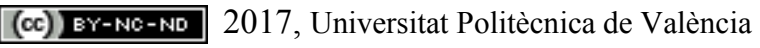


De esta forma, la medida de resultados V en GIT se obtiene mediante la fórmula que aparece en la ecuación (2) que incluye el criterio de calidad $Q$, la evaluación del DERS $\left(N_{D E R S}\right)$ y la evaluación de la defensa del trabajo desarrollado para capturar requisitos $\left(N_{P R E S}\right)$; estas dos últimas, recordemos, realizadas por el profesor. Dado que la medida de calidad $Q$ obtenida es un valor porcentual entre 0 y 1 , para poder promediar con las notas de los alumnos que van en el rango 0 a 10, se debe multiplicar por 10 para poder obtener la media ponderada equitativamente.

$$
\mathrm{V}=\frac{Q * 10+\left(N_{D E R S}+N_{P R E S}\right) / 2}{2}
$$

Por su parte, la medida de resultados $\mathrm{V}$ en GIM sólo tiene en cuenta la evaluación del DERS $\left(N_{D E R S}\right)$ y la evaluación de la defensa del trabajo desarrollado para capturar requisitos $\left(N_{P R E S}\right)$; también ambas realizadas por el profesor con valores entre 0 y 10.

$$
V=\frac{N_{D E R S}+N_{P R E S}}{2}(3)
$$

Una vez definido el parámetro $V$ que permite comparar los resultados entre GIT y GIM, lo primero que se hizo fue analizar el impacto del empleo del factor de calidad $Q$ en esta medida, únicamente usando el grupo GIT. La Fig. 1 muestra el valor promedio para el parámetro $V$ entre todos los grupos de alumnos. En azul se muestran los resultados sin tener en cuenta el parámetro de calidad $Q$, lo que equivaldría a aplicar la misma fórmula empleada con los alumnos de GIM, es decir, empleando la ecuación (3). Como puede observarse, el empleo del valor de calidad supone una reducción, inferior a un punto, en la valoración media de los alumnos.

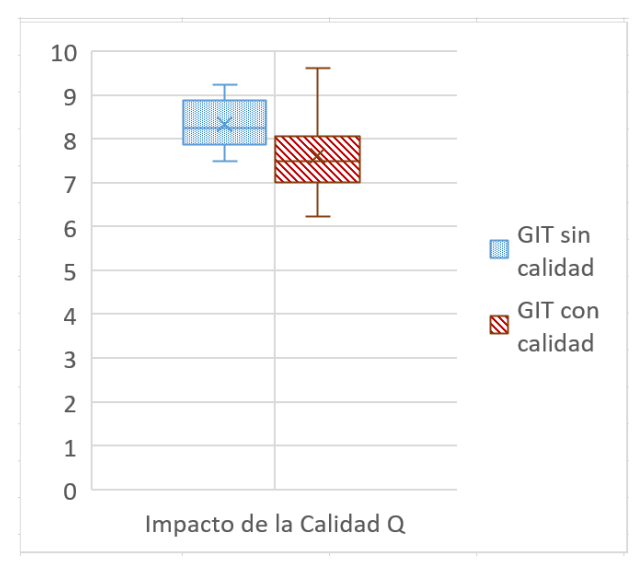

Fig. 3 Impacto de la Calidad Q en la Medida de Resultados en GIT

Posteriormente se pasó a comparar los resultados del parámetro $V$ obtenidos entre las titulaciones analizadas. Para ello se compararon los resultados obtenidos en GIM con los obtenidos en GIT tanto con el empleo del factor de calidad $Q$ como sin él. En la figura Fig. 4 se representan los valores promedio para el parámetro $V$ entre todos los grupos de alumnos de GIT (en azul) frente a los de GIM (en rojo). En la figura de la izquierda se 
muestran los resultados de GIT sin el factor de calidad $Q$, mientras que en la figura de la derecha aparecen los resultados de GIT empleando dicho factor. Como puede observarse en dichas gráficas, los resultados entre GIT y GIM son mucho más equiparables al introducir el factor de calidad $Q$, aunque en ambos casos son muy similares. Nótese que no disponemos de sujetos suficientes como para hacer un estudio estadístico y comprobar si hay resultados significativos entre ambas titulaciones.
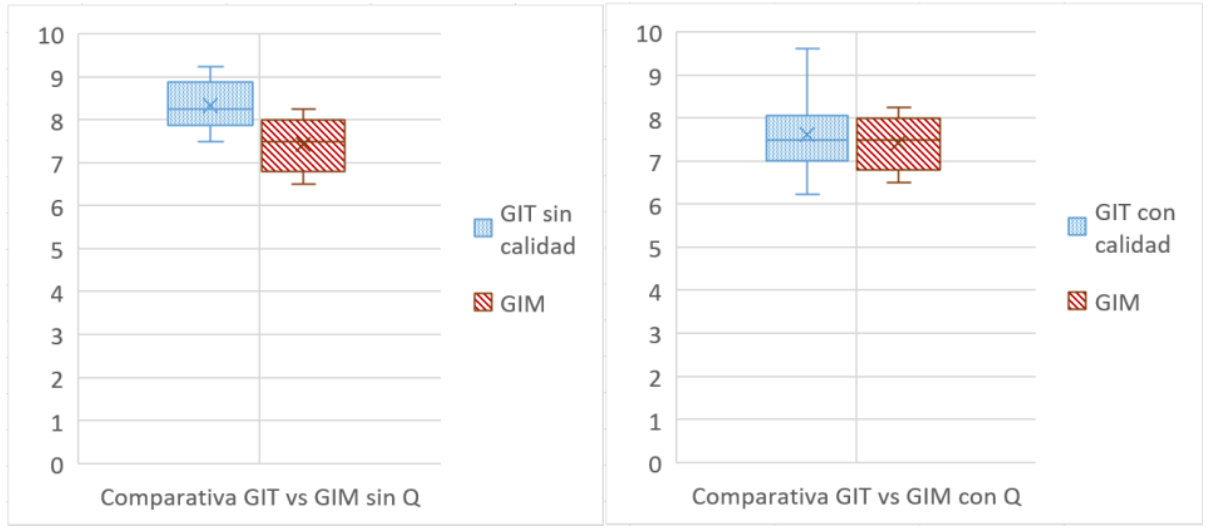

Fig. 4 Comparativa de la Medida de Resultados entre GIT y GIM sin calidad (izqda.) y con calidad (dcha.)

A continuación, vamos a comparar resultados cualitativos obtenidos durante un "focus group" realizado al final de ambos cursos.

Respecto a GIT, hemos identificado las siguientes ventajas:

- Todos los miembros del equipo han asumido distintas responsabilidades para poder desarrollar el proyecto.

- La retroalimentación que proporciona el cliente ayuda al equipo de trabajo a corregir deficiencias que hubieran sido difíciles de detectar con una especificación escrita.

- El profesor puede garantizar que los requisitos no son cambiantes a lo largo de las distintas entrevistas.

- El profesor puede guiar de forma homogénea a todos los equipos de alumnos porque conoce bien el proyecto que deben desarrollar.

- Se puede garantizar que la carga de trabajo es la misma para todos los alumnos.

Los inconvenientes detectados a través del focus group son:

- Inversión de mucho tiempo para capturar los requisitos si lo comparamos con el esfuerzo que les supone hacer el mismo trabajo si les facilitamos una descripción del trabajo a realizar por escrito.

- Difícil coordinación entre todos los miembros del equipo. Había equipos de hasta 6 personas y era difícil coincidir todos juntos.

- El profesor debe dedicar una media de 3 entrevistas por cada equipo de trabajo, lo que implica una inversión de tiempo importante.

(cc) EY-NC-ND 2017, Universitat Politècnica de València

Congreso IN-RED (2017) 
Respecto a GIM, hemos identificado las siguientes ventajas:

- Los participantes desempeñan tanto el rol de cliente como el de desarrolladores, lo que les permite tener la visión y experiencia de ambos perfiles profesionales.

- La comunicación entre el cliente y los desarrolladores en las sesiones de laboratorio facilita al equipo de trabajo resolver las deficiencias existentes en el documento de especificación de requisitos.

- El profesor se limita a orientar a los alumnos en el desempeño de su trabajo, y a la evaluación técnica del mismo, pero no interviene en las decisiones en cuanto a los requisitos de las aplicaciones.

- Cada pareja del grupo de laboratorio comparte su solución con el resto de compañeros. Esto permite a los alumnos conocer diferentes diseños para un mismo problema, observar y comentar sus ventajas e inconvenientes.

Los inconvenientes detectados son los siguientes:

- La heterogeneidad en las aplicaciones a desarrollar puede suponer grados diferentes de dificultad para cada equipo.

- Las aplicaciones solicitadas por los alumnos, en el papel de cliente, no siempre están suficientemente detalladas en la fase de especificación de requisitos. Esto implica que surjan dudas respecto a los requisitos durante la fase de análisis y diseño.

\section{Conclusiones}

Este trabajo muestra una comparativa de dos puestas en práctica distintas de un juego de roles en una misma asignatura (Ingeniería del Software) impartida en dos titulaciones distintas (GIT y GIM) en la Universidad de Valencia. En GIT, el profesor juega el rol de cliente mientras que los alumnos juegan el rol de desarrolladores. En GIM, los alumnos juegan ambos roles (cliente y desarrollador) para dos proyectos distintos.

Los resultados nos muestran que los alumnos de ambas titulaciones han conseguido realizar unos DERS considerablemente buenos, ya que las notas medias de los grupos están siempre por encima de 7,5. Además, el uso del factor de calidad, ha permitido equiparar las notas entre ambas titulaciones, eliminando el factor de disparidad de los profesores a la hora de evaluar.

Centrándonos en comparar ambas técnicas, la empleada en la titulación de GIM requiere de un menor esfuerzo por parte del profesor a la hora de preparar el desarrollo de la actividad. El profesor no debe dedicar horas de tutorías grupales adicionales ya que son los alumnos los que actúan de clientes. Sin embargo, el esfuerzo a la hora de evaluar los documentos es mucho mayor, ya que el profesor debe analizar cuáles deberían ser los requisitos de cada uno de los proyectos y si coinciden con los que el grupo ha entregado, más allá de determinar si la expresión de los mismos es adecuada o no.

Por el contrario, en el caso de GIT, el esfuerzo se realiza principalmente en la fase de preparación de la actividad. Pues los profesores de la asignatura deben elaborar en común el DERS solución y es el profesor responsable el que hace de cliente en lugar de los alumnos. 
El proceso de evaluación en este caso es mucho más sencillo, ya que tan solo se debe comparar el DERS de los alumnos con el DERS solución.

También se aprecian diferencias en cuanto al control que los profesores acaban teniendo sobre lo que se ajusta el DERS de los alumnos al DERS del profesor. En el caso de GIM, el control es mucho menor, ya que el profesor no está presente en todas las entrevistas (ya que se producen en el aula de forma simultánea) y por lo tanto no tienen un conocimiento real de lo que pedían los clientes y de si el DERS obtenido por los alumnos incluye o no todo lo que los clientes deseaban.

En cualquier caso, podemos afirmar que cualquiera de las dos técnicas permite alcanzar los tres objetivos básicos que se pretendía cubrir mediante esta innovación educativa:

- L1: Los estudiantes participan activamente en grupos de 5 a 6 personas para lograr un objetivo común. Esto trabaja la competencia de trabajo en equipo para resolver problemas con iniciativa, toma de decisiones, autonomía y creatividad. Además, también se trabaja la capacidad para saber comunicar y transmitir los conocimientos, las habilidades y las destrezas de un Ingeniero Informático.

- L2: El juego de rol permite que los estudiantes aprendan en un contexto similar al mundo real, donde los requisitos no vienen impresos en un papel, sino que deben extraerlos a través de entrevistas.

- L3: La innovación docente y la preparación de los estudiantes al mundo laboral futuro es una forma de mejorar los planes de estudio del Grado de Ingeniería Telemática y facilitar la obtención del sello de calidad.

\section{Agradecimientos}

Este trabajo se ha desarrollado dentro del proyecto de innovación educativa "Desarrollo de Software desde una Perspectiva Industrial” de la Universidad de Valencia.

\section{Referencias}

[1] UML: http://www.uml.org/.

[2] Al-Ani, B. and N. Yusop (2004). Role-Playing, Group Work and Other Ambitious Teaching Methods in a Large Requirements Engineering Course(ed.): Proceedings of the 11th IEEE Intl. Conference and Workshop on the Engineering of Computer-Based Systems

[3] Basili, V. R. and F. Lanubile (1999).Building Knowledge through Families of Experiments. IEEE Transaction on Software Engineering 25(4): 456-473.

[4] Beecham, S., T. Clear, D. Damian, J. Barr, J. Noll and W. Scacchi (2017).How Best to Teach Global Software Engineering? Educators Are Divided. IEEE Software 34(1): 16-19.

[5] Rueda, S., J. I. Panach, J.-B. Cabotà and F. Valverde (2016).Applying Role-Playing Game in Software Development Subjects(ed.): ICERI2016 3532-3538

(cc) EY-NC-ND 2017, Universitat Politècnica de València

Congreso IN-RED (2017) 


\title{
Resultados de la implantación de un método de aprendizaje basado en proyectos, con transversalidad con otras asignaturas. Metodología Flip Teaching
}

\author{
Raquel Giménez-Ibáñez ${ }^{a}$ y Emma Barelles-Vicente ${ }^{b}$ \\ ${ }^{a}$ Universitat Politècnica de València, raquel@,raquelgimenez.es y ${ }^{\mathrm{b}}$ Universitat Politècnica de \\ València, ebarelle@arq.upv.es.
}

\begin{abstract}
The project consists in the implementation of an active learning methodology that motivates students and implies in the subject. For this we have considered different strategies, the first that he is an active part in his learning since the subject is taught using the method Flipteaching, the second transverse collaboration with other subjects which gives an overview of the profession, the third is that we have involved a professional association to bring you closer to the real contact with professionals and finally, the creation of a competition that will reward and recognize the work of those who have worked hardest. All this will be based on available digital media and feedback with the teacher will be constant. Rubrics will be used for the corrections and all data will be collected for further evaluation.
\end{abstract}

Keywords: Projects, professional, transversality, methodology, teaching, educational innovation, flip-teaching

\begin{abstract}
Resumen
El proyecto consiste en la implantación de una metodología de aprendizaje activa que motive al alumno y le implique en la asignatura. Para ello nos hemos planteado diferentes estrategias, la primera es, que él sea parte activa de su aprendizaje ya qu,e la asignatura se imparte mediante el método Flipteaching, la segunda es la colaboración transversal con otras asignaturas, lo que le da una visión global de la profesión, la tercera es que hemos implicado a un colegio profesional para que le acerque al contacto real con profesionales y por último la creación de un concurso que premiará y reconocerá el trabajo de aquellos que más se hayan esforzado. Todo ello se apoyará en los medios digitales disponibles y la retroalimentación con el profesor será constante. Se emplearán rúbricas para las correcciones y todos los datos serán recopilados para la posterior evaluación.
\end{abstract}

Palabras clave: proyectos, profesional, transversalidad, metodología, docencia, innovación educativa, flip-teaching 


\section{Introducción}

La asignatura en la que se introduce la innovación educativa pertenece al $4^{\circ}$ curso del Grado en Arquitectura Técnica. Se trata de una asignatura eminentemente práctica, en la que se aborda el estudio y análisis de las lesiones que pueden sufrir los elementos constructivos que componen los edificios.

La necesidad de introducir esta innovación surge de la observación directa del alumnado en cursos anteriores, que sufren una desmotivación provocada por varias razones, entre ellas, la situación del mercado laboral, la crisis económica, etc.

Por ello se decide en el curso anterior, implantar la metodología flipteaching, como base fundamental del cambio de estrategia. En este curso se continúa con la nueva metodología y se introducen algunas herramientas más con las que conseguir motivar al alumno por la asignatura y la profesión.

Estas herramientas son tres. En primer lugar, se plantea una transversalidad con otras asignaturas del grado que hagan que el alumno entienda la carrera como un aprendizaje global. En segundo lugar, se fomenta el acercamiento del alumno a la realidad profesional mediante la organización de cursos prácticos, realizados con empresas externas que les permita conocer características concretas de los materiales a emplear. La realidad profesional también se consigue de la mano del colegio profesional involucrado en el convenio firmado con la Universida. Y por último, se convoca un concurso de la asignatura en el que los agentes externos (empresa y colegio profesionales) entregarán premios a los alumnos con trabajos más brillantes de entre los presentados.

La finalidad de todas estas aportaciones es conseguir la motivación de los alumnos hacia la asignatura y que se refleje en los resultados obtenidos.

\section{Objetivos}

El planteamiento de los objetivos viene fundamentado por la detección de algunas carencias, tanto en los resultados obtenidos, como en las manifestaciones realizadas por los alumnos. Es por ello que se plantean los siguientes objetivos específicos:

Objetivo 1. Los alumnos tienen un problema importante a la hora de encontrar un edificio real sobre el que hacer su trabajo de curso, lo que demora mucho el inicio de su trabajo. El objetivo sería reducir este tiempo y controlar el tipo de edificio sobre el que van a trabajar, para asegurarnos de que es adecuado.

Objetivo 2. Se percibe, en general, que el alumno no consigue entender qué relación tienen las asignaturas de los diferentes cursos o del mismo curso entre ellas. El objetivo, en este caso se plantea con la intención de hacerles ver que esta interrelación existe con el uso del mismo edificio en varias asignaturas, optimizando así también sus recursos.

Objetivo 3. La falta de motivación del alumnado genera resultados inadecuados. El tercer objetivo sería conseguir que la motivación aumente.

(cc) EY-NC-ND 2017, Universitat Politècnica de València 


\section{Desarrollo de la innovación}

Como consecuencia de los objetivos específicos citados con anterioridad se planifica la innovación.

Para reducir el tiempo de búsqueda de un edificio real sobre el que trabajar se ha firmado un un convenio de colaboración con un colegio profesional. Este será el que pondrá a nuestra disposición edificios que tengan lesiones y previa supervisión nuestra, serán estudiados y analizados por nuestros alumnos como si fuesen profesionales en pleno ejercicio.

Para transmitirles la relación entre las diferentes materias del grado, se ha planteado la transversalidad con otras asignaturas. Se había detectado que durante el proceso de desarrollo del proyecto de curso en nuestra asignatura, necesitaban conocimientos que no tenían adquiridos por ser de un campo muy concreto como es el de la rehabilitación. Por ello, esas asignaturas lo van a tratar aprovechando el mismo edificio de estudio de cada equipo de trabajo. También al utilizar un mismo proyecto en más de una asignatura les hacer ahorrar tiempo que pueden dedicar a otra tarea. Para evaluar los proyectos se emplean rúbricas, que este año vamos a elaborar con los alumnos en clase para que sean conscientes, desde el principio, de los objetivos que deben alcanzar.

La motivación se consigue con la colaboración de entidades externas, tanto de las empresas del sector invitadas, como de los colegios profesionales involucrados en el curso, con la finalización de la convocatoria de un concurso entre los alumnos de la asignatura, en el que se premien los resultados más brillantes.

Este año, como continuación del curso pasado, se han incluido varias novedades para mejorar los resultados de aprendizaje de los alumnos.

En primer lugar, se han programado tareas complementarias enfocadas al acercamiento del alumno a la realidad de la profesión. Para ello se ha organizado un ciclo de conferencias relacionadas con la asignatura, que apoyan los contenidos impartidos en la asignatura, por profesionales especialistas del sector y que han contado con una parte práctica que les ha permitido conocer de primera mano, diferentes técnicas de intervención. 


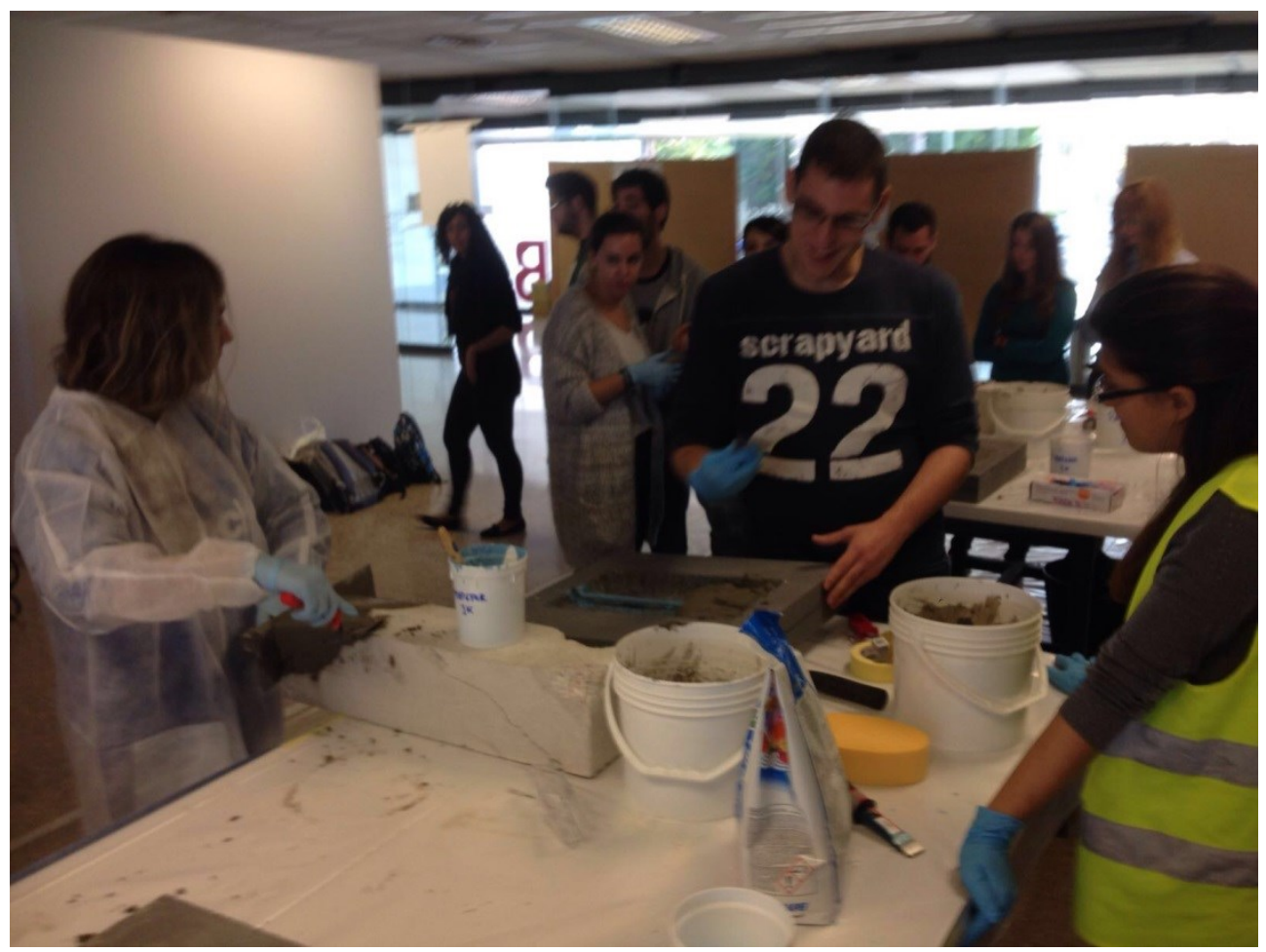

Fig. 2 Imagen de uno de los cursos prácticos

En segundo lugar, se ha concretado la transversalidad con la asignatura de tercero Gestión Presupuestaria y con la asignatura de cuarto Tasaciones.

La elaboración del Proyecto de curso donde se hace un estudio patológico del edificio, genera una serie de fichas donde en cada una de ellas se identifican las lesiones que manifiesta el edificio, las causas que la han provocado y se hace una propuesta de intervención. Estas fichas se van a facilitar a los profesores de la asignatura de Gestión Presupuestaria para que en el segundo Cuatrimestre sus alumnos puedan trabajar con ellas aprendiendo a elaborar precios en obras de rehabilitación. De forma que al año siguiente lleguen a nuestra asignatura de cuarto mucho más formados y preparados. Con este planteamiento se consigue que los alumnos accedan al curso siguiente con un trabajo realizado sobre conceptos específicos que serán tratados a posteriori.

La transversalidad con la asignatura de cuarto, Tasaciones, es una forma de aprovechar el hecho de que el trabajo de curso de nuestra asignatura se realiza sobre un edificio real, al que deben realizar varias visitas. Así pues, se puede plantear una práctica real también en la asignatura de Tasaciones reduciendo mucho el trabajo invertido De forma que los alumnos de cuarto que cursaran ambas asignaturas emplearían menos tiempo en la realización de los trabajos.

La evaluación de los mismos se realizará por parte de los profesores responsables de cada una de las asignaturas. 
La asignatura de tercero Gestión Presupuestaria al ser del segundo cuatrimestre tendrá ya disponible el material (fichas) generado en el primer cuatrimestre por la asignatura de Construcción VI.

La asignatura Tasaciones dispondrá de la planimetría y del edificio la séptima semana de curso para poder trabajar en su asignatura con este material.

\begin{tabular}{|l|l|}
\hline \multicolumn{2}{|c|}{$\begin{array}{l}\text { TRANSVERSALIDAD DE CONSTRUCCION VI CON PERITACIONES, TASACIONES Y } \\
\text { VALORACIONES }\end{array}$} \\
\hline 1 CUATRIMESTRE (SEMANA 1 -7) & 1 CUATRIMESTRE (SEMANA 8-14) \\
\hline CONSTRUCCIÓN VI & PERITACIONES, TASACIONES Y VALORACIONES \\
\hline $\begin{array}{l}\text { Se asigna el edificio a cada grupo para } \\
\text { realizar el proyecto de curso. }\end{array}$ & $\begin{array}{l}\text { Ya disponen de la planimetría y por lo tanto } \\
\text { pueden repartirse los tipos de vivienda entre } \\
\text { los componentes el grupo para su tasación }\end{array}$ \\
\hline $\begin{array}{l}\text { Hace el levantamiento. Realizan la } \\
\text { planimetría y las primeras visitas al edificio. }\end{array}$ & $\begin{array}{l}\text { En las visitas al edificio se puede aprovechar y } \\
\text { hacer un estudio de la zona y de los servicios }\end{array}$ \\
\hline & \\
\hline TRANSVERSALIDAD DE CONSTRUCCION VI CON TECNICAS DE GESTIÓN PRESUPUESTARIA \\
\hline PRIMER CUATRIMESTRE & SEGUNDO CUATRIMESTRE \\
\hline CONSTRUCCIÓN VI & TÉCNICAS DE GESTIÓN PRESUPUESTARIA \\
\hline $\begin{array}{l}\text { Se generan las fichas de LESION Se } \\
\text { identifica, se determinan las causas y la } \\
\text { propuesta de intervención }\end{array}$ & $\begin{array}{l}\text { Se crea el precio desCompuesto de la } \\
\text { intervención }\end{array}$ \\
\hline $\begin{array}{l}\text { Se mide la superficie, metros lineales } \\
\text { afectados por la lesión }\end{array}$ & $\begin{array}{l}\text { Se multiplica por la medición y se obtiene el } \\
\text { presupuesto de lo que vale reparar }\end{array}$ \\
\hline
\end{tabular}

Fig. 2 Cuadros explicativos de la aplicación temporal de la transversalidad

En tercer lugar, se ha convocado un concurso, dividido en tres categorías, en el que participan todos los alumnos de la asignatura, con un jurado externo formado por miembros de una empresa del sector de la construcción, del Colegio de aparejadores y arquitectos técnicos de Valencia y del colegio de administradores de fincas de Valencia y Castellón. Se establecen tres premios, uno por cada categoría. $\mathrm{Y}$ se premia a todos los miembros de cada uno de los grupos ganadores. Este año los premios han consistido en cursos de especialización profesional, contribuyendo a la formación de los alumnos.

\section{Resultados}

Analizados los datos recogidos en las encuestas realizadas por el ICE en su Proyecto Clase Inversa se extraen los siguientes resultados:

\begin{tabular}{|l|l|l|l|l|}
\hline ¿Qué tipo de actividades se han realizado en el aula (puedes marcar varias)? & $\begin{array}{c}\text { NO se ha hecho y } \\
\text { NO me gustaria que } \\
\text { se hiciera }\end{array}$ & $\begin{array}{c}\text { NO se ha hecho y Sí } \\
\text { me gustaría que se } \\
\text { hiciera }\end{array}$ & $\begin{array}{c}\text { Se ha hecho y lo } \\
\text { eliminaria }\end{array}$ & $\begin{array}{c}\text { Se ha hecho y lo } \\
\text { mantendria }\end{array}$ \\
\hline Repaso y resolución de dudas en el aula, de las actividades previas a la clase & $0 \%$ & $0 \%$ & $0 \%$ & $100 \%$ \\
\hline Ejercicios prácticos de profundización & $0 \%$ & $0 \%$ & $0 \%$ & $100 \%$ \\
\hline Explicación de nuevos contenidos teóricos & $0.0 \%$ & $55.6 \%$ & $0.0 \%$ & $44.4 \%$ \\
\hline Desarrollo de proyectos & $9.1 \%$ & $0.0 \%$ & $9.1 \%$ & $81.8 \%$ \\
\hline Exposiciones y presentaciones de los alumnos & $0.0 \%$ & $0.0 \%$ & $18.2 \%$ & $81.8 \%$ \\
\hline
\end{tabular}

Fig. 3 Resultados de la encuesta sobre el tipo de actividades realizadas en el aula y su opinión 


\begin{tabular}{|c|c|c|c|c|c|c|c|}
\hline \multirow{2}{*}{ Con la aplicación de la metodología de clase inversa realizada en esta asignatura } & \multicolumn{7}{|c|}{ muestra tu grado de acuerdo con las siguientes afirmaciones. } \\
\hline & 1 & 2 & 3 & 4 & 5 & Media & Mediaup \\
\hline He ido a clase con un trabajo previo realizado & $16.7 \%$ & $8.3 \%$ & $41.7 \%$ & $33.3 \%$ & $0.0 \%$ & 2,9 & 3,6 \\
\hline Ha contribuido a aumentar mi implicación en la asignatura & $0.0 \%$ & $8.3 \%$ & $33.3 \%$ & $50.0 \%$ & $8.3 \%$ & 3,6 & 3,7 \\
\hline Me ha resultado gratificante & $16.67 \%$ & $25.00 \%$ & $16.67 \%$ & $25.00 \%$ & $16.67 \%$ & 3 & 3,5 \\
\hline Ha requerido mucho tiempo por mi parte & $0.0 \%$ & $25.0 \%$ & $33.3 \%$ & $16.7 \%$ & $25.0 \%$ & 3,4 & 3,7 \\
\hline Ha permitido que el profesor dispusiera de más tiempo en clase para aclarar dudas & $8.3 \%$ & $16.7 \%$ & $16.7 \%$ & $33.3 \%$ & $25.0 \%$ & 3,5 & 3,5 \\
\hline Ha fomentado el trabajo en grupo & $16.7 \%$ & $8.3 \%$ & $16.7 \%$ & $33.3 \%$ & $25.0 \%$ & 3,4 & 3,3 \\
\hline Me ha ayudado a llegar mejor preparado a los exámenes & $33.3 \%$ & $8.3 \%$ & $25.0 \%$ & $8.3 \%$ & $25.0 \%$ & 2,8 & 3,5 \\
\hline
\end{tabular}

Fig. 4 Resultados de la encuesta sobre el grado de acuerdo con la metodología implantada en la asignatura. (1 totalmente en desacuerdo. 5 totalmente de acuerdo)

\begin{tabular}{|c|c|c|c|c|c|c|c|}
\hline & 1 & 2 & 3 & 4 & 5 & Media & Mediaup \\
\hline Los materiales facilitados por el profesor (vídeos y documentos utilizados). & $8.3 \%$ & $16.7 \%$ & $16.7 \%$ & $33.3 \%$ & $25.0 \%$ & 3,5 & 3,7 \\
\hline El trabajo realizado en clase (actividades de aula). & $16.7 \%$ & $16.7 \%$ & $33.3 \%$ & $25.0 \%$ & $8.3 \%$ & 2,9 & 3,7 \\
\hline El trabajo realizado en casa necesario para seguir las clases. & $33.3 \%$ & $16.7 \%$ & $16.7 \%$ & $33.3 \%$ & $0.0 \%$ & 2,5 & 3,2 \\
\hline La relación con el profesor, más cercana y de trabajo conjunto. & $0.0 \%$ & $0.0 \%$ & $9.1 \%$ & $72.7 \%$ & $18.2 \%$ & 4,1 & 3,7 \\
\hline La relación con mis compañeros. & $0.0 \%$ & $0.0 \%$ & $18.2 \%$ & $36.4 \%$ & $45.5 \%$ & 4,3 & 3,8 \\
\hline El sistema de evaluación empleado. & $16.7 \%$ & $25.0 \%$ & $33.3 \%$ & $16.7 \%$ & $8.3 \%$ & 2,8 & 3,6 \\
\hline La preparación de la asignatura por part & $8.3 \%$ & $16.7 \%$ & $50.0 \%$ & $8.3 \%$ & $16.7 \%$ & 3,1 & 4 \\
\hline
\end{tabular}

Fig. 5 Resultados de la encuesta sobre la aplicación de la metodología aplicada. (1totalmente en desacuerdo. 5 totalmente de acuerdo)

De las respuestas de los alumnos encuestados se puede ver, en cuanto a las actividades realizadas en el aula, que su percepción general es positiva. Pero destacando que aproximadamente la mitad alumnos expresan la necesidad de incluir más contenidos teóricos durante las clases.

La mayoría de los alumnos no se decantan ni en positivo ni en negativo. El resto de los alumnos que sí se manifiestan en acuerdo o desacuerdo, dentro de los ítems concretos, a la pregunta de si fomenta el trabajo en grupo, la implicación en la asignatura, el haber realizado un trabajo previo o haber requerido mucho tiempo por su parte, la mayoría está de acuerdo. Sin embargo a los ítems de si les ha resultado gratificante o si han llegado mejor preparados a los exámenes, la mitad de los alumnos están de acuerdo y la otra mitad en desacuerdo.

\section{Conclusiones}

Nuestra percepción sigue siendo positiva porque aumenta la implicación de los alumnos en la asignatura y el trabajo colaborativo.

Sin embargo al igual que en el curso anterior se han detectado algunas deficiencias que se mejorarán el próximo curso.

Analizando las respuestas de los alumnos en las encuestas y a través de la percepción de su actitud en el aula, se observa que el método es positivo, porque aumenta la participación activa y la implicación del alumno en la asignatura de una forma constante, durante todo el curso, ayudándole en su planificación personal. Aun así se observa que hay un perfil de alumno que se muestra reticente a este método porque su capacidad de esfuerzo y de trabajo está basada en mínimos.

(cc) EY-NC-ND 2017, Universitat Politècnica de València 
Cabe destacar que en el momento de la matrícula, los alumnos no son conocedores de que se matriculan en un grupo con un tipo de docencia determinada, ya que no se especifica de ningún modo. Y es el primer día de clase cuando se les explica la metodología. Y en este momento ya no se pueden realizar cambios de grupo, lo que hace que algunos alumnos que no simpatizan con el método, tengan que asumirlo.

En cuanto a las innovaciones complementarias incluidas este curso, tanto el ciclo de conferencias con sus cursos prácticos y el concurso final lo han recibido de forma muy positiva y con una alta implicación.

Sin embargo, la transversalidad planteada no se ha podido llevar a cabo de una forma adecuada. La mayoría de los alumnos, sorprendentemente, no cursan todas las asignaturas en el mismo grupo, lo cual hace que se formen grupos de trabajo diferentes para cada asignatura. Esto imposibilita la utilización del mismo edificio, por un mismo grupo en varias asignaturas. Que es el objetivo a perseguir para optimizar su tiempo y recursos.

\section{Referencias}

BAKER, J.W. (2000). The" classroom flip": Using web course management tools to become the guide by the side. Selected Papers from the 11 th International Conference on College Teachig and Learning.

BISHOP, J. L., \& VERLEGER, M. A. (2013). The flipped classroom: A survey of the research. In ASEE National Conference Proceedings, Atlanta, GA (Vol. 30, No. 9, pp. 1-18).

CUBILLOS, J. (2007) “A Comparative Stuy of hybrid versus Traditional Instruction in Foreign Languages" NECTFL Review 60 pp 30-38

GUIDRY, K; CUBILLOS J; PUSECKER K.L. (2013) "The connection between self-regulated learning and student success in a hybrid course" Long Beach, California.

LAGE, M. J., PLATT, G. J., \& TREGLIA, M. (2000). Inverting the classroom: A gateway to creating an inclusive learning environment. The Journal of Economic Education, 31(1), 30-43.

MULDROW, K. (2013) “A new approach to language instruction-flipping the classroom” The language educator. pp 28-31

STRAYER, JF. (2012) "How learning in an inverted classroom influences cooperation, innovation and task orientation" Learning environments research 15.2 pp 171-193. CrossRef. Web. 2 noviembre 2014

TALBERT, R. ( 2013) “Inverted Classroom” Colleagues 9.1. pp 1-3 


\title{
Aplicando Flipped Teaching en Física del Grado en Ingenieria de Sistemas de Telecomunicación, Sonido e Imagen
}

\author{
Jesús Alba Fernández ${ }^{\mathrm{a}}$, Constantino Torregrosa Cabanilles ${ }^{\mathrm{b}}$, Anna Vidal Meló ${ }^{\mathrm{c}}$ y \\ Romina del Rey Tormos ${ }^{\mathrm{d}}$ \\ ajesalba@fis.upv.es, ${ }^{\text {b }}$ ctorregr@fis.upv.es, ${ }^{\text {cavidal@mat.upv.es, }, \text { roderey@upvnet.upv.es }}$
}

Grup d'Innovació Educativa i recerca en Matèries Científiques (GIERMAC)

EPSG. Escola Politècnica Superior de Gandía. Departament de Física Aplicada i Departement de Matemàtica Aplicada. EPSA. Escola Politècnica Superior d'Alcoi. Departament de Física Aplicada.

\begin{abstract}
In November 2016, the GIERMAC team (Grup d'Innovación Educativa $i$ Recerca en Matèries Cientifiques) received a PIME-UPV project. This project was entitled "Startup of several experiences with the Flip Teaching approach in Physics and Mathematics subjects" and it is a continuation of a previous project entitled "Study on the application of Flipped Teaching in Mathematics and Physics subjects". This paper presents the application of Flip Teaching during two academic years in the subject of Physics of the Bachelor's Degree in Engineering of Telecommunications Systems, Sound and Image (GISTSI). Experience focuses on thermodynamics items. Students present in volunteer way and are compensated with additional points for strive.
\end{abstract}

Keywords: Flippled Teaching, class reverse, physics, thermodynamics, project-based learning.

\footnotetext{
Resumen

Al "Grup d'Innovación Educativa i Recerca en Matèries Cientifiques (GIERMAC)", se le concedió en noviembre de 2016 el proyecto PIME-UPV, "Puesta en marcha de diversas experiencias con el enfoche Flip Teaching en asignaturas de Física y matemáticas", continuación de otro proyecto anterior titulado "Estudio sobre la aplicación del Flip Teaching en asignaturas de Matemáticas y Física". En el trabajo se presenta la aplicación del Flip Teaching en dos cursos académicos en la asignatura de Fisica del Grado en Ingeniería de Sistemas de Telecomunicación, Sonido e Imagen (GISTSI). La experiencia se centra en temas de termodinámica a la que los alumnos se presentan de forma voluntaria y son compensados con puntos adicionales por el esfuerzo.
} 
Palabras clave: Flippled Teaching, clase inversa, Física, Termodinamica, Aprendizaje basado en proyectos

\section{Introducción}

En noviembre de 2016 se concede al "Grup d'Innovación Educativa i Recerca en Matèries Científiques (GIERMAC)" el proyecto PIME-UPV "Puesta en marcha de diversas experiencias con el enfoche Flip Teaching en asignaturas de Física y matemáticas", continuación de otro proyecto anterior titulado"Estudio sobre la aplicación del Flip Teaching en asignaturas de Matemáticas y Física”. En el primer proyecto se presentó ya una primera experiencia completa realizada con los alumnos de Física del Grado en Ingeniería de Sistemas de Telecomunicación, Sonido e Imagen (GISTSI) durante los meses de noviembre y diciembre de 2015 y en esta continuación se analiza la evolución en los dos cursos (2015-2016 y 2016-2017).

El modelo pedagógico Flip Teaching o Clase Inversa envía el trabajo de determinados procesos de aprendizaje fuera del aula, y usa el tiempo de clase para potenciar procesos más prácticos. Suele ser común que el alumno no reciba la tradicional clase de pizarra y/o transparencias de materias concretas, puesto que en esta metodología se supone que lo hará el alumno fuera de clase con materiales, documentación e información preparados con antelación por el profesor (Bergamm, 2005; Lage, 2000; Talbert, 2012a; Talbert, 2012b; Moravec, 2010; Gannod, 2008; Talbert 2014). La Universitat Politécnica de Valencia tiene un programa específico que apoya los proyectos piloto basados en Flip Teaching, lo que da idea de la importancia que se le está dando al modelo.

Para facilitar el proceso de aprendizaje fuera del aula, dentro del proyecto PIME-UPV citado se están preparando una serie de fichas de recursos con la siguiente información:

1. Datos Básicos de la Asignatura a la que se aplicará: Asignatura o asignaturas a las que afecta y ámbito

2. Tema-Sección: Qué temas/materiales son los que se trabajan con esta metodología

3. Objetivo de Aprendizaje: al finalizar la actividad FLIP, qué será capaz el alumnado.

4. Actividad Flip: qué tipo de metodologías se deciden, programación, etc.

5. Recursos y Descripción: de qué materiales van a disponer los alumnos

6. Evaluación: que áctos evaluativos se consideran

En el caso concreto de Física, se aplica en el primer semestre, durante los meses de noviembre y diciembre, esta metodología a temas de Termodinámica (Serway y Jewett, 2005 ; Serway y Jewett, 2008 ; Tipler, 1992 ; Tipler, 1994). Para ello se prepara la ficha correspondiente, y se desarrolla una metodología basada en el aprendizaje basado en proyectos (PBLs) de carácter voluntario como en (Alba et al, 2015a; Alba et al, 2015b) (Alba et al, 2016) y cuya evaluación supone un premio adicional al alumno, de viene a ser equivalente a subir medio punto la nota final de la asignatura.

(cc) EY-NC-ND 2017, Universitat Politècnica de València

Congreso IN-RED (2017) 


\section{Objetivos}

El objetivo principal es asentar la metodología de clase inversa en la asignatura FISICA del Grado en Ingeniería de Sistemas de Telecomunicaciones, Sonido e Imagen (GISTSI), para contrarestar la desmotivación en los alumnos que la enseñanza más clásica en esta asignatura puede producir. Para ello se prepara la ficha de actuación y recursos que forma parte del proyecto PIME-UPV citado.

La asignatura FISICA es una asignatura anual fundamental de primer curso. En el primer semestre se tratan las siguientes unidades didácticas:

1. Leyes del movimiento

2. Energía

3. Momento

4. Oscilaciones

5. Ondas

6. Temperatura y calor

7. La segunda ley

Estos siete bloques temáticos deben impartirse en 15 semanas de clase en el primer semestre. Además realizan 3 prácticas de 2 horas durante el dicho semestre. Por tanto, el alumno tiene 45 horas presenciales en el citado semestre y 67,5 no presenciales realizando el cómputo de horas según créditos.

En el caso que nos ocupa se decide trabajar con las unidades temáticas "6. Temperatura y Calor" y "7. La Segunda Ley". Para ponerla en práctica se propone una metodología basada en PBLs de termodinámica, ya que parece que el PBL es recomendable en grados de ingeniería (Aparicio et al, 2005 ; Case y Light 2011 ; Calvo et al, 2010 ; De Miguel, 2006).

Se plantean los siguientes objetivos de aprendizaje. El alumno al finalizar la actividad FLIP debe ser capaz de:

- Explicar las diferencias entre calor y temperatura

- Explicar las diferentes escalas termométricas y tipos de termómetros

- Formular con expresiones matemáticas con los efectos del calor

- Identificar la primera Ley de la Termodinámica

- Formular la transmisión de energía a través de la conducción, convección y radiación.

- Explicar el concepto de máquina térmica

- Identificar los ciclos conocidos (Carnot y Otto)

- Identificar y formular la segunda ley de la termodinámica

\section{Desarrollo de la Innovación}

Como se ha comentado, se plantea la actividad flip en base a PBLs de los dos temas de termodinámica de la asignatura Física. Se ha creado una ficha-recurso en base a los puntos

(c)) EY-NC-ND 2017, Universitat Politècnica de València

Congreso In-Red (2017) 
citados en la parte de introducción. La primera versión de la ficha se usó en el curso 20152016 y los resultados se mostraron en el In-red 2016 (Alba et al, 2016). La segunda versión de la ficha, aplicada en el curso 2016-2017 es la que se presenta a continuación.

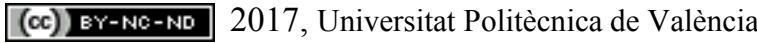




\begin{tabular}{|c|c|}
\hline $\begin{array}{c}\text { PROYECTO DE INNOVACIÓN Y MEJORA EDUCATIVA } \\
\text { CURSO 2016-2017 } \\
\text { UPV }\end{array}$ & \begin{tabular}{c} 
Estudio sobre la aplicación del Flip Teaching en asignaturas de Matemáticas y Fisica \\
\hline
\end{tabular} \\
\hline
\end{tabular}

\section{DATOS BASICOS DE LA ASIGNATURA}

Nombre: FISICA. Código: 11264

Grado en Ingenieria de Sistemas de Telecomunicación, Sonido e Imagen. Carácter: Formación básica Créditos: 9,00 --Teoría: 4,5 --Prácticas: 4,5

\section{TEMA-SECCIÓN \\ Temas 6 y 7. Termodinámica: Temperatura y Calor. La segunda Ley. \\ Proyecto sobre termodinámica}

3. OBJETIVOS DE APRENDIZAJE
Al finalizar la actividad FLIP propuesta, el alumnado será capaz de:
1. Explicar las diferencias entre calor y temperatura
2. Explicar las diferentes escalas termométricas y tipos de termómetros
3. Formular con expresiones matemáticas con los efectos del calor
4. Identificar la primera Ley de la Termodinámica
5. Formular la transmisión de energía a través de la conducción, convección y radiación.
6. Explicar el concepto de máquina térmica
7. Identificar los ciclos conocidos (Carnot y Otto)
8. Identificar y formular la segunda ley de la termodinámica

\section{ACTIVIDAD FLIP}

Realización de proyectos de los dos temas. Se asigna un proyecto por defecto pero los grupos pueden elegir temas alternativos. La descripción del proyecto básico es la siguiente:

TITULO DEL PROYECTO: Fabricación y calibración de un termómetro casero.

ENUNCIADO: Diseñar y fabricar un termómetro casero con cierta calibración. Debe permitir ciertos rangos de temperatura.

PREGUNTA MOTRIZ ¿Todos los termómetros son de mercurio?

PLANIFICACIÓN: 4 semanas

Semana 1: Búsqueda de información y lectura de materiales.

Semana 2: Trabajo en grupo. Entregable 1: Descripción del posible prototipo y materiales a utilizar. Respuesta a la pregunta motriz. Previsión de cálculos teóricos del prototipo.

Semana 3: Trabajo en grupo. Avance de borrador de poster, presentación o audiovisual. Semana 4: Presentación del poster o audiovisual y de los prototipos en clase.

5. RECURSOS Y DESCRIPCIÓN

En la descripción del PBL básico se recomiendan los siguientes videos de construcción de termómetros: 


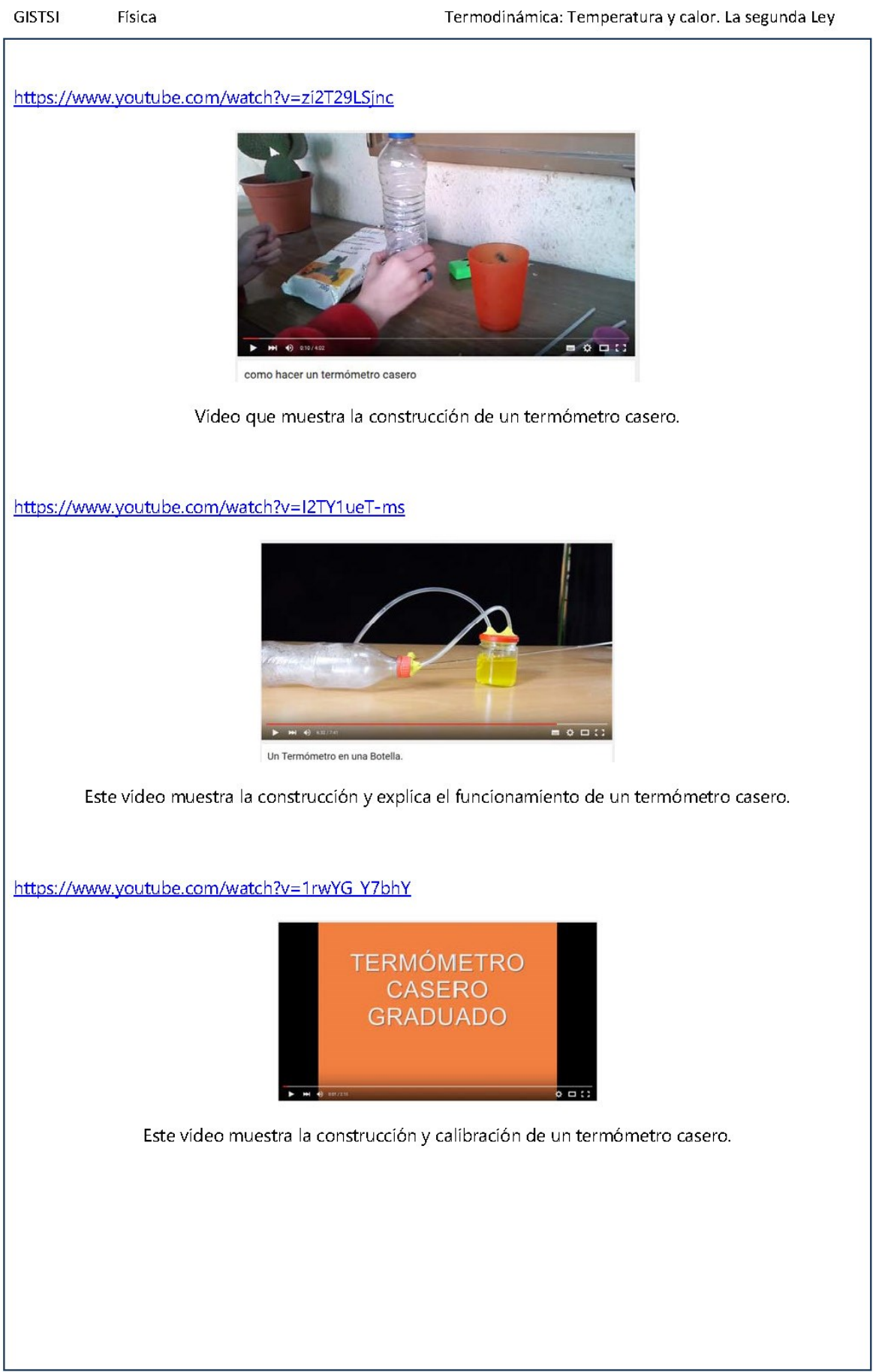

(cc) EY-NC-ND 2017, Universitat Politècnica de València

Congreso IN-RED (2017) 


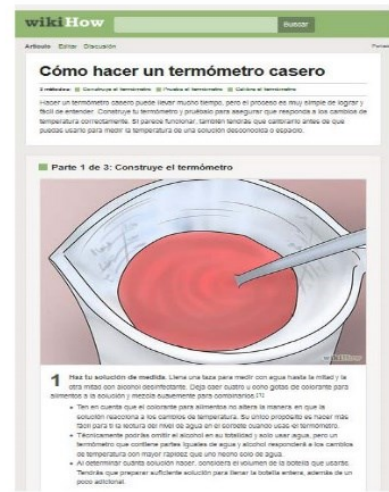

6. OTROS RECURSOS Y DESCRIPCIÓN

Además de la documentación del PBL básico sobre el termómetro, se tienen los siguientes recursos:

* Transparencias resumen de los temas 6 "Calor y temperatura" y 7 "La segunda Ley".

* Boletín de problemas de los dos temas

* Memoria de práctica sobre los dos temas "interpretación estadística de la entropía"

* Videos de trabajos realizados

* Páginas web con trabajos y experimentos resueltos

\section{EVALUACIÓN}

Se valoran 20 puntos (sobre 400 puntos) en tres partes: el entregable 1, el poster o similar y la presentación pública. Para la presentación se prepara rúbrica de profesores y alumnos.

Para ponerla en práctica se realiza una planificación de cinco semanas, que para el curso 2016-2017 puede verse en la tabla 1.

Tabla 1. PLANIFICACION del PBL

\begin{tabular}{|l|l|l|}
\cline { 2 - 3 } \multicolumn{1}{l|}{} & SEMANA & TAREAS \\
\hline Semana 1 & $14 / 11 / 16-18 / 11 / 16$ & $\begin{array}{l}\text { Búsqueda de información. Lectura de materiales. } \\
\text { Entrega de hoja firmada }\end{array}$ \\
\hline Semana 2 & $21 / 11 / 16-25 / 11 / 16$ & Trabajo en grupo \\
\hline Semana 3 & $28 / 11 / 16-02 / 12 / 16$ & Trabajo en grupo. Entregable 1 \\
\hline Semana 4 & $05 / 12 / 16-10 / 12 / 16$ & $\begin{array}{l}\text { Trabajo en grupo. Avance de borrador de poster o } \\
\text { similar. }\end{array}$ \\
\hline Semana 5 & $12 / 12 / 16-16 / 12 / 16$ & Problema de clase 3 y Test 3.Presentación de trabajos. \\
\hline
\end{tabular}

Entregable 1. 02/12/16. Entrega de la descripción del posible prototipo y materiales a utilizar. Previsión de cálculos teóricos del prototipo.

POSTER. 10/12/16. Avance del póster o similar 
Problema 3 y Test 3. 12/12/16. Problema de clase 3 y test 3(MAS y ondas). Avance del póster o similar

Presentación. 16/12/16. Todos los miembros del grupo presentan su prototipo en clase. Todos los entregables y la presentación son de grupo. Como en el curso 2015-2016 (Alba et al, 2016) varios grupos decidieron trabajar otros proyectos distintos (hornos solares, coche a vapor, barco pop-pop, generador eléctrico, Stirling, cohete, etc.).

La asignatura Fisica se evalúa sobre 400 puntos (400 puntos se corresponde con el 10) con diferentes actos evaluativos que van acumulando puntos. Esta actividad se propone como premio adicional con 20 puntos (sobre 400 puntos) en tres partes: el entregable 1, el poster o similar y la presentación. Para la presentación se prepara rúbrica de profesores y alumnos. En otros actos evaluativos (parcial de enero) los temas de termodinámica también se evalúan en preguntas tipo test.

Se prepara una rúbrica única para profesores y alumnos en el curso 2016-2017. Esto se ha modificado y simplificado respecto al curso anterior, donde se usan dos rúbricas diferentes donde el lenguaje no facilitaba cuplimentarlas. Por ello se ha optado en una simplificación que facilite y agilice la coevaluación.

Tabla 2. Rúbrica de coevaluación

\begin{tabular}{|l|l|l|l|l|}
\hline Competencias & GR-1 & GR-2 & GR-3 & GR-4 \\
\hline 1) Es capaz de diseñar el equipo/objeto & & & & \\
\hline 2) Define los objetivos y las variables del trabajo & & & & \\
\hline 3) Resolución del problema & & & & \\
\hline 4) Mecánica de la presentación & & & & \\
\hline 5) Póster/material de presentación & & & & \\
\hline NOTA GLOBAL PROPUESTA (0 A 10) & & & & \\
\hline
\end{tabular}

Como novedad, en el curso 2016-2017 se incorpora la competencia transversal de "comunicación oral efectiva", como se había señalado en un trabajo anterior (Alba et al, 2016). Las presentaciones de los proyectos se presentaron tras la asistencia de los alumnos a un curso del ICE sobre Comunicación Efectiva, con el objetivo de que los alumnos aprendan a expresar ideas de forma estructurada e inteligible en presentaciones orales de duración breve o en intervenciones puntuales.

Se solicita a los alumnos que en el proyecto apliquen lo aprendido en el curso para la presentación de los proyectos. Además se utilizó para evaluar las presentaciones la rúbrica UPV CT-08 sobre comunicación efectiva, en la dimensión de comunicación oral y el nivel de dominio I.

(cc) EY-NC-ND 2017, Universitat Politècnica de València 


\section{Resultados}

En el curso 2015-2016 se acogieron a la primera experiencia 33 alumnos de 53 en equipos de 3 o 4 alumnos (un 62\%). Como curiosidad, la mayoría de repetidores de la asignatura no realizaron la actividad (Alba et al, 2016). Respecto a las notas, todas estaban entre 8 y 10 puntos obtenidas combinando las rúbricas de alumnos y profesores.

En el curso 2016 - 2017 se presentaron inicialmente 10 proyectos en grupos de 2 a 4 estudiantes, de los cuales 8 llegaron a término: un termómetro casero, un horno solar, un coche a vapor, dos barcos a vapor, un motor stirling, un cohete y un generador eléctrico a vapor. Participaron 28 de los 48 alumnos de la assignatura (58\%). Los porcentajes de alumnos que deciden de forma voluntaria realizar la actividad. Las notas, como resultado del promedio de notas asignadas por los propios alumnos a cada proyecto, en base a una sencilla rúbrica de evaluación, oscilaron entre 7.5 y 8.7 puntos sobre 10 (media 8.1 y desv 0.5 ), con desviaciones estándar de cada nota entre 0.8 y 1.3 puntos. A continuación se muestran algunas fotografías de la edición 2016-2017.
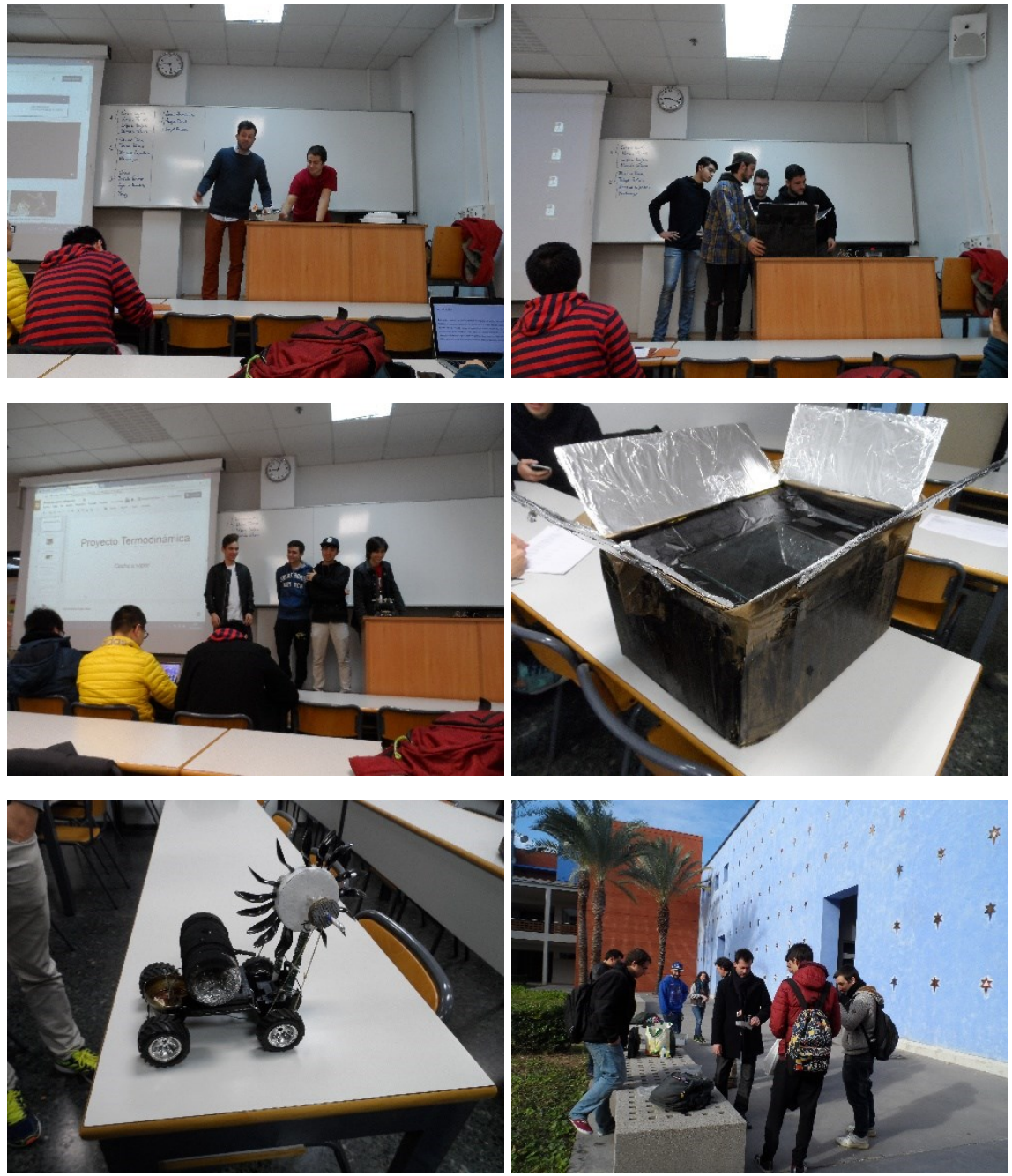

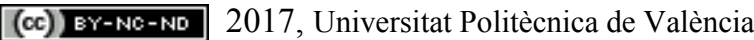

Congreso In-Red (2017) 

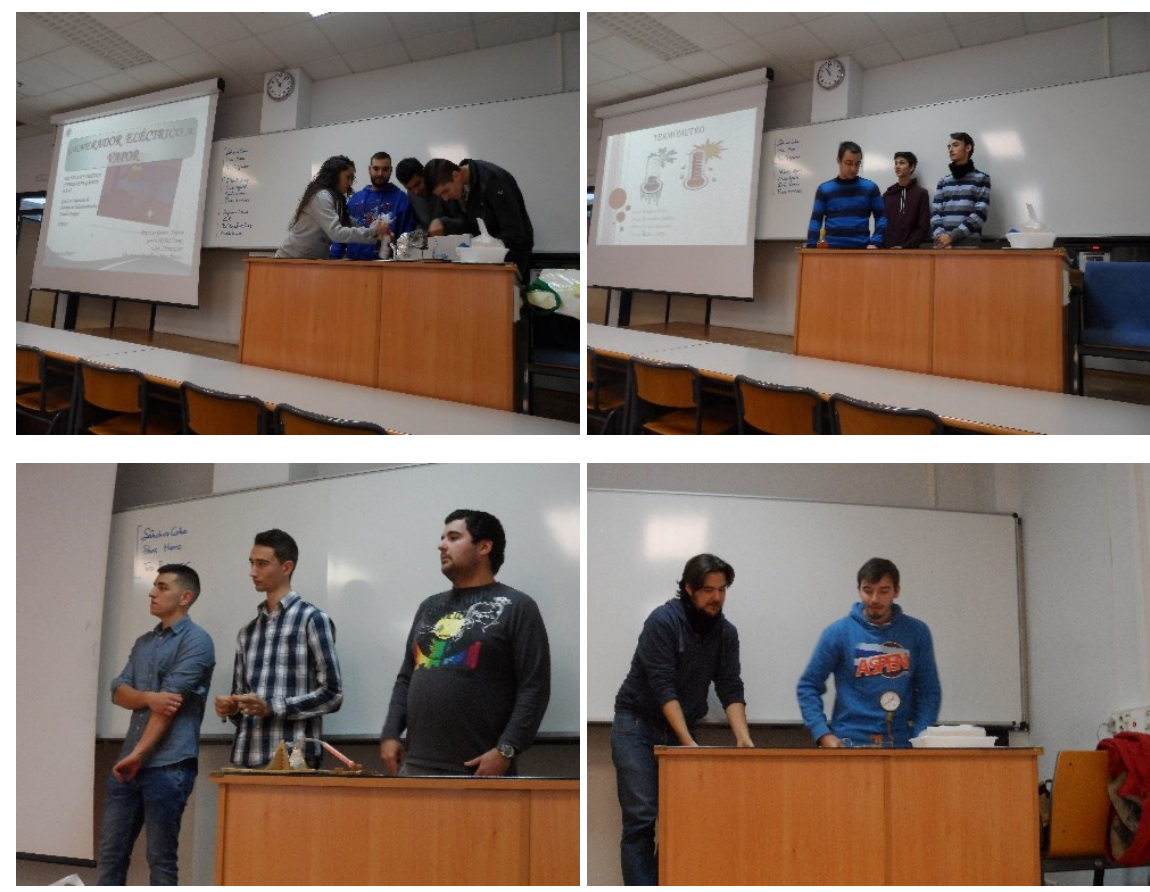

\section{Conclusiones}

En este trabajo se ha mostrado un resumen de la experiencia de poner en marcha y asentar la metodología Flip Teaching en la asignatura Física del Grado en Ingenieria de Sistemas de Telecomunicación, Sonido e Imagen. La previsión para el próximo curso es seguir manteniendo esta actividad.

Se realiza una revisión sobre fortalezas, debilidades, amenazas y oportunidades respecto a a la aplicación de esta metodología.

Las fortalezas observadas en los dos cursos son las siguientes:

- Se reactiva la asistencia a clase. La experiencia muestra un aumento claro de la asistencia.

- La elección de múltiples opciones de proyectos refuerza la confianza del alumno.

- Se potencia el trabajo en grupo y la comunicación oral efectiva, que se trabaja como competencia transversal.

- Los mismos alumnos pueden crear materiales para usar en cursos siguientes. Ya se dispone material de dos cursos.

- Se aumenta la motivación del alumnado

Las debilidades actuales: 
- La carga de trabajo de alumnos y profesores es mucho mayor. Se calcula que se ha triplicado el número de horas de faena en el primer año de implantación, aunque se ha rebajado algo el segundo año.

- El ritmo de los trabajos no es fluido. Viene afectado por festivos y sobre todo por interferencias de otras asignaturas con evaluaciones clásicas o tradicionales.

- Hay que elegir bien los contenidos. Hay material erróneos o con inexactitudes en las redes.

Las amenazas detectadas:

- No existe una apuesta real por este tipo de metodologías por parte de la universidad, aunque el mensaje sea el contrario. Un ejemplo claro: para el curso 2016-2017 se redujeron los grupos de prácticas de la asignatura. Al mismo tiempo que se nos anima a realizar este tipo de iniciativas, nos recortan los recursos para realizarlas.

- Hay que limitar los proyectos puesto que algunos pueden tener riesgos, creando un protocolo acorde.

- Los alumnos pueden llegar a pensar que no se ha impartido el tema correspondiente.

Existe una oportunidad clara de centrar el tiempo de aula en cuestiones más prácticas, pero la actual manera de asignar la carga docente no contempla este tipo de iniciativas.

\section{Agradecimientos}

Este trabajo se ha realizado gracias al apoyo del Vicerrectorado de Estudios, Calidad y Acreditación de la UPV al Proyecto PIME 2016-2017 "Puesta en marcha de diversas experiencias con el enfoque Flipped Teaching en asignaturas de Matemáticas y Física".

\section{Referencias}

ALBA J., DEL REY, R., VIDAL A., ROIG B. (2015a) Aprendizaje Basado en Proyectos en el Grado en Ingeniería de Sistemas de Telecomunicaciones, Sonido e Imagen. Caso práctico del electroscópio como experiencia interdisciplinar entre Física y Matemáticas. 23 Congreso Universitario de Innovación Educativa de las Enseñanzas Técnicas (XXIII CUIEET). Valencia 15-17 de julio de 2015.

ALBA J., TORREGROSA C., DEL REY R. (2015b) Aprendizaje basado en proyectos: Primera experiencia en la asignatura de Física del Grado en Ingeniería de Telecomunicación, Sonido e Imagen. Universitat Politècnica de València Congreso IN-RED (2015)

ALBA J., TORREGROSA C., VIDAL A., DEL REY R. (2016) Flipped Teaching en Física del Grado en Ingenieria de Sistemas de Telecomunicación, Sonido e Imagen: primeros resultados. Universitat Politècnica de València Congreso IN-RED (2016)

(c)) EY-NC-ND 2017, Universitat Politècnica de València

Congreso In-Red (2017) 
PARICIO, F., GONZALEZ, R. M. Y SOBREVILA, M. A. (2005). Formación de Ingenieros. Objetivos, métodos y estrategias. Instituto de Ciencias de la Educación, UPM.

BERGMANN, J., SAMS, A. (2015). Dale la vuelta a tu clase: Lleva tu clase a cada estudiante, en cualquier momento y cualquier lugar. SM.

CASE, J. M. Y LIGHT, G. (2011). Emerging Methodologies in Engineering Education Research. Journal of Engineering Education, 100 (1), 186-210.

CALVO, I., LOPEZ-GUEDE, J.M. Y ZULUETA, E. (2010). Aplicando la metodología Project Based Learning en la docencia de Ingeniería Técnica en Informática de Gestión, Revista de Formación e Innovación Educativa Universitaria. Vol. 3, No 4, 166-181

DE MIGUEL, M. (2006). Modalidades de Enseñanza centradas en el desarrollo de competencias. Universidad de Oviedo.

GANNOD, G., BURGE, J., HELMICK, M. (2008). "Using the inverted classroom to teachsoftware engineering" en Proceedings of the International Conference on Software Engineering (ICSE). Leipzig, Germany. p. 10-18

LAGE, M.J., PLATT, G.J., TREGLIA, M. (2000). "Inverting the classroom: A gateway to creating an inclusive learning environment" en The Journal of Economic Education, vol. 31 , issue 1 , p. $30-43$

MORAVECD, M., WILliAMS, A., AGUILAR-ROCA, N., O’DOWD, D.K. (2010). "Learn before lecture: a strategy that improves learning outcomes in a large introductory biology clas" en CBE Life Sci Educ, vol. 9, p. 473-481

SERWAY, R. A. Y JEWETT, J. W. (2005). Física para ciencias e ingeniería. Volumen 1. México D.F. International Thomson, $6^{\mathrm{a}}$ ed.

SERWAY, R. A. Y JEWETT, J. W. (2008). Física para ciencias e ingenierías. Volumen II. México D.F. : Cengage Learning.

TALBERT, R. (2012a). "Learning MATLAB in the Inverted classroom" en Proceedings of the ASEE Annual Conference. San Antonio, Texas. 25.883.1-25.883

TALBERT, R. (2012b). “Inverted Classroom” en Colleagues, vol. 9, issue 1, article 7

TALBERT, R. (2014). "Inverting the Linear Algebra Classroom" en PRIMUS (Problems, Resources, and Issues in Mathematics Undergraduate Studies), vol. 24, issue 5, p. 361-374

TIPLER, P. A. (1992) Física Tomo 1. Barcelona etc. : Reverté

TIPLER, P. A. (1994) Física Tomo 2. Barcelona etc. : Reverté

UPV, UNIVERSITAT POLITECNICA DE VALENCIA. Competencias transversales UPV $<$ http://competenciast.webs.upv.es/> [Consulta: 2 de abril de 2016]

VILLA, A. Y POBLETE, M. (2007): Aprendizaje basado en competencias. Una propuesta para la evaluación de las competencias genéricas. Ediciones Mensajero. Bilbao. 


\title{
Experiencia piloto de aula invertida para mejorar el proceso de enseñanza-aprendizaje en la asignatura de Termodinámica Técnica
}

\author{
Begoña Peñaa , Ignacio Zabalza, Sergio Usón, Eva María Llera, Amaya Martínez, Luis \\ Miguel Romeo \\ Universidad de Zaragoza - Departamento de Ingeniería Mecánica (España) a e-mail: bpp@unizar.es.
}

\begin{abstract}
The European Higher Education Area stands for important changes in the teaching-learning model in the university context, specifically requires a deep revision of the roles of teachers and students. In this sense, the so-called flipped classroom model (FCM) shifts the traditional information transfer at home by means of digital resources, allowing to apply active methodologies in the attendant classes. This procedure results in an increase of the students motivation and a deeper learning degree.

The present paper gathers the results obtained in the subject of Engineering Thermodynamics of the Degree in Industrial Technologies Engineering during the first semester of the 2016-2017 academic course within a teaching innovation project with the objective of improving the exploitation of the attendance classes.

An opinion poll shows that the traditional model is followed almost in all of the subjects, while just the $28 \%$ of students considers that their use of attendance classes is high. After the implementation of FCM in an essential lesson of the subject, a 51\% of them consider the learning level was high. The percentage of the students which pass the final exam increase in 18 points regarding to previous courses, meaning a substantial improving in satisfaction degree and learning level.
\end{abstract}

Keywords: flipped classroom, active methodologies, engineering education, University innovation

\footnotetext{
Resumen

El Espacio Europeo de Educación Superior conlleva cambios importantes en el modelo de enseñanza-aprendizaje en el contexto universitario, exigiendo una revisión del papel de profesor y estudiante. En este sentido, el modelo de aula invertida (FCM) desplaza la tradicional transferencia de información fuera del aula mediante recursos digitales, permitiendo aplicar metodologías activas en las clases presenciales. Esto se traduce en un aumento de la motivación de los estudiantes y en un aprendizaje más profundo.
} 
Experiencia piloto de aula invertida para mejorar el proceso de enseñanza-aprendizaje en la asignatura de Termodinámica Técnica

El presente trabajo recoge los resultados obtenidos en la asignatura de Termodinámica Técnica del Grado en Ingeniería de Tecnologías Industriales durante el primer semestre del curso académico 2016-2017, desarrollado en un proyecto de innovación docente con el objetivo de mejorar el aprovechamiento de las clases presenciales.

Una encuesta previa muestra que el modelo tradicional se sigue en casi todas las clases, mientras que sólo el $28 \%$ de los estudiantes consideran que su aprovechamiento es alto. Después de la implementación de FCM en una lección esencial de la asignatura, el $51 \%$ de ellos consideró que el nivel de aprendizaje era alto. El porcentaje de estudiantes que superaron el examen final aumentó en 18 puntos respecto a cursos anteriores, lo que significa una mejora sustancial en el grado de satisfacción y en el nivel de aprendizaje.

Palabras clave: clase invertida, metodologías activas, enseñanza de la ingeniería, innovación universitaria.

\section{Introducción}

La idea de "invertir el aula" ha sido propuesta y desarrollada en los últimos años por diversos autores (Lage 2000, Baker 2000, Baker 2012, Bergmann 2012) con el objetivo de trasladar fuera del aula las actividades que tradicionalmente se desarrollan en las clases presenciales, y viceversa. Este modelo pedagógico conocido como clase invertida (flipped classroom) presenta muchas ventajas frente al modelo tradicional de clase centrada en la transferencia de información del profesor al alumno:

- permite implantar en el aula metodologías activas que de otro modo no tendrían cabida por cuestiones de tiempo,

- el profesor puede detectar dificultades en la comprensión de ciertos conceptos o procedimientos e incidir más en ellos,

- las TIC (Tecnologías de la Información y de la Comunicación) se integran de manera natural en el proceso de aprendizaje,

- el alumno cobra protagonismo en las clases presenciales, aumentando su grado de motivación y de satisfacción y consiguiendo un aprendizaje más profundo,

- el profesor puede realizar una mejor gestión de la diversidad,

- ciertas competencias trasversales, como el trabajo en grupo, se pueden trabajar y evaluar en el aula.

Este modelo fue inicialmente adoptado en las escuelas de Primaria y Secundaria, para más recientemente llegar a la Universidad. Actualmente se está implantando en los mejores centros de enseñanza del mundo, como el Shireland Collegiate Academy (Inglaterra), la Universidad de Harvard o el Instituto Tecnológico de Massachusetts (MIT). En España, la Universidad Politécnica de Valencia es pionera en su implantación en cursos completos de varias titulaciones, contando con una buena acogida entre los alumnos (UPV, 2017).

(cc) EY-NC-ND 2017, Universitat Politècnica de València

Congreso IN-RED (2017) 
En la bibliografía puede encontrarse un buen número de trabajos en el campo de la Ingeniería, entre otros, utilizando diferentes recursos y metodologías: aprendizaje basado en proyectos (Alba, 2017), video-tutoriales distribuidos en plataformas de Internet junto con breves cuestionarios de seguimiento (Morera, 2017), gamificación en el aula (Artal-Sevil, 2017), uso de entornos virtuales o software específico (Gutiérrez, 2017; Fita, 2017), etc. En todos ellos, se obtuvieron resultados positivos, pudiendo cubrir un temario más extenso, aumentando el grado de satisfacción de los estudiantes y mejorando los resultados de aprendizaje.

La gran diversidad de metodologías y recursos utilizados en estos trabajos pone de manifiesto que el modelo de aula invertida (FCM) es mucho más que grabar videos para sustituir a las clases magistrales. El rol del profesor cambia, eso es cierto, pero sigue teniendo un papel esencial en el aprendizaje del estudiante para seleccionar los recursos y metodologías de trabajo, para planificar, guiar y servir de apoyo en las actividades de aprendizaje y para evaluar tanto los resultados alcanzados por el estudiante, como el éxito del proceso en sí (Tourón, 2015).

Los autores de esta ponencia han querido sumarse a estas iniciativas mediante un proyecto de innovación docente en el que llevar a cabo una experiencia piloto sobre clase invertida en diversas asignaturas y titulaciones de Ingeniería en la Universidad de Zaragoza. Aquí se presentan los resultados recogidos en un caso concreto.

\section{Objetivos}

El objetivo principal del presente trabajo es mostrar los resultados obtenidos en la asignatura de segundo curso de "Termodinámica Técnica y Fundamentos de Transmisión de Calor" del Grado en Ingeniería de Tecnologías Industriales. Esta experiencia piloto se ha desarrollado durante el primer semestre del curso académico 2016-2017 en la Escuela de Ingeniería y Arquitectura de la Universidad de Zaragoza, dentro del proyecto de innovación docente antes mencionado, con el objetivo de mejorar el aprovechamiento de las clases presenciales y los resultados de aprendizaje, como consecuencia de una mayor preparación, motivación y participación del estudiante.

En este trabajo se recogen, concretamente, los principales resultados y conclusiones derivados de los siguientes objetivos parciales:

- Seleccionar y elaborar materiales y estrategias de enseñanza para que el alumno prepare en casa los contenidos de la asignatura antes de la clase presencial.

- Seleccionar y elaborar materiales y estrategias de enseñanza para un mejor aprovechamiento de las clases presenciales.

- Seleccionar herramientas TIC adecuadas para facilitar el proceso de aprendizaje y aumentar la motivación del alumno, sin que aumente excesivamente el tiempo requerido para su corrección y evaluación.

- Desarrollar formularios para evaluar el éxito de la experiencia piloto.

(c)) EY-NC-ND 2017, Universitat Politècnica de València 
Experiencia piloto de aula invertida para mejorar el proceso de enseñanza-aprendizaje en la asignatura de Termodinámica Técnica

- Llevar a cabo la experiencia piloto, recogiendo y analizando la información para evaluar el éxito de la misma, en base a los resultados de aprendizaje y a la satisfacción de alumnos y profesores.

\section{Desarrollo de la innovación}

La experiencia piloto sobre FCM se realizó en el Grado en Ingeniería de Tecnologías Industriales de la Universidad de Zaragoza, concretamente en la asignatura "Termodinámica Técnica y Fundamentos de la Transferencia de Calor", que se imparte durante el primer cuatrimestre del segundo curso. La asignatura cuenta con 6 ECTS, equivalentes a 150 horas de trabajo, correspondientes a 45 horas de clases presenciales de teoría y resolución de problemas, 15 horas de prácticas de laboratorio y 90 horas de trabajo personal del alumno (estudio individual, resolución de problemas y cuestiones con o sin la supervisión y evaluación del profesor).

Siendo un primer contacto con algunas metodologías tanto para profesores como para estudiantes, las diferentes estrategias y herramientas se han aplicado sólo a ciertas partes de la asignatura, para evaluar su idoneidad y efectividad para el objetivo planteado y para identificar posibles problemas o posibilidades de mejora antes de su implementación en una asignatura completa. Para ello se han abordado los siguientes aspectos:

- Mejorar el aprovechamiento académico durante las prácticas de laboratorio.

- Poner a prueba diferentes herramientas TIC para la implementación de la metodología one minute paper.

- Aplicar el FCM en una lección esencial de la asignatura.

\subsection{Metodología general}

La metodología seguida en el proyecto se resume en la Figura 1.

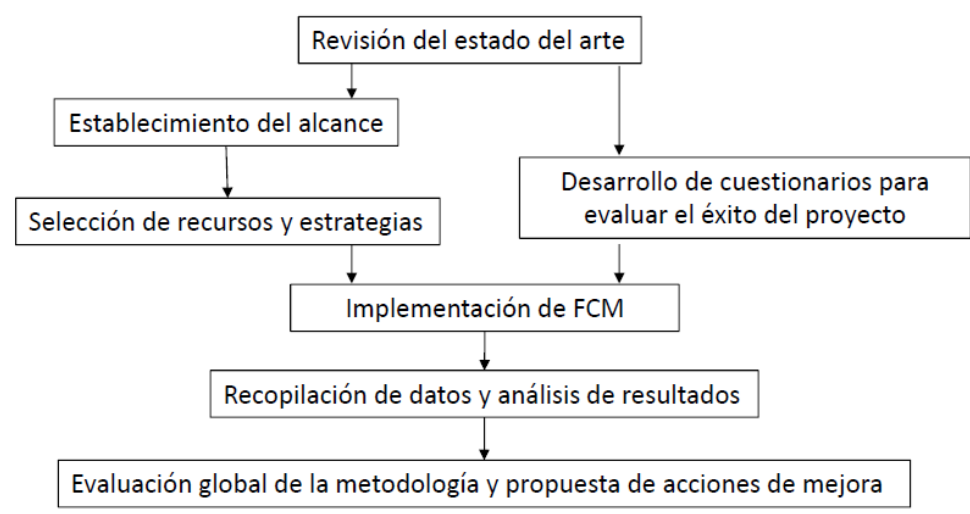

Fig. 1 Resumen general de la metodología seguida en el proyecto de innovación docente.

(c) EY-NC-ND 2017, Universitat Politècnica de València

Congreso IN-RED (2017) 
En primer lugar, se llevó a cabo una revisión del estado del arte sobre metodologías activas, herramientas libres de TIC en Internet y sobre el modelo de aula invertida. De acuerdo con esto, se estableció el alcance de la experiencia.

Por un lado, con el fin de lograr el máximo impacto en la calificación final académica, se seleccionó la Lección 2 de la asignatura, titulada "Propiedades termodinámicas de sustancias puras", para la plena implementación del modelo FCM. Es una lección esencial en la que el alumno aprende diferentes procedimientos para el cálculo y representación de propiedades: diagramas, tablas y modelos. Tales procedimientos son la base del resto de la asignatura, ya que las propiedades de las sustancias son necesarias para el análisis termodinámico de cualquier sistema energético.

Por otro lado, se abordó el problema de la desincronización temporal entre las clases magistrales y las prácticas de laboratorio, que a veces no se pueden evitar por la rigidez del horario oficial, tanto para mejorar la satisfacción del estudiante como para aprovechar al máximo la asistencia a esas sesiones.

El siguiente paso fue la selección de los recursos y las estrategias a aplicar. La Tabla 1 resume las actividades desarrolladas por los estudiantes durante el proceso de aprendizaje en el marco del presente proyecto.

Las tareas destacadas en negrita son elementos de evaluación que forman parte de la calificación global a las que hay que añadir el examen final. Dichas actividades incluyen tanto las que se orientan hacia las prácticas de laboratorio, como las asociadas a las clases presenciales. Se explican con detalle en las subsecciones 2.2 y 2.3 , respectivamente.

Tabla 1. Actividades planificadas dentro y fuera del aula

\begin{tabular}{lllll}
\hline & \multicolumn{2}{c}{ Sesiones prácticas } & \multicolumn{1}{c}{ Clases } \\
\hline Trabajo previo & $\bullet$ & Visualización de videos & $\bullet$ & Estudio con textos \\
& $\bullet$ & Resolución de cuestiones & $\bullet$ & Visualización de videos \\
Trabajo & $\bullet$ & Resumen del profesor & $\bullet$ & Resumen del profesor \\
presencial & $\bullet$ & Resolución de dudas & $\bullet$ & Resolución de dudas \\
& - Resol. de problemas complejos & $\bullet$ & Aprendizaje basado en \\
& $\bullet$ & Aprendizaje del uso de software & & problemas \\
& $\bullet$ & Entrega de resultados & & Gamificación con Kahoot! \\
Trabajo & & & & Resol. problemas complejos \\
posterior & & & $\bullet$ & Entrega de los resultados \\
& & & & Resolución de cuestionarios \\
\hline
\end{tabular}

Simultáneamente, se diseñaron y desarrollaron diferentes cuestionarios y formularios para cuantificar la mejora en el proceso de enseñanza-aprendizaje y para evaluar el grado de satisfacción de los alumnos, como se detalla en la subsección 2.4.

Después de la implementación de estas actividades, el equipo de investigación recolectó y analizó los datos de los cuestionarios para realizar una evaluación global de la metodología y proponer futuras acciones de mejora.

(cc) BY-NC-ND 2017, Universitat Politècnica de València Congreso In-Red (2017) 
Experiencia piloto de aula invertida para mejorar el proceso de enseñanza-aprendizaje en la asignatura de Termodinámica Técnica

\subsection{Materiales y estrategias para las prácticas}

El objetivo principal con respecto a las prácticas de laboratorio ha sido facilitar la comprensión de la teoría relacionada, ya que en la mayoría de los casos existe un desfase temporal con las clases teóricas correspondientes. Las sesiones prácticas consisten en una breve explicación inicial por parte del profesor para posteriormente resolver diferentes casos de estudio. Los estudiantes recogen datos de un sistema experimental o virtual y aplican el procedimiento termodinámico para calcular ciertas variables o parámetros de funcionamiento.

La estrategia seguida se basa en una combinación de videos desarrollados por el grupo de profesores sobre el tema de la sesión de laboratorio de unos 10 minutos (Zabalza, 2016) con la lectura de un capítulo de un libro (Peña, 2009) que incluye un resumen de los principales contenidos teóricos. Tras este trabajo individual, el estudiante completa un cuestionario que entrega al comienzo de la sesión de prácticas. Durante la misma, resuelve los problemas planteados en el guion y al finalizarla entrega los resultados para su evaluación.

\subsection{Materiales y estrategias para las clases presenciales}

Como se ha mencionado, el modelo FCM se implementó en la Lección 2 "Propiedades termodinámicas de sustancias puras”, ya que es la base de las lecciones posteriores. En cualquier caso, a lo largo del curso, el estudiante dispone de las transparencias de la próxima sesión a través de la plataforma Moodle y de la bibliografía recomendada para preparar el tema en casa. Las siguientes subsecciones se refieren principalmente a las clases presenciales de la lección bajo análisis, aunque algunas actividades de evaluación se realizan a lo largo de todo el curso.

\subsubsection{Preparación fuera del aula}

Los recursos y metodologías para trabajar fuera del aula están relacionados con actividades que el estudiante desarrolla antes y después de las clases. Con respecto a los primeros, se han proporcionado textos didácticos propios y recursos audiovisuales propios y ajenos (Zabalza, 2016; Zabalza, 2017) mediante la plataforma Moodle en el campus virtual de la Universidad de Zaragoza.

Además, se ha investigado la posibilidad de incluir comentarios y preguntas durante los videos como una forma efectiva de enfatizar ciertos conceptos o errores habituales. Edpuzzle es una plataforma gratuita de Internet que permite administrar fácilmente videos propios o videos de Internet (youtube, vimeo, etc.) para la inclusión de notas o comentarios cortos, con la ventaja de disponer de un entorno virtual donde el trabajo individual del estudiante queda registrado para ser analizado o evaluado. En el presente trabajo se ha implementado esta técnica para evaluar su aceptación por parte de los alumnos y sus ventajas y desventajas con respecto a la evaluación y a los procesos de aprendizaje.

(c) EY-NC-ND 2017, Universitat Politècnica de València 
En cuanto a las actividades a desarrollar después de clase, se desarrollaron cuestionarios para la evaluación y autoevaluación en la plataforma de Moodle para cada tema. Los primeros forman parte de la nota final, mientras que los últimos son un recurso de aprendizaje con el que el estudiante obtiene una retroalimentación inmediata. Además, los estudiantes entregan un informe de resultados sobre diferentes problemas de cierta complejidad después del final de cada lección que también forman parte de la nota final.

\subsubsection{Metodología dentro del aula}

Con el fin de aprovechar el tiempo de clase, se ha evaluado la utilidad de varias metodologías activas. En base a la experiencia previa, se ha considerado que la opción más adecuada es el aprendizaje basado en problemas (ABP) combinado con el aprendizaje colaborativo para promover la adquisición de habilidades técnicas y la capacidad de trabajo en equipo. Además, se ha decidido utilizar una variante de la metodología one minute paper (OMP, Bain 2006) para mejorar la atención de los estudiantes durante las clases, basada en herramientas como Socrative, Kahoot! o GoogleForms, ya que presentan muchas ventajas con respecto al OMP tradicional. Concretamente se ha utilizado la herramienta Kahoot!, por sus ventajas adicionales derivadas de la gamificación (Artal-Sevil, 2017).

\subsection{Materiales y estrategias para las clases presenciales}

Esta actividad se centra en el diseño de una plantilla de observación y de varios cuestionarios con diversos propósitos. La plantilla de observación consiste de una tabla que reúne información sobre la experiencia en el aula, incluyendo datos generales, datos específicos de la sesión, incidencias y posibilidades de mejora (Peña, 2017).

Para la evaluación de la experiencia piloto, se han desarrollado dos cuestionarios: en primer lugar, una encuesta general respondida por los estudiantes antes de aplicar el modelo FCM sobre su experiencia y opinión relacionada con las clases universitarias y, en segundo lugar, una encuesta de satisfacción para ser respondida después de la experiencia piloto. Además, la evaluación de cada video educativo se ha realizado y analizado a través de una encuesta muy breve con sólo cinco preguntas de la escala de Likert para promover la participación. Los detalles de este trabajo se recogen en (Zabalza, 2017).

\section{Resultados}

\subsection{Uso de los videos}

La actividad sobre el uso de los videos se ha registrado en Moodle para su posterior análisis. Los videos correspondientes a la preparación de las sesiones prácticas tienen un valor medio de 65 visualizaciones por video, habiendo sido vistos en torno a dos veces por el $50 \%$ de los estudiantes. Los videos asociados a la aplicación del modelo FCM en la Lección 2 tienen más de 300 visualizaciones de media por video, habiendo sido consultados por el $92 \%$ de los estudiantes alrededor de 5 veces.

(c)) EY-NC-ND 2017, Universitat Politècnica de València 
Experiencia piloto de aula invertida para mejorar el proceso de enseñanza-aprendizaje en la asignatura de Termodinámica Técnica

Con respecto a la inserción de comentarios y cuestiones en los videos a través de EdPuzzle, la experiencia desde el punto de vista del profesor fue positiva, ya que su preparación fue rápida y sencilla. Sin embargo, tan solo un $30 \%$ de los estudiantes vió el video, indicando que el hecho de tener que registrarse en otra plataforma desanimó a un buen número de estudiantes. Por otro lado, el $100 \%$ de los estudiantes que lo vieron consideraron que este formato es más claro y más útil para su proceso de aprendizaje.

\subsection{Encuestas de opinión}

La encuesta inicial, respondida por 46 alumnos, se compone de cinco preguntas sobre las metodologías de enseñanza utilizadas en otras asignaturas y sobre su propia experiencia. La Figura 3 muestra la opinión de los alumos sobre las clase magistral tradicional.

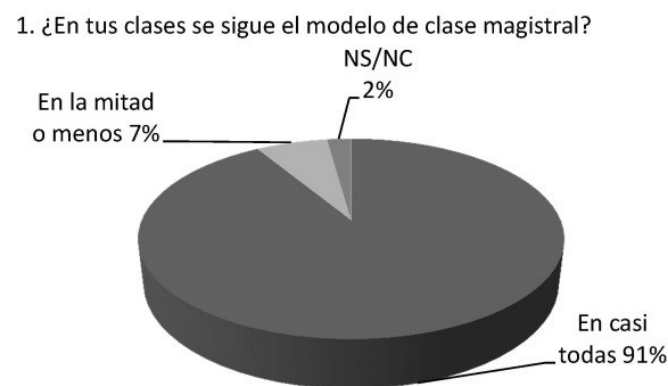

2. ¿Qué grado de asistencia tienes a esas clases?

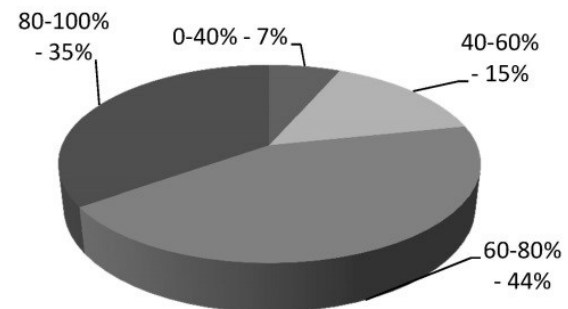

3. ¿Qué grado de aprovechamiento consideras que alcanzas?

4. ¿Cómo crees que se podría mejorar este aprovechamiento?
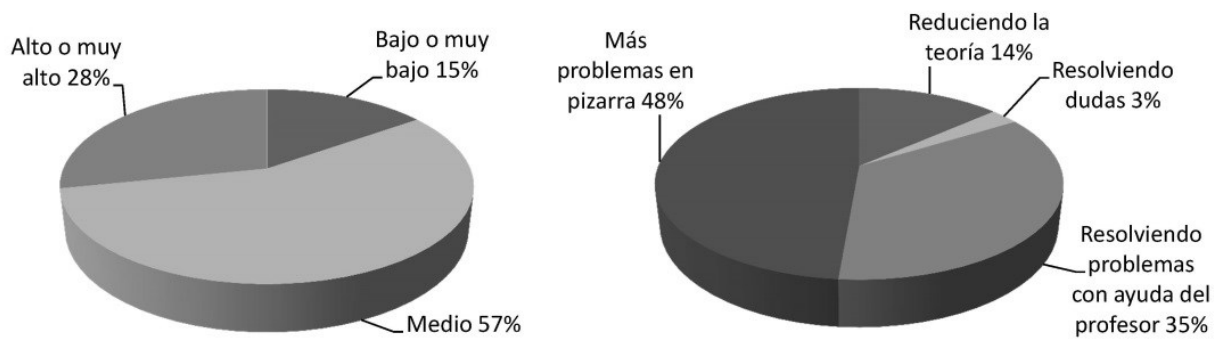

Fig. 3 Opinión de los estudiantes sobre la clase magistral y el aprovechamiento que hacen de ella .

La última pregunta del test, no mostrada en la Figura 3, era relativa al grado de satisfacción de otras metodologías de enseñanza conocidas por los estudiantes. Alrededor de la mitad de los estudiantes tiene un grado de satisfacción del $50 \%$ con el método basado en proyectos. El mismo porcentaje considera que las TIC promueven la participación. Con respecto al uso de videos con fines didácticos, el $15 \%$ de los alumnos encuestados tiene un grado de satisfacción del $57 \%$. La mejor valoración fue para el método de aprendizaje basado en problemas con un $74 \%$ otorgado por un $20 \%$ de los estudiantes.

Tras la experiencia piloto en FCM, se recabó información con una encuesta acerca del grado de satisfacción de los estudiantes. El $47 \%$ de los encuestados consideró muy útiles los recursos de Moodle, un 34\% los consideraron interesantes pero no dedicaron suficiente tiempo para trabajar con ellos, el $11 \%$ sugiere la inclusión de textos preparados por el profesor y sólo un $6 \%$ considera que quitan tiempo de estudio.

(c)) EY-NC-ND 2017, Universitat Politècnica de València

Congreso IN-RED (2017) 
El 70\% de ellos afirman haber asistido a todas o casi todas las clases de la Lección 2 en la que se centró la experiencia piloto de FCM. El 44\% prefiere el FCM, mientras que el mismo porcentaje prefiere el modelo tradicional. El 10\% restante sugiere una combinación de ambos métodos. Acerca del grado de satisfacción, se obtuvo un claro aumento en el aprovechamiento de las clases presenciales: del 28\% mostrado en la Figura 3 a un 51\% de alumnos que lo consideraron alto o muy alto.

En cuanto a cómo mejorar la implementación del modelo FCM, un 38\% solicita los recursos en Moodle con más antelación, un 47\% reconoce que deben dedicar más tiempo a esudiar antes de la clase, y un 12\% solicita más problemas resueltos por el profesor.

El 30\% que no asistió a las clases de la Lección 2 respondió a la pregunta de cómo aumentar la motivación para asistir a clase. El 56\% prefiere más problemas resueltos por el profesor, el 25\% requiere más tiempo para trabajar en casa antes de las clases presenciales y el $23 \%$ reconocen que deberían invertir más tiempo en los recursos de Moodle.

Se ha realizado un análisis cruzado para identificar sesgos o relaciones ocultas. El resultado más sorprendente es que todos los estudiantes con un aprovechamiento muy bajo o muy alto de las clases prefieren el nuevo modelo. El estudiante promedio parece ser más tradicional mientras que los estudiantes más motivados y los menos adaptados al sistema actual están más abiertos al modelo FCM.

En este sentido hay que hacer notar que un $34 \%$ de los estudiantes matriculados no estaban en clase para hacer la encuesta y es posible que el FCM les motive más para asistir a clase que el modelo tradicional. En futuros cursos se tratará de hacer la encuesta el primer día de clase, para que la respondan el mayor número posible de alumnos o dar la opción de responderla a través de Moodle.

\subsection{Evaluación del éxito de las actividades orientadas a las sesiones prácticas}

El uso de vídeos ha demostrado ser una opción efectiva durante los cursos 2015-2017 para resolver en gran medida el desfase temporal entre las clases en las que se explica la teoría y las sesiones de prácticas (Zabalza, 2016; Zabalza, 2017). Sin embargo, alrededor del 50\% de los estudiantes no ve los videos antes de la sesión y, en opinión de los que sí los ven, los contenidos más importantes de los videos no se enfatizan lo suficiente. Observaciones similares se han obtenido en experiencias de clase inversa en la misma titulación (Vidal, 2017; Llácer, 2017), siendo necesarias medidas adicionales para forzar al alumno a preparar la práctica, facilitando a la vez la asimilación de la materia más importante.

Por esta razón, se ha propuesto la siguiente estrategia para el futuro: la resolución de un test obligatorio que debe realizarse antes de las sesiones de laboratorio, con preguntas estrechamente relacionadas con el contenido de cada video en particular. Si es posible, se utilizará la herramienta EdPuzzle (o una equivalente) para insertar las preguntas en el video, registrar las respuestas y evaluar y supervisar la actividad de los estudiantes. 
Experiencia piloto de aula invertida para mejorar el proceso de enseñanza-aprendizaje en la asignatura de Termodinámica Técnica

\subsection{Evaluación del éxito de las actividades orientadas a las sesiones en el aula}

Las principales observaciones durante la experiencia piloto sobre FCM en la Lección 2 de la asignatura se resumen en Tabla 2.

Tabla 2. Observaciones y posibilidades de mejora sobre la implementación de la clase invertida

\begin{tabular}{|c|c|}
\hline Observaciones & Posibilidades de mejora \\
\hline $\begin{array}{l}\text { El primer día el } 70 \% \text { de estudiantes no trajo } \\
\text { el material necesario (calculadora, tablas). }\end{array}$ & $\begin{array}{l}\text { Enviar a través de Moodle un mensaje para } \\
\text { recordárselo. }\end{array}$ \\
\hline $\begin{array}{l}\text { El primer día, los estudiantes se tomaron de } \\
\text { media unos } 20 \text { min para comenzar a } \\
\text { trabajar. En los siguientes días este tiempo } \\
\text { se acortó a sólo unos minutos. }\end{array}$ & $\begin{array}{l}\text { Detallar en el mensaje las cuestiones y } \\
\text { problemas que resolveran en clase para que los } \\
\text { preparen y vayan a clase con dudas concretas. }\end{array}$ \\
\hline $\begin{array}{l}\text { La mayoría de los estudiantes no pueden } \\
\text { acabar las tareas en clase. }\end{array}$ & $\begin{array}{l}\text { El profesor puede realizar una breve } \\
\text { explicación, orientando a los estudiantes hacia } \\
\text { los conceptos o procedimientos más } \\
\text { importantes, dejando para casa cuestiones } \\
\text { simples o procedimientos más repetitivos. }\end{array}$ \\
\hline $\begin{array}{l}\text { Se crea un clima de trabajo y colaboración, } \\
\text { desarrollándose la competencia de trabajo } \\
\text { en equipo. }\end{array}$ & $\begin{array}{l}\text { El profesor puede realizar una evaluación de la } \\
\text { competencia de trabajo en equipo (Fita, 2017). }\end{array}$ \\
\hline
\end{tabular}

Las sesiones presenciales consistieron en un breve resumen de los contenidos tratados en los videos $\mathrm{y}$, después de resolver algunas dudas, en la resolución por parte de los estudiantes de las preguntas y ejercicios propuestos en pequeños grupos. En general, la experiencia fue bien recibida por los estudiantes, creándose un clima de trabajo y colaboración.

Respecto a la gamificación (Tabla 3), se desarrollaron tres cuestionarios en Kahoot! con cinco preguntas simples de cuatro opciones. Sin embargo, por limitaciones de tiempo sólo uno de ellos se utilizó en el aula.

Tabla 3. Observaciones y posibilidades de mejora sobre la gamificación.

\begin{tabular}{|c|c|}
\hline Observaciones & Posibilidades de mejora \\
\hline $\begin{array}{l}\text { Buena acogida y participación de Kahoot! } \\
\text { Los alumnos comentan los resultados tras } \\
\text { mostrar la solución. }\end{array}$ & $\begin{array}{l}\text { Se tratará de ampliar el número de cuestionarios } \\
\text { en futuros cursos. }\end{array}$ \\
\hline $\begin{array}{l}\text { El juego duró } 10 \mathrm{~min} \text {, lo que supone una } \\
\text { reducción importante sobre una clase de } 50 \\
\text { min. }\end{array}$ & $\begin{array}{l}\text { Se espera reducir este tiempo una vez que los } \\
\text { alumnos se habitúen a esta dinámica } \\
\text { Probablemente, será más fácil implementarlo en } \\
\text { el contexto de la clase invertida, ya que tiener } \\
\text { menor dedicación a explicaciones teóricas. }\end{array}$ \\
\hline
\end{tabular}

(cc) EY-NC-ND 2017, Universitat Politècnica de València

Congreso IN-RED (2017) 


\subsection{Evaluación del éxito con respecto a los resultados de aprendizaje}

Después de cada lección, los estudiantes deben resolver un cuestionario en Moodle, que representa un $5 \%$ de la nota final y entregan la solución de varios problemas que suponen el $10 \%$ de la calificación final. Las calificaciones medias obtenidas en estas actividades durante el presente curso, junto con las del examen de la primera convocatoria de Febrero, se comparan en Tabla 4 con las obtenidas en cursos anteriores.

Tabla 4. Comparativa de resultados de aprendizaje bajo la experiencia piloto (2016-2017) y los obtenidos en cursos anteriores

\begin{tabular}{lccc}
\hline & $\mathbf{2 0 1 4 - 2 0 1 5}$ & $\mathbf{2 0 1 5 - 2 0 1 6}$ & $\mathbf{2 0 1 6 - 2 0 1 7}$ \\
\hline Número total de estudiantes matriculados & 56 & 42 & 69 \\
Nota media en los cuestionarios de Moodle & 6.2 & 5.2 & 6.4 \\
Nota media en las entregas de problemas & 7.3 & 6.8 & 7.4 \\
Nota media en la entrega de la Lección 2 & 8.0 & 6.0 & 7.7 \\
Nota media en el examen final & 6.2 & 6.5 & 6.2 \\
Porcentaje de alumnos presentados al examen & $87.5 \%$ & $90.7 \%$ & $91.3 \%$ \\
Porcentaje de alumnos aprobados & $\mathbf{4 7 \%}$ & $\mathbf{4 8 . 7} \%$ & $\mathbf{6 6 . 7} \%$ \\
\hline
\end{tabular}

Se observa que, en general, se han mejorado las calificaciones obtenidas con respecto al curso 2015-2016 y se han mantenido muy parecidas a las de 2014-2015. También se ha mantenido el mismo orden de alumnos que se han presentado al examen final de la convocatoria de Febrero. El mayor cambio se ha obtenido en el porcentaje de alumnos aprobados en esta convocatoria: ha aumentado en prácticamente 18 puntos porcentuales, lo que supone un incremento tan significativo que no puede achacarse por completamente a las fluctuaciones estadísticas derivadas del cambio de las características de los alumnos.

Estos resultados están en la línea de otros resultados publicados para grados de Ingeniería en asignaturas diferentes (Llácer, 2017; Giménez, 2017), demostrándose la versatilidad del modelo de clase inversa para implantarse en disciplinas diversas.

\section{Conclusiones}

En este trabajo se han recogido los resultados obtenidos de la aplicación del modelo de clase invertida en una asignatura de grado en la Escuela de Ingeniería y Arquitectura de la Universidad de Zaragoza. El proyecto ha servido para evaluar diferentes recursos y estrategias para la mejora del proceso de enseñanza-aprendizaje. Los resultados han sido positivos desde ese punto de vista, ya que han supuesto un relevante aumento en el número de aprobados en la primera convocatoria, pero además ha servido para formar a los autores en nuevas metodologías y herramientas TIC que podrán aplicar en otras asignaturas.

(c)) EY-NC-ND 2017, Universitat Politècnica de València 
Experiencia piloto de aula invertida para mejorar el proceso de enseñanza-aprendizaje en la asignatura de Termodinámica Técnica

Las principales conclusiones del proyecto se resumen a continuación.

- Los videos educativos han demostrado ser un recurso de aprendizaje útil, incluso para aquellos estudiantes que prefieren el modelo tradicional y para aquellos que no asisten a clase habitualmente.

- La principal demanda de los estudiantes para mejorar el proceso de aprendizaje es aumentar el tiempo dedicado por el profesor a la resolución de problemas durante las clases presenciales.

- Las herramientas TIC, como EdPuzzle o Kahoot!, son recursos eficaces para mejorar la motivación de los estudiantes y el proceso de aprendizaje y facilitar el seguimiento de los alumnos y el proceso de evaluación.

- El modelo de aula invertida ha permitido trabajar dos competencias trasversales, aprendizaje autónomo y trabajo en equipo, siendo posible incluso su evaluación en el próximo curso.

- El modelo de aula invertida ha podido contribuir al aumento significativo el porcentaje de alumnos que han superado la asignatura en la primera convocatoria.

En base a estas conclusiones, se pretende expandir el modelo de clase invertida dentro de la asignatura evaluada en el proyecto y extender su aplicación a otras asignaturas, utilizando las técnicas y recursos que han probado su utilidad para mejorar el proceso de enseñanzaaprendizaje.

\section{Agradecimientos}

Este trabajo ha sido financiado por medio de los proyectos de innovación docente PIIDUZ_16_032 y PIIDUZ_16_165 (Programa de Proyectos de Innovación Docente para Grupos de Profesores del Vicerrectorado de Política Académica de la Universidad de Zaragoza)

\section{Referencias}

ALBA, J., TORREGROSA, C., VIDAL, A. y DEL REY, R. (2017) "Flipped teching en Física del grado de Ingeniería de Sistemas de Telecomunicación, Sonido e Imagen. Primeros resultados" En: Actas del Congreso In-Red 2016. http://ocs.editorial.upv.es/index.php/INRED/INRED2016/paper/view/4430 [Consulta: 17 de mayo 2017].

ARTAL-SEVIL, J.S., ROMERO, E. y ARTACHO, J.M. (2017) "Quick surveys in classroom. mobile phone, a powerful teaching tool". En: INTED17 Proceedings of the $11^{\text {th }}$ annual International Technology, Education and Development Conference, Valencia, IATED Academy, pp. 9282-9291.

BAIN, K. (2006) "Lo que hacen los mejores profesores universitarios", Valencia, Publicaciones de la Universidad de Valencia. 
BAKER, J.W (2000) “The 'classroom Flip': Using web course management tools to become the guide by the side", In J. A. Chambers (Ed.), Selected papers from the $11^{\text {th }}$ international conference on college teaching and learning, Jacksonville, FL; Floride Community College at Jacksonville, pp. 9-17.

BAKER, C. (2012) "Flipped classrooms: turning learning upside down", Deseret News, publicado en http://wwwdeseretnews.com/article/765616415/Flippedclassrooms-Turning-learning-upside-down.html?pg=all.

BERGMANN, J. y SAMS, A. (2012) "Flip your classroom: Reach every student in every class every day", Washington, DC: Internal Society for Technology in Education, 2012.

EDPUZZLE, https://edpuzzle.com/ [Consulta: 18 de enero 2017].

FITA, I., MONSERRAT, J.F. y MOLTÓ, G. (2017) "Aula Inversa: una oportunidad para el desarrollo de compentencias trasversales" En: Actas del Congreso In-Red 2016. http://ocs.editorial.upv.es/index.php/INRED/INRED2016/paper/view/4430 [Consulta: 17 de mayo 2017].

HARVARD UNIVERSITY, School of Engineering and Applied Sciences, https://www.seas.harvard.edu/ [Consulta: 19 de enero 2017].

GIMÉNEZ, R. y BARELLES, E. (2017) "Resultados de la implantación de un método de innovación docente en el aula. Flip-teaching" En: Congreso In-Red 2016. http://ocs.editorial.upv.es/index.php/INRED/INRED2016/paper/view/4430 [Consulta: 17 de mayo 2017].

GUTIÉRREZ, O. y VICENTE, J. (2017) "Un año de FLIP: corrigiendo errores" En: Actas del Congreso In-Red 2016. http://ocs.editorial.upv.es/index.php/INRED/INRED2016/paper/view/4430 [Consulta: 17 de mayo 2017].

KAHOOT!, https://getkahoot.com/ [Consulta: 13 de enero 2017].

LAGE, M.J., PLATT, G.J. y TREGLIA, M. (2000) "Inverting the Classroom: a Gateway to Creating an Inclusive Learning Environment", The Journal of Economic Education, vol. 31 (1), pp. 30-43.

LLÁCER, R. y MARTíNEZ-SOLANO, F.J. (2017) "Experiencia en la aplicación de la docencia inversa para el aprendizaje de Máquinas Hidráulicas (Grado de Ingeniería en Tecnologías Industriales" En: Actas del Congreso In-Red 2016. http://ocs.editorial.upv.es/index.php/INRED/INRED2016/paper/view/4430

[Consulta: 17 de mayo 2017].

MASSACHUSETTS INSTITUTE OF TECHNOLOGY, http://web.mit.edu/ [Consulta: 19 de enero 2017].

MORERA, I. (2017) "Hacia la clase inversa. Una experiencia de aprendizaje de la Química y de Desarrollo de Competencias en el primer curso de Grado de Ingenierías" En: Actas del Congreso In-Red 2016. http://ocs.editorial.upv.es/index.php/INRED/INRED2016/paper/view/4430 [Consulta: 17 de mayo 2017].

PEÑA B. y GIL, A. (2009) "Prácticas de Termodinámica”, Prensas Universitarias de Zaragoza. 
PEÑA, B. et al. (2017) "Development of educational videos as reusable learning objects for their integration into an Open Courseware on fundamentals of thermodynamics and thermal engineering". En: INTED17 Proceedings of the $11^{\text {th }}$ annual International Technology, Education and Development Conference, Valencia, IATED Academy, pp. 3601-3610.

SCA (2017). Flipped Learning. SHIRELAND COLLEGIATE ACADEMY, http://shirelandflippedlearning.co.uk/Schools.htm [Consulta: 19 de enero 2017].

TOURÓN, J. y SANTIAGO, R. (2015). "El modelo Flipped Learning y el desarrollo del talento en la escuela". Revista de Educación, n 368, p. 196-231.

UPV (2017). Flip Teaching. UNIVERSIDAD POLITÉCNICA DE VALENCIA https://www.upv.es/entidades/ETSINF/info/967104normalc.html [Consulta: 19 de enero 2017].

VIDAL, A., ESTRUCH, V., BOIGUES, F., DEL REY, R. et al. (2017) "Flipped Teaching: una metodología en construcción..." En: Actas del Congreso In-Red 2016. http://ocs.editorial.upv.es/index.php/INRED/INRED2016/paper/view/4430 [Consulta: 17 de mayo 2017].

ZABALZA, I., PEÑA, B., LLERA, E.M. y USÓN, S. (2016) "Improving the teachinglearning process using educational videos as reusable learning objects in the field of thermal engineering", Proceedings of the $8^{\text {th }}$ International Conference on Education and New Learning Technologies (EDULEARN 2016), Barcelona, IATED Academy, pp. 363-372.

ZABALZA, I., et al. (2017) "Development of educational videos as reusable learning objects for their integration into an Open Courseware on fundamentals of thermodynamics and thermal engineering", En: INTED17 Proceedings of the 11 annual International Technology, Education and Development Conference, Valencia, IATED Academy, pp. 4453-4461. 


\title{
INNOVACION DOCENTE MEDIANTE LA GESTION Y PARTICIPACION EN SIMULACROS DE CONGRESOS CIENTIFICOS.
}

\author{
Lucia Aparicio Chofre ${ }^{a}$, Maria Cristina Escamilla ${ }^{b}$ y Carla de Paredes Gallardo ${ }^{c}$ \\ a (Universidad Europea de Valencia y Universidad de Valencia, lucia.aparicio@universidadeuropea.es), b (Universidad Europea \\ de Valencia, mariacristina.escamilla@universidadeuropea.es), c (Universidad Europea de Valencia, \\ carla.deparedes@universidadeuropea.es)
}

\begin{abstract}
The objective of the present work is to show the results obtained in a teaching experience with the students of the 3rd year of the Degree of Criminology and of the Double Degree of Criminology and Psychology of the European University of Valencia, through the performance of a simulation of "congress Scientific "and with the purpose of having contact with the professional reality. The simulacrum was carried out during the 2 nd quarter of the academic year, within the subject of Penitentiary Law and Penology, and consisted in the elaboration of a scientific communication in póster format. This activity was part of the subject, in its practical part, using at first a methodology of training in skills of scientific communication and later of execution of the póster, following established norms with respect to format, structure and extension. The apprentice of the elaboration of this type of scientific communications, allows to carry out works of rigorous form, while pleasant, pleasant and attractive. The result of the work was evaluated by the students as an innovator and motivator in the evaluation surveys. There was a notable improvement in the communicative skills of the participants, which is reflected in the positive evolution of most of them.
\end{abstract}

Keywords: Method, simulacrum, congress, innovation

\section{Resumen}

El objetivo del presente trabajo es mostrar los resultados obtenidos en una experiencia docente con los estudiantes del $3^{\circ}$ curso del Grado de Criminología y del doble Grado de Criminología y Psicología de la Universidad Europea de Valencia, a través de la realización de un simulacro de "congreso científico" y con la finalidad de tener contacto con la realidad profesional. El simulacro se llevó a cabo durante el $2^{\circ}$ trimestre del curso 
académico, dentro de la asignatura de Derecho Penitenciario y Penologia, y consistió en la elaboración de una comunicación científica en formato "póster" y su posterior exposición en salón de actos, diseñado para la celebración de un congreso. Dicha actividad formó parte de la asignatura, en su parte práctica, utilizando en un primer momento una metodología de entrenamiento en habilidades de comunicación científica y pósteriormente de ejecución del póster, siguiendo unas normas establecidas con respecto al formato, estructura y extensión. El aprendizaje de la elaboración de este tipo de comunicaciones científicas, permite realizar trabajos de forma rigurosa, a la vez que amena, agradable y atractiva. El resultado del trabajo fue valorado por el alumnado como innovador y motivador en las encuestas de evaluación. Se produjo una mejora notable en las competencias comunicativas de los participantes, que se refleja en la evolución positiva de la mayoría de ellos.

Palabras claves: competencia, simulacro, comunicación científica, congreso, innovación.

\section{Introducción}

En los últimos tiempos se está produciendo un cambio intenso en la concepción y el objeto de la Educación Superior. La nueva realidad del Espacio Europeo de Educación Superior, propone nuevas metodologías educativas y persigue diferentes objetivos pedagógicos. Esta transformación aboga por un proceso formativo centrado en la adquisición de competencias y en el desarrollo de todo el potencial humano de los estudiantes.

Algunas de las competencias que mayor importancia adquieren son las relacionadas con la esfera comunicativa, especialmente en aquellos estudios o disciplinas en las que la divulgación y la transferencia científica resultan indispensables, siendo este el caso en ciencias sociales. En este sentido, una comunicación científica eficaz requiere el conocimiento y dominio de diversas herramientas de transferencia del conocimiento. Entre ellas, aquellas relacionadas con la exposición en el marco de los congresos científicos, como la comunicación oral (Gonzalez y Barquero, 2012).

Con el cambio metodológico, la Universidad Europea de Valencia pretende reforzar el aprendizaje de los estudiantes de manera flexible y entretenida, fomentando la

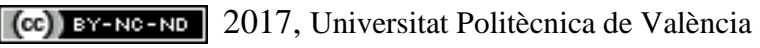


participación del estudiante en el aula, con la finalidad de prepararles para el mundo profesional, por ello considera que el "simulacro de congreso" es una forma de acercarles a la realidad investigadora.

La realización del simulacro de congreso científico es una estrategia didáctica, útil en la adquisición de las competencias y destrezas necesarias para una correcta exposición de unos resultados de una investigación realizada, sabiendo concluir lo importante de dicha temática para finalmente saber plasmarlo en un póster científico, siendo capaces de poder sintetizar todo el estudio realizado así como transmitir, explicar y defender la información del póster. Dicha alternativa de comunicación, ofrece la oportunidad de presentar estudios, proyectos o experiencias, de forma clara y concisa, con la necesaria información y donde el autor puede desarrollar su creatividad y plasmarla de forma permantente (Guardiola, 2010).

En este sentido, la comunicación en formato póster, recoge las aportaciones más interesantes de un congreso. En algunos congresos científicos se han eliminado las clásicas presentaciones en forma de comunicaciones orales, y donde se ha dado especial protagonismo a las contribuciones en formato póster, dejando así las presentaciones orales para conferencias, mesas redondas, seminarios, etc., donde participan los ponentes o autores más reconocidos en cada temática de interés (Guardiola, 2010).

\section{Objetivos}

El objetivo general de este trabajo es desarrollar un recurso formativo e innovador en el proceso de enseñanza universitaria, donde el alumno adquiera las competencias comunicativas del "saber" científico, además del conocimiento de la asignatura concreta donde se trabaja esta actividad. Es imporante tener en cuenta que ahora mas que nunca, nuestra sociedad se articula alrededor de la comunicación, siendo un pilar fundamental de buen hacer en las tareas profesionales o investigadoras siendo cauces eficaces para compartir conocimiento científico.

Los alumnos conseguirán los siguientes objetivos específicos:

- Aprender parte de los contenidos de una asignatura a través de la elaboración de un póster científico.

- Conocer y dominar una herramienta de transferencia del conocimiento.

- Desarrollar la creatividad en relación a unos contenidos, de manera clara, concisa y atractiva. 
- Prácticar habilidades comunicativas en un entorno académico y científico.

- El uso de las tecnologías de la información y comunicación (TICS)

\section{Desarrollo de la innovación}

El presente trabajo se desarrolló con la implementación dentro de una asignatura, de una actividad dirigida a intervenir en un congreso científico simulado. Para conseguir el objetivo de aprendizaje, la actividad se llevó a cabo dentro de la asignatura de Derecho Penitenciario y Penologia del tercer curso del grado de criminología, Derecho y psicología durante el segundo trimestre del curso académico 2015-2016 y 2015-2016 .

El simulacro se realizó con 15 alumnos del $3^{\circ}$ curso del Grado de Criminología y del doble Grado de Criminología/Psicología del curso 2015-2016 y con 11 alumnos del curso 2016-2017. La actividad se incluyó en el segundo trimestre del curso académico 2015-2016 y curso 2016-2017, como ejercicio obligatorio de la asignatura "Penología y Derecho Penitenciario" asignándole un valor del $30 \%$ de la nota final de la asignatura.

El simulacro del Congreso Científico comenzó poniendo en conocimiento por parte del profesor a los alumnos del contenido del proyecto, incluyendo la metodología a usar para el desarrollo del trabajo, que fue la siguiente:

- Fase informativa, donde se establecieron las fechas de entrega de cada fase del póster. Para que dichos plazos fueran recordados por los alumnos y los tuvieran a su disposición en todo momento, se editó un perfil del simulacro en una red social la cual podían consultar los estudiantes en cualquier momento con cualquier dispositivo para poder tener toda la información necesaria del simulacro, véase Figura 1.

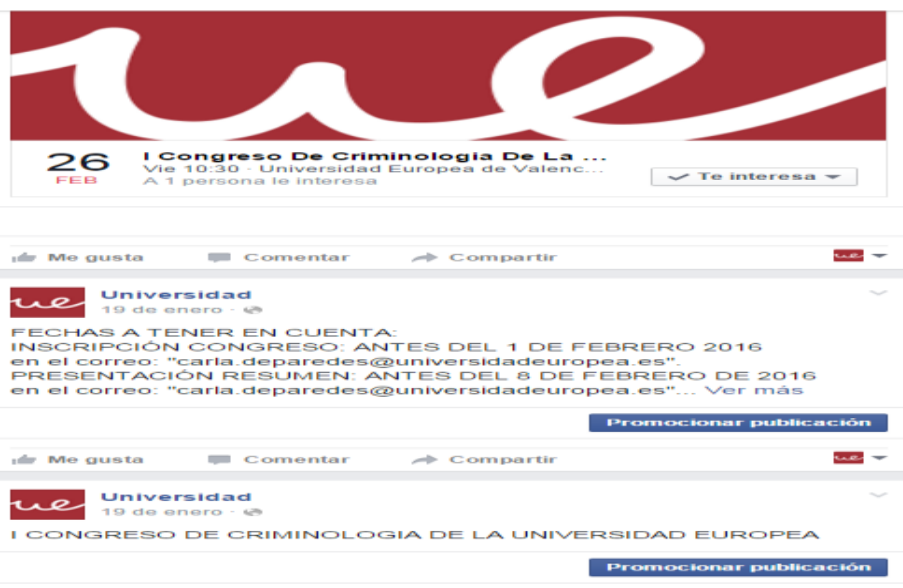

Fig. 1. Información en red social.

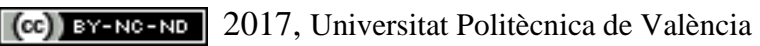

Congreso IN-RED (2017) 
De la misma manera, en esta fase se comunicó a los alumnos los criterios de evaluación de la actividad, siendo un $30 \%$ de la nota final de la asignatura de "Penología y Derecho penitenciario", asignando un 5\% al cumplimiento de los plazos establecidos en cada momento del congreso, por la importancia del cumplimiento de los plazos en Ciencias Sociales, un 5\% a la originalidad del tema elegido así como la investigación realizada sobre el tema electo, otro 5\% a la síntesis realizada en el póster y por último un $15 \%$ a la presentación y defensa del póster ante iguales,

- Fase de elección de la temática: la elección del tema a plasmar en el póster era libre pero siempre dentro del contexto de la asignatura, es decir relacionada con la pena, el derecho Penitenciario, permitiendo la presentación de pósters basados en estudios de datos, de derecho comparado y proyectos de investigación enfocados a la futura realización del Trabajo fin de Grado. Para ello se les recomendó el uso de bibliografía disponible en la biblioteca de la Facultad de Ciencias Sociales, así como de distintas revistas sobre Derecho Penitenciario.

- Fase de inscripción, por parte de los alumnos en el Congreso. Para ello se les facilito un formulario vía virtual, que debían cumplimentar simplemente con sus datos y remitirlo por correo electrónico, dentro del plazo establecido, a una dirección de correo electrónico que se creo exclusivamente para esta actividad.

- Fase de elaboración del póster, en esta fase se ofrecieron pautas a los alumnos para la elaboración del trabajo, referidas tanto a la redacción como a su estructura y creatividad: titulo, autores, centro, introducción, hipótesis y objetivos, metodología (materiales y métodos), resultados, conclusiones, etc. Se ofrecieron explicaciones de las diferentes normas que los congresos solicitan, se vieron ejemplos y plantillas de pósters, además de la revisión de las diferentes características que deben de cumplir a la hora del desarrollo: que sea comprensible, que contenga los puntos esenciales del estudio, proyecto o experiencia, extensión limitada según la organización, claridad, brevedad, lenguaje, tablas, figuras, etc.

- Fase de entrenamiento en habilidades de comunicación científica, en comunicación verbal y no verbal, y sobre el procedimiento a seguir para que la explicación oral sea coherente y justa con un hilo conductor adecuado. 
- Fase presentación en Congreso La fase final del proyecto consistio en el simulacro del congreso científico, los días 26 de Febrero de 2016 y 29 de Marzo de 2017 desde las 10.30 a 12:30 horas respectivamente. Para hacer el simulacro lo mas real posible a la situación real de presentar un póster o comunicación en un congreso, se reservó el salón de actos de la Facultad de Ciencias Sociales y se aconsejó a los estudiantes que acudieran con una vestimenta adecuada para el congreso. Una vez colgado el póster en el sitio asignado a cada autor, se invito a distintos profesores y alumnos para que asistieran como publico, actuando los alumnos como ponentes de las distintas comunciaciones y póster, véase Figura 2.

Dichas comunicaciones se valoraron según la adecuación a la temática de la asignatura, la coherencia en los contenidos, el grado de innovación del trabajo.

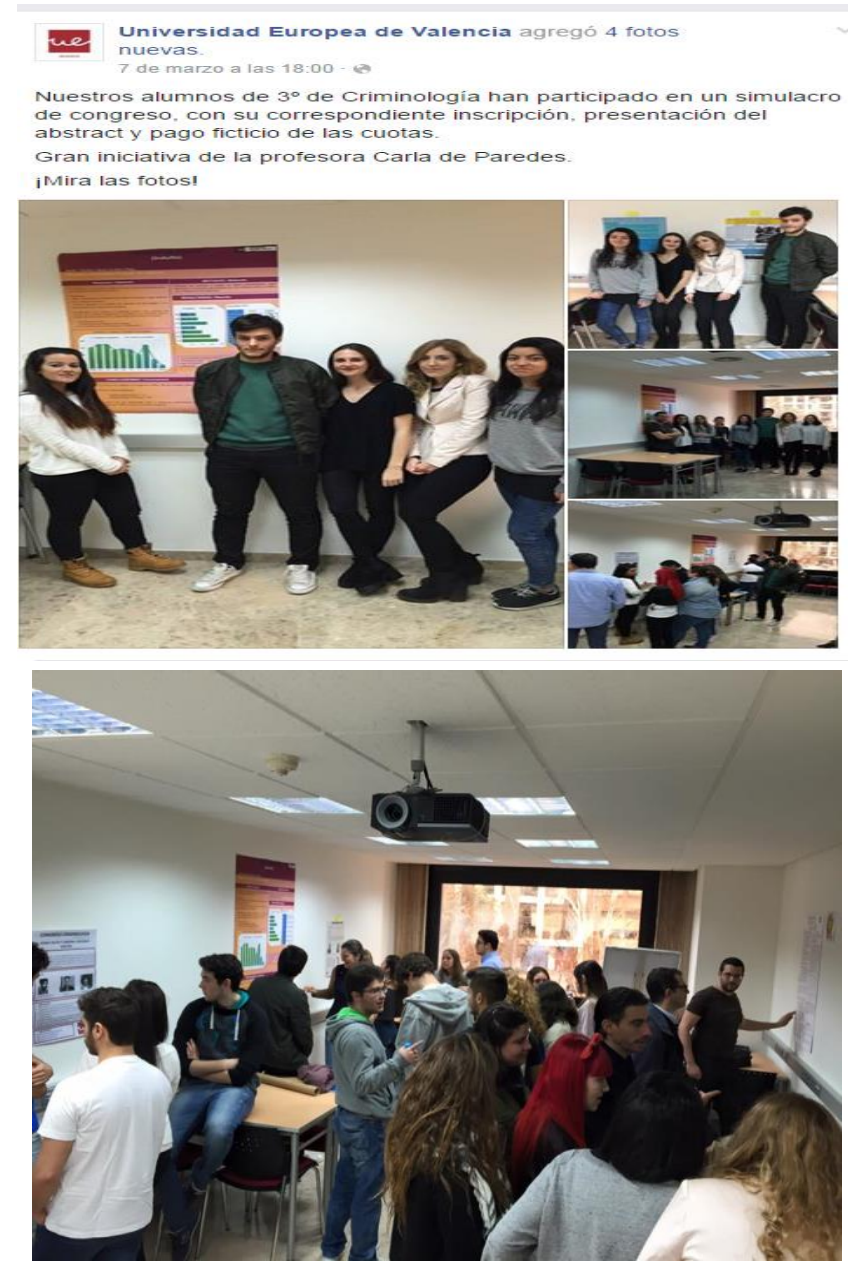

Fig. 2. Imágenes de la experiencia

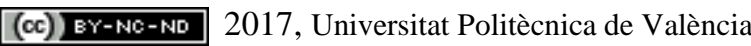

Congreso IN-RED (2017) 


\section{Resultados}

Los resultados obtenidos con esta actividad innovadora fue muy positiva por parte de los alumnos, que manifestaron la iniciativa como novedosa y motivadora al tener un contacto con la realidad investigadora. El proyecto les facilitó conocer los pasos a seguir para contribuir a los congresos científicos profesionales.

Para conocer la opinión de los estudiantes se les paso a todos los participantes una encuesta final de evaluación del simulacro de congreso, el cual consistía en un listado de 15 preguntas cerradas sobre la mejora de las competencias, innovación de la actividad y organización del simulacro, con opciones de respuestas entre A, B, C y D con un valor de total acuerdo, bastante, alguna vez y nada, respectivamente.

El resultado de las encuestas fue mayoritariamente en total acuerdo como actividad innovadora, obteniendo un $80 \%$ de estudiantes con respuestas "A" (sí en total acuerdo) y un $20 \%$ con respuestas "B" (bastante de acuerdo), véase Figura 3.

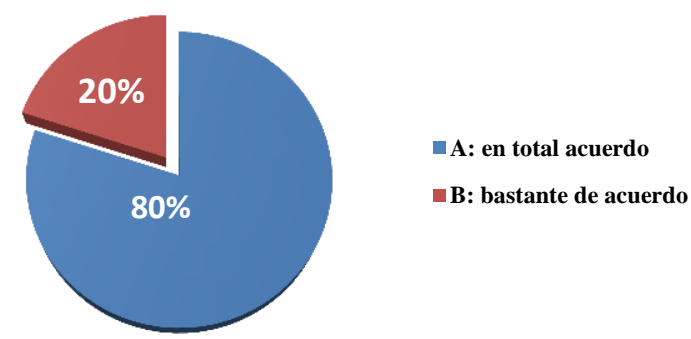

Figura 3. Resultado evaluación de la actividad.

Se observó una mejoraría en la puntuación obtenida por parte de los alumnos en sus competencias comunicativas, entre las dos mediciones que difieren entre sí, 5 semanas, utilizando para ellos los mismos criterios de evaluación.

Los alumnos y los profesores de otras asignaturas que acudieron al simulacro de congreso, manifestaron que les pareció muy enriquecedor el simulacro, no solo por la buena acogida que tuvo entre los alumnos y por los buenos resultados sino también por favorecer una reflexion sobre la innovación docente en general y la comunicación científica en particular, haciendo hincapié del buen trabajo realizado por los estudiantes.

(c) ) EY-NC-ND 2017, Universitat Politècnica de València 
En el aspecto negativo de las encuestas, señalado por 4 alumnos, es la escasez del tiempo para realizar las tareas encomendadas, siendo bastante alto el nivel de exigencia que require para un alumno enfrentarse a la metodología desconocida, buscar información para realizar la comunicación o póster

\section{Conclusiones:}

La puesta en marcha de esta actividad ofreció diferentes desarrollos de capacidades y aprendizajes al alumno. En primer lugar se vio un gran esfuerzo por sintetizar toda la información recopilada durante el trimestre sobre su tema elegido, eligiendo la información principal que debía figurar en el póster y descartando ideas secundarias. Por lo tanto, los contenidos de la asignatura se interiorizaron desde otra perspectiva y no solo con el estudio. $\mathrm{Y}$ en segundo lugar, conocer una herramienta para la comunicación científica, muy eficaz para desarrollar en el mundo academémico y científico.

Por otra parte, se observó una mejoría considerable en las competencias comunicativas, a la hora de explicar entre iguales contenidos criminológicos y jurídicos a otros estudiantes que los desconocen y tener que explicar como concluyen sus ideas. Por todo ello con el entrenamiento en dichas competencias puede afirmarse una gran desarrollo profesional una vez terminados los estudios universitarios.

Por último, un mayor uso de las TICS a la hora de diseñar y elaborar el póster, distinguiendo aquellos alumnos que hacen uso de las TICS de aquellos otros que no las usan y lo hacen a mano.

\section{Referencias}

Galindo, F.; (2009) “El aprendizaje del Derecho y la reforma de Bolonia”. Revista La Ley, Madrid, número 7121. Wolkers Kluwer.

Gonzalez Sanz, J. y Barquero González, A (2012) “ Simulacro de congresos cientifico como entrenamiento en competencias comunicativas". Revista Iberoamericana en Educacion e investigación", Vol. 2, nº 4. pags. 20-28

Guardiola, E. (2010). El póster científico. Serés E, Rosich L, Bosch F, coordinadores. Presentaciones orales en biomedicina. Aspectos a tener en cuenta para mejorar la comunicación. Cuadernos de la Fundación Dr. Antonio Esteve, (20), 85-102.

(cc) EY-NC-ND 2017, Universitat Politècnica de València

Congreso IN-RED (2017) 


\title{
Análisis de la calidad de los informes de prácticas de laboratorio en Ingeniería Química: comparación del trabajo presencial con el no presencial
}

\author{
María Sancho Fernández ${ }^{\mathrm{a}}$, Beatriz García-Fayos ${ }^{\mathrm{a}}$ y Miguel Arnal Arnal ${ }^{\mathrm{a}}$ \\ ${ }^{a}$ Dpto. Ingeniería Química y Nuclear, Universitat Politècnica de València, emails: \\ msanchof@iqn.upv.es, beagarfa@iqn.upv.es, jarnala@iqn.upv.es
}

\begin{abstract}
In the degree of Chemical Engineering it is essential students training through labs, which are traditionally evaluated by a report in which the students present and analyse the experimental results. Generally, this report is carried out offsite, which has certain inconveniences such as: distribution of work without interaction between members of the group, errors or omissions in the description of the experimental work since time has passed from the lab session, cheat of reports from other years' ones, etc. All this affects the quality of reports and produces lower qualifications than expected. Therefore, this work presents a new methodology for working the lab reports, which consists of writing them, partly or entirely,during the lab session. This article discusses if this insite working methodology of the reports means an improvement of their quality when compared with reports made offsite. In addition, assessment by students of the new methodology, collected through an anonymous survey, is shown and analyzed.
\end{abstract}

Keywords: reports, laboratory, Chemical Engineering, insite working

\begin{abstract}
Resumen
En la titulación de Ingeniería Química es fundamental la formación de los estudiantes a través de prácticas de laboratorio, que tradicionalmente son evaluadas a través de un informe en el que los estudiantes presentan y analizan los resultados experimentales obtenidos. Generalmente, dicho informe se realiza de manera no presencial, lo que supone ciertos inconvenientes como: reparto del trabajo sin interacción entre los miembros del grupo, errores u omisiones en la descripción del trabajo experimental por haber transcurrido cierto tiempo desde la sesión de laboratorio, copia de informes de otros cursos, etc. Todo ello repercute en una baja calidad de los informes y en unas calificaciones inferiores a las esperadas. Por ello, en este trabajo se plantea una nueva metodología de trabajo de los informes de laboratorio, consistente en la realización de los mismos, en parte o en su totalidad, de manera presencial. En este artículo se analiza si esta metodología de trabajo presencial de los informes supone una mejora de la calidad de los mismos, comparándolos con informes realizados de forma no
\end{abstract}


presencial. Además, se presentan y analizan las valoraciones de los alumnos de la nueva metodología, recogidas a través de una encuesta anónima.

Palabras clave: informes, laboratorio, Ingeniería Química, trabajo presencial

\section{Introducción}

En la titulación de Ingeniería Química es fundamental la formación de los estudiantes a través de prácticas de laboratorio. En algunos casos, las asignaturas incluyen prácticas de laboratorio puntuales, pero también existen asignaturas totalmente prácticas como son las de experimentación. Este trabajo de laboratorio permite la formación de los estudiantes en tres principales áreas, tal y como señalaron Carnduff y Reid (citados por Reid, 2007):

1) Competencias específicas como el manejo de equipos analíticos, la descripción de procedimientos experimentales, la toma de datos y su análisis, etc.

2) Competencias transversales como el trabajo en equipo, la gestión del tiempo, la comunicación efectiva, etc.

3) Motivación intelectual, a partir del modo de trabajo similar al profesional.

Tradicionalmente, las prácticas de laboratorio se evalúan a través de una memoria o informe realizado en grupos en el que los estudiantes presentan y analizan los resultados experimentales obtenidos. Estos informes de laboratorio deben ser más que una simple presentación de datos, debiendo ser un documento más elaborado que demuestre la comprensión e integración de los conocimientos en los que se basan los experimentos realizados (Abidin, 2013).

Generalmente, dicho trabajo académico se realiza de manera no presencial, y se presenta para su corrección en una fecha posterior a la sesión de laboratorio. La experiencia ha demostrado que este modo de trabajo de los informes presenta ciertos inconvenientes:

- aunque los informes deben ser realizados en grupo, los estudiantes se reparten el trabajo, realizando el informe cada vez un miembro del grupo o realizando cada miembro una parte del informe por separado, y no existe ninguna interacción entre los miembros del grupo durante la elaboración del informe;

- los alumnos no llevan a cabo ninguna revisión conjunta del informe a presentar, tras la unión de las partes realizadas individualmente, lo que conlleva ciertas inconexiones e incoherencias entre los distintos apartados presentados;

- se producen numerosos errores u omisiones en la descripción del trabajo experimental (montaje, material, procedimiento, etc.) por haber transcurrido cierto tiempo desde la sesión de laboratorio;

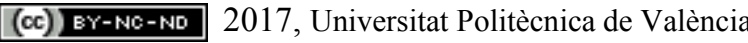


- se detectan copias de cursos anteriores, de algunas partes o de la totalidad de los informes.

Todo ello repercute en una baja calidad de los informes presentados, tanto de estructura como de contenidos, de forma de presentación de los resultados y de su interpretación, lo que se traduce en bajas calificaciones, tanto en el trabajo académico como en el examen de prácticas (ya que la herramienta de estudio de los alumnos es el propio informe).

Estos inconvenientes encontrados con los informes de laboratorio son bastante generales en otras universidades y titulaciones (Hilosky, 1998 \& Del Carlo, 2004 \& Reid, 2007). Como consecuencia de ello, han surgido distintas estrategias, encontradas en la literatura consultada, para tratar de superar dichos inconvenientes y mejorar el aprendizaje de los estudiantes a través de los informes de laboratorio.

En unos casos, las estrategias están encaminadas a modificar la metodología de trabajo de los informes para conseguir un aprendizaje más profundo de los estudiantes, y que la realización del informe no sea una simple tarea de recopilación de datos y seguimiento de instrucciones. En relación con este tipo de cambios, se encuentra el trabajo desarrollado por Haagen-Schuetzenhoefer, de la Universidad de Viena, quien implementó con sus estudiantes la "replicación" de las prácticas. Una metodología que consiste en que los alumnos repitan el experimento siguiendo las instrucciones escritas por ellos mismos en el informe de la primera vez que lo hicieron. Según la autora, esta estrategia mejora la calidad de los informes a la vez que fomenta el trabajo de tipo científico (Haagen-Schuetzenhoefer, 2012). Otra estrategia encontrada ha sido la llevada a cabo por Berry y Fawkes en dos asignaturas de química a nivel de universidad. Estos autores han implementado una innovación que ha consistido en una elaboración gradual de los informes (se van incorporando apartados nuevos conforme se avanza en la asignatura), combinada con una evaluación por pares; habiendo conseguido de esta forma una mejora sustancial de las competencias de comunicación escrita de los estudiantes (Berry, 2009).

En otros casos, se ha decidido directamente sustituir el informe de laboratorio por otra herramienta de evaluación similar. Así, por ejemplo, Brian Lane sustituyó el informe de laboratorio por un documento más informal con una escritura más directa, que obliga a los estudiantes a una mayor interiorización y comprensión de los conceptos manejados (Brian Lane, 2014). En una estrategia más compleja implementada a nivel de estudios de máster/doctorado, Alaimo y colaboradores plantean la sustitución del informe de laboratorio por un documento análogo a un artículo científico, con el objetivo de conseguir un aprendizaje más profundo de los estudiantes y un acercamiento al modo de pensar y hacer de los investigadores (Alaimo, 2009).

Por todos los inconvenientes comentados al respecto del trabajo tradicional de los informes de laboratorio, los profesores de algunas asignaturas de Experimentación en Ingeniería Química de la Universitat Politècnica de València decidimos hace varios cursos cambiar la metodología de trabajo de los mismos en algunas prácticas, pasando a realizarse durante la propia sesión de laboratorio, de manera simultánea al desarrollo experimental. En este 
trabajo se aborda el análisis de las posibles mejoras que hayan podido producirse con dicho cambio de metodología de trabajo de los informes de laboratorio.

\section{Objetivos}

Tras la implantación de la nueva metodología de trabajo presencial de los informes de laboratorio en dos asignaturas experimentales del Grado de Ingeniería Química de la UPV, en este trabajo se pretende:

1) Comparar la calidad de los informes de prácticas de laboratorio trabajados de manera presencial y no presencial.

2) Analizar el grado de satisfacción de los estudiantes con el modo de trabajo presencial de los informes de laboratorio.

3) Valorar por parte de los profesores las mejoras detectadas tras la implementación del modo de trabajo presencial de los informes.

\section{Desarrollo de la innovación}

La innovación ha consistido en que los alumnos elaboren de manera presencial los informes de las prácticas de laboratorio, parcialmente o en su totalidad, en la propia sesión de laboratorio o en una sesión informática posterior.

Mediante esta forma de trabajo de los informes se pretende aumentar la interacción de los estudiantes, que deben colaborar necesariamente para poder desarrollar la memoria en el tiempo de la sesión presencial. Por otra parte, se espera mejorar la calidad de dichos informes al ser realizados en simultáneo al trabajo experimental, y por el hecho de contar con la presencia del profesor como guía y ayuda para la resolución de dudas.

Las asignaturas seleccionadas para la implementación de la nueva metodología son "Experimentación en Ingeniería Química II" (EIq2) y "Experimentación en Ingeniería Química III" (EIq3), ambas de $3^{\text {er }}$ curso del Grado en Ingeniería Química. En la Tabla 1 se resumen las principales características de las dos asignaturas.

Tabla 1. Asignaturas en las que se ha implementado la innovación

\begin{tabular}{|l|l|l|}
\hline Asignatura & Curso (cuatrimestre) & $\mathrm{N}^{\circ}$ alumnos \\
\hline EIq2 & $3^{\circ}(\mathrm{A})$ & $60-85$ \\
\hline EIq3 & $3^{\circ}(\mathrm{B})$ & $55-80$ \\
\hline
\end{tabular}

\subsection{Metodologías para el trabajo presencial de los informes de laboratorio}

En este trabajo se abordan dos metodologías de trabajo presencial de los informes de laboratorio, en las dos asignaturas indicadas en la Tabla 1, que se diferencian en las partes del informe que son elaboradas presencialmente:

(cc) EY-NC-ND 2017, Universitat Politècnica de València

Congreso IN-RED (2017) 
a) Metodología de "Experimentación en Ingeniería Química III" (EIq3). En la práctica analizada de esta asignatura se realiza parte del informe en la sesión de laboratorio, pero algunos resultados no pueden realizarse hasta tomar medidas al día siguiente, por lo que hay una parte del informe que se elabora de forma no presencial. Se pretende comparar la calificación obtenida en la parte del informe realizada presencialmente con la realizada fuera de la sesión de laboratorio. Para ello se cuenta con resultados de 4 cursos académicos, incluido el presente curso 2016-17.

b) Metodología de "Experimentación en Ingeniería Química II" (EIq2). Este curso 2016-2017 se ha introducido el trabajo presencial de informes en esta asignatura de experimentación, dado el buen funcionamiento de esta metodología en EIq3. En este caso, además de elaborar una parte del informe durante la sesión de laboratorio, en algunas prácticas se ha programado una sesión informática posterior para el desarrollo también presencial de la parte de resultados del informe. Se compararán, para una misma práctica, los resultados de dos cursos anteriores, con la metodología no presencial, con los de este curso 2016-17.

La Tabla 2 resume las metodologías de cada asignatura analizada, los cursos considerados y el número de grupos en cada curso y asignatura.

Tabla 2. Asignaturas con trabajo presencial de informes de laboratorio

\begin{tabular}{|l|l|l|l|}
\hline Asignatura & Curso & $\begin{array}{l}\mathrm{N}^{\mathrm{o}} \text { grupos } \\
\left(\mathrm{n}^{\mathrm{o}} \text { alumnos }\right)\end{array}$ & Metodología informe laboratorio \\
\hline \multirow{4}{*}{ EIq3 } & $2012-13$ & $11(56)$ & Presencial / no presencial \\
\cline { 2 - 4 } & $2014-15$ & $16(78)$ & Presencial / no presencial \\
\cline { 2 - 4 } & $2015-16$ & $16(76)$ & Presencial / no presencial \\
\cline { 2 - 5 } & $2016-17$ & $15(69)$ & Presencial / no presencial \\
\hline \multirow{3}{*}{ EIq2 } & $2013-14$ & $20(71)$ & No presencial \\
\cline { 2 - 5 } & $2015-16$ & $16(72)$ & No presencial \\
\cline { 2 - 5 } & $2016-17$ & $14(62)$ & Todo presencial \\
\hline
\end{tabular}

\subsection{Evidencias empleadas para el análisis de resultados}

Para alcanzar los objetivos marcados se han recogido datos a través de distintas herramientas o evidencias, que se describen a continuación.

\subsubsection{Informes de laboratorio realizados de manera presencial y no presencial}

Para comparar la calidad de los informes realizados de manera presencial y no presencial se han utilizados las siguientes herramientas en cada asignatura: 
a) En EIq3 se analizan las calificaciones de los informes de una misma práctica, realizados en cuatro cursos académicos distintos. El número de informes considerados coincide con el número de grupos de cada curso mostrado en la Tabla 2. Se compara la calificación de la parte presencial con la de la parte no presencial. La parte presencial incluye los apartados del informe realizados en el laboratorio: objetivos, procedimiento experimental, material y montaje, seguridad, resultados parciales y conclusiones parciales. La parte no presencial incluye el apartado de resultados completo, su discusión y las conclusiones globales del trabajo. Cada parte tiene el mismo peso en la nota final del informe (50\%).

b) En la asignatura EIq2 se han analizado las calificaciones de los informes de una misma práctica, comparando dos cursos en los que se realizó de manera no presencial con este curso en el que se ha trabajado de forma presencial. El número de informes considerados coincide con el número de grupos de cada curso mostrado en la Tabla 2. Para obtener la calificación del informe se han evaluado los mismos apartados ya indicados para los informes de EIq3. Además, en el caso de EIq2 se ha estudiado también la posible influencia del modo de trabajo de los informes en las calificaciones obtenidas en el examen, en la pregunta relativa a la práctica objeto de análisis.

Los criterios de calidad de los informes de las prácticas se pueden resumir en los siguientes indicadores:

- Adecuado planteamiento de objetivos, acordes al alcance de la práctica.

- Descripción completa del procedimiento experimental detallando todos los pasos realizados durante la práctica, incluyendo la gestión de los residuos generados.

- Representación del montaje de la práctica con identificación de los principales elementos, y relación completa del material auxiliar empleado.

- Presentación de todos los datos experimentales recogidos en el laboratorio y posterior procesamiento de los mismos para alcanzar los objetivos planteados.

- Análisis y discusión de los resultados, justificando las posibles desviaciones respecto a la teoría en base al desarrollo experimental.

- Adecuado planteamiento de conclusiones, dando respuesta a todos los objetivos planteados.

\subsubsection{Encuesta sobre el grado de satisfacción de los estudiantes con la nueva metodología}

Los alumnos de este curso 2016-17 de las dos asignaturas experimentales objeto de este trabajo, EIq2 y EIq3, son los primeros que han trabajado los informes de manera presencial en ambas asignaturas. Por ello, al finalizar la parte experimental de EIq3 (mitad cuatrimestre B) se les ha realizado una encuesta para averiguar el grado de satisfacción con este modo de trabajo de los informes de prácticas.

(cc) EY-NC-ND 2017, Universitat Politècnica de València 
En la encuesta, los alumnos tienen que valorar los siguientes ítems relativos a la metodología de trabajo de los informes:

1) “La realización de los informes de prácticas durante la sesión de laboratorio mejora la calidad de los mismos"

2) “La realización de los informes de prácticas durante la sesión de laboratorio supone una descarga de trabajo significativa"

La escala de Likert para la valoración de dichos ítems es la indicada en la Tabla 3.

Tabla 3. Escala de Likert empleada en la encuesta de satisfacción de los estudiantes

\begin{tabular}{|l|l|l|ll|}
\hline A & B & C & D \\
\hline $\begin{array}{l}\text { Totalmente de } \\
\text { acuerdo }\end{array}$ & $\begin{array}{l}\text { Parcialmente de } \\
\text { acuerdo }\end{array}$ & $\begin{array}{l}\text { Parcialmente en } \\
\text { desacuerdo }\end{array}$ & $\begin{array}{l}\text { Totalmente } \\
\text { desacuerdo }\end{array}$ & en \\
\hline
\end{tabular}

Se ha encuestado a los 69 alumnos de EIq3 de este curso, de los cuales un total de 53 han cursado también EIq2. Los restantes 16 alumnos cursaron EIq2 en algún curso anterior, por lo tanto, es la primera vez que trabajan los informes de manera presencial. Se analizará si existe alguna diferencia significativa en las valoraciones entre los dos grupos de alumnos.

\subsubsection{Valoraciones del profesorado respecto a las mejoras detectadas tras la innovación}

Para completar el análisis de las posibles mejoras conseguidas tras la implementación del nuevo modo de trabajo de los informes de laboratorio, se ha querido considerar las valoraciones de los profesores implicados. Para ello se ha tenido en cuenta el análisis crítico del equipo de profesores de las asignaturas objeto del trabajo, para el que se han considerado aspectos como: la participación e interacción de los miembros de cada grupo, la disminución de errores habituales en los informes, la existencia o no de copias de informes de otros cursos, etc.. 


\section{Resultados}

En este apartado se analizan los resultados de la metodología de trabajo presencial de los informes de laboratorio. Por un lado, se comparan las calificaciones de las partes de los informes realizadas presencialmente con las realizadas de manera no presencial. Por otra parte, se analizan las encuestas de satisfacción pasadas a los alumnos que han cursado EIq3 el presente curso académico 2016-17. Finalmente, se indican las apreciaciones de los profesores al respecto de la metodología implementada.

\subsection{Análisis de la calidad de los informes realizados presencialmente}

\subsubsection{Comparación parte presencial y no presencial de los informes de EIq3}

En primer lugar, se comparan las calificaciones obtenidas en cuatro cursos académicos en los informes de laboratorio de una misma práctica de la asignatura EIq3, en la que, como se ha descrito en la metodología, parte del informe se realiza de manera presencial y parte de manera no presencial.

En la Fig. 1 se muestran los valores de la nota media en base diez de cada parte (presencial y no presencial) de los informes de laboratorio de una de las prácticas de EIq3, para cuatro cursos académicos. Como se observa en la figura, la nota media de la parte presencial de los informes ha sido superior en todos los cursos a la nota media de la parte no presencial, aunque la diferencia parece haberse visto reducida en los dos últimos cursos.

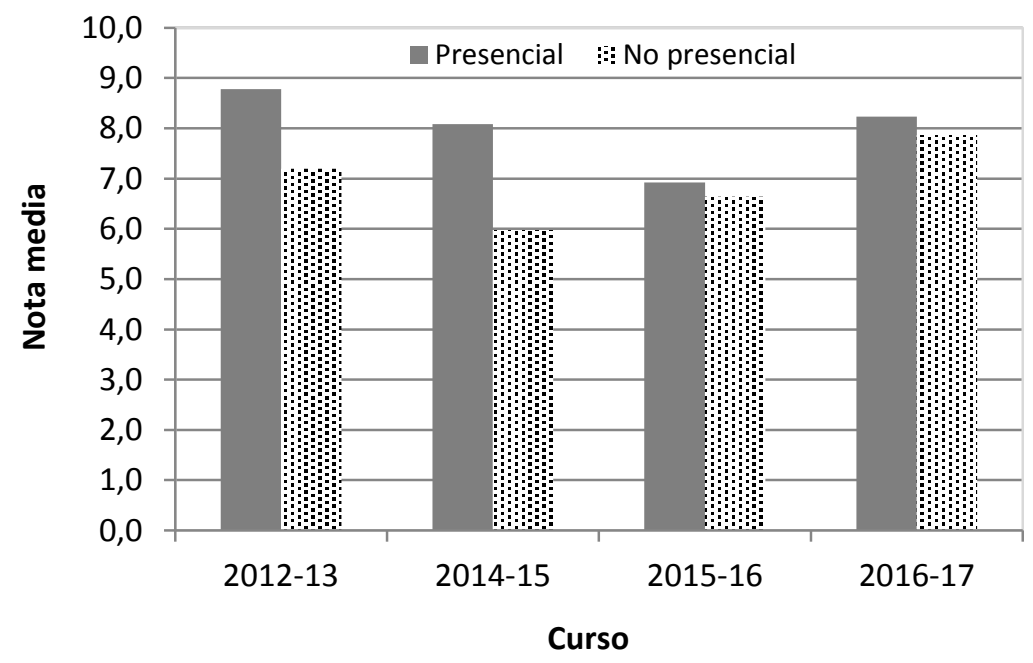

Fig. 1 Nota media de la parte presencial y no presencial de los informes de EIq3

Si se analizan con más detalle las calificaciones de los informes de todos los grupos, se obtienen los resultados mostrados en la Tabla 4, donde se indican, además de la nota media,

(cc)) EY-NC-ND 2017, Universitat Politècnica de València

Congreso IN-RED (2017) 
las notas máxima (NMX) y mínima (NMN) y su diferencia, para cada curso y para cada parte del informe. Como se observa en la tabla, las notas máximas de ambas partes de los informes son muy similares, con variaciones inferiores al $4 \%$. Sin embargo, las notas mínimas de la parte no presencial son bastante diferentes entre sí. Esto implica que la diferencia entre la nota máxima y mínima sea mucho mayor en la parte no presencial que en la presencial (entre el 35 y el $71 \%$ superior), lo que denota que las calificaciones de la parte presencial del informe son más homogéneas. Cabe señalar que ninguna nota mínima de la parte presencial es inferior a 5, lo que sí sucede en el caso de la parte no presencial en dos de los cuatro cursos analizados.

Tabla 4. Calificaciones de la parte presencial y no presencial de los informes de EIq3

\begin{tabular}{|l|c|c|c|c|c|c|c|c|}
\cline { 2 - 9 } \multicolumn{1}{c|}{} & \multicolumn{2}{c|}{ Curso 2012-13 } & \multicolumn{2}{c|}{ Curso 2014-15 } & \multicolumn{2}{c|}{ Curso 2015-16 } & \multicolumn{2}{c|}{ Curso 2016-17 } \\
\cline { 2 - 9 } \multicolumn{1}{c|}{} & Pres. & No pres. & Pres. & No pres. & Pres. & No pres. & Pres. & No pres. \\
\hline Nota media & 8.78 & 7.20 & 8.08 & 5.98 & 6.93 & 6.64 & 8.24 & 7.87 \\
\hline $\begin{array}{l}\text { Nota máxima } \\
\text { (NMX) }\end{array}$ & 9.5 & 9.4 & 9.1 & 9.0 & 8.5 & 8.8 & 9.6 & 10 \\
\hline $\begin{array}{l}\text { Nota mínima } \\
\text { (NMN) }\end{array}$ & 8.1 & 6.0 & 7.4 & 3.1 & 5.9 & 4.8 & 7.1 & 5.6 \\
\hline $\begin{array}{l}\text { Diferencia } \\
\text { (NMX - NMN) }\end{array}$ & 1.4 & 3.4 & 1.7 & 5.9 & 2.6 & 4.0 & 2.5 & 4.4 \\
\hline
\end{tabular}

Pres. $=$ Presencial $\quad$ No pres. $=$ No presencial

Para comprobar si las diferencias entre las notas de la parte presencial y de la no presencial de los informes son significativas, se ha realizado un test de diferencias de medias para cada uno de los cursos considerados. El análisis se ha llevado a cabo utilizando el software Statgraphics (versión Centurión). Los resultados del análisis muestran que las diferencias son significativas (p-valor $<0,05$ ) en los cursos 2012-13 y 2014-15, en los cuales, por lo tanto, si parece que la metodología presencial mejoraba las calificaciones. Sin embargo, el análisis estadístico para los cursos 2015-16 y 2016-17 ha resultado en p-valores superiores a 0,05 (entorno a 0,4 ), por lo que las diferencias en las calificaciones en dichos cursos no pueden considerarse significativas. Probablemente esto se deba a cierto "entrenamiento" en el trabajo presencial en la asignatura experimental anterior. Concretamente, en el caso del curso 2016-17 se ha trabajado completamente de forma presencial los informes en EIq2 (este análisis se presenta en punto 4.1.3); y en el caso del curso 2015-16 se trabajó la elaboración de resultados de manera presencial en un par de prácticas, lo que pudo repercutir en la mejora de la parte no presencial (donde se procesan los resultados) en la asignatura experimental del siguiente cuatrimestre, EIq3.

En el apartado 4.1.3. se analizará precisamente la posible influencia del "entrenamiento" en el trabajo presencial en EIq2 sobre los resultados de aprendizaje de EIq3. 


\subsubsection{Comparación informes presenciales y no presenciales de EIq2}

A continuación, se comparan las calificaciones de los informes de laboratorio de una misma práctica de la asignatura EIq2 en tres cursos diferentes: en los dos primeros los informes se realizaron de manera no presencial, y en el último curso han sido realizados de manera totalmente presencial, en la propia sesión de laboratorio y en una sesión informática posterior.

En la Fig. 2 se muestran los valores de la nota media de los informes para los tres cursos considerados, en la que se observa que las notas medias de los dos cursos en los que los informes se realizaron de manera no presencial son similares. La nota media de los informes en este curso, en el que se han realizado totalmente presenciales es algo superior a la de los otros dos cursos ( $7.8 \%$ y $11.3 \%$, respectivamente).

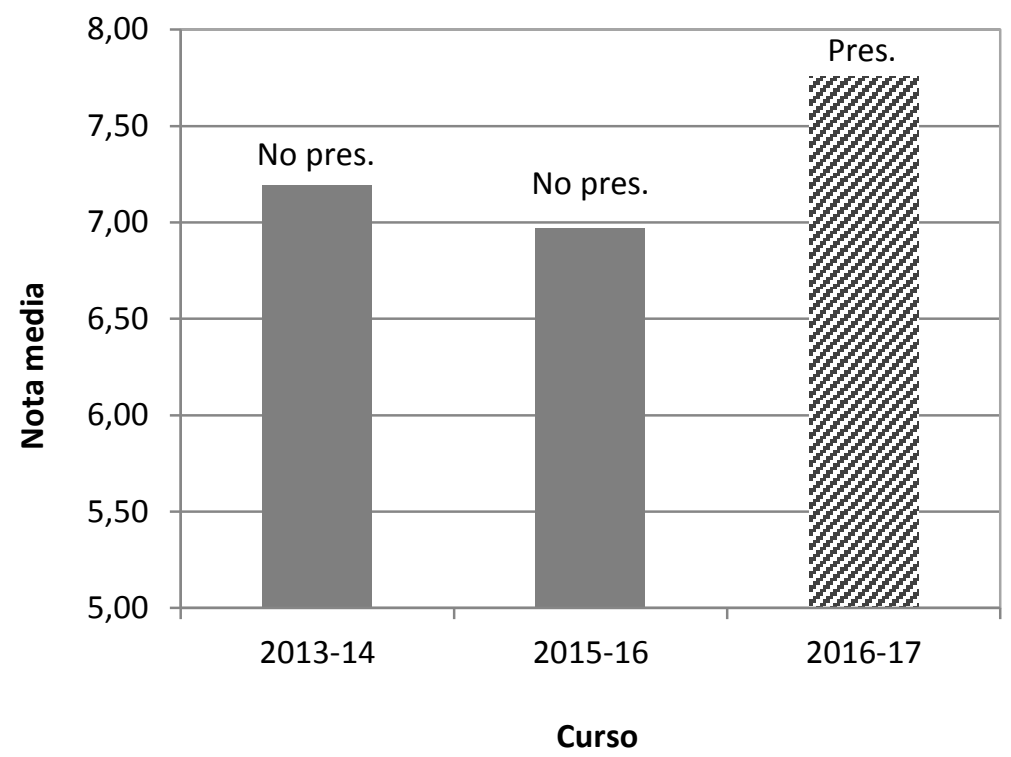

Fig. 2 Nota media de los informes de EIq2

En la Tabla 5 se muestran con más detalle las calificaciones de los informes de los tres cursos analizados, indicando valores análogos a los ya explicados para la Tabla 4. En este caso, no se aprecia mucha diferencia entre las notas máximas y mínimas. No parece, por tanto, que pueda extraerse ninguna conclusión al respecto de la influencia de la nueva metodología de trabajo de los informes en cuanto a la calidad de los mismos en esta asignatura. Esto podría ser debido a la falta de experiencia de los alumnos en el modo de trabajo implementado, ya que es la primera vez que realizan los informes de manera presencial, y por tanto, tienden a reproducir el reparto de trabajo al que están acostumbrados sin aprovechar del todo la oportunidad de coordinación e interacción que tienen ahora. Sin embargo, al repetir esta metodología en la asignatura siguiente, EIq3, sí se

(cc) EY-NC-ND 2017, Universitat Politècnica de València 
observa cierta mejoría, probablemente debido a la experiencia adquirida, tal y como se ha comentado en el apartado 4.1.1, y se analizará con más detalle en el siguiente apartado.

Tabla 5. Calificaciones de los informes de EIq2

\begin{tabular}{|l|c|c|c|}
\cline { 2 - 4 } \multicolumn{1}{c|}{} & Curso 2013-14 & Curso 2015-16 & Curso 2016-17 \\
\cline { 2 - 4 } \multicolumn{1}{c|}{} & No presencial & No presencial & Presencial \\
\hline $\begin{array}{l}\text { Nota media } \\
\text { (NMX) }\end{array}$ & 7.2 & 6.9 & 7.7 \\
\hline $\begin{array}{l}\text { Nota mínima } \\
\text { (NMN) }\end{array}$ & 6.5 & 8.5 & 9.2 \\
\hline $\begin{array}{l}\text { Diferencia } \\
(\mathrm{NMX}-\mathrm{NMN})\end{array}$ & 3.5 & 5.0 & 6.0 \\
\hline
\end{tabular}

Para comprobar si el trabajo presencial de los informes de laboratorio ha tenido alguna repercursión en el aprendizaje de los alumnos, se han analizado también las calificaciones obtenidas en la pregunta del examen sobre la práctica considerada. En la Tabla 6 se muestran las notas medias en dicha pregunta en los tres cursos considerados, así como el porcentaje de alumnos que obtuvieron calificaciones iguales o superiores a $9, \mathrm{y}$ calificaciones inferiores a 5 .

Tabla 6. Calificaciones de los exámenes de EIq2

\begin{tabular}{|l|c|c|c|}
\cline { 2 - 4 } \multicolumn{1}{c|}{} & Curso 2013-14 & Curso 2015-16 & Curso 2016-17 \\
\cline { 2 - 4 } \multicolumn{1}{c|}{} & No presencial & No presencial & Presencial \\
\hline Nota media & 6.6 & 5.2 & 7.4 \\
\hline $\begin{array}{l}\text { Alumnos con } \\
\text { nota } \geq 9\end{array}$ & $9.8 \%$ & $8.3 \%$ & $32.2 \%$ \\
\hline $\begin{array}{l}\text { Alumnos con } \\
\text { nota }<5\end{array}$ & $18.3 \%$ & $48.6 \%$ & $17.7 \%$ \\
\hline
\end{tabular}

En la tabla se observa que la nota media en la pregunta de examen ha sido algo superior en este último curso en el que se han realizado los informes de manera totalmente presencial. Para comprobar si dicha mejora en la nota media de los alumnos está relacionada con la metodología de trabajo presencial, se ha realizado una correlación de Pearson entre las calificaciones de los informes y las de los exámenes, para los tres cursos considerados.

Los resultados del análisis estadístico (realizado con Statgraphicsn) han proporcionado pvalores superiores a 0,05 en los tres casos. Por lo tanto, no se puede afirmar que la metodología presencial mejore las calificaciones del examen. Sin embargo, cabe señalar que el tamaño de las muestras analizadas no es muy alto (entre 66 y 70 alumnos) y que el pvalor para este curso 2016-17, en el que se ha introducido la nueva metodología, ha sido el 
menor de los tres, con un valor de 0,083 . Por lo tanto, los resultados son esperanzadores e indican que se debe seguir trabajando en la línea de la nueva metodología para comprobar si en cursos siguientes se mejoran los resultados.

Por otra parte, observando los rangos de notas superiores e inferiores de la tabla, se aprecia un aumento de alumnos en el rango de calificaciones superiores a 9, que en este curso se ha incrementado hasta un $32 \%$, frente a porcentajes entorno a $8-9 \%$ en los cursos anteriores. Parece, por tanto, que el trabajo presencial del informe de laboratorio permite contar con una mejor herramienta de estudio y un mejor aprendizaje, que se traduce en un mayor porcentaje de estudiantes mejor preparados para la realización del examen.

Por todo ello, pensamos que se debe seguir trabajando del modo en que se ha hecho este curso, realización presencial de los informes, y analizar en asignaturas y cursos posteriores la mejora del aprendizaje de los estudiantes, con otras herramientas diferentes al examen que sean más adecuadas para medir el tipo de aprendizaje adquirido con la nueva metodología.

\subsubsection{Influencia del modo de trabajo en EIq2 en los resultados de EIq3}

En este apartado se analiza la influencia del modo de trabajo de EIq2 en los resultados alcanzados en EIq3. Para ello, se ha realizado un análisis discriminante entre dos cursos:

- 2015-16, en el que en EIq2 se trabajó de manera no presencial

- 2016-17, en el que EIq2 se ha cambiado a metodología presencial

En ambos cursos, en la asignatura EIq3 se ha mantenido la misma forma mixta de trabajo de los informes: parte presencial y parte no presencial.

Los resultados del análisis estadístico (realizado con Stagraphics) han mostrado un p-valor igual a $0(<0,05)$, por lo que se puede afirmar que el trabajo de manera presencial en EIq2 sí mejora significativamente los resultados en los informes de EIq3. Esto se debe, por un lado, a la práctica que adquieren los estudiantes en el modo de trabajo presencial, y por otro, a la mejora añadida por el feedback recibido en la asignatura previa.

\subsection{Satisfacción de los estudiantes con los informes presenciales}

En este apartado se muestran los resultados de los dos ítems relacionados con el trabajo presencial de los informes de laboratorio, incluidos en la encuesta realizada tras la finalización del bloque de diseño de la asignatura. EIq3. En la Fig. 3 se muestran los resultados de valoración del primer ítem, diferenciados entre los alumnos que han cursado EIq2 este mismo curso, y los que la cursaron anteriormente. La escala de valoración corresponde a la mostrada en la Tabla 3.

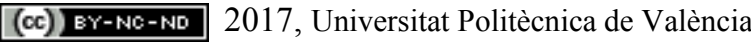

Congreso IN-RED (2017) 


\section{" La realización de los informes de prácticas durante la sesión de laboratorio mejora la calidad de los mismos"}

Z Elq2 cursada en 2016-17 Elq2 cursada antes de 2016-17

A



B

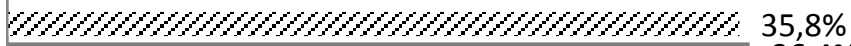

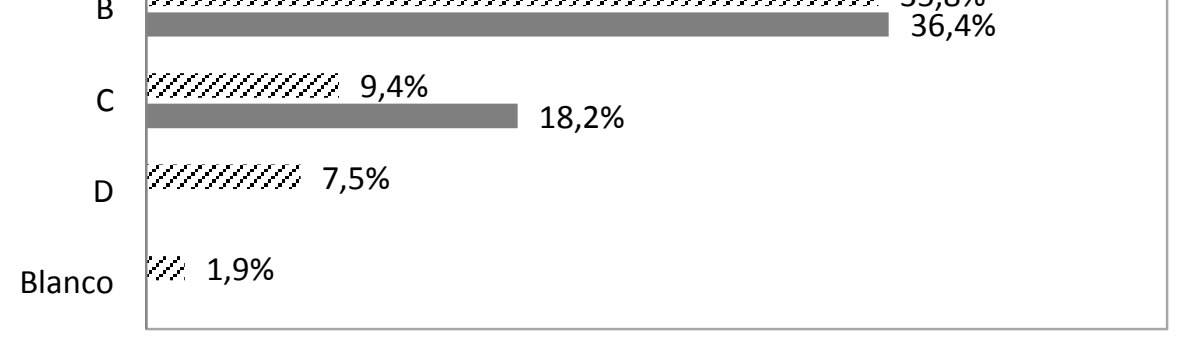

Fig. 3 Valoración de los alumnos de la mejora de la calidad de los informes con la metodología presencial

Como se observa en la figura, la realización presencial de los informes de prácticas ha sido muy bien valorada por los alumnos: más del $80 \%$ de los estudiantes lo han valorado con $\mathrm{A}$ ("Totalmente de acuerdo") ó B ("Parcialmente de acuerdo"), y menos del 20\% la valoran con C ("Parcialmente en desacuerdo") ó D ("Totalmente en desacuerdo"). Comparando los alumnos que han cursado EIq2 en 2016-17 (metodología de trabajo presencial de los informes) con los que la cursaron con la metodología convencional (anterior al curso 201617), se observan porcentajes de valoración muy similares para las mejores valoraciones (A y B), mientras que hay una mayor discrepancia en las opiniones en las que no se está de acuerdo con el ítem. Concretamente, en el caso de los que cursaron EIq2 en años anteriores todas las opiniones en desacuerdo se concentran en la valoración $\mathrm{C}$ de la escala. Parece, por tanto, que hay un grado de satisfacción importante con la metodología presencial, independientemente de haberla o no practicado anteriormente.

Respecto al segundo ítem, en la Fig. 4 se muestran los resultados de valoración, diferenciando de nuevo los de los alumnos que han cursado EIq2 este mismo curso, y los que la cursaron anteriormente. 


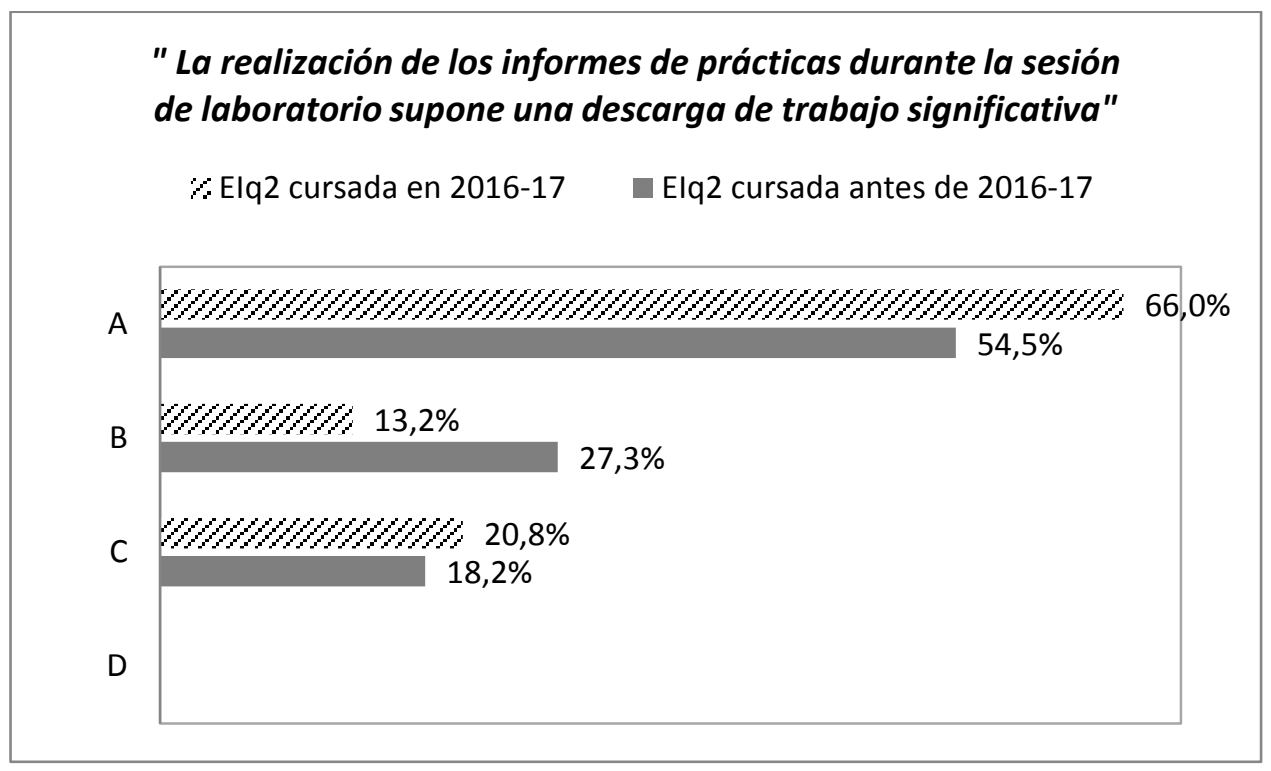

Fig. 4 Valoración de los alumnos de la descarga de trabajo de la metodología presencial

Los alumnos opinan mayoritariamente (porcentajes superiores al 54\% para la valoración A y entorno al $80 \%$ acumulada $A \& B)$ ) que la metodología de trabajo presencial les descarga de trabajo frente a la metodología no presencial, a pesar de tener que realizar parte de los informes de manera no presencial (debido a la toma de datos tras la sesión de laboratorio). Alrededor del $20 \%$ de los alumnos encuestados no está de acuerdo con que la metodología de trabajo les descarga significativamente, probablemente debido al trabajo no presencial exigido en algunas prácticas por la toma de datos, tal y como algunos han manifestado en el apartado de opiniones abiertas de la encuesta. Comparando los estudiantes que sí han cursado EIq2 este año con los que no, se aprecia cierta diferencia en el reparto de las valoraciones A y B, pero el global de las opiniones de acuerdo con el ítem es muy similar.

Por lo tanto, de acuerdo a las valoraciones manifestadas por los alumnos del curso 2016-17 de la asignatura EIq3, se puede afirmar que la metodología de trabajo presencial de los informes de laboratorio es positiva desde el punto de vista de mejora de la calidad de los informes y de la descarga de trabajo que supone a los estudiantes.

\subsection{Valoración de los profesores de la metodología implementada}

Además de las mejoras en las calificaciones ya comentadas, se ha podido comprobar una evidente mejora en el modo de trabajo de los alumnos que se puede resumir en los siguientes puntos:

- Mejora del trabajo en equipo al contar con un espacio común de trabajo (laboratorio o aula informática) y estar realizando conjuntamente el informe, aumentado así la interacción y comunicación entre todos los miembros.

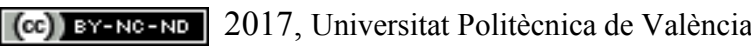


- Reducción de los errores y omisiones en los informes, fundamentalmente en la representación gráfica de los montajes experimentales y en la descripción de los procedimientos y metodologías llevadas a cabo.

- Eliminación casi total de las copias de informes de otros cursos.

- Mejora del rendimiento en el examen al contar con una herramienta de estudio de mejor calidad, que es el informe presencial.

Por todo ello, los profesores estamos muy satisfechos con la metodología implementada, que consideramos fácilmente transferible a otras áreas de conocimiento y otro tipo de prácticas en las que se realicen informes similares.

\section{Conclusiones}

En este trabajo se ha implementado una nueva metodología de trabajo de los informes de laboratorio, que se realizan ahora de manera presencial. Este modo de trabajo presencial de los informes ha supuesto que el rendimiento en el examen mejore ligeramente en términos de porcentaje de alumnos con altas calificaciones ( $\geq 9$ ), al contar los estudiantes con una herramienta de estudio de mejor calidad. Respecto a la mejora en la calidad de los informes, puede decirse que es fundamental la práctica en el modo de trabajo y el aprendizaje adquirido a través del feedback de los profesores para que se alcance una mejora en la calidad de los informes.

Desde el punto de vista de los estudiantes, la mayoría opina que la nueva metodología de trabajo presencial de los informes mejora la calidad de los mismos y reduce significativamente su carga de trabajo. Además, los profesores apreciamos una mayor interacción entre los miembros de los grupos, y una reducción importante en errores y omisiones de la parte experimental de los informes.

A la vista de los resultados analizados en este trabajo, sería recomendable la extensión de este modo de trabajo de los informes de laboratorio a un mayor número de prácticas y asignaturas, para que se produjera un cambio de hábitos de trabajo que repercutiera en un mayor y mejor aprendizaje de los estudiantes de Ingeniería Química.

\section{Agradecimientos}

Parte de los resultados publicados en este trabajo pertenecen al PIME "Integración del Aprendizaje Orientado a Proyectos en una asignatura experimental del Grado de Ingeniería Química" (referencia B14) del curso 2016-17, financiado por el Vicerrectorado de Estudios, Calidad y Acreditación de la Universitat Politècnica de València. 


\section{Referencias}

ABIDIN, I.I.Z., ZAIN, S.F.H.S., RASIDI, F.E.M., KAMARZAMAN, S. (2013) "Chemistry lab reports at university: to write or not to write?” Journal of College Teaching \& Learning, Vol. 10(3), pp. $203-212$

ALAIMO, P.J., LANGENGHAN, J.M., NICHOLS, L. (2009) "Eliminating lab reports: A rhetorical approach for teching the scientific paper in sophomore organic chemistry" The WAC Journal, Vol. 20, pp. 17-33.

BERRY, D.E., FAWKES, K.L. (2010). "Constructing the components of a lab report using peer review” en J. Chem. Educ., Vol. 87(1), pp. 57-61.

BRIAN LANE, W. (2014). "Letters Home as an Alternative to Lab Reports" en The Physics Teacher, Vol. 52, pp. 397-399.

DEL CARLO, D.I., BODNER G.M. (2004). "Students' perceptions of academic dishonesty in the chemistry classroom laboratory" en J. Res. Sci. Teach., Vol. 41, pp. 47-64.

HAAGEN-SCHUETZENHOEFER, C. (2012). "Improving the Quality of Lab Reports by Using Them as Lab Instructions" en The Physics Teacher, Vol. 50, pp. 430-433.

HILOSKY, A., SUTMAN, F., SCHMUCKLER. (1998). "Is laboratory-based instruction in beginning college-level chemistry worth the effort and expense?" en J. Chem. Educ., Vol. 75, pp. 100-104.

REID, N., SHAH, I. (2007). "The role of laboratory work in university chemistry" en Chem. Educ. Res. Pract., Vol. 8(2), pp. 172-185. 


\title{
Valoración del alumnado sobre distintos formatos de vídeos utilizados en docencia inversa en prácticas de laboratorio.
}

J.A. Gómez-Tejedor ${ }^{a}$, R. Martínez Salaa , J.M. Meseguer-Dueñas ${ }^{a}$, J. Molina-Mateo ${ }^{a}$, S. Quiles Casado $^{a}$, J. Riera ${ }^{a}$, M.A. Serrano-Jareño ${ }^{a}$, I. Tort-Ausina ${ }^{a}$ y A. Vidaurre ${ }^{a}$

${ }^{a}$ ETS de Ingeniería del Diseño, Universitat Politècnica de València (SPAIN)

\begin{abstract}
The students'opinion about the videos used in the flipped teaching in laboratory sessions is analized in this work. A survey with 7 multiple choice questions and one open question has been performed, obtanining 54 replies, from a total number of 155 students whi are attending the laboratory sessions. Students were asked about their preference between videos and written material (with some images), and about their preference between the three types of videos pffered: screencast (one of them including the image of the teacher and the other one with his/her voice only), and "Polimedia". Results have shown that students prefer video files instead of written docuements when they have to prepare their laboratory sessions. Moreover, there is a statistically significant preference for the videos where the image of the professor is shown. On the other hand, despite the format of video "Poliformat" has been the best valuated, there are certain aspects to be added, as the valuation thay made of the other types of videos (which is also good), or the critrica comments on this format shown in the open question of the survey.
\end{abstract}

Keywords: videos, Polimedia, screencast, laboratory, flipped teaching

\section{Resumen}

En este trabajo se analiza la opinión de los estudiantes sobre los vídeos utilizados en la docencia inversa de prácticas de laboratorio. Se ha realizado una encuesta con 7 preguntas de respuesta múltiple y una de respuesta abierta, contestada por 54 alumnos de los 155 que asisten al laboratorio. En ella se pregunta sobre la valoración del video frente documentos de texto e imagen, y sobre tres modelos de vídeo: dos de ellos responden al modelo de "screencast" (en uno de ellos está presente la imagen del profesor y en otro no) y el tercero es un "Polimedia". Los resultados indican que los estudiantes, en general, prefieren archivos de video a documentos de texto para la preparación de las prácticas de laboratorio. Además, se observa una preferencia estadísticamente significativa a favor de los videos en los que se muestra la imagen del profesor. Por otra parte, aunque el formato de video "Polimedia" ha sido el mejor valorado, hay ciertos matices a destacar, como es la valoración que hacen de los otros dos tipos de vídeos, que también es buena, o los comentarios críticos con este formato mostrados en la pregunta de respuesta abierta.

Palabras clave: videos, Polimedia, screencast, laboratorio, docencia inversa 


\section{Introducción y objetivos}

Un screencast es un video tutorial que combina información visual (capturada directamente del monitor del ordenador) y de audio y es accesible a través de internet (Peterson, 2007). Es una herramienta muy versátil para complementar la enseñanza de materias basadas en habilidades, como la física o las matemáticas (Ahmad \& Doheny, 2014), (Jordan, Loch, Lowe, Mestel, \& Wilkins, 2012). Puede usarse como complemento de la enseñanza presencial y son especialmente útiles en la aplicación de la metodología de clase inversa. En la metodología de clase inversa las sesiones tradionales de clases y trabajo en casa están invertidas (Zaphiris \& Ioannou, 2015). El tiempo de clase se optimiza porque el profesorado se dedica a resolver dudas en lugar de presentar toda la información (Lasry, Dugdale, \& Charles, 2014), (Blasco, Lorenzo, Sarsa, \& Sarsa, 2016). En el caso del laboratorio se optimiza el tiempo porque se empieza a trabajar desde el momento en que se entra en el laboratorio, sobre algo que ya se ha asimilado (al menos parcialmente).

Screencast ofrece múltiples beneficios para preparar el material de estudio. Tanto en el caso de que se use como complemento de las clases presenciales como de material de preparación de las sesiones de clase inversa, los estudiantes deben disponer, con antelación a la clase del material adecuado. Screencast ofrece la ventaja de adpatarse a cada estudiante permitiendo seleccionar la cantidad de información que quieren ver y con qué ritmo; ellos deciden si van hacia adelante, pausan o repiten un fragmento de screencast.

Para conseguir screencast efectivos es preciso prestar atención a su diseño, tanto formal como de contenidos (Sugar, Brown, \& Luterbach, 2010), (Oud, 2009). Se ha demostrado que los screencast cortos con un objetivo concreto producen mejores resultados de aprendizaje (Jordan et al., 2012), (Sutton-Brady, Scott, Taylor, Carabetta, \& Clark, 2011). En general, la combinación de gráficos, vídeos grabados en el laboratorio, con la narración del profesor, produce una mejora en proceso de aprendizaje cuando es comparado con el texto en formato tradicional (Mayer, 2014). Dunn et al. (Dunn, McDonald, \& Loch, 2015) han comprobado que los estudiantes utilizan activamente los screencast y lo consideran un importante material que les ayuda a estudiar.

En este trabajo se analiza la opinión de los estudiantes sobre una serie de vídeos desarrollados por los profesores de las asignatura de física y electricidad de primer curso de la Universitat Politècnica de València (UPV, http://www.upv.es) del Grado en Ingeniería Electrónica y Automática Industrial en la ETS de Ingeniería del Diseño (ETSID). Los vídeos, junto con textos en formato tradicional, sirven como material de apoyo para preparar las sesiones de laboratorio, impartidas en la modalidad de docencia inversa. Se han elaborado tres modelos de vídeo: dos de ellos responden al modelo habitual de screencast (en uno de ellos está presente la imagen del profesor y en otro no) y el tercero es un Polimedia (sistema diseñado en la UPV para la creación de contenidos multimedia como apoyo a la docencia presencial, que abarca desde la preparación del material docente hasta la distribución a través de distintos medios a los destinatarios). Todos tienen una duración similar, entre 10 y 15 minutos, y abordan contenidos de similar dificultad.

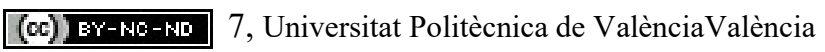


El objetivo de este trabajo es comprobar si son ciertas las siguientes hipótesis nulas:

H1. Para preparar los contenidos de las sesiones de laboratorio los estudiantes prefieren el material en vídeo al formato tradicional.

H2. Los estudiantes consideran que la presencia de la imagen del profesor en la pantalla ayuda a fijar las ideas fundamentales de la práctica.

H3. Los estudiante prefieren los vídeos en formato Polimedia a los screencast.

\section{Desarrollo de la innovación}

La metodología de docencia inversa se ha aplicado en las prácticas de laboratorio de la materia Física (asignaturas de Física y Electricidad), en los tres grupos de primer curso del Grado en Ingeniería Electrónica y Automática Industrial, en la ETS de Ingeniería del Diseño (ETSID) de la UPV. Se han realizado un total de 14 prácticas a lo largo del curso académico.

El material de que disponen los alumnos para preparar y realizar las prácticas se ha organizado utilizando la herramienta Lessons de Poliformat. Un valor añadido a este material es el de que sus contenidos son multilingües, utilizando las dos lenguas oficiales, valenciano y castellano, y el inglés.

La organización, en páginas, es la siguiente:

- Calendario + Instrucciones, para antes de iniciar las sesiones de prácticas, con la información general sobre las prácticas, calendario, método de evaluación...

- Para cada práctica de laboratorio:

- Antes de la sesión de la práctica, disponen de toda la información necesaria para iniciar la práctica de forma autónoma desde el momento en el que acceden al laboratorio: material escrito y vídeos que hemos elaborado con una explicación detallada de los objetivos y metodología a seguir durante la sesión. Estos vídeos y su diferente tipología son el objeto de análisis en el presente trabajo.

- Durante la sesión de la práctica, disponen de documentos de ayuda que pueden necesitar mientras están realizando la práctica, y el enlace a una actividad donde deberán subir la hoja de cálculo que han utilizado para recoger los datos experimentales durante la práctica.

- Después de la sesión de la práctica, disponen del enlace a la actividad donde deben subir la memoria de la práctica realizada para su evaluación.

En las sesiones de laboratorio, de dos horas de duración, los estudiantes comienzan su trabajo desde que acceden al laboratorio y el profesor se dedica a tutorizar y complementar su trabajo, y a discutir sus resultados. Esto supone una diferencia de unos 30 minutos más de tiempo efectivo de trabajo de los estudiantes, si lo comparamos con el aprovechamiento que se hacía con la metodología tradicional, en cursos anteriores.

Para introducir el trabajo en el laboratorio hemos realizado un conjunto de vídeos donde se presenta cada una de las prácticas a realizar, se plantean las hipótesis a comprobar, los fundamentos teóricos, los montajes experimentales con detalle (en algunos casos con fotografías y en otros grabados sobre el material que se van a encontrar los alumnos al realizar la práctica), y el tratamiento posterior de los datos experimentales. Los vídeos tienen tres formatos diferentes: 
- Screencast en el que la presentación va acompañada únicamente por la voz del profesor (figura 1).

- Screencast en el que se incluye la imagen del profesor en un marco incrustado en la imagen de una presentación (figura 2).

- Formato Polimedia: se trata de un sistema diseñado en la UPV para la creación de vídeos multimedia de contenido educativo de alta resolución. Consisten en una grabación en estudio, tras la cual se realiza una edición por parte del personal técnico, dando lugar a un archivo en formato MP4, disponible online, con la presentación combinada con la imagen del profesor (figura 3).

En este trabajo evaluamos la opinión de los alumnos sobre la utilización de estos tres tipos de vídeos, en el contexto de ser material de presentación de prácticas de laboratorio.

En los vídeos se han utilizado presentaciones digitales, hojas de cálculo, imágenes fijas y vídeos capturados mediante smartphone de partes de la explicación que lo necesitaban. Los screencast se han grabado y editado por los propios profesores mediante programas de software libre, y los Polimedia mediante los medios y técnicos de la UPV. Todos los vídeos están disponibles en el repositorio de la UPV (media.upv.es).

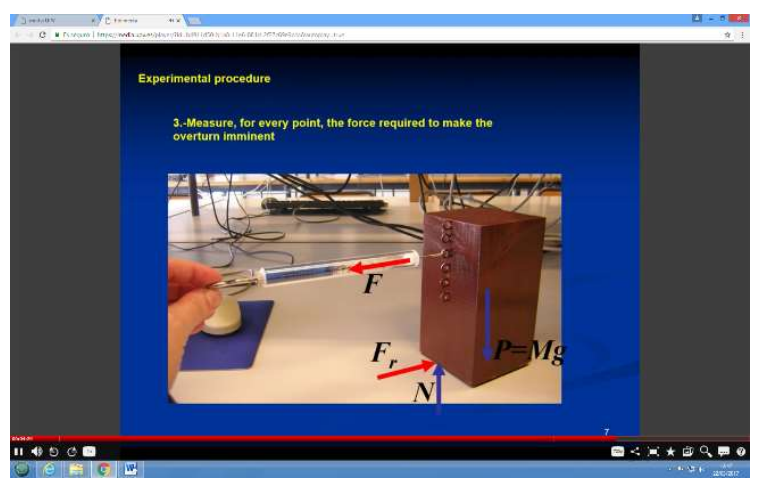

Fig. 1: video Tipo A: screencast con la voz del profesor

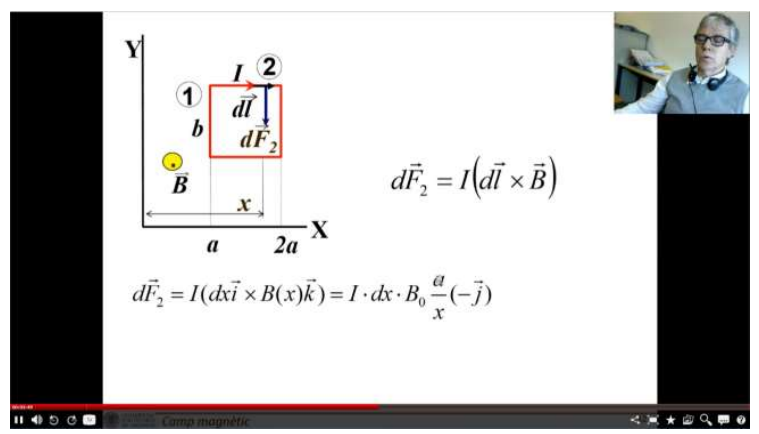

Fig. 2: video Tipo B: screencast con imagen de profesor incrustrada 


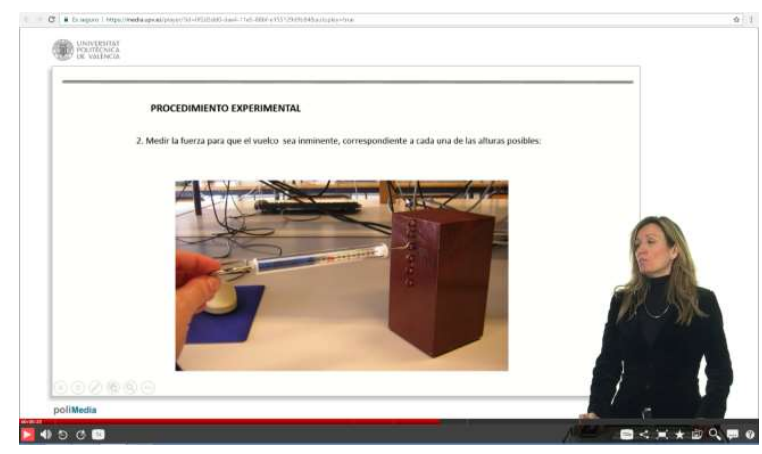

Fig. 3: video Tipo C: formato Polimedia (UPV)

La opinión del alumnado se ha obtenido mediante una encuesta realizada con la herramienta exámenes de Poli[formaT]. Las preguntas, valoradas con una escala tipo Likert de respuesta múltiple, se describen con los resultados en el siguiente apartado.

\section{Resultados y discusión}

De los 155 alumnos de la asignatura, la encuesta fue contestada por una muestra formada por 54 alumnos, obteniéndose los resultados que mostramos a continuación.

\subsection{Análisis de la opinión del alumnado a las preguntas de respuesta cerrada.}

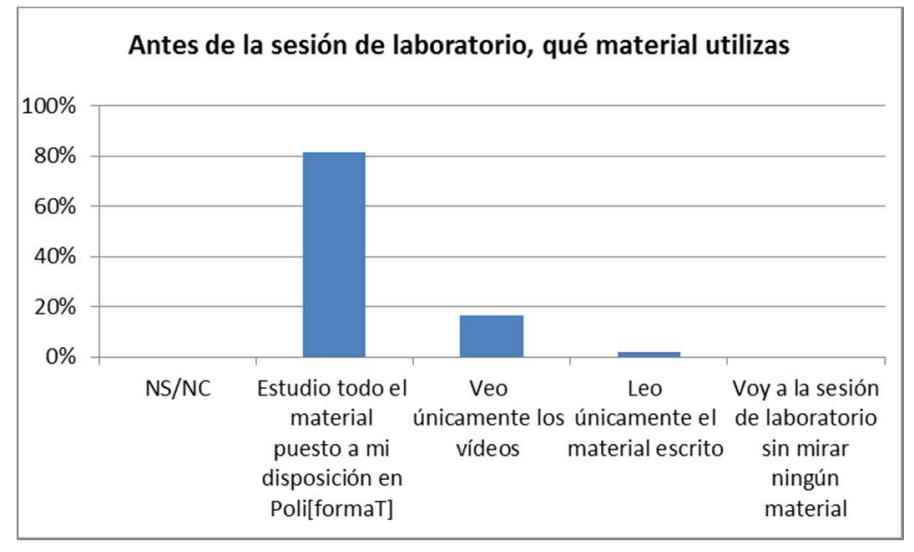

Fig.4:Material utilizado antes de la sesión de laboratorio

La Figura 4 muestra el material que el alumnado ha utilizado para la preparación de las prácticas de laboratorio, con anterioridad a la sesión. La gran mayoría estudia todo el material que ha sido puesto a su disposición, tanto audiovisual como escrito. Este resultado confirma, aunque no era objeto de estudio, que los alumnos encuestados han asimilado la metodología de "clase inversa".

La Figura 5 muestra la preferencia por parte del alumnado entre el material escrito y el material audiovisual, en el contexto de la preparación de las prácticas de laboratorio. Como se observa, prefieren el material audiovisual, según indica el porcentaje de respuestas que muestran su acuerdo (54\%). Este resultado, esperado por otro lado, no debe disuadirnos de desarrollar la competencia en comprensión lectora, tan necesaria en el contexto social actual. 


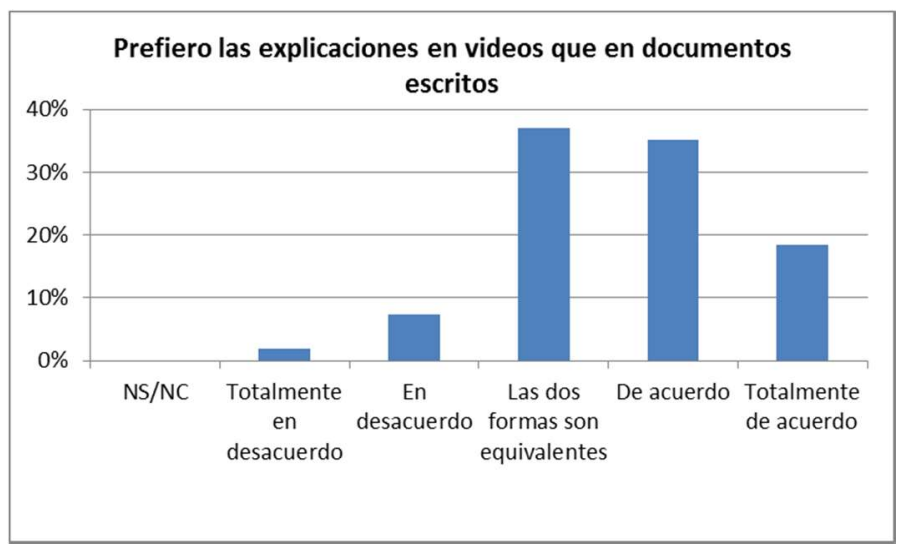

Fig.5: Preferencia entre material audiovisual o escrito

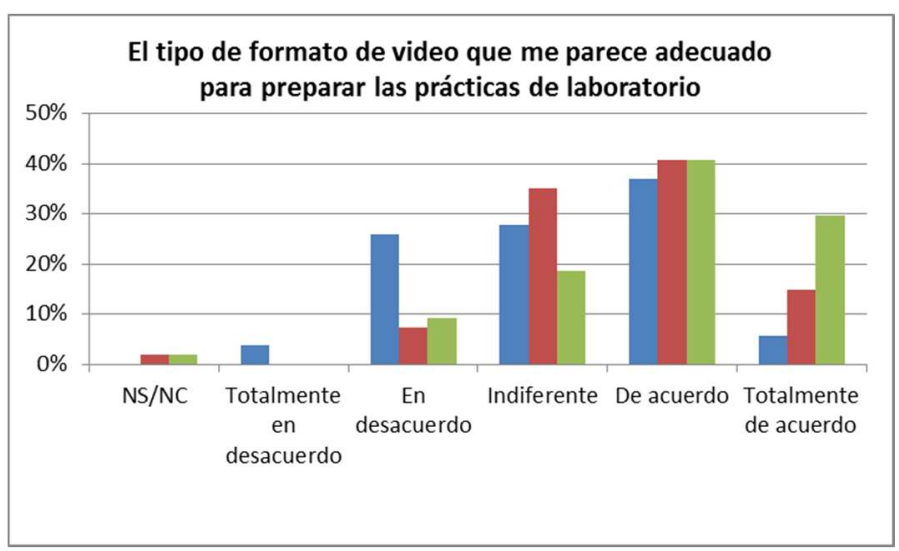

Fig. 6: Preferencia entre tipos de video tipo A (barra azul), tipo B (barra roja) y tipo C (barra verde)

En la figura 6 se puede ver la opinión por parte del alumnado sobre la adecuación de los ditintos formatos de video. Los resultados muestran que el $43 \%$ del alumnado considera adecuado el video tipo A, el 56\% el tipo B y el 70\% el Tipo C.

Se ha hecho una transformación de la escala de Likert a valores numéricos, entre 0 y 10 puntos, para obtener la media y la desviación estándar de la valoración de cada uno de los formatos de video. Los resultados se presentan en la tabla 1 .

Tabla 1. Valoración de los tres formatos de video

\begin{tabular}{ccc}
\hline & Promedio & Desviación Estándar \\
\hline Tipo A & 5,4 & 2,5 \\
Tipo B & 6,5 & 2,1 \\
Tipo C & 7,2 & 2,3 \\
\hline
\end{tabular}

Con objeto de evaluar la relevancia de estas diferencias, se ha realizado un análisis de Varianzas (ANOVA) (SPSS para Windows v.16 ) tomándose como nivel de significación, alfa=0,05. El test de Levene no muestra diferencias significativas entre

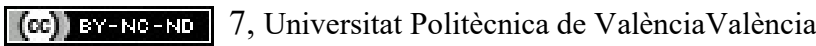
Congreso IN-RED (2017) 
las varianzas de los diferentes grupos, por lo que se ha utilizado el método paramétrico para llevarlo a cabo. El test ANOVA mostró diferencias significativas entre las medias de los tres grupos $(\mathrm{F}=9,40 ; \mathrm{p}<0,001)$, por lo que se procedió a realizar un análisis de contrastes. El resultado obtenido fue consistente con nuestras espectativas. El análisis ANOVA obtuvo diferencias estadísticamente significativas para un contraste definido "a priori" para el vídeo tipo A con respecto al $\mathrm{B}(\mathrm{A}<\mathrm{B}$, $\mathrm{t}=2,72 ; \mathrm{p}<0,01)$ y del vídeo tipo A respecto al $\mathrm{C}(\mathrm{A}<\mathrm{C}, \mathrm{t}=4,29 ; \mathrm{p}<0,001)$, no encontrándose diferencia significativas entre el B y el C.

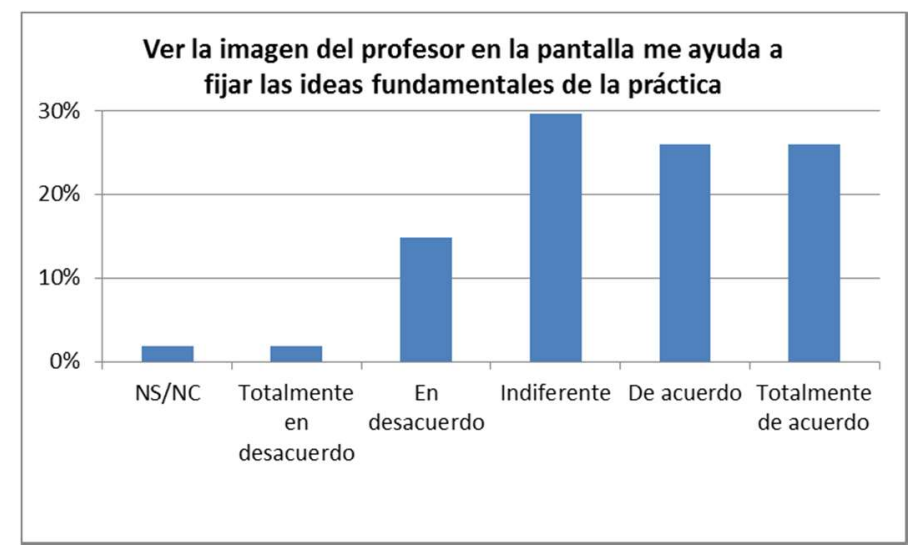

Fig. 7: Preferencia sobre la presencia de la imagen del profesor

La Figura 7 refleja la valoración de la presencia de la imagen del profesor en el material audiovisual, en el contexto de ayudar a fijar las ideas más importantes. Se observa que un $52 \%$ del alumnado la valora positivamente.

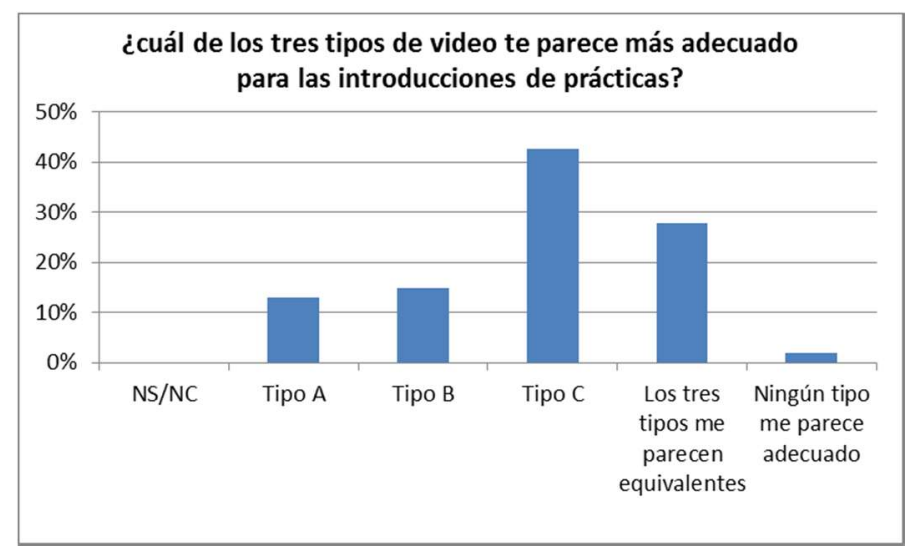

Fig. 8: Preferencia sobre el formato de video

En la Figura 8 puede verse el resultado del formato que los estudiantes consideran más apropiado, en caso de tener que elegir. Observando esta gráfica, concluimos que los alumnos prefieren el formato Tipo $\mathrm{C}$, aunque es de destacar también que hay un porcentaje muy significativo (28\%) del alumnado que considera equivalente los tres tipos. El sentido que dan a esta equivalencia se concreta con el análisis del apartado siguiente, en el que se recoge la 
respuesta abierta de los alumnos: en cierta forma la equivalencia se transforma en complementariedad.

\subsection{Análisis de la opinión del alumnado a la pregunta de respuesta abierta.}

Hemos analizado las opiniones del alumnado expresadas en la pregunta: "Añade cualquier comentario que creas conveniente sobre los distintos tipos de vídeos utilizados en la preparación de las prácticas de laboratorio. En particular nos interesa saber lo que más te gusta y lo que menos te gusta de estos tipos de vídeo". De los 54 alumnos que han contestado la encuesta, el $40 \%$ ha contestado a esta pregunta.

Destacamos las opiniones relacionadas con los contenidos del trabajo. Las opiniones de los alumnos sobre la utilización de vídeos en la presentación de prácticas, en general, es positiva: "los vídeos son una gran apuesta para la preparación de las prácticas de laboratorio", porque "se combina la explicación oral con la imagen visual, de manera que el aprendizaje es más completo". "El nivel de calidad lo considero alto". Destacan que "son concisos y claros, van directamente al grano", "el formato es el correcto, no son muy largos, en los que la gente desconecta". También destacan el problema fundamental de la docencia inversa cuando afirman que "si algún día se te olvida ver el vídeo estás totalmente perdido y no te vuelves a enganchar a la clase en toda la sesión de laboratorio".

Hay un grupo de alumnos que consideran los vídeos un complemento, o un conjunto, de la documentación escrita: "completar la información escrita con las explicaciones del profesor en algún vídeo me resulta de gran ayuda", ya que les "aportan claridad".

Cabe mencionar que, como es lógico en una metodología docente basada en la evaluación continuada y trabajo en equipo, hay alumnos con una opinión crítica y cuestionan el exceso de documentación de que disponen (vídeos, documentación escrita, para antes y durante la realización de la práctica): "llevamos exceso de información a la práctica" lo que hace que "nos cuesta más hacerlas", consultando los documentos y vídeos si "mientras la estamos realizando tenemos que volver a consultar algunos pasos". Proponen hacer "un resumen que ordenaría y aclararía las ideas".

En opinión de varios alumnos, "es preferible ver al profesor explicar", "ya que es un formato más cercano. A muchos estudiantes les reconforta la presencia de una persona que explica, la pueden ver". Ver al profesor hace "más amena la explicación". Por otro lado te "ayuda a sintetizar", "a prestar atención" y "a entender y concentrarte en las ideas fundamentales". Sin embargo, también hay una respuesta en la que consideran que "en determinadas, ocasiones la presencia del profesor puede disminuir la concentración necesaria en ejercicios complejos". Ningún alumno destaca el Tipo C de formato de vídeo, pero sí que hay opiniones que destacan el B: "En mi opinión el mejor tipo de vídeos es el B, ya que en el tipo C la imagen completa del profesor ocupa la pantalla y puede llegar a ser molesto".

En cuanto a los contenidos hay opiniones contradictorias. Mientras que alguno considera que "lo que menos me gusta es la parte excesivamente teórica que dificulta la comprensión", a otros les gustaría profundizar en temas teóricos: “dedicar más tiempo a la explicación del cálculo de incertidumbres o errores". Hay opiniones de que los vídeos deben contener ejemplos filmados de cómo realizar partes de la práctica: "a veces mostrar las herramientas

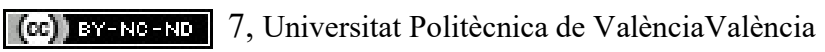


no ayuda a entender cómo usarlas", y por lo tanto "ayudaría que el profesor realizase un ejemplo práctico de las conexiones de los elementos de un circuito de medida", ya que "sólo una imagen (una fotografía) no explica bien cómo y por qué conectar" los componentes y equipos de medida.

Sobre cuestiones técnicas de los vídeos, de todos los formatos destacan los problemas relacionados con el audio: "alguns vídeos l'audio estava molt baix i no es podia entendre", "tienen defectos de sonido", "la calidad del sonido podría ser mejor". Algunos consideran que "la imagen del profesor estaría mejor fuera del espacio utilizado para explicar la práctica", y otros, aunque la herramienta de visualización de los vídeos permite acelerar hasta 1.5 la velocidad de reproducción, consideran que "algunos vídeos explican cosas de forma lenta, y es más rápido leerte la documentación escrita" y "tienes la sensación de que pierdes el tiempo".

\section{Conclusiones}

Los resultados analizados han demostrado que los estudiantes, en general, prefieren archivos de vídeo a documentos de texto para el estudio y la preparación de las prácticas de laboratorio. Esto confirma la primera hipótesis planteada.

En cuanto a los resultados acerca de los tipos de vídeos, se observa una preferencia estadísticamente significativa a favor de los videos en los que se muestra la imagen del profesor, lo cual parece confirmar la segunda hipótesis.

Aunque el formato de video Polimedia ha sido el mejor valorado, existen factores que pueden añadir ciertos matices a esta consideración. Por una parte, la valoración que hacen de los otros dos tipos de vídeos (screencast con o sin imagen del profesor) también es buena. Por otra parte, en los comentarios mostrados por los estudiantes en la pregunta de respuesta abierta resulta frecuente que el alumnado sea crítico con el formato Polimedia y que valoren positivamente el screencast con imagen del profesor. Además, resulta destacable también que hay un 30\% de alumnos que manifiestan que los tres formatos utilizados pueden ser válidos. Por lo tanto, y respecto de la tercera hipótesis planteada, quedan abiertos nuevos factores en los que profundizar, y no se puede afirmar con rotundidad que los estudiantes prefieran el formato Polimedia frente a los screencast. Posiblemente, un formato híbrido de los tres tipos conseguiría un mayor consenso.

\section{Agradecimientos}

Los autores agradecen al Instituto de Ciencias de la Educación de la universitat Politècnica de València su apoyo al grupo de Innovación e-MACAFI y al Proyecto PIME/2016/A/017.

\section{Referencias}

Ahmad, T., \& Doheny, F. (2014). Six key benefits of screencasts in learning Maths. In Recent Trends in Social and Behaviour Sciences (pp. 283-288). CRC Press. 
https://doi.org/10.1201/b16658-50

Blasco, A. C., Lorenzo, J., Sarsa, J., \& Sarsa, J. (2016). The flipped classroom and the use of educational software videos in initial teaching education. Qualitative study. @tic. RevistaD’innovacióEducativa, O(17), 12-20. https://doi.org/10.7203/attic.17.9027

Dunn, P. K., McDonald, C., \& Loch, B. (2015). StatsCasts: screencasts for complementing lectures in statistics classes. International Journal of Mathematical Education in Science and Technology. https://doi.org/10.1080/0020739X.2014.990530

Jordan, C., Loch, B., Lowe, T., Mestel, B., \& Wilkins, C. (2012). Do short screencasts improve student learning of mathematics? MSOR Connections. https://doi.org/10.11120/msor.2012.12010011

Lasry, N., Dugdale, M., \& Charles, E. (2014). Just in Time to Flip Your Classroom. The Physics Teacher, 52(1), 34. https://doi.org/10.1119/1.4849151

Mayer, R. E. (2014). The Cambridge Handbook of Multimedia Learning (2nd Edition).

Oud, J. (2009). Guidelines for effective online instruction using multimedia screencasts. Reference Services Review, 37(2), 164-177. https://doi.org/10.1108/00907320910957206

Peterson, E. (2007). Incorporating screencasts in online teaching. International Review of Research in Open and Distance Learning, 8(3).

Sugar, W., Brown, A., \& Luterbach, K. (2010). Examining the anatomy of a screencast: Uncovering common elements and instructional strategies. International Review of Research in Open and Distance Learning, 11(3), 120.

Sutton-Brady, C., Scott, K. M., Taylor, L., Carabetta, G., \& Clark, S. (2011). The value of using short-format podcasts to enhance learning and teaching. Research in Learning Technology, 17(3), 219-232. https://doi.org/10.3402/rlt.v17i3.10878

Zaphiris, P., \& Ioannou, A. (2015). Learning and Collaboration Technologies: Second International Conference, LCT 2015 Held as Part of HCI International 2015 Los Angeles, CA, USA, August 2???7, 2015 Proceedings. Lecture Notes in Computer Science (Including Subseries Lecture Notes in Artificial Intelligence and Lecture Notes in Bioinformatics), 9192, 714-723. https://doi.org/10.1007/978-3-319-20609-7 


\title{
Desarrollo de una Actividad de Aprendizaje Experiencial a través de un juego.
}

\author{
Ángel Peiró-Signes ${ }^{a}$, Oscar Trull-Domínguez ${ }^{b}$, Marival Segarra-Oña ${ }^{c}$, Blanca de \\ Miguel-Molina $^{\mathrm{d}}$
}

${ }^{a}$ Departamento de Organización de Empresas (Universitat Politècnica de València, anpeisig@omp.upv.es), bepartamento de Estadística e Investigación Operativa Aplicada y Calidad (Universitat Politècnica de València, otrull@eio.upv.es), 'Departamento de Organización de Empresas (Universitat Politècnica de València, maseo@omp.upv.es) y ${ }^{a}$ Departamento de Organización de Empresas (Universitat Politècnica de València, bedemigu@omp.upv.es),

\begin{abstract}
This paper focuses on the development of an Experimental Learning activity through a children's game. We want to show instructors a powerful tool to motivate and generate meaningful learning from a simple experience that allows us to test new teaching methodologies that are more appropriate to current educational environments. The activity is developed as a simulation of an industrial process using a car track game, where we intend to learn the basic principles to apply and analyze control charts. The results of the first two experiences indicate a high impact on the motivation and learning perception of the most basic concepts. On the other hand, the results also reveal the necessity for the instructor to emphasize the most complex concepts during the execution and the debriefing phases of the experience.
\end{abstract}

Keywords: Experiential Learning Activities, control charts, statistics, quality.

\section{Resumen}

Este artículo se centra en el desarrollo de una Actividad de Aprendizaje Experiencial a través de un juego de niños. Pretendemos mostrar a los instructores una potente herramienta de motivación y de generación de aprendizaje significativo a partir de una experiencia sencilla que nos puede permitir testar nuevas metodologías docentes más adecuadas a los entornos actuales de la educación. La actividad desarrollada a partir de la simulación de un proceso industrial mediante una pista de coches de juguete, donde pretendemos aprender los aspectos básicos para la aplicación y análisis de gráficos de control. El resultado de las primeras experiencias nos indican un alto impacto en la motivación y en la percepción de aprendizaje de los conceptos más básicos. Por otro lado, de los resultados también se desprende la necesidad del instructor de incidir en los conceptos más complejos de forma más importante durante las fases de ejecución y discusión de la experiencia.

Palabras clave: Aprendizaje experiencial, gráficos de control, estadística, calidad. 


\section{Introducción}

En el mundo educativo muchos aspectos han cambiado en los últimos años. El tiempo es escaso, las competencias que hay que desarrollar son muy amplias y mantener a los alumnos interesados en la materia cada vez es más y más duro.

En estas situaciones los profesores tenemos la opción de mantenernos con las metodologías que hemos ido usando durante años o enfrentarnos al cambio con decisión. El cambio supone en muchos casos adentrarnos en aspectos y ámbitos desconocidos de la enseñanza. Nuevas metodologías, nuevas actividades, una aproximación al problema diferente, etc. El cambio para adaptarse al nuevo entorno educacional parece cada vez más necesario.

Pensamos que la actividad en clase tiene que ser interesante para el alumno. Para despertar el interés en los alumnos tenemos múltiples opciones y cada una de las metodologías tiene sus elementos clave que permiten su aplicación con éxito. Además las actividades de clase deben estar relacionadas con el aprendizaje pasado (Ausubel,2000) y deben de poder ser recordadas por los alumnos después de algún tiempo. En otras palabras, las actividades deben producir un aprendizaje significativo y deben al mismo tiempo ser motivantes.

La experiencia nos indica que las Actividades de Aprendizaje Experiencial o Experiential Learning Activities (ELAs), son una herramienta poderosa para desarrollar aprendizajes experienciales sobre diversos conceptos, permiten trabajar competencias transversales y al mismo tiempo mantener el interés y la motivación en la asignatura (Peiró-Signes y SegarraOña, 2015), incluso en distintos niveles educativos (Peiró-Signes, 2015).

En este artículo se explica cómo se ha desarrollado una Actividad de Aprendizaje Experiencial (AAE) y los resultados preliminares de la experiencia. De esta forma, pretendemos mostrar a instructores o profesores un ejemplo de cómo a partir de un simple juego, podemos realizar un cambio en nuestra forma de abordar las clases para adaptarnos a este nuevo entorno educativo.

\section{Objetivos}

El cambio que tienen que realizar los instructores para introducir Actividades de Aprendizaje Experiencial en sus clases es grande. Hay un giro importante en cómo debe de enfrentarse el profesor a la sesión. En muchos casos requerirá que el propio profesor desarrolle nuevas habilidades y competencias.

El aspecto más importante a la hora de desarrollar una AAE es sin duda la planificación. Para planificar una AAE debemos considerar los conceptos que queremos transmitir, las habilidades y competencias que los estudiantes deben de tener y las que queremos desarrollar, entre otras. Además, debemos tener en cuenta aspectos relacionados con la infraestructura (tamaño y disposición de la clase, número de alumnos, recursos disponibles, etc.. El elemento clave en esta fase de planificación es determinar el propósito de la 
experiencia. Los objetivos de aprendizaje deben estar claros desde el primer momento para que toda la actividad pueda construir sobre ellos.

LaForge y Busing (1998) indicaron que el desarrollo de una AAE abarca desde la planificación hasta el debriefing o discusión final a través de las fases de introducción y ejecución de la actividad.

Este artículo se centra en el desarrollo de una AAE para mostrar a los estudiantes como construir, usar y analizar Gráficos de Control. Basándonos en un juego infantil hemos desarrollado una experiencia para cambiar la forma en que impartimos los conceptos relacionados con los gráficos de control. Con ello pretendemos conseguir un aprendizaje significativo y aumentar la motivación del estudiante durante la clase.

\section{Desarrollo de la innovación.}

\section{a. Planificación}

La planificación es vital para el desarrollo de la AAE. Es la fase clave para garantizar el éxito de la actividad. Empieza desarrollando los objetivos y continua con el desarrollo de las bases de la experiencia. Termina indicando cómo debe gestionarse y conducirse la fase final de debriefing.

Como indicaron Halpern y Hakelh (2003), desde el punto de vista del instructor la parte más complicada es el diseño de la experiencia. Una experiencia que sin la complejidad de una situación real, es capaz de reflejar de forma relevante los aspectos importantes que queremos transmitir. La experiencia debe permitir a los estudiantes tomar decisiones y reflexionar al final del proceso sobre aquellos aspectos que han ocurrido durante la experiencia (Kolb, 1984; Wheeler y McLeod, 2002). Es en esta fase final, es donde los estudiantes alcanzan el aprendizaje significativo.

La calidad ha sido un aspecto importante para las empresas en las últimas décadas. Dentro de la gestión de la calidad existen técnicas y metodologías que permiten recoger datos de un proceso, mostrar dichos datos y tomar decisiones a partir de su análisis. Los gráficos de control son una aplicación típica que permite monitorear procesos pasando por todos estos aspectos. Su aplicación permite detectar cuando están ocurriendo problemas en un proceso, diferenciar situaciones normales de anormales, establecer la estabilidad y los patrones del proceso o el resultado esperado. En otras palabras, permite diferenciar las causas comunes de variabilidad de las especiales.

La aplicación de los gráficos de control se divide en dos fases. En la primera se recogen los datos para establecer los límites de control y posteriormente se monitoriza el proceso para detectar causas especiales de variabilidad que nos indiquen que el proceso está fuera de control.

Los objetivos de aprendizaje en una sesión regular en esta área tienen que ver con la capacidad de aplicar y analizar gráficos de control: preparar y usar gráficos de control en un proceso, determinar situaciones fuera de control o diferenciar fuentes comunes de variabilidad. 
La experiencia ha sido diseñada sobre un juego de niños. El juego es bastante básico. Varios coches se mueven a través de una pista por la acción de la gravedad. Dos elevadores de correa, suben los coches de las zonas más bajas de la pista a las zonas más altas para que los coches se deslicen a través de una pista a modo de tobogán de nuevo hacia abajo. El juego tiene varios coches de colores distintos. Estos coches completan la vuelta en tiempos ligeramente distintos porque no son exactamente iguales y ni las trayectorias seguidas en la pista son exactamente iguales. Cada coche completa la pista, en promedio, en un tiempo por vuelta diferente, representando, cada uno de ellos un proceso distinto.

El objetivo de la experiencia es controlar el proceso (tiempo por vuelta) como un medio para lograr los objetivos mencionados anteriormente relacionados con los gráficos de control.

Para la experiencia necesitaremos otros recursos (ver fig. 1) además del juguete que se comentarán a continuación.

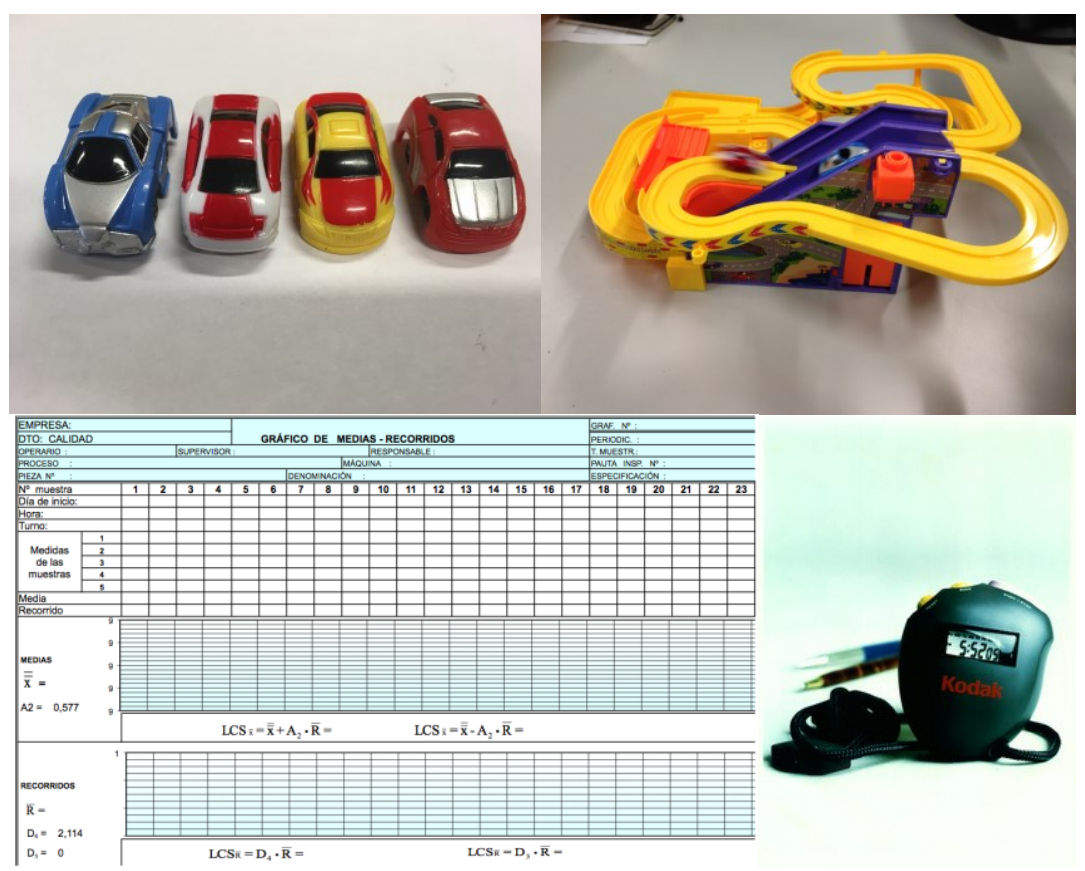

Fig. 1 Recursos de la actividad

\section{b. Introducción.}

Los materiales deben ser preparados por el instructor antes de que los estudiantes entren en el aula. El juego requiere partir el grupo en cuatro equipos de tres a cuatro estudiantes que serán asignados a cada coche. A cada estudiante se les asigna diferentes funciones: controlar el tiempo, anotar resultados, etc. 


\section{c. Actividad}

El primer objetivo es construir el gráfico de control. Necesitaremos una hoja de datos especial preparada por el profesor y que incluye los datos para la toma de muestras, cálculo de los límites de control y área milimetrada para el dibujo de los gráficos. En este caso, utilizamos un gráfico de control de rango promedio.

Los estudiantes necesitarán un cronómetro o teléfono móvil para controlar el tiempo por vuelta. Dos miembros de cada grupo comenzarán a tomar medidas de la vuelta en series de 5 vueltas. Inicialmente, los estudiantes permitirán que los coches funcionen de cuatro a seis vueltas hasta que el tiempo por vuelta sea más o menos estables y no se detecten problemas de circulación de los coches a lo largo de la pista. Escogiendo la parte superior de una de las cintas como el punto de inicio y final, los estudiantes harán 25 series de 5 medidas, dejando 3 a 4 vueltas entre series. Los resultados serán registrados por los otros miembros del grupo en la hoja de datos.

Una vez recuperados los datos "históricos", se instruirá a los estudiantes sobre el cálculo de la línea central y los límites de control superior e inferior, siguiendo las fórmulas indicadas en la hoja de datos.

El segundo objetivo es aprender a utilizar el gráfico de control. En este paso de la experiencia, el alumno tomará muestras a intervalos de muestreo especificados y trazarán valores en promedio y rango en una nueva hoja donde primero incluirán los límites de control previamente calculados.

Los límites de control son líneas de decisión, que en el primer análisis más simple permitirá a los estudiantes discriminar entre una proceso bajo control y uno fuera de control. Para esta parte, los roles de los estudiantes se cambian, para que todos los miembros puedan experimentar los diferentes roles dentro del equipo.

Después de unas cuantas rondas de medición, los estudiantes se darán cuenta de que los valores de promedio y rango trazados están entre los límites. El proceso es estable, funcionando dentro de los límites deseados. El proceso se está ejecutando bajo la influencia solo de causas comunes de la variabilidad y no deben adoptarse contramedidas.

En este momento se introducen causas especiales de variación. El juego está preparado para introducir varias causas de variación que podrían resultar en diferentes señales típicos de situaciones fuera control.

La primera señal de fuera de control es provocada deliberadamente por el instructor bajo la observación de los estudiantes. El instructor ralentiza las cintas poniendo el dedo sobre una de ellas mientras al menos uno de los coches se está elevando. Esto hará que uno o varios coches aumenten significativamente el tiempo de vuelta. Cuando los estudiantes trazan el resultado de la muestra el punto grafiado estará fuera del límite superior, lo que está indicando un comportamiento anormal del proceso. Esto puede alentar algunas discusiones sobre las causas de la variación que deberían introducir a los estudiantes en la siguiente parte de la experiencia. 
Para simular causas especiales, incorporamos un dispositivo de alimentación de corriente continua externa (DC). El juego original funciona con un paquete de 2 baterías del AA $1.5 \mathrm{~V}$ (fuente de alimentación $3 \mathrm{~V}$ ). Sin embargo, el motor de $\mathrm{CC}$ en el juguete es capaz de funcionar a un voltaje más alto y más bajo. Utilizamos una fuente de alimentación variable que nos permite alterar la tensión suministrada al juguete de 2 a $5 \mathrm{~V}$. Un aumento en el voltaje aumentará la velocidad del motor y viceversa. Aumentar la velocidad de la fuente de alimentación acelerará el proceso y eventualmente creará un resultado en un punto fuera de los límites de control. Preparamos un conjunto de experiencias para descubrir posibles situaciones fuera de control para que los estudiantes puedan experimentarlas.

La figura 2 muestra ejemplos de la configuración y el resultado esperado en el gráfico de control de control.
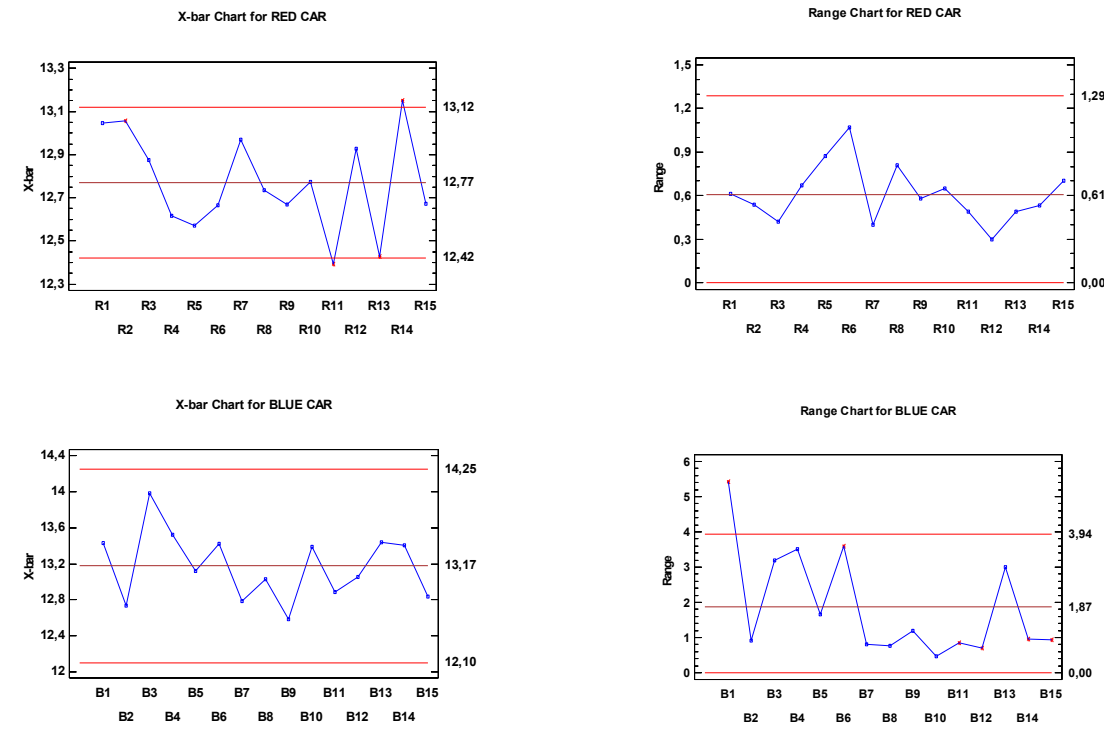

Fig. 2 Ejemplos de Gráficos de control obtenidos en la experiencia

Los estudiantes pasarán entre 30 minutos y 40 minutos para desarrollar todas estas experiencias.

\section{d. Debriefing}

Una vez completadas las experiencias los estudiantes discutirán durante 10 minutos los patrones que sigue cada una de las experiencia, las posibles razones de la variación en un proceso del mundo real.

La discusión comienza después de la discusión en pequeños grupos. El instructor resumirá la experiencia centrándose inicialmente en cuáles son las causas de la variabilidad común en el juego. Los estudiantes deben llegar con respuestas como: los coches no son exactamente los mismos (tienen diferentes formas, las ruedas y el eje no tienen la misma

(cc) EY-NC-ND 2017, Universitat Politècnica de València

Congreso IN-RED (2017) 
fricción, etc.), los coches no siguen exactamente el mismo camino (las curvas se toman de manera diferente, las cinta coge el coche de forma diferentemente cada vez, etc.), la cinta puede tener distinta velocidad (micro variaciones en la velocidad de la cinta), el controlador del tiempo no está parando el cronómetro en el mismo punto exacto cada vuelta, etc. Después de la primera parte de la discusión, las causas comunes deben estar claras y el instructor puede querer discutir las causas especiales y cómo afectan a la media y los valores de rango en el gráfico. El propósito es dejar que el estudiante se dé cuenta de que cuando el proceso está bajo variabilidad común todas las muestras estarán entre los límites y normalmente distribuidas alrededor de la línea central, mientras que las situaciones fuera de control terminarán en puntos fuera del límite o con patrones que están descubriendo comportamiento anormal.

El instructor debe usar situaciones reales relacionadas con el grado que los estudiantes están realizando para que visualicen su aplicación a un proceso real y asienten así los conocimientos. Por ejemplo, en un grado de ingeniería mecánica, podríamos usar el diámetro de un eje como ejemplo para mostrar situaciones que podrían ocurrir cuando el proceso de mecanización no está bajo control debido, por ejemplo, al desgaste de la herramienta, falta de lubricación en el proceso, error de posicionamiento de la herramienta o sobrecontrol del proceso.

Al final del periodo de retroalimentación y debate, el profesor puede reforzar los conceptos experimentados mediante una lección magistral, centrada en que los estudiantes evalúen de una forma más profunda sobre lo vivido en la experiencia para llegar a niveles superiores de aprendizaje (Meyers, 1986; Smith, 2003).

\section{Resultados}

Este artículo plantea la utilización de una actividad de aprendizaje experiencial en el aula. El éxito o fracaso de la actividad deberá evaluarse en forma de resultados. Para ello se ha previsto una evaluación de resultados después de introducir la actividad experiencial en base a las percepciones de los alumnos que la han realizado y su comparación con experiencias pasadas en la misma u otras asignaturas. Se plantea un pequeño cuestionario mediante una escala a Likert 1 a 5 donde 1 corresponde a totalmente en desacuerdo y 5 a totalmente de acuerdo.

Este test permite al instructor evaluar el impacto del ejercicio en particular y determinar los ajustes necesarios para conseguir los objetivos propuestos. La tabla 1 y la figura 3 muestran el resultado del cuestionario de evaluación de la actividad realizado sobre las dos primeras experiencias y un total de 32 alumnos. 
Tabla 1. Cuestionario y resultados de evaluación de la actividad

\begin{tabular}{|c|c|}
\hline Preguntas & Promedio \\
\hline $\begin{array}{l}\text { ¿Hasta qué punto se considera que la actividad ha ayudado al equipo a conocer } \\
\text { cómo se toman los datos necesarios para construir los Gráficos de Control? }\end{array}$ & 4,86 \\
\hline $\begin{array}{l}\text { ¿Hasta qué punto se considera que la actividad ha ayudado al equipo a conocer } \\
\text { cómo se calculan los límites de control? }\end{array}$ & 4,21 \\
\hline $\begin{array}{l}\text { ¿Hasta qué punto se considera que la actividad ha ayudado al equipo a conocer } \\
\text { como se monitoriza un proceso a través de los Gráficos de Control? }\end{array}$ & 4,64 \\
\hline $\begin{array}{l}\text { ¿Hasta qué punto se considera que la actividad ha ayudado al equipo a detectar } \\
\text { cuándo un proceso está bajo control utilizando Gráficos de Control? }\end{array}$ & 4,57 \\
\hline $\begin{array}{l}\text { ¿Hasta qué punto se considera que la actividad ha ayudado al equipo a detectar } \\
\text { cuándo un proceso está fuera de control utilizando Gráficos de Control? }\end{array}$ & 4,07 \\
\hline las posibles causas de que un proceso esté fuera control? & 3,79 \\
\hline $\begin{array}{l}\text { ¿Hasta qué punto se considera que la actividad ha ayudado al equipo a diferenciar } \\
\text { entre variabilidad común y variabilidad debido a causas especiales? }\end{array}$ & 4,50 \\
\hline $\begin{array}{l}\text { ¿En qué medida piensas que podrías realizar el control de un proceso por ti mismo } \\
\text { a partir de lo aprendido en la experiencia? }\end{array}$ & 3,93 \\
\hline $\begin{array}{l}\text { En qué medida ha sido motivadora la experiencia y preferible sobre una clase } \\
\text { magistral }\end{array}$ & 4,79 \\
\hline $\begin{array}{l}\text { ¿Crees que la actividad ha ayudado al equipo a tener la sensación de "en esto } \\
\text { estamos todos juntos"? }\end{array}$ & 4,71 \\
\hline ¿En que medida la comunicación ha sido importante para resolver la actividad? & 4,14 \\
\hline $\begin{array}{l}\text { ¿En que medida has podido participar y expresar tus opiniones en la discusión de } \\
\text { grupo y en la discusión general? }\end{array}$ & 4,07 \\
\hline $\begin{array}{l}\text { ¿Recomendarías la experiencia para el aprendizaje de los aspectos relacionados } \\
\text { con los Gráficos de Control? }\end{array}$ & 4,86 \\
\hline
\end{tabular}

Los resultados del test resaltan la potencia de la experiencia en relación a la motivación y a la adquisición de las habilidades y conceptos esenciales. Por otro lado, como era de esperar, los aspectos más complejos y de mayor nivel intelectual recibieron puntuaciones inferiores de los alumnos. Estos resultados preliminares nos indican los conceptos que deben reforzarse en futuras sesiones, especialmente en la parte de feedback y conclusiones, para garantizar un mayor cumplimiento de los objetivos planteados. 


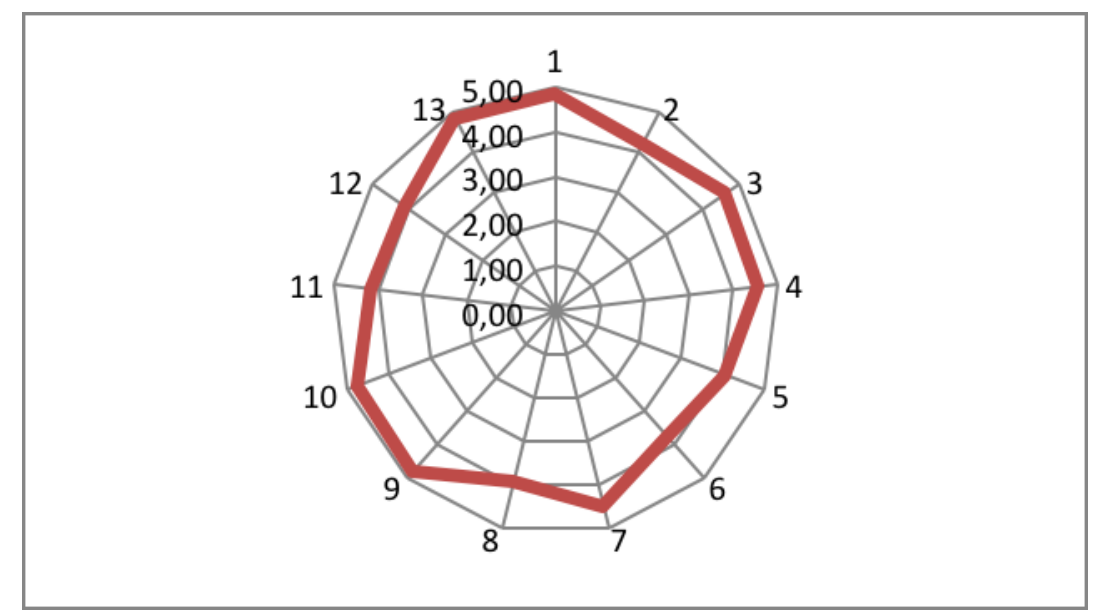

Fig. 3 Promedios de las preguntas de evaluación del uso de la AAE. Fuente: elaboración propia.

\section{Conclusiones}

Este artículo presenta el desarrollo de una actividad de aprendizaje experiencial diseñada para la enseñanza de los conceptos y habilidades necesarias en el uso y análisis de los Gráficos de Control. La actividad pretende ayudar a los alumnos dentro del proceso de enseñanza aprendizaje a conseguir un aprendizaje más significativo y relacionado con las actividades futuras de los egresados de asignaturas de grado en el área industrial y de ingeniería. Esta experiencia muestra cómo a partir del diseño de una Actividad de Aprendizaje Experiencial sencilla y mediante la utilización de un sencillo juego de niños se puede construir una sesión de aula motivadora para el alumnado y, que al mismo tiempo, permite a los alumnos visualizar aspectos complejos de los entornos productivos que, mediante metodologías docentes tradicionales, serían difíciles de cubrir.

Tras la experiencia acumulada se observa que el instructor debe poner especial énfasis en los conceptos y análisis de los aspectos más complejos de los Gráficos de Control en la fase de debriefing como refuerzo necesarios para alcanzar niveles significativos de aprendizaje en la experiencia.

Asimismo, es necesario evaluar si los resultados alcanzados son los esperados en las pruebas de evaluación de los conocimientos de la asignatura. El control de las percepciones de los alumnos a través del cuestionario y de los resultados a través de las pruebas de evaluación servirán al instructor para ajustar la experiencia y conseguir mayor eficacia en la consecución de los objetivos planteados.

\section{Agradecimientos}

Este trabajo forma parte del estudio desarrollado por el Grupo de Aprendizaje Experiencial (GAE) creado como EICE en la Universidad Politécnica de Valencia (UPV). Los autores desean agradecer a la UPV por el apoyo a través del PIME 2017 " Adaptación y desarrollo de aprendizajes experienciales al contexto de las asignaturas ". 


\section{Referencias}

HALPERN, D. y HAKEL, M. (2003). “Applying the science of learning”. Change, vol. 35, issue 4, p. $36-41$.

KOLB, D. (1984). Experiential learning: Experience as the source of learning and development.

Englewood Cliffs, NJ: Prentice Hall.

LAFORGE, R. y BUSING, M. (1998). "The use of industrial software to create experiential learning activities in operations management courses". Production and Operations Management, vol. 7, issue 3, p. 325-334.

MEYERS, C. (1986). Teaching students to think critically. San Francisco, CA: Jossey-Bass.

PEIRO-SIGNES, A., SEGARRA-OÑA, M., DE MIGUEL-MOLINA, M., J. ALBORS-GARRIGÓS, J. y DE-MIGUEL-MOLINA B. (2015). "The experiential learning activity: benefits and difficulties in real learning environments”. Proceedings of ICERI2015 Conference, p. 7231-7237.

PEIRO-SIGNES, A. y SEGARRA-OÑA, M.; (2015). "Experiential learning as a dynamizer of class activity". Proceedings of ICERI2015 Conference, p. 1010-1013.

SMITH, G. (2003). "Beyond critical thinking and decision making: Teaching business students how to think". Journal of Management Education, vol. 27, issue 1, p. 24-51.

WHEELER, J., y MCLEOD, P. (2002). "Expanding our teaching effectiveness: Understanding our responses to in-the-moment classroom events". Journal of Management Education, vol. 26, issue 6, p. 693-716. 


\title{
Evaluación en FLIP-Teaching: una alternativa a los exámenes parciales. Evaluación continua mediante tareas y casos.
}

Juan Vte. Oltra Gutiérrez ${ }^{a}$

${ }^{a}$ Universitat Politécnica de Valencia, Departamento de Organización de Empresas (jvoltra@omp.upv.es)

\begin{abstract}
The FLIP teaching experience have many challenges, one of the most unique is evaluation. Faced with the current that defends to maintain the traditional in a way that remains the same as the rest of groups with face-to-face teaching, in the present work an experience of continuous evaluation is presented that allows to use for this the time of classroom released by the classroom teaching that is has taken out of it
\end{abstract}

Keywords: FLIP-Teaching, continuous evaluation, classroom cases, work outside the classroom, methodology.

\begin{abstract}
Resumen
La experiencia FLIP teaching plantea muchos retos, uno de los más singulares es la evaluación. Frente a la corriente que defiende mantener la tradicional de forma que permanezca igual que el resto de grupos con docencia presencial, en el presente trabajo se presenta una experiencia de evaluación continua que permite utilizar para ello el tiempo de aula liberado por la docencia presencial que se ha sacado de la misma
\end{abstract}

Palabras clave: FLIP-Teaching, evaluación continua, casos de aula, trabajo fuera del aula, metodología.

\section{Introducción}

La introducción del modelo de docencia inversa o FLIP Teaching en la Universitat Politècnica de València supuso si no una revolución si al menos un pequeño seísmo entre los profesores implicados. Múltiples prismas, desde aquellos que miraban con recelo la experiencia a quienes se mostraron partidarios de la misma, campos de aplicación tan diversos como son las materias en las que se forman los alumnos de nuestra universidad (de la matemática al derecho pasando por la programación)...

Esta diversidad de origen produjo que convivieran, y conviven, ejecuciones de la experiencia que poco más que el nombre comparten. Prueba de ello son los testimonios de los alumnos en las distintas jornadas de docencia Inversa que se han convocado desde el origen de la experiencia. Podríamos decir, dibujando con trazo grueso, que poco más que el uso de vídeos y el empleo de tiempo en casa, son los elementos comunes. Y aun en algún caso, particularmente me permitiría dudar de ello. 
Uno de los elementos que más controversia genera cuando se organizan reuniones, formales o informales, entre docentes que aplican FLIP-Teaching es el de la evaluación. Sobre una plasmación de ella versa el presente trabajo

\section{Antecedentes}

La asignatura sobre la que se efectúa la presente experiencia es Deontología y Profesionalismo, de segundo semestre en el segundo curso del grado de informática, impartido en la Escuela Técnica Superior de Ingeniería Informática, con un peso de 4,5 créditos (tres créditos correspondientes a teoría, y uno y medio de prácticas)

Cuando hace tres años nos enfrentamos al reto de transformar uno de sus grupos al formato FLIP-Teaching, el primer paso que se dio fue el de localizar información que diera pistas sobre las mejores prácticas, las formas de actuar más adecuadas, además de la formación que el Instituto de Ciencias de la Educación nos facilitó a los docentes implicados.

Así, tras largas lecturas (BENNETT, 2011), (BETHANY, 2012), (MCKEACHIE, 2014), (MARTINEZ, 2014), (MOWAFY, 2013), (RIZZO, 2015), (ROSHAN, 2011), (SAMS, 2013), (SPENCER, 2011), (VASILEVA-STOJANOVSKA, 2015), se conformó el modelo. Para una visión detallada del modelo de partida y las correcciones que en el siguiente curso se aplicaron, pueden consultarse nuestros trabajos (OLTRA, 2015) y (OLTRA, 2016), que sirven de precedente para la presente comunicación.

\section{Evaluación}

Si bien cualquier aspecto del diseño de una experiencia docente en general y en FLIP en particular está sujeto a discrepancias de todo tipo y grado, al ser la evaluación el aspecto que ofrece más datos cuantificables, y por tanto medibles, es la estrella en las discusiones en todo tipo de foros, formales o informales.

La pregunta principal que se suele plantear es: ¿aplicamos a todos los alumnos la misma evaluación? Es una pregunta delicada porque, por una parte, se enarbola la idea de que todos tienen que tener la misma igualdad de oportunidades, y por tanto, las pruebas, sean exámenes parciales o cualquier otra, deben ser idénticas o al menos muy parecidas para todos. Por otra parte, sin embargo, se plantea a modo de respuesta otra pregunta: ¿Podemos aplicar una innovación docente despreciando su ventaja más evidente? La respuesta que se da en la presente comunicación es un NO rotundo. La mayor ventaja de la clase inversa es permitir usar el tiempo de aula para cosas distintas a la exposición magistral, en concreto para la realización de trabajos, debates... Pues bien, si los hacemos, el paso que de forma obvia sigue es evaluarlo. Asignarles nota y que sirvan tanto al alumno para ir avanzando por la asignatura como al profesor para poder tomar la temperatura a su clase en todo momento, y no solo cuando llegan los parciales.

Particularmente siempre he detectado una trampa en esa afirmación, pues desde el momento en que reciben de forma distinta la docencia, de modo que no hay clase magistral en muchos casos, ya estamos alterando la premisa de partida: todos no tienen ya igualdad de oportunidades. Unos tiene la cercanía del profesor que otros, en cambio pierden, pero

(c) EY-NC-ND 2017, UniversitatPolitècnica de València 
disponen de la posibilidad de ver o leer una y otra vez el material que lo sustituye, además de por supuesto acudir a las sesiones de tutoría como todos.

Pero es que aun hay más: si sacamos a la docencia tradicional, a la clase magistral del aula, porque la estamos, permítaseme la expresión, enlatando para su consumo fuera de ella, y las clases las dedicamos a afianzar la teoría mediante ejercicios, test, casos, preguntas del minuto, rol... ¿tiene sentido entonces hacer trabajar a los alumnos de modo que podemos ir comprobando sus avances y no aprovechar esto para alcanzar esa meta que parecía tan utópica y a fuerza de ser empleada vacuamente queda manida y ajada, relegada a buenos propósitos o directamente a eufemismos que cubren una mentira conocida en la guía docente?

Con la idea de partida fija en conseguir este extremo, año a año, se han ido efectuando correcciones hasta llegar a lo que, hoy por hoy, consideramos una versión estable para la evaluación de los grupos FLIP de la asignatura (grupos, pues desde el curso anterior, al grupo piloto sumamos otro grupo, "robándolo" de la docencia convencional)

Para desarrollar el esquema de este modelo de evaluación partiremos de la descripción del modelo convencional: el cómo se evalúa la asignatura en los grupos no FLIP, para así poder establecer las necesarias comparaciones al mostrar el modelo seguido.

\subsection{Evaluación de los grupos "No-Flip"}

Podemos ver un desglose en la tabla siguiente:

Tabla 1. Evaluaciones en grupos convencionales

\begin{tabular}{|l|l|l|l|}
\hline Corresponde a & Tipo & Actos & Peso \\
\hline Práctica & Trabajo académico & 4 & $30 \%(1+1+0,5+0,5)$ \\
\hline Práctica & Coevaluación & 1 & $5 \%(0,5)$ \\
\hline Teoría & Caso & 3 & $15 \%(0,5+0,5+0,5)$ \\
\hline Teoría & $\begin{array}{l}\text { Examen (test } \\
\text { desarrollo) }\end{array}$ & 2 & $\begin{array}{l}50 \%(2,5+2,5) \\
(\text { cada examen: test, } \\
1 \text { punto, desarrollo } \\
1,5 \text { puntos })\end{array}$ \\
\hline
\end{tabular}

Además hay que incluir las actividades de gamificación y extras de la asignatura, que permiten de algún modo "pre-recuperar" partes de la misma, como por ejemplo un pequeño trabajo sobre una jornada con invitados del mundo profesional que cada año se celebra.

Sobre la evaluación en grupos "NO-FLIP" vemos que nada escapa a lo convencional: desde las prácticas diseñadas como boletines de entrega, con importante trabajo en el laboratorio con asesoramiento del profesor (un modelo clásico que se aproxima mucho a lo que queremos lograr con la metodología presente, incluida una breve coevaluación) a la teoría, que se mueve por los cauces largo tiempo hollados de los exámenes. 
Así, cada parcial, con un peso de 2,5 puntos cada uno (luego entre los parciales se obtiene el $50 \%$ de la nota total) compuesto por un test y dos preguntas de desarrollo, tienen una forma que no difiere demasiado a la que tenían los exámenes que el autor de esta comunicación realizó hace ya décadas en el mismo centro donde ahora imparte clase. Y con respecto a los casos, dado el celo en no perder el precioso tiempo de exposición en aula, el proceso de obtención de nota se resume en un test por cada caso, de 5 preguntas y 0,5 puntos cada uno, a realizar un día concreto, idéntico para todos los grupos, mediante la herramienta de test de la plataforma poliformat.

En este esquema se percibe que mientras las prácticas si se van evaluando con escalas (5 notas para 10 sesiones), con lo que respecta a la teoría, por estar ocupadas las horas de las sesiones por la clase magistral, queda solo resquicio para tres casos pequeños, a realizar en la última media hora de tres sesiones. O, dicho de otra forma, una hora y media dedicada a la evaluación de las 30 horas de aula de teoría.

Resulta claro que no solo "había que llenar" el tiempo que se recuperaba al sacar de la pizarra y trasladar a la plataforma los contenidos teóricos, sino que se presentaba la mejor oportunidad para llevar a cabo esa evaluación continua que desde todos los estamentos nos llega como una realidad. Realidad que, todo hay que decirlo, resulta ilusoria a poco que rasquemos la pintura de la escayola en algunas materias (y si alguien precisa pruebas de ello, solo tiene que visitar los foros extraoficiales de los alumnos, una de las mejores maneras de averiguar la percepción que tienen de nosotros y nuestras clases).

Para llevar esto a cabo, creamos el modelo que presentamos ahora.

\subsection{Evaluación de los grupos FLIP}

De igual modo que en el caso anterior, vamos a empezar con una tabla sintética que, en este caso, desglosaremos con detalle.

Tabla 2. Evaluaciones en grupos FLIP

\begin{tabular}{|l|l|l|l|}
\hline Corresponde a & Tipo & Actos & Peso \\
\hline Práctica & Trabajo académico & 4 & $30 \%(1+1+0,5+0,5)$ \\
\hline Práctica & Coevaluación & 1 & $5 \%(0,5)$ \\
\hline Teoría & Caso de aula & 3 & $15 \%(0,5+0,5+0,5)$ \\
\hline Teoría & $\begin{array}{l}\text { Tarea a realizar en } \\
\text { casa, basada en un } \\
\text { caso }\end{array}$ & 3 & $30 \%(1+1+1)$ \\
\hline Teoría & Caso de aula & 2 & $20 \%(1+1)$ \\
\hline
\end{tabular}

¿Qué cambios se han hecho?

En cuanto a las prácticas, dado que estas, organizadas en grupos de trabajo, se hacen en laboratorio, quedando la memoria a elección de ellos el realizarla allí o, dedicar más tiempo

(c) EY-NC-ND 2017, UniversitatPolitècnica de València 
de laboratorio para terminar de forma más cumplida los trabajos y con apoyo de los profesores de prácticas, y terminarlas en casa (de cualquier forma, se entregan mediante una tarea de la plataforma Poliformat), se decidió dejarlas como estaban. El seguimiento permite evaluar el trabajo de los estudiantes no solo a lo largo del tiempo, sino con más cercanía, pues los grupos de prácticas son más reducidos que los de teoría, y además, sus trabajos se realizan en grupos de tres o cuatro alumnos, lo que permite jugar con la tutoría interpares que se produce de forma natural en ellos.

En la teoría, aunque en apariencia no todo se ha cambiado, lo cierto es que la renovación ha sido total. Vamos a ver lo cambios, centrándonos en la evaluación.

Decíamos que en el aula se usaba una escasa hora y media para tres casos, que sumaban 0,5 puntos. Esos casos se evalúan tras un breve debate con un test online. Puede percibirse que el tiempo es en extremo reducido, pero dado que el temario tiene una extensión considerable y hay que verlo todo en clase, poco tiempo resta para las alharacas docentes. El resto de la teoría se evaluaba con dos exámenes parciales que con un peso total de 5 puntos completaba la carga destinada a evaluar la teoría en la nota de la asignatura.

Hemos insistido en el cambio en sí de las clases. Vale la pena detenerse unos instantes en este punto y ver cuál ha sido ese cambio.

En la docencia convencional, la clase de dos horas tiene una pequeña introducción de 10 minutos que ubica al alumno en la materia, haciendo un breve resumen de lo visto, $\mathrm{y}$, salvo cuando hay un caso a ver en aula, el resto del tiempo se dedica a la exposición de los temas de teoría. Si es una de las tres sesiones donde se evalúa con un caso, la última media hora en lugar de emplearla para el desarrollo de teoría, se invierte en unos 20 minutos de debate y diez para la cumplimentación de un test.

En los grupos que siguen el modelo FLIP se decidió emplear cuatro de las cinco sesiones como clase de repaso, de tutoría abierta, y el resto, con un esquema como el siguiente:

- Los primeros diez minutos se dedican a ubicar nuestro punto de mira: no solo donde estamos en el temario, que contenidos son los que deben ver durante la semana en curso (videos, audios, documentos de lectura) y que tareas permanecen abiertas y han de responder si no lo han hecho ya, junto con la previsión de actividades en aula para las siguientes sesiones.

- En la siguiente media hora se hace un repaso de los ejes principales de la teoría. No se trata de volver a contar lo que ya han leído, sino de subrayar lo más importante de ella, donde deben prestar atención y, dado que en la siguiente parte de la sesión se va a trabajar con un caso, se incide en los elementos más relevantes de la teoría para el mismo.

- Durante la siguiente hora y veinte minutos se trabaja un caso. Este puede tener formas muy diversas.

- Pueden ser los tres casos cortos pre-existentes, que mantienen su peso y se desarrollan en la misma fecha que en el resto de los grupos, pero a los que se da más tiempo para el debate, se examinan elementos que puedan aportar luz, se profundiza en las implicaciones que podrían suponerles situaciones similares en 
su vida laboral... Los últimos veinte minutos se evalúa, pero no con un test, pues éste es sustituido por un breve desarrollo.

- Los cinco puntos que sustituyen a los parciales corresponden a casos (inciso: se les ofrece cuando se presenta la asignatura que escojan entre la evaluación convencional o está basada en casos de aula. Generalmente la respuesta es que un $100 \%$ del alumnado escoge la opción propuesta. Salvo este año, pues alumnos procedentes de otros grupos han pedido cursar la asignatura en grupos FLIP al oír hablar del modelo y gustarles más), casos que pueden ser evaluados mediante una tarea o en el aula. Con estos últimos poca diferencia hay sobre los anteriores, salvo que el desarrollo no es tan breve, y se les da treinta minutos para cumplimentarlo. Pero hay algunos que necesitan de bien el manejo de alguna herramienta informática, bien la búsqueda de información por su parte. Estos son los que se evalúan mediante tarea. Una vez visto el caso en el aula, disponen de una semana para entregarla mediante Poliformat.

Otros aspectos a considerar:

- Gracias a la centralización de los materiales que van a usar en el apartado "Contenidos" de Poliformat, algunos casos van apoyados de vídeos documentales que bien les aportan ayuda para preparar el debate, bien les da pistas para su trabajo autónomo al preparar las tareas. Un par de ejemplos significativos serían los documentales '¡COPIAD, MALDITOS!': LOS CAMINOS ALTERNATIVOS AL 'COPYRIGHT' y OJO CON TUS DATOS. En estos casos se habilita también un foro en poliformat para que se pueda discutir en ellos antes y después de la clase.

- Las clases dedicadas a clase de repaso se emplean para apoyar a aquellos alumnos "atascados" en el desarrollo de una tarea, o para aclarar aspectos de teoría (o ampliar para los interesados. Por ejemplo, en los temas de profesionalismo se desarrollan dos modelos y se cita tan solo a un tercero, que aun no está en vigor: ese modelo por petición de algunos alumnos se desarrollo en una de esas clases, pese a que no "va para examen").

- Vemos que se permite un mayor conocimiento del alumno, al trabajar directamente con él. Esto, aunque no se refleja directamente en la nota, permite al docente apoyarle en su proceso de formación de una forma muy directa, dándole consejos de lecturas, respondiendo dudas puntuales que de otra manera no se hubieran planteado, etc.

\section{Resultados}

En el momento de redactar esta comunicación, la asignatura se encuentra en su punto medio del recorrido. Dos elementos cuantitativos podríamos comparar, la asistencia y la nota acumulada. Pero quedaría cojo sin hablar también de un elemento tan importante, aunque cualitativo, que es la opinión expresada por los alumnos.

\subsection{Asistencia}

Sería trampa considerar tan solo las hojas de firmas. Y lo sería, pues hemos tenido sesiones de tutoría donde solo los interesados (aquellos que querían ampliar algo, aquellos con una tarea atascada o aquellos con interés en aclarar algún punto, acuden). El resto, tiene ese

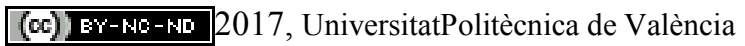

Congreso IN-RED (2017) 
tiempo como apoyo para las actividades de fuera de aula, que son abundantes. (Aunque de hecho un buen grupo de ellos acude a clase y trabaja en el aula con sus portátiles en esas actividades, así, si se encuentran un problema al hacerlas, tienen al profesor para que les apoye). Considerando las clases no de repaso, la asistencia supera en un 5\% al resto de grupos (en la ETSINF se pasa parte de firmas y la asistencia de por sí, es elevada)

\subsection{Nota acumulada}

La nota acumulada es sensiblemente más alta en los grupos FLIP (en torno a un 20\%, aunque no se puede establecer una relación directa por el distinto calendario de evaluaciones, pero si se puede jugar con las proporciones). Aquí hay que ser sincero y dar una explicación que permite una lectura del dato más completa: las tareas entregadas (de momento dos) son revisables si se entregan en un plazo determinado. El profesor las corrige e indica sus fallos. Si deciden rehacerlas, evidentemente su nota sube.

\subsection{Opiniones}

No solo tenemos, como se ha apuntado antes, alumnos que cambian de grupo, sino que los comentarios informales con ellos son realmente gratos. A modo de ejemplo, vemos en la figura siguiente un par de líneas procedentes de un intercambio de correos con una alumna.

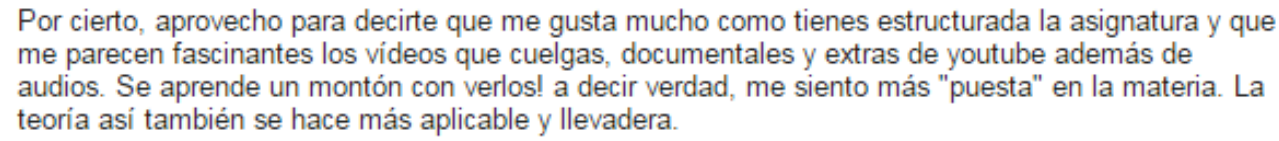

Por cierto, aprovecho para decirte que me gusta mucho como tienes estructurada la asignatura y que me parecen fascinantes los vídeos que cuelgas, documentales y extras de youtube además de audios. Se aprende un montón con verlos! a decir verdad, me siento más "puesta" en la materia. La teoría así también se hace más aplicable y llevadera.

Figura 1. Intercambio epistolar con una alumna, sobre la estructura de los contenidos FLIP

\section{Conclusiones}

En los dos primeros años de docencia FLIP, el problema a batir era el tiempo que el profesor dedicaba a la corrección. Con el modelo actual, donde se han evitado trabajos largos (como en el primer año) y se han reducido el número de casos y tareas, parece que se alcanza el punto de equilibrio.

En las Jornadas de Innovación Docente se escuchó una voz repetida: se decía que las asignaturas con mucha carga teórica no eran susceptibles de seguir un modelo FLIP. Con este trabajo se demuestra que mi creencia en lo contrario no estaba desencaminada. Alumnos con mejores notas, con más interés (de verdad, muy pocas veces me ha sucedido que me pidieran que explicase en clase cosas que seguro que no iban a entrar en la evaluación de la materia, aunque considerase que eran interesantísimas) y alguna que otra felicitación capaz de sonrojar, animan a proseguir con el trabajo.

Por no cerrar el mismo solo con notas positivas, que de todo hay, cabe apuntar un par de elementos que no pueden dejarse de lado: la elaboración de materiales, búsqueda de documentación o vídeos de elementos de actualidad que sirvan para la evaluación de la asignatura, conllevan un tiempo elevado, que nadie se llame a engaño. Por otra parte, también implican una dedicación no puntual, sino continua. Lo que más valoran los 
alumnos es la respuesta inmediata. Las quejas que he tenido que escuchar (a modo de maestro armero, pues eran quejas ajenas a la asignatura) siempre tenían de fondo una constante: "el poco caso que me hacen" o "lo mucho que se retrasa la respuesta de los profesores".

Ambos problemas, es obvio, se traducen en tiempo. Ese tiempo que siempre nos es escaso al docente y que muchas veces no da de sí, por muy bien que creamos gestionarlo.

\section{Referencias}

';Copiad, malditos!': los caminos alternativos al 'copyright' (director: Stéphane M. Grueso). RTVE, 2011. <http://www.rtve.es/television/documentales/copiad-malditos/> [Consultado: 31 de marzo de 2017]

BENNETT B., KERN J., GUDENRATH A., MCINTOSH P (2011). "The Flipped Class Revealed" The Daily Riff. $<\mathrm{http}: / / \mathrm{www}$. thedailyriff.com/articles/the-flipped-class-what-does-a-good-one-looklike-692.php>[Consulta: 31 de marzo de 2017]

BETHANY B. S- (2012) "Flip Your Classroom to Increase Active Learning and Student Engagement" VV.AA. 28th Annual Conference on Distance Teaching \& Learning Wisconsin, EE.UU. University of Wisconsin, 1-5

MARTÍNEZ, A., HERNANDO, A. (2014). "Cómo darle la vuelta al aula: flipped classroom, una metodología para la interacción, la colaboración, el compromiso y la motivación en la clase de ELE" XXV Congreso Internacional de la ASELE. La enseñanza de ELE centrada en el alumno. $<$ http://cvc.cervantes.es/Ensenanza/biblioteca_ele/asele/pdf/25/25_1117.pdf $>$ [Consulta: 31 de marzo de 2017]

MCKEACHIE, W.J., SVINICKI, M.D. (2014).McKeachie'sTeaching Tips: Strategies, Research, and Theory for College and University Teachers, Belmont: Wadsworth

MOWAFY A., KUHN, M., SNOW, T (2013) "Blended learning in highere ducation: Current and future challenges in surveying education in Issues" Educational Research, 23(2): Special Issue, 132150

Ojo con tus datos (Guion: Marisol Soto). RTVE, 2013 $<\mathrm{http}$ //www.rtve.es/alacarta/videos/documentos-tv/documentos-tv-ojo-tus-datos/2270048/> [Consultado: 31 de marzo de 2017]

OLTRA, J.V. (2015) "Diseño de una experiencia de Flip-Teaching para la asignatura Deontología y Profesionalismo a impartir en la Escuela Técnica Superior de Ingeniera Informática de la UPV" INRED $2015 \quad<$ http://ocs.editorial.upv.es/index.php/INRED/INRED2015/paper/view/1646> [Consultado: 31 de marzo de 2017]

OLTRA, J.V. (2016) “ Un año de FLIP: Corrigiendo errores” IN-RED 2016 $<$ http://ocs.editorial.upv.es/index.php/INRED/INRED2016/paper/view/4415> [Consultado: 31 de marzo de 2017]

RIZZO, S. [et al.]. (2015). "Flipped classroom, LCA y materiales de construcción: una experiencia didáctica para una actividad de aprendizaje cooperativa y activa". Jornades sobre Innovació Docent en Arquitectura (JIDA). "III Workshop on Educational Innovation in Architecture (JIDA'15), Barcelona School of Architecture, 25th to 29th May 2015". Barcelona: Grup per a la Innovació i la LogísticaDocent en l'Arquitectura, 2015.<http://hdl.handle.net/2117/81700> [Consulta: 31 de marzo de 2017]

(cc) EY-NC-ND 2017, UniversitatPolitècnica de València 
ROSHAN S. (2011) "The best way to reacheach student? Private school Math teacher flips learning" The Daily Riff. $<$ http://www.thedailyriff.com/articles/the-best-way-to-reach-each-student-privateschool-flips-learning-547.php> [ Consulta: 31 de marzo de 2017]

SAMS A., BERGMANN J. (2013) "Flip Your Students' Learning" Technology-Rich Learning Vol 70 $\mathrm{n}^{\circ} 6$

SPENCER D., WOLF D.\& SAMS A (2011) "Are you ready to flip?" The Daily Riff. $<$ http://www.thedailyriff.com/articles/are-you-ready-to-flip-691.php $>$ [Consulta: 31 de marzo de 2017]

VASILEVA-STOJANOVSKA T., MALINOVSKI T., DOBRIJOVEVSKI M.V., TRAJKOVIK V. (2015) "Impact of satisfaction, personality and learning style on educational outcomes in a blended learning environment" Learning and Individual Differences $<$ do:10.1016/j.lindif.2015.01.018>[ Consulta: 31 de marzo de 2017] 


\title{
Primeras impresiones sobre una Actividad de Aprendizaje Experiencial aplicada al desarrollo de nuevos productos.
}

\author{
Ángel Peiró-Signes ${ }^{a}$, Marival Segarra-Oña ${ }^{b}$, María de Miguel-Molina ${ }^{c}$, Blanca de \\ Miguel-Molina $^{\mathrm{d}}$ \\ aDepartamento de Organización de Empresas (Universitat Politècnica de València, \\ anpeisig@omp.upv.es), bDepartamento de Organización de Empresas (Universitat Politècnica de \\ València, maseo@omp.upv.es), ${ }^{c}$ Departamento de Organización de Empresas (Universitat Politècnica \\ de València, mademi@omp.upv.es) y aDepartamento de Organización de Empresas (Universitat \\ Politècnica de València, bedemigu@omp.upv.es)
}

\begin{abstract}
In this paper we describe the results of the first application and the proposed adaptations for the use of an existing Experimental Learning Activity (ELA). Using the experience developed by Joe Tidd and John Bessant "New Product Development Game" which is oriented to illustrate the students some concepts related to the development of new products, we propose small improvements to guide the action of the students and to reach the activity objectives. The results of the activity are encoraging regardless the difficulties we encountered. The students evaluation of the activity indicated a high motivation towards the activity and also a high perception of the utility of the activity.
\end{abstract}

Keywords: Experiential Learning Activities, New product development, transversal competences.

\begin{abstract}
Resumen
En este trabajo describimos el resultado de la primera aplicación y las adaptaciones propuestas para utilizar una Actividad de Aprendizaje Experimental (AAE) existente. A partir de la experiencia desarrollada por Joe Tidd and John Bessant "New product development game" orientada a ilustrar a los estudiantes algunos conceptos relacionados con el Desarrollo de Nuevos Productos proponemos pequeñas mejoras para orientar la acción de los alumnos y conseguir los objetivos propuestos en la actividad. Los resultados de la actividad son esperanzadores a pesar de algunas dificultades encontradas. La evaluación de la actividad por los alumnos participantes indica una motivación alta hacia la actividad y una percepción de la utilidad de la actividad también elevada.
\end{abstract}

Palabras clave: Actividad de Aprendizaje experiencial, Desarrollo de nuevos productos, competencias transversales. 


\section{Introducción}

A la hora de planificar una asignatura a partir de los objetivos de aprendizaje y las competencias que pretendemos que adquieran los alumnos establecemos los contenidos, actividades y metodologías que pensamos más adecuadas en cada caso. El éxito depende en gran medida del grado de participación y la motivación del alumnado. De hecho, uno de los aspectos más complicados de la tarea docente consiste en motivar o, al menos, no desmotivar al alumno mientras se consiguen los objetivos de aprendizaje esperados.

Las estrategias que utilizan los profesores en este sentido son variadas y pasan normalmente por el aumento de la participación y responsabilidad del alumno en el aula. Las Actividades de Aprendizaje Experiencial (AAE) han demostrado en distintos niveles educativos (PeiroSignes, 2015) su capacidad y eficacia a la hora de dinamizar el trabajo del aula (PeiroSignes and Segarra-Oña, 2015).

LaForge y Busing (1998), indicaron los pasos a seguir para el desarrollo de una AAE planificación, introducción, ejecución de la actividad y retroalimentación. La mayor dificultad a la que se enfrenta el profesor se produce a la hora de planificar. Debe diseñar una actividad que sin llegar a la complejidad del mundo real refleje de forma relevante los aspectos importantes que se quieren desarrollar durante el curso (Halpern y Hakel, 2003). Adicionalmente, la actividad debe poner a los estudiantes frente a distintas situaciones que requieran de la toma de decisiones.

Sin embargo, es en la fase de retroalimentación, al final de la experiencia, donde se busca un proceso de reflexión sobre aquellos aspectos que han aflorado durante la actividad. Esta reflexión crítica es la que permite conseguir un aprendizaje significativo (Kolb, 1984; Wheeler y McLeod, 2002).

Por otro lado, las Actividades de Aprendizaje Experiencial permiten, de forma paralela, trabajar y reflexionar sobre la actuación de los alumnos a la hora de utilizar competencias de tipo transversal como: la comunicación, el trabajo en equipo o el liderazgo. Estas competencias son hoy de gran importancia para el desarrollo profesional de nuestros graduados.

\section{Objetivos}

En este trabajo describimos el resultado de la primera aplicación y las adaptaciones propuestas para utilizar una Actividad de Aprendizaje Experimental (ELA) existente. A partir de la experiencia desarrollada por Joe Tidd and John Bessant (2015) "New product development game", orientada a ilustrar a los estudiantes algunos conceptos relacionados con el Desarrollo de Nuevos Productos, proponemos pequeñas mejoras para orientar la acción de los alumnos y conseguir los objetivos propuestos en la actividad. "New product development game" es una actividad flexible diseñada para ilustrar algunos de los conceptos clave en el desarrollo de nuevos productos o servicios. Permite su adaptación y ampliación de forma que puede servir tanto como punto de partida para una sesión de clase magistral, como para su utilización más profunda evaluando las interrelaciones existentes

(cc) EY-NC-ND 2017, Universitat Politècnica de València

Congreso IN-RED (2017) 
entre diversos actores involucrados en el desarrollo de nuevos productos. La actividad original se puede escalar en función del grado de complejidad que deseemos introducir en el proceso.

En este artículo pretendemos exponer las primeras impresiones y resultados obtenidos de la actividad, evaluar los puntos de mejora y formular propuestas para en el futuro conseguir un mayor ajuste a los objetivos propuestos en la actividad.

\section{Desarrollo de la innovación}

Utilizamos una actividad tal y como originalmente fue diseñada por Joe Tidd and John Bessant. La actividad se inicia partiendo el grupo en varios equipos que van a competir entre ellos. A todos los alumnos se les indica que estarán involucrados en el diseño y producción de un nuevo producto y que es una competición. En el trabajo original se propone que el cliente sea el propio profesor y se les indica a los alumnos que deben de satisfacerle con su producto final.

Dentro de cada grupo, los alumnos se distribuyen según tres roles: Producción, Diseño y Observadores. Para el rol de Diseño se asignan 4 o más personas, 1 o 2 para el de Producción y, al menos, una desempeña el papel de observador.

A los alumnos que forman parte de producción se les envía a otra aula cercana, se les dan las instrucciones relacionadas con su tarea y se les indica que deben esperar allí. Posteriormente, se asignan distintas funciones dentro del equipo de diseño: Líder del proyecto (1 persona), responsable de Marketing (1 persona), responsable de I+D (1 persona) y Diseñadores (todos los demás).

Cada uno de ellos recibe una hoja informativa con el rol que debe de jugar, se reparten los materiales previamente preparados para la fase de diseño y se dan las instrucciones de inicio. Finalmente, fuera del aula donde se encuentra el equipo de diseño, se informa a los observadores de su rol como observadores de las dinámicas, comunicación y coordinación, de cada grupo.

Cada grupo debe diseñar un prototipo de coche autopropulsado en 30 minutos. Este prototipo deberá ser replicado por los operarios de Producción en 5 minutos. Finalmente, el cliente (profesor) realizará una evaluación del coche fabricado en relación a tres factores: cumplimiento de las expectativas del cliente, cumplimiento de los requisitos normativos establecidos en el juego y distancia recorrida por el vehículo autopropulsado.

La actividad está diseñada para establecer varias "trampas" en las que los grupos caigan y permitan reflexionar posteriormente en la fase de discusión y debate. Cada una de estas trampas se corresponde con un problema típico en el desarrollo de nuevos productos o servicios. El más que probable fracaso de los equipos nos permite explorar temas clave que deben de tenerse en cuenta a la hora de desarrollar nuevos productos.

En primer lugar, la deliberada separación de los equipos de producción y diseño permite trabajar aspectos de falta de comunicación o de involucramiento de los distintos 
departamentos desde el inicio del proceso o el diseño orientado a la fabricación. Por otra parte, nos permite ver la reacción de algunos alumnos ante la falta de información completa de lo que está ocurriendo en el proceso. En este sentido, los grupos Producción y Diseño disponen de información complementaria que es útil para el proceso de diseño y de producción. Esta información, al no establecer un canal de comunicación se pierde en el proceso. A pesar de no haber instruido al equipo de Diseño sobre ninguna limitación en cuanto a la comunicación con Producción, los equipos de Diseño no acuden al aula donde se encuentra el equipo de Producción a preguntar que tareas tienen asignadas o de que información disponen que pueda ser relevante. Tampoco los invitan a participar en el proceso de diseño, ya que se encuentran centrados exclusivamente en su tarea.

En segundo lugar, el equipo de diseño se pone rápidamente a diseñar, olvidando en muchos casos quién es el cliente. Aunque el profesor da una indicaciones sobre lo que pretende, un coche autopropulsado, es necesario entender de forma más profunda las necesidades que hay que satisfacer del cliente. Cuando los alumnos preguntan sobre dichas especificaciones, el instructor les ofrece un estudio de mercado. El estudio de mercado refleja unos requisitos distintos en cuanto a color y configuración a las que realmente quiere el cliente, el profesor. De esta forma se resalta otro punto clave a la hora del éxito en el Desarrollo de Nuevos Productos, la participación del cliente desde el inicio y a lo largo de todo el proyecto.

Por último, debido al escaso tiempo disponible y a la falta de implicación de producción en la fase de diseño, es difícil comprender los detalles de las ideas que el equipo de diseño trata de comunicar al Departamento de Producción para la fabricación del modelo definitivo. A esta falta de entendimiento se une una cierta desmotivación en el equipo de Diseño cuando ven las dificultades adicionales que el equipo de Producción tiene por las restricciones tecnológicas en el uso de algunos materiales.

\section{Resultados}

La actividad se llevó a cabo con estudiantes de nivel Master. La sesión de clase semanal consta de 2 horas. La actividad planificada estaba prevista para realizarse aproximadamente en una hora y quince minutos. Se inició la actividad tras los primeros 45 minutos de sesión, distribuyendo a los alumnos en 2 equipos con 7 componentes y uno con 8 ( 1 observador, $4 / 5$ en el equipo de diseño y 2 alumnos en producción). El primer análisis nos permite proponer una serie de cambios para futuras ediciones que mejoran de forma previsible los resultados obtenidos.

En primer lugar, en la sesión prácticamente todos los equipos pidieron una extensión en el tiempo de diseño, lo que impidió que la actividad se completara en el tiempo inicialmente estimado. De hecho, la discusión y retroalimentación de la actividad se tuvo que realizar en la siguiente sesión. Esto nos lleva a proponer que la actividad debe de plantearse desde el inicio de la sesión y debe dejarse un margen importante ante las eventualidades que pudieran concurrir. Estimamos que la próxima realización debería de disponer del tiempo completo de una sesión semanal ( 2 horas). En caso de finalización anticipada el instructor

(c)) BY-NC-ND 2017, Universitat Politècnica de València

Congreso IN-RED (2017) 
puede incidir brevemente, después de la fase de discusión, sobre los aspectos teóricos que se han experimentado en la actividad.

En segundo lugar, los equipos de producción en un aula aparte se encuentran sin saber cómo deben de actuar, desconocen completamente que ocurre la otra aula y no tienen que hacer nada básicamente durante el tiempo que dura el diseño. En este sentido, propondríamos dotar a estos equipos con algunos de los materiales de la actividad para que puedan experimentar con ellos. Por ejemplo, producción conoce las restricciones en el manejo de algunos de los materiales como los productos amarillos que deben manipularse con unos guantes de jardinería que dificultan enormemente el proceso. Dotar de estos materiales a los equipos de Producción mantendría la sensación la falta de comunicación con diseño a la vez que incrementaría su interés por la actividad.

En tercer lugar, los alumnos rápidamente preguntaron al cliente (el profesor) sobre los requerimientos del producto, para facilitar que los alumnos se centraran en las tendencias del mercado y no en el resto, el profesor ofreció rápidamente el estudio de mercado. En este sentido, dentro de las instrucciones generales y especialmente de las de la persona responsable de marketing debería de incorporarse la posibilidad y el coste de adquisición de un estudio de mercado. En este sentido el estudio de mercado debe tener un precio muy atractivo para incitar a los alumnos a caer en la segunda "trampa" preparada en la actividad.

En cuarto y último lugar, a pesar de que la gran mayoría de alumnos de la experiencia tenían una formación ingenieril, ninguno de los equipos llegó a completar dentro del tiempo esperado un prototipo viable para la prueba de distancia. Este aspecto es importante de cara a la satisfacción del alumno tras la experiencia. Las trampas nos permitirán forzar las situaciones de debate que deseamos de la experiencia pero es importante que los alumnos extraigan aspectos positivos sobre lo que han hecho. Además, esta situación también provoca que el impacto del diseño en el coste sea irrelevante, lo que impide que se pueda llevar a cabo una discusión tras la experiencia sobre estos aspectos. En este sentido, vistas las dinámicas en los distintos equipos y el uso que se dio a cada uno de los materiales, se propone limitar el uso de algunos de ellos a determinadas partes del vehículo. De esta forma los alumnos pueden llegar con mayor facilidad a un prototipo viable para posteriormente fabricarlo y probarlo. Por ejemplo, se puede limitar el uso de las cartas a las ruedas, el uso del cartón grande al chasis y los colores a la pintura del vehículo. Estas restricciones centrarán más la labor del equipo de diseño e incrementarán de forma notable las posibilidades de finalizar la etapa de diseño del prototipo. Además, como consecuencia, podremos evaluar el coste de cada prototipo y extraer conclusiones al respecto.

Por otro lado, se pasó una encuesta sobre aspectos relevantes relacionados con la motivación, utilidad y aspectos sobre como afrontaron los alumnos la actividad. Los resultados relativos a la motivación y percepción de aprendizaje son esperanzadores. Las medias sobre las preguntas contestadas por los 22 alumnos participantes en la actividad indican una motivación alta hacia la actividad y una percepción de la utilidad de la actividad también elevada. 


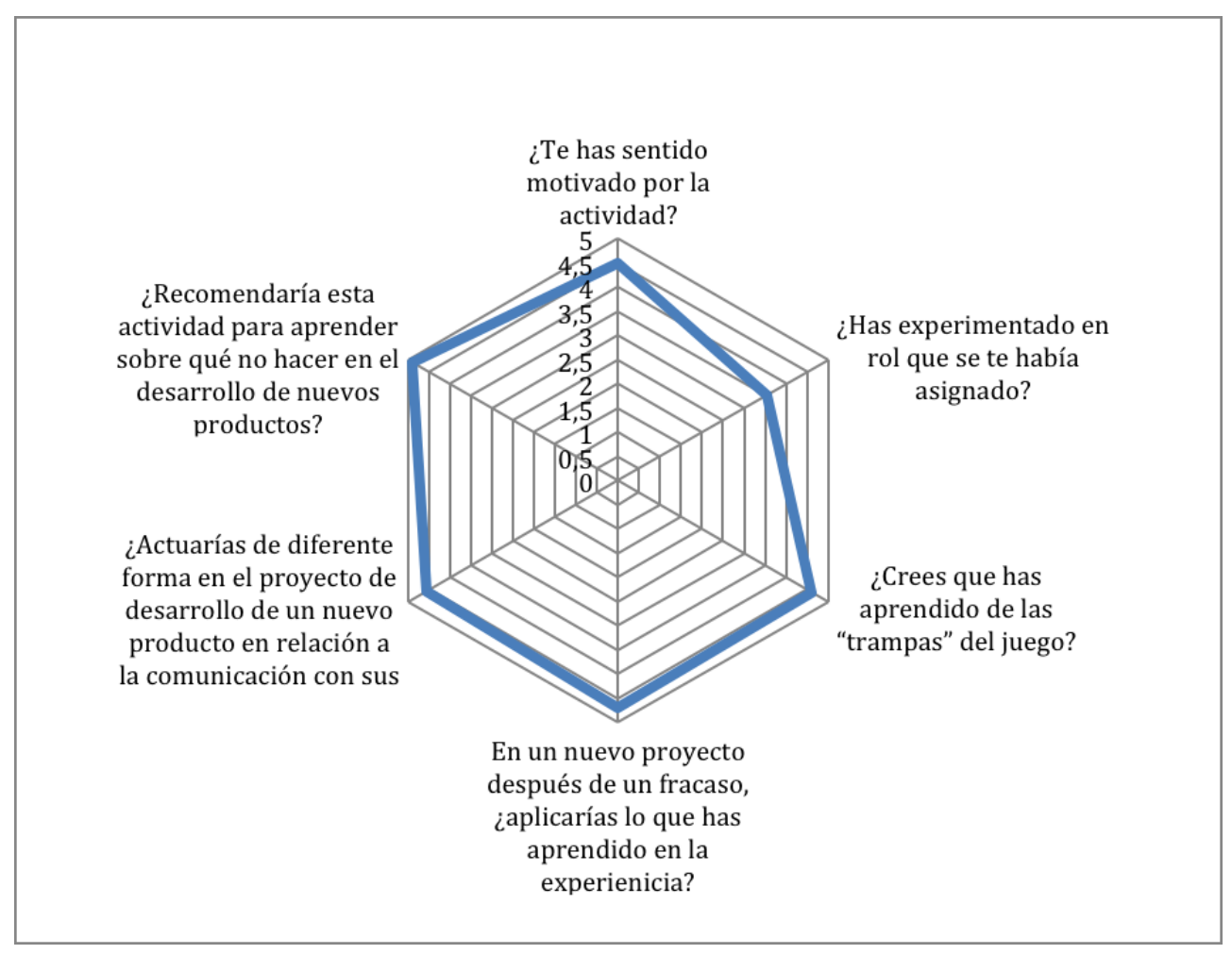

Fig. 1 Promedios de las preguntas de evaluación del uso de la AAE. Fuente: elaboración propia.

\section{Conclusiones}

Este artículo presenta los resultados preliminares de una actividad de aprendizaje experiencial diseñada para la enseñanza de los conceptos y habilidades necesarias el desarrollo de nuevos productos. La actividad pretende adentrar a los alumnos en varias "trampas" que pueden limitar de forma importante el éxito a la hora de desarrollar un nuevo producto. Tras la experiencia los alumnos deben apreciar la importancia que tiene la incorporación temprana de clientes y de otros departamentos implicados en desarrollo de los productos, como por ejemplo el Departamento de Producción. Por otro lado, deben poder evaluar el gran impacto que tiene la comunicación o la falta de ella en el proceso de desarrollo de nuevos productos.

Estos resultados, con las propuestas de mejora planteadas y la experiencia en la gestión de la actividad adquirida nos motiva como profesores a incorporarla dentro de las actividades de la asignatura. Futuras ediciones de la actividad aportarán nueva información relevante que permitirá realizar nuevos ajustes para mantener una actitud de mejor continua de nuestra labor docente. 


\section{Agradecimientos}

Este trabajo forma parte del estudio desarrollado por el Grupo de Aprendizaje Experiencial (GAE) creado como EICE en la Universidad Politécnica de Valencia (UPV). Los autores desean agradecer a la UPV por el apoyo a través del PIME 2017 "Adaptación y desarrollo de aprendizajes experienciales al contexto de las asignaturas".

\section{Referencias}

TIDD, J. y BESSANT, J. (2015). New Product Development Game. <http://www.innovation--portal.info/> [Consulta: 5 de enero 2017] John Wiley and Sons Ltd.

HALPERN, D. y HAKEL, M. (2003). “Applying the science of learning”. Change, vol. 35, issue 4, p. $36-41$.

KOLB, D. (1984). Experiential learning: Experience as the source of learning and development. Englewood Cliffs, NJ: Prentice Hall.

LAFORGE, R. y BUSING, M. (1998). "The use of industrial software to create experiential learning activities in operations management courses". Production and Operations Management, vol. 7, issue 3, p. 325-334.

MEYERS, C. (1986). Teaching students to think critically. San Francisco, CA: Jossey-Bass.

PEIRO-SIGNES, A., SEGARRA-OÑA, M., DE MIGUEL-MOLINA, M., J. ALBORS-GARRIGÓS, J. y DE-MIGUEL-MOLINA B. (2015). "The experiential learning activity: benefits and difficulties in real learning environments". Proceedings of ICERI2015 Conference, p. 7231-7237.

PEIRO-SIGNES, A. y SEGARRA-OÑA, M.; (2015). "Experiential learning as a dynamizer of class activity”. Proceedings of ICERI2015 Conference, p. 1010-1013.

SMITH, G. (2003). "Beyond critical thinking and decision making: Teaching business students how to think". Journal of Management Education, vol. 27, issue 1, p. 24-51.

WHEELER, J., y MCLEOD, P. (2002). "Expanding our teaching effectiveness: Understanding our responses to in-the-moment classroom events". Journal of Management Education, vol. 26, issue 6, p. 693-716. 


\section{3}

Enfoques para la formación integral del alumno en competencias 


\title{
Estrategias de evaluación para las competencias transversales CT- 02, CT-04 y CT-06
}

\section{Amparo Baviera-Puig ${ }^{\mathrm{a}}$, Carmen Escriba-Perez ${ }^{\mathrm{b}}$ y Juan Buitrago-Vera ${ }^{\mathrm{c}}$}

${ }^{a}$ Facultad de Administración y Dirección de Empresas (FADE), Universitat Politècnica de València, ambapui@upv.es, bFADE, Universitat Politècnica de València, carespe@upv.es y 'Escuela Técnica Superior de Ingeniería Agronómica y del Medio Natural, Universitat Politècnica de València, jmbuitrago@esp.upv.es.

\begin{abstract}
In this educational innovation, we intend to verify the rubrics developed by the Universitat Politècnica de València for the following generic skills: CT02 (Application and practical thinking), CT-04 (Innovation, creativity and entrepreneurship) and CT-06 (Teamwork and leadership ). To do this, we developed the same methodology in two groups with different student profiles (Mornings/ARA). The assessment results of the skills reveal that there are no significant differences between groups. In conclusion, we could say that the rubrics are adequate to assess all types of students.
\end{abstract}

Keywords: skills, learning, assessment, rubric, profile, verification.

\begin{abstract}
Resumen
En esta innovación educativa, pretendemos verificar las rúbricas desarrolladas por la Universitat Politècnica de València para las siguientes competencias transversales: CT-02 (Aplicación y pensamiento práctico), CT04 (Innovación, creatividad y emprendimiento) y CT-06 (Trabajo en equipo y liderazgo). Para ello, desarrollamos la misma metodología en dos grupos con perfiles de estudiantes diferentes (Mañanas/ARA). Los resultados de evaluación de las competencias revelan que no hay diferencias significativas entre grupos. Como conclusión, podríamos decir que las rúbricas son adecuadas para evaluar a todo tipo de estudiante.
\end{abstract}

Palabras clave: competencias, aprendizaje, evaluación, rúbrica, perfil, verificación.

\section{Introducción}

En la actualidad, muchos autores coinciden en afirmar que la educación universitaria de excelencia y la investigación científica y tecnológica, son los elementos clave para el desarrollo competitivo de los países y el soporte científico y tecnológico de las empresas (Clemenza, Ferrer y Araujo, 2004). En consecuencia, es necesario abordar la educación universitaria desde nuevas perspectivas.

En Europa, el proceso de Bolonia (Ministros Europeos de Educación Superior, 1999) inició parte de este cambio, transformando los programas educativos por objetivos (básicamente, contenidos disciplinares) a programas por competencias. Este cambio trajo consigo la

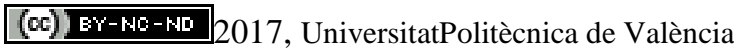


subordinación de los contenidos disciplinares a dichas competencias. Según Lasnier (2000), las competencias son un "saber hacer complejo e integrador", lo que implica un modo completamente diferente de organización curricular y de los métodos de enseñanza y aprendizaje.

El aprendizaje de competencias supone conocer, comprender y usar pertinentemente (De la Cruz, 2005). Por consiguiente, el protagonista de los métodos de enseñanza y aprendizaje en la actualidad ya no es el profesor sino que es el alumno. El objetivo es que el alumno vaya logrando autonomía e independencia en su aprendizaje. El nuevo papel del profesor es acompañar, guiar, evaluar y apoyar al alumno siempre que lo necesite, con el fin de enseñar al estudiante a aprender a aprender.

Cuando se diseñan los planes de estudios, se deben concretar dos tipos de competencias que los estudiantes deben desarrollar: las competencias específicas y las transversales.

- Las competencias específicas son las propias de un ámbito o título y están orientadas a la consecución de un perfil específico del estudiante al finalizar el título o los estudios en cuestión.

- Las competencias transversales denominadas de formas diversas y bajo diferentes perspectivas (generic competencies, core competencies, key competencies, transfereable competencies, soft skills, etc.), responden a aquellas competencias que son claves y transferibles en relación a una amplia variedad de contextos personales, sociales, académicos y laborales a lo largo de la vida. Se caracterizan por ser integradoras, transferibles, interdependientes, multifuncionales y evaluables. Por tanto, constituyen una parte fundamental del perfil profesional y del perfil formativo de todas o de la mayoría de las titulaciones. En definitiva, se trata de competencias que incluyen un conjunto de habilidades cognitivas y metacognitivas, conocimientos instrumentales y actitudinales de gran valor para la sociedad actual del conocimiento.

La Universitat Politècnica de València está desarrollando el proyecto de competencias transversales UPV (Universitat Politècnica de València, 2016) que tiene como objetivo principal acreditar las competencias transversales UPV a los estudiantes egresados en cualquiera de los títulos oficiales impartidos en la Universitat Politècnica de València.

En mayor o menor medida, las competencias específicas se enseñan, se trabajan y son adquiridas por los estudiantes y certificadas mediante la superación de las diferentes materias de los planes de estudio. Sin embargo, no parece que las competencias transversales incluidas en la definición de los planes de estudios hayan tenido el mismo tratamiento. En general, se han enunciado y se han asignado a diferentes materias, pero no se trabajan sistemáticamente y no se evalúan, lo que implica que no pueda garantizarse su adquisición.

Por consiguiente, el objetivo fundamental del proyecto institucional UPV es doble y consiste en: 
- Establecer una estrategia de evaluación sistemática de las competencias transversales, definiendo dónde se adquieren y cómo deben ser evaluadas.

- Acreditar la adquisición de dichas competencias.

Las competencias transversales UPV, que pretenden sintetizar un perfil competencial para todos los alumnos egresados de la UPV, garantizando que se cubre el marco de referencia de todas las titulaciones, son las siguientes:

CT-01. Comprensión e integración

CT-02. Aplicación y pensamiento práctico

CT-03. Análisis y resolución de problemas

CT-04. Innovación, creatividad y emprendimiento

CT-05. Diseño y proyecto

CT-06. Trabajo en equipo y liderazgo

CT-07. Responsabilidad ética, medioambiental y profesional.

CT-08. Comunicación efectiva

CT-09. Pensamiento crítico

CT-10. Conocimiento de problemas contemporáneos

CT-11. Aprendizaje permanente

CT-12. Planificación y gestión del tiempo

CT-13. Instrumental específica

Para cada una de ellas, se han elaborado diferentes rúbricas para facilitar la evaluación de las mismas. Las rúbricas son documentos que articulan las expectativas de una asignación o un conjunto de tareas, enumerando los criterios de evaluación y describiendo los niveles de calidad en relación con cada uno de estos criterios (Reddy y Andrade, 2010). Permite clarificar lo que se espera del trabajo del alumno, valorar su ejecución y facilitar tanto la retroalimentación como la autoevaluación (Jonsson y Svingby, 2007).

Dada la situación actual, el reto al que nos enfrentamos es cómo plantear estrategias evaluativas que se centren en la realización, por parte de los estudiantes, de actividades lo más auténticas posibles y con un nivel adecuado de complejidad según el momento formativo y el contexto en el que se desarrolla la docencia. Fernández (2006) destaca que los métodos de enseñanza en los que participa el alumno, donde la responsabilidad del aprendizaje depende directamente de lo que él hace, por un lado, generan aprendizajes más profundos, significativos y duraderos y, por otro lado, facilitan la transferencia a contextos más heterogéneos. De hecho, un alumno sin demasiado interés puede mejorar su rendimiento y calidad del aprendizaje cuando el docente utiliza metodologías centradas en los alumnos (Biggs, 2004). 


\section{Objetivos}

El objetivo genérico de esta comunicación consiste en verificar las rúbricas desarrolladas en el proyecto institucional de la UPV de competencias transversales para su evaluación, utilizando estrategias diferentes siempre centradas en los alumnos. Esta verificación se realiza para 3 de las 13 competencias transversales consideradas por la Universidad: la CT02, la CT-04 y la CT-06.

El objetivo general se concreta en los siguientes objetivos específicos:

- Conocer el nivel del logro de la competencia transversal CT-02 "Aplicación y pensamiento práctico”.

- Conocer el nivel del logro de la competencia transversal CT-04 "Innovación, creatividad y emprendimiento".

- Conocer el nivel del logro de la competencia transversal CT-06 "Trabajo en equipo y liderazgo".

- Comparar si hay diferencias significativas entre los dos grupos participantes de la misma asigatura.

\section{Desarrollo de la innovación}

La asignatura dónde hemos desarrollado la innovación educativa es "Investigación Comercial”, de nivel II. Se imparte en el primer semestre del tercer curso del Grado de Administración y Dirección de Empresas de la Facultad de Administración y Dirección de Empresas (FADE). La innovación educativa se ha llevado a cabo en el Grupo de Mañanas y en el Grupo ARA.

Para empezar, se dividió a los alumnos en grupos de 2 a 4 personas. En total, se formaron 32 grupos de alumnos, 20 en el Grupo de Mañanas y 12 en el Grupo ARA. Una vez organizados, se les planteó que propusieran un nuevo producto/servicio para un supermercado. Para ello, han tenido que elaborar un test de concepto con el objetivo de determinar la idoneidad del nuevo producto/servicio. Han trabajado en este test de concepto tanto en horas de teoría (para esbozarlo y generar ideas) como en horas de prácticas (para la realización del cuestionario y análisis de las respuestas obtenidas a partir del mismo). A partir del trabajo realizado, han redactado un informe por grupo.

Este informe grupal es el que vamos a utilizar para la evaluación de las competencias CT02 “Aplicación y pensamiento práctico" y CT-04 "Innovación, creatividad y emprendimiento". Para evaluar la competencia CT-06 "Trabajo en equipo y liderazgo", hemos utilizado la autoevaluación y la coevaluación entre los miembros del mismo grupo.

Tanto para el informe como para la autoevaluación y coevaluación, utilizamos las rúbricas desarrolladas por la UPV. Siguiendo lo establecido en el proyecto institucional, se van a establecer 4 categorías diferentes para cada una de las 3 competencias transversales:

A. Excelente/ejemplar.

B. Bien/adecuado. 
C. En desarrollo.

D. No alcanzado.

Con el fin de facilitar una media por grupo, estas 4 categorías se han traducido a números siguiendo la siguiente escala: $A=4, B=3, C=2$ y $D=1$.

\section{Resultados}

\subsection{Descripción de la muestra}

La innovación se ha desarrollado en una única asignatura pero en dos grupos diferentes. El número total de alumnos en ambos grupos es de 110. En la Tabla 1, se muestran todas las variables consideradas para la descripción y análisis de la muestra. El Grupo Mañanas representa el 59,09\% del total de la muestra, mientras que el Grupo ARA representa el 40,91\%. En total, hay más mujeres $(54,55 \%)$ que hombres $(45,45 \%)$ y los alumnos no Erasmus (79,82\%) superan en gran medida a los Erasmus (20,18\%). El 54,37\% de los alumnos trabajan o han trabajado en los últimos 2 años y el 91,42\% consideran bastante o muy interesante la asignatura "Investigación Comercial”.

Tabla 1. Descripción de la muestra

\begin{tabular}{|c|c|c|c|}
\hline \multicolumn{2}{|c|}{ Variable } & \multirow{2}{*}{$\begin{array}{c}\text { Frecuencia } \\
65\end{array}$} & \multirow{2}{*}{$\begin{array}{c}\% \\
59,09\end{array}$} \\
\hline & Mañanas & & \\
\hline Ui & ARA & 45 & 40,91 \\
\hline \multirow{2}{*}{ Sexo } & Hombre & 50 & 45,45 \\
\hline & Mujer & 60 & 54,55 \\
\hline \multirow{2}{*}{ Erasmus } & Erasmus & 22 & 20,18 \\
\hline & No Erasmus & 87 & 79,82 \\
\hline \multirow{2}{*}{$\begin{array}{l}\text { Trabaja o ha trabajado } \\
\text { en los últimos } 2 \text { años }\end{array}$} & Trabaja & 56 & 54,37 \\
\hline & No trabaja & 47 & 45,63 \\
\hline \multirow{5}{*}{$\begin{array}{l}\text { Satisfacción con la } \\
\text { asignatura }\end{array}$} & Nada interesante & 1 & 0,95 \\
\hline & Poco interesante & 2 & 1,90 \\
\hline & Indiferente & 6 & 5,71 \\
\hline & Bastante interesante & 69 & 65,71 \\
\hline & Muy interesante & 27 & 25,71 \\
\hline
\end{tabular}

\subsection{Perfil del grupo}

Para determinar el perfil de cada uno de los grupos, se ha realizado una tabulación cruzada de frecuencias entre los datos del Grupo Mañanas y ARA con las diferentes variables 
consideradas (Sexo, Erasmus, Trabaja y Satisfacción con la asignatura). Como test estadístico, se ha utilizado la prueba Ji Cuadrado $(\chi 2)$ de Pearson. A partir de los resultados obtenidos, se puede observar que no hay diferencias significativas respecto a la variable Sexo (Tabla 2) entre el Grupo Mañanas y el Grupo ARA, pero sí respecto al resto de variables.

En cuanto a la variable Erasmus (p < 1\%), el 44,44\% de los alumnos en el Grupo ARA son Erasmus y en el Grupo Mañanas sólo un 3,13\% (Tabla 3). En el Grupo ARA, trabajan o han trabajado en los últimos 2 años el 71,11\%, mientras que en el Grupo Mañanas este porcentaje se reduce al 41,38\% ( $<1 \%$ ) (Tabla 4). Por último, en el Grupo Mañanas los alumnos que consideran la asignatura bastante o muy interesante es del $88,33 \%$, ascendiendo al 95,56\% en el Grupo ARA ( $p$ < 5\%) (Tabla 5).

En definitiva, podemos afirmar que, a pesar de haber analizado una única asignatura, los perfiles de los dos grupos participantes son diferentes en cuanto al número de alumnos Erasmus, al número de alumnos que trabajan o han trabajado en los últimos 2 años y su satisfacción con la asignatura.

Tabla 2. Tabulación cruzada de frecuencias entre Grupo y Sexo

\begin{tabular}{ccccc}
\hline \multirow{2}{*}{ Sexo } & \multicolumn{2}{c}{ G. Mañanas } & \multicolumn{2}{c}{ G. ARA } \\
& Frecuencia & \% & Frecuencia & \% \\
\hline Hombre & 28 & 43,08 & 22 & 48,89 \\
Mujer & 37 & 56,92 & 23 & 51,11 \\
TOTAL & 65 & 100,00 & 45 & 100,00 \\
\hline
\end{tabular}

$\chi 2$ con 1 grado de libertad $=0,3623(p=0,5472)$

Tabla 3. Tabulación cruzada de frecuencias entre Grupo y Erasmus

\begin{tabular}{ccccc}
\hline \multirow{2}{*}{ Erasmus } & \multicolumn{2}{c}{ G. Mañanas } & \multicolumn{2}{c}{ G. ARA } \\
& Frecuencia & $\mathbf{\%}$ & Frecuencia & \% \\
\hline Erasmus & 2 & 3,13 & 20 & 44,44 \\
No Erasmus & 62 & 96,88 & 25 & 55,56 \\
TOTAL & 64 & 100,00 & 45 & 100,00 \\
\hline
\end{tabular}

$\chi 2$ con 1 grado de libertad $=28,0018(p=0,0000)$

(c) EY-NG-ND 2017, UniversitatPolitècnica de València

Congreso IN-RED (2017) 
Tabla 4. Tabulación cruzada de frecuencias entre Grupo y Trabaja

\begin{tabular}{ccccc}
\hline $\begin{array}{c}\text { Trabaja o ha } \\
\text { trabajado }\end{array}$ & Frecuencia & \% & Frecuencia & \% \\
\hline Trabaja & 24 & 41,38 & 32 & 71,11 \\
No Trabaja & 34 & 58,62 & 13 & 28,89 \\
TOTAL & 58 & 100,00 & 45 & 100,00 \\
\hline
\end{tabular}

$\chi^{2}$ con 1 grado de libertad $=9,0289(p=0,0027)$

Tabla 5. Tabulación cruzada de frecuencias entre Grupo y Satisfacción con la asignatura

\begin{tabular}{ccccc}
\hline \multirow{2}{*}{ Satisfacción con la asignatura } & \multicolumn{2}{c}{ G. Mañanas } & \multicolumn{2}{c}{ G. ARA } \\
& Frecuencia & $\%$ & Frecuencia & \% \\
\hline Nada interesante & 1 & 1,67 & 0 & 0,00 \\
Poco interesante & 1 & 1,67 & 1 & 2,22 \\
Indiferente & 5 & 8,33 & 1 & 2,22 \\
Bastante interesante & 44 & 73,33 & 25 & 55,56 \\
Muy interesante & 9 & 15,00 & 18 & 40,00 \\
TOTAL & 60 & 100,00 & 45 & 100,00 \\
\hline
\end{tabular}

$\chi^{2}$ con 4 grados de libertad $=9,9589(p=0,0411)$

\subsection{Comparación de la evaluación de las competencias por grupo}

Con el objetivo de mostrar los resultados de la evaluación de las 3 competencias, se ha calculado la media de cada uno de los indicadores considerados en las rúbricas por Grupo (Mañanas/ARA) y para el total de la muestra. Para comprobar si existen diferencias significativas entre los resultados de cada grupo, se ha realizado una tabulación cruzada de valores medios. Como test estadístico, se ha utilizado la prueba F de Snedecor.

Para la CT-02 (Tabla 6), no existen diferencias significativas por indicador entre ambos grupos. El indicador que tiene una mayor media en cada grupo y en el total de la muestra es "Establece objetivos concretos en relación con las situaciones que se le plantean". En cambio, el indicador que tiene menor media en el total de la muestra y en el Grupo ARA es "Evalúa la calidad de la información de que dispone para su aplicación”. Por su parte, el Grupo Mañanas obtiene la menor media en "Plantea indicadores de control para realizar el seguimiento del plan”. Las medias superiores e inferiores aparecen subrayadas en la Tabla 6. 
Tabla 6. Resultados de la evaluación de la CT-02 para cada uno de los grupos y para la muestra

\begin{tabular}{|c|c|c|c|c|}
\hline Indicadores de la rúbrica & $\begin{array}{c}\text { Grupo } \\
\text { Mañanas }\end{array}$ & $\begin{array}{l}\text { Grupo } \\
\text { ARA }\end{array}$ & $\begin{array}{c}\text { Total } \\
\text { Muestra }\end{array}$ & $\mathbf{p}$ \\
\hline $\begin{array}{c}\text { Establece objetivos concretos en relación con las } \\
\text { situaciones que se le plantean }\end{array}$ & $\underline{3,40}$ & $\underline{3,75}$ & $\underline{3,53}$ & 0,5051 \\
\hline $\begin{array}{c}\text { Obtiene la información necesaria para abordar las } \\
\text { situaciones }\end{array}$ & 3,05 & 3,00 & 3,03 & 0,9900 \\
\hline $\begin{array}{l}\text { Evalúa la calidad de la información de que dispone } \\
\text { para su aplicación }\end{array}$ & 2,90 & $\underline{2,42}$ & $\underline{2,72}$ & 0,4237 \\
\hline $\begin{array}{c}\text { Elabora un plan coherente para resolver las } \\
\text { situaciones que se le planteen }\end{array}$ & 2,95 & 2,67 & 2,84 & 0,7315 \\
\hline $\begin{array}{c}\text { Plantea indicadores de control para realizar el } \\
\text { seguimiento del plan }\end{array}$ & $\underline{2,80}$ & 3,25 & 2,97 & 0,2120 \\
\hline
\end{tabular}

Para la CT-04 (Tabla 7), no existen diferencias significativas por indicador entre ambos grupos salvo para "Controla resultados” ( $\mathrm{p}<5 \%$ ). En este caso, el Grupo Mañanas obtiene su menor media $(2,55)$ en este indicador, mientras que el Grupo ARA obtiene una mayor valoración $(3,25)$. El indicador que tiene menor media en el Grupo ARA es "Emplea estrategias y/o técnicas creativas para plasmar de manera formal las ideas y soluciones”. La muestra total obtiene sus menores medias $(2,81)$ en ambos casos. Por el contrario, el indicador que tiene una mayor media en cada grupo y en el total de la muestra es "Identifica oportunidades y/o aspectos de mejora”. Las medias superiores e inferiores aparecen subrayadas en la Tabla 7, así como, la probabilidad significativa al 5\%.

Tabla 7. Resultados de la evaluación de la CT-04 para cada uno de los grupos y para la muestra

\begin{tabular}{|c|c|c|c|c|}
\hline Indicadores de la rúbrica & $\begin{array}{l}\text { Grupo } \\
\text { Mañanas }\end{array}$ & $\begin{array}{l}\text { Grupo } \\
\text { ARA }\end{array}$ & $\begin{array}{c}\text { Total } \\
\text { Muestra }\end{array}$ & $\mathbf{p}$ \\
\hline Identifica oportunidades y/o aspectos de mejora & $\underline{3,20}$ & $\underline{3,67}$ & $\underline{3,38}$ & 0,2415 \\
\hline Aporta ideas y planteamientos originales & 3,05 & 3,58 & 3,25 & 0,2593 \\
\hline $\begin{array}{l}\text { Emplea estrategias y/o técnicas creativas para } \\
\text { plasmar de manera formal las ideas y soluciones }\end{array}$ & 2,90 & $\underline{2,67}$ & $\underline{2,81}$ & 0,7866 \\
\hline Controla resultados & $\underline{2,55}$ & 3,25 & $\underline{2,81}$ & $\underline{0,0433}$ \\
\hline
\end{tabular}

Para la CT-06 (Tabla 8), no existen diferencias significativas por indicador entre ambos grupos. El indicador que tiene una mayor media en cada grupo y en el total de la muestra es "Participa en la planificación de objetivos”, mientras que el indicador con menor media es “Actúa para afrontar los conflictos del equipo”. Las medias superiores e inferiores aparecen subrayadas en la Tabla 8.

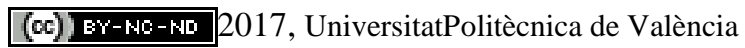


Tabla 8. Resultados de la evaluación de la CT-06 para cada uno de los grupos y para la muestra

\begin{tabular}{ccccc}
\hline Indicadores de la rúbrica & $\begin{array}{c}\text { Grupo } \\
\text { Mañanas }\end{array}$ & $\begin{array}{c}\text { Grupo } \\
\text { ARA }\end{array}$ & $\begin{array}{c}\text { Total } \\
\text { Muestra }\end{array}$ & p \\
\hline $\begin{array}{c}\text { Participa en la planificación de objetivos } \\
\text { Actúa para afrontar los conflictos del } \\
\text { equipo }\end{array}$ & $\underline{3,77}$ & $\underline{3,71}$ & $\underline{3,74}$ & 0,8465 \\
$\begin{array}{c}\text { Se compromete en la realización de la } \\
\text { tarea colectiva }\end{array}$ & 3,71 & $\underline{3,58}$ & $\underline{3,64}$ & 0,6399 \\
\hline
\end{tabular}

\subsection{Comparación entre competencias}

Al haber evaluado cada competencia de manera diferente, nos planteamos si existen diferencias entre ellas. Las competencias CT-02 y CT-04 han sido evaluadas a partir del informe elaborado por los alumnos, siendo el evaluador el profesor de la asignatura. La competencia CT-06 ha sido evaluada por los alumnos, utilizando la autoevaluación y la coevaluación entre los miembros del grupo.

En las Tablas 9 y 10, podemos observar como el profesor ha utilizado la totalidad de la escala de evaluación (desde el 1 al 4) para las competencias CT-02 y CT-04. No obstante, en la Tabla 11, los alumnos no han descendido del 2 para autoevaluarse y evaluar a sus iguales, siendo la moda el valor de 4. Del mismo modo, las medias de los indicadores de la CT-06 son superiores a las de CT-02 y CT-04 (superando el valor de 3,6 en todos los indicadores) y las desviaciones típicas son inferiores (en torno a 0,54 ).

Tabla 9. Estadísticos de los resultados de evaluación de la CT-02

\begin{tabular}{cccccc}
\hline Indicadores de la rúbrica & Media & $\begin{array}{c}\text { Desv. } \\
\text { Típica }\end{array}$ & Max & Min & Moda \\
\hline $\begin{array}{c}\text { Establece objetivos concretos en } \\
\text { relación con las situaciones que se le } \\
\text { plantean }\end{array}$ & 3,53 & 0,79 & 4 & 1 & 4 \\
$\begin{array}{c}\text { Obtiene la información necesaria para } \\
\quad \text { abordar las situaciones }\end{array}$ & 3,03 & 0,92 & 4 & 1 & 3 \\
$\begin{array}{c}\text { Evalúa la calidad de la información de } \\
\text { que dispone para su aplicación }\end{array}$ & 2,72 & 0,98 & 4 & 1 & 3 \\
$\begin{array}{c}\text { Elabora un plan coherente para resolver } \\
\text { las situaciones que se le planteen }\end{array}$ & 2,84 & 0,94 & 4 & 1 & 2 \\
$\begin{array}{c}\text { Plantea indicadores de control para } \\
\text { realizar el seguimiento del plan }\end{array}$ & 2,97 & 0,68 & 4 & 2 & 3 \\
\hline
\end{tabular}


Tabla 10. Estadísticos de los resultados de evaluación de la CT-04

\begin{tabular}{cccccc}
\hline Indicadores de la rúbrica & Media & $\begin{array}{c}\text { Desv. } \\
\text { Típica }\end{array}$ & Max & Min & Moda \\
\hline $\begin{array}{c}\text { Identifica oportunidades y/o aspectos de } \\
\text { mejora }\end{array}$ & 3,38 & 0,74 & 4 & 1 & 4 \\
$\begin{array}{c}\text { Aporta ideas y planteamientos originales } \\
\begin{array}{c}\text { Emplea estrategias y/o técnicas creativas } \\
\text { para plasmar de manera formal las ideas } \\
\text { y soluciones }\end{array}\end{array}$ & 2,81 & 0,88 & 4 & 1 & 3 \\
$\begin{array}{c}\text { Controla resultados } \\
\text { (2,81 }\end{array}$ & 0,77 & 4 & 1 & 3 \\
\hline
\end{tabular}

Tabla 11. Estadísticos de los resultados de evaluación de la CT-06

\begin{tabular}{cccccc}
\hline Indicadores de la rúbrica & Media & $\begin{array}{c}\text { Desv. } \\
\text { Típica }\end{array}$ & Max & Min & Moda \\
\hline $\begin{array}{c}\text { Participa en la planificación de } \\
\text { objetivos }\end{array}$ & 3,75 & 0,51 & 4 & 2 & 4 \\
$\begin{array}{c}\text { Actúa para afrontar los conflictos } \\
\text { del equipo }\end{array}$ & 3,64 & 0,53 & 4 & 2 & 4 \\
$\begin{array}{c}\text { Se compromete en la realización de } \\
\text { la tarea colectiva }\end{array}$ & 3,69 & 0,57 & 4 & 2 & 4 \\
\hline
\end{tabular}

\section{Conclusiones}

La UPV se encuentra inmersa en el desarrollo del proyecto de competencias transversales que tiene como objetivo principal acreditar las competencias transversales UPV a los estudiantes egresados en cualquiera de los títulos oficiales impartidos. En este proyecto, se han desarrollado distintas rúbricas de evaluación para 13 competencias transversales que pretenden sintetizar un perfil competencial para todos los alumnos egresados de la UPV.

El siguiente paso, después de la elaboración de las rúbricas, es su verificación. Con esta innovación educativa, pretendemos verificar las rúbricas elaboradas para las competencias: CT-02. Aplicación y pensamiento práctico, CT-04. Innovación, creatividad y emprendimiento, y CT-06. Trabajo en equipo y liderazgo.

La innovación educativa se ha desarrollado en los Grupos de Mañanas y ARA de la asignatura "Investigación Comercial” (nivel II) del Grado de Administración y Dirección de Empresas de FADE de la UPV. La muestra total analizada es de 110 alumnos. A pesar de haber analizado una única asignatura, los perfiles de los dos grupos participantes son diferentes en cuanto al número de alumnos Erasmus, al número de alumnos que trabajan o han trabajado en los últimos 2 años y su satisfacción con la asignatura.

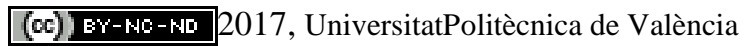


Sin embargo, a pesar de esta diferencia de perfil, no se han encontrado diferencias significativas en cuanto a la evaluación de las 3 competencias. Se han evaluado cada uno de los indicadores considerados en las rúbricas y no se han obtenido diferencias significativas en el valor medio de cada grupo. Sólo tenemos una diferencia significativa en el indicador “Controla resultados” de la competencia CT-04.

Como no hay diferencias significativas entre el Grupo Mañanas y el Grupo ARA en la evaluación de las competencias, podríamos decir que las rúbricas son adecuadas para evaluar a todo tipo de estudiante: Erasmus o no erasmus, trabajando o habiendo trabajado en los últimos 2 años o sin experiencia laboral, e independientemente de su satisfacción con la asignatura.

$\mathrm{Al}$ haber evaluado cada competencia con una metodología diferente, observamos como los alumnos son más generosos al autoevaluarse y al evaluar a sus iguales en la competencia transversal CT-06. Por el contrario, los profesores de la asignatura son más rigurosos al evaluar las competencias transversales CT-02 y CT-04 a partir del informe elaborado por el grupo.

El reto al que nos enfrentamos es cómo plantear estrategias evaluativas que se centren en la realización, por parte de los estudiantes, de actividades lo más auténticas posibles y con un nivel adecuado de complejidad según el momento formativo y el contexto en el que se desarrolla la docencia. Además, estas actividades han de dar respuesta a los distintos indicadores que aparecen en las rúbricas para evaluar las competencias transversales según la escala establecida que va desde A (Excelente/ejemplar) a D (No alcanzado).

\section{Referencias}

BIGGS, J. (2004). Calidad del aprendizaje universitario. Madrid: Narcea Ediciones.

CLEMENZA, C., FERRER, J. y ARAUJO, R. (2004). "La investigación universitaria como vía de fortalecimiento de la relación Universidad-Sector Productivo. Caso: la Universidad del Zulia” en Multiciencias, vol. 4, nº. 2, p. 104-112.

DE LA CRUZ, M.A. (2005). Taller sobre el proceso de aprendizaje-enseñanza de competencias. Zaragoza: Instituto de Ciencias de la Educación de la Universidad de Zaragoza.

FERNÁNDEZ, A. (2006). "Metodologías activas para la formación de competencias" en Educatio siglo XXI, vol. 24, p. 35-56.

JONSSON, A. y SVINGBY, G. (2007). "The use of scoring rubrics: Reliability, validity and educational consequences" en Educational Research Review, vol. 2, nº. 2, p. 130144.

LASNIER, R. (2000). Réussir la formation par compétences. Montréal: Guérin.

MINISTROS EUROPEOS DE EDUCACIÓN SUPERIOR. (1999). Declaración de Bolonia. <http://tecnologiaedu.us.es/mec2011/htm/mas/2/21/6.pdf> [Consulta: 30 de junio de 2016].

REDDY, Y.M. y ANDRADE, H. (2010). “A review of rubric use in higher education” en Assessment \& Evaluation in Higher Education, vol. 35, nº. 4, p. 435-448.

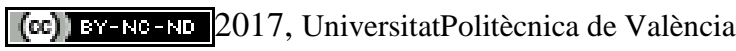


Estrategias de evaluación para las competencias transversales CT-02, CT-04 y CT-06

UNIVERSITAT POLITÈCNICA DE VALÈNCIA. (2016). Competencias transversales. $<$ http://www.upv.es/entidades/ICE/info/U0724624.pdf > [Consulta: 30 de junio de 2016]. 


\title{
La co-docencia en el contexto universitario como estrategia para la innovación docente
}

\author{
Castro Zubizarreta, Ana ${ }^{a}$; Briones Pérez, Elena ${ }^{\mathrm{b}}$, Izquierdo Magaldi, Belén ${ }^{\mathrm{c}}$ \\ anuniversidad de Cantabria (castroza@unican.es), ${ }^{\mathrm{b}}$ Universidad de Cantabria \\ (elena.briones@unican.es)y ${ }^{\mathrm{c}}$ Universidad de Cantabria (mariabelen.izquierdo@unican.es)
}

\begin{abstract}
Co-teaching has been described as one of the successful educational actions in the university context. It implies practices of cooperative teaching developed by two or more teachers generating a constant feedback for the teachers involved, sharing their experience and knowledge during their classes.

This paper presents the design and evaluation of a co-teaching experience developed at the Faculty of Education of the University of Cantabria. This educational experience is designed as a modality of co-teaching as station teaching and mentoring among students. The initial expectations, the benefits derived from this educational practice, the difficulties encountered and the proposals for improvement for this teaching practice are approached from the perspective of the teachers involved in the development of the co-teaching designed. Some learning outcomes are also described in the students. The results of this project show the positive evaluation of the experience and the commitment to this type of activities in spite of some temporal and organizational limitations.
\end{abstract}

Keywords: Co-teaching, educational innovation, Higher Education, methodology, mentoring.

\section{Resumen}

La co-docencia ha sido descrita como una de las actuaciones educativas de éxito en el contexto universitario. Supone prácticas de enseñanza cooperativa desarrollada por dos o más docentes generando un marco de retroalimentación constante para el profesorado implicado, al compartir su experiencia y conocimientos durante el desarrollo de las clases.

En este trabajo se presenta el diseño y valoración de una experiencia de codocencia desarrollada en la Facultad de Educación de la Universidad de Cantabria. Esta experiencia educativa se diseña como una modalidad de codocencia en estaciones a través de la mentoría entre estudiantes. Se abordan desde la perspectiva de las docentes implicadas en el desarrollo de la codocencia, sus expectativas iniciales, los beneficios que según ellas se deriva de esta práctica educativa, las dificultaddes encontradas y las propuestas de mejora para la continuidad de esta práctica docente. Asimismo se recogen algunos resultados de aprendizaje en los estudiantes. Los resultados del 
trabajo ponen de manifiesto la valoración positiva de la experiencia y el compromiso de las docentes con este tipo de actividades a pesar de las limitaciones temporales y organizativas encontradas.

Palabras clave: co-docencia, innovación educativa, Educación Superior, metodología, mentoría.

\section{Introducción}

La co-docencia o co-enseñanza ha sido considerada durante años, siguiendo a Suárez-Díaz (2016), como una estrategia eficaz para fortalecer la inclusión de alumnado con necesidades específicas de apoyo educativo en las aulas escolares. En el ámbito de la Educación Superior encontramos algunas experiencias de co-docencia que, insertadas bajo prácticas de innovación docente, se desarrollan con éxito en esta etapa educativa (Picheira y Otondo, 2016; Suárez-Díaz, 2016). En esta línea de desarrollo de prácticas de innovación docente en la Educación Superior, presentamos en este trabajo, un diseño de codocencia y la valoración de su práctica desarrollada en la Facultad de Educación de la Universidad de Cantabria durante el curso 2016-17 y que se enmarca dentro de un proyecto de innovación docente que lleva por título: "Co-docencia y Mentoría en el contexto universitario. Una propuesta metodológica para la coordinación docente y el aprendizaje activo del alumnado" aprobado en la III Convocatoria de Proyectos de innovación docente de la Universidad de Cantabria.

La co-docencia ha sido descrita como una de las actuaciones educativas de éxito (AEE) en el contexto universitario (Flecha et al., 2014). De hecho, tal y como señalan Cook y Friend (1995) la co-docencia ya fue recomendada tanto en Inglaterra como en Estados Unidos en los años sesenta como estrategia para reorganizar la Educación Secundaria. A pesar de este antecedente tan temprano de su uso en la escuela, su desarrollo sigue siendo menor en las aulas universitarias.

El término co-docencia también conocido como co-enseñanza o co-teaching define aquellas prácticas de enseñanza cooperativa desarrollada por dos o más docentes (Beamish, Bryer y Davies, 2006). La co-docencia favorece la generación de un marco de retroalimentación constante para el profesorado implicado, al compartir su experiencia y conocimientos durante el desarrollo de las clases (Rodríguez, 2014). Al respecto, la coordinación, el consenso de objetivos, la alternancia de roles y la interdependencia son elementos clave en esta práctica educativa pues, tal y como señalan Chanmugam y Gerlach (2013), requiere de la participación igualitaria de los docentes durante la planificación de la docencia, la instrucción y el proceso de evaluación. Estos elementos, co-planificación, co-instrucción y co-evaluación según Conderman y Hedin (2012), se convierten en ejes vertebradores para la aplicación de cualquier práctica de co-docencia.

(c) ) EY-NC-ND 2017, Universitat Politècnica de València 
Se han planteado además, unos principios que orientan las prácticas de co-docencia. Siguiendo las orientaciones de Villa et al. (2008) y Rodríguez (2014) concluimos las siguientes:

1. La coordinación del trabajo de los docentes para el logro de objetivos comunes.

2. El reconocimiento de la valía del otro, su experiencia y conocimiento.

3. La alternancia de roles entre los docentes participantes y la interdependencia para el logro de los objetivos comunes.

4. La utilización de un liderazgo compartido entre los co-docentes.

5. El carácter voluntario de la participación en la co-docencia y el compromiso individual de todos los docentes participantes.

Chanmugam y Gerlach (2013) destacan como beneficio potencial de la co-docencia para el propio profesorado participante, la posibilidad de conocer otras perspectivas, o formas de pensar, facilitando el intercambio de reflexiones y pareceres en un diálogo abierto donde el docente tiene la oportunidad de compartir impresiones que de otra forma hubieran quedado en una reflexión introspectiva.

Compartir la docencia según Crow y Smith (2005) y Rodríguez (2014), amplía la formación del profesorado participante y mejora su competencia interpersonal. En este sentido, Tobin y Roth, (2005) afirman que co-docencia es aprender en la práctica, dado que durante ella los docentes comparten sus competencias, habilidades, estilos docentes y estrategias metodológicas para el desarrollo de la docencia a un mismo grupo de estudiantes. A nuestro entender, la co-docencia es garante de coordinación, dada la necesidad de colaboración constante favoreciendo la integración interdisciplinar de los docentes.

Otros beneficios a destacar de la co-docencia en el ámbito universitario son los apuntados por Bekerman y Dankner (2010) quienes refieren una visión positiva de los alumnos respecto a la solvencia y coherencia de los co-educadores. Concretamente, estos autores demuestran que la retroalimentación aportada por el profesorado implicado creaba desde la perspectiva del alumnado mayores oportunidades de aprendizaje y enriquecimiento personal.

En todo caso, la co-docencia, también presenta aspectos limitadores, o dificultades en su práctica tal y como apuntan Castro y Figueroa (2006); Ginther, Phillips, y Grinseki (2007) y Rodríguez (2014). Entre las dificultades identifacadas por estos autores destacan el factor tiempo y la ausencia de espacios para planificar e implementar los programas; la ausencia de coordinación, el trabajo pedagógico aislado, la resistencia al trabajo colaborativo o la presencia de sentimientos de desconfianza o inseguridad.

A pesar de los aspectos limitadores anteriormente apuntados, las bonanzas que se desprenden del uso de la co-docencia en el ámbito universitario han alentado el desarrollo del proyecto y animado al profesorado participante a su desarrollo en las aulas. 


\subsection{Diferentes enfoques de co-docencia pero un mismo propósito: la enseñanza colaborativa}

La co-docencia al igual que tiene otros términos para referirse a ella como co-enseñanza, co-teaching, enseñanza colaborativa, enseñanza en equipo, cátedra compartida (SuárezDíaz, 2016) tiene también diferentes enfoques o tipos a la hora de llevarla a la práctica.

A partir de la revisión realizada por Rodríguez (2014) de los modelos de co-docencia propuestos por Friend y Cook (1996), y Hughes y Murawski (2001) a continuación presentamos una síntesis de las aportaciones de estos autores (Tabla 1), que se concreta en una tipología basada en el grado de interacción entre los docentes participantes y los estudiantes en escala ascendente:

Tabla 1. Modelos de co-docencia

\begin{tabular}{|l|l|}
\multicolumn{2}{|c|}{ MODELOS DE CO-DOCENCIA } \\
\hline \multicolumn{1}{|c|}{ TIPOLOGÍA } & \multicolumn{1}{c|}{ DESCRIPCIÓN } \\
\hline $\begin{array}{l}\text { Uno enseña, el otro observa o } \\
\text { Co-docencia de observación. }\end{array}$ & $\begin{array}{l}\text { Mientras uno enseña el otro recoge información de interés. } \\
\text { Requiere la coordinación en la información a recoger y el análisis } \\
\text { posterior de la información. }\end{array}$ \\
\hline $\begin{array}{l}\text { Uno enseña, el otro circula o } \\
\text { Co-docencia de apoyo. }\end{array}$ & $\begin{array}{l}\text { Mientras uno es el responsable principal de la enseñanza el otro } \\
\text { profesor circula ofreciendo ayuda puntual al estudiante que lo } \\
\text { demande. }\end{array}$ \\
\hline $\begin{array}{l}\text { Co-docencia en grupos } \\
\text { simultáneos o Enseñanza } \\
\text { paralela. }\end{array}$ & $\begin{array}{l}\text { Los profesores enseñan y comparten los mismos materiales } \\
\text { didácticos, pero dividen la clase en dos y asisten simultáneamente a } \\
\text { los estudiantes. }\end{array}$ \\
\hline $\begin{array}{l}\text { Co-docencia en rotación } \\
\text { con/sin Estaciones de } \\
\text { enseñanza }\end{array}$ & $\begin{array}{l}\text { Los profesores dividen el contenido y la clase en dos, cada uno } \\
\text { enseña el contenido que le correspondió a su grupo, luego el mismo } \\
\text { contenido al otro. Además, se puede establecer un tercer grupo } \\
\text { "estación" para que los estudiantes trabajen independientemente. }\end{array}$ \\
\hline $\begin{array}{l}\text { Co-docencia complementaria } \\
\text { Enseñanza alternativa o } \\
\text { diferenciada }\end{array}$ & $\begin{array}{l}\text { Consiste en que un profesor del equipo realiza acciones } \\
\text { para mejorar o complementar la enseñanza provista por el otro } \\
\text { profesor (e.g. parafraseo, enseñanza con un estilo diferente, enseñar } \\
\text { previamente las habilidades sociales requeridas para el aprendizaje } \\
\text { cooperativo). }\end{array}$ \\
\hline Equipo docente & $\begin{array}{l}\text { Un profesor es responsable del grupo mas amplio, y el otro del más } \\
\text { pequeño. }\end{array}$ \\
\hline $\begin{array}{l}\text { Los docentes brindan la misma instrucción de forma simultánea, en } \\
\text { un flujo de acción invisible que impide distinguir a un líder. Es el } \\
\text { enfoque más complejo y que más se ajusta a la idea de co- } \\
\text { enseñanza. }\end{array}$ \\
\hline
\end{tabular}

Esta diversidad de enfoques o modalidades de co-docencia responde a los distintos objetivos en el proceso de enseñanza-aprendizaje. Así, lo realmente interesante es ver cómo la co-docencia se erige como una propuesta metodológica flexible y abierta a las necesidades docentes y alumnado, pudiéndose generar nuevas fórmulas o variantes. 


\section{Objetivos}

Los objetivos que orientan el proyecto son los siguientes:

- Proponer y desarrollar una docencia innovadora en la Universidad de Cantabria utilizando actuaciones educativas de éxito (AEE) en el contexto universitario, optando en nuestro proyecto por la co-docencia y la mentoría entre el alumnado.

- Facilitar al alumnado la articulación de conocimientos teóricos y prácticos impartidos desde ramas epistemológicas diferentes ampliando la visión y perspectiva sobre un mismo foco temático y favoreciendo así un aprendizaje globalizado.

- Generar prácticas de trabajo cooperativo entre el alumnado a través de la mentoría entre alumnos de tres cursos del Grado en Educación Infantil que facilite un conocimiento más profundo del plan de estudios, organización y conexiones, así como potenciar las relaciones sociales entre el alumnado.

- Generar procesos de mejora de la coordinación docente y articulación de asignaturas a través de la co-docencia y el aprendizaje dialógico.

\section{Desarrollo de la innovación}

\subsection{Marco contextual de la experiencia: tres docentes, tres asignaturas distintas y un mismo plan de estudios}

El desarrollo de la co-docencia en equipo supone prestar en primer lugar atención a las personas implicadas en dicha práctica. Este aspecto requiere como hemos comentado anteriormente voluntariedad, pero sobre todo, conocimiento mutuo, diálogo, intercambio y la retroalimentación constante (Álvarez-Arregui, Rodríguez, Madrigal, Grossi y Arreguit, 2017). En el proyecto desarrollado, atendiendo a estas premisas, se coordinaron tres asignaturas, pertenecientes a tres áreas epistemológicas distintas impartidas por profesoras diferentes. Una asignatura de $1^{\circ}$ curso del Grado de Educación Infantil, Fundamentos teóricos de la Educación Infantil, con 43 estudiantes, impartida por el área de Teoría e historia de la educación. Una asignatura de $2^{\circ}$ curso, Psicopedagogía de la expresión y de la comunicación con 45 estudiantes, impartida por el área de Psicología del desarrollo y de la educación, y una asignatura de $3^{\circ}$ curso, Contextos didácticos y organizativos de la educación infantil, con 44 estudiantes, impartida desde el área de Didáctica y organización escolar. Las tres asignaturas presentan nexos de unión, en los contenidos de sus programas que conllevan una gradualidad en complejidad y desarrollo, de ahí, su ubicación temporal en el plan de estudios.

Concretamente, en la asignatura Fundamentos teóricos de la Educación Infantil ( $1^{\circ}$ curso) se abordan entre otros contenidos, la transición educativa, en la que desde una perspectiva teórica, sustentada en el modelo de la teoría crítica se identifican las discontinuidades entre las etapas educativas de Educación Infantil y Educación Primaria, así como, el derecho de participación de los niños en el proceso de transición. Asimismo, el fenómeno de la transición vuelve a ser recogido en la asignatura Psicopedagogía de la expresión y de la comunicación en el $2^{\circ}$ curso del Grado de Educación Infantil ligado a los procesos de alfabetización inicial y escolar que se producen en la Educación Infantil y se continúan y afianzan en la Educación Primaria. Finalmente, en $3^{\circ}$ se abordan en la asignatura Contextos didácticos y organizativos de la educación infantil, las nuevas alfabetizaciones, que entendemos como la transición que el niño realiza de la alfabetización inicial y escolar a la 
alfabetización en medios y digital.

Las docentes de las tres asignaturas realizaron prácticas de co-docencia en el grupo de $1^{\circ}$ donde iban introduciéndose desde el área de conocimiento de las profesoras implicadas, información relevante sobre el contenido objeto de estudio (la transición educativa). Se plantea por tanto, una práctica de co-docencia con base en el grupo de $1^{\text {er }}$ curso con estaciones de mentoría junto con los estudiantes de $2^{\circ}$ y $3^{\circ}$ curso del Grado de Magisterio de Educación Infantil, que favorezca tanto la coordinación docente como la percepción por parte del alumnado de los vínculos existentes entre las asignaturas, su gradualidad y posibilidades de relación de su contenido con la realidad educativa actual.

\subsection{Diseño de la experiencia}

Para el desarrollo de la experiencia planteamos un diseño metodológico que denominamos co-docencia en estaciones de mentoría que se desarrolla en dos fases, descrito en la Tabla 2. En cada una de estas fases se combina el enfoque de co-docencia de equipo docente, con la co-docencia en estaciones y la mentoría entre estudiantes. En las dos fases se trabaja con los estudiantes de primero, que reciben la co-docencia, es decir, las docentes brindan la misma instrucción de forma simultánea al mismo grupo de alumnos (véanse los contenidos en la Tabla 2). Además, se contempla la estación, que consiste en la mentoría entre estudiantes de primero y de segundo en la primera fase, y de estudiantes de primero y de tercero en la segunda fase. Esta agrupación entre estudiantes responde a la temática trabajada.

La singularidad de este diseño radica en que el proceso de enseñanza se plantea a través de la mentoría entre estudiantes por favorecer "un proceso de feed-back continuo de ayuda y orientación entre el mentor (alumno de curso superior que atesora los conocimientos y habilidades necesarias para ayudar), y un estudiante o un grupo de estudiantes de nuevo ingreso con la finalidad de paliar las necesidades de estos y optimizar su desarrollo y potencial de aprendizaje" (Valverde, Ruiz de Miguel, García Jímenez y Romero, 2004; p. 92).

De este modo, el diseño de la experiencia comprendió el desarrollo de co-docencia en modalidad de equipo docente y estaciones de mentorías desarrolladas por los estudiantes de cursos superiores al alumnado de primer curso.

Tabla 2. Diseño metodológico de la experiencia de co-docencia en el contexto universitario

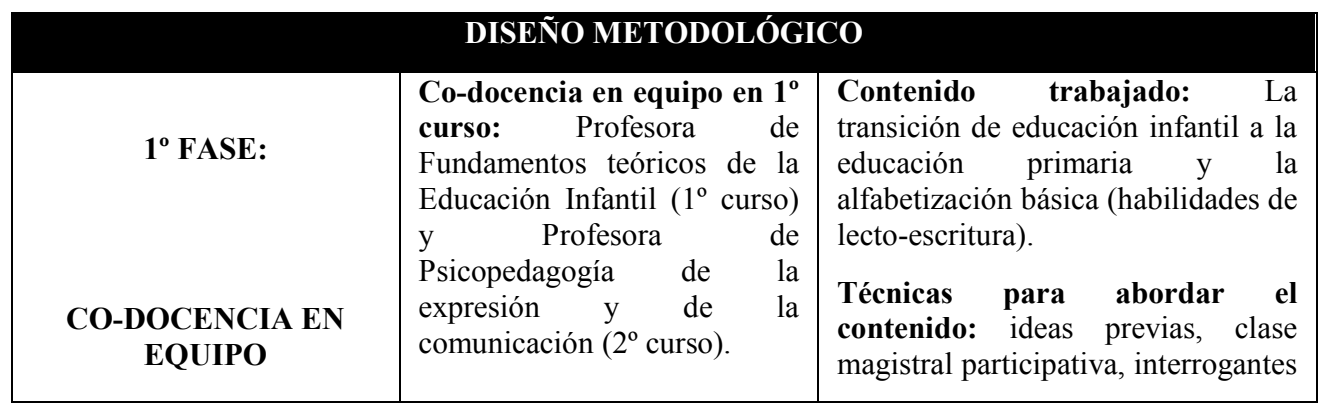

(c) ) EY-NC-ND 2017, Universitat Politècnica de València

Congreso IN-RED (2017) 


\begin{tabular}{|c|c|c|}
\hline $\begin{array}{c}\text { Y } \\
\text { ESTACIÓN DE } \\
\text { MENTORÍA } \\
\left(\mathbf{1}^{\mathbf{0}} \text { y } \mathbf{2}^{\mathbf{o}} \text { curso del Grado }\right. \\
\text { de Magisterio en } \\
\text { Educación Infantil }) \\
\text { Temporalización: } 2 \text { horas }\end{array}$ & $\begin{array}{l}\text { Mentoría del alumnado de } 2^{\circ} \\
\text { curso que de la asignatura } \\
\text { Psicopedagogía de la } \\
\text { expresión y de la } \\
\text { comunicación al alumnado de } \\
1^{\circ} \text { curso de la asignatura de } \\
\text { Fundamentos Teóricos de la } \\
\text { Educación Infantil. }\end{array}$ & $\begin{array}{l}\text { Contenido trabajado: la transición } \\
\text { educativa de Educación Infantil a } \\
\text { Educación Primaria y el proceso de } \\
\text { adquisición de las habilidades lecto- } \\
\text { escritoras ante la escolaridad } \\
\text { obligatoria. } \\
\text { Técnicas/actividades: Recuerdos } \\
\text { de la transición escolar y } \\
\text { experiencias vivenciadas por el } \\
\text { alumnado de } 2^{\circ} \text { sobre la transición } \\
\text { educativa y la adquisición de los } \\
\text { niños de las habilidades de lecto- } \\
\text { escritura percibida a raíz de sus } \\
\text { prácticas de enseñanza. }\end{array}$ \\
\hline $2^{\circ}$ FASE & $\begin{array}{l}\text { Co-docencia en equipo en } \mathbf{1}^{\circ} \\
\text { curso: Profesora de } \\
\text { Fundamentos teóricos de la } \\
\text { Educación Infantil }\left(1^{\circ} \text { curso }\right) \\
\text { y Profesora de Contextos } \\
\text { didácticos y organizativos de } \\
\text { la educación infantil }\left(^{\circ}\right. \\
\text { curso). }\end{array}$ & $\begin{array}{l}\text { Contenido trabajado: } \\
\text { transición de Educación Infantil a la } \\
\text { Educación Primaria y la } \\
\text { alfabetización digital. } \\
\text { Técnicas para abordar el } \\
\text { contenido: ideas previas, clase } \\
\text { magistral participativa, interrogantes } \\
\text { para la reflexión. }\end{array}$ \\
\hline $\begin{array}{c}\text { EQUIPO } \\
\text { Y } \\
\text { ESTACIÓN DE } \\
\text { MENTORÍA } \\
\left(1^{\circ} \text { y } 3^{\circ} \text { curso del Grado }\right. \\
\text { de Magisterio en } \\
\text { Educación Infantil) } \\
\text { Temporalización: } 2 \text { horas }\end{array}$ & $\begin{array}{l}\text { Mentoría del alumnado de } 3^{\circ} \\
\text { curso que de la asignatura } \\
\text { Contextos didácticos y } \\
\text { organizativos de la educación } \\
\text { infantil, al alumnado de } 1^{\circ} \\
\text { curso de la asignatura de } \\
\text { Fundamentos Teóricos de la } \\
\text { Educación Infantil. }\end{array}$ & 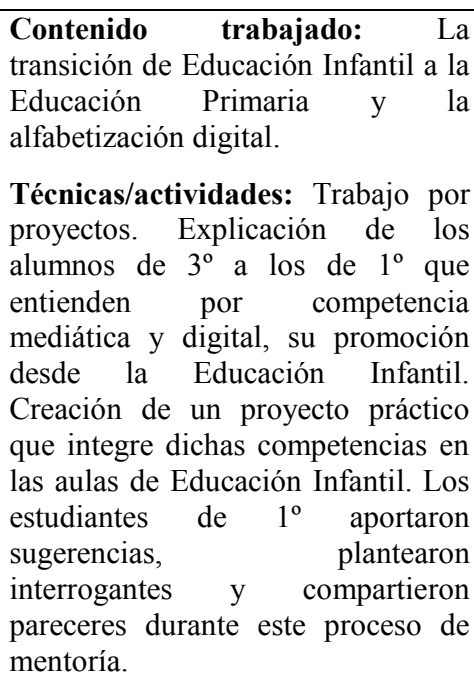 \\
\hline
\end{tabular}




\section{Resultados}

A continuación se presentan los resultados derivados del análisis de contenido realizado sobre la valoración de las tres profesoras responsables de la actividad de co-docencia explicada anteriormente. Las nueve preguntas realizadas a las profesoras una vez concluida la actividad de co-docencia nos permite identificar las expectativas, las dificultades y beneficios percibidos en la experiencia de innovación en co-docencia llevada a cabo, además del grado en el cual se valora su puesta en práctica en la Educación Superior. Asimismo, estas profesoras comparten su intención de compromiso con este tipo de actividad y sus propuestas para favorecer su desarrollo en el contexto universitario. Además, las cuestiones sobre aprendizajes adquiridos dirigidas a los estudiantes mentorizados y mentores (Castro, Izquierdo-Magaldi y García-Ruiz, 2017), nos permiten confirmar la percepción de las docentes.

\subsection{Expectativas iniciales y valoración final}

Del análisis de las expectativas iniciales de las profesoras identificamos cinco categorías con matiz positivo y tan sólo una con un carácter más negativo. Las primeras se refieren a la posibilidad de poner en práctica la co-docencia con otras compañeras, el conocimiento de la conexión entre las asignaturas consideradas, el reto personal que supone el trabajo conjunto con otros compañeros, el ofrecer a los estudiantes una transmisión del conocimiento en espiral y el poder comprobar los beneficios que suponen estas experiencias innovadoras en el proceso de enseñanza-aprendizaje. Así lo observamos en los siguientes comentarios:

"El inicio del proyecto supuso para mí un reto personal, el escuchar a las compañeras, conocer su manera de entender la docencia, su metodología, y su enfoque sobre el tema a tratar: la transición educativa"

"Esperaba comprobar cómo estas propuestas innovadoras mejoraban el proceso de enseñanza aprendizaje”

Pero no todas las expectativas iniciales fueron positivas, también se expresaron ciertas incertidumbres tales como la dificultad percibida de su puesta en marcha, en relación a su gestión de tiempos, a la dificultad de los contenidos, y la apertura de los estudiantes a estas propuestas, tal como se expresa en el siguiente comentario:

"Pensaba que hablarles de una asignatura e un curso superior, con contenidos relacionados con procesos de lectura y escritura iba a resultar lejano para el alumnado de primer curso".

En cuanto al balance final realizado por las profesoras sobre el grado en el que se cumplieron sus expectativas, nos encontramos que este se inclina hacia lo positivo junto con algún elemento que ha generado cierta inquietud. Entre los resultados positivos nos encontramos la posibilidad que ha ofrecido esta actividad de conocer los diferentes enfoques y perspectivas de las compañeras, la oportunidad de sentirse seguro y cómodo en el desarrollo de las actividades y la oportunidad que supone para la formación. También ha incidido en este balance positivo la actitud receptiva mostrada por los estudiantes. Los

(c)) EY-NC-ND 2017, Universitat Politècnica de València 
elementos que han generado cierto ruido en este balance positivo han sido la dedicación temporal destinada a la co-docencia, pues se ha considerado escaso. Por tanto, podríamos resumir el balance entre las expectativas iniciales y finales con la siguiente observación realizada por una de las profesoras:

"Afortunadamente, el resultado ha superado de forma positiva todas las expectativas que tenía. A pesar de la carga lectiva y de trabajo de los participantes, su actitud receptiva ante la experiencia, su participación y muestras de interés por los temas tratados han motivado la continuidad del proyecto".

\subsection{Dificultades de la experiencia de innovación en co-docencia y de su aplicación en la Educación Superior}

Cuatro han sido las categorías que se han extraído de la valoración de las profesoras sobre las dificultades encontradas en la experiencia de co-docencia desarrollada:

- La organización de tiempos y espacios de encuentros entre las co-docentes y también entre los estudiantes.

- Las actitudes hacia la apertura de la docencia a otros compañeros de otras asignaturas, pues se perciben dificultades para la escuchar y la percepción del enriquecimiento mutuo de la colaboración.

- La limitación en el número de actividades ofrecidas a los estudiantes, debido a la falta de tiempo.

- "El diseño de una evaluación que revierta en la mejora de la participación e implicación de los participantes, tanto docentes como estudiantes", en palabras de una de la profesoras.

En cuanto a las dificultades de la aplicación de la co-docencia en la Educación Superior, observamos semejantes categorías a las anteriormente mencionadas. Pues se vuelve a mencionar la dificultad de gestión de tiempos y espacios, unido a la rigidez de la temporalidad y fragmentación de los planes de estudio y a la necesidad de un buen diseño con objetivos claros en evaluación y resultados de aprendizaje. También se mencionan elementos actitudinales propios del docente como: "la cultura individualista a la hora de impartir docencia" y "compartir su trabajo y experiencia profesional", y por otra parte, la necesidad de compromiso para mantener el "esfuerzo y dedicación que conlleva una experiencia continuada" de este tipo. Esta requisito actitudinal se describe en la siguiente cita :

"En general, una experiencia de este tipo necesita de la compenetración de los docentes implicados, de tal manera que formen un tándem educativo en la interacción con sus estudiantes".

\subsection{Beneficios de la co-docencia para docentes y estudiantes}

Los beneficios expresados por y para las profesoras que han participado en la experiencia de co-docencia hacen referencia tanto a aspectos personales, como profesionales. Entre los primeros expresan ganancias en su seguridad y confianza, y desarrollo de capacidades tales 
como la implicación, la observación, la reflexión y la innovación. Entre las profesionales destacan la oportunidad de intercambiar ideas y conocimientos, la actualización profesional, el trabajo en equipo y el conocimiento de las líneas de investigación de las compañeras y sus aportaciones.

Entre los beneficios que los estudiantes pueden haber disfrutado, las co-docentes han señalado también elementos tanto académicos (e.g. formativos, perspectivas, contenidos, vivencias, conexión entre teoría y práctica) como elementos más personales e interpersonales tales como la confianza y entusiasmo transmitida por todos los implicados y la posibilidad de crear vínculos que supongan apoyos en su formación, como expresaba una profesora en la siguiente cita:

"La interacción entre iguales como instrumento de intercambio de información y conocimiento, así como de creación de vínculo de apoyo educativo".

Por otra parte, los estudiantes que ejercieron el rol de mentores han visto favorecidas sus habilidades sociales, su sentimiento de competencia autopercibida en relación a la temática que estaban explicando y su satisfacción al sentirse escuchados y valorados. Algunas manifestaciones que lo evidencian son los siguientes fragmentos:

"Me ha ayudado a explicarme mejor en grupo hacia gente desconocida"; "No solo me he sentido competente sino que también me ha servido para darme cuenta de que realmente creo y confio en lo que estoy explicando".

Por su parte, los estudiantes mentorizados destacan el conocimiento profundo adquirido sobre la temática abordada y un mayor conocimiento del plan de estudios y la organización de las materias que tendrán en futuros cursos. Así lo dicen:

"Tener una idea de a lo que nos enfrentaremos el curso que viene, qué aspectos tenemos que tener en cuenta".

\subsection{Intención de compromiso en actividades de co-docencia}

Las reacciones de las co-docentes ante la cuestión de si volverían a desarrollar una experiencia de co-docencia han sido afirmativas, aunque han diferido en la intensidad y rotundidad con la que lo han expresado. Desde una clara afirmación apoyada en la consideración de sus resultados positivos por haber favorecido el diálogo entre los estudiantes y el profesorado; pasando por una afirmación con ligeras matizaciones ("esta vez ha sido una experiencia breve, por supuesto me entusiasma la idea de poder desarrollarla en todas sus dimensiones"), a la expresión de los motivos por los que no podría hacerlo ("mis horarios lectivos no me permiten encontrar momentos para compartir con otros colegas") que por otra parte tampoco denota una falta de interés.

\subsection{Propuestas para la co-docencia en la Educación Superior}

De las dos últimas cuestiones planteadas a las profesoras, relativas a qué cambios propondrías y cuándo recomendarías este tipo de experiencias, extraemos información de interés para la puesta en marcha de la co-docencia en la Educación Superior.

(cc) EY-NC-ND 2017, Universitat Politècnica de València 
En cuanto a los cambios que propondrías las co-docentes señalan la necesidad de disponer de más tiempo para realizar co-docencia (para su planificación y desarrollo de forma efectiva), así como de apoyo por parte del decanato a través de "proyectos compartidos".

Por otra parte, hemos detectado un acuerdo en la propuesta de co-docencia en el Practicum y TFG, además de en asignaturas cuyos contenidos suponen procesos en espiral a lo largo de los cursos, o para desarrollar competencias básicas como "escribir para aprender y aprender a escribir". No obstante, una de las docentes considera que es muy complicada la co-docencia en la Educación Superior dadas la características actuales del Plan de estudios.

\section{Conclusiones}

En este trabajo se ha presentado el diseño y la valoración de una experiencia de innovación docente que combina el enfoque de co-docencia en la modalidad de equipo docente con la co-docencia en estaciones planteada esta última a través de la mentoría entre estudiantes.

La valoración de la experiencia realizada por parte de las co-docentes participantes refleja los beneficios apuntados ya por autores como Chanmugam y Gerlach (2013), Crow y Smith (2005) y Rodríguez (2014), presentando a la práctica de co-docencia como un medio posibilitador de formación, intercambio de reflexiones, de conocimiento de otras perspectivas y mejora de la competencia interpersonal y personal. En este sentido, las docentes participantes señalaron un incremento en su nivel de seguridad y autoconfianza. Además en nuestro estudio se identifican beneficios para los estudiantes percibidos por el profesorado tanto a nivel académico como personal vinculados con un mayor conocimiento de las conexiones existentes entre las asignaturas así como la creación de vínculos de apoyo educativo entre el alumnado participante. Se triangula esta valoración con los resultados del estudio de Castro, Izquierdo-Magaldi y García-Ruiz (2017) dónde los mismos estudiantes vienen a confirmar los beneficios percibidos por estas docentes.

No obstante, también se han identificado limitaciones propias de la práctica de co-docencia señaladas también por Castro y Figueroa (2006); Ginther, Phillips, y Grinseki (2007) y Rodríguez (2014) tales como la dificultad de la gestión de tiempos y espacios, el trabajo individualista. En nuestro estudio se ha identifico también la dificultad para llegar a un diseño que incluya dentro del proceso de enseñanza-aprendizaje una evaluación que implique la participación de todos los participantes. A nivel de su desarrollo dentro del contexto de la Educación Superior además de los elementos limitadores anteriormente apuntados se señalan, la necesidad de compromiso para mantener el esfuerzo y dedicación que conlleva una experiencia continuada de co-docencia.

Estas limitaciones no suponen un obstáculo para propuestas destinadas a la generalización de estas actividades en la Educación Superior si bien, en todas ellas se manifiesta la necesidad de contar con el respaldo y apoyo de la Administración para que facilite los tiempos, los espacios y la flexibilidad del currículo. 


\section{Referencias}

ÁlVAREZ-ARREGUI, E., RODRIGUEZ, A., MADRIGAL, R., GROSSI, B.A., Y ARREGUIT, X. (2017). "Ecosistemas de formación y competencia mediática: Valoración internacional sobre su implementación en la educación superior". Comunicar, Vol. 51, preprint.

BEAMISH, W., BRYER, F. y DAVIES, M. (2006). "Teacher reflections on co-teaching a unit of work". International Journal of Whole Schooling, Vol. 2 (2), pp. 3 - 18

BEKERMAN, D. y DANKNER, L. (2010). "La pareja pedagógica en el ámbito universitario, un aporte a la didáctica colaborativa". Formación Universitaria, Vol. 3 (6), pp. $3-8$.

CASTRO, R. y FIGUEROA, B. (2006). “Trabajo colaborativo en escuelas especiales de lenguaje, un enfoque educativo curricular". Paideia, Vol.41, pp. 117-127.

CASTRO, A., IZQUIERDO-MAGALDI, B. y GARCÍA-RUIZ, R. (2017). “Innovación docente en la universidad mediante co-docencia y mentoría". Comunicación presentada en el XIV Congreso Internacional de Educación Inclusiva, Oviedo.

CHANMUGAM, A. y GERLACH, B. (2013). "A Co-Teaching Model for Developing Future. Educators". Teaching Effectiveness International Journal of Teaching and Learning in Higher Education, Vol. 25 (1), pp. 110-117. $<$ http://www.isetl.org/ijtlhe/pdf/IJTLHE1412.pdf> [Consulta: 15 de octubre de 2016]

CONDERMAN, G. y HEDIN, L. (2012). "Purposeful assessment practices for coteachers". Teaching Exceptional Children, Vol. $44 \quad$ (4), pp. 19 - 27. $<$ http://studentimpact.wmwikis.net/file/view/Assessment $\% 20$ for $\% 20 \mathrm{Co}-$ teachers.pdf/433004592/Assessment $\% 20$ for $\% 20$ Co-teachers.pdf $>$ [Consulta: 5 de octubre de 2016]

COOK, L. y FRIEND, M. (1995). "Co-teaching: guidelines for creating effective practices". Focus on Exceptional Children, Vol. 28(3), pp. 1-25. $<$ http://plaza.ufl.edu/mrichner/Readings/Cook\%20\&\%20Friend\%20(1995).pdf> [Consulta: 20 de enero de 2017]

CROW, J., y SMITH, L. (2003). "Using co-teaching as a means of facilitating interprofessional collaboration in health and social care". Journal of Interprofessional Care, Vol. 17(1), pp. 45-55.

FLECHA, R. et al. (2014). "Actuaciones de Éxito en la Universidad. Hacia la excelencia tomando las mejores universidades como modelo". Multidisciplinary Journal of Educational Research, Vol.4(2), pp. 131-150.

FRIEND, M. y COOK., L. (1996). Interactions: collaboration skills for school professionals. White Plains: Longman Publisher USA.

GINTHER, S. D., PHILLIPS, A., y GRINESKI, S. (2007). "Team-teaching the HBSE curriculum: Considerations and advice". Journal of Teaching in Social Work, Vol. 27(1-2), pp.199-211.

HUGHES, C. y MURAWSKI, W. (2001). "Lessons from another field: applying coteaching strategies to gifted education". Gifted Child Quarterly, Vol. 45 (3), pp. 195 203. 
PICHEIRA, J y OTONDO, M. (2016). "Habilidades de co-docencia en alumnos de Pedagogía en Educación Diferencial de la Universidad Católica de la Santísima Concepción". Revista de Estudios y Experiencias en Educación, Vol. 15 (29), pp. 95 - 108.

RODRÍGUEZ, F. (2014). "La co-enseñanza una estrategia para el mejoramiento educativo y la inclusion". Revista Latinoamericana de inclusión educativa, Vol. 8 (2), pp. 219-233.

SUÁREZ-DÍAZ, G. (2016). "Co-enseñanza: concepciones y prácticas en profesores de una Facultad de Educación en Perú”. Revista Electrónica de Investigación Educativa, Vol.18(1), pp.166-182. <http://redie.uabc.mx/redie/article/view/786> [Consulta: 10 de marzo de 2017]

TOBIN, K. y ROTH, W. (2005). "Implementing coteaching and cogenerative dialoguing in urban science education". School Science and Mathematics, Vol. 105 (6), pp. 313 - 321.

VALVERDE, A., RUIZ DE MIGUEL, C., GARCÍA JÍMENEZ, E. y ROMERO, S. (2004). "Innovación en la orientación universitaria: la mentoría como respuesta". Contextos educativos, Vol. 6-7, pp. 87-112.

VILLA, R. A., THOUSAND, J. S. y NEVIN, A. I. (Eds.). (2008). A guide to co-teaching: practical tips for facilitating student learning. Thousands Oaks, CA: Corwin Press. 


\title{
EI debate como instrumento complementario de aprendizaje en la competencia de responsabilidad ética, medioambiental y profesional.
}

Modesto Pérez-Sánchez ${ }^{\text {, }}$ P. Amparo López-Jiménez ${ }^{a}$

${ }^{a}$ Departamento de Ingeniería Hidráulica y Medio Ambiente. Universitat Politècnica de València. palopez@upv.es; mopesan1@upv.es.

\begin{abstract}
This manuscript proposes a methodology for working and evaluating activities related to the transversal competence so called Ethics, Environmental and Professional Responsibility. The method was based on two different stages. The first stage was not face-to-face while the second stage was face-to-face and it was developed in class. The first stage allowed students know, analyze, and define their value judgments depending on their domain level and according to ethic, professional and environmental component. The second stage (face-to-face) was developed by a discussion in which the student must show its knowledge and value judgment to persuade the rest of the students about its defended rol. The experience showed results, which were very favourable. Adequate or excellent degree was reached over $80 \%$ of the students in both cases, being the student's satisfictation activity over $75 \%$.
\end{abstract}

Keywords: ethic; discussion, environmental, professional competence, value jugdment.

\footnotetext{
Resumen

La presente comunicación propone una metodología de trabajo para trabajar y poder evaluar actividades relacionadas con la competencia transversal Responsabilidad Ética, Medio Ambiental y Profesional. El método de trabajo está basado en una parte no presencial y otra presencial es descrito y mostrado sus resultados. La parte no presencial permite al alumno acorde al dominio en el que se encuentra, analizar y definir sus juicios de valor atendiendo a la componente ética, profesional y medioambiental. La parte presencial es llevada a cabo mediante un debate, en el cual el alumno debe mostrar su conocimiento y juicios de valor para convencer al resto de compañeros de su rol defendido. La experiencia muestra unos resultados muy favorables con un grado adecuado y excelente del alcance de los indicadores por encima del $80 \%$ en ambos casos y con una satisfacción de la actividad del alumnado superior al 75\%.
}

Palabras clave: ética, debate, medioambiental, competencia profesional, juicios de valor. 


\section{Introducción}

Los campos de estudio de ingeniería deben apoyarse en aspectos ambientales, pues cada vez más, debe realizarse un ambientalización curricular en los diferentes niveles de formación. En este sentido, la necesidad de motivar a los alumnos y hacer que los conceptos que se presentan, sean aprendidos de formas innovadoras y eficaces, hace que las técnicas utilizadas por los docentes sean cada vez más creativas. El debate se convierte en una técnica de intercambio y confrontación de ideas y conocimientos en ámbitos concretos, que hacen que los alumnos se identifiquen con unos roles que deben representar, para lo cual deberán haberse documentado convenientemente.

El modelo de debate que se describe en la presente contribución gira en torno a una postura a defender que el profesor comunica a los alumnos con tiempo suficiente para prepararlo, y para la que los alumnos tienen que haber escogido roles y representantes que defiendan de forma argumentada sus posturas. El debate es definido por Cattani (Cattani, 2003) como "Una competición (un reto, un desafio) entre dos antagonistas, en los que, a diferencia de lo que ocurre en una simple discusión, existe una tercera parte (un juez, un auditorio) cuya aprobación buscan los dos contendientes. Se puede debatir, incluso sobre cuestiones que se consideran imposibles de resolver con el objetivo de persuadir a otros". En este sentido amplio, los alumnos de diversos niveles, deben elegir un rol frente a diferentes temas planteados, prepararlo, defenderlo y finalmente verse sometidos a un escrutinio en que sus compañeros decidan cuál de las alternativas presentadas es la más convincente. Todo ello ligado a aspectos de temática ambiental, con la controversia que estos aspectos conllevan. Con esta mezcla, los alumnos desarrollan sólidas argumentaciones preparadas con antelación que motivan en ellos un proceso de aprendizaje autónomo muy deseable para los niveles últimos de la educación (Sánchez, 2007).

\section{Objetivos}

El debate permite a los alumnos conseguir el conocimiento profundo de los temas a los que se enfrentan, a la vez que desarrollar sus habilidades expositivas y de representación y análisis de problemas. Algunos de los objetivos docentes conseguidos con el debate son los siguientes (Rodriguez, 2010):

1. Utilizar el leguaje específico de forma correcta, argumentando sus ideas con un vocabulario adecuado a los conceptos presentados. Asimismo, esto se consigue de forma mucho más eficiente cuando la temática que se desarrolla se presenta en una lengua que no es la materna para los alumnos.

2. Presentar los conceptos con una calidad argumental, que permita convencer a sus compañeros del rol que han adoptado para defender sus posturas y describir sus argumentos, particularmente ligado a aspectos ambientales de contaminación de agua o aire, siempre controvertidos.

3. Defender el contenido de los argumentos presentados a través de fuentes bibliográfica con verosimilitud de forma que se validen dichos argumentos a través de la confianza científica de fuentes fidedignas y reconocidas por todos los participantes.

4. Demostrar el dominio del tema abordado, con lo que se desarrolla por parte de los ponentes de cada uno de los roles un conocimiento específico del tema presentado. Este conocimiento fundado con una toma de contacto en muchas fuentes, todas

(cc) EY-NC-ND 2017, Universitat Politècnica de València

Congreso IN-RED (2017) 
ellas documentadas, propone un aprendizaje motivador y que, en la experiencia de los autores, permanece fuertemente presente en la memoria de los alumnos.

Por tanto, con estos objetivos generales, la presente investigación docente versa sobre el desarrollo de debates sobre temas ambientales en asignaturas del campo de la ingeniería. Desde el Departamento de Ingeniería Hidráulica y Medio Ambiente de la Universitat Politèncica de València se plantean una serie de debates en asignaturas de grado y master con temáticas de diferentes grados de profundización, pero todas ellas con una fuerte ambientalización curricular. De esta forma se espera que los alumnos, a través del argumento razonado, adquieran los conocimientos y la base para el diálogo, que permite la herramienta del debate como estrategia docente, permitiendo trabajar no solo la comunicación efectiva sino la competencia transversal de Responsabilidad Ética, Medioambiental y Profesional.

\section{Desarrollo de la innovación}

La innovación que presenta el presente trabajo radica en dos vertientes. De un lado el propio desarrollo y planteamiento de la técnica de debate como motivadora para el aprendizaje en el aula en dos niveles bien diferenciados: segundo curso de grado y segundo curso de máster, sobre temas ambientales relativamente similares. De otro lado, la comparación de los resultados obtenidos en estos dos niveles cuando la formación inicial, madurez de los alumnos y tamaño medio de grupo son muy diferentes. Ambos aspectos presentan una innovación docente de la que pueden extraerse conclusiones para futuras puestas en escena de estrategias similares en niveles tan diferentes.

Los alumnos deben seleccionar los roles a defender y sus representantes. Los propios alumnos deben representar las diferentes posturas y actuar de moderadores para que el diálogo sea efectivo. Estos mismos alumnos deben conocer bien el tema a presentar y seleccionar fuentes fidedignas. Todo ello resulta finalmente en una interiorización de los conceptos y un nivel de satisfacción del alumno que ve reconocida la defensa de su postura por el colectivo, que hacen del debate una herramienta novedosa y eficaz (de Oña et al. 2010).

\subsection{Metodología de trabajo en Grado}

El debate propuesto en grado constituye el punto final del proceso de una tarea que se inicia de forma individual y no presencial, continuando en una tarea en grupo presencial, obteniendo un único resultado final derivado del trabajo de liderazgo y expositivo del alumno, que consigue "convencer" al resto de compañeros sobre su rol definido. La metodología de trabajo tiene una duración temporal de 4 semanas y está definida en las siguientes fases (Figura 1):

- Fase 1. Tarea no presencial: viene precedido de una tarea individual no presencial.

Esta tarea es adjuntada a través de la sección de tareas de la herramienta de PoliformaT. En ella, viene definido el problema o actuación que se pretende desarrollar. A partir de la exposición y antecedentes definidos, el alumno debe posicionarse en cuatro roles diferentes que derivan del problema medioambiental y ético planteado. El alumno dispone de tres semanas para elaborar su respuesta en cada uno de los roles, la cual está supeditada a dos factores limitantes que los estudiantes conocen:

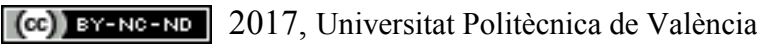


oLimite de palabras; el alumno tiene un mínimo de 250 palabras y un máximo de 500 para argumentar cada rol, atendiendo a la problemática planteada.

- Comprobación de Plagio; como el problema planteado es un tema de actualidad o que ha ocurrido en una fecha anterior, la tarea es verificada con la herramienta Turitin de la herramienta PoliformaT.

Estos dos factores garantizan la independencia y originalidad de los resultados, así como la esquematización y definición de las ideas principales del rol adoptado, en el cual, deben introducir el problema, desarrollarlo de forma breve donde exponen ventajas e inconvenientes y desarrollar una conclusión.

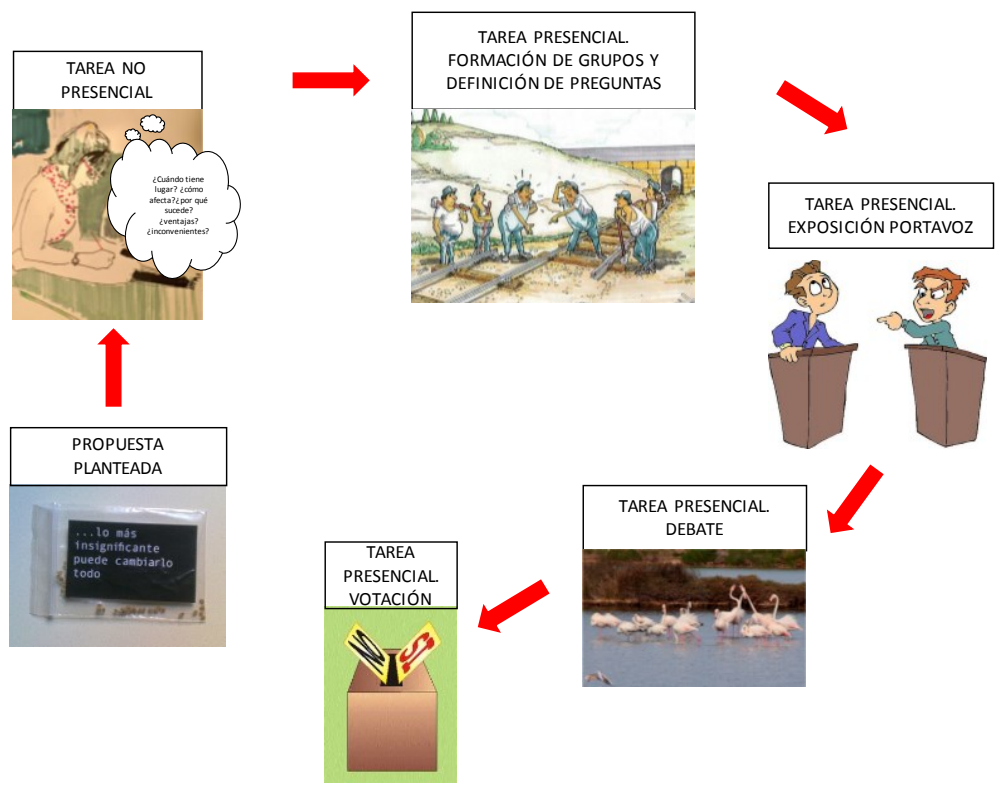

Fig. 1 Fase propuesta en la actividad desarrollada. Elaboración propia

- Fase 2 Trabajo presencial y en grupo: transcurridas las tres semanas de desarrollo de la tarea no presencial, el problema planteado en esta tarea se lleva al aula. En este caso, la actividad se nutre del 'feedback' que cada tarea ha dado al alumno en cuanto a análisis y búsqueda de ventajas e inconvenientes en cada uno de los roles. Esta actividad que concluye con un debate está dividida en tres partes:

$\circ$ Fase 2.1 Formación de grupos y elección de representante: debido al elevado número de alumnos matriculados por grupo (67), se propone la formación de grupos, evitando que se agrupen los alumnos que normalmente comparten mesa durante las clases, para de este modo dotar de una mayor heterogeneidad al grupo. Una vez la clase es dividida en 4 grupos, cada grupo debe elegir a su representante o delegado, el cual será el encargado de desarrollar la exposición (Fase

(cc) EY-NC-ND 2017, Universitat Politècnica de València 
2.3). Para la formación de grupos y elección de representante, los alumnos cuentan con un tiempo de $5 \mathrm{~min}$.

o Fase 2.2 Sorteo de Rol y Elaboración de preguntas: tras la elección de representante, los cuatro representantes realizan un sorteo donde es determinado el rol que cada uno debe adoptar. En base a ese Rol, el grupo de alumnos, los cuales conocen la problemática y previamente han adoptado todos los roles, preparan una batería de preguntas ( 5 por rol diferente al que les ha sido asignado en el sorteo), que posteriormente podrán utilizar en el debate). El tiempo para la elaboración de las preguntas es de $15 \mathrm{~min}$.

oFase 2.3 Exposición por parte del representante: transcurrido ese tiempo, el representante de cada grupo realiza una exposición de la postura del grupo defendiendo su rol adoptado. Esta exposición tiene una duración máxima de tres minutos (3 $\mathrm{min})$, los cuales no pueden ser interrumpidos por ningún integrante del resto de grupos. El tiempo total de exposiciones son $12 \mathrm{~min}$.

o Fase 2.4 Debate: desarrollada la exposición se abre el debate, en el cual, cada grupo debe seleccionar 2 preguntas de las 5 que ha preparado y realizársela a cada uno del resto de los roles. Estas preguntas son la semilla del debate, puesto que a partir de las misma es de donde nace el debate y aparecen las diferentes posturas entre todos los alumnos. En esta fase pueden participar todos los alumnos, siendo moderado el turno de palabra por el profesor. El tiempo de debate se extiende a 30 $\min$.

o Fase 2.5 Votación: finalmente, tras concluir el debate, se realiza una votación secreta a urna cerrada, donde cada uno de los alumnos debe votar la persona que considera que ha ganado el debate, así como si personalmente está a favor o en contra de la problemática propuesta. La votación en este caso se aprovecha para conocer, el grado de satisfacción del alumno con el desarrollo de actividades similares en la clase. El tiempo aproximado de la votación es $5 \mathrm{~min}$.

En el caso presentado en la asignatura de grado se correspondía con la asignatura Ingeniería Fluidomecánica de tercer curso del Grado de Ingeniería Mecánica impartida en la Escuela Politécnica Superior de Alcoy. Esta asignatura es punto de control de la competencia transversal "Responsabilidad Ética, Medioambiental y Profesional". La actividad está planificada para desarrollarla entre las semanas 2 y 6 del cuatrimestre $\mathrm{B}$, cuando se está impartiendo la unidad didáctica 3 , denominada "Turbinas Hidráulicas".

La tarea plantea la posibilidad de recrecer una presa para que un inversor pueda instalar una central hidroeléctrica. Entre las ventajas se encuentra la reducción de efectos de gases invernadero y que los municipios afectados tendrán el consumo de energía eléctrica gratuito. Como desventaja principal se cita que el recrecimiento de la presa provoca que zonas con viviendas habitadas tengan que ser expropiadas. Se

(cc)) EY-NC-ND 2017, Universitat Politècnica de València 
propone que el alumno debe posicionarse en un primer momento (tarea no presencial) en 4 roles diferentes:

- ROL 1. Adoptando el rol de inversor, argumentar la necesidad de ejecutar dicha actuación.

- ROL 2. Adoptando el rol de Alcalde del municipio, argumentar la evaluación positiva de dicha actuación.

- ROL 3. Adoptando el rol de ingeniero/a del municipio, argumentar la evaluación considerada (positiva o negativa) para informar al Alcalde.

- ROL 4. Adoptando el rol de portavoz de "Plataforma de Afectados por el Recrecimiento de la Presa", defender el posicionamiento contrario a dicha actuación.

\subsection{Metodología de trabajo en Master}

El debate propuesto en master, presenta una metodología similar, pero adaptada a un número reducido de alumnos. En este caso la tarea no presencial consta de preparar una presentación que durante 5 min el alumno deberá exponer de forma individual en clase. Posteriormente los diferentes alumnos, tras la exposición y argumentación de cada uno de ellos, se inicia el debate por un periodo de $30 \mathrm{~min}$, finalizando con una votación, que determina la idea y ponente ganador. En el caso de Máster, la pregunta planteada fue: ¿Es el aumento de la temperatura de la atmósfera debido a un cambio climático provocado por la acción antropogénica?

Las posibles posturas defendidas fueron:

- ROL 1. Sí. Existe una relación directa entre la acción antropogénica y el calentamiento global.

- ROL 2. No. No existe relación entre la acción antropogénica y el calentamiento global. La atmósfera tiene una dinámica cíclica debida a acciones ajenas al ser humano y en el tiempo en el que se tienen lecturas se encuentra en un ciclo de temperatura creciente, que no siempre ha sido así.

\subsection{Evaluación de la competencia transversal}

Como ambas asignaturas son puntos de control en Nivel de Dominio II y III, se adapta la rúbrica propuesta desde el Instituto de Ciencias de la Educación, desarrollando los indicadores y descriptores de acuerdo a nuestro caso de estudio planteado. En estos casos de estudio presentado, al tener una fuerte componente ética y profesional, al tener que desarrollar la opinión, se toman los cuatro indicadores éticos y profesionales y el primer indicador medio ambiental. Estos son definidos en la Tablas 1 y 2 (Nivel Dominio II) y Tablas 3 y 4 (Nivel Domino III).

(cc) EY-NC-ND 2017, Universitat Politècnica de València 
Modesto Pérez-Sánchez, P. Amparo López-Jiménez

Tabla 1. Rúbrica de evaluación de las actividades para Nivel de dominio II (considerando indicadores medioambientales, éticos y profesionales)

\begin{tabular}{|c|c|c|c|c|}
\hline \multirow{2}{*}{ INDICADOR } & \multicolumn{4}{|c|}{ DESCRIPTOR } \\
\hline & D. No alcanzado & C. En desarrollo & B. Adecuado & A. Excelente \\
\hline $\begin{array}{c}\text { 1. Interpreta y valora } \\
\text { críticamente la } \\
\text { información y la } \\
\text { realidad. } \\
\text { Define los elementos } \\
\text { necesarios para el } \\
\text { diseño de actuaciones } \\
\text { (Medioambiental) }\end{array}$ & $\begin{array}{l}\text { No hay pruebas de que } \\
\text { cuestione la situación }\end{array}$ & $\begin{array}{c}\text { En ocasiones se } \\
\text { cuestiona ciertas } \\
\text { situaciones de la realidad } \\
\text { en la que vive }\end{array}$ & $\begin{array}{c}\text { Formula preguntas e } \\
\text { indaga sobre la realidad a } \\
\text { partir de su reflexión } \\
\text { sistemática con el objetivo } \\
\text { de buscar la verdad }\end{array}$ & $\begin{array}{l}\text { Reconoce la complejidad } \\
\text { de las situaciones y adopta } \\
\text { una situación crítica, } \\
\text { formulando sus propios } \\
\text { juicios y valoraciones }\end{array}$ \\
\hline $\begin{array}{c}\text { Evaluación atendiendo a } \\
\text { la actividad }\end{array}$ & $\begin{array}{c}\text { El alumno no desarrolla } \\
\text { la actividad }\end{array}$ & $\begin{array}{l}\text { El alumno desarrolla la } \\
\text { tarea no presencial pero } \\
\text { no adopta todos los roles }\end{array}$ & $\begin{array}{l}\text { El alumno desarrolla la } \\
\text { tarea no presencial, } \\
\text { adoptando todos los roles. } \\
\text { En su argumentación se } \\
\text { observa que ha } \\
\text { desarrollado una fase } \\
\text { inicial de busqueda de } \\
\text { información }\end{array}$ & $\begin{array}{l}\text { El alumno desarrolla la } \\
\text { tarea no presencial, } \\
\text { adoptando todos los roles. } \\
\text { En su argumentación se } \\
\text { observa que ha } \\
\text { desarrollado un análisis } \\
\text { profundo de información y } \\
\text { argumenta sus propias } \\
\text { decisiones (valores de } \\
\text { plagio del Turitin } \\
\text { prácticamente nulos) }\end{array}$ \\
\hline $\begin{array}{c}\text { 2. Fundamenta y } \\
\text { argumenta los juicios } \\
\text { propios }\end{array}$ & $\begin{array}{l}\text { Se muestra incapaz de } \\
\text { mostrar juicios y } \\
\text { valoraciones propios }\end{array}$ & $\begin{array}{l}\text { En ocasiones asume } \\
\text { como propios los juicios } \\
\text { y decisiones de los } \\
\text { demás, y los acepta } \\
\text { incondicionalmente }\end{array}$ & $\begin{array}{l}\text { Es capaz de formular sus } \\
\text { propios juicios y } \\
\text { valoraciones } \\
\text { congruentemente y con } \\
\text { consistencia }\end{array}$ & $\begin{array}{l}\text { Argumenta y defiende con } \\
\text { convicción sus propios } \\
\text { juicios y valoraciones }\end{array}$ \\
\hline $\begin{array}{c}\text { Evaluación del } \\
\text { indicador atendiendo a } \\
\text { la actividad }\end{array}$ & $\begin{array}{c}\text { El alumno no participa } \\
\text { en el debate }\end{array}$ & $\begin{array}{c}\text { El alumno participa en el } \\
\text { debate, acepta el rol } \\
\text { asignado de forma } \\
\text { incondicional, no } \\
\text { defendiendo la postura }\end{array}$ & $\begin{array}{l}\text { El alumno participa en el } \\
\text { debate, aunque el rol } \\
\text { asignado no sea de su } \\
\text { agrado, se introduce en el } \\
\text { personaje, desarrollando } \\
\text { valoraciones consistentes. }\end{array}$ & $\begin{array}{c}\text { El alumno participa en el } \\
\text { debate, aunque el rol } \\
\text { asignado no sea de su } \\
\text { agrado, se introduce en el } \\
\text { personaje, desarrollando } \\
\text { valoraciones consistentes, } \\
\text { que consigue ganarse las } \\
\text { posturas contrarias } \\
\text { (alumno ganador del } \\
\text { debate) }\end{array}$ \\
\hline $\begin{array}{l}\text { 3. Reconoce las } \\
\text { limitaciones propias y } \\
\text { considera los juicios de } \\
\text { los demás (autocrítica) }\end{array}$ & $\begin{array}{l}\text { No hay pruebas de que } \\
\text { sea consciente de sus } \\
\text { propias limitaciones ni } \\
\text { muestra interés por los } \\
\text { juicios y las opiniones, } \\
\text { ajenas }\end{array}$ & $\begin{array}{l}\text { Solo en situaciones de } \\
\text { dificultad o limitación } \\
\text { incorpora } \\
\text { mecánicamente los } \\
\text { juicios de los demas en } \\
\text { sus decisiones }\end{array}$ & $\begin{array}{c}\text { Analiza adecuadamente y } \\
\text { tiene en cuenta los juicios } \\
\text { y las opiniones ajenas en } \\
\text { su discurso }\end{array}$ & $\begin{array}{c}\text { Incorpora } \\
\text { constructivamente las } \\
\text { ideas de los demás: } \\
\text { muestra voluntad de } \\
\text { superación personal }\end{array}$ \\
\hline $\begin{array}{c}\text { Evaluación del } \\
\text { indicador atendiendo a } \\
\text { la actividad }\end{array}$ & $\begin{array}{l}\text { El alumno no participa } \\
\text { en el debate ni en la } \\
\text { tarea no presencial }\end{array}$ & $\begin{array}{c}\text { El alumno adopta las } \\
\text { opiniones de los demás } \\
\text { en el debate, en el turno } \\
\text { de preguntas cuando no } \\
\text { tiene argumentos para la } \\
\text { réplica }\end{array}$ & $\begin{array}{l}\text { El alumno matiza su } \\
\text { opinión, teniendo en } \\
\text { cuenta algunas de las } \\
\text { preguntas desarrolladas } \\
\text { en el turno de réplica }\end{array}$ & $\begin{array}{l}\text { El alumno, no solo matiza } \\
\text { su opinión, sino que toma } \\
\text { como suyas las } \\
\text { valoraciones que } \\
\text { determina que mejoran su } \\
\text { posicionamiento en el } \\
\text { debate }\end{array}$ \\
\hline
\end{tabular}

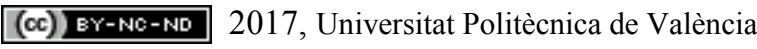

Congreso In-Red (2017) 
El debate como instrumento complementario de aprendizaje en la competencia de responsabilidad ética, medioambiental y profesional.

Tabla 2. Rúbrica de evaluación de las actividades para Nivel de dominio II (considerando indicadores medioambientales, éticos y profesionales) [Continuación]

\begin{tabular}{|c|c|c|c|c|}
\hline \multirow{2}{*}{ INDICADOR } & \multicolumn{4}{|c|}{ DESCRIPTOR } \\
\hline & D. No alcanzado & C. En desarrollo & B. Adecuado & A. Excelente \\
\hline $\begin{array}{l}\text { 4. Incorpora y valora } \\
\text { críticamente de los } \\
\text { conceptos éticos y } \\
\text { deontológicos de la } \\
\text { profesión }\end{array}$ & $\begin{array}{l}\text { No hay pruebas de que } \\
\text { tenga en cuenta las } \\
\text { implicaciones prácticas } \\
\text { de la ética profesional en } \\
\text { su quehacer diario }\end{array}$ & $\begin{array}{l}\text { En ocasiones expresa su } \\
\text { desacuerdo ante } \\
\text { situaciones que no } \\
\text { respetan los principios } \\
\text { éticos y deontológicos de } \\
\text { la profesión }\end{array}$ & $\begin{array}{l}\text { Toma partido a favor de } \\
\text { los conceptos éticos y } \\
\text { deontoloógicos de la } \\
\text { profesión en situaciones } \\
\text { poco coherentes con los } \\
\text { mismos }\end{array}$ & $\begin{array}{c}\text { Defiende y se } \\
\text { compromete a actuar } \\
\text { coherente con los } \\
\text { conceptos éticos y } \\
\text { deontológicos atendiendo } \\
\text { a toda su complejidad e } \\
\text { integrando una } \\
\text { perspectiva crítcia y } \\
\text { responsable }\end{array}$ \\
\hline $\begin{array}{c}\text { Evaluación del } \\
\text { indicador atendiendo a } \\
\text { la actividad }\end{array}$ & $\begin{array}{c}\text { El alumno a través de la } \\
\text { actividad no presencial } \\
\text { en su rol de ingeniero, } \\
\text { no desarrolla su } \\
\text { posicionamiento }\end{array}$ & $\begin{array}{l}\text { El alumno a través de la } \\
\text { actividad no presencial } \\
\text { en su rol de ingeniero, } \\
\text { vela por el interes } \\
\text { general pero no con una } \\
\text { postura definitiva, } \\
\text { dejandola abierta al } \\
\text { beneficio aportado por el } \\
\text { inversor }\end{array}$ & $\begin{array}{l}\text { El alumno a través de la } \\
\text { actividad no presencial en } \\
\text { su rol de ingeniero, actua } \\
\text { de forma ética en todo } \\
\text { momento basandose en el } \\
\text { proyecto presentado, no } \\
\text { dejandose influir por } \\
\text { ninguna parte }\end{array}$ & $\begin{array}{l}\text { El alumno a través de la } \\
\text { actividad no presencial en } \\
\text { su rol de ingeniero, actua } \\
\text { de forma ética en todo } \\
\text { momento basandose en el } \\
\text { proyecto presentado, no } \\
\text { dejandose influir por } \\
\text { ninguna parte. Del mismo } \\
\text { modo desarrolla en el } \\
\text { debate una posición } \\
\text { crítica en el debate con } \\
\text { las partes que intentan } \\
\text { modificar su postura en el } \\
\text { debate }\end{array}$ \\
\hline
\end{tabular}

En el caso de la asignatura de Máster, la rúbrica para evaluar esta actividad ha sido desarrollada sobre 3 indicadores únicamente (dos éticos y profesionales y uno medioambiental). El resto de indicadores, son trabajados de forma puntual, pero serán incorporados en otras actividades el próximo curso.

Tabla 3. Rúbrica de evaluación de las actividades para Nivel de dominio III (considerando indicadores medioambientales, éticos y profesionales)

\begin{tabular}{|c|c|c|c|c|}
\hline \multirow{2}{*}{ INDICADOR } & \multicolumn{3}{|c|}{ DESCRIPTOR } \\
\cline { 2 - 5 } & D. No alcanzado & C. En desarrollo & B. Adecuado & A. Excelente \\
\hline $\begin{array}{c}\text { 1. Actúa de modo } \\
\text { coherente y responsable } \\
\text { en sus decisiones }\end{array}$ & $\begin{array}{c}\text { No hay pruebas de que } \\
\text { reflexiones sobre su } \\
\text { conducta y no analiza las } \\
\text { consecuencias de sus } \\
\text { acciones. No se muestra } \\
\text { una actuación coherente }\end{array}$ & $\begin{array}{c}\text { Analiza a posteriori las } \\
\text { consecuencias de sus } \\
\text { acciones }\end{array}$ & $\begin{array}{c}\text { Asume la responsabilidad } \\
\text { de sus acciones y } \\
\text { conductas }\end{array}$ & $\begin{array}{c}\text { En su conducta argumenta } \\
\text { la coherencia entre sus } \\
\text { creencias y acciones. } \\
\text { Actúa según los valores } \\
\text { que declara }\end{array}$ \\
\cline { 2 - 5 } Evaluación atendiendo a \\
la actividad
\end{tabular}

(cc) EY-NC-ND 2017, Universitat Politècnica de València 
Modesto Pérez-Sánchez, P. Amparo López-Jiménez

Tabla 4. Rúbrica de evaluación de las actividades para Nivel de dominio III (considerando indicadores medioambientales, éticos y profesionales) [Continuación]

\begin{tabular}{|c|c|c|c|c|}
\hline \multirow{2}{*}{ INDICADOR } & \multicolumn{4}{|c|}{ DESCRIPTOR } \\
\hline & D. No alcanzado & C. En desarrollo & B. Adecuado & A. Excelente \\
\hline $\begin{array}{l}\text { 1. Actúa de modo } \\
\text { coherente y responsable } \\
\text { en sus decisiones }\end{array}$ & $\begin{array}{l}\text { No hay pruebas de que } \\
\text { reflexiones sobre su } \\
\text { conducta y no analiza las } \\
\text { consecuencias de sus } \\
\text { acciones. No se muestra } \\
\text { una actuación coherente }\end{array}$ & $\begin{array}{c}\text { Analiza a posteriori las } \\
\text { consecuencias de sus } \\
\text { acciones }\end{array}$ & $\begin{array}{c}\text { Asume la responsabilidad } \\
\text { de sus acciones y } \\
\text { conductas }\end{array}$ & $\begin{array}{l}\text { En su conducta argumenta } \\
\text { la coherencia entre sus } \\
\text { creencias y acciones. } \\
\text { Actúa según los valores } \\
\text { que declara }\end{array}$ \\
\hline $\begin{array}{c}\text { Evaluación atendiendo a } \\
\text { la actividad }\end{array}$ & $\begin{array}{c}\text { El alumno no cuestiona } \\
\text { el problema planteado en } \\
\text { la actividad ni aporta } \\
\text { ideas }\end{array}$ & $\begin{array}{c}\text { El alumno cuestiona el } \\
\text { problema planteado en } \\
\text { la actividad, aportando } \\
\text { alguna idea desarrollada } \\
\text { en clase }\end{array}$ & $\begin{array}{l}\text { El alumno cuestiona el } \\
\text { problema planteado en la } \\
\text { actividad, detallando las } \\
\text { causas del mismo y } \\
\text { aportando opiniones } \\
\text { fundamentadas que } \\
\text { justifican su decisión. }\end{array}$ & $\begin{array}{l}\text { El alumno cuestiona el } \\
\text { problema planteado en la } \\
\text { actividad, detallando las } \\
\text { causas del mismo y } \\
\text { aportando opiniones } \\
\text { fundamentadas que } \\
\text { justifican su decisión, } \\
\text { mostrandose representado } \\
\text { con la postura que } \\
\text { defiende. }\end{array}$ \\
\hline $\begin{array}{l}\text { 2. Gestiona de forma } \\
\text { adecuada situaciones } \\
\text { desde un punto de vista } \\
\text { ético resulten } \\
\text { significativas, complejas } \\
\text { o conflictivas }\end{array}$ & $\begin{array}{l}\text { Evita o no se implica } \\
\text { ante la exigenica de } \\
\text { resolver una práctica } \\
\text { concreta que simule } \\
\text { situaciones éticamente } \\
\text { significativas }\end{array}$ & $\begin{array}{l}\text { Contribuye y coopera } \\
\text { aunque de forma poco } \\
\text { comprometida en la } \\
\text { resolución de una } \\
\text { situación éticamente } \\
\text { significativa }\end{array}$ & $\begin{array}{l}\text { Contribuye y coopera a } \\
\text { nivel colectivo en la } \\
\text { resolución de una } \\
\text { situación éticamente } \\
\text { significativa }\end{array}$ & $\begin{array}{c}\text { Muestra un } \\
\text { comportamiento reflexivo, } \\
\text { crítico y proactivo en la } \\
\text { realización de una práctica } \\
\text { que desde el punto de } \\
\text { vista moral resulta } \\
\text { significativa, compleja y } \\
\text { conflictiva }\end{array}$ \\
\hline $\begin{array}{c}\text { Evaluación del } \\
\text { indicador atendiendo a } \\
\text { la actividad }\end{array}$ & $\begin{array}{l}\text { El alumno no aporta } \\
\text { ninguna idea, } \\
\text { determinando que el } \\
\text { problema no tiene } \\
\quad \text { solución }\end{array}$ & $\begin{array}{c}\text { El alumno aporta pocas } \\
\text { ideas nuevas (1), siendo } \\
\text { algunas de ejemplos } \\
\text { dados en clase, y en } \\
\text { algunos casos que no } \\
\text { pueden solventar el } \\
\text { problema }\end{array}$ & $\begin{array}{l}\text { El alumno aporta ideas } \\
\text { relacionadas con la } \\
\text { mecánica de los fluidos } \\
\text { (2-3). En este caso, la } \\
\text { mayoría de las ideas } \\
\text { resuelven la problemática } \\
\quad \text { planteada. }\end{array}$ & $\begin{array}{l}\text { El alumno aporta ideas } \\
\text { relacionadas con la } \\
\text { mecánica de los fluidos y } \\
\text { las relaciona con } \\
\text { conceptos desarrollados } \\
\text { en otras aplicaciones } \\
\text { (>3). En este caso todas } \\
\text { las ideas resuelven la } \\
\text { problemática planteada }\end{array}$ \\
\hline $\begin{array}{l}\text { 3. Coordina acciones } \\
\text { integrales respetuosas } \\
\text { en el ambito profesional }\end{array}$ & $\begin{array}{l}\text { No muestra interés en la } \\
\text { coordinación de acciones } \\
\text { integrales ni valora su } \\
\text { finalidad }\end{array}$ & $\begin{array}{c}\text { Coordina acciones } \\
\text { integrales con } \\
\text { deficiencias, de manera } \\
\text { incompleta y mejorable }\end{array}$ & $\begin{array}{c}\text { Coordina acciones } \\
\text { integrales, correctamente, } \\
\text { identificando los } \\
\text { elementos clave según } \\
\text { criterios consensuados }\end{array}$ & $\begin{array}{c}\text { Lidera sin abusos la } \\
\text { coordinación de acciones } \\
\text { integrales de los } \\
\text { profesionales con actitud } \\
\text { colaborativa y } \\
\text { constructiva }\end{array}$ \\
\hline $\begin{array}{c}\text { Evaluación del } \\
\text { indicador atendiendo a } \\
\text { la actividad }\end{array}$ & $\begin{array}{c}\text { El alumno no desarrolla } \\
\text { ninguna exposición }\end{array}$ & $\begin{array}{c}\text { El alumno desarrolla la } \\
\text { exposición, presenta los } \\
\text { aspectos favorables y } \\
\text { desfavorables } \\
\text { relacionados con el } \\
\text { medio ambiente, pero de } \\
\text { una forma incompleta }\end{array}$ & $\begin{array}{l}\text { El alumno expone de } \\
\text { forma clara los aspectos } \\
\text { positivos y negativos, } \\
\text { identifica el factor clave } \\
\text { que desencadena el } \\
\text { proceso. }\end{array}$ & $\begin{array}{l}\text { El alumno expone de } \\
\text { forma clara los aspectos } \\
\text { positivos y negativos, } \\
\text { identifica el factor clave } \\
\text { que desencadena el } \\
\text { proceso. No tiene } \\
\text { problema de coordinar su } \\
\text { discurso en lineas } \\
\text { similares que otros } \\
\text { compañeros desarrollen, } \\
\text { formando un único hilo } \\
\text { conductor sobre esa } \\
\text { posición sin intentar } \\
\text { destacar sobre el resto. }\end{array}$ \\
\hline
\end{tabular}

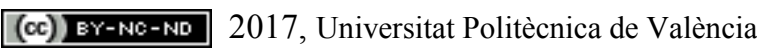

Congreso In-Red (2017) 


\section{Resultados}

\subsection{Resultados obtenidos en la asignatura Ingeniería Fluidomecánica}

La actividad propuesta como una de las evidencias de punto de control de la competencia transversal comenzó el 10/02/2017 y finalizó el 01/03/2017, desarrollándose el debate el día 16/03/2017. En la tarea no presencial participaron 115 alumnos de 136 matriculados $(84.55 \%)$. La tarea presencial fue desarrollada en dos grupos (los correspondientes a los grupos de teoría). En total asistieron un total de 120 personas, 63 personas en el grupo A y 57 personas en el grupo B, por lo tanto, se desarrollaron dos debates. En el primer caso se formaron 3 grupos de 16 personas y un grupo de 15. En el segundo caso, se hizo un grupo de 15 personas y 3 grupos de 14 personas, adoptando en cada caso el rol sorteado y desarrollando las 15 preguntas tal y como se ha descrito en la metodología. Tras finalizar el debate, en el cual el moderador anotaba todos los nombres de alumnos que participaban, se desarrolló una votación en la cual se preguntaba:

1. ¿Alumno ganador del debate?

2. ¿Estás de acuerdo con la actuación?

3. Consideras interesante el desarrollo de actividades similares en clase para fomentar la participación y desarrollo del conocimiento adquirido en la asignatura.

En el grupo A, el alumno ganador logró 39 votos de 63 posibles. Concretamente, se correspondía con el portavoz que representaba al grupo del inversor y en el debate participaron un total de 32 personas. Claramente el alumno mostró un discurso que, aunque a priori, no era el rol que más adeptos presentaba según la evaluación de la tarea no presencial, las argumentaciones en su exposición y posterior debate con ayuda en las réplicas de sus compañeros de grupo establecieron la "victoria". En el grupo B, pasó algo similar, pero con una menor diferencia. El alumno ganador fue el portavoz que representaba al grupo inversor con 19 votos de 57 posibles, participando en el debate un total de 24 personas.

En cuanto a la segunda pregunta, teniendo en cuenta ambos grupos se obtuvo que 67 personas estaban a favor de la instalación y 53 personas en contra, mostrando un porcentaje del 55.83\% a favor de la instalación. Analizando esta respuesta, se observa que el debate logró cambiar la opinión de una gran mayoría, puesto que en los comentarios de la tarea no presencial el $77.39 \%$ de los alumnos estaban en contra de la instalación.

El resultado de la tercera pregunta en la votación fue que el $74.16 \%$ de los alumnos estaba de acuerdo con realizar actividades similares, el $10.83 \%$ estaba en desacuerdo y el $28.33 \%$ se encontraba indiferente (voto en blanco).

Finalmente, los resultados de valoración de los indicadores 1 y 3 (Tabla 1) que tienen en cuenta la evaluación de la tarea no presencial, así como indicador 2 y 4 que tienen en cuenta la actividad presencial son mostrados en la Figura 3. En ellos se observa que el

(cc) EY-NC-ND 2017, Universitat Politècnica de València

Congreso IN-RED (2017) 
$82.88 \%$ de los alumnos como media obtiene un grado de alcanzado de la competencia de A o B.

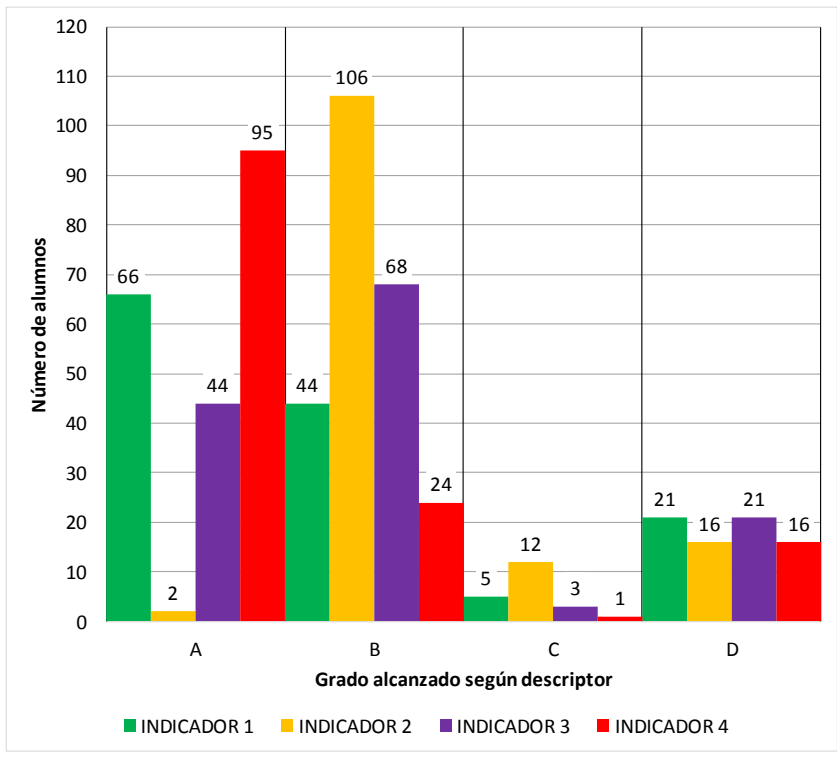

Fig. 3 Resultados de evaluación de los indicadores

Por otro lado, la figura establece que el desarrollo de la actividad permite a la mayoría de los alumnos desarrollar la competencia y únicamente destacan los alumnos con calificación $\mathrm{D}$, que en ambos casos coinciden y se corresponden con alumnos que actualmente no participan en los diferentes actos de evaluación continua de la asignatura.

\subsection{Resultados obtenidos en la asignatura Dispersión de Contaminantes en Agua y Atmósfera}

La actividad propuesta como una de las evidencias de punto de control de la competencia transversal comenzó el 10/02/2016 y finalizó el 14/03/2016. Durante este periodo de tiempo el alumno tenía que seleccionar un tema para defender la postura de a favor o en contra. El debate fue desarrollado el 21/04/20146. La participación en ambos casos fue del 100\%, tanto en la realización de la presentación (tarea no presencial) como de la participación del debate (actividad presencial). En este caso como únicamente son seis alumnos, no se desarrolló la formación de grupos. Tres de los alumnos eligieron un tema para defender su postura contraria al cambio climático, mientras que otros tres eligieron una postura a favor del cambio climático como consecuencia del incremento de la temperatura por acción antropogénica. Los temas escogidos fueron

- ROL Sí:

1) La influencia antropogénica sobre el efecto invernadero

2) El calentamiento global como consecuencia de la acción humana

3) El incremento de temperatura en la atmósfera a causa de las actividades antropogénicas

- ROL No:

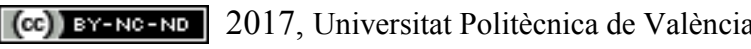


4) La pequeña edad del hielo como indicador de la periodicidad climática

5) La falta de evidencias en las edades antiguas para el establecimiento del cambio climático a largo plazo

6) El efecto invernadero como fuente de vida

La presentación tuvo una duración de 20 minutos por rol y el debate, en el cual cada alumno tuvo que preparar preguntas a partir de las presentaciones, fue 20 minutos también. Finalmente, el 'Rol Sí' obtuvo 2 votos a favor mientras que el 'Rol No' obtuvo 4 votos a favor resultando ganador el trabajo que llevaba por título La pequeña edad del hielo como indicador de la periodicidad climática.

En cuanto a la evaluación de la competencia transversal, teniendo en cuenta la actividad desarrollada y la rúbrica presentada en la Tablas 3 y 4, fue la que se adjunta en la Figura 4.

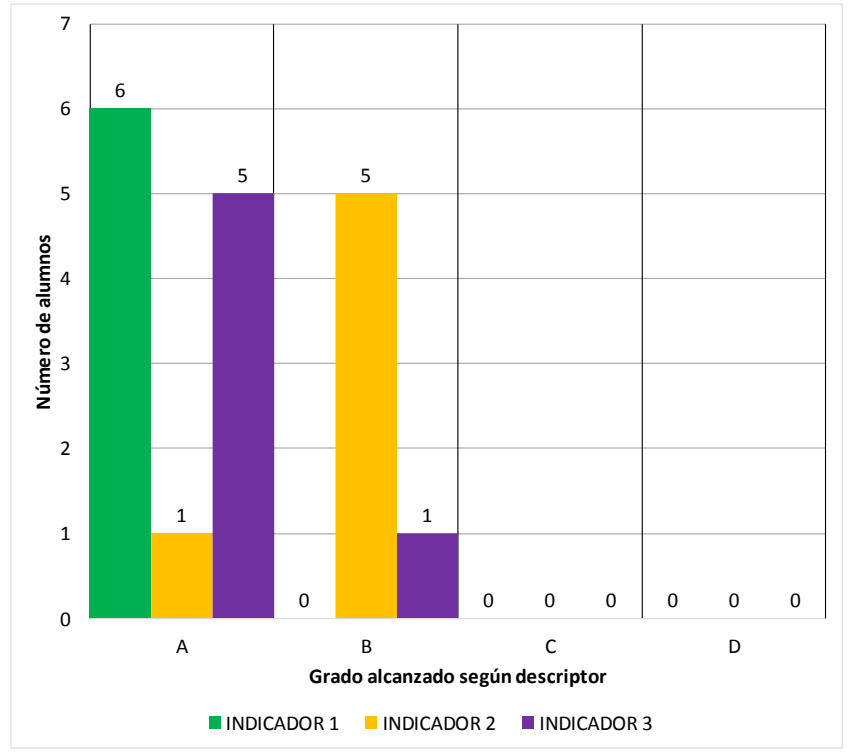

Fig. 4 Resultados de evaluación de los indicadores en la asignatura de master

\section{Conclusiones}

La técnica del debate permite la adquisición y puesta en práctica de muchas de las competencias transversales más valoradas para nuestros alumnos. Competencias como la comunicación efectiva, el trabajo en equipo, la capacidad de liderazgo, el análisis de problemas, la responsabilidad ética o ambientalización curricular son conseguidas tras los resultados de los debates descritos en la presente contribución. A través de los debates realizados en las asignaturas Ingeniería Fluidomecánica y Dispersión de Contaminantes en Agua y en Atmósfera de Grado de Ingeniería Mecánica y Máster Universitario de Ingeniería Industrial, se ha conseguido que los alumnos se involucren de forma activa y motivada en una argumentación que les permite adquirir conocimientos concretos que serán permanentes en el futuro para su vida profesional.

(c)) EY-NC-ND 2017, Universitat Politècnica de València 


\section{Referencias}

Cattani, Adelino. Los usos de la retórica. Alianza Ensayo. Madrid. 2003.

De OñA, R. López, G. ; GARACh, L.; CAlvo, DF. J.; De OÑA, J. (2010). Nueva conceptualización del debate, como herramienta de aprendizaje para la nueva enseñanza universitaria. Actas de las I Jornadas sobre Innovación Docente y Adaptación al EEES en las Titulaciones Técnicas, Granada 2010, pp. 61-66

Rodriguez, M. L. (2010). El debate como herramienta pedagógica. Plataforma de Metodología de la Investigación Científica y para la Guía de Tesis de Grado. Consultado en Internet en marzo de 2017 en: https://metodologiasdelainvestigacion.wordpress.com/2010/11/24/el-debate-comoherramienta-pedagogical

SANCHEZ PRIETO, G. (2007). El debate académico en el aula como herramienta didáctica y evaluativa. Universidad Europea de Madrid. Madrid. 


\title{
El Trabajo Fin de Grado en el Grado de Criminología: una herramienta de integración de competencias para los estudiantes y una experiencia de trabajo coordinado para los profesores ${ }^{1}$
}

\author{
Ana Isabel Cerezo Domíngueza ${ }^{a}$, María José Benítez Jiménez y Lorea Arenas García ${ }^{\mathrm{c}}$ \\ aProfesora Titular de Derecho penal y Criminología de la Universidad de Málaga \\ (aicerezo@uma.es), bAyudante doctor de Derecho penal y Criminología de la Universidad \\ de Málaga (mjbenitez@uma.es) y ${ }^{\mathrm{c}}$ Docente investigadora en formación de la Universidad \\ de Málaga (lorea@uma.es).
}

\begin{abstract}
In the Faculty of Law at the University of Malaga we have created an educational tool that aims students to achive an optimal level in developing the final degree work, compulsory subject in the last year of the Criminology studies. To do this, teachers will be working with students fron the first year all the necessary skills to achive this objective. In a coordinated way, by semester and year, each teacher will perform with students certain educational activities that allow the acquisition of skills such as improving written expression, proper management of ICT, the correct use of quotations literature, developing group work and oral expression, among others.
\end{abstract}

Keywords: final degree work, educational skills, coordination.

\begin{abstract}
Resumen: En la Facultad de derecho de la Universidad de Málaga hemos creado una herramienta docente que persigue que los alumnos alcancen un nivel óptimo en la elaboración del trabajo fin de grado, asignatura obligatoria del último curso del Grado de Criminología. Para ello, los profesores van a ir trabajando con los alumnos, desde el primer curso, todas las competencias necesarias para alcanzar este objetivo. De forma coordinada por curso y semestre, cada profesor realizará con los alumnos determinadas actividades docentes que permitan la adquisición de competencias tales como la mejorar la expresión escrita, el manejo adecuado de las tecnologías de la información y de la comunicación, la utilización correcta de citas bibliográficas, la elaboración de trabajos en grupo así como la expresión oral, entre otras.
\end{abstract}

Palabras clave: trabajo fin de grado, competencias, coordinación.

\footnotetext{
${ }^{1}$ El presente trabajo forma parte del Proyecto de Innovación Educativa denominado "El Trabajo Fin de Grado en la Facultad de Derecho: una herramienta de integración de competencias para los estudiantes y una experiencia de trabajo coordinado para los profesores", PIE 15-75. Entidad financiadora: Universidad de Málaga. Duración 01/01/2015 a 01/01/2017 (24 MESES) Investigadora principal: CARMEN MARÍA ÁVILA RODRÍGUEZ. Número de investigadores participantes: 41.
} 


\section{Introducción}

El art. 2 de la Ley Orgánica 6/2001, de 21 de diciembre, de Universidades (en adelante, LOU) afirma en su apartado $1^{\circ}$ la autonomía de las Universidades (las Universidades ... desarrollan sus funciones en régimen de autonomía), precisando en su apartado $2^{\circ}$ el elenco de facultades o competencias en las cuales aquélla se expresa ${ }^{2}$ Pues bien, de acuerdo con el citado precepto la autonomía de las Universidades comprende "la elaboración y aprobación de sus planes de estudios" [art. 2.2. d)], que en el caso de enseñanzas conducentes a la obtención de títulos de carácter oficial y validez en todo el territorio nacional deberá ajustarse a lo dispuesto en el Título VI de la LOU relativo a las enseñanzas y títulos, donde se remite al Gobierno la ordenación de las enseñanzas universitarias oficiales ${ }^{3 .}$

En consonancia con los principios consagrados en la LOU, el Real Decreto 1393/2007, de 29 de octubre, por el que se establece la ordenación de las enseñanzas universitarias oficiales ${ }^{4}$, profundiza en la concepción de la autonomía universitaria, dejando que sean las propias Universidades las que, de acuerdo con las reglas fijadas en el mismo, creen y propongan las enseñanzas y títulos que han de impartir y expedir, sin necesidad de sujetarse a un catálogo previo establecido por el Gobierno, como sucedía hasta ese momento 5 .

Por otra parte, como se advierte en el Preámbulo del propio Real Decreto, la nueva organización de las enseñanzas universitarias no se limita a un cambio estructural, sino que pretende además impulsar un cambio en las metodologías docentes, cuyo objetivo nuclear ha de ser el proceso de aprendizaje del estudiante. De ahí que, sin excluir el enfoque tradicional basado en contenidos y horas lectivas, los planes de estudios conducentes a la obtención de un título deben ahora centrarse en la adquisición de competencias por parte de los estudiantes, haciendo especial hincapié en los métodos de aprendizaje de dichas competencias y en los procedimientos para evaluar su adquisición.

\footnotetext{
${ }^{2}$ Sobre la autonomía de las Universidades, en general, y su regulación en la LOU, en particular, ver Souviron y Palencia (2002).

${ }^{3}$ Arts. 35.1 y 37 de la LOU, ambos en redacción dada por la Ley Orgánica 4/2007, de 12 de abril, por la que se modifica la Ley Orgánica 6/2001, de 21 de diciembre, de Universidades. Art. 35.1: "El Gobierno establecerá las directrices y las condiciones para la obtención de los títulos universitarios de carácter oficial y con validez en todo el territorio nacional..."; y art. 37: "Las enseñanzas universitarias se estructurarán en tres ciclos: Grado, Máster y Doctorado. La superación de tales enseñanzas dará derecho, en los términos que establezca el Gobierno, previo informe del Consejo de Universidades, a la obtención de los títulos oficiales correspondientes",

${ }^{4}$ BOE núm. 260, de 30 de octubre de 2007. El Real Decreto 1393/2007 ha sido modificado por el Real Decreto 861/2010, de 2 de julio (BOE núm. 161, de 3 de julio de 2010), si bien la modifícación no afecta a la regulación de la asignatura TFG.

${ }^{5}$ De acuerdo con el art. 34.1 y 2 de la LOU, en su redacción originaria, los diferentes títulos de carácter oficial y validez en todo el territorio nacional eran establecidos específicamente por el Gobierno de la Nación, integrándose en el Catálogo de Títulos Universitarios Oficiales, que también debía aprobar el Gobierno; como bien señalan Souviron y Palencia (2002) en la pág. 322, ello suponía que tales títulos oficiales constituían "un $<<$ numerus clausus $>>$, ampliable tan solo con el establecimiento por el Gobierno de un nuevo título oficial".
}

(cc) EY-NC-ND 2017, Universitat Politècnica de València 
En este marco conceptual, el art. 12 del citado Real Decreto 1393/2007, relativo a las directrices para el diseño de títulos de Graduado, establece en sus apdos $2^{\circ}, 3^{\circ}$ y $7^{\circ}$ las siguientes reglas básicas sobre el Trabajo de Fin de Grado:

-La obligatoriedad de que las enseñanzas de Grado concluyan con la elaboración y defensa de un TFG, lo cual significa que el TFG es una asignatura obligatoria que el alumno debe superar para poder obtener su título;

-La asignación al TFG de un mínimo de 6 créditos y un máximo de 30;

-El momento temporal en que debe realizarse el TFG, a saber, la fase final del plan de estudios: $\mathrm{y}$

-La necesidad de que el TFG esté orientado a la evaluación de competencias asociadas al título de que se trate.

En aplicación de tales preceptos, el Plan de Estudios del Grado en Criminología de la Universidad de Málaga establece la superación por el alumno de una asignatura de TFG de carácter obligatorio, con un contenido de 12 créditos ECTS, que se desarrolla en el segundo cuatrimestre del cuarto curso. Los estudiantes podrán matricularse en la misma siempre que cumplan los requisitos establecidos en la Memoria de Verificación del título, esto es, que haya superado el $70 \%$ de los créditos que conforman el plan de estudios.

El TFG consiste en un trabajo autónomo e individual que cada estudiante realizará bajo la orientación de un tutor, quien actuará como dinamizador y facilitador del proceso de aprendizaje (Ferrer, Carmona y Soria, 2012). Debe ser un trabajo original no presentado con anterioridad por el estudiante para superar otras materias en cualquiera de las Titulaciones a las que resulta de aplicación el presente Reglamento, o en otras titulaciones previamente cursadas en esta $\mathrm{u}$ otras universidades. Teniendo en cuenta las características mencionadas, podrán plantearse, en cuanto a su contenido, distintos tipos de TFG que permitan, a su vez, evaluar el grado de adquisición por parte de los estudiantes de las competencias definidas para esta materia en las respectivas Memorias de Verificación.

El contenido del TFG puede referirse a: trabajos empíricos o de campo; análisis y estudio acerca de la jurisprudencia de tribunales tanto nacionales como internacionales en relación a las materias establecidas por los Departamentos; estudios, informes o dictámenes originales vinculados a alguna/s de la materias desarrolladas en el Grado; cualquier otra investigación que se adecue a los contenidos y competencias que conforman la titulación de Graduado en Criminología.

La función de evaluación y calificación del TFG se atribuye en exclusiva a los Tribunales de Evaluación, mediante la aplicación de las rúbricas para la evaluación de competencias del Trabajo de Fin de Grado establecidas en el Reglamento del TFG de la Facultad de Derecho de la UMA (art. 11.1), las cuales se dividen en tres categorías: aspectos formales y estructura del TFG, expresión escrita y expresión oral y capacidad de síntesis del alumno en la exposición del trabajo, con una ponderación del $50 \%, 25 \%$ y $25 \%$, respectivamente (Castro, Cerezo y Benítez, 2015). 
Los criterios de valoración son los siguientes:

Aspectos formales y estructurales del TFG. (50\%)

El TFG cumple los requisitos formales de presentación.

El alumno ha acudido a las sesiones de trabajo con el tutor, incorporando sus sugerencias y comentarios y ha seguido el plan de trabajo establecido.

Originalidad.

Dificultad

Están definidas de forma clara las hipótesis y los objetivos del TFG.

Están identificadas las partes fundamentales del TFG.

Se exponen con claridad los resultados y se realiza una discusión de los mismos.

Las conclusiones del TFG responden a las hipótesis y objetivos planteados inicialmente.

Expresión escrita: $(25 \%)$

El alumno expresa, por escrito, de forma clara las ideas y objetivos, siguiendo las normas gramaticales y ortográficas.

El alumno utiliza apropiadamente terminología y vocabulario adecuados al tema.

El alumno cita adecuadamente el material empleado, utilizando bibliografía actualizada y apropiada al tema del TFG.

Expresión oral y capacidad de síntesis: $(25 \%)$

El alumno se expresa con claridad en la presentación oral del TFG.

El alumno muestra capacidad de síntesis en la presentación del trabajo realizado.

El alumno responde adecuadamente y de forma razonada a las preguntas que se le formulan.

De acuerdo con la normativa que acabamos de analizar, el TFG debe estar orientado a la adquisición tanto de las competencias generales del título de que se trate, en nuestro caso, el Grado en Criminología de la UMA, como de las competencias específicas asignadas a esta asignatura, recogidas ambas en la Memoria de Verificación del Grado en Criminología (arts. 12.7 del Real Decreto 1393/2007; 3.2 del Reglamento del TFG de la UMA; y 2.1 del Reglamento del TFG de la Facultad de Derecho de la UMA).

Si bien no es éste el lugar para detenernos en el estudio del concepto de competencia en el ámbito educativo, dada la importancia que la determinación de las 
competencias correspondientes a las titulaciones universitarias presenta en el diseño de los respectivos planes de estudio ${ }^{6,}$ nos parece oportuno ofrecer un breve esbozo del mismo.

La Comisión Europea define la competencia como "la capacidad demostrada de utilizar conocimientos y destrezas", considerando el conocimiento como el resultado de la asimilación de información que tiene lugar durante el proceso de aprendizaje y la destreza como la habilidad para aplicar conocimientos y utilizar técnicas a fin de completar tareas y resolver problemas (Feito, 2010). Por su parte, en el denominado Informe DeSeCo (Definición y Selección de Competencias), elaborado por la OCDE, se afirma que "la competencia es más que conocimientos y destrezas. Involucra la habilidad de enfrentar demandas complejas, apoyándose en y movilizando recursos psicosociales (incluyendo destrezas y actitudes) en un contexto en particular"7 Así, pues, la educación basada en competencias trata de formar a las personas no solo para que puedan participar en el mundo laboral, sino para que sean capaces de desarrollar un proyecto personal de vida (Feito, 2010).

Como puede apreciarse, el concepto de competencia educativa se presenta como un concepto complejo, lo que, unido a la falta de acuerdo entre los agentes llamados a intervenir en el contexto del EEES (el Ministerio de Educación, las Agencias para la calidad del sistema universitario -estatal y autonómicas-, y los expertos en pedagogía) en cuanto a su utilización en un sentido unívoco, ha podido coadyuvar a que el catálogo competencial establecido en los planes de estudio de nuestras titulaciones universitarias no presente en muchas ocasiones la formulación más adecuada (Bolivar, 2008).

Aclarados estos extremos, pasamos a enunciar las competencias generales y específicas $^{8}$ asociadas a la asignatura TFG en la Memoria de Verificación del Grado en Criminología de la UMA:

\footnotetext{
${ }^{6}$ A este respecto, Bolivar (2008), afirma que "el debate sobre el nuevo diseño de las titulaciones en términos de competencias no es sólo técnico, primariamente es político e ideológico: cuál debe ser la función de la Universidad en relación con la formación (formar para empleo o introducir en un ámbito cultural) y el tipo de profesionalidad requerida. El discurso de las "competencias" supone redefinir la profesionalidad como la regulación de un listado de competencias para la enseñanza, que los estudiantes han de adquirir para conseguir el título. En un plano general, lo que se discute es el mismo modelo de Universidad, que debe mediar entre modelo académico (Humboldt) y el profesionalizador (anglosajón o neoliberal). Una herencia de la educación liberal es que la enseñanza universitaria ha de proporcionar una formación de la inteligencia y el saber crítico, conjugada con un saber especializado profesionalizador".

${ }^{7}$ No obstante, como señala Bolivar (2008), conviene advertir que el Proyecto DeSeCo se dirige a la educación obligatoria, no a la universitaria.

${ }^{8}$ Como ponen de manifiesto Sánchez-Elvira, López y Fernández (2010), la necesidad de que la educación superior asuma como objetivo final la preparación de los ciudadanos para los nuevos retos del siglo XXI ha llevado a incorporar en los diseños de las titulaciones, junto a las competencias profesionales específicas, las denominadas competencias genéricas o transversales, entendidas como capacidades y destrezas que pueden ser utilizadas en muchas situaciones, no sólo en aquellas relacionadas con el área de estudio concreta, las cuales constituyen piezas clave de la nueva formación universitaria en su apuesta por potenciar la empleabilidad y el aprendizaje a lo largo de la vida. De este modo, el estudiante podrá desempeñarse de forma eficaz en un mercado laboral
} 


\section{-Competencias generales del Título (CG):}

CG 1.6. Utilizar herramientas propias del método científico para la planificación, diseño y ejecución de investigaciones básicas y aplicadas desde la etapa de reconocimiento hasta la evaluación de resultados y conclusiones.

CG 1.7. Realizar, evaluar y ejecutar proyectos e informes científico-técnicos relacionados con la criminalidad.

CG 1.8. Conocer y aplicar técnicas y procedimientos para la resolución de problemas y la toma de decisiones (desde una perspectiva sistémica que fomente la visión global del problema, su análisis y las interrelaciones existentes entre los mismos).

CG 1.9. Saber transmitir información, ideas, problemas y soluciones de carácter criminológico tanto a un público especializado como no especializado.

CG 1.10. Ser capaz de trabajar en equipo con otros profesionales en las diferentes vertientes de la actividad criminológica.

CG 1.12. Utilizar las Tecnologías de la Información y la Comunicación en la resolución de problemas y búsqueda de información en el ámbito de la Criminología.

-Competencias específicas (CE):

CE 2.7. Saber diseñar un proyecto de investigación empírico, aplicar técnicas de investigación cuantitativa y cualitativa, y analizar estadísticamente los datos.

CE 2.8. Saber difundir y exponer adecuadamente los resultados de una investigación en congresos académicos y a los medios de comunicación.

2.9. Saber elaborar e interpretar un informe criminológico.

2.10. Saber elaborar y evaluar programas y estrategias de prevención y/o intervención de la criminalidad.

CE 2.11. Conocer las técnicas de evaluación de riesgo de violencia y delincuencia y saber aplicarlas a casos concretos.

CE 2.19. Manejar los términos criminológicos en lengua inglesa.

\section{Objetivos}

El objetivo principal del presente trabajo es facilitar tanto a profesores como a alumnos la oportunidad de que los segundos vayan adquiriendo y reforzando durante la carrera las competencias que con posterioridad se van a exigir en la asignatura de trabajo fin de grado (en adelante TFG) del Grado de Criminología de la Universidad de Málaga.

dinámico, adaptarse de forma flexible a los rápidos cambios y demandas sociales y, en definitiva, constituirse en agente activo en la construcción de la sociedad del conocimiento.

(c)) EY-NC-ND 2017, Universitat Politècnica de València

Congreso IN-RED (2017) 
Desde que se comenzó a impartir la asignatura de TFG venimos observando una importante carencia en los alumnos que cursan esta asignatura en el último año de carrera. Los tutores que dirigimos estos trabajos nos hemos encontrado con alumnos que redactan con mucha dificultad, incluso con faltas de ortografía, que no saben realizar citas bibliográficas o incluso ignoran una serie de normas básicas estructurales respecto a la elaboración de un trabajo. Ello produce una situación de alta frustración tanto en los alumnos como en sus profesores.

Entendemos que este problema se pueda resolver a través de una herramienta docente que sea capaz de integrar las competencias que deben adquirir los estudiantes y, al mismo tiempo, sea una experiencia de trabajo coordinado para los profesores.

\section{Desarrollo de la inovación. Plan de trabajo por competencias y semestre: una nueva herramienta docente.}

La metodología que se va a seguir a fin de conseguir nuestro objetivo consiste en fijar durante los tres primeros cursos de la titulación del grado de Criminología un plan de trabajo determinado, de tal forma que durante un curso y un semestre se trabajen de manera coordinada por los profesores que imparten docencia en ese curso y semestre una competencia específica del Grado.

El profesor de una asignatura elegirá, en función de la competencia asignada a trabajar en ese curso y semestre, qué actividades quiere poner en práctica con los alumnos de su grupo. Para ello seleccionará aquellas que les parezca oportunas de un amplio cuadro que se ofertará, a modo de sugerencia. A la vez que el alumno va adquiriendo los conocimientos propios y exigidos de la materia, va trabajando conscientemente sobre las competencias que con posterioridad le serán valoradas en la asignatura de Trabajo Fin de Grado. En cada curso académico se van añadiendo competencias de modo que el alumnado de cuarto curso que se matricule del Trabajo Fin de Grado habrá podido ir aprendiendo tanto una metodología como el uso de las herramientas oportunas para superar satisfactoriamente la asignatura.

Para realizar este plan de trabajo será imprescindible la colaboración del mayor número posible de profesores, de tal modo que para cada curso y semestre se creen equipos docentes que sean capaces de coordinarse de cara a lograr que el estudiante adquiera las correspondientes competencias. Ello significa que a los alumnos de un curso, semestre y grupo se le deben proponer actividades no reiterativas. Aconsejamos igualmente que estas pequeñas actividades se incardinen en la evaluación docente de las correspondientes asignaturas, de tal forma que su realización sea prácticamente preceptiva. Como apoyo al sistema descrito se realizarán seminarios y sesiones informativas y de trabajo con los profesores de cada curso y semestre para incrementar la coordinación en la práctica docente. 


\section{Resultados preliminares}

La lista de habilidades a trabajar en cada competencia y propuesta de actividades en el Grado de Criminología son las siguientes:

\section{Primer curso primer y segundo semestre.}

Objetivo: Uso de las Tecnologías de la Información y la Comunicación en la búsqueda de información en el ámbito de la Criminología:

a) Realización del curso que se oferta en biblioteca: Manejar bibliografía adecuada e indicar correctamente las referencias bibliográficas empleadas tanto a lo largo del texto del trabajo como en el apartado de bibliografía.

b) Búsqueda de fuentes de información estadística o de carácter secundario.

c) Búsqueda de Bibliografía: Lectura y recensión de artículos doctrinales para cuya localización se facilitará solamente la referencia de la Revista científica.

\section{Segundo curso primer semestre}

Objetivo: Utilización de herramientas propias del método científico para la planificación y diseño de investigaciones empíricas. Se persigue la adquisición de las siguientes habilidades:

a) Diseño de un proyecto de investigación empírico.

b) Elaboración del marco teórico

c) Elaboración de objetivos e hipótesis de estudio

d) Aplicación de técnicas de investigación cuantitativa y/o cualitativa.

\section{Segundo curso segundo semestre}

Objetivo: Realización de proyectos e informes científico-técnicos relacionados con la criminalidad. Se persigue que se trabajen las siguientes habilidades:

a) Orden expositivo escrito.

b) Cumplimiento del formato establecido.

c) Expresión escrita ortográfica y gramatical.

d) Idoneidad de las referencias usadas.

e) Trabajo en equipo

f) Análisis cuantitativo y/o cualitativo de los datos recogidos

g) Revisión crítica y aplicación práctica a partir de las conclusiones obtenidas.

\section{Tercer Curso primer semestre:}

Objetivo: Exposiciones orales de temas de programación docente o de trabajos de investigación. Se persigue que se trabajen las siguientes habilidades:

a) Orden expositivo oral.

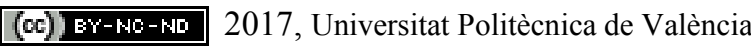

Congreso IN-RED (2017) 
b) Cumplimiento de los tiempos establecidos.

c) Adecuada modulación de la voz.

d) Uso del lenguaje corporal y oral.

e) Claridad, ritmo y organización de la exposición.

f) Respuesta adecuada y pertinente argumentación a las preguntas y comentarios del profesor y los compañeros.

\section{Tercer Curso segundo semestre:}

Objetivo: Análisis crítico y toma de decisiones. Se persigue que se trabajen las siguientes habilidades:

a) Grado de coherencia en el razonamiento.

b) Justificación del desarrollo y conclusiones.

c) Resolución de problemas desde distintos ámbitos de la Criminología.

d) Toma de decisiones desde una perspectiva sistémica que fomente la visión global del problema, su análisis y las interrelaciones existentes entre los mismos.

Para los profesores-tutores de trabajos fin de grado se elaborará y facilitará un diario de evaluación para los alumnos a los que tutorizan. Ese diario estará formado por una serie de documentos que se ofrecerán como herramienta que facilite tener un control documentado de la evaluación de las competencias, del ritmo y resultado del trabajo del estudiante a lo largo de la elaboración del Trabajo fin de Grado y en el que se haga constar la dedicación real a cada alumno y trabajo para que en la medida de los posible se refleje la necesidad de reforma de la dedicación a estos trabajos que reconoce el POD.

A modo de ejemplo contará con los siguientes documentos:

a) Acuerdo suscrito entre alumno y profesor por el cual el alumno se compromete a asistir con aprovechamiento a las tutorías que determine el profesor tutor y a cumplir con el plan de trabajo que fije el tutor.

b) Hoja de control de entregas periódicas del trabajo al tutor, con observaciones de si el estudiante ha incorporado sus sugerencias y comentarios y ha seguido el plan de trabajo establecido.

c) Hoja de verificación de definición de hipótesis, objetivos y conclusiones del trabajo.

d) Hoja de verificación de metodología y partes del trabajo.

e) Hoja de verificación de terminología y uso adecuado de vocabulario.

f) Hoja de verificación de uso de Bibliografía apropiada y actualizada.

g) Hoja de verificación del tiempo dedicado a cada alumno.

\section{Conclusiones}

La asignatura de Trabajo Fin de Grado en las nuevas titulaciones españolas está suponiendo un cambio docente significativo. Muchos asimilan esta asignatura a los 
anteriores proyectos fin de carrera, pero lo cierto es que nos encontramos ante una situación diferente y novedosa. En el Grado de Criminología que se imparte en la Facultad de Derecho de la Universidad de Málaga llevamos un tiempo trabajando para conseguir dotar de contenido y coherencia a esta híbrida asignatura.

La tarea no es fácil, si tenemos en cuenta que se trata de una asignatura como otra cualquiera del plan de estudios pero con unas características muy específicas, ya que son un gran número de profesores los implicados en la misma. Por otro lado, nos encontramos con la especificidad de que para superarla es necesaria la elaboración de un trabajo de investigación, a través del cual el alumno tiene que demostrar que ha alcanzado todas las competencias que ha ido adquiriendo durante la carrera.

En el presente artículo hemos intentado dar solución a todas las dificultades que atraviesa esta asignatura de Trabajo Fin de Grado. Principalmente, hemos querido plasmar la idea, basada en nuestra corta experiencia como docentes de dicha asignatura, de que los estudiantes se enfrentan a la realización de un TFG sin los conocimientos suficientes acerca de su elaboración y desarrollo. Ello es debido a que durante la carrera no han ido adquiriendo de forma paulatina las competencias necesarias para alcanzar el nivel que se les exige en la etapa final de sus estudios universitarios.

Para solventar esta dificultad, hemos ideado una herramienta de trabajo que se basa en la coordinación de los profesores de cara a proponer diferentes actividades durante el desarrollo de las asignaturas curriculares y de esta forma preparar adecuadamente al alumno que se enfrenta a la elaboración de un TFG.

\section{Referencias}

Bolivar Botia, A. (2008). "El discurso de las competencias en España: educación básica y educación superior", en Red U. Revista de Docencia Universitaria, 2, p.1-23.

Castro, M.P., Cerezo, A.I. y BeníteZ, M.J. (2015). "Diseño de un procedimiento objetivo para la evaluación y calificación de la asignatura de Trabajo Fin de Grado en el Grado de criminología de la Universidad de Málaga”, en Revista Jurídica de Investigación e Innovación Educativa (REIJE), 12, p.1-19.

Feito Alonso, R. (2010). "De las competencias básicas al currículum integrado", en Qurriculum: Revista de teoría, investigación y práctica educativa, 23.

Ferrer, V., CARmona, M. y Soria, V. (2012). El Trabajo de Fin de Grado. Guía para estudiantes, docentes y agentes colaboradores. Nueva York: MacGraw-Hill.

OCDE, Informe DeSeCo: La definición y selección de competencias clave. Resumen Ejecutivo.

SÁNCHEZ-ELVIRA, A., LÓPEZ-GONZÁLEZ M.A. Y FernANDEZ-SÁNCHEZ, M.V. (2010). "Análisis de las competencias genéricas en los nuevos títulos de grado del EEES en las Universidades españolas", en Red U. Revista de Docencia Universitaria, vol 8, 1, p. 1-39.

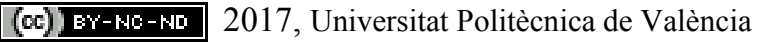


SOUVIRON Morenilla, J.M. y PALENCIA HERREJón, F. (2002). La nueva regulación de las Universidades. Comentarios y Análisis sistemático de la Ley Orgánica 6/2001, de 21 de diciembre, de Universidades. Granada: Comares.

\section{Legislación y normas}

España. Ley Orgánica 6/2001, de 21 de diciembre, de Universidades. BOE, 14 de diciembre de 2001, núm. 307, p. 49400 - 49425.

España. Ley Orgánica 4/2007, de 12 de abril, por la que se modifica la Ley Orgánica 6/2001,

de 21 de diciembre, de Universidades. BOE, de 13 de abril de 2007, núm. 89, p. 16241 -

16260.

España. Real Decreto 1393/2007, de 29 de octubre, por el que se establece la ordenación de las enseñanzas universitarias oficiales. $B O E$, de 30 de octubre de 2007, núm. 260, p. 44037 $-44048$.

España. Real Decreto 861/2010, de 2 de julio, por el que se modifica el Real Decreto 1393/2007, de 29 de octubre, por el que se establece la ordenación de las enseñanzas universitarias oficiales. $B O E$, de 3 de julio de 2010, núm. 161, p. 58454 - 58468. 


\title{
Evaluar la competencia "Innovación, Creatividad y Emprendimiento" en asignaturas del área de la Mecánica de los Fluidos. Caso de estudio en Grado y Máster
}

\author{
P. Amparo López-Jiménez ${ }^{\text {, Modesto Pérez-Sánchez }}{ }^{a}$ \\ ${ }^{a}$ Departamento de Ingeniería Hidráulica y Medio Ambiente. Universitat Politècnica de València. \\ palopez@upv.es; mopesan1@upv.es.
}

\begin{abstract}
The UPV generic student outcomes "Innovation, creativity and entrepreneurship" belongs to the strategic plan of the UPV to reach all transversal competences, being in itself a competence to be used as a learning strategy for students to fix complex contents in a deductive way. This contribution describes the experience of the authors in the implementation of this competence in different Bachelor and Master's Degrees, in matters related to Fluid Mechanics. Different activities 6-3-5 were performed in these levels with groups of very diverse students, with a similar programming of the activity. The experience allowed the authors affirm that this strategy is a powerful technique for students to develop their creativity, as well as their curiosity for acquiring the knowledge. The reach of the knowledge is finally expected of the curricular content of the subjects at both levels. Two rubbrics were developed, which enable to evaluate the domain level with various indicators considering weighted values each activity.
\end{abstract}

Keywords: UPV generic student outcomes, creativity, innovation, entrepreneurship, fluid mechanics, dispersion of pollutants

\footnotetext{
Resumen

La competencia transversal "Innovación, creatividad y emprendimiento" pertenece al plan estratégico de la UPV para alcanzar todas las competencias transversales, siendo en sí misma una competencia que puede ser utilizada tambien como estrategia de aprendizaje para que los alumnos fijen contenidos complejos de una forma deductiva. La presente contribución describe la experiencia de los autores en la implementación de esta competencia a nivel de Grado y Master en diferentes titulaciones, en materias relacionadas con la Mecánica de Fluidos. La realización de actividades 6-3-5 en estos niveles, con grupos de alumnos diversos, con una programación similar de la actividad, permite afirmar que es una técnica potente para que los alumnos desarrollen su creatividad a la vez que su curiosidad para adquirir los conocimientos que finalmente se esperan del contenido curricular de las asignaturas en ambos niveles. Se presenta una rúbrica para ambos dominios que permite evaluar varios indicadores con diferentes pesos ponderados cada actividad propuesta.
} 
Palabras clave: competencia transversal, creatividad, innovación, emprendimiento, mecánica de fluidos, dispersión de contaminantes

\section{Introducción}

La creatividad, innovación y emprendimiento son conceptos que están fuertemente ligados a la ingeniería, en la cual, la búsqueda de soluciones a un problema así como adoptar la solución definitiva son actividades y funciones que un ingeniero debe adoptar en su día a día. No obstante, aunque los tres términos pueden conducir a pensar que son sinónimos, existen diferencias entre ellos. Por ello, si atendemos a su definición (RAE, 2017) de los verbos:

- Crear: "Establecrr, fundar intr-ducir por vez -rimer algo"

- Innovar: "Mudar o alterar algo, introduciendo novedades"

- Emprender: "Acometer y comenzar una obra"

Atendiendo a las definiciones anteriormente expuestas, se pone de manifiesto que aunque se encuentran relacionados no son sinónimos, existiendo una correlación temporal en la toma de decisiones entre las acciones de creatividad, innovación y emprendimiento. Aunque en un principio, estos conceptos pueden ser asociados a temáticas empresariales, el trinomio definido anteriormente esta asociado a cualquier ámbito de la vida social y profesional. Por tanto, la sociedad necesita de gente con un espíritu emprendedor (Fernandes et al., 2017), la cual innove soluciones a los problemas que presente la sociedad, emprendiendo ideas que conduzcan a crear nuevos productos, servicios y/o propuestas que mejoren a las existentes.

La Universidad debe ser pionera en la mejora de estos profesionales y por tanto, ser parte de la unidad formadora en los estudiantes que cursan los estudios de grado y/o máster. Estos alumnos se encuentran en una fase terminal de formación, y en un breve periodo corto de tiempo, se encontraran con situaciones en las cuales, deberán detectar el problema, buscar posibles soluciones y emprender la que se considere que lo solventa de una forma más éficaz. Relacionado con lo anteriormente expuesto, la Universitat Politècnica de València puso en marcha el proyecto de competencias transversales denominado Plan Estratégico UPV2020, donde el primer reto es "La Universitat Politècnica de València tiene como objetivo avanzar hacia modelos de formación que logren que sus estudiantes adquieran las competencias necesarias para poder tener una adecuada inserción laboral" (Vidal-Carreras et al., 2016). Estas competencias, las cuales suman un total de 13, buscan complementar la formación del estudiante junto con las competencias genéricas y específicas de cada uno de los planes de estudios.

Dentro de esas 13 competencias transversales, se encuentra la competencia tranversal $C T$ 04 “Innovación, Emprendimiento y Creatividad", la cual es trabajada por el alumno a lo largo de su formación universitaria en tres niveles diferentes en los estudios de grado (Nivel I y II) y de máster (Nivel III). Entre las diferentes asignaturas impartidas en el Departamento de Ingeniería Hidráulica y Medio Ambiente, las asignaturas Mecánica de Fluidos (impartida en segundo curso del Grado de Ingeniería Química de la EPSA) y Dispersión de Contaminantes en Agua y Atmósfera (impartida en segundo curso del Máster Universitario en Ingeniería Industrial) son punto de control en Nivel I y III, respectivamente.

Aunque en un principio, puede parecer que esta competencia es difícil de aplicar en asignaturas que no están directamente aplicadas a un mundo empresarial, el presente trabajo muestra que la competencia puede ser desarrollada y evaluada en asignaturas con una fuerte

(cc) EY-NC-ND 2017, Universitat Politècnica de València 
componente teórica o técnica, cómo puede ser las relacionadas con el área de la mecánica de fluidos. Del mismo modo, se muestra la planificación propuesta para desarrollar durante el curso, así como los resultados obtenidos durante una de las evaluaciones desarrolladas.

\section{Objetivos}

El objetivo de la experiencia es desarrollar una estrategia de tareas presenciales y no presenciales, en la cual se muestre cómo se trabaja a lo largo del curso esta competencia, así como, mostrar la metodología propuesta, desarrollada y evaluada en una de las tareas que sirven como envidencia de punto de control.

Finalmente, se analizan las semejanzas y diferencias existentes entre alumnos de nivel de dominio I y de nivel III.

\section{Desarrollo de la innovación}

\subsection{Identificando el problema}

En todos los casos, a lo largo de las diferentes unidades didácticas el docente expone al alumno la metodología de trabajo necesaria para poder resolver un problema. En este caso, la metodología esta centrada en seis intervalos diferentes, los cuales definidos, tal y como se recoge en la Figura 1.

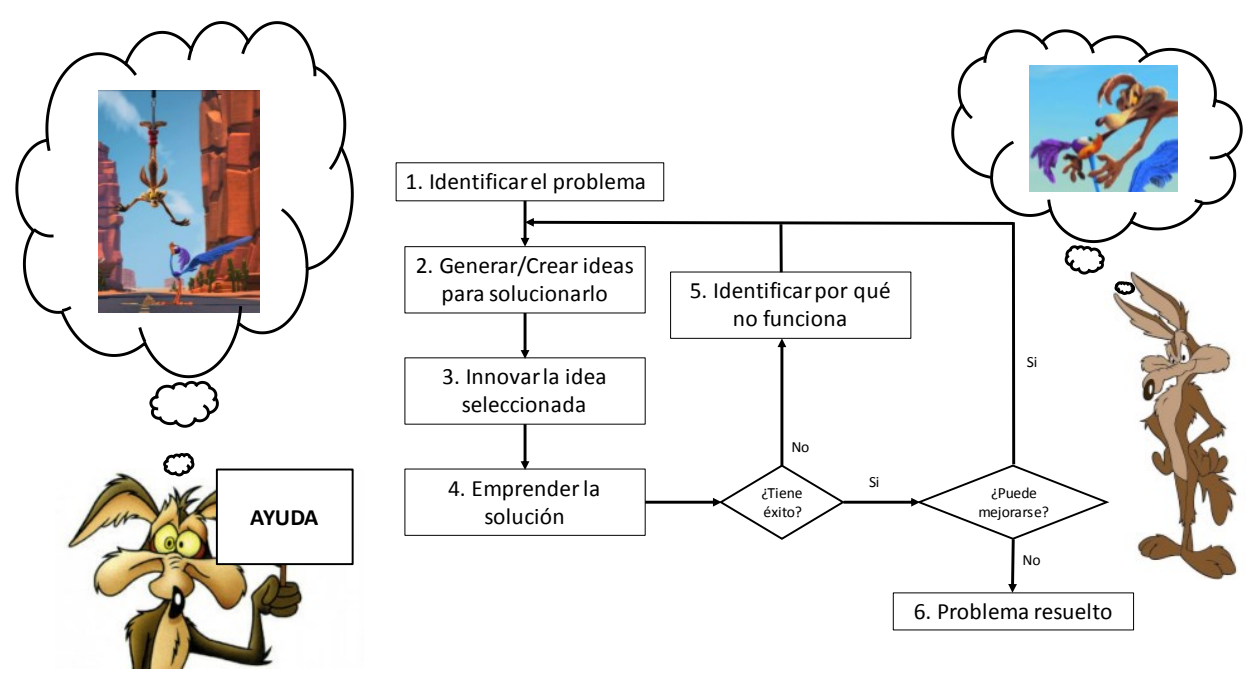

Fig. 1 Identificando el problema y buscando su solución. Elaboración propia

1. Identificando el problema: si se pretende innovar, emprender y crear en cualquier situación que pretenda resolver o mejorar un proceso, el primer paso es detectar el problema. Esta es la primera fase, la cual requiere un análisis previo de la situación. Esta parte de indentificación del problema o deficiencia, está ligada con la competencia transversal CT-03 Análisis y Resolución de Problemas.

2. Generar/Crear ideas: Es la primera de las fases de trabajo, una vez detectado el problema, la búsqueda de ideas que mejoren la situación de partida, constituye uno 
de los procesos claves. Esta búsqueda puede desarrollarse de forma individual o en grupo con diferentes métodos que facilitan el trabajo. Esa generación de ideas será desarrollada en menor o mayor profundidad de acuerdo al nivel de dominio analizado (Figura 2).

3. Innovar la idea seleccionada: Definidas las ideas propuestas, el alumno o grupo de alumnos deben establecer el plan de acción a desarrollar para seleccionar el resultado idóneo, el cual dote de solución al problema planteado. Este plan de acción, en su nivel de dominio I estará centrado unicamente en plasmar las ideas mientras que en un nivel III, los alumnos deben desarrollar el plan de acción a acometer para solventar el problema.

4. Emprender la solución: el trabajo y consecución de los resultados de aprendizaje en los indicadores anteriores (Indicador I y II en la Figura 2), permite al individuo seleccionar la idea (la cual entiende que mejor soluciona o determina el problema planteado), pasando de enumerar el resultado obtenido de la solución (Nivel de dominio I) hasta analizar y/o determinar el valor alcanzado con la solución propuesta en un nivel de dominio III (Figura 2)

5. Identificar el fallo: establecida la solución o idea propuesta, al igual que en cualquier ámbito laboral, debe considerarse si la solución tiene éxito. En caso de que la respuesta sea negativa, el estudiante debe generar o crear nuevas ideas que resuelvan el problema propuesto. En caso de que la respuesta sea positiva, un análisis de la idea adoptada debe ser realizado, con el objeto de buscar nuevas mejoras.

6. Problema resuelto: desarrollado el análisis, sino se considera necesarios adoptar nuevas mejoras, el problema o idea se da por finalizado.

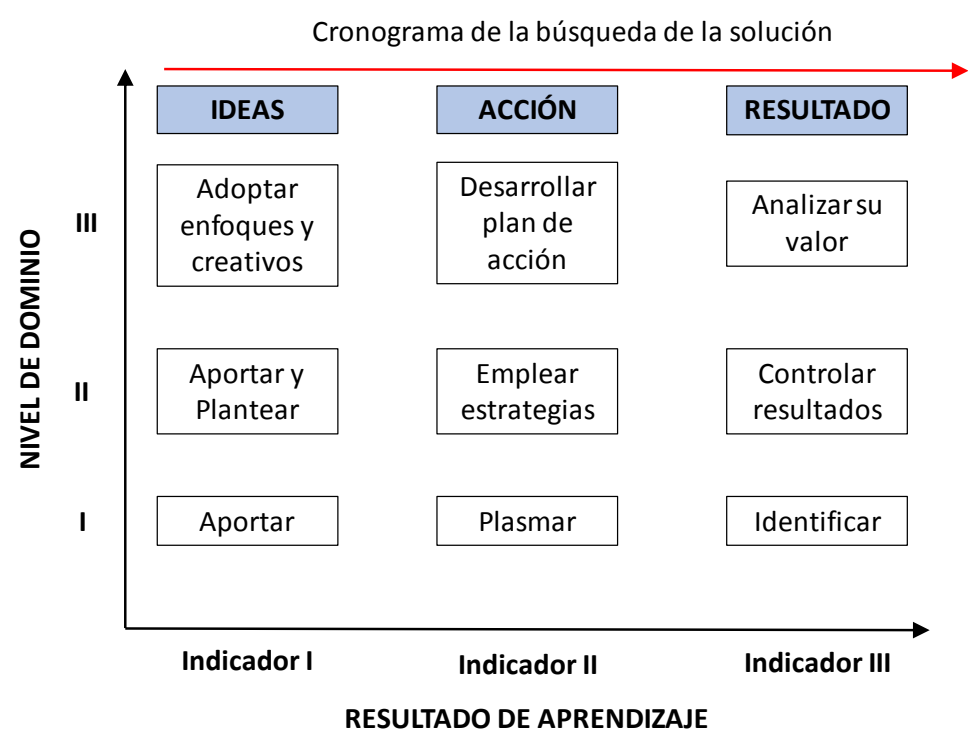

Fig. 2 Resultados de aprendizaje en función del nivel de dominio y cronograma en el tiempo (adaptado de Cuenca et al., 2015)

\subsection{Metodología de trabajo}

(cc) EY-NC-ND 2017, Universitat Politècnica de València 
La competencia transversal ha sido introducida dentro del desarrollo de ambas asignaturas, estableciendo diferentes puntos de control a lo largo de la misma. Estos actos de evaluación permiten medir la evolución de los alumnos a lo largo del curso, a medida que se trabaja.

El trabajo de la competencia ha sido propuesto de una forma lineal y progresiva, en la cual el alumno, guiado por el profesor, trabaja de forma activa la innovación y creatividad en la toma de decisiones. Esta toma de decisiones esta fundamentada en los conceptos desarrollados en cada una de las unidades que se desarrollan en las sesiones presenciales. La creación, innovación y emprendimiento el alumno lo trabaja en las diferentes prácticas de aula e informáticas propuestas y guiadas por el profesor. De forma lateral y no presencial, el alumno puede complementar su formación de forma asíncrona con el uso de objetos de aprendizaje (López-Jimenez \& Pérez-Sánchez, 2016; Pérez-Sánchez \& López-Jimenez, 2017).

Finalmente, se establecen cuatro puntos de control que permiten evaluar la competencia durante el semestre B del curso. Esta evaluación está distribuida temporalmente, tal y como se adjunta en la Figura 3.

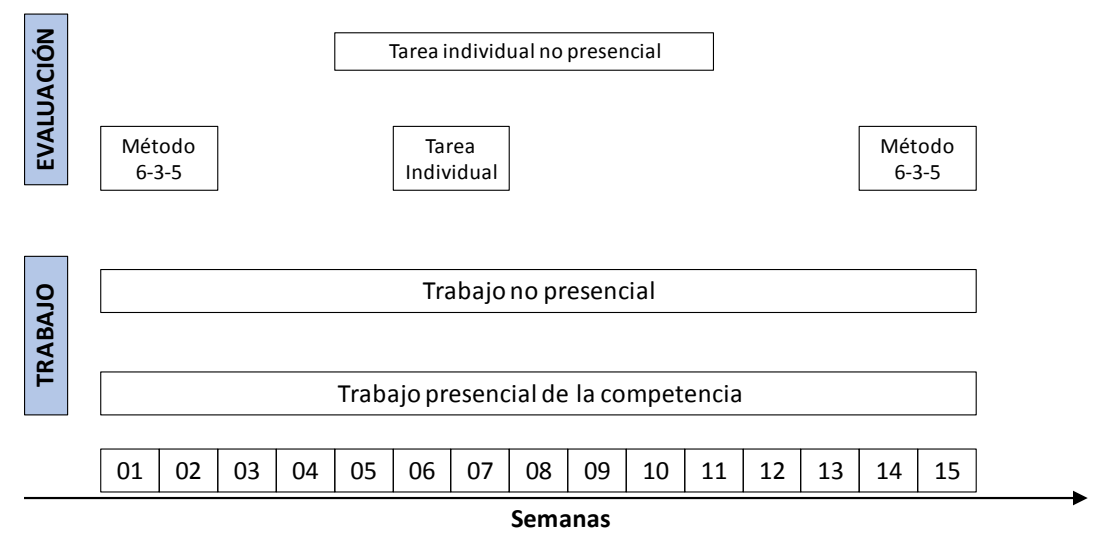

Fig. 3 Cronograma de la asignatura. Elaboración propia

La evaluación está centrada en cuatro actividades, de las cuales, tres son presenciales y una de ellas no presencial. Las actividades presenciales buscan que el alumno tenga que establecer la creación e innovación de ideas en un tiempo limitado (aproximadamente $1 \mathrm{~h}$ que dura la actividad). En cambio, la actividad de evaluación no presencial, dota al alumno de una mayor libertad de tiempo para desarrollar dicha actividad. Por tanto, dispone de un mayor tiempo para la generación y razonamiento de las ideas, las cuales pueden ser abordadas de una forma más pausada y ser consideradas en una mayor profundidad. Las tareas presenciales han sido el Método 6-3-5 (Cuenca et al., 2015), una al inicio de cuatrimestre y otra al final, así como una "Fast task", la cual es propuesta a mitad de cuatrimestre que coincide con la evaluación del primer parcial. En todos los casos, las tareas son adaptadas al curso de grado o máster, dependiendo donde se esté impartiendo. La tarea no presencial propuesta, contempla el mismo problema que debe ser abordado tanto por los alumnos de grado como de máster. El objetivo, es poder analizar las diferencias 
existentes entre las ideas aportadas por los diferentes alumnos en función del nivel de dominio donde se encuentren.

En cuanto al método 6-3-5, éste ha sido complementado de forma que el alumno además de trabajar la CT-04, permita trabajar y mejorar otras competencias transversales incluidas en el Plan Estrategico UPV2020 (Vidal-Carreras et al., 2016). La metodología desarrollada es descrita en la siguiente sección.

\subsection{Ejemplo de tarea desarrollada. Método 6-3-5 con decisión final}

Tal y como se ha descrito, dos de las actividades desarrolladas se corresponden con el Método 6-3-5. Este método es una técnica de creatividad derivada de la tormenta de ideas, en la cual, el alumno debe trabajar en grupo (Beitz et al., 1996). En esta actividad, los alumnos deben establecer grupos de 6 personas, los cuales deben escribir 3 ideas cada uno sobre una problemática planteada en un tiempo de $5 \mathrm{~min}$ cada uno. Esto permite establecer un total de 18 ideas en $30 \mathrm{~min}$.

Este metodo que presenta ventajas como la facilidad de desarrollo, no necesidad de un moderador cualificado y el incremento del aprendizaje activo por parte del estudiante. En cambio, tiene ciertas desventajas como la falta de creatividad por la limitación del tiempo o por falta de discusión y reflexión.

Cómo novedad en el método planteado, en la actividad además de establecer la metodología normal de desarrollo del método 6-3-5, fue introducida una actividad complementaria para trabajar tanto las competencias de comunicación efectiva como de trabajo en equipo y liderazgo.

De este modo, la metodología de trabajo durante el desarrollo de la clase fue:

1) Formación de grupos de trabajo de 6 personas (en el caso de máster de 4, porque el número era más reducido). En estos grupos de trabajo se evita que sean alumnos que habitualmente estudien o asistan juntos a clase en el mismo grupo. Con esta decisión, se fomenta el trabajo en equipo en ambientes de menor confianza.

2) Presentación del problema. El profesor a través de una imagen y/o pregunta, presenta el problema que en todos los casos (grado y máster) estaba relacionado con una unidad didáctica impartida en el curso. Por lo tanto, los alumnos pueden basarse en los resultados de aprendizaje de la asignatura así como otros alcanzados en otras asignaturas relacionadas o no con la Mecánica de los Fluidos.

3) Desarrollo del Método 6-3-5. Planteada la cuestión que engloba el problema, los alumnos forman los grupos de 6 personas, y tras seleccionar el turno de participación escribe cada uno de ellos sus tres ideas.

4) Fase de filtrado de ideas. Una vez el grupo ha desarrollado las 18 ideas, entre los seis integrantes deben de ponerse de acuerdo cual es la mejor idea, seleccionandola y argumentando su decisión en un máximo de 35 palabras, con ello se prentende que el alumno pueda sintetizar y plasmar las ideas, así como plantear de forma esquemática el plan acción en el caso de Nivel de Dominio III.

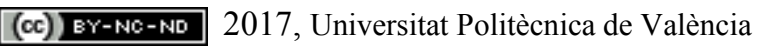


5) Defensa de la idea seleccionada. Una vez el grupo ha decidido la idea, la ha justificado y ha nombrado un portavoz (todo ello en $5 \mathrm{~min}$ ), se genera un debate en clase, en el cual cada portavoz: enumera las 18 ideas, expone la idea seleccionada (durante un tiempo máximo de $3 \mathrm{~min}$, sin turno de réplica), argumentando porque la ha seleccionado frente a otras, así como plasmando las lineas de acción para solventar el problema (Nivel de Dominio III, únicamente). Finalmente, se realiza una votación a mano alzada en la cual se selecciona la mejor idea para solventar el problema.

\subsection{Evaluación de la competencia transversal}

La evaluación de la competencia transversal se ha planteado mediante el uso de rúbrica. La rúbrica utilizada ha sido adaptada por la propuesta desde el grupo de trabajo del Instituto de Ciencias de la Educación (Cuenca et al., 2015b) para ambos niveles. Está rúbrica ha sido adaptada atendiendo a las actividades desarrolladas en los cuatro indicadores tanto para el Nive I como Nivel III, tal y como se refleja en la Tabla 1 y Tabla 2 adjuntadas a continuación.

Tabla 1. Rúbrica de evaluación de las actividades para Nivel de dominio I.

\begin{tabular}{|c|c|c|c|c|}
\hline \multirow{2}{*}{ INDICADOR } & \multicolumn{4}{|c|}{ DESCRIPTOR } \\
\hline & D. No alcanzado & C. En desarrollo & B. Adecuado & A. Excelente \\
\hline $\begin{array}{l}\text { 1. Se cuestiona la } \\
\text { realidad }\end{array}$ & $\begin{array}{l}\text { No se cuestiona la } \\
\text { realidad }\end{array}$ & $\begin{array}{l}\text { Se plantea alguna } \\
\text { pregunta sobre la } \\
\text { realidad }\end{array}$ & $\begin{array}{c}\text { Aporta sus propias ideas } \\
\text { elaboradas con suficiente } \\
\text { detalle }\end{array}$ & $\begin{array}{l}\text { Aporta gran variedad de } \\
\text { ideas y planteamientos } \\
\text { novedosos, con fluidez } \\
\text { bien elaborados }\end{array}$ \\
\hline $\begin{array}{c}\text { Evaluación atendiendo a } \\
\text { la actividad }\end{array}$ & $\begin{array}{c}\text { El alumno no cuestiona } \\
\text { problema planteado en } \\
\text { la actividad }\end{array}$ & $\begin{array}{l}\text { El alumno cuestiona el } \\
\text { problema planteado en } \\
\text { la actividad, con } \\
\text { ejemplos planteados en } \\
\text { clase }\end{array}$ & $\begin{array}{c}\text { El alumno cuestiona el } \\
\text { problema planteado en la } \\
\text { actividad, detallando las } \\
\text { causas del mismo }\end{array}$ & $\begin{array}{l}\text { El alumno cuestiona el } \\
\text { problema planteado en la } \\
\text { actividad, detallando en } \\
\text { profundidad las causas } \\
\text { del mismo }\end{array}$ \\
\hline 2. Aporta Ideas & $\begin{array}{c}\text { No aporta ideas y } \\
\text { muestra actitud pasiva } \\
\text { ante las tareas }\end{array}$ & $\begin{array}{l}\text { Plantea alguna idea ante } \\
\text { situaciones nuevas }\end{array}$ & $\begin{array}{c}\text { Aporta sus propias ideas, } \\
\text { elaborados con suficiente } \\
\text { detalle }\end{array}$ & $\begin{array}{c}\text { Aporta una gran variedad } \\
\text { de ideas y planteamientos } \\
\text { novedosos, con fluidez, } \\
\text { bien elaborados }\end{array}$ \\
\hline $\begin{array}{c}\text { Evaluación del } \\
\text { indicador atendiendo a } \\
\text { la actividad }\end{array}$ & $\begin{array}{l}\text { El alumno no aporta } \\
\text { ninguna idea, } \\
\text { determinando que el } \\
\text { problema no tiene } \\
\text { solución }\end{array}$ & $\begin{array}{c}\text { El alumno aporta pocas } \\
\text { ideas nuevas (1-2), } \\
\text { siendo algunas de } \\
\text { ejemplos dados en clase, } \\
\text { y en algunos casos que } \\
\text { no pueden solventar el } \\
\text { problema }\end{array}$ & $\begin{array}{l}\text { El alumno aporta ideas } \\
\text { (>3) relacionadas con la } \\
\text { mecánica de los fluidos. } \\
\text { En este caso, la mayoria } \\
\text { de las ideas resuelven la } \\
\text { problemática planteada. }\end{array}$ & $\begin{array}{l}\text { El alumno aporta ideas } \\
\text { relacionadas con la } \\
\text { mecánica de los fluidos y } \\
\text { las relaciona con } \\
\text { conceptos desarrollados } \\
\text { en otras aplicaciones } \\
\text { (>3). En este caso todas } \\
\text { las ideas resuelven la } \\
\text { problemática planteada }\end{array}$ \\
\hline $\begin{array}{l}\text { 3. Plasma de manera } \\
\text { formal las ideas }\end{array}$ & $\begin{array}{l}\text { No plasma de manera } \\
\text { formal las ideas }\end{array}$ & $\begin{array}{c}\text { Plasma de manera } \\
\text { limitada las ideas que se } \\
\text { han generado }\end{array}$ & $\begin{array}{c}\text { Plasma de manera } \\
\text { correcta las ideas que se } \\
\text { han generado }\end{array}$ & $\begin{array}{c}\text { Plasma de manera } \\
\text { enriquecida las ideas que } \\
\text { se han generado }\end{array}$ \\
\hline $\begin{array}{c}\text { Evaluación del } \\
\text { indicador atendiendo a } \\
\text { la actividad }\end{array}$ & $\begin{array}{c}\text { El alumno no aporta ni } \\
\text { plasma ninguna idea } \\
\text { para solucionar el } \\
\text { problema }\end{array}$ & $\begin{array}{l}\text { El alumno aporta ideas, } \\
\text { pero las plasma de una } \\
\text { manera confusa, como } \\
\text { consecuencia que no } \\
\text { resuelven el problema }\end{array}$ & $\begin{array}{c}\text { El alumno plasma las } \\
\text { ideas, fundamentándose } \\
\text { en los conceptos } \\
\text { desarrollados en la } \\
\text { asignatura }\end{array}$ & $\begin{array}{l}\text { El alumno plasma las } \\
\text { ideas, fundamentándose } \\
\text { en los conceptos } \\
\text { desarrollados en la } \\
\text { asignatura, asi como en } \\
\text { otros conceptos } \\
\text { desarrollados en otras }\end{array}$ \\
\hline $\begin{array}{l}\text { 4. Identifica los } \\
\text { resultados }\end{array}$ & No identifica resultados & $\begin{array}{l}\text { Identifica de manera } \\
\text { limitada resultados }\end{array}$ & $\begin{array}{l}\text { Identifica adecuadamente } \\
\text { resultados }\end{array}$ & $\begin{array}{c}\text { Define parámetros } \\
\text { asociados a los resultados }\end{array}$ \\
\hline
\end{tabular}


Evaluar la competencia "Innovación, Creatividad y Emprendimiento" en asignaturas del área de la Mecánica de los Fluidos. Caso de estudio en Grado y Máster

\begin{tabular}{|c|c|c|c|c|}
$\begin{array}{c}\text { Evaluación del } \\
\text { indicador atendiendo a }\end{array}$ & $\begin{array}{c}\text { El alumno no puede dar } \\
\text { una solución a la } \\
\text { problemática planteada }\end{array}$ & $\begin{array}{c}\text { El alumno no tiene gran } \\
\text { variedad de resultados } \\
\text { para poder solventar la } \\
\text { problemática, como } \\
\text { consecuencia del número } \\
\text { reducido de ideas }\end{array}$ & $\begin{array}{c}\text { El alumno tiene posibles } \\
\text { resultados que ofrecer, } \\
\text { relacionados únicamente } \\
\text { con la asignatura }\end{array}$ & $\begin{array}{c}\text { El alumno tiene diferentes } \\
\text { resultados válidos que } \\
\text { todos ellos podrían dar } \\
\text { solución al problema, } \\
\text { relacionando no solo con } \\
\text { la asignatura sino con } \\
\text { otras asignaturas ya } \\
\text { cursadas }\end{array}$ \\
\end{tabular}

Tabla 2. Rúbrica de evaluación de las actividades para Nivel de dominio III.

\begin{tabular}{|c|c|c|c|c|}
\hline \multirow{2}{*}{ INDICADOR } & \multicolumn{4}{|c|}{ DESCRIPTOR } \\
\hline & D. No alcanzado & C. En desarrollo & B. Adecuado & A. Excelente \\
\hline $\begin{array}{l}\text { 1. Integra } \\
\text { conocimientos de otras } \\
\text { disciplinas }\end{array}$ & $\begin{array}{l}\text { No es capaz de integrar } \\
\text { sus conocimientos } \\
\text { previos para generar } \\
\text { nuevos conocimientos o } \\
\text { ideas }\end{array}$ & $\begin{array}{l}\text { Integra conocimientos de } \\
\text { diversos campos pero sin } \\
\text { que ello sirva para } \\
\text { generar ideas novedosas }\end{array}$ & $\begin{array}{c}\text { Genera nuevas ideas } \\
\text { integrando conocimientos } \\
\text { de varias disciplinas, } \\
\text { fuentes o ambitos }\end{array}$ & $\begin{array}{l}\text { La integración que realiza } \\
\text { de conocimientos genera } \\
\text { ideas que mejoran las } \\
\text { soluciones anteriores a un } \\
\text { problema o situación } \\
\text { determinada }\end{array}$ \\
\hline $\begin{array}{c}\text { Evaluación atendiendo a } \\
\text { la actividad }\end{array}$ & $\begin{array}{c}\text { El alumno no cuestiona } \\
\text { el problema planteado en } \\
\text { la actividad ni aporta } \\
\text { ideas }\end{array}$ & $\begin{array}{c}\text { El alumno cuestiona el } \\
\text { problema planteado en } \\
\text { la actividad, aportando } \\
\text { alguna idea desarrollada } \\
\text { en clase }\end{array}$ & $\begin{array}{l}\text { El alumno cuestiona el } \\
\text { problema planteado en la } \\
\text { actividad, detallando las } \\
\text { causas del mismo y } \\
\text { aportando ideas } \\
\text { relacionadas con la } \\
\text { asignatura }\end{array}$ & $\begin{array}{l}\text { El alumno cuestiona el } \\
\text { problema planteado en la } \\
\text { actividad, detallando en } \\
\text { profundidad las causas } \\
\text { del mismo y aportando } \\
\text { ideas relacionada con la } \\
\text { asignatura y otras } \\
\text { diferentes ya cursadas }\end{array}$ \\
\hline $\begin{array}{l}\text { 2. Adopta enfoques } \\
\text { creativos en el } \\
\text { contenido y modo de } \\
\text { realización }\end{array}$ & $\begin{array}{c}\text { No propone ideas } \\
\text { originales a la situación } \\
\text { planteada }\end{array}$ & $\begin{array}{l}\text { Propone ideas y enfoques } \\
\text { que no se adaptan a la } \\
\text { situación y/o no } \\
\text { especifica correctamente } \\
\text { el modo de ejecución }\end{array}$ & $\begin{array}{c}\text { Adopta enfoques } \\
\text { adecuados de la situación } \\
\text { y un correcto } \\
\text { planteamiento del modo } \\
\text { de realización }\end{array}$ & $\begin{array}{c}\text { Adopta enfoques } \\
\text { originales, genera nuevas } \\
\text { ideas divergentes a partir } \\
\text { de perspectivas diferentes } \\
\text { y aporta creatividad en lo } \\
\text { que hace, mejorando } \\
\text { sistemas, procedimientos } \\
\text { y procesos }\end{array}$ \\
\hline $\begin{array}{c}\text { Evaluación del } \\
\text { indicador atendiendo a } \\
\text { la actividad }\end{array}$ & $\begin{array}{l}\text { El alumno no aporta } \\
\text { ninguna idea, } \\
\text { determinando que el } \\
\text { problema no tiene } \\
\text { solución }\end{array}$ & $\begin{array}{c}\text { El alumno aporta pocas } \\
\text { ideas nuevas (l), siendo } \\
\text { algunas de ejemplos } \\
\text { dados en clase, y en } \\
\text { algunos casos que no } \\
\text { pueden solventar el } \\
\text { problema }\end{array}$ & $\begin{array}{l}\text { El alumno aporta ideas } \\
\text { relacionadas con la } \\
\text { mecánica de los fluidos } \\
\text { (2-3). En este caso, la } \\
\text { mayoría de las ideas } \\
\text { resuelven la problemática } \\
\text { planteada. }\end{array}$ & $\begin{array}{l}\text { El alumno aporta ideas } \\
\text { relacionadas con la } \\
\text { mecánica de los fluidos y } \\
\text { las relaciona con } \\
\text { conceptos desarrollados } \\
\text { en otras aplicaciones } \\
\text { (>3). En este caso todas } \\
\text { las ideas resuelven la } \\
\text { problemática planteada }\end{array}$ \\
\hline $\begin{array}{l}\text { 3. Propone un plan de } \\
\text { acción }\end{array}$ & $\begin{array}{l}\text { No genera una lista } \\
\text { completa de tareas }\end{array}$ & $\begin{array}{c}\text { Genera una lista de } \\
\text { tareas que establezca el } \\
\text { plan de acción pero falta } \\
\text { información relevante }\end{array}$ & $\begin{array}{l}\text { Plantea de forma completa } \\
\text { un plan de acción }\end{array}$ & $\begin{array}{l}\text { Plantea de manera formal } \\
\text { y detallada un plan de } \\
\text { acción, ejecutando alguna } \\
\text { de sus fases }\end{array}$ \\
\hline $\begin{array}{c}\text { Evaluación del } \\
\text { indicador atendiendo a } \\
\text { la actividad }\end{array}$ & $\begin{array}{c}\text { El alumno no es capaz de } \\
\text { generar una lista de } \\
\text { tareas para desarrollar } \\
\text { su plan }\end{array}$ & $\begin{array}{l}\text { El alumno es capaz de } \\
\text { generar una lista de } \\
\text { tareas, al menos sus } \\
\text { puntos fundamentales, } \\
\text { pero no es capaz de } \\
\text { completar las variables } \\
\text { directos e indirectos que } \\
\text { afectan al problema }\end{array}$ & $\begin{array}{c}\text { El alumno completa el } \\
\text { plan de acción con la } \\
\text { información necesaria } \\
\text { para desarrollarlo, } \\
\text { describiendo la totalidad } \\
\text { de variables directas e } \\
\text { indirectas que afectan a la } \\
\text { solución de la } \\
\text { problemática }\end{array}$ & $\begin{array}{c}\text { El alumno completa el } \\
\text { plan de acción, define la } \\
\text { totalidad de las variables } \\
\text { y es capaz de llevarlo en } \\
\text { parte o en su totalidad, } \\
\text { sino de forma práctica a } \\
\text { través de una descripción } \\
\text { teórica. }\end{array}$ \\
\hline $\begin{array}{l}\text { 4. Analiza el valor de la } \\
\text { innovación }\end{array}$ & $\begin{array}{c}\text { No lleva a cabo ningún } \\
\text { análisis }\end{array}$ & $\begin{array}{l}\text { Identifica algunos } \\
\text { riesgos de la innovación } \\
\text { de forma limitada }\end{array}$ & $\begin{array}{l}\text { Realiza algun análisis del } \\
\text { valor de la innovación }\end{array}$ & $\begin{array}{c}\text { Realiza un análisis global } \\
\text { del valor de la innovación, } \\
\text { utilizando herramientas } \\
\text { adecuadas }\end{array}$ \\
\hline $\begin{array}{c}\text { Evaluacion del } \\
\text { indicador atendiendo a }\end{array}$ & $\begin{array}{l}\text { El alumno no aporta } \\
\text { idea o si la aporta no }\end{array}$ & $\begin{array}{l}\text { El alumno identifica al } \\
\text { menos un punto débil de }\end{array}$ & $\begin{array}{l}\text { El alumno identifica los } \\
\text { puntos fuertes y débiles de }\end{array}$ & $\begin{array}{l}\text { El alumno identifica los } \\
\text { puntos fuertes y débiles de }\end{array}$ \\
\hline
\end{tabular}

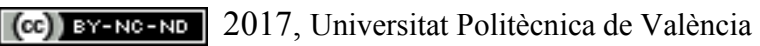

Congreso IN-RED (2017) 


\begin{tabular}{|c|c|c|c|c|}
\hline la actividad & $\begin{array}{l}\text { puede desarrollar un } \\
\text { análisis de la solución a } \\
\text { problemática planteada }\end{array}$ & $\begin{array}{l}\text { su innovación o idea, no } \\
\text { siendo capaz de } \\
\text { identificar los riesgos } \\
\text { que conlleva }\end{array}$ & $\begin{array}{l}\text { la innovación (>3), siendo } \\
\text { crítico con aspectos } \\
\text { relacionados con la } \\
\text { mecánica de los fluidos }\end{array}$ & $\begin{array}{l}\text { la innovación ( } 5 \text { ), siendo } \\
\text { crítico con aspectos } \\
\text { relacionados con la } \\
\text { mecánica de los fluidos } \\
\text { así como con aspectos de } \\
\text { su entorno de los cuales } \\
\text { no depende la mecánica } \\
\text { de fluidos }\end{array}$ \\
\hline
\end{tabular}

Definidas las rúbricas, adaptando el indicador a la evaluación de la actividad realizada, y teniendo en cuenta que es el primer año que se desarrollaba la actividad y se evaluaba la competencia, los autores decidieron otorgar un mayor peso escecifico al indicador 1 y 2 de cada uno de las rúbricas. Ambos indicadores compuntan un $60 \%$ (30\% cada uno) de la evaluación de la competencia y los indicadores 3 y 4 de cada rúbrica un $20 \%$ cada uno.

Cómo existian 4 actividades diferentes, se desarrolló una equiparación númerica a cada una de los grados alcanzados en cada uno de los indicadores y actividades, para posteriormente, poder establecer el grado final alcanzado por el alumno. La equivalencia númerica fues establecida de acuerdo a la Tabla 3.

Tabla 3. Evaluación de competencia transversal.

\begin{tabular}{|c|c|}
\hline Grado Alcanzado en el Indicador & Equivalencia Númerica \\
\hline Excelente (A) & 5 \\
\hline Bien (B) & 2 \\
\hline En desarrollo (C) & 1 \\
\hline No alcanzado (D) & 3 \\
\hline
\end{tabular}

Definida cada actividad como $\left(\mathrm{A}_{\mathrm{i}}\right)$, la nota obtenida en la competencia transversal viene definida por la expresión:

$$
N C=\frac{\sum_{i=1}^{n}\left(0.3 * I_{1}+0.3 * I_{2}+0.2 * I_{3}++0.2 * I_{4}\right)}{n}
$$

Donde NC es la nota numérica obtenida en la evaluación de la competencia transversal; $I_{1}$ es el nivel alcanzado en el indicador $1 ; I_{2}$ es el nivel alcanzado en el indicador $2 ; \mathrm{I}_{3}$ es el nivel alcanzado en el indicador $3 ; \mathrm{I}_{4}$ es el nivel alcanzado en el indicador 4; y n es el número de actividades desarrolladas.

La evaluación de la competencia viene establecida según la Tabla 4:

Tabla 4. Evaluación de competencia transversal.

\begin{tabular}{|c|c|}
\hline Evaluación Competencia & Equivalencia Númerica \\
\hline Excelente (A) & $3.5 \leq \mathrm{NC} \leq 5$ \\
\hline Bien (B) & $2 \leq \mathrm{NC}<3.5$ \\
\hline
\end{tabular}

(cc)) BY-NC-ND 2017, Universitat Politècnica de València 


\begin{tabular}{|c|c|}
\hline En desarrollo (C) & $1<N C<2$ \\
\hline No alcanzado (D) & 1 \\
\hline
\end{tabular}

\section{Resultados}

La metodología descrita se ha puesto en marcha en el curso 2016/17, y ambas asignaturas se imparten en el cuatrimestre B. Por lo tanto, no se pueden mostrar los resultados finales de la evaluación final de los alumnos, pero sí que se pueden mostrar resultados parciales de evaluación, así como los resultados obtenidos en el Método 6-3-5. Aunque son resultados parciales, muestran un buen grado de satisfación tanto en los resultados académicos como en la opinión personal de los alumnos que han desarrollado las actividades.

\subsection{Resultados Método 6-3-5}

Como ejemplo, se adjunta la pregunta (Figura 4) que fue planteada en la primera actividad del Método 6-3-5 a los alumnos de Grado. La asignatura se denomina Mecánica de Fluidos es troncal de segundo curso de Grado de Ingeniería Química. En ella el profesor mostraba una imagen de un jugador de baloncesto que se disponía a saltar sobre una piscina llena de fluido. El objetivo del jugador era realizar un "mate" en una canasta cuya proyección se encontraba dentro de la piscina. Para alcanzar el objetivo, el jugador debía saltar sobre el fluido para poder alcanzar la canasta.

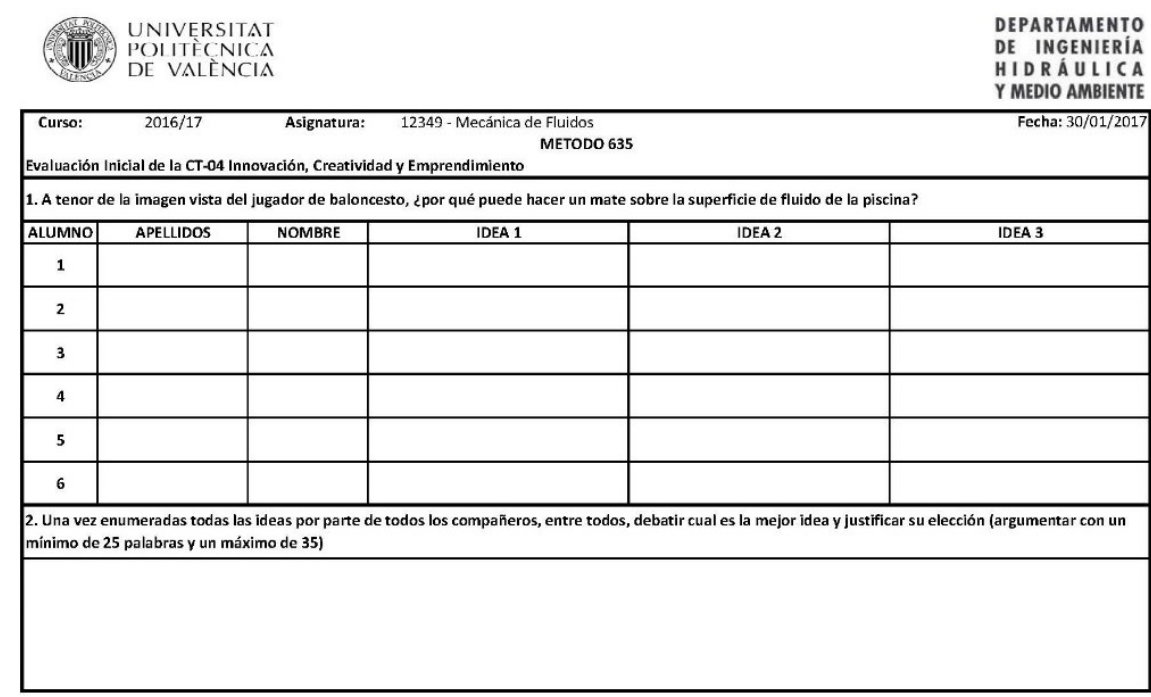

Fig. 4 Plantilla aportada a cada grupo

En la experiencia participaron 30 alumnos formandose 5 grupos diferentes. El número total de ideas desarrolladas fueron 90 en un tiempo total de $30 \mathrm{~min}$. De ese número de ideas únicamente el 13.33\% (12 de 90 fueron repetidas por el conjunto de alumnos). Una vez propuestas las ideas, se debatieron en grupo y seleccionaron una idea que posteriormente 
expusieron. De las 5 ideas seleccionadas, 3 de ellas dieron con la solución correcta del problema. Evaluando posteriormente las ideas aportadas por cada alumno y grupo, mediante la rubrica adjuntada en la Tabla 1, se obtuvieron los siguientes resultados en los diferentes indicadores (adjuntados en la Tabla 5). Los resultados obtenidos de los indicadores 3 y 4 son resultados que todos los miembros del grupo tenían la misma nota, como consecuencia de que fue analizado y debatido en grupo.

Tabla 5. Resultados de la evaluación del Método 6-3-5 aplicado a la asignatura de Grado.

\begin{tabular}{|c|c|c|c|c|}
\hline \multirow{2}{*}{ GRADO ALCANZADO } & \multicolumn{4}{|c|}{ INDICADOR } \\
\cline { 2 - 5 } & $\mathbf{I 1}$ & $\mathbf{I 2}$ & $\mathbf{I 3}$ & $\mathbf{I 4}$ \\
\hline $\mathbf{A}$ & $66.67 \%$ & $63.33 \%$ & $80.00 \%$ & $40.00 \%$ \\
\hline $\mathbf{B}$ & $33.33 \%$ & $30.00 \%$ & $20.00 \%$ & $40.00 \%$ \\
\hline $\mathbf{C}$ & $0.00 \%$ & $6.67 \%$ & $0.00 \%$ & $20.00 \%$ \\
\hline $\mathbf{D}$ & $0.00 \%$ & $0.00 \%$ & $0.00 \%$ & $0.00 \%$ \\
\hline
\end{tabular}

En cuanto a la experiencia desarrollada en los alumnos de Master, las características de la asignatura, con solamente 8 participantes, hacen que la participación sea completa y con una especificidad mucho mayor.

La asignatura se denomina Dispersión de Contaminantes en Aire y Atmósfera y es troncal de intensificación de segundo curso de Master en Ingeniería Industrial en la especialidad de Medio Ambiente. En este caso, el método en lugar de realizarse en grupos de 6 alumnos se realizó unicamente con dos grupos de 4 alumnos.

La ficha entregada a los mismos fue idéntica a la presentada en la Figura 1, con la siguiente pregunta: ¿Por qué la alcaldesa de Madrid no permite la entrada al tráfico de los coches durante ciertos días al año?. La participación fue completa y se generaron 24 ideas, algunas de ellas con verdadera innovación sobre la respuesta. La pregunta se ha realizado en el primer contacto con los alumnos, cuando aún no tienen los conocimientos adquiridos, y la experiencia además es muy significativa del grado de conocimientos previos adquiridos.

En este caso particular, la verdadera solución con una explicación científica profunda requería de un conocimiento muy específico de la materia, que ninguno de los alumnos había adquirido previamente. Sin embargo, en la votación, todos coincidieron en la misma idea como la más verosimil y en verdad, la más cercana a la solución final.

Cabe decir que a lo largo de la asignatura se introducen los conceptos necesarios para la correcta respuesta de la misma; y realizada la misma pregunta en semanas posteriores, la respuesta sí es la correcta en todos los casos. El aprendizaje en este caso ha sido completo.

\section{Conclusiones}

En cuanto a las conclusiones obtenidas en la experiencia desarrollada, se pueden enumerar las siguientes conclusiones: 
1) Se ha conseguido despertar el interes de los alumnos (tanto de Grado como de Máster) en temas poco seductores para su estudio, como puede ser el análisis de la propiedades de fluidos no newtonianos, que en otros tipos de aprendizaje más deductivo no se muestran tan paticipativos.

2) La limitación del tiempo en la creacción de ideas muestra que no es un factor limitante en el desarrollo del aprendizaje del alumno. Según las experiencias desarrolladas, los alumnos son capaces de generar un gran número de ideas con un bajo índice de repeticiones entre todos los alumnos en un breve periodo de tiempo.

3) Se ha desarrollado una rubrica de evaluación con base a los indicadores y descriptores propuestos desde el Instituto de Ciencias y de la Educación, la cual ha sido adaptada a ambas asignaturas, impartidas tanto a nivel I como nivel III, en función de las actividades propuestas.

4) Para permitir trabajar al alumno en diferentes ambientes, se han propuesto: (i) dos tareas presenciales grupales del Método 6-3-5, incorporando la discusión y comunicación en la actividad; (ii) una tarea presencial que el alumno de forma individual en un tiempo corto $(10 \mathrm{~min})$ debe proponer ideas y realizar un plan de acción a una problemática planteada; y (iii) una tarea no presencial en la cual el alumno, cuenta con más tiempo (1 mes) para desarrollarla. En esta tarea, el alumno debe: identificar el problema, aportar ideas, identificar ventajas e inconvenientes, relacionandolo con otros posibles afecciones colaterales y seleccionando la mejor idea que considera.

5) Dos rúbricas han sido propuestas para la evaluación de actividades que esten incluidas dentro de la evaluación. Del mismo modo, se ha propuesto una expresión matemática que permita combinar las evaluaciones de los indicadores en las distintas actividades. El establecimiento de la nota final de la competencia (grado alcanzado) es desarrollado considerando un peso ponderado de cada uno de los indicadores.

6) La rúbrica planteada y método de evaluación se puede adaptar a otras asignaturas $\mathrm{u}$ otras actividades en próximos cursos, en los cuales se trabajen los indicadores de forma diferente.

7) Se han mostrado resultados parciales de dicha evaluación, teniendo en cuenta las actividades de generación de ideas que sí se han realizado.

Finalmente, la técnica se ha mostrado muy motivadora para los alumnos tanto de Grado como de Máster. Los autores de la presente investigación perciben una buena acogida de la actividad, así como unos resultados satisfactorios en cuanto a la fijación de los conceptos finales en los alumnos. Esto convierte a la metodología desarrolada en una estrategia motivadora para el alumnado, en su proceso de aprendizaje de conceptos complejos.

\section{Referencias}

Beitz, G. P. W., Wallace, K., Blessing, L., Bauert, F. (1996). Engineering Design: A Systeatic Approach.MRS BULLETIN, 71.

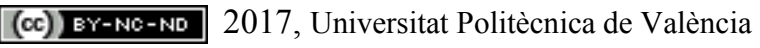


Cuenca, L., Alarcon, F., Boza, A., Fernández-Diegno, M., Ruíz, L., Gordo, ML., Poler, R., Alemany, M.M.E. (2015). "Rúbrica para la Evaluación de la Competencia Innovación, Creatividad y Emprendimiento en máster”. Congreso In-Red 2015-Universitat Politècnica de València. ISBN: 978-84-9048-396-1. Disponible en < http://ocs.editorial.upv.es/index.php/INRED/INRED2015>

Cuenca, L., Bonet Espinosa, M.P., Boza Garcia, A., Fuentes-Durá, P., LajaraCAMILleri, N., MARÍN GARcÍA, JA., Peris-OrTIZ, M. (2015). Innovation, Creativity and Entreprenaeurship Learning Outcomes in Higher Education. IATED, International Association of Technology, Education and Development. http://hdl.handle.net/10251/72847.

Fernandes, J.M., Afonso, P., Fonte, V., Alves, V., Ribeiro, A.N. (2017) Promoting entrepreneurship among informatics engineering students:insights from a case study. European Journal of Engineering Education, 42:1, 91-108, DOI: 10.1080/03043797.2016.1197891

LÓPEZ-JIMÉNEZ, P.A., PÉREZ-SÁNCHEZ, M. "Los objetos de aprendizaje como conductores para favorecer el aprendizaje autónomo en el campo de la mecánica de fluidos”. II Congreso Nacional de Innovación Educativa y de Docencia en Red (Valencia, 7 y 8 de julio, 2016). Editorial Universitat Politècnica de València, 2016. Doi:http://dx.doi.org/10.4995/INRED2016.2016.4347

PÉREZ-SÁnCHEZ, M., LÓPEZ-JiMÉnEZ, P.A. (2017) “The Use of Learning Objects in Environmental Education: The Experience of Distance Asynchronous Teaching in Pollutant Dispersion Topics". Environmental Education: Perspectives, Challenges and Opportunities

RAE, Real Academia Española de la Lengua http://www.rae.es/ [Consulta 14 de marzo de 2017]

Vidal-Carreras, P.I., CANOS-Daros, L., GarcíA-SABAter, J.P. "Marcadores para una herramienta de evaluación de Wikis". II Congreso Nacional de Innovación Educativa y de Docencia en Red (Valencia, 7 y 8 de julio, 2016). Editorial Universitat Politècnica de València, 2016. Doi:http://dx.doi.org/10.4995/INRED2016.2016.4347 


\title{
Diseño y Evaluación de una Actividad para Desarrollar el Trabajo en Equipo en Primero de Turismo de la EPSG
}

\author{
Alberto Palomares Chusta, Ana Ábalos Galcerá ${ }^{\mathrm{b}}$ \\ åDepartamento de Sistemas Informático y Computación, UPV, apalomares@dsic.upv.es \\ bInstituto de Ciencias de la Educación, UPV, ana@ice.upv.es.
}

\begin{abstract}
Resumen
En este trabajo presentamos el diseño, desarrollo y evaluación de una actividad para trabajar la competencia "Trabajo en Equipo y Liderazgo" (CT6). Esta actividad se desarrolló en el marco de una Sesión Tutorial del programa PATU (Plan de Acción Tutorial Universitario) de la UPV, durante el primer cuatrimestre del curso 2016-2017, en la asignatura Informática de Gestión (IG) del primer curso del Grado de Turismo (GT) que se imparte en de la Escuela Politécnica Superior de Gandia (EPSG). El objetivo principal era trabajar y evaluar la CT6 con el requisito de que la actividad propuesta estuviera integrada con los contenidos propios de la asignatura. La actividad consistió en la preparación, en un periodo de tiempo limitado (30 minutos), de una única presentación sobre el turismo en la provincia de Valencia. Para coordinar el desarrollo de la actividad se asignaron diferentes roles a los alumnos en función de su posición en la clase. Los alumnos tuvieron que preparar pequeñas presentaciones sobre temáticas y zonas especificas, que se fueron integrando en presentaciones más amplias hasta tener una única presentación. El resultado fue evaluado por los alumnos mediante una encuesta de satisfacción que puso de manifiesto el cumplimiento de los objetivos previstos.
\end{abstract}

Palabras clave: Competencia Transversal, Trabajo en Equipo, Liderazgo, Punto de Control, Tutoría, Grado en Turismo, Rol, Coordinación, 


\section{Introducción}

La Universitat Politècnica de València (UPV) se encuentra inmersa en un proyecto institucional que tiene como objetivo principal desarrollar y acreditar las denominadas Competencias Transversales (CT) a los estudiantes egresados en cualquiera de los títulos oficiales impartidos en la UPV ${ }^{1}$. Las $13 \mathrm{CT}$ definidas en este proyecto son las siguientes:

1. Comprensión e integración (CT1).

2. Aplicación y pensamiento práctico (CT2).

3. Análisis y resolución de problemas (CT3).

4. Innovación, creatividad y emprendimiento (CT4).

5. Diseño y proyecto (CT5).

6. Trabajo en equipo y liderazgo (CT6 $)^{2}$.

7. Responsabilidad ética, medioambiental y profesional (CT7).

8. Comunicación efectiva (CT8).

9. Pensamiento crítico (CT9).

10. Planificación y gestión del tiempo (CT10).

11. Aprendizaje permanente (CT11).

12. Conocimiento de problemas contemporáneos (CT12).

13. Instrumental específica (CT13).

Graduados y empleadores no han dudado en subrayar la gran importancia que tienen estas CT en el desempeño profesional de los egresados. Por esta razón los nuevos títulos de grado y posgrado que se imparten en la UPV incorporan, de manera explícita, la exigencia de que los estudiantes sean formados en estas CT y que sea evaluado su nivel de logro (Blanco, 2009; Cano, 2008; De Miguel, 2006; Sánchez, 2010). Existen tres líneas para incorporar las CT en los estudios:

- En los propios planes de estudios ${ }^{3}$.

- En los trabajos final de grado (TFG) o de master (TFM).

- Mediante actividades extracurriculares.

Para su incorporación en los planes de estudio, las Estructuras Responsables del Título (ERT) asignan estas $\mathrm{CT}$ a las distintas materias/asignaturas que conforman el plan de estudios de una titulación, garantizando que se desarrollan y evalúan todas las CT en el plan, realizando un proceso de seguimiento y revisión, a través de la CAT, para comprobar que se está realizando correctamente. La evaluación de las CT se realiza en determinadas materias/asignaturas seleccionadas y que se denominan puntos de control (PC). Sin embargo es importante señalar que las $\mathrm{CT}$ se tienen que trabajar y desarrollar en diferentes asignaturas de una titulación, no sólo en las que son PC específico de alguna CT.

\footnotetext{
1 http://www.upv.es/contenidos/COMPTRAN/

2 En este trabajo nos centraremos en la competencia CT6

${ }^{3}$ En este trabajo nos centraremos en la incorporación de la CT6 en los propios planes de estudio
} 
En general, todas las asignaturas deberían diseñar y desarrollar actividades que permitieran ir trabajando alguna CT. Lógicamente estas actividades tienen que estar relacionadas con los contenidos de las propias asignaturas. Además, para que los alumnos adquieran progresivamente las CT durante su todo periodo formativo en la UPV hay que empezar a desarrollar este tipo de actividades desde el primer curso de las titulaciones.

Los alumnos de primero requieren de un tratamiento especial. La dificultad del proceso de transición de secundaria a la universidad provocó la puesta en marcha, en la UPV, de algunas iniciativas institucionales que facilitaran al alumnado ese proceso de cambio, como por ejemplo el denominado Programa INTEGRA ${ }^{4}$, que consta, a su vez, de dos acciones: las Jornadas de Acogida y el Plan de Acción Tutorial Universitario (PATU) ${ }^{5}$.

El programa PATU ha experimentado recientemente un cambio metodológico en su implementación en la EPSG, con el objetivo de relacionar las tutorías con el desarrollo preliminar de algunas $\mathrm{CT}$ en determinadas asignaturas obligatorias de primer curso. Para hacerlo se han introducido, dentro del horario lectivo de estas asignaturas, las denominadas "Sesiones Tutoriales" en las que se trabajan específicamente algunas de las CT. Si prestamos atención al término "competencia", veremos que la competencia implica:

- Integración de conocimientos, puesto que requieren la adquisición de conocimientos, habilidades, actitudes, etc.

- Ejecución, puesto que se desarrollan en la práctica.

- Contextualización, puesto que se es competente en situaciones concretas en cuanto a espacio, tiempo y circunstancias. No son generalizables.

- Progresión, en el sentido de que de aquiere de forma paulatina, mediante la formación y la experiencia.

- Toma de decisiones, porque implican reflexión dirigida a una ejecución efectiva.

Como profesores debemos plantear situaciones de enseñanza-aprendizaje que permitan a los alumnos adquirir este tipo de aprendizaje práctico, contextualizado, progresivo y reflexivo. Y esto, no lo podemos conseguir mediante métodos tradicionales de enseñanza. Hemos de crear los escenarios pertinentes para la adquisición de este tipo de aprendizajes.

Esto lo conseguimos seleccionando estrategias de enseñanza que estén relacionadas con el tipo de aprendizaje que queremos promover. Si queremos que los alumnos aprendan a trabajar en equipo tendremos que diseñar actividades de enseñanza-aprendizaje y evaluación que pongan a los alumnos en situación de trabajar junto con sus compañeros en algún tema de la asignatura. $\mathrm{Y}$ esto es lo que se ha perseguido con el desarrollo de esta actividad. Una actividad de aprendizaje cooperativo informal, es aquella que se desarrolla en un momento puntual.

\footnotetext{
${ }^{4}$ https://www.upv.es/perfiles/futuro-alumno/integra-patu-es.html

5 Este trabajo nos centraremos en actividades relacionadas con el programa PATU de la UPV.
}

\begin{tabular}{ll}
\hline (c) EY-NC-ND 2017, UPV & 20
\end{tabular} 
El aprendizaje en equipo es fundamental para los alumnos (Borrell, 2007; Exley, 2007; Serrano, 1996; Slavin, 1999; West, 2003). Tal y como señala (Barkley, 2007) la investigación sobre el aprendizaje en equipo en la educación superior, aunque limitada, es concluyente: los alumnos que estudiaron en pequeños equipos demostraron mayor rendimiento, mayor constancia y unas actitudes más favorables con respecto al aprendizaje que aquellos que lo hicieron en un sistema de enseñanza tradicional (Springer, 1999).

Los mismos autores afirman que un gran número de estudios evidencia que los alumnos que estudian en interacción con sus compañeros muestran unas actitudes más positivas hacia la asignatura, mayor motivación para aprender la materia así como una mayor satisfacción con su experiencia de aprendizaje (Johnson, 1991). Además aprecian más al profesor tanto a nivel académico como personal (Fiechtner, 1992 y Johnson, 1991).

Por último, exponen que el trabajo en grupos cooperativos está relacionado con el progreso percibido en el desarrollo personal, el aprecio de las bellas artes, las CT analíticas y la comprensión de las ciencias y la tecnología (Cabrera, 2008). Veremos cómo la valoración de sus participantes (tutores, tutelados y coordinadores) nos da información del impacto del programa y nos permite reflexionar, en las consideraciones finales, sobre la repercusión del mismo.

En este trabajo presentamos el diseño de una actividad para el desarrollo de la CT6 en una sesión tutorial, realizada con alumnos de primero del Grado de Turismo (GT) que se imparte en la EPSG. 


\section{Objetivos}

Esta innovación ha consistido en el diseño, desarrollo y evaluación de una actividad para trabajar la Competencia de Trabajo en Equipo y Liderazgo (CT6) en la asignatura Informática de Gestión (IG) en el primer curso del Grado de Turismo (GT) que se imparte en la Escuela Politecnica Superior de Gandia (EPSG), en el marco de una Sesión Tutorial realizada dentro del programa PATU.

El objetivo principal es Promover la enseñanza y la evaluación de la competencia transversal Trabajo en equipo y liderazgo de forma integrada con los contenidos y objetivos de la asignatura Informática de Gestión. Otros objetivos secundarios son:

- Mejorar la motivación del alumnado.

- Aumentar el rendimiento académico del alumnado en la asignatura.

\section{Desarrollo de la innovación}

\section{Instrucciones para los alumnos}

Objetivo: preparar entre toda la clase (equipo del proyecto) una única presentación sobre el turismo en Valencia (resultado del proyecto).

Tiempo máximo: 30 minutos (plazo).

Reparto de Tareas: dependen de la posición de los alumnos en la clase (fila y puesto):

\begin{tabular}{|l|cccc|c|}
\hline PUERTA & PUESTO 1 & PUESTO 2 & PUESTO 3 & PUESTO 4 & PASILLO \\
\hline FILA 5 & 5.1 & 5.2 & 5.3 & 5.4 & \\
FILA 4 & 4.1 & 4.2 & 4.3 & 4.4 & \\
FILA 3 & 3.1 & 3.2 & 3.3 & 3.4 & \\
FILA 2 & 2.1 & 2.2 & 2.3 & 2.4 & \\
FILA 1 & 1.1 & 1.2 & 1.3 & 1.4 & \\
\hline
\end{tabular}

Figura 1: posición de los alumnos en el aula (fila y puesto)

\section{A cada fila le corresponderá una zona distinta de la provincia de Valencia:}

1. Norte:Sagunt, Camp Turia,...

2. Valencia:Ciudad, Horta,...

3. Xuquer: Albufera, Ribera Baixa, Ribera Alta, Cullera,...

4. Safor: Gandía, Oliva,...

5. Interior: Serranos, Utiel, Bunyol, Ademuz, Cofrentes, Navarrés,.... 


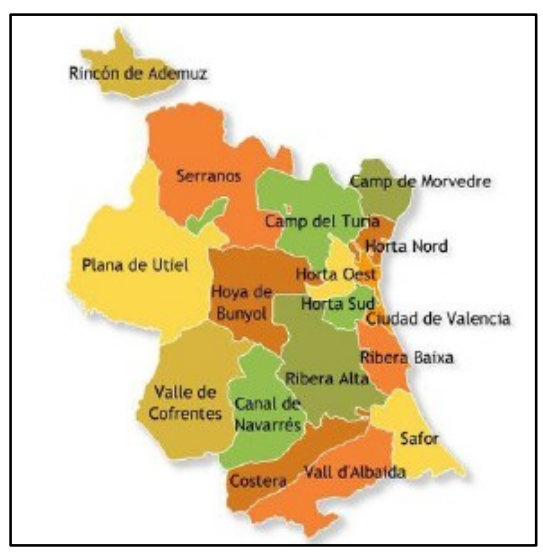

Figura 2: comarcas de la provincia de Valencia

A cada posición en la fila le corresponderá un rol específico ( $n^{0}$ puesto):

1. Coordinador Presentación de la Zona.

2. Crear Presentación sobre el Patrimonio Cultural y Artístico de la Zona.

3. Crear Presentación sobre el Patrimonio Natural de la Zona.

4. Crear Presentación sobre la Gastronomía de la Zona.

Los roles 2, 3 y 4 tienen que preparar una presentación en Drive sobre el tema asignado:

- Crear presentación en GoogleDrive.

- Nombre Documento “zona-rol” (por ejemplo Valencia-Gastronomía).

- Compartir la presentación con el coordinador de la fila.

- Utilizar plantilla Drive sin diseño (facilita elproceso de unir las presentaciones).

- Primera Diapositiva Tipo Título. El Título será la zona y el subtítulo el tema.

- Segunda Diapositiva. Índice de las diapositivas con los contenidos asignados.

- 5 diapositivas sobre el tema (1 imagen+texto). Buscar las imágenes/texto en Google.

- Tiempo máximo 20 minutos.

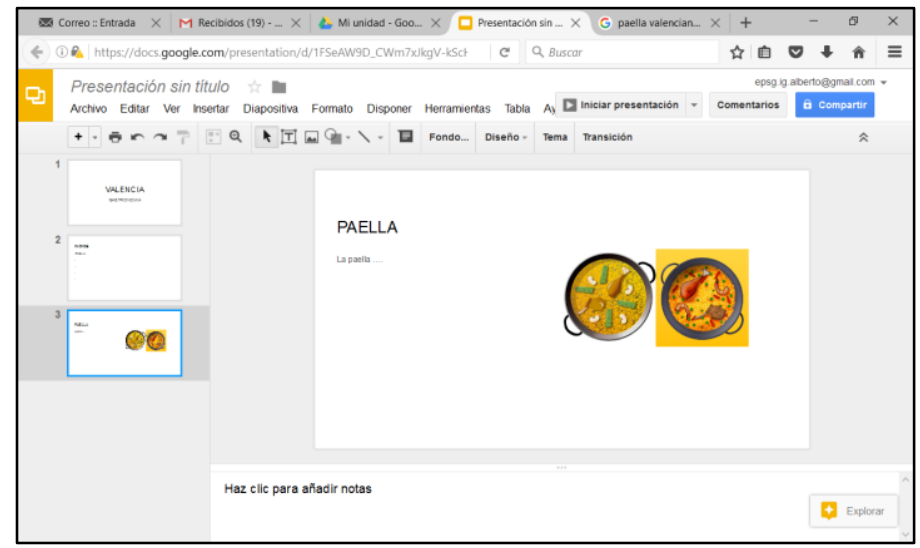

Figura 3: ejemplo de presentación en Drive (Valencia - Gastronomia) 


\section{El coordinador tiene que:}

- Crear la Presentación General de su Zona y llamarla "Nombre de la Zona".

- Compartirla con toda su fila y con el profesor.

- La presentación empezará con 2 diapositivas: título (nombre de la zona) e índice.

- A partir del minuto 20 unirá todas las presentaciones de su fila.

- Comprobar que todos los alumnos de su fila (zona) comparten sus presentaciones

- Comprobar que todas las presentaciones cumplen los requisitos indicados $\left(\mathrm{n}^{\mathrm{o}} \mathrm{de}\right.$ diapositivas y características básicas).

- Comprobar que en su fila se realiza el trabajo en el tiempo previsto (20 minutos).

Tareas de todo el equipo:

- Durante los 10 minutos finales, todos los componentes del equipo pueden revisar, corregir, añadir, quitar, etc. lo que quieran en la presentación del equipo (zona).

A los 30 minutos se parará el cronómetro y no se podrá hacer nada más.

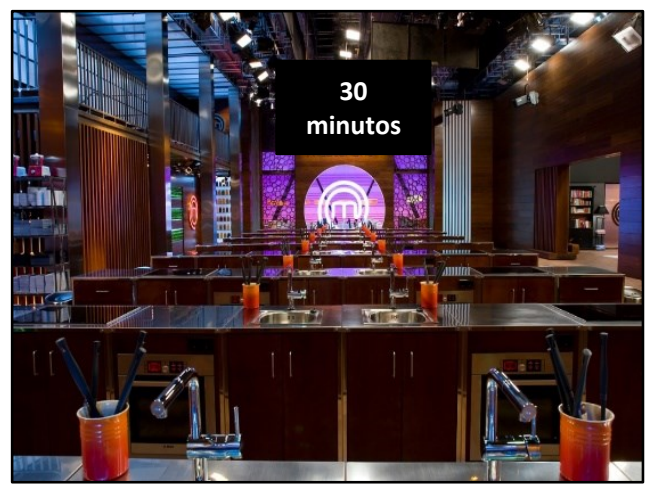

Figura 4: tiempo máximo para realizar la actividad

Para finalizar la actividad, el profesor tiene que:

- Preparar una única presentación uniendo las presentaciones prepardas por toda la clase en una única presentación.

- Subirla a Poliformat para que todos los alumnos de la asignatura tengan acceso a la misma y puedan evaluar el resultado final. 


\section{Resultados (encuesta de evaluación de la actividad)}

Esta experiencia se llevo a cabo el 8 de Noviembre de 2016 con los alumnos de la asignatura Informática de Gestión del primer curso del Grado de Turismo y del Doble Grado Turismo-ADE (la asignatura es común para las 2 titulaciones) en el marco de una Sesión Tutorial del programa PATU prevista para trabajar la CT6.

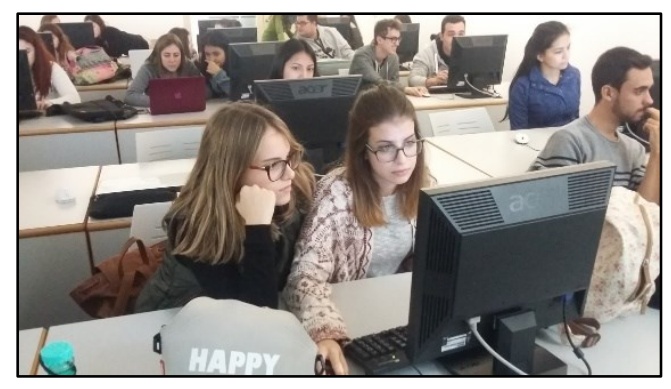

Figura 5: Alumnos de Informática de Gestión trabajando en equipo

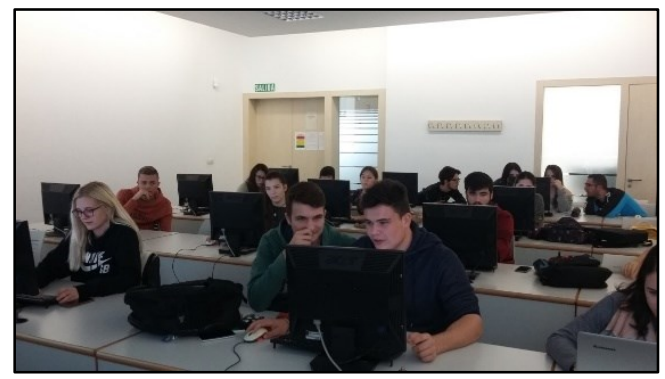

Figura 6: Alumnos de Informática de Gestión trabajando en equipo

Se diseño una encuesta en Drive para que los alumnos evaluaran la actividad. 49 alumnos de los aproximadamente 70 que realizaron la actividad completaron la encuesta. A continuación se muestran las preguntas de esta encuesta y los resultados obtenidos.

Pregunta 1: Como impresión general, me he sentido satisfecho participando en esta actividad sobre el trabajo en grupo

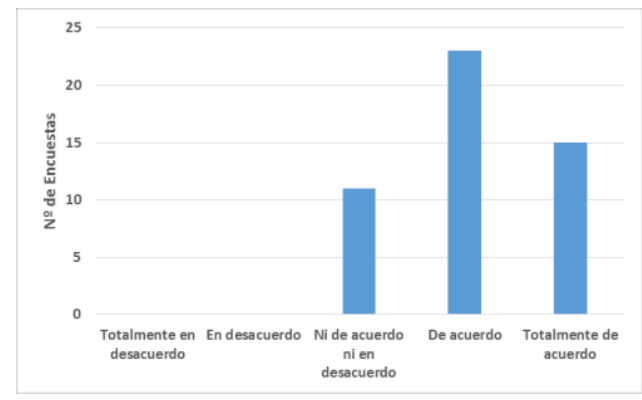

Figura 7: Resultados Encuesta (Pregunta 1) 
Pregunta 2: En particular, me siento satisfecho con respecto a mi aportación al trabajo de nuestro equipo (zona, rol)

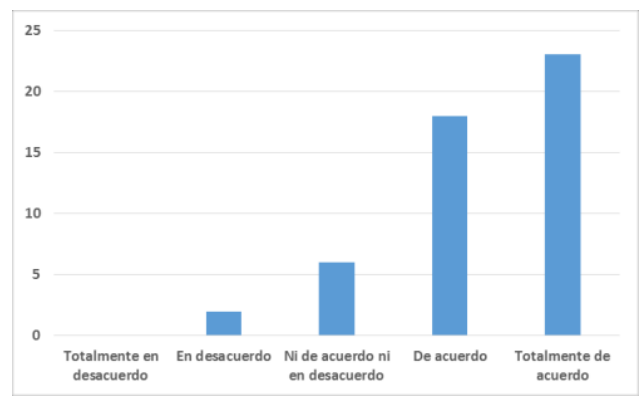

Figura 8: Resultados Encuesta (Pregunta 2)

Pregunta 3: La figura de "coordinador" ha sido útil para alcanzar el objetivo de nuestro equipo

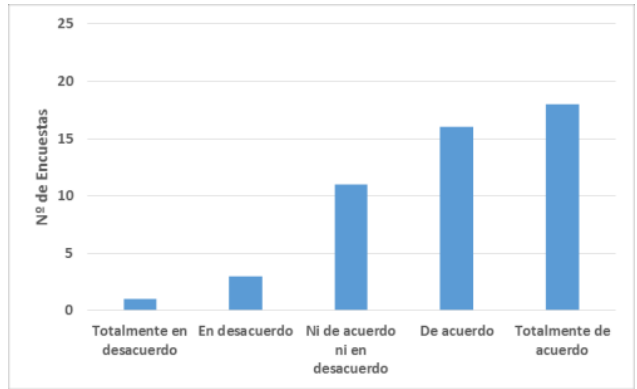

Figura 9: Resultados Encuesta (Pregunta 3)

Pregunta 4: Creo que la calidad del trabajo conseguido por el equipo es superior a la que se hubiera alcanzado trabajando individualmente

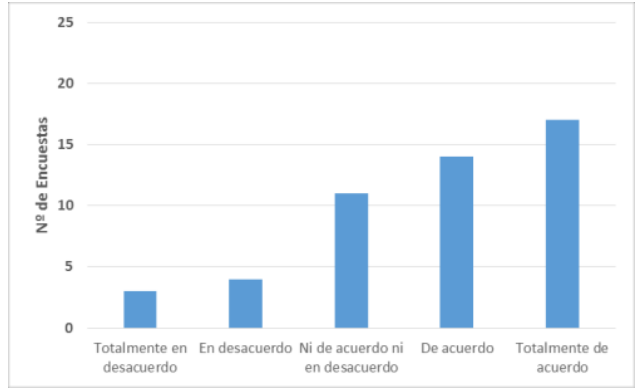

Figura 10: Resultados Encuesta (Pregunta 4) 
Pregunta 5: Todos los miembros del equipo hemos realizado las tareas asignadas en el plazo establecido

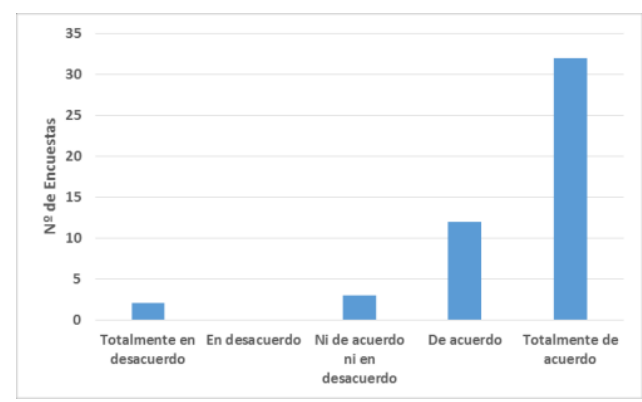

Figura 11: Resultados Encuesta (Pregunta 5)

Pregunta 6: El líder (profesor) ha sido importante para la definición de los objetivos y para saber con claridad lo que teníamos que hacer cada uno

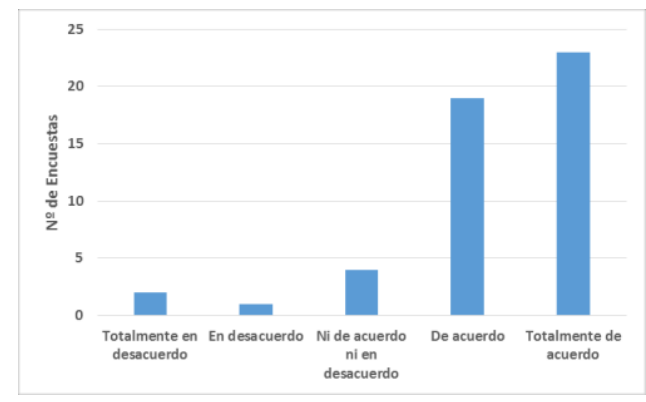

Figura 12: Resultados Encuesta (Pregunta 6)

Pregunta 7: Además me siento satisfecho con respecto a la aportación de mis compañeros al trabajo del equipo

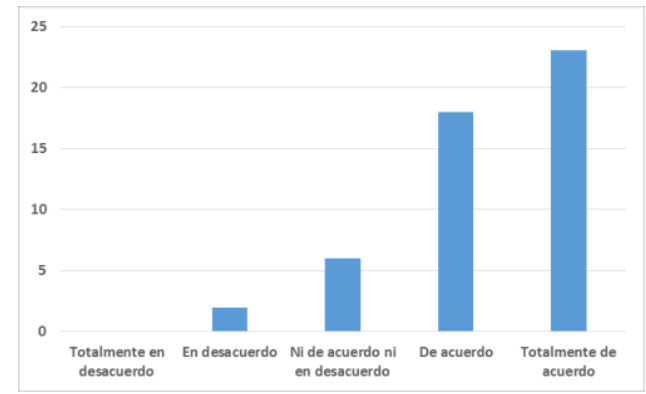

Figura 13: Resultados Encuesta (Pregunta 7) 
Pregunta 8 (respuesta libre): si quieres describe brevemente algo que hayas aprendido trabajando en equipo al realizar esta actividad que quizás no hubieras aprendido haciéndolo solo:

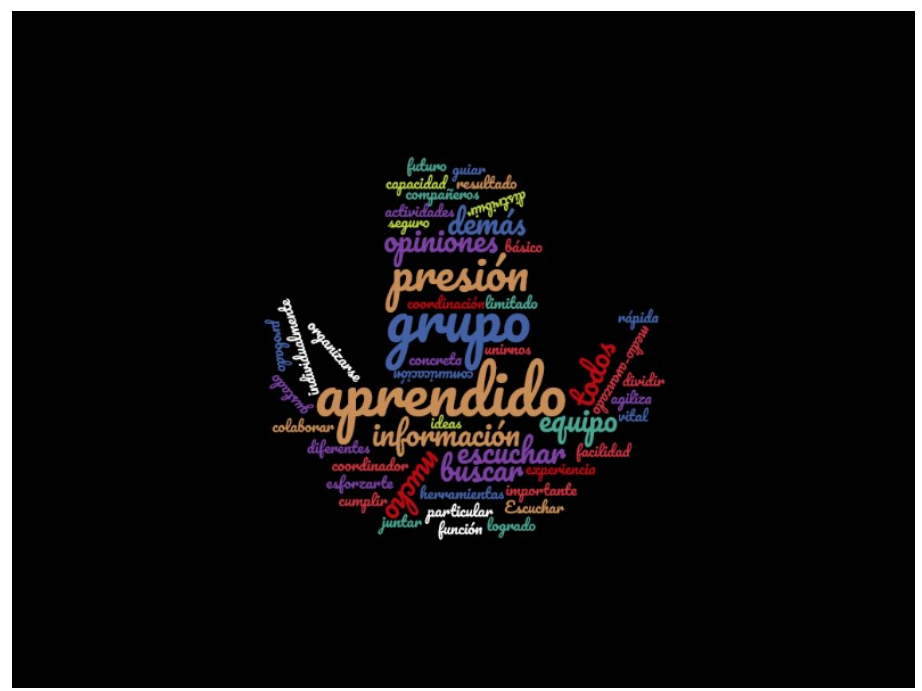

Figura 14: : Resultados Encuesta (Pregunta 9). Nube de Palabras

Pregunta 9 (respuesta libre): Si quieres puedes proponer algún cambio o sugerencia en el desarrollo de la actividad para que el equipo hubiera funcionado mejor:

A continuación se muestran, a modo de ejemplo, algunas de las respuestas proporcionadas por los alumnos:

- Me hubiera gustado haber hablado de otra provincia así de paso podemos aprender culturas, tradiciones.

- Muy buen trabajo.

- En el tiempo que teníamos, y sin planificación previa el desarrollo de la actividad para mí no necesita ningún cambio.

- Más tiempo para distribuirnos las partes del trabajo antes de empezar a realizarlo.

- Más orden a la hora de trabajar.

- Hubiera sido más práctico que las mesas hubiesen estado puestas en forma de círculo, para poder hablar mejor con el grupo todos juntos.

- Más tiempo para hacerlo.

- La distribución del tiempo es esencial.

- Hablándose más entre el equipo.

- Ninguna sugerencia. 


\section{Conclusiones}

Tras el análisis de las respuestas dadas por el alumnado a la encuesta de valoración de la actividad podemos afirmar que el nivel de satisfacción general es alto. Los alumnos valoran de forma positiva tanto el desarrollo de la actividad como su aportación y la aportación de los compañeros y el profesor al trabajo en equipo realizado.

En este caso, y puesto que nos encontramos en un primer nivel de dominio de la CT, por tratarse de alumnos de primer curso, el trabajo en equipo ha estado dirigido por el profesor, siendo él mismo el que ha fijado los criterios para el establecimiento de las normas básicas y el funcionamiento del equipo (número de miembros, el tipo de agrupación, los roles). Los alumnos han valorado de forma positiva el papel del profesor como líder del grupo por lo que parece que la función de orientador, motivador y guía del trabajo se ha cumplido de forma adecuada.

En cursos superiores se prevé diseñar actividades similares pero otorgando un mayor nivel de autonomía a los equipos en la organización de su funcionamiento.

Afirman los alumnos que se han cumplido los objetivos del trabajo y, más aún, que la calidad del trabajo conseguido es superior a la que se hubiera conseguido trabajando de forma individual. Un concepto esencial al referirnos al trabajo en equipo es el de sinergia, según el cual, gracias al concurso y la participación activa y concertada de varios individuos, el resultado del grupo supera a la suma de las aportaciones individuales $(2+2=5)$.

Hemos visto que es posible diseñar, desarrollar y evaluar actividades que permitan a los alumnos la adquisición de competencias transversales como el Trabajo en Equipo y Liderazgo (CT6) de forma coordinada con competencias específicas de la asignatura Informática de Gestión (IG) de primer curso del Grado de Turismo (GT), en este caso la utilización de herramientas informáticas como Google Drive.

Podemos afirmar pues, que hemos conseguido el objetivo propuesto al inicio de esta actividad de promover la enseñanza y la evaluación de la competencia transversal Trabajo en equipo y liderazgo de forma integrada con los contenidos y objetivos de la asignatura Informática de Gestión.

Respecto al objetivo de "Aumentar el rendimiento académico del alumnado en la asignatura" habría que hacer un análisis comparativo de las calificaciones obtenidas por el alumnado en cursos anteriores, en los que no se hubiera implementado la actividad descrita, para poder afirmar que ha habido un aumento en el mismo. O bien, analizar la satisfacción del alumnado en el desarrollo de la misma actividad en el caso de haberla llevado a cabo de forma individual. Sin embargo, y así lo han señalado diversos estudios, parece haber una correlación positiva entre la satisfacción del alumnado y el rendimiento académico, y es obvio que el factor motivacional influye en el aprendizaje. Consideramos que la introducción de este tipo de actividades de equipo pueden repercutir en un aumento del rendimiento académico de los alumnos, aunque de momento no disponemos de datos que permitan evidenciarlo. 


\section{Referencias}

BARKLEY, E.; CROSS, P. y HOWELL, C. (2007): Técnicas de aprendizaje colaborativo. Madrid: Ed. Morata.

BLANCO, A. (2009): Desarrollo y evaluación de competencias en Educación Superior. Madrid: Narcea.

BORRELL F. (2007): Cómo trabajar en equipo. Barcelona: Ed. Gestión 2000.

CABRERA, E. (2008): La colaboración en el aula: Más que uno más uno. Bogotá: Cooperativa Editorial Magisterio.

CANO, E. (2008): La evaluación por competencias en la educación superior Competences assessment in higher education. Revista de curriculum y formación del profesorado. $<$ https://www.ugr.es/ recfpro/rev123COL1.pdf $>>$ [Consulta: 8 de marzo de 2017]

DE MIGUEL, M. (2006): Metodologías de enseñanza y aprendizaje para el desarrollo de competencias. Madrid: Alianza Editorial.

EXLEY, K y DENNICK, R. (2007): Enseñanza en pequeños grupos en Educación Superior. Madrid: Narcea.

FIECHTNER, S. y DAVIS, E. (1992): Why some groups fail? A survey of students' experiences with learning groups. In: Collaborative Learning: A Sourcebook for Higher Education. A. S. Goodsell, M. R. Maher, and V. Tinto, Eds. National Center on Postsecondary Teaching, Learning, and Assessment. University Park, PA: Syracuse University.

JOHNSON, D.; JOHNSON, R. y SMITH, K. (1991): “Cooperative Learning: Increasing College Faculty Instructional Productivity". ASHE-ERIC Higher Education Report No. 4, Washington, DC: The George Washington University. Johnson, D.W.

SÁNCHEZ GONZÁLEZ, Mª P. (2010): Técnicas docentes y sistemas de evaluación en educación superior. Madrid: Narcea.

SERRANO, J.M. (1996). El aprendizaje cooperativo. En Beltrán, J.L. y Genovard, C. (Edit.) Psicología de la Instrucción I. Variables y procesos básicos. Madrid: Editorial Síntesis, S.A. Cap.5, págs. 217-244.

SLAVIN, R. (1999): Aprendizaje cooperativo. Buenos Aires: Aique Grupo Editor.

SPRINGER, L.; STANNE, M. y DONOVAN, S. (1999): Effects of small-group learning on undergraduates in Science, Mathematics, Enrineering and Technology: a meta-analysis. Review of Educational Research, vol. 69, 1, págs. 21-51.

UNIVERSITAT POLITĖCNICA DE VALÈNCIA. Proyecto institucional de competencias transversales. $\quad<\mathrm{http}: / /$ www.upv.es/contenidos/COMPTRAN/info/955712normalc.html> [Consulta: 8 de marzo de 2017]

WEST, M. (2003): El trabajo eficaz en equipo. 1+1=3. Barcelona: Paidós. 
Experimentos de anoxia/inanición en $C$. elegans y preacondicionamiento anestésico. Una actividad práctica de laboratorio para la formación integrada en las competencias del diseño de experimentos, análisis e interpretación de datos en la experimentación científica.

Isaias Sanmartin Santos ${ }^{\mathrm{a}}$, Ana Lloret Alcañiz ${ }^{\mathrm{b}}$, Ignacio Ventura González ${ }^{\mathfrak{c}}$, Jesús Prieto Ruiz $^{\text {a }}$

a. Departamento de Ciencias Médicas Básicas. Facultad de Veterinaria y Ciencias Experimentales. Universidad Católica de Valencia San Vicente Mártir.

b. Departamento de Fisiología. Facultad de Medicina. Universidad de Valencia.

c. Departamento de Ciencias Médicas Básicas. Facultad de Medicina. Universidad Católica de Valencia San Vicente Mártir.

\begin{abstract}
Competence in the design of experiments and the interpretation of their results is closely linked to the ability to understand and analyze information in the scientific-technical literature. In the present work, we present a project of integral activity that links the research, reading and interpretation of scientific articles together with the design and interpretation of experimental results, through a system of "step by step guide" very appropriate for an introduction to these competences To the students of the first courses of the university education.
\end{abstract}

Keywords: Competencies, training, design of experiments, writing of scientific articles, information management, biotechnology

\title{
Resumen
}

La competencia en el diseño de experimentos y la interpretación de sus resultados está íntimamente unida a la capacidad para entender y analizar la información en la bibliografía científico-técnica. En el presente trabajo, presentamos un proyecto de actividad integral que enlaza la búsqueda, lectura e interpretación de artículos científicos conjuntamente con el diseño e interpretación de resultados experimentales, mediante un sistema de "guía paso a paso" muy apropiado para una introducción a estas competencias a los alumnos de los primeros cursos de la educación universitaria.

Palabras clave: competencias, formación, diseño de experimentos, redacción de artículos científicos, gestión de la información, biotecnología 
Experimentos de anoxia/inanición en C. elegans y preacondicionamiento anestésico. Una actividad práctica de laboratorio para la formación integrada en las competencias del diseño de experimentos, análisis e interpretación de datos en la experimentación científica.

\section{Introducción}

La competencia en la lectura e interpretación de artículos técnicos o científicos es un contenido clave de los programas universitarios de aprendizaje en biotecnología, biomedicina y ciencias relacionadas. La competencia en el diseño e interpretación de experimentos es un contenido esencial que debiera ser parte necesaria de cualquier programa de formación en biotecnología. A pesar de ello, a menudo estas competencias son obviadas o dispersas a lo largo de las múltiples asignaturas y cursos que constituyen un grado. A menudo, en los programas de estudio no existe una asignatura que se encargue específicamente de desarrollar estas competencias, precisamente a causa de su transversalidad. No se considera que formen parte del cuerpo de contenidos de ninguna asignatura específica, y se relega la adquisición de estas competencias a los pequeños aportes que van sumando a lo largo del Grado las actividades y prácticas de las distintas asignaturas relacionadas con el diseño e interpretación de experimentos y la lectura de artículos científicos.

No obstante, consideramos que este goteo diluido de las pequeñas partes que constituyen la competencia no es la mejor forma de proporcionar una formación en estos aspectos. Se requiere una actividad integral que los contemple conjuntamente, ya que el diseño del experimento y la interpretación de sus resultados están íntimamente unidos. La capacidad para entender, analizar e interpretar los resultados en un artículo de la bibliografía científica no es más que la capacidad para entender el diseño e interpretación de los experimentos realizados por otros autores.

Un aspecto adicional es en qué momento debe introducirse a los estudiantes en la adquisición de estas competencias. Es nuestra opinión deben situarse cuanto antes en el plan de estudios, ya que proporcionan aspectos formativos muy interesantes para el estudiante. Por ejemplo es fundamental para entender cómo se ha generado el conocimiento que se encuentra en los libros de texto. Por otra parte y no menos importante, estimula la madurez intelectual que debiera adquirirse en el paso desde la educación secundaria a la universidad.

En el presente trabajo presentamos un proyecto de actividad que enlaza la búsqueda, lectura e interpretación de artículos científicos conjuntamente con el diseño e interpretación de resultados experimentales, mediante un sistema de "guía paso a paso". Este procedimiento es fundamental para una introducción en dichas competencias y habilidades científicas iniciales. Por su sencillez en el planteamiento resulta atractivo para estudiantes de los primeros cursos en grados de ciencias experimentales tales como el Grado en Biotecnología. Asimismo, otra característica de este diseño que enlaza actividades de aula con prácticas de laboratorio es que puede ser aplicado a múltiples asignaturas. El presente proyecto ha sido realizado en

(cc) EY-NC-ND 2017, Universitat Politècnica de València

Congreso IN-RED (2017) 
la asignatura "biología celular" del primer curso del Grado en Biotecnología de la Universidad Católica de Valencia.

\section{Objetivos}

- Adquisición de la competencia en el diseño de experimentos en biotecnología, así como la capacidad de reunir e interpretar datos relevantes de índole científica para valorar un producto biotecnológico.

- Desarrollar habilidades en la gestión de la información en biotecnología y ciencias biomédicas (habilidad para buscar y analizar información procedente de bases de datos de artículos científicos).

- Introducir competencias de investigación, tales como describir y medir variables relevantes de procesos o experimentos y ser capaz de analizar e interpretar datos científicos en el ámbito de la biotecnología.

\section{Desarrollo de la innovación}

La actividad consiste en la realización de un experimento de laboratorio con el nematodo C. elegans para encontrar moléculas que protejan del daño tisular que se produce durante una intervención quirúrgica. Los resultados se reportarán en un informe final que constituye un mini artículo científico con un único experimento, pero estructurado en los habituales apartados (introducción, material y métodos, resultados, discusión y bibliografía). Para facilitar la realización de la actividad en estudiantes principiantes (ya que se realiza con estudiantes de primer curso) es clave el acompañamiento de una "guía paso a paso" para un abordaje simplificado y sistemático que facilita mucho la realización de la actividad.

El proyecto se realiza en tres fases:

- Primera fase. Elección de la sustancia farmacológica a ensayar, extracción del principio activo y diseño experimental.

- Segunda fase. Realización del experimento.

- Tercera fase. Análisis de los resultados del experimento e interpretación.

\subsection{Elección de la sustancia farmacológica a ensayar}

El profesor presenta a los alumnos el fenómeno del preacondicionamiento anestésico (Murry, 1986), por el cual ciertos gases inhalatorios utilizados en la anestesia protegen los tejidos de los daños por la hipoxia/reperfusión que sufren las células durante una intervención quirúrgica. Se plantea a los estudiantes el siguiente contexto motivador: deben tratar de encontrar una molécula con actividad de protección celular similar a la que se describe en el fenómeno del preacondicionamiento anestésico, con el objeto de desarrollar un posible fármaco que mejore el postoperatorio de pacientes intervenidos quirúrgicamente (Gilsanz, 
1996). Los grupos de estudiantes son instados a seleccionar su propia molécula farmacológica para realizar los ensayos. Este factor de libertad en la elección, así como el comentario por el profesor de que las moléculas que elijan probablemente no han sido ensayadas nunca antes con este propósito, constituyen un importante factor favorecedor de la motivación y por tanto del aprendizaje. Los estudiantes se enfrentan a su primer experimento, y aunque se permite que cada grupo escoja qué sustancia desea testar, el profesor introduce unas breves directrices para una selección más adecuada. Algunos ejemplos de estas directrices serían:

- Es necesario una pequeña investigación sobre el mecanismo de acción del fármaco para asegurarse de que su selección tiene sentido. Por ejemplo, un inhibidor de la ECA como el captopril (utilizado en los tratamientos para la hipertensión) no es adecuado, ya que $C$. elegans carece de esta enzima y presumiblemente no va a tener ningún efecto fisiológico sobre este organismo.

- Se deben elegir con preferencia fármacos que tengan mecanismos de acción o efectos relacionados con la biología celular. Por ejemplo, el paracetamol resulta adecuado desde el punto de vista de su acción tóxica deplecionando los depósitos de glutatión intracelulares, lo que causa daños en las membranas por el efecto tóxico de los radicales libres.

- Los neurofármacos o fármacos para el sistema nervioso autónomo que afectan receptores nerviosos se consideran buenos candidatos si se comprueba en la bibliografía que el receptor está representado en la fisiología del nematodo. Por ejemplo, se encuentra que la dopamina, serotonina y otras aminas biógenas tienen efectos en la fisiología de $C$. elegans, aunque su papel no está claro (Lawal, 2013).

- Asimismo se consideran adecuadas vitaminas, suplementos alimenticios tales como aminoácidos, hierro, etc.

\subsection{Extracción del principio activo}

Se proporcionan los instrumentos y materiales necesarios para una sencilla extracción del principio activo desde la forma farmacéutica en la que se presenta en el medicamento seleccionado por el grupo de estudiantes. Por ejemplo, si se trata de comprimidos, estos pueden ser pulverizados en un mortero, mezclando el polvo con agua, disolviendo el principio activo mediante agitación en vórtex, centrifugando a continuación y filtrando el sobrenadante en papel o con un filtro 0,22 micras. Para cuantificar la concentración en principio activo del líquido resultante, se hace a partir de la dosis del comprimido o medicamento utilizado, con la asunción simplificadora de que se ha disuelto completamente durante la extracción. No se considera importante un cálculo preciso de la concentración del principio activo ni de la dosis 
que se aplicará a los animales, con la salvedad de que debe ser una dosis suficientemente pequeña para evitar problemas de toxicidad. El profesor sencillamente intervendrá para aconsejar a los estudiantes sobre qué dosis usar, asegurándose de que utilizan soluciones suficientemente diluidas y evitando así que los animales puedan morir por una dosis excesiva del compuesto a ensayar. Se trata de una práctica de simulación de un experimento, no de un experimento real, y no se consideran importantes aspectos como una optimización del rango de dosis aplicada ya que despistan a los alumnos primerizos del objetivo de aprendizaje real y consumen tiempo.

\subsection{Diseño del experimento}

Esta fase se realiza bajo la guía y supervisión del profesor. El grupo de alumnos dialoga y decide cómo cómo va a realizarse la experiencia, guiados por el profesor. El diseño experimental es muy sencillo: los animales de cada cepa del nematodo que reciban la sustancia a evaluar se dividen en dos grupos, el grupo que recibirá el fármaco y el grupo control. Asimismo, se preparan grupos de control adicionales que permanecerán en la bancada del laboratorio a temperatura ambiente, sin ser sometidos a anoxia/inanición. Se explica también cómo se evaluarán los animales tras las condiciones de hipoxia inanición, es decir, se explica en qué consiste el modelo experimental y cómo se utilizará para evaluar el fármaco que testamos como posible protector celular.

\subsection{Desarrollo de la experiencia de laboratorio}

C. elegans es un nematodo microscópico usado como animal modelo de laboratorio en biología celular y en biomedicina. En la siguiente experiencia, los animales se someterán a condiciones de anoxia e inanición durante 24 horas. Estas condiciones simulan los procesos de isquemia seguida de reperfusión que se dan durante las intervenciones quirúrgicas y que son fuente de posibles complicaciones y repercusiones postoperatorias en los pacientes. El modelo experimental completo, así como los detalles de la construcción de la cámara de hipoxia, pueden encontrarse en (Queliconi, 2014). En esta experiencia de laboratorio, usaremos este modelo para evaluar la posible actividad protectora celular de una sustancia farmacológica elegida por los estudiantes. Asimismo, pueden utilizarse los gases anestésicos inhalatorios como isofluorano, halotano, etc. responsables del fenómeno de preacondicionamiento anestésico descrito en la bibliografía (Murry, 1986).

Los nematodos se separan de su fuente de alimento (bacterias) y se colocan en condiciones de anoxia durante 24 horas (isquemia simulada); posteriormente se trasladan a una atmósfera normal con presencia de oxígeno y de las bacterias que les sirven de alimento, simulando reperfusión. Como consecuencia, se producen muertes de los animales, así como daño neuronal. En el siguiente experimento, se 
evalúa la viabilidad del nematodo, las alteraciones en la morfología de los axones neuronales y pérdida de la sensibilidad táctil (indicando daños neuronales), que representan al normal funcionamiento de las células neuronales estudiadas. El "preacondicionamiento anestésico" es una respuesta celular adaptativa que se observa tras la administración de anestésicos volátiles (isofluorano, halotano) durante una intervención quirúrgica (Gilsanz, 1986). La exposición a estos agentes desarrolla una respuesta adaptativa en las células que las protege frente a daños por la hipoxia/isquemia durante la intervención, especialmente en neuronas cerebrales y cardiomiocitos, que se ha investigado en modelos experimentales en C. elegans (Jia, 2008).

Utilizaremos un modelo experimental para evaluar la capacidad de la sustancia farmacológica problema para inducir el fenómeno de preacondicionamiento celular y proteger del daño neuronal. Se emplean tres cepas del nematodo en el experimento:

- $\quad$ N2 Bristol Wild type strain.

- TU2589 uIs25 [mec-18::GFP + dpy-20(+)]

- $\quad$ CB1338 mec-3 (e1338)IV

Estas cepas pueden obtenerse fácilmente desde el Caenorhabditis Genetics Center (CGC) del NIH en la University of Missouri, Columbia.

La cepa N2 procede del C. elegans salvaje aislado original. La cepa TU contiene una proteína de fusión con GFP, que proporciona fluorescencia a las neuronas mec implicadas en la respuesta al toque. La cepa $\mathrm{CB}$ es un mutante de las neuronas mec que no responde al toque, que usaremos para calibrar la fuerza con la que tocar a los animales en los ensayos de respuesta al toque.

\subsection{Experimento de anoxia/inanición}

Las cepas de $C$. elegans se encuentran en medio líquido conteniendo las bacterias $E$. coli OP50 que les sirven de alimento, mediante métodos de cultivo estándar. Se coloca la cantidad adecuada del líquido de cultivo que contiene los nematodos en tubos de microcentrífuga a los que se ha practicado un agujero en la tapa superior, mediante una aguja. Se disponen los tubos en hielo, hasta que los gusanos hayan caído a la parte inferior ( 1-2 min), ya que el frio los inmoviliza y les impide nadar. Se elimina el sobrenadante, añadiendo seguidamente medio de cultivo fresco sin bacterias. Se repite la operación por 3 veces, usando en el último paso medio de cultivo previamente desgasificado por 30 minutos mediante burbujeo de gas $\mathrm{N}_{2}$. Esto limpiará a los nematodos de los restos de bacterias del líquido del frasco de cría, y eliminará el oxígeno del medio circundante.

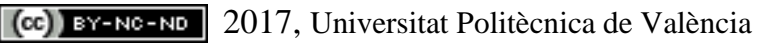


A continuación, se colocan los tubos de microcentrífuga con los gusanos en el medio desoxigenado dentro de una cámara de hipoxia, que consiste en un recipiente herméticamente cerrado pero conectado por un tubo a una botella de gas $\mathrm{N}_{2}$ comprimido y con un tubo adicional para la salida de gas. La cámara se sumerge en un baño termostático a $26^{\circ} \mathrm{C}$, bajo un flujo de gas $\mathrm{N}_{2}$ constante $(100 \mathrm{ml} / \mathrm{min})$ durante 20-24 horas. Tras este período, se sacan los tubos de la cámara de hipoxia y se colocan los gusanos en placas de agar NPM provistas de las bacterias que les sirven de alimento, durante 24 horas, antes de proceder a la observación. Los detalles de la construcción de la cámara de hipoxia y el montaje del dispositivo pueden encontrarse en (Queliconi., 2014)

\subsection{Identificación de gusanos vivos vs. muertos}

Con el asa de platino se toca suavemente la parte superior de la cabeza del gusano. Los gusanos vivos se moverán hacia atrás después de ser tocados. Si los gusanos no manifiestan respuesta, se marcan como "muerte".

Deben retirarse ambos tipos de gusanos, vivos y muertos, de la placa en la que se realiza el contaje para evitar conteos duplicados. Los gusanos vivos se mueven a una placa separada para realizar ensayos de respuesta al contacto. La cantidad de gusanos que viven en relación con el total se representa como el "\% de supervivientes".

\subsection{Ensayos de respuesta al contacto}

Para el recuento de las respuestas al toque, se identifican los gusanos que se mueven y se tocan ligeramente por el lado anterior del gusano (cerca de la parte media de la faringe) con el asa. Si el gusano se mueve hacia atrás, se marcar como "respondedor". Si no, se anota como "no respondedor". Se repite este paso para cada 10-15 gusanos con intervalos de 10 segundos. Para obtener datos precisos, es necesario testar al menos 10 gusanos en cada grupo. Hay que asegurarse de no tocar la cabeza o la cola del gusano, ya que esto estimula un comportamiento distinto. La cepa CB1338 mec-3 puede utilizarse para calibrar la fuerza con la que deben ser tocados los gusanos. Un estímulo demasiado duro provocará una respuesta de comportamiento en los mutantes mec, en cambio si el estímulo es demasiado suave no provocará un efecto en los controles de tipo salvaje N2.

\subsection{Modificaciones neuronales}

Para visualizar las modificaciones neuronales, se utiliza la cepa de $C$. elegans TU2589 uIs25 que expresa GFP en las neuronas mec respondedoras al contacto. Estas neuronas tienen largos axones, que discurren a lo largo de la pared del cuerpo y que son fácilmente visibles al microscopio para su revisión y constatación de posibles anormalidades en su morfología. Bajo el microscopio de fluorescencia con el objetivo de inmersión en aceite 100X, con la iluminación adecuada, las neuronas 
dañadas mostrarán un patrón citosólico de membrana en collar de perlas en los axones, compuesto de múltiples puntos, y/o anormalidades locales que aparecen como interrupciones o rupturas del axón. Para obtener datos significativos, los puntos y las anormalidades o rupturas deben contarse en ambas neuronas laterales en cada nematodo, y debe realizarse el recuento en un total de al menos 10 gusanos. Sin embargo, debido a la limitada duración de una sesión de prácticas, no se considera necesario el contaje en 10 ejemplares, ya que consume un tiempo excesivo $\mathrm{y}$ en cualquier caso ulteriormente se proporciona a los alumnos un set de datos con resultados experimentales ficticios. Por lo que durante la sesión los alumnos se limitan a observar y contar tan solo algunos de los gusanos de la muestra.

\subsection{Análisis de los resultados del experimento e interpretación.}

Los resultados se reportan en un miniartículo científico sobre este experimento único. Para ello, se considera importante la realización sistemática de los siguientes pasos, que pretenden enseñar cómo escribir artículos científicos. Para verificar que los alumnos siguen los pasos en el orden indicado, la actividad debe entregarse mediante una tarea de tipo "Wiki" en la plataforma LMS Moodle de la asignatura. Esta modalidad de tarea permite al profesor seguir la evolución en la redacción de la actividad por los alumnos, ya que queda un registro histórico de los cambios en la página que permite seguir la evolución en su construcción. De esta manera puede controlarse que el informe final se ha redactado siguiendo secuencialmente los pasos anteriores.

La actividad usualmente no se realiza con los datos obtenidos por los alumnos durante la sesión de prácticas pues, debido a su inexperiencia en el laboratorio y a la duración limitada de una sesión de prácticas, no es posible obtener en estas un número suficiente de datos (limitándose los alumnos a contar los gusanos vivos y muertos, realizar algunas experiencias de toque y respuesta, y observar algunas de las neuronas dañadas al microscopio). En su lugar se elaboran varios sets de datos completos, pero que conducen a resultados experimentales diferentes. Estos sets son asignados al azar, uno a cada alumno, desde la plataforma Moodle. La mayoría de los alumnos elige utilizar estos datos para la realización del informe final, pero en ocasiones los alumnos más competentes pueden obtener sets de datos propios útiles de los experimentos de respuesta al toque y contaje vivos/muertos y deciden usarlos para su informe. Los datos de contaje de lesiones neuronales son siempre tomados desde el set de datos del profesor, ya que este es un experimento lento que consumiría días, por lo que sólo se realiza alguna observación a nivel testimonial de las lesiones neuronales durante la sesión de prácticas. 


\subsection{Guía "paso a paso"}

Inicio Cada alumno descarga un set de datos individual desde la plataforma Moodle de la asignatura

Paso 1 El alumno redacta un breve apartado sobre "material y métodos" a partir de la información proporcionada en el cuadernillo de prácticas.

Paso 2 A continuación, debe establecer cuál es el propósito del experimento en "objetivos".

Paso 3 El siguiente paso es usar las palabras clave proporcionadas (keywords) para buscar artículos en la bibliografía en los que se realicen experimentos análogos (que sirvan para inspirarse acerca de qué tipo de gráfico o tabla elegir para representar e interpretar el set de datos).

Paso 4 Una vez seleccionada la forma en que se representarán los datos, debe utilizarse el programa Excel u otro similar para construir las correspondientes gráficas o tablas.

Paso 5 Se debe redactar un pie de figura en cada gráfico o tabla, que se situarán en el apartado "resultados".

Paso $6 \mathrm{El}$ alumno debe describir, sin interpretar su significado, los resultados que se muestran en sus gráficos y tablas. Este texto se sitúa en el apartado "resultados".

Paso $7 \mathrm{El}$ alumno debe interpretar qué significan de sus resultados, e incluirlo este texto en el apartado "discusión".

Paso $8 \mathrm{El}$ alumno debe redactar una pequeña "introducción", usando para ello el cuadernillo de prácticas proporcionado y los artículos que haya seleccionado en el paso 3.

Paso 9 El alumno elabora una pequeña lista bibliográfica (los dos o tres artículos citados en la introducción u otros apartados) para incluirla en el apartado "bibliografía". Introduce las citas en el cuerpo del texto del informe en su lugar correspondiente.

La realización en la secuencia temporal programada que indica esta guía "paso a paso" es importante, pues pretende enseñar un modelo de proceder estructurado para la redacción de un artículo o informe científico. Los trabajos se realizan en la plataforma Moodle de la asignatura mediante una Tarea Moodle de tipo "wiki" que permite realizar un seguimiento de la evolución temporal de un texto.

\subsection{Seminarios}

La actividad se acompaña además de los siguientes seminarios independientes, que proporcionan la competencia necesaria en aspectos específicos: 
Experimentos de anoxia/inanición en C. elegans y preacondicionamiento anestésico. Una actividad práctica de laboratorio para la formación integrada en las competencias del diseño de experimentos, análisis e interpretación de datos en la experimentación científica.

Seminario 1 Uso de programas de hoja de cálculo (Excel)

Seminario 2 Búsqueda de información científica en bases de datos (pubmed)

Seminario 3 Interpretación de resultados experimentales

El hecho de que el contenido de estos seminarios tenga utilidad y aplicabilidad inmediata en la elaboración de la actividad es otro valor adicional, pues son seguidos con mayor interés y aprovechamiento por los estudiantes. Por ello, deben intercalarse durante el período en que los alumnos están ocupados realizando la actividad, cubriendo la necesidad de formación en estos aspectos que surge de la propia actividad.

\subsection{Evaluación de la actividad}

Para la evaluación, se utilizará la siguiente rúbrica:

1. El informe contiene una correcta introducción, objetivos, resultados y discusión

2. La representación gráfica de los datos es correcta (gráficos adecuados, completos y con un pie de figura)

3. La descripción e interpretación de los datos en "resultados" y "discusión" es correcta

4. Se ha realizado una bibliografía con los artículos elegidos y estos son citados correctamente

\section{Resultados}

La actividad se ha realizado durante dos cursos académicos consecutivos, con carácter voluntario, aunque se trata de una actividad evaluable. Auqnue se oferta como "voluntaria" a los estudiantes (la realización del informe final o mini artículo científico), se recompensa con un pequeño porcentaje de nota adicional que se suma a su evaluación final.

Durante el primer año la participación fue del $71 \%$, mientras que el segundo año ha sido de sólo el 17\%. Se observa asimismo que muchos alumnos comienzan el trabajo, pero no lo terminan. Las diferencias entre los dos años son atribuibles a la mejor situación en el primer año del rango de fechas de entrega de la actividad con respecto a los exámenes del fin de cuatrimestre, que fue bastante más desfavorable en el segundo año. No considerando este segundo año, por el efecto que haya tenido la cercanía de la entrega con las fechas de los exámenes finales, se puede considerar que la actividad tiene una elevada participación pese al carácter voluntario y la dificultad intrínseca de la competencia a desarrollar (especialmente si se tiene en cuenta que se trata de alumnos recién llegados a la universidad desde la educación

(cc) EY-NC-ND 2017, Universitat Politècnica de València 
secundaria). Atribuimos el éxito en la participación al buen funcionamiento de la guía estructurada "paso a paso", que facilita mucho la realización de la actividad.

\section{Conclusiones}

La competencia en el diseño de experimentos va íntimamente ligada a la interpretación de los resultados y a la competencia en la lectura e interpretación de artículos científicos. Estas importantes competencias a menudo se dispersan en las múltiples actividades y prácticas de laboratorio de las asignaturas del Grado, que tratan sólo aspectos parciales, y su implementación en el programa de estudios queda diluida precisamente a causa de esta importancia y de la transversalidad a muchas asignaturas diferentes, por lo que no existe una asignatura específica encargada de enseñarlas. A los alumnos no se les presenta una visión integrada centrada en una única actividad, lo que en nuestra opinión desfavorece de manera importante la adquisición de estas competencias. En el presente trabajo, presentamos una actividad integral para su desarrollo. La estructuración en una "guía paso a paso" permite un aprendizaje fácil, y su integración con experimentos reales realizados en las prácticas de laboratorio genera aprendizajes muy interesantes a la vez que motivadores en el alumnado.

\section{Referencias}

GILSANZ F, CELEMIN R, BLANC G, ORTS MM. (1996) "Sevoflurane" en Rev Esp Anestesiol Reanim. 1996 Aug-Sep;43(7):243-8.

JIA B, CROWDER CM. (2008) "Volatile Anesthetic Preconditioning Present in the Invertebrate Caenorhabditis elegans". en Anesthesiology. 2008 Mar;108(3):426-33.

LAWAL HO, KRANTZ DE. (2013) “SLC18: Vesicular neurotransmitter transporters for monoamines and acetylcholine" en Molecular Aspects of Medicine. Volume 34, Issues 2-3, April-June 2013, Pages $360-372$

MURRY CE, JENNINGS RB, REIMER KA. (1986) "Preconditioning with ischemia: a delay of lethal cell injury in ischemic myocardium" en Circulation. 1986 Nov;74(5):1124-36.

QUELICONI BB, KOWALTOWSKI AJ, NEHRKE K. (2014) "An anoxia-starvation model for ischemia/reperfusion in C. elegans" en J Vis Exp. 2014 Mar 11;(85).

THE C. ELEGANS RESEARCH COMMUNITY, WormBook <http://www.wormbook.org> [Consulta: 3 de junio de 2016] 


\title{
Formación Integral en competencias para Impresión 3D
}

Rut Benavente ${ }^{a}$, Iván Patrao ${ }^{\mathrm{a}}$, Graham Small ${ }^{\mathrm{b}}$ y Nikos Tsianos ${ }^{\mathrm{c}}$

a rbenavente@florida-uni.es, ipatrao@florida-uni.es , Unidad de ingenería, Florida Centre de Formació, 46470, Catarroja, España.

b.small@amrc.co.uk, AMRC Training Centre, University of Sheffield, United Kingdom.

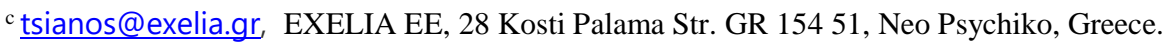

\begin{abstract}
Competences, skills and habilities adquired by students in the learning process must be determined by the learning outcomes, previously defined. In the 3D-PRISM European Project, the learning outcomes for 3D-printing students have been stablished.

The process for determining the learning outcomes did take in consideration the opinion of University and Professionals of the manufacturing industry. The proposed methodology comprises 4 phases: creation of the profiles for the professionals in the 3D-printing industry, creation of the questionnaire based in previous documental research, on-line questionnaire and data collection and processing
\end{abstract}

Keywords: Learning outcomes, skills, ETC's, ECVET's, 3D printing

\section{Resumen}

Los conocimientos, competencias y/o habilidades adquiridas por el alumnado en el proceso de formación, han de estar determinadas por los resultados de aprendizaje previamente establecidos.

En el Proyecto Europeo 3D-PRISM se han establecido los resultados de aprendizaje en materia de Impresión $3 D$. El proceso ha sido llevado a cabo mediante el dialogo establecido entre la Universidad y la sociedad representada por expertos profesionales y docentes en la materia. La metodología propuesta en este trabajo se basa en cuatro fases: elaboración de los perfiles de los expertos en materia de impresión $3 D$, elaboración de un cuestionario basado en una investigación documental previa, distribución on-line de los cuestionarios y la recopilación de los datos obtenidos y tratamiento de los datos.

Palabras clave: Resultados de aprendizaje, Competencias, ECT's, ECVET's, Impresión $3 D$ 


\section{Introducción}

\subsection{Conocimientos, Habilidades y Competencias}

En el desarrollo de un programa docente deben cubrirse tres pilares básicos: Conocimientos, Habilidades y Competencias (European Communities, 2008; Gonçalves, 2013).

- Conocimientos: Resultado de la información asimilada a través del aprendizaje Se consideran "conocimientos" los principios básicos, teoremas y desarrollos teóricoprácticos que forman parte de una determinada área de estudio.

- Habilidades: Capacidad adquirida para aplicar el concimiento y usar los recursos disponibles para llevar a término una tarea y resolver problemas.

- Competencias: Hace referencia a la capacidad para el uso del conocimiento, las habilidades y habilidades personales y sociales a la hora de resolver problemas personales y profesionales. Las competencias pueden entenderse como una forma de responsabilidad y autonomía.

El alumno habrá alcanzado el grado de aprendizaje óptimo cuando haya interiorizado conocimientos y habilidades que le permitan desarrollarse tanto en el campo de estudio como en otros relacionados, habiendo adquirido autonomía a la hora de afrontar problemas de tipo innovador, es decir, cuando haya desarrollado las competencias trabajadas en el curso.

La adquisición por parte del alumno de conocimientos, habilidades y competencias se comprueba durante el desarrollo del curso mediante los "Resultados de aprendizaje". Así, los "Resultados de aprendizaje" se utilizan para definir de forma precisa qué se espera enseñar en un curso. Se centran en la visión del alumno, especificando qué será capaz de hacer una vez finalizado (European Union, 2011). Un resultado de aprendizaje debe definir aquello que una persona sabrá, entenderá y será capaz de hacer al completar el proceso de aprendizaje.

Los Resultados de aprendizaje se enuncian basándose en las siguientes reglas:

- Se debe usar un verbo activo para expresar qué se espera que los estudiantes sean capaces de hacer.

- Se debe especificar a qué habilidad/es hace referencia cada resultado de aprendizaje

- Se debe especificar de qué modo se demostrará el cumplimiento de los resultados de aprendizaje.

En necesario definir cómo se medirá la carga de trabajo asociada a cada resultado de aprendizaje. A nivel europeo se han definido varios sistemas de créditos asociados a la carga de trabajo asociada a cada resultado de aprendizaje: ECTS y ECVET, descritos a continuación.

(cc) EY-NC-ND 2017, Universitat Politècnica de València

Congreso IN-RED (2017) 


\subsection{Sistema Europeo de Transferencia y Acumulación de Créditos (ECTS) y Sistema de Créditos en Educación y Formación Vocacional (ECVET)}

El Sistema Europeo de Transferencia y Acumulación de Créditos (European Credit Transfer and Accumulation System, ECTS) constituye en la actualidad una pieza clave del Espacio Europeo de Educación (European Higher Education Area, EHEA). En la actualidad el sistema basado en créditos ECTS es utilizado en todos los programas de estudios superiores del EHEA, aunque es aplicable a todo tipo de programas educativos, tanto presenciales como a distancia; pues traslada la visión del programa de estudios desde una visión centrada en el profesor a una visión centrada en el estudiante, siendo este uno de los pilares básicos de EHEA.

Los créditos ECTS expresan el volumen de carga de trabajo para cada resultado de aprendizaje. La carga de trabajo debe reflejar la totalidad de horas necesarias para alcanzar un resultado de aprendizaje: presenciales, trabajo en aula, en casa, prácticas, talleres, etc.

Por otro lado, el Sistema de Créditos en Educación y Formación Vocacional (Credit System in Vocational and Educational Training, ECVET) pretende servir de ayuda para la transferencia, reconocimiento y acumulación de resultados de aprendizaje, facilitando itinerarios formativos personalizados. Una mejor comprensión de los resultados de aprendizaje que acumula un individuo llevará, así, a una mayor movilidad internacional dentro de las fronteras de la Unión Europea, como se ha desmostrado en recientes ensayos de implantación del sistema ECVET (Cedefop 2013; European Commission 2014; Cedefop 2016).

Aunque la recomendación de la Unión Europea (European Parliament and Council of the European Union, 2009) es que se apliquen los ECVET a todas las titulaciones relacionadas con la formación vocacional y educacional (VET), la experiencia ha demostrado que, en las instituciones de educación superior, la aplicación práctica de este sistema encuentra una firme oposición.

Así, aunque el sistema ECVET todavía no ha sido implementado de forma masiva en todos los estados miembros de La Unión Europea, la aplicación de este sistema en educación superior parece ser, en el mejor de los casos, limitada. De hecho, los proveedores de formación VET de tercer nivel siguen prefiriendo un enfoque basado en ECTS, debido proincipalmente a su metodología más sencilla y a que, en educación superior, la ponderación de la carga de trabajo es un factor clave. Esto resuleve el problema de estructurar los curriculum docentes y agendas de profesores y alumnos, además de dar al estudiante una idea de la carga de trabajo que requiere cada curso ofertado.

Aunque podría parecer que un enfoque basado en ECVET es poco compatible con uno basado en ECTS, se ha demostrado que realizar una planificación basada en resultados de aprendizaje facilita enormemente la conversion bilateral entre ambos sistemas.

En este trabajo se presenta el proceso de identificación de los resultados de aprendizaje de un programa formativo en impresión 3D. Debido a la alta demanda de nuevos profesionales formados en esta técnica, se ha contado con la doble colaboración Universidad-Sociedad a la hora de determinar qué resultados de aprendizaje es necesario cubrir en esta formación. 


\section{Objetivos}

Mediante el díalogo establecido entre los expertos del sector de la fabricación aditiva (impresión 3D) y la Universidad, se pretende llegar a un entendimiento de lo que la sociedad demanda de los estudiantes egresados, de manera que se pueda establecer un perfil con las competencias perfectamente desarrolladas.

Por lo tanto, el principal objetivo de este trabajo se resume en:

- Establecer los resultados de aprendizaje en la formación sobre impresión 3D.

Para alcanzar el objetivo principal se han cubierto los siguientes objetivos secundarios:

- Apoyar la formación para el desarrollo de habilidades necesarias en el ámbito de la impresión 3D, mediante metodologías de formación específicas.

- Identificar nuevos perfiles en el sector de la fabricación aditiva, para facilitar y agilizar la integración de nuevas habilidades y cualificaciones en los alumnos en formación.

- Ayudar a aplicar las políticas de la UE para la cualificación, la transparencia, la movilidad y el renacer de la industria europea a través de puestos de trabajos seguros y sostenibles.

\section{Desarrollo de la innovación}

La metodología propuesta en este trabajo se llevó a cabo en cuatro fases. En la primera fase se elaboró el perfil de los expertos en materia de impresión 3D que formarán parte del estudio. En la segunda fase se llevó a cabo una investigación documental que culminó en la elaboración del cuestionario mediante el cual los expertos del sector, definirían las competencias y habilidades requeridas para el alumnado tanto en fase de preparación como en fase de producción. La tercera fase consistió en la distribución de los cuestionarios y la recopilación de los datos obtenidos. Por último, el tratamiento de los datos, originó los perfiles que demanda la sociedad para los expertos en material de fabricación 3D.

\subsection{Fase primera: Perfil del experto}

Las competencias adquiridas durante el periodo de formación del alumnado han de ser establecidas por la sociedad que les va a contratar. Es, por lo tanto, necesario consultar a la sociedad sobre qué competencias han de ser cubiertas. El papel de la sociedad, tendrá que ser cubierto por expertos en la materia.

Se consultó a expertos profesionales y expertos docentes. Como experto profesional, se engloban las personas que trabajan en empresa privada, tanto por cuenta propia como por cuenta ajena, en el ámbito de la fabricación aditiva. El experto docente, comprende a los profesionales docentes de la Universidad Pública, que imparten clases relacionadas con la fabricación asistida.

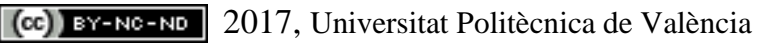


En el perfil de expertos profesionales se ha logrado contactar con representantes de multinacionales, pymes y autónomos, así como fabricantes y vendedores de maquinaria y equipamiento, cubriendo todo el espectro de empresas dedicadas a la fabricación aditiva.

En el perfil de expertos docentes se ha logrado contactar tanto con titulares de Universidad como con profesores asociados, tanto del sector de fabricación asistida, de ingeniería mecánica y de ciencia de materiales, cubriendo así las áreas más relevantes de la ingeniería relacionadas con la impresión 3D.

\subsection{Fase segunda: Elaboración del cuestionario}

En primer lugar se realizaron entrevistas personales a profesionales del sector, buscando su punto de vista sobre el presente y futuro de los profesionales que trabajan en la fabricación aditiva. El formato de respuesta a las preguntas fue respuesta abierta. Las preguntas se agruparon en 4 áreas:

- Tendencias y desarrollos sectoriales

- ¿Consideras que la impresión 3D contribuirá a la eficiencia en la fabricación la productividad?

- ¿Piensa que tendrá un impacto en la cadena de suministro global y/o traerá cambios en los modelos de negocio existentes? En caso afirmativo, indíquelos

- ¿Qué sectores de fabricación serán más probablemente afectados por la proliferación de la impresión 3D?

- ¿En cuánto se refiere a los trabajadores de la fabricación, cuáles son, según su conocimiento, los principales puestos de trabajo y tareas que requieren habilidades de impresión 3D? ¿Cuáles son los nuevos roles emergentes?

- Habilidades y competencias

- ¿Será posible para alguien sin formación especializada hacer frente a la integración de la impresión $3 D$ en la fabricación?

- ¿Qué habilidades, competencias y conocimientos necesitan los empleados de fábrica para trabajar eficientemente con equipos de impresión 3D?

- ¿Puede listar por orden de importancia los requisitos que usted ha mencionado?

- Basado en su respuesta anterior, ¿cree que hay falta de habilidades y habilidades que no se ajustan a las necesidades?

- ¿Conoce algún plan o iniciativa de la industria para identificar y hacer frente a estos desajustes?

- Formación Profesional y Cualificaciones

- ¿En términos de cualificaciones ofrecidas, ¿los cursos existentes para los empleados de fabricación cubren las necesidades y requisitos necesarios para la integración de la impresión 3D? ¿Hay diferencias entre la formación profesional y la formación para personal en activo?

- ¿Crees que habrá cambios significativos en los cursos de FP para los trabajadores destinados a la industria? 
- En tu opinión, ¿Cómo de exhaustiva o extensa debería ser la oferta de formación profesional 3D para los empleados de fabricación? [Especifique duración, frecuencia, temas de ingeniería a cubrir, interdisciplinariedad, etc]

- ¿Cómo tendrá lugar el desarrollo de competencias para la impresión 3D? [Indique si piensa que será por iniciativa de empresas de fabricación (formación interna o bajo demanda), o sobre todo a través del desarrollo de nuevos cursos por los proveedores de cursos de FP]

- Marco de Cualificaciones Europeo (EQF) y ESCO (para quien corresponda)

- ¿Cuál es el nivel de cualificación según el marco europeo (o NQF, si procede) de los trabajadores involucrados en procesos de impresión $3 D$ ? ¿Debería ser superior al de los trabajadores involucrados en los procesos de fabricación tradicional?

- ¿Sabe si la ESCO (Clasificación Europea de Capacidades, Competencias, Cualificaciones y Ocupaciones) está planeando tener en cuando los desarrollos en fabricación aditiva respecto a las habilidades y competencias en los trabajos de fabricación?

- Se ha planeado o puesto en marcha en su país algún marco de cualificación en referencia a la fabricación aditiva, que pudiera servir de información para la ESCO?

- ¿Cree que sería útil para la formación de FP, transparencia de las cualificaciones y la movilidad el desarrollo de nuevos perfiles ocupacionales para los empleados de fabricación implicados en procesos de impresión $3 D$ ?

A partir de las respuestas de las entrevistas se generó la encuesta, cuyo propósito es la recopilación de información para desarrollar y actualizar los perfiles ocupacionales de personas que trabajan, o trabajarán, en la industria de fabricación aditiva. La encuesta se estructuró en 4 áreas, de acuerdo con las diferentes etapas del proceso del aditivo (por ejemplo la producción de fabricación, montaje y producción). Se muestran a continuación las preguntas de la encuesta, agrupadas por área. El formato de respuesta fue de respuesta múltiple, con cinco posibles respuestas (No requerido, Prioridad baja, Prioridad media, Prioridad Alta, No sabe/No contesta), donde el experto debe indicar la importancia que estima para los futuros profesionales en impresión 3D que tiene cada una de las habilidades por las que se le pregunta.

- Conocimientos requeridos para técnicos de fabricación aditiva

- Comprender los diferentes tipos de procesos de fabricación aditiva disponibles, así como sus ventajas y desventajas

- Comprender los diferentes materiales, y sus propiedades, que se utilizan para producir componentes en los procesos de fabricación aditiva

- Comprender cómo pueden ocurrir problemas y defectos en componentes producidos mediante procesos de fabricación aditiva, así como las medidas preventivas

- Comprender las técnicas de acabado (por ejemplo, mecanizado, cadena, capa, tratamiento térmico) utilizadas para las diferentes técnicas de fabricación aditiva

- Aplicación de prácticas de seguridad en el trabajo y los procedimientos en todo momento

(c)) BY-NC-ND 2017, Universitat Politècnica de València

Congreso IN-RED (2017) 
- Habilidades/competencias requeridas para la fase de preproducción.

- comprobar que todo el equipo está en condiciones de trabajo seguro

- estimación de la cantidad materiales necesarios, correcta manipulación y almacenamiento de materiales y chequeo de documentación

- obtener todos los datos necesarios, documentación y especificaciones para el componente a producir

- interpretación de dibujos, sistemas imperial y métrico, puntos de referencia de la pieza de trabajo, sistemas de tolerancias

- Chequeo de archivos de fabricación correctos para producir los componentes

- Comprobación de la adecuación de los archivos de datos

- comprensión de los principios básicos de los equipos de fabricación aditiva que se utilizan

- Habilidades/competencias requeridas para la fase de puesta en marcha.

- capacidad de iniciar o detener el equipo durante una situación de uso normal, finalización y situaciones de emergencia

- comprender los riesgos asociados con el uso de máquinas de fabricación aditiva y cómo minimizarlos

- Uso de equipos de protección apropiados y mantenimiento del área de trabajo de manera ordenada y segura

- importación de archivos correspondientes (por ejemplo STL) de un sistema de CAD a software de fabricación aditiva

- capacidad de comprobación del conjunto de parámetro de funcionamiento de equipos (acceso programa, edición, facilidad para hacer ajustes menores para la producción...)

- Habilidades/competencias para la fase de producción.

- seguimiento de parámetros del proceso para el control de calidad

- saber cuándo las piezas pueden ser retiradas de la máquina

- eliminación de material de soporte y desechos

- inspección de la pieza para el control dimensional, revisión de la apariencia, y detección de defectos visibles

- detección y definición de los componentes a limpiar, empaquetar y almacenar con toda su documentación asociada (p. ej. $N^{o}$ de lote, número de archivo CAD, fecha, operador, etc...)

- dejar la máquina en condiciones seguras y óptimas para el próximo uso, por ejemplo: cierre del programa, limpieza de la máquina, retirada y acondicionamiento de residuos

\subsection{Fase tercera: Distribución y recopilación del cuestionario}

Se realizaron entrevistas personales a candidatos relevantes. En total se llevaron a cabo 26 entrevistas en 3 países (Italia, Reino Unido y España).

(c) ) EY-NC-ND 2017, Universitat Politècnica de València 
Además, una vez seleccionados los profesionales que serían encuestados, se realizó la distribución del cuestionario en línea. Se enviaron 200 cuestionarios, de los cuáles 119 resultaron contestados en su totalidad.

\subsection{Fase cuarta: Tratamiento de datos}

Como resultado de las entrevistas se pudo plantear un cuestionario adaptado a la realidad del sector.

Los resultados de las encuestas fueron tratados minuciosamente para extraer los resultados de aprendizaje que la sociedad demanda del alumno de fabricación en impresión 3D.

No se incluyen las respuestas ni de las entrevistas ni de los cuestionarios debido a su extensión, que resulta excesiva para el presente documento. Sin embargo, sí que se presentan los resultados de aprendizaje derivados del trabajo previo.

\section{Resultados}

A partir del análisis de los datos obtenidos en el cuestionario, se han identificado una serie de requisitos de conocimiento y habilidades / competencias requeridas para las fases de preproducción, puesta en marcha y producción de la implementación industrial.

En las tablas siguientes se asignan resultados de aprendizaje a cada uno de los requisitos de conocimiento, habilidades y competencias.

Tabla 1. Conocimientos previos.

\begin{tabular}{cc}
\hline Conocimientos previos & \multicolumn{1}{c}{ Resultados de aprendizaje } \\
\hline Aplicación de prácticas y & - Conocer las prácticas y procedimientos de trabajo seguros \\
procedimientos seguros de & - Comprender las consecuencias de no adoptar prácticas y \\
trabajo en todo momento & procedimientos de trabajo seguros \\
& - Saber cómo mejorar las prácticas y procedimientos de trabajo \\
& seguros si se descubre que son subóptimos \\
\hline Comprender los diferentes tipos & - Ser capaz de enumerar y describir los principios operativos de \\
de procesos de fabricación de & todos los procesos FA relevantes \\
aditivos (FA) disponibles, así & - Describir las aplicaciones de cada proceso y sus ventajas para \\
como sus ventajas y & dichos procesos \\
desventajas. & - Describir las desventajas de cada proceso para sus aplicaciones \\
\hline Comprender los diferentes & - Enumerar los materiales metálicos y no metálicos adecuados para \\
materiales, y sus propiedades,, & - Describir las propiedades físicas y químicas de cada material \\
utilizados para producir & - Estar al tanto de los requisitos de salud y seguridad para materiales \\
componentes por el proceso FA & seleccionados \\
& - Describir cualquier pretratamiento requerido para preparar cada \\
& material para FA \\
\hline
\end{tabular}

(c) EY-NC-ND 2017, Universitat Politècnica de València

Congreso IN-RED (2017) 
- FA describir cualquier post-procesamiento requerido para hacer que el producto producido por FA sea apto para el propósito

- Enumerar y describir los tipos de defectos que potencialmente

Comprender cómo los problemas y defectos pueden ocurrir en los componentes producidos por los procesos de

FA, así como las medidas preventivas. podrían surgir en cada proceso FA

- Explicar técnicas (no destructivas) para la detección de defectos

- Comprender las razones por las que se produce cada categoría de defecto

- Describir las técnicas de control de calidad, preprocesamiento, en proceso, post-proceso y otras utilizadas para prevenir o corregir problemas o defectos

- Conocer las diversas tecnologías utilizadas para el acabado (post-

Comprender las técnicas de proceso) de los productos FA

acabado (por ejemplo,

Mecanizado, HIP,

Recubrimiento, Tratamiento

Térmico) utilizadas para las diversas técnicas FA.

- Conocer los procedimientos operativos necesarios para las técnicas de acabado

- Explicar los beneficios / mejoras realizadas a los productos de FA por las operaciones de acabado

- Describir los métodos de control de calidad utilizados para comprobar la eficacia de estas técnicas de acabado

\begin{tabular}{|c|c|}
\hline $\begin{array}{l}\text { Posee habilidades de diseño } \\
\text { CAD en relación con el diseño } \\
\text { de fabricación / producto. }\end{array}$ & $\begin{array}{l}\text { - Conocer el sistema (s) CAD utilizado (s) para los productos FA } \\
\text { - Ser capaz de aplicar los sistemas CAD de manera efectiva a los } \\
\text { productos FA }\end{array}$ \\
\hline $\begin{array}{l}\text { Entienda cómo la posición y la } \\
\text { orientación afectan las } \\
\text { propiedades de la construcción. }\end{array}$ & $\begin{array}{l}\text { - Apreciar la influencia de la posición del producto en la calidad del } \\
\text { producto final de la FA } \\
\text { - Comprender los efectos de las diferentes orientaciones sobre la } \\
\text { calidad del producto } \\
\text { - Ser capaz de seleccionar la mejor combinación de posición y } \\
\text { orientación para un producto determinado }\end{array}$ \\
\hline
\end{tabular}

Tabla 2. Habilidades / competencias: fase de pre-producción.

\begin{tabular}{cc}
\hline $\begin{array}{c}\text { Habilidades / competencias: } \\
\text { fase de pre-producción }\end{array}$ & Resultados de aprendizaje \\
\hline & - Comprender las características de seguridad y procedimientos de \\
& verificación de seguridad para todos los equipos \\
Compruebar que todo el equipo & - Saber informar y/o corregir los problemas relacionados con la \\
está en condiciones de trabajo & seguridad \\
seguras y utilizables. & - Comprender los principios de funcionamiento del equipo \\
& - Saber cómo comprobar previamente todas las funciones de \\
& funcionamiento y cómo informar y/o corregir cualquier problema \\
\hline Obtener cantidades suficientes & - Conocer los materiales y cantidades requeridos para cada \\
de todos los materiales & proceso/producto \\
requeridos, manejo correcto / & - Comprender los requisitos de manipulación y almacenamiento para \\
almacenamiento de materiales y & cada material \\
revise la documentación. & - Estar familiarizado con la documentación y cómo debe ser \\
& verificada/completada \\
\hline Obtener todos los datos, & - Conocer qué datos, documentación y especificaciones se requieren \\
\hline
\end{tabular}

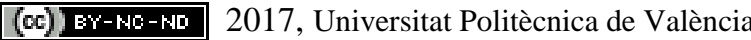




\begin{tabular}{|c|c|}
\hline $\begin{array}{l}\text { documentación y } \\
\text { especificaciones necesarios para } \\
\text { que el componente se produzca. }\end{array}$ & $\begin{array}{l}\text { de cada componente } \\
\text { - Conocer dónde encontrar los datos, la documentación y las } \\
\text { especificaciones pertinentes si alguno de ellos falta o está } \\
\text { incompleto }\end{array}$ \\
\hline $\begin{array}{l}\text { Descargar los archivos de } \\
\text { compilación correctos para } \\
\text { producir los componentes. }\end{array}$ & $\begin{array}{l}\text { - Conocer dónde se almacenan los archivos de compilación y cómo } \\
\text { descargarlos } \\
\text { - Comprender cómo comprobar que el archivo de compilación se } \\
\text { relaciona con el componente correcto }\end{array}$ \\
\hline $\begin{array}{l}\text { Compruebar que los archivos de } \\
\text { datos son adecuados para la } \\
\text { aplicación. }\end{array}$ & $\begin{array}{l}\text { - Estar familiarizado con las especificaciones y la nomenclatura que } \\
\text { relacionan los archivos de datos con componentes específicos } \\
\text { - Conocer cómo ejecutar en seco software para comprobar que } \\
\text { construir y archivos de datos son correctos }\end{array}$ \\
\hline $\begin{array}{l}\text { Entender los principios básicos } \\
\text { del equipo FA que se está } \\
\text { utilizando. }\end{array}$ & $\begin{array}{l}\text { - Comprender los roles físicos que desempeña cada equipo } \\
\text { - Ser capaz de describir los procesos físicos que ocurren durante el } \\
\text { ciclo FA } \\
\text { - Conocer los parámetros y sistemas de control y por qué son } \\
\text { importantes }\end{array}$ \\
\hline $\begin{array}{l}\text { La comunicación clara con los } \\
\text { compañeros de trabajo y los } \\
\text { clientes es importante para } \\
\text { asegurar que los componentes } \\
\text { se fabrican correctamente. }\end{array}$ & $\begin{array}{l}\text { - Saber quién es responsable de todas las etapas de la producción y } \\
\text { de la interacción con el cliente } \\
\text { - Elaborar una lista de verificación de la información interna y de los } \\
\text { clientes clave, sin la que no se pueda iniciar la fabricación } \\
\text { - Entender qué hacer o quién consultar si falta información clave o } \\
\text { no está claro }\end{array}$ \\
\hline $\begin{array}{l}\text { Interpretar dibujos, sistemas de } \\
\text { medida imperial y métrica, } \\
\text { puntos de referencia de piezas, } \\
\text { sistemas de tolerancia. }\end{array}$ & $\begin{array}{l}\text { - Conocer dibujo de ingeniería } \\
\text { - Ser capaz de convertir fácilmente entre sistemas de medición } \\
\text { imperial y métrica } \\
\text { - Conocer la metrología y tolerancia de ingeniería }\end{array}$ \\
\hline
\end{tabular}

Tabla 3. Habilidades / competencias: fase de puesta en marcha.

\begin{tabular}{|c|c|}
\hline $\begin{array}{l}\text { Habilidades / competencias: } \\
\text { fase de puesta en marcha }\end{array}$ & Resultados de aprendizaje \\
\hline $\begin{array}{l}\text { Capaz de arrancar / parar el } \\
\text { equipo en situaciones normales, } \\
\text { completas y de emergencia. }\end{array}$ & $\begin{array}{l}\text { - Estar familiarizado con los mecanismos y procedimientos de } \\
\text { inicio/parada de rutina } \\
\text { - Estar familiarizado con los procedimientos y consecuencias de } \\
\text { cierre de emergencia }\end{array}$ \\
\hline $\begin{array}{l}\text { Comprender los peligros, y } \\
\text { cómo se minimizan, que están } \\
\text { asociados con el } \\
\text { funcionamiento de máquinas } \\
\text { FA. }\end{array}$ & $\begin{array}{l}\text { - Comprender todos los peligros potenciales asociados con los } \\
\text { materiales utilizados en FA y cómo manejar materiales para } \\
\text { prevenir incidentes } \\
\text { - Comprender todos los peligros potenciales asociados con el } \\
\text { funcionamiento del equipo de FA y cómo prevenir incidentes a } \\
\text { través de prácticas de operación seguras }\end{array}$ \\
\hline $\begin{array}{l}\text { Use EPI's apropiado y } \\
\text { mantenga el área de trabajo } \\
\text { segura y ordenada. }\end{array}$ & $\begin{array}{l}\text { - Tener un conocimiento detallado de las EPI's } \\
\text { - Comprender los principios de "5S" (ordenar, establecer en orden, } \\
\text { brillo, estandarizar, mantener) y cómo se utilizan para establecer y } \\
\text { mantener un entorno de trabajo seguro }\end{array}$ \\
\hline Importe archivos apropiados & - Entender qué archivos son apropiados para una aplicación dada \\
\hline
\end{tabular}

(c) EY-NC-ND 2017, Universitat Politècnica de València

Congreso IN-RED (2017) 


\begin{tabular}{cc}
\hline $\begin{array}{c}\text { desde un sistema de datos al } \\
\text { software FA }\end{array}$ & - Conocer importar los archivos apropiados \\
\hline Capaz de comprobar/fijar los & - Entender los parámetros operativos para una gama de producción \\
parámetros de funcionamiento & - Estar familiarizado con los procedimientos de ajuste de los \\
del equipo. & parámetros de funcionamiento \\
\hline
\end{tabular}

Tabla 4. Habilidades / competencias: fase de producción.

\begin{tabular}{|c|c|}
\hline $\begin{array}{l}\text { Habilidades / competencias: } \\
\text { fase de producción }\end{array}$ & Resultados de aprendizaje \\
\hline $\begin{array}{l}\text { Conocer cuándo se puede } \\
\text { descargar el (los) } \\
\text { componente(s) de la máquina. }\end{array}$ & $\begin{array}{l}\text { - Entender cuándo se ha completado el ciclo de producción } \\
\text { - Conocer cuándo es seguro extraer el (los) componente (s) de la } \\
\text { máquina, con respecto a la salud y seguridad personal }\end{array}$ \\
\hline $\begin{array}{l}\text { Retire la parte de la materia } \\
\text { prima restante y los soportes. El } \\
\text { almacenamiento seguro y la } \\
\text { eliminación de filtros usados y } \\
\text { material de desecho en polvo es } \\
\text { muy importante en este proceso. }\end{array}$ & $\begin{array}{l}\text { - Estar familiarizado con los procesos de extracción segura de piezas } \\
\text { y soportes } \\
\text { - Estar familiarizado con los procedimientos y requisitos de } \\
\text { seguridad para la eliminación y eliminación de filtros usados y } \\
\text { polvos de desecho } \\
\text { - Comprender los riesgos potenciales para la salud y la seguridad } \\
\text { asociados con los polvos de desecho y los filtros contaminados }\end{array}$ \\
\hline $\begin{array}{l}\text { Deje la máquina en condiciones } \\
\text { seguras al completar la } \\
\text { actividad de FA, p. Cerrar } \\
\text { programas, limpiar la máquina, } \\
\text { eliminar y eliminar residuos. }\end{array}$ & $\begin{array}{l}\text { - Estar familiarizado con todos los procedimientos para cerrar el } \\
\text { software } \\
\text { - Estar familiarizado con todos los procedimientos para apagar y } \\
\text { limpiar máquinas FA después de su uso } \\
\text { - Comprender los procedimientos para la eliminación segura de } \\
\text { materiales de desecho } \\
\text { - Comprender las consecuencias de no cumplir con los } \\
\text { procedimientos de reducción prescritos }\end{array}$ \\
\hline $\begin{array}{l}\text { Consciente de qué soporte está } \\
\text { disponible de los ingenieros de } \\
\text { servicio y los ingenieros de } \\
\text { aplicaciones. }\end{array}$ & $\begin{array}{l}\text { - Conocer los parámetros de control del proceso y la forma en que se } \\
\text { controlan / miden } \\
\text { - Conocer, registrar y reportar parámetros de control de procesos } \\
\text { - Reconocer cuando los parámetros de control del proceso están }\end{array}$ \\
\hline $\begin{array}{l}\text { Supervisión de los parámetros } \\
\text { del proceso para el control de } \\
\text { calidad. }\end{array}$ & $\begin{array}{l}\text { - Estar familiarizado con las especificaciones / normas para las } \\
\text { dimensiones de los componentes, defectos y apariencia } \\
\text { - Comprender el equipo y procedimientos utilizados para el control } \\
\text { de calidad de los componentes }\end{array}$ \\
\hline $\begin{array}{l}\text { nspección del componente para } \\
\text { precisión dimensional, defectos } \\
\text { visibles y apariencia. }\end{array}$ & $\begin{array}{l}\text { - Entender perfectamente los equipos y procedimientos para limpiar } \\
\text { los componentes, empaquetarlos y almacenarlos } \\
\text { - Estar familiarizado con la documentación de los registros de } \\
\text { componentes y clientes }\end{array}$ \\
\hline $\begin{array}{l}\text { Componentes a limpiar, } \\
\text { empaquetar y almacenar con } \\
\text { toda la documentación } \\
\text { necesaria (por ejemplo, número } \\
\text { de lote, número de archivo...) }\end{array}$ & $\begin{array}{l}\text { - Estar familiarizado con los equipos y procedimientos utilizados } \\
\text { para el mantenimiento de máquinas FA } \\
\text { - Conocer cómo operar el equipo de acuerdo con los procedimientos } \\
\text { prescritos }\end{array}$ \\
\hline
\end{tabular}




\section{Conclusiones}

La definición de los objetivos de aprendizaje de un programa formativo es de gran interés, pues permite generar la estructura de un curso que pueda adaptarse tanto a un sistema basado en ECTS como a uno basado en ECVET.

Con el apoyo de las políticas de la UE para la cualificación, la transparencia, la movilidad y el renacer de la industria europea, se han identificado las competencias que el alumnado ha de cubrir durante su formación, en cada uno de los estadios de la misma.

En este trabajo se han establecido los resultados de aprendizaje en la formación sobre impresión 3D, a partir del dialogo Universidad-Sociedad. En primer lugar se realizaron entrevistas personales a profesionales de varios países de la Unión Europea (Italia, Reino Unido y España). El análisis de las respuestas (en formato respuesta abierta) ha conducido a la elaboración de un cuestionario con preguntas (en formato respuesta múltiple) que permiten determinar la percepción de la importancia de las distintas competencias por los profesionales del sector de la impresión 3D. En total se han obtenido un total de 119 encuestas completas, siendo esta información una base robusta para la enumeración de los objetivos de aprendizaje del programa formativo.

Este trabajo, por lo tanto, ha permitido establecer unos objetivos de aprendizaje perfectamente adaptados a la realidad profesional. En el desarrollo del proyecto Europeo 3D-PRISM, estos objetivos de aprendizaje servirán para el desarrollo de un curso en impresión 3D.

\section{Agradecimientos}

Los autores desean agradecer el apoyo financiero recibido a través del proyecto ERASMUS +: 3D PRINTING SKILLS FOR MANUFACTURIN G 2015-1-UK01-KA202-013432.

\section{Referencias}

CEDEFOP-EUROPEAN CENTRE FOR THE DEVELOPMENT OF VOCATIONAL TRAINING (2016a) Application of learning outcomes approaches across Europe. A comparative study. Cedefop reference series No $105 . \quad<\mathrm{http} / / / \mathrm{www} . c e d e f o p . e u r o p a . e u / e n / p u b l i c a t i o n s-a n d-$ resources/publications/3074> [Consulta: 20 de mayo de 2017]

CEDEFOP-EUROPEAN CENTRE FOR THE DEVELOPMENT OF VOCATIONAL TRAINING (2016b) ECVET in Europe: monitoring report 2015. Cedefop research paper No 56 <http://www.cedefop.europa.eu/en/publications-and-resources/publications/5556> [Consulta: 20 de mayo de 2017]

CEDEFOP-EUROPEAN CENTRE FOR THE DEVELOPMENT OF VOCATIONAL TRAINING (2013) Monitoring ECVET implementation strategies in Europe. Cedefop working Paper No 18. <www.cedefop.europa.eu/files/6118_en.pdf> [Consulta: 20 de mayo de 2017]

(cc) EY-NC-ND 2017, Universitat Politècnica de València

Congreso IN-RED (2017) 
EUROPEAN COMMISSION-EDUCATION AND CULTURE DG (2011) Using learning outcomes European Qualification Framework series: Note 4. <http://www.cedefop.europa.eu/en/news-andpress/news/using-learning-outcomes $>$ [Consulta: 20 de mayo de 2017]

EUROPEAN COMMISSION-EDUCATION AND TRAINING (2014) Implementation of the Recommendation of the European Parliament and of the Council of 18 June 2009 on the establishment of a European Credit System for Vocational Education and Training (ECVET). <http://ec.europa.eu/dgs/education_culture/more_info/evaluations/docs/education/ecvet14_en.pdf > [Consulta: 20 de mayo de 2017]

EUROPEAN COMMUNITIES (2008). The European Qualifications Framework <http://eurlex.europa.eu/legal-content/EN/TXT/PDF/?uri=CELEX:32008H0506(01)\&from=EN> [Consulta: 20 de mayo de 2017]

EUROPEAN PARLIAMENT; COUNCIL OF THE EUROPEAN UNION (2009) Recommendation of the European Parliament and the Council of 18 June 2009 on the establishment of a European credit system for vocational education and training (ECVET). Official Journal of the European Union. <http://eur-lex.europa.eu/legal-content/EN/ALL/?uri=CELEX\%3A32009H0708(02> [Consulta: 20 de mayo de 2017]

GONCALVES, M., PIMENTA, P., BRAGA, L. y COTA, M. (2013) "Defining and Classifying Learning Outcomes: A Case Study" en Proceedings of the Informing Science and Information Technology Education Conference, vol. 2013, issues 1, p. 209-226. 


\section{¿Cuántas competencias transversales podemos diferenciar en un auto-diagnóstico?}

Marin-Garcia, Juan A. ${ }^{\text {a }}$, Atarés, Lorena ${ }^{\text {; }}$, Aznar-Mas, Lourdes E. ${ }^{\text {c }}$

a ROGLE. Dpto. de Organización de Empresas. Universitat Politècnica de València. Camino de Vera S/N 46021 Valencia. ${ }^{a}$ jamarin@omp.upv.es, ${ }^{\mathrm{b}}$ julien.maheut@gmail.com and ${ }^{\mathrm{c}}$ jugarsa@omp.upv.es. ${ }^{b}$ Departamento de Tecnología de Alimentos. Universidad Politécnica de Valencia. Camino de Vera S/N 46022 Valencia. loathue@tal.upv.es

c EICE IEMA, Dpto. Lingüística Aplicada, UPV, laznar@idm.upv.es,

\section{Abstract}

The UPV has identified 12 soft-skills based on the lists of EURACE, ANECA and ABET. However, are they sufficiently independent or overlapping? Our work explores by factor analysis how many dimensions can be obtained sufficiently different from each other. To do this we will analyze a sample of students and professionals with data based on a self-assessment

Keywords: :self-assessment; soft skills; higher education; practitioners

\section{Resumen}

La UPV ha identificado 12 competencias transversales basadas en los listados de EURACE, ANECA y ABET. Sin embargo, ¿son suficientemente independientes o están solapadas?

Nuestro trabajo explora mediante análisis factorial cuántas dimensiones se pueden obtener suficientemente diferentes entre sí. Para ello analizaremos una muestra de alumnos y de profesionales con datos basados en un autodiagnóstico.

Palabras clave: calificación; desempeño de estudiantes; educación universitaria; evaluación sumativa; competencias transversales; comparación pareada

\section{Introducción}

Las competencias transversales (soft skills) han sido incorporadas a las memorias y planes de estudios de los grados universitarios de ingeniería, u otros grados, a instancias de los requisitos de diferentes normativas españolas (RD 1393/2007, 861/2010, 1027/2011; Orden CIN/311/2009, CIN/351/2009; resolución 12977/2009) y de las agencias nacionales o internacionales de acreditación: ANECA/AVAP (Argos \& Ezquerra, 2014; Miró \& Jaume i Capó, 2010; Tovar \& Castro, 2007), EURACE (Patil \& Codner, 2007; Tovar \& Castro, 2007) y ABET (McGourty et al., 2002; Passow, 2012; Shuman et al., 2005; Terry et al., 2002; Weiss \& Aldridge, 2002; Williams, 2002).

El grado de solape o congruencia entre las competencias elegidas por las diferentes agencias es bastante bajo. En unos casos, se requieren unas competencias que otros sistemas no contemplan. En otros, competencias con nombres similares tienen definiciones radicalmente diferentes. Por último, también se da el caso de que definiciones similares tienen nombres o rótulos diferentes en cada uno de los sistemas.

En cualquier caso, la Universitat Politècnica de València (UPV) realizó un proceso de integración de las propuestas de las tres agencias (ANECA/AVAP, ABET y EURACE) que culminó con un listado de 12 competencias transversales (más una $13^{\mathrm{a}}$ que no es transversal a todos los grados sino que son competencias específicas del grado), que pretenden dar cobertura completa a los requisitos de las tres agencias (http://www.upv.es/contenidos/COMPTRAN/info/955709normalc.html):

- CT-01. Comprensión e integración

- CT-02. Aplicación y pensamiento práctico

- CT-03. Análisis y resolución de problemas 
- CT-04. Innovación, creatividad y emprendimiento

- CT-05. Diseño y proyecto

- CT-06. Trabajo en equipo y liderazgo

- CT-07. Responsabilidad ética, medioambiental y profesional

- CT-08. Comunicación efectiva

- CT-09. Pensamiento crítico

- CT-10. Conocimiento de problemas contemporáneos

- CT-11. Aprendizaje permanente

- CT-12. Planificación y gestión del tiempo

Sin embargo, hasta la fecha, no hemos encontrado ningún estudio empírico que compruebe si estas 12 competencias son elementos independientes y diferenciados, o si todas ellas no son más que reflejo de un constructo subyacente o meta-competencia de ingeniería que las resume todas. Tampoco hemos encontrado trabajos que comparen la estructura dimensional de estas competencias en estudiantes universitarios y en profesionales de empresa.

\section{Objetivos}

Obj. 1) Comprobar la correlación que existe entre 9 de estas competencias transversales

Obj. 2) Analizar la estructura subyacente de este conjunto de competencias e identificar los constructos latentes en los que se podrían agrupar estas competencias

Obj. 3) Comprobar si la estructura es similar en una muestra de estudiantes y otra de profesionales. Hemos recogido datos de una muestra de profesionales porque las competencias transversales se han incluido en los procesos de verificación de títulos porque son aspectos demandados por las empresas y están asociados al éxito de los profesionales. De modo que queremos analizar si las relaciones entre las competencias que aparecen en los estudiantes son parecidas a las que se obtienen con profesionales

\section{Desarrollo de la innovación}

Los datos se tomaron en mayo de 2016 mediante un cuestionario web.

Los datos de estudiantes proceden de alumnos de la titulación de Grado en Ingeniería de Organización Industrial. De los 312 alumnos matriculados en la titulación respondieron 128 (41\% de tasa de respuesta).

Los datos de profesionales provienen las plantas de valencia de dos empresas multinacionales del sector de la electrónica donde la innovación es su característica distintiva. En cada planta los directores de recursos humanos seleccionaron a 30 y 29 personas incorporadas al programa de gestión de talento innovador. De los 59 trabajadores seleccionados, 47 respondieron ( $80 \%$ de tasa de respuesta).

Las definiciones de las competencias para construir los mono-ítems se han obtenido a partir de las definiciones publicadas en la página web http://www.upv.es/contenidos/COMPTRAN/info/957657normalc.html (las CT-04 y CT-06 se han desdoblado en dos para responder a los dos matices diferenciadores de la competencia base). Se seleccionaron 9 de las 12 competencias transversales, dejando de lado las que los autores consideraron que era complicado construir una definición de una frase que representara de manera unívoca y completa la competencia (ver tabla 1).

Tabla 1 . Definición de las variables

\begin{tabular}{|l|l|l|}
\hline CT & Código & Descripción \\
\hline CT-01 & A_compre & [Comprender e integrar el conocimiento del que dispones] \\
\hline CT-02 & A_aplic & $\begin{array}{l}\text { [Aplicar los conocimientos a la práctica, atendiendo a la } \\
\text { información disponible, y estableciendo el proceso a seguir } \\
\text { para alcanzar los objetivos con eficacia y eficiencia.] }\end{array}$ \\
\hline
\end{tabular}

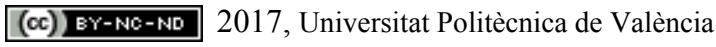

Congreso IN-RED (2017) 


\begin{tabular}{|l|l|l|}
\hline CT-03 & A_proble & $\begin{array}{l}\text { [Analizar y resolver problemas de forma efectiva, } \\
\text { identificando y definiendo los elementos significativos que } \\
\text { los constituyen.] }\end{array}$ \\
\hline CT-04 & A_empre & $\begin{array}{l}\text { [Innovar para responder satisfactoriamente y de forma } \\
\text { original, a las necesidades y demandas personales, } \\
\text { organizativas y sociales con una actitud emprendedora. }\end{array}$ \\
\hline CT-04 & A_creat & $\begin{array}{l}\text { [pensar más allá de las ideas tradicionales, normas, patrones } \\
\text { orelaciones yenerar o adaptar alternativas, ideas, productos, } \\
\text { procesos, métodos o servicios, independientemente de su } \\
\text { viabilidad o valor añadido }]\end{array}$ \\
\hline CT-05 & A_project & $\begin{array}{l}\text { [Diseñar y evaluar una idea de manera eficaz hasta } \\
\text { concretarla en un proyecto] }\end{array}$ \\
\hline CT-06 & A_leader & $\begin{array}{l}\text { [Liderar equipos de forma efectiva para la consecución de } \\
\text { objetivos comunes] }\end{array}$ \\
\hline CT-06 & A_teamw & $\begin{array}{l}\text { [trabajar eficazmente con otros en grupo] } \\
\text { [Comunicarse de manera efectiva, tanto de forma oral como } \\
\text { escrita] }\end{array}$ \\
\hline CT-08 & A_commu & $\begin{array}{l}\text { [analizar asuntos con un propósito, evaluar las ventajas o } \\
\text { desventajas, y estimar los riesgos asociados] }\end{array}$ \\
\hline CT-09 & A_criti & $\begin{array}{l}\text { [Planificar adecuadamente el tiempo disponible y programar } \\
\text { las actividades necesarias para alcanzar los objetivos, tanto } \\
\text { académico-profesionales como personales. }\end{array}$ \\
\hline CT-12 & A_time \\
\hline
\end{tabular}

Tanto en la muestra de alumnos, como en la de profesionales, las variables se mostraban a cada persona en orden aleatorio y la pregunta introductoria fue: "Toma como referencia lo que has demostrado en un contexto donde necesitas ser innovador o ayudar a un equipo a serlo (bien en un puesto de trabajo en tu organización o en tus tareas como estudiante). Cómo consideras que es tu capacidad para ..."

En las dos sub-muestras (alumnos y profesionales) las escalas de respuesta usaban similares anclas verbales. Sin embargo la escala de alumnos era una escala discreta con 5 niveles de respuesta (1 a 5), más un "no demostrado" (valor 0) (Figura 1). Para los profesionales las escalas iban desde Necesita mejorarla mucho (valor 1) hasta Excelente (valor 100), con la posibilidad de marcar “(..)" si no podían valorar esa capacidad (valor 0) (Figura 2).

Figura 1. Ejemplo de parte del cuestionario para alumnos universitarios

\begin{tabular}{|c|c|c|c|c|c|c|}
\hline & $\begin{array}{c}\text { No } \\
\text { demostrado }\end{array}$ & $\begin{array}{c}\text { Necesito } \\
\text { mejorarla } \\
\text { mucho }\end{array}$ & $\begin{array}{l}\text { Necesito } \\
\text { mejorar }\end{array}$ & Suficiente & Buena & Excelente \\
\hline $\begin{array}{r}\text { Aplicar los conocimientos a la práctica, } \\
\text { atendiendo a la información disponible, y } \\
\text { estableciendo el proceso a seguir para alcanzar } \\
\text { los objetivos con eficacia y eficiencia. }\end{array}$ & 0 & 0 & 0 & 0 & 0 & 0 \\
\hline $\begin{array}{r}\text { Analizar y resolver problemas de forma efectiva, } \\
\text { identificando y definiendo los elementos } \\
\text { significativos que los constituyen. }\end{array}$ & 0 & 0 & 0 & 0 & 0 & 0 \\
\hline $\begin{array}{r}\text { Diseñar y evaluar una idea de manera eficaz } \\
\text { hasta concretarla en un proyecto }\end{array}$ & 0 & 0 & 0 & 0 & 0 & 0 \\
\hline $\begin{array}{l}\text { Liderar equipos de forma efectiva para la } \\
\text { consecución de objetivos comunes }\end{array}$ & 0 & 0 & 0 & 0 & 0 & 0 \\
\hline $\begin{array}{r}\text { Comunicarse de manera efectiva, tanto de } \\
\text { forma oral como escrita }\end{array}$ & 0 & 0 & 0 & 0 & 0 & 0 \\
\hline $\begin{array}{l}\text { Planificar adecuadamente el tiempo disponible y } \\
\text { programar las actividades necesarias para } \\
\text { alcanzar los objetivos, tanto académico- } \\
\text { profesionales como personales. }\end{array}$ & 0 & 0 & 0 & 0 & 0 & 0 \\
\hline $\begin{array}{r}\text { Innovar para responder satisfactoriamente y de } \\
\text { forma original, a las necesidades y demandas } \\
\text { personales, organizativas y sociales con una } \\
\text { actitud emprendedora. }\end{array}$ & 0 & 0 & 0 & 0 & 0 & 0 \\
\hline
\end{tabular}

(c)) BY-NC-ND 2017, Universitat Politècnica de València Congreso In-Red (2017) 
Figura 2. Ejemplo de parte del cuestionario para profesionales

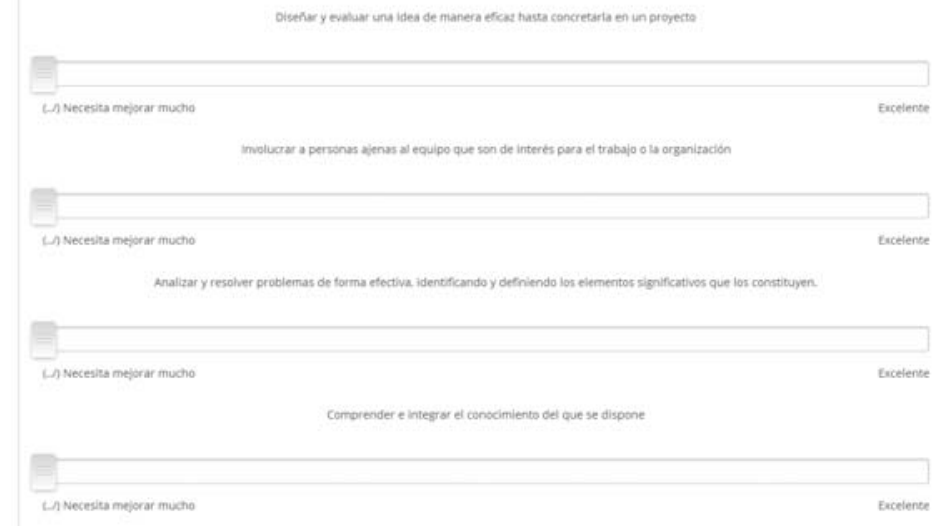

Para dar respuesta al objetivo 1 presentaremos la tabla de correlaciones de Pearson entre las competencias. Para el objetivo 2, realizaremos un análisis factorial exploratorio, con componentes principales, analizando correlaciones y con rotación ortogonal varimax (Hair et al., 1995; Losilla et al., 2005; Marin-Garcia, 2012; Marin-Garcia et al., 2013). El número de factores extraídos se basa en el criterio de eigenvalue $>1$, el análisis de pendiente de número de componentes y el criterio de varianza extraída superior al $80 \%$.

\section{Resultados}

En la Tabla 2 podemos apreciar cómo, en la muestra de estudiantes universitarios, se utilizan todos los valores de las escalas. El valor promedio, una vez re-escalados los valores de 0 a 100, están en torno a 60-70 puntos. Es decir, la media está en la parte alta de la escala. En la muestra de profesionales (Tabla 3), existe un efecto suelo en todas las dimensiones (en algunas en la cuarta parte de la escala y en otras en la mitad). Los valores medios son bastante más altos en la muestra de profesionales que en la de estudiantes. Hecho, éste, que resulta lógico pues indica que los profesionales (elegidos entre los mejores en empresas con clara tendencia innovadora), tienen más desarrolladas estas competencias que los estudiantes de ingeniería.

\begin{tabular}{|l|l|r|r|r|r|r|r|}
\hline & N & Range & Minimum & Maximum & $\begin{array}{c}\text { Mean } \\
(0-100)\end{array}$ & $\begin{array}{c}\text { Mean } \\
(0-5)\end{array}$ & $\begin{array}{c}\text { Std. } \\
\text { Deviation }\end{array}$ \\
\hline A_compre & 128 & 5 & 0 & 5 & 67.60 & 3,38 & 1,095 \\
\hline A_aplic & 128 & 5 & 0 & 5 & 64.00 & 3,20 & 1,075 \\
\hline A_proble & 128 & 5 & 0 & 5 & 67.60 & 3,38 & 1,129 \\
\hline A_empren & 128 & 5 & 0 & 5 & 61.80 & 3,09 & 1,230 \\
\hline A_creat & 129 & 5 & 0 & 5 & 64.00 & 3,20 & 1,114 \\
\hline A_project & 128 & 5 & 0 & 5 & 60.40 & 3,02 & 1,167 \\
\hline A_leader & 128 & 5 & 0 & 5 & 70.20 & 3,51 & 1,143 \\
\hline A_teamw & 128 & 4 & 1 & 5 & 74.00 & 3,70 & 1,062 \\
\hline A_commu & 128 & 5 & 0 & 5 & 71.00 & 3,55 & 1,162 \\
\hline A_criti & 129 & 5 & 0 & 5 & 72.20 & 3,61 & 1,127 \\
\hline A_time & 128 & 5 & 0 & 5 & 64.80 & 3,24 & 1,195 \\
\hline
\end{tabular}

Tabla 2. Estadísticos descriptivos de la muestra de alumnos

(c)) EY-NG-ND 2017, Universitat Politècnica de València

Congreso IN-RED (2017) 


\begin{tabular}{|l|l|r|r|r|r|r|}
\hline & N & Range & Minimum & Maximum & Mean & Std. Deviation \\
\hline A_compre & 45 & 75 & 25 & 100 & 77,44 & 14,692 \\
\hline A_aplic & 45 & 45 & 55 & 100 & 78,53 & 11,177 \\
\hline A_proble & 45 & 48 & 52 & 100 & 79,04 & 12,411 \\
\hline A_empren & 45 & 75 & 25 & 100 & 71,98 & 16,479 \\
\hline A_creat & 45 & 75 & 25 & 100 & 75,02 & 15,775 \\
\hline A_project & 45 & 75 & 25 & 100 & 74,76 & 14,808 \\
\hline A_leader & 45 & 75 & 25 & 100 & 71,84 & 10,247 \\
\hline A_teamw & 45 & 45 & 55 & 100 & 82,11 & 14,038 \\
\hline A_commu & 45 & 71 & 29 & 100 & 76,38 & 12,374 \\
\hline A_criti & 45 & 50 & 50 & 100 & 75,47 & 14,177 \\
\hline A_time & 45 & 55 & 45 & 100 & 72,04 & \\
\hline
\end{tabular}

Tabla 3. Estadísticos descriptivos de la muestra de profesionales

Las correlaciones son prácticamente todas significativas y de intensidad moderada alta. Destacando la existente entre emprendedurismo y creatividad.

\begin{tabular}{|c|c|c|c|c|c|c|c|c|c|c|c|}
\hline & $\begin{array}{c}\text { A_com } \\
\text { pre }\end{array}$ & $\underset{c}{\text { A_apli }}$ & $\underset{\text { le }}{\text { A_prob }}$ & $\underset{\text { ren }}{\text { A_emp }}$ & A_crea & $\begin{array}{l}\text { A_proj } \\
\text { ect }\end{array}$ & $\begin{array}{c}\text { A_lead } \\
\text { er }\end{array}$ & A_tea & $\underset{\mathrm{mu}}{\text { A_com }}$ & A_criti & A_time \\
\hline A_compre & 1 & ,488* & ,197 & ,719“ &, $500 "$ & ,499"* &, 556 & ,293 &, $516 “$ & $321^{\circ}$ & , $341^{*}$ \\
\hline A_aplic & ,663" & 1 & ,564" & ,475“ & ,440" &, 582 " & , 464" &, $538^{* *}$ & ,580" & ,444" & ,557" \\
\hline A_proble & ,539" & ,585* & 1 & $378^{\circ}$ & ,444" &, 524 &, $372^{*}$ & ,392" & ,226 & ,525 & ,522" \\
\hline A_empren & ,379" & ,457** & ,532* & 1 & ,786"* & ,651"* & $647^{* *}$ &, $357^{\star}$ &, $371^{*}$ & ,462" & $326^{*}$ \\
\hline A_creat & ,470" & , 471"* & ,632" & ,620" & 1 & ,704" & ,650" &, $374^{\star}$ & ,266 & ,531“ & ,442" \\
\hline A_project &, $486^{\prime \prime}$ & ,436" & ,609" & $608^{*}$ & ,609" & 1 &, $526^{* *}$ & $340^{*}$ & ,420" & $365^{\circ}$ & ,501“ \\
\hline A_leader & ,454" & ,524" &, $510^{* *}$ & ,490" &, 553 "* &, $510^{* *}$ & 1 & ,494" &, $503^{\prime \prime}$ &, 512 &, $513^{\prime \prime}$ \\
\hline A_teamw &, $514 "$ & ,462" & $365^{* \prime}$ & ,328" & ,455" & ,374" & ,589** & 1 & ,454" & , 188 & ,423“ \\
\hline A_commu & ,469" & ,438* & ,434" & ,418“ & , 475" & ,461** & ,628* & ,515" & 1 & ,244 & $371^{*}$ \\
\hline A_criti & ,431" & ,447** & ,625* & ,522" & ,617** &, 574 & ,481"* & , $447^{* *}$ & ,433" & 1 & ,576" \\
\hline A_time & ,386" & ,452" & ,399" & ,350" & $405^{*}$ &, $216^{*}$ & , 405" & 276 & ,390" & $413^{* *}$ & 1 \\
\hline
\end{tabular}

Tabla 4. Matriz de correlaciones. Diagonal inferior correlaciones para muestra de estudiantes y diagonal superior muestra de profesionales. ** correlación significativa 0.01 (2-tailed), * correlación significativa 0.05 (2-tailed).

Los estadísticos de adecuación de las muestras al análisis factorial exploratorio tienen unos valores excelentes (Kaiser-Meyer-Olkin Measure of Sampling Adequacy: 0.91 para estudiantes y 0.83 para profesionales. En ambos casos el Bartlett's Test of Sphericity tiene una significación 0.000 ).

Con el criterio de eigen value mayor que 1, tanto para estudiantes como para profesionales, se extraería un solo factor (no se considerarían variables independientes sino indicadores de un mismo constructo latente), el cual explicaría un $53 \%$ de la varianza de la muestra de estudiantes y un 51.6 de la de profesionales.

Analizando los gráficos de valores propios (Figura 3), en la muestra de estudiantes existe un cambio de pendiente notable con dos factores y luego uno más sutil al pasar a 5 . En la muestra de profesionales, el segundo cambio se produce con cuatro factores.

\begin{tabular}{|l|l|}
\hline Estudiantes & Profesionales \\
\hline
\end{tabular} 


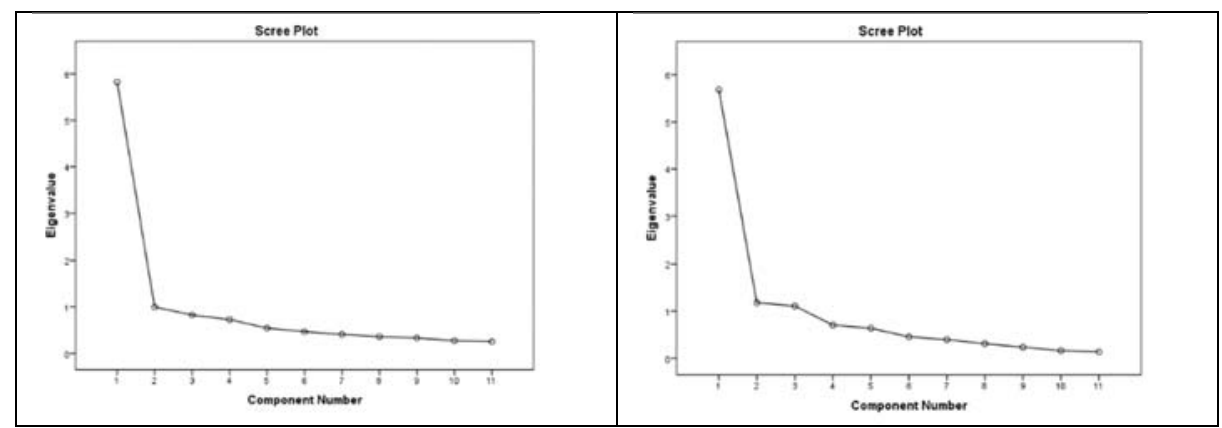

Figura 3.Grafico de valores propios en función de numero de factores extraídos.

Por último, con 5 factores se explica un $81 \%$ de la varianza de la muestra de estudiantes y un $84.6 \%$ de la de profesionales.

Las soluciones factoriales rotadas se muestran en la Tabla 5. En ella podemos ver que existen diferencias en la forma en la que se agrupan las variables en lo factores. Estas diferencias pueden ser debidas a estructuras de correlación diferentes o a que la muestra de profesionales es excesivamente escasa y la propuesta mostrada pueda no ser estable cuando se amplíe o cambie la muestra.

\begin{tabular}{|c|c|c|c|c|c|c|c|c|c|c|}
\hline & \multicolumn{5}{|c|}{ Estudiantes } & \multicolumn{5}{|c|}{ Profesionales } \\
\hline & 1 & 2 & 3 & 4 & 5 & 1 & 2 & 3 & 4 & 5 \\
\hline A_compre & ,198 & ,269 & ,829 & , 173 & ,081 & ,651 & ,118 & ,619 &, 001 &,- 025 \\
\hline A_aplic & ,274 & ,232 & ,787 & 074 & ,261 & ,191 & ,237 &, 563 & ,597 & ,236 \\
\hline A_proble & ,581 & ,080 &, 463 & ,383 & , 199 & ,162 & ,382 &,- 016 & ,784 & , 190 \\
\hline A_empren & ,814 & ,227 & ,141 & ,043 & ,195 & ,881 & ,155 & ,219 & , 171 & 100 \\
\hline A_creat & ,626 & ,280 & ,184 & ,428 & ,206 & ,826 & ,281 &,- 025 & ,279 & , 198 \\
\hline A_project & ,770 & ,242 & ,280 & ,227 &,- 122 & ,621 & ,071 & ,249 & ,611 & ,056 \\
\hline A_leader & ,368 & ,727 & ,212 & ,147 & ,192 & ,595 &, 460 & ,280 &,- 029 & ,432 \\
\hline A_teamw &,- 012 & ,709 & ,337 &, 501 &,- 053 & , 162 & , 070 & ,236 & ,236 & ,893 \\
\hline A_commu & ,322 & ,775 & ,184 &,- 002 & ,211 & ,141 & , 125 & ,855 & , 108 & ,258 \\
\hline A_criti & ,465 & ,171 &, 160 & ,725 & ,236 & ,295 & ,866 & ,068 & ,203 &,- 040 \\
\hline A_time & ,120 & ,193 & ,222 & ,154 & ,903 & , 105 & ,678 & ,266 & ,380 & ,246 \\
\hline
\end{tabular}

Tabla 5. Cargas factoriales

\section{Conclusiones}

Los datos presentados no permiten dar una respuesta concluyente a nuestra pregunta. Por un lado, una sola dimensión que agrupara las 9 competencias transversales analizadas explicaría en torno al $50 \%$ de la varianza de los datos de ambas muestras. A pesar de ser la solución más parsimoniosa, quizás no sea una cantidad suficiente de varianza para el estudio del efecto de estas competencia sobre otras variables. Es probable que el modelo con 5 dimensiones (no 9 como aparecen en la propuesta oficial de la UPV) sea una buena solución de compromiso entre nivel de detalle y cantidad de variables a manejar. Sin embargo la estructura factorial no parece respetarse entre la muestra de profesionales y la de estudiantes universitarios.

Esta investigación presenta algunas limitaciones que la investigación futura debería intentar superar:

- El uso de escalas de medida diferentes para estudiantes y para profesionales. Esto puede ser uno de los motivos para que los resultados en ambas muestras sean diferentes (en mayo de 2017 hemos recogido datos de una muestra equivalente de alumnos con la escala de medida igual a las de los profesionales y hemos ampliado

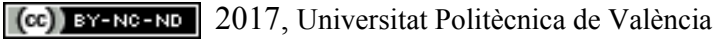


la muestra de profesionales. En una investigación futura compararemos los resultados).

- Tenemos pocos datos de profesionales (comentada solución en el punto anterior)

- El uso de mono-ítem para el diagnóstico de competencias, que presenta ciertas desventajas frente a modelos de medida multi-ítem (Fisher et al., 2016; GiraldoO'Meara et al., 2014; Nagy, 2002; Sarstedt et al., 2016)

- Los datos analizados proceden sólo de auto-diagnóstico y en el futuro habría que añadir datos de evaluación de profesores o de mandos o compañeros

- No se han contemplado las 12 competencias transversales UPV

\section{Agradecimientos}

GVA/20161004: Project of Conselleria d'Educació, Investigació, Cultura i Esport de la Generalitat Valenciana a través del proyecto "Validación de la competencia transversal de innovación mediante un modelo de Medida formativo"

FINCODA: "Project 554493-EPP-1-2014-1-FI-EPPKA2KA" (The European Cornission support for the production of this publication does not constitute an endorsement of the contents which reflects the views only of the authors, and the Commission cannot be held responsible for any use which may be made of the information contained therein).

\section{Referencias}

AVAP Agència Valenciana d'Avaluació i Prospectiva

ANECA Agencia Nacional de Evaluación de la Calidad y Acreditación

EUR-ACE European Network for the Acreditation of Engineering Education (ENAEE)

ABET Accreditation Board for Engineering and Technology, Inc. (EEUU)

Argos, J., \& Ezquerra, P. (2014). Universities and skills for employability. Procedia - Social and Behavioral Sciences, 290-296. doi:http://dx.doi.org/10.1016/j.sbspro.2014.08.002

Fisher, G., Russell, A. M., \& Gibbons, A. M. (2016). Developing and investigating the use of single-item measures in organizational research. Journal of Occupational Health Psychology, 21(1), 3-23. doi:http://dx.doi.org/10.1037/a0039139

Giraldo-O'Meara, M., Marin-Garcia, J. A., \& Martínez-Gómez, M. (2014). Validation of the jds satisfaction scales applied to educational university environments. Journal of Industrial Engineering and Management, 7(1), 72-99.

Hair, J. F., Anderson, R. E., Tatham, R. L., \& Black, W. C. (1995). Multivariate data analysis ( $4^{\mathrm{o}}$ ed.). New Jersey: Prentice Hall.

Losilla, J. M., Navarro, J. B., Palmer, A., Rodrigo, M. F., \& Ato, M. (2005). Análisis de datos. Del contraste de hipótesis al modelado estadístico. Barcelona: Edicions a Petició.

Marin-Garcia, J. A. (2012). ¿cómo medir el grado de exigencias psicológicas requeridas por el entorno educativo español en el alumno universitario? (how to measure the degree of psychological demands required for university students in spanish environment?). WPOM-Working Papers on Operations Management, 3(2), 58-70.

Marin-Garcia, J. A., Alfalla-Luque, R., \& Medina-López, C. (2013). Supply chain integration scales validation and benchmark values. Journal of Industrial Engineering and Management, 6(2), 423-440. doi:http://dx.doi.org/10.3926/jiem.517

McGourty, J., Shuman, L., Besterfield-Sacre, M., Atman, C., Miller, R., Olds, B., ... Wolfe, H. (2002). Preparing for abet ec 2000: Research-based assessment methods and processes. International Journal of Engineering Education, 18(2), 157-167. 
Miró, J., \& Jaume i Capó, A. (2010). Repositorio de actividades para enseñar competencias transversales. REDU. Revista de Docencia Universitaria, 8(1), 101-110. doi: $10.4995 /$ redu. 2010.6219

Nagy, M. S. (2002). Using a single-item approach to measure facet job satisfaction. Journal of Occupational \& Organizational Psychology, 75(1), 77-86. doi:Article

Passow, H. J. (2012). Which abet competencies do engineering graduates find most important in their work? Journal of Engineerig Education, 101(1), 95-118.

Patil, A., \& Codner, G. (2007). Accreditation of engineering education: Review, observations and proposal for global accreditation. European Journal of Engineering Education, 32(6), 639-651. doi:10.1080/03043790701520594

Sarstedt, M., Diamantopoulos, A., \& Salzberger, T. (2016). Should we use single items? Better not. Journal of Business Research, 69(8), 3199-3203. doi:http://dx.doi.org/10.1016/j.jbusres.2016.02.040

Shuman, L. J., Besterfield-Sacre, M., \& McGourty, J. (2005). The abet "professional skills" - can they be taught? Can they be assessed? Journal of Engineering Education, 94(1), 41-55.

Terry, R. E., Harb, J. N., Hecker, W. C., \& Wilding, W. V. (2002). Definition of student competencies and development of an educational plan to assess student mastery level. International Journal of Engineering Education, JAM-PDF(2), 225-235.

Tovar, E., \& Castro, M. (2007). Building common spaces in engineering education: A review from icece05. IEEE Transactions on Education, 50(1), 79-84. doi:10.1109/TE.2006.888908

Weiss, M., \& Aldridge, M. D. (2002). Assessing the effects of the abet/nsf/industry regional faculty workshop. International Journal of Engineering Education, 18(2), 245-253.

Williams, J. M. (2002). The engineering portfolio: Communication, reflection, and student learning outcomes assessment. International Journal of Engineering Education, $J A M-P D F(2), 199-207$.

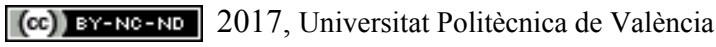




\title{
Formación y aplicación didáctica de las TIC en proyectos para trabajar la lengua y la literatura
}

\author{
Pilar Garcia Vidala, Alícia Martí Climent ${ }^{\text {b }}$ \\ aUniversitat de València, pilar.garcia-vidal@uv.es \\ bUniversitat de València, alicia.marti@uv.es
}

\begin{abstract}
In order to study the ICT training received by university students and the didactic application that the future teachers make of these kind of resources, we have made a qualitative analysis based on questionnaires made to the students of the Master's Degree in Secondary School Training at the University of Valencia from 2011 to 2016. We consider that students are continually increasing their knowledge of ICT technology. However, we think that they still need to use ICT with a didactic purpose in the academic work. This research shows both the ICT knowledge of these students and it's implementation considered to be useful to work in language and literature projects in Secondary Education.
\end{abstract}

Keywords: Project work, ICT, teacher training, secondary education, language and literatura teaching.

\footnotetext{
Resumen

Con el fin de indagar en la formación en TIC que han recibido los estudiantes universitarios y en la aplicación didáctica que hacen de este tipo de recursos los futuros docentes, hemos realizado un análisis cualitativo a partir de cuestionarios realizados al alumnado del Máster de profesor/a de Secundaria de la Universitat de València desde el curso 2011-12 hasta el 2015-16. Partimos de la hipótesis que los estudiantes conocen cada vez más recursos TIC pero les falta práctica en su uso en el trabajo académico con una finalidad didáctica. El presente análisis muestra el grado de conocimiento de las TIC de estos estudiantes, así como la implementación de determinadas TIC que han considerado útiles para trabajar en proyectos de lengua y literatura en Secundaria.
}

Palabras clave: Trabajo por proyectos, TIC, formación del profesorado, enseñanza secundaria, didáctica de la lengua y la literatura. 


\section{Introducción}

La innovación y la mejora de las prácticas educativas mediante las tecnologías depende del buen uso en su aplicación didáctica. En este trabajo presentamos una selección de recursos TIC utilizados habitualmente en el trabajo académico por los estudiantes universitarios con el objetivo de conocer cuáles son los que utilizan con más frecuencia y el rendimiento que consideran que pueden obtener para conseguir un trabajo más eficaz. El estudio se ha realizado a partir de cuestionarios planteados a los alumnos sobre el uso que hacen de las TIC y sobre las ventajas e inconvenientes que encuentran en el trabajo académico. Además, se ha analizado el uso que han hecho de las TIC en proyectos de trabajo sobre lengua y literatura dirigidos al alumnado de secundaria. De esta forma, hemos comprobado cómo determinados recursos TIC pueden contribuir a mejorar la escritura académica de forma que el aprendizaje lingüístico resulte más eficaz y motivador para el alumnado.

Los estudios sobre alfabetización académica permiten conocer las dificultades del alumnado para interpretar y producir textos académicos. Carlino (2013) indica que alfabetizar académicamente equivale a ayudar a participar en prácticas discursivas contextualizadas. Se trata de favorecer el aprendizaje de las "literacidades" 1 académicas, es decir, la participación de los alumnos en sus culturas escritas.

Es cada vez más evidente, tal como establece el currículum oficial en las diferentes etapas educativas, que el alumnado debería saber utilizar las TIC como instrumentos habituales de trabajo: conocer diferentes herramientas para bajar, colgar, enviar y compartir diferentes tipos de documentos; usar vídeos educativos como recurso formativo e interactivo entre alumnado y profesorado; hacer uso de los enlaces; elaborar y publicar noticias; emplear la prensa digital como recurso y estrategia para aprender a aprender, fomentando la selección y el procesamiento de la información; interactuar, relacionarse con los otros, cooperar, gestionar y resolver conflictos, etc.

Tomaremos como ejemplo el trabajo realizado por los estudiantes del Máster Universitario en Profesor/a de Educación Secundaria basado en proyectos para enseñar y aprender lengua y literatura con el uso de las TIC. En este trabajo se emplea el modelo de enseñanza de composición escrita conocido como secuencia didáctica (SD) que se articula alrededor de la composición de un género discursivo. Los objetivos de aprendizaje propuestos y las

${ }^{1}$ El término Literacy, traducido como "literacidad" por Carlino (2013) se refiere a la formación continua en lectura y escritura que nos convierte en persones letradas que pueden hacer uso de habilidades discursivas de forma activa y ajustada a las exigencias de los contextos en que participan (Castelló, 2014).

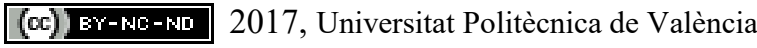


actividades para conseguirlos suponen diferentes procesos de elaboración lingüística: planificación, textualización y revisión.

En este tipo de proyectos, los alumnos tienen que reflexionar sobre la manera de usar la lengua para conseguir hacer un determinado producto: un programa de radio, un periódico, un videolit, etc. La introducción de las TIC permite considerar las formas lingüísticas desde una perspectiva más funcional puesto que supone plantear el uso de la lengua en determinadas situaciones de comunicación y con unos géneros discursivos concretos que requieren la interacción entre los alumnos, para coordinarse y decidir los recursos que emplearán, y tener en cuenta los receptores del trabajo puesto que se trata de proyectos que presuponen una difusión en la red mediante las TIC. Los géneros discursivos son instrumentos de participación en la actividad social y suponen aprender a usar la lengua de forma adecuada en cada uno de los ámbitos de la actividad humana (Camps, Castelló, 2013). En este caso, la actividad discursiva que se da en el entorno académico se refiere a las situaciones en las que los alumnos de secundaria tienen que aprender a usar el lenguaje en diferentes situaciones comunicativas. Tenemos que tener en cuenta que, junto a géneros marcadamente académicos, hay otros que responden a situaciones comunicativas diferentes que han ido apareciendo con la incorporación de las nuevas tecnologías, como la participación en las redes sociales, la elaboración de un blog o página web.

\section{Objetivos}

Este trabajo tiene como principales objetivos:

- Conocer la formación recibida y el uso de las TIC de los estudiantes universitarios en los trabajos académicos

- Identificar las principales ventajas e inconvenientes que encuentra el alumnado en el uso de las TIC y si hay cambios significativos en los últimos cursos

- Valorar la implementación y la repercusión que han tenido estas herramientas en los proyectos para trabajar la lengua y la literatura en Secundaria.

\section{Desarrollo de la innovación}

En la metodología utilizada para este estudio se ha realizado un análisis cualitativo a partir de la revisión de los cuestionarios iniciales y finales contestados por un centenar de alumnos del Máster de profesor/a de Secundaria de la Universitat de València desde el curso 2011-12 hasta el 2015-16. De esta forma, se ha comprobado qué tipo de recursos TIC conocen y usan los alumnos con más frecuencia y cómo han ido cambiando y modificándose durante los últimos años a lo largo de su formación académica y en su

(c)) EY-NC-ND 2017, Universitat Politècnica de València 
aplicación en el trabajo académico. Esta evolución nos permite conocer las herramientas TIC que los estudiantes consideran más efectivas.

En cuanto a la formación recibida y el uso de las TIC, hemos destacado lo que indica el alumnado de forma recurrente respecto a la frecuencia de conexión a Internet, el conocimiento que tiene de las diferentes TIC y las ventajas e inconvenientes que encuentra en su utilización en el trabajo académico.

Además, se han identificado las TIC utilizadas en proyectos para trabajar la lengua y la literatura por estos mismos alumnos durante los cinco cursos indicados. Con estos datos hemos podido comprobar el tipo de recursos TIC que el alumnado considera que son más eficaces para la aplicación didáctica de determinados contenidos de lengua y literatura del currículum de Secundaria ya que les han facilitado la planificación, elaboración y presentación de proyectos en una gran diversidad de géneros académicos.

\section{Resultados}

A partir del análisis de los cuestionarios realizados por los alumnos, se han detectado los siguientes resultados:

\subsection{Conocimiento de las TIC y uso en la formación académica anterior}

Sobre la frecuencia de conexión a la red, los alumnos del máster contestan un cuestionario inicial sobre el conocimiento, el grado de dominio y el uso de las TIC. El 78,66\% del alumnado afirma conectarse a Internet una, dos o tres veces al día. Predomina la opción de 2 o 3 veces al día en todos los cursos y es el alumnado de los últimos cursos el que emplea con más frecuencia Internet.

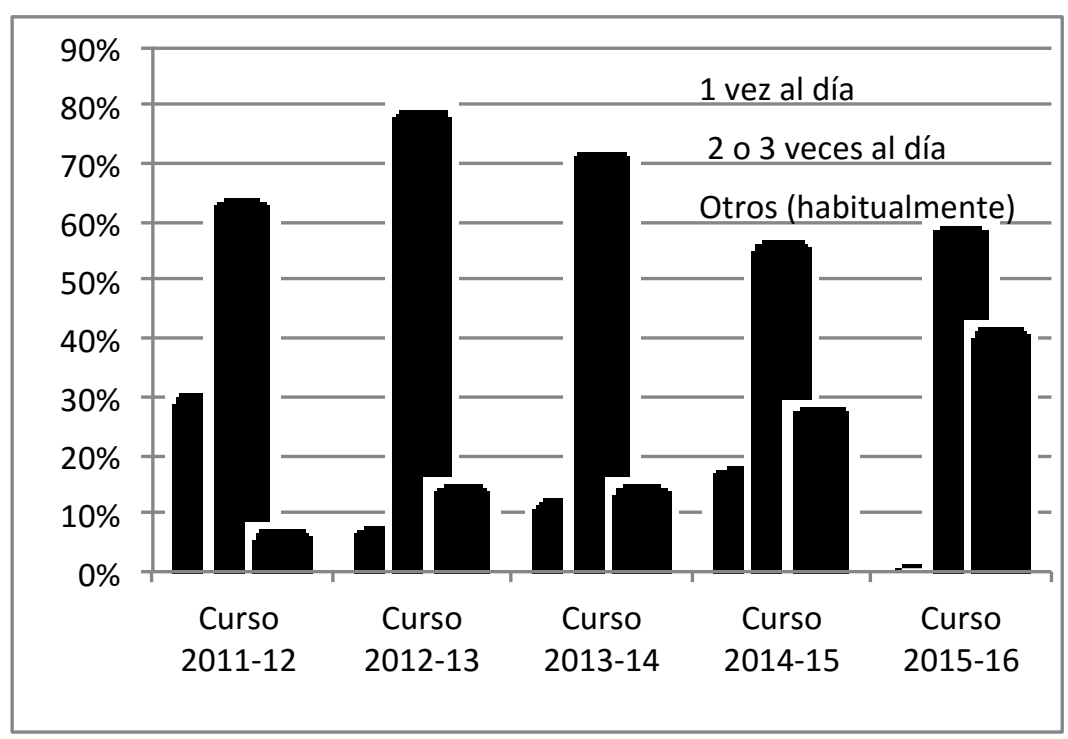

Gráfica 1: Frecuencia de conexión a la red

\begin{tabular}{|l|l|l|l}
\hline (cc) EY-NC-ND 2017, Universitat Politècnica de València &
\end{tabular}

Congreso IN-RED (2017) 
En relación al conocimiento de las TIC, también se manifiesta una progresión cronológica. Los porcentajes de conocimiento son mucho más altos los últimos cursos, por ejemplo en el curso 2015-16 la mayor parte del alumnado afirma conocer la mayoría de las herramientas planteadas.

Tabla 1. Conocimiento de las TIC

\begin{tabular}{|c|c|c|c|c|c|}
\hline CURSO & 2011-12 & 2012-13 & 2013-14 & 2014-15 & 2015-16 \\
\hline Blog & $96,40 \%$ & $100 \%$ & $97,60 \%$ & $100 \%$ & $100 \%$ \\
\hline Wiki & $64,30 \%$ & $57,10 \%$ & $64,30 \%$ & $72,40 \%$ & $62,10 \%$ \\
\hline Drive & $39,30 \%$ & $7,10 \%$ & $35,70 \%$ & $82,80 \%$ & $89,70 \%$ \\
\hline Box & $7,10 \%$ & $50 \%$ & $71,40 \%$ & $34,50 \%$ & $65,50 \%$ \\
\hline Moodle & $14,30 \%$ & $21,40 \%$ & $33,30 \%$ & $27,60 \%$ & $58,60 \%$ \\
\hline Prezi & & $35,70 \%$ & $38,10 \%$ & $62,10 \%$ & $79,30 \%$ \\
\hline Movie Maker & & & $61,90 \%$ & $72,40 \%$ & $82,80 \%$ \\
\hline Slideshire & $10,70 \%$ & $42,90 \%$ & $28,60 \%$ & $58,60 \%$ & $62,10 \%$ \\
\hline Audacity & & & $26,20 \%$ & $41,40 \%$ & $27,60 \%$ \\
\hline Webquest & $28,60 \%$ & $14,30 \%$ & $16,70 \%$ & $17,20 \%$ & $13,80 \%$ \\
\hline CMapTools & $7,10 \%$ & $0 \%$ & $7,10 \%$ & $0 \%$ & $13,80 \%$ \\
\hline Hot Potatoes & & & $2,40 \%$ & $3,40 \%$ & $3,40 \%$ \\
\hline Glogster & & & $7,10 \%$ & $3,40 \%$ & $0 \%$ \\
\hline
\end{tabular}

No obstante, los alumnos manifiestan que, durante su formación académica, en la mayor parte de las materias no han utilizado nunca ningún recurso TIC. Aún así, observamos que aumenta considerablemente en los últimos cursos el uso y la variedad de las TIC empleadas: si en el curso 2011-12 predomina el blog y los alumnos usan 8 herramientas diferentes, en el 2015-16 predomina también de forma destacada el drive y, además, en este último curso se emplean 12 herramientas TIC diferentes.

\subsection{Ventajas e inconvenientes sobre el uso de las TIC}

En los últimos cursos aumentan las valoraciones positivas y disminuyen las negativas sobre el uso de las TIC. La mayoría de los cursos coinciden en las siguientes ventajas: utilidad, inmediatez/rapidez, fácil acceso, trabajo colaborativo, coordinación, facilidad para compartir, trabajo a distancia, variedad de información, comodidad y facilidad. Como inconvenientes, en la mayoría de los cursos se apunta la escasa formación en TIC, la 
dependencia del acceso a Internet, la carencia de infraestructuras y la pérdida de proximidad personal.

\subsection{Implementación de las TIC en proyectos para trabajar la lengua y la literatura}

En relación a las herramientas TIC que emplean los alumnos desde el curso 2011-12 hasta el 2015-16 en los trabajos por proyectos con diferentes géneros académicos ${ }^{2}$, se constata el aumento de las TIC empleadas en cada curso puesto que los alumnos conocen más cantidad y variedad de ellas, y encuentran que son más efectivas para trabajar en los proyectos.

Tabla 2. Herramientas TIC empleadas en los trabajos por proyectos de los diferentes cursos. Indicamos en negrita las que se van incorporando en cada curso

\begin{tabular}{|c|c|c|c|c|}
\hline $2011-12$ & $2012-13$ & $2013-14$ & $2014-15$ & $2015-16$ \\
\hline $\begin{array}{l}\text { Google } \\
\text { Maps }\end{array}$ & Blog & Google Maps, Blog & Google Maps, Blog & Google Maps, Blog, \\
\hline $\begin{array}{l}\text { Editor de } \\
\text { vídeo }\end{array}$ & $\begin{array}{l}\text { Editor de } \\
\text { vídeo }\end{array}$ & Editor de vídeos & Editor de vídeo & Editor de vídeo, \\
\hline $\begin{array}{l}\text { Editor de } \\
\text { fotografia }\end{array}$ & Webquest & $\begin{array}{l}\text { Webquest, editor de } \\
\text { fotos }\end{array}$ & Webquest, Youtube & Youtube \\
\hline \multirow[t]{14}{*}{ Wiki } & & Wiki & Google Drive, & Google Drive \\
\hline & & Editor d'àudio & Editor d'àudio & Editor d'àudio \\
\hline & & Viquipèdia & Viquipèdia & Viquipèdia, \\
\hline & & Editor d'àudio & Editor d'àudio & Editor d'àudio \\
\hline & & $\begin{array}{l}\text { Línia del temps } \\
\text { digital }\end{array}$ & Línia del temps digital & Instagram \\
\hline & & Facebook & Facebook & Videoconferència \\
\hline & & Podcast & Podcast & Videoquiz \\
\hline & & Gmail & Gmail & Vídeos d'animació \\
\hline & & Twitter & Twitter & $\begin{array}{l}\text { Videojoc Second } \\
\text { Life }\end{array}$ \\
\hline & & Hot potatoes & Wordle & \\
\hline & & Petxa-kutxa & $\begin{array}{l}\text { Wikimedia } \\
\text { Commons }\end{array}$ & \\
\hline & & Cartell en línia & Issuu & \\
\hline & & $\begin{array}{l}\text { Slideshare, fòrum } \\
\text { de debat }\end{array}$ & $\begin{array}{l}\text { Web } \\
\text { d'emmagatzematge }\end{array}$ & \\
\hline & & Wix & Power Point & \\
\hline
\end{tabular}

${ }^{2}$ Nos referimos al concepto de "género" como construcción social que posee cierta estabilidad, pero a la vez es dinámico y cambiante (Camps y Castelló, 2013). En el caso de los géneros académicos que nos ocupan, incluidos en los proyectos de lengua y literatura de secundaria, se refieren a todos aquellos que forman parte de las actividades académicas que se desarrollan en este contexto relacionados con las prácticas de lectura y escritura que predominan en las aulas: géneros literarios, periodísticos, comentarios, resúmenes, reseñas, informes, etc.

(c) EY-NC-ND 2017, Universitat Politècnica de València 


\begin{tabular}{|l|l|l|l|}
\hline & Tuenti & Videoconferència & \\
\hline & & Kahoo it & \\
\hline
\end{tabular}

Observamos un aumento evidente en los últimos cursos de la diversidad de herramientas empleadas por los alumnos, sobre todo plataformas digitales para publicar los trabajos como blogs, wiki, webquest, Slideshare, Issuu; editores de sonido, de vídeos y de fotografía; podcast; videojuegos; videoquiz; videoconferencias; líneas del tiempo; Goggle Maps; Goggle Drive; realización de entradas para Viquipèdia; utilización de las redes sociales $^{3}$.

Se pueden observar en los siguientes ejemplos algunas imágenes donde aparecen TIC empleadas por los alumnos para trabajar diferentes proyectos de lengua y literatura en Secundaria, como una línea del tiempo para trabajar la Renaixença literaria o un mapa de Google para llevar a cabo una ruta literaria.

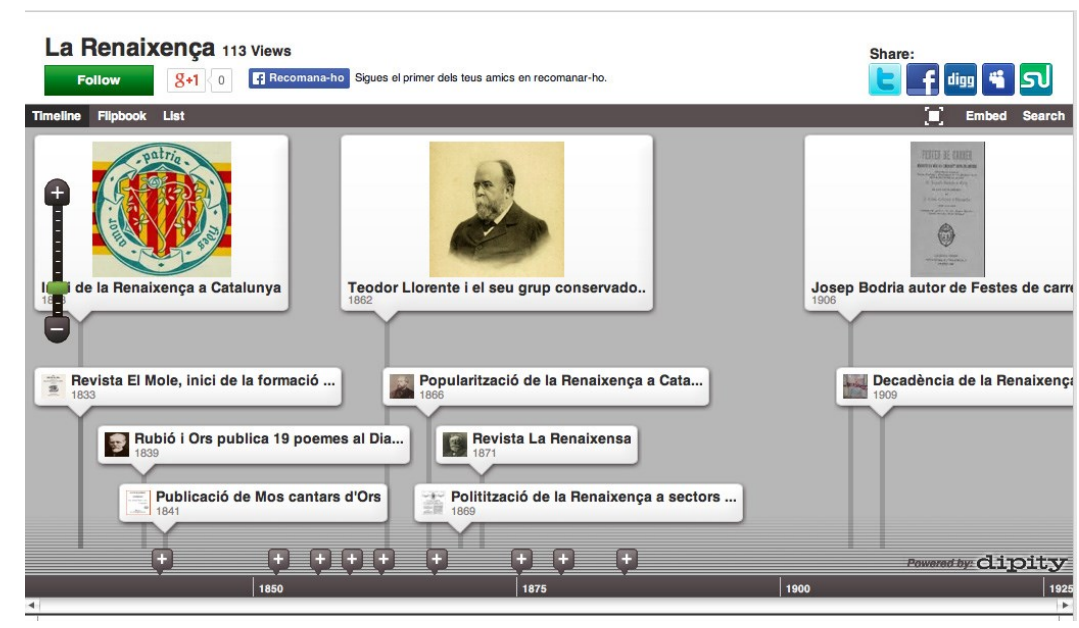

Fig. 1: Linea del tiempo sobre el periodo literario de La Renaixença

\footnotetext{
${ }^{3}$ Además de este recursos, que son los más empleados por el alumnado participante en este estudio, hemos recogido en una web otras recursos que consideramos útiles para mejorar la planificación y el aprendizaje lingüístico ya que en nuestra experiencia como profesoras de secundaria i de universidad los hemos utilizado habitualmente en los proyectos realizados con el alumnado: Del núvol a l'aula.
} 


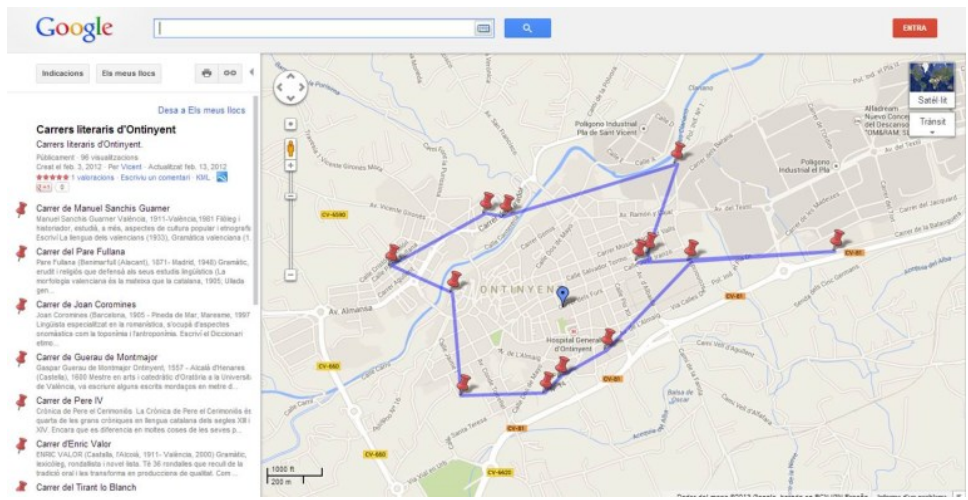

Fig. 2: Ejemplo de la utilización del Google Maps de un grupo de alumnos del máster para indicar una ruta literaria denominada Carrers literaris d'Ontinyent.

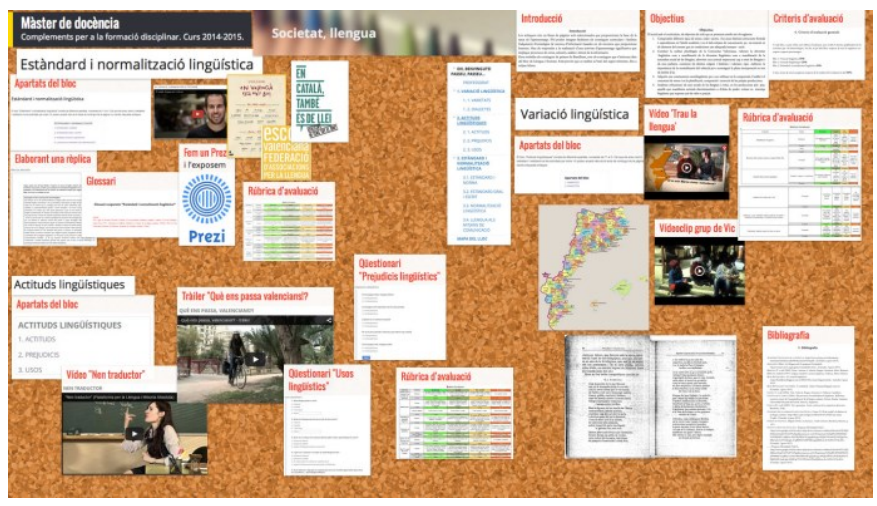

Fig. 3: Ejemplo de presentación de un proyecto de sociolingüistica realizado con un póster en línea con Padlet

\subsection{Ventajas e inconvenientes de las TIC en el trabajo académico}

Según la perspectiva del alumnado del Máster de profesor/a de Secundaria respecto al uso de las TIC en los trabajos académicos, hay más ventajas que inconvenientes y observamos un aumento de las valoraciones positivas en los últimos cursos. Ahora bien, continúa poniéndose en evidencia un déficit en la formación en TIC a pesar del aumento del conocimiento y del uso de las TIC por parte del alumnado. Este déficit en la formación parece que está compensado por el conocimiento y el autoaprendizaje en TIC que realiza una gran parte del alumnado que tiene al alcance ordenadores y dispositivos móviles con aplicaciones que cada vez resultan más accesibles y fáciles de emplear. El déficit de formación no sería el resultado tanto del desconocimiento del funcionamiento de las TIC como de la falta de experiencia para emplearlas con una finalidad didáctica. En este sentido, conviene recordar que hay que partir de lo que es importante que aprenda el alumnado y considerar en qué medida la tecnología ayudará a lograr este propósito, como ya apunta Area (2007) en su decálogo para planificar buenas prácticas docentes con tecnologías.

(c) EY-NC-ND 2017, Universitat Politècnica de València 
Presentamos una muestra de trabajos desarrollados por el alumnado para implementar las TIC en los proyectos de lengua y literatura:

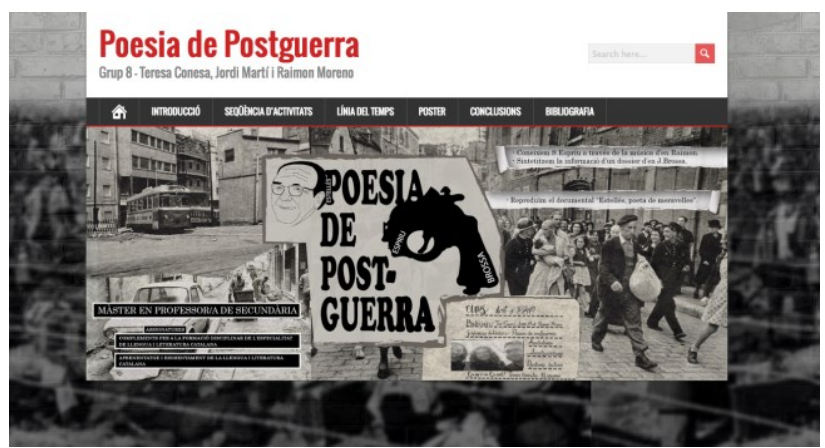

Fig. 4: Ejemplo de una web realizada por los alumnos del máster para trabajar la poesía de posguerra

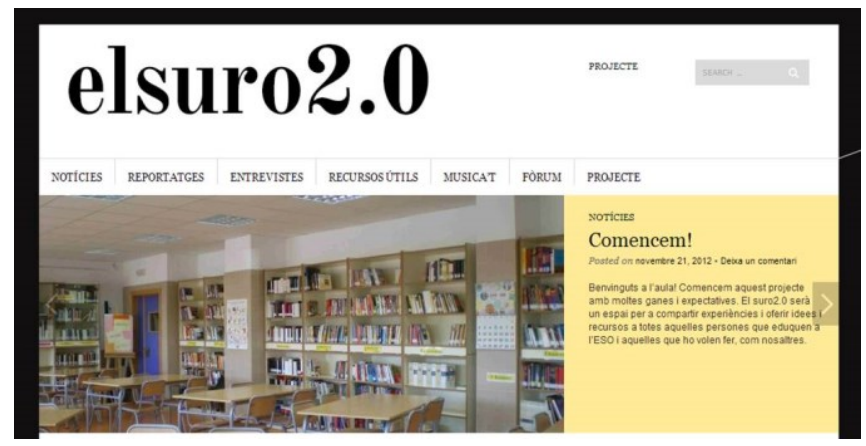

Fig. 5: Periódico digital realizado por los alumnos del máster mediante la creación de una web para trabajar los géneros periodísticos

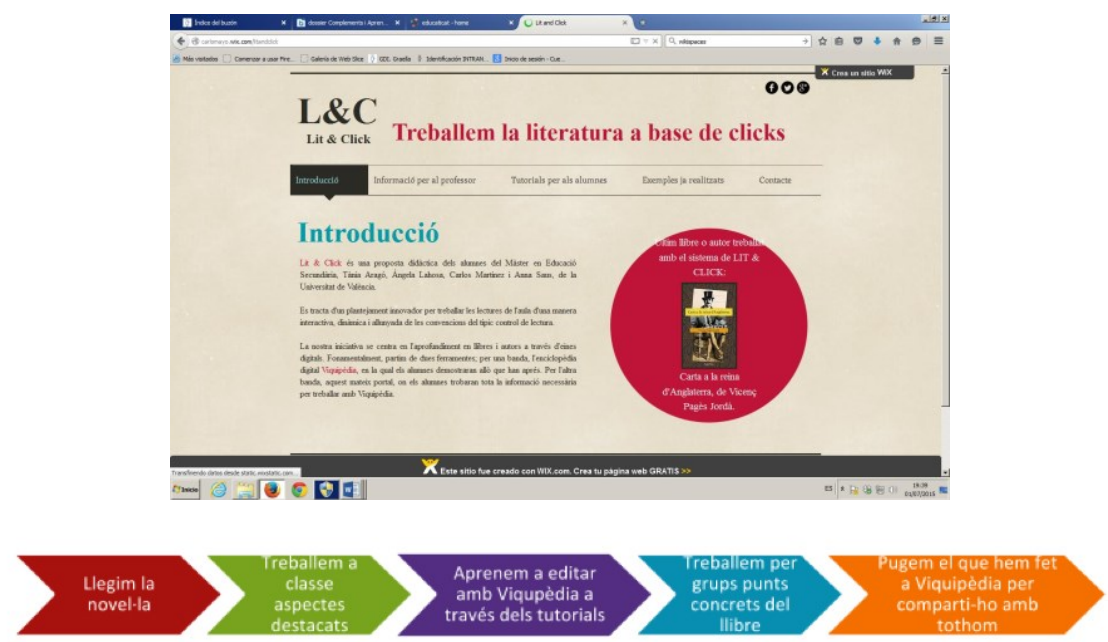

Fig. 6 y 7: Proyecto para trabajar una lectura con la realización de una entrada a Viquipèdia y de una web donde se presentan los tutoriales que tienen que seguir los alumnos

(c)) EY-NC-ND 2017, Universitat Politècnica de València

Congreso In-Red (2017) 
En el cuestionario final sobre las ventajas y los inconvenientes de utilizar las TIC en la materia del máster, predominan las ventajas sobre los inconvenientes en todos los cursos y de forma más evidente en los últimos. Las ventajas principales son:

- innovación educativa

- utilidad

- diversidad de maneras de trabajar

- $\quad$ aprender a trabajar con TIC y usar nuevas plataformas

- motivación

- mejora del trabajo en general, especialmente el del profesorado.

Por otro lado, los inconvenientes señalados son:

- tiempo necesario para trabajar con las TIC

- $\quad$ saturación de recursos y exceso de entornos virtuales

- dependencia de la conexión a Internet

- $\quad$ falta de hábitos de uso.

\section{Conclusiones}

En el análisis que hemos realizado centrado en el área de lengua y literatura, los estudiantes han utilizado las TIC de forma ventajosa para la organización de las ideas, la presentación de trabajos académicos, la consulta de recursos lingüísticos en red, la posibilidad de compartir documentos de diferentes formatos y la utilización de sitios web para trabajar en el aula.

La aportación más evidente de las TIC a la escritura académica sería la incorporación de nuevos géneros dentro del ámbito académico que han surgido con la introducción de las TIC en nuestro contexto sociocomunicativo que implican unas nuevas formas de escritura y una inmediatez en la difusión de los textos, como en el caso del post en el Facebook o en el blog, el tuit en el Twitter, el podcast en la radio. Esto comporta que los productos elaborados por los alumnos son más públicos, lo cual supone que se tiene que tener más cuidado en la presentación y, por lo tanto, requiere más dedicación la revisión y la finalización del proyecto. Tal como dice Castelló (2017), se han distinguido diferentes géneros académicos en función de sus objetivos: profesionales (reportajes, noticias, informes), para demostrar conocimientos (exámenes, ejercicios), para manifestar una postura crítica (ensayos, debates), para buscar información (revisiones, estudios), para expresar las propias vivencias (narraciones, diarios, Facebook). Lo importante es que los estudiantes sean capaces de comunicar de manera adecuada lo que han aprendido y tengan al alcance las herramientas adecuadas para conseguirlo.

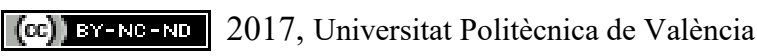


Otra ventaja importante que aportan las TIC, según señalan los mismos alumnos, es favorecer el trabajo colaborativo, la coordinación, la facilidad para compartir. Cómo dice Castelló (2009), es importante favorecer la posibilidad de una escritura colaborativa y que los estudiantes interactúen y reflexionen con las herramientas apropiadas.

En un anterior estudio sobre la utilización de las TIC en trabajos académicos (Martí y Garcia, 2014), ya comentamos que este tipo de recursos permiten desarrollar competencias básicas diversas: la competencia comunicativa, lingüística y audiovisual; la competencia en el tratamiento de la información y la competencia digital; la competencia de aprender a aprender, y la competencia de autonomía y de iniciativa personal. Además, la valoración de los alumnos siempre ha resultado muy satisfactoria dado que el uso de las TIC les motiva a participar en las actividades propuestas en la materia, les facilita acceder a los contenidos del currículum, interaccionar entre ellos y con las profesoras, y compartir otras actividades de interés cultural, referentes musicales y cinematográficos, vídeos, fotografías, etc.

En este análisis hemos visto algunas herramientas TIC que los alumnos consideran útiles para el trabajo en proyectos de lengua y literatura. Sería conveniente, pues, favorecer el conocimiento y el uso de estas herramientas entre el alumnado y el futuro profesorado para mejorar las condiciones de la escritura académica. Los mismos alumnos manifiestan esta carencia de formación en TIC, al tiempo que destacan su utilidad y, por lo tanto, la conveniencia de completar esta formación.

Las conclusiones del estudio muestran que el alumnado cada vez tiene un grado mayor de conocimiento de las TIC, lo cual pone de manifiesto la importancia de implementar más recursos TIC en la docencia con el fin de mejorar la planificación didáctica, la organización de las ideas, la presentación de trabajos académicos, la consulta de recursos en red, la posibilidad de compartir documentos de diferentes formatos y la utilización de sitios web para trabajar en el aula.

Sin embargo, se constata la escasa formación en TIC con finalidades didácticas que demuestra la mayoría de los estudiantes del máster. Por lo tanto, consideramos que es necesario completar la formación universitaria de los futuros docentes en las TIC que se manifiestan más convenientes para favorecer la elaboración de los diferentes géneros académicos, puesto que tienen que saber utilizarlas con solvencia como herramientas de trabajo habituales que les sirvan para aprender a exponer, argumentar, resumir, buscar información, valorar, debatir, etc. Todo ello implica una formación prolongada ya que continuamente aparecen nuevas TIC y se mejoran las anteriores, lo que supone incorporarlas también en el aprendizaje continuo a lo largo de la vida, tanto personal como profesional.

\section{Referencias}

Area Moreira, M. (2007). Decálogo de buenas prácticas con TIC en el aula. $<$ http:/huilliche.blogspot.com/2007/08/declogo-de-buenas-prcticas-con-tic-en.html $>$ [Consulta: 20/10/2016] 
CAmps, A.; CASTElló, M. (2013): "La escritura académica en la Universidad". Revista de Docencia Universitaria, 11 (1), p. 17-36.

CARlino, P. (2013): “Alfabetización acadèmica diez años después". Revista Mexicana de Investigación Educativa, 57, p. 355-381.

CAStelló, M. (2014): "Los retos actuales de la alfabetitzación acadèmica: estado de la cuestión y últimas investigaciones" en Enunciación, 19 (2), p. 346-365.

CASTElló, M. (2017): “Tot mirant-se al mirall”. Articles de Didàctica de la Llengua i la Literatura, 73, p. 7-13.

Martí Climent, A.; Garcia Vidal, P. (2014). "El treball per projectes amb les TIC a l'àrea de Llengua i Literatura. Una experiència didàctica en la formació del professorat de Secundària" en Articles de Didàctica de la Llengua i la literatura, 64. Disponible en:

$<$ https://www.google.es/search?q=el+treball + per+projectes + amb + les + TIC $+\mathrm{a}+1 \% 27 \% \mathrm{C} 3 \% \mathrm{~A} 0 \mathrm{rea}+\mathrm{de}+$ llengua $+\mathrm{i}+$ literatura $\& \mathrm{ie}=$ utf- 8 \&oe $=$ utf- $8 \&$ client $=$ firefoxb\&gfe $r d=c r \& e i=$ LvDfWNCrKuys 8 wf 93 pSQCQ $>$ 


\title{
Innovación docente para el desarrollo de la competencia transversal "Conocimiento de problemas contemporáneos" en el marco del proyecto de competencias transversales de la UPV
}

\section{Oltra-Badenes, Raúl a y Gil-Gómez, Hermenegildo ${ }^{b}$}

${ }^{a}$ Departamento de Organización de Empresas. Universitat Politècnica de València ${ }^{b}$ Departamento de Organización de Empresas. Universitat Politècnica de València

\begin{abstract}
This paper presents a teaching innovation based on the implementation of different training activities to be able to develop the competence "CT-10 Knowledge of contemporary problems" of the Transversal Competences Project of the Polytechnic University of Valencia (UPV). In order to work this competence, we have to look for training scenarios in which students have contact with their environment, always from a practical point of view, and close to the real environment in which they will find themselves in their future employment, once their studies are finished. The innovation presented is based on the use of different training activities within the subject, such as the use of Case Analysis, Projects, Report Writing and Oral Presentations, as well as the organization of talks with professionals.

In order to know the opinion of the students regarding the use of these teaching activities, a brief survey was carried out. The results obtained demonstrate the acceptance and positive evaluation by the students of this type of activities, which allow to develop the contents of the subject in a practical and applied way, while allowing the development and application of transversal competence "CT- 10 Knowledge of contemporary problems"
\end{abstract}

Keywords: Knowledge of contemporary problems, Transversal competences, Learning activities

\section{Resumen}

En este artículo se presenta una innovación docente basada en la puesta en marcha de diferentes actividades formativas para poder desarrollar la competencia "CT-10 Conocimiento de problemas contemporáneos" del Proyecto de competencias transversales de la Universitat Politècnica de València (UPV). Para trabajar esta competencia, se tienen que buscar escenarios formativos en los que los alumnos tengan contacto con su entorno, siempre desde un punto de vista práctico, y cercano al entorno real en el que se encontrarán en su futuro laboral, una vez finalizados sus estudios. La innovación que se presenta, se basa en la utilización de diferentes actividades formativas dentro de la asignatura, como es el uso de 
Innovación docente para el desarrollo de la competencia transversal "Conocimiento de problemas contemporáneos" en el marco del proyecto de competencias transversales de la UPV

\begin{abstract}
Análisis de Casos, Proyectos, Redacción de Informes y Presentaciones orales, además de la organización de charlas con profesionales.

Para conocer la opinión de los alumnos ante la utilización de estas actividades docentes, se ha realizado una breve encuesta. Los resultados obtenidos demuestran la aceptación y valoración positiva por parte del alumnado de este tipo de actividades, que permiten desarrollar los contenidos de la asignatura de una forma práctica y aplicada, al mismo tiempo que permiten el desarrollo y aplicación de la competencia transversal "CT-10 Conocimiento de problemas contemporáneos"
\end{abstract}

Palabras clave: Conocimiento de problemas contemporáneos, Competencias transversales, Actividades formativas

\title{
1. Introducción
}

El proyecto institucional de "competencias transversales" de la UPV comenzó en 2013 y el curso académico 2014/15 fue el de la experiencia piloto, en la que se realizaron diferentes actividades de prueba, con el objetivo de que el curso académico 2015/16 fuera ya el del comienzo de la implantación definitiva del proyecto.

El objetivo principal del proyecto institucional en la UPV es certificar los niveles de los alumnos en "competencias transversales", pero valorando estas a partir de actividades que las usen explícitamente. Es decir, mediante actividades dentro de las diversas asignaturas. Con esas actividades se trabajarán y desarrollarán las competencias específicas al mismo tiempo que las transversales, facilitándose así el proceso de aprendizaje de ambas competencias (UPV, 2012)

Para comprender este proyecto, es necesario definir las "competencias transversales", que podemos definir como "aquellas competencias que son claves y transferibles en relación a una amplia variedad de contextos personales, sociales, académicos y laborales a lo largo de la vida. En este sentido, constituyen una parte fundamental del perfil profesional y del perfil formativo de todas o de la mayoría de las titulaciones. Se trata de competencias que incluyen un conjunto de habilidades cognitivas y metacognitivas, conocimientos instrumentales y actitudinales de gran valor para la sociedad del conocimiento" (ICE, 2017). Se trata por tanto de un saber hacer muy complejo, por lo que es necesario concretarla en resultados de aprendizaje más específicos. Por ello, será necesario recurrir a estrategias metodológicas que propicien el cambio de roles. Ya no se puede utilizar una metodología "tradicional" basada en clases magistrales y problemas que el profesor resuelve en el aula. Incluso las prácticas de laboratorio deben cambiar su enfoque para conseguir nuevos objetivos, y lograr que los alumnos adquieran una serie de capacidades, que, por lo general, antes no se tenían en cuenta ni se evaluaban, como son la capacidad de trabajo en grupo, la capacidad de realizar exposiciones orales, etc. (Oltra-Badenes y GilGómez, 2015)

(cc) EY-NC-ND 2017, Universitat Politècnica de València

Congreso IN-RED (2017) 
En el proyecto de Competencias Transversales de la UPV, se han tenido en cuenta las normativas y directrices más importantes nacionales e internacionales, así como la numerosa literatura científica existente sobre las mismas, llegando a la definición del siguiente listado de competencias transversales UPV:

- CT-01. Comprensión e integración

- CT-02. Aplicación y pensamiento práctico

- CT-03. Análisis y resolución de problemas

- CT-04. Innovación, creatividad y emprendimiento

- CT-05. Diseño y proyecto

- CT-06. Trabajo en equipo y liderazgo

- CT-07. Responsabilidad ética, medioambiental y profesional

- CT-08. Comunicación efectiva

- CT-09. Pensamiento crítico

- CT-10. Conocimiento de problemas contemporáneos

- CT-11. Aprendizaje permanente

- CT-12. Planificación y gestión del tiempo

- CT-13. Instrumental específica

De entre ellas, en este artículo, se presenta una propuesta de actividades que, de forma integrada en la asignatura, van a ayudar a desarrollar y alcanzar la CT-10, Conocimiento de problemas contemporáneos.

En esta Competencia transversal, se hace referencia a la necesidad de que los estudiantes comprendan las cuestiones y valores políticos, sociales, legales y medioambientales contemporáneos, así como los mecanismos de expansión y difusión del conocimiento. Se trata de que desarrollen la capacidad de "estar al día" de los eventos actuales en su campo de conocimiento y en la sociedad en general.

Para saber si se alcanza esa competencia en concreto, se utilizan unos indicadores a modo de evidencia, para dar cuenta de que el resultado de aprendizaje ha sido alcanzado. Concretamente, el proyecto de la UPV propone utilizar los siguientes indicadores:

1. Identificar las causas que han llevado a la situación actual de un problema.

2. Identificar las consecuencias sociales, económicas, culturales y de diverso ámbito del problema en el contexto de su campo profesional.

3. Distinguir las partes que componen un problema y relacionarlas entre ellas, identificando los principales actores en sus diferentes dimensiones (económica, social, ética, tecnológica...).

4. Razonar (críticamente) las soluciones ya propuestas para un problema.

5. Proponer nuevas soluciones al problema que se ha planteado a partir de la propia experiencia y de la información disponible.

Estos indicadores, se integran en una rúbrica, que es un recurso para la evaluación y calificación del aprendizaje, de los conocimientos o del desempeño de los estudiantes en 
una actividad concreta y que establece indicadores (evidencias) y una escala de valoración para cada uno de ellos. Es decir, una rúbrica fija los criterios en los que el profesor va a centrar su atención para evaluar la actividad. Por tanto, esta rúbrica, junto con otras herramientas, se puede utilizar como elemento de evaluación. Pero evidentemente, para alcanzar las competencias, es necesario realizar acciones formativas. Dichas acciones, deben estar basadas en metodologías activas para la formación de competencias, en métodos con participación del alumno, que generan un aprendizaje más profundo, significativo y duradero (Fernández March, 2006). Además, si se utilizan metodologías activas, y cooperativas. En este caso, las que se proponen en el Proyecto UPV como más adecuadas para alcanzar la competencia CT-10, son las siguientes:

- Estudio de casos

- Dilemas éticos

- Exposiciones orales

- Foros y debates

- Juego y simulación

- Lecturas

- Preguntas

- Problemas

- Redacción de informes

- Seminario

- Visitas externas

En este artículo se presenta la aplicación de algunas de estas acciones formativas a una asignatura del Grado de Ingeniería en Organización Industrial que se imparte en la ETSII de la UPV. En concreto, de las propuestas por la UPV, las acciones formativas que se han implantado son:

- Estudio de casos

- Exposiciones orales

- Foros y debates

- Juego y simulación

- Lecturas

- Preguntas

- Redacción de informes

Además, se han añadido otras dos acciones formativas, que son:

- Proyecto

- Charlas de profesionales

Cabe destacar que, tanto la actividad formativa de Proyecto, como las Charlas de profesionales, no están definidos como actividad formativa adecuada para esta competencia. Sin embargo, como se verá más adelante, se considera que es adecuada en el contexto de la asignatura, y por ello se propone utilizarlas junto con las otras dos, para que el alumno sea capaz de alcanzar la competencia transversal.

(cc) EY-NC-ND 2017, Universitat Politècnica de València 


\section{Objetivos}

El objetivo fundamental de la experiencia que se presenta en este trabajo, es conseguir desarrollar la competencia transversal CT-10 Conocimiento de problemas contemporáneos. Dicha competencia se desarrollará en el marco de una asignatura que se presenta a continuación.

\subsection{Contexto de la Innovación docente: La asignatura}

La asignatura en la que se realiza esta acción de innovación docente es la asignatura con código 11517, que se denomina "Sistemas Integrados de Información en Empresas Industriales" (SIIEI) y se imparte en el Grado de Ingeniería de Organización Industrial (GIOI), en la Escuela Técnica de Ingenieros Industriales (ETSII), de la UPV.

Esta asignatura se imparte en el $4^{\circ}$ curso, y en el segundo cuatrimestre, dentro de la intensificación de "Sistemas de Información y Gestión del Conocimiento". Por tanto, se puede decir que los alumnos están en la fase final del Grado, y tras finalizar la asignatura, estarán en disposición de realizar y presentar el Trabajo de Fin de Grado, e incorporarse al mercado laboral, como Graduados en Ingeniería de Organización Industrial.

Por este motivo, se considera por parte de los autores, que la CT-10 Conocimiento de problemas contemporáneos, es fundamental, debido a que, en breve, los alumnos se incorporan al mundo laboral, en el que el dominio de esta competencia es imprescindible. Seguramente, este razonamiento es compartido por la ETSII, y posiblemente sea una de las causas por las que se ha establecido, dentro del plan de estudios de la titulación, que esta asignatura sea Punto de Control de la competencia en cuestión.

\section{Desarrollo de la innovación}

Para alcanzar el objetivo anteriormente descrito, es decir, desarrollar la competencia transversal CT-10 Conocimiento de problemas contemporáneos, se han desarrollado diferentes actividades formativas, que se detallan a continuación.

\subsection{Acciones formativas llevada a cabo}

Además de las explicaciones del profesor, que en todo momento tratan de transmitir los conocimientos de forma que se puedan desarrollar las competencias transversales, es decir, explicando casos prácticos, poniendo ejemplos del entorno empresarial, utilizando preguntas, proponiendo lecturas, moderando foros y debates, etc. se han llevado a cabo algunas actividades para desarrollar la CT-10 de forma específica.

Estas son, concretamente Análisis de casos, Proyecto, Redacción de Informes, Exposición Oral y Charlas de profesionales. A continuación, se hace una explicación de cómo se han llevado a cabo cada una de estas actividades formativas.

(c)) EY-NC-ND 2017, Universitat Politècnica de València 
- Análisis de casos

Para desarrollar esta acción formativa, se presentan casos basados en situaciones reales Estos casos son facilitados a los alumnos, junto con una serie de preguntas que les hacen reflexionar sobre el mismo en relación a los objetivos de aprendizaje y competencias a alcanzar en la asignatura. Los alumnos, divididos en grupos de 4 personas, discuten la solución durante unos treinta minutos, aproximadamente. Posteriormente, se realiza una puesta en común general, en la que participa todo el grupo con el profesor. De esta forma, se consigue la participación activa y se motiva al estudiante, a la vez que se le enseña a analizar problemas. Se consigue de este modo que los alumnos puedan entrar en contacto con ideas diferentes, incluso contrarias a las propias.

De hecho, en alguno de los casos propuestos, el caso se plantea de forma que las respuestas que parecen más lógicas, o las conclusiones hacia las que parece que va enfocado el caso en función de su redacción, son erróneas, en función de algunos errores comunes que se producen en el área de conocimiento. De esta forma, se consigue que el alumno sea crítico con el caso con el que se encuentra, bien porque detecta esta situación, o bien porque no la detecta, pero en la explicación y debate del grupo, es consciente de ella.

Así se desarrolla también el pensamiento crítico del estudiante, otra de las competencias transversales de la UPV

\section{- Proyecto}

En esta actividad formativa, los alumnos deben buscar ellos mismo un Proyecto a realizar, en base a una temática indicada por el profesor. El Proyecto debe ser desarrollado en un entorno empresarial real, en el que deben buscar ellos mismos una situación problemática concreta, que requiera soluciones prácticas en relación con la asignatura y el resto de conceptos vistos en la titulación. De esta forma, en grupos de 3 alumnos, deben:

1.- Seleccionar el proyecto a ejecutar, basándose en la identificación de un problema a resolver del entorno real. 2. Planificar todos los detalles del Proyecto, definiendo y distribuyendo las tareas a realizar para llegar al objetivo. 3. Obtener y estructurar la información del entorno real (por lo general, de una empresa). 4. Desarrollar el Proyecto, proponiendo soluciones. 5. Realizar un seguimiento del proyecto. 6. Presentar el proyecto. 7. Analizar y evaluar el trabajo realizado, tanto de forma conjunta, como cada una de las aportaciones individuales.

Mediante esta metodología de proyectos, se estimula en el alumnado la iniciativa y la creatividad, pero también profundiza en la gestión del tiempo, la responsabilidad y, sobre todo, le permite formular y evaluar hipótesis, planificar, encontrar soluciones, consultar fuentes de información, redactar informes, etc.

(cc) EY-NC-ND 2017, Universitat Politècnica de València 
- Redacción de informes y Exposición oral

Estas dos acciones formativas, se realizan en relación con el Proyecto. Como resultado final del mismo, los alumnos deben realizar una memoria en la que presentan de forma escrita el Proyecto, su desarrollo, planificación, resultados y conclusiones. Esto se hace en base a una guía de orientación, que se facilita a les estudiantes mediante una plantilla, con un guión que pueden seguir (pero también modificar en base a las necesidades concretas del Proyecto) para la redacción del informe final.

Finalmente, los alumnos también deben hacer una exposición oral del trabajo en clase, en la que participan todos los integrantes del grupo.

De este modo, se trabajan también las competencias transversales de Comunicación, tanto oral como escrita, que se corresponden con la CT-08 Comunicación efectiva, de las desarrolladas en el proyecto de la UPV

- Charlas de profesionales

Este tipo de acción o actividad formativa, no está recogida como tal en ninguno de los documentos relacionados con las competencias transversales de la UPV. Sin embargo, se considera una acción formativa muy interesante, en la que los alumnos se relacionan con el mundo profesional a través de las experiencias de profesionales del sector en el que, previsiblemente, trabajarán en el futuro.

En concreto, en esta asignatura, se han realizado 4 charlas de profesionales reconocidos, en relación con diferentes temas tratados en la asignatura.

\section{Resultados}

Para valorar los resultados obtenidos, se ha querido averiguar la acogida de este tipo de actividades por parte de los alumnos, y para ello se les ha realizado una pequeña encuesta que se analiza a continuación. La encuesta se ha realizado en papel, y posteriormente se ha trasladado a Google Drive, plataforma gratuita, para poder tener el registro en formato electrónico. En la encuesta a los alumnos, se les plantean cuatro cuestiones, y ellos deben valorarlas mediante una escala Likert, del 1 al 5.

Concretamente las cuestiones plantadas fueron:

Los alumnos debían valorarlas en una escala del 1 al 5, siendo:

1. Totalmente en desacuerdo

2. Más bien en desacuerdo

3. Ni de acuerdo ni en desacuerdo

4. Más bien de acuerdo

5. Totalmente de acuerdo

En el curso había 30 alumnos matriculados, y se registraron un 100\% de respuestas (30).

Las respuestas a cada una de estas preguntas se resumen en gráfica siguiente

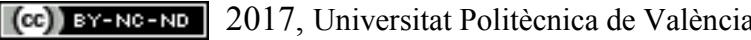




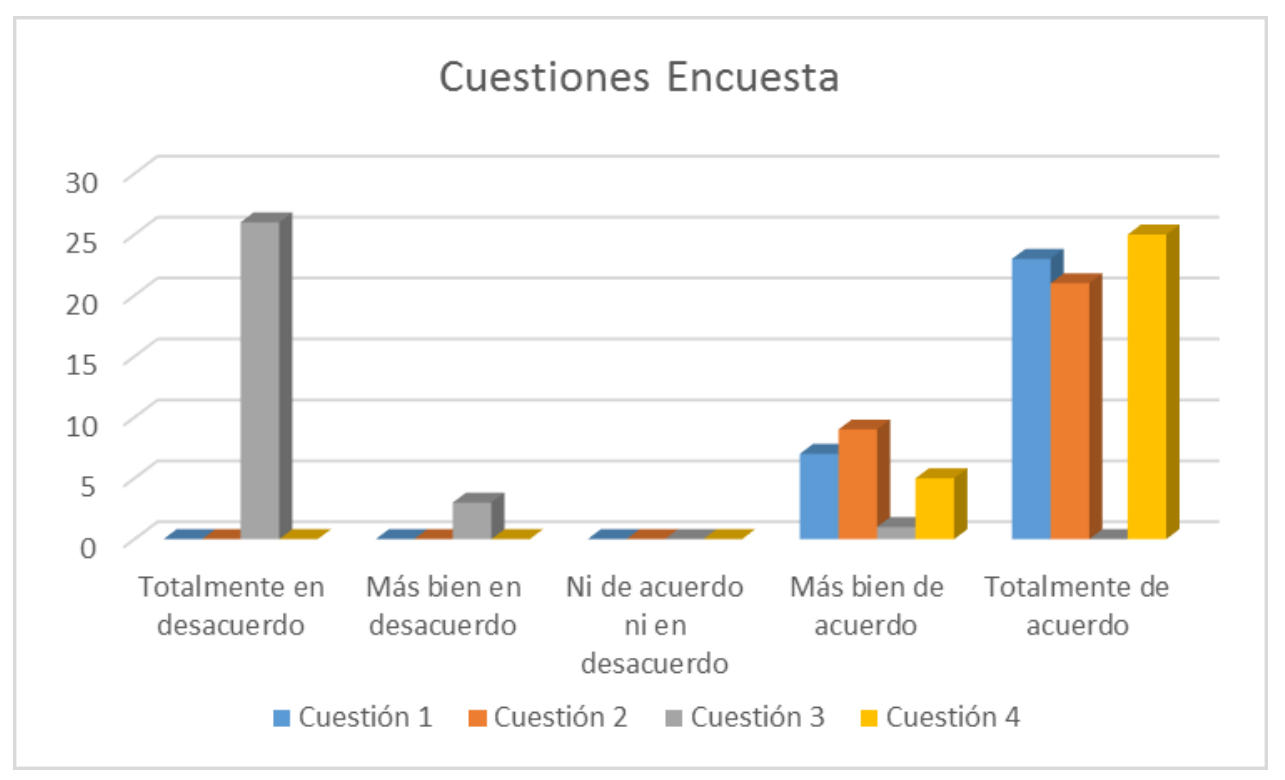

Gráfica 1. Resumen de respuestas a la encuesta realizada

En esta gráfica, se representan los valores del número de respuestas para cada pregunta.

De este modo, se observa que en la pregunta 1, ningún alumno optó por las opciones "Totalmente en desacuerdo", "Más bien en desacuerdo" y "Ni de acuerdo ni en desacuerdo", mientras que 7 alumnos declararon que estaban "Más bien de acuerdo" y 23 que estaban "Totalmente de acuerdo" con la afirmación. Es decir, el 100\% de los alumnos está de acuerdo con que las actividades desarrolladas permiten conocer mejor los problemas contemporáneos, siendo además que un $77 \%$ de los alumnos declararon estar Totalmente de acuerdo, y el 23\% restante, indicó estar Más bien de acuerdo.

Realizando el mismo análisis para las respuestas al resto de preguntas, se obtiene que el $100 \%$ de los alumnos está de acuerdo en que las actividades le ayudan a comprender la asignatura de forma práctica, sien el porcentaje de "Totalmente de acuerdo" del $70 \%$.

En cuanto a la pregunta en que se indica si piensan que sería mejor dedicar el tiempo a otro tipo de actividades, más tradicionales, el $97 \%$ está en desacuerdo, destacando en este caso que el $87 \%$ está Totalmente en desacuerdo. Cabe decir también que, como respuesta a esta pregunta, hay un único valor que indica estar "Más bien de acuerdo".

Por último, en cuanto a la pregunta que se hace para saber la valoración que los alumnos hacen de las actividades, el $100 \%$ indica que valora positivamente las actividades desarrolladas, siendo que el $83 \%$ está totalmente de acuerdo, y el 17\% está Más bien de acuerdo. 


\section{Conclusiones}

En este trabajo se ha presentado una acción de innovación docente en una asignatura del Grado en Ingeniería de Organización Industrial de la UPV. La innovación docente ha consistido en la implantación de diferentes actividades formativas, con el objetivo principal de desarrollar la competencia CT-10 Conocimiento de Problemas contemporáneos, en los alumnos de la asignatura al mismo tiempo que se desarrollaban los objetivos de aprendizaje de la asignatura y sus competencias específicas.

Las acciones formativas llevadas a cabo han sido: Análisis de casos, Proyecto, Redacción de Informes, Exposición oral y charlas de profesionales. Con la finalidad de obtener feedback y saber si las acciones llevadas a cabo habían sido beneficiosas para el desarrollo de la Competencia transversal, y de la asignatura en general, se desarrolló una breve encuesta, que fue pasada a los alumnos de la asignatura. Tras analizar los datos que se pueden obtener del estudio de las respuestas, se puede concluir que las acciones llevadas a cabo son de un efecto positivo evidente para el desarrollo de la actividad docente, destacando que el $100 \%$ de los alumnos encuestados (que es el 100\% de los alumnos de la asignatura) tiene una valoración positiva de las actividades desarrolladas, que el $100 \%$ declara que estas actividades les permiten conocer mejor los problemas contemporáneos, y que también el $100 \%$ declara que estas actividades les han ayudado a aprender la asignatura de forma práctica. Por tanto, se puede decir que las actividades tienen una incidencia positiva en el desarrollo de la Competencia Transversal, así como en el desarrollo de la asignatura y la motivación del alumnado, que valora de forma muy positiva este tipo de actividades formativas, prefiriéndolas a las actividades de clase tradicionales.

\section{Referencias}

FERNÁNDEZ MARCH A (2006). "Metodologías activas para la formación en competencias". Educatio Siglo XXI, 24. pp 35-56

ICE - Instituto de Ciencias de la Educación. Universitat Politècnica de València. (2015) Proyecto Competencias Transversales UPV. $\quad<$ http://www.upv.es/entidades/ICE/info/U0724624.pdf $>$ [Consulta: 27 de marzo de 2017].

OLTRA-BADENES R. y GIL-GÓMEZ, H. (2015). «Técnicas de aprendizaje cooperativo: aplicación de metodologías activas en la asignatura de Recursos Humanos en Empresas Industriales". En: 3rd International Conference on Innovation, Documentation and Teaching Technologies (INNODOCT/15). Open Innovation and Coolhunting in Education. 374-382

UPV. Universitat Politècnica de València (2012). Competencias Transversales. $<$ http://www.upv.es/contenidos/COMPTRAN/ > [Consulta: 27 de Marzo de 2017] 


\title{
Propuesta y desarrollo de la evaluación de la competencia transversal de trabajo en equipo para la asignatura de Métodos Cuantitativos para la Ayuda a la Toma de Decisiones de $3^{\circ}$ GADE
}

\section{Josefa Mula ${ }^{a}$, Raquel Sanchis ${ }^{a}$ y Manuel Díaz-Madroñero ${ }^{a}$}

aDpto. Organización de Empresas. Escuela Politécnica Superior de Alcoy. Universitat Poliècnica de València. Plaza Ferrándiz y Carbonell, 2, 03801, Alcoy, Alicante, España. (fmula, rsanchis, fcodiama, (a)cigip.upv.es)

\begin{abstract}
This article proposes and develops a procedure for the evaluation of the transversal competence of teamwork in the subject of Quantitative Methods to Support Decision Making of the third course of the Degree in Business Administration and Management. This subject is delivered at the Escuela Politécnica Superior de Alcoy of the Universitat Politècnica de València. The proposal includes the approach of an academic work made by students groups, a rubrik that supports the evaluation of the teamwork and a self-assessment questionnaire to be filled by the students involved. Additionally, we provide details of the quantitative procedure carried out to obtain the final assessment as well as the summary of the quantitative results obtained until the moment which shows a high acquisition level in the evaluation of the teamwork transversal competence in the considered degree.
\end{abstract}

Keywords: Evaluation by competences, transversal competences, teamwork, quantitative methods.

\section{Resumen}

Este articulo propone y desarrolla un procedimiento para la evaluación de la competencia transversal de trabajo en equipo en la asignatura de Métodos Cuantitativos para la Ayuda a la Toma de Decisiones del tercer curso del Grado en Administración y Dirección de Empresas. Dicha asignatura se imparte en la Escuela Politécnica Superior de Alcoy de la Universitat Politècnica de València. La propuesta incluye el planteamiento de un trabajo académico a realizar de forma grupal, una rúbrica que se utiliza de soporte para la evaluación del trabajo en equipo y un cuestionario de autoevaluación a cumplimentar por parte de los alumnos implicados. Adicionalmente, se proporcionan detalles del procedimiento cuantitativo llevado a cabo para obtener la valoración final así como el resumen de los resultados cuantitativos obtenidos hasta el momento, que muestran un nivel de adquisición alto en la evaluación de la competencia transversal de trabajo en equipo en el título de grado considerado. 
Propuesta y desarrollo de la evaluación de la competencia transversal de trabajo en equipo para la asignatura de Métodos Cuantitativos para la Ayuda a la Toma de Decisiones de $3^{\circ}$ GADE

Palabras clave: Evaluación por competencias, competencias transversales, trabajo en equipo, métodos cuantitativos.

\section{Introducción}

La Universitat Politècnica de València (UPV) está, actualmente, inmersa en el proyecto de incorporación de las competencias transversales al currículo de los egresados. Estas competencias transversales se han clasificado en trece: CT1. Comprensión e integración; CT2. Aplicación y pensamiento práctico; CT3. Análisis y resolución de problemas; CT4. Innovación, creatividad y emprendimiento; CT5. Diseño y proyecto; CT6. Trabajo en equipo y liderazgo; CT7. Responsabilidad ética, medioambiental y profesional; CT8. Comunicación efectiva; CT9. Pensamiento crítico; CT10. Conocimiento de problemas contemporáneos; CT11. Aprendizaje Permanente; CT12. Planificación y gestión del tiempo; y CT13. Instrumental específica. Para el estudiante, esto supone una oportunidad para adquirir competencias transversales y acreditar su formación en dichas competencias. Para el empleador esto supondrá una oportunidad para conocer el nivel adquirido por el egresado en competencias transversales. De esta forma, mientras que para la UPV, puede suponer un valor añadido en cuanto a la mejora de los títulos, acreditaciones nacionales e internacionales, esta acreditación de la adquisición de las competencias transversales debe servir para definir un perfil de los egresados que sea útil para los empleadores.

En este contexto, la contribución principal de este artículo es definir y verificar una metodología para evaluar el nivel de adquisición de la competencia transversal de trabajo en equipo en la asignatura de Métodos Cuantitativos para la ayuda a la Toma de Decisiones, que es punto de control de nivel 2 (tercer y cuarto curso) de las competencias transversales: CT3, CT6 y CT8; que se imparte en el tercer curso del Grado en Administración y Dirección de Empresas (GADE) de la Escuela Politécnica Superior de Alcoy (EPSA) de la UPV. Otras propuestas alternativas pueden encontrarse en Villa y Poblete (2007), Solé-Català et al. (2011), Casanella-Chuecos y Solé-Català (2012) y Alsina-Masmitjà (2013).

El resto del artículo se estructura como sigue. La Sección 2 introduce la competencia transversal de trabajo en equipo. La Sección 3 describe la propuesta de evaluación de la competencia transversal de trabajo en equipo en el contexto de la asignatura de Métodos Cuantitavos para la Ayuda a la Toma de Decisiones. La Sección 4 presenta el desarrollo llevado a cabo hasta el momento y los resultados de su aplicación. Finalmente, la Sección 5 identifica las conclusiones extraídas a lo largo del proceso considerado y las líneas futuras de trabajo.

\section{La competencia transversal de trabajo en equipo en GADE}

De acuerdo con ICE (2017), "el trabajo en equipo implica crear y desarrollar un clima de confianza mutua entre los componentes que permita trabajar de forma responsable y

(cc) EY-NC-ND 2017, Universitat Politècnica de València

Congreso IN-RED (2017) 
cooperativa. El término más apropiado para describir esta situación es compartir: conocimientos, compromiso y responsabilidad. Supone el reparto de tareas y roles y el respeto a las normas y reglas de juego establecidas por y para el grupo". Por tanto, la CT6 puede definirse como trabajar y liderar equipos de forma efectiva para la consecución de objetivos comunes, contribuyendo al desarrollo personal y profesional de los mismos (Ballenato Priego 2005; ICE, 2017).

Una vez definida la competencia transversal de trabajo en equipo, es necesario identificar los resultados del aprendizaje esperados de acuerdo con el nivel de adquisición al que corresponden las asignaturas definidas como puntos de control de las correspondientes competencias transversales. En este sentido, la UPV define tres niveles de adquisición de las competencias transversales en función del curso en el que se encuentren las asignaturas que son puntos de control. Estos son: nivel 1, que corresponde al primer y segundo curso de grado; nivel 2; tercero y cuarto curso de grado; y nivel tres, primer y segundo curso de máster.

Inicialmente, para el curso 2015-2016, la CT06 fue asignada a las asignaturas obligatorias denominadas puntos de control: Investigación Comercial y Métodos Cuantitativos para la Ayuda a la Toma de Decisiones. En este artículo, se considerarán los resultados obtenidos durante dicho curso 2015-2016.

No obstante, en el GADE impatido en la EPSA y para el curso 2016-2017, la CT06 ha sido asignada a las siguientes asignaturas puntos de control:

Nivel 1

- Introducción a la Administración de Empresas 1ª (Materia: Empresa)

- Economía Mundial 2B (Materia: Entorno Económico y Marco Jurídico)

Nivel 2

- Dirección de Recursos Humanos 4A (Materia: Organización de Empresas)

- Métodos cuantitativos para la toma de decisiones 3B (Materia: Métodos Cuantitativos para la Empresa). Esta asignatura cuenta con un número medio de alumnos matriculados de 83 desde la implantación del grado (2012-2013) hasta la actualidad. Desde el curso 20132014, los estudiantes se dividen en dos grupos, uno impartido en inglés y el otro en español. La asignatura cuenta en la actualidad con tres profesores para impartir la totalidad de los ECTS asignados (7,5 ECTS).

\section{Propuesta de evaluación de la competencia transversal de trabajo en equipo}

En primer lugar, la Tabla 1 describe los resultados de aprendizaje que se espera que los alumnos consigan en el nivel 2 al que corresponde la asignatura punto de control de Métodos Cuantitativos para la Ayuda a la Toma de Decisiones. Adicionalmente, se proporcionan las evidencias o actividades que se proponen para conseguir dichos resultados de aprendizaje. 
Propuesta y desarrollo de la evaluación de la competencia transversal de trabajo en equipo para la asignatura de Métodos Cuantitativos para la Ayuda a la Toma de Decisiones de $3^{\circ}$ GADE

A partir de los resultados de aprendizaje definidos en la Tabla $1 \mathrm{y}$, en concordancia con las competencias generales y específicas del título, se define la actividad de aprendizaje que soportará asimismo el proceso de adquisición de la competencia transversal de trabajo en equipo en la asignatura punto de control de Métodos Cuantitativos para la Ayuda a la Toma de Decisiones del GADE en la EPSA. Concretamente, esta actividad engloba el denominado Caso Brunswick, que fue introducido originalmente por Vatter et al. (1978). Este caso de estudio hace referencia a un trabajo académico grupal realizado por un máximo de 4 alumnos organizados libremente que consiste en el modelado y resolución de un caso de teoría de decisión.

Tabla 1. Resultados de aprendizaje y evidencias para la evaluación

\begin{tabular}{|c|c|c|}
\hline & Resultados de aprendizaje & Evidencias para la evaluación \\
\hline $\begin{array}{c}\text { Nivel 2. Cursos guiados } \\
\text { (tercero y cuarto de grado) }\end{array}$ & $\begin{array}{l}\text { Capacidad para trabajar en la } \\
\text { planificación del desarrollo de } \\
\text { un trabajo en equipo. } \\
\text { Capacidad para trabajar en } \\
\text { equipo para obtener una } \\
\text { resolución adecuada de un } \\
\text { problema o caso de estudio. } \\
\text { Capacidad para comprometerse } \\
\text { en la realización y desarrollo } \\
\text { de un trabajo o estudio de } \\
\text { manera colectiva. }\end{array}$ & $\begin{array}{l}\text { Informe colectivo en el que } \\
\text { quede recogida la comprensión } \\
\text { de la tarea a llevar a cabo por } \\
\text { el grupo de trabajo así como la } \\
\text { planificación y resolución que } \\
\text { se ha adoptado para llevarla a } \\
\text { cabo. } \\
\text { Cuestionario de autoevaluación } \\
\text { individual del proceso de } \\
\text { trabajo grupal. }\end{array}$ \\
\hline
\end{tabular}

El caso Brunswick se contextualiza en una empresa del sector del mueble que debe decidir sobre el precio al cual ofertar unos contratos ofrecidos por una administración pública, concretamente, una universidad. La evaluación general del nivel de adquisición de las competencias generales, específicas y transversales asignadas a la asignatura considerada contempla: presentación oral (30\%), defensa pública de los resultados obtenidos; modelado, resolución y análisis de los resultados (50\%). En este apartado se tiene en cuenta la aplicación correcta de las técnicas utilizadas así como las conclusiones y análisis de los resultados; e informe colectivo (20\%). Se valora positivamente la estructura y claridad del informe de acuerdo con las rúbricas proporcionadas, pues a través del informe también se evalúa parte de la competencia transversal CT8 de comunicación efectiva y la CT3 de análisis y resolución de problemas. Blanco et al. (2008) definen las rúbricas como guías de puntuación usadas en la evaluación del desempeño de los estudiantes que describen las características específicas de un producto, proyecto o tarea en varios niveles de rendimiento, con el fin de clarificar lo que se espera del trabajo del alumno, de valorar su ejecución y de facilitar la retroalimentación. En el caso de la evaluación de la competencia transversal de trabajo en equipo y partiendo de lo definido en la Tabla 1, así como en las

(c)) BY-NC-ND 2017, Universitat Politècnica de València

Congreso IN-RED (2017) 
recomendaciones proporcionadas por ICE (2017), se ha desarrollado la siguiente rúbrica para la evaluación del trabajo en equipo, tal y como se muestra en la Tabla 2.

Tabla 2. Rúbrica para la evaluación del trabajo en equipo

\begin{tabular}{|c|c|c|c|c|}
\hline \multirow{2}{*}{ Indicadores } & \multicolumn{4}{|c|}{ Descriptores } \\
\cline { 2 - 5 } & D. No alcanzado & C. En desarrollo & $\begin{array}{c}\text { B. Bien/ } \\
\text { adecuado }\end{array}$ & $\begin{array}{c}\text { A. Excelente/ } \\
\text { ejemplar }\end{array}$ \\
\hline $\begin{array}{c}\text { Participa en la } \\
\text { planificación del } \\
\text { desarrollo del } \\
\text { caso Brunswick }\end{array}$ & $\begin{array}{c}\text { No se implica en la } \\
\text { planificación }\end{array}$ & $\begin{array}{c}\text { Acepta la } \\
\text { planificación } \\
\text { propuesta por los } \\
\text { demás }\end{array}$ & $\begin{array}{c}\text { Participa } \\
\text { activamente en } \\
\text { la planificación }\end{array}$ & $\begin{array}{c}\text { iniciativa en la } \\
\text { planificación y } \\
\text { fomenta la } \\
\text { colaboración }\end{array}$ \\
\hline $\begin{array}{c}\text { Trabaja en equipo } \\
\text { para obtener una } \\
\text { resolución }\end{array}$ & $\begin{array}{c}\text { Quiere imponer su } \\
\text { criterio y provoca } \\
\text { conflictos que } \\
\text { adecuada del caso } \\
\text { Brunswick } \\
\text { merman la resolución } \\
\text { adecuada del caso } \\
\text { Brunswick }\end{array}$ & $\begin{array}{c}\text { Actúa de forma } \\
\text { pasiva ante la } \\
\text { resolución del caso }\end{array}$ & $\begin{array}{c}\text { Escucha } \\
\text { activamente y } \\
\text { participa en la } \\
\text { resolución del } \\
\text { caso }\end{array}$ & $\begin{array}{c}\text { Consensua las } \\
\text { opiniones de los } \\
\text { demás para } \\
\text { resolver el caso }\end{array}$ \\
\hline $\begin{array}{c}\text { Se compromete en } \\
\text { la realización y } \\
\text { desarrollo del } \\
\text { caso Brunswick } \\
\text { de manera } \\
\text { colectiva }\end{array}$ & $\begin{array}{c}\text { Realiza sus tareas de } \\
\text { manera }\end{array}$ & $\begin{array}{c}\text { Realiza sus tareas } \\
\text { de forma } \\
\text { individualista }\end{array}$ & $\begin{array}{c}\text { Reordinada } \\
\text { tarealiza sus pide y } \\
\text { ofrece ayuda } \\
\text { cuando se } \\
\text { necesita }\end{array}$ & $\begin{array}{c}\text { Realiza sus } \\
\text { tareas y las } \\
\text { comparte para } \\
\text { identificar } \\
\text { dependencias y/o } \\
\text { sinergias }\end{array}$ \\
\hline
\end{tabular}

Esta rúbrica, basada en la guía para el cuestionario de autoevaluación de la CT6. Trabajo en equipo y liderazgo (ICE,2016), es presentada y discutida con los alumnos al inicio del curso y siempre está disponible para ellos en el sitio web de la asignatura. Adicionalmente, a la rúbrica, que se basa, principalmente, en la planficación y desarrollo colectivo del caso Brunswick, se ha propuesto la evaluación de la competencia transversal a través de la autoevaluación por parte de los alumnos que forman el grupo de trabajo utilizando una plantilla especialmente diseñada para que de forma conjunta evalúen los diferentes indicadores (Figura 1). Tras el modelado y la resolución del caso Brunswick, los alumnos deben evaluar, de forma conjunta, los tres indicadores propuestos en la plantilla del cuestionario de autoevaluación para cada uno de los integrantes del grupo. La intersección entre las celdas del nombre del alumno y los diferentes indicadores proporciona una lista desplegable en la cual, se pueden seleccionar una de las 4 opciones disponibles (A, B, C o D). El cuestionario de autoevaluación, implementado en un fichero .xls, también posee mecanismos de control para garantizar la adecuada cumplimentación del mismo. La valoración global de la competencia se obtiene como el promedio de los tres indicadores que autoevalúan los alumnos a través del cuestionario. 


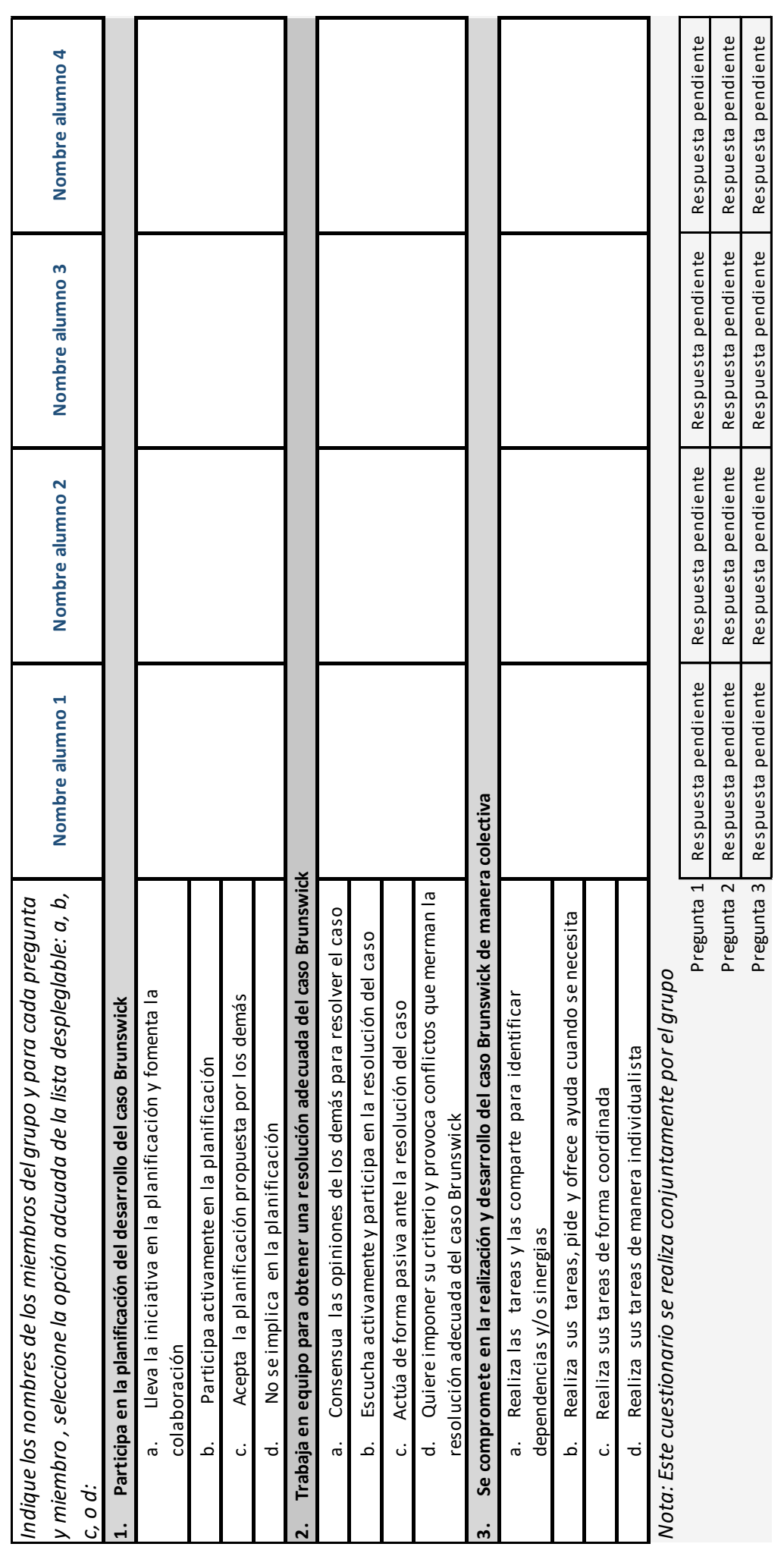

Fig. 1 Cuestionario para la autoevaluación conjunta del trabajo en equipo.

(c)) EY-NC-ND 2017, Universitat Politècnica de València 


\section{Desarrollo y resultados}

La evaluación de la competencia transversal de trabajo en equipo en el GADE impartido en la EPSA durante el curso 2015-2016 proporcionan los siguientes resultados globales (Tabla $3)$ :

Tabla 3. Resultados globales de la evaluación del trabajo en equipo en el GADE-EPSA

\begin{tabular}{|l|c|c|c|c|c|c|c|c|c|c}
\cline { 2 - 10 } \multicolumn{1}{c|}{} & \multicolumn{9}{c|}{ Valoraciones } \\
\hline Competencia & D & C & B & A & Total & Media & Moda & \%ABC & \%AB & Moda \\
\hline CT_06 & 2 & 3 & 30 & 102 & 137 & 2.7 & A & 98.5 & 96.4 & A \\
\hline & $1.5 \%$ & $2.2 \%$ & $21.9 \%$ & $74.5 \%$ & & & & & & \\
\hline
\end{tabular}

Mientras que la evaluación de la competencia transversal de trabajo en equipo en el caso concreto de la asignatura de Métodos Cuantitativos para la Ayuda a la Toma de Decisiones del GADE en la EPSA, los resultados específicos son descritos en la Tabla 4 diferenciando a los dos grupos, G1, que es el grupo en el que las clases son impartidas en español y G2, en el cual las clases son impartidas en inglés:

Tabla 4. Resultados específicos de la evaluación del trabajo en equipo en la asignatura de Métodos Cuantitativos para la Ayuda a la Toma de Decisiones de la EPSA

\begin{tabular}{|c|c|c|c|c|c|c|c|}
\hline & & & & & & \multirow[b]{3}{*}{$\begin{array}{c}\text { No } \\
\text { evaluada }\end{array}$} & \multirow[b]{3}{*}{ Total } \\
\hline & \multicolumn{4}{|c|}{ Valoraciones } & & \\
\hline Grupo & Idioma & D & $\mathbf{C}$ & B & $\mathbf{A}$ & & \\
\hline G1 & Español & 0 & 0 & 7 & 39 & 2 & 48 \\
\hline G2 & Inglés & 0 & 1 & 3 & 24 & 7 & 35 \\
\hline & Total & 0 & 1 & 10 & 63 & 9 & 83 \\
\hline
\end{tabular}

Los resultados de la Tabla 3 muestran un nivel de adquisición alto en la evaluación de la competencia transversal de trabajo en equipo en el título de grado considerado. Asimismo, se puede confirmar que los resultados específicos de la asignatura considerada (Tabla 4) están alineados con los globales de la Tabla 3. La Figura 2 muestra que el nivel de adquisición en la evaluación de la competencia transversal es más elevado en el grupo impartido en español que en el grupo impartido en inglés. Dicho aspecto puede ser debido a que, en el grupo impartido en español, los alumnos han cursado todas las asignaturas juntos desde el primer curso, mientras que en el grupo impartido en inglés, muchos de los alumnos son erasmus que provienen de otras universidades y tan sólo cursan el semestre B del tercer año. Cabe indicar que anteriormente no se evaluaba la competencia transversal de trabajo en equipo por lo que no se ha podido llevar a cabo una comparación entre la situación actual y la anterior a la aplicación de la metodología presentada. 
Propuesta y desarrollo de la evaluación de la competencia transversal de trabajo en equipo para la asignatura de Métodos Cuantitativos para la Ayuda a la Toma de Decisiones de $3^{\circ}$ GADE

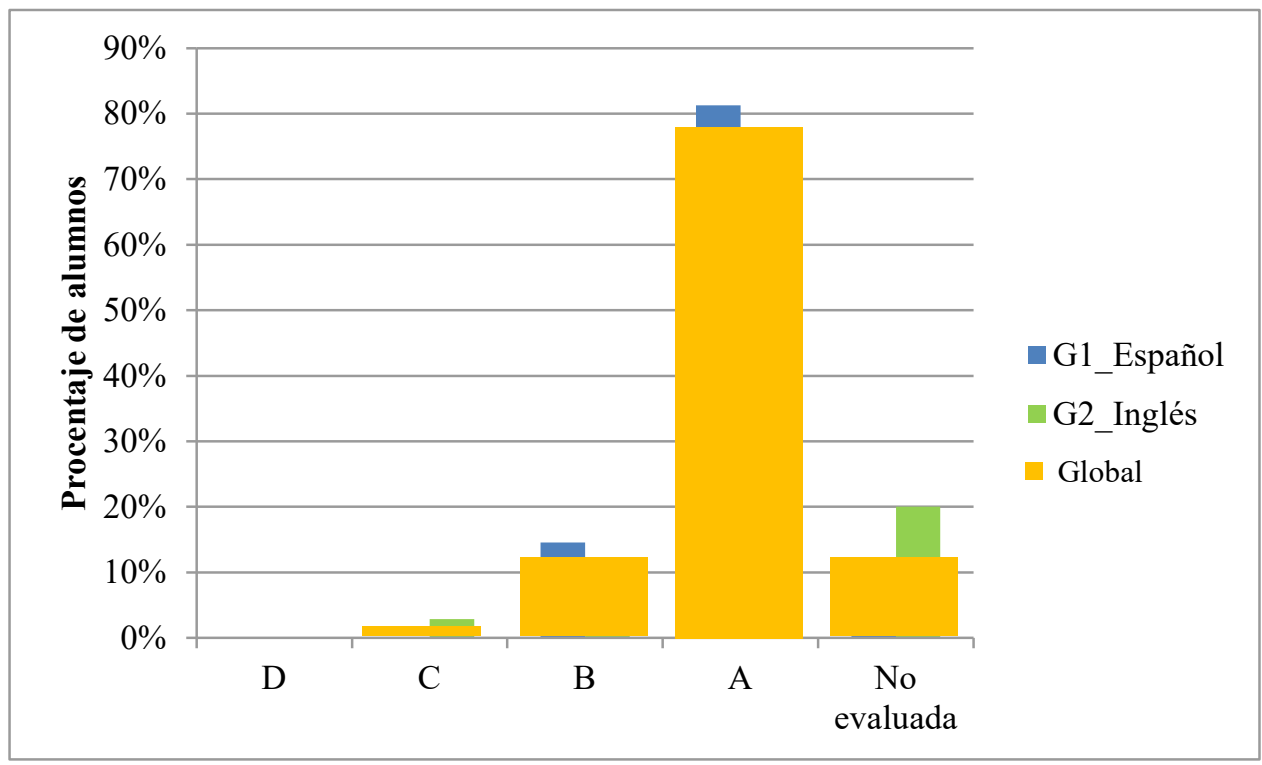

Fig. 2 Representación de los porcentajes de alumnos, de los dos grupos y del global, según las diferentes valoraciones.

Además, comparado con el nivel de adquisición de otras competencias transversales de la titulación, el informe de gestión de 2015-2016 del GADE de la EPSA (UPV, 2017) indica que, de forma general, los alumnos del GADE de la EPSA adquieren con un nivel A las competencias de: Trabajo en equipo y liderazgo (CT6) y comunicación efectiva (CT8). Con un nivel de $\mathrm{C}$, comprensión e integración (CT1), aplicación y pensamiento práctico (CT2), aprendizaje permanente (CT11) y planificación y gestión del tiempo (CT12). El resto de las competencias transversales de la UPV se han evaluado de forma mayoritaria con un nivel B. En el caso de la competencia de Responsabilidad, ética, medioambiental y profesional (CT7) se ha identificado que no ha sido evaluada durante el curso 2015-2016.

\section{Conclusiones}

En este artículo se ha abordado el proceso de evaluación de la competencia transversal de trabajo en equipo para la titulación de GADE de la EPSA. Concretamente, este proceso se ha llevado a cabo en la asignatura de Metodos Cuantitativos para la Ayuda a la Toma de Decisiones. Para ello, en primer lugar, se han identificado los resultados de aprendizaje y las evidencias a utilizar para la evaluación. Seguidamente, se han identificado las actividades de aprendizaje. Cabe resaltar que dichas actividades están en línea con las definidas para la adquisición de las competencias generales y específicas y no supone un trabajo adicional para el estudiante. Para llevar a cabo la evaluación de la competencia transversal de trabajo en equipo a través de las actividades de aprendizaje definidas se ha propuesto, por un lado, una rúbrica y, por otro lado, un cuestionario de autoevaluación a cumplimentar de forma conjunta por los miembros que han desarrollado el trabajo en equipo. Se considera que la metodología y experiencia presentada se puede replicar en otros

(cc) EY-NC-ND 2017, Universitat Politècnica de València

Congreso IN-RED (2017) 
contextos, titulaciones o asignaturas con las adaptaciones pertinentes en la rúbrica para la evaluación del trabajo en equipo (Figura 2).

Las líneas de trabajo futuro identificadas se orientan a: (i) coordinación de equipos de trabajo docentes para la evaluación de la competencia transversal de trabajo en equipo tanto en el GADE como en el Máster Universitario de Dirección de Empresas (MBA) impartido en la EPSA de la UPV; (2) exportar las rúbricas utilizadas actualmente a la aplicación IRUBRIKS, que integrará, con la aplicación Poliforma T de la UPV, la evaluación de las competencias transversales; y (iii) utilización de la herramienta LESSONS, dentro de Poliforma T, con el objetivo, al igual que en el caso de IRUBRIKS, de lograr una mayor integración de la evaluación de las competencias transversales con el resto de competencias generales y específicas de los títulos considerados.

\section{Referencias}

ALSINA MASMITJÀ, J. (coord.) (2013). Rúbricas para la evaluación de competencias. Cuadernos de Docencia Universitaria 26. ICE (UB) y Ediciones Octaedro. Barcelona.

BALLENATO PRIETO, G. (2005). Trabajo en Equipo. Pirámide. Madrid

BLANCO BLANCO, A. (2008). Las rúbricas: un instrumento útil para la evaluación de competencias en la enseñanza universitaria centrada en el aprendizaje, OCTAEDRO, ICE-UB, Barcelona.

CASANELLA-CHUECOS, M., SOLÉ-CATALÀ, M. (2012). "La competencia transversal de trabajo en equipo. Instrumentos para su implementación y evaluación“" en III Jornades sobre Docència del Dret $i$ Tecnologies de La Informació $i$ La Comunicació, Barcelona. Disponible en http://www.uoc.edu/symposia/dret tic2012/pdf/3.4.casanellas-montserrat-y-sole-marina.pdf

[Consulta: 31 de marzo de 2017]

INSTITUTO DE CIENCIAS DE LA EDUCACIÓN - ICE (2017). Competencias transversales. Universitat Politècnica de València. http://www.upv.es/contenidos/COMPTRAN/info/954872normalc.html [Consulta: 31 de marzo de 2017]

INSTITUTO DE CIENCIAS DE LA EDUCACIÓN - ICE (2016). Cuestionario de Autoevaluación de la CT-06. Trabajo en Equipo y Liderazgo.

SOLÉ-CATALÀ, M., CASANELlAS-CHUECOS, M., COLlADO-SEVILlA, A., PÉREZMONEO AGAPITO, M., SAYÓS SANTIGOSA, R. (2011). Treball en equip. Indicacions per al desenvolupament $\mathrm{i}$ avaluació de la competència genèrica al grau de Gestió i Administració Pública (http://hdl.handle.net/2445/16222).

UPV (2016) Informe de gestión 2015-2016 del Grado en Administración y Dirección de Empresas de la Escuela Politécnica Superior de Alcoi ((http://www.upv.es/titulaciones/GADEA/menu_urlc.html?/titulaciones/GADE-A/info/U0743829.pdf)

[Consulta: 31 de marzo de 2017]

VATTER, P.A., BRADLEY, S.P., FREY Jr. S.C. JACKSON, B.B. (1978). Quantitative methods in management: Text and cases. Ed. Homewood, IL: Richard D. Irwin.

VILLA, A., POBLETE, M. (2007). Aprendizaje basado en competencias. Una propuesta para la evaluación de las competencias genéricas. Ediciones Mensajero. Bilbao.

(c)) EY-NC-ND 2017, Universitat Politècnica de València 


\title{
Simulación y Juegos de rol como herramienta de innovación en la asignatura Deontología y Profesionalismo
}

\author{
MariLuz Gordo ${ }^{\mathrm{a}}$, Marta Fernández-Diego ${ }^{\mathrm{a}}$, Faustino Alarcón ${ }^{\mathrm{a}}$, Andrés Boza ${ }^{\mathrm{a}}$ \\ ${ }^{a}$ Departamento de Organización de Empresas. Universitat Politècnica de València. \\ Equipo de Innovación Educativa AEGECATE. (magormon@upvnet.upv.es, \\ marferdi@omp.upv.es, faualva@omp.upv.es, aboza@omp.upv ).
}

\begin{abstract}
Simulation and role-playing are techniques that allow working the competence Innovation, Creativity and Entrepreneurship. This article presents the design and development of an activity based on simulation and role play totally located in the future professional field of our students, Computer Engineering. It should be highlight, the high degree of participation of the students in the activity carried out and their involvement in the role that they have to assume.
\end{abstract}

Keywords: Simulation, Role Playing, Competition, Innovation, Creativity, Entrepreneurship.

\begin{abstract}
Resumen
La simulación y los juegos de rol son técnicas que permiten trabajar la competencia Innovación, Creatividad y Emprendimiento. En este artículo se presenta el diseño y desarrollo de una actividad basada en la simulación y los juegos de rol, totalmente ubicado en el futuro ámbito profesional de nuestros estudiantes, la Ingeniería Informática. Cabe destacar, el alto grado de participación del alumnado en la actividad realizada y su implicación dentro del rol que se le propone asumir.
\end{abstract}

Palabras clave: Simulación, Juego de Rol, Competencia, Innovación, Creatividad, Emprendimiento.

\section{Introducción}

La innovación, creatividad y emprendimiento ha sido un tema de considerable interés en la educación desde hace algún tiempo, y una de las competencias más demandadas por las empresas. Promover la adquisición de esta competencia es uno de los aspectos a resolver. La innovación, la creatividad y el espíritu empresarial son un saber hacer complejo que se desarrollará en la educación superior. Este complejo conocimiento debe especificarse en el diseño de nuevos currículos a través del conjunto de competencias específicas y transversales que los estudiantes deben desarrollar.

La simulación y juegos de rol son técnicas que permiten trabajar esta competencia.

De acuerdo con lo establecido en el artículo de García et al. (2011) dentro de las metodologías activas que fomentan la innovación, son ampliamente empleadas el trabajo en parejas, lluvia 
Simulación y Juegos de rol como herramienta de innovación en la asignatura Deontología y Profesionalismo

de ideas, rueda de ideas, debates, grupos de discusión, etc. Si bien estos autores indican lo siguente sobre la técnica de la simulación:

Además de estas técnicas, se encuentra el uso de la simulación en el proceso de enseñanza aprendizaje, que, según Ruben (1999), basándose en los enfoques de aprendizaje de finales de los años 60, es una metodología que supera las limitaciones de la enseñanza tradicional. De hecho, y de acuerdo con este autor, el uso de las simulaciones como metodología educativa conlleva una mejora en el proceso de aprendizaje del propio estudiante, facilita la interactividad entre los estudiantes, el trabajo colaborativo y, en definitiva, un aprendizaje más activo.

También en dicho artículo se define juego de rol (rol play o rol playing) como:

Técnica en la que cada participante desempeña un papel concreto en el contexto de una situación simulada siguiendo determinadas reglas y en la que interactúa con otros participantes del mismo juego de simulación.

La aplicabilidad de los juegos de rol tambien la encontramos en el trabajo de Perea (2008) :

Por ejemplo, el hecho de que un jugador de rol diseñe creativamente un personaje con un conjunto de caracteristicas morales especificas, le permite experimentar y explorar principios de acción y criterios de estilo de existencia, en su relación consigo mismo y con otros, en el juego estratégico entre las libertades que intervienen.

Y ligándolo con la competencia de Innovación, emprendimiento y creatividad, viene al hilo la mención a los autores Jiménez y Moncholi (2009) :

La sociedad ya ha tomado conciencia de que la creatividad es un derecho y una exigencia social; esta creatividad, indispensable en muchas disciplinas, puede desarrollarse a través de la técnica de juegos de rol, con la que, además, se potencia el aprendizaje y se suscita la curiosidad de los jugadores. Los juegos de rol, a pesar de que los personajes y la situación que se simula vienen definidos a priori, atendiendo a determinadas reglas impuestas por un director (normalmente el profesor o grupo de profesores que imparten una determinada materia), no exigen un diálogo concreto a los jugadores, siendo éstos libres para poder reconducir la situación o problemática planteada en aras de encontrar ciertas soluciones.

Por ello se puede concluir que estas técnicas abren una ventana a la imaginación y la creatividad de forma muy espontánea y natual, y por tanto facilitan el desarrollo de la competencia Creatividad, Innovación y Emprendimiento.

La innovación docente sobre la competencia de Creatividad, Innovación y Emprendimiento se desarrolla en el marco de la asignatura Deontología y Profesionalismo.

Esta asignatura se encuentra en el segundo año del Grado de Ingeniería Informática de la Escuela Tècnica Superior de Ingeniería Informática y se divide en tres bloques: "Profesionalismo", "Aspectos legales" y "Ética". 
- Profesionalismo

La asignatura comienza con el estudio de la "profesión" en general para, rápidamente, particularizar en la profesión informática. El tema pasa sobre la historia de la informática y analiza cuándo la informática comenzó a ser consciente de su existencia, desvinculada de otras profesiones.

- Aspectos jurídicos

En esta parte del curso, la asignatura da una idea de las principales facetas de esta profesión sujetas a la ley, teniendo en cuenta las principales normas. Obviamente, es imposible abordar con plenitud cada ley, regulación y otros preceptos legales que afectan a la profesión. Por lo tanto, el tema centra la atención en aquellas áreas que reciben más interés, tanto por la atención prestada por los tribunales, como por el impacto en la sociedad civil. Así, la asignatura trata de cubrir al menos el marco legal básico para la buena práctica profesional.

- Deontología y ética

El tema introduce la ética y su relación con la empresa y, sobre todo, con la profesión informática. La razón de su inclusión es elemental: si es cierto que la ley marca algunos canales de acción, la última barrera, que nos marca las delgadas líneas rojas que no deben cruzarse, se llama ética. Como es un tema inusual para una carrera en tecnología, comienza con el establecimiento de algunos conceptos básicos, para luego discutir la ética empresarial sin olvidar la ética individual o la ética de la sociedad en general. El tema introduce cuestiones clave como el equilibrio social o los códigos de ética y, por supuesto, pone especial énfasis en la relación entre la ética y la ciencia de la computación.

\section{Objetivos}

El objetivo del trabajo es presentar el diseño y desarrollo de una actividad basada en simulación y juego de rol, llevada a cabo en la asignastura Deontología y Profesionalismo para la adquisición de la competencia transversal creatividad, innovación y emprendimiento. La actividad han sido creada íntegramente por los profesores basándose en la experiencia en la docencia de la asignatura.

\section{Desarrollo de la Innovación}

La actividad propuesta se basa en simular situaciones en contextos determinados en las que los alumnos deben ubicarse. En esta actividad, denominada "Fuga de Datos del Hospital de Fuenlabrada", los alumnos simulan estar en un determinado puesto de trabajo y formar parte de un proceso de investigación. Se introduce la simulación recreando en el aula el contexto de un hospital, y más concretamente el departamento de informática de este.

La base de la simulación está en presentar situaciones reales (o realistas), y en el caso de la actividad "Fuga de datos" la actividad toma su origen en la existencia de una noticia publicada en prensa sobre la difusión de datos de carácter personal por parte del hospital incurriendo en una infracción legal. Se escogió esta situación por considerarse que facilita al alumno la conexión con la realidad, la aplicabilidad de los conceptos trabajados y el conocimiento de problemas contemporáneos.

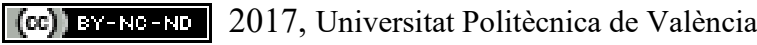


Simulación y Juegos de rol como herramienta de innovación en la asignatura Deontología y

\subsection{Contexto}

Como se indicó anteriormente, la actividad se desarrolla en la asignatura Deontología y Profesionalismo, asignatura cuatrimestral obligatoria de segundo curso del Grado de Ingeniería Informática, y tiene un tamaño medio de alumnos por grupo: de 20 a 50 alumnos.

\subsection{Desarrollo}

La actividad pretende, de una forma práctica y amena, reforzar la aplicación de la normativa española de protección de datos. Asimismo se plantean varios dilemas morales para provocar la reflexión de los alumnos. La actividad se realiza en parejas.

La actividad se divide en varias partes:

- PARTE I (10 minutos)

\section{LECTURA DE NOTICIA}

"Hospital de Fuenlabrada releva a dos cargos por la filtración datos" 11/04/2014 El País http://ccaa.elpais.com/ccaa/2014/09/11/madrid/1410432868_373337.html

- $\quad$ PARTE II (20 minutos):

JUEGO DE ROL Preparación entrevista Trabajo en equipos de 4 personas: Dos alumnos adoptarán el rol de informáticos del hospital y los otros dos investigadores. Se presenta a continuación parte del enunciado que se da a los alumnos:

\section{Alumnos informáticos del Hospital:}

Trabajáis como responsables de informática en el hospital de Fuenlabrada cuando ha tenido lugar el suceso que reporta la noticia. Os han informado de que van a abrir una investigación y que posiblemente alguien quiera entrevistarse con vosotros. Ante ello conviene que os preparéis bien la información que os pueden solicitar. Tenéis que trazar un argumento sólido.

Algunas preguntas que podéis plantearos (y cuyas respuestas deberéis plasmar en el documento)

1) ¿Qué tipo de datos manejáis? ¿A qué nivel de seguridad corresponden?

2) ¿Quién es el responsable del fichero y el encargado del tratamiento?

3) ¿Tenéis documento de seguridad? ¿Lo empleáis habitualmente?

4) ¿Qué sistemas de seguridad tenéis diseñado en vuestro sistema?

5) ¿Quién os ordenó realizar la cesión de datos?

6) ¿Cómo se desarrolló esta actuación?

(c) EY-NC-ND 2017, Universitat Politècnica de València

Congreso IN-RED (2017) 


\section{Alumnos investigadores:}

Sois los informáticos encargados de llevar a cabo la investigación sobre lo ocurrido en el Hospital de Fuenlabrada. Os entrevistaréis con los responsables de informática del hospital. Preparar las preguntas que les plantearíais con el fin de valorar las responsabilidades y determinar si ha habido una actuación inadecuada argumentándolo con la ley en la mano. Este caso ha tenido mucha repercusión mediática y se requiere actuar con profesionalidad y con rigor. ;Se buscan responsables!

Elementos a considerar:

1) Preguntas a plantear (Las elaboran los investigadores a modo de borrador para la entrevista)

2) Artículos de la legislación (Por ejemplo Ley Orgánica 15/1999 de Protección de Datos de Carácter Personal, RD 1720/2007 por el que se aprueba el Reglamento de desarrollo de la Ley Orgánica 15/1999 de protección de datos de carácter personal, etc.) a tener en consideración por ser aplicables a este caso.

3) Y si, además de hablar de datos, nos encontráramos con los siguientes casos, valora los posibles delitos cometidos. Indica legislación y clasificación del delito según el convenio de ciberdelincuencia, en su caso:

- Se ceden los datos junto con la aplicación que los contiene

- Se ceden los datos a cambio de dinero

- $\quad$ PARTE III (20 minutos):

JUEGO DE ROL Realización entrevista. Los alumnos con el rol "informático" se unen con los del rol "investigador" llevando a cabo una entrevista para obtener la información necesaria. Se presenta a continuación parte del enunciado que se da a los alumnos:

1) Resume lo acontecido durante el interrogatorio

2) Valora a tus compañeros con la información proporcionada

En el caso de los investigadores, además:

3) Determinar qué tipo de responsabilidad se deriva

4) Si consideráis que se ha cometido algún delito clasificarlo e indicar el artículo concreto y normativa incumplidos.

- $\quad$ PARTE IV (15 minutos):

DILEMA MORAL en EQUIPO. Todos los alumnos asumen el rol de informático para introducir dos situaciones nuevas. Se presenta a continuación parte del enunciado que se da a los alumnos: 
Pongámonos en situación: Ahora somos todos informáticos del departamento de informática en el Hospital de Fuenlabrada.

1) Observamos que se está realizando la cesión de datos sin tener seguridad de que se cumplen todas las garantías que exige la ley, por ejemplo no se está pidiendo autorización a los interesados. ¿Qué haríamos?

2) Observas que uno de los pacientes afectados es un familiar tuyo. Si dices algo a tus superiores sobre los incumplimientos es posible que se paralice el proceso y se demore la operación de tu tío. ¿Cómo actuarías?

\section{Resultados}

\subsection{Implicación del alumnado en la actividad:}

Cuando se introduce la actividad, se distingen dos tipos de reacciones entre el alumnado, los "favorables" a este tipo de actividades más dinámicas y animadas, y los "reacios" que, al salirse de las actividades típicas o tradiconales, pueden encontrar dificultades o que por tener que teatralizar les supone un esfuerzo mayor que una actividad convencional.

La experiencia como docente en la aplicación de juegos de rol es que, al finalizar la actividad,se unifican las reacciones y los alumnos, en general, muestran entusiasmo. La realidad es que se ponen en la piel de otros empatizando con los personajes, elucubran argumentos con inmediatez y se divierten, a la vez que asimilan conceptos. Por tanto, resumiendo, es de destacar el alto grado de participación del alumnado en la actividad realizada y su implicación dentro del rol que debe asumir en la actividad.

\subsection{Implicaciones para el profesorado:}

Se tratade una actividad que requiere de gran implicación del profesor, ya que debe ser totalmente guiada por varias razones: Es una actividad que se sale de los estándares habituales, hay que conseguir una contextualización lo más fidedigna posible de la situación - dentro de las limitaciones existentes-, y puesto que es muy participativa, se debe asegurar que se mantenga el orden y unas cuotas no excesivas de sonoridad en la sala.

\subsection{Evaluación}

El resultado de la actividad en lo que se refiere a participación se maximiza al trabajar en grupos pequeños.Con ello se consigue, además, que los alumnos actúen de forma totalmente espontánea.

En cuanto a notas, las puntuaciones de los alumnos valoradas por el profesor son bastante buenas. La práctica se dio en 2 grupos, uno de 14 alumnos y otro de 10. Las notas oscilaron entre 0,2 y 0,25 sobre 0,25 (entre 8 y 10 en base 10), lo cual es un resultado bastante satisfactorio.

Como evidencias, se dispone de los documentos cumplimentados con los alumnos y corregidos por el profesor. 


\subsubsection{Mejoras para futuras evaluaciones}

A posteriori de la realización de la actividad, se consideró interesante introducir el concepto de co-evaluación desde una perspectiva cualitativa para ser utilizada en próximos cursos. Para ello se diseñó un sencillo cuestionario que deberá ser respondido por los alumos. Se trata de que dentro del equipo de cuatro alumnos, evalúen por pares, el rol de los otros, lo cual sumará información y podrá ser incorporada a la nota final, adicionándola a la obtenida por el profesor, aplicando el peso que se considere.

\begin{tabular}{|c|c|c|c|}
\hline \multicolumn{4}{|c|}{$\begin{array}{c}\text { EVALUA.A.TUS.COMPANEEROS.SIENDO. } \\
\text { IMPARCIAL.Y.JUSTOA }\end{array}$} \\
\hline$a$ & $\theta r$ & $\Theta r$ & \\
\hline \multicolumn{4}{|l|}{ Contestan-TODOSa } \\
\hline $\begin{array}{l}\text { ¿Las·preguntas/respuestas· } \\
\text { estaban·preparadas?a. }\end{array}$ & $a$ & $a$ & $a$ \\
\hline \multicolumn{4}{|l|}{ a } \\
\hline \multicolumn{4}{|l|}{ Contestan-LOS·INFORMÁTICOSá } \\
\hline $\begin{array}{l}\text { ¿Nos·han'explicado·el·motivo· } \\
\text { de·la·entrevistaপ̆ }\end{array}$ & $a$ & $a$ & $a$ \\
\hline 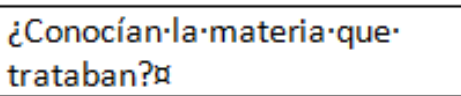 & $a$ & $a$ & $a$ \\
\hline \multicolumn{4}{|l|}{ व } \\
\hline \multicolumn{4}{|c|}{ Contestan-LOS·INVESTIGADORES, } \\
\hline $\begin{array}{l}\text { ¿Tenían·los·informáticos·un* } \\
\text { argumento·sólido?ă }\end{array}$ & $a$ & $a$ & $a$ \\
\hline ¿Han-sabido·defenderse?a & $a$ & $a$ & $a$ \\
\hline
\end{tabular}

Figura 1 Co-evaluación entre alumnos

El anterior cuestionario se enfoca hacia la co-evaluación de la participación del alumnado en la actividad. Otra cuestión es la valoración de la actividad en si misma por parte del alumnado. Se ha diseñado una pequeña encuesta para evidenciar la percepción de los alumnos. De esta manera, les solicitamos que sean parte activa de la mejora. Asimismo, las aportaciones facultarán al profesor para realizar adaptaciones de la actividad con el fin de adecuarla lo máximo posibles a las necesidades y expectativas de los alumos, sin sacrificar los contenidos del aprendizaje. 


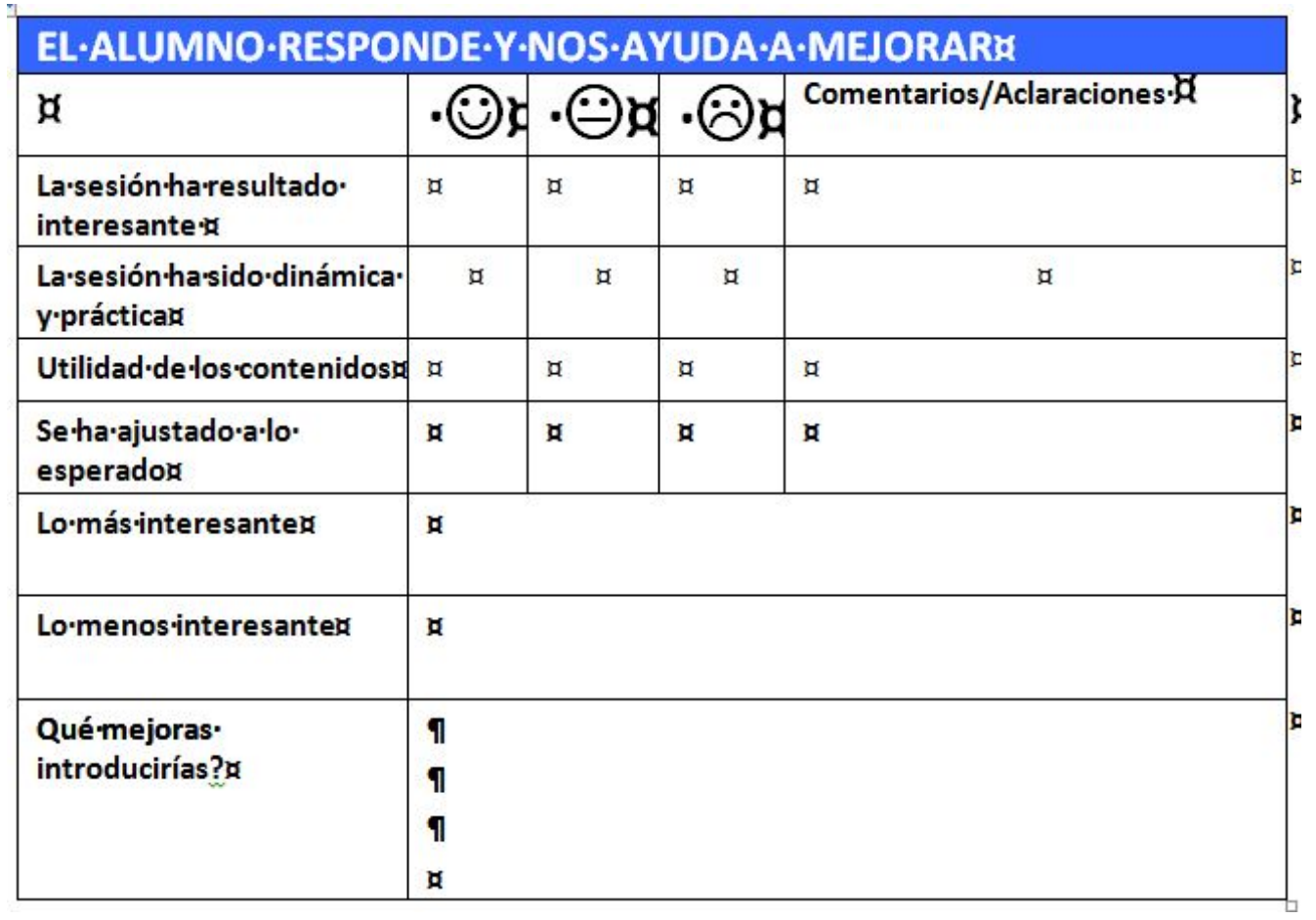

Figura 2 Encuesta de satisfacción planteada

\subsection{Ventajas y dificultades en la aplicación de esta técnica}

El diseño de la actividad vino precedido del análisis de diferentes metodologías como i) la lectura de un texto y posterior reflexión, debate y extracción de conclusiones en el documento de la memoria, o ii) proponer el artículo de prensa que se presenta en la práctica y debatir sobre él. Sin bien, finalmente se consideró más adecado el diseño final planteado en este artículo, presentando las siguientes ventajas:

- La aplicación de la simulación y los juegos de rol permite dinamizar y convertir en algo ameno la aplicación de un tema cuyo enfoque teórico pueda ser tedioso.

- Es extremadamente versátil y permite tratar temas diversos en cuanto a contenido y complejidad.

- Contribuye a crear un alto grado de participación del alumnado en la actividad realizada.

- Se fomenta el trabajo en equipo.

- Con la ayuda del profesor se puede lograr fácilmetne la implicación del alumno en el rol que debe asumir.

- Se desarrolla la creatividad del alumnado al permitir libertad en el enfoque que debe dar cada alumno o grupo de alumnos a su intervención,

- Se fomenta la capacidad de empatizar con otros, al ponerse en su piel (responsables de informática del hospital) y entender la verdadera situación en que se encuentran y en la que ellos podrían encontrarse en un futuro como profesionales. 
Cabe no olvidar, no obstante, que el empleo de esta técnica también persenta ciertas dificultades que deben ser considerados por el profesor

- Requiere cierto conocimiento de los alumnos, para poder reforzar, aquellas intervenciones menos fluidas.

- Hay que crear y aproximarse a la situación que se simula, y dadas las limitaciones del aula facilitar al máximo la atmósfera y el cambio de rol. Por ejemplo, disponiendo las sillas y mesas de modo adecuado a la entrevista, haciendo a los alumnos investigadores salir del aula y entrar como investigadores, etc.

- Es necesaria la total implicación del docente, revisando la actuación de los grupos, y evitando que se excedan en la compostura para no afectar a aulas cercanas o perder la perspectiva del tema tratado.

- Asimismo, hay que contar que en algunos casos, cuando se plantea este tipo de práctica, hay alumnos que lo ven como algo superfluo y otros como un obstáculo. Hay que lidiar con ambos y defenderla con entusiasmo y convencimiento.

\section{Conclusiones}

En la asignatura cuatrimestral de segundo curso del Grado de Ingeniero Informático de la ETSIINF, Deontología y Profesionalismo, se aplicaron las técnicas de simulación y juegos de rol a través de estas la actividad "FUGA DE DATOS EN EL HOSPITAL DE FUENLABRADA" para la realización de una de las prácticas de la asignatura.

Estas técnicas permiten de forma directa el desarrollo de la competencia CT04. La competencia innovación, creatividad y emprendimiento.

Aprovechando el uso de esta versátil actividad, se introducen conceptos relacionados con el cumplimiento de la legalidad y la actuación ética, propios de la asignatura.

La actividad permite, por tanto, trabajar en la competencia con elementos ligados a su futura profesión como ingenieros en informática que no son abordados en otras asignaturas. Cabe destacar que dicha actividad se lleva a cabo de una forma amena, interiorizada y compartida, lo cual consideramos que resulta de gran ayuda para el desarrollo de otra competencia.

Para los alumnos, una vez realizada la actividad, la sensación fue muy positiva y surgieron deseos de volver a repetir este tipo de actividades.

\section{Referencias}

García Magna, D., Castillo Rodríguez, C., Rios Moyano, S., Cristofol Rodríguez, C., Carrasco Santos, M., Rodríguez Mérida, R. M., ... \& Pastor García, I. (2011). La interdisciplinariedad en la educación superior: propuesta de una guía para el diseño de juegos de rol. Teoría de la Educación,12(1)27.

Jiménez Martín, S. y Moncholi Chaparro, M.A. (2009). El entrenamiento en técnicas creativas en el Espacio Europeo de Educación Superior. Actas del I Congreso Internacional Latina de Comunicación Social (pp. 1-12) Universidad de La Laguna. http://www.revistalatinacs.org/09/Sociedad/actas/12silvia.pdf 
Simulación y Juegos de rol como herramienta de innovación en la asignatura Deontología y

Profesionalismo

Perea Acevedo, A. J. (2008). Los juegos de rol como estrategia para la formación ética de niños y jóvenes: razones y oportunidades desde la noción foucaultiana de libertad. Infancias Imágenes, 7(1), 38-42.

Ruben, B.D. (1999). Simulations, Games, and Experience Based Learning: The Quest for a New Paradigm for Teaching and Learning. Simulation and Gaming. 30 (4), 498-505.

(c) EY-NC-ND 2017, Universitat Politècnica de València

Congreso IN-RED (2017) 


\title{
Innovación docente en la asignatura Gestión Integral para reforzar la competencia transversal Instrumental Específica
}

Andrés Boza, Raúl Oltra, Llanos Cuenca

${ }^{a}$ Universitat Politècnica de València. Dpto. Organización de Empresas. aboza@omp.upv.es; roltra@doe.upv.es; 1lcuenca@omp.upv.es

\begin{abstract}
The teaching innovation presented in this paper has as main objective that students are able to make use of the most appropriate software solutions for a given business context, knowing their uses and possibilities of integration to improve an organization. All this in the context of the transversal competence "Specific Instruments". The innovation is based on the design of a set of activities to achieve this goal: i) Laboratory practices. To have contact with real ERP systems; ii) Fieldwork. To approach a business reality and apply the knowledge acquired to prescribe improvement proposals.
\end{abstract}

The indicators that include the scoring rubric used for its evaluation are: II: Identifies advanced tools and their usefulness; I2: Handles advanced tools; 13: Selects and combines the right tools to prescribe an improvement in a real business context.

For each indicator, the evidence to be gathered from laboratory practices and field practices has been established.

The proposed activities have allowed the students to manage tools both in the laboratory and in real contexts. Also note that the use of the rubric has facilitated the design and structuring of activities for teachers.

Keywords: Design of activities, Scoring Rubric, Cross-curricular competence, Specific Instrumental

\footnotetext{
Resumen

La innovación docente presentada tiene como objetivo principal que el alumno sea capaz de hacer uso de las soluciones software más adecuadas para un determinado contexto empresarial, conociendo sus utilidades y las posibilidades de integración para la mejora de una organización. Todo ello en el contexto de la competencia transversal "Instrumental Especifica". La innovación se basa en el diseño de un conjunto de actividades para alcanzar dicho objetivo: i)Prácticas de laboratorio. Para tener contacto con sistemas ERP reales; ii) Trabajo de campo. Para acercarse a una realidad empresarial y aplicar los conocimientos adquiridos para prescribir propuestas de mejora.
}

Los indicadores que incluye la rúbrica utilizada para su evaluación son: I1: Identifica las herramientas avanzadas y su utilidad; I2: Maneja las 
Innovación docente en la asignatura Gestión Integral para reforzar la competencia transversal Instrumental Especifica

herramientas avanzadas; I3: Selecciona y combina las herramientas adecuadas para prescribir una mejora en un contexto empresarial real.

Para cada indicador se han establecido las evidencias a recoger de las prácticas de laboratorio y prácticas de campo realizadas.

Las actividades planteadas han permitido el manejo de las herramientas por parte de los alumnos tanto en el laboratorio como en contextos reales. También destacar que el uso de la rúbrica ha facilitado el diseño y estructuración de las actividades al profesorado.

Palabras clave: Diseño de actividades, Rúbrica, Competencia Transversal, Instrumental Especifica

\section{Introducción}

Una competencia representa lo que los participantes en la formación deben ser capaces de hacer al final de dicha formación (Boza y Cuenca, 2014). Las competencias específicas pertenecen a un área específica del conocimiento (en un grado o máster) y tienen como objetivo lograr un perfil específico. Las competencias transversales (también denominadas competencias genéricas) son genéricas y transferibles en una amplia variedad de aspectos personales, sociales, académicos y profesionales. Por lo tanto, contribuyen a una parte fundamental del perfil educativo (Cuenca et al., 2016).

La competencia transversal "Instrumental Específica" hace referencia al uso de las herramientas y tecnologías necesarias para el ejercicio profesional asociado a cada titulación. El estudiante será capaz de identificar las herramientas más adecuadas en cada caso, conociendo sus utilidades y siendo capaz de integrarlas y combinarlas para poder resolver un problema, realizar un proyecto o un experimento. Para el desarrollo de esta competencia podemos realizar algunas de las siguientes actividades formativas (UPV,2017): Prácticas de laboratorio, Problemas, Proyectos y Portafolio.

La inclusión de elementos que permitan reforzar esta competencia de una manera explicita mediante el diseño de nuevas actividades o el rediseño de las existentes es una labor compleja, así como, su posterior proceso de evaluación.

Para facilitar y unificar criterios para la evaluación de las competencias, la UPV ha creado tres rubricas con diferente nivel de dominio, primer nivel para $1^{\circ}$ y $2^{\circ}$ de grado, segundo nivel para $3^{\circ}$ y $4^{\circ}$ de grado y tercer nivel para master (ICE, 2015).

\subsection{Contexto académico}

La asignatura Gestión Integral se imparte en el Master de Ingeniería Informática de la Escuela Técnica Superior de Ingeniería Informática. Se trata de una asignatura incluida en el Módulo de Asignaturas Optativas de $2^{\circ}$ curso de master y el número de alumnos participantes en las actividades fueron 22 (9 curso 2016-2017 y 13 curso 2015-2016).

(cc) EY-NC-ND 2017, Universitat Politècnica de València

Congreso IN-RED (2017) 
La asignatura pone el foco en la gestión integrada de la información en las organizaciones que esta permitiendo una mejora significativa en sus procesos de negocio. En concreto se analizan y trabajan de forma principal los sistemas ERP (Enterprise Resource Planning) que participan en estos cambios y los profesionales informáticos en estos ámbitos se sitúan como actores principales en estos procesos de cambio empresarial.

Los sistemas ERP son sistemas de información diseñados para integrar y optimizar los principales procesos de negocio de la empresa, siendo aceptados por la industria como una solución práctica para lograr sistemas integrados de información (Oltra, 2012). Integran todas las áreas funcionales de la empresa, procesos y datos, en una única base de datos, incluyendo la definición de vistas y roles de usuarios. Los sistemas ERP han evolucionado para convertirse en sistemas más amplios y más inclusivos. Su desarrollo continuo ha dado lugar a varios tipos de sistemas ERP con un enfoque en la industria o sector específico (Boza et al., 2015).

En el contexto de la asignatura se han llevado a cabo diversas innovaciones (Boza y Cuenca, 2014).

Entre los contenidos de la materia se encuentran:

Los sistemas de gestión empresarial, su evolución hacia sistemas ERP, los procesos de negocio soportados por los sistemas ERP (compras, ventas, producción, recursos humanos...), el proceso de selección de un ERP, el proyecto de implantación, la gestión del cambio, el mercado de soluciones ERP, nuevas tendencias en el campo de los sistemas de gestión integral y casos prácticos.

\section{Objetivo}

El objetivo último es que los alumnos de la asignatura Gestión Integral trabajen la competencia transversal Instrumental Específica y sean evaluados de acuerdo a dicho trabajo.

Para ello, se ha diseñado un conjunto de actividades que incluyen prácticas de laboratorio y trabajo de campo con el propósito de que el alumno, en el contexto de la competencia, sea capaz de hacer uso de las soluciones software más adecuadas para un determinado contexto empresarial, conocer sus utilidades y posibilidades de integración para la mejora de una organización.

\section{Desarrollo de la innovación}

Como se indicó anteriormente, las actividades a desarrollar incluyen prácticas de laboratorio y trabajo de campo.

El objetivo de las prácticas de laboratorio consiste en que los alumnos tengan contacto con sistemas ERP reales, y que sean capaces de identificar las diferentes funciones que se pueden llevar a cabo en los diferentes módulos, las posibilidades de adaptación a las diferentes necesidades de las empresas mediante parametrización, el alcance de cada uno de ellos y las posibilidades de integración con otras herramientas. En concreto trabajan con el ERP Openbravo, y con el ERP SAP .

(cc)) EY-NC-ND 2017, Universitat Politècnica de València 
En ambos sistemas, las prácticas se centran en que los alumnos realicen procesos sobre la aplicación ERP en concreto (Openbravo o SAP según el caso) al igual que los realizarían en una empresa real. De este modo, incluyen artículos, que luego deben fabricar, vender o comprar, según la práctica se centre en uno u otro módulo del sistema ERP. Además, ven las diferentes de posibilidades que ofrece un ERP a través de su modularidad, parametrización y configuración (Gil et al, 2010), para que pueda adaptarse a las necesidades particulares de cada organización.

Por otro lado, el objetivo del trabajo de campo es doble, en primer lugar, consiste en acercarse a una realidad empresarial visitando una mediana empresa, identificando sus principales procesos y realizando un análisis de la situación de su sistema de información. Además, el trabjo de campo tiene tambien como objetivo aplicar los conocimientos adquiridos para prescribir propuestas de mejora.

\subsection{Prácticas de laboratorio}

En prácticas los alumnos trabajan en el laboratorio con dos herramientas ERP que facilitan la gestión de la información en las organizaciones pero que tienen un carácter diferenciado respecto a elementos como el número de funcionalidades que proporciona cada una de ellas, la cobertura internacional, el precio de la solución ERP o la facilidad de uso. A su vez, cada herramienta incluye un conjunto de módulos que pueden o no ser implementados en las empresas dependiendo de las características y necesidades de la misma.

La primera de las soluciones puestas a disposición de los alumnos es el ERP Openbravo. Se trata de una solución instalada en un servidor del Departamento de Organización de Empresas a disposición de los alumnos durante las sesiones de prácticas y con el que pueden seguir trabajando de forma remota fuera de horas de laboratorio. Además, esta herramienta puede ser instalada en los equipos de los propios alumnos al tratarse de una solución de software libre disponible en http://wiki.openbravo.com/wiki/Main_Page. Los módulos principales son los de Configuración General, Gestión de Datos Maestros, Gestión de Compras, Gestión de Almacén, Gestión de Producción, Gestión del MRP, Gestión de Ventas, Gestión de Proyectos y Servicios y Gestión Financiera.

La segunda solución software ERP con la que trabajan los alumnos en el laboratorio es SAP $\mathrm{R} / 3$. Se trata de una herramienta instalada en servidores de SAP en Alemania y que están a disposición de la comunidad universitaria gracias a la participación de la UPV en SAP University Alliance. Esta alianza permite la utilización de herramientas de SAP así como facilita abundante información sobre soluciones y herramientas avanzadas (SAP UA 2017). Al igual que en el anterior caso, los alumnos tienen acceso al software en el laboratorio, así como de forma remota. Los módulos principales que se encuentran en SAP R/3 son Fianzas, Costos y Control, Ventas y Distribución, Gestión de Materiales, Producción y Recursos Humanos (Akhtar 2013).

En cada una de las prácticas de laboratorio el alumno trabaja con diferentes módulos de SAP y Openbravo siguiendo unas instrucciones de forma autónoma. Concretamente, se realizan procesos de empresa en las áreas de compras, ventas, producción y almacén de una compañía de fabricación de bicicletas configurada en el sistema a tal efecto, realizando

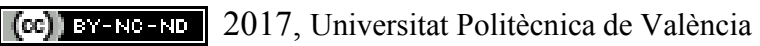

Congreso IN-RED (2017) 
ciclos completos tal y como lo harían en una empresa real, desde que se crea un artículo nuevo, con sus componentes, pasando por su producción y almacenamiento, hasta la venta, facturación y cobro del mismo. Finalmente, después de realizar la práctica, los alumnos entregan, mediante una memoria, el resultado de los procesos que han realizado en la aplicación. De este modo, tanto al revisar la memoria, como mediante la observación durante la realización de las prácticas, el profesor puede evaluar la actividad realizada.

\subsection{Trabajo de campo}

El trabajo de campo consiste en visitar una pequeña o mediana empresa para analizar su sistema integrado de información para la gestión empresarial y proponer, de forma justificada, soluciones informáticas que permitan mejorar dicho sistema.

Cada grupo decide la empresa que quiere analizar, avisándolo previamente para no coincidir en la misma empresa diferentes grupos. Los grupos realizarán las gestiones necesarias para visitar la empresa, tomar imágenes de la misma y entrevistarse con las personas que consideran oportuno.

De esta manera, los alumnos ven el entorno real de una empresa y sus necesidades en cuanto a los sistemas de información y herramientas informáticas, y pueden hacer una comparativa con lo visto tanto en las clases de teoría, como en las prácticas de laboratorio, para ver cuáles son las necesidades y requerimientos reales que pueden ser cubiertos con las herramientas vistas en clase, y cuáles deberían desarrollarse a medida, dado que se trata de necesidades muy particulares que no están cubiertas en un sistema estándar, pero que son necesarias para el funcionamiento de la organización

Para estructurar el trabajo a desarrollar, a los alumnos se les proporciona una plantilla con los principales puntos que deberían abordar, este documento base incluye tres apartados principales:

i) Información relativa a la empresa (nombre, sector, misión, ubicación, empleados, facturación, ...)

ii) Descripción del Sistema de Información actual ( sistemas operacionales, sistemas para la toma de decisiones, sistemas de relación con el entorno, ...)

iii) Análisis de situación y propuestas de mejora (modificaciones/ampliaciones de las soluciones implantadas, cambios en la forma de utilización, propuesta de soluciones más adecuadas, ...)

\section{Evaluación}

Para la evaluación se ha utilizado la rúbrica diseñada en el marco del proyecto de competencias trasversales puesto en marcha por la UPV. En concreto se ha empleado la rúbrica CT13 de nivel de dominio III al tratarse de una asignatura de Master. En este nivel de dominio se busca: "Integrar correctamente las herramientas avanzadas del ámbito profesional". Para evaluar el grado alcance de la competencia, la rúbrica define tres indicadores: 1) Identificar las herramientas avanzadas y su utilidad, 2) Manejar las 
Innovación docente en la asignatura Gestión Integral para reforzar la competencia transversal Instrumental Especifica

herramientas avanzadas y 3) Seleccionar y combinar las herramientas adecuadas para realizar un proyecto profesional o de investigación.

Resultado de aprendizaje: integrar correctamente las herramientas avanzadas del ámbito profesional.

\begin{tabular}{|c|c|c|c|c|}
\hline \multirow{2}{*}{ INDICADORES } & \multicolumn{4}{|c|}{ DESCRIPTORES } \\
\hline & D. No alcanzado & C. En desarrollo & B. Bien / adecuado & A. Excelente/ejemplar \\
\hline $\begin{array}{l}\text { Identifica las } \\
\text { herramientas } \\
\text { avanzadas y su } \\
\text { utilidad }\end{array}$ & $\begin{array}{l}\text { No identifica las } \\
\text { herramientas avanzadas }\end{array}$ & $\begin{array}{c}\text { Identifica las } \\
\text { herramientas avanzados } \\
\text { pero no reconoce su } \\
\text { utilidad }\end{array}$ & $\begin{array}{l}\text { Identifica las } \\
\text { herramientas avanzados } \\
\text { y su función principal }\end{array}$ & $\begin{array}{l}\text { Identifica funciones } \\
\text { adicionales de las } \\
\text { herramientas avanzados }\end{array}$ \\
\hline $\begin{array}{l}\text { Maneja las } \\
\text { herramientas } \\
\text { avanzadas }\end{array}$ & $\begin{array}{l}\text { No es capaz de manejar } \\
\text { las herramientas sin unas } \\
\text { instrucciones detalladas }\end{array}$ & $\begin{array}{l}\text { Maneja las herramientas } \\
\text { siguiendo unas } \\
\text { indicaciones detalladas }\end{array}$ & $\begin{array}{l}\text { Maneja las herramientas } \\
\text { de forma autónoma }\end{array}$ & $\begin{array}{l}\text { Maneja las herramientas } \\
\text { con soltura, explotando } \\
\text { todas sus funcionalidades }\end{array}$ \\
\hline $\begin{array}{l}\text { Selecciona y combina } \\
\text { las herramientas } \\
\text { adecuadas para } \\
\text { realizar un proyecto } \\
\text { profesional o de } \\
\text { investigación }\end{array}$ & $\begin{array}{l}\text { No identifica las } \\
\text { herramientas adecuadas } \\
\text { para el desarmollo del } \\
\text { proyecto }\end{array}$ & $\begin{array}{c}\text { Identifica las } \\
\text { herramientas a emplear } \\
\text { pero no las combina de } \\
\text { forma adecuada para el } \\
\text { desarrollo completo del } \\
\text { proyecto }\end{array}$ & $\begin{array}{l}\text { Combina } \\
\text { adecuadamente las } \\
\text { diferentes herramientas } \\
\text { para completar el } \\
\text { desarrollo del proyecto }\end{array}$ & $\begin{array}{l}\text { Vislumbra nuevas formas } \\
\text { de combinar } \\
\text { nerramientas para } \\
\text { completar el proyecto de } \\
\text { la forma más adecuada } \\
\text { posible, valorando sus } \\
\text { pros y contras }\end{array}$ \\
\hline
\end{tabular}

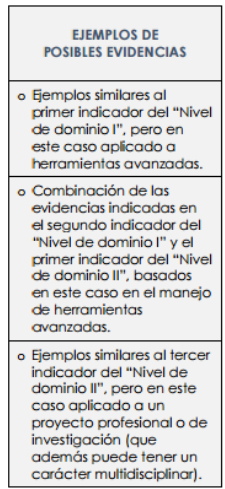

Fig. 1 Rubrica CT Instrumental Específica

Como se puede observar en el cuadro de la derecha de la figura 1, la rúbrica propone también ejemplos de posibles evidencias para evaluar el nivel alcanzado en cada indicador.

Para la evaluación de los tres indicadores que incluye la rúbrica en el contexto de la asignatura se ha realizado con la recogida de las siguientes evidencias:

INDICADOR 1: Identifica las herramientas avanzadas y su utilidad

- Evidencia:

Cuestionario para identificar que el alumno realiza correctamente las prácticas, utiliza las herramientas adecuadas e identifica claramente sus funciones principales.

INDICADOR 2: Maneja las herramientas avanzadas

- Evidencia:

Memoria de ejecución de las prácticas para evidenciar que realiza la tarea siguiendo la secuencia de pasos correctamente y de forma autónoma.

INDICADOR 3: Selecciona y combina las herramientas adecuadas para prescribir una mejora en un contexto empresarial real

- Evidencias :

Informe y presentación del contexto empresarial y análisis del sistema de información.

Informe y presentación de propuestas de mejora del sistema de información de la empresa proponiendo una combinación de nuevas soluciones tecnológicas o modificaciones en el sistema actual.

(cc) EY-NC-ND 2017, Universitat Politècnica de València 


\section{Resultados y Conclusiones}

El avance en el desarrollo de las prácticas de laboratorio repercute claramente en un mejor manejo de las herramientas por parte de los alumnos, el trabajo de campo les aporta la verdadera posición que tienen las herramientas trabajadas en un contexto real, lo que les obliga a cuestionarse aspectos que no han sido previamente tratados en el aula y realizar propuestas en dicha realidad. Por último indicar que el uso de la rúbrica ha facilitado al profesorado el diseño de estas actividades.

\section{Referencias}

AKHTAR, J. (2013) Production planning and control with SAP ERP Boston: Galileo Pressa.

BOZA A.,CUENCA L. (2014) Strategy of online assessment in case study methodology. A particular case in the subject enterprise computers tools. ICERI2014 Proceedings, pp. 3207-3211.

BOZA A., CUENCA L., POLER R. \& MICHAELIDES Z.(2015): The interoperability force in the ERP field. Enterprise Information Systems Vol. 9 , Iss. 3,2015

CUENCA L., BOZA B., GORDO M.L., FERNANDEZ-DIEGO M., RUIZ L., ALARCON A., ALEMANY M.M.E. (2016) Extension of the 6-3-5 technique for incorporating creativity, innovation and entrepreneurship competence in higher education. ICERI2016 Proceedings, pp. 79-83.

GIL GÓMEZ, H, OLTRA BADENES, R., (2010) Evolution and trends of information systems for business management: the M-Business. A Review. DYNA vol.77 no.163

ICE - Instituto de Ciencias de la Educación. Universitat Politècncia de València. (2015) Proyecto Competencias Transversales UPV. <http://www.upv.es/entidades/ICE/info/U0724624.pdf > [Consulta: 27 de marzo de 2017].

OLTRA BADENES, R. (2012). Sistemas Integrados de Gestión Empresarial: Evolución histórica y tendencias de futuro. Editorial Universitat Politècnica de València.

SAP University Alliances UPV (2017). http://suaupv.blogs.upv.es/. [Consulta: 27 de marzo de 2017].

UPV - UNIVERSITAT POLITĖCNICA DE VALÈNCIA - (2017). Competencias Transversales. http://www.upv.es/contenidos/COMPTRAN/info/955174normalc.html [Consulta: 10 de marzo de 2017]. 


\title{
Aprendizaje activo del alumnado en la asignatura "Energía solar fototérmica" \\ Jorge Payá ${ }^{a}$ \\ ${ }^{a}$ Instituto de Ingeniería Energética, Universitat Politècnica de València
}

Camino de Vera s/n Edificio 8E semisótano frente acceso J, Valencia, España

E-mail: jorge.paya@iiie.upv.es (Jorge Payá)

\begin{abstract}
The present work describes the methodology which has been applied in the subject "Energía solar fototérmica" of the Universitat Politècnica de Valencia. With the aim of promoting an active student participation, different methods have been continously applied such as continously mixing theory and problems, self-assessment tests, projects or business games. In comparison with previous years, the attendence was very high (92\% mean value). The evaluation system which was chosen (60\% practical work) seems a good strategy to assimilate concepts and develop competences according to $94 \%$ of the students. $88 \%$ of them agrees that their personal involvement and active participation is essential to reach this goal. In the subject, the students have to defend an oral presentation in groups of two. $75 \%$ of the students support that this work was favourable to develop oral communication skills.
\end{abstract}

Keywords: project-based learning, transversal competences, evaluation, active learning

\section{Resumen}

En el presente trabajo se describe la metodología adoptada en la asignatura de "Energía solar fototérmica" de la Universitat Politècnica de València. Con el objetivo de favorecer el aprendizaje activo de los alumnos, se plantea una metodología basada en intercalar frecuentemente teoría con problemas, tests de autoevaluación, prácticas, proyectos o juegos de empresa. Frente a experiencias anteriores en la misma asignatura, se consiguió una asistencia altísima ( $92 \%$ de media). El sistema de evaluación escogido (60\% mediante trabajos prácticos) parece favorable a un $94 \%$ de los alumnos de cara a asimilar mejor los conceptos. Un $88 \%$ de ellos considera que la participación activa en clase favorece la asimilación de conceptos y el desarrollo de competencias. En la asignatura, los alumnos realizan una presentación en grupos de dos. Un 75\% de los alumnos está de acuerdo en que ésto mejoró su capacidad para comunicar resultados en público.

Palabras clave: evaluación por proyectos, competencias transversales, aprendizaje activo 


\section{Introducción}

En los últimos años, dentro del ámbito universitario, y de manera más acusada desde el proceso de Bolonia, el modelo educativo ha sufrido una transición progresiva hacia un modelo centrado en el aprendizaje del alumno y hacia un enfoque basado en competencias. Estudios recientes (Perrenoud, 2008) muestran reflexiones interesantes acerca de la relación entre competencias y saberes o acerca de las competencias a privilegiar.

El nuevo modelo educativo se centra en enseñar el alumno a aprender, dejando atrás el sistema anterior donde el alumno actuaba en clase de forma más pasiva en clases magistrales. La integración de competencias y su valoración ha abierto un amplio debate acerca de la evaluación (Fernandez, 2010, Villa, 2011).

En el presente trabajo se exponen los resultados de la incorporación de distintas técnicas de enseñanza-aprendizaje adoptadas en el curso 2016-2017. El trabajo consiste en la aplicación de técnicas para favorecer la participación activa del alumnado. A continuación se exponen los objetivos, la metodología y los resultados más relevantes.

\section{Objetivos}

El trabajo realizado se enmarca dentro de la asignatura de "Energía solar fototérmica" impartida en la Escuela Técnica Superior de Ingeniería del Diseño (Universitat Politècncia de València). Se trata de una asignatura optativa de tercer curso dentro del Grado de Ingeniería Mecánica.

\section{Desarrollo de la innovación}

\subsection{Metodología}

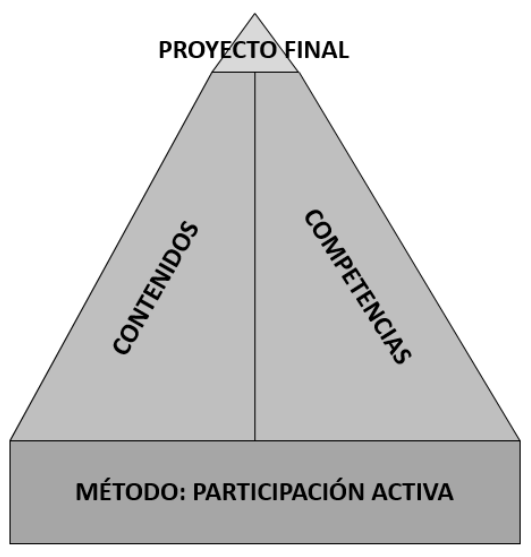

Fig. 1 Metodología planteada 
La metodología planteada (Fig. 1) consiste en favorecer la participación activa de los alumnos en la mayor medida posible, dadas las restricciones existentes en cuanto a recursos, tiempo y contenidos. Al igual que en muchas otras asignaturas, en "Energía solar fototérmica" hay unos contenidos básicos que hay que tratar, y que requieren de clases magistrales.

Sin embargo, en las clases magistrales el profesor realiza frecuentemente preguntas a los alumnos para mantener así su atención y favorecer su pensamiento crítico. En conjunto, se han adoptado las siguientes técnicas en las clases:

- Preguntas a los alumnos

- Ejercicios

- Prácticas

- Proyecto final

- Discusiones en grupo

- Juego de empresa

- Tests de auto-evaluación

Las herramientas utilizadas dentro de la interfaz alumnos-profesores (aplicación de "PoliformaT" disponible en la UPV), fueron básicamente los recursos, el espacio compartido y los exámenes.

\section{Resultados}

Los resultados del presente proyecto se desglosan a continuación en tres ejes que son la evaluación, los resultados en sí del método y el desarrollo de competencias transversales. El trabajo se basa en un sondeo que se realizó al final del curso y al que contestaron 16 de los 17 alumnos matriculados, es decir que los resultados son altamente significativos.

\subsection{Sistema de evaluación}

Un aspecto importante es el impacto que tiene el sistema de evaluación sobre la asimilación de conceptos. Tal y como muestra la Fig. 2, un 94\% de los alumnos está de acuerdo en que es favorable de cara a la asimilación de conceptos el ponderar un $60 \%$ su nota final mediante trabajos prácticos (esto incluye el trabajo final de la asignatura, la asistencia a las clases así como la defensa de presentaciones en clase).

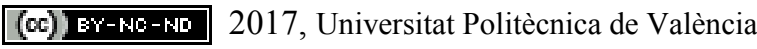

Congreso In-Red (2017) 
La evaluación de la asignatura (60\% por trabajos prácticos) favorece más la asimilación de conceptos que únicamente con

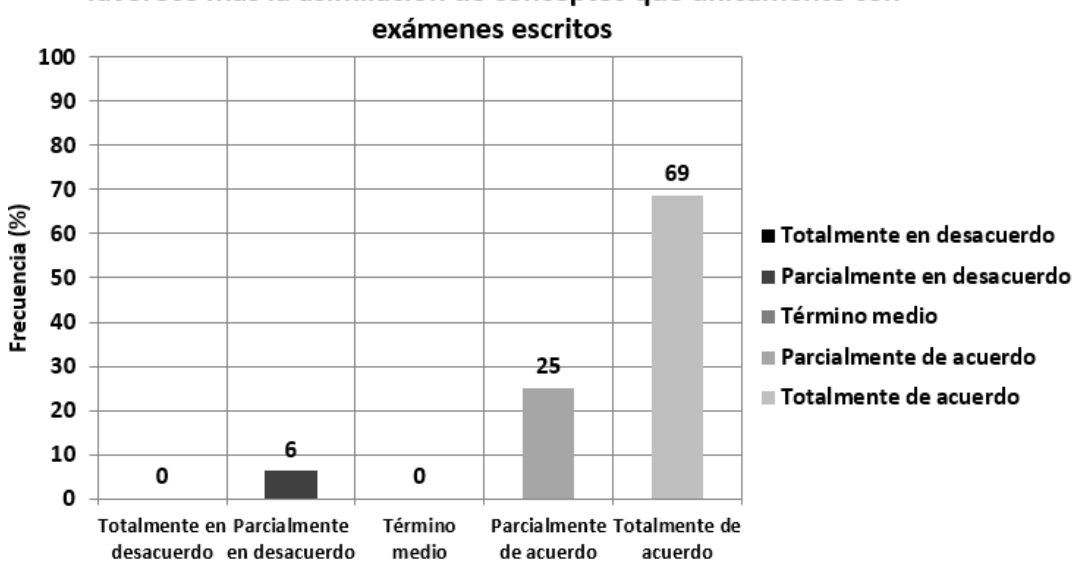

Fig. 2 Impacto de la evaluación sobre el aprendizaje

La Fig. 3 muestra la percepción que tienen los alumnos sobre el carácter contínuo de su trabajo. Aunque el profesor tiene la sensación de que una evaluación contínua les obliga a trabajar de forma regular, sólo un $51 \%$ de los alumnos está de acuerdo con esta afirmación. Los alumnos siguen teniendo la percepción de que trabajan fundamentalmente la semana anterior a cada acto de evaluación, al igual que en otras asignaturas de complejidad similar.

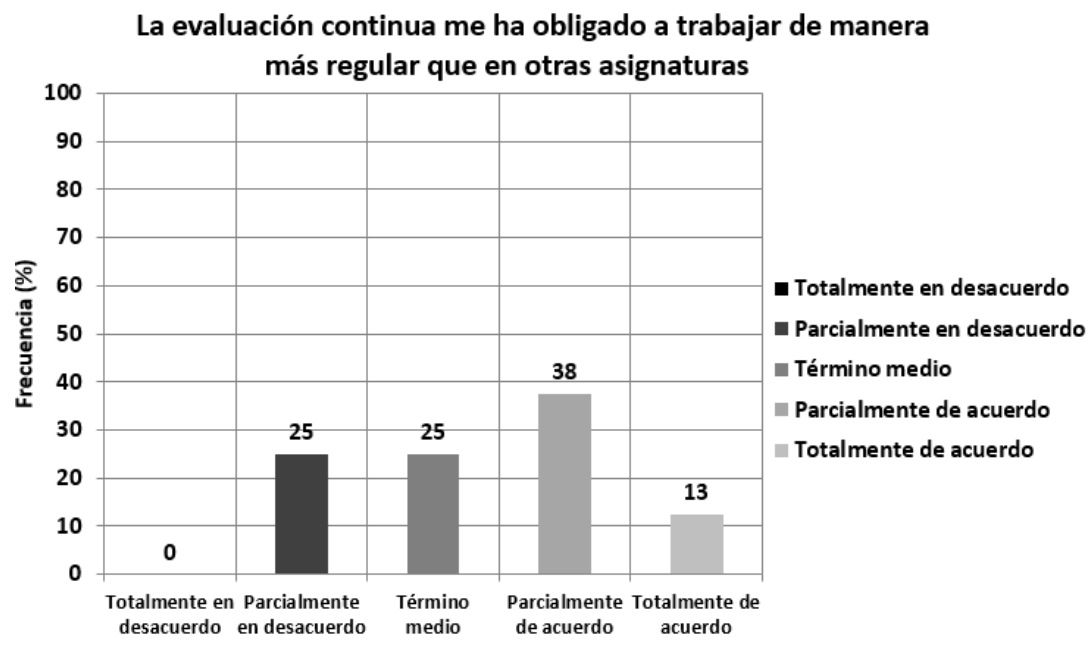

Fig.3 Valoración de la continuidad del trabajo de los alumnos 


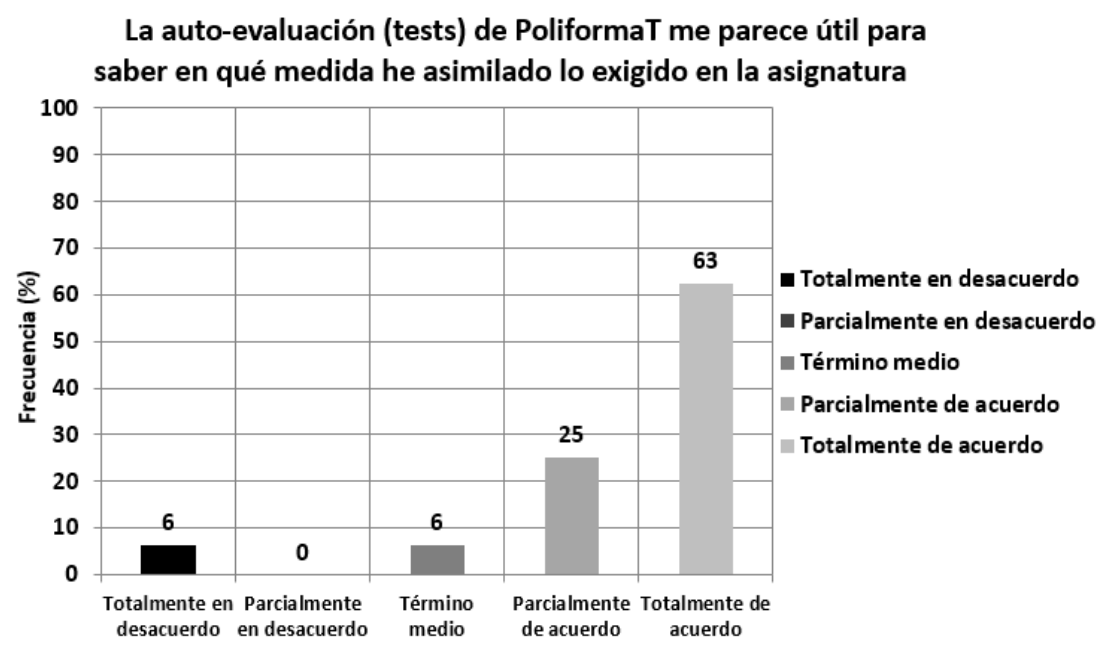

Fig. 4 Utilización de tests de auto-evaluación para valorar la asimilación de conceptos

Para que los alumnos valoren su grado de asimilación de los conceptos desarrollados en la asignatura, disponen durante todo el curso de preguntas de tipo test en PoliformaT, que pueden contestar tantas veces como consideren necesario. Tal y como muestra la Fig. 4, un $88 \%$ de los alumnos está de acuerdo con que los tests son útiles como medida para autoevaluarse. Cabe destacar que para ello, también es necesario que el test realizado en la evaluación sea de la misma dificultad que los que encuentran en PoliformaT.

\subsection{Repercursión del método activo sobre los conceptos y competencias}

Además de la estrategia adoptada en la evaluación del alumnado, un aspecto importante sobre la participación activa del alumnado es la actitud que adopta el profesor. La Fig. 4 muestra que un $75 \%$ de los alumnos está de acuerdo con que la actitud del profesor es clave para favorecer su participación activa.

Si el profesor da importancia a la participación activa y la fomenta en cada clase, el interés de los alumnos en asistir a clase también aumenta. La asistencia a clase fue altísima, con una media de un $92 \%$. Únicamente un alumno asistió a menos de $75 \%$ de las clases y se trataba de un deportista de élite que no podía compatibilizar el curso con el resto de sus actividades. 
Por la actitud del profesor, he participado en clase de manera más activa que en otras asignaturas

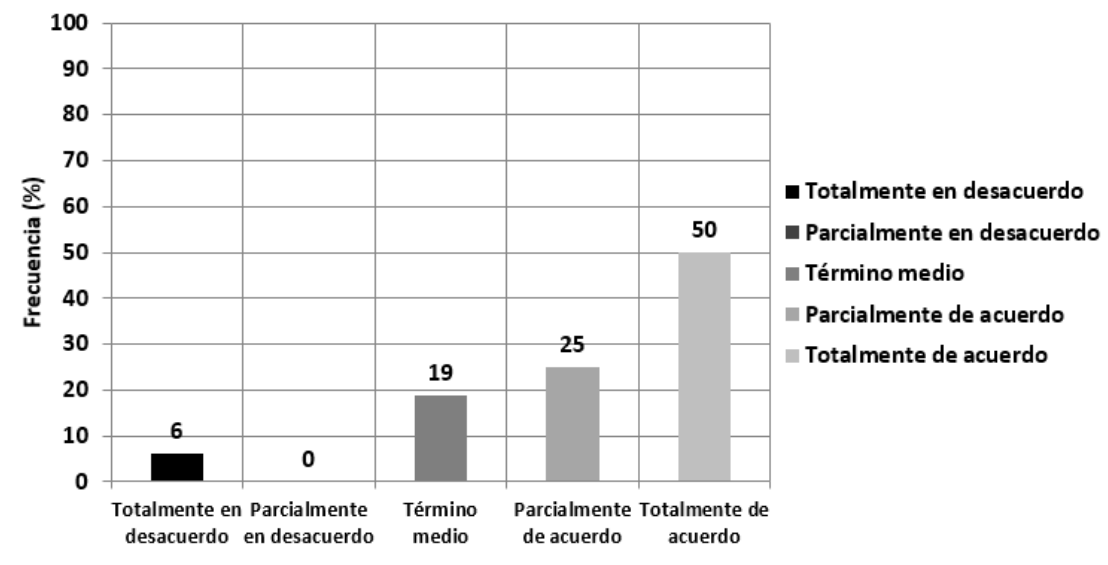

Fig. 5 Impacto de la actitud del profesor sobre la participación activa de los alumnos

Creo que participar en clase de manera activa favorece la asimilación de conceptos y el desarrollo de competencias

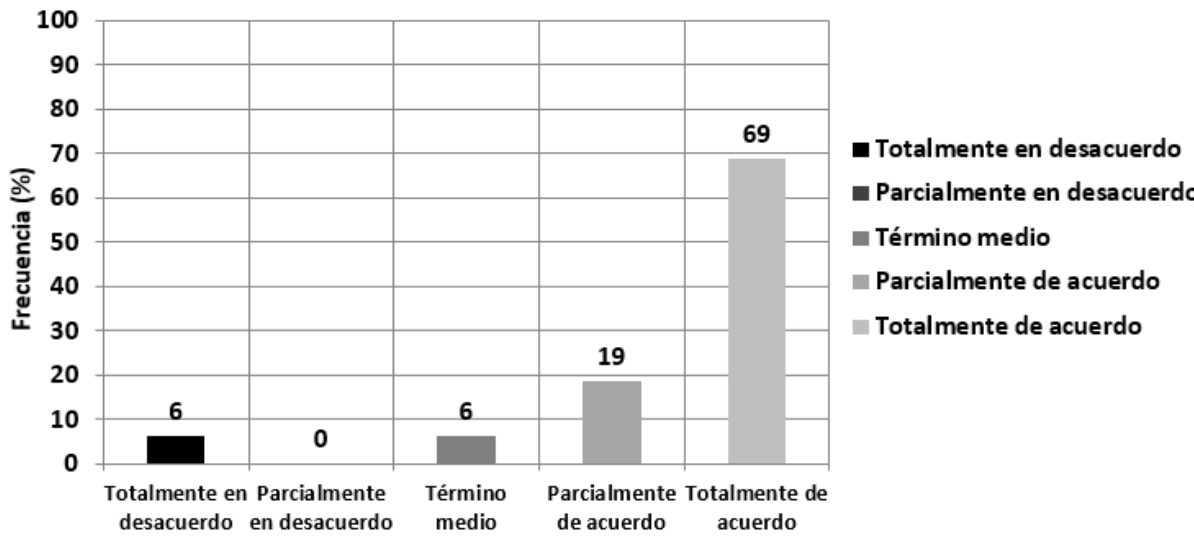

Fig. 6 Opinión del alumnado sobre los beneficios de la participación activa en clase

La Fig. 6 muestra que un $88 \%$ de los alumnos considera que la participación activa en clase favorece la asimilación de conceptos y el desarrollo de competencias, luego su opinión es prácticamente unánime en ese sentido.

En esta asignatura es necesario adquirir unos conocimientos básicos en energía solar térmica, y una vez adquiridos el curso se centra en el desarrollo de competencias. Tal y como muestra la Fig. 7, un 94\% de los alumnos cree que la compensación entre contenidos y competencias es buena. 
Creo que en esta asignatura hay una buena compensación entre contenidos y competencias

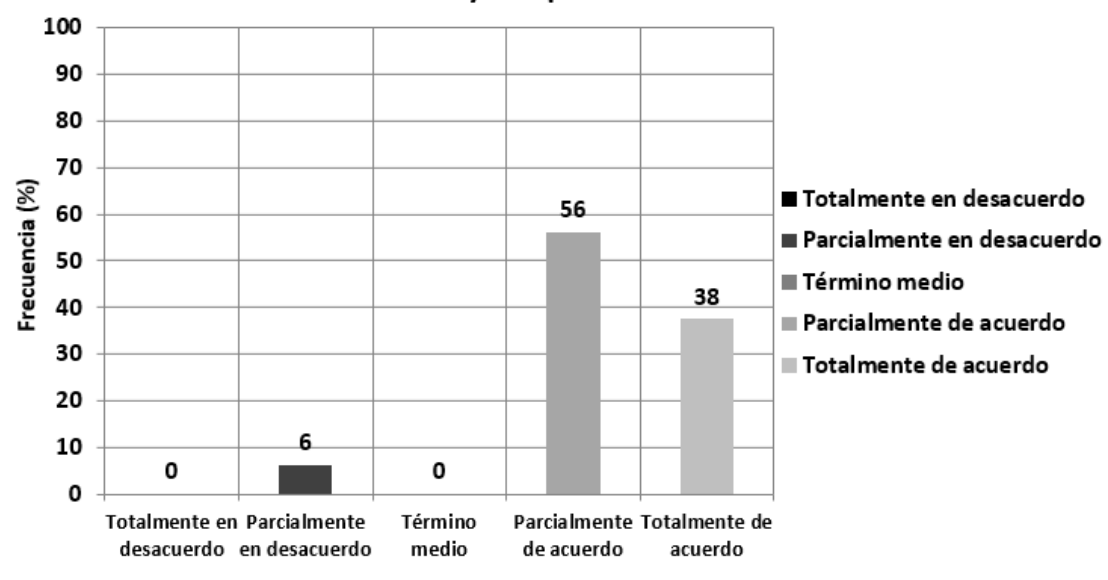

Fig. 7 Valoración del alumnado sobre el peso de las competencias y contenidos desarrollados

\subsection{Desarrollo de competencias}

Con la metodología y evaluación adoptados, se perseguía tanto una mayor asimilación de conceptos como el desarrollo de competencias.

El trabajo final que se escogió es un proyecto de ingeniería para el diseño de una instalación de energía solar de un hotel. Tiene por tanto carácter completamente profesional. Un $63 \%$ de los alumnos opinan que el trabajo es aplicado y adaptado a su futuro entorno profesional. Para entender por qué la opinión no es unánime, conviene tener en cuenta que la asignatura es optativa y pertenece a un grado donde sólo tratan la energía solar en esta asignatura optativa. Por tanto, el entorno profesional de la mayoría de egresados de dicha titulación no suele trabajar en este ámbito. Quizás el 12\% de alumnos que no consideran el trabajo adaptado a su entorno profesional piensen que no van a trabajar en este campo.

El trabajo de la asignatura me parece aplicado y adaptado a mi futuro entorno profesional

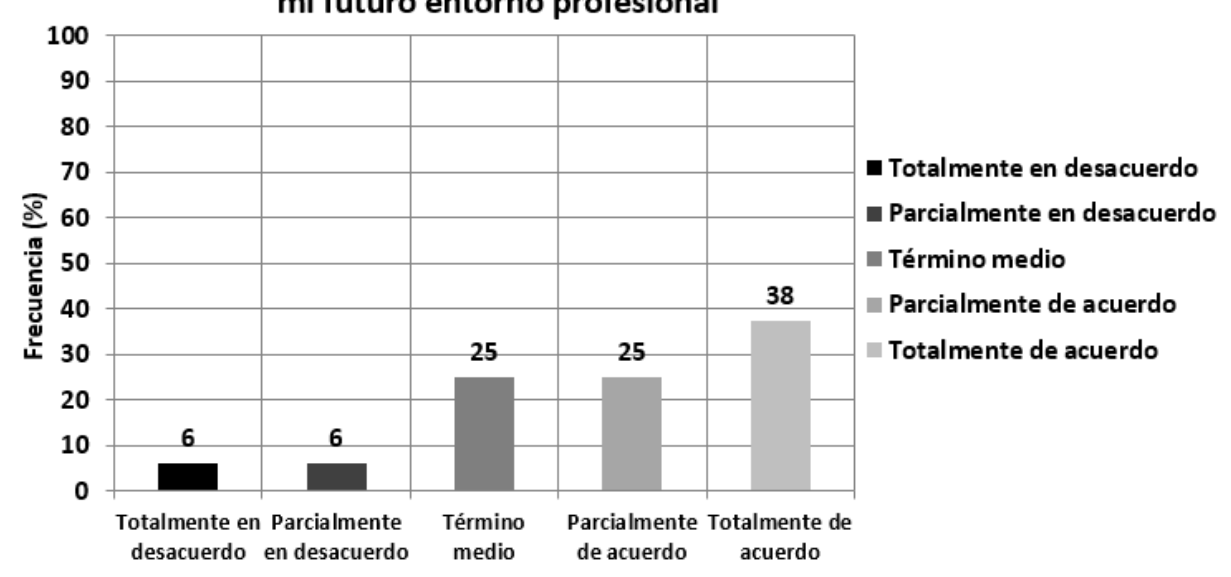

Fig. 8 Opinión del alumnado sobre el carácter aplicado del trabajo de la asignatura

(cc)) BY-NC-ND 2017, Universitat Politècnica de València

Congreso In-Red (2017) 
Es interesante señar que durante la asignatura se planteó una de las prácticas como un juego de empresa en el cual los alumnos debían llevar a cabo un proyecto de ingeniería y entregarlo de manera conjunta al final de la clase. Un $88 \%$ de los alumnos contestaron que recomenderían a futuros alumnos asistir a dicha práctica, pues les pareció una experiencia interesante y dinámica, aunque habría sido más conveniente preguntarles más específicamente acerca de las competencias transversales que trabajaron durante dicha práctica.

La Fig. 9 refleja los resultados de las presentaciones que tuvieron que hacer los alumnos en clase sobre un tema propuesto por el profesor, y relacionado con la energía solar. La asistencia al día de las presentaciones fue obligatoria, y además cada grupo debía evaluar tanto a sus compañeros como a sí mismos. Un $75 \%$ de los alumnos está de acuerdo con que dichas presentaciones mejorararon su capacidad para comunicar resultados en público, fue esencial para esto explicarles los puntos fuertes y débiles de las presentaciones, pues sino no habrían tenido una retro-alimentación tan específica más allá de su nota.

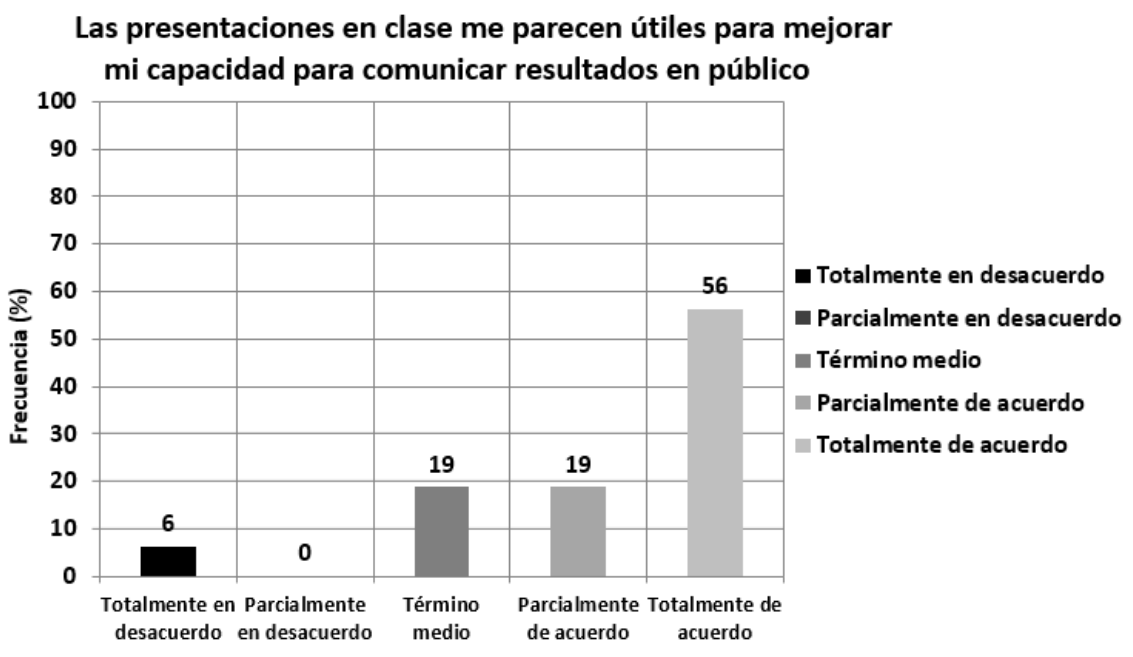

Fig. 9 Desarrollo de la competencia transversal de comunicación oral

Finalmente, en la Fig. 10 se muestra la relación entre las notas que obtuvo cada grupo, tanto por el profesor, como por la evaluación de los propios alumnos. Se aprecia claramente una relación directa entre ambas notas, aunque probablemente ambas notas evalúen aspectos distintos. Probablemente, la percepción de los alumnos se ve principalmente influída por el formato de la presentación y la comunicación oral, mientras que el profesor también valora el contenido y calidad del trabajo. En todo caso, para la nota final de las presentaciones el profesor escogió realizar la media entre su evaluación y la auto-evaluación realizada por el conjunto de alumnos. El mayor beneficio de esta experiencia fue sin duda el que los alumnos prestaran atención a todas las presentaciones y fueran más críticos con su trabajo.

(cc) EY-NC-ND 2017, Universitat Politècnica de València 


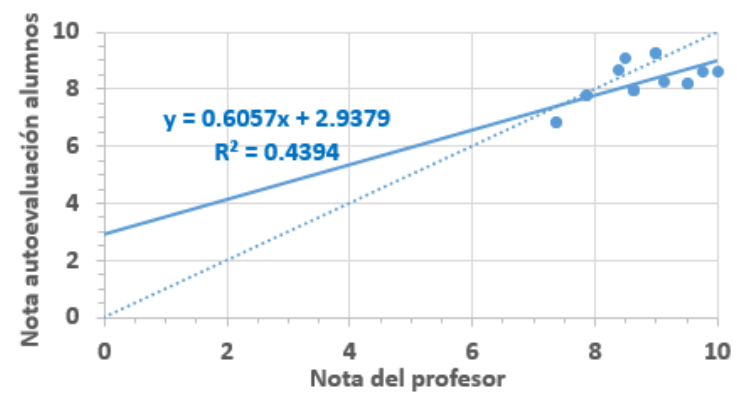

Fig. 10 Comparativa entre las notas de las presentaciones puestas por el profesor y por los alumnos

La nota media de la asignatura en el curso 2016-2017 fue de 7.2, frente a un 7.9 en el curso anterior. Sin embargo, no es posible obtener una relación directa con la metodología adoptada, pues las diferencias son mínimas y los factores muy diversos, ya que hubo dos profesores distintos en el curso anterior y con menos alumnos en dicho curso ( 5 únicamente) frente a los 17 del curso 2016-2017. Sin embargo, y al margen de la nota final en la asignatura, los puntos positivos han sido el alto nivel de atención, participación y asimilación de conceptos por parte del alumnado. En las encuestas oficiales realizadas al alumnado, el profesor recibió una nota media de 9.67 y 9 en el curso anterior.

\section{Conclusiones}

En este trabajo se ha planteado la metodología activa planteada en la asignatura de "Energía solar fototérmica" de la Escuela Técnica Superior de Ingeniería del Diseño. Se han adoptado distintos métodos con el objetivo de aumentar el interés del alumnado, favorecer la asimilación de conceptos y el desarrollo de competencias transversales.

En una asignatura de 17 alumnos matriculados, los resultados muestran una asistencia altísima a las clases (92\% de media). Los alumnos destacan la importancia de escoger un sistema de evaluación eminentemente práctico como aspecto clave para asimilar conceptos. Un $88 \%$ de los alumnos considera que la participación activa en clase favorece la asimilación de conceptos y el desarrollo de competencias, pero también destacan en un $75 \%$ de los casos que su papel activo depende completamente de la actitud del profesor.

En cuanto al desarrollo de competencias transversales, un $63 \%$ de los alumnos están de acuerdo con que el trabajo es aplicado y adaptado a su futuro entorno profesional. La opinión al respecto no es unánime ya que se trata de una asignatura optativa y probablemente la única que trate con energías renovables. Por ello, los alumnos consideran en general el trabajo como muy útil para aprender, pero algunos lo consideran excesivo en cuanto al esfuerzo que exige comparado con otras asignaturas optativas.

Finalmente, cabe destacar que un $75 \%$ de los alumnos está de acuerdo con las presentaciones en clase de los alumnos mejorararon su capacidad para comunicar resultados en público. Para el profesor, implantar un sistema de evaluación de las mismas que integre 
también la auto-evaluación del alumnado fue una experiencia muy interesante pues aumentó la atención de los alumnos durante las exposiciones y desarrolló el desarrollo de análisis crítico por parte del alumnado.

\section{Referencias}

FERNÁNDEZ, A. (2010). "La evaluación orientada al aprendizaje en un modelo de formación por competencias en la educación universitaria” en Revista de Docencia Universitaria, vol. 8, issue 1, p. 11-34.

PERRENOUD, P. (2008). “Construír las competencias, ¿es darle la espalda a los saberes?” en Revista de Docencia Universitaria, núm. monograf. II.

VILLA, A. y POBLETE, M. (2011). "Evaluación de competencias genéricas: principios, oportunidades y limitaciones” en Bordón, vol. 63, issue 1, p. 147-170.

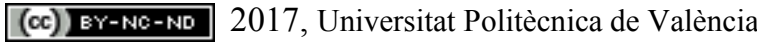

Congreso IN-RED (2017) 


\title{
Incorporación de técnicas para favorecer el aprendizaje activo en la asignatura "Evaluación técnico-económica de sistemas energéticos"
}

Jorge Payáa

${ }^{a}$ Instituto de Ingeniería Energética, Universitat Politècnica de València

Camino de Vera s/n Edificio 8E semisótano frente acceso J, Valencia, España

E-mail: jorge.paya@iiie.upv.es (Jorge Payá)

\begin{abstract}
The present work describes the active learning approach followed in the subject "Techno-economical assessment of energy systems". In first place, the employed techniques are described and in second place, the results are discussed from the point of view of the teacher and the students, by means of a survey which was answered by 34 of the 36 students. The results indicate that the students have a very positive perception with respect to their training when adopting techniques such as group discussion, evaluation with projects or oral presentations. A novel aspect has been including half an hour of autonomous work of the students in each practical lesson, where they had to solve on their own typical simulation errors. $73 \%$ of the students agreee that this method developed their autonomy. Globally, and although the results are very positive (97\% satisfaction with the teacher and $86 \%$ with the subject), the teaching can still be improved by further working on the teaching material (contents) aswell as by better adapting the project to the contents and competences which are developed through the subject.
\end{abstract}

Keywords: project-based learning, transversal competences, evaluation, active learning

\footnotetext{
Resumen

El presente trabajo describe la metodología de aprendizaje activo adoptada en la asignatura de "Evaluación técnico-económica de sistemas energéticos". En primer lugar se describen las distintas técnicas empleadas en clase y en segundo lugar se comenta su utilidad tanto desde el punto de vista del profesor como de los alumnos, a través de un sondeo al que contestaron 34 de los 36 alumnos matriculados. Los resultados muestran que los estudiantes perciben de manera muy positiva en su formación técnicas como presentaciones orales de los alumnos, evaluación por proyectos o discusión en grupos. Un aspecto novedoso ha sido incluir en las prácticas media hora de trabajo autónomo de los alumnos para detectar problemas típicos de simulación. $73 \%$ de los alumnos indican que esto aumentó su autonomía. Globalmente, aunque los resultados son muy buenos $197 \%$ de
} 
satisfacción con el profesor, 86\% con la asignatura en general), todavia hay margen de mejora sobre todo en los contenidos y en el enfoque del proyecto, para que sea más acorde con los conceptos y competencias trabajados en la asignatura.

Palabras clave: evaluación por proyectos, competencias transversales, aprendizaje activo

\section{Introducción}

La tendencia actual en la educación es enseñar al alumno a que aprenda, dejando atrás metodologías más pasivas como las clases magistrales donde la interacción con el alumno era muy reducida. También se está tendiendo hacia un sistema de enseñanza-aprendizaje basado en competencias (Tardif, 2006), lo cual abre preguntas importantes acerca de su posible evaluación (Castro, 2011, Fernandez, 2010, Villa, 2011).

Con el objetivo de favorecer el aprendizaje activo de los alumnos, una parte esencial consiste en variar las técnicas empleadas. Esto rompe la rutina o parsimonia de parte del alumnado, que de otra manera estaría más distraído, y favorece una mayor atención.

El presente trabajo describe las metodologías implantadas así como los resultados obtenidos, tanto desde el punto de vista de los alumnos como del profesor. La metodología adoptada es una continuación del trabajo publicado recientemente (Payá, 2014).

\section{Objetivos}

El trabajo realizado se enmarca dentro del Máster Universitario en Tecnología Energética para el Desarrollo Sostenible impartido en la Universitat Politècnica de València (UPV). En concreto, en la asignatura de "Evaluación técnico-económica de sistemas energéticos" que se imparte íntegramente en inglés en la Escuela Técnica Superior de Ingenieros Industriales (ETSII).

\section{Desarrollo de la innovación}

\subsection{Metodología}

Las clases se han enfocado con el objetivo de favorecer el aprendizaje activo de los alumnos. Para ello, se han combinado distintas técnicas tales como:

- Preguntas frecuentes a los alumnos durante las clases

- Discusiones en grupo

- Ejercicios

- Prácticas

- Resolución de problemas en prácticas informáticas

- Proyecto final

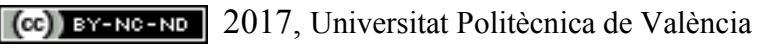

Congreso IN-RED (2017) 
Se han utilizado como herramientas, dentro de la aplicación de "PoliformaT" disponible en la UPV, los recursos así como el espacio compartido entre alumnos y profesor.

El sistema de evaluación escogido y la forma en el que se adapte a los contenidos y competencias que se trabajan en clase es un aspecto fundamental. En la presente asignatura, la evaluación se realiza mediante los siguientes pesos:

- $40 \%$ examen escrito de respuesta abierta

- $20 \%$ prácticas informáticas (6 de dos horas cada una)

- $40 \%$ proyecto en parejas evaluado mediante una presentación oral

\section{Resultados}

A continuación, se comentan los resultados más relevantes de la aplicación de la metodología anterior, basándose en un sondeo que se realizó a los alumnos, y al que contestaron 34 de los 36 alumnos matriculados.

\subsection{Evaluación}
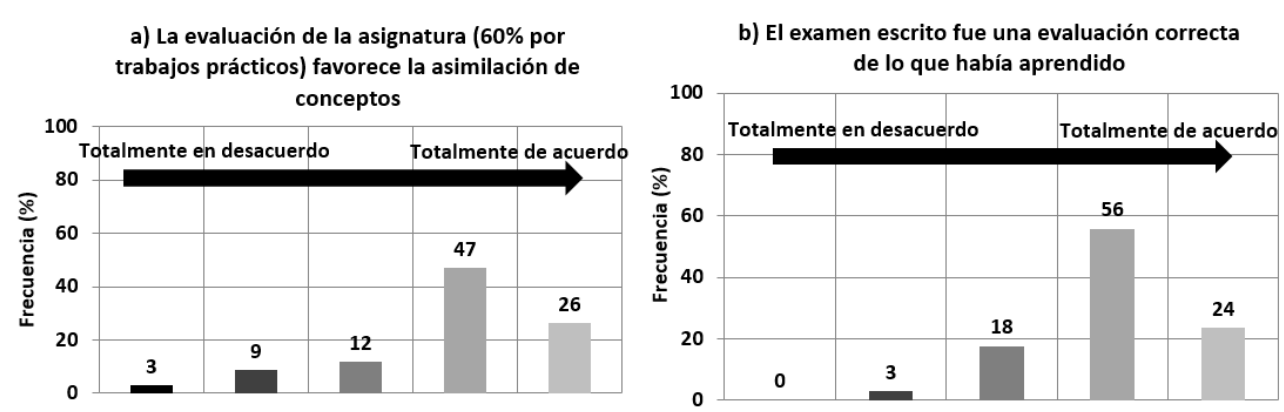

c) El proyecto final de la asignatura es una manera buena de trabajar los conceptos y competencias que debería alcanzar en la asignatura

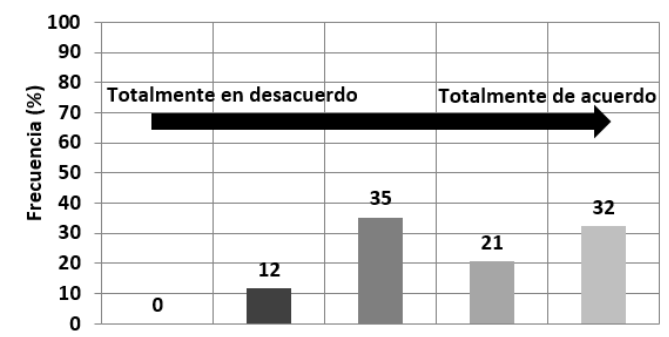

Fig. 1 Resultados de la evaluación de la asignatura

En la Fig. 1 se ha resumido la opinión del alumnado respecto a la evaluación de la asignatura. Cabe destacar que el hecho de evaluar con un peso del $60 \%$ los trabajos de tipo práctico (tanto las prácticas informáticas como el proyecto lo son) parece favorecer la asimilación de conceptos (Fig. 1a) para un $73 \%$ de los alumnos. El examen escrito, según $80 \%$ de los alumnos, evaluó correctamente lo que habían aprendido los alumnos. Esta retro- 
alimentación de los alumnos es importante para garantizar que se les evalúa acorde a lo que se les enseña en clase.

Un 53\% de los alumnos están de acuerdo en que el proyecto final es una buena manera de trabajar los conceptos y competencias que deberían adquirir en la asignatura (Fig. 1c). Sin embargo, 35\% seleccionaron el término medio y un $12 \%$ estaban parcialmente en desacuerdo, luego la opinión respecto a los proyectos fue bastante dispersa. En la sección 4.3 de balance general se comenta qué aspectos se podrían mejorar tanto en el proyecto como en el resto de la asignatura.

\subsection{Desarrollo de competencias}

En general, tal y como muestra la Fig. 2, las distintas técnicas empleadas favorecieron con éxito el desarrollo de competencias transversales. Por ejemplo, $79 \%$ de los alumnos consideran que las presentaciones fueron útiles para desarrollar habilidades de comunicación oral (Fig. 2a). Conviene señalar que algo que los alumnos valoran muy positivamente es que tras concluír las presentaciones, el profesor destaca aspectos positivos de las presentaciones, así como puntos a mejorar de las mismas. En caso contrario, si los alumnos no tuvieran otra retro-alimentación más allá de la nota, seguramente las presentaciones habrían tenido un impacto menor en su proceso de aprendizaje.
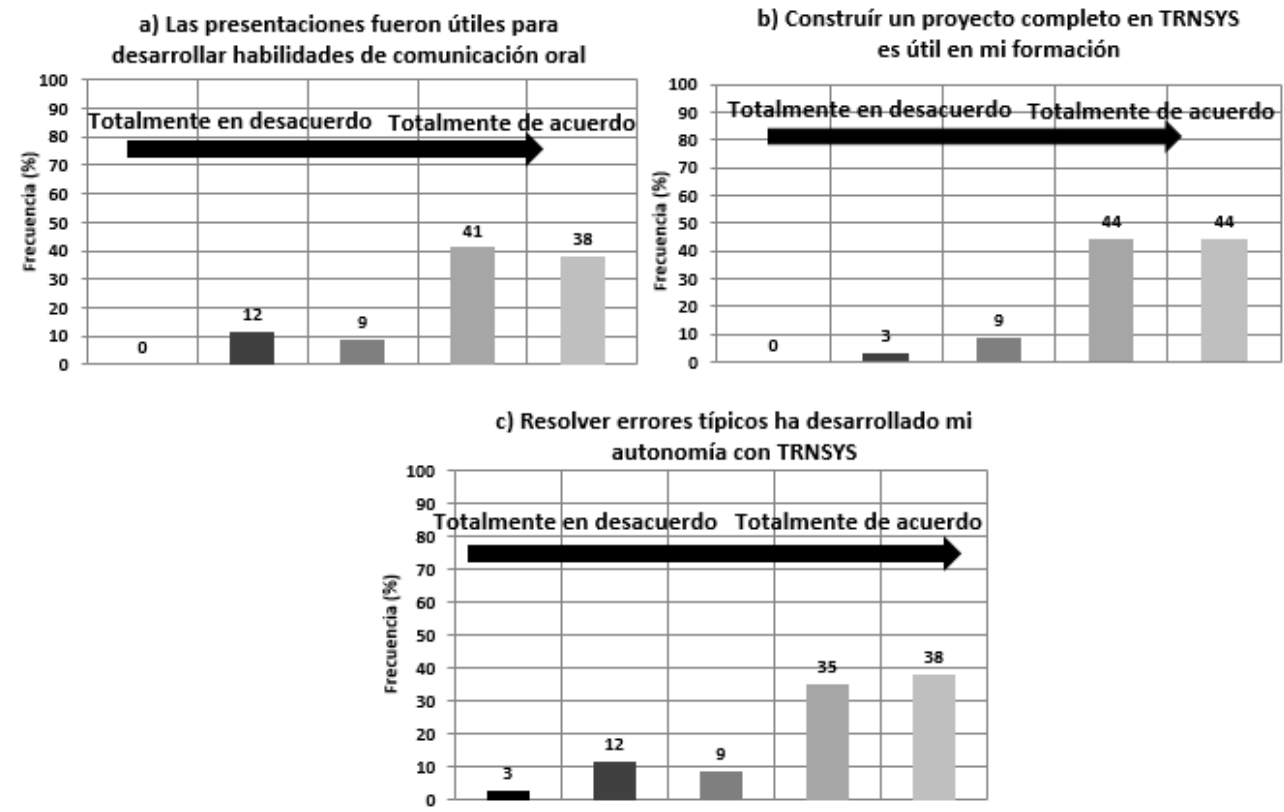

Fig. 2 Impacto de las técnicas empleadas sobre el desarrollo de competencias

En la asignatura, se trabaja con una herramienta informática llamada TRNSYS para la simulación de sistemas energéticos en régimen transitorio. Se trata de una herramienta compleja, por lo que, además de utilizarse en 6 prácticas, se dedicó una clase entera para que los alumnos construyeran un proyecto completo empezando desde cero, tal y como

(cc) EY-NC-ND 2017, Universitat Politècnica de València

Congreso IN-RED (2017) 
harían si tuvieran que afrontar un problema sólos por su cuenta. Un $88 \%$ de los alumnos están de acuerdo en que este proyecto fue útil en su formación (Fig. 2b).

Finalmente, conviene señalar que en todas las prácticas, se dedicó la última media hora para que los alumnos resolvieran errores que aparecían en distintos proyectos que les entregaba el profesor. Todos ellos contenían los errores típicos que suelen cometer los alumnos. Los resultados fueron muy bien acogidos, pues un $73 \%$ de los alumnos están de acuerdo con que este enfoque desarrolló su autonomía trabajando con TRNSYS (Fig. 2c). Aunque el sondeo no lo preguntaba de forma explícita, esto permitió trabajar tanto su autonomía como su sentido crítico, pues en lugar de partir de que las simulaciones eran todas correctas, partían asumiendo que contenían un error, y muchos tenían una gran motivación por encontrarlo.

\subsection{Balance general}

Como balance general de las distintas técnicas empleadas, se preguntó a los alumnos acerca de la utilidad de cada una de ellas (Fig. 3). Tanto la discusión en grupos acerca de preguntas abiertas, como realizar preguntas continuamente en las clases fue apreciado positivamente. Además, $91 \%$ de los alumnos opinan que es esencial acompañar las clases de teoría con ejercicios para asimilar mejor los conceptos.
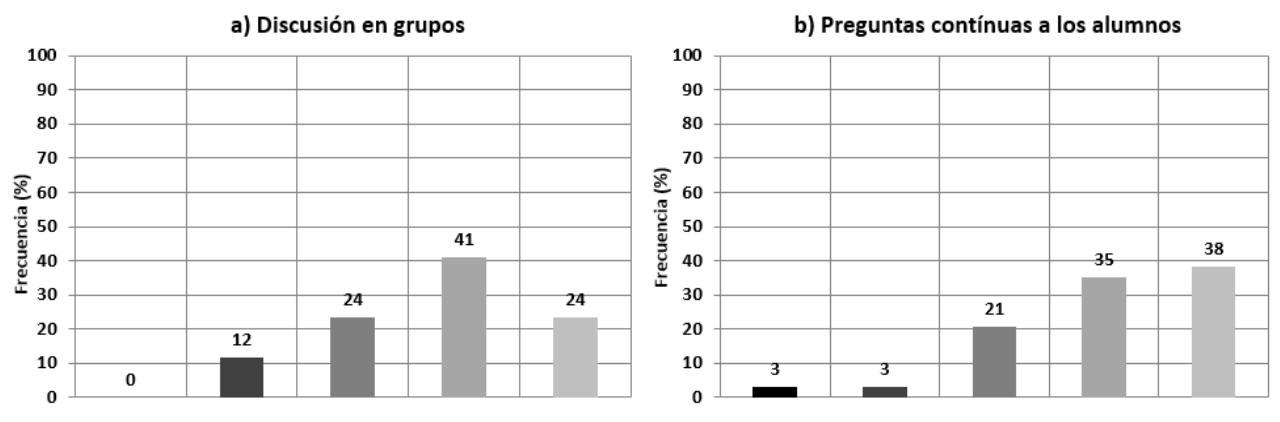

c) Proyecto final
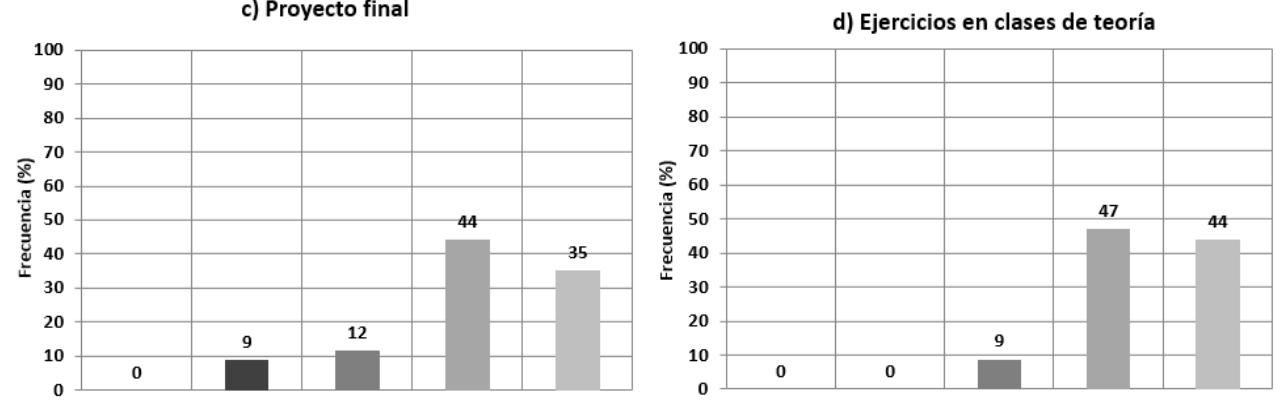

Fig. 3 Utilidad de distintas técnicas empleadas desde el punto de vista del alumnado

Curiosamente, en la pregunta 3c) los alumnos contestaron en un 79\% que les parecía positivo en su formación realizar un proyecto final. Sin embargo, sólo un $53 \%$ de los alumnos están de acuerdo en que el proyecto final es una buena manera de trabajar los

(cc)) BY-NC-ND 2017, Universitat Politècnica de València 
conceptos y competencias que deberían adquirir en la asignatura (Fig. 1c). Esta diferencia parace deberse a que la realización de un proyecto les hace trabajar competencias como la autonomía, la capacidad de autocrítica, la búsqueda y selección de información, y como sistema de evaluación en sí, parece ser muy positivo. Sin embargo, a la hora de llevarlo a la práctica, quizás los alumnos no tuvieron suficiente tiempo para realizar los proyectos, y deberían mejorarse en años posteriores los conceptos y competencias que se trabajan en los mismos.

A nivel global, en la Fig. 4 se muestra el nivel de satisfacción general respecto al profesor, y respecto a la asignatura en sí. Pese a que la encuesta es anónima, probablemente haya alumnos que no contesten libremente a esta pregunta, lo cual tendería a favorecer los resultados de las encuestas. En todo caso, en las respuestas al sondeo, un $97 \%$ de los alumnos estaban satisfechos positivamente con el profesor, lo cual parece responder a que perciben positivamente la actitud dinámica del profesor y su voluntad de mejorar continuamente. Un 15\% de los alumnos seleccionaron el término medio respecto al nivel de satisfacción de la asignatura, lo cual pese a ser una cifra baja, parece indicar que a nivel de asignatura, todavía hay margen para mejorar el material que se entrega a los alumnos, añadiendo algún ejercicio adicional y renfocando ligeramente el proyecto final.
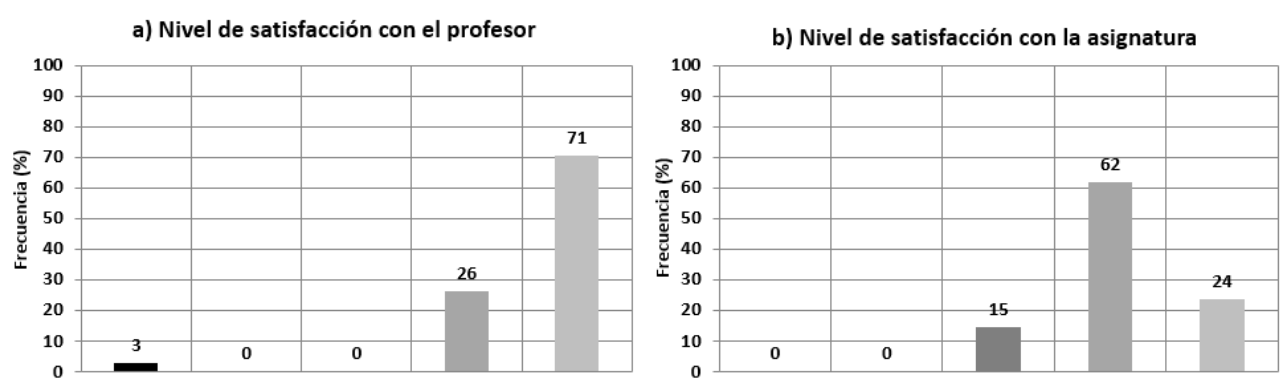

Fig. 4 Desarrollo de la competencia transversal de comunicación oral

La nota media de la asignatura en el curso 2016-2017 fue de 7.8, frente a un 8.7 en el curso anterior. Sin embargo, no se puede deducir una relación directa con la metodología adoptada, pues las diferencias son pequeñas y los factores muy diversos, ya que hubo dos profesores distintos en el curso anterior y con menos alumnos en dicho curso (25) frente a los 35 del curso 2016-2017. En las encuestas oficiales realizadas al alumnado, el profesor recibió una nota media de 9.57 frente al 8.23 del curso anterior, lo cual parece indicar la buena repercusión que ha tenido la metodología adoptada sobre la opinión de los alumnos.

\section{Conclusiones}

En el presente trabajo se ha presentado la metodología planteada dentro de la asignatura de "Evaluación técnico-económica de sistemas energéticos". Se han incorporado en las clases una gran variedad de técnicas con el objetivo de favorecer el aprendizaje activo de los

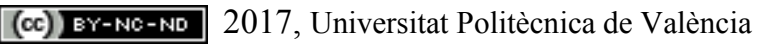

Congreso IN-RED (2017) 
alumnos, los cuales han valorado muy positivamente todas ellas. Entre las metodologías más apreciadas por los alumnos, cabe destacar la introducción sistemática de ejercicios en clases de teoría, la discusión entre grupos, las preguntas contínuas a los alumnos, y la resolución de errores típicos por parte de los alumnos en la última media hora de las prácticas.

Pese a que un $86 \%$ de los alumnos han valorado positivamente la asignatura, las encuestas muestran que hay margen de mejora, sobre todo en lo referente al material que se les entrega, mejorando contenidos, por ejemplo introduciendo más ejercicios, o renfocando el proyecto para que puedan desarrollarlo con más tiempo y que esté más acorde con los contenidos y competencias trabajados durante la asignatura.

\section{Referencias}

CASTRO, M. (2011). “¿Qué sabemos de la medida de las competencias? Características y problemas psicométricos en la evaluación de competencias" en Bordón, vol. 63, issue 1, p. 109-123.

FERNÁNDEZ, A. (2010). "La evaluación orientada al aprendizaje en un modelo de formación por competencias en la educación universitaria" en Revista de Docencia Universitaria, vol. 8, issue 1, p. 11-34.

PAYÁ, J., y ROYO, R. (2014). “ Experiencia de un proyecto de aprendizaje basado en proyectos prácticos: Análisis de la eficiencia energética de una vivienda" en Jornadas de Innovación Educativa $y$ Docencia en Red (In-Red 2014). Valencia : Universitat Politènica de València. 878-886.

TARDIF, J. (2006). L'évaluation des compétences. Documenter le parcours de développement. Montréal: Chenelière Education.

VILLA, A. y POBLETE, M. (2011). "Evaluación de competencias genéricas: principios, oportunidades y limitaciones" en Bordón, vol. 63, issue 1, p. 147-170. 


\title{
La investigación visita el aula: la promoción del conocimiento y la práctica de la investigación como estrategia docente innovadora
}

\author{
Faraj A. Santirso ${ }^{a}$, Manuel Martin-Fernandez ${ }^{b}$, Miriam Marco ${ }^{c}$, Viviana Vargas ${ }^{d}$, \\ Marisol Lila ${ }^{\mathrm{e}}$ y Enrique Graciaf. \\ aDepartamento de Psicología Social. Universitat de València. E-mail: Faraj.Santirso@uv.es, \\ bDepartamento de Psicología Social. Universitat de València. E-mail: Manuel.Martin@uv.es, \\ 'Departamento de Psicología Social. Universitat de València. E-mail: Miriam.Marco- \\ Francisco@uv.es, ${ }^{\mathrm{d} D e p a r t a m e n t o}$ de Psicología Social. Universitat de València. E-mail: \\ vivianav@gmail.com, ${ }^{e}$ Departamento de Psicología Social. Universitat de València. E-mail: Marisol. \\ Lila@uv.es, ${ }^{\mathrm{f}}$ Departamento de Psicología Social. Universitat de València. E-mail: \\ Enrique.Gracia@uv.es
}

\begin{abstract}
Recently, an increasingly number of authors emphasize the benefits of research oriented teaching and the integration of research in the curriculum of undergraduate students. The main aim of this project of educational innovation is to enhance learning based on the promotion of knowledge and the practice of research, emphasizing the processes that are generated in the research work and using an approach in which the student plays the role of an active researcher. In order to assess whether there are changes in the attitudes of the students towards research, the intervention group was compared with a control group of undergraduated students. The results showed that the questionnaire of attitudes towards research was a reliable instrument to assess this variable. Using this questionnaire, significant differences were found in favour of the intervention group in the perceived relevance of the research, the predisposition to choose research as a profession, the perceived competence to investigate and the role of the teacher as a researcher.
\end{abstract}

Keywords: research-based learning, teacher innovation, attitudes towards research.

\section{Resumen}

En los últimos años cada vez son más los autores que subrayan los beneficios de la enseñanza dirigida desde la investigación y de la integración de la investigación en el currículum de las estudiantes de grado. El objetivo principal de este proyecto de innovación educativa es potenciar el aprendizaje basado en la promoción del conocimiento y la práctica de la investigación de manera que se enfaticen los procesos que se generan en el quehacer investigador y se utilice un acercamiento en el que el estudiante 
desempeñe el rol de participante activo. A su vez, se pretende evaluar si existen diferencias en las actitudes hacia la investigación entre el grupo que recibe la intervención y un grupo control. Los resultados muestran que el cuestionario de actitudes hacia la investigación es una herramienta fiable en la evaluación de esta variable. Utilizando este cuestionario, se observan diferencias significativas a favor del grupo de intervención en la relevancia percibida de la investigación, la predisposición a elegir la investigación como profesión, la competencia percibida para investigar y el papel del profesor.

Palabras clave: Aprendizaje basado en investigación,innovación docente, actitudes hacia la investigación.

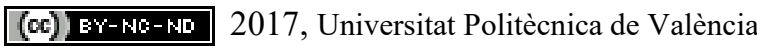




\section{Introducción}

En el ámbito universitario, a menudo la investigación y la docencia se interpretan como dos ámbitos independientes. Sin embargo, cada vez son más los autores que subrayan los beneficios de la enseñanza dirigida desde la investigación y de la integración de la investigación en el currículum de los estudiantes de grado. Entre los beneficios que se derivan de la vinculación investigación-docencia, destacan el incremento de la implicación y comprensión de los estudiantes, el proporcionar a los estudiantes habilidades adicionales (i.e., cuestionamiento crítico, evaluación del conocimiento, habilidades de investigación, dominio adecuado de la búsqueda de información relevante para su quehacer profesional, etc.), o el que se les transmita el interés por la investigación.

Esta relación entre investigación y docencia no sucede de manera automática y requiere de actuaciones que las unan. En este sentido, se han identificado diferentes fórmulas en el nexo docencia-investigación. En este proyecto se apuesta por la fórmula de docencia basada en la investigación (research-based), donde los estudiantes aprenden y actúan como investigadores, el currículum está diseñado en torno a actividades basadas en la curiosidad científica, y la división de roles entre estudiante y profesor se minimiza; ambos son participantes en el proceso de investigación y el profesor actúa como un "partner" o compañero con más experiencia. Por otra parte, el nexo entre investigación y docencia puede entenderse en base a tres ejes o dimensiones. En nuestro proyecto, frente al énfasis en el contenido de la investigación, pondremos el énfasis en los procesos y problemas de la investigación; frente a los acercamientos centrados en el profesor, situaremos el foco en el estudiante, y frente al estudiante tratado como audiencia, definiremos al estudiante como participante.

\section{Objetivos}

El objetivo principal es potenciar el aprendizaje basado en la promoción del conocimiento y la práctica de la investigación de manera que se enfaticen los procesos que se generan en el quehacer investigador y se utilice un acercamiento en el que el estudiante desempeñe el rol de participante activo. A su vez, se pretende evaluar si existen cambios en los las actitudes hacia la investigación antes y después de la puesta en marcha del proyecto de innovación.

\section{Desarrollo de la innovación}

\subsection{Programa de innovación educativa "la investigación visita el aula"}

La asignatura implicada es la asignatura de Psicología de la Intervención Social y Comunitaria (Código 33315). Esta asignatura pertenece al Grado en Psicología, y se imparte durante el tercer curso. Su duración es de 6 créditos lectivos durante el primer cuatrimestre del año. El proyecto se implementó en 3 grupos. El número de estudiantes con el que se trabajó fue de $\mathrm{N}=140$. Dos de los grupos fueron en línea castellana $(\mathrm{N}=51$ y $\mathrm{N}=$ 
43), y uno de los grupos era un grupo de alto rendimiento académico (ARA) que se imparte en inglés $(\mathrm{N}=46)$.

El desarrollo del programa se llevó a cabo por profesorado con experiencia en investigación psicosocial. Todos los miembros del equipo y los colaboradores habían participado directa o indirectamente en un programa de investigación/intervención psicosocial con hombres penados por violencia de género que se desarrolla en la Universitat de València, el Programa Contexto (Lila, Oliver, Galiana, \& Gracia, 2013). De hecho, la directora de este programa fue uno de los profesores responsables del proyecto de innovación. A su vez, en el desarrollo del programa participaron estudiantes de doctorado y personal en formación, lo cual supuso una cercanía generacional con los estudiantes que podría servir como estímulo y elemento generador de interés por la investigación como herramienta docente.

Inicialmente se presentó a los estudiantes el Programa Contexto (Lila et al., 2013). De este modo, los estudiantes pudieron conocer el diseño de la intervención, el diseño de la evaluación del programa, los retos que supone para los profesionales y los resultados de la investigación/evidencia científica obtenida hasta la fecha. Después, basándonos en la metodología de aprendizaje basado en problemas (ABP: Barrows, 1986), los estudiantes se plantearon diferentes problemas sociales y se les solicitó que diseñaran un programa de intervención basado en la evidencia. Para seleccionar estos problemas sociales se tuvieron en cuenta los ámbitos de intervención que se trabajan en la asignatura recogidos en la guía docente. Estos ámbitos de intervención son: familia, jóvenes y adolescentes, violencia en la pareja, vejez, inmigración y salud. Los problemas sociales que se les presentaron a los estudiantes fueron: conductas sexuales de riesgo, violencia dentro de la pareja en jóvenes, bullying, problemas de salud en cuidadores, exclusión social, maltrato infantil, conducta antisocial en jóvenes, conductas adictivas y homofobia.

Para la realización del trabajo los grupos contaron con seis participantes, ya que se ha propuesto que la formación de grupos de entre cinco y ocho integrantes favorece que los estudiantes gestionen eficazmente los posibles conflictos que pueden surgir entre ellos y que todos se responsabilicen de la consecución de los objetivos previstos (Exley y Dennick, 2007).

El trabajo se dividió en tres fases en las que se hizo hincapíe en la evidencia científica que está detrás de la intervención. En una primera fase se solicitó a los estudiantes que definieran el problema que iban a tratar, su prevalencia y los factores de riesgo y protectores asociados al mismo. Para abordar esta primera fase se llevó a cabo una sesión de formación donde trabajamos la competencia de los estudiantes para obtener e interpretar datos. En está sesión se realizaron búsquedas en bases de datos de carácter general suscritas por la Universitat de València (Scopus, Web of Science, PsycINFO....) y también en registros especializados acerca de programas y prácticas basados en la evidencia (Blueprints, Violence Prevention, The Campbell Library...). A continuación, los estudiantes llevaron a cabo una búsqueda en bases bibliográficas donde encontraron y contrastaron diferentes definiciones del problema, autores relevantes en la materia, y también la tipología o características de estos problemas sociales. Además, se les solicitó

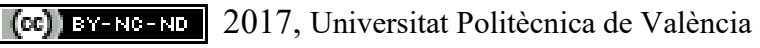

Congreso IN-RED (2017) 
que buscaran datos actualizados acerca de la prevalencia y que prestaran especial atención a las fuentes de información empleadas. Respecto a la prevalencia, se les instó a que analizaran las diferencias en la prevalencia del problema entre España y otros países, entre hombres y mujeres, etc. En la segunda fase, se pidió a los estudiantes que realizaran una búsqueda en bases de datos para encontrar revisiones sistemáticas sobre la problemática social asignada a cada grupo, así como programas de intervención psicosocial que trabajaran dicha problemática, atendiendo a las variables que trabaja cada programa, sus principales resultados y las buenas prácticas de dichos programas. En la tercera fase, se solicitó a los estudiantes que diseñaran un programa de intervención psicosocial enfocado a la problemática social que se les había asignado, indicando el nombre del programa, su estructura (el tiempo de realización del programa y los módulos que incluía), la población a la que se dirigía, sus objetivos generales y la forma de evaluación de los resultados del programa. Además, se les pidió que explicaran en profundidad una de las actividades del programa.

Se estructuró un calendario con los estudiantes en el que se establecieron los tiempos para cada fase del trabajo, y los días de revisión de los trabajos y de retroalimentación a los estudiantes.

\subsection{Procedimiento de evaluación}

Para evaluar el efecto del proyecto de innovación sobre las actitudes hacia la investigación de los estudiantes, se administró una escala tipo Likert de 5 categorías, siendo 1 "muy en desacuerdo " y 5 "muy de acuerdo". Los ítems de dicha escala se muestran en la Tabla 1. Para determinar las propiedades psicométricas (fiabilidad y validez) de la escala, se realizó un primer estudio piloto administrándosela a 182 estudiantes del grado de psicología (139 mujeres y 43 hombres) de entre 19 y 59 años de edad $(M=20.59, S D=$ 4.33). Estos estudiantes no habían participado en ningún proyecto de innovación educativa de estas características con anterioridad.

Una vez concluido el programa de innovación, la escala fue administrada a un grupo de intervención, compuesto por 101 participantes en el programa (68 mujeres y 33 hombres, de entre 21 y 50 años de edad, $M=21.50, S D=4.74$ ); y a un grupo control, compuesto de 100 estudiantes de psicología ( 80 mujeres y 20 hombres de edades comprendidas entre los 18 y los 59 años, $M=23.06, S D=5.35$ ).

Tabla 1. Ítems del cuestionario de actitudes hacia la investigación

\section{Cuestionario de conocimientos, actitudes y conductas vinculadas a la investigación}

1 Sé cuáles son algunas de las revistas científicas más importantes en mi carrera.

2 Sé cómo diseñar un estudio científico. 
3 Sé plantear hipótesis de investigación.

4 Sé seleccionar instrumentos para evaluar las variables de interés de una investigación.

5 Sé cómo buscar artículos científicos en bases de datos.

6 No creo que la investigación me sirva para mucho.

7 Me pierdo con facilidad realizando búsquedas bibliográficas.

8 La investigación es una pérdida de tiempo.

9 En mi carrera la investigación no es tan relevante como en otras disciplinas.

10 Investigación y docencia no deberían estar relacionados.

11 Creo que tener conocimientos de investigación aumentará mis posibilidades de trabajo.

12 Creo que la investigación es necesaria para el avance del conocimiento.

13 La mayoría de mis profesores insisten en la importancia de la investigación.

14 Me gustaría participar en alguna investigación.

15 La mayoría de mis profesores son científicos de reconocido prestigio.

16 No tengo las capacidades necesarias para ser un buen investigador.

17 No me planteo ser investigador al acabar mi carrera.

18 Investigar es aburrido.

19 Creo que la investigación debe quedar fuera de las clases.

20 La investigación es un mundo desconocido para mí.

21 Me gustaría dedicarme a la investigación en el futuro.

22 En general conozco la investigación que hacen los profesores que me han dado clase.

23 Cuando un tema de mi carrera me interesa, suelo realizar búsquedas en las bases de datos académicas (Scopus, Web of Science, PsycInfo, etc).

24 He colaborado en las investigaciones de algún profesor.

25 En las asignaturas de la carrera hemos tenido que utilizar muchos artículos de revistas científicas.

26 Los profesores de la carrera potencian el interés por la investigación.

27 Un buen profesor universitario debería ser también un buen investigador.

28 Soy capaz de leer y entender un artículo científico.

29 Sé cómo citar correctamente las referencias bibliográficas que utilizo en los trabajos que presento en las asignaturas.

(cc)) EY-NC-ND 2017, Universitat Politècnica de València

Congreso IN-RED (2017) 
$30 \mathrm{Si}$ ya se ha investigado mucho sobre un tema, no creo que merezca la pena invertir más tiempo en seguir investigándolo.

Fuente: Elaboración propia

\subsection{Analisis de datos}

Los siguientes análisis se llevaron a cabo para estudiar las propiedades psicométricas de la escala. La fiabilidad de la escala se midió en términos de la consistencia interna a través del alfa de Cronbach. Valores de este estadístico por encima de 0.70 son indicativos de una buena consistencia interna (Nunnally \& Bernstein, 1994).

Para estudiar la estructura factorial del instrumento se emplearon modelos multidimensionales de la teoría de respuesta al ítem (TRI; Reckase, 2009). Estos modelos son equivalentes al análisis factorial para variables categóricas. Los modelos fueron estimados mediante el algoritmo Metropolis-Hastings Robbins-Monroe, especialmente indicado para estimar modelos de varias dimensiones en tamaños muestrales reducidos (Martín-Fernández \& Revuelta, 2017). Estudiamos el ajuste del modelo a través del estadístico M2 para modelos ordinales (Maydeu-Olivares \& Garcia-Forero, 2010). Este estadístico se interpreta de manera similar al estadístico $\chi^{2}$ para los modelos factoriales con datos continuos. Con el M2 es posible calcular los índices de ajuste RMSEA, CFI y TLI. Modelos con valores del RMSEA inferiores a 0.06 y valores del CFI/TLI superiores a 0.90 se consideran con un buen ajuste.

Para analizar si hubo efecto en las actitudes hacia la investigación de los estudiantes tras la implementación del programa, se comparó mediante una prueba $t$ para muestras independientes si había diferencias entre los estudiantes del grupo control y los del grupo de intervención.

\section{Resultados}

\subsection{Estudio piloto:}

La escala tuvo una consistencia interna de $\alpha=0.80$. Eliminar alguno de los ítems no mejoraba la consistencia interna del instrumento.

Respecto a su estructura factorial, se encontró que con un modelo de 4 factores relacionados se obtenía un buen ajuste a los datos $(\mathrm{M} 2(231)=332, \mathrm{RMSEA}=.047$, TLI $=$ .92 , CFI $=.95)$, para el que se propusieron las siguientes etiquetas: F1: "relevancia percibida de la investigación"; F2: "competencia percibida para investigar"; F3: "papel del profesor", y F4: “investigación como profesión". Las saturaciones factoriales se muestran en la Tabla 2. Los ítems 6, 8, 9, 10, 11, 12, 19, 27 y 30 saturaron en el factor 1 . Los ítems 1 , $2,3,4,5,7,16,20,28$ y 29 saturaron en el factor 2 . Los ítems 13, 15, 22, 24, 25 y 26 en el factor 3. Los ítems 6, 14, 17, 18, 21 y 23 saturaron en el factor 4 .

Tabla 2. Saturaciones factoriales del estudio piloto

\begin{tabular}{llllll}
\hline \multicolumn{1}{c}{ Ítem } & F1 & F2 & F3 & F4 \\
\hline 6 & $\begin{array}{l}\text { No creo que la investigación me sirva para } \\
\text { mucho }\end{array}$ & $\mathbf{0 . 5 1}$ & -0.02 & -0.01 & $\mathbf{0 . 4 5}$ \\
& & & &
\end{tabular}

(cc)) EY-NC-ND 2017, Universitat Politècnica de València 
8 La investigación es una pérdida de tiempo

9 En mi carrera la investigación no es tan relevante como en otras disciplinas

10 Investigación y docencia no deberían estar relacionados

11 Creo que tener conocimientos de investigación aumentará mis posibilidades de trabajo

12 Creo que la investigación es necesaria para el avance del conocimiento

19 Creo que la investigación debe quedar fuera de las clases

27 Un buen profesor universitario debería ser también un buen investigador

$30 \mathrm{Si}$ ya se ha investigado mucho sobre un tema, no creo que merezca la pena invertir más tiempo en seguir investigándolo

1 Se cuáles son algunas de las revistas científicas más importantes en mi carrera

2 Sé cómo diseñar un estudio científico

3 Sé plantear hipótesis de investigación

4 Sé seleccionar instrumentos para evaluar las variables de interés de una investigación

5 Sé cómo buscar artículos científicos en bases de datos

$7 \mathrm{Me}$ pierdo con facilidad realizando búsquedas bibliográficas

16 No tengo las capacidades necesarias para ser un buen investigador

20 La investigación es un mundo desconocido para mí.

28 Soy capaz de leer y entender un artículo científico

29 Sé cómo citar correctamente las referencias bibliográficas que utilizo en los trabajos que presento en las asignaturas

13 La mayoría de mis profesores insisten en la importancia de la investigación

15 La mayoría de mis profesores son científicos de reconocido prestigio

22 En general, conozco la investigación que hacen los profesores que me han dado clase.

$24 \mathrm{He}$ colaborado en las investigaciones de algún profesor

25 En las asignaturas de la carrera hemos tenido que utilizar muchos artículos de revistas científicas

$\begin{array}{rrrr}\mathbf{0 . 6 1} & 0.28 & -0.11 & 0.12 \\ \mathbf{0 . 6 0} & 0.04 & 0.06 & 0.00 \\ \mathbf{0 . 8 2} & -0.05 & 0.06 & -0.06 \\ \mathbf{0 . 4 2} & 0.00 & 0.07 & 0.32 \\ & & & \\ \mathbf{0 . 6 4} & -0.03 & 0.10 & 0.11 \\ \mathbf{0 . 6 3} & 0.05 & 0.10 & 0.10 \\ \mathbf{0 . 4 7} & -0.21 & 0.06 & 0.03 \\ \mathbf{0 . 5 0} & 0.17 & -0.27 & -0.16\end{array}$

$\begin{array}{llll}0.05 & \mathbf{0 . 4 3} & 0.24 & 0.15\end{array}$

$\begin{array}{llll}-0.16 & \mathbf{0 . 5 5} & 0.33 & 0.04\end{array}$

$\begin{array}{llll}-0.09 & \mathbf{0 . 4 8} & 0.20 & 0.13\end{array}$

$\begin{array}{llll}-0.08 & \mathbf{0 . 5 0} & 0.27 & 0.01\end{array}$

$\begin{array}{llll}-0.01 & \mathbf{0 . 6 3} & 0.10 & 0.02\end{array}$

$\begin{array}{llll}-0.02 & \mathbf{0 . 6 2} & -0.31 & -0.02\end{array}$

$\begin{array}{llll}0.06 & \mathbf{0 . 4 6} & -0.09 & 0.28\end{array}$

$\begin{array}{llll}0.11 & \mathbf{0 . 5 8} & 0.13 & 0.01\end{array}$

$\begin{array}{llll}0.17 & \mathbf{0 . 6 5} & -0.08 & -0.10\end{array}$

$\begin{array}{llll}0.14 & \mathbf{0 . 4 6} & 0.01 & -0.06\end{array}$

$\begin{array}{llll}0.18 & -0.04 & \mathbf{0 . 7 6} & -0.04\end{array}$

$\begin{array}{llll}0.16 & -0.13 & \mathbf{0 . 5 3} & 0.08\end{array}$

$\begin{array}{llll}-0.08 & 0.30 & \mathbf{0 . 5 3} & 0.03\end{array}$

$\begin{array}{llll}0.00 & 0.31 & \mathbf{0 . 3 2} & 0.05\end{array}$

$\begin{array}{llll}-0.03 & 0.35 & \mathbf{0 . 5 2} & -0.08\end{array}$ 


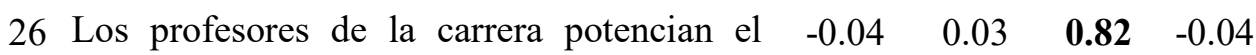
interés por la investigación

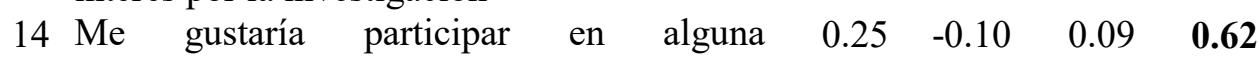
investigación

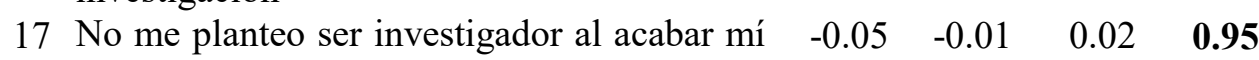
carrera

18 Investigar es aburrido

$\begin{array}{llll}0.27 & 0.13 & -0.11 & \mathbf{0 . 6 7}\end{array}$

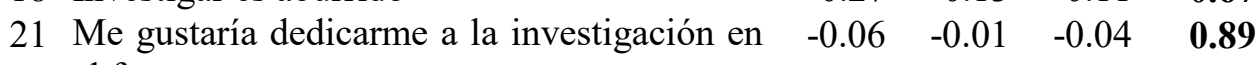
el futuro

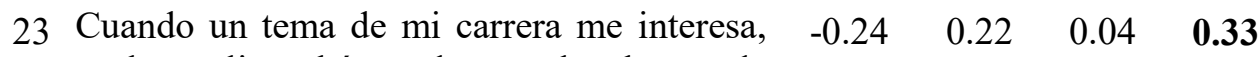
suelo realizar búsquedas en las bases de datos académicas (Scopus, Web of Science, PsycInfo, etc)

Fuente: Elaboración propia

\subsection{Evolución de las actitudes hacia la intervención tras la realización del proyecto:}

Como se observa en la Figura 1, al comparar el grupo control con el grupo de la intervención, se encontraron puntuaciones superiores en los 4 factores a favor de los participantes en el programa de innovación. Especialmente relevantes fueron las diferencias encontradas en el factor "Relevancia percibida de la investigación" $(t(199)=$ $18.02, p<.0001, d=2.54$ ), con un tamaño del efecto muy elevado. Este resultado implica que el $99 \%$ de los participantes en el programa de intervención obtuvieron una media superior a los del grupo control (los no participantes). Las diferencias encontradas en el cuarto factor, "investigación como profesión", también resultaron significativas con un tamaño del efecto elevado $(t(199)=9.77, p<.0001, d=1.37)$, de manera que el $91 \%$ de los participantes del grupo de intervención obtuvieron una media superior a la del grupo control. Las diferencias en el segundo factor, "Competencia percibida para investigar", y el tercer factor, "Papel del profesor", resultaron asimismo significativas, si bien con tamaños del efecto mucho más moderados $(t(199)=2.89, p=.0004, d=0.41 ; t(199)=2.47, p=$ $.0014, d=0.35$ respectivamente) . 


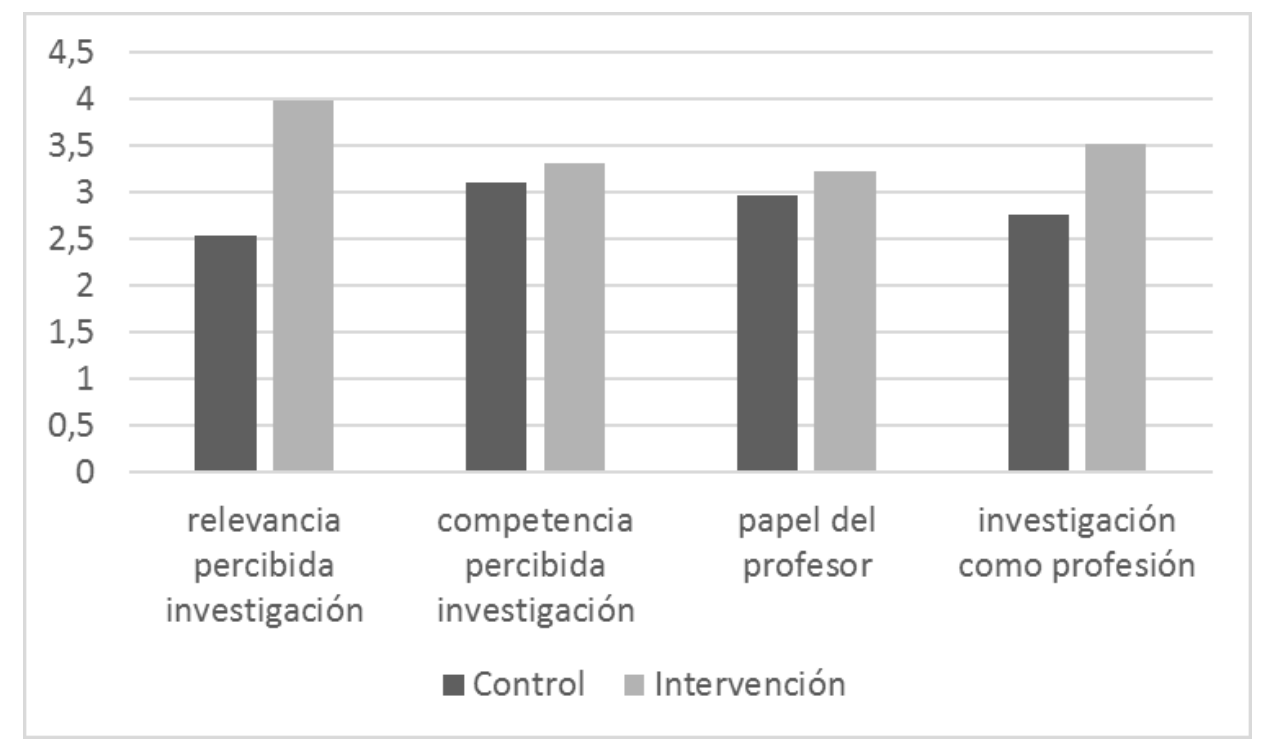

Fig. 1: Media del grupo control e intervención en los factores del cuestionario de actitudes hacia la investigación.

\section{Conclusiones}

Los resultados muestran que el cuestionario de actitudes hacia la investigación es una herramienta precisa y fiable en la evaluación de esta variable. Su estructura factorial con estos participantes apunta a la agrupación de los ítems en cuatro factores: "relevancia percibida de la investigación", "competencia percibida para investigar", "papel del profesor" e "investigación como profesión". Como esperábamos, hemos encontrado diferecias positivas y significativas a favor del grupo de intervención frente al grupo control.

Podemos afirmar que este proyecto de innovación docente ha aumentado el interés de los estudiantes por la investigación, animándoles a participar y a considerar la investigación como una oportunidad laboral. Futuros estudios podrían llevar a cabo esta experiencia en otras disciplinas, para conocer las actitudes hacia la investigación de los estudiantes y si se ven beneficiados por la intervención. Por último, dados los beneficios de la integración de la investigación en la docencia, en la asignatura objeto de la intervención, sería de gran interés incorporar de manera específica algunas de las competencias tratadas como la búsqueda de información relevante en bases de datos científicas en la guía docente de la asignatura.

\section{Agradecimientos}

Este proyecto ha sido realizado en el marco de la convocatoria de innovación del Vicerectorat de Polítiques de Formació i Qualitat Educativa de la Universitat de València (UV-SFPIE_RMD16-417684). Faraj A. Santirso es beneficiario del programa FPU del Ministerio de Educación, Cultura y Deporte (FPU15/00864). Manuel Martin-Fernandez es beneficiario del programa FPI del Ministerio de Economía y Competitividad 
(BES15/075576). Miriam Marco es beneficiaria del programa FPU del Ministerio de Educación, Cultura y Deporte (FPU13/00164).

\section{Referencias}

BARROWS, H. S. (1986). "A taxonomy of problema-based learning methods" en Medical Education, 20, p. 481-486.

EXLEY, K. y DENNICK, R. (2007). Enseñanza en pequeños grupos en educación superior. Tutorías, seminarios y otros agrupamientos. Madrid: Narcea.

FENSHAM, P. J. (2004). Defining an identity: The evolution of science education as a field of research (Vol. 20). Dordrecht: Springer Science \& Business Media.

GARCÍA, J. F., GRACIA, E., FUENTES, M. C., LILA, M., \& PASCUAL, J. (2010). "La innovación educativa desde la metodología: Mejora de las actitudes y competencias científicas de los estudiantes" en Escritos de Psicología (Internet), 3, p. 1-10.

LILA, M., OLIVER, A., GALIANA, L., y GRACIA, E. (2013). "Predicting success indicators of an intervention programme for convicted intimate-partner violence offenders: The Contexto Programme" en The European Journal of Psychology Applied to Legal Context, 5, p. 73-95.

MARTIN-FERNANDEZ, M., y REVUELTA, J. (2017). "Bayesian estimation of multidimensional item response models. A comparison of analytic and simulation algorithms" en Psicológica, 38, p. 25-55.

MAYDEU-OLIVARES, A., y GARCIA-FORERO, C. (2010). "Goodness-of-fit testing" en International encyclopedia of education, 7, p. 190-196.

NUNNALLY, J. C., Y BERNSTEIN, I. H. (1994). “The assessment of reliability" en Psychometric theory, 3, p. 248-292.

RIGA, F., WINTERBOTTOM, M., HARRIS, E., Y NEWBY, L. (2017). "Inquiry-Based Science Education" en Taber, K. S, Akpan, B. Science Education. Rotterdam: SensePublishers.

RECKASE, M. (2009). Multidimensional item response theory. New York: Springer. 


\title{
Espacios de creación: Innovación y mejora docente en Historia del Arte [Ars Memoriae]
}

\section{Marta Serrano Coll ${ }^{a}$ y Esther Lozano López}

a Universidad Rovira i Virgili. Departamento de Historia e Historia del Arte (marta.serrano@urv.cat) y ${ }^{\mathrm{b}}$ UNED - (elozano.tortosa@uned.es)

\begin{abstract}
After the reflection on the role and function of Art History in society, the interdisciplinary group "Ars Memoriae" has decided to focus its efforts on post-compulsory education. Convinced that an improvement in the dialogue between the professors of the University and High School has positive repercussions on the teaching-learning of our discipline, the project presented here aims to encourage students to enjoy Art from an updated, critical and rigorous perspective in which the latest contributions of the specialists are put in value. Only from the cooperation between the two formative stages the needs and problems of teachers and students can be better understood. Our project aims to open an innovative way in the creation of digital materials and resources of History of Art, a task that affects the improvement of teaching methods and of student learning.
\end{abstract}

Keywords: History of Art, teaching-learning, strategies, technologies, multidisciplinarity, updating, quality, "Selectivity" (Spanish University admissions requirement.

\section{Resumen}

Tras la reflexión acerca del papel y la función de la Historia del Arte en la sociedad, el grupo interdisciplinar "Ars Memoriae" ha decidido focalizar sus esfuerzos en la educación postobligatoria. Convencidos de que una mejora en la relación de diálogo entre los profesores de la Universidad y Secundaria repercute positivamente en la enseñanza-aprendizaje de nuestra disciplina, el proyecto que aqui se presenta pretende estimular a los alumnos a disfrutar del Arte desde una perspectiva actualizada, crítica y rigurosa en la que se ponen en valor las últimas aportaciones de los especialistas. Sólo desde la cooperación entre las dos etapas formativas se pueden entender mejor las necesidades y los problemas de los profesores y los alumnos. Nuestro proyecto abre una vía innovadora en la creación de materiales y recursos digitales de Historia del Arte, tarea que repercute en la mejora de los métodos docentes y en la mejora del aprendizaje de los estudiantes.

Palabras clave: Historia del Arte, enseñanza-aprendizaje, estrategias, tecnología, multidisciplinariedad, actualización, calidad, selectividad. 


\section{Introducción}

El proyecto educativo que presentamos, Ars Memoriae, nace de una necesidad detectada a partir de la reflexión sobre la disciplina de la Historia del Arte en el presente. Nos hemos interrogado acerca del papel que ocupan los historiadores y sus investigaciones en la sociedad, y hemos tratado de entender las necesidades de quienes encarnan su futuro, los alumnos. Como docentes, hemos analizado nuestros modelos pedagógicos y las prácticas educativas, las estrategias metodológicas, la calidad de los recursos didácticos, los criterios e instrumentos de evaluación, y las características (fortalezas, debilidades y nivel académico) de los estudiantes de esta etapa de transición (Bachillerato y primeros años del Grado universitario de Historia del Arte), principales protagonistas de este proyecto. El punto de partida previo al trabajo que aquí presentamos ha sido tratar de encontrar el origen de alguno de los problemas que derivan en el escaso protagonismo de los historiadores del Arte en la sociedad y en buena parte de las intervenciones que se realizan sobre el Patrimonio. Sabemos que no hay una única causa que pueda explicar el insuficiente reconocimiento de nuestra disciplina, pero sabemos que los alumnos de Secundaria y los de Universidad son protagonistas activos que pueden contribuir al cambio, siendo ellos, además, quienes permiten entender parte del diagnóstico.

\section{Objetivos}

\subsection{Precedentes}

Con frecuencia la Universidad no tiene en cuenta la docencia en Secundaria, por lo que no dialoga con ella para establecer vías de cooperación. Nuestra clara voluntad es la de contribuir, en la medida de lo posible, a invertir esta situación desde las propias aulas, queriendo establecer una verdadera conversación, fundamental, con intercambio de opiniones y debates, entre las dos etapas formativas. En una primera valoración hemos constatado la falta de información (contenidos y experiencias, principalmente) entre profesores de Secundaria y Universidad, además de una escasa coordinación interdepartamental en ambas etapas. La propuesta pedagógica que desarrollamos fue presentada a la convocatoria, de concurrencia competitiva

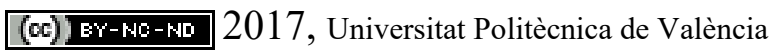


anual ${ }^{1}$, de 2016 "Ajut Pont per a Projectes educatius" del Consell Social y del Institut de Ciències de l'Educació de la Universitat Rovira i Virgili, siendo beneficiada con una de las diez ayudas económicas concedidas a los proyectos más relevantes.

La iniciativa de generar puentes entre Secundaria y Universidad, como acabamos de comentar, ha partido de una conciencia sobre la Historia del Arte y su papel en nuestro entorno, tarea que llevamos realizando desde hace años. Esta preocupación derivó en la realización de dos Workshop, celebrados en el seno de la URV, dirigidos por Marta Serrano y abiertos a docentes de las dos etapas formativas: el 12 de diciembre de 2012 se llevó a cabo El rol actual de la Historia del Arte (I): Del purgatorio académico al compromiso social ${ }^{2}$ y el 18 de diciembre de 2013 El rol actual de la Historia del Arte (II): Visiones periféricas de una profesión"3. Muy pronto se puso de manifiesto la necesidad y la posibilidad de focalizar nuestros esfuerzos para generar un diálogo fructífero con el fin de establecer nexos entre las principales etapas formativas de nuestros estudiantes, los futuros

1 El proyecto está coordinado por E. Lozano, conformado por profesores de cinco centros de Secundaria y uno de la Universidad Rovira i Virgili, y lleva por título "Espais de creació: innovació, formació, recerca i millora docent en Història de l'Art (Ars Memoriae)". La convocatoria fue resuelta el 13 de julio de 2016. Aprovechamos desde estas líneas para agradecer el soporte del Consell Social y del ICE a nuestro proyecto, uno de los 30 galardonados en tres años de un total de 89 presentados.

2 Este seminario tenía como objetivo principal analizar y profundizar sobre la epistemología y problemática de la Historia del Arte a partir de la visión de los Historiadores del Arte que trabajan dentro y fuera de nuestra disciplina. Participaron como invitados R. Martínez, de la Diputación de Palencia y Responsable del Departamento de Cultura, que ofreció la conferencia La Historia del Arte y su destino social. El grado universitario desde fuera de la Universidad; G. Boto, Profesor Titular de la Universitat de Girona, que intervino con Intersecciones epistemológicas de la Historia del Arte con otras disciplinas: estado de la cuestión; J. Martínez de Aguirre, Catedrático de la Universidad Complutense, presentó ¿Crisis de identidad, crisis de crecimiento? Una reflexión desde la implantación del Grado en Historia del Arte; E. Lozano, Profesora-Tutora de la UNED y Profesora del INS Jaume I de Salou ofreció Para una enseñanza de base de la Historia del Arte: precepciones desde Secundaria y Bachillerato; mientras que, finalmente, A. García Avilés, Catedrático de la Universidad de Murcia y Miembro de la ANECA, presentó La Historia del Arte del siglo XXI: en busca del tiempo perdido.

${ }^{3}$ Este segundo seminario tenía por objeto ofrecer una visión exógena de nuestra disciplina. En él participaron C. García de Castro, Arqueólogo de la Consejería de Educación, Cultura y Deporte del Principado de Asturias, que presentó La Historia del Arte y la Arqueología, ¿una relación condenada al fracaso? Propuestas sobre las que trabajar; J. Portal, Arquitecto Responsable del Plan Director de la Restauración de Poblet ofreció El Historiador del Arte: su papel en los proyectos de restauración del patrimonio arquitectónico; M. Vendrell, Profesor Titular de la Universitat de Barcelona-Patrimoni 2.0 presentó ¿La Historia del Arte distante del análisis científico? Visión de la profesión dentro del ámbito de la conservación; J. Á. Montañés, Periodista de El País (Área de Cultura) intervino con La Historia del Arte desde un punto de vista periodístico: encuentros y desencuentros de una relación condenada a entenderse; I. Salgado, Subdirectora del Área de Cultura de la Fundació La Caixa presentó La Historia del Arte del siglo XXI. Legitimación y legitimidad de la disciplina en el mundo de la exhibición de las obras artísticas, y R. M. Guijarro, Catedrática del INS Jaume I de Salou, intervino con La Historia del Arte en Secundaria: pronósticos y diagnósticos.

(c)) BY-NC-ND 2017, Universitat Politècnica de València 
profesionales de la disciplina, y así reflexionar sobre los procesos de enseñanza-aprendizaje, y valorar y mejorar las herramientas docentes. De este modo, el 15 de diciembre de 2014, se desarrolló, también en la Universidad y coordinado por las aquí firmantes, el primer Workshop Secundaria y Universidad (I): A la búsqueda de colaboraciones, intercambios y espacios compartidos en la Historia del Arte donde se llevó a cabo un intercambio de conocimientos y experiencias entre profesores de ambas etapas formativas ${ }^{4}$. Casi veinte docentes de Secundaria y Universidad, entre asistentes e invitados, expusimos sin cortapisas la realidad diaria que nos encontramos en las aulas, reflexionamos sobre la problemática del formato de las evaluaciones, el carácter enciclopédico del temario (desde la Prehistoria hasta las Últimas tendencias artísticas, incrementado ahora en la asignatura "Historia y fundamentos de las Artes I y II" con las artes escénicas, la música, el cine y los nuevos medios digitales), la repetición (en libros de texto y fichas) de tópicos ya superados, y también la presión de las Pruebas de Acceso a la Universidad, evidenciando que en ellas no se evalúan las competencias tal y como se trabajan en las aulas. Finalmente, recalcamos que los listados de obras de las que se examinan los alumnos para Selectividad, en ocasiones contienen piezas locales de discutible relevancia y se dejan de lado otros conjuntos excepcionales. Estas cuestiones, entre otras, resultaron fundamentales para entender cómo es la formación de los alumnos que llegan a la Universidad, pero además, en el diagnóstico se evidenció la falta de diálogo ya aludida y el estado de orfandad (término empleado por más de un participante) en el que se encuentran tantas veces los profesores de la última etapa formativa previa a la universitaria. Así, ante la urgencia de que los profesionales de los dos niveles trabajaran sistemáticamente sobre muchos aspectos, consideramos imperioso generar un espacio, con continuidad en el tiempo, para intercambiar ideas y generar nuevas experiencias. Prueba de nuestra

\footnotetext{
${ }^{4}$ Para debatir sobre los problemas con los que se enfrentan los docentes de Historia del Arte (entonces sólo en Segundo de Bachillerato) y reflexionar acerca de los contenidos y metodologías de ambas etapas formativas, asistieron como invitados J. R. Triadó, Catedrático de la Universitat de Barcelona y Coordinador de las PAU en Catalunya, que presentó la conferencia Las pruebas de acceso a la Universidad. Qué son y cómo son: valoraciones generales; R. M. Guijarro, Catedrática de Secundaria en el INS Jaume I de Salou, ofreció Los planes de estudio y el currículum: cuestiones sobre las que debatir; H. Calvo, Profesor de Secundaria del Estonac-Enseñanza de Tarragona, presentó La asignatura de Historia del Arte. Visión desde una institución concertada; E. Lozano, Profesora-Tutora de la UNED y Profesora del INS Jaume I de Salou, intervino con ¿Es necesario generar puentes entre Secundaria y la Universidad? Visión a dos bandas; y L. Buttà, Profesora Agregada de la URV, presentó Diálogos sobre arte: una iniciativa consolidada.
}

(c) EY-NC-ND 2017, Universitat Politècnica de València 
voluntad de cambio ha sido la celebración, el 11 de diciembre de 2015, de Secundaria y Universidad (II): El aprendizaje reciproco del alumnado de Historia del Arte a través de una experiencia de innovación docente donde se mostró una novedosa práctica en la que los alumnos de Secundaria y de Universidad fueron los verdaderos protagonistas de su aprendizaje. La actividad presentada se desarrolló a lo largo de los meses de octubre, noviembre y diciembre. El objetivo era la construcción del conocimiento colaborativo, en este caso, entre estudiantes de diversas etapas académicas que tenían en común el vínculo con Tarragona, ciudad Patrimonio de la Humanidad que aún hoy está marcada en su fisonomía por los restos romanos. En una primera sesión los alumnos de la Universidad acudieron al Instituto Jaume I de Salou para realizar la jornada Comitium (primer encuentro) y desarrollar la plataforma virtual La Égida de Minerva a través de la cual se comunicarían entre ellos y colgarían materiales. Semanas después, en la Universidad y también con los alumnos de Secundaria, se realizaron las sesiones Concilium y Plebiscita, mediante las cuales los alumnos, por grupos, presentaron y escogieron una de las propuestas de itinerarios a realizar en la actividad final. Una vez llegado al consenso, entre todos perfilaron el recorrido por la Tarraco romana que los alumnos del Bachillerato artístico, siempre asesorados y tutorizados por los de Universidad, debían ejecutar. Las competencias e inquietudes de los estudiantes de Secundaria permitieron recrear, mediante dibujos, maquetas y performances, el ambiente de la ciudad en época flavia. La actividad se llevó a cabo el 11 de diciembre y culminó en la "Reial Societat Arqueològica Tarraconense", una muy relevante asociación cultural de la ciudad.

Dos años después, el 5 de mayo, y con otro carácter, aunque otra vez integrando al profesorado de las dos etapas formativas, se celebró Secundaria y Universidad (III): De la teoría a la práctica en la innovación y mejora docente en la Historia del Arte ${ }^{5}$.

\footnotetext{
${ }^{5}$ En la jornada, M. Serrano, Profesora Agregada interina de la URV, presentó Ars Memoriae: un largo proceso de trabajo en equipo; E. Lozano, Profesora-Tutora de la UNED y Profesora del INS Jaume I de Salou, ofreció Presentación del Proyecto "Espais de creació: innovació i millora docent en Història de l'Art (Ars Memoriae)"; I. Solla, de Gecko Diseño Gráfico, explicó La plataforma virtual arsmemoriae.cat; B. Porres, Profesora de la Escuela Mare de Déu del Carme de Tarragona, ofreció Creación de nuevos materiales de enseñanza-aprendizaje: las fichas y los nuevos contenidos; B. Travieso, también de la Escuela Mare de Déu del Carme de Tarragona, se centró en Otras disciplinas afines a la Historia del Arte y la importancia del mundo clásico; por su parte, À. Gasol, de
} 
Así, tras varias jornadas académicas, tras algunas experiencias con alumnos $\mathrm{y}$ tras varias reuniones de reflexión en torno a la disciplina de la Historia del Arte en la Educación postobligatoria ${ }^{6}$, llegamos a la conclusión de que era imprescindible elaborar un material docente innovador a partir de la praxis educativa y la investigación universitaria para las asignaturas que se desarrollan en el Bachillerato: "Historia y fundamentos de las Artes I y II"7, e "Historia del Arte". Era necesario generar un material unificado, riguroso, actualizado, sin lagunas y sin tópicos, con carácter interdisciplinario, que ayudase a alcanzar los requisitos demandados en las asignaturas de los primeros cursos universitarios y que sirviese para poner fin a los desajustes detectados entre las dos etapas académicas.

\subsection{Propósito de Ars Memoriae}

Las reuniones (primero informales y ahora formales) del Grupo de Trabajo reconocido por el Institut de Ciències de la Educació de la URV de Mejora docente Ars Memoriae (con las aquí firmantes Esther Lozano como coordinadora desde Secundaria y Marta Serrano desde la Universidad) han servido para cumplir el objetivo de contribuir a superar una parte del tan generalizado, y para muchos irresoluble, aislamiento que mantienen las Universidades y los Institutos, pero también para detectar el porqué de las carencias formativas de los alumnos. Nuestro trabajo, siempre de carácter cooperativo, supone, si no un primer paso, un paso más para solucionar los problemas con los que nos enfrentamos los docentes de las dos etapas académicas. Diseñar mecanismos que permitan lograr diagnósticos compartidos, crear trabajos colaborativos con continuidad en el tiempo, y divulgar, visibilizar y valorar la Historia del Arte también en las enseñanzas

la Escuela Camp Joliu de l'Arboç, explicó Tareas novedosas en torno a la obra de Arte para un aprendizaje estimulador; y E. Rabasa, Profesor del INS Jaume I de Salou, participó con Las obras de arte desde la perspectiva de los textos. Por la tarde intervinieron C. Mas, Catedrático del INS Andalán de Zaragoza, con la ponencia Una carrera de fondo: recursos clave para mejorar la docencia en Historia del Arte y C. Fuentes, Profesora Agregada de la Universitat de Barcelona, con Nuevos caminos por recorrer: didáctica de la Historia del Arte.

${ }^{6}$ Las múltiples reformas educativas, siete desde 1970, no han ayudado a potenciar el interés por el Arte y no han revisado la extensión de los contenidos de Ciencias Sociales, que dejan muy poco espacio para el estudio del Patrimonio. Los estudiantes de la ESO deberían ser capaces de comprender cómo una obra de Arte se transforma a partir de las lecturas que de ella se hacen, pero no hay tiempo: en cuatro cursos se tiene que explicar toda la Historia de la Humanidad y en este contexto el Arte no es más que un apoyo visual de los textos. Por tanto, al llegar a Bachillerato tienen muy poca base.

${ }^{7}$ Es interesante la nomenclatura de la asignatura en Catalunya "Història i fonaments de les arts" frente a "Fundamentos del Arte", una terminología que requeriría una reflexión de base.

(cc) EY-NC-ND 2017, Universitat Politècnica de València 
medias (aunque no únicamente) ${ }^{8}$ son algunos de los más relevantes objetivos que nos hemos marcado.

También consideramos fundamental el impacto, especialmente el que redunde en los estudiantes, porque defendemos su participación pro-activa, que tiene tan buenos resultados, como podemos acreditar tras haberlos hecho partícipes como elemento imprescindible y activo en el caso del ya aludido aprendizaje recíproco a través de una experiencia de innovación docente que llevamos a cabo durante el primer trimestre del curso 20152016, experiencia escogida para ser presentada en el IX Congreso Internacional de Docencia e Innovación (CIDUI_16, Barcelona) y luego publicada ${ }^{9}$. También los alumnos han sido los protagonistas del Proyecto "La Galería", vinculado con Ars Memoriae y puesto en marcha este curso escolar 2016-2017. De forma permanente, en el vestíbulo del INS Jaume I de Salou cada dos meses se escogen dos pinturas del largo listado de las obras a analizar para las Pruebas de Acceso a la Universidad y se exponen sus reproducciones en gran formato y calidad. El día escogido, estos cuadros son confrontados en un espacio frente al que pasan todos los días todos los estudiantes del centro, y sus contenidos son trabajados mediante diversas metodologías. Una de ellas, la de la clase magistral, es la que llevan a cabo miembros de otros departamentos, quienes tras una hora de exposición de sus conocimientos aplicados a las obras de Arte escogidas, conversan y dialogan con los alumnos ${ }^{10}$.

\footnotetext{
${ }^{8}$ La escasa presencia de la Historia del Arte en Secundaria ha llevado a J. Díaz, Profesor Titular de Historia del Departamento de Historia del Arte de la Universidad de Castilla-La Mancha, a la redacción de un escrito reivindicativo de nuestra disciplina dirigido a la subcomisión para el Pacto Educativo (Congreso de los Diputados) y que han firmado la mayor parte de directores de departamentos universitarios que tutelan docencia e investigación en Historia del Arte.

${ }^{9}$ E. Lozano y M. Serrano (2016), "Estratègia d'Innovació Docent en l'àmbit d'Història de l'Art a través d'una experiència de col·laboració activa entre Secundària i Universitat", en Revista CIDUI (puede descargarse a través del enlace www.cidui.org/revistacidui).

${ }_{10}$ Antes de que se cambien las obras del vestíbulo, los estudiantes realizan una actividad profesionalizadora: se convierten en "comisarios" de la "exposición": piensan el hilo argumental de la historia, diseñan las evidencias materiales que utilizarán (trípticos, por ejemplo), justifican en un portafolio la elección de las piezas a trabajar, destacan los aspectos más significativos de sus propuestas, determinan qué tipo de relaciones que buscan establecer con los destinatarios finales, y deben demostrar que conocen otros diseños de materiales para discriminar las estrategias educativas más frecuentes. Los contenidos que analizan se completan con la conferencia de un profesor de otro departamento (lo que manifiesta la transversalidad) que constituye la "Visión invitada": por ejemplo, las pinturas del Nacimiento de Venus de Botticelli y La Virgen de las Rocas de Da Vinci fueron explicadas por un miembro del Departamento de Ciencias Naturales que se centró en la botánica; la Capilla Sixtina de Miguel Ángel y la Escuela de Atenas de Rafael por un profesor de Religión que profundizó en las estancias del Vaticano; y Danae de Tiziano y Judith decapitando a Holofernes de
} 
Además de hacer intervenir a los estudiantes, el proyecto Espais de creació: Ars Memoriae se ha marcado como objetivo incidir directamente en los profesores de Secundaria, porque se sumerge en la programación de la propia materia del Bachillerato. Es un reto para todos reflexionar sobre los contenidos curriculares y sus condicionantes, el carácter memorístico del aprendizaje, el volumen de datos demandado, el escaso tiempo del que dispone el profesor para que los alumnos "saboreen" y no "deglutan" la asignatura, la presión de las PAU y la finalización de la materia en mayo, la ausencia de contextualizaciones, la complicada explicación de la naturaleza dialéctica de los procesos históricos, e incluso las competencias reales que tienen los alumnos en esta etapa que podríamos denominar "de transición", porque en menos de tres meses concluyen el Instituto y empiezan la Universidad. El proyecto aparte de integrar a los alumnos y crear herramientas útiles para los profesores tiene también el objetivo de cumplir con la misión de la transferencia y difusión de los conocimientos científicos y pedagógicos, puesto que una de las finalidades fundamentales es, precisamente, generar y compartir nuevos materiales docentes, abiertos y de dominio público, a partir de las nuevas investigaciones de los más prestigiosos académicos. Avala esta voluntad el hecho de que dos de los miembros del equipo son doctoras, trabajan en el ámbito de la investigación y cuentan con experiencia tanto en la docencia Universitaria y como en la de Secundaria. Nuestro grupo de trabajo tiene un carácter interdisciplinar al estar integrado por profesorado de Educación Secundaria que es especialista en Historia, Arte, Geografía, Literatura, Latín, Religión e Inglés. Pensamos que sólo podemos comprender un efectivo y correcto análisis del Arte mediante un diálogo, integrador, entre diversas perspectivas y disciplinas.

\section{Desarrollo de la innovación}

Al margen que consideremos que la presencia de la Historia del Arte en el marco de la LOMCE debería incrementarse, en el presente sigue siendo necesario actualizar herramientas y materiales (tantas veces con interpretaciones ya superadas o incluso con errores) para conseguir que los alumnos superen los ejercicios de mera descripción, sean instados a

Artemisia Gentileschi por una profesora del Departamento de Lenguas Clásicas que ahondó en la mitología y la pervivencia de algunos modelos de mujeres clásicas en la religión cristiana.

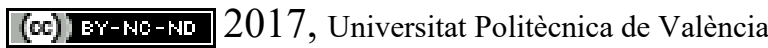


desarrollar la argumentación y, también, se vean capacitados para conectar los datos aprehendidos en otras asignaturas. En esta línea, nuestro proyecto se ha marcado como principal objetivo generar materiales docentes competenciales, actualizados y de la mayor calidad posible, para las asignaturas de Arte (sobre todo las de segundo de Bachillerato).

En el marco del estudio por competencias (generales y específicas de la materia) hemos empezado a realizar parrillas de análisis que, consensuadas en nuestras reuniones, son utilizadas para impartir todos los temas. Las rúbricas se colgarán en la red y quedarán a disposición pública (mediante licencias por la reutilización no comercial de los datos), porque queremos ofrecer a quien lo desee herramientas actualizadas en consonancia con las nuevas interpretaciones de las arquitecturas, pinturas o esculturas, yendo más allá de los tópicos ${ }^{11} \mathrm{y}$ de las interpretaciones superadas y monolíticas que podemos aseverar tras el concienzudo análisis del material de las editoriales más utilizadas en Secundaria, tarea que nos ha permitido comprobar que casi ningún contenido está actualizado desde los años 80 .

También es nuestra intención reflexionar y ayudar al profesorado a construir nuevos útiles que permitan educar la mirada y trabajar de forma atractiva para conseguir una mejor comprensión del alumno. Dado el ingente temario de las asignaturas, un objetivo claro del Proyecto es cumplir con las propuestas, ser realistas y no proponer más de lo que se puede hacer en el tiempo previsto, por lo que hemos decidido centrar nuestros esfuerzos, de momento, sólo en las obras de época medieval. De todos modos, nuestra propuesta nace con proyección en el tiempo: es cierto que hemos empezado en la Edad Media, pero nuestra intención es, desde la misma perspectiva actualizada, globalizadora y con idénticas metodologías a las que estamos aplicando en las obras del medioevo, volver a repensar, en una segunda y tercera fases, sobre el resto de grandes obras de la Humanidad. Sólo así, los alumnos serán conscientes de que el Patrimonio cultural es una de las fuentes de riqueza e identidad de nuestra sociedad, y que además es uno de los principales agentes para configurar y articular el bienestar económico e

\footnotetext{
${ }^{11}$ Como por ejemplo, el tan generalizado cliché de que en el románico se construyen iglesias pequeñas y oscuras, mientras que en el gótico son grandes y luminosas, algo que además de falso también se enseña en otros países, como Francia, según expresaba, no sin indignación, la profesora Quitterie Cazes en su conferencia "Jerarquizar los espacios en las iglesias románicas de Francia: topografía, márgenes y significado del coro", ofrecida en el V Ars Mediaevalis. La arquitectura como imagen en la Edad Media, en Aguilar de Campoo, 25-27 de septiembre de 2015.
}

(c)) BY-NC-ND 2017, Universitat Politècnica de València 
intelectual de quienes habitan un territorio. No podemos dar la espalda a lo que tenemos, no podemos no entender los testimonios de nuestro pasado. El Arte es esencial, porque supone tanto para el profesor como para el alumno una formación integral, a pesar de que su consideración en la actualidad está muy alejada de la realidad.

En cuanto a la metodología, en las primeras reuniones interdisciplinares se consensuó el modelo de los recursos; se determinó la forma de la página web que hemos creado http://www.arsmemoriae.cat/en/home-2/ (que aún estamos implementando con nuevos contenidos, aunque ya está abierta al público) ${ }^{12}$; se diseñaron las guías de algunas de las actividades que debería realizar el alumnado, proponiendo entre ellas algunos ejercicios de autoevaluación e incluso coevaluación, se determinó cómo realizar la ubicación espacial y temporal de las obras (mediante un google maps y un timeline); se están elaborando plantas a escala para hacer comparativas de tamaños, y se propuso una primera guía de comentario para fomentar el interés y el aprendizaje del alumno. Dado que nuestro trabajo tiene un fuerte componente colaborativo, la elección de los contenidos se debate entre todos, teniéndose muy en cuenta la experiencia de Esther Lozano y Marta Serrano porque dedican parte de su esfuerzo profesional a la investigación dentro de proyectos financiados por el Ministerio y por la Generalitat ${ }^{13}$. Evidentemente también, la de Rosa $\mathrm{M}^{\mathrm{a}}$ Guijarro como catedrática de Enseñanza Secundaria que ha impartido la asignatura de Historia del Arte durante casi 30 años ${ }^{14}$.

En el proyecto se implican varios centros de Secundaria entre los cuales destaca el INS Jaume I de Salou con dos profesores: una licenciada en Historia y doctora en Historia del Arte, quien lidera el proyecto y que también es profesora-tutora en la UNED, y un licenciado en Historia y Graduado en Magisterio que hoy imparte Religión. A ellos se suma una catedrática cuya formación primera fue en Geografía y que, como se ha comentado ya, ha impartido Historia del Arte durante casi tres décadas. El

\footnotetext{
12 En la página web se han colgado las fichas actualizadas con nuestros criterios de bibliografía reciente y datos científicos de los más relevantes estudios de las obras de las que los alumnos serán evaluados en Selectividad según el "Llistat d'obres d'Història de l'Art. PAU" (que no ha cambiado desde 2014). Cada estudio se completa con una propuesta de actividades de trabajo, los textos que permiten entender la iconografía o el estilo, anécdotas, restauraciones, ubicación espacial y cronológica y, por supuesto, fotografías de calidad con detalles.

${ }^{13}$ Véase Academia.edu o https://sites.google.com/templamedieval.com/templa/templa.

${ }^{14}$ En la actualidad está jubilada, aunque participa activamente en el Proyecto.
}

(cc) EY-NC-ND 2017, Universitat Politècnica de València 
carácter transversal viene remachado con la implicación del resto de profesores: uno de la Escuela Superior de Diseño y Arte, la Llotja de Barcelona, codirector de la Galería The Grey Square de Tarragona; una docente del INS de Altafulla que imparte lengua inglesa; un profesor de la Escuela Camp Joliu de l'Arboç que cuenta con un máster en Museología y Gestión del patrimonio cultural; y dos profesoras del Colegio Mare de Déu del Carme de Tarragona que imparten, entre otras asignaturas, Historia del Arte y Latín. En el ámbito de la Universidad el proyecto cuenta con una profesora agregada interina, licenciada en Historia y doctora en Historia del Arte que imparte docencia en los grados de Historia y de Historia del Arte y en un máster interuniversitario en Cultura Medieval. Así, además de la interdisciplinariedad, el equipo de trabajo cuenta con profesionales de reconocido prestigio que trabajan directamente en el ámbito del Arte y con un papel activo en la sociedad, desde la misma creación artística, la investigación o la difusión de contenidos. Igualmente, nuestro grupo de trabajo Ars Memoriae se ve beneficiado por las diversas perspectivas que confluyen del ámbito profesional de sus componentes y de los proyectos en los que algunos de los miembros participamos ${ }^{15}$, porque parte de las líneas de trabajo y las conclusiones se aplican, en la medida de lo posible y siempre que se considere adecuado, en la creación de los nuevos materiales.

En cuanto a innovación, podemos acreditar también que el impacto del proyecto entre el alumnado de los centros participantes es directo y efectivo, porque los materiales que estamos realizando están sirviendo para mejorar el conocimiento de las obras estudiadas, ahora más profundo, transversal e incluso emocionante con las nuevas herramientas de aprendizaje. En este sentido, y de acuerdo con el plan estratégico de la URV, nuestro proyecto se inserta en la llamada Tercera Misión (transferencia), porque, detectada la carencia de canales de coordinación entre Secundaria y Universidad y el desajuste entre el nivel de conocimientos y competencias logrados en Secundaria y las exigencias en los primeros cursos del Grado de Historia del

\footnotetext{
15 Por citar los más recientes, TEMPLA: "Taller de Estudios Medievales. Programas, Liturgia, Arquitectura", constituido por investigadores de universidades, museos y archivos de diferentes precedencias españolas y europeas, con especial relevancia de Cataluña. También mencionaremos el proyecto financiado por el Ministerio Sedes Memoriae. Espacios, Usos y discursos de la memoria en las catedrales medievales de la Tarraconense I: memoria institucional, legados personales [HAR2015-63870-R]; el Grup de Recerca financiado por la Generalitat de Catalunya Edificis $i$ escenaris religiosos medievals a la Corona d'Aragó [2014SGR 110]; y el proyecto Recercaixa Cathedral Cities: Memories, Landscapes and Identitarian Heritage of Europe.
} 
Arte, procuramos consensuar los niveles, recursos y habilidades de nuestros alumnos. Esta propuesta encaja también con el Plan estratégico del INS Jaume I, concretamente con el objetivo 1 de mejora de los resultados educativos, destinado a conseguir un elevado nivel académico, mejorar en el logro de las competencias básicas y profundizar en la coordinación curricular interdepartamental. Para finalizar, tan sólo diremos que el progreso en la práctica reflexiva que proponemos es fundamental para profesores y alumnos, como lo es, igualmente, el uso de las TIC, las TAC e incluso las TEP en los procesos de enseñanza-aprendizaje, por lo que nuestro proyecto conecta también con el objetivo de favorecer la integración de las tecnologías y los recursos digitales en la gestión en el aula.

La mejora que proponemos es extensible al proyecto educativo de otros centros al contribuir al fortalecimiento de las competencias profesionales del profesorado mediante la elaboración de acciones conjuntas y propuestas prácticas que promueven la cooperación entre niveles de enseñanzas para asegurar una mayor conexión y coherencia disciplinaria. Y todo ello sin olvidar que supone la potenciación de la Historia del Arte y la creatividad como estrategias para alcanzar el objetivo estratégico 3 de la URV que consiste en la mejora de la confianza de los grupos de interés. Nos consta que el Departamento de Enseñanza de la Generalitat de Catalunya tiene como líneas prioritarias la identificación, recogida y difusión de prácticas educativas de referencia, así como también el reconocimiento de los proyectos apoyados por redes internacionales, el soporte para los grupos que trabajen para la creación de acciones innovadoras para el desarrollo del plurilingüismo (en nuestro caso catalán, castellano $\mathrm{y}$, progresivamente aunque ya desde el inicio, inglés), y la promoción de la educación intercultural, de la que forma parte, sin duda, la Historia del Arte. Por tanto, concluimos asegurando que el proyecto multidisciplinar Ars Memoriae es coherente y viable y contribuye a la mejora de las competencias básicas como la lectura gráfica y visual en una sociedad saturada por las imágenes (aunque muchos alumnos no sepan, todavía, leer lo que ven), y cuenta ya, desde el origen, con una serie de resultados que ayudan al alumnado, de forma distinta y atractiva, a adquirir nuevos saberes y destrezas.

\section{Resultados}

(c) EY-NC-ND 2017, Universitat Politècnica de València 
Dejando a un lado la creación del grupo interdisciplinar, costosa pero muy satisfactoria, y el trabajo resultante de las numerosas reuniones y decisiones que ya se han puesto de manifiesto con anterioridad, el resultado más relevante que queremos destacar aquí es la página web arsmemoriae.cat que ya está en uso. En ella pueden consultarse las "fichas" de las obras que hemos escogido en esta primera fase y que incluyen sus datos básicos y sus comentarios respectivos acompañados por un mapa de localización de coordenadas GPS (la inicial; es decir, el lugar de creación de la pieza, y/o la actual, es decir; la ubicación de la obra si está descontextualizada), y una detallada y aclaratoria referencia del marco geográfico. En página pueden consultarse los comentarios actualizados de las obras medievales, y también se pueden encontrar las referencias bibliográficas más recientes y de más fácil acceso. Esta información, en abierto, se ve reforzada a través de recursos didácticos de calidad con restituciones virtuales, o incluso presentaciones y vídeos colgados por grupos de trabajo de diferentes universidades $^{16}$. Igualmente, aparecen recursos de museología mayoritariamente procedentes de las sedes que custodian las obras estudiadas; material documental como fotografías antiguas en las que se vean modificaciones, destrucciones, pérdidas, reutilizaciones y restauraciones como resultado de actitudes y valores cambiantes; películas, con fragmentos a analizar; artículos; textos literarios que son escogidos como fuente de conocimiento histórico con los que aproximarnos a la obra desde un estudio comparado; glosarios, a veces visuales de técnicas artísticas y de construcción; etc. Asimismo, cuando es posible, se ofrece un recorrido por la vida de cada obra, comentándose, en un apartado dedicado a curiosidades, las vicisitudes más importantes a las que ha sido sometida, las restauraciones, etc. Cuando ha sido preciso, hemos establecido las relaciones literarias que permiten entender los temas o el contexto histórico, poniendo especial énfasis en la filosofía o incluso en la música, o la trayectoria vital del artista. Esta base de datos, sencilla para el usuario, pero muy compleja en su elaboración, es colaborativa y se está creando mediante la participación y la consulta de profesores y alumnos, teniendo siempre en cuenta las licencias (principalmente creative-commons) y los derechos de autor. Por el momento, la visibilidad, edición y difusión del material

16 Entre las que destaca la UB Didàctica del Patrimoni, Museografia comprensiva $i$ noves Tecnologies; Didáctica de la Historia, la Geografía y otras Ciencias Sociales; Histodidàctica; o Didàctica de les Ciències Socials de la Universitat Autònoma de Barcelona, por ejemplo. 
didáctico elaborado se hace a partir de la página web, si bien nos planteamos la posibilidad de poder publicarlo en papel más adelante, porque queremos poner estas herramientas al servicio de la docencia y queremos que nuestro proyecto se convierta en un espacio de referencia. Las lenguas oficiales son el catalán y el castellano (aún se está montando), aunque con keywords y summary en inglés, puesto que, dejando al margen el interés por la internacionalización, una de las competencias del alumno en Secundaria y en la Universidad es adquirir un nivel medio de esta lengua.

Queremos subrayar que no nos proponemos dar más información, sino ofrecer contenidos actualizados, atractivos y pertinentes que contribuyan a la mejora efectiva de la calidad educativa, siempre partiendo del análisis de los temarios y contenidos de los principales manuales de Bachillerato con el fin de determinar qué es adecuado también para los requisitos y necesidades de las asignaturas de la Universidad, porque nuestro proyecto de creación de material docente competencial y actualizado sirve para preparar las pruebas de acceso a las carreras de Humanidades. Y para ello hemos diseñado también acciones formativas para el profesorado de Secundaria, mediante talleres didácticos para visibilizar la disciplina y para dar a conocer el grupo de trabajo, como el de Secundaria y Universidad III, cuya asistencia, como las de las anteriores, ha sido reconocida por la Generalitat de Catalunya.

\section{Conclusiones}

Nuestro proyecto pretende abrir una vía innovadora en la creación de materiales de Historia del Arte, tarea que repercute en la mejora de los métodos docentes y en la mejora del aprendizaje de los estudiantes. Es evidente que en la red hay mucho material sobre esta materia, pero no existe un lugar (repositorio o plataforma) en el cual se presenten, de manera sistemática y al tiempo creativa, estudios interdisciplinares actualizados con las más recientes aportaciones de investigadores de reconocido prestigio sobre las principales obras de Arte de la Historia de la Humanidad. A veces, el exceso y dispersión de la información dificulta, tanto para profesores como para alumnos, encontrar lo que necesitan: arsmemoriae.cat ofrece, en abierto, una solución al problema.

Con Ars Memoriae hemos sido capaces de potenciar las competencias actitudinales del trabajo en equipo, y hemos realizado de forma colaborativa

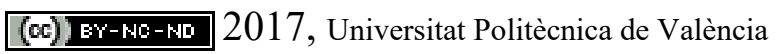


la toma de decisiones, sin perder autonomía y responsabilidad tanto por parte de profesores de Secundaria como de Universidad, que en esta ocasión actúan como iguales y superan, por tanto, la tan problemática -y falsarelación de "inferioridad-superioridad". Y, por supuesto, a través de nuestro equipo transversal, hemos sido capaces de fomentar la interdisciplinariedad en la comprensión de los testigos de nuestro pasado, promoviendo una cultura de la calidad, y fortaleciendo la formación cultural de los alumnos, pilar fundamental de la sociedad, a través de un aprendizaje verdaderamente competencial. Si queremos que nuestros estudiantes sean cultos y tengan espíritu crítico, hay que reivindicar el papel del conocimiento en Historia del Arte ya desde los primeros años de la escuela porque, tal y como se destaca en la Petición de Florencia (2009): "una formación de al menos una hora semanal en Historia del Arte en los 27 países miembros de la Unión sería para los jóvenes europeos una preciosa ocasión de encuentro con la riqueza artística de su ciudad, de su país y de Europa, de invitación a la movilidad y al descubrimiento en el seno del continente y de integración cultural europea en el respeto a la historia"17.

\section{Referencias}

Anderson, J. R. (2001), Aprendizaje y memoria: un enfoque integral, Mexico: Mc-Graw-Hill. Alcoverro, C. (2000). "Comentar obres d'art a Batxillerat" en Articles de Didàctica de la Llengua i de la Literatura 22, p. 76-87.

CALAF, R. (2003). Arte para todos. Miradas para enseñar y aprender el patrimonio, Gijón: Trea. CALAF, R., FONTAL, O. (2010), Cómo enseñar arte en la escuela, Madrid: Síntesis.

Chalmers, F. G. (1978), "Teaching and Studing Art History: Some Anthropological and Sociological Considerations", en Studies in Art Education. A Journal of Issues and Research, vol. 20, p. 18-25. Cuenca, J. M. (2002). El Patrimonio en la Didáctica de las Ciencias Sociales. Análisis de las concepciones, dificultades y obstáculos para la integración en las enseñanzas obligatorias: Universidad de Huelva, tesis doctoral.

Efland, A.D. (1990), A History of Art Education. Intellectual and Social Currents in Teaching Visual Arts, New York and London: Teachers College Press.

JoHnSON, D. W. y JoHnson F. P. (1999), Learning toghether and alone: cooperative, competitive and individualistic learning, Needham Heights: L\&TA Sharan.

MANRiQue, J. A. (2007), Una visión del arte y de la Historia, México: UNAM.

Rico, L. (2009). La difusión del patrimonio en los materiales curriculares. El caso de los gabinetes pedagógicos de Bellas Artes: Universidad de Málaga, tesis doctoral.

TREPAT, C.A. (2003), "Didácticas de la Historia del Arte: criterios para una fundamentación teórica", en Didáctica de las Ciencias Sociales, Geografía e Historia, núm. 37, p. 7-17

TREPAT, C.A. (2006), "las pruebas de corrección objetiva en la enseñanza y aprendizaje en la Historia del Arte. Una propuesta didáctica”, en Didáctica de las Ciencias Sociales, Geografía e Historia, núm. 49, p. 57-73.

VEGA, J. (2007), "Del pasado al futuro de la Historia del Arte en la universidad española", Ars Longa, núm. 16, p. 205-219.

\footnotetext{
${ }^{17}$ http://peticion.ceeh.es/index.php (consultado 06/11/2012). Petición de Florencia (2009)
} 


\title{
Una nueva mirada a la competencia transversal de trabajo en equipo desde los enfoques de participación y cuidados: El caso del Máster en Cooperación al Desarrollo por la UPV
}

\author{
Carola Calabuig Tormo a , Sergio Belda Miquel ${ }^{\mathrm{b}}$ y Álvaro Fernández-Baldor \\ $\mathrm{a}, \mathrm{b}, \mathrm{c}$ Departamento Proyectos de Ingeniería, Universitat Politècnica de València
}

\begin{abstract}
This communication presents the work carried out to improve and evaluate the development of the transversal competence "teamwork" in the students of the Master's Degree in Development Cooperation by the Universitat Politècnica de València. During the academic years 2015-2016 and 2016-2017 it has been realized emphasizing the approaches of participation and care ethics. The results are being satisfactory and encouraging, due in part to the collaboration with an external Development NGO. But some improvements can be introduced such as deepening the approaches adopted and their transfer to the competence, to extend the proposal to the whole master progressively or to improve the monitoring of the process and the accompaniment of the students.
\end{abstract}

Keywords: teamwork, transversal competences, participation, care ethics, evaluation

\section{Resumen}

La comunicación presenta el trabajo realizado durante los cursos académicos 2015-2016 y 2016-2017 para mejorar y evaluar el desarrollo de la competencia transversal "trabajo en equipo" en el alumnado del Máster en Cooperación al Desarrollo por la Universitat Politècnica de València, desde los enfoques de la participación y los cuidados. Los resultados están siendo satisfactorios y alentadores, debido en parte a la colaboración con una ONGD externa; si bien evidencian elementos susceptibles de reflexión y mejora, como son profundizar en los enfoques adoptados y su traslado a la competencia estudiada, hacer extensible el trabajo en esta competencia a todo el máster progresivamente o mejorar el seguimiento y el acompañamiento al alumnado.
\end{abstract}

Palabras clave: trabajo en equipo, competencias transversales, participación, enfoque de cuidados, evaluación

\section{Introducción}

En el marco de los estudios de gestión de la cooperación al desarrollo existe un intenso debate sobre el rol que la formación superior debe tener en la formación de profesionales del desarrollo. Esta cuestión conecta a su vez con las reflexiones acerca de qué capacidades son 
necesarias para la gestión del desarrollo, y cómo pueden desarrollarse en un proceso de educación formal (Clarke y Oswald, 2010).

En este debate existe una corriente hegemónica, dominada por una perspectiva instrumental y poco crítica con la gestión del desarrollo (Gulrajani, 2010; Mosse, 2005). Según esta visión, las personas dedicadas a la gestión del desarrollo deben ser "buenos técnicos", capaces de manejar los instrumentos de gestión adecuados para identificar las mejores soluciones y guiar adecuadamente el cambio en la dirección deseada (Johnson y Thomas, 2007). Como Peris et al. (2013) mencionan, esta perspectiva implicaría que los procesos formativos en gestión de proyectos de desarrollo se centren en proveer a las y los estudiantes capacidades para manejar herramientas para alcanzar de manera eficiente objetivos prefijados de desarrollo mediante una secuencia lineal de pasos, o al menos mediante una planificación estricta (Clarke and Oswald, 2010).

En cambio, otra corriente más crítica consideraría que estas perspectivas, tecnocráticas y gerenciales, no contribuirían a abordar las causas estructurales de la pobreza y la exclusión sino que, al contrario, reforzarían relaciones desiguales de poder. Esta perspectiva considera que los gestores del desarrollo deberían poner en el centro la naturaleza siempre compleja y política de los procesos de desarrollo, en los que las relaciones de poder juegan un lugar fundamental (McCourt y Gulrajani, 2010; Eyben et al, 2015). Esta visión entendería que los programas de educación superior en gestión del desarrollo, en lugar de centrarse únicamente en el desarrollo de habilidades para el manejo de instrumentos gerenciales de gestión, deberían focalizarse más bien en generar competencias para entender, desvelar y moverse en contextos complejos y embebidos en relaciones de poder, desde una perspectiva, abierta, flexible, colaborativa y adaptativa. Entre estas competencias, tiene un rol fundamental el trabajo en equipo y la actitud cooperativa para un trabajo productivo, respetuoso y transformador.

Esta perspectiva apuntaría por lo tanto a replantear las metodologías de enseñanzaaprendizaje actualmente empleadas en la gestión del desarrollo, así como las metodologías dominantes en el ámbito universitario en general. Distintos autores del ámbito del desarrollo han apuntado que existen numerosos métodos y aproximaciones pedagógicas para desarrollar capacidades que vayan más allá del gerencialismo en la práctica del desarrollo (ver ejemplos específicos en Ortiz Aragon, 2010; Pearson, 2010; Pettit, 2010; Soal, 2010), y que van desde el aprendizaje experiencial a métodos creativos que apelan a las emociones y el uso del cuerpo.

\subsection{Propuesta educativa del Máster en Cooperación al Desarrollo por la UPV}

Es en esta perspectiva crítica del desarrollo y la formación para la gestión del desarrollo que se sitúa la propuesta educativa del Máster Universitario en Cooperación al Desarrollo por la Universitat Politècnica de València (UPV), Especialidad en Gestión de Proyectos y Procesos de Desarrollo (en adelante MCAD). El MCAD es un título oficial de 90 ECTS, orientado a formar profesionales de la gestión del desarrollo con competencias que les permitan una práctica crítica de la cooperación. Aunque arranca en el curso 2011-2012 como título oficial,

(c) EY-NC-ND 2017, Universitat Politècnica de València 
desde 2007 ya se impartía un máster título propio con contenidos y enfoque muy similares, que fue el precedente del actual título.

El MCAD se imparte en dos cursos académicos. Durante el primer año se cursan presencialmente 60 ECTS de asignaturas en la UPV: en el primer cuatrimestre, Conceptos básicos del desarrollo (12 ECTS) y Cooperación al desarrollo (12 ECTS). En el segundo semestre, las asignaturas de la especialidad: Procesos de desarrollo (12 ECTS), Gestión del ciclo del proyecto de cooperación al desarrollo (14 ECTS) y Metodologías de investigación en proyectos de desarrollo (10 ECTS). En el segundo año se cursan de manera no presencial 30 ECTS, divididos entre prácticas externas realizadas en una organización de desarrollo, tanto en el extranjero como en España, y el Trabajo Fina de Máster.

El MCAD se desarrolla en el entorno de la UPV, una universidad técnica con una perspectiva aún muy instrumental, racionalista y limitada de las capacidades que una universidad debe desarrollar en su alumnado; muy orientada a la empleabilidad, y con un uso aún muy extendido de prácticas de enseñanza-aprendizaje poco activas. Sin embargo, la UPV ha ido generando también estrategias y espacios alternativos, para tratar de que su profesorado genere y proponga una perspectiva más amplia de la enseñanza superior y de los procesos de enseñanza-aprendizaje. Por ejemplo, está tratando de impulsar progresivamente el trabajo en trece "competencias transversales" en todas las titulaciones y asignaturas, así como en el uso de metodologías activas de enseñanza-aprendizaje para desarrollarlas.

El MCAD ha tratado de alinearse con estos procesos facilitados por la UPV y se ha sumado al trabajo en determinadas competencias transversales. Entre estas, el MCAD ha considerado clave la denominada CT06 Trabajo en equipo y liderazgo, ya que está especialmente alineada con su visión del desarrollo, la gestión del desarrollo y la enseñanza-aprendizaje. Como veremos, el máster ha tratado de desarrollar la competencia en su alumnado mediante distintos métodos, basados en dos enfoques clave que reorientan el sentido habitualmente dado a esta competencia: desde un enfoque eficientista, a un enfoque participativo y de cuidados.

Así, en este contexto, el presente trabajo expone los resultados obtenidos al poner en práctica entre los años 2016 y 2017 la competencia transversal denominada Trabajo en equipo y liderazgo, desde un enfoque de participación y cuidados, en el seno del Máster Universitario en Cooperación al Desarrollo por la UPV.

\subsection{El Equipo de Innovación y Calidad Educativa del MCAD}

Para profundizar en el trabajo en esta competencia en el profesorado del máster, se decide coordinar esfuerzos en el marco del Equipo de Innovación y Calidad Educativa denominado "Innovación pedagógica en el Máster en Cooperación al Desarrollo: integrando la participación y la acción en el proceso de enseñanza-aprendizaje" (en adelante EICEMACODE), creado en junio de 2012. Estos equipos de innovación educativa se han ido desarrollando en la UPV por iniciativa del Vicerrectorado de Estudios, Calidad y Acreditación, con el respaldo del Instituto de Ciencias de la Educación. 
El EICE-MACODE, desde sus inicios, volcó su trabajo en apoyar el enfoque participativo y crítico propio del Máster que se ha señalado. Integrado desde sus inicios por profesorado del MCAD perteneciente a diversos departamentos y categorías docentes, el EICE-MACODE ha ido aportando al máster un acervo de procesos y propuestas concretas en sus diversas asignaturas y en el planteamiento mismo del máster. Los resultados de este trabajo se pueden ver en distintas publicaciones (por ejemplo, Belda et al., 2012; Peris et al.; 2013; Pellicer y Calabuig, 2015; Boni-Aristizábal, Calabuig-Tormo y Pellicer-Sifres 2017; Belda et al., 2016), y han contribuido a la mejora progresiva del Máster, por ejemplo, incorporando nuevas metodologías de enseñanza-aprendizaje, así como la investigación-acción participativa.

El equipo de innovación se reorganiza durante el curso 2015-2016, actualiza sus miembros (en la actualidad lo componen siete docentes del MCAD) y decide concentrar sus esfuerzos, tras las recomendaciones del ICE de la UPV, en profundizar e innovar en competencias transversales de la propuesta UPV que son especialmente claves en el enfoque del Máster. Es por ello que se decide apostar, de manera progresiva y con diferentes grados de intensidad, por las competencias: Trabajo en equipo y liderazgo; Responsabilidad ética, medioambiental y profesional; Pensamiento crítico y Conocimiento de problemas contemporáneos. En un primer momento, se decide centrar los esfuerzos de manera más específica en trabajar la competencia de trabajo en equipo y liderazgo, y hacerlo en tres asignaturas: Cooperación al desarrollo, Procesos de desarrollo y Gestión del ciclo del proyecto de cooperación al desarrollo. Los autores de la presente comunicación son los profesores responsables de cada una de ellas y miembros a su vez del EICE-MACODE. Se decide además trabajar el desarrollo de la competencia en el alumnado desde dos enfoques específicos: el enfoque participativo y el enfoque de cuidados, combinando la experiencia y esfuerzo del personal docente del Máster con el apoyo de profesionales externas.

\section{Objetivos}

La presente comunicación recoge el trabajo realizado durante los cursos académico 20152016 y 2016-2017 (hasta marzo de 2017 inclusive) para mejorar y evaluar el desarrollo en el alumnado del MCAD de la competencia transversal trabajo en equipo y liderazgo, en tres asignaturas del primer curso del MCAD, desde los enfoques de la participación y los cuidados, siendo los objetivos al poner en marcha la iniciativa los siguientes.

- Incorporar la competencia de trabajo en equipo (colaborativo) y liderazgo (social), de forma más intensa en la formación del máster.

- Integrar en la competencia trabajo en equipo y liderazgo los enfoques de participación y de cuidados.

- Disponer de herramientas para la adecuada evaluación cualitativa y/o cuantitativa de dicha competencia, tanto en el seno del máster como a futuro.

- Potenciar entre el alumnado la reflexión sobre el proceso seguido en el trabajo en equipo, tanto el llevado a cabo de forma presencial en el aula, como fuera de ella.

(cc) EY-NC-ND 2017, Universitat Politècnica de València

Congreso IN-RED (2017) 
- Identificar durante la iniciativa elementos de mejora para contribuir a un mejor desempeño en la puesta en práctica y evaluación de la competencia de trabajo en equipo y liderazgo.

\section{Desarrollo de la innovación}

\subsection{El enfoque de la innovación: participación y cuidados}

Para el desarrollo de la competencia de trabajo en equipo en el alumnado se ha construido tanto sobre la experiencia, enfoques y perspectivas que venían siendo propias del máster como sobre otras que han despertado la atención del mismo. En concreto, se trató de trabajar sobre los mencionados enfoques de participación y de cuidados, de trayectoria más incipiente. Es necesario, no obstante, hacer ver que desde el EICE-MACODE se ha priorizado la dimensión trabajo en equipo frente a liderazgo, aunque esta segunda ha estado presente en todo momento. Ello obedece a querer evitar dispersión y por la limitación de recursos para abordar ambos elementos con la debida especificidad.

En primer lugar, se trabajó desde el enfoque de participación, que ha sido esencial en la definición del enfoque pedagógico general y en la metodología de enseñanza-aprendizaje del MCAD (ver Peris et al., 2013; Belda et al., 2016). Por un lado, en el máster se aprenden y aplican un buen número de metodologías y técnicas participativas: por ejemplo, se aprenden y aplican, en clase y en contextos reales, herramientas de planificación participativa como los mapeos comunitarios, los sociogramas o los flujogramas; o se desarrollan proyectos de investigación-acción participativa. Por otro lado, se emplean técnicas participativas como métodos de enseñanza-aprendizaje, tales como debates o el teatro social. Así, tanto la enseñanza de técnicas de participación como el uso mismo de la participación para la enseñanza-aprendizaje han tenido su reflejo en el trabajo en equipo como competencia: no solo se diseñan y aplican en grupo herramientas participativas, sino que se emplea el trabajo en equipo como espacio básico para generar participación.

En segundo lugar, se ha trabajado desde el denominado enfoque de cuidados, que algunas ONGD están implementando desde la llamada pedagogía de cuidados. Se trata de un planteamiento sobre el que había un creciente interés, pero no había sido trabajado hasta la fecha como estrategia pedagógica por el profesorado del máster. Por ello, se solicitó el apoyo de InteRed, ONG española de referencia en materia de educación para el desarrollo y educación para la ciudadanía global, que cuenta con delegación en Valencia, para trabajar la competencia desde esta perspectiva. Este enfoque pone en el centro una combinación de la ética de la justicia y la ética del cuidado, centrándose en el reconocimiento del derecho individual y colectivo al cuidado (Carrasco, Borderías y Torns, 2011), la dimensión política de lo personal y la dimensión ecológica. Esto implica poner en el centro la igualdad dentro de las relaciones personales, desmontando jerarquías y privilegios, así como la atención de las necesidades que todas las personas pueden tener. El reconocimiento del otro/a como sujeto de derecho al cuidado lleva además a atender a la singularidad de cada persona o comunidad, a tener que dar espacio a la diversidad para que la diferencia no se convierta en desigualdad (de Blas, 2016). En general, un enfoque de cuidados supone implicarse en el 
bienestar de las demás personas, desde posturas ecofeministas (Herrero, 2013), siendo consciente que el bienestar es una experiencia personal, vinculada a los intereses y deseos personales, a la razón, al cuerpo y a las emociones.

\subsubsection{Proceso preparatorio y de ensayo durante el curso 2015-2016}

Durante el curso 2015-2016 el trabajo llevado a cabo en el seno del EICE-MACODE, y trasladado al resto de profesorado y al alumnado del máster, combinó la reactivación de la planificación del equipo, como ya fue expuesto, con la aplicación de la evaluación de las dimensiones trabajo en equipo y participación, mediante rúbricas definidas al efecto para la asignatura Procesos de Desarrollo (cuatrimestre B). Dentro de la mencionada asignatura (aunque también se llevó a cabo trabajo en equipo en otras), fueron dos los espacios en los que se aplicó especialmente la participación y evaluación de la misma: Por un lado, la unidad temática 2 relativa a procesos de planificación, en la que el alumnado realizaba trabajos en el aula por equipos emulando talleres de planificación estratégica participativa. La particularidad en el curso 2015-2016 es que debían hacerlo en un barrio de la ciudad de Valencia, previa visita por su cuenta (por equipos) al mismo, lo que confería un carácter de mayor realismo. En las sesiones se intercambiaban los roles: en algunos momentos todos eran parte del equipo de planificación; en otros, una persona ejercía de facilitadora para aplicar una herramienta de diagnóstico o planificación, mientras que el resto de miembros del equipo actuaban con vecinas del barrio. Al final de las sesiones, se dedicaba algún tiempo para valorar y reflexionar cómo se habían sentido en el rol. Los grupos se autoevaluaron también en dos sesiones empleando métodos visuales. Por otro lado, la unidad temática 3 denominada Investigación-Acción Participativa (IAP), sobre la cual se venía ya trabajando durante los dos cursos académicos anteriores. En este módulo el alumnado se dividía en equipos de 4-5 personas, escogía una entidad del entorno de Valencia de las ofertadas (principalmente ONGD u organizaciones sociales) y durante dos meses realizaba un trabajo real práctico en diálogo con la entidad de acogida; es decir, los objetivos de la investigación de cada equipo de estudiantes se definían conjuntamente con la entidad y la investigación se llevaba a cabo desde un diseño flexible y emergente.

En esta asignatura la participación ha sido una dimensión que se lleva evaluando (con una contribución de un $10 \%$ a la nota final) desde que el máster es oficial, tanto la individual en el aula, como la desarrollada en el marco de los trabajos en equipo; sin embargo, es en el curso 2015-2016 que se decide revisar las rúbricas establecidas y profundizar en cómo evaluar la participación individual de cada estudiante. Para el curso 2015-2016 se redefinió el cuestionario de evaluación con sus rúbricas, basándose en parte en materiales facilitados por el ICE (entre ellos, Ábalos et al, 2015), que quedó compuesto por ocho dimensiones: gestión, ideas propias, voz, aceptación de otras ideas, crítica constructiva, actitud, cooperación y resolución de problemas. Este cuestionario ha sido la base, con sus modificaciones, para la etapa en la que actualmente se encuentra la innovación objeto de estudio.

(cc) EY-NC-ND 2017, Universitat Politècnica de València 


\subsubsection{Actividades propuestas para el curso 2016-2017}

Fruto de la evaluación de final y de los aprendizajes obtenidos, que serán expuestos en el siguiente apartado, se decide a final del curso 2015-2016 planificar desde el EICE-MACODE el curso siguiente, con una apuesta decidida por la competencia CT06 Trabajo en equipo y liderazgo. Si bien las diversas asignaturas del máster seguirían siendo punto de control de otras competencias, se toma la decisión de profundizar en la mencionada anteriormente: garantizando una mejor coordinación entre el profesorado; buscando una mayor coherencia entre métodos empleados en las diferentes asignaturas; incorporando las demandas del alumnado fruto de co-evaluaciones realizadas en los comités de seguimiento de las asignaturas (por ejemplo: precisar las rúbricas, dar más herramientas para el trabajo en equipo o dimensionar mejor el trabajo en equipo autónomo); revisando el sistema de rúbricas para la evaluación; e implicando a las ONG de Desarrollo que forman parte del Consejo Asesor del máster.

Es por ello que para el curso 2016-2017 se han redefinido unidades temáticas de algunas asignaturas y se ha realizado el esfuerzo de revisar internamente tanto los métodos docentes como de evaluación, de forma que el trabajo en equipo fuera puesto en práctica con el rigor y profundidad requeridos, así como de forma coherente con los planteamientos del máster expuestos con anterioridad.

Las actividades previstas para el curso 2016-2017, algunas ya finalizadas y otras en estado de implementación, son las siguientes:

Taller sobre trabajo en equipo, específicamente diseñado para el alumnado de primer año del máster e impartido por personal especializado de la ONGD Intered. El taller, llevado a cabo el 14 de octubre de 2016 y con 8 horas de duración, tuvo lugar en la cuarta semana de clase, de manera que servía tanto para abordar los conceptos considerados básicos, como para facilitar la integración y conocimiento mutuo de las y los estudiantes recién llegados. El taller se diseñó desde un enfoque de trabajo en equipo de corte colaborativo y con elevada componente emocional. De forma coherente con el trabajo de esta ONGD, se decide incorporar en la formación solicitada el enfoque de cuidados.

Redefinición del sistema de evaluación de la competencia CT6 Trabajo en equipo y liderazgo, incorporando más espacios y actividades secuenciadas y reduciendo el número de ítems o dimensiones a evaluar en el cuestionario, para hacerlo menos complejo. La figura 1 recoge el esquema de trabajo planteado para las tres asignaturas que han sido elegidas como punto de control de esta competencia.

Respecto a los cuestionarios de autoevaluación y evaluación por pares, se decide reducir a cuatro los criterios de evaluación, gran parte de ellos definidos como agregado de varios ítems del cuestionario de evaluación empleado en el curso anterior. Este cuestionario es propuesto por el profesorado y revisado por la ONGD Intered, recibiendo aportes para matizar el primer criterio e incorporar el enfoque de cuidados. Se decide para 2016-2017 no emplear un sistema de rúbricas como tal, sino aplicar una escala cualitativa de valoración para el cuatrimestre A, y una escala cuantitativa para el cuatrimestre B. Ello es debido a que en las asignaturas del segundo semestre la participación sí es calificada y contribuye a la nota 
final de las mismas. La figura 2 muestra la tabla empleada para la valoración. De la misma se generó el cuestionario de autoevaluación y evaluación por pares, de forma que cada estudiante valorase el desempeño del resto de miembros de su equipo y así mismo/a (cuatro columnas) según los cuatro criterios definidos. Junto a él se incorporaron una serie de preguntas que permitieran valorar aspectos de contexto relativos al proceso que cada equipo y persona han experimentado. Este cuestionario se aplica a las tres asignaturas mencionadas, con algunas particularidades.

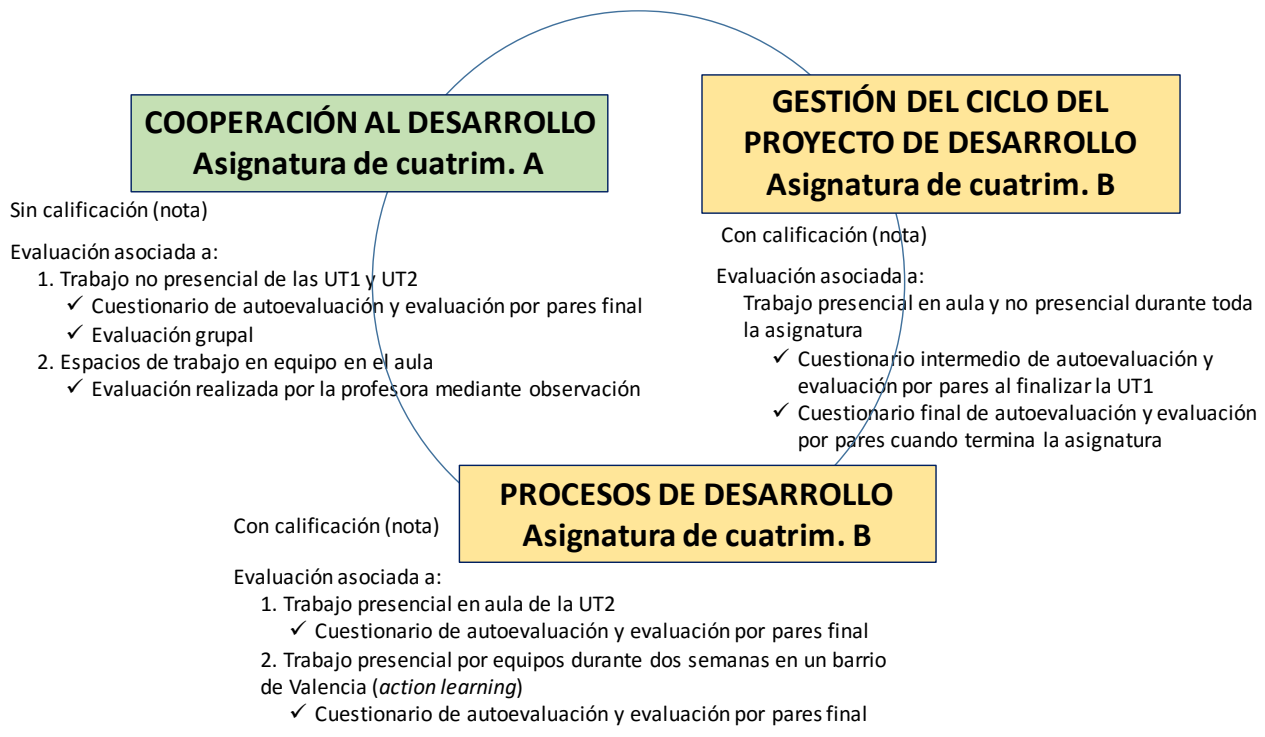

Figura 1: Planteamiento de la evaluación de la competencia en las diversas asignaturas Fuente: elaboración propia

Evaluación de los mecanismos puestos en marcha al final del cuatrimestre A, tanto en el seno del EICE-MACODE, como con el alumnado del máster (en aula y a través de los Comités de Seguimiento de asignaturas), para reformular si fuera el caso los cuestionarios de evaluación. En el caso de las asignaturas del semestre B, es el propio alumnado quien replantea el cuestionario para que no se valorase (y calificase) a personas en concreto, sino que cada persona evaluase el desempeño suyo y del equipo. Manteniendo los cuatro criterios del trabajo en equipo, esto se traduce en plantear solamente las columnas de autoevaluación y evaluación global del desempeño del equipo.

Rediseño de la propuesta de Aprendizaje-Servicio en la asignatura de Gestión del ciclo del proyecto y diseño de la propuesta de action learning o aprendizaje en la acción, vinculada a la UT3 de la asignatura Procesos, tomando en consideración los aprendizajes respecto a la competencia trabajo en equipo obtenidos en el transcurso del curso académico. No será objeto de la presente comunicación describir estas propuestas de innovación docente, a desarrollar de manera intensiva con ONG externas (caso del APS) o conviviendo con organizaciones sociales durante dos semanas de mayo-junio de 2017 en el barrio de Benicalap de Valencia.

(cc) EY-NC-ND 2017, Universitat Politècnica de València 
Diseño de un segundo taller sobre trabajo en equipo, a llevar a cabo el 25 de mayo de 2017 en la UPV como continuación del realizado en octubre. En este caso, vinculado a cómo abordar desde el enfoque de cuidados los conflictos en el seno de los equipos de trabajo

\begin{tabular}{|c|c|c|c|c|c|}
\hline \multicolumn{6}{|c|}{ Valoración de la competencia trabajo en equipo y liderazgo } \\
\hline \multirow[t]{2}{*}{ Criterio } & \multirow[t]{2}{*}{ Qué comprende el criterio } & \multicolumn{4}{|c|}{ Descriptores } \\
\hline & & A & B & $\mathrm{C}$ & $\mathrm{D}$ \\
\hline $\begin{array}{l}\text { Escucha activa, } \\
\text { empatía, cuidados } \\
\text { y respeto }\end{array}$ & $\begin{array}{l}\text { En los espacios de trabajo se muestra una persona con interés. } \\
\text { Focaliza la atención en la dinámica de grupo, sin desviarse a } \\
\text { otros asuntos. Diferencia lo que son espacios de comunicación } \\
\text { relativos al trabajo del máster de los espacios privados. Da su } \\
\text { opinión sin monopolizar las conversaciones. El lenguaje } \\
\text { empleado en las intervenciones en general es inclusivo y } \\
\text { respetuoso. Es capaz de empatizar con l@s compañer@s y } \\
\text { actúa desde la cultura de los cuidados, no buscando solamente } \\
\text { un enfoque "eficientista" de la tarea. }\end{array}$ & & & & \\
\hline $\begin{array}{l}\text { Gestión de } \\
\text { conflictos }\end{array}$ & $\begin{array}{l}\text { Tiene en cuenta diferencias culturales o de otro tipo que } \\
\text { pueden dificultar un adecuado entendimiento y provocar } \\
\text { malestar. Busca integrar a todas las personas que forman parte } \\
\text { del equipo, incorporándolas a la conversación o a la sesión } \\
\text { concreta. Es capaz de aclarar su punto de vista de manera } \\
\text { adecuada frente a sus compañeras, así como reaccionar bien } \\
\text { ante visiones contrapuestas. Es capaz de aportar soluciones a } \\
\text { posibles conflictos generados entre los miembros del equipo }\end{array}$ & & & & \\
\hline Liderazgo social & $\begin{array}{l}\text { Sus intervenciones invitan a otros/as a profundizar en } \\
\text { cuestiones particulares. Valora, recoge e integra ideas } \\
\text { formuladas por sus compañeros/as para profundizar en ellas. } \\
\text { Motiva a las compañeras, promueve la distribución de roles y } \\
\text { la cohesión del grupo. }\end{array}$ & & & & \\
\hline $\begin{array}{l}\text { Responsabilidad, } \\
\text { compromiso y } \\
\text { rendición de } \\
\text { cuentas }\end{array}$ & $\begin{array}{l}\text { Se muestra como una persona proactiva en el trabajo en equipo } \\
\text { y comprometida con los objetivos a conseguir. Es responsable } \\
\text { con las tareas encomendadas y da cuentas de las mismas, } \\
\text { comunicando avances, resultados, etc., al resto del equipo. Es } \\
\text { puntual para el inicio de las reuniones. }\end{array}$ & & & & \\
\hline $\begin{array}{l}\text { Descriptores cualit } \\
\text { A: Ocurre casi siem } \\
\text { B: Ocurre con frecu } \\
\text { C: Ocurre con poca } \\
\text { D: No ocurre casi nu }\end{array}$ & $\begin{array}{l}\text { tivos: } \\
\text { re / Se da de forma ejemplar } \\
\text { encia / Se da de forma adecuada } \\
\text { recuencia/ Se da de forma mejorable } \\
\text { nca/ Se da de forma claramente insatisfactoria }\end{array}$ & & & & \\
\hline
\end{tabular}

Figura 2: Tabla tipo para la valoración de la competencia trabajo en equipo Fuente: elaboración propia

\section{Resultados}

Expuestas las actividades previstas y/o ya desarrolladas, se ofrecen a continuación los primeros resultados obtenidos al aplicar la competencia de trabajo en equipo y liderazgo en el máster desde la participación y el enfoque de cuidados, mostrando solo aquellos más relevantes. Los aprendizajes obtenidos durante 2015-2016 han sido considerados como insumos para redefinir y configurar las acciones previstas para 2016-2017, por lo que en el presente apartado los resultados se centrarán en lo evidenciado en el actual curso académico. 


\subsection{Resultados relativos al desempeño de la competencia}

$\mathrm{Si}$ bien las competencias se adquieren (caso de lograrse, y especialmente con las transversales) con la contribución del conjunto de materias de una titulación, consideramos que es posible evidenciar algunos resultados de aprendizaje obtenidos con la experiencia llevada a cabo en dos de las asignaturas, si comparamos éstos con lo acontecido en cursos académicos anteriores.

\subsubsection{Elementos positivos identificados}

Si atendemos a la calidad académica de los trabajos como producto tangible (la memoria entregada), estos han sido muy similares a años anteriores, pero con la particularidad de que sí se ha logrado un mayor trabajo en equipo colaborativo. Es decir, los equipos no han llevado a cabo un reparto sin más de tareas, sino que se han reunido fuera del aula, han dialogado y han afrontado los conflictos cuando éstos han surgido, ya fuera durante la realización del trabajo o al final del mismo. No ha habido en ningún caso personalismos, sino que se han superado los obstáculos anteponiendo la consideración del otro/a frente a una crítica fácil ante las diferencias de pareceres. Las causas de que el posible conflicto no haya quebrado la confianza de los miembros o haya afectado gravemente a la dinámica del equipo, cuando se ha producido algún problema, no se han identificado de forma fehaciente. Sin embargo, se aprecia que el taller sobre trabajo en equipo desarrollado en octubre de 2016 y los espacios de encuentro del alumnado, han generado dinámicas muy positivas de convivencia que han favorecido ir más allá del conflicto concreto y abordarlo.

"Creo que el taller sobre trabajo en equipo ha sido positivo para la dinámica de relación de grupo en el máster y a que exista una buena disposición general. Gracias al taller, entiendo que cada compañera se ha mostrado tal como es, una prolongación del estar de cada una en el máster, o así es como es para mí". (testimonio de estudiante 1, asign Cooperación curso 2016-2017)

Cada estudiante y equipo de trabajo identificó numerosos elementos positivos como aprendizaje de la experiencia de trabajo en equipo, tanto mediante los cuestionarios como en la sesión final de evaluación llevada a cabo el 1 de diciembre de 2016. Se destaca la autocrítica y honestidad de las aportaciones del estudiantado, así como buenas reflexiones. De entre todo lo identificado, han sido capaces de discriminar aquellos elementos más relacionados con los contenidos del taller llevado a cabo en octubre de 2016, que como se expuso en anteriores apartados, incorporó el enfoque de cuidados a la formación sobre trabajo en equipo. A continuación se muestra un listado de elementos identificados por todos los equipos durante la dinámica de trabajo en equipo en la asignatura del primer cuatrimestre. Las palabras subrayadas corresponden a aquellos valores y actitudes relacionados con el taller de trabajo en equipo realizado, encontrándose numerosas coincidencias entre los equipos al respecto: participación colaborativa, complicidad, empatía, buen clima y dinámica de trabajo, optimismo al afrontar la tarea, sinceridad (con tacto), inclusión, aprendizaje mutuo, escucha $\underline{\text { activa, }}$ espacios externos buscando la convivencia, todas han trabajado, resiliencia, iniciativa, flexibilidad en las agendas, compañerismo, cohesión (a pesar de las dificultades), respeto,

(c)) EY-NC-ND 2017, Universitat Politècnica de València 
confianza mutua, enriquecimiento mutuo, compromiso, adecuada división del trabajo, sentido crítico, conocimiento mutuo, apoyo mutuo, esfuerzo, resolución de problemas, ser activos y propositivos, dinamismo, buena predisposición, ser capaces de pedir ayuda, relación y comunicación, cuidar el lenguaje, paciencia, considerar las circunstancias de cada persona que han podido afectar a su ritmo, entendimiento, comprensión, mostrarse cada una $\underline{\text { como es, }}$ cumplimiento de tareas, responsabilidad, conexión entre compañeras, $\underline{\text { hablar de los }}$ sentimientos (educación emocional), solidaridad y relaciones de horizontalidad, enriquecimiento de ideas, asertividad, predisposición al debate, agilidad.

De entre todos los elementos, ha sido una constante la constatación de que ha habido un mayor diálogo y escucha activa en el seno de los equipos de trabajo. Esta actitud favorece la comprensión de las situaciones de las otras personas, la empatía con las mismas (claramente en sintonía con el enfoque de cuidados) y el aumento de confianza personal y en el grupo, derivando en un mejor clima de trabajo y consecución de metas establecidas:

"Nuestro equipo ha trabajado de una forma muy unida y respetuosa; no hemos tenido en ningún momento problemas y hemos sabido resolver los momentos de enfrentamiento sin caer en conflictos; la clave fue escuchar para entender la posición recíproca". (testimonio de estudiante 2, asign Cooperación curso 2016-2017)

"Creo que lo que más he podido trabajar durante el desarrollo del trabajo en equipo ha sido la capacidad o necesidad de escuchar activamente y de ponerme en situación del otro, de empatizar con las circunstancias personales de cada uno. Usualmente estaba acostumbrada a trabajar en ambientes de equipo donde no había tanta predisposición al debate ni poníamos tanta atención al lenguaje" (testimonio de estudiante 3, asign Cooperación curso 2016-2017)

\subsubsection{Elementos negativos evidenciados}

Si bien la sensación general es que los mecanismos aplicados han permitido que el alumnado no solo lleve a la práctica el trabajo en equipo, sino que reflexione sobre él y desarrolle (de forma limitada) dimensiones más relacionadas con el enfoque de cuidados, también han aflorado valoraciones negativas durante el desempeño. En primer lugar, es unánime la opinión de que el tiempo dedicado es insuficiente (o excesivo, si se lo compara con el que se supone deben invertir respecto a las horas docentes y discentes previstas en el plan de estudios), y que es realmente difícil cuadrar agendas y abrir espacios de reflexión interna, más allá de realizar las tareas definidas para cada equipo. Este aprendizaje es de gran interés, no solo para modificar los métodos empleados por el profesorado, sino para que ellos mismos/as experimenten lo que les sucederá cuando desempeñen su actividad profesional, especialmente en contextos complejos y con elevada incertidumbre.

También se identificaron aspectos negativos de carácter actitudinal observados en algunas personas de los equipos: pasividad, responsabilidad diluida, personalidades dominantes, egocentrismo. Esto les permitió evidenciar que el trabajo en equipo depende en gran parte de lo que cada miembro sea como persona y proyecte al grupo y les animó a solicitar un segundo 
taller formativo. Sin duda, los espacios de reflexión provocados permitieron identificar estos elementos que consideraron no deseables desde los enfoques trabajados.

\subsection{Resultados relativos al sistema de implementación y evaluación definido}

\subsubsection{Adecuación del seguimiento}

En primer lugar, se aprecian diferencias en cuanto a si el trabajo en equipo se realizaba de manera presencial (cuatrimestre B) o no presencial (cuatrimestre A). Para el segundo caso, al no disponerse de espacio específico en aula para su realización, ello dificultó el seguimiento y favoreció que el trabajo fuera realizado de manera no constante por cada equipo. Aunque sí ha habido buen trabajo en equipo y el alumnado está en general muy contento y sorprendido por el clima logrado, la profesora no ha dispuesto de información completa del transcurso de las tareas. La profesora, así mismo, consideró que cada equipo debía ser autónomo como para solicitar reuniones de seguimiento, no provocadas por así decirlo, cosa que no ocurrió. Esto denota una no interiorización de que se estaba trabajando esta competencia.

En relación a la reunión de evaluación final, ésta fue muy importante, ya que salieron a la luz conflictos habidos en los equipos y se evidenció que, de forma autónoma (como se ha expuesto), ningún equipo de trabajo había dedicado tiempo expreso a dialogar sobre la marcha del trabajo en equipo. Al ser planteada en el cuatrimestre A, se identifica como posible causa la dificultad de atender gran cantidad de procesos nuevos para estudiantes que recién inician el título, con el añadido de la diferencia cultural al ser el alumnado de procedencias diversas; en ese sentido, lo importante para ellxs era lograr alcanzar los objetivos del trabajo, que velar por monitorizar la dinámica propiamente dicha del equipo.

\subsubsection{Flexibilidad en la evaluación}

Respecto al trabajo presencial llevado a cabo en la asignatura Gestión del Ciclo de Proyecto de Cooperación al Desarrollo (cuatrimestre B), de momento solo se ha podido realizar la evaluación intermedia pues la asignatura no ha finalizado. Como ya se expuso, fue el propio alumnado del máster quien consideró más interesante en el cuatrimestre $\mathrm{B}$ evaluar al equipo como conjunto, además de autoevaluarse. Esto se puede deber a que la evaluación en el cuatrimestre B conllevaba calificación para la nota o que bien no querían personalizar las opiniones, sino valorar el trabajo realizado por cada grupo, sin particularizar a cada miembro, y no romper así la buena sintonía de los grupos. Curiosamente la mayor parte del alumnado valoró mejor al equipo que así mismos. Esto confirma la buena sintonía y ambiente en los grupos.

Otro aprendizaje relacionado con la evaluación fue el hecho de que el profesor responsable de la asignatura había planificado al final de la clase 40 minutos para la evaluación: 20 minutos de aula para reflexionar por grupos (los mismos grupos que los realizados durante el trabajo en equipo de la asignatura) y otros 20 minutos para rellenar las hojas de

(cc) EY-NC-ND 2017, Universitat Politècnica de València

Congreso IN-RED (2017) 
autoevaluación y evaluación del equipo. Sin embargo, el alumnado, de manera dialógica y reflexiva, sugirió que preferían dedicar los últimos 20 minutos a una reflexión grupal de toda la clase para compartir las reflexiones de cada grupo y rellenar personalmente fuera del aula la autoevaluación y la coevaluación. Fruto de esta última reflexión grupal surgieron elementos muy interesantes relacionados con el enfoque de trabajo colaborativo que queremos destacar en esta comunicación. A modo de ejemplo, un grupo que había tenido ciertos problemas durante el trabajo en equipo, porque una persona siempre mostraba una opinión diferente al resto, comentó lo siguiente:

"Gracias al enfoque que se nos ha inculcado desde el máster hemos convertido esa debilidad en una fortaleza, aprendiendo de las diferencias de opinión como grupo y creando debates más constructivos" (testimonio de equipo de trabajo, curso 2016-2017)

\subsection{Resultados globales}

Como fue expuesto anteriormente, trasladar a una competencia transversal como es el trabajo en equipo elementos que se alejan de un modelo que podríamos calificar como eficientista, supone reinterpretar los marcos conceptuales y de trabajo en el aula, deconstruyendo ideas y experiencias previas y animando al alumnado a que participe activamente y a que realice un trabajo reflexivo en paralelo a su estudio habitual. Para quienes suscriben la presente comunicación, está siendo alentador ver cómo el alumnado potencia sus capacidades personales (lo cual se traslada a las colectivas), si la mirada no solo considera elementos esenciales del trabajo en equipo (como la responsabilidad, la cooperación o la gestión), sino que incorpora la educación emocional y el enfoque de cuidados: comprensión de la situación de la otra persona, empatía o compañerismo, entre otros.

Como valoración global, se evidencia como esencial continuar con la aplicación del enfoque y herramientas participativas en el máster, lo que permite un co-aprendizaje y potenciar su autonomía y responsabilidad; pero también es necesario seguir considerando que el trabajo en equipo es un espacio básico para generar cultura de la participación, concepto que también es impartido en el MCAD como dimensión básica del desarrollo humano sostenible. Todo ello desde un enfoque más político, ligado al empoderamiento y al aumento de la libertad para ser capaces de contribuir a la transformación de la realidad.

\section{Conclusiones}

Si bien la adopción de la competencia transversal trabajo en equipo y liderazgo en cualquier titulación universitaria es ya un hecho y una opción ineludible, consideramos imprescindible una reflexión sobre el enfoque desde el cual esta competencia es interpretada, si queremos contribuir a la formación de profesionales que sean capaces de llevar a la práctica valores y actitudes más cercanos al desarrollo humano sostenible. Tal es el caso de la solidaridad frente a la competitividad exacerbada o bien la empatía, la sensibilidad, la comprensión y el cuidado del otro/a frente a la desafección por las situaciones de las otras personas que nos rodean, la apatía o la exclusión de las emociones en los espacios profesionales. 
Adoptar el enfoque de la participación y de cuidados para reinterpretar el trabajo en equipo en las aulas universitarias es una de las vías que consideramos pueden hacernos transitar hacia una cultura menos gerencialista y eficientista. A pesar de disponer de evidencias limitadas que no nos permiten hacer afirmaciones totalmente contrastadas, sí estamos constatando con la adopción de ambos enfoques en esta competencia transversal en el máster, que el alumnado demanda una nueva visión del trabajo en equipo y valora positivamente las mejoras desarrolladas. Visión que tome en consideración su ser como sujetos con capacidad de participar, y que no pueden eludir (aunque sí tratar de controlar) sus estados emocionales y personales cuando afrontan una tarea en equipo. Esta necesidad de reorientar el trabajo en equipo requiere, a su vez, de redefinir las asignaturas del plan de estudios, puesto que no se trata solamente de una cuestión de mejora de los métodos de evaluación, sino de llegar realmente a incorporar de forma transversal y coordinada esta competencia. En el caso que nos ocupa, la existencia de un equipo de innovación docente en el seno del máster, así como los propios planteamientos del mismo (visión crítica, participación, etc.) favorecen sin duda que ello pueda lograrse. De igual modo, la colaboración universidad-tercer sector, en este caso UPV-ONG de Desarrollo, permite trasladar la realidad al aula y construir de forma conjunta ese espacio educativo con vocación transformadora.

Finalmente, se evidencian diversas necesidades a abordar, como pueden ser: sistematizar las experiencias como práctica institucionalizada; profundizar en los enfoques adoptados y su traslado a la competencia estudiada; mantener la colaboración, y con carácter más estratégico, con agentes y entidades externas; lograr que la universidad comprenda la dotación de recursos que se precisa para abordar adecuadamente el trabajo en equipo como competencia transversal.

\section{Referencias}

ÁBALOS, A. et al. (2015). Rúbrica UPV CT-06. trabajo en equipo y liderazgo. Accesible en $<$ http://poliformat.upv.es $>$ [Consulta: marzo de 2016]

BELDA, S., BONI, A., PERIS, J. y TEROL, L. (2012). "Capacity development for emancipator social change. Reimaging university learning and teaching for critical development practitioners", en Journal of International Development, vol. 24, p. 571-584.

BELDA, S. PERIS, J., y CUESTA, I. (2016). "Participation for transformative learning in development management: The case of a Master in international development projects in the Universitat Politècnica de València (Spain)". Comunicación en el 2nd International Conference on Higher Education Advances, HEAd'16, 21-23 June 2016, València, Spain.

BONI-ARISTIZABAL, A., CALABUIG-TORMO, C. y PELLICER SIFRES, V. (2017) "Transforming the system from within: the experience of the Development Cooperation", en Walker, M. y Wilson-Strydom, M. (Eds.) Socially Just Pedagogies, Capabilities and Quality in Higher Education, London: Palgtrave MacMillan.

CARRASCO, C., BORDERÍAS, C., y TORNS, T. (Eds) (2011). El trabajo de los cuidados. Historia, teoría y políticas. Madrid: Los libros de la catarata.

CLARKE, P., y OSWALD, K. (2010). "Why reflect collectively on capacities for change?" en IDS Bulletin, issue 41, p. 1-12.

(cc) EY-NC-ND 2017, Universitat Politècnica de València

Congreso IN-RED (2017) 
DE BLAS, A. (2016). La revolución de los cuidados. Tácticas y estrategias. Madrid: InteRed.

EYBEN, R., GUIJT, I., ROCHE, C. y C. SHUTT (Eds.) (2015). The Politics of Evidence and Results in International Development: Playing the game to change the rules?. Rugby: Practical Action Publishing.

GULRAJANI, N. (2010). "New vistas for development management: examining radical-reformist possibilities and potential" en Public Administration and Development, vol. 30, p. 136-148.

HERRERO, Y. (2013). "Miradas ecofeministas para transitar a un mundo justo y sostenible" en Revista de Economía Crítica, ${ }^{\circ} 16$, segundo semestre 2013, p. 278-307.

JOHNSON, H. y THOMAS, A. (2007). "Individual learning and building organizational capacity for development" en Public Administration and Development, vol. 27, p. 39-48.

MCCOURT, W., y GULRAJANI, N. (2010). “The future of development management: Introduction to the Special Issue" en Public Administration and Development, vol.30, p. 81-90.

MOSSE, D. (2005). Cultivating development: An ethnography of aid policy and practice. London: Pluto Press.

ORTIZ ARAGON, A. (2010). "A case for surfacing theories of change for purposeful organizational capacity development" en IDS Bulletin, vol.41, p. 36-46.

PELLICER SIFRES, V.; CALABUIG TORMO, C. (2015). "El potencial de los espacios educativos informales en la universidad para una práctica crítica del desarrollo", en $4^{\circ}$ Congreso Internacional Multidisciplinar de Investigación Educativa (CIMIE 2015). Valencia, España.

PERIS, J., BELDA, S., y CUESTA, I. (2013). "Educating development professionals for reflective and transformative agency". En Boni A. \& Walker M. (Eds.). Human Development and Capabilities: Reimagining the University of the Twenty-first Century, London and New York: Routledge.

SOAL, S. (2010). "The more things change, the more they stay the same?", en IDS Bulletin, vol.41, p. $128-137$.

PEARSON, J. (2010). "Pushing at a half-open door" en IDS Bulletin, vol. 41, p. 118-127.

PETTIT, J. (2006). "Power and pedagogy: Learning for reflective development practice" en IDS Bulletin, vol.37, p. 69-78. 


\title{
Aprender, enseñar, investigar: una experiencia de Aprendizaje- Servicio en Trabajo Fin de Grado en Fisioterapia.
}

Raquel Lafuente Ureta ${ }^{\text {a,b }}$,Carolina Jiménez Sánchez ${ }^{a, b, c}$, María Pilar Herrer Arosteguia, Yoanna Giraldez Martín ${ }^{\mathrm{a}}$.

a'Departamento de Fisioterapia. Universidad San Jorge. Zaragoza (rlafuente@usj.es; cjimenez@usj.es; alu.46559@usj.es; alu.38521@usj.es) bocente del Grado de Fisioterapia. Universidad San Jorge. Zaragoza. ${ }^{\circ}$ Grupo de Investigación iPhysio. Universidad San Jorge. Zaragoza.

\begin{abstract}
Service- learning(SL) is a pedagogical proposal that promotes the student's engagement with their social environment, so as to increase its civic conscience, and regarding the curricular competencies achievement.

This paper describes the research led with students of the Physiotherapy Degree Progra of the Faculty of Health Sciences at Universidad San Jorge in the subject of Final Project Graduation (FPG). Among the objectives of this study there is the assessment of the participants in the Service-Learning project and also to assess the applicability of the Service Learning methodology in this subject. The developed initiatives consist of the implementation of a Health Education(HE) program in associations of disabled people in Zaragoza.

Through this project, the applicability and increase of the professional student's competencies has been achieved, in term of academic and scientific contents as much as in term of personal competencies, because of the promotion of the reflexing and the personal development of civic values.

The participation of FPG students in Physiotherapy in SL projects is an optimal pedagogic model for the curricular development, with a significative impact in the personal and social student's skills.
\end{abstract}

Keywords: Service- Learning, Final Project Graduation, Healht Education, Physiotherapy, methodology, formation

\footnotetext{
Resumen

El Aprendizaje y Servicio (ApS) es una propuesta pedagógica que busca implicar al alumno en medios sociales de su ámbito cercano, con el fin de promover la conciencia ciudadana, y sin olvidar la adquisición de competencias curriculares por parte del estudiante.

El presente trabajo describe la investigación llevada a cabo con estudiantes del Grado de Fisioterapia, de la Facultad de Ciencias de la Salud de la Universidad San Jorge, en la asignatura Trabajo de Fin de Grado, Entre los
} 
objetivos, valorar la aplicabilidad de la metodología de ApS en TFG y el grado de satisfacción de los participantes en el proyecto. Las iniciativas desarrolladas consisten en eboración y la implementación de un programa de Educación para la Salud (EPS) en asociaciones de personas con discapacidad.

A través de este proyecto se ha conseguido aplicar e incrementar las competencias profesionales de los alumnos a nivel de contenidos académicos y científicos así como las competencias personales a través del fomento de la reflexión y el desarrollo personal de valores cívicos.

La participación de alumnos de TFG en Fisioterapia en proyectos ApS es un modelo pedagógico óptimo para el desarrollo curricular, con un impacto significativo a nivel personal y social.

Palabras clave: Aprendizaje y Servicio, Trabajo fin de Grado, Educación para la Salud, Fisioterapia, metodología, formación.

\section{INTRODUCCIÓN}

\subsection{Qué es y en qué consiste el Aprendizaje-Servicio}

Siguiendo la definición de Puig, el Aprendizaje y Servicio (ApS) es una propuesta pedagógica que se dirige a la búsqueda de fórmulas concretas para implicar al alumnado en la vida cotidiana de las comunidades, barrios, instituciones cercanas y ONGD (Puig, 2007).

Por lo tanto, esta metodología pedagógica va a fomentar el aprendizaje activo (DALE, 1959) de los estudiantes a través de su participación en experiencias asociadas al servicio comunitario (Folgueiras, 2013) (Gráfico 1).

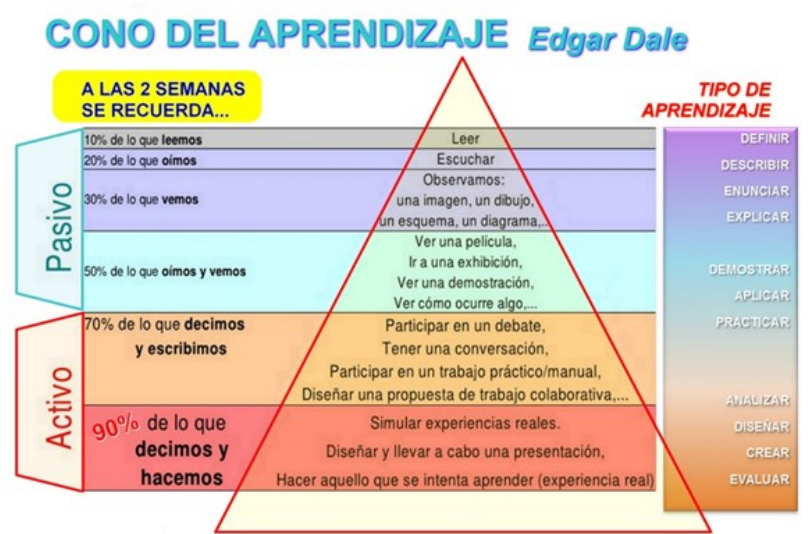

Gráfico 1: cono del aprendizaje de Dale

Fuente: (Urquizu, 2012)

(cc) EY-NC-ND 2017, Universitat Politècnica de València

Congreso IN-RED (2017) 
El alumno sale del aula, donde habitualmente realiza su actividad discente, para encontrarse directamente con las personas a las que va a ofrecer un servicio, teniendo que hacer un análisis de las necesidades que presente ese colectivo, elegir y ejecutar el proyecto del servicio en sí, con el que se paliarán o resolverán esas dificultades, para posteriormente realizar un proceso de reflexión, sin el cual se perdería la esencia del Aprendizaje y Servicio, y finalmente una evaluación (Tapia, 2006; Folgueiras, 2013). Todo esto se debe de llevar a cabo sin perder de vista un objetivo primordial de esta actividad, que es la adquisición de contenidos, reflejados a través de los resultados de aprendizaje y las competencias propias de cada asignatura (Puig, 2009).

Lejos de lo que pueda parecer, el Aprendizaje y Servicio no se trata de una actividad de tipo voluntariado. No se debe simplificar su definición, ni pensar que se trata tan sólo de una actividad o un trabajo en beneficio de la comunidad, sino que se deben de poner en relieve todos los aspectos educativos que implica, como son la adquisición de conocimientos, competencias y valores vinculados a lo curricular (Rodriguez, 2013). Un estudiante dentro de un programa de Aprendizaje y Servicio va a vivenciar simultáneamente dos dimensiones básicas: la contribución a una comunidad y el trabajo de conocimientos, competencias y valores (Kendall y Asociados, 1990; Puig, 2006; Tapia, 2006, Páez, 2013).

\subsection{ApS y Educación para la Salud: semejanzas y diferencias.}

Uno de los ámbitos educativos en los que se trabaja dentro de las titulaciones universitarias de tipo sanitario, social y de educación es la Educación para la Salud. La educación para la salud se define como el proceso que permite a las personas incrementar el control sobre su salud para mejorarla (Aibar, 2000). La educación para la salud comprende las oportunidades de aprendizaje destinadas a mejorar el autoconocimiento en el ámbito sanitario, incluyendo el fomento del aprendizaje por parte de la población y el desarrollo de habilidades personales que conduzcan a la mejora de la salud. Es un proceso educativo que tiene como finalidad responsabilizar a los ciudadanos en la defensa de la salud propia y colectiva (Gutiérrez, 2003).

Se puede concluir que el Aprendizaje y Servicio presenta un paralelismo claro con la Educación para la Salud en términos de adquisición de conceptos y como metodología educativa, si bien presenta ciertas diferencias como la población a la que va dirigida cada uno de ellos y que en la metodología de la Educación para la Salud no se contempla el proceso de reflexión, pilar básico en el Aprendizaje y Servicio.

\subsection{El Aprendizaje y Servicio en la Fisioterapia.}

El Aprendizaje y Servicio es una estrategia educativa relativamente poco frecuente a día de hoy en el ámbito de la fisioterapia. Esta metodología de aprendizaje puede ser muy útil en esta profesión, puesto que se trata de una disciplina eminentemente práctica, que se basa en el análisis de las problemáticas del paciente y que debe aportar una solución a las mismas, analizando siempre los resultados obtenidos de la intervención para valorar si ésta ha sido 
eficaz o no. Además, la fisioterapia como otras profesiones sanitarias, destaca por su labor asistencial a colectivos desfavorecidos, como entidades de personas con discapacidad, que pueden ser susceptibles de ser participantes en un proyecto, en este caso, de Aprendizaje y Servicio a través de la Educación para la Salud (Capella, 2014).

\subsection{El ApS en el Espacio Europeo de Estudios Superiores.}

La perspectiva de acercamiento del estudiante universitario a la sociedad y a la realidad que le rodea, viene enmarcada en del proceso de convergencia del Espacio Europeo de Estudios Superiores (EEES), que en sus conferencias y declaraciones alude a la importancia del papel de la universidad en la realización personal de los estudiantes, la promoción de la cohesión social, el desarrollo de valores compartidos y la consolidación de una ciudadanía europea que comparta un conjunto de valores sociales que en último término reduzcan las desigualdades (Declaración de Bolonia, 1999; Comunicado de Londres, 2007; Manifestación de Salamanca, 2001; Unesco, 1998 ; Tejada, 2013). Todos estos aspectos se tienen en cuenta en el Aprendizaje y Servicio, que pretende contribuir al bien común y proporcionar conocimientos, competencias y valores a los estudiantes (Kendall, 1990; Puig, 2006; Tapia, 2006; Tejada, 2013).

\subsection{El Aprendizaje y Servicio en el Trabajo de Fin de Grado.}

Asimismo, uno de los aspectos que supuso un cambio importante en las instituciones universitarias a raíz de la integración en el Espacio Europeo de Estudios Superiores fue la incorporación de la asignatura de Trabajo Fin de Grado (TFG) en los planes de estudio de las titulaciones (Sáenz de Jubera, 2016). Uno de los objetivos de la enseñanza superior debe consistir en dotar a los estudiantes de las herramientas necesarias para enfrentarse a la que será su realidad profesional cuando finalicen sus estudios de grado y posgrado. Siguiendo esta idea, el objetivo principal de la asignatura de TFG en el grado de Fisioterapia de la Universidad San Jorge consiste en desarrollar y defender un trabajo de carácter científico dentro del campo de la fisioterapia, integrando todos los conocimientos teóricos y prácticos adquiridos durante la titulación. Al igual que en otras titulaciones y otras universidades, aunque esta asignatura plantea la realización de proyectos científicos, dentro de la Guía Docente de la asignatura se contempla un perfil de trabajo de tipo educativo siguiendo una metodología científica. Por lo tanto, citando a Sáenz de Jubera "el TFG se establece en el marco idóneo para que el alumnado reconstruya los contenidos, capacidades, competencias pedagógicas y habilidades adquiridas durante el grado, y se sitúe en contextos próximos a un entorno laboral propio de la sociedad de la información y la comunicación" (Sáenz de Jubera, 2016); asimismo, se promueve la iniciativa personal, la responsabilidad social, la toma de decisiones, la valoración de riesgos y el afrontamiento a los posibles problemas (Ponce de León, 2013). 


\section{Objetivos}

A través de este trabajo se pretende llevar a cabo una exposición de los proyectos de Educación para la Salud a través de la metodología de Aprendizaje y Servicio dentro de la asignatura Trabajo Fin de Grado del Grado de Fisioterapia.

Los objetivos específicos son:

- Valorar si el Aprendizaje y Servicio es una buena metodología para la integración de contenidos dentro de la asignatura de Trabajo de Fin de Grado.

- Diseñar e implementar un "perfil" específico de tipo educativo en la asignatura de Trabajo de Fin de Grado

- Valorar el grado de satisfacción y la mejoría clínica de los participantes en los proyectos.

\section{Metodología}

Este trabajo se enmarca dentro de los proyectos de perfil educativo de la asignatura de Trabajo Fin de Grado del Grado de Fisioterapia de la Universidad San Jorge. Dichos proyectos cuentan con profesorado del Grado de Fisioterapia, y con entidades de personas con discapacidad de Zaragoza, con el fin de crear una serie de programas educativos por parte del alumnado. Ambos proyectos han comenzado en el curso académico 2016/2017 y está previsto completarlos y, en alguno de los casos, implementarlos a lo largo del curso académico 2017/2018. En dichos proyectos, el alumno selecciona la temática que quiere desarrollar de Educación para la Salud en el ámbito de la fisioterapia tras búsqueda de necesidades específicas en cada colectivo, incorporando el Aprendizaje y Servicio, para ser llevadas a cabo en asociaciones de personas con discapacidad.

\subsection{Participantes:}

En este proyecto piloto se cuenta desde el ámbito universitario con la participación activa y directa de dos docentes y dos estudiantes de la asignatura Trabajo Fin de Grado del Grado en Fisioterapia, desde las etapas de diagnóstico y planificación hasta las de gestión, ejecución, reflexión y evaluación.

Desde el ámbito comunitario participan miembros de entidades no lucrativas de personas con discapacidad con sede en Zaragoza: 5 socios de la Asociación de Lupus y Síndrome Antifosfolípido De Aragón (ALADA) y 3 socios de la Asociación de Amputados y Agenesias Ibérica de Aragón (ADAMPI- Aragón).

\subsection{Diseño del programa formativo:}

Dentro de este apartado, se desarrollará el diseño del programa formativo en Aprendizaje y Servicio ( Martínez- Usarralde, 2014) y de Trabajo de Fin de Grado.

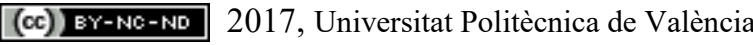




\subsubsection{Diseño programa formativo de Aprendizaje y Servicio.}

La metodología para el diseño del programa formativo sigue el formato propuesto por Martínez Usarralde (Martínez- Usarralde, 2014).

- Preparación ó Planificación:

Inicialmente los alumnos de la asignatura Trabajo Fin de Grado que participan en este proyecto realizaron, junto a los docentes asignados, un diagnóstico en el área de la fisioterapia de las necesidades educacionales de las asociaciones participantes dentro del proyecto ApS (Tabla 1). Dicho diagnóstico se realizó mediante una entrevista inicial directa con cada una de las asociaciones en la que participaron alumnos, docentes y socios de las diferentes asociaciones.

Tabla 1. Necesidades detectadas en ADAMPI Aragón en la entrevista realizada con socios, docentes y alumnos.

\section{NECESIDADES DETECTADAS SOCIOS ADAMPI-Aragón (entrevista)}

- Estrategias para mejorar el dolor de miembro fantasma

- Trabajo del equilibrio

- Trabajo del muñón: cicatriz, desensibilización, ajuste del encaje protésico

- Fortalecimiento muscular general, flexibilidad y acondicionamiento físico general

- Consejos para reeducación de la marcha

- Corrección de posturas viciosas

- Estrategias para la mejora del dolor lumbar

- $\quad$ Aprendizaje de ejercicios en el agua

- $\quad \ldots$

Tras estas reuniones los alumnos analizaron la información y eligieron, en base a las necesidades detectadas, la temática sobre la que versarían sus proyectos. Posteriormente, se establecieron conjuntamente entre los alumnos y los docentes los objetivos curriculares y la planificación del servicio a las entidades.

\section{- Diseño:}

En esta fase los alumnos llevaron a cabo los programas educativos, es decir, elaboraron y ejecutaron de forma práctica, organizada y guiada por sus tutores el programa planificado.

En un primer tiempo, se llevó a cabo por parte de los estudiantes una amplia búsqueda bibliográfica sobre la patología, fisiopatología e intervenciones educativas en el ámbito de la fisioterapia de los colectivos con los que se iba a trabajar, con el fin de dar soporte científico a sus respectivos proyectos.

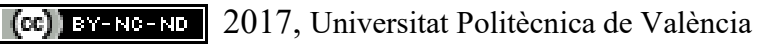


- Ejecución: Las acciones propuestas en la elaboración del programa se abordaron desde una metodología participativa y dinámica, mediante la cual se pretende motivar e implicar a los estudiantes y a los participantes de las asociaciones en un aprendizaje activo y comprometido (Tabla 2).

Tabla 2. Fases de diseño y ejecución de los proyectos ApS de Fisioterapia en TFG

\begin{tabular}{|c|c|c|}
\hline & Proyecto ALADA & Proyecto ADAMPI- Aragón \\
\hline $\begin{array}{l}\text { Necesidad detectada } \\
\text { sobre la que el } \\
\text { alumno } \\
\text { trabajar }\end{array}$ & $\begin{array}{l}\text { Realización de actividad física } \\
\text { controlada }\end{array}$ & $\begin{array}{l}\text { Realización de ejercicios } \\
\text { adaptados en el medio acuático }\end{array}$ \\
\hline $\begin{array}{l}\text { Tipo de proyecto } \\
\text { ApS }\end{array}$ & $\begin{array}{l}\text { Servicio directo y de } \\
\text { investigación }\end{array}$ & Servicio directo \\
\hline Tipo de intervención & $\begin{array}{l}\text { Programa de actividad física } \\
\text { mediante sesiones presenciales y } \\
\text { online }\end{array}$ & $\begin{array}{l}\text { Programa de actividad física } \\
\text { acuática mediante vídeos y } \\
\text { folletos en papel }\end{array}$ \\
\hline $\begin{array}{l}\text { Participantes en la } \\
\text { intervención }\end{array}$ & $\begin{array}{l}\text { Directos: } 5 \text { socios de ALADA } \\
\text { con Lupus Eritematoso Sistémico } \\
\text { (focuss group) }\end{array}$ & $\begin{array}{l}\text { Directos: } 3 \text { socios de } \\
\text { ADAMPI, amputados de } \\
\text { miembro inferior, que } \\
\text { participaron en la grabación de } \\
\text { los vídeos }\end{array}$ \\
\hline $\begin{array}{l}\text { Desarrollo de la } \\
\text { intervención }\end{array}$ & $\begin{array}{l}\text { Realización de actividad física } \\
\text { durante } 6 \text { semanas, con } 1 \text { clase } \\
\text { de forma presencial y } 2 \text { sesiones } \\
\text { online cada semana de } 60 \\
\text { minutos de duración } \\
\text { Las sesiones online son en } \\
\text { formato vídeo, a través de la } \\
\text { plataforma "Edpuzzle". }\end{array}$ & $\begin{array}{l}\text { Realización de una grabación } \\
\text { con socios de distintos } \\
\text { ejercicios para su ejecución en } \\
\text { el agua. Los ejercicios están } \\
\text { clasificados en } 3 \text { niveles de } \\
\text { dificultad según el estado del } \\
\text { paciente. } \\
\text { Elaboración de unos folletos } \\
\text { en papel para poder llevar a la } \\
\text { piscina. }\end{array}$ \\
\hline $\begin{array}{l}\text { Evaluación de la } \\
\text { intervención }\end{array}$ & $\begin{array}{l}\text { Valoración de parámetros } \\
\text { clínicos previos y posteriores } \\
\text { respecto al dolor, fatiga, } \\
\text { frecuencia cardiaca, calidad de } \\
\text { vida y velocidad de la marcha. } \\
\text { Cuestionario de satisfacción }\end{array}$ & Cuestionario de satisfacción \\
\hline
\end{tabular}


Esta metodología permitrá ser aplicada después por los propios participantes. Posteriormente, se llevó a cabo la intervención en sí en los proyectos en los que estaba contemplado para el presente curso académico 2016/2017 (Fig. 1 y 2)

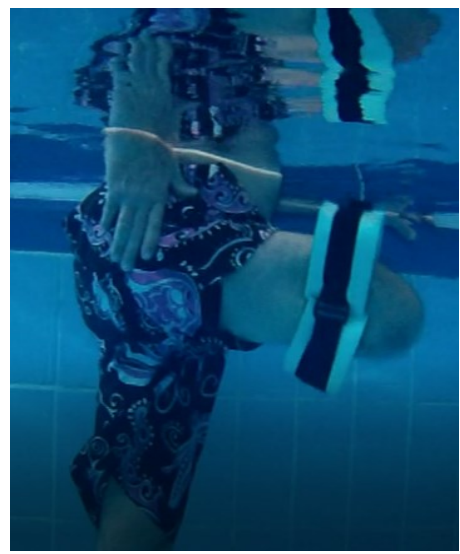

Figura.1: grabación de ejercicios en medio acuático con personas amputadas

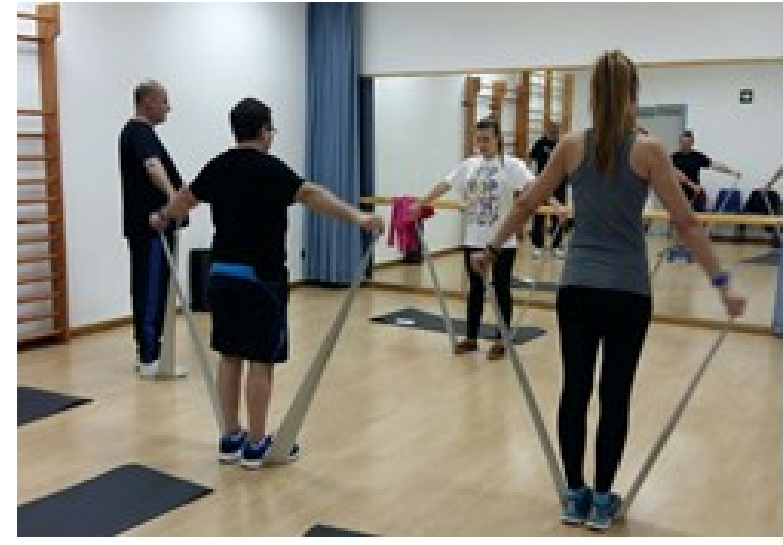

Figura.2: sesión presencial de actividad fisica con personas con Lupus

La demostración de los proyectos se llevará a cabo a través de varias vías:

- Dentro de la asignatura de TFG, mediante la presentación oral dentro de los distintos seminarios a sus compañeros de clase y a través de la defensa de su trabajo, tras la entrega de su redacción final, ante un tribunal.

- A las entidades participantes mediante la participación en jornadas divulgativas, reuniones, talleres, etc.

- A otros colectivos y población en general: a través de ponencias y pósters en distintas jornadas (Jornada de Innovación en Fisioterapia de la USJ), congresos, etc.

\section{- Reflexión:}

La reflexión por parte de los alumnos se llevará a cabo en 3 niveles:

- Individual: a través de un diario reflexivo estructurado y con preguntas guiadas

- Colectiva: mediante la exposición oral ante sus compañeros y el tribunal de Trabajo de Fin de Grado, y también en jornadas y congresos.

- Con las entidades mediante la presentación a las entidades en sus jornadas de su experiencia en el servicio.

- Reconocimiento:

(cc) BY-NC-ND 2017, Universitat Politècnica de València

Congreso IN-RED (2017) 
Tal y como se ha comentado en las fases de reflexión y demostración, el reconocimiento al trabajo realizado viene a través de la presentación/difusión de los proyectos tanto en la universidad (exposición a los otros alumnos, defensa del TFG, ponencia en Jornadas de innovación del grado, etc.) como en las respectivas entidades (jornadas, reuniones, etc.) y en otras instituciones (jornadas de $\mathrm{ApS}$, presentaciones en congresos, etc.).

\section{- Evaluación:}

La evaluación de los proyectos se llevará a cabo valorando los conocimientos y aprendizajes adquiridos, las experiencias de los alumnos, entidades y docentes y se analizará la consecución/no de los objetivos. Como herramientas principales de evaluación, destacaremos:

- Rúbricas de evaluación, por parte de los docentes que tutorizan los trabajos (gráfico 2).

- Defensa del Proyecto Fin de Grado ante Tribunal Académico donde se justificará su elaboración, ejecución y se realizarán la discusión y conclusión obtenidas pudiendo establecer recomendaciones para mejoras detectadas tras el análisis de los resultados.

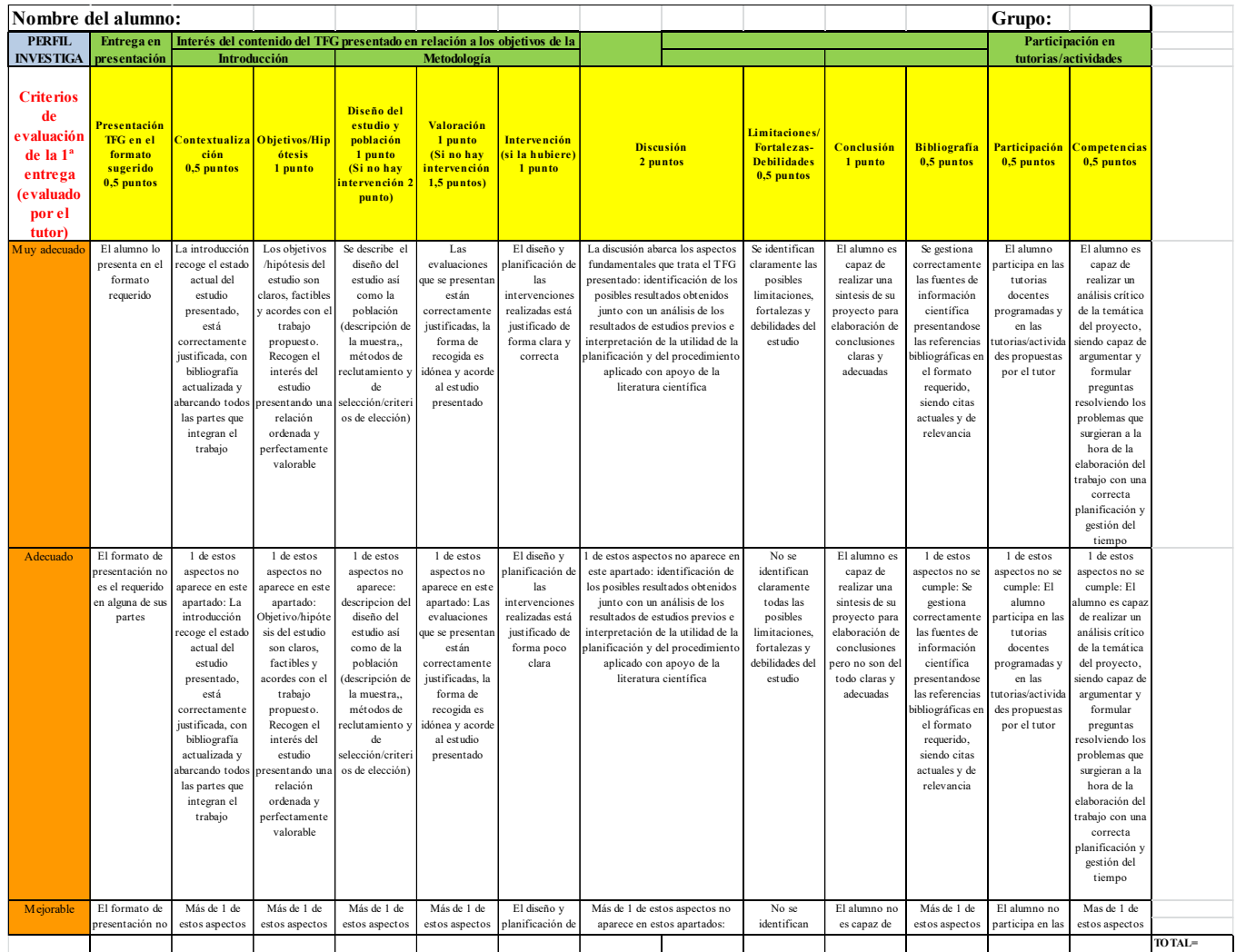

Gráfico 2: rúbrica de evaluación del tutor académico de TFG

(cc)) EY-NC-ND 2017, Universitat Politècnica de València 


\subsubsection{Diseño del programa formativo de Trabajo de Fin de Grado}

Cada estudiante tiene asignado un tutor académico con una disponibilidad asignada cuyo papel consiste en el seguimiento y asesoramiento sobre el Trabajo Fin de Grado, evaluando las entregas del proyecto.

El alumno cuenta con diferentes recursos y actividades presenciales y virtuales para poder tener las herramientas necesarias para un correcto desarrollo de dicho proyecto que deberá presentar rigor científico y metodológico.

- Tutoriales: manuales y guías para la transmisión vía virtual de información para el desarrollo del proyecto.

- Foro: recurso virtual para resolución de dudas, planteamiento de casos, análisis de artículos científicos, etc.

- Seminarios teórico-prácticos y expositivos grupales: desarrollo de los apartados propios de proyectos de investigación con ejemplos por parte de los docentes y exposición de los proyectos de los alumnos para planteamiento y resolución de dudas.

- Evaluación: espacios habilitados para evaluación del proceso de elaboración de los borradores sucesivos del Trabajo Fin de Grado.

Tras la elaboración e implementación del proyecto, el alumno podrá defender dicho proyecto ante Tribunal siempre y cuando exista informe favorable del tutor académico.

\section{Resultados}

Tal y como se ha indicado en el apartado de metodología, al tratarse este trabajo de un proyecto de carácter bianual con finalización prevista en julio de 2018, a día de hoy presentamos cómo se realizará el análisis de la información y los datos obtenidos.

A continuación se muestran los resultados que se esperan obtener divididos en diversos apartados:

\subsection{Resultados específicos de los alumnos:}

- Valoración de la experiencia personal y profesional de la participación en un Proyecto ApS: a través de un cuaderno reflexivo estructurado y guiado, que han ido cumplimentando a lo largo del desarrollo de todo el proyecto. Como experiencias por parte de los alumnos se puede destacar "el hecho de trabajar con un colectivo, no con un único paciente como mis compañeros que están trabajando con un caso clínico para su TFG “, donde esta alumna compara su experiencia de intervención con la de otros alumnos que no están trabajando con el perfil educativo en TFG. También relevante la siguiente reflexión: "lo que me parece más interesante del trabajo realizado es que he aportado algo diferente, totalmente

(c)) BY-NC-ND 2017, Universitat Politècnica de València 
nuevo a un grupo de personas que lo necesita, y que lo he realizado de forma autónoma”, en donde vemos que se refleja una parte de la esencia del Aprendizaje y Servicio, que es el trabajo autónomo y el aprendizaje como servicio a una comunidad.

- Adquisición de competencias curriculares, que se valora a través de la utilización de rúbricas propias de la asignatura TFG y de la redacción del trabajo final TFG junto a la defensa del proyecto ante Tribunal.

\subsection{Resultados propios del proyecto realizado:}

- Valoración personal de los usuarios de la intervención realizada. Dicha valoración se evalúa a través de unos cuestionarios de satisfacción creados "adhoc", de tipo Test de Likert en los que se analizan diferentes aspectos relacionados con la intervención realizada como son: información general con cuestiones sobre el desarrollo del programa; factor físico con cuestiones en cuanto a su estado general, fatiga y dolor; factor psicológico y social con cuestiones sobre la satisfacción, autoestima y expectativas del programa y finalmente un factor educativo con cuestiones en relación directa con la Educación para la Salud.

- Resultados de la investigación: Puesto que el trabajo que se está llevando a cabo consiste en programas de Educación para la Salud con una intervención clínica sobre los usuarios, se espera obtener una serie de cambios en los participantes en ciertos parámetros clínicos que han sido valorados, y cuya medición se ha realizado antes y después de la intervención. Los datos que se obtengan serán estudiados mediante un análisis estadístico siguiendo el método científico propio del área de Ciencias de la Salud.

Asimismo se pretende incrementar las competencias del paciente desde el punto de vista de la fisioterapia respecto a sus necesidades de salud para prevenir, reconocer y actuar ante problemas derivados de su patología aprendiendo a responsabilizarse de sus propios cuidados.

\subsection{Resultados específicos para los docentes implicados en los proyectos:}

- Valoración de la experiencia ApS: Si bien la asignatura de TFG es una asignatura que ya está eminentemente centrada en el alumno puesto que presenta una elevada carga de trabajo autónomo por parte de éste, hemos detectado que, al igual que otros autores (referencia), en un trabajo de TFG en ApS, el alumno pasa a ser el eje central del trabajo. También, teniendo en cuenta que esta es la primera experiencia que tenemos como docentes en proyectos de ApS, destacamos el cambio que ha supuesto para los docentes de la asignatura el tipo de metodología de trabajo, que nos ha implicado una transformación profunda en nuestra práctica 
docente. Es importante asimismo poner de manifiesto lo enriquecedor del contacto y trabajo con entidades, puesto que favorece el estrechamiento de lazos con colectivos de personas no vinculadas directamente con la docencia. También nos gustaría destacar el hecho de sacar metafóricamente la universidad de los campus universitarios y acercarla a la ciudadanía, puesto que esta "salida del aula" supone un beneficio tanto para la entidad universitaria en sí, como para los colectivos con los que hemos trabajado y la ciudadanía en general.

- Valoración como tutores académicos del TFG: se evaluó a los alumnos mediante el uso de rúbricas específicas para la evaluación de TFG.

\section{Conclusiones:}

En este tipo de trabajo el alumno se convierte en protagonista principal de su aprendizaje, pasando a asumir el docente un rol de guía y tutor a lo largo del proceso. Este protagonismo implica un empoderamiento del estudiante para su desarrollo profesional y personal (Folgueiras, 2013).

Se ha conseguido con los alumnos un acercamiento, tanto teórico como experiencial a la que será su futura profesión, que ha permitido una contextualización de su aprendizaje dentro de la esfera tanto social como educativa, con el fin de aumentar su motivación en cuanto a su formación, haciendo ésta más enriquecedora (Zubillaga, 2012; Martínez, 2013; Martínez, 2015; Sáenz de Jubera, 2016) y favoreciendo que nuestros alumnos tengan una mayor sensibilidad por la sociedad que les rodea, y que, en resumen, se conviertan en mejores ciudadanos (Francisco, 2010; Tejada, 2013).

La consecución de este último objetivo de una mayor sensibilidad social y cívica ha tenido mucho que ver con la asunción de responsabilidad por parte de los alumnos (Tejada, 2013). Por una parte, se generó un contexto de trabajo que les dio la oportunidad de desarrollar habilidades sociales y cooperativas, como son el diálogo, la escucha activa, el consenso, la negociación, la asertividad, la empatía, el respeto, la solidaridad o el compromiso (Ruiz, 2010; Mendía, 2009; Francisco, 2010). Dicho trabajo se ha llevado a cabo gracias a la detección de las necesidades de los colectivos con los que se ha trabajado, mediante la interacción con ellos y con el objetivo de contribuir a la resolución de la problemática abordada en un contexto real.

Los alumnos han sido capaces de contrastar sus vivencias, conocimientos y experiencias, para así ejecutar un programa de trabajo de forma responsable, tanto de cara a sus compañeros como a los miembros de las entidades, lo que también les ha permitido llevar a cabo una reflexión profunda sobre las experiencias vivenciadas, y ser capaces de autoevaluarse y evaluar el proceso vivido (Capella, 2016; Páez, 2013).

Por otro lado, el proceso de tutorización ha contribuido, con los seminarios, talleres y los encuentros realizados, a trabajar las competencias planteadas en la asignatura desde los conocimientos, destrezas, actitudes y valores de cada estudiante, logrando una mayor 
autonomía e iniciativa personal que les ayude a vivenciar el proceso desde la participación, la cooperación y la reflexión conjunta (Rodriguez, 2014).

Siguiendo a Andreu y Francisco, la metodología de ApS establece una relación más igualitaria entre el estudiante y el docente, este cambio en las relaciones profesor-alumno facilita en gran medida la comunicación y el diálogo igualitario entre ambos (Andreu, 2009; Francisco, 2010)

Por parte del equipo docente, la integración del ApS implica un gran esfuerzo dinamizador e innovador, que además ha sido documentado durante todo el proceso, pero se traduce en una mejora del proceso de enseñanza-aprendizaje (Rodríguez, 2015). Además, este tipo de iniciativas docentes favorece la creación de redes de trabajo de colaboración más amplias. No se trata de llevar a cabo la labor docente en solitario, puesto que esto puede causar cansancio y frustración, sino de generar espacios comunes para el encuentro y el intercambio donde se pueda conseguir una actividad más dinámica, motivante y satisfactoria (Francisco, 2010).

Como conclusiones finales podemos afirmar:

Si bien en los grados de fisioterapia y en la asignatura de Trabajo de Fin de Grado, no es todavía habitual el uso del ApS, existen ya muchas instituciones educativas de diversos niveles y distintas disciplinas que aplican esta metodología con sus alumnos, por lo que el beneficio que aportan tanto al ámbito docente como al ámbito de la ciudadanía está ya ampliamente documentado.

En el mundo actual en el que vivimos, caracterizado por el fácil acceso a gran cantidad de contenidos y donde prácticamente todos los sistemas se renuevan con una frecuencia asombrosa, consideramos que el ámbito de la educación no debe quedarse atrás en este sentido y debe trabajar con aquellas herramientas que supongan una innovación en la práctica docente, en este caso el ApS, intentando reflejar y documentar todo el proceso siempre que sea posible, puesto que esto permite un mejor análisis y reflexión de lo vivido.

En nuestro caso, el desarrollo de la propuesta de ApS en TFG comenzó siendo una experiencia puntual, casi piloto, pero cabe destacar la gran acogida que ha tenido por parte de la universidad, los alumnos y los colectivos con los que se están participando. Además, hemos tenido la oportunidad de poder dar a estos trabajos una mayor proyección gracias a diversas iniciativas de Aprendizaje y Servicio y de Innovación Docente por parte de la USJ $\mathrm{y}$ otras universidades, fundaciones y entidades.

En conclusión, si la universidad pretende formar a ciudadanos críticos, reflexivos y responsables con el medio que les rodea, el aprendizaje y servicio es una metodología que puede contribuir a éstos y otros retos de la educación superior, construyendo una sociedad más comprometida con la realidad que le rodea.

\section{Referencias:}

AIBAR REMON, C. (2000). La formación en educación para la salud en las profesiones sanitarias. Trabajo Social y Salud 35 (marzo 2000) 205-210.

(c)) EY-NC-ND 2017, Universitat Politècnica de València 
ANDREU LL., SANZ, M. \& SERRAT, E. (2009). "Una propuesta de renovación metodológica en el marco del Espacio Europeo de Enseñanza Superior: los pequeños grupos de investigación cooperativos" REIFOP, 12 (3), 111-126 (Enlace web: $\mathrm{http} / / \mathrm{www}$.aufop.com)

CAPELLA PERIS C., GIL GÓMEZ J., MARTí PUIG M. La metodología del aprendizaje-servicio en la educación fisica. Apunts. Educación Física y Deportes 2014, n. ${ }^{\circ}$ $116,2 .^{\circ}$ trimestre (abril-junio), pp. 33-43

DALE, E. (1954) Audiovisual methods in teaching, revised edition. New York: A Holt Dryden Book, Henry Holt and Company.

DECLARACIÓN DE BOLONIA (junio 1999). Declaración conjunta de los Ministros Europeos de Educación.. Disponible en http://eees.es/pdf/Bolonia_ES.pdf

COMUNICADO DE LONDRES (mayo 2007). Hacia el Espacio Europeo de Educación Superior: respondiendo a los retos de un mundo globalizado. Disponible en http://eees.es/pdf/London_communique18may2007.pdf

FRANCISCO, A. \& MOLINER, L. (2010). El aprendizaje servicio en la universidad: una estrategia en la formación de ciudadanía crítica. Revista Electrónica Interuniversitaria de Formación del Profesorado, 13 (4), 69-77.

FOLGUEIRAS, P., LUNA, E. \& PUIG, G. (2013). Aprendizaje y servicio: estudio del grado de satisfacción de estudiantes universitarios. Revista de Educación, 362, 159 185.doi:10.4438/1988-592X-RE-2011-362-157

GUTIERREZ ET AL. (2003). Formación en promoción y educación para la salud. Informe del Grupo de Trabajo de Promoción de la Salud a la Comisión de Salud Pública del Consejo Interterritorial del Sistema Nacional de Salud. MADRID: Ministerio de Sanidad y consumo

KENDALL, J. C. (1990). Combining service and learning: An introduction. In J. C. Kendall (Ed.)Combining service and learning: A resource book for community and public service, Vols. 1-2 (pp.1-36).

MARTÍNEZ, B. Y MARTÍNEZ, I. (2015). El aprendizaje servicio y la formación inicial de profesionales de la educación. Revista de currículum y formación del profesorado, 19 (1), 244-260. Recuperado de: http://www.ugr.es/ recfpro/rev191ART10.pdf.

MARTÍNEZ, B., MARTÍNEZ, I., ALONSO, I. Y GEZURAGA, M. (2013). El Aprendizaje-Servicio, una oportunidad para avanzar en la innovación educativa dentro de la Universidad del País Vasco. Tendencias Pedagógicas, 21, 99- 117.

MARTÍNEZ-USARRALDE, M.J. (2014). “Otras metodologías son posibles... y necesarias. Cuando la cooperación para el desarrollo en educación encontró al APS (Aprendizaje Servicio)" en Centro de Cooperación al Desarrollo: Universidad y cooperación al desarrollo. Contribuciones de las Universidades al desarrollo humano. Valencia: Universitat Politècnica de València, pp. 135- 153.

(cc) EY-NC-ND 2017, Universitat Politècnica de València 
MENDÍA, R. (2009). “Aprendizaje y servicio solidario: una propuesta educativa para el desarrollo de la competencia ciudadana”. Organización y Gestión Educativa, 17(2), 7-10.

MENSAJE DE SALAMANCA (marzo 2001). I Convención de Instituciones europeas de Enseñanza Superior: Perfilando un Espacio Europeo de Enseñanza Superior. Recuperado el 30 de septiembre 2005. Disponible en http://www.crue.org/mensajeconvESP.htm

PÁEZ SÁNCHEZ, M. Y PUIG ROVIRA, J.M. (2013). "La reflexión en el AprendizajeServicio”, Revista internacional de educación para la justicia social (RIEJS), Vol. 2, Núm. 2, pp. 13-32.

PUIG, J. M., BATLLE, R., BOSCH, C., \& PALOS, J. (2007). Aprendizaje servicio. Educar para la ciudadanía. Barcelona: Octaedro.

PONCE DE LEÓN, A., SANZ, E. Y VALDEMOROS, M.A. (2013). El Trabajo Fin de Grado, marco para el desarrollo del emprendimiento entre los jóvenes. En Torío, S., García-Pérez, O., Peña, J.V. y Fernández, C.M., La crisis social y el Estado del Bienestar: las respuestas de la Pedagogía Social. Oviedo: Universidad de Oviedo, 324-328.

RODRIGUEZ GALlEGO, M.(2013). El Aprendizaje y Servicio como estrategia metodológica en la universidad. Revista Complutense de Educación. Vol. 25 Núm. 1 (2014) 95-113

Rodríguez-Gallego, M., Ordóñez-Sierra, R. Una experiencia de aprendizaje servicio en comunidades de aprendizaje. Revista de currículum y formación de profesorado.Vol. 19, $\mathrm{n}^{\circ}$ 1

RUIZ, J. M. (2010). Evaluación del diseño de una asignatura por competencias, dentro del EEES, en la carrera de Pedagogía: Estudio de un caso real. Revista de Educación, 351, 435-460.

SÁENZ DE JUBERA OCÓN,M., PONCE DE LEÓN ELIZONDO, A., SANZ ARAZURI, E. El aprendizaje-servicio como proyecto de trabajo fin de grado en el marco de la educación del ocio. Revista Interuniversitaria de Formación del Profesorado, vol. 30, núm. 2, agosto, 2016, pp. 63-76

TAPIA, N. (2006). Aprendizaje y servicio solidario en el sistema educativo y las organizaciones juveniles. Buenos Aires:Ciudad Nueva.

TEJADA, J. (2013) La formación de las competencias profesionales a través del aprendizaje servicio, Cultura y Educación, 25:3, 285-294, DOI:10.1174/113564013807749669

UNESCO (1998). Declaración final de la Conferencia Mundial de Educación Superior. Primera Conferencia Mundial de Educación Superior, 5-9 octubre, París

URQUIZU CABALLÉ, A. La importancia de la innovación educativa para la Docencia jurídica en el contexto internacional de la Educación superior. III Jornada sobre docència del dret i tecnologies de la informació i la comunicació. Uoc. Recuperado de: http://www.uoc.edu/symposia/dret_tic2012/pdf/2.7.urquizu-angel.pdf

ZUBILlAGA, A. Y GUINOT, C. (2012). Aprendizaje-servicio: propuesta metodológica para trabajarcompetencias. Portularia: Revista de Trabajo Social, 12, 187-195. 


\title{
Aplicación de metodologías activas para mejora del aprendizaje y desarrollo de competencias transversales. Experiencia en una asignatura de calidad de aguas de máster universitario.
}

\section{Carmen Hernández-Crespo ${ }^{a}$, Miguel Martín ${ }^{\mathrm{b}}$ y Javier Paredes}

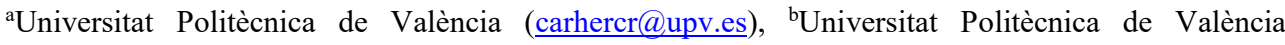
(mmartin@hma.upv.es) ycUniversitat Politècnica de València (jparedea@hma.upv.es).

\begin{abstract}
Integration in the European Higher Education Area requires the implementation of active learning methodologies that focus on the student and promote the development of transversal competences. In the present study the experience carried out in a subject of University Master is exposed. The active methodologies applied are the resolution of practical cases and the field visit where various activities are carried out to recognize in situ the knowledge acquired in the classroom. The results of a specific survey completed by the students at the end of the course are very positive, indicating a good acceptance of the applied methodologies. The grades obtained by the students in the evaluation activities also show that the learning has been deep and that different transversal competences have been adequately worked.
\end{abstract}

Keywords: Active learning methodologies, transversal competences, mathematical modeling, water quality, wetlands

\begin{abstract}
Resumen
La integración en el Espacio Europeo de Educación Superior requiere la implementación de metodologías activas de aprendizje, que centren el protagonismo en el alumno y fomenten el desarrollo de competencias transversales. En el presente estudio se expone la experiencia llevada a cabo en una asignatura de Máster Universitario. Las metodologías activas aplicadas son la resolución de casos prácticos y la visita de campo durante la que se realizan diversas actividades para reconocer in situ los conocimientos adquiridos en el aula. Los resultados de una encuesta especifica cumplimentada por los estudiantes al finalizar el curso son muy positivos, indicando una buena aceptación de las metodologías aplicadas. Las calificaciones obtenidas por los alumnos en las actividades de evaluación también muestran que el aprendizaje ha sido profundo y que se han trabajado adecuadamente diversas competencias transversales.
\end{abstract}

Palabras clave: metdologías activas de aprendizaje, competencias transversales, modelación matemática, calidad del agua, humedales. 


\section{Introducción}

El Espacio Europeo de Educación Superior (EEES) nace en 1988 con el objetivo fundamental de armonizar los sistemas de educación superior de los estados miembros, fomentando la creación de empleo y favoreciendo la movilidad de estudiantes, profesores y personal administrativo de las universidades (www.eees.es), así como ayudar a mejorar la empleabilidad de los titulados y la movilidad laboral.

El reciente informe de seguimiento del Parlamento Europeo (2015/2039(INI)) destaca que las reformas de Bolonia han posibilitado la consecución de un avance importante en cuanto a convergencia estructural de las estructuras de educación superior, pero pone de relieve la brecha todavía existente en la adaptación de los sistemas educativos a las necesidades del mercado laboral, con el fin de mejorar la empleabilidad y la competitividad. El concepto de empleabilidad implica que los estudiantes deben dominar una amplia gama de diversas competencias, para lo cual se alienta a la cooperación nacional e internacional entre la comunidad universitaria y las empresas. Así mismo, el informe pone énfasis en la necesidad de un cambio de paradigma educativo, hacia un enfoque centrado en el estudiante, que contemple su desarrollo personal, destacando la importancia de su participación en la gobernanza del sistema de educación superior.

Por tanto, entre los compromisos adquiridos en este nuevo marco de educación se encuentra el de fomentar el aprendizaje activo por parte de los estudiantes. El aprendizaje activo centra el protagonismo del proceso en el alumno, quien participa activamente en la creación de significado, es autónomo, auto-regulado y conocedor de sus propios procesos cognitivos. y el papel del docente es el de mediador entre el conocimiento y el alumnado (Olmedo, 2013). Además, las metodologías activas favorecen la formación en determinadas competencias transversales y permiten el acercamiento del estudiante a su futura labor profesional (Sancho et al., 2016).

La eficacia de las metodologías activas se puede evaluar por diferentes vías, como son las encuestas de satisfacción o la mención en el portafolio de la asignatura (Santiago, 2016), la comparación de las calificaciones obtenidas por los alumnos en años anteriores y posteriores a la implementación de la técnica objeto de estudio (Trigueros et al. 2016), o mediante la comparación de resultados de encuestas de conocimientos pasadas al inicio y al final del curso (Sancho et al., 2016).

\section{Objetivos}

El presente estudio tiene por objetivos compartir la experiencia en la aplicación de metodologías activas de aprendizaje desarrollada en una asignatura de máster universitario, así como evaluar el resultado de la experiencia a través de la consulta a los estudiantes. Por su parte, la aplicación de las metodologías seleccionadas, trabajo de casos prácticos y visita de campo, tenían por finalidad fomentar el aprendizaje activo y profundo por parte de los estudiantes así como la puesta en práctica de muchas de las competencias transversales definidas en la UPV, principalmente: la aplicación y el pensamiento práctico; el análisis y

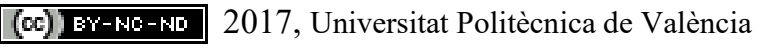

Congreso IN-RED (2017) 
la resolución de problemas; la innovación y la creatividad; el trabajo en equipo y liderazgo; la responsabilidad ética, medioambiental y profesional; la comunicación efectiva; el pensamiento crítico; el conocimiento de problemas contemporáneos; el aprendizaje permanente; y la planificación y gestión del tiempo.

\section{Desarrollo de la innovación}

La experiencia descrita en la presente comunicación viene aplicándose desde el primer curso de impartición del Máster de Ingeniería Hidráulica y Medio Ambiente, concretamente en la asignatura de Modelación matemática de calidad de aguas, habiéndose observado buenos resultados en cuanto al aprendizaje adquirido por los alumnos y buena opinión por parte de los estudiantes, a través de las encuestas realizadas por el Instituto de Ciencias de la Educación de la UPV. La novedad aplicada el pasado curso reside en la introducción de una nueva metodología activa, la visita de campo, y la evaluación específica de ambas metodologías mediante una encuesta de satisfacción creada al efecto y pasada a los alumnos al finalizar el curso.

Las dos metodologías activas aplicadas son: a) la resolución de un caso práctico mediante trabajo en equipos de dos personas y b) una visita de campo a un ecosistema acuático donde se dan los problemas de contaminación vistos en la asignatura.

a) Caso práctico.

La resolución del caso práctico consiste en la implementación de un modelo matemático para evaluar la evolución de la calidad del agua de una masa acuática, comprobar si cumple los objetivos de calidad y en caso contrario proponer medidas para recuperar su buen estado, las cuales deben ser comprobadas previamente mediante simulación en el modelo desarrollado. Hacia mediados de cuatrimestre se convoca a todos los grupos a una presentación parcial del trabajo, para controlar que van progresando adecuadamente en la implementación del modelo y en la búsqueda de la información necesaria. Otro aspecto positivo es que es un buen momento para resolver las dudas que les han ido surgiendo hasta el momento. Esta entrega parcial es evaluada y forma parte de la nota final, con el fin de que se preocupen por avanzar el trabajo debidamente. Al final del curso, el trabajo completo es presentado oralmente y mediante un informe escrito, acompañado del correspondiente archivo del modelo. Ambas presentaciones, parcial y final, son en formato reunión con los profesores, quienes van formulando preguntas y comentarios a medida que se va avanzando en la presentación. Consideramos que esta modalidad es más eficiente que una presentación oral unidireccional ante toda la clase, ya que permite al estudiante sentirse más cómodo, y reflexionar y dialogar más tranquilamente con el profesor durante toda la reunión.

A lo largo del curso, los estudiantes trabajan las competencias específicas de la asignatura, como la implementación y resolución de ecuaciones diferenciales, establecimiento de cinéticas para los diferentes procesos, búsqueda de información relativa a los contaminantes a modelar (fuentes y comportamiento en la naturaleza principalmente), algunas de las cuales están estrechamente relacionadas con diversas competencias transversales. En la 
Tabla 1 se recogen las tareas desarrolladas a lo largo del caso práctico y las competencias transversales con las que se relacionan.

Tabla 1. Tareas enmarcacadas en el caso práctico y competencias transversales relacionadas.

\begin{tabular}{|c|c|}
\hline Tareas & Competencias transversales UPV \\
\hline $\begin{array}{l}\text { Búsqueda de información sobre los contaminantes } \\
\text { a modelar. }\end{array}$ & CT-01, CT-06; CT-10; CT-12 \\
\hline $\begin{array}{l}\text { Implementación del modelo matemático y } \\
\text { resolución. }\end{array}$ & $\begin{array}{l}\text { CT-01; CT-02; CT-03; CT-05; CT-06; CT- } \\
\text { 12; CT-13. }\end{array}$ \\
\hline $\begin{array}{l}\text { Búsqueda de normative aplicable y comprobación } \\
\text { de su cumplimiento. }\end{array}$ & CT-01; CT-06; CT-07; CT-10. \\
\hline $\begin{array}{l}\text { Simulación de medidas para recuperar el buen } \\
\text { estado de la masa de agua. }\end{array}$ & $\begin{array}{l}\text { CT-01; CT-02; CT-03; CT-04; CT-05; CT- } \\
\text { 06; CT-07; CT-09; CT-11; CT-12 }\end{array}$ \\
\hline $\begin{array}{l}\text { Exposición del caso mediante presentación oral e } \\
\text { informe escrito. }\end{array}$ & $\begin{array}{l}\text { CT-01; CT-02; CT-04; CT-06; CT-07; CT- } \\
08 \text {; CT-09; CT-12. }\end{array}$ \\
\hline \multicolumn{2}{|c|}{$\begin{array}{l}\text { CT-01. Comprensión e integración; CT-02. Aplicación y pensamiento práctico; CT-03. Análisis y } \\
\text { resolución de problemas; CT-04. Innovación, creatividad y emprendimiento; CT-05. Diseño y proyecto; } \\
\text { CT-06. Trabajo en equipo y liderazgo; CT-07. Responsabilidad ética, medioambiental y profesional; CT-08. } \\
\text { Comunicación efectiva; CT-09. Pensamiento crítico; CT-10. Conocimiento de problemas contemporáneos; } \\
\text { CT-11. Aprendizaje permanente; CT-12. Planificación y gestión del tiempo; CT-13. Instrumental específica. }\end{array}$} \\
\hline
\end{tabular}

b) Visita de campo.

La visita de campo se realizó a una masa de agua que sufre algunos de los problemas de contaminación del agua explicados en la asignatura, l'Albufera de València. Concretamente dentro del Parque Natural de la Albufera visitamos el área de reserva del Tancat de la Pipa, el cual dispone de unas zonas de humedal artificial como sistema de tratamiento del agua procedente del lago seguido de unas lagunas someras.

En el Tancat de la Pipa pudieron conocer, de la mano de los técnicos de gestión de la reserva, la historia sobre el proceso de formación de l'Albufera y el proceso de deterioro ambiental que sufrió a partir de la década de los 60, así como las medidas que hay actualmente en marcha para revertir su estado. Posteriormente se realizó un recorrido a lo largo del Tancat y fueron identificando, con ayuda del profesor, las diferencias entre los distintos ambientes creados en el área de reserva, así como proponiendo formas de introducir los distintos procesos y variables observadas in situ en los modelos matemáticos. También ser realizó un ejercicio de tomar muestra en la entrada del sistema (procedente del lago de la Albufera) y salida del mismo, observando las grandes diferencias entre las mismas y poniendo de manifiesto el buen funcionamiento del mismo en cuanto a mejora de la calidad de las aguas.

De forma resumida, los principales procesos que se identificaron fueron los de sedimentación y resuspensión de partículas, los aportes por parte de la fauna (peces y aves), los procesos de degradación de materia orgánica, la eutrofización del agua procedente del lago, la asimilación de nutrientes por parte de la vegetación helófita. Las principales 
variables a modelar observadas fueron: la materia orgánica, el fitoplancton, la vegetación, las aves y la ictiofauna.

En definitiva, los humedales son espacios de gran valor educativo, caracterizados por ofrecer una amplia variedad de funciones y valores, tanto ambientales como sociales, económicos y culturales, por lo que representan áreas adecuadas para el desarrollo de actividades con enfoque holístico, integrando diferentes áreas de conocimiento (hidrología, calidad del agua, biología, geomorfología, ordenación del territorio, etc) (García et al. 2012).

Tras finalizar el recorrido por el Tancat de la Pipa, nos recogió una barca que nos trasladó al embarcadero de la Gola de Puchol atravesando el lago, de manera que pudieron comprobar los problemas de eutrofización que éste sufre y conocer un poco más la idiosincrasia del entorno gracias a las anécdotas contadas por el barquero. En la Figura 1 se muestran algunas imágenes de la visita realizada.
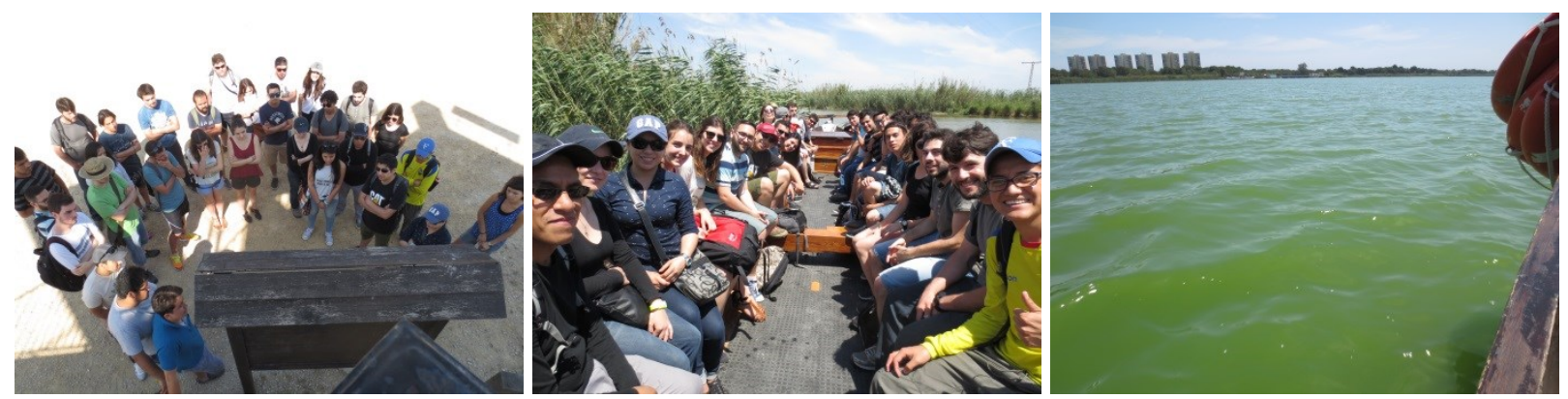

Figura 1. Imágenes de la visia al Tancat de la Pipa en l'Albufera de València.

\section{Resultados}

Los resultados de la aplicación de metodologías activas fueron satisfactorios, los alumnos demostraron haber adquirido un aprendizaje profundo de la materia, siendo capaces de resolver los casos prácticos de manera adecuada, algunos incluso con simulaciones muy creativas y en general unas presentaciones orales estructuradas y bien explicadas. Las calificaciones obtenidas fueron muy buenas, obteniendo todos los grupos entre notable (34\% de los grupos) y sobresaliente (66\% de los grupos).

La visita no fue evaluada y calificada pero sí se preguntó a los asistentes si les había parecido una actividad interesante, que les acercaba del papel y el ordenador a la realidad, y la respuesta fue positiva. Los autores consideran que para poder modelar bien un problema es preciso conocerlo personalmente, visitando el lugar, ya que te permite conocer detalles que son difícilmente detectables a través del análisis de la información numérica.

Como se comentaba en la introducción, existen diversas vías para medir la eficacia de las metodologías empleadas. En nuestro caso, la impresión que tuvieron los docentes al hacer la evaluación de los trabajos realizados fue buena, se comprobó que los estudiantes habían comprendido la materia y eran capaces de explicar adecuadamente las tareas desarrolladas 
en el trabajo. Por otro lado, se deseaba conocer la percepción de los estudiantes sobre las técnicas de aprendizaje aplicadas, para lo cual se elaboró una encuesta de satisfacción anónima que fue respondida por los alumnos $(\mathrm{N}=20)$.

En la encuesta se formularon seis preguntas de satisfacción y una de selección de competencias transversales que consideran haber desarrollado durante la asignatura. Las preguntas seguían la escala de valoración de las encuestas realizadas por el ICE, con la que ya estaban familiarizados los estudiantes, esto es: 1) totalmente en desacuerdo (valoración muy negativa), 2) más bien en desacuerdo, 3) término medio, 4) más bien de acuerdo, 5) totalmente de acuerdo (valoración muy positiva). A continuación se datallan las preguntas realizadas:

1. El sistema de evaluación de la asignatura, con puntuación distribuida entre exámenes y trabajos, me ha parecido adecuado.

2. El trabajo de la asignatura, basado en la resolución de un caso práctico, me ha parecido interesante y de utilidad para reforzar los conocimientos adquiridos en la asignatura.

3. La revisión parcial del trabajo con el profesor me parece una tarea importante porque me ha ayudado a detectar errores y poder corregirlos, plantear dudas y obligarme a avanzar una parte del trabajo y no dejarlo todo para el final.

4. La presentación final del trabajo en un formato de reunión, con diálogo con el profesor me ha servido para sentirme cómodo/a a la hora de expresarme y explicar el trabajo realizado. Lo prefiero respecto a presentación oral unidireccional.

5. La visita de campo de la asignatura me ha permitido reconocer en el mundo real los procesos y problemas de contaminación que hemos aprendido a modelar en la asignatura.
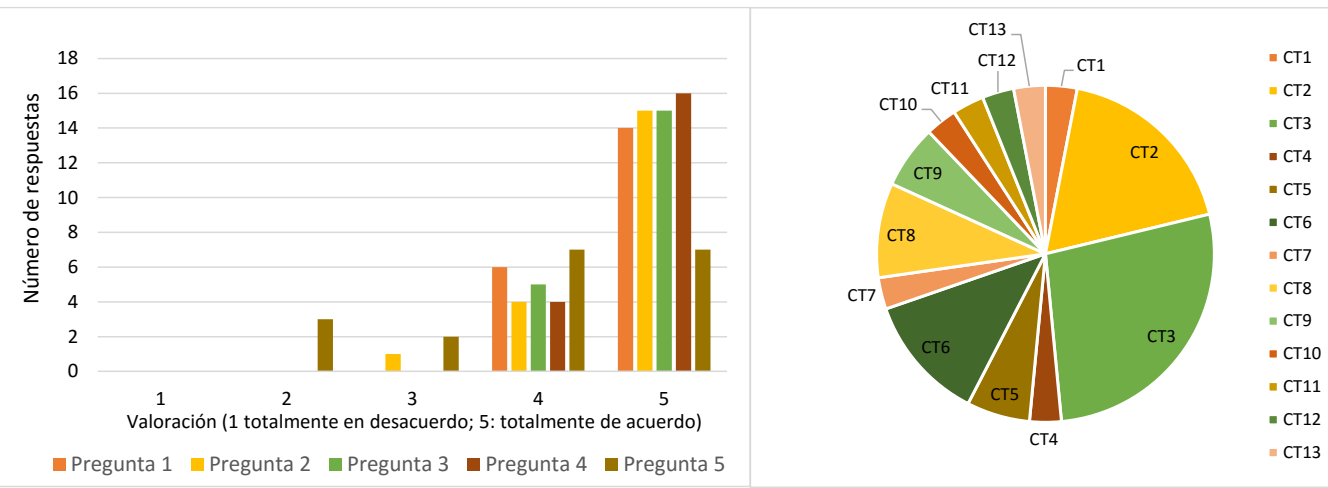

Figura 2. Resultados de la encuesta de valoración de las metodologías activas realizadas. Izda: histograma de las respuestas a las distintas preguntas realizadas. Dcha: competencias transversales desarrolladas por los alumnos.

Los resultados de la valoración fueron muy positivos, ya que la mayor parte de los encuestados calificaron con la puntuación máxima las cinco preguntas (Figura 2).

(c) EY-NC-ND 2017, Universitat Politècnica de València

Congreso IN-RED (2017) 
Por otro lado, otra de las preguntas consistía en que el estudiante seleccionase aquellas competencias transversales que consideraba haber desarrollado a lo largo de la asignatura. Las que en mayor medida se identificaron fueron la CT2 - aplicación y pensamiento práctico (18\%), CT3 - análisis y resolución de problemas (27\%), CT6 - trabajo en equipo y liderazgo (12\%) y CT8 - Comunicación efectiva (9\%). Estos resultados nos indican que sí que fueron perfectamente reconocidas aquellas más explícitas, pero que debemos poner mayor énfasis en mostrar cómo las actividades desarrolladas contribuyen a poner en práctica prácticamente todo el conjunto de competencias transversales definidas en la UPV.

Así mismo, se les preguntó si el momento de la visita, que en este curso se hizo al final del curso, les había parecido adecuado. La respuesta fue positiva por parte del $58 \%$ de los alumnos, mientras que el resto habría preferido a mitad de curso (26\%) o al inicio del curso $(16 \%)$. Esta valoración será tenida en cuenta de cara a la programación de la visita para el siguiente curso, ya que es posible que hacia mitad del curso se le pueda sacar un mayor partido y sirva como referencia para los siguientes temas a impartir, así como para comprender mejor algunos de los aspectos del caso práctico.

\section{Conclusiones}

La principal conclusión extraída del estudio es que las metodologías activas de aprendizaje fomentan un aprendizaje más profundo, centrado en el estudiante, viéndose reflejado en las actividades de evaluación y en las calificaciones. Además, el estudiante es capaz de reconocer la eficacia de las metodologías, valorándolas muy positivamente, e identificar las principales competencias transversales que han trabajado durante la asignatura.

\section{Referencias}

García Fernández, B., Sánchez Emeterio, G., Sánchez Ramos, D. (2012). La transposición didáctica de la investigación en humedales. Estudios sobre el Mensaje Periodístico, 18, 347-356. http://dx.doi.org/10.5209/rev ESMP.2012.v18.40988.

Olmedo Moreno, E. M. (2013). Enfoques de aprendizaje de los estudiantes y metodología docente: Evolución hacia el nuevo sistema de formación e interacción propuesta en el EEES. Revista de Investigación Educativa, 31 (2), 411-429. http://dx.doi.org/10.6018/rie.31.2.133501.

Parlamento Europeo. 2015/2039(INI). Informe sobre el seguimiento de la aplicación del Proceso de Bolonia. Comisión de cultura y educación.

Sancho Fernández, M., García-Fayos, B. y Arnal Arnal, M. (2016). "Análisis de la mejora del aprendizaje tras la incorporación de metodologías activas en una asignatura optativa del Grado de Ingeniería Química” en Congreso Nacional de Innovación Educativa y de Docencia en Red. Editorial Universitat Politècnica de València. http://dx.doi.org/10.4995/INRED2016.2016.4407.

Santiago Martín de Madrid, P. (2016). "La motivación del alumnado derivada de la realización de prácticas en contextos reales" en en Congreso Nacional de Innovación Educativa y de Docencia en Red. Editorial Universitat Politècnica de València. http://dx.doi.org/10.4995/INRED2016.2016.4375. 
Trigueros Preciado, S., Pérez González, D., Solana González, P., García Ruiz, E. (2016). "Experiencia docente universitaria mediante el uso de metodologías activas para el aprendizaje como la evaluación formativa compartida y el trabajo de competencias trasnversales" en Congreso Nacional de Innovación Educativa y de Docencia en Red. Editorial Universitat Politècnica de València. http://dx.doi.org/10.4995/INRED2016.2016.4351.

2017, Universitat Politècnica de València 


\title{
Evaluación del aprendizaje combinado para la enseñanza de Cirugía Bucal en alumnos de pregrado de Odontología
}

\section{Berta García ${ }^{1}$ y Verónica Odeh ${ }^{2}$}

${ }^{1}$ Profesor asocido de Cirugía Oral. Master en Cirugía Oral e Implantología, Facultad de Medicina y Odontología de la Universidad de Valencia. Valencia, España.

${ }^{2}$ Estudiante de pregrado de Odontología, Facultad de Medicina y Odontotología de la Universidad de Valencia. Valencia, España.

\begin{abstract}
Dentistry students not only have to gain theorical knowledge, but also practical skills. For these reasons it becomes increasingly important to investigate the potential of alternative learning tools. The aim of the study was to compare the efficacy of blended learning versus conventional learning for the teaching of Oral Surgery in terms of academic results, quality, satisfaction and motivation of students. To do this, the sample was divided into a GE and $G C$ that jointly attended a theorical class and, subsequently, completed the training with the visualization of videos in a web platform and with the reference book, respectively. The GE scored better on the practical exam ( $p$ $<0.001)$, had more positive opinions about training, felt more satisfied and more motivated than the $C G$.
\end{abstract}

Keywords: Oral surgery, anesthesia, new technologies, combined learning.

\begin{abstract}
Resumen
Los estudiantes de Odontología no sólo tienen que adquirir conocimientos teóricos, sino también habilidades prácticas. Por estas razones se hace cada vez más importante investigar el potencial de las herramientas de aprendizaje alternativas. El objetivo del estudio fue comparar la eficacia del aprendizaje combinado frente al convencional para la enseñanza de la Cirugía Bucal, en términos de resultados académicos, calidad, satisfacción y motivación de los alumnos. Para ello, se divide la muestra en un GE y GC que asistieron conjuntamente a una clase teórica y, posteriormente, completaron la formación con la visualización de vídeos en una plataforma web y con el libro de referencia, respectivamente. El GE obtuvo mejores calificaciones en el examen práctico $(p<0,001)$, tuvieron opiniones más positivas sobre la formación, se sintieron más satisfechos y mas motivados que el GC.
\end{abstract}

Palabras clave: cirugía bucal, anestesia, nuevas tecnologías, aprendizaje combinado. 


\section{Introducción}

La enseñanza en el campo de la salud presenta un gran reto para los alumnos, quienes tienen que adquirir no solo conocimientos teóricos, sino también las habilidades prácticas necesarias para su ejercicio profesional. Estas habilidades requieren de una enseñanza preclínica y clínica, con la atención a pacientes reales. Pero uno de los problemas que surge con mayor frecuencia en la enseñanza de la Medicina y la Odontología, es la dificultad de enfrentar al alumno al número de pacientes que asegure su formación idónea. Al no ser siempre posible la formación completa con pacientes, se complementa con otros recursos que limitan la comprensión de los conceptos más difíciles y el traslado de la teoría a la práctica. Así, la enseñanza clínica resulta, en ocasiones, complicada y dificulta la oportunidad de desarrollar competencias clínicas.

Los avances tecnológicos de los últimos años y el desarrollo acelerado de las Tecnologías de la Información y la Comunicación (TIC), han dado solución a estos problemas. La introducción del aprendizaje asistido por ordenador, con resolución de casos, ejercicios interactivos, videos demostrativos, simuladores y plataformas de Internet (Web, foros, etc.) constituyen un recurso docente muy útil para optimizar la enseñanza práctica. Permiten crear entornos de aprendizaje más cercanos a la realidad, fomentar la interacción y el aprendizaje práctico, presentando la información de una manera más atractiva y manteniendo al alumno motivado durante su proceso de formación. Tanto es así que, aunque el uso de las tecnologías informáticas no reemplaza los escenarios clínicos reales, constituyen una herramienta adicional y complementaria que facilita la adquisición de conocimientos y habilidades prácticas.

La utilización de estos nuevos medios debe entenderse siempre como apoyo y complemento a los modelos de enseñanza clásicos, que han demostrado durante años ser eficientes para la formación del alumnado. La combinación de los métodos de enseñanza tradicionales con las modernas tecnologías de la información, se conoce como aprendizaje combinado.

En el área de la Odontología, se están empleando cada vez más las nuevas tecnologías de la información, pero son pocos los trabajos que se han dedicado a diseñar y promover una propuesta que innove los tradicionales modelos de enseñanza. Se han encontrado trabajos publicados sobre innovación docente en disciplinas de la Odontología como son Radiología para el diagnóstico (Meckfessel y cols, 2011; Kavadella y cols, 2011; Santos y cols, 2016) y Ortodoncia (Aly y cols, 2011; Linjawi y cols, 2009), en los que se observa una mejora en los resultados académicos y respuestas positivas en cuanto a eficacia, motivación y compromiso activo. Sin embargo, la bibliografía publicada con respecto a la Cirugía Oral en particular es poca o casi nula. Solo se encontró un estudio en el que se evaluó un programa de simulación basado en una Web para enseñar razonamiento clínico y evaluación de pacientes en Cirugía Oral de pregrado (Kruger, 2016). El estudio concluyó que era una herramienta valiosa, mejorando los resultados de aprendizaje, en comparación con la enseñanza tradicional por sí sola. Es por ello que se lleva a cabo el presente estudio, donde se trató de evaluar cuán efectivo resulta el uso de una página web con vídeos interactivos, como apoyo y complemento para la enseñanza de la Cirugía Oral.

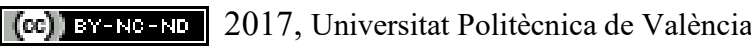

Congreso IN-RED (2017) 


\section{Objetivos}

En un grupo de estudiantes de pregrado de Odontología de la Universitat de València, que fueron sometidos al aprendizaje combinado frente al convencional, para la enseñanza de Cirugía Bucal, se plantearon los siguientes objetivos:

1. Estudiar los resultados académicos.

2. Evaluar la motivación de los estudiantes.

3. Conocer las opiniones y actitudes frente a la metodología empleada.

\section{Desarrollo de la innovación}

\subsection{Diseño del estudio}

Se realizó, en el Departamento de Cirugía Bucal de la Universitat de València, entre septiembre de 2016 y Mayo de 2017, un estudio para valorar el impacto del aprendizaje combinado mediante material multimedia (web: www.cirubuca.wixsite.com/ciruvestic) en alumnos de pregrado de Odontología. El estudio fue aprobado por el comité de ética de la Universitat de València H1486051731594. A todos los participantes se les explicó previamente en qué consistía el estudio y se les pidió firmar un consentimiento informado para participar en el mismo.

Se estableció un grupo de estudio (GE) o grupo de aprendizaje combinado, en el que se introdujo material didáctico en línea y un grupo de aprendizaje convencional, que sirvió de grupo control (GC). Los participantes fueron asignados de manera aleatoria.

\subsection{Población de estudio}

Los cristerios de inclusión fueron:

- Alumnos de pregrado de Odontología de la Universidad de Valencia.

- Disponibilidad horaria

- Disponer de un ordenador y auriculares por persona para poder visualizar los vídeos, en el caso del grupo de aprendizaje combinado.

- Firma de un consentimiento informado tras recibir información acerca del estudio. Se excluyeron de la muestra aquellos alumnos que no hubiesen completado los cuestionarios en su totalidad.

De un total de 81 alumnos que se inscribieron inicialmente a la clase, solo se presentaron 55 alumnos, de los cuales 2 fueron excluidos por no haber rellenado por completo los cuestionarios. Finalmente, un total de 53 alumnos cumplieron todos los criterios de inclusión y fueron incluidos en este estudio, de los cuales 25 asistieron a la enseñanza convencional y 28 a la combinada. 


\subsection{Material}

\section{Material didáctico:}

1. Una presentación de Keynote de 37 diapositivas sobre anatomía, anestesia local y exodoncia simple de dientes mandibulares, conteniendo dibujos esquemáticos, imágenes clínicas y cuadros-resumen, así como textos cortos, simples y fáciles de leer.

2. El capítulo 6 "Técnicas anestésicas primarias" del libro "Anestesia local en odontología” escrito por Miguel Peñarrocha, Jose Ma Sanchís y Jose Ma Martínez ${ }^{29}$, junto con imágenes en 2D.

3. Práctica 5 "Introducción a la exodoncia” de la libreta de prácticas de Cirugía Bucal de $3^{\circ}$ de Odontología de la Universidad de Valencia.

4. Una página Web (Fig.1-2) de elaboración propia, que fue presentada en el curso académico 2014-2015 como proyecto ESTIC, titulado "Educación asistida por ordenador: aplicación de las nuevas tecnologías en el proceso de aprendizaje de la anestesia dental y la cirugía bucal", con el código ESTIC1415_09 y bajo la convocatoria recogida en la Resolución del Vicerrector de Políticas de Formación y Calidad Educativa, del 8 de Octubre de 2014, obteniendo el reconocimiento de grupo ESTIC de excelencia. La Web incluye herramientas como imágenes, vídeos, cuestionarios de autoevaluación, plataforma de discusión en línea para exposición y resolución de dudas y acceso a enlaces externos.

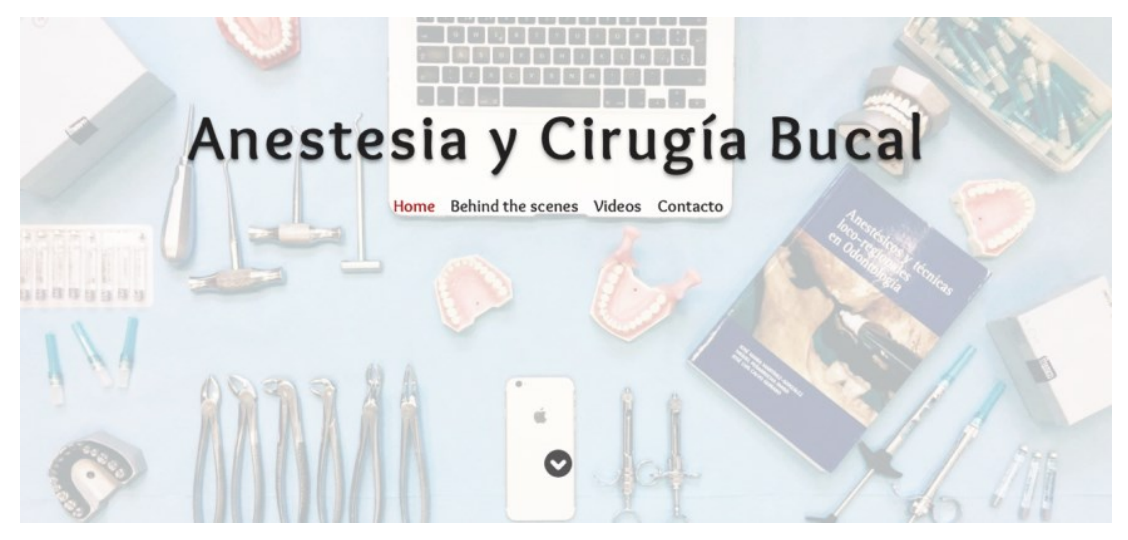

Fig.1 Página principal de la web.

5. Fantomas e instrumental de anestesia y extracción (jeringas, botadores y fórceps) cedidos por el Departamento de Cirugía Bucal de la Facultad de Medicina y Odontología de la Universitat de València.

Material para la evaluación y recogida de datos: Cuestionarios, fantomas de anestesia y extracción e instrumental quirúrgico (jeringas de anestesia, botadores, fórceps, etc.)

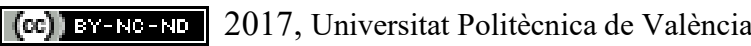

Congreso IN-RED (2017) 


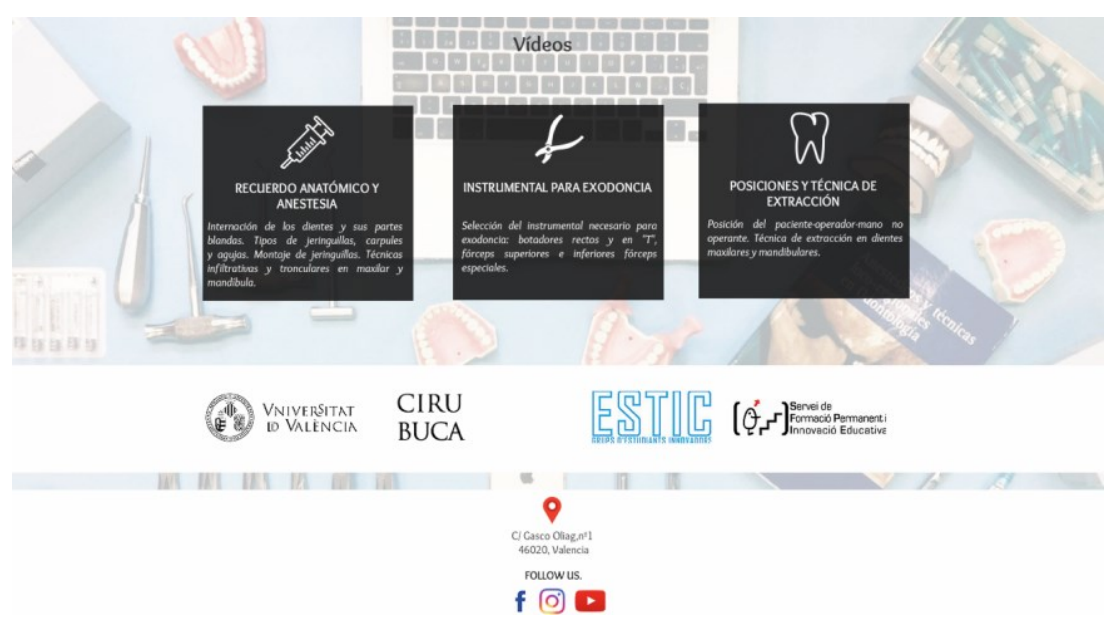

Fig.2 Menú principal de los videos, con acceso directo a cada sección pichando sobre el icono.

\subsection{Procedimiento}

Para evaluar la eficacia del aprendizaje combinado frente al convencional, se siguió el procedimiento empleado por otros autores (Hu J y cols, 2008) en un estudio similar. A continuación, se esquematiza el procedimiento llevado a cabo para el aprendizaje y la recogida de datos (Fig.3).

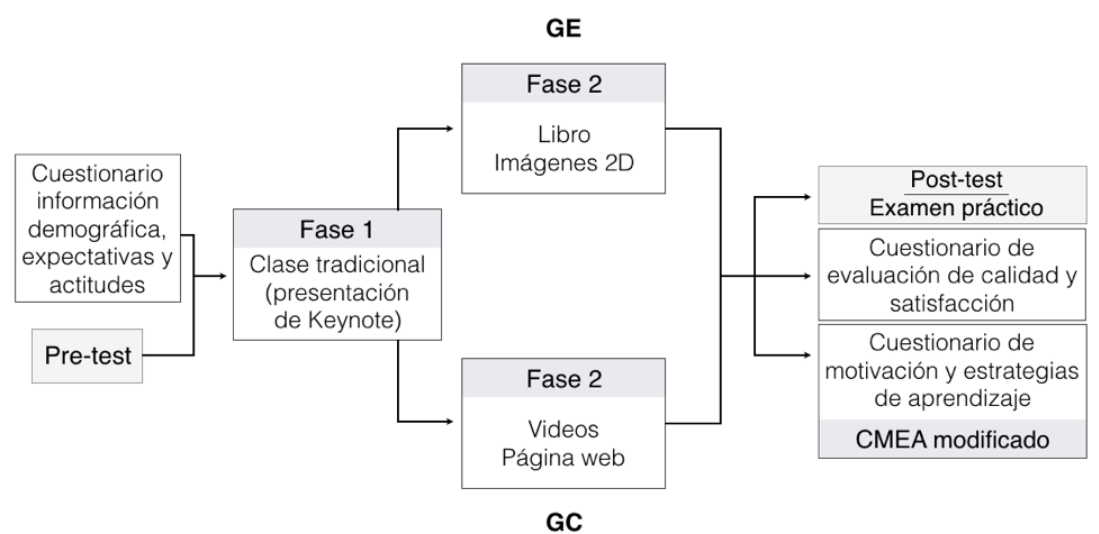

Fig. 3 Procedimiento de la investigación

\subsubsection{Actividad formativa}

La actividad de formación consistió en un curso de una hora de duración, que fue desarrollado especialmente para este propósito, que no modificó el plan de estudios y que se llevó a cabo dentro del horario de los estudiantes. El curso se dividió en dos tiempos. En primer lugar, ambos grupos asistieron conjuntamente a una clase tradicional, con el apoyo de una presentación de Keynote, que duró aproximadamente 30 minutos.

(c)) EY-NC-ND 2017, Universitat Politècnica de València 
Fue impartida por el profesor encargado de la asignatura (BGM), que acostumbra a dar la clase sobre el tema específico del que se trató.

Una vez finalizada la clase teórica, se aleatorizó y dividió a todos los pacientes en GE y GC. De tal manera que, en una segunda fase, de otros 30 minutos de duración, se entregó material complementario para el aprendizaje:

- En el grupo control (GC), el material complementario se compuso del capítulo 6 "Técnicas anestésicas primarias" del libro "Anestesia local en odontología" y la práctica 5 "Introducción a la exodoncia" de la libreta de prácticas de Cirugía Bucal de $3^{\circ}$ de Odontología de la Universidad de Valencia.

- En el grupo estudio (GE), los alumnos navegaron por la página web "Anestesia y cirugía bucal" (www.cirubuca.wixsite.com/ciruvestic), dirigidos por VOO para evitar el riesgo de un conocimiento incompleto.

\subsubsection{Protocolo de evaluación y recogida de datos}

Todos los estudiantes completaron cuestionarios, de la siguiente manera: (A) antes de iniciar el curso, ambos grupos completaron (i) un cuestionario de información demográfica, expectativas y actitudes y (ii) una prueba de evaluación de conocimientos teóricos (pre-test); (B) al final del curso, ambos grupos completaron (i) una prueba de conocimiento (post-test), (ii) un examen práctico sobre fantomas de anestesia y extracción, (iii) un cuestionario de calidad de la actividad formativa y satisfacción y (iv) un cuestionario de motivación y estrategias de aprendizaje.

Los cuestionarios fueron establecidos en base a los encontrados en estudios educativos similares (Kavadella y cols, 2011; Santos y cols, 2016; Hu J y cols, 2008; Varthis y cols, 2016; Linjawi y cols; 2009; Neuhaus y cols, 2008; Zambrano y cols, 2016). Fueron los mismos para ambos grupos, a excepción del cuestionario de calidad, en el que los estudiantes del grupo de aprendizaje combinado respondieron a una serie de preguntas adicionales.

\subsection{Análisis estadístico}

Todos los datos fueron almacenados en un documento Excel y procesados estadísticamente. Los análisis se realizaron con el programa SPSS 15.0 para Windows. Para la comparación del GE y GC se utilizó la prueba de Kolmogorov-Smirnov que evaluó las puntuaciones en los test de conocimiento y el modelo no paramétrico de Brunner-Langer para comparar la puntuación pre y post-test del examen teórico de ambos grupos. Se evaluó si mejoró el conocimiento de uno y otro grupo en la misma magnitud mediante un estadístico tipo ANOVA (ATS). La comparación de las puntuaciones en escala Likert se realizó mediante la prueba de Mann-Whitney (MW), por ejemplo, para contrastar el grado de acuerdo con los ítems de calidad de la actividad formativa y satisfacción o con los del CMEA. Para comprobar si las respuestas dependían de haber formado parte del GE o GC, se empleó el test $\mathrm{Chi}^{2}$ de asociación. El nivel de significancia empleado en los análisis fue del $5 \%(\alpha=0.05)$.

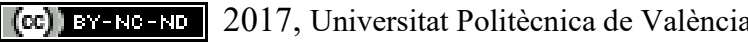

Congreso IN-RED (2017) 
Se desarrolló un estudio previo del tamaño muestral, seleccionando como variable primaria la nota del examen de conocimientos teóricos al finalizar la formación (post-test). Para determinar la diferencia entre las notas medias del grupo estudio y grupo control que quisimos detectar como estadísticamente significativo, se consultó la literatura ${ }^{3}$, encontrándose notas medias de $6,9 \pm 1,4$ y $8,1 \pm 1,4$ en dos grupos similares control y estudio. Ello supone una diferencia media de 1,2 puntos y, por tanto, un tamaño de efecto grande. Mediante un t-test (Tabla 1), se concluyó que eran necesarios 52 alumnos para alcanzar una potencia del $80 \%$ con el objeto de detectar una diferencia en la nota media de 1,2 puntos y una desviación estándar de 1,4 puntos. Se asumió una confianza del 95\% para un t-test de grupos independientes.

Tabla 1. Tamaño muestral total necesario según diferencia mínima relevante para la nota media y potencia (t-test). Calculado para un nivel de confianza del $95 \%$.

\begin{tabular}{lllll}
\hline Medias para la diferencia & Tamaño efecto & \multicolumn{3}{l}{ Potencia alcanzada } \\
\cline { 3 - 5 } mínima relevante & (d) & $\mathbf{6 0 \%}$ & $\mathbf{7 0 \%}$ & $\mathbf{8 0 \%}$ \\
$\mathbf{6 , 9}-\mathbf{7 , 2}$ & $\mathbf{0 , 2}$ (pequeño) & 492 & 620 & 788 \\
$\mathbf{6 , 9}-\mathbf{7 , 6}$ & $\mathbf{0 , 5}$ (medio) & 82 & 102 & 128 \\
$\mathbf{6 , 9}-\mathbf{8 , 1}$ & $\mathbf{0 , 8}$ (grande) & 34 & 42 & $\mathbf{5 2}$ \\
\hline
\end{tabular}

\section{Resultados}

\subsection{Resultados académicos}

\subsubsection{Pre-test/post-test}

Antes de la formación, los alumnos del GC consiguieron una nota media 4,1 $\pm 1,3$ frente a $3,9 \pm 1,5$ en el GE. Se trata de una mínima diferencia media de 0,2 puntos. Tras la formación, las notas medias se elevaron a $6,1 \pm 1,4$ y $6,6 \pm 1,2$ en GC y GE respectivamente. La diferencia fue, entonces, de 0,5 puntos a favor del GE (Fig.4).

Para evaluar si el incremento de nota en uno y otro grupo fue comparable, se estimó un modelo de Brunner-Langer (Tabla 2), donde se observó la mejora del nivel de conocimientos que supuso participar en la acción formativa $(p<0,001)$, siendo mayor en el grupo estudio $(\mathrm{p}=0,054)$, que en el grupo control.

\subsubsection{Examen práctico}

La nota media de la parte práctica se elevó a $8,1 \pm 1,1$ en el GE y a $6,9 \pm 1,2$ del grupo GC (Fig.5), siendo las diferencias estadísticamente significativas $(\mathrm{p}<0,001)$ para la prueba MW. 


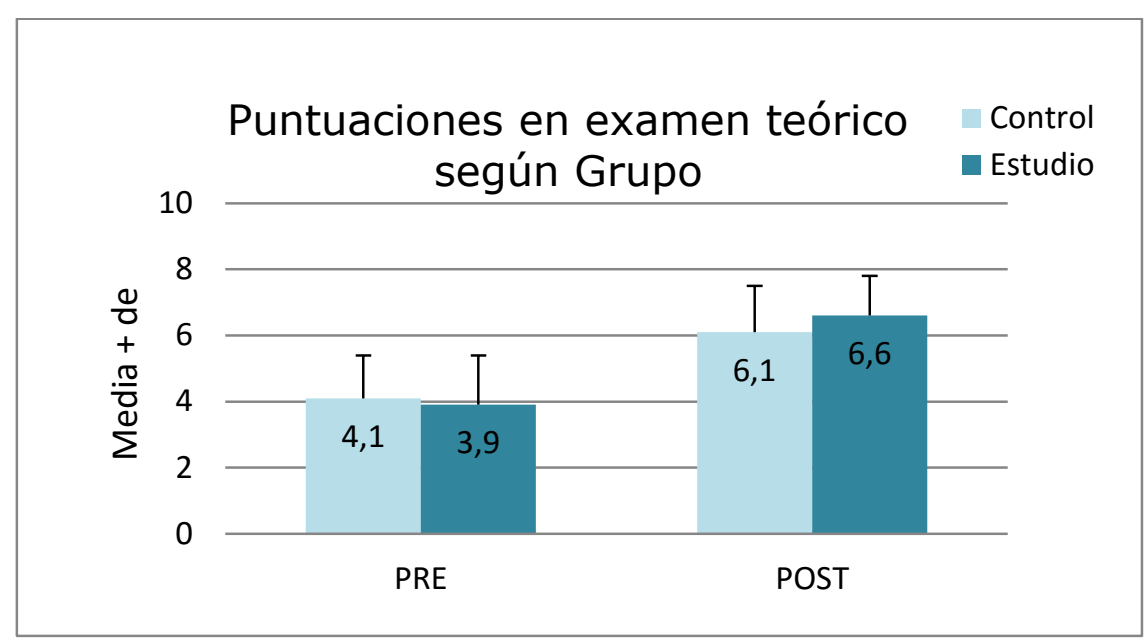

Fig.4 Puntuaciones del examen teórico según grupo

Tabla 2. Cambios en la distribución de notas teóricas de los grupos: resultados modelo de Brunner-Langer y test ATS tipo ANOVA.

\begin{tabular}{rc}
\hline & p-valor \\
\hline Tiempo & $<0,001 * * *$ \\
Grupo & 0,549 \\
Interacción & 0,054 \\
\hline$* \mathrm{p}<0,05 ; \quad * * \mathrm{p}<0,01 ;$ & $* * * \mathrm{p}<0,001$
\end{tabular}

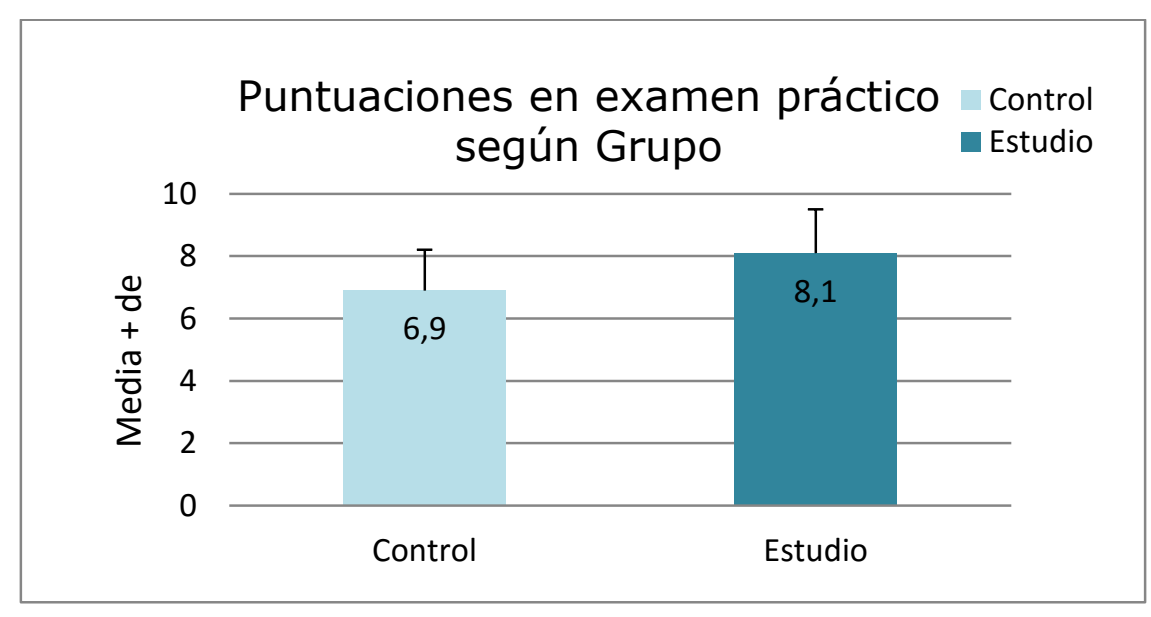

Fig.5 Puntuaciones en examen práctico según grupo

(cc) EY-NC-ND 2017, Universitat Politècnica de València 
La tabla 3 describe la evaluación a cada uno de los 5 ítem que componen la parte de anestesia y los 5 de la parte de extracción, donde se observa en qué aspectos en concreto se maximizaron las diferencias entre grupos. El 53,6\% en el GE realizó la aspiración, frente a sólo el 32\% en el GC ( $\mathrm{p}<0,025)$. El 71,4\% de los participantes del GE cogieron correctamente el botador, frente a sólo el $36 \%$ de los controles $(p<0,001)$. Asimismo, el 75\% del GE colocó correctamente la mano no operante frente a sólo el $40 \%$ de los controles $(p<0,001)$. Una batería de test de Fisher identifica las diferencias más significantes.

Tabla 3. Proporción de actuaciones correctas según grupo: resultados test exacto de Fisher (Fis).

\begin{tabular}{rcc}
\hline & p-valor \\
\hline ANESTESIA & Montaje jeringa & 0,418 \\
Forma coger jeringa & 0,633 \\
Entrada desde premolares & 1,000 \\
Lugar inyección & 0,091 \\
Realiza aspiración & $\mathbf{0 , 0 2 5 *}$ \\
EXTRACCIÓN & Selección instrumental & 0,145 \\
& Forma coger botador & $<\mathbf{0 , 0 0 1 * * *}$ \\
Forma coger fórceps & 0,418 \\
& Posición mano no operante & $<\mathbf{0 , 0 0 1 * * *}$ \\
& Técnica de extracción & 0,905 \\
\hline
\end{tabular}

${ }^{*} \mathrm{p}<0,05 ; \quad * * \mathrm{p}<0,01 ; \quad * * * \mathrm{p}<0,001$

\subsection{Evaluación de calidad de la actividad formativa y satisfacción}

\subsubsection{Calidad de la actividad formativa}

Con respecto a la opinión general de la clase, se encontró un porcentaje de satisfacción muy similar en ambos grupos: $84 \%$ el GC y $89,3 \%$ el GE, correspondiente a las valoraciones buenas y muy buenas (códigos 4 y 5 de la escala de Likert). Sin embargo, si atendemos sólo al máximo grado de satisfacción (código 5 de la escala de Likert), el 50\% del GE asignó esta categoría, frente a solo el $20 \%$ del GC. Estas diferencias fueron estadísticamente significativas $(\mathrm{p}=0,003, \mathrm{MW})$.

Con respecto a cuestiones específicas relacionadas con la estructura y materiales de la docencia recibida, aspectos como la organización, el diseño y la cobertura integral del tema fueron valorados positivamente por, al menos, el 80\% del GC. En el GE, la cifra se elevó al $92 \%$, destacando los aspectos de contenido, organización, material y facilidad para entender. 
Además, el 32\% del GC se mostró indiferente (código 3 de la escala Likert) cuando se preguntó sobre la facilidad para entender los contenidos, frente a solo el 7,1\% del GE.

El GE, además, valoró las hipotéticas ventajas del aprendizaje combinado frente a los métodos de enseñanza convencionales que conocían. La mayoría de ellos estuvo de acuerdo o muy de acuerdo (códigos 4 y 5 de la escala Likert) en que el aprendizaje combinado es más efectivo y motivador, promueve un compromiso activo para el aprendizaje individual y la auto-evaluación y mejora el pensamiento crítico.

\subsubsection{Satisfacción}

El 76\% del GC consideró que la clase fue una experiencia formativa agradable e instructiva (36\% muy de acuerdo $+40 \%$ de acuerdo), frente $96,4 \%$ del GE (50\% muy de acuerdo + $46,4 \%$ de acuerdo). El $72 \%$ del GC recomendaría la experiencia a compañeros ( $24 \%$ muy de acuerdo $+48 \%$ de acuerdo), frente al 100\% del GE ( $75 \%$ muy de acuerdo $+25 \%$ de acuerdo), que también tuvo intención de seguir utilizando la web para su aprendizaje.

\subsection{Motivación y estrategias de aprendizaje}

Los resultados del cuestionario de motivación y estrategias de aprendizaje (CMEA) se presentan haciendo referencia, en primer lugar, a la escala de motivación y, posteriormente al uso de estrategias de aprendizaje.

\subsubsection{Escala de motivación}

El análisis de la motivación de los estudiantes se realizó en base a las respuestas de los 18 ítems de la escala de motivación del CMEA. Como se mencionó, estos ítems están agrupados en 5 sub-escalas que evalúan aspectos motivacionales diferentes. Los resultados presentan, en términos de medias (rango de variación entre 1 y 5), el grado de acuerdo con los diferentes ítems. El GE presentó mayor motivación que el GC ( $\mathrm{p}<0,034)$, especialmente en las secciones de valoración de la tarea $(\mathrm{p}<0,001)$ y control de autoeficacia $(\mathrm{p}<0,013)$ (Tabla 4$)$.

Tabla 4. Puntuaciones sub-escala y escala de motivación del CMEA según grupo: resultados test Mann-Whitney (MW).

\begin{tabular}{rc}
\hline & p-valor \\
\hline ORIENTACIÓN META INTRÍNSECA & 0,770 \\
ORIENTACIÓN META EXTRÍNSECA & 0,872 \\
VALOR DE LA TAREA & $\mathbf{0 , 0 0 1 * *}$ \\
CONFIANZA EN CONTROL DEL APRENDIZAJE & 0,971 \\
CONTROL DE AUTOEFICACIA & $\mathbf{0 , 0 1 3 *}$ \\
APRECIACIÓN GENERAL & $\mathbf{0 , 0 3 *}$ \\
\hline $\mathrm{p}<0,05 ; \quad * * \mathrm{p}<0,01 ; \quad * * * \mathrm{p}<0,001$ &
\end{tabular}

(cc) EY-NC-ND 2017, Universitat Politècnica de València 
Los resultados fueron similares en ambos grupos con respecto a la orientación de meta intrínseca y meta extrínseca. Sin embargo, el GE evidenció una alta valoración de las tareas, donde la media adoptó un valor de 4,54 frente a 4,1 en el GC $(\mathrm{p}<0,001)$. Los alumnos del GE se sintieron, tras la clase, más capaces y con mayor confianza para afrontar sus prácticas clínicas, con una media de 4,46 frente a 3,68 del GC ( $\mathrm{p}<0,001)$ y creyeron que el material de la clase fue útil para su aprendizaje, con una media de 4,71 en comparación con una media de 4,16 en el GC $(p<0,002)$.

Con respecto a la confianza en el control del aprendizaje, no se encontraron diferencias significativas entre el GE y GC. En cambio, si se encontraron diferencias estadísticamente significativas en el control de autoeficacia $(p=0,013)$. Los alumnos del GE creyeron que tendrían una buena nota en el práctico con una media de 4,29 frente a 3,56 en el GC $(p<0,001)$, entendieron en mayor medida los conceptos más complejos enseñados en la clase con una media de 4,36, en comparación con el GC que obtuvo una media de 3,92 ( $\mathrm{p}=0,011)$ y estuvieron más seguros de haber adquirido las habilidades necesarias para su práctica clínica con valores 4,14 frente a 3,68 del GC $(p=0,030)$.

\subsubsection{Escala de aprendizaje}

El análisis de las estrategias de aprendizaje se realizó en base a las respuestas de los alumnos a los 15 ítems de la escala del cuestionario CMEA, encontrándose respuestas similares en ambos grupos.

En cuanto a las estrategias de manejo de los recursos, el GE mostró niveles más altos con respecto a la regulación del esfuerzo, con una media de 4,31 frente a 3,51 en el GC ( $<<0,001)$ (Tabla 5). Concretamente, se encontraron diferencias estadísticamente significativas que reflejaron menor aburrimiento $(\mathrm{p}<0,001)$ y menos ganas de abandonar la clase por parte del GE $(\mathrm{p}<0,001)$.

Tabla 5. Puntuaciones sub-escala y escala de estrategias del aprendizaje del CMEA según grupo: resultados test Mann-Whitney (MW).

\begin{tabular}{rc}
\hline & p-valor \\
\hline PENSAMIENTO CRÍTICO & 0,462 \\
AUTORREGULACIÓN METACOGNITIVA & 0,389 \\
REGULACIÓN DEL ESFUERZO & $<\mathbf{0 , 0 0 1 * * *}$ \\
APRENDIZAJE PARALELO & 0,575 \\
BÚSQUEDA DE AYUDA & 0,134 \\
APRECIACIÓN GENERAL & 0,714 \\
\hline *p $<0,05 ; \quad * * \mathrm{p}<0,01 ;$ & $* * * \mathrm{p}<0,001$
\end{tabular}

(cc)) EY-NC-ND 2017, Universitat Politècnica de València 
En síntesis, los alumnos del GE, en comparación con el GC:

1. Tras la clase, se sintieron más capaces y con mayor confianza para afrontar las prácticas clínicas

2. Consideraron que el material les fue útil para el aprendizaje

3. Previeron una buena nota en la parte práctica

4. Entendieron los conceptos más complejos explicados en la clase

5. Estuvieron seguros de haber adquirido las habilidades necesarias para la práctica clínica

Del mismo modo, se mostraron menos de acuerdo, en comparación a los del GC, con:

6. Sensación de desgana y aburrimiento durante la clase

7. Ganas de abandonar la tarea antes de acabarla

\section{Conclusiones}

- El estudio demostró la mayor eficacia del método de aprendizaje combinado en términos de incremento de conocimientos. Los alumnos del GE aumentaron en 2,7 puntos la nota media del examen teórico, frente al GC, que sólo lo hicieron en 2,0 puntos. Las diferencias se situaron al límite de la significancia estadística. El resultado del examen práctico también fue más alto también en el GE, donde aspectos como la realización de la aspiración anestésica, la forma de coger el botador o la posición de la mano no operante fueron mejor adquiridos que en el GC.

- Los alumnos del GE se mostraron más satisfechos con aspectos como el contenido, organización, material, cobertura, y diseño de la clase que el GC. El 92,9\% del GE consideró que la metodología empleada les permitió entender la clase con facilidad, frente a solo el $64 \%$ del GC. En general, los alumnos del GE consideran que el aprendizaje combinado es más efectivo, motivador y promueve la auto-evaluación y el pensamiento crítico. La experiencia fue más instructiva y agradable para los alumnos del GE, que seguirán utilizando la web y la recomendarán en el $100 \%$ de los casos.

- Los alumnos del grupo GE presentaron una puntuación significativamente superior en la escala de motivaciones del CMEA, sobre todo, con respecto a la valoración de la tarea y control de la autoeficacia. Los alumnos de ambos grupos exhibieron una puntuación similar en la escala de estrategias del aprendizaje, encontrándose diferencias sólo en la regulación del esfuerzo. Así, el GE se vio más preparado para afrontar las prácticas clínicas, valoraron mejor el material y creyeron haber asimilado mejor los conceptos difíciles. Por el contrario, el GC experimentó más deseos de abandonar la sesión formativa.

(c)) EY-NC-ND 2017, Universitat Politècnica de València 


\section{Referencias}

ALY M, WILLEMS G, VAN DEN NOORTGATE W, ELEN J. (2011). "Effect of multimedia information sequencing on educational outcome in orthodontic training" en Eur J Orthodont, vol. 34 , issue. 4 , p. 458-65.

HU J, YU H, SHAO J, LI Z, WANG J, WANG Y. (2008). "Effects of dental 3D multimedia system on the performance of junior dental students in preclinical practice: a report from China" en Advances in Health Sciences Education, vol. 14, issue. 1, p. 123-133.

KAVADELLA A, TSIKLAKIS K, VOUGIOUKLAKIS G, LIONARAKIS A. (2011). "Evaluation of a blended learning course for teaching oral radiology to undergraduate dental students." en European Journal of Dental Education, vol. 16, issue. 1, p. 88-95.

KRUGER C, SKALEN M, HARJU-JEANTY D, HEYMANS R, ROSEN A, LUN B. (2016). "Implementation of a Web-Based Patient Simulation Program to Teach Dental Students in Oral Surgery” en J Dent Educ, vol. 80, issue. 2, p. 133-140.

LAVARÍAS RIBES, B., ODEH OLMEDA, V. Anestesia y cirugia bucal. <http://www. http://cirubuca.wixsite.com/ciruvestic > [Consulta: 30 de Marzo de 2014]

LINJAWI A, HAMDAN A, PERRYER D, WALMSLEY A, HILL K. (2009). 'Students' attitudes towards an online orthodontic learning resource” en Eur J Dent Educ, vol. 13, issue. 2; p. 87-92.

PEÑARROCHA DIAGO, M., SANCHÍS BIELSA, J.M., MARTÍNEZ GONZALEZ, J.M., (2010). "Técnicas anestésicas primarias" en Peñarrocha Diago, M., Martínez Gonzalez, J.M., Martí Bowen, E. Anestesia local en Odontología. Barcelona: Editorial Ars Medica.

MECKFESSEL S, STÜHMER C, BORMANN K, KUPKA T, BEHRENDS M, MATTHIES H. (2011). "Introduction of e-learning in dental radiology reveals significantly improved results in final examination" en J Craniomaxillofac Surg, vol. 39, issue 1, p. 40-8.

NEUHAUS K, SCHEGG R, KRASTL G, AMATO M, WEIGER R, WALTER C. "Integrated learning in dentistry: baseline data and first evaluation at the Dental School of Basel" en Eur J Dent Educ, vol. 12, issue 3, p. 163-69.

SANTOS G, LEITE A, FIGUEIREDO P. (2016). "Effectiveness of E-Learning in Oral Radiology Education: A Systematic Review” en J Dent Educ, vol. 80, issue. 9, p. 1126-39.

VARTHIS S, ANDERSON O. "Students' perceptions of a blended learning experience in dental education” en Eur J of Dent Educ, p. 1-7.

ZAMBRANO RAMÍREZ, J. "Factores predictores de la satisfacción de estudiantes de cursos virtuales" en Revista Iberoamericana de Educación a Distancia, vol. 19, issue. 2, p. 217-35. 


\title{
Desarrollo competencial del alumno: el espíritu emprendedor y la responsabilidad social
}

\author{
Tiziana Priede Bergamini ${ }^{a}$, Cristina López-Cózar Navarro ${ }^{b}$ y Sonia Benito \\ Hernández ${ }^{c}$
}

${ }^{a}$ Profesora de la Universidad Europea de Madrid tiziana.priede@universidadeuropea.es, ${ }^{b}$ Profesora de la Universidad Politécnica de Madrid cristina.lopezcozar@upm.es y ${ }^{c}$ Profesora de la Universidad Politécnica de Madrid sonia.benito@upm.es.

\begin{abstract}
In order to achieve a business framework in which companies are able to respond adequately to the economic, social and environmental challenges; it is necessary to take a step further in higher education. Accordingly, the university teaching staff must assume the commitment to contribute to the development of competences, not only linked with entrepreneurial spirit, but also with social responsibility and ethical commitment at work. All those proposals that aim to bring students to responsible, sustainable and committed business initiatives with the community acquire a special relevance today. For this reason, this paper presents an interesting teaching experience for university students trying to stimulate their curiosity for social entrepreneurship, and at the same time, bringing them closer to the business reality.
\end{abstract}

Keywords: Entrepreneurial spirit, responsible behavior, social enterprise, sustainability, training, higher education, skills.

\begin{abstract}
Resumen
Con el objetivo de conseguir un tejido productivo en el que las empresas sean capaces de responder adecuadamente a los retos económicos, sociales y medioambientales, es preciso dar un paso más en la formación universitaria. En este sentido, el profesorado debe asumir el compromiso de contribuir al desarrollo de competencias relacionadas, no solo con el espíritu emprendedor, sino también con la responsabilidad social y el compromiso ético en el trabajo. Todas aquellas propuestas que pretendan acercar al alumnado a iniciativas empresariales responsables, sostenibles $y$ comprometidas con la comunidad adquieren una especial relevancia en el momento actual. Por ello, en el presente trabajo se expone una experiencia educativa interesante para el alumnado de educación superior, con la que se pretende estimular su curiosidad por el emprendimiento social, así como su acercamiento a la realidad empresarial.
\end{abstract}

Palabras clave: espíritu emprendedor, comportamiento responsable, empresa social, sostenibilidad, formación, educación superior, competencias. 


\section{Introducción}

La implantación del Espacio Europeo de Educación Superior (EEES) ha proporcionado el marco adecuado para lograr un desarrollo competencial integral del alumnado. Entre las competencias que se pueden encontrar en los planes de estudios de los grados universitarios suele hacerse alusión al fomento del emprendimiento. Se trata de una competencia muy amplia, que puede adoptar diferentes denominaciones tales como iniciativa, capacidad emprendedora o espíritu emprendedor. En el presente trabajo se ha optado por esta última denominación, coincidiendo tanto con el informe "Educación y Formación 2010" de la Comisión Europea, en el que se le otorga la importancia de competencia clave; con el informe elaborado por Accenture y Universia (2007), así como con en el Libro Blanco de Economía y Empresa (ANECA), el cual la incluye dentro de las competencias genéricas sistémicas.

Por otra parte, también es frecuente hallar referencias sobre la importancia de desarrollar en los estudiantes el compromiso ético y la responsabilidad social en el trabajo. Así por ejemplo, en la recomendación 2006/962/CE del Parlamento Europeo y del Consejo, de 18 de diciembre de 2006, sobre las competencias clave para el aprendizaje permanente, se señala que este espíritu empresarial debe implicar una concienciación sobre los valores éticos e impulsar la buena gobernanza. Asimismo, entre las competencias clave incluye la social y la cívica, y se señala que las personas deben interesarse por el desarrollo socioeconómico sostenible, la diversidad de valores, el apoyo a la cohesión social y estar dispuestas a comprometerse. Por su parte, en el citado Libro Blanco de la ANECA, entre las competencias genéricas personales se incluye el compromiso ético en el trabajo.

Actualmente en nuestro país, tras una larga situación de crisis económica y de valores, se debaten nuevos modelos de desarrollo, con el fin de lograr la recuperación y un futuro crecimiento sostenible. Ante este panorama, consideramos que es especialmente importante que los jóvenes universitarios adquieran estas dos competencias de manera conjunta: el espíritu emprendedor y la responsabilidad social unida al comportamiento ético en el trabajo. Hoy más que nunca, es preciso transmitir a nuestros estudiantes que las empresas deben modificar sus actitudes y comportamientos. Por tanto, es fundamental fomentar en las aulas el espíritu emprendedor responsable, con el propósito de conseguir un tejido empresarial en el que los nuevos proyectos empresariales sean capaces de asegurar su viabilidad económica y, al mismo tiempo, avanzar hacia una mayor integración social, mayor respeto medioambiental y un modelo de crecimiento más coherente y equilibrado.

\section{Objetivos}

En los últimos años es notable el interés que el emprendimiento social ha despertado como reflejo del importante desarrollo que estas iniciativas están experimentando (Santos, 2012), por lo que la comunidad universitaria no debería permanecer ajena a esta realidad. Consideramos, pues, que resulta muy oportuno ampliar el conocimiento existente para contribuir a comprender mejor el concepto de emprendedor social, sus peculiaridades y sus aspectos diferenciadores. Se trata, en general, de ofrecer a los estudiantes una visión global

(c)) BY-NC-ND 2017, Universitat Politècnica de València 
de manera que contemplen este tipo de emprendimiento como una alternativa económica, social y laboral interesante para su futuro profesional. Por ello, el presente trabajo plantea una propuesta educativa interesante para los universitarios intentando estimular su curiosidad por el emprendimiento social, así como su acercamiento a la realidad empresarial, considerando que el deporte ofrece una excelente oportunidad para el desarrollo de estas iniciativas innovadoras.

Se presenta, por tanto, una experiencia de innovación docente claramente orientada a la formación en competencias del estudiante, cuyos principales objetivos son: promover el compromiso social mediante el aprendizaje activo; fomentar el emprendimiento ligado a un proyecto sostenible y responsable en el ámbito deportivo; acercar al alumnado a la realidad empresarial y a las prácticas empresariales responsables; y ofrecer nuevas alternativas profesionales. Dicha experiencia ha sido realizada con estudiantes del Grado en Gestión Deportiva -a través de la asignatura de Economía de la Empresa- durante el curso 20152016.

Con el fin de describir el desarrollo de la actividad propuesta para alcanzar estos objetivos, el presente trabajo se estructura de la siguiente manera: en primer lugar, en cuanto al desarrollo de la innovación, se presenta el contexto en el que se lleva a cabo la actividad; se realiza una aproximación al concepto de emprendedor social y su aplicación en el entorno deportivo a través del cual es posible la consecución de objetivos sociales en diferentes ámbitos, tales como la salud, la integración o la educación, entre otros. Así mismo, se plantean las competencias que se pretenden desarrollar y se presenta la descripción de la propuesta. En el siguiente epígrafe se muestran los resultados obtenidos de la encuesta de valoración realizada al grupo de estudiantes que ha participado en la experiencia. El análisis de estos datos permitirá verificar si se han alcanzado los objetivos iniciales propuestos. Finalmente, se procede a exponer las principales conclusiones extraídas del trabajo.

\section{Desarrollo de la innovación}

\subsection{Contextualización de la actividad}

En la actualidad, una de las competencias más demandadas por la sociedad a sus jóvenes graduados es el espíritu emprendedor (Toledano, 2006; López-Cózar y Priede, 2009; Benavides et al., 2010; Priede et al, 2013; Juliá, 2013). No obstante, como ya se ha dicho anteriormente, esta competencia debería estar sustentada sobre una base de valores compartidos. En efecto, lamentablemente hoy en día es frecuente encontrar empresarios que presentan importantes carencias de ética y principios a la hora de tomar decisiones llevar a cabo sus negocios. Es recomendable, por lo tanto, fomentar en los jóvenes el emprendimiento ligado a un proyecto responsable y sostenible, que aporte valor global. El profesorado debe, no sólo desarrollar competencias sino también contribuir a la formación de buenos ciudadanos (Marina, 2009), por lo que resulta interesante impulsar esta actitud emprendedora dentro del ámbito de la empresa social (Fisac et al., 2011; Lejarriaga, et al., 2013; Martín et al., 2013; López-Cózar y Priede, 2014). Como se señala en la citada 
recomendación del Parlamento Europeo (2006), "las personas deben ser conscientes también de la postura ética de las empresas y de cómo éstas pueden ser un impulso positivo, por ejemplo, mediante el comercio justo y las empresas sociales". Consideramos, pues, que el espíritu emprendedor debe desarrollarse desde el lado más humano, buscando el compromiso social para alcanzar un progreso continuo, justo y equitativo.

El emprendedor social es aquel que reconoce una oportunidad de negocio buscando la resolución creativa de un problema social o medioambiental. Se trata de una persona con un marcado carácter innovador, que posee un gran sentido de la responsabilidad y un claro compromiso con la comunidad. Este fuerte compromiso se materializa en el desarrollo de una iniciativa empresarial motivada por la voluntad de ayudar a los demás y de llevar a cabo un cambio en la sociedad. Como señala Bornstein (2005), el emprendedor social es aquel que es capaz de identificar recursos allí donde los demás sólo ven dificultades. No se trata de filantropía o caridad, al contrario, deben ser negocios rentables, si bien, la reinversión de los beneficios económicos en su propio objetivo favorece que estas organizaciones sean idóneas para impulsar a las comunidades a las que pertenecen. En definitiva, consiste en la creación de un modelo de negocio que permita descubrir, definir y aprovechar las oportunidades para incrementar la riqueza social (Mair y Martí, 2006; Zahra et al, 2009; Defourny y Nyssens, 2012; Defourny et al., 2014; Priede et al., 2014).

Por su parte, este tipo de emprendimiento encuentra en el ámbito deportivo diversas oportunidades ya que el deporte puede ser empleado como vía para fomentar soluciones a determinados problemas sociales. El término deporte es un concepto abierto que se refiere a una amplia variedad de actividades, que pueden ser practicadas con diferentes objetivos (competición, ocio, salud, etc.) y que abarca múltiples aspectos de diferentes ámbitos (educativo, social, económico, etc.). La práctica deportiva como aficionado es básica en la sociedad moderna, ya que puede desarrollar la salud, la integración social, la educación, etc. Diversas investigaciones realizadas sobre la relación entre el deporte y la salud, han demostrado los efectos beneficiosos de la práctica continuada de actividades deportivas (World Health Organization, 2003).

Al mismo tiempo, el deporte es un elemento de cohesión y relación social, que ayuda al desarrollo de la personalidad y al establecimiento de relaciones entre sus practicantes, con el resultado positivo que ello implica. Por tanto, además de los efectos sobre la salud, el deporte supone educación -el deporte inculca valores- e integración social (Carranza y Maza, 2011; del Arco y Rodríguez, 2013; López-Cózar et al., 2015). Así pues, a través del deporte se pueden plantean actividades para diversos colectivos con necesidades específicas como, por ejemplo, personas con discapacidad, personas en situación de maltrato, desempleados de larga duración, entre otros. Los emprendedores sociales pueden actuar en la comunidad deportiva de manera innovadora con el fin de crear un beneficio económico y social. De este modo, el deporte y el emprendimiento social persiguen objetivos semejantes como la cohesión y la integración, junto con el logro de una sociedad mejor para todos, dentro de un proyecto responsable en todas sus dimensiones, por lo que pueden considerarse buenos aliados. 


\subsection{Capacidades desarrolladas con la actividad}

La actividad planteada permite a los estudiantes desarrollar diversas competencias establecidas en el ámbito de educación superior:

- Espíritu emprendedor: observación de la realidad económica y social, detección de oportunidades para la puesta en marcha de un negocio vinculado a un problema social con el fin de promover, la integridad, la sostenibilidad, la inclusión, etc.

- Responsabilidad social: comportamiento responsable, ético y comprometido.

- Aprendizaje activo: el alumnado se sitúa en el centro de su propio aprendizaje, participando, reflexionando y desarrollando el pensamiento crítico. Conocer desde la experiencia.

- Innovación y creatividad: esfuerzo por presentar algo diferente, por buscar alternativas no exploradas. Presentación de ideas de forma atractiva e interesante.

- Trabajo en equipo y cooperación: se forman equipos de trabajo para realizar la actividad. El alumnado debe cooperar para aprender.

- Habilidades comunicativas: saber transmitir las principales ideas y explicar la esencia del trabajo realizado, hacerlo además de forma atractiva e interesante.

\subsection{Descripción de la actividad}

La actividad comienza con una sesión teórica en la que el docente sensibiliza al alumnado sobre el concepto de emprendimiento social y empresa social, sus principales características y sus posibilidades de aplicación en el ámbito deportivo. Esta primera toma de contacto con el concepto es necesaria para sentar las bases que permitan desarrollar posteriormente el trabajo práctico con éxito.

A continuación, se constituyen los equipos de trabajo supervisados por el profesor con el fin de formar grupos homogéneos. Es importante la elección de un líder que acepte la figura de coordinador y un secretario que apoye su tarea. Se deja libremente al grupo la asignación de estos roles.

Posteriormente, el profesor proporciona a los equipos las pautas concretas de la actividad a desarrollar, la cual consiste en hacer un seguimiento de una empresa social del ámbito deportivo; dicho seguimiento puede hacerse sobre una empresa real ya existente en el mercado, o bien sobre una empresa ideada por los propios estudiantes. En cualquiera de las dos opciones, se proporciona un documento en el que se recogen las cuestiones que obligatoriamente deben ser tratadas. Igualmente, se indica a los estudiantes que deberán entregar un documento escrito donde se recoja el estudio realizado y se dé respuesta a las preguntas previamente planteadas, así como un breve video, lo más creativo posible, que recoja las principales conclusiones extraídas de su análisis. Tanto las pautas facilitadas por el profesor, como las entregas de los estudiantes estarán centralizadas en la plataforma virtual blackboard.

La parte final de la actividad consiste en la presentación de los resultados. Cada grupo deberá realizar una presentación oral con el fin de compartir la experiencia y el 
conocimiento con el resto del alumnado. En dicha presentación deben participar todos los miembros del equipo, que tienen que presentar un breve informe sobre la investigación realizada, además de proyectar el video elaborado. Tras la exposición, el docente dirige preguntas concretas a los diferentes componentes del grupo que le permitan comprobar el nivel de conocimiento global e individual, así como con el propósito de evitar que sólo aprendan la parte del trabajo que han realizado. Así mismo, el resto de los estudiantes debe plantear cuestiones al equipo que presenta el video con el fin de promover la generación de conocimiento conjunto, la cooperación y la participación de todos.

Respecto a la evaluación, el peso de esta actividad sobre la calificación global de la asignatura es del $20 \%$. Un $15 \%$ representa la nota del informe escrito y la elaboración del video, y es común a todos los integrantes del grupo, y un 5\% corresponde a la presentación oral que es una nota individual para cada estudiante.

\section{Resultados}

Una vez finalizada la actividad, se realizó una encuesta a los estudiantes para conocer su opinión sobre el grado de desarrollo de las competencias que se estaban trabajando, así como su nivel de satisfacción con la misma. El grupo estaba compuesto por 18 estudiantes, de los que 13 contestaron a la encuesta ( $72 \%$ de respuesta), lo cual se puede considerar una alta participación. En la tabla 1 se presentan las cuestiones planteadas y su relación con los objetivos y competencias objeto del estudio.

Tabla 1. Preguntas de la encuesta

\begin{tabular}{|c|c|c|}
\hline Pregunta encuesta & Objetivos & Competencias \\
\hline $\begin{array}{l}\text { ¿Considera que esta actividad ha } \\
\text { despertado su interés por el } \\
\text { emprendimiento social y las } \\
\text { prácticas empresariales responsables? }\end{array}$ & $\begin{array}{l}\text { Acercar al alumnado a la } \\
\text { realidad empresarial y a las } \\
\text { prácticas empresariales } \\
\text { responsables. }\end{array}$ & Espíritu emprendedor \\
\hline $\begin{array}{l}\text { ¿Considera que esta actividad le ha } \\
\text { enseñado nuevas alternativas para } \\
\text { su futuro profesional? }\end{array}$ & $\begin{array}{l}\text { Ofrecer nuevas alternativas } \\
\text { profesionales. }\end{array}$ & Espíritu emprendedor \\
\hline $\begin{array}{l}\text { ¿Considera que con esta actividad se } \\
\text { ha incrementado su propio } \\
\text { compromiso social? }\end{array}$ & $\begin{array}{l}\text { Promover el compromiso } \\
\text { social mediante el } \\
\text { aprendizaje activo. }\end{array}$ & Responsabilidad social \\
\hline $\begin{array}{l}\text { ¿Considera que con esta actividad } \\
\text { ha despertado su espíritu } \\
\text { emprendedor? }\end{array}$ & $\begin{array}{ll}\text { Fomentar } & \mathrm{el} \\
\text { emprendimiento ligado } & \mathrm{a} \\
\text { un proyecto sostenible } & \mathrm{y} \\
\text { responsable. } & \end{array}$ & Espíritu emprendedor \\
\hline $\begin{array}{l}\text { ¿Considera que con esta actividad } \\
\text { ha desarrollado la competencia de } \\
\text { trabajo en equipo? }\end{array}$ & $\begin{array}{l}\text { Promover el compromiso } \\
\text { social mediante el } \\
\text { aprendizaje activo. }\end{array}$ & $\begin{array}{l}\text { Trabajo en equipo y } \\
\text { cooperación }\end{array}$ \\
\hline
\end{tabular}

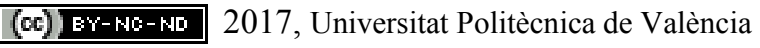




\begin{tabular}{|c|c|c|}
\hline $\begin{array}{l}\text { ¿Considera que con esta actividad } \\
\text { promueve el aprendizaje activo } \\
\text { (aprender con las experiencias)? }\end{array}$ & $\begin{array}{l}\text { Promover el compromiso } \\
\text { social mediante el } \\
\text { aprendizaje activo. }\end{array}$ & Aprendizaje activo \\
\hline 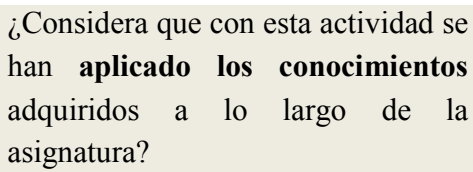 & $\begin{array}{ll}\text { Promover el compromiso } \\
\text { social mediante el } \\
\text { aprendzaje activo. }\end{array}$ & \\
\hline $\begin{array}{l}\text { ¿Considera que con esta actividad } \\
\text { ha desarrollado las competencias de } \\
\text { creatividad e innovación? }\end{array}$ & & Innovación y creatividad \\
\hline $\begin{array}{l}\text { ¿Considera que con esta actividad } \\
\text { ha desarrollado la competencia de } \\
\text { comunicación oral? }\end{array}$ & & Habilidades comunicativas \\
\hline $\begin{array}{l}\text { Nivel de satisfacción global con la } \\
\text { actividad desarrollada }\end{array}$ & & \\
\hline
\end{tabular}

Fuente: Elaboración propia

Por su parte, en la figura 1 se muestran las frecuencias de los resultados obtenidos empleando una escala Likert 1 (muy bajo) a 5 (muy alto) para cada una de las cuestiones que se plantearon.

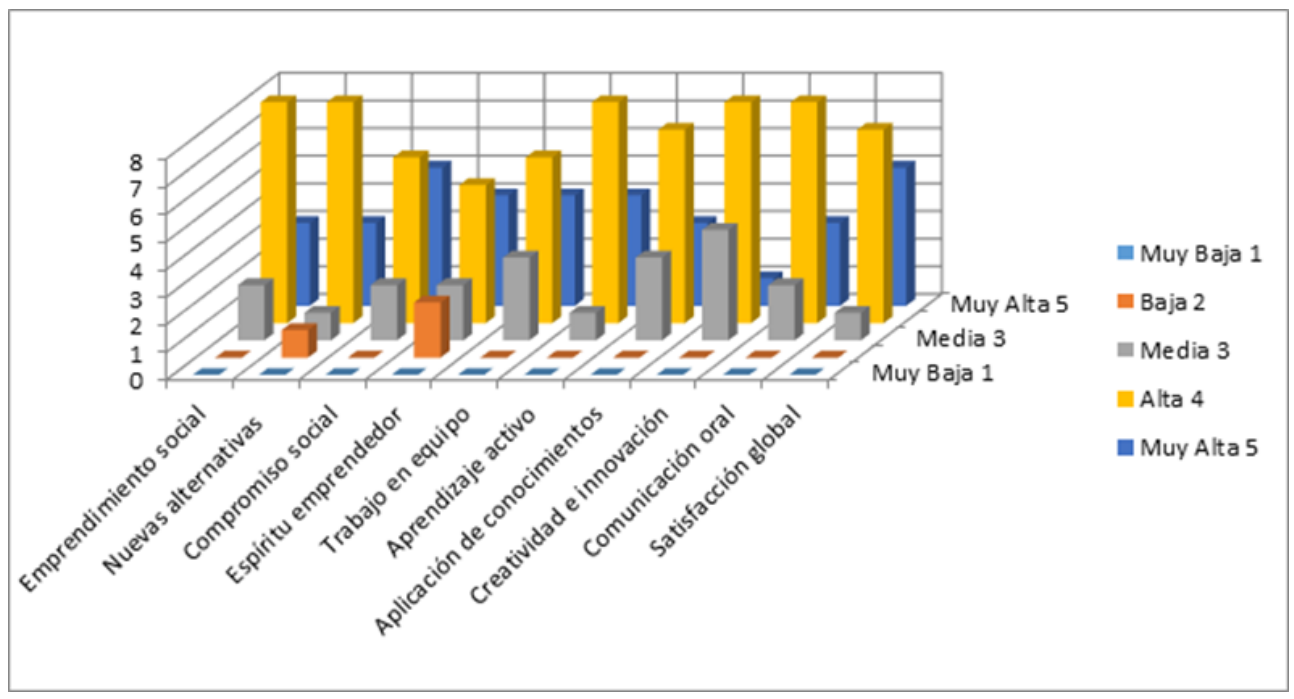

Fig. 1 Frecuencias de los resultados obtenidos

Como puede observarse en la figura 1, la mayoría de los estudiantes valoró la actividad muy positivamente, mostrando alta satisfacción con el aprendizaje obtenido, el desarrollo de compencias y, en general, con la utilidad de la actividad para su formación. 


\section{Conclusiones}

En el presente trabajo se ha expuesto una actividad formativa llevada a cabo con los alumnos de la carrera de gestión deportiva durante el curso 2015-2016, con la que se ha pretendido desarrollar conjuntamente el espíritu emprendedor y la responsabilidad social unida al comportamiento ético en el trabajo, dos competencias que presentan especial relevancia en un contexto económico y social como el actual, en el que es preciso la búsqueda de un modelo de crecimiento sostenible, más justo y equitativo. Es precisamente en las aulas universitarias donde los docentes tenemos la oportunidad de poder alcanzar a nuestros jóvenes y orientarlos en esta dirección, lo que ha inspirado sin duda la realización de esta experiencia.

Las propuestas presentadas por los estudiantes fueron tres: la creación de una empresa social denominada Bizitza (vida), cuya actividad es una academia de deportes para promover la igualdad de los niños con discapacidad; el seguimiento de la empresa de orientación social Vaude de ropa y equipamiento para deportes de montaña en la que se combina la sostenibilidad e innovación; y el seguimiento de la empresa social Senda, la cual se dedica a la fabricación y comercialización -a través del comercio justo- de balones y equipamiento deportivo. Los tres ejemplos presentados fueron de gran interés $\mathrm{y}$, cada uno en su estilo, resultaron generadores de debate y opinión, además de servir de ejemplos para la posible orientación del futuro profesional de estos estudiantes.

Tras el análisis de los resultados de la encuesta de satisfacción realizada a los propios implicados, se desprende que efectivamente consideran que se trata de una actividad formativa que promueve el aprendizaje activo y con la que se pueden desarrollar las competencias que les permitan la consecución de un mundo más equilibrado y responsable, en el ejercicio de su futuro profesional. Concretamente podermos afirmar que se ha conseguido: aplicar el aprendizaje activo; fomentar el emprendimiento social y responsable en el ámbito deportivo; fomentar el compromiso social; desarrollar diversas competencias; aplicar conocimientos y ofrecer alternativas profesionales.

La tendencia en todos los sistemas educativos europeos, incluyendo los distintos niveles, debe encamimarse hacia el desarrollo de actitudes y comportamientos de estas características con el fin de formar ciudadanos con empuje, capaces de generar empleo y riqueza, y a la vez también capaces de llevar a cabo sus actividades de manera ética, responsable y sostenible. En este sentido, el emprendimiento social se configura como una alternativa factible y adaptable al orden económico actual, capaz de combinar la consecución de objetivos económicos, medioambientales y sociales, tres elementos clave de la sostenibilidad empresarial citados por las Naciones Unidas el Global Reporting Initiative (Izquierdo y Grañana, 2005).

Si bien actualmente es habitual encontrar en las universidades diversas propuestas que fomentan el espíritu emprendedor entre el alumnado, son todavía escasas las iniciativas que centran de manera concreta en el emprendimiento social. Consideramos que el desarrollo de iniciativas como la planteada a lo largo de este trabajo, consiguen estimular el espíritu

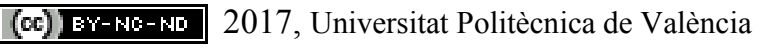

Congreso IN-RED (2017) 
emprendedor y fomentar al mismo tiempo una actitud responsable hacia la sociedad en general.

\section{Referencias}

ACCENTURE Y UNIVERSIA (2007). Las competencias profesionales en los titulados. Contraste y diálogo Universidad-Empresa. Presentación final de resultados. Disponible: http://www.unizar.es/ice/images/stories/calidad/EstudioCompleto.pdf [Consulta: 22 de febrero de 2017].

AlEMANY, L., ÁlVAREZ, C., PLANELlAS, M. y URBANO, D. (2011). Libro Blanco de la iniciativa emprendedora en España. Barcelona: Fundación Príncipe de Gerona ESADE.

BENAVIDES, M., SÁNCHEZ, I. y LUNA-AROCAS, R. (2010). "El proceso de aprendizaje para los emprendedores en la situación actual; un análisis cualitativo en el ámbito universitario". Revista de Dirección, Organización y Administración de Empresas, vol. 30 , p. 34-48.

BORNSTEIN, D. (2005). Cómo cambiar el mundo: los emprendedores sociales y el poder de las nuevas ideas. Barcelona: Editorial Debate.

CARRANZA, M. y MAZA, G. (Coords.) (2011). Deporte, actividad fisica e inclusión social. Una guía para la intervención social a través de las actividades deportivas. Madrid: Consejo Superior de Deportes.

CONSEJO DE LA UNIÓN EUROPEA (2004). "Educación y formación 2010" - Urgen las reformas para coronar con éxito la estrategia de Lisboa. Bruselas. Disponible: http://register.consilium.europa.eu/doc/srv?l=ES\&f=ST\%206905\%202004\%20INIT.

[Consulta: 10 de febrero de 2017].

DEFOURNY, J. y NYSSENS, M. (2012). "El enfoque EMES de la empresa social desde una perspectiva comparada". CIRIEC-España, Revista de Economía Pública, Social y Cooperativa, vol. 75, p. 7-34.

DEFOURNY, J., HULGÅRD, L. y PESTOFF, V. (2014). Social enterprise and the third sector: Changing European landscapes in a comparative perspective. Oxon: Routledge.

DEL ARCO, J. y RODRÍGUEZ, A. (2013). "Interrelación entre Actividad Deportiva y Desarrollo Socio-económico" en Revista Internacional de Deportes Colectivos, vol. 16, p. $12-21$.

FISAC, R., MORENO, A., PALACIOS, M., PEREZ, D. y URIBE, D. (2011). “La empresa social como modelo organizativo para la implicación de la universidad en iniciativas de cooperación al desarrollo" en V Congreso Universidad y Cooperación al Desarrollo. Cádiz 6/8 abril 2011. Disponible en linea (consulta 18 de enero de 2017).

(cc)) EY-NC-ND 2017, Universitat Politècnica de València Congreso In-Red (2017) 
IZQUIERDO, R. S. y GRAÑANA, I. V. (2005). "La Responsabilidad Social Corporativa (RSC) y su gestión integrada”. CIRIEC-España, Revista de Economía Pública, Social y Cooperativa, vol. 53, p. 137-161.

JULIÁ, J. F. (2013). "Emprendimiento y universidad. Una referencia al caso de España ya la UPV”. REVESCO, Revista de Estudios Cooperativos, vol. 113, p. 7-27.

LEJARRIAGA, G., BEL, P. y MARTÍN, S. (2013). "El emprendimiento colectivo como salida laboral de los jóvenes: análisis del caso de las empresas de trabajo asociado" en REVESCO: Revista de Estudios Cooperativos, vol. 112, p. 36-65

LÓPEZ-CÓZAR, C. y PRIEDE, T. (2009). "La necesidad de un enfoque estratégico ante el planteamiento de los nuevos grados en el área de administración y dirección de empresas" en Revista de Docencia Universitaria, vol. 3, p. 1-14.

LÓPEZ-CÓZAR, C. y PRIEDE, T. (2014). "Una propuesta para acercar al alumnado al emprendimiento responsable y sostenible" en XI Jornadas Internacionales de Innovación Universitaria. Educar para transformar, Madrid: Universidad Europea de Madrid. 874881.

LÓPEZ-CÓZAR, C., PRIEDE, T. y DEL ARCO, J. (2015). "La empresa social. Experiencias innovadoras a través del deporte" en REVESCO: Revista de Estudios Cooperativos, vol. 119, p. 107-131.

MAIR, J. y MARTI, I. (2006). « Social entrepreneurship research: A source of explanation, prediction, and delight" en Journal of World Business, vol. 41, issue 1, p. 36-44.

MARINA, J. A. (2010). “La competencia de emprender”. Revista de Educación, 351, 4971.

MARTÍN, S., FERNÁNDEZ, J., BEL, P. y LEJARRIAGA, G. (2013). "Necesidad de medidas para impulsar la creación de las empresas de participación desde los diferentes niveles de enseñanza". CIRIEC-España, Revista de Economía Pública, Social y Cooperativa, vol. 78, p. 71-99.

PRIEDE, T., BENITO, S. y LÓPEZ-CÓZAR, C. (2013). “Cómo fomentar el espíritu emprendedor en las aulas universitarias. Descripción de una experiencia docente". Revista de Enseñanza Universitaria, vol. 39, p. 1-13.

PRIEDE, T., LÓPEZ-CÓZAR, C. y RODRÍGUEZ, A. (2014). “Análisis del marco económico-jurídico específico para los emprendedores sociales. Un estudio comparado entre diversos países". CIRIEC-España Revista de Economía Pública, Social y Cooperativa, vol. 80, p. 115-138.

SALINAS F. y OSORIO, L. (2012). "Emprendimiento y Economía Social, oportunidades y efectos en una sociedad en transformación". CIRIEC-España, Revista de Economía Pública, Social y Cooperativa, vol. 75, p. 128-151.

SANTOS, N.J. (2012). "A positive theory of social entrepreneurship". Journal of Business Ethics, Vol. 111, issue 3, p. 335-351.

(cc) EY-NC-ND 2017, Universitat Politècnica de València Congreso IN-RED (2017) 
TOLEDANO, N. (2006). "Las perspectivas empresariales de los estudiantes universitarios" en Revista de Educación, vol. 341, p. 803-828.

WORLD HEALTH ORGANIZATION (2003). Health and development through physical activity and sport. Ginebra: World Health Organization Health Education and Health Promotion Unit.

ZAHRA, S.A., GEDAJLOVIC, E., NEUBAUM, D.O. y SHULMAN, J.M. (2009). “A typology of social entrepreneurs: Motives, search processes and ethical challenges" en Journal of Business Venturing, vol. 24, issue 5, p. 519-532. 


\title{
Estrategias para establecer un sistema que determine el seguimiento, estructura y evaluación de los trabajos final de grado en el Grado de Ingeniería en Diseño Industrial y Desarrollo de Productos de la UPV
}

E. Juliá Sanchis ${ }^{a}$, M. Valor Valor ${ }^{\text {, }}$ L. Pla Ferrando ${ }^{a}$, S. Sempere Ripoll ${ }^{\mathrm{a}}$, J.F. Picó Silvestre $^{a}$, M. Bonet-Aracila, J.A. Martínez Cervera ${ }^{a}$, A. Jordá-Vilaplana ${ }^{a}$

${ }^{\text {a } U n i v e r s i t a t ~ P o l i t e ̀ c n i c a ~ d e ~ V a l e ̀ n c i a ~ 03801, ~ A l c o y, ~ S p a i n ~}$

erjusan@upv.es, mvalor@upv.es, mlpla@upv.es, ssempere@upv.es, juapisil@upv.es, maboar@upv.es, jcerver@upv.es, amjorvi@upv.es

\begin{abstract}
The aim of this work is to establish a system that will determine the follow-up, structure and evaluation of final Degree Project Engineering in Industrial Design and Product Development, where a document has been prepared with the guidelines to be followed, Scheme with the recommendations according to the type of Final Degree Project (TFG) and the items to be taken into account by the professor to evaluate the TFG before its defense.
\end{abstract}

Keywords: final project, examination, signature, monitoring, structure, Industrial Design

\begin{abstract}
Resumen
El pretende trabajo trata de establecer un sistema que determine el seguimiento, la estructura y la evaluación de los trabajos final de grado en el Grado de Ingeniería en Diseño Industrial y desarrollo de productos, donde se han realizado un documento con las pautas a seguir, el esquema con las recomendaciones según el tipo de Trabajo fin de grado (TFG) y las rubricas a tener en cuenta por el profesor para evaluar el TFG antes de su defensa.
\end{abstract}

Palabras clave: Trabajo final de grado, evaluación, rubrica, seguimiento, estructura, diseño industrial.

\section{Introducción.}

La instauración de los nuevos planes de estudio ha supuesto un cambio en la manera de afrontar los Trabajos Final de Grado (TFG), estableciéndose, entre otros temas, nuevas competencias y capacidades, nuevos créditos asignados, nuevo sistema de funcionamiento y nueva normativa, lo cual preocupa a profesores y alumnos al no disponer de documentación que determine la nueva forma de proceder. 
En la actualidad no existe una sistematización del seguimiento, estructura y evaluación de los TFG en el Grado de Ingeniería en Diseño Industrial y Desarrollo de Productos en la Escuela Politécnica Superior de Alcoy, por lo que para mejorar el aprendizaje se considera necesario definir las estrategias que permitan establecer esos procedimientos.

Por otro lado, se ha detectado una dificultad derivada de la Normativa Marco de Trabajos Fin de Grado y Fin de Master de la UPV que obliga a que cada TFG tenga asignado un tutor encargado de orientar al alumno en el desarrollo del TFG (UPV, 2013). Esta exigencia hace que en la asignatura TFG se involucren muchos profesores que dirigen TFG de manera aislada y según el personal modo de entender la materia y que, como consecuencia, los alumnos recaban información de otros docentes con el fin de complementar la orientación del tutor y obtener TFG más completos e interdisciplinares. Estos docentes, que ayudan al alumno y complementan al tutor, actúan sin ningún tipo de reconocimiento docente y por lo tanto hay que buscar una solución a esta manera de proceder.

Al mismo tiempo, la manera de concebir el diseño industrial y el desarrollo de productos tiene ámbitos diversos que hacen necesario fijar las características de cada uno de ellos con tal de plantear posturas objetivas y comparables cara a la evaluación de los TFG.

Debido a toda esta problemática se plantea dentro de los Proyectos de Innovación y Mejora Educativa (PIME) del año 2016, promovidos y financiados por la Universidad Politécnica de Valencia (UPV), un proyecto mediante el cual se defina un sistema que especifique las estrategias a seguir para establecer el seguimiento, estructura, y evaluación de los TFG en los estudios de Ingeniería en Diseño Industrial y Desarrollo de Productos en la Escuela Politécnica Superior de Alcoy (EPSA).

\section{Objetivos.}

Con la finalidad de definir el alcance del proyecto se han establecido tres objetivos:

- Establecer un sistema que regule el procedimiento de tutoría y seguimiento de los TFG, definiendo los distintos actores y nivel de participación en el desarrollo de un TFG, así como las distintas fases que deben realizarse para un adecuado seguimiento de un TFG, indicando actores de cada una de ellas y duración estimada.

- Determinar la estructura de las distintas tipologías de TFG que pueden plantearse en el Grado en función del histórico disponible.

- Definir la metodología de evaluación de los TFG.

\section{Desarrollo de la Innovación.}

Para llevar a cabo el proyecto, dada la amplitud del mismo, se definen tres grupos de trabajo, cada uno de los cuales es el encargado de analizar la problemática de cada uno de los objetivos propuestos. Los grupos de trabajo se han denominado:

- Tutoría y seguimiento

(cc) EY-NC-ND 2017, Universitat Politècnica de València

Congreso IN-RED (2017) 
E. Juliá Sanchis, M. Valor Valor, L. Pla Ferrando, S. Sempere Ripoll, J.F. Picó Silvestre, M. BonetAracil, J.A. Martínez Cerver, A. Jordá Vilaplana

- $\quad$ Estructura

- Evaluación

Seguidamente se describe el trabajo desarrollado por cada uno de estos grupos.

\subsection{Tutoría y seguimiento.}

Este grupo tiene como tarea definir los distintos actores y su nivel de participación en el desarrollo de un TFG, al mismo tiempo que se precisan las distintas fases que deben realizarse para un adecuado seguimiento de un TFG, indicando actores de cada una de ellas y duración estimada. Son varias las propuestas de este grupo:

- Crear la modalidad de TFG coordinado por varios profesores que consiste en tutorizar los TFG en sesiones abiertas para los alumnos que opten por esta modalidad. Esta modalidad de tutorización no descarta el actual modelo de tutorización individual y pretende solucionar el problema que a menudo supone tutorizar un TFG un solo profesor.

- Preestablecer un horario para realizar las sesiones de tutoría de los TFG coordinados, de esta manera se pretende que el alumno vaya desarrollando el TFG desde el inicio del semestre.

- Establecer un seguimiento de las tutorías mediante una hoja de actividad, en donde se deben reflejar las indicaciones que los distintos profesores realizan sobre el trabajo que se les presenta a revisión.

\subsection{Estructura.}

Este otro grupo está encargado de determinar las distintas tipologías de TFG que pueden surgir en el Grado, así como concretar para cada tipo de TFG el contenido recomendable.

Para concretar las distintas tipologías se han analizado los 198 TFG presentados durante los cursos 2013/14, 2014/15 y 2015/16 distinguiéndose cuatro tipologías combinables de TFG:

- Diseño de producto

- Diseño interior

- Diseño textil

- Diseño de comunicación

Estas tipologías reflejan la demanda por parte del alumnado y del entorno socio-económico de la EPSA.

Es fundamental comprender que estas tipologías no son estancas, la experiencia evaluativa en anteriores TFG revela que, en la mayor parte de los proyectos defendidos, la materia se desarrolla de manera muy diversa y normalmente interrelacionando algunas de estas tipologías. Así por ejemplo un TFG de diseño textil puede contener un estudio con entidad propia relativo al diseño de un producto en donde se aplique el diseño textil, otro ejemplo podría ser el TFG de un producto en donde se desarrolla un estudio con entidad propia relativo al diseño de la comunicación del producto.

En cuanto a contenido y dadas las diferentes tipologías de TFG y con la finalidad de unificar la documentación a presentar se ha tomado en consideración lo indicado en la norma UNE 
Estrategias para establecer un sistema que determine el seguimiento, estructura y evaluación de los trabajos final de grado en el Grado de Ingeniería en Diseño Industrial y Desarrollo de Productos

157001:2014 Criterios generales para la elaboración formal de los documentos que constituyen un proyecto técnico lo indicado en la misma ha servido como punto de partida para definir los distintos documentos del TFG (AENOR, 2009). Recalcar que, dependiendo del tipo y alcance del proyecto, será o no necesario incluir la totalidad de los documentos ya que en última instancia será el tutor y la Comisión Académica del Título los que indique el contenido.

También se han considerado otros aspectos no contemplados en la norma con tal de enriquecer el contenido del TFG ya que se ha tenido en cuenta que los documentos del TFG constituyen un trabajo académico, algo diferente a un trabajo profesional ya que en este último basta describir la solución y en un trabajo académico hay que justificar y razonar la solución adoptada.

Como novedad, respecto a la documentación presentada hasta el momento en la EPSA en un TFG, se incluye un poster presentación con un resumen explicativo del proyecto. Este resumen del proyecto tiene por finalidad dar difusión a través de la UPV de los trabajos que desarrollan los alumnos mediante exposiciones, publicaciones impresas, divulgación por web, etc., sirviendo al mismo tiempo como curriculum para el alumno.

A modo de ejemplo se ofrece en (Tabla.1) los contenidos recomendados para un TFG de diseño de producto y en (Tabla. 2) los recomendados para el de comunicación.

Tabla. 1 Esquema contenidos recomendados de los TFG de DISEÑO DE PRODUCTOS.

\begin{tabular}{|c|c|}
\hline \multicolumn{2}{|l|}{ Portada normalizada } \\
\hline \multicolumn{2}{|c|}{ Resumen y palabras clave } \\
\hline Portada personalizada & Título, grado, alumno, curso, tutor/a \\
\hline \multicolumn{2}{|c|}{ Declaración de autoría y originalidad. } \\
\hline \multicolumn{2}{|c|}{$\begin{array}{l}\text { Documento de cesión de derechos y autorización para la difusión de trabajos } \\
\text { académicos }\end{array}$} \\
\hline Poster presentación & \\
\hline
\end{tabular}

\begin{tabular}{|c|c|c|c|}
\hline \multicolumn{4}{|c|}{ ÍNDICE GENERAL } \\
\hline \multirow[t]{6}{*}{ MEMORIA } & \multicolumn{3}{|c|}{1 Objeto y justificación } \\
\hline & \multicolumn{3}{|l|}{2 Antecedentes } \\
\hline & \multicolumn{3}{|c|}{3 Normas y referencias } \\
\hline & \multicolumn{3}{|c|}{4 Definiciones y abreviaturas } \\
\hline & \multirow{2}{*}{$\begin{array}{l}5 \text { Requisitos de } \\
\text { diseño }\end{array}$} & \multicolumn{2}{|c|}{ Descripción de las necesidades/ p.c.i. } \\
\hline & & $\begin{array}{l}\text { Funciones del } \\
\text { producto }\end{array}$ & $\begin{array}{l}\text { Valoración de funciones / Valoración } \\
\text { entre funciones / Tablas de valoración de } \\
\text { funciones }\end{array}$ \\
\hline
\end{tabular}

(c) EY-NC-ND 2017, Universitat Politècnica de València

Congreso IN-RED (2017) 
E. Juliá Sanchis, M. Valor Valor, L. Pla Ferrando, S. Sempere Ripoll, J.F. Picó Silvestre, M. BonetAracil, J.A. Martínez Cerver, A. Jordá Vilaplana

\begin{tabular}{|c|c|c|c|c|}
\hline & \multicolumn{4}{|c|}{6 Análisis de soluciones } \\
\hline & \multirow{6}{*}{$\begin{array}{l}7 \quad \text { Resultados } \\
\text { finales }\end{array}$} & \multicolumn{3}{|c|}{ Descripción y justificación del diseño adoptado } \\
\hline & & Viabilidad & \multicolumn{2}{|c|}{$\begin{array}{l}\text { Viabilidad técnica y física / Viabilidad } \\
\text { económica / Viabilidad financiera }\end{array}$} \\
\hline & & \multicolumn{3}{|c|}{ Diagrama sistémico del producto } \\
\hline & & \multicolumn{3}{|c|}{ Esquema de desmontaje del producto } \\
\hline & & \multicolumn{3}{|c|}{ Análisis estructural } \\
\hline & & \multicolumn{3}{|c|}{ Dimensionado previo } \\
\hline & \multicolumn{4}{|l|}{8 Conclusiones } \\
\hline \multirow[t]{7}{*}{ ANEXOS } & \multirow[t]{5}{*}{1 Prototipado } & Elementos & \multicolumn{2}{|c|}{$\begin{array}{l}\text { Elementos normalizados / Elementos } \\
\text { comerciales / Productos intermedios o } \\
\text { semielaborados / Elementos ya fabricados } \\
\text { por la empresa }\end{array}$} \\
\hline & & $\begin{array}{l}\text { Maquinas, } \\
\text { herramientas y } \\
\text { útiles }\end{array}$ & \multicolumn{2}{|c|}{ Para fabricación / Para el ensamblaje } \\
\hline & & \multicolumn{3}{|c|}{ Construcción de los elementos } \\
\hline & & \multicolumn{3}{|c|}{ Ensamblaje de subconjuntos } \\
\hline & & \multicolumn{3}{|c|}{ Acabado superficial } \\
\hline & \multicolumn{4}{|l|}{2 Cálculos } \\
\hline & \multicolumn{4}{|c|}{3 Otros documentos } \\
\hline \multirow[t]{3}{*}{ PLANOS } & $\begin{array}{l}1 \text { Planos de } \\
\text { conjunto. }\end{array}$ & \multicolumn{3}{|c|}{$\begin{array}{l}\text { Planos de conjunto, en proyección ortogonal, con marcas de } \\
\text { elementos, cotas generales y listado de elementos }\end{array}$} \\
\hline & $\begin{array}{l}2 \text { Planos de } \\
\text { subconjuntos }\end{array}$ & \multicolumn{3}{|c|}{$\begin{array}{l}\text { Planos de todos los subconjuntos con acotación funcional/ } \\
\text { para construcción }\end{array}$} \\
\hline & $\begin{array}{l}3 \text { Planos de } \\
\text { despiece }\end{array}$ & \multicolumn{3}{|c|}{$\begin{array}{l}\text { Planos de todos los elementos componentes con acotación } \\
\text { funcional / para construcción }\end{array}$} \\
\hline \multirow{2}{*}{\multicolumn{2}{|c|}{$\begin{array}{l}\text { PROTOTIPOS, MAQUETAS } \\
\text { Y/O MODELOS }\end{array}$}} & \multicolumn{2}{|c|}{ Presentación del producto } & $\begin{array}{l}\text { Perspectivas, simulaciones, } \\
\text { animaciones o similares }\end{array}$ \\
\hline & & \multicolumn{3}{|l|}{ Prototipo } \\
\hline \multicolumn{5}{|c|}{ PLIEGO DE CONDICIONES } \\
\hline \multicolumn{5}{|c|}{ ESTADO DE MEDICIONES/PRESUPUESTO } \\
\hline \multicolumn{5}{|c|}{ ESTUDIOS COMPLEMENTARIOS } \\
\hline
\end{tabular}

(c)) EY-NC-ND 2017, Universitat Politècnica de València 
Estrategias para establecer un sistema que determine el seguimiento, estructura y evaluación de los trabajos final de grado en el Grado de Ingeniería en Diseño Industrial y Desarrollo de Productos

Tabla 2 Esquema contenidos recomendados de los TFG de DISEÑO DE COMUNICACIÓN.

\begin{tabular}{|c|c|}
\hline \multicolumn{2}{|l|}{ Portada normalizada } \\
\hline \multicolumn{2}{|c|}{ Resumen y palabras clave } \\
\hline Portada personalizada & Título, grado, alumno, curso, tutor/a \\
\hline \multicolumn{2}{|c|}{ Declaración de autoría y originalidad. } \\
\hline \multicolumn{2}{|c|}{ Documento de cesión de derechos y autorización para la difusión de trabajos académicos } \\
\hline
\end{tabular}

\begin{tabular}{|c|c|c|c|c|c|}
\hline \multicolumn{6}{|c|}{ ÍNDICE GENERAL } \\
\hline \multirow[t]{18}{*}{ MEMORIA } & \multicolumn{5}{|c|}{1 Objeto y justificación. } \\
\hline & 2 & \multicolumn{2}{|c|}{ Antecedentes } & \multicolumn{2}{|c|}{$\begin{array}{l}\text { Gráficos, estilísticos y análisis de la } \\
\text { competencias }\end{array}$} \\
\hline & \multicolumn{5}{|c|}{3 Normas y referencias } \\
\hline & \multicolumn{5}{|c|}{4 Definiciones y abreviaturas } \\
\hline & 5 & \multicolumn{2}{|c|}{ Requisitos de diseño: } & \multicolumn{2}{|c|}{ Informe de instrucciones o Briefing: } \\
\hline & 6 & \multicolumn{4}{|c|}{$\begin{array}{l}\text { Análisis de soluciones: Documentación gráfica del proceso de ideación de } \\
\text { la comunicación }\end{array}$} \\
\hline & \multirow{12}{*}{\multicolumn{2}{|c|}{$\begin{array}{l}7 \text { Resultados } \\
\text { finales }\end{array}$}} & \multicolumn{3}{|c|}{ Descripción y justificación del diseño adoptado } \\
\hline & & & Aspectos & \multicolumn{2}{|c|}{ Herramientas y técnicas empleadas } \\
\hline & & & tecnicos & \multicolumn{2}{|c|}{ Aspectos técnicos de la imagen } \\
\hline & & & & \multirow[t]{3}{*}{ Arte final } & Soporte de la comunicación \\
\hline & & & & & $\begin{array}{l}\text { Características técnicas para su } \\
\text { reproducción }\end{array}$ \\
\hline & & & & & Procesos de impresión \\
\hline & & & Aspectos & \multicolumn{2}{|c|}{ Imagen: creación y tratamiento } \\
\hline & & & esteticos & \multicolumn{2}{|c|}{$\begin{array}{l}\text { Gráficos( logotipo, isotipo...): creación y } \\
\text { tratamiento }\end{array}$} \\
\hline & & & & \multicolumn{2}{|c|}{ Tipografía: selección, creación y tratamiento } \\
\hline & & & & \multicolumn{2}{|c|}{ Pruebas y variaciones cromáticas } \\
\hline & & & & \multicolumn{2}{|c|}{$\begin{array}{l}\text { Composición: pruebas de composición y/o } \\
\text { retículas }\end{array}$} \\
\hline & & & & \multicolumn{2}{|c|}{$\begin{array}{l}\text { Significado de la comunicación: adecuación de } \\
\text { la estética a las exigencias y/o eficacia } \\
\text { perseguida con el diseño de la comunicación. }\end{array}$} \\
\hline
\end{tabular}


E. Juliá Sanchis, M. Valor Valor, L. Pla Ferrando, S. Sempere Ripoll, J.F. Picó Silvestre, M. BonetAracil, J.A. Martínez Cerver, A. Jordá Vilaplana

\begin{tabular}{|l|l|l|}
\hline \multicolumn{2}{|l|}{8 Conclusiones } \\
\hline ANEXOS \\
\hline PLANOS \\
\hline $\begin{array}{l}\text { PROTOTIPOS, } \\
\text { MAQUETAS } \\
\text { Y/O } \\
\text { MODELOS }\end{array}$ & $\begin{array}{l}\text { Presentación } \\
\text { del producto }\end{array}$ & $\begin{array}{l}\text { Maquetas digitales y/o pruebas impresas (cartelería } \\
\text { dípticos, etiquetas...) sobre papel o volúmenes (envases, } \\
\text { fajitas retráctiles..) }\end{array}$ \\
\cline { 2 - 3 } & Prototipos \\
\hline PLIEGO DE CONDICIONES \\
\hline ESTADO DE MEDICIONES/ PRESUPUESTO \\
\hline ESTUDIOS COMPLEMENTARIOS \\
\hline
\end{tabular}

\subsection{Evaluación}

Este último grupo tiene por tarea definir la metodología de evaluación, debiendo establecer los criterios e instrumentos de evaluación del TFG. Para ello se han analizado diversas experiencias previas sobre metodologías de evaluación (CIESE, 2016), (Universidad de Granada ,2015), (UPC, 2013), (UPC, 2014) y artículos publicados en revistas educativas basadas en el TFG de distintas Universidades Nacionales,(ROISS, S. 2015) (Capó, A.J.; Guerrero, C.; Miró, J; Egea, A. 2012) (Valderrama, E.; Rullán, M.; Sánchez, F.; Pons, J.; Cores, F.; Bisbal, J. 2009), (Rekalde Rodríguez, I. 2011), (Bonilla Priego M.J.; Fuentes Moraleda, L.; Vacas Guerrero, C.; Vacas Guerrero, T.2012)

A partir de estas experiencias previas se han considerado fundamental evaluar tres aspectos del TFG: el desarrollo del trabajo, la documentación final y la defensa del proyecto. Cada uno de estos aspectos es objeto de evaluación mediante el empleo de rúbricas, ya que se ha considerado que este instrumento de evaluación permite al alumno conocer de antemano los detalles de cómo va a ser evaluado, además de ser objetivas y justificar mejor una calificación.

Para evaluar el desarrollo del trabajo se ha considerado que debe ser el tutor el que la lleva a cabo, de manera que evalúe el seguimiento, las capacidades y la documentación lograda. Por una parte, el tutor evalúa las competencias transversales empleando la rúbrica relativa a las Competencias Transversales que la UPV ha introducido en la aplicación EBRON (EBRON, 2014). Por otra parte, el tutor emite un informe del TFG también a través de la aplicación Ebrón. Este informe no forma parte de la calificación de la asignatura ya que su finalidad es servir de información al tribunal.

Otro de los aspectos a evaluar es la documentación presentada, en este caso es el tribunal asignado el que lleve a cabo la evaluación. La calificación de esta fase se realizará previamente a la defensa mediante la rúbrica (Tabla.3) y será la media aritmética de las calificaciones de cada miembro del tribunal. Tendrá un peso del $70 \%$ sobre la nota final. 
Estrategias para establecer un sistema que determine el seguimiento, estructura y evaluación de los trabajos final de grado en el Grado de Ingeniería en Diseño Industrial y Desarrollo de Productos

Tabla. 3 Rubrica para la evaluación de la documentación.

\begin{tabular}{|c|c|c|c|c|c|}
\hline & 1 INSUFICIENTE & $\begin{array}{c}2 \\
\text { REGULAR }\end{array}$ & $\begin{array}{c}3 \\
\text { BIEN }\end{array}$ & $\begin{array}{c}4 \\
\text { EXCELENTE }\end{array}$ & $\%$ \\
\hline $\begin{array}{l}\text { Organización } \\
\text { de la } \\
\text { memoria }\end{array}$ & $\begin{array}{l}\text { La información } \\
\text { está mal } \\
\text { organizada, no } \\
\text { existe una } \\
\text { continuidad lógica } \\
\text { en el contenido. }\end{array}$ & $\begin{array}{l}\text { En general la } \\
\text { información } \\
\text { apenas se } \\
\text { organiza de } \\
\text { manera lógica } \\
\text { encontrándose } \\
\text { varios párrafos, } \\
\text { subtítulos o títulos } \\
\text { relevantes } \\
\text { erróneamente } \\
\text { dispuestos. }\end{array}$ & $\begin{array}{l}\text { En general la } \\
\text { información está } \\
\text { bien organizada } \\
\text { aunque con algún } \\
\text { párrafo, subtitulo } \\
\text { o título relevante } \\
\text { erróneamente } \\
\text { dispuesto. }\end{array}$ & $\begin{array}{l}\text { La información } \\
\text { está bien } \\
\text { organizada con } \\
\text { párrafos bien } \\
\text { redactados y con } \\
\text { subtítulos, } \\
\text { siguiendo un índice } \\
\text { lógico. }\end{array}$ & $1 \%$ \\
\hline $\begin{array}{l}\text { Redacción, } \\
\text { expresión y } \\
\text { ortografía. }\end{array}$ & $\begin{array}{l}\text { El trabajo escrito } \\
\text { presenta muchos } \\
\text { errores } \\
\text { ortográficos, } \\
\text { gramaticales y de } \\
\text { expresión. }\end{array}$ & $\begin{array}{l}\text { El trabajo escrito } \\
\text { presenta unos } \\
\text { cuantos errores } \\
\text { ortográficos, } \\
\text { gramaticales y de } \\
\text { expresión. }\end{array}$ & $\begin{array}{l}\text { El trabajo escrito } \\
\text { presenta algún } \\
\text { error ortográfico, } \\
\text { gramatical y/o de } \\
\text { expresión muy } \\
\text { puntual. }\end{array}$ & $\begin{array}{l}\text { Está redactado de } \\
\text { forma clara y sin } \\
\text { errores } \\
\text { ortográfico. }\end{array}$ & $2 \%$ \\
\hline $\begin{array}{l}\text { Fuentes de } \\
\text { información }\end{array}$ & $\begin{array}{l}\text { Solo maneja } \\
\text { información } \\
\text { procedente de } \\
\text { internet que no es } \\
\text { fiable ni apropiada. } \\
\text { No usa un sistema } \\
\text { de citación y no la } \\
\text { integra en el trabajo. }\end{array}$ & $\begin{array}{l}\text { La bibliografía } \\
\text { es muy básica. } \\
\text { No usa un sistema } \\
\text { de citación y no } \\
\text { siempre se integra } \\
\text { adecuadamente en } \\
\text { el trabajo. }\end{array}$ & $\begin{array}{l}\text { La bibliografía } \\
\text { es de interés } \\
\text { para el trabajo, } \\
\text { pero incompleta. } \\
\text { El trabajo } \\
\text { presenta algunos } \\
\text { fallos en el } \\
\text { sistema de } \\
\text { citación o en la } \\
\text { integración de las } \\
\text { referencias } \\
\text { bibliográficas en } \\
\text { el trabajo escrito. }\end{array}$ & $\begin{array}{l}\text { La bibliografía es } \\
\text { la esencial e } \\
\text { importante. Usa } \\
\text { las referencias } \\
\text { bibliográficas de } \\
\text { forma correcta y en } \\
\text { el momento } \\
\text { apropiado durante } \\
\text { el trabajo escrito. }\end{array}$ & $2 \%$ \\
\hline $\begin{array}{l}\text { Objetivos del } \\
\text { trabajo }\end{array}$ & $\begin{array}{l}\text { Los objetivos son } \\
\text { confusos y/o no } \\
\text { adecuados al tema } \\
\text { y/o sin interés para } \\
\text { el grado. }\end{array}$ & $\begin{array}{l}\text { Varios objetivos } \\
\text { son imprecisos o } \\
\text { no adecuados al } \\
\text { tema y/o no se ha } \\
\text { justificado el } \\
\text { cumplimiento de } \\
\text { algún objetivo } \\
\text { planteado. }\end{array}$ & $\begin{array}{l}\text { Aunque los } \\
\text { objetivos son } \\
\text { claros y realistas } \\
\text { resultan de escaso } \\
\text { interés en el } \\
\text { grado. Se han } \\
\text { cumplido todos } \\
\text { los objetivos } \\
\text { planteados. }\end{array}$ & $\begin{array}{l}\text { Los objetivos son } \\
\text { claros, realistas, } \\
\text { adecuados al tema } \\
\text { y de interés } \\
\text { relevante en el } \\
\text { grado. Se han } \\
\text { cumplido todos los } \\
\text { objetivos } \\
\text { planteados. }\end{array}$ & $\begin{array}{l}15 \\
\%\end{array}$ \\
\hline $\begin{array}{l}\text { Elaboración } \\
\text { de } \\
\text { conclusiones }\end{array}$ & $\begin{array}{l}\text { Las conclusiones no } \\
\text { se vinculan con la } \\
\text { información que se } \\
\text { maneja y/o con la } \\
\text { realidad en que se } \\
\text { deben aplicar y/o no } \\
\text { son significativos. }\end{array}$ & $\begin{array}{l}\text { Las conclusiones } \\
\text { tienen que ver } \\
\text { tangencialmente } \\
\text { con la realidad } \\
\text { analizada y la } \\
\text { información } \\
\text { manejada en el } \\
\text { trabajo, además } \\
\text { no son } \\
\text { significativos para } \\
\text { la globalidad del } \\
\text { TFG. }\end{array}$ & $\begin{array}{l}\text { Las conclusiones } \\
\text { parten de la } \\
\text { realidad analizada } \\
\text { y de la } \\
\text { información } \\
\text { manejada en el } \\
\text { trabajo, sin } \\
\text { embargo son } \\
\text { parciales, están } \\
\text { incompletas o } \\
\text { están poco } \\
\text { definidas. }\end{array}$ & $\begin{array}{l}\text { Las conclusiones } \\
\text { son adecuadas a la } \\
\text { información que se } \\
\text { maneja y a la } \\
\text { realidad analizada, } \\
\text { son significativos } \\
\text { para la globalidad } \\
\text { del TFG. }\end{array}$ & $\begin{array}{l}15 \\
\%\end{array}$ \\
\hline
\end{tabular}




\begin{tabular}{|c|c|c|c|c|c|}
\hline Resultados & $\begin{array}{l}\text { Los resultados } \\
\text { reflejan } \\
\text { pobremente la } \\
\text { idea, careciendo de } \\
\text { la calidad mínima } \\
\text { deseable para ese } \\
\text { tipo de producto. }\end{array}$ & $\begin{array}{l}\text { Los resultados } \\
\text { reflejan } \\
\text { aceptablemente } \\
\text { la idea, pero } \\
\text { varios detalles- } \\
\text { algunos relevantes } \\
\text { - podrían haber } \\
\text { sido refinados } \\
\text { para una correcta } \\
\text { resolución. }\end{array}$ & $\begin{array}{l}\text { Los resultados son } \\
\text { idóneos y reflejan } \\
\text { adecuadamente } \\
\text { la propuesta, } \\
\text { pero algún detalle } \\
\text { - no relevante - } \\
\text { podría haber sido } \\
\text { refinado para una } \\
\text { mejor resolución.. }\end{array}$ & $\begin{array}{l}\text { Los resultados son } \\
\text { inteligentes } \\
\text { reflejando } \\
\text { excelentemente la } \\
\text { idea, además la } \\
\text { calidad es } \\
\text { sobresaliente para } \\
\text { ese tipo de } \\
\text { producto. }\end{array}$ & $\begin{array}{l}15 \\
\%\end{array}$ \\
\hline $\begin{array}{l}\text { Originalidad, } \\
\text { innovación }\end{array}$ & $\begin{array}{l}\text { El alumno solo } \\
\text { aporta síntesis de } \\
\text { informaciones } \\
\text { diversas. Realiza } \\
\text { una actuación } \\
\text { imitativa. No hace } \\
\text { ninguna aportación } \\
\text { novedosa. }\end{array}$ & $\begin{array}{l}\text { La propuesta } \\
\text { aporta soluciones } \\
\text { poco } \\
\text { innovadoras lo } \\
\text { que supone una } \\
\text { baja o escasa } \\
\text { incidencia en el } \\
\text { campo de } \\
\text { conocimiento al } \\
\text { que pertenece el } \\
\text { TFG. }\end{array}$ & $\begin{array}{l}\text { El alumno } \\
\text { plantea ciertas } \\
\text { ideas originales. } \\
\text { El trabajo } \\
\text { presenta todavía } \\
\text { algunas } \\
\text { aportaciones } \\
\text { débiles al campo } \\
\text { de conocimiento } \\
\text { al que pertenece } \\
\text { el TFG. }\end{array}$ & $\begin{array}{l}\text { El alumno plantea } \\
\text { ideas originales } \\
\text { suficientemente } \\
\text { fundamentadas y } \\
\text { argumentadas } \\
\text { desde la diferencia, } \\
\text { mejora o avance } \\
\text { con respecto al } \\
\text { entorno de } \\
\text { referencia } \\
\text { inmediato. El } \\
\text { trabajo representa } \\
\text { una aportación } \\
\text { importante al } \\
\text { campo de } \\
\text { conocimiento al } \\
\text { que pertenece el } \\
\text { TFG. }\end{array}$ & $\begin{array}{l}15 \\
\%\end{array}$ \\
\hline $\begin{array}{l}\text { Calidad de } \\
\text { los } \\
\text { contenidos }\end{array}$ & $\begin{array}{l}\text { Solo se contempla } \\
\text { una dimensión o } \\
\text { aspecto del tema } \\
\text { estudiado, Presenta } \\
\text { un nivel muy bajo } \\
\text { en cuanto a la } \\
\text { profundidad del } \\
\text { contenido. }\end{array}$ & $\begin{array}{l}\text { El tema del } \\
\text { trabajo se describe } \\
\text { de forma } \\
\text { superficial, no se } \\
\text { contemplan las } \\
\text { dimensiones } \\
\text { fundamentales ni } \\
\text { los aspectos del } \\
\text { tema necesarios. } \\
\text { Los contenidos se } \\
\text { tratan, en algún } \\
\text { caso, sin la } \\
\text { calidad adecuada } \\
\text { en un trabajo de } \\
\text { estas } \\
\text { características. }\end{array}$ & $\begin{array}{l}\text { Los contenidos } \\
\text { presentan un nivel } \\
\text { de profundidad } \\
\text { medio, adecuado } \\
\text { a los requisitos } \\
\text { del TFG. El tema } \\
\text { se trata teniendo } \\
\text { en cuenta las } \\
\text { dimensiones } \\
\text { adecuadas de } \\
\text { manera que, se } \\
\text { describe de forma } \\
\text { correcta y } \\
\text { completa a este } \\
\text { nivel. Las ideas } \\
\text { aportadas son de } \\
\text { calidad. }\end{array}$ & $\begin{array}{l}\text { El TFG incluye } \\
\text { contenidos que se } \\
\text { analizan en } \\
\text { profundidad. Se } \\
\text { consideran las } \\
\text { dimensiones } \\
\text { fundamentales y, } \\
\text { de modo completo, } \\
\text { todos los aspectos } \\
\text { clave del tema de } \\
\text { estudio. El } \\
\text { desarrollo de los } \\
\text { contenidos tiene un } \\
\text { elevado nivel de } \\
\text { calidad. }\end{array}$ & $\begin{array}{l}20 \\
\%\end{array}$ \\
\hline $\begin{array}{l}\text { Documentaci } \\
\text { ón gráfica }\end{array}$ & $\begin{array}{l}\text { Falta } \\
\text { documentación } \\
\text { gráfica básica para } \\
\text { la definición formal } \\
\text { del tema }\end{array}$ & $\begin{array}{l}\text { La documentación } \\
\text { gráfica presenta } \\
\text { errores } \\
\text { relevantes o muy } \\
\text { frecuentes }\end{array}$ & $\begin{array}{l}\text { Complementa la } \\
\text { documentación } \\
\text { escrita y aporta } \\
\text { los documentos } \\
\text { necesarios para la } \\
\text { definición formal } \\
\text { del tema, pero } \\
\text { parte de esa } \\
\text { documentación } \\
\text { gráfica presenta } \\
\text { algún error de } \\
\text { carácter menor. }\end{array}$ & $\begin{array}{l}\text { Complementa } \\
\text { perfectamente la } \\
\text { documentación } \\
\text { escrita, aportando } \\
\text { los documentos } \\
\text { necesarios para la } \\
\text { definición formal } \\
\text { del tema. Toda la } \\
\text { documentación } \\
\text { gráfica es correcta }\end{array}$ & $\begin{array}{l}15 \\
\%\end{array}$ \\
\hline
\end{tabular}


Estrategias para establecer un sistema que determine el seguimiento, estructura y evaluación de los trabajos final de grado en el Grado de Ingeniería en Diseño Industrial y Desarrollo de Productos

El último aspecto a evaluar es la exposición y defensas del trabajo. Esta evaluación la realiza el tribunal una vez acabada la defensa mediante otra la rúbrica en donde se evalúa la presentación y defensa del trabajo. La calificación será la media aritmética de las calificaciones de cada miembro del tribunal y tendrá un peso del $30 \%$ sobre la nota final.

\section{Resultados}

Los resultados esperados son documentos que permitan informar a profesores y alumnos sobre cómo proceder en el seguimiento, estructura y evaluación de los TFG.

Actualmente se dispone de un borrador del documento que se ha ofrecido a los profesores y alumnos de cuarto curso del Grado solicitándoles cualquier aportación que pueda mejorar la propuesta, estando a la espera de las mismas.

A modo de ejemplo se ofrece parte de los resultados obtenidos en cuanto a contenido (Tabla. 1 y 2) y rúbrica (Tabla.3) expuestos en los apartados anteriores. Se prentede que estos resultados sirvan de apoyo a los profesores que dirigen TFG en el Grado en Diseño Industrial y desarrollo de productos.

También se pretende ofrecer un documento guía para los miembros de tribunal, de modo que la evaluación del alumno se realice bajo los mismos criterios con idependencia de los miembros del tribunal asignados. Con todo ello se pretende -en la medida de lo posibleobjetivar el proceso de evaluación.

\section{Conclusiones}

Después de realizar el trabajo de estrategias para establecer un sistema que determine el seguimiento, estructura y evaluación de los trabajos final de grado en el Grado de Ingeniería en Diseño Industrial y desarrollo de productos se pretende implantar el nuevo método de evalución del TFG en el curso 2017-2018, pero no obstante, para este presente curso se les ha ofrecido a los profesores los esquemas de los contenidos del TFG mencionados anteriormente para que sus alumnos tutorizados puedan tener un guion fácil de seguir.

Para el próximo curso se está formando el grupo de profesores que realizará la tutorización de los TFG. Se incluyen profesores de distintas áreas de conocimiento, de manera que se tenga un seguimiento de los distintos partes o contenidos del TFG.

Al finalizar cada curso se realizará una exposición de todos los proyectos tutorizados, con la misma temática.

Con todo ello se ha perseguido unificar criterios dentro del trabajo fin de grado y que faciliten la labor de cada uno de los actores que intervienen en el proceso, alumno, director y miembros del tribunal.

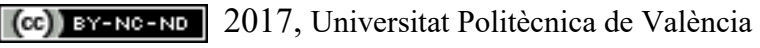

Congreso IN-RED (2017) 
E. Juliá Sanchis, M. Valor Valor, L. Pla Ferrando, S. Sempere Ripoll, J.F. Picó Silvestre, M. BonetAracil, J.A. Martínez Cerver, A. Jordá Vilaplana

\section{Referencias}

AENOR (2009) Criterios generales para la elaboración formal de los documentos que constituyen un proyecto técnico. UNE 157001:2014 Madrid. AENOR

Bonilla Priego M.J.; Fuentes Moraleda, L.; Vacas Guerrero, C.; Vacas Guerrero, T. (2012) "Análisis del proceso de evaluación del Trabajo Fin de Grado en las nuevas titulaciones". Revista de Educación en Contabilidad, Finanzas y Administración de Empresas (2012, nº 3, p. 5-21).

Capó, A.J.; Guerrero, C.; Miró, J; Egea, A. (2012) “Elaboración de una rúbrica para la evaluación TFG y TFM de informática en la Universitat de les Illes Balears". En Actas Simposio-Taller JENUI 2012. Ciudad Real (2012, p. 17-24).

CIESE, (2016) Centro Universitario CIESE de la Fundación Comillas, guía de trabajo para profesores y alumnos, así como modelos de evaluación y rubricas de evaluación

http://www.fundacioncomillas.es/centro-universitario/estudios-universitarios/grado/plan-deestudios/trabajo-fin-de-grado

EBRON (2014) Aplicación informática donde se gestionan los TFG en la UPV, Universitat Politécnica de Valencia. https://aplicat.upv.es/tfgtfmapp/seleccionRol.xhtml

Rekalde Rodríguez, I. (2011) “¿Cómo afrontar el trabajo fin de grado? Un problema o una oportunidad para culminar con el desarrollo de las competencias". Revista Complutense de Educación, (2011, vol. $22, n^{\circ} 2$, p. 179-193).

ROISS, S. (2015) "El Trabajo de Fin de Grado en el Grado de Traducción e Interpretación: evaluación de competencias y contenidos asociados al título. Estudio analítico y consecuencias didácticas". En Quaderns: revista de traducció ( 2015, $\mathrm{n}^{\circ}$ 22, p. 273-288)

Universidad de Granada, (2015) Plantillas para la evaluación de competencias en los TFG. http://docencia.ugr.es/pages/trabajo-fin-de-grado/instrumentos-evaluacion/rubricas

UPC, (2013) Universidad Politécnica de Cataluña y Universidad de Barcelona, marco normativo para realizar el TFG en el grado de estadística.

http://www.ub.edu/economiaempresa/grau/est/estadistica normativa TFG.pdf

(UPC, (2014) Universidad politécnica de Cataluña, Facultad de Náutica. Pasos, normativa, guía y plantilla de los TFG

http://www.fnb.upc.edu/content/treballs-fi-de-grau-i-m\%C3\%A0ster

UPV (2013) Normativa marco de trabajos fin de grado y fin de máster universitat politècnica de valència Aprobada en Consejo de Gobierno 7 de marzo de 2013

Valderrama, E.; Rullán, M.; Sánchez, F.; Pons, J.; Cores, F.; Bisbal, J. (2009) "La evaluación de competencias en los Trabajos Fin de Estudios". En Actas XV Jornadas de Enseñanza Universitaria de la Informática. Barcelona: (2009, p.405-412) 


\title{
Diseño de actividades y uso de la coevaluación para fomentar el desarrollo de competencias transversales en ingeniería mecánica y de materiales
}

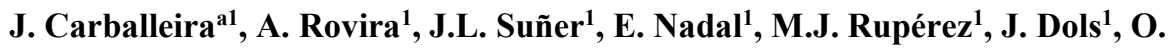 \\ Sahuquillo $^{1}$, J. Martínez-Casas ${ }^{1}$, P. Vila ${ }^{1}$, A. Pedrosa ${ }^{1}$, F.D. Denia ${ }^{1}$, J.J. Ródenas ${ }^{1}$, M. \\ Tur $^{1}$ \\ a(jacarmo@mcm.upv.es)
}

\author{
${ }^{1}$ Departamento de Ingeniería Mecánica y de Materiales \\ Universitat Politècnica de València, Camino de Vera s/n, 46022, Valencia
}

\begin{abstract}
The evaluation activities developed within the frame of a project on innovation and improvement of teaching, and some preliminary results, are presented in this paper. The main goal of this project is to work on the design of evaluation activities that truly force the students to put their soft skills (generic competences) into play and, at the same time, that allow the instructors to grade their students' performance on the technical-scientific competences.An assessment for learning approach is used, so that the evaluation activities are useful for the students to improve their learning experience.
\end{abstract}

Keywords: generic competences, evaluation activities, peer-assessment

\footnotetext{
Resumen

En esta comunicación se presentan las actividades de evaluación desarrolladas en el marco de un Proyecto de Innovación y Mejora Educativa, junto con algunos resultados preliminares. El principal objetivo de este proyecto es el diseño de actividades de evaluación que fuercen a los estudiantes a desarrollar sus competencias transversales, al mismo tiempo que permitan a los profesores evaluar su desempeño en las competencias científico-técnicas. Se emplea un enfoque de evaluación formativa, de forma que las actividades de evaluación sean útiles a los estudiantes para mejorar su aprendizaje.
}

Palabras clave: competencias transversales, actividades de evaluación, coevaluación 


\section{Introducción}

La evaluación de competencias transversales requiere de la puesta en juego de los distintos componentes de la propia competencia: conocer, saber aplicar, y actitudes y valores manifiestos (Villa et al., 2011). De ahí que las actividades de evaluación deban ser más completas que las empleadas tradicionalmente. De las conclusiones y experiencia obtenida tras la aplicación de los resultados de un proyecto de innovación y mejora educativa anterior (Carballeira et al., 2015), se comprobó que un diseño adecuado de las actividades de evaluación resulta clave para mejorar la motivación de los estudiantes y la experiencia de enseñanza-aprendizaje, así como para desarrollar las competencias transversales. Disponer de actividades de evaluación que pongan en juego estas competencias, y al mismo tiempo, sean rigurosas y completas a la hora de evaluar las competencias específicas científico-técnicas, las convierten en herramientas muy útiles para el aprendizaje, y no sólo la calificación de los estudiantes.

En una de las asignaturas involucradas en aquel proyecto se empleó la coevaluación para, en principio, disponer de más calificaciones y poder comprobar la bondad de los instrumentos de evaluación empleados (rúbricas y listas de control) (Carballeira et al. 2016). Cuando se estaban estudiando las respuestas obtenidas por parte de los estudiantes, se planteó que esta coevaluación decía mucho acerca del nivel de dominio del propio estudiante actuando como evaluador.

El empleo de la coevaluación ha sido ampliamente estudiado en la literatura. Son numerosas las referencias en las que se muestra que la aceptación por parte de los estudiantes suele ser favorable (Cavas et al., 2011). Las ventajas que se suelen nombrar son, entre otras (Nulty, 2008; Langan et al., 2003):

- Mejora la motivación de los estudiantes al aumentar su autonomía e incrementar su implicación en la evaluación.

- Favorece que los estudiantes se responsabilicen de su aprendizaje.

- Considera la evaluación como parte del proceso de aprendizaje, de forma que los errores se ven como oportunidades más que como fallos.

- Implica la práctica de competencias genéricas de tipo instrumental, interpersonal y sistemáticas para la evaluación, lo que es especialmente interesante para desarrollar la capacidad de aprendizaje autónomo a largo plazo.

- Proporciona a los estudiantes una realimentación de su propio trabajo desde la perspectiva de otros iguales, lo que mejora su capacidad para autoevaluarse.

- Promueve aprendizajes profundos y no superficiales.

- Aporta un valor de objetividad que propicia el diálogo, revisión y mejora continua del proceso de evaluación.

Entre las desventajas, se mencionan:

- La validez y la consistencia de la coevaluación, de forma que no haya desviaciones en positivo, o en negativo, frente a la heteroevaluación del experto.

(cc) EY-NC-ND 2017, UniversitatPolitècnica de València 
- La inexperiencia de los estudiantes a la hora de evaluar, lo que puede desincentivarles y generar un rechazo por su parte.

Estas desventajas se pueden minimizar siguiendo las recomendaciones habituales para que la coevaluación tenga éxito: simplificar y explicitar al máximo los criterios, formulando los diferentes indicadores en forma de preguntas (Lim, 2003); llevarla a cabo de forma anónima y validar la coherencia con las evaluaciones del profesor (Bostock, 2000).

\section{Objetivos}

Los objetivos de esta innovación han sido dos:

- Por un lado, el diseño y/o mejora de actividades de evaluación en asignaturas del departamento de ingeniería mecánica y de materiales en diferentes títulos y niveles académicos. Se trata de enriquecer el proceso de evaluación de las asignaturas desde el punto de vista formativo, desarrollando para ello actividades más completas que permitan trabajar y evaluar tanto las competencias científicotécnicas, específicas de las materias, como las competencias transversales.

- Por otro lado, en algunas de estas actividades se ha planteado el uso de la coevaluación como herramienta de evaluación adicional, para afinar la calificación de los estudiantes, y mejorar su aprendizaje. La idea es que el análisis de la coevaluación llevada a cabo por un estudiante de otro igual puede ser una fuente de información muy relevante para que el experto pueda evaluar a este mismo estudiante. La forma en que un estudiante puede reconocer y apreciar el dominio de otro igual en una competencia también indica hasta qué punto domina este estudiante la competencia, y además, le puede ayudar a desarrollar la competencia hasta niveles de logro superiores.

En esta comunicación se presentan tres experiencias destacadas, entre las iniciadas en el desarrollo del proyecto de innovación y mejora educativa. Se trata de experiencias relacionadas con las competencias transversales "Diseño y Proyecto", "Compresión e Integración" y "Aplicación y Pensamiento Práctico", siguiendo las denominaciones y definiciones empleadas en el proyecto institucional de la Universitat Politècnica de València, UPV, sobre competencias transversales (UPV, 2014).

\section{Desarrollo de la innovación}

\subsection{Diseño y Proyecto}

La primera experiencia que se va a describir es la propuesta de un trabajo académico para la evaluación y desarrollo de la competencia transversal "Diseño y Proyecto". La experiencia se ha llevado a cabo en la titulación del Máster Universitario en Ingeniería Industrial, en la asignatura Diseño y Aplicación de Equipos Industriales, del primer curso del máster. Participaron alrededor de 90 estudiantes trabajando en equipos de 4. 
El objetivo del trabajo es resolver un problema real en una empresa real. Los estudiantes deben visitar la empresa, detectar problemas relacionados con la logística interna (que es una competencia específica de la asignatura), y proponer soluciones en base al estudio del caso y los conocimientos técnicos adquiridos en la asignatura. Finalmente, deben entregar un informe escrito y realizar una defensa oral de sus conclusiones para el resto de sus compañeros.

La competencia "Diseño y Proyecto" se va a evaluar a través del informe escrito. Los resultados de aprendizaje de esta competencia son:

- Comprobar el contexto del proyecto.

- Plantear los objetivos.

- Establecer un plan de acción para alcanzar los objetivos.

- Obtener realimentación de las acciones y resultados.

- Identificar los posibles riesgos.

Para evaluar estos resultados, la UPV ha desarrollado unas rúbricas según el nivel académico. En este caso, para el nivel de máster, los indicadores asociados a estos resultados son:

1. El estudiante identifica el contexto y las necesidades del proyecto.

2. El estudiante especifica los objetivos del proyecto de forma coherente con las necesidades identificadas en el contexto.

3. El estudiante planifica las acciones de forma eficiente.

4. El estudiante establece herramientas para seguir el desarrollo de las acciones.

5. El estudiante identifica posibles riesgos del proyecto.

6. El estudiante revisa los resultados esperados.

La propuesta es asociar estos indicadores a la evaluación de las diferentes partes del informe escrito, que debe seguir la estructura tradicional de un trabajo académico: Introducción, Desarrollo, Discusión y Conclusiones.

En la Introducción se deben establecer el contexto del problema a resolver, las limitaciones y principales características a tener en cuenta, así como los objetivos; de modo que la calidad de la Introducción en el informe se asocia al nivel de logro en los indicadores 1 y 2.

Siguiendo la misma idea, en el Desarrollo del trabajo se incluyen las acciones y los mecanismos para monitorizar la implementación del plan. Se trata del núcleo de cualquier proyecto. La calidad de esta sección estaría directamente relacionada con los indicadores 3 y 4.

La sección de Discusión suele incluir comentarios acerca de las limitaciones del proyecto, que estarán vinculados a los riesgos del mismo, de forma que se puede asociar al indicador 5. Finalmente, en el apartado de Conclusiones se realiza un análisis de los resultados esperados cuando se pongan en marcha las acciones, por lo que nos proporcionará evidencias para evaluar el indicador 6.

(cc) EY-NC-ND 2017, UniversitatPolitècnica de València 


\subsection{Comprensión e integración}

Esta experiencia se ha llevado a cabo en la titulación del Máster Universitario en Ingeniería del Mantenimiento, en la asignatura Análisis de Vibraciones, y participaron 23 estudiantes.

La actividad de evaluación consistía en la redacción de un trabajo académico y el empleo de la coevaluación para su calificación. Además de los resultados de aprendizaje específicos de la materia, con este trabajo se pretendía desarrollar las competencias en “compresión e integración”, y "comunicación escrita efectiva”. Para la calificación del trabajo, se combinan la evaluación del "experto" (el profesor de la asignatura), y la evaluación entre pares llevada a cabo por los estudiantes. El objetivo de esta experiencia era mejorar la compresión del curso mediante la implicación de los estudiantes en la evaluación de los trabajos de sus compañeros.

El trabajo era realizado en grupos de 2 o 3 estudiantes, o de forma individual. Cada estudiante debía evaluar otro trabajo en el que no hubiese participado, de forma que cada trabajo fue evaluado tantas veces como componentes tuviese el equipo. La nota del trabajo se asignaba a partir de la suma ponderada de la calificación otorgada por el experto y la calificación promediada de la evaluación por pares. En particular, se empleó la siguiente expresión:

$$
\mathrm{C}=0,7 \cdot \mathrm{C}^{\text {experto }}+0,3 \cdot \mathrm{C}^{\text {pares }}
$$

Se empleó una rúbrica con varios indicadores para evaluar el trabajo: la presentación del trabajo escrito; la descripción del modelo; los cálculos; las conclusiones; y el uso adecuado de referencias. La nota obtenida mediante la rúbrica iba de 0 a 9 , ya que se otorgaba un punto extra en función del nivel de autonomía del estudiante en la realización del trabajo.

Si la desviación entre la nota otorgada por el experto y la nota propuesta por el estudianteevaluador era mayor de 3 puntos, se aplicaba un corrección a la nota del evaluador, y para la nota del trabajo evaluado sólo se consideraba la nota del experto.

Los evaluadores fueron asignados de forma aleatoria por el profesor, de forma que los estudiantes no sabían quién o quiénes habían sido sus evaluadores.

\subsection{Aplicación y pensamiento práctico}

Esta experiencia se ha llevado a cabo en el $4^{\circ}$ curso del Grado en Ingeniería en Tecnologías Industriales, en la asignatura Diseño Mecánico Asistido por Ordenador, y participaron 35 estudiantes.

La actividad de evaluación planteada consiste en la redacción de unas instrucciones de montaje de un motor de 4 cilindros en V (ver Fig. 1). Con este trabajo se puede evaluar la competencia Aplicación y Pensamiento Práctico ya que para construir el modelo final no existe una única secuencia de pasos, sino que, utilizando los comandos de edición y gestión de entidades del programa ADAMS/View (ADAMS, 2014), se puede crear el modelo de manera más o menos rápida y con un número de pasos mayor o menor. Estas diferentes vías 
son aplicables tanto a la copia y reubicación de elementos físicos del modelo como a la copia y reprogramación de las funciones de las fuerzas en los pistones.

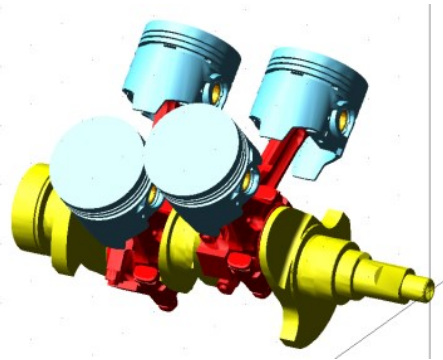

Fig. 1 Motor de 4 cilindros en V modelado mediante ADAMS/View (ADAMS, 2014).

Además, para la creación del motor de 4 cilindros en $\mathrm{V}$, es necesaria la incorporación de elementos nuevos, debido al alargamiento del asiento de las muñequillas del cigüeñal, ya que se calan dos bielas por muñequilla. El modo en que realizan esta modificación se deja por completo a los estudiantes, que pueden hacerla mediante los elementos propios del programa de simulación o con programas externos de CAD, que permiten trabajar con los modelos originales de las piezas.

Dado que en una vez finalizado el modelo del motor policilíndrico puede ser difícil o imposible detectar la secuencia de pasos que han llevado a ese modelo, se pide una memoria del trabajo bajo la forma de un manual de instrucciones, con un formato similar al utilizado por los profesores de la asignatura en sus clases, de manera que cualquier persona con conocimientos del programa y partiendo de la misma situación inicial sea capaz de llegar al mismo modelo que el realizado por los estudiantes. En esas instrucciones se comprobará si los estudiantes alcanzan los resultados de aprendizaje previstos.

Las memorias de los trabajos son evaluadas empleando las dos listas de control mostradas en las Tablas 1 y 2. La lista de control en la Tabla 1 está adaptada a la actividad desarrollada para evaluar la competencia específica, mientras que la lista de la Tabla 2 sirve para evaluar la competencia transversal, pero evitando un lenguaje abstracto, y utilizando uno con más referencias al trabajo realizado.

La evaluación mediante la lista de la Tabla 1 se realiza tanto por parte del profesorado (heteroevaluación) como por parte del alumnado (coevaluación). La nota obtenida se utiliza para calificar la competencia específica, y como una primera aproximación en la evaluación de la competencia transversal, ya que la actividad está basada en su utilización. La valoración final de esta calificación es de $70 \%$ la heteroevaluación y $30 \%$ la coevaluación.

Las preguntas de la lista de control mostrada en la Tabla 2 para evaluar la competencia transversal tienen un valor de 0 a 3 puntos, salvo una cuya casuística no podía tener la misma valoración y tiene una de 0 a 2 puntos.

Las preguntas se dividen en dos bloques. Las 6 primeras hacen hincapié en la evaluación de la competencia transversal. Las 2 últimas están formuladas para que el evaluador de una

(cc) BY-NC-ND 2017, UniversitatPolitècnica de València

Congreso IN-RED (2017) 
opinión comparativa entre su propio trabajo y el trabajo evaluado. Es importante resaltar que esta opinión es útil para confirmar si el evaluador, partiendo de un nivel de asimilación y comprensión de la competencia transversal, es capaz de reconocerla en el evaluado. En el caso de que el nivel del evaluador esté en tramos bajos, si el nivel del evaluado es alto, la coevaluación le puede poner en contacto con la competencia a ese nivel más alto. En este caso, si la puntuación en estas dos preguntas es alta, se tiene un indicio de que el dominio del evaluador en esta competencia ha aumentado.

El primer bloque de 6 preguntas da una puntuación máxima de 17 puntos, tal y como está diseñada. El segundo bloque da una puntuación máxima de 6 , pero puede hacerse una utilización menos numérica y más de apreciación por parte del profesorado.

La utilización de esta lista para evaluar la competencia transversal es la siguiente: a todos los estudiantes o equipos se les hace una heteroevaluación (experto), la cual se tomará como referencia principal. Por otro lado, un estudiante o equipo evaluador, A, evalúa a otro estudiante o equipo, B, que, se recuerda, ya ha sido evaluado por el profesorado. Tomando la heteroevaluación de B como referencia, se contrastará la coevaluación de A sobre B para determinar si A domina y tiene asimiladas las competencias específicas y transversales. Dicho de otro modo, el acto de evaluación de A sobre B se convierte, a su vez, en una evaluación de A sobre la competencia transversal.

Para poder establecer una valoración en el dominio de la competencia por parte de un evaluador, se propone una fórmula que toma, como punto de partida, la calificación otorgada al evaluador, A, con la heteroevaluación y se modifica con la comparación entre las notas de la heteroevaluación y la coevaluación del evaluado, B. Todas las evaluaciones se hacen con el primer bloque de 6 preguntas, con su puntuación máxima de 17 puntos.

Los elementos de la fórmula son las siguientes:

- La nota otorgada a un estudiante o grupo evaluador, A, en la heteroevaluación, se denomina Nota1.

- La nota otorgada a un estudiante o grupo evaluado, B, en la heteroevaluación, se denomina Nota2H.

- La nota otorgada a un estudiante o grupo evaluado, B, por el estudiante o grupo evaluador, A, en la coevaluación, se denomina Nota2C.

- La diferencia entre los valores recibidos por la heteroevaluación y la coevaluación por el estudiante o grupo evaluado, B, se denomina Nota2 y se define como:

$$
\text { Nota } 2=\text { Nota } 2 H-N o t a 2 C
$$

La fórmula propuesta es una función definida a tramos, con la siguiente expresión:

$$
\left.\begin{array}{c}
\text { Si } \mid \text { Nota } \mid \leq 2 \rightarrow \text { Nota }=\operatorname{MiN}(\text { Nota } 1+(2-\mid \text { Nota } \mid), 17) \\
\text { Si } 3 \leq \mid \text { Nota } 2 \mid \leq 6 \rightarrow \text { Nota }=\text { Nota } 1-(\mid \text { Nota } 2 \mid-2) \\
\text { Si } \mid \text { Nota } 2 \mid \geq 7 \rightarrow \text { Nota }=\text { Nota } 1-6
\end{array}\right\}
$$

La puntuación que puede obtener un estudiante o grupo evaluador será de 0 a 17 puntos, pero puede no ser la misma con la que se partió inicialmente, sino que puede verse modificada de acuerdo a la calidad de la evaluación efectuada al otro estudiante o equipo. 
Las dos últimas preguntas sirven al profesorado como preguntas de control para validar el resultado obtenido y, sobre todo, para hacer visible si, en el caso de que el estudiante o equipo evaluador no partiera antes de la coevaluación de un nivel alto en el dominio de la competencia, ha mejorado su comprensión y asimilación de ésta después. Dado el carácter más subjetivo de esta apreciación, se deja al criterio del profesorado el que estas dos preguntas tengan mayor o menor influencia en la calificación final de la competencia.

Por último, para ajustar la calificación obtenida a la normativa de calificaciones de competencias transversales de la UPV, la cual contempla 4 niveles, A, B, C y D, de acuerdo con el nivel de dominio de la competencia alcanzado, se establece la siguiente correlación.

Nivel A (excelente) $\quad \Rightarrow 15 \leq$ Nota $\leq 17$.

Nivel B (bien) $\quad \Rightarrow 12 \leq$ Nota $\leq 14$.

Nivel C (en desarrollo) $\Rightarrow 8 \leq$ Nota $\leq 11$.

Nivel D (no alcanzado) $\Rightarrow 0 \leq$ Nota $\leq 7$.

Los niveles más inferiores son más amplios que los superiores, ya que, las calificaciones que contienen implican un trabajo escaso en la competencia.

(cc) BY-NC-ND 2017, UniversitatPolitècnica de València

Congreso IN-RED (2017) 
Tabla 1. Lista de control para evaluación de la competencia específica en la experiencia sobre Aplicación y Pensamiento Práctico

1. Calidad de las instrucciones. Si son claras, detalladas correctas y no dejan pasos por describir.

Calificación (mínimo 0, máximo 2).

Justificar brevemente la calificación:

2. Modelo geométrico. Las carreras forman $90^{\circ}$ entre sí. La muñequilla de los pistones 2 y 4 está desfasada $180^{\circ}$ respecto la otra muñequilla. Si faltan piezas, se han creado adecuadamente.

Calificación (mínimo 0, máximo 2).

Justificar brevemente la calificación:

3. Procedimiento de construcción del modelo. Creación, copia, desplazamiento y giros de grupos y piezas.

Calificación (mínimo 0, máximo 2).

Justificar brevemente la calificación:

4. Programación del modelo. Creación de contadores Ang_Cig_720 de cada cilindro. Definición de polinomios, polin_1 y polin_2 de cada cilindro. Definición correcta de la fuerza en cada pistón.

Calificación (mínimo 0, máximo 2).

Justificar brevemente la calificación:

5. Funcionamiento en régimen permanente. Correcto funcionamiento, resultado coherente, comparación con el resultado del modelo propio del equipo evaluador.

Calificación (mínimo 0, máximo 2).

Justificar brevemente la calificación:

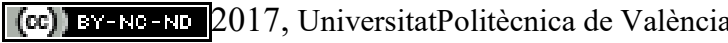

Congreso In-Red (2017) 
Tabla 2. Lista de control para la evaluación de la competencia transversal en Aplicación y Pensamiento Práctico.

Nombre:

Nombre:

Trabajo evaluado:

\begin{tabular}{|c|c|c|c|c|}
\hline & CRITERIOS & ¿Sí o no? & ¿En qué medida & \\
\hline 1 & $\begin{array}{l}\text { ¿Han entendido la tarea propuesta? ¿Lo explican de } \\
\text { forma adecuada en el trabajo? }\end{array}$ & $\begin{array}{l}\text { Sí } \square \\
\text { No } \square\end{array}$ & $\begin{array}{ll}\text { 1. } & \text { Inadecuado } \\
\text { 2. } & \text { Suficiente } \\
\text { 3. } & \text { Adecuado }\end{array}$ & $\begin{array}{l}\square \\
\square \\
\square\end{array}$ \\
\hline 2 & $\begin{array}{l}\text { ¿Han redactado un índice para el trabajo? ¿Resulta } \\
\text { adecuado? }\end{array}$ & $\begin{array}{l}\text { Sí } \square \\
\text { No } \square\end{array}$ & $\begin{array}{ll}\text { 1. } & \text { Inadecuado } \\
\text { 2. } & \text { Suficiente } \\
\text { 3. } & \text { Adecuado }\end{array}$ & $\begin{array}{l}\square \\
\square\end{array}$ \\
\hline 3 & $\begin{array}{l}\text { ¿Han interpretado los diagramas cinemáticos y de } \\
\text { encendido? }\end{array}$ & $\begin{array}{l}\text { Sí } \square \\
\text { No } \square\end{array}$ & $\begin{array}{ll}\text { 1. } & \text { Mal } \\
\text { 2. } & \text { Regular } \\
\text { 3. } & \text { Bien }\end{array}$ & $\begin{array}{l}\square \\
\square\end{array}$ \\
\hline 4 & $\begin{array}{l}\text { ¿Han introducido todas las partes del modelo } \\
\text { necesarias? }\end{array}$ & $\begin{array}{l}\text { Sí } \square \\
\text { No } \square\end{array}$ & $\begin{array}{l}\text { 1. No todas } \\
\text { 2. Todas }\end{array}$ & $\square$ \\
\hline 5 & $\begin{array}{l}\text { ¿Tienen claros los pasos a seguir para realizar el } \\
\text { trabajo? ¿Están bien enumerados? }\end{array}$ & $\begin{array}{l}\text { Sí } \square \\
\text { No } \square\end{array}$ & $\begin{array}{ll}\text { 1. } & \text { Mal } \\
\text { 2. } & \text { Regular } \\
\text { 3. } & \text { Bien }\end{array}$ & $\begin{array}{l}\square \\
\square\end{array}$ \\
\hline 6 & ¿Describen con precisión las operaciones a realizar? & $\begin{array}{l}\text { Sí } \square \\
\text { No } \square\end{array}$ & $\begin{array}{ll}\text { 1. } & \text { Mal } \\
\text { 2. } & \text { Regular } \\
\text { 3. } & \text { Bien }\end{array}$ & $\begin{array}{l}\square \\
\square \\
\square\end{array}$ \\
\hline 7 & ¿Difiere vuestro trabajo del que habéis evaluado? & $\begin{array}{l}\text { Sí } \square \\
\text { No } \square\end{array}$ & $\begin{array}{ll}\text { 1. } & \text { Poco } \\
\text { 2. } & \text { Bastante } \\
\text { 3. } & \text { Mucho }\end{array}$ & $\begin{array}{l}\square \\
\square \\
\square\end{array}$ \\
\hline 8 & $\begin{array}{l}\text { ¿Podríais mejorar vuestro trabajo después de haber } \\
\text { evaluado el del otro equipo? }\end{array}$ & $\begin{array}{l}\text { Sí } \square \\
\text { No } \square\end{array}$ & $\begin{array}{ll}\text { 1. } & \text { Poco } \\
\text { 2. } & \text { Bastante } \\
\text { 3. } & \text { Mucho }\end{array}$ & $\begin{array}{l}\square \\
\square \\
\square\end{array}$ \\
\hline
\end{tabular}

(cc) EY-NC-ND 2017, UniversitatPolitècnica de València 


\section{Resultados}

\subsection{Diseño y Proyecto}

En este curso 2016-2017 se han evaluado 23 informes. En la Fig. 2 se muestra un histograma con las respuestas obtenidas en los diferentes apartados, y la evaluación de la competencia transversal. Se puede observar que los mejores resultados se obtienen en el apartado de Desarrollo, y los resultados más bajos en Discusión y Conclusiones. Esto nos indica que los estudiantes son capaces de planificar acciones adecuadas para resolver los objetivos del proyecto de forma eficiente, pero que tienen más dificultades a la hora de ser críticos con su propuesta, o de establecer formas para controlar el desarrollo de su plan.

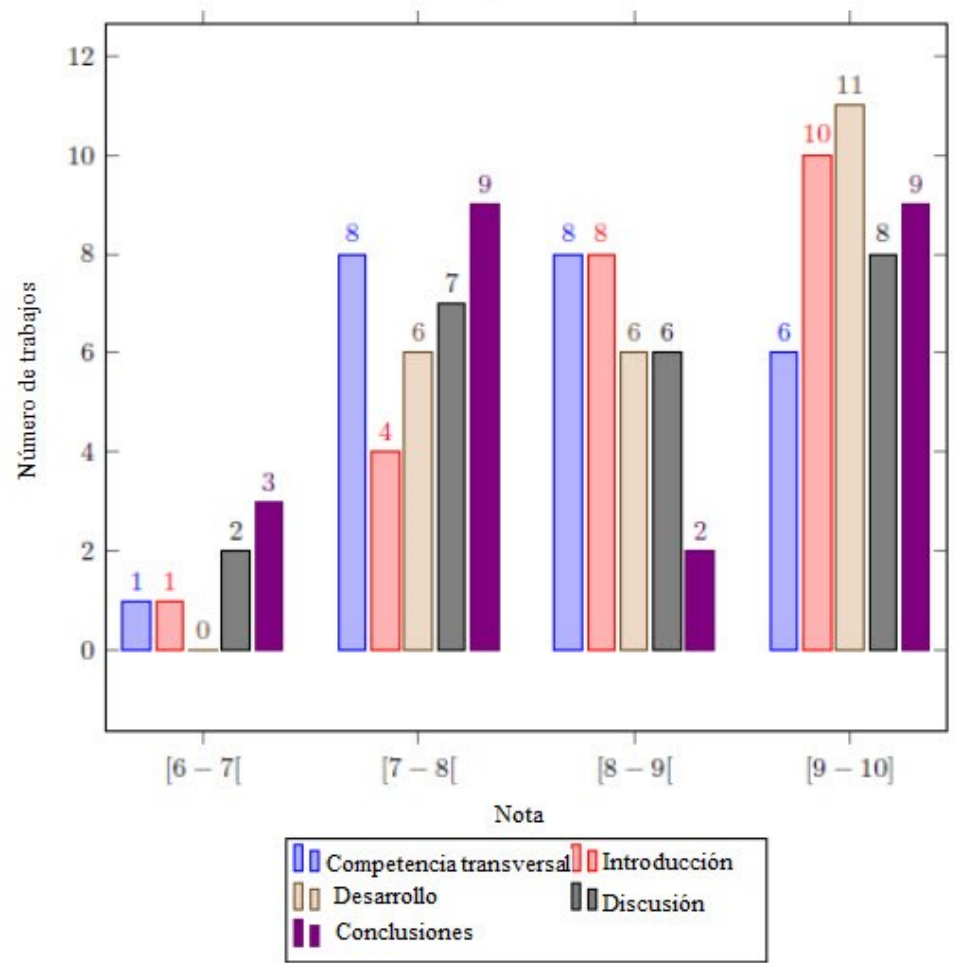

Fig. 2 Histograma que muestra las calificaciones de los diferentes apartados del trabajo, y de la competencia transversal, en una escala de 0 a 10.

\subsection{Compresión e integración}

En este curso 2016-2017 han participado 23 estudiantes y se han evaluado 11 trabajos. En la Fig. 3 se muestra una gráfica con las notas obtenidas, en la que se marca la línea que corresponde a la misma nota por parte del experto y de los pares, junto con las líneas que indican que hay una diferencia mayor de 3 puntos entre ambas.

(cc) EY-NC-ND 2017, UniversitatPolitècnica de València 
De los 23 estudiantes, sólo 19 realizaron correctamente la evaluación. Tres estudiantes no usaron la rúbrica correctamente y no pudieron ofrecer una nota razonable para los trabajos evaluados; otro estudiante no pudo evaluar porque hubo un error a la hora de asignar los trabajos a evaluar.

11 estudiantes realizaron una buena evaluación (diferencia menor de 3 puntos), mientras que 8 no lo hicieron, y su calificación se vió penalizada. Teniendo en cuenta este alto porcentaje de desviaciones, se considera que la evaluación por pares no es adecuada en esta actividad. Ello se debe a que para llevar a cabo una buena evaluación, los estudiantes deben tener un buen dominio de la asignatura. De forma que, como se pudo comprobar empíricamente, los estudiantes con buenas notas asignadas por el experto hicieron una buena evaluación de sus pares, pero los estudiantes con notas más bajas tuvieron mayores desviaciones respecto a esta referencia.

Aún así, se valora positivamente que la exposición de estos estudiantes con notas más bajas a los trabajos de otros compañeros puede mejorar su aprendizaje.

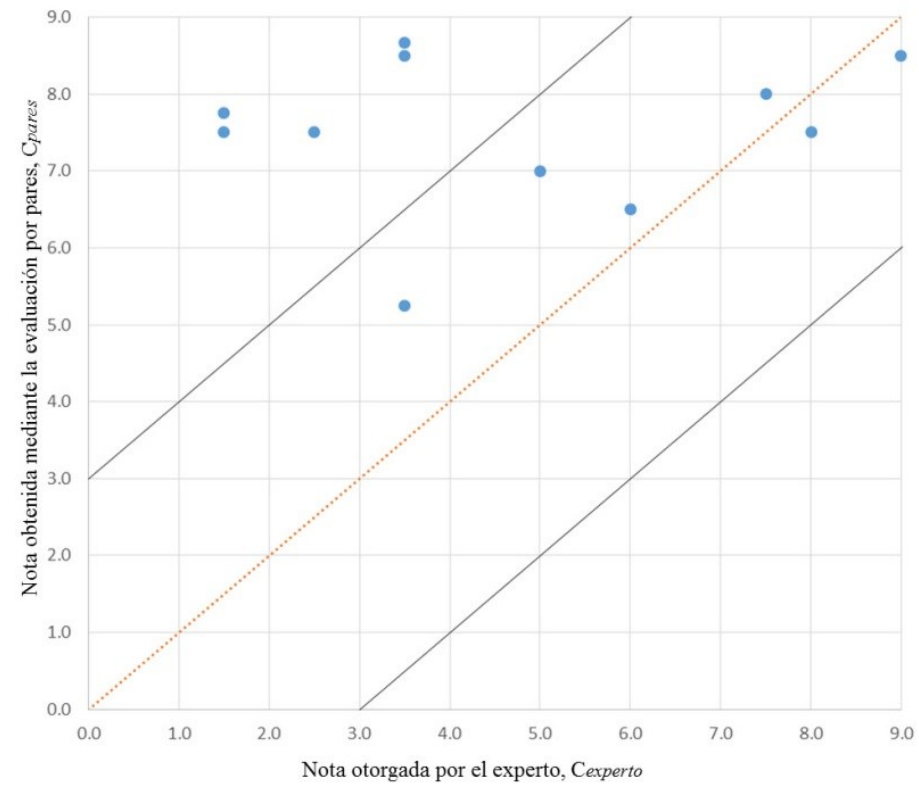

Fig. 3 Comparación entre las notas obtenidas por los diferentes trabajos por parte del experto y por parte de sus pares.

\subsection{Aplicación y Pensamiento Práctico}

En el desarrollo de la asignatura durante el curso 2015-2016, ya que no se dispone de los datos de este curso por ser una asignatura de segundo semestre, el número de coevaluaciones realizadas fue de 16 .

En la Tabla 3 se muestran las diferencias entre las valoraciones otorgadas en la heteroevaluación, es decir, por los profesores de la asignatura, en calidad de expertos, y en la coevaluación para la competencia específica. La variación se ha calculado como el valor absoluto de la diferencia entre la heteroevaluación y la coevaluación y normalizado sobre 10 puntos. Se opta por definir tres umbrales, los cuales se reflejan en la Tabla 3.

(c)) BY-NC-ND 2017, UniversitatPolitècnica de València 
Tabla 3. Variación entre valoraciones de heteroevaluación y coevaluación en la competencia específica.

\begin{tabular}{|c|c|c|c|}
\hline Variación & Menor o igual a 5\% & Entre 5\% y 10\% & Mayor que 10\% \\
\hline Núm. Evaluaciones & 11 & 4 & 1 \\
\hline \% Evaluaciones & 68,75 & 25,00 & 6,25 \\
\hline
\end{tabular}

Se puede apreciar que las valoraciones no difieren en exceso y que la poca presencia de casos con alta diferencia confirma la bondad del método.

En la Tabla 4 se muestran las diferencias entre las valoraciones otorgadas en la heteroevaluación y en la coevaluación para la competencia transversal. Los umbrales ahora se ajustan a los del procedimiento de calificación mostrado anteriormente.

Tabla 4. Variación entre valoraciones de heteroevaluación y coevaluación en la competencia transversal.

\begin{tabular}{|c|c|c|c|}
\hline Variación & Menor o igual a 2 p. & Entre 3 y 6 p. & Mayor que 7 p. \\
\hline Núm. Evaluaciones & 11 & 5 & 0 \\
\hline \% Evaluaciones & 68,75 & 31,25 & 0,00 \\
\hline
\end{tabular}

Los resultados son muy parecidos a los de la competencia específica.

La valoración del profesor de la competencia transversal, según los niveles marcados por la UPV son los siguientes.

Tabla 5. Valoración del profesor.

\begin{tabular}{|c|c|c|c|c|c|}
\hline Nivel & A & B & C & D & Total \\
\hline Núm. Equipos & 4 & 6 & 6 & 0 & 16 \\
\hline
\end{tabular}

La aplicación de la corrección en las calificaciones de los diferentes equipos según su coevaluación da como resultado la siguiente modificación:

Tabla 4. Modificación de la calificación.

\begin{tabular}{|c|c|c|c|c|c|}
\hline Nivel & A & B & C & D & Total \\
\hline Núm. Equipos & 5 & 4 & 5 & 2 & 16 \\
\hline
\end{tabular}

Se observan bastantes modificaciones en la calificación definitiva. Haciendo un estudio más detallado, se observó que los resultados modificados correspondían a valores 
fronterizos entre niveles y que la modificación venía a confirmar la tendencia que mostraban anteriormente.

Las dos últimas preguntas de la encuesta se consideraron de manera subjetiva, pero no aportaron información adicional a la que ya se había obtenido con el primer bloque y su puntuación.

\section{Conclusiones}

El desarrollo de actividades y herramientas de evaluación adecuadas es crítico para trabajar y evaluar competencias transversales. En este trabajo se han mostrado tres experiencias en las que se han enriquecido las actividades de evaluación empleadas anterioremente, para conseguir una experiencia de aprendizaje más completa por parte de los estudiantes.

El uso de la coevaluación en la evaluación de las competencias transversales es muy prometedor en cuanto a que añade valor formativo a la evaluación, y mejora la experiencia docente y de aprendizaje de los estudiantes. De las dos experiencias mostradas en esta comunicación, los resultados son valorados muy positivamente tanto por profesores como por los estudiantes en el caso de la competencia "Aplicación y Pensamiento Práctico". Las dificultades encontradas en la implementación de esta metodología para evaluar la competencia de "Compresión e Integración" sirven de aprendizaje para mejorar la propuesta en el próximo curso.

\section{Agradecimientos}

Los autores quieren mostrar su agradecimiento al Vicerrectorado de Estudios, Calidad y Acreditación de la Universitat Politècnica de València por la financiación obtenida a través del programa PIME 2016-17 bajo la referencia A26.

\section{Referencias}

ADAMS team at MSC Software. (2014). Adams Tutorial Kit for Mechanical Engineering Courses. MSC Software.

BOSTOCK, S. (2000). Student peer assessment. Learning Technology.

CARBALLEIRA, J., MARTÍNEZ-CASAS, J., SAHUQUILLO, O., SONSECA, A., DENIA, F.D., SUÑER, J.L., VILA, P., RÓDENAS, J.J., MARCO, O. (2015).

"Desarrollo de estrategias de evaluación de competencias transversales en asignaturas de ingeniería mecánica y de materiales." En Congreso Nacional de Innovación Educativa y Docencia en Red de la Universitat Politècnica de València. (ISSN 978-849048-396-1). Valencia: Editorial UPV. 923-937.

CARBALLEIRA, J., MARTÍNEZ-CASAS, J., SAHUQUILLO, O., SONSECA, A., SUÑER, J.L., VILA, P., DENIA, F. D., RÓDENAS, J.J., MARCO, O. (2016). "Assessment of problem-solving skills and capacity for applying knowledge in practice 
in subjects related to mechanical and materials engineering" en Advances in Higher Education, Ed. Universitat Politècnia de València, Chapter 5, pp. 71-88.

CAVAS TOLEDO, M., CHICANO GARCÍA, F., LUNA VALERO, F., y MOLINA TANCO, L. (2011). "Autoevaluación y evaluación entre iguales en una asignatura de redes de ordenadores." En Jornadas de Enseñanza Universitaria de la Informática (17es: 2011: Sevilla).

LANGAN, M., y WHEATER, P. (2003). "Can students assess students effectively? Some insights into peer-assessment". Learning and Teaching in ACTION, 2 (1).

LIM, L.A. (2003). "Implementing effective peer assessment". CTDL Brief, 6 (3).

NULTY, D. (2008). "A Guide to Peer and Self Assessment: Approaches and Practice Strategies for Academics". Griffith Institute for Higher Education. Griffith University.

VILLA, A., y POBLETE, M. (2011). "Evaluación de competencias genéricas: principios, oportunidades y limitaciones". Bordón. Revista de pedagogía, 63(1), 147 170.

UPV (2014). Proyecto institucional sobre Competencias Transversales. http://www.upv.es/contenidos/COMPTRAN/ [Consulta: 21 Marzo 2017] 


\title{
SCAMPER-3-5 para generación de ideas y su análisis de valor.
}

\section{MME Alemanya ${ }^{a}$ Llanos Cuenca ${ }^{a}$, Leonor Ruiz ${ }^{\text {a }}$ Andrés Boza ${ }^{a}$}

${ }^{a}$ Departamento de Organización de Empresas. Universitat Politècnica de València. Equipo de Innovación Educativa AEGECATE. (mareva@omp.upv.es, llcuenca@omp.upv.es, 1ruiz@omp.upv.es, aboza@omp.upv).

\begin{abstract}
At the Universitat Politècnica de València, thirteen competency dimensions have been defined, among which is the competency of creativity, innovation and entrepreneurship. This competency has become in recent years one of the most demanded in the labor market. This paper presents the design and development of the SCAMPER-3-5 activity designed to foster the acquisition of the transversal competency. The proposed technique is based on the combination of the SCAMPER and 6-3-5 extended techniques, to eliminate the limitations encountered and to design an activity that reaches the whole process associated to creativity, innovation and entrepreneurship. This process includes the phases of search for opportunities, generation of ideas, action plan and value analysis. The proposed activity is easily applicable and transferable to any subject, and can be used in any context. It contributes to the development of transversal competence in students.
\end{abstract}

Keywords: Transversal competency, Creativity, Innovation, Entrepreneurship, SCAMPER, 6-3-5

\section{Resumen}

En la Universitat Politècnica de València se han definido un total de trece dimensiones competenciales, entre las que se encuentra, la competencia de creatividad, innovación y emprendimiento. Esta competencia, se ha convertido en los últimos años en una de las más demandadas en el mercado laboral. En este trabajo se presenta el diseño y desarrollo de la actividad SCAMPER-3-5 diseñada para favorecer la adquisición de la competencia transversal. La técnica propuesta se basa en la combinación de las técnicas SCAMPER y 6-3-5 extendida, para eliminar las limitaciones encontradas y diseñar una actividad que alcance todo el proceso asociado a la competencia de creatividad, innovación y emprendimiento. Dicho proceso incluye las fases de búsqueda de oportunidades, generación de ideas, plan de acción y análisis de valor. La actividad propuesta es fácilmente aplicable y transferible a cualquier asignatura, pudiendo ser utilizada en cualquier contexto. Contribuye por tanto al desarrollo de la competencia transversal en los alumnos.

Palabras clave: Competencia transversal, Creatividad, Innovación, Emprendimiento, SCAMPER, 6-3-5. 


\section{Introducción}

La innovación se ha convertido en un requisito para la ventaja competitiva de las organizaciones, por lo que es en un aspecto cada vez más importante y demandado. Favorecer la adquisición de la competencia en innovación es, por tanto, uno de los aspectos a resolver (Boza \& Cuenca 2014), especialmente en las enseñanzas universitarias que preparan al egresado para su inserción en el mundo laboral.

En la UPV Se han definido un total de 13 dimensiones competenciales. DC1-Comprensión e integración; DC2-Aplicación del pensamiento práctico; DC3-Análisis y resolución de problemas; DC4-Innovación, creatividad y emprendimiento; DC5-Diseño y proyecto; DC6Trabajo en equipo y liderazgo; DC7-Responsabilidad ética y profesional; DC8Comunicación efectiva; DC9-Pensamiento crítico; DC10-Conocimiento de los problemas contemporáneos; DC11-Aprendizaje permanente; DC12-Planificación y gestión del tiempo; DC13-Instrumental específica.

La adquisición de las anteriores competencias se establece en base al nivel de alcance de unos determinados resultados de aprendizaje en los que se desglosan estas competencias.

La manera que en que transmiten los conocimientos para la consecución de los resultados de aprendizaje puede ser a través de las actividades desarrolladas y objetos de aprendizaje complementarios(Fernández-Diego et al. 2015) que permitan su evaluación (Cuenca, Alarcón, Boza, et al. 2016). Diversas actividades han sido propuestas y aplicadas por los autores, para facilitar la adquisición de la competencia de creatividad, innovación y emprendimiento en las aulas (Ruiz et al. 2015); (Boza et al., 2016).

La Universitat Politècnica de València recoge las directrices para la incorporación de las competencias transversales en las titulaciones. El sistema de evaluación debe procurar una evaluación continua del alcance de los resultados de aprendizaje y de las competencias previstas en la asignatura o la materia objeto de evaluación. Es un objetivo transformar el proceso de enseñanza-aprendizaje para hacer del alumno su principal protagonista $\mathrm{y}$, en este sentido, es necesario orientar las programaciones y metodologías docentes de las asignaturas centrándolas en el aprendizaje de los estudiantes y no exclusivamente en las horas lectivas. La clave está en incluir en el programa de cada asignatura un conjunto de actividades que aseguren el aprendizaje del alumno e introducir los mecanismos necesarios para motivar al alumno a realizarlas.

Para garantizar la adquisición de la competencia en las titulaciones, se han definido asignaturas punto de control que garanticen que la competencia se trabaja y se evalúa en el aula. Sin embargo el número de asignaturas candidatas a ser punto de control, para esta competencia es inferior al que se puede encontrar para otras competencias transversales, el profesorado encuentra dificultades para incorporarla en sus asignaturas. Es por esto, que la competencia transversal, creatividad, innovación y emprendimiento, se presenta como un reto a la hora de definir actividades que favorezcan su adquisición y transferencia a distintas asignaturas y puedan ser utilizadas en diversos contextos.

(c) EY-NC-ND 2017, Universitat Politècnica de València 


\section{Objetivos}

El objetivo del trabajo es presentar el diseño y desarrollo de la actividad SCAMPER-3-5 para la adquisición de la competencia transversal creatividad, innovación y emprendimiento.

Se puede entender esta competencia como un proceso que parte de la búsqueda de oportunidades, pasando por la generación de ideas, para finalmente, llevar a cabo su implementación a través de un plan de acción y su análisis de valor (Figura 1).

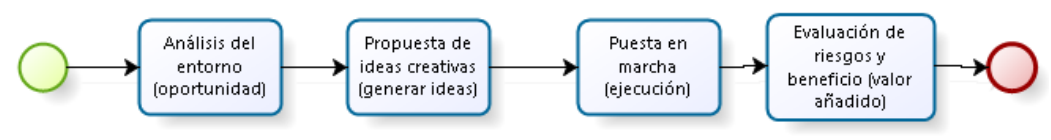

Figura 1 Proceso asociado a la competencia transversal creatividad, innovación y emprendimiento

La actividad desarrollada aborda todas las fases del proceso.

\section{Desarrollo de la Innovación}

En primer lugar se revisaron y aplicaron las técnicas básicas para generación de ideas que se tomaron como base para el diseño de la innovación y posteriormente se desarrolló la innovación propuesta.

\subsection{Técnicas básicas: Scamper y 6-3-5}

\subsubsection{Técnica SCAMPER}

Scamper es una técnica de creatividad o de desarrollo de ideas creativas elaborada por Bob Eberle a mediados del siglo 20 (Eberle 2008). Esta técnica permite la generación de nuevas ideas al realizar acciones sobre una idea base. Parte de la base de que un producto, servicio, o proceso existentes, tanto si son propios como si son de la competencia, se pueden mejorar, si aplico una serie de verbos y preguntas relacionadas y persigo las respuestas para ver donde le llevan.

Básicamente es una lista de chequeo que corresponde a las letras de la técnica y puede incluir las siguientes preguntas:

- S: Sustituir. ¿Quién más puede ser sustituido?¿Qué más puede ser sustituido? ¿Podemos cambiar las reglas?¿Otros ingredientes?¿Otros materiales?

- C: Combinar. ¿Qué ideas se pueden combinar?¿Podemos combinar propósitos, intenciones?¿Qué tal una colección?¿Qué tal una mezcla, una aleación, una agrupación?¿Combinar unidades?

- A: Adaptar. ¿Qué más es como esto?¿Qué otra idea te sugiere esto?¿El pasado nos ofrece algún paralelismo?¿Qué podríamos copiar?¿Qué idea podríamos incorporar?

- M: Magnificar. ¿Qué podemos magnificar, ampliar, o extender?¿Qué podemos exagerar?¿Qué podemos sobredimensionar?¿Qué podemos añadir?¿Más tiempo? 
¿Más fuerte? Modificar ¿Cómo lo podemos alterar para mejorarlo? ¿Se puede modificar?¿Hay alguna peculiaridad?¿Cambiar el significado, el color, el movimiento, el sonido, el olor, la forma, la medida? ¿Cambiarle el nombre?

- P: Poner en otros usos. ¿Para qué más se podría usar? ¿Hay nuevas maneras de usarlo tal y como es, tal y como está? ¿Otros usos si lo modificamos?

- E: Eliminar. ¿Qué pasaría sí fuese más pequeño?¿Qué habría que omitir?¿Lo tendría que dividir? ¿Trocearlo? ¿Separarlo en diferentes partes? ¿Reducir? ¿Hacer más eficiente? ¿Hacerlo en miniatura?

- R: Reorganizar. ¿Qué otras organizaciones podrían ser mejores? ¿Intercambiar componentes?¿Un modelo diferente?¿Una distribución diferente?¿Otra secuencia?

Se basa en la idea de que mucho de lo que es nuevo, en realidad es una modificación de lo que ya existe

\section{Limitaciones}

Al aplicar la técnica en grupo, en ocasiones las ideas no surgen con facilidad. Al tener delante la hoja con las 7 letras, el alumno no sabe por cual debe empezar, cambia de opinión a mitad de desarrollo y le resulta difícil saber en qué letra encaja su idea. Por otra parte no existe tiempo limitado por lo que se debe dimensionar la actividad en el aula y marcar los tiempos a criterio del profesor.

\subsubsection{Técnica 6-3-5}

La técnica 6-3-5 es una forma específica de brainwriting (Rohrbach, 1969). Trata de resolverlos problemas típicos en el brainstorming, como son las barreras a la creatividad. 63-5 se refiere a seis personas que desarrollan y anotan tres ideas dentro de un marco de tiempo definido de cinco minutos antes de pasar sus ideas para el compañero. En el siguiente paso cada miembro del equipo tiene que evolucionar ideas, basadas en las dadas a través de su predecesor. Esto puede ocurrir mediante la modificación de las ideas existentes o nuevas ideas inspiradas en los otros datos. Este procedimiento se continúa hasta que cada miembro del equipo recibe su hoja inicial de ideas, lo cual deberá hacerse después de cinco rondas considerando seis participantes. Este paso es desarrollado por grupos a lo largo de 30 minutos. La actividad está específicamente orientada a mejorar la creatividad y la generación de ideas.

\section{Limitaciones}

Cada alumno debe generar un número de ideas relacionadas con el tema indicado. Aunque la técnica es de muy fácil aplicación y delimitada en el tiempo, lo que favorece el desarrollo en el aula, en ocasiones genera frustraciones entre los alumnos. La generación de nuevas ideas puede verse favorecida al leer las ideas de los compañeros, y la retroalimentación que se produce. Sin embargo, la libertad en la generación de ideas, y el límite de tiempo, lleva a no concretar qué se pretende hacer, y a no saber cuál es el objetivo de la idea propuesta, o cómo se llevará a cabo. Por otra parte, si una de las ideas propuestas no está bien planteada y el resto se basa en ella, provoca un efecto en cadena negativo, que obligará a descartar muchas de las ideas que se hayan generado.

(cc) EY-NC-ND 2017, Universitat Politècnica de València 


\subsubsection{Técnica 6-3-5 extendida}

La técnica 6-3-5 extendida es una variación de la anterior, que ha sido propuesta por los autores (Cuenca, Alarcón, Alemany, et al. 2016), considerando que para la competencia de creatividad, innovación y emprendimiento, no solo se necesita generar ideas, sino que éstas aporten valor y sean llevadas a cabo con una actitud emprendedora.

A las etapas de generación de ideas se añaden las fases de Selección (individual y en grupo), Plan de Acción, Análisis de Valor y Debate (Boza et al., 2016). En esta actividad no solo se ha prestado atención a la generación de ideas, sino también al planteamiento propuesto para su puesta en marcha y su análisis de valor. Completando así la competencia transversal CT-4 creatividad, innovación y emprendimiento.

Las limitaciones para la fase de generación de ideas son similares a las que se producen en la técnica básica 6-3-5 para las primeras fases.

\subsection{PropuestaSCAMPER-3-5}

La técnica propuesta se basa en la combinación de las técnicas SCAMPER y 6-3-5 extendida, para por una parte, eliminar las limitaciones encontradas y por otra, diseñar una actividad que alcance todo el proceso asociado a la competencia de creatividad, innovación y emprendimiento.

\section{Fase 1. Identificación de la oportunidad y generación de Ideas}

Al principio de la actividad, cada alumno del grupo dispone de una hoja que se corresponde con cada una de las letras que componen el acrónimo SCAMPER y una tabla con 3 columnas (ideas) y 7 filas (miembros del grupo). Por ejemplo, la primera persona tendrá una hoja con la letra "S" que indica que tiene que colocar en la primera fila de la tabla correspondiente a su hoja, tres ideas encaminadas a "Sustituir" alguno de los elementos de un producto/servicio/elemento/sistema (Figura 2). La segunda persona una hoja con la letra "C" de "combinar" y la misma tabla ya sí con las 7 letras de SCAMPER para las 7 personas del grupo

\begin{tabular}{|c|c|c|c|}
\hline & & JMERO: & \\
\hline & 5 para $\mathrm{Di}$ & roductive & Simulación \\
\hline & & IIUIR & \\
\hline $\begin{array}{l}\text { COMPONENEE } \\
\text { GUVPOO }\end{array}$ & $\begin{array}{c}\text { IDEA } 1 \\
\text { S-SUSTITIIR }\end{array}$ & $\begin{array}{l}\text { IDEA2 } \\
\text { S-SUSTITIR }\end{array}$ & $\begin{array}{l}\text { IDEA } 3 \\
\text { S-SUSTITIR }\end{array}$ \\
\hline 1 & & & \\
\hline 2 & & & \\
\hline & & & \\
\hline & & & \\
\hline 4. & & & \\
\hline 5. & & & \\
\hline 6 & & & \\
\hline & & & \\
\hline & & & \\
\hline
\end{tabular}

Figura 2 Ejemplo plantilla actividad SCAMPER-3-5 
Los alumnos disponen de 5 minutos para rellenar las 3 casillas correspondientes a las 3 ideas de la letra SCAMPER que corresponda a su hoja. Finalizados los 5 minutos, los alumnos se intercambiarán las hojas en el sentido de las agujas del reloj y tendrán de nuevo otros 5 minutos para aportar 3 ideas pero ahora para la letra de SCAMPER que aparezca en la nueva hoja. Tras 7 iteraciones (35minutos) todos los alumnos del grupo deben haber rellenado una fila de cada una de las 7 hojas con 3 ideas.

\section{Fase 2. Selección de ideas individual}

Selección de ideas individual para cada una de las letras SCAMPER (5- 10min). En esta fase, cada uno de los alumnos se queda con la última hoja que ha rellenado que se corresponderá con una letra de SCAMPER y en la que se habrán generado 21 ideas. Como existen 7 hojas, un por cada letra de la palabra SCAMPER, en total se habrán generado $21 * 7$ ideas. Cada alumno tendrá que escoger 5 ideas de entre las 21 existentes una hoja para la letra de SCAMPER de que disponga en ese momento según los siguientes criterios:

- Idea más original

- La que implica menor riesgo

- La más urgente

- La que aporta más benefício

- La que aporta más valor

El análisis de riesgo, urgencia, beneficio y valor, variará en función del contexto donde se lleve a cabo la innovación. La originalidad puede medirse en función de su novedad, su capacidad de comunicar el objetivo perseguido y lo atractivo de la propuesta.

\section{Fase 3. Selección de ideas grupal.}

Selección de ideas grupal (10-15min) finalizado el proceso anterior, se ponen en común las 5 ideas seleccionadas por cada participante. De nuevo se seleccionan 5 de acuerdo a los criterios anteriores.

\section{Fase4. Plan de acción}

Por último en base a los criterios definidos en el grupo, se selecciona una de las ideas a implantar (10 minutos) (la más urgente, la que mayor beneficio aporta, ...) o bien se genera una idea integrada. El grupo propone un plan de acción inicial para implantar la idea seleccionada.

\section{Fase5. Análisis de valor}

El grupo define (10 minutos) en base a qué parámetros se espera medir el valor de la/s nueva/s alternativa/s de manera que se pueda justificar su utilidad.

\section{Fase6. Presentación de la actividad por el representante del grupo}

El grupo elige un representante que deberá exponer ante sus compañeros:

- Alternativa seleccionada

- Valor esperado: para el cliente, empresa o sociedad

- Indicadores definidos para medir el valor de la alternativa generada.

(cc)) EY-NC-ND 2017, Universitat Politècnica de València 


\section{Fase7. Coevaluación}

La coevaluación (5min) es la fase final de la actividad, que junto con la evaluación del profesor conforman la puntuación final de la actividad. Es recomendable que la coevaluación se realice por medio de una rúbrica aunque puede hacerse sin ella de manera que los alumnos ordenan de mejor a peor alternativa las ideas planteadas salvo las de su grupo y se le otorga una puntuación predefinida dependiendo de la posición que ocupa sobre el total del número de grupos: la máxima puntuación se le asignará a la idea situada en el primer puesto.

\section{Fase 8. Selección de la mejor idea}

Finalmente, se suma la puntuación obtenida para cada idea por cada uno de los grupos, seleccionando como mejor idea la que obtenga mayor puntuación.

Con esta técnica se da respuesta a las limitaciones encontradas anteriormente, consiguiendo las siguientes ventajas:

- En cada momento cada alumno sabe hacia dónde debe enfocar su solución, y por tanto su esfuerzo, les hace actuar más rápido.

- Se introduce el factor tiempo en la técnica SCAMPER lo que favorece la aplicación en el aula.

- El alumno no se agota o se enroca en generar ideas en la misma dirección (cambiar nivel, cambiar texto, cambiar persona,...), sino que se le ayuda a tener un punto de vista distinto (sustituir, combinar, adaptar....).

- Los alumnos formalizan mejor su idea al ir enfocada a una pregunta concreta.

- Los alumnos completan el proceso asociado a la competencia de creatividad, innovación y emprendimiento. Desde la identificación de una oportunidad para la generación de ideas, hasta la definición del plan de acción y análisis de valor.

\section{Resultados}

\subsection{Aplicación}

\subsubsection{Contexto}

La actividad SCAMPER-3-5 se aplicó en una de las prácticas de aula de la asignatura "Métodos Cuantitativos de Organización Industrial". Se trata de una asignatura anual de tercer curso del Grado de Ingeniero de Organización de la ETSII con aproximadamente 80 alumnos matriculados. En esta asignatura los alumnos desarrollan modelos y aplican técnicas y herramientas matemáticas y de simulación para la resolución de múltiples problemas relacionados con la Ingeniería de Organización. La mayoría de estos problemas tiene como foco principal el proceso de toma de decisiones en el que se debe seleccionar la/s alternativa/s que optimice/n o alcance/n de manera satisfactoria uno o varios objetivos, al tiempo que respetan las restricciones del sistema con objeto de asegurar su implementación. 
La CT04-Innovación, creatividad y emprendimiento tiene una especial relevancia a la hora generar diversas alternativas, evaluarlas e implementar la alternativa seleccionada. Además los modelos diseñados como ayuda a la toma de decisiones requieren no sólo de ciencia (conocimientos previos) sino también de un cierto arte (creatividad).

\subsubsection{Desarrollo}

En la asignatura anual de tercer curso del Grado de Ingeniero de Organización de la ETSII, Métodos Cuantitativos de Organización Industrial, se aplicó la actividad SCAMPER-3-5.

La actividad propuesta pretendía que los alumnos fueran capaces de plantear alternativas de diseño/funcionamiento de un supermercado, cuyo comportamiento pudiera ser evaluado posteriormente a través de la simulación. En la clase previa, se les proyectó un video sobre la metodología SCAMPER para, en la clase en cuestión, explicarles la actividad completa.

\subsection{Resultados de la innovación}

\subsubsection{Evaluación}

Se formaron 7 grupos y una vez finalizada la actividad, un representante del grupo salió a la pizarra a explicar su idea para mejorar un supermercado bajo el lema "el carrito inteligente". Los alumnos puntuaron a cada grupo, de manera que se eligió como mejor idea la de mayor puntuación. La actitud de los alumnos fue muy participativa y algunas de las ideas generadas fueron muy interesantes.

\subsubsection{Evidencias}

Se muestran a continuación algunas de las evidencias recogidas durante el desarrollo de la actividad.

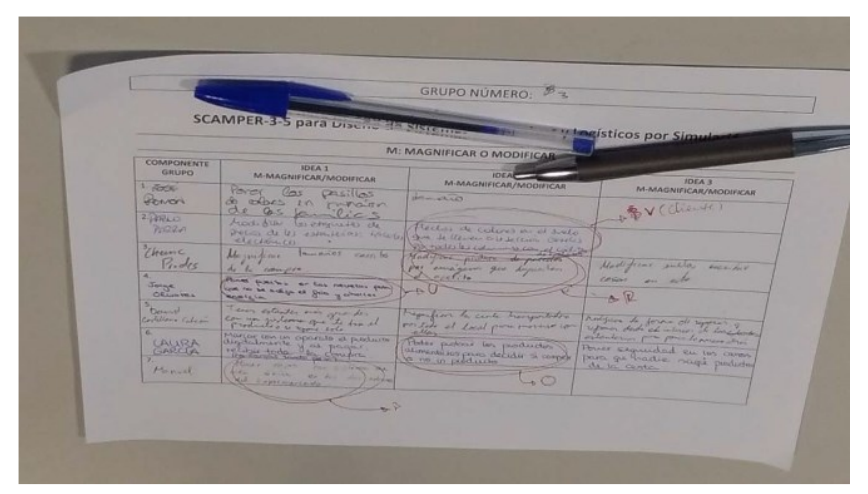

(cc) EY-NC-ND 2017, Universitat Politècnica de València 

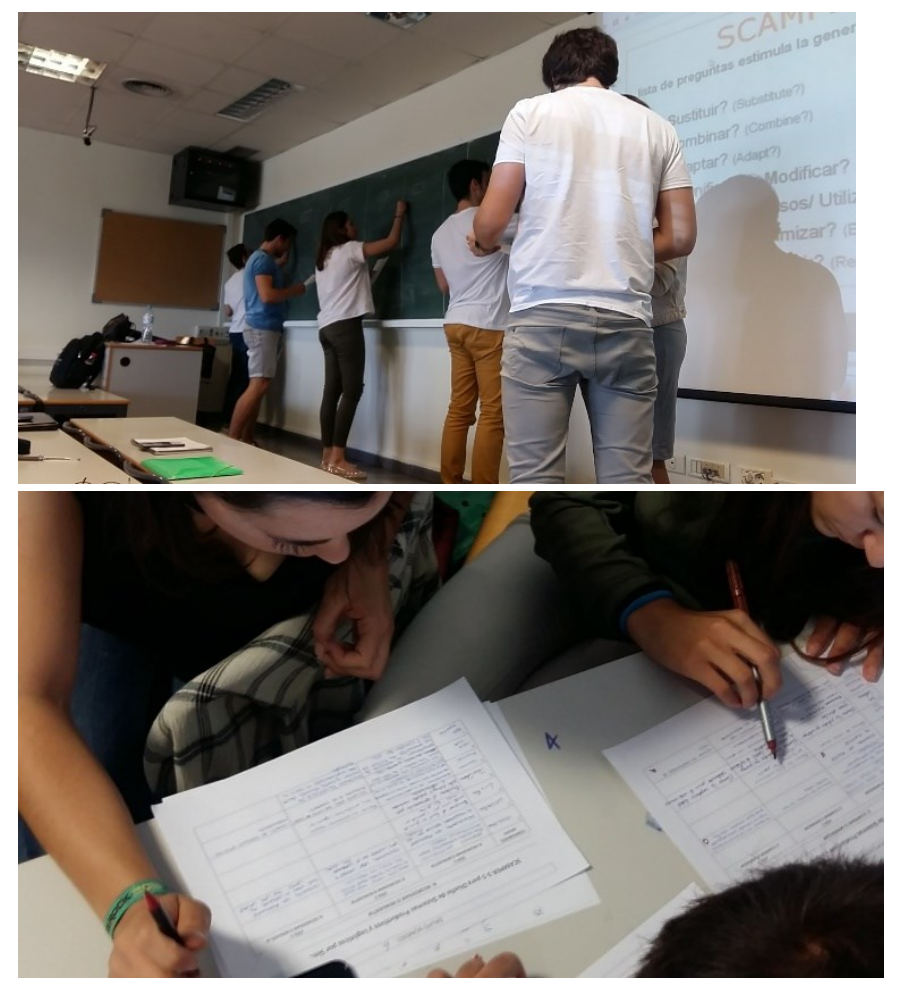

\section{Conclusiones}

La actividad propuesta permite abordar la competencia transversal de creatividad, innovación y emprendimiento de manera completa, pasando por las diferentes fases, identificación de la oportunidad, generación de ideas, plan de acción y análisis de valor. Consigue reducir las limitaciones identificadas en las técnicas básicas que han servido como punto de partida al diseño de la actividad.

La actividad propuesta es fácilmente aplicable y transferible a cualquier asignatura, pudiendo ser utilizada en cualquier contexto. Contribuye por tanto al desarrollo de la competencia transversal en los alumnos. Se ha ampliado el número de actividades que se pueden aplicar en el aula, lo que contribuye también a reducir el temor a esta competencia transversal que algunos profesores habían manifestado, y por tanto podrá aumentar el número de asignaturas punto de control.

La actividad fue valorada muy positivamente, aunque algunos alumnos indicaron la falta de tiempo en algunas fases. Esto puede ser debido a que los alumnos no están familiarizados con este tipo de técnicas.

Recomendamos, que la adquisición de la competencia no se trabaje y evalúe con una sola actividad puntual, sino en varias actividades a lo largo del curso, para ello se puede iniciar con alguna actividad previa y sencilla, sólo con las técnicas básicas, de manera que se vayan familiarizando y poder ser más ágiles en la ejecución de la actividad propuesta. 
Como futura línea de investigación se propone comparar los resultados de la coevaluación con/sin rúbrica, y analizar con más detalle el valor de la actividad propuesta.

\section{Referencias}

Boza, A. \& Cuenca, L., 2014. Strategy of online assessment in case study methodology. A particular case in the subject enterprise computers tools. ICERI2014 Proceedings, pp.32073211.

Boza A., Fernandez-Diego M., Ruiz L., Gordo M.L., Alemany M., Alarcón F., Cuenca L (2016). Transversal Competences as a Medium of Teaching. The case of creativity, innovation and entrepreneurship. 5th International Conference on Strategic Innovative Marketing. September 23-26, 2016 . Athens, Greece

Cuenca, L., Alarcón, F., Alemany, M.M.E., et al., 2016. La técnica 6-3-5 extendida, para la competencia de creatividad, innovación y emprendimiento. https://riunet.upv.es/handle/10251/68332.

Cuenca, L., Alarcón, F., Boza, A., et al., 2016. Rubric to assess the competence of innovation, creativity and enterpreneurship in bachelor degree. Brazilian Journal of Operations \& Production Management, 13(1), pp.118-123.

Eberle, B., 2008. Scamper : creative games and activities for imagination development,

Fernández-Diego, L. et al., 2015. Metadata, repository and methodology in learning objects. EDULEARN15 Proceedings, pp.4755-4761.

Rohrbach, B., (1969) "Kreativ Nach Regeln - Methode 635, Eine Neue Technik Zum Lösen VonProblemen", Absatzwirtschaft, 12, No.19, 1969, pp. 73-75.

Ruiz, L. et al., 2015. Implementación de actividades de aprendizaje y evaluación para el desarrollo de competencias genéricas: un caso práctico de aplicación de técnicas de Pensamiento de Diseño, y evaluación mediante rúbricas, de las competencias de Creatividad, Innovación y E. In Libro de Actas IN-RED 2015 - Congreso Nacional de Innovación Educativa y de Docencia en Red. Editorial Universitat Politècnica de València, pp. 1074-1088.

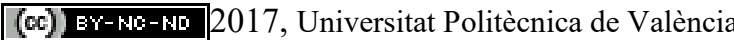
Congreso IN-RED (2017) 


\title{
'Learning-by-doing' - Formando en Competencias para el Emprendimiento. Estudio de Caso: Grado en Liderazgo Emprendedor e Innovación (LEINN)
}

\section{Vicent Gassóa ${ }^{\text {, Aitor Lizarza }}{ }^{\mathrm{b}}$ y Enrique Garcia ${ }^{\mathrm{c}}$}

aFlorida Universitària - Mondragon Team Academy, vgasso@florida-uni.es, bMondragon Unibertsitatea - Mondragon Team Academy, alizarza@mondragon.edu y ${ }^{c}$ Florida Universitària Mondragon Team Academy, egarcia@florida-uni.es.

\begin{abstract}
Entrepreneurship has become one of the main strategic axis for employment creation, competitiveness improvement and societal economic growth. This situation pushes the educational institutions to take on the challenge of developing the key competences for entrepreneurship in the training-learning processes. The objectives of this study are to evaluate the results of the case study methodology and its application - Bachelor Degree in Entrepreneurial Leadership and Innovation of Mondragon Team Academy - and to extract recommendations for the development of methodologies in relation to university training in Entrepreneurship. The results of this study demonstrate that current university training in entrepreneurship has significant results on the development of key competencies for entrepreneurship, level of employability and creation of new companies. Likewise, the use of learningby-doing methodologies facilitates the development of these competences. In this sense, a good praxis is the creation of Junior Companies, where students develop real entrepreneurship projects and manage their own organization; complementing therefore their theoretical skills with practical experience.
\end{abstract}

Keywords: competences, entrepreneurship, leadership, innovation, learningby-doing, team learning, self-management, junior company, international experience, university bachelor degree.

\section{Resumen}

El emprendimiento se ha convertido en uno de los ejes estratégicos principales para la creación de empleo, la mejora de la competitividad y el crecimiento económico de la sociedad. Esta situación empuja a las diferentes instituciones educativas a asumir el reto de desarrollar las competencias para el emprendimiento en el proceso de formación-aprendizaje. Los objetivos de este estudio son evaluar los resultados de la metodología y su aplicación del estudio de caso del Grado en Liderazgo Emprendedor e Innovación de Mondragon Team Academy y extraer recomendaciones para el desarrollo de metodologías en relación a la formación universitaria en emprendimiento. Los resultados de este estudio demuestran que la formación universitaria en emprendimiento actual tiene significantes resultados en el desarrollo de las 
competencias clave para el emprendimiento, nivel de empleabilidad y creación de nuevas empresas. Así mismo, el uso de metodologías "learning-by-doing" facilitan el desarrollo de estas competencias. En este sentido, una buena praxis es la creación de Junior Empresas donde los estudiantes desarrollan proyectos de emprendimiento reales y gestionan su propia organización; complementando así sus habilidades teóricas con la experiencia práctica.

Palabras clave: competencias, emprendimiento, liderazgo, innovación, learning-by-doing, aprendizaje en equipo, autogestión, junior empresa, experiencia internacional, grado universitario.

\section{Introducción}

El emprendimiento se ha convertido en uno de los ejes estratégicos principales para la creación de empleo, la mejora de la competitividad y el crecimiento económico de la sociedad (Comisión Europea, 2012). Esta situación empuja a las diferentes instituciones educativas a asumir el reto de desarrollar las competencias para el emprendimiento en el proceso de formación-aprendizaje. La propia Comisión Europea ha marcado objetivos específicos en torno a la formación en emprendimiento:

- Promocionar el desarrollo de cualidades en los estudiantes tales como la creatividad, la proactividad, y la toma de decisiones, riesgos y responsabilidades.

- Fomentar la capacidad de resolver problemas, incluyendo la capacidad de planificación, comunicación, cooperación y trabajo en red.

- Desarrollar la auto-confianza y la motivación por actuar, aprender a pensar de manera crítica e independiente, y adquirir la voluntad y la capacidad de aprender de forma autónoma.

- Aportar las competencias y conocimientos empresariales necesarios para poner en marcha una nueva empresa.

La educación universitaria tradicional de la rama de empresariales, si bien satisface las competencias necesarias para gestionar empresas existentes, es criticada por no ser adecuada para satisfacer las necesidades de un entorno empresarial altamente cambiante y para el desarrollo de nuevos negocios (Bechard y Toulouse, 1998; Mitra, 2002; Gibb 2002). Según Jones y English (2004), la educación universitaria en emprendimiento "requiere un estilo de educación orientado a la acción que fomente el aprendizaje experimental, la resolución de problemas, la creatividad, el aprendizaje centrado en proyectos y que soporte un método de auto-evaluación". Es importante que estos programas también contemplen fundamentos básicos de las disciplinas de gestión empresarial (Gibb 2002), como por ejemplo economía, marketing y finanzas. Así mismo, según Garavan (1994), la duración de estos programas debería de ser lo suficientemente amplia para permitir una buena adquisición de las

(cc) EY-NC-ND 2017, Universitat Politècnica de València

Congreso IN-RED (2017) 
competencias pertinentes, que exigen no solo la gestión de multi-tareas a nivel empresarial sino también la operativa y relación con clientes y personas de la empresa.

Hasta el momento, pocos estudios han analizado los resultados de las metodologías existentes en formación universitaria en emprendimiento (Brown 2000; Comisión Europea, 2012). La mayoría de estos estudios se centran bien en el contexto de los EEUU, en programas tradicionales de empresariales complementados en emprendimiento, $y / o$ en programas de corta duración ( $\leq 2$ años). Hay una necesidad de estudios adicionales analizando programas universitarios de grado en el contexto europeo en formación integral en emprendimiento, para mejorar el estado del arte de la metodología y contribuir mejor a la creación de empleo y el crecimiento económico a nivel nacional y europeo.

\section{Objetivos}

El principal objetivo de este estudio es analizar, a través de un estudio de caso, los resultados de la metodología utilizada en el contexto europeo en formación universitaria de grado integral en emprendimiento. Para este estudio se han analizado los resultados del Grado en Liderazgo Emprendedor e Innovación de Mondragon Team Academy.

Los objetivos específicos de este estudio son:

1. Evaluar los resultados de la metodología y su aplicación del estudio de caso en las siguientes dimensiones: (a) adquisición de competencias clave, (b) emprendimiento después de la graduación y (c) empleabilidad del individuo.

2. Extraer recomendaciones para el desarrollo de metodologías y toma de decisiones institucionales en relación a la formación universitaria en emprendimiento.

\section{Metodología}

\subsection{Recopilación y análisis de datos}

Los resultados presentados en este estudio se basan en los datos de: (1) encuestas de valoración del grado realizadas a las tres primeras generaciones de egresados del Grado en Liderazgo Emprendedor e Innovación de Mondragon Team Academy después de su graduación (2013-2015); (2) encuestas de los tutores de empresas en los Proyectos Fin de Grado de las tres primeras generaciones de egresados (2013-2015); (3) una sesión de grupo focal con 10 personas de las cuatro generaciones de egresados (2013-2016) para evaluar su perfil competencial y la experiencia en el grado (octubre, 2016); y (4) informe de empleabilidad de Mondragon Unibertsitatea (2016).

Los datos adquiridos se analizaron de acurdo a las siguientes dimensiones: Adquisición de competencias clave, Emprendimiento después de la graduación y Empleabilidad del individuo. La identificación de las competencias clave para el emprendimiento se basaron principalmente en Heinonen y Poikkijoki (2006), Chell y Rosemary (2009) y Comisión Europea (2007). 


\subsection{Descripción del Grado en Liderazgo Emprendedor e Innovación (LEINN)}

El Grado en Liderazgo Emprendedor e Innovación (LEINN) es un grado desarrollado e implantado desde el 2009/2010 por Mondragón Team Academy (MTA) - unidad de emprendimiento de la Facultad de Empresariales de Mondragon Unibertsitatea, País Vasco. Este grado es impartido en diferentes ciudades del mundo - Valencia, Bilbao, Oñati, Irún, Barcelona, Madrid, Querétaro y Shanghái. El Plan de estudios de este grado se estructura en un único ciclo compuesto por cuatro cursos que suman un total de 240 ECTS.

El objetivo general del grado es formar profesionales capacitados para liderar de forma eficiente la creación de empresas y equipos autogestionados destacando su capacidad como agentes de cambio en las empresas existentes y la generación y desarrollo de nuevas empresas, preparados para trabajar en un mundo globalizado y multilingüe, contribuyendo así al desarrollo de la sociedad del conocimiento cuya clave de competitividad sea la innovación.

\subsubsection{Características del grado}

A continuación, se detallan brevemente las características de formación propias de la titulación:

\section{Aprendizaje en equipo con empresas reales}

La metodología utilizada combina el ejercicio de las competencias personales individuales a través del trabajo en equipo. De esta forma se permite la identificación y consecución de resultados mayores a nivel individual al tiempo que se desarrolla la capacidad de aprendizaje y consecución de objetivos comunes en equipo. Es este sentido, se toma como referencia la teoría de "La quinta disciplina" de Senge (1998), la cual considera a las organizaciones como una integración de individuos que, al trabajar y aprender de forma conjunta, son más grandes que la suma de las partes individuales. Los alumnos forman empresas reales (Junior Empresas) de 10-15 personas, como herramientas de aprendizaje fundamental del grado cuyo fin es dotar a los alumnos de un entorno real donde experimentar durante los cuatro años, adquiriendo las competencias prácticas necesarias para la creación y gestión de proyectos empresariales. Parte de la adquisición de las competencias prácticas se realiza en estancias empresariales en el extranjero cada año, con una duración de 1 a 4 meses por curso en países como, por ejemplo, Finlandia, Estados Unidos, India y China.

Estos procesos de aprendizaje práctico son apoyados por formación teórica basada en la lectura de libros y asignaturas básicas, tales como matemáticas financieras, estadística aplicada, contabilidad, derecho de la empresa, economía de la empresa, ética empresarial, ingeniería de producto, informática (programación básica), inglés empresarial y chino conversacional. Los procesos de aprendizaje se llevan a cabo en

Las empresas necesitan profesionales con una visión global, dado que el mundo empresarial se fundamenta cada día más en la interacción entre países a nivel mundial y la actuación en mercados internacionales.

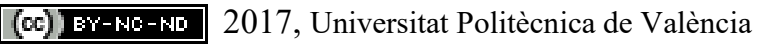




\section{Aprendizaje en espacios de emprendimiento e innovación empresarial}

Los alumnos desarrollan sus principales actividades de aprendizaje en espacios de emprendimiento e innovación empresarial (laboratorios de emprendimiento) con el objetivo de ofrecer un entorno que favorezca la experimentación, creatividad y desarrollo de nuevos conceptos y proyectos emprendedores. Físicamente, los laboratorios de emprendimiento son espacios con una estructura similar a los espacios de co-working (trabajo colaborativo). Funcionalmente, son "ecosistemas de emprendimiento e innovación”, donde a través de la colaboración los diferentes agentes pertenecientes al laboratorio (emprendedores, empresas, estudiantes, etc.), desarrollan colaboraciones, nuevas empresas e ideas de negocios contribuyendo al desarrollo económico y social del entorno.

\section{Alumnos protagonistas en el proceso de aprendizaje teórico-práctico}

La metodología de aprendizaje definida permite que el alumno asuma el papel primordial en el proceso de aprendizaje. De esta forma se evoluciona de un rol pasivo, controlado, teórico y sujeto a una evaluación y calificación puntual semestral a un rol activo, auto responsable, teórico-práctico y sujeto a un proceso de evaluación continuo y calificación semestral. Del mismo modo se asume un cambio en el rol del profesorado cuya función evoluciona de la de ponente magistral a la de un agente facilitador/coach del proceso de aprendizaje del alumno a nivel de equipo e individual. El coach tiene como principios, por ejemplo, fomentar el aprender haciendo, promover la confianza y el diálogo en el equipo, ayudar a convertir los conflictos en oportunidades y las diferencias en fortalezas y ayudar a alinear las energías para la consecución de una visión y objetivos compartidos.

La lectura de libros y la posterior elaboración de un informe/ensayo de cada uno es uno de los pilares del rol del alumno en el proceso de aprendizaje. De esta forma, el nuevo grado contempla que cada alumno deberá leer de media entre 40 y 60 libros a lo largo de la formación. Estos libros son elegidos por el alumno de una lista propuesta por materias y competencias siendo algunos de lectura obligatoria. Los alumnos desde sus empresas, como fruto de un trabajo individual y en equipo previo, llevarán a cabo proyectos con empresas, siendo ellos los protagonistas de todo el proceso y contando con el apoyo y supervisión de los tutores en el desarrollo de los proyectos. La existencia de un proceso de evaluación $360^{\circ}$ que incorpora la valoración de compañeros, coaches, profesores, clientes y proveedores asegura la evolución en el aprendizaje donde el alumno es máximo responsable y protagonista.

\section{Aprendizaje integral por procesos a través de un conocimiento implícito}

Se toma como modelo de referencia la teoría de gestión de conocimiento y aprendizaje organizacional (Nonaka y Tackeuchi, 1995) y su aplicación práctica en el modelo de enseñanza finlandés - Tiimiakatemia. Este modelo de aprendizaje integral por procesos es una evolución de la lógica histórica del aprendizaje por materias estancas y aisladas a un modelo de aprendizaje fundamentado en los procesos que permitan la interconexión entre materias, así como el desarrollo de competencias basado en el proceso del ciclo de vida de la creación de conocimiento "autorreflexión-experimentación-retroalimentación" (Nonaka y Tackeuchi, 1995). El programa del nuevo título dispone de mecanismos específicos 
(proyectos con empresas, evaluación $360 \%$, etc.) y herramientas (contrato de aprendizaje, sesiones de diálogo, etc.) que aseguren el paso del conocimiento explícito a un conocimiento implícito y propio por parte de los alumnos a través de la experiencia (Figura 1).

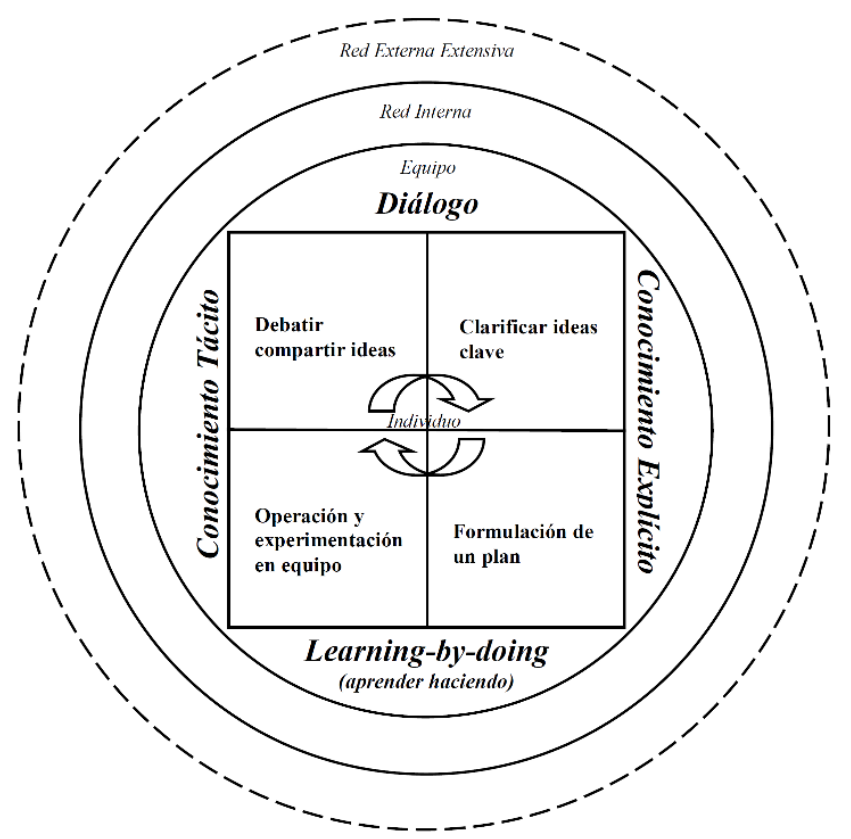

Fig. 1 Modelo de gestión de conocimiento en el Grado en Liderazgo Emprendedor e Innovación (Partanen, 2016 - adaptación de Nonaka y Takeuchi, 1995)

\subsubsection{Competencias del título}

Las competencias adquiridas por los graduados de esta titulación se agrupan en dos categorías:

- Competencias adquiridas a través del desarrollo de proyectos reales: (a) aprender en equipo, (b) liderar en equipo y (c) emprender en equipo (Tabla 1).

- Comprender e interpretar conocimientos acerca de: (a) la empresa y su entorno, (b) conocimientos instrumentales y (c) creación y gestión de empresas (Tabla 2).

Tabla 1. Competencias del grado Liderazgo Emprendedor e Innovación (LEINN) Categoría 1. Competencias adquiridas a través del desarrollo de proyectos reales

Competencias adquiridas a través del desarrollo de proyectos reales

\begin{tabular}{ll}
\hline Aprender en & - Tecnologías de la información y habilidades informáticas \\
equipo & - Técnicas de aprendizaje en equipo \\
& - Métodos personales de aprendizaje y actitudes (modelos mentales) \\
& - Creatividad \\
& - Visión internacional \\
& Habilidades comunicativas \\
\hline
\end{tabular}

(c)) EY-NC-ND 2017, Universitat Politècnica de València 


\begin{tabular}{ll}
\hline & - Auto-orientación \\
\hline Liderar en & - Habilidades de autogestión \\
equipo & - Gestión de proyectos \\
& - Capacidad de liderazgo de equipos \\
& - Habilidades de Coaching \\
& - Habilidades estratégicas \\
& - Toma de decisiones y determinación \\
\hline Emprender en & - Servicio al consumidor y técnicas de negociación y venta \\
equipo & - Comprensión de elementos financieros \\
& - Marketing \\
& - Innovación \\
& - Habilidades teóricas y de modelización de un emprendedor \\
& - Creación de redes o networking \\
&
\end{tabular}

Tabla 2. Competencias del grado Liderazgo Emprendedor e Innovación (LEINN) Categoría 2. Comprender e interpretar conocimientos

\begin{tabular}{|c|c|}
\hline \multicolumn{2}{|c|}{ Comprender e interpretar conocimientos } \\
\hline $\begin{array}{c}\text { La empresa y su } \\
\text { entorno }\end{array}$ & $\begin{array}{l}\text { - Principios de Microeconomía } \\
\text { - Características de la toma de decisiones y las teorías empleadas para } \\
\text { describirlas } \\
\text { - Naturaleza y comportamiento de la empresa } \\
\text { - Principios de Contabilidad } \\
\text { - Principios de Derecho Civil, Mercantil, Fiscal y Laboral } \\
\text { - Principios de ética }\end{array}$ \\
\hline $\begin{array}{l}\text { Conocimientos } \\
\text { Instrumentales }\end{array}$ & $\begin{array}{l}\text { - Principios de Matemática financiera y Estadística aplicada a la empresa } \\
\text { - Principales herramientas informáticas de aplicación en la empresa } \\
\text { - Principales herramientas de gestión de equipos, comunidades y trabajo en red } \\
\text { - Conocimientos de Inglés aplicado a la empresa } \\
\text { - Conocimientos de chino aplicado a la empresa }\end{array}$ \\
\hline $\begin{array}{l}\text { Creación y } \\
\text { gestión de } \\
\text { empresas }\end{array}$ & $\begin{array}{l}\text { - Proceso de creación de empresas, desde la conceptualización de la idea hasta } \\
\text { el desarrollo del plan estratégico de empresa y su puesta en marcha } \\
\text { - Gestión económica-financiera del desarrollo de nuevos negocios } \\
\text { - Gestión técnica de ingeniería de producto para el desarrollo de nuevos } \\
\text { productos y/o servicios } \\
\text { - Técnicas de desarrollo de la creatividad e identificación de oportunidades de } \\
\text { negocio y de innovación } \\
\text { - Técnicas de gestión de la innovación } \\
\text { - Técnicas de gestión de redes sociales y procesos de innovación abierta } \\
\text { - Principales técnicas de cálculo de costes y la consiguiente toma de decisiones } \\
\text { - Definición de la estrategia comercial, marketing y gestión de nuevos clientes } \\
\text { - Principales técnicas de selección de proyectos de inversión, estructura de } \\
\text { financiación, coste de capital, y análisis de riesgo-rentabilidad }\end{array}$ \\
\hline
\end{tabular}




\section{Resultados}

\subsection{Adquisición de competencias clave}

La evaluación que hacen los egresados en el informe de empleabilidad de Mondragon Unibertsitatea con respecto a la contribución de los estudios para el desarrollo de sus competencias profesionales es muy positiva. Asimismo, las empresas en las que han trabajado los estudiantes al realizar el Proyecto Fin de Grado, valoran muy positivamente sus competencias y consideran que su perfil es bueno para el desarrollo de actividades empresariales relacionados con el emprendimiento y la innovación. Además, los egresados consiguen numerosos contratos y colaboraciones posteriores en aquellas empresas donde realizan el Proyecto Fin de Grado.

Los egresados destacan y valoran como 'fuerte' la adquisición de competencias de visión internacional, iniciativa, pensamiento crítico, resolución de problemas, aprender a aprender, la autonomía responsable, y 'aceptable a reforzar' la adquisición de competencias tales como empatía, diversidad, humildad y atracción de inversión. Los alumnos reconocen la metodología de aprendizaje como diferenciadora y que les permite obtener las principales competencias clave de forma satisfactoria.

Otros estudios han demostrado que la formación universitaria en emprendimiento tiene un impacto positivo en las competencias clave (Comisión Europea, 2012). En estos estudios, los egresados formados en emprendimiento, en comparación con los egresados sin esta formación, se identifican más en que la educación superior contribuyó al desarrollo de actitudes relacionadas con la iniciativa, propensión al riesgo y necesidad de alcanzar logros. Sin embargo, los egresados formados en emprendimiento puntúan más bajo en actitudes relacionadas con la habilidad de trabajar de manera estructurada y en la capacidad de perseverar frente a retrocesos y obstáculos. En estos estudios no se han encontrado diferencias significantes con respecto al nivel de autoeficacia. Los egresados en emprendimiento puntúan más alto en competencias relacionadas con creatividad, capacidad analítica, capacidad de adaptación, capacidad de motivar a otros y con habilidades de networking y trabajo en red. Además, se identifican más en que la educación superior les ha dado las habilidades y el conocimiento que les permite manejar un negocio y ha contribuido a su comprensión del papel de los empresarios en la sociedad.

En los estudios revisados (Comisión Europea, 2012), los programas de formación utilizando metodologías learning-by-doing, como la creación de Junior Empresas, puntúan mejor en muchos aspectos relacionados con las competencias clave, en comparación con los programas de formación en emprendimiento sin este tipo de metodologías.

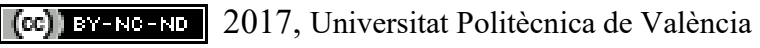




\subsection{Empleabilidad del individuo}

La tasa de empleo de los egresados durante los cursos 2012/13, 2013/14 y 2014/15 muestra unos datos muy positivos sobre la inserción laboral. Específicamente, de los egresados encuestados en cada curso, un $88.9 \%, 88.5 \%$ y 91,7\% están trabajando en la actualidad, respectivamente. Estos datos son especialmente significantes considerando que el desempleo en menores de 25 años con formación superior en España es aproximadamente del 37\% (INE, 2015). La salida laboral del egresado LEINN puede bien enfocarse en el desarrollo de proyectos emprendedores propios o en la incorporación a departamentos de empresas ya consolidadas. La mayoría de los egresados de LEINN están trabajando en aquellas actividades relacionadas con el grado; es decir, en temas de liderazgo, emprendimiento/intraemprendimiento e innovación, incluyendo áreas como marketing, ventas, educación, negocios digitales y diseño.

Otros estudios también han demostrado que la formación universitaria en emprendimiento tiene un efecto positivo en la empleabilidad de los individuos, especialmente en términos de experiencia laboral, creatividad en el puesto de trabajo e ingresos anuales (Comisión Europea, 2012). Según estos estudios, parece ser más fácil para los individuos con formación en emprendimiento encontrar empleo inmediatamente después de su graduación y es menor la posibilidad de estar desempleados en los primeros años después de la graduación. En la muestra de estos otros estudios, entre el 78 y el $66 \%$ de los egresados en formación en emprendimiento indican que han comenzado su primer período de empleo inmediatamente después de su graduación, frente al 59\% de los egresados sin este tipo de formación.

\subsection{Emprendimiento después de la graduación}

Después de cuatro generaciones egresadas con un total de 150 graduados, se han creado un total de 14 empresas cofundadas en equipo por egresados de LEINN (no se incluyen aquellas empresas en las que los egresados se incorporan a equipos emprendedores y existentes). Más de 75 personas están directamente implicadas en el desarrollo de estos proyectos emprendedores por lo que desde la perspectiva de generación de empleo directo es significativo. El ritmo de creación es de 3,5 empresas por año y de una empresa por cada 10 graduados. Los equipos de emprendedores en las empresas creadas están formados por aproximadamente por 5 personas por empresa. La mayoría de las empresas (64\%) tienen una fuerte vocación de crecimiento con modelos de negocio que son escalables, además de ser interesantes para la inversión; con potencial de impacto en la economía y sociedad. Por otro lado, algunos proyectos están más enfocados en el autoempleo y micropymes (36\%). Predominan las empresas de servicios avanzados y las digitales, y varias de ellas incorporan tecnología en sus proyectos.

Otros estudios han demostrado que la formación universitaria en emprendimiento estimula el emprendimiento y el auto-empleo (Comisión Europea, 2012). En la muestra de estos estudios, el 16\% de los egresados con formación universitaria en emprendimiento son autoempleados, con respecto al $10 \%$ de los egresados sin esta formación. Además, los primeros comienzan en su primera empresa antes de la graduación ( 0,7 años de promedio) y los 
segundos comienzan después de la graduación (2,8 años de promedio). Los egresados con formación en emprendimiento también suelen tener ingresos netos anuales mayores que los egresados en otros programas. Así mismo, los egresados en programas en emprendimiento valoraron más su empresa como innovadora, en cuanto a introducir nuevos productos y servicios, o introducir nuevos procesos y formas de organización y prácticas empresariales.

Estos estudios también han demostrado que la formación universitaria en emprendimiento también estimula las intenciones de los estudiantes para convertirse en empresarios (Comisión Europea, 2012). Las principales razones para auto-emplearse expuestas por los estudiantes con formación en emprendimiento son la realización de una oportunidad de negocio y el deseo de independencia personal. Por otro lado, las razones para auto-emplearse expuestas por los estudiantes de otros programas son la falta de oportunidades de empleo atractivas y evitar la incertidumbre relacionada con ser empleado; es decir, más debido a las desventajas de ser empleado que a las ventajas de ser auto-empleado, como ocurre con los estudiantes con formación en emprendimiento. Los alumnos que prefieren ser empleados lo atribuyen a razones de seguridad y estabilidad, como disponer de ingresos regulares y fijos, horarios fijos, protección por la seguridad social y posibles problemas con las autoridades públicas.

\section{Conclusiones}

El uso de metodologías learning-by-doing en programas de formación universitaria en emprendimiento, como en el estudio de caso del grado LEINN, facilitan en los alumnos el desarrollo de las competencias clave para el emprendimiento. Asimismo, el perfil competencial de los formados en este tipo de metodologías presenta un gran potencial en términos de empleabilidad y creación efectiva de nuevas empresas.

La capacitación práctica debe de considerarse como ingrediente clave en estos programas de formación centrados en la adquisición de competencias. En este sentido, una buena práctica es la creación de Junior Empresas donde los estudiantes desarrollan proyectos de emprendimiento reales, se enfrentan a la relación con clientes y lideran y gestionan su propia organización en equipo; complementando así sus habilidades teóricas con la experiencia práctica.

El apoyo al desarrollo de la formación en emprendimiento en instituciones de educación superior debe de considerarse como clave para favorecer la creación de nuevos puestos de trabajo, así como mejorar su calidad e impacto positivo en la sociedad.

\section{Referencias}

BECHARD, J.P. y TOULOUSE, J.M. (1998). "Validation of a didactic model for the analysis of training objectives in entrepreneurship" en Journal of Business Venturing, vol. 13, issue 4, p. 317-332.

BROWN, C. (2000). Entrepreneurial Education Teaching Guide. CELCEE Digest 00-7. Adjunct ERIC Clearinghouse on Entrepreneurship Education, Los Angeles, CA.

(cc) EY-NC-ND 2017, Universitat Politècnica de València

Congreso IN-RED (2017) 
CHELL, E. y ROSEMARY, A. (2009). The identification and measurement of innovative characteristics of young people: development of the Youth Innovation Skills Measurement Tool. London: NESTA. http://socialwelfare.bl.uk/subject-areas/services-client-groups/children-youngpeople/nesta/1516842009_identification_measurement_innovative_characteristics_young.pdf [Consulta: 20 de mayo de 2017].

COMISIÓN EUROPEA (2007). Key competences for lifelong learning, European Reference Framework. Luxemburgo. <https://erasmusplus.org.uk/file/272/download > [Consulta: 20 de mayo de 2017].

COMISIÓN EUROPEA (2012). Effects and impact of entrepreneurship programmes in higher education. Bruselas. [Consulta: 20 de mayo de 2017].

EUROSTAT (2015). Encuesta Europea de Fuerza del Trabajo (LFS) [Consulta: 20 de mayo de 2017].

GARAVAN, T.N. (1994). "Entrepreneurship Education and Training Programmes: A Review and Evaluation" en Journal of European Industrial Training, vol. 18, issue 11, p. 13-21.

GIBB, A.A. (2002) “Creating Conducive Environments for Learning and Entrepreneurship; living with, dealing with, creating and enjoying uncertainty and complexity" en Industry and Higher Education, vol. 16 , issue 3 .

HEINONEN, J. y POIKKIJOKI, S.A. (2006). An entrepreneurial-directed approach to entrepreneurship education: mission impossible? en Journal of Management Development, vol. 25, issue 1.

JONES, C. y ENGLISH, J. (2004) "A contemporary approach to entrepreneurship education", en Education + Training, vol. 46, issue 8/9, p. 416-423.

MITRA, J. (2002). "Consider Velasquez: reflections on the development of entrepreneurship programmes" en Industry and Higher Education Journal, vol. 13, issue 4, p. 317-332.

NONAKA, I., TAKEUCHI, H. (1995). La Organización Creadora de Conocimiento. Oxpford: Oxford University Press.

PARTANEN, J. (2016). The Team Coach's Best Tools. Jyväskylä: Partus.

SENGE, P. (1998). La Quinta Disciplina: Como Impulsar el Aprendizaje en la Organización Inteligente. Hospitalet de Llobregat: Ediciones Granica. 


\title{
Evaluación de Competencias Transversales en un entorno 3.0: Lessons (Sakai)
}

Héctor Moreno-Ramón, Sara Ibáñez-Asensio, Ignacio Guillén Guillamón, Miguel Ferrando Bataller, Salva Calvet Sanz, Marta Cabedo Fabrés, Ana I. Jiménez Belenguer y Alfonso Martínez García.

${ }^{a}$ GRIPAU, Grupo Interdisciplinar para el Aprendizaje Universitario. Universitat Politècnica de València (hecmora@prv.upv.es )

\begin{abstract}
Transversal skills have led to restructuring subjects, methodology and materials in Higher Education. The Universitat Politècnica of Valencia $(U P V)$ has begun to apply and assess these skills in their degrees where the students are the center of the learning process. Faced with these problems, the following study aims to facilitate and test the assessment of tranversal skills in the UPV through an advanced tool (Lessons) that has been developed by Sakai, and it is available to the entire university community within the PoliformaT platform. This tool allows not only the evaluation of skills in a traditional way (student-teacher), but also establishes an environment based on the philosophy of web 3.0 where 3 types of learning interactions are produced (student-teacher, teacher-student and Studentstudent). In addition, it allows to redirect the students according to theis knowledge and allows self-evaluation before the activity development. The experience was carried out on 730 students who belong to 11 subjetcs in different degrees/master/doctorate courses. Outcomes registered in Lessons expressed that more than $80 \%$ of them believe that they should be selfassessed at the beginning. In this sense, more than $70 \%$ of the students express that they have achieved the transversal skill, although this outcomes contrast with the teachers' evaluation, which reduce the level of skill achievement.
\end{abstract}

Keywords: Transversal skill, Lessons, PoliformaT, ICTs. 


\begin{abstract}
Resumen
Las competencias transversales han provocado una reestructuración de materias, metodologías y materiales en la Educación Superior. La Universitat Politècnica de Valencia (UPV) ha comenzado a aplicar y evaluar estas competencias en sus grados, donde los alumnos son el centro del proceso de aprendizaje. Frente a esta situación, el presente estudio tiene como objetivo facilitar y probar la evaluación de competencias transversales en la UPV a través de una herramienta avanzada (Lessons) que ha sido desarrollada por Sakai, y está disponible para toda la comunidad universitaria dentro de la plataforma PoliformaT. Esta herramienta permite no sólo la evaluación de competencias de manera tradicional (estudianteprofesor), sino que también establece un entorno basado en la filosofia de la web 3.0, donde se producen 3 tipos de interacciones de aprendizaje (estudiante-profesor, profesor- estudiante y estudiante-estudiante). Además, permite reorientar a los estudiantes según su conocimiento además de la autoevaluación antes del desarrollo de la actividad. La experiencia se llevó a cabo en 730 estudiantes que pertenecen a 11 asignaturas en diferentes grados / master y doctorado. Los resultados registrados en Lessons reflejaron que más del $80 \%$ de los alumnos vieron idóneamente el uso de Lessons para la autoevaluación inicial. En este sentido, más del 70\% de los estudiantes creian tener adquirida la competencia transversal, aunque estos resultados contrastaron con la evaluación de los profesores, que indicaron que no todos los alumnos tenían un nivel de adquisición de la competencia tan elevado como ellos creían.
\end{abstract}

Palabras clave: Competencias transversales, Lessons, PoliformaT, TIC.

\title{
Introducción
}

En los últimos años, el sistema de enseñanza universitario ha derivado hacia un modelo basado y centrado en el alumno, siendo éste la figura en torno a la cual gira la planificación de las asignaturas. El estudiante pasa de ser un "objeto inmóvil" a ser el motor propio del mismo proceso educativo. Así pues, el alumno aprende cuando construye nuevos conocimientos o perfecciona los que ha adquirido, reordenándolos, reflexionando, razonando y obteniendo sus propias conclusiones (Bain, 2007). De este modo se reemplaza la metodología tradicional por un sistema combinado de enseñanza-aprendizaje en el que el alumno se siente motivado y partícipe de sus avances (Lucena, 2015).

Este cambio de roles hizo replantearse de arriba abajo la Educación Superior y de acuerdo con Fernández (2006) supuso un gran cambio cultural para la Universidad como institución educativa. Preguntas como: ¿Cómo estamos enseñando?, ¿Qué pide la sociedad de nuestro

(c)) BY-NC-ND 2017, Universitat Politècnica de València

Congreso IN-RED (2017) 
sistema educativo? ¿Satisfacemos sus necesidades? ¿Qué podemos ofrecer de forma única y diferenciada?, etc., fueron la clave para una vorágine de cambios que alumnado y profesorado comienzan a asimilar claramente en la actualidad.

En este nuevo contexto, se descubrió que el mundo laboral no requería tanto "conocimiento", sino más bien precisaba de una serie de habilidades y destrezas que carecían los egresados y que les impedía el buen desempeño de las labores en su puesto de trabajo. De ahí nace la educación basada en competencias, cuya finalidad es dar respuesta a las exigencias de la sociedad y ofrecer una educación de calidad no solamente basada en la enseñanza (Córdova et al., 2015; Munuera y Navarro, 2015).

La Universitat Politècnica de València no se ha mantenido ajena a este proceso y ha hecho suya la filosofía docente derivada de estos nuevos paradigmas. Dentro del plan estratégico UPV2020, la Universidad ha lanzado un proyecto de competencias transversales que "pretende acreditar las competencias transversales UPV a los estudiantes egresados en cualquiera de los títulos oficiales impartidos en la Universitat Politècnica de València" (UPV, 2014). Conscientes que las competencias específicas se trabajan, son adquiridas por los estudiantes y certificadas mediante la superación de las diferentes materias de los planes de estudio, no ocurría lo mismo con las competencias transversales incluidas en los planes de estudio. Éstas no se trabajaban sistemáticamente y no se evaluaban. Esto implicaba que no se garantizaba su adquisición al lanzar al mundo laboral a los egresados en la UPV. De este modo, si la Universidad planteaba unos cánones de calidad y en cambio no se podía acreditar dichas competencias, existía un claro desajuste asociado al proceso de enseñanzaaprendizaje. Con el plan UPV2020, junto al trabajo colaborativo entre el Instituto de Ciencias de la Educación (ICE) y el profesorado de la Universidad, dicha falta de control se está subsanando. La creación de grupos de trabajo que han desarrollado rúbricas para la evaluación de competencias o la reflexión profunda sobre la aplicación de éstas en el quehacer diario de alumnos y profesores, ha dado lugar a una mejora sustancial de dicho proceso de enseñanza-aprendizaje.

El Grupo Interdisciplinar para el Aprendizaje Universitario (GRIPAU) es un equipo multidisciplinar formado por profesores que imparten docencia en diferentes escuelas de la UPV y que desde hace años trabaja para desarrollar y evaluar competencias transversales con el objetivo de promover la excelencia del alumnado. Para ello GRIPAU, participa activamente de los grupos de trabajo de las 13 competencias transversales definidas por la UPV en su proyecto institucional.

La tecnología ha modificado los hábitos sociales y culturales, propiciando la aparición de nuevos métodos de enseñanza-aprendizaje que se basan en las tecnologías de la información y comunicación (TIC's). Es una obviedad como subraya Lucena (2015) que las acciones que se desarrollen desde el punto de vista educativo no pueden dejar de lado el nuevo contexto digital y su papel dentro del proceso formativo. Una facilidad que ofrecen las TIC's de cara al docente es el papel de tutelaje que el profesor puede ejercer sobre el proceso de aprendizaje, puesto que el alumno, dispone de herramientas para su propia 
preparación. Con ellas, el profesor es un gestor de contenidos, siendo las TIC's un elemento dinamizador para el desarrollo de las diferentes competencias (Mezarina et al., 2014). La motivación intrínseca del alumno (conocedor de este tipo de herramientas) y su facilidad de uso (puesto que están inmersos en la sociedad de la tecnología) favorece que el estudiante se mantenga activo y motivado durante el proceso de aprendizaje, ya que es el mismo individuo el que elige qué y cómo aprender (Anderson, 2016). Además, el profesor va cediendo terreno a favor del alumno que va logrando más autonomía e independencia en su aprendizaje, siendo en última instancia consciente de lo adquirido en el proceso (Fernández, 2006; Munuera y Navarro, 2015). Por tanto, la finalidad es ayudar al alumno a desarrollarse, propiciando el crecimiento de habilidades, destrezas y conocimientos con el objetivo final de mejorar en el desarrollo integral del alumno en consonancia con el entorno.

Actualmente, algunos docentes han desarrollado pequeñas experiencias en las que han combinado TIC's y el trabajo y evaluación de competencias transversales (Echazarreta et al., 2009; Córdova et al., 2015; Munuera y Navarro, 2015). Por ejemplo, Lucena (2016) establece que mediante su combinación, se ha logrado una participación mayor, más eficaz, fluida y efectiva por parte del alumnado. Para todos, la evaluación de competencias constituye una actividad relevante en el proceso educativo, siendo este proceso facilitado por el uso de TIC's ya que en este caso, cabe la posibilidad de que el alumno pueda constatar que efectivamente adquiere las competencias transversales comparándose con un estado inicial que es capaz de medirse mediante el uso de TIC's.

Con todo ello, y dentro del entorno UPV, este estudio propone la combinación del trabajo en competencias transversales y su evaluación mediante una TIC avanzada y que está disponible en la plataforma PoliformaT: Lesson builder.

Lesson builder es una herramienta desarrollada recientemente por Sakai e incorporada muy recientemente por nuestra universidad a la plataforma PoliformaT. Esta permite estructurar los contenidos con el objetivo de guiar a los alumnos a través de actividades y tareas de aprendizaje (Duke University, 2013). Aunque a priori, parezca que Lessons es una herramienta únicamente para planificar, esta tiene una virtud que la hace especialmente buena para la evaluación de competencias: Lessons permite la inclusión de recursos didácticos (videos, apuntes, etc.), pero además permite la interacción entre alumno-profesor y alumno-alumno. Por tanto, Lessons tiene un aliciente más a las tradicionales TIC's, y es que además de permitir la secuenciación de la docencia, permite interactuar en un mismo espacio entre todos los actores del proceso (favoreciendo el enriquecimiento en conocimientos y aprendizaje dispuesto de modo accesible en la herramienta), con la ventaja de que es utilizable de forma inmediata por todos los profesores de la UPV, sin ninguna inversión adicional.

\section{Objetivos}

El objetivo de este estudio es diseñar un modelo estándar, guía metodológica o plantilla de evaluación de competencias con el fin de trabajar y testar las competencias transversales, mediante la herramienta avanzada Lessons (Sakai), que está disponible en PoliformaT.

(c)) BY-NC-ND 2017, Universitat Politècnica de València

Congreso IN-RED (2017) 
Los objetivos secundarios de este estudio son:

- Definir, generar y evaluar un modelo estándar o una guía metodológica para trabajar y evaluar competencias mediante la herramienta Lessons con la finalidad de extrapolarlo a cualquier asignatura impartida en la Universidad.

- Testar la utilidad de dicho modelo en diversas escuelas y tamaño de grupos de aula para las competencias transversales

- Fomentar la participación activa y la motivación del estudiante al intentar aumentar la percepción propia en el proceso de adquisición de competencias.

\section{Desarrollo de la Innovación}

El presente trabajo se ha desarrollado en 10 asignaturas que comprenden unos 730 alumnos matriculados. Estas asignaturas pertenecen a diferentes escuelas o facultades y se imparten en diferentes titulaciones oficiales de la UPV (tabla 1).

Tabla 1: Asignaturas y titulaciones incluidas en el estudio.

\begin{tabular}{|c|c|c|c|c|c|c|c|}
\hline \multirow{2}{*}{ Titulación } & \multirow{2}{*}{$\begin{array}{l}\mathrm{N}^{\mathbf{0}} \\
\text { asignaturas }\end{array}$} & \multicolumn{4}{|c|}{ Curso } & \multirow{2}{*}{ Master } & \multirow{2}{*}{ Doctorado } \\
\hline & & 1 & 2 & 3 & 4 & & \\
\hline $\begin{array}{l}\text { Grado de Ing. Forestal y del Medio } \\
\text { Natural }\end{array}$ & 1 & $\mathrm{X}$ & & & & & \\
\hline $\begin{array}{l}\text { Grado de Ing. Agroalimentaria y del } \\
\text { Medio Rural }\end{array}$ & 3 & $\mathrm{X}$ & & $\mathrm{X}$ & $\mathrm{X}$ & & \\
\hline $\begin{array}{l}\text { Grado en Ciencia y Tecnología de los } \\
\text { Alimentos }\end{array}$ & 1 & & & $\mathrm{X}$ & & & \\
\hline $\begin{array}{l}\text { Grado de Ing. de Sistemas de } \\
\text { Telecomunicación, Sonido e Imagen }\end{array}$ & 2 & & & $\mathrm{XX}$ & & & \\
\hline $\begin{array}{l}\text { Master Universitario en Ingeniería de } \\
\text { Telecomunicación }\end{array}$ & 2 & & & & & $\mathrm{X}$ & \\
\hline Master Universitario en Edificación & 1 & & & & & $\mathrm{X}$ & \\
\hline Escuela de Doctorado & 1 & & & & & & $\mathrm{X}$ \\
\hline
\end{tabular}

Los 8 profesores que componen GRIPAU, establecieron para cada una de las asignaturas las competencias transversales a trabajar mediante Lessons. De este modo las asignaturas y su breve descripción se adjuntan en la tabla 2.

Tabla 2: Asignaturas y competencias trabajadas

\begin{tabular}{|c|c|c|}
\hline Asignatura & Descripción & $\begin{array}{c}\text { Competencia } \\
\text { transversal }\end{array}$ \\
\hline $\begin{array}{l}\text { Geología, Edafología y } \\
\text { Climatología } \\
\text { (En dos grados) }\end{array}$ & $\begin{array}{l}\text { Asignatura de ler curso de los grados de } \\
\text { Ing. Agronómica y Forestal en la que los } \\
\text { alumnos deben de comprender la } \\
\text { génesis, composición y propiedades de } \\
\text { los suelos formados en diferentes }\end{array}$ & СТ.09 \\
\hline
\end{tabular}




\begin{tabular}{|c|c|c|}
\hline & condiciones ambientales. & \\
\hline $\begin{array}{c}\text { Recuperación y } \\
\text { Restauración de Suelos } \\
\text { Degradados }\end{array}$ & $\begin{array}{l}\text { Asignatura de } 40 \text { curso en la que los } \\
\text { alumnos deben identificar los factores } \\
\text { que determinan la degradación del suelo, } \\
\text { poniendo especial atención en los } \\
\text { procesos de erosión hídrica. }\end{array}$ & $\begin{array}{l}\text { CT.09 y } \\
\text { CT.07 }\end{array}$ \\
\hline $\begin{array}{l}\text { Sistemas y Servicios de } \\
\text { Transmisión por Radio }\end{array}$ & $\begin{array}{l}\text { Asignatura del ler curso del Máster de } \\
\text { Ingeniería de Telecomunicación. Está } \\
\text { orientada hacia el diseño de sistemas de } \\
\text { radiocomunicaciones. }\end{array}$ & $\begin{array}{l}\text { CT.06 y } \\
\text { CT.08 }\end{array}$ \\
\hline Carrera Investigadora & $\begin{array}{l}\text { Curso Transversal de Doctorado, que se } \\
\text { imparte utilizando metodología on-line. } \\
\text { Los alumnos planifican su futura carrera } \\
\text { profesional en el ámbito de la } \\
\text { investigación. }\end{array}$ & CT.11 \\
\hline $\begin{array}{l}\text { Acondicionamiento } \\
\text { Acústico }\end{array}$ & $\begin{array}{l}\text { Asignatura de Master, en la que los } \\
\text { alumnos desarrollan un proyecto acústico } \\
\text { de un centro docente. }\end{array}$ & CT.05 \\
\hline $\begin{array}{c}\text { Tecnología de la Producción } \\
\text { Animal }\end{array}$ & $\begin{array}{l}\text { Asignatura de } 3 \text { er curso que pretende } \\
\text { abordar todos los aspectos necesarios } \\
\text { para diseñar alojamientos ganaderos. }\end{array}$ & $\begin{array}{l}\text { CT.05 y } \\
\text { CT.13 }\end{array}$ \\
\hline $\begin{array}{l}\text { Equipos y Subsistemas de } \\
\text { Comunicaciones }\end{array}$ & $\begin{array}{l}\text { Asignatura de master que diseñar } \\
\text { diferentes tipos de antenas y determinar } \\
\text { sus contextos de aplicación, así como } \\
\text { integrar componentes de comunicaciones } \\
\text { en la banda de microondas. }\end{array}$ & CT.03 \\
\hline Sistemas de TV y Video & $\begin{array}{l}\text { Asignatura de grado que pretende } \\
\text { profundizar en la televisión analógica y } \\
\text { digital }\end{array}$ & $\begin{array}{l}\text { CT.03 y } \\
\text { CT.12 }\end{array}$ \\
\hline Comunicaciones ópticas & $\begin{array}{l}\text { Asignatura de } 3 \text { er curso que define los } \\
\text { fundamentos de los sistemas de } \\
\text { comunicaciones ópticas }\end{array}$ & $\begin{array}{l}\text { CT.03 y } \\
\text { CT.12 }\end{array}$ \\
\hline Salud Pública & $\begin{array}{l}\text { Asignatura de } 3 \text { er curso que introduce el } \\
\text { ámbito de la protección y promoción de } \\
\text { la Salud Pública. }\end{array}$ & CT.01 \\
\hline \multicolumn{3}{|c|}{$\begin{array}{l}\text { CT.01. Comprensión e integración; CT.02. Aplicación y pensamiento práctico; CT.03. Análisis y resolución de } \\
\text { problemas; CT.04. Innovación, creatividad y emprendimiento ; CT.05. Diseño y Proyecto; CT.06. Trabajo en } \\
\text { equipo y liderazgo; CT.07. Responsabilidad ética, profesional y medio ambiental; CT.08. Comunicación efectiva; } \\
\text { CT.09. Pensamiento crítico; CT.10 Planificación y gestión del tiempo; CT.11. Aprendizaje permanente; CT.12. } \\
\text { Conocimiento de problemas contemporáneos y CT.13. Instrumentación específica. }\end{array}$} \\
\hline
\end{tabular}

(cc) EY-NC-ND 2017, Universitat Politècnica de València 
Una vez seleccionadas las competencias a trabajar se estableció el guion a desarrollar en la plataforma Lessons para cada actividad. La plantilla base tenía 3 apartados: Introducción, desarrollo de la actividad y Evaluación. En la Introducción se preguntaría a los alumnos sobre si conocían el proyecto institucional de la UPV, así como si conocían la competencia que iban a trabajar (Figura 1). En el caso de contestar negativamente a dicha cuestión eran redirigidos a la página web institucional de competencias transversales de la UPV, o tenían que ver el vídeo de competencias que el ICE había preparado para su mejor comprensión.

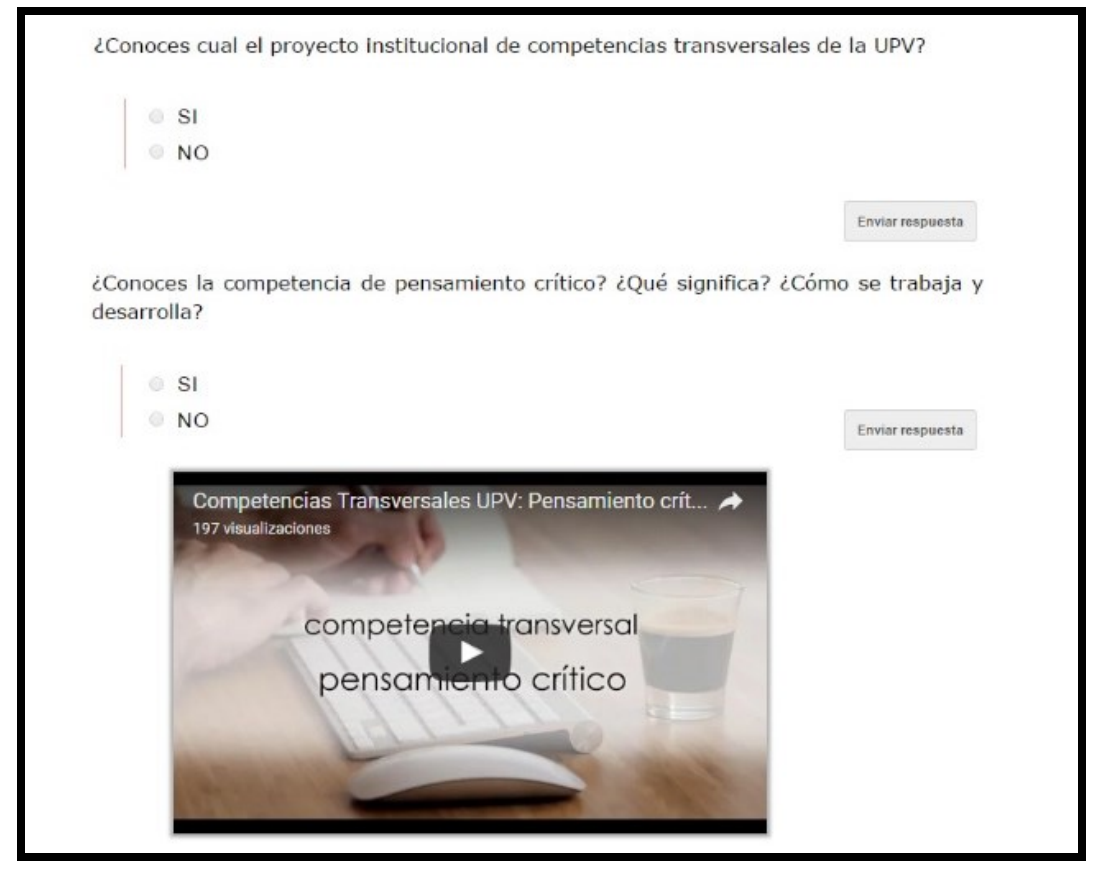

Figura 1: Preguntas iniciales en la plantilla de evaluación de competencias transversales (Lessons)

Una vez completados estos apartados, se contextualizaba al alumno con un link a la guía docente, exponiéndole que se le iba a exigir y el nivel de dominio en el que íbamos a trabajar la competencia. Posteriormente, se introdujo una encuesta sobre el estado inicial de la adquisición de la competencia en base a los ítems del nivel de dominio trabajado. Con estas cuestiones se pretendía que el alumno se autoevaluara, para posteriormente con el resultado adquirido al realizar la actividad, pudiera producirse un feedback entre profesor y alumno.

Una vez completadas las preguntas de nivel de domino, se procedía a cambiar de sección. En este caso se completó la sección Desarrollo de la actividad, en la que se describía la actividad a realizar por parte del alumno. Antes de su realización, se subió la rúbrica a emplear por el profesorado en la corrección de la actividad para que el alumno supiera cuales eran los criterios de corrección. Tras ver la rúbrica, el alumno tenía que realizar la actividad que cada profesor estableció de acuerdo a los contenidos propios de la asignatura. Las actividades propuestas se establecen en la tabla 3. 
Tabla 3: Actividades desarrolladas

\begin{tabular}{|c|c|}
\hline Asignatura & Actividad \\
\hline $\begin{array}{l}\text { Geología, Edafología y } \\
\text { Climatología }\end{array}$ & $\begin{array}{l}\text { Situación real planteada en clase donde el alumno tenía } \\
\text { que decidir cual de las dos opciones planteadas por dos } \\
\text { alumnos diferentes era la correcta. }\end{array}$ \\
\hline $\begin{array}{c}\text { Recuperación y } \\
\text { Restauración de Suelos } \\
\text { Degradados }\end{array}$ & $\begin{array}{l}\text { Caso práctico en el que los alumnos tienen que aplicar la } \\
\text { ética profesional y el pensamiento crítico al valorar los } \\
\text { datos reales de un caso de degradación/erosión. }\end{array}$ \\
\hline $\begin{array}{l}\text { Sistemas y Servicios de } \\
\text { Transmisión por Radio }\end{array}$ & $\begin{array}{l}\text { Trabajo en grupo realizado durante } 11 \text { sesiones, para } \\
\text { diseñar un sistema real. Se concluye con una redacción de } \\
\text { memoria y presentación oral de los resultados finales }\end{array}$ \\
\hline Carrera Investigadora & $\begin{array}{l}\text { Búsqueda de información sobre Carrera Investigadora, } \\
\text { difusión en los foros de la asignatura y debate con los } \\
\text { compañeros. Realización de un trabajo sobre acreditación } \\
\text { como Ayudante Doctor. }\end{array}$ \\
\hline $\begin{array}{l}\text { Acondicionamiento } \\
\text { Acústico }\end{array}$ & $\begin{array}{l}\text { Desarrollo de un proyecto acústico sobre un centro } \\
\text { docente, aplicando la metodología de proyecto de cara a la } \\
\text { resolución de una situación compleja con múltiples } \\
\text { variables y criterios diferentes. }\end{array}$ \\
\hline $\begin{array}{c}\text { Tecnología de la Producción } \\
\text { Animal }\end{array}$ & $\begin{array}{l}\text { Desarrollo de un proyecto de granja avícola y un proyecto } \\
\text { de granja porcina. Los alumnos deberán seleccionar una } \\
\text { ubicación adecuada y diseñar la granja de acuerdo con los } \\
\text { condicionantes de esa localización, respetando los } \\
\text { condicionantes legales, considerando las necesidades de } \\
\text { cada especie y teniendo en cuenta las recomendaciones } \\
\text { generales para facilitar el manejo de la misma. }\end{array}$ \\
\hline $\begin{array}{l}\text { Equipos y Subsistemas de } \\
\text { Comunicaciones }\end{array}$ & $\begin{array}{l}\text { Diseño de un proyecto en el cual el alumno debe analizar y } \\
\text { resolver problemas referentes a la asignatura }\end{array}$ \\
\hline Sistemas de TV y Video & Trabajos y resolución de problemas \\
\hline Comunicaciones ópticas & $\begin{array}{l}\text { Trabajos y resolución de problemas sobre la viabilidad de } \\
\text { un sistema de comunicación óptima }\end{array}$ \\
\hline Salud pública & $\begin{array}{l}\text { Resolución de una situación real planteada que presenta } \\
\text { problemas de solución múltiple. }\end{array}$ \\
\hline
\end{tabular}

Por último, se establece la sección de Evaluación que consistía en la evaluación del profesorado (en algunos casos), o por pares (en otros) de la actividad realizada por los alumnos. La calificación final se obtenía en base a una serie de letras que indicaban el grado de consecución de la competencia trabajada: A (Excelente/ejemplar); B (Bien /adecuado); C (En desarrollo) y D (No alcanzado).

(cc) EY-NC-ND 2017, Universitat Politècnica de València 
De este modo, se establecía un feedback con el alumno que comparaba los resultados de su test de autoevaluación final con el real (alcanzado con el desarrollo de la actividad). Por otro lado, el alumnado también tuvo que contestar a 3 simples preguntas para evaluar Lessons y su idoneidad.

\section{Resultados}

Desde el punto de visto de los profesores, al iniciar el Proyecto, conocían la herramienta Lessons un $33 \%$, por haberla utilizado previamente o haber seguido un curso de formación previo. Esto ha implicado a un aprendizaje interno, en el que el profesorado conocedor de la herramienta ha vehiculado la información hacia los profesores que desconocían dicha herramienta. En este caso, para el resto de los participantes en el Grupo se realizaron dos sesiones de formación, con el apoyo de los profesores que ya conocían la herramienta. Resultó especialmente útil el disponer de una plantilla inicial, la cual ha sido mejorada por el profesorado que ya conocía la herramienta, y por aquel profesorado que ha realizado el curso de Lessons del Instituto de Ciencias de la Educación.

En general la implementación se ha realizado en algunas asignaturas para la totalidad de los contenidos, mientras que en otras solo se ha desarrollado Lessons para trabajar la competencia transversal seleccionada. La valoración por parte de los miembros del grupo de innovación de Lessons es muy favorable, estando prevista la migración de los Contenidos de las herramientas anteriores en un período relativamente breve. En este sentido, aquellos alumnos que tenían todos los contenidos y tareas de la asignatura ya estructurados en Lessons, la aceptación de la herramienta ha sido mucho mejor que aquellos que solo han desarrollado la competencia transversal como veremos a continuación.

También es de destacar que el estudio se ha aplicado de forma satisfactoria en grupos de diferente tamaño y diferentes escuelas y la respuesta ha sido homogénea a todas estas variables. Lessons por tanto facilita el manejo de grupos de pequeño, mediano y gran tamaño, siendo de aplicación multidisciplinar la plantilla creada para el desarrollo de la actividad.

Por lo que respecta a los alumnos, del total que realizaron las actividades de las asignaturas, el $80 \%$ como media considera que tiene un nivel de desarrollo de la competencia transversal bueno o excelente. No obstante, tras realizar la actividad, únicamente un $46 \%$ de los alumnos presentan dicho estatus, siendo únicamente un $23 \%$ los que realmente tienen un nivel de adquisición de las competencias excelente. En este sentido, el alumno comprobó que el nivel competencial que tenía no se correspondía con el real, viéndose en el feedback con los alumnos de forma individual el porqué de dicho desfase.

(c)) EY-NC-ND 2017, Universitat Politècnica de València 
Por lo que respecta al conocimiento de proyecto institucional de la UPV, un $18.6 \%$ dicen no conocer el proyecto de competencias transversales UPV, siendo el $84 \%$ de media aquellos que conocen la competencia que van a trabajar puesto que la están trabajando en otras asignaturas o porque han oído hablar de ellas en otras asignaturas o en las jornadas de acogida (en los alumnos de primer curso). En este sentido, han valorado positivamente la redirección con links de aquellos conceptos o recursos que desconocían. No obstante, un 12 $\%$ asegura que dichos links están bien para tenerlos como recurso pero que le tomaron poca importancia por las tareas restantes de otras asignaturas y el tiempo para la realización.

Por último, destacar que el $81.6 \%$ de los alumnos creen que es necesario la autoevaluación previa a la realización de las actividades pues fomenta el conocimiento propio del estado de adquisición de la competencia una vez el profesor ha evaluado dicha actividad. En este sentido el 56\% de los alumnos cree que Lessons es un buen secuenciador de contenidos. Por el contrario, en alumnos de primero el $55 \%$ de los alumnos cree que podría haberse trabajado la competencia sin la necesidad de utilizar Lessons. No obstante, el 30\% del alumnado cree que Lessons le ha facilitado el trabajo y la adquisición de la competencia. Hay una gran diferencia entre los alumnos de primero (en el primer cuatrimestre) y los alumnos de otros cursos en cuanto al manejo de la plataforma PoliformaT, puesto que no están aún acostumbrados al entorno Lessons/PoliformaT. Además, hay que destacar la diferencia también entre los alumnos que únicamente han desarrollado la actividad de Competencia Transversal por Lessons, frente aquellos que tienen todos los contenidos de la asignatura estructurados en Lessons. En este caso, el nivel de idoneidad/satisfacción de Lessons es mayor.

\section{Conclusiones}

Como conclusión general, este estudio y el trabajo realizado por los 8 profesores que conforman este proyecto ha facilitado la creación de una plantilla efectiva para la evaluación de Competencias Transversales mediante Lessons. Así mismo, se ha testado la utilidad de la plantilla a diferentes niveles: grado, master y doctorado; grupos de tamaño pequeño, mediano y grande, y en diferentes escuelas de la UPV.

Por último, mediante Lessons y su filosofía 3.0 se ha motivado al alumnado en la realización y adquisición de competencias, puesto que de forma rápida y concreta han podido desarrollar las tareas preparadas para tal fin. Además, han participado activamente del proceso de autoevaluación y evaluación de la competencia.

\section{Referencias}

ANDERSON, M. (2016). Learning to Choose, Choosing to Learn: The Key to Student Motivation and Achievement. Association for Supervision \& Curriculum Development.

(c)) BY-NC-ND 2017, Universitat Politècnica de València

Congreso IN-RED (2017) 
BAIN, K. (2007). Lo que hacen los mejores profesores universitarios. Universidad de Valencia Valenca (España)

CÓRDOVA, A, et al. (2015). "Construcción de un instrumento para evaluar competencias profesionales durante la formación preclínica en Medicina". Investigación en Educación Médica 4: $145-154$

DUKE University (2013). Getting started with the Lessons tool. https://support.sakai.duke.edu/2013/05/17/lessons/ 02/03/2017

ECHAZARRETA, C, et al.. (2009). "La competencia «El trabajo colaborativo»: una oportunidad para incorporar las TIC en la didáctica universitaria. Descripción de la experiencia con la plataforma ACME (UdG) ". Revista sobre la sociedad del conocimiento $8: 1-11$.

FERNÁNDEZ, A. (2006). "Metodologías activas para la formación de competencias". Educatio siglo $X X I, 24:$ 35-56.

LUCENA, I (2015). "La aplicación de las TIC y la evaluación por competencias en el Grado de Derecho". International journal of educational research and innovation, 5: 42-54

MEZARINA, C., et al., (2014). "Aplicación de las TIC en educación superior como estrategia innovadora para el desarrollo de competencias digitales". Revista científica de tecnología educativa 1 : 88-101

MUNUERA, P, y NAVARRO, E. (2015). "Innovación en la Evaluación de Competencias Transversales. El instrumento PIAESCE”. Opción 1: 510-528

UPV (2014). Plan Estratégico UPV 2015-2020. Universitat Politècnica de València. 43p. 


\title{
Analisis bibliométrico de la integración de la competencia "ética y responsabilidad profesional" en el ámbito de la docencia de la Dirección de Empresas.
}

\section{Elies Seguí-Mas ${ }^{a}$, Irene Jiménez-Arribas ${ }^{b}$ y Guillermina Tormo-Carbóc}

${ }^{a}$ Universitat Politécnica de València esegui@cegea.upv.es ${ }^{b}$ Universitat Politécnica de València irjiar@ade.upv.es y ${ }^{\mathrm{c}}$ Universitat Politécnica de València gtormo@omp.upv.es.

\begin{abstract}
The global economic, ecological and social crisis leads to education to provide commitment regarding sustainable development and social responsibility. In recent years, business ethics is expanding worldwide, implying an exponential role of education (among other ways, developing generic competences within the curricula). Accordingly, research into this phenomenon has been also rising: contributions have rocketed, including increasingly complex and sophisticated analytical frameworks and empirical studies.

This investigation offers, through bibliometric analysis, a comprehensive picture of empirical research on Business Ethics in Strategic Management Education published in Web of Science journals over the 1995-2017 period.
\end{abstract}

Keywords: Business ethics, education, management, literature review; bibliometric analysis.

\begin{abstract}
Resumen
La crisis económica, ambiental y social que hemos sufrido ha motivado a la educación a proporcionar compromisos respecto al desarrollo sostenible y la responsabilidad social. Así, en los últimos años el interés por la ética empresarial ha crecido en todo el mundo, trasladándose ese interés creciente también al campo de la educación (entre otras vías, en forma de desarrollo de competencias transversales en los estudios). Consiguientemente, la investigación de estas cuestiones ha ido también aumentando, incluyendo cada vez más complejos y marcos analíticos sofisticados y estudios empíricos.
\end{abstract}

Esta investigación tiene como objetivo ofrecer, a través del análisis bibliométrico, un cuadro completo de la investigación empírica sobre ética empresarial en educación en dirección de empresas publicada en las revistas Web of Science durante el período 1995-2017.

Palabras clave: Ética empresarial, educación, gestión, revisión de literatura; análisis bibliométrico 


\section{Introducción}

El proceso de confluencia con el Espacio Europeo de Educación Superior (EEES) ha puesto de manifiesto el rol de las denominadas competencias transversales o genéricas en el dsesempeño aacadémico y profesional de los titulados universitarios. Diversas son las referencias existentes en la literatura acerca de las competencias en la educación superior (Lozano, 2010), destacando el Proyecto Tuning (González y Wagenaar, 2004), muy conocido debido a su incidencia en el proceso de convergencia europea en educación superior.

El Proyecto Tuning define las competencias como "una combinación de atributos que describen el nivel o grado de suficiencia con que una persona es capaz de desempeñarlos" (González y Wagenaar, 2004: 80). Este proyecto hace una diferencia entre las llamadas competencias especificas (propias del área de estudio) y las competencias genéricas o transversales (transferibles y comunes a cualquier titulación). Entre estas últimas, se hace mención explícita al compromiso ético dentro de las competencias interpersonales.

Con motivo de la adaptación de la enseñanza superior al espacio de Bolonia en la universidad española, la ANECA publicó en 2005, entre otros, el Libro Blanco del Grado en Economía y Empresa (ANECA, 2005). En este libro, la ética se presentaba como una materia relevante y necesaria en la adecuación de los estudios para la inserción laboral de acuerdo con la opinión de académicos y profesionales. Así, la ética se identificó como una materia específica en la propuesta de plan de estudios para dichos Grados.

Todo ello ha propiciado una mayor incorporación de contenidos éticos y aspectos morales en los planes de estudios de todas las universidades en general. Así, a modo de ejemplo, en el curso 2010/2011 (momento en el cual empiezan a impartirse los nuevos grados adaptados al EEES), las asignaturas específicas de ética empresarial estaban presentes en el 36\% de los títulos ofertados en Administración y Dirección de Empresas por las universidades españolas, con la particularidad de ser, en la mayoría de los casos, optativas y no obligatorias (Larrán, López y Andrades, 2011).

El enfoque adoptado por este trabajo está basado en el modo en que la ética empresarial (o la responsabilidad social) se aborda en la educación superior de nuestros futuros directivos. En ese sentido, cabe destacar las aportaciones de Nejati y Nejati (2013) y de Yuan y Zuo (2013) quienes evaluaron las percepciones de estudiantes sobre los factores que contribuyen en la educación superior a la sostenibilidad.

Por otra parte, otros autores también analizaron aproximaciones educativas a la sostenibilidad (Buchan et al., 2007). A modo de ejemplo, Velazquez et al. (2005) y Stephens et al., (2008) evaluaron los factores que bloquean la presencia de iniciativas de sostenibilidad en las universidades. En el mismo sentido, Hammond y Churchman (2008) y Lee et al. (2013) examinaron diversos casos en distintas universidades donde existen estrategias de sostenibilidad, principalmente en relación a cuestiones medioambientales. Finalmente, señalar como Larran y Madueño (2015) argumentaron que la promoción de la sostenibilidad en las instituciones de educación superior puede ser conseguida a través de

(c)) BY-NC-ND 2017, Universitat Politècnica de València

Congreso IN-RED (2017) 
difundir el conocimiento del significado y la importancia de la sostenibilidad, de mejorar la gestión medioambiental y de transmitir conocimiento a la sociedad (p. 3).

Este trabajo se estructura en cinco secciones. La primera ofrece una breve introducción a la educación en ética empresarial en la dirección de empresas, y la segunda sección determina el objetivo de esta investigación. La tercera sección presenta la metodología utilizada en este estudio, la cuarta desarrolla los resultados del análisis, y -finalmente- el estudio concluye con una discusión de los resultados, limitaciones e implicaciones para la investigación futura.

\section{Objetivos}

Hasta donde sabemos, no ha habido trabajos académicos centrados en cómo se ha integrado la competencia "ética y responsabilidad profesional" en la docencia universitaria de directivos de empresas. En consecuencia, este trabajo pretende cubrir ese vacío aplicando técnicas bibliométricas a un conjunto representativo de trabajos de investigación. Su objeto es complementar y estructurar los hallazgos conseguidos en los estudios anteriores.

Para ello, se analiza la investigación sobre educación en la confluencia entre ética empresarial y dirección estratégica. Los trabajos analizados han sido publicados en una amplia gama de revistas indexadas en a lo largo de un período de 23 años (1995-2017) y se han utilizado los elementos bibliográficos para analizar / identificar:

1. Los patrones de distribución de la investigación.

2. Los principales autores, instituciones y revistas que directamente (por publicación) e indirectamente (por citación) contribuyen a la literatura en educación en la confluencia de la ética empresarial y la dirección estratégica.

3. Los artículos clave en la literatura internacional

4. Los principales temas utilizados en la literatura científica (y sus relaciones).

Estas preguntas de investigación proporcionarán a los investigadores interesados en el campo diversos beneficios, tales como una mejor comprensión de la relevancia del tema, así como una más clara identificación tanto de las líneas de investigación actuales como de las lagunas a contemplar en trabajos futuros.

\section{Metodología}

\section{El Análisis Bibliométrico.}

El análisis bibliométrico es una técnica de investigación que utiliza análisis cuantitativos y estadísticos para describir los patrones de distribución de artículos de investigación con un tema y un período de tiempo determinados (Diodato y Gellatly, 2013). Su uso se ha generalizado en los últimos tiempos para evaluar y monitorear el desempeño de la investigación (Tijssen, 1992). 
El enfoque metodológico adoptado para cuantificar el flujo de información utiliza técnicas escalares. Estas técnicas se basan en recuentos directos (ocurrencias) de elementos bibliográficos específicos, como artículos (Gupta y Bhattacharya, 2004), y proporcionan las principales características de los resultados de investigación de diversos actores (investigadores individuales, países, campos, etc.) (Verbeek et al., 2002), así como su evolución y tendencias en el tiempo (Gupta y Bhattacharya, 2004). Este enfoque se considera una medida satisfactoria de la producción científica, pero puede considerarse como un indicador parcial de las contribuciones al conocimiento (Martin, 1996).

\section{Fuentes y datos.}

Se ha realizado una búsqueda en la base de datos Web of Science (WoS). En este estudio se ha utilizado SSCI de 1995 a 2017. La búsqueda se inició en 2004 porque fue la primera publicación donde el término ética empresarial en educación aparece en WoS, pero hay una brecha entre 1995 y 2001. La Figura 1 muestra todo el proceso metodológico.

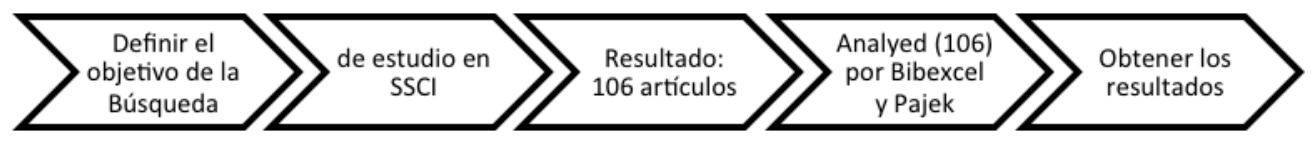

Fig. 1 proceso metodológico

La búsqueda únicamente ha contemplado los artículos de investigación publicados en una revista porque éstos han sido sometidos a un examen crítico y a la aprobación de otros investigadores $\mathrm{y}$, por lo tanto, han pasado un proceso de certificación (a diferència de otros formatos de comunicación científica) (Callon et al., 1993).

El ISI Web of Science (WoS) es probablemente la base de datos más importante para los análisis bibliométricos, lo que constituye la principal la razón para su elección. WoS abarca todas las publicaciones y citas correspondientes de más de 12.000 revistas que constituyen el núcleo de la literatura científica internacional en serie para muchos campos (Garfield, 1979; Moed et al., 1985; Tijssen, 1992; WoS, 2017).

Los criterios de búsqueda incluyen la aparición conjunta de uno de los términos estrategia o estratégico, ética empresarial o RSC o responsabilidad social y educación o aprendizaje y gestión (todo ello para su búsqueda en las categorías 'título', 'resumen' y 'palabras clave').

Se obtuvo un conjunto de datos de 106 artículos para el período 1995-2017. Para analizar este conjunto de datos, este estudio utilizó técnicas de bibliometría mediante el software Bibexcel. Además de mostrar la red, el software Pajek fue utilizado como el análisis de datos y la herramienta de visualización para la investigación.

\section{Resultados}

Esta sección contiene los resultados de los análisis de citas y co-citas de las referencias bibliométricas hechas por los 236 autores en los 106 artículos publicados en el conjunto de datos que cubre el período de estudio 1995-2017.

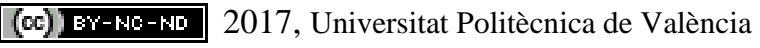

Congreso IN-RED (2017) 


\section{Patrón de distribución de la literatura}

En primer lugar, se analizó la evolución de las publicaciones a lo largo de los años desde 1995 hasta la actualidad.

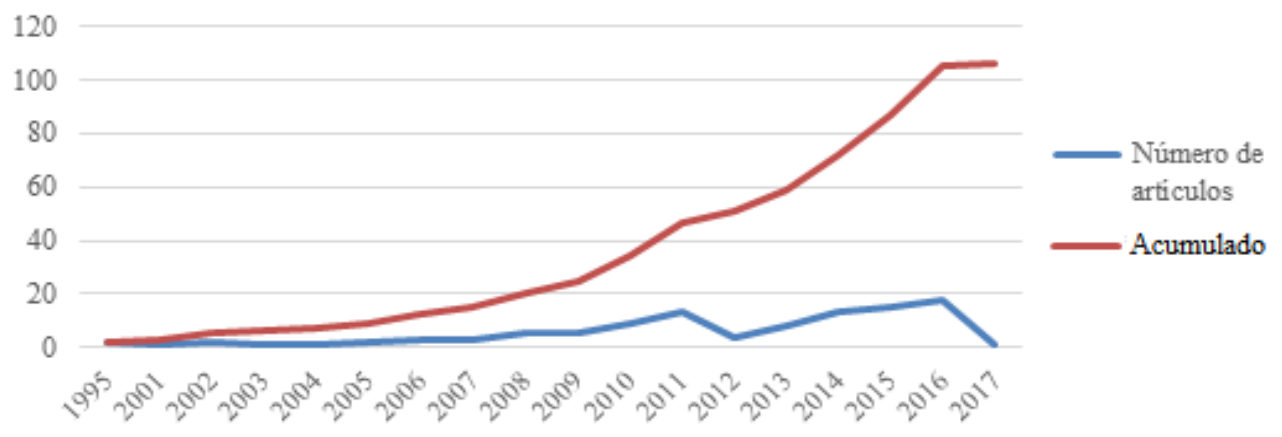

Fig. 2 Evolución de publicaciones

A pesar de contar con un amplio periodo de estudio (23 años), la mayoría de los artículos se publicaron recientemente según la Figura 2. Hay varias razones para justificar el creciente volumen de estudios sobre este tema (Muijen, 2004): es una cuestión de interés para las corporaciones, y también para el debate de política internacional y, especialmente, de educación.

En cuanto a las lenguas de los artículos, se han escrito principalmente en inglés $(\mathrm{n}=100)$, pero también hay trabajos escritos en español $(n=4)$, rumano $(n=1)$ y alemán $(n=1)$.

\section{Autores, instituciones y revistas más productivos}

Doscientos treinta y seis autores diferentes participaron en 106 artículos, de los cuales 97 (92\%) publicaron un solo artículo. La Tabla 1 presenta a los 9 investigadores con dos o más trabajos publicados. El autor más productivo ha sido Dierksmeier $(n=3)$.

Tabla 1. Autores, instituciones y revistas más productivos

\begin{tabular}{cccll}
\hline & $\mathbf{N}^{\mathbf{0}}$ & Autor & \multicolumn{1}{c}{ Institución } & \multicolumn{1}{c}{ País } \\
\hline 1 & 3 & Dierksmeier C & University Tuebingen & Alemania \\
2 & 2 & Millington A & University of Bath & Reino Unido \\
3 & 2 & Bonn I & Griffith University & Australia \\
4 & 2 & Karam CM & American University of Beirut & USA \\
5 & 2 & McShane L & Queen's University & Canadá \\
6 & 2 & Fisher J & University of New England & Australia \\
7 & 2 & Dentoni D & Wageningen University and Research & Países Bajos \\
8 & 2 & Panwar R & The University of British Columbia & Canadá \\
9 & 2 & Cruz LB & HEC Montrea & Canadá
\end{tabular}

(c)) EY-NC-ND 2017, Universitat Politècnica de València 
Ochenta y nueve instituciones diferentes firmaron los 157 documentos encontrados. Las instituciones más productivas fueron la Natl Cheng Kung University $(n=6)$ y la Wageningen University $(n=6)$. Lógicamente, varios de los autores más productivos en este campo pertenecen a estas instituciones principales.

Se puede comprobar cómo los autores que han investigado en el campo se localizan principalmente en economías desarrolladas: Europa y América del Norte. Si se analizaran autores europeos, se encuentra que el grupo más grande de investigadores proviene de España, seguido de Reino Unido y Alemania. Cuando analizamos por continente, Estados Unidos aparece en segundo lugar. El gran número de países que han investigado en este campo refleja el alto prestigio y el impacto de este tema de investigación. Estos resultados se relacionan directamente con los autores más productivos, ya que los países de los autores principales también fueron los principales productores de los artículos que analizaron este tema.

\section{Revistas más productivas}

Las 106 obras aparecieron en 59 revistas diferentes. Las revistas con tres o más de tres trabajos se presentan en la Tabla 2, de las cuales las más productivas son Journal of Business Ethics (Reino Unido, $\mathrm{n}=25$ ), Journal of Cleaner Production (Países Bajos, $\mathrm{n}=$ 6), Management Decision , N = 4), Responsabilidad Social Corporativa y Gestión Ambiental (Reino Unido, $\mathrm{n}=4$ ) y Business and Society (Reino Unido, $\mathrm{n}=3$ ). De todos los artículos publicados, el 40\% (42 de 106) figuraban entre estos top.

Tabla 2. Revistas más productivas.

\begin{tabular}{|c|c|c|c|c|c|}
\hline Revistas & $\mathbf{N}^{\mathbf{o}}$ & $\begin{array}{c}\% / \\
106\end{array}$ & $\underset{2015}{\text { IF }}$ & Cuartil & Alcance \\
\hline $\begin{array}{l}\text { Journal of } \\
\text { Business Ethics }\end{array}$ & 25 & $24 \%$ & 1.83 & Q1 & $\begin{array}{l}\text { Sistemas de producción, consumo, } \\
\text { marketing, publicidad, contabilidad, } \\
\text { relaciones laborales, relaciones } \\
\text { públicas y comportamiento } \\
\text { organizacional desde un punto de vista } \\
\text { moral }\end{array}$ \\
\hline $\begin{array}{l}\text { Journal of } \\
\text { Cleaner } \\
\text { Production }\end{array}$ & 6 & $6 \%$ & 4.95 & Q1 & $\begin{array}{l}\text { Tecnologías, conceptos y políticas } \\
\text { diseñadas para el progreso hacia } \\
\text { sociedades sostenibles }\end{array}$ \\
\hline $\begin{array}{l}\text { Management } \\
\text { Decision }\end{array}$ & 4 & $4 \%$ & 1.13 & Q1-Q2 & $\begin{array}{l}\text { Gestión financiera y de operaciones, } \\
\text { motivación, emprendimiento, solución } \\
\text { de problemas, estrategia y política, y } \\
\text { crisis empresariales. }\end{array}$ \\
\hline $\begin{array}{l}\text { CSR and } \\
\text { Environmental } \\
\text { Management }\end{array}$ & 4 & $4 \%$ & 2.64 & Q1 & $\begin{array}{lll}\text { Responsabilidades } & \text { sociales } & \text { y } \\
\text { ambientales en el } & \text { contexto del } \\
\text { desarrollo sostenible. } & \end{array}$ \\
\hline $\begin{array}{l}\text { Business and } \\
\text { Society }\end{array}$ & 3 & $3 \%$ & 2.13 & Q1 & $\begin{array}{l}\text { Ética empresarial, relaciones entre } \\
\text { empresa y gobierno, gobierno } \\
\text { corporativo, desempeño } \\
\text { corporativo y gestión ambiental. }\end{array}$ \\
\hline
\end{tabular}

(cc) EY-NC-ND 2017, Universitat Politècnica de València

Congreso IN-RED (2017) 
Todas las revistas se situan en el Cuartil 1 de alguna categoría de la WoS, es decir son de alto impacto. Decir también que se trata de revistas bastante amplias en alcance, aunque la mayoría están centradas la ética y la responsabilidad.

\section{Artículos más citados en la literatura internacional}

La Tabla 3 ofrece una clasificación de los artículos más citados dentro de la muestra. El más citado es "Gestión estratégica: Un enfoque de grupos e interés" de Freeman, publicado en 1984 en Strategic Management, que obtuvo 13 citas. Éste es claramente el trabajo más notable en el campo. Destacar también que sólo 8 artículos (7\%) fueron citados más de 10 veces.

Tabla 3. Artículos más citados.

\begin{tabular}{|c|c|c|c|c|c|}
\hline & Titulo & Autores & Año & Citas & $\begin{array}{c}\text { Citas } \\
\text { media/año }\end{array}$ \\
\hline 1 & $\begin{array}{l}\text { Strategic management: A } \\
\text { stakeholder approach }\end{array}$ & Freeman & 1984 & 13 & 0,40 \\
\hline 2 & $\begin{array}{l}\text { Toward a theory of stakeholder } \\
\text { identification and salience: } \\
\text { Defining the principle of who and } \\
\text { what really counts }\end{array}$ & Mitchell et al. & 1997 & 12 & 0,63 \\
\hline 3 & $\begin{array}{l}\text { A three dimensional conceptual } \\
\text { model of corporate performance }\end{array}$ & Carroll & 1979 & 11 & 0,29 \\
\hline 4 & $\begin{array}{l}\text { Corporate social responsibility: } \\
\text { evolution of a definitional construct }\end{array}$ & Carroll & 1999 & 11 & 0,64 \\
\hline 5 & $\begin{array}{l}\text { Bad management theories are } \\
\text { destroying good management } \\
\text { practices }\end{array}$ & Ghoshal & 2005 & 11 & 1 \\
\hline 6 & $\begin{array}{l}\text { Corporate social responsibility: A } \\
\text { theory of the firm perspective } \\
\text { Strategy and society. The link }\end{array}$ & McWilliams & 2001 & 11 & 0,68 \\
\hline 7 & $\begin{array}{l}\text { between competitive advanta- ge } \\
\text { and corporate social responsibility }\end{array}$ & Porter & 2006 & 10 & 1 \\
\hline 8 & $\begin{array}{l}\text { Managing legitimacy: Strategic and } \\
\text { institu- tional approaches }\end{array}$ & Suchman & 1995 & 10 & 0,47 \\
\hline
\end{tabular}

Los artículos clave serían -en términos absolutos- "Strategic management: A stakeholder approach" (Freeman, 1984), y -por su impacto relativo- "Bad management theories are destroying good management practices" (Ghoshal, 2005) y "Strategy and society. The link between competitive advantage and corporate social responsibility" (Porter, 2006).

\section{Principales temas utilizados en la literatura}

Un análisis de palabras clave se puede utilizar en varios campos. Este método examina el contenido de las obras científicas o de otros tipos (Berelson, 1952; Kassarjian, 1977). Se utiliza no sólo para identificar temas y enfoques estadísticos preferentes (Helgeson et al., 1984), sino también identificar tendencias (Roznowski, 2003; Yale y Gilly, 1988). En este estudio se analizaron las co-palabras clave para describir y descubrir las interacciones entre 
diferentes palabras clave en la literatura del campo. Este análisis reduce el espacio de palabras clave a un conjunto de gráficos de red que explican las asociaciones más fuertes entre palabras clave (Coulter et al., 1998). El análisis de Co-Keyword utilizó Bibexcel y analizó la co-ocurrencia de palabras clave en los descriptores o palabras clave en cada artículo. La Figura 4 está representada por Pajek, junto con el algoritmo 2D de Fruchterman-Reingold. La matriz de co-ocurrencia está formada por la frecuencia de coocurrencia de dos palabras clave en las que estas dos palabras clave aparecen juntas en el campo de descriptores o palabra clave de cada artículo. Varias palabras clave están interconectadas en esta figura, donde el volumen de las esferas es un vector, que representa la frecuencia de ocurrencia de palabras clave en la literatura básica. Para obtener este resultado, se utilizó el proceso descrito por (Persson et al., 2009).

Así, la figura ilustra el análisis de las palabras clave y sus interconexiones, y representa un gráfico de red que representa los temas incluidos en la ética empresarial básica de la literatura. Las palabras clave mejor estudiadas, en pesos relativos en el número de trabajos, fueron sostenibilidad $(n=16)$ y gestión estratégica $(n=4)$. La sostenibilidad aparece en el centro del cluster y conecta la mayor parte de las palabras clave, representando así la importancia de estas palabras en el estudio de la ética empresarial en educación. Sin embargo, la red es muy pequeña, por lo que es difícil ver las palabras clave principales. Hay dos patrones diferentes: por un lado, hay un grupo sobre cómo mejorar la ética empresarial en las empresas a través de la educación; Y por otra parte, hay otro grupo sobre el compromiso entre los centros educativos y la ética.

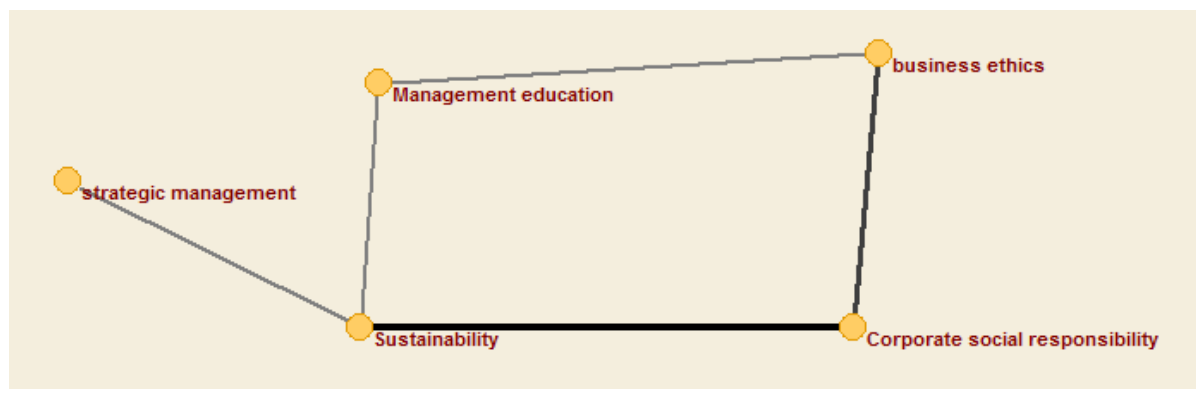

Figura 4. Coocurrencia de palabra clave (minimo de 2)

Las tablas 4 y 5 muestran la frecuencia de palabras clave y su coocurrencia, respectivamente.

Tabla 4. Frecuencia de palabras clave

\begin{tabular}{cl}
\hline No. & \multicolumn{1}{c}{ Keyword } \\
\hline 16 & Sustainability \\
4 & Strategic Management \\
3 & Stakeholder Engagement \\
3 & Stakeholder Theory \\
3 & Organizational Learning
\end{tabular}

(cc) EY-NC-ND 2017, Universitat Politècnica de València

Congreso IN-RED (2017) 
3 Stakeholders

3 Management Education

$3 \quad$ Leadership

Table 5. Coocurrencia de palabras clave

\begin{tabular}{cll}
\hline No. & Keyword & Keyword \\
\hline 2 & Stakeholder Dialogue & Strategic Management \\
2 & Management Education & Sustainability \\
2 & Strategic Management & Sustainability \\
2 & Stakeholder Theory & Sustainability
\end{tabular}

\section{Conclusiones}

El entorno competitivo es global y las instituciones educativas deben comprometerse con el desarrollo sostenible y la responsabilidad social. Es por ello que hay un creciente interés en la ética empresarial en la literatura educativa en dirección de empresas. Las razones para explicar el creciente número de trabajos sobre este campo pueden estar relacionadas con los planes que los docentes, los gobiernos y las compañías privadas han desarrollado para apoyar la ética empresarial (Muijen, 2004). Estos programas han proporcionado una amplia gama de medidas para mejorar el entorno empresarial.

Sin embargo, a pesar del gran número de países que han investigado en este campo, el debate sobre la ética empresarial en la educación en dirección de empresas se ha centrado principalmente en Europa (Dierksmeier y Millington) y en América del Norte (Karam y McShane). Como consecuencia, los autores más relevantes pertenecen a estas áreas.

En general, la ética empresarial en la literatura educativa ha tenido un elevado (y creciente) impacto. Por lo tanto, la mayoría de los artículos recibieron citas, aunque únicamente el $7 \%$ de ellos tenía más de 10 citas.

El gran número de revistas que han publicado artículos denota la vitalidad de la temática y los campos de estudio de las revistas analizadas han mostrado una elevada heterogeneidad entre ellos. Además, la mayor parte de las revistas más activas en el campo son también las revistas muy prestigiosas en las categorías de empresa y de gestión. Así, revistas como Journal of Business Ethics o Journal of Cleaner Production son muy populares en cuanto a la ética empresarial en la educación y cuentan con un alto factor de impacto (todas ellas se encuentran en el cuartil 1 de sus categorías). El gran interés de estas revistas en la ética empresarial en educación indica la alta calidad de los estudios publicados.

En el contexto de la ética empresarial en la educación, hay varios temas comunes en la literatura. Los temas principales relacionados con la ética empresarial en educación son la sostenibilidad y la gestión estratégica. También hay un gran número de artículos sobre la teoría de las partes interesadas, la gestión de la educación y el liderazgo. Esto significa que 
hay dos líneas de investigación principales en la literatura: una sobre cómo mejorar la ética empresarial en las empresas a través de la educación; y otra sobre el compromiso entre los centros educativos y la ética.

Por otro lado, cabe indicar que tan sólo 6 de los 106 artículos de la muestra analizaban competencias por lo que este aspecto cuenta con un amplio potencial de desarrollo. En el caso del estudio de barreras y facilitadores para trabajar la competencia ética en la docencia universitaria ocurre algo similar al caso anterior: únicamente 6 trabajos tratan este tema.

Finalmente, este estudio no está exento de sus limitaciones en la búsqueda, selección y análisis de datos. Una limitación clara es la posible no inclusión de alguno de los artículos clave considerados, o de otras bases de datos no consideradas. Ambas limitaciones no responden a una falta de metodología.

\section{Referencias}

ANECA (2005): "Libro Blanco del Grado en Economía y Empresa". Documento online: http://www.aneca.es/var/media/150292/libroblanco_economia_def.pdf [Consultado 10/07/2014]

BERELSON, B. (1952). "Content analysis in communications research”.

BUCHAN, G. D., SPELLERBERG, I.F., y BLUM, W.E. (2007). Education for sustainability: Developing a postgraduate-level subject with an international perspective. International Journal of Sustainability in Higher Education, 8(1), 4-15.

CALlON, M., COURTIAL, J.P., y PENAN, H. (1993). "La scientométrie” (Vol. 2727). Presses universitaires de France.

CARROLL, A. B. (1979). A three-dimensional conceptual model of corporate performance. Academy of management review, 4(4), 497-505.

CARROLL, A. B. (1999). Corporate social responsibility: Evolution of a definitional construct. Business \& society, 38(3), 268-295.

COULTER, N., MONARCH, I., y KONDA, S. (1998). Software engineering as seen through its research literature: A study in co-word analysis. Journal of the Association for Information Science and Technology, 49(13), 1206-1223.

DIODATO, V.P., \& GELLATLY, P. (2013). “Dictionary of bibliometrics". Routledge.

FREEMAN, R. E. (1983). Strategic management: A stakeholder approach. Advances in strategic management, 1(1), 31-60.

GARFIELD, E. (1979). Is citation analysis a legitimate evaluation tool?. Scientometrics, 1(4), 359-375.

GONZÁLEZ, J., WAGENAAR, R., y BENEITONE, P. (2004). Tuning-América Latina: un proyecto de las universidades. Revista Iberoamericana de Educación, 35(1), 151-164.

(cc) EY-NC-ND 2017, Universitat Politècnica de València

Congreso IN-RED (2017) 
GHOSHAL, S. (2005). Bad management theories are destroying good management practices. Academy of Management learning \& education, 4(1), 75-91.

GUPTA, B.M., y BHATTACHARYA, S. (2004). Bibliometric approach towards mapping the dynamics of science and technology. DESIDOC Journal of Library \& Information Technology, 24(1).

HAMMOND, C., y CHURCHMAN, D. (2008). Sustaining academic life: A case for applying principles of social sustainability to the academic profession. International Journal of Sustainability in Higher Education, 9(3), 235-245.

HELGESON, J.G., KLUGE, E.A., MAGER, J., y TAYLOR, C. (1984). Trends in consumer behavior literature: a content analysis. Journal of Consumer Research, 10(4), 449-454.

KASSARJIAN, H.H. (1977). Content analysis in consumer research. Journal of consumer research, 4(1), 8-18.

LARRÁN JORGE, M., HERRERA MADUEÑO, J., y JAVIER ANDRADES PEÑA, F. (2015). Factors influencing the presence of sustainability initiatives in the strategic planning of Spanish universities. Environmental Education Research, 21(8), 1155-1187.

LARRÁN, M., LÓPEZ, A. y ANDRADES, F.J. (2011): “¿Ha propiciado la reciente reforma de títulos universitarios una mayor incorporación de la responsabilidad social corporativa en los estudios relacionados con la economía y la empresa?”. Accounting Education Conference (ASEPUC), Palma de Mallorca.

LEE, K. H., BARKER, M., y MOUASHER, A. (2013). Is it even espoused? An exploratory study of commitment to sustainability as evidenced in vision, mission, and graduate attribute statements in Australian universities. Journal of Cleaner Production, 48, 20-28.

LOZANO, R. (2010). Diffusion of sustainable development in universities' curricula: an empirical example from Cardiff University. Journal of Cleaner Production, 18(7), 637-644.

MARTIN, B.R. (1996). The use of multiple indicators in the assessment of basic research. Scientometrics, 36(3), 343-362.

MCWILLIAMS, A., \& SIEGEL, D. (2001). Corporate social responsibility: A theory of the firm perspective. Academy of management review, 26(1), 117-127.

MITCHELL, R. K., AGLE, B. R., \& WOOD, D. J. (1997). Toward a theory of stakeholder identification and salience: Defining the principle of who and what really counts. Academy of management review, 22(4), 853-886.

MOED, H., BURGER, W., FRANKFORT, J., \& VAN RAAN, A. (1985). The application of bibliometric indicators: important field-and time-dependent factors to be considered. Scientometrics, 8(3-4), 177-203.

MUIJEN, H. S. (2004). Corporate social responsibility starts at university. Journal of Business Ethics, 53(1), 235-246. 
NEJATI, M., \& NEJATI, M. (2013). Assessment of sustainable university factors from the perspective of university students. Journal of Cleaner Production, 48, 101-107.

PERSSON, O., DANELL, R., \& SCHNEIDER, J. W. (2009). "How to use Bibexcel for various types of bibliometric analysis". Celebrating scholarly communication studies: A Festschrift for Olle Persson at his 60th Birthday, 5, 9-24.

PORTER, M. E., \& KRAMER, M. R. (2007). Strategy and society: The link between competitive advantage and corporate social responsibility. Harvard Business Review, 85(6), 136-137.

ROZNOWSKI, J. L. (2003). A content analysis of mass media stories surrounding the consumer privacy issue 1990-2001. Journal of interactive marketing, 17(2), 52-69.

STEPHENS, J. C., HERNANDEZ, M. E., ROMÁN, M., GRAHAM, A. C., \& SCHOLZ, R. W. (2008). Higher education as a change agent for sustainability in different cultures and contexts. International Journal of Sustainability in Higher Education, 9(3), 317-338.

SUCHMAN, M. C. (1995). Managing legitimacy: Strategic and institutional approaches. Academy of management review, 20(3), 571-610.

TIJSSEN, R.J. (1992). A quantitative assessment of interdisciplinary structures in science and technology: co-classification analysis of energy research. Research Policy, 21(1), 2744.

VELAZQUEZ, L., MUNGUIA, N., y SÁNCHEZ, M. (2005). Deterring sustainability in higher education institutions: An appraisal of the factors which influence sustainability in higher education institutions. International Journal of Sustainability in Higher Education, 6(4), 383-391.

VERBEEK, A., DEBACKERE, K., LUWEL, M., \& ZIMMERMANN, E. (2002). Measuring progress and evolution in science and technology-I: The multiple uses of bibliometric indicators. International Journal of management reviews, 4(2), 179-211.

WEB OF SCIENCE. Web of Science. <https://apps.webofknowledge.com> [Consulta: 30 de marzo de 2017]

YALE, L., \& GILLY, M. C. (1988). Trends in advertising research: A look at the content of marketing-oriented journals from 1976 to 1985. Journal of Advertising, 17(1), 12-22.

YUAN, X., \& ZUO, J. (2013). A critical assessment of the Higher Education For Sustainable Development from students' perspectives-a Chinese study. Journal of Cleaner Production, 48, 108-115. 


\title{
Análisis de la percepción del alumnado ante la metodología de trabajar en grupos tutorizados
}

Eva Serna ${ }^{\mathrm{a}}$, Teresa San Miguel ${ }^{\mathrm{a}}$, Javier Megías ${ }^{\mathrm{a}}$, y María Dolores Mauriciob.

${ }^{a}$ Departamento de Patología, Universitat de València. Eva.serna@uv.es ${ }^{\mathrm{b}}$ Departamento de Fisiología, Universitat de València.m.dolores.mauricio@uv.es

\begin{abstract}
The main objective of this paper is to analyze the opinion and perspective that the students have in view of the methodology of working in tutored groups. This methodology adopted in the teaching-learning process is important for the development of competences. The ability to work in a team and the ability to communicate are very significant transversal competences that have a great impact or potential in student learning. This paper presents an analysis of student assessments collected through anonymous opinions after the elaboration of a tutorial work carried out in a group in the Medicine Degree of the University of Valencia during the years 2015-2016 and 20162017. It is essential to take into account the opinion of the students to adopt measures of teacher improvement, correct or modify the methodology and solve situations arising in the real learning environment. Our conclusion is the students' perspective is very positive and they like the methodology of working in tutored groups.
\end{abstract}

Keywords: Teamwork, turored groups, competences, university teaching

\section{Resumen}

El objetivo de este trabajo es analizar la opinión y perspectiva que tiene el alumnado ante la metodología de trabajar en grupos tutorizados. Esta metodología adoptada en el proceso de enseñanza-aprendizaje es importante para el desarrollo de competencias. La capacidad de trabajo en equipo y la capacidad para comunicarse son competencias transversales muy significativas y que tienen un gran impacto o potencial en el aprendizaje del alumno. Se presenta en este trabajo un análisis de las valoraciones del alumnado recogidas mediante opiniones anónimas después de la elaboración de un trabajo tutorizado realizado en grupo en el Grado de Medicina de la Universitat de València durante los cursos 2015-2016 y 2016-2017. Es fundamental tener en cuenta la opinión del alumnado para adoptar medidas de mejora docente, corregir o modificar la metodología y resolver situaciones surgidas en el entorno real de aprendizaje. Nuestra conclusión es que la perspectiva del alumnado es muy positiva que les gusta la metodología de trabajar en grupos tutorizados.

Palabras clave: Trabajo en equipo, grupo tutorizado, competencias, educación universitaria 


\section{Introducción}

Las universidades españolas se encuentran inmersas en el Espacio Europeo de Educación Superior (EEES) (Declaración de Bolonia, 1999). La adecuación al EEES ha supuesto una profunda renovación en la estructura curricular, las estrategias de aprendizaje y modelos de evaluación. Los pilares metodologógicos y pedagógicos de este nuevo de modelo vienen marcados por un lado, el alumno es el centro de su propio aprendizaje dotándolo de las herramientas necesarias (diferente papel del docente, (Fernández, 2006) y permitiéndole un aprendizaje más autonomo, efectivo, creativo y activo (Salaburu, 2011; González y Wagenaar, 2006; Gijon y Crisol, 2012). Y por otro, en cambios en la organización de los aprendizajes como es el aprendizaje en grupo que precisa de un seguimiento del trabajo realizado (Zabalza, 2003) y que crea una interdependencia positiva. (Ovejero, 1990; Jonson y Jonson 1999).

En este proceso adquiere gran importancia el aprendizaje por competencias. Por ello, se requieren de nuevas metodologías docentes que ayuden y contribuyan al desarrollo integrado de competencias. El hecho de incluir este término a los currículos universitarios permite dar una formación más completa y real al alumnado ya que se integrarían los componentes personales (conocimientos, habilidades cognitivas, motivación, actitudes, emociones), componentes sociales y de conductas (acciones, comportamientos, iniciativas) guiadas por unos fines u objetivos. El hecho de trabajar por competencias hace que la posterior incorporación al mundo laboral del alumnado sea mejor.

Dentro de este contexto el Grado de Medicina tiene unas competencias básicas, generales, transversales y específicas que ha de cumplir un alumno cuando acaba su etapa de formación. Dentro de las competencias transversales más significativas están la capacidad para trabajar en equipo y para relacionarse con otras personas del mismo o distinto ámbito profesional así como la competencia de tener la capacidad para comunicarse. Dentro de las competencias específicas destacamos:

1.Conocer,valorar críticamente y saber utilizar las tecnologías y fuentes de información clínica y biomédica, para obtener, organizar, interpretar y comunicar información clínica, científica y sanitaria.

2.Comprender e interpretar críticamente textos científicos.

3.Conocer los principios del método científico, la investigación biomédica y el ensayo clínico.

4.Saber realizar una exposición en público, oral y escrita, de trabajos científicos y/o informes profesionales.

Nuestra hipótesis es que este tipo de metodología propuesta mediante el desarrollo de un trabajo en equipo tutorizado por el docente permitiría desarrollar y adquirir las competencias propuestas. Para ello, es necesario acercar la opinión del alumnado al docente sobre su experiencia con este tipo de metodología de trabajo y así poder adoptar medidas de mejora docente, corregir o modificar la metodología y resolver situaciones surgidas en el entorno real de aprendizaje.

(c)) BY-NC-ND 2017, Universitat Politècnica de València 


\section{Objetivos}

El objetivo fundamental del presente trabajo es analizar la percepción del alumnado sobre el desarrollo de un tema tutorizado trabajando en grupo.

Para ello los objetivos específicos son:

1- Analizar las valoraciones positivas y negativas desde el punto de vista del alumnado.

2- Desarrollar estrategias de mejora por parte del equipo docente.

\section{Descripción de la metodología docente:}

La experiencia se llevó a cabo con el alumnado matriculado en la asignatura de Biología de $1^{\text {er }}$ Curso en los grupos ARA y V, del Grado de Medicina de la Universitat de València en el curso académico 2015-2016 y 2016-2017 (Código de Asignatura: 34446 con 6 ECTS y con carácter de formación básica). El número total de alumnos que participaron en el feedback al docente fue de 11 de un total de 32 en el curso 2015-16 y 25 de un total 26 alumnos en el curso 2016-2017.

Los trabajos tutorizados para los dos cursos se plantearon de la misma forma. Grupos con un número reducido de estudiantes (4-5 personas). El tema que se designaba a cada equipo era una enfermedad no muy común que tenían que investigar realizando una búsqueda bibliográfica, centrándose en los aspectos desde el punto de vista de la biología celular que fallaban o se alteraban y desencadenaban dicha patología. Cabe destacar que todo el marco teórico de la biología celular se ha dado en las cláses teóricas de la asignatura. Finalmente, el grupo tiene que realizar un póster sintetizando la información encontrada y exponerla a todos los demás grupos.

Para ello, el contenido del trabajo sigue el esquema que muestra la Figura 1 que les sirve de orientación y está basado en el método científico. 


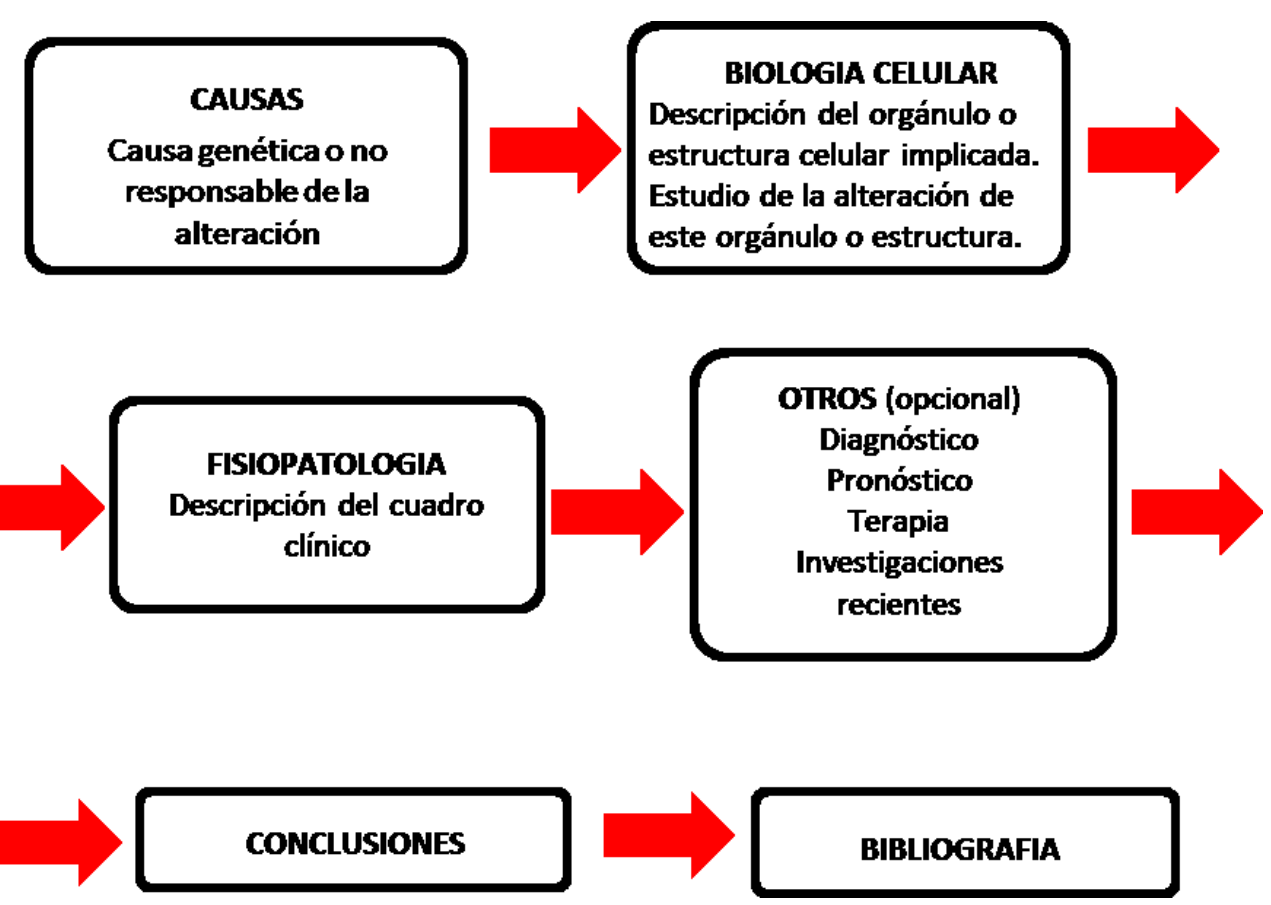

Figura 1. Esquema del contenido del trabajo tutorizado.

Primeramente, describir la enfermedad, el orgánulo o componente celular responsable del desarrollo de la patología. En concreto, elegimos enfermedades raras que son enfermedades que no van a profundizar mucho en el desarrollo de su Grado, para que sea un tema atractivo y curioso. Después, profundizar en la causa (genética o no) responsable de la alteración.

De ahí pasar de manera muy general a la Fisiopatología de la enfermedad y dependiendo de la información encontrada y de la patología en cuestión, profundizar en aspectos como diagnóstico, pronóstico, terapia e investigaciones recientes. El equipo docente remarcamos como muy importante la investigación y publicaciones científicas actuales que encuentren de su tema en concreto.

Como apartado final realizar unas conclusiones del trabajo y especificar de manera formal la bibliografía empleada. 
Los temas planteados fueron:

Tabla 1. Temas designados a cada grupo

\begin{tabular}{cc}
\hline Biología celular & Patología asociada \\
\hline Uniones tipo GAP & Síndrome de Vohwinkel \\
Membrana & Esferocitosis hereditaria \\
plasmática & \\
Desmosoma & Pénfigo vulgar \\
Retículo & Pseudoacondroplasia \\
endoplásmico & \\
Lisosoma & Enfermedad de Pompe \\
Mitocondria & MERRF
\end{tabular}

El esquema de la metodología docente empleada generando una dinámica de grupo se ilustra en la siguiente Figura 2.

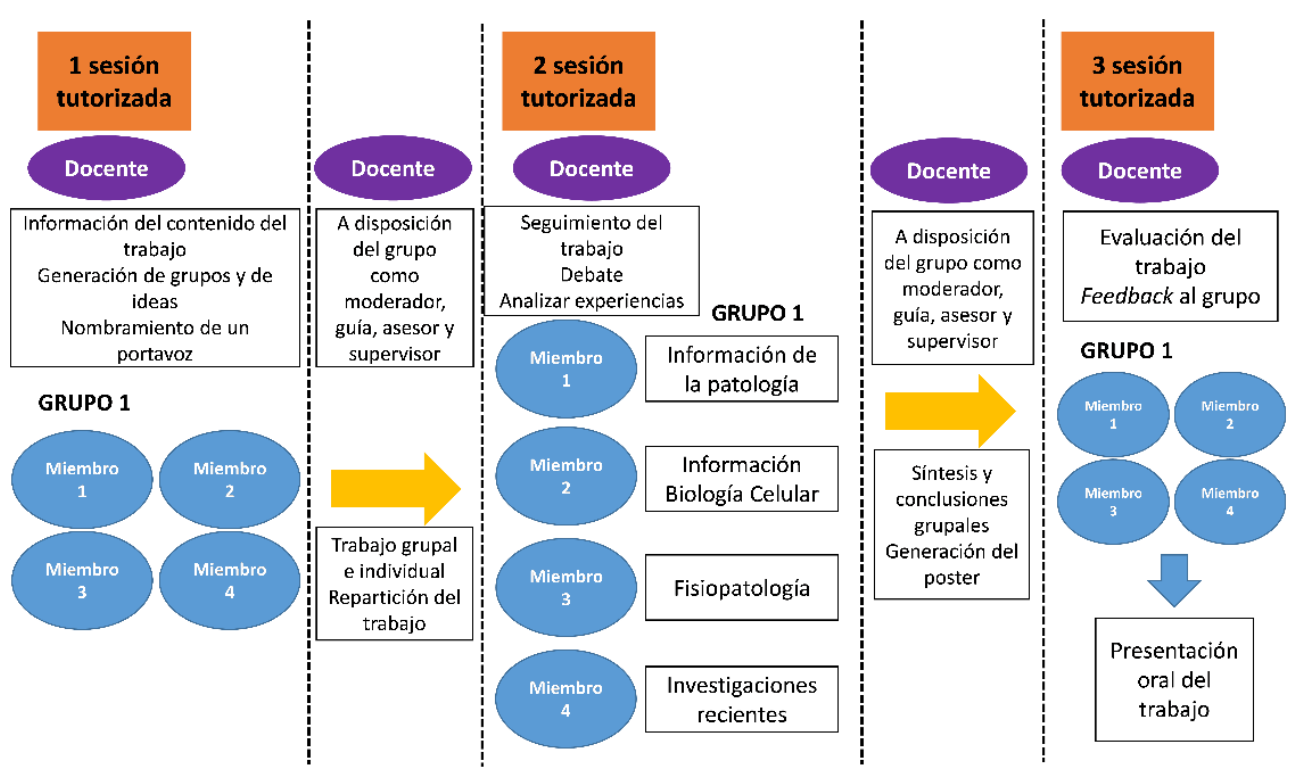

Figura 2. Metodología de trabajo en grupo empleada.

(c)) EY-NG-ND 2017, Universitat Politècnica de València

Congreso In-Red (2017) 
La metodología docente consiste en 3 sesiones tutorizadas. En la primera se informa a los alumnos sobre el procedimiento de trabajo, se generan los grupos y se elige al portavoz de cada equipo. A partir de este momento, los estudiantes empiezan a trabajar y se reparten el contenido. En todo momento el equipo docente está como moderador, guía, asesor y supervisor. La segunda sesión con el docente consiste en compartir su experiencia grupal hasta ese momento, detectar posibles conflictos, favorecer el debate y corroborar que el trabajo se está desarrollando de forma correcta. En la tercera y última sesión se presenta oralmente el trabajo y el docente evalúa el resultado final compartiendo su perspectiva con el alumnado.

Después de la exposición del trabajo grupal se les invita a dar un feedback al docente sobre los aspectos positivos y negativos que ha encontrado cada alumno de manera individual en el desarrollo del trabajo en equipo de manera anónima.

Este trabajo es evaluado sobre 1 punto sobre un total de 4 puntos de la parte de Evaluación Práctica de la asignatura de Biología siguiendo una rúbrica diseñada específicamente para evaluar tanto el proceso como el resultado final.

\section{Resultados}

Los resultados que obtenemos tras el análisis de las valoraciones del alumnado se pueden dividir en, por una lado, valoraciones positivas (Figura 3) y, por el otro, valoraciones negativas (Figura 4) para las dos anualidades estudiadas. Cabe destacar que los resultados se han porcentuado al total de las contribuciones del alumnado obtenidas para cada anualidad.

Si profundizamos en detalle en las valoraciones positivas (Figura 3), en primer lugar, utilizan mucho el verbo "aprender" en cualquiera de las contribuciones que nos devuelven, ya sea en el curso 2015-2016 como para el 2016-2017. Siendo el porcentaje más elevado para las dos anualidades (aproximadamente 91\% para 2015-2016 y un 52\% para 20162017). Es la contribución mejor valorada por el alumnado en general.

(c)) EY-NC-ND 2017, Universitat Politècnica de València 


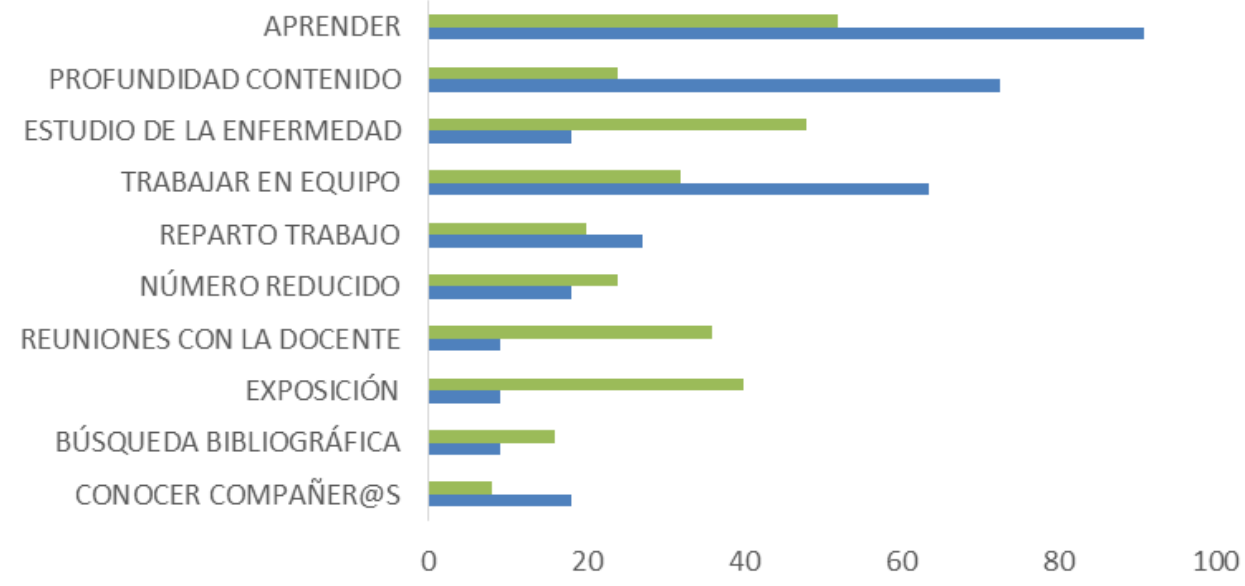

Figura 3. Valoraciones positivas del alumnado frente al grupo tutorizado.

En segundo lugar, coinciden también los dos cursos que el contenido y temas planteados son valoradas positivamente, aunque en 2015-2016 destacan más la profundidad del contenido (72\%) y en 2016-2017 el estudio de la enfermedad (48\%).

Existe también una coincidencia en valores de porcentaje para los dos cursos cuando hablan de reparto del trabajo (27\% en $2015-2016$ y $20 \%$ en $2016-2017)$ y en trabajar con un número reducido de personas (18\% en 2015-2016 y 24\% en 2016-2017).

El trabajar en equipo lo destacan el 64\% en 2015-2016 y el 32\% en 2016-2017.

En 2016-2017 se destaca un aumento de contribuciones haciendo referencia a las reuniones planteadas por el docente (36\%) y a la exposición (40\%). En 2015-2016 se detecta un aumento de contribuciones que son importantes en el aspecto de conocer a compañeros $(18 \%)$. Y en las dos anualidades también valoran la búsqueda de referencias bibliográficas ( $9 \%$ en $2015-2016$ y $16 \%$ en 2016-2017).

Si profundizamos en el análisis de las valoraciones negativas (Figura 4) coindiden los dos cursos en destacar que trabajar en equipo es difícil, siendo la contribución más elevada dentro de las negativas (36\% en 2015-2016 y 32\% en 2016-2017). Además este tipo de trabajo lo consideran una pérdida de tiempo (27\% en 2015-2016 y 28\% en 2016-2017).

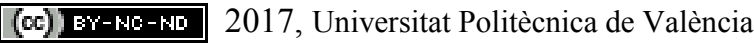




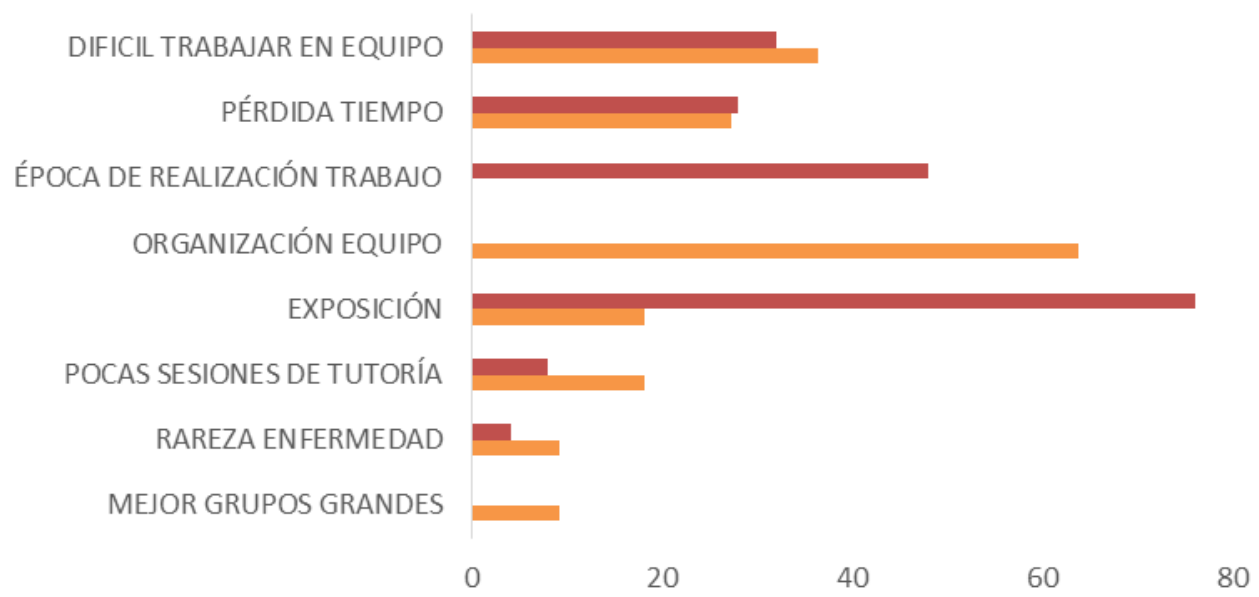

Figura 4. Valoraciones negativas del alumnado frente al grupo tutorizado.

En 2015-2016 consideraron un aspecto negativo la organización del equipo, ya que destacaban difícil cuadrar agendas con horarios. Mientras que en el curso 2016-2017 lo más destacable negativamente fue la época de realización del trabajo.

La exposición fue destacada muy positivamente para un gran grupo de alumnos pero también hay un porcentaje de alumnado que lo valoran negativamente sobre todo por el tema de las vergüenzas (2015-2016 fue 18\% mientras que en 2016-2017 llegó a tener un porcentaje del $76 \%$ ).

Valoraciones negativas de menor relevancia fueron que creen necesitar más sesiones de tutoría y el tema que proponemos de la enfermedad no es muy común. Así como hay gente que prefiere trabajar con grupos más grandes.

\section{Conclusiones}

En la guía docente de la asignatura de Biología se tiene como uno de los objetivos de resultados de aprendizaje la de adquirir "capacidad de trabajo en equipo y habilidades para el desarrollo y exposición de temas de Biología Celular”. Es en este contexto donde se desarrolla este trabajo tutorizado.

Para fomentar esta competencia universitaria creamos grupos reducidos y dinámicos en un entorno colectivo estructurado en la que el docente actua de mediador, moderador, guía, asesor y supervisor, y además planteamos un tema atractivo para fomentar la motivación.

$\mathrm{Si}$ profundizamos en detalle en las opiniones del alumnado encontramos resultados sorprendentes que iremos discutiendo a continuación.

En primer lugar, nos llama la atención que este trabajo lo valoren con una palabra “APRENDER". Este verbo está presente en muchos alumnos/as siendo el mejor valorado tanto para la anualidad 2015-2016 como para la anualidad 2016-2017 y, por tanto,

(c)) BY-NC-ND 2017, Universitat Politècnica de València

Congreso IN-RED (2017) 
coinciden que con este trabajo aprenden. Comentarios como "aprender a aceptar que tus propuestas no siempre pueden tener éxito", "aprender a realizar investigaciones más exhaustivas y con mejores fuentes que nos servirá para trabajos futuros", "aprender a trabajar en grupo y convivir con ellos además de que te aporten una serie de conocimientos o ideas creativas muy interesantes", "conocer a gente nueva y nuevos enfoques y formas de trabajar. Aprender de los demás", "aprender conceptos muy específicos sobre los diferentes orgánulos", "se aprende de una forma más dinámica", "aprender a hablar en público", "aprender a buscar en páginas de webs científicas", "aprender todo el trabajo y profundizar más sobre la enfermedad"...son algunos de los ejemplos.

Sobre todo porque es justamente un pilar de los que comentábamos por el que apuesta la nueva reforma metodológica en la que el docente es un guía para el alumno y le ayuda a construir su propio aprendizaje.

Además afirman que les parece interesante el tema del trabajo con comentarios como "enfermedad relacionada con la materia", "el conocimiento que he extraido del trabajo", "todo lo que sé ahora acerca de la enfermedad y de la estructura celular", "me ha parecido muy interesante y agradezco este tipo de oportunidades para aprender", "profundizar en una enfermedad interesante", "me ha gustado el tema del trabajo que trata de enfermedades y son aspectos no vistos en clase", "relación entre la biología y las enfermedades raras muy interesantes "...es decir, los resultados muestran que les gusta este tipo de trabajos, les parece atractivo e integrador con la materia dada en la clase teórica, y es por ello, que se puede extrapolar a una mayor motivación e interés por la asignatura, siendo la motivación el motor fundamental para un aprendizaje activo.

Como valoraciones positivas también coinciden las dos clases que les gusta repartir el trabajo, les gusta trabajar en equipo y de manera cooperativa. Y que además trabajan mejor con un número reducido de integrantes. Sobre todo es destacable que su percepción sea tan positiva aunque opinen en menor medida que es difícil trabajar en equipo y que se pierde mucho tiempo.

Centrándonos en la exposición, podemos decir que la perspectica es buena ya que muchos la califican de positiva pero existe un colectivo que el tema de la vergüenza y los nervios hace que no le gusten este tipo de situaciones. Esto se refleja en sus comentarios "exponer me supone mucho esfuerzo y lo paso realmente mal y más delante de los compañeros", "me ha ayudado a perder la vergüenza en publico", "una ocasión más para hablar en público", "deberiamos exponer la parte que hemos preparado solo", "críticas constructivas de la profesora al final de la exposición", "realizar la exposición delante de la clase es incómodo así como responder a las preguntas", "las preguntas ponen nerviosos a las personas que exponen"....

Además la época en la que se plantea el trabajo también es un hándicap porque la diferencia entre la anualidad 2015-2016 es que el trabajo se planteó el primero de todos los del cuatrimestre, mientras que en la anualidad 2016-2017 fue el último de todas las asignaturas. Es por ello, que en las valoraciones negativas se observe que la época de trabajo sea 
importante para el alumnado ya que tienen más presentes las fechas de examen y su perspectiva sea más negativa a la hora de valorar este tipo de trabajos.

Como resultado final podemos destacar que la perspectiva del alumnado fue muy positiva a este tipo de metodología. Esto hecho contrarresta con las devoluciones verbales que nos dan en clase y durante el desarrollo del trabajo donde tan solo destacan "la pérdida de tiempo" que les causa. Es por ello, que tras el análisis estamos muy motivados para seguir en esta misma línea de trabajo. $\mathrm{Y}$ nos da que pensar que cuando les pedimos que reflexionen sobre su proceso de aprendizaje es cuando emergen las opiniones más sinceras y profundas.

Además el trabajo grupal les ayuda a desarrollar una sensibilización positiva de trabajo con sus iguales y se fomenta el respeto a la cohesión y un clima de cooperación. De manera también directa la responsabilidad de un objetivo final común hace que se generen conflictos, importantes para su desarrollo y crecimiento personal y profesional.

Podemos concluir, por tanto, que no solo aprenden competencias transversales sino que también trabajan competencias específicas como: “conocer, valorar críticamente y saber utilizar las tecnologías y fuentes de información clínica y biomédica, para obtener, organizar, interpretar y comunicar información clínica, científica y sanitaria", "comprender e interpretar críticamente textos científicos", "conocer los principios del método científico, la investigación biomédica y el ensayo clínico" y "saber realizar una exposición en público, oral y escrita, de trabajos científicos y/o informes profesionales".

Con nuestra experiencia de análisis concluimos que este tipo de trabajos tutorizados funcionan, con sus opiniones podemos mejorar la práctica de apoyo al alumno y, por tanto, el aprendizaje. Y cuyas opiniones son mayoritariamente valoradas positivamente, les gusta trabajar en equipo con un apoyo docente.

\section{Referencias}

FERNÁNDEZ MARCH, A. (2006). "Metodologías activas para la formación de competencias". Educatio Siglo XXI, vol 24, p. 35-56

OVEJERO BERNAL, A. (1990). El aprendizaje cooperativo, una alternativa eficaz a la enseñanza tradicional. Barcelona: Promociones y Publicaciones Universitarias.

JONSON, D. W. y JONSON, R. J. (1999). Aprender juntos y solos. Buenos Aires: Grupo Editorial Aique.

GONZÁlEZ, J. y WAGENAAR, R. (eds.). (2006). Tuning Educational Structures in Europe. Informe final. Proyecto piloto, Fase 2. Bilbao: Universidad de Deusto.

GIJÓN, J. y CRISOL, E. (2012).” La internacionalización de la Educación Superior. El caso del Espacio Europeo de Educación Superior". Revista de Docencia Universitaria. REDU. Monográfico: "Buenas prácticas docentes en la enseñanza universitaria". vol 10 (1), p. 349-414.

SALABURU, P. (dir.) (2011). España y el proceso de Bolonia. Un encuentro imprescindible. Madrid: Academia Europea de Ciencias y Artes de España.

ZABALZA, M. A. (2003). Competencias docentes del profesorado universitario. Calidad y desarrollo profesional. Madrid: Narcea.

(c)) EY-NC-ND 2017, Universitat Politècnica de València 


\title{
Aprender enseñando. Una experiencia para desarrollar la quinta competencia.
}

\section{María Jano Salagrea y Salvador Ortiz Serrano ${ }^{\mathrm{b}}$}

aProfesora del Departamento de Economía Aplicada de la Universidad Autónoma de Madrid, dolores.jano@uam.es y ${ }^{b}$ Profesor del Departamento de Economía Aplicada de la Universidad Autónoma de Madrid, salvador.ortiz@uam.es

\begin{abstract}
The students who today arrive in our classrooms at the university soon forget the learnings that are not relevant to them and prefer to learn by doing. By means of evaluations we measure what they remember of the previous concepts that are required for Theoretical Statistics, and see that in general there are important gaps. They are offered an active and autonomous learning experience to develop what is known as the "fifth skill".

The proposal is that the students become teachers for one day and prepare a topic to explain it to their classmates. They are also provided with the materials and support needed to complete the task.

The scores from various evaluations conducted throughout the course are analyzed to determine whether the participation results in an improvement in student performance and whether the quality of participation has a significant effect on the results.

Finally, from the experience, a series of lessons are derived to advance the process of the flipped classroom. The students prepare the contents on their own and carry out in class activities that result in deeper and longer lasting learning.
\end{abstract}

\section{Keywords:}

Active learning, Flipped Classroom, Higher Education, Statistics, Learning Outcomes

\footnotetext{
Resumen

Los alumnos que hoy llegan a nuestras aulas en la universidad olvidan muy pronto aprendizajes que no son para ellos relevantes y prefieren aprender haciendo. Mediante una prueba se mide lo que recuerdan de los conceptos previos que se requieren para Estadística Teórica, comprobando que en general hay importantes lagunas, y se les propone una experiencia de aprendizaje activo y autónomo para desarrollar la que se conoce como quinta competencia.
} 
La propuesta es que los alumnos sean profesores por un día y preparen un tema para explicárselo a sus compañeros. Se les proporcionan los materiales y el apoyo necesario para realizar la tarea.

Se analizan las calificaciones en diversas pruebas realizadas a lo largo del curso para determinar si el hecho de participar supone una mejora en el desempeño de los estudiantes, y si la calidad de la participación tiene efectos significativos en los resultados.

Por último, de la experiencia se derivan una serie de lecciones para avanzar en el proceso de dar la vuelta a la clase; los estudiantes se preparan por su cuenta contenidos y en clase se hacen actividades que fomentan aprendizajes significativos.

Palabras clave: Aprendizaje Activo, Clase Inversa, Educación Superior, Estadística, Resultados de Aprendizaje

\section{Introducción}

Con el plan Bolonia se aprovechó para renovar las metodologías docentes con la intención de lograr que los alumnos se impliquen en su aprendizaje, sean autónomos y aprendan a aprender a lo largo de la vida. El Real Decreto 1393/2007, de 29 de octubre establece una serie de competencias básicas que se han de trabajar en el grado. La quinta competencia establece: "Que los estudiantes hayan desarrollado aquellas habilidades de aprendizaje necesarias para emprender estudios posteriores con un alto grado de autonomía". Para conseguirlo se necesitan claves para despertar su motivación intrínseca, sus ganas de aprender y ofrecer escenarios que favorezcan el aprendizaje activo. Pasados ya algunos años, se puede afirmar que se han dado pasos muy importantes, aunque todavía queda un largo camino por recorrer.

Los alumnos que llegan a nuestras aulas casi nacieron con el nuevo siglo. Se dice de esta generación, a veces denominada como Millennials, que piensan y procesan la información de manera diferente a sus predecesores. Algunos de los calificativos y de los rasgos que se han apuntado sobre ellos son: prefieren aprender haciendo, están hiperconectados, acostumbrados a vivir inmersos en tecnología y a realizar varias tareas a la vez. Son inteligentes, aunque impacientes y con dificultades para mantener mucho tiempo la atención, orientados al logro y muy prácticos. También se afirma que son colaborativos, reivindicativos y aparentemente con una elevada confianza en sí mismos (Phillips, 2014), (Ash, 2015) y (Taylor, 2011). La educación superior se enfrenta a un reto difícil y a la vez muy importante, conseguir aprendizajes significativos en esta nueva generación de jóvenes tan diferentes en su manera de aprender y que requieren metodologías de aprendizaje más activas.

La metodología de clase inversa ha irrumpido en la educación superior con gran fuerza, y se están haciendo muchas experiencias exitosas, aunque todavía no se ha evaluado suficientemente en términos de aprendizaje significativo (Zuber, 2016). En esta línea y de manera muy preliminar se enmarca la propuesta que se presenta, invitar a los alumnos a "actuar de profesores por un día", asumiendo la responsabilidad de preparar un tema y hacérselo entender a sus compañeros.

En esta comunicación se describe cómo se organizó la experiencia, los resultados obtenidos en términos de calificaciones y por último se hace un balance de lecciones aprendidas.

(c)) BY-NC-ND 2017, Universitat Politècnica de València 


\section{Objetivos}

Año tras año se vienen detectando en las clases de Estadística Teórica que impartimos en el segundo curso del grado de Administración de Empresas la Facultad de Ciencias Económicas de la Universidad Autónoma de Madrid, las dificultades que tienen los alumnos en esta asignatura porque no tienen los conocimientos previos que se supone que ya han visto y superado de Estadística Descriptiva que se imparte en el primer curso. El primer objetivo general que se pretende alcanzar es valorar si el aprendizaje de Estadística Descriptiva ha sido significativo y perdura en el tiempo, y más concretamente, qué conceptos han quedado menos grabados y requieren una revisión. Para ello se hizo una prueba de nivel por sorpresa (Anexo I) que pretende cuantificar y detectar cuánto y qué se recuerda de Estadística Descriptiva.

Con la intención de lograr en este curso un aprendizaje más duradero y significativo, se propuso una experiencia que involucre al estudiante activamente en su aprendizaje. Siguiendo en parte la propuesta de (Ambrose, 2010), y teniendo presente que cada alumno tiene un estilo y unas ideas previas sobre el aprendizaje, se consideran cinco pasos a tener en cuenta para fomentar la autonomía en el estudiante. En primer lugar definir claramente la tarea, en segundo lugar evaluar las capacidades del estudiante para poder realizar, en tercer lugar planificar actividades, tanto dentro como fuera del aula para llevarla a cabo, en cuarto lugar realizar y monitorizar la tarea y por último reflexionar y corregir los errores detectados.

La experiencia se resume en que los alumnos preparan por su cuenta un tema y se lo explican a sus compañeros. Se propuso de manera voluntaria para que los estudiantes según sus estilos de aprendizaje pudieran elegir si participaban o no.

El objetivo que se pretende es doble. En primer lugar poner en marcha una experiencia muy preliminar de clase inversa estableciendo una serie de actividades dotando a los alumnos de las herramientas básicas para poder abordarlo. En segundo lugar, se analizarán los resultados obtenidos y los errores cometidos a lo largo del proceso para poder generalizarla a otros temas y con más recursos basados en las nuevas tecnologías. En este sentido, se pretende valorar si aquellos que han participado en la experiencia logran mejores resultados y si su aprendizaje es más significativo. Se utilizarán las calificaciones en diversas pruebas y se les hará una prueba a principios del curso siguiente para detectar si persisten las diferencias entre los que participaron y no en la actividad en cuanto a lo que recuerdan de ese tema en concreto y de la asignatura en general.

En concreto las preguntas a las que se pretende dar respuesta son:

- ¿Cuál es el nivel de conocimientos previos en Estadística Descriptiva y en qué medida se recuerdan conceptos básicos para abordar con éxito la asignatura Estadística Teórica?

- ¿Los que deciden participar en la propuesta tienen mejores notas en Estadística Descriptiva y por tanto tienen una mejor predisposición para abordar con más éxito la Estadística Teórica? Si fuera así, se debería considerar como un factor corrector para evaluar los resultados de la experiencia.

- ¿La participación en la experiencia mejora los resultados finales en la asignatura? ¿El efecto en la nota final es diferente según la calidad de la participación en la actividad propuesta?

- ¿Aquellos que participan logran un aprendizaje significativo y duradero?

- ¿Cuáles son las dificultades y qué lecciones se han aprendido? 


\section{Desarrollo de la Innovación}

Para fomentar el trabajo autónomo y que el aprendizaje sea más permanente en el tiempo, a lo largo del curso 2016/2017 se llevó a cabo una experiencia para fomentar la participación activa del estudiante, que pretende trabajar sobre todo la conocida como "quinta competencia". De una manera resumida, la propuesta pretende que el alumno se prepare el tema 3 (Modelos de distribución: Binomial, Poisson, Normal, Relacionadas con la Normal, Teorema Central del Límite) por su cuenta y lo exponga ante sus compañeros. Se propone como experiencia piloto de manera voluntaria como parte de la evaluación continua de la asignatura. Se considera que es un tema que ellos pueden preparar, puesto que ya se han explicado conceptos como función de densidad, cuantía, distribución y momentos que caracterizan una distribución de probabilidad, por lo que podrán aplicarlos a modelos concretos discretos y continuos. El alumno dispuso de materiales básicos: apuntes del tema, enunciados de problemas básicos y complementarios, varios manuales de referencia que pueden consultar y otros materiales como apps y simulaciones para comprender mejor el tema.

Para organizar las exposiciones y garantizar en lo posible que fuera una experiencia positiva tanto para el alumno que la prepara, como para el que tiene que aprender el tema con las explicaciones de sus compañeros, se organizaron dos sesiones de tutorías de asistencia obligatoria. Además, se les ofrece la posibilidad de concertar tantas tutorías como sean necesarias a lo largo del proceso. En la primera sesión el alumno debía venir con el tema leído y las dudas que le hubieran surgido. En esa sesión el profesor comprueba que el alumno tiene claros los contenidos que se han de abordar en las exposiciones y hace el reparto entre los alumnos de las partes que deberán exponer en clase. La segunda tutoría pretende comprobar que efectivamente los alumnos están preparados para impartir la clase. Las exposiciones se realizaron en clase a lo largo de dos días. Se calificó la participación en la experiencia sobre 10 en base a diversos aspectos: actitud, participación en tutorías, exposición en clase de la parte que se le asignó, valorada tanto por el profesor como por sus propios compañeros, y un control por escrito sobre todo el tema.

\section{Evaluación de los resultados}

Los resultados se refieren a 115 estudiantes, de los cuales 33 participaron voluntariamente en la experiencia. De ellos 112 hicieron la prueba de nivel.

\section{1- Conocimientos previos y resultados de la prueba de nivel}

En la tabla 1.- Se resumen los resultados de la prueba de nivel y la nota media en la asignatura Estadística Descriptiva. Los resultados son desalentadores, tanto para los que participan en la experiencia como para los que no. Las nota media en la prueba es muy baja, menos de un 2,5, y los alumnos solo recuerdan el nombre de alguna medida de posición, dispersión, concentración o correlación, pero no pueden decir para qué sirven o cómo se interpretan. Sin embargo si se observa diferencias significativas en las calificaciones en descriptiva, ya que en media casi tienen un punto más los que se animan a realizar la propuesta $(7,2$ frente a 6,3$)$. Este resultado apunta a que los alumnos que se presentan voluntarios, son los más interesados y mejor predispuestos en las asignaturas de corte cuantitativo.

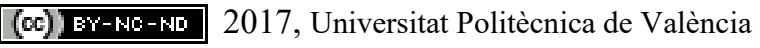


Tabla 1.- Resultados de la prueba de Nivel según partipan o no en la experiencia.

\begin{tabular}{|c|c|c|c|c|c|}
\hline & Todos & $\begin{array}{c}\text { No } \\
\text { Participan } \\
\end{array}$ & $\begin{array}{c}\% \text { acierto } \\
\text { No Participan }\end{array}$ & Participan & $\begin{array}{l}\text { \% acierto } \\
\text { Participan }\end{array}$ \\
\hline Número de alumnos & 115 & 82 & $71 \%$ & 33 & $29 \%$ \\
\hline Hacen la Prueba de Nivel & 112 & 79 & $71 \%$ & 33 & $29 \%$ \\
\hline Sabe definir medidas posición & 19 & 14 & $18 \%$ & 5 & $15 \%$ \\
\hline $\begin{array}{l}\text { Recuerda alguna media } \\
\text { posición }\end{array}$ & 79 & 54 & $68 \%$ & 25 & $76 \%$ \\
\hline Sabe elegir media o mediana & 21 & 14 & $18 \%$ & 7 & $21 \%$ \\
\hline Sabe interpretar percentiles & 33 & 19 & $24 \%$ & 14 & $42 \%$ \\
\hline $\begin{array}{l}\text { Sabe definir medidas } \\
\text { dispersión }\end{array}$ & 21 & 16 & $20 \%$ & 5 & $15 \%$ \\
\hline $\begin{array}{l}\text { Recuerda alguna media de } \\
\text { dispersión }\end{array}$ & 50 & 36 & $46 \%$ & 14 & $42 \%$ \\
\hline $\begin{array}{l}\text { Sabe cuándo usar Coeficiente } \\
\text { de Variación }\end{array}$ & 8 & 5 & $6 \%$ & 3 & $9 \%$ \\
\hline $\begin{array}{l}\text { Sabe que indice Gini es una } \\
\text { medida de concentración }\end{array}$ & 33 & 22 & $28 \%$ & 11 & $33 \%$ \\
\hline $\begin{array}{l}\text { Sabe cómo interpretar el Indice } \\
\text { Gini }\end{array}$ & 8 & 5 & $6 \%$ & 3 & $9 \%$ \\
\hline $\begin{array}{l}\text { Sabe que el coeficiente de } \\
\text { correlación mide relación entre } \\
\text { variables }\end{array}$ & 37 & 24 & $30 \%$ & 13 & $39 \%$ \\
\hline $\begin{array}{l}\text { Sabe interpretar coefiente de } \\
\text { correlación }\end{array}$ & 1 & 0 & $0 \%$ & 1 & $3 \%$ \\
\hline $\begin{array}{l}\text { Sabe para qué sirve una } \\
\text { regresión lineal }\end{array}$ & 25 & 17 & $22 \%$ & 8 & $24 \%$ \\
\hline $\begin{array}{l}\text { Sabe interpretar coeficientes de } \\
\text { una regresión lineal }\end{array}$ & 11 & 9 & $11 \%$ & 2 & $6 \%$ \\
\hline $\begin{array}{l}\text { Sabe interpretar un índice de } \\
\text { precios }\end{array}$ & 26 & 19 & $24 \%$ & 7 & $21 \%$ \\
\hline $\begin{array}{l}\text { Ha estudiado previamente el } \\
\text { Teoermea de Bayes }\end{array}$ & 63 & 41 & $52 \%$ & 22 & $67 \%$ \\
\hline $\begin{array}{l}\text { Ha estudiado previamente } \\
\text { modelos de Distribución de } \\
\text { Probabilidad }\end{array}$ & 65 & 43 & $54 \%$ & 22 & $67 \%$ \\
\hline $\begin{array}{l}\text { Ha estudiado previamente } \\
\text { Intervalos de Confianza }\end{array}$ & 77 & 54 & $68 \%$ & 23 & $70 \%$ \\
\hline $\begin{array}{l}\text { Ha estudiado previamente } \\
\text { Contrastes de Hipótesis }\end{array}$ & 21 & 15 & $19 \%$ & 6 & $18 \%$ \\
\hline
\end{tabular}

Fuente: Elaboración propia

\subsection{Análisis de los resultados del aprendizaje}

Para llevar a cabo el análisis de los resultados se han utilizado una serie de variables que se recogen en la tabla siguiente: 
Tabla 2. Variables analizadas

\begin{tabular}{|l|}
\hline \multicolumn{2}{|c|}{ Etiquetado y codificación de variables } \\
\hline Calificación en Descriptiva: $\boldsymbol{N F D}$ \\
\hline Participan en la Experiencia $(\boldsymbol{P E P}): 1=\mathrm{si} ; 0=$ no. \\
\hline Calificación en la Actividad Voluntaria: $\boldsymbol{N T 3}$ \\
\hline Calidad de la participación: \\
- Participan con perfil alto, con nota superior a la mediana $(\boldsymbol{P P A}): 1=$ sí $0=$ no participan o participan \\
con perfil bajo \\
Participan con perfil bajo, con nota por debajo de la mediana $(\boldsymbol{P P B}): 1=$ sí; $0=$ no participan o \\
participan con perfil alto \\
\hline Calificación en el Primer control, que incluye probabilidad, distribuciones de probabilidad y \\
modelos de distribución de probabilidad y Teorema Central del Límite. $(\boldsymbol{N 1 C})$ \\
\hline Calificación Final del curso $(\boldsymbol{N F C})$ \\
\hline
\end{tabular}

Un simple análisis de correlaciones entre las calificaciones que se presentan en la tabla 3 permite detectar que existe asociación positiva entre ellas, siendo especialmente alta entre la nota previa en Descriptiva y la nota final en Teórica $(0,74)$.

Tabla 3. Correlaciones entre los indicadores usados para valorar el resultado de la experiencia

\begin{tabular}{lcccc}
\hline & Nota Descriptiva & Nota T3 & Nota Control & Nota Final \\
\hline Nota Descriptiva & & & \\
Nota T3 & 0,29 & & \\
Nota Control & 0,51 & 0,67 & \\
Nota Final & 0,74 & 0,57 & 0,75 \\
\hline
\end{tabular}

Como puede observarse en la tabla 4 , los resultados en Teórica y en el primer control son 1,5 puntos superiores en el caso de los alumnos que participan en el proyecto.

Tabla 4. Nota media en los indicadores según participación

\begin{tabular}{lccc}
\hline & Nota Final & Primer Control & Nota Descriptiva \\
\hline No participa & $4,6(2,2)$ & $4,6(2,3)$ & $6,3(1,4)$ \\
Participa & $6,2(2,4)$ & $6,1(2,9)$ & $7,2(1,6)$ \\
Total & $5,0(2,4)$ & $5,0(2,6)$ & $6,6(1,5)$ \\
\hline Nota: Los valores entre paréntesis se corresponden con la desviación típica \\
\multicolumn{4}{r}{ Fuente: Elaboración propia }
\end{tabular}

No obstante, este resultado puede estar influenciado por diversas características de los alumnos, ya que la nota previa en Descriptiva de los alumnos que participan en el proyecto también es mayor y cabe esperar que, con independencia de su participación, habrían sacado una mejor nota.

Para descontar el efecto de las características previas del alumno sobre la nota final se hace una regresión lineal donde se explica la nota final del alumno en la asignatura (NFC) utilizando como regresores la nota en descriptiva (NFD) y un variable dicotómica que identifica a los alumnos que participan en la prueba, y en la que se toma como categoría de referencia los que no participan en la prueba. El modelo resultante es el siguiente: 


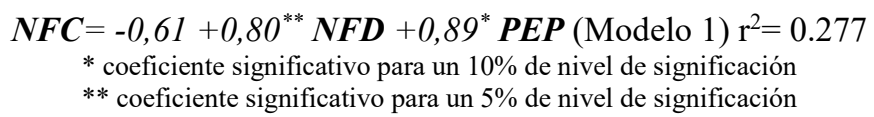

Tal y como se desprende del modelo, descontando el efecto de la participación en el proyecto, por cada punto adicional en descriptiva, el alumno suma en media 0,80 puntos en la nota final de la asignatura y aquellos que participan en la prueba, independientemente de la nota que tengan en descriptiva suman 0,89 puntos a la nota final.

Una situación similar la observamos cuando la variable a explicar es la nota del primer control (N1C) como puede verse en la ecuación siguiente:

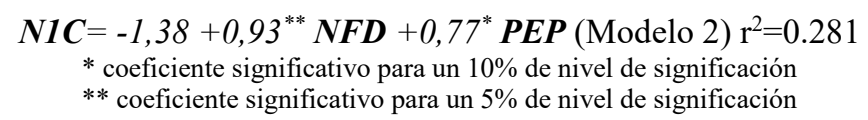

Pero la pregunta inmediata que surge es si se observan diferencias significativas según la calidad de participación, y para analizarlo se propone un modelo de regresión en el que se explica la nota final en teórica (NFC) en función de la nota de descriptiva (NFD) y la nota obtenida en la experiencia (NT3).

$$
\begin{aligned}
\boldsymbol{N F C} & =-2,97+0,52^{* *} \boldsymbol{N F D}+0,69^{* *} \mathrm{NT3} \text { (Modelo 3) } \mathrm{r}^{2}=0.424 \\
& * \text { coeficiente significativo para un } 10 \% \text { de nivel de significación } \\
& * * \text { coeficiente significativo para un } 5 \% \text { de nivel de significación }
\end{aligned}
$$

Los resultados ponen de manifiesto que al 5\% de significación ambas variables tienen un efecto significativo y positivo, y que sin tener en cuenta el efecto de las notas en descriptiva, las notas que se obtienen por participar en la experiencia tienen una relación positiva con la nota final en teórica. Un punto más en la nota en la experiencia sube 0,69 puntos la nota final.

Pero además interesa determinar si sólo por el hecho de participar mejoran los resultados o si depende de la manera en la que se participe. Para ello, se divide a los participantes en la prueba en aquellos que lo han hecho de una manera superior (nota por encima de la mediana o de perfil alto) y aquellos que lo hacen de manera inferior y con peores resultados (nota por debajo de la mediana o de perfil bajo). Los resultados se presentan en la tabla 5 y permiten afirmar que sí existen diferencias entre estos dos grupos. De hecho, los que participan a menor nivel obtienen resultados muy parecidos a aquellos que no participan.

Tabla 5. Calificaciones medias según intensidad en la participación

\begin{tabular}{lcccc}
\hline & Nota Final & $\begin{array}{c}\text { Primer } \\
\text { Control }\end{array}$ & $\begin{array}{c}\text { Nota } \\
\text { Descriptiva }\end{array}$ & Nota T3 \\
\hline No participa & $4,6(2,2)$ & $4,6(2,3)$ & $6,3(1,4)$ & $0,0(0,0)$ \\
Participa & $6,2(2,4)$ & $6,1(2,9)$ & $7,2(1,6)$ & $7,7(1,6)$ \\
$\quad$ Perfil bajo & $5,1(2,1)$ & $4,1(2,1)$ & $6,9(1,4)$ & $6,4(1,3)$ \\
$\quad$ Perfil alto & $7,1(2,2)$ & $7,7(2,4)$ & $7,5(1,6)$ & $8,8(0,8)$ \\
Total & $5,0(2,4)$ & $5,0(2,6)$ & $6,6(1,5)$ & $7,7(1,6)$ \\
\hline
\end{tabular}

Sin embargo es interesante confirmar si estas diferencias se mantienen cuando se descuenta el efecto de la nota en descriptiva. Para ello se proponen los modelos de regresiones anteriores incluyendo esta diferenciación entre los que lo hacen con perfil alto (PPA) y los que lo hacen con perfil bajo (PPB), Los resultados obtenidos fueron: 


$$
\begin{gathered}
\boldsymbol{N F C}=-0,31+0,76^{* *} \boldsymbol{N F D}+0,11 \boldsymbol{P P B}+1,64^{* *} \boldsymbol{P P A} \text { (Modelo 4) } \mathrm{r}^{2}=0.308 \\
\boldsymbol{N 1 C}=-0,85+0,84^{* *} \boldsymbol{N F D}-0,84 \boldsymbol{P P B}+2,21 * * \boldsymbol{P P A} \text { (Modelo 5) } \mathrm{r}^{2}=0.389 \\
\text { * coeficiente significativo para un } 10 \% \text { de nivel de significación } \\
\text { ** coeficiente significativo para un 5\% de nivel de significación }
\end{gathered}
$$

En ambos modelos la variable de la participación de perfil bajo no es significativa, confirmando lo que ya se apuntaba a nivel descriptivo, que en la nota final no tiene prácticamente efecto y en la del control es contraproducente, resta casi un punto. Sin embargo, la participación de perfil alto muestra en este caso su influencia en la nota, tanto en el control, donde suma más de dos puntos, como en la nota final, donde suma más de punto y medio. Por tanto se podría decir que no basta con participar en la experiencia, sino que hay que hacerlo bien para que tenga un efecto sobre la calificación y presumiblemente conduzca a aprendizajes más significativos.

\subsection{Lecciones aprendidas}

A la luz de los resultados y de los errores cometidos se concretan algunas lecciones aprendidas.

En primer lugar hay que explicar detenidamente todos los detalles para que el alumno, en base a sus estilos de aprendizaje, puede elegir libremente si desea participar en la propuesta. Se debería ofrecer como algo voluntario, sobre todo en grupos grandes, para que los alumnos que participan en la propuesta tengan la opción de sentir la responsabilidad y la posibilidad de explicar todo un tema, y sus compañeros no se vean sometidos a varios "profesores" con distintos estilos explicando un tema.

En segundo lugar, se les debe dejar tiempo suficiente para que vayan organizando sus materiales, resolviendo sus dudas y preparando actividades de aprendizaje para impartir la clase.

En tercer lugar, se debe exigir un alto nivel de compromiso a los estudiantes, porque los costes de hacerlo a un nivel inferior al deseado tiene consecuencias sobre el resto de alumnos. Esto exige también un alto compromiso por parte de los profesores para acompañar todo el proceso en tutorías y controlar que se pasan unos filtros adecuados y que dominan el tema como para llegar a actuar con garantías de éxito como profesores ante sus compañeros.

En cuarto lugar es aconsejable trabajar las habilidades de comunicación ante el público, corrigiendo materiales y ensayando las presentaciones.

La quinta lección aprendida es que hay que ofrecer un respaldo, poniendo en Moodle materiales audiovisuales y en otros formatos para que los alumnos puedan preparar sus exposiciones y para que los que no participan en la experiencia puedan complementar y comprender mejor las explicaciones de sus compañeros.

Otro aspecto a tener en cuenta es el peso en la evaluación, que en nuestra opinión no tendría por qué ser demasiado alta, puesto que se trata de aumentar la motivación intrínseca y el compromiso del estudiante con su aprendizaje. El análisis de los resultados, pone de manifiesto que el hecho de participar a nivel superior ya se traduce en una recompensa importante en la calificación final.

Por último, también resultaría muy interesante recoger la opinión de los estudiantes, realizando no sólo una encuesta, sino un grupo de discusión donde los propios alumnos nos informen de cómo creen ellos que se podría mejorar la experiencia.

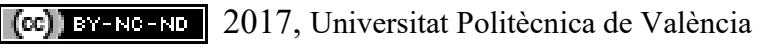




\section{Conclusiones}

Ante las evidencias de aprendizajes poco significativos que se olvidan al poco tiempo de superar la asignatura, se propone una experiencia que consiste en que los alumnos asuman el rol de profesores por un día. El tema elegido es el de modelos de distribución, para el que los alumnos ya cuentan con las herramientas y conceptos previos que necesitan para abordarlo con éxito.

El análisis de resultados, con las cautelas que impone el reducido número de estudiantes que participan, pone de manifiesto, que son precisamente los alumnos que sacan mejores notas los que más se animan a participar en la propuesta, de manera que para analizar los resultados habrá que descontar este efecto.

Participan en la experiencia aproximadamente un tercio de los alumnos, y el análisis de las calificaciones en diversas pruebas permite afirmar que el hecho de prepararse un tema tiene consecuencias positivas en la calificación final del curso. Sin embargo, no basta con participar, ya que sólo si se hace bien tiene consecuencias relevantes en la nota final. Aquellos que participan sin mucho compromiso o con perfil bajo tienen resultados muy parecidos a aquellos que no participan. No obstante todavía no se ha podido comprobar si los aprendizajes son duraderos y persisten en el tiempo, a la espera de poder abordar este objetivo el próximo curso.

En resumen, los resultados obtenidos ponen de manifiesto la utilidad que tiene preparar actividades que fomenten el aprendizaje activo de nuestros estudiantes, ponerles en el centro del escenario y que asuman su responsabilidad de aprender a aprender a lo largo de su vida en entornos VUCA (volátil, incierto, complejo y ambiguo) en los que probablemente se desarrollarán profesional y personalmente. Estos primeros pasos nos animan hacia una experiencia más completa de clase inversa, en la que los alumnos preparen los contenidos previamente y en clase se propongan actividades para lograr entender, comprender y poner en práctica conceptos abstractos y difíciles de una asignatura como es Estadística Teórica. Pero para ello es imprescindible el compromiso y la implicación de todos los estudiantes.

A modo de reflexión final, el camino a recorrer pasa por crear las condiciones y acompañar a los estudiantes hacia un aprendizaje significativo, en el espíritu de la frase atribuída a Einstein "No entiendes realmente algo hasta que eres capaz de explicárselo a tu abuela".

\section{Referencias}

AMBROSE, S. A. et al. (2010) "How Learning Works. Seven research based principles for smart teaching" Capitulo 7. JOSSEY-BASS, 2010 https://teaching.temple.edu/sites/tlc/files/resource/pdf/What $\% 20$ Factors $\% 20$ Motivate $\% 20 \mathrm{St}$ udents $\% 20$ to $\% 20$ Learn_.pdf

ASH, B.L. (2015) Using Twitter to Engage Digital Natives. Journal of Applied Research for Business Instruction. Vol. 13. Issue 2.

DE LOS REYES, E. (2016) Materiales del curso de formación de profesorado.'La quinta competencia" desarrollado en la Universidad Autónoma de Madrid los días 28 y 29 de Octubre 2015. 
PHILLIPS, C.R. and TRAINOR, J.E. (2014) Millennial Students and the Flipped Classroom. Proceedings of ASBBS Anual Conference: Las Vegas.

TAYLOR, M. (2011) Teaching Generation NeXt: Methods and Techniques for Today's Learners. http://www.taylorprograms.com/images/Techniques_article_2011.pdf

ZUBER, W.J. (2016) “The flipped classroom, a review of the literature" Industrial an Commercial Training, Vol 48 Issue:2, pp. 97-103.

\section{ANEXO. Prueba de nivel}

Apellidos _ Nombre

¿Para qué sirven las medidas de posición y cuáles conoce?

¿Cuándo utilizaría la mediana en vez de la media aritmética?

¿Qué significa que usted está en el percentil 5 de las notas de estadística?

¿Para qué sirven las medidas de dispersión y cuáles conoce?

¿Qué medida utilizaría para comparar la dispersión entre dos variables medidas en distintas unidades y cómo la interpretaría?

¿Qué medida utilizaría para medir la desigualdad en el reparto de la masa salarial y cómo se interpretan los resultados?

¿Qué medida utilizaría para medir la asociación o relación lineal entre variables? ¿Cómo interpretaría los resultados?

¿Cómo puede analizar el comportamiento de una variable a partir de otra? ¿Qué resultados espera obtener al analizar la relación entre la demanda de un producto en función de su precio?

Interprete los resultados del IPC base 2011 correspondiente a los meses junio y julio de 2016 que fueron respectivamente 103,55 y 102,8 .

¿Qué opción de bachillerato cursó?

¿En qué curso aprobó Estadística Descriptiva? 201_/201__ ¿Qué nota sacó?

¿Fue a academia para preparar la asignatura?

Marque con una cruz sobre el círculo los temas que le suenan porque ya los ha estudiado antes:

- Teorema de Bayes:

- Distribuciones (Binomial, Poisson, Normal, $\chi^{2}, \mathrm{t}, \mathrm{F}$ )

- Intervalos de confianza

- Contrastes de hipótesis estadística

(cc) EY-NC-ND 2017, Universitat Politècnica de València

Congreso IN-RED (2017) 


\title{
¿Cómo evaluamos la competencia transversal "Comprensión e Integración" a alumnos de cuarto curso del grado en Ingeniería Química?
}

\section{María José Muñoz Portero}

Departamento de Ingeniería Química y Nuclear, Universitat Politècnica de València, Camino de Vera s/n, 46022, Valencia (SPAIN), mjmunoz@iqn.upv.es, Equipo de Innovación y Calidad Educativa sobre Técnicas de Evaluación Continua Formativa (TECOF)

\begin{abstract}
The aim of the present work is the proposal of a methodology for working and evaluation of the transferable competence UPV "Comprehension and Integration" to students of fourth course in a subject that is control point in the academic year 2015-2016 in the degree of Chemical Engineering, specifically in the subject of "Manufacture Processes of the Building Materials". The design of two learning activities is realized: written questions and academic work in group. The evaluation of the transferable competence with the learning activity of written questions is realized with a question in the written exam of theory at the end of the semester. In the event of the activity of academic work in group, the evaluation of the transferable competence is realized with a written report and an oral exposition. A rubric adapted to the learning activities designed in the subject has been constructed for the evaluation of the transferable competence. Such rubric allows to assess the acquisition degree of the transferable competence "Comprehension and Integration" in the subject. The scores obtained by the students in the academic year 2015-2016 are shown in the present work.
\end{abstract}

Keywords: transferable competence, comprehension and integration, fourth course, evaluation, oral exposition, written report, written question, written exam, rubric, academic work in group 


\section{Resumen}

El objetivo del presente trabajo es la propuesta de una metodología para el trabajo y evaluación de la competencia transversal UPV "Comprensión e Integración” a alumnos de cuarto curso a través de una asignatura que es punto de control en el curso académico 2015-2016 en la titulación del Grado en Ingeniería Química, concretamente en la asignatura de "Procesos de Fabricación de los Materiales de Construcción". Para ello se realiza el diseño de dos actividades de aprendizaje: preguntas escritas y trabajo académico en grupo. La evaluación de la competencia transversal con la actividad de aprendizaje de preguntas escritas se realiza mediante una cuestión en una prueba escrita de teoría al final del cuatrimestre. En el caso de la actividad de trabajo académico en grupo, la evaluación de la competencia transversal se realiza mediante un informe escrito y una exposición oral. Para la evaluación de la competencia transversal se ha construido una rúbrica adaptada a las actividades de aprendizaje diseñadas en la asignatura. Dicha rúbrica permite evaluar el grado de adquisión de la competencia transversal "Comprensión e Integración” en la asignatura. Las calificaciones obtenidas por los alumnos en el curso 2015-2016 se muestran en el presente trabajo.

Palabras clave: competencia transversal, comprensión e integración, cuarto curso, evaluación, exposición oral, informe escrito, pregunta escrita, prueba escrita, rúbrica, trabajo académico en grupo.

(cc) EY-NC-ND 2017, Universitat Politècnica de València 


\section{Introducción}

En el marco del Espacio Europeo de Educación Superior (EEES), la formación en competencias adquiere un protagonismo muy relevante (Universitat Politècnica de Catalunya, 2009). Los nuevos títulos de grado y posgrado adaptados al EEES incorporan la exigencia de que los estudiantes sean formados en competencias transversales o genéricas, formación cuyo logro debe ser constatado, es decir, evaluado. En este sentido, la Universitat Politècnica de València (UPV) inicia en el curso académico 2013-2014 un Proyecto sobre Competencias Transversales (Instituto de Ciencias de la Educación, 2016), desarrollándose de forma piloto en el curso académico 2014-2015 y comenzando a implantarse de forma definitiva en el curso académico 2015-2016. El objetivo fundamental del proyecto consiste en:

- Establecer una estrategia de evaluación sistemática de las competencias transversales, definiendo dónde se adquieren y cómo deben ser evaluadas.

- Acreditar la adquisición de dichas competencias.

Con la puesta en marcha de este proyecto, la UPV va a estar en situación de:

- Proporcionar a sus egresados un valor añadido que puede diferenciarlos de otros egresados y, en consecuencia, hacer más atractivos los estudios ofertados frente a ofertas similares de otras universidades.

- Poner en valor la capacitación de sus egresados de cara a los empleadores.

- Explicitar la adquisición de las competencias de cara a acreditaciones internacionales.

La UPV ha definido 13 competencias transversales UPV:

CT-01. Comprensión e integración.

CT-02. Aplicación y pensamiento práctico.

CT-03. Análisis y resolución de problemas.

CT-04. Innovación, creatividad y emprendimiento.

CT-05. Diseño y proyecto.

CT-06. Trabajo en equipo y liderazgo.

CT-07. Responsabilidad ética, medioambiental y profesional.

CT-08. Comunicación efectiva.

CT-09. Pensamiento crítico.

CT-10. Conocimiento de problemas contemporáneos.

CT-11. Aprendizaje permanente.

CT-12. Planificación y gestión del tiempo.

CT-13. Instrumental específica.

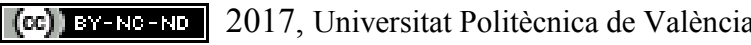

Congreso In-Red (2017) 
La UPV ha definido tres vías de evaluación para las competencias transversales UPV:

1. Durante el proceso formativo: a través de asignaturas que son punto de control.

2. Al finalizar los estudios: a través del TFG (Trabajo Final de Grado) y del TFM (Trabajo Final de Máster).

3. A través de actividades extracurriculares que evidencien el nivel alcanzado en cualquiera de las competencias transversales UPV.

En el caso de una asignatura que es punto de control de una competencia transversal UPV, además de trabajar la competencia, se deben:

- Diseñar actividades de aprendizaje y evaluación para poder evidenciar la adquisición o no de la competencia.

- $\quad$ Recoger evidencias de que la competencia se está trabajando y evaluando.

De ese modo, las competencias transversales se trabajarán en las asignaturas a través de las actividades de aprendizaje que diseñemos, enmarcadas en los contenidos de las asignaturas. Si pretendemos que los estudiantes adquieran las competencias transversales que propone la UPV, lo más importante será diseñar actividades que integren estas competencias con las propias de la materia (específicas) para que se adquieran ambas competencias de manera integrada. En esta línea, deberemos evaluar tanto el contenido propio de la asignatura como el nivel de adquisición de la competencia transversal.

El presente trabajo presenta una propuesta que describe el modo de adquirir y evaluar la competencia transversal UPV "Comprensión e integración" (CT-01) a alumnos de cuarto curso a través de una asignatura que es punto de control en la titulación del Grado en Ingeniería Química.

Según la definición de la UPV, la competencia transversal UPV "Comprensión e Integración" hace referencia a demostrar la comprensión e integración del conocimiento tanto de la propia especialización como en otros contextos más amplios. Comprender quiere decir "percibir y tener una idea clara de lo que se dice, se hace o sucede o descubrir el sentido profundo de algo". Para demostrar que algo se ha comprendido, la persona identifica y recupera la información y la explica con sus propias palabras, interpretando e integrando las ideas desde su propia perspectiva (Universitat Politècnica de València, 2016).

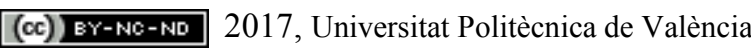




\section{Objetivos}

El objetivo del presente trabajo es la propuesta de una metodología para trabajar y evaluar el desarrollo de la competencia transversal UPV "Comprensión e Integración" en una asignatura de cuarto curso del grado en Ingeniería Química, la cual es punto de control para la evaluación de dicha competencia en el curso académico 2015-2016. Para ello se realiza el diseño de distintas actividades de aprendizaje y se construye una rúbrica adaptada a la asignatura, la cual permite evaluar el grado de adquisición de la competencia transversal.

\section{Desarrollo de la innovación}

\subsection{Contexto}

El ámbito de aplicación del presente trabajo corresponde a la asignatura de "Procesos de Fabricación de los Materiales de Construcción (PFMC)" de $4^{\circ}$ curso del grado en Ingeniería Química impartida en la Escuela Técnica Superior de Ingenieros Industriales (ETSII) de la UPV. Se trata de una asignatura optativa en la materia Menciones-ETSII (Procesos Industriales) dentro del Módulo de Itinerarios. La asignatura se imparte en el segundo cuatrimestre y consta de 4,5 créditos ECTS: 2,5 créditos de teoría, 1,1 créditos de prácticas de aula, 0,3 créditos de prácticas de laboratorio y 0,6 créditos de prácticas de campo. El número de alumnos matriculados en el curso académico 2015-2016 es 25. La asignatura es punto de control de la competencia transversal UPV “Comprensión e Integración”(CT-01) en el curso 2015-2016, siendo este curso el primero en el que se evaluará dicha competencia. Además, en la asignatura también se trabajan las competencias transversales UPV “Aplicación y Pensamiento Práctico" (CT-02) y “Comunicación Efectiva” (CT-08).

\subsection{Metodología}

La metodología propuesta en el presente trabajo consiste en la realización del diseño de dos tipos de actividades, una realizada de forma presencial y otra realizada de forma autónoma, las cuales permite trabajar y evaluar la competencia transversal UPV "Comprensión e Integración" en el curso académico 2015-2016:

1) Preguntas escritas. Actividad realizada de forma presencial a lo largo del cuatrimestre mediante la realización en clase de cuestiones de repaso al final de cada tema o cuestiones tras la observación de videos didácticos. La evaluación de dicha actividad se realiza al final del cuatrimestre mediante una prueba escrita de teoría de forma presencial ( $40 \%$ de la nota final de la asignatura).

2) Trabajo académico en grupo (informe escrito + exposición oral). Actividad realizada de forma autónoma a lo largo del cuatrimestre. La evaluación de dicha actividad se realiza al final de cuatrimestre mediante la redacción de un informe escrito ( $15 \%$ de la nota final de la asignatura) y la realización de una exposición oral de forma presencial (10\% de la nota final de la asignatura). 
El nivel de dominio en el que se trabaja y evalúa la competencia transversal UPV "Comprensión e Integración" corresponde al nivel de dominio II (4º curso de Grado). El resultado de aprendizaje que sería deseable que el alumno hubiese alcanzado al finalizar el $4^{\circ}$ curso de Grado es "proceder con lógica y relacionar e integrar conceptos en situaciones complejas". Para ello se definen una serie de indicadores, adaptados a las actividades diseñadas en la asignatura, los cuales serán las concreciones de ese resultado de aprendizaje y que ayudarán a centrar la atención en los aspectos que se han de analizar para detectar el grado de adquisión de la competencia transversal por parte de los alumnos.

\section{Resultados}

En el presente trabajo se muestran las distintas actividades de aprendizaje diseñadas para trabajar y evaluar la competencia transversal UPV “Comprensión e Integración” en la asignatura de "Procesos de Fabricación de los Materiales de Construcción" en el curso académico 2015-2016. También se muestra la rúbrica utilizada para evaluar la competencia transversal y las calificaciones obtenidas por los alumnos en el curso 2015-2016.

\subsection{Actividad de aprendizaje: Preguntas escritas \\ 4.1.1. Descripción de la actividad}

Los alumnos deben realizar a los largo del cuatrimestre una actividad de trabajo presencial en el aula basada en preguntas escritas. Las Unidades Didácticas de la asignatura donde se trabajará la competencia transversal corresponden a la Unidad Didáctica 2 sobre "Procesos de Fabricación de los Materiales Cerámicos usados en la Construcción" y a la Unidad Didáctica 3 sobre "Procesos de Fabricación de los Materiales Metálicos usados en la Construcción". Una de las formas en las que se trabaja dicha actividad en el aula es mediante la realización de cuestiones de repaso al final de cada tema. La otra forma en la que se trabaja la actividad es mediante la realización de cuestiones tras la observación de videos didácticos. La profesora entrega una hoja con diferentes cuestiones del tema finalizado o del video visto en clase, deja un tiempo en clase para que los alumnos las contesten de forma individual y luego se resuelven en clase entre todos preguntando a distintos alumnos al azar. En algunas de las cuestiones planteadas los alumnos tienen que clasificar y relacionar ideas o conceptos sobre los procesos de fabricación de los materiales usados en la construcción.

\subsubsection{Evaluación de la actividad}

La evaluación de dicha actividad se realiza al final del cuatrimestre mediante una prueba escrita de teoría de forma presencial (40\% de la nota final de la asignatura). En dicha prueba se plantean 4 cuestiones, una de estas cuestiones (10\% de la nota final de la asignatura) se usa para evaluar la competencia transversal sobre "Comprensión e Integración".

(c)) BY-NC-ND 2017, Universitat Politècnica de València 


\subsubsection{Duración de la actividad}

La actividad basada en la realización de preguntas escritas se desarrolla durante todo el cuatrimestre de forma presencial en clase.

\subsubsection{Resultados de aprendizaje concretos (indicadores)}

Partiendo de los indicadores de la rúbrica de la UPV para la competencia transversal “Comprensión e Integración", se vuelven a redactar los indicadores adaptándolos a las distintas actividades diseñadas en la asignatura. Para ello se hace uso de la Taxonomía de Bloom (Instituto de Ciencias de la Educación, 2006). El indicador redactado para evaluar la competencia transversal mediante la actividad de preguntas escritas queda de la siguiente forma:

Indicador 1-Rúbrica UPV: Clasifica y establece relaciones significativas entre distintas ideas o conceptos.

Adaptación del Indicador 1: Establece relaciones significativas entre distintas ideas o conceptos sobre los procesos de fabricación de los materiales usados en la construcción.

El indicador 1 se evalúa mediante una cuestión en la prueba escrita de teoría.

\subsection{Actividad de aprendizaje: Trabajo académico en grupo}

\subsubsection{Descripción de la actividad}

Los alumnos deben realizar a lo largo del cuatrimestre una actividad de trabajo autónomo basada en un trabajo académico en grupo (2-3 alumnos) sobre aplicaciones de los materiales usados en la construcción. La Unidad Didáctica de la asignatura donde se trabajará la competencia transversal corresponde a la Unidad Didáctica 4 sobre "Aplicaciones de los Materiales usados en la Construcción". La profesora presenta la actividad en clase al inicio del cuatrimestre (segunda semana del cuatrimestre) durante 1/2 hora presencial aproximadamente. La profesora propone distintas aplicaciones de los materiales usados en la construcción y la asignación a cada grupo se realiza por sorteo. Junto con el tema del trabajo, la profesora proporciona un guión con los puntos básicos a tratar en todos los trabajos.

Los alumnos entregan un informe escrito del trabajo (semanas 9-10). Previamente se les proporciona el formato que debe de tener el informe escrito.

Los alumnos realizan una exposición oral del trabajo 2 semanas después de la entrega del informe escrito (semanas 11-12). De esa forma la profesora puede corregir previamente el informe del trabajo y así comentar con los alumnos los posibles errores detectados antes de la exposición oral. El tiempo máximo para la realización de la exposición oral es de 15 minutos para cada grupo. La exposición oral la realizan todos los miembros del grupo. Antes de la exposición la profesora realiza un sorteo para determinar en qué orden van a 
intervenir cada miembro del grupo. No existe un guión-modelo para la presentación, pero si se les proporciona previamente las normas para la exposición oral. Al final de la exposición, la profesora realiza preguntas sobre aquellos aspectos que no han quedado claros. También se invita al resto de compañeros a que realicen preguntas a los alumnos que han realizado la exposición oral. Se realiza feedback de la exposición oral.

En cuanto al seguimiento por parte de la profesora, los alumnos pueden asistir a tutorías durante todo el cuatrimestre para resolver las dudas que puedan surgir en el trabajo. Se realiza una tutoría obligatoria presencial a mitad del cuatrimestre (semanas 6-7), durante $1 / 2$ hora presencial aproximadamente con cada grupo, para que la profesora pueda comprobar cómo están enfocando el trabajo y poderles orientar en la mejora del mismo (feedback).

\subsubsection{Evaluación de la actividad}

La nota del trabajo académico representa un $15 \%$ de la nota final de la asignatura: $10 \%$ el informe escrito y $5 \%$ la exposición oral. El informe escrito es evaluado solo por la profesora, mientras que utilizando la exposición oral es evaluada tanto por la profesora como por el resto de compañeros (evaluación entre iguales). La nota de cada alumno en la exposición oral es el promedio de la nota de la profesora y la media del resto de compañeros.

\subsubsection{Duración de la actividad}

La parte presencial de la actividad se realizará en 4 horas: $1 / 2$ hora al inicio del cuatrimestre para presentar la profesora la actividad a los alumnos y asignar los trabajos a cada grupo, $1 / 2$ hora a mitad del cuatrimestre para la tutoría obligatoria con cada grupo y 3 horas para las exposiciones orales de todos los trabajos.

La parte no presencial de la actividad consistirá en la elaboración del trabajo académico, tanto del informe escrito como de la presentación, durante todo el cuatrimestre.

\subsubsection{Resultados de aprendizaje concretos (indicadores)}

Partiendo de los indicadores de la rúbrica de la UPV para la competencia transversal "Comprensión e Integración", se vuelve a redactar los indicadores adaptándolos a la actividad de trabajo académico en grupo. Los indicadores redactados para evaluar la competencia transversal mediante la actividad de trabajo en grupo quedan de la siguiente forma:

Indicador 2-Rúbrica UPV: Proporciona sentido a los planteamientos que se le presentan para poder interpretarlos.

Adaptación del Indicador 2: Describe las características de una aplicación de los materiales usados en la construcción.

(cc) EY-NC-ND 2017, Universitat Politècnica de València

Congreso IN-RED (2017) 
Indicador 3-Rúbrica UPV: Diferencia los factores causantes o consecuentes de un hecho.

Adaptación del Indicador 3: Distingue las ventajas y los inconvenientes de una aplicación de los materiales usados en la construcción.

Indicador 4-Rúbrica UPV: Transfiere los contenidos a la práctica, integrándolos en un contexto.

Adaptación del Indicador 4: Proporciona y describe ejemplos reales de una aplicación de los materiales usados en la construcción.

Indicador 5-Rúbrica UPV: Integra elementos de distintas asignaturas o áreas en sus análisis de la realidad.

Adaptación del Indicador 5: Integra conocimientos de Corrosión, Economía, Seguridad, etc., en el análisis de ejemplos reales de una aplicación de los materiales usados en la construcción.

Los indicadores 2, 3 y 4 se evalúan mediante el informe escrito, mientras que el indicador 5 se evalúa mediante la exposición oral.

\subsection{Evaluación de la competencia transversal: rúbrica}

Partiendo de los indicadores adaptados a la asignatura se construye una rúbrica que permite evaluar el grado de adquisión de la competencia transversal UPV "Comprensión e Integración" mediante las actividades de preguntas escritas y trabajo académico en grupo. En el Anexo 1 se muestra la rúbrica que se usa para la evaluación de la Competencia Transversal UPV "Comprensión e Integración" en la asignatura de "Procesos de Fabricación de los Materiales de Construcción”. La rúbrica presenta 5 indicadores, que son concreciones del resultado de aprendizaje que el alumno debe adquirir en ese nivel de dominio. Para cada indicador se muestran los descriptores, que definen el comportamiento del alumno con respecto al indicador que se evalúa, los cuales se establecen en una escala de 4 valores: $\mathrm{D}$ (no alcanzado), C (en desarrollo), B (bien/adecuado) y A (excelente/ejemplar). El indicador 1 se evalúa mediante una cuestión en la prueba escrita de teoría. Los indicadores 2,3 y 4 se evalúan mediante el informe escrito del trabajo académico en grupo, mientras que el indicador 5 se evalúa mediante la exposición oral. En la Tabla 1 se muestra un resumen de la metodología seguida para el trabajo y evaluación de la Competencia Transversal UPV “Comprensión e Integración, con indicación de las actividades de aprendizaje y los instrumentos de evaluación utilizados para evaluar cada indicador, así como el peso asignado a cada indicador. 
Tabla 1. Metodología para el trabajo y evaluación de la competencia transversal UPV "Comprensión e Integración" en la asignatura "Procesos de Fabricación de los Materiales de Construcción”.

\begin{tabular}{|c|c|c|c|}
\hline Indicador & Peso & $\begin{array}{l}\text { Actividad de } \\
\text { aprendizaje }\end{array}$ & $\begin{array}{l}\text { Instrumento de } \\
\text { evaluación }\end{array}$ \\
\hline $\begin{array}{l}\text { Establece relaciones significativas entre } \\
\text { distintas ideas o conceptos sobre los } \\
\text { procesos de fabricación de los materiales } \\
\text { usados en la construcción }\end{array}$ & $20 \%$ & Preguntas escritas & $\begin{array}{c}\text { Una cuestión en la } \\
\text { prueba escrita de } \\
\text { teoría }\end{array}$ \\
\hline $\begin{array}{l}\text { Describe las características de una } \\
\text { aplicación de los materiales usados en la } \\
\text { construcción }\end{array}$ & $20 \%$ & $\begin{array}{c}\text { Trabajo académico } \\
\text { en grupo }\end{array}$ & Informe escrito \\
\hline $\begin{array}{l}\text { Distingue las ventajas y los } \\
\text { inconvenientes de una aplicación de los } \\
\text { materiales usados en la construcción }\end{array}$ & $20 \%$ & $\begin{array}{c}\text { Trabajo académico } \\
\text { en grupo }\end{array}$ & Informe escrito \\
\hline $\begin{array}{l}\text { Proporciona y describe ejemplos reales } \\
\text { de una aplicación de los materiales } \\
\text { usados en la construcción }\end{array}$ & $20 \%$ & $\begin{array}{c}\text { Trabajo académico } \\
\text { en grupo }\end{array}$ & Informe escrito \\
\hline $\begin{array}{l}\text { Integra conocimientos de Corrosión, } \\
\text { Economía, Seguridad, etc., en el análisis } \\
\text { de ejemplos reales de una aplicación de } \\
\text { los materiales usados en la construcción }\end{array}$ & $20 \%$ & $\begin{array}{c}\text { Trabajo académico } \\
\text { en grupo }\end{array}$ & Exposición oral \\
\hline
\end{tabular}

\subsection{Calificaciones de los alumnos}

En la Tabla 2 se muestran las calificaciones obtenidas por los alumnos en la evaluación de la competencia transversal UPV “Comprensión e Integración” en la asignatura de "Procesos de Fabricación de los Materiales de Construcción” en el curso 2015-2016. Cada casilla de la Tabla 2 se divide en dos partes: en la parte de la izquierda se muestra el número de alumnos que obtiene cada una de las calificaciones (D, C, B o A) y en la parte de la derecha se muestra el porcentaje de alumnos. El número de alumnos evaluados en el curso 2015 2016 fue 25.

Los resultados mostrados en la Tabla 2 indican que los alumnos obtienen buenos resultados en la evaluación de la competencia transversal. Para cada uno de los indicadores evaluados con la rúbrica (a excepción del indicador 1), el mayor porcentaje de alumnos obtiene una calificación de B (Bien/adecuado), no habiendo alumnos con calificación de D (No alcanzado). En el caso del indicador 1, el mayor porcentaje de alumnos (40\%) obtiene una calificación de A (Excelente/ejemplar), mientras que un $16 \%$ de los alumnos obtiene calificación de D (No alcanzado) y un $36 \%$ una calificación de C (En desarrollo). Tal como se muestra en la Tabla 1, la actividad de aprendizaje utilizada para trabajar ese indicador fue las preguntas escritas y el instrumento de evaluación utilizado fue una cuestión en la 
prueba escrita de teoría. Quizás esta actividad de aprendizaje e instrumento de evaluación no sean los más adecuados para trabajar y evaluar este indicador. Como propuesta de mejora para próximos cursos se debería de buscar otro tipo de actividad de aprendizaje e instrumento de evaluación, para así mejorar las calificaciones de los alumnos en ese indicador. Para ello sería conveniente realizar una encuesta a los alumnos sobre su percepción de la competencia transveral, lo que podría ayudar al profesorado en el diseño de las actividades para trabajar y evaluar la competencia transversal en la asignatura en próximos cursos.

Tabla 2. Calificaciones obtenidas por los alumnos en la evaluación de la competencia transversal UPV “Comprensión e Integración” en la asignatura "Procesos de Fabricación de los Materiales de Construcción” en el curso 2015-2016.

\begin{tabular}{|c|c|c|c|c|}
\hline \multirow[b]{2}{*}{ Indicador } & \multicolumn{4}{|c|}{ CALIFICACIONES } \\
\hline & 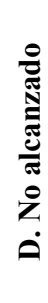 & 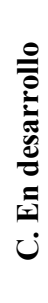 & 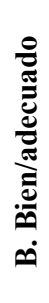 & 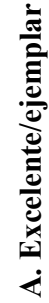 \\
\hline Indicador 1 & & & & \\
\hline Indicador 2 & & & & \\
\hline Indicador 3 & & & & \\
\hline Indicador 4 & & & & \\
\hline Indicador 5 & & & & \\
\hline
\end{tabular}

Indicador 1: Establece relaciones significativas entre distintas ideas o conceptos sobre los procesos de fabricación de los materiales usados en la construcción.

Indicador 2: Describe las características de una aplicación de los materiales usados en la construcción.

Indicador 3: Distingue las ventajas y los inconvenientes de una aplicación de los materiales usados en la construcción.

Indicador 4: Proporciona y describe ejemplos reales de una aplicación de los materiales usados en la construcción.

Indicador 5: Integra conocimientos de Corrosión, Economía, Seguridad, etc., en el análisis de ejemplos reales de una aplicación de los materiales usados en la construcción. 


\section{Conclusiones}

En este trabajo se ha realizado la propuesta de una metodología para el trabajo y evaluación de la competencia transversal UPV "Comprensión e integración" a alumnos de cuarto curso a través de una asignatura que es punto de control en el curso académico 2015-2016 en la titulación del Grado en Ingeniería Química. Para ello se realiza el diseño de dos actividades de aprendizaje: preguntas escritas y trabajo académico en grupo. La evaluación de la competencia transversal mediante la actividad de aprendizaje de preguntas escritas se realizará mediante una cuestión en una prueba escrita de teoría. En el caso de la actividad de trabajo académico en grupo, la evaluación de la competencia transversal se realizará mediante un informe escrito y una exposición oral. Para la evaluación de la competencia transversal se ha construido una rúbrica adaptada a las actividades de aprendizaje diseñadas en la asignatura. Dicha rúbrica permite evaluar el grado de adquisión de la competencia transversal "Comprensión e Integración" en la asignatura. Los alumnos obtienen buenos resultados en la evaluación de la competencia transversal. Para cada uno de los indicadores evaluados con la rúbrica (a excepción del indicador 1), el mayor porcentaje de alumnos obtiene una calificación de B (Bien/adecuado), no habiendo alumnos con calificación de D (No alcanzado). En el caso del indicador 1 aparacen alumnos con calificación de D (No alcanzado) y C (En desarrollo), por lo que quizás se debería de buscar para próximos cursos otro tipo de actividad de aprendizaje e instrumento de evaluación para trabajar y evaluar ese indicador, para así mejorar las calificaciones de los alumnos.

\section{Referencias}

INSTITUTO DE CIENCIAS DE LA EDUCACIÓN (2006). Plan de Acciones para la Convergencia Europea (PACE). Guía docente de la UPV: criterios para su elaboración. Valencia: Editorial de la Universidad de Politécnica de Valencia.

INSTITUTO DE CIENCIAS DE LA EDUCACIÓN (2016). http://www.upv.es/entidades/ICE/info/U0702452.pdf

UNIVERSITAT POLITÈCNICA DE CATALUNYA (2009). Sostenibilitat i compromís social. Quadern per treballar les competències genèriques a les assignatures. Institut de Ciències de l'Educació. Universitat Politècnica de Catalunya.

UNIVERSITAT POLITÈCNICA DE VALÈNCIA (2016). Competencias Transversales UPV. https://poliformat.upv.es/portal/site/ESP 0 2254/page/237ac1a0-4979-470e-bdcc$\underline{09 \mathrm{cc} 990 \mathrm{c} 3 \mathrm{f} 8 \mathrm{~b}}$ 
Anexo 1. Rúbrica para la evaluación de la competencia transversal UPV "Comprensión e Integración" en la asignatura de "Procesos de Fabricación de los Materiales de Construcción".

\begin{tabular}{|c|c|c|c|c|}
\hline \multirow{2}{*}{ INDICADORES } & \multicolumn{4}{|c|}{ DESCRIPTORES } \\
\hline & D. No alcanzado & C. En desarrollo & B. Bien/adecuado & A. Excelente/ejemplar \\
\hline $\begin{array}{l}\text { Establece relaciones significativas } \\
\text { entre distintas ideas o conceptos } \\
\text { sobre los procesos de fabricación } \\
\text { de los materiales usados en la } \\
\text { construcción }\end{array}$ & $\begin{array}{ll}\text { Solo } & \text { establece } \\
\text { relaciones } & \text { obvias o } \\
\text { establece relaciones } \\
\text { incorrectas }\end{array}$ & $\begin{array}{l}\text { Establece relaciones } \\
\text { correctas pero poco } \\
\text { significativas }\end{array}$ & $\begin{array}{l}\text { Establece relaciones } \\
\text { significativas (de tipo } \\
\text { temporal, jerárquico, } \\
\text { etc.) entre distintas } \\
\text { ideas o conceptos }\end{array}$ & $\begin{array}{l}\text { Argumenta las } \\
\text { relaciones identificadas } \\
\text { y extrae conclusiones }\end{array}$ \\
\hline $\begin{array}{l}\text { Describe las características de una } \\
\text { aplicación de los materiales usados } \\
\text { en la construcción }\end{array}$ & $\begin{array}{lr}\text { Describe } & \text { las } \\
\text { características de la } \\
\text { aplicación de forma } \\
\text { incorrecta }\end{array}$ & $\begin{array}{l}\begin{array}{l}\text { Describe } \\
\text { parcialmente } \\
\text { características } \\
\text { aplicación }\end{array} \text { de las } \\
\text { la }\end{array}$ & $\begin{array}{l}\begin{array}{l}\text { Describe de } \\
\text { significativa }\end{array} \\
\begin{array}{l}\text { forma } \\
\text { características }\end{array} \\
\begin{array}{l}\text { aplicación } \\
\text { de }\end{array}\end{array}$ & $\begin{array}{lr}\text { Describe con detalle } \mathbf{y} \\
\text { claridad } & \text { las } \\
\text { características de la } \\
\text { aplicación }\end{array}$ \\
\hline $\begin{array}{l}\text { Distingue las ventajas y los } \\
\text { inconvenientes de una aplicación } \\
\text { de los materiales usados en la } \\
\text { construcción }\end{array}$ & $\begin{array}{l}\text { Distingue las ventajas } \\
\text { e inconvenientes de la } \\
\text { aplicación de forma } \\
\text { incorrecta }\end{array}$ & 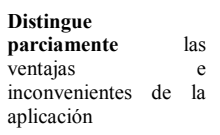 & $\begin{array}{lr}\begin{array}{l}\text { Distingue } \\
\text { adecuadamente }\end{array} & \text { las } \\
\text { ventajas } & \text { e } \\
\text { inconvenientes de } & \text { la } \\
\text { aplicación } & \end{array}$ & $\begin{array}{l}\text { Distingue las ventajas } \\
\text { e inconvenientes de la } \\
\text { aplicación, realizando } \\
\text { una clasificación por } \\
\text { orden de importancia }\end{array}$ \\
\hline $\begin{array}{l}\text { Proporciona y describe ejemplos } \\
\text { reales de una aplicación de los } \\
\text { materiales usados en la } \\
\text { construcción }\end{array}$ & $\begin{array}{l}\text { No proporciona } \\
\text { ejemplos reales de la } \\
\text { aplicación }\end{array}$ & $\begin{array}{l}\text { Proporciona algunos } \\
\text { ejemplos reales de la } \\
\text { aplicación, pero los } \\
\text { describe parcialmente }\end{array}$ & $\begin{array}{l}\text { Proporciona ejemplos } \\
\text { reales de la aplicación } \\
\text { y los describe de } \\
\text { forma adecuada }\end{array}$ & $\begin{array}{l}\text { Proporciona ejemplos } \\
\text { reales de la aplicación, } \\
\text { realizando una } \\
\text { descripción detallada }\end{array}$ \\
\hline $\begin{array}{l}\text { Integra conocimientos de } \\
\text { Corrosión, Economía, Seguridad, } \\
\text { etc., en el análisis de ejemplos } \\
\text { reales de una aplicación de los } \\
\text { materiales usados en la } \\
\text { construcción }\end{array}$ & $\begin{array}{l}\text { No relaciona } \\
\text { elementos o conceptos } \\
\text { de distintas asignaturas }\end{array}$ & $\begin{array}{l}\text { Establece relaciones } \\
\text { entre } \quad \text { algunos } \\
\text { elementos o conceptos } \\
\text { de distintas asignaturas }\end{array}$ & $\begin{array}{l}\text { Integra conocimientos } \\
\text { de distintas asignaturas } \\
\text { de la misma área de } \\
\text { conocimiento }\end{array}$ & $\begin{array}{l}\text { Integra conocimientos } \\
\text { de r distintas } \\
\text { disciplinas o áreas de } \\
\text { conocimiento }\end{array}$ \\
\hline
\end{tabular}




\title{
Estrategia para evaluar la competencia transversal "Aprendizaje Permanente" en la asignatura Transductores e Instrumentación Acústica
}

\author{
Jesús Alba Fernández ${ }^{a}$ y Romina del Rey Tormos ${ }^{a}$ \\ ${ }^{a}$ Universitat Politècnica de Valéncia, Escuela Politécnica Superior de Gandia, Departamento de Física \\ Aplicada, C/Paraninfo n ${ }^{\circ} 1$ - 46715 Grao de Gandia. jesalba@fis.upv.es, roderey@doctor.upv.es
}

\begin{abstract}
Use the learning in a strategically, autonomously and flexibly way, throughout life, according to the pursued objective is one of the transversal competences that is control item of the subject entitled "Transducers and Acoustic Instrumentation". This subject belong to the Bachelor's Degree in Engineering of Telecommunications Systems, Sound and Image. During the 2015-2016 academic year, we have initiated and presented strategies for start up the mechanisms in order to work and evaluate this transversal competence. We have defined a number of improvements for the 2016-2017 academic year. These improvements have based on the results obtained during the 2015-2016 academic year. This paper shows the evolution and valuation of the last two academic years
\end{abstract}

Keywords: transversal competence, lifelong learning, rubrics, the minute test, assessment, learning outcomes.

\section{Resumen}

Utilizar el aprendizaje de manera estratégica, autónoma y flexible, a lo largo de toda la vida, en función del objetivo perseguido es una de las competencias transversales que es punto de control de la asignatura "Transductores e Instrumentación Acústica" de la titulación del Grado en Ingeniería de Sistemas de Telecomunicación, Sonido e Imagen. En el curso 2015-2016 se iniciaron y presentaron estrategias de puesta en marcha de mecanismos para trabajarla en la asignatura y evaluarla. En base a los resultados obtenidos se definieron una serie de mejoras para el curso 20162017. En este trabajo se muestra la evolución y valoración de los dos cursos.

Palabras clave: competencia transversal, aprendizaje permanente, rúbricas, prueba del minuto, evaluación, resultados del aprendizaje. 


\section{Introducción}

Una definición de consenso de "competencia transversal" hace referencia a aquella habilidad relacionada con el desarrollo personal, que no depende de un ámbito temático o disciplinario especifico sino que aparece en todos los dominios de la actuación profesional y académica (González y Wagenaar, 2003). Estas habilidades deben utilizarlas los alumnos en base a diferentes estrategias. Su certificación, como un resultado de aprendizaje más, pasa por definir la forma en que se van a evaluar. Las competencias transversales toman más relevancia en los procesos de acreditación de la calidad de las titulaciones, en sellos internacionales. Es interesante también tener en cuenta referencias sobre la enseñanza basada en competencias (De Miguel, 2006) (Villa y Poblete, 2007).

A nivel particular de cada asignatura pueden proponerse diferentes actividades formativas que colaboren en el desarrollo de la competencia (actividades grupales, exposición oral, proyectos, trabajos, etc.) que deben tener mecanismos de evaluación acordes con la competencia (prácticas, proyectos, cuestionarios, etc.).

La competencia transversal "Aprendizaje Permanente" es una de las 13 competencias transversales que la Universitat Politécnica de Valencia pretende acreditar (UPV, 2016). Esta competencia se define como "Utilizar el aprendizaje de manera estratégica, autónoma y flexible, a lo largo de toda la vida, en función del objetivo perseguido". Un punto fundamental de esta competencia es el no conformarse con reproducir de manera rutinaria soluciones ya conocidas, sino generar nuevas soluciones o soluciones adaptadas a nuevas situaciones (UPV, 2016). Es una competencia transversal compleja de implementar con menor tradición en evaluarse, que requiere una estrategia distinta en función de la asignatura donde se aplique.

En este trabajo se resume la experiencia de la evaluación de esta competencia transversal en la asignatura "Transductores e Instrumentación Acústica" durante los cursos 2015-2016 y 2016-2017. En el curso 2015-2016 la asignatura pasó a ser punto de control de dicha competencia y se presentaron diferentes iniciativas para su evaluación, planteando actividades para trabajarla, y recogiendo evidencias de los logros alcanzados. Resultados al respecto se presentaron en el congreso IN-RED 2016 (Alba y Del Rey, 2016). En 20162017 se han realizado algunos cambios, en base al DAFO que se planteó en el citado trabajo.

\section{Objetivos}

En la Escuela Politécnica Superior de Gandía (EPSG), en el Grado en Ingeniería de Sistemas de Telecomunicación Sonido e Imagen (GISTSI) se ubica la asignatura "Transductores e Instrumentación Acústica" (TIA) de tercer curso (quinto semestre) en la

(c)) BY-NC-ND 2017, Universitat Politècnica de València

Congreso IN-RED (2017) 
que se ha trabajado durante dos cursos académicos (2015-2016 y 2016- 2017) la competencia transversal "Aprendizaje Permanente", siendo esta asignatura punto de control. En el curso 2015-2016 se incorporó esta competencia transversal y mecanismos para poder evaluarla, y se hizo un análisis DAFO (Alba y Del Rey, 2016). En base al análisis de lo desarrollado en 2015-2016 se plantean modificaciones que se han aplicado en 2016-2017.

Son varios los actos evaluativos que aparecen en la guía docente de la asignatura, que se detallan en el apartado siguiente. La idea fundamental de los cambios aplicados es buscar en cada acto evaluativo indicios de esta competencia transversal. La UPV usa una escala que se utiliza de forma normalizada con los siguientes saltos: A-Excelente, B-Adecuado, CEn Desarrollo y D-No alcanzada. Por tanto, además de buscar estos indicios, han de poder clasificarse o categorizarse para poder obtener una valoración final.

Hay que tener en cuenta que, en general, las competencias transversales no parecen fáciles de evaluar. En el caso concreto del "Aprendizaje Permanente" que se define en la UPV como "utilizar el aprendizaje de manera estratégica, autónoma y flexible, a lo largo de toda la vida, en función del objetivo perseguido" aún parece más complicada. Sin embargo, en la asignatura "Transductores e Instrumentación Acústica", están claros los objetivos perseguidos respecto a sistemas electroacústicos y conocimientos y aplicabilidad de la instrumentación en el campo de la acústica, lo que puede facilitar la búsqueda de indicios.

\section{Desarrollo de la innovación}

La asignatura "Transductores e Instrumentación Acústica" se ubica en tercer curso del GISTSI con 4,5 créditos ECTS distribuidos en 2,5 créditos para teoría de aula, 1 crédito en práctica de aula y 1 crédito de práctica de laboratorio. Es una asignatura optativa de la materia "Sonido e Imagen", que se ubica en tercero y optativa para alumnos de cuarto. Para el curso 2015-2016 sólo se tenía un grupo para teoría de aula y práctica de aula, y dos grupos para práctica de laboratorio. Los recortes de recursos han hecho que en el curso 2016-2017 se eliminara el segundo grupo de prácticas, reduciendo así la capacidad docente y aumentando el tamaño del grupo.

La planificación seguida este último curso 2016-2017 se muestra en la tabla 1. En (Alba y Del Rey, 2016) puede verse la del curso anterior. En la tabla 1 se observa la carga semanal del alumno y los diferentes actos evaluativos definidos. En la tabla 2 se muestra un resumen de los porcentajes de evaluación. Se ha seguido durante los dos cursos el mismo procedimiento.

(c)) EY-NC-ND 2017, Universitat Politècnica de València

Congreso In-Red (2017) 
Tabla 1. Planificación TIA 2016-2017

\begin{tabular}{|c|c|c|c|c|c|}
\hline Fecha & Día & Hora & RECINTO & CONTENIDO & EVALUACION \\
\hline $05 / 09 / 2016$ & $\mathrm{~L}$ & $10: 45$ & AULA 18 & $\begin{array}{l}\text { PRESENTACION. } \\
\text { TEMA } 1\end{array}$ & \\
\hline $07 / 09 / 2016$ & $X$ & $12: 15$ & AULA 18 & TEMA 1 & \\
\hline $12 / 09 / 2016$ & $\mathrm{~L}$ & $10: 45$ & AULA 18 & TEMA 1 & \\
\hline $14 / 09 / 2016$ & $\mathrm{X}$ & $12: 15$ & AULA 18 & TEMA 1 & \\
\hline $19 / 09 / 2016$ & $\mathrm{~L}$ & $10: 45$ & AULA 18 & TEMA 1 & \\
\hline $21 / 09 / 2016$ & $X$ & $12: 15$ & AULA 18 & TEMA 1 & PRUEBA ESCRITA 1 \\
\hline $26 / 09 / 2016$ & $\mathrm{~L}$ & $10: 45$ & AULA 18 & TEMA 2 & \\
\hline $28 / 09 / 2016$ & $X$ & $12: 15$ & AULA 18 & TEMA 2 & \\
\hline $05 / 10 / 2016$ & $X$ & $12: 15$ & AULA 18 & TEMA 2 & \\
\hline $10 / 10 / 2016$ & $\mathrm{~L}$ & $10: 45$ & AULA 18 & TEMA 2 & PRUEBA ESCRITA 2 \\
\hline $17 / 10 / 2016$ & $\mathrm{~L}$ & $10: 45$ & AULA 18 & TEMA 2 & \\
\hline $19 / 10 / 2016$ & $\mathbf{X}$ & 12:15 & B009 & PRACTICA 1 & \\
\hline $24 / 10 / 2016$ & $\mathrm{~L}$ & $10: 45$ & AULA 18 & TEMA 2 & PRUEBA ESCRITA 3 \\
\hline $26 / 10 / 2016$ & $\mathbf{X}$ & $12: 15$ & B004 & PRACTICA 2 & $\begin{array}{l}\text { Entrega práctica } 1 . \\
\text { Prueba minuto } 1 .\end{array}$ \\
\hline $02 / 11 / 2016$ & $\mathrm{X}$ & $12: 15$ & AULA 18 & TEMA 3 & \\
\hline $07 / 11 / 2016$ & $\mathrm{~L}$ & $10: 45$ & AULA 18 & TEMA 3 & \\
\hline $09 / 11 / 2016$ & $\mathbf{X}$ & 12:15 & B009 & PRACTICA 3 & $\begin{array}{l}\text { Entrega práctica } 2 . \\
\text { Prueba minuto } 2\end{array}$ \\
\hline $14 / 11 / 2016$ & $\mathrm{~L}$ & $10: 45$ & AULA 18 & TEMA 3 & PRUEBA ESCRITA 4 \\
\hline $16 / 11 / 2016$ & $\mathrm{X}$ & $12: 15$ & AULA 18 & TEMA 4 & \\
\hline $21 / 11 / 2016$ & $\mathrm{~L}$ & $10: 45$ & AULA 18 & TEMA 4 & \\
\hline $23 / 11 / 2016$ & $\mathbf{X}$ & 12:15 & B009 & PRACTICA 4 & $\begin{array}{l}\text { Entrega práctica } 3 . \\
\text { Prueba minuto } 3 .\end{array}$ \\
\hline $28 / 11 / 2016$ & $\mathrm{~L}$ & $10: 45$ & AULA 18 & TEMA 4 & PRUEBA ESCRITA 5 \\
\hline $30 / 11 / 2016$ & $\mathbf{X}$ & $12: 15$ & B009 & PRACTICA 5/PROYECTO & $\begin{array}{l}\text { Entrega práctica } 4 . \\
\text { Prueba minuto } 4 .\end{array}$ \\
\hline $05 / 12 / 2016$ & $\mathrm{~L}$ & $10: 45$ & B009 & TEMA 5/PROYECTO & PRUEBA ESCRITA 6 \\
\hline $07 / 12 / 2016$ & $\mathrm{X}$ & $12: 15$ & B009 & PROYECTO/TEMA 5 & \\
\hline $12 / 12 / 2016$ & $\mathrm{~L}$ & $10: 45$ & B009 & PROYECTO/TEMA 5 & \\
\hline $14 / 12 / 2016$ & $\mathrm{X}$ & $12: 15$ & B009 & PROYECTO/TEMA 5 & \\
\hline $19 / 12 / 2016$ & $\mathrm{~L}$ & $10: 45$ & B009 & PROYECTO/TEMA 5 & \\
\hline $21 / 12 / 2016$ & $\mathrm{X}$ & $12: 15$ & B009 & PROYECTO/TEMA 5 & $\begin{array}{l}\text { Entrega práctica } 5 . \\
\text { Prueba minuto } 5 . \\
\text { PROYECTO }\end{array}$ \\
\hline
\end{tabular}

(c) EY-NC-ND 2017, Universitat Politècnica de València 
Tabla 2. Resumen de la evaluación TIA

\begin{tabular}{|l|l|l|l|}
\hline Tipo & Descripción & Actos & Peso \\
\hline $\begin{array}{l}\text { Pruebas escritas } \\
\text { de respuestas } \\
\text { abierta }\end{array}$ & $\begin{array}{l}\text { Prueba cronometrada, efectuada bajo control, en la } \\
\text { que el alumno construye su respuesta. (Clásico } \\
\text { problema). }\end{array}$ & 5 & $30 \%$ \\
\hline $\begin{array}{l}\text { Evaluación de } \\
\text { prácticas }\end{array}$ & $\begin{array}{l}\text { Informe de cada práctica (informe redactado) y } \\
\text { prueba del minuto. }\end{array}$ & 5 & $25 \%$ \\
\hline Proyecto/PBL & $\begin{array}{l}\text { Los estudiantes por grupos desarrollan un producto } \\
\text { nuevo y propio. }\end{array}$ & 1 & $35 \%$ \\
\hline Coevaluación & Coevaluación unos grupos a otros & 1 & $5 \%$ \\
\hline Autoevaluación & Autoevaluación del grupo y personal. & 1 & $5 \%$ \\
\hline
\end{tabular}

En el curso 2016-2017 se unifican y se simplifican las rúbricas de evaluación entre pares, ya que como se evidenció en el curso anterior, las primeras versiones eran bastante complejas y a los alumnos les costaba interpretarlas (Alba y Del Rey, 2016). En la tabla 4 se muestra la rúbrica de autoevaluación del grupo. En la tabla 5 se muestra la rúbrica de autovaloración individual y por último, en la tabla 6 se muestra la rúbrica de valoración del resto de compañeros de un grupo. Estás últimas se han mantenido en casi su totalidad respecto al curso anterior.

Tabla 3. Rúbrica de evaluación entre pares para presentación oral

\begin{tabular}{|l|l|l|l|l|l|l|}
\hline $\begin{array}{l}\text { Competencias } \\
\text { (1-Malo 2-Regular } \\
\text { 3-Bueno 4-Excelente) }\end{array}$ & GR-1 & GR-2 & GR-3 & GR-4 & GR-5 & GR-6 \\
\hline $\begin{array}{l}\text { 1) Es capaz de diseñar el } \\
\text { equipo/objeto }\end{array}$ & & & & & & \\
\hline $\begin{array}{l}\text { 2) Define los objetivos y las } \\
\text { variables del trabajo }\end{array}$ & & & & & & \\
\hline $\begin{array}{l}\text { 3) Aplicación de criterios } \\
\text { ingenieriles }\end{array}$ & & & & & & \\
\hline $\begin{array}{l}\text { 4) Define los objetivos y las } \\
\text { variables de decisión de su } \\
\text { proyecto }\end{array}$ & & & & & & \\
\hline 5) Resolución del problema & & & & & & \\
\hline 6) Mecánica de la presentación & & & & & & \\
\hline 7) Material de presentación & & & & & & \\
\hline $\begin{array}{l}\text { NOTA GLOBAL PROPUESTA } \\
\text { (0 A 10) }\end{array}$ & & & & & & \\
\hline
\end{tabular}

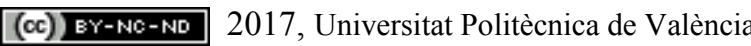

Congreso In-Red (2017) 
Tabla 4. Rúbrica Autoevaluación 1. Cada miembro del grupo evalua a todo el grupo pensando que funcionan como un equipo

\begin{tabular}{|c|c|c|c|c|c|}
\hline Criterios & $\begin{array}{l}\text { EXCELENTE } \\
(4)\end{array}$ & $\begin{array}{l}\text { BIEN } \\
(3)\end{array}$ & $\begin{array}{l}\text { REGULAR } \\
(2)\end{array}$ & $\begin{array}{l}\text { FLOJO } \\
(1)\end{array}$ & $(1-4)$ \\
\hline $\begin{array}{l}\text { Participación } \\
\text { GRUPAL }\end{array}$ & $\begin{array}{l}\text { Todos hemos } \\
\text { participado con } \\
\text { entusiasmo }\end{array}$ & $\begin{array}{lr}\text { Al menos } & \text { el } \\
75 \% & \text { ha } \\
\text { participado } & \\
\text { activamente } & \end{array}$ & $\begin{array}{l}\text { Al menos la } \\
\text { mitad presentan } \\
\text { ideas propias }\end{array}$ & $\begin{array}{l}\text { Sólo una } \\
\text { persona } \\
\text { participa } \\
\text { activamente }\end{array}$ & \\
\hline $\begin{array}{l}\text { Responsabilidad } \\
\text { COMPARTIDA }\end{array}$ & $\begin{array}{l}\text { Todos } \\
\text { compartimos } \\
\text { por igual la } \\
\text { responsabilidad }\end{array}$ & $\begin{array}{l}\text { La mayor parte } \\
\text { de los miembros } \\
\text { comparten la } \\
\text { responsabilidad }\end{array}$ & $\begin{array}{l}\text { La } \\
\text { responsabilidad } \\
\text { es compartida } \\
\text { por la mitad de } \\
\text { los miembros }\end{array}$ & $\begin{array}{l}\text { La } \\
\text { responsabilidad } \\
\text { recae en una } \\
\text { sola persona }\end{array}$ & \\
\hline $\begin{array}{l}\text { Calidad de la } \\
\text { INTERACCION }\end{array}$ & $\begin{array}{lr}\text { Habilidades } & \text { de } \\
\text { liderazgo } & y \\
\text { saber escuchar; } & \\
\text { conciencia de } \\
\text { los puntos de } \\
\text { vista } \\
\text { opiniones de los } \\
\text { demás }\end{array}$ & $\begin{array}{l}\text { Se conducen } \\
\text { animadas } \\
\text { discusiones } \\
\text { centradas en la } \\
\text { tarea }\end{array}$ & $\begin{array}{lr}\begin{array}{l}\text { Alguna } \\
\text { habilidad }\end{array} \\
\text { interacción: } & \text { se } \\
\text { escucha } & \text { con } \\
\text { atención. } & \\
\text { Alguna } & \\
\text { evidencia de } & \text { discusión } \\
\text { planteamiento } \\
\text { de alternativas }\end{array}$ & $\begin{array}{l}\text { Muy poca } \\
\text { interacción: } \\
\text { conversación } \\
\text { muy breve, } \\
\text { algunos } \\
\text { compañeros } \\
\text { distraídos o } \\
\text { desinteresados }\end{array}$ & \\
\hline $\begin{array}{l}\text { ROLES dentro } \\
\text { del grupo }\end{array}$ & $\begin{array}{l}\text { Cada miembro } \\
\text { tiene un rol } \\
\text { definido: } \\
\text { desempeño } \\
\text { efectivo de roles }\end{array}$ & $\begin{array}{l}\text { Cada miembro } \\
\text { tiene un rol } \\
\text { asignado pero } \\
\text { no } \\
\text { claramente } \\
\text { definido o no es } \\
\text { consistente }\end{array}$ & $\begin{array}{l}\text { Hay roles } \\
\text { asignados pero } \\
\text { no se adhieren } \\
\text { consistentement } \\
\text { e a ellos }\end{array}$ & $\begin{array}{l}\text { No hay ningún } \\
\text { esfuerzo de } \\
\text { asignar roles }\end{array}$ & \\
\hline
\end{tabular}

Tabla 5. Rúbrica Autoevaluación 2: cada miembro se autoevalua -autocalifica la participacion el proyecto (mi autoevaluación) Puntos: 0-nada, 1-poco, 2-suficiente, 3 - mucho

\begin{tabular}{|c|c|c|c|}
\hline CRITERIO & $\begin{array}{l}\text { PUNTOS } \\
(0-3)\end{array}$ & CRITERIO & $\begin{array}{l}\text { PUNTOS } \\
(0-3)\end{array}$ \\
\hline a. Respeto turnos o tiempo & & j. Soy paciente & \\
\hline $\begin{array}{l}\text { b. Intervengo en el contexto del } \\
\text { trabajo cuando creo necesario }\end{array}$ & & k. Mostré conocimientos previos & \\
\hline c. Aporto sugerencias & & $\begin{array}{lcr}\text { l. Poseo } & \text { habilidad } & \text { para } \\
\text { determinar } & \text { alternativas } & \text { de } \\
\text { solución frente a problemas } & \\
\end{array}$ & \\
\hline d. Apoyo otras sugerencias & & $\begin{array}{l}\text { m. Considero consecuencias al } \\
\text { momento de decidir sobre cómo } \\
\text { aporto al trabajo }\end{array}$ & \\
\hline e. Apoyo otras opiniones & & n. Identifico las oportunidades & \\
\hline f. Aporté con temas al grupo & & ñ. Tengo facilidad para tomar & \\
\hline
\end{tabular}




\begin{tabular}{|c|c|}
\hline & decisiones \\
\hline g. Opino razonadamente & o. Mi nivel de aportación es... \\
\hline h. Acepto ideas & p. Cumplo tareas \\
\hline $\begin{array}{l}\text { i. Favorezco las actitudes } \\
\text { integradoras }\end{array}$ & $\begin{array}{l}\text { q. Mis tareas al interior del grupo } \\
\text { fueron terminadas }\end{array}$ \\
\hline
\end{tabular}

Tabla 6. Rúbrica 3 autoevaluación. Cada miembro del grupo evalua al resto de sus compañeros.

Hay una tabla para cada compañero

\begin{tabular}{|c|c|c|c|c|c|}
\hline Criterios & EXCELENTE (4) & BIEN (3) & REGULAR (2) & FLOJO (1) & $P(1-4)$ \\
\hline $\begin{array}{l}\text { Interactividad } \\
\text { uno a uno }\end{array}$ & $\begin{array}{lr}\text { Parafrasea } & \text { para } \\
\text { mostrar } & \text { la } \\
\text { comprensión. } & \\
\text { Aprende de } & \text { los } \\
\text { demás. } & \text { Da } \\
\text { retroalimentación } \\
\text { positiva. } \\
\text { sugerencias. }\end{array}$ & $\begin{array}{l}\mathrm{Da} \\
\text { retroalimentación } \\
\text { positivar } \quad \mathrm{Se} \\
\text { muestra algo } \\
\text { interesado. }\end{array}$ & $\begin{array}{l}\text { Hace saber a sus } \\
\text { compañeros que lee } \\
\text { los mensajes }\end{array}$ & $\begin{array}{lr}\text { Sigue } & \text { el } \\
\text { proceso } & \text { del } \\
\text { grupo } & \end{array}$ & \\
\hline Contribución & $\begin{array}{l}\text { Genera nuevas ideas } \\
\text { con base en un } \\
\text { análisis cuidadoso } \\
\text { del proceso y de los } \\
\text { recursos }\end{array}$ & $\begin{array}{l}\text { Fundamenta las } \\
\text { ideas del grupo } \\
\text { usando múltiples } \\
\text { fuentes }\end{array}$ & $\begin{array}{l}\text { Muestra información } \\
\text { relevante de fuentes } \\
\text { de información } \\
\text { válidas } \\
\text { identificadas }\end{array}$ & $\begin{array}{l}\text { Envía datos } \\
\text { o } \\
\text { información }\end{array}$ & \\
\hline $\begin{array}{l}\text { Responsabilid } \\
\text { ad }\end{array}$ & $\begin{array}{l}\text { Ayuda a organizar el } \\
\text { trabajo y planea } \\
\text { contactos. Ayuda a } \\
\text { todos a cumplir con } \\
\text { sus compromisos }\end{array}$ & $\begin{array}{l}\text { Planea el trabajo } \\
\text { con otros } \\
\text { miembros. } \\
\text { Comparte su plan } \\
\text { individual. }\end{array}$ & $\begin{array}{l}\text { Es confiable, entrega } \\
\text { la información en los } \\
\text { tiempos convenidos }\end{array}$ & $\begin{array}{l}\text { Entrega la } \\
\text { información } \\
\text { pero fuera } \\
\text { de los } \\
\text { tiempos } \\
\text { convenidos }\end{array}$ & \\
\hline $\begin{array}{l}\text { Discusión } \\
\text { para la } \\
\text { construcción } \\
\text { del } \\
\text { conocimiento }\end{array}$ & $\begin{array}{l}\text { Muestra acuerdos y } \\
\text { desacuerdos. Sirve } \\
\text { de mediador para } \\
\text { hacer que las ideas } \\
\text { avancen }\end{array}$ & $\begin{array}{l}\text { Construye ideas, } \\
\text { resume, sintetiza }\end{array}$ & $\begin{array}{l}\text { Anima a los demás, } \\
\text { parafrasea ideas, } \\
\text { mantiene la } \\
\text { conversación } \\
\text { enfocada en el } \\
\text { problema, construye } \\
\text { argumentos lógicos. }\end{array}$ & $\begin{array}{lr}\text { Hace } & \text { saber } \\
\text { a r sus } \\
\text { compañeros } \\
\text { que está } \\
\text { leyendo sus } \\
\text { mensajes }\end{array}$ & \\
\hline
\end{tabular}

La competencia transversal de "aprendizaje permanente" se va evaluando en base a indicadores que se definen en las pruebas evaluativas (tabla 2), teniendo en cuenta la escala A-Excelente, B-Adecuado, C-En Desarrollo y D-No alcanzada:

- Pruebas escritas: se revisan los materiales que usan los alumnos cuando la resuelven valorando si se limitan a cumplir los mínimos o han buscado materiales alternativos. No traer nada se califica "D", limitarse a traer lo aportado por el profesor se califica " $\mathrm{C}$ " o " $\mathrm{B}$ " en función de si el material está trabajado y traer nuevo material relevante para la prueba escrita se califica " $\mathrm{A}$ ".

- Memorias de prácticas: han de hacer referencia a normativas, leyes y procedimientos en las que se basa, viendo el grado de profundización. No aportar

(c)) EY-NC-ND 2017, Universitat Politècnica de València

Congreso In-Red (2017) 
ninguna referencia se califica " $D$ ". Aportar alguna referencia pero incompleta $u$ obsoleta se califica "C". "B" para el caso en que hayan referencias actualizadas y "A" en el caso de revisar normativas o referencias alternativas.

- Pregunta del minuto: se relaciona directamente con el aprendizaje permanente. En el desarrollo de cada práctica se citan enlaces y referencias. Por ejemplo, en el caso de medidas de directividad se cita a la Audio Engineering Society, muy relacionada con este tipo de medidas. En la pregunta del minuto se pregunta sobre el parámetro de medida y su unidad. Quien ha tenido interés contesta hablando de lo que la AES recomienda. El que no se ha preocupado, contesta simplemente lo medido con la memoria de prácticas. Las preguntas evolucionan hasta el punto de dar diferentes referencias y formas de búsqueda que permiten más de una contestación válida, pero que requiere profundizar en el tema. No contestar se califica "D". Contestar en base a lo medido se califica como "C" o "B" en función del grado de detalle y claridad. Aportar alguna magnitud adicional no explicada en la práctica se califica como “A.

- PBL: en principio el proyecto se puede definir de forma abierta. El grado de autonomía y estrategia seguido para la realización es lo que se tiene en cuenta. Se puede proponer un trabajo por parte del alumno. En función del grado de detalle, su grado de resolución y las rúbricas, se califica " $A$ " o "B". En el caso del trabajo proporcionado por el profesor se califica "B" o " $\mathrm{C}$ " en función del grado de realización y rubricas. En casos excepcionales como "A" si aporta algo nuevo no contemplado en el diseño original. Proyectos inacabados o con resolución inapropiada se califican como " $\mathrm{D}$ ".

Como hay que aportar una única valoración desde "A" hasta " $D$ ", se valora una evaluación progresiva. Se ponderan con más peso las últimas entregas, y en función del porcentaje de ponderación de las pruebas. Se ordinalizan las letras de $D=1$ hasta $A=4$. Se obtiene un valor numérico entre 1 y 4 que se redondea al valor entero más cercano y se le reasigna la letra de la calificación final.

\section{Resultados}

En el curso 2015-2016 hubo 21 alumnos matriculados y 18 en el curso 2016-2017. Se ha partido del planing de la tabla 1 en la organización para el curso 2016-2017 (y hubo uno similar adaptando fechas para el curso anterior). Este planing no ha sufrido cambios apreciables. En los dos cursos ha pasado lo mismo. Hasta mediados de noviembre todos los alumnos han seguido el ritmo planificado. En la primera semana de noviembre ya estaban los trabajos elegidos y los grupos distribuidos. Los actos evaluativos han seguido la tabla 2 . Se pueden realizar los siguientes comentarios:

- 5 pruebas escritas individuales, con los apuntes delante: Los alumnos las han resuelto sin dificultad.

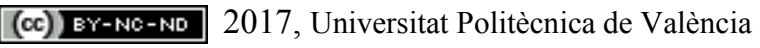

Congreso IN-RED (2017) 
- 5 memorias de prácticas grupales: se producen retrasos y caída de la calidad de la memoria en las entregas finales, a partir de finales de noviembre. La mayoría de grupos opta a mejorar nota de prácticas.

- 5 preguntas del minuto asociadas a las prácticas individuales: se han detectado anomalías de grupo que luego se han visto en las rúbricas de evaluación entre pares y autoevaluación.

- Proyecto grupal de la asignatura. Estos dos cursos han realizado diferentes trabajos: bocinas de exteriores, software de altavoces, fabricación de cajas, construcción de un altavoz dinámico de bajo coste, construcción de un bass-reflex, construcción de un line-array, construcción de una unidad Leslie Tremolo, Medidas de las vibraciones del aire acondicionado. A continuación se muestran algunas fotografías del curso 2016-2017 (figura 1):
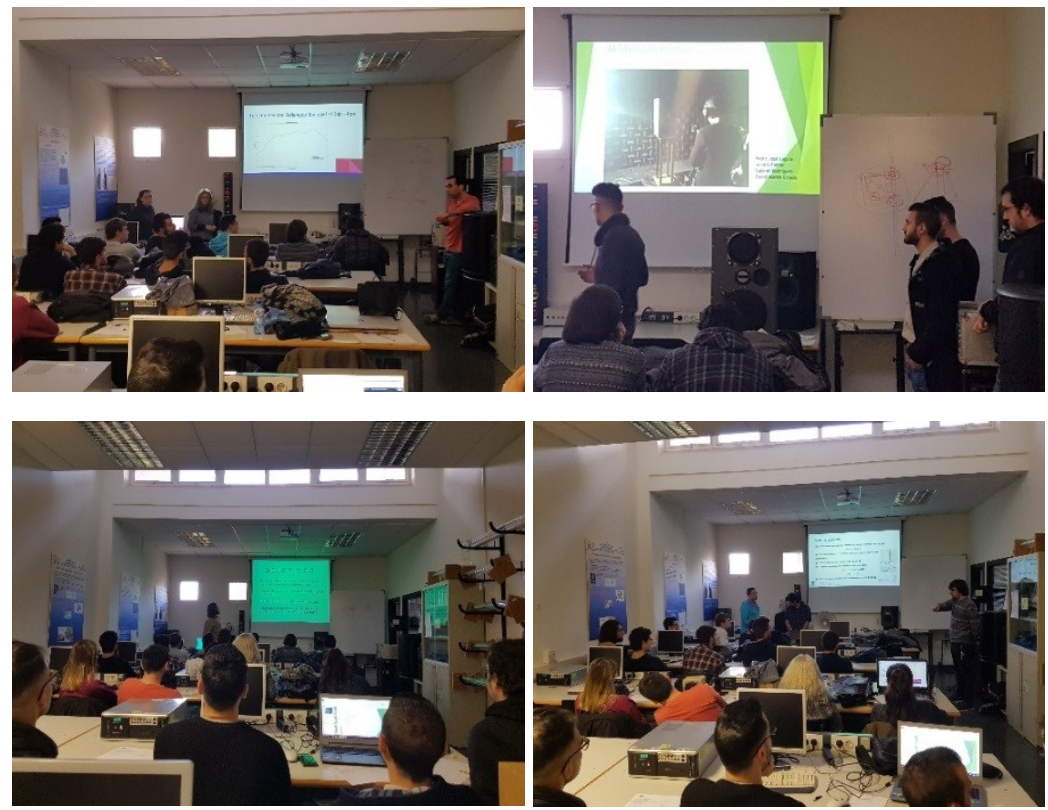

Fig. 1 Imágenes de una clase durante el curso 2016-2017.

Los trabajos se entregan en enero pero la presentación del trabajo se realiza antes de las vacaciones de Navidad. Esto obliga a los grupos a presentar lo que tienen preparado hasta la fecha. Este formato es una novedad para los alumnos, pero sirve para saber realmente si están avanzando en su proyecto, si saben lo que están haciendo, y si son capaces de defender su trabajo. Para ello disponen de las siguientes rúbricas:

- Rúbrica de evaluación entre pares del trabajo: El día de la presentación los alumnos realizan una rúbrica de todos los grupos menos el suyo (tabla 3). La mayoría de los resultados se califican de "excelente" aunque se evidencia que algún grupo aún no ha avanzado nada en su proyecto. El profesor también realiza la rúbrica en la misma tabla. Realmente se ven diferencias en la nota global propuesta y no tanto en cada ítem.

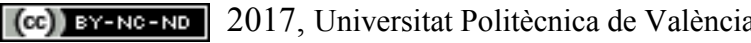

Congreso In-Red (2017) 
- Rúbricas de autoevaluación de los grupos (prácticas y trabajo). A la entrega del trabajo también entregan las rubricas de las tablas 4, 5 y 6 . Los datos generales son casi siembre un 4 en la valoración del grupo y de sus compañeros. La autoevaluación entre 2 y 3 casi siempre, excepto algún caso de problema en un grupo.

En estos dos últimos cursos todos los alumnos han superado la asignatura. En el diagrama siguiente (figura 2) puede verse la distribución en porcentaje de la valoración del curso 2016-2017 en funcion de los siguientes ítems: A-Excelente, B-Adecuado, C-En Desarrollo y D-No alcanzada.

\section{CT-11. Aprendizaje permanente}

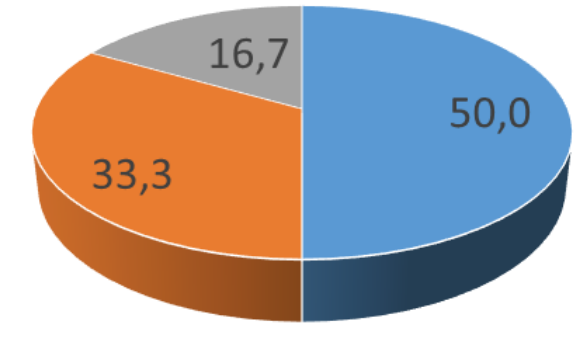

$\square \mathrm{C} \square \mathrm{B}=\mathrm{A}$

Fig 2. Diagrama de valoración de la competencia transversal “Aprendizaje Permanente” durante el curso 2016-2017.

La mitad de los alumnos tienen la competencia en desarrollo, un tercio se puede considerar como adecuado y el resto han mostrado una buena capacidad para el aprendizaje permanente. Esto es resultado de aplicar los criterios descritos en el desarrollo de la innovación. La mitad de los alumnos se están limitando a realizar los procesos que le indica el profesor, pero esto no es garantía de aprendizaje permanente. Un tercio han aportado indicios basados en propuestas propias con búsquedas propias y un grado adecuado de aprendizaje permanente. El resto han demostrado gran interés en el aprendizaje permanente, llegando a aportar elementos propios y con un buena parte de las propuestas con alternativas.

\section{Conclusiones}

Se plantea una reflexión en base a un DAFO de estos dos cursos.

Respecto a las fortalezas:

(cc) EY-NC-ND 2017, Universitat Politècnica de València

Congreso IN-RED (2017) 
- Realmente existe un seguimiento del alumno durante toda la asignatura con la combinación de varias técnicas, sin necesidad de realizar examen final.

- La pregunta del minuto es una buena herramienta para detectar carencias en prácticas y también de anomalías en el grupo de prácticas.

- La presentación oral intermedia en base a 3-4 transparencias facilita el seguimiento de los trabajos y de los grupos.

- Los alumnos prefieren que no haya examen en la asignatura

- Los pequeños actos evaluativos hacen que el alumno siga la asignatura y se obligue a estar al día.

- La segunda revisión de memorias de prácticas facilita la comprensión y la asimilación de conceptos por parte de los alumnos. También ayuda a distinguir qué alumnos tienen mayor interés.

Las debilidades detectadas:

- La carga de trabajo de alumnos y profesores es mucho mayor que en otras asignaturas del mismo semestre, sobre todo en el primer curso de implantación (en el segundo se rebaja algo la carga).

- El ritmo de los trabajos no es fluido cuando se convive con asignaturas de evaluación tradicional en base a exámenes. Esto se observa en la bajada de resultados a partir de mediados de noviembre.

- Las rúbricas de coevaluación no aportan mucha información, si se analiza cada ítem. Sólo hay diferencias en la calificación global de siempre es superior a 7. Debe normalizarse de otra forma.

- Las rúbricas de autoevaluación han servido para detectar problemas entre compañeros de un grupo. Hay casos donde todos los compañeros ponen la calificación más baja a un miembro. Otros casos donde todos tienen calificación baja, menos un miembro. Esto hay que analizarlo con detalle.

Las amenazas de se han detectado estos dos cursos:

- Las asignaturas que siguen una evaluación más clásica, con exámenes finales, interfieren de forma clara. Los alumnos acumulan en las últimas semanas a veces hasta dos exámenes al día de otras asignaturas. Esto rompe el ritmo de los trabajos.

- No existe una apuesta real por este tipo de metodologías. Del curso 2015-2016 al 2016-2017 se eliminó un grupo de prácticas.

Evaluar las competencias transversales es una oportunidad real de poder realizar un cambio en la manera de enfocar la educación en las asignaturas, aumentando su calidad y proporcionando herramientas que ayuden a certificar las titulaciones en el ámbito internacional. Debe revisarse el método de valoración de la competencia transversal para bajar su grado de complejidad evaluativo.

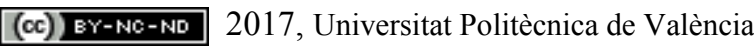

Congreso In-Red (2017) 


\section{Referencias}

ALBA J., DEL REY R. (2016) Competencia transversal "Aprendizaje Permanente": experiencia en la asignatura Transductores e Instrumentación Acústica. Universitat Politècnica de València Congreso IN-RED 2016.

ALBA J., DEL REY, R., VIDAL A., ROIG B. (2015a) Aprendizaje Basado en Proyectos en el Grado en Ingeniería de Sistemas de Telecomunicaciones, Sonido e Imagen. Caso práctico del electroscópio como experiencia interdisciplinar entre Física y Matemáticas. 23 Congreso Universitario de Innovación Educativa de las Enseñanzas Técnicas (XXIII CUIEET). Valencia 15-17 de julio de 2015.

ALBA J., TORREGROSA C., DEL REY R. (2015b) Aprendizaje basado en proyectos: Primera experiencia en la asignatura de Física del Grado en Ingeniería de Telecomunicación, Sonido e Imagen. Universitat Politècnica de València Congreso IN-RED (2015)

APARICIO, F., GONZALEZ, R. M. Y SOBREVILA, M. A. (2005). Formación de Ingenieros. Objetivos, métodos y estrategias. Instituto de Ciencias de la Educación, UPM.

CASE, J. M. Y LIGHT, G. (2011). Emerging Methodologies in Engineering Education Research. Journal of Engineering Education, 100 (1), 186-210.

CALVO, I., LOPEZ-GUEDE, J.M. Y ZULUETA, E. (2010). Aplicando la metodología Project Based Learning en la docencia de Ingeniería Técnica en Informática de Gestión, Revista de Formación e Innovación Educativa Universitaria. Vol. 3, No 4, 166-181

DE MIGUEL, M. (2006). Modalidades de Enseñanza centradas en el desarrollo de competencias. Universidad de Oviedo.

GONZÁLEZ, J. y WAGENAAR, R. (2003): Tuning Educational Structures in Europe. Informe Final - Proyecto Piloto, Fase 1, Bilbao, Universidad de Deusto.

UPV, UNIVERSITAT POLITECNICA DE VALENCIA. Competencias transversales UPV $<$ http://competenciast.webs.upv.es/> [Consulta: 1 de abril de 2016]

VILLA, A. Y POBLETE, M. (2007): Aprendizaje basado en competencias. Una propuesta para la evaluación de las competencias genéricas. Ediciones Mensajero. Bilbao.

(cc) EY-NC-ND 2017, Universitat Politècnica de València

Congreso IN-RED (2017) 


\title{
La competencia "Diseño y Proyecto" coordinada en la Mecánica de Fluidos de Ingeniería Química en los campus de la UPV: resultado de un Proyecto de Innovación y Mejora Educativa
}

Modesto Pérez-Sánchez ; Juan Manzano Juarez'; Rosa M. Llacer-Iglesias ${ }^{\mathrm{a}}$; Jorge García-Serra García ${ }^{\text {, }}$ P. Amparo López-Jiménez ${ }^{a}$,"

a Departamento de Ingeniería Hidráulica y Medio Ambiente. Universitat Politècnica de València. mopesan1@upv.es; rollaig@hma.upv.es; palopez@upv.es;

${ }^{b}$ ITA. Departamento de Ingeniería Hidráulica y Medio Ambiente. Universitat Politècnica de València. jgarcias@ita.upv.es.

c Departamento de Ingeniería Rural y Agroalimentaria. Universitat Politècnica de València. juamanju@agf.upv.es.

(*) autor de correspondencia

\begin{abstract}
The student's learning should be connected to correct coordination within the curriculum in which is taught. This coordination increases its complexity when the same Bachelor's Degree is taught in two different Campus of the Universitat Politècnica de València (Alcoy and Vera's Campus). This communication shows the results of the developed coordination in the matter Fluid Mechanics, which is taught in Chemical Bachelor's Degree. The obtained results are getting and documenting for the development of innovation project and improvement of the education (PIME), which is currently developing. The work shows the advantages of the transversal and vertical coordination, which affect on the student positively. Likewise, the coordination establishes the development of the programming of the Matter in both Campus, showing the good practice sheet, which enables to develop the proposed project. This sheet contains a rubric with new indicators, which were adapted to knowledge area of hydraulic engineering. This sample of coordination ca be extrapolated to other matters, sensing the student, homogeneity in the criteria and methodologies of active learning in the UPV generic student outcomes.
\end{abstract}

Keywords: design and Project; cross coordination, vertical coordination, rubric, UPV generic student outcomes

\section{Resumen}

El aprendizaje del alumno debería estar sujeto a una buena coordinación dentro del plan de estudios donde se imparte. Esta coordinación se hace más compleja cuando una misma titulación se imparte en dos Campus diferentes de la Universitat Politècnica de València (Alcoy y Vera). La comunicación 
La competencia "Diseño y Proyecto" coordinada en la Mecánica de Fluidos de Ingeniería Química en los campus de la UPV: resultado de un Proyecto de Innovación y Mejora Educativa

presentada muestra el resultado de coordinación de la asignatura Mecánica de Fluidos del Grado de Ingeniería Química. Este resultado se ha conseguido y documentado dentro del Proyecto de Innovación y Mejora en la Educación que actualmente se está desarrollando. El trabajo muestra las ventajas de la coordinación horizontal y vertical, la cual repercute de forma positiva al estudiante. Así mismo, establece el desarrollo de la programación de la asignatura en ambos Campus, mostrando la hoja de buenas prácticas que permite desarrollar el proyecto propuesto. Esta hoja contiene una rúbrica con nuevos indicadores que se adaptan de una forma más adecuada al área de la ingeniería hidráulica. Esta muestra de coordinación puede ser extrapolada a otras asignaturas, percibiendo el alumno, una homogeneidad en los criterios y metodologías de trabajo de aprendizaje activo en las competencias transversales.

Palabras clave: diseño y proyecto, coordinación horizontal, coordinación vertical, rúbrica, planificación

\section{Introducción}

El trabajo de la competencia transversal 'Diseño y Proyecto' en términos generales, pretende que el alumno aprenda integrando conocimientos y habilidades de diferentes ámbitos disciplinares aplicados al campo de trabajo concreto en que se aplique, desarrollando habilidades intelectuales de alto nivel, promoviendo el aprendizaje y trabajo autónomo, el trabajo en equipo y la autoevaluación, aplicando a su vez criterios de responsabilidad ética y profesional.

De esta forma, esta estrategia puede implementarse en muchos ámbitos de los actuales planes de estudios, donde la adquisición de competencias es también muy valorada por los docentes y empleadores. En la presente contribución se va a describir particularmente su propuesta de aplicación en el campo de las materias relacionadas con la Mecánica de Fluidos en las diferentes titulaciones de Ingeniería Química impartidas en los campus de la UPV.

Diferentes autores han trabajado esta competencia en diferentes niveles de forma individual (Part-Escriva,2015; Gonzalvez-Zafrilla et al., 2015; Lajara-Camilleri et al., 2015; Rullán et al, 2010). Sin embargo, son menos las experiencias que analizan el trabajo a un mismo nivel de dominio de la competencia cuando se trata de la misma titulación en diferentes Campus.

Particularmente, las materias relacionadas con la mecánica de fluidos son especialmente importantes en las titulaciones de Ingeniería Química. El comportamiento de los fluidos como medios continuos cuando se encuentran en reposo (estática) o cuando se encuentran en movimiento (cinemática y dinámica de fluidos) son aspectos fundamentales que afectan a prácticamente todas las operaciones básicas de un ingeniero químico. Así pues, la aplicación de la competencia se propone para estudiantes de grado, de segundo curso, donde se ubica la materia que se considera, por lo que el docente se encuentra frente a una aplicación de la competencia en la fase final del primer nivel de dominio. El desarrollo de

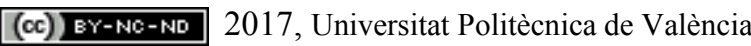

Congreso IN-RED (2017) 
la asignatura y aprendizaje del alumno se basa en un contenido que en algunas fases tiene una importante componente teórica (Streter, 1963; White, 2008) una vez el alumno ya tiene fundamentadas las bases de la física y la matemática necesarias

Este nivel incluye acciones por parte del alumno, tales como: diseñar una instalación a nivel de anteproyecto; indicadores, justificar razonadamente la necesidad del proyecto, establecer los objetivos claros del proyecto planteado, proponer y programar en el tiempo las acciones para la consecución de los objetivos e identificar posibles riesgos inherentes al proyecto.

Asimismo, el caso de la UPV es particular, en tanto que la misma titulación se imparte en dos campus diferentes, separados espacialmente en dos provincias de la Comunidad Valenciana, Campus de Vera (Valencia) y Campus de Alcoy (Alicante), con dos Estructuras Responsable de Título (ERT) diferentes, de manera que la coordinación en la titulación se hace fundamental para asegurar que los contenidos que se imparten son similares y que los alumnos pueden intercambiarse en todo momento. Esta coordinación ha sido mejorada y documentada, como consecuencia del desarrollo del Proyecto de Innovación y Mejora en la Educación “B07. Desarrollo de Metodologías de Evaluación y Diseño de Rúbricas de la 'CT-05 Diseño y Proyecto' aplicado al campo de la Ingeniería Hidráulica” durante el curso 2016/2017.

La competencia "Diseño y Proyecto" se relaciona con una metodología de enseñanza y aprendizaje en la que los estudiantes desarrollan un trabajo completo en un tiempo determinado, con el objetivo fundamental de abordar una tarea mediante la planificación, diseño y realización de una serie de actividades (De Miguel, 2005). Se implementan así los conocimientos prácticos adquiridos, donde el proceso autónomo de aplicación a la solución de problemas tiene gran importancia, para dar una solución que puede ser abierta y diferente para cada alumno o grupo de ellos.

Para que los alumnos desarrollen un proyecto se necesita integrar el aprendizaje que han adquirido previamente en varias áreas y materias (Barrio Perrotti et al, 2010). En este caso, los alumnos que se enfrenten a un problema de mecánica de fluidos deberán integrar sus conocimientos en aspectos de física como control de magnitudes, cambios de unidades, cálculos de fuerzas y momentos o determinación de velocidades y caudales; con otros de matemáticas como integración o análisis de sistemas de ecuaciones diferenciales. En este sentido, el alumno combina conocimientos que ha adquirido fragmentados en otras materias y les encuentra una aplicación práctica y real en el campo de la aplicación hidráulica, muy cercana a la experiencia profesional, que después desarrollará como egresado en ingeniería química.

\section{Objetivos}

El objetivo de la presente contribución es presentar la planificación desarrollada en la asignatura Mecánica de Fluidos del Grado de Ingeniería Química, la cual es coordinada de manera transversal en los Campus de Vera y Alcoy.

Esta planificación busca por un lado, tener una distribución temporal similar en cuanto a los contenidos teóricos desarrollados, puesto que ambas asignaturas tienen los mismos contenidos teóricos reflejados en la Guía Docente, al ser las dos, el mismo título de la 
La competencia "Diseño y Proyecto" coordinada en la Mecánica de Fluidos de Ingeniería Química en los campus de la UPV: resultado de un Proyecto de Innovación y Mejora Educativa

Universitat Politècnica de València. Por otro lado, la coordinación transversal entre centros, busca ir más allá, y trata de desarrollar un mismo proyecto (a nivel de domino I) en ambos Campus, donde el alumno, de forma no presencial, tutorizado por el docente y apoyado en las prácticas informáticas realizadas, pueda desarrollarlo. El proceso se ha iniciado este curso 2016/2017 dentro del PIME anteriormente citado, y tratará de complementarlo totalmente en el curso 2017/2018, momento en que el acto de evaluación del proyecto desarrollado será introducido dentro de la Guía Docente al igual que los contenidos teóricos.

En la fase actual, durante el curso 2016/2017, se ha formado los grupos de trabajo de los profesores responsables de asignatura y profesores de prácticas informáticas, y a partir de ellos, se ha desarrollado la metodología de trabajo a seguir para poder desarrollar el trabajo no presencial.

\section{Desarrollo de la innovación}

El desarrollo de la metodología de trabajo propuesta busca conseguir una coordinación de la transversalidad en caso de existir la misma asignatura en diferentes centros o titulaciones. Esta coordinación, definida en la sección 3.1, viene presentada para una asignatura en dos centros diferentes, pero puede ser extrapoladas a asignaturas diferentes que estén relacionadas, pero sean del mismo o de diferentes Departamentos, para evitar solapamientos que reduzcan el tiempo de aprendizaje del alumno y esto sea percibido por éste como una muestra de desorganización del título. La coordinación puede venir establecida por estrategias similares a la definida en la sección 3. 2..

\subsection{Coordinación horizontal entre centros con perspectivas a la coordinación vertical}

En el presente contexto, debemos entender la coordinación docente como el conjunto de medidas orientadas a facilitar y mejorar el proceso de adquisición de las competencias de una titulación por parte de sus estudiantes (Parra et al, 2011). En este sentido, la materia que se presenta es, de un lado, complementaria a los conocimientos previos o que se desarrollan en paralelo para los estudiantes de Ingeniería Química; y de otro lado, fundamental para materias que han de adquirir en cursos superiores tales como máquinas hidráulicas, análisis de dispersión de contaminantes u operaciones complejas en ingeniería química.

Así pues, la coordinación entre los docentes (y más entre los que pertenecen a campus de la misma universidad), es importante en varios aspectos. El alumno debe percibir que se han ordenado convenientemente los contenidos de las distintas asignaturas, se han homogeneizado los sistemas de evaluación, y se ha gestionado de forma coordinada la carga de trabajo entre asignaturas y a lo largo de cada curso. En este sentido, se hace particularmente útil, el desarrollo de tareas complejas organizadas en un proyecto que permitan integrar todos estos conocimientos con una correcta planificación del tiempo.

(c) EY-NC-ND 2017, Universitat Politècnica de València 
La coordinación es fundamental en los procesos de innovación, siempre teniendo en cuenta las competencias adquiridas y planificación del tiempo del alumno. Todos los procesos de innovación se verán profundamente comprometidos en su futuro inmediato si se dan en un entorno descoordinado. Por otra parte, la coordinación, debe ser facilitada desde los centros, venciendo el individualismo de algunos profesores y la libertad de cátedra mal entendida, problemas en ocasiones endémicos en nuestros sistemas docentes (García Martin, 2015).

La coordinación de los equipos docentes en asignaturas de un mismo curso (coordinación horizontal) afecta también a futuras materias curriculares del alumno en cursos subsiguientes. Esta debe ser entendida como coordinación vertical, referida a toda la titulación y relacionada con los objetivos generales de la misma, y su coherencia en cuanto a todos los aspectos de adquisición de competencias y contenidos (Agudo y Gonzalo, 2006). En este sentido, la presente contribución muestra el interés desde el grupo de profesorado promotor, para que la realización de diseño y anteproyecto de los alumnos en las materias relacionadas con la mecánica de fluidos, sirvan como base para similares metodologías de proyectos con alcance mayor implementadas en cursos superiores para los alumnos, o incluso en el desarrollo de su trabajo final de grado, finalmente necesario para la adquisición de la titulación.

\subsection{Diseño de la coordinación de la asignatura}

La coordinación de la asignatura Mecánica de Fluidos está focalizada en dos términos diferenciados. La coordinación presencial desarrollada en la teoría de aula, práctica de aula e informáticas y la coordinación no presencial que deriva de la propuesta del proyecto a desarrollar por los alumnos, la coordinación está resumida en la Figura 1. Aunque los contenidos teóricos vienen establecidos en la Guía Docente, así como el tiempo dedicado presencialmente a cada unidad didáctica, el desarrollo de coordinación establece como prioridades:

1) Definir unos resultados de aprendizaje comunes, tanto a nivel del proyecto planteado como de la asignatura.

2) Que el desarrollo sea paralelo en ambos centros, de forma que el alumno se encuentre en el mismo nivel de adquisición de aprendizaje durante el cuatrimestre, no existiendo diferencia de contenidos dependiendo el Campus donde se localice. 


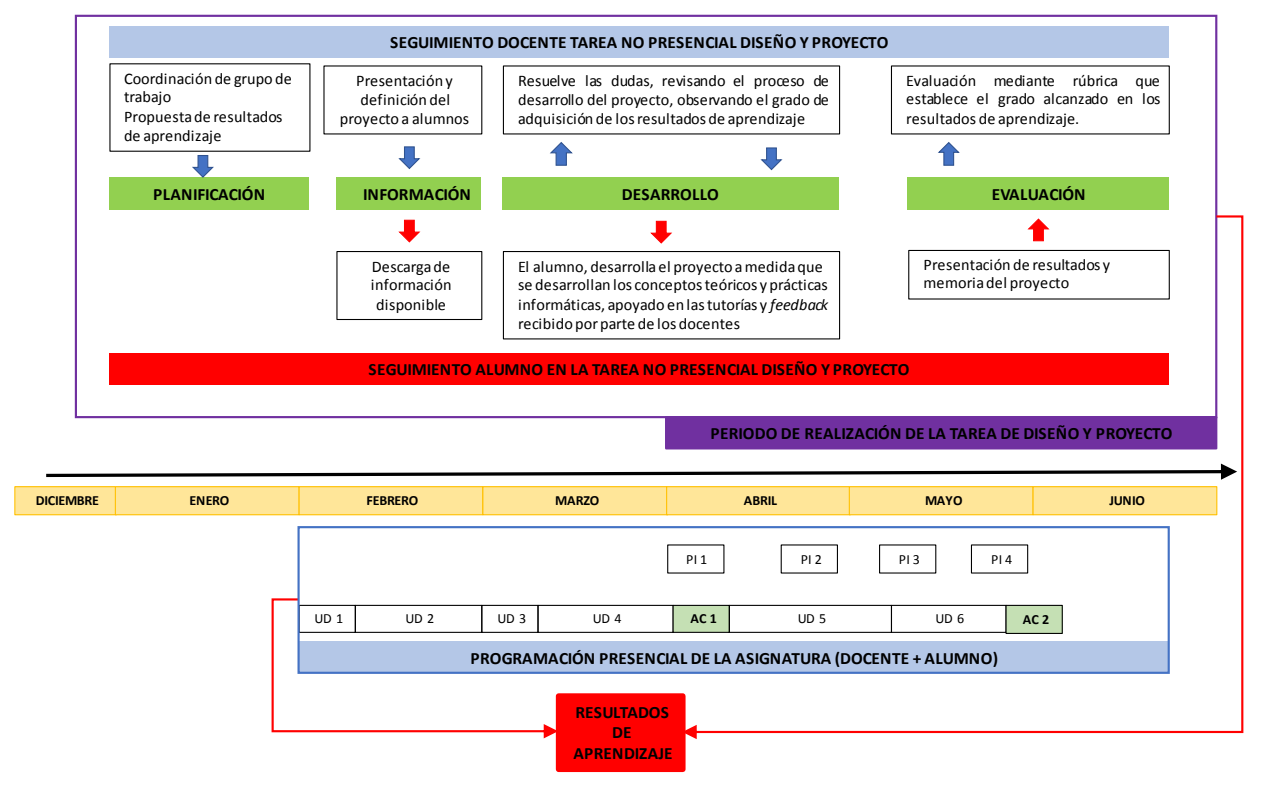

Fig. 1 Esquema temporal de desarrollo de acciones docentes y del alumnado

3) El proyecto está centrado en el Diseño de una red ramificada a flujo a presión, por lo que será abordado a partir del mes de Abril (desde la semana 10 hasta la semana 18). Iniciar la actividad al alumno en esta semana le permite:

- Recibir de manera síncrona los conceptos teóricos relacionados con el flujo a presión, relacionándolos con términos y aplicaciones desarrolladas en las unidades anteriores.

- De forma paralela a la teoría de aula y práctica de aula, el alumno realiza de forma presencial prácticas informáticas, donde el docente presenta un software con el cual poder analizar y comprobar redes de flujo a presión. Las prácticas informáticas están establecidas en cuatro sesiones de dos horas de duración en la EPSA y tres sesiones de $2.5 \mathrm{~h}$ en la ETSII.

- A medida que la docencia síncrona se desarrolla, el alumno comienza a desarrollar el proyecto. El desarrollo del proyecto se produce de forma no presencial. Es en esta etapa, donde el alumno comienza a mostrar el grado de alcanzado de aprendizaje, ya que debe aplicar al proyecto propuesto, los conceptos desarrollados presencialmente. Este aprendizaje no presencial, se sigue de forma tutorizada por los docentes a medida que se desarrolla el proyecto y el alumno lo solicita. Estas tutorías, sirven al alumno como 'feedback' para mejorar sus resultados de aprendizaje. Es en esta etapa, donde el alumno si lo desea puede complementar su aprendizaje mediante la utilización de recursos docentes asíncronos (p.e., Polimedias) que le ayuden a alcanzar con éxito sus resultados de aprendizaje (López-Jiménez y Pérez-Sánchez, 2016). No obstante, los alumnos deben ser, en la medida de lo posible, motivados para asistir a estas tutorías específicas, así como relacionar los conceptos teóricos y prácticos desarrollados en las clases 
presenciales, que son de aplicación directa al proyecto que deben desarrollar.

4) Permite medir el grado de adquisición de la competencia alcanzado por el alumno en su nivel I, atendiendo a los siguientes indicadores:

- Justificar razonadamente la necesidad del proyecto

- Establecer unos objetivos claros del proyecto

- Proponer las acciones para la consecución de los objetivos

- Desarrollar las acciones para la consecución de los objetivos

- Identificar posibles riesgos inherentes al proyecto

\section{Resultados}

El resultado en la presente comunicación no muestra los resultados alcanzados por los alumnos, sino el material generado por el docente para poder llevar a cabo esta coordinación transversal entre centros. Los resultados de dicha coordinación han sido documentados a través de:

- El desarrollo de la hoja de buenas prácticas de la asignatura, la cual permite en todo momento conocer a los docentes involucrados, las tareas a desarrollar (presenciales y no presenciales) así como la planificación temporal de las diferentes fases en la cual se encuentre el proyecto.

- Rubrica de evaluación que permita evaluar el proyecto desarrollado, definir el grado alcanzado en cada uno de los indicadores, permitiendo establecer una valoración descriptiva y no numérica.

\subsection{Hojas de buenas prácticas}

El desarrollo de la hoja de buenas prácticas ha permitido desarrollar la organización, de la asignatura, en base a la experiencia de los docentes implicados en años anteriores y a las reuniones de coordinación desarrolladas. La hoja de buenas prácticas ha sido implantada en el curso 2016/2017, lo que constituye un documento totalmente 'abierto', el cual irá ajustándose (fundamentalmente) los tiempos de dedicación de cada actor (docente y/o alumno) en próximos cursos.

Se resume a continuación, esta primera hoja de buenas prácticas coordinada entre centros, la cual conduce a la consecución de los resultados de aprendizaje a través del trabajo y adquisición de la competencia 'Diseño y Proyecto'.

- Título de Actividad: Dimensionado y análisis de una red ramificada de abastecimiento de agua a presión

- $\quad$ Asignatura: Mecánica de Fluidos; $2^{\circ}$ Curso; Cuatrimestre B; Troncal

- Número de Alumnos:

- UPV-ETSII: 99 alumnos (1 grupo de TA y PA; 4 grupos de PI)

- UPV-EPSA: 47 alumnos (1 grupo de TA y PA; 2 grupos de PI)

- Resultado de Aprendizaje del Proyecto planteado en la asignatura:

○ Definir los objetivos por los cuales se desarrolla una red presurizada. 
La competencia "Diseño y Proyecto" coordinada en la Mecánica de Fluidos de Ingeniería Química en los campus de la UPV: resultado de un Proyecto de Innovación y Mejora Educativa

- Representar y describir todas las etapas del proceso de dimensionado de nuevas redes o ampliación de existentes, a partir de un diseño y trazado ya realizado.

o Dominar diferentes métodos de dimensionado (elección de diámetros nominales) de las tuberías de las redes de agua a presión ramificadas en sistemas de distribución urbanos o internos de una industria.

- Evaluar la idoneidad de los resultados obtenidos de forma numérica siguiendo los métodos propuestos, y proponer mejoras sobre el diseño inicial.

- Elegir el método de cálculo idóneo para cada caso, atendiendo a principios de calidad, garantía de suministro, económicas y sociales.

- Programación de la actividad desarrollada: a continuación, se adjunta la Tabla 1, donde se observa el tiempo dedicado a cada acción de acuerdo al desarrollo de la tarea y distribución temporal mostrada en la Figura 1, así como mostrando si es presencial o no presencial. Cada una de estas etapas está totalmente definida en la hoja de buenas prácticas, indicando las acciones de cada uno (docente o alumno) así como estableciendo las fechas 'deadline' de cada momento.

Tabla 1. Programación temporal de cada una de las acciones que intervienen en la actividad.

\begin{tabular}{|c|c|c|c|c|c|c|c|c|}
\hline \multirow{2}{*}{ FASES DE LA ACTIVIDAD } & \multicolumn{4}{|c|}{ DOCENTE } & \multicolumn{4}{|c|}{ ALUMNO } \\
\hline & PRESENCIAL & $t$ (min) & $\begin{array}{c}\text { NO } \\
\text { PRESENCIAL }\end{array}$ & $t$ (min) & PRESENCIAL & $t(\min )$ & $\begin{array}{c}\text { NO } \\
\text { PRESENCIAL }\end{array}$ & $t(\min )$ \\
\hline PLANIFICACIÓN & -- & -- & $\mathbf{X}$ & 300 & -- & -- & -- & -- \\
\hline \multicolumn{9}{|l|}{ INFORMACIÓN } \\
\hline $\begin{array}{l}\text { Elaboración de propuesta de } \\
\text { proyecto }\end{array}$ & -- & -- & $\mathbf{X}$ & 180 & -- & -- & -- & -- \\
\hline Presentación de proyecto & $\mathbf{X}$ & 30 & -- & -- & $\mathbf{X}$ & 30 & -- & -- \\
\hline $\begin{array}{l}\text { Descarga y recopilación de } \\
\text { información }\end{array}$ & -- & -- & -- & -- & -- & -- & $\mathbf{X}$ & 180 \\
\hline \multicolumn{9}{|l|}{ DESARROLLO } \\
\hline $\begin{array}{l}\text { TA, PA y PI relacionadas con el } \\
\text { proyecto }\end{array}$ & $\mathbf{X}$ & 1080 & -- & -- & $\mathbf{X}$ & 1080 & -- & -- \\
\hline Desarrollo del proyecto & -- & -- & -- & -- & & & $\mathbf{X}$ & 600 \\
\hline $\begin{array}{l}\text { Tutorías y análisis de la } \\
\text { evolución del aprendizaje }\end{array}$ & $\mathbf{X}$ & 720 & -- & -- & -- & -- & -- & -- \\
\hline \multicolumn{9}{|l|}{ EVALUACIÓN } \\
\hline $\begin{array}{c}\text { Presentación de resultados, } \\
\text { acorde a las instrucciones de la } \\
\text { actividad }\end{array}$ & -- & -- & -- & -- & -- & -- & $\mathbf{X}$ & 120 \\
\hline $\begin{array}{l}\text { Evaluación y determinación del } \\
\text { grado de aprendizaje alcanzado }\end{array}$ & -- & -- & $\mathbf{X}$ & 900 & -- & -- & -- & -- \\
\hline Feedback del proyecto & $\mathrm{X}$ & 100 & & & $\mathbf{X}$ & 100 & -- & -- \\
\hline
\end{tabular}

- Recursos: incluye la bibliografía recomendada, software EPANET, memorias de prácticas, documentos adjuntos en la tarea de PoliformaT (enunciado del proyecto, datos de partida para cada alumno, notas y aclaraciones para la correcta resolución del proyecto, ejemplo de plantilla de resultados a entregar, guion de la memoria y rúbrica de evaluación).

- Evaluación: la evaluación viene establecida mediante rúbrica, la cual permite establecer el grado alcanzado en el aprendizaje en función de los indicadores propuestos. Esta rúbrica es definida en la sección siguiente.

\subsection{Rúbricas desarrolladas}

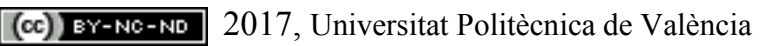

Congreso IN-RED (2017) 
Los integrantes del PIME, en base a los indicadores establecidos por el Plan Estratégico de la UPV para Nivel de Dominio I, han desarrollado una rúbrica con nuevos indicadores, que permite evaluar los ítems englobados en el proyecto propuesto.

Tabla 2. Rubrica desarrollada para la evaluación de la competencia 'Diseño y Proyecto' Nivel de Dominio I

\begin{tabular}{|c|c|c|c|c|}
\hline \multirow{2}{*}{ INDICADORES } & \multicolumn{4}{|c|}{ DESCRIPTORES } \\
\hline & D. No alcanzado & C. En desarrollo & B. Bien /adecuado & A. Excelente/ejemplar \\
\hline $\begin{array}{c}\text { Define los } \\
\text { objetivos por los } \\
\text { cuales se } \\
\text { desarrolla una red } \\
\text { presurizada } \\
\end{array}$ & $\begin{array}{c}\text { No establece } \\
\text { objetivos o lo hace } \\
\text { incorrectamente }\end{array}$ & $\begin{array}{l}\text { Establece objetivos, pero } \\
\text { son ambiguos o imprecisos }\end{array}$ & $\begin{array}{c}\text { Establece objetivos de } \\
\text { forma suficiente }\end{array}$ & $\begin{array}{c}\text { Establece objetivos claros y } \\
\text { operativos }\end{array}$ \\
\hline $\begin{array}{l}\text { Introducción, } \\
\text { objetivos y } \\
\text { justificación }\end{array}$ & $\begin{array}{c}\text { No existe el primer } \\
\text { punto }\end{array}$ & $\begin{array}{c}\text { Establece objetivos, pero } \\
\text { son ambiguos o imprecisos }\end{array}$ & $\begin{array}{l}\text { Establece objetivos de } \\
\quad \text { forma suficiente }\end{array}$ & $\begin{array}{c}\text { Establece objetivos claros y } \\
\text { operativos }\end{array}$ \\
\hline $\begin{array}{c}\text { Representa y } \\
\text { describe todas las } \\
\text { etapas del proceso } \\
\text { de dimensionado } \\
\text { de nuevas redes }\end{array}$ & $\begin{array}{l}\text { No describe la } \\
\text { metodología de } \\
\text { cálculo } \\
\text { incorrectamente }\end{array}$ & $\begin{array}{l}\text { Describe la metodología, } \\
\text { pero no es correcta, } \\
\text { faltando alguno de los } \\
\text { procesos intermedios }\end{array}$ & $\begin{array}{c}\text { Describe la metodología } \\
\text { de cálculo } \\
\text { correctamente }\end{array}$ & $\begin{array}{l}\text { Describe la metodología de } \\
\text { cálculo correctamente y propone } \\
\text { alternativas o análisis de } \\
\text { sensibilidad al variar algún } \\
\text { parámetro sin desarrollarlo. }\end{array}$ \\
\hline $\begin{array}{l}\text { Para cada uno de } \\
\text { los puntos }\end{array}$ & $\begin{array}{l}\text { No existe ningún tipo } \\
\text { de introducción del } \\
\text { punto a desarrollar }\end{array}$ & $\begin{array}{c}\text { Hace una breve descripción } \\
\text { de lo contiene el punto }\end{array}$ & $\begin{array}{c}\text { Describe y justifica el } \\
\text { punto a desarrollar, pero } \\
\text { desde una perspectiva } \\
\text { académica }\end{array}$ & $\begin{array}{c}\text { Describe y justifica la necesidad de } \\
\text { punto a desarrollar desde un } \\
\text { punto de vista técnico }\end{array}$ \\
\hline $\begin{array}{l}\text { Domina diferentes } \\
\text { métodos de } \\
\text { dimensionado de } \\
\text { conducciones }\end{array}$ & $\begin{array}{l}\text { No es capaz de } \\
\text { desarrollar el método } \\
\text { de dimensionado }\end{array}$ & $\begin{array}{c}\text { Es capaz de iniciar el } \\
\text { proceso de dimensionado, } \\
\text { pero no consigue } \\
\text { concluirlo }\end{array}$ & \begin{tabular}{|} 
Consigue desarrollar el \\
método, extrae \\
resultados correctos, \\
pero no los justifica \\
completamente
\end{tabular} & $\begin{array}{l}\text { Consigue desarrollar el método, } \\
\text { extrae resultados correctos, pero } \\
\text { justificándolo completamente }\end{array}$ \\
\hline $\begin{array}{l}\text { Cálculo de los } \\
\text { caudales }\end{array}$ & $\begin{array}{c}\text { No aparece el punto } \\
\text { del cálculo de } \\
\text { caudales }\end{array}$ & $\begin{array}{c}\text { Se explica el método } \\
\text { seguido para calcular los } \\
\text { caudales y asignar las } \\
\text { demandas base a los } \\
\text { nudos, pero no se justifica }\end{array}$ & $\begin{array}{l}\text { Se explica y justifica el } \\
\text { método seguido para el } \\
\text { cálculo de los caudales }\end{array}$ & $\begin{array}{c}\text { Se explica y justifica el método } \\
\text { seguido para el cálculo de los } \\
\text { caudales. Se aporta una } \\
\text { valoración personal al método } \\
\text { seguido. }\end{array}$ \\
\hline $\begin{array}{l}\text { Dimensionado por } \\
\text { el método de la } \\
\text { velocidad }\end{array}$ & $\begin{array}{l}\text { No aparece el punto } \\
\text { del dimensionado }\end{array}$ & $\begin{array}{l}\text { Se explica el método } \\
\text { seguido para calcular los } \\
\text { diámetros, pero no se } \\
\text { justifica }\end{array}$ & $\begin{array}{l}\text { Se explica y justifica el } \\
\text { método seguido para el } \\
\text { cálculo de los diámetros }\end{array}$ & $\begin{array}{c}\text { Se explica y justifica el método } \\
\text { seguido para el cálculo de los } \\
\text { diámetros. Se aporta una } \\
\text { valoración personal al método } \\
\text { seguido. }\end{array}$ \\
\hline $\begin{array}{l}\text { Análisis de la red } \\
\text { con los resultados } \\
\text { obtenidos }\end{array}$ & $\begin{array}{c}\text { No aparece el punto } \\
\text { del análisis }\end{array}$ & $\begin{array}{c}\text { Se muestran los resultados } \\
\text { de las variables, pero no se } \\
\text { analizan }\end{array}$ & $\begin{array}{l}\text { Se analizan los } \\
\text { resultados y se } \\
\text { introducen posibles } \\
\text { mejoras }\end{array}$ & $\begin{array}{c}\text { Se analizan los resultados y se } \\
\text { realizan posibles mejoras, } \\
\text { comparando ambos estados de la } \\
\text { red }\end{array}$ \\
\hline $\begin{array}{l}\text { Dimensionado por } \\
\text { el método de la } \\
\text { pendiente } \\
\text { hidráulica }\end{array}$ & $\begin{array}{l}\text { No aparece el punto } \\
\text { del dimensionado }\end{array}$ & $\begin{array}{l}\text { Se explica el método } \\
\text { seguido para calcular los } \\
\text { diámetros, pero no se } \\
\text { justifica }\end{array}$ & $\begin{array}{l}\text { Se explica y justifica el } \\
\text { método seguido para el } \\
\text { cálculo de los diámetros }\end{array}$ & $\begin{array}{c}\text { Se explica y justifica el método } \\
\text { seguido para el cálculo de los } \\
\text { diámetros. Se aporta una } \\
\text { valoración personal al método } \\
\text { seguido. }\end{array}$ \\
\hline
\end{tabular}

(c) EY-NC-ND 2017, Universitat Politècnica de València 
La competencia "Diseño y Proyecto" coordinada en la Mecánica de Fluidos de Ingeniería Química en los campus de la UPV: resultado de un Proyecto de Innovación y Mejora Educativa

Tabla 3. Rubrica desarrollada para la evaluación de la competencia 'Diseño y Proyecto' Nivel de Dominio I [Continuación]

\begin{tabular}{|c|c|c|c|c|}
\hline \multirow{2}{*}{ INDICADORES } & \multicolumn{4}{|c|}{ DESCRIPTORES } \\
\hline & D. No alcanzado & C. En desarrollo & B. Bien /adecuado & A. Excelente/ejemplar \\
\hline $\begin{array}{l}\text { Evalúa la } \\
\text { idoneidad de los } \\
\text { resultados } \\
\text { obtenidos }\end{array}$ & No realiza el análisis & $\begin{array}{c}\text { Solo muestra resultados, } \\
\text { sin comentarlos }\end{array}$ & $\begin{array}{l}\text { Muestra resultados, } \\
\text { analizando los valores } \\
\text { obtenidos y causas a } \\
\text { las que se deben }\end{array}$ & $\begin{array}{l}\text { Muestra resultados, analizando } \\
\text { los valores obtenidos y causas a } \\
\text { las que se deben, proponiendo } \\
\text { mejoras e incluso abordándolas }\end{array}$ \\
\hline $\begin{array}{l}\text { Análisis de la red } \\
\text { con los resultados } \\
\text { obtenidos }\end{array}$ & $\begin{array}{c}\text { No aparece el punto } \\
\text { del análisis }\end{array}$ & $\begin{array}{l}\text { Se muestran los resultados } \\
\text { de las variables, pero no se } \\
\text { analizan }\end{array}$ & $\begin{array}{l}\text { Se analizan los } \\
\text { resultados }\end{array}$ & $\begin{array}{c}\text { Se analizan los resultados y se } \\
\text { realizan posibles mejoras, } \\
\text { comparando ambos estados de la } \\
\text { red }\end{array}$ \\
\hline $\begin{array}{c}\text { Elige el método de } \\
\text { cálculo idóneo } \\
\text { para cada caso, } \\
\text { atendiendo a } \\
\text { principios de } \\
\text { calidad, garantía } \\
\text { de suministro, } \\
\text { económicas y } \\
\text { sociales } \\
\end{array}$ & No lo realiza & $\begin{array}{c}\text { Selecciona método, pero } \\
\text { no justifica }\end{array}$ & $\begin{array}{l}\text { Selecciona método } \\
\text { atendiendo a análisis } \\
\text { comparativo }\end{array}$ & $\begin{array}{l}\text { Selecciona método atendiendo } \\
\text { a los resultados, y desarrolla } \\
\text { una comparación a través de } \\
\text { cálculos complementarios }\end{array}$ \\
\hline Conclusión & No existe conclusión & $\begin{array}{l}\text { La conclusión aparece } \\
\text { únicamente como último } \\
\text { punto del proyecto, sin } \\
\text { análisis ni crítica de los } \\
\text { resultados }\end{array}$ & $\begin{array}{c}\text { Se analizan los } \\
\text { diferentes resultados y } \\
\text { se comparan métodos }\end{array}$ & $\begin{array}{c}\text { Se analizan los resultados, } \\
\text { comparando ambos métodos e } \\
\text { identificando ventajas e } \\
\text { inconvenientes de cada uno de } \\
\text { ellos }\end{array}$ \\
\hline $\begin{array}{l}\text { Lenguaje, formato } \\
\text { y redacción del } \\
\text { proyecto }\end{array}$ & \begin{tabular}{|} 
La presentación es \\
deficiente, la \\
redacción y el \\
lenguaje utilizados no \\
se corresponden con \\
el nivel académico \\
esperado
\end{tabular} & $\begin{array}{l}\text { La presentación es } \\
\text { correcta, aunque } \\
\text { mejorable, el lenguaje y la } \\
\text { redacción no son técnicos }\end{array}$ & $\begin{array}{c}\text { La presentación, el } \\
\text { lenguaje y la redacción } \\
\text { son correctas. El } \\
\text { contenido excede o no se } \\
\text { ajusta a lo requerido }\end{array}$ & $\begin{array}{l}\text { La presentación, el lenguaje y la } \\
\text { redacción son correctas. EI } \\
\text { contenido se ajusta } \\
\text { perfectamente a lo requerido para } \\
\text { explicar cada uno de los puntos }\end{array}$ \\
\hline
\end{tabular}

La evaluación se realiza atendiendo al contenido de la memoria y anexos presentados por el alumno, relacionándolos con el indicador correspondiente. Tal y como muestran las Tablas 2 y 3 , la rúbrica recoge la totalidad de los indicadores para evaluar la competencia, así como los apartados de los cuales se componen el proyecto y que los alumnos deben desarrollar a lo largo del cuatrimestre. La metodología, así como la rúbrica de evaluación planteada dotan al alumno de una base que le permite desarrollar la competencia en próximas asignaturas con una estructura similar relacionadas con el área de Mecánica de Fluidos o Ingeniería Hidráulica. Mantener una operatividad y sistemática de trabajo dota a la competencia de una transversalidad vertical que enriquece en un mayor grado la formación del estudiante.

\section{Conclusiones}

La presente comunicación ha mostrado la importancia de la existencia de coordinación transversal entre dos Campus de la UPV, con dos ERT diferentes, en una misma asignatura (Mecánica de Fluidos), en el Grado de Ingeniería Química. Esta coordinación se ha

(c)) EY-NC-ND 2017, Universitat Politècnica de València 
intensificado este curso 2016/2017 cuando la asignatura ha sido integrada en el PIME 'B07. Desarrollo de Metodologías de Evaluación y Diseño de Rúbricas de la 'CT-05 Diseño y Proyecto’ aplicado al campo de la Ingeniería Hidráulica”.

Sentar las bases de metodologías de trabajo y consecución de los objetivos en actividades de 'Diseño y Proyecto' en su nivel de Dominio I es fundamental para dotar al alumno de una estrategia de actuación que trasladada a otras asignaturas relacionadas con el área de estudio o similar le confieren a la competencia una coordinación vertical, en la cual el estudiante puede maximizar el alcance de los resultados de aprendizaje.

Esta transversalidad y verticalidad mostrada en este documento puede ser extendida a otras asignaturas que también trabajen dicha competencia y como actividad tengan propuestos proyectos en los cuales intervengan sistemas hidráulicos que necesiten de otros elementos complementarios (p.e., estructuras, instalaciones eléctricas para los grupos de bombeo).

Finalmente, una rúbrica ha sido desarrollada para Nivel de Dominio I, para llevar a cabo la evaluación del grado de adquisición de los resultados de aprendizaje del alumno en función de la actividad propuesta, la cual ha sido previamente definida en forma (estableciendo las funciones del docente y alumno, tanto presencial como no presencial) y tiempo (definiendo los tiempos de trabajo de cada fase).

\section{Referencias}

Agudo, C., Gonzalo, I. (2006). Coordinación docente: dónde estamos y a dónde querríamos llegar. Miscelánea Comillas. Vol. 64 (2006), núm. 124, pp. 63-82

Barrio Perotti, R., Blanco, E., Martínez de la Calle, J., Galdo Vega, M. (2010). RED. Docencia Universitaria en la Sociedad del Cono cimiento, número 2. http://www.um.es/ead/reddusc/2/

De Miguel, M. (2005). Metodologías de enseñanza para el desarrollo de competencias. Orientaciones para el profesorado universitario ante el Espacio Europeo de Educación Superior. Madrid: Alianza.

GARCIA MARTIN, A. (2015). Coordinación docente horizontal y vertical. Universidad Politécnica de Cartagena, España.

LÓPEZ-JIMÉNEZ, P.A., PÉREZ-SÁNCHEZ, M. "Los objetos de aprendizaje como conductores para favorecer el aprendizaje autónomo en el campo de la mecánica de fluidos”. II Congreso Nacional de Innovación Educativa y de Docencia en Red (Valencia, 7 y 8 de julio, 2016). Editorial Universitat Politècnica de València, 2016. Doi:http://dx.doi.org/10.4995/INRED2016.2016.4347

Parra Costa, C., Periago, P., García Baño, R., Maciá Sánchez, J.F., Peñalver Martínez, M.J., Martínez Segura, M.A., Múlas PÉrez, J., Doménech Asensi, G. (2011) Estrategias de coordinación horizontal y vertical en los planes de estudios adaptados al EEES. En: Congreso Internacional de Innovación Docente, Cartagena, 2011. Cartagena: Universidad Politécnica de Cartagena, 2011. p.1815-1824

Streeter, V.L., 1963. Mecánica de los Fluidos, Segunda. ed. Ediciones del Castillo SA, Madrid, Spain. 
La competencia "Diseño y Proyecto" coordinada en la Mecánica de Fluidos de Ingeniería Química en los campus de la UPV: resultado de un Proyecto de Innovación y Mejora Educativa

WHITE, F.M., 2008. Fluid Mechanics, Sixth edit. ed. McGrau-Hill.

(c) EY-NC-ND 2017, Universitat Politècnica de València

Congreso IN-RED (2017) 


\title{
Empleo de la estrategia puzle de Aronson para fomentar la cooperación en grupos
}

\section{Francesc A. Esteve-Turrillas, Sergio Armenta}

Departamento de Química Analítica, Universitat de València, Edificio Jeroni Muñoz, c/ Dr. Moliner 50, 46100 Burjassot, España (francesc.a.esteve@uv.es, sergio.armenta@uv.es)

\begin{abstract}
The main objective of the present communication was the implementation of an strategy based on the Puzzle of Aronson in the tutorials corresponding to the Food Additives course of the Degree in Science and Food Technology. The competences of students regarding cooperative learning increased using this dynamic and functional methodology. This type of methodologies are easy to apply in heterogeneous groups of students and are easy to adapt to the characteristics of the classroom.
\end{abstract}

Keywords: Cooperative learning, Aronson Puzzle, Group work, Food additives

\begin{abstract}
Resumen
Se ha implementado una estrategia tipo Puzle de Aronson en las tutorías correspondientes a la asignatura Aditivos Alimentarios del Grado de Ciencia y Tecnología de Alimentos. Con esta metodología dinámica y funcional se han aumentado las competencias del alumnado referentes al trabajo cooperativo, desarrollo de habilidades sociales y de comunicación, y resolución de conflictos. Este tipo de metodologías resultan fáciles de aplicar en grupos heterogéneos de alumnos y resultan fáciles de adaptar a las características del aula.
\end{abstract}

Palabras clave: Aprendizaje cooperativo, Puzle de Aronson, Trabajo en grupo, Aditivos Alimentarios

\section{Introducción}

El aprendizaje cooperativo es un método de aprendizaje basado en el trabajo en equipo en el que los alumnos trabajan conjuntamente para lograr determinados objetivos comunes de los que son responsables todos los miembros del grupo. El aprendizaje cooperativo se basa en la teoría constructivista en la que se otorga un papel fundamental al alumno, que es actor principal de su propio proceso de aprendizaje (Kagan, 1994). El trabajo cooperativo lleva implícito la interrelación entre los estudiantes de un grupo para trabajar juntos y lograr objetivos compartidos, por lo que los resultados obtenidos resultan beneficiosos, tanto para cada miembro, como para la totalidad del grupo (Johnson, 1991). La técnica del puzle de Aronson emplea una metodología dinámica y funcional que permite aumentar las competencias del alumnado referentes al trabajo cooperativo, en el que se confrontan diversos puntos de vista y se fomentan situaciones de conflicto y discusión. En esta estrategia de aprendizaje los estudiantes trabajan en pequeños grupos, preferiblemente 
no superiores a 4 personas. Se realiza un reparto cooperativo de tareas, lo que fomenta la responsabilidad de cada miembro, las relaciones sociales y la solución de conflictos internos. La técnica del Puzle de Aronson consta de tres etapas claramente diferenciadas (García, 2001). En la primera de ellas se divide a los alumnos en grupos aleatoriamente para solucionar un problema. En una segunda etapa, cada uno de los miembros del grupo se separa en diferentes grupos de expertos para que aprendan sobre una temática concreta, debatan las posibles dudas y recopilen información complementaria. En la tercera etapa, los miembros del grupo de trabajo inicial se reúnen, con conocimientos especializados cada uno de ellos, y se disponen a la resolución del problema de tipo práctico. De esta forma todos los estudiantes se reubican en grupos integrados por un experto de cada una de las áreas temáticas a considerar $\mathrm{y}$ han de ser capaces de transmitir efectivamente sus conocimientos al resto de compañeros para resolver el problema propuesto. En esta etapa es crucial que todos los miembros del grupo de trabajo discutan las posibles soluciones del problema, se generen y resuelvan conflictos, y se llegue a un resultado final consensuado por todos los miembros. El conflicto es empleado como situación de aprendizaje, ya que fomenta las relaciones humanas y la asertividad. La superación de un conflicto consolida al grupo, lo prepara y anima para enfrentarse en un fututo a problemas más complejos.

Esta estrategia de aprendizaje debe ser evaluada de forma independiente, por una parte el proceso de aprendizaje cooperativo, y por otra la capacidad de resolución del problema propuesto. La evaluación de la productividad del grupo, obliga a que los alumnos dependan unos de otros para lograr su objetivo y de esta forma se reduce la competencia interna entre sus integrantes. Los objetivos que se persiguen con el empleo de una estrategia tipo puzle de Aronson para el trabajo en grupo de estudiantes se basan en (Traver, 2004):

- Mejorar el aprendizaje cooperativo.

- Desarrollar habilidades sociales, asertivas y de comunicación.

- Desarrollar la solidaridad y el compromiso cívico entre el alumnado.

- Fomentar la autonomía en el aprendizaje.

- Aumentar el rendimiento académico.

- Desarrollar competencias académicas y profesionales.

\section{Objetivos}

El objetivo de la presente comunicación consiste en la implementación de una estrategia tipo Puzzle de Aronson en las tutorías correspondientes a la asignatura Aditivos Alimentarios del Grado de Ciencia y Tecnología de los Alimentos de la Universitat de València. Con esta metodología, dinámica $\mathrm{y}$ funcional, se pretende aumentar las competencias del alumnado referentes a aprendizaje cooperativo, desarrollar habilidades sociales y de comunicación, fomentar la autonomía en el aprendizaje, y también aumentar el rendimiento académico.

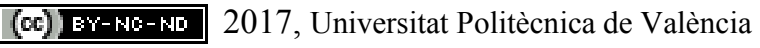




\section{Desarrollo de la innovación}

\subsection{Contexto de aprendizaje}

La propuesta de trabajo cooperativo, basada en el empleo de estrategias tipo Puzle de Aronson, se ha aplicado a la asignatura Aditivos Alimentarios correspondiente al Grado de Ciencia y Tecnología de los Alimentos que se imparte en la Facultad de Farmacia de la Universitat de València. La asignatura incluye 25 horas de teoría, 15 horas de prácticas de laboratorio, 2 horas de seminario coordinado y 2 horas de tutoría presencial. La asignatura es optativa y se imparte en el cuarto curso del grado con una frecuencia de 2-3 horas semanales. El número habitual de alumnos es de aproximadamente 25-30 miembros, siendo 29 en el curso 2016-2017. La asignatura se imparte en una aula con asientos y mesas fijos con una capacidad de 120 personas. El perfil de los estudiante en el curso 2016-2017 es el siguiente: $68.97 \%$ mujeres y $31.03 \%$ hombres, edad promedio de 23.34 años, un $93.10 \%$ no realiza ningún tipo trabajo renumerado, y un $13.79 \%$ proceden de programas internacionales de intercambio (Erasmus,...).

\subsection{Contenidos de la asignatura}

Los contenidos que se imparten en la asignatura Aditivos Alimentarios se dividen en 13 temas, correspondientes a las distintas categorías de aditivos alimentarios permitidos en la Unión Europea, así como un tema inicial introductorio y dos finales relativos a evaluación toxicológica y legislación actual. El título de cada tema con el número de horas aproximado se muestra en la Tabla 1.

Tabla 1. Temas correspondientes a la asignatura Aditivos Alimentarios

\begin{tabular}{lll}
\hline Tema & Título & Horas \\
\hline Tema 1 & Introducción & 1 \\
Tema 2 & Aditivos antioxidantes & 3 \\
Tema 3 & Aditivos antimicrobianos. & 3 \\
Tema 4 & Agentes depresores de la actividad de agua. & 1 \\
Tema 5 & Antiendurecedores. & 2 \\
Tema 6 & Aromatizantes y potenciadores del sabor. & 2 \\
Tema 7 & Edulcorantes. & 2 \\
Tema 8 & Colorantes & 2 \\
Tema 9 & Espesantes y gelificantes & 2 \\
Tema 10 & Emulgentes & 1 \\
Tema 11 & Auxiliares tecnológicos de fabricación & 2 \\
Tema 12 & Evaluación toxicológica & 2 \\
Tema 13 & Legislación relativa a aditivos & 2 \\
\hline
\end{tabular}

(c) $)$ EY-NC-ND 2017, Universitat Politècnica de València 


\subsection{Temporalización de la actividad}

La actividad propuesta se ha realizado en dos sesiones de tutorías presenciales en el aula (1 hora cada sesión) que se realizan a mitad del semestre en el que aproximadamente ya se ha impartido la mitad del temario. Las dos tutorías han tenido lugar en un plazo corto de tiempo (1-2 semanas), por lo que los alumnos han tenido un plazo de tiempo adecuado para la asimilación de los conceptos adquiridos y meditación de las ideas concebidas. Asimismo, ha permitido la búsqueda fuera del aula de conocimientos adicionales y complementarios al temario impartido en la asignatura para su aplicación en la segunda tutoría.

\subsection{Descripción de la tarea}

En las tutorías de esta asignatura se ha desarrollado una actividad basada en el puzle de Aronson para fomentar el trabajo cooperativo. Los alumnos se dividen en dos grupos de 15 personas aproximadamente para realizar las tutorías, por lo que el número de alumnos fue reducido. La actividad propuesta consiste en la resolución por grupos de diferentes problemas prácticos relacionados con el empleo de Aditivos Alimentarios en la formulación de alimentos.

La idea general consiste, en una primera etapa, en la selección aleatoria de 4 personas para formar un grupo al que se le asignará la tarea de resolver un problema de tipo práctico. En una segunda etapa cada uno de los miembros del grupo inicial se divide en 4 grupos de expertos para que se formen en una materia específica (ver esquema en Figura 1). En este caso cada grupo se centró en una categoría de aditivos alimentarios, como antioxidantes, antimicrobianos, edulcorantes, y colorantes. Cada grupo se sitúa en los extremos del aula para no interferir entre ellos y el profesor va coordinando las actividades dentro de cada grupo de expertos, para orientar al grupo y dirigir su aprendizaje en aquellos temas clave. Durante esta etapa, la formación consiste en la consulta y discusión de los apuntes de clase, clasificando los aditivos por naturaleza, riesgo, frecuencia de uso, características físico-químicas y coste. Tras la primera sesión de tutorías, los expertos en aditivos buscan información adicional fuera del aula para complementar los conocimientos necesarios para poder ser empleados en la segunda etapa. Esta búsqueda de información se realiza tanto por bibliografía reglada (libros, revistas, periódicos), como no reglada (consulta en internet, foros, redes sociales, etc).

En una tercera fase ( $2^{\circ}$ día de tutoría) cada uno de los expertos formados en cada tipo de aditivos alimentarios se reagrupa en los cuatro grupos de trabajo iniciales que abordarán la resolución de un problema relacionado con la formulación de los aditivos adecuados para diferentes tipos de alimentos: productos cárnicos, vegetales, panadería y bollería, y lácteos (ver Figura 1). En esta etapa, los alumnos disponen de diversas etiquetas reales de alimentos correspondientes a dichas categorías y proceden a una evaluación del tipo de aditivos que lleva, el por qué, posibles riesgos toxicológicos, consecuencias de su retirada de la formulación, y propuesta de posibles sustitutos. La Figura 2 muestra alguna de las etiquetas modelo empleadas en la actividad propuesta. Adicionalmente, existen

(c)) BY-NC-ND 2017, Universitat Politècnica de València

Congreso IN-RED (2017) 
efectos sinérgicos en el uso de aditivos de distintas familias, por lo que se fomenta la discusión para ver qué aditivos son más necesarios que otros y cuáles de ellos se complementan. Finalmente, se les propuso un caso de un alimento ficticio en el que cada grupo de alumnos debía de proponer de forma consensuada y razonada la adición de aditivos si fuera necesario y el por qué.

\section{Grupo de expertos: 1a sesión}

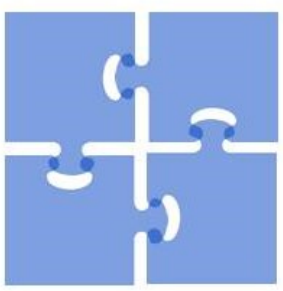

Antioxidantes

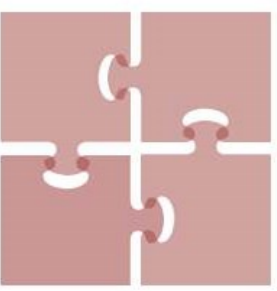

Antimicrobianos

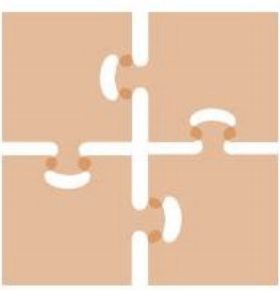

Edulcorantes

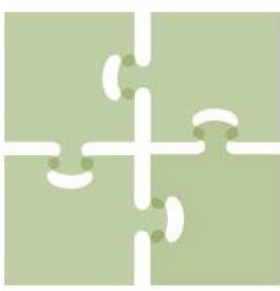

Colorantes

\section{Grupo de trabajo: 2a sesión}

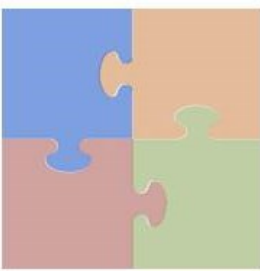

Productos cárnicos

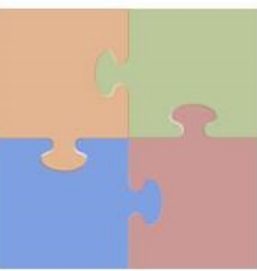

Vegetales

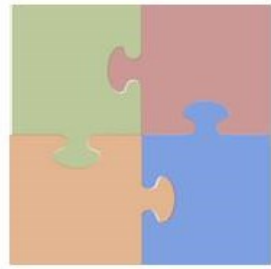

Panadería y bollería

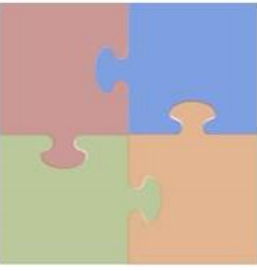

Lácteos

Fig. 1 Esquema de los grupos de expertos y de trabajo seleccionados en la actividad propuesta.

\section{Resultados}

\subsection{Resultados de aprendizaje}

La presente tarea pretende en su primera sesión afianzar los conceptos teóricos que se imparten en la asignatura a través de la autoformación de expertos en aquellos aditivos alimentarios más frecuentes e importantes, que se imparten en los primeros temas del curso (Temas 2: Antioxidantes, Tema 3: Antimicrobianos, Tema 7: Edulcorantes, y Tema 8: Colorantes). Considerando la temática elegida en la actividad, existe gran cantidad de información no reglada, sobre todo en búsquedas por internet y foros de opinión que permitió al grupo de expertos discutir la veracidad o falsedad parcial de los datos encontrados en la red. Esto contribuyó a incrementar el interés del estudiante por la búsqueda e interpretación de mayor cantidad de información, lo que fomenta su capacidad crítica, que se complementó con los conocimientos impartidos en las clases teóricas. Además, el empleo de estas metodologías de aprendizaje fomenta el estudio continuado de la materia, de forma que el alumnado no solo memoriza conceptos, sino que madura el conocimiento y fomenta su aplicación a casos reales. 


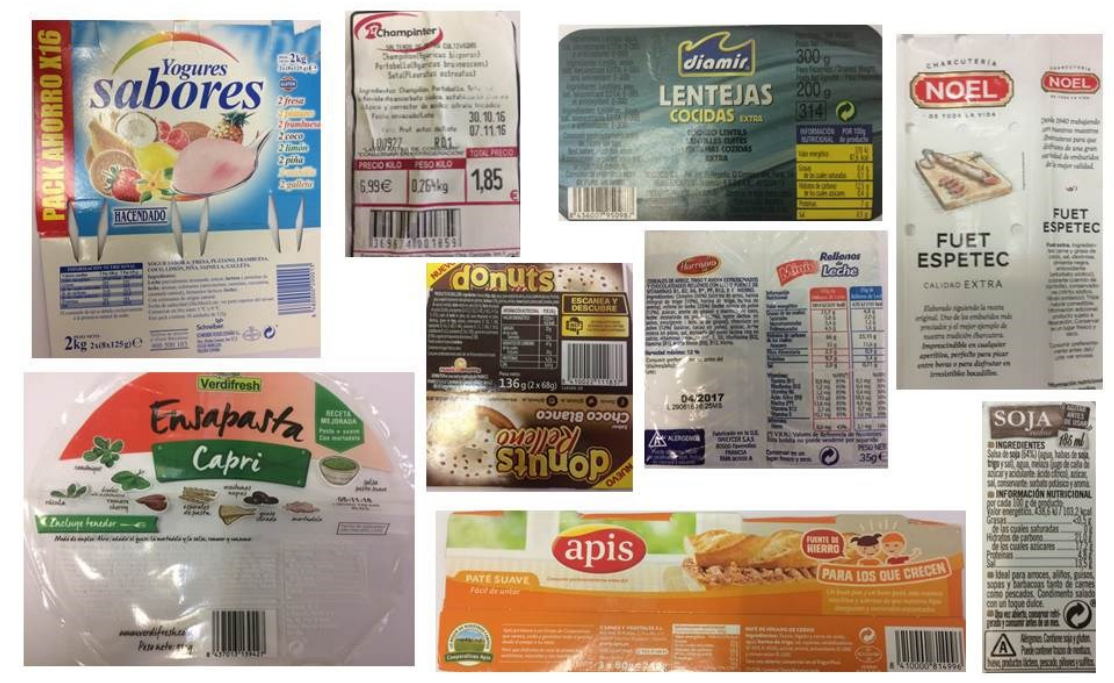

Fig. 2. Ejemplo de alguna de las etiquetas empleadas.

En la segunda sesión se aplicaron los conocimientos adquiridos por los distintos expertos en aditivos a etiquetas reales de alimentos que se les proporcionó en el aula. Los grupos de trabajo, discutieron la adecuación de los aditivos alimentarios presentes en cada producto y valoraron la posible eliminación/sustitución de los aditivos presentes. Finalmente, se les propuso un alimento modelo a cada grupo de trabajo para que decidieran por consenso y de una forma razonada los aditivos que debía incluir en su formulación para conseguir una elevada vida útil del alimento manteniendo unas características organolépticas adecuadas. Esto permitió que cada uno de los expertos defendiera y justificara la presencia o no de determinados aditivos alimentarios críticos en la formulación del alimento, adquiriendo competencias que les resultarán de gran utilidad en el desarrollo de su futura carrera profesional.

Durante la implantación de la tarea propuesta, sobre todo en la primera sesión de turorías, a los alumnos le costó un poco entender el proceso que se les proponía, sin embargo durante la segunda sesión se observó una dinámica mucho mas fluída. Por lo que para el año que viene, se emplearán unos minutos en las clase de teoría para explicarles el el fundamento del trabajo cooperativo propuesto.

A través del empleo de la técnica de trabajo cooperativo propuesta se desarrollaron competencias y habilidades sociales que figuran en la correspondiente guía docente de la asignatura, tales como:

- Capacidad de aplicar los conocimientos a la práctica.

- Razonamiento crítico que les permita emitir juicios argumentados y defenderlos con rigor y tolerancia.

- Capacidad de trabajar en grupo, responsabilidad compartida, gestión de conflictos, y propuesta de soluciones objetivas.

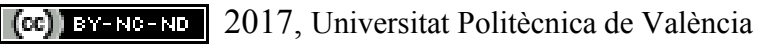

Congreso IN-RED (2017) 


\subsection{Evaluación de la actividad}

El aprendizaje por trabajo cooperativo se ha incorporado a la asignatura de Alimentos Alimentarios por primera vez en el curso 2016-2017 dentro de las 2 horas correspondientes a tutorías. Durante este primer año de aplicación de la actividad la evaluación de los resultados de aprendizaje obtenidos ha sido meramente cualitativa. Respecto al rendimiento académico, los resultados han estado en sintonía con cursos anteriores, con $3.4 \%$ matrícula de honor, $10.3 \%$ sobresaliente, $68.9 \%$ notable, 10.3 aprobado, y $6.9 \%$ no presentado. Gracias a la actividad propuesta se ha observado un aumento en el interés de los alumnos por incrementar sus conocimientos teóricos relativos al empleo de aditivos alimentarios y justificar su presencia en los alimentos. Fomentando su estudio en actividades del día a día tales como realizar la compra o seleccionar el alimento más saludable para la dieta. Debido a la respuesta favorable y elevado interés mostrado por los alumnos se pretende incorporar esta actividad al desarrollo de la asignatura en cursos venideros y evaluarla de una forma cuantitativa.

Considerando los resultados de aprendizaje que se trabajan con la actividad propuesta se propone una evaluación de tipo mixta con una parte formativa para valorar solo el proceso de aprendizaje (trabajo cooperativo), y otra sumativa para valorar la viabilidad y adecuación de las propuestas finales desarrolladas por cada grupo de trabajo. Además de la evaluación del profesor, la autoevaluación del alumno resulta clave para conocer lo útil que ha sido esta herramienta para fomentar el trabajo cooperativo. Con el objeto de cuantificar la evolución de las habilidades y competencias adquiridas por los alumnos respecto a su capacidad para realizar trabajo cooperativo se propone el empleo de la rúbrica mostrada en la Tabla 2. En la actualidad no se dispone de cuantificadores para la evaluación del trabajo cooperativo realizado, pero dicha rúbrica se aplicará en años futuros para ver, tanto la eficiencia, como la evolución, de las habilidades referentes al trabajo cooperativo de los estudiantes. La contribución de las tutorías en la nota final de la asignatura es de un $10 \%$. Se propone que un $50 \%$ de dicha nota evalúe el proceso y el otro $50 \%$ evalúe el resultado obtenido. La nota del proceso se obtendrá como la media de la evaluación del profesor y la autoevaluación del propio grupo. Mientras que la nota del resultado obtenido se obtendrá como la media de la evaluación del profesor y la del resto de grupos de trabajo.

\section{Conclusiones}

La técnica de aprendizaje cooperativo basada en el empleo de Puzle de Aronson ha sido utilizada por primer año en las tutorías de la asignatura optativa de Aditivos Alimentarios incluida en el Grado de Ciencia y Tecnología de los Alimentos. Los resultados obtenidos, a pesar de preliminares, han sido muy positivos, no solo respecto al rendimiento académico de los estudiantes, sino también respecto a la mejora de su capacidad para trabajar en grupo. Esta estrategia ha fomentado el desarrollo de las habilidades sociales de los alumnos y su capacidad de integración dentro de grupos, reduciendo la competitividad y rivalidad entre sus miembros. Además ha capacitado a los alumnos para la resolución creativa de problemas, y a la adaptación y aplicación de los conocimientos teóricos a situaciones reales. 
Tabla 2. Rúbrica propuesta para evaluar la capacidad de cooperación del grupo para solucionar un problema propuesto.

\begin{tabular}{|c|c|c|c|c|}
\hline & Excepcional & Admirable & Aceptable & Mejorable \\
\hline $\begin{array}{l}\text { Participación } \\
\text { grupal }\end{array}$ & $\begin{array}{l}\text { Todos los } \\
\text { estudiantes } \\
\text { participan } \\
\text { activamente en la } \\
\text { actividad }\end{array}$ & $\begin{array}{l}\text { La mayoría de los } \\
\text { estudiantes } \\
\text { participan } \\
\text { activamente }\end{array}$ & $\begin{array}{l}\text { Al menos la mitad } \\
\text { de los estudiantes } \\
\text { presentan ideas } \\
\text { propias }\end{array}$ & $\begin{array}{l}\text { No existe } \\
\text { participación activa. }\end{array}$ \\
\hline $\begin{array}{l}\text { Roles dentro del } \\
\text { grupo }\end{array}$ & $\begin{array}{l}\text { Cada estudiante } \\
\text { tiene un rol } \\
\text { asignado bien } \\
\text { definido. }\end{array}$ & $\begin{array}{l}\text { Cada estudiante } \\
\text { tiene un rol } \\
\text { asignado, pero no } \\
\text { está claramente } \\
\text { definido o no es } \\
\text { consistente. }\end{array}$ & $\begin{array}{l}\text { Hay roles asignados } \\
\text { a los estudiantes, } \\
\text { pero no se adhieren } \\
\text { consistentemente a } \\
\text { ellos. }\end{array}$ & $\begin{array}{l}\text { No hay ningún } \\
\text { esfuerzo de asignar } \\
\text { roles a los } \\
\text { miembros. }\end{array}$ \\
\hline $\begin{array}{l}\text { Responsabilidad } \\
\text { compartida }\end{array}$ & $\begin{array}{l}\text { Todos comparten } \\
\text { por igual la } \\
\text { responsabilidad } \\
\text { sobre la tarea }\end{array}$ & $\begin{array}{l}\text { La mayor parte de } \\
\text { los miembros del } \\
\text { grupo comparten } \\
\text { la responsabilidad } \\
\text { en la tarea }\end{array}$ & $\begin{array}{l}\text { La responsabilidad } \\
\text { es compartida por la } \\
\text { mitad de los } \\
\text { integrantes del } \\
\text { grupo }\end{array}$ & $\begin{array}{l}\text { La responsabilidad } \\
\text { recae en una sola } \\
\text { persona }\end{array}$ \\
\hline $\begin{array}{l}\text { Delegación de } \\
\text { responsabilidad }\end{array}$ & $\begin{array}{l}\text { Cada estudiante } \\
\text { en el grupo puede } \\
\text { explicar qué } \\
\text { información es } \\
\text { necesaria para el } \\
\text { grupo y qué } \\
\text { información es } \\
\text { responsable de } \\
\text { localizar. }\end{array}$ & $\begin{array}{l}\text { Cada estudiante } \\
\text { en el grupo puede } \\
\text { explicar qué } \\
\text { información es } \\
\text { responsable de } \\
\text { localizar. }\end{array}$ & $\begin{array}{l}\text { Cada estudiante en } \\
\text { el grupo puede, con } \\
\text { la ayuda de sus } \\
\text { compañeros, } \\
\text { explicar qué } \\
\text { información es } \\
\text { responsable de } \\
\text { localizar. }\end{array}$ & $\begin{array}{l}\text { Uno o más } \\
\text { estudiantes en el } \\
\text { grupo no pueden } \\
\text { explicar qué } \\
\text { información ellos } \\
\text { son responsables de } \\
\text { localizar. }\end{array}$ \\
\hline $\begin{array}{l}\text { Calidad de } \\
\text { interaccion }\end{array}$ & $\begin{array}{l}\text { Todos los } \\
\text { alumnos se } \\
\text { expresan } \\
\text { adecuadamente, } \\
\text { saben escuchar y } \\
\text { se respetan los } \\
\text { puntos de vista y } \\
\text { opiniones de los } \\
\text { demás }\end{array}$ & $\begin{array}{l}\text { La mayor parte de } \\
\text { los alumnos se } \\
\text { expresa } \\
\text { adecuadamente, } \\
\text { sabe escuchar y } \\
\text { respeta los puntos } \\
\text { de vista y } \\
\text { opiniones de los } \\
\text { demás }\end{array}$ & $\begin{array}{l}\text { Una minoria de los } \\
\text { alumnos se expresa } \\
\text { adecuadamente, } \\
\text { sabe escuchar y } \\
\text { respeta los puntos de } \\
\text { vista y opiniones de } \\
\text { los demás }\end{array}$ & $\begin{array}{l}\text { Existe muy poca } \\
\text { interacción, } \\
\text { conversación muy } \\
\text { breve, distracciones } \\
\text { o desinterés. }\end{array}$ \\
\hline $\begin{array}{l}\text { Calidad de las } \\
\text { fuentes }\end{array}$ & $\begin{array}{l}\text { Se han utilizado } \\
\text { los apuntes de la } \\
\text { signatura y se han } \\
\text { ampliado en } \\
\text { búsquedas por } \\
\text { internet y } \\
\text { legislación oficial. }\end{array}$ & $\begin{array}{l}\text { Se han utilizado } \\
\text { los apuntes de la } \\
\text { signatura y se han } \\
\text { ampliado en } \\
\text { búsquedas por } \\
\text { internet. }\end{array}$ & $\begin{array}{l}\text { Se han utilizado los } \\
\text { apuntes de la } \\
\text { asignatura } \\
\text { exclusivamente. }\end{array}$ & $\begin{array}{l}\text { No se ha utilizado } \\
\text { ningún tipo de } \\
\text { fuente. }\end{array}$ \\
\hline $\begin{array}{l}\text { Se han cumplido } \\
\text { los objetivos del } \\
\text { equipo? }\end{array}$ & $\begin{array}{l}\mathrm{Si} \text {, con gran } \\
\text { probailidad de } \\
\text { implantación. }\end{array}$ & $\begin{array}{l}\text { Sí, con poca } \\
\text { posibilidad de } \\
\text { implantación. }\end{array}$ & Parcialmente & No \\
\hline
\end{tabular}

(cc) EY-NC-ND 2017, Universitat Politècnica de València 


\section{Referencias}

GARCÍA, R., TRAVER, J., y CANDELA, I. (2001). Aprendizaje cooperativo. Fundamentos, características y técnicas. Madrid: CCS.

JOHNSON, D. y JOHNSON, R. (1991). Learning together and alone. Cooperative, competitive and individualistic learning. Needham Heights, Allyn and Bacon.

KAGAN, S. (1994). Cooperative Learning. San Clemente, CA: Kagan

TRAVER, J. A., y GARCÍA, R. (2004). La enseñanza-aprendizaje de la actitud de solidaridad en el aula: una propuesta de trabajo centrada en la aplicación de la técnica puzzle de Aronson, en Revista Española de Pedagogía, 229, pp. 419-437. 


\title{
Experiencias Teórico-Prácticas de Física en un Entorno Virtual
}

\section{0}

\section{José Daniel Sierra Murillo ${ }^{\mathrm{a}}$}

a Universidad de La Rioja, Departamento de Química, Área de Física Aplicada; Complejo Científico-Tecnológico, C/ Madre de Dios 51 26006-Logroño, daniel.sierra@unirioja.es.

\begin{abstract}
An innovative project on Experimental Theoretical Practices in Physics in a Virtual Environment 3.0 is proposed. The aim is to improve the competences of the student's autonomous and collaborative work. Supported both on a variant of the "Flipped Learning" Methodology and within a Virtual Environment 3.0. Obviously, in addition to the improvement in the learning of Physics, it is of great interest the acquisition by students of computer skills, very important in a scientific-technological environment of the 21st century. The development of the project is carried out in three Phases: Introduction, Preparation and Application of the methodology used to achieve the fundamental objectives of this project. Some of the results pursued by this project are, among others, corroborate the importance of using the new technologies of the information and communication society, not only in the transmission of information, but also in the processes of University learning. All of it, within a Virtual Environment 3.0 or, even, within an approximation to 4.0. This profile of the project combines with the philosophy of Bologna 2020 regarding changes in teaching-learning models.
\end{abstract}

\section{Keywords:}

Theoretical-Practical Experiences, Physics, Competences, Autonomous and Collaborative Work, Flipped Learning Methodology, Informatica Skills, Virtual Environment 3.0

\section{Resumen}

Se propone un proyecto innovador sobre Experiencias Teórico-Prácticas en Física en un Entorno Virtual 3.0. Se pretende la mejora de las competencias del trabajo autónomo y colaborativo del alumno. Apoyadas ambas sobre una variante de la Metodología "Flipped Learning" y dentro de un Entorno Virtual 3.0. Obviamente que además de la mejora en el aprendizaje de la Física, es de gran interés la adquisición por parte del alumnado de habilidades informáticas, muy importantes en un entorno científicotecnológico del siglo XXI. El desarrollo del proyecto se lleva a cabo en tres Fases: Introducción, Preparación y Aplicación de la metodología utilizada para alcanzar los objetivos fundamentales de este proyecto. Alguno de los resultados que se persiguen con este proyecto son, entre otros, corroborar la importancia de la utilización de las nuevas tecnologías de la sociedad de la información y de la comunicación, no solo en la transmisión de información, 
sino también en los procesos de aprendizaje universitario. Todo ello, dentro de un Entorno Virtual 3.0 ó, incluso, dentro de una aproximación al 4.0. Este perfil del proyecto conjuga con la filosofía de Bolonia 2020 relativa a los cambios en los modelos de docencia-aprendizaje.

Palabras clave: Experiencias Teórico-Prácticas, Física, Competencias, Trabajo Autónomo y Colaborativo, Metodología "Flipped Learning", Habilidades Informáticas, Entorno Virtual 3.0.

\section{Introducción}

La educación superior ha experimentado un gran cambio dentro del sistema educativo de la sociedad actual en diferentes ámbitos (Ortega Carrillo, 2004; González Mariño, 2008) como, por ejemplo:

- La evolución de los procesos de formación desde entornos presenciales convencionales hacia otros ámbitos más amplios.

- La demanda generalizada para que los estudiantes adquieran competencias específicas y transversales (Bolonia, 2009), así como ciertas habilidades necesarias para su aprendizaje continuo.

El espacio de aprendizaje ha progresado de forma vertiginosa. Las instituciones educativas, ya sean presenciales o a través de entornos virtuales, tienen que reajustar sus sistemas de intercambio de información y comunicación. Estos cambios traen consigo el desarrollo de nuevas estructuras organizativas de la enseñanza, caracterizadas por la modularidad, la interconexión y la flexibilidad/capacidad de intercambio sobre entornos virtuales diversos.

Esto exige a las instituciones de educación, entre otras la superior, flexibilidad en sus procedimientos y en su estructura administrativa, de acuerdo a las necesidades de una nueva sociedad (Ortega Carrillo, 2004).

Las instituciones actuales deben responder a este desafío, revisar sus referentes actuales y promover experiencias innovadoras en los procesos de enseñanza-aprendizaje. Para ello, pueden apoyarse en las nuevas Tecnologías de la sociedad de la Información y de la Comunicación (TIC), sin olvidar hacer énfasis en la docencia. Cambios de estrategias didácticas de los profesores y alumnos para acceder, buscar, compartir y gestionar toda la información referida a diferentes materiales objeto de estudio y aprendizaje, es decir, en los procesos de innovación docente. (Mora Mora H., Signes Pont, M. T., De Miguel Casado, G. and Gilart Iglesias, V., 2015)

La Universidad dispone de multitud de experiencias de «enseñanza virtual», «aulas virtuales», etc. No obstante, se necesita la participación activa y la motivación del profesorado y alumnado, además de un fuerte compromiso institucional con la innovación

(c)) EY-NC-ND 2017, Universitat Politècnica de València 
docente y su puesta en valor al mismo nivel que la investigación específica de dichos actores, profesorado y alumnos. El devenir actual de la actividad universitaria promueve la investigación, a veces, en detrimento de la docencia y de los proyectos de innovación docente (Salinas, 2004). Cuando estos procesos innovadores docentes pueden ser métodos de mejora de la actividad universitaria, tanto docente como investigadora. Más aún, se olvida a veces en algunas instituciones que la formación básica en los primeros cursos de las diferentes titulaciones es fundamental para un sólido crecimiento del aprendizaje del alumnado en la diversidad de conocimientos necesarios hoy en día. Como competencias específicas y transversales, así como habilidades asociadas, relacionados todos ellos con el afán de mejora profesional de los actores implicados.

En cuanto al Entorno Virtual 3.0 (EV-3.0), se considera como un estado en el que Internet proporciona condiciones de gran interés para que los individuos y las organizaciones puedan compartir información independientemente de las redes y dispositivos que utilicen. (Mora Mora H., Azorín López, J., Jimeno Morenilla, A., Sánchez Romero, J. L., Pujol López, F., García Rodríguez, J., Serra Pérez, J. A., Morell Giménez, V., Rives Pérez, M. F., Saval Calvo, M., García García, A. and Orts Escolano, S., 2016) Las Webs 3.0 también se han venido a denominar Webs semánticas (Berners-Lee, 2001; W3C, 2001). Este nuevo concepto de $W e b$ semántica constituye esencialmente una extensión de la Web tradicional en la que la información se coloca de forma estructurada para permitir su fácil consulta y acceso tanto por interlocutores humanos como por sistemas automáticos (Silva, J. M., Mahfujur, A. S. Md. and El Saddik, A., 2008; Nacer and Aissani, 2014).

En el ámbito educativo esas herramientas adquieren más relevancia debido a que contribuyen a revisar los planteamientos docentes actuales. Los estudiantes, ya no solo tienen que ser buenos conocedores de cada materia en cuestión, sino también deben desarrollar otras actitudes como la creatividad, el espíritu crítico y la capacidad para el aprendizaje continuo que la sociedad les demanda. Todo ello, en línea con la Declaración Mundial para la Educación Superior en el siglo XXI (Granados, 2011) y la Declaración de Bolonia 2020 (Bolonia, 2009).

Seguidamente se describen brevemente los apartados de los que consta este artículo. A continuación (Sección "Objetivos"), se exponen los objetivos que se pretenden alcanzar a través de este proyecto innovador. Posteriormente, y dentro de la Sección "Desarrollo de la innovación", se describe el desarrollo de la metodología utilizada en este proyecto mediante una planificación en tres Fases. Por lo que respecta a la Sección titulada "Resultados", en ella se muestra una comparativa de las mejoras observadas en los mismos. Finalmente, se termina con unas breves conclusiones que confirman el potencial del uso racional de las TIC en el estudio Teórico-Práctico de la Física.

\section{Objetivos}

Los objetivos principales de este proyecto innovador, basado en Experiencias TeóricoPrácticas en Física sobre un EV-3.0, son la mejora de las competencias del trabajo autónomo y colaborativo del alumnado. Para la mejora de éste último, los tradicionales 
Grupos Reducidos (GR $\rightarrow$ entre 25 y 30 alumnos) se subdividen en pequeños subGrupos Reducidos (sbGR $\rightarrow$ entre 3 y 5 alumnos) con el objetivo de un mejor seguimiento (individual y colectivo) por parte del profesor (Mazur, 1997). Dichos objetivos competenciales se consiguen de una forma más eficiente mediante la utilización de la Metodología "Flipped Learning" (MFL), (Prieto, 2015), dentro de un EV-3.0. Aunque es obvio el objetivo de mejora en el aprendizaje de la Física, es de gran interés la adquisición por parte del alumno diversas habilidades informáticas, muy importantes en un entorno científico-tecnológico en pleno siglo XXI. (Karpicke and Blunt, 2011; Deslauriers, L., Schelew, E. and Wieman C., 2011; Freeman, S., Eddy, S. L., McDonough, M., Smith M. K., Okoroafor N., Jordt, H. and Wenderoth, M. P., 2014) En la sección correspondiente a la parte metodológica, se describen los objetivos y, además, se muestra el desarrollo del proyecto llevado a cabo en tres Fases: Introducción, Preparación y Aplicación de la metodología utilizada para alcanzar los objetivos fundamentales de este proyecto. Alguno de los resultados que se persiguen con este proyecto son, entre otros, corroborar la importancia de la utilización de las nuevas tecnologías de la sociedad de la información y de la comunicación, no solo en la transmisión de información, sino también en los procesos de aprendizaje universitario, todo ello, dentro de un EV-3.0. Este perfil del proyecto conjuga con la filosofía de Bolonia 2020 relativas a los cambios en los modelos de docencia-aprendizaje.

\section{Desarrollo de la innovación}

La planificación de la metodología utilizada en este proyecto consta de tres Fases. Pretendería evolucionar la enseñanza tradicional (centrada en el protagonismo del profesor que explica todo a sus alumnos) hacia otro tipo de enseñanza en la que el protagonismo se reparta más entre el profesor y sus alumnos. Para que sean estos los que profundicen en el estudio de los temas objeto de investigación teórico-práctica a partir de los materiales y/o referencias proporcionados previamente por el profesor. Todo ello, a través de un trabajo autónomo-colaborativo dentro de un EV-3.0.

El trabajo autónomo y colaborativo del alumno en la preparación de experiencias teóricoprácticas de Física a través de la MFL y la utilización de un EV-3.0 es sumamente interesante. Por ello, el objetivo fundamental de una de las Fases (Fase 2), es buscar la eficacia autónoma y colaborativa de cada alumno en dicho trabajo de preparación como miembro activo de un sbGR. La optimización de esta Fase 2, con un posible asesoramiento complementario del profesor, promueve una mejora sustancial en el buen desarrollo posterior de la experimentación teórico-práctica.

Sobre todo, porque otra de las Fases en este proyecto (Fase 3) necesita un trabajo constructivo/eficiente de los equipos de alumnos (denominados sbGR) en el desarrollo resolutivo de las mencionadas experiencias teórico-prácticas: análisis de las mismas, propuestas de posibles vías de resolución (una o varias) y comprobación de las mismas, reflejando en el correspondiente documento los razonamientos por los que se ha elegido

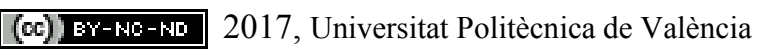

Congreso IN-RED (2017) 
dichas vías de resolución, el proceso de resolución matemático y la selección física de las soluciones matemáticas obtenidas.

Además, la posibilidad de transmitir/compartir la información obtenida/generada en todo el proceso de aprendizaje a través de los mencionados entornos virtuales crea hábitos de transparencia y superación entre los alumnos.

\section{Fase 1: Introducción metodológica.}

Una vez se haya impartido uno de los temas de la asignatura de Física, el profesor propondrá a cada equipo de trabajo (sbGR con 3-5 alumnos) una tipología de experiencias teórico-prácticas para su estudio y preparación mediante una variante de la MFL. Los alumnos, a través del EV-3.0 (sobre todo, con la ayuda del aula virtual Blackboard Learn ${ }^{\mathrm{TM}}$ versión 9.1, que forma parte de este entorno), dispondrán de la información necesaria: número de sbGR al que pertenecen (sbGR.A1.01, el alumno pertenece al subgrupo reducido 01, dentro del Grupo Reducido (GR) A1), la mencionada tipología de ejercicios teóricoprácticos asignada a cada sbGR, documentación correspondiente a la temática vinculada con dicha tipología y ya tratada en clase, con amplia información sobre la misma: referencias bibliográficas en papel y online, etc.; pero podrán complementarla con información obtenida por ellos de forma autónoma pero contrastada con el profesor.

No obstante, en la $1^{\text {a }}$ sesión de experiencias teórico-prácticas, el profesor expondrá/mostrará a los alumnos, dentro del entorno presencial (también posible en el EV3.0) del aula, los siguientes puntos fundamentales para un buen trabajo teórico-práctico:

- El programa de trabajo.

- La forma de trabajo de un científico/tecnólogo en un proceso resolutivo teórico-práctico basado en una variante del Método Científico.

- El material relativo a las experiencias teórico-prácticas utilizado para la realización de cada una de las mencionadas experiencias de Física.

- El material informático (hardware y software) que forma parte del EV-3.0 del que disponen en la universidad.

\section{Fase 2: Preparación metodológica.}

Para comenzar el proceso de preparación del trabajo teórico-práctico (trabajo autónomo y/o colaboración virtual entre los miembros de cada sbGR y el profesor), cada sbGR utilizará toda la información recibida por parte del profesor a través de una vía fundamental del mencionado EV-3.0 (Aula Virtual de la asignatura). También se permite la utilización de otras vías de obtención de información complementarias, pero sujetas a un control científico-tecnológico llevado a cabo por el profesor. A lo largo de esta $2^{\mathrm{a}}$ Fase, cada sbGR podrá consultar dudas al profesor mediante tutorías presenciales y/o virtuales, y también con sus compañeros de sbGR, GR y/o curso. El objetivo fundamental de esta Fase 2 es buscar la efíciencia en el aquí indicado trabajo de preparación de cada sbGR, así como un buen desarrollo posterior de cada experiencia teórico-práctica en la correspondiente sesión en GR. Cada sbGR añadirá en un documento Word, correspondiente a su práctica, toda la 
información (textual, imágenes/audio/video y referencias de todo tipo) obtenida/generada en esta Fase 2.

\section{Fase 3: Aplicación metodológica.}

Una vez trabajada con suficiencia por parte de los alumnos (...con posibilidad de apoyo del profesor...) la Fase 2, previa, y ya dentro del aula en la correspondiente sesión en GR:

a) Cada sbGR comenzará el trabajo resolutivo de una experiencia teórico-práctica vinculada con la tipología que se les haya propuesto, para su realización y finalización al cabo de una hora de cada sesión en GR. Hará uso del material obtenido/generado en el proceso de preparación previo, ya que las observaciones anotadas por los miembros del sbGR a lo largo del proceso de preparación anteriormente indicado (Fase 2) serán de gran ayuda. Las posibles dudas que podrían permanecer insatisfechas, además de otras que sobre el proceso resolutivo definitivo surgieran en el mismo, podrán ser consultadas al profesor, teniéndolas en cuenta en la evaluación de esta Fase 3:

- Es muy importante recordar al alumno la importancia de una completa/correcta preparación sobre la tipología teórico-práctica que se les asignó con la finalidad de evitar posibles errores conceptuales y/o metodológicos.

- Por otra parte, también es conveniente supervisar que el alumno utilice adecuadamente la mencionada información/metodología con el fin de que consolide unas muy útiles habilidades necesarias en su posterior dedicación discente/docente, investigadora $\mathrm{y} / \mathrm{o}$ profesional en general.

b) Una vez terminado el proceso resolutivo, los alumnos de cada sbGR completarán el documento (en el que se introduce toda la información generada en las tres Fases) con una interpretación de los resultados obtenidos, así como de la justificación de la vía/metodología resolutiva elegida para llegar a ellos.

- Conviene recordar al alumno la importancia del correcto uso del Método Científico en el proceso de experimentación teórico-práctica en ciencia/tecnología y objeto de nuestro estudio en Física. La forma de trabajo de un científico/tecnólogo en un proceso resolutivo teórico-práctico debe tener siempre presente la filosofía del "importantísimo" Método Científico.

c) Con toda la información obtenida en el proceso global de Experimentación TeóricoPráctica (textual, imágenes/audio/video y referencias de todo tipo que complementen todo el proceso de aprendizaje), el responsable de cada sbGR enviará al profesor y compartirá con sus compañeros de asignatura esa información a través de la plataforma virtual de la misma.

La posibilidad de transmitir/compartir la información obtenida/generada en todo el proceso de aprendizaje a través de los mencionados entornos virtuales crea hábitos de transparencia y superación entre los alumnos.

En cuanto a la planificación temporal o cronograma del proyecto, cada una de las Experiencias Teórico-Prácticas en Grupos Reducidos (GR) podrá desarrollarse en periodos de dos semanas, a la finalización de cada tema de la asignatura relacionada con la Física.

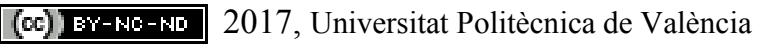


Las horas estimadas de dedicación al proyecto por cada uno de los componentes del grupo de innovación serán en torno a 20 horas, dependiendo de la titulación a la que pertenezca cada Grupo Reducido (GR) de alumnos.

\section{Resultados}

Dentro de diversas muestras de resultados, se ha analizado la mejoría que supone el método aquí presentado respecto al tradicional sobre un mismo tipo de alumnado (estudiantes de Ingeniería Industrial) y a través de dos tipos de medidas. Una subjetiva, relacionada con la satisfacción expresada por el alumnado al profesor a la finalización del trabajo, así como su actitud en el desarrollo del mismo a través de esta metodología. La otra cuantitativa, (ver Fig. 1), con base en la nota obtenida en la $1^{a}$ prueba presencial o convocatoria de febrero. ${ }^{1}$ En ella se aprecia la influencia del Método 3.0 (Con esta denominación se hará referencia a la Metodología "Flipped Learning" dentro de un EV-3.0) sobre los alumnos a lo largo del semestre que dura el desarrollo del trabajo teórico-práctico poniéndose de manifiesto el compromiso que adquieren y el reto de asumir presentarse casi la totalidad de los alumnos matriculados a dicha $1^{\text {a }}$ convocatoria $(98 \%)$, cuando antes lo hacía el $65 \%$. Y sobra decir que con mucho mejores resultados: Superan la $1^{\text {a }}$ convocatoria $41 \%$ (Método 3.0 ) por $18 \%$ (Método tradicional).

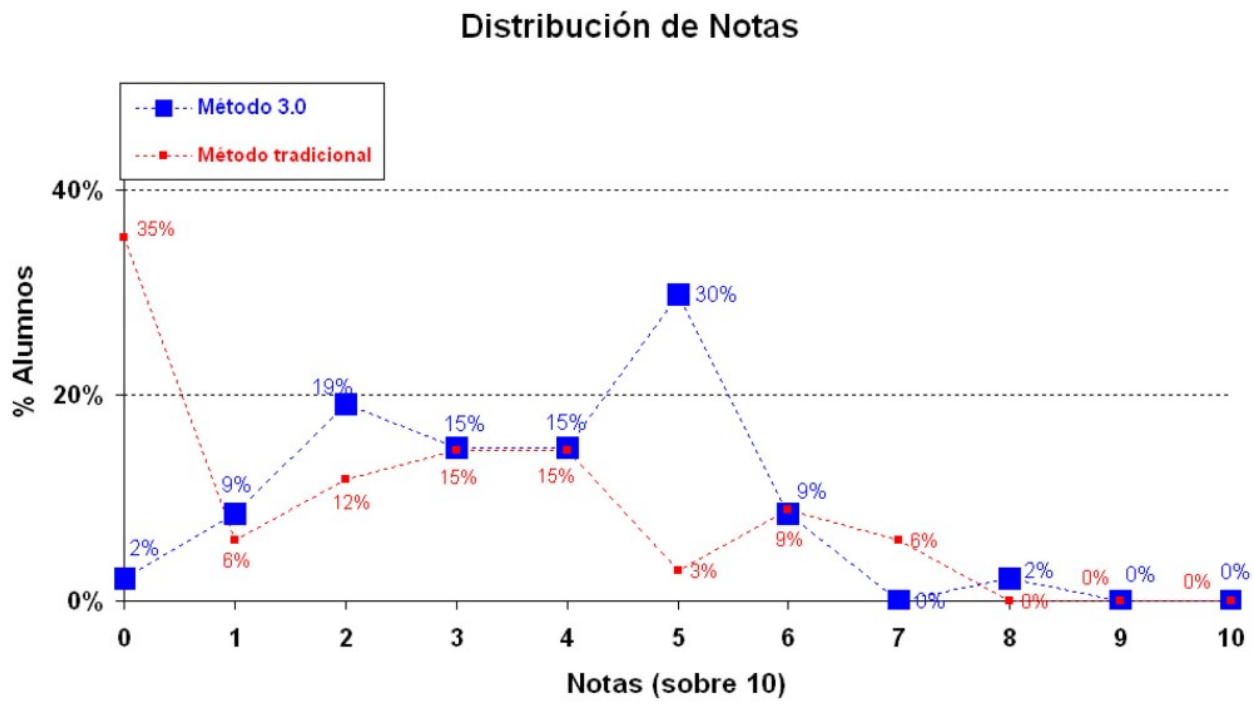

Figura 1. Comparativa de dos modelos utilizados antes (tradicional) y ahora (Método 3.0).

\footnotetext{
1 Es importante tener en cuenta que el \% de alumnos se refiere a la Tasa de Rendimiento. Se calcula sobre el número de alumnos matriculados. Sobra decir que el rendimiento llega a niveles razonables una vez agotadas el resto de convocatorias,
} 
Dentro de los resultados obtenidos a lo largo de la puesta en práctica del proyecto de innovación aquí presentado, se exponen a continuación los puntos más significativos observados a lo largo del periodo utilizado (semestre):

* Se produce una evidente mejoría del trabajo autónomo y colaborativo entre los alumnos de cada sbGR, y también entre alumnos-profesor, principalmente a través del EV-3.0.

Además, es significativo el progreso del alumnado en la utilización de:

- La conexión entre plataformas informáticas (hardware y software) con sistemas experimentales donde la adquisición de datos se realiza de forma automática.

- Las plataformas informáticas (hardware y software) para el análisis de las resoluciones teórico-prácticas por parte del alumno.

- Ciertos entornos virtuales utilizados para la transmitir y compartir la información utilizada y generada en todo el proceso por los mismos alumnos y entre alumnosprofesor.

* Pero, sobre todo, existe una muy apreciable mejora cualitativa y cuantitativa en el proceso de aprendizaje Teórico-Práctico en Física por parte de los alumnos, así como de sus resultados académicos. (Fig. 1)

Me gustaría remarcar que los resultados académicos obtenidos mediante esta variante de la MFL son más realistas pues la nota máxima (10) no existe en las calificaciones obtenidas por los alumnos. Con ello, se intenta recordar a los alumnos relacionados con el mundo científico-tecnológico que "a la perfección se intenta tender...", a través de una adecuada utilización de Método Científico.

\section{Conclusiones}

Las conclusiones que pueden extraerse de los resultados obtenidos a lo largo del desarrollo de este proyecto de innovación docente confirman un potencial real de la utilización racional de las TIC y la MFL. En un proceso sólido y fiable de aprendizaje TeóricoPráctico de la Física de los Sistemas Naturales y Artificiales (I+D+i), y con la inestimable ayuda de un EV-3.0.

Una óptima preparación previa del trabajo teórico-práctico que se va a desarrollar en el GR mediante esta variante de la MFL, así como la puesta en común de este proceso a través del mencionado EV-3.0 hacen de dicha metodología una herramienta muy interesante para obtener una mejora, tanto en el aprendizaje consolidado de la Física como los resultados académicos.

Igualmente, el intercambio a través del EV-3.0 de las resoluciones teórico-prácticas, el análisis de las mismas, los resultados obtenidos a partir de ellos y el debate constructivo entre alumnos y entre alumnos-profesor proporcionan un rico caldo de cultivo que alimenta un crecimiento científico-tecnológico sólido y respetuoso con el medio ambiente.

(c)) EY-NC-ND 2017, Universitat Politècnica de València 
Sobra decir que todo el proceso está embebido en una praxis en torno a las TIC, que mejora las habilidades del alumnado respecto a todo aquello relacionado con esta nueva realidad virtual que ya está instalada entre nosotros.

\section{Referencias}

BERNERS-LEE, T., HENDLER, J. y LASSILA, O. (2001). The Semantic Web: A new form of Web content that is meaningful to computers will unleash a revolution of new possibilities. Scientific American, Vol. 284: pp. 35-43.

BOLONIA. (2009). The Bologna Process 2020 - The European Higher Education Area in the new decade. Communiqué of the Conference of European Ministers Responsible for Higher Education.

DESLAURIERS, L., SCHELEW, E. y WIEMAN C.. (2011). Improved Learning in a LargeEnrollment Physics Class, Science, Vol. 332, pp. 862-864. DOI: 10.1126/science.1201783.

FREEMAN, S., EDDY, S. L., MCDONOUGH, M., SMITH M. K., OKOROAFOR N., JORDT, H. y WENDEROTH, M. P. (2014). Active learning increases student performance in science, engineering, and mathematics, Proc. Natl. Acad. Sci. USA, Vol. 111, pp. 8410-8415.

GONZÁLEZ MARIÑO, J. C. (2008). TIC y la transformación de la práctica educativa en el contexto de las sociedades del conocimiento. Revista de Universidad y Sociedad del Conocimiento (RUSC). Vol. 5, n. ${ }^{\circ} 2$.

GRANADOS, J. (2011). The Challenges of Higher Education in the 21st Century, GUNi Newsletter, 5/11. (http://www.guninetwork.org/articles/challenges-higher-education-21st-century).

KARPICKE, J. D. y BLUNT, J. R. (2011). Retrieval Practice Produces More Learning than Elaborative Studying with Concept Mapping, Science, Vol. 331, pp. 772-775. DOI: 10.1126/science. 1199327.

MAZUR, E. (1997). Peer Instruction: A User's Manual. New York: Prentice Hall Series in Educational Innovation.

MORA MORA H., AZORÍN LÓPEZ, J., JIMENO MORENILLA, A., SÁNCHEZ ROMERO, J. L., PUJOL LÓPEZ, F., GARCÍA RODRÍGUEZ, J., SERRA PÉREZ, J. A., MORELL GIMÉNEZ, V., RIVES PÉREZ, M. F., SAVAL CALVO, M., GARCÍA GARCÍA, A. y ORTS ESCOLANO, S. (2016). Nuevas tendencias web 3.0 para la mejora de los procesos docencia-aprendizaje. Innovaciones metodológicas en docencia universitaria: resultados de investigación (pp.1543-1558). Alicante: Universidad de Alicante, Vicerrectorado de Estudios, Formación y Calidad, Instituto de Ciencias de la Educación.

MORA MORA H., SIGNES PONT, M. T., DE MIGUEL CASADO, G. y GILART IGLESIAS, V. (2015). Management of social networks in the educational process, Computers in Human Behavior, Vol. 51, Part B, pp. 890-895. doi:10.1016/j.chb.2014.11.010.

NACER, H. y AISSANI, D. (2014). Semantic web services: Standards, applications, challenges and solutions, Journal of Network and Computer Applications, Vol. 44, pp. 134-151. DOI: 10.1016/j.jnca.2014.04.015. 
ORTEGA CARRILLO, J. A.. (2004). Redes de aprendizaje y curriculum intercultural. Actas del XIII Congreso Nacional y II Iberoamericano de Pedagogía. Ed. Sociedad Española de Pedagogía. Valencia.

PRIETO MARTÍN, A. (2015-12-21). Decálogo de innovación metodológica para que los alumnos aprendan más y mejor en las asignaturas universitarias. Blog Profesor 3.0. http://profesor3punto0.blogspot.com.es/2015/12/decalogo-de-innovacion-metodologica.html.

SALINAS, J. (2004). Innovación docente y uso de las TIC en la enseñanza universitaria. Revista Universidad y Sociedad del Conocimiento. Vol. 1, n. ${ }^{\circ} 1$.

SILVA, J. M., RAHMAN, A. S. y EL SADDIK, A. (2008). Web 3.0: a vision for bridging the gap between real and virtual. Paper presented at the 1st ACM international workshop on Communicability design and evaluation in cultural and ecological multimedia system, Vancouver British Columbia, Canada.

W3C. (2001). W3C Semantic Web Activity. URL: http://www.w3.org/2001/sw/, Acceso: mayo 2016. 


\title{
Desarrollo y evaluación de la competencia transversal 'Creatividad, innovación y emprendimiento' en la asignatura 'Explotación del transporte aéreo y organización aeronáutica'.
}

\section{José María Mateu ${ }^{a}$}

${ }^{a}$ Departamento de ingeniería e infraestructura de los transportes de la Universitat Politècnica de València (UPV), jomaces1@tra.upv.es.

\begin{abstract}
'Creativity, innovation and entrepreneurship' is a competence included into its transversal competences by the Polytechnic University of Valencia. It is an essential competence for the development of the students, as well as for their engagement in the society with the role they deserve for their qualifications. The development of this competence must be embedded in the development of other more technical competences, to ensure that they are properly internalized and added to the students' automatic reasoning mechanisms. We show an experience in this line, consisting in a classroom practice designed to develop the competence under the subject of 'Air transport exploitation and aeronautical organization', in the aeronautical studies. The practice includes the co-assessment by peers.
\end{abstract}

Keywords: creativity, innovation, entrepreneurship, competences, assessment, air transport, business model, lateral thinking.

\begin{abstract}
Resumen
La competencia 'Creatividad, innovación y emprendimiento', incluida por la Universitat Politècnica de València en su lista de competencias transversales, es una competencia esencial en el desarrollo de los estudiantes, y en su preparación para asumir el rol que como titulados superiores la sociedad les asigna. El desarrollo de la competencia debe estar enmarcado en el desarrollo de las demás competencias de carácter más técnico, como vía para garantizar que el estudiante la interioriza y la añade a sus mecanismos automáticos de razonamiento. Presentamos una experiencia en esta línea, consistente en una Práctica que desarrolla la competencia en el curso de la asignatura 'Explotación del transporte aéreo y organización aeronáutica', de los estudios de Ingeniería aeronáutica. La Práctica incorpora además la evaluación de la misma a cargo de los compañeros y compañeras de los y las estudiantes (co-evaluación).
\end{abstract}

Palabras clave: creatividad, innovación, emprendimiento, competencias, evaluación, transporte aéreo, modelo de negocio, pensamiento lateral. 


\section{1.- Introducción}

El Espacio Europeo de Educación Superior, con la Universidad como principal referente, constituye en la actualidad el principal agente de la planificación e impartición de los procesos formativos de mayor nivel en Europa. En la medida en que no existe un nivel superior, las exigencias sobre el ámbito universitario son elevadas, puesto que sus egresados y egresadas acceden directamente a puestos de responsabilidad en las instituciones que configuran la sociedad real. Deben estar pues preparados para ello, deben de estar en condiciones de asumir los roles que la sociedad les confía.

Desde hace unas décadas se sostiene incluso la conveniencia de que la Universidad asuma de manera más directa la tarea de crear oportunidades, la creación de empleo y riqueza. Es la denominada 'tercera misión', que se añade a las dos tradicionales: la creación de conocimiento, o investigación, y su transmisión, o docencia (Martin y Etzkowitz, 2000).

Algunos van más allá y enmarcan en el relativamente nuevo ámbito de la Responsabilidad Social Universitaria la responsabilidad cívica que empuja a las universidades a convertirse en agentes de cambio social (Naval et al., 2011).

Con mayor o menor decisión, las Universidades han tomado iniciativas en este sentido, creando parques científicos, dando soporte a empresas spin-off, promoviendo acuerdos de investigación con empresas, comercializando los resultados de la investigación desarrollada, etc. El éxito ha sido desigual, dependiendo además de las expectativas previstas, el esfuerzo desplegado y los recursos involucrados.

En todo caso, todas estas medidas sirven preferentemente para apoyar las iniciativas personales de los miembros más activos de la comunidad universitaria, no para promover un cambio social que generalice la actitud emprendedora entre los distintos colectivos universitarios. Hay que recordar que sólo el $5,7 \%$ de la población adulta española está involucrada en actividades emprendedoras en fase inicial, algo que apenas ha variado a lo largo de los años (Peña, Guerrero y González-Pernía, 2015).

La generalización del espíritu emprendedor requiere de un esfuerzo formativo y cultural de mayor alcance, un esfuerzo que embeba la actitud emprendedora en toda la actividad desarrollada en la universidad, o al menos en una buena parte de ella. La introducción de competencias transversales en los planes de estudio de nuestras universidades es en este sentido una buena noticia, porque construye y avanza en esta dirección.

La Universitat Politècnica de València, en particular, ha concretado en 13 las competencias transversales que todos sus estudiantes deberían adquirir a lo largo de su paso por la Universidad, incluyendo entre ellas la competencia denominada 'Innovación, creatividad y emprendimiento'. Se trata de una competencia que no se venía trabajando en los estudios de ingeniería, por lo que su introducción requiere en sí misma de una clara convicción por parte del personal docente, y una firme voluntad de acometer el cambio.

Algunas propuestas precursoras, desarrolladas en otros estudios y especialidades, nos sirven de inspiración y guía (López, 2016; Marin-Garcia, Ramirez y Andreu, 2015). Más próxima a nuestra propuesta está la de Ruiz y otros (2015), que aplica herramientas creativas

(c) EY-NC-ND 2017, Universitat Politècnica de València

Congreso IN-RED (2017) 
(Design Thinking) en busca de nuevos modelos de negocio en un contexto genérico (no directamente relacionado con la especialidad de los estudiantes), empleando también instrumentos de evaluación (rúbricas) de carácter genérico.

Nuestra experiencia avanza sobre éstas al menos en tres direcciones:

1. proponiendo una Práctica que embebe la innovación en la especialidad concreta que cursan los estudiantes,

2. empleando instrumentos de evaluación específicos para medir el potencial de la innovación en modelos de negocio desplegada por los estudiantes, y

3. poniendo esa evaluación en manos de los compañeros y compañeras de los que han propuesto los nuevos modelos (co-evaluación).

La experiencia se enmarca en la asignatura 'Explotación del transporte aéreo y organización aeronáutica', que forma parte del plan de estudios del Máster Universitario en Ingeniería Aeronáutica de la Universitat Politècnica de València, tratándose además de un Máster habilitante para el ejercicio de la profesión de ingeniería aeronáutica.

La asignatura ha sido escogida como contribuidora al desarrollo de dos de las trece competencias transversales, las de 'Pensamiento crítico' e 'Innovación, creatividad y emprendimiento'. La asignatura ha sido escogida además como punto de control para ambas competencias (una asignatura es punto de control de una competencia cuando no sólo tiene la misión de trabajar la competencia, sino que debe además evaluar el progreso del alumno o alumna en la competencia).

\section{2.- Objetivos}

El objetivo de este trabajo es mostrar una experiencia concreta, desarrollada en el contexto de la citada asignatura, que desarrolla y evalúa la competencia transversal 'Innovación, creatividad y emprendimiento'.

La acción que exponemos perseguía el objetivo comentado asumiendo ciertas exigencias autoimpuestas. Además del rigor y la actualización en los contenidos que el marco universitario presupone, se pretendía:

- Que los contenidos aportados estuvieran encuadrados en el contexto real de las necesidades de desarrollo de una empresa innovadora del sector del transporte aéreo.

- Que la parte más sustancial del aprendizaje se desarrollara de manera armónica en el curso de una actividad práctica que involucrara tanto la competencia transversal en cuestión como las competencias de carácter general desarrolladas por la asignatura, por ejemplo 'que los estudiantes sepan aplicar los conocimientos adquiridos y su capacidad de resolución de problemas en entornos nuevos o poco conocidos dentro de contextos más amplios (o multidisciplinares) relacionados con su área de estudio'.

- Que esa actividad práctica incorporara el desarrollo de otras competencias que en el mundo real van intrínsecamente entrelazadas al proceso creativo, innovador y 
emprendedor, como la 'comprensión e integración', el 'trabajo en equipo y liderazgo' y el 'pensamiento crítico'.

\section{3.- Desarrollo de la innovación}

La asignatura 'Explotación del transporte aéreo y organización aeronáutica' se encuadra en la agenda del segundo semestre del primer curso del 'Máster Universitario en Ingeniería Aeronáutica'. La Práctica que se describe fue propuesta y desarrollada por primera vez en el segundo semestre del curso 2015-2016, con el detalle y resultados que a continuación se describen.

\section{1.- Contenidos previos aportados por la asignatura}

El programa de la asignatura comienza por el estudio del marco institucional del transporte aéreo, para adentrarse a continuación en las claves para la explotación eficaz y eficiente de las distintas modalidades del mismo: transporte comercial de pasajeros, transporte comercial de mercancías, aviación corporativa o ejecutiva, otros trabajos aéreos, la asistencia aeroportuaria o handling, etc.

En lo relativo al apartado de la Innovación el programa incorpora aspectos como 'los roles que puede jugar la innovación en la empresa de transporte aéreo', 'los ámbitos de aplicación de la misma' y, con especial énfasis, el aspecto de 'la innovación en modelos de negocio en el transporte aéreo'.

De relativamente reciente aparición, la innovación en modelos de negocio ha recibido una notable atención a lo largo de los años transcurridos de este siglo, tanto entre académicos de la Dirección de empresas como entre directivos y consultores. Este significativo interés en el concepto deviene del potencial teórico y práctico del mismo: "La innovación en modelos de negocio ha reconfigurado industrias enteras y ha redistribuido valor por miles de millones de dólares" (Johnson, Christensen y Kagermann, 2008; pág. 52). Las expectativas depositada en él son aún mayores: "Una empresa tiene tanto que ganar desarrollando un innovador modelo de negocio nuevo como desarrollando una innovadora nueva tecnología" (Chesbrough, 2010; pág. 356).

El ámbito del transporte aéreo se postula además como un ámbito donde la innovación en modelos de negocio ha dado y puede producir en el futuro importantes resultados. La literatura interpreta como innovaciones en modelos de negocio dos ejemplos paradigmáticos que han supuesto saltos cualitativos de alcance en sus respectivos mercados:

- la introducción de la 'aviación de bajo coste', en el mercado de transporte aéreo de pasajeros (Casadesus-Masanell y Ricart, 2010).

- la irrupción en el mercado de transporte aéreo de mercancías de los denominados 'integradores', empresas que asumen todos los pasos en una cadena de valor antes totalmente fragmentada (Shaw, 2007).

(cc) EY-NC-ND 2017, Universitat Politècnica de València

Congreso IN-RED (2017) 
Cuando estos ejemplos se proyectan al futuro, podemos concluir que "las innovaciones importantes no vendrán probablemente del vehículo de transporte, sino del sistema en el cual este vehículo se incorpora" (Crozet, 2010; pág. 20).

\section{2.- Planteamiento de la Práctica}

Siguiendo las directrices de Bolonia, se trataba entonces de configurar actividades en las que el alumno pudiera alcanzar los objetivos de aprendizaje de manera práctica, aplicada, partiendo de los contenidos explicitados en el apartado anterior.

La Práctica diseñada recibe por título 'Modelos de negocio en la aviación ejecutiva', y consiste en aplicar herramientas creativas de innovación en modelos de negocio al ámbito de esta modalidad de aviación, en busca de modelos de negocio innovadores y potencialmente capaces de crear servicios y mercados nuevos.

La aviación ejecutiva se define como la actividad de transportar grupos pequeños de personas (hasta 20) de manera segura, cómoda y eficiente en aeronaves apropiadas para ello. El modelo de negocio tradicional de la aviación ejecutiva consiste en el alquiler de la aeronave completa por parte de una empresa, institución o particular, durante un periodo de tiempo determinado. Ese periodo puede ser de horas, días, semanas o hasta años, y durante el mismo los clientes dispondrán de la aeronave y su tripulación con total dedicación y flexibilidad. Otros modelos de negocio han sido ensayados con mayor o menor fortuna. Entre los más utilizados la compra de la aeronave por el usuario (aviación privada), la compra compartida por varios usuarios (multipropiedad), la compartición del vuelo entre varias empresas o usuarios, etc.

La Práctica propone el uso de instrumentos creativos en busca de innovaciones en los modelos de negocio aplicables a la aviación ejecutiva. Los métodos creativos propuestos consisten concretamente en la aplicación del Pensamiento lateral (De Bono, 1967) a herramientas conceptuales habitualmente utilizadas en el ámbito del análisis e innovación en modelos de negocio, como es el caso del lienzo, o canvas, del modelo de negocio (Osterwalder y Pigneur, 2010) o la cadena de valor (Porter, 1985). Se trata de una metodología creativa ya empleada con éxito por el autor de este trabajo en el desarrollo de su Tesis doctoral (Mateu, 2015). En aquel caso se aplicaba a industrias más diversas (construcción, hostelería, fabricación cerámica, etc.).

La Práctica se estructura según la agenda detallada en la Tabla 1.

Tabla 1. Agenda de la Práctica

\begin{tabular}{|l|r|}
\hline Tarea & Duración aprox. \\
\hline $\begin{array}{l}\text { Presentación por el profesor del Pensamiento Lateral y la forma de } \\
\text { aplicarlo al Lienzo del modelo de negocio (ya expuesto en clase al }\end{array}$ & \multirow{2}{*}{ minutos } \\
hablar de Innovación en modelos de negocio), y a la cadena de valor. \\
Todo ello ilustrado con ejemplos de aplicación a otras modalidades de
\end{tabular}




\begin{tabular}{|l|r|}
\hline aviación y otros sectores. & 30 minutos \\
\hline $\begin{array}{l}\text { Trabajo en equipos de tres o cuatro estudiantes, aplicando lo anterior a } \\
\text { la búsqueda de nuevos modelos de negocio en el ámbito de la aviación } \\
\text { ejecutiva (parte principal de la Práctica) }\end{array}$ & 10 minutos \\
\hline $\begin{array}{l}\text { Elección del mejor Modelo de entre los encontrados por el Equipo y } \\
\text { preparación de la presentación del mismo }\end{array}$ & 5 minutos por \\
\hline $\begin{array}{l}\text { Presentación por el portavoz de cada Equipo de su nuevo Modelo al } \\
\text { resto de la clase }\end{array}$ & \\
\hline
\end{tabular}

\section{3.- Evaluación de los modelos}

Durante la exposición por cada equipo de su modelo, se instó a que escribieran en la pizarra los elementos esenciales y definitorios del mismo, de manera que quedaran todos ellos expuestos ante la clase, a modo de recordatorio para la posterior evaluación. La Figura 1 muestra el aspecto de la pizarra durante el desarrollo de la Práctica en una de las clases, una vez presentados tres de los modelos.

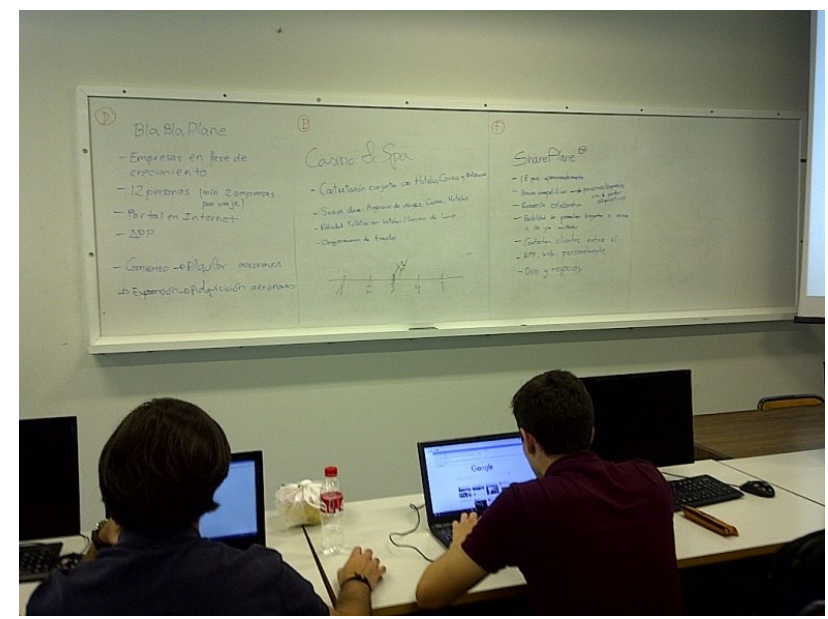

Fig. 1 Aspecto de la pizarra tras la presentación de tres de los modelos

La evaluación de los modelos fue acometida por los propios estudiantes, siguiendo las instrucciones facilitadas por el profesor. Primero se realizó una estimación meramente intuitiva, a efectos de ir introduciendo a los estudiantes en el proceso evaluador. A continuación se aplicó el verdadero 'Baremo de evaluación', desarrollado por el autor de esta comunicación en trabajos anteriores (Mateu, 2015; Mateu y March, 2016), y que se propuso a modo de rúbrica de evaluación (Moskal, 2000). Al tratarse de una rúbrica específica para modelos de negocio, su aplicación resulta más objetiva en nuestra opinión que otras rúbricas más generales propuestas para la evaluación de la innovación (por ejemplo la propuesta por Cuenca y otros (2015)). 
El Baremo de evaluación contempla ocho indicadores. Cada uno de ellos se evalúa mediante una escala de tipo Lickert de cinco posibles valores (1 a 5). Se facilitó a los estudiantes una plantilla con el detalle de los indicadores y una escala para que situaran en ella la letra identificadora de cada modelo. La mecánica consistió en que el profesor expusiera, indicador a indicador, lo que cada uno de ellos mide, dando tiempo a continuación para que los estudiantes valoraran cada modelo para ese indicador. La plantilla facilitada a los estudiantes incorporaba en cualquier caso la descripción de modelos merecedores de los valores extremos de cada indicador ( 1 y 5), así como ejemplos de modelos conocidos con valoraciones intermedias. Dicha plantilla, incorporando el Baremo de evaluación, se incluye como Anexo al presente documento.

La puntuación de cada modelo en cada indicador se obtuvo como media de las puntuaciones aportadas por los distintos estudiantes que lo evaluaron: todos los estudiantes de la clase en que se presentó, a excepción de los que habían diseñado el modelo evaluado (co-evaluación). La nota final del modelo se obtuvo como media de los ocho indicadores.

\section{4.- Aportación a la evaluación de la competencia}

La normativa de la UPV establece cuatro posibles calificaciones para las competencias transversales: desarrollo no alcanzado (D), en desarrollo (C), adecuado (B) y excelente (A).

Se consideró que el 'desarrollo no alcanzado' debería reservarse para modelos con valoración inferior a 2,5 y que las valoraciones superiores a 3,7 son difíciles de alcanzar, por lo que el Baremo propuesto fue:

- D: para valoraciones inferiores a 2,5

- $\quad$ : para valoraciones superiores a 2,5 e inferiores o iguales a 2,9

- B: para valoraciones superiores a 2,9 e inferiores o iguales a 3,3

- A: para valoraciones superiores a 3,3

Hay que tener en cuenta no obstante que la Práctica contribuía al desarrollo y evaluación de la competencia transversal, pero este desarrollo y sobre todo la evaluación se complementaba con otras acciones de carácter individual.

\section{4.- Resultados}

La Práctica fue planteada en los tres grupos de prácticas de la asignatura, involucrando un total de 56 estudiantes, que desarrollaron y presentaron un total de 17 modelos de negocio. Ello supone medias de 3,29 estudiantes por grupo y 5,67 equipos/modelos por clase.

Los estudiantes no evaluaban su propio modelo, pero sí los demás modelos presentados en su clase. Ello aportó una media de 15,53 evaluaciones para cada uno de los 17 modelos presentados.

Los modelos presentados exhibieron una casuística muy diversa en lo que a elementos innovadores se refiere. Resulta difícil catalogar esta casuística por cuanto que las 
innovaciones en modelos de negocio suelen afectar a varias partes del modelo. No obstante, y a efectos de tener una primera aproximación de los resultados, catalogaremos los modelos presentados en base al elemento innovador más característico del modelo propuesto. De este modo, y siguiendo la taxonomía de Osterwalder y Pigneur mostrada en la figura 2 (Osterwalder y Pigneur, 2010), podemos catalogar las innovaciones incorporadas a los modelos desarrollados en la Práctica en las siguientes categorías:

- Innovaciones basadas en cambios en la propuesta de valor mediante mejora de la experiencia en vuelo: entretenimiento a bordo (casino en vuelo), vistas exteriores (mediante ventanas panorámicas), descanso en vuelo (hotel a bordo),...

- Innovaciones basadas en cambios en la propuesta de valor tendentes a ofrecer otras utilidades: oportunidades de networking aprovechando el servicio,...

- Innovaciones basadas en la forma de ofrecer el vuelo (canales): incluido en paquetes turísticos de alto valor, a través de portales web y apps móviles, en el momento de perder un vuelo regular,...

- Innovaciones basadas en el tipo de aeronave utilizado (recurso clave): aeronaves capaces de transportar el automóvil a bordo, jets equipados con elementos de comodidad particulares, helicópteros,...

- Innovaciones basadas en fórmulas de precios bajos (flujo de ingresos): tarifa plana, paquetes de horas, fórmulas de tarificación especiales,...

- Innovaciones basadas en cambios más radicales del modelo tradicional: economía colaborativa (compartir avión), venta de asientos en rutas programadas,...

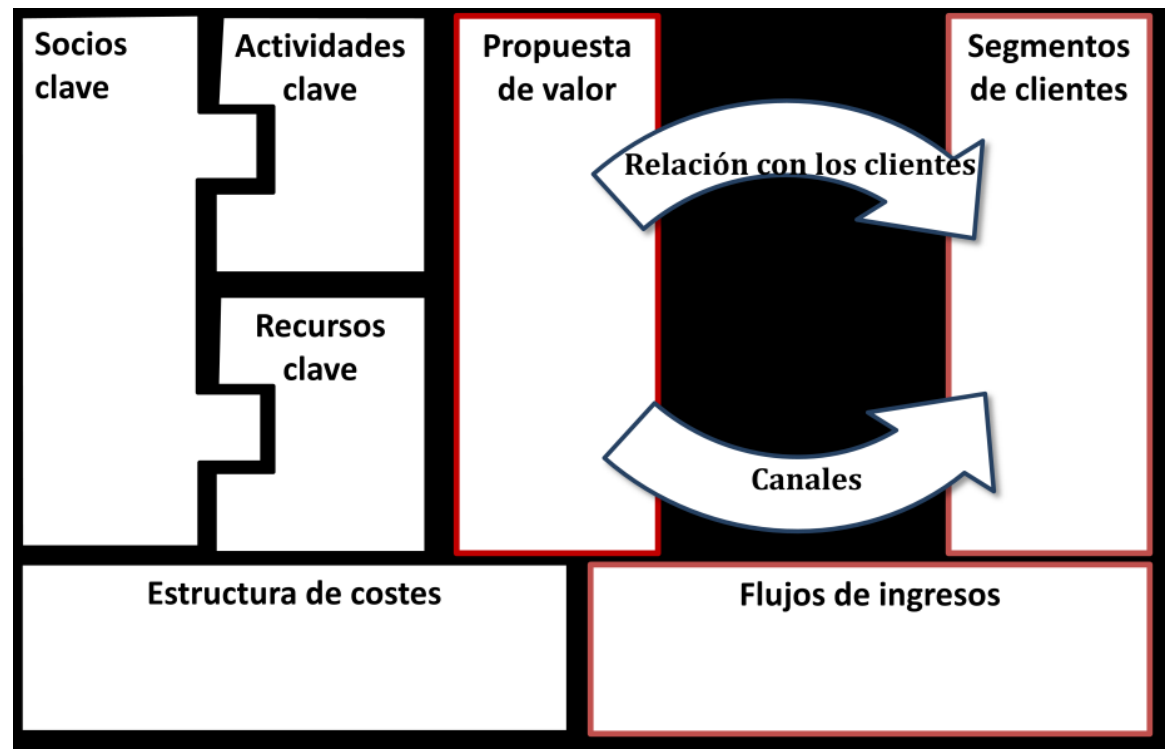

Fig.2 Lienzo del modelo de negocio (Osterwalder y Pigneur, 2010)

El modelo evaluado con menor nota obtuvo un 1,65 en el indicador peor evaluado, y un 3,41 en el mejor puntuado, para una nota media de los ocho indicadores de 2,50. Se trataba 
de un modelo que sustituía los jets ejecutivos por helicópteros, reduciendo el radio de acción a núcleos urbanos.

El modelo evaluado con mayor nota obtuvo un 2,50 en el indicador peor evaluado, y un 4,29 en el mejor puntuado, para una nota media de los ocho indicadores de 3,64. Se trataba de un modelo que aplicaba la lógica de la aviación de bajo coste a la ampliación de la base de clientes de la aviación ejecutiva.

La evaluación de los 17 modelos y de sus autores, derivada de esta Práctica, se ajustó a:

- ningún modelo evaluado con $\mathrm{D}$,

- 8 modelos evaluados con $\mathrm{C}$,

- 6 modelos evaluados con B

- y 3 modelos evaluados con A.

El comportamiento mostrado por los estudiantes durante la Práctica fue mayoritariamente de aplicación e interés. Se mostraron entretenidos y muy participativos.

No hubo objeciones, y se aceptó de buen grado, que las valoraciones de los compañeros (co-evaluación) sirvieran para la evaluación de la competencia, si bien hay que decir que los estudiantes no parecen tener excesivo conocimiento ni dar demasiada importancia a la evaluación de estas competencias.

\section{5.- Conclusiones}

Este trabajo se limita a mostrar una experiencia concreta de desarrollo y evaluación de una competencia como la 'creatividad, innovación y emprendedurismo' en el contexto de una asignatura de un plan de estudios de una Ingeniería. No obstante, y hasta donde esta experiencia pueda servir de ejemplo, se pueden extraer las siguientes conclusiones:

- El aprendizaje puede verse notablemente facilitado con el uso de actividades que combinen el desarrollo de competencias técnicas y transversales, en particular la competencia transversal en cuestión. El aprendizaje de ambos tipos de competencia se ve mutuamente reforzado.

- Esa combinación resulta además amena y estimulante para los estudiantes.

- La evaluación por los compañeros y compañeras (co-evaluación) de los resultados prácticos obtenidos es bien acogida por los estudiantes evaluados, al menos en la medida en que se base en una metodología clara y objetiva.

- La utilización de una rúbrica más específica facilita una co-evaluación más objetiva, lo que a la postre puede evitar los efectos indeseados identificados por algunos autores, como es el caso de evaluaciones "generalmente elevadas y con poca dispersión entre los distintos items" (Pérez-Zuriaga y otros, 2015, pág. 848).

- Lo más complicado, y en lo que habría que profundizar, sería el traslado de la evaluación de los resultados objetivos a la escala de evaluación de la competencia transversal. 
Desarrollo y evaluación de la competencia transversal 'Creatividad, innovación y emprendimiento' en la asignatura 'Explotación del transporte aéreo y organización aeronáutica'

\section{6.- Referencias}

CASADESUS-MASANELL, R., y RICART, J. E. (2010). "From Strategy to Business Models and onto Tactics " en Long Range Planning, vol. 43, issue 2-3, p. 195-215.

CHESBROUGH, H. (2010). "Business Model Innovation: Opportunities and barriers" en Long Range Planning, vol. 43, issue 2-3, p. 354-363.

CROZET, Y. (2010) "Driving forces of innovation in the transport sector". En: Transport and Innovation. Unleashing the potential. International Transport Forum (2010. Leipzig, Alemania). $\mathrm{OECD} / \mathrm{ITF}$.

CUENCA, LL., ALARCÓN, F., BOZA, A., FERNÁNDEZ-DIEGO, M., RUIZ, L., GORDO, M. L., POLER, R. y ALEMANY, M. (2015). "Rúbrica para la Evaluación de la Competencia Innovación, Creatividad y Emprendimiento en máster" en In-Red 2015 Congreso Nacional de Innovación Educativa y Docencia en Red (30 de junio y 1 de julio de 2015. València).

DE BONO, E. (1967). New think. The use of lateral thinking. New York: Basic Books.

JOHNSON, M. W., CHRISTENSEN, C. M. y KAGERMANN, H. (2008). "Reinventing your business model" en Harvard Business Review, vol. 86, issue 12, p. 50-59.

LÓPEZ, A. (2016). "Cooperación, creatividad y emprendimiento para el desarrollo de competencias. Una experiencia docente en Periodismo" en In-Red 2016 Congreso de Innovación Educativa y Docencia en Red de la Universitat Politècnica de València (7-8 de julio de 2016. València).

MARIN-GARCIA, J. A., RAMIREZ, L. y ANDREU, M. A. (2015). "Comparación de los métodos de escalas y frecuencia de comportamiento para valorar la competencia de innovación. El punto de vista de alumnos y profesor en el caso de una asignatura de máster" en In-Red 2015 Congreso Nacional de Innovación Educativa y Docencia en Red (30 de junio y 1 de julio de 2015. València).

MARTIN, B. R. y ETZKOWITZ, H. (2000). "The origin and evolution of the university species" en VEST Journal for Science and Technology Studies, vol. 13, issue 3-4, p. 9-34.

MATEU, J. M. (2015). Herramientas para la .generación y evaluación ex-ante de modelos de negocio. Tesis Doctoral. Valencia: Universitat de València, http://roderic.uv.es/handle/10550/47833

MATEU, J. M. y MARCH, I. (2016). "Searching for better business models assessment methods" en Management Decision, vol. 54, issue 10, p. 2433 - 2446.

MOSKAL, B. M. (2000). "Scoring rubrics: what, when and how?" en Practical Assessment Research \& Evaluation, vol. 7, issue 3 .

NAVAL, C. N., y CORBELLA-RUIZ, M. R. (2012). "Aproximación a la responsabilidad social universitaria: la respuesta de la Universidad a la sociedad" en Bordón. Revista de pedagogía, vol. 64, issue 3 , p. 103-115.

OSTERWALDER, A. y PIGNEUR, Y. (2010). Business Model Generation. Hoboken, Nueva Jersey: John Wiley \& Sons, Inc.

PEÑA, I., GUERRERO, M. y GONZÁLEZ-PERNÍA, J. L. (2015). Global Entrepreneurship Monitor. Informe GEM España 2015. Santander: Editorial de la Universidad de Cantabria

PEREZ-ZURIAGA, A. M., LLORCA, C. y MORENO, A. T. (2015). "Desarrollo de competencias transversales y evaluación de su adquisición en el Grado de Ingeniería Civil" en In-Red 2015 Congreso Nac. de Innovación Educat. y Docencia en Red (30 de junio/1 de julio de 2015. València).

PORTER, M. E. (1985). Competitive Advantage. New York: Free Press.

(cc) EY-NC-ND 2017, Universitat Politècnica de València

Congreso IN-RED (2017) 
RUIZ, L., GORDO, M., FERNÁNDEZ-DIEGO, M., BOZA, A., CUENCA, LL. ALARCÓN, F. y ALEMANY-DÍAZ, M. M. (2015). "Implementación de actividades de aprendizaje y evaluación para el desarrollo de competencias genéricas: un caso práctico de aplicación de técnicas de Pensamiento de Diseño, y evaluación mediante rúbricas, de las competencias de Creatividad, Innovación y Emprendimiento" en In-Red 2015 (30 de junio y 1 de julio de 2015. València).

SHAW, S. (2007). Airline Marketing and Management (sixth edition). Hampshire, England: Ashgate

ANEXO.-

\section{CUESTIONARIO DE EVALUACIÓN EX-ANTE DE MODELOS DE NEGOCIO}

Fecha: 120

$\rightarrow$ Información estadística ${ }^{1}$ :

Nombre Edad (años):

Nivel educativo: Género $(\mathrm{H} / \mathrm{M})$ :

País de origen: Experiencia profesional (años):

¿En qué industrias (años)? $(\ldots)$

¿Has emprendido alguna vez o estás involucrado en algún emprendimiento $(\mathrm{S} / \mathrm{N})$ ?

$\rightarrow$ Equipo de trabajo en el que se ha integrado en esta Práctica:

\section{$\rightarrow$ Primer ejercicio: Evaluación intuitiva:}

0.- Por favor evalúe con $1,2,3,4$ ó 5 las expectativas de cada modelo de negocio presentado, en términos de posibilidades de éxito. Escriba para ello la letra identificativa de cada modelo de negocio presentado junto al número con el que lo evalúa. Puede haber varios modelos con la misma evaluación (junto al mismo número). Los valores de los extremos (1 y 5) aparecen descritos a continuación):

El nuevo Modelo de Negocio sería un fracaso notable en caso de implementarlo
El nuevo Modelo de Negocio cosecharía un gran éxito en caso de implementarlo

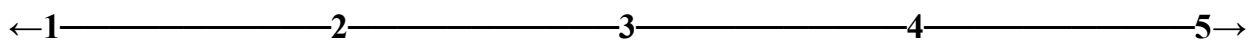

${ }^{1}$ Esta información sólo será utilizada con fines estadísticos en el marco de acciones de investigación científica. 
$\rightarrow \underline{\text { Segundo ejercicio: }}$ Este ejercicio propone evaluar cada Modelo de Negocio según una escala de ocho indicadores:

- Los cuatro primeros indicadores evalúan la fortaleza de la propuesta de valor.

- El quinto y sexto indicadores evalúan el balance entre ingresos y gastos.

- Los dos últimos indicadores (séptimo y octavo) evalúan la amenaza que suponen los competidores.

Cada indicador se presenta mediante una pregunta de evaluación y la descripción de los valores extremos. Ocasionalmente se añaden ejemplos y la descripción de los valores intermedios para facilitar la aplicación de la escala.

Cada nuevo Modelo de Negocio debe ser evaluado en cada indicador, mediante un número entero (1, 2, 3, 4 ó 5). Por favor indique la calificación escogida poniendo la letra que identifica al Modelo junto al número que indica la evaluación escogida.

1.- ¿Cómo aportará utilidad al potencial cliente la propuesta de valor incluida en nuestro modelo de negocio? ¿En qué orden de magnitud lo hará?

El modelo no aporta valor añadido o diferenciación respecto a las alternativas existentes
El modelo aporta ventajas importantes al potencial cliente, bien ahorros espectaculares de esfuerzo o dinero, bien utilidades capaces de apasionarle

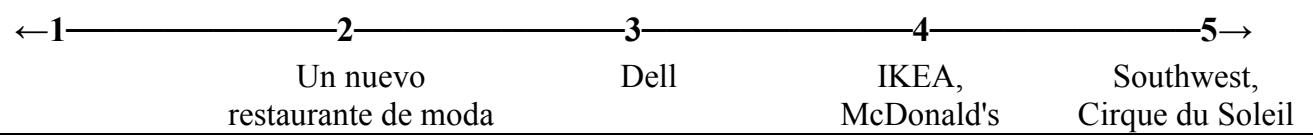

2.- ¿Están todos los elementos complementarios necesarios a disposición del cliente a un precio razonable? En caso contrario, ¿está en nuestras manos incorporarlos?, ¿en qué plazo y con qué esfuerzo?

El modelo requiere de desarrollo normativo que está fuera del alcance del emprendedor
El nuevo modelo incorpora una solución completa y no requiere ningún tipo de cambio, o bien los cambios requeridos son perfectamente entendibles por el cliente potencial

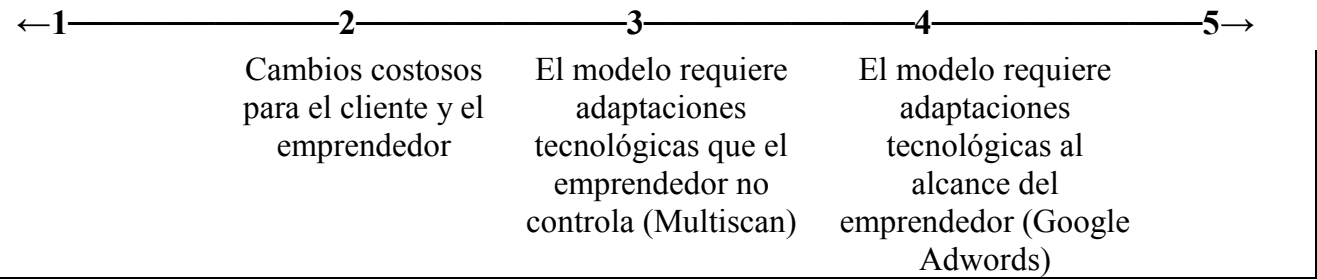


3.- ¿Cómo es de grande el segmento de potenciales clientes? ¿Qué volumen de compra representa?

\begin{tabular}{|c|c|c|}
\hline \multicolumn{2}{|l|}{$\begin{array}{l}\text { El mercado es muy reducido (local, } \\
\text { compuesto de muy pocos clientes, } \\
\text { con poca repetición y pequeñas } \\
\text { compras) }\end{array}$} & $\begin{array}{c}\text { Existe un mercado masivo glob } \\
\text { con muchos clientes potencial } \\
\text { que gastan mucho en este tipo } \\
\text { productos o servici }\end{array}$ \\
\hline$\leftarrow 1-2-$ & 3 & $-4 \longrightarrow$ \\
\hline $\begin{array}{l}\text { Mercados } \\
\text { limitados o con } \\
\text { baja tasa de } \\
\text { repetición }\end{array}$ & $\begin{array}{l}\text { Mercados } \\
\text { numerosos pero con } \\
\text { poco gasto o baja } \\
\text { repetición }\end{array}$ & $\begin{array}{l}\text { Mercados no } \\
\text { masivos pero } \\
\text { atractivos por la } \\
\text { repetición o sus } \\
\text { grandes compras }\end{array}$ \\
\hline
\end{tabular}

\section{4.- ¿Cómo de complicado resultará demostrar al potencial cliente que la propuesta le aportará valor y no se trata de una mera moda pasajera?}

El modelo representa un cambio radical en la forma en que el cliente viene haciendo las cosas y la manera de extraer el valor no resulta intuitiva
La forma de extraer valor al nuevo modelo por el cliente es evidente y no requiere mayores explicaciones, ni costes, ni esfuerzos de adaptación para el cliente

$\begin{array}{ccc}\text { Sistemas CRM } & \begin{array}{c}\text { Plataformas } \\ \text { multilaterales: } \\ \text { Google Adwords }\end{array} & \text { Southwest } \\ & \end{array}$

5.- ¿Estarán los potenciales clientes dispuestos a pagar el precio y a hacer el esfuerzo que les pedimos a cambio del valor que les ofrecemos?

\begin{tabular}{|c|c|c|c|}
\hline $\begin{array}{l}\text { Los potenciales clientes son reacios a } \\
\text { pagar por el tipo de servicios que } \\
\text { ofrece el modelo, o no están } \\
\text { dispuestos a asumir los esfuerzos que } \\
\text { se les piden }\end{array}$ & & \multicolumn{2}{|c|}{$\begin{array}{l}\text { Los potenciales clientes pagarán } \\
\text { gustosos lo que les pide el modelo y } \\
\text { harán el esfuerzo que se les pide } \\
\text { con buena predisposición }\end{array}$} \\
\hline-2 & $-3-$ & $-4-$ & $-5 \rightarrow$ \\
\hline $\begin{array}{l}\text { Clientes } \\
\text { industriales } \\
\text { atrapados en } \\
\text { inversiones } \\
\text { recientes }\end{array}$ & $\begin{array}{l}\text { Inversiones } \\
\text { importantes en } \\
\text { tecnología }\end{array}$ & $\begin{array}{l}\text { Esfuerzos } \\
\text { importantes } \\
\text { para los } \\
\text { clientes } \\
\text { (IKEA) }\end{array}$ & $\begin{array}{c}\text { Esfuerzo } \\
\text { limitado y bajos } \\
\text { precios } \\
\text { (Southwest, } \\
\text { Starbucks) }\end{array}$ \\
\hline
\end{tabular}

- ¿Será costoso ofrecer el valor prometido al cliente o contaremos por el contrario con un margen atractivo? ¿Existen mecanismos (directrices de coste) que nos permitan ampliar ese margen?

El modelo no cuenta con economías de

El modelo cuenta con economías de 


\begin{tabular}{|c|c|c|c|c|}
\hline \multicolumn{3}{|c|}{$\begin{array}{l}\text { escala u otros mecanismos que reduzcan } \\
\text { los costes unitarios proporcionando } \\
\text { márgenes atractivos, ni con efectos de } \\
\text { red u otros mecanismos que actúan como } \\
\text { motores de crecimiento }\end{array}$} & \multicolumn{2}{|c|}{$\begin{array}{r}\text { escala u otros mecanismos que reducen } \\
\text { los costes unitarios proporcionando } \\
\text { márgenes atractivos, o con efectos de red } \\
\text { u otros mecanismos que actúan como } \\
\text { motores de crecimiento }\end{array}$} \\
\hline \multicolumn{3}{|c|}{$\leftarrow 1-2-$} & $-4-$ & $-5 \rightarrow$ \\
\hline $\begin{array}{l}\text { Servicios con } \\
\text { alta } \\
\text { componente } \\
\text { de prestación } \\
\text { personal }\end{array}$ & $\begin{array}{l}\text { Economías de } \\
\text { escala sólo } \\
\text { aplicables a } \\
\text { actividades } \\
\text { corporativas o } \\
\text { asimiladas } \\
\text { (Starbucks) }\end{array}$ & $\begin{array}{l}\text { Economías de } \\
\text { escala relativas } \\
\text { en distribución } \\
\text { o fabricación } \\
\text { (Dell) }\end{array}$ & $\begin{array}{c}\text { Economías de } \\
\text { escala notables } \\
\text { y/o delegación en } \\
\text { el cliente de } \\
\text { alguna actividad } \\
\text { (Cirque du Soleil, } \\
\text { IKEA) }\end{array}$ & $\begin{array}{l}\text { Costes ínfimos } \\
\text { por alta } \\
\text { digitalización o } \\
\text { delegación casi } \\
\text { total en el } \\
\text { cliente: Google } \\
\text { Adwords }\end{array}$ \\
\hline
\end{tabular}

7.- ¿Existen propuestas de valor de competidores que resuelvan el mismo problema al cliente? ¿Cómo es el valor creado por ellas frente al creado por la nuestra? ¿Cómo de poderosos son esos competidores comparados con nosotros?

\begin{tabular}{|c|c|c|c|c|}
\hline \multicolumn{3}{|c|}{$\begin{array}{l}\text { Existe una fuerte, numerosa y } \\
\text { solvente competencia frente a la que } \\
\text { nuestro modelo no presenta unas } \\
\text { ventajas significativas }\end{array}$} & \multicolumn{2}{|c|}{$\begin{array}{r}\text { La competencia a la que nos } \\
\text { enfrentamos es escasa, débil y poco } \\
\text { solvente, y nuestro modelo es } \\
\text { claramente superior al suyo }\end{array}$} \\
\hline$-1-$ & $-2-$ & & $-4-$ & $-5 \rightarrow$ \\
\hline $\begin{array}{l}\text { Mercados } \\
\text { maduros con } \\
\text { competidores } \\
\text { más fuertes que } \\
\text { nosotros en los } \\
\text { que somos uno } \\
\text { más } \\
\end{array}$ & $\begin{array}{c}\text { Mercados maduros } \\
\text { con competidores } \\
\text { fuertes en los que } \\
\text { aportamos un } \\
\text { valor diferencial } \\
\text { relativo } \\
\text { (Starbucks) }\end{array}$ & $\begin{array}{c}\text { Mercados } \\
\text { maduros con } \\
\text { competencia } \\
\text { solvente en los } \\
\text { que aportamos } \\
\text { valor diferencial } \\
\text { (Dell) } \\
\end{array}$ & $\begin{array}{l}\text { Mercados en } \\
\text { los que } \\
\text { podemos } \\
\text { competir con } \\
\text { relativa } \\
\text { superioridad } \\
\text { (IKEA) } \\
\end{array}$ & $\begin{array}{c}\text { Mercados en } \\
\text { los que la } \\
\text { competencia no } \\
\text { existe o es } \\
\text { despreciable } \\
\text { (Cirque du } \\
\text { Soleil) } \\
\end{array}$ \\
\hline
\end{tabular}

\section{8.- ¿Tiene el modelo de negocio mecanismos para evitar la copia por parte de imitadores?}

El modelo no puede ser protegido de la copia y no incorpora mecanismo o activo específico inaccesible para la competencia y potencial competencia
El modelo dispone de mecanismos legales de protección (patentes que protegen elementos esenciales del modelo) o incorporan recursos y capacidades de difícil consecución por la competencia

\begin{tabular}{|c|c|c|c|c|}
\hline \multicolumn{5}{|c|}{$\leftarrow 1-2-$} \\
\hline $\begin{array}{l}\text { Modelos de } \\
\text { fácil } \\
\text { imitación }\end{array}$ & $\begin{array}{l}\text { Modelos de fácil } \\
\text { imitación, } \\
\text { protección } \\
\text { mediante } \\
\text { marketing } \\
\text { (Starbucks) }\end{array}$ & $\begin{array}{l}\text { Protección relativa } \\
\text { debido al volumen } \\
\text { de inversión } \\
\text { exigido para su } \\
\text { puesta en marcha } \\
\text { (Dell) }\end{array}$ & $\begin{array}{c}\text { Efectos de red o } \\
\text { similares que ayudan } \\
\text { al primer movedor a } \\
\text { mantener su ventaja } \\
\text { (Adwords) }\end{array}$ & $\begin{array}{c}\text { Protección } \\
\text { legal } \\
\text { (patentes). }\end{array}$ \\
\hline
\end{tabular}




\title{
Desarrollo de la Competencia de Trabajo en Equipo en la Asignatura de Dirección de Producción y Operaciones
}

\author{
Sofía Estelles-Miguel ${ }^{\mathrm{a}}$, José Miguel Albarracín Guillem ${ }^{\mathrm{b}}$, Marta Elena Palmer Gato ${ }^{\mathrm{c}}$ y \\ Marta Peris-Ortiz ${ }^{\text {d }}$ \\ a,b,c Facultad de Administración y Dirección de Empresas, Departamento de Ortanización de \\ Empresas-Universitat Politècnica de València soesmi@omp.upv.es; jmalbarr@omp.upv.es; \\ marpalga@omp.upv.es y ${ }^{\mathrm{d}}$ Escuela Técnica Superior de Ingenieros Industriales de Valencia \\ mperis@doe.upv.es. Todos del Departamento de Organización de Empresas de la Universitat \\ Politècnica de València.
}

\begin{abstract}
Teamwork has become one of the demands in the labor market. This is due to the changes, the incorporation of technologies and the new processes that make the tasks become increasingly complex and in many cases it is not possible to obtain and individual resolution of them. Therefore, in many organizations are trying to create a culture of collaboration as the best strategy for problem solving. However the education that should promote cooperation and teamwork currently still promotes competitiveness. Based on all this, a teamwork experience has been developed in the Operations Management subject and this paper presents the results of the same.
\end{abstract}

Keywords:competences, skills, teamwork, cooperative and collaborative education.

\footnotetext{
Resumen

El trabajo en equipo se ha convertido en una exigencia en el mercado laboral. Esto es debido a que los cambios, la incorporación de tecnologías y los nuevos procesos dentro de las organizaciones hacen que las tareas sean cada vez más complejas y en muchas ocasiones no es posible realizar una resolución individual de las mismas. Por todo esto, en la mayoría de las organizaciones se pretende crear una cultura de colaboración, como la mejor estrategia para la resolución de problemas. Sin embargo, la educación que debería promover la cooperación y el trabajo en equipo, actualmente todavía promueve la competitividad. En base a todo esto, se ha desarrollado una experiencia de trabajo en equipo en la asignatura de Dirección de Producción y Operaciones y el presente trabajo presenta los resultados de la misma.
}

Palabras clave: competencias, habilidades, trabajo en equipo, educación cooperativa y colaborativa. 


\section{Introducción}

Algunos estudios demuestran que los niños que trabajan de forma cooperativa en el colegio, consiguen mejores resultados académicos y se comprometen en actividades sociales más frecuentemente (Ricard, 2010). Sin embargo en la mayoría de centros educativos se sigue incentivando, algunas veces sin ser conscientes de ello, la competitividad. Pero sabemos que es más efectivo trabajar en equipo que hacerlo de forma individual. Algunas razones para ello son (Gómez Pereira, 2016):

- Porque se complementan las habilidades y los talentos.

- Porque se terminan más rápido las tareas.

- Porque confías y te vuelves confiable.

- Porque aumenta el sentido de pertenencia.

- Porque es gratificante para todos.

- Porque no estarás solo.

- Porque únicamente así se alcanzan las metas.

- Porque de esa manera aprendes más de ti.

- Porque puedes resolver mejor los conflictos y encontrar nuevas ideas.

- Porque es más divertido.

En la actualidad la mayoría de las organizaciones está fomentando una manera de trabajar más cooperativa y colaborativa. La complejidad del mundo laboral actual y la innovación generan situaciones en las que se requieren de distintas habilidades, altos niveles de conocimiento, adaptabilidad y rápidas respuestas. Y sólo a través del trabajo en equipo es donde se puede obtener todas estas características juntas (Kozlowski e Illgen, 2006).

Por todo ello, cada vez se utiliza más el trabajo en equipo en la mayoría de empresas y organizaciones (Alcover et al, 2004; Aritzeta y Balluerka, 2006; Ellis et al, 2005; Gruenfeld et al, 1996; Hollenbeck et al, 2004; Janz et al, 1996; Kozlowski e Illgen, 2006; Miklavic et al, 2007; Park et al, 2005, Yeh et al, 2006 y Torrelles et al, 2011).

El trabajo en equipo precisa de la colaboración y cooperación de distintos miembros de las empresas con diferentes habilidades, de esta forma se mejora la participación, la comunicación y se incrementa la calidad (Cohen y Bailey, 1997; Ellis et al, 2005 y Park et al, 2005).

Hollenbeck et al (2004) dice que el trabajo en equipo ha ido incrementándose notablemente desde los años 80 del pasado siglo en las empresas. Pero se ha introducido si cabe más desde la década de los 90 del siglo XX (Mazany et al, 1995; McDermott, 1999 y Park et al, 2005).

Los equipos se consideran entidades complejas, dinámicas, adaptables e integradas en un sistema de distintos niveles. Estos sistemas deben de tener en cuenta por un lado al individuo, por otro al equipo y finalmente a la organización (Torrelles et al, 2011). El trabajo en equipo necesita de la movilización de recursos tanto propios como externos. Por otro lado también necesita que el individuo disponga de ciertos conocimientos, habilidades $\mathrm{y}$ aptitudes para adaptarse al equipo y a las situaciones que se van a ir presentando. $\mathrm{Si}$

(c)) BY-NC-ND 2017, Universitat Politècnica de València

Congreso IN-RED (2017) 
alguno de los miembros del equipo no dispone de los elementos imprescindibles para el trabajo en equipo, puede hacer que el equipo fracase y no se obtengan los resultados esperados. Por todo esto, hay que generar dinámicas que ayuden a las personas a prepararse para el trabajo en equipo.

Trabajar en equipo requiere de una serie de habilidades como:

- El dar y recibir realimentación, es decir, saber que estamos haciendo bien y mal y saber corregirlo, siempre desde el punto de vista de la mejora continua y no de la crítica.

- La adaptación, es decir, saber adaptarnos a las distintas situaciones y a las distintas necesidades del grupo y cubrir aquellos espacios que queden vacíos o flojos.

- La gestión del tiempo. En el trabajo en grupo es tan importante el saber gestionar el tiempo del que disponemos para la realización de la tarea como el resto de habilidades.

- La escucha activa, saber escuchar las informaciones que nos aportan los demás y no sólo querer que se oiga nuestra opinión.

- La colaboración, que todos somos parte del equipo y todos debemos aportar nuestros granos de arena y participar de la mejor manera que sepamos y que podamos.

- Optimismo, apoyar el equipo incluso cuando las situaciones son adversas. La gente quizás en esos momentos es cuando más apoyo necesita.

Con todo esto en mente y pretendiendo que los alumnos de Facultad de Administración y Dirección de Empresas (FADE) de la Universitat Politècnica de València (UPV) salgan preparados para el trabajo en equipo los profesores de la asignatura de Dirección de Producción y Operaciones (DPO) han desarrollado el presente trabajo. Con este trabajo se pretende desarrollar la habilidad del trabajo en grupo a través de dinámicas y la realización de trabajos en grupo en parte de la asignatura.

\section{Desarrollo de la Metodología en la Asignatura}

Cuanto más se aprende es cuanto más se parece el contexto del aprendizaje a la vida real. Es decir, si la simulación o práctica que estoy realizando, se parece a lo que me voy a encontrar en la realidad, el alumno aprende más. Por esto, es importante que los estudiantes puedan aplicar lo que aprenden, o por lo menos puedan verle una aplicabilidad, en dicho caso será mejor entendido. La implantación de metodologías activas en el aula permite la formación en competencias del alumnado (González y Wagenaar, 2003 y Estelles-Miguel et al, 2013).

En la presente asignatura se propuso un proyecto a los alumnos en el cual tenían que trabajar en grupos para la resolución del mismo, además el trabajo debía realizarse de forma cooperativa y colaborativa para poder alcanzar un resultado no sólo lógico sino coherente.

Los objetivos al plantear este trabajo a los alumnos fueron:

- Potenciar la autonomía de los alumnos, el trabajo en equipo, el pensamiento reflexivo y crítico. 
- Que los alumnos desarrollen destrezas profesionales, que adquieran capacidades para identificar, plantear y resolver problemas relacionados con los contenidos prácticos de la asignatura.

Aunque algunos autores dicen que es mejor que los grupos sean formados por alumnos con diferentes habilidades y características, y normalmente para ello deben ser seleccionados por los profesores, en el presente caso, se les dejo a los propios alumnos seleccionar los participantes del grupo de trabajo.

Los grupos de trabajo debían ser de cinco componentes, existían 5 roles distintos que luego comentaremos y entre ellos también debían seleccionar que rol ocuparía cada uno de ellos.

En la primera parte del ejercicio y antes de que definan sus roles, se les entrega un problema claramente definido. En el que se indica que, dos alumnos van a crear una empresa y se les dice cual va a ser su proceso de fabricación (incluyendo máquinas y tiempos de las mismas), cuáles van a ser sus productos finales (incluyendo ingredientes, cantidades, etc.). En este caso se supone que el proceso de fabricación es artesanal, es decir, disponen de un horno casero y las empanadillas son fabricadas por los propios alumnos. Con estos datos tienen que calcular tiempos de procesado de un lote y cuantos lotes pueden realizar en un turno de trabajo. Para ello, tendrán que ver cuál es el cuello de botella del proceso aunque no se les indica este dato. Una vez han realizado esta primera parte y la han entregado se corregirá en la pizarra para que vean sus errores.

Para la segunda parte del trabajo, los alumnos deberán asignar los roles, éstos son los siguientes:

- Director: Es el responsable de coordinar el grupo de trabajo, de gestionar los tiempos, de realizar aquellas tareas que por cualquier motivo no pueda realizar otro. Es el encargado del portafolio y de su presentación. Y finalmente deberá realizar una valoración del trabajo de sus compañeros de grupo.

- Responsable de Producto: Es el especialista en este tema, deberá preparar una presentación sobre esta parte, y será el que más conozca este tema y apoye a su grupo durante la realización de esta parte del trabajo.

- Responsable de Proceso: Es el especialista en este tema, deberá preparar una presentación sobre esta parte, y será el que más conozca este tema y apoye a su grupo durante la realización de esta parte del trabajo.

- Responsable de Distribución en Planta: Es el especialista en este tema, deberá preparar una presentación sobre esta parte, y será el que más conozca este tema y apoye a su grupo durante la realización de esta parte del trabajo.

- Responsable de Localización: Es el especialista en este tema, deberá preparar una presentación sobre esta parte, y será el que más conozca este tema y apoye a su grupo durante la realización de esta parte del trabajo.

Una vez repartidas las tareas empezarán a trabajar en grupo en el problema y en cada una de estas partes. El proyecto consiste en crear una empresa de fabricación de empanadillas. Al comenzar con cada una de las partes, los especialistas del tema de los distintos grupos saldrán y expondrán el tema a toda la clase. A partir de ese momento, se pondrán a trabajar

(cc) EY-NC-ND 2017, Universitat Politècnica de València

Congreso IN-RED (2017) 
cada uno en su grupo, y dependiendo de la tarea tendrán una o dos semanas para cada una de las partes. Las partes son las siguientes:

- El primer tema es diseño de producto. En el mismo los grupos deberán definir que producto van a fabricar todos harán empanadillas, pero deben decidir: tamaño, sabores, materias primas, forma, variedades, etc. Además de la información que se les entrega pueden consultar toda la información que necesiten en internet, y tienen que seguir los pasos de diseño de producto que habrán visto con su responsable.

- En segundo lugar se llega a diseño de proceso. Todos los grupos deberán definir cómo van a fabricar las empanadillas que han decidido fabricar en el primer paso, las decisiones que hayan tomado en el diseño de producto les afectarán en este paso. Deberán elegir máquinas, herramientas, cuantas personas van a trabajar, turnos, etc. Deberán seguir todos los pasos que su responsable les habrá indicado. Al igual que en el caso anterior los profesores les pasaremos información sobre máquinas, pero pueden buscar otras.

- Distribución en Planta, una vez han decidido que máquinas van a comprar deberán ver como las van a instalar en su proceso productivo y como les afecta. Las decisiones que hayan tomado en el paso anterior afectarán en este paso.

- Finalmente tendrán que decidir la localización de sus instalaciones, que no será la misma si van a tener una fábrica que suministre a un gran supermercado que si tienen un horno tradicional.

Los alumnos deberán tener en cuenta que, cada decisión tomada influye en los siguientes pasos a realizar y no existe una única solución buena. Cada grupo tendrá una empresa distinta, con unos productos distintos, unos procesos distintos, una distribución en planta distinta y una localización única y distinta. Las decisiones deben ser coherentes unas con otras para que la solución sea lógica y razonable. Para ello tendrán que utilizar además de los cálculos, la información que los profesores les aportan y la información que obtengan por distintos medios una herramienta muy necesaria es el sentido común. Todo ello se llevará en un portafolio. No existe un modelo único de portafolio, al existir distintas modalidades en función de los objetivos que se persiguen con su desarrollo (EstellesMiguel et al, 2013).

Si algún día un responsable de un grupo no puede acudir, tendrá que ser sustituido en sus labores por el director del grupo, es decir, el show no puede parar.

\section{Resultados obtenidos}

En los trabajos en equipo a través de las interdependencias entre sus miembros se revelan las distintas personalidades de los participantes del equipo. Cada uno de nosotros tiene unas características en su personalidad, parte de ellas debida a la genética y otras fruto de la educación y las experiencias. Cuando trabajamos en equipo la personalidad de cada uno de los miembros del equipo se revela en función de los roles que cada uno de ellos asumen.

(c)) EY-NC-ND 2017, Universitat Politècnica de València 
El desarrollo de trabajos supone un complemento adecuado a las clases teóricas y prácticas, ya que con ello no sólo se transmiten conocimientos al alumno sino también la posibilidad de desarrollar destrezas y habilidades (Flórez y Albelda, 2012).

En el trabajo en equipo realizado durante el curso 2016/2017 en la asignatura de Dirección de Operaciones se ha observado que nuestros alumnos no están acostumbrados al trabajo en equipo. Sino más bien a un trabajo seriado, en el que se reparten cada uno una parte del trabajo, para posteriormente juntarlas y presentarlas. En el presente caso, ese método no les ha servido, por lo que se han visto obligados a trabajar de otra forma y adaptarse al trabajo cooperativo y colaborativo. Es más, se han visto obligados a realizar sesiones de tormentas de ideas, en las que todos colaboraban y posteriormente se seleccionaban las mejores ideas. Con ello, se han dado cuenta de que cada persona puede aportar una forma distinta de ver las cosas y que eso es enriquecedor.

Se paso un cuestionario con escala Likert ( 1 a 3 ) siendo 1 nada de acuerdo y 3 totalmente de acuerdo sobre el trabajo en equipo con las siguientes preguntas:

- Consideras que el trabajo en equipo :

- Fomenta la capacidad de organización y planificación del trabajo.

- Facilita las relaciones con tus compañeros y con los profesores.

- Ayuda a potenciar la autonomía en el aprendizaje.

- Ayuda a reflexionar sobre los problemas encontrados y los resultados.

- Favorece la motivación.

- Ayuda a aplicar conocimientos.

- Ayuda en la gestión del tiempo.

- Las respuestas obtenidas fueron:

- Fomenta la capacidad de organización y planificación del trabajo: 3\% nada de acuerdo, $33 \%$ de acuerdo y $64 \%$ completamente de acuerdo.

- Facilita las relaciones con tus compañeros y con los profesores: $10 \%$ nada de acuerdo, 39\% de acuerdo y 51\% completamente de acuerdo.

- Ayuda a potenciar la autonomía en el aprendizaje: 5\% nada de acuerdo, $26 \%$ de acuerdo y $79 \%$ completamente de acuerdo.

- Ayuda a reflexionar sobre los problemas encontrados y los resultados: $48 \%$ de acuerdo y $52 \%$ completamente de acuerdo.

○ Favorece la motivación: 7\% nada de acuerdo, 26\% de acuerdo y $67 \%$ completamente de acuerdo.

○ Ayuda a aplicar conocimientos: $23 \%$ de acuerdo y $77 \%$ completamente de acuerdo.

- Ayuda en la gestión del tiempo: 3\% nada de acuerdo, $36 \%$ de acuerdo y $61 \%$ completamente de acuerdo.

Los profesores consideran que incrementa su carga de trabajo pero que es adecuado para mejorar el aprendizaje y las habilidades de los alumnos.

(cc) EY-NC-ND 2017, Universitat Politècnica de València

Congreso IN-RED (2017) 


\section{Conclusiones}

El presente trabajo presenta la experiencia realizada en la aplicación del trabajo en equipo desarrollada en la asignatura de Dirección de Operaciones en el primer semestre de segundo curso en el Grado de Administración y Dirección de Empresas en la Universitat Politècnica de València. En estos momentos todavía son escasos los datos para poder valorarla.

En este trabajo se ha comprobado que la realización de trabajo en grupo potencia algunas habilidades como: la autonomía en el aprendizaje (según los alumnos lo que más), seguida de que es útil para llevar los conocimientos a la práctica, favorece la motivación de los alumnos, fomenta la capacidad de organización y planificación del trabajo, aprenden a gestionar su tiempo. Habilidades todas ellas muy necesarias para el desarrollo de la vida laboral.

Los alumnos dijeron en sus comentarios que se deberían realizar esté tipo de prácticas en más asignaturas. Si bien es cierto que les consume mucho tiempo y si se hicieran en todas las asignaturas no saben si serían capaces de llevarlos a buen término.

Según Thomas (2000), el trabajo en proyectos que se ha utilizado en el presente caso para la aplicación del trabajo en equipo, es relativamente difícil de planificar y de llevar a cabo. Todos los profesores participantes en esta experiencia en la asignatura de Dirección de Operaciones encontraron alguna dificultad a la hora de llevarlo a cabo, las cuálesse fueron superando. También el diseñar una actividad de aprendizaje basada en el trabajo colaborativo y cooperativo supone para el docente una importante carga de trabajo, además de un reto diario en el aula.

La mayor carga de trabajo para los profesores fue la elaboración del proyecto en sí, y posteriormente las actividades a realizar durante las clases en las que se trabajaba en equipo y posteriormente la corrección de dicho trabajo. Teniendo en cuenta de que no existe una única solución correcta. Qué todas las soluciones son válidas siempre que sean lógicas y consecuentes y que hayan tenido en cuenta tanto los parámetros indicados en el trabajo como las decisiones tomadas en cada uno de los pasos previos. A todo ello, hay que sumar la incertidumbre y la falta de control en algunos casos al realizar estas tareas "en vivo" cosa que no ocurre en las clases magistrales.

Existen evidencias de que algunos estudiantes encuentran dificultades a la hora de auto dirigirse, especialmente en proyectos complejos, con la gestión del tiempo y de proyectos (Thomas, 2000). Nosotros diríamos no sólo de auto dirigirse como personas, sino de trabajar en equipo y coordinar un equipo de trabajo. Pero con esto aprenden o mejoran una de las habilidades que las empresas demandan la del trabajo en equipo. Además, es mejor que salgan de la universidad enseñados, que se hayan enfrentado a un reto de este tipo, antes de hacerlo por primera vez en una empresa. Todo esto puede solucionarse siempre que haya ganas de hacerlo, actitud y un apoyo (que no dirección) por parte de los profesores. Los profesores deben actuar de facilitadores.

En la experiencia realizada se ha visto que con este tipo de trabajos los alumnos aprenden haciendo y lo hacen con problemas reales. Además interiorizan las habilidades de trabajo 
colaborativo, cooperativo y trabajo en equipo, al tener que trabajar con otras personas y que su trabajo influya en el de los demás. Otras de las competencias que desarrollan es la gestión del tiempo (como existe un tiempo limitado para cada tarea se tienen que gestionar), la responsabilidad individual, la capacidad reflexiva (al influir unas decisiones en las siguientes), a manejar las relaciones interpersonales (que no todos somos ni pensamos igual y que hay que aceptar a los demás). Todas esta habilidades y capacidades les servirán en su vida profesional, en ocasiones incluso más que sus conocimientos académicos.

Habrá que corregir los problemas que se han detectado. Aunque habría que añadir que aún con todos los fallos encontrados los autores del presente trabajo entienden que ha sido una experiencia completamente gratificante para ellos y para sus estudiantes.

\section{Referencias}

ALCOVER, C, FIL, F y BARRASA A. (2004). "Team Learning: Adaptation of learning activities scales in a Spanish sample" en Psicothema, vol. 16, No 3, p. 378-383.

ARITZETA, A y BALLUERCA, N. (2006). "Cooperation, competition and goal interdependence in work teams : A multilevel approach” en Psicothema, vol. 18, No 4, pp. 757-765.

COHEN, S y BAILEY, D. (1997). "What makes teams work : Group effectiveness research from the shop floor to the executive suite" en Journal of Management, vol. 23, No 3, pp. 239-290.

ELLIS, A, BELL, B, PLOYHART, R, HOLLENBECK, J e ILLGEN, D. (2005). “An evaluation of generic teamwork skills training with action teams: Effects on congnitive and skill-based outcomes" en Personnel Psycology, vol. 58, pp. 641-672.

ESTELLÉS-MIGUEL, S, BARBERA RIBERA, T y DEMA PÉREZ, CM. (2013). ). “Aplicación del portafolio grupal en la asignatura de Dirección de Producción y Logística: Resultados de una prueba poiloto", No4, pp. 124-138.

FLÓREZ R. y ALBELDA, E. (2012). "Una experiencia de trabajo en equipo con soporte documental para la formación de competencias en contabilidad financiera" en Revista Educade, $\mathrm{N}^{\mathrm{o}} 3$, pp. 67-94.

GÓMEZ PEREIRA, Belén (2016). "10 Razones para Trabajar en Equipo". https://www.entrepreneur.com/article/267218 Publicado: 04 de julio de 2016. [Consulta: 14 de marzo de 2017].

GONZÁLEZ, J. y WAGENAAR, R (EDS) (2003). "Tuning Educational Structures in Europe. Informe Final. Fase Uno”. Bilbao : Universidad de Deusto y Universidad de Groningen.

GRUENFELD, D, MANNIX,E, WILLIANS, K y NEALE, M. (1996). “Group Composition and Decision Making: How Member Familiarity and Information Distribution Affect Process and Performance.” en Organizational Behaviour and Human Decision Processes, vol. 67, No 1, pp. 1-15.

HOLLENBECK, J, DEREUE, D. y FUZZO, R. (2004). "Bridging the gap between I/O research and HR practice: Improving team composition, team training and team task design" en Resource Management, vol. 43, pp. 353-366.

JANZ, B, COLQUITT, J y NOE R. (1997). "Knowledge Yorker Team Effectiveness : The role of autonomy, interdependence, team, development and contextual support variabless" en Personnel Psycology, vol. 50, pp. 877-904.

KOZLOWSKI, S.W. y ILLGEN, D.R.. (2006). "Enhancing the Effectiveness of Works Groups and Teams" en Psychological Science in the Public Interest, vol. 7, № 3, pp. 77-124.

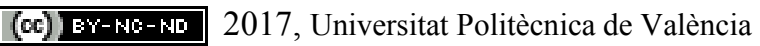

Congreso IN-RED (2017) 
MAZANY, P, FRANCIS,S y SUMICH, P. (1995). "Evaluating the Effectiveness of an Outdoor Workshop for Team Building in an MBA Programme" en Journal of Management Development, vol. $14, \mathrm{~N}^{\mathrm{o}} 3$, pp. $50-68$.

McDERMOTT, R. (1999). "Learning Across Teams: The Role of Communities of Practice in Team Organizations" en Knowledge Management Review, pp. 1-8.

MIKLAVCIC SAMANSKI, M, KOLENC, I y MARKIC, M.. (2007). "Teamwork and refining group structures" en Team Performance Management, vol. 13, No 3/4, pp. 102-116.

PARK, S, HENKIN, A. y EGLEY, R. (2005). "Teacher team commitment, teamwork and trust: Exploring associations" en Journal of Educational Administration, vol. 43, No 5, pp.462-479.

RICARD, Matthieu (2010). "Educación: Promueve la cooperación, no la competitividad". http://www.matthieuricard.org/es/blog/posts/educacion-promueve-la-cooperacion-no-lacompetitividad [Consulta: 14 de marzo de 2017].

THOMAS, J. (2000). "A Review of Research on Project-Based Learning". http://www.autodesk.com/foundation Publicado en Marzo de 2000. [Consulta 17 de marzo de 2017.

TORREllES, C, COIDURAS, J, ISUS, S, CARRERA, X, PARÍS, G. Y CELA, J.M. (2011). "Competencia de Trabajo en Equipo: Definición y Categorización" en Revista del Currículum y $\begin{array}{llllll}\text { Formación del } & \text { Profesorado } & \text { Vol. } & \text { 15, } 329-345 .\end{array}$ http://www.ugr.es/local/recfpro/rev153COL8.pdf

YEH, E, SMITH,C, JENNINGS, C y CASTRO, N. (2006). "Team Building : a3-Dimensional teamwork model" en Team Performance Management, vol. 12, № 5-6, pp. 192-197. 
04

Innovación en los procesos de evaluación del aprendizaje 


\title{
La evaluación formativa: un análisis desde la perspectiva de los estudiantes
}

Juan Antonio Llorens-Molina ${ }^{a}$

${ }^{a}$ ETS de Ingeniería Agronómica y del Medio Natural - Grupo IEMA, Universidad Politècnica de València. Mail: juallom2@qim.upv.es

\begin{abstract}
Results from weekly online self-assessment activities are shown in this work. It has been developed over two consecutive years in an introductory organic chemistry course. These activities were also complemented by the availability of short video recording lessons (polimedia) related to key issues of subjectmatter content. The objectives of this work were mainly to know the students' opinions concerning the usefulness of these educational resources, as well as some aspects of their design and mode of use. Likewise, self-assessment practice is also related to students' performance in term final examination. The results showed a strongly positive perception of both resources although they also suggest modifying some aspects of their design and mode of use, such as their timing and duration of their availability.
\end{abstract}

Keywords: Self-assessment, feed-back, formative assessment, chemistry, Poliformat, multiple choice test.

\footnotetext{
Resumen

En este trabajo se presentan los resultados de la aplicación de actividades de autoevaluación online semanales. Estas han sido desarrolladas a lo largo de dos años consecutivos en un curso introductorio de química orgánica. Dichas actividades vienen también complementadas por la disponibilidad de grabaciones en video de corta duración (polimedia) centradas en aspectos clave del contenido. Los objetivos de este estudio son principalmente conocer las opiniones de los estudiantes acerca de la utilidad de estos recursos, así como de algunos aspectos de su diseño y utilización. Asimismo, también se relaciona la práctica de la autoevaluación con el rendimiento en el examen de la asignatura. Los resultados muestran una percepción claramente positiva de estos recursos, aunque también aconsejan modificar algunos aspectos de su diseño y modo de utilización, tal como el momento en que se utilizan y el tiempo de disponibilidad.
}

Palabras clave: Autoevaluación, retroalimentación, evaluación formativa, química, Poliformat, prueba de opción múltiple. 


\section{Introducción}

La evaluación como instrumento de aprendizaje se concreta en múltiples modos de evaluación formativa basados en diferentes recursos, tanto presenciales como online. El impacto de esta práctica educativa en el rendimiento académico es un hecho ampliamente contrastado en múltiples investigaciones realizadas en contextos similares al de este trabajo: asignaturas básicas al comienzo de la educación superior (Parker y Loudon, 2012). Tal como indican Sadler y Good, (2006), la autoevaluación contribuye a la mejora del aprendizaje a través de cuatro clases de aportaciones: (1) pedagógicas, dado que la retroalimentación proporciona oportunidades para el cambio conceptual y la profundización en los contenidos, así como para adquirir nuevas habilidades y recursos metodológicos; (2) metacognitivas, al contribuir a una mayor consciencia por parte de estudiante acerca de sus carencias y limitaciones, potencialidades y evolución de su aprendizaje, (3) de carácter práctico, ya que si se le asigna también una función sumativa, supone un importante ahorro de tiempo para el profesorado, sobre todo cuando imparte docencia a grandes grupos y (4) afectivas, ya que el alumno percibe la evaluación como un instrumento de aprendizaje más que como un elemento meramente sancionador de sus logros académicos.

Considerando estas aportaciones, y pese a la evidencia de un impacto positivo en el rendimiento académico, puede afirmarse que la aplicación de la evaluación formativa no necesita justificarse por su eficacia, ya que es una consecuencia directa de una concepción del aprendizaje como un proceso continuo de reestructuración cognitiva en el que la actividad metacognitiva del estudiante cobra un protagonismo esencial. Tal como afirman Ibabe y Jauregizar, (2010) la práctica de la autoevaluación es un factor que contribuye en gran medida al desarrollo de las habilidades metacognitivas de los estudiantes, por lo cual favorece el desarrollo de un conocimiento crítico del estudiante acerca de su propio aprendizaje (Wiediger y Hutchinson, 2002).

Por este motivo, este trabajo no tiene como objetivo comparar el rendimiento académico de los estudiantes tras la aplicación o no de una estrategia de evaluación formativa. Desde una perspectiva ética no hay motivo para privar a un grupo de estudiantes de una práctica educativa cuya bondad está suficientemente fundamentada, tanto teórica como empíricamente tanto en lo relativo a la mejora del aprendizaje como a su percepción positiva por los estudiantes. (McDonald y Boud, 2003; Sadler y Good, 2006; Poulos y Mahony, 2008). Sin embargo, hay múltiples aspectos en el diseño de la evaluación formativa que son susceptibles de análisis y mejora, siendo para ello una dato especialmente valioso la opinión de los estudiantes. También cabe precisar que, a diferencia del enfoque que generalmente se asigna a la autoevaluación en la literatura, como complemento o alternativa a la evaluación sumativa, en este trabajo la evaluación formativa se plantea exclusivamente con un objetivo orientador y de mejora del aprendizaje. Consecuentemente, es necesario también describir el contexto en que las actividades de autoevaluación se utilizan, tanto en relación al diseño global del proceso de aprendizaje como al resto de actividades de evaluación. Estos aspectos serán tratados detalladamente al describir el desarrollo de la innovación.

(cc) EY-NC-ND 2017, Universitat Politècnica de València 


\section{Objetivos}

Los objetivos de este trabajo se centran en la aplicación de dos innovaciones concretas:

- La realización semanal de autoevaluaciones online, con feed-back inmediato a través de la herramienta "exámenes" de Poliformat.

- La introducción de grabaciones en polimedia destinadas a reforzar los contenidos del programa considerados a priori como más difíciles o relevantes, poniendo así, a disposición del estudiante una herramienta que le permite revisarlos en cualquier momento.

Esta última herramienta se plantea como un aspecto más de la evaluación formativa, al hacer posible una retroalimentación de mayor alcance que la proporcionada por la mera corrección de la prueba de opción múltiple. De este modo, los estudiantes pueden, a la vista de sus carencias, recurrir a las grabaciones para aclarar dudas y profundizar en los conceptos implicados.

Más concretamente, el objetivo de este trabajo es analizar desde la perspectiva de los estudiantes, los siguientes aspectos de las actividades de autoevaluación:

- Su utilidad en general, así como el grado en que facilitan llevar al día la asignatura

- Aspectos de su diseño como la extensión, periodicidad y número máximo de envíos.

- Modo de proporcionar la retroalimentación.

- Momento en que el estudiante la realiza.

En cuanto a las grabaciones en polimedia, se pretende conocer también:

- El grado en que son utilizadas y en qué momentos.

- Si se visualizan completamente.

- En qué medida es valorada su utilidad.

\section{Desarrollo de la innovación}

El presente trabajo ha sido realizado a lo largo de dos cursos consecutivos (2015-16 y 201617) en la asignatura Fundamentos Químicos para la Ciencia y Tecnología de Alimentos, en el primer curso de dicho grado. Esta materia consta de tres unidades didácticas de una duración aproximada de diez semanas cada una. En la primera de ellas, dedicada a la introducción a la química orgánica, se ha desarrollado la innovación descrita en este trabajo.

Desde el punto de vista metodológico, la unidad dedicada a la química orgánica está planteada como una transición a la "clase invertida". Sus contenidos están divididos en dos subunidades claramente definidas: una parte introductoria, dedicada a los conceptos básicos, y otra, en la que se tratan las diferentes familias de compuestos orgánicos en cuanto a estructura, formulación y nomenclatura, propiedades físicas y reactividad, con un 
enfoque claramente agroalimentario. Para la subunidad de conceptos básicos, el alumnado tiene disponible en "contenidos" de poliformaT un material didáctico estructurado a modo de curso online, de modo que puede seguir la asignatura de modo relativamente autónomo, estando las clases presenciales centradas preferentemente en la realización y discusión de ejercicios prácticos. El contenido de la segunda subunidad va desarrollándose a través de las clases presenciales, alternando la presentación teórica con la realización de ejercicios de aplicación.

En cuanto a la evaluación, se lleva a cabo en sus tres aspectos: inicial, formativo y sumativo. La evaluación inicial es una sesión de trabajo presencial basada en el video: "Algunas ideas importantes al empezar a estudiar química orgánica" (https://riunet.upv.es/handle/10251/51372). Esta actividad se basa en una selección muy estricta de los prerrequisitos imprescindibles para comenzar la asignatura.

La evaluación formativa se basa en el empleo de dos recursos:

- Autoevaluaciones online publicadas cada viernes a través de "exámenes" de Poliformat, basadas en los contenidos impartidos esa semana -también alguna pregunta de contenidos anteriores-. Estas pruebas son de opción múltiple, con una extensión entre 10 y 20 ítems, no se restringe el tiempo para su realización, se permiten dos envíos y están disponibles hasta después del examen. La calificación del segundo es registrada automáticamente y la valoración conjunta del resultado de todas estas pruebas se contabiliza aumentando hasta en un $10 \%$ la nota obtenida en los exámenes, siempre que ésta sea superior a 4.0. En cada uno de los cursos se han realizado un total de 10 autoevaluaciones, siendo su contenido el mismo, salvo pequeñas modificaciones.

- Autoevaluaciones realizadas en clase utilizando el teléfono móvil mediante la aplicación "socrative". Su utilización es puntual y encaminada a centrar la atención del alumnado en aspectos particularmente relevantes, a modo de repaso para aclarar dudas.

La evaluación sumativa se desarolla a través tres actos de evaluación:

- Un primer examen parcial cuyo objetivo prioritario es familiarizar al alumnado con el formato y criterios de corrección utilizados en la asignatura. Su contenido está referido a la primera subunidad y vale un $30 \%$. Al final de la unidad, tiene lugar el segundo parcial cuyo contenido es opcional: puede referirse a toda la unidad, si el resultado del primero no fue satisfactorio, o bien estar centrado exclusivamente en la segunda subunidad, en cuyo caso se valora un $70 \%$.

- Independientemente de los exámenes, se plantea un trabajo voluntario (cuyo realización ha sido prácticamente generalizada en los dos cursos) consistente en la

(c) EY-NC-ND 2017, Universitat Politècnica de València

Congreso IN-RED (2017) 
elaboración en grupos de tres estudiantes de un poster (curso 2015-16) o de un "screencast" (2016-17), centrado en moléculas orgánicas de importancia agroalimentaria. Su calificación se realiza mediante coevaluación por parte de todo el grupo y se valora aumentando hasta en un $15 \%$ la nota global de la unidad, siempre que los exámenes se haya obtenido más de 4.0

Los datos relacionados con los objetivos del trabajo han sido obtenidos a partir de un conjunto de cuestiones planteadas como ítems de opción múltiple o mediante la aplicación de escalas Likert, incluidos como anexo a la última prueba de autoevaluación semanal.

\section{Resultados}

De cierto interés pueden ser los resultados globales de las autoevaluaciones, así como su correlación con el rendimiento académico (nota global de los exámenes, sin contabilizar la realización de las propias autoevaluaciones y los trabajos en grupo) y la mayor o menor puntuación media alcanzada en cada una de las autoevaluaciones.

La tabla 1 refleja estos resultados, considerando separadamente cada curso. Se muestra el promedio de las autoevaluaciones y las puntuaciones máxima y mínima registradas. Se incluye también la calificación media del examen y el coeficiente de correlación lineal con su significación entre las puntuaciones medias de las autoevaluaciones y la del examen.

Tabla 1. Resultados de las pruebas de autoevaluación y de los exámenes

\begin{tabular}{|l|c|c|c|c|c|c|}
\hline \multicolumn{1}{|c|}{ Curso } & $\mathrm{N}$ & $\begin{array}{c}\text { media } \\
\text { autoeval. }\end{array}$ & Rango & $\begin{array}{c}\text { media } \\
\text { examen }\end{array}$ & $\mathrm{r}$ & Sign. $\mathrm{r}$ \\
\hline $2015-16$ & 91 & 7.5 & $9.1-6.2$ & 5.5 & 0.18 & $\alpha<0.05$ \\
\hline $2016-17$ & 81 & 7 & $9.3-5.5$ & 5.2 & 0.34 & $\alpha<0.005$ \\
\hline
\end{tabular}

$\mathrm{N}$ : número de estudiantes evaluados

$\mathrm{R}$ : coeficiente de correlación lineal de Pearson

A partir de la tabla de valores críticos de $\mathrm{r}$ (Meliá, 2017) se desprende que la correlación lineal es estadísticamente significativa en ambos casos $(\alpha<0.05$ en 2015-16 y $\alpha<0.005$ en 2016-17, para contraste unilateral -test de una cola-). A partir de estos resultados puede aceptarse cierto valor predictivo al resultado de la autoevaluación con respecto al rendimiento obtenido en el examen. Estos resultados pueden considerarse convergentes con los referidos por Ibabe y Jauregizar, (2010) utilizando también herramientas online. No obstante, dicho valores deben interpretarse con cierta reserva por la influencia de los datos procedentes del colectivo de estudiantes relativamente desvinculado de la asignatura que, obteniendo calificaciones muy bajas en el examen, dejaron de realizar varias autoevaluaciones que son puntuadas con 0 . 
Se muestran a continuación los resultados globales para los dos cursos (120 cuestionarios procesados) de la encuesta relativa a la valoración de las actividades de autoevaluación por los estudiantes y de algunos factores de su diseño.

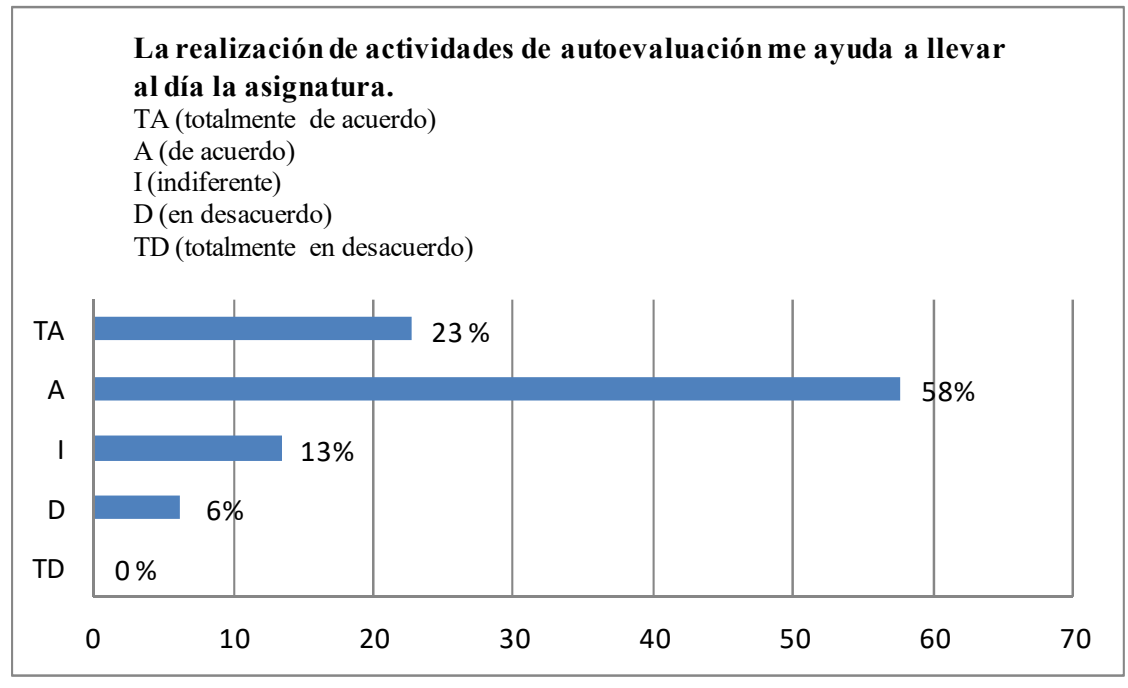

Fig. 1 Autoevaluación y seguimiento de la asignatura

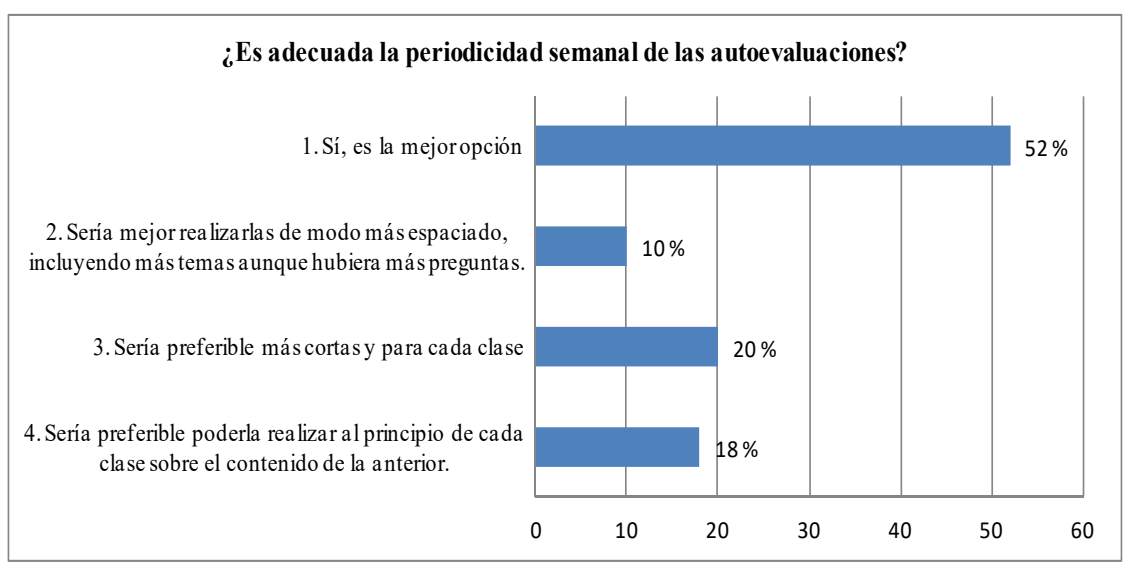

Fig. 2 Periodicidad de la autoevaluación

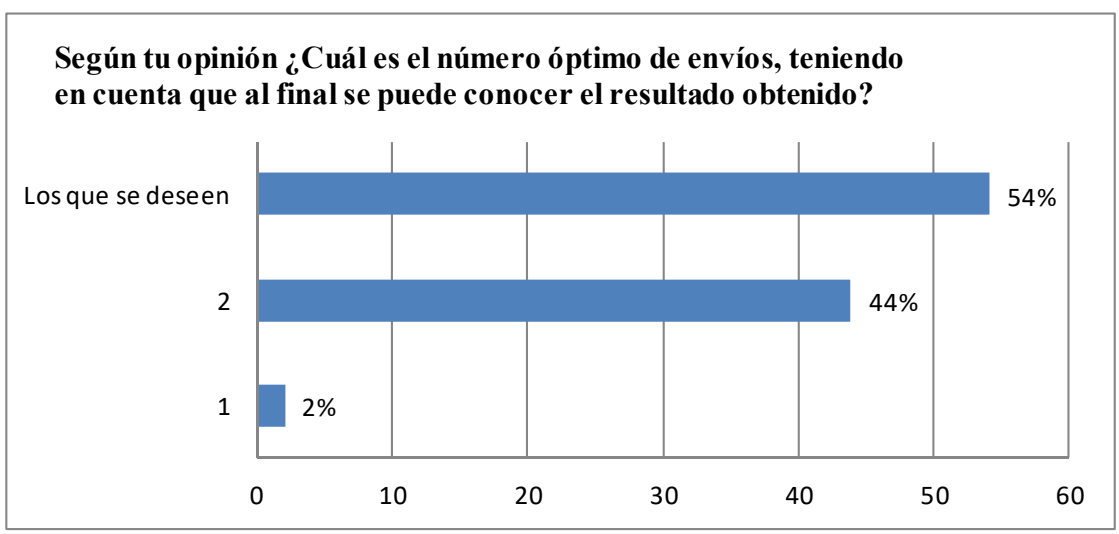

(cc) EY-NC-ND 2017, Universitat Politècnica de València 
Fig. 3 Preferencias acerca del número de envíos al realizar las pruebas de autoevaluación

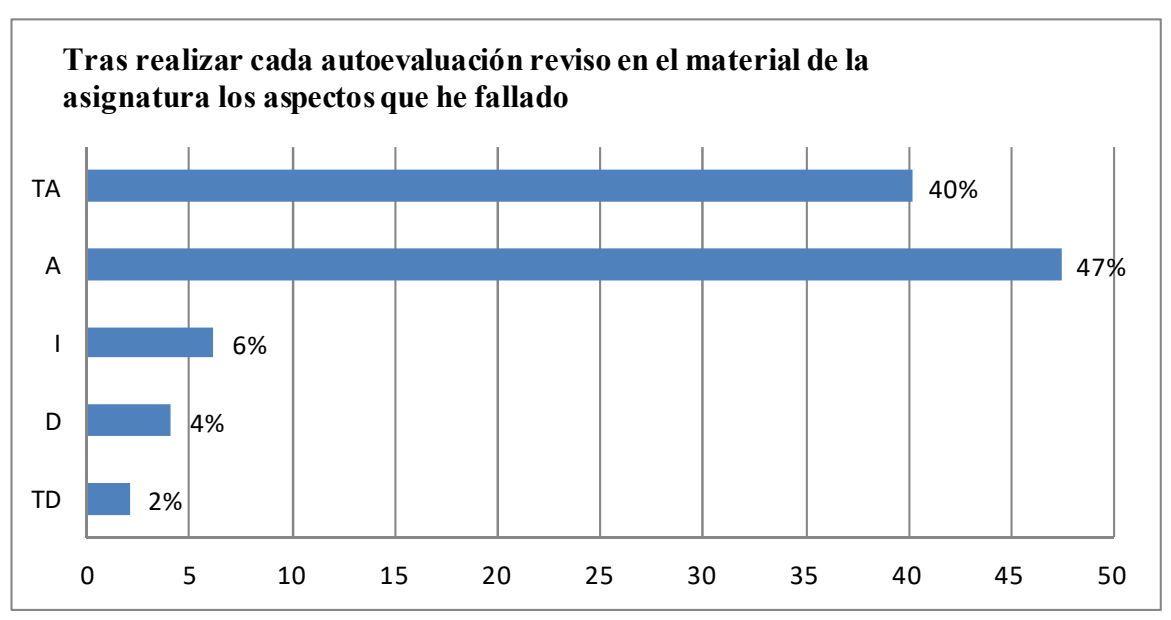

Fig. 4 Retroalimentación efectiva

¿Cuál es, a tu juicio, el número óptimo de preguntas para una autoevaluación semanal?

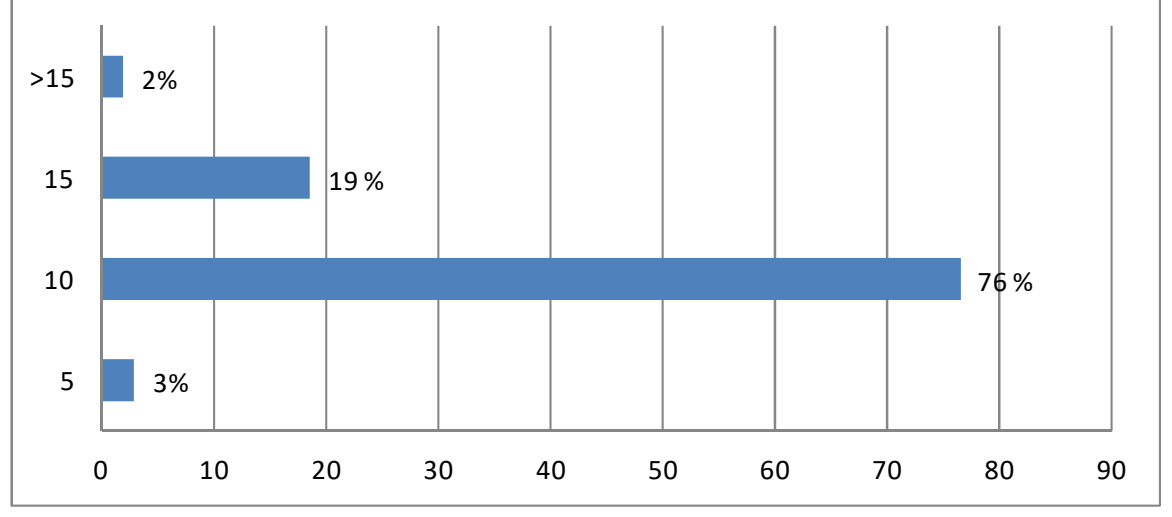

Fig. 5 Preferencias en cuanto a la extensión de las prebas

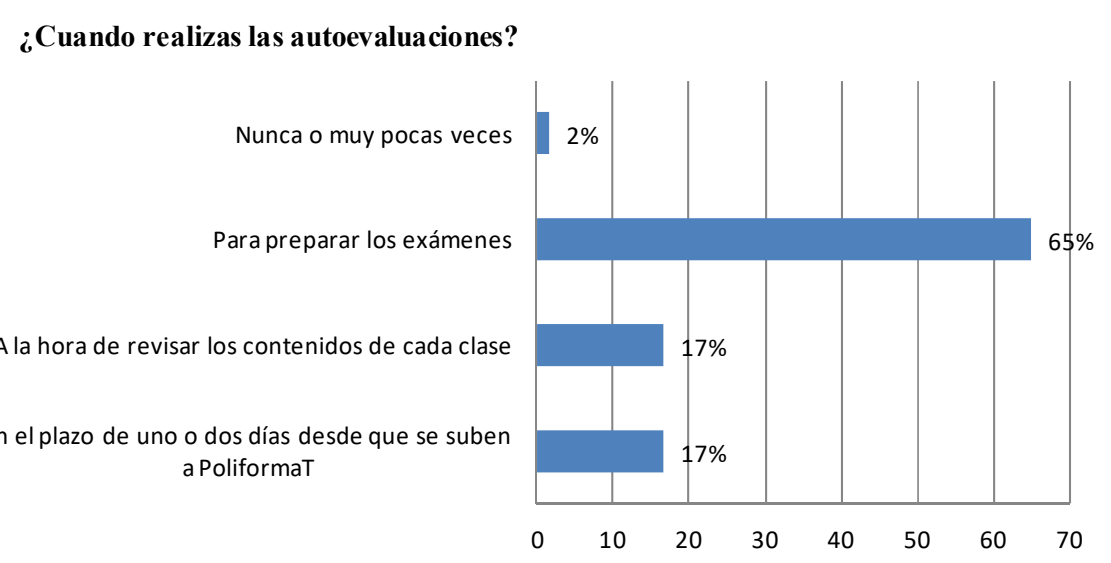

Fig. 6 Momento en que se realizan las pruebas de autoevaluación

(cc) EY-NC-ND 2017, Universitat Politècnica de València

Congreso In-Red (2017) 


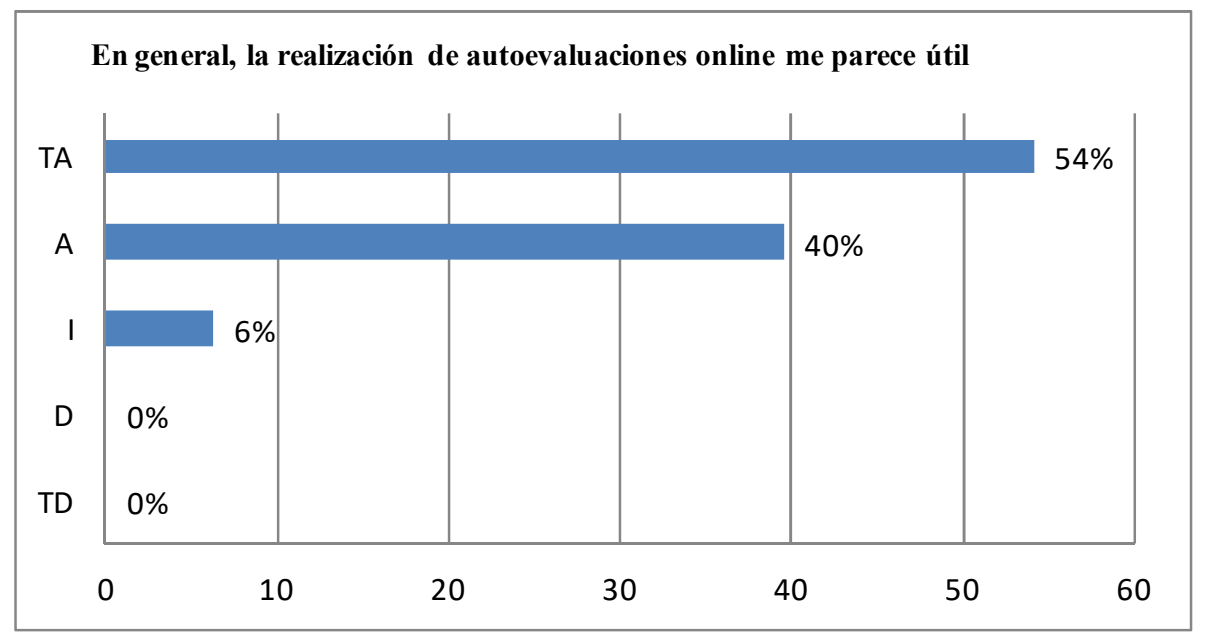

Fig. 7 Valoración general de la utilidad de la actividades de autoevaluación.

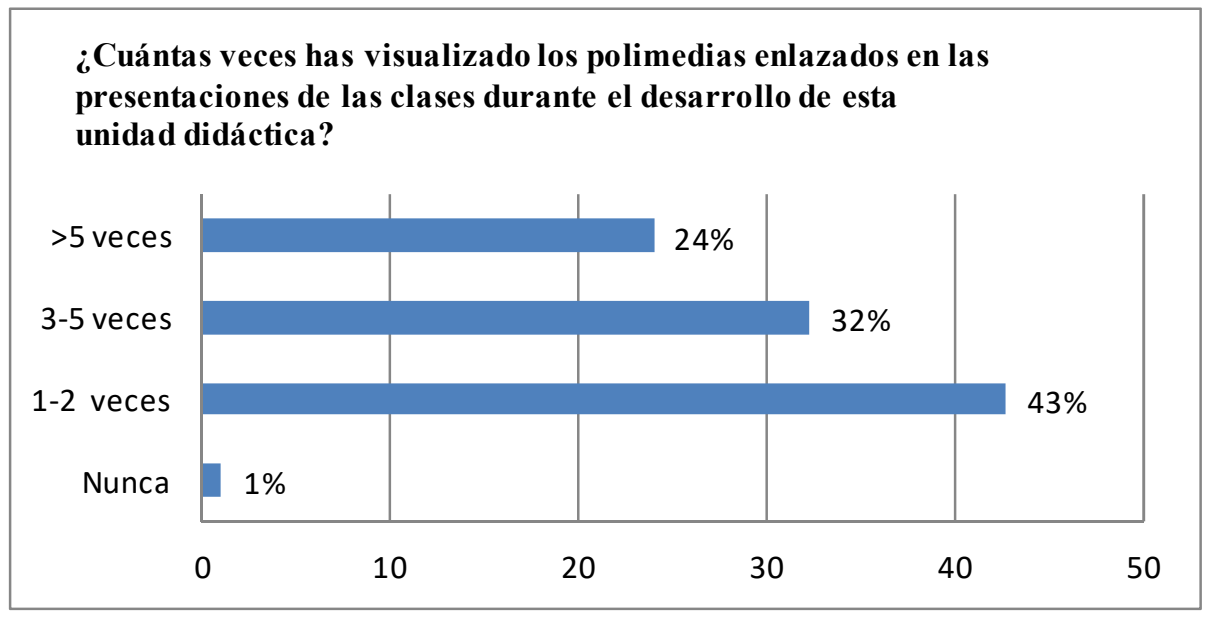

Fig. 8 Grado de visualización de las grabaciones polimedia

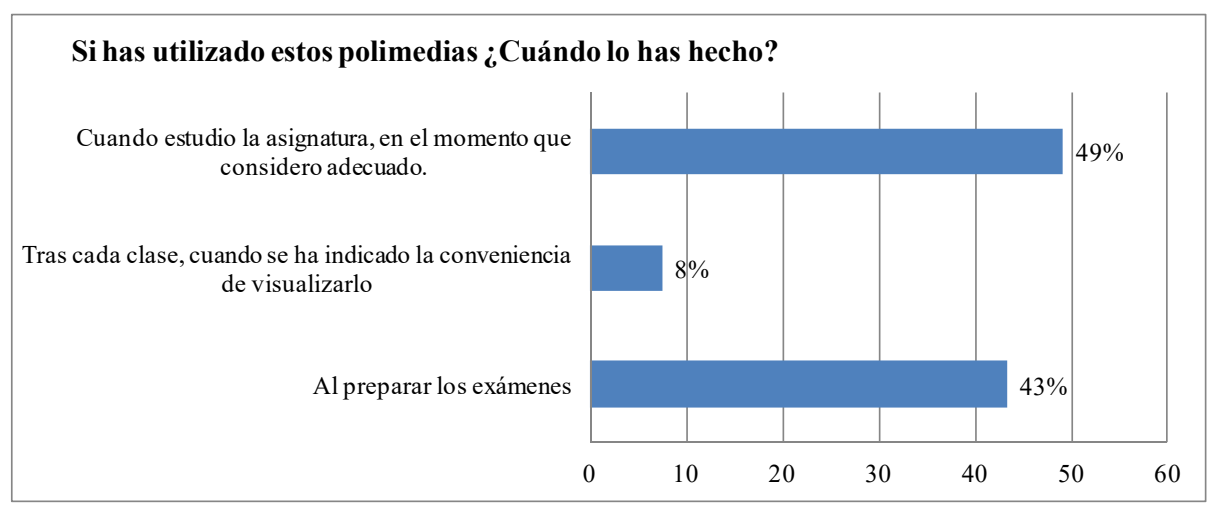

Fig. 9 Momento en que se utilizan las grabaciones polimedia

(cc) EY-NC-ND 2017, Universitat Politècnica de València

Congreso IN-RED (2017) 


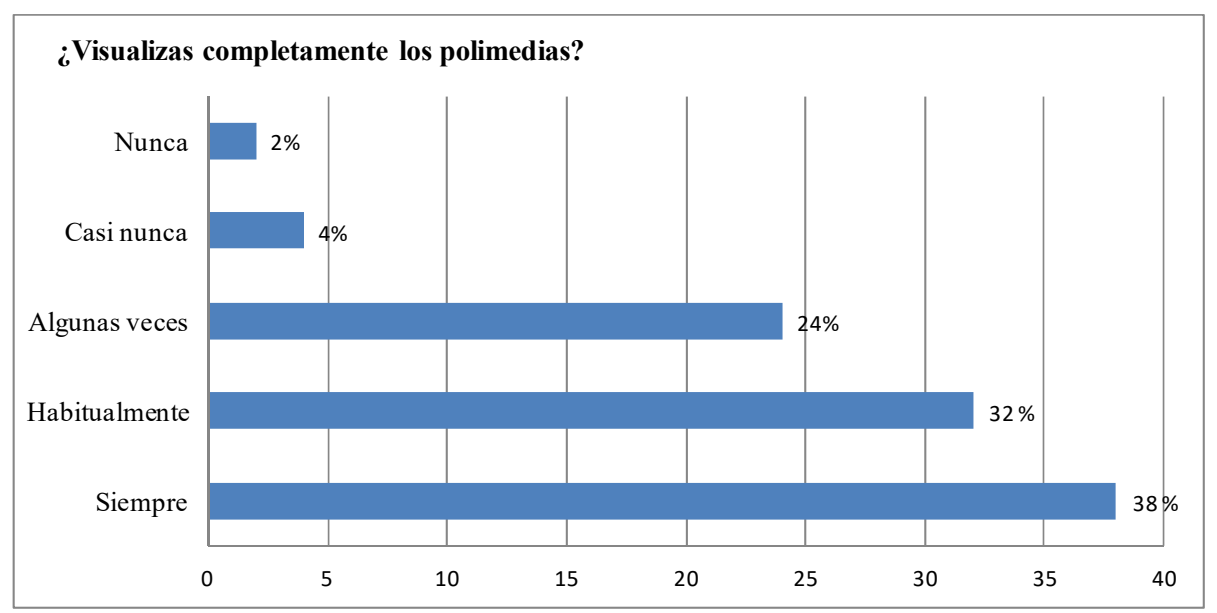

Fig. 10 Visualización completa de los polimedia

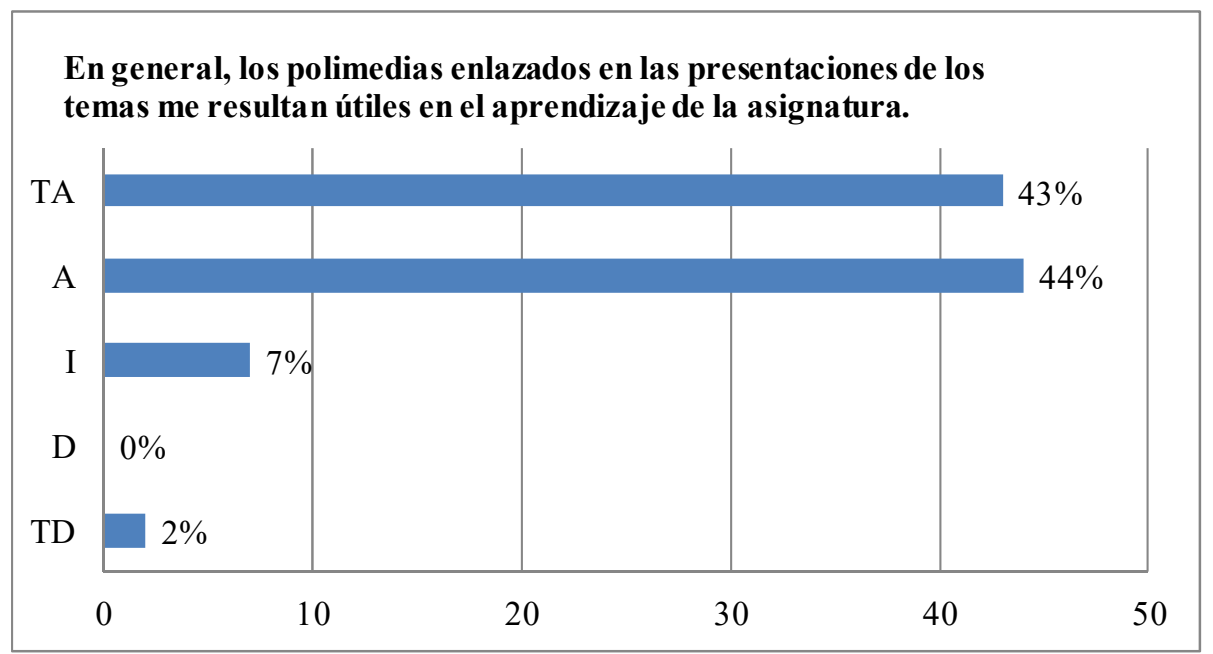

Fig. 11. Valoración general de la utilidad de las grabaciones polimedia

Los resultados muestran que la realización de actividades de autoevaluación es una práctica positivamente valorada por una gran mayoría del alumnado (Un $94 \%$ está de acuerdo o totalmente de acuerdo en su utilidad y un $81 \%$ también está de acuerdo o totalmente de acuerdo en que le ayuda a llevar al día la asignatura).

De estas valoraciones, consideradas globalmente, se desprende que los estudiantes perciben estos instrumentos como un complemento a su actividad académica cotidiana, más que como parte sustancial de la misma. Estos resultados son, en este sentido, coincidentes con los referidos por Ibabe y Jauregizar, (2010). Este carácter complentario es discutido por autores como McDonald y Boud, (2003), que proponen una mayor integración de la evaluación formativa en el diseño del curriculum como actividad capaz de modificar sustancialmente los ambientes de aprendizaje.

Acerca de su diseño y utilización, el alumnado manifiesta de modo mayoritario (87 \%) que la retroalimentación proporcionada al dar las soluciones correctas es acompañada por una 
revisión de los fallos con ayuda del material didáctico de la asignatura. La posibilidad de realizar un único envío es ampliamente rechazada siendo mayoritaria (54 \%) la opción por un número indefinido de envíos. Este hecho puede interpretarse teniendo en cuenta la seguridad que proporciona el obtener una calificación mayor tras recibir retroalimentación y repetir la actividad. Una vez más se confirma la importancia de la componente afectiva asociada a la evaluación formativa, a la que aluden diferentes autores como Poulos (2008), quién hace referencia explícita al efecto motivador e integrador en la vida universitaria que esto tipo de actividades aportan a los estudiantes de primer curso.

La periodicidad semanal es la opción más aceptada (52\%). No obstante, también es apreciable el número de estudiantes (38\%) que preferirían realizar la autoevaluación en cada clase, bien al principio (sobre la clase anterior), bien al final.

Existe un claro consenso ( $76 \%$ ) en torno al número más adecuado de ítems: 10. En cuanto al objetivo de su utilización, la preparación de los exámenes es la opción prioritaria (65\%), lo cuál puede explicarse teniendo en cuenta que son accesibles hasta el mismo momento del examen.

La introducción de grabaciones en polimedia como apoyo para la enseñanza presencial es valorada positivamente por una gran mayoría del alumnado (un $87 \%$ está de acuerdo o totalmente de acuerdo en su utilidad). Por otra parte, su grado de utilización es apreciable, aún teniendo en cuenta las reservas con qué deben interpretarse estos datos. Pese a que las estadísticas de visualización en upv media y youtube suelen mostrar aumentos puntuales del número de visualizaciones en las dos semanas previas a los exámenes, dado que éstas proceden también de ámbitos ajenos a la UPV, no es posible concluir de manera categórica que dichos aumentos son consecuencia de la preparación de los exámenes. Lo mismo puede comentarse acerca del grado en que los polimedia son visualizados completamente. Un $70 \%$ afirma que siempre o habitualmente proceden de este modo, pero la fiabilidad de este dato puede considerarse limitada.

En cuanto al momento de su utilización, un $92 \%$ de los estudiantes lo utiliza como material de repaso cuando estudian la asignatura y en la preparación de los exámenes. Su vinculación a cada clase presencial es muy limitada (8\%). Este hecho confirma la tendencia ya comentada anteriormente, acerca del carácter complementario que el alumnado asigna a estos recursos didácticos.

\section{Conclusiones}

Teniendo en cuenta las limitaciones que ofrece la interpretación de los datos de rendimiento académico en relación al desarrollo de las actividades de autoevaluación, existe una cierta evidencia de que lo favorecen. De todos modos, el contexto en que la actividad de autoevaluación se realiza es difícilmente controlable, por lo que cualquier predicción del rendimiento académico ha de realizarse con suma prudencia.

A partir de las preferencias del alumnado puede establecerse un perfil para las actividades de autoevaluación que podría definirse así:

(cc) EY-NC-ND 2017, Universitat Politècnica de València

Congreso IN-RED (2017) 
- Pruebas de 10 cuestiones planteadas al final de cada semana o bien al principio o final de cada clase (en este caso, su adaptación a socrative u otras aplicaciones similares utilizando el teléfono móvil sería la solución)

- Constituyen un recurso disponible en todo momento para el alumnado y lo que lo emplea discrecionalmente en función de su ritmo de trabajo, como un material didáctico más, a modo de complemento. No obstante, aún teniendo en cuenta estas preferencias, podría lograrse una mayor racionalización en el desarrollo de esta actividad abriéndola durante un tiempo limitado (una semana, por ejemplo) durante el periodo docente y volviéndolas a abrir durante un perido previo al examen para que sirviera como material de repaso.

- La retroalimentación consistente en proporcionar exclusivamente las respuestas correctas parace ser una opción adecuada, ya una elevada proporción de los estudiantes encuestados reconoce consultar el material docente de la asignatura para aclarar las dudas surgidas. El modo de aplicar la retroalimentación requeriría un estudio más específico y riguroso ya que puede ser la cuestión clave en el logro de una evaluación formativa eficaz.

Aún reconociendo la utilidad de las grabaciones en polimedia como recurso para ser utilizado discrecionalmente por el alumnado, un mayor control de su uso sería adecuado. En este sentido, cabría dirigir el diseño de los polimedia hacia la elaboración de verdaderas actividades de aprendizaje, dotándolas de interactividad. De este modo sería posible integrarlas como tareas específicas dentro del desarrollo ordinario de la asignatura. Se trataría, en definitiva, de elaborar un modelo de objeto de aprendizaje que, sin olvidar las características que lo definen, favorecieran una participación activa del alumnado cuando lo visualiza.

\section{Referencias}

IBABE, I. y JAUREGIZAR, J. (2010). "Online self-assessment with feedback and metacognitive knowledge”. Higher Education, vol. 59, 2, p. 243-258.

DOI 10.1007/s10734-009-9245-6 [consulta: 3 de marzo de 2017]

MCDONALD, B. y BOUD, D. (2003). "The impact of self-assessment on achievement: The effects of self-assessment training on performance in external examinations". Assessment in Education: Principles, Policy \& Practice, vol. 10, 2, p. 209-220.

MELIÁ, J. L. (2017). Valores críticos del coeficiente de correlación $r$ de Pearson. $<$ http://www.uv.es/meliajl/Docencia/Tablas/TablaR.PDF $>$ [consulta: 1 de marzo de 2017]

PARKER, L. L. y LOUDON, G. M. (2012). "Case study using online homework in undergraduate organic chemistry: results and student attitudes". Journal of Chemical Education, vol. 90, 1, p. 37-44.

POULOS, A. y MAHONY, M. J. (2008). "Effectiveness of feedback: The students' perspective". Assessment \& Evaluation in Higher Education, vol. 33, 2, p. 143-154.

SADLER, P. M. y GOOD, E. (2006). "The impact of self-and peer-grading on student learning". Educational assessment, vol. 11, 1, p. 1-31.

(cc) EY-NC-ND 2017, Universitat Politècnica de València

Congreso In-Red (2017) 
$<\underline{\text { https://www.cs.auckland.ac.nz/courses/compsci747s2c/lectures/paul/2006_Sadler_PeerAssessment. }}$ pdf> [consulta: 6 de marzo de 2017]

WIEDIGER, S. D. y HUTCHINSON, J. S. (2002). "The significance of accurate student selfassessment in understanding of chemical concepts". Journal of Chemical Education, vol. 79, 1, p 120.

DOI: 10.1021/ed079p120 [consulta: 3 de marzo de 2017]

(cc) EY-NG-ND 2017, Universitat Politècnica de València

Congreso IN-RED (2017) 


\title{
Evaluación de la competencia transversal CT09 Pensamiento crítico a través de series de ficción en la asignatura de Gestión empresarial de la edificación en el Máster de Edificación de la Universitat Politècnica de València
}

\begin{abstract}
Francisca Ramón Fernándeza, Vicente Cabedo Mallol, María Emilia Casar Furióc Vicent Giménez Chornet ${ }^{\mathrm{d}}$ Cristina Lull Noguera ${ }^{\mathrm{e}}$ y Juan Vicente Oltra Gutiérrez ${ }^{\mathrm{f}}$

${ }^{a}$ Profesora titular. Departamento de Urbanismo, Universitat Politècnica de València, frarafer@urb.upv.es, ${ }^{b}$ Profesor contratado doctor, acreditado a titular. Departamento de Urbanismo, Universitat Politècnica de València, vicamal@urb.upv.es, ${ }^{c}$ Profesora contratada doctora, acreditada a titular. Departamento de Urbanismo, Universitat Politècnica de València, macafu@urb.upv.es, ${ }^{\mathrm{d}}$ Profesor titular. Departamento de Comunicación Audiovisual, Documentación e Historia del Arte, Universitat Politècnica de València, vigicho@har.upv.es ${ }^{\mathrm{e}}$ Profesora contratada doctora, Departamento de Química, Universitat Politècnica de València, clull@upvnet.upv.es, ${ }^{\text {PP }}$ rofesor titular de Escuela Universitaria. Departamento de Organización de Empresas, Universitat Politècnica de València, jvoltra@omp.upv.es
\end{abstract}

\begin{abstract}
This paper analyzes the use of fiction series for the evaluation of transversal competence CT 09 Critical thinking, after the granting of a project of innovation teaching (PIME) by the Universitat Politècnica de València, for the year 2016.

The results obtained with 33 students of the subject of Bulding Business Management, in the Master's Degree in Building Constructions, and the evaluation of the indicated competence after watching, in which the students make a critique of the situations observed in the selected episode. The rubric established by the Universitat Politècnica de València is used for selfevaluation.

We believe that the understanding is facilitated and that the students have a tool to evaluate the competence, and the ability to perceive situations related to the concepts explained in the subject is strengthened. It combines the new information and communication technologies (ICTS), which is the main objective of the innovation group, with activities that allow students to be evaluated in this competition.
\end{abstract}

Keywords:

Transversal competence, critical thinking, fiction series, evaluation, Master level

\section{Resumen}

En el presente trabajo se analiza la utilización de series de ficción para la evaluación de la competencia transversal CT 09 Pensamiento crítico, tras la 
Evaluación de la competencia transversal CT09 Pensamiento crítico a través de series de ficción en la asignatura de Gestión empresarial de la edificación en el Máster de Edificación de la Universitat Politècnica de València

concesión de un proyecto de innovación docente (PIME) por parte de la Universitat Politècnica de València, para el año 2016.

Se analizan los resultados obtenidos en 33 alumnos de la asignatura de Gestión empresarial de la edificación, en el Máster Universitario en Edificación, y la evaluación de la competencia indicada tras el visionado de una serie de ficción, en la que el alumnado realiza una crítica de las situaciones observadas en el episodio seleccionado. Se utiliza la rúbrica establecida por la Universitat Politècnica de València para la autoevaluación.

Consideramos que se facilita la comprensión y que el alumnado dispone de una herramienta para evaluar la competencia, y se potencia la capacidad de percepción de situaciones relacionadas con los conceptos explicados en la asignatura. Se combina las nuevas tecnologías de la información y la comunicación (TICs), que es el objetivo principal del grupo de innovación, con las actividades que permiten al alumnado ser evaluado en dicha competencia.

Palabras clave: Competencia transversal, pensamiento crítico, series de ficción, evaluación, nivel Máster

\section{Introducción}

En el ámbito de la Universitat Politècnica de València se encuentran determinadas asignaturas que son puntos de control de diversas competencias transversales (Véase: Villa y Poblete, 2007). En el caso de la CT-09. Pensamiento crítico se pretende que el alumno se involucre en los fundamentos en los que se basan las ideas, acciones y juicios que se plantean.

Se trata de discernir sobre los fundamentos que se aportan para sostener dichas ideas, acciones y valoraciones o juicios tanto de la misma persona, como de los demás, y determinar si son adecuados o no.

Esta competencia se aplica en tres distintos niveles de dominio (primero, segundo y tercero), en los que se analizan distintos parámetros como son la actitud crítica ante determinada situación, opiniones, emisión de juicios, argumentación de distintas posturas.

Es por ello que el análisis y el cuestionamiento de la información es lo que va a ser el soporte evaluatorio de dicha competencia a través de la elaboración de la rúbrica elaborada por la UPV (Cabedo, Castelló, Ibáñez, Jiménez y Serra, 2016).

No obstante, nos encontramos con que esa rúbrica se tiene que materializar en distintas actividades que nos puedan servir para evaluar al alumno en dicha competencia y eso es lo que pretendemos en la presente propuesta, a través del diseño de actividades que nos lo permitan, pero tomando como soporte para su diseño series de ficción, que nos muestren situaciones reales con personajes ficticios que puedan ayudar al alumno a posicionar su pensamiento crítico.

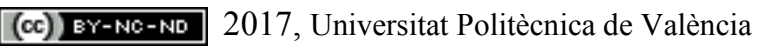


Se pretende, pues, diseñar esas actividades teniendo en cuenta el perfil de varias series de ficción (Mad Men, The big bang theory...) (Cabezuelo y Cabrera, 2011; Carrasco, 2012) que desarrollan situaciones en las que se puede aplicar el pensamiento crítico a la situación, teniendo en cuenta la evaluación del pensamiento crítico en el caso de los conflictos en el seno de una empresa; en la práctica deontológica en el seno de la investigación, en el caso del flujo de información dentro de los medios culturales (García, Ramos, Rey y Suárez, 2014), y en situaciones en el ámbito jurídico al desarrollarse aspectos que permitan al alumnado la decisión sobre la correcta interpretación de una norma (Kovacsics, 2015).

\section{Objetivos}

La finalidad es elaborar una serie de actividades, similar a las elaboradas para evaluar la competencia transversal 06 Trabajo en equipo y liderazgo que se realizó anteriormente (Cabedo, Casar, Giménez, Oltra y Ramón, 2016) que permitan evaluar la competencia transversal CT-09. Pensamiento crítico mediante la utilización de series de ficción en las que el alumno pueda emitir juicios, opiniones, determinar la conformidad o no con los argumentos.

Se pretende que el alumnado a través de fragmentos de series de ficción pueda emitir su propia opinión, y para ello se diseñarán las actividades que pueden consistir, entre otras, en las siguientes:

1. Búsqueda de dossier de prensa relacionados con el fragmento visualizado.

2. Extrapolación de la situación ficticia a una real y argumentación de posturas.

3. Determinación de las erratas e incoherencias mostradas en el fragmento audiovisual y corrección por parte del alumnado.

4. Foro de debate con participación de diversas posturas contradictorias.

5. Elaboración de un mapa conceptual de los principales argumentos utilizados.

6. Repercusión de la situación ficticia en el ámbito social actual.

7. Cumplimiento de la normativa en la situación ficticia planteada y crítica de la solución adoptada.

Como objetivos específicos podemos señalar los expresados a continuación:

1. Utilización de series de ficción para la utilización de la rúbrica elaborada por la UPV para la evaluación de la competencia transversal CT-09. Pensamiento crítico.

2. Elaboración de distintas actividades, en función de la asignatura, para utilizarlas en la rúbrica y poder evaluar la competencia.

3. Familiarizar al alumno con la competencia transversal CT-09. Pensamiento crítico y las rúbricas para su evaluación.

4. Potenciar el espíritu crítico ante determinadas situaciones ficticias y su aplicación en la vida real.

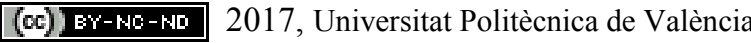




\section{La evaluación de la competencia transversal CT09 Pensamiento crítico mediante la utilización de series de ficción: una innovación aplicada en la Universitat Politècnica de València}

Las series de ficción que se han previsto utilizar para evaluar la competencia transversal CT09. Pensamiento crítico quedan recogidas en la Figura 1:

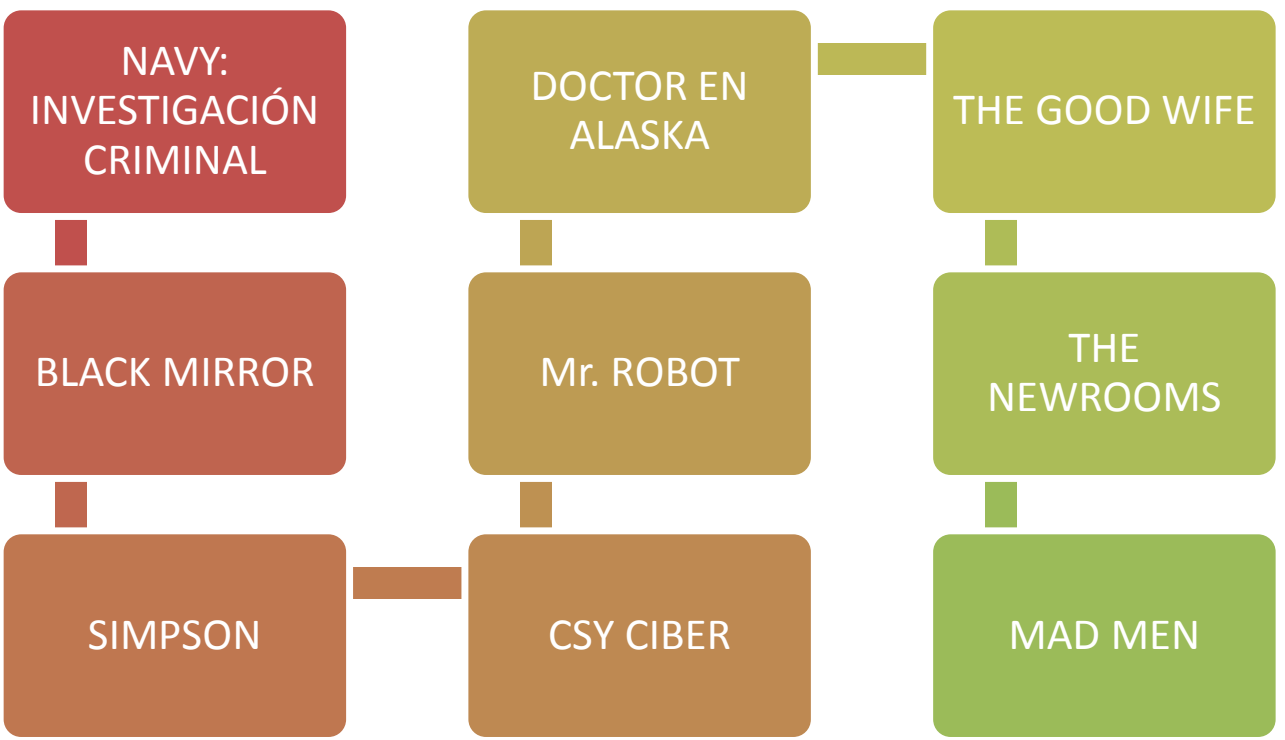

Fig. 1. Algunas series de ficción que se han elegido por su temática para evaluar la competencia transversal CTO9. Pensamiento critico

\subsection{Niveles en los que se va a aplicar la innovación}

La innovación propuesta se aplicará en las asignaturas recogidas en la Tabla 1, abarcando por tanto dos niveles de dominio: el primero que incluye el primer y segundo curso de Grado y el tercero (Máster).

Tabla 1. Asignaturas involucradas en la innovación docente

\begin{tabular}{|l|l|c|}
\hline \multicolumn{1}{|c|}{ Asignatura } & Titulación en que se imparte & Nivel/Curso \\
\hline $\begin{array}{l}\text { Gestión empresarial de la } \\
\text { edificación }\end{array}$ & Master Universitario en Edificación & 3 \\
\hline $\begin{array}{l}\text { Gestión del conocimiento y } \\
\text { recursos informáticos }\end{array}$ & Máster en Gestión Cultural & 3 \\
\hline Gestión Urbanística & Grado en Arquitectura Técnica & $1 / 2$ \\
\hline Medio abiótico & Grado en Ciencias Ambietales & $1 / 2$ \\
\hline
\end{tabular}




\begin{tabular}{|l|l|c|}
\hline $\begin{array}{l}\text { Deontología } \\
\text { profesionalismo }\end{array}$ & Grado en Ingeniería Informática & $1 / 2$ \\
\hline $\begin{array}{l}\text { Marco legal y deontológico } \\
\text { de la información }\end{array}$ & $\begin{array}{l}\text { Máster en Gestión de la } \\
\text { Información }\end{array}$ & 3 \\
\hline $\begin{array}{l}\text { Contaminación de suelos y } \\
\text { tratamiento de residuos }\end{array}$ & Grado en Ciencias Ambietales & $1 / 2$ \\
\hline Derecho constitucional & $\begin{array}{l}\text { Diplomado en Gestión y } \\
\text { Administración Pública }\end{array}$ & $1 / 1$ \\
\hline
\end{tabular}

En este trabajo se presentan los resultados relativos a la aplicación de la innovación en la asignatura Gestión empresarial de la edificación, impartida en el Master Universitario en Edificación.

\section{Desarrollo de la innovación}

En este caso hemos realizado la innovación docente en la asignatura Gestión empresarial de la Edificación que se imparte en el Master Universitario en Edificación (nivel 3) y que cuenta con una matrícula de 33 alumnos.

Se trata de una asignatura de 6 créditos ECTS, de los cuales, se aplica la innovación a la parte de 2 créditos impartida por la profesora Ramón Fernández.

Se inicia la innovación explicándole a los alumnos unas nociones básicas referentes a los siguientes conceptos:

-Organización empresarial

-Organigrama de las empresas

-Flujo y gestión de la información en la empresa

-Protección de datos de carácter personal y legislación aplicable

-Derechos de propiedad intelectual e industrial aplicados al ámbito empresarial

-Utilización correcta e incorrecta de la información y consecuencias en el ámbito penal

Después, se visiona en el aula el episodio de los Simpson 12x06. Este episodio lleva por título "El ordenador que acabó con Homer" en España y "Amenaza informática" en Latinoamérica. Se ha escogido esta serie por varios motivos, por un lado debido a que es conocida mundialmenteeste y el perfil de los alumnos es mayoritariamente de países latinoamericanos (México, República Dominicana, Colombia, Ecuador...) y europeos (Francia e Italia), y por otro lado se ha escogido el capítulo mencionado porque tiene una gran relación con la parte de la asignatura dedicada al flujo de la información dentro de una empresa, y en el episodio se tratan temas relacionados como es el caso de la protección de datos de carácter personal, la utilización de un blog para difundir información no 
contrastada, delitos relacionados con la información, así como la infracción de derechos de autor, que previamente se han indicado en el aula.

Tras el visionado, se les propone a los alumnos la lectura del caso: La realidad virtual. Verdades y mentiras en la red. El ordenador que acabó con Homer (véase Cabedo, Casar, Giménez, Oltra y Ramón, 2016).

Los alumnos, después, del visionado, tienen que contestar a una serie de preguntas y realizar un comentario sobre los aspectos relacionados con lo explicado previamente y el episodio en cuestión.

Se realiza la actividad en grupos habiéndose constituido un total de 8 grupos.

A continuación, y tal y como trataremos en el siguiente punto, se autoevaluarán y evaluarán a los compañeros del grupo, a través de una rúbrica la competencia transversal de pensamiento crítico.

\section{Resultados obtenidos: Utilización de la rúbrica y análisis de los resultados obtenidos tras la evaluación de la competencia por parte de los alumnos}

Para evaluar la competencia transversal CT09. Pensamiento crítico se les pasa a los alumnos un breve cuestionario al finalizar la docencia en el que se tienen que autoevaluar y evaluar a los compañeros del equipo de trabajo acerca de los indicadores que se indican en la Figura 2 y que se corresponden con la rúbrica elaborada por la Universitat Politècnica de València. Los alumnos valoran los indicadores con una máxima calificación de 4 y una mínima de 1 puntos, además tienen la posibilidad de que puedan añadir los comentarios que estimen oportunos.

Indicador 1 . Verifica la
conformidad de un
planteamiento
respecto a una norma
o estandar

Indicador 2. Argumenta juicios en función de criterios externos

Indicador 3. Extrapola principios o modelos a nuevas situaciones

Fig. 2. Indicadores de la rúbrica en el cuestionario pasado a los alumnos respecto a la evaluación de la competencia transversal CTO9. Pensamiento crítico 
Los comentarios a la evaluación de la competencia transversal CT09. Pensamiento crítico fueron los siguientes:

-«Miembro 1, no le conozco muy bien no tengo una mejor forma de valorarle».

-«Durante el máster no hemos tenido esta metodología de ver el tema y poder defender nuestro punto de vista».

-«Somos un buen grupo, nos compenetramos muy bien y estamos muy a gusto».

-«Me pareció muy innovador, durante el máster hemos tenido audiovisuales, pero no los suficientes, en esta metodología entiendo que estimula el razonamiento y la comprensión».

-«El trabajo en equipo me parece muy bueno y la gente se hace más responsable».

-«Todos los miembros, sin excepción son colaborativos y trabajadores. Trabajamos muy a gusto y nos completamos. No hemos encontrado un grupo mejor».

-«Siempre tomamos en consideración la opinión de nuestros compañeros, de todos los integrantes del grupo. Buscamos hacer los trabajos».

-«Soy estudiante Erasmus entonces mi grupo trabaja mucho y bien entonces no tengo nada que criticar sobre su trabajo. No hecho muchas cosas y necesitaba ayuda. Mi grupo fue muy bueno»».

-«Somos un grupo que se soporta en nuestra ayuda mutua. Los logros los conseguimos en equipo».

En relación a los resultados obtenidos en los cuestionarios de autoevaluación y evaluación de los compañeros, la Figura 3 recoge el número de coincidencias obtenidas para cada calificación e indicador.

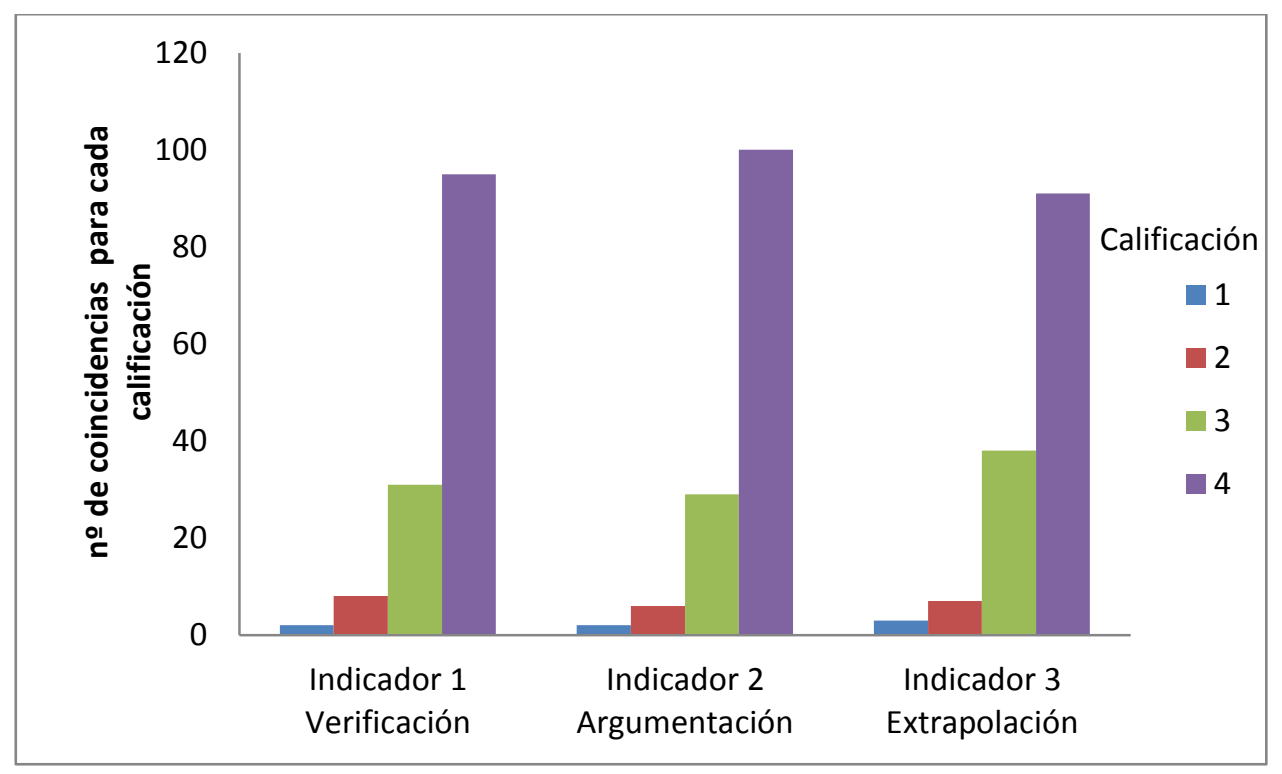

Fig.3. Número de coincidencias obtenidas para cada calificación e indicador. 
La encuesta fue contestada por un total de 33 alumnos. Como se ha realizado en grupo, se realiza una autoevaluación y también evalúan a los compañeros/as del grupo. De los resultados, podemos ver que en el indicador 1 referente a si verifica la conformidad de un planteamiento respecto a una norma estándar los resultados negativos (1 y 2 puntos) son muy pocos, solo diez alumnos calificaron con un 1 o un 2, siendo la mayoría de resultados obtenidos de valoración 3 y 4 . En cuanto al indicador 2 relativo a la argumentación de juicios en función de criterios externo, se observa lo mismo que en el indicador anterior, en este caso ocho alumnos calificaron con un 1 o un 2, siendo la mayoría de resultados favorales ( 3 y 4 puntos). Por último en el indicador 3 referente a la extrapolación de principios o modelos a nuevas situaciones, se repite el mismo comportamiento numérico que en el caso de los dos indicadores anteriores, siendo la mayoría de alumnos favorablemente evaluados.

\section{Conclusiones}

La innovación propuesta y aplicada en este caso nos arroja una serie de conclusiones que vamos a indicar:

Utilizar una herramienta para la evaluación de la competencia transversal CT09. Pensamiento crítico resulta positivo para el alumnado, ya que le permite potenciar su capacidad crítica sobre su participación, así como la del resto de compañeros en el grupo.

En este caso se ha utilizado una serie de ficción en la que se planteaban cuestiones relativas a buenas y malas prácticas en el ámbito de la informática, combinando aspectos legislativos y sociológicos, mediante el método del caso, y después la valoración a través de la rúbrica de la Universitat Politècnica de València la competencia transversal utilizada en la asignatura.

Los alumnos, en este caso, un total de 33 en una asignatura de tercer nivel, Máster, no valoran de forma unitaria y sistemática a todos los compañeros/as, sino que, al contrario, se observa que son capaces de discernir entre los miembros del equipo que peor han aplicado y comprendido la competencia evaluada, es decir, que no han realizado el pensamiento crítico, o bien han adoptado una actitud pasiva, y se han valorado con la puntuación más negativa, 1 punto.

Ello significa que el trabajo en equipo se ha realizado efectivamente, y que no utilizan un sistema de puntuación pretederminado por ellos; sino que han valorado efectivamente el comportamiento de los miembros del grupo.

Consideramos que el visionado de una serie de ficción es una herramienta que nos resulta positiva y perfectamente evaluable para la competencia transversal CT09. Pensamiento crítico, dado los resultados favorables obtenidos en su implantación.

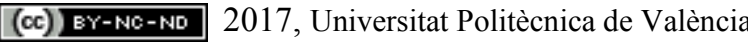




\section{Agradecimientos}

Trabajo realizado en el marco del PIME «La evaluación de la competencia transversal pensamiento crítico mediante la utilización de series de ficción» de la Universitat Politècnica de València, 2016-2017. Coordinado por la Dra. D ${ }^{\mathrm{a}}$. Francisca Ramón Fernández; Proyecto MINECO (DER2013-4256R), siendo los Investigadores Principales la Dra. $D^{\text {a }}$. Luz María Martínez Velencoso, Profesora Titular de Derecho civil, Universitat de València-Estudi General, y el Dr. D. Javier Plaza Penadés, Catedrático de Derecho civil, Universitat de València-Estudi General, y Proyecto «Derecho civil valenciano y europeo» del Programa Prometeo para Grupos de Investigación de Excelencia de la Conselleria de Educación, Cultura y Deporte, GVPROMETEOII2015-014 y del Microcluster «Estudios de Derecho y empresa sobre TICs (Law and business studies on ICT)», dentro del VLC/Campus, Campus de Excelencia Internacional (International Campus of Excellence), coordinado por el Dr. D. Javier Plaza Penadés, Catedrático de Derecho civil, Universitat de València-Estudi General, y Proyecto I+D Excelencia del Ministerio y Competitividad. "El avance del Gobierno Abierto. Régimen jurídico constitucional de la implantación de políticas de transparencia, acceso a la información, datos abiertos, colaboración y participación especialmente a través de las TIC y del Gobierno electrónico". DER201565810-P (2016-2018). Investigador Principal: Dr. D. Lorenzo Cotino Hueso. Catedrático acreditado de Derecho constitucional. Universitat de València.

\section{Referencias}

CABEdo Fabrés, M., CASTElló Fos, S., iBÁÑEZ ASENSiO, S., JiMÉNeZ Belenguer, A. I. y SERRA CARbonell, B. (2016). Rúbrica. CT-09. Pensamiento crítico. Universitat Politècnica de València.

CABEDO MALlOL, V., CASAR FURIÓ, M. E., GIMÉNEZ CHORNET, V., OLTRA GUTIÉRREZ, J. V. y RAMÓN FERNÁNDEZ, F. (2016). Casos prácticos jurídicos basados en series de animación. Francisca Ramón Fernández (coord.). Valencia: Tirant lo Blanch.

CABeZUelo lorenzo, f. y CABRera garcía-OchoA, y. (2011). Análisis y crítica del discurso audiovisual y su dimensión social en "Mad Men”. En: La comunicación pública, secuestrada por el mercado. Concha Mateos Martín, Alberto Isaac Ardévol Abreu y Samuel Toledano Buendía (coords.). Universidad de La Laguna, págs. 1-15. Disponible en: $<$ http://www.revistalatinacs.org/11SLCS/actas_2011_IIICILCS/179.pdf> [Consulta: 25 de marzo de 2017].

CARrasco, M. (2012). Del Big Band a Springfield: prácticas sobre "Big Bang Theory" y "Los Simpson”. En: Prácticas sobre ética y deontología basadas en series de televisión contemporáneas. Leandro Martínez Peñas (coord.). Asociación Veritas para el Estudio de la Historia, el Derecho y las Instituciones, págs. 39-52.

UPV. (2016). Papel de las rúbricas en la evaluación de las competencias transversales UPV. Disponible en: <http://www.upv.es/entidades/ICE/info/U0702453.pdf $>$ [Consulta: 25 de marzo de 2017].

GARCÍA GONZÁlez, A., RAMOS REgUeiro, L. REY MOURULlo, T. y SUÁREZ GONZALO, S. (2014). La opinión pública en la serie de televisión "The newsroom" la transmisión de una perspectiva racional. Investigación: cultura, ciencia y tecnología, núm. 11, págs. 65-71.

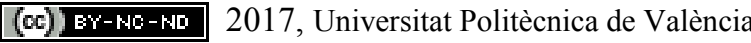


Evaluación de la competencia transversal CT09 Pensamiento crítico a través de series de ficción en la asignatura de Gestión empresarial de la edificación en el Máster de Edificación de la Universitat Politècnica de València

KOVACSICS, V. (2015). The good wife: de cordero a lobo, en cinco temporadas. Caimán cuadernos de cine, núm. 35, pág. 13.

VILlA, A. Y POBLETE, M. (2007). Aprendizaje basado en competencias. Una propuesta para la evaluación de las competencias genéricas. Bilbao: Ediciones Mensajero.

(c) EY-NC-ND 2017, Universitat Politècnica de València 


\title{
Evaluación de competencias transversales por rúbricas. Aplicación a competencia de presentación mediante elementos multimedia
}

\section{J. Orozco-Messana ${ }^{a}$, A. Navarro Gomez ${ }^{b}$ y M. Siurana Paula ${ }^{c}$}

a Departamento de Ingeniería Mecánica y de Materiales (jaormes@upv.es), ${ }^{b}$ Instituto de Ciencia y Tecnología del Hormigón (alnagme@upvnet.upv.es) y ${ }^{\mathrm{c}}$ Departamento de Matemática Aplicada (masiupau@upv.es).

\begin{abstract}
The need to evaluate transversal competencies in teaching has grown without applying a systematic research to the procedures used. On this paper we present a rubric based procedure for evaluating the presentation competency from a video based item. This paper validates a procedure allowing independent neutral evaluations and providing results statistically independent from other conflicting elements thanks to the multimedia support.
\end{abstract}

Keywords:

Transversal competencies, evaluation, video rubric

\begin{abstract}
Resumen
La necesidad de evaluar competencias transversales ha crecido en los últimos años sin disponer de una investigación sistemática sobre los procedimientos a utilizar. Este trabajo valida un procedimiento que permite obtener resultados neutrales e independientes en base al tratamiento estadístico de los resultados sin variables cruzadas a través del apoyo multimedia.
\end{abstract}

Palabras clave:

Competencias transversales, evaluación, rúbrica para videos

\section{Introducción}

Este trabajo analiza la validez de la evaluación sumativa de las habilidades de comunicación oral con apoyo visual de videos. Se parte del establecimiento de una $r^{\prime \prime}$ ubrica genérica calificando la validez de su aplicación a través de la convergencia de los resultados obtenidos por distintos profesores (con diferentes trasfondos) en disciplinas muy diferenciadas. Se parte de la presentación de trabajos de grupos de estudiantes universitarios para su evaluación por profesorado de diversas áreas. La evaluación se centra en la competencia transversal de comunicación oral, sin interferencia con la calidad académica de los contenidos presentados. 
En los últimos años se ha evidenciado en nuestro contexto universitario un notable auge de los modelos de enseñanza centrados en el aprendizaje, en gran parte promovidos por el Espacio Europeo de Educación Superior, que enfatizan la importancia de integrar los procesos de enseñanza, aprendizaje y evaluación en el desarrollo de una amplia variedad de tareas abiertas, auténticas y realistas -p.e., proyectos de trabajo, realización de investigaciones, análisis de casos, ...- que faciliten la adquisición de las competencias generales y específicas consideradas en las distintas titulaciones.

Desde esta perspectiva resulta ineludible considerar técnicas de evaluación alternativas, no convencionales o innovadoras, que permitan (a) utilizar la evaluación como un recurso instruccional más para promover el aprendizaje activo, la puesta en marcha de procesos cognitivos de alto nivel y la adquisición de competencias, (b) facilitar a los estudiantes los criterios de ejecución a alcanzar en la realización de las tareas, favoreciendo el desarrollo de las habilidades de autorregulación y autoevaluación realista de sus trabajos, (c) recibir retroalimentación específica sobre cómo mejorar sus niveles de ejecución y, (d) facilitar al profesorado información de los resultados de aprendizaje que van alcanzando sus estudiantes. Las estrategias de evaluación tradicionales resultan claramente insuficientes para conseguir estos propósitos, dado que (a) los resultados en los exámenes tradicionales pueden ayudar en parte a los estudiantes a monitorizar su aprendizaje, pero muy poco a promoverlo y, (b) plantear tareas auténticas y realistas implica considerar un amplio rango de respuestas y elaboraciones satisfactorias posibles que difícilmente pueden quedar reflejadas en las mismas (Huba y Freed, 2000).

Las rúbricas constituyen herramientas de evaluación no convencionales que pueden definirse como guías para evaluar la calidad de las elaboraciones y el nivel de ejecución alcanzado por los estudiantes en una amplia variedad de tareas complejas, especificando los criterios a considerar y los niveles de adecuación en cada uno de ellos (desde inadecuado a excelente) (Andrade y Du, 2005). En la actualidad, las rúbricas constituyen un método de evaluación extendido en la enseñanza obligatoria, especialmente en el ámbito anglosajón véase la amplitud de recursos web disponibles en Dornish y Sabatini (2006)-, aunque su consideración todavía resulta escasa en nuestro contexto.

Quizá una de las cuestiones que explica en mayor grado las resistencias del profesorado universitario a introducir este tipo de herramientas de evaluación sea la controversia sobre su fiabilidad y validez para valorar las elaboraciones de los estudiantes -algunos autores sugieren que junto a su escasa formación docente y sobre técnicas de evaluación-, cuestión que debe seguir ocupando un lugar central en la investigación (Malini y Andrade, 2010). Desde esta perspectiva, a nadie le resultará extraño que numerosos estudios previos se hayan centrado en (a) analizar la fiabilidad intrajueces e interjueces en su aplicación para valorar los trabajos de los estudiantes (p.e., Thaler, Kazemi y Huscher, 2009), (b) la consistencia entre las valoraciones efectuadas por los estudiantes al evaluar el trabajo de sus compañeros o sus propias elaboraciones (p.e., Roblyer y Wiencke, 2003; Sadler y Good, 2006) y, (c) la consistencia entre los criterios que utilizan estudiantes y profesorado en su aplicación (p.e., Hafner \& Hafner, 2003; Kocaküla, 2010; López-Pastor, Fernández-Balboa, Santos y Fraile, 2011; Stellmack, Konheim-Kalskstein, Manor, Massey y Schmitz, 2009).

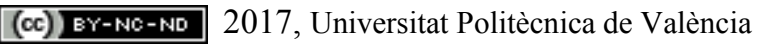


Sus conclusiones básicas son que la rúbricas permiten incrementar la consistencia entre las valoraciones interjueces e intrajueces, facilitando al profesorado emitir juicios válidos sobre el nivel de ejecución de los estudiantes al evaluar competencias complejas (Jonsson y Svingby, 2007).

En definitiva, se detecta una necesidad de verificar la validez de la utilización de rúbricas y se desarrolla un trabajo experimental que avale los procedimientos habituales a través de la consistencia en la aplicación de una rúbrica tipo en la evaluación la competencia transversal de comunicación oral, por parte del profesorado de distintas áreas. Esto se consigue estableciendo un análisis de la relación entre las calificaciones derivadas de las mismas. Adicionalmente, también se analiza la percepción de utilidad y validez que los rúbricas pueden tener como soporte para el desarrollo de sus presentaciones orales con apoyo visual.

El trabajo experimental parte de una muestra de áreas tecnológicas muy diferentes a fin de sistematizar la aplicación de la rúbrica seleccionada para evaluar la competencia de presentación en público verificando la objetividad de los resultados a través del análisis estadístico cruzado entre profesores.

\section{Procedimiento utilizado}

\subsection{Método}

Se analiza el nivel de convergencia entre las valoraciones efectuadas por 3 profesores de distintas áreas, y sobre 6 presentaciones de alumnos, desde una perspectiva analítica criterio a criterio- y holística - puntuación global-. La percepción de validez y utilidad se determina a partir de las valoraciones efectuadas por los profesores en relación a la rúbrica propuesta y que se basa en los usos habituales en las titulaciones de la UPV.

Siguiendo los principios destacados en la introducción, se ha seleccionado la rúbrica desarrollada por la ETSID (de la UPV) para a evaluar las habilidades de presentación oral con apoyo visual, dado que es la más frecuentemente utilizada para evaluar esta competencia transversal en las distintas Escuelas de la UPV, durante la evaluación de las Proyectos Final de Grado (PFGs) se especifican los siguientes elementos:

- Criterios de evaluación. Incorpora once criterios distintos en la evaluación de las elaboraciones de los estudiantes, aplicados sobre el documento soporte (PPT) de la presentación en sí mismo y la fase de presentación (centradas en el discurso y su resumen).

- Niveles de ejecución. La rúbrica considera cinco niveles de ejecución graduados en función de su adecuación para cada presentación.

- Descripción de los niveles de ejecución. Los niveles de ejecución se describen de forma clara, reflejando las diferencias entre los mismos.

- Estrategia de calificación. La rúbrica incorpora una valoración cuantitativa para cada criterio y nivel de ejecución, permitiendo efectuar una valoración analítica (criterio a criterio, asignando a cada uno de ellos una valoración entre 0 y 5) y holística (sumatorio de las puntuaciones obtenidas en todos los criterios, con un rango entre 0 y 42) de las presentaciones efectuadas por los estudiantes. 
En el estudio participan 9 estudiantes de las titulaciones de: Máster Universitario en Tecnologías Industriales (2), Grado en Ingeniería de Obras Públicas (2) y Grado en Biotecnología (5), en el curso académico 2016-2017. Un 44\% son mujeres y un 56\% varones. Las edades oscilan entre los 21 y 24 años y todos son estudiantes a tiempo completo, mientras que el $83 \%$ desarrolla algún tipo de actividad profesional. La distribución por sexo, edad y dedicación es característica en este tipo de estudios universitarios en la Universitat Politécnica de Valencia.

Tras especificar a los estudiantes el proyecto de trabajo a desarrollar (elaboración y presentación oral con apoyo visual con grabación en video) se presentaron y discutieron los objetivos académicos de la competencia transversal de presentación oral, sin concretar las líneas específicas de evaluación en la rúbrica.

Con el objetivo de familiarizar a los estudiantes en su aplicación, facilitar su comprensión y eliminar posibles resistencias, se efectuó y discutió su aplicación para evaluar dos presentaciones previas efectuadas por el propio profesor. Seis grupos de trabajo desarrollaron y efectuaron sus presentaciones, que fueron evaluadas a través de la aplicación de la rúbrica por 3 profesores de distintas áreas de conocimiento (los firmantes del artículo). La aplicación de la rúbrica se cumplimentó individualmente tras observar los videos de cada presentación.

\subsection{Percepción de utilidad y de validez}

Siguiendo los principios y orientaciones de la investigación previa (p.e., Moskal, 2003; Moskal y Leydens, 2000), se desarrolló un cuestionario dirigido a evaluar la percepción de utilidad de la rúbrica para el desarrollo del proyecto de trabajo (10 ítems) y la percepción de validez de la misma (11 ítems). Se utilizó una escala de respuesta tipo Likert de cinco niveles (desde "totalmente inadecuado" valorado con 1, hasta "totalmente adecuado" con un 5).

Los profesores evaluaron la calidad de las presentación oral a través de la rúbrica (www.etsid.upv.es/.../Borrador\%20Trabajo\%20Fin\%20de\%20Gradov11\%20(002).pdf)

más consensuada en la UPV, tanto desde un punto de vista analítico como holístico. La valoración analítica permitirá determinar el nivel de acuerdo criterio a criterio entre profesores. La valoración holística permitirá determinar la existencia de una relación significativa entre las valoraciones globales efectuadas por ambos. La aplicación de la rúbrica se hizo en diferido sobre los videos grabados de las presentaciones.

La percepción de la utilidad y validez de la rúbrica se determina a través de la concordancia estadística de las valoraciones de los 3 profesores participantes pertenecientes a diversas áreas y con bagajes muy diferentes.

El grado de acuerdo en la aplicación de la rúbrica se calcula con dos procedimientos de estimación distintos, uno conservador y otro laxo, aceptados y comúnmente utilizados en este ámbito (Tinsley y Weiss, 2000). En el procedimiento conservador se define que existe acuerdo entre profesores cuando otorgan exactamente la misma valoración (nivel) en los

(cc) EY-NC-ND 2017, Universitat Politècnica de València 
criterios de la rúbrica. El procedimiento laxo considera que existe acuerdo entre profesores cuando otorgan una valoración en los criterios que difiere como máximo un nivel entre los mismos. En ambos casos, el grado de acuerdo o convergencia se determina a través del estadístico kappa. También se calculó el nivel de asociación entre las valoraciones globales efectuadas por los profesores (sumatorio de las puntuaciones en los distintos criterios, con un máximo de 55 puntos) a través del coeficiente de correlación de Pearson.

\subsection{Resultados}

En la tabla 1 se recogen las medias y desviaciones típicas de las respuestas independientes de cada elemento de valoración de la rúbrica propuesta, así como el coeficiente Kappa de Fleiss aplicada a una comparativa entre alumnos.

Posteriormente, la tabla 2 realiza un análisis similar pero para la valoración entre distintas presentaciones.

Se puede observar que las valoraciones obtenidas tiene baja dispersión y alta Kappa de Fleiss $\left(\kappa>00^{\prime} 7\right)$. El nivel de acuerdo entre profesores es alto ( $\kappa$ siempre superior a $\left.0^{\prime} 7\right)$ en cualquier tipo de valoración. Las diferencias del análisis comparativo y el laxo son bajas correspondiendo a una valoración fuerte de la concordancia.

Tabla 1. Resultados del análisis comparativo

de valoraciones para las 6 presentaciones ( 9 alumnos)

\begin{tabular}{cccc}
\hline $\begin{array}{c}\text { Dimensiones } \\
\text { de la escala }\end{array}$ & Media & Desviación típica & K de Fleiss \\
\hline 1 & 3,9 & 0,5 & 0,72 \\
2 & 4,2 & 0,6 & 0,84 \\
3 & 4,2 & 0,4 & 0,94 \\
4 & 3,4 & 1,5 & 0,70 \\
5 & 4,3 & 0,5 & 0,98 \\
6 & 3,7 & 0,4 & 0,82 \\
7 & 4,1 & 0,5 & 0,83 \\
8 & 1,3 & 0,9 & 0,99 \\
9 & 3,8 & 0,7 & 0,75 \\
10 & 4,1 & 0,6 & 0,88 \\
11 & 4,3 & 0,8 & 0,96 \\
\hline
\end{tabular}

(cc)) EY-NG-ND 2017, Universitat Politècnica de València

Congreso In-Red (2017) 
Evaluación de competencias transversales por rúbricas. Aplicación a competencia de presentación mediante elementos multimedia

Tabla 2. Resultados del análisis laxo de la rúbrica por presentación (6 presentaciones)

\begin{tabular}{cccc}
\hline $\begin{array}{c}\text { Proyecto } \\
\text { presentado }\end{array}$ & Puntuación total & $\begin{array}{c}\text { Acuerdos en } \\
\text { valoración }\end{array}$ & K de Fleiss \\
\hline 1 & 39,0 & 54 & 0,85 \\
2 & 40,9 & 62 & 0,92 \\
3 & 39,3 & 66 & 0,94 \\
4 & 40,1 & 66 & 0,91 \\
5 & 44,0 & 64 & 0,88 \\
6 & 43,4 & 64 & 0,81 \\
\hline
\end{tabular}

\subsection{Discusión y conclusiones}

El primer objetivo del trabajo ha consistido en analizar la percepción de validez de la rúbrica presentada en este trabajo. Los resultados son excelentes. En definitiva, la rúbrica es de utilidad para promover y dar soporte a procesos cognitivos de alto nivel, favoreciendo la concordancia en la evaluación de la competencia transversal de presentación mediante herramientas multimedia. La rúbrica propuesta es adecuada pues para evaluar la competencia transversal de presentación en este tipo de proyectos, destacando que integra los criterios y elementos clave a considerar en su elaboración, que permite evaluar competencias importantes para el ejercicio profesional y que les ha permitido desarrollar habilidades que utilizarán en situaciones futuras.

Estas conclusiones coinciden, básicamente, con las destacadas en estudios previos, centrados en otras competencias y titulaciones universitarias (p.e., Cothran, 2003; Hafner \& Hafner, 2003; Rohrbach, 2008; Struyven, Dochy \& Janssen, 2008). Sin embargo, a partir de las valoraciones obtenidas, cabría plantearse en trabajos futuros (a) reducir el número de criterios que incorpora, coincidiendo con el principio de que un número reducido de criterios resulta más práctico para el desarrollo de las actividades de aprendizaje (p.e., Thaler et al., 2009) y, (b) analizar la moderada percepción de utilidad para reducir la ansiedad que genera la elaboración de los proyectos de trabajo -quizá provocada porque las presentaciones orales siguen constituyendo una de las tareas en que los estudiantes universitarios manifiestan mayores niveles de ansiedad (García-Ros \& Pérez-González, 2011b)-, que sí se destaca en estudios previos (p.e., Andrade \& Du, 2005) .

Desde una perspectiva analítica (análisis criterio a criterio), el grado de acuerdo entre profesores es significativo, mostrando un grado de convergencia incluso superior a los escasos estudios previos dirigidos a determinar la utilidad de las rúbricas como soporte para la evaluación a través de los pares de las elaboraciones de los estudiantes (p.e., Sadler \& Good, 2006; Stellmack et al., 2009).

(cc) EY-NC-ND 2017, Universitat Politècnica de València 
Desde una perspectiva holística, la relación entre la valoración global de las presentaciones efectuada por los profesores alcanzó una relación de elevada magnitud. De forma más concreta, la mayoría de trabajos que analizan esta cuestión, Falchicov \& Goldfinch (2000), obtienen valores similares.

Estos resultados apoyan la idea de que los profesores aplican la rúbrica de forma similar y que puede constituir una herramienta válida para valorar y calificar las presentaciones de los estudiantes, facilitando adicionalmente la comprensión de los criterios de calidad implicados en los proyectos de trabajo (Lu \& Law, 2011). Todos estos aspectos destacan la importancia de seguir centrando la investigación en determinar las medidas que pueden permitir incrementar la validez y fiabilidad de este tipo de herramientas como soporte para la autoevaluación y heteroevaluación de las elaboraciones de los compañeros (Malini \& Andrade, 2010).

\subsection{Referencias complementarias}

Andrade, H. (2001). Using rubrics to promote thinking and learning. Educational Leadership, 57 (5), 13-18. Andrade, H. (2005). Teaching with rubrics: The Good, the Bad, and the Ugly. College teaching, 53 (1), 27-31.

Andrade, H., \& Du, Y. (2005). Student perspectives on rubric-referenced assessment. Practical Assessment, Research \& Evaluation, 10 (3). Recuperado el 11 de mayo de 2009, http://pareonline.net/getvn.asp?v=10\&n=3. Andrade, H.; Du, Y., \& Mycek, K. (2010).

Baron, J., \& Keller, M. (2003). Use on rubrics in online assessment. Evaluation and Assessment Conference, 23-25 novembre 2003.

Cho, K.; Schunn, Ch. D., \& Wilson, R. W. (2006). Validity and reliability of scaffolded peer assessment of writing from instructor and student perspectives. Journal of Educational Psychology, 98(4), 891-901. Cothran, D. J. (2003).

Students's use of and perspective on rubrics. Educational Research, Risks and Dilemmas. NZARE/AARE Conference. Auckland, Nueva Zelanda. Recuperado el 17 de octubre de 2009, http://www.aare.edu.au/03pap/cot03119.pdf.

Dornisch, M., \& Sabatini, A. (2006). Limitations of web-based rubric resources: Addressing the challenges. Practical Assessment Research \& Evaluation, 11(3). Recuperado el 11 de mayo de 2010, http://pareonline.net/getvn.asp?v=11\&n=3.

Falchicov, N., \& Goldfinch, J. (2000). Student peer assessment in higher education: A metaanalysis comparing peer and teacher marks. Review of Educational Research, 70 (3), 287-322.

García-Ros, R., \& Pérez-González (2011). Assessment preferences of preservice teachers: analysis according to academic level and relationship with learning styles and motivational orientation. Teaching in Higher Education, published online ahead of print publication, doi: 10.1080/13562517.2011.570434. 


\title{
Combinación de cuestionarios simples y gamificados utilizando gestores de participación en el aula: experiencia y percepción del alumnado*
}

\author{
Sandra Roger ${ }^{1}$, Maximo Cobos $^{1}$, Miguel Arevalillo-Herráez ${ }^{1}$ y Miguel \\ García-Pineda $^{1}$ \\ ${ }^{1}$ Departament d'Informàtica, Universitat de València
}

\begin{abstract}
The growing use of mobile devices has motivated the development of a wide range of applications to help manage the students' participation in the classroom. Socrative allows the lecturer to use multiple-choice questionnaires in the classroom, either in a simple or a gamified mode (Space Race). In this paper, we describe our experience at using this tool to promote competitive learning, at both undergraduate and post-graduate levels. The student's perception indicates that the use of the application helped at increasing engagement and motivation. However, relevant differences were found between both modes of use, underlining the importance of an adequate activity design.
\end{abstract}

Keywords: gamification, student response system, Socrative.

\section{Resumen}

En los últimos años y gracias a la utilización masiva de dispositivos móviles, han proliferado múltiples aplicaciones para la gestión de la participación del alumnado en el aula. Específicamente, Socrative, permite el lanzamiento por el profesor de cuestionarios de opción múltiple en modo simple o en modo gamificado (carrera espacial), fomentando asi el juego y la competitividad. En este trabajo se describe la experiencia obtenida mediante la combinación de ambos modos en una asignatura de Grado y otra de Máster. Los resultados obtenidos así como la percepción del alumnado indican que los alumnos se ven altamente motivados por este tipo de herramientas, si bien existen diferencias importantes en ambos modos de utilización que conviene tener presentes en el diseño de la actividad.

Keywords: gamificación, gestor de participación, Socrative. 


\section{Introducción}

La gamificación en la docencia presencial universitaria se ha convertido actualmente en un elemento clave de la innovación educativa (Kay y LeSage 2009, Melhuish y Falloon 2010). Son muchos los estudios que demuestran que la utilización de actividades lúdicas en el aula es un recurso muy efectivo para mejorar la implicación de los estudiantes en el proceso de enseñanza-aprendizaje (Benítez-Porres 2015, Frías, Arce y Flores-Morales 2016). El establecimiento de reglas de juego y la recompensación con puntos, niveles o rankings, consigue formentar la autoafirmación del estudiante, su esfuerzo personal y la colaboración con el resto de sus compañeros. Además, las estrategias de gamificación pueden ser muy diversas, ayudando no sólo al afianzamiento de los conocimientos relativos a los contenidos impartidos, sino también al desarrollo personal y social del alumnado.

Por otro lado, la introducción de herramientas digitales y el uso masivo de dispositivos móviles en la aulas han llevado a un importante cambio tecnológico que ha desembocado en la aparición de nuevas herramientas en línea y aplicaciones que tienen como objetivo introducir elementos innovadores en las clases (Eisele-Dyrli 2011). Algunas de estas herramientas no sólo incorporan funcionalidades de respuesta de audiencia, sino que también implementan modos de utilización que fomentan el uso de estrategias gamificadoras (Calvillo y Martín 2017). Si bien la forma en la que estas aplicaciones pueden ser utilizadas pueden variar de un contexto docente a otro, es importante dar el peso adecuado y adaptar su uso de acuerdo al contenido y a las consideraciones pedagógicas del contexto de aprendizaje específico.

Entre las herramientas de gestión de la participación que más popularidad han adquirido en los últimos años se encuentran Kahoot y Socrative (Fuertes y col. 2016). Estas herramientas pueden ser utilizadas en aulas de tamaños muy variados y de cualquier nivel educativo. El tipo de respuesta que recoge el sistema viene determinado por el diseño de la actividad, siendo el cuestionario de múltiple opción el más habitual. A medida que los estudiantes van respondiendo, el profesor puede ir descubriendo las respuestas correctas, obteniendo una estadística instantánea del grado de acierto conseguido por la clase. Si bien ambas herramientas son excelentes y tienen una funcionalidad similar, Socrative introduce un modo de participación especialmente diseñado para fomentar la gamificación, la llamada carrera espacial (Space Race). Este modo divide a los alumnos por grupos en cohetes de distinto color, los cuales avanzan en función de las respuestas correctas observadas.

En este artículo valoramos la experiencia obtenida a través de la combinación de estos dos modos de utilización de Socrative: el llamado modo simple (lanzamiento de cuestionarios de opción múltiple) y el modo gamificado de carrera espacial (juego de competición). Ambos modos han sido utilizados en dos asignaturas de la Escola Tècnica Superior d'Enginyeria de la Universitat de València, una de ellas perteneciente al Grado de Ingeniería Telemática y otra al Máster Universitario de Ingeniería de Telecomunicación. En la experiencia analizamos tres aspectos que consideramos importantes para plantear estrategias de evaluación futuras basadas en estas herramientas:

- Impacto que ambos modos de operación tienen en la motivación del alumnado. 
- Grado de preparación por parte de los estudiantes para cada tipo de cuestionario.

- Diferencia en las calificaciones obtenidas por los alumnos bajo ambos modos.

Para evaluar los anteriores aspectos, se tuvieron en cuenta tanto los informes de resultados proporcionados por Socrative correspondientes a los cuestionarios técnicos, como los resultados de encuestas que los alumnos rellenaron al final del curso (también mediante Socrative). Los resultados muestran que, si bien la motivación y la implicación en la actividad son mayores en el modo gamificado, las calificaciones obtenidas son menores que en el caso del modo simple.

El artículo está estructurado en las siguientes secciones. La sección 2 describe brevemente las herramientas de gestión de participación y los modos de operación utilizados en este trabajo. La sección 3 describe la metodología seguida en el mismo. La sección 4 discute los resultados obtenidos a partir de la utilización de las herramientas y los cuestionarios. Finalmente, la sección 5 resume las conclusiones extraídas de esta experiencia.

\section{Gestores de participación}

Los gestores de participación o herramientas de respuesta de audiencia como Kahoot (Kahoot s.f.) o Socrative (Socrative s.f.) se basan en un sistema inteligente de respuesta a través de Internet, accediendo a través de un dispositivo conectado, ya sea un ordenador, un teléfono inteligente o una tableta. El diseño de la actividad lo realiza el profesor, controlando el flujo de preguntas a su elección. El acceso a la actividad por los alumnos es muy sencillo, consistiendo únicamente en una identificación (en algunos casos sin registro previo) que les permite interactuar con el contenido de la actividad de forma inmediata. El tipo de respuesta que recoge el sistema viene determinado por el diseño de la actividad, siendo el cuestionario de múltiple opción el más habitual. A medida que los estudiantes van respondiendo, el profesor puede ir descubriendo las respuestas correctas, obteniendo una estadística instantánea del grado de acierto conseguido por la clase. Una vez terminada la actividad, estas herramientas suelen ofrecer un informe donde se muestran las respuestas individuales proporcionadas por cada alumno, así como las estadísticas globales obtenidas en la misma. La principal ventaja de estas herramientas es que no existe la necesidad de disponer de aparatos electrónicos adicionales a los utilizados de forma habitual por los alumnos, siendo el único requisito tener algún tipo de dispositivo con conexión a Internet. Otra ventaja muy interesante es que los resultados de los cuestionarios no tienen por qué ser públicos, siendo únicamente conocidos por el profesor.

En este trabajo nos hemos centrado exclusivamente en la herramienta Socrative por ofrecer un modo especial diseñado para la gamificación. Describimos a continuación esta herramienta y los dos modos utilizados. 


\subsection{Socrative}

Socrative es un software de uso muy intuitivo que puede ser utilizado para diversas actividades, ofreciendo, entre otras, las siguientes funcionalidades:

- Obtención de feedback en tiempo real. El planteamiento de cuestiones al alumnado mediante Socrative permite de manera cómoda y eficiente obtener información sobre el seguimiento de la clase.

- Evaluación de conocimientos previos. Los quizzes o cuestionarios pueden ser utilizados con anterioridad o al principio de una clase para evaluar, por ejemplo, prerrequisitos de una asignatura, o para comprobar si los estudiantes han revisado algún material y lo han entendido antes de la clase.

- Accesibilidad a la participación. Realizar los cuestionarios mediante la aplicación favorece que todo el alumnado pueda tener accesible la participación, sean cuales sean sus capacidades de comunicación.

- Evaluación continua. Socrative permite conocer de forma reiterada a lo largo de la clase o del curso los conocimientos que se deben ir adquiriendo.

\subsection{Modos simple y gamificado}

Los dos modos de operación de Socrative utilizados en este trabajo son los siguientes:

1. Modo simple: Este modo consiste en la presentación de cuestionarios de opción múltiple al ritmo marcado por el profesor (Fig. 1). El profesor lanza el cuestionario al que acceden los alumnos mediante sus dispositivos, desvelando la respuesta a cada una de las preguntas cuando todos los estudiantes han seleccionado una respuesta. No existe limitación temporal, por lo que los alumnos disponen del tiempo que necesiten para seleccionar su respuesta. Al desvelar la opción correcta la puntuación se mantiene anónima, por lo que los alumnos no saben qué ha contestado cada compañero, sólo el porcentaje de acierto general.

2. Modo gamificado: Este modo hace uso de la opción "Space Race" (carrera espacial) de Socrative (Fig. 2). Los alumnos se organizan en equipos, con la opción de establecer los equipos de forma aleatoria. Cada equipo se representa por un cohete de un determinado color, que avanza siempre que un miembro del equipo acierta la respuesta correcta. Como en este trabajo se pretende comparar el rendimiento individual del alumno en ambos modos, se consideran tantos equipos como alumnos, por lo que la competición es individual y no a nivel de grupo. Aunque no existe cronómetro para responder cada pregunta, el alumno puede observar cómo avanzan el resto de compañeros, lo que crea cierta presión para responder.

El uso de dispositivos electrónicos, usados de manera habitual por el alumnado en la actualidad, proporciona una motivación extra para responder. Además, el modo gamificado favorece una competitividad sana con uno mismo para mejorar. 


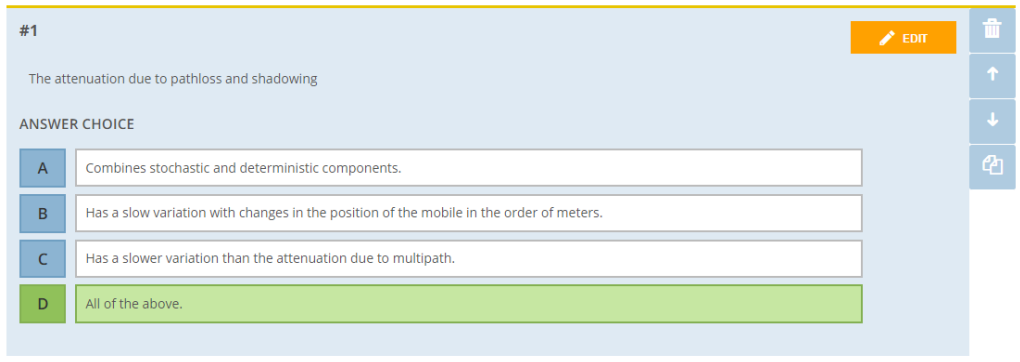

Fig. 1: Ejemplo de cuestionario de opción múltiple en modo simple.

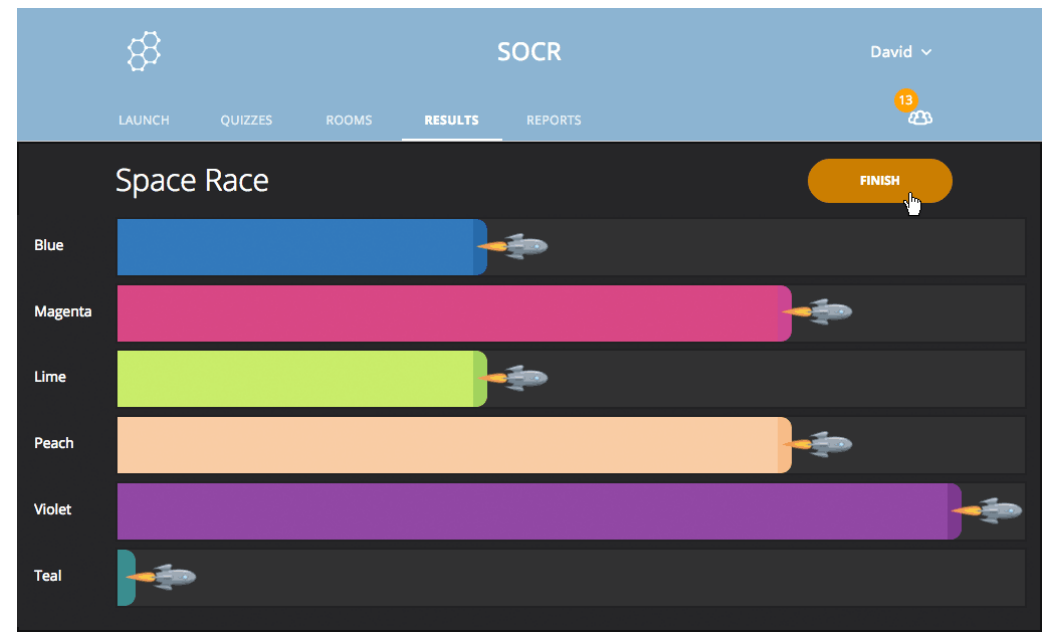

Fig. 2: Ejemplo de carrera espacial (modo gamificado).

\subsection{Consideraciones generales}

Algunas de las consideraciones previas tenidas en cuenta antes de la implementación práctica de actividades basadas en este tipo de herramientas son las siguientes:

- El profesor debe conocer la aplicación con suficiente profundidad antes de iniciar cualquier tipo de actividad.

- Es importante que los alumnos también conozcan la herramienta, por lo se deben realizar diversas pruebas antes de iniciar la actividad en sí.

- Dado que este tipo de herramientas funcionan únicamente bajo conexión a Internet, es necesario asegurar que tanto los alumnos como el profesor tienen un acceso adecuado a la red.

- Los estudiantes deben estar bien informados sobre lo que se espera de ellos, tanto en términos de la tecnología a utilizar como en reglas del juego.

- La gamificación debe utilizarse con moderación. Una sobreutilización puede arruinar el efecto deseado. 
- La variedad en las herramientas o modos de utilización ayuda a evitar el aburrimiento.

- Se debe recordar a los alumnos que la actividad debe servir para aprender y repasar conceptos a través de actividades de gamificación.

- Tal como ocurre en otras aplicaciones tecnológicas, a veces se producen diferencias en velocidad del acceso a la red o en las velocidades de los dispositivos que los alumnos utilizan. Controlar estos factores es importante.

\section{Metodología}

\subsection{Participantes}

El estudio se realizó sobre todos los alumnos y alumnas de dos asignaturas relacionadas con la Ingeniería de Telecomunicación. Por un lado, se consideró la asignatura Comunicaciones Móviles e Inalámbricas de $4^{\circ}$ curso del Grado de Ingeniería Telemática y, por otro, la asignatura Advanced Wireless Communications and Mobility del Máster de Ingeniería de Telecomunicación. Concretamente, la totalidad de alumnos que asistieron regularmente a clase en alguna de las dos asignaturas dio lugar a una muestra total de 25 estudiantes (12 de grado y 13 de máster).

\subsection{Procedimiento}

En todas las sesiones relativas al presente estudio, todo el alumnado contó con un dispositivo electrónico con conexión a internet (smartphone, tablet u ordenador portátil) para utilizar la aplicación gestora de participación a evaluar, es decir, Socrative.

En particular, el estudio se centró en el uso de los modos simple (cuestionario de opción múltiple) y modo gamificado (carrera espacial). Se realizaron cuestionarios de 10 preguntas con 4 posibles respuestas a elegir en 12 de las sesiones asociadas a cada una de las asignaturas. Cabe destacar que ambos modos no se utilizaron con la misma frecuencia, sino que el modo gamificado se consideró en solamente un $25 \%$ de las ocasiones frente a un $75 \%$ de veces en las que la opción fue el modo simple. Concretamente, al final de cada tema de la asignatura, se lanzó un cuestionario en modo simple, realizando en total 9 cuestionarios en este modo. Los cuestionarios gamificados se realizaban tras haber cubierto 3 temas diferentes y, por tanto, el contenido evaluado correspondía al de los tres cuestionarios de modo simple anteriores. Para motivar a los estudiantes a preparar los temas, se decidió dar el siguiente peso a los cuestionarios en la evaluación:

- La totalidad de los cuestionarios simples tenia un peso máximo de 1 punto adicional en la nota final de la asignatura. Por tanto, cada cuestionario simple tenía un peso máximo de $1 / 9$, que dependía del número de respuestas correctas del mismo.

- La totalidad de los tres cuestionarios gamificados también podía suponer un punto adicional en la nota final, de modo que cada carrera espacial valía 1/3. Sin embargo, para fomentar la competitividad en este modo, sólo el estudiante que 
ganara la carrera podía sumar esta cantidad, que era fija independientemente de que todas las respuestas hubieran sido correctas.

Los participantes fueron informados a principio de curso de la propuesta para incrementar su nota final anteriormente descrita y de las sesiones en las que se llevarían a cabo los cuestionarios.

\subsubsection{Encuestas}

Con el fin de estudiar la percepción del alumno respecto a la actividad propuesta, se realizó un breve cuestionario al final del curso (también mediante Socrative), en el cual aparecían los siguientes ítems a evaluar según una escala Likert de 5 niveles (1-Totalmente en desacuerdo, 2-En desacuerdo, 3- Ni de acuerdo ni en desacuerdo, 4-De acuerdo, 5- Totalmente de acuerdo):

- A - El modo Space Race me ha parecido más divertido que el modo normal.

- B - El modo Space Race me ha resultado más estresante que el modo normal.

- C - He dedicado más esfuerzo a preparar el modo Space Race que el normal.

- D - La actividad, en general, ha sido motivadora.

\section{Resultados del estudio}

Las Figuras 3 y 4 muestran los resultados de los 4 ítems evaluados en las encuestas de satisfacción que se realizaron a los alumnos de Grado y Máster, respectivamente. Las respuestas de los alumnos han sido representadas mediante histogramas, con una barra para cada puntuación, y donde la puntuación media se ha representado con una línea vertical roja.

En la Figura 3, se puede observar que la mayoría de alumnos de Grado ha encontrado el modo Space Race más divertido que el modo normal, a pesar de que también lo ha evaluado como más estresante. En cuanto al esfuerzo dedicado a preparar ambos tipos de cuestionarios, no hay un consenso entre los alumnos, ya que se observa bastante dispersión de puntuaciones en el histograma. Por último, cabe destacar que la mayoría del alumnado de grado ha encontrado la actividad en general motivadora. Los resultados mostrados en la Figura 4 muestran, a grandes rasgos, una opinión similar para los alumnos de Máster, aunque las puntuaciones medias son superiores a las de Grado para los 4 ítems. Se puede también observar que los alumnos de Máster han dado puntuaciones menos dispersas en las preguntas A y D.

Una vez discutidos los resultados de las encuestas, pasamos a analizar el rendimiento de los alumnos en los cuestionarios. La Figura 5 contiene el número de respuestas correctas en cada uno de los cuestionarios realizados en los distintos temas de la asignatura, tanto del tipo simple (un cuestionario por tema) como de tipo gamificado (un cuestionario cada tres temas). Las barras grises muestran los resultados del cuestionario simple y las barras amarillas los del gamificado. La media de respuestas correctas en cada cuestionario se ha representado mediante líneas horizontales continuas, en rojo para el tipo simple (MT_simple) y en verde para el tipo gamificado 

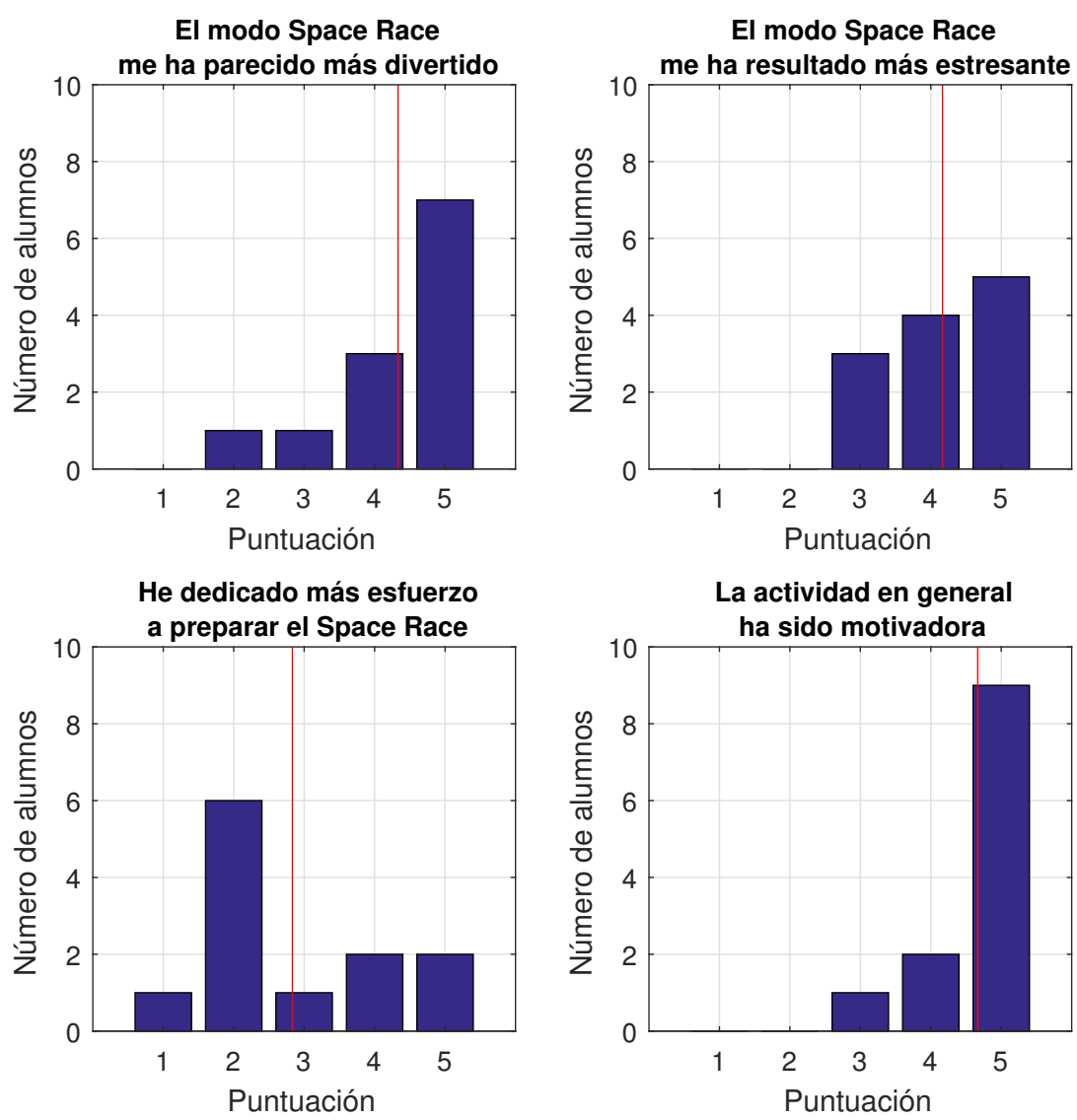

Fig. 3: Resultados de las encuestas de satisfacción para los alumnos de Grado.

(MT_gamificado). Se han utilizado también líneas punteadas horizontales para mostrar la media de respuestas correctas en el cuestionario simple en grupos de tres temas (M123, M456, M789). Esta última medida es útil para realizar una comparación justa con el número de respuestas correctas en cada cuestionario gamificado. La figura muestra resultados análogos para el caso de los alumnos de Máster.

En vista de los resultados, los alumnos de Grado han tenido un mejor rendimiento en los cuestionarios simples, siendo el número medio de respuestas correctas cerca de dos unidades mayor que en los gamificados (aproximadamente 5 frente a casi 7). Para el caso de los alumnos de Máster, también se ha observado el mismo efecto, pero la diferencia de rendimiento en ambos tipos de cuestionarios ha sido menor ( 5 respuestas correctas en gamificado frente a cerca de 6 en simple). En el caso de la asignatura de Grado, se puede observar una mejoría en los resultados a medida que los temas avanzan. Este hecho se puede extraer comparando las medias para los grupos de tres temas (M123 es menor que M456 y esta última menor a M789), lo que deja entrever que quizás los alumnos de grado se prepararon mejor los últimos temas que los primeros visto el funcionamiento y dificultad de los cuestionarios. En el caso del Máster, sin embargo, el número de respuestas correctas se ha mantenido 

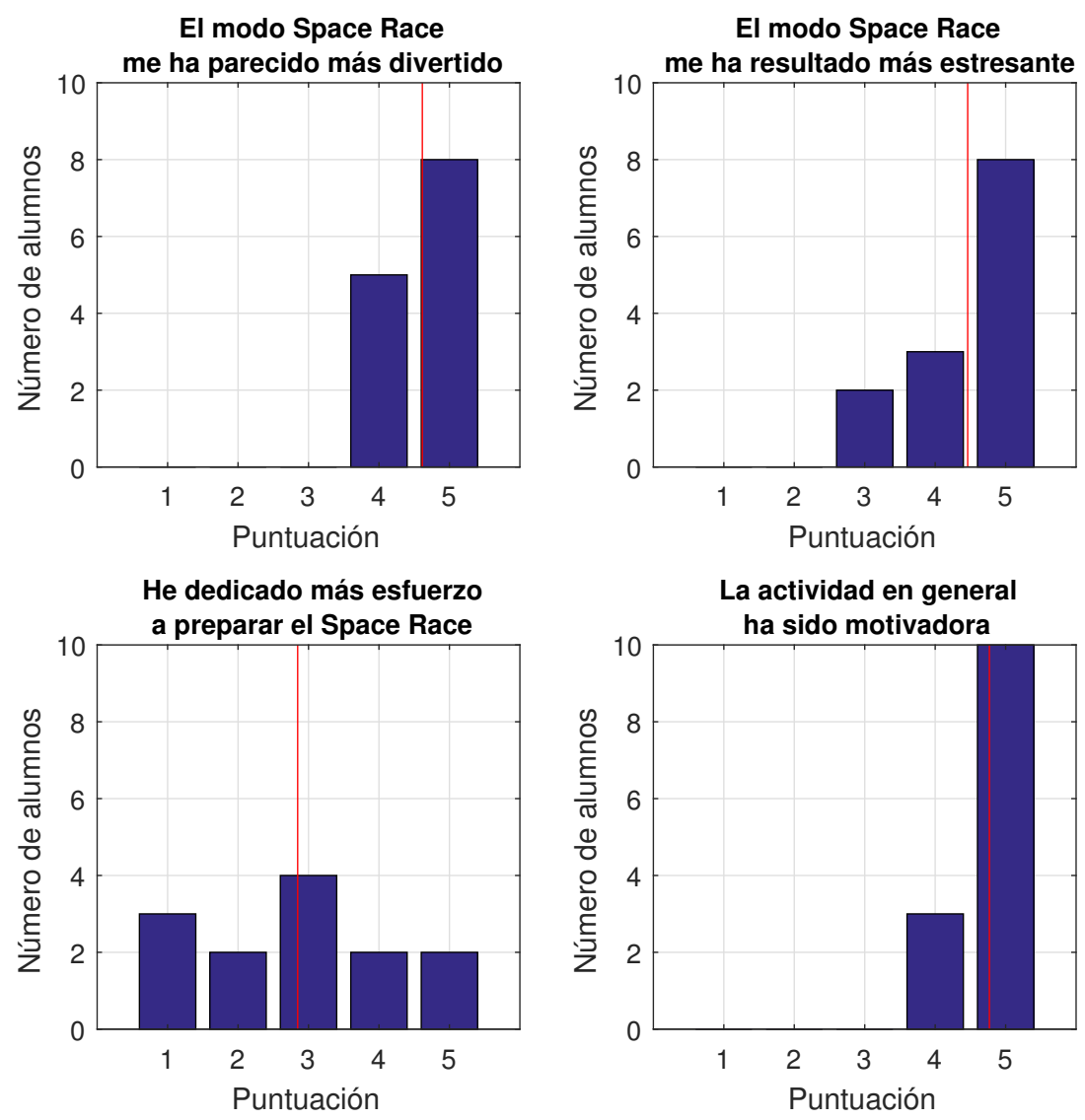

Fig. 4: Resultados de las encuestas de satisfacción para los alumnos de Máster.

bastante estable a lo largo del curso, siendo incluso inferior en media para los temas 7, 8 y 9. Por tanto, una hipótesis es que los alumnos de Máster se preparan por igual todos los cuestionarios, siendo los últimos de mayor dificultad, por ser partes de la asignatura de nivel más avanzado. Otro aspecto que puede influir en las diferencias observadas es el carácter optativo de la asignatura de Grado, lo cual podría explicar una mayor motivación por parte de los alumnos que la cursaban y, consecuentemente, unos mejores resultados en la misma.

Por último, la Figura 7 alberga la relación entre el esfuerzo subjetivo dedicado por los alumnos para preparar los cuestionarios de ambos tipos (según la puntuación reflejada en la pregunta $\mathrm{C}$ de las encuestas) y el número de respuestas correctas en cada uno de los cuestionarios. Nótese que para construir esta figura se han contabilizado solamente aquellas puntuaciones iguales a 4 y 5 como casos en los que el alumno empleó más esfuerzo en preparar el modo gamificado, y las puntuaciones iguales a 1 y 2 como casos en los que el alumno dedicó más esfuerzo en preparar el modo simple. Se ha prescindido del caso de puntuación 3, ya que implicaría que el alumno dedicó el mismo esfuerzo a ambos tipos de cuestionarios. Para los dos escenarios evaluados (Grado y Máster), se puede observar un número mayor de respuestas correctas en el modo 


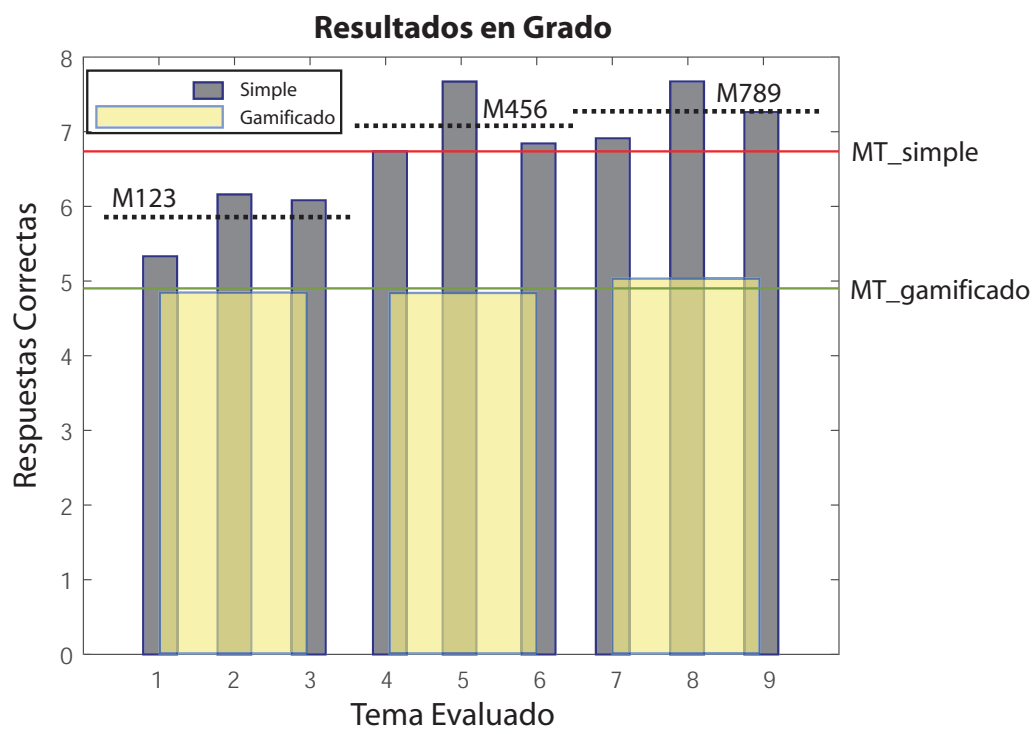

Fig. 5: Número medio de respuestas correctas en todos los cuestionarios realizados de ambos modos para los alumnos de Grado.

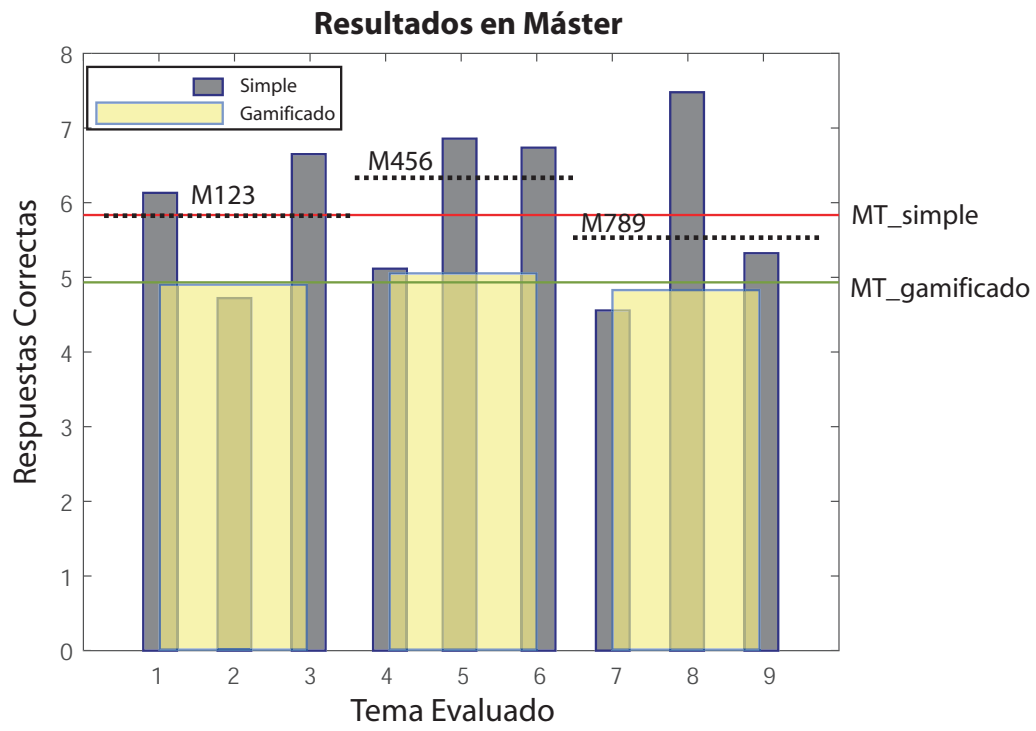

Fig. 6: Número medio de respuestas correctas en todos los cuestionarios realizados de ambos modos para los alumnos de Máster.

simple, independientemente de que se trate de alumnos que hayan preparado más este tipo de cuestionario o el gamificado. Por tanto, en general se puede concluir que el tipo de cuestionario gamificado supuso una mayor dificultad para el alumnado, algo que ya dejaban entrever las figuras 5 y 6 . De hecho, los resultados obtenidos en los cuestionarios gamificados fueron en media algo mayores para aquellos alumnos que habían dedicado más esfuerzo a la preparación de los cuestionarios simples, tanto en la asignatura de Grado como en la de Máster. Esta observación hace suponer que los alumnos que habían preparado mejor los cuestionarios simples de una forma 
continuada a lo largo del curso también lo hacían mejor en el modo gamificado, por lo que probablemente afianzaron mejor sus conocimientos.

\section{Conclusiones}

El presente artículo se ha centrado en la realización de cuestionarios al alumnado combinando los modos simple y de carrera espacial del gestor de participación Socrative. El estudio del uso de ambos modos se ha realizado sobre dos asignaturas relacionadas con la Ingeniería de Telecomunicación, una de nivel de Grado y otra de Máster. Se ha podido observar, tras realizar encuestas de opinión a los participantes, que el uso de Socrative para realizar cuestionarios resulta muy motivador, habiendo mostrado los alumnos preferencia por los de tipo gamificado (carrera espacial). En cuanto al rendimiento de los alumnos en los cuestionarios de ambos tipos, los resultados indican un mayor número de respuestas acertadas con los cuestionarios de tipo simple. Por tanto, la preferencia por los cuestionarios de tipo gamificado no implica una mejora en la nota obtenida. Cabe remarcar que los resultados obtenidos en los cuestionarios gamificados fueron en media algo mejores para aquellos alumnos que habían dedicado más esfuerzo a la preparación de los cuestionarios simples, tanto en la asignatura de Grado como en la de Máster. A raíz de los resultados se puede concluir que los alumnos que habían preparado mejor los cuestionarios simples de una forma continuada a lo largo del curso también lo hubieran hecho mejor para los del modo gamificado, afianzando así mejor sus conocimientos.

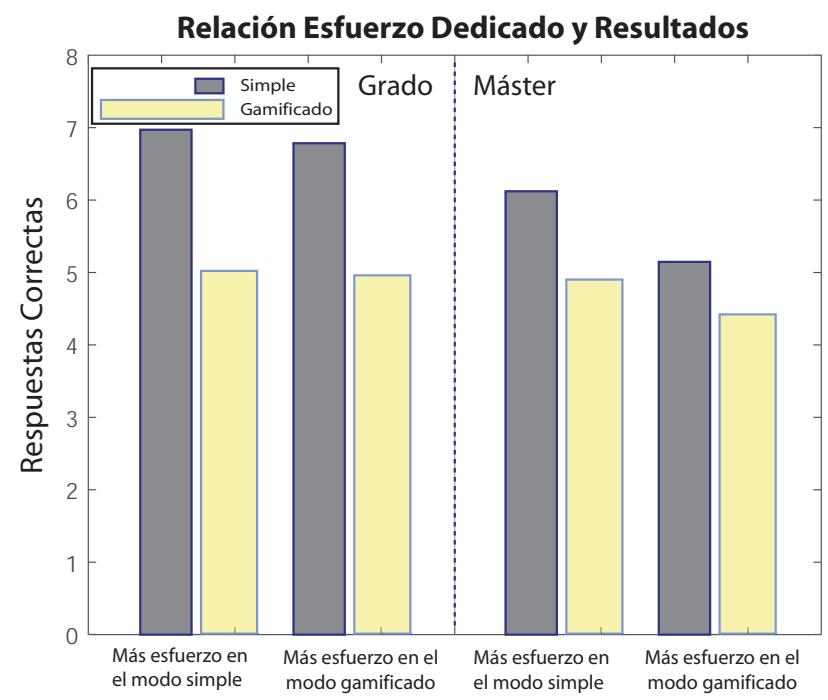

Fig. 7: Relación entre el esfuerzo dedicado por el alumnado para cada tipo de cuestionario y sus resultados medios obtenidos. 
Combinación de cuestionarios simples y gamificados utilizando gestores de participación en el aula: experiencia y percepción del alumnado

\section{Referencias bibliográficas}

Benítez-Porres, J. (2015). "Socrative como herramienta para la integración de contenidos en la asignatura "Didáctica de los Deportes"". En: XII Jornadas Internacionales de Innovación Universitaria Educar para transformar: Aprendizaje experiencial, Madrid, Julio 2015, págs. 824-831.

Calvillo, A.J. y D. Martín (2017). The Flipped Learning: Guía "gamificada"para novatos y no tan novatos. Universidad Internacional de La Rioja (UNIR Editorial).

Eisele-Dyrli, K. (2011). "Mobile Goes Mainstream". En: District Administration 47.2, págs. 46-55.

Frías, M.V., C. Arce y P. Flores-Morales (2016). "Uso de la plataforma socrative.com para alumnos de Química General”. En: Educación Química 27.1, págs. 59-66.

Fuertes, A. y col. (2016). "Uso de herramientas de respuesta de audiencia en la docencia presencial universitaria. Un primer contacto." En: XXII Jornadas sobre la Enseñanza Universitaria de la Informática (JENUI 2016), Almería, Spain, Julio 2016, págs. 257-265.

Kahoot. https://kahoot.it/.

Kay, R. y A. LeSage (2009). "A strategic assessment of audience response systems used in higher education". En: Australasian Journal of Educational Technology 25.2, págs. 235-249.

Melhuish, K. y G. Falloon (2010). "Looking to the future: M-learning with the iPad Computers in New Zealand Schools". En: Learning, Leading, Technology 22.3, págs. 1-16.

Socrative. https://www. socrative.com. 


\title{
¿Cómo comprobar si 500 alumnos son competentes en el uso de un entorno de programación?
}

\author{
Marisa Llorens, Francisco Marqués y Natividad Prieto \\ Dep. Sistemes Informàtics i Computació. Universitat Politècnica de València \\ $\{$ mllorens,pmarques,nprieto\}@dsic.upv.es
}

\begin{abstract}
In view of the challenge to evaluate the CT-13 Specific Tools in a subject with more than 500 students, like Introduction to Computing and Programming in the first course of Bachelor's Degree in Computer Engineering in the UPV, we have developed a computer application which, from the assessment tasks designed by the teacher, proposes it to the student, pick the evidences up and provides a qualification. The teacher can check the gathered information, and, where appropriate, she can change this qualification. In this communication, we describe the developed system, we cross-check the efficiency of the proposal and debate the strong and weak points, pointing out possible improvements.
\end{abstract}

Keywords: transversal competences, specific tools, rubric, automatic assessment, computer programming.

\section{Resumen}

Ante el reto de evaluar la CT-13 Instrumental específica en una una asignatura de más de 500 alumnos, como es Introducción a la Informática y la Programación de primer curso del Grado en Ingeniería Informática de la UPV, se ha desarrollado una aplicación informática que, a partir de la tarea de evaluación diseñada por el profesor, la propone al alumno, recoge las evidencias y provee una calificación. El profesor puede revisar la información recogida y, en su caso, modificar dicha calificación. En esta comunicación se describe el sistema desarrollado, se contrasta la efectividad de la propuesta y se discuten los puntos fuertes y débiles, señalando posibles mejoras.

Keywords: competencias transversales, instrumental específica, rúbrica, evaluación automática, programación de ordenadores. 


\section{Introducción}

Al menos en lo legislativo, ya parece aceptado, también en los niveles educativos superiores, la necesidad de explicitar la adquisición de competencias transversales, esto es, habilidades relacionadas con el desarrollo personal, que no son (solo) específicas de un área de conocimiento y son requeridas para el desarrollo profesional y académico. En el curso 2013/14, la Universitat Politècnica de València (UPV) lanza el Proyecto de Competencias Transversales (ICE-UPV 2017) en el que se definen trece competencias transversales, se establece una estrategia de evaluación sistemática de las mismas y se dan las pautas sobre dónde se adquieren, cómo deben ser evaluadas y las formas de acreditar dicha adquisición. Una de las formas previstas de incorporar estas competencias transversales es a través de los propios planes de estudios. Las ERTs son, entonces, las encargadas de asignar el desarrollo de las competencias a las distintas materias, definiendo lo que se denominan puntos de control, esto es, materias que, además de desarrollar la competencia, deben calificarla. El proyecto institucional concreta tres niveles de dominio para cada una de las 13 competencias definidas y establece las actividades formativas y las formas de evaluación más adecuadas para cada una de ellas.

Una de las competencias transversales definidas es la denominada CT-13: Instrumental específica, que hace referencia al uso de las herramientas y tecnologías necesarias para el ejercicio profesional asociado a cada titulación. En (ICE-UPV 2017) se describe como sigue:

"El estudiante será capaz de identificar las herramientas más adecuadas en cada caso, conociendo sus utilidades y siendo capaz de integrarlas y combinarlas para poder resolver un problema, realizar un proyecto o un experimento."

En una asignatura como Introducción a la Informática y a la Programación (IIP), en el semestre A de primer curso del Grado en Ingeniería Informática (GII), punto de control de esta competencia, se concreta en el siguiente resultado de aprendizaje:

Capacitar al alumno en el uso de las herramientas básicas del entorno de programación a partir de las instrucciones que se le proporcionan.

Nótese que es un resultado de aprendizaje del nivel más bajo (nivel 1), como típicamente corresponde a asignaturas de los primeros cursos. En lo que sigue se detallarán los objetivos de la asignatura IIP y se describirán las actividades formativas para el desarrollo de la competencia y las formas previstas para autoevaluación y evaluación (evaluación formativa y sumativa).

El objeto de esta comunicación es describir una propuesta de evaluación sumativa de la CT-13 en IIP, realizada mediante un sistema (semi)automático de evaluación; así como contrastar la efectividad de la misma. 


\subsection{Objetivos generales de la asignatura IIP del GII}

El objetivo general de una asignatura de introducción a la programación, como IIP, es facultar a los alumnos en la escritura de programas correctos de baja complejidad en un lenguaje orientado a objetos como es Java (Gosling y col. 2014); todo ello como parte de su formación inicial en la construcción de sistemas informáticos. Se trata de que el alumno aprenda a resolver problemas utilizando el computador; para ello, debe aprender a definir clases Java y aplicaciones que, utilizando objetos de las clases definidas o predefinidas en el lenguaje, resuelvan el problema planteado. En concreto, debe aprender nociones básicas de la programación orientada a objetos, como la definición de atributos y métodos de una clase y el uso de la misma mediante la creación y manipulación de objetos, que incluye aspectos propios de la programación imperativa como son el manejo de variables de tipos elementales o agregados como los arrays, el operador de asignación y las estructuras de control condicionales e iterativas. Los problemas abordados son de tipo numérico o de manejo de secuencias de datos y su complejidad se restringe a aquellos que puedan ser resueltos aplicando las estrategias algorítmicas de búsqueda secuencial, recorrido o combinación de estos.

En la enseñanza de la programación de hace unas décadas había una brecha importante entre lo que se podría llamar el diseño de la solución algorítmica del problema y el proceso de programación o traducción a un cierto lenguaje de programación, lo cual se manifestaba incluso utilizando lenguajes distintos para la descripción del algoritmo y para su traducción al programa ejecutable en el computador. La evolución de los lenguajes de programación para facilitar la descripición de los algoritmos y la accesibilidad de computadores con entornos de programación que facilitan todos los procesos relacionados con la escritura de programas para ser ejecutados en ellos, hacen que capacitar al alumno en el uso y manejo de estos entornos sea indiscutible en la actualidad (Robins, Rountree y Rountree 2003; Pettit y col. 2015). Es precisamente este aspecto el que se ha vinculado con la competencia transversal CT-13.

Esta competencia se desarrolla esencialmente a través de las actividades que se proponen en las prácticas de laboratorio y también en la resolución de los problemas propuestos en las clases de teoría y seminario. En concreto, las sesiones de prácticas se organizan en torno al desarrollo de programas para la resolución de problemas de complejidad creciente. Con la realización de estas actividades el alumno debe ser capaz de, además de diseñar la solución algorítmica del problema que se le plantee:

1. Acceder a un sistema compartido en una red de computadores como la del Departamento de Sistemas Informáticos y Computación (DSIC) utilizando el sistema operativo GNU/Linux ${ }^{1}$.

2. Mantener organizado su directorio de trabajo siguiendo las pautas que se le proporcionan, para lo cual debe saber manejar de forma básica el sistema operativo, tanto a nivel de consola como de interfaz gráfica.

3. Usar un entorno de programación, como Blue $\mathrm{J}^{2}$, para editar código, compilarlo, depurarlo y ejecutarlo.

4. Interpretar los mensajes del compilador para corrección de errores sintácticos.

\footnotetext{
${ }^{1}$ http://www.gnu.org/

2http://www.bluej.org/
} 
5. Utilizar las indicaciones del corrector de estilo.

6. Utilizar el depurador para detectar y corregir errores lógicos y de ejecución.

7. Escribir conjuntos de prueba para asegurar la corrección del código producido.

8. Utilizar las JUnits ${ }^{3}$ o programas de prueba que proporcionan los profesores para constatar la corrección del código diseñado.

9. Documentar el código siguiendo las pautas establecidas.

La evaluación de la capacidad del alumno en el diseño de las soluciones algorítmicas a los problemas planteados se realiza de forma completa mediante exámenes escritos en pruebas comunes. La evaluación del resto de capacidades, las que se han asociado a la CT-13, no se pueden (deben) realizar de esta misma manera.

1.2 Evaluación de la competencia del alumno en la utilización del entorno de trabajo

Para conseguir la evaluación de la capacidad del alumno para manejar el entorno de trabajo y, por ello, para realizar las tareas anteriormente mencionadas, es necesario observar su destreza en la resolución de un ejercicio de programación de dificultad acorde a los objetivos a evaluar, en un escenario idéntico al utilizado en la realización de las prácticas y que refleja lo que sería un posible entorno de trabajo profesional, aunque adaptado al nivel de formación en el que se encuentra el alumno. Esto es, el alumno puede consultar la documentación de las prácticas, del lenguaje, del entorno, y el código que el propio alumno ha ido desarrollando en las sesiones de prácticas.

Para que la evaluación sea objetiva y fiable, es necesario que se realice de forma individual, presencial, en el mismo momento del proceso de aprendizaje y con ejercicios de evaluación y criterios de corrección comunes. La idea es asegurar la igualdad de oportunidades a los alumnos, independientemente del instante de evaluación o de los criterios de corrección del profesor. El problema es entonces el elevado número de alumnos matriculados en esta asignatura (más de 500) así como el número de profesores (11) y los recursos de los que dispone el departamento.

Para ello, se ha desarrollado en Java una aplicación propia que plantea al alumno los ejercicios a resolver y le proporciona ciertas clases Java que debe utilizar. El alumno debe ser capaz de ubicar las clases en las carpetas que se le indica y resolver los ejercicios propuestos utilizando el entorno de programación. La aplicación se encarga de almacenar las soluciones de los alumnos en un servidor y de ejecutarlas con los casos de prueba, que definen la rúbrica de evaluación, haciendo una primera calificación de forma automática que después debe ser ratificada por el profesor. De este modo, se pueden organizar 3 sesiones de evaluación consecutivas que, utilizando prácticamente todos los recursos disponibles del departamento (9 laboratorios con 20 computadores cada uno), permiten evaluar de forma individual, presencial y de la forma más equitativa posible a todos los alumnos en un período de tiempo de aproximadamente 3 horas y 30 minutos.

La calificación obtenida de esta manera se utiliza para asignar el nivel de adquisición de la CT-13 siguiendo la rúbrica que se muestra en la Tabla 1; en ella se se detallan los

\footnotetext{
${ }^{3}$ http://junit.org/
} 
indicadores a considerar, los descriptores o marcas de evaluación y la calificación que se asigna: A si la competencia se supera excelentemente; B si se alcanza completamente; C si se alcanza parcialmente y D si la competencia no se alcanza, es decir, el alumno no logra el nivel mínimo.

Tabla 1: Rúbrica de la CT-13 en IIP

\begin{tabular}{|c|c|c|c|c|c|}
\hline Indicadores & \multicolumn{5}{|c|}{ Descriptores } \\
\hline \multirow{2}{*}{$\begin{array}{l}\text { 1. Utiliza el entorno de trabajo (GNU/Linux, } \\
\text { Java y BlueJ) para situar el material que se le } \\
\text { proporciona y compila y ejecuta un programa }\end{array}$} & \multicolumn{4}{|c|}{ Bien } & Mal \\
\hline & \multicolumn{4}{|c|}{ Lo hace } & No lo hace \\
\hline \multirow{2}{*}{$\begin{array}{l}\text { 2. Resuelve el problema de programación que } \\
\text { se le plantea }\end{array}$} & Bien & Regular alto & Regular bajo & Mal & \\
\hline & Sin errores & Error leve & Error grave & Errores graves & \\
\hline Calificación de la CT-13 & $\mathbf{A}$ & B & \multicolumn{2}{|c|}{$\overline{\mathrm{C}}$} & D \\
\hline
\end{tabular}

El resto del trabajo se organiza como sigue: en la sección 2 se comentan algunos trabajos que comparten, de algún modo, objetivos con la herramienta que aquí se presenta; en la sección 3 se describe el sistema que permite la evaluación automática de la CT-13 y, a continuación, en la sección 4, se muestran evidencias de la adecuación del sistema a los requerimientos; finalmente, en la sección 5, se discuten las conclusiones del trabajo que permiten señalar algunas direcciones de mejora.

\section{Trabajos relacionados}

El sistema software que aquí se presenta permite proponer y evaluar ejercicios de programación. En (Douce, Livingstone y Orwell 2005) y (Ihantola y col. 2010) se presenta un resumen de los diferentes sistemas que, con este propósito, se han presentado en la literatura entre los años 1960 y 2005 y en los 5 años siguientes, respectivamente. Las diferentes propuestas varían según el uso pedagógico que se haga de ellas (Ala-Mutka 2005) y de la tecnología que usan. Las diferencias más significaticas entre ellos se encuentran en si realizan un análisis sólo dinámico o también estático del código (ISO 2010), la forma en la que se definen los conjuntos de prueba, cómo se manejan las entregas y cómo se garantiza la seguridad.

Desde el punto de vista del uso pedagógico que se realiza de la herramienta, se pueden agrupar los sistemas en dos grandes grupos:

- Aquellos que únicamente comprueban si el código del alumno cumple con las especificaciones dadas; generalmente sólo realizan análisis dinámico de caja negra, siendo la salida del sistema de tipo lógico: cumple o no cumple. Este es el uso que se requiere en las competiciones de programación.

- Aquellos que pretenden tutelar, en mayor o menor medida, el proceso de aprendizaje; estos suelen realizar análisis estático y dinámico del código del alumno para poder identificar errores que permitan proporcionar al alumno pistas que le ayuden en la resolución del ejercicio. La salida del sistema, obviamente, no es de tipo lógico sino que es una lista de los problemas encontrados e incluso recomendaciones para su resolución.

Todos estos sistemas, en mayor medida los segundos, son unas buenas herramientas de autoaprendizaje y autoevaluación. También, casi todos ellos, permiten llevar un registro de la actividad de cada alumno, con lo que tanto alumnos como profesores pueden tener realimentación del proceso de aprendizaje y actuar cuando y como 
sea oportuno. Obviamente, siempre que se den las condiciones apropiadas, también pueden usarse como herramienta de evaluación.

Los autores coinciden con (Ihantola y col. 2010) en que existen demasiados sistemas y que el desarrollo de los mismos se ha realizado de forma desorganizada y acientífica (¿será necesario redescubrir la rueda?) debido principalmente a los problemas de documentación y distribución. En la mayoría de los casos, un grupo de profesores desarrollan una herramienta para un curso concreto de forma completamente altruista y pensando única y exclusivamente en la mejora del sistema de aprendizaje y de evaluación, dejando de lado los detalles relacionados con la publicidad y distribución de la misma. Así se entiende la proliferación de este tipo de herramientas, siguiendo quizás este menosprecio, frecuente en las universidades, en la difusión del material desarrollado para mejora de la actividad docente. De hecho, en IIP y en otras asignaturas del DSIC se utiliza CAP (Sapena y col. 2013), una herramienta de ayuda al aprendizaje de la programación que realiza, entre otras funciones, el análisis dinámico y estático del código y proporciona pautas para la resolución de problemas, o ASys (Insa y Silva 2016), que facilita la corrección de ejercicios de programación en Java.

La pregunta evidente es ¿por qué un sistema más? y la respuesta es que ahora el objetivo es "observar" la habilidad del alumno en el manejo del entorno de trabajo concreto en el que desarrolla las prácticas, y entonces comprobar si, utilizando su usuario habitual, en el sistema operativo GNU/Linux y en un entorno de desarrollo concreto de programación en Java, BlueJ, el alumno es capaz de resolver un problema de programación. Dado que el número de alumnos a observar es muy elevado (siempre más de 500), la herramienta desarrollada resulta de gran utilidad. Ninguna de las herramientas anteriores es directamente aplicable, aunque la experiencia en el uso y diseño de CAP ha ayudado en el diseño de la herramienta presentada en este trabajo.

\section{Descripción de la herramienta}

En esta sección se describen las características más relevantes de la herramienta siguiendo para ello la clasificación en (Ihantola y col. 2010), su descripción técnica y el uso de la misma por parte de profesores y alumnos.

\subsection{Características relevantes}

Para la resolución de los problemas de programación que se le proponen, el alumno utiliza el lenguaje Java. Del mismo modo, el conjunto de módulos que integran la propia herramienta están escritos, en su mayor parte, en dicho lenguaje.

La herramienta no está integrada en el sistema de publicación de contenidos de la Universidad (una variación de Sakai ${ }^{4}$, denominada PoliformaT (Busquets y col. 2006)) aunque sí que utiliza información relativa a los alummos y de su distribución en grupos, que se encuentra centralizada en los servidores de la Universidad.

La evaluación del trabajo de los alumnos se efectúa mediante la ejecución del código remitido por el alumno (análisis dinámico). No se efectúa análisis estático.

\footnotetext{
${ }^{4}$ https://sakaiproject.org/
} 
La valoración del trabajo del alumno se efectúa mediante una evaluación automática inicial, que está sujeta a una reevaluación, parcial o completa, posterior realizada por el profesor. El profesor siempre puede modificar la calificación del alumno a la vista de los trabajos remitidos.

La valoración inicial del trabajo de los alumnos se realiza mediante la aplicación de una solución de evaluación propia, especializada (no industrial); aunque la misma se basa en el modelo de Test de Unidad (ISO 2010; Craig y Jaskiel 2008) ya que, principalmente, se evalúan operaciones (métodos Java) que realiza el alumno, sometidos a pre y postcondiciones enunciadas textualmente.

Esta valoración se obtiene mediante:

1. La determinación de que el alumno estructura su trabajo de la forma que se le solicita: generalmente un conjunto de directorios, programas fuente y ejecutables, sometidos a algunas restricciones; por ejemplo, se le puede exigir una estructuración similar a la realizada durante el curso en el laboratorio, o la importación de bibliotecas propias (paquetes realizados durante el curso), etc.

2. La revisión del resultado obtenido por la ejecución del método (o métodos) ante distintos casos de entrada significativos, elegidos de forma que, del resultado obtenido en la ejecución del envío, puedan inferirse las características del mismo.

3. Y, ocasionalmente, del examen del estado de los objetos manipulados (por ejemplo, es posible examinar la evolución del valor de un atributo de un objeto) para determinar la adecuación de la solución.

El alumno puede enviar su solución tantas veces como desee durante el tiempo que dura una prueba que, por lo general, es de una hora. El sistema, además, es configurable para que la evaluación automática se realice bien de la última entrega, bien de aquella en la que obtuvo una mejor calificación. Al alumno se le informa, cuando efectúa una entrega de que la misma ha tenido lugar, aunque solo se le indica que esta se considera correcta cuando el sistema automático le otorga la máxima calificación.

Las pruebas se realizan en ordenadores individuales pertenecientes a la infraestructura docente del DSIC, mediante los que el alumno tiene acceso a su espacio de trabajo habitual en condiciones idénticas a las que tiene durante el resto del curso; a excepción de que tiene limitado el acceso externo, esto es, no puede acceder a internet ni conectarse remotamente ni mediante mensajería, etc., a otros equipos.

El alumno, tras identificarse y obtener acceso legítimo al sistema, descarga al inicio de la prueba algunos elementos de la misma, como enunciados, estructura básica del sistema de corrección, etc. El sistema está preparado para detectar, rechazar e informar de conexiones no autorizadas como, por ejemplo, desde ordenadores fuera del ámbito del laboratorio o desde ambientes no GNU/Linux (que es el s.o. que se utiliza en los laboratorios para la realización de las prácticas).

Además, el sistema identifica y anota el ordenador en el que se trabaja, así como al alumno que realiza la prueba, usando para ello la gestión de cuentas de los laboratorios de prácticas, proporcionada por la infraestructura docente, cuya información se hereda, a su vez, del sistema de cuentas de la propia Universidad. Idénticamente, se anota la fecha y hora en la que se produce cada envío. 
La evaluación inicial se realiza en el ordenador del propio alumno, sin que este último tenga acceso al servidor ni al trabajo o calificación de ningún otro compañero.

Todos los envíos del alumno se almacenan, con su calificación inicial, en un servidor realizado en lenguaje $\mathrm{PHP}^{5}$ sobre una infraestructura Apache ${ }^{6}$.

Posteriormente, todos los envíos junto con los datos relevantes de cada uno son clasificados y resumidos, para que cada profesor pueda acceder, a través de una gestión de datos común a los mismos, bien de forma individual (es posible acceder a cualquier entrega de cualquier alumno) como, de forma resumida, a los resultados de un grupo o de todos los alumnos.

Por último, indicar que el sistema se puede configurar para que las pruebas se realicen en cualquiera de las tres lenguas de uso en la UPV (Castellano, Valenciano e Inglés).

\subsection{Descripción técnica}

La herramienta de evaluación consta de un conjunto de módulos cuyas funcionalidades básicas son:

- Administrativa: permite distribuir, organizar y recoger los enunciados y todas las respuestas de los alumnos de forma eficiente y segura.

- Evaluación de la respuesta del alumno: mediante la que se comprueba la estructuración de cada solución del alumno y su corrección.

- Acceso a los resultados: para lo que se utiliza un repositorio común.

La función administrativa comprende módulos con los siguientes objetivos:

- Distribución del material de la prueba. Se efectúa mediante un grupo de scripts en GNU/Linux, ejecutados en el momento del comienzo de cada turno.

- Identificación y validación de los usuarios e implementación de políticas de seguridad. El día del examen solo pueden efectuar una entrega los alumnos debidamente identificados. Estas entregas solo pueden hacerse desde un conjunto de ordenadores reconocidos (que deben utilizar GNU/Linux). La identificación se hace con el sistema de cuentas de la infraestructura docente (que utiliza, a su vez, el de la propia Universidad).

- Remisión a la base de datos de las entregas. Se hace siguiendo el protocolo $\operatorname{HTTP}^{7}$ (un comando put), siguiendo un modelo cliente-servidor, en el que el cliente es ejecutado en el espacio del alumno mientras que el servidor, que interactúa con la base de datos, se ejecuta en la infraestructura docente. Estos espacios de ejecución están completamente separados. La remisión incluye, además del código respuesta, los datos de identificación personal y horaria del envío, así como la calificación automática del mismo.

\footnotetext{
${ }^{5}$ http://php.net/

${ }^{6}$ https://www . apache.org/

${ }^{7}$ https://www.w3.org/Protocols/
} 
En el lado del servidor se anotan en un fichero todas las entregas realizadas por un alumno, junto con las características de cada una de ellas (en Figura 1).

\begin{tabular}{|c|c|c|c|c|c|c|}
\hline ALUMNO: & hutarsan & PC: & pс0604 & FECHA: & 09/11/16 13:11 & NOTA: \\
\hline ALUMNO: & hutarsan & PC: & pc0604 & FECHA: & & NOTA: \\
\hline ALUMNO: & hutarsan & PC: & 00604 & FECHA: & & NOTA: \\
\hline ALUMNO: & hutarsan & PC: & & FECHA: & & NOTA: \\
\hline ALUMNO: & hutarsan & PC: & pс0604 & FECHA: & & NOTA: \\
\hline ALUMNO: & hutarsan & PC: & pс0604 & FECHA: & & NOTA: \\
\hline ALUMNO: & hutarsan & $\mathrm{PC}$ & & FECHA: & & NOTA: \\
\hline ALUMNO: & hutarsan & PC: & & FECHA: & & NOTA: \\
\hline ALUMNO: & hutarsan & PC: & & FECHA: & & NOTA: \\
\hline INO: & hutarsan & PC: & & FECHA: & & NOTA: \\
\hline ALUMNO: & hutarsan & PC: & & FECHA: & & NOTA: \\
\hline ALUMNO: & hutarsan & PC: & & FECHA: & & NOTA: \\
\hline ALUMNO: & hutarsan & PC: & & FECHA: & & NOTA: \\
\hline ALUMNO: & hutarsan & PC: & pc06 & FECHA: & & NOTA: \\
\hline
\end{tabular}

Fig. 1: Resumen de las entregas realizadas por un alumno

- Clasificación posterior de resultados y obtención de información resumen. Después de una copia de seguridad de las entregas efectuadas que se realiza al final de cada turno de examen, se distribuye la información (varios miles de ficheros) en distintos directorios de forma que sea fácilmente accesible por los profesores. Simultáneamente a lo anterior, se elaboran listados resumen con los resultados obtenidos (uno por cada grupo de laboratorio y uno para toda la asignatura).

El proceso de evaluación, que ya ha sido descrito, se concreta en una clase Java, que deriva de una clase más general con las características de la estructura de una prueba, cuyo objetivo es la evaluación inicial del envío efectuado por el alumno. Normalmente supone la ejecución de un conjunto de tests, de los cuales es posible inferir la calidad de la solución propuesta.

Finalmente, el acceso a los resultados por parte de los profesores, se organiza mediante un repositorio común en el que cada profesor puede acceder a todas las entregas (y calificaciones) de cada alumno, así como a los listados resúmenes obtenidos tras el procesamiento correspondiente. El soporte de este repositorio $\left(\mathbf{s v n}^{8}\right)$ lo dota la infraestructura docente, y es el utilizado por los profesores para compartir a lo largo del curso todo el material común.

\subsection{Uso de la herramienta: profesor y alumno}

\subsubsection{Rol del profesor}

El profesor debe elegir los ejercicios que reflejen los objetivos de las prácticas a evaluar, preparar el enunciado asociado y el material necesario para que los alumnos realicen el examen usando la herramienta.

El enunciado debe ser lo más claro posible y sin ambigüedades. En (Douce, Livingstone y Orwell 2005) se insiste en que la especificación de los requisitos para una evaluación automatizada debe ser más precisa que para la evaluación manual equivalente. En (Ala-Mutka 2005) se advierte que no se permiten ambigüedades en la especificación del problema, especialmente cuando se consideran los formatos de entrada/salida. Como se indica en (Pieterse 2013), si la especificación es ambigua, son posibles diferentes

\footnotetext{
${ }^{8}$ https://subversion.apache.org/
} 
interpretaciones y, por tanto, es probable que algunas soluciones válidas de los alumnos puedan ser rechazadas por la herramienta de evaluación automática simplemente porque no esté configurada para reconocerlas.

El diseño de un ejercicio requiere, en primer lugar, la definición de su rúbrica (ver Tabla 1), en particular, establecer una escala de valoración para el indicador 2 :

Resuelve el problema de programación que se le plantea.

Se definen 4 descriptores: bien, regular alto, regular bajo y mal que se corresponden, respectivamente, con una solución sin errores, con un error leve, con un error grave y con más de un error. El profesor debe ponerse en el papel del alumno y tratar de prever los errores que el alumno puede cometer y cuantificarlos, esto es, debe identificar soluciones correctas y aproximadas, definiendo las distintas instancias y casos de prueba y la nota asociada. La elección de los casos de prueba es un aspecto muy importante de la evaluación automática (Pieterse 2013); por un lado, se debe evitar que programas erróneos pasen los tests y, por otro lado, se debe asegurar que se cubren todas las posibles soluciones.

Una vez definida la rúbrica, el profesor la implementa en un test que comprueba la solución del alumno, identificando el descriptor correspondiente al indicador 2.

\subsubsection{Rol del alumno}

$\mathrm{Al}$ alumno se le proporciona un enunciado con las condiciones para la realización de la prueba y los pasos a seguir para efectuarla. Las condiciones habituales de realización de la prueba son las siguientes:

- 60 minutos de duración.

- Uso exclusivo de los recursos del laboratorio en GNU/Linux, en la cuenta personal del alumno. No se pueden usar, por tanto, portátiles, tablets o cualquier otro tipo de instrumento electrónico.

- Sin acceso a internet.

En la Figura 2 se muestra el esquema de la realización de una prueba de laboratorio por parte de un alumno.

El alumno tiene que copiar en un directorio determinado un fichero .jar que se le proporciona y abrir dicho fichero como un proyecto BlueJ. El proyecto contiene los ficheros .class y . java necesarios para la realización de la prueba. Es condición necesaria tener dicho proyecto BlueJ y ser capaz de ubicar adecuadamente los ficheros que se proponen para poder realizar la prueba. Para comprobar que el alumno ha creado el proyecto con los ficheros indicados, tiene que compilar el código y ejecutar los métodos main correspondientes y pulsar Enviar solución; lo que corresponde con el indicador 1 de la rúbrica (ver Tabla 1 ):

Utiliza el entorno de trabajo (GNU/Linux, Java y BlueJ) para situar el material que se le proporciona y compila y ejecuta un programa. 


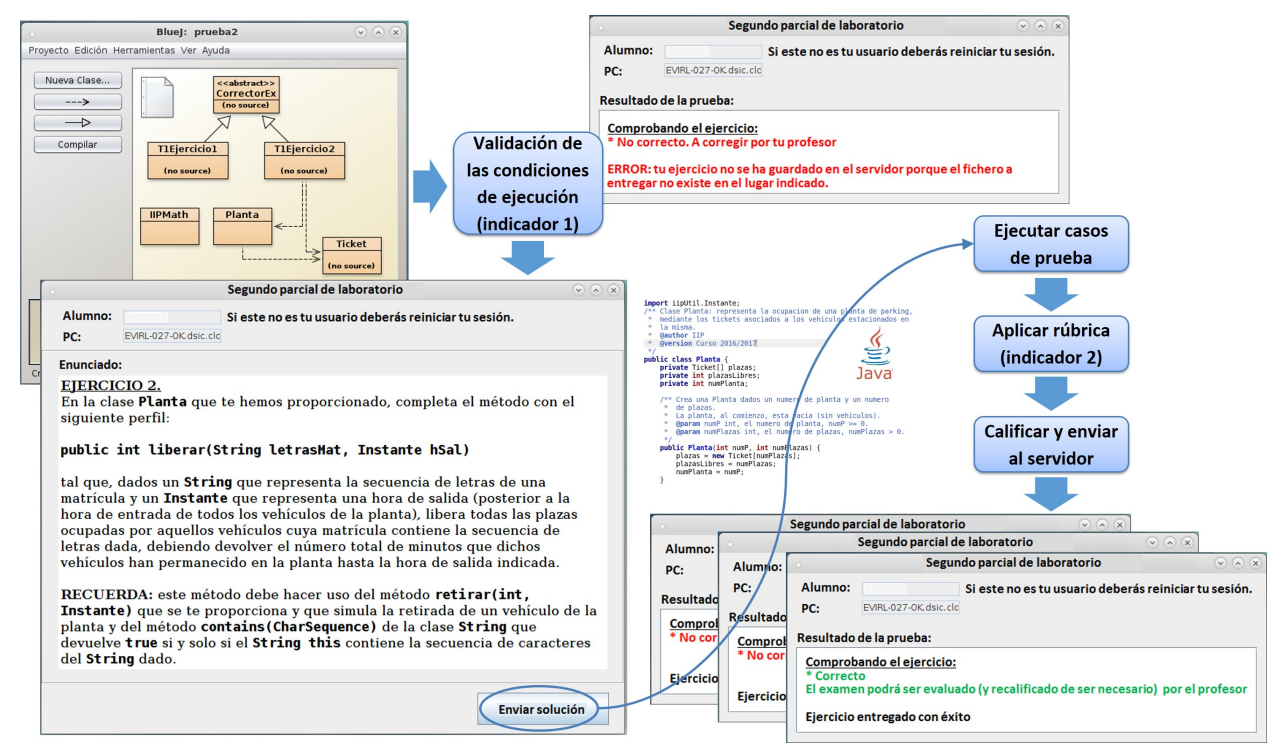

Fig. 2: Esquema de realización de una prueba de laboratorio por un alumno

Al alumno se le muestra el mensaje "Ejercicio entregado con éxito" o un mensaje de error si no ha llevado a cabo el indicador 1 correctamente.

Una vez validadas las condiciones de ejecución, el alumno ya puede resolver los ejercicios que se le proponen. Típicamente, un ejercicio consiste en completar un método de una clase Java dada. Una vez resuelto, tiene que volver a pulsar el botón Enviar solución. Se ejecutan los diferentes casos de prueba definidos para el ejercicio y se aplica la rúbrica correspondiente al indicador 2 (ver Tabla 1):

Resuelve el problema de programación que se le plantea.

Se le asigna una calificación de acuerdo a la rúbrica y la solución se envía al servidor. El alumno únicamente recibe un mensaje que indica si la solución enviada es correcta o incorrecta. Si no lo es, puede corregir su código y volverlo a enviar todas las veces que quiera, asignándosele la mejor nota obtenida. Esta primera calificación automática, como ya se ha comentado, debe ser ratificada después por el profesor.

\section{Resultados}

En esta sección se aportan evidencias que permiten asegurar que la herramienta presentada permite evaluar de manera efectiva esta instancia de la CT-13.

El escenario de uso de la herramienta en el curso 2016/17 fue, de forma resumida y aproximada, el que sigue:

- Personal involucrado: 510 alumnos, 11 profesores, 2 becarios y 2 técnicos de laboratorio. 
- Recursos técnicos: 3 turnos cada uno de ellos en 9 laboratorios, 20 puestos de trabajo por laboratorio, 1 servidor Apache e infraestructura proporcionada por el departamento.

- Volumen de entregas: más de 4000 ficheros Java y más de 500 ficheros resumen, esto es, 8 entregas en promedio por cada alumno.

La nota que proporciona el sistema, una vez revisada, se utiliza para:

1. Calificar la CT-13, siguiendo los criterios ya comentados en Tabla 1.

2. Contribuir como Nota de Prácticas de Laboratorio (NPL) en un $20 \%$ a la calificación final del alumno en Actas. El resto de la calificación se corresponde en un $60 \%$ a la Nota Ponderada de Parciales (NPP) y en un $20 \%$ a la Nota de Actividades de Seguimiento (NAS) en clase.

En la Figura 3 se muestra el histograma de las diferentes notas de los alumnos por intervalos de calificación. La calificación de la CT-13 se ha hecho según estos intervalos en NPL. Se observa que los alumnos obtienen peores calificaciones en los exámenes de laboratorio. Por el contrario, las notas de actividades de clase son las más elevadas por el carácter motivacional que suelen tener.

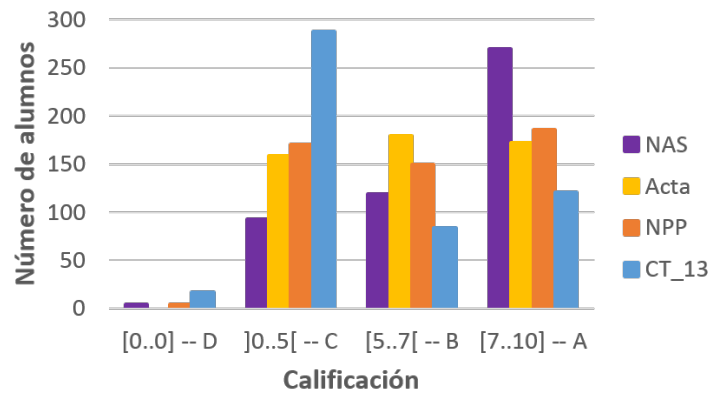

Fig. 3: Relación entre número de alumnos e intervalos de calificación en Acta, NPP, NAS y CT-13

Del 56, 47\% de alumnos que en la CT-13 tienen la calificación C (NPL $\in$ ]0.,5[), más del $41 \%$ (23,53\% del total) tienen $0<\mathrm{NPL} \leq 1$, lo que corresponde con el indicador 1 de la rúbrica; el 3, 33\% tiene la calificación D (NPL $=0)$. Por lo tanto, casi un $27 \%$ del total de alumnos no ha sido capaz de puntuar en la resolución del problema (indicador 2). Casi el $33 \%$ tienen la calificación C con $1<\mathrm{NPL}<5$ por haber cometido algún error grave. Más del $16 \%$ tienen la calificación B (NPL $\in[5 ., 7[)$ por haber cometido algún error leve y casi el $24 \%$ tienen la calificación A (NPL $\in[7 ., 10])$ por haber resuelto el problema planteado, al menos de forma aproximada.

En los gráficos de dispersión de la Figura 4, se muestra la relación entre la Nota Ponderada de Parciales (NPP) y la Nota de Prácticas de Laboratorio (NPL). En el gráfico de la Figura 4(a) se confirma que existe una relación lineal positiva entre las dos variables medidas, si bien la correlación existente entre ambas es moderada baja. El coeficiente de determinación, $R^{2}$, indica que solo un $50 \%$ de la NPP queda explicado por la NPL. Se puede observar que la mayor parte de los alumnos que no tiene 
aprobados los parciales de la asignatura tienen una nota inferior a 2 en NPL. También que los alumnos que tienen la máxima calificación en NPL obtienen notas superiores a 7 en NPP, en la mayor parte de los casos. Del grupo de alumnos con NPP $\geq 5$ se observa que hay tanto alumnos que superaron las pruebas de laboratorio como que no lo hicieron. En la Figura 4(b), se observa que las calificaciones de NPL presentan una estratificación debida a la discretización de las notas por el sistema automático. En definitiva, se puede concluir que las pruebas de laboratorio, sorprendentemente (aunque es lo habitual), dan lugar a resultados peores que en el resto de pruebas.

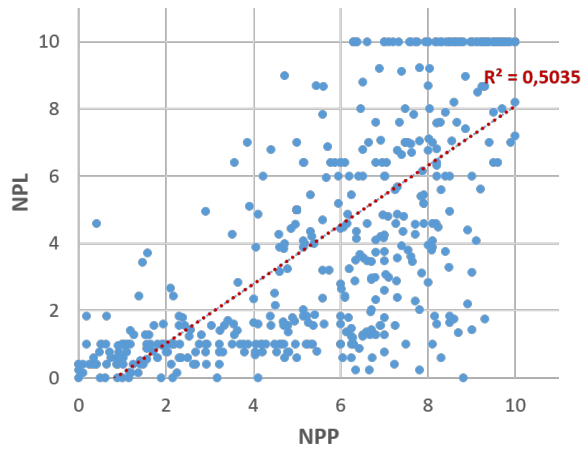

(a) Dispersión y correlación entre NPP y NPL

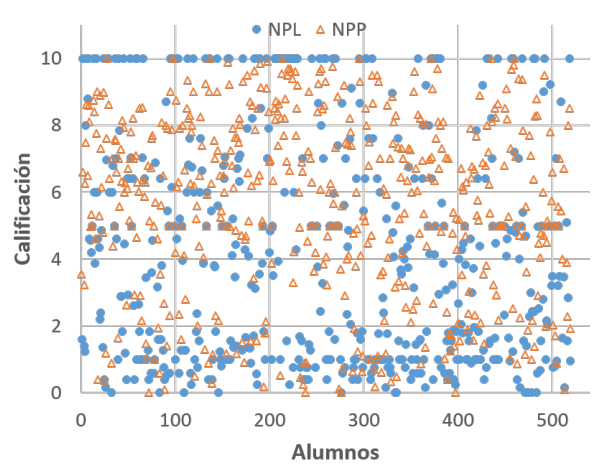

(b) Distribución de NPL y NPP

Fig. 4: Relación entre NPL y NPP

En la Figura 5 se muestra la relación entre la nota de prácticas obtenida con la herramienta (NPL1-Tool y NPL2-Tool) y dicha nota tras la revisión del profesor para cada uno de los parciales realizados (NPL1 y NPL2). Se observa, en primer lugar, una muy alta correlación entre la nota automática y la nota final, es decir, la calificación obtenida por la herramienta es ratificada por los profesores. Las diferencias se deben principalmente a redondeos de las calificaciones y a que, en un porcentaje reducido de casos, el profesor ha considerado modificar la calificación. En segundo lugar, se observa, una vez más, una discretización de las notas.

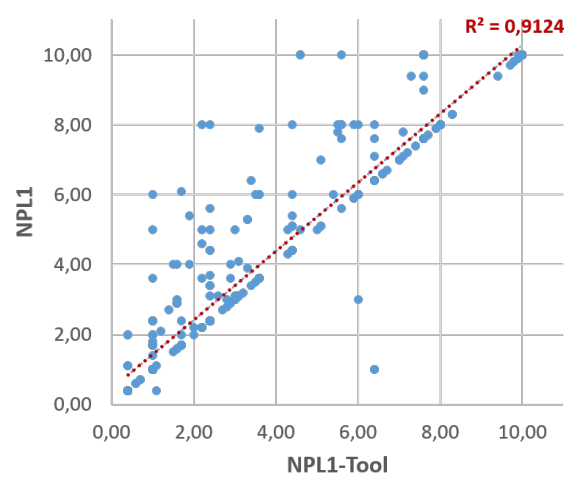

(a) NPL1-Tool y NPL1

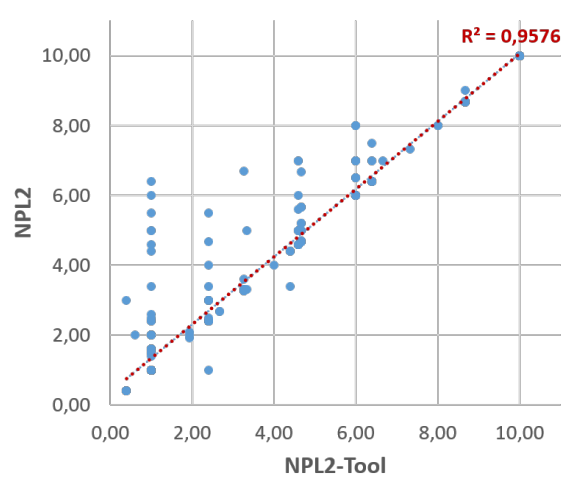

(b) NPL2-Tool y NPL2

Fig. 5: Dispersión y correlación entre la Nota de Prácticas de Laboratorio con la herramienta (NPL-Tool) y tras la revisión del profesor (NPL) 


\section{Conclusiones}

En este artículo se ha descrito una propuesta de evaluación sumativa de la CT-13 Instrumental específica, realizada mediante un sistema automático de evaluación para IIP en el GII, que se puede extender a otras asignaturas relacionadas con la programación en Java (como, de hecho se utiliza, en la asignatura de segundo curso Estructuras de Datos y Algoritmos).

Se demuestra la efectividad de la propuesta al permitir evaluar la CT-13 a más de 500 alumnos de una manera objetiva, equitativa y con criterios de calificación homogéneos. Descartando cualquier tipo de corrección no realizada en el laboratorio y buscando una evaluación en un contexto similar al que se desarrolla la propia actividad de la programación, la aquí presentada reduce significativamente el tiempo de evaluación. A pesar del automatismo del sistema, el profesor siempre puede revisar la calificación final del alumno.

La preparación y realización de una prueba es laboriosa y exige una planificación cuidadosa de los laboratorios y los recursos. Sin embargo, siempre supone menos trabajo que el que implicaría la evaluación individual de cada alumno. Además, no requiere que todos los profesores se involucren en la preparación de cada prueba.

En lo que respecta a las líneas de actuación a medio y largo plazo, se proponen la siguientes mejoras en la herramienta: limitar el número de envíos para evitar la programación "compulsiva"; introducir análisis estático (evaluando el estilo de codificación); sistematizar la definición del enunciado y desarrollo de los tests; y por último mejorar la realimentación de la nota alumno justificando, de esta manera, la calificación que obtiene.

Finalmente, los autores consideran que este tipo de actividades docentes adicionales, aunque imprescindibles para una evaluación de calidad, deberían tener un reconocimiento explícito en la carga docente del profesor.

\section{Agradecimientos}

Los autores quieren mostrar su agradecimiento a los compañeros que colaboraron, en algún momento, en el desarrollo del sistema; en particular, a los profesores Óscar Sapena, Isabel Galiano y Carlos Herrero. También al DSIC, cuyos técnicos proporcionaron siempre la mejor de las ayudas, y, por supuesto, a los estudiantes que realizaron los exámenes.

\section{Referencias bibliográficas}

Ala-Mutka, Kirsti M. (2005). "A Survey of Automated Assessment Approaches for Programming Assignments". En: Computer Science Education 15.2, págs. 83-102. DOI: $10.1080 / 08993400500150747$.

Busquets, Jaime y col. (2006). "PoliformaT: una estrategia para la formación on-line en la Educación Superior". En: Virtual Educa. 
Craig, Rick David y Stefan P. Jaskiel (2008). Systematic Software Testing. Artech House computing library. Boston: Artech House. ISBN: 1580535089, 9781580535083.

Douce, Christopher, David Livingstone y James Orwell (2005). "Automatic Testbased Assessment of Programming: A Review". En: Journal of Educational Resources in Computing 5.3. ISSN: 1531-4278. DOI: 10.1145/1163405.1163409.

Gosling, James y col. (2014). The Java Language Specification, Java SE 8 Edition. 1st ed. Addison-Wesley Professional. IsBn: 013390069X, 9780133900699.

ICE-UPV (2017). Portal de competencias transversales de la Universitat Politècnica de València. http : //www . upv . es / contenidos / COMPTRAN/. [Online; acceso 07-Marzo-2017].

Ihantola, Petri y col. (2010). "Review of Recent Systems for Automatic Assessment of Programming Assignments". En: Proceedings of the 10th Koli Calling International Conference on Computing Education Research. Koli Calling '10. Koli, Finland: ACM, págs. 86-93. DOI: 10.1145/1930464.1930480.

Insa, David y Josep Silva (2016). "Corrección Semi-Automática de Programas Java". En: In-Red 2016 - II Congreso Nacional de Innovación Educativa y Docencia en Red de la Universitat Politècnica de València. Ed. por Vicente Botti Navarro y Miguel Ángel Fernández Prada. Colección Congresos UPV. Editorial Universitat Politècnica de València. DOI: 10.4995/INRED2016.2016.4326.

ISO, International Organization for Standardization (2010). ISO/IEC/IEEE 24765: 2010 - Systems and Software Engineering - Vocabulary, págs. 1-418. DOI: 10. 1109/IEEESTD . 2010.5733835.

Pettit, Raymond Scott y col. (2015). "Are Automated Assessment Tools Helpful in Programming Courses?" En: 2015 ASEE Annual Conference 83 Exposition. Seattle, Washington: ASEE Conferences. DOI: 10.18260/p.23569.

Pieterse, Vreda (2013). "Automated Assessment of Programming Assignments". En: Proceedings of the 3rd Computer Science Education Research Conference on Computer Science Education Research. CSERC '13. Arnhem, Netherlands: Open Universiteit, Heerlen, 4:45-4:56.

Robins, Anthony, Janet Rountree y Nathan Rountree (2003). "Learning and Teaching Programming: A Review and Discussion". En: Computer Science Education 13.2, págs. 137-172. DOI: 10.1076/csed.13.2.137.14200.

Sapena, Óscar y col. (2013). "Aprender, enseñar y evaluar con CAP, un Corrector Automático de tareas de Programación". En: Actas de las XIX Jornadas sobre la Enseñanza Universitaria de la Informática: Jenui 2013: Castellón, del 10 al 12 de julio de 2013. Ed. por Mercedes Marqués Andrés, José Manuel Badía Contelles, Sergio Barrachina Mir y col. Publicacions de la Universitat Jaume I, págs. 343-350. DOI: 10.6035/e-TIiT.2013.13. 


\title{
Diseño de una rúbrica para la obtención de criterios de evaluación de los Trabajos Final de Grado de la Escuela Técnica Superior de Ingeniería Agronómica y del Medio Natural
}

\author{
Mercedes Verdeguer Sanchoa, Juan Antonio Llorens Molinab, Francisco García \\ Breijo $^{a}$, Josefa Roselló Caselles ${ }^{a}$, Alberto García Prats ${ }^{c}$, Constanza Rubio Michavilad, \\ María Vargas Colás ${ }^{\mathrm{e}}$, María Pilar Santamarina Siurana ${ }^{a}$ \\ a(Departamento de Ecosistemas Agroforestales (DEPEAF), Escuela Técnica Superior de Ingeniería \\ Agronómica y del Medio Natural (ETSIAMN), Universitat Politécnica de València (UPV), \\ merversa@doctor.upv.es, fjgarci@eaf.upv.es, jrosello@upvnet.upv.es, mpsantam@eaf.upv.es) \\ b(Departamento de Química, ETSIAMN, UPV, juallom2@qim.upv.es) \\ c(Departamento de Ingeniería Hidráulica y Medio Ambiente, agprats@upvnet.upv.es) \\ d(Departamento de Física Aplicada, crubiom@fis.upv.es) \\ e(Departamento de Tecnología de Alimentos, mavarco@tal.upv.es)
}

\begin{abstract}
The present paper includes some results obtained in the context of the teaching innovation project "Tools for the planning, realization and assesment of the Bachelor's Degree Thesis (BDT)". The project aims to solve the problems that students, advisors and members of the evaluation board have to face in terms of the assesment of the BDT, providing evaluation tools (rubrics). At present, there are no clear and objective criteria for assessing the BDTs, and their evaluation sometimes is submitted to the subjective assessment of the members of the board. What is more, at the moment the formulary that is used to evaluate the transversal UPV outcomes is more complete and detailed than the one used for the evaluation of the BDT. Therefore, it is necessary to develop a document named as "Bachelor's Degree Thesis Guide", which will provide tools for an adequate and optimal planning and evaluation of BDTs. One of the key points of the project has been the elaboration of a rubric with measurable indicators that facilitate and clarify the evaluation of the BDTs. This rubric will be distributed among the different interested groups (professors, students and academic boards) to improve and validate it.
\end{abstract}

Keywords: evaluation, assessment, criteria, rubric

\section{Resumen}

El presente trabajo recoge parte de los resultados obtenidos en el marco del proyecto de innovación docente "Herramientas para la planificación, realización y valoración de los Trabajo Fin de Grado (TFGs)". Se pretende resolver la problemática a la que se enfrenta el alumnado, los tutores y los tribunales en cuanto a los criterios de valoración de los TFGs, aportando herramientas para su evaluación (rúbricas). Actualmente, no existen unos 
criterios claros y objetivos para la evaluación de los TFGs, quedando en ocasiones su calificación sometida a valoraciones subjetivas, por parte del tribunal evaluador. Así, es más detallado el documento para la evaluación de las competencias trasversales que el utilizado para la evaluación del TFG. Por tanto, es necesario desarrollar un documento "Guía del Trabajo Fin de Grado", que proporcione instrumentos para una adecuada y óptima planificación y evaluación de los TFGs. Uno de los puntos clave del proyecto, ha sido la elaboración de una rúbrica con indicadores medibles que faciliten y clarifiquen la evaluaciónn de los TFGs. Dicha rúbrica, se pasará a los diferentes grupos de interés (profesorado, alumnado y comisiones académicas) para mejorarla y validarla.

Palabras clave: evaluación, valoración, criterios, rúbrica

\section{Introducción}

Los Trabajos Fin de Grado, en adelante (TFGs), constituyen un trabajo de naturaleza profesional original en el que quedan de manifiesto los conocimientos, habilidades y competencias adquiridas por el estudiante a lo largo de sus estudios de Grado. Los tutores del TFG determinarán cuáles son los contenidos específicos del TFG, de acuerdo con las temáticas recogidas en la normativa correspondiente:

(http://www.upv.es/entidades/ETSIAMN/info/Normativa_Trabajo_Final1.pdf).

Actualmente existe cierta dificultad a la hora de planificar, realizar el seguimiento, y evaluar los TFGs, ya que no existe ninguna guía de referencia que regule estos aspectos, ya que los documentos que se han preparado hasta el momento se han centrado en aspectos formales y de contenidos mínimos. Además, en muchos trabajos no se estima adecuadamente la dedicación del alumno, que frecuentemente invierte para la realización del TFG muchas más horas de trabajo que las reflejadas en los créditos correspondientes (12 ECTS).

Los profesores tutores de los TFGs tienen que verificar durante la realización de los mismos que el alumno está llevando a cabo un desarrollo adecuado de las tareas correspondientes para alcanzar sus objetivos, de acuerdo con las competencias profesionales que debe trabajar durante su realización. No obstante, no se dispone actualmente de un documento donde se puedan recoger los progresos del alumno durante la realización del TFG y que permita al tutor del mismo verificar que se está ejecutando de forma adecuada.

Entre las estrategias habitualmente utilizadas para analizar las diferentes dimensiones y/o aspectos objeto de preocupación en torno a los principales agentes implicados en los procesos de elaboración, tutorización, presentación y/o defensa y evaluación de los TFGs, se encuentran las encuestas de opinión y las entrevistas al alumnado y a los tutores (Webster, et al., 2000). Además, otro de los aspectos críticos es la evaluación de los TFGs, cada vez más azarosa, pues al no disponer de unos criterios objetivos claros y establecidos, el alumnado puede percibir que se le está evaluando de manera subjetiva. Actualmente no

(cc) EY-NC-ND 2017, Universitat Politècnica de València

Congreso IN-RED (2017) 
Mercedes Verdeguer Sancho, Juan Antonio Llorens Molina, Francisco García Breijo, Josefa Roselló Caselles, Alberto García Prats, Constanza Rubio Michavila, María Vargas Colás, María Pilar Santamarina Siurana

se dispone de un documento de referencia (rúbrica), donde se recojan de forma clara y objetiva, los criterios que va a tener en cuenta el tribunal para evaluar el TFG en los diferentes Grados de la ETSIAMN. En dicha rúbrica, deberán recogerse los indicadores a las acciones de evaluación, así como exactamente el nivel de cumplimiento que se le exige al alumnado en cada indicador para que la evaluación sea lo más objetiva posible, independientemente de quién sea el agente evaluador (Valderrama et al., 2009).

Para ayudar a resolver esta problemática en la realización de los TFGs, varios profesores de la Escuela Técnica Superior de Ingeniería Agronómica y del Medio Natural planteamos un proyecto de Innovación Docente titulado "Herramientas para la planificación, realización y valoración de los Trabajos Fin de Grado". El equipo de trabajo del proyecto de innovación ha querido trabajar de la mano de la Dirección de la Escuela Técnica Superior de Ingeniería Agronómica y del Medio Natural. Por ello, está formado por la Jefa de Estudios de la Escuela, la Subdirectora de la Comisión Académica del Título Grado en Ingeniería Agroalimentaria y del Medio Rural, el Subdirector de la Comisión Académica del Título Grado en Ingeniería Forestal y del Medio Natural, y por cinco profesores de las áreas de química, biología, botánica y tecnología de alimentos, que imparten docencia tanto en el Grado como en los Masteres, entre ellos una Directora de Departamento.

El proyecto responde a la necesidad con la que se encuentran tanto el alumnado como los tutores y tribunales en relación a la planificación y, fundamentalmente, la evaluación del Trabajo Fin de Grado (TFG), el tema más prioritario en estos momentos, aportando una herramienta adecuada y objetiva, una rúbrica. Es imprescindible que el alumno conozca de antemano el sistema de evaluación utilizado para valorar su trabajo, al igual que sucede con las asignaturas que cursa.

Las rúbricas se han propuesto y utilizado como elementos para la tutorización y evaluación del aprendizaje de los alumnos en enseñanzas universitarias (Torres y Perea, 2010; GarcíaRos, 2011; Raposo y Martínez, 2011), pero es imprescindible elaborar rúbricas que cumplan con criterios de fiabilidad y validez (Berrocoso, 2014). Existe una experiencia previa en cuanto al uso de rúbricas para el seguimiento y evaluación de los Proyectos Fin de Carrera, llevada a cabo en la Escuela Superior Politécnica de la Universitat Pompeu Fabra (Moreno et al., 2012), cuyos primeros resultados, basados en informaciones provenientes tanto de directores, miembros de tribunal como de los propios estudiantes, muestran que, de manera global, el uso de rúbricas permite sistematizar tanto el seguimiento como la evaluación de los trabajo realizados, a la vez que facilita la homogenización de criterios (en clave de rigurosidad y transparencia). Otras Universidades, como la Universitat de les Illes Balears, también están desarrollando proyectos de innovación docente para elaborar rúbricas para la evaluación de TFGs y TFMs (Jaume-iCapó et al., 2012).

\section{Objetivos}

El objetivo de este trabajo es desarrollar un documento-rúbrica en el que se establezcan los criterios de valoración que se tendrán en cuenta a la hora de evaluar un TFG en la ETSIAMN. 
Para la consecución del mismo, se plantean los siguientes objetivos específicos:

1. Obtener información sobre la situación actual en relación a la valoración de los TFGs en la ETSIAMN, reunir la documentación utilizada para la evaluación de los mismos.

2. Analizar cómo se realiza la evaluación de TFGs en otras Escuelas de la UPV o en otras Universidades y reunir la documentación utilizada para la evaluación de los mismos.

3. Elaborar un documento (rúbrica) en el que se establezcan los criterios e indicadores de valoración que se tendrán en cuenta por el tribunal de calificación para evaluar los TFG, que deberá ser validado por los diferentes grupos de interés.

\section{Desarrollo de la innovación}

De acuerdo con los objetivos planteados, se procedió a recopilar la información actualmente disponible y se analizó la situación actual de los TFGs en diferentes Escuelas de la Universitat Politècnica de València, revisando las rúbricas e instrumentos de evaluación disponibles para la valoración de los TFGs. En una primera aproximación, se elaboró una primera versión de la rúbrica que fue mostrada en Comisiones Académicas para recoger los comentarios de los miembros de las mismas (Figura 1).

\begin{tabular}{|c|c|c|c|c|}
\hline \multicolumn{5}{|c|}{ Rúbrica para la evaluación del documento TFG y de la defensa } \\
\hline INDICADOR & NIVEL 1 & NIVEL 2 & NIVEL 3 & NIVEL 4 \\
\hline $\begin{array}{l}\text { Adecuación a objetivos } \\
\text { formativos y competencias de la } \\
\text { titulación }\end{array}$ & $\begin{array}{l}\text { No se adecúa a los } \\
\text { objetivos formativos }\end{array}$ & $\begin{array}{l}\text { Se adecúa de forma } \\
\text { parcial }\end{array}$ & $\begin{array}{l}\text { Se adecúa en gran medida } \\
\text { a los objetivos formativos }\end{array}$ & $\begin{array}{l}\text { Se adecúa de forma } \\
\text { completa a los objetivos } \\
\text { formativos }\end{array}$ \\
\hline Introducción y Objetivos & $\begin{array}{l}\text { No aparecen los objetivos } \\
\text { o se confunden con plan } \\
\text { de trabajo o metodología. }\end{array}$ & $\begin{array}{l}\text { Los objetivos no están } \\
\text { claros y no se justifica el } \\
\text { TFG. El problema a } \\
\text { resolver no está definido. }\end{array}$ & $\begin{array}{l}\text { No se especifican todos } \\
\text { los objetivos o no quedan } \\
\text { muy claros. La temática y } \\
\text { contribución se justifica }\end{array}$ & $\begin{array}{l}\text { Justifica la temática, } \\
\text { especifica todos los } \\
\text { objetivos y evidencia la } \\
\text { contribución original. }\end{array}$ \\
\hline $\begin{array}{l}\text { Antecedentes y reconocimiento } \\
\text { de trabajos previos ajenos. }\end{array}$ & No cita & $\begin{array}{l}\text { Cita otros trabajos sin } \\
\text { sistematización }\end{array}$ & $\begin{array}{l}\text { Cita otros trabajos de } \\
\text { forma sistemática }\end{array}$ & $\begin{array}{l}\text { Cita el trabajo ajeno } \\
\text { sistemáticamente y } \\
\text { diferencia su aportación }\end{array}$ \\
\hline Resultados & $\begin{array}{l}\text { No se ha resuelto el } \\
\text { problema planteado o la } \\
\text { solución es errónea. }\end{array}$ & $\begin{array}{l}\text { Muestra errores y } \\
\text { omisiones y no se ajustan } \\
\text { a la metodología. }\end{array}$ & $\begin{array}{l}\text { Algunos errores u } \\
\text { omisiones que no } \\
\text { comprometen las } \\
\text { conclusiones. }\end{array}$ & $\begin{array}{l}\text { Adecuados al objetivo y } \\
\text { coherentes con la } \\
\text { metodología. }\end{array}$ \\
\hline $\begin{array}{l}\text { Evaluación de la solución } \\
\text { aportada para alcanzar los } \\
\text { objetivos del trabajo }\end{array}$ & No valora el resultado & $\begin{array}{l}\text { Analiza el resultado sin } \\
\text { valorarlo }\end{array}$ & $\begin{array}{l}\text { Analiza el resultado y lo } \\
\text { valora sin validarlo }\end{array}$ & $\begin{array}{l}\text { Analiza el resultado, lo } \\
\text { valora y lo valida }\end{array}$ \\
\hline $\begin{array}{l}\text { Organización de la información } \\
\text { presentada durante la defensa }\end{array}$ & $\begin{array}{l}\text { La presentación está } \\
\text { desordenada y sin } \\
\text { estructura lógica }\end{array}$ & $\begin{array}{l}\text { La presentación está } \\
\text { estructurada de forma } \\
\text { confusa }\end{array}$ & $\begin{array}{l}\text { La presentación está } \\
\text { estructurada de forma } \\
\text { clara, con algunos fallos } \\
\text { menores }\end{array}$ & $\begin{array}{l}\text { La presentación está } \\
\text { estructurada de forma } \\
\text { clara, lógica y bien } \\
\text { cohesionada }\end{array}$ \\
\hline $\begin{array}{l}\text { Estilo, lenguaje corporal y } \\
\text { registro ajustado a la defensa } \\
\text { ante un tribunal académico }\end{array}$ & $\begin{array}{l}\text { El nivel y registro no se } \\
\text { ajusta al destinatario }\end{array}$ & $\begin{array}{l}\text { Con frecuencia no se } \\
\text { tiene en cuenta el } \\
\text { destinatario }\end{array}$ & $\begin{array}{l}\text { En general el estilo es } \\
\text { adecuado }\end{array}$ & El estilo es adecuado \\
\hline $\begin{array}{l}\text { Recursos gráficos y medios para } \\
\text { comunicar de forma efectiva. }\end{array}$ & $\begin{array}{l}\text { No utiliza recursos } \\
\text { gráficos ni ayudas visuales }\end{array}$ & $\begin{array}{l}\text { Utiliza medios de apoyo } \\
\text { que no ayudan }\end{array}$ & $\begin{array}{l}\text { Utiliza medios de apoyo y } \\
\text { recursos gráficos que } \\
\text { ayudan pero no mejoran } \\
\text { la efectividad }\end{array}$ & $\begin{array}{l}\text { Diseño y utilización de } \\
\text { recursos gráficos } \\
\text { excelente y equilibrada. }\end{array}$ \\
\hline $\begin{array}{l}\text { Gestión del tiempo de la } \\
\text { presentación. }\end{array}$ & $\begin{array}{l}\text { Se excede el tiempo y el } \\
\text { tribunal interrumpe }\end{array}$ & $\begin{array}{l}\text { Se corta sin el cierre } \\
\text { adecuado- }\end{array}$ & $\begin{array}{l}\text { Demasiado deprisa o } \\
\text { demasiado lento }\end{array}$ & $\begin{array}{l}\text { Se ajusta al tiempo } \\
\text { previsto }\end{array}$ \\
\hline $\begin{array}{l}\text { Interacción con los miembros del } \\
\text { tribunal }\end{array}$ & $\begin{array}{l}\text { No contesta o responde } \\
\text { algo que no se } \\
\text { corresponde con lo } \\
\text { preguntado. }\end{array}$ & $\begin{array}{l}\text { No es capaz de contestar } \\
\text { a las preguntas }\end{array}$ & $\begin{array}{l}\text { Responde pero en algunos } \\
\text { casos, parece no entender } \\
\text { la pregunta. }\end{array}$ & $\begin{array}{l}\text { Responde de manera clara } \\
\text { y concisa a las preguntas. }\end{array}$ \\
\hline Resumen Indi & & & & \\
\hline & & & 78. & \\
\hline
\end{tabular}

Fig.1 Versión inicial de la rúbrica para la evaluación de los TFGs.

(c) EY-NC-ND 2017, Universitat Politècnica de València 
Mercedes Verdeguer Sancho, Juan Antonio Llorens Molina, Francisco García Breijo, Josefa Roselló Caselles, Alberto García Prats, Constanza Rubio Michavila, María Vargas Colás, María Pilar Santamarina Siurana

\section{Resultados}

Se ha conseguido elaborar una rúbrica con diferentes criterios para la valoración de los TFGs, que lleva asociada un intervalo de calificaciones para cada indicador, lo que permite realizar una evaluación objetiva. Los indicadores se han seleccionado de manera que es posible evaluar tanto el documento de TFG como la exposición realizada por el alumno durante la defensa pública del mismo.

Se han establecido cinco indicadores para evaluar el documento y otros cinco indicadores para evaluar la exposición del mismo. Asímismo, para cada indicador se han definido cuatro niveles de desarrollo, y cada nivel lleva asociada una puntuación númerica, para que la valoración del TFG se ciña a criterios objetivos y medibles.

Con el fin de validar la rúbrica y realizar las mejoras y correcciones oportunas, se ha preparado una encuesta (Figura 2), que se va a distribuir entre los diferentes grupos de interés (estudiantes de $4^{\circ}$ curso, profesorado y miembros de tribunales de evaluación) para que muestren su conformidad (Sí) o disconformidad con cada indicador (No) y añadan las observaciones que consideren necesarias. 


\begin{tabular}{|c|c|c|c|c|c|c|}
\hline \multicolumn{7}{|c|}{ MEMORIA } \\
\hline INDICADOR & NIVEL1 & NIVEL2 & NIVEL3 & NIVEL4 & \begin{tabular}{|l|} 
ESTOY DE \\
ACUERDO
\end{tabular} & OBSERVACIONES/SUGERENCIAS \\
\hline 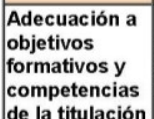 & $\begin{array}{l}\text { No se adecúa } \\
\text { a los objetivos } \\
\text { formativos. }\end{array}$ & $\begin{array}{l}\text { Se adecúa } \\
\text { de forma } \\
\text { parcial. }\end{array}$ & $\begin{array}{l}\text { Se adecúa en } \\
\text { gran medida a } \\
\text { los objetivos } \\
\text { formativos. }\end{array}$ & \begin{tabular}{|l|} 
Se adecúa de \\
forma completa a \\
los objetivos \\
formativos.
\end{tabular} & $\begin{array}{ll}\text { OSI } \\
\text { NO }\end{array}$ & \\
\hline $\begin{array}{l}\text { Introducción } \\
\text { (antecedentes) } \\
\text { y Objetivos }\end{array}$ & $\begin{array}{l}\text { No cita o lo } \\
\text { hace } \\
\text { exclusivamente } \\
\text { con fuentes } \\
\text { meramente } \\
\text { divulgativas. } \\
\text { No aparecen } \\
\text { de manera } \\
\text { explicita los } \\
\text { objetivos o se } \\
\text { confunden con } \\
\text { plan de trabajo } \\
\text { o metodologia. } \\
\text { No se plantea } \\
\text { el problema } \\
\text { que da sentido } \\
\text { al TFG. }\end{array}$ & \begin{tabular}{|l|} 
Cita otros \\
trabajos, \\
pero \\
obviando \\
aspectos \\
importantes \\
del tema \\
tratado. \\
Los objetivos \\
están \\
enumerados \\
pero el \\
problema al \\
que \\
responde el \\
TFG no está \\
planteado.
\end{tabular} & $\begin{array}{l} \\
\text { Cita otros } \\
\text { trabajos, } \\
\text { abarcando los } \\
\text { distintos } \\
\text { aspectos del } \\
\text { tema tratado. } \\
\text { Los objetivos } \\
\text { son definidos y } \\
\text { enumerados, } \\
\text { aunque de } \\
\text { forma } \\
\text { incompleta. } \\
\end{array}$ & \begin{tabular}{|l|} 
Cita el trabajo \\
ajeno \\
sistemáticamente \\
relacionándolos \\
con los \\
contenidos del \\
TFG. \\
Los objetivos \\
están claramente \\
definidos y \\
enumerados. \\
Responden a \\
problemas \\
claramente \\
definidos.
\end{tabular} & No & \\
\hline Resultados & $\begin{array}{l}\text { La expresión } \\
\text { de los } \\
\text { resultados es } \\
\text { claramente } \\
\text { inadecuada o } \\
\text { existen errores } \\
\text { metodológicos } \\
\text { que afectan a } \\
\text { su validez. No } \\
\text { dan respuesta } \\
\text { a los objetivos } \\
\text { planteados. }\end{array}$ & $\begin{array}{l}\text { Muestran } \\
\text { errores y } \\
\text { omisiones } \\
\text { en la } \\
\text { expresión de } \\
\text { los } \\
\text { resultados } \\
\text { (gráficos, } \\
\text { unidades, } \\
\text { etc.) o no se } \\
\text { ajustan a la } \\
\text { metodología. }\end{array}$ & $\begin{array}{l}\text { La expresión de } \\
\text { los resultados } \\
\text { es formalmente } \\
\text { correcta. } \\
\text { Se aprecian } \\
\text { errores u } \\
\text { omisiones que } \\
\text { no afectan } \\
\text { sustancialmente } \\
\text { a las } \\
\text { conclusiones. } \\
\end{array}$ & \begin{tabular}{|l} 
Los resultados \\
están \\
correctamente \\
expresados, \\
están bien \\
relacionados con \\
los objetivos del \\
TFG y son \\
coherentes con \\
su metodología.
\end{tabular} & @isı & \\
\hline $\begin{array}{l}\text { Evaluación de } \\
\text { la solución } \\
\text { aportada para } \\
\text { alcanzar los } \\
\text { objetivos del } \\
\text { trabajo }\end{array}$ & $\begin{array}{l}\text { No valora el } \\
\text { resultado. }\end{array}$ & $\begin{array}{l}\text { Analiza el } \\
\text { resultado sin } \\
\text { valorarlo. }\end{array}$ & \begin{tabular}{|l|}
$\begin{array}{l}\text { Analiza los } \\
\text { resultados y los } \\
\text { valora. }\end{array}$ \\
\end{tabular} & \begin{tabular}{|l|} 
Analiza los \\
resultados, los \\
valora, valida y \\
los contrasta con \\
los objetivos \\
planteados.
\end{tabular} & Nosi O & \\
\hline \begin{tabular}{|l} 
Adecuación \\
del documento \\
a la normativa \\
en cuanto a \\
estructura y \\
aspectos \\
formales
\end{tabular} & $\begin{array}{l}\text { Ausencia } \\
\text { injustificada de } \\
\text { alguna de las } \\
\text { secciones del } \\
\text { documento y/o } \\
\text { errores } \\
\text { importantes en } \\
\text { cuestiones } \\
\text { formales. }\end{array}$ & \begin{tabular}{|l|} 
Aparecen \\
todas las \\
secciones \\
del \\
documento \\
pero se \\
observan \\
errores \\
sistemáticos \\
en \\
cuestiones \\
formales: \\
tablas, pies \\
de figuras, \\
etc.
\end{tabular} & $\begin{array}{l}\text { Aparecen todas } \\
\text { las secciones } \\
\text { del documento } \\
\text { pero se } \\
\text { observan fallos } \\
\text { puntuales en } \\
\text { cuestiones } \\
\text { formales: } \\
\text { tablas, pies de } \\
\text { figuras, etc. }\end{array}$ & $\begin{array}{l}\text { Aparecen todas } \\
\text { las secciones del } \\
\text { documento y no } \\
\text { se observan } \\
\text { errores } \\
\text { significativos en } \\
\text { cuestiones } \\
\text { formales: tablas, } \\
\text { pies de figuras, } \\
\text { etc. }\end{array}$ & Nosi & \\
\hline \multicolumn{7}{|c|}{ PRESENTACIÓN } \\
\hline $\begin{array}{l}\text { Organización } \\
\text { de la } \\
\text { información } \\
\text { presentada } \\
\text { durante la } \\
\text { defensa }\end{array}$ & \begin{tabular}{|l} 
La \\
presentación \\
está \\
desordenada y \\
sin estructura \\
lógica.
\end{tabular} & \begin{tabular}{|l|} 
La \\
presentación \\
está \\
estructurada \\
de forma \\
confusa. \\
\end{tabular} & \begin{tabular}{|l|} 
La presentación \\
está \\
estructurada de \\
forma clara, con \\
algunos fallos \\
menores.
\end{tabular} & \begin{tabular}{|l|} 
La presentación \\
está estructurada \\
de forma clara, \\
logica y bien \\
cohesionada.
\end{tabular} & $\begin{array}{l}\text { @SI O } \\
\text { NO }\end{array}$ & \\
\hline
\end{tabular}

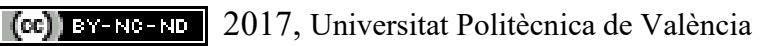


Mercedes Verdeguer Sancho, Juan Antonio Llorens Molina, Francisco García Breijo, Josefa Roselló Caselles, Alberto García Prats, Constanza Rubio Michavila, María Vargas Colás, María Pilar Santamarina Siurana

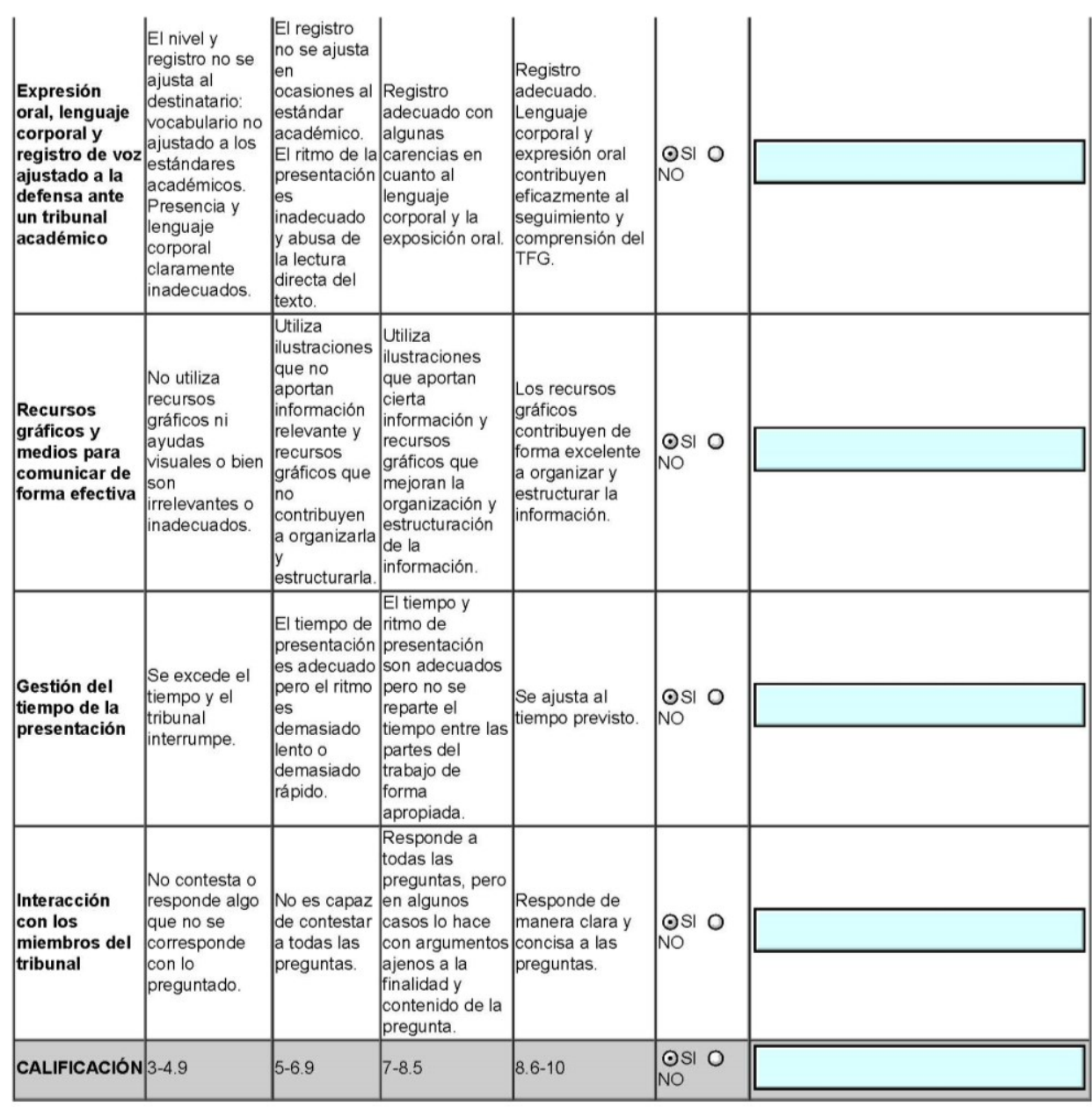

Fig. 2. Encuesta sobre la rúbrica elaborada para evaluar los TFGs.

\section{Conclusiones}

Se ha conseguido elaborar una encuesta rúbrica para valorar los TFGs en la ETSIAMN con criterios de evaluación medibles y puntuables numéricamente. Es necesario que la rúbrica sea distribuída entre los diferentes grupos de interés para que puedan expresar sus opiniones y revisar los indicadores y descriptores actuales, con el fin de validar la rúbrica y que pueda ser utilizada en las próximas convocatorias de defensa de TFGs

\section{Referencias:}

BERROCOSO, J. V. (2014). "El uso de e-rúbricas para la evaluación de competencias en estudiantes universitarios. Estudio sobre fiabilidad del instrumento". REDU. Revista de Docencia Universitaria, 12(1), 49-79.

GARCÍA-ROS, R. (2011). "Análisis y validación de una rúbrica para evaluar habilidades de presentación oral en contextos universitarios". Electronic Journal of Research in Educational Psychology, 9(3), 1043-1062. 
JAUME-I-CAPÓ, A., GUERRERO, C., MIRÓ, J., \& EGEA, A. (2012). “Elaboración de una rúbrica para la evaluación TFG y TFM de informática en la Universitat de les Illes Balears". Jornadas de Enseñanza de la Informática (18es: 2012: Ciudad Real). Disponible en http://upcommons.upc.edu/handle/2099/15089 [Consulta 30 de mayo de 2017]

MORENO, V., HERNÁNDEZ-LEO, D., CAMPS, I., MELERO, J. (2012). "Uso de rúbricas para el seguimiento y evaluación de los trabajos de fin de grado". En: II Congreso Internacional sobre evaluación por competencias mediante eRúbricas (24-26 octubre 2012 Málaga). Disponible en https://repositori.upf.edu/handle/10230/19801 [Consulta 30 de mayo de 2017]

TORRES GORDILLO, J. J., PERERA RODRÍGUEZ, V. H. (2010). "La rúbrica como instrumento pedagógico para la tutorización y evaluación de los aprendizajes en el foro online en educación superior". Pixel-Bit, 36, 141-149.

RAPOSO, M., MARTÍNEZ, E. (2011). "La rúbrica en la enseñanza universitaria: un recurso para la tutoría de grupos de estudiantes". Formación universitaria, 4(4), 19-28.

VALDERRAMA VALLÉS, E., RULLÁN AYZA, M., SÁNCHEZ CARRACEDO, F., PONS, J., CORES PRADO, M. F., BISBAL RIERA, J. (2009). "La evaluación de competencias en los Trabajos Fin de Estudios". XV JENUI. Barcelona, 405-412.

WEBSTER, F., PEPPER, D., JENKINS, A. (2000). "Assessing the undergraduate dissertation". Assessment and Evaluation in Higher Education, 25(1), 71-80. doi:10.1080/02602930050025042 


\title{
Análisis del grado de consistencia entre diferentes modos de evaluar las competencias transversales de creatividad, pensamiento crítico, liderazgo y trabajo en equipo/red ${ }^{1}$
}

\author{
Marin-Garcia, Juan A. ${ }^{\text {, }}$, Maheut, Julien ${ }^{\mathrm{b}}$,Garcia-Sabater, Julio J.c
}

a,b,c ROGLE. Dpto. de Organización de Empresas. Universitat Politècnica de València. Camino de Vera S/N 46021 Valencia. ${ }^{\mathrm{a}}$ jamarin@omp.upv.es, ${ }^{\mathrm{b}}$ julien.maheut@gmail.com and ${ }^{\mathrm{c}}$ jugarsa@omp.upv.es.

\begin{abstract}
In this paper, we analyze three different ways of qualifying soft skills in a Master course with 21 students. Both the holistic qualification of the 4 competences together and the analytical qualification in paired comparison present an excellent degree of agreement. However, the analytical qualification based on the qualification of exercises and tasks, despite reproduce quite well the order of the qualifications with respect to the judgment of the expert (teacher) has very different absolute values that indicate that the grades are concentrated and do not adequately represent the differences in the competences between the students
\end{abstract}

Keywords: marks; grade; student performance; higher education; summative assessment; soft skills; paired comparison

\section{Resumen}

En este trabajo analizamos tres modos diferentes de calificar las competencias transversales en una asignatura de Máster con 21 alumnos. Tanto la calificación holística de las 4 competencias juntas, como la calificación analítica usando comparación pareada presentan un excelente grado de acuerdo. Sin embargo, la calificación analítica basada en calificación de ejercicios y tareas, pese a respetar el orden de las calificaciones respecto al juicio del experto (profesor) tiene unos valores absolutos muy dispares que indican que las notas se concentran y no representa adecuadamente las diferencias en cuanto a competencias entre los alumnos.

Palabras clave: calificación; desempeño de estudiantes; educación universitaria; evaluación sumativa; competencias transversales; comparación pareada

\footnotetext{
${ }^{1}$ Esta comunicación puede considerarse un paso previo de otra publicación de los autores (Marin-Garcia et al., 2017a) cuyo objetivo, contribución y marco teórico son diferentes y amplían de manera significativa los objetivos de esta comunicación.
} 


\section{Introducción}

Las competencias transversales (soft skills) forman parte de la educación de estudiantes de ingeniería, no sólo por tratarse de requerimientos de agencias nacionales o internacionales (ANECA, EURACE, ABET), sino porque permiten equipar a los alumnos con herramientas que necesitarán en su trabajo como profesionales (Andersen, 2004; Anthony \& Garner, 2016; Halfhill \& Nielsen, 2007; Perello-Marin et al., 2016).

Sin embargo, la evaluación de estas competencias no es una tarea fácil (Halfhill \& Nielsen, 2007; Ingols \& Shapiro, 2014), porque se trata de conceptos multidimensionales (Balasundaram Ramakishnan \& Ramadoss, 2009; Villa Sánchez \& Poblete, 2007; Watts et al., 2006), no abundan los instrumentos validados (Marin-Garcia \& Santandreu-Mascarell, 2015) y existen varias opciones de escalas de respuesta para cada instrumento (Marin-Garcia et al., 2015).

A pesar de la dificultad, es una tarea exigida en algunas universidades para tener los datos necesarios a la hora de confeccionar el expediente académico de los alumnos. En la Universitat Politècnica de València esta iniciativa se concreta en las asignaturas punto de control y queda reflejada en las guías docentes.

En este contexto, parece que las calificaciones de las competencias transversales no son tan fiables como se desearía. Al menos esa es la impresión, usando como fuente las reuniones de las Comisiones Académicas de varios Títulos de grado/master o conversaciones con profesores. La sensación de los profesores es que no están convencidos de las calificaciones otorgadas. Por otra parte, tomando los datos de cada asignatura, las calificaciones de las competencias transversales presentan poca dispersión entre los alumnos de un grupo y quizás inconsistencia entre diferentes asignaturas que ejercen de punto de control de la misma competencia.

Es posible que ambos fenómenos no sean un problema del sistema de calificación. Si todos los alumnos muestran unas competencias muy parecidas (porque las desarrollan hasta un nivel muy similar), es normal que las calificaciones estén concentradas en sólo unos pocos valores. Por otra parte, los alumnos pueden presentar comportamientos muy diferentes en asignaturas distintas, bien sea por la motivación de la temática, el método de enseñanza/aprendizaje, el profesorado, el horario de la asignatura o por los compañeros con los que interactúen. De modo que, por ejemplo, un alumno puede mostrarse muy creativo, en una asignatura y muy poco en otra que esté siendo, al mismo tiempo, punto de control de esta competencia. En esta situación, que el mismo alumno, el mismo año, reciba calificaciones diferentes en distintas asignaturas punto de control, no sería un problema de calificación; sino que el alumno se comporta de manera diferente en las asignaturas. Esto es algo que no nos extraña en las competencias específicas y, sin embargo, puedo parecer raro en competencias transversales, quizás porque asumamos que son aspectos de personalidad que no son afectados por el contexto. Asunción que probablemente es errónea.

En la literatura existen algunas rúbricas o herramientas de diagnóstico que intentan mejorar la fiabilidad o validez de la calificación de las competencias transversales de

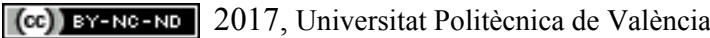

Congreso IN-RED (2017) 
creatividad/innovación (Marin-Garcia et al., 2016a; Villa Sánchez \& Poblete, 2007), pensamiento crítico (Marin-Garcia et al., 2016a; Villa Sánchez \& Poblete, 2007); trabajo en equipo (Marin-Garcia et al., 2016a; Perello-Marin et al., 2016; Pratten et al., 2014; Villa Sánchez \& Poblete, 2007) y comunicación (Marin-Garcia et al., 2017b; Marin-Garcia et al., 2008; Villa Sánchez \& Poblete, 2007). Adicionalmente, en la Universitat Politècnica de València (UPV) se han propuesto unas rúbricas como orientación para la evaluación de esas competencias (http://www.upv.es/contenidos/COMPTRAN/)

\section{Objetivos}

- Comparar tres modos de evaluar las competencias transversales:

o Evaluación holística de 0 a 10 basada en superación de objetivos de aprendizaje

- Evaluación analítica mediante comparación pareada y incluyendo niéveles de referencia inspirados en las rúbricas de competencias trasversales UPV

o Evaluación analítica del producto y proceso de aprendizaje de los alumnos utilizando rúbricas, listas de comprobación o baremos específicos creados por el profesor responsable de la asignatura

- Analizar la consistencia y la viabilidad de las tres alternativas

\section{Desarrollo de la innovación}

"Los datos utilizados provienen del curso 2016-17 en una asignatura de master con 21 alumnos. La asignatura se imparte durante 13 semanas lectivas en sesiones de 3,5 horas (una sesión semanal)" (Marin-Garcia et al., 2017a). La asignatura es punto de control de las competencias:

- CT4: innovación, creatividad y emprendimiento

- CT6: trabajo en equipo y liderazgo

- CT8: comunicación efectiva

- CT9: pensamiento crítico

Un aspecto particular de nuestra experiencia es que las competencias analizadas, no son "transversales" para la asignatura, sino que constituyen la esencia de la misma y representan el $100 \%$ de los objetivos de aprendizaje y, por lo tanto, de la nota final de los alumnos.

A continuación describimos los tres modos de obtener las calificaciones que hemos usado en esta investigación (Marin-Garcia et al., 2017a):

- “SE0.1: calificación de 0 a 10 holística, basada en los resultados de aprendizaje superados por la persona, utilizando las anotaciones tomadas en observaciones en clase, las preguntas directas a los alumnos, las preguntas que formulan los alumnos y los errores conceptuales que manifiestan. Cada semana el profesor dedicaba unas dos horas y media de clase a esta actividad mientras los alumnos realizaban actividades en su presencia”

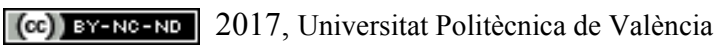
Congreso In-Red (2017) 
- "SE0.2: utilizando un método de comparación pareada (Marin-Garcia et al., 2016b) derivada de trabajos previos (Marin-Garcia et al., 2014; Marin-Garcia et al., 2015). El proceso se inicia comparando parejas de alumnos indicando quién, a juicio del profesor, había mostrado mejor desempeño en creatividad, pensamiento crítico, intra-emprendimiento, trabajo en equipo, trabajo en red (figura 1). Se añadieron 3 alumnos ficticios para las comparaciones con niveles de referencia (figura 2), cada uno de ellos representaban el nivel excelente (equivalente a un 10), medio (equivalente a un 7) y bajo (equivalente a un 3) de las competencias analizadas (basado en las rúbricas orientadoras de la UPV). Para calificar las comparaciones se ofrecían 3 opciones (la persona A tiene mayor rendimiento que B, igual rendimiento, la persona B tiene mayor rendimiento que A)". En la Figura 1 mostramos la pantalla de calificación cuando se comparaban dos alumnos; y en la Figura 2 cuando se comparaba un alumno de la asignatura con la descripción de comportamientos que representaban el nivel de referencia. "El sistema utiliza un algoritmo de grafos para decidir cuáles son las parejas a mostrar. En lugar de ser necesarias las 210 comparaciones posibles (para 21 alumnos), el procedimiento ha convergido a una solución tras 50 comparaciones (ver Tabla 1). El tiempo invertido por el profesor han sido 10 minutos en total. El resultado muestra 10 grupos (cada uno con uno o varios alumnos). Los alumnos que comparten grupo, son equivalentes en cuanto a desempeño. La distancia entre los grupos es proporcional al desempeño en las competencias analizadas. Una vez identificados los nodos (grupos de alumnos con similares resultados de aprendizaje) se ha procedido a volver a escalar las distancias en una nota de 0 a 10. Para ello, se ha identificado el nodo que contenía a cada nivel de referencia y se le ha imputado la nota (10, 7 o 3 ) correspondiente (ver Tabla 2). Al resto de nodos se les ha asignado una nota numérica proporcional a la distancia con los nodos ya calificados"

- "SE1: es una media ponderada. Consta de 30 registros por cada alumno. Estos registros están agrupados (se calcula el promedio) en 6 categorías cuya ponderación para el cálculo de la nota final de la asignatura aparece reflejado en la Tabla 3. Se han elaborado rúbricas detalladas para puntuar cada una de las actividades que se contemplan en los registros. En algunos casos son listas de comprobación Sí/no y en otros casos son rúbricas analíticas con ejemplos de comportamientos o resultados en 3-5 niveles de desempeño. Los alumnos han dispuesto de una copia de las rúbricas desde el principio del curso y han sido explicadas con detalle antes del inicio de cada una de las actividades. En algunos casos se han utilizado con ejercicios de ejemplos para que los alumnos tuvieran información de cómo se emplearían en la calificación de sus trabajos. El desempeño excepcional en alguno de los trabajos daba origen a notas por encima de 10/10"

Entre la calificación SE0.1 y SE0.2 transcurrieron 15 días en los que el profesor ya no trabajaba en la asignatura, por lo que consideramos que esas calificaciones son independientes y no están sesgadas por la secuencia en la que se han realizado.

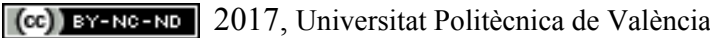

Congreso IN-RED (2017) 
Figura 1. Comparación cuando se mostraban dos alumnos

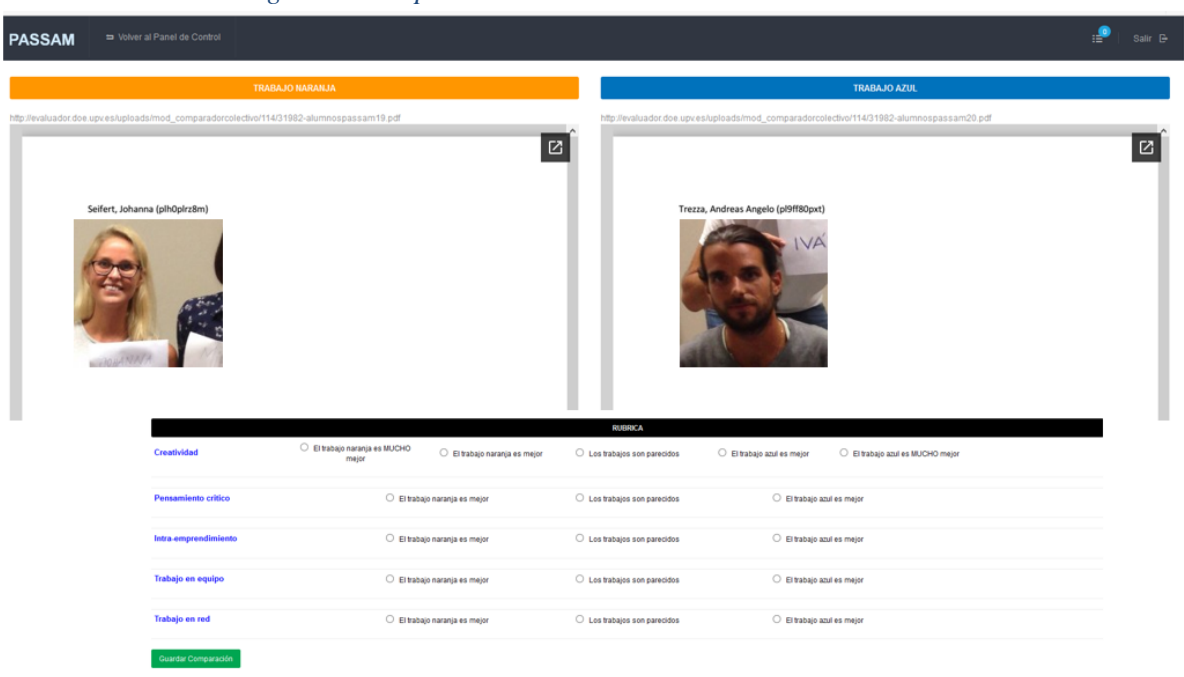

Figura 2. Comparación cuando se mostraba un alumno y un nivel de referencia

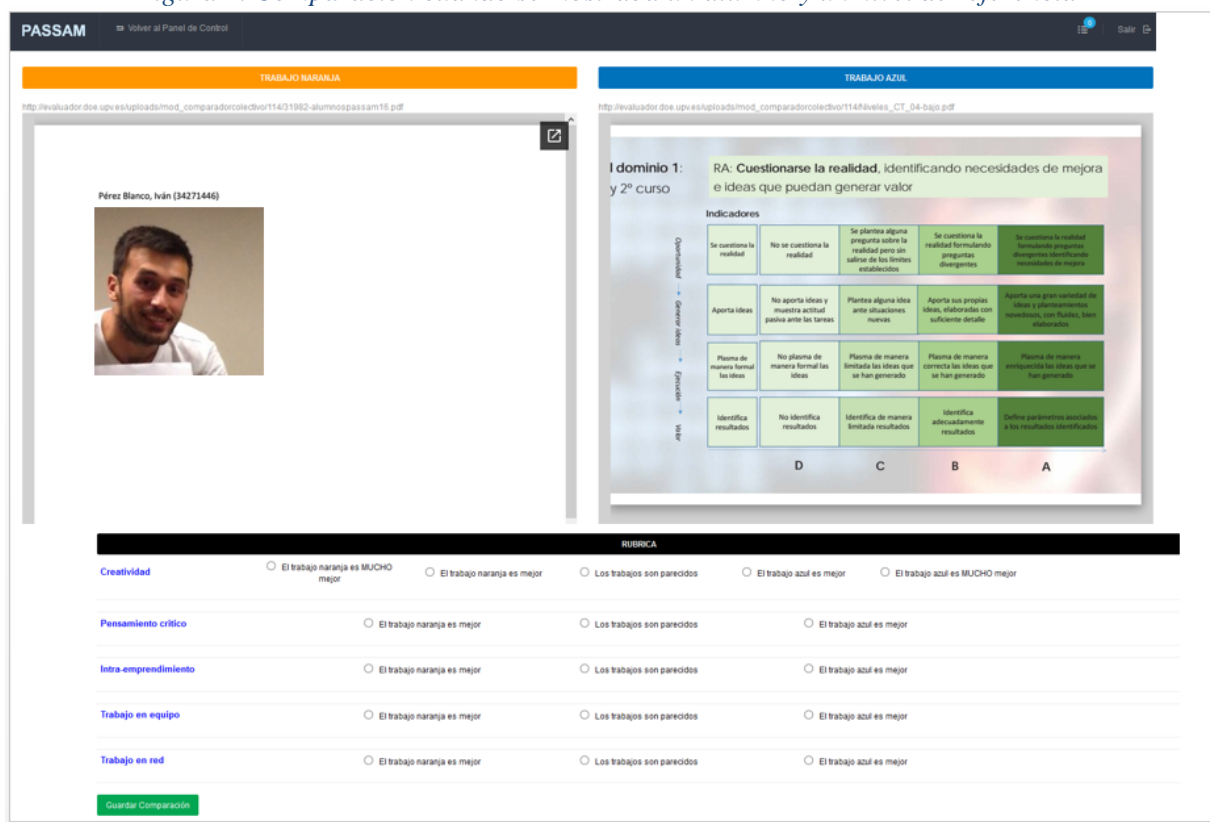

(c) EY-NC-ND 2017, Universitat Politècnica de València Congreso In-Red (2017) 


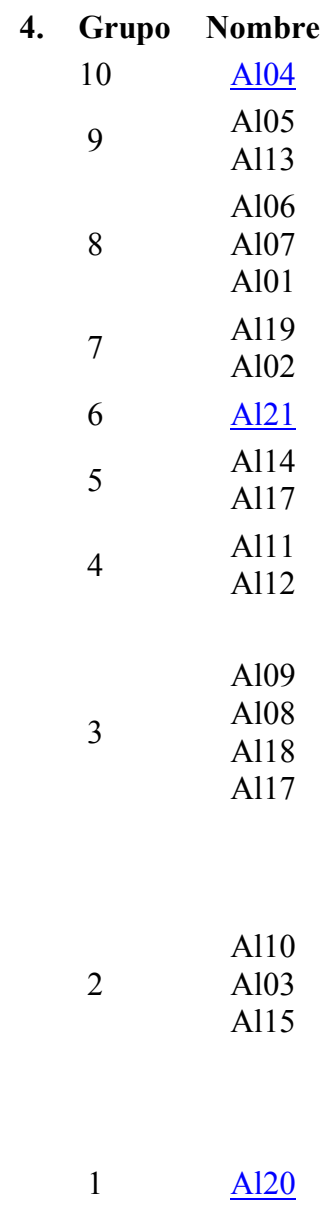

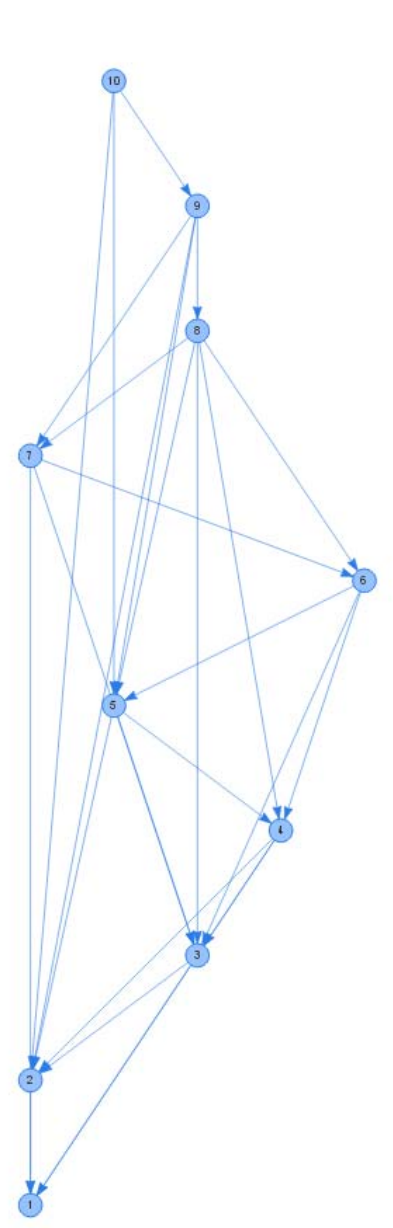

Tabla 1 . Nodos del paso 1 en SE0.2

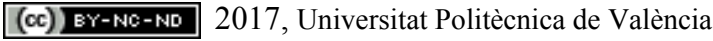

Congreso IN-RED (2017) 


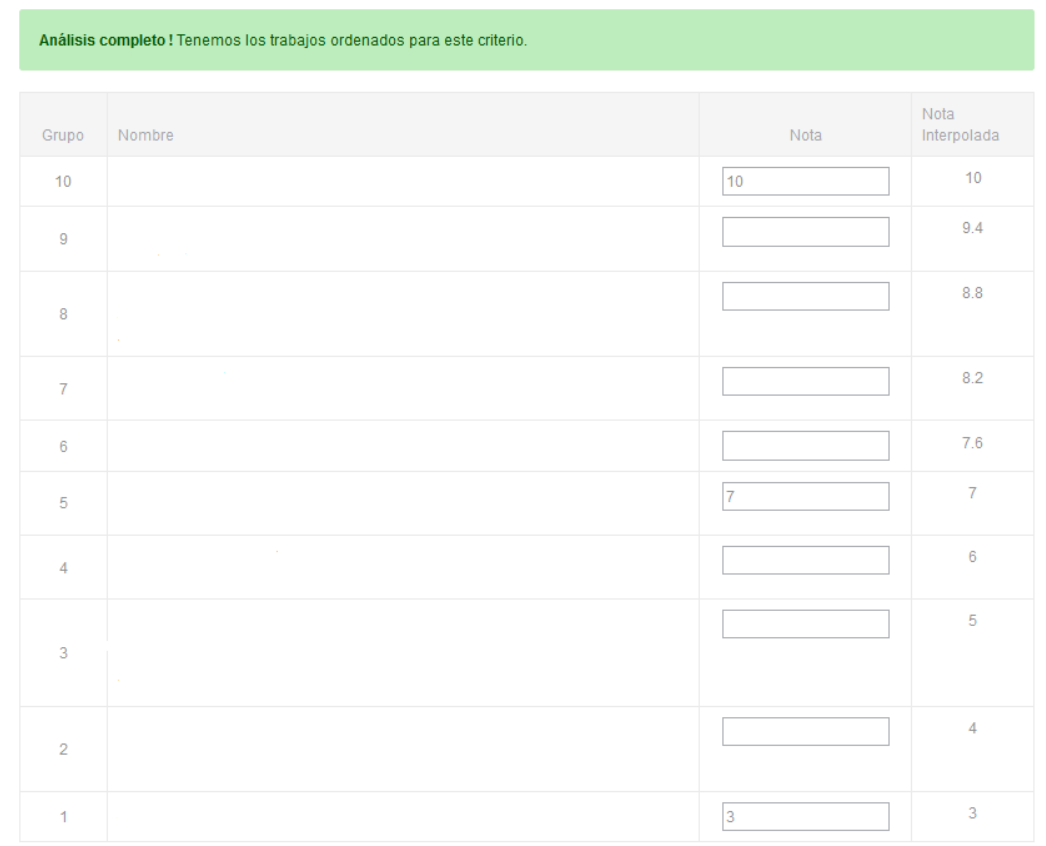

Tabla 2 . Re-escalado de notas. Paso 2 en SE0.2

\begin{tabular}{|l|l|l|l|}
\hline \multicolumn{1}{|c|}{ Categoría } & \multicolumn{1}{|c|}{$\begin{array}{c}\mathrm{N}^{\mathrm{o}} \text { de } \\
\text { registros }\end{array}$} & $\begin{array}{c}\text { Nota media de } \\
\text { la clase }\end{array}$ & $\begin{array}{c}\text { Peso } \\
\mathbf{( \% )}\end{array}$ \\
\hline Asistencia (S) & 13 & 8.5 & $24 \%$ \\
\hline Diario y tareas en el Foro (V) & 2 & 6.9 & $20 \%$ \\
\hline Exámenes On-line (Y) & 3 & 9.4 & $17 \%$ \\
\hline Producto individual (T) & 3 & 9.0 & $18 \%$ \\
\hline $\begin{array}{l}\text { Proyecto de mejora en equipo -Proceso de } \\
\text { grupo (X) }\end{array}$ & 2 & 10.0 & $14 \%$ \\
\hline $\begin{array}{l}\text { Puntos profesor (Z) (incluyendo rubrica de } \\
\text { presentaciones orales) }\end{array}$ & 1 & 8.7 & $7 \%$ \\
\hline
\end{tabular}

Tabla 3 . Componentes del sistema de evaluación SE1

Nuestro objetivo es comparar SE1, SE0.1 y SE0.2 Consideraremos el ajuste como el coeficiente de correlación de rangos de Spearman y el coeficiente de correlación intra-clase (ICC(2,1) agreement) (Hair et al., 1995; Losilla et al., 2005; Marin-Garcia, 2009; MarinGarcia et al., 2014; Marin-Garcia et al., 2017b).

\section{Resultados}

En la Tabla 4 resumimos los resultados de las calificaciones finales.

(cc) EY-NC-ND 2017, Universitat Politècnica de València Congreso In-Red (2017) 


\begin{tabular}{|c|c|c|c|}
\hline PERSONA & SE0.1 & SE0.2 & SE1 \\
\hline AL01 & 8 & 8.8 & 9.1 \\
\hline AL02 & 9.5 & 8.2 & 9.3 \\
\hline AL03 & 4 & 4 & 8.3 \\
\hline AL04 & 10 & 10 & 10.8 \\
\hline AL05 & 9.8 & 9.4 & 9.6 \\
\hline AL06 & 9.5 & 8.8 & 9.6 \\
\hline AL07 & 9.5 & 8.8 & 10.1 \\
\hline AL08 & 6.5 & 5 & 7.9 \\
\hline AL09 & 6 & 5 & 7.8 \\
\hline AL10 & 4 & 4 & 8.1 \\
\hline AL11 & 7 & 6 & 7.9 \\
\hline AL12 & 6 & 6 & 8.2 \\
\hline AL13 & 8.5 & 9.4 & 9.1 \\
\hline AL14 & 8 & 7 & 9.4 \\
\hline AL15 & 4 & 4 & 8.0 \\
\hline AL16 & 7 & 7 & 7.1 \\
\hline AL17 & 5 & 5 & 7.8 \\
\hline AL18 & 5 & 5 & 8.0 \\
\hline AL19 & 9 & 8.2 & 9.6 \\
\hline AL20 & 4 & 3 & 7.6 \\
\hline AL21 & 7 & 7.6 & 10.0 \\
\hline
\end{tabular}

Tabla 4 . Calificaciones finales de las 21 personas matriculadas, dependiendo del sistema de cómputo elegido

Las correlaciones de rangos entre los diferentes métodos son todas elevadas (Tabla 5). Esto indica que, independientemente del valor absoluto de la calificación, todos los métodos ordenan de manera bastante similar a los estudiantes. Sin embargo, nosotros estamos interesados no en la correlación, sino en el acuerdo entre puntuaciones, ya que es la puntuación absoluta la que genera la categoría de calificaciones en el acta de la asignatura y queremos ver qué método genera unas calificaciones similares a las del evaluador experto.

Observando los valores de $\operatorname{ICC}(2,1)$ podemos comprobar que el método SE0.1 tienen un grado de acuerdo excelente con SE0.2. Es decir, el juicio del experto tiene una fiabilidad elevada tanto al cambiar el método para realizar la calificación, como al dejar pasar el tiempo y hacer un Test/re-test. Si tomamos las calificaciones SE0.2 como "gold standard", se manifiesta un elevado desacuerdo con las calificaciones obtenidas con la media aritmética ponderada (SE1). 


\begin{tabular}{l|rrr} 
& SE0.1 & SE0.2 & SE1 \\
\hline SE0.1 & - & $\mathbf{0 . 9 4 0}$ & \\
SE0.2 & $0.950^{* *}$ & - & $\mathbf{0 . 3 5 4}$ \\
SE1 & $0.727^{* *}$ & $0.733^{* *}$ & -
\end{tabular}

Tabla 5 .Grado de acuerdo entre las medidas. En la diagonal inferior correlación Spearman's rho. En la submatriz superior (negrita) las $\operatorname{ICC}(2,1)$ de cada variable comparada con SE0.2. ** nivel de significación $1 \%$

\section{Conclusiones}

Presentamos los resultados de comparar varios modos de calificar competencias transversales. La principal contribución para los profesores se aplica a grupos poco numerosos donde se puede llegar a conocer con detalle el grado de aprendizaje de los alumnos, el método de comparación pareada es el que presenta unas calificaciones más acordes con el juicio experto del profesor. La comparación pareada se hace de una manera muy eficiente en tiempo. Requiriendo solo 10 minutos adicionales respecto a las horas dedicadas a observación y feedback formativo realizado durante el curso. La comparación pareada es un método muy poco usado en la evaluación de estudiantes y convendría seguir investigando sobre las ventajas e inconvenientes de este método, que parece prometedor, con los datos del caso estudiado en este artículo.

La principal limitación de este trabajo es que sólo se ha probado en un grupo. Sería recomendable replicar la investigación con asignaturas similares y asignaturas con grupos masificados, de otros niveles (grado con 70-90 alumnos por grupo) y de otras titulaciones.

\section{Agradecimientos}

Este trabajo ha sido parcialmente financiado por la Universitat Politécnica de Valencia (PIME/2016/A/027/A) "La evaluación pareada como metodología para la evaluación del pensamiento crítico de los alumnos".

\section{Referencias}

Andersen, A. (2004). Preparing engineering students to work in a global environment to cooperate,to communicate and to compete. European Journal of Engineering Education, 29(4), 549-558.

Anthony, S., \& Garner, B. (2016). Teaching soft skills to business students: An analysis of multiple pedagogical methods. Business and Professional Communication Quarterly, 79(3), 360-370. doi:10.1177/2329490616642247

Balasundaram Ramakishnan, S., \& Ramadoss, B. (2009). Assessment using multi-criteria decision approach for higher order skills learning domains. International Journal on E-Learning, 8(2), 241-262.

Hair, J. F., Anderson, R. E., Tatham, R. L., \& Black, W. C. (1995). Multivariate data analysis ( $4^{\mathrm{o}}$ ed.). New Jersey: Prentice Hall. 
Halfhill, T. R., \& Nielsen, T. M. (2007). Quantifying the "softer side" of management education: An example using teamwork competencies. Journal of Management Education, 31(1), 64-80.

Ingols, C., \& Shapiro, M. (2014). Concrete steps for assessing the soft skills in an mba program. Journal of Management Education, 38(3), 412-435.

Losilla, J. M., Navarro, J. B., Palmer, A., Rodrigo, M. F., \& Ato, M. (2005). Análisis de datos. Del contraste de hipótesis al modelado estadístico. Barcelona: Edicions a Petició.

Marin-Garcia, J. A. (2009). Los alumnos y los profesores como evaluadores. Aplicación a la calificación de presentaciones orales. Revista Espanola De Pedagogia, 67(242), 7997.

Marin-Garcia, J. A., Andreu Andres, M. A., Atares-Huerta, L., Aznar-Mas, L. E., GarciaCarbonell, A., González-Ladrón-de-Guevara, F., . . . Watts, F. (2016a). Propossal of framework for innovation competencies development and assessment (fincoda). WPOM-Working Papers on Operations Management, 7(2), 119-126. doi:http://dx.doi.org/10.4995/wpom.v7i2.6472

Marin-Garcia, J. A., Aragonés Beltran, P., \& Melón, G. (2014). Intra-rater and inter-rater consistency of pair wise comparison in evaluating the innovation competency for university students. WPOM-Working Papers on Operations Management, 5(2), 2446. doi:http://dx.doi.org/10.4995/wpom.v5i2.3220

Marin-Garcia, J. A., Garcia-Sabater, J. P., Morant Llorca, J., \& Conejero, J. A. (2016b). Passam: Peer assessment and monitoring system. Paper presented at the Congreso Nacional de Innovación Educativa y Docencia en Red- Universitat Politècnica de València-Valencia 07/07/16 al 08/07/16.

Marin-Garcia, J. A., Maheut, J., \& Garcia-Sabater, J. J. (2017a). Comparison of different ways of compute the grades of continuous assessment in the final grade. WPOMWorking Papers on Operations Management, 8(SpIss), in press.

Marin-Garcia, J. A., Maheut, J., \& Santandreu-Mascarell, C. (2017b). Protocol: Inter-rater and intra-rater consistency validation of a rubric to assess oral presentation skills for university students. WPOM-Working Papers on Operations Management, 7(2), (in press).

Marin-Garcia, J. A., Miralles Insa, C., \& Marin Garcia, P. (2008). Oral presentation and assessment skills in engineering education. International Journal of Engineering Education, 24(5), 926-935.

Marin-Garcia, J. A., Ramirez Bayarri, L., \& Atares-Huerta, L. (2015). Protocol: Comparing advantages and disadvantages of rating scales, behavior observation scales and paired comparison scales for behavior assessment of competencies in workers. A systematic literature review. WPOM-Working Papers on Operations Management, 2(6), 49-63. doi:http://dx.doi.org/10.4995/wpom.v6i2.4032

Marin-Garcia, J. A., \& Santandreu-Mascarell, C. (2015). What do we know about rubrics used in higher education? Intangible Capital, 11(1), 118-145. doi:http://dx.doi.org/10.3926/ic.

Perello-Marin, M. R., Vidal-Carreras, P. I., \& Marin-Garcia, J. A. (2016). What do undergraduates perceive about teamwork? International Journal of Engineering Education, 32(3), 1171-1181.

Pratten, M. K., Merrick, D., \& Burr, S. A. (2014). Group in- course assessment promotes cooperative learning and increases performance. Anatomical Sciences Education, 7(3), 224-233. doi:10.1002/ase.1397

Villa Sánchez, A., \& Poblete, M. (2007). Aprendizaje basado en competencias. Una propuesta para la evaluación de las competencias genéricas. Bilbao: Universidad de Deusto.

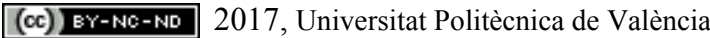


Watts, F., García-Carbonell, A., \& Llorens, J. (2006). Introducción a la evaluación compartida: Investigación multidisciplinar. In F. Watts \& A. García-Carbonell (Eds.), La evaluación compartida: Investigación multidisciplinar (1 ed., pp. 1-9). Valencia: Editorial de la UPV 


\title{
Sesión de posters apoyada en plataformas de e-learning
}

\section{Luis Antonio Tortajada Genaro ${ }^{\mathrm{a}, \mathrm{b}}$, Rosa Puchades ${ }^{\mathrm{a}}$}

a Departamento de Química. UNIVERSITAT POLITÈCNICA DE VALÈNCIA. Camí de Vera S/N, Valencia (España). 46022.

b Grupo de innovación docente TECOF "Trabajo y Evaluación de Asignaturas mediante Técnicas de Evaluación Continua Formativa”. UNIVERSITAT POLITÈCNICA DE VALÈNCIA. Camí de Vera S/N, Valencia (España). 46022.

\begin{abstract}
The poster sessions are a teaching-learning strategy, that simulates working scenarios in the university classroom. The success of this exercice is related to how the previous tasks have been addressed. In this communication, the results of a teaching action focused on the elaboration and exhibition of a poster as materialization of a learning process by inquiry are presented. Given its complexity, the proposed approach has been a colaborative activity and supported by a virtual educational space that facilitates an active and flexible interaction between teachers and students and between the students themselves. Furthermore, a system of continuous formative assessment has been set up so that the feedback can be highlighted during its development. The student results achieved show the excellent combination of quality and satisfaction for the academic work carried out. In addition to inducing the acquisition of knowledge in specialized topics, it has been possible to promote skills related to communication, critical thinking, creativity, and cooperation.
\end{abstract}

Keywords: inquiry-based learning, collaborative learning, poster evaluation, Sakai platform

\footnotetext{
Resumen

Las sesiones de posters son una estrategia de enseñanza-aprendizaje que permiten simular escenarios laborales en el aula universitaria. El éxito de esta actividad está relacionado con el modo con que se han abordado tareas anteriores. En esta comunicación, se presentan los resultados de una acción docente dirigida a la elaboración y exposición de un póster como materialización de un proceso de aprendizaje por indagación. Dada su complejidad, el enfoque propuesto ha consistido en una actividad colaborativa apoyada por un espacio virtual educativo que facilite una interacción activa y flexible entre los profesores y los alumnos, y entre los propios alumnos. Al mismo tiempo, se ha instaurado un sistema de evaluación continua formativa para que la retro-alimentación fuera una acción destacada durante su desarrollo. Los resultados alcanzados por los alumnos ponen de manifiesto la excelente combinación de calidad y satisfacción por el trabajo académico realizado. Además de inducir la adquisición de conocimiento en temáticas especializadas, se ha logrado fomentar habilidades relacionadas con la
} 
comunicación, pensamiento crítico, creatividad, trabajo en equipo y cooperación.

Palabras clave: aprendizaje por indagación, aprendizaje colaborativo, evaluación de posters, plataforma Sakai

\section{Introducción}

En un modelo educativo basado en la adquisición de competencias, el profesor debe inducir que el estudiante abandone una posición de pasividad en las aulas y buscar vías para cubrir sus necesidades particulares. Una interesante aproximación es el aprendizaje por indagación, o inquiry-based learning en inglés (Edelson et al. 1999). Se trata de una enseñanza reflexiva donde los alumnos deben construir el nuevo conocimiento, pero no se les proporciona toda la información necesaria para el desarrollo de las actividades, por lo que deben involucrarse en el problema plateado y aportar soluciones (Gormally et al. 2009). Este enfoque facilita la participación activa, ayuda a desarrollar el pensamiento crítico y fomenta la capacidad para resolver proyectos.

Realizar este aprendizaje por indagación de forma colaborativa es un área creciente de investigación pedagógica (Kaartinen y Kumpulainen, 2002; Wenzel, 2007; Redondo, 2008). Las habilidades más fuertes de un estudiante pueden compensar las habilidades más débiles de otro. Para alcanzar este objetivo, la principal limitación es encontrar maneras de apoyar adecuadamente la comunicación y el proceso de creación de conocimiento. En este punto, el papel del profesor es ayudar a proporcionar pautas y vías claras de colaboración.

Durante los últimos 20 años, el uso de las tecnologías de la información y comunicación han facilitado ese aprendizaje por descubrimiento. Actualmente, no se realiza la búsqueda de información sin utilizar buscadores web y bases de datos on-line. Dichas tecnologías también se han utilizado para crear ambientes que involucran a los estudiantes en actividades como simulaciones, visualización de datos, comunicación científica, etc. (Van Joolingen et al. 2007; Carabantes, 2010). Hay que destacar que los espacios digitales han pasado de ser un mero repositorio de contenidos y recursos, a convertirse en espacios en los que el estudiante puede llevar a cabo procesos de autoaprendizaje personalizados y colaborativos. Esa es la finalidad de las plataformas empleadas en la educación a distancia o e-learning (Yang y Tsai, 2010; Roffe, 2002). Proporcionan entornos holísticos para la prestación y gestión de experiencias educativas y poseen herramientas que apoyan la creación de cursos en línea, permiten compartir recursos, abren vías flexibles de corrección y retro-alimentación, y permiten gestionar tareas o exámenes. Destacan especialmente las plataformas denominadas Iniciativas de Código Abierto (Open source initiatives) tipo Moodle (www.moodle.org), Sakai (www.sakaiproject.org) y ATutor (www.atutor.ca), sistemas que permiten adaptarse a las necesidades particulares.

Si el aprendizaje por indagación concluye con la realización de un póster, el ejercicio posee un valor añadido (Sisak, 1997). Los posters son importantes para la distribución de información desde la investigación básica a la divulgación empresarial. En la futura carrera profesional, los egresados universitarios participarán en congresos, seminarios y ferias donde

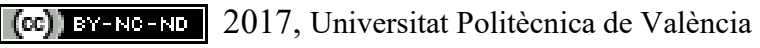

Congreso IN-RED (2017) 
presentar sus resultados o productos y observarán los de otros en formato de póster. Sin embargo, los estudiantes no conocen las características específicas que deben tenerse en cuenta en su preparación y su defensa (Newbrey, 2006). Por ello, varios investigadores han propuesto el póster para diferentes actividades académicas, desde la presentación de resultados de proyectos de investigación de pregrado hasta exponer los resultados de actividades de laboratorio (Wimpfheimer, 2004).

Diferentes autores han publicado el amplio rango de beneficios derivados de la realización de posters en el aula. Las sesiones de posters se centran en los estudiantes y fomentan un aprendizaje más profundo (Marino et al. 2000; Scott, 2008). Los animan a reflexionar sobre su aprendizaje durante el proceso, les obliga a enfatizar los importante frente a lo superficial, y les permiten demostrar su aprendizaje y aprender de las experiencias de otros estudiantes (Denzine, 1999). Este tipo de actividad fomenta la creatividad y los aspectos visuales de la temática estudiada y tienen la oportunidad de mejorar las habilidades de comunicación escrita, visual y verbal. Frente las presentaciones orales estándar, son consideradas menos intimidantes, lo que activa de forma más natural un flujo de discusión alrededor de las experiencias de los estudiantes (Stegemann y Sutton-Brady, 2009). Finalmente, la evaluación es más directa y sencilla, permitiendo diferentes aproximaciones respecto a los sistemas evaluadores (propio alumno, compañeros, profesor, externo o modelos mixtos). No obstante, el análisis de la bibliografía indica la necesidad de seguir investigando para que se afiance como una herramienta efectiva de enseñanza-aprendizaje.

\section{Objetivos}

El objetivo del estudio era la realización de una actividad basada en el aprendizaje por indagación colaborativo y cuyo resultado final se expusiera en una sesión de posters. Nuestra investigación se ha centrado en las herramientas que ayuden a que los estudiantes comprendan la meta marcada y el modo de alcanzarla, implicándolos en todo el proceso. Por tanto, se ha estudiado cómo planificar, desarrollar y evaluar la actividad, asistido por la herramienta de e-learning PoliformaT (tecnología Sakai). Para ello, se plantean objetivos secundarios

- Elaboración de materiales que transformen el reto académico ofrecido por los docentes en acción

- Establecimiento de vías de retro-alimentación

- Generar un ambiente de conferencia simulada

- Implementación de un sistema de evaluación

- Análisis de los resultados

- Propuestas de futuras acciones

El estudio se ha realizado con alumnos de $2^{\circ}$ de grado en una asignatura de contenidos químicos. No obstante, en la presente comunicación, se describe desde un enfoque más generalista para facilitar que la innovación docente pueda ser implementada en otras asignaturas. 


\section{Desarrollo de la innovación}

Alumnos. La acción propuesta se ha aplicado en la asignatura de Análisis Químico I del Grado en Ciencia y Tecnología de los Alimentos. Está impartida por la Unidad Docente Química Analítica en la Escuela Técnica Superior de Ingeniería Agronómica y del Medio Natural. Es una asignatura de segundo curso (cuatrimestre B) con dos subgrupos. Los alumnos que participaron en la actividad fueron 83 (curso 15-16) y 77 (curso 16-17), respectivamente, siendo el 93,3\% y 95,1 \% de los alumnos matriculados.

Herramientas informáticas. Se utilizó la plataforma docente de e-learning PoliformaT basada en el LMS (Learnig Management System) open source Sakai (https://sakaiproject.org/). El profesor prepara y pone a disposición de los alumnos el material necesario para el desarrollo de las actividades. Cada alumno accede al programa con su clave personalizada para descargarse los ficheros, colgar los informes y completar el cuestionario. Para el acceso de los alumnos a las fuentes bibliográficas, se han recomendado los portales genéricos Google Académico (https://scholar.google.es/), Scopus (https://www.scopus.com) y Polibuscador (http://polibuscador.upv.es); para apoyar la traducción de textos, se han recomendado los portales Google Traductor (https://translate.google.es/) y poli [Traductor] (https://politraductor.upv.es). La herramienta anti-plagio recomendada es Plagiarisma (http://plagiarisma.net/).

El análisis estadístico de las evidencias de la experiencia se realizó con Statgraphics Centurion XVI a un nivel de confianza del $95 \%$ (www.statgraphics.net).

Descripción de las actividades. La aproximación propuesta de aprendizaje por indagación ha sido aplicada para profundizar en temáticas especializadas de la asignatura. Cada grupo de 5-6 alumnos aborda un tema de interés en análisis químico para el sector agroalimentario, entre un listado que propone el profesor (menú Recursos de PoliformaT).

Existen una serie de tareas, denominadas pre-seminario, que comienzan seis semanas antes de la sesión de posters (menú Calendario de PoliformaT). Siguiendo un modelo de aprendizaje colaborativo, los alumnos en grupo buscan, analizan y procesan información relevante del campo en estudio. El progreso de estas actividades y del desarrollo del trabajo en equipo está supervisado por el profesor mediante tutorías a demanda o programadas. El documento resultante se envía a la plataforma de e-learning en una zona de espacio compartido (menú Espacio Compartido de PoliformaT) para que puedan acceder los distintos miembros del curso (profesor y el resto de compañeros) y aportar una retro-alimentación (menú Tareas de PoliformaT). También, permite evaluar las nuevas versiones y establecer si se han realizado las modificaciones sugeridas.

El seminario, denominado workshop en "Tendencias actuales en el análisis químico", se realiza en dos sesiones de 90 min cada una, en la clase y horario habitual de la asignatura. Para simular una reunión científico-técnica, se reorganiza el mobiliario del aula, los póster se cuelgan en las propias paredes del aula y en paneles y se generan pequeños espacios de discusión grupal. La primera parte del seminario es analizar los posters preparados por el resto de grupos, estableciendo una secuencia rotatoria con aproximadamente $5 \mathrm{~min} /$ póster. En la segunda parte, cada grupo de alumnos se reúne con el profesor para compartir los

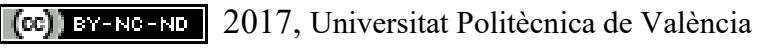

Congreso IN-RED (2017) 
resultados de la primera observación. Se debate sobre los puntos fuertes y puntos débiles de los posters presentados, incidiendo especialmente en el preparado por el grupo (aprox. $5 \mathrm{~min}$ ). Durante ese tiempo el resto de alumnos completa una rúbrica de evaluación. En la tercera parte del seminario se realiza una breve exposición oral del póster por todos los miembros de un grupo (10 min) y, posteriormente, se dedica un tiempo para que el resto de los grupos y el profesor realicen alguna pregunta $(5 \mathrm{~min})$. Tanto el profesor como los alumnos, rellenan una rúbrica sobre el desarrollo de la defensa. El seminario concluye con un análisis grupal de la experiencia, resaltando los objetivos de aprendizaje alcanzados. Además se completa la rúbrica, valorando globalmente la experiencia.

Se recogieron las evidencias de la experiencia desde el servidor de la UPV y se realizó el tratamiento de datos, el análisis de los resultados y las propuestas de mejora.

\section{Resultados}

\section{Desarrollo de las actividades previas a la sesión de posters}

La elaboración del póster se ha planificado como una actividad de aprendizaje por indagación en formato grupal. La experiencia ha mostrado que la clave del éxito de la actividad depende drásticamente de que los alumnos comprendan desde el primer momento los objetivos de aprendizaje que se buscan al realizarla. Particularmente, deben conocer las propiedades de un póster como herramientas de comunicación científico-técnica. También deben de disponer de directrices claras sobre la obtención de información que alimentará los contenidos del póster y el modo de plasmarlos en un reducido espacio, de forma clara y comprensible para un público con conocimientos suficientes pero no especialista en el campo que se recoge en el mismo. Aunque se incentive que cada grupo presente un póster con su propio estilo, debe asegurarse que el póster posea la suficiente calidad para que origine un aprendizaje significativo en los compañeros cuando sea expuesto y posteriormente defendido.

Nuestra innovación basada en el uso de herramientas como la plataforma de e-learning PoliformaT ha resultado ser una aproximación excelente para conseguir el objetivo marcado. La Figura 1 muestra la red de interconexiones diseñadas para la generación del póster. El nódulo central es el conjunto de dispositivos de cada grupo de alumnos. Éstos están conectados con la red global y con los servidores que controlan la plataforma. La figura recoge también el listado de tareas que pueden ser realizadas en cada uno de los nódulos. La hipótesis de trabajo planteada era que se gestionasen ciertas tareas clave desde la plataforma de e-learning. La funcionalidad asignada abarca desde facilitar los recursos necesarios (ej. plantillas, modelos) hasta regular el desarrollo (ej. plazos, retro-alimentación). 


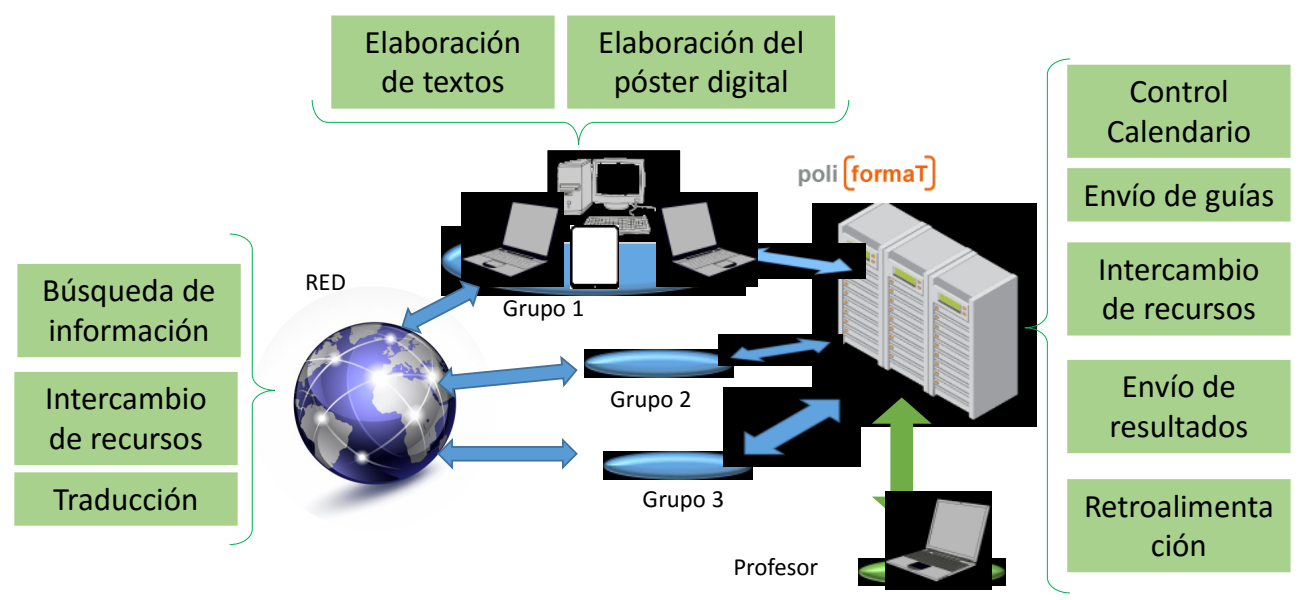

Fig. 1. Esquema de conectividad para la generación del póster. Los recuadros indican las actividades realizadas en cada nódulo.

Frente a aproximaciones anteriores basadas en papel o uso de plataformas digitales de forma puntual, las ventajas observadas al aplicar este enfoque son numerosas. La primera es que el alumno, a nivel individual y en grupo, están asistidos de forma accesible, disponiendo de los recursos elaborados por el profesor o por el resto de compañeros desde cualquier dispositivo. Los recursos preparados por el profesor actúan como guías, recogiendo ejemplos de actividades correctamente realizadas y de errores comúnmente cometidos por alumnos de anteriores promociones, facilitando el aprendizaje por indagación. Se suministran como material digital almacenado en un servidor educativo de acceso a los alumnos de la asignatura. Esto repercute en la capacidad de realizar la actividad en diferentes escenarios (casa particular, espacios de trabajo en el campus, etc) y facilita el trabajo en grupo incluso en el caso que los alumnos se encuentren físicamente distantes. La flexibilidad siempre repercute positivamente especialmente cuando se tratan de acciones grupales.

La segunda ventaja es que se obtienen evidencias del progreso de la actividad. Esto permite confirmar que los alumnos avanzan por el camino correcto y promueve un sentido de la responsabilidad personal y grupal que puede ir unido a una motivación por constatar la materialización de cada etapa del trabajo realizado. Además, se puede regular una adecuada gestión del tiempo, si se fijan plazos para los hitos intermedios del proyecto. En este sentido, para próximos cursos, se está analizando la implementación de registros o listas de verificación que faciliten la gestión de la actividad grupal y la consecución de los objetivos marcados de forma progresiva y no precipitada.

La tercera ventaja deriva de la capacidad para abrir vías para la retro-alimentación por la existencia de espacios compartidos en la plataforma y de menús específicos para cumplir con este fin. La consecuencia es una mejora la calidad del aprendizaje, evita confusiones o ambigüedades y ayudar a buscar soluciones alternativas más eficaces. Se trata de una evaluación formativa más que una simple calificación. Hay que indicar que este apoyo a través de la plataforma no es incompatible con otras vías de comunicación profesor-alumno (ej. correo electrónico, tutorías presenciales). En los cursos que se ha realizado la innovación, esta retro-alimentación sólo deriva de la evaluación por los distintos miembros del grupo y

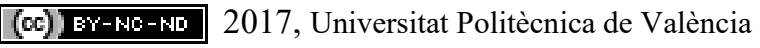

Congreso IN-RED (2017) 
del profesor. No obstante, sería interesante explorar formas de implementar una retroalimentación basada en un tipo de evaluación constructivista por pares. A través de la plataforma PoliformaT, podría diseñarse una pequeña tarea con la finalidad de comparar los trabajos de los compañeros con la propia labor realizada. De este modo, los aspectos positivos y negativos se transmitirían de forma inter-grupal y se contribuiría a una revisión del proceso y no únicamente del producto final.

\section{Sesión de posters}

Las tareas grupales culminan en un seminario especializado (workshop) que simula las condiciones de una reunión científica o seminario comercial. Los alumnos presentan en formato cartel los posters que han sido revisados a través de la plataforma PoliformaT (Figura 2). Cualquier programa para la creación del póster digital es válido (Microsoft PowerPoint, GoogleSlides, KeyNote), pero se restringió el envío en formato pdf para garantizar la compatibilidad entre dispositivos. Todos los posters deben incluir: Título, Nombre de los alumnos, Filiación, Descripción de la técnica, Ejemplo práctico, Tendencias de futuroConclusión, Referencias. La composición y estructura del póster es libre, aunque se fija un rango de dimensiones.

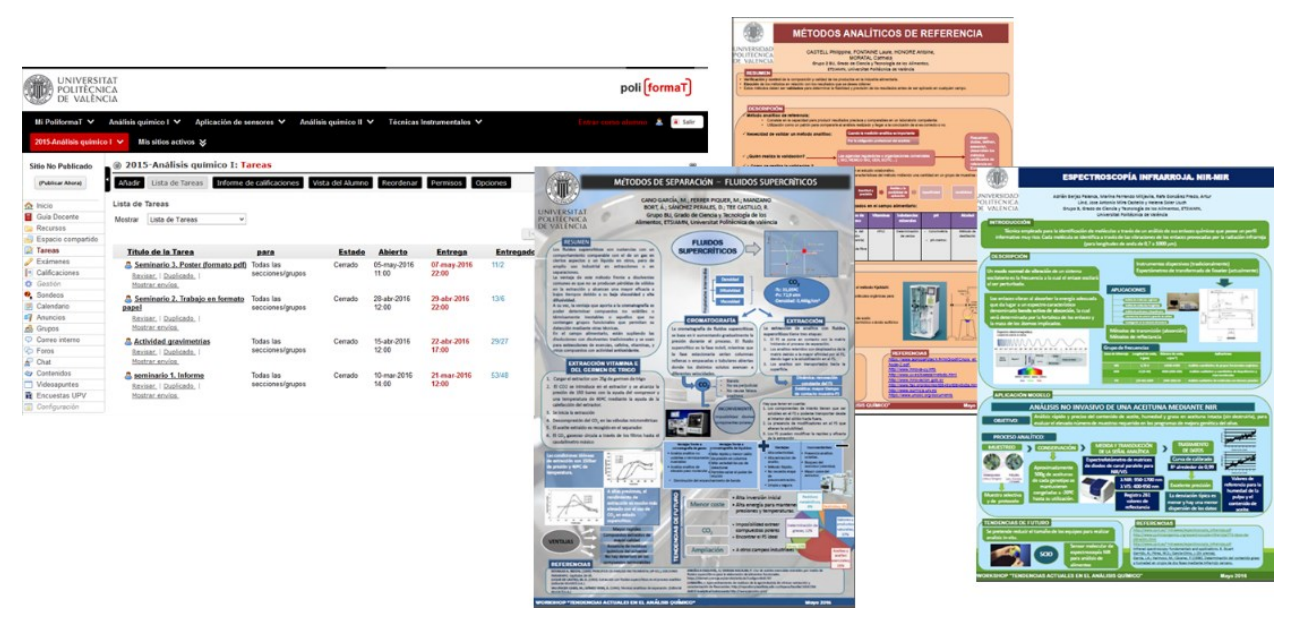

Fig. 2. Captura de pantalla y posters elaborados por los alumnos en formato digital compartidos a través de la plataforma e-learning

En los espacios habilitados en el aula y en los entornos de los posters, los alumnos discutieron sobre el trabajo realizado por los compañeros, comparándolo con el realizado por uno mismo. Así, se logra un escenario educativo donde desarrollaran sus habilidades de comunicación oral. La conclusión del ejercicio es una presentación oral colaborativa sobre el contenido del póster al conjunto de la clase. Se consiguió que la defensa fuese ágil, concisa y enfocada a transmitir las características fundamentales de la técnica o tema de estudio y sus aplicaciones, evitando una mera lectura del póster. El profesor actúa de moderador y ejerce un papel más activo solamente para solucionar aquellas dudas que no pueden ser contestadas por el grupo. 
Se confirmó la hipótesis del presente estudio, es decir, el éxito de esta sesión depende del trabajo realizado con anterioridad. La organización y planificación previa del profesor tiene que ser suficiente para que los alumnos adopten una posición protagonista y sean el auténtico motor de la actividad. Para ello, debe haber suministrado suficiente información que permita ese elevado grado de independencia sin perder de vista que se trata de una actividad académica con unos claros objetivos de aprendizaje. Del mismo modo se comprobó que este tipo de actividades son fundamentales para superar las principales carencias constatadas en profesionales universitarios, tales como habilidades relacionadas con la comunicación, pensamiento crítico y trabajo en grupo (Asharf et al. 2010).

\section{Evaluación}

El desarrollo de la experiencia es valorada por los alumnos mediante rúbricas (evaluación por iguales) y por el profesor. La Tabla la recoge los aspectos del póster que fueron evaluados. Se centran principalmente sobre los objetivos de aprendizaje relacionados con la temática en estudio y sobre los aspectos más formales o de diseño. El alumno al participar del proceso de evaluación afianza que atributos del póster son prioritarios y cuales son secundarios, comprendiendo que su finalidad es proporcionar información sintetizada pero comprensible y útil. Su finalidad es el desarrollo del pensamiento crítico, vía observación guiada, resaltando los efectos positivos del aprendizaje cuando se realiza de manera reflexiva.

Tabla 1. Criterios de valoración del póster (a) y de la exposición (b)

(a)

\begin{tabular}{ll}
\hline Criterio & Comentario \\
\hline Contenido & $\begin{array}{l}\text { La información presentada es relevante, específica y exacta, abordando el } \\
\text { fundamento, descripción y aplicaciones de la técnica. El ejemplo de aplicación } \\
\text { ayuda a comprender la técnica. } \\
\text { Las distintas secciones del póster están ordenadas y con la información } \\
\text { relevante claramente organizada y resaltada. } \\
\text { El lenguaje científico general y el vocabulario propio del área profesional son } \\
\text { conguaje }\end{array} \quad \begin{array}{l}\text { Diseño atractivo con toda la información legible y figuras de calidad. } \\
\text { Formato }\end{array}$ \\
Comprensión & importantes de la técnica y podría explicársela a un/una compañero/a. \\
\hline
\end{tabular}

(b)

\begin{tabular}{ll}
\hline Criterio & Comentario \\
\hline Lenguaje & $\begin{array}{l}\text { El lenguaje científico en general y el vocabulario propio del área profesional } \\
\text { son correctamente utilizados. }\end{array}$ \\
Liscurso & $\begin{array}{l}\text { La exposición es clara y organizada, centrándose en los aspectos relevantes de } \\
\text { la técnica }\end{array}$ \\
Resolución de las & Las distintas preguntas han sido contestadas de forma correcta y resolviendo \\
cuestiones & las dudas planteadas. \\
Comprensión & La información presentada ha permitido comprender los aspectos más \\
& importantes de la técnica y podría explicársela a un/una compañero/a.
\end{tabular}

La Tabla $1 \mathrm{~b}$ muestra los aspectos de la defensa grupal del póster evaluados en la rúbrica con su descripción. Las máximas calificaciones se alcanzan cuando el grupo expone su póster

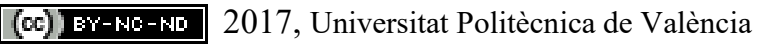

Congreso IN-RED (2017) 
utilizando las características de la comunicación científica, y consigue transmitir los elementos objeto del aprendizaje. Los distintos grupos reciben una retro-alimentación de sus compañeros y del profesor en la propia sesión, de modo que se origina un escenario donde se profundiza en el aprendizaje sin generar una situación intimidatoria en el aula.

\section{Valoración de la experiencia docente}

La opinión de la experiencia innovadora por los estudiantes es recogida mediante una cuestión con respuesta en escala Likert. La pregunta era "Evalúa la aportación de la actividad del workshop (trabajo no presencial + presencial) en tu aprendizaje frente otras estrategias educativas más convencionales. 0: Nula, 1: Poca, 2: Normal, 3: Notable, 4: Destacada”. La Figura 3 recoge la frecuencia de cada una de las respuestas para los datos recogidos en el primer curso. La mayoría de los alumnos (97 \%) otorgaron una valoración positiva del impacto de la actividad sobre su aprendizaje. Estos resultados coinciden con las observaciones recogidas durante el propio desarrollo y con las manifestaciones indicadas directamente a los profesores. Los principales comentarios positivos son el orgullo sobre el trabajo realizado y la novedad para abordar un trabajo académico grupal. No obstante, el primer año de implementación de la experiencia también manifestaron la necesidad de mayor guía en la fase de pre-seminario, es decir, en la búsqueda de información y elaboración del póster. Por ello, la acción docente del segundo año se está centrando en mejorar dicho aspecto.

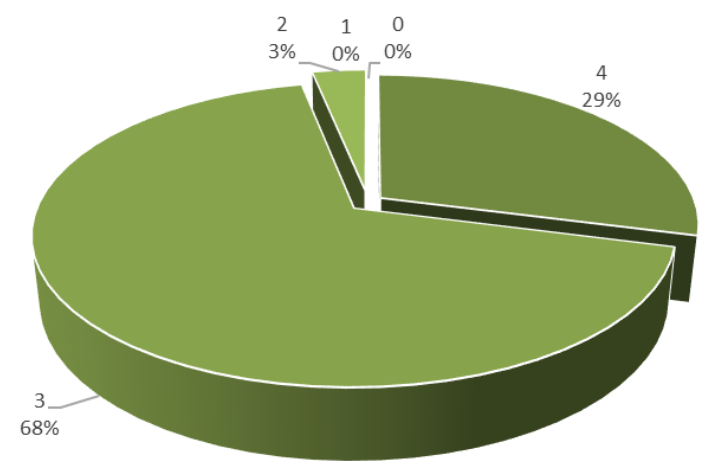

Fig. 3. Valoración global de la experiencia por los alumnos. 0: Nula, 1: Poca, 2: Normal, 3: Notable, 4: Destacada

\section{Conclusiones}

Las directrices de educación universitaria están enfocadas a promover actividades donde los estudiantes puedan tener una participación más activa. Nuestra experiencia ha confirmado la máxima en educación que dice que una tarea abordada en profundidad origina un aprendizaje más significativo y relevante que la realización de una multitud de pruebas superficiales. Nuestra propuesta de aprendizaje por indagación combinada con una sesión de posters, es una aproximación que permite fomentar ciertas habilidades imprescindibles pero 
generalmente no instruidas en modelos tradicionales de enseñanza. Este objetivo se logra sin renunciar a contenidos básicos de una titulación universitaria.

Su aplicación en una asignatura con contenidos químicos ha sido satisfactoria, dando lugar a una actividad práctica centrada en el problema, que estimula la relación del conocimiento con una cuestión específica de interés y favorece la comprensión. En este entorno de aprendizaje, los alumnos se aproximan a la realidad de la investigación científica actual. Al apoyarse en una plataforma de e-learning, es más fácil la adaptación a la pluralidad escenarios que se pueden originar en un trabajo en grupo (ej. incompatibilidades de horarios para reunirse). La presentación en una sesión de posters es una estrategia que conduce a un ambiente agradable y gratificante para los estudiantes. En este escenario, se logra que expongan con naturalidad comentarios sobre sus trabajos y el de los compañeros de una manera constructiva, reflexionen sobre los errores cometidos y puedan encontrar puntos de apoyo para próximas situaciones.

En futuras aplicaciones de la estrategia docente, se prevén incluir acciones que podría ayudar a complementar la experiencia. Primero, se puede revisar el proceso de retroalimentación de los trabajos/posters subidos a la plataforma. Una opción a estudiar es considerar la asignación aleatorizada de cada trabajo para una revisión por pares. Posteriormente, cada grupo argumente los cambios que ha realizado en base a las sugerencias de sus revisores previo a la presentación definitiva en el seminario. Segundo, las rúbricas de evaluación se han realizado en formato papel, mientras que en próximos cursos, se plantea el uso de rúbricas digitales (menú Exámenes de PoliformaT). Tercero, las actividades sugeridas, con el formato actual, no presentan un claro control del aprendizaje colaborativo. Una futura aproximación es la incorporación de dinámicas de aprendizaje cooperativo, estableciendo roles y mecanismos de control del aprendizaje por los propios alumnos. Cuarto, la utilización por el alumnado de recursos web colaborativos, como https://awwapp.com/, https://realtimeboard.com/o https://ziteboard.com/, podría ayudar en la elaboración digital del póster.

Aunque existe todavía un margen importante de mejora, se trata de una actividad recomendable para ser transferida a otras asignaturas.

\section{Referencias}

ASHRAF, S. S., MARZOUK, S. A., SHEHADI, I. A., \& MURPHY, B. M. (2010). “An integrated professional and transferable skills course for undergraduate chemistry students". Journal of Chemical Education, 88(1), 44-48.

CARABANTES, D. (2010). "Innovación en la creación de materiales y actividades para la enseñanza en red”. Relada 4,4, pp. 290-297.

DENZINE, G. M. (1999). “An example of innovative teaching: Preparing graduate students for poster presentations". Journal of College Student Development, 40(1), 91-93.

EDELSON, D. C., GORDIN, D. N., \& PEA, R. D. (1999). "Addressing the challenges of inquiry-based learning through technology and curriculum design". Journal of the Learning Sciences, 8(3-4), 391-450.

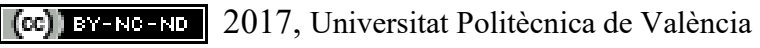


GORMALLY, C., BRICKMAN, P., HALLAR, B., \& ARMSTRONG, N. (2009). "Effects of inquiry-based learning on students' science literacy skills and confidence". International Journal for the Scholarship of Teaching and Learning, 3(2), 16.

KAARTINEN, S., \& KUMPULAINEN, K. (2002). "Collaborative inquiry and the construction of explanations in the learning of science". Learning and Instruction, 12(2), 189-212.

MARINO, R., CLARKSON, S., MILLS, P. A., SWEENEY, W. V., \& DEMEO, S. (2000). "Using poster sessions as an alternative to written examination-the poster exam". Journal of Chemical Education, 77(9), 1158.

NEWBREY, M. AND BALTEZORE, J. (2006). "Poster Presentations: Conceptualizing, Constructing and Critiquing". American Biology Teacher 68(9), 550-4.

REDONDO, F. (2008). "Trabajo colaborativo, espacio digital y e-learning”. Relada 2,3, pp.143-149.

ROFFE, I. (2002). "E-learning: engagement, enhancement and execution", Quality Assurance in Education, 10, 40-50.

SCOTT, P. (2008). "Poster Presentations: An Effective Assessment Tool". Journal of the Further Education Alliance, 2, 5-16.

SISAK, M. (1997). "Poster Sessions as a Learning Technique". Journal of Chemical Education, 74(9), 1065-1067.

STEGEMANN, N., \& SUTTON-BRADY, C. (2009). "Poster sessions in marketing education an empirical examination". Journal of Marketing Education, 31(3), 219-229.

VAN JOOLINGEN, W. R., DE JONG, T., \& DIMITRAKOPOULOU, A. (2007). "Issues in computer supported inquiry learning in science". Journal of Computer Assisted Learning, 23(2), 111-119.

WIMPFHEIMER, T. (2004). "Peer-evaluated poster sessions: an alternative method to grading general chemistry laboratory work". Journal of Chemical Education, 81(12), 1775.

WENZEL, T. J. (2007). "Collaborative and project-based learning in analytical chemistry" en Active Learning, ACS Symposium Series, Chapter 5, pp 54-68

YANG, Y. F. y TSAI, C. C. (2010). "Conceptions and approaches to learning through online peer assessment”, Learning and Instruction, 20, 72-83. 


\title{
Análisis del empleo de la metodología aprendizaje basado en proyectos como herramienta de desarrollo y evaluación de múltiples competencias transversales. Aplicación en grupos numerosos de asignaturas en la rama de ingeniería.
}

\author{
Y. Ye-Lin ${ }^{a}$, G. Prats-Boluda ${ }^{a}$, J. Garcia-Casado ${ }^{a}$, E. Guijarro Estelles ${ }^{\text {a }}$ y J.L. \\ Martinez-de-Juan ${ }^{\mathrm{a}}$ \\ a Universitat Politècnica de València. Departamento de Ingeniería Electrónica (yiye@eln.upv.es; \\ geprabo@eln.upv.es; jgarciac@eln.upv.es; eguijarro@eln.upv.es; jlmartinez@eln.upv.es).
}

\begin{abstract}
Previous experience has shown the feasibility of implementing active methodologies in small groups to work and evaluate cross skills. However, the assessment of cross skills in groups with a large number of students could lead to an excessive workload for teachers, questioning its sustainability. In the present work we propose the use of the project-based learning methodology and the portfolio to work and evaluate multiple skills in a core subject of 301 students, and report the experiences carried out. The results show that it is feasible to design and develop a formative activity to work and evaluate multiple skills in large groups without involving an excessive workload for students and teachers. In addition, $86.1 \%$ of the students positively valued the applied methodology that provides a more applied vision of the electronic instrumentation, favoring the acquisition of cross skills.
\end{abstract}

Keywords: projected based learning, comprehension and integration skill, practical thinking skill, problem solving skill, cross skills

\footnotetext{
Resumen

Experiencias previas han demostrado la viabilidad de implantar metodologías activas en grupos reducidos para trabajar y evaluar las competencias transversales. No obstante la evaluación de estas competencias en grupos numerosos puede suponer una carga de trabajo excesiva para el profesorado, cuestionando su sostenibilidad. En el presente trabajo se propone utilizar la metodología aprendizaje basado en proyectos y el portafolio para trabajar y evaluar múltiples competencias transversales en grupos numerosos. Concretamente se resumen las experiencias llevadas a cabo en una asignatura troncal de máster con 301 alumnos. Los resultados muestran que es factible diseñar y desarrollar una actividad formativa para trabajar y evaluar múltiples competencias en grupos numerosos sin suponer una carga de trabajo excesiva para el alumnado y el profesorado. Además el $86.1 \%$ de los alumnos valoraron positivamente la actividad manifestando que les proporciona una visión más aplicada de la instrumentación electrónica y favoreciendo la mejora en varias competencias transversales.
} 
Palabras clave: aprendizaje basado en proyectos, comprensión e integración, aplicación y pensamiento práctico, análisis y resolución de problemas, comunicación efectiva, competencias transversales

\section{Introducción}

La sociedad actual requiere de los egresados la formación en competencias transversales además de la formación en conocimientos genéricos y específicos de cada titulación. De hecho los empleadores muchas veces valoran las habilidades de empleabilidad transversales por encima de las habilidades específicas (Cotton, 2001). Con la implantación del Espacio Europeo de Educación Superior (EEES) y la entrada de los nuevos títulos aparece un cambio en el enfoque de la docencia desde la formación en contenidos a la formación en competencias. El enfoque del aprendizaje basado en competencias se fundamenta en la responsabilidad de aprender del estudiante y en el desarrollo de sus competencias iniciales a lo largo de su carrera. Esto supone que el aprendizaje no sólo se refiere al conocimiento nuevo que puede y debe adquirir el estudiante sino al desarrollo y evolución del modo de aprender, de aprender y mejorar cómo aplica los conocimientos a situaciones nuevas, cómo integra las actitudes y valores y los pone en juego, cómo incorpora las técnicas y métodos en su modo de actuar y afrontar las situaciones (Villa, 2011). Este nuevo enfoque requiere un aprendizaje significativo por parte del alumno que dote de sentido al material de aprendizaje mediante su interiorización. Esto también conlleva al cambio del modo de evaluación que no debe centrarse únicamente en la adquisición de conocimientos específicos. Como consecuencia de esta forma de evaluación, el examen, si bien continúa siendo un método de valoración de los contenidos asimilados, ha de combinarse con otras metodologías más adecuadas para determinar el nivel de dominio de las competencias. Esta circunstancia obliga al docente al uso de determinadas actividades académicas, que permitan una evaluación continua del estudiante a lo largo de todo el curso, y no sólo de una calificación a través de un examen final. En resumen, la adaptación al EEES ha supuesto una sustancial transformación de la docencia universitaria, tanto en lo referente a las metodologías empleadas, en las estructuras de las enseñanzas, o en la implantación de sistemas de evaluación y control de su calidad (Hermosilla, 2013).

En este contexto, la Universidad Politécnica de Valencia (UPV) ha puesto en marcha el proyecto de competencias transversales UPV, que tiene como objetivo principal acreditar las competencias transversales los estudiantes egresados en cualquiera de los títulos oficiales impartidos. Con el fin de unificar las competencias genéricas y analizando las clasificaciones de distintas agencias y organismos públicos de acreditación (EUR-ACE, $\mathrm{ABET}$, órdenes ministeriales $\mathrm{CIN}$, MECES, RD), se ha definido las competencias trasversales UPV (CT) que incluye un total de 13 competencias. Con la definición de las CT se pretende sintetizar el perfil competencial que adquieren los alumnos de la UPV. Partiendo de la hipótesis de que se trabajan las competencias transversales UPV en las distintas materias/asignaturas, a nivel institucional se realiza el seguimiento del progreso de los estudiantes a través de materias/asignaturas seleccionadas como puntos de control. En este contexto, la UPV contempla 3 niveles para cada CT: $1^{\circ}$ y $2^{\circ}$ de grado, $3^{\circ} \mathrm{y} 4^{\circ}$ de grado, y máster; que suponen diferentes niveles de dominio de las CT. Dentro de este marco,

(cc) EY-NC-ND 2017, Universitat Politècnica de València

Congreso IN-RED (2017) 
"Instrumentación y Control Industrial" es una asignatura troncal de primer curso del Máster Universitario en Ingeniería Industrial. Tiene cerca de 300 alumnos, y es punto de control de 4 competencias transversales que la entidad responsable de título recomienda evaluar. Éstas son: CT01 Comprensión e Integración; CT02 Aplicación y pensamiento práctico; CT03 Análisis y resolución de problemas; y CT08 Comunicación efectiva.

Existen diversas metodologías docentes que permiten a alumnos y docentes trabajar, desarrollar y evaluar el nivel de dominio de las distintas competencias, como el aprendizaje basado en proyectos y/o el uso del portafolio. El portafolio es una técnica de recopilación, compilación, colección y repertorio de evidencias y competencias profesionales que ha sido ampliamente utilizado como una herramienta de evaluación del desarrollo de competencias (Barragán, 2005; Villardón, 2006). El aprendizaje basado en proyectos se basa en el principio de usar problemas reales como punto de partida para la adquisición e integración de los nuevos conocimientos (Barrows, 1986). Es una metodología eficaz y flexible para ayudar al alumno a desarrollar y trabajar diversas competencias, i.e, análisis y resolución de problemas (habilidades de identificación de problemas relevantes del contexto profesional, búsqueda y manejo de información, etc..), integración de conocimientos multidisciplinares, aprendizaje autónomo y permanente, planificación de las estrategias que se van a utilizar para aprender, trabajo en equipo, pensamiento crítico, habilidades de manejar las herramientas, habilidades de comunicación (argumentación y representación de la información), habilidades de evaluación y autoevaluación (De Miguel, 2006, Prieto, 2006).

En cuanto a la implantación de nuevas metodologías docentes, experiencias piloto han demostrado la viabilidad de implantar y evaluar dichos métodos de enseñanza-aprendizaje en grupos reducidos (Prats-Boluda, 2016). Sin embargo puede suponer una dificultad adicional en grupos masivos y podría generar una excesiva carga de trabajo probablemente por encima de las posibilidades reales del profesorado (De la Peña, 2012; Grangel, 2013; Sánchez 2011), convirtiendo la actividad en insostenible de cara a cursos subsiguientes. A continuación se destacan las principales dificultades para el diseño de actividades para la evaluación de las competencias transversales en grupos numerosos (Sánchez, 2011):

- Los alumnos centran su esfuerzo en lo que se evalúa; el profesor concibe que es imposible abordar una evaluación continua, y que la única solución es el examen final

- La masificación es una característica de todo el centro y la cultura dominante todavía mantiene una tendencia clara a la importancia del examen final, predominando la calificación sobre la evaluación.

- Las resistencias al cambio pueden venir generadas de malas experiencias imbuidas por un diseño erróneo en las actividades propuestas.

- La falta de experiencia puede generar un grado de dificultad añadido. En muchas ocasiones, el hecho de no tener formación apropiada en la materia hace que el profesorado rehúya de ciertas actividades, limitándose a una evaluación superficial.

- El llevar a cabo un sistema de seguimiento del proceso de aprendizaje orientado a ir viendo cómo va aprendiendo el alumno, no siempre es posible debido a cuestiones de recursos. 
- Abordar una evaluación profunda del alumnado implica una dedicación mayor del profesorado, que en ocasiones puede desbordar las posibilidades reales del profesor.

En este trabajo se pretende diseñar una actividad formativa para trabajar y evaluar múltiples competencias transversales (CT01, CT02, CT03 y CT08 ) en grupos numerosos empleando la metodología aprendizaje basado en proyectos y haciendo uso del portafolio.

\section{Desarrollo de la innovación}

La experiencia que se presenta en el presente trabajo se ha desarrollado en el contexto de la asignatura troncal "Instrumentación y Control Industrial", ofertada en primer curso de la titulación Máster Universitario en Ingeniería Industrial, y específicamente en la parte relativa a la instrumentación electrónica. Se trata de una asignatura con un amplio temario que abarca desde la descripción de los principios básicos de los sensores, selección de los sensores apropiados para una aplicación concreta, instrumentación de las señales provenientes de los sensores, desarrollo del sistema de adquisición de datos, así como la estimación de los errores que aparecen en la cadena de medida. Como se indicó anteriormente, la asignatura tiene cerca de 300 alumnos matriculados cada curso, divididos en 6 grupos de teoría de alrededor de 50 alumnos.

Con el objetivo de trabajar y evaluar las múltiples competencias que son puntos de control en esta asignatura, se ha diseñado una actividad centrándose en el aprendizaje basado en proyectos y el uso del portafolio. En concreto, se han propuesto 8 retos abiertos que consisten en la monitorización de una magnitud física en un proceso industrial. En cada grupo de teoría se forman unos 12 equipos (entre 3-5 alumnos/equipo) para resolver 3 retos en el área de instrumentación electrónica. Los retos a resolver en cada grupo de teoría fueron seleccionados por el profesorado para que éstos estuvieran distribuidos lo más uniformemente posible entre los distintos grupos. El desarrollo del proyecto tiene un peso del $15 \%$ de la nota final de la asignatura y se divide en 3 fases que se describirán con detalle en las siguientes subsecciones y por tanto tendrá 3 actos de evaluación.

\subsection{Fase 1}

Durante esta fase, el profesor plantea en cada grupo de teoría 3 retos abiertos (de los 8 posibles) relativos a la monitorización de una cierta magnitud en un proceso industrial. En una primera aproximación se plantean de forma genérica e.g. la medida del volumen de un compuesto líquido en un depósito. No se aportan detalles específicos del caso planteado; en el ejemplo de un medidor de nivel no se detalla la composición o características del líquido, forma y dimensiones del depósito, condiciones ambientales, etc. El objetivo es que los alumnos, en el seno de cada equipo, propongan y valoren ideas lo más libremente posible para resolver el reto planteado, todo ello sin estar inicialmente condicionado por detalles específicos de cada aplicación.

Ante el reto planteado, cada equipo de trabajo dispone de 20 minutos para proponer distintas alternativas de posibles soluciones al reto planteado sin ningún tipo de restricción (sesión de Brainstorming). Es importante destacar que en primera actividad todo tipo de

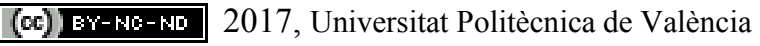

Congreso IN-RED (2017) 
soluciones es susceptible de ser considerada. Al concluir dicho tiempo cada grupo entrega un listado al profesor con todas las alternativas propuestas, en principio cuantas más mejor.

Tras el primer acercamiento al problema y propuesta de ideas, cada equipo procede a valorar más en detalle la viabilidad y adecuación de las propuestas del listado anterior, a fin de reducir la lista de posibilidades a un máximo de 3. Cabe señalar que todavía no se conocen las condiciones específicas de aplicación por lo que estas soluciones deben cubrir un amplio espectro de posibles aplicaciones específicas (que será concretada en la siguiente fase). Los equipos disponen de 40 minutos para proporcionar un documento con las 3 soluciones posibles seleccionadas, indicando brevemente su principio de funcionamiento y sus potenciales ventajas y desventajas. La fase 1 es evaluada exclusivamente por el profesorado de cada grupo de teoría en base a la rúbrica de evaluación de la Fase 1 publicada previamente a la sesión de trabajo y que se adjunta en el anexo 1.

\subsection{Fase 2}

Una vez concluida la fase 1, el profesor proporciona a cada equipo los detalles de una aplicación concreta para cada uno de los retos planteados. En el ejemplo propuesto podrían ser detalles respecto a la composición del líquido, forma y dimensiones del depósito, condiciones específicas de la aplicación, etc. Con esta nueva información cada equipo debe elaborar su propuesta de solución definitiva. Para ello es necesario realizar un análisis crítico en mayor profundidad de las distintas alternativas preseleccionadas en la Fase 1.

Durante el desarrollo del trabajo, cada equipo debe preparar un portafolio que contenga: el plan de trabajo del equipo (PT) detallado, incluyendo la asignación de tareas, el diagrama de Gantt, y las actas de reuniones del equipo de trabajo; un documento explicativo de la estrategia de búsqueda de información (BI) empleada para la resolución del problema y la forma de valorar la calidad de la información encontrada; y por último la justificación de la toma de decisiones (TD) a lo largo del proyecto. Para ello, se les proporciona a los alumnos un documento donde se explica detalladamente en qué consiste el portafolio y los documentos que debe contener.

La evaluación del portafolio se realiza mediante la técnica de coevaluación. En cada grupo de teoría se formarán 9 (3 item x 3 retos) comités de "expertos" para cada ítem evaluable (documentos PT, BI y TD) y cada reto planteado en ese grupo. Cada comité de "expertos" de cada ítem evaluable (PT, BI y TD) estará formado por al menos un miembro de cada equipo siendo éste asignado libremente por cada equipo, es decir, la asignación de los roles alumnos expertos es una decisión de cada equipo y no del profesor. Los miembros de cada comité de expertos tienen asignado un reto a evaluar distinto al que debían desarrollar con sus equipos. En la figura 1 se muestra la formación de los comités evaluadores del ítem PT y la agrupación de los ítems evaluables del mismo tipo.

Como resultados de la evaluación del portafolio, cada comité evaluador rellena la rúbrica correspondiente de cada ítem (PT, BI y TD) de cada equipo. Al final de la sesión, los comités evaluadores se intercambia las rúbricas para generar una valoración global de cada equipo que contiene la evaluación de cada indicador de cada ítem y se proporciona el feedback a cada equipo.

(c)) EY-NC-ND 2017, Universitat Politècnica de València Congreso In-Red (2017) 


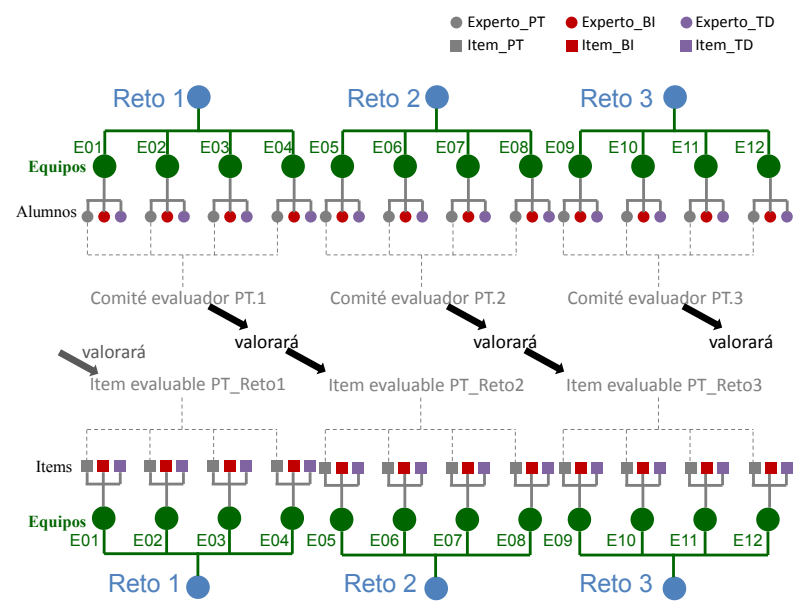

Figura 1: Esquema del método de coevaluación llevado a cabo para la evaluación del portafolio.

\subsection{Fase 3}

Una vez finalizada la sesión de evaluación del portafolio, cada equipo debe preparar una presentación con los detalles de la solución propuesta: tipo de sensor, principio de medida, montaje/colocación, posibles fuentes de error, limitaciones, principales ventajas e inconvenientes, valorando además aspectos como coste, mantenimiento, prestaciones de medida, etc. En los casos que sea posible se valora presentar sensores/sistemas industriales existentes en el mercado que puedan satisfacer las especificaciones del problema planteado de acuerdo a la solución propuesta por el grupo.

La presentación oral del trabajo se realiza en el aula de cada grupo de teoría con los medios disponibles, y tiene una duración máxima de 12 minutos para cada equipo. Tras la presentación de cada equipo se abre un turno abierto de preguntas y comentarios por parte del resto de equipos hacia el equipo que ha realizado la presentación (unos $3 \mathrm{~min}$ ).

Una vez concluidas las presentaciones de propuestas de solución de los grupos asociados a cada reto, el profesor evalúa la presentación del trabajo mediante la rúbrica de evaluación de la fase 3 (ver Anexo 1). Cada equipo valora qué solución le parece más adecuada de entre todas las presentadas tomando como referencia la rúbrica de evaluación de la fase 3 , entregando su valoración numérica global entre 0 y 10 al profesor. El resultado de dicha valoración por parte del alumnado se tiene en cuenta en la evaluación final de cada equipo.

En la tercera sesión de presentación que coincide con la última clase de la asignatura, se realiza una encuesta a los alumnos para conocer sus opiniones acerca del conjunto de actividades propuestas y determinar si el desarrollo del seminario ha permitido mejorar las competencias mediante un test auto-evaluación. Asimismo, también se pretende conocer el tiempo de dedicación del alumnado para desarrollar el proyecto. En el anexo 2 se adjunta la encuesta que se realizó al alumnado.

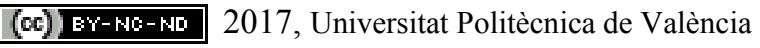




\subsection{Evaluación de las competencias}

Con el objeto de evaluar las distintas competencias, se ha identificado la contribución de cada indicador de cada fase del proyecto a cada una de las competencias transversales (ver la última columna de las rúbricas adjuntas en el anexo I). Con ello para cada competencia a valorar se tiene el resultado de un determinado número de indicadores $\left(\mathrm{N}_{\mathrm{i}}\right)$ relativos a dicha competencia (CT01: 3 indicadores; СТ02: 8 indicadores; CT03: 10 indicadores; CT08: 6 indicadores). La evaluación final de cada competencia, así como de cada uno de sus indicadores, se corresponde con una escala categórica de 4 niveles: A Excelente/ejemplar; B Bien/Adecuado; C En desarrollo; D No alcanzado. La evaluación final de cada competencia a partir de las $\mathrm{N}_{\mathrm{i}}$ evaluaciones de cada indicador admite distintos enfoques. En un primer acercamiento, la evaluación final de cada competencia se corresponde con el resultado de evaluación más repetido entre sus indicadores asociados.

\section{Resultados}

En el proyecto participaron 288 alumnos matriculados en la asignatura. Se formaron inicialmente 70 equipos de trabajo de 3 a 5 alumnos. En la figura 2 se muestra la distribución de los equipos de trabajo en los 6 grupos de teoría. Todos los equipos han seguido la dinámica de actividad preprogramada, siendo la tasa de abandono de la actividad $0 \%$. Del total de alumnos matriculados, 237 alumnos han contestado la encuesta de autoevaluación en la última sesión de la presentación del trabajo.

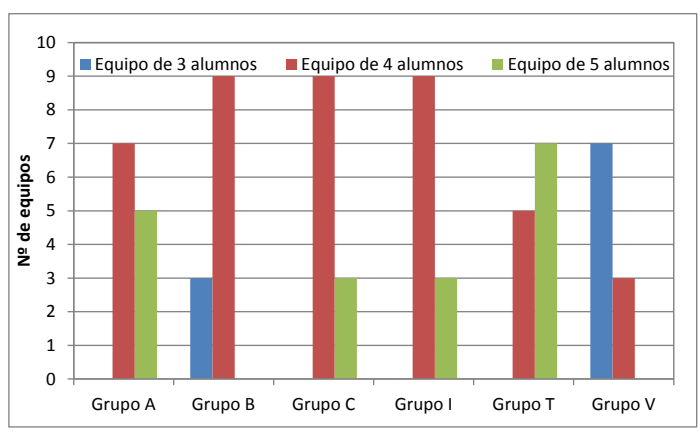

Figura 2: Distribución de los equipos de trabajo en función del número de alumnos por equipo en cada uno de los 6 grupos.

En la tabla 1 se detalla el tiempo de dedicación estimado del profesorado y del alumnado para el desarrollo del proyecto. Para el total de los alumnos encuestados, la dedicación promedio es de unas $17.3 \pm 8.1 \mathrm{~h}$, lo que se aproxima bastante a la estimación inicial del profesorado al diseñar la tarea $(13.8 \mathrm{~h} /$ alumno que corresponde a unos 0.7 créditos ECTS dedicado a esta parte de la asignatura). Por otro lado, la dedicación promedio del profesorado es de unos $26.6 \pm 9.8 \mathrm{~h}$, lo cual está dentro de lo que se puede considerar sostenible. Cabe señalar que el tiempo de dedicación del profesorado está principalmente destinado a la reunión grupal, y la preparación de los materiales docentes (preparación de los retos a resolver, definición y elaboración de las rúbricas, preparación del documento explicativo del proyecto y del portafolio). Parte de este trabajo en necesario únicamente en el primer curso de puesta en marcha de la acividad, que se ve amortizado en cursos subsiguientes. 
Tabla 1: Estimación del tiempo de dedicación al proyecto del profesorado y del alumnado.

\begin{tabular}{lccc}
\hline \multicolumn{1}{c}{ Tiempo de dedicación } & Individual $(\mathrm{h})$ & Grupal $(\mathrm{h})$ & Total $(\mathrm{h})$ \\
\hline Alumnado & $7.5 \pm 5.0$ & $9.8 \pm 6.0$ & $17.3 \pm 8.1$ \\
Profesorado & $17.0 \pm 8.9$ & $9.6 \pm 1.5$ & $26.6 \pm 9.8$ \\
\hline
\end{tabular}

En la figura 3 se muestra la autoevaluación de los alumnos sobre sus competencias (CT01 Comprensión e Integración, CT02 Aplicación y pensamiento práctico, CT03 Análisis y resolución de problemas y CT08 Comunicación efectiva) antes y después de cursar la asignatura. Al inicio del curso, la gran mayoría de alumnos (entre $77.6 \%$ y $86.5 \%$ ) posee un nivel de dominio de las competencias trabajadas y evaluadas "Buena" y "Muy buena". En general, el número de alumnos cuyo nivel de dominio de las competencias se sitúa en el nivel "Muy bajo" y "Bajo" es reducido, lo cual es el resultado esperable dado que son alumnos de primero de máster y están cursando un nivel 3 de las competencias transversales de la UPV. Tras cursar la asignatura, se puede apreciar que en general el $\mathrm{n}^{\mathrm{o}} \mathrm{de}$ alumnos cuyo nivel de dominio de las competencias se sitúa en "Muy bajo", "Bajo" y "Buena" ha disminuido. El porcentaje de alumnos cuya competencia se sitúa en el nivel "Muy buena" y/o "Excelente" ha aumentado considerable (ver tabla 2) con incrementos de 24.9\% para el CT01, 28.3\% para el CT02 y CT03, 21.6\% para el CT08. Por otro lado, destacar que el porcentaje de alumnos con un nivel de competencia "Muy buena" y/o "Excelente" para CT01 y CT08 es considerablemente inferior que en el caso de las competencias CT02 y CT03. Este resultado fue sorprendente para los profesores, dado que la CT01 supuestamente es una de las competencias que se trabajan desde los primeros cursos del grado. En cambio, el resultado obtenido de la competencia CT08 muestra una carencia de formación en esta competencia en asignaturas de grado que puede ser debido a la dificultad asociada al trabajo de la misma en grupos numerosos.
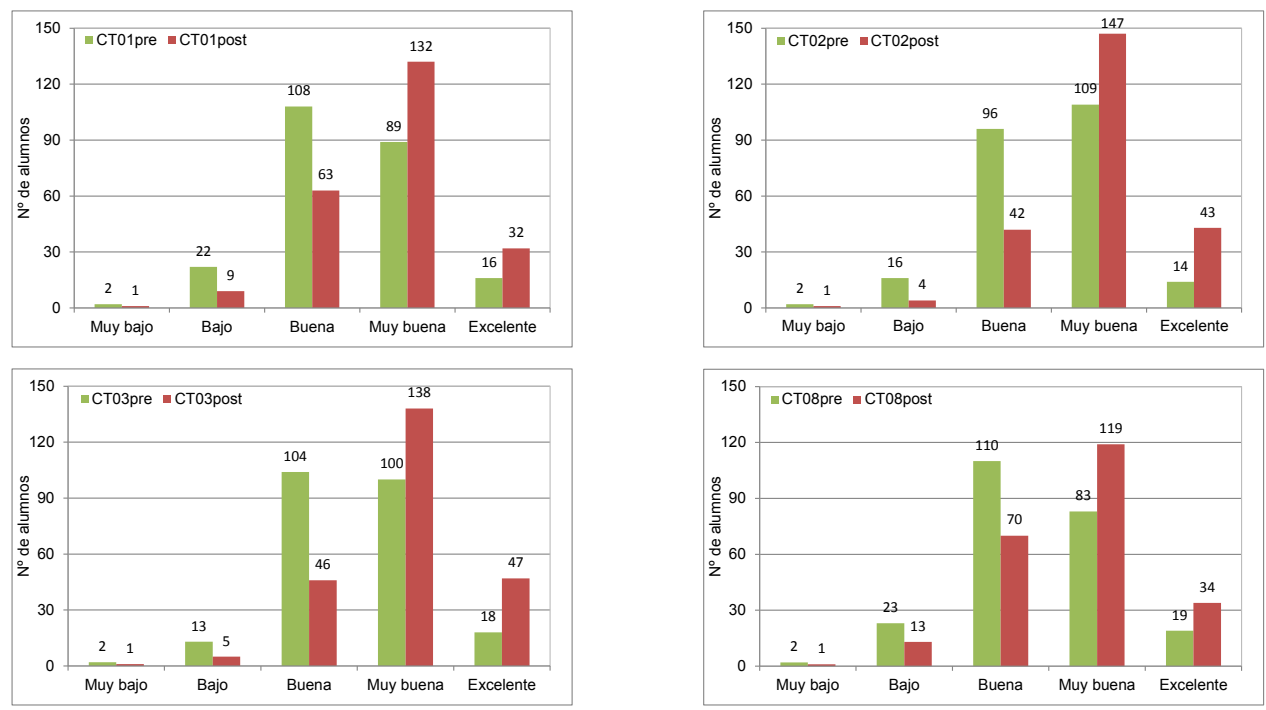

Figura 3: Resultados de la autoevaluación de los alumnos sobre el nivel de dominio de las competencias CT-01 (Comprensión e Integración), CT-02 (Aplicación y pensamiento práctico), CT-03 (Análisis y resolución de problemas), CT-08 (Comunicación efectiva) antes y después de cursar la asignatura.

(c)) BY-NC-ND 2017, Universitat Politècnica de València

Congreso IN-RED (2017) 
Tabla 2: Porcentaje de alumnos que posee un nivel de dominio de las competencias "Muy buena" o "Excelente" antes y después de cursar la asignatura.

\begin{tabular}{ccc}
\hline CT & Antes & Después \\
\hline CT01 & $44.3 \%$ & $69.2 \%$ \\
CT02 & $51.9 \%$ & $80.2 \%$ \\
CT03 & $49.8 \%$ & $78.1 \%$ \\
CT08 & $43.0 \%$ & $64.6 \%$
\end{tabular}

En la figura 4 se muestra la distribución de la evaluación de las 4 competencias objeto de estudio de acuerdo con el apartado 2.4. En general, la gran mayoría de alumnos (por encima del 95\%) posee un nivel de dominio de las competencias "Bien/Adecuado" y "Excelente". Se observa que el porcentaje de alumnos que han alcanzado un nivel de competencia "Excelente" es del orden 50\% o superior (СТ01: 50\%: СТ02: 64.2\%; СТ03 58.7\%; СТ08: $48.9 \%$ ). Estos resultados coinciden parcialmente con la auto-evaluación de los alumnos en la que se ponía de manifiesto que la competencia CT08 eran el punto débil de los alumnos, es decir, es la competencia más difícil de adquirir/desarrollar por parte del alumnado.

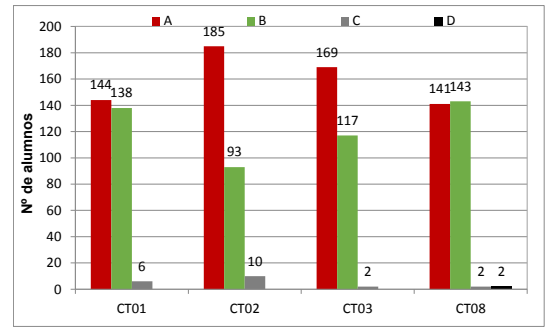

Figura 4: Distribución de la evaluación categórica de las competencias analizadas. A: Excelentelejemplar, B: Bien/adecuado, C: En desarrollo, D: No alcanzado

Además de las competencias puntos de control de la asignatura, un ratio importante de los alumnos consideran que el aprendizaje basado en proyectos ha permitido trabajar otras competencias (ver figura 5) como la "CT06 Trabajo en equipo y liderazgo" (70\%) y en menor medida "CT09 Pensamiento crítico" (54\%), "CT10 Planificación y gestión del tiempo" (48\%), "CT11 Aprendizaje permanente: Capacidad de auto-aprendizaje" (47\%) y "CT04 Innovación, creatividad y emprendimiento" (40\%). Destacar que también se obtuvieron indicadores de las competencias CT04 y CT09 en el desarrollo de las actividades propuestas y que también podrían ser de utilidad.

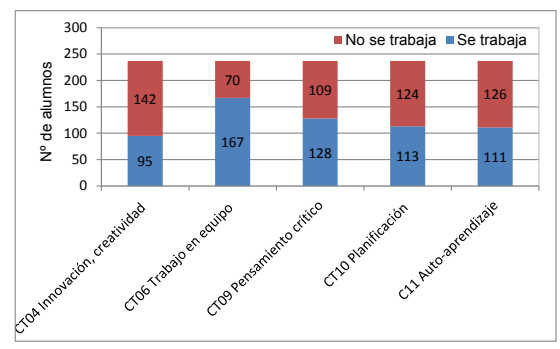

Figura 5: Número de alumnos que consideran que el desarrollo del proyecto han contribuido a la adquisición de otras competencias de las que la asignatura no es punto de control. 
En la figura 6 se muestra la valoración de los alumnos hacia el uso de metodología docente "aprendizaje basado en proyecto" en la asignatura Instrumentación y Control Industrial. En general, los alumnos han mostrado una actitud y una valoración muy positiva de la metodología docente aplicada. El $86.1 \%$ de alumnos valoran positivamente la metodología "aprendizaje basado en proyecto" e indican que les ha proporcionado una visión más aplicada de la instrumentación electrónica y favoreciendo a su vez la mejora en el nivel de dominio de diferentes competencias transversales. A pesar de ello existe un porcentaje reducido de alumnos (13.9\%) que mostró cierta resistencia al cambio en favor de las metodologías activas, arguyendo que las horas dedicadas a la actividad no compensan a los conocimientos adquiridos.

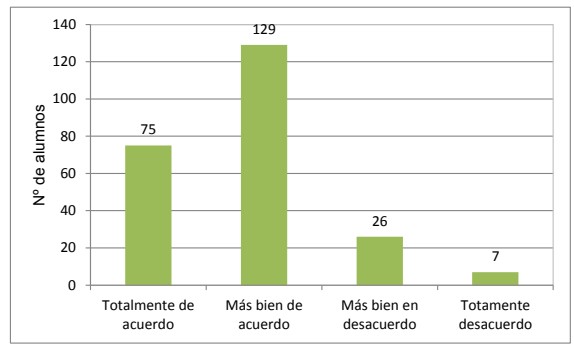

Figura 6: Valoración de los alumnos acerca del uso de la metodología docente "aprendizaje basado en proyecto" en la asignatura Instrumentación y Control industrial. Curso 16-17.

\section{Conclusión}

Se ha diseñado y llevado a cabo una actividad formativa para trabajar y evaluar las múltiples competencias transversales en grupos numerosos, empleando la metodología de aprendizaje basado en proyectos y el portafolio . El análisis de los resultados obtenidos indica que dicha actividad no supone una excesiva carga de trabajo ni para el alumnado ni para el profesorado. Tras finalizar el conjunto de actividades la consideración de los alumnos refleja un incremento en el número de alumnos que alcanzan dominio "muy bueno" o "excelente" de las competencias trasversales evaluadas (CT-01 Comprensión e Integración, CT-02 Aplicación y pensamiento práctico, CT-03 Análisis y resolución de problemas, CT-08 Comunicación efectiva). Los resultados de la evaluación del profesorado reflejan que la gran mayoría de alumnos (por encima del 95\%) posee un nivel de dominio de las competencias trabajadas y evaluadas de "Bien/Adecuado" y "Excelente". Además, tanto los alumnos $(86.1 \%)$ como el profesorado valoran positivamente la metodología aprendizaje basado en proyectos reflejando que proporciona una visión más aplicada de la instrumentación electrónica y favorece la adquisición de las competencias transversales.

\section{Agradecimientos}

Este trabajo está subvencionado parcialmente por la Escuela Técnica Superior de Ingenieros Industriales y el Vicerrectorado de Estudios, Calidad y Acreditación de la UPV (PIME B17, Convocatoria 2016-2017).

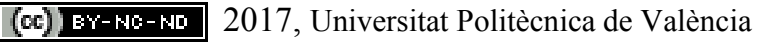




\section{Referencias}

BARRAGAN SANCHEZ, R (2005) "El portafolio, metodología de evaluación y aprendizaje de cara al nuevo Espacio Europeo de Educación Superior. Una experiencia práctica en la Universidad de Sevilla." en Revista Latinoamericana de Tecnología Educativa, Vol 4, nº1, pp121-139.

BARROWS, H.S. (1986). "A Taxonomy of problema-based learning methods" en Medical Education, Vol 20 n6, pp481-486.

DE MIGUEL, M. (2006) "Metodologías de enseñanza para el desarrollo de competencias. Orientaciones para el profesorado universitario ante el Espacio Europeo de Educación Superior." en Educatio siglo XXI, Vol 24, pp 207-210.

COTTON K. (2001) "Developing Employability Skills" [online]. Available at: $<$ http://www.bikume.com/descargas/5/archivos/tesis-sobre-competencias-transversales-para-mejorarla-empleabilidaed.pdf $>$ [Consulta Junio 2016].

DE LA PEÑA AMORÓS M. (2012) "La evaluación de los alumnos a través del portafolio" en Revista Jurídica de Investigación e Innovación Educativa, Nº, pp81-94.

GRANGEL SEGUER R., CAMPOS SANCHO C. (2013) "Contratos de aprendizaje y evaluación entre iguales para responsabilizar al alumno de su aprendizaje" Actas de las XIX Jenui Castellón. pp 45-52.

HERMOSILlA Z., CLEMENTE M., TRINIDAD A., ANDRÉS J. (2013) “Competencia en comunicación oral: un reto para el ingeniero" En Garrigos et al. "New changes in technology and innovation." INNODOCT 2013. Universidad Politécnica de Valencia.

PRATS-BOLUDA G., YE-LIN Y., TRENÓR GOMIS B. (2016) “Análisis del uso del póster científico y de la revisión por pares como herramienta desarrollo de la competencia comunicación efectiva en estudiantes de grado en ingeniería" Congreso Nacional de Innovación Educativa y de Docencia en Red (IN-RED). Valencia.

PRIETO, L. (2006) "Aprendizaje activo en el aula universitario: el caso del aprendizaje basado en problemas, en Miscelánea Comillas.” Revista de Ciencias Humanas y Sociales, Vol. 64. №124, pp 173-196.

SÁNCHEZ SANTAMARÍA J. (2011) "Evaluación de los aprendizajes universitarios: una comparación sobre sus posibilidades y limitaciones en el Espacio Europeo y Educación Superior" Revista de Formación e Innovación Educativa Universitaria, Vol $4 \mathrm{~N}^{\circ} 1$, pp 40-54

VILLA SÁNCHEZ A., POBLETE RUIZ M. (2011) "Evaluación de competencias genéricas: principios, oportunidades y limitaciones" Bordón, Vol 63 NoI, pp147-170.

VILLARDÓN GALLEGO M.L. (2006) "Evaluación del aprendizaje para promover el desarrollo de competencias" Educatio siglo XXI, Vol. 24, pp57-76.

(cc)) EY-NC-ND 2017, Universitat Politècnica de València

Congreso In-Red (2017) 
ANEXO I. Rúbricas de evaluación de la Fase 1

\begin{tabular}{|c|c|c|c|c|c|}
\hline \multirow{2}{*}{ Indicadores } & \multicolumn{4}{|c|}{ Descriptores } & \multirow{2}{*}{ Competencia } \\
\hline & D. No alcanzado & C. En desarrollo & B. Bien/adecuado & A. Excelente/ejemplar & \\
\hline $\begin{array}{c}\text { Aporta ideas y planteamiento } \\
\text { originales } \\
\text { (F1.1) }\end{array}$ & $\begin{array}{l}\text { No aporta ideas ni } \\
\text { planteamientos y muestra } \\
\text { una actitud cerrada y/o } \\
\text { pasiva antes las tareas }\end{array}$ & $\begin{array}{l}\text { Aporta alguna idea o } \\
\text { planteamiento ante } \\
\text { situaciones nuevas }\end{array}$ & $\begin{array}{c}\text { Aporta de forma detallada sus } \\
\text { propias ideas y/o planteamientos } \\
\text { originales }\end{array}$ & $\begin{array}{c}\text { Aporta una gran variedad de ideas y } \\
\text { planteamientos novedosos, con fluidez, } \\
\text { bien elaborados, aplicables a diferentes } \\
\text { casos }\end{array}$ & $\begin{array}{l}\text { CT-01 Comprensión e } \\
\text { Integración } \\
\text { CT-04 Innovación, } \\
\text { creatividad y } \\
\text { emprendimiento }\end{array}$ \\
\hline $\begin{array}{c}\text { Plasma de manera formal las } \\
\text { ideas } \\
\text { (F1.2) }\end{array}$ & $\begin{array}{l}\text { No plasma de manera } \\
\text { formal las ideas }\end{array}$ & $\begin{array}{c}\text { Plasma de manera limitada } \\
\text { las ideas que se han } \\
\text { generado }\end{array}$ & $\begin{array}{l}\text { Plasma de manera correcta las } \\
\text { ideas que se han generado }\end{array}$ & $\begin{array}{c}\text { Plasma de manera enriquecida las ideas } \\
\text { que se han generado }\end{array}$ & $\begin{array}{l}\text { CT-08 Comunicación } \\
\text { efectiva }\end{array}$ \\
\hline $\begin{array}{l}\text { Valora las implicaciones } \\
\text { prácticas (pros-contras) de } \\
\text { diversas alternativas o } \\
\text { soluciones (F1.3) }\end{array}$ & $\begin{array}{l}\text { No dispone de elementos de } \\
\text { juicio para identificar las } \\
\text { ventajas e inconvenientes de } \\
\text { diferentes soluciones }\end{array}$ & $\begin{array}{l}\text { Es capaz de comparar } \\
\text { diferentes soluciones, pero } \\
\text { no sabe valorar sus } \\
\text { implicaciones prácticas }\end{array}$ & $\begin{array}{l}\text { Identifica pros y contras de } \\
\text { diferentes soluciones y valora } \\
\text { sus implicaciones prácticas }\end{array}$ & $\begin{array}{l}\text { Reconsidera las alternativas en función de } \\
\text { la reflexión y valoración de las } \\
\text { implicaciones que tienen }\end{array}$ & $\begin{array}{l}\text { CT-02 Aplicación } \\
\text { pensamiento práctico } \\
\text { CT-03 Análisis y resolución } \\
\text { de problemas } \\
\text { CT-09 Pensamiento crítico }\end{array}$ \\
\hline
\end{tabular}

ANEXO I. Rúbrica de evaluación de la Fase 2: Plan de Trabajo

\begin{tabular}{|c|c|c|c|c|c|}
\hline \multirow{2}{*}{ Indicadores } & \multicolumn{4}{|c|}{ Descriptores } & \multirow{2}{*}{ Competencias } \\
\hline & D. No alcanzado & C. En desarrollo & B. Bien/adecuado & A. Excelente/ejemplar & \\
\hline $\begin{array}{c}\text { Identificación y Asignación de } \\
\text { las tareas } \\
\text { (PT.1) }\end{array}$ & $\begin{array}{l}\text { Distribución de las tareas } \\
\text { inapropiada con el número de } \\
\text { miembros del grupo. Las tareas } \\
\text { no se han identificado } \\
\text { correctamente }\end{array}$ & $\begin{array}{l}\text { Distribución de las tareas } \\
\text { inapropiada con el número de } \\
\text { miembros del grupo. No se } \\
\text { identifican todas las tareas }\end{array}$ & $\begin{array}{l}\text { Distribución de las tareas } \\
\text { adecuada con el número de } \\
\text { miembros del grupo. Definición } \\
\text { correcta. }\end{array}$ & $\begin{array}{l}\text { Distribución de las tareas } \\
\text { coherente con el número de } \\
\text { miembros del grupo. Definición } \\
\text { correcta y precisa. De las tareas }\end{array}$ & $\begin{array}{c}\text { CT-01 Comprensión e } \\
\text { Integración } \\
\text { CT-03 Análisis y resolución de } \\
\text { problemas }\end{array}$ \\
\hline $\begin{array}{l}\text { Diagrama de Gantt } \\
\text { (PT.2) }\end{array}$ & $\begin{array}{l}\text { Temporización inadecuada de la } \\
\text { programación de las tareas y/o } \\
\text { Formato de presentación pobre }\end{array}$ & $\begin{array}{l}\text { Temporización poco adecuada } \\
\text { de la programación de las tareas } \\
y / o \\
\text { Formato de presentación regular }\end{array}$ & $\begin{array}{l}\text { Temporización adecuada de la } \\
\text { programación de las tareas y/o } \\
\text { Formato de presentación bueno }\end{array}$ & $\begin{array}{l}\text { Temporización adecuada de la } \\
\text { programación de las tareas y/o } \\
\text { Formato de presentación } \\
\text { excelente }\end{array}$ & $\begin{array}{l}\text { CT-03 Análisis y resolución de } \\
\text { problemas }\end{array}$ \\
\hline $\begin{array}{l}\text { Actas de reunión } \\
\text { (PT.3) }\end{array}$ & $\begin{array}{l}\text { Incompletas: la recopilación de } \\
\text { la información es muy } \\
\text { deficiente en cuanto al } \\
\text { contenido tratado y el informe } \\
\text { elaborado }\end{array}$ & $\begin{array}{l}\text { Parcialmente incompleta: No } \\
\text { recopila todos los puntos a } \\
\text { tratar. Los informes están poco } \\
\text { elaborados y/o con } \\
\text { incorrecciones. }\end{array}$ & $\begin{array}{l}\text { Completa: recopila todos los } \\
\text { puntos tratados. Los informes } \\
\text { son claros, concisos y con } \\
\text { leguaje adecuado. }\end{array}$ & $\begin{array}{l}\text { Exhaustivas: recopila todos y } \\
\text { cada uno de los puntos tratados. } \\
\text { Los informes son muy claros, } \\
\text { concisos y excelentes en la } \\
\text { corrección léxica y gramatical } \\
\text { empleando el lenguaje adecuado }\end{array}$ & CT-08 Comunicación efectiva \\
\hline
\end{tabular}


ANEXO I. Rúbrica de evaluación de la Fase 2: Búsqueda de Información

\begin{tabular}{|c|c|c|c|c|c|}
\hline \multirow{2}{*}{ Indicadores } & \multicolumn{4}{|c|}{ Descriptores } & \multirow{2}{*}{ Competencias } \\
\hline & D. No alcanzado & C. En desarrollo & B. Bien/adecuado & A. Excelente/ejemplar & \\
\hline $\begin{array}{l}\text { Definición de } \\
\text { conceptos y uso de } \\
\text { palabras clave } \\
\text { adecuadas } \\
\text { (BI.1) }\end{array}$ & $\begin{array}{l}\text { Se escasa o incorrecta definición de los } \\
\text { conceptos asociados a la resolución del } \\
\text { problema planteado y/o deficiente o } \\
\text { incorrecta definición de las palabras } \\
\text { clave. No se combinan de forma } \\
\text { adecuada }\end{array}$ & $\begin{array}{c}\text { No se han identificado en su } \\
\text { totalidad los conceptos } \\
\text { asociados a la resolución del } \\
\text { problema planteado. } \\
\text { Falta de concreción en } \\
\text { definición de las palabras clave. } \\
\text { Escasez de palabras clave o no } \\
\text { se combinan de la forma más } \\
\text { adecuada } \\
\end{array}$ & $\begin{array}{l}\text { Se han identificado en su mayoría } \\
\text { los conceptos asociados a la } \\
\text { resolución del problema } \\
\text { planteado. } \\
\text { Buena definición de las palabras } \\
\text { clave aunque puede que no } \\
\text { cubran la totalidad de los } \\
\text { aspectos a tratar. Se combinan de } \\
\text { forma adecuada. }\end{array}$ & $\begin{array}{l}\text { Se han identificado perfectamente los } \\
\text { conceptos asociados a la resolución del } \\
\text { problema planteado. Excelente definición de } \\
\text { las palabras clave. Se combinan de forma } \\
\text { adecuada. }\end{array}$ & $\begin{array}{c}\text { CT-01 } \\
\text { Comprensión e } \\
\text { integración } \\
\text { CT-02 Aplicación } \\
\text { y pensamiento } \\
\text { práctico } \\
\text { CT-03 Análisis y } \\
\text { resolución de } \\
\text { problemas } \\
\end{array}$ \\
\hline $\begin{array}{l}\text { Correcta selección de } \\
\text { los resultados } \\
\text { relevantes (BI.2) }\end{array}$ & $\begin{array}{l}\text { Fuentes poco o nada contrastadas } \\
\text { (artículos de opinión de autores sin } \\
\text { reconocido prestigio, páginas web no } \\
\text { oficiales) Y/O } \\
\text { Resultados insuficientes para poder } \\
\text { resolver el problema planteado }\end{array}$ & $\begin{array}{l}\text { La mayoría de las fuentes no } \\
\text { están contrastadas } Y / O \\
\text { Resultados incompletos } \\
\text { permiten resolver parciamente } \\
\text { el problema }\end{array}$ & $\begin{array}{l}\text { Incluye Fuentes contrastadas } \\
\text { pero algunas no lo son tanto. } \\
\text { Y/O } \\
\text { Resultados completos para poder } \\
\text { resolver el problema }\end{array}$ & $\begin{array}{l}\text { Fuentes contrastadas (fabricantes, } \\
\text { distribuidores, autores, de reconocido } \\
\text { prestigio) Y/O Resultados exhaustivos para } \\
\text { poder seleccionar de forma correcta la } \\
\text { solución óptima al problema }\end{array}$ & $\begin{array}{l}\text { CT-02 Aplicación } \\
\text { y pensamiento } \\
\text { práctico } \\
\text { CT-03 Análisis y } \\
\text { resolución de } \\
\text { problemas }\end{array}$ \\
\hline $\begin{array}{l}\text { Documentación } \\
\text { adecuada de los } \\
\text { resultados (BI.3) }\end{array}$ & $\begin{array}{l}\text { El documento está muy poco elaborado, } \\
\text { incompleto y/o la selección del } \\
\text { contenido no es adecuada (contenido } \\
\text { irrelevante o falta contenido) }\end{array}$ & $\begin{array}{l}\text { El documento poco elaborado, } \\
\text { una parte importante del } \\
\text { contenido no ha sido } \\
\text { seleccionado de forma } \\
\text { adecuada (irrelevante, } \\
\text { redundante) } \\
\end{array}$ & $\begin{array}{l}\text { El documento es completo con } \\
\text { una buena selección del } \\
\text { contenido aunque puede contener } \\
\text { alguna información poco } \\
\text { relevante. }\end{array}$ & $\begin{array}{l}\text { El documento es completo y se detallan de } \\
\text { forma clara los resultados de la búsqueda } \\
\text { con una excelente selección del contenido } \\
\text { (no contenido irrelevante) }\end{array}$ & $\begin{array}{l}\text { CT-08 } \\
\text { Comunicación } \\
\text { efectiva }\end{array}$ \\
\hline
\end{tabular}

ANEXO I. Rúbrica de evaluación de la Fase 2: Toma de Decisión

\begin{tabular}{|c|c|c|c|c|c|}
\hline \multirow{2}{*}{ Indicadores } & \multicolumn{4}{|c|}{ Descriptores } & \multirow{2}{*}{ Competencias } \\
\hline & D. No alcanzado & C. En desarrollo & B. Bien/adecuado & A. Excelente/ejemplar & \\
\hline $\begin{array}{l}\text { Alternativas propuestas } \\
\text { como solución al } \\
\text { problema (TD.1) }\end{array}$ & $\begin{array}{l}\text { Muy pocas alternativas de } \\
\text { solución }\end{array}$ & $\begin{array}{l}\text { Se echa en falta alguna } \\
\text { alternativas de solución }\end{array}$ & $\begin{array}{l}\text { Suficientemente representativas } \\
\text { alternativas de solución }\end{array}$ & $\begin{array}{l}\text { Gran abanico de alternativas de } \\
\text { solución }\end{array}$ & $\begin{array}{c}\text { CT-02 Aplicación y pensamiento } \\
\text { práctico } \\
\text { CT-03 Análisis y resolución de } \\
\text { problemas } \\
\end{array}$ \\
\hline $\begin{array}{l}\text { Criterios de valoración de } \\
\text { las alternativas (TD.2) }\end{array}$ & $\begin{array}{c}\text { Inadecuados para resolver el } \\
\text { problema y/o } \\
\text { escasos, no cubren todos los } \\
\text { aspectos del problema }\end{array}$ & $\begin{array}{c}\text { En general adecuados pero } \\
\text { quedan aspectos por definir para } \\
\text { la correcta resolución del } \\
\text { problema }\end{array}$ & $\begin{array}{c}\text { Adecuados, } \\
\text { cubren la gran mayoría aspectos } \\
\text { para resolver del problema }\end{array}$ & $\begin{array}{l}\text { Perfectamente definidos para } \\
\text { resolver el problema } \\
\text { Cubren todos los aspectos del } \\
\text { problema }\end{array}$ & $\begin{array}{l}\text { CT-02 Aplicación y pensamiento } \\
\text { práctico } \\
\text { CT-03 Análisis y resolución de } \\
\text { problemas } \\
\end{array}$ \\
\hline
\end{tabular}

(c) BY-NC-ND 2017, Universitat Politècnica de València 


\section{ANEXO I. Rúbrica de evaluación de la Fase 3: Presentación Oral del trabajo}

\begin{tabular}{|c|c|c|c|c|c|}
\hline \multirow{2}{*}{ Indicadores } & \multicolumn{4}{|c|}{ Descriptores } & \multirow{2}{*}{ Competencias } \\
\hline & D. No alcanzado & C. En desarrollo & B. Bien/adecuado & A. Excelente/ejemplar & \\
\hline $\begin{array}{c}\text { La exposición está debidamente } \\
\text { preparada y se ajusta al tiempo } \\
\text { establecido (F3.1) }\end{array}$ & $\begin{array}{c}\text { La exposición no está } \\
\text { debidamente estructurada y/o } \\
\text { no se ajusta al tiempo } \\
\text { establecido }\end{array}$ & $\begin{array}{l}\text { La exposición está organizada, } \\
\text { pero hay demasiada o escasa } \\
\text { información y/o no se ajusta al } \\
\text { tiempo establecido }\end{array}$ & $\begin{array}{l}\text { La audiencia puede captar } \\
\text { claramente la eficaz estructura } \\
\text { del contenido y la exposición se } \\
\text { ajusta al tiempo establecido }\end{array}$ & $\begin{array}{l}\text { La selección y organización del } \\
\text { contenido y su ilustración } \\
\text { (ejemplo, analogías...) son } \\
\text { coherentes y la exposición se } \\
\text { ajusta al tiempo establecido }\end{array}$ & CT-08 Comunicación efectiva \\
\hline $\begin{array}{l}\text { Respeta las normas lingüísticas } \\
\text { (corrección) y se expresa de } \\
\text { manera correcta (claridad). La } \\
\text { comunicación no verbal es } \\
\text { apropiada (F3.2) }\end{array}$ & $\begin{array}{c}\text { No realiza un buen uso del } \\
\text { lenguaje y/o no utiliza la } \\
\text { terminología específica de la } \\
\text { materia } \\
\text { Su lenguaje no verbal no } \\
\text { respalda y/o distrae su discurso } \\
\text { verbal }\end{array}$ & $\begin{array}{l}\text { La presentación no es fluida } \\
\text { (lenguaje limitado) y utiliza } \\
\text { escasa terminología específica o } \\
\text { lo hace inapropiadamente } \\
\text { Su lenguaje no verbal muestra } \\
\text { alguna/s deficiencia/s }\end{array}$ & $\begin{array}{l}\text { Respeta las normas lingüísticas } \\
\text { y se expresa de manera correcta, } \\
\text { utilizando de modo pertinente la } \\
\text { terminología específica } \\
\text { Su lenguaje no verbal es } \\
\text { coherente con el verbal }\end{array}$ & $\begin{array}{l}\text { La exposición se adapta a la } \\
\text { audiencia, haciendo uso de un } \\
\text { lenguaje y de una terminología } \\
\text { específicos, apropiados, } \\
\text { precisos y ricos } \\
\text { Su lenguaje no verbal refuerza } \\
\text { el verbal: gestos firmes, ritmo } \\
\text { variado y entonación } \\
\text { intencional }\end{array}$ & CT-08 Comunicación efectiva \\
\hline $\begin{array}{l}\text { Refuerza sus ideas con la ayuda } \\
\text { de los medios de apoyo (F3.3) }\end{array}$ & $\begin{array}{l}\text { No utiliza los medios de apoyo } \\
\text { apropiados o hace de un mal } \\
\text { uso de los mismos }\end{array}$ & $\begin{array}{l}\text { No siempre utiliza los medios } \\
\text { de apoyo más apropiados o no } \\
\text { hace el mejor uso de los mismos }\end{array}$ & $\begin{array}{c}\text { Los medios de apoyo } \\
\text { contribuyen a que el discurso se } \\
\text { comprenda mejor, enfatizando } \\
\text { sus puntos clave }\end{array}$ & $\begin{array}{c}\text { Los medios de apoyo destacan } \\
\text { por su calidad/originalidad y } \\
\text { contribuyen a que el discurso se } \\
\text { comprenda mejor }\end{array}$ & CT-08 Comunicación efectiva \\
\hline $\begin{array}{l}\text { Búsqueda de alternativas y } \\
\text { criterios de valoración de las } \\
\text { alternativas (F3.4) }\end{array}$ & $\begin{array}{l}\text { Inadecuados para resolver el } \\
\text { problema y/o escasos, no } \\
\text { cubren todos los aspectos del } \\
\text { problema }\end{array}$ & $\begin{array}{c}\text { En general adecuados pero } \\
\text { quedan aspectos por definir para } \\
\text { la correcta resolución del } \\
\text { problema }\end{array}$ & $\begin{array}{c}\text { Adecuados, cubren la gran } \\
\text { mayoría aspectos para resolver } \\
\text { el problema }\end{array}$ & $\begin{array}{l}\text { Perfectamente definidos para } \\
\text { resolver el problema. Cubren } \\
\text { todos los aspectos del problema }\end{array}$ & $\begin{array}{c}\text { CT-02 Aplicación y } \\
\text { pensamiento práctico } \\
\text { CT-03 Análisis y resolución de } \\
\text { problemas }\end{array}$ \\
\hline $\begin{array}{l}\text { Selección y desarrollo de la } \\
\text { solución (F3.5) }\end{array}$ & $\begin{array}{l}\text { Deficiente comparativa entre las } \\
\text { diferentes alternativas } \\
\text { propuestas. La justificación de } \\
\text { la solución muy poco elaborada }\end{array}$ & $\begin{array}{l}\text { Coherente con los criterios de } \\
\text { selección. La comparativa entre } \\
\text { las alternativas propuestas es } \\
\text { incompleta. Justificación pobre } \\
\text { de la solución }\end{array}$ & $\begin{array}{l}\text { Es coherente con los criterios de } \\
\text { selección. La comparativa entre } \\
\text { las diferentes alternativas } \\
\text { propuestas completa. } \\
\text { Justificación adecuada. }\end{array}$ & $\begin{array}{c}\text { Es coherente con los criterios de } \\
\text { valoración. Excelente } \\
\text { comparativa entre las } \\
\text { alternativas y justificación } \\
\text { exhaustiva de la solución } \\
\text { adoptada }\end{array}$ & $\begin{array}{c}\text { CT-02 Aplicación y } \\
\text { pensamiento práctico } \\
\text { CT-03 Análisis y resolución de } \\
\text { problemas }\end{array}$ \\
\hline
\end{tabular}




\section{ANEXO II. Encuesta sobre el seminario de instrumentación Curso 16-17}

1.- Indique el $\mathrm{n}^{\mathrm{o}}$ de horas de trabajo ha dedicado a nivel individual (fuera del horario de clase y sin contar las reuniones grupales) en el proyecto: búsqueda de información, elaboración del portafolio y la presentación, etc. Respuesta: horas

2.- Indique el $\mathrm{n}^{\circ}$ de horas ha dedicado a nivel grupal en el desarrollo del proyecto (fuera del horario de clase y sólo las reuniones grupales). Respuesta: horas

3.- Realice una autoevaluación de las siguientes competencias antes de comenzar el curso:

CT01 Comprensión e Integración $\quad \square$ Muy bajo $\square$ Bajo $\square$ Buena $\square$ Muy buena $\square$ Excelente
CT02 Aplicación y pensamiento práctico $\square$ Muy bajo $\square$ Bajo $\square$ Buena $\square$ Muy buena $\square$ Excelente
CT03 Análisis y resolución de problemas $\square$ Muy bajo $\square$ Bajo $\square$ Buena $\square$ Muy buena $\square$ Excelente
CT08 Comunicación efectiva $\quad \square$ Muy bajo $\square$ Bajo $\square$ Buena $\square$ Muy buena $\square$ Excelente

4.- Realice una autoevaluación de las siguientes competencias después de cursar la asignatura:

CT01 Comprensión e Integración $\quad \square$ Muy bajo $\square$ Bajo $\square$ Buena $\square$ Muy buena $\square$ Excelente
CT02 Aplicación y pensamiento práctico $\square$ Muy bajo $\square$ Bajo $\square$ Buena $\square$ Muy buena $\square$ Excelente
CT03 Análisis y resolución de problemas $\square$ Muy bajo $\square$ Bajo $\square$ Buena $\square$ Muy buena $\square$ Excelente
CT08 Comunicación efectiva $\quad \square$ Muy bajo $\square$ Bajo $\square$ Buena $\square$ Muy buena $\square$ Excelente

5.- Además de las competencias anteriores, el desarrollo del proyecto le ha ayudado a mejorar en las siguientes competencias (multi-respuesta):

$\square$ Capacidad auto-aprendizaje para emprender estudios posteriores con alto grado de autonomía

$\square$ Trabajo en equipo y liderazgo

$\square$ Planificación y gestión del tiempo

$\square$ Innovación, creatividad y emprendimiento

$\square$ Pensamiento crítico

6.- ¿Considera que el aprendizaje basado en proyecto es una buena metodología docente que favorece una visión más aplicada de la instrumentación electrónica y el desarrollo de las competencias transversales y por tanto deberá seguir empleándose en la asignatura?

$\square$ Totalmente de acuerdo

$\square$ Más bien en desacuerdo $\square$ Más bien de acuerdo

$\square$ Totalmente en desacuerdo 


\title{
Incorporación de la aplicación Kahoot! para la evaluación de las prácticas de la asignatura de "Ciencia de Materiales"
}

\section{Garcia-Garcia ${ }^{a}$, A. Carbonell-Verdu ${ }^{a}$, N. Montañes ${ }^{a}$, L. Quiles ${ }^{a}$ y V. Fombuena ${ }^{a}$}

${ }^{a}$ Universitat Politècnica de València. Departamento de Ingeniería Mecánica y de Materiales. Plaza Ferrándiz y Carbonell, 03801 Alcoy (Alicante) España. e-mail: dagarga4@epsa.upv.es

\begin{abstract}
During the accomplishment of the "Material science" laboratory practices in the Degree of Chemical Engineering, we have incorporated the use of the multi-platform application "Kahoot!" to evaluate the subject. The incorporation of this application improves the attention of the student during the development of the laboratory practices in an efficient and dynamic way. Furthermore, the application allows individual participation of students and debate between them in a dynamic and entertaining mode. The application improves student collaboration and attention in the development of the practices. The implementation of the multi-platform application "Kahoot!" encourages the attention and participation of the student in the laboratory practices in a very effective way.
\end{abstract}

Keywords: Gamification, methodology, applications, Kahoot!, game, competition, training, evaluation, mobile device.

\footnotetext{
Resumen

Durante la realización de las prácticas de laboratorio de la asignatura de "Ciencia de Materiales" en el Grado de Ingeniería Química se ha incorporado el uso de la aplicación multiplataforma Kahoot! para su evaluación. Con la incorporación de esta aplicación se consigue incrementar la atención del alumno de forma efectiva y dinámica durante el desarrollo de las mismas. Además la aplicación permite tanto la participación individual como el debate entre los propios alumnos de manera dinámica y entretenida, mejorando la colaboración y la atención del alumno en el transcurso de las prácticas. Con la implementación de la aplicación multiplataforma Kahoot! se fomenta la atención y participación del alumnado en las clases prácticas de una forma muy efectiva.
}

Palabras clave: gamificación, metodología, aplicaciones, Kahoot!, juego, competición, formación, evaluación, dispositivo móvil. 


\section{Introducción}

El gran avance tecnológico de los últimos años, así como el fácil acceso de los alumnos a dispositivos electrónicos ha dado lugar a nuevas formas de enseñanza en el aula [1]. Con el paso de los años, la aparición de nuevas técnicas ha facilitado a los docentes el gran reto de conseguir promover tanto la atención como la colaboración del alumno en clase. Incluso, permiten conocer rápidamente y de una manera mucho más efectiva, que métodos tradicionales como las preguntas de respuesta oral lanzadas a todo el grupo, si el alumnado está comprendiendo los conceptos y está realizando, por consiguiente, un correcto seguimiento de la asignatura [2].

Inicialmente, los sistemas de evaluación de respuesta personal (Clickers) obligaban a los centros a realizar inversiones en la adquisición de dispositivos de mano y equipos para que el alumno pudiera responder a las preguntas planteados por el profesor [3]. En la actualidad herramientas de trabajo como la aplicación multiplataforma Kahoot! están facilitando el aprendizaje y la evaluación en red con la utilización de los dispositivos electrónicos personales.

La aplicación Kahoot! es una herramienta evaluativa de carácter lúdico que permite realizar la misma función que los "Clickers" de una manera más sencilla [4]. Es un juego divertido y dinámico que consiste en proyectar una a una las preguntas sobre la pantalla del aula y el alumno con la utilización de un dispositivo electrónico, conectado previamente a internet, tratará de seleccionar la respuesta que crea correcta [5]. El alumno será puntuado distintamente dependiendo de la respuesta seleccionada y el tiempo empleado para ello. Al finalizar cada pregunta, el profesor aprovecha para generar un debate sobre la respuesta, involucrando al alumno en el proceso de aprendizaje [6]. Además, presenta ventajas como repasar los errores más comunes, conocer al alumnado con mayores dificultades y tener una visión general del alcance de conocimientos de una manera muy rápida y fácil.

Existen multitud de opciones para la evaluación mediante cuestionarios, un ejemplo es el caso de los exámenes tipo test disponibles en la plataforma "PoliformaT" de la UPV. Sin embargo, existen notables diferencias en cuanto a la dinámica de evaluación y la retroalimentación alumno-profesor de dichos cuestionarios con respecto a la aplicación Kahoot!. El principal inconveniente de dichos test es que están pensados para que el alumno conteste a todas las preguntas en un determinado tiempo, obteniendo la solución de todas ellas una vez finalizado el test, lo cual impide la posibilidad de retroalimentación con el profesor en cada pregunta, sin embargo, mediante Kahoot! el profesor puede interactuar con los alumnos tras cada cuestión realizada. Otra de las características que diferencian los cuestionarios habituales de la aplicación Kahoot! es la ausencia de competición entre los alumnos, omitiendo así la parte lúdica que sí se encuentra en Kahoot!.

En las encuestas y diferentes estudios consultados en bibliografía referentes a la utilización de los nuevos métodos interactivos, Kahoot! ha sido evaluado por parte del alumnado positivamente tanto en diversión de la actividad como utilidad [4].

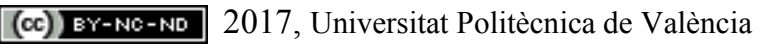

Congreso IN-RED (2017) 


\section{Objetivos}

El objetivo principal del presente estudio es valorar la implementación de la aplicación multiplataforma Kahoot! en la evaluación de las prácticas de la asignatura de "Ciencia de Materiales" de segundo curso del Grado de Ingeniería Química. Con la incorporación de esta aplicación para la evaluación de la asignatura no se desea únicamente evaluar al alumno, sino que también se pretende mejorar la atención de los alumnos en clase, así como afianzar los conceptos importantes de la misma de una forma divertida y utilizando las nuevas tecnologías.

\section{Desarrollo}

Como se ha comentado, se ha introducido la aplicación Kahoot! como método de evaluación de las prácticas de la asignatura de "Ciencia de Materiales" de segundo curso del Grado de Ingeniería Química. En total se han realizado cinco pruebas con dicha aplicación (una por cada una de las sesiones de prácticas) a un total de 30 alumnos divididos en dos grupos. Para poder implementar dicha aplicación en las prácticas de la asignatura es necesario que cada alumno disponga de un dispositivo electrónico (móvil, tableta u ordenador) conectado a internet. También es necesario que en cada uno de los dispositivos esté instalada la aplicación Kahoot!, exceptuando en los ordenadores, ya que en estos se puede acceder a la aplicación directamente a través de la web.

\subsection{Preparación de los test de evaluación}

Para poder evaluar a los alumnos mediante la aplicación Kahoot!, en primer lugar el profesor creó cinco test (uno por cada sesión práctica de la asignatura) con 20 preguntas cada uno. Esto se realizó con antelación al inicio de las clases a través de la web de la aplicación (www.create.kahoot.it/). En dicha web el profesor puede crear una plantilla con las preguntas que desea realizar (Fig.1), además debe proponer diferentes soluciones a las preguntas planteadas, siendo al menos una de ellas la correcta, ya que la aplicación consiste en seleccionar la respuesta correcta dentro de las soluciones propuestas. Una vez preparados los test con las preguntas y las posibles soluciones ya se puede realizar la evaluación de cada una de las prácticas. Los test creados pueden ser guardados, lo cual permite su utilización para posteriores cursos. 


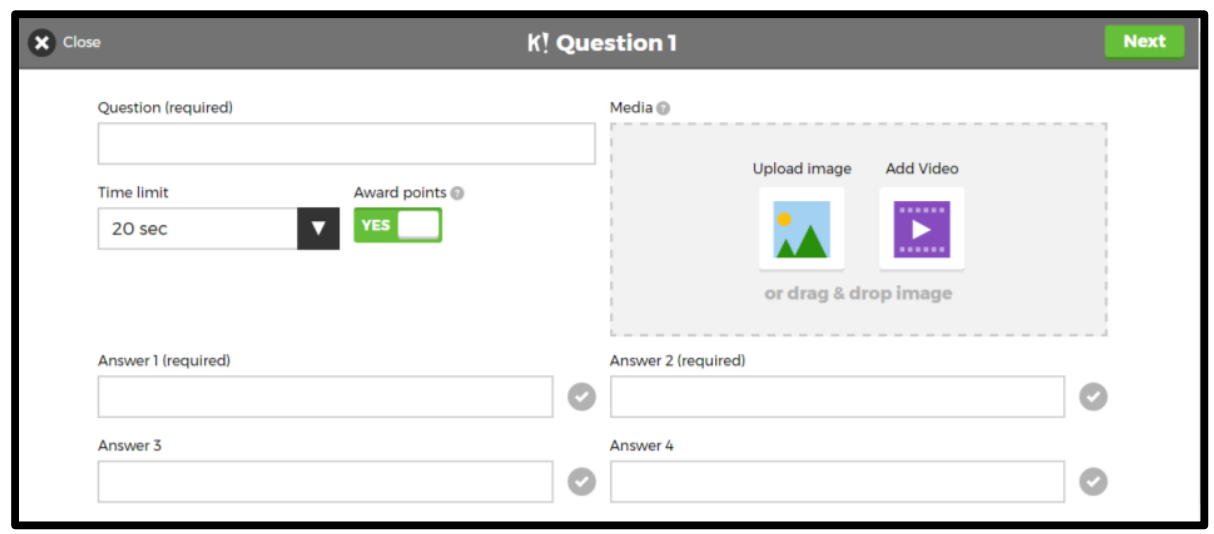

Fig. 1 Plantilla para la creación de preguntas en la aplicación Kahoot!

\subsection{Aplicación de los test de evaluación}

En este caso se consideró que el mejor momento para realizar la evaluación mediante Kahoot! era el inicio de cada una de las cinco sesiones prácticas, esto permite refrescar conceptos dados en clases anteriores y obliga al alumno a llevar un seguimiento constante de la asignatura. Para evitar que el inicio de la clase se alargase demasiado se dotó de un límite de tiempo para responder a cada una de las preguntas (20 segundos para cada pregunta). Para llevar a cabo la evaluación, en primer lugar el profesor debe de indicar a los alumnos el código del test, el cual proporciona la aplicación (Fig. 2). Una vez todos los alumnos han entrado en la aplicación deben identificarse mediante su nombre y apellidos, apareciendo todos los participantes en la pantalla del proyector.

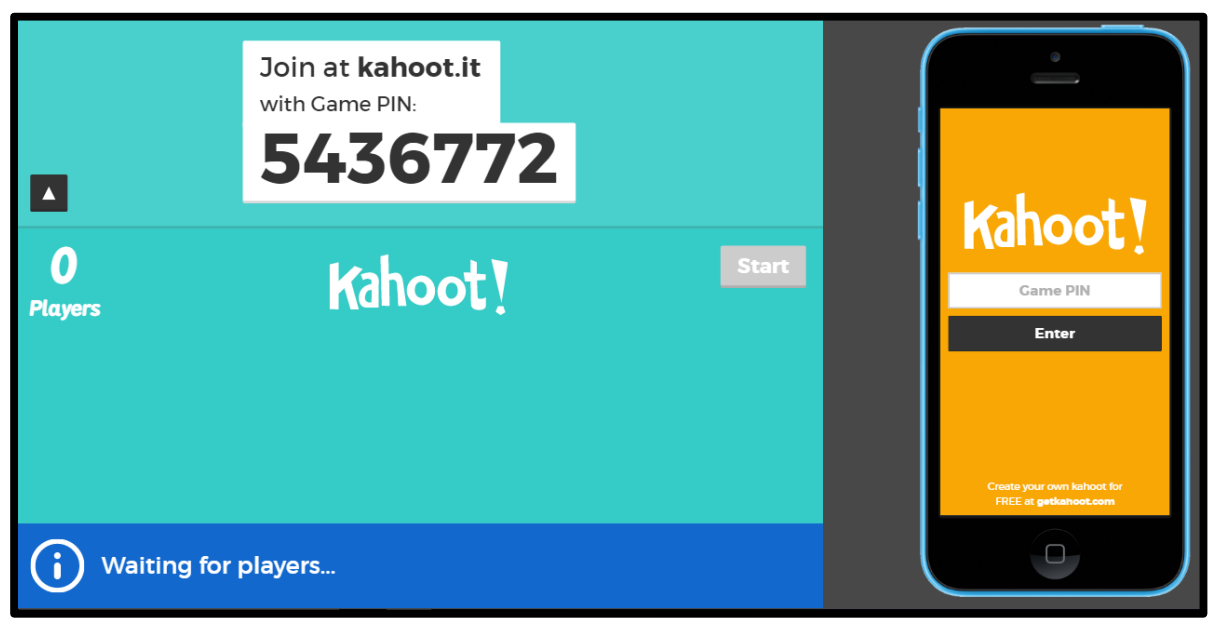

Fig. 2 Código del test proporcionado por la aplicación Kahoot! 
Cuando todos los alumnos están identificados el profesor inicia el test. Las preguntas con las posibles respuestas aparecen una tras otra en el proyector de clase y el alumno a través del dispositivo móvil dispone de un límite de tiempo para seleccionar la respuesta que consideren correcta (Fig. 3).

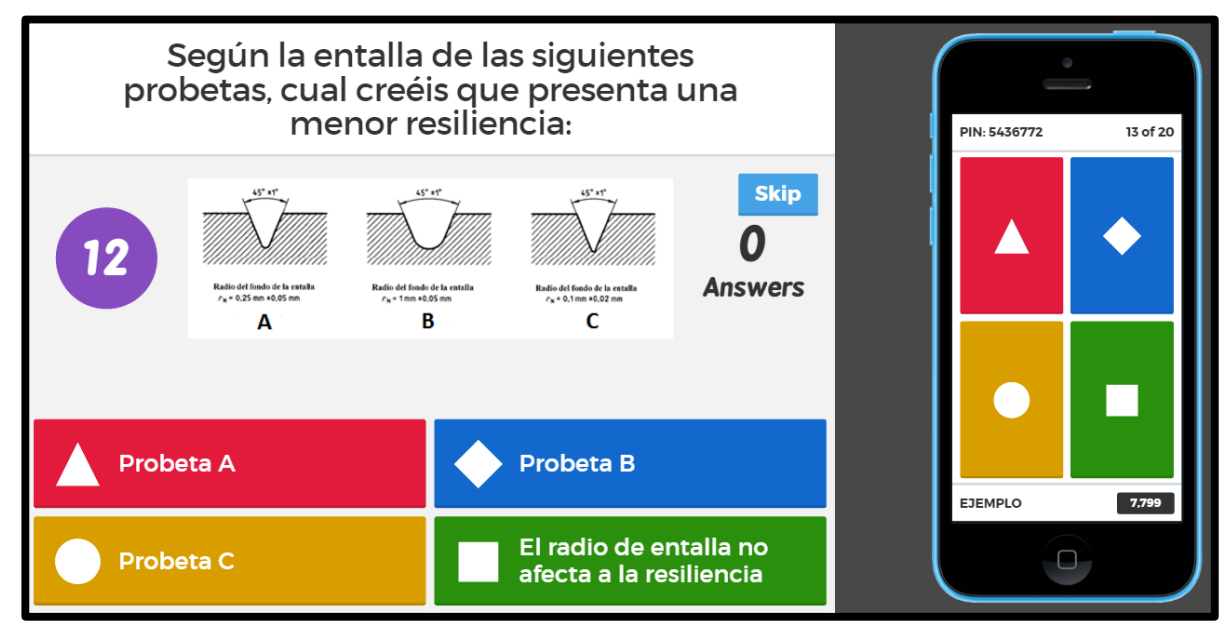

Fig. 3 Ejemplo de pregunta en la aplicación Kahoot!

Una vez finalizado el tiempo de la pregunta o cuando todos los alumnos hayan contestado a la misma, la aplicación dota a cada uno de ellos de una puntuación, la cual depende de si la respuesta seleccionada es la correcta y del tiempo que hayan empleado en seleccionarla. La aplicación también dota de puntos extra al alumno que haya acertado varias preguntas de forma consecutiva. Tras cada pregunta el nombre de los alumnos con las mayores puntuaciones aparece en la pantalla, motivando al alumno a superarse en preguntas posteriores (Fig. 4). Las preguntas planteadas en cada inicio de clase estarán relacionadas con las prácticas de laboratorio realizadas anteriormente, con el objetivo de refrescar conceptos ya impartidos y de evaluar lo aplicado en sesiones anteriores. 


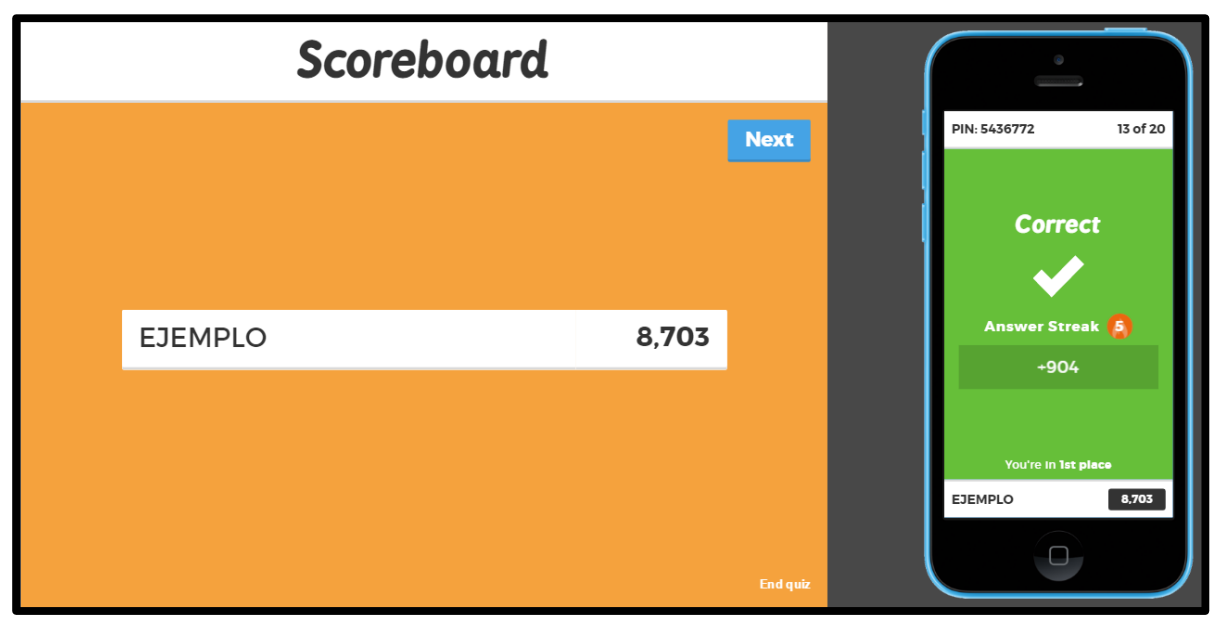

Fig. 4 Pantalla de resultados de la aplicación Kahoot!

\subsection{Evaluación de los test}

Una vez finalizado el test la aplicación permite descargar en el ordenador del profesor una hoja Excel con los resultados obtenidos por cada uno de los alumnos participantes, sabiendo las preguntas acertadas y falladas por cada uno de ellos (Fig. 5). Esto permite evaluar el test realizado de forma individual así como dotar de una puntuación numérica (del 0 al 10) a cada alumno de una forma objetiva. Tras finalizar los cinco cuestionarios el profesor dispuso de varias notas numéricas de cada uno de los alumnos permitiendo realizar una media para así obtener una nota final, la cual tuvo un peso específico del $20 \%$ en la nota final de la asignatura. Para motivar al alumno, se otorgó la máxima puntuación de cada test (un 10) a los cinco alumnos con la mayor puntuación obtenida en cada test, independientemente del número de fallos que cometieron, el resto de alumnos fue valorado teniendo en cuenta el número de aciertos y de fallos de cada test. Esta aplicación no sólo permite evaluar al alumno de forma numérica sino que también proporciona al profesor un conocimiento sobre el seguimiento de la asignatura por parte de cada alumno. 


\begin{tabular}{|c|c|c|c|c|c|c|c|}
\hline 4 & A & & $B$ & & C & $\mathrm{D}$ & $\mathrm{E}$ \\
\hline 1 & Prá & cas Ciencia de & Aateriales & & & & \\
\hline 2 & Final & ores & & & & & \\
\hline 3 & Rank & Players & & Total Sco & re (points) & Correct Answers & Incorrect Answers \\
\hline 4 & & 1 Manu Cartagena & & & 13106 & 14 & 6 \\
\hline 5 & & 2 raquel & & & 12313 & 13 & 7 \\
\hline 6 & & 3 Cami & & & 11837 & 12 & 8 \\
\hline 7 & & 4 Silvia & & & 11119 & 12 & 8 \\
\hline 8 & & 5 Andrés & & & 10076 & 11 & 9 \\
\hline 9 & & 6 Maria & & & 9939 & 11 & 8 \\
\hline 10 & & 7 Jordina & & & 9599 & 11 & 8 \\
\hline 11 & & 8 Mar lópez & & & 8195 & 10 & 9 \\
\hline 12 & & 9 irene & & & 7918 & 9 & 11 \\
\hline 13 & & 10 Luis & & & 6321 & 7 & 13 \\
\hline 4 & ' & Final Scores & Question Summary & Question 1 & Question 2 & .. $\oplus: 4$ & \\
\hline
\end{tabular}

Fig. 5 Hoja Excel con los resultados de una de las pruebas

\section{Resultados}

Tras finalizar las cinco sesiones prácticas de la asignatura de "Ciencia de Materiales" se realizó una encuesta anónima a los 30 alumnos que cursaron la asignatura con el fin de que evaluaran el método de evaluación empleado en las prácticas, obteniéndose los resultados que se muestran en la Fig. 6.

Tabla 1. Resultados de la encuesta sobre la metodología de evaluación

\begin{tabular}{ccccc}
\hline & \multicolumn{4}{c}{ VALORACIÓN } \\
\cline { 2 - 4 } Cuestión & $\begin{array}{c}\text { Nada } \\
\text { Favorable }\end{array}$ & $\begin{array}{c}\text { Poco } \\
\text { Favorable }\end{array}$ & Favorable & $\begin{array}{c}\text { Muy } \\
\text { Favorable }\end{array}$ \\
\hline $\begin{array}{c}\text { ¿Qué te ha parecido el sistema } \\
\text { de evaluación de las prácticas } \\
\text { de "Ciencia de Materiales" } \\
\text { mediante la aplicación } \\
\text { Kahoot!? }\end{array}$ & 0 & 0 & 7 & 23 \\
\hline
\end{tabular}

Como se puede observar a más de un $76 \%$ le pareció muy favorable el método de evaluación empleado, mientras que al $24 \%$ restante le pareció favorable. Por tanto, se deduce que el sistema de evaluación de las prácticas mediante la aplicación Kahoot! resulta totalmente satisfactorio para el alumnado.

Además, también se observó un incremento de la nota media de las prácticas con respecto a los dos últimos cursos (2014/2015 y 2015/2016) donde la evaluación se realizó mediante informes individuales de cada una de las cinco sesiones de prácticas. Como se puede ver en 
la Fig. 5, tras la introducción de la aplicación multiplataforma Kahoot! como sistema de evaluación se obtuvo un incremento de la nota media superior al $12 \%$ con respecto al curso académico anterior (2015/2016). Dicho incremento de la nota media puede ser debido a un aumento de la atención en clase por parte del alumno debido al sistema de evaluación, así como a la mayor objetividad en la evaluación de las prácticas que permite la aplicación Kahoot! con respecto a los informes tradicionales. Además, como se muestra en la Tabla 1, la satisfacción del sistema de evaluación por parte de los alumnos, principalmente debido a su carácter lúdico y competitivo puede influir de forma positiva en el aumento de la nota media.

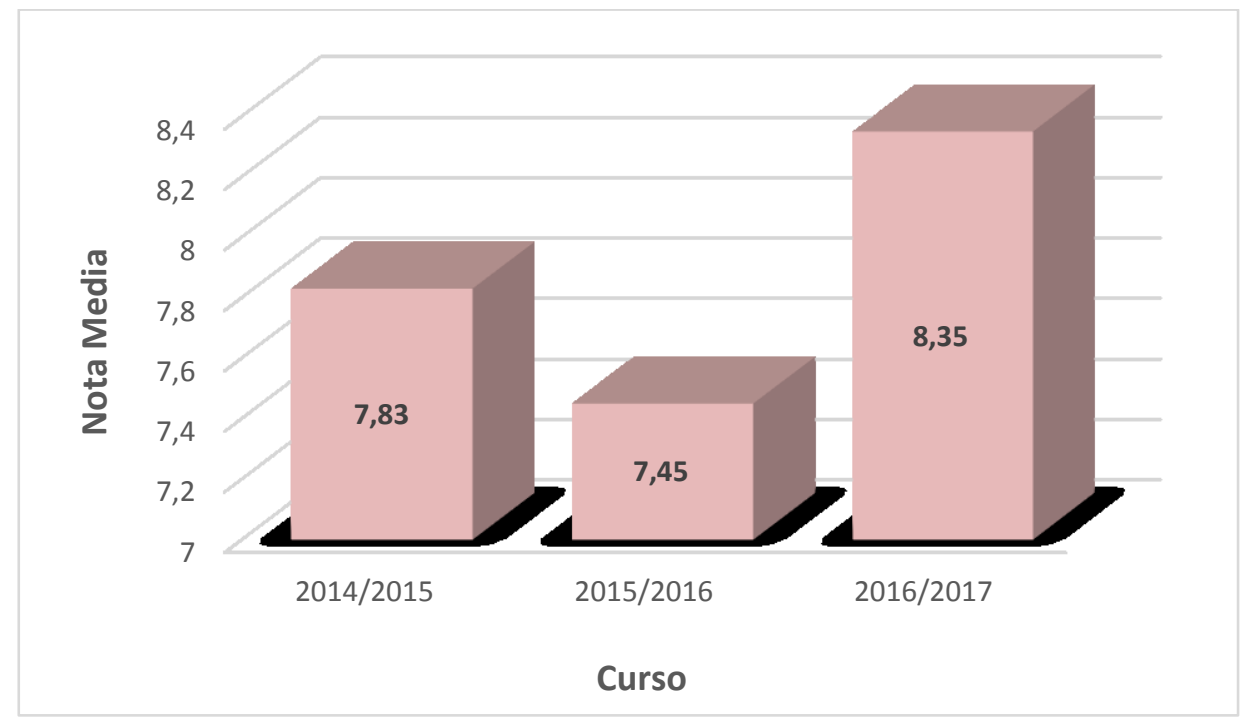

Fig. 5 Nota media de las prácticas de la asignatura de "Ciencia de Materiales"

\section{Conclusiones}

El empleo de la aplicación Kahoot! para la evaluación de las prácticas de laboratorio de las asignaturas resulta de gran interés ya que mediante este sistema de evaluación se consigue calificar al alumno de forma individual y se evita de esta manera el copiado de los informes de prácticas tan habitual. Además mediante este sistema el profesor puede tener un mayor seguimiento de cada uno de los alumnos. Con la implementación de este sistema de evaluación también se ha observado un aumento de la atención del alumno en clase así como una mayor participación de los mismos en las prácticas. Este tipo de aplicación también favorece la asimilación de conceptos fundamentales por parte del alumno y todo esto se consigue de una forma amena y divertida con el empleo de las nuevas tecnologías. Uno de los principales inconvenientes de la aplicación es la posible salida de algún alumno del test en curso debido a problemas de conexión a la red, lo cual le excluye de la evaluación final mediante la aplicación, este tipo de inconvenientes debería ser uno de los puntos débiles a mejorar por la aplicación.

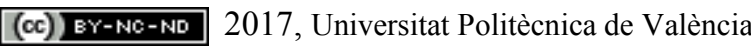




\section{Referencias}

[1] WANG, AI (2015). "The wear out effect of a game-based student response system" en Computers \& Education, vol. 82, p. 217-227.

[2] CEMBREROS, Diana (2016). “Prevención de errores frecuentes en Inglés mediante sistemas electrónicos de respuesta personal” en Revista de Ciencias Humanas y SocialesEspecial, vol. 11, p. 282-295.

[3] ROIG-VILA, R. et al (2016). Investigación e Innovación Educativa en Docencia Universitaria. Retos, Propuestas y Acciones. Alicante: Universidad de Alicante. Instituto de Ciencias de la Educación.

[4] HOlguíN, E., GARGANTILla MADERA, P., HERREROS RUIZ-VALDEPEÑAS., B. y LÓPEZ DEL HIERRO, M. (2015). "Kahoot en docencia: una alternativa práctica a los clickers" en XI Jornadas Internacionales de Innovación Universitaria Educar para transformar. Universidad Europea de Madrid. Disponible en: <http:/hdl.handle.net/11268/3603> [Consulta: 30 de marzo de 2017].

[5] BICEN, H y KOCAKOYUN, S. (2017). "Determination of university students' most preferred mobile application for gamification" en World Journal on Educational Technology: Current Issues, vol. 9, issue 1, p. 18-23.

[6] ALBA FERRE, E., MORENO BLESA, L. y RUIZ GONZALEZ, M. "The Star System apps to bridge educational gaps: Kahoot, Screencast y tableta gráfica” en XII Jornadas Internacionales de Innovación Universitaria Educar para transformer:aprendizaje experiencial. Universidad Europea de Madrid. Disponible en: < http://hdl.handle.net/11268/4493> [Consulta: 30 de marzo de 2017]. 


\title{
Coordinación de competencias transversales en asignaturas de ámbito nuclear en el Grado de Ingeniero de la Energía
}

\section{Sergio Gallardo ${ }^{a}$, Sofía Carlos ${ }^{b}$, Sebastián Martorell ${ }^{c}$ y José Ródenas ${ }^{\mathrm{d}}$}

aDepartamento de Ingeniería Química y Nuclear, Universitat Politècnica de València, Spain, email: sergalbe@iqn.upv.es; ${ }^{b}$ Departamento de Ingeniería Química y Nuclear, Universitat Politècnica de València, Spain, email: scarlos@iqn.upv.es; 'Departamento de Ingeniería Química y Nuclear, Universitat Politècnica de València, Spain, email: smartore@iqn.upv.es; ${ }^{\circ}$ Departamento de Ingeniería Química y Nuclear, Universitat Politècnica de València, Spain, email: smartore@iqn.upv.es; ${ }^{\mathrm{d} D e p a r t a m e n t o ~ d e ~ I n g e n i e r i ́ a ~ Q u i ́ m i c a ~ y ~ N u c l e a r, ~ U n i v e r s i t a t ~ P o l i t e ̀ c n i c a ~ d e ~ V a l e ̀ n c i a, ~ S p a i n, ~ e m a i l: ~}$ jrodenas@iqn.upv.es;

\begin{abstract}
After the implantation of the new Bachelor and Master Degrees and in order to group different skills profiles, the Universitat Politècnica de València (UPV) defined a list of generic competences. This list consists of a total of 13 competences to be trained and assessed in different subjects. In this frame, coordination between subjects should be improved to ensure that all the compentences are considered in the Degree. The coordination must consider the design and the assessment of activities. In the nuclear field subjects, we propose to promote the relationship between subjects taking profit of the synergy between them. One way to achieve this goal is to design activities that are related to other subjects, so that the same transversal skill can be worked on one subject but establishing connections with others. Based on this premise, this paper presents the benefits of coordination in transverse skills and their impact on the integration of nuclear subjects.
\end{abstract}

Keywords: Transversal skill; Bachelor Degree in Energy Engineering; Nuclear field subjects.

\footnotetext{
Resumen

Después de la implantación de los nuevos Grados y Másteres, la Universitat Politècnica de València (UPV) publicó una lista de competencias genéricas para agrupar los diferentes perfiles competenciales. Esta lista consta de un total de 13 competencias que deben trabajarse y evaluarse en las diferentes materias. En este marco, se debe mejorar la coordinación entre las asignaturas para asegurar que todas las competencias se trabajan a lo largo de la titulación. La coordinación debe considerar el diseño y la evaluación de las actividades. En las asignaturas de ámbito nuclear, se propone potenciar la relación entre asignaturas aprovechando las sinergias que exiten entre ellas. Una manera de conseguirlo es diseñando actividades que estén relacionadas con otras asignaturas, de forma que una misma competencia transversal
} 
pueda trabajarse en una asignatura pero estableciendo conexiones con otras. Partiendo de esta premisa, en este trabajo se presentan los beneficios de la coordinación en materia de competencias transversales y su repercusión en la integración de las asignaturas de ámbito nuclear.

Palabras clave: competencia transversal, grado ingeniero de la energía, asignaturas de ámbito nuclear.

\section{Introducción}

Los actuales planes de estudio del Espacio Europeo de Educación Superior (EEES) incluyen una serie de competencias transversales y específicas que deben adquirir los alumnos al finalizar las distintas titulaciones (Sanz de Aceo, 2010). A través del proceso de acreditación Accreditation Board for Engineering and Technology (ABET) llevado a cabo en algunas titulaciones en la Universitat Politècnica de València (UPV), ha quedado patente la necesidad de evaluar y de obtener evidencias de las competencias, principalmente transversales, que deben trabajarse en las titulaciones en cuestión. En este contexto, la UPV definió las Competencias Transversales UPV (UPV, 2015a), con el fin de abordar el problema de trabajo y evaluación de las distintas competencias transversales en todas las titulaciones que imparte. El establecimiento de 13 competencias tranversales según la UPV, obliga a realizar un importante trabajo para asegurar que el alumno egresado haya trabajado de manera adecuada y balanceada todas ellas. La coordinación es esencial para poder asegurar este punto. Sin embargo, la coordinación no debe quedarse únicamente en el nivel de toda la titulación, bien sea grado o máster. La coordinación debe descender al nivel de las materias y al nivel de la optatividad. Un caso muy concreto es el relativo a las asignaturas de ámbito nuclear. La especificidad de contenidos obliga a redoblar los esfuerzos de coordinación para evitar solapes y asegurar un diseño, desarrollo y evaluación coherente de las competencias transversales. La coordinación exige realizar un ejercicio de síntesis de contenidos y mostrar de forma explícita la integración de las distintas asingaturas, en este caso del campo de conocimiento de nuclear.

\section{Objetivos}

Según lo expuesto en la introducción, parece necesario desarrollar instrumentos que faciliten la evaluación de las competencias y por tanto trasladar progresivamente el sistema tradicional a una "evaluación POR competencias", y además resulta imprescindible integrar dichas competencias en las asignaturas, plasmándolas en actividades.

El diseño, desarrollo y evaluación de actividades para trabajar estas competencias debe ser conocido por todos los profesores involucrados en el mismo campo de conocimiento, en este caso, nuclear.

(cc) EY-NC-ND 2017, Universitat Politècnica de València

Congreso IN-RED (2017) 
En este contexto, el objetivo fundamental de este trabajo es estudiar la importancia de la coordinación en las asignaturas de ámbito nuclear en el Grado de Ingeniero de la Energía (GIE) para trabajar de manera efectiva e integrada diversas competencias transversales.

En un primer estadio, se ha establecido un grupo de trabajo que afecta únicamente a tres asignaturas de ámbito nuclear y de carácter optativo con el objetivo de poder exportar la experiencia al resto de asignaturas, incluidas las obligatorias (en $2^{\circ}$ y $4^{\circ}$ curso de GIE).

Los objetivos específicos de este trabajo son los siguientes:

1. Identificación, análisis y comprensión de competencias transversales comunes en algunas asignaturas de ámbito nuclear.

2. Diseño de actividades en las diferentes asignaturas, utilizando los mismos criterios en cuanto al significado de cada competencia.

3. Identificación de puntos comunes y sinergias entre asignaturas para poder trabajar diferentes competencias de distintas asignaturas en una misma actividad.

4. Establecimiento de indicadores para la evaluación mediante rúbricas, de forma que se potencie la interrelación con las otras asignaturas.

Este plan de trabajo redunda en la idea de mejora continua en el desarrollo y evaluación de las competencias transversales y pone el foco en las asignaturas de ámbito nuclear.

\section{Desarrollo de la innovación}

\subsection{Contexto}

Desde el punto de vista curricular, es esencial cubrir de manera completa y coherente todas las competencias tranversales de una titulación, bien sea a nivel de grado o de máster. En este contexto, la coordinación entre asignaturas es esencial no solo para evitar solapes y vacíos en los contenidos, si no además para reforzar la coherencia en el desarrollo y evaluación de las competencias transversales. La coordinación debe realizarse a nivel de titulación y materia, pero además debe realizarse a un nivel más profundo. En este trabajo se propone una coordinación de competencias transversales desde el punto de vista de un determinado campo: el campo de conocimiento nuclear. En el caso concreto de la ingeniería nuclear, el escenario que nos encontramos al analizar el Grado de Ingeniero de la Energía (GIE) es el mostrado en la Tabla 1.

Como se puede apreciar a partir de la Tabla 1, el contenido nuclear explícito se concentra en $4^{\text {o }}$ curso, especialmente en el bloque de optatividad del segundo cuatrimestre.

Tanto la asignatura "Energía y Desarrollo Sostenible" como la asignatura "Tecnología Nuclear" son obligatorias y por tanto, todos los alumnos matriculados en el grado deben cursarlas. Durante el tiempo en el que se ha impartido estas asignaturas, el número de matriculados ha permanecido relativamente constante, entre 75 y 85 alumnos. El caso de "Centrales Nucleares Avanzadas", "Seguridad Nuclear", "Operación de Reactores Nucleares" y "Protección Radiológica" es muy distinto. Se trata de asignaturas optativas y de un carácter marcadamente específico, por lo que el número de alumnos que eligen cursarlas en muy reducido. De hecho, el número medio de matriculados en los últimos cursos 
académicos ha sido de 3 o 4 alumnos en cada una por término medio. Sin embargo, y de manera totalmente justificada, los alumnos que deciden cursar alguna de estas asignaturas, suelen matricularse en alguna de las otras. En conclusión, debe existir cierta coherencia en cuanto al desarrollo, trabajo y evaluación de las competencias específicas y transversales en estas asignaturas.

Tabla 1. Asignaturas de ámbito nuclear en GIE

\begin{tabular}{ccccc}
\hline Asignatura & Curso & Cuatrimestre & Tipo & Créditos \\
\hline Energía y Desarrollo Sostenible & $2^{\circ}$ & B & Obligatoria & 6 \\
Tecnología Nuclear & $4^{\circ}$ & B & Obligatoria & 6 \\
Centrales Nucleares Avanzadas & $4^{\circ}$ & B & Optativa & 4,5 \\
Seguridad Nuclear & $4^{\circ}$ & B & Optativa & 4,5 \\
Operación de Reactores & $4^{\circ}$ & B & Optativa & 4,5 \\
Nucleares & & & & \\
Protección Radiológica & $4^{\circ}$ & B & Optativa & 4,5 \\
\hline
\end{tabular}

\subsection{Las competencias transversales en la optatividad nuclear}

En la Tabla 2 se muestra la asignación de puntos de control a las asignaturas de ámbito nuclear en GIE.

Como se puede apreciar, las competencias transversales de las cuales estas asignaturas son punto de control son básicamente "Comprensión e integración", "Aplicación y pensamiento práctico", "Responsabilidad ética, medioambiental y profesional", "Pensamiento crítico", "Conocimiento de problemas contemporáneos" e "Instrumental específica". Es importante señalar que el hecho de no ser punto de control, no implica que no se trabajen otras competencias transversales. Existe una gran concentración en cuanto a puntos de control en tres de las competencias transversales: "Comprensión e integración", "Conocimiento de problemas contemporáneos" e "Instrumental específica".

Si nos centramos en las asignaturas de carácter optativo, se observa que son punto de control preferentemente de "Comprensión e integración" e "Instrumental específica".

Es evidente que todas estas asignaturas, por su contenido y ámbito son especialmente aptas para ser punto de control en temas de compresión e integración de conocimientos y en temas de mejora de la capacidad en el uso de herramientas específicas.

Una vez caracterizado el contexto, parece claro que es importante aunar esfuerzos para mejorar la coherencia en el trabajo y evaluación de este reducido número de competencias transversales. 
Tabla 2. Competencias transversales en las ssignaturas de ámbito nuclear en GIE

\begin{tabular}{cl}
\hline Identificador & \multicolumn{1}{c}{ Asignatura } \\
\hline 1 & Energía y Desarrollo Sostenible \\
2 & Tecnología Nuclear \\
3 & Centrales Nucleares Avanzadas \\
4 & Seguridad Nuclear \\
5 & Operación de Reactores Nucleares \\
6 & Protección Radiológica \\
\hline
\end{tabular}

\begin{tabular}{|c|c|c|c|c|c|c|c|c|c|c|c|c|c|}
\hline 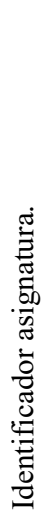 & 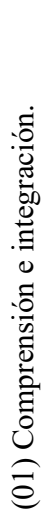 & 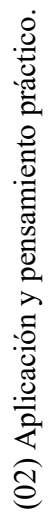 & 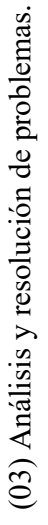 & 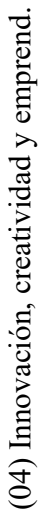 & 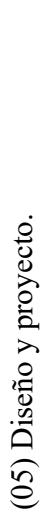 & 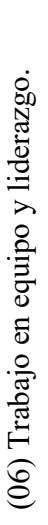 & 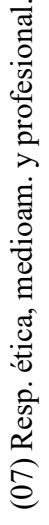 & 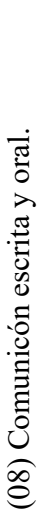 & 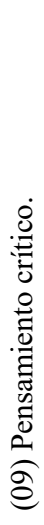 & 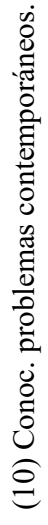 & 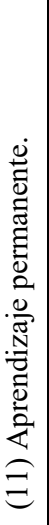 & 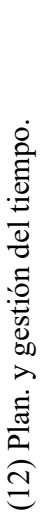 & 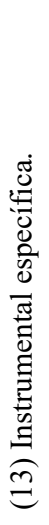 \\
\hline 1 & & & & & & & $\mathrm{x}$ & & & $\mathrm{x}$ & & & X \\
\hline 2 & & $\mathrm{X}$ & & & & & & & & $\mathrm{X}$ & & & $\mathrm{X}$ \\
\hline 3 & & $\mathrm{X}$ & & & & & & & $\mathrm{X}$ & $\mathrm{X}$ & & & \\
\hline 4 & $\mathrm{X}$ & & & & & & & & & & & & $\mathrm{x}$ \\
\hline 5 & $\mathrm{X}$ & & & & & & & & & & & & $\mathrm{x}$ \\
\hline 6 & $\mathrm{X}$ & & & & & & & & & & & & $\mathrm{x}$ \\
\hline
\end{tabular}

\subsection{Los niveles de dominio}

El siguiente problemas que se plantea se refiere a cómo se están trabajando actualmente muchas de esas asignaturas. En este trabajo nos vamos a centrar en las asignaturas de carácter optativo por una razón. Como se ha expuesto anteriormente, los alumnos de estas asignaturas optativas suelen elegir muchas de ellas, por lo que se puede disponer de una retroalimentación muy valiosa de cómo percibe la coherencia en la evaluación un mismo alumno en las diferentes asignaturas. En el proyecto institucional de competencias transversales que está llevando a cabo la Universitat Politècnica de València, se han identicado 13 competencias transversales y se han desarrollado rúbricas (UPV, 2015b) de evaluación genéricas para los

(cc)) BY-NC-ND 2017, Universitat Politècnica de València 
tres niveles de dominio en grado y máster. En estas rúbricas se establece el/los resultado/s de aprendizaje en función de cada nivel de dominio y para cada competencia transversal (Villa, 2007). En el caso de las asignaturas optativas de ámbito nuclear, nos interesan especialmente los siguientes resultados de aprendizaje por nivel de dominio:

1. Comprensión e integración:

- Dominio I: describir, relacionar e interpretar situaciones y planteamientos sencillos.

- Dominio II: proceder con lógica y relacionar e integrar conceptos en situaciones complejas.

- Dominio III: identificar las carencias de información y utilizar el conocimiento con un enfoque globalizador.

2. Aplicación y pensamiento práctico.

- Dominio I: aplicar a la práctica su capacidad y los recursos de los que dispone para alcanzar objetivos en situaciones habituales, siguiendo instrucciones.

- Dominio II: diseñar un plan coherente con acciones concretas para abordar situaciones nuevas con un enfoque propio

- Dominio III: diseñar un plan coherente en acciones concretas para abordar situaciones complejas de forma individual o en colaboración con otros.

3. Conocimiento de problemas contemporáneos:

- Dominio I: reconocer los problemas contemporáneos que afectan a su campo profesional.

- Dominio II: analizar los problemas contemporáneos que afectan a su campo profesional.

- Dominio III: valorar y tomar conciencia de los problemas contemporáneos que afectan a su campo profesional y campos

afines.

4. Instrumental específica.

- Dominio I: emplear correctamente las herramientas básicas del ámbito profesional de forma guiada.

- Dominio II: integrar correctamente las herramientas básicas del ámbito profesional de forma autónoma.

- Dominio III: integrar correctamente las herramientas avanzadas del ámbito profesional.

(c) EY-NC-ND 2017, Universitat Politècnica de València

Congreso IN-RED (2017) 
Puesto que todas las asignaturas de este estudio son de $4^{\circ}$ curso de Grado, se optado por trabajar los resultados de aprendizaje del nivel de dominio II.

\subsection{La coordinación en la optatividad nuclear}

La coordinación de la optatividad comienza por identificar los siguientes resultados de aprendizaje:

- Proceder con lógica y relacionar e integrar conceptos en situaciones complejas.

- Diseñar un plan coherente con acciones concretas para abordar situaciones nuevas con un enfoque propio

- Analizar los problemas contemporáneos que afectan a su campo profesional.

- Integrar correctamente las herramientas básicas del ámbito profesional de forma autónoma.

Es importante señalar que todas las acciones (relacionar, diseñar, analizar e integrar) se encuentran en un nivel similar de complejidad según la taxonomía de Bloom.

\subsection{Diseño, desarrollo y resultados de actividades}

El siguiente paso en la coordinación de la optatividad consiste en diseñar actividades adecuadas para trabajar y evaluar las competencias transversales objeto de este estudio. La idea es aprovechar y potenciar las sinergias entre las diferentes asignaturas para reforzar el trabajo, destacando la coherencia de planteamientos y estrategias de evaluación. Con este objetivo, es primordial programar reuniones entre los responsables antes y durante el periodo de impartición de estas asignaturas. En nuestro caso, puesto que todas las asignaturas se imparten en el cuatrimestre B, se propone una reunión de coordinación en el cuatrimestre A y dos reuniones en el B. Finalmente se aconseja realizar una reunión de coordinación al finalizar las asignaturas (en el mes de mayo). En la primera reunión de coordinación, los responsables de las asignaturas exponen qué actividades van a realizar para trabajar las diferentes competencias. Es en este momento cuando la coordinación cobra mayor importancia. El hecho de informar a los responsables de las asignaturas, de las actividades que vamos a realizar en las nuestras, permite diseñar estrategias comunes. En el presente curso, y en el ámbito que nos ocupa, se han diseñado tres actividades fundamentalmente, tal y como se expone a continuación.

En la asignatura de "Centrales Nucleares Avanzadas" se planifica mediante 4 sesiones de prácticas, la elaboración de un modelo del núcleo de un reactor ACR (Advance CANDU Reactor) con un código de Monte Carlo. Esta actividad es un claro ejemplo de trabajo en las competencias transversales de "Aplicación y Pensamiento Práctico" e "Instrumental específica". En este caso, los autores disponemos de cierta experiencia previa (Gallardo, 2015 y Villanueva, 2016) en el trabajo y evaluación de "Conocimiento de Problemas Contemporáneos". 
En la asignatura "Seguridad Nuclear" se simula mediante un código termohidráulico un accidente de pérdida de refrigerante en una central nuclear, trabajando con ello las competencias transversales de "Comprensión e Integración" e "Instrumental específica".

En la asignatura "Protección Radiológica" se propone la búsqueda, análisis y exposición de un accidente radiológico y sus consecuencias, trabajándose de esa manera la competencia transversal de "Comprensión e Integración".

Si analizamos con detenimiento las tres actividades por separado, podremos concluir que de manera natural, se está estudiando un mismo problema desde tres puntos de vista distintos. En el primer caso se estudia el diseño, en el segundo caso se estudia la seguridad y en el tercer caso, las consecuencias de un accidente. Con esta idea clara en mente, la coordinación se centra en aportar coherencia a los objetivos, metodología y resultados de las tres actividades para que el alumno perciba las componentes multidisciplinares de un mismo caso o de casos análogos, importando la propia filosofía del aprendizaje basado en problemas (Escribano, 2008).

Queda pues claro que los objetivos de la coordinación son los siguientes: presentar la actividad de una manera transversal relacionándola con las tres asignaturas, guiar al alumno de manera coherente y señalar los resultados relacionándolos con las competencias transversales de las tres asignaturas.

De esta manera, se llega a la conclusión de que se necesita que el diseño, desarrollo y resultados de las actividades debe ser compartida por los responsables de las tres asignaturas. En este contexto, se decide adaptar las rúbricas que originalmente se utilizan en las asignaturas para que incluyan algunos indicadores comunes a las tres.

\subsection{La evaluación de competencias transversales en la optatividad nuclear}

Una vez que la coordinación ha permitido identificar las relaciones entre las tres actividades y se ha establecido una estrategia común para guiar al alumno en la realización de la misma, es necesario realizar el mismo ejercicio de coherencia en la evaluación. Recordemos que el objetivo es realizar la evaluación teniendo en cuenta la capacidad para relacionar, integrar, diseñar y analizar contenidos en situaciones complejas utilizando herramientas adecuadas.

Este punto es especialmente delicado ya que implica realizar un ejercicio de abstracción que afecta a nuestra asignatura y a las otras asignaturas de la optatividad.

A modo de ejemplo se va a realizar la explicación de la metodología seguida en la evaluación sobre la competencia transversal de "Aplicación y pensamiento práctico" de la asignatura "Centrales Nucleares Avanzadas". En este caso concreto se parte de una rúbrica con la que se está trabajando en los último dos cursos. En dicha rúbrica se reflejan los siguientes indicadores:

1. Analiza lo que es y no es un problema y toma la decisión de abordarlo.

2. Lee $y / o$ escucha activamente. Hace preguntas para definir el problema planteado.

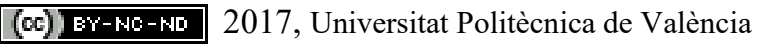

Congreso IN-RED (2017) 
3. Recoge y analiza la información significativa que necesita para resolver los problemas en base a datos y no sólo a opiniones subjetivas y sigue un método lógico de análisis de la información.

4. Sigue un método lógico para identificar las causas de un problema y no quedarse en los síntomas.

5. Diseña un plan de acción para la aplicación de la solución escogida.

A partir de la coordinación entre las asignaturas de la optatividad ha quedado patente que queremos incluir en la evaluación referencias directas a las otras asignaturas. Con este objetivo, buscaremos mecanismos para incluir en alguno de los indicadores anteriores, la valoración a dicho indicador a partir de lo trabajado en las otras asignaturas.

En el caso del indicador 1, "Analiza lo que es y no es un problema y toma la decisión de abordarlo", para evaluarlo se ha pensado realizar un check-list que recoja explícitamente información de qué manera el problema que se está analizando, está relacionado con las asignaturas "Seguridad Nuclear" y "Protección Radiológica".

En el caso del indicador 3, "Recoge y analiza la información significativa...", se ha pensado incluir en el enunciado referencias bibliográficas e información general que el alumno puede (aunque no necesariamente) utilizar y que pertenece a las otras asignaturas. Por ejemplo, en el caso de la actividad del reactor ACR (en la asignatura de Centrales Nucleares Avanzadas), el objetivo es realizar el diseño, pero en el enunciado de la actividad se incluirá información de la seguridad y de los posibles accidentes y sus consecuencias. Recordemos que tanto la seguridad como el estudio de las consecuencias radiológicas son objeto de aprendizaje de las otras asignaturas optativas. De esta manera, el alumno debe manejar un mayor volumen de información y se ve obligado a cribarla discerniendo la que es relevante para la tarea, pero al mismo tiempo está realizando un ejercicio de integración de la información. El ejercicio de criba de información no es trivial, ya que en muchas ocasiones es muy complejo poder separar el diseño respecto de la seguridad y respecto de las implicaciones radiológicas.

En resumen, en el caso de "Centrales Nucleares Avanzadas", la evaluación de la competencia transversal de "Aplicación y pensamiento práctico" se realizará mediante una rúbrica de nivel de dominio II con 5 indicadores. Estos indicadores, a su vez, recogerán la información de diferentes preguntas planteadas en la actividad que no están directamente relacionadas con el objeto principal de la actividad, pero que es transversal con las otras asignaturas de la optatividad.

\section{Resultados}

Tal y como se ha explicado en el apartado 2.1, la optatividad de ámbito nuclear tiene actualmente un número reducido de alumnos matriculados (entre 3 y 7 dependiendo de la asignatura), por lo que la obtención de conclusiones desde el punto de vista de la significancia estadística es casi imposible. Conscientes de esta limitación, los autores de este trabajo consideramos que podemos aprovechar el hecho de tener baja matrícula para realizar entrevistas informales a los alumnos para poder obtener una retroalimentación de calidad. 
Con esta premisa, se elabora un pequeño cuestionario con el objetivo principal de saber si el alumno ha percibido o no que el trabajo realizado en el ámbito de las competencias transversales ha aportado un análisis "multi-dimensional" (es decir, de las diferentes asignaturas) y ha permitido ampliar el campo de visión del problema estudiado.

El cuestionario que se ha elaborado es el siguiente (a discutir informalmente en una entrevista):

- ¿Os hemos transmitido de forma adecuada que las tres asignaturas están íntimimamente relacionadas?

- ¿Crees que es bueno aislar un problema sin tener en cuenta las implicaciones y efectos no estudiados en la asignatura?

- ¿Crees que la actividad desarrollada es adecuada para la asignatura? ¿Ha sido buena idea incluir mucha más información que la que estrictamente necesitabas para llevarla a cabo?

- Con tus propias palabras, ¿qué crees que te ha aportado realizar esta actividad más allá de estudiar los contenidos de la asignatura?

- Desde el punto de toda la titución (GIE), ¿crees que esta actividad te ha servido para constatar la importancia de relacionar los conocimientos adquiridos a otros ámbitos de la profesión?

- ¿Has percibido que hemos trabajado de forma conjunta competencias mediante tres asignaturas?

- En general, ¿estás safisfecho con la actividad desarrollada?

En general, las entrevistas realizadas muestran que los alumnos perciben claramente que estamos trabajando un mismo contenido desde puntos de vista distintos y que esta diversidad de puntos de vista enriquece el mensaje final de la propia asignatura y refuerza la compactación y coherencia de contenidos, metodología y evaluación.

Pretendemos que esta experiencia no se quede en eso, una experiencia. Para ello, los trabajos futuros que vamos a realizar van a ir encaminados a ampliar la coordinación y el trabajo integrado de competencias al resto de asignaturas de ámbito nuclear, incluidas las de carácter obligatorio.

\section{Conclusiones}

En este trabajo se ha expuesto una primera experiencia realizada para mejorar la coordinación de las asignaturas de ámbito nuclear y carácter optativo en el Grado de Ingeniero de la Energía (GIE). La coordinación ha puesto de manifiesto que no siempre entendemos todos de igual manera el significado de una misma competencia tranversal y que es necesario unificar criterios para no trasladar la incertidumbre a los alumnos. Además de este primer beneficio, la coordinación en competencias transversales permite aprovechar sinergias entre diferentes asignaturas, evitando solapes y potenciando integración de conceptos que tradicionalmente transmitimos de manera atomizada a los alumnos. En general, la

(c)) BY-NC-ND 2017, Universitat Politècnica de València 
experiencia es muy positiva, recibiendo una buena acogida por parte de los alumnos y abriendo la puerta a ampliar esta coordinación al resto de asignaturas de contenido nuclear en GIE.

\section{Referencias}

UNIVERSITAT POLITĖCNICA DE VALÈNCIA, (2015a). Presentación de Competencias Transversales UPV CT-10. Conocimiento de problemas contemporáneos.

UNIVERSITAT POLITÈCNICA DE VALÈNCIA, (2015b). Rúbrica UPV CT-10. Conocimiento de problemas contemporáneos.

VILLA, A. y POBLETE, M. (2007), Aprendizaje basado en competencias. Una propuesta para la evaluación de las competencias genéricas, Universidad de Deusto, Bilbao

ESCRIBANO, A., DEL VALlE, A. (2008), El aprendizaje basado en problemas. Una propuesta metodológica en Educación Superior, Narcea, S.A. de Ediciones.

SANZ DE ACEO, M. L. (2010), Competencias cognitivas en Educación Superior, Narcea, Madrid.

GALLARDO, S., CARLOS, S. (2015), "Desarrollo de la competencia transversal de "Análisis y Resolución de Problemas" en la asignatura Centrales Nucleares Avanzadas", IN-RED, Valencia, Universitat Politècncia de València.

VILLANUEVA, J.F. et al. (2016), "Integración de la competencia transversal de "conocimiento de problemas contemporáneos" en Asignaturas de Grado", IN-RED, Valencia, Universitat Politècncia de València. 


\title{
Análisis del uso de autoevaluaciones en una plataforma digital en el entorno de la Fisiología Médica. \\ ESTHER ESCUDERO ${ }^{a}$, ISABEL SANCHEZ-VERA ${ }^{\mathrm{b}}$, RIMA BARHOUM ${ }^{\mathrm{c}}$, JUAN ENRIQUE PUCHE; URSULA MUÑOZ, $\mathrm{d}$ e
}

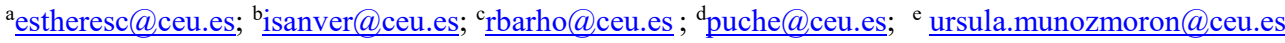
Todos los autores tienen como procedencia: Sección de Fisiología. Dpto. Ciencias Médicas Básicas. Facultad de Medicina. Universidad CEU San Pablo, Madrid.

\begin{abstract}
In the Medicine School of Universidad CEU San Pablo, a group of professor involving in the Physiology area is actively engaged in updating the teaching methodology to be used. To this end, in the last years we have tried to encourage the acquisition of different competences by students such as: increasing their autonomy to manage their progress in this area, finding information in various sources, managing different communication modalities and collaborative work. The aim of these objectives is to expand students' skills so that they can deepen the acquisition of knowledge and promote their dissemination in the academic environment. With this intention, in the last years we have presented to the students different learning tools, and in this report we show the results obtained from the analysis and reflection of the realization of self-evaluations in the platform Blackboard among all Physiology students in this academic year 2016-2017
\end{abstract}

Keywords: Self-study, self-assessment, progress, BlackBoard, surveys, participation.

\section{Resumen}

En la asignatura de Fisiología I del Grado de Medicina los profesores están comprometidos de forma activa en actualizar la metodología docente a utilizar. En los últimos años, se ha fomentado que el alumno adquiriera distintas competencias como son: el aumento de su autonomía para gestionar su progreso en la asignatura, la búsqueda de información en fuentes diversas, el manejo de distintas modalidades de comunicación y el trabajo colaborativo. El objetivo de estas competencias está dirigido a que amplien sus destrezas para profundizar en la adquisición de los conocimientos y que sean capaces de divulgarlos en el entorno académico. Con esta intención, en la asignatura de Fisiología, se han ofrecido a los alumnos distintas herramientas de aprendizaje, y en la presente memoria se aborda el análisis sobre la realización de autoevaluaciones en la plataforma BlackBoard y el grado de utilidad que los alumnos han otorgado a esta herramienta de aprendizaje.

Palabras clave: trabajo autónomo, autoevaluación, test, progreso en la asignatura, BlackBoard, encuestas, participación. 


\section{Introducción}

Para la adquisición de conocimiento por parte del alumnado es imprescindible el compromiso de realizar un trabajo autónomo de adquisición, integración, comprensión, relación y almacenamiento de conceptos relacionados con el saber. (Jensen et al., 2003). Además, es parte vertebral del aprendizaje que los conocimientos que se transmiten en clase sean asimilados, entendidos y relacionados de forma integral por los alumnos (Arceo et al., 2002). Por otro lado, es importante conseguir un abanico amplio de destrezas cognitivas y para ello es importante proporcionar métodos de aprendizaje activos de diferentes características (Zabalza, 2012), de tal manera que el proceso de aprendizaje no esté basado únicamente en el profesor como instructor, sino que en el aula se genere un binomio de "aprendizaje/facilitación del aprendizaje" (Barr y Tagg, 1995; García Valcárcel, 1993; Monereo y Pozo, 2003). Este último modelo está enfocado a favorecer la adquisición del saber a través de un aprendizaje autónomo de tal manera que el conocimiento se elabore de forma colaborativa entre iguales y que el profesor actúe como un mediador (Gargallo 2015). Así el alumno pasa a estar directamente implicado en su proceso de aprendizaje investigando, cuestionando, haciendo aportaciones propias y siendo capaz de autoevaluarse y regular la evolución de su conocimiento (Machemer 2007),

En este sentido y con el objeto de propiciar esta metodología, los profesores usualmente les mandamos tareas para realizar fuera del aula, a veces de forma individual y otras veces en grupo (Fernández, 2007). La experiencia de los profesores de la asignatura de Fisiología I de la Facultad de Medicina, ha detectado que no todos los tipos de actividades fuera del aula que han sido utilizadas a lo largo de estos últimos años han sido realmente eficaces para favorecer el aprendizaje de esta materia. Los alumnos trasmiten que, en ocasiones, tienen la sensación de estar haciendo trabajos que les llevan mucho tiempo pero que académicamente les rentan poco a la hora de estudiar la asignatura. Esto hace que prenda en ellos la sensación de que estas actividades lejos de ayudarles son una sobrecarga excesiva y poco útil, situación que es referenciada de forma similar por otros autores (Álvarez et al., 2008). Además de esto, el profesor no siempre es capaz de poder evaluar de forma objetiva el esfuerzo realizado por los alumnos con estas prácticas docentes (Molero López-Barajas et al., 2005), y encuentra dificultades a la hora de calificar las competencias inherentes a este tipo de trabajo autónomo, lo que se ha planteado como un reto desde hace varios años. (Spencer et al., 1984).

Existe una variedad de metodologías de evaluación que proporcionan diferentes evidencias sobre la adquisición de las competencias por parte de los alumnos (Ferro Soto et al., 2009), siendo la creación de un portafolio personal una de las que más interés ha interesado, no sólo en el ámbito artístico en el que lleva implantado mucho tiempo, sino que parece crecer como corriente de evaluación en otras áreas didácticas (Gil et al., 2015).

En los últimos años, los profesores de la asignatura de Fisiología I han pretendido implementar el método "aprendizajelfacilitación del aprendizaje" pretendiendo obtener distintas competencias por parte del alumnado como son: la búsqueda de información en diversas fuentes fiables, el manejo de distintas modalidades de comunicación, el trabajo colaborativo y el aumento de la autonomía para gestionar su progreso en la asignatura.

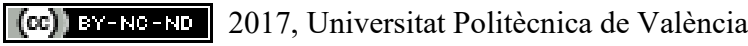

Congreso IN-RED (2017) 
El objetivo ha estado dirigido a ampliar las destrezas de los alumnos para que profundicen en el conocimiento y a formarles como divulgadores de su pensamiento en el entorno académico. Con esta intención, se ha planteando que el alumno realice distintas actividades, que han sido:

- manejo de motores de búsquedas informáticos y repositorios bibliográficos,

- exposición de trabajos orales,

- realización de videos didácticos,

- realización de autoevaluaciones en la plataforma BlackBoard,

- uso de un foro informático para la puesta en común de información aportada por los alumnos,

- cumplimentación de un cuestionario para valorar la utilizad docente de cada una de las actividades propuestas.

Con la realización de estas actividades se ha ido completando una carpeta personal de cada alumno a modo de portafolio que ha servido para evaluar su aprendizaje de forma particular, y además al profesor le ha orientado sobre el pulso de la progresión de cada uno de los cuatro grupos que cursaban la asignatura.

\section{Objetivos}

Con la puesta en marcha de esta experiencia se buscaba saber el grado de implicación de cada alumno en el trabajo realizado fuera del aula, siendo el objetivo principal el fomentar el uso de distintas herramientas que les ayudaran en su trabajo autónomo y que a su vez permitieran al profesor evaluarles objetivamente. Además se planteó como objetivo secundario valorar la aceptación por los alumnos de estas propuestas como mecanismo de estudio.

\section{Desarrollo de la innovación}

En esta memoria se presenta el análisis y las reflexiones obtenidas sobre la realización de autoevaluaciones en la plataforma BlackBoard en el curso académico 2016-2017 en la asignatura de Fisiología I. La asignatura se imparte en el primer semestre del $2^{\circ}$ curso del Grado en Medicina. Es de carácter obligatorio y consta de 7,5 créditos ECTS. El estudio se ha realizado con los 148 alumnos matriculados en los cuatro grupos del curso

\section{Técnicas, instrumentos y recursos utilizados}

Se ha empleado la plataforma BlackBoard de la Universidad San Pablo CEU, que integra un ambiente de enseñanza y aprendizaje "en línea". Ofrece varios recursos docentes para impartir contenidos en distintos formatos (texto, audio, video y animación), y en este caso se ha utilizado para realizar las autoevaluaciones "en línea".

\section{Metodología de trabajo respecto a la actividad de las autoevaluaciones.}

Para que el alumno pudiera llevar un control de su progresión en la asignatura, después de la explicación de cada tema se subió al campus virtual una autoevaluación, que se debía realizar fuera de las horas presenciales. Estas autoevaluaciones suponían un 2\% de la nota de la asignatura. Este porcentaje estaba ajustado a las circunstancias en cómo se 
realizaba la prueba, fuera del aula y con la posibilidad de consultar apuntes y priorizando mas el compromiso de realizar el estudio de forma continuada que a ponderar la adquisición del conocimiento. Si la prueba no se completaba suponía un 0 .

Los requisitos establecidos para las autoevaluaciones fueron:

- Tiempo máximo de disponibilidad de la autoevaluación en la plataforma de quince días desde que se subía al campus virtual. Se pretendía incentivar a los alumnos a estudiar progresivamente evitando el acúmulo de materia.

- Limitación del tiempo para responder a las preguntas una vez que se empezaba la prueba. En general había entre 10 y 25 preguntas por tema, ajustando el tiempo al número de preguntas.

- Ordenación aleatoria de las preguntas para cada test y por cada alumno.

- Obligatoriedad de finalizar el test sin opción de volver atrás y envió automático de la prueba corregida por la plataforma al profesor.

La autoevaluación permitía a los alumnos repasar el tema que acababan de estudiar y al mismo tiempo el profesor comprobaba el grado de comprensión de los aspectos más importantes de la materia. Esto facilitaba la identificación de los conceptos más difíciles de comprender para poder reforzarlos. Además servía como parámetro orientativo sobre el esfuerzo realizado por el alumno y reflejarlo en la nota final de la asignatura.

\section{Resultados.}

La cumplimentación de las autoevaluaciones fuera del aula se ofreció como herramienta al alumno para controlar su avance en la comprensión de la materia y al profesorado le aportaba una visión objetiva sobre el aprendizaje de los alumnos.
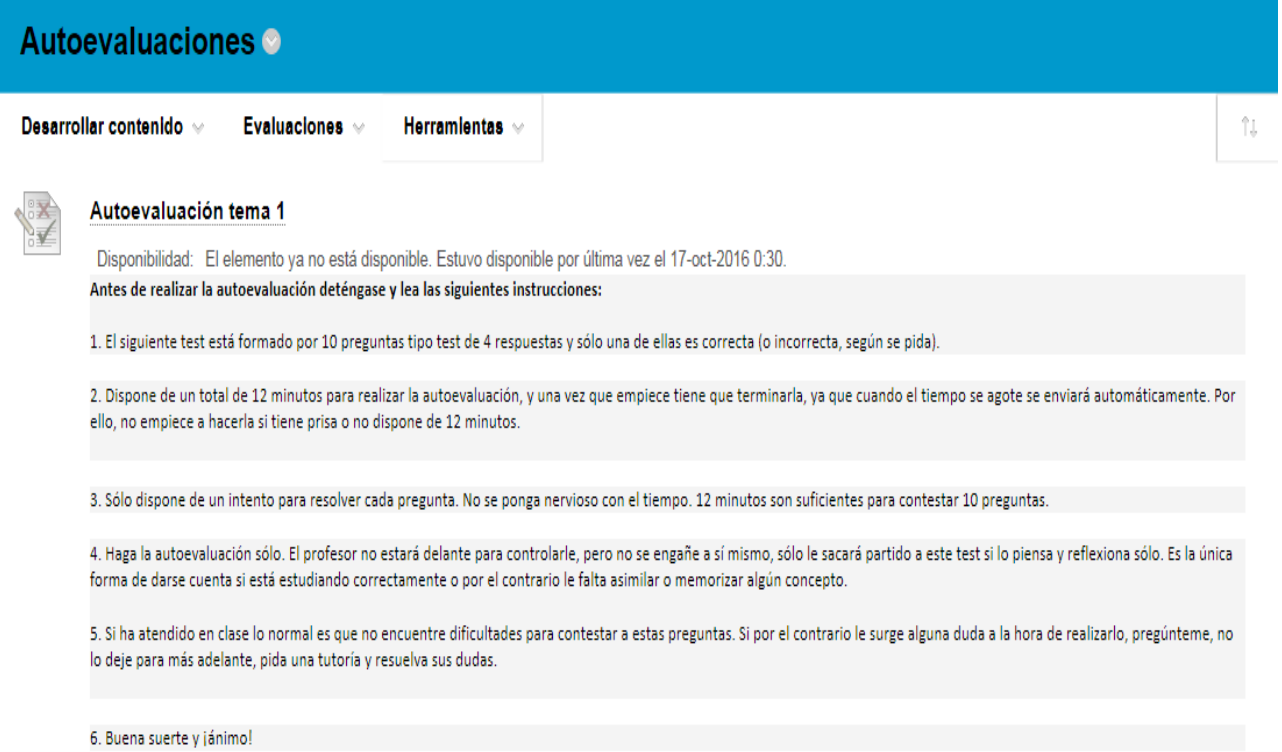

Figura1: Imagen de una de las autoevaluaciones subidas a la plataforma BalckBoard 


\section{Resultados sobre la realización de las autoevaluaciones.}

Tras analizar el número de autoevaluaciones efectuadas por la totalidad de los alumnos matriculados en los cuatro grupos (148), se han encontrado siguientes resultados:

\section{I.a. Participación de los alumnos en la actividad}

- Participación total

Como se ve en la figura 2, la participación de los alumnos fue mayoritaria. El 98\% de los alumnos realizó alguna de las pruebas de autoevaluación (en rojo) frente al $2 \%$ que no participó en la experiencia (azul).

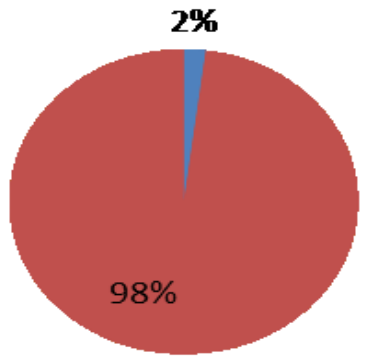

Figura 2. Porcentaje de participación en las autoevaluaciones de los 148 alumnos matriculados

-Participación total por sexo

En la figura 3 se representa el análisis de los datos por sexos, observando que el $69 \%$ de las participantes fueron mujeres (representado en rosa) frente al 31\% que fueron hombres (representado en azul).

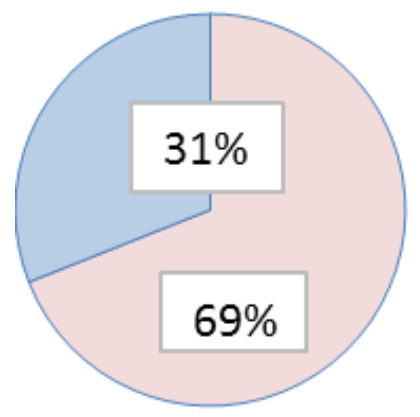

Figura 3. Porcentaje de participación por sexo

\section{-Participación por grupos}

En la figura 4 se representa el análisis de los resultados referidos a cada uno de los cuatro grupos en los que se dividía la asignatura. Se observó que en el grupo 01(que constaba de 36 alumnos) y en el grupo 02 (que constaba de 38 alumnos) hubo un $100 \%$ de participación en la realización de la experiencia. En los grupos 03 (con 37 alumnos) y 04 
Análisis del uso de autoevaluaciones en una plataforma digital en el entorno de la Fisiología Médica.

(con 37 alumnos), el porcentaje de participación fue del 97\%. Siendo en todos los casos el grado de participación en la propuesta muy exitoso.

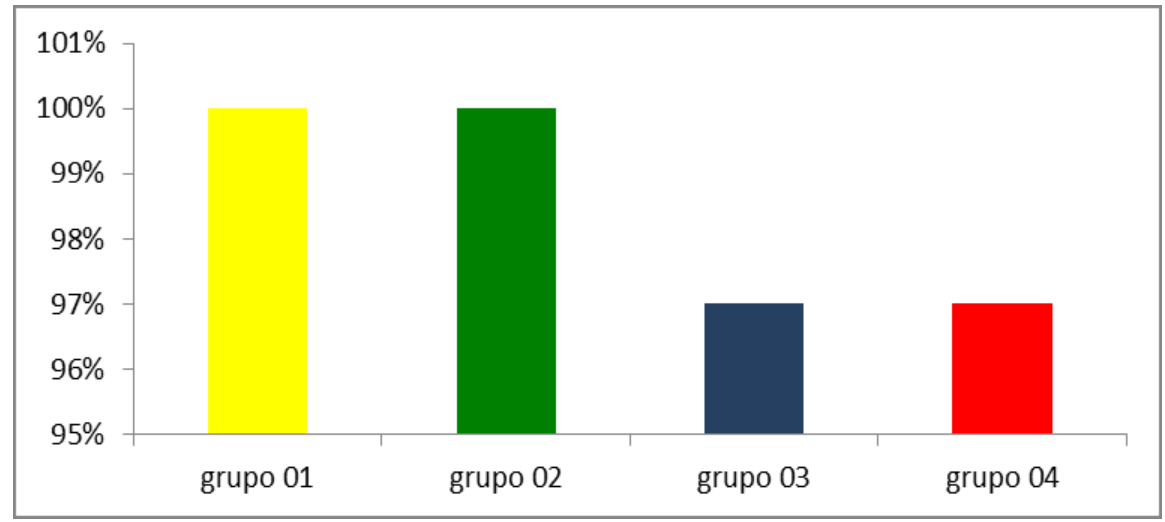

Figura 4. Porcentaje de realización de las autoevaluaciones por grupos de la asignatura.

\section{I.b. Número de pruebas realizadas.}

-Participación total

Se analizó el porcentaje de participación de todos los alumnos teniendo en cuenta el número de evaluaciones que había hecho cada uno de ellos. El número total de autoevaluaciones que se podían realizar era de 14. Los resultados obtenidos se representan en la figura 4 .

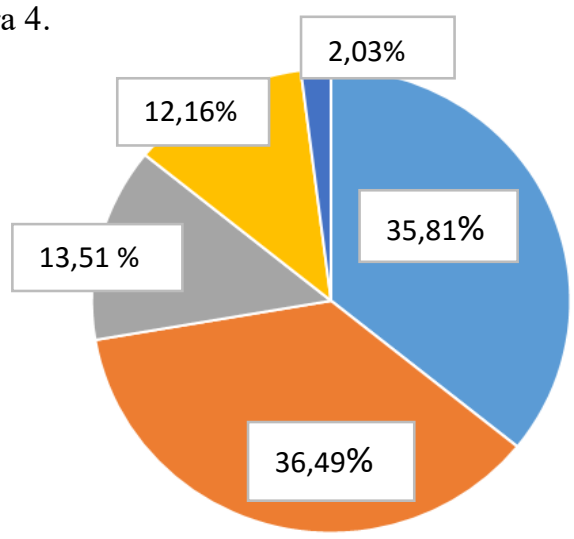

Figura 4. Porcentaje de realización de las autoevaluaciones.

Los datos reflejan que el 36,49\% de los alumnos realizó el $100 \%$ de las evaluaciones (lo que supone hacer los 14 test y está representado en naranja); el 35,81\% hizo entre el 75$99 \%$ de ellas (se hicieron de 10 a 13 test y está representado en azul claro). El 13.51\% hizo el 50-74\% de las evaluaciones (lo que indica realizar entre 7 a 9 test y se representa en color gris); el $12,16 \%$ de los alumnos realizó entre el 1-50\% de las autoevaluaciones (se hicieron entre 1-6 test y se representa en color en naranja); y aproximadamente el 2\% de los alumnos no hizo ninguna de las evaluaciones (color azul intenso). (Figura 4)

(c)) EY-NC-ND 2017, Universitat Politècnica de València

Congreso IN-RED (2017) 
-Participación por sexos y pruebas realizadas.

En la figura 5 a y b se representa la participación en la experiencia por sexos, Se encontró que en el grupo de las mujeres hubo aproximadamente un $98 \%$ que participó realizando al menos una de las pruebas (representado en rosa) frente a un 2\% que no participó en la experiencia y no realizó ninguna (se representa en rosa intenso). Sin embargo, todos los hombres participaron en la experiencia realizando al menos una de las autoevaluaciones.

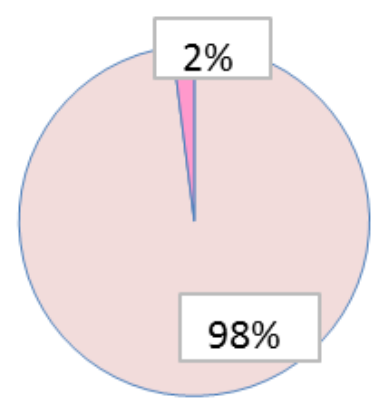

Fig. 5a. Participación de mujeres

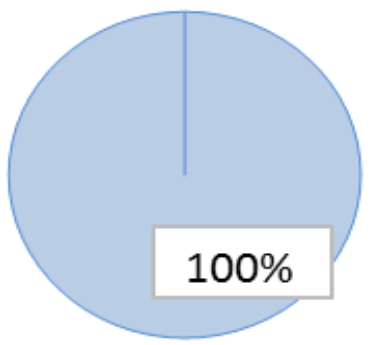

Fig.5b Participación de hombres

En la figura 6 se representan los datos encontrados cuando se cuantificó cuantas personas habían realizado la totalidad de las 14 evaluaciones. El análisis hecho por sexo reveló que la participación fue similar en ambos grupos. Un 58.3\% de las mujeres hicieron todas las autoevaluaciones (representado en rosa) frente al $46.2 \%$ de los hombres (representado en azul).

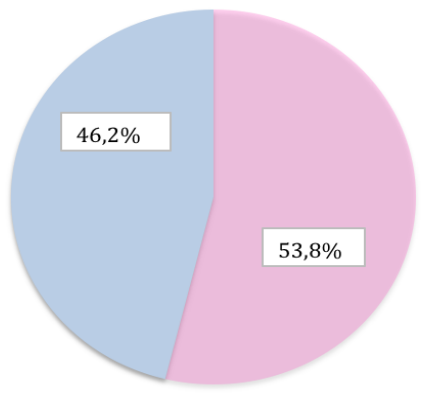

Figura 6. Distribución del \% de alumnos que han realizado todas las autoevaluaciones separados por sexos.

En la figura 7 se analizan los datos cuando se distribuyó el número de test realizados en cuartiles y se analizó la participación por sexos. Los resultados evidencian que aunque al número de mujeres y hombres que hicieron la totalidad de las 14 autoevaluaciones fue similar, se observó que las mujeres realizaron un mayor número de test (entre 10 y 13 
autoevaluaciones). Los hombres participaron en mayor porcentaje en los cuartiles inferiores realizando sólo entre 2 a 9 exámenes. Sin embrago fue en el grupo de las mujeres donde algunas alumnas decidieron no participar en la experiencia.

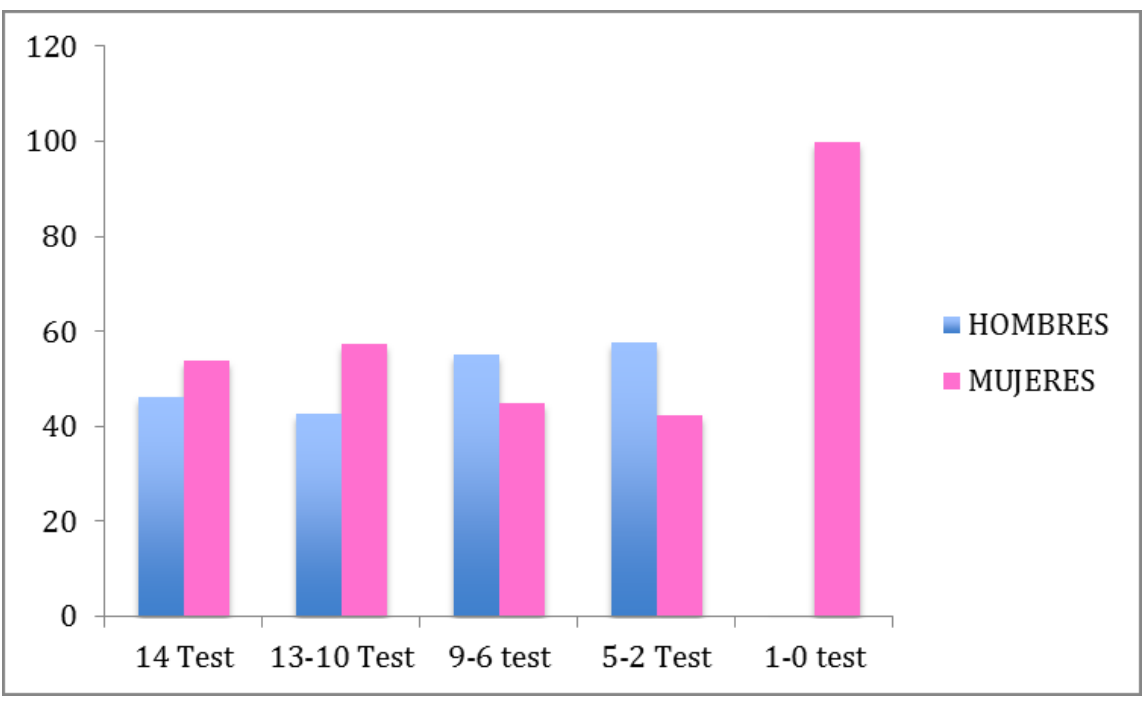

Figura 7.Análisis de la participación de hombres y mujeres en el número de autoevaluaciones realizadas. En el eje de abscisas se representa las autoevaluaciones distribuidas en cuartiles, en el eje de ordenadas el porcentaje de alumnos

\section{-Participación por grupos y pruebas realizadas}

Cuando se cuantificó el número de autoevaluaciones que había hecho cada alumno, en cada uno de los cuatro grupos de la asignatura, los datos revelaron que los grupos 03 y 04 fue donde hubo un mayor número de alumnos que realizaron las 14 pruebas. Así, en la figura 8 se observa que el $100 \%$ de las autoevaluaciones fueron realizadas en el grupo 03 por 16 alumnos de un total de 37, en el grupo 04 por 15 alumnos de un total de 37, en el grupo 01 por 11 alumnos un total de 36, y en el grupo 02 por 11 de un total de 38. Estos datos representan que el $43 \%$ de los alumnos del grupo 03, el 40\% de los alumnos del grupo 04, y el $30 \%$ de los alumnos de los grupos 01 y 02 completaron las 14 pruebas.

Se observa que el grupo 03 destaca por tener más alumnos que hicieron las 14 autoevaluaciones y por ser el grupo donde la participación resultó más constate. Todos los alumnos (a excepción de uno) hicieron como mínimo el 50 \% de las pruebas y cada alumno había realizado como mínimo 8. Únicamente hubo un alumno que realizó sólo una prueba. (Figura 8)

El grupo 01 destaca por tener el mayor número de alumnos que no ha realizado ninguna de las autoevaluaciones. Además 10 alumnos hicieron menos de 7 pruebas, lo que representa que el $28 \%$ de la clase hizo menos del $50 \%$ de las pruebas. (Figura 8 )

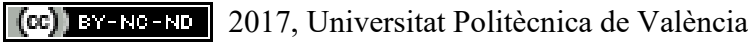

Congreso IN-RED (2017) 
Los grupos 02 y 04 se caracterizaron por ser en donde un mayor número de alumnos decidió hacer menos de 5 autoevaluaciones (Figura 8).
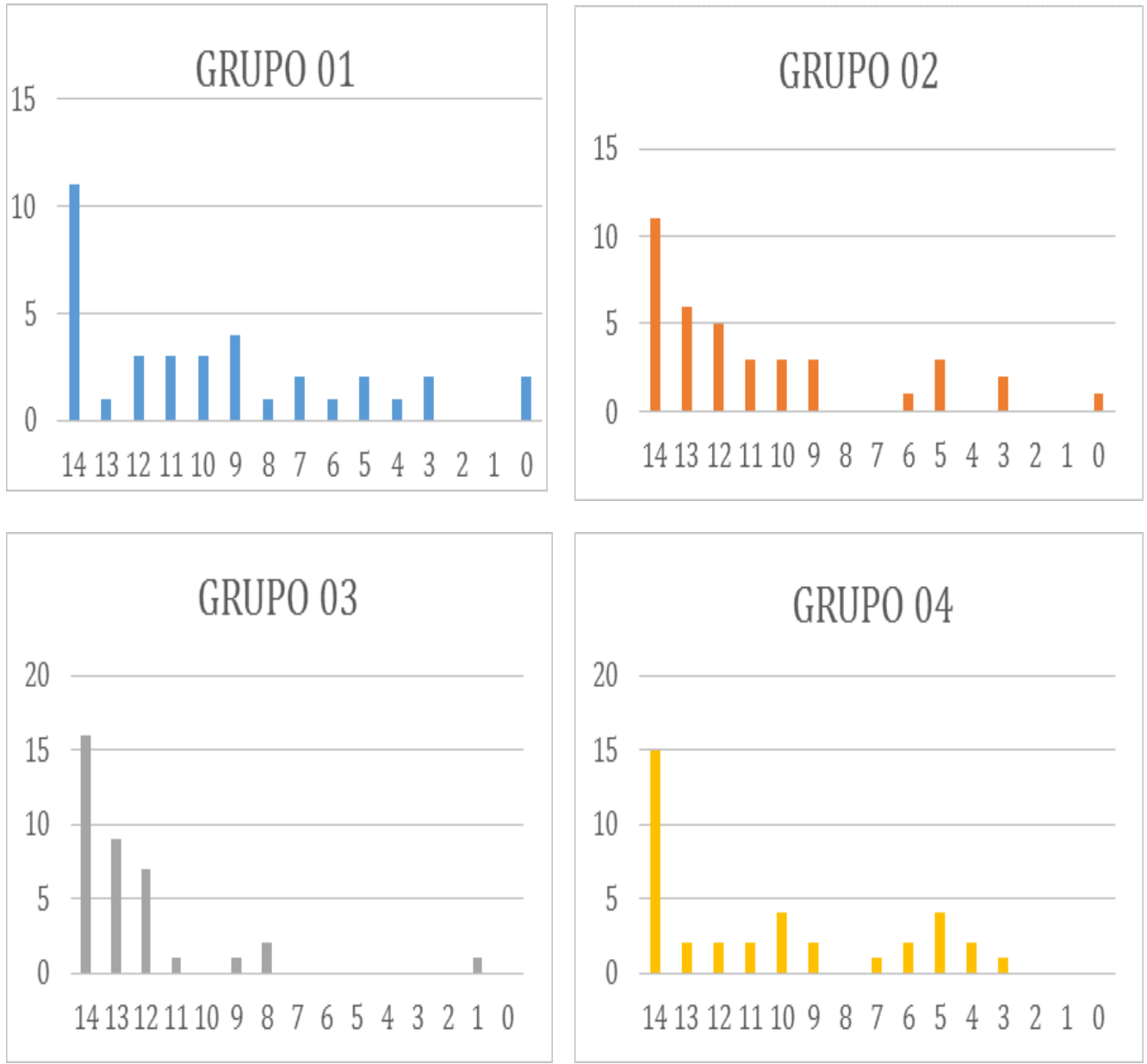

Figura 8.Distribuciones del número de alumnos que han realizado cada una de las autoevaluaciones. En el eje de abscisas se representan las autoevaluaciones, en el eje de ordenadas el número de alumnos que las han hecho.

-Participación por grupos separados por sexo y pruebas realizadas

Cuando se valoraron los resultados según el sexo y separados por grupos se observó que en general no aparecían diferencias entre el número de mujeres y hombres que realizaron las autoevaluaciones (Figura 9).

Se podría reseñar que en el grupo 02 el doble de mujeres que hombres completaron las 14 evaluaciones, lo que se ajustaría al mayor número de hombres que participaron realizando un menor número de autoevaluaciones. Esto además se añadiría a que este grupo tuvo una participación más baja. 
Por otro lado, se observó en el grupo 01 que los hombres doblaron a las mujeres en el cuartil de los que realizaron entre 10 y 13 pruebas, contrariamente a lo que sucedería en el grupo 03, donde más mujeres se encontrarían en este cuartil, como se ve en la figura 9.
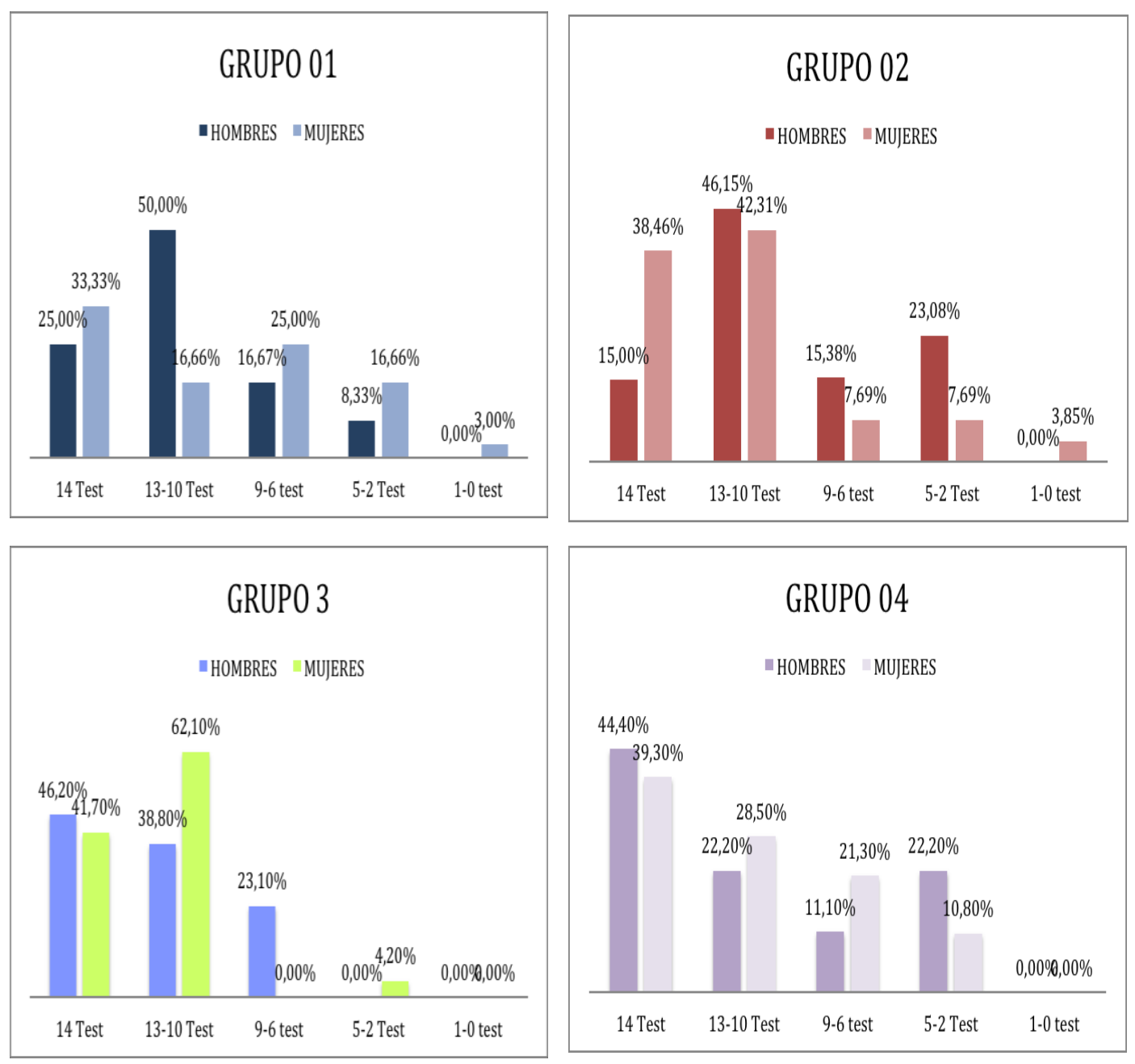

Figura 9. Análisis de la participación de hombres y mujeres de cada grupo del curso en la realización de las autoevaluaciones distribuidas en cuartiles que se representan en el eje de las abscisas.

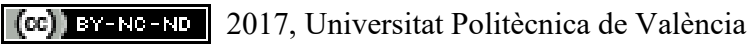

Congreso IN-RED (2017) 


\section{Resultados sobre el grado de satisfacción de los alumnos con esta actividad.}

Una vez terminada la experiencia de las autoevaluaciones a los alumnos se les hizo rellenar una encuesta como la que aparece en la imagen de la figura 10 en la que se le hacían varias preguntas

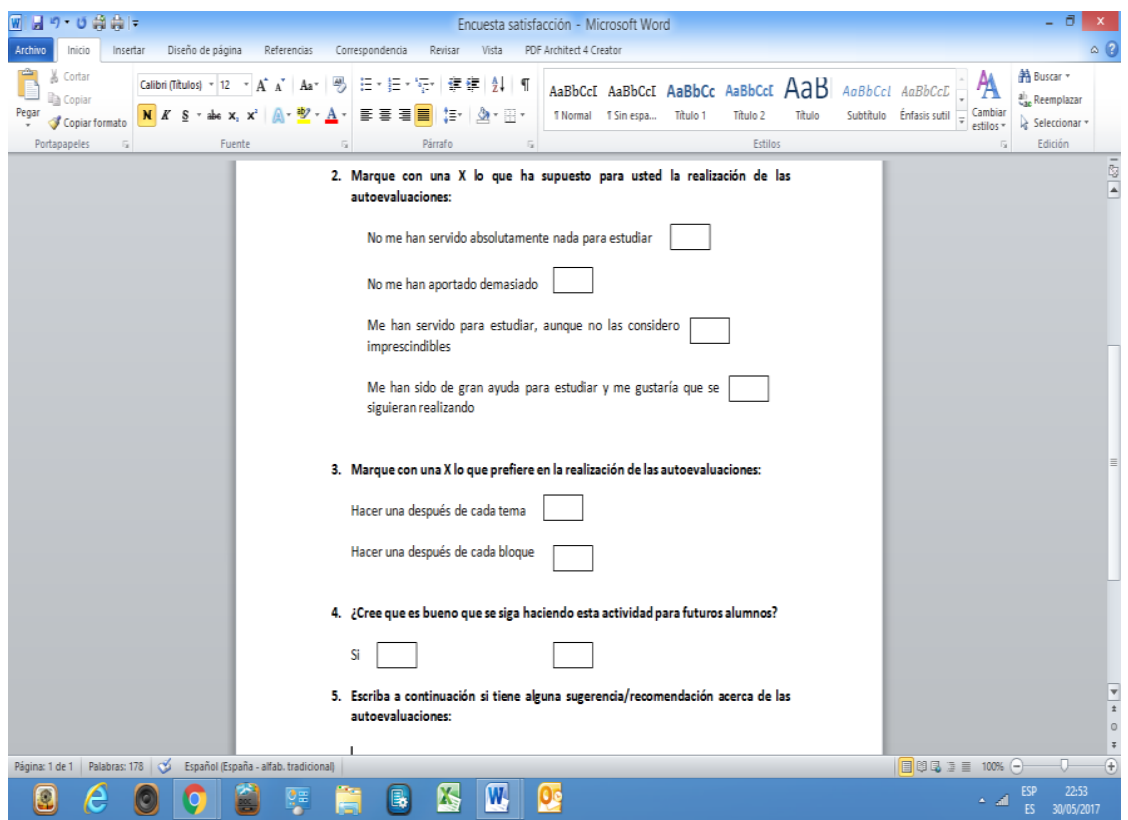

Figura 10. Tipo de encuesta

Las respuestas a la pregunta sobre su preferencia de hacer la autoevaluaciones una después de cada tema o una agrupando los temas por bloques de sistemas corporales, dio como resultados que no había gran diferencia entre las dos opciones. Aunque se evidencia una ligera preferencia a realizarlas agrupadas por bloques (Figura 11)

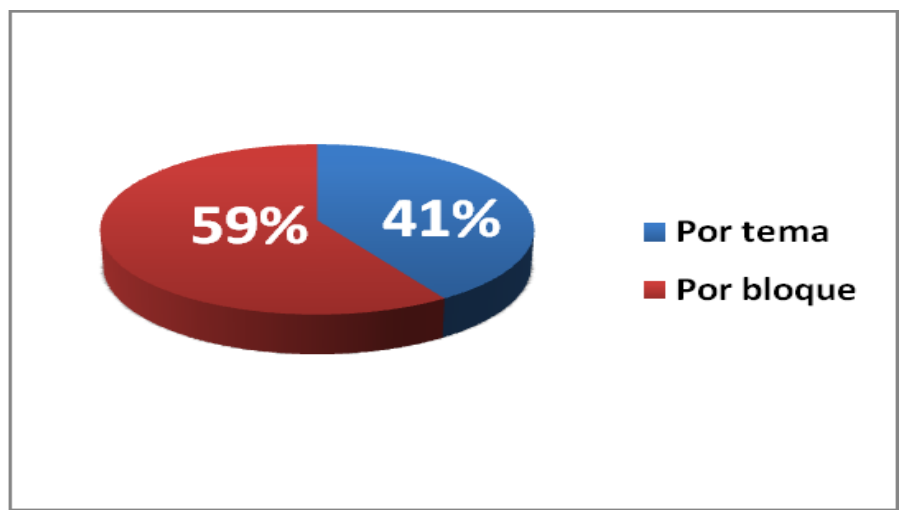

Figura 11: representación de la preferencia de los alumnos a realizar las autoevaluaciones por bloques o por temas individuales 
Respecto a si consideraban que debería de mantenerse esta actividad en los cursos venideros los resultados evidencian que los alumnos sí recomendarían que se mantuvieran estas autoevaluaciones (Figura 12).

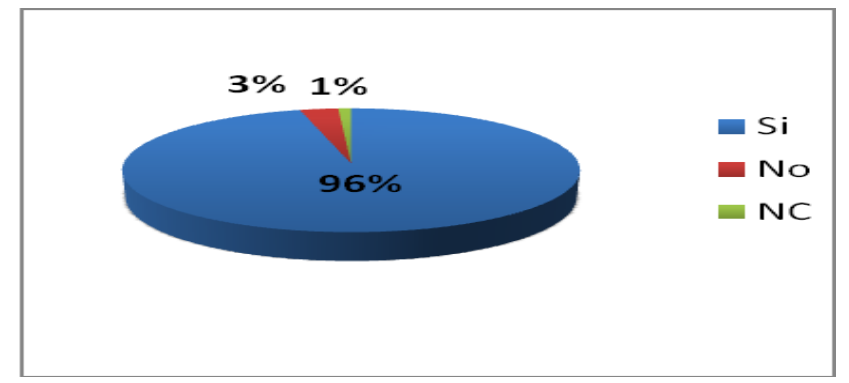

Figura 12. Respuestas a la pregunta recomendación de hacer la actividad en cursos posteriores:

Además el $86 \%$ consideró que les había servido de forma positiva y al $63 \%$ eligió que le gustaría que la actividad se hiciera en otras asignaturas. (Figura 13)

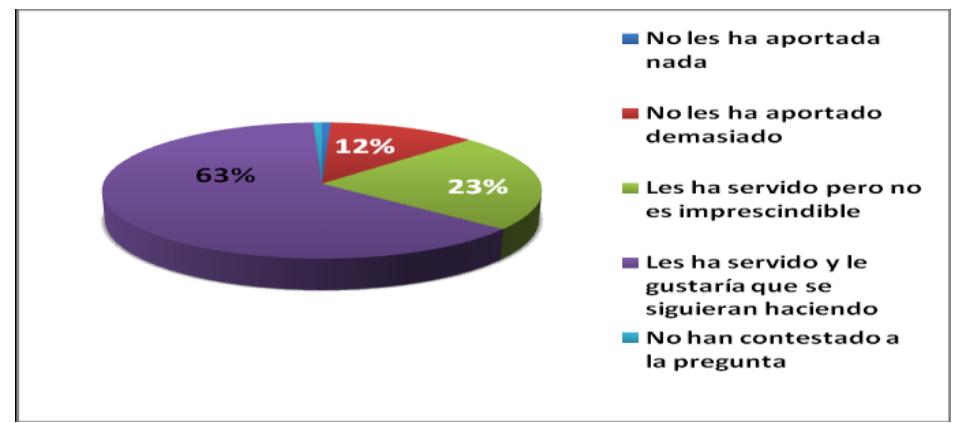

Figura 13 Respuestas a la pregunta de cómo valoran los alumnos la actividad de las autoevaluaciones.

El análisis de la relación entre la calificación final de la asignatura y su rendimiento en la autoevaluaciones reveló que hay una relación directa entre el éxito en la asignatura y las autoevaluaciones (figura $14 \mathrm{a}$ y b)

\section{Correlaciones}

\begin{tabular}{ll|r|r} 
& \multicolumn{1}{c}{$\begin{array}{c}\text { Nota del } \\
\text { examen }\end{array}$} & \multicolumn{1}{c}{$\begin{array}{c}\text { Nota de la } \\
\text { autoevaluación }\end{array}$} \\
\hline Nota delexamen & $\begin{array}{l}\text { Correlación de } \\
\text { Pearson }\end{array}$ & 1 &, $322^{*}$ \\
\cline { 2 - 4 } & Sig. (bilateral) & 147 &, 000 \\
\hline N & $\begin{array}{l}\text { Correlación de } \\
\text { Pearson }\end{array}$ &, $322^{* *}$ & 147 \\
\hline $\begin{array}{l}\text { Nota de la } \\
\text { autoevaluación }\end{array}$ & Sig.(bilateral) &, 000 & 1 \\
\cline { 2 - 4 } & $\mathrm{N}$ & 147 & 147 \\
\hline
\end{tabular}

**. La correlación es significativa en el nivel 0,01 (bilateral).

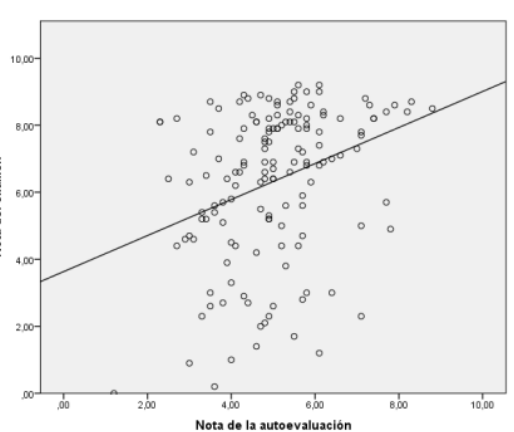

Figura 14 a y b. Éxito en la asegura Fisiología I y la realización de la actividad de autoevaluación.

2017, Universitat Politècnica de València

Congreso IN-RED (2017) 


\section{Conclusiones.}

En general, y tomando todos estos resultados en conjunto, se pone de manifiesto que los alumnos han abordado la asignatura de manera bastante positiva. Han generado un ritmo de estudio mantenido a lo largo del cuatrimestre, lo que probablemente se traduzca en la consecución de la prueba ordinaria de manera más exitosa.

Dado que la herramienta está disponible durante un periodo determinado ayuda al alumno a generar un encuadre de la asignatura, facilitándole la distribución del tiempo requerido para no abandonar el estudio continuado de la materia. Así el alumno puede jerarquizar la importancia de los distintos contenidos de cada tema. Además, una vez obtenida la calificación, el alumno puede valorar los puntos débiles en los que debe hacer hincapié. Por otro lado al profesor le permite valorar la progresión del alumnado en cada tema y valorar de forma cuantitativa la progresión del aprendizaje de forma personalizada, además de tener una baliza de referencia sobre la motivación de los alumnos con la materia. También, los resultados de los alumnos sirven de feedback para que el profesor refuerce aquellos conceptos importantes que no hayan quedado lo suficientemente claros a la luz de las respuestas de los alumnos en las autoevaluaciones.

Otra de las observaciones que podemos concluir observando los datos es que el número de pruebas fue elevado y que conseguiríamos aumentar el porcentaje de alumnos que realizaran la totalidad de las autoevaluaciones si las distanciáramos en el tiempo agrupándolas por bloques de temas.

Los profesores valoramos de manera muy positiva los resultados obtenidos respecto a la alta participación de los alumnos en esta actividad, lo que nos anima a mantenerla en los próximos cursos.

Las autoevaluaciones han tenido una muy buena acogida en todos los grupos lo que nos invita a mantenerlas en los sucesivos cursos elaborando modificaciones de mejora. Principalmente nos enfocaremos en la reducción de su número, realizando una compilación por bloques de contenidos con el propósito de aumentar el número de alumnos que realicen la totalidad de las pruebas, lo que nos permitirá además establecer un seguimiento de la asignatura continuo y constante.

Consideramos que esta herramienta es válida para favorecer un sistema de aprendizaje más activo y participativo de los alumnos, que no sólo les permitirán alcanzar los conocimientos de Fisiología, sino que también les ayudará a formarse en el uso de nuevas tecnologías como instrumento laboral, les ayudará a comprender la racionalización de los tiempos y a relacionarse entre ellos en un ambiente colaborativo, competencias todas ellas que les serán demandadas cuando se sumerjan en la vida profesional.

En definitiva, como conclusión final podemos decir que:

Las autoevaluaciones además de su gran acogida por parte de los alumnos son una buena herramienta para mantener una constancia en el estudio y permiten al profesor valorar a cada alumno de forma global, según su progreso en la evaluación continua. 


\section{Referencias}

Álvarez Álvarez B, González Mieres C, García Rodríguez N (2008) La motivación y los métodos de evaluación como variables fundamentales para estimular el aprendizaje autónomo. Revista de Educación Universitaria 1

Arceo FDB, Rojas GH, González ELG (2002) Estrategias docentes para un aprendizaje significativo: una interpretación constructivista. Libro electrónico: mapas.eafit.edu.co

Barr, R.b y Tagg, j. (1995). "From teaching to learning. A new paradigm for undergraduate education”, en Change, 27 (6), pp. 13-25.

Ferro Soto C, Martínez Senra AI, Otero Neira MC (2009) Ventajas del uso de las TICs en el proceso enseñanza-aprendizaje desde la óptica de los docentes universitarios españoles. Revista electrónica de Tecnología Educativa, $\mathrm{n}^{\circ} 29$

García Valcárcel, A. (1993). "Análisis de los modelos de enseñanza empleados en el ámbito universitario”, en Revista Española de Pedagogía, 194, 27-53.

Gargallo, B, García- Félix , I, Morera, C. y Benavent, A. (2015). Métodos innovadores y enfoques de aprendizaje en estudiantes universitarios

Doi: http://dx.doi.org/10.4995/INRED2015.2015.1576

Gil, M. G., Nieto, J. E. S., \& Ramos, A. D. (2015). The Students Portfolio as an Alternative Strategy to the Standardized Competencies Assessment Tests. Qualitative Research in Education, 4(1), 71-101

Jensen E, Villalba A (2003) Cerebro y aprendizaje: competencias e implicaciones educativas. Sumario Editorial

Machemer, P. L . . y Crawford, P. (2007). "Student perceptions of active learning in a large cross disciplinary classroom", en Active Learning in Higher Education, 8 (1), 9-30.

Molero López-Barjas D., Ruiz Carrascosa J (2005) La evaluación de la docencia universitaria. Dimensiones y variables más relevantes. Revista de Investigación Educativa $23(1)$

Monereo C. y Pozo J. I. (2003). La universidad ante la nueva cultura educativa. Enseñar y aprender para la autonomía. Madrid: Síntesis

Olalla, A. G. (2015). El portafolio docente. Un instrumento para evaluación y mejora de la práctica docente. Revista del Congrés Internacional de Docència Universitària i Innovació (CIDUI), (2).

Spencer, L. M., McClelland, D. C., \& Spencer, S. M. (1994). Competency assessment methods: History and state of the art. Hay/McBer Research Press.

Zabalza, M.A. (2012). "Metodología docente", en REDU (Revista de Docencia Universitaria, 9 (3), 75-98 


\title{
Implementando metodologías de evaluación en proyectos de redes de saneamiento en el Máster Universitario en Ingeniería Hidráulica y Medio Ambiente. Caso de estudio.
}

\author{
P. Amparo López-Jiménez ${ }^{\text {a; }}$ Ignacio Andrés-Doménecha ${ }^{\text {; }}$ Modesto Pérez-Sánchez ${ }^{\text {a, }}$ \\ ${ }^{a}$ Departamento de Ingeniería Hidráulica y Medio Ambiente. Universitat Politècnica de València. \\ palopez@upv.es; igando@hma.upv.es; mopesan1@upv.es.
}

(*) autor de correspondencia

\begin{abstract}
Development of projects as teaching strategy is a powerful tool to activate and strengthen the students' learning. The classical evaluation of projects by numeric items has been the usual way but the introduction of UPV generic student outcomes within student's curricula obliges to update the evaluation criteria as well as the way to achieve it. This communication presents the time planning of a subject, which represents a level III (Master Degree) control point for the generic outcome 'Design and Project'. As a consequence of the wide range of the students background in this subject, there are many of them which did not previously work this outcome for levels I and II (Bachelor). A rubric was developed to do the evaluation in which descriptors were defined according to traditional used items. These defined descriptors were used to evaluate the reached degree by the students for each indicator. Finally, the experience demonstrated the possibility to evaluate the ability to develop a project using competences. A comparison between marks obtained by traditional system and marks obtained by competences was developed, getting similar results that did not change the final mark in the student curricula.
\end{abstract}

Keywords: hydraulic engineering, sewage network, descriptor, indicator

\footnotetext{
Resumen

El desarrollo de proyectos como estrategia de aprendizaje resulta una herramienta muy potente para activar y potenciar el aprendizaje de los alumnos. Tradicionalmente, la evaluación de proyectos mediante items numéricos ha sido la técnica más habitual pero la introducción de las competencias transversales en la evaluación del alumno, obliga a actualizar los criterios y formas de evaluación. La presente comunicación presenta la planificación temporal de una asignatura punto de control de Nivel de Dominio III (Master) con un gran número de alumnos que no han trabajo previamente los anteriores dominios. Dentro de la planificación, se encuentra la evaluación para la cual una rúbrica ha sido desarrollada, en la cual los descriptores contienen los items que tradicionalmente han sido
} 
evaluados y con los que ahora, se evalúa el grado alcanzado por el alumno en cada indicador. Finalmente, se demuestra que la evaluación del grado de adquisición de los resultados de aprendizaje a través de competencias es posible. Se realiza una comparación de notas obtenidas por el sistema tradicional y por competencias, obteniendo resultados muy similares, cuyas diferencias no afectan a la nota final del expediente del alumno.

Palabras clave: ingeniería hidráulica, redes de saneamiento, descriptor, indicador

\section{Introducción}

El desarrollo de proyectos como estrategia de aprendizaje es una metodología en la que los alumnos planean, implementan y evalúan trabajos completos que tienen aplicación en el mundo real más allá del aula (Blank, 1997; Dickinson, et al, 1998; Galeana, 2003); pero que a su vez, deben servir como trabajo académico para la evaluación particular de la asignatura en que se enmarcan.

Así pues, la evaluación de los estudiantes a través de los trabajos por ellos desarrollados es una tarea tremendamente compleja en ocasiones, y que conlleva muchas implicaciones para ellos. Asimismo, las tareas de evaluación en tiempos más recientes no sólo conllevan una toma de decisiones sobre cómo el alumno ha adquirido los conocimientos, sino que implican un análisis por parte del profesor de cómo se han implementado en sus desarrollos las diferentes competencias transversales que comienzan a formar parte de los programas educativos, particularmente de la Universitat Politècnica de València (UPV). El caso de asignaturas relacionadas con el área de conocimiento de Ingeniería Hidráulica no es diferente, y el docente tiene que alinear los conocimientos impartidos con los resultados de aprendizaje no solo de la materia en cuestión sino de aquellas competencias transversales (CT) que trabaje o sea punto de control. Dentro de las 13 CT que incluye el Plan Estratégico UPV2020 (PEUPV2020) del Vicerrectorado de Estudios, Calidad y Acreditación, se encuentra la CT-05 'Diseño y Proyecto' (UPV, 2015).

La evaluación es necesaria para regular el aprendizaje, conocer por parte del profesor y las estructuras que proponen el plan de estudios, que las asignaturas que se ofertan con los contenidos y competencias asignadas, son aprendidas por los alumnos. De otro lado, para informar a los propios alumnos y a la sociedad de la que forman parte, de los resultados de su aprendizaje, valorados bajo criterios comunes para todos, los cuales puedan ser cuantificados y comparados (Trujillo, 2013; Harwell, S., 1997). Es más, la evaluación diseñada como parte del proceso de aprender es más enriquecedora que como cuantificación de los resultados obtenidos, al menos en la experiencia de los autores, desde el punto de vista del docente.

Las estrategias de evaluación en la actualidad son variadas, sin embargo entre ellas, en este documento se analiza en profundidad aquella que evalúa los conocimientos en un tema determinado (en este caso las redes de drenaje y saneamiento en el marco curricular del Máster en Ingenieria Hidráulica y Medio Ambiente) a través del desarrollo de un trabajo, asimilado a un proyecto. Este tipo de aprendizaje es motivador para el alumno, porque le permite entre otras cosas, tener un producto final completo, lo que le da una visión más amplia de la asignatura que la evaluación centrada en otro tipo de estrategias con cuestionarios de menor alcance. 
Además, esta asignatura cuenta con una gran diversidad de orígenes de alumnos (estudiantes propios de la UPV, de otras Universidades españolas, de países del Norte de Europa e Iberoamérica ). En la mayoría de las Universidades de las cuales proceden los estudiantes no cuentan con un sistema de trabajo y evaluación de competencias transversales. Este hecho determina que tanto profesores como alumnos, tengan que realizar un esfuerzo en la programación y seguimiento de la asignatura para poder trabajar y evaluar un nivel de competencia de dominio III (Master), intentando alcanzar el máximo grado de aprendizaje en los diferentes descriptores.

\section{Objetivos}

La asignatura en que se implementa la presente metodología es 'Redes de saneamiento', enmarcada en el Master Universitario en Ingeniería Hidraulica y Medio Ambiente. Los alumnos que acceden a esta asignatura ya tienen un grado de conocimiento y madurez que permiten el desarrollo de proyectos o tareas complejas de manera muy adecuada. Tanto los conocimientos previos necesarios, como el desarrollo de otras competencias ,como el trabajo autónomo o el trabajo en equipo han sido suficientemente desarrollados por los alumnos, que ya se encuentran en esta fase final de su aprendizaje, perfectamente capacitados para proponer ideas de proyectos con mucha entidad.

Los proyectos desarrollados por los alumnos deben cumplir con ciertos condicionantes, que serán tenidos en cuenta a través de su evaluación posterior:

1) Deben estar centrados en los contenidos de la asignatura, pero reconociendo aspectos previos que ya han sido adquiridos en otras asignaturas relacionadas.

2) Deben estar claramente definidos, con un enunciado que permita plantear condiciones iniciales, un desarrollo y un final.

3) Deben proponer problemas interesantes y relacionados con la asignatura y el contexto curriucular del Máster en que se integran.

4) Deben permitir al alumno tener un producto final tangible que pueda compartir con sus compañeros.

5) Debe suponer una oportunidad para el alumno y sus compañeros de reflexionar sobre los temas tratados y de comparar diferentes soluciones.

En este sentido, el objetivo de implementar metodologías de evaluación por proyectos en una asignatura como la que se presenta en esta contribución, permite a los alumnos comprobar su grado de conocimiento y capacidad de comunicación en el tema que a su vez tiene una gran ambientalización curricular por las implicaciones que tienen las redes de saneamiento en la gestión de problemas medioambientales. Así, se persiguen objetivos que permiten implementar diferentes estrategias relacionadas con el proyecto de CT de la UPV, importante para la Institución como colectivo.

De la misma manera, los conocimientos y competencias adquiridos se vuelven a implementar con fuerza en fases finales del presente Máster. Al ser un momento final en el currículum de los estudiantes, el desarrollo de su Trabajo Final de Máster con un contenido muy relacionado con los temas que se implementan en la asignatura de Redes de Saneamiento, permite a algunos de los estudiantes, volver a aplicar lo que se ha desarrollado en esta asignatura, con mucha mayor complejidad en algunos de los trabajos ya defendidos en dicha titulación. 


\section{Desarrollo de la innovación}

El desarrollo de la competencia transversal 'Diseño y Proyecto' aplicada a la asignatura de Redes de Saneamiento tiene por objeto:

1) En un Nivel de Dominio III, ser capaz de trabajar la competencia y evaluarla, teniendo en cuenta la gran diversidad en el origen de alumnos que la cursan. Además, se debe considerar que en pocas ocasiones el alumno ha trabajado o ha sido evaluado por competencias en sus Universidades donde cursaron los estudios de Grado. Esto dota de una mayor dificultad a la hora de programar el nivel de Dominio III, puesto que los niveles I y II no han sido trabajados previamente por el alumno.

2) Planificar el desarrollo temporal del proyecto definido a través de las diferentes fases presenciales y no presenciales. En la fase presencial el alumno adquiere los resultados de aprendizaje necesarios que le permiten poner en práctica de manera progresiva el desarrollo del proyecto. Es el desarrollo del proyecto, el que se realiza de forma no presencial, con ayuda de los recursos disponibles a través de la plataforma PoliformaT. En la fase no presencial, el alumno trabaja el aprendizaje autónomo, el cual se ve complementado y/o apoyado con la tutorización del profesor a lo largo del tiempo que la actividad se encuentra en proceso de realización para lograr alcanzar con éxito los resultados de aprendizaje propuestos (Figura 1).

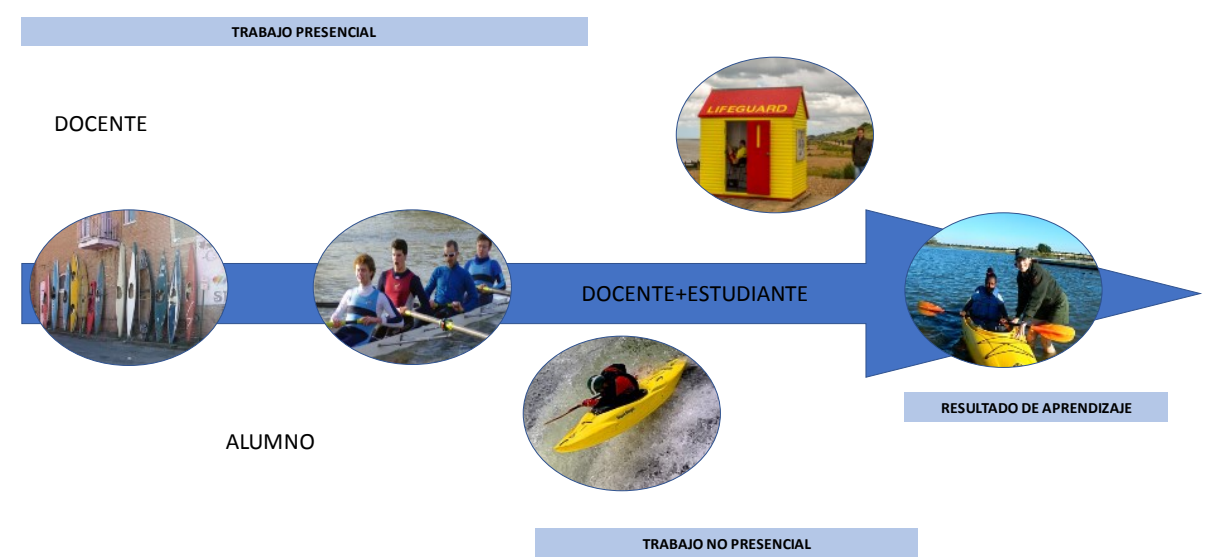

Fig 1. Evolución temporal del trabajo presencial y no presencial hasta alcanzar el resultado de aprendizaje

3) Desarrollar una transición de la nota numérica tradicionalmente establecida en el trabajo a establecer un grado de adquisición de la competencia mediante indicadores y descriptores, a través de una rúbrica que contemple los resultados de aprendizaje a alcanzar por el alumno en dicho proyecto. No obstante, esta transición tiene por finalidad que una vez establecida la rúbrica, pueda operarse de forma inversa. Conocido el grado de adquisición de cada uno de los indicadores

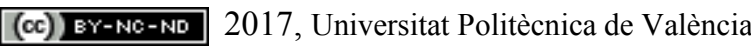

Congreso IN-RED (2017) 
definidos, se puede establecer un valor numérico que pueda ser tenido en cuenta para la nota del expediente del alumno, puesto que el trabajo representa un acto de evaluación dentro de la Guía Docente de la asignatura con un peso del 10\% sobre la calificación final.

\section{Resultados}

\subsection{Resultados del seguimiento del alumno}

La asignatura "Redes de saneamiento" se fundamenta en dos asignaturas obligatorias del plan de estudios del Máster en Ingeniería Hidráulica y Medio Ambiente del semestre A del primer curso: "Hidráulica avanzada" e "Hidrología superficial y subterránea".

La asignatura "Hidráulica Avanzada" es una asignatura troncal que tiene como objetivo lograr que todos los alumnos del Máster tengan unos conocimientos de hidráulica avanzada suficientes para poder desarrollar proyectos relacionados con la ingeniería hidráulica. Sirve de base para poder seguir profundizando, en el segundo semestre, en las asignaturas de intensificación relacionadas. En concreto, establece las bases para el cálculo hidráulico en lámina libre de colectores que se desarrollan en la asignatura "Redes de saneamiento" y que, en particular, son objeto de la práctica que aquí se analiza.

La asignatura "Hidrología superficial y subterránea" es igualmente una asignatura troncal del primer semestre en la que se establecen, en relación con "Redes de saneamiento" los conocimientos teóricos a problemas reales relacionados con la estimación del riesgo de las crecidas, profundizando en los métodos necesarios para el análisis de la precipitación, la producción de escorrentía y su propagación en la cuenca.

Así pues, la existencia previa en el plan de estudios de estas dos asignaturas garantiza que el alumno que aborda la asignatura "Redes de saneamiento" ha cursado, independientemente de su procedencia, los conceptos necesarios para poder abordar con solvencia esta asignatura de intensificación. Por otra parte, el alumno que se enfrenta a esta asignatura es un alumno de máster y, por tanto, con un nivel de madurez que le permite enfrentarse a una actividad en la cual pretenda demostrar que es capaz de alcanzar el nivel III de dominio de la competencia transversal CT-05, aunque no haya trabajado específicamente previamente los niveles I y II (propios de titulaciones de grado).

No obstante, en las mencionadas asignaturas previas del primer semestre, el alumno ha sido evaluado, entre otros, mediante el análisis de casos, planteando el análisis y la resolución de una determinada situación que presenta problemas de solución múltiple, a través de la reflexión y el diálogo para un aprendizaje grupal, integrado y significativo. Esto supone sin duda, un buen entrenamiento previo a la resolución completa de un proyecto, en unas condiciones más ambiciosas y donde el contexto previo está, deliberadamente, poco estructurado por parte del profesor. En cualquier caso, el apoyo por parte del profesor, tanto en la fase presencial como en la no presencial a través de las tutorías, es una pieza fundamental para conseguir que el alumno consiga demostrar un nivel de dominio III en esta competencial transversal, la cual debe adquirir sin haber trabajado previamente niveles anteriores. 


\subsection{Resultados de planificación temporal del trabajo}

El proyecto se comienza a desarrollar en una fase presencial de dos horas de duración en la cuarta semana del curso y en una fase no presencial de duración un mes, hasta la octava semana del curso, momento en el cual, el alumno debe entregar la memoria de la actividad.

La fase presencial ocurre cuando, en las tres primeras semanas del curso, el alumno ha adquirido los conocimientos referentes a las generalidades del diseño de una red de colectores y a los métodos hidrológicos e hidráulicos de diseño de este tipo de redes. Durante las dos horas de esta fase presencial, el profesor dirige a los alumnos a reflexionar y trabajar los puntos clave para la realización de la actividad, desarrollando en cada paso una puesta en común que subraye estos aspectos fundamentales.

En primer lugar, se realiza una lectura conjunta con los alumnos del enunciado de la práctica, discutiendo en grupo la problemática planteada y las líneas maestras conceptuales de la solución. A continuación, cada alumno desarrolla una propuesta de topología de la red, enfrentándose a la toma de ciertas decisiones que condicionarán en todo el desarrollo posterior del proyecto. Conforme surgen problemas y dudas por parte de los alumnos, el profesor las resuelve y remarca las estrategias más adecuadas para establecer dicha topología. Establecida la topología de la red, se analiza en grupo la información de partida consistente en la ortofotografía de la zona y cómo a partir de ésta deben asociarse los usos del suelo a los parámetros del modelo de cálculo hidrológico. A continuación, el profesor plantea a los alumnos la idea general para proceder a la delimitación y asignación de cuencas tributarias y deja que los alumnos se enfrenten a este paso del proceso de diseño. Por último, se trabajan los condicionantes para el encaje de los perfiles longitudinales de los distintos ramales de la red de colectores. Con esta actividad, concluye la sesión presencial de dos horas y a partir de este punto, comienza la fase no presencial de trabajo autónomo e individual del alumno.

La fase no presencial se extiende durante las siguientes cuatro semanas. Se estima en unas 10-15 horas el tiempo necesario para que el alumno complete el diseño de la red y lo plasme en la memoria requerida. Durante este mes, el profesor apoya con tutorías a los alumnos que así lo demandan para resolver los aspectos puntuales que hayan podido ir surgiendo durante la elaboración del proyecto.

\subsection{Propuesta de rúbrica}

El proyecto está estratificado en 9 ítems los cuales han servido tradicionalmente para establecer un valor numérico que computase en la nota final del alumno. Los autores de la presente comunicación han desarrollado una rúbrica (adaptada de la realizada por un equipo de profesores de la UPV y el ICE), la cual toma como referencia los indicadores propuestos a estos ítems, con el objetivo de no realizar una valoración numérica sino una valoración objetiva del grado alcanzado de los resultados de aprendizaje del alumno. Los ítems que tradicionalmente han sido corregidos son los que se adjuntan a continuación:

- Ítem 1 Establecimiento de la topología de la red

- Ítem 2 Justificación de los coeficientes de escorrentía adoptados

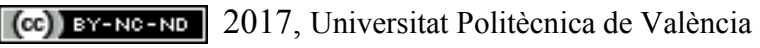

Congreso IN-RED (2017) 
- Ítem 3 Delimitación y asignación de subcuencas

- Ítem 4 Encaje de los perfiles longitudinales de los colectores

- Ítem 5 Cálculo de los diámetros de los conductos

- Ítem 6 Cálculo de las velocidades en los conductos

- Ítem 7 Representación gráfica de los perfiles longitudinales

- Ítem 8 Expresión escrita en la memoria

- Ítem 9 Edición de la memoria

Todos los ítems tenían una puntuación máxima de un punto, a excepción del Ítem 5 cuya puntuación es de dos puntos. La suma total era de 10 puntos, repercutiendo un $10 \%$ sobre la nota final.

A continuación, en las Tablas 1 y 2, se muestran los indicadores evaluados en el desarrollo de la competencia transversal.

Tabla 1. Rúbrica de evaluación de las actividades para Nivel de dominio III

\begin{tabular}{|c|c|c|c|c|c|}
\hline \multirow{2}{*}{ INDICADOR } & \multicolumn{4}{|c|}{ DESCRIPTORES } & \multirow{2}{*}{$\begin{array}{l}\text { EVIDENCIAS DE } \\
\text { CADA UNO DE LO } \\
\text { INDICADORES }\end{array}$} \\
\hline & $\begin{array}{l}\text { No Alcanzado } \\
\text { (D) }\end{array}$ & $\begin{array}{c}\text { En desarrollo } \\
\text { (C) }\end{array}$ & $\begin{array}{c}\text { Bien /adecuado } \\
\text { (B) }\end{array}$ & $\begin{array}{l}\text { Excelente } \\
\text { (A) }\end{array}$ & \\
\hline $\begin{array}{l}\text { 1. Valora las } \\
\text { necesidades en } \\
\text { un contexto } \\
\text { real de } \\
\text { intervención }\end{array}$ & $\begin{array}{c}\text { No las valora } \\
\text { o lo hace } \\
\text { incorrectame } \\
\text { nte }\end{array}$ & $\begin{array}{c}\text { Hace una } \\
\text { valoración en la } \\
\text { que comete } \\
\text { algún/os fallos/s o } \\
\text { en algunos casos } \\
\text { incorrecta }\end{array}$ & $\begin{array}{l}\text { Hace una } \\
\text { valoración } \\
\text { suficiente, } \\
\text { aunque no } \\
\text { completa, pero } \\
\text { siempre } \\
\text { correcta }\end{array}$ & $\begin{array}{l}\text { Hace una valoración } \\
\text { suficiente, correcta y } \\
\text { completa }\end{array}$ & \\
\hline $\begin{array}{c}\text { Evaluación } \\
\text { atendiendo a la } \\
\text { actividad }\end{array}$ & $\begin{array}{c}\text { El alumno no define } \\
\text { la necesidad de la } \\
\text { actuación en la } \\
\text { memoria }\end{array}$ & $\begin{array}{c}\text { El alumno cita la } \\
\text { necesidad de la } \\
\text { actuacion pero no } \\
\text { la justifica }\end{array}$ & $\begin{array}{c}\text { El alumno define la } \\
\text { necesidad y } \\
\text { desarrolla una } \\
\text { justificación de la } \\
\text { misma en la memoria } \\
\text { con justificaciones } \\
\text { correctas pero } \\
\text { incompletas }\end{array}$ & \begin{tabular}{|} 
El alumno enumera y \\
justifica la necesidad de \\
actuación de forma \\
correcta y completa
\end{tabular} & $\begin{array}{c}\text { Existe el } \\
\text { apartado en } \\
\text { la memoria } \\
\text { "Necesidad } \\
\text { de la } \\
\text { actuación" }\end{array}$ \\
\hline $\begin{array}{l}\text { 2. Concreta } \\
\text { objetivos } \\
\text { operativos } \\
\text { del proyecto } \\
\text { yestablece } \\
\text { plazos }\end{array}$ & $\begin{array}{c}\text { No concreta } \\
\text { objetivos ni plazos }\end{array}$ & $\begin{array}{l}\text { Concreta } \\
\text { algunos } \\
\text { objetivos y } \\
\text { algunos plazos }\end{array}$ & $\begin{array}{c}\text { Concreta } \\
\text { objetivos } \\
\text { operativos del } \\
\text { proyecto y } \\
\text { establece plazos }\end{array}$ & $\begin{array}{l}\text { Concreta todos } \\
\text { los objetivos y } \\
\text { todos los plazos } \\
\text { con perspectivas } \\
\text { de futuro }\end{array}$ & \\
\hline $\begin{array}{c}\text { Evaluación } \\
\text { atendiendo a la } \\
\text { actividad }\end{array}$ & $\begin{array}{c}\text { El alumno no define } \\
\text { en la memoria } \\
\text { entregable los } \\
\text { objetivos del } \\
\text { proyecto }\end{array}$ & $\begin{array}{l}\text { El alumno no } \\
\text { define todos los } \\
\text { objetivos }\end{array}$ & $\begin{array}{c}\text { El alumno define } \\
\text { todos los objetivos } \\
\text { del proyecto }\end{array}$ & $\begin{array}{c}\text { El alumno define todos } \\
\text { los objetivos del } \\
\text { proyecto, estableciendo } \\
\text { una priorización de los } \\
\text { mismos y expresándolos }\end{array}$ & $\begin{array}{l}\text { La } \\
\text { memoria } \\
\text { contiene el } \\
\text { apartado de } \\
\text { objetivos }\end{array}$ \\
\hline $\begin{array}{c}\text { 3. Planifica } \\
\text { las acciones } \\
\text { y prevé } \\
\text { contingencia } \\
\text { s }\end{array}$ & $\begin{array}{l}\text { No planifica las } \\
\text { acciones ni } \\
\text { prevé } \\
\text { contingencias }\end{array}$ & $\begin{array}{c}\text { Planifica las } \\
\text { acciones y/o } \\
\text { contingencias, } \\
\text { pero comete } \\
\text { fallos: no lo } \\
\text { hace de la } \\
\text { manera más } \\
\text { adecuada }\end{array}$ & $\begin{array}{l}\text { Planifica las } \\
\text { acciones y } \\
\text { prevé las } \\
\text { contingencias }\end{array}$ & $\begin{array}{c}\text { Planifica las } \\
\text { acciones y además } \\
\text { prevé las } \\
\text { contingencias } \\
\text { proponiendo } \\
\text { alternativas }\end{array}$ & \\
\hline
\end{tabular}




\begin{tabular}{|c|c|c|c|c|c|}
\hline $\begin{array}{c}\text { Evaluación } \\
\text { atendiendo a la } \\
\text { actividad }\end{array}$ & $\begin{array}{c}\text { El alumno no planifica } \\
\text { el proceso de resolución } \\
\text { del proyecto, no } \\
\text { dibujando los perfiles } \\
\text { longitudinales finales. }\end{array}$ & $\begin{array}{c}\text { El alumno planifica la } \\
\text { metodología de } \\
\text { resolución pero no es } \\
\text { correcta, en ningún } \\
\text { caso. }\end{array}$ & $\begin{array}{l}\text { El alumno planifica la } \\
\text { metodología de } \\
\text { resolución de forma } \\
\text { correcta, pero no es } \\
\text { capaz de desarrollar } \\
\text { todos los perfiles }\end{array}$ & $\begin{array}{c}\text { El alumno planifica la } \\
\text { metodología de resolución } \\
\text { de forma correcta y justifica } \\
\text { la toma de decisiones, } \\
\text { demostrandolo con los } \\
\text { perfiles finales longitudiales } \\
\text { de energía }\end{array}$ & $\begin{array}{l}\text { El alumno además de } \\
\text { definirlo en la } \\
\text { memoria, finaliza el } \\
\text { proyecto con la } \\
\text { representación de los } \\
\text { perfiles longitudinales }\end{array}$ \\
\hline
\end{tabular}

Tabla 2. Rúbrica de evaluación de las actividades para Nivel de dominio III (Continuación)

\begin{tabular}{|c|c|c|c|c|c|}
\hline \multirow{2}{*}{ INDICADOR } & \multicolumn{4}{|c|}{ DESCRIPTORES } & \multirow{2}{*}{$\begin{array}{l}\text { EVIDENCIAS DE } \\
\text { CADA UNO DE LOS } \\
\text { INDICADORES }\end{array}$} \\
\hline & $\begin{array}{l}\text { No Alcanzado } \\
\text { (D) }\end{array}$ & $\begin{array}{c}\text { En desarrollo } \\
\text { (C) }\end{array}$ & $\begin{array}{c}\text { Bien /adecuado } \\
\text { (B) }\end{array}$ & $\begin{array}{l}\text { Excelente } \\
\text { (A) }\end{array}$ & \\
\hline $\begin{array}{c}\text { 4. Gestiona } \\
\text { adecuadamente } \\
\text { los recursos } \\
\text { disponibles }\end{array}$ & $\begin{array}{l}\text { No gestiona los } \\
\text { recursos } \\
\text { disponibles }\end{array}$ & $\begin{array}{l}\text { Gestiona los } \\
\text { recursos pero } \\
\text { comete fallos: } \\
\text { no lo hace de la } \\
\text { manera más } \\
\text { adecuada }\end{array}$ & $\begin{array}{l}\text { Gestiona } \\
\text { adecuada } \\
\text { mente los } \\
\text { recursos } \\
\text { disponibl } \\
\text { es } \\
--.-\end{array}$ & $\begin{array}{c}\text { Gestiona } \\
\text { adecuadamente } \\
\text { todos los } \\
\text { recursos } \\
\text { disponibles }\end{array}$ & \\
\hline $\begin{array}{c}\text { Evaluación } \\
\text { atendiendo a la } \\
\text { actividad }\end{array}$ & $\begin{array}{c}\text { El alumno no es capaz } \\
\text { de analizar la } \\
\text { informaicón disponible } \\
\text { en PoliformaT para } \\
\text { desarrollar el proyecto }\end{array}$ & $\mid \begin{array}{c}\text { El alumno es capaz de } \\
\text { analizar la } \\
\text { información, la } \\
\text { enumera en la } \\
\text { memoria pero no la } \\
\text { utiliza correctamente }\end{array}$ & $\begin{array}{l}\text { El alumno es capaz de } \\
\text { analizar la informción, } \\
\text { enumerandola en la } \\
\text { memoria y utilizándola } \\
\text { de una forma correcta }\end{array}$ & \begin{tabular}{|} 
El alumno utiliza toda la \\
información disponible, la \\
enumera en la memoria y la \\
complementa con otros \\
recursos buscados por él \\
mismo, mejorando la \\
informaicón de partida del \\
proyecto (modelos digitales, \\
catálogos de fabricantes, \\
información urbanistica...)
\end{tabular} & $\begin{array}{l}\text { El alumno procesa } \\
\text { la información } \\
\text { disponible para } \\
\text { desarrollar el } \\
\text { proyecto, } \\
\text { presentándola en } \\
\text { la memoria }\end{array}$ \\
\hline $\begin{array}{c}\text { 5. Realiza un } \\
\text { seguimiento } \\
\text { de la } \\
\text { implementac } \\
\text { ión del } \\
\text { proyecto }\end{array}$ & $\begin{array}{l}\text { No evidencia el } \\
\text { seguimiento }\end{array}$ & $\begin{array}{l}\text { Hay algunas } \\
\text { evidencias de } \\
\text { realizar el } \\
\text { seguimiento }\end{array}$ & $\begin{array}{c}\text { Hace un } \\
\text { seguimiento } \\
\text { coherente del } \\
\text { proyecto hacia } \\
\text { la consecución } \\
\text { de los objetivos, } \\
\text { con alguna } \\
\text { omisión }\end{array}$ & $\begin{array}{l}\text { Hace un seguimiento } \\
\text { completo y } \\
\text { coherente del } \\
\text { proyecto hacia la } \\
\text { consecución de los } \\
\text { objetivos }\end{array}$ & \\
\hline $\begin{array}{c}\text { Evaluación } \\
\text { atendiendo a la } \\
\text { actividad }\end{array}$ & $\begin{array}{c}\text { El alumno únicamente } \\
\text { es capaz de definir la } \\
\text { topologia de la red }\end{array}$ & $\begin{array}{c}\text { El alumno define la } \\
\text { topologia de la red, es } \\
\text { capaz de establecer de } \\
\text { forma correcta las } \\
\text { subcuencas de la red } \\
\text { (Anexo } 2 \text { y), pero } \\
\text { desarrolla de forma } \\
\text { incorrecta la } \\
\text { determinación de los } \\
\text { diametros (Anexo 4) }\end{array}$ & $\begin{array}{c}\text { El alumno define } \\
\text { correctamente las } \\
\text { subcuencas y perfiles, } \\
\text { determinando de forma } \\
\text { correcta los diámetros } \\
\text { (Anexo 4) y comprueba } \\
\text { las velocidades con } \\
\text { diámetros comerciales } \\
\text { (Anexo 5) }\end{array}$ & \begin{tabular}{|} 
El alumno desarrolla de \\
forma correcta todos los \\
anexos, desarolla los planos \\
de la red solicitada tanto en \\
planta como en perfil, \\
justificando de forma \\
escrita toda la toma de \\
decisiones
\end{tabular} & $\begin{array}{l}\text { El alumno desarrolla } \\
\text { los } 7 \text { puntos } \\
\text { considerados en el } \\
\text { enunciado del } \\
\text { proyecto dentro de la } \\
\text { memoria, } \\
\text { justificándolo en los } \\
\text { diferentes anexos }\end{array}$ \\
\hline $\begin{array}{c}\text { 6. Gestiona } \\
\text { adecuadamente } \\
\text { los riesgos del } \\
\text { proyecto }\end{array}$ & $\begin{array}{l}\text { No evidencia la } \\
\text { gestión de los } \\
\text { riesgos }\end{array}$ & $\begin{array}{l}\text { Gestiona los } \\
\text { riesgos pero } \\
\text { comete fallos: } \\
\text { no lo hace de } \\
\text { la manera más } \\
\text { adecuada }\end{array}$ & $\begin{array}{l}\text { Gestiona } \\
\text { adecuada } \\
\text { mente los } \\
\text { riesgos } \\
\text { del } \\
\text { proyecto }\end{array}$ & $\begin{array}{l}\text { Gestiona } \\
\text { adecuadamente } \\
\text { todos los riesgos } \\
\text { del proyecto }\end{array}$ & \\
\hline
\end{tabular}

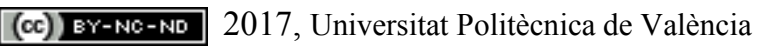




\begin{tabular}{|c|c|c|c|c|c|}
\hline $\begin{array}{c}\text { Evaluación } \\
\text { atendiendo a la } \\
\text { actividad }\end{array}$ & \begin{tabular}{|} 
El alumno no toma los \\
coeficientes necesarios \\
para determinar la \\
producción de \\
escorrentía asi como los \\
coeficientes de \\
rugosidad de la \\
conducciones. No \\
respeta la normativa \\
vigente
\end{tabular} & $\mid \begin{array}{c}\text { El alumno toma los } \\
\text { coeficientes de } \\
\text { escorrentía y } \\
\text { rugosidad de manera } \\
\text { correcta, pero los } \\
\text { considera inferiores a } \\
\text { los valores } \\
\text { recomendados en la } \\
\text { bibliografia, teniendo } \\
\text { en cuenta la normativa } \\
\text { vigente }\end{array}$ & $\begin{array}{c}\text { El alumno toma los } \\
\text { coeficientes de forma } \\
\text { correcta, tomando } \\
\text { valores usualmente } \\
\text { utilizados por la } \\
\text { bibliografia, teniendo en } \\
\text { cuenta la normativa } \\
\text { vigente }\end{array}$ & $\begin{array}{c}\text { El alumno toma valores de } \\
\text { coeficientes correctos, } y \\
\text { desarrolla un ánalisis de } \\
\text { sensibilidad, discutiendo la } \\
\text { diferencia de los resultados, } \\
\text { teniendo en cuenta la } \\
\text { normativa vigente }\end{array}$ & $\begin{array}{l}\text { Justificación de los } \\
\text { esquemas de } \\
\text { funcionamiento } \\
\text { seleccionados y } \\
\text { adaptación a la } \\
\text { normativa }\end{array}$ \\
\hline
\end{tabular}

La tabla 3 muestra la correlación entre los 9 ítems y los 6 indicadores definidos, así como el peso ponderado del indicador para a partir del grado alcanzado en la competencia, dotar de un valor numérico para poder ser tenido en cuenta en el expediente del alumno en la evaluación de las competencias específicas.

Tabla 3. Correlación entre los indicadores e items

\begin{tabular}{|cl|c|c|}
\hline \multicolumn{2}{|c|}{ Indicador } & Ítem & Peso ponderado \\
& & & del indicador \\
\hline $1 . \quad$ Valora necesidades & Ítem 9 & 0.1 \\
\hline $2 . \quad$ Concreta objetivos & Ítem 8 & 0.1 \\
\hline $3 . \quad$ Planifica acciones & Ítem 7 & 0.1 \\
\hline $4 . \quad$ Gestiona recursos & Ítems 1 y 4 & 0.15 \\
\hline $5 . \quad$ Realiza seguimiento de implementación & Ítems 3 y 5 & 0.35 \\
\hline $6 . \quad$ Gestiona los riesgos & Ítems 2 y 6 & 0.20 \\
\hline
\end{tabular}

En cuanto a los criterios para definir la valoración de la competencia considerando los 6 indicadores se adjuntan a continuación la Tabla 4 que muestra dicha equivalencia propuesta.

Tabla 4. Correlaciones principales entre grado alcanzado de la competencia e indicadores

\begin{tabular}{|l|c|}
\hline \multicolumn{1}{|c|}{ Grado alcanzado en los indicadores } & Calificación \\
\hline $\begin{array}{l}\text { Todos los indicadores son A } \\
\text { Existen hasta dos indicadores calificados como B que no coinciden con los indicadores de 4 a 6, } \\
\text { siendo éstos A }\end{array}$ & A \\
\hline $\begin{array}{l}\text { Dos indicadores de 4 a 6 son B, y al menos uno de 1 a 3 es B } \\
\text { Los tres indicadores de 4 a 6 son B, y cómo máximo solo existe un indicador C de 1 a 3 }\end{array}$ & B \\
\hline $\begin{array}{l}\text { Uno de los indicadores de 4 a 6 es C, dando igual el número de A existentes } \\
\text { Todos los indicadores de 4 a 6 son B, y existen dos indicadores C o uno D }\end{array}$ \\
\hline $\begin{array}{l}\text { Existe un indicador de 4 a 6 evaluado como D } \\
\text { Todos los indicadores entre 4 y 6 son inferiores a A, y al menos existen dos indicadores de 1 a 3 }\end{array}$ \\
\hline
\end{tabular}

(c)) EY-NG-ND 2017, Universitat Politècnica de València 


\subsection{Resultados obtenidos}

Los resultados obtenidos en el cuatrimestre B del curso 2015/2016, en el cual estuvieron matriculados 23 alumnos, fueron los que se adjuntan a continuación en la Tabla 5. En esta tabla pueden observarse los resultados de las calificaciones y correlaciones para cada uno de los alumnos, presentados de forma anónima. 
Tabla 5. Correlación entre los indicadores e items

\begin{tabular}{|c|c|c|c|c|c|c|c|}
\hline \multirow{2}{*}{ ALUMNO } & \multicolumn{6}{|c|}{ INDICADORES } & \multirow{2}{*}{$\begin{array}{l}\text { CALIFICACIÓN } \\
\text { GLOBAL }\end{array}$} \\
\hline & 1 & 2 & 3 & 4 & 5 & 6 & \\
\hline A01 & A & A & A & $\mathrm{A}$ & A & A & A \\
\hline $\mathrm{A} 02$ & A & $\mathrm{A}$ & B & A & B & A & A \\
\hline $\mathrm{A} 03$ & A & C & C & B & B & B & B \\
\hline A04 & D & C & D & B & C & C & C \\
\hline A05 & A & A & C & A & B & A & B \\
\hline A06 & B & A & A & A & B & A & A \\
\hline $\mathrm{A} 07$ & A & $\mathrm{A}$ & C & B & A & C & B \\
\hline A08 & B & A & C & A & A & B & B \\
\hline A09 & D & C & C & A & A & B & C \\
\hline A10 & A & $\mathrm{A}$ & B & B & B & B & B \\
\hline A11 & A & A & C & A & B & A & B \\
\hline A12 & B & $\mathrm{B}$ & $\mathrm{D}$ & A & $\mathrm{B}$ & A & B \\
\hline A13 & A & A & D & $\mathrm{A}$ & B & B & C \\
\hline A14 & $\mathrm{B}$ & C & D & D & D & C & D \\
\hline A15 & B & A & A & A & C & A & B \\
\hline A16 & D & A & B & A & C & B & B \\
\hline A17 & A & A & A & A & B & A & A \\
\hline A18 & A & A & $D$ & A & C & B & B \\
\hline A19 & A & A & A & A & B & B & B \\
\hline A20 & D & B & B & A & C & A & B \\
\hline A21 & D & A & B & A & B & B & B \\
\hline A22 & D & D & D & A & C & C & D \\
\hline A23 & A & A & B & A & C & A & B \\
\hline
\end{tabular}

Finalmente, en la Tabla 6 se comparan las notas numéricas evaluadas mediante ítems $\left(\mathrm{N}_{\mathrm{i}}\right)$, tal y como se ha venido desarrollando, y las notas numéricas obtenidas por competencias cuando se hace la transformación numérica $\left(\mathrm{N}_{\mathrm{c}}\right)$. Para desarrollar esta equivalencia se tienen en cuenta, los pesos ponderados de la Tabla 3, y se dota al descriptor de un valor igual a 5 cuando es $\mathrm{A} ; 4$ cuando es $\mathrm{B} ; 2$ cuando es $\mathrm{C}$; y 0.5 cuando es D.

La tabla describe que las calificaciones obtenidas son muy similares no existiendo cambios sustanciales en las notas obtenidas, manteniéndose los alumnos que obtienen una muy buena calificación por ítems, así como aquellos que no han conseguido superar la asignatura porque no han logrado alcanzar los resultados de aprendizaje. 
Tabla 6. Comparación de notas obtenidas mediante items y por equivalencia de competencias

\begin{tabular}{|c|c|c|c|c|c|c|c|}
\hline ALUMNO & $\left(\mathbf{N}_{\mathrm{i}}\right)$ & $\left(\mathbf{N}_{c}\right)$ & {$\left[\mathbf{N}_{\mathrm{c}}-\mathbf{N}_{\mathrm{i}}\right]$} & ALUMNO & $\left(\mathbf{N}_{\mathrm{i}}\right)$ & $\left(\mathbf{N}_{\mathrm{c}}\right)$ & {$\left[\mathbf{N}_{\mathrm{c}}-\mathbf{N}_{\mathrm{i}}\right]$} \\
\hline A01 & 10 & 10 & 0 & A13 & 8 & 8 & 0 \\
\hline A02 & 9.5 & 9.1 & -0.4 & A14 & 1.5 & 2.6 & 1.1 \\
\hline A03 & 7 & 7.4 & 0.4 & A15 & 8.5 & 7.7 & -0.8 \\
\hline A04 & 4 & 4 & 0 & A16 & 7 & 6.4 & -0.6 \\
\hline A05 & 9 & 8.7 & -0.3 & A17 & 9.5 & 9.3 & -0.2 \\
\hline A06 & 8.5 & 9.1 & 0.6 & A18 & 7.25 & 6.6 & -0.65 \\
\hline A07 & 7.5 & 7.9 & 0.4 & A19 & 8.5 & 8.9 & 0.4 \\
\hline A08 & 8.5 & 8.8 & 0.3 & A20 & 6.5 & 6.6 & 0.1 \\
\hline A09 & 7 & 7.5 & 0.5 & A21 & 7.5 & 7.8 & 0.3 \\
\hline A10 & 8.25 & 8.4 & 0.15 & A22 & 3.5 & 4 & 0.5 \\
\hline A11 & 9 & 8.7 & -0.3 & A23 & 7.75 & 7.7 & -0.05 \\
\hline A12 & 8 & 8 & 0 & & & & \\
\hline
\end{tabular}

\section{Conclusiones}

En la presente comunicación se ha mostrado un caso de estudio de nivel de Dominio III, concretamente de la asignatura Redes de Saneamiento, la cual ha permitido comprobar su grado de conocimiento y capacidad de comunicación, en un tema que a su vez tiene una gran ambientalización curricular por las implicaciones que tienen las redes de saneamiento en la gestión de problemas medioambientales.

El desarrollo se ha establecido a traves de la descripción de una metodología de trabajo la cual ha combinado la tarea presencial y no presencial de los alumnos. Evaluada la competencia transversal Diseño y Proyecto, un $78.26 \%$ de los alumnos han adquirido con un un nivel adecuado o excelente dicha competencia, mostrando el éxito de la misma.

Para evaluar dicha competencia, los autores han propuesto una rúbrica la cual han adaptado a partir de los indicadores propuestos por el Instituto de Ciencias de la Educación de la UPV. Estos indicadores han sido descritos en función de los items que tradicionalmente han sido evaluados en dicho proyecto.

Finalmente, se ha mostrado la posibilidad de trabajar de un modo inverso a lo realizado hasta la fecha. A partir de los grados alcanzados en cada indicador, éstos han sido ponderados y se ha obtenido una nota númerica, la cual es introducida en el expediente académico para valorar las competencias generales y específicas de la asignatura. Tras realizar la transformación se ha observado que las notas obtenidas son muy similares, no mostrando ni variando los resultados finales del expediente académico del alumno.

(c)) EY-NC-ND 2017, Universitat Politècnica de València 


\section{Referencias}

TrujILlo SÁEZ, F. (2013) Aprendizaje basado en proyectos. Formación en Red. Instituto Nacional de Tecnologías Educativas y de Formación del Profesorado .

Blank, W. (1997). Authentic instruction. In W.E. Blank \& S. Harwell (Eds.), Promising practices for connecting high school to the real world (pp. 15-21). Tampa, FL: University of South Florida. (ERIC Document Reproduction Service No. ED407586)

Dickinson, K.P., Soukamneuth, S., Yu, H.C., Kimball, M., D’Amico, R., PrRy, R., et al. (1998). Providing educational services in the Summer Youth Employment and Training Program [Technical assistance guide]. Washington, DC: U.S. Department of Labor, Office of Policy \& Research. (ERIC Document Reproduction Service No. ED420756)

Galeana DE LA O. L. (2003) Aprendizaje basado en proyectos. Universidad de Colima. Mexico.

Harwell, S. (1997). Project-based learning. In: W. E. Blank and S. Harwell (Eds.), Promising practices for connecting high school to the real world (pp. 23-28). Tampa, FL: University of South Florida. (ERIC Document Reproduction Service No. ED 407586).

UPV (2015) "Plan estratégico 2015-2020". Universidad Politécnica de Valencia. [Consultado 20 marzo de 2017] 


\title{
Herramientas de trabajo colaborativo para la dinamización de la competencia transversal responsabilidad ética, medioambiental y profesional
}

\section{M.T. Sebastiá-Frasquet ${ }^{\mathrm{a}}$, S. Asensio-Cuesta ${ }^{\mathrm{b}}$, I. Gasch ${ }^{\mathrm{c}}$, N. Pascual-Seva ${ }^{\mathrm{d}}$, M. Vargas ${ }^{\mathrm{e}}$}

${ }^{a}$ Dpto de Ingeniería Hidráulica y Medio Ambiente. Universitat Politècnica de València (mtsebastia@hma.upv.es) ${ }^{b}$ Dpto. de Proyectos de Ingeniería. Universitat Politècnica de València (sasensio@dpi.upv.es). ${ }^{\mathrm{D} D}$ pto. de Mecánica de los Medios Continuos y Teoría de Estructuras. Universitat Politècnica de València (igasch@mes.upv.es). ${ }^{\mathrm{d}}$ Dpto. de Producción Vegetal. Universitat Politècnica de València (nupasse@prv.upv.es). ${ }^{e}$ Dpto. de Tecnología de Alimentos. Universitat Politècnica de València (mavarco@tal.upv.es).

\begin{abstract}
This article analyzes the experience of using different collaborative work tools to dynamize the tasks that help to acquire and improve key competence ethical, environmental and professional responsibility. The selected tools are integrated in the learning management system (LMS), PoliformaT, of the Universitat Politècnica de València. In particular, we have worked with the forum and the wiki, and the blog which is integrated in Poliblogs. In this experience three Bachelor degrees and a Master degree of engineering and life sciences have been involved: Bachelor's Degree in Environmental Sciences, Bachelor's Degree in Rural and Agrifood Engineering, Bachelor's Degree in Mechanical Engineering and Master's Degree in Design Engineering. The results show that the students value the experience satisfactorily thanks to the virtual interaction with other colleagues and they highlight the extra motivation offered by the use of these tools. It is noteworthy that to obtain good results there are two key elements: 1) clear rules of operation and evaluation and 2) high participation of the teacher as moderator.
\end{abstract}

Keywords: blog, forum, wiki, learning management system, key competences

\section{Resumen}

En el presente artículo se analiza la experiencia de uso de distintas herramientas de trabajo colaborativo para dinamizar las tareas que ayudan a adquirir y mejorar la competencia transversal responsabilidad ética, medioambiental y profesional. Las herramientas seleccionadas están integradas en la plataforma de gestión del aprendizaje, poliformat, de la Universitat Politècnica de València. En particular hemos trabajado con el foro y la wiki, además de con el blog integrado en Poliblogs. En esta experiencia han participado tres titulaciones de Grado y un Máster de ingeniería y ciencias de la vida: Grado en Ciencias Ambientales, Grado en Ingeniería Agroalimentaria y del Medio Rural, Grado en Ingeniería Mecánica, y Máster Universitario en Ingeniería del Diseño. Los resultados obtenidos muestran que el alumnado valora satisfactoriamente la experiencia gracias a la interacción 
virtual con otros compañeros y destacan la motivación extra que les ofrece el uso de estas herramientas. Es destacable que para la obtención de buenos resultados hay dos elementos clave: 1) Normas claras de funcionamiento y evaluación y 2) Alta participación del profesor como moderador.

Palabras clave: blog, foro, wiki, sistemas de gestión del aprendizaje, competencias transversales

\section{Introducción}

Las competencias transversales son habilidades relacionadas con el desarrollo personal útiles en múltiples áreas (González et al., 2003). Las competencias transversales constituyen una parte fundamental del perfil profesional y formativo del alumno.

En los últimos años, la Universidad Politécnica de València (UPV) ha desarrollado una nueva política de acreditación de competencias transversales en los planes de estudios de sus alumnos (UPV, 2017). En la UPV se han definido un total de trece competencias entre las que se encuentra la correspondiente a "Responsabilidad ética, ambiental y profesional" objeto del presente trabajo. Además, se han definido las rúbricas para evaluar estas competencias (Fernández et al., 2017).

El equipo de innovación docente que presenta este artículo lleva trabajando varios años sobre la competencia transversal "Responsabilidad ética, medioambiental y profesional", lo que se ha plasmado en diversas publicaciones (Pascual-Seva et al., 2015, Sebastiá-Frasquet et al., 2016, Asensio et al., 2017). Durante el curso académico 2016-2017 el equipo ha llevado a cabo su innovación bajo el Proyecto de Innovación y Mejora Educativa "A10: Herramientas de trabajo colaborativo para la dinamización del competencia transversal responsabilidad ética, medioambiental y profesional".

\section{Objetivos}

El principal objetivo es explorar el uso de herramientas de trabajo colaborativo para evaluar la competencia transversal de responsabilidad ética, medioambiental y profesional.

\section{Desarrollo de la innovación}

La innovación se ha desarrollado en dos partes diferenciadas por la herramienta de trabajo colaborativo utilizada. Las herramientas utilizadas han sido el blog, la wiki y el foro de la plataforma de aprendizaje PoliformaT de la Universitat Politècnica de València (UPV). La actividad de innovación se ha realizado durante el cuatrimestre A del curso académico 2016-2017.

\subsection{Blog}

El blog se ha utilizado en las siguientes asignaturas:

1) Necesidades y Programación del Riego y la Fertilización. Esta asignatura pertenece al $4^{\circ}$ curso de la especialidad Hortofruticultura y Jardinería del Grado en Ingeniería 
Agroalimentaria y del Medio Rural. En el curso en el que se realiza la innovación hay un total de 40 alumnos matriculados en la asignatura.

2) Estructuras de Hormigón Armado. Esta asignatura pertenece al $4^{\circ}$ curso de la especialidad Diseño Estructural del Grado en Ingeniería Mecánica. En el curso en el que se realiza la innovación hay un total de 22 alumnos matriculados en la asignatura.

3) Ergonomía en el Diseño. Esta asignatura se imparte en el Máster Universitario en Ingeniería del Diseño.

Se utiliza el mismo blog para las 3 asignaturas implicadas. El blog está desarrollado en Wordpress y se integra en los Poliblog de la UPV. El blog se ha denominado "Responsabilidad ética, medioambiental y profesional en ingeniería y ciencias de la vida" y se puede acceder en la siguiente dirección: http://responsabilidad.blogs.upv.es. La finalidad del blog es que los alumnos interactúen aportando evidencias relacionadas con la competencia tranversal abordada y generando un debate crítico en torno a estas evidencias que permita evaluarlos. Las evidencias son de dos tipos. Por una parte, en las asignaturas de "Necesidades y Programación del Riego y la Fertilización" y "Estructuras de Hormigón Armado", las evidencias aportadas son noticias y artículos científicos de la materia de la asignatura que abordan la responsabilidad profesional, ética y/o medioambiental. Por otra parte, en la asignatura "Ergonomía en el Diseño", la evidencia aportada por los alumnos es su propio proyecto desarrollado en la asignatura. En Ergonomía del Diseño se trabaja con aprendizaje basado en proyectos. El uso del blog permite que los estudiantes tengan acceso al proyecto de sus compañeros y se establece un debate crítico acerca de los criterios éticos y medioambientales que se deben tener en cuenta en el diseño. La experiencia en esta asignatura ha sido descrita de forma más extensa en Asensio et al. (2017).

En el primer caso se pretende evaluar el nivel de competencia transversal adquirida por los alumnos, por lo que se califica con los niveles A-D, establecidos por la UPV.

Las aportaciones de noticias, información, etc. al blog se evalúan siguiendo los siguientes criterios:

A-La aportación, relacionada con la CT "Responsabilidad ética, medioambiental y profesional”, tiene carácter científico (revistas científicas).

B-La aportación, relacionada con la CT "Responsabilidad ética, medioambiental y profesional", tiene carácter divulgativo (noticia de prensa, webs especializadas, etc.).

C-La aportación no está relacionada con la CT "Responsabilidad ética, medioambiental y profesional" o es poco relevante.

D-La aportación carece de sentido.

El debate se inicia por el estudiante que aporta la evidencia (artículo). El profesor evalúa las contribuciones de los estudiantes al debate siguiendo los criterios:

Inicio del debate: 
A-El comentario es apropiado y presenta un buen planteamiento.

B-Aunque el comentario presenta una idea buena, podría mejorarse.

C-El comentario no está justificado.

D-Se aporta la noticia sin comentar.

Resto de comentarios, aportados por los compañeros:

A-El comentario es apropiado, está debidamente justificado y elaborado.

B-El comentario es apropiado, pero no está debidamente justificado y/o elaborado.

C-El comentario no aporta ninguna idea nueva (e.g. Estoy de acuerdo con los compañeros)

D-El comentario carece de sentido.

Para alcanzar la máxima calificación (A) se requiere: una aportación con calificación A + un inicio de debate con calificación $\mathrm{A}+$ dos comentarios con calificación A.

Las profesoras participaron en la moderación del foro, contribuyendo con observaciones sobre los comentarios. Además, en clase se dedicó un tiempo breve al final de una sesión para mostrar a los alumnos las evidencias y comentarios. Esto se hizo para tratar de implicar a alumnos que no habían participado ya que la actividad no tenía en ningún caso carácter obligatorio.

\subsection{Wiki y foro}

La wiki y el foro se han utilizado en la asignatura optativa Groundwater Management in the Coastal Zone, del $4^{\circ}$ curso del Grado en Ciencias Ambientales. En el curso en el que se realiza la innovación hay un total de 19 alumnos matriculados, de los cuales 7 son alumnos de intercambio del programa Erasmus.

En esta asignatura se plantearon dos tipos de actividades a los alumnos, ha realizar con distintas herramientas, la wiki y el foro. A continuación, se describen las 2 experiencias.

La wiki se utilizó para elaborar información detallada sobre uno de los "hot topics" de la asignatura. Cabe decir, que la asignatura se imparte en inglés y la wiki se elaboró en inglés. En este caso es la profesora la que selecciona un tema de complejidad suficiente para tratar los distintos aspectos de la competencia transversal. Durante el curso 2016/17 se seleccionó la problemática de la zona húmeda de las Tablas de Daimiel. Esta zona experimentó graves incendios de turba durante el año 2009 debido a la sobreexplotación de los acuíferos. En la actualidad este ecosistema se ha recuperado parcialmente gracias a distintos factores. En este caso de estudio los factores ambientales son evidentes, pero también la ética y la responsabilidad profesional tienen un gran peso debido a la gran conflicitividad social que surge alrededor del aprovechamiento del recurso hídrico. La profesora elabora el esquema de la wiki y asigna a cada grupo de alumnos (parejas o grupos de tres máximo) uno de los apartados para que lo desarrollen. En una segunda etapa, cada grupo debe revisar y evaluar de forma crítica los apartados elaborados por el resto de compañeros. Los alumnos son

(c)) EY-NC-ND 2017, Universitat Politècnica de València

Congreso IN-RED (2017) 
evaluados tanto por los contenidos que desarrollan como por la capacidad de detectar las carencias en los contenidos de los compañeros.

El foro se utilizó tras una salida de campo que en el curso 2016/17 se realizó a la Junta de Usuarios del Alto Vinalopó. Esta actividad pretende ver en la práctica todo lo aprendido en la asignatura sobre la gestión integral de recursos hídricos. Durante la visita los técnicos de la Junta de Usuarios realizan una exposición sobre su funcionamiento y se plantea un debate de distintos factores sociales, políticos y económicos que tienen una clara vertiente de responsabilidad ética, profesional y medioambiental. El foro en el PoliformaT de la asignatura se inaugura al terminar la visita. La profesora plantea diversas preguntas que los alumnos deben contestar y razonar. La escala de valoración es al igual que en la experiencia descrita para el blog cualitativa. El foro estuvo abierto únicamente durante una semana, y en este periodo la profesora ejerció de moderadora.

\section{Resultados}

En todas las experiencias descritas el alumnado se mostró dispuesto a participar de forma activa. Sin embargo, en términos cuantitativos los resultados de participación muestran una clara diferenciación entre las asignaturas en las que la actividad era obligatoria y aquellas en las que era voluntaria. Tanto en "Ergonomía en el diseño" como en "Groundwater management" la participación fue del $100 \%$ dada la obligatoriedad de la tarea. En cambio, en las asignaturas "Necesidades y Programación del Riego y la Fertilización" y "Estructuras de Hormigón Armado" el porcentaje de participación fue inferior al 30\% de los matriculados (15 y $28 \%$ respectivamente).

El bajo porcentaje de participación en las asignaturas en las que la actividad era optativa se atribuye en gran medida a las dificultades técnicas con el uso del blog. El administrador/administradores del blog deben dar de alta a todos los alumnos que vayan a participar, para ello los alumnos tienen que haber entrado al menos una vez en Poliblogs previamente. Una vez dados de alta, les llega un correo electrónico en el que tienen que aceptar las condiciones de uso. En las 3 asignaturas en las que se utilizó el blog esto generó bastantes problemas. Se tuvo dificultades para dar de alta a los alumnos y se tuvieron que presentar diversas incidencias al servicio técnico de PoliformaT a través de la aplicación Gragal. Aún así, en dos de las asignaturas no se pudo completar el proceso de alta del 100\% de los matriculados.

En las siguientes figuras se muestran algunas de las contribuciones de los alumnos al blog. 
Herramientas de trabajo colaborativo para la dinamización del competencia transversal responsabilidad ética, medioambiental y profesional

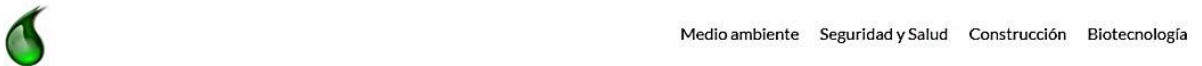

Desarrollan un hormigón compuesto por bacterias que se repara por sí solo

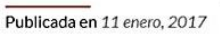

Investigadores holandeses han desarrollado un nuevo tipo de material de construcción que repara sus grietas sin ayuda externa, sino gracias a los microorganismos que hayensuinterior.

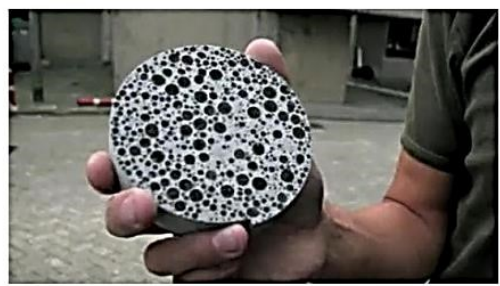

Este material constará de hormigón en sí, al que se le añadirán bacterias de origen biológico, dando lugar al llamado "biohormigonn. Este tiene la capacidad de repararse por si solo, al rellenar con la caliza sintetizada por los reforzado con acero que se puede oxidar por el contacto con el agua $y$ son estas bacterias las que impediran dich oxidación e incluso reconstruir las grietas por las que se filtra el agua. Este sistema aumenta la esperanza de vida de hormigón y permite ahorrar en reparaciones y mantenimiento de este.

A continuación, les dejo un enlace donde podrán obtener m información sobre este avance en la construcción:

COMENTARIOS RECIENTES

http://www.elconfidencial.com/tecnologia/2015-05-19/hormigon-cemento-bacterias-grietas-

juquisan en La agricultura ecológica valenciana busca ser "referente europeo"

Isabel Gasch Molina en Desarrollan un hormigón compuesto por bacterias que se repara por sísolo

rogiha en La paja del arroz. Consecuencias de su manejo y alternativas de aprovechamiento.

mirodpon en La agricultura ecológica valenciana busca ser "referente europeo"

samocna en Autorizado un sondeo de investigaciónpreexplotación contra la sequía en el río Serpis en Valencia 208 autorreparacion_807312/

Esta entrada fue publicada en Construcción. Guarda el permalink.

$\leftarrow$ Valdemoro construye su primer Edificio de Consumo de Energía Casi Nulo

ERGONOMÍA EN EL DISEÑO - SILLA DE PLAYA -

Fig. 1 Entrada al blog de un estudiante de la asignatura Estructuras de hormigón armado

(cc) EY-NC-ND 2017, Universitat Politècnica de València

Congreso IN-RED (2017) 


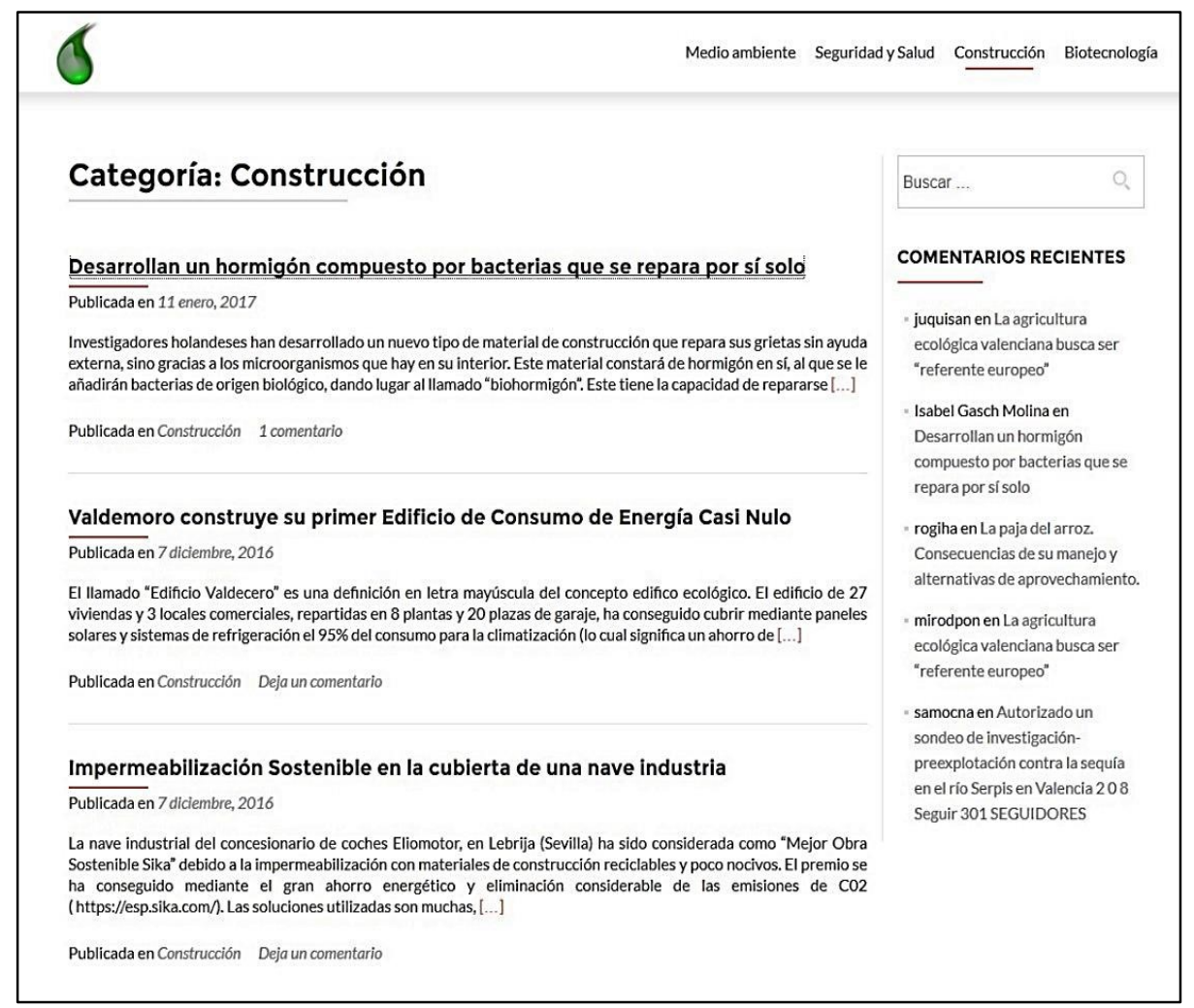

Fig. 2 Vista de varias entradas al blog de la asignatura Estructuras de hormigón armado

Las aportaciones de los alumnos a las asignaturas "Necesidades y Programación del Riego y la Fertilización" y "Estructuras de Hormigón Armado" fueron valoradas con una A, ya que fueron aportaciones de calidad, relacionadas con la competencia estudiada y los comentarios fueron significantes. El bajo porcentaje de participación pudo ser la causa de que todos los participantes estuvieran realmente motivados por participar en la actividad y de ahí el buen resultado obtenido.

En la asignatura de "Ergonomía en el diseño" los resultados observados fueron también buenos. Estos resultados están descritos en Asensio et al. (2017), pero cabe destacar que los alumnos valoraron el uso del blog de forma muy positiva. Ver su trabajo expuesto al público (profesora, compañeros de clase, expertos en la materia invitados y público en general) de forma "permanente" fue un factor motivador para tratar de hacer un buen trabajo. El diseño se evaluó en base a criterios ambientales y éticos. La responsabilidad profesional se demostró al tener que exponer su proyecto de forma profesional.

En la asignatura "Groundwater management in the coastal zone" se observaron los siguientes resultados. La creación de una wiki sobre el caso de estudio propuesto (Gestión del agua en las Tablas de Daimiel) fue valorada positivamente por los alumnos. La realización en 2 etapas de la actividad permitió a los alumnos analizar de forma crítica su propia contribución y la de sus compañeros. La nota media de la actividad de los alumnos en la mayoría de los grupos de trabajo mejoró en la segunda etapa al tener que subsanar las 
deficiencias observadas. Evaluar de forma crítica el trabajo de otros técnicos (en este caso compañeros de clase) forma parte de la competencia transversal responsabilidad profesional y ética. Aquellos alumnos que no fueron capaces de valorar de forma crítica la wiki creada de forma colaborativa obtuvieron una menor calificación.

Es importante llamar la atención sobre la "usabilidad" de las herramientas de PoliformaT. En este caso la edición de la wiki es un tanto rígida. Los alumnos se desmotivan cuando encuentran dificultades en la creación y edición de documentos. Por ello se plantea la posibilidad de en próximos cursos utilizar herramientas externas a la plataforma de la UPV pero de uso habitual entre los alumnos, tales como las que ofrece google drive. Se pretende con ello centrar la atención de los alumnos en la propia actividad y no tanto en la herramienta.

En el uso del foro los resultados observados fueron variados. A continuación, se muestra en las siguientes figuras los datos estadísticos ofrecidos por la herramienta estadísticas de PoliformaT sobre participación en la actividad.
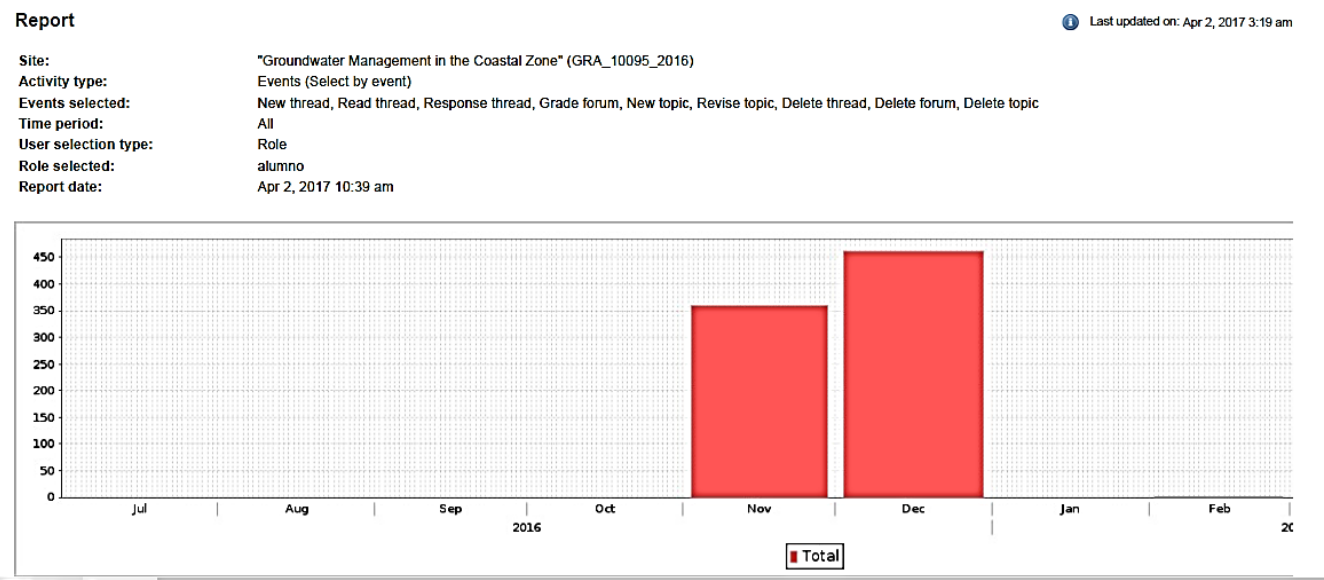

Fig. 3 Estadisticas de uso del foro en Groundwater management, rol alumno 


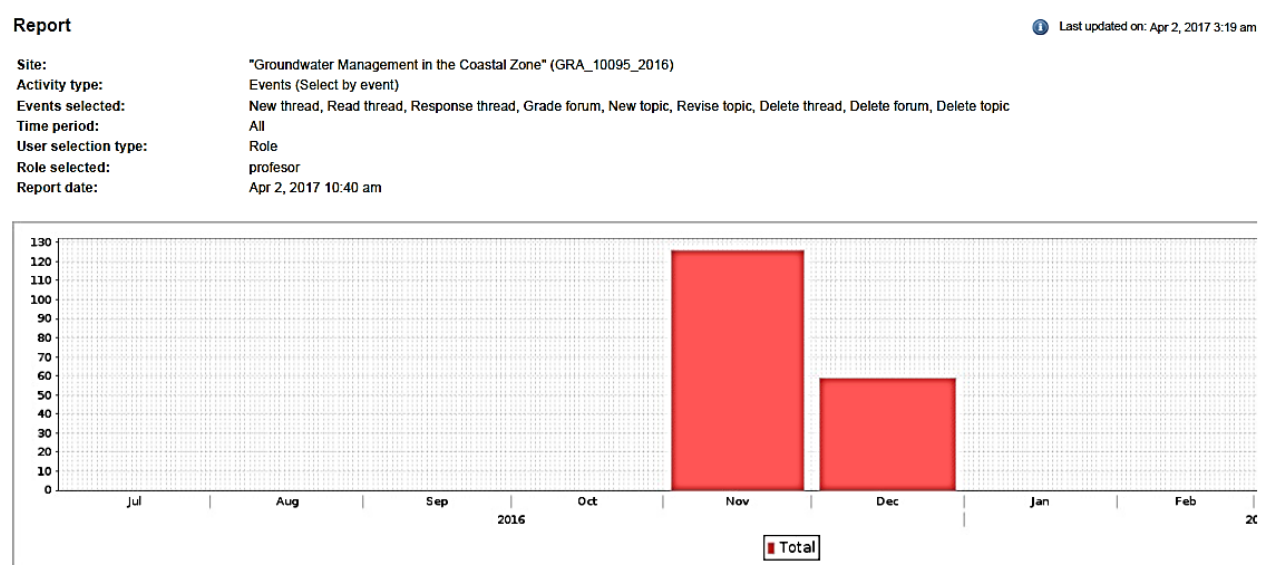

Fig. 4 Estadísticas de uso del foro en Groundwater management, rol profesor

La actividad en el foro empezó el día 29 de noviembre de 2016, por ello se muestra actividad en los meses de noviembre y diciembre. Las estadísticas muestran un total de 823 eventos por parte de los alumnos y 185 por parte del profesor. Se consideran como evento la siguientes acciones: Crear Nuevo hilo, Leer hilo, Responder al hilo, Grado foro, Crear Nuevo tema, Revisar tema, Eliminar hilo, Eliminar foro, Eliminar tema. De todos estos eventos los alumnos únicamente leyeron hilos de conversación o respondieron al hilo.

En la siguiente figura se muestra desglosada la actividad de los alumnos para las acciones responder y leer, obtenida desde la herramienta foro con su opción de generar estadísticas. La primera fila corresponde a la actividad de la profesora. Se ha eliminado el nombre de los alumnos por privacidad. 


\begin{tabular}{|c|c|c|c|}
\hline Authored $\bar{Z}$ & Read & Unread & Percent Read \\
\hline 32 & 119 & 0 & $100 \%$ \\
\hline 12 & 119 & 0 & $100 \%$ \\
\hline 11 & 97 & 22 & $82 \%$ \\
\hline 8 & 20 & 99 & $17 \%$ \\
\hline 8 & 15 & 104 & $13 \%$ \\
\hline 6 & 78 & 41 & $66 \%$ \\
\hline 5 & 10 & 109 & $8 \%$ \\
\hline 5 & 9 & 110 & $8 \%$ \\
\hline 5 & 10 & 109 & $8 \%$ \\
\hline 5 & 14 & 105 & $12 \%$ \\
\hline 5 & 59 & 60 & $50 \%$ \\
\hline 4 & 14 & 105 & $12 \%$ \\
\hline 4 & 41 & 78 & $34 \%$ \\
\hline 3 & 116 & 3 & $97 \%$ \\
\hline 3 & 40 & 79 & $34 \%$ \\
\hline 2 & 4 & 115 & $3 \%$ \\
\hline 1 & 2 & 117 & $2 \%$ \\
\hline 0 & 0 & 119 & $0 \%$ \\
\hline 0 & 1 & 118 & $1 \%$ \\
\hline 0 & 0 & 119 & $0 \%$ \\
\hline 0 & 1 & 118 & $1 \%$ \\
\hline
\end{tabular}

Fig. 5 Estadísticas del foro para las acciones responder (authored) y leer (read/unread)

En primer lugar, destacar que las estadísticas de lectura no son representativas. Para que se registre en el sistema la lectura de un comentario, el alumno debe seleccionar activamente la opción marcar como leído, y esto muchas veces no se hace. Así pues, la información más valiosa es el número y la calidad de sus contribuciones. Evaluando la contribución de cada alumno se puede conocer si el alumno ha leído en efecto los comentarios de sus compañeros, ya que se pueden detectar repeticiones, contradicciones, etc. A medida que transcurre el tiempo desde la apertura de la actividad es más complejo ser capaz de aportar nueva información relevante, por lo que los alumnos que realizan diversas aportaciones a lo largo de la actividad son aquellos con mejor nota. Ser capaz de matizar, criticar y mejorar lo aportado hasta el momento demuestra una mejor adquisición de la competencia. Destacar el rol de la profesora con una actividad moderadora continuada. La profesora no realiza en el foro una corrección directa de ninguno de los comentarios pero sí plantea dudas sobre estos que deben ser respondidas por los alumnos. Esta labor de moderación requiere un esfuerzo bastante relevante, y podría mejorarse con una ampliación de las posibilidades del foro. Por ejemplo, poder seguir las respuestas de un alumno dentro de cada conversación de forma automatizada permitiría una moderación y evaluación más eficiente. En la actualidad para seguir a un alumno es necesario releer uno a uno cada comentario.

(c)) EY-NC-ND 2017, Universitat Politècnica de València 


\section{Conclusiones}

El uso de herramientas de trabajo colaborativo es adecuado para trabajar y evaluar la competencia transversal Responsabilidad ética, medioambiental y profesional. En este sentido las herramientas ofrecidas por la plataforma de gestión del aprendizaje de la UPV, PoliformaT, son útiles pero susceptibles de alguna mejora. En concreto, la accesibilidad y alta de alumnos en el blog ha presentado dificultades técnicas que han empobrecido la participación del alumnado. En cuanto a la wiki, a los alumnos se les hace más difícil editar los contenidos que con otros tipos de herramientas a las que están más acostumbrados como las aplicaciones que ofrece google drive. Además, el resultado final que alcanzan con la wiki, en cuanto a formato es de menor calidad. Por último, las estadísticas y opciones automáticas del foro podrían ser ampliadas. En concreto, un seguimiento personalizado automático de las respuestas de cada alumno permitiría un moderación y evaluación más eficientes.

\section{Referencias}

ASENSIO-CUESTA, S.; GASCH, I.; PASCUAL-SEVA, N.; RUBIO, C.; VARGAS, M.; SEBASTIÁ-FRASQUET, M.T. (en prensa). "Poliblog como medio de presentación y evaluación de un proyecto de diseño" En Comunica2, Congreso Internacional sobre Redes Sociales ( $7^{\mathrm{a}}$ edición). Gandia. UPV.

FERNÁNDEZ MARCH, A., GIMÉNEZ CARBÓ, E., GÓMEZ NAVARRO, T., LOZANO AGUILAR, JOSÉ F., LÓPEZ SIEBEN, M., PASCUAL SEVA, N., SEGUÍ MÁS, E., TORMO CARBÓ, G., VARGAS COLÁS, M.A. (2017) "Rúbrica UPV CT-07. Responsabilidad ética, medioambiental y profesional".

GONZÁLEZ, J. WAGENAAR, R. (2003) “Tuning Educational Structures in Europe. Informe Final”. Bilbao: Universidad de Deusto.

PASCUAL-SEVA, N.; ASENSIO CUESTA, S.; SEBASTIÁ-FRASQUET, M.T.; VARGAS, M. (2015). "Evaluación de la competencia transversal UPV:"Responsabilidad ética, medioambiental y profesional" mediante herramientas de ludificación". En XXIII Congreso Universitario de Innovación Educativa en las Enseñanzas Técnicas (CUIEET 2015). Valencia: Escuela Técnica Superior de Ingeniería del Diseño. p. 250-259.

SEBASTIÁ-FRASQUET, M.T.; VARGAS, M.; ASENSIO CUESTA, S.; PASCUAL-SEVA, N. (2016). "Comparison of gamification tools for evaluating the ethical, environmental and professional responsibility skills in science degrees." En 9th International Conference of Education, Research and Innovation (ICERI 2016). Sevilla. IATED Academy. P 3609-3614.

UPV. Competencias Transversales. Available at: https://www.upv.es/entidades/ICE/info/U0724624.pdf. Last access date: 25/04/2017 


\title{
Combinación de una metodología basada en proyectos y de una evaluación competitiva en la asignatura Análisis y modelación de redes de distribución de agua
}

Pedro L. Iglesias-Rey ${ }^{\text {a }}$ F F. Javier Martínez-Solano ${ }^{b}$

${ }^{a}$ Dpto. Ingeniería Hidráulica y Medio Ambiente. Universitat Poltècnica de València. email: piglesia@upv.es, ํDpto. Ingeniería Hidráulica y Medio Ambiente. Universitat Poltècnica de València. email: jmsolano@upv.es.

\begin{abstract}
One of the challenges arising from the implementation of the European Higher Education Area is the search for new methods of evaluation and learning. This paper proposes a new project-based learning initiative and a competitive evaluation system in the student's knowledge related to the analysis and planning of water distribution networks. The methodology is based on the development of a team work project to improve an existing water supply network. Based on computer simulations and acquired learning, students must find the best solution for system operation. Finally, the works (presented and exposed) are evaluated in a competitive way, giving the highest score to the best solution according to previously established criteria. This initiative has been implemented in the subject "Analysis and modeling of water distribution networks" that is taught in the Master in Hydraulic Engineering and Environment of the UPV. The initial results show a better perception of the subject by the students and a certain improvement in their academic results.
\end{abstract}

Keywords: project-based learning, competitive evaluation, team work, water distribution networks

\begin{abstract}
Resumen
Uno de retos derivados de la puesta en marcha del Espacio Europeo de Educación Superior es la búsqueda de nuevos métodos de evaluación y aprendizaje. En este trabajo se plantea una nueva iniciativa de aprendizaje basada en proyectos y en una evaluación competitiva de los alumnos en sus conocimientos relacionados con el análisis y planificación de las redes de distribución de agua. La metodología se basa en el desarrollo en grupo de un proyecto de mejora de una red de abastecimiento existente. A partir de simulaciones computacionales y de los conocimientos adquiridos los alumnos deben encontrar la mejor solución de funcionamiento del sistema. Finalmente los trabajos presentados y expuestos son valorados de forma competitiva otorgando la máxima puntuación a la mejor solución de acuerdo a unos criterios previamente establecidos. Esta iniciativa ha sido implementada en la asignatura "Análisis y modelación de redes de distribución de agua" que se imparte en el Máster en Ingeniería Hidráulica y Medio Ambiente de la UPV. Los resultados iniciales muestran una mejor
\end{abstract}


percepción de la asignatura por parte de los alumnos y una cierta mejora en los resultados académicos de los mismos.

Palabras clave: aprendizaje basado en proyectos, evaluación competitiva, trabajo en grupo, redes de distribución de agua

\section{Introducción}

Desde un punto de vista estrictamente profesional es cada día más evidente la la preocupación por la docencia de los futuros ingenieros. Así diferentes organizaciones empresariales (Henry, 2002) se han preocupado por los retos profesionales de la ingeniería civil ante el nuevo milenio. Tras varios estudios preliminares y encuestas a diferentes miembros de la American Society of Civil Engineering (ASCE) se enunciaron 6 retos fundamentales:

- Concienciación pública sobre el papel de la ingeniería civil en las infraestructuras.

- Interacción de los ingenieros civiles con la sociedad: su relación con los cargos públicos, la política y el servicio a la comunidad.

- El máster: primer título directamente relacionado con la actividad profesional.

- Recuperar el rol de liderazgo lo relacionado con el desarrollo de infraestructuras.

- El impacto del diseño constructivo en los profesionales de la ingeniería civil.

- La competitividad del precio de las soluciones.

Este interés en dar a la ingeniería civil un enfoque práctico (Luce y Henry, 2002) ha originado que en los sistemas escolares y principalmente en las carreras de ingeniería sea cada día más necesario diseñar y emplear juegos basados en simulaciones del ejercicio profesional. De este tipo es el bien conocido concurso de diseño de puentes realizado durante más de 15 años por ASCE y la United States Militaty Academy (USMA).

La mejora de los sistemas de aprendizaje y evaluación es una de las líneas de trabajo en las que se centran todas las innovaciones educativas desarrolladas a partir de la puesta en marcha del Espacio Europeo de Educación Superior (EEES). Los cambios acaecidos en la universidad española a raíz de la entrada del EEES (Espacio Europeo de Educación Superior) han originado la necesidad de actualizar gran parte de las metodologías docentes utilizadas (Caro et al., 2008). Una de las iniciativas de este EEES es aumentar la motivación del alumnado. Es decir, se hace necesario transformar de forma continua el método de aprendizaje para garantizar una continua atención por parte de los estudiantes (Álvarez et al., 2008).

Sin duda una de las mejores formas de cambiar la actitud del alumnado respecto de una materia es introducir novedades tanto en la metodología desarrollada como en el método de evaluación empleado. Es por ello que en este trabajo se analiza la influencia que puede tener el cambio de una metodología de evaluación y de trabajo en la percepción e interés de los alumnos sobre la materia. 
En la literatura científica existen multitud de referencias a nuevas experiencias relacionadas con metodologías de aprendizaje y de evaluación innovadoras, en las cuales la presencia del ordenador forma parte del día a día. Así Merino y Abel (2003) demuestran en sus experimentos que un método de aprendizaje basado en ordenador puede ser alternativo a los modelos clásicos de aprendizaje. En esta línea, Chumbley et al. (2002) presentan la experiencia de una plataforma web desarrollada para complementar la formación de determinados alumnos en clase.

Sin embargo, la idea no es sólo introducir el ordenador o las herramientas de simulación, sino acercar el desarrollo de nuestros ingenieros a lo que será su futura vida profesional. Así Bourgault et al. (2002) presentan un enfoque pedagógico consistente en recrear el contexto en el cual deben desenvolverse los ingenieros a la hora de gestionar sus proyectos. De hecho, al igual que en la mayoría de proyectos este enfoque educativo requiere de soluciones tecnológicas innovadoras y hace imprescindible desarrollar habilidades para la coordinación del trabajo en grupo (Slavin y Johnson, 1999). Más aún, las innovaciones en la tarea educativa pueden alcanzar la evaluación. Así, una experiencia alternativa (Romero et al., 2009) en la que se evalúa a los estudiantes a través del uso de teléfonos en lugar de evaluaciones basadas en páginas web permite aumentar el nivel de motivación de los alumnos.

\subsection{La utilización de los juegos y las herramientas de simulación como apoyo a la docencia}

Uno de de los elementos que más ha contribuido durante los últimos años al desarrollo de nuevas metodologías de aprendizaje es el auge que han experimentado los modelos de simulación prácticamente en todas las áreas del conocimiento. Así, la presencia de juegos o roles de simulación como parte de los métodos de aprendizaje (Mayer et al., 2014) no es algo nuevo. No es extraño encontrar soluciones en campos tan diversos como la electrónica (Zavalani, 2015), la gestión de proyectos (Davidovich et al., 2006) o la ingeniería hidráulica (Morley et al., 2016).

En este contexto aparecen conceptos nuevos que pretenden definir las nuevas metodologías educativas disponibles. Expresiones como Serious Games (juegos serios o con contenido educativo) introducido por Abt (1970) o la idea de Simulation Gaming (juegos de simulacion) presentada por Duke (1974) han conducido finalmente a la definición de lo que se conoce como Ciencia del aprendizaje basado en el juego (Sánchez et al., 2010).

A partir de estas herramientas de simulación y estos juegos es posible desarrollar cursos completos de formación que utilicen estas herramientas de forma extensiva (Wu, 2012). De forma específica, en el campo de la asignatura objeto del presente de estudio cabe destacar las contribuciones de (Savic et al., 2016), quienes desarrollan una herramienta interactiva que permite el diseño, planificación y estudio de las redes de distribución de agua a través de un juego de simulación. Dicho juego presenta una interface web tras la cual se encuentra la herramienta de simulación EPANET (Rossman, 2000) de análisis de redes hidráulicas a presión. Más aún, su desarrollo se realizado con una filosofía de código abierto. Sin duda el 
disponer de referencias de código abierto o libre es una notable ventaja en el desarrollo de este tipo de metodologías, tal y como ponen de manifiesto Illie-Zudor et al. (2013).

\subsection{El aprendizaje basado en proyectos}

La utilización de técnicas educativas basadas en el desarrollo de proyectos en el área de la ingeniería civil es algo que viene realizándose desde hace tiempo (Mahendran, 1995). De forma más reciente (González-Marcos et al., 2014) utilizan ya este tipo de metodologías para evaluar el desarrollo de las competencias transversales que deben desarrollarse en cualquier titulación.

El aprendizaje basado en proyectos surge de la necesidad de exponer a los estudiantes a situaciones tales como: la necesidad de realizar procesos iterativos de diseño, la necesidad de formular hipótesis, de desarrollar soluciones, analizar o validar de estrategias. Todo ello incorporando experiencias propias y argumentos de la literatura científica. Por ello, este tipo de ejercicios son la oportunidad que los estudiantes tienen de inicializarse en la experiencia del diseño en proyectos. Este tipo de problemas además permite desarrollar otras habilidades relacionadas con la comunicación técnica (redacción de informes técnicos y presentación oral de soluciones y diseños) y con el trabajo en equipo (incluida la gestión de conflictos y la coordinación de equipos).

En este escenario existen experiencias previas en campos tan diversos como la simulación mediante modelos de elementos finitos (Ural, 2013), el desarrollo de algoritmos para el procesamiento de imágenes (García, 2013), el desarrollo de modelos de instrumentación virtual (See, 2006) utilizando la herramienta LabVIEW (Travis y Kring, 2006) o el diseño de células de fuel (Gadhamshetty et al., 2016).

En definitiva las experiencias analizadas son combinaciones entre el aprendizaje tradicional y el aprendizaje basado en proyectos. Un paso más allá es el trabajo realizado por De los Ríos et al. (2010), quienes proponen un proyecto basado en proyectos de tipo colaborativo. Este proyecto se enmarca dentro de los objetivos del EEES ya que la metodología empleada presenta respecto a casos anteriores tres ventajas principales: facilitar el entrenamiento en competencias de tipo personal, familiarizar al alumno con problemas de la práctica profesional (Clarke, 2007) e introducir a los estudiantes al aprendizaje colaborativo.

\subsection{La evaluación competitiva}

Existen muchos estudios sobre la evaluación del aprendizaje en la universidad, si bien uno de los más exhaustivos es el realizado por Valdivia (2008). En este trabajo realiza una profunda revisión bibliográfica sobre los métodos de evaluación del aprendizaje en la universidad. Esta revisión pretende resolver tres preguntas fundamentales: ¿cuáles son los principales problemas en la evaluación del aprendizaje en las universidades?, ¿son estos problemas similares o tienen manifestaciones diferentes en función del contexto? y ¿qué referencias científicas que permitan mejorar los métodos de evaluación? La discusión sobre este tipo de problemas es profunda, y existen multitud de referencias bibliográficas al respecto. 
En particular resulta de interés analizar los métodos de evaluación diferentes de los utilizados convencionalmente. Así, algunos de estos métodos serían: realización de trabajos, desarrollo de proyectos, confección de diarios, evaluaciones basadas en portafolio, desarrollo de mapas conceptuales o sistemas de evaluación por parte de los propios estudiantes, bien sea en forma de autoevaluación o en sistemas de evaluación por pares. En la Figura 1 se recoge la distribución de las diferentes técnicas de evaluación alternativa. Tal como puede apreciarse la evaluación basada en proyectos es todavía poco significativa.

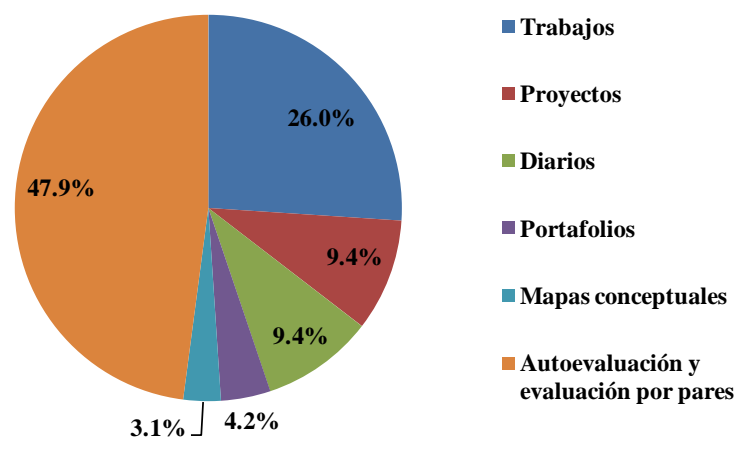

Figura 1. Porcentaje de métodos de evaluación alternativos (Valdivia, 2008).

Sin lugar a dudas las nuevas técnicas de evaluación juegan un papel crucial en el nuevo marco normativo derivado del EEES (Hernández-Linares et al., 2015). Así, aparecen experiencias en las que se fórmulas de evaluación alternativas Carpenter et al., (2007) proponen la utilización de ensayos técnicos para la evaluación en cursos de ingeniería, mientras que Baba et al., (2012) muestran como la lógica difusa puede ser utilizada para mejorar la calidad de los método educativos, la motivación y la fiabilidad y coherencia en los criterios de evaluación. Pero sin duda una de las formas de evaluación que últimamente ha tomado más auge es la basada en la competitividad de las soluciones de los alumnos ante problemas, proyectos o diseños planteados.

La competencia en diseño o en el desarrollo de proyectos es una aptitud que únicamente puede alcanzarse con un entrenamiento adecuado y a través de la acumulación de experiencia en el desarrollo de la misma. Uno de los caminos para proporcionar este tipo de competencias es a través de la resolución de proyectos complejos que finalmente requieran enfrentar entre sí las soluciones de los estudiantes (Labossière y Bisby, 2009). La competición entre estudiantes no es algo nuevo. Existen referencias (Wankat, 2005) que muestran la gran cantidad de competiciones entre estudiantes en el ámbito universitario. Algunas de estas competiciones cuentan con el apoyo de asociaciones profesionales tan importantes como la ASHRAE (American Society of Heating, Refrigeration and AirConditioning Engineers) o la AIChE (American Institute of Chemical Engineers). Sin embargo, este tipo de competiciones se centran más en la comparación entre los niveles de diferentes universidades.

Por el contrario, la idea de los métodos competitivos como herramienta de evaluación en nuestras universidades es algo diferente. Se centra en comparar entre sí las soluciones y resultados de los estudiantes que han tenido una misma formación: mismo temario, misma 
metodología docente, mismo profesor. Ejemplos estos métodos son los desarrollados por Adin Marcos et al., (2010), quien aplica esta metodología de evaluación para el diseño de circuitos electrónicos mediante el uso de herramientas CAD, o el propuesto por Shyr, (2012) en el campo de la ingeniería mecatrónica.

El trabajo en equipo es una parte esencial de la práctica de la ingeniería. Por lo general la educación universitaria centra su atención en el desarrollo de las habilidades técnicas de los estudiantes en actividades fundamentalmente centradas en el aula. Al mismo tiempo, se hace muy poco hincapié en el trabajo en equipo, a pesar de que esta habilidad es una de las más reconocidas para la actividad profesional de cualquier ingeniero. Por ello las competiciones grupales (Cerato et al., 2011) permiten complementar la enseñanza en clase y son fundamentales para aumentar las habilidades de trabajo en grupo. Es decir, las experiencias de evaluación competitiva deben combinarse con la organización de grupos de trabajo en clase (Çulça, 2016) o la presentación y defensa de los resultados (Beriain et al., 2014) frente a sus pares (sus compañeros). De esta forma aumenta la capacidad de auto aprendizaje de los alumnos (Schaffer et al, 2012), aumentan las capacidades de resolución de proyectos y mejoran la motivación hacia la materia objeto de estudio.

\section{Objetivos}

El objetivo de este trabajo es plantear un sistema de aprendizaje basado en proyectos en el campo de la hidráulica de sistemas de distribución de agua. Éste utilizará como técnica de evaluación un sistema de competitivo a partir de una serie de criterios previamente definidos. Finalmente el método se complementa con la elaboración de un informe técnico sobre la solución obtenida y la exposición oral de la misma. El campo de aplicación de la metodología a desarrollar será la asignatura Análisis y modelación de redes de distribución de agua (AMRDA) que se imparte en el Máster en ingeniería hidráulica y medio ambiente (MIHMA) de la Universidad Politécnica de Valencia (UPV).

De forma resumida el objetivo general del trabajo la mejora de la percepción por parte de los alumnos de la asignatura AMRDA a través del desarrollo de una metodología de aprendizaje basada en proyectos combinada con un sistema de evaluación competitivo. Este objetivo general se logrará en base al desarrollo de los siguientes objetivos específicos:

- Análisis previo de la motivación de los alumnos por la asignatura.

- Desarrollo de un método de aprendizaje basado en proyectos.

- Desarrollo de un método de evaluación competitivo para grupos de trabajo.

- Desarrollo de un método complementario a la evaluación competitiva.

- Análisis del impacto de la puesta en marcha del proyecto de innovación educativa.

En definitiva, la consecución de estos objetivos permitirá no solo mostrar la innovación educativa desarrollada, sino también ver los resultados de aplicación de la misma a lo largo del tiempo. 


\section{Desarrollo de la innovación}

\subsection{Descripción del tipo de proyecto}

El objeto central de la metodología docente planteada es el desarrollo de un proyecto de mejora de una red de abastecimiento de agua existente. Los antecedentes de este tipo de proyecto hay que encontrarlos en los desafíos sobre redes de abastecimiento de agua que eventualmente se realizan dentro de la comunidad científica (Walski et al., 1987; Ostfeld et al., 2008; Ostfeld et al., 2011; Marchi et al., 2013; Giustolisi et al., 2015) y que de forma genérica se han dado en llamar la Batalla de las Redes de Agua (The Battle of Water Networks). De hecho, los profesores de la asignatura tienen cierta experiencia en el desarrollo de este tipo de ejercicios (Iglesias et al, 2015).

El proyecto toma como punto de partida el modelo de una red de distribución de agua construido mediante el modelo EPANET (ver Figura 2). El funcionamiento de la red de forma general presenta algún tipo de deficiencia: insuficiencia de presiones, excesivo gasto energético en bombeo, gran cantidad de agua perdida por fugas, etc. A partir de dicho momento el objetivo del alumno es encontrar un grupo de trabajo (de máximo 3 personas) que de forma conjunta deben mejorar la red existente.

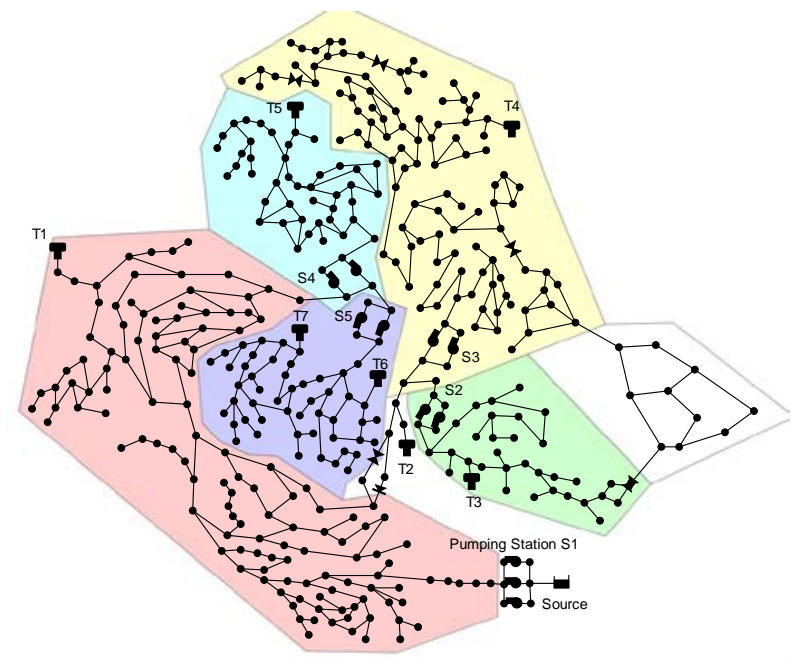

Figura 2. Modelo en EPANET de la red de distribución objeto de estudio. Proyecto año 2012.

Para ello, a lo largo de las diferentes clases se van desarrollando aspectos específicamente relacionados con la mejora de la red. A continuación se recogen estos temas y su inmediata aplicación en el proyecto:

- Análisis en régimen estático: aplicación para el estudio alternativas de funcionamiento.

- Análisis en régimen dinámico: definición del comportamiento real del sistema mediante la determinación de las consignas de operación (controles) del mismo.

- Caracterización de los consumos: representación de las pérdidas de agua en la red y estudios sobre mejora de la eficiencia hídrica del sistema. 
- Caracterización y comportamiento de depósitos: capacidad de regulación de depósitos existentes, y ampliación o redimensionado de los mismos.

- Caracterización de estaciones de bombeo: valoración energética del funcionamiento de los grupos de bombeo, selección de nuevos grupos de bombeo y mejora de la eficacia de funcionamiento de los mismos.

- Caracterización de las válvulas: ubicación de válvulas de control y regulación y determinación de sus consignas de funcionamiento.

Estos aspectos, aunque orientados por los alumnos a la resolución del proyecto planteado, constituyen el contenido fundamental de la asignatura.

De forma específica en la Tabla 1 se recoge un resumen de los elementos objeto de estudio y las diferentes opciones que sobre los mismos se han ido considerando a lo largo de los diferentes proyectos desarrollados. Como puede apreciarse cada uno de los elementos u objetos u objetos de estudio no se analizan y consideran de la misma forma en todos los proyectos. De esta forma, dependiendo del objetivo de cada año se orienta el proyecto hacia unos contenidos específicos u otros.

Tabla 1. Elementos y características definidos en cada año del proyecto.

\begin{tabular}{|c|c|c|c|c|}
\hline \multirow{2}{*}{$\begin{array}{c}\text { Elemento / Objeto } \\
\text { de estudio }\end{array}$} & \multirow{2}{*}{ Tipo de Acción } & \multicolumn{3}{|c|}{ Año del proyecto } \\
\hline & & 2012 & 2013 & 2014 \\
\hline \multirow{3}{*}{ Tuberías } & Sustituir una tubería existente & & & \\
\hline & Instalar una tubería en paralelo & & & \\
\hline & Cerrar la tubería & & & \\
\hline \multirow{4}{*}{ Bombeos } & Sustituir bomba por otra igual características & & & \\
\hline & Sustituirla bomba por otra diferente & & & \\
\hline & Rendimiento de la bomba constante & & & \\
\hline & Rendimiento de la bomba variable & & & \\
\hline \multirow{3}{*}{ Válvulas } & Cambiar la consigna la válvula & & & \\
\hline & Instalar una válvula de control & & & \\
\hline & Cerrar la válvula de control & & & \\
\hline \multirow{3}{*}{$\begin{array}{l}\text { Fugas y perdidas de } \\
\text { agua en la red }\end{array}$} & No considerar las pérdidas de agua en la red & & & \\
\hline & Pérdidas de agua constantes & & & \\
\hline & Cambiar las pérdidas al cambiar las tuberías & & & \\
\hline \multirow{2}{*}{ Calidad del agua } & Considerar la calidad del agua & & & \\
\hline & No considerar la calidad del agua & & & \\
\hline \multirow{2}{*}{$\begin{array}{l}\text { Definición de } \\
\text { sectores }\end{array}$} & No considerar sectores en la red & & & \\
\hline & Considerar los sectores definidos en la red & & & \\
\hline \multirow{3}{*}{$\begin{array}{l}\text { Controles de } \\
\text { regulación de la red }\end{array}$} & Control simples sobre elementos predefinidos & & & \\
\hline & Control simples sobre cualquier elemento & & & \\
\hline & Considerar acciones de control complejas & & & \\
\hline
\end{tabular}

\subsection{Descripción de la metodología de evaluación}

A la hora de realizar la evaluación de las diferentes soluciones se han definido una serie de criterios mediante los cuales puntuar la totalidad de los proyectos presentados. Estos criterios son:

- $\quad \mathrm{C}_{1}$ : Criterios económicos. Se valora económicamente como la suma de los costes de inversión en nuevos equipamientos (tuberías, válvulas, depósitos o bombas) y el coste explotación de la red (costes energéticos, coste del agua suministrada).

(cc)) EY-Nc-ND 2017, UniversitatPolitècnica de València 
- $\mathrm{C}_{2}$ : Criterios medioambientales. Se valoran mediante criterios como las tasas de emisión de $\mathrm{CO}_{2}$ o asignando un coste económico al agua consumida.

- $\quad \mathrm{C}_{3}$ : Criterios de calidad del agua. Se valora considerando el número de nudos que normalmente exceden un tiempo máximo de permanencia del agua en la red.

- $\quad \mathrm{C}_{4}$ : Criterios operativos. Son criterios como número mínimo de sectores o número máximo de arranques y paradas de un grupo de bombeo en un cierto periodo.

En primer lugar se analiza que todos los proyectos presentados cumplan las restricciones de funcionamiento impuestas (normalmente, presiones máximas y mínimas de funcionamiento, volúmenes máximos de producción, etc.). Aquellos equipos que no cumplen estas especificaciones son eliminados de la fase de concurso y su valoración deja de ser competitiva, siendo en todo caso siempre inferior a la de aquellos que cumplieron las restricciones.

Con el resto de proyectos se realiza la valoración numérica de los mismos, de forma que el proyecto i tiene en cada uno de los criterios (j) una valoración $\mathrm{C}_{\mathrm{i}, \mathrm{j}}$. Asimismo se define para cada criterio j el valor máximo $\mathrm{C}_{\max , \mathrm{j}} \mathrm{y}$ mínimo $\mathrm{C}_{\min , \mathrm{j}}$ de entre todos los grupos que cumplen las restricciones del proyecto.

La valoración final $\mathrm{C}_{\mathrm{i}}$ de cada grupo se obtiene mediante la expresión

$$
C_{i}=\sum_{j=1}^{N_{\min }} \frac{C_{i, j}-C_{\text {min }, j}}{C_{\text {max }, j}-C_{\text {min }, j}}+\sum_{j=1}^{N_{\max }} \frac{C_{\text {max }, j}-C_{i, j}}{C_{\max , j}-C_{\text {min }, j}}
$$

donde existen dos sumandos ya que pueden existir criterios que se deseen minimizar $\left(\mathrm{N}_{\min }\right)$ y criterios que se deseen maximizar $\left(\mathrm{N}_{\max }\right)$.

De esta forma, la evaluación final de esta fase de concurso se realiza asignando la máxima calificación $\left(\mathrm{P}_{\max }=10\right.$ puntos) al equipo con menor valor del coeficiente $\mathrm{C}_{\mathrm{i}}$. Posteriormente, el profesorado realiza un análisis pormenorizado del trabajo realizado por el equipo peor clasificado (mayor valor de $\mathrm{C}_{\mathrm{i}}$ ), asignándole una calificación $\mathrm{P}_{\min }$. Finalmente la calificación $\mathrm{P}_{\mathrm{i}}$ de cada grupo se obtiene mediante la expresión

$$
\mathrm{P}_{\mathrm{i}}=\mathrm{P}_{\min }+\frac{\mathrm{C}_{\max }-\mathrm{C}_{\mathrm{i}}}{\mathrm{C}_{\max }-\mathrm{C}_{\text {min }}} \cdot\left(\mathrm{P}_{\max }-\mathrm{P}_{\min }\right)
$$

donde $\mathrm{C}_{\max }$ y $\mathrm{C}_{\min }$ son respectivamente las puntuaciones de acuerdo a la expresión (1) obtenidas por el peor y el mejor grupo.

En paralelo con la fase de concurso del trabajo el profesorado evalúa de forma conjunta tanto la memoria presentada como la presentación realizada, otorgando una calificación $\mathrm{D}_{\mathrm{i}}$. Asimismo, para garantizar el trabajo equitativo de los diferentes miembros del equipo, durante la fase de exposición el profesorado decide quién debe realizar la exposición del trabajo y quien debe contestar a cada una de las preguntas. La calificación final es una media ponderada a partes iguales entre la fase de concurso (Pi) y la calificación obtenida en la fase documental $D_{i}$. 


\section{Resultados}

La valoración de la puesta en marcha de la metodología definida en el apartado anterior se ha realizado en base a la encuesta de evaluación de la actividad del profesorado de la UPV. Dicha encuesta se imparte a los alumnos de cada asignatura al finalizar la misma y consta de una valoración global del profesorado y diversas preguntas agrupadas en cinco dominios de actuación diferentes:

- D1. Dominio de la asignatura, organización y claridad en la exposición.

- D2. Motivación del alumnado. Interacción del profesorado con el alumno.

- D3. Valoración del método de evaluación utilizado por el profesor.

- D4. Recursos utilizados.

- D5. Satisfacción general con la labor del profesor.

Tal como puede verse en la Figura 3, los resultados de las encuestas en la asignatura AMRDA desde el año 2006 hasta el año 2011 habían ido decreciendo, tanto en valor absoluto como en valores normalizados respecto de la media del MIHMA. Este hecho iba en consonancia con el aumento del número de alumnos que se inscribían en el máster. Tal como puede verse en la Figura 4, el número de alumnos inscritos en la asignatura objeto de estudio ha ido aumentando prácticamente desde la puesta en marcha de la misma hasta el año 2013 en el que se puso un límite de matrícula para la misma de 25 alumnos.
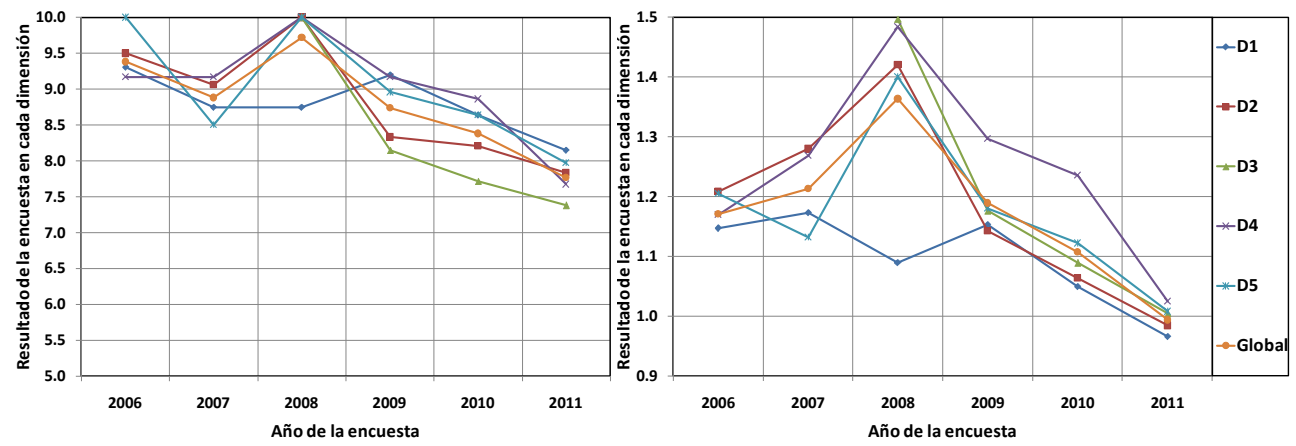

Figura 3. Resultados de las encuestas de evaluación del profesorado hasta el año 2011. En la izquierda valores absolutos. En la derecha valores normalizados con la media del MIHMA.

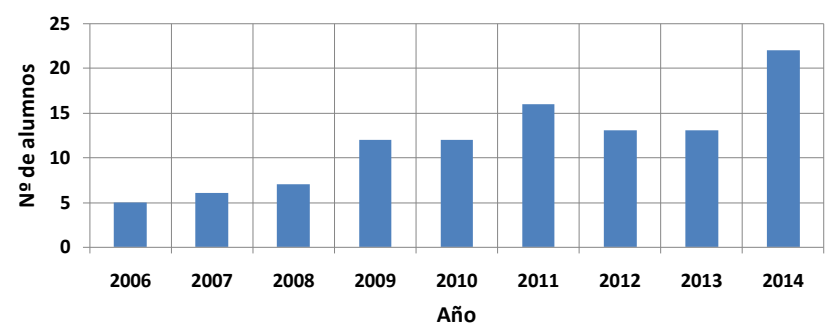

Figura 4. Evolución del número de alumnos matriculados en la asignatura AMRDA del MIHMA

Como puede apreciarse, el análisis inicial muestra una tendencia a la disminución tanto de la motivación del alumnado (D2) como de la satisfacción global con la labor del profesor (D5). Este hecho en principio podría achacarse a que la metodología empleada hasta ese 
momento (basada en un portafolio de ejercicios) no ofrecía los resultados esperados cuando el tamaño del grupo iba aumentando.

Ante esta circunstancia se implementó para el año 2012 la metodología definida, siendo sus resultados los mostrados en la Figura 5. Como puede apreciarse, aunque el número de alumnos continuó aumentando en los años 2012-2014, todos los resultados de las encuestas mejoraron sensiblemente respecto de los valores de 2011. Más aún, manteniéndose prácticamente constante el número de alumnos en los últimos años, parece que la valoración de la motivación y valoración global del profesorado se mantengan también prácticamente constantes.
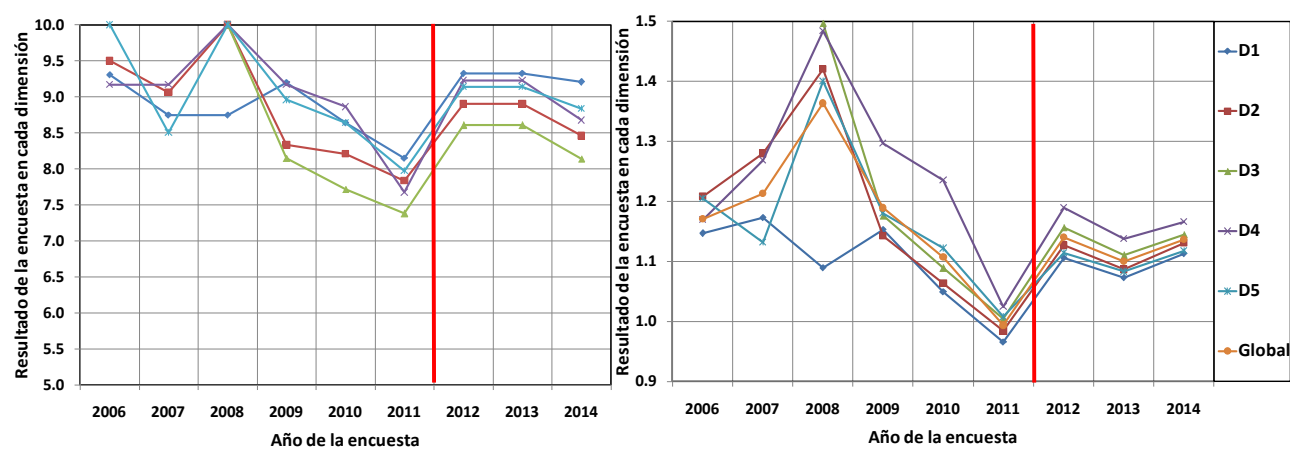

Figura 5. Resultados de las encuestas de evaluación del profesorado tras la puesta en marcha del método. En la izquierda valores absolutos. En la derecha valores normalizados con la media del MIHMA.

\section{Conclusiones}

A lo largo del presente trabajo se ha descrito una metodología de innovación educativa consistente en combinar un sistema de aprendizaje basado en proyectos con un modelo de evaluación competitivo. Tras la implantación del sistema durante tres años consecutivos, y una vez analizados los resultados, es posible extraer las siguientes conclusiones:

- Las metodologías de aprendizaje y evaluación deben estar en continua actualización y adaptarse tanto al contexto como al número de alumnos en clase. La misma metodología con el paso del tiempo suele deteriorarse, lo que requiere continuar actualizaciones.

- Algunos problemas de desafío a nivel internacional e investigador como los descritos en la Batalla de las Redes de Agua pueden ser adaptados al ámbito educativo para mejorar las dinámicas en las aulas universitarias.

- El sistema de aprendizaje basado en proyectos se ha mostrado muy flexible y capaz de adaptarse fácilmente al temario de la asignatura. Este sistema permite al alumno abordar los conocimientos desde una perspectiva práctica y muy cercana a lo que en el futuro será su realidad profesional.

- La evaluación competitiva ha supuesto sin duda una enorme mejora tanto en los resultados de la valoración del profesorado como en la motivación por parte de los alumnos. Aunque los datos empíricos de las encuestas no lo recojan, se ha detectado un notable interés de los alumnos por la asignatura. De hecho, su 
intensidad en la dedicación al trabajo sobre la misma ha aumentado fomentando en muchas ocasiones la curiosidad por explorar ámbitos de conocimiento más allá de los contenidos de la materia objeto de estudio.

El sistema definido se ha mostrado exitoso tal como ponen de manifiesto los resultados de las encuestas realizadas. No obstante, dicho método puede irse adaptando más poco a poco para aumentar dinámicas de grupo como el liderazgo o la formación colaborativa entre grupos.

\section{Referencias}

ABT, C. (1970). Serious games. New York: Viking Press.

ADIN MARCOS, I., BERENGUER PÉREZ, R., BISTUÉ GARCÍA, G., GUTIÉRREZ GARCÍA, I., \& MENDIZABAL SAMPER, J. (2010). Introducing CAD Tools for Electronic Design Using a Competition Based Evaluation Method. IX Congreso del Tecnologías Aplicadas a la Enseñanza de la Electrónica - TAEE, pp. 641-697. Madrid, noviembre 2010.

ÁLVAREZ, B. Á., MIERES, C. G., y RODRÍGUEZ, N. G. (2008). La motivación y los métodos de evaluación como variables fundamentales para estimular el aprendizaje autónomo. Revista de Docencia Universitaria, 1(2).

BABA, A.F., CIN, F.M., \& BAKANAY, D. (2012). A fuzzy system for evaluating students' project in engineering education. Computer Applications in Engineering Education, 20(2), 287-294.

BERIAin, A., DEL RIO, D., SOlAR, H., AlVARADO, U., \& DEL PORTILlO, J. (2014). Challenge oriented methodology for analog integrated circuit layout design training. In Tecnologias Aplicadas a la Ensenanza de la Electronica (Technologies Applied to Electronics Teaching)(TAEE), 2014 XI (pp. 1-5). IEEE.

BOURGAULT, M., \& LAGACE, D. (2002). A seminar for real-time interactive simulation of engineering projects: An innovative use of video-conferencing and IT-based educational tools. Journal of Engineering Education, 91(2), 177.

CARO, M. I., GONZÁLEZ, S. Á., y RUBIO, R. Á. (2008). Métodos de evaluación en la enseñanza superior. Revista de Investigación educativa, 26(2), 539-552.

CARPENTER, S.L., DELUGACH, H.S., ETZKORN, L.H., FARRINGTON, P.A., FORTUNE, J.L., UTLEY, D.R., \& VIRANI, S.S. (2007). A knowledge modeling approach to evaluating student essays in engineering courses. Journal of Engineering Education, 96(3), 227-239.

CHUMBLEY, L. S., HARGRAVE, C. P., CONSTANT, K., \& HAND, B. (2002). Project ExCEL: Web-based scanning electron microscopy for K-12 education. Journal of Engineering Education, 91(2), 203. 
CERATO, A., ELTON, D., \& SHANNON, D. (2011). Building student teamwork with the student geo-challenge. Journal of Professional Issues in Engineering Education \& Practice, 138(1), 14-20.

CLARKE, B. G. (2007). Introducing students to professional practice in civil engineering. Journal of Professional Issues in Engineering Education and Practice, 133(2), 107-115.

ÇULHA, D. (2016). Applying competition-based learning to agile software engineering. Computer Applications in Engineering Education, 24(3), 382-387.

DAVIDOVITCH, L., PARUSH, A., \& SHTUB, A. (2006). Simulation-based Learning in Engineering Education: Performance and Transfer in Learning Project Management. Journal of Engineering Education, 95(4), 289-299.

DE LOS RIOS, I., CAZORLA, A., DÍAZ-PUENTE, J. M., \& YAGÜE, J. L. (2010). Project-based learning in engineering higher education: two decades of teaching competences in real environments. Procedia-Social and Behavioral Sciences, 2(2), 1368-1378.

DUKE, R. D. (1974). Gaming: the future's language (1st ed., p. 223). New York: Sage Publications.

GADHAMSHETTY, V., SHRESTHA, N., \& KILDUFF, J. E. (2016). Project-Based Introduction to an Engineering Design Course Incorporating Microbial Fuel Cells as a Renewable Energy Technology. Journal of Professional Issues in Engineering Education and Practice, 142(3), 05016001.

GIUSTOLISI, O., BERARDI, L., LAUCELLI, D., SAVIC, D., \& KAPELAN, Z. (2015). Operational and tactical management of water and energy resources in pressurized systems: Competition at WDSA 2014. Journal of Water Resources Planning and Management, 142(5), C4015002.

GONZÁLEZ-MARCOS, A., ALBA-ELÍAS, F., ORDIERES-MERÉ, J., \& NAVARIDASNALDA, F. (2014). Cross-analysis of Transversal Competences in Project Management. In CSEDU (2) (pp. 34-41).

GUZMÁN-RAMÍREZ, E., \& GARCIA, I. A. (2013). Using the project-based learning approach for incorporating an FPGA-based integrated hardware/software tool for implementing and evaluating image processing algorithms into graduate level courses. Computer Applications in Engineering Education, 21(S1), E73-E88.

HENRY, W. P. (2002). Professional issues in civil engineering in the 21st century. Journal of Professional Issues in Engineering Education and Practice, 128(4), 160-161.

HERNANDEZ-LINARES, R., AGUDO, J. E., RICO, M., \& SÁNCHEZ, H. (2015). Transversal competences of university students of engineering. Croatian Journal of Education17(2), 383-409.

IGLESIAS-REY, P.L., MARTÍNEZ-SOLANO, F.J., MORA MELIÁ, D., \& MARTÍNEZSOLANO, P.D. (2015). Combining Engineering Judgment and an Optimization Model 
to Increase Hydraulic and Energy Efficiency in Water Distribution Networks. Journal of Water Resources Planning and Management, 142(5), C4015012.

ILIE-ZUDOR, E., KEMÉNY, Z., SZATHMÁRI, M., \& MONOSTORI, L. (2013). The role of OSC-based projects in meeting new challenges of education-concept and exemplification. Computer Applications in Engineering Education, 21(S1), E141-E151.

LABOSSIÈRE, P., \& BISBY, L. A. (2009). Lessons learned from a design competition for structural engineering students: The case of a pedestrian walkway at the Universite de Sherbrooke. Journal of Professional Issues in Engineering Education and Practice, 136(1), 48-56.

LUCE, L., \& HENRY, W. P. (2002). Public awareness of civil engineering and the infrastructure. Journal of Professional Issues in Engineering Education and Practice, 128(4), 165-166.

MAHENDRAN, M. (1995). Project-based civil engineering courses. Journal of Engineering Education, 84(1), 75-79.

MARCHI, A., SALOMONS, E., OSTFELD, A., KAPELAN, Z., SIMPSON, A. R., ZECCHIN, A. C., ... \& WALSKI, T. (2013). Battle of the water networks II. Journal of water resources planning and management, 140(7), 04014009.

MAYER, I., BEKEBREDE, G., HARTEVELD, C., WARMELINK, H., ZHOU, Q., RUIJVEN, T., ... \& WENZLER, I. (2014). The research and evaluation of serious games: Toward a comprehensive methodology. British Journal of Educational Technology, 45(3), 502-527.

MERINO, D. N., \& ABEL, K. D. (2003). Evaluating the Effectiveness of Computer Tutorials Versus Traditional Lecturing in Accounting Topics. Journal of Engineering Education, 92(2).

MORLEY, M. S., KHOURY, M., \& SAVIC, D. (2016). Serious Game Approach to Water Distribution System Design and Rehabilitation Problems. 14th International Conference on Computing and Control in the Water Industry - CCWI 2016, At Amsterdam, Netherlands.

OSTFELD, A., UBER, J. G., SALOMONS, E., BERRY, J. W., HART, W. E., PHILLIPS, C. A., ... \& DI PIERRO, F. (2008). The battle of the water sensor networks (BWSN): A design challenge for engineers and algorithms. Journal of Water Resources Planning and Management, 134(6), 556-568.

OSTFELD, A., SALOMONS, E., ORMSBEE, L., UBER, J. G., BROS, C. M., KALUNGI, P., ... \& LANSEY, K. (2011). Battle of the water calibration networks. Journal of Water Resources Planning and Management, 138(5), 523-532.RESSLER, S. J., \& RESSLER, E. K. (2004). Using a nationwide Internet-based bridge design contest as a vehicle for engineering outreach. Journal of Engineering Education, 93(2), 117.

(cc)) EY-NC-ND 2017, UniversitatPolitècnica de València

Congreso IN-RED (2017) 
ROMERO, C., VENTURA, S., \& DE BRA, P. (2009). Using mobile and web-based computerized tests to evaluate university students. Computer Applications in Engineering Education, 17(4), 435-447.

ROSSMAN, L. A. (2000). EPANET 2: user's manual. EPA/600/R- 00/057, Water Supply and Water Resources Division, National Risk Management Research Laboratory, Office of Research and Development, U.S. EPA, Cincinnati.

SANCHEZ, A., CANNON-BOWERS, J. \& BOWERS, C. (2010). Establishing a science of game based learning. In J. A. Cannon-Bowers \& C. Bowers (Eds.), Serious game design and development: technologies for training and learning (pp. 290-304). Hershey, PA: IGI Global. doi:10.4018/978-1-61520-739-8.ch016.

SAVIC, D. A., MORLEY, M. S., \& KHOURY, M. (2016). Serious Gaming for Water Systems Planning and Management. Water, 8(10), 456.

SCHAFFER, S. P., CHEN, X., ZHU, X., \& OAKES, W. C. (2012). Self-Efficacy for Cross-Disciplinary Learning in Project-Based Teams. Journal of Engineering Education, 101(1), 82-94.

SEE, A. (2006). Challenging computer-based projects for a Mechatronics course: Teaching and learning through projects employing virtual instrumentation. Computer Applications in Engineering Education, 14(3), 222-242.

SHYR, W. J. (2012). Teaching mechatronics: An innovative group project-based approach. Computer Applications in Engineering Education, 20(1), 93-102.

SLAVIN, R. \& \& JOHNSON, R. T. (1999). Aprendizaje cooperativo: teoría, investigación y práctica. Buenos Aires: Aique.

TRAVIS, J., \& KRING, J. (2006). LabVIEW for everyone: Graphical programming made easy and fun (National instruments virtual instrumentation series). Prentice Hall PTR.

URAL, A. (2013). A hands-on finite element modeling experience in a multidisciplinary project-based freshman course. Computer Applications in Engineering Education, 21(2), 294-299.

VALDIVIA, I.Á. (2008). Evaluación del aprendizaje en la universidad: una mirada retrospectiva y prospectiva desde la divulgación científica. Electronic Journal of Research in Educational Psychology, 6(14), 235-271.

WALSKI, T. M., BRILL JR, E. D., GESSLER, J., GOULTER, I. C., JEPPSON, R. M., LANSEY, K., ... \& ORMSBEE, L. (1987). Battle of the network models: Epilogue. Journal of Water Resources Planning and Management, 113(2), 191-203.

WANKAT, P. C. (2005). Undergraduate student competitions. Journal of Engineering Education, 94(3), 343.

WU, Y. (2012). Courseware design of project research based on interactive game design. Computer Applications in Engineering Education, 20(3), 510-517. 
Combinación de una metodología basada en proyectos y de una evaluación competitiva en la asignatura Análisis y modelación de redes de distribución de agua

ZAVALANI, O. (2015). Computer-based simulation development of a design course project in electrical engineering. Computer Applications in Engineering Education, 23(4), 587-595.

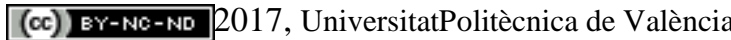




\title{
Evaluación formativa basada en la interacción con profesionales externos al ámbito universitario
}

\section{Cristina López-Cózara ${ }^{a}$ Silverio Alarcón ${ }^{\mathrm{b}}$ y Arturo Serrano ${ }^{\mathrm{c}}$}

a Profesora de la Universidad Politécnica de Madrid cristina.lopezcozar@upm.es, ${ }^{\text {b }}$ Profesor de la Universidad Politécnica de Madrid silverio.alarcon@upm.es y ${ }^{c}$ Profesor de la Universidad Politécnica de Madrid arturo.serrano@upm.es.

\begin{abstract}
In order to contribute to the design of the continuous evaluation and training evaluation, this paper presents a teaching experience proposing a shared assessment, with the assistance of three independent experts (nonacademic), who participated in the overall grade of the course and in the students' learning process. The results show that this involvement of professionals in the classroom allow extending and enriching the information received by the students on their learning development.
\end{abstract}

Keywords: assessment, feedback, entrepreneurs, learning, skills, higher education.

\begin{abstract}
Resumen
Con la finalidad de contribuir al diseño de sistemas de evaluación continua y formativa, se presenta una experiencia docente con una propuesta de valoración compartida del trabajo de los alumnos. Para ello se contó con la colaboración de tres profesionales externos al ámbito universitario, quienes participaron tanto en la calificación de la asignatura, como en el proceso de aprendizaje del alumnado. Los resultados muestran que la implicación de los profesionales, a través de sus comentarios, recomendaciones y sugerencias de mejora, permitió ampliar y enriquecer la información que recibe el alumno sobre su propio desarrollo.
\end{abstract}

Palabras clave: evaluación, retroalimentación, emprendedores, aprendizaje, competencias, educación superior.

\section{Introducción}

Desde la implantación del Espacio Europeo de Educación Superior (EEES), uno de los mayores desafíos al que nos hemos enfrentado los profesores universitarios es al cambio en nuestra propia labor docente. Para lograr que el alumnado adopte un comportamiento activo y se implique en su proceso de aprendizaje, ha sido necesario introducir nuevas estrategias didácticas. En general, los docentes hemos asumido la responsabilidad de desarrollar e 
implantar actividades formativas que ayuden a adquirir las distintas competencias vinculadas a las asignaturas. En el diseño de dichas actividades, uno de los aspectos más importantes es la concreción de los procedimientos para la evaluación, que es preciso planificar desde el principio (Quesada et al., 2017).

Una evaluación es la emisión de un juicio de valor sobre alguien y en relación con algo. El proceso de enseñanza de una asignatura culmina con la evaluación que se realiza a cada estudiante sobre los conocimientos y capacidades adquiridos. Por ello, uno de los principales objetivos de los sistemas de evaluación es acreditar el progreso académico; es decir, mediante la evaluación, el docente puede constatar si el alumno ha adquirido el nivel de conocimientos previsto e indicar su aptitud para resolver situaciones relacionadas con la materia. En segundo lugar, la evaluación permite valorar la asignatura en sí misma: el desarrollo del programa, los contenidos, la distribución del tiempo, etc. En este sentido, resulta útil para introducir cambios en la asignatura durante el curso, cuando se detectan aspectos que no están funcionando bien, así como extraer conclusiones sobre posibles modificaciones y mejoras para cursos posteriores. Además, también sirve para analizar la actuación del propio docente. La evaluación del alumnado es reflejo de los resultados de un proceso de aprendizaje en el que el profesor es una parte fundamental. Por lo tanto, este puede y debe utilizar la información de la evaluación para reflexionar sobre su desempeño, y determinar qué hay que mejorar de cara al próximo curso y qué aspectos se deben potenciar porque han dado buenos resultados. Finalmente, se puede considerar la evaluación como un instrumento para impulsar la formación de los estudiantes; con la evaluación se pretende ayudarles a superar las dificultades y a que aprendan a valorar por sí mismos la calidad del trabajo que van desarrollando.

Efectivamente, el sistema de evaluación no puede considerarse como una parte independiente o aislada del proceso de enseñanza, sino como una parte integrante del mismo (Quesada et al., 2017). La literatura demuestra que cuando se plantea la evaluación con una finalidad formativa, más que como una herramienta de control, se mejoran considerablemente los resultados de aprendizaje (Álvarez, 2009; López-Pastor, 2011; Martínez-Figueira et al., 2013; Cortés et al., 2015; López-Cózar et al., 2015). Un uso adecuado de la retroalimentación o feedback permite mejorar tanto las actividades docentes como las calificaciones de los estudiantes (Fraile et al., 2013). En este contexto, los profesores debemos proponer sistemas de evaluación activa, en la que los alumnos participen, haciéndoles que reflexionen, decidan y actúen sobre el progreso de su propia evolución.

\section{Objetivos}

Siguiendo a Fraile et al. (2013, p. 24), entendemos la evaluación formativa como aquella que está integrada en el proceso de enseñanza aprendizaje, de manera que sirve de guía al estudiante y le ayuda a aprender. Estos sistemas de evaluación son coherentes con las nuevas metodologías docentes impulsadas por el EEES, pues se ha demostrado que son los más adecuados para favorecer el desarrollo de competencias entre el alumnado (López-

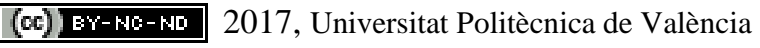

Congreso IN-RED (2017) 
Pastor, 2011). Consideramos, por tanto, que resulta muy oportuno seguir avanzado en el diseño de estrategias de evaluación orientadas al aprendizaje.

Así pues, el objetivo del presente trabajo es dar a conocer una iniciativa en la que se desarrolla una evaluación participativa, continua y formativa. Se trata de una experiencia docente desarrollada con profesionales externos a la universidad, quienes se involucraron en la valoración del trabajo del alumnado. En concreto, se contó con la colaboración de tres emprendedores que participaron tanto en la calificación de la asignatura, como en el proceso de aprendizaje de los estudiantes. Dicha experiencia ha sido realizada con alumnos de postgrado de la Universidad Politécnica de Madrid a través de la asignatura Creación de empresas.

Para conseguir el objetivo propuesto, el trabajo se estructura de la siguiente manera: a continuación, se presenta el contexto en el que se lleva a cabo la experiencia; se plantea la necesidad de la enseñanza del emprendimiento en la universidad y se describe la actividad docente llevada a cabo. En el siguiente epígrafe se muestran los resultados obtenidos de la encuesta de valoración realizada al grupo de estudiantes que han participado en la actividad. Por último, el trabajo termina con la presentación de las principales conclusiones.

\section{Desarrollo de la innovación}

\subsection{Contextualización.}

Hoy en día es ampliamente reconocida la importancia de impulsar entre el alumnado el espíritu emprendedor, y así se reconoce de manera expresa en la mayoría de los países europeos (Castro et al., 2014). La propia Comisión Europea ha llevado a cabo varias iniciativas al respecto a través de distintos documentos (Sobrado y Fernández, 2010). Cabe destacar el Libro Verde sobre el Espíritu empresarial en Europa (2003), en el cual se señala que desde la universidad se debe fomentar una actitud favorable hacia la profesión de empresario. En el informe sobre la puesta en práctica del programa de trabajo "Educación y Formación 2010", se incluye el espíritu emprendedor como una competencia clave, y se define como la "capacidad para inducir cambios como la habilidad para acoger, apoyar y adaptarse a los cambios debidos a factores externos. El espíritu emprendedor implica ser responsable de las acciones propias, ya sean positivas o negativas, el desarrollo de una visión estratégica, marcar y cumplir objetivos y estar motivado para triunfar" (COM, 2004, p. 9). De igual forma, en la Recomendación 2006/962/CE, entre las ocho competencias clave para el aprendizaje permanente se encuentra el "sentido de iniciativa y espíritu empresarial", que el propio Consejo define como la "habilidad de transformar las ideas en actos", y lo relaciona con "la creatividad, la innovación, la asunción de riesgos y la capacidad para planificar y gestionar proyectos con el fin de alcanzar objetivos" (DOUE, 2006, p. 18). Con el mismo propósito de impulsar el emprendimiento, en el año 2009 se pone en marcha el programa Erasmus jóvenes emprendedores para facilitar el intercambio de empresarios y emprendedores entre los distintos países de la Unión Europea. 
Por su parte, en nuestro país, en el Libro Blanco de la iniciativa emprendedora en España (Alemany et al., 2011) se afirma que la educación puede contribuir de manera importante a la creación de una cultura emprendedora, lo cual beneficia a la sociedad; se reconoce que está adquiriendo relevancia en los programas educativos, si bien, se pone de manifiesto que todavía queda mucho por hacer. La Ley Orgánica 2/2006, de 3 de mayo, de Educación, señala en su preámbulo que es preciso desarrollar el espíritu emprendedor entre el alumnado; y, más recientemente, la Ley Orgánica 8/2013, de 9 de diciembre, para la mejora de la calidad educativa, reconoce la importancia de tener un sistema educativo que estimule el espíritu emprendedor de manera que permita conducir a los estudiantes hacia las trayectorias más adecuadas a sus propias capacidades. Igualmente, en la Ley 14/2013, de 27 de septiembre, de apoyo a los emprendedores y su internacionalización, también se apunta la importancia de promover la cultura del emprendimiento desde el sistema educativo; señala la necesidad de que el profesorado adquiera las competencias y habilidades necesarias, y propone que desde las universidades se impulse la iniciación de proyectos empresariales facilitando a los estudiantes la información y ayuda precisa.

En la misma línea, el profesorado universitario coincide en señalar que es necesario fomentar el espíritu emprendedor en todos los estudiantes (Benavides et al., 2010; Sobrado y Fernández, 2010; Priede et al, 2013; Castro et al., 2014). De hecho, en las universidades españolas es frecuente encontrar desde hace varios años, diversas iniciativas (seminarios, programas, talleres, concursos, premios, etc.) que se centran en desarrollar la actividad emprendedora entre el alumnado, como queda reflejado en varios estudios (por ejemplo, ipyme, 2012 y Cicero et al., 2012).

\subsection{Organización de la asignatura}

La experiencia presentada se ha desarrollado en la asignatura Creación de empresas. Se trata de una asignatura optativa, de 4 ECTS, que se imparte en el cuarto semestre del Máster Universitario en Ingeniería Agronómica y en el segundo semestre del Máster Universitario en Economía Agraria, Alimentaria y de los Recursos Naturales de la Universidad Politécnica de Madrid.

En la primera clase del curso, se conciencia al alumnado sobre la trascendencia de la creación de nuevas empresas para el crecimiento económico de cualquier país, así como sobre la necesidad de realizar una adecuada planificación de la puesta en marcha del nuevo proyecto empresarial. A continuación, durante las siguientes semanas, se exponen en el aula los temas relacionados con los principales aspectos que tiene que contener un business plan. Estas primeras sesiones teóricas son importantes para sentar las bases que les permitan poder desarrollar posteriormente el trabajo práctico, consistente precisamente en la elaboración de un plan de empresa. Una vez concluidas, se realiza un examen sobre los temas abordados, cuya nota tiene un peso del $25 \%$ en la calificación final de la asignatura.

Durante el resto del curso, los alumnos tienen que realizar el citado trabajo con el que se pretende conseguir que adquieran los conocimientos y las habilidades necesarias para enfrentarse al reto de montar una empresa. Para ello, se forman grupos compuestos por $2 \mathrm{o}$

(c)) EY-NC-ND 2017, Universitat Politècnica de València

Congreso IN-RED (2017) 
3 personas. A continuación, se les proporciona un guion con las pautas concretas del business plan a desarrollar y se les explica que al final tienen que entregar un documento escrito y realizar dos presentaciones. La primera tiene lugar a las tres semanas de haber comenzado a realizar los trabajos; en esta primera presentación, los diferentes equipos tienen que exponer su idea de negocio, especificando qué producto van a ofrecer y a qué mercado se quieren dirigir, aspecto crucial y previo al desarrollo de las demás partes del plan de empresa. La segunda presentación se realiza a final de curso y tienen que exponer las principales partes del trabajo desarrollado y las conclusiones más relevantes.

La nota obtenida en el trabajo supone el $75 \%$ de la calificación final de la asignatura. A su vez, las presentaciones orales tienen un peso del $20 \%$ y el $30 \%$ respectivamente, y el $25 \%$ de la nota corresponde al trabajo escrito. Se trata, por tanto, de una actividad docente que promueve el aprendizaje activo, y con la que se pretende desarrollar, además del espíritu emprendedor, las competencias de trabajo en equipo y habilidades comunicativas (oral y escrita).

\subsection{Descripción de la experiencia}

Para la primera exposición oral (presentación de las ideas de negocio), se propuso realizar un encuentro con emprendedores relacionados con el ámbito profesional de los alumnos. Para ello, se contactó con egrasados de la universidad. La actividad se planteó con un doble objetivo: por un lado, se pretendía despertar entre el alumnado el interés por el emprendimiento mediante el contacto directo con iniciativas reales. Por otro lado, se planteó como una oportunidad para que los estudiantes pudieran validar la idoneidad de sus proyectos empresariales.

Así pues, la jornada constó de dos partes; en primer lugar, se organizó una mesa redonda con los emprendedores, los cuales expusieron su experiencia en la creación de sus respectivas empresas: cómo surgió la idea, las principales dificultades encontradas, sus principales satisfacciones y logros, y aquellos aspectos que consideraban más importantes para culminar con éxito el proceso. A continuación, los estudiantes pudieron plantearles las dudas o curiosidades que les habían surgido tras sus intervenciones. En la segunda parte de la actividad, fueron los propios alumnos los que presentaron sus ideas de negocio ante los tres emprendedores, quienes debían actuar como business angel, haciéndoles observaciones y recomendaciones.

Un business angel es una persona que toma la decisión de invertir en una empresa con cuyo promotor (o promotores) no mantiene una relación personal previa. Aunque su participación se puede producir en cualquier etapa del desarrollo del negocio, suele desempeñar un papel fundamental en el momento de la creación, apoyando a los emprendedores en las fases iniciales de sus proyectos. La aportación de capital se realiza por un tiempo limitado y en forma minoritaria, pues su objetivo no es permanecer en la empresa durante un largo período de tiempo. Al contrario, invierte con la expectativa de retirarse a medio plazo, cuando la nueva empresa consolide su posición en el mercado y pueda obtener una plusvalía como resultado de la revalorización del proyecto. Además de 
recursos financieros, un business angel también aporta su experiencia, su conocimiento, su red de contactos y ofrece asesoramiento. Esta es, lógicamente, la función que debían desempeñar los emprendedores en el aula.

También les pedimos a los tres profesionales externos que evaluaran el trabajo de los alumnos, sabiendo que la nota que pusieran tendría un peso del $20 \%$ de la calificación final de la asignatura. En su valoración debían tener en cuenta, no solo el contenido del trabajo idoneidad de la idea propuesta, innovación y viabilidad de la misma- sino también la manera de presentarlo. De esta manera, los emprendedores se involucraron tanto en el proceso de aprendizaje del alumnado, como en la calificación de la asignatura.

\section{Resultados}

En el caso de la experiencia que se presenta, había un total de 20 estudiantes matriculados en la asignatura, por lo que se constituyeron 7 equipos de trabajo (un grupo de 2 personas y seis grupos de 3). Los proyectos empresariales propuestos recogían ideas de negocio muy variadas, tales como la comerciacialización de productos ecológicos, la producción de microalgas, la distribución nacional e internacional de diversos productos agroalimentarios, la fabricación de compost orgánico o la prestación de un servicio de intermediación entre agricultores a partir de una aplicación para dispositivos móviles.

Con el propósito de conocer la utilidad de la actividad y el grado de satisfacción con la misma, se realizó una encuesta a los estudiantes. Así, una vez finalizada la jornada, se les plantearon una serie de cuestiones, asegurando el anonimato de las respuestas. Para ello, se elaboró un cuestionario con 8 ítems a valorar sobre una escala Likert de 1 (muy bajo) a 5 (muy alto), y dos preguntas abiertas, en las que se pedía señalar los aspectos más positivos y negativos de la jornada. En la tabla 1 se exponen dichas variables.

Tabla 1. Cuestiones planteadas en la encuesta

Utilidad de la jornada en tu proceso de aprendizaje

Acercamiento a la realidad empresarial

Nivel de desarrollo de la competencia iniciativa emprendedora

Nivel de desarrollo de la competencia trabajo en equipo

Nivel de desarrollo de la competencia habilidades comunicativas

Después de esta jornada, te planteas el emprendimiento como una opción laboral inmediata

Después de esta jornada, te planteas el emprendimiento como una opción laboral a medio plazo

Valoración global de la jornada

En la figura 1 se muestran los resultados de la encuesta, con la valoración de los estudiantes según su nivel de satisfacción con cada ítem. El cuestionario se realizó con la herramienta

(cc) EY-NC-ND 2017, Universitat Politècnica de València

Congreso IN-RED (2017) 
google drive; fue enviado por correo electrónico y además, estaba disponible en la plataforma virtual de la asignatura. Se obtuvieron 18 respuestas (90\% de participación).

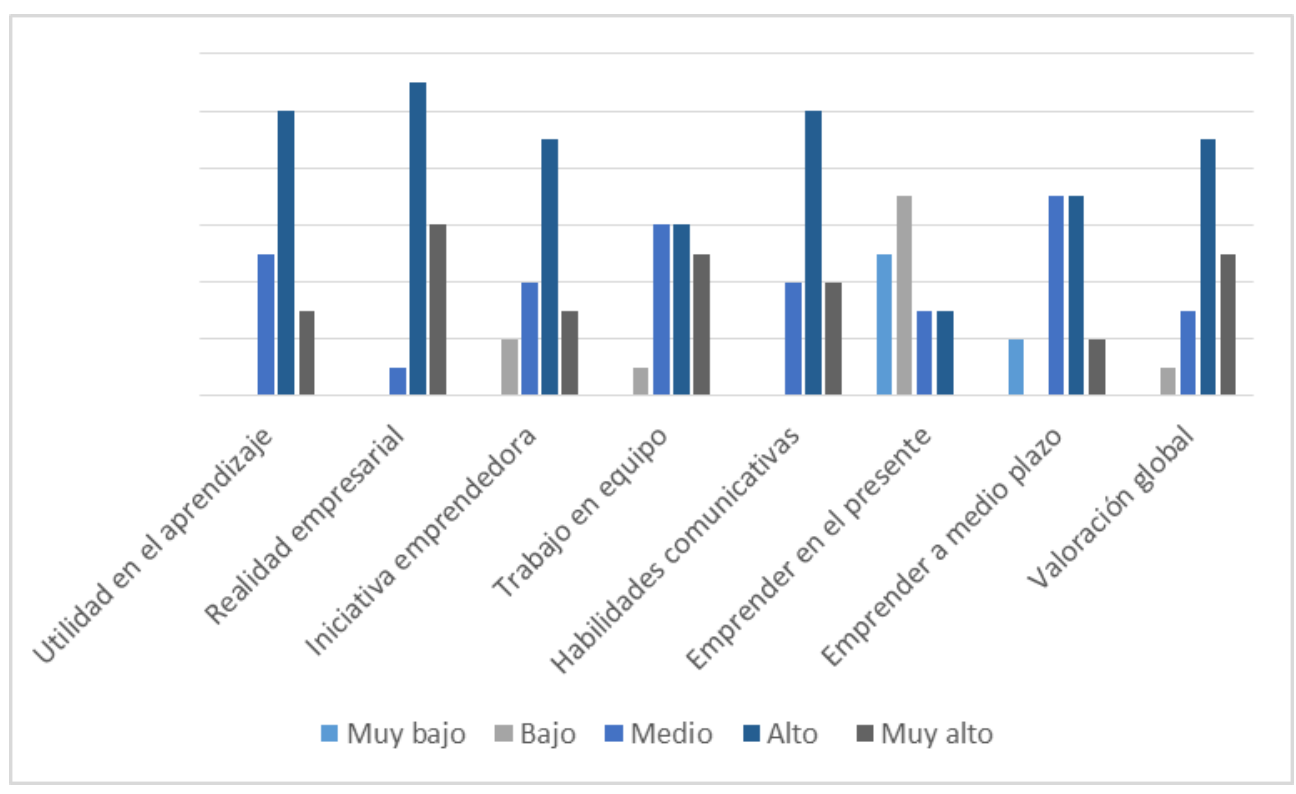

Fig. 1 Resultados obtenidos

En general, el grado de satisfacción que mostraron los alumnos es bastante elevado. Para la pregunta "Utilidad de la jornada en tu proceso de aprendizaje", el 72\% de las respuestas se situa en las categorías alto o muy alto; si bien, el aspecto que más valoran los estudiantes es el "Acercamiento a la realidad empresarial", pues 17 de las 18 (94\%) respuestas están incluidas en estos niveles de satisfacción.

Con respecto a la valoración del desarrollo de competencias, en las tres el porcentaje de respuestas en las categorías alto y muy alto es superior al 60\%. En concreto, 11 de los 18 alumnos consideran alto o muy alto el nivel de desarrollo de la competencia trabajo en equipo; 12 otorgan esta misma valoración al desarrollo de la competencia iniciativa emprendedora; y, cabe destacar que el 78\% (14 de 18) están satisfechos o muy satisfechos con el nivel de desarrollo de las habilidades comunicativas.

Las dos preguntas sobre la intención de emprender un nuevo proyecto empresarial en el futuro tienen una respuesta desigual. En el corto plazo, los alumnos no lo perciben como una opción laboral atractiva, pues solamente se obtienen 3 respuestas en la categoría alto y ninguna en muy alto. Sin embargo, a medio plazo, la mitad de los estudiantes sí contempla la posibilidad de autoempleo, pues se obtienen 7 respuestas en el nivel alto y 2 en el muy alto. Finalmente, la respuesta a la pregunta "Valoración global de la jornada" es considerada bastante satisfactoria pues la mayoría, 14 de 18, se posicionan en las dos categorías superiores.

Respecto a la pregunta abierta en la que se pedía su opinión sobre los aspectos más positivos de la jornada, los alumnos inciden nuevamente en el acercamiento a la realidad 
empresarial y consideran de gran interés las experiencias e ideas innovadoras narradas por los tres emprendedores. Así mismo, la mayoría también destacó el valor de los comentarios y consejos recibidos. En este sentido, una respuesta mencionaba como positivo haber recibido "feedback desde diferentes puntos de vista" y otra "poder escuchar recomendaciones y críticas". Por lo que se refiere a los aspectos más negativos, varios estudiantes señalaron que les hubiera gustado tener más tiempo para poder debatir y trabajar con los emprendedores, llegando a sugerir como posible mejora para próximos cursos dividir la jornada en dos días.

Por su parte, los tres emprendedores también manifestaron su satisfacción con la jornada. En relación con las ideas de negocio propuestas por los estudiantes, resaltaron especialmente el hecho de que la mayoría de los equipos hubiera eligido ideas con alto contenido sostenible y cuidado del medioambiente; así mismo, valoraron positivamente las presentaciones realizadas. En general, comentaron que había resultado una experiencia muy enriquecedora.

\section{Conclusiones}

Actualmente, en los estudios de grado y postgrado universitarios es indispensable aplicar sistemas de evaluación que permitan valorar, de forma continua, tanto la asimilación de conocimientos, como la adquisición de aquellas capacidades que aparecen recogidas en las correspondientes guías docentes de cada asignatura. En el presente trabajo se ha expuesto una experiencia en la que se ha llevado a cabo una evaluación formativa realizada por profesionales externos a la universidad.

Se pidió a los emprendedores que participaran en la calificación del trabajo realizado por los estudiantes y en su proceso de aprendizaje. Así pues, además de compartir su experiencia empresarial, se involucraron en la mejora de las ideas de negocio presentadas por los distintos grupos.

El contacto directo con emprendedores permite a los estudiantes conocer en profundidad la realidad empresarial, así como aprender de sus experiencias. Por otro lado, el hecho de tener claras evidencias sobre el trabajo que están desarrollando hace que los alumnos sean conscientes de su propio progreso. El feedback recibido sobre las fortalezas de su proyecto reafirma la línea a seguir y contribuye a incrementar la motivación para continuar mejorando; en su caso, tener conocimiento de los puntos débiles del trabajo realizado posibilita introducir los cambios y rectificaciones necesarias antes de la presentación final del mismo. Igualmente, los resultados sugieren que la implantación de actividades con un sistema de evaluación formativa contribuye a lograr el desarrollo competencial del alumnado.

Para finalizar, es preciso señalar que la principal dificultad encontrada a la hora de desarrollar la iniciativa propuesta es, precisamente, la consecución de los contactos con los emprendedores dispuestos a colaborar. En nuestro caso, se contó con antiguos alumnos de la universidad con los que se mantenía cierta relación. Una vez habían aceptado la invitación, fue necesario coordinar la fecha para la celebración de la jornada. Dado que las

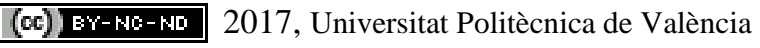

Congreso IN-RED (2017) 
presentaciónes de los alumnos debían hacerse respetando guía de aprendizaje, fue necesario planificar la organización de la jornada con suficiente antelación para poder conciliar la disponibilidad de los emprendedores con las fechas establecidas en el cronograma de la asignatura.

\section{Referencias}

ALEMANY, L., ÁlVAREZ, C., PLANELlAS, M. y URBANO, D. (2011). Libro Blanco de la iniciativa emprendedora en España. Barcelona: Fundación Príncipe de Gerona ESADE.

ÁLVAREZ, I.M. (2009). "Evaluar para contribuir a la autorregulación del aprendizaje" en Electronic Journal of Research in Educational Psychology, vol. 7, p. 1007-1030.

BENAVIDES, M., SÁNCHEZ, I. y LUNA-AROCAS, R. (2010). "El proceso de aprendizaje para los emprendedores en la situación actual; un análisis cualitativo en el ámbito universitario" en Revista de Dirección, Organización y Administración de Empresas, vol. 30, p. 34-48.

CASTRO, A., RENÉS, P. y DE LEÓN, B. (2014). "Education for Entrepreneurship: The case of Cantabria" en Procedia-Social and Behavioral Sciences, vol. 139, p. 512-518.

CICERO, S., ASÓN, J.M. y SANTAMARÍA, A (2012). 100 buenas prácticas de emprendimiento universitario. La Coruña: Redemprendia - Netbiblo.

COMISIÓN DE LAS COMUNIDADES EUROPEAS (2003). Libro verde. El espíritu empresarial en Europa. Bruselas.

COMISIÓN EUROPEA (2004). Puesta en práctica del programa de trabajo "Educación y formación 2010". Competencias clave para un aprendizaje a lo largo de la vida. Un marco de referenica Europeo". Bruselas.

CORTÉS, M., LÓPEZ-CÓZAR, C. y PRIEDE, T. (2015). "Una propuesta de evaluación participativa mediante la aplicación de métodos de gestión empresarial" en Revista Docencia e Investigación, vol. 25, issue 1, p. 9-28.

DE LA CRUZ, M. E., MIRA, I. y GÓMEZ, J. M. (2016). "El entorno universitario como generador de capacidades emprendedoras: un análisis de percepciones" en XIV Jornadas de Redes de Investigación en Docencia Universitaria: Investigación, innovación y enseñanza universitaria: enfoques pluridisciplinares, Instituto de Ciencias de la Educación, p. 29262946.

DIARIO OFICIAL DE LA UNIÓN EUROPEA (2006). Recomendación del Parlamento Europeo y del Consejo de 18 de diciembre de 2006 sobre competencias clave para el aprendizaje permanente. Bruselas.

FRAILE, A., LÓPEZ-PASTOR, V.M., CASTEJÓN, J. y ROMERO, R. (2013). "La evaluación formativa en docencia universitaria y el rendimiento académico del alumnado" en Aula Abierta, vol. 41, issue 2, p. 23-34.

(c)) EY-NC-ND 2017, Universitat Politècnica de València Congreso In-Red (2017) 
IPYME (2012). Educación emprendedora: buenas prácticas en la universidad española. Madrid: Dirección General de Industria y de la Pequeña y Mediana Empresa y Fundación Universidad-Empresa.

LÓPEZ-CÓZAR, C., ARIAS, P., ALARCÓN, S. y VILlA, A. (2015). "Evaluación continua coordinada a través de una plataforma virtual" en Libro de actas en V Congreso Internacional Univest, Gerona, 9-10 de julio de 2015, p. 255-259.

LÓPEZ-PASTOR, V.M. (2011). "El papel de la evaluación formativa en la evaluación por competencias: aportaciones de la red de evaluación formativa y compartida en docencia universitaria" en REDU, Revista de Docencia Universitaria, vol. 9, issue 1, p. 159-173.

MARINA, J. A. (2010). "La competencia de emprender" en Revista de Educación, vol. 351, p. 49-71.

MARTÍNEZ-FIGUEIRA, E., TELLADO-GONZÁLEZ, F. y RAPOSO-RIVAS, M. (2013). "La rúbrica como instrumento para la autoevaluación: un estudio piloto" en Revista de Docencia Universitaria, REDU, vol. 11, issue 2, p. 373-390.

PRIEDE, T., BENITO, S. y LÓPEZ-CÓZAR, C. (2013). "Cómo fomentar el espíritu emprendedor en las aulas universitarias. Descripción de una experiencia docente" en Revista de Enseñanza Universitaria, vol. 39, p. 1-13.

QUESADA V., RODRÍGUEZ GÓMEZ, G. e IBARRA, M. S. (2017). "Planificación e innovación de la evaluación en educación superior: la perspectiva del profesorado" en Revista de Educación Educativa, vol. 35, issue 1, p. 53-70.

SOBRADO, L. y FERNÁNDEZ E. (2010). “Competencias emprendedoras y desarrollo del espíritu empresarial en los centros educativos” en Educación XX1, vol. 13, issue 1, p. 1538.

(cc) EY-NC-ND 2017, Universitat Politècnica de València 


\title{
Comparación de herramientas de evaluación de la competencia comunicación oral efectiva
}

\author{
O. Sahuquillo ${ }^{\text {, A. A. Sonseca }}$, J. Martínez ${ }^{\mathrm{c}}$ y J. Carballeira ${ }^{\mathrm{d}}$ \\ a (ossana@upvnet.upv.es), (agsonol@posgrado.upv.es), \\ c(jomarc12@mcm.upv.es), ${ }^{d}$ (jacarmo@mcm.upv.es) \\ Departamento de Ingeniería Mecánica y de Materiales \\ Universitat Politècnica de València, Camino de Vera s/n, 46022, Valencia
}

\begin{abstract}
With the main objective of evaluating oral communication skills, a coevaluation methodology has been carried out for the last years to obtain quantitative results from data collected in the lab sessions on Materials Science, from the Bachelor degree in Chemical Engineering. The evaluation methodology followed is focus on students encouragement to participate more actively in the continuous learning of the subject. Students were asked to prepare oral presentations to explain to the class a summary about a previous lesson. These presentations were evaluated by a rubric-based method. The evaluation was done by using two different rubrics. The first one developed by the authors as a part of a Universitat Politècnica de Valencia project in educational innovation and improvement (PIME); and the second one an institutional one. The last one was developed later at UPV and also based on the experience derived from PIMEs projects. The idea is to compare both of them to prove if there is a good correlation between them.
\end{abstract}

Keywords: generic competences, oral communication, rubric

\section{Resumen}

Con el objetivo principal de evaluar la competencia de comunicación oral, se ha empleado durante los últimos años una metodología basada en la coevaluación, para obtener resultados cuantitativos de las sesiones de laboratorio de la asignatura Ciencia de Materiales del Grado en Ingeniería Química. La metodología pretende que los alumnos participen más activamente la evaluación continua de la asignatura. Los alumnos tienen que preparar y realizar una presentación oral resumen de la sesión anterior al resto de sus compañeros. La presentación será evaluada usando una rúbrica como herramienta de evaluación. La evaluación fue realizada utilizando dos rúbricas diferentes, una de ellas diseñada por los autores como parte del "Proyecto de Innovación y Mejora Educativa" (PIME) de la Universitat Politècnica de València (UPV). Otra desarrollada posteriormente en la 
UPV, basándose en la experiencia derivada de diferentes PIMEs. Se busca comparar si hay una buena correlación entre los resultados obtenidos con ambas rúbricas.

Palabras clave: competencias transversales, comunicación oral, rúbrica

\section{Introducción}

Actualmente en las titulaciones universitarias se ha evolucionado hacia un modelo en el que parece que no hay duda en considerar las competencias transversales como parte fundamental del curriculum de los estudiantes universitarios, dirigiéndose de este modo hacia una formación más completa. Los programas de Grado y Máster ofertados por la Universitat Politècnica de València (UPV), dentro del marco de la Espacio Europeo de Educación Superior, siguen un enfoque basado en competencias [Sursock (2010), Rieckmann (2012)].

Dentro de las competencias se puede diferenciar entre competencias de tipo específico y transversales. Las de tipo específico son las que se han venido evaluando hasta ahora y en las que se tiene gran experiencia en cómo realizarlo. En los últimos años ha surgido la necesidad de evaluar las competencias transversales y donde profesores y las instituciones están enfocando su esfuerzo y recursos.

El presente estudio es un continuación en el trabajo iniciado dentro del marco del "Proyecto de Innovación y Mejora Educativa (PIME Project B12/14: Desarrollo de estrategias para la evaluación de competencias transversales en asignaturas de Ingeniería Mecánica y de Materiales" desarrollado en la UPV. Cómo parte de la primera etapa de este proyecto, se asumió la necesidad de buscar y desarrollar herramientas para la evaluación de las habilidades en comunicación oral por parte de los alumnos [Carballeira (2015)].

En ese momento no se disponía de herramientas de evaluación institucionales para ese propósito. De ese modo fue una oportunidad para el desarrollo de experiencias en este área, junto con soporte a nivel institucional en la UPV mediante programas para la motivación y apoyo a las investigaciones y experiencias relacionadas con este tema [UPV (2014)]. Algunos de los resultados de este proyecto PIME fueron el desarrollo de una metodología y de herramientas para la evaluación de la habilidad en la comunicación basado en un método de rúbricas, teniendo en consideración que la comunicación está considerada como un punto clave de acuerdo al proyecto Tuning (2014).

\section{Objetivos}

El objetivo primordial se centra en evaluar competencias transversales, y más concretamente las habilidades en comunicación oral por parte de los alumnos.

Desde esa premisa, se plantea por un lado el ser capaces de desarrollar herramientas que permitan llevar a cabo esa evaluación, y consecuentemente el poder realizarlo de una forma fiable, con una metodología sencilla y atractiva, basada en una metodología activa.

(cc)) BY-NC-ND 2017, UniversitatPolitècnica de València

Congreso IN-RED (2017) 
$\mathrm{Y}$ en un segundo nivel y considerando que actualmente se disponen de herramientas de evaluación a nivel institucional, contrastar los resultados con la herramienta desarrollada por los autores.

\section{Desarrollo de la innovación}

Considerando como principal objetivo, el definido en el apartado anterior, la evaluación de la competencia comunicación oral efectiva, se ha llevado a cabo durante los últimos años una metodología basada en la coevaluación para la obtención de resultados cuantitativos. La experiencia se ha llevado a cabo en la titulación del Grado en Ingeniería Química en la asignatura Ciencia de Materiales y más concretamente en las sesiones de laboratorio de la misma.

La metodología empleada para la evaluación y las tareas a desarrollar por el alumno en esta experiencia, están basadas en metodologías activas enfocadas hacia el aprendizaje del alumno. Esta experiencia tiene una doble intención, en primer lugar la evaluación de la competencia comunicación oral efectiva y en segundo lugar, e igual de importante, motivar a los alumnos a participar más activamente en el aprendizaje continuo en la asignatura.

En particular, en esta asignatura hay matriculados 90 alumnos este año, de ese modo y aunque las presentaciones orales son individuales, el trabajo de elaboración de la presentación se realiza en grupos formados por 4-5 estudiantes. Los estudiantes tienen que preparar una presentación con una duración comprendida entre 10-15 minutos. En dicha presentación los alumnos deberán exponer a sus compañeros un resumen de lo visto en la sesión anterior. La preparación de la tarea requiere realizar una síntesis de los aspectos y conclusiones más relevantes, así como el esfuerzo de estructurar y explicar dichos contenidos al resto de compañeros. De este modo, se busca que los alumnos lleven un seguimiento más continuo de la asignatura, así como se espera que consigan una comprensión más profunda que les ayude en el aprendizaje del contenido.

Las presentaciones orales fueron evaluadas por un lado por el profesor y por otro lado por los compañeros de clase, utilizando la misma herramienta de evaluación, la rúbrica desarrollada.

La evaluación se realizó utilizando dos rúbricas diferentes: la primera de ellas desarrollada por los autores como parte del "Proyecto PIME B12/14", ver Tabla 1, y que fue utilizada por alumnos y profesor. Y la segunda es la institucional (ver Tabla 2), utilizada por el profesor, que fue desarrollada posteriormente por un grupo de profesores expertos de la UPV, basándose en su propia experiencia y en los resultados obtenidos por otros profesores participantes en los proyectos PIME de la UPV. 
Tabla 1. Rúbrica comunicación oral desarrollada por los autores

\begin{tabular}{|c|c|c|c|c|c|c|c|}
\hline & CRITERIOS & 0-No cumple & 1-Deficiente & 2-Regular & 3-Bueno & 4-Muy bueno & 5-Excelente \\
\hline 1 & $\begin{array}{l}\text { Realiza una } \\
\text { introducción } \\
\text { efectiva al tema }\end{array}$ & no la realiza & $\begin{array}{l}\text { realiza } \\
\text { introducción } \\
\text { mayoritariamente } \\
\text { incompleta }\end{array}$ & $\begin{array}{l}\text { realiza } \\
\text { introducción } \\
\text { incompleta }\end{array}$ & $\begin{array}{l}\text { realiza } \\
\text { introducción }\end{array}$ & $\begin{array}{l}\text { realiza } \\
\text { introducción y } \\
\text { pone en situación } \\
\text { a la audiencia }\end{array}$ & $\begin{array}{l}\text { realiza } \\
\text { introducción } \\
\text { indicando } \\
\text { ejemplos del } \\
\text { interés del tema }\end{array}$ \\
\hline 2 & $\begin{array}{l}\text { Señala los objetivos } \\
\text { e ideas principales }\end{array}$ & no lo realiza & $\begin{array}{l}\text { señala alguno de } \\
\text { los objetivos }\end{array}$ & $\begin{array}{l}\text { señala los } \\
\text { objetivos de forma } \\
\text { incompleta }\end{array}$ & $\begin{array}{l}\text { señala todos los } \\
\text { objetivos }\end{array}$ & $\begin{array}{l}\text { señala todos los } \\
\text { objetivos de forma } \\
\text { organizada y } \\
\text { sintética }\end{array}$ & $\begin{array}{l}\text { señala todos los } \\
\text { objetivos de forma } \\
\text { organizada y } \\
\text { sintética, con un } \\
\text { enfoque aplicado }\end{array}$ \\
\hline 3 & $\begin{array}{l}\text { Presenta resultados } \\
\text { fundamentados } \\
\text { adecuadamente }\end{array}$ & no presenta & $\begin{array}{l}\text { presenta algún } \\
\text { resultado }\end{array}$ & $\begin{array}{l}\text { presenta de forma } \\
\text { incompleta }\end{array}$ & $\begin{array}{l}\text { presenta todos los } \\
\text { resultados }\end{array}$ & $\begin{array}{l}\text { presenta los } \\
\text { resultados } \\
\text { relevantes }\end{array}$ & $\begin{array}{l}\text { presenta los } \\
\text { resultados } \\
\text { relevantes y los } \\
\text { fundamenta }\end{array}$ \\
\hline 4 & $\begin{array}{l}\text { Conclusiones } \\
\text { apropiadas y } \\
\text { sintéticas }\end{array}$ & no las realiza & $\begin{array}{l}\text { señala alguna } \\
\text { conclusión }\end{array}$ & $\begin{array}{l}\text { señala } \\
\text { conclusiones de } \\
\text { forma incompleta }\end{array}$ & $\begin{array}{l}\text { señala todas las } \\
\text { conclusiones }\end{array}$ & $\begin{array}{l}\text { señala las } \\
\text { conclusiones más } \\
\text { relevantes } \\
\text { organizaday y } \\
\text { sintéticamente }\end{array}$ & $\begin{array}{l}\text { señala las } \\
\text { conclusiones más } \\
\text { relevantes de } \\
\text { forma organizada, } \\
\text { sintética y } \\
\text { evalúa/analiza sus } \\
\text { consecuencias }\end{array}$ \\
\hline 5 & $\begin{array}{l}\text { Interpreta, } \\
\text { argumenta y } \\
\text { justifica la } \\
\text { información } \\
\text { presentada }\end{array}$ & no lo realiza & $\begin{array}{l}\text { Lo realiza de } \\
\text { manera errónea }\end{array}$ & $\begin{array}{l}\text { Lo realiza bien } \\
\text { pero de manera } \\
\text { muy limitada }\end{array}$ & $\begin{array}{l}\text { Lo realiza bien } \\
\text { pero incompleto }\end{array}$ & $\begin{array}{l}\text { Lo realiza de } \\
\text { manera correcta }\end{array}$ & $\begin{array}{l}\text { Lo realiza } \\
\text { correctamente, y } \\
\text { enfatizando los } \\
\text { aspectos } \\
\text { relevantes }\end{array}$ \\
\hline 6 & \begin{tabular}{|l} 
Presentación \\
estructurada, clara, \\
coherente y eficaz
\end{tabular} & no cumple ninguna & $\begin{array}{l}\text { parcialmente } \\
\text { estructurada }\end{array}$ & es estructurada & $\begin{array}{l}\text { al menos es } \\
\text { estructurada y } \\
\text { clara }\end{array}$ & $\begin{array}{l}\text { al menos es } \\
\text { estructurada, clara } \\
\text { y coherente }\end{array}$ & $\begin{array}{l}\text { al menos es } \\
\text { estructurada, } \\
\text { clara, coherente y } \\
\text { eficaz }\end{array}$ \\
\hline 7 & $\begin{array}{l}\text { Utiliza un lenguaje } \\
\text { técnico adecuado }\end{array}$ & nunca & $\begin{array}{l}\text { lo usa con errores } \\
\text { reiterados }\end{array}$ & $\begin{array}{l}\text { lo usa con algún } \\
\text { error }\end{array}$ & $\begin{array}{l}\text { lo utiliza } \\
\text { ocasionalmente }\end{array}$ & $\begin{array}{l}\text { lo utiliza habitual y } \\
\text { adecuadamente }\end{array}$ & $\begin{array}{l}\text { lo utiliza habitual y } \\
\text { adecuadamente, e } \\
\text { introduce nuevos } \\
\text { conceptos }\end{array}$ \\
\hline 8 & $\begin{array}{l}\text { Utiliza los recursos } \\
\text { disponibles para una } \\
\text { comunicación más } \\
\text { eficiente }\end{array}$ & $\begin{array}{l}\text { no utiliza los } \\
\text { recursos } \\
\text { disponibles }\end{array}$ & $\begin{array}{l}\text { utiliza los recursos } \\
\text { de forma } \\
\text { inadecuada }\end{array}$ & $\begin{array}{l}\text { utiliza los recursos } \\
\text { pero no para } \\
\text { clarificar ideas }\end{array}$ & $\begin{array}{l}\text { utiliza los recursos } \\
\text { para clarificar las } \\
\text { ideas principales }\end{array}$ & $\begin{array}{l}\text { utiliza los recursos } \\
\text { para clarificar las } \\
\text { ideas de forma } \\
\text { generalizada }\end{array}$ & $\begin{array}{l}\text { utiliza los recursos } \\
\text { disponiblese e } \\
\text { introduce nuevos } \\
\text { para clarificar las } \\
\text { ideas de forma } \\
\text { generalizada }\end{array}$ \\
\hline 9 & $\begin{array}{l}\text { La presentación se } \\
\text { ajusta al tiempo } \\
\text { disponible }\end{array}$ & $\begin{array}{l}\text { Ningún control } \\
\text { temporal de la } \\
\text { extensión parcial y } \\
\text { total }\end{array}$ & $\begin{array}{l}\text { Se excede o le } \\
\text { sobra demasiado } \\
\text { tiempo }\end{array}$ & $\begin{array}{l}\text { Se ajusta al tiempo } \\
\text { disponible de } \\
\text { forma aproximada }\end{array}$ & $\begin{array}{l}\text { Se ajusta al tiempo } \\
\text { disponible }\end{array}$ & $\begin{array}{l}\text { Se ajusta al tiempo } \\
\text { disponible, dedica } \\
\text { el tiempo } \\
\text { apropiado en cada } \\
\text { parte }\end{array}$ & $\begin{array}{l}\text { Se ajusta al tiempo } \\
\text { disponible, dedica } \\
\text { el tiempo } \\
\text { apropiado en cada } \\
\text { parte y se } \\
\text { reorganiza en caso } \\
\text { necesario }\end{array}$ \\
\hline 10 & $\begin{array}{l}\text { Dicción clara, sin } \\
\text { muletillas, tono } \\
\text { adecuado, postura } \\
\text { corporal adecuada y } \\
\text { contacto visual }\end{array}$ & no cumple ninguna & cumple 1 & $\begin{array}{l}\text { Dicción clara y } \\
\text { tono monótono }\end{array}$ & $\begin{array}{l}\text { Dicción clara y } \\
\text { postura corporal }\end{array}$ & $\begin{array}{l}\text { Dicción clara, } \\
\text { postura corporal y } \\
\text { tono adecuado }\end{array}$ & $\begin{array}{l}\text { Dicción clara, } \\
\text { postura corporal, } \\
\text { tono adecuado y } \\
\text { contacto visual }\end{array}$ \\
\hline 11 & $\begin{array}{l}\text { Analiza, valora y } \\
\text { responde a las } \\
\text { preguntas que se } \\
\text { formulan }\end{array}$ & \begin{tabular}{|l} 
No cumple \\
ninguna
\end{tabular} & $\begin{array}{l}\text { Analiza, pero ni } \\
\text { valora ni responde }\end{array}$ & $\begin{array}{l}\text { Analiza y valora, } \\
\text { pero no responde }\end{array}$ & $\begin{array}{l}\text { Analiza, valora y } \\
\text { responde de } \\
\text { manera limitada, } \\
\text { con ayuda del } \\
\text { profesor }\end{array}$ & $\begin{array}{l}\text { Analiza, valora y } \\
\text { responde con } \\
\text { enfoque propio }\end{array}$ & $\begin{array}{l}\text { Analiza, valora y } \\
\text { responde con } \\
\text { enfoque propio, y } \\
\text { plantea cuestiones } \\
\text { relacionadas }\end{array}$ \\
\hline
\end{tabular}

(cc) EY-NC-ND 2017, UniversitatPolitècnica de València 
Tabla 2. Rúbrica comunicación oral UPV

\begin{tabular}{|c|c|c|c|c|}
\hline \multirow{2}{*}{ INDICADORES } & \multicolumn{4}{|c|}{ DESCRIPTORES } \\
\hline & D. No alcanzado & C. En desarrollo & B. Bien /adecuado & A. Excelente/ejemplar \\
\hline $\begin{array}{l}\text { Muestra una } \\
\text { disposición personal } \\
\text { positiva hacia la } \\
\text { comunicación }\end{array}$ & $\begin{array}{l}\text { No se implica en las } \\
\text { actividades propuestas o } \\
\text { lo hace faltondo a las } \\
\text { normas básicas de } \\
\text { educación y convivencia }\end{array}$ & $\begin{array}{l}\text { Se implica mínimamente } \\
\text { y/o lo hace manifestando } \\
\text { actitudes poco apropiados }\end{array}$ & $\begin{array}{l}\text { Muestra una disposición } \\
\text { personal positiva hacia } \\
\text { la comunicación }\end{array}$ & $\begin{array}{l}\text { Sus presentaciones } \\
\text { voluntarias fomentan la } \\
\text { participación de oftos y } \\
\text { aportan valor añadido }\end{array}$ \\
\hline $\begin{array}{l}\text { Realiza exposiciones } \\
\text { interesantes y } \\
\text { convincentes, que } \\
\text { desarrolla cuando le } \\
\text { formulan preguntas }\end{array}$ & $\begin{array}{l}\text { Es posible que exponga } \\
\text { algunas ideas } \\
\text { importantes, pero no logra } \\
\text { captar la atención y, ante } \\
\text { las preguntas, a menudo, } \\
\text { no responde o lo hace de } \\
\text { manera incorrecta }\end{array}$ & $\begin{array}{l}\text { Expone solo algunas ideas } \\
\text { importantes y logra captar } \\
\text { la atención } \\
\text { intermitentemente. Ante las } \\
\text { preguntas, sus respuestos } \\
\text { repiten la presentación, } \\
\text { pero no la amplían }\end{array}$ & $\begin{array}{c}\text { Realiza exposiciones } \\
\text { interesantes y } \\
\text { convincentes, que } \\
\text { apoya y desarrolla } \\
\text { cuando le formulan } \\
\text { preguntas }\end{array}$ & $\begin{array}{l}\text { Su exposición de ideas } \\
\text { resulta completa, } \\
\text { interesante y convincente. } \\
\text { Sus respuestas generan } \\
\text { nuevas intervenciones } \\
\text { (preguntas) }\end{array}$ \\
\hline $\begin{array}{l}\text { La exposición está } \\
\text { debidamente } \\
\text { preparada y se ajusta } \\
\text { al tiempo establecido }\end{array}$ & $\begin{array}{l}\text { La exposición no está } \\
\text { debidamente } \\
\text { estructurada y/o no se } \\
\text { ajusta al tiempo } \\
\text { establecido }\end{array}$ & $\begin{array}{l}\text { La exposición está } \\
\text { organizada, pero hay } \\
\text { demasiada o escasa } \\
\text { información y/o no se ajusto } \\
\text { al tiempo establecido }\end{array}$ & $\begin{array}{l}\text { La audiencia puede } \\
\text { captar claramente la } \\
\text { eficaz estructura del } \\
\text { contenido y la } \\
\text { exposición se ajusto al } \\
\text { tiempo establecido }\end{array}$ & $\begin{array}{c}\text { La selección y organización } \\
\text { del contenido y su } \\
\text { ilustración (ejemplos, } \\
\text { analogías...) son coherentes } \\
\text { y la exposición se ajusta al } \\
\text { tiempo establecido }\end{array}$ \\
\hline $\begin{array}{l}\text { Respeta las normas } \\
\text { lingǘsticas } \\
\text { (corrección) y se } \\
\text { expresa de manera } \\
\text { correcta (claridad) }\end{array}$ & $\begin{array}{l}\text { No realiza un buen uso del } \\
\text { lenguaje y/o no utiliza la } \\
\text { terminología específica } \\
\text { de la materia }\end{array}$ & $\begin{array}{l}\text { La presentación no es fluida } \\
\text { (lenguaje limitado] y utiliza } \\
\text { escasa terminología } \\
\text { especifica o lo hace } \\
\text { inapropiadamente }\end{array}$ & $\begin{array}{c}\text { Respeta las normas } \\
\text { lingúisticas y se expresa } \\
\text { de manera correcto, } \\
\text { utilizando de modo } \\
\text { pertinente la } \\
\text { terminología especifica } \\
\text { de la materia }\end{array}$ & $\begin{array}{l}\text { La exposición se adapta a } \\
\text { la audiencia, haciendo uso } \\
\text { de un lenguaje y de una } \\
\text { terminología específicos, } \\
\text { apropiados, precisos y ricos }\end{array}$ \\
\hline $\begin{array}{l}\text { La comunicación no } \\
\text { verbal es apropiada }\end{array}$ & $\begin{array}{l}\text { Su lenguaje no verbal no } \\
\text { respalda y/o distrae su } \\
\text { discurso verbal }\end{array}$ & $\begin{array}{l}\text { Su lenguaje no verbal } \\
\text { muestra alguna } / \mathrm{s} \\
\text { deficiencia } / \mathrm{s}\end{array}$ & $\begin{array}{l}\text { Su lenguoje no verbal es } \\
\text { coherente con el verbal }\end{array}$ & $\begin{array}{l}\text { Su lenguaje no verbal } \\
\text { refuerza el verbal: gestos } \\
\text { firmes, ritmo variado y } \\
\text { entonación intencional }\end{array}$ \\
\hline $\begin{array}{l}\text { Refuerza sus ideas } \\
\text { con la ayuda de los } \\
\text { medios de apoyo }\end{array}$ & $\begin{array}{l}\text { No utiliza los medios de } \\
\text { apoyo apropiados o hace } \\
\text { un mal uso de los mismos }\end{array}$ & $\begin{array}{l}\text { No siempre utiliza los medios } \\
\text { de apoyo más apropiados } \\
\text { o no hace el mejor uso de } \\
\text { los mismos }\end{array}$ & $\begin{array}{l}\text { Los medios de apoyo } \\
\text { contribuyen a que el } \\
\text { discurso se comprenda } \\
\text { mejor, enfatizando sus } \\
\text { puntos clave }\end{array}$ & $\begin{array}{c}\text { Los medios de apoyo } \\
\text { destacan por su } \\
\text { calidad/originalidad y } \\
\text { contribuyen a que el } \\
\text { disourso se comprenda } \\
\text { mejor }\end{array}$ \\
\hline
\end{tabular}

Posteriormente la idea es realizar una comparación entre ambas herramientas, viendo si hay una buena correlación entre ambas, pudiendo confirmar en ese caso que hay una buena fiabilidad en los resultados obtenidos previamente en el proyecto PIME llevado a cabo. La rúbrica PIME, es la que se utilizó inicialmente como parte de este estudio y fue diseñada y desarrollada por los autores [Carballeira (2016)]. De otro lado, la rúbrica UPV recoge los siguientes items para la evaluación de la competencia: actitud en la comunicación; selección de contenido y organización; estructura y ajuste al tiempo disponible; uso del lenguaje científico; comunicación no verbal y uso de medios de apoyo. Cada uno de estos items se gradúa en cuatro grados o niveles de consecución: A. Excelente, B. Adecuado, C. En desarrollo y D. No alcanzado.

Para poder hacer la comparación entre ambas herramientas de evaluación, se realizó una correspondencia entre los items evaluados en cada una de las rúbricas, debido a que se encontró un ítem o un grupo de items en la rúbrica de los autores (rúbrica PIME) que también se encuentra como ítem evaluable en la rúbrica UPV. A continuación se detallan los ítems evaluados en la rúbrica UPV y entre paréntesis los correspondientes en la rúbrica de la Tabla 1: exposición interesante y respuesta a preguntas (ítems 5 y 11); estructura y ajuste al tiempo disponible (ítems 6 y 9); uso del lenguaje científico (ítem 7); comunicación no verbal (ítem 10) y uso de medios de apoyo (ítems 8). 
Para poder hacer la comparación entre ambos sistemas de evaluación, fue necesario hacer una correspondencia numérica y la normalización de los valores para cada aspecto evaluado. A los ítems de la rúbrica UPV se les asignó un puntuación del 1 al 4, siendo 1 el nivel no alcanzado y el 4 el nivel excelente. Posteriormente esas puntuaciones se normalizaron a una escala de 5 puntos si hay correspondencia con un ítem de la rúbrica PIME o de 10 puntos en el caso de haber dos ítems. Finalmente, mediante la suma de la puntuación de todos los ítems se obtuvo la valoración de cada uno de los actos de evaluación con las dos rúbricas y se procedió a su comparación.

\section{Resultados}

De acuerdo con el trabajo previo realizado por los autores en la evaluación de las competencias transversales [Sahuquillo (2015), Sonseca (2015)], a continuación se resumen los resultados más relevantes. En la evaluación realizada por los alumnos utilizando la rúbrica mostrada en la Tabla 1, se observaron pequeñas diferencias en las evaluaciones realizadas entre los diferentes alumnos para un mismo acto de evaluación. De este modo se puede deducir que los usuarios de la herramienta no tuvieron ningún problema en su utilización ni en la comprensión de los criterios a valorar, de este modo se puede considerar que la rúbrica desarrollada en el proyecto PIME es una herramienta de evaluación sencilla pues se consigue una valoración uniforme entre usuarios no expertos como pueden ser los alumnos.

En el estadio inicial de la evaluación de la competencia transversal y para comprobar la bondad de la rúbrica, se llevaron a cabo valoraciones a cargo de dos profesores para cada uno de los actos de evaluación. De los resultados se obtuvieron diferencias mínimas entre las evaluaciones realizadas por los dos profesores, con diferencias incluso inferiores a las encontradas entre las valoraciones de los alumnos [Sonseca (2015)].

En la Fig. 1 (a) y (b), se muestran a modo de ejemplo la comparativa entre las calificaciones de alumnos y profesores para un mismo acto de evaluación, mostrándose los resultados obtenidos en dos años académicos diferentes.

A la vista de estos resultados se puede deducir que hay una buena correlación entre las evaluaciones realizadas por los alumnos y por los profesores, siendo como es obvio las calificaciones de los alumno superiores a las de los profesores, pero a pesar de ese detalle, sin mucha diferencia entre la valoración entre los distintos evaluadores. Indicando por tanto que los criterios de evaluación son fácilmente comprensibles y claros para los distintos evaluadores, profesores y alumnos, incluso aunque no se trate de evaluadores expertos. Este hecho permite considerar a priori la rúbrica desarrollada como una herramienta de evaluación válida, permitiendo por tanto y en base a los resultados obtenidos involucrar a los alumnos como parte de la evaluación de la asignatura.

(c)) EY-NC-ND 2017, UniversitatPolitècnica de València 


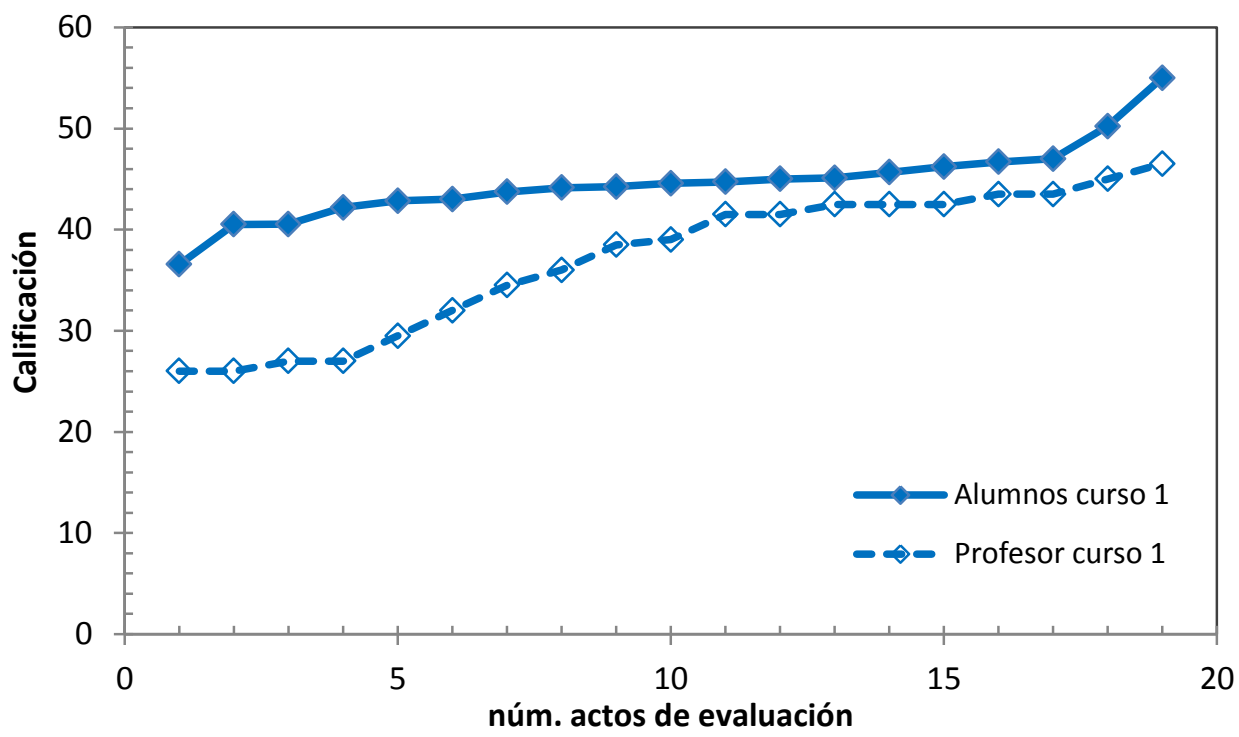

(a)

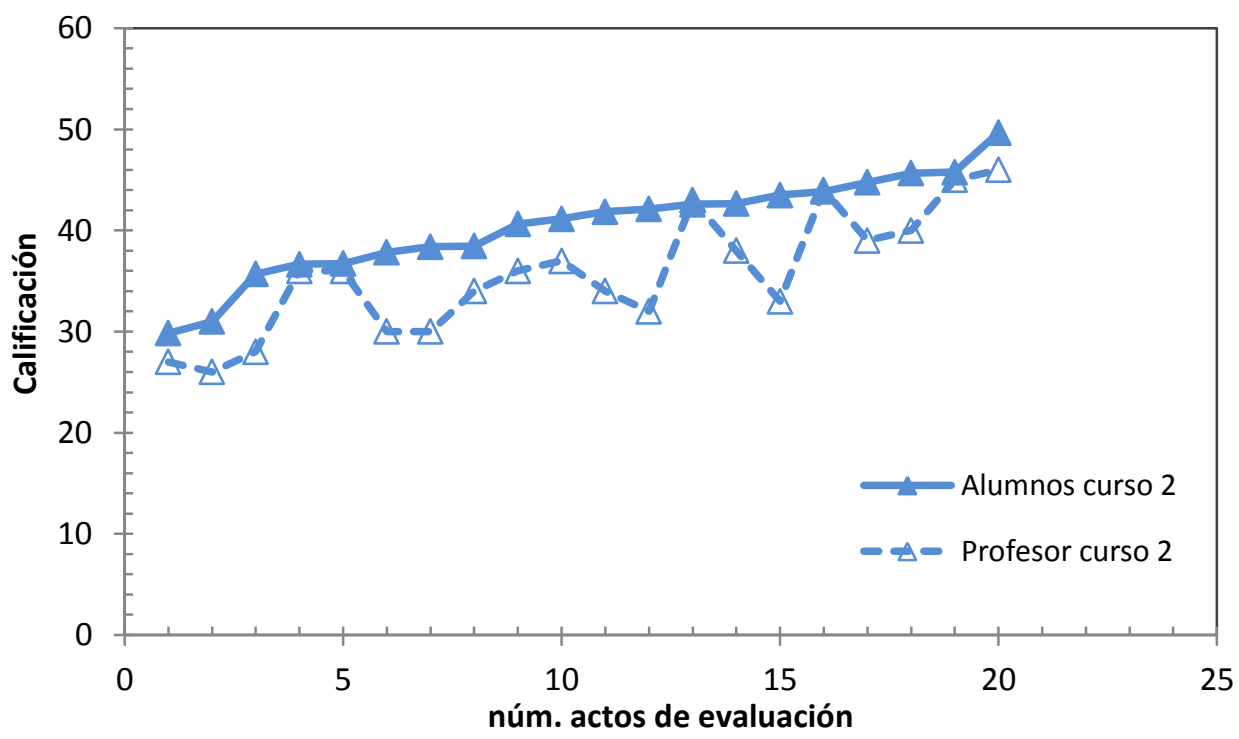

(b)

Fig. 1 Comparativa calificaciones alumnos y profesor (a) curso académico 1 y (b) curso académico 2.

A partir de los resultados obtenidos en el proyecto PIME, parece que se cuenta con un herramienta de evaluación sólida, pero con la intención de intentar confirmarlo se busca el comparar los resultados de la rúbrica que se desarrollo durante el PIME con la rúbrica que se desarrolló posteriormente en la UPV. Para ello se ha procedido a evaluar por parte del profesor un mismo acto de evaluación con las rúbricas mostradas en la Tabla 1 y 2 . Se evaluaron un total de 19 actos de evaluación, para la presentación de los resultados se ha 
procedido a ordenar las calificaciones de menor a mayor para una presentación y visualización de los resultados más sencilla, ver Fig. 2. En el gráfico se comparan los resultados obtenidos por el profesor con las dos rúbricas, teniendo en cuenta que la calificación máxima posible es de 35 puntos.

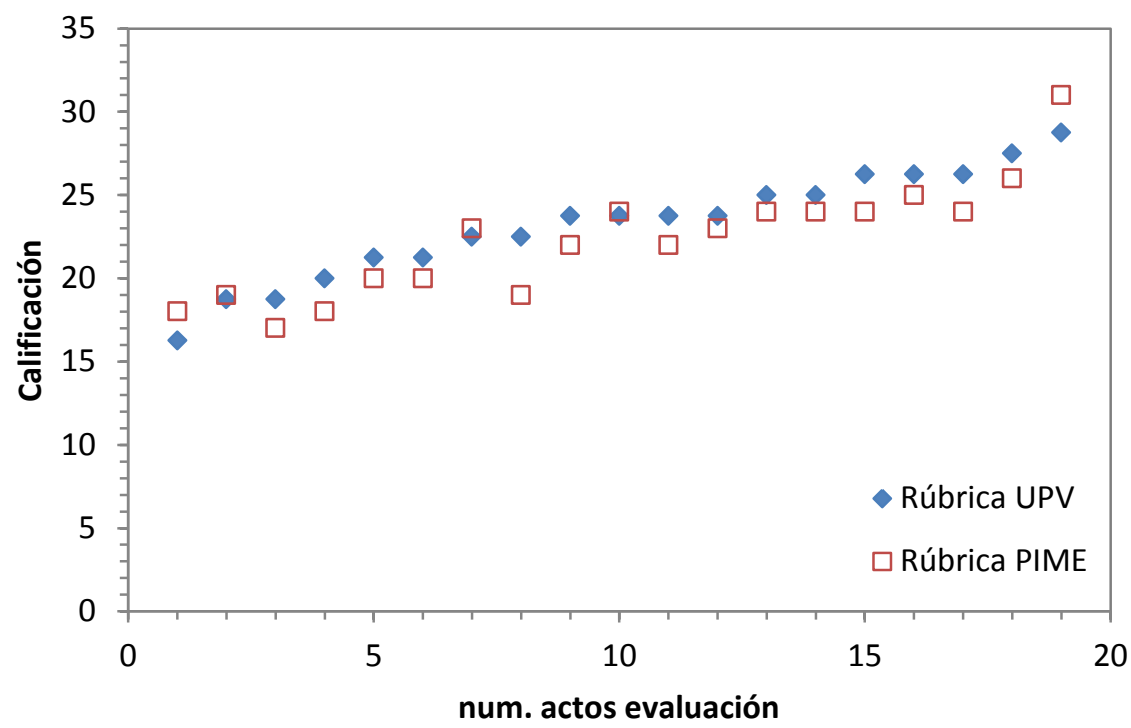

Fig. 2 Comparativa calificaciones profesor con dos rúbricas diferentes

En todos los actos de evaluación realizados, se obtuvieron pequeñas diferencias entre las valoraciones realizadas por el profesor empleando las dos rúbricas. De las 19 valoraciones, 14 de ellas, cerca del 75\% de los casos, presentan diferencias entre las valoraciones de las dos rúbricas inferiores o iguales al 5\% (en porcentaje y relativo a los 35 puntos totales). También se observa que en general, las calificaciones son superiores en la rúbrica UPV, quizá debido a que hay definidos cuatro niveles de consecución en lugar de los seis de la rúbrica PIME.

De este modo y dado que las diferencias entre las rúbrica utilizadas son muy pequeñas, y teniendo en cuenta que la rúbrica UPV fue desarrollada por un conjunto de profesores multidisciplinar y con experiencia en este campo, se puede concluir que la rúbrica desarrollada en el PIME se confirma como una herramienta que permite obtener resultados consistentes y fiables para la evaluación de la competencia comunicación oral efectiva. Además las pequeñas diferencias obtenidas en las valoraciones entre los diferentes posibles evaluadores, alumno-alumno, profesor-profesor y alumno-profesor, en el proceso de coevaluación con la rúbrica UPV, dan validez, consistencia a la metodología y a la herramienta de evaluación desarrollada, permitiendo incorporar al alumno en el proceso de evaluación e intentar que tomen conciencia de su nivel de consecución y qué aspectos revisar con el objetivo de mejorar sus competencias.

(cc) BY-NC-ND 2017, UniversitatPolitècnica de València 


\section{Conclusiones}

En la etapa previa del estudio, con la rúbrica PIME, se obtuvieron mínimas diferencias entre las evaluaciones realizadas por dos profesores. Con diferencias algo superiores entre las valoraciones entre los alumnos y una buena concordancia entre las evaluaciones realizadas por profesores y alumnos. Todo ello lleva a pensar que la herramienta desarrollada para la evaluación era sencilla y reporta resultados fiables aún siendo utilizada por evaluadores no experimentados como los alumnos.

La buena correlación entre las evaluaciones permite deducir que los criterios a evaluar son fácilmente comprensibles y claros para los distintos evaluadores, profesores y/o alumnos. Esto permite considerarla como una herramienta de evaluación válida, permitiendo involucrar a los alumnos como parte de la evaluación de la asignatura.

La comparación de la evaluación realizada con la rúbrica desarrollada en el PIME y la institucional reporta resultados muy similares y por tanto reproducibles independientemente de la rúbrica utilizada.

Los resultados obtenidos con la rúbrica desarrollada en el PIME, en base a las pequeñas diferencias entre las valoraciones realizadas por distintos evaluadores, así como con la rúbrica institucional, permite concluir que se trata de una herramienta valida, fiable y consistente para la evaluación de la competencia.

Respecto a la metodología, el hecho de hacer exponer a los estudiantes al trabajo realizado, y convertirlos en evaluadores, les hace ser más conscientes de su nivel de logro y de qué pueden hacer para mejorar sus competencias.

\section{Agradecimientos}

El proyecto has sido financiado por el Vicerrectorado de Estudios, Calidad y Acreditación de la Universitat Politècnica de València a través del programa PIME 2016-17 bajo la referencia A26.

\section{Referencias}

CARBALlEIRA, J., MARTÍNEZ, J., SAHUQUILlO, O., SONSECA, A., DENIA, F.D., SUÑER, J.L., VILA, P., RÓDENAS, J.J., MARCO, M. (2015). "Desarrollo de estrategias de evaluación de competencias transversales en asignaturas de ingeniería mecánica y de materiales" en Congreso Nacional de Innovación Educativa y Docencia en Red (IN-RED 2015). Valencia: Universitat Politècnica de València. (923 - 937).

CARBALLEIRA, J., MARTÍNEZ-CASAS, J., SAHUQUILLO, O., SONSECA, A., SUÑER, J.L., VILA, P., DENIA, F. D., RÓDENAS, J.J., MARCO, O. (2016). "Assessment of problem-solving skills and capacity for applying knowledge in practice in subjects related to mechanical and materials engineering" en Advances in Higher Education, Ed. Universitat Politècnia de València, Chapter 5, pp. 71-88. 
RIECKMANN, M. (2012). Future-oriented higher education: Which key competencies should be fostered through university teaching and learning? en Futures, 44, 127-135.

SURSOCK, H. S. (2010). A decade of change in european higher education. Trends 2010. Brussels: European University Association.

SAHUQUILLO, O., SONSECA, A., MARTÍNEZ, J., CARBALLEIRA, J., DENIA, F.D., RÓDENAS, J.J., MARCO, M. (2015). Propuesta de evaluación de las competencias de comunicación oral y escrita en asignaturas de Ingeniería Mecánica y Ciencia de Materiales en Congreso Nacional de Innovación Educativa y Docencia en (IN-RED 2015). Valencia: Universitat Politècnica de València. (973 - 987)

SONSECA, A., SAHUQUILlO, O., MARTÍNEZ, J., CARBALLEIRA, J., DENIA, F.D., RÓDENAS J.J. (2015). Assessment of oral and written communication competences in the European Higher Education Area: a proposal of evaluation methodologies in 1st International Conference on Higher Education Advances (HEAd'15). Valencia, Spain: Editorial Universitat Politècnica de València. (2 - 9).

TUNING PROJECT. (2014). Approaches to teaching, learning and assessment in competences based degree programmes. http://www.unideusto.org/tuningeu/teachinglearning-a-assessment.html [Consulta: 23 Marzo 2017]

UPV (2014). Competencias Transversales. http://competencias.webs.upv.es/wp/ [Consulta: 21 Marzo 2017] 


\title{
Mejora de la implicación del alumnado en "Diseño y síntesis de sistemas digitales" usando e-learning colaborativo, gamificación y aprendizaje basado en problemas
}

\section{Oscar Alonso $^{\text {a }}$, Jordi Colomer ${ }^{\mathrm{a}}$, Nil Franch ${ }^{\mathrm{a}}$ y Angel Diéguez ${ }^{\mathrm{a}}$}

åDepartamento de Inenierías: Sección Electrónica, Universitad de Barcelona, oalonso@el.ub.edu

\begin{abstract}
During the last 3 years, it has been observed that the students do not have a solid base to understand the concepts that are introduced in the subject. In addition, the attitude of the students, in general, is negligence, do not review concepts to prepare the subject, do not prepare laboratory practices and stop attending class. This results in a high dropout rate, fear of doing the subject and discomfort with the teaching staff.

To solve this problem, we apply the teaching innovation presented in this article. Such innovation takes advantage of teaching strategies such as gamification or problem-based learning, uses virtual tools to motivate elearning and collaboration with other students. The results, to date, are satisfactory since they reduce the dropout rate and increase the number of students who assimilate the concepts introduced in the subject
\end{abstract}

Keywords: gamification, e-learning, digital

\begin{abstract}
Resumen
Durante los últimos 3 años se ha observado que el alumnado no tiene una base sólida para entender los conceptos que se introducen en la asignatura. Además, la actitud de los alumnos, en general, es de dejadez, no repasan conceptos para preparar la asignatura, no se preparan las prácticas de laboratorio y dejan de asistir a las clases presenciales. Dando como resultado una alta tasa de abandono, miedo a realizar la asignatura y malestar con el profesorado.

Para resolver esta problemática, se aplica la innovación docente presentada en este artículo. Dicha innovación saca beneficio de estratégias docentes como la gamificación o el aprendizaje basado en problemas, usa herramientas virtuales para motivar el "e-learning" y la colaboración con el resto de estudiantes. Los resultados, hasta la fecha, son satisfactorios dado que reducen la tasa de abandono e incrementan el número de estudiantes que asimilan los conceptos introducidos en la asignatura.
\end{abstract}

Palabras clave: gamificación, e-learning, digital, cuestionarios, prácticas integradas 


\section{Introducción}

"Diseño y síntesis de sistemas digitales" es una asignatura obligatoria impartida durante el $6^{0}$ semestre del grado de Ingeniería Electrónica y de Telecomunicaciones. La asignatura permite cerrar el bloque de enseñanza sobre sistemas digitales dentro la Ingeniería ya que, previamente, el alumno debe haber cursado "Diseño Digital Básico" y "Sistemas Digitales y Estructura de Procesadores" y "Diseño microelectrónico", en los semestres $1^{\circ}, 3^{\circ}$ y $5^{\circ}$ respectivamente.

La metodología formativa que se sigue en la asignatura está dividida en un bloque teórico que ocupa el $40 \%$ de las clases y un bloque práctico que ocupa el $60 \%$ restante. Dentro del bloque teórico, el profesor imparte una clase magistral y hace de moderador en debates sobre textos técnicos que el alumnado debe haber leído previamente. Dentro del bloque práctico, se realizan diversos ejercicios guiados y un proyecto final autónomo que proporcionan las capacidades básicas para ejercer la profesión de ingeniero electrónico en el ámbito del diseño de circuitos digitales.

Aunque no es la continuación de ninguna asignatura troncal, Diseño y Síntesis de Sistemas Digitales sí que se basa en conceptos previamente enseñados en asignaturas de $1^{\circ}, 3^{\circ}$ y $5^{\circ}$ semestre (Diseño Digital Básico, Sistemas Digitales y Estructura de Procesadores y Diseño microelectrónico).

La problemática que observamos los profesores de la asignatura es que los alumnos no tienen una base sólida para entender los conceptos que se introducen en la asignatura. Además, la actitud de los alumnos, en general, es de dejadez, no repasan conceptos para preparar la asignatura, no se preparan las prácticas de laboratorio y dejan de asistir a las clases presenciales.

Las principales consecuencias para el alumnado se pueden resumir como:

- El estudiante no puede seguir el día a día de la asignatura

- El estudiante tiene que hacer un sobreesfuerzo para poder entender los nuevos conceptos

- El alumnado no utiliza las 3 horas de prácticas presenciales para hacer la práctica (debe repasar conceptos).

- El estudiante ve que tiene una carga docente mayor a la que realmente le correspondería a esta asignatura.

- Malestar general por parte del alumnado al creer que la carga docente no es la adecuada.

- Una parte minoritaria del alumnado deja la asignatura por no poder seguir las otras asignaturas.

El profesorado también se ve afectado dado que:

- Se produce una avalancha de alumnos durante las horas de visita del profesorado.

- La actitud del alumnado hacia el profesor, en ocasiones, deja de ser cordial.

- Los debates en las clases de teoría son entre el profesor y una minoría de alumnos

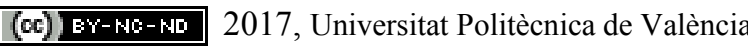

Congreso IN-RED (2017) 
- Los profesores en las clases prácticas deben invertir más tiempo aclarando conceptos de asignaturas pasadas.

Delante de esta problemática, el equipo docente de la asignatura se propone implementar una innovación docente basada en el trabajo colaborativo en red, uso de herramientas para la evaluación continuada y debates en grupo. A continuación se describen los antecedentes de la asignatura, los objetivos y desarrollo de la innovación para finalizar presentando los resultados preliminares obtenidos durante este curso y las conclusiones.

\subsection{Antecedentes}

La parte práctica de la asignatura estaba dividida de la siguiente manera:

- Un proyecto (implementación de un sistema de comunicación UART) dividido en 4 partes ( 8 sesiones de laboratorio):

- Introducción (estudio de un sistema de comunicación)

- Diseño de un sistema de comunicación propio (transmisor y receptor)

○ Verificación a nivel funcional (test del sistema mediante simulaciones)

- Implementación física en un sistema real (FPGA)

- Una sesión magistral donde los profesores introducimos como llevar los conocimientos adquiridos a la fabricación de chips (como por ejemplo los microprocesadores Intel) (1 sesión de laboratorio)

- Un proyecto final individual que el alumno realiza fuera del entorno de prácticas. El alumnado tenía un mes desde la propuesta del proyecto hasta el día de entrega.

Anteriormente el equipo docente ya había iniciado diversas actuaciones:

- Iniciar los laboratorios dos semanas antes para introducir/repasar los conceptos necesarios para comenzar las prácticas.

- Cuestionarios tipo test obligatorios antes de entrar al laboratorio para hacer que el alumno lea las prácticas. Estos cuestionarios afectan a la nota final y se hacen durante los primeros 20 minutos de cada práctica para obligar al alumno a ser puntual.

- La evaluación de cada práctica es diferente si el alumno la ha entregado en la fecha de entrega o a posteriori. Si el alumno hace la entrega antes de la fecha límite su nota puede ir de 0 a 10 . Si el alumno la entrega fuera del límite, la máxima nota será un 5. Si por algún motivo la práctica del alumno no está aprobada, el alumno tiene tantas oportunidades como sean necesarios de volver a presentarla hasta que alcance el 5.

Los resultados de estas actuaciones se pueden calificar de malos ya que:

- El alumnado motivado se aburre durante las prácticas introductorias. Las prácticas tienen una duración de 3 horas y se está volviendo habitual ver este tipo de alumno navegando por internet (facebook, diarios online, ...) y no realizando la práctica. 
- La mayoría del alumnado llega sin leerse la práctica y parece no tener ningún problema en suspender el cuestionario, el número máximo de cuestionarios aprobados es de 6 sobre 30 alumnos). Además, continuamos viendo alumnos que llegan más de 30 minutos tarde, a los que parece que tampoco afecta tener un 0 al cuestionario.

- El hecho de tener la opción de entregar más tarde la práctica ha hecho que más de un $60 \%$ de los alumnos las entregue el último día de clase.

\section{Objetivos}

En general, aunque el alumnado suele haber demostrado que alcanza los conocimientos mínimos de cada asignatura previa, hemos detectado que el alumnado, ya sea por olvido, dejadez o el itinerario que han seguido en el grado, demuestra no tener el nivel mínimo al comienzo de la asignatura.

Por lo tanto, el objetivo de la innovación es pasar a un sistema de prácticas integradas donde inicialmente se evaluará el nivel inicial de cada alumno y se le acompañará, a través de las prácticas, durante el resto del curso para alcanzar el nivel final requerido. En consecuencia, pretendemos asegurar que el alumno pueda realizar el curso, con el nivel de exigencia requerido, sin que tenga que dedicar un sobre esfuerzo debido a su falta de conocimientos o falta de interés. Para alcanzar estos objetivos se plantean diversas actuaciones:

- Hacer uso del entorno "Moodle" para generar cuestionarios en línea para motivar que el alumno repase los conceptos previos a la asignatura, detectar su nivel y guiarlo para alcanzar los conceptos requeridos, preparar las sesiones de discusión técnicas en clase y obligar al alumno a preparar las prácticas antes de la clase presencial.

- Hacer uso del entorno "Moodle" y "Wikispaces" moderado por el profesor para generar lo que se llama «e-learning» colaborativo. Con estas herramientas el alumno pasa a ser parte activa en el aprendizaje ya que puede proponer, solucionar o preguntar dudas. El hecho de que el moderador sea el profesor asegura que el resultado final siempre será el adecuado y que lo verán todos los alumnos. Así pues, el profesor tendrá que dedicar menos horas de visita a solucionar dudas.

- Hacer uso del entorno "Moodle" para motivar el trabajo colaborativo en red para aquellas prácticas que puedan hacer en grupo.

- Uso de estratégias docentes como "aprendizaje basado en problemas" y "gamificación" para la realización del proyecto final. Por ejemplo, proponiendo proyectos finales que consistan en la implementación de juegos en FPGAs.

(c)) EY-NC-ND 2017, Universitat Politècnica de València 


\section{Desarrollo de la innovación}

Lo que hacía el equipo docente durante las sesiones prácticas de la asignatura era preparar al alumno para poder realizar un proyecto de manera autónoma. Para motivar al alumno, estas sesiones prácticas también tenían incidencia en la nota final.

Para que el equipo docente haya transformado estas prácticas compartimentadas en prácticas integradas han sido necesarias varias actuaciones:

- Buscar el nivel del alumno durante el inicio de la primera práctica. La metodología empleada es un cuestionario con preguntas de respuesta abierta, Cierto / Falso y con preguntas de múltiples opciones.

- Agrupar a los alumnos en 4 niveles diferentes (de hasta 20 alumnos) según los resultados del test de nivel inicial. A partir de este punto adaptamos los contenidos a cada grupo para que todos puedan llegar al final del curso con el nivel requerido. Por lo tanto, generamos y fomentamos el uso de material docente de refuerzo, de obligada lectura y adaptado al nivel de cada grupo para alcanzar el nivel mínimo requerido para realizar la práctica. Además, los grupos de nivel más alto se les puede motivar con ejemplos y aplicaciones más avanzadas.

- Con el fin de motivar a los alumnos a realizar los cuestionarios y las prácticas hemos cambiado la forma de evaluarlos. Hasta la aplicación de la innovación, tanto los cuestionarios como las prácticas contaban en un pequeño porcentaje en la nota final. Lo que se ha aplicado es cambiar el concepto de práctica puntuable al concepto de práctica necesaria para el proceso de aprendizaje. Así pues, a aplicamos el siguiente sistema de evaluación: si el cuestionario o práctica está correcto, la nota es un 0 . Si por el contrario está suspendida, la nota es -1. Si se ha realizado el correcto aprendizaje, la nota del proyecto final no queda penalizada por la nota de prácticas. Por el contrario, si no se ha llevado a cabo el proceso de aprendizaje, la nota final del alumno sí quedará penalizada. Dicho de otra manera, el equipo docente pretende fomentar la realización de los cuestionarios y las prácticas y pretende penalizar en la nota final el no haber realizado las actividades.

- Uso del entorno "Moodle" para generar cuestionarios en línea de respuesta abierta para motivar que el alumno prepare las sesiones de discusión técnicas en clase y obligar al alumno a preparar las prácticas antes de la clase presencial. Estos cuestionarios son obligatorios y se realizan antes de la realizar los debates. Esto Por también permite conocer las carencias de cada alumno y, por tanto, permite hacer una actuación sobre cada alumno para que alcance los conceptos mínimos requeridos.

- Uso del entorno "Moodle" y "Wikispaces" moderado por el profesor para generar lo que se llama «e-learning» colaborativo. Con estas herramientas el alumno es parte activa en el aprendizaje ya que tanto puede proponer actividades a los compañeros como solucionar o preguntar dudas. El hecho de que el moderador sea el profesor asegura que el resultado final siempre es el adecuado. De esta manera, el profesor dedica menos horas de visita para solucionar dudas. De igual manera, 
permite al alumno realizar el aprendizaje de manera autónoma y, como utiliza herramientas virtuales, el estudiante se desinhibe a la hora de resolver dudas.

La innovación en este punto reside en que el alumnado puede preguntar dudas y también puede contestar las dudas de otros compañeros. Si esto no sucede, el equipo docente es el encargado de provocar/fomentar la participación de los alumnos. En un futuro próximo, el equipo docente tendrá todos los datos necesarios para generar un documento de "preguntas frecuentes" que habrá sido generarado por los propios alumnos.

- Uso del entorno "Moodle" para motivar el trabajo colaborativo en red para aquellas prácticas que puedan hacer en grupo. La innovación reside en hacer que la mitad de cada grupo realice un transmisor y la otra mitad realice un receptor para fomentar la colaboración (para que el sistema final funcione, los alumnos deben utilizar el sistema de comunicación complementario de otro compañero). El principal beneficio es la mejora del trabajo en equipo de los alumnos ya que no nos encontramos con las típicas excusas como "no tenía tiempo de quedar con los compañeros" o "no le hemos dicho nada a la otro compañero porqué no nos cae bien".

En resumen, la innovación docente ha adaptado la asignatura a una serie de prácticas integradas donde se evalua el nivel de cada alumno mediante una serie de cuestionarios creados especialmente para esta tarea y, actuamos sobre cada alumno a través de material docente extra y el uso de herramientas «online» que permiten el aprendizaje colaborativo y acompañar al alumno hasta alcanzar el nivel requerido.

\section{Resultados}

La implementación de la innovación docente se está llevando a cabo durante este curso 2016-17 (semestre de primavera). Los resultados que presentamos aquí son provisionales, dado que sólo podemos comparar el numero de abandonos que ha habido hasta la mitad de las prácticas. Tabla 1 presenta los detalles de alumnos matriculados, abandonos (no presentados más des-matriculados), numero de aprobados (dos convocatorias) y suspensos de la asignatura durante los años previos a la implementación de la innovación y a partir de ella.

Tabla 1. Num. De alumnos matriculados, abandonos, aprobados y suspensos por curso

\begin{tabular}{ccccc}
\hline Alumnos & $\mathbf{2 0 1 3}$ & $\mathbf{2 0 1 4}$ & $\mathbf{2 0 1 5}$ & $\mathbf{2 0 1 6}$ \\
\hline Matriculados & 17 & 24 & 27 & 28 \\
Abandonos & 9 & 10 & 15 & $3 *$ \\
Aprobados & 11 & 17 & 12 & \\
Suspendidos & 2 & 1 & 0 & \\
\hline
\end{tabular}

(cc) EY-NC-ND 2017, Universitat Politècnica de València 
*Datos provisionales

Los indicadores de evaluación que esperamos que determinen si el alumnado ha mejorado son los siguientes:

- Reducción de errores de conceptos básico a los exámenes. Hasta la aplicación de la innovación, entre un $15 \%$ y $20 \%$ de los alumnos matriculados no terminaba el curso sabiendo realizar las estructuras mínimas enseñadas a principio de este. Esperamos reducir este porcentaje al 2\% o 3\%.

- Disminución de la tasa de abandono.

- Reducción del esfuerzo dedicado del alumno. Actualmente el alumnado no encuentra que el esfuerzo de la asignatura se adecue a los créditos de esta (6 creditos) y, según las quejas del alumnado, la asignatura debería tener "muchos más" créditos. Esperamos reducir este esfuerzo para que el alumno tenga la percepción real de las horas dedicadas a la asignatura. Los resultados los mediremos con las encuestas, donde se mide el tiempo real dedicado a la asignatura.

- Tasa de aprobados y aumento del número de alumnos presentados

\section{Conclusiones}

La innovación docente presentada pretende medir y cuantificar de manera objetiva los resultados sobre el estudiante a través de las acciones indicadas previamente. Es por eso que como resultado final se obtendrá:

- Tiempo real que ha dedicado cada estudiante en la asignatura. Esto se obtendrá a través de las encuestas realizadas durante el curso. De esta manera el esfuerzo del alumnado deja de ser una percepción.

- Medida de la tasa de abandono.

- Logro por parte del alumnado del nivel final requerido para aprobar.

- Mejora en la realización de las prácticas.

Durante la aplicación de la innovación docente hemos observado que, de momento, la tasa de abandono se ha reducido, aunque no nula. Además, la implicación del alumnado es más alta: se preparan las prácticas, trabajan en el laboratorio (sólo en un par de casos excepcionales se les ha tenido que llamar la atención por no estar trabajando), el $85 \%$ aprueba sin problemas los cuestionarios (de los suspendidos la mitad lo hace con un 4 o más), casi el $80 \%$ de los alumnos ha hecho una propuesta de proyecto.

El único problema que, a día de hoy, observamos es la baja participación nos los foros. La mayoría de las participaciones han sido promovidas por el equipo docente. 
Mejora de la implicación del alumnado en "Diseño y sintesis de sistemas digitales" usando e-learning colaborativo, gamificación y aprendizaje basado en problemas

\section{Referencias}

FONT, A. (2004) "Líneas maestras del Aprendizaje por Problemas", Revista Interuniversitaria de

Formación del Profesorado. vol. 18, num. 1, p. 79-92.

MICHAELSEN, L.K.; SWEET, M. (2009) "The essential elements of team-based learning", Team-Based Learning: Small Group Learning's Next Big Step. New Directions in Teaching and Learning, p. 7-27.

KAPP, K. (2012) The gamification of learning and instruction. Game-based methods and strategies for training and education. San Francisco: Pfeiffer-Wiley.

KHAIRY, B. (2015) "The Standards of Intelligent Collaborative e-Learning of e-Courses Based on Web”, Conference on e-Learning (econf), 2015 Fifth International, p. 486-493.

WILLEY, K. (2016) "Combining a collaborative learning framework with an e-learning tool to improve learning and professional development in blended learning environments", Future Technologies Conference (FTC), p. 1303-1304.

(c) EY-NC-ND 2017, Universitat Politècnica de València 


\title{
Herramientas Software para Enseñanzas Relacionadas con la Energía Solar Fotovoltaica
}

\author{
Rafael Peña Capilla ${ }^{a}$, María del Pilar García Díaz ${ }^{a}$, Cristina Alén Cordero ${ }^{a}$, Pablo \\ Díaz Villar ${ }^{a}$, Ricardo Mallol Poyato ${ }^{a}$, Ana M. Díez-Pascual ${ }^{b}$.
}

a'Departamento de Teoría de la Señal y Comunicaciones (rafael.pena@uah.es, pilar.garcia@uah.es, cristina.alen@uah.es, pablo.diaz@uah.es, ricardo.mallol@uah.es), ${ }^{b}$ Departamento de Química Analítica, Química Física e Ingeniería Química (am.diez@uah.es).

\begin{abstract}
This paper describes different simulation tools developed in the Universidad de Alcalá in order to teach photovoltaic energy engineering. A web application is compared to other tools, such as spreadsheets and applications in Matlab environment, developed by the authors.
\end{abstract} In all the cases, the tools are focused on learning project engineering.

Keywords: E-learning, Solar Engineering, Software Tools.

\section{Resumen}

En este trabajo, se describen diferentes herramientas de simulación empleadas en asignaturas de la Universidad de Alcalá para la enseñanza de la energía solar fotovoltaica.

Se compara el uso de una aplicación web con otras herramientas como hojas de cálculo y aplicaciones en entorno Matlab. Todas las herramientas descritas han sido desarrolladas por los autores, haciendo especial énfasis en su enfoque didáctico, sin por ello perder todo el rigor y la funcionalidad necesarios en este tipo de simuladores.

Palabras clave: E-learning, Energías Renovables, Herramientas software.

\section{Introducción}

Las herramientas software son comúnmente empleadas como apoyo al desarrollo de proyectos de ingeniería en muy diferentes campos. En particular, en el área de las energías renovables (solar fotovoltaica, térmica, eólica...), tecnologías en fuerte expansión a lo largo de los últimos años.

En el campo de la energía solar, existen programas comerciales que permiten dimensionar las instalaciones y evaluar su rendimiento. Algunos de los ejemplos más representativos son PVGIS, PVSYS o Censol (Dunlop y Wald, 2006). 
Además, es muy común emplear hojas de cálculo o programas desarrollados en lenguajes como Matlab, Python, Octave, etc.

Dichas aplicaciones suelen estar enfocadas a la fase de diseño de la instalación, en la que ya se conocen con cierto detalle las características básicas de ésta: emplazamiento de los componentes, características constructivas de dicho emplazamiento, trazado aproximado del cableado de la instalación, etc. Además, las mencionadas herramientas están concebidas para ser utilizadas por proyectistas ya formados, con los conocimientos teórico-prácticos adquiridos y con cierta experiencia en el sector.

En consecuencia, todas estas herramientas suelen ser poco eficientes a la hora de realizar tareas propias de la fase de anteproyecto, en la que es fundamental obtener un dimensionado aproximado de la instalación en poco tiempo y con suficiente precisión. Y teniendo en cuenta que, en ocasiones, las citadas herramientas son empleadas por ingenieros en formación.

Además, los simuladores para instalaciones solares no están diseñados con un enfoque didáctico, que permita reforzar los conceptos teóricos que subyacen tras las ecuaciones empleadas.

\section{Objetivos}

El objetivo principal del trabajo es analizar las diferentes opciones disponibles como herramientas de diseño de proyectos de energía solar enfocadas al aprendizaje de la ingeniería. E identificar las principales ventajas e inconvenientes de cada alternativa en cuanto a su eficacia en los aspectos didácticos.

Se presenta en primer lugar el proyecto PVLEARNING, desarrollado en un entorno web. La herramienta asiste al ingeniero en la realización de diversas tareas de diseño de sistemas fotovoltaicos entre las que cabe destacar las siguientes:

- Evaluación de la radiación solar disponible en el emplazamiento seleccionado.

- Selección de los módulos fotovoltaicos y del inversor o inversores.

- Configuración del campo solar (filas de módulos en serie y/paralelo) y del inversor.

- Cálculo del rendimiento de la instalación.

También se han empleado con el mismo propósito una hoja de cálculo desarrollada por los autores y un programa en entorno Matlab. En el artículo se discuten las ventajas e inconvenientes de las diferentes opciones, y su influencia en los procesos de enseñanza / aprendizaje. 
Rafael Peña Capilla, María del Pilar García Díaz, Cristina Alén Cordero, Pablo Díaz Villar, Ricardo

Mallol Poyato, Ana M. Díez-Pascual

\section{Desarrollo de la innovación}

Se describen a continuación las herramientas desarrolladas en la Universidad de Alcalá para la simulación de sistemas solares fotovoltaicos.

\subsection{Entorno web PVLEARNING}

El proyecto PVLEARNING se ha desarrollado en sucesivas fases, que se describen a continuación.

- Elaboración de un modelo teórico para la producción energética de instalaciones fotovoltaicas con conexión a red.

Se ha realizado una búsqueda bibliográfica para determinar qué modelos teóricos se han utilizado hasta la fecha como base de los actuales programas de simulación. En particular, se han seleccionado los descritos en (Schmid 1992; Lorenzo 2002, Lorenzo 2006, Caamaño \& Egido, Alonso \& Chenlo).

Con esta base, se ha desarrollado un nuevo modelo con las características ya descritas: enfocado al aprendizaje de la ingeniería de proyectos pero manteniendo toda la funcionalidad y precisión en su utilización en la fase de diseño de proyecto.

Así, el modelo de cálculo empleado toma como base fundamentos teóricos que cumplen un compromiso entre sencillez y rigurosidad. Por ello, emplea pocos parámetros que, además, son de fácil obtención e interpretación.

PVLEARNING calcula la energía generada por un sistema fotovoltaico mediante la siguiente expresión:

$$
E_{A C}=P \cdot G_{a e f} \cdot F P
$$

Siendo P la potencia de pico del generador fotovoltaico, Gaef el valor de la irradiación anual efectiva en el plano de los módulos (en horas de sol de pico) y FP un factor que engloba las pérdidas del sistema.

Para el cálculo de dicho factor, se han tenido en cuenta las siguientes pérdidas:

- Pérdidas debidas al rendimiento del inversor

- Pérdidas debidas a la presencia de suciedad en los módulos

- Pérdidas debidas a la temperatura

- Pérdidas por sombreado

- Pérdidas espectrales y angulares

- Pérdidas por dispersión de parámetros (mismatch)

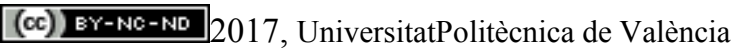

Congreso In-Red (2017) 
- Pérdidas por efecto Joule en el cableado de corriente continua y corriente alterna

- Otras pérdidas, como la disminución del rendimiento de los componentes a baja irradiancia o la no disponibilidad de éstos en paradas por mantenimiento o por averías.

El detalle de las ecuaciones utilizadas para cada una de los factores de pérdidas queda fuera del alcance de este artículo.

PVLEARNING 10-11

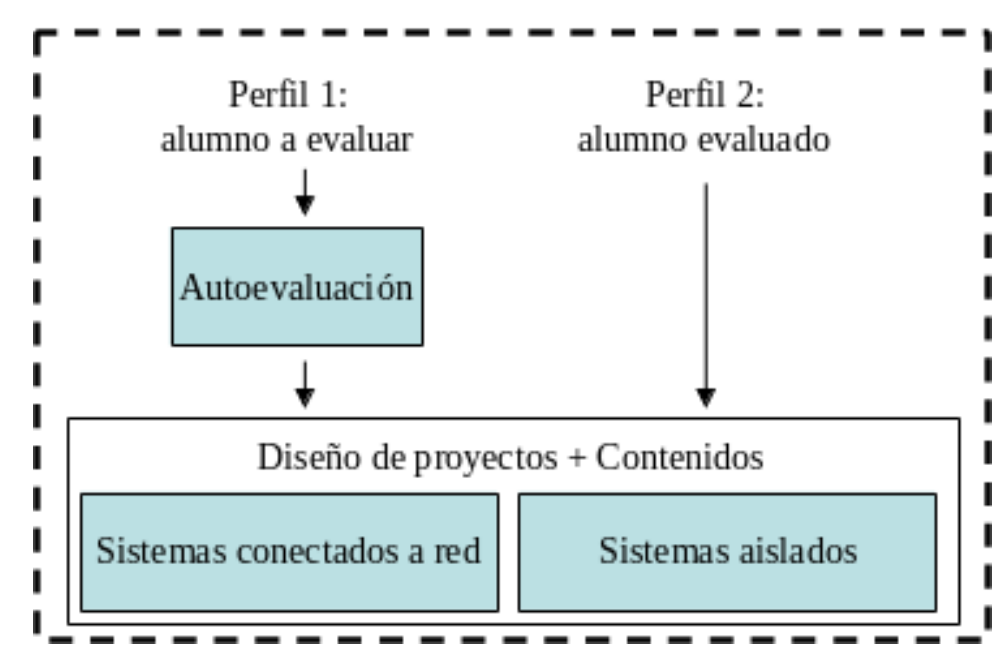

Figura 1: esquema simplificado de la estructura de la plataforma PVLEARNING.

- Desarrollo del programa fuente para la simulación de sistemas fotovoltaicos. Verificación de los resultados.

Tras obtener las expresiones analíticas del modelo, se ha realizado la herramienta software que constituye el núcleo de cálculo de PVLEARNING. Para ello, se ha utilizado Matlab, lenguaje de programación muy adecuado para este tipo de simulaciones.

El programa se ha probado exhaustivamente, realizando múltiples simulaciones de sistemas fotovoltaicos. En particular, se ha comparado con PVSYST, la herramienta más utilizada en este campo.

Se han obtenido diferencias entre los resultados obtenidos con PVLEARNING y los de PVSYST menores del $2 \%$ en sistemas fijos y menores del $5 \%$ en sistemas con seguimiento. Estos valores son muy notables, teniendo en cuenta la sencillez del modelo desarrollado y la facilidad de uso de la aplicación.

- Desarrollo de la interfaz gráfica para la utilización del software en un entorno web.

Tras obtener el núcleo del programa y una vez depurado éste, se ha implementado la interfaz gráfica para su utilización en Web. Dicha interfaz ha sido realizada con

(c) ) EY-NG-ND ValènciaValènciaValènciaValènciaValènciaValència 
los lenguajes PHP y Java Script. Para las bases de datos empleadas por la aplicación se ha utilizado MySQL.

- $\quad$ Puesta en marcha de la plataforma desarrollada. Aplicación a la mejora de la docencia en asignaturas del Área de Ingeniería Industrial de la Universidad de Alcalá.

Los usuarios de PVLEARNING pueden acceder, previa autenticación, a dos perfiles o modalidades diferentes (véase figura 1).

- Modalidad de autoevaluación

Los usuarios que acceden al tipo de perfil 1, pueden crear un proyecto con toda la funcionalidad del sistema. Sin embargo, la solución para el problema seleccionado no está disponible hasta que éste ha introducido la suya propia, tras haberla calculado por su cuenta. En ese momento, el sistema proporciona la solución correcta y la compara con la introducida previamente. En el caso de que la comparación sea favorable (solución correcta), el usuario pasa a tener perfil 2 , de diseño de proyecto.

- Modalidad de diseño de proyecto

Los usuarios que acceden con este tipo de perfil o bien ya han adquirido los conocimientos básicos, asistidos por la herramienta en la modalidad de autoevaluación, o están autorizados directamente por los administradores. Esta última opción permite que ingenieros ya formados no tengan que pasar por el filtro del perfil 1.

La Figura 2 muestra la interfaz principal en ésta modalidad, para el caso de instalaciones conectadas a la red, en la que el programa funciona como un simulador "al uso". Dicha interfaz dispone de dos bases de datos, una para la selección del emplazamiento de la instalación (primer paso a la hora de diseñar un sistema) y otra para la selección de los principales componentes (paneles solares e inversor). 


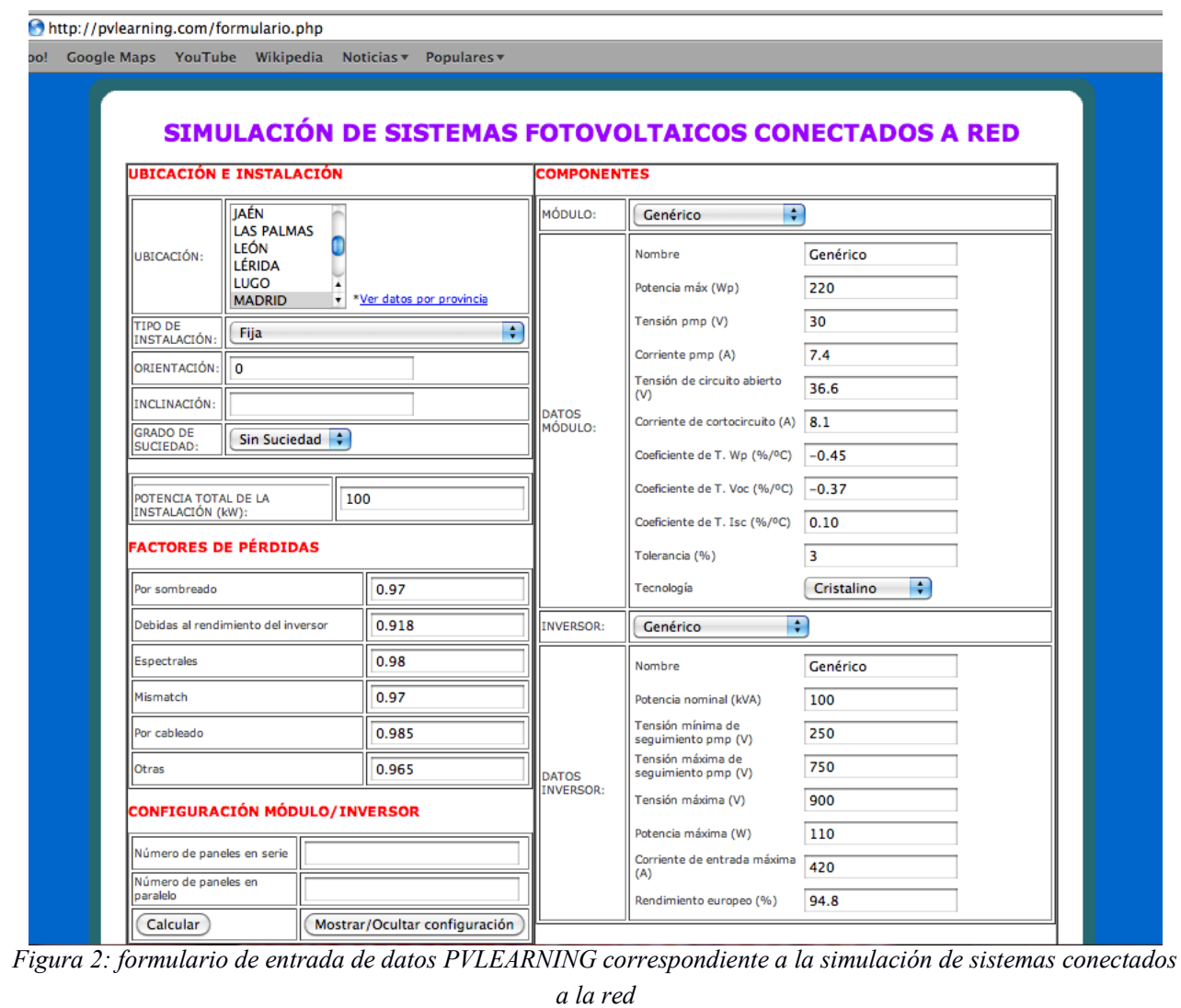

Al elegir una determinada ubicación, la interfaz asigna los valores correspondientes para la irradiación disponible en ella. El usuario también debe elegir el tipo de instalación (fija, con seguimiento en un eje o en dos ejes). En el primer caso, además habrá de introducir la orientación o azimut de los paneles y su inclinación con respecto a la horizontal. Todos estos parámetros son utilizados por el modelo descrito anteriormente.

También es necesario seleccionar el grado de suciedad de los módulos, sin suciedad en el caso de que estén limpios y grado medio para el caso de que tengan el nivel de suciedad típico esperado en instalaciones solares.

Por último, el usuario puede modificar los factores de pérdidas calculados por el programa, o bien dejar los valores por defecto (opción recomendada).

Una vez configurada la simulación, el programa muestra los resultados que aparecen en la figura 3: la energía anual producida por el sistema, la productividad final, el performance ratio (PR) y los valores de irradiación anual característicos del sistema (con y sin sombras).

Además de sistemas conectados a la red eléctrica, PVLEARNING permite dimensionar sistemas fotovoltaicos aislados (figura 4). El modelo empleado para este tipo de sistemas es una simplificación del método del mes peor, de amplia utilización. Los parámetros de entrada para dicho modelo son la irradiación mensual en el plano del generador en la ubicación seleccionada, el consumo anual previsto y las características básicas de los paneles solares y de las baterías a emplear.

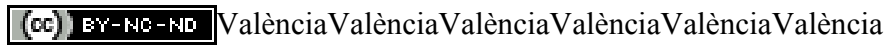


Rafael Peña Capilla, María del Pilar García Díaz, Cristina Alén Cordero, Pablo Díaz Villar, Ricardo Mallol Poyato, Ana M. Díez-Pascual

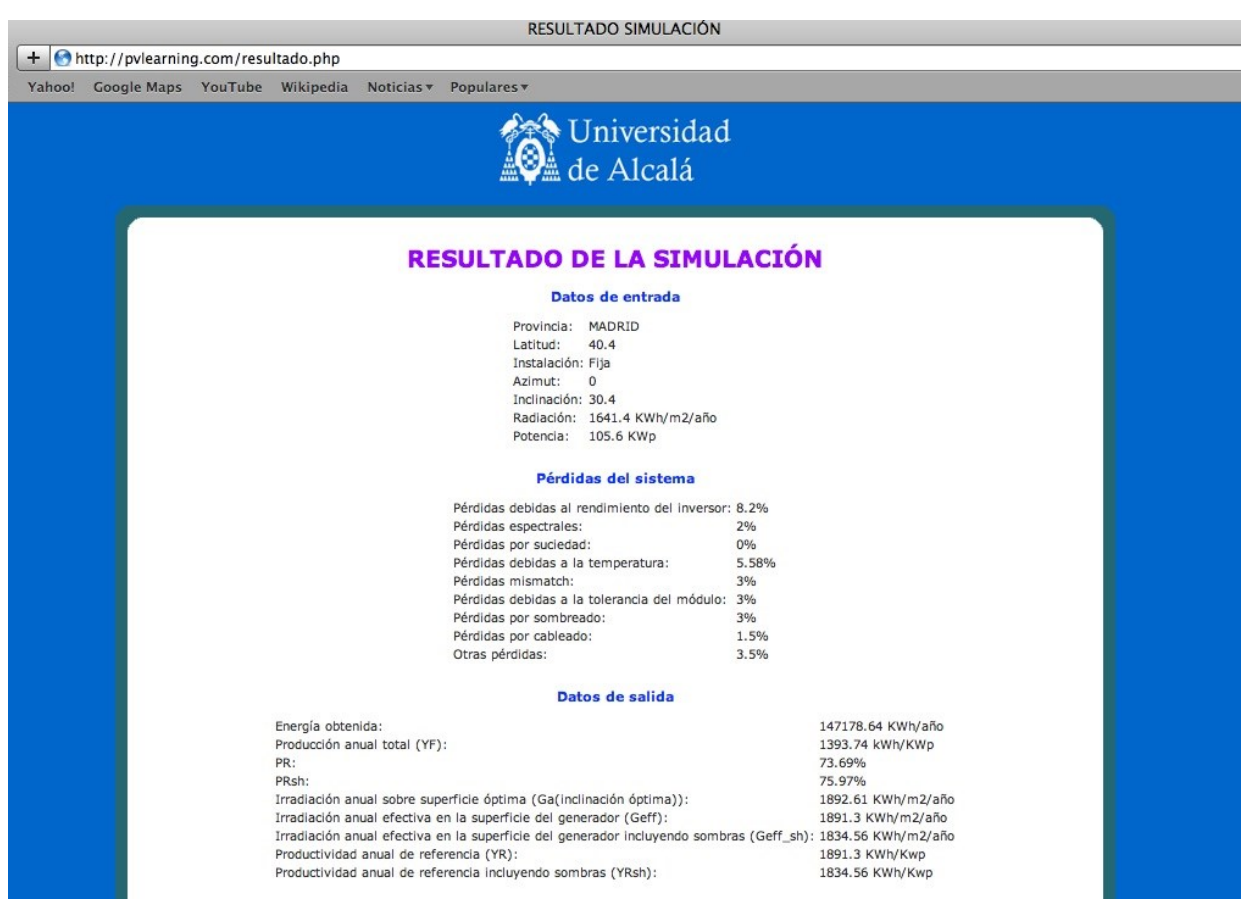

Figura 3: formulario de salida de PVLEARNING con los resultados para un sistema conectado a la red

\begin{tabular}{|c|c|c|c|c|c|c|c|c|c|}
\hline \multicolumn{10}{|c|}{ Q http://pvlearning.com/formulario1.php } \\
\hline \multicolumn{10}{|c|}{ o! Google Maps YouTube Wikipedia Noticiasv Populares- } \\
\hline \multicolumn{10}{|c|}{ SIMULACIÓN DE SISTEMAS FOTOVOLTAICOS AISLADOS DE LA RED } \\
\hline \multicolumn{6}{|c|}{ UBICACTÓN } & \multicolumn{4}{|c|}{ COMPONENTES } \\
\hline \multirow{3}{*}{\multicolumn{2}{|c|}{ |ustcación: }} & \multirow{3}{*}{\multicolumn{2}{|c|}{ 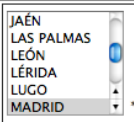 }} & & & MḾoulo: & Genérico & \multicolumn{2}{|l|}{ 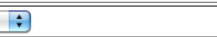 } \\
\hline & & & & & & \multirow{5}{*}{$\begin{array}{l}\text { arros } \\
\text { Moovilo: }\end{array}$} & Nombre & \multicolumn{2}{|l|}{ Genérico } \\
\hline & & & & ycdotos oor oro & & & Potencia máx (WP) & \multicolumn{2}{|l|}{75} \\
\hline \multicolumn{2}{|c|}{ Inclinación (0): } & \multicolumn{4}{|c|}{$60 \div$} & & Tensión pmp (V) & \multicolumn{2}{|l|}{17.3} \\
\hline \multirow{2}{*}{\multicolumn{6}{|c|}{ CONSUMOS DC }} & & $\begin{array}{l}\text { Corriente pmp (A) } \\
\text { Tensión de circutoto abierto }\end{array}$ & \multicolumn{2}{|l|}{4.34} \\
\hline & & & & & & & {$\left[\begin{array}{l}M \\
\text { Corriente de cotocircuito }\end{array}\right.$} & \\
\hline Tripo & Nimero & Potencia(W) & Hores/dia & 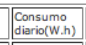 & $\begin{array}{l}\text { Consumon } \\
\text { diario(A.h) } \\
\end{array}$ & EATERTiA: & & & \\
\hline Televisión & 0 & 100 & 2 & 0 & 0.00 & \multirow{2}{*}{$\begin{array}{l}\text { DaATOS } \\
\text { OATERA: }\end{array}$} & Capacidad C100 (Ah) & \multicolumn{2}{|l|}{250} \\
\hline Firigoritico & 0 & 100 & 2 & 0 & 0.00 & & Tensiön (v) & \multicolumn{2}{|l|}{12} \\
\hline 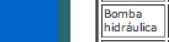 & 0 & 150 & 1 & 0 & 0.00 & \multicolumn{4}{|c|}{ PARÁmetros del sistema } \\
\hline Bambilises & 0 & 11 & 4 & 0 & 0.00 & \multirow{2}{*}{\multicolumn{2}{|c|}{ Factor de seguridad del generador }} & & \\
\hline Ordenasort & $\longdiv { 0 }$ & 200 & $\sqrt{2}$ & 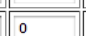 & 0.00 & & & & 1.25 \\
\hline otros & $\sqrt{0}$ & 100 & 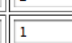 & (0 & 0.00 & \multicolumn{2}{|c|}{ Oias de autonomia de la bateria } & 5 & \\
\hline & TOTAL & 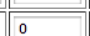 & & 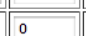 & 0.00 & \multicolumn{2}{|c|}{ POmax } & & 0.8 \\
\hline & & & & & & \multicolumn{2}{|c|}{ Rendimiento del inversor } & & 0.9 \\
\hline Calcular & consum & & & & & \multicolumn{2}{|c|}{ Tensibin del sistema (V) } & (1. & \\
\hline & \multicolumn{5}{|c|}{ CONSUMOS AC } & & & & \\
\hline Tripo & Número & Potencia(W) & Horess/dia & 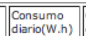 & $\begin{array}{llll}\begin{array}{c}\text { Consumono } \\
\text { diaribitAn }\end{array} \\
\end{array}$ & & & & \\
\hline Televisión & $\mid 0$ & $\mid 100$ & 2 & 0 & 0.00 & & & & \\
\hline 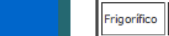 & $\overline{0}$ & 100 & $\sqrt{2}$ & 0 & 0.00 & & & & \\
\hline 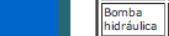 & 0 & 150 & 1 & 0 & 0.00 & & & & \\
\hline
\end{tabular}

Figura 4: formulario de entrada de datos de www.pvlearning.com correspondiente a la simulación de sistemas aislados.

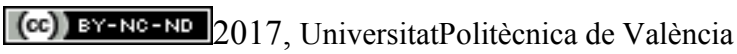
Congreso In-Red (2017) 
Tras estimar los consumos de la instalación y seleccionar los componentes y la ubicación, el programa calcula la potencia necesaria para los paneles y la capacidad de las baterías del sistema.

\subsection{Herramientas de simulación en forma de hoja de cálculo y en entorno Matlab}

El modelo teórico para la simulación de instalaciones fotovoltaicas se ha programado en Matlab, lenguaje de programación muy adecuado para este tipo de simulaciones, y también se ha desarrollado una hoja de cálculo con las mismas ecuaciones (figuras 5 y 6). En ambos casos, se han incluido las herramientas para simular instalaciones conectadas y aisladas de la red.

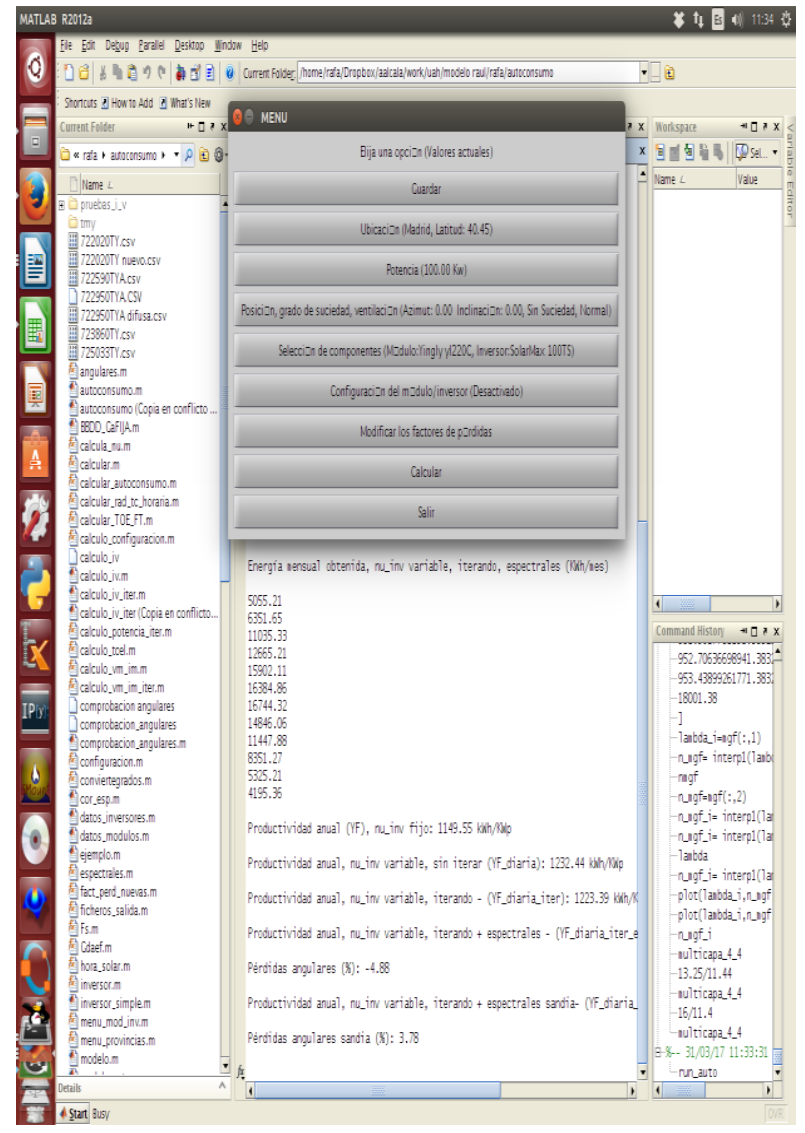

Figura 5: herramienta desarrollada en entorno Matlab para la simulación de sistemas fotovoltaicos conectados a la red. 


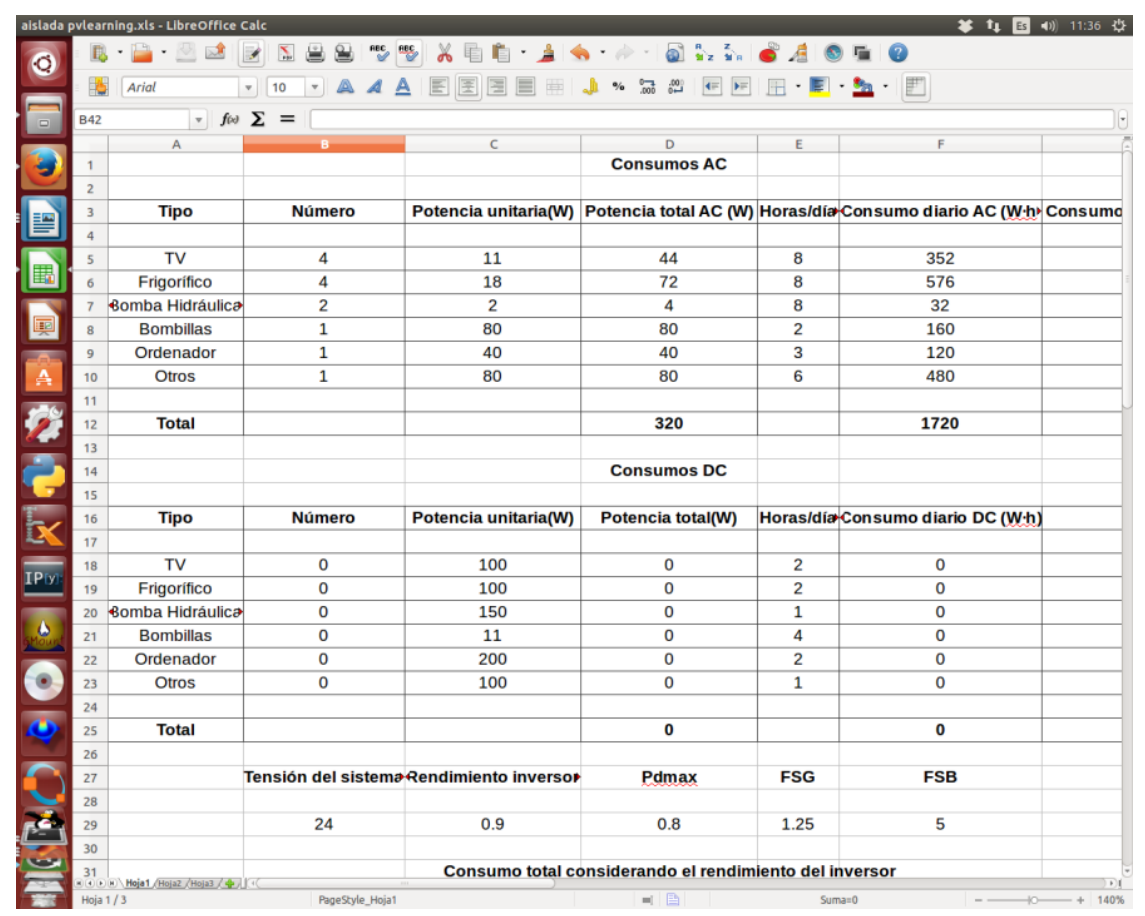

Figura 6: hoja de cálculo desarrollada para la simulación de sistemas fotovoltaicos aislados de la red.

\section{Resultados}

La primera opción presentada, la web PVLEARNING, ha sido utilizada en asignaturas de grado y postgrado del Área de Ingeniería Industrial de la Universidad de Alcalá. Además, el programa servirá también para la enseñanza de la energía solar en cursos de formación impartidos a profesionales.

En particular, desde el curso 2010-2011 hasta el 2014-2015, PVLEARNING se empleó en las asignaturas Suministro Eléctrico de Instalaciones Autónomas mediante Energías Renovables, del Máster Universitario en Tecnologías de la Información y las Comunicaciones (optativa de primer curso) y Proyecto Fin de Carrera, de la Ingeniería Técnica Industrial, especialidad en Electrónica Industrial (troncal de tercer curso, recientemente extinguida). Además, se está utilizando en asignaturas optativas del Grado en Ingeniería en Electrónica y Automática Industrial y en trabajos fin de grado y fin de máster realizados en el área de Ingeniería Eléctrica.

Como se comentó con anterioridad, una de las características diferenciadoras del proyecto PVLEARNING es su enfoque al aprendizaje de la ingeniería solar fotovoltaica. Las simulaciones se emplean en el aula como complemento a las clases teóricas, al final de éstas, para servir de nexo entre los contenidos puramente teórico-académicos y los relacionados con las tareas de diseño de proyecto-ingeniería. De esta manera, se refuerzan los conceptos expuestos y se hace énfasis en su utilidad práctica. Además, el alumno toma 
el primer contacto con una herramienta de diseño como las que habrá de utilizar en su trayectoria profesional. Todo ello no sólo tiene como consecuencia un aumento de la eficacia del proceso enseñanza - aprendizaje, si no que también redunda en una mayor motivación del alumno a la hora de estudiar conceptos con un elevado nivel de dificultad.

Además, los estudiantes emplean PVLEARNING para realizar trabajos de evaluación de la asignatura, de manera autónoma (de manera semejante a como lo hacen los estudiantes de Trabajo fin de Grado). Para ello, han de superar la fase de autoevaluación, descrita con anterioridad.

Con respecto a la influencia de la herramienta en el proceso enseñanza-aprendizaje, ésta se ha utilizado sobre una muestra de 90 alumnos, en las asignaturas mencionadas con anterioridad. La propia página web ha servido como herramienta para la recogida de la información, puesto que los estudiantes hubieron de acceder a la modalidad de autoevaluación antes de poder realizar las simulaciones correspondientes a su trabajo.

Los resultados obtenidos son muy positivos. Con respecto a la experiencia anterior con las mismas asignaturas, se ha detectado un menor número de abandonos y una mejora significativa en la calidad de los trabajos de evaluación presentados. Cabe achacar esta mejora a los siguientes factores relacionados con la utilización de PVLEARNING:

- La herramienta sirve de nexo entre los contenidos puramente teórico-académicos y los relacionados con las tareas de diseño de proyecto-ingeniería. Así, la utilización de las TIC en el estudio permite reforzar los conceptos, haciendo énfasis en su utilidad práctica.

- Hay un aumento en la motivación del alumno a la hora de estudiar conceptos con un elevado nivel de dificultad. Esto es consecuencia del empleo de una herramienta de diseño como las que habrá de utilizar en su trayectoria profesional.

- Se ha detectado un mayor nivel de participación en clase, como consecuencia del aumento de la motivación de los estudiantes.

Con respecto a PVLEARNING, el programa en Matlab y la hoja de cálculo anteriormente descritos presentan las siguientes desventajas:

- Requieren de la instalación previa en el ordenador del alumno, que además debe tener un sistema operativo compatible con Matlab o con Microsoft Office / LibreOffice / OpenOffice.

- La implementación de la modalidad de autoevaluación es posible, pero el envío y registro de los resultados no es automático, debe ser realizado de manera "manual" por los estudiantes y el profesor. En el caso de PVLEARNING, la propia página web sirve como herramienta para la recogida de la información

- La incorporación de los conceptos teóricos que hay tras las ecuaciones del modelo se puede realizar tanto en entorno Matlab como en una hoja de cálculo. Sin embargo, el entorno web permite una integración visual mucho más atractiva, más intuitiva, y una mayor usabilidad.

(c) ) EY-NG-ND ValènciaValènciaValènciaValènciaValènciaValència 
Rafael Peña Capilla, María del Pilar García Díaz, Cristina Alén Cordero, Pablo Díaz Villar, Ricardo Mallol Poyato, Ana M. Díez-Pascual

- Ambas opciones no permiten la interacción directa entre el estudiante y el profesor, algo que si permite la alternativa "online".

\section{Conclusiones}

En este trabajo, se presentan 3 herramientas para el diseño de proyectos de energía solar, todas ellas enfocadas al aprendizaje de la ingeniería; y se identifican las principales ventajas e inconvenientes de cada alternativa en cuanto a su eficacia en los aspectos didácticos.

Así, se presentan el proyecto PVLEARNING, desarrollado en un entorno web, una hoja de cálculo y un programa en entorno Matlab, todos desarrollados por los autores.

En todos los casos, las herramientas sirven de nexo entre los contenidos puramente teóricoacadémicos y los relacionados con las tareas de diseño de proyecto, reforzando los conceptos y haciendo énfasis en su utilidad práctica. Se ha observado un aumento en la motivación del alumno, como consecuencia del empleo de una herramienta de diseño como las que habrá de utilizar en su trayectoria profesional; y se ha detectado un mayor nivel de participación en clase.

Además de aspectos de índole más práctico (no es necesaria la instalación previa en el ordenador del alumno, ni disponer de un sistema operativo compatible), PVLEARNING permite integrar herramientas de autoevaluación, de recogida de datos relacionados con la evolución del aprendizaje y la integración de contenidos teóricos de forma mucho más atractiva y más intuitiva; y en general, una mayor usabilidad.

\section{Referencias}

ALONO, M., CHENLO, F. Estimación de la energía generada por un sistema fotovoltaico conectado a red. $\quad<$ http://www.energiasrenovables.ciemat.es/adjuntos_documentos/Alonso-chenlo.pdf $>$ [Consulta: mayo 2016].

DUNLOP, E., WALD, L. (2006). Solar Energy Resource Management for Electricity Generation from Local to Global Scale. New York: Nova Science Publishers.

LORENZO, E. (2006). Radiación Solar y Dispositivos Fotovoltaicos. Volumen II. Sevilla: Editorial Progensa.

LORENZO, E. (2002). La Energía que Producen los Sistemas Fotovoltaicos Conectados a la Red. Era Solar, 107, 22-28.

SCHMID, J. (1992). PV in Buildings. Actas del XI Congreso europeo de Energía Solar fotovoltaica. 1659-1663. 


\title{
¿Puede un conjunto de tareas evaluar la competencia "Análisis y Resolución de problemas" en una asignatura de grado?
}

\author{
Modesto Pérez-Sánchez ${ }^{a}$; M. Isabel Pérez-Sánchez, P. Amparo López-Jiménez ${ }^{\text {, }}$, \\ a Departamento de Ingeniería Hidráulica y Medio Ambiente. Universitat Politècnica de València. \\ palopez@upv.es; mopesan1@upv.es. \\ b Junta de Comunidades de Castilla La Mancha.
miperezs@edu.jccm.es
}

(*) Autor de correspondencia

\begin{abstract}
The active methodologies in which the student are involved in the learning process are crucial for the motivation in the current curriculum. In this sense, the proposal of tasks, in which the student confront a problem, is interesting for the teacher. The results, obtained by learning based on tasks, are shown through the developed case study in the matter Fluid-mechanics Engineering (Iti. 2), which is taught in the third course in the Mechanical Engineering Bachelor's Degree of the Escuela Politècnica Superior de Alcoy. The manuscript aim is to show six tasks make possible to evaluate the cross competence 'CT-03 Analysis and Solving the problems' as well as to improve the learning results of the specifics competences. The experience was developed throughout Poliformat platform, using Tasks tool, in which, the students were applied the evaluation peer review. The manuscript describes the developed rubrics and shows the high participation and satisfaction degree of the students when this learning methodology was applied.
\end{abstract}

Keywords: inductive methods, tasks, learning methods, evaluation peer review, tutorial

\section{Resumen}

Las metodologías activas en que los alumnos se involucran en el proceso de aprendizaje son cruciales para la motivación en los actuales planes de estudio. En este sentido, la propuesta de tareas en las que a través de pequeños análisis, el alumno se enfrenta a un problema, es una interesante para el docente. A través del caso de estudio, en la asignatura Ingeniería Fluidomecánica (Iti. 2) de tercer curso del Grado de Ingeniería Mecánica de la Escuela Politécnica Superior de Alcoy, el objetivo de la comunicación es mostrar que el desarrollo de 6 tareas puede evaluar la adquisición de la competencia transversal 'CT-03 Análisis y resolución de problemas' así como mejorar los resultados de aprendizaje en las competencias específicas. La experiencia ha sido llevada a cabo mediante el uso de la plataforma
} 
¿Puede un conjunto de tareas evaluar la competencia “Análisis y Resolución de problemas” en una asignatura de grado?

\begin{abstract}
PoliformaT, mediante la herramienta 'Tareas' empleando el uso de la evaluación por pares. La comunicación describe las rubricas desarrolladas, muestra la gran participación y resultados obtenidos de aplicar esta técnica, así como el alto grado de satisfación por parte del alumnado.
\end{abstract}

Palabras clave: métodos inductivos, tareas, métodos de aprendizaje, evaluación por pares, tutorías.

\title{
1. Introducción
}

Desarrollar las competencias de autonomía y responsabilidad en los alumnos, es un objetivo imprescindible, no solo en la etapa universitaria, sino también, desde las etapas escolares más tempranas (Infantil, Primaria, Educación Secundaria y Bachillerato).

Actualmente, las nuevas estrategias educativas impulsadas por las leyes educativas, implican la puesta en marcha de metodologías activas con las que se pretende hacer al alumno protagonista de su proceso de aprendizaje y de la evaluación de los mismos ('aprender a aprender') con el fin de alcanzar el desarrollo máximo en los resultados de aprendizaje planificados.

Educar, enseñar por competencias, incluye la incorporación de conocimientos, habilidades y actitudes que en los sistemas educativos anteriores no se tenían presentes. La formación por competencias considera el papel activo del aprendiz en su aprendizaje apoyándose en las teorías del constructivismo (Fernández March, 2010).

Algunos autores definen "competencia" como:

- Nivel de consecución y puesta en práctica de todas las habilidades y destrezas aprendidas en cualquiera de las situaciones que se presenten en la práctica profesional (Kane, 1992).

- Saber hacer uso de las capacidades, habilidades y conocimientos integrados en cualquier situación común que se presente (Lasnier, 2000).

- Capacidad de resolver problemas de forma autónoma haciendo uso del conjunto de conocimientos, procedimientos y actitudes adquiridas. (OIT, 2000).

- Asimilación e integración de ciertas habilidades, conocimientos y actitudes que nos permiten que nuestras acciones sean eficientes y efectivas (Collins, 2007).

Los docentes deben conseguir que los alumnos adquieran habilidades y destrezas que les permitan ser capaces de analizar y resolver problemas propuestos en cada una de las materias y contenidos impartidos a través de diferentes estrategias:

- Facilitando "tareas" que permita a los alumnos implicarse en la organización y desarrollo de cada uno de los contenidos impartidos.

Realizar actividades lo más auténticas posibles y con un nivel adecuado de complejidad según el momento formativo, convierte a las tareas en una experiencia de aprendizaje en sí misma y fundamental para el desarrollo de esta competencia. La contextualización de la evaluación puede ser desarrollada a

(c) EY-NC-ND 2017, Universitat Politècnica de València

Congreso IN-RED (2017) 
través de: tareas de evaluación similares a las desarrolladas en el campo profesional, atendiendo a las condiciones del ejercicio de la profesión y contexto social donde se desarrollan, con criterios de evaluación utilizados por expertos en el área de conocimiento (Barmant et al, 2007).

- El uso de las TIC favorece el intercambio de conocimientos y de la participación de los alumnos-docentes a través de foros o tutorías virtuales, llegando incluso a la autoevaluación o corrección entre alumnos.

La acción tutorial posibilita que los alumnos aprendan de sus errores, facilitar ayuda para superar sus dificultades, motivarles y consolidar sus aprendizajes.

En definitiva, consiste en orientar a los estudiantes en sus experiencias de aprendizaje para llegar a ser un aprendiz autónomo, competente y crítico.

- Desarrollo de la evaluación formativa y compartida para mejorar la calidad de la enseñanza (López, 2005). Algunas de las razones son:

- Permite mejorar los procesos de aprendizaje del alumnado ya que ayuda a corregir a tiempo las lagunas y problemas que surgen en el proceso de enseñanza-aprendizaje.

- Propicia el desarrollo de la capacidad de análisis crítico y la autocrítica.

- Aumenta la motivación e implicación del alumnado en el proceso de aprendizaje.

- Desarrolla la responsabilidad y autonomía del alumnado en los procesos de aprendizaje.

- Apoya la aparición de estrategias metacognitivas siendo estas fundamentales en la formación y estrategias de aprendizaje (Lifelong Learning).

- De acuerdo a lo marcado por EEES este tipo de evaluación es el más lógico ya que tiene en cuenta modelos de aprendizaje basados en el desarrollo de las competencias.

- Se observa un aumento y mejora en el rendimiento académico y de la calidad de la enseñanza, lo cual hace lógico la implantación y uso de este tipo de evaluación..

Desarrollar la competencia de análisis y resolución de problemas, consiste no solamente resolver un problema puntual sino en adquirir estrategias explicitas que permitan crear y transferir nuevos conocimientos. Esta competencia de resolución de problemas es una competencia fundamental por las siguientes razones:

- es una metodología para la acción, con enfoque global favoreciendo el aprendizaje permanente,

- es una estrategia innovadora y desafiante a las soluciones conocidas,

- es una estrategia que posibilita "ver de nuevo", el mejoramiento continuo,

- articula las tareas inmediatas con las perspectivas de largo plazo,

- posibilita identificar soluciones diferentes. 
¿Puede un conjunto de tareas evaluar la competencia “Análisis y Resolución de problemas” en una asignatura de grado?

\section{Objetivos}

El objetivo de la presente comunicación es mostrar la estrategia de aprendizaje llevada a cabo en la asignatura Ingeniería Fluidomecánica (Iti. 2) de tercer curso del Grado de Ingeniería Mecánica de la Escuela Politécnica Superior de Alcoy por docentes del Departamento de Ingeniería Hidráulica y Medio Ambiente. Esta asignatura troncal, se imparte en el segundo cuatrimestre, cuando el alumno ha cursado asignaturas troncales fundamentales para un grado de ingeniería, como son matemáticas, física y mecánica de fluidos. El alcance de estas asignaturas no solamente tienen un resultado en el aprendizaje de las competencias específicas sino que además, trabajan la capacidad de analizar y resolver problemas que aunque en ocasiones no están ligados directamente con la futura profesión del alumno, permiten desarrollar la capacidad de análisis y búqueda de soluciones en unas condiciones más abstractas.

Desde el punto de vista de los autores, cursar la asignatura Ingeniería Fluidomecánica, no sólo debe conseguir alcanzar los resultados de aprendizaje establecidos en las competencias generales y específicas definidas por el Plan de Estudios, sino que además los docentes implicados deben ser capaces de trabajar con el alumno su capacidad cognitiva para que a través de metodologías activas, el aprendizaje profundo sea desarrollado por el mismo, alcanzando un nivel de domino II en el análisis y resolución de problemas. Asíel estudiante debe:

- Identificar las variables que intervienen en el problema, simplificándolo en unidades más sencillas que permitan su resolución,

- Contrastar los datos aportados por el problema y búsqueda de aquellos que deben ser supuestos, con un resultado favorable,

- Desarrollar una metodología en base a las condiciones de contorno y problemática planteada, adoptando una solución lo más eficiente posible,

- Determinar la solución óptima a partir de criterios fundamentados en el aprendizaje adquirido por parte del alumno en dicha asignatura y cursos anteriores. Elegir una solución óptima mediante criterios justificados.

Este primer punto de partida, en el nuevo diseño del aprendizaje del alumno en la asignatura de Ingeniería Fluidomecánica, busca no sólo incorporar la evaluación de la competencia 'CT-03 Análisis y Resolución de Problemas' por ser ésta, punto de control, sino que trata de 'movilizar' el aprendizaje del alumno desde un punto de vista de su actividad en el proceso de aprendizaje, trabajando para intentar que el alumno abandone actitudes pasivas dentro del rol del aprendizaje y pase a un rol de mayor actividad, en la cual se sienta el actor principal, provocando un incremento de su actividad y participación en la asignatura, máxime cuando la asignatura tiene una importante carga teórica y de desarrollo durante el desarrollo del curso.

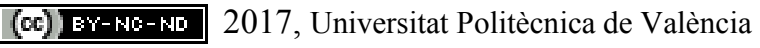

Congreso IN-RED (2017) 


\section{Desarrollo de la innovación}

\subsection{Condicionantes de partida}

El desarrollo la innovación establecida esta fundamentada por los siguientes condicionantes que fueron detectados en cursos anteriores:

- Incapacidad de extraer los datos necesarios que aporta el problema para la resolución del mismo.

- En muchas ocasiones el alumno no era capaz de establecer una metodología de resolución del problema.

- Se detecta que el alumno no relaciona los resultados con las implicaciones que tiene en la operatividad del sistema o infraestructura analizado

- El docente detecta pasividad en el intéres mostrado por el alumno hacia el aprendizaje de los contenidos de la asignatura

- El alumno no está tutorizado para optimizar al máximo el tiempo no presencial requerido por la asignatura en el Plan de Estudios y que el nuevo espacio de Educación Superior establece

- Dentro del plan de estudios, la asignatura es punto de control de Nivel de Dominio II en dicha competencia transversal.

\subsection{Metodología desarrollada para el aprendizaje}

La metodología desarrollada busca incrementar la participación de los alumnos el desarrollo de la asignatura así como mejorar los resultados de aprendizaje. Por ello, se diseña una estrategia que permita, por un lado, trabajar los conceptos téoricos desarrollados en clase. Por otro lado, apoyado en el uso de las TICs desarrollar una plataforma de trabajo que permita guiar al alumno en su aprendizaje durante la fase no presencial. Finalmente, se inserta al alumno dentro del proceso de evaluación de las actividades planteadas.

Esta metodología la cual ha sido denominada por los autores 'desde el inicio, buscando el problema' está basada en una fase presencial y una fase no presencial, la cual en este caso, tiene una gran importancia en cuanto a dedicación temporal y capacidad de aprendizaje del alumno.

\subsubsection{Fase presencial}

Esta fase se ha mantenido de igual forma a la que ya estaba programada. Constituye la fase presencial de la asignatura, donde el profesor desarrolla los conceptos teóricos, los cuales están estructurados en ocho unidades didácticas. En las diferentes clases presenciales, además de impartir la docencia, el profesor define las estrategias de resolución de problemas en cada una de las unidades. Además, en las primeras unidades el profesor tutoriza al alumno a la hora de comprender y analizar el problema, extraer los datos, adoptar la metodología de resolución e iniciar un análisis crítico de la solución obtenida. 
¿Puede un conjunto de tareas evaluar la competencia “Análisis y Resolución de problemas” en una asignatura de grado?

\subsubsection{Fase no presencial}

Sin lugar a dudas, constituye la parte fundamental de la estrategía y la misma, esta apoyada en la herramienta informática de Tareas de la plataforma PoliformaT. Esta es una herramienta de "campus virtual" basada en el proyecto "Sakai". del espacio "sakai". Es a partir de esta herramienta donde el docente, establece tareas semanalmente a medida que se desarrollan los conceptos teóricos y estrategias para la resolución de los problemas. La asignatura está dividida en dos bloques. Un primer bloque que constituye el acto de evaluación 1 y engloba las primeras cuatro unidades didácticas de la asignatura. Este bloque está centrado en el análisis teórico de las turbomáquinas hidráulicas tanto de bombas como turbinas. El segundo bloque, compuesto por otras cuatro unidades está centrado en el funcionamiento de los equipos de bombeo en instalaciones hidráulicas.

En cada uno de los dos bloques se han propuesto 6 tareas que engloban el análisis y resolución de 12 problemas que buscan guiar al alumno en el proceso de aprendizaje de la asignatura así como trabajar la evaluación de la competencia transversal. La dificultad de los problemas es progresiva partiendo de problemas en los cuales los datos especificados están perfectamente identificados, hasta el problema 6 y 11, los cuales presenta una mayor complejidad a la hora de obtener los datos del enunciado, el alumno debe suponer algunos valores en función del problema planteado, los cuales puede encontrar en la bibliografía recomendada ( $p . e$., valores de viscosidad, presión de vapor del fluido) y debe combinar tanto estrategias de resolución como métodos vistos en clase con anterioridad. Finalmente, la última tarea de cada bloque, la tarea 6, se denomina “iProponemos un ejercicio de examen?”. Esta tarea busca que el alumno sea capaz de analizar un problema de la sociedad en el cual se encuentren inmerso las máquinas hidráulicas y con una temática relacionada a la de cada uno de los bloques sea capaz de:

1) Proponer un enunciado del problema que pueda comprender otro lector (alumno), resumiendo lo que se plantea.

2) Dotar de datos al mismo para que le confiera una posibilidad de solución.

3) Llevar a cabo la resolución del problema a través del aprendizaje desarrollado durante el primer bloque

4) Analizar la solución, buscando las ventajas e inconvenientes que puede sucederse

Cada una de las tareas propuestas, está divida en dos fases en la cual, el alumno realiza espaciadas temporalmente.

- Fase 1. Resolución del problema planteado: en esta fase, el alumno descarga la tarea, una vez los conceptos han sido impartidos y estrategias de resolución planteadas en la fase presencial por el docente. El alumno dispone de una semana desde que se abre la tarea para analizar el problema, plantearlo y resolverlo. Si tiene dudas en alguna etapa se puede apoyar tanto en tutorías realizadas con el profesor (a través de tutorías presenciales) o consultas puntuales vía e-mail o espacio compartido. Además, el alumno dispone de material docente asíncrono (p.e. Polimedias, (Pérez-Sánchez, 2017)) el cual le puede servir de apoyo para reforzar algunos de los resultados de

(cc) EY-NC-ND 2017, Universitat Politècnica de València

Congreso IN-RED (2017) 
aprendizaje que no lograron alcanzarse totalmente en la fase presencial. De esta forma, el alumno que pretende alcanzar hasta el máximo grado de alcance el resultado de aprendizaje, cuando sube la resolución del problema, se garantiza el éxito del mismo.

- Fase 2. Evaluación por pares: una vez la tarea es finalizada el alumno sube un archivo en formato PDF que contiene la resolución desarrollada. La tarea ha sido programada de tal modo que la opción evaluación por pares ha sido activada. De este modo, una vez se cierra el plazo de resolución (1 semana), se abre otra semana, en la cual el alumno tiene que llevar a cabo la corrección del problema de uno de sus compañeros. Esta labor, en un principio, la puede realizar el alumno puesto que anteriormente ha tenido la oportunidad de resolver todas las dudas planteadas. No obstante el alumno cuenta con:

- Guía de apoyo a la corrección; para guiar la corrección el alumno debe contestar a las siguientes preguntas:

1) Tu compañero, ¿Ha realizado el esquema que ayuda la resolución del problema?

2) En el ejercicio resuelto, ¿Ha extraído los datos correctamente?

3) La resolución desarrollada, ¿Plantea las expresiones correctamente? ¿Por qué?

4) El estudiante, ¿alcanza el resultado correcto? ¿Las unidades son correctas?

5) Finalmente, ¿Te ha servido realizar la tarea para comprender mejor los conceptos y métodos desarrollados en clase presencial?

- Tutorias; el alumno puede recurrir a tutorías con el profesor en el cual docente y alumno completen la tarea de corrección del ejercicio planteado. Estas tutorías pueden llevarse a cabo de forma presencial o no presencial.

\subsection{Evaluación propuesta para el aprendizaje}

Dentro de la evaluación propuesta, se considera que los resultados de aprendizaje se mejoran si previamente, los criterios de evaluación son publicados, los cuales, dotan de transparencia al proceso y permiten seguir el progreso en el aprendizaje tanto a docente como alumno. Un ejemplo de transparencia son las denominadas rúbricas, documentos que articulan de una manera objetiva y equitativa el proceso de evaluación, dotando de un feedback al alumno durante el progreso del aprendizaje. En este sentido, la competencia es evaluada mediante una rúbrica. Por lo tanto, el alumno recibe, por un lado, la nota establecida por su compañero y por otro lado, la respuesta a las preguntas. Estas respuestas, realmente dotan al alumno corregido de un feedback continuo de los indicadores que muestran su capacidad de resolver problemas. Finalmente, el proceso de evaluación por pares, empuja al alumno a desarrollar conceptos, no solo a analizar el problema, sino a analizar el mismo problema que anteriormente él mismo ha resuelto, desde un punto de observación exterior Ello obliga al estudiante a realizar un segundo análisis, que en ocasiones es diferente al que había planteado en su resolución. Para esta competencia se ha desarrollado una rúbrica que establece el grado alcanzado en dicha competencia. 
¿Puede un conjunto de tareas evaluar la competencia “Análisis y Resolución de problemas” en una asignatura de grado?

\section{Resultados}

La experiencia se programó durante el primer cuatrimesre del curso 2016/2017, y se llevó a cabo durante las ocho primeras semanas del cuatrimestre B del mismo curso. Durante este tiempo, un total de 136 alumnos estaban matriculados de la asignatura. Referente a los resultados, se muestran los obtenidos en el primer bloque de la asignatura febrero-abril 2017, así como mostrando los resultados de opinión del alumnado respecto al desarrollo de las tareas, obtenida tras la realización de un sondeo a través de PoliformaT.

Las tareas propuestas para el primer bloque de la asignatura, están reflejadas en la Tabla 1.

Tabla 1. Tareas y resultados de participación en las mismas

\begin{tabular}{|c|l|c|c|c|}
\hline Tarea & \multicolumn{1}{|c|}{ Titulo } & Unidad & $\begin{array}{c}\text { Alumnos } \\
\text { participantes }\end{array}$ & $\begin{array}{c}\text { Tareas } \\
\text { evaluadas por } \\
\text { pares }\end{array}$ \\
\hline 1 & Triángulos de velocidad & 1 y 2 & 112 & 100 \\
\hline 2 & Turbinas Pelton & 3 & 117 & 108 \\
\hline 3 & Turbina Francis I & 3 & 106 & 89 \\
\hline 4 & Turbina Francis II & 3 & 105 & 78 \\
\hline 5 & Bombas cinéticas y de desplazamiento positivo & 4 & 114 & 99 \\
\hline 6 & iproponemos un ejercicio de examen? & $1-4$ & 95 & 95 \\
\hline
\end{tabular}

En la tabla anterior se observa que la participación oscila entre el $69.85 \%$ en la Tarea 6 y el $86.02 \%$ en la Tarea 2, con una participación media del 79.53\%. Desde el punto de vista de los autores, teniendo en cuenta que el grupo de alumnos es elevado (136) y la no obligatoriedad de tener que realizar las tareas, supone un éxito de participación y aprovechamiento por parte del alumno. En cuanto, a la segunda fase, la evaluación por pares, la participación de los alumnos oscila entre $74.28 \%$ en la Tarea 4 y el $100 \%$ en la Tarea 6, índices de participación de nuevo por parte del alumnado. En el caso de esta segunda fase, las tareas que no son corregidas por el alumno, son evaluadas por los docentes de la asignatura, para que todos los alumnos tengan el 'feedback' de la asignatura. En cuanto, a la última tarea de cada bloque (“¿Proponemos un ejercicio de examen?”), es evaluada por todos los alumnos, por lo que todos ellos tienen a disposición una batería variada de ejercicios para poder seguir trabajando la asignatura así como la competencia transversal al mismo tiempo. Entre los resultados obtenidos, en la revisión por pares de los ejercicios se muestran dos ejemplos de respuesta del alumno (Tabla 2 y 3), los cuales, por regla general, contestan y realizan correctamente la revisión, existiendo un número de tutorías por cada unidad para la revisión que oscila entre 8 y 10, las cuales ser resuelven en su mayoría vía online.

La nota calificada por el alumno no tiene ningún efecto en la calificación de las competencias específicas de la asignaturas, pero sí que el hecho de tener que calificar con un valor, dota de responsabilidad al trabajo de corrección, siendo muchas de las tutorías recibidas relativas a consultas sobre que nota final establece al ejercicio. Con esta revisión, el alumno además, toma conciencia de la dificultad del docente a la hora de tener que poner una nota.

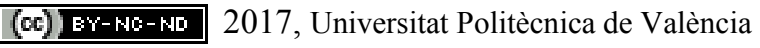

Congreso IN-RED (2017) 
Tabla 2. Ejemplo de revisión por pares

\section{1) ¿ Ha realizado el esquema que ayuda la resolución del problema?}

Sí.

2) ¿Ha extraído los datos correctamente?

Sí, excepto en los apartados $g$ y $h$.

3) ¿Plantea las expresiones correctamente? ¿Por qué?

Sí, las expresiones son correctas y lógicas, expceptuando los apartados $g$ y $h$ cuyas expresiones son incorrectas. Esto se debe a que en el apartado g) para calcular las pérdidas en el tubo de aspiración a tomado como solución el valor de la altura teórica de Euler. Debería haber hecho un balance energético: $H 2=H 3+h 23$, siendo h23 las pérdidas en el tubo de aspiración.

En el apartado h) ha utilizado la expresión del rendimiento hidráulico para calcular las pérdidas totales en el interior de la turbina. Esto no es correcto ya que debería haber sumado las demás pérdidas calculadas anteriormente.

4) ¿alcanza el resultado correcto?

Sí, excepto en los apartados $g$ y $h$.

5) ¿Las unidades son correctas?

Si.

6) ¿Te ha servido realizar la tarea para comprender mejor la teoría impartida en clase? Si.

Nota: $7,5 / 10$

Tabla 3. Ejemplo II de revisión por pares

Primero de todo: el formato del archivo, las fotografias borrosas y la falta de orden no me han ayudado a la hora de mi corrección. La próxima vez no entregues un trabajo tan cutre.

1) : Ha realizado el esquema que ayuda la resolución del problema?

El "esquema" planteado es pobre y carece de datos para su funcionalidad.

2) ¿Ha extraído los datos correctamente?

Todos los datos han sido extraídos de forma correcta.

3) ¿Plantea las expresiones correctamente? ¿Por qué?

Todas las expresiones que utiliza para realizar los cálculos son correctas, pero algunas expresiones no están previamente definidas y, en ámbito general, está bastante mal organizado; costándome así seguir los cálculos.

4) ¿alcanza el resultado correcto?

Los resultados son correctos pero la mayoría están redondeados a la décima siendo así más inexactos. Falta el resultado del apartado $G$.

5) ¿Las unidades son correctas?

Las unidades empleadas son las correctas y definidas por el SI.

6) ¿Te ha servido realizar la tarea para comprender mejor la teoría impartida en clase? Sí que me ha sido de ayuda para asimilar mejor los conceptos

Nota: $8 / 10$

En cuanto a las tutorías recibidas, la Figura 2 muestra una comparativa por semanas entre el primer bloque de la asignatura del curso 2015/2016 y el curso 2016/2017. 
¿Puede un conjunto de tareas evaluar la competencia “Análisis y Resolución de problemas” en una asignatura de grado?

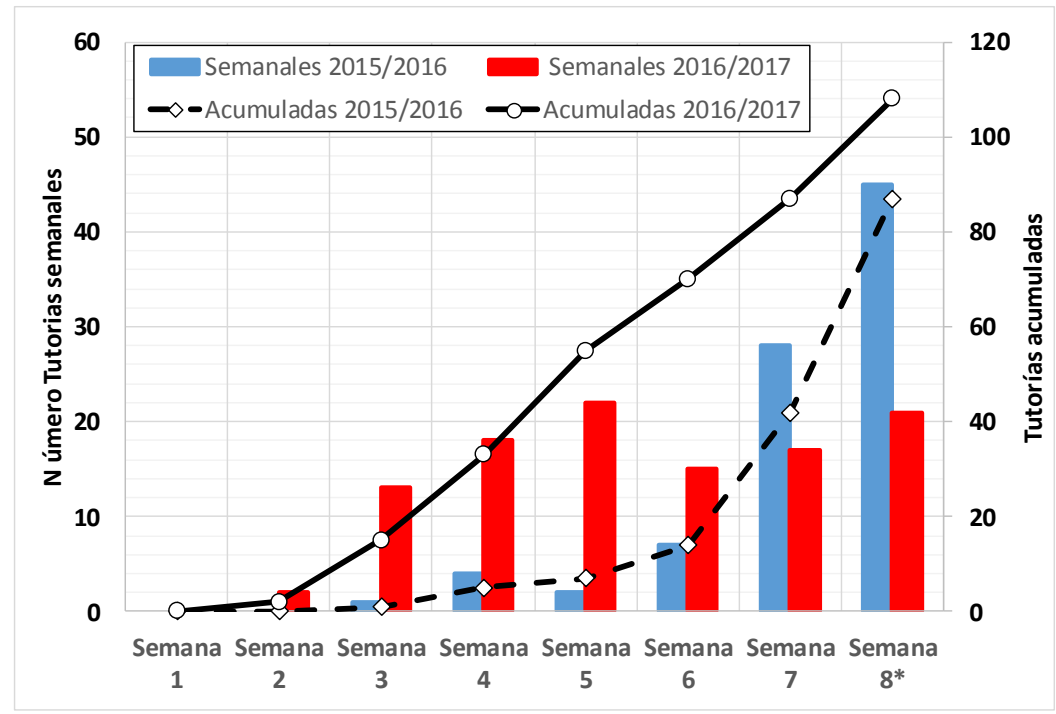

Fig 2. Comparativa de tutorias en el primer bloque entre 2015/2016 y 2016/2017

En la figura se observa como en el caso del curso 2016/2017, las tareas han propiciado que haya un mayor número de tutorías totales 108 , respecto al curso anterior 87 , lo que significa un $124,14 \%$ más. Del mismo modo se observa que las tareas han propiciado que estas tareas sean constantes a lo largo del tiempo, a excepción de la semana 1, que se corresponde con la presentación de la asignatura. De esta forma, han existido una media de 14 tutorias semanales en el último curso, mientras que la media en el 2015/2016 fue de 11, aunque como se aprecia en el gráfico, la media no es representativa puesto que 45 de 87 tutorias $(51.72 \%)$ fueron realizadas en la semana previa al parcial, por lo que el aprendizaje permanente y progresivo no tuvo lugar en los alumnos. Esta concentración de tutorías indica que el alumno se dejaba la asignatura para el final, y que la propuesta de tareas, no solamente nos permite poder evaluar la competencia, sino que conduce al alumno a llevar la asignatura de forma paralela a como se desarrolla temporalmente.

La Tabla 4 muestra la rúbrica utilizada para llevar a cabo la definición del grado de alcance de los indicadores de la competencia transversal. El último indicador [Indicador $4(*)$ ] permite a la vez, evaluar parte de la competencia responsabilidad ética, medioambiental y profesional. El indicador analiza el grado de adquisición de la componente ética del alumno, a la hora de llevar a cabo la corrección de una manera objetiva. Este indicador, también entra a formar parte de la evaluación de esta competencia, que no es objeto de la presente comunicación. . 
Tabla 4. Rúbrica desarrollada de evaluación de CT-03 Análisis y resolución de problemas para Nivel de dominio II.

\begin{tabular}{|c|c|c|c|c|}
\hline \multirow{2}{*}{ INDICADOR } & \multicolumn{4}{|c|}{ DESCRIPTOR } \\
\hline & D. No alcanzado & C. En desarrollo & B. Adecuado & A. Excelente \\
\hline $\begin{array}{l}\text { 1. Define el problema, } \\
\text { segmentandolo en } \\
\text { diferentes partes que le } \\
\text { permiten estructurar } \\
\text { un proceso de } \\
\text { resolución }\end{array}$ & $\begin{array}{l}\text { El alumno no es capaz de } \\
\text { determinar el problema }\end{array}$ & $\begin{array}{l}\text { El alumno determina el } \\
\text { problema, estructura el } \\
\text { proceso de resolución, } \\
\text { pero no correctamente }\end{array}$ & $\begin{array}{c}\text { El alumno determina el } \\
\text { problema, estructura el } \\
\text { proceso de resolución } \\
\text { correctamente }\end{array}$ & $\begin{array}{c}\text { El alumno determina el } \\
\text { problema y estructura el } \\
\text { proceso de resolución } \\
\text { correctamente, } \\
\text { complementandolo con } \\
\text { comentarios que ayudan a } \\
\text { comprenderlo }\end{array}$ \\
\hline $\begin{array}{l}\text { 2. Extrae los datos } \\
\text { aportados del problema } \\
\text { complementado con } \\
\text { datos existentes en la } \\
\text { bibliografía }\end{array}$ & $\begin{array}{l}\text { El alumno no es capaz de } \\
\text { extraer los datos }\end{array}$ & $\begin{array}{c}\text { El alumno extrae los } \\
\text { datos, pero algunos son } \\
\text { incorrectos }\end{array}$ & $\begin{array}{c}\text { El alumno extrae los datos } \\
\text { y en caso de ser necesario, } \\
\text { busca información en } \\
\text { bibiliografia }\end{array}$ & $\begin{array}{c}\text { El alumno extrae los datos } \\
\text { y los contrasta con la } \\
\text { bibliografia, comentando } \\
\text { las diferencias que } \\
\text { pudiese encontrar con los } \\
\text { datos considerados en el } \\
\text { problema. }\end{array}$ \\
\hline $\begin{array}{l}\text { 3. Determina la solución } \\
\text { óptima }\end{array}$ & $\begin{array}{c}\text { El alumno no es capaz de } \\
\text { obtener ninguna solución } \\
\text { del problema }\end{array}$ & $\begin{array}{l}\text { El alumno obtiene la } \\
\text { solución, pero no es la } \\
\text { óptima o correcta. }\end{array}$ & $\begin{array}{l}\text { El alumno obtiene la } \\
\text { solución correctamente }\end{array}$ & $\begin{array}{c}\text { El alumno obtiene la } \\
\text { solución óptima, y la } \\
\text { compara con otras } \\
\text { posibles soluciones, } \\
\text { analizando la diferencia. }\end{array}$ \\
\hline $\begin{array}{l}\text { 4. Analiza el problema } \\
\qquad(*)\end{array}$ & $\begin{array}{l}\text { El alumno no realiza la } \\
\text { corrección del problema }\end{array}$ & $\begin{array}{c}\text { El alumno realiza la } \\
\text { corrección del problema, } \\
\text { únicamente pone una } \\
\text { nota sin definir los } \\
\text { criterios que le llevan a } \\
\text { hacerlo }\end{array}$ & $\begin{array}{l}\text { El alumno realiza la } \\
\text { corrección del problema, } \\
\text { contestando a todas las } \\
\text { preguntas guía planteadas. }\end{array}$ & $\begin{array}{c}\text { El alumno desarrolla la } \\
\text { corrección del problema, } \\
\text { responde a las preguntas y } \\
\text { orienta a su compañero en } \\
\text { los errores, proponiendo la } \\
\text { metodología de resolución } \\
\text { o mostrandole } \\
\text { metodologías alternativas } \\
\text { que logran la solución } \\
\text { optima. }\end{array}$ \\
\hline
\end{tabular}

Finalmente se adjunta los resultados de un sondeo realizado sobre la realización de la actividad durante el primer bloque de la asignatura en el cuatrimestre B del curso 2016/2017 (Figura 3), donde participaron el 73\% del alumnado, con un $90.40 \%$ de alumnos que están a favor del desarrollo de las tareas. 
¿Puede un conjunto de tareas evaluar la competencia “Análisis y Resolución de problemas” en una asignatura de grado?

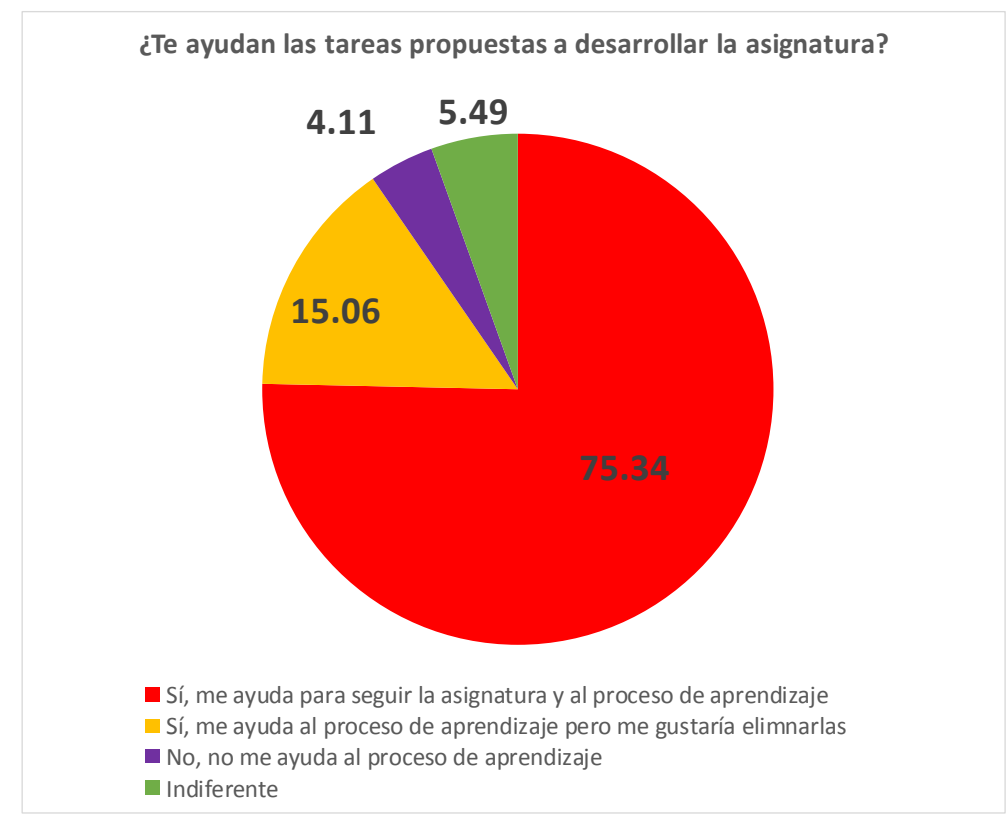

Fig 3. Porcentaje de satisfacción de sondeo realizado

\section{Conclusiones}

La presente comunicación muestra la innovación llevada a cabo en la asignatura Ingeniería Fluidomecánica del Grado de Ingeniería Mecánica de la EPSA por docentes del Departamento de Ingeniería Hidráulica y Medio Ambiente, en la cual se ha aprovechado la plataforma PoliformaT, para desarrollar un sistema de aprendizaje permanente relacionado con las competencias específicas de la asignatura y al mismo tiempo, con la competencia transversal "Análisis y resolución de problemas" en la cual se es punto de control. La estrategia establecida no solo permite el análisis de esta competencia transversal, sino que otras como el aprendizaje permanete y responsabilidad ética, medioambiental y profesional también son trabajadas y en parte, evaluadas.

El seguimiento de las tareas propuesto, aunque los autores no tienen todavía resultados de los actos de evaluación, al menos en el primer bloque de la asignatura, ha mostrado una redistibución de las tutorías. Esta redistribución ha hecho que las tutorías no se concentren en la semana del acto de evaluación sino que se distribuyan a lo largo del tiempo, lo que demuestra, que el alumno lleva un aprendizaje continuado de la asignatura.

Se ha mostrado que la evaluación por pares de la herramienta PoliformaT, puede ser una herramienta que permita a los alumnos mejorar su proceso de aprendizaje, dotándolos de una mayor autonomía a la hora de enfocar tanto su responsabilidad a la hora de realizarlo como de corregirlo, al saber que van a ser evaluados por sus propios compañeros, mostrando índices de participación muy elevados tanto en la realización de las tareas como en la corrección.

(cc) EY-NC-ND 2017, Universitat Politècnica de València

Congreso IN-RED (2017) 
Relacionado con la actividad y teniendo en cuenta el nivel de dominio II, una rúbrica ha sido desarrollada con cuatro indicadores, que permite evaluar la competencia transversal de análisis y resolución de problemas y parte de la competencia de responsabilidad ética, medioambiental y profesional.

Finalmente, un sondeo ha mostrado un alto grado de satisfacción por parte del alumnado que ha desarrollado estas tareas durante el primer bloque de la asignatura.

\section{Referencias}

BaArtman, L.K.J.; Prins, F.; KIRChner, P.A.; VAn Der Vleuten, C.P.M. (2007) Determining the quality of competence assessment programs: a self-evaluation procedure. Studies in Educational Evaluation, 33:258-281.

CANO, E., (2008). Competences assessment in higher education. Profesorado. Revista de currículum y formación del profesorado, 12 (3), 1-16

Collins, B. (2007). Perspectivas de disseny a l'educatió per competencias. Simposio Internacional organizado pro CIDUI, Barcelona: Universidad Politécnica de Cataluña

FERnÁndez MARch, A. (2010). La Evaluacion Orientada Al Aprendizaje En Un Modelo De Formación. Revista de Docencia Universitaria, Vol.8 (n.1) 11-34 ISSN:1887-4592 22

KANE, M.T. (1992). The assessment of professional competence. Education and the Health Professions, 15:163-182.

LASNIER, F. (2000). Réussir la formation par compétences. Montréal : Guérin.

LÓPEZ PAstor, V.M. (2005). La participación del alumnado en la evaluación: la autoevaluación, la coevaluación y la evaluación compartida. Revista Tándem 17

PÉREZ SÁNCHEZ, M. (2017). Bombas y Turbinas en la instalación hidráulica. Diferencias. http://hdl.handle.net/10251/78683. 


\title{
Innovación y competencia pragmática en las pruebas de evaluación de inglés como segunda lengua
}

\author{
Martín Marchante, Beatriz
}

Univesitat Politècnica de València, beamarm2@upvnet.upv.es

\begin{abstract}
In the communicative approach of second language teaching, pragmatics has a capital place. However, its treatment still remains insatisfactory in the field of language testing and assessment. There is currently a large amount of standardized tests which are administered to thousands of users to measure their language and communicative competence in English as a second language (ESL). In the work at hand we analyze 14 of these commercial tests developed by the most relevant organizations in USA and UK. Two of them are described as an example of teaching innovation and conclusions are drawn about the similarities and divergences between these different tests. The treatment of pragmatic competence assessment offered by each of them is also analized here. The following parameters were taken into account in the analysis: purpose of the test, parts and sections, type of questions, duration, score, pragmatic competence assessment, format and availability of computerized version or computerized adaptive test (CAT)
\end{abstract}

Keywords: pragmatics, evaluation, Computer adaptive test (CAT), standardized commercial language tests, TESL.

\section{Resumen}

En el enfoque comunicativo de la enseñanza de segundas lenguas, la pragmática ocupa un lugar primordial. Sin embargo, su tratamiento sigue siendo insuficiente en el ámbito de la evaluación y las pruebas de lengua. Actualmente hay una gran cantidad de pruebas estandarizadas que se comericializan y administran a miles de usuarios para medir su competencia lingüistica y comunicativa en inglés como segunda lengua (ISL). En el presente trabajo se analizan 14 de estas pruebas comerciales desarrolladas por las organizaciones de mayor relevancia en EEUU y Reino Unido; se extraen conclusiones acerca de las similitudes y divergencias que entre estas distintas pruebas encontramos y se describen dos de ellas como ejemplo de innovación docente. Se estudia también el tratamiento que de la evaluación de la competencia pragmática ofrece cada una de ellas. Para llevar a cabo la investigación se han tenido en cuenta los siguientes parámetros: propósito de la prueba, partes y secciones, tipo de preguntas, duración, puntuación, evaluación de 
la competencia pragmática, formato y disponibilidad de versión informatizada o test adaptativo informatizado (TAI).

Palabras clave: pragmática, evaluación, tests adaptativos informatizados (TAI), pruebas de lengua estandarizadas comerciales, TESL.

\section{Introducción}

Las pruebas de lengua comerciales son, por definición, estandarizadas. Según Iglesias y Sánchez (2007:98) por estandarización se entiende "presentar a todos los sujetos la misma prueba exactamente en las mismas condiciones y aplicando los mismos criterios de corrección". Estandarizar es por tanto, normalizar o tipificar un grupo de datos a través de la creación de un patrón o norma para trabajar con ellos. El concepto de normalización consiste en la transformación de una distribución de valores o puntuaciones brutas en una distribución de valores o puntuaciones normales o típicas y supone el establecimiento de valores típicos o representativos de una población, de manera que se puedan utilizar como normas para juzgar los valores y puntuaciones de determinados individuos en relación con esas puntuaciones representativas.

Cuando hablamos de las pruebas en educación, en primer lugar es necesario distinguir entre las pruebas más o menos informales realizadas por los profesores y las pruebas a gran escala que son instrumentos estandarizados realizados por servicios especializados (Harris, 1969:1).

Las pruebas estandarizadas dan información del grado de dominio o de conocimiento en una tarea o habilidad determinada, es decir, se compara la puntuación de cada estudiante con la de los demás y los resultados se suelen representar en percentiles o en la curva de Gauss. Se les llama también pruebas referidas a la norma. (Madrid, 1997).

\section{Las pruebas comerciales a gran escala de inglés como segunda lengua (ISL)}

Las características de las pruebas estandarizadas a gran escala que no pueden ser implementadas por las pruebas individuales son las siguientes:

(cc) EY-NC-ND 2017, Universitat Politècnica de València

Congreso IN-RED (2017) 
- Las cualidades psicométricas básicas de validez en sus variantes (que lo que mide el instrumento corresponda a los objetivos y contenidos del currículo), fiabilidad (que las mediciones sean consistentes) y ausencia de sesgo;

- Cualidades técnicas que permiten comparaciones tanto transversales (entre diversas partes del sistema educativo -como entidades federativas- o con otros países) como longitudinales (esto es a lo largo del tiempo): equiparabilidad de versiones, estabilidad de la escala;

- Pueden aplicarse a muestras numerosas, compuestas por decenas de miles de sujetos, en forma casi simultánea, y los resultados son procesados rápidamente y de manera fiable, todo ello dentro de límites razonables de costo.

Teniendo en cuenta las ventajas que las pruebas estandarizadas ofrecen, no es extraño que su uso vaya en aumento:

27 países o provincias han incrementado el número de pruebas estandarizadas a gran escala, en el cuarto de siglo transcurrido de 1974 a 1999. Esta cifra incluye Alemania, Bélgica, Canadá, China, Dinamarca, Escocia, España, Finlandia, Francia, Hungría, Inglaterra, Irlanda, Japón, Holanda, Nueva Zelanda, Portugal, la Rep. Checa y Suecia y las provincias canadienses de Alberta [...] En sentido contrario, solamente Australia, Grecia y la provincia canadienses de la Isla del Príncipe Eduardo muestran un decrecimiento en las pruebas a gran escala (Phelps, 2000: 13-15).

Phelps (ibíd.) analiza 31 países o provincias, y muestra que en la mayoría de ellos el uso de pruebas a gran escala está aumentando notoriamente. Dada la gran cantidad de pruebas estandarizadas que se administran actualmente para medir la competencia lingüística y comunicativa de los sujetos, es lógico pensar en la conveniencia de supervisar y analizar dichas pruebas, especialmente el tratamiento que dan a la evaluación de la competencia pragmática ya que como explica Purpura (2009:2 ) “ [...] it is important to have specific information on the students' grammatical and pragmatic ability if we expect to help them improve in these domains".

Madsen (1983) distingue tres tipos de pruebas comerciales, las pruebas de dominio/maestría, las de progreso y las de aptitud.

Las primeras son las más comunes. Muestran la habilidad general que se tiene de una lengua o nos dicen la capacidad de una persona en un área específica de la lengua, como 
por ejemplo la oral. Las pruebas de aptitud, por otra parte, nos pueden mostrar si una persona está preparada o capacitada para ingresar en determinados centros académicos o acceder a puestos de trabajo como es el caso de las pruebas de inglés como segunda lengua. En Estados Unidos lo más cercano a un cuerpo examinador oficial es el Educational Testing Service copatrocinador del Test of English as a Foreing language (TOEFL). En el Reino Unido existen varios cuerpos examinadores reconocidos y cada uno de ellos ofrece varios tipos de pruebas. Algunas de estas organizaciones son:

- English Language Testing Service (ELTS). Patrocinado por el British Council y el University of Cambridge Local Examinations Syndicate.

- $\quad$ La Royal Society of Arts Examinations Board (RSA).

- University of Cambridge Local Examinations Syndicate (Cambridge).

- Asssociation of Recognized English Language Schools Examinations Trust (ARELS).

- Oxford Delegacy of Local Examinations (Oxford).

- Joint Matriculation Board (JMB).

- $\quad$ Associate Examining Board (AEB).

- University of London.

\section{Objetivos}

En la actualidad, las pruebas de segundas lenguas se ven a menudo como una amenaza más que como una oportunidad para aprender y mejorar. Los efectos negativos inesperados del uso de pruebas de alto impacto así como la necesaria rendición de cuentas son, con frecuencia, más importantes que los efectos positivos que se pretenden (Linn, 2000; Shephard, 2006; Martinez, 2008). Es por ello que nuestro objetivo general es avanzar en la visión de la evaluación y pruebas de segundas lenguas como parte integral del proceso de enseñanza y poder contribuir en su mejora.

Dada la repercusión que los resultados de las pruebas de lengua extranjera tienen en la vida académica y profesional de los examinandos vemos la necesidad de examinar de qué modo y en qué condiciones se está midiendo y evaluando la competencia pragmática en las principales pruebas comerciales desarrolladas por las organizaciones de mayor relevancia en EEUU y Reino Unido.

(cc) EY-NC-ND 2017, Universitat Politècnica de València 
Por tanto el primer objetivo específico en este estudio es averiguar si estas pruebas de inglés como segunda lengua evalúan la competencia pragmática de los examinandos.

El segundo objetivo es estudiar, en los casos en los que la respuesta a la pregunta de investigación planteada sea afirmativa, cómo se aborda en estas pruebas la medición de la competencia pragmática

\section{Metodología}

Para llevar a cabo este estudio se ha realizado una búsqueda en la Red de las pruebas de conocimientos de inglés más comercializadas (Tabla 1). En segundo lugar se registraron todas las características correspondientes a los siguientes parámetros: propósito, partes o secciones, tipo de preguntas, duración, puntuación, evaluación de la competencia pragmática, formato y disponibilidad de versión informatizada o CAT (Anexo1). En cuanto al parámetro "evaluación de la competencia pragmática" es necesario precisar que para determinar si la prueba bajo estudio contenía ítems de pragmática se siguió, en el análisis, el criterio propuesto por Levinson (1983) que propone delimitar el campo de estudio de la pragmática centrando cada definición de ésta en relación a los siguientes aspectos, o procesos:

- Las reglas y los principios: la pragmática define las condiciones de uso apropiadas de las oraciones.

- El contexto: la pragmática estudia los emparejamientos que los usuarios hacen entre los enunciados y sus contextos.

- El significado y las inferencias.

- La gramaticalización: los deícticos, por ejemplo, que solo se llenan de contenido preciso en contexto de uso particular (yo, tú, pasan a referirse a una persona en concreto).

- La funcionalidad: la estructura del texto (narrativo, descriptivo, expositivo...) descansa en la función lingüística ligada a la intencionalidad del interlocutor).

No se consideraron, por tanto, ítems de pragmática aquellos que no reunían todos estos aspectos, como es el caso del siguiente ítem (ej.1) encontrado en el Preliminary English Test (PET) 
Ejemplo 1:

\section{"PLEASE CLOSE THE GATE"}

Where would you NOT see this sign?

\begin{tabular}{|ll|}
\hline a) & In a building \\
b) & In a playground \\
c) & In a field \\
\hline
\end{tabular}

Este ítem (ej.1) ciertamente tiene en cuenta la contextualización, aspecto fundamental en la concepción de la pragmática, pero consideramos que la la incorporación únicamente de este rasgo no es suficiente para ser calificado definitivamente como un ítem de pragmática .

En la tabla 1 se pueden ver los exámenes más utilizados en EE.UU y en U.K. (a excepción de los de Oxford University Press) y su equivalencia con los niveles del Marco Común Europeo de Referencia para las Lenguas (MCERL, Consejo de Europa, 2002 ).

Tabla 1. Comparación de los niveles del MCERL con las puntuaciones de pruebas de ISL

\begin{tabular}{|c|c|c|c|c|c|c|c|c|}
\hline$\frac{\text { CEF }}{\text { Level }}$ & $\frac{\text { Cambridge }}{\text { ESOL }}$ & $\underline{\text { IELTS }}$ & $\frac{\text { TOEFL }}{\text { iBT }}$ & $\underline{\text { TOEIC }}$ & Michigan & BULATS & $\begin{array}{l}\text { PTE } \\
\text { General }\end{array}$ & $\begin{array}{l}\text { PTE } \\
\text { Academic }\end{array}$ \\
\hline \multirow[t]{2}{*}{$\mathrm{C} 2$} & $\underline{\mathrm{CPE}}$ & 9 & & 990 & ECPE & & level 5 & $85+$ \\
\hline & & 8 & & & & 90 & & \\
\hline \multirow[t]{2}{*}{$\mathrm{C} 1$} & $\begin{array}{l}\text { CAE, } \\
\text { BEC Higher }\end{array}$ & 7.5 & $110-120$ & 880 & & & level 4 & $76-84$ \\
\hline & & 6.5 & & & & 75 & & \\
\hline B2 & $\begin{array}{l}\text { FCE, } \\
\text { BEC Vantage }\end{array}$ & 6 & $87-109$ & & $\underline{\mathrm{ECCE}}$ & & level 3 & $59-75$ \\
\hline & & 5 & & & & 60 & & \\
\hline B1 & $\begin{array}{l}\text { PET, } \\
\text { BEC Prelim }\end{array}$ & 4.5 & $57-86$ & 550 & & & level 2 & $43-58$ \\
\hline & & 4 & & & & 40 & & \\
\hline A2 & $\underline{\mathrm{KET}}$ & & & & & & level 1 & $30-42$ \\
\hline
\end{tabular}

Fuente: http://www.examenglish.com/TOEFL/index.html

En la primera columna empezando por la izquierda aparecen los diferentes niveles de competencia en inglés según el MCERL. En las siguientes columnas se presentan las puntuaciones de cada una de las pruebas de inglés como segunda lengua (ISL) equivalentes a estos niveles. Por ejemplo, 9 puntos en el IELTS equivalen al Cambridge English 
Proficiency (CPE) y al nivel C2 del MCERL, mientras que en el TOEIC la puntuación equivalente se da partir de 990 puntos, y en el Pearson Test of English Academic (PTE Academic), a partir de 85. Como se puede comprobar en la tabla 1, en ella no se tienen en cuenta ni el Oxford Quick Placement Test (OOPT) ni el Oxford Online Placement Test (OOPT) pero en nuestro análisis los hemos incluido dada su gran divulgación y comercialización. Tras realizar la descripción y registro de las características de cada una de las pruebas aquí citadas se obtuvieron los resultados referentes a las divergencias y similitudes entre las distintas pruebas que a continuación se exponen.

\section{Resultados}

En cuanto al tratamiento específico de la pragmática en las pruebas analizadas, encontramos que los dos únicos tests que incluyen ítems específicos que evalúan dicha competencia son el Next generation TOEFL ${ }^{\circledR}$ iBT test y el Oxford Online Placement Test cuyas características se detallan seguidamente.

Test of English as a Foreign Language ( TOEFL)

La prueba de Inglés como Lengua Extranjera (TOEFL) es necesaria para acceder a cualquier universidad norteamericana. Es una prueba de lenguaje académico que mide la habilidad de los hablantes no nativos de inglés para utilizar y comprender el inglés americano hablado, escrito y oído en los colleges y universidades. Muchas agencias gubernamentales, programas de becas y agencias de certificación utilizan la puntuación del TOEFL para evaluar el dominio del inglés de los examinandos. Existen dos versiones , una en papel y otra informatizada.

El examen en papel sigue el siguiente formato:

Comprensión oral: 30-40 minutos y 50 preguntas.

Expresión escrita: 25 minutos y 40 preguntas.

Comprensión lectora: 55 minutos, y 50 preguntas.

Redacción: 30 minutos y un tema.

(cc)) EY-NC-ND 2017, Universitat Politècnica de València Congreso In-Red (2017) 
El Next generation TOEFL ${ }^{\circledR}$ iBT test tiene cuatro secciones:

Lectura: contiene entre 3-5 pasajes de 12-14 preguntas cada uno y dura entre 60-100 min. Comprensión oral: contiene 4-6 lecturas de 6 preguntas cada una, y conversaciones de 5 preguntas cada una. (60-90 min).

Oral: se incluyen 6 tareas, dos de las cuales son independientes y dos de ellas son integradas. (20 $\mathrm{min})$.

Redacción: en esta sección hay una tarea integrada y una tarea independiente siendo su duración de unos 50 minutos (http://www.examenglish.com/TOEFL/index.html. [Fecha de acceso: 08-08-2013]).

\section{English Placement Test (Oxford University).}

La prueba original de nivel en formato papel, Oxford Placement Test (OPT), fue desarrollada por Dave Allan en 1985. La versión flexible de esta prueba es el Oxford Quick Placement Test $(O Q P T)$, diseñado por la Oxford University Press y Cambridge ESOL (English for Speakers of Other Languages). Se trata de una prueba de nivel dividida en dos partes, la primera de las cuales consta de 40 preguntas para todos los alumnos, y la segunda contiene 20 (desde la 41 a la 60) que solo realizan los examinandos que el supervisor decide. El tiempo para realizarlo es de 30 minutos. En las 5 primeras preguntas los examinandos tienen que contextualizar una serie de imágenes eligiendo entre tres opciones. Las siguientes preguntas son de rellenar los espacios en blanco y de frases incompletas con 3 o 4 opciones a elegir. Todos los ítems son del tipo elección múltiple.

También se puede disponer de la versión informatizada adaptativa, el Oxford Online Placement Test (OOPT) constituido por dos partes principales, una de uso del inglés y otra de comprensión oral. La primera contiene 30 preguntas aproximadamente y evalúa el vocabulario, la gramática y el significado en la conversación. Además en esta parte se incluye una subprueba de pragmática. La parte de comprensión oral la conforman 15 preguntas. Los ítems son también del tipo cumplimentación y de opción múltiple. Se puede realizar, entre 50 y 90 minutos. (http:/ /www. Oxfordenglishtesting .com/ Default MR. aspx?id=3034\&menuId=1).

A continuación se muestran ejemplos de preguntas de pragmática de cada uno de estas pruebas:

(c)) EY-NC-ND 2017, Universitat Politècnica de València 
Ejemplo 2 del Test of English as a Foreign Language (TOEFL):

\section{You will hear:}

\begin{tabular}{|l|l|}
\hline (man) & Do you mind if I turn the television off? \\
\hline \hline (woman) & Well, I'm in the middle of watching a program. \\
\hline \hline (narrator) & What does the woman imply? \\
\hline
\end{tabular}

\section{You will read:}

A. The man should watch the program too.

B. The man should leave the television on.

C. The program will be over soon.

D. She'll watch television later.

Ejemplo 3 del Test of English as a Foreign Language (TOEFL):

Conversación y preguntas:

\begin{tabular}{|c|c|}
\hline (narrator) & Questions 4 through 7. Listen to a conversation about a trip. \\
\hline (man) & Are you ready for "The Big Apple"? \\
\hline (woman) & Excuse me? \\
\hline (man) & $\begin{array}{l}\text { You know, New York City. You are going to New York with us, aren't } \\
\text { you? I wanted to show everybody around my old neighborhood. }\end{array}$ \\
\hline (woman) & $\begin{array}{l}\text { Oh...sure! I wouldn't miss it especially when the tour guide is a native } \\
\text { New Yorker. }\end{array}$ \\
\hline (man) & $\begin{array}{l}\text { I thought we could start at the Museum of Modern Art. Right now there's } \\
\text { an exhibit on twentieth-century American painters. }\end{array}$ \\
\hline (woman) & Fine with me...but what were you saying about... a big apple? \\
\hline (man) & "The Big Apple." It's a nickname for New York. I think I heard once that \\
\hline
\end{tabular}

(cc)) EY-NG-ND 2017, Universitat Politècnica de València 


\begin{tabular}{|c|c|}
\hline & it started with jazz musicians in the 20 's. \\
\hline (woman) & Oh. \\
\hline (man) & $\begin{array}{l}\text { Whenever they played a concert in a city, they called that city an } \\
\text { "apple." In those days, New York was the biggest city in the country, so } \\
\text { they called it "The Big Apple." }\end{array}$ \\
\hline (woman) & Hey, I have an idea! Let's go to a jazz club while we're there. \\
\hline (man) & Sounds good. \\
\hline
\end{tabular}

What can be inferred about the man?
A. He is a jazz musician.
B. He wants to join the woman's club.
C. He is in his twenties.
D. He was born in New York.

Ejemplo 4 del Oxford Online Placement Test (OOPT)

\begin{tabular}{|l|l||}
\hline Woman: & Finished fixing that plug yet? \\
\hline Man: & It's proving trickier than I thought. \\
\hline Woman: & It's not exactly rocket science, you know. \\
\hline
\end{tabular}

What does the man mean?
A. It was difficult but I managed to fix the plug.
B. I haven't been able to fix the plug yet.
C. Fixing the plug was no problem.

En estos ejemplos observamos la presencia reveladora de los verbos "inferir", "implicar" y "querer decir", lo cual indica que a través de estos ítems se pretende evaluar la capacidad del examinando para captar la intención del hablante (the man), y la capacidad del examinando para entender las máximas conversacionales y el proceso inferencial que llevan a cabo los interlocutores de los distintos diálogos que conforman las preguntas de 
pragmática de este test. El proceso inferencial (Grice,1975) explica que el locutor expresa la información de manera que el interlocutor puede entender lo que éste quiere decir. El interlocutor hace su interpretación del enunciado partiendo de la base de que el locutor sigue el proceso inferencial. El proceso inferencial es, según Sperber (1986), una actividad deductiva en la que no disponemos de todas las premisas, sólo se dispone de un enunciado explícito, de manera que la segunda premisa se rescata del conocimiento "enciclopédico" (según la Teoría Cognitiva) o del contexto para llegar a una conclusión coherente con la situación. Las máximas conversacionales son cuatro principios que, se supone, siguen los participantes en una conversación racional:

1. Máxima de cantidad: no digas más de lo necesario; haz tus contribuciones tan informativas como sea preciso

2. Máxima de cualidad: no digas aquello de lo que no tengas evidencia o creas falso

3. Máxima del modo: sé breve y ordenado, evita la oscuridad y ambigüedad

4. Máxima de la relevancia: haz tus contribuciones relevantes.

En el ejemplo 5, si se interpretase literalmente la respuesta del hombre (quien aparentemente estaría violando el proceso inferencial, la máxima de la cantidad y la de la relevancia), se podría pensar que lo que éste intenta es cambiar de tema. Pero como explica Levinson (1983), a un nivel más profundo asumimos que está siendo cooperativo. El hombre hace uso del principio de la implicatura, es decir, en su enunciado se implica la información de que a) sí puede hablar y b) la conversación debe ser breve, como máximo de cinco minutos. Como puede comprobarse en este ejemplo, una conversación puede tener sentido aunque no exista una conexión directamente semántica y lógica entre los dos enunciados. Generalmente, cuando se transgrede una máxima del proceso inferencial, no se hace porque se esté dejando de cooperar, más bien se espera que quien escuche se dé cuenta de ello e inicie un proceso inferencial a través del cual desvelar la implicatura o, lo que es lo mismo, la información implícita.

Ejemplo 5:

(c)) EY-NC-ND 2017, Universitat Politècnica de València Congreso In-Red (2017) 


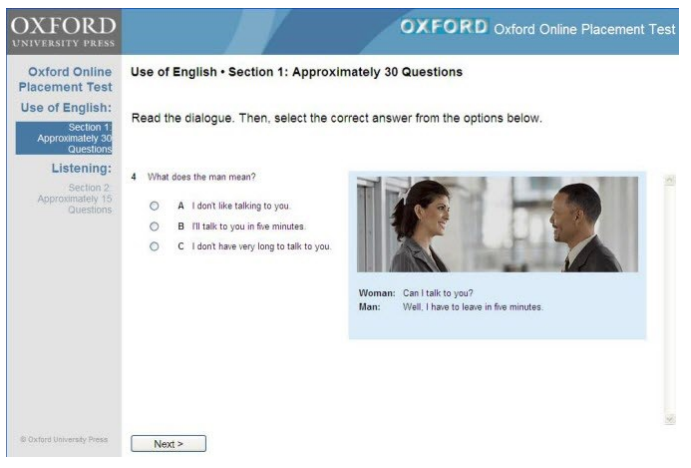

Fig 1 Muestra de significado implícito en OOPT

En la figura 1 la mujer pregunta al hombre si puede hablar con él. El hombre le contesta que se tiene que ir en cinco minutos. No le contesta que "sí" directamente . Asiente, por tanto, de manera indirecta y le proporciona información adicional indicándole de manera implícita que la conversación debe ser breve y que se tiene que limitar a cinco minutos. El significado en este contexto es que puede hablar, pero este significado es implícito más que explícito. Diciendo que tiene que irse, lo que desea comunicar es lo siguiente:

- "Yes let's talk, but I can only do so, for five minutes".

En el ejemplo 6 (ilustrado en la figura 2), el chico pregunta a la chica "Have you seen the newspaper?". Al examinando se formula la siguiente cuestón: ¿Qué quiere decir el chico? y se le dan tres opciones de respuesta.

Ejemplo 6:

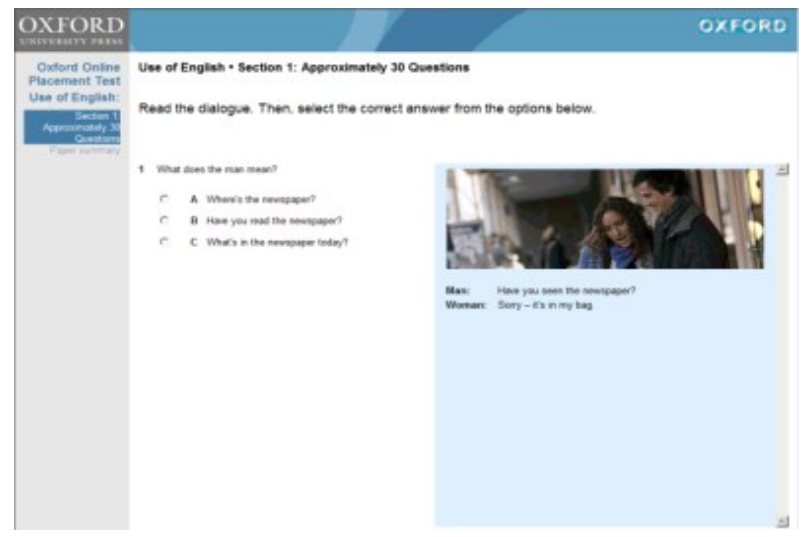

Fig. 2 Muestra de significado intencional en OOPT

(cc) EY-NC-ND 2017, Universitat Politècnica de València

Congreso IN-RED (2017) 
La opción correcta es la "A" "Where's the newspaper?" en este ejemplo vemos representada una de las categorías pragmáticas más estudiadas, los actos de habla (Austin,1962; Searle ,1975). Los ítems de pragmática en el OOPT están diseñados, como señala Purpura, (2009:2) "to measure the students' knowledge of the pragmatic (i.e., implied) meanings encoded in situated interactions".

\section{Conclusión}

Tras haber analizado todas las pruebas anteriormente descritas se observa que todas, a excepción de las pruebas comercializadas por Oxford University Press y Next generation TOEFL $^{\circledR}$ iBT test, constan de una parte de expresión oral. Además, todas ellas tienen una versión informatizada (Business Language Testing Service (BULATS), Cambridge English: Business (BEC), Key English test ( KET), Preliminary English Test (PET), First Certificate in English (FCE), Advance Certificate in English (CAE), Cambridge Michigan Certificate of Proficiency in English (CPE)), con la excepción del International English Language Testing System (IELTS), o bien se realizan únicamente por ordenador, como el Pearson Test of English. En el TOEIC (Test of English for International Communication) se realiza la prueba oral en red. El TOEFL iBT Y el OOPT se realizan también en red, pero solo éste último es adaptativo. Otro aspecto a tener en cuenta en estas pruebas es que algunas de ellas ofrecen una versión académica y otra general como es el caso de IELTS y de PEARSON. Otras como el BULATS y el BEC miden el nivel de inglés para negocios, el TOEIC para el ámbito laboral, mientras que el TOEFL y el ECPE (Examination for the Certificate of Proficiency in English) se centran en el lenguaje académico.

Algunas de estas pruebas no tienen en cuenta el carácter interactivo de la lengua ni su finalidad, de igual modo, la contextualización es a menudo deficientemente definida. Las únicas pruebas que contienen ítems de pragmática específicos son el TOEFL (IBT), en su sección de comprensión oral, y el OOPT que contiene una subprueba de pragmática. Otra

(c)) BY-NC-ND 2017, Universitat Politècnica de València 
característica de las pruebas de lengua anteriormente detalladas es que contienen preguntas cerradas, de tipo elección múltiple y de cumplimentación (véase anejos). Este tipo de ítems son criticados por algunos como Carroll (1980), Morrow (1979) y Bachman (1990) entre otros porque, como advierten estos autores, no miden la genuina actuación comunicativa sino más bien algo que se asemeja a ésta, pero que no deja de ser artificial.

En este estudio se ha podido comprobar cómo, a pesar de la importancia de la competencia pragmática en el ámbito de la enseñanza comunicativa de segundas lenguas, el tratamiento de la evaluación de esta competencia sigue siendo insuficiente y en algunos casos incluso inexistente en muchas de las pruebas comerciales. En la mayoría de las pruebas analizadas en este trabajo no existe correspondencia entre el avance tecnológico y el avance en la investigación sobre la evaluación de la competencia pragmática, ámbito en el que todavía queda mucho por investigar. Cabe decir que no suele ser posible reproducir las actuaciones dependientes del contexto a través de los procedimientos formales de las pruebas de lengua de una manera completamente fiable. Entendemos, por tanto, que las pruebas estandarizadas a gran escala sólo logran ser fiables para evaluar aspectos del lenguaje claramente definidos, pero no son todavía completamente válidas para evaluar aquellos aspectos más problemáticos que implican dependencia del contexto y que requieren, sobre todo, la interpretación del destinatario .

\section{Referencias}

AUSTIN, J.L. (1962). How to Do Things with Words. Oxford. England, Calderon Press.http: //www.dwrl.utexas.edu / davis/crs/rhe321/Austin-How-To Do Things .pdf [ Consulta:25 de febrero de 2015]

BACHMAN, L.F. (1990). Fundamental considerations in language testing. Oxford: Oxford University Press.

CARROLL, B.J (1980): Testing Communicative Performance. An Interim Study. Oxford. Pergamon Press.

DE EUROPA, C. (2002). Marco Europeo Común de Referencia para las Lenguas: Aprendizaje,Enseñanza,Evaluación.Strasbourg,Francia. $<$ http://cvc.cervantes.es/ob ref/marco>[Consulta: 22/10/2016]

EXAM ENGLISH. "Examenglish". $<$ http://www.exa men glish.com/exams comparison. php $>$ [Consulta: 08 de agosto de 2013]

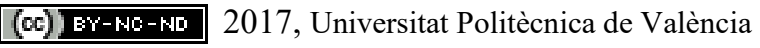


HARRIS, D.P (1969). Testing English as a Second Language. New York: McGrawHill.Hatch, E. 1972.

IGLESIAS, Ma.J.y SÁNCHEZ, C. (2007). Diagnóstico e Intervención Didáctica del Lenguaje Escolar. La Coruña. Netbiblo.

LEVINSON, S. (1983). Pra FCE gmatics. Cambridge. Cambridge University Press.

LINN, R.L. (2000). “Assessments and accountability”, Educational Researcher, 29(2), 4-16.

MADRID, D. (1997): "La evaluación del área curricular de la lengua extranjera". H. Salmerón (ed.) (1997): Evaluación Educativa: Teoría, metodología y aplicaciones en áreas de conocimiento, pp. 252-290. Granada. Grupo Editorial Universitario.

MADSEN, H.S. (1983). Techniques in Testing. Teaching techniques in English as a second Language. Oxford.Oxford University Press.

MARTÍNEZ RÍO, F.(2008). Proyecto de creación del INEE.<en: http://www.fmrizo.net/fmrizo_pdfs/libros/L\%2045\%202008\%20ProyectoINEE2002.pdf $>$ [Consulta: 10-03-2014].

MORROW, K., (1979). “Communicative language testing: revolution of evolution?”. Brumfit, C.K., Johnson, K. (eds.), The Communicative Approach to Language Teaching. (pp. 143 \pm 159 ). Oxford. Oxford University Press.

OXFORD UNIVERSITY PRESS. “Oxfordenglishtesting”. < http://www. Oxfordenglish tes ting.co m/ Default MR.aspx?id=3034\&menuId=1>[ Consulta:12 de febrero de 2016 ]

PHELPS, R. P. (2005). "Persistently positive: Forty years of public opinion on standardized testing”. En R. P. Phelps (ed.), Defending standardized testing (pp. 1-22). Mahwah, New Jersey: Lawrence Erlbaum Associates.

PURPURA, J.(2009).The Oxford Online Placement Test: What does it measure and how?< https://www .ox fordenglish testing. com /uploaded files/6_N ew_Look_and_Feel / Content / oopt_measure. Pdf > [Consulta: 08 de agosto de 2016]

SEARLE, J. (1975). "Indirect speech acts". P. Cole and J. Morgan (Eds.), Syntax and semantics, vol. 3: Speech Acts (pp. 59-82). New York.

SHEPHARD, L. A. (2006). "Classroom assessment”. En R. L. Brennan (ed.), Educational measurement (4a. ed., pp. 623-646). Westport, CT, Estados Unidos: Praeger.

(c)) EY-NC-ND 2017, Universitat Politècnica de València Congreso In-Red (2017) 
SPERBER, D. (1986). Relevance: Communication and Cognition.Cambridge. Harvard University Press (2a ed. 1995, Oxford, Blackwell). Traducción española de Eleanor Leonetti, La relevancia. Comunicación y procesos cognitivos, Madrid, Visor, 1994.

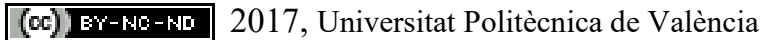




\title{
Cineforum-virtual criminológico como estrategía de aprendizaje teorico-práctico para el análisis del comportamiento criminal en el Grado de Criminología
}

\author{
Lucía Aparicio Chofréa , Carla de Paredes Gallardo ${ }^{b}$ y Cristina Escamilla Robla ${ }^{c}$ \\ a (Universidad Europea de Valencia y Universidad de Valencia, \\ lucia.aparicio@universidadeuropea.es), b(Universidad Europea de Valencia, \\ carla.deparedes@universidadeuropea.es) y c(Universidad Europea de Valencia, \\ mariacristina.escamilla@universidadeuropea.es).
}

\begin{abstract}
It deals with a cinematographic activity in the classroom and in a virtual context, with consecutive debates, in order to analyze behaviors and to elaborate, where appropriate, the reports or projects, main competences of the studies of the Degree of Criminology. This activity has been integrated in the 3rd academic year 2015-2016, with a multidisciplinary, progressive and integrative character. It is part of the practical work of the subjects, which in turn are integrated with each other. Due to the difficulty of being able to present students with real cases of crime, the films were carefully selected in order to be able to observe many of the actions, factors and indications that concur in these events. In this way, the student was able to analyze and evaluate, as demanded on the events developed, to later elaborate his practical work. The films were projected during the last month of each quarter, so that the students had knowledge of the case to be treated. They were also available on the virtual platform of the University so they can review those difficult scenes to interpret or the signs to assess. The results on the evaluation of this resource conclude that the students have worked with a high level of motivation, a greater internalization of knowledge and a more applied and creative learning.
\end{abstract}

Keywords: Analysis of film viewing, practical and virtual application, integration, motivation.

\footnotetext{
Resumen

Trata de una actividad cinematográfica en aula y en contexto virtual, con los debates consecutivos, con el fin de analizar conductas y elaborar, en su caso, los informes o proyectos, competencias principales de los estudios del Grado de Criminología. Esta actividad se ha integrado en el $3^{\text {er }}$ curso académico 2015-2016, con carácter multidisciplinar, progresivo e integrador. Forma parte de los trabajos prácticos de las asignaturas, que a su vez se integran unas con otras. Debido a la dificultad de poder presentar al alumnado casos reales sobre criminalidad, se seleccionaron las películas cuidadosamente con el fin de poder observar muchas de las acciones, factores e indicios que
} 
concurren en dichos sucesos. De esta manera, el alumno pudo analizar y evaluar, según lo demandado sobre los acontecimientos desarrollados, para posteriormente elaborar su trabajo práctico. Las películas se proyectaron durante el último més de cada trimestre, para que los alumnos tuvieran conocimientos del caso a tratar. También estuvieron disponibles en la plataforma virtual de la Universidad para que puedan volver a visionar aquellas escenas más díficiles de interpretar o los indicios a valorar. Los resultados sobre la valoración de este recurso concluyen que los estudiantes han trabajado con un alto nivel de motivación, una mayor interiorización de los conocimientos y un aprendizaje más aplicado y creativo.

Palabras clave: Análisis de visionado de películas, aplicación práctica y virtual, integración, motivación.

\section{Introducción}

El cine, como recreación humana, es de las más extraordinarias que existen desde la perspectiva de la comunicación. Toda la información que codifica el individuo que visiona una película, describe situaciones reales o fictícias y genera emociones, cuyo análisis posterior es útil para valorar diferentes hechos, conductas e incluso para provocar actitudes y acciones distintas a las habituales (Icart-Isern, 2008). Desde la enseñanza primaria y secundaria, se ha ido utilizando el cine comercial con fines formativos (Martínez, 2003), incluso en educación superior, en áreas específicas, como por ejemplo, medicina (GarcíaSánchez, Fresnadillo y García-Sánchez, 2002), o en farmacología (Bosch y Baños, 1999).

Los avances técnológicos que popularizaron el séptimo arte, surgieron en la última década del siglo XX, donde apareció el "home cinema", así como el DVD, la televisión digital, entre otros. Esta evolución permite conseguir con facilidad dichos materiales, incluso para uso exclusivo de aquel que quisiera disfrutarlo para sí mismo. De esta manera, el cine se convierte en un medio de comunicación de masas (De la Torre, 1996).

El lenguaje cinematográfico trae consigo diferentes niveles de comunicación. Por una parte, se encuentra el nivel de los sistemas perceptivos, como la vista y el oído, combinándose con lenguajes asociados, como la música y los efectos especiales; además, actúa un tercer nivel donde se pone en marcha procesos subconscientes, como los encuadres, los espacios escénicos, los movimientos, etc., (Domínguez y Guercia, 2005), que juntos con los anteriores hace de este recurso, en un contexto educativo, uno de los más óptimos para la adquisición de conocimientos, habilidades y actitudes, cuando se acompaña por docentes que comparten los códigos de este lenguaje (Icart-Isern, 2008).

El cine formativo utilizado frecuentemente, según de la Torre, catedrático de Didáctica e Innovación Educativa (Universitat de Barcelona), es "la emisión y recepción intencional de películas portadoras de valores culturales, humanos, técnico-científicos o artísticos, con la finalidad de mejorar el conocimiento, las estrategias o las actitudes y opiniones de los espectadores". Asimismo, enfocando el cine con un carácter formativo, desde su argumento y con la intención de promover la reflexión y el análisis de un tema, problema, situación o

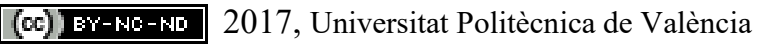

Congreso IN-RED (2017) 
acontecimientos, se convierte en un proceso dínamico, creativo y de complicidad entre el docente y el alumno (Icart-Isern, 2008).

Las nuevas tecnologías son un valor añadido a la transmisión de conocimientos y un cambio del modelo docente en los procesos de enseñanza-aprendizaje para el desarrollo de competencias, y donde el docente es el encargado de guiar, planificar y evaluar el método utilizado. Un buen ejemplo de la utilización del cine dentro de la metodología docente, es el desarrollado por Pérez y López (2007) en sus enseñanzas de recursos humanos:

\begin{abstract}
A través del cine el alumno/espectador puede recibir información que le ayude a ordenar cognitivamente sus conocimientos, dándole la oportunidad de participar en muchas situaciones diferentes que, de no ser por este medio, no hubiera tenido a su alcance. El cine propone al espectador una historia, facilitando la identificación del espectador con los diferentes matices del discurso. A través de la identificación de los personajes, la trama, la acción, el espectador pasa de ser mero testigo de la narración a convertirse en actor esta. De esta forma el aprendizaje se produce activamente, a través de la experiencia (Pérez y López, 2007:66).
\end{abstract}

Otro ejemplo sobre la utilización del cine en las enseñanzas, en este caso en Sociología, confirman los profesores Fernández y Olmedo (2003) tras su experiencia sobre el apoyo audiovisual. Describen que puede ser un camino eficaz para presentar de manera comprensible la materia y conseguir que atraiga y despierte el interés de los alumnos hacia ella y les resulte relevante.

Trabajos como el de Betanzo (2010), obtuvieron valores positivos, destacando la conveniencia de abordar los conceptos con carácter multidisciplinar en lugar de abordarlos de forma aislada, así como la importancia de la motivación en los procesos de aprendizaje con la inclusión de medios audiovisuales.

Este proyecto se integró en las enseñanzas del 3er curso de Criminología y durante todo el curso académico 2015-2016, proyectando las películas a medida que se iban adquiriendo los conocimientos adecuados de cada asignatura. Posteriormente, con un guión previo, se trabajaron los casos, conceptos, situaciones, etc., pertinentes relacionadas con los contenidos a tratar. Al finalizar el curso, se valoró este proyecto con mucha satisfacción, tanto por parte de los alumnos como del profesorado afectado.

Este recurso, con una selección adecuada de películas, ofrece una visión global y a la vez individual sobre los elementos que estudia la Criminología como el delincuente, el delito y la víctima, además del control social, para la prevención de la delincuencia. Además, ayuda al estudiante a analizar la presencia del fenómeno delictivo en toda su extensión y con las distintas dimensiones de estudio.

En conclusión, el presente trabajo tuvo como fin la utilización de la actividad cinematográfica como innovación docente en la enseñanza universitaria, con carácter multidisciplinar, integrador y progresivo. Multidisciplinar porque una misma película va ser utilizada para diferentes asignaturas; integrador, porque dichas asignaturas están relacionadas en sus contenidos y própositos finales, y otras, en los procesos que se 
desarrollan dentro del argumento (ejemplo: trastorno de conducta de un agresor que a su vez va a ser juzgado por un tribunal. Psicología + Derecho); y progresivo, porque se va a planificar de forma progresiva para que exista una continuidad en los conocimientos teóricos y prácticos de dichas asignaturas. Todo ello, se ha teniendo en cuenta puesto que en el grado de Criminología se desarrollan asignaturas de diferentes áreas de conocimiento como la Psicología, la Sociología y el Derecho.

A continuación se detallan los objetivos de este recurso; su desarrollo en temporalidad, participantes, material utilizado; la metolodogía llevada a cabo, con un cronograma ejemplo, y breve explicación del procedimiento; resultados de la valoración por parte de los alumnos; y unas conclusiones.

\section{Objetivos}

El objetivo general de este trabajo es desarrollar un recurso formativo en aula y en formato virtual, como innovación docente, para conseguir el aprendizaje aplicado multidisciplinar, integrador y progresivo de los conocimientos y competencias de diversas asignaturas interrelacionadas del Grado de Criminología.

Como objetivos específicos:

- Crear una plataforma en red de profesorado universitario con el recurso "Cineforum-virtual Criminológico", como metodología para la enseñanza de un grupo de asignaturas interrelacionadas.

- Motivar a los estudiantes de Criminología a la asistencia, debate y participación en aula y, posteriormente, también en la plataforma virtual.

- Motivar a los estudiantes al trabajo individual-virtual, al tener la posibilidad de visionar de nuevo y con exahustividad las escenas de las películas necesarias para su análisis.

- Comprender casos-problemas desde una perspectiva global e individual, desde los inicios de los acontecimientos y su evolución, en un caso partícular, hasta las posibles alternativas de solución.

- Afianzar los contenidos teóricos de manera creativa y motivadora.

- Participar de forma activa en el análisis y valoración de casos, así como en la elaboración de los informes pertinentes, en su caso.

- Aprender a debatir y defender argumentos desde toda la información que se recoge en las películas.

- Manejar las emociones para la toma de decisiones más adecuadas.

\section{Desarrollo de la innovación}

A continuación se desarrolla el proceso del recurso formativo de innovación docente, "Cineforum-virtual Criminológico".

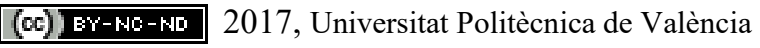

Congreso IN-RED (2017) 


\subsection{Temporalidad}

El “Cineforum-virtual Criminológico", se llevó a cabo durante todo el curso académico 2015-2016, en tres momentos, coincidentes con los tres trimestres: T1, T2 y T3. Se proyectaron a medida que se iban adquiriendo los conocimientos adecuados para poder evaluar, valorar y analizar los acontecimientos que iban sucediendo en el desarrollo de la película seleccionada. Aproximadamente, se proyectaron a partir de la mitad de cada trimestre. Posteriormente, el alumno disponía del recurso en la plataforma o se facilitaba por el profesor para su visionado individual y exhaustivo en casa.

\subsection{Participantes}

Asistieron 11 alumnos, los matriculados en el Grado de Criminología, en el $3^{\text {er }}$ curso. Además, según el argumento de la película proyectada, también asistieron los profesores/as de las asignaturas relacionadas con la misma.

\subsection{Películas proyectadas y asignaturas intervinientes en el proyecto}

Como se puede observar en la Tabla 1, se distribuyen, en primer lugar, las películas que se proyectaron para trabajar las asignaturas de $3^{\circ}$ de Criminología, divididas en dos bloques: el bloque I, todas aquellas que se relacionan entre sí, en algún contenido; y el bloque II, donde con dichas películas o capítulos se podrán observar aquellos indicios sobre criminalística.

Tabla 1. Listado de películas y asignaturas donde se proyectan

\begin{tabular}{|c|c|c|c|c|}
\hline & Películas & Asignaturas 3 Criminología & Carácter & ECTS \\
\hline \multirow{8}{*}{$\frac{\grave{g}}{\frac{0}{0}}$} & \multirow{8}{*}{$\begin{array}{l}\text { 1. "El Bola" } \\
\text { 2. "Volando Voy" } \\
\text { 3. "El cadáver de Anna Fritz" } \\
\text { 4. "Musarañas" } \\
\text { 5. "Relatos Salvajes" } \\
\text { 6. "Hard Candy" } \\
\text { 7. "American Psycho" } \\
\text { 8. "Tenemos que hablar de Kevin" } \\
\text { 9. "No hay país para viejos" } \\
\text { 10. "Las dos caras de la verdad" } \\
\text { 11. "Mentes Criminales" } \\
\text { 12. "Celda 211" } \\
\text { 13. "El experimento" }\end{array}$} & $\begin{array}{l}\text { Prevención y Tratamiento de la } \\
\text { Delincuencia }\end{array}$ & $\mathrm{OB}$ & 6 \\
\hline & & Delincuencia y Control Social & $\mathrm{OB}$ & 6 \\
\hline & & Conductas Criminales Tipificadas & $\mathrm{OB}$ & 6 \\
\hline & & Procesos y Procedimientos Penales & $\mathrm{OB}$ & 6 \\
\hline & & $\begin{array}{l}\text { Habilidades para la Intervención } \\
\text { Social y Educativa en el } \\
\text { Delincuente }\end{array}$ & $\mathrm{OB}$ & 6 \\
\hline & & Víctimología & $\mathrm{OB}$ & 6 \\
\hline & & Penología y Derecho Penitenciario & $\mathrm{OB}$ & 6 \\
\hline & & Psiquiatría Forense & $\mathrm{OB}$ & 6 \\
\hline \multirow{2}{*}{$\begin{array}{l}\frac{1}{0} \\
\frac{0}{2}\end{array}$} & \multirow{2}{*}{$\begin{array}{l}\text { 14. Seven } \\
\text { 15. Series "CSI" }\end{array}$} & Taller de Criminalística I & $\mathrm{OB}$ & 6 \\
\hline & & Taller de Criminalística II & $\mathrm{OB}$ & 6 \\
\hline
\end{tabular}

Fuente: Elaboración propia (2016) 
Cineforum-virtual criminológico como estrategía de aprendizaje teorico-práctico para el análisis del comportamiento criminal en el Grado de Criminología

\subsection{Métodología}

3.4.1. Cronograma ejemplo

$\mathbf{T 1}$ (trimestre 1)

Asig: Delincuencia y Control Social

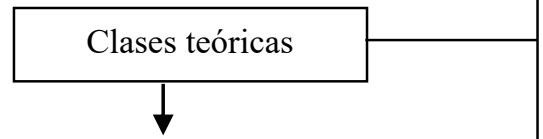

Enlace en T3 con asig:

Habilidades para la Intervención

Social del Delincuente

\section{T1 (trimestre 1)}

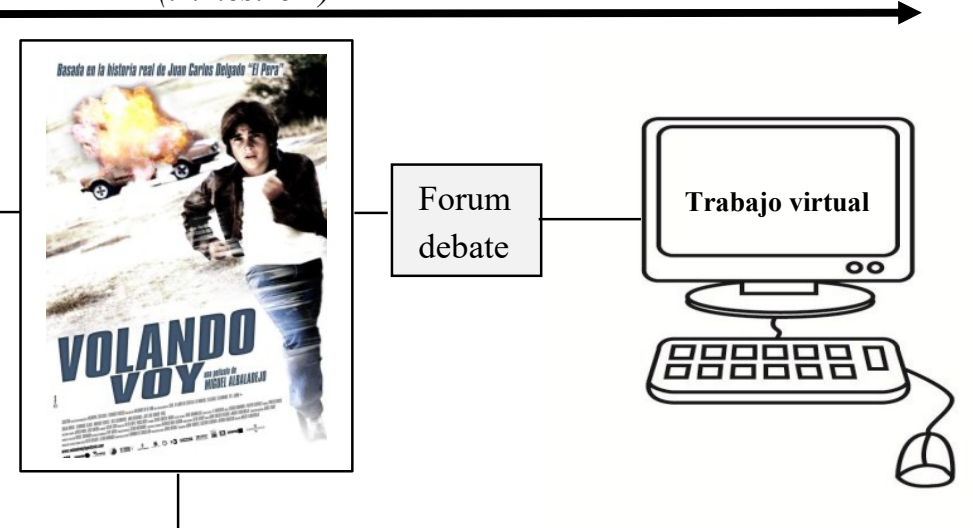

Asig: Conductas Criminales Tipificadas

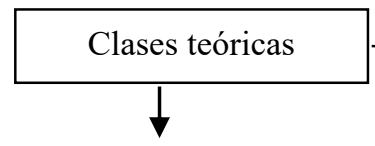

Enlace en T3 con asig:

Psiquiatría Forense

Asig: Procesos y Procesimientos Penales

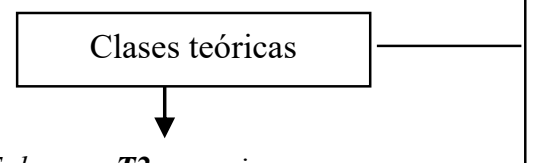

Enlace en $\boldsymbol{T} 2$ con asig:

Penología y Derecho Penitenciario

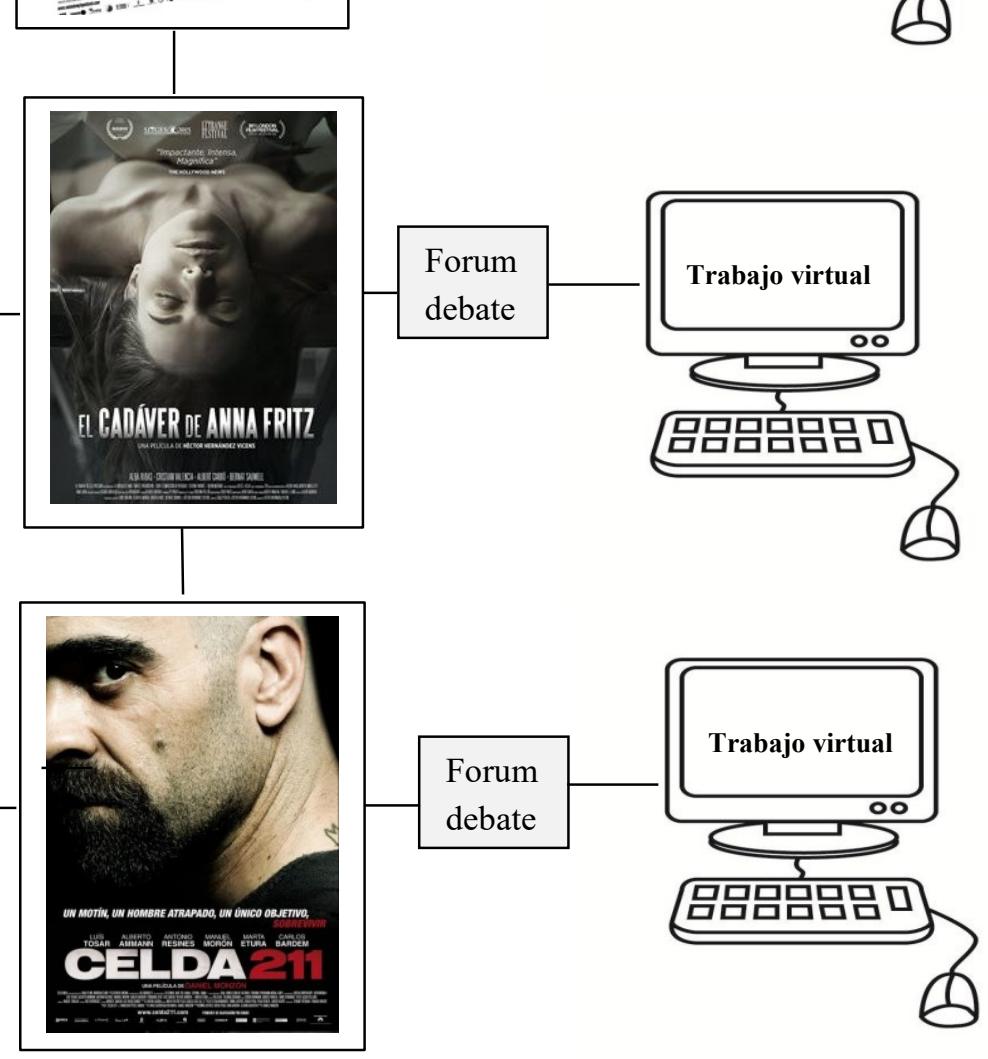

Fig. 1 Cronograma ejemplo del funcionamiento del Cineforum-virtual Criminologico en el primer trimestre del curso académico.

(c)) BY-NC-ND 2017, Universitat Politècnica de València

Congreso IN-RED (2017) 


\subsubsection{Procedimiento}

Antes de empezar el curso académico, el profesorado que imparte las asignaturas de $3^{\text {er }}$ curso del Grado de Criminología de la Universidad Europea de Valencia, formó una plataforma virtual y mantuvo una reunión para establecer el programa que se llevaría a cabo en el "Cineforum-virtual Criminológico", como actividad perteneciente a la parte práctica de las asignaturas, y así poder desarrollar además del aprendizaje de los conocimientos, las competencias prácticas.

Se elaboró un listado de peliculas, estudiando con exhaustividad los argumentos y sucesos que se desarrollan en las sinopsis de las mismas. Se encargó cada uno de los profesores/as, de visionar las películas susceptibles de introducir en el programa, para tener la seguridad de que eran adecuadas con los temas de las asignaturas. Una vez elaborado el listado, véase Tabla 1, se distribuyeron las proyecciones, los debates y los posteriores trabajos virtuales, a lo largo de los tres trimestres.

El primer día de clase, los profesores que forman parte de esta plataforma, explicaron a sus alumnos la actividad de "Cineforum-virtual Criminológico", su funcionamiento y un calendario de proyecciones y forum, fechas límites de utilización virtual de la película y de entregas de trabajos, teniendo en cuenta, que aunque se dispusiera de una película concreta hasta el último trimestre, por trabajar con ella en varias asignaturas, los trabajos o informes concretos de cada una de las mismas, sí que tenían fecha límite de entrega.

Las películas se proyectaron en aula a principio del último mes de cada trimestre (en algunos casos a mitad del trimestre), una vez que los estudiantes habían recibido los conomientos necesarios para poder analizar, valorar, y resolver, en su caso, lo que se le solicitó, según el argumento. Como indica el cronograma ejemplo de la Figura 1, el proceso fue el siguiente:

$1^{\circ}$. Explicación teórica de los contenidos.

$2^{\circ}$. Proyección de la película + fórum, con un guíon propuesto por cada profesor.

$3^{\circ}$. Trabajos individuales con posibilidad de visionar de nuevo la película en casa. En la plataforma, cada profesor indicó los trabajos a realizar según asignatura, mínimo tres. Ejemplos: valoración de posible enfermedad mental según la trayectoria de vida del protagonista, o del transcurso de los hechos; factores de riesgo o protección del delincuente; penas que deberían imponerse según un caso particular; qué victimología se desdibujaba desde el principio de los hechos o indicios; qué tipología de delitos se han visto y qué penas se derivarian, en su caso, con atenuantes o eximentes, o incluso posibilidad de inimputabilidad, etc.

$4^{\circ}$. Participación virtual una vez habían entregado los trabajos. Se abrió un foro de discusión sobre las problemáticas y las valoraciones realizadas por los alumnos, después de que los trabajos se presentaron en fecha. 
$5^{\circ}$. Sesión presencial sobre reflexiones y, en su caso, soluciones, de los trabajos solicitados.

\section{Resultados}

Para comprobar el aprendizaje y valoración de esta actividad como recurso formativo y complementario para el aprendizaje de las asignaturas de $3^{\circ}$ del Grado de Criminología, se pasó a los estudiantes un breve cuestionario de 5 ítems con valores cuantitativos de 0 a 10 . Se obtuvieron resultados muy satisfactorios:

Tabla 2. Cuestionario de valoración del “Cineforum-virtual Criminológico”

\begin{tabular}{lc}
\hline Items & Medias \\
\hline $\begin{array}{l}\text { 1. Con esta metodología he aprendido con más eficacia y relación } \\
\text { los contenidos de esta asignatura. }\end{array}$ & 9 \\
2. Me ha servido para venir a clase con más motivación. & 9 \\
$\begin{array}{l}\text { 3. Con esta metodología he puesto en práctica lo explicado en } \\
\text { clase de mejor forma que con casos escritos. }\end{array}$ & 10 \\
$\begin{array}{l}\text { 4. Me gustaría que el próximo curso se trabajara alguna asignatura } \\
\text { con esta metodología. }\end{array}$ & 10 \\
5. Recomendaría esta metodología. &
\end{tabular}

Por lo que se refiere a la evaluación de la actividad, se divide en dos partes. La entrega de los trabajos sobre la película, suponía un 30\% de la nota final de la asignatura correspondiente y otro $10 \%$ la participación en los debates y forum, tanto presenciales como virtuales. Un $10 \%$ fue para otras actividades y el $50 \%$ restante fue para el examen final escrito, con un formato de preguntas abiertas. Los resultados que se obtuvieron han sido muy satisfactorios, puesto que de los 11 alumnos, 9 han sacado la máxima clasificación sobre la actividad (4), 2 alumnos han sacado un 3. También se detectó que las notas de los exámenes escritos habían sido superiores que las del grupo del año anterior.

\section{Conclusiones}

La valoración global del profesorado al finalizar el curso, fue muy satisfactoria por varias razones. En primer lugar, por los resultados positivos de los exámenes finales y de los trabajos. En segundo lugar, por el carácter motivador que se respiraba en las aulas y en los debates; además de prácticar la capacidad de interrelacionar una problemática a varios

(c)) BY-NC-ND 2017, Universitat Politècnica de València 
ámbitos de trabajo, cuestión difícil de demostrar con otros recursos. Además, por la aplicación práctica de la legislación como solución a diversos acontecimientos y conflictos, así como para valorar las diferentes conductas criminales y los posibles estados psicológicos que pueden sufrir las personas para desarrollar ciertas acciones. La involucración de los alumnos ha sido muy llamativa, en comparación con otras actividades y el aprendizaje de gestión de las emociones para tomar decisiones, ha sido un experiencia para los alumnos muy práctica y necesaria para estos estudios.

Para finalizar, esta metodología, ha resultado positiva por la capacidad de conseguir con este recurso y el trabajo posterior, que los alumnos adquieran la mayoría de competencias que describe el Grado de Criminología.

\section{Referencias}

ALEXANDER, M., HALL, M. N., \& PETTICE, Y. J. (1993). Cinemeducation: an innovative approach to teaching psychosocial medical care. Family medicine, 26(7), 430-433.

BETANZO, P. B. (2010). "El Cine como herramienta eficaz para un aprendizaje concreto, activo y reflexivo: una experiencia en Aula“. Buenos Aires: Congreso Iberoamericano de Educación.

BOSCH, F., \& BAÑOS, J. E. (1999). Empleo de películas comerciales en la docencia de la farmacología. Educ Med, 4(2), 197.

DE LA TORRE, S. (1996). Cine formativo. Una estrategia innovadora para los docentes. Editorial Octaedro, España.

DOMÍNGUEZ, M. D. C. P., \& GUERCIA, C. U. (2005). Cine y juventud: una propuesta educativa integral. Revista de estudios de juventud, (68), 73-90.

FERNANDEZ PALOMARES, F. Y OLMEDO REINOSO, A. (2003). "Barbiana y las «escuelas japonesas: apoyos audiovisuales para ayudar a comprender la dimensión social de la enseñanza“, $X$ Conferencia de Sociología de la Educación, Valencia, 18-20 septiembre.

GARCÍA-SÁNCHEZ, J. E., FRESNADILLO, M. J., \& GARCÍA-SÁNCHEZ, E. (2002). El cine en la docencia de las enfermedades infecciosas y la microbiología clínica. Enfermedades infecciosas y Microbiología clínica, 20(8), 403-406.

GONZÁLEZ, E. M. Á. (2015). El cine como metodología docente aplicable a la enseñanza del Derecho Administrativo. REJIE: Revista Jurídica de Investigación e Innovación Educativa, (11), 97 109.

ICART-ISERN, M. T. (2008). "Metodología de la investigación y cine comercial: claves de una experiencia docente". Educación médica, 11(1), 13-18.

MARTÍNEZ ÁlVAREZ, J. (2003). Peliculas para usar en el aula. Madrid: UNED

RODRÍGUEZ, R. (2006). Diseño de entornos para el desarrollo de la autonomía en el aprendizaje. Aula Abierta, 87, 89-104

SALAS, D. P., \& CASAREJOS, M. N. G. (2013). El cine como herramienta de aprendizaje en el aula. Claves de una experiencia docente multidisciplinar en el ámbito económico. Revista Internacional de Organizaciones, (10), 181-197.

\section{Películas}

(cc)) EY-NG-ND 2017, Universitat Politècnica de València

Congreso In-Red (2017) 
Cineforum-virtual criminológico como estrategía de aprendizaje teorico-práctico para el análisis del comportamiento criminal en el Grado de Criminología

Volando Voy (Dir. Miguel Albaladejo). Mediapro. 2006.

El cadáver de Anna Fritz (Dir. Héctor Hernández). A Contraluz Films / Benecé Produccions / Corte y Confección de Películas / Playtime Movies / Silendum Films. 2015.

Celda 211 (Dir. Daniel Monzón). Coproducción España-Francia; La Fabrique de Films / Morena Films / Telecinco Cinema / Vaca Films. 2009.

(c)) BY-NC-ND 2017, Universitat Politècnica de València

Congreso IN-RED (2017) 


\title{
Comparativa de la Experiencia de Flip Teaching en dos asignaturas y centros distintos en la UPV
}

\author{
Oltra Gutierrez, Juan Vicente ${ }^{\mathrm{a}}$; Sofía Estelles-Miguel ${ }^{\mathrm{b}}$, Fernando Garrigos-Simon ${ }^{\mathrm{c}}$ y \\ Montesa Andrés, José Onofre ${ }^{d}$ \\ a,c,d Escuela Técnica Superior de Ingeniería Informática jvoltra@omp.upv.es; fgarrigos@doe.upv.es y \\ jomontes@omp.upv.es y b Facultad de Administración y Dirección de Empresas, \\ soesmi@omp.upv.es. Todos los autores del Departamento de Organización de Empresas de la \\ Universitat Politècnica de València.
}

\begin{abstract}
In this paper has been carried out a comparative of two different subjects, taught in two different degrees, both of them have been taught with the Flip Teaching methodology. Evidently, the specific characteristics of each of them have been taken into account. The subjects, degrees and school in which the experience has been realized are: Deontology and Professionalism in Computer Engineering degree in the School of Informatics and Operations Management in the Business Administration and Management in the Faculty of Business Administration and Management. Both subject are taught by professors of Deparment of Business Organization. The experience began in the academic year 2014/2015 and has lasted until the current 2016/2017.
\end{abstract}

Keywords: Flip-Teaching, High Education, Deontology, Operations Management.

\footnotetext{
Resumen

En el presente trabajo se ha llevado a cabo una comparativa entre dos asignaturas diferentes, impartidas en dos grados distintos, pero donde ambas han sido impartidas utilizando la metodología de Flip Teaching o Docencia Inversa. Evidentemente, se han tenido en cuenta las características especificas de cada una de ellas. Las asignaturas, titulaciones y cursos en los se que ha realizado la experiencia son: Deontología y Profesionalismo en el grado de Ingeniería Informática en la Escuela Técnica Superior de Ingeniería Informática y Dirección de Producción y Operaciones en el Grado de Administración y Dirección de Empresas en la Facultad del mismo nombre. Ambas materias son impartidas por profesores del Departamento de Organización de Empresas. La experiencia comenzó en el curso 2014/2015 y se ha extendido hasta el actual 2016/2017.
}

Palabras clave: Flip Teaching, Docencia Inversa, Educación Universitaria, Deontología, Dirección de Operaciones. 


\section{Introducción}

El Vicerrectorado de Tecnologías de la Información y de las Comunicaciones (VTIC) de la Universitat Politècnica de València (UPV), inició la experiencia de "Flip Teaching" o Docencia Inversa durante el curso 2014-2015. La misma se realizó en los segundos cursos de los grados de Administración y Dirección de Empresas e Ingeniería Informática. Se planteó en los siguientes términos (UPV, 2014):

- Las clases presenciales teóricas (teoría de aula) o, al menos, un porcentaje elevado de éstas se elaborarán, por parte de los profesores de la asignatura, como materiales audiovisuales de alta calidad.

- Los alumnos que participen en está metodología se estudiarán los conceptos teóricos visualizando estos materiales y consultando el material docente que el profesor estime oportuno de forma no presencial.

- Los grupos en los que se realice la experiencia serán reducidos, de 20 a 30 alumnos. Siendo el criterio de acceso el orden de matrícula establecido en la normativa académica UPV.

- El tiempo dedicado por parte del alumno a actividades presenciales disminuirá en valor absoluto (dependiendo de la cantidad de teoría de aula que se elabore de forma audiovisual).

- Existirá una interacción bidireccional profesor/alumno en el proceso de aprendizaje. Las horas presenciales se dedicarán a la realización de actividades de consolidación de los conceptos teóricos y en una atención personalizada por parte del profesor para resolver las dudas que se planteen y una actitud proactiva del alumno en el aula.

En base a los parámetros arriba indicados y que habían sido establecidos por el VTIC (remarcando que la docencia inversa tiene como objetivo aprender metodologías docentes que nos permitan integrar en la docencia presencial contenidos docentes digitales utilizando las tecnologías que hoy en día tenemos a nuestro alcance (Botti, 2014)), las distintas asignaturas rediseñaron sus estructuras, de forma que la forma de impartición y la evaluación casaran con el formato conocido como FlipTeaching o de Docencia Inversa. (Bennett et al, 2011) y (Oltra, 2015).

Otro cambio importante introducido por la adaptación al Espacio Europeo de Educación Superior (EEES) es centrar la atención en el desarrollo de competencias y habilidades que preparan a los alumnos para su integración en el mundo laboral (Estellés et al, 2016). Partiendo de la base de la necesidad de cambiar la dinámica de las clases tradicionales basadas en el aprendizaje memorístico de conocimientos, en otra donde los estudiantes sean una parte activa, pasando de ser sujetos pasivos a ser protagonistas y responsables de su propio aprendizaje (Zabala y Arnau, 2007). Además de ayudar a que el alumno aprenda a su ritmo y permite al profesor atender las necesidades específicas de cada alumno (EstellesMiguel, et al, 2015).

El Departamento de Organización de Empresas, es transversal en la universidad, lo que ha permitido impartir este modelo de docencia en las dos titulaciones piloto. Sin embargo, en

(c)) BY-NC-ND 2017, Universitat Politècnica de València

Congreso IN-RED (2017) 
su momento se consideró que sería un error aplicar los mismos esquemas y organización de evaluaciones para alumnos con procedencia y fin tan dispar.

La personalización de la educación para los estudiantes, produce múltiples beneficios en relación con el rendimiento académico. A la vez que mejora la posibilidad de que muchos estudiantes continúen estudiando, desarrolla mayor responsabilidad, ayuda en el entendimiento por encima de la pura memorización y desarrolla habilidades como la colaboración, la comunicación y la resolución de problemas (Vasileva et al, 2015). Además de mejorar la participación de los alumnos y aumentar la interacción entre estudiantes y profesores (Bethany, 2012).

Por supuesto para ello se necesita un cambio de rol por parte del profesor, acostumbrado a la docencia con clases magistrales en aula. De esta forma el profesor ayuda a los alumnos a desarrollar sus conocimientos y competencias (Tedesco, 2010). A la vez que se hace imprescindible la participación activa del alumno que no puede tomar una actitud pasiva en la clase sino todo lo contrario.

En el presente trabajo se presentan las dos experiencias en cada uno de los centros piloto, en la Escuela Técnica Superior de Ingeniería Informática (ETSInf) y en la Facultad de Administración y Dirección de Empresas (FADE), ambas de la Universitat Politècnica de Valencia, con las divergencias esperables sobre tipo de alumno y contenidos. Siendo la principal convergencia la metodología y el departamento al que pertenecen los profesores. Las asignaturas en las que se desarrollo la experiencia han sido Deontología y Profesionalismo en ETSInf y Dirección de Producción y Operaciones en FADE, ambas impartidas en segundo curso de grado.

\section{Dirección de Producción y Operaciones}

Esta asignatura es troncal obligatoria de 6 créditos, ubicada en el primer cuatrimestre del segundo curso de Grado de Administración y Dirección de Empresas en FADE de la UPV. $\mathrm{Su}$ contenido se fundamenta sobre la forma en que las organizaciones producen bienes $\mathrm{y}$ servicios. En ella se explica que cada objeto que se utiliza en la vida cotidiana ó cada tratamiento o servicio que se recibe por ejemplo en un banco, en una agencia de viajes o en una peluquería, incluso cada clase que se imparte en la universidad llegan a nosotros gracias a los Directores de Operaciones, que son los que gestionan la producción de los mismos. Con esta asignatura se pretende que los alumnos adquieran conocimientos específicos sobre las características fundamentales de la Dirección de Operaciones en las empresas (Albarracín et al., 2013). Es eminentemente práctica, aunque recoge también la explicación de algunos conceptos básicos para la realización de la parte práctica.

Las horas de impartición de la asignatura se distribuyen de la siguiente manera:

- 30 horas de teoría de aula:

- 10 horas de diseño del sistema de operaciones.

- 15 horas de sistema de planificación y control de operaciones.

- 5 horas de sistema logístico.

- 15 horas de prácticas de aula: 
- 3 horas de diseño del sistema de operaciones.

- 10 horas de sistema de planificación y control de operaciones.

- 2 horas de sistema logístico.

- 15 horas de prácticas de laboratorio:

- 3 horas de diseño del sistema de operaciones.

- 9 horas de sistema de planificación y control de operaciones.

- 3 horas de sistema logístico.

La asignatura se presenta mediante lecciones magistrales a los alumnos en las que se explica la teoría y a continuación se realizan problemas aplicados a los contenidos explicados. Además, los alumnos elaboran un aprendizaje basado en proyectos que se recoge en un portafolio en el que desarrollan el diseño del sistema productivo de una empresa, en el mismo, diseñan el producto, diseñan el proceso, finalmente realizan la distribución en planta de dicho proceso y finalmente deciden su localización.

La evaluación consiste en una prueba escrita de respuesta abierta que supone el $40 \%$ del peso de la nota, dos pruebas objetivas que suponen el $30 \%$ entre las dos, un portafolio (comentado en el párrafo anterior) que supone el 15\% y un caso que supone el 15\% del peso de la nota. No existen notas mínimas en ninguna de las partes para aprobar y entre todas las notas hay que llegar a una nota mínima de 5 .

\section{Deontología y Profesionalismo}

Es una asignatura troncal obligatoria de 4,5 créditos ( 3 en su parte teórica, 1,5 en su parte práctica), impartida durante el segundo semestre del curso segundo del Grado de Informática ETSInf de la UPV.

La asignatura tiene unas características que la hacen distinta al resto, como se puede apreciar dando un vistazo a los nombres del resto de asignaturas que comparten semestre: Redes de Computadores, Estructura de computadores, Concurrencia y sistemas distribuidos, Estructuras de datos y algoritmos e Interfaces persona computador. Esto permite con una rápida apreciación intuitiva, que resulta confirmada por la realidad, hacerse una idea aproximada de lo que el alumno ve en el resto de sus asignaturas. Que es una practicidad inmediata, mientras que en ésta, donde se les habla de las buenas prácticas y la deontología profesional, además de darles una visión del marco legal en el que se van a mover, resultará a priori para su percepción algo más apartado de su día a día, lo que implica un mayor esfuerzo del docente para lograr su implicación.

Se intenta acercar al alumno la legislación más importante que afecta a su desarrollo profesional (Propiedad intelectual -tipos de licencias-, Protección de datos, Código penal, leyes, reglamentos y otras). A los aspectos deontológicos y éticos de la profesión y el estudio de los códigos éticos más significativos, se añade el análisis del profesionalismo y competencias en el ámbito de las Tecnologías de la Información (TI) y una visión del asociacionismo y colegios profesionales.

Los contenidos se dividen en tres categorías, tras un tema introductorio: Profesionalismo Informático, donde ven conceptos básicos de profesionalismo e historia de la profesión

(cc) EY-NC-ND 2017, Universitat Politècnica de València

Congreso IN-RED (2017) 
informática, y relacionados con el profesional en la organización y fuera de ella. Posteriormente se ven Aspectos Legales en la Informática, donde partiendo de conceptos básicos y marco legal de la actividad del profesional informático, se pone acento en protección de datos, propiedad intelectual y pruebas periciales informáticas. Finalmente, una tercera parte, Deontología Informática, donde partiendo de conceptos básicos se llega a las particularidades de la deontología informática: lo qué nos diferencia de otras profesiones.

La evaluación de la misma en su modalidad ordinaria -no FLIP- se realiza mediante boletines de prácticas (cuatro entregas, con un peso total de 3,5 puntos), tres casos de aula con un peso total de 1,5 puntos y dos parciales de 2,5 puntos cada uno, totalizando así los 10 puntos de la asignatura. Además, se les proponen distintas actividades y trabajos que les sirven para subir nota y, en cierto modo, para recuperar alguna actividad que no hubiese sido superada.

\section{Adaptación al Flip Teaching}

\subsection{Dirección de Producción y Operaciones}

Para la conversión de la asignatura en Docencia Inversa se ha intentado combinar las mejores prácticas de la formación tradicional y del enfoque on-line, intentando orientarlo de forma que el aprendizaje sea el adecuado para el estudiante. Hay que tener en cuenta las necesidades de aprendizaje de los estudiantes actuales consumidores masivos de pantallas y no tanto de papel (Vasileva et al, 2015). Al proporcionar un ambiente adaptativo a las necesidades del estudiante, les ayudamos a conseguir un rendimiento óptimo. Para ello es necesaria una cuidadosa planificación del trabajo a realizar por el alumno.

Con la utilización de las nuevas tecnologías un estudiante puede ver u oír una y otra vez aquello que no le quede claro, o que quiera volver a repasar, ir a su propio ritmo, pudiendo recuperar esa clase a la que no pudieron asistir (Sams y Bergmann, 2013). Indicar que las grabaciones se pusieron a disposición tanto de los alumnos del grupo Flip Teaching como del resto. Aunque el primer año sólo las utilizaron los alumnos del grupo Docencia Inversa, en el siguiente año se ha ido incrementando la visualización de los vídeos por parte de todos los alumnos de la asignatura con el fin de aclarar conceptos.

La UPV dispone de la plataforma Poliformat (basada en Sakai) que permite muchas posibilidades: colgar recursos de distintos tipos, enlaces, uso de foros, exámenes online, cuestionarios, programación de tareas, uso de chat y correo interno... Además también posee estudios de grabación que favorecen la elaboración de vídeos multimedia (polimedias), dentro de estos estarían los objetos de aprendizaje que deben cumplir unos requisitos determinados como estar descontextualizados y tener una duración inferior a 10 minutos (Estelles et al, 2014).

Con la implantación de la nueva metodología, la parte de teoría de aula se "enlato" al máximo (70\%) con vídeo-apuntes, objetos de formación y documentos en formato texto. 
Estos se clasificaron y ordenaron el apartado contenidos, con el fin de facilitar al máximo el seguimiento de los mismos por parte del alumno. Para la parte de teoría de aula, todos los temas se pusieron a disposición del alumno en formato testo, de cada tema había como mínimo un vídeo que explicaba lo esencial del tema. Además había una fecha de examen tipo test por Poliformat para cada tema, el alumno tenía todo un día para poder realizar el examen pero una vez lo iniciaba tenía un tiempo límite que se había establecido en el programa. Aún así se dejó una clase de dos horas por semana para hacer un seguimiento de los alumnos, explicarles los conceptos que se veía a través de los test que no estaban tan claros o para consultas o tutorías. Las prácticas de laboratorio se realizaron de la misma forma que para el resto de grupos. Sin embargo la parte de prácticas de aula, se "enlato" un $40 \%$, utilizando video-apuntes, de problemas grabados, realizados en pizarra, además los alumnos disponían de una extensa colección de problemas resueltos que se ponen a su disposición a través de la plataforma.

\subsection{Deontología y Profesionalismo}

Se imparten en ella temas, como hemos visto antes, con suficiente disimilitud con el resto de las asignaturas como para que resulte al docente un reto el lograr su homologación con ellas en el imaginario colectivo del alumnado. En la otra parte de la balanza, tenemos el hecho de que se trate de una población con no solo altos conocimientos, sino también fuerte interés en las TIC. Lo que nos facilita el uso de recursos que en otras titulaciones no tendrían un éxito claro, más allá del mero visionado de vídeos. Estos alumnos tienen tecnología líquida en las venas, así que piden mucho más.

En la experiencia, la carga práctica (laboratorio) quedó igual que en el resto de los grupos. Pero la teoría sufrió un cambio radical.

Así, todo el material de teoría se encuentra en la plataforma Poliformat, en su sección de contenidos, que, apoyándonos en el lenguaje html, permitió diseñar una hoja de ruta para cada tema donde se intercalaban los apuntes en formato pdf, (se quiera o no, imprescindibles para un conocimiento exhaustivo de la materia) con las clases grabadas en formato vídeo, en esas píldoras llamadas polimedias que se han citado, además de enlaces a documentales que pueden servir de apoyo, vídeos de youtube relacionados y otro material. A destacar una sección de "conceptos" grabados como audio, para que los alumnos puedan usar de esos ficheros mp3 mientras hacen deporte, esperan al tranvía, etc. También cada tema consta de una sección titulada "Para saber más", con documentos adicionales para el alumno curioso.

Esto queda plasmado en el siguiente esquema:

- Usamos material que nos permita sustituir la clase directa, de forma que al favorecer que los alumnos la puedan seguir en casa, trasladamos ese tiempo de trabajo allí, liberándonos el tiempo de aula para esas actividades de refuerzo que asumimos deben realizar por su cuenta y que cuya realización no siempre podemos constatar. Además, como nos indica (Sams y Bergmann, 2013) podemos usar ese tiempo para ayudar a los estudiantes que no llegan, con material de apoyo

(c)) BY-NC-ND 2017, Universitat Politècnica de València

Congreso IN-RED (2017) 
complementario, y lanzar desafíos a aquellos que ya han dominado el contenido, facilitándoles otro tipo de material que de una forma un tanto coloquial, bautizamos con la etiqueta "Para saber más". Del total de sesiones, una tercera parte se dedican a una tutoría presencial pura y dura, de manera que el alumno que no la precisa, no tiene porqué acudir. Los que si vienen son los que se encuentran atascados con alguna de las tareas a realizar en el curso o con algún concepto teórico que precise una mayor aclaración.

- Por otra parte, siguiendo el ejemplo de (Roshan, 2011) tratamos de romper otra atadura: la que los liga a un ordenador, sea portátil o de sobremesa. Para ello preparamos material que puede ser consumido también desde un smartphone o una tableta, y así arañaremos tiempo de una mina que suele estar sin explotar: el que habitualmente se pierde en el metro, el autobús... buscando la conversión de los transportes públicos en pequeñas aulas portátiles.

La diferencia fundamental que existe, y provocamos, con los materiales clásicos está en su adaptabilidad. Un estudiante puede volver a recibir una clase, como repaso antes del examen, escuchar de nuevo aquellos conceptos que le queden confusos y, no lo perdamos de vista, todo a su propio ritmo, pues no hay dos alumnos iguales, y el tiempo parecer ir a distinta velocidad en unos casos u otros. Recuperar clases perdidas por enfermedad se hace más fácil y, algo casi imposible, el lograr la concentración en el aula para asimilar conceptos complejos, resulta fácil al poder trasladar el aula su propia casa (Roshan, 2011).

A la hora de seleccionar las herramientas a emplear, el punto de partida necesario es revisar que herramientas pone a nuestra disposición la Universitat Politècnica de València. Centrándonos en la plataforma Poliformat antes citada (basada en Sakai), con sus muchas posibilidades, algunas elementales y otras de mayor complejidad, como colgar recursos de distintos tipos, almacenar enlaces, uso de foros, exámenes online, cuestionarios, programación de tareas, uso de chat y correo interno... Conviene destacar desde éste primer momento a una de éstas herramientas en concreto, Contenidos, con la que se pueden elaborar guías que ayuden a los alumnos a descubrir los materiales y a usar el resto de herramientas y funcionalidades de Poliformat en el orden adecuado y en el plazo correspondiente.

Si se añade a esto la posibilidad de generar contenidos de calidad, gracias a los estudios de grabación de la universidad que favorecen la creación de vídeos docentes (llamados polimedias), de unos 10 minutos de duración.

Para cubrir la totalidad de la asignatura, se usan una gran diversidad de elementos digitales distintos:

- Ficheros con formato pdf:

- Apuntes de la asignatura, en su versión clásica. Para su estudio reposado, mediante su impresión, envío a reprografía o uso de una pantalla. Aunque de una u otra manera sus contenidos resulten redundantes al encontrarse también repartidos en el resto de contenidos, siempre son un elemento de interés para el alumno. 
- Guiones de trabajo para casos de aula o prácticas de laboratorio. Instrucciones precisas para trabajar en el aula como seminario, con adaptaciones de casos reales, o para guía de trabajo durante las prácticas.

- Artículos, documentos de trabajo (normas y códigos) o libros con licencia "creative commons", sirven para actividades de refuerzo, o para ayuda al alumno inquieto que quiere "saber más". Siempre identificables como tales.

- $\quad$ Audio

- Ficheros en formato $\mathrm{mp} 3$, con resúmenes, definiciones o fragmentos muy breves de teoría, preparados para apoyar actividades de repaso, con plena movilidad del estudiante, que no dependerá así de una pantalla.

- Videos:

- Documentales, con contenido de interés, con licencia "creative commons" o abiertos en la plataforma de su propietario (generalmente documentales de RTVE). Otros vídeos docentes, en plataformas como youtube. Sirven de apoyo a los casos planteados, o para ampliación de conocimientos.

- Capturas de pantalla (screencast) y los citados polimedias, vídeos con contenido docente. La creación de éstos y otros materiales con distinto software e instalaciones de apoyo, quedan fuera del ámbito de la presente comunicación, pero resulta conveniente siquiera dejar la idea de que, al margen de los medios que proporciona la universidad, existe una gran cantidad de software libre, con licencias freeware, creativecommons, etc., muy útil para tal fin.

- Actos académicos grabados. Cada año se trae a conferenciantes afines a los contenidos de la materia. Sus conferencias se graban y están disponibles para su visionado, durante el año académico en la plataforma Poliformat, y a partir de entonces, en Youtube.

Estos elementos por si solos no son útiles si no se introducen en el proceso de comunicación con los alumnos, poniéndolos en el orden adecuado y estableciendo mecanismos de retroalimentación para evaluar su impacto y para calificarlos.

La herramienta principal que se usa para ordenarlos, y que de paso sirve de nexo de unión, conduciendo con textos breves de unos a otros e introduciéndolos, es "Contenidos", de PoliformaT. La herramienta "Contenidos" es un editor html donde se puede introducir texto, imágenes y enlaces a los elementos que antes se han citado, permitiendo de esta forma dar paso a sencillos tests de comprensión sin que el alumno abandone su navegación, y así se convierte en algo intuitivo.

Cuando los alumnos disponen del material necesario, pautado en tiempos, se hace necesario que el profesor no quede a ciegas, sin saber si van digiriendo la información en su poder, más allá de la clásica evaluación mediante un examen en papel, que reviste el peligro de llegar tarde para enmendar problemas que puedan ir surgiendo.

Para conseguir este fin, se emplean diferentes herramientas que superan al examen permitiendo un uso asíncrono de las mismas, en el que docente no tienen por qué coincidir.

(cc) EY-NC-ND 2017, Universitat Politècnica de València 
Algunas, como los "Foros", requieren de un seguimiento en tiempo. En la actualidad, estos foros son de acceso libre y voluntario, pero las mejores participaciones se premian (uso de la ludificación). Otros, como los "Encuestas" ó "Exámenes" online, permiten distintos grados de automatización. Todo ello sin perder de vista que para las entregas de pequeños trabajos o resultados de prácticas, mediante la programación de "Tareas" de esta forma el camino del alumno queda balizado, y además también la corrección del profesor, se agiliza mucho.

La evaluación pasa por trabajo en aula y casa. Los dos parciales, que sumaban 5 puntos, se sustituyen por cinco casos de aula y/o tareas a entregar, además de los tres casos de aula de 0,5 puntos que el resto de sus compañeros realizan.

De forma adicional se incluyen actividades de gamificación, en las que se premian las mejores intervenciones en debates, en los foros y en Twitter. En este último se hace un seguimiento de las noticias destacadas relacionadas con la asignatura.

Los alumnos también pueden optar a realizar un trabajo basado en la creación de un vídeo de 5 minutos sobre un tema propuesto, con dos premisas: el profesor revisará el guión antes de grabarlo y dará el material teórico necesario para construirlo.

Cuando se establecieron los cambios para la modalidad Flip Teaching, se mantuvieron los exámenes convencionales como una opción a la que el alumno podía optar. Cabe decir que no la eligió ninguno de ellos.

Las notas se descomponen en partes muy pequeñas. Eso implica que en el caso de no realizar, o fracasar en unas pocas, la continuidad en la asignatura no se resiente. Se intenta así evitar el abandono, al enganchar a los discentes en la sucesión, como un goteo, no molesto por su pequeño tamaño, pero persistente. Los casos permiten "tocar la realidad", de forma que la aplicación de los conocimientos teóricos es inmediata.

\section{Resultados}

En el presente apartado se habla de los resultados obtenidos en ambas asignaturas. La encuesta que se realizó fue la misma.

De las encuentas efectuadas a los alumnos se ha podido ver que la mayoría no eligió la modalidad Flip Teaching por su metodología, sino por incompatibilidad de horarios, o por tener un horario de clase presencial más reducido y poder gestionar mejor su tiempo.

Hay distintos elementos de medición aplicables a la docencia en general (Andrés, 2005) que resultan de interés por permitirnos comparativas entre grupos.

Porcentaje de Asistencia del alumnado. Con éste indicador se alude al porcentaje de alumnos que no han faltado más del $20 \%$ de las horas lectivas. El dato viene condicionado por la indicación, en la guía docente de la asignatura, de una asistencia mínima a un $80 \%$ de la asignatura. Dado que se reducen las horas lectivas, también las ausencias declinan su presencia. El dato se expresa como la división entre el número de alumnos que cumplen la condición de asistencia y el número total de alumnos, multiplicado por cien. En nuestro caso la tasa es de un $100 \%$. Para el resto de alumnos, el dato es de un $90 \%$.

(c) $)$ EY-NC-ND 2017, Universitat Politècnica de València 
Porcentaje de aprobados: clásico indicador de rendimiento global, calculado como el número de alumnos con una nota igual o superior a 5, dividido por el total de matriculados, multiplicado por 100. En el caso de los alumnos que cursan por Flip Teaching, al ir generando pequeñas calificaciones durante el curso, el dato es ya de un $100 \%$ de éxito. Ningún alumno ha suspendido la asignatura. Con respecto a la asignatura impartida en ADE, se constata una subida de la nota media en un $25 \%$ con respecto a los alumnos que no optaron por esta modalidad.

Al margen de éstos indicadores, hay otros elementos que pasan por la percepción del alumnado, y que sin dejar de ser muy interesantes para verificar el interés conseguido por la experiencia y el grado de aceptación de la materia en éste formato, son imposibles de captar sin su participación activa. Para éste fin, se ha diseñado un cuestionario, inspirado entre otros por (Bethany, 2012), para ser respondido por los alumnos al fin de la misma.

Los elementos que la componen oscilan en torno a puntos como:

- La utilidad de los contenidos, desde la percepción del alumnado.

- La satisfacción de los alumnos tanto con los contenidos como con las herramientas empleadas y con el propio profesor.

- Los tiempos invertidos realmente por ellos, como comparativo de los cálculos previos realizados en la planificación: número de horas dedicadas, carga de trabajo con respecto a otras materias...

- Observaciones que los alumnos quieran aportar al proceso.

\subsection{Respuestas más Significativas}

\subsubsection{Modelo de Evaluación}

Se les pregunta sobre su preferencia entre el modelo clásico, con exámenes y un número reducido de casos de aula, frente al propuesto, basado en casos y tareas. Esto se les pregunta tanto al principio de la asignatura, para conocer su postura y obrar en consecuencia, como al final, cuando ya conocen con detalle la ruta que se ha seguido.

La primera respuesta la tenemos, obviamente, tanto para el curso anterior como para el presente. Y el resultado es virtualmente idéntico, situándose en un $90 \%$. La respuesta al final del curso anterior cambió, situando en un 100\% la cifra de alumnos que preferían el modelo seguido al clásico.

Puede parecer que esta información no es relevante para lo que nos ocupa, pero lo es, y mucho: el modelo clásico les da a los alumnos unos momentos de tensión máxima, los próximos a las pruebas, y largos periodos de relajación, mientras que de la manera en que se trabaja, mantienen en todo momento un nivel bajo de trabajo, equivalente a la división de los créditos ECTS de la asignatura en su tiempo de desarrollo.

\subsubsection{Uso de la Herramienta "Foros"}

(c)) BY-NC-ND 2017, Universitat Politècnica de València

Congreso IN-RED (2017) 
En este caso tenemos datos sobre el uso de los foros. Sobre el conocimiento de los mismos y el uso previo, los datos son también parecidos en ambas ediciones: un $90 \%$ de ellos han sido usuarios de foros, aunque solo un $10 \%$ de ellos los han usado dentro de Poliformat.

Su uso es algo voluntario, aunque los foros de "FAQ" (de ayuda, apoyo a las tutorías) se han incrementado, dando respuestas no solo sobre la teoría de la asignatura, sino a entregas, mecánicas del Flip Teaching, etc.

\subsubsection{Utilización del Material en Formato Texto}

Las respuestas obtenidas indicaban que no había mayor problema con este tipo de material, pero en algunos casos preferían documentales a tener que leer. Estos alumnos son muy visuales y las nuevas tecnologías hacen que los profesores al final nos tengamos que ir adaptando a ellas.

\subsubsection{Tiempo Invertido por el Alumno}

Cuando se prepararon los materiales, se hizo teniendo muy en cuenta la inversión de tiempo que los alumnos tendrían que hacer en casa. Ese cálculo incluía la visualización, lectura, audición... etc. de los materiales, con un tiempo holgado para su correcta comprensión.

Al analizar los datos, comprobamos que con la excepción del material depositado en formato texto, los tiempos empleados quedaban muy por debajo de los cálculos previos. Sin embargo, en lo que respecta a los ficheros de texto, sus cifras eran prácticamente las del profesor, indicando que si bien el cálculo era acertado en este aspecto, se habían ponderado mal en relación al resto de materiales.

\section{Conclusiones}

Con respecto a la aplicación del modelo de docencia inversa también conocido como Flip Teaching en la asignatura de Dirección de Producción y Operaciones en $2^{\circ}$ curso de FADE, cabe destacar que en esta asignatura se ha "enlatado" un 70\% de la teoría de aula y un $40 \%$ de las prácticas de aula y se ha mantenido el método de evaluación, se han incorporado exámenes tipo test para realizar un seguimiento de los conocimientos adquiridos por los alumnos. Todo ello, ha representado un importante esfuerzo tanto de planificación como de trabajo previo (conversión de material, edición, grabaciones, y preparación de material adicional) por parte de los profesores. No es fácil la creación de este tipo de materiales e incluso el tomar la decisión de qué parte pasar a este tipo de formato. De igual manera, ha representado un esfuerzo importante para los alumnos a la hora de adaptarse a esta nueva forma de trabajo. Pero la mayor parte de ellos lo han valorado como una experiencia positiva.

Con respecto a la asignatura Deontología y Profesionalismo, en $2^{\circ}$ curso del grado de informática, cabe destacar que de los elementos que se suelen considerar a la hora de medir la docencia en general, tanto porcentaje de asistencia, el de trabajos entregados en plazo, como el de aprobados (considerando las pruebas realizadas y evaluadas hasta la fecha), los datos son magníficos, superando las perspectivas iniciales, que venían matizadas por la inclusión de un grupo grande con alumnos que no se habían presentado voluntarios a la experiencia. En cuanto al porcentaje de contenidos impartidos, siendo este expresado como 
los contenidos impartidos, dividido por el total contenidos programados, multiplicado por cien, cumplimos a rajatabla con el calendario previsto que, por otra parte, supone una semana de adelanto con respecto a los grupos no Flip Teaching, permitiéndonos reservar el tiempo sobrante al final para dedicarlo a actividades de seminario y prácticas. Quedaría por último un factor puramente cualitativo, de muy difícil medición, por lo personal: la satisfacción del docente. Y solo cabe decir que ésta es muy elevada, dando la sensación, en expresión manida, del "deber cumplido".

\section{Referencias}

ALBARRACIN GUILLEM, J.M., ESTELLES-MIGUEL, SOFIA y BABILONI, E. (2013). Guía Docente de la Asignatura de Dirección de Producción y Operaciones. Disponible en: https://poliformat.upv.es/portal/site/GRA_11748_2014/page/a6f58684-73a5-4c54-8b53-

180ccdf69557 consulta: [9 de marzo de 2015].

ANDRÉS, M.A. (2005). "Propuesta de indicadores del proceso de enseñanza/aprendizaje en la formación profesional en un contexto de gestión de calidad total" Revista Electrónica de Investigación y Evaluación Educativa, Vol. 11, №.1 doi: 10.7203/relieve.11.1.4197 http://www.uv.es/RELIEVE/v10n2/RELIEVEv11n1 4.htm [Consulta: 2 de marzo 2016].

BENNETT B., KERN J., GUDENRATH A., MCINTOSH P (2011). "The Flipped Class Revealed" The Daily Riff.<http://www.thedailyriff.com/articles/the-flipped-class-what-does-a-good-one-looklike-692.php $>$ [Consulta: 15 de marzo de 2016].

BETHANY B. S- (2012) "Flip Your Classroom to Increase Active Learning and Student Engagement"VV.AA. En 28th Annual Conference on Distance Teaching \& LearningWisconsin, EE.UU. University of Wisconsin, pp,1-5.

BOTTI V. (2014). "Comunicación. En Vicerrectorado de las Tecnologías de la Información y las Comunicaciones Valencia", UPV

ESTELLES-MIGUEL, S., ALBARRACIN GUILLEM, J.M.. y PALMER GATO, M.E. (2015). "Flip Teaching en la Asignatura de Dirección de Producción y Operaciones". Publicado en Congreso INRED 2015. pp 1-9. Doi : hrrp//dx.doi.org/10.4995/INRED2015.2015.1645.

ESTELLES-MIGUEL, S., RIUS SOROLLA, G y GIL, M. (2014). "Designing Practical Activities for Skills Development". Publicado en Innovation and Teaching Technologies-New Directions in Research, Practice and Policy. Editorial Springer. Suiza, pp 139-147.

ESTELLES-MIGUEL, S, ALBARRACIN GUILLEM, JM, PALMER GATO, ME Y PERIS-ORTIZ, M. (2016). "Aprendizaje y Evaluación basada en Proyectos en una Asignatura de Dirección de Operaciones". Publicado en IN-RED 2016 Congreso Nacional de Innovación Educativa y de Docencia en Red, pp 434-441.

OLTRA, J.V. (2015) "Diseño de unaexperiencia de Flip-Teaching para la asignaturaDeontología y Profesionalismoa impartir en la EscuelaTécnica Superior de IngenieraInformática de la UPV" INRED $2015 \quad<$ http://ocs.editorial.upv.es/index.php/INRED/INRED2015/paper/view/1646> [Consultado: 2 de abril de 2016]

ROSHAN S. (2011) "The best way to reach each student? Private school Math teacher flips learning" en The Daily Riff.< http://www.thedailyriff.com/articles/the-best-way-to-reach-each-student-privateschool-flips-learning-547.php $>$ [Consulta: 2 de mayo 2015]

SAMS A., BERGMANN J. (2013) "Flip Your Students' Learning" en Technology-Rich Learning Vol $70 \mathrm{n}^{\circ} 6$, pp. 16-20.

(c)) EY-NC-ND 2017, Universitat Politècnica de València

Congreso IN-RED (2017) 
TEDESCO, J.C. (2010). "La educación en el horizonte 2020". Madrid. Fundación Santillana.

UPV (2014) "Comunicado de la Universitat Politècnica de València sobre Flip Teaching” Disponible en www.upv.es/entidades/ETSINF/info/U0663284.pdf consultado 20/03/2015 consulta: [23 de marzo de 2015].

VASILEVA-STOJANOVSKA T., MALINOVSKI T., DOBRIJOVEVSKI M.V. y TRAJKOVIK V.(2015) "Impact of satisfaction, personality and learning style on educational outcomes in a blended learning environment" en Learning and Individual Differences (Article in press) $<$ do:10.1016/j.lindif.2015.01.018>[Consulta: 18 de mayo 2015].

ZABALA VIDELA, A. y ARNAU BELMONTE, L. (2007). "11 ideas clave. Cómo aprender y enseñar competencias" en Colección Ideas Clave. Serie Didáctica/Diseño y desarrollo curricular. Editorial GRAÓ de IRIF, SL. Barcelona. 